Portland State University

PDXScholar

TREC Final Reports

Transportation Research and Education Center

(TREC)

3-2021

\title{
Transit Impacts on Jobs, People and Real Estate
}

Arthur C. Nelson

University of Arizona

Robert Hibberd

University of Arizona

Kristina Marie Currans

University of Arizona, curransk@gmail.com

Nicole Iroz-Elardo

University of Arizona

Follow this and additional works at: https://pdxscholar.library.pdx.edu/trec_reports

Part of the Transportation Commons, Urban Studies Commons, and the Urban Studies and Planning Commons

Let us know how access to this document benefits you.

\section{Recommended Citation}

Nelson, Arthur C., Hibberd, R., \& Currans, K. Transit Impacts on Jobs, People and Real Estate. NITC-

RR-1253. Portland, OR: Transportation Research and Education Center (TREC), 2021. https://dx.doi.org/ $10.15760 /$ trec. 258

This Report is brought to you for free and open access. It has been accepted for inclusion in TREC Final Reports by an authorized administrator of PDXScholar. Please contact us if we can make this document more accessible: pdxscholar@pdx.edu. 


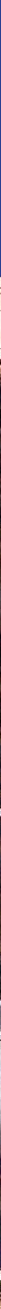

\section{Transit Impacts on Jobs, People and Real Estate}

Arthur C. Nelson, Ph.D. Robert Hibberd

Kristina Currans, Ph.D. Nicole Iroz-Elardo, Ph.D.

\section{A THE UNIVERSITY $\mathbb{A}$. OF ARIZONA。}




\section{TRANSIT IMPACTS ON \\ JOBS, PEOPLE AND REAL ESTATE}

\section{Final Report \\ NITC-RR-1253}

by

Arthur C. Nelson

Robert Hibberd

Kristina Currans

with Nicole Iroz-Elardo

University of Arizona

for

National Institute for Transportation and Communities (NITC)

P.O. Box 751

Portland, OR 97207
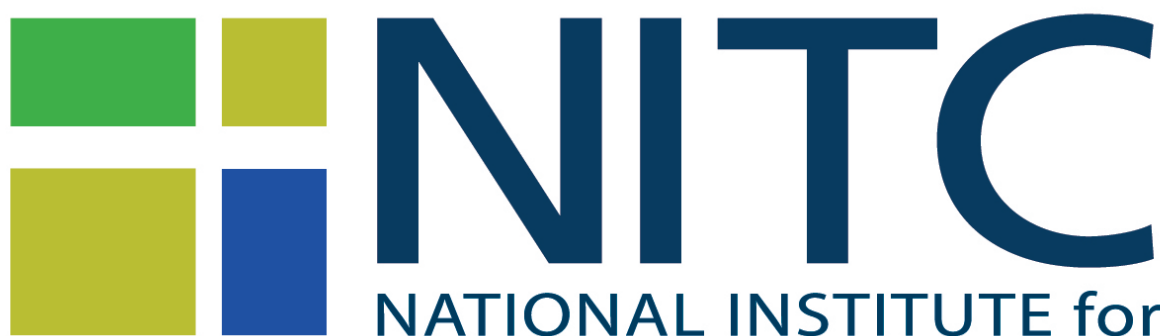

NATIONAL INSTITUTE for

TRANSPORTATION and COMMUNITIES

April 2021 


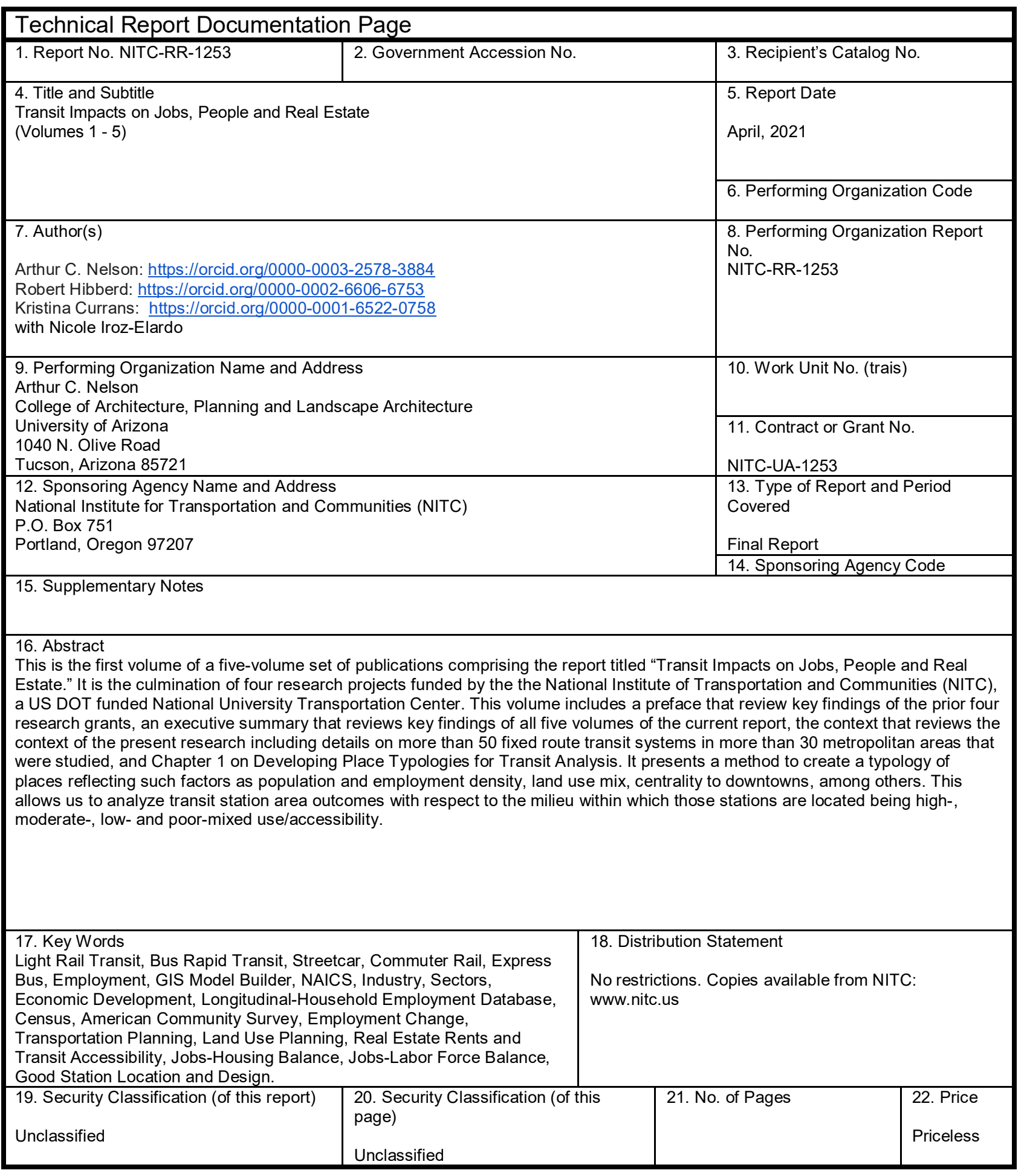




\section{ACKNOWLEDGEMENTS}

This report is a culmination of a genre of research that started in 2011 with generous support from the National Institute for Transportation and Communities (NITC), led by Jennifer Dill and Hau Hagedorn at Portland State University along with leadership by Keith Bartholomew at the University of Utah and Arlie Adkins at the University of Arizona.

We are grateful for financial and matching support for this and prior reports from NITC, the City of Tucson, Regional Transportation Commission of Southern Nevada, Mid-America Regional Council (Kansas City metropolitan area), Wasatch Front Regional Council, Portland Metro, the University of Utah and the University of Arizona.

We also acknowledge CoStar for allowing us to use its data on real estate rents.

We acknowledge especially Nicole Iroz-Elardo for invaluable contributions to Chapter 1 as well as Appendix B, and Matt Dixon for equally invaluable contributions to Appendix A, Appendix G, and assembling CoStar real estate rent data used in chapters 7, 8 and 9.

We also acknowledge that a special debt is due to Lauri Johnson, director of the School of Landscape Architecture and Planning at the University of Arizona, whose timely and even heroic efforts in $\mathbf{2 0 1 6}$ helped the University of Arizona become part of the NITC team.

Finally, we thank Robert Hibberd's wife, Trista, and children Emily, Nathan, Isabelle, Abigail and Nancy for lending him to this project.

\section{DISCLAIMER}

The contents of this report reflect the views of the authors, who are solely responsible for the facts and the accuracy of the material and information presented herein. This document is disseminated under the sponsorship of the U.S. Department of Transportation University Transportation Centers Program and the Utah Department of Transportation in the interest of information exchange. The U.S. Government and the Utah Department of Transportation assume no liability for the contents or use thereof. The contents do not necessarily reflect the official views of the U.S. Government and the Utah Department of Transportation. This report does not constitute a standard, specification, or regulation.

\section{RECOMMENDED CITATION}

Nelson, Arthur C., Hibberd, R., Currans, K \& Iroz-Elardo, N. Transit Impacts on Jobs, People and Real Estate. NITC-RR-1253. Portland, OR: Transportation Research and Education Center (TREC), 2021. 


\section{TABLE OF CONTENTS}

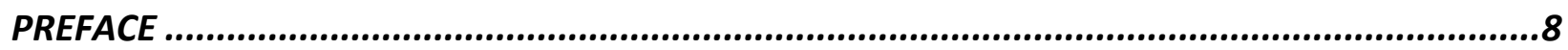

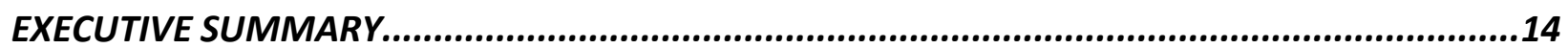

Chapter 1: Developing Place Typologies for Transit Analysis ......................................................... 14

Chapter 2: The Link between Transit Station Proximity and Typology and Change in Jobs Over Time

Chapter 3: The Link between Transit Station Proximity and Typology and Change in Jobs by

Economic Groups and Wage Categories Over Time .........................................................................19

Chapter 4: Toward an Index of Employment-Worker Balance by Transit Station Mode ...................21

Chapter 5: The Link between Transit Station Proximity and Typology and Change in Households, Housing tenure and commuting choice Over Time ..................................................................22

Chapter 6: The Link between Transit Station Proximity and Typology and Change in People by Demographic Groups Over Time

Chapter 7: The Link between Transit Station Proximity, Place Typology and Transportation Costs Incurred by Household Types.

Chapter 8: The Variation in Real Estate Rents with Respect to Place Typology and Transit Station Proximity

Chapter 9: The (Overlooked) Association between Express Bus Station/Stop Proximity and Multifamily Rents with Implications for Transit and Land Use Planning.

Chapter 10: How the Intersection of Light Rail Transit Stations with other Transit Modes Influences

Real Estate Rent.

Chapter 11: Regional Differences in the U.S. Real Estate Market Response towards Proximity of Fixed Route Transit Systems ............................................................................................................... 32

Chapter 12: The Need for Good Transit and Land Use Planning, and Design .................................... 33

Epilogue. .34

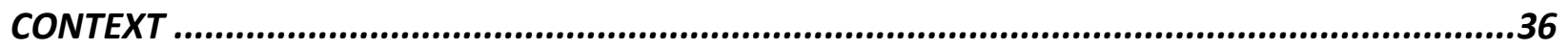

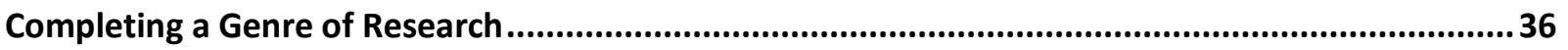

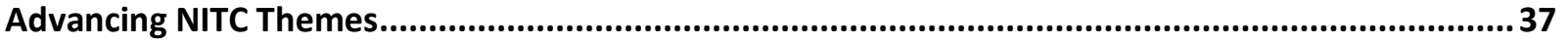

Problems Addressed and Research Questions .................................................................................38

CHAPTER 1: Developing Place Typologies for Transit Analysis ............................................51

APPENDIX A: Summary of Fixed Guideway Systems used in Analysis .................................79

APPENDIX B: Developing Place Typologies for Transit Analysis .......................................2271

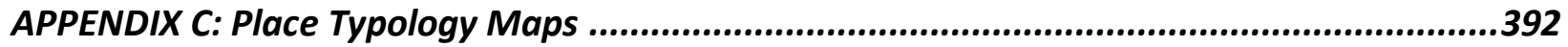

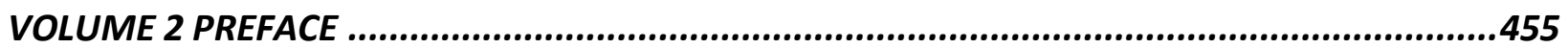


CHAPTER 2: The Link between Transit Station Proximity and Typology and Change in Jobs

Over Time .465

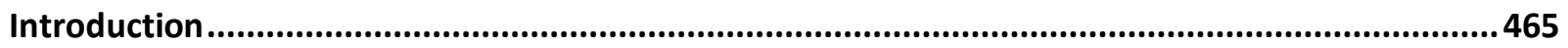

Literature Review and Research Questions.....................................................................................474

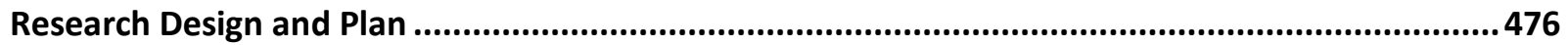

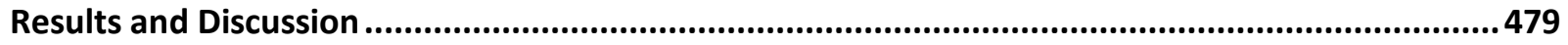

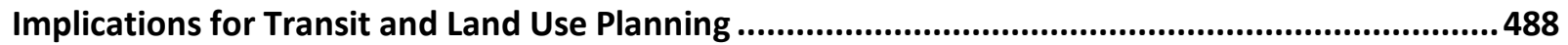

CHAPTER 3: The Link between Transit Station Proximity and Typology and Change in Jobs by Economic Groups and Wage Categories Over Time.........................................................492

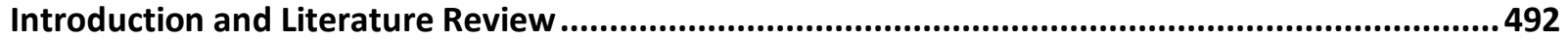

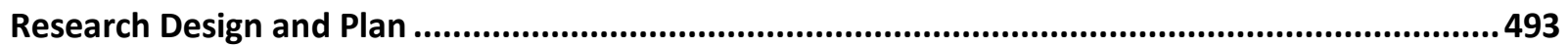

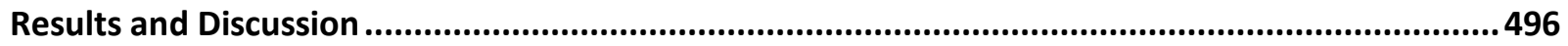

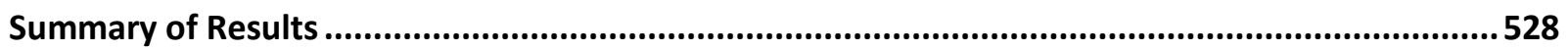

Implications for Transit and Land Use Planning ..........................................................................531

CHAPTER 4: Toward an Index of Employment-Worker Balance by Transit Station Mode ......537

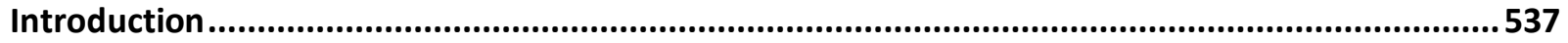

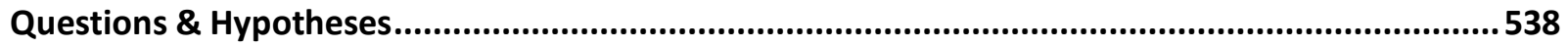

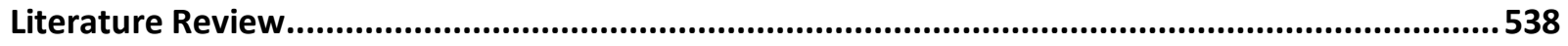

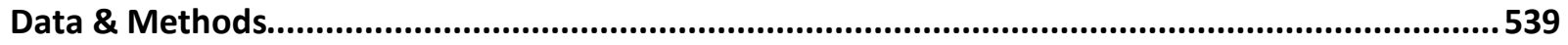

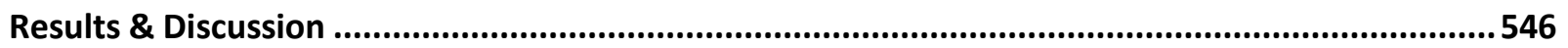

Conclusions and Implications for Transit and Land Use Planning............................................553

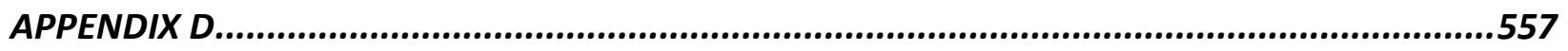

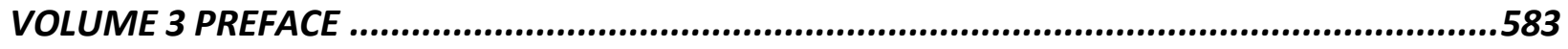

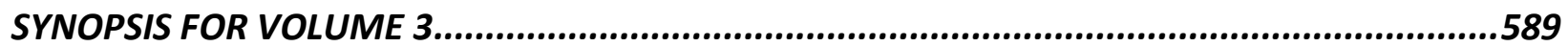

CHAPTER 5: The Link between Transit Station Proximity and Place Typology with Change in Households, Housing tenure and commuting choice Over Time........................................591

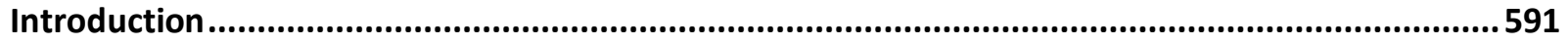

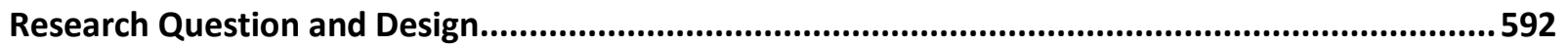

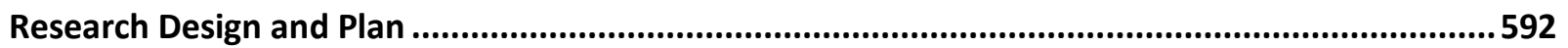

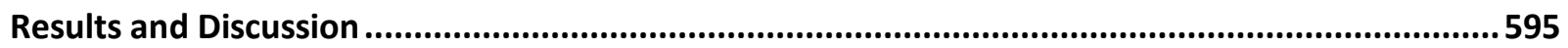

Implications for Transit and Land Use Planning ...........................................................................654

CHAPTER 6: The Link between Transit Station Proximity and Typology and Change in People by Demographic Groups Over Time ..................................................................................656 


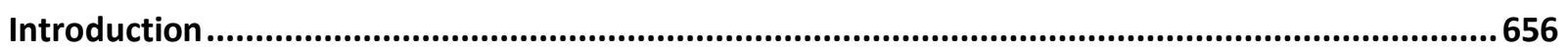

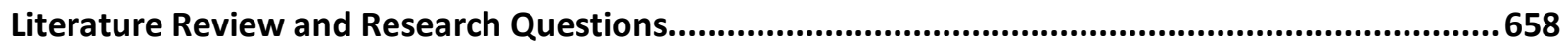

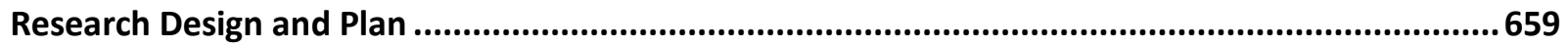

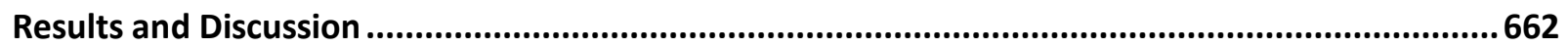

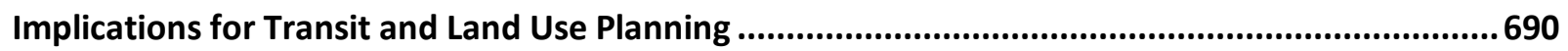

CHAPTER 7: The Link between Transit Station Proximity, Place Typology and Transportation

Costs Incurred by Household Types ......................................................................694

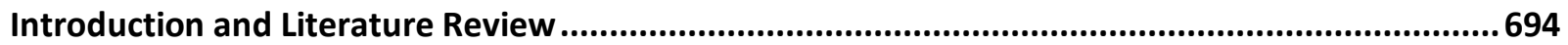

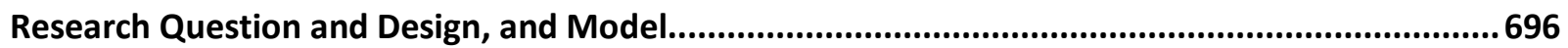

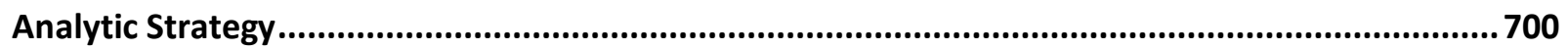

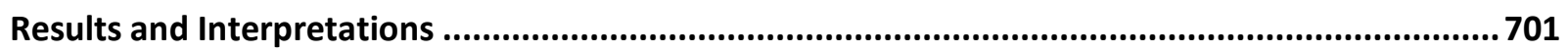

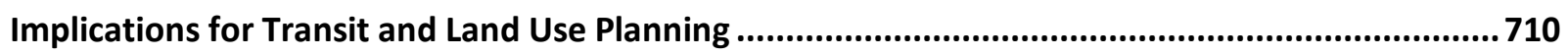

Implications for Selected Households ................................................................................................718

APPENDIX F: Supplemental Tables for Chapter 5 .........................................................722

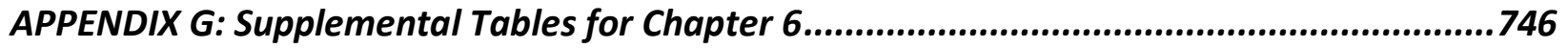

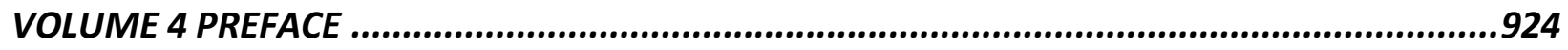

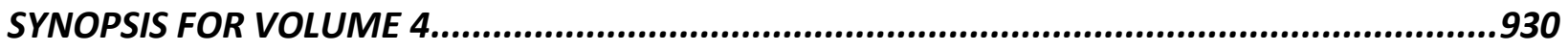

CHAPTER 8: The Variation in Real Estate Rents with Respect to Place Typology and Transit

Station Proximity...........................................................................................934

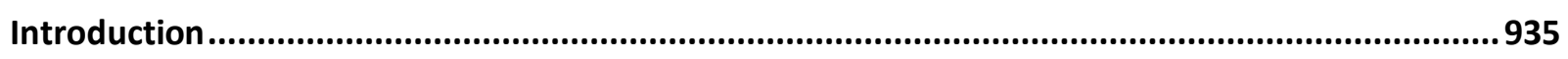

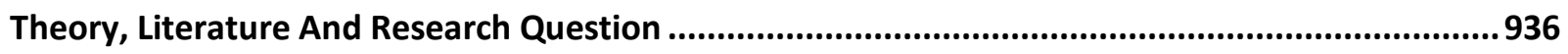

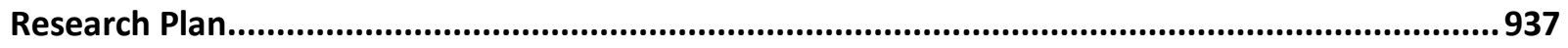

CHAPTER 9: The (Overlooked) Association between Express Bus Station/Stop Proximity and

Multifamily Rents with Implications for Transit and Land Use Planning ............................ 1071

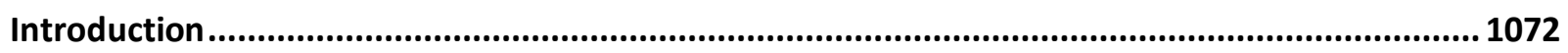

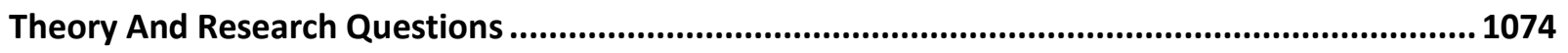

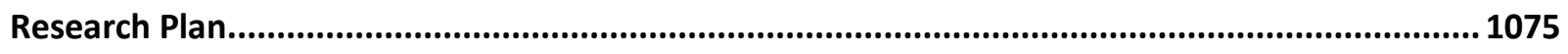

Implications for Express Bus Transit and Land Use Planning ........................................................ 1091

CHAPTER 10: How the Intersection of Light Rail Transit Stations with other Transit Modes Influences Real Estate Rent .............................................................................. 1096

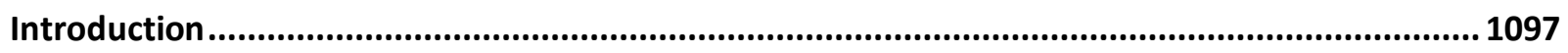

Theory and Research Questions.................................................................................................. 1098

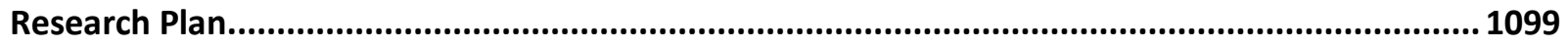

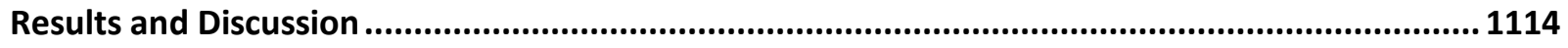


Synthesizing Perspectives .......................................................................................................... 1132

Implications For Transit, Land Use Planning, And Urban Design ...............................................1139

CHAPTER 11: Regional Differences in the U.S. Real Estate Market Response towards Proximity of Fixed Route Transit Systems .............................................................................1144

Relevant Literature, Theory and Research Question............................................................... 1144

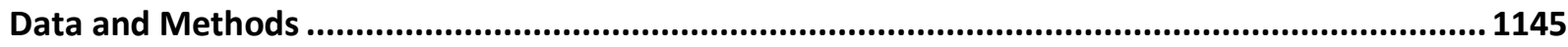

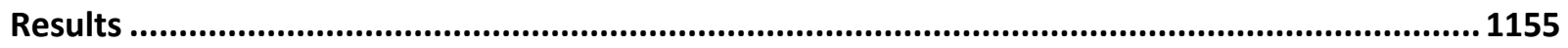

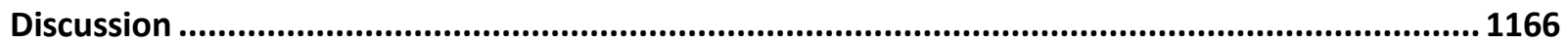

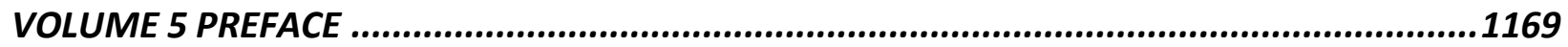

SYNOPSIS FOR VOLUME 5.................................................................................... 1175

Chapter 12: The Need for Good Transit and Land Use Planning, and Design ......................1177

Good, Bad and Ugly Transit Station Planning and Design .........................................................1177

Toward A Typology Of Good, Bad and Ugly Transit Station Planning and Design ......................... 1182

Improved Transit Station Planning and Design To Achieve Positive Outcomes............................. 1189

Research Agenda to Further Understand the Role of Fixed Route Transit Systems in Shaping

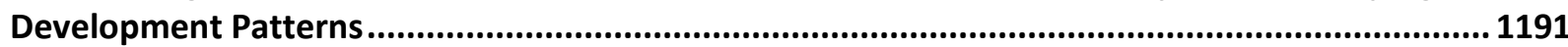

Concluding Perspectives About the Role of Fixed Route Transit Systems in Meeting America's Future Development Needs 1192

EPILOGUE: Transit Funding Options, Assessments, and Approach to Capturing Regional and Spatially-Related Value ........................................................................................1196

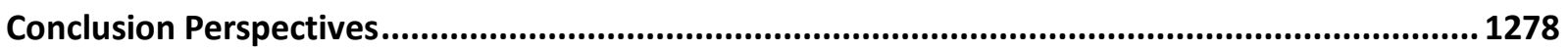

APPENDIX H: Selected FRT Stations for Perceptual Good-Bad-Ugly Assessment.................. 1281 


\section{PREFACE}

Transit Impacts on Jobs, People, and Real Estate is the fourth report in a series that started with funding from the National Institute of Transportation and Communities (NITC), a US DOT funded National University Transportation Center. While it completes the "quadrilogy" of work comprising a unique genre of transit and land use planning research it is by no means the last work-it is more likely the foundation for future work.

This document is Volume 1 of five volumes from the full report Transit Impacts on Jobs, People, and Real Estate:

- Volume 1: Orientation, Executive Summary, Context and Place Typologies

- Volume 2: Impact on Job Location Over Time with Respect to Transit Station Proximity Considering Economic Groups by Transit Mode and Place Typology with Implications for Transit and Land Use Planning

- Volume 3: Impact on Where People Live Over Time with Respect to Transit Station Proximity Considering Race/Ethnicity and Household Type and Household Budget by Transit Mode and Place Typology with Implications for Transit and Land Use Planning

- Volume 4: Impact on Real Estate Rents with Respect to Transit Station Proximity Considering Type of Real Estate by Transit Mode and Place with Implications for Transit and Land Use Planning

- Volume 5: Improving Transit Impacts by Reconsidering Design and Broadening Investment Resources

Each of these volumes, and the full report, can be found at https://nitc.trec.pdx.edu/research/project/1253

The genre of research within which four research projects call is grounded in trend that is common throughout all reports: That America is becoming increasingly focused on the need for transit to meet a growing number of social, economic and environmental objectives. But it is also rooted is simple market dynamics.

America will add at least 100 million new residents, 40 million new households, and 60 million new jobs by 2050. We know from demographic analysis and consumer preference surveys that at least a third of America's 150 million households (50+ million) in 2050 will want to live in locations providing them with transit options, in addition to mixed-use and mixed-housing options. We also know from research on firm location behavior that up to 100 million jobs will be attracted to locations with transit options. Indeed, some research has estimated that even if all new development to 2050 occurred within one-half mile of existing and planned transit stations-such as transit oriented development (TOD) planning areas-the market demand for such development would not be met.

Our prior research outlines the extent to which fixed route transit (FRT) systems can meet future demand. But each system has its own niche. Light rail transit (LRT) systems serve metropolitan wide markets, connecting multiple nodes to each other. Bus rapid transit (BRT) systems can accomplish many of the same objectives as LRT systems at lower cost per mile but also lower capacity - which is fine for the Eugene-Springfield metropolitan area though not necessarily the Portland metropolitan area which, being four times larger and more densely settled, relies on LRT. At the lowest scale of operations are street car transit (SCT) systems that serve mostly downtowns such as Seattle or connect employment centers near downtown to downtown such as Portland, Tucson and Dallas. At the other end of the spectrum are commuter rail transit 
(CRT) systems that are intercity systems that connect cities within a metropolitan area to downtown such as San Diego's Coaster, or multiple metropolitan areas such as the SeattleTacoma Sounder or the Albuquerque-Santa Fe Rail Runner or the Utah Transit Authority's FrontRunner connecting three metropolitan areas.

Here we will summarize the purpose and key findings of each of the three prior reports and then frame the role of the fourth report. 


\section{(2015) Do TODs Make a Difference?}

The first report in the Quadrilogy was Do TODs Make a Difference? (Nelson et al. 2015). NITC contracts 547 and 650 were used to build station area databases for 12 light rail transit (LRT) systems, nine bus rapid transit (BRT) systems, four streetcar transit (SCT), and five commuter rail transit (CRT) systems. In this report, we presented research that measures the outcomes of TOD areas in relation to their metropolitan area controls with respect to:

- Jobs by sector;

- Housing choice for household types based on key demographic characteristics;

- Housing affordability based on transportation costs; and

- Job-worker balance as a measure of accessibility.

Prior literature has not systematically evaluated TOD outcomes in these respects with respect to light rail transit (LRT), commuter rail transit (CRT), bus rapid transit (BRT), and streetcar transit (SCT) systems. Our analysis helps close some of these gaps. We applied our analysis to 23 fixed guideway transit systems operating in 17 metropolitan areas in the South and West that have one or more of those systems. We found:

- Most TOD areas gained jobs in the office, knowledge, education, health care and entertainment sectors, adding more than $\$ 100$ billion in wages capitalized over time;

- In assessing economic resilience associated with LRT systems, jobs continued to shift away from TOD areas before the Great Recession, the pace slowed during the Recession, but reversed during recovery leading us to speculate that LRT TOD areas may have transformed metropolitan economies served by LRT systems;

- Rents for offices, retail stores and apartments were higher when closer to SCT systems, had mixed results with respect LRT systems, but were mostly lower with respect to CRT systems (our earlier BRT sample size was too small to evaluate);

- SCT systems performed best in terms of increasing their TOD area shares of metropolitan population, households and householders by age, housing units, and renters with BRT systems performing less well while LRT and CRT systems experienced a much smaller shift in the share of growth;

- Household transportation costs as a share of budgets increase with respect to distance from LRT transit stations to seven miles suggesting the proximity to LRT stations reduces total household transportation costs;

- Emerging trends that may favor higher-wage jobs locating in transit TOD areas over time than lower or middle wage jobs perhaps because TOD areas attract more investment which requires more productive, higher-paid labor to justify the investment; and

- The share of workers who commute 10 minutes or less to work increases nearly one-half of one percent for each half-mile their resident block group is to an LRT transit station, capping at a gain of 1.3 percent, which is not a trivial gain.

This work identified a missing element of research relating to one of the fastest growing modes of fixed route transit systems: Bus rapid transit (BRT). That led to a second NITC-funded project. 


\section{(2016) National Study of BRT Development Outcomes}

The second report was the nation's largest and most comprehensive assessment of the influence of bus rapid transit (BRT) systems on jobs, people and households, and real estate rents (Nelson and Ganning 2016).

Public transit systems are often promoted as offering a plethora of social, economic and environmental benefits to urban populations by transforming urban forms from auto-centric designs into more sustainable ones. The "next big thing" in public transit is bus rapid transit (BRT) systems. From virtually no systems a generation ago, there are now nearly 20 lines operating with at least seven under construction and more than 20 in the planning stages. Part of this recent popularity in BRT stems from its more affordable capital investment costs and its potential to be utilized by municipal planning organizations as an economic development tool. Yet, research into development outcomes associated with BRT station/stop proximity is small. This study found:

- For metropolitan counties with BRT systems, (0.50-mile) transit corridors increased their share of new office space by a third, from 11.4 percent to 15.2 percent and although new multifamily apartment construction was small, its share more than doubled since 2008;

- BRT station areas gained share of central county jobs at a faster pace or even at the expense of the rest of the central county and that more technologically advanced BRT systems may contribute to positive economic development outcomes;

- However, when disaggregating data to sectors, BRT is found to influence employment change in only one sector-manufacturing though that sector is broad and includes such activities as assembly, food processing (think beer making) and fashion design;

- Evidence of an office rent premium for location within a BRT corridor for most albeit not all of the metropolitan areas studied;

- Household transportation costs as a share of budgets increase with respect to CBD distance to about 19 miles and about eight miles with respect to BRT stations;

- Before the recession, the shift in jobs for all wage groups was about the same between BRT station areas and counterfactual locations but during recovery, BRT station areas saw larger shifts compared to counter-factual locations for lower-wage but upper-wage jobs had the largest change share in BRT station areas during recovery while the share of lower-wage jobs in BRT station areas fell; and

- There is little difference in BRT study area performance compared to their metropolitan areas in terms of influencing population and residential patterns though we did find indirect evidence that BRT systems choosing higher-quality design and technology options tended to enjoy better population and housing outcomes than those that chose lesser options.

We conclude that, on the whole, BRT systems are associated with positive development and job location outcomes, though not necessarily population or housing outcomes. By the time this study was completed more robust data had become available allowing for updates and expansions of prior work, which led to the third grant in this genre. 
(2019) The Link between Transit Station Proximity and Real Estate Rents, Jobs, People and Housing with Transit and Land Use Planning Implications This report updates and expands prior research in the genre of research that has used economic base analysis (especially shift-share) and CoStar commercial rent data to estimate the development outcomes to transit (Nelson and Hibberd 2019). The study period for prior economic base analysis was 2002-2011 and census data for 2000 and 2010, as well as CoStar data for 2013. This report expands the number of systems used in analysis to 17 LRT systems, 14 BRT systems, nine SCT systems and 12 CRT systems. It also expands the period of analysis to 2015 for jobs-related data, 2016 for census data, and 2018 for CoStar data. The expanded and updated databases allow for more comprehensive assessment of their outcomes. Key findings include:

- Market rents increase with respect to Fixed Guideway Transit (FGT) station proximity for nearly all commercial types and for all modes, except there no rent premium for BRT in the closet $(0.125$ mile $)$ distance band and office responds positively only within the closets ( 0.125 mile) distance band from LRT stations, with rent premiums extend one to two miles away from FGT stations for many commercial types;

- On the whole, more mature Fixed Guideway Transit (FGT) system saw gains in regional share of jobs in closer in ( 0.25 mile and 0.50 mile) distance bands if not up to the 1.00 mile distance band from transit stations-BRT being an exception in gaining share only in the nearest ( 0.25 mile) distance band - while ones build during and since the Great Recession saw small or negative shifts in regional share;

- There are only modest gains in the regional share of population and housing before/during the Great Recession (2000-2009) bit somewhat more gains afterward (2010-2016) for all transit types except BRT with larger gains associated with households without children and early/middle aged households (35-49); and

- For the most part for all transit modes saw reductions in regional share of driving alone and carpooling, and increases in regional share of transit, biking, walking, and working at home with respect to FGT station proximity.

The report also featured illustrations of "good, bad and ugly" transit station/stop planning and design, suggesting that systems may be underperforming because of these limitations.

A missing element of prior work was the milieu or type of place within which transit stations are located. Addressing this is the key purpose of this report (Nelson, Hibberd and Currans 2021). 
(2021) Transit Impacts on Jobs, People and Real Estate

This is the fourth report in the genre of research supported by NITC. This project entailed updating data and disaggregating it to assess outcomes based on station area types or what we call Place Typologies. This research is guided by two overarching questions and analytic contexts:

\begin{abstract}
How do Transit Development Outcomes Vary by Mode and Place Typology? This analysis includes each transit system for each metropolitan area studied during appropriate time periods for that system, as well as systems combined across metros. Trends that are assessed include: (1) Changes in the number and share of jobs by sector with respect to type of system and distance from stations, by type of station based on Place Typology; (2) Changes in the number and share of jobs by wage category with respect to transit mode and station proximity by Place Typology; and (3) Changes in number and share of population, households, householders by age, and housing by tenure with respect to transit mode, station proximity, and Place Typology.
\end{abstract}

\title{
How does the real estate market for office, retail and apartment properties respond to proximity to transit stations by mode and Place Typology? Our prior
} work pioneered the use of CoStar commercial rental data for very broad assessments of real estate market responsiveness to transit by type but not really by location except for corridor distance bands. The new research conducts more refined relationships in those metropolitan areas based on mode and Place Typology where CoStar data are sufficient for analysis.

In addition, we updated our complete database with a codebook for anyone to access through NITC.

\section{References}

Nelson, Arthur C., Matt Miller, Dejan Eskic, Keuntae Kim, Joanna P. Ganning, Reid Ewing, Jenny Liu, Matt Berggren, Zakari Mumuni (2015). Do TODs Make a Difference? Portland OR: Portland State University, National Institute for Transportation and Communities Final Report NITC-RR-547 and NITC-RR-763. Available along with related materials at https://nitc.trec.pdx.edu/research/project/547/

Nelson, Arthur C. and Joanna P. Ganning (2016). National Study of BRT Development Outcomes. Portland OR: Portland State University, National Institute for Transportation and Communities Final Report 650. Available along with related materials at http://nitc.trec.pdx.edu/research/project/650

Nelson, Arthur C. and Robert Hibberd (2019). The Link between Transit Station Proximity and Real Estate Rents, Jobs, People and Housing with Transit and Land Use Planning Implications. Portland OR: Portland State University, National Institute for Transportation and Communities Final Report 1103.

Available along with related materials at https://nitc.trec.pdx.edu/research/project/1103

Nelson, Arthur C., Robert Hibberd and Kristian Currans with Nicole Iroz-Elardo (2021). Transit Impacts on Jobs, People and Real Estate, five volumes. Portland OR: Portland State University, National Institute for Transportation and Communities Final Report 1253.

Available along with related materials at https://nitc.trec.pdx.edu/research/project/1253 


\section{EXECUTIVE SUMMARY}

What follows is an overall summary of the entire five-volume report. The overall report itself is comprised of five substantive elements. The first is crafting a scientifically sound framework for identifying landscapes within the metropolitan areas we studied. The second is applying those Place Typologies and spatial analysis to economic and demographic change for the transit system in each metropolitan area. The third is analyzing how real estate markets respond to transit system proximity with special reference to the Place Typologies. Fourth, this is followed by specialized studies into how urban form and society are shaped by transit systems. The fifth is providing an overall perspective of our research as well as a framework for unlocking the potential to leverage economic benefits of transit to advance social well-being. What follows are key products or findings from each chapter.

\section{Chapter 1: Developing Place Typologies for Transit Analysis}

Ours is the first study to create typologies of urban development patterns for national-scale research. To expand on the analyses explored in prior studies, we begin by exploring how the literature and practice identifies different types of transit-based development. For the purposes of this report, we are focusing mainly on fixed-route transit (FRT) systems and corresponding place typologies. In this project, we aim to capture differing built environment contexts that might be more-or-less resilient or responsive to economic development (jobs, housing, populations, or real estate values). We orient our analyses towards the neighborhood-level-instead of stationlevel—so that we might compare and quantify the relative impacts of FRT on economic outcomes, compared with areas without FRT access. And finally, we aim to develop place types that might more readily align with planning practice.

We then explore the academic and white paper literatures to identify the purposes of place and transit station typologies. We then synthesize a framework and corresponding measurements for delineating different dimensions of transit-oriented development. From there, we describe the different quantitative methods for categorization of place types so that we might expand a consistent approach to compare-and-contrast similar development patterns across vastly different regions. In the last section, we explore the guiding principles for place-type development, and we describe the data and methods used to develop the place typologies used throughout this project.

At the outset, we advise readers that an extensive annotated bibliography of materials used to create the Place Typology is provided in Appendix A.

Our scientific analysis generates four Place Typologies: High-, Moderate-, Low- and Poor-Mixed Use/Accessibility places and areas. Table ES.1 summarizes the results of this analysis. Figure ES.1 illustrates how these Place Typologies are used to frame spatial analysis.

While these place types enable us to compare similar built environments across sometimes drastically different metropolitan areas, they are driven largely by the distribution of environments included in our study areas. And the built environment measures included in this study were limited to those generally available and consistent throughout the US at a blockgroup level. In future work, more robust transit and walkability accessibility measures within 
each block group could provide an improved representation of local and regional accessibility in a measurable way for comparing across metropolitan areas.

Table ES. 1

Average Built Environment Characteristics Across Mix/Accessible Place Types

\begin{tabular}{|c|c|c|c|c|}
\hline & \multicolumn{4}{|l|}{ Place Types } \\
\hline & $\begin{array}{l}\text { High } \\
\text { Mix/Access } \\
\text { ible } \\
\text { Centers }\end{array}$ & $\begin{array}{l}\text { Moderate } \\
\text { Mix/Accessible } \\
\text { Areas }\end{array}$ & $\begin{array}{l}\text { Low } \\
\text { Mix/Accessible } \\
\text { Areas }\end{array}$ & $\begin{array}{l}\text { Poor } \\
\text { Mix/Accessible } \\
\text { Areas }\end{array}$ \\
\hline & (High MA) & (Mod MA) & (Low MA) & (Poor MA) \\
\hline Scores & $\begin{array}{l}\text { Greater } \\
\text { than } 2.5\end{array}$ & $2-2.5$ & $1.5-2$ & $0-1.5$ \\
\hline Built Environment Variables & \multicolumn{4}{|c|}{ Average Values by Place Types } \\
\hline Jobs per acre & 0.42 & 1.38 & 3.26 & 8.11 \\
\hline $\begin{array}{l}\text { Proportion of jobs that are retail and } \\
\text { arts }\end{array}$ & 0.06 & 0.17 & 0.25 & 0.27 \\
\hline Total population per acre & 4.45 & 10.97 & 28.33 & 72.85 \\
\hline Total households per acre & 1.71 & 4.19 & 11.04 & 26.96 \\
\hline Percent of households with no kids & 0.71 & 0.66 & 0.63 & 0.51 \\
\hline Percent of owner-occupied housing & 0.83 & 0.63 & 0.40 & 0.22 \\
\hline Intersections per square mile & 45.78 & 78.98 & 112.58 & 149.81 \\
\hline $\begin{array}{l}\text { Proportion of intersections with } 3 \text { to } 4 \\
\text { vertices }\end{array}$ & 0.10 & 0.26 & 0.45 & 0.70 \\
\hline
\end{tabular}




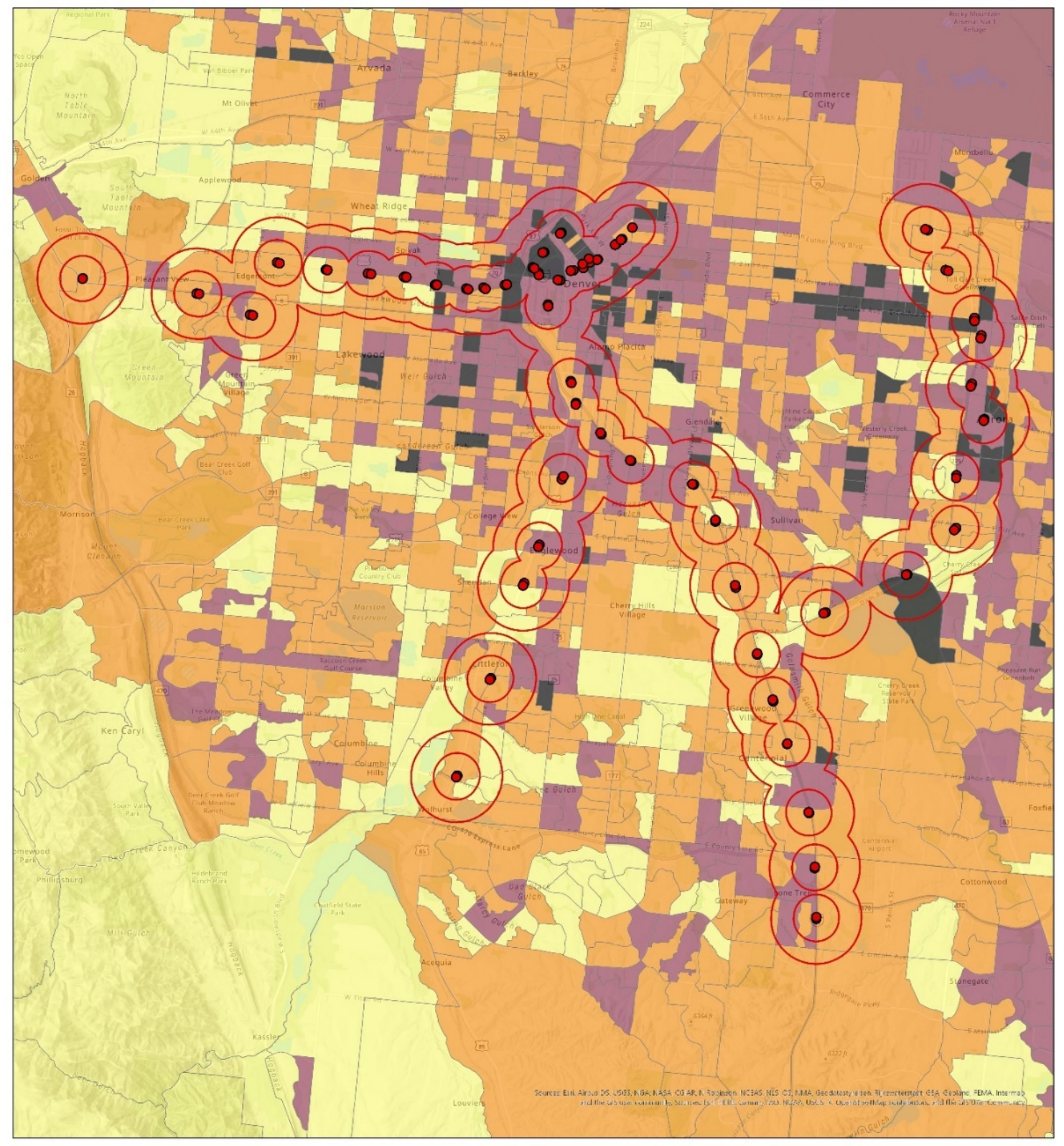

Station Typology for Light Rail Transit:

Buffers: Half \& 1 Mile Denver-Aurora-Lakewood, CO

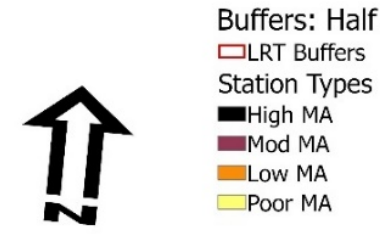

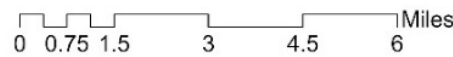

Figure ES.1. Light Rail Transit in Denver, Colorado show a wide variety of station place types. A brief visual inspection of the map implies that Low MA and Mod MA are the most prevalent station place types. Further, the map demonstrates the wide variety of place types at each individual transit station. Competition for revenue-generating land uses may be drawn into those higher-intensity areas, with a concomitant loss of land uses in less intense locations. 


\section{Chapter 2: The Link between Transit Station Proximity and Typology and Change in Jobs Over Time}

The research reported in this chapter expands upon previous work by assessing the extent to which jobs by sector are attracted to transit stations over time and across a range of station area intensities. Analysis is given of the land area encompassed by transit systems by mode and station type. Using economic base theory and relying upon shift-share and location quotient analyses, the economic development outcomes of station areas are assessed by transit mode, such as light rail, and by station typology. Transit modes include light rail transit, commuter rail transit, streetcar transit, and bus rapid transit systems. The station area types are characterized as lying somewhere along a continuum of land use mix, intensity, and accessibility. These types are based upon the relative intensity of a combination of characteristics of jobs, households, and the built environment. The analysis will advance the understanding of how transit stations by type effect the economy in a multimodal transportation system context. Case studies comprise metropolitan areas across the United States, in the Urbanized Area of the counties served by the transit systems under study. Each station area is analyzed by distance from the station in eighth-mile distance bands.

For each transit mode:

- BRT proved to be quite flexible to the variations of each place type, showing robust growth across three four place types, shining in the two mid-range classes, while losing share slightly in the lowest-mix areas. This indicates, first, that BRT stations and technology need to adapt to the context of the outlying areas to better attract firms to these station areas. Second, it also may indicate that the challenges from low-density dispersed land use impede the efficient use of these stations, just as is the case for most other transit modes.

- $\quad$ CRT showed mostly modest gains in job share for the Low MA place type stations, to the first half mile. It had flat share gains or slight declines in three of the four place type stations. This might indicate that in these stations the firms are opting for locations farther from the station due to the disamenities involved in this large-scale transit mode, such as noise and air pollution. Newer systems such as that in Salt Lake City, Utah use quieter, less polluting train technology for these commuter-oriented stations. This update may be necessary in other metropolitan areas to attract further job share gain near these stations.

- $\quad$ LRT saw modest growth at the Poor MA station areas but saw great share gains in the Low MA and Mod MA place type areas, with acceptable gains in the High MA areas. This seems reasonable given the scale of the trains, the competition from SCT systems for the most urban land, and the low response to transit proximity in all of the transit mode stations. A great deal of focus could shift to the Poor MA station areas, to increase accessibility in the most outlying areas. This will provide gains across all segments of the transit network. The challenge of cost structures for providing greater-quality LRT may impede gains for the lowest-intensity place type. One option is to consider ways to increase integration of LRT and BRT systems to provide higher-quality transit connections to outlying areas. 
- SCT did best in the context for which it was designed, the High MA and Mod MA areas. It did reasonably well in Low MA areas, which may include the streetcar suburbs of New Orleans. It saw a slight loss of job share in the Poor MA place type areas, for reasons that are likely to be similar to the other transit modes. However, the scale of the streetcar transit system, and the capacity of the trains may impact its utility in the most outlying areas. SCT, like LRT, may benefit from efforts at greater integration of BRT and other transport mode to increase the utility of the system for all place types.

We will apply shift share analysis by Place Typology to economic sectors and workers by wage groups in the next chapter. 


\section{Chapter 3: The Link between Transit Station Proximity and Typology and Change in Jobs by Economic Groups and Wage Categories Over Time}

Our research expands upon previous work by assessing the extent to which jobs by wage and economic group are attracted to transit stations over time. Station areas are assessed by transit mode, such as light rail, and by station typology. The types are characterized as lying somewhere along a continuum from low to high land use mix and accessibility. These types are based upon the relative intensity a combination of jobs, households, and the built environment. The analysis will advance the understanding of how transit stations effect the economy in a multimodal transportation system context. It will highlight these trends by wage and economic group stratifications. We allocate jobs by economic sector groups based upon NAICS classifications, and group jobs by wage based upon the salary levels of each sector. This chapter focuses on economic development outcomes first by job sector groups, then by job wage groupings. It follows up with summary findings, implications and recommendations. Analysis is based on Place Typologies developed on Chapter 1 with a spatial dimension based on 0.125-mile distance bands (DB) from transit stations.

Competition between economic sector groups and wage groups is evident at stations for many transit mode-place type combinations. Also very evident is a trend away from the DB closest to the station, or the station area itself, for many transit modes at many station place types. In highly competitive station areas, land use policy may be of help in improving the utility of underutilized land parcels, to bring them into alignment with the most productive level of mix and intensity for the context. Also true is that many stations repelled firms away from the first $D B$, at the station itself.

In many station areas, upper and lower-income jobs are partners in growth trends, co-locating in the same DB or nearby. This has left many stations with relatively low growth rates in the middle-income jobs. This is also in part due to the nature of those sector groups, which include such occupations as transport and warehousing. They often require an inordinate land area for the first mile from a station.

For BRT, CRT and LRT, transit share of job shift in this time period was most pronounced at the Low MA and Mod MA place types. For SCT, that trend was most pronounced at the Mod MA and High MA place types. This highlights the urban orientation of the SCT systems.

For SCT, job growth and concentration at the station (the 0.125-mile DB) was the highest at the Low MA place type, possibly due to the built-out nature of the more intensely developed locations. For CRT and LRT, growth at the station was highest at the Poor MA place type. For BRT, growth was quite pronounced at all stations for the upper-income jobs. The rest mostly declined at the BRT station. CRT saw upper-income jobs grow at the Mod MA type, while both upper and lower-income jobs grew at the High MA type. This indicates that upper-income jobs pushed away other jobs at the Mod MA level while lower-income jobs supported upper-income jobs at the High MA level where low-income jobs can support upper-income jobs. This phenomenon is present at the Mod MA LRT, as well, with middle-income jobs declining seemingly as a result of significant growth of the upper and lower-income jobs in the same locations. 
For some place types, industries gained spatial concentration at a lower rate than the region as a whole, which resulted in negative LQ trends at the station. This occurred for Education, Office and Light Industry at the High MA LRT stations. This may point to these industries losing the competition for transit-proximate land to those who gained in concentration such as Retail and the Arts-Entertainment-Recreation groups. This also happened in the Poor MA SCT stations, as Health and Knowledge outcompeted Retail and Light Industry.

These results indicate the market responses to transit proximity across a range of place types and transit modes. Various policy approaches could be taken in these areas, including 1) encouraging the most competitive land uses to increase their presence at a given station place type and transit mode, 2) increasing the land use mix, intensity and accessibility at specific stations by place type and transit mode by encouraging target land uses to the stations to fill the gaps needed for mixed-use development, and 3) make modifications to the local built environment and zoning code that will support the desired targets. 


\section{Chapter 4: Toward an Index of Employment-Worker Balance by Transit Station Mode}

An "Employment-Worker Balance" (EWB) is created. It is viewed as a key to economic growth through agglomeration economies is also a key to social equity. This is due to its ability to both increase workers' access to employment and firms' access to a strong, diverse, and resilient workforce. Smart Growth advocates frequently identify Employment-Worker Balance as a key metric in compact urban design. Because of its potential synergistic effects with EWB, another key element of Smart Growth, Fixed-Rail Transit systems (FRT), needs to be studied for its effects on EWB: is the latter improved by the former, and for which job sectors and which workers? Principle Component Analysis will be used to produce a EWB Index that is able to map EWB across multifarious spatial contexts across the U.S., taking into its scope the multiple types of transit system modes, real estate types, and the many sectors of the economy that surround FRT stations. The EWB Index will provide a tool for practitioners and researchers to utilize in regression analysis, and policy and decision support. The paper will follow up on this significant increase of available evidence to work towards further theoretical refinement of EWB.

Theoretical implications of the employment-worker balance phenomenon are drawn from the spatial and attribute clusters revealed by the EWBI. A more accessible workplace translates to a more productive and resilient workforce through potential improvements in work-life balance and overall cost of living, which in turn benefits the firm through higher output. Additionally, existing discrepancies in EWB near transit stations reveal low-hanging fruit for planners who wish to increase economic and housing resiliency. The employment-worker spatial regimes identified in this study through PCA may require targeted solutions to increase EWB. This may reveal some significant patterns of outcomes to transit development. One main implication is that there is a great deal of potential to develop spatial balance between employment and worker residence. The built environment in Eugene far better supports walkability than in the other larger cities of the study. The built environment also plays a role in a positive response to transit proximity. Road and intersection densities seem to correlate well with a positive response to transit.

Workers remain separated from their workplaces. This may be seen by a portion of the population as a significant benefit, but many are paying excessive transportation costs, spending excessive time to commute, and high municipal taxes to support this separation of land uses. These results have significant workforce as well as workplace implications, as accessibility outcomes provide agglomeration economies. The regions in which workers have greater TOD-driven access to firms also provide a more business-friendly environment with increased situs via a more accessible, active workforce. When appropriate housing is provided for workers of all sectors of the economy, greater economic diversification is possible.

The results indicate a modestly positive response to TOD. The political implications of increasing employment-worker balance depend upon the local typology of imbalance needing correction. In neighborhoods that are job-rich and housing poor for a lower- to moderate-income worker, challenges may include potential for local opposition from businesses that benefit from larger numbers of workers than residents, businesses seeking to protect their market share from newcomer firms, or from residents who fear negative externalities of lower or moderate-income housing development in their neighborhoods. Neighborhoods with upper-income jobs that seek to improve EWB may face gentrification pressures. Bedroom communities for blue-collar workers needing more jobs may face challenges from industrial externalities. 


\section{Chapter 5: The Link between Transit Station Proximity and Typology and Change in Households, Housing tenure and commuting choice Over Time}

Our research expands upon previous work by assessing the extent to which households are attracted to transit stations over time. Households are classified by several salient characteristics, including household type, householder age, and housing tenure. Station areas are assessed by transit mode, such as light rail, and by station typology. The types are characterized as lying somewhere along a continuum from urban core to suburban. These types are based upon the relative intensity a combination of jobs, households, and the built environment. The analysis will advance the understanding of how transit stations effect the pattern of household residence in a multimodal transportation system context, how commuters respond to transit proximity, what transportation modes seem to complement each other, and what demographics may be in competition for transit station proximity. Also evident from the study will be which transit modes in which place types (from low to high land use intensity, mix, and accessibility) are repelling or attracting population to the transit station and beyond to 1 mile.

The shifts in the regional populations of this study were measured in terms of household by age, type, tenure, and commuting choice. Variations in demographic response to transit proximity are broad across transit modes (e.g., LRT or SCT) and place types from low to high degrees of land use mix, intensity and accessibility.

There are results that hold true across most of the mode-place type categories. For example, walking, biking, transit use, and working from home gained share in most of these locations and categories, in the aggregate. On the other hand, some categories repelled certain groups while others attracted them. Further, some categories attracted people to the station while other categories repelled them.

At the station, the market was attracted or repelled dependent upon the transit mode as well as the place type. For most transit modes, the Poor MA place type repelled the market, in varying degrees, from the direct vicinity of the station. In many cases, growth was evident just beyond the station, mostly within the first half-mile radius of distance from the station. In many cases, growth occurred at the station while the regional figures declined, or vice-versa. Those demographic segments that grew faster than the regional trend, or faster than the station area total population highlight important market responses to transit proximity and help policy makers determine the relative change in importance over time of being connected to transit stations for those specific segments of the population.

One important takeaway from this study for planners is the classification of the stations into attractors and repellants, by what transit mode and place type, and for whom, and at what distance from the transit station. There are indications of competition and synergy between the measured households by size and age, housing tenure and commuting choice. It also increases the evidence that households with children are being attracted to many transit stations by mode and place type. This is contrary to the traditional wisdom. It gives evidence as well of the consistent increases in positive market response to the presence of transit, but the ongoing concurrent problem of many households being repelled from the station at the first distance band (0.125-mile) away.

For Household by type and age, Poor MA BRT stations lost total population both at the station and cumulatively at the half-mile distance away. These losses occurred for virtually all population segments, but were of particular strength among households with children. This is of 
further importance when the numbers of households involved in the rates of change are considered. Far more householders of age 45 to 64 left the station area than did householders under age 25, for example. For Mod MA LRT stations, households with children were attracted to the direct station area at a 3\% increase over the whole region while this change represented a full $30 \%$ of the overall population change. The cumulative half-mile DB captured $5 \%$ of that same demographic. Householders under 25 actually left these LRT stations at roughly $6 \%$ at the cumulative half-mile DB. This occurred at the same time these younger householders were attracted to the Poor MA BRT stations.

Implications for planners from these results mainly consist of a clear set of evidence of which transit mode and place type needs to address challenges or unfavorable characteristics of station areas, the larger neighborhood context, or transit systems that need to be overcome in order to increase the favorable response of target demographic groups, such as a certain segment of the worker population that is needed in greater numbers along CRT lines.

An unexpected trend in these data include the rising popularity of "other" transportation modes at the stations. This indicates that the market is indeed responding in significant ways to these new forms of transport that may include bike shares and e-scooters. 


\section{Chapter 6: The Link between Transit Station Proximity and Typology and Change in People by Demographic Groups Over Time}

Our research in this chapter expands upon previous work by assessing the extent to which jobs by sector are attracted to transit stations over time and across a range of station area intensities. Analysis is given of the land area encompassed by transit systems by mode and station type. Using economic base theory and relying upon shift-share and location quotient analyses, the demographic dynamics of station areas are assessed by transit mode, such as light rail, and by station area "place" typology. Transit modes include light rail transit, commuter rail transit, streetcar transit, and bus rapid transit systems. The station area place types are characterized as lying somewhere along a continuum of land use mix, intensity, and accessibility. These types are based upon the relative intensity of a combination of characteristics of jobs, households, and the built environment. The analysis will advance the understanding of how transit stations by type effect the spatial dynamics in a multimodal transportation system context. Demographic change is evaluated as an important result of the makeup of the transportation system, and particularly the effects of transit stations on the changing aspects of demographic concentrations across the landscape. Case studies comprise aggregations of multiple metropolitan areas across the United States, in the Urbanized Area of the counties served by the transit systems under study, grouped by place type. Each station area is analyzed by distance from the station in eighth-mile distance bands.

We find that a good deal of sorting occurs across the various place type-transit mode combinations. However, some basic trends are evident: White populations increased presence at varying rates: modest for BRT, and mostly at the higher-intensity places. Whites saw modest increases at CRT stations in lower-intensity land uses; and declines in growth at higher-intensity stations. For LRT, Whites declined at low intensities, then gradually increased growth at the stations, ending finally with robust growth at the High MA stations. For SCT, Whites saw moderate growth rates at all land use intensities.

For Hispanics, growth was present but mostly modest, with the strongest rates at Mod MA place types. For CRT, Hispanics experienced strong growth rates at Poor and Low MA place type stations but declines at the Mod and High MA station areas. Hispanics grew at the first DB, at the station, and then declined in growth thereafter. For SCT, Hispanics grew at modest to moderate rates at the station, with the exception of the High MA station areas, at which they saw very strong growth.

Blacks at BRT stations had negligible growth at the Poor and Low MA station areas, with robust growth at the station for Mod MA place types, and then mostly declined at High MA stations. Blacks at CRT stations saw modest to moderate growth at the first DB of the station, but mostly declines between a quarter and half-mile DB from the stations. Blacks at LRT stations saw declines at the Poor and Low MA stations, experienced modest gains at the Mod MA stations while seeing decline at subsequent DB's, and then saw robust growth at the half-mile DB. Blacks at SCT stations saw, surprisingly, declines at all place types.

These results strongly suggest further research to determine the impetus for such consistent rates of decline, overall, for Black populations near most stations by transit mode and place type. White populations saw mostly modest to robust growth in most stations by mode and place type. Hispanics saw a range of growth and decline, with many examples of growth being confined mainly to the station area. There appear to be some hints at competitive sorting between these population segments, but perhaps the strongest influence on these patterns is 
the underlying locations of jobs most held by each group, the part of the city most inhabited by each group, and the kind of housing each group usually occupies. These elements vary greatly between metropolitan areas.

These findings may be considered a preliminary search of these patterns, with some important hints at policy directions to improve these patterns, such as zoning for a wider range of housing across the metropolitan area, and provision of transit system extensions into less-served areas of regions.

Regression and spatial regression may improve the clarity of these outcomes through hypothesis testing and significance levels. 


\section{Chapter 7: The Link between Transit Station Proximity, Place Typology and Transportation Costs Incurred by Household Types}

It seems an article of faith that transportation costs as a share of household income increase with respect to distance from downtowns, freeway interchanges, and light rail transit stations. Considerable literature reports price effects of these points on residential property values but none measure explicitly differences in household transportation costs as a share of household budgets. Our study helps close this gap in literature. Using the U.S. Department of Housing and Urban Development's (HUD) Location Affordability Index (LAI) database, which estimates the share of household budgets consumed by transportation at the block group level based on the 2012 5-year American Community Survey (ACS) and census tracts based on the 2016 5-year ACS. We evaluate the association between median household transportation costs and distance from light rail transit (LRT) stations using both ACS data sets. We find clear associations between transit station proximity and lower household transportations for both periods, with what appears to be increasing savings over time. We also find important differences in transportation costs incurred by different households with respect to the type of urban place in which they live and proximity to LRT stations. While not surprising intuitively, social equity issues arise. Insights are offered for specific types of households.

\section{Median-Income Household}

These households enjoy lower VMT and lower transportation costs the closer they are to LRT stations. And their savings has increased between the two time periods with savings accelerating near LRT stations.

\section{Working Individual @ 50\% MHHI}

These households have gained considerable transportation cost savings between ACS 20082012 and ACS 2012-2016 in the first three distance bands, to 0.375-mile from LRT stations. Thereafter, the gain in savings between the two study periods is modest though not trivial. (We cannot explain the anomalous dip at the 0.175 -mile distance band.) Combined with being in High MA places, these households save the most in transportation costs being close to LRT stations. It is also remarkable that this is the lowest income group studied. It is also likely they are predominantly renters occupying small units close to transit and high activity centers.

\section{Single Professionals @ 135\% MHHI}

In a sense, these are households with the most choices because of their higher incomes and presumably fewer household obligations than other household types. Then would be expected to gravitate to transit stations as well as locate in High MAS areas. Although ostensibly their transportation costs savings might be the most modest because such accounts for only 12.1 percent of their total budget, in the ACS 2012-2016 period, they still realize more than 60 percent savings when living in the first (0.125-mile) distance band and High MA places. Given their higher incomes, total household savings would be in the range of $\$ 11,000$, the most of any household group. Allocating one third of that to a mortgaged based on 2020 rates could increase the mortgage by nearly $\$ 150,000$. 


\section{Single Parent Family @ 50\% MHHI}

These are perhaps the most challenged households as they have the lowest budgets with the highest transportation cost share at $\$ 31,829$ and 31.2 percent in the ACS 2012-2016, respectively. Our analysis shows that their VMT has also increased between the study periods. Moreover, there appears to be a trend where transportation cost savings with respect to LRT station proximity has eroded compared to the first three groups. We surmise that these households are being displaced from locations with lower transportation costs.

\section{Moderate-Income Family @ 80\% MHHI}

With the second lowest income of the household types included in this study, these households may be nearly as challenged as single parent households, although their transportation cost share is about in the middle of the five other groups. Nonetheless, our analysis shows they are similar to single parent households. It would seem that perhaps moderate income households are also being displaced from locations near LRT transit as well as in High MA areas.

\section{Dual-Professional Family @ 150\% MHHI}

While these households have the highest incomes of the types we used in this analysis, their transportation costs are nearly the highest as well. One challenge these households may face is finding a location that meets the needs of both professionals. Although our analysis shows that their annual VMT increased between the study periods, they also gain considerable savings when locating near LRT transit stations, and especially if they also live in High MA areas.

Our analysis reveals that there can be considerable transportation cost savings when locating near LRT stations and especially when also locating in High MA areas but only to some households and notably not to others. We offer implications for transit and land use planning and housing, as well as for future research. 


\section{Chapter 8: The Variation in Real Estate Rents with Respect to Place Typology and Transit Station Proximity}

There is a dearth of systematic research into the relationship between fixed route transit (FRT) systems such as light rail transit (LRT), bus rapid transit (BRT), streetcar transit (SCT) and commuter rail transit (CRT) with respect to real estate rents and transit station proximity. Though there are numerous case studies of individual systems in individual metropolitan areas, they focus mostly on a single property type. Those studies also vary in the type of data used, methodologies, and functional form specifications. In other words, research lacks a consistent cross-section approach to estimate variation in real estate rents between FGT systems and different types of real estate. This chapter seeks to close this gap in the literature.

This chapter presents cross-section regression analysis that uses CoStar, census and GISderived location data in a common methodology to estimate the association between FGT station proximity and office, retail and multifamily rents. In all, nearly 60 FRT systems serving more than 30 metropolitan areas are studied, which includes about 300,000 cases. Numerous variables are used to control for structural attributes, occupancy, socioeconomic characteristics, land use, location and other influences.

For the most part-with some surprising exceptions-real estate rents tend to rise the closer the property is to transit stations. There also appears to be a sorting that occurs between real estate types and transit station proximity, which is to be expected in the competition for locations nearest to transportation services.

A sample of key findings is illustrated in Figure ES.2 with respect to multifamily rents as a function of distance from rail transit stations. With the exception of streetcar transit (SCT) station proximity, multifamily rent generally increases with respect to distance from transit stations indicating the presence of externalities at and near those stations.

Implications for fixed guideway transit system and land use planning are offered. 


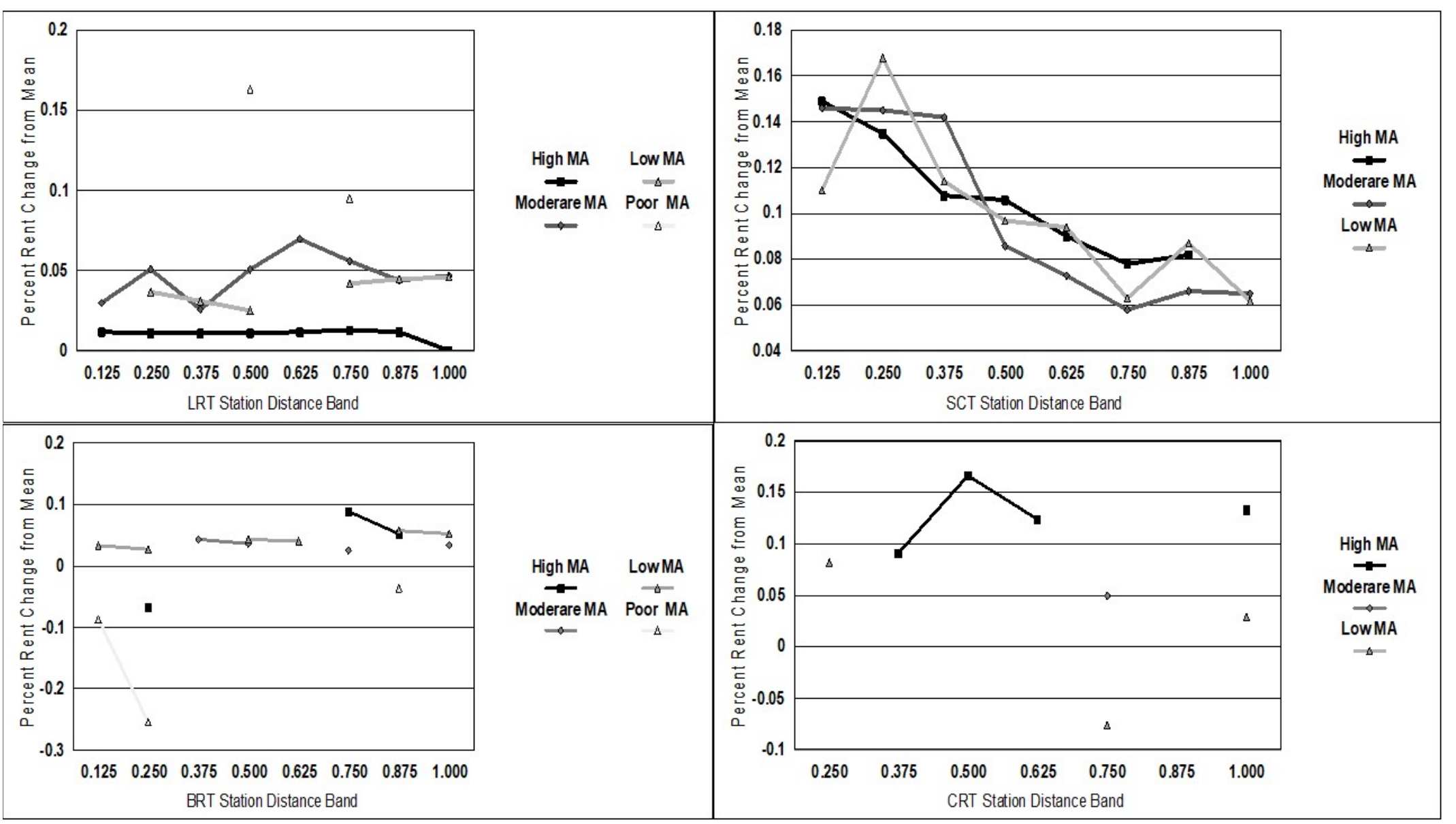

Figure ES.2

Plot of significant and contingent significant LRT, SCT, BRT and CRT multifamily rent coefficients with lines connecting respective points with respect to Place Typology 


\section{Chapter 9: The (Overlooked) Association between Express Bus Station/Stop Proximity and Multifamily Rents with Implications for Transit and Land Use Planning}

Despite hundreds of studies into the association between real estate value and proximity to fixed route transit (FRT) systems, none has assessed the association with respect to express bus transit (XBT) stations/stops. Ours is the first to do so. Using a static, cross-section quasiexperimental research design, we evaluate CoStar multifamily (MF) rent per square foot to estimate the difference in rent with respect to proximity to (XBT) stations/stops. However, we are also interested in knowing whether there are synergistic price effects at the intersection of $\mathrm{XBT}$ and other FRT systems such as light rail transit (LRT). In this article, we estimate the MF rent premium with respect to XBT and LRT (XBT+LRT) station/stop proximity separately, rent premiums for combined XBT and LRT stations/stops, and for those MF cases that are more than 1.0 mile beyond the nearest LRT station. In all cases, whether separately or combined with LRT stations or away from LRT stations, with find positive associations between MF rent and proximity to XBT stations/stops. However, we also find evidence of negative externalities at or near XBT, LRT, and XBT+LRT stations/stops. Express bus transit and land use planning implications are offered.

The research and modeling used in this chapter is essentially a "proof of concept" in creating a simple yet robust method of measuring interactive effects of two different transit modes intersecting at or near the same location. As the proof of concept appears successful, we expand it in Chapter 9 to include Place Typologies and extend the interactive construct to evaluate differential rent outcomes associated with light rail transit systems intersecting streetcar transit (SCT) systems, bus rapid transit (BRT) systems, and commuter rail transit (CRT) systems.

Our over-arching perspective is that future economic returns to local economies and local government resources may be maximized by increasing development opportunities near XBT stations/stops. For instance, while there has been a concerted effort to create transit oriented developments (TODs) across the nation, they tend to focus on rail systems, and recently bus rapid transit systems. We are not aware of any express bus TODs-maybe the time has come. In any event, transit and land use planners would be advised to assess the development potential for multifamily investment and other land uses near XBT stations/stops. Transit and land use planners might also consider rethinking drop-off/park-and-ride lots for their development potential while retaining those options.

Our analysis suggests that because of positive market responsiveness to XBT station/stop proximity, transit agencies may consider expanding XBT services as well as creating more synergies between XBT systems and other transit modes. Though our analysis was of XBT stations/stops within metropolitan areas served by LRT systems, our research suggests that more US metropolitan areas may benefit from them, and those with XBT systems may consider adding to their inventory.

As noted earlier, the research and modeling reported here is a "proof of concept" showing how one may create measures of interactive effects where two transit modes intersect. We will extend this proof of concept to Chapter 9, which will also incorporate the Place Typologies created in Chapter 1. 


\section{Chapter 10: How the Intersection of Light Rail Transit Stations with other Transit Modes Influences Real Estate Rent}

Using lessons of the "proof of concept" developed in Chapter 8, we extend the analysis of the interactive effects of light rail transit (LRT) stations shared with streetcar transit * $S C T$ ), bus rapid transit (BRT) and commuter rail transit (CRT) on office, multifamily and retail real estate rents.

For the most part, we found that where a metropolitan area includes more than just an LRT system -in our case being one or more of SCT, BRT and CRT systems - it may be important to evaluate interactive effects between them. In nearly all comparisons between the original model in Chapter 7 and the expanded model here for office and retail estate, the combined LRT+SCT, LRT+BRT and LRT+CRT coefficients were higher meaning interactive effects were greater than just for LRT alone. This is reasonable, a priori.

However, less impressive are comparisons with respect to multifamily real estate where relevant coefficients for only the LRT+SCT expanded model were larger than the original model. For LRT+BRT and LRT+CRT, results were less impressive for the first 0.50-mile distance bands. But this begs the question. In these cases, it is important to know that combined LRT+BRT and LRT+CRT stations actually result in multifamily rents falling below the mean in the first 0.50-mile DBs. Perhaps it is also important that the relevant coefficients of the combined LRT+CRT stations exceed those of the original LRT model in distance bands from 0.50-mile to the end of the 1.00-mile study area. Indeed, these particular results suggest that multifamily real estate is more sensitive to potential externalities associated with BRT and CRT stations which is also reasonable, a priori.

Through this chapter and in Chapter 7 as well, we counsel for improved transit and land use planning, and urban design to help overcome externality effects of transit station proximity, and improve rent premiums with respect to transit station proximity. A framework for this is outlined in Chapter 12. 


\section{Chapter 11: Regional Differences in the U.S. Real Estate Market Response towards Proximity of Fixed Route Transit Systems}

Fixed-route transit (FRT) systems have operated in the US for more than one hundred years with the majority developed during the last half a century. While many single-system studies exist, there has not been rigorous, systematic cross-section analysis of whether and the extent to which these systems influence the real estate market. This article helps close the gap in research. In particular, in this article we apply hedonic regression to estimate the association between FRT station proximity and office, retail and multifamily rents and extend the analysis to compare the structural differences of these responses across metropolitan areas and markets.

In this chapter, we explored the structural differences between associations of proximity to Fixed-Route Transit and real estate rents across regions. The summaries of this analysis explored in the paper (and documented further in the supplementary material) indicate some clear patterns of market responses to light-rail transit and bus-rapid transit, mostly when considering associations with multifamily and office land uses. For streetcar, we were generally limited by small sample sizes in the distance band buffers across regions. While the overall interpretation of streetcar indicates generally positive associations with rent and proximity, this may be conflated by the fact that most streetcar systems are circulators in central city areas where rents are generally high anyway. A larger sample size of developments in proximity to streetcar may help parse out the implications across different cities.

For cities planning FRT expansions or additions in their region, these results help inform other cities that may be useful case comparisons to set expectations. These findings also hint at the contexts in which new FRT additions or expansions might pressure low-income residents. In many cases, access to high-quality transit can elevate travel opportunities low-income households towards lower cost choices. If FRT systems and corresponding land use development are expected to add competition associated with increases in rent, this information can help inform mitigation strategies near FRT to reduce gentrification pressures and avoid pushing out low-income residents in the name of higher rents. These are areas in need of research. 


\section{Chapter 12: The Need for Good Transit and Land Use Planning, and Design}

In this chapter we assert that fixed route transit (FRT) station planning (the process leading to locations) and design (how stations are integrated with transport systems and nearby land uses) can dictate (a) use of the system by passengers, (b) development outcomes around the station, sometimes to a few miles away, and (c) real estate markets. The vast literature on FRT station planning and design may boil down to these over-arching principles that FRT systems and their stations can:

- Reduce adverse impacts of transit stations on surrounding land uses;

- Facilitate positive interactions between land uses near stations; and

- Maximize accessibility of passengers to transit stations and nearby land uses.

Unfortunately, the statistical evidence presented throughout our study indicates that poor station planning and design can undermine the very purposes and promises of transit in America. Indeed, beyond scope, we undertook a remote visual reconnaissance of what we call "good" and "bad" and even "ugly" station locations and design. This reported in Appendix G. Some "good" station locations and design have low to modest WBT scores while others that in our opinion are "bad" locations and design have modest to high WBT scores. We conclude that there does not appear to be an easy way to predict transit station development outcomes based on transit station planning and design. This is an area where new research is needed. This is the theme of the first section of this chapter. The second section identifies the need for future research and includes an overall perspective on the role of transit in meeting America's market demand for mixed-use communities that are accessible to transit. 
Epilogue

Transit Funding Options, Assessments, and Approach to Capturing Regional and SpatiallyRelated Value

Toward A Proportionate-Share, Spatially-Related Value Capture Funding Scheme for Transit

As our research demonstrates, fixed-route transit (FRT) systems confer both regional and local benefits. Regionally, they elevate overall economic performance as well as provide a wide range of public goods such as lower levels of greenhouse gas emissions and more mobility options. Locally, they generate value to private property that is spatially related to transit station proximity. Based on economic development, real estate value added, and fiscal benefits, there is much to be said for expanding existing systems and launching new ones.

However, in these days of declining federal support for fixed-guideway transit capital investments, new sources of funding are needed. The inventory is surprisingly large but largely untapped. In some cases, state enabling legislation may be needed but in others local popular and political support needs to be generated. The choice of funding option can make a difference. In this report, we introduce the role of fixed-guideway transit in creating value, identify numerous transit funding options, review criteria that may be used to choose those options that maximize key public finance objectives including capturing part of the value created by transit investments, and posing a funding approach that captures part of the value-added to regions and to areas around transit stations in relation to the distance of benefiting property from those stations.

The epilogue is comprised of four sections:

Section 1 reviews how transit can improve property values and it includes the proposition that a portion of the value-added can be captured to help finance transit.

In Section 2, we present a large list of transit funding options including how they operate and the extent Appendix D

Supplemental tables for Chapter 2 repair-rehabilitation-replacement costs.

Section 3 identifies public finance criteria that should be used to guide the selection of funding options to best meet planning, efficiency, equity, administrative and other objectives.

We conclude the epilogue with Section 4 that poses an approach to fairly apportion the burdens of financing transit across a region that broadly benefits from its services and within areas around transit stations based on spatially-related benefits.

The nation will add about 100 million people between now and mid-century. One of us (Nelson 2013) has estimated that about a quarter of American households want to live near fixed guideway transit opportunities though less than 10 percent have those options now. Perhaps one reason is that Americans understand the cost savings associated with living near transit stations. Yet, even if all new homes built between now and mid-century were located near existing or planned fixed-guideway transit stations the demand for living near those stations would still not be met. 
The report includes seven appendices:

Appendix A

Graphic and statistical inventory of transit systems used in the study

Appendix B

Annotated literature review of materials used to create the Place Typologies in Chapter 1

Appendix C

Place Typology figures for each transit system of each metropolitan area

Appendix D

Supplemental tables for Chapter 3

Appendix $\mathrm{E}$

Supplemental tables for Chapter 4

Appendix F

Supplemental tables for Chapter 5

Appendix G

Good-Bad-Ugly framework and application for Chapter 12

In addition, the National Institute for Transportation and Communities has archived our public data, though not data from CoStar because of licensing agreements. 


\section{CONTEXT}

This report is the culmination of a genre of research into the relationship between various modes of fixed route transit (FRT) systems and development outcomes. Those modes include light rail transit (LRT), bus rapid transit (BRT), streetcar transit (SCT), and commuter rail transit (CRT). We have pioneered methods to evaluate development outcomes using simple-tounderstand economic base methods applied to jobs by sector, wages, population, households, and housing tenure. Shift-share analysis in particular has been used to assess the extent to which FGT systems were associated with increasing or decreasing shares of jobs, people and housing not only over time but with respect to pre-recession, recession, and post-recession periods. We have also become leaders in using commercial real estate data-CoStar-to evaluate the relationship between proximity to FGT systems and commercial rents, controlling for the usual suspects. But our prior work has been limited to assessing outcomes based only on systems as a whole.

This report decomposes our systemwide studies into categories or types of FGT stations including individual stations. In many ways this would have been difficult if not impossible in our prior work because of the sheer amount of processing needs across FGT systems in more than 30 metropolitan areas studied. Because of prior work, what had been impractical is now possible because we have already collected, cleaned, and refined the data, and developed and refined our analytic techniques so they can be applied to disaggregated analysis for individual FGT systems in individual metropolitan areas. This report applies statistical techniques, such as factor/cluster analyses, to identify station areas typologies and then assess the extent to which station types influence economic development (based on LEHD data), people (using census data), and real estate values (based on CoStar data) during each study period for each system and mode.

\section{Completing a Genre of Research}

Our work helps fill gaps in research, much of which we actually pioneered. LRT, BRT, SCT and CRT systems are growing in number and expanding where they exist. Until our work, there was no systematic assessment about how they influence the location of jobs by type of sector and wages, people and their housing choices and tenure, and real estate market values (Nelson 2015; Nelson et al. 2015). Key among findings, our prior research found:

Before the Great Recession (GR), transit station areas lost share of jobs relative to their regions. During the GR and early recovery years they gained share though there were variations by type of transit system; distance from stations (BRT for instance gained job share only within the first one-quarter mile [see Nelson et al. 2013] while LRT and SCT stations gained share up to a mile away and CRT stations lost share during both time periods [see Nelson 2017a]); and sector. Since recovery LRT and SCT systems have continued to gain share while BRT and CRT systems have not (Nelson et al. 2018),

Before the GR, transit station areas lost share of higher-wage jobs relative to their regions. During the GR and early recovery years, LRT station areas gained upper and middle wage job share though lost lower wage ones, SCT station areas gained upper and lower wage job share but lost middle wage jobs, and BRT station areas lost share of all jobs by wage category (though there were exceptions for individual systems) (Nelson 2018). 
As expected, LRT and SCT station areas gained small shares of their region's population between the pre-GR and GR-recovery periods. Surprisingly the effect was roughly equal between those under 35 ("Millennials") and those 35-64 while declining shares occurred at 65 and older. In contrast, BRT station areas lost share across all age groups. These trends continued after the recession (Hinners, Nelson \& Buchert 2018; Nelson et al 2018).

Market rents for office, retail and apartment properties with respect to distance from different kinds of transit systems varied considerably; LRT and SCT showed the most robust positive effects, BRT modest and limited positive effects, and CRT mixed effects (Nelson et al. 2015; Nelson and Hibberd 2018a, 2018b).

Using keywords relating to station area development for published works in the past five years, we find no studies that disaggregate the influence of transit by mode on jobs, wages, people, housing, tenure and commercial rent by or between metropolitan areas by type of station. That is the purpose of this study and final in a genre of work that we pioneered.

\section{Advancing NITC Themes}

Our sponsor for this research, the National Institute for Transportation and Communities (NITC) is one of five US DOT-funded National University Transportation Centers. NIIT sponsors research that advances three themes around which our work has been organized.

\section{Increasing access to opportunities}

Well-connected regions and communities can improve social equity by providing access to jobs, services, recreation, and social opportunities.

Our research expands on prior related work, including much of our own, to assess the extent to which jobs and people are attracted to transit station areas with respect to jobs by wage level and households by income; station distance; and type of FGT station by mode. Analyzing both jobs and households concurrently improves upon the understanding of the spatial mismatch that often occurs for low-income households.

\section{Improving multi-modal planning and shared use of infrastructure} Improved mobility requires a range of options for moving people and goods.

As will be seen, our analysis improves understanding of how cities and regions vary in the performance of development outcomes associated with transit through estimations of rent premiums, or the willingness of the market to pay for transit station proximity. It is thus a much more refined analysis compared to our prior work. Our analysis advances evidence needed by planners to demonstrate the benefits of transit systems in the context of multi-modal transportation systems.

\section{Developing data, models, and tools}

Our complex transportation system demands better data and tools for decision-making. Our planned factor/cluster analysis helps describe types of station development patterns, supporting practitioners in identifying the specific characteristics needed for their particular situation and development goals. Additionally, a key feature of our work is updating and expanding the databases and making them open source through NITC. New data generated from our work is now available at no cost to researchers through NITC. This democratization of data enhances examination of the implications of changes to transit system on a range of outcomes relating to mobility, economic equity, the environment, and health at a variety of 
scales (from the station area to the nation) by researchers, policy analysts and students everywhere.

These themes help shape the problems addressed in our research in analysis that is guided by our research questions, reviewed next.

\section{Problems Addressed and Research Questions}

Our prior research has established that development outcomes to LRT/BRT/SCT/CRT systems vary by type of system and station distance, among other things. Our earlier work was limited to the period before the GR (2000-2007) and during the GR/recovery years (2008-2011). It was further limited because many BRT systems emerged late in the 2000s while many LRT, BRT and SCT systems have been added or expanded since then. Our current work expands the number of systems and updates data through 2018, with commercial rent data through 2019. In all, our report considers 18 LRT systems, 16 BRT systems, 12 SCT systems and seven CRT systems serving 36 metropolitan areas.

In particular, the report disaggregates data used to assess systemwide outcomes to outcomes based on types of stations by mode. Our analysis is guided by two overarching research questions:

\section{Q1: How do Transit Outcomes Vary by Mode and Type of Transit Station?}

This analysis includes each transit system for each metropolitan area studied during appropriate time periods for that system, as well as systems combined across metros. Trends tested include:

- Changes in the number and share of jobs by sector with respect to type of system and distance from stations, by type of station based on factor/cluster analysis;

- Changes in the number and share of jobs by wage category with respect to type of system and distance from stations by type of station based on factor/cluster analysis; and

- Changes in number and share of population, households, householders by age, and housing by tenure with respect to type of system and distance from stations by type of station based on factor/cluster analysis.

\section{Q2: How does the real estate market for office, retail and apartment properties respond to proximity to transit stations by mode and type of station?}

- Our prior work pioneered the use of CoStar commercial rental data for very broad assessments of real estate market responsiveness to transit by type but not really by location except for corridor distance bands. The report presents results of more refined, continuously measured relationships in those metropolitan areas based on mode and type of transit station where CoStar data are sufficient for analysis.

How the research questions are addressed is guided by our overall research plan and design. 


\section{RESEARCH PLAN AND DESIGN}

Because of the nature of data, our research establishes only associations and not causality. That said, our overall research design is comprised of these elements:

Quasi-experimental design wherein controls and treatments are used albeit not in the way in which rigorous testing is conducted in physics, chemistry, medicine and the lile.

Pre-Post (before-and-after) analysis to establish associations over time with the introduction or expansion of transit systems.

Interrupted time-series analysis to establish trends before a major event such as the Great Recession, trends during the event, and trends afterward.

Our research plan is multifaceted in using different kinds of data to address the two research questions.

\section{Transit Station Typology}

We start by creating a typology of transit stations. Using factor/cluster analysis, we create a typology of stations based on these dimensions:

- $\quad$ Land use mix (an entropy measure);

- Jobs-population balance (a measure of jobs versus population concentration);

- Distance to downtown and other major activity centers (a centrality measure);

- Employment sector composition (a measure of economic concentration); and

- Socioeconomic composition (a measure of demographic concentration)

These dimensions are used to create station typologies based on their spatial characteristics (downtown, suburban center, isolated), economic features (high-middle-low wage corresponding to relative education and skill levels), and social attributes (age-incomerace/ethnicity-tenure). As will be seen, we settled on a typology that assigns transit stations to relatively few types.

\section{Economic Base Analysis}

Our prior going research used quasi-experimental, economic base methods to assess change in concentration in:

- Jobs by sector (using Location Employment-Household Dynamics [LEHD] data),

- Jobs by wage category (also using LEHD),

- Population and households by age and other demographic features (Census), and

- Residential units and tenure (Census)

in distance-band based station areas relative to transit regions by transit mode over different time periods. Shift-share analysis is used mostly but so are variations of location quotient analysis. We continue this tradition using updated data but also applying our station typology to the analysis. 


\section{Hedonic Analysis}

We pioneered the use of CoStar rent data to assess the association between transit station distance and rent with respect to different system types and metropolitan areas. In this report, we disaggregated transit stations into types to show that difference types of station have different outcomes-albeit not as much as we expected.

\section{BROAD IMPACTS}

NITC seeks research that: can achieve long-lasting impacts; leverage prior research into new research that may also leverage future research; is groundbreaking; can advance the state of the art or practice of a genre of research; and distinguish NITC. Although only time will tell whether all of these impacts will be achieved from research presented in this report, we are hopeful.

\section{What long-lasting impact might this research have?}

America will add at least 100 million new residents, 40 million new households, and 60 million new jobs by 2050 . We know from demographic analysis and consumer preference surveys that at least a third of America's 150 million households (50+ million) in 2050 will want to live in locations providing them with transit options, in addition to mixed-use and mixed-housing options. We also know from research on firm location behavior that up to 100 million jobs will be attracted to locations with transit options. Our prior research outlines the extent to which LRT/BRT/SCT/CRT systems can meet future demand. The current research expands our on our prior work to include types of stations which will likely help guide LTR/BRT/SCT/CRT planning, design, investment, and implementation for many years if not decades to come.

\section{Are there any opportunities for leveraging of the research results for future research or practice? \\ Our prior work included several partners whose contributions have helped create the robust database were used in the current work. A key product of our work is an updated database allowing researchers to explore detailed development outcomes to transit stations that prior research only introduces.}

\section{Is the research groundbreaking?}

We have pioneered the genre of research that associates development outcomes with respect to different transit systems across the nation. Our report expands our genre of research by addressing outcomes to different types of transit stations for each mode and each transit system over time with special reference to pre-recession, recession and post-recession periods.

\section{Will it advance the state of the art or practice?}

As will be shown, our report advances the state of the art of research by: updating and expanding our prior work, much if it pioneering; expanding analysis to include types of stations by mode; and making our expanded database available freely through NITC.

\section{How might this project distinguish NITC?}

NITC's prior support allowed our research to make NITC reasonably synonymous with this genre of research among policy-makers, researchers, students, and the informed public when it comes to learning how fixed-guideway transit systems can improve mobility of people to build strong communities. In this report, we elevate NITC's distinction through disaggregated analysis of outcomes based on the types of stations overall and with respect to pre-recession, recession and post-recession periods. 


\section{FIXED ROUTE TRANSIT SYSTEMS STUDIED}

In this section we first characterize the types of fixed route transit (FRT) systems studied in this report these systems so readers can differentiate between them. We then summarize what and where those systems are.

\section{Types of Fixed Route Transit Systems}

FRT systems include rail and bus rolling stock. Consider rail transit systems. While CRT may seem different obviously from LRT and SCT, differences between those two systems may not be so obvious. Table 1 compares key design features of these systems. Visual differences between these types of rail transit rolling stock are noted in figures 1 through 3 .

Perhaps even more subtle are differences between local bus transit (LBT), bus rapid transit (BRT), and express bus transit (XBT). Although we address only BRT outcomes in this report, ongoing work is also addressing XBT systems. Box 1 is an edited description of differences between these systems provided by the Greater Richmond Transit Company. Figure 2 illustrates visually what those types of busses look like. Table 2 lists the FRT systems studied and when they commenced operations while Figure 3 illustrates their location. 
Table 1

Key Design Differences between LRT, SCT and CRT Systems

$\begin{array}{llll}\text { Key Differences } & \text { Light Rail } & \begin{array}{l}\text { Street Car } \\ \text { Transit (LRT) }\end{array} & \begin{array}{l}\text { Commuter Rail } \\ \text { Transit (CRT) }\end{array} \\ \text { Right-of-way } & \text { Primarily exclusive } & \text { Primarily mixed flow } & \text { Primarily with freight rail } \\ \text { Trains / Capacity } & 1 \text { to } 4 \text { cars / } 125 \text { to } 500 & 1 \text { to } 2 \text { cars } / 120-240 & 1 \text { to } 4 \text { cars / 170 to } 680 \\ \text { Station Spacing } & 1 / 2 \text { to } 1 \text { mile or more } & 2-3 \text { blocks to } 1 / 2 \text { mile } & \text { Multiple miles }(\sim 5-10+) \\ \text { Peak Passengers } & 1,000-7,500 \text { per hour } & 1,440-5,760 \text { per hour } & 2,000-8,000 \text { per day } \\ \text { Seats / Standees } & 64 / 61 \sim 125 \text { per car } & 30 / 90 \sim 120 \text { per car } & 91 / 79 \sim 170 \text { per car } \\ \text { Speed } & \sim 1+\text { mile } \sim 50-60 \mathrm{mph} & \text { close spacing } \sim 25-35 \mathrm{mph} \text { Multi-mile } \sim 80 \mathrm{mph}\end{array}$

Sources:

LRT and SCT adapted from https://nacto.org/wp-content/uploads/2016/04/4 RTD-Streetcarand-Light-Rail-Characteristics 2012.pdf

CRT adapted from http://www.rtd-fastracks.com/main 398. 


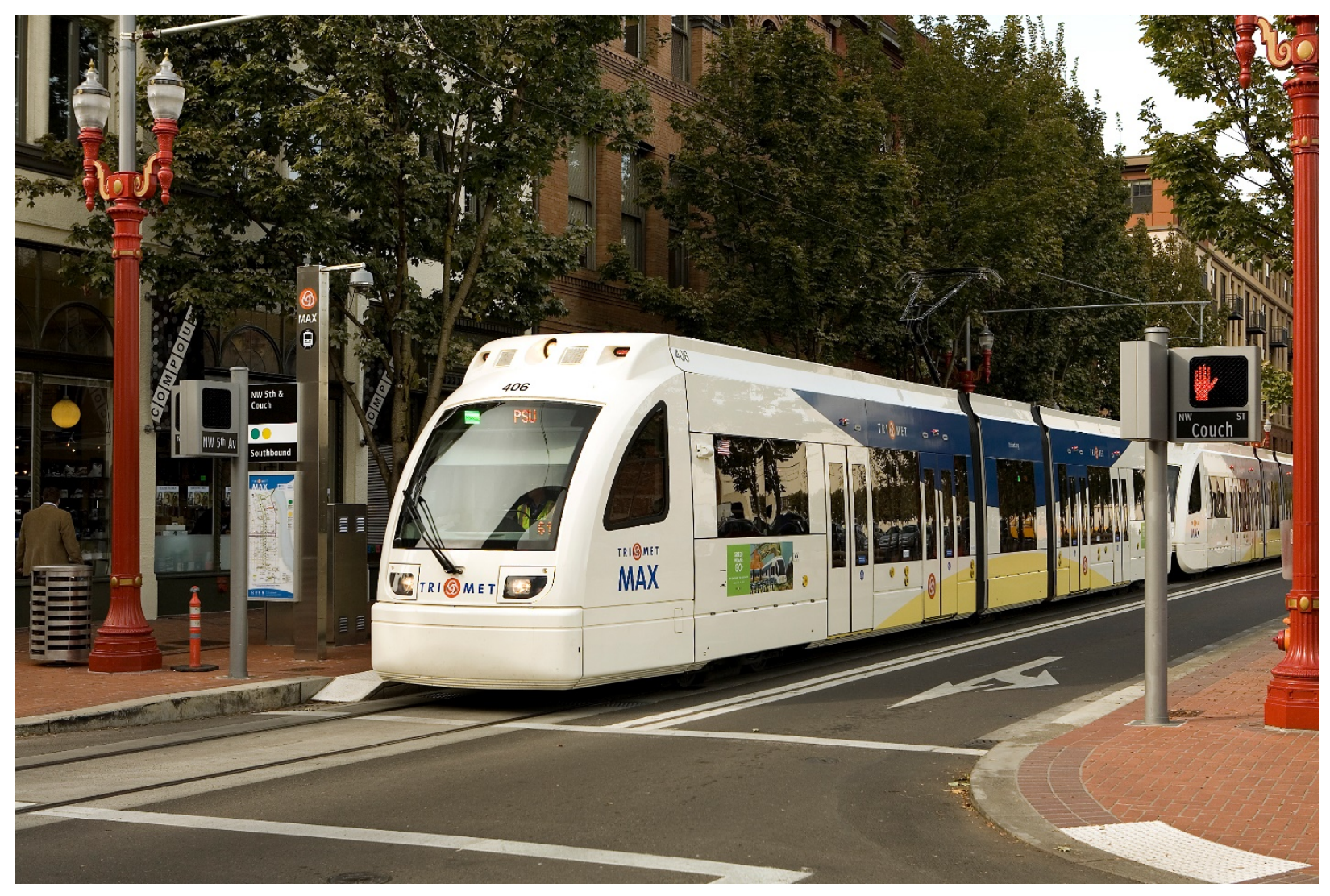

Figure 1

Light Rail Transit example

This is an image of the Portland light rail transit system, MAX.

Source: TriMet, https://www.flickr.com/photos/trimet/4518340197 


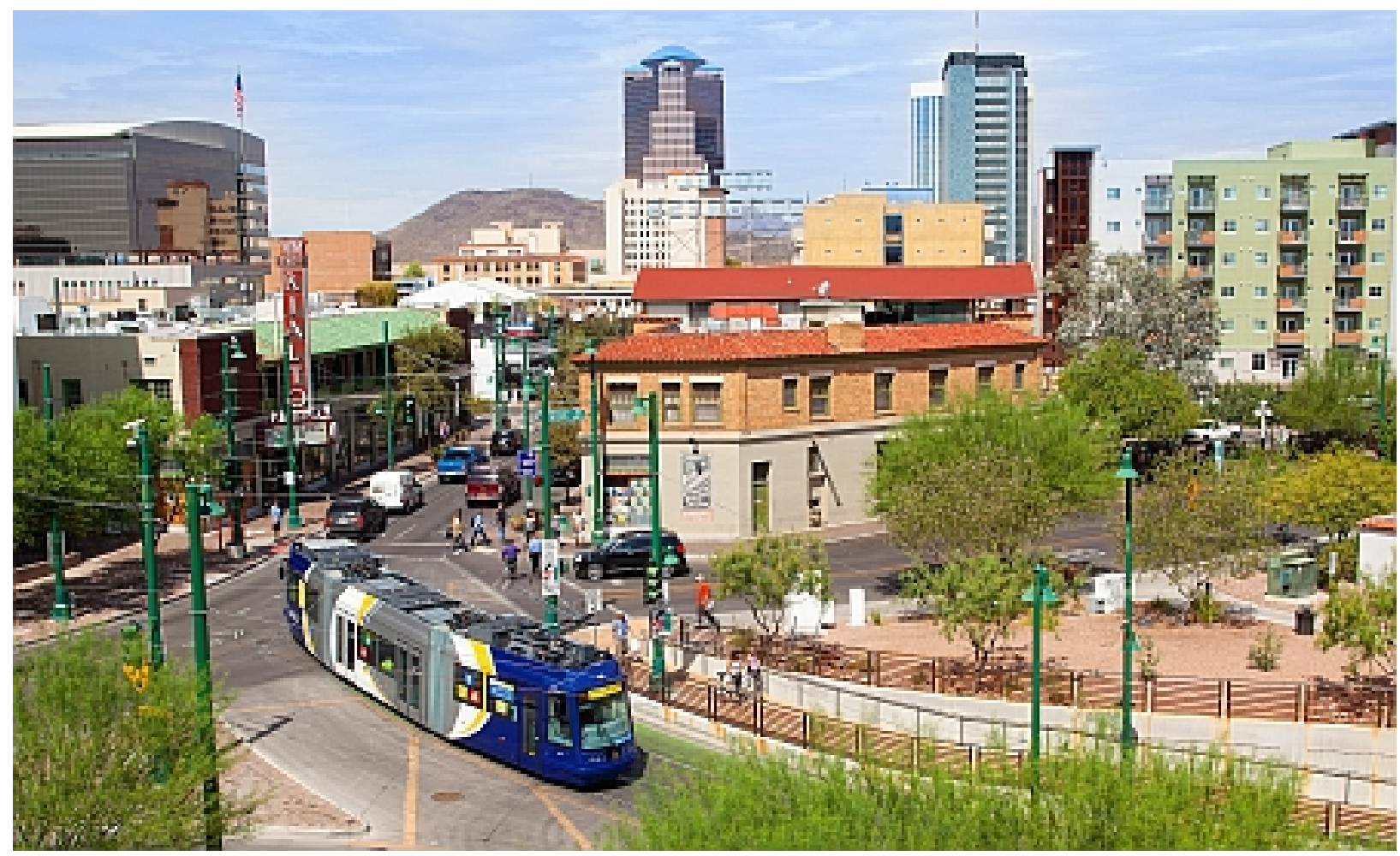

Figure 2

Street Car Transit example

This is an image of the Tucson street car transit system, SunLink.

Source: Regional Transit Authority, https://www.sunlinkstreetcar.com/history 


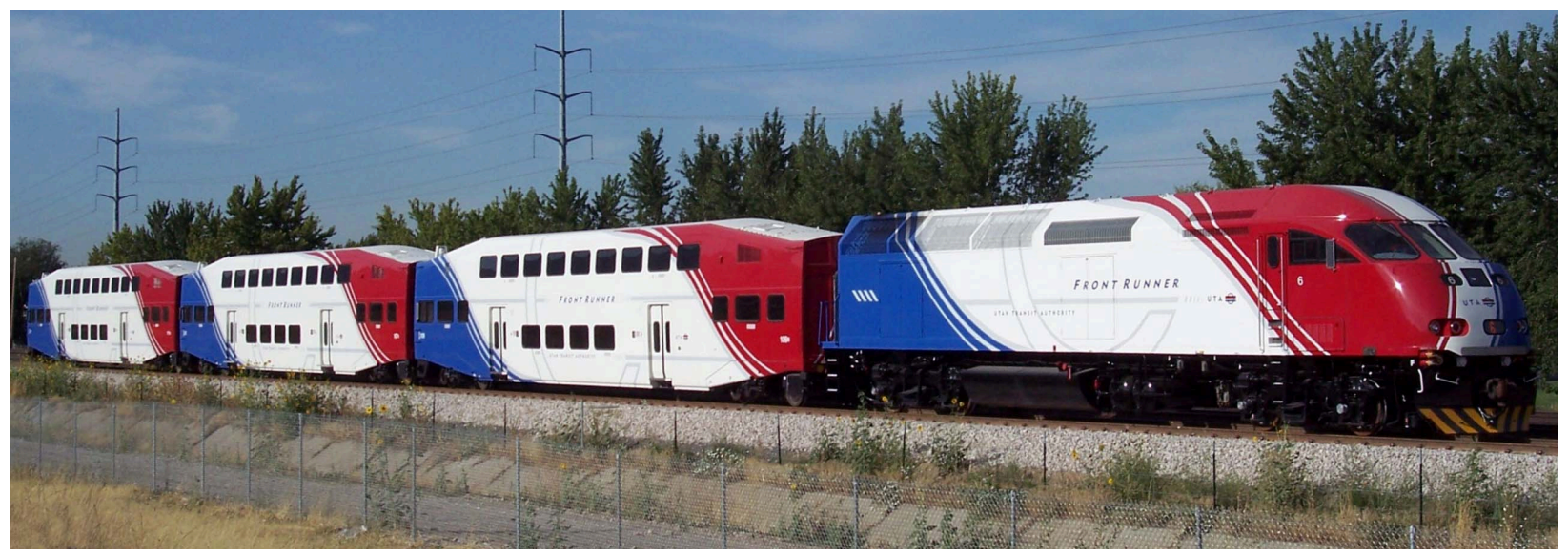

Figure 3

Commuter Rail Transit example

This is an image of the Utah Transit Authority's commuter rail transit system, FrontRunner. Source: Utah Transit Authority, http://www.rideuta.com/uploads/commuterRailHighRes.jpg 


\section{Box 1 \\ Differences between LBT, BRT and XBT Systems}

\section{What is Local Bus Transit (LBT)?}

Local bus transit (LBT) runs on-street, stopping every few blocks, with only a sign marking a stop location. As a result, a local route trip time is much longer than a BRT or XBT trip. Stops with heavier usage may feature a bench or a shelter. A few, very heavily used stops may have information kiosks with bus arrival information. The frequency of local bus service and the time of day that local bus service is available can vary substantially by route. With these features, local bus service typically serves local riders who are not traveling far.

\section{What is Bus Rapid Transit (BRT)?}

Bus rapid transit (BRT) is a high quality, high capacity rapid transit system that offers many of the advantages of rail transit but at a lower and more affordable cost. BRT buses typically operate on local streets, with stops about every half-mile, run every 10 to 15 minutes and serve both local and regional riders. BRT buses may travel in dedicated lanes and often use signal priority systems to reduce delays from traffic congestion. In typical BRT systems, passengers wait for the bus at higher-quality stations and pay before they board using ticket vending machines at the station. These qualities add up to an efficient, reliable, frequent and convenient transit service that meets the needs of many types of travelers.

Instead of trains/trolleys and tracks, BRT invests in improvements to vehicles, stations, operations, roadways, rights-of-way, intersections and traffic signals to speed up bus transit service. BRT is not a uniform, turn-key transit technology, but represents a spectrum of service enhancements. BRT systems are constructed by choosing and integrating various BRT elements, such as dedicated lanes, signal priority for buses, branded vehicles and enhanced station amenities. An example of a BRT system is shown in Figure 4.

\section{How is Express Bus Transit (XBT?)}

Express bus transit (XBT) service generally pick up passengers at one or multiple park and ride locations in suburban communities and then travel, non-stop, via freeways or other high speed corridors to the central downtown district or other major employment centers where passengers disembark. Where available, they will use dedicated high occupancy vehicle lanes on freeways and in some cases they use specially designed shoulder lanes on local streets. These buses tend to operate only during peak commute times and mainly serve regional riders providing increased pedestrian traffic to local businesses, retail, restaurants and healthcare, but during limited times. Some XBT services are made available during off-peak and weekends for special events such as major sporting events, concerts, and fairs.

Source: Adapted for purposes this report from Greater Richmond Transit Company, http://www.ridegrtc.com/media/annual reports/BRT FAQ 7-20-2015.pdf. 


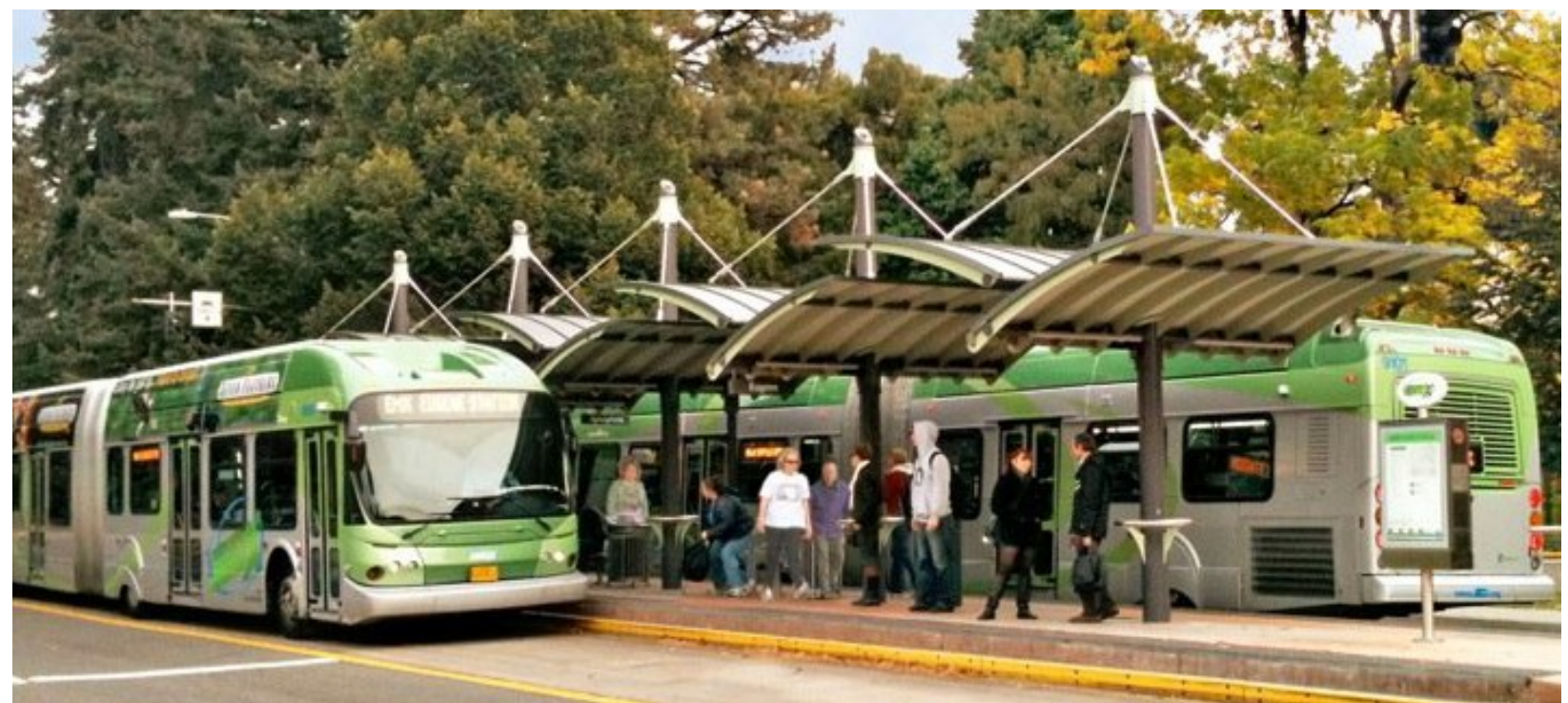

\section{Figure 4}

\section{Bus Rapid Transit system example}

This is an image of the Eugene-Springfield Emerald Express.

Source: The Institute for Policy Research and Engagement, University of Oregon, https://cpbus-e1.wpmucdn.com/blogs.uoregon.edu/dist/2/1652/files/2014/05/Eugene-BRT-2743795e1400605109615.jpeg. 
Table 2

Fixed Route Transit Systems Studied

\begin{tabular}{|c|c|c|c|c|c|c|}
\hline & & Bus Rapid & & Streetcar & Commuter Rail & \\
\hline Light Rail Transit & Year & Transit & Year & Transit & Year Transit & Year \\
\hline Buffalo & 1984 & Cleveland & 2008 & Atlanta & $2014 \begin{array}{l}\text { Albuquerque-Santa } \\
\mathrm{Fe}\end{array}$ & 2006 \\
\hline Charlotte & 2007 & $\begin{array}{l}\text { Eugene- } \\
\text { Springfield }\end{array}$ & 2007 & Dallas & 2015 Austin & 2010 \\
\hline Cleveland & 1980 & Kansas City & 2005 & Little Rock & 2004 Dallas-Fort Worth & 1996 \\
\hline Dallas & 1996 & Nashville & 2009 & Portland & 2001 Miami Tri-Rail & 1989 \\
\hline Denver & 1994 & Pittsburgh & 1977 & Salt Lake City & 2013 Minneapolis & 1997 \\
\hline Houston & 2004 & Reno & 2010 & Seattle & 2007 Nashville & 2006 \\
\hline $\begin{array}{l}\text { Minneapolis-St. } \\
\text { Paul }\end{array}$ & 2004 & Salt Lake City & 2008 & Tacoma & Orlando-Daytona & 2014 \\
\hline Virginia Beach & 2011 & San Antonio & 2012 & Tampa & 2002 Portland & 2009 \\
\hline Phoenix & 2008 & San Diego & 2014 & Tucson & 2014 Salt Lake City & 2008 \\
\hline Pittsburgh & 1984 & Seattle & 2010 & & San Diego & 1995 \\
\hline Portland & 1986 & Stockton & 2007 & & San Jose-Bay Area & 1988 \\
\hline Sacramento & 1987 & Washington DC & 2014 & & San Jose-Stockton & 1998 \\
\hline Salt Lake City & 1999 & & & & Seattle-Tacoma & 2000 \\
\hline San Diego & 1981 & & & & Washington, DC & $1980 s-90 s$ \\
\hline San Jose & 1987 & & & & & \\
\hline Seattle & 2003 & & & & & \\
\hline St. Louis & 1993 & & & & & \\
\hline
\end{tabular}




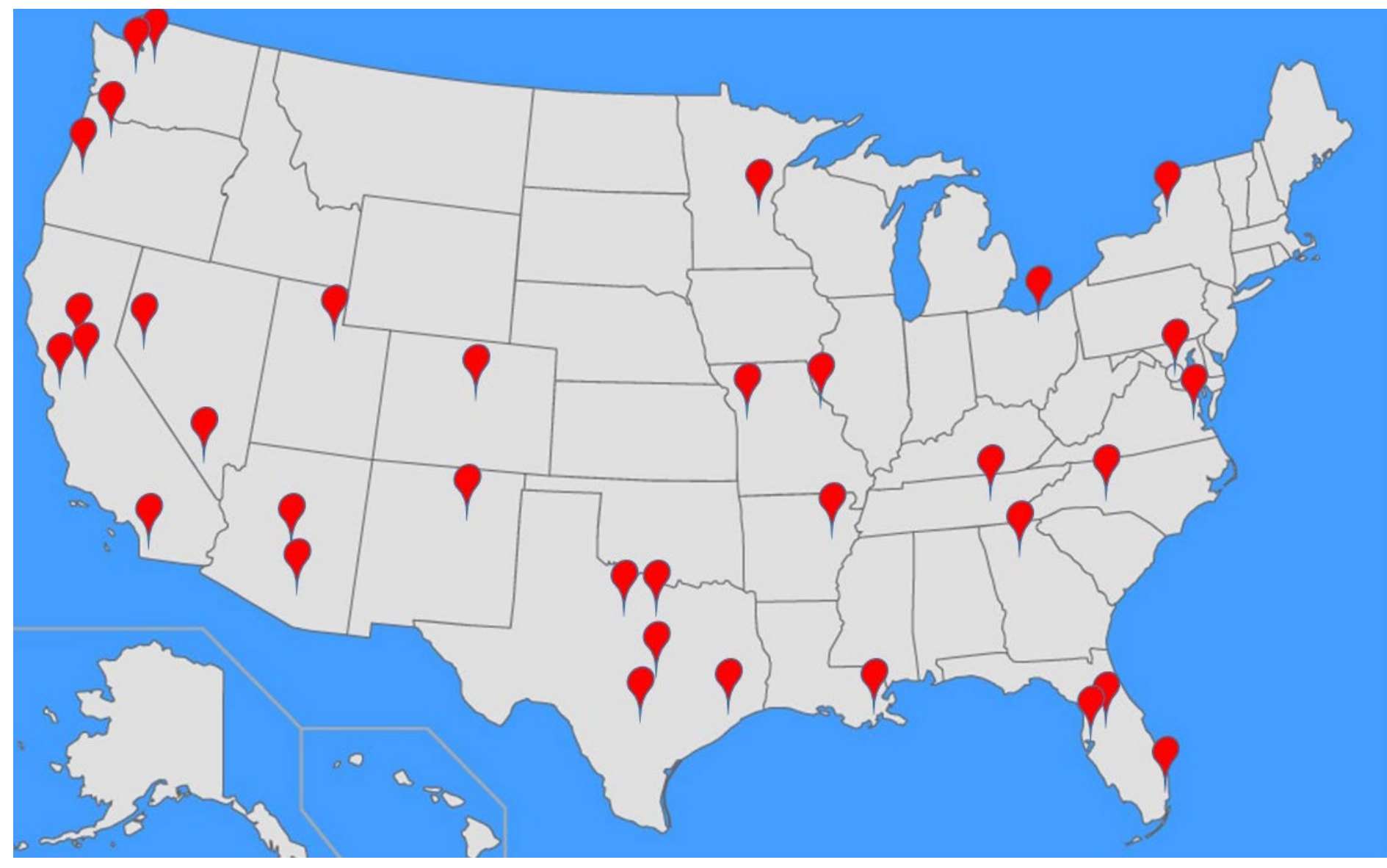

Figure 5

Metropolitan Areas with Transit Systems Studied 


\section{REFERENCES}

Hinners, Sarah Jack, Arthur C. Nelson and Martin Buchert, 2018. Streetcars and Equity. Transportation Research Record.

Nelson, Arthur C. 2018. Transit and Wages: The Association between Wages and Transit Station Proximity over Time. Transportation Research Board annual meetings.

Nelson, Arthur C. and Robert Hibberd, 2018a. Analysis of the Variation in Apartment and Office Market Rents with Respect to 1 Commuter Rail Transit Station Distance in Metropolitan San Diego and Salt Lake City. Transportation Research Board annual meetings.

Nelson, Arthur C. and Robert Hibberd, 2018a. Using the Real Estate Market to Estimate Streetcar Catchment Areas in Tucson. Transportation Research Board annual meetings.

Nelson, Arthur C. et al. 2018. Transit and Demographic Outcomes Before, During and After the Great Recession. In progress.

Nelson, Arthur C. 2017a. The Effect of TODs on Jobs, Wages, People and Housing. Fordham Law Review.

Nelson, Arthur C. 2017b. Transit and Real Estate Rents. Transportation Research Record.

Nelson, Arthur C. et al. 2015. Do TODs Make a Difference? Portland, OR: National Institute for Transportation and Communities.

Nelson, Arthur C. 2015. National Study of BRT Development Outcomes. Portland, OR: National Institute for Transportation and Communities.

Nelson, Arthur C. et al. 2015. Office Rent Premiums with Respect to Distance from Light Rail Transit Stations in Dallas. Transportation Research Record.

Nelson, Arthur C. et al. 2013. Bus Rapid Transit and Economic Development. Journal of Public Transportation.

Petheram, Susan J., Arthur C. Nelson et al. 2014. Using the Real Estate Market to Establish Light Rail Station Catchment Areas: Case Study of Attached Residential Property Values in Salt Lake County with Respect to Light Rail Station Distance, Transportation Research Record. 


\section{CHAPTER 1: Developing Place Typologies for Transit Analysis ${ }^{1}$}

\section{OVERVIEW}

Ours is the first study to create typologies of urban development patterns for national-scale research. To expand on the analyses explored in prior studies, we begin by exploring how the literature and practice identifies different types of transit-based development. For the purpose of this report, we are focusing mainly on fixed-route transit (FRT) systems and corresponding place typologies. In this project, we aim to capture differing built environment contexts that might be more or less resilient or responsive to economic development (jobs, housing, populations, or real estate values). We orient our analyses towards the neighborhood-level-instead of stationlevel-so that we might compare and quantify the relative impacts of FRT on economic outcomes, compared with areas without FRT access. And finally, we aim to develop place types that might more readily align with planning practice.

In the following section, we first explore the academic and white paper literatures to identify the purposes of place and transit station typologies. We then synthesize a framework and corresponding measurements for delineating different dimensions of transit-oriented development. From there, we describe the different quantitative methods for categorization of place types so that we might expand a consistent approach to compare and contrast similar development patterns across vastly different regions. In the last section, we explore the guiding principles for place types development, and we describe the data and methods used to develop the place typologies used throughout this project.

At the outset, we advise readers that an extensive annotated bibliography of materials used to create the Place Typology is provided in Appendix B.

\section{Typologies of Transit Stations in Planning, Design, and Analysis}

Typologies, in the context of transit design and evaluation, are the categorization of contexts that distinguish across areas or locations based on characteristics determined to impact the outcomes of interest in the analysis. For behavioral studies that focus on transit ridership, for example, typologies would consider characteristics that distinguish across built environments that enable (or inhibit) more (or less) ridership or demographic markets indicative of higher (or lower) propensities to ride. For economic strategy development, typologies would need to be sensitive to both measures that describe current economic situations (such as jobs and wage levels) as well as metrics that might indicate responsiveness to various strategic initiatives (such as race/ethnicity or propensity to gentrify). Through performance-driven evaluations, typologies can align known correlates of success for a number of outcomes to provide a relative basis for understanding how any one station or system functions today or has the potential to function in the future.

For agencies and practitioners, the typing of transit areas is driven by the realization that not all transit-oriented development (or transit-adjacent development or transit neighborhoods) are the same. The categorization of different contexts provides a means for distinguishing between different design guidelines, different evaluative frameworks, or the identification and

\footnotetext{
1 We are pleased to acknowledge invaluable assistance in preparing this chapter as well as Appendix B by Nicole Iroz-Elardo.
} 
implementation of different strategies that improve economic, sustainable, or equitable situations.

Throughout our initial literature and background review, we identified three main types of applications of transit typologies. First, typologies can be used as conceptual design guides for conceptual planning and discussion. The main goal of these applications is to align a common vocabulary for 'current' or 'target' built environment or transportation infrastructure locations. To develop these typologies, practitioners and agencies often rely on previously developed typologies, local knowledge of the area(s), and manual development of definitions. These typologies are usually based on an urban intensity hierarchy-moving up and down in intensity level, like from central business district to urban neighborhood to suburban neighborhood - with special considerations for 'special attractor' neighborhoods-such as stadiums or concert halls. The metrics embedded in these definitions most commonly rely on land use measures (like employment or population densities, floor-to-area ratios or height of buildings) or supportive transportation infrastructure (like walkability or intersection density) defined within some close proximity to specific types of transit stations (most often defined within 0.5 -miles of the station). These definitions are commonly used for the development of overlay zones that define, describe, and sometimes encourage what 'appropriate development' might look like for different transit areas or contexts.

Second, typologies may be developed specifically to evaluate the performance of transit or transit areas on economic, sustainability, or social outcomes, sometimes called performancedriven or performance-based typologies. These typologies may incorporate measures that define the land use contexts, but often also include additional characteristics that correspond with the market area demographics and/or other performance-based measures (like estimated vehicle miles traveled). The methods commonly used these applications include compiling 'indices' calculated using weighted averages of scaled variables selected to represent various dimensions. Indices may be broken into categories using statistical breaks techniques (such as Jenks) and adjusted based on local knowledge or the areas. A subset of the evaluation-use applications include typologies used for the identification and implementations of planning or policy strategies to improve planning or policy outcomes. In this application, an outcome variable (such as vehicle miles traveled) is used predictively as a function of the location typology and/or additional policy-sensitive variables to provide guidance that identifies the 'levers' which may improve the outcome.

Third, typologies may be developed specifically to allow for analysts to controlling for urban contexts or the bundle of environmental or locational characteristics. In this type of application, the analyst uses typologies to distill various inputs (mainly built environment measures) into a handful of dummy variables to aide in controlling for different types of contexts. These types of approaches are sometimes data-driven using more statistically onerous techniques with little-to-no manual specification of categories (e.g., density thresholds). Sometimes, this application uses a simple 'decision-tree' definition-categorizing sites based on a short series of 'yes or no' responses to questions about the location, transit availability, or land use situation. More complicated methods or performance measures may limit the ease of transferability of research findings to practice.

In this section of the chapter, we explore the use and development of typologies related to developing and/or evaluating transit neighborhoods. This chapter aims to understand the relationship between place and different economic outcomes (changes in jobs, housing, population, and real estate). 


\section{Dimensions of Transit-Oriented Development}

While there are dozens of different examples that type transit areas and neighborhoods, we utilize Bertonlini's node-place framework (Bertolini 1999; Lyu, Bertolini, and Pfeffer 2016) to organize the academic and white paper literature reviewed in this study to frame our discussion of typologies. Bertolini's framework aligns transport node (e.g., transit stations) with land use places (e.g., urban development characteristics) to discuss and interpret the 'balance' of values of node and place. In the 1999 framework (Bertolini 1999), dimensions of transit and urban development characteristics were graphically related to explore areas of balance (see Figure 1.1). Locations were the node and place are out of balance are 'unsustained'. In the 2016 expansion of Bertolini's node-place framework, a third dimension 'orientation' is added. In this dimension, the proximity of place (land use, development) relative to node (transit) is considered. Together, the node-place-orientation framework brings into practice the alignment of transit system design, land use policies, and orientation, making it useful to discuss the common correlates of success with fixed-guideway transit-oriented development.

The first dimension is the 'node' dimension representing transit (or, more broadly, transportation). The primary way to distinguish across transit accessibility, quality, and availability is in differentiating between transit systems. In this current study, we focus on fixedguideway transit (FGT) systems, including: heavy rail, commuter rail, light rail, street car, express bus, and bus rapid transit. Additionally, several agencies incorporate 'supportive transportation infrastructure', which includes access to local bus systems or circulation shuttles, high-quality walkability and other alternative access/egress modes. For some agencies, parking supply and types (e.g., surface parking) is an important way to distinguish the ways in which higher-quality transit may be accessed (or constrained) by car. Measure of the 'node' dimension may also include transit 'quality' measures as well. For example, measures of transit quality could be defined as the frequency or headways of service, the number of lines or stops within a service area, the number and hierarchy of the types of transit within a service area.

The second dimension represents 'place' or land development. These measures can broadly be defined as descriptors of the built and/or social environment, either at the present moment or capturing recent changes in either. Measures of population, household, or job densities segmented by housing types, demographics (e.g., income, wages, ages, children or household size), or industries are common measures. Descriptors of development, including intensities (floor-to-area ratio, stories, dwelling units, square footage, business establishment), real estate and land values (land, rent, residential sales, vacancies), or land use mix (e.g., entropy, balance, adjacent nature).

For several of these characteristics, the recent (10-15 year) change in characteristics are also seen in the literature aimed at capturing the acceleration and direction of growth and change, including displacement of vulnerable populations. In more than one agency report, measures capturing 'change of demographics' (e.g., income, wages, household size, education levels) were treated as a separate, but related, dimension labeled 'displacement risk' (Puget Sound Regional Council; City of Bellevue; King County Metro 2014) or 'neighborhood change' (Central Maryland Transportation Alliance and Center for Transit-Oriented Development 2009) or 'market opportunity' (Center for Transit-Oriented Development and Nelson/Nygaard 2011). This 'market or neighborhood change' dimension is often intended to capture recent movement in demographics that might indicate the need for policy intervention. 


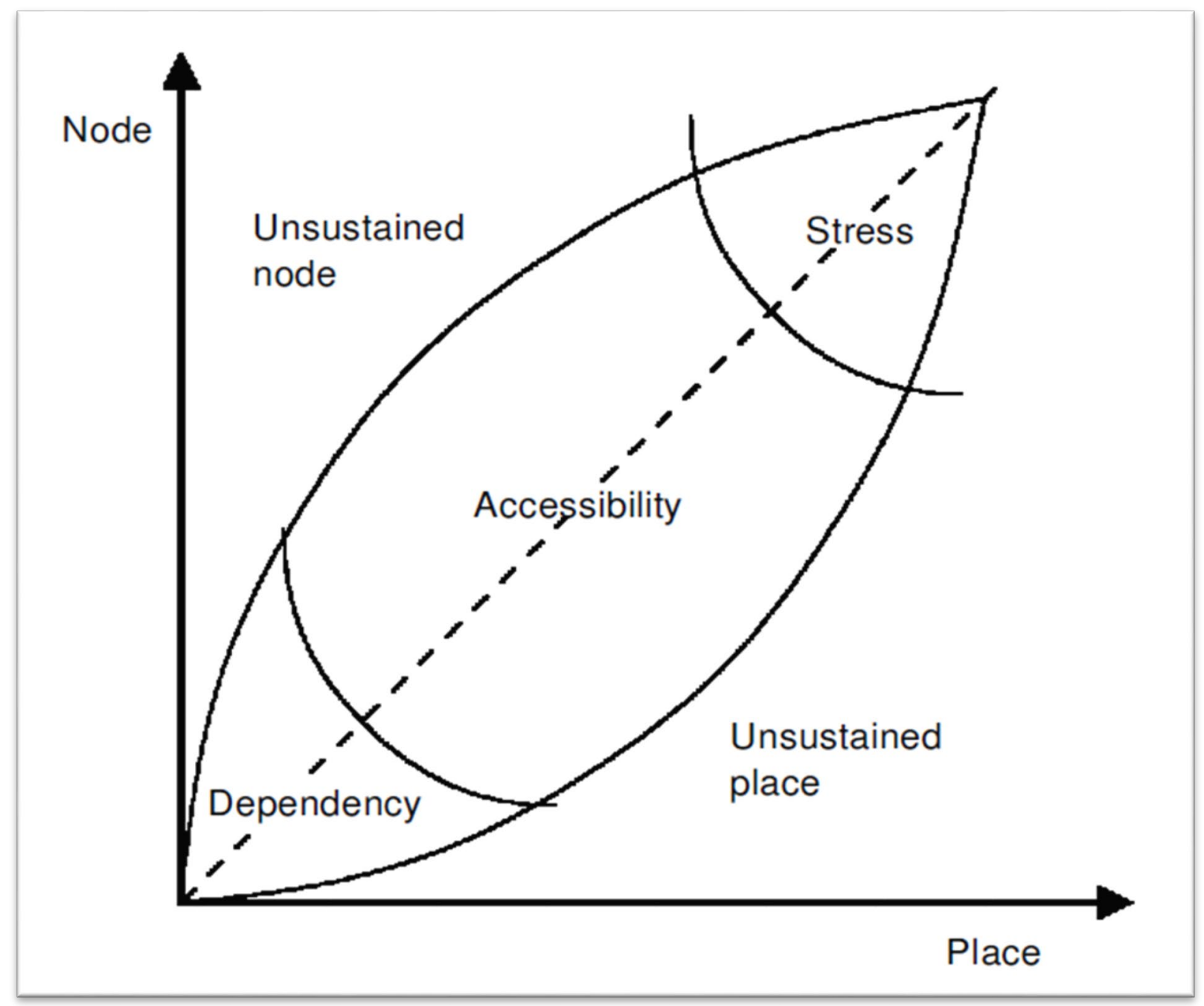

Figure 1.1

Bertolini's (1999) node-place framework 
In Lyu et al (2016), the authors also identify several characteristics of place that capture the process of development (e.g., presence of redevelopment authorities) and qualitative evaluations of planning initiatives related to station area planning or zoning, recent development activity, or securing funding/financing for projects. These measures aim to capture the ease or incentives of the development process and may be ranked similarly in places that look drastically different in terms of the built environment. These characteristics were not determined to be the most valuable based on presence in the literature and a review of practitioners by Lyu et al (2016), and they were not the focus on this current national study, but future analyses that examine systems and districts along these dimensions may determine these characteristics important in distinguishing economically successful locations.

The third dimension is 'orientation' representing scales and proximity. In this dimension, measures aim to align the node and development dimensions through distance. Many of these measures capture proximity of populations or destinations to transit (or vice versa). Additionally, this dimension captures the means by which transit is accessed, such as connectivity of street networks that might facilitate easier access/egress (e.g., walking or biking). For many agency reports, typologies distinguish site or station area scales based on the 'scale' of supporting area. Figure 1.2 is a common example from Renaissance Planning Group (2011), similar examples or descriptions are found in other reports such as the Arizona Department of Transportation (2012). For most agencies, characteristics of the area are often defined by 0.5-mile buffer areas, but some focus on the likely transition of intensities aimed to orient the majority of the development in closer proximity to the stations or 'transit core'. These measures are sometimes embedded in node or place dimensions-specifically because many of the measures from the former dimensions are calculated at a 0.5-mile buffer. 


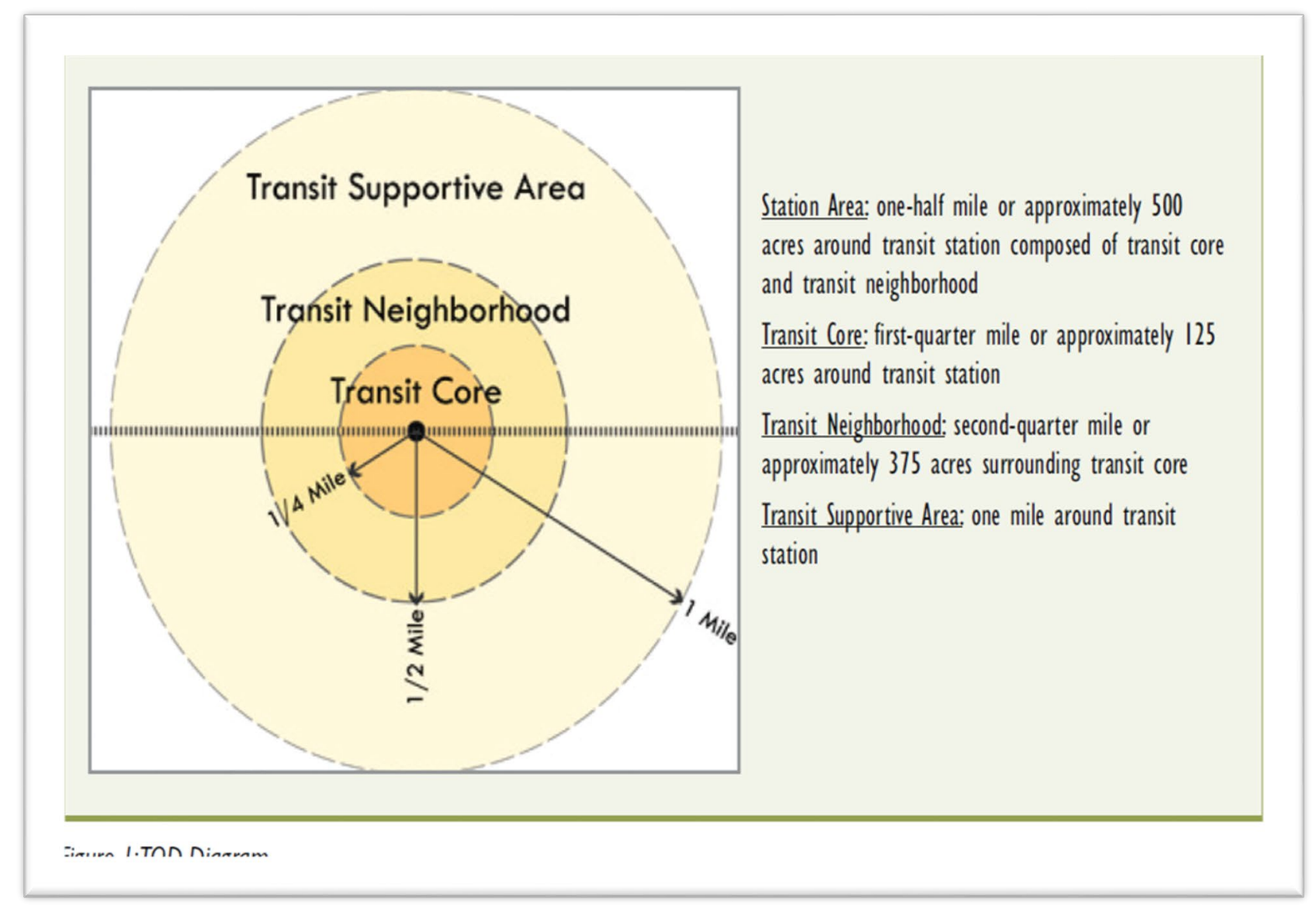

Figure 1.2

Station Service Area Proximities Source: (Renaissance Planning Group 2011) 
TABLE 1.1

Transit-Oriented Development Indicators

\begin{tabular}{|c|c|c|c|}
\hline Transit/Node & Orientation/Proximity & evelopment/Place & \\
\hline $\begin{array}{l}\text { Number of directions } \\
\text { served by Metro or bus } \\
\text { Number of metros } \\
\text { stations in one TOD } \\
\text { Number of bus stops in } \\
\text { one TOD } \\
\text { Daily frequency of } \\
\text { metro services } \\
\text { Number of other public } \\
\text { transport modes (bus, } \\
\text { tram) departing on a } \\
\text { workday } \\
\text { Public transport } \\
\text { accessibility level } \\
\text { (calculated by } \\
\text { scheduled waiting time, } \\
\text { walk access time to } \\
\text { station) } \\
\text { Number of passengers } \\
\text { per day by metro } \\
\text { Changing rate of Metro } \\
\text { passengers in } 10 \text { years } \\
\text { Number of stations } \\
\text { within } 45 \text { min. travel by } \\
\text { metro } \\
\text { Number of stations } \\
\text { within } 20 \text { min. travel by } \\
\text { metro } \\
\text { Geographic distance to } \\
\text { CBD } \\
\text { Travel time to CBD by } \\
\text { metro } \\
\text { Travel times to major } \\
\text { employment and } \\
\text { activity centers by } \\
\text { metro } \\
\text { Type of metro service } \\
\text { (old, new, slow, rapid) } \\
\text { Whether station } \\
\text { connects to airport } \\
\text { directly (no transfer) } \\
\text { Whether station is a } \\
\text { terminal } \\
\text { Car parking capacity } \\
\text { capacity }\end{array}$ & $\begin{array}{l}\text { Average distance } \\
\text { from station to jobs } \\
\text { Average distance } \\
\text { from station to } \\
\text { residents } \\
\text { Percentage of } \\
\text { housing units owner- } \\
\text { occupied } \\
\text { Percentage of } \\
\text { households with } \\
\text { access to one or } \\
\text { more private vehicles } \\
\text { Percentage workers } \\
\text { who use non- } \\
\text { automobile } \\
\text { commuting } \\
\text { Percentage of } \\
\text { households with low } \\
\text { income } \\
\text { Percentage of } \\
\text { income spent on } \\
\text { transportation } \\
\text { Walking time to a } \\
\text { metro station from } \\
\text { the center of each } \\
\text { block } \\
\text { Length of paved foot- } \\
\text { path per acre } \\
\text { Length of sidewalks } \\
\text { and low-stress bike } \\
\text { ways } \\
\text { Number of cul-de- } \\
\text { sacs } \\
\text { Intersection density } \\
\text { Number of entry } \\
\text { points into the } \\
\text { neighborhood } \\
\text { Average block size } \\
\text { Closeness index of } \\
\text { urban street } \\
\text { networks (space- } \\
\text { syntax, network } \\
\text { structure index) } \\
\text { Between-ness index } \\
\text { of urban street } \\
\text { networks (space- }\end{array}$ & $\begin{array}{l}\text { Number of residents } \\
\text { Percentage of working-age } \\
\text { population } \\
\text { Percentage of elderly } \\
\text { population (above 65) } \\
\text { Changing rate of } \\
\text { residential population or } \\
\text { working-age population in } \\
10 \text { years } \\
\text { Changing rate of elderly } \\
\text { population (above 5) in } 10 \\
\text { years } \\
\text { Numbers of jobs } \\
\text { Jobs per resident } \\
\text { Number of workers in } \\
\text { retail/hotel and catering } \\
\text { Number of workers in } \\
\text { education/health/culture } \\
\text { Number of workers in } \\
\text { public administration and } \\
\text { services } \\
\text { Number of workers in } \\
\text { industry } \\
\text { Housing density } \\
\text { (units/acre), flats } \\
\text { Percentage of public } \\
\text { housing above } 6 \text { floors; } \\
\text { private housing } \\
\text { Total gross floor area of } \\
\text { development } \\
\text { Building floor area by use } \\
\text { Floor area ratio; height of } \\
\text { buildings } \\
\text { Height of buildings } \\
\text { Number of neighborhood } \\
\text { retail and service } \\
\text { establishments } \\
\text { Size of built-up area for } \\
\text { housing and services } \\
\text { Areas with commercial } \\
\text { urban amenities } \\
\text { Number of massive } \\
\text { commercial facilities } \\
\text { (>1000 square meter in } \\
\text { areas) } \\
\text { Number of public facilities }\end{array}$ & $\begin{array}{l}\text { Land-use mix } \\
\text { Proportion of similar } \\
\text { adjacent land use types } \\
\text { Mixed-use attributes } \\
\text { (Building floor area) } \\
\text { Housing types (e.g., } \\
\text { multifamily, single } \\
\text { family) } \\
\text { Dispersion of different } \\
\text { income groups } \\
\text { Geographic position of } \\
\text { station area (e.g., urban } \\
\text { downtown, urban } \\
\text { neighborhood) } \\
\text { Percentage of TOD- } \\
\text { (in)compatible land use } \\
\text { (neither residential nor } \\
\text { vacant, allowed in future } \\
\text { development in overlay } \\
\text { zoning) } \\
\text { Percentage of vacant } \\
\text { land use } \\
\text { Areas of green or open } \\
\text { space } \\
\text { Changing rate of public } \\
\text { facility in } 15 \text { years } \\
\text { Changing rate of floor } \\
\text { area ratio in } 10 \text { years } \\
\text { Changing rate of office } \\
\text { jobs in } 10 \text { years } \\
\text { Qualitative rating of } \\
\text { planning initiatives (e.g., } \\
\text { station area } \\
\text { planning/zoning) } \\
\text { Presence of } \\
\text { redevelopment authority } \\
\text { Qualitative rating of } \\
\text { recent development } \\
\text { activity } \\
\text { Qualitative rating of } \\
\text { securing funding and } \\
\text { financing for projects } \\
\text { Private investment in the } \\
\text { area } \\
\text { Percentage of people } \\
\text { with bachelor's degree } \\
\text { Household income }\end{array}$ \\
\hline
\end{tabular}




\begin{tabular}{|c|c|c|c|}
\hline $\begin{array}{l}\text { Distance to the closest } \\
\text { motorway access by } \\
\text { car } \\
\text { Number of free- } \\
\text { standing bicycle paths } \\
\text { (separated bicycle } \\
\text { paths) } \\
\text { Total bike path length } \\
\text { within } 2 \mathrm{~km} \text { around } \\
\text { metro stations } \\
\text { Number of staff in the } \\
\text { station }\end{array}$ & $\begin{array}{l}\text { syntax, network } \\
\text { structure index) } \\
\text { Walk Scores } \\
\text { (calculated based on } \\
\text { distance to amenities } \\
\text { weighted equally and } \\
\text { summed) }\end{array}$ & $\begin{array}{l}\text { Arriving tourists per } 1000 \\
\text { residents of the district } \\
\text { Average real estate sales } \\
\text { per square foot, average } \\
\text { residential rents, or land } \\
\text { prices per square meter } \\
\text { Degree of functional mix } \\
\text { (workers by economic } \\
\text { sections and residents) }\end{array}$ & $\begin{array}{l}\text { Unemployment levels } \\
\text { Rate of unemployed with } \\
\text { basic education } \\
\text { Tax earnings of district }\end{array}$ \\
\hline $\begin{array}{l}\text { te: } \\
\text { Id and Italic text rep } \\
\text { d Pfeffer 2016). }\end{array}$ & & & \\
\hline
\end{tabular}

Source: Adapted from Lyu, Bertolini, and Pfeffer (2016) (see also Chapter 1 Addenum.) 


\section{Categorization Methods Used in Previous Studies}

We considered four types of methods for categorization that show up in the academic and white literature related to transit neighborhood classification: (1) manual classification; (2) thresholds or qualifying criteria; (3) scaling and weighting measures and breaking them along statistical breaks; and (4) factor and/or cluster analysis. In this section, we first define and describe each approach with examples and then we compare the features of each of these methods for the application of typologies for a large national dataset.

The first method broadly considered was (1) manual classification, which relies on quantitative data (such as thresholds or any of the previously described metrics) and/or qualitative rankings or evaluations using local expertise to group similar stations into categories. Ewing et al (2017) provides one example of the TOD qualifications that rely on a combination of quantitative data, site (or google earth) visits, and local expertise to categorize sites based on the following criteria:

- Dense (mid-rise or higher multifamily housing);

- Mixed use (residential, retail, entertainment, and sometimes office uses within one development);

- Pedestrian friendly (streets built for pedestrian as well as cars/transit);

- Adjacent to transit (literally abutting related);

- Built after transit was constructed/proposed (indicates parking supply decisions that took transit access into consideration);

- Fully developed (or near so); and

- Self-contained/dedicated parking.

The second method for categorization we consider in this study uses (2) thresholds or qualifying criteria. A threshold-based approach is typically data-driven, but the qualifying thresholds are typically determined by the analyst (not a statistical approach). The most commonly known threshold-based transit neighborhood definition would be the transit-oriented and -adjacent development (TOD and TAD, respectively) area types. (See Figure 1.3 for Renne's (2009) qualitative spectrum for developments that are near high-quality transit but may not be 'oriented' towards the transit.) 


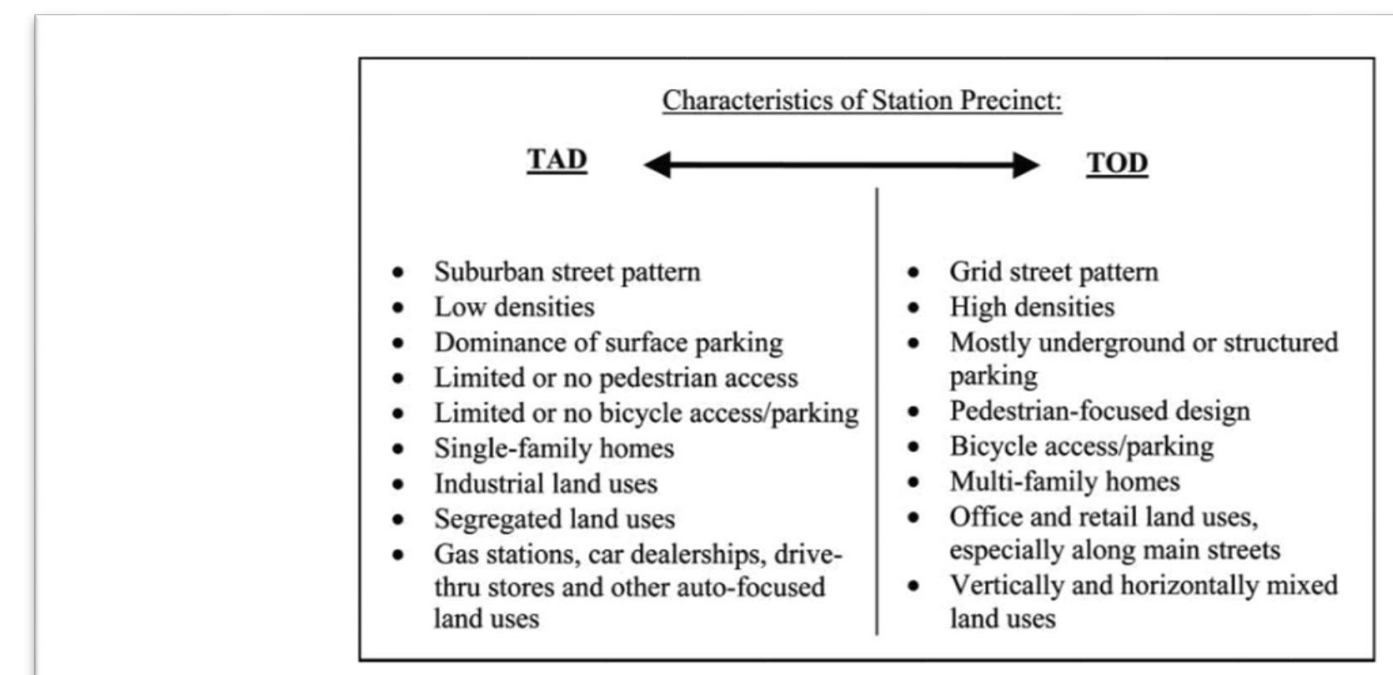

Figure 3. The TAD-TOD spectrum.

Figure 1.3

Transit-Oriented to Transit-Adjacent Development Spectrum Source: (Renne 2009, 3) 
Cervero and Guerra (2011) use thresholds to qualify cost-effective systems based on an analysis of the investments and ridership; they qualify any light rail station area with 30 people per gross acre or more and any heavy rail station area with 45 people per cross acre as costeffective systems. In Renne and Ewing (2013), the authors define quantitative qualifying criteria and rank the site based on how many criteria the development area meets. Developments that have all three criteria determined to be 'transit-oriented', while those with two criteria are 'TODTAD Hybrid', and those that have zero to one points are 'transit-adjacent'.

- Greater than 30 jobs or residents per gross acre;

- Not having $100 \%$ of land uses either residential or commercial; and

- Average block size less than 6.5 acres.

For Jeihani and Zhang (2013), the authors use an 'all or nothing' approach to incorporate a "TOD" definition at a traffic analysis zone level (TAZ) into a regional travel demand model, assigning areas to the definition based on their relative performance across the region using the following criteria:

- Residential density OR employment density higher than the regional average;

- Average block size for each TAZ (square miles) should be less than the regional average;

- Land use entropy falls within the top 30\% regional entropy scores;

- Housing and transportation affordability (\% of housing/transportation cost of household income) is less than $45 \%$; and

- The area within a $1 / 2$ mile of the transit station location.

The third methods we considered for this analysis includes some combination of (3) scaling and weighting measures and breaking them along statistical breaks (e.g., natural breaks, Jenks breaks, or quartiles). In this approach, the user selects multiple measures that capture various dimensions and scales them so that each site is ranked relative to all other sites in the sample dataset. Similar metrics can be average (or weighted, depending on importance) to distill the metrics into a one dimensional index. Using natural breaks along this index provides a means for categorizing high/low performers on any one dimension.

In Puget Sound, the analysts develop two aspects of their transit evaluation: People and Place. The Place aspect is a two-dimensional set of measures that aim to capture Physical Form + Activity/Transit-Orientation (lower or higher) and Change/Market Strength (weaker or stronger); the People aspect is a two dimensional set of measures aimed to capture Social Infrastructure \& Access to Opportunity (limited or good) and Change \& Displacement Risk (low, potential, immediate). In this approach, the analysts started with dozens of measures describing characteristics of each of these four dimensions. Measures were scaled relative to the entire sample, averaged together to develop an index for each dimension, and then the dimension was 'broken' into categories. In this application, the analysts tweak the location of each statistical break according to local expertise that may identify locations near the break lines as being inaccurately categorized (Puget Sound Regional Council; City of Bellevue; King County Metro 2014).

The fourth method we considered was (4) factor and/or cluster analysis. Most broadly used in the academic literature, this approach is similar in concept to the previous 'scaling and breaking' technique with more advanced multivariate dimensional reduction techniques. In this approach, multiple measures selected to represent different dimensions are distilled into indices (or 
factors) using factor analysis. Similar metrics, however, might contribute in large and small ways cross different measures. Once indices are identified, the index scores (also called 'factor scores') are inputted into a cluster analysis that groups each observation based on their multidimensional distance between their index scores and each cluster's index scores. Similar to the 'breaks' approach, the number of clusters can be determined in part by quantitative observations and distributions and examination of how much variation is explained by $\mathrm{N}$ number of clusters. The cluster analysis process is an iterative estimation technique that refines clusters assignment over and over again until the error between each site and clusters is minimized, explaining the maximum about of variation across all dimensions (index or factor scores). Similar factor/cluster methods have been used to identify existing 'neighborhoods' by aligning measures in multiple dimensions of the built environment (Cervero and Kockelman 1997), studying the development patterns of new single-family home neighborhoods (Song and Knaap 2007), estimating automobile ownership (Shay and Khattak 2007), incorporating aspects of behavior in neighborhood definitions (Jacques and El-Geneidy 2014) or social environments to study physical activity and obesity (Nelson et al. 2006), exploring residential decision on household travel (Lin and Long 2008; Gehrke, Currans, and Clifton 2014), and estimating development-level travel impacts (Clifton et al. 2012).

The following Table 1.2 summarizes the features of methods (2) through (4) described above. Given the national focus on this study and the burden of categorizing hundreds of stations across dozens of systems and regions, (1) manual classification falls outside of our initial scope of work in this project. In general, there are benefits and costs to any of these methods. On the simpler end of applications, typologies can often be easily implemented in practice but may lack the nuances of contextual assignment into categories. These 'qualifying criteria' typologies are often reduced to a few supporting measures for a couple of categories. On the more complex end of the spectrum, factor/cluster analysis is a commonly used academic technique, but the translation of these typologies into practice may be problematic, particularly when expanding the application of the typology to a large set of new locations. However, methods (3) and (4) are more readily able to capture a variety of measures to describe and aggregate multiple dimensions, making both of the methods more nuanced to patterns of development. 
Table 1.2

Comparison of Methods Used in Previous Studies

\begin{tabular}{|c|c|c|c|}
\hline $\begin{array}{l}\text { Method } \\
\text { Features: }\end{array}$ & $\begin{array}{l}\text { (2) Thresholds or } \\
\text { Qualifying Characteristics }\end{array}$ & $\begin{array}{l}\text { (3) Scaled Variables with } \\
\text { Natural Breaks }\end{array}$ & (4) Factor and/or Cluster \\
\hline Complexity & Low & Medium & High \\
\hline $\begin{array}{l}\text { Common } \\
\text { Application }\end{array}$ & $\begin{array}{l}\text { Practice or practice- } \\
\text { oriented academic } \\
\text { exercises. } \\
\text { Defining typology for } \\
\text { design and/or planning } \\
\text { considerations. }\end{array}$ & $\begin{array}{l}\text { Practice or practice- } \\
\text { oriented academic } \\
\text { exercises. } \\
\text { Defining typology for } \\
\text { design and/or planning } \\
\text { considerations. } \\
\text { Identifying and } \\
\text { Implementing Strategic } \\
\text { Policies. }\end{array}$ & $\begin{array}{l}\text { Academic exercises. } \\
\text { Defining typology for } \\
\text { design and/or planning } \\
\text { considerations. } \\
\text { Identifying and } \\
\text { Implementing Strategic } \\
\text { Policies. }\end{array}$ \\
\hline $\begin{array}{l}\text { Selection of } \\
\text { measures } \\
\text { across } \\
\text { dimensions }\end{array}$ & $\begin{array}{l}\text { Subjective process of the } \\
\text { analyst. Method does not } \\
\text { compensate for } \\
\text { problematic selection of } \\
\text { measures. }\end{array}$ & $\begin{array}{l}\text { Subjective process of the } \\
\text { analyst. Method does not } \\
\text { compensate for } \\
\text { problematic selection of } \\
\text { measures. }\end{array}$ & $\begin{array}{l}\text { Subjective process of the } \\
\text { analyst. Method does not } \\
\text { compensate for } \\
\text { problematic selection of } \\
\text { measures. }\end{array}$ \\
\hline $\begin{array}{l}\text { Number of } \\
\text { measures } \\
\text { allowed }\end{array}$ & $\begin{array}{l}\text { Fewer is likely better, but } \\
\text { a 'scoring' criteria rubric } \\
\text { is a possible way to } \\
\text { increase measures } \\
\text { included. }\end{array}$ & $\begin{array}{l}\text { Many measures for each } \\
\text { dimension is encouraged } \\
\text { to capture a broader } \\
\text { narrative of the context of } \\
\text { each site. }\end{array}$ & $\begin{array}{l}\text { Many measures for each } \\
\text { dimension is encouraged } \\
\text { to capture a broader } \\
\text { narrative of the context of } \\
\text { each site. }\end{array}$ \\
\hline $\begin{array}{l}\text { Definition of } \\
\text { thresholds } \\
\text { between } \\
\text { categories }\end{array}$ & $\begin{array}{l}\text { May be based on other } \\
\text { metrics of success (e.g., } \\
\text { minimum densities for } \\
\text { cost effectiveness) } \\
\text { May be relative to other } \\
\text { sites (e.g., more than the } \\
\text { average for the region) }\end{array}$ & $\begin{array}{l}\text { Relative to other sites in } \\
\text { the sample (scaled \& } \\
\text { statistically broken). }\end{array}$ & $\begin{array}{l}\text { Relative to other sites in } \\
\text { the sample (scaled \& } \\
\text { statistically clustered). }\end{array}$ \\
\hline $\begin{array}{l}\text { Estimation } \\
\text { process (once } \\
\text { data for each } \\
\text { site is } \\
\text { compiled }\end{array}$ & Simple (possible in excel) & $\begin{array}{l}\text { Moderate (possible in } \\
\text { excel with more complex } \\
\text { functions) }\end{array}$ & $\begin{array}{l}\text { Hard (specialty software } \\
\text { is needed) }\end{array}$ \\
\hline $\begin{array}{l}\text { Replication of } \\
\text { results }\end{array}$ & $\begin{array}{l}\text { Static thresholds will not } \\
\text { change. If regional } \\
\text { averages are used, } \\
\text { replication depends on } \\
\text { the distribution of the } \\
\text { 'universe' of } \\
\text { observations. }\end{array}$ & $\begin{array}{l}\text { Depends on the } \\
\text { distribution of the } \\
\text { 'universe' of } \\
\text { observations. }\end{array}$ & $\begin{array}{l}\text { Depends on the } \\
\text { distribution of the } \\
\text { 'universe' of } \\
\text { observations. }\end{array}$ \\
\hline $\begin{array}{l}\text { Classification } \\
\text { of new sites } \\
\text { into clusters }\end{array}$ & Simple & $\begin{array}{l}\text { Moderate, requires new } \\
\text { sites be scaled according }\end{array}$ & $\begin{array}{l}\text { Moderate to hard, } \\
\text { requires new sites be } \\
\text { scaled according to the }\end{array}$ \\
\hline
\end{tabular}




\begin{tabular}{|l|l|l|l|}
\hline & $\begin{array}{l}\text { to the distribution of all } \\
\text { existing sites. }\end{array}$ & $\begin{array}{l}\text { distribution of all existing } \\
\text { sites. }\end{array}$ \\
$\begin{array}{l}\text { May be problematic if } \\
\text { new sites fall outside of } \\
\text { the range of observations } \\
\text { or many new sites are } \\
\text { introduced. }\end{array}$ & $\begin{array}{l}\text { May be problematic if } \\
\text { new sites fall outside of } \\
\text { the range of observations } \\
\text { or many new sites are } \\
\text { introduced. }\end{array}$ \\
\hline
\end{tabular}




\section{Creating Typologies: Methods and Data}

\section{Guiding principals}

Based on the review of academic and practice-based TOD place typologies, we identify three guiding principles for developing typologies in our own work. First, the typologies must capture existing variation in the built environments using similar dimensions of development, as studied in academia and applied in practice before us. Second, the categories must be mutually exclusive and collectively exhaustive so that potential systems outside of our study might be able to classify their contexts within our framework, making the place types more readily available for practitioners.

Third, the typologies must enable comparison of similar built environment patterns across metropolitan areas. Not all central business districts look the same, for example, but there may exist similar patterns of density, design, and access across different city that allows us to compare relative market-responses to transit. This third guiding principal added a level of complexity to the development of place types not commonly observed in other studies. Most place type development occurs within a single region, which ground the analysis in local knowledge and expertise. As part of our research question, we desire to explore the role of place type in market response across regions, which require our typology to be transferable.

\section{Differences Between Station Area and Block Group Analysis}

Before the proposed analysis plan is explored, this section briefly touches on the differences between the transit-oriented development literature and this approach. One of our research questions in this study is whether varying area types are more responsive to development goals (e.g., increasing jobs, housing opportunities or real estate values) with greater proximity to FGT systems. Our hypothesis is that different outcomes may respond differently for different area types and regional contexts depending on the FGT systems. The literature explored in the previous section focuses on station-level development, but the economic analyses implemented in this study are not easily implemented at a station-level analysis. For example, hedonic price analyses are implemented at a development-level, with some sites in close proximity to transit and others farther away. For economic base analyses, the unit of analysis is typically a region or type of neighborhood.

The main limitation of applying the station-level literature to a neighborhood-level analysis is reconfiguring the interpretation and development of the variable from stations to neighborhoods. For example, the station area interpretation of the Place dimension describes job accessibility as 'Job Density within a 0.5-mile'. But the interpretation of the same indicator may take into account job density of the neighborhood and whether the neighborhood is within 0.5 -miles of transit. In this change, a TOD-station analysis may combine descriptors of Place or Node with measures of Orientation, while a neighborhood analysis will likely separate the Place and Node descriptions of the neighborhood with measures that capture the Orientation (specifically, proximity) of the neighborhood to transit.

\section{Existing Variables from Prior NITC Projects}

The usable data immediately available for this study was collected in prior NITC studies, compiled at a block-group level using the Longitudinal Employer-Household Data (LEHD) and the American Community Survey (see Table 1.1). The data were collected for 39 U.S. metropolitan areas, including 4 heavy rail systems (HRT), 19 light rail systems, 21 bus rapid transit systems, 11 express bus systems, 12 streetcar systems, and 8 commuter rail systems. In general, the type of data compiled for these studies captures jobs (by income and sector) and population (by race, worker status, commute mode, household composition, tenure). The 
distance of each block (group) to the nearest transit station (by transit system type) was computed in GIS to categorize the access of that geography to transit. All variables were compiled for each of the three years of analysis: 2002, 2009, and 2017.

Considering these available variables and the dimensions of transit-oriented development described previously, we are largely missing one type of variable. The Oriented dimension has two main components: proximity to high-quality transit and walkability or supportive access/egress street network. The former is represented in the transit variables calculated for each type of FRT system (all of which fall into the 'higher quality transit' category, but with varying degrees of regional accessibility and mobility). The latter may be missing from our existing datasets. 'Walkability' by definition is the ability to access to destinations-generally retail, service, transit stations-by walking. This, in some ways, may be represented by proxy using the block-level (smallest geography) retail or service jobs or something similar. However, even areas with higher retail and service jobs may have lower walkability if the street network design is not conducive-this means higher intersection density and lower block sizes. Fortunately, even when land is re-developed, it is not all that common for existing street networks to change substantially. To incorporate a proxy for street network design in the Oriented dimension, we will append our existing data with the EPA Smart Location Database measures for intersection density ${ }^{2}$. These variables were calculated using the 2011 street network, while all other variables calculated using the LEHD, ACS, or geographic location were calculated using their given year of analysis (2002, 2009, or 2017). Future analysis should include the processing of archived street networks to capture potential changes in the supportive street network design.

The data are therefore organized at a block (group) level, meaning we are examining the block or block group's access to transit and not any one transit station's access to jobs or population (etc). This is an important distinction for this research as many studies of transit-oriented development focus on any one station's built environment and social demographics even if that station's service area overlaps with other stations on the same line. In this work, we consider the typology of neighborhoods at a block or block group level with respect to its access to transit. We will discuss this distinction later in this chapter.

\footnotetext{
2 EPA Smart Location Database Documentation User Guide, page 7 (2014); Accessed on May 30 ${ }^{\text {th }}, 2019$ from here: https://www.epa.gov/sites/production/files/2014-03/documents/sld userguide.pdf
} 
TABLE 1.3

Variable Compiled in Previous NITC study

\begin{tabular}{l}
\hline LEHD variables (unit of analysis: census block) \\
\hline Jobs by income level: \\
Upper ( $>\$ 333 /$ month); Middle ( $\$ 1251-3333 /$ month); and Lower (<\$1250/month). \\
Jobs by sector: \\
Manufacturing; Light Industry; Retail/ Lodging/ Food; Knowledge; Office; Education; Health; \\
and Arts/Entertainment/Recreation. \\
\hline ACS data (unit of analysis: census block group) \\
\hline Population \\
Population by Race/Ethnicity (counts): \\
Not Hispanic or Latino - White alone; Not Hispanic or Latino - Black or African American \\
alone; Not Hispanic or Latino - American Indian and Alaska Native alone; Not Hispanic or \\
Latino - Asian alone; Not Hispanic or Latino - Native Hawaiian and Other Pacific Islander \\
alone; Not Hispanic or Latino - Some other race alone \\
Total Workers \\
Commute Mode \\
Car, truck, or van (Drove alone or Carpooled); Public transportation (excluding taxicab); \\
Bicycle; Walked; Other means; Worked at home \\
Households with and without children (<18 years) present by family type: \\
Total with and total without; With/without by family households (general, male householder- \\
no wife present, female householder-no husband present); married-couple family; family \\
households; nonfamily households (1-person households). \\
Households by age of householder \\
$<25 ; 25-44 ; 45-64 ;>65$ years. \\
Households by tenure \\
Owner Occupied; Renter Occupied \\
Households by tenure and vehicles available: \\
Owner/renter occupied and ( $0,1,2,3,4,5+)$ vehicles available. \\
\hline Processed Transit Variables (unit of analysis: census block for LEHD and census block group \\
for ACS) \\
\hline Euclidean distance (miles) of edge of block (group) to the nearest transit station by transit \\
system type. \\
Categorization of distances into 'distance buffer' bands. \\
Notes: \\
Variables should be available for stations across all years (2002, 2009, 2015). Densities can \\
be calculated by dividing the counts by the gross area of the block group. \\
\end{tabular}




\section{Data}

To represent the built environment measures relevant to understand the market-response towards transit-oriented development, we identified eight measures described in Table 1.4. While additional measures were tested, for any cases where variables were highly correlated, we simplified by selecting the one more commonly referenced in the literature. Job and population densities are among the most commonly referenced TOD built environment measures. For one measure of land use diversity, we use the proportion of job densities from retail also provides a sense of the mix or diversity of land uses. We also consider the percent of owner-occupied housing - a proxy that largely represents the proportion of single-family housing in the area-and the proportion of households without kids-a proxy for the size of dwelling units. Lastly, we consider the street network design, and therefore connectivity, by including the intersection density and proportion of intersections that are four-way. It is worth noting that the measures of street network design are built from slightly older data; however, unlike development which can change from year to year, once the street network is in place, it is not readily changed.

\section{Table 1.4}

\section{Descriptive Statistics of Built Environment Variables}

\begin{tabular}{|c|c|c|c|c|}
\hline Variables & Calculated from Source & Average & Minimum & Maximum \\
\hline Jobs per acre & $\begin{array}{l}\text { Longitudinal Employer-Household } \\
\text { Dynamics }\end{array}$ & 1.94 & 0 & 851 \\
\hline $\begin{array}{l}\text { Proportion of jobs that } \\
\text { are retail and } \\
\text { entertainment }\end{array}$ & $\begin{array}{l}\text { Longitudinal Employer-Household } \\
\text { Dynamics }\end{array}$ & 0.16 & 0 & 1.00 \\
\hline $\begin{array}{l}\text { Total population per } \\
\text { acre }\end{array}$ & American Community Survey & 16.8 & 0 & 1027.1 \\
\hline $\begin{array}{l}\text { Total households per } \\
\text { acre }\end{array}$ & American Community Survey & 6.4 & 0 & 619.0 \\
\hline $\begin{array}{l}\text { Percent of households } \\
\text { with no kids }\end{array}$ & American Community Survey & 0.66 & 0 & 1.00 \\
\hline $\begin{array}{l}\text { Percent of owner } \\
\text { occupied housing }\end{array}$ & American Community Survey & 0.61 & 0 & 1.00 \\
\hline $\begin{array}{l}\text { Intersections per } \\
\text { square mile }\end{array}$ & $\begin{array}{l}\text { Smart Location Database, } 2014, \\
\text { Variable: D3b }\end{array}$ & 82.0 & 0 & 5175 \\
\hline $\begin{array}{l}\text { Proportion of } \\
\text { intersections with four } \\
\text { approaching streets }\end{array}$ & $\begin{array}{l}\text { Smart Location Database, } 2014, \\
\text { Variable: D3bmm4, and D3bmm3 }\end{array}$ & 0.28 & 0 & 1.00 \\
\hline
\end{tabular}
Notes:

All data are measured at the block-group level. 


\section{Method}

Considering the above guiding principles, we utilize a typology methodology by Gehrke and Clifton (2016) that allows for easily classifiable place types that are both transferable in comparisons across regions and customizable to common TOD-related built environment characteristics. In this process, each built environment measure is first segmented into five categories using a Jenks natural breaks classification method, which groups observations into categories that minimize the deviation from each group's mean value. This also orders the data into low to high values for each variable-effectively representing a five-tier degree of urban access and/or land use mix.

For each variable, the groupings are given a score from 1 (least accessible or mixed-use) to 5 (most accessible or mixed use). These scores are then added up for each block group, and the block groups are then cut into groups that represent high to low mix and accessibility. We start by cutting the areas into eight equal groups. However, those considered the most exurban or the most densely urban had little variation across the average built environment characteristics and were aggregated. The result is four place types, as described in Table 1.5.

While these place types enable us to compare similar built environments across sometimes drastically different metropolitan areas, they are driven largely by the distribution of environments included in our study areas. And the built environment measures included in this study were limited to those generally available and consistent throughout the US at a blockgroup level. In future work, more robust transit and walkability accessibility measures within each block group could provide an improved representation of local and regional accessibility in a measurable way for comparing across metropolitan areas (see Table 1.6).

As mentioned earlier, an extensive annotated bibliography of materials used to create the Place Typology is provided in Appendix B. Appendix C includes images of the Place Typology applied to many transit regions used in our study. Examples are also shown below for NITC member metropolitan areas, being Dallas-Fort Worth, Eugene, Portland, Salt Lake City, and Tucson, respectively. 
Table 1.5

Average Built Environment Characteristic by Jenks Natural Break Classification Grouping

\begin{tabular}{|c|c|c|c|c|c|}
\hline \multirow[b]{2}{*}{ Score: } & \multicolumn{5}{|c|}{ Average Built Environment Characteristics by Jenks Grouping } \\
\hline & 5 & 4 & 3 & 2 & 1 \\
\hline \multicolumn{6}{|l|}{ Built Environment Metric: } \\
\hline Jobs per acre & 851 & 414.4 & 158.7 & 52.7 & 10.8 \\
\hline $\begin{array}{l}\text { Proportion of jobs that are } \\
\text { retail and arts }\end{array}$ & 1.00 & 0.71 & 0.47 & 0.27 & 0.09 \\
\hline Total population per acre & 1027.1 & 252.9 & 131.00 & 58.5 & 19.4 \\
\hline Total households per acre & 619.0 & 131.6 & 65.3 & 28.1 & 8.6 \\
\hline $\begin{array}{l}\text { Percent of households with } \\
\text { no kids }{ }^{1}\end{array}$ & 0.00 & 0.38 & 0.56 & 0.69 & 0.81 \\
\hline $\begin{array}{l}\text { Percent of owner occupied } \\
\text { housing }^{1}\end{array}$ & 0.00 & 0.21 & 0.44 & 0.65 & 0.83 \\
\hline $\begin{array}{l}\text { Intersections per square } \\
\text { mile }\end{array}$ & 5175 & 456 & 196 & 111 & 53 \\
\hline $\begin{array}{l}\text { Proportion of intersections } \\
\text { with } 3 \text { to } 4 \text { vertices }\end{array}$ & 1.00 & 0.82 & 0.54 & 0.31 & 0.12 \\
\hline
\end{tabular}


Table 1.6

Average Built Environment Characteristics Across Mix/Accessible Place Types

\begin{tabular}{|c|c|c|c|c|}
\hline & \multicolumn{4}{|l|}{ Place Types } \\
\hline & $\begin{array}{l}\text { High } \\
\text { Mix/Accessible }\end{array}$ & $\begin{array}{l}\text { Moderate } \\
\text { Mix/Accessibl } \\
\text { e }\end{array}$ & $\begin{array}{l}\text { Low } \\
\text { Mix/Accessibl } \\
\text { e }\end{array}$ & $\begin{array}{l}\text { Poor } \\
\text { Mix/Accessible }\end{array}$ \\
\hline & (High MA) & (Mod MA) & (Low MA) & (Poor MA) \\
\hline Scores & $\begin{array}{l}\text { Greater than } \\
2.5\end{array}$ & $2-2.5$ & $1.5-2$ & $0-1.5$ \\
\hline Built Environment Variables & \multicolumn{4}{|c|}{ Average Values by Place Types } \\
\hline Jobs per acre & 0.42 & 1.38 & 3.26 & 8.11 \\
\hline $\begin{array}{l}\text { Proportion of jobs that are } \\
\text { retail and arts }\end{array}$ & 0.06 & 0.17 & 0.25 & 0.27 \\
\hline Total population per acre & 4.45 & 10.97 & 28.33 & 72.85 \\
\hline Total households per acre & 1.71 & 4.19 & 11.04 & 26.96 \\
\hline $\begin{array}{l}\text { Percent of households with } \\
\text { no kids }\end{array}$ & 0.71 & 0.66 & 0.63 & 0.51 \\
\hline $\begin{array}{l}\text { Percent of owner-occupied } \\
\text { housing }\end{array}$ & 0.83 & 0.63 & 0.40 & 0.22 \\
\hline Intersections per square mile & 45.78 & 78.98 & 112.58 & 149.81 \\
\hline $\begin{array}{l}\text { Proportion of intersections } \\
\text { with } 3 \text { to } 4 \text { vertices }\end{array}$ & 0.10 & 0.26 & 0.45 & 0.70 \\
\hline
\end{tabular}




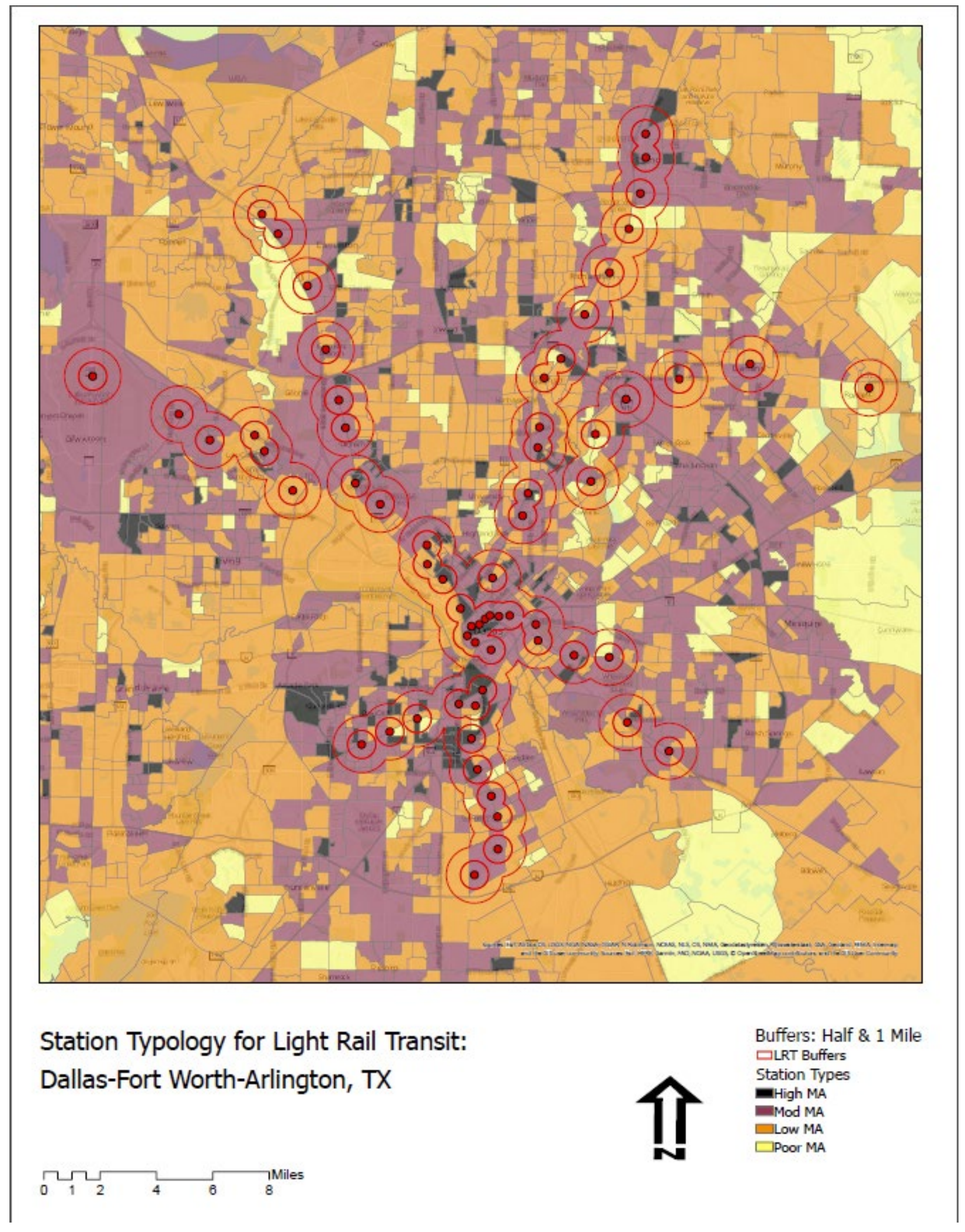




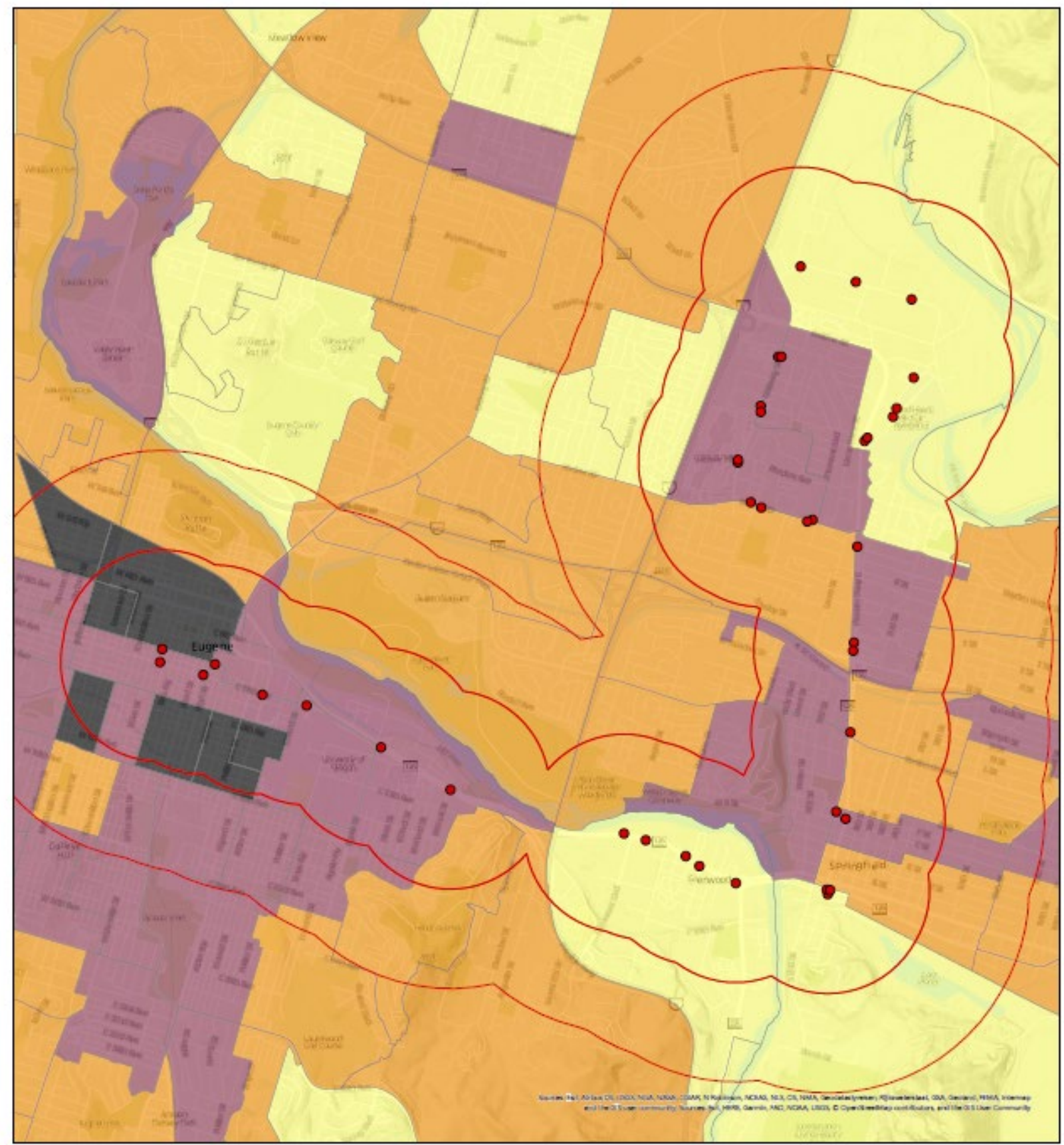

Station Typology for Bus Rapid Transit:

Buffers: Half \& 1 Mile Eugene, OR $\square$ BRT Buffers Station Types -High MA - Mod MA $\square$ Low MA $\overbrace{0.170 .35} 0.7$ 1.05 


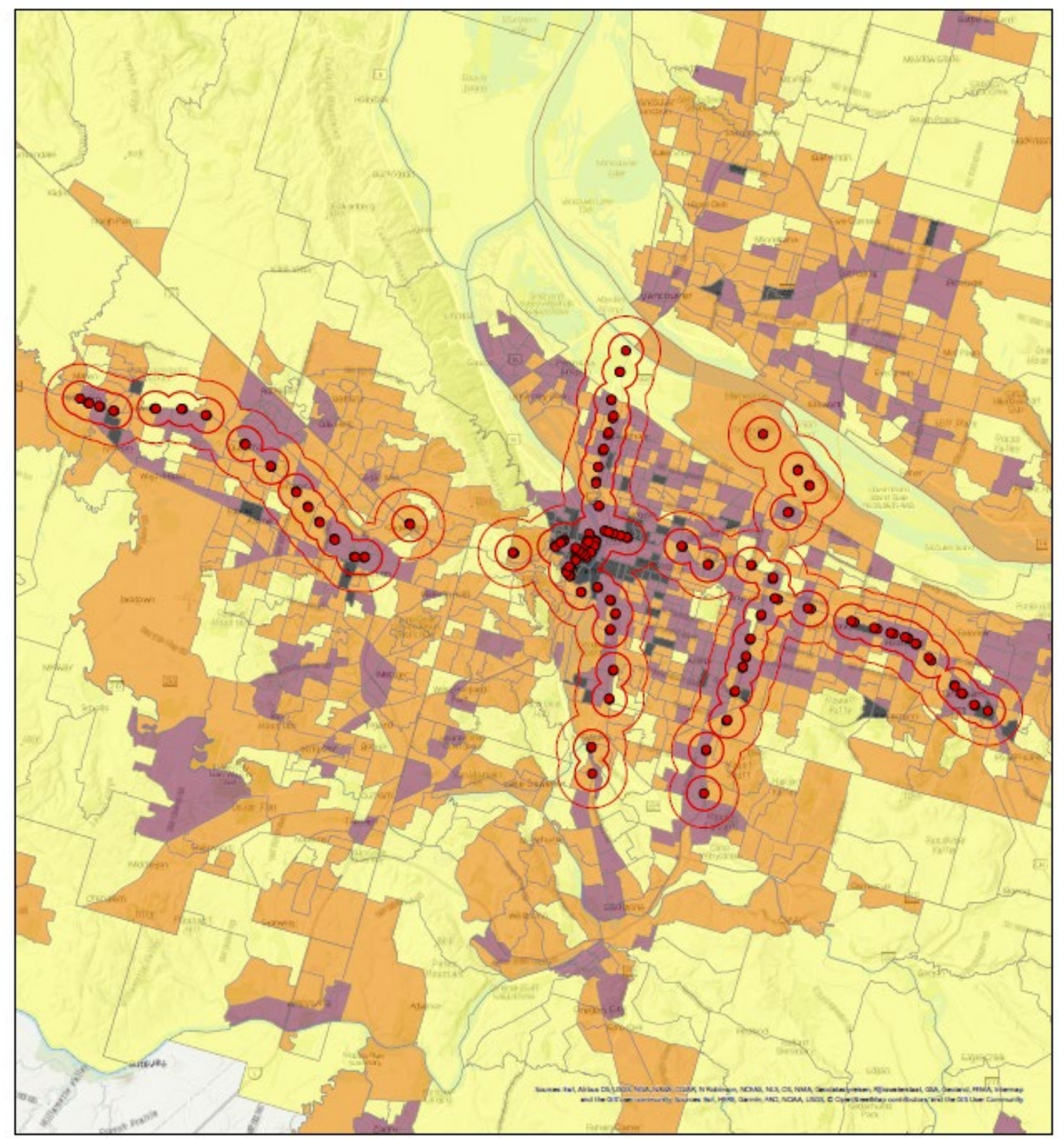

Station Typology for Light Rail Transit:

Buffers: Half \& 1 Mile Portland-Vancouver-Hillsboro, OR-WA

$\bigcap_{0}^{7} \int_{2} \overbrace{6}{ }_{8}^{\text {Miles }}$ 


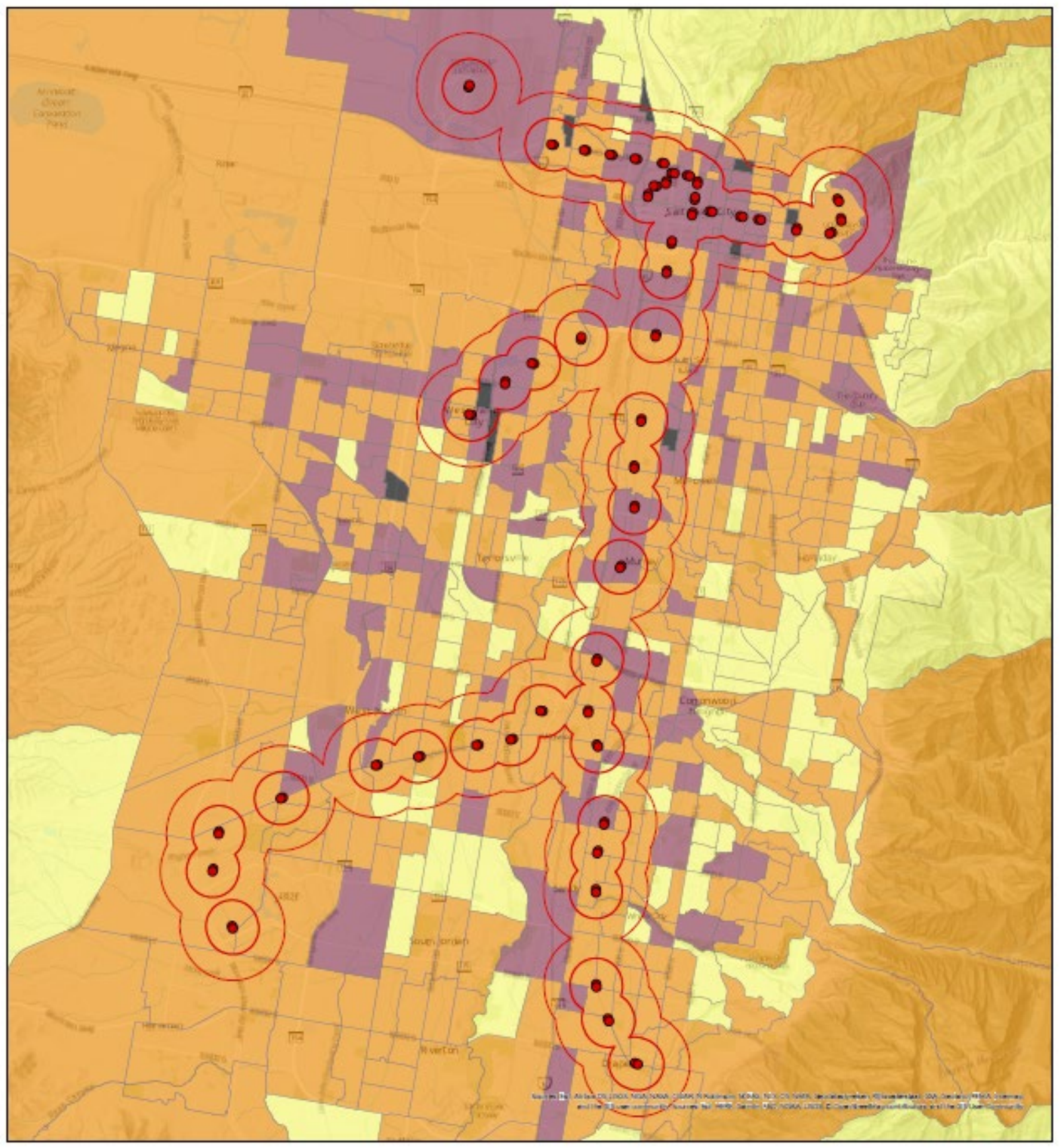

Station Typology for Light Rail Transit:

\section{Salt Lake City, UT}

Buffers: Half \& 1 Mile $\square$ LRT Buffers
Station Types

Station Types

19 Mod MA

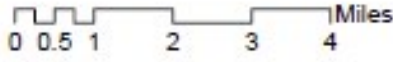




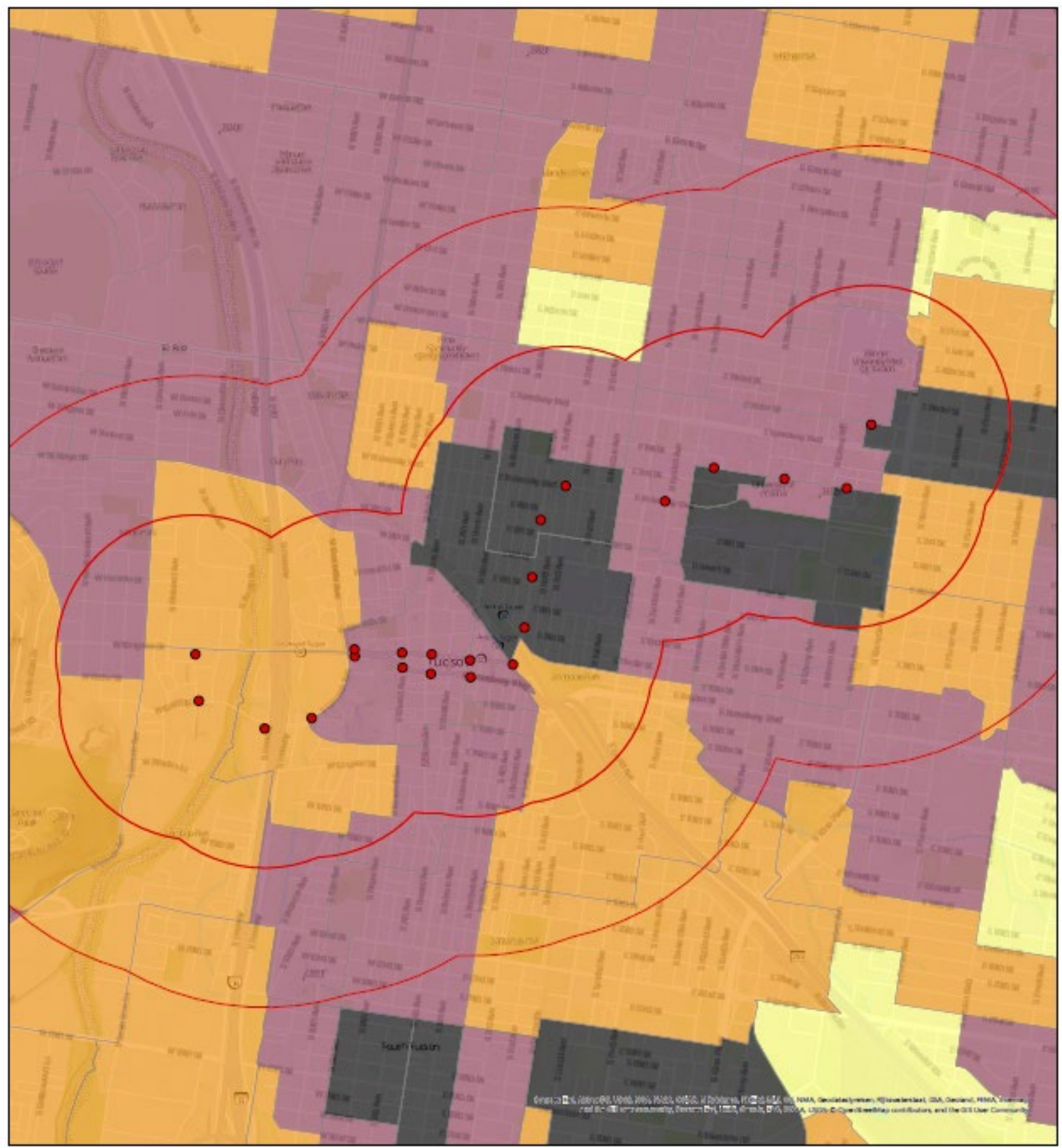

Station Typology for Streetcar Transit: Tucson, AZ

Buffers: Half \& 1 Mile $\square$ SCT Buffers Station Types -High MA - Mod MA Low MA $\square$ Poor MA 
References

Arizona Department of Transportation. 2012. "Station Area Typology Definitions." Passenger Rail Corridor Study: Tucson to Phoenix. Phoenix, Arizona: Federal Transit Administration.

Bertolini, L. 1999. "Spatial Development Patterns and Public Transport: The Application of an Analytical Model in the Netherlands." Planning Practice and Research 14 (2): 199-210. https://doi.org/10.1080/02697459915724.

Center for Transit-Oriented Development, and Nelson/Nygaard. 2011. "Transit-Oriented Development Strategic Plan." Portland, Oregon: Metro. http://ctod.org/pdfs/2011PortlandTODweb.pdf.

Central Maryland Transportation Alliance, and Center for Transit-Oriented Development. 2009. "Central Maryland TOD Strategy: A Regional Action Plan for Transit-Centered Communities." http://ctod.org/pdfs/2009CentralMarylandTODStrategy.pdf.

Cervero, Robert, and Erick Guerra. 2011. "Urban Densities and Transit: A Multi-Dimensional Perspective." Working Paper UCB-ITS-VWP-2011-6. Institute of Transportation Studies: University of California, Davis.

Cervero, Robert, and Kara Kockelman. 1997. "Travel Demand and the 3Ds: Density, Diversity, and Design." Transportation Research Part D 2 (3): 199-219.

Clifton, Kelly J., Kristina M. Currans, April Cutter, and Robert Schneider. 2012. "Household Travel Surveys in a Context-Based Approach for Adjusting ITE Trip Generation Rates in Urban Contexts." Transportation Research Record: Journal of the Transportation Research Board 2307: 108-19.

Clifton, Kelly J., and Steven Gehrke. Memo. 2016. "Technical Memorandum: Place Typology Data Sources and Development Procedure," August 23, 2016.

Ewing, Reid, Guang Tian, Torrey Lyons, Preston Stinger, Rachel Weinberger, Ben Kaufman, and Kevin Shivley. 2017. "Trip and Parking Generation at Transit-Oriented Developments." Research Report NITC-RR-767. http://nitc.trec.pdx.edu/research/project/767/Trip_and_Parking_Generation_at_TransitOriented_Developments.

Gehrke, Steven R., Kristina M. Currans, and Kelly J. Clifton. 2014. "The Impact of Residential Location Decisions on Miles Traveled, Trip Frequency, and Automobile Ownership for Households in the Portland Metropolitan Region." In https://trid.trb.org/view/1289730.

Jacques, Cynthia, and Ahmed El-Geneidy. 2014. "Does Travel Behavior Matter in Defining Urban Form? A Quantitative Analysis Characterizing Distinct Areas within a Region." Journal of Transport and Land Use 7 (1): 1. https://doi.org/10.5198/jtlu.v7i1.377.

Jeihani, Mansoureh, and Lei Zhang. 2013. "Development of a Framework for Transit-Oriented Development." Final Report SP209B4N. State Highway Administration; Maryland Department of Transportation.

Lin, Jie, and Liang Long. 2008. "What Neighborhood Are You in? Empirical Findings of Relationships between Household Travel and Neighborhood Characteristics." Transportation 35 (6): 739-58. https://doi.org/10.1007/s11116-008-9167-7.

Lyu, Guowei, Luca Bertolini, and Karin Pfeffer. 2016. "Developing a TOD Typology for Beijing Metro Station Areas." Journal of Transport Geography 55 (July): 40-50. https://doi.org/10.1016/j.jtrangeo.2016.07.002. 
Nelson, Melissa C., Penny Gordon-Larsen, Yan Song, and Barry M. Popkin. 2006. "Built and Social Environments." American Journal of Preventive Medicine 31 (2): 109-17. https://doi.org/10.1016/j.amepre.2006.03.026.

Puget Sound Regional Council; City of Bellevue; King County Metro. 2014. "Appendix D. Growing Transit Communities Strategy People + Place Implementation Typology Methods and Results." Puget Sound, Washington. https://www.nap.edu/read/23630/chapter/11.

Renaissance Planning Group. 2011. "A Framework for Transit Oriented Development in Florida." Florida Department of Transportation and Department of Community Affairs. http://www.fltod.com/renaissance/docs/Products/FrameworkTOD_0715.pdf.

Renne, John L. 2009. "From Transit-Adjacent to Transit-Oriented Development." Local Environment 14 (1): 1-15. https://doi.org/10.1080/13549830802522376.

Renne, John L., and Reid Ewing. 2013. "Transit-Oriented Development: An Examination of America's Transit Precincts in 2000 \& 2010." New Orleans, LA: University of New Orleans Transportation Institute. https://scholarworks.uno.edu/cgi/viewcontent.cgi?article=1016\&context=unoti_pubs.

Shay, Elizabeth, and Asad J. Khattak. 2007. "Automobiles, Trips, and Neighborhood Type: Comparing Environmental Measures." Transportation Research Record: Journal of the Transportation Research Board 2010 (1): 73-82. https://doi.org/10.3141/2010-09.

Song, Yan, and Gerrit-Jan Knaap. 2007. "Quantitative Classification of Neighbourhoods: The Neighbourhoods of New Single-Family Homes in the Portland Metropolitan Area." Journal of Urban Design 12 (1): 1-24. https://doi.org/10.1080/13574800601072640. 


\section{APPENDIX A: Summary of Fixed Guideway Systems used in Analysis $^{3}$}

\section{Light Rail Transit (LRT)}

Bus Rapid Transit (BRT)

Streetcar Transit (SCT)

Commuter Rail Transit (CRT)

Express Bus Transit (XBT)

Heavy Rail Transit (HRT) [reserved for future analysis]

3 We are pleased to acknowledge invaluable assistance in preparing this appendix by Matt Dixon. 


\section{APPENDIX A - LRT}

\section{LIGHT RAIL SYSTEMS USED IN ANALYSIS}

\begin{tabular}{lllll} 
Light Rail Transit Systems Metro Area \& Name & \multicolumn{1}{c}{ Year } & Miles & Stations & $\begin{array}{l}\text { Riders } \\
\text { (Daily) }\end{array}$ \\
Buffalo: Metro Rail & 1984 & 6.4 & 13 & 18,500 \\
Charlotte: Lynx Blue Line & 2007 & 19.3 & 26 & 16,900 \\
Cleveland: Blue Line, Green Line, and Waterfront & & & & \\
Line & 1980 & 15.3 & 35 & 7,671 \\
Dallas: DART Light Rail & 1996 & 93 & 64 & 82,466 \\
Denver: RTD Rail & 1994 & 47 & 53 & 200,000 \\
Houston: METRORail & 2004 & 22.7 & 39 & 50,137 \\
Minneapolis-St. Paul: Metro Blue Line & 2004 & 12 & 19 & 29,041 \\
Norfolk: The Tide & 2011 & 7.4 & 11 & 4,900 \\
Phoenix: Valley Metro & 2008 & 26.3 & 35 & 50,000 \\
Pittsburgh: The T & 1984 & 26.2 & 52 & 27,700 \\
Portland: MAX Rail & 1986 & 86 & 97 & 121,000 \\
Sacramento: RT & 1987 & 42.9 & 54 & 40,000 \\
Salt Lake City: Transit Express / TRAX & 1999 & 44.8 & 50 & 67,300 \\
San Diego: Trolley & 1981 & 53.5 & 55 & 119,800 \\
San Jose: VTA Light Rail & 1987 & 42.2 & 62 & 30,219 \\
Seattle: Link Light Rail & 2003 & 21.95 & 22 & 65,753 \\
St. Louis: Metrolink & 1993 & 46 & 38 & 53,123
\end{tabular}




\section{BUFFALO LIGHT RAIL SYSTEM}

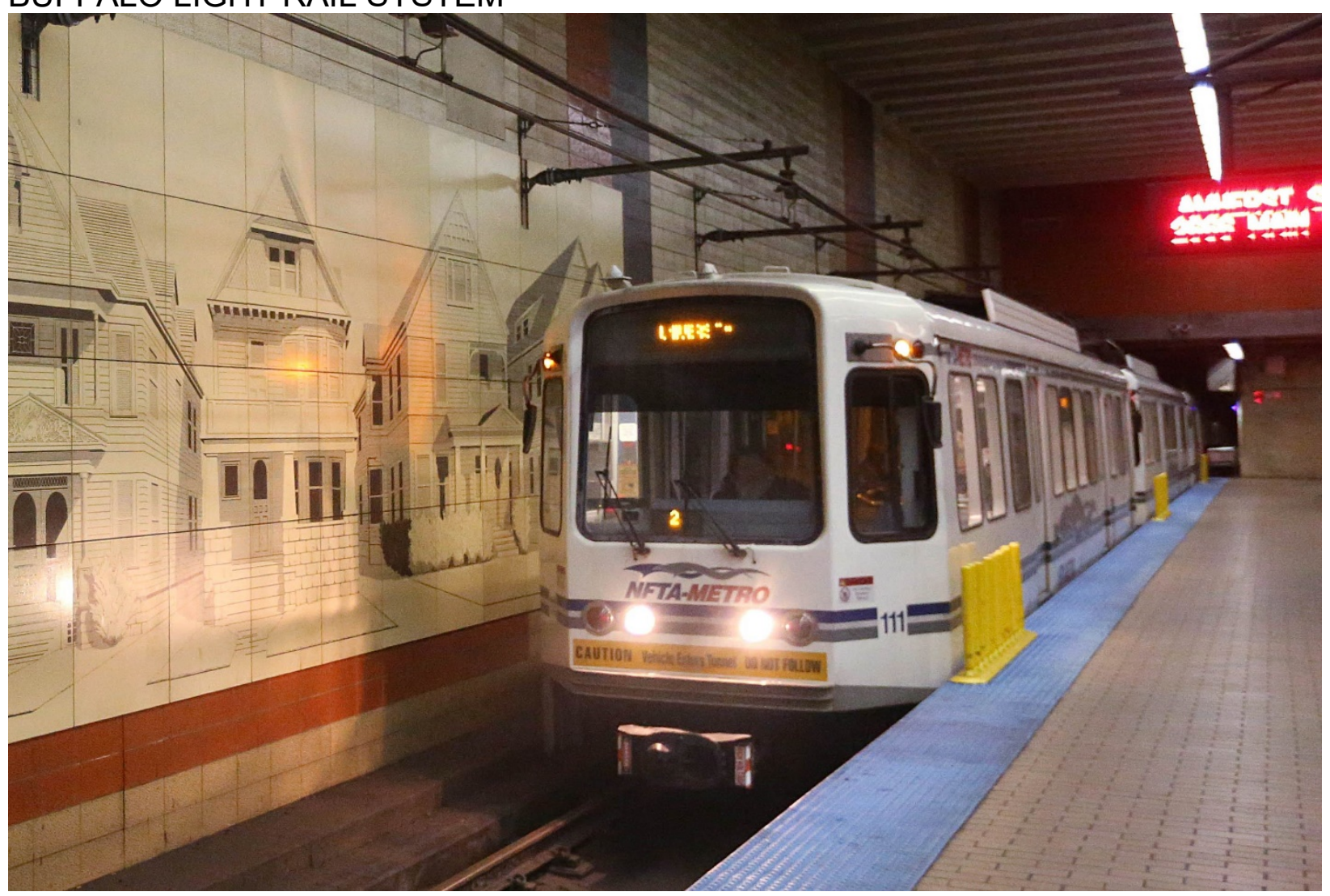

Figure LRT Buffalo 1

Buffalo Metro

Source: https://buffalonews.com/2017/04/18/plan-metro-rail-extension-amherst-coming-focus/ Running from downtown Buffalo to the University at Buffalo, the Buffalo Metro Rail is a singleline, 6.4-mile light rail system. Between 2008 and 2009 during the Great Recession, the line saw an increase of 1.2 million passengers annually. Currently, the daily ridership is about 18,500. The line launched in October of $1984 .^{4}$

\footnotetext{
${ }^{4}$ Adapted from: https://en.wikipedia.org/wiki/Buffalo_Metro_Rail.
} 


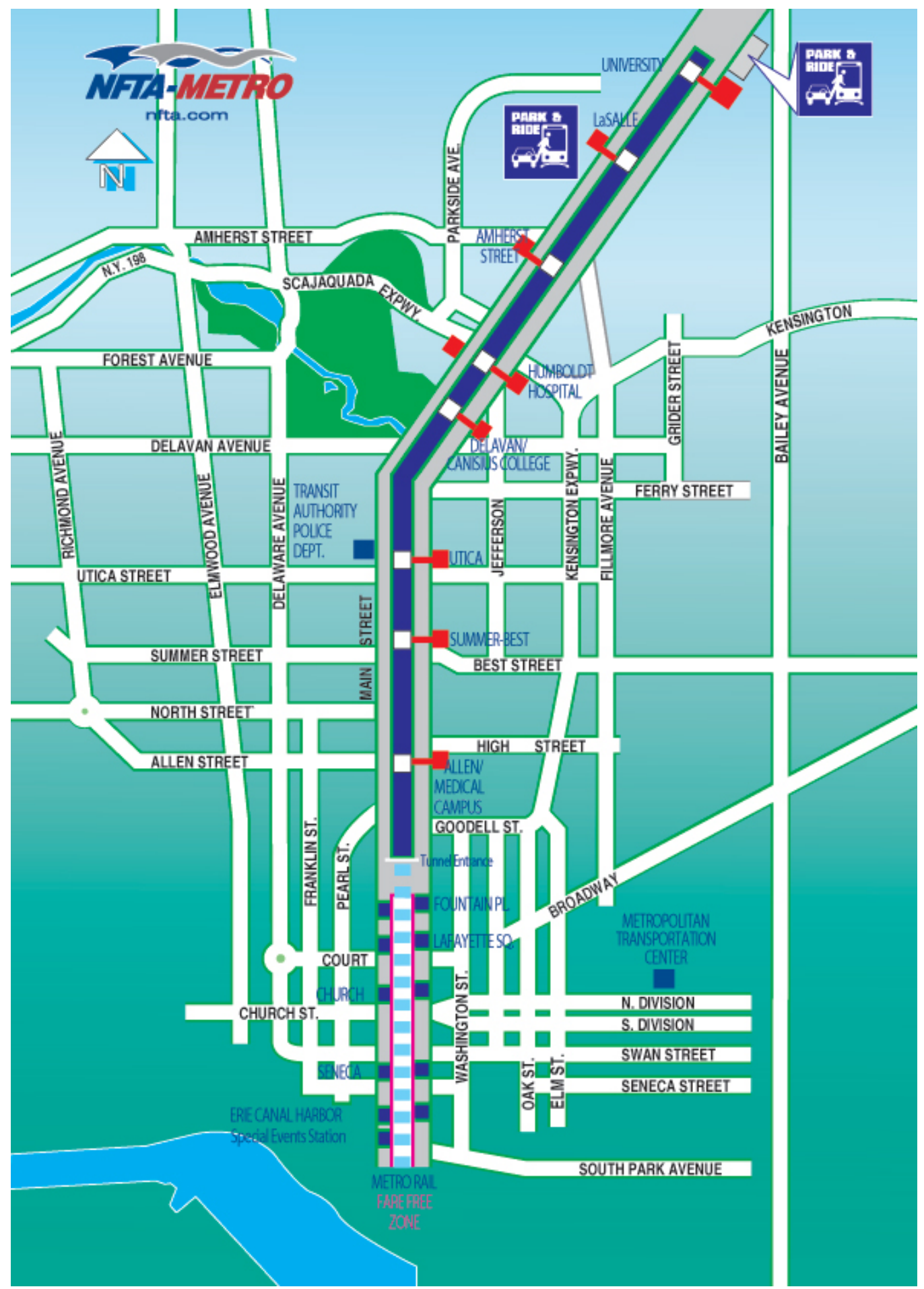

Figure LRT Buffalo 2

Buffalo Metro Service Map

Source: http://metro.nfta.com/img/Rail.jpg

CHARLOTTE LIGHT RAIL SYSTEM 


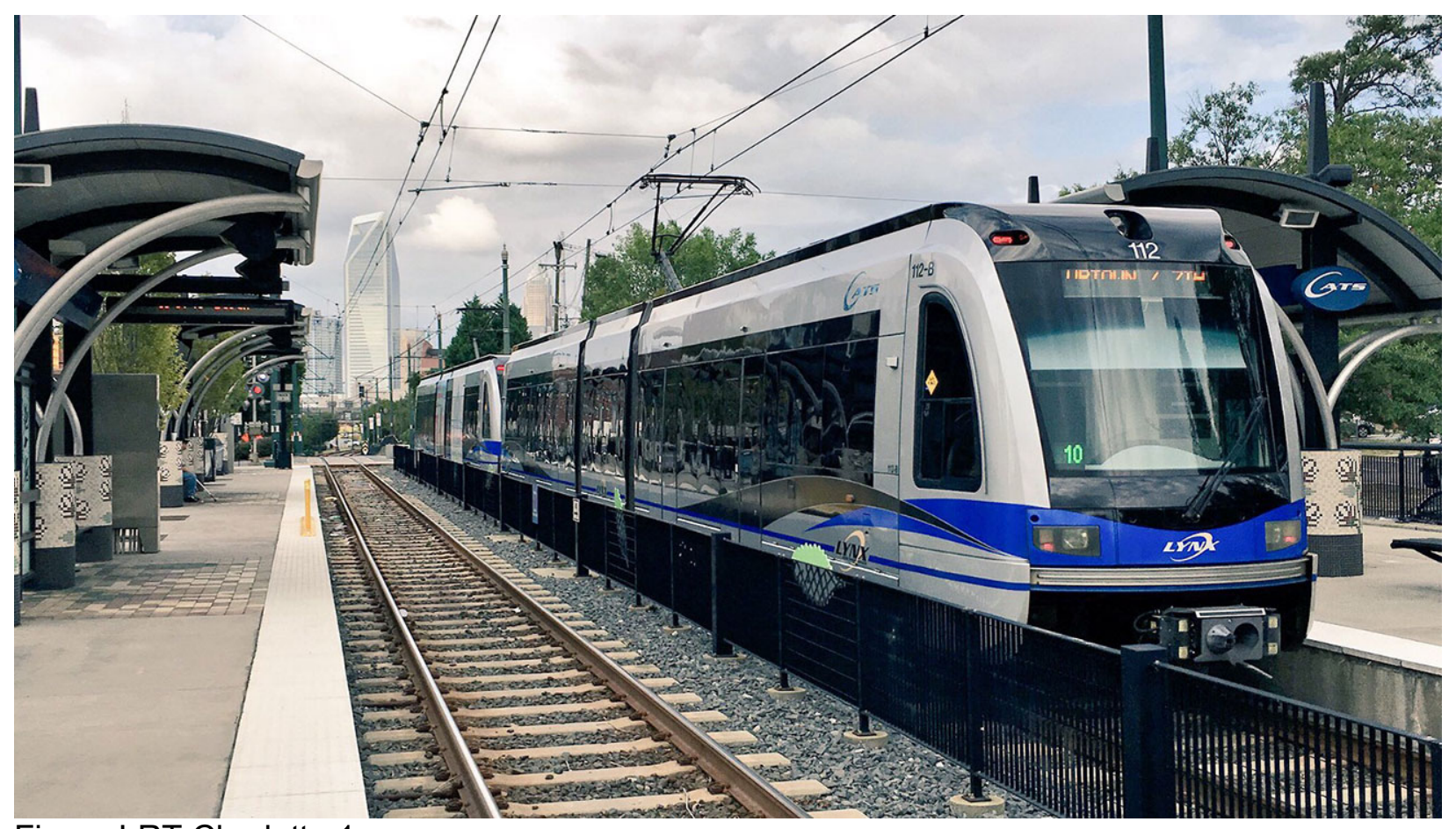

Figure LRT Charlotte 1

Charlotte Light Rail System

Source: https://www.charlotteagenda.com/81876/inside-john-lewiss-6-billion-vision-bring-lightrail-across-city/

The Lynx Blue Line in Charlotte, North Carolina was the first transit system of its kind in the entire state. The 19.3-mile line goes from the University of North Carolina Charlotte to a northern suburb called Pineville. The system has 26 stations along its route. It first opened in November of 2007, and an extension was unveiled in March of 2018. ${ }^{5}$

\footnotetext{
${ }^{5}$ Adapted from: https://en.wikipedia.org/wiki/Lynx_Blue_Line.
} 


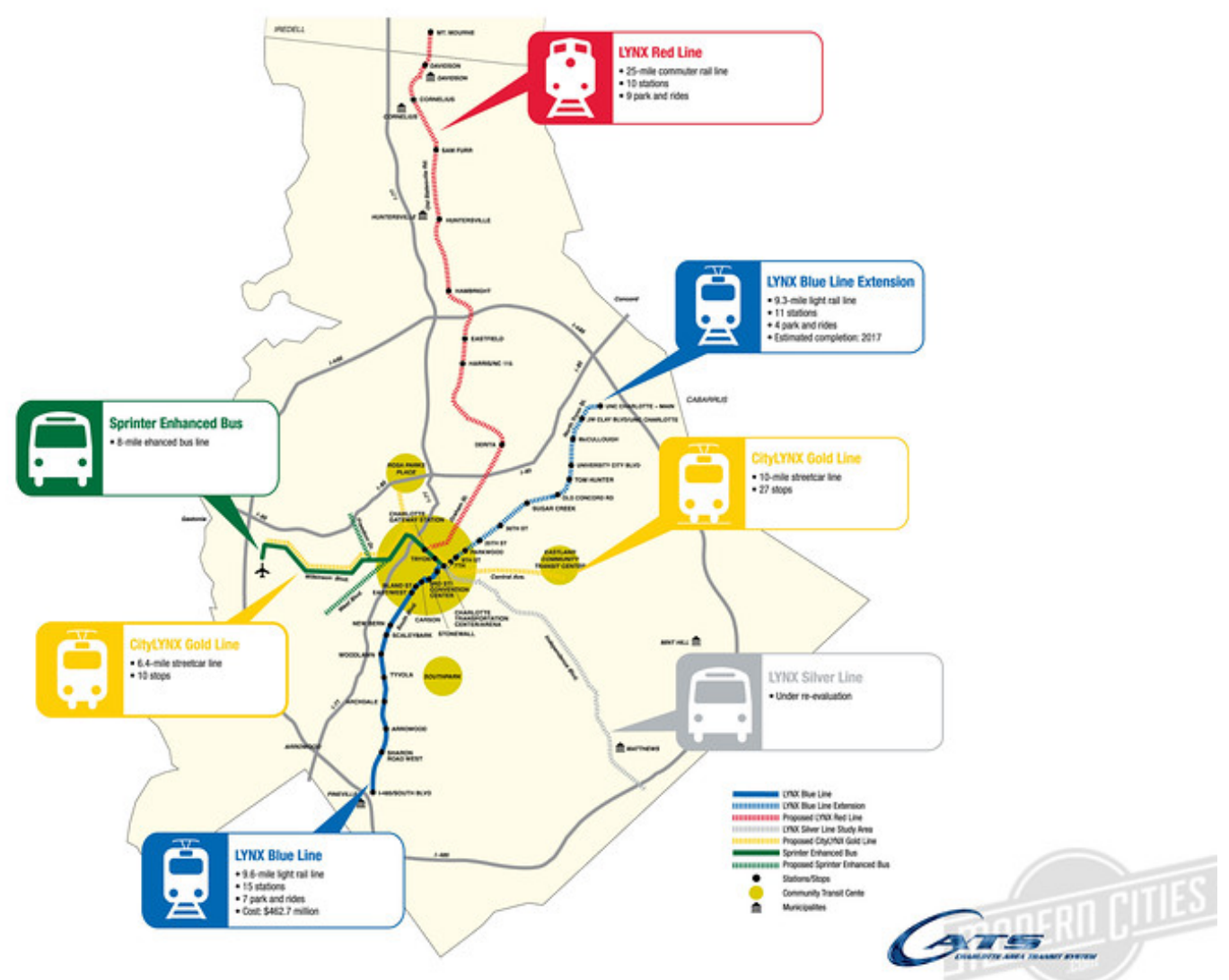

Figure LRT Charlotte 2

Lynx Blue Line Service Map

Source: https://www.moderncities.com/article/2017-apr-aerial-video-of-charlottes-new-light-railline

CLEVELAND LIGHT RAIL SYSTEM 


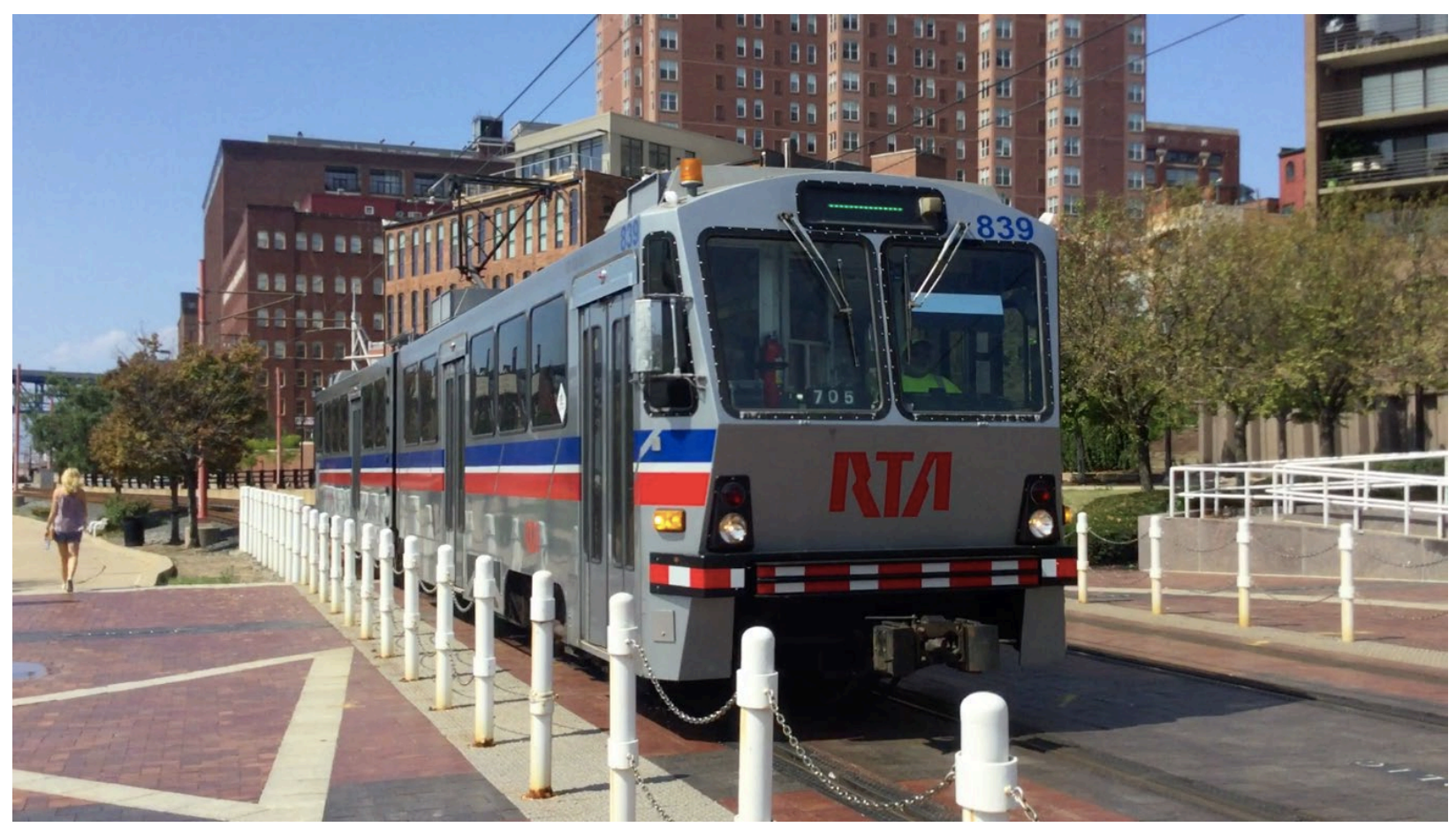

Figure LRT Cleveland 1

Cleveland Light Rail Line

Source: https://en.wikipedia.org/wiki/Blue,_Green,_and_Waterfront_Lines_(Cleveland)

The light rail system serving metro Cleveland, Ohio is the Blue Line, Green Line, and Waterfront Line. The line is 15.3 miles in total length and carries more than 2,800,000 passengers annually. The line was originally a streetcar system that opened in 1913. The system has, in total, 35 stations. ${ }^{6}$

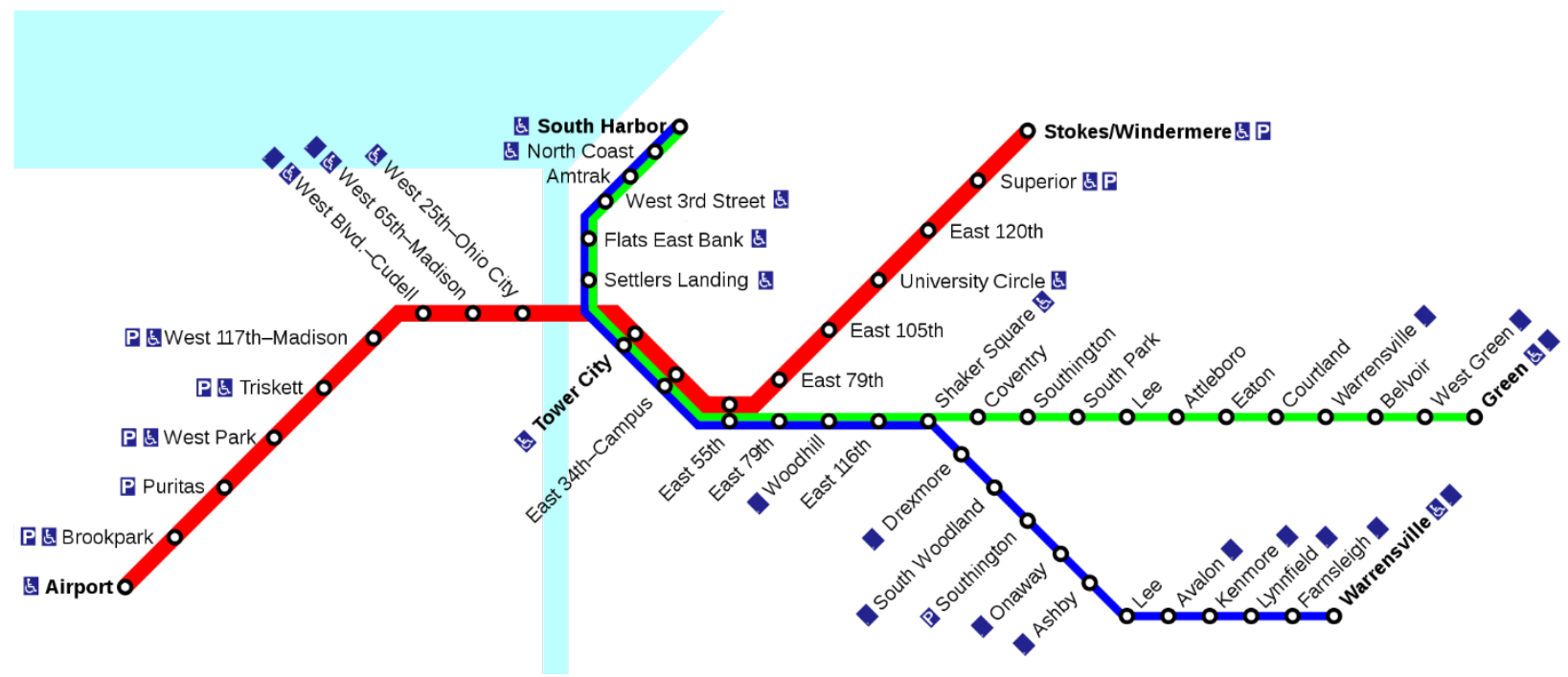

${ }^{6}$ Adapted from: https://en.wikipedia.org/wiki/Blue,_Green,_and_Waterfront_Lines_(Cleveland). 
Figure LRT Cleveland 2

Cleveland Metro Service Map

Source: http://mapa-metro.com/mapas/Cleveland/mapa-metro-cleveland.png

\section{DALLAS LIGHT RAIL SYSTEM}

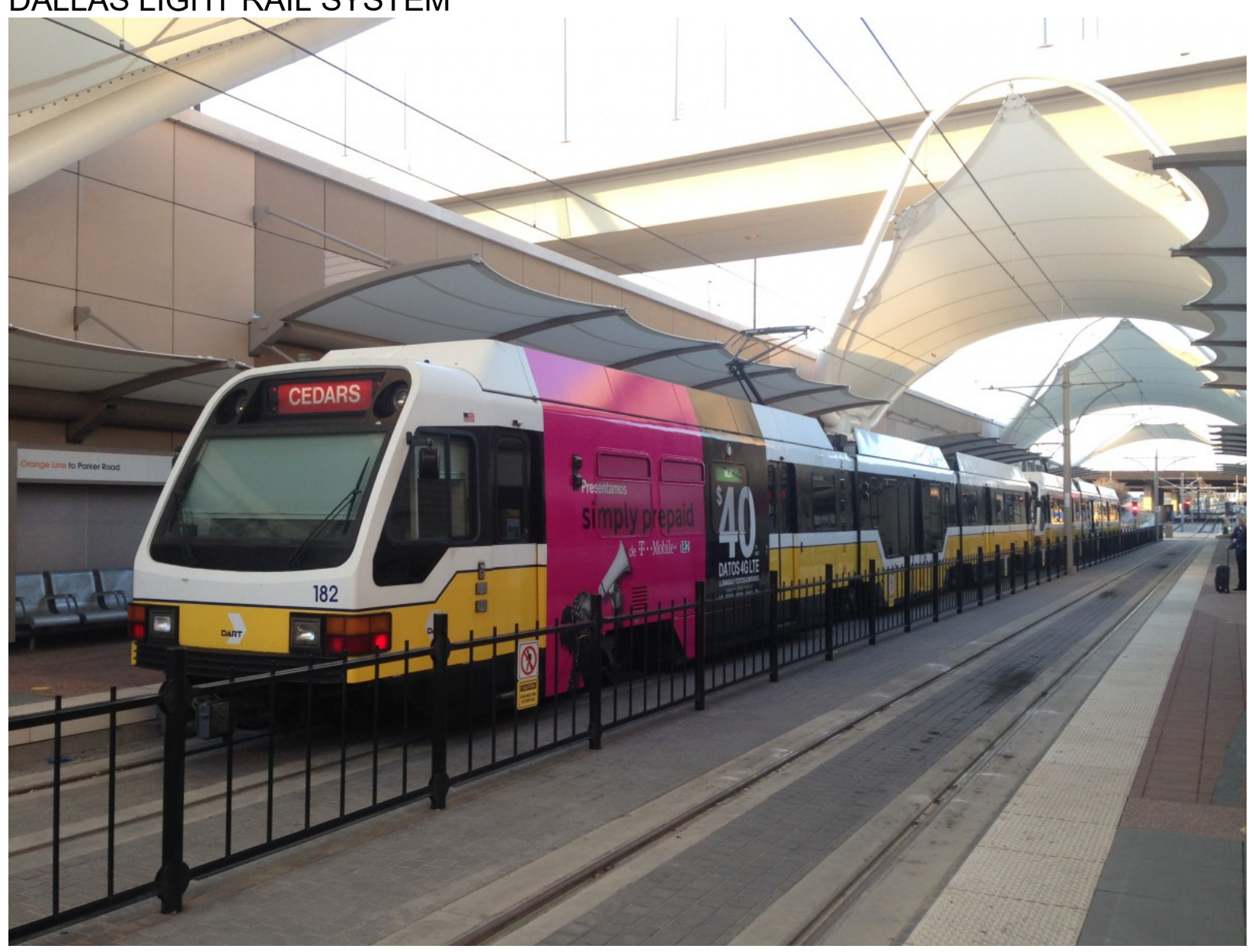

Figure LRT Dallas 1

Dallas Light Rail Rolling Stock 
Source: https://ggwash.org/view/37371/would-you-have-guessed-dallas-has-the-countrysbiggest-light-rail-system

Operated by the Dallas Area Rapid Transit (DART), the DART Light Rail system had a ridership rate of 30.1 million as of the 2017 fiscal year. The system, serving the second largest city in Texas, has a 163-vehicle fleet and serves 64 stations along 93 miles of track. ${ }^{7}$

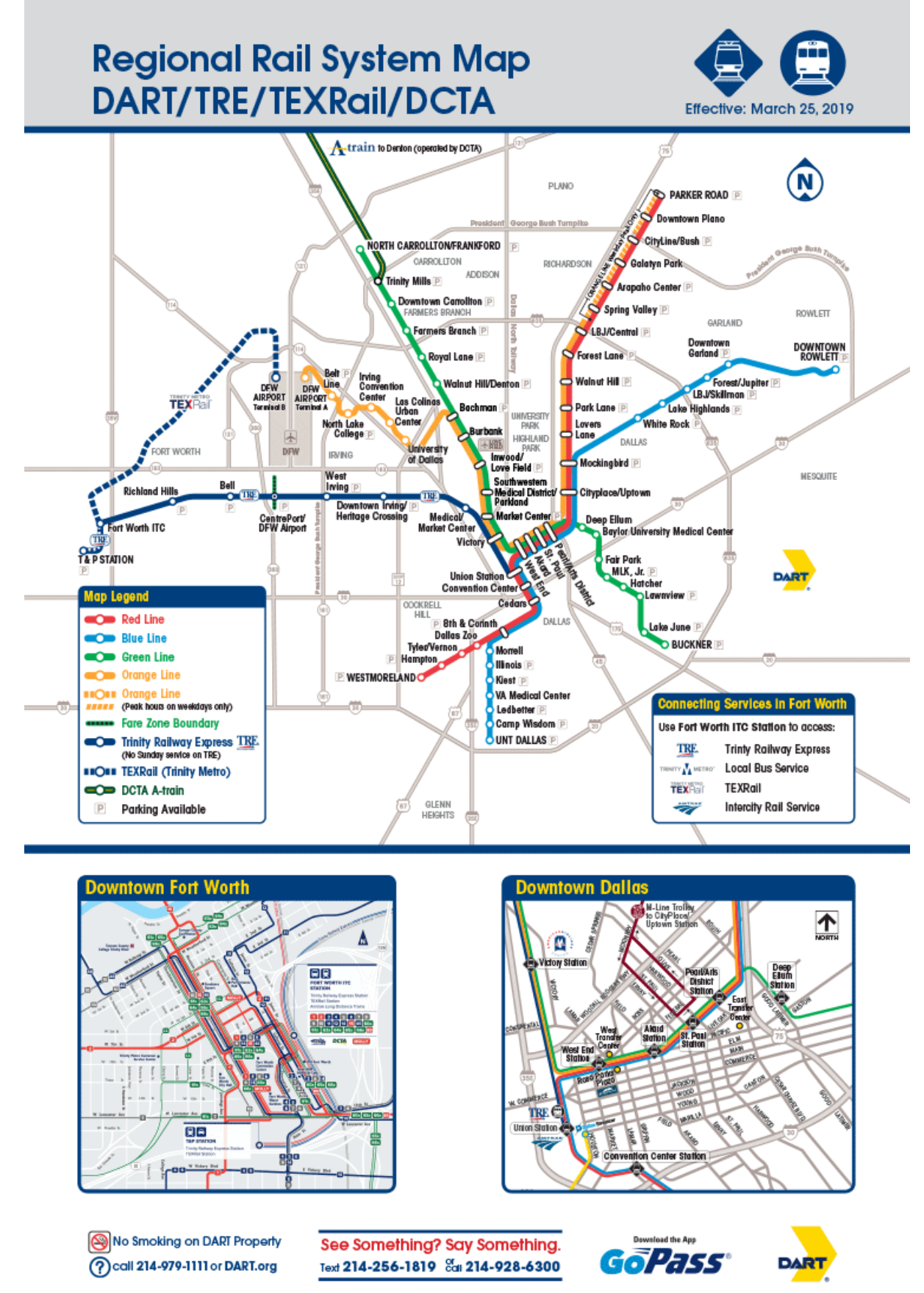

${ }^{7}$ Adapted from: https://www.dart.org/newsroom/dartrailfacts.asp. 
Figure LRT Dallas 2

DART Light Rail System Map

Source: https://www.dart.org/maps/printrailmap.asp

DENVER LIGHT RAIL SYSTEM

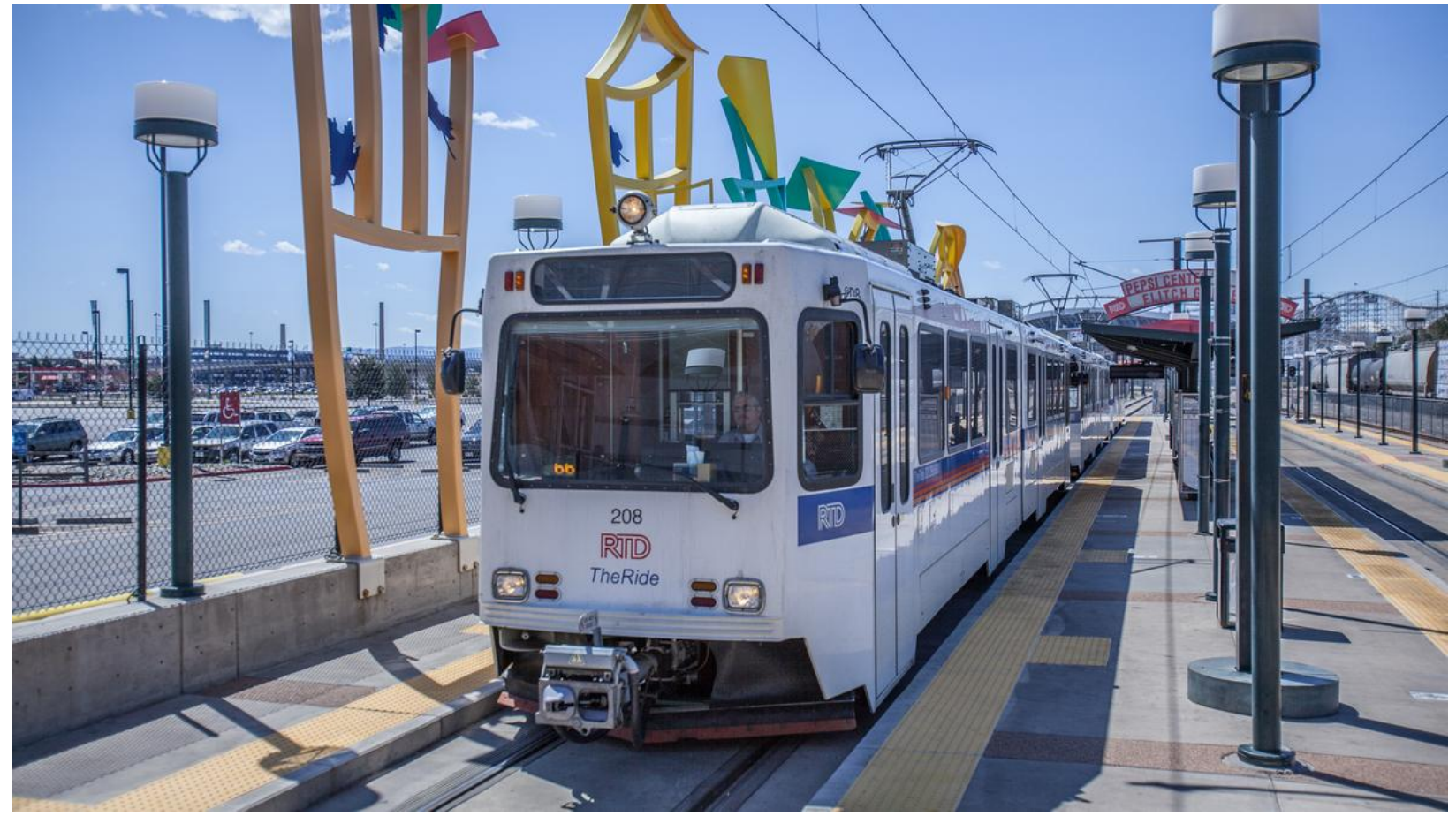

Figure LRT Denver 1

RTD Light Rail Rolling Stock

Source: https://www.bizjournals.com/denver/blog/earth to power/2015/10/rtd-returns-to-thewell-to-bolster-its-light-rail.html

The Regional Transportation District (RTD) of Denver, Colorado operates the RTD Rail Line.

The system serves nine rail lines and 53 stations in the greater Denver area. ${ }^{8}$

${ }^{8}$ Adapted from: http://www.rtd-denver.com/lightrail.shtml. 


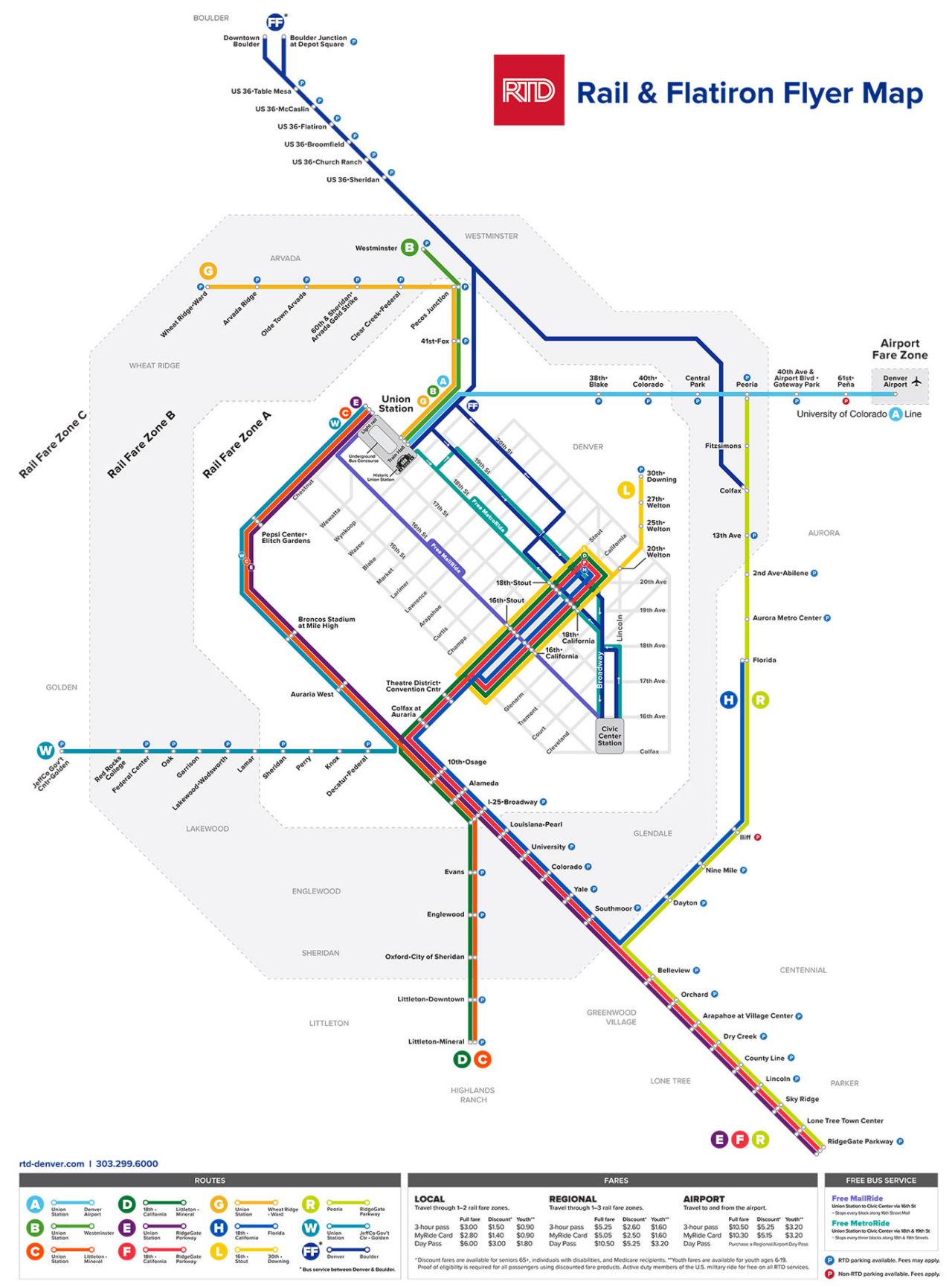

Figure LRT Denver 2

RTD Light Rail Map

Source: http://www.rtd-denver.com/img/map/rail-fare-map.jpg?v=1.2 


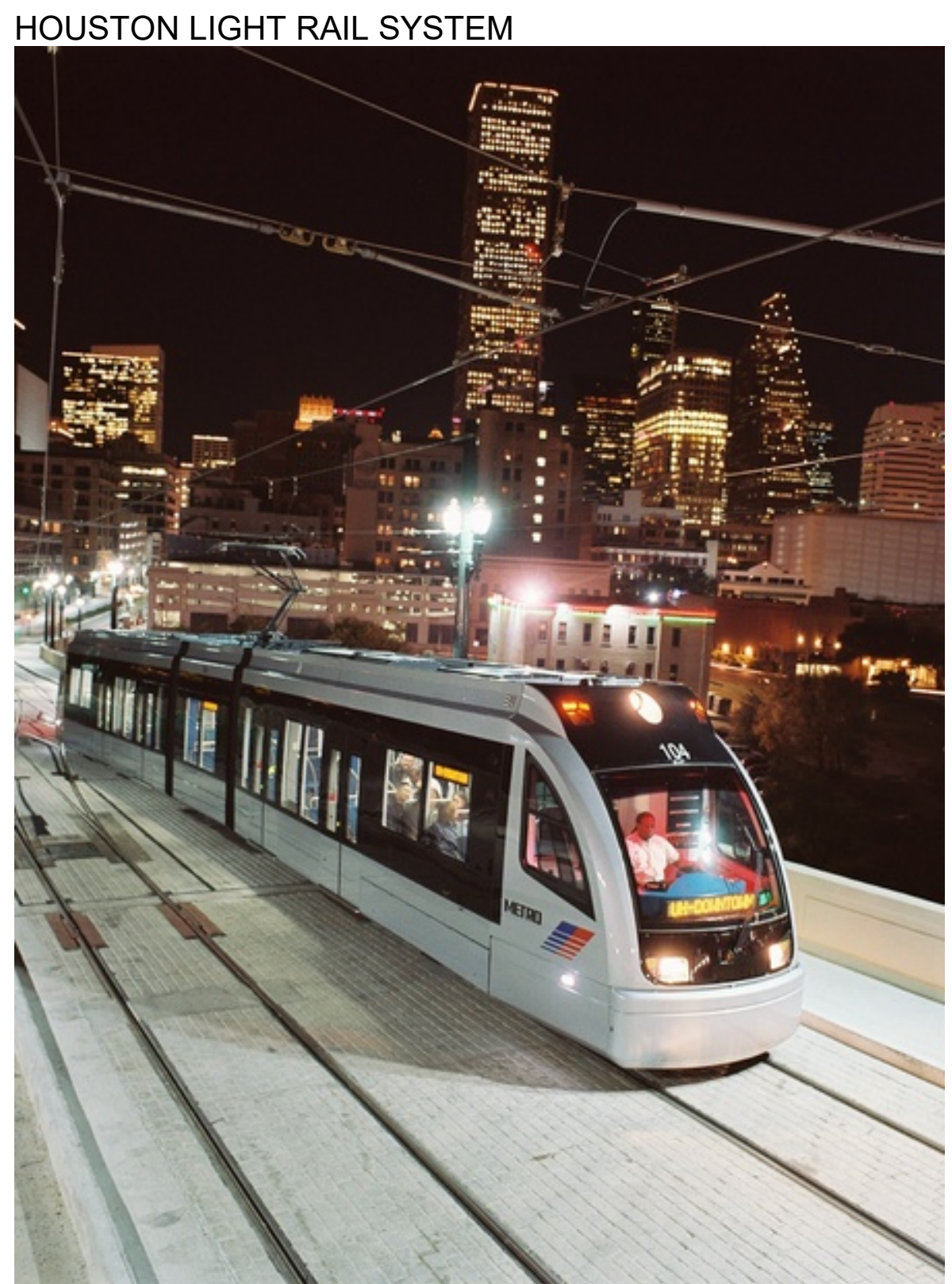

Figure LRT Houston 1

Houston METRORail

Source:

http://media.culturemap.com/crop/35/e9/600x600/METRO_Houston_skyline_light_rail_CVB.jpg With three lines in operation and an additional two in the works, Houston, Texas' METRORail serves over $18,300,000$ passengers on a yearly basis. The system began operation on January 1 , 2004. METRORail serves 39 stations along a 22.7 -mile route in total. There are 76 cars in total, with each train being two cars long. ${ }^{9}$

\footnotetext{
${ }^{9}$ Adapted from: https://en.wikipedia.org/wiki/METRORail.
} 


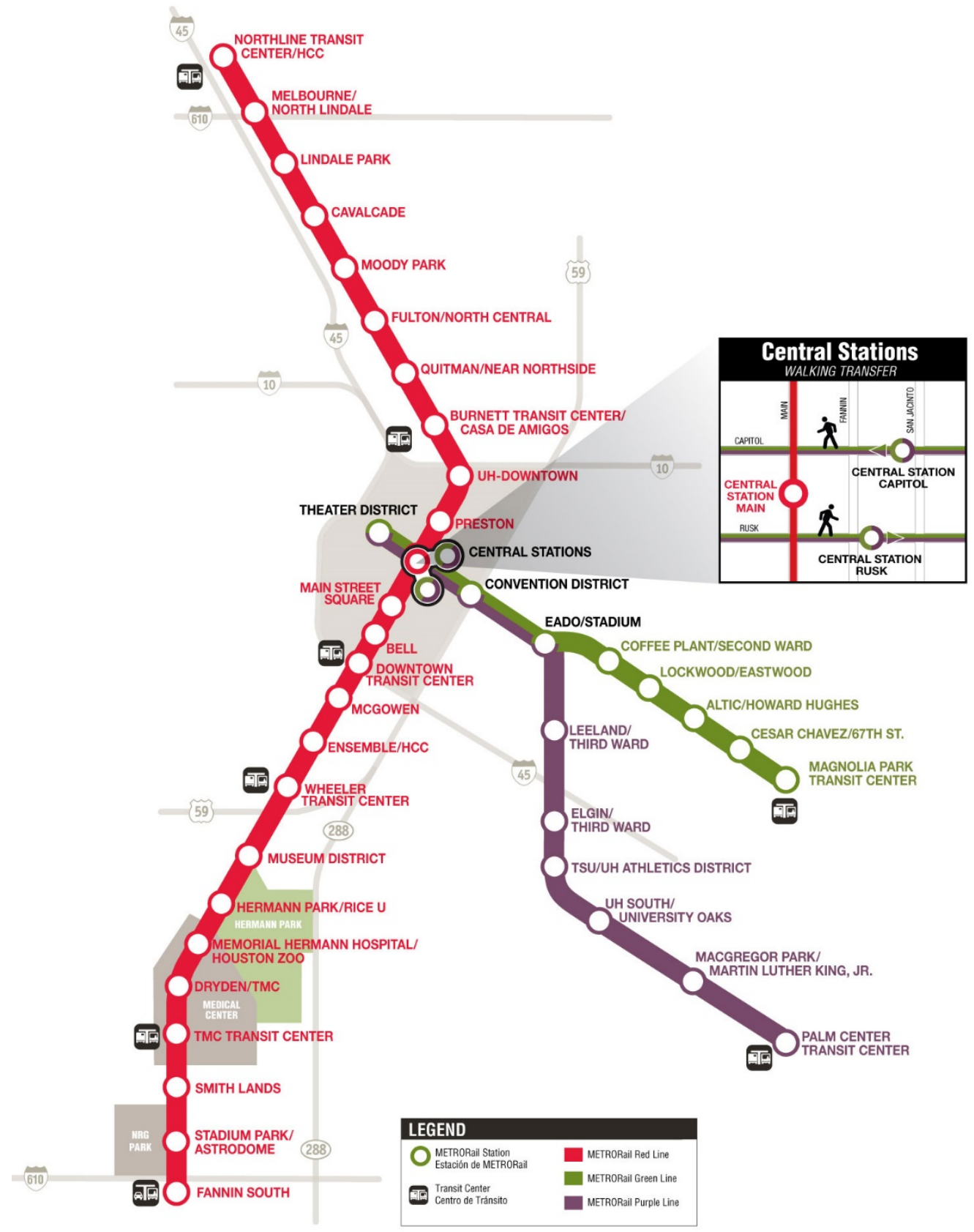

Figure $X$

Houston Metro System Service Map

Source: https://www.ridemetro.org/Sitelmage/SchedulesAndMaps/METRORail-LinesMap.jpg

MINNEAPOLIS - ST. PAUL LIGHT RAIL SYSTEM 


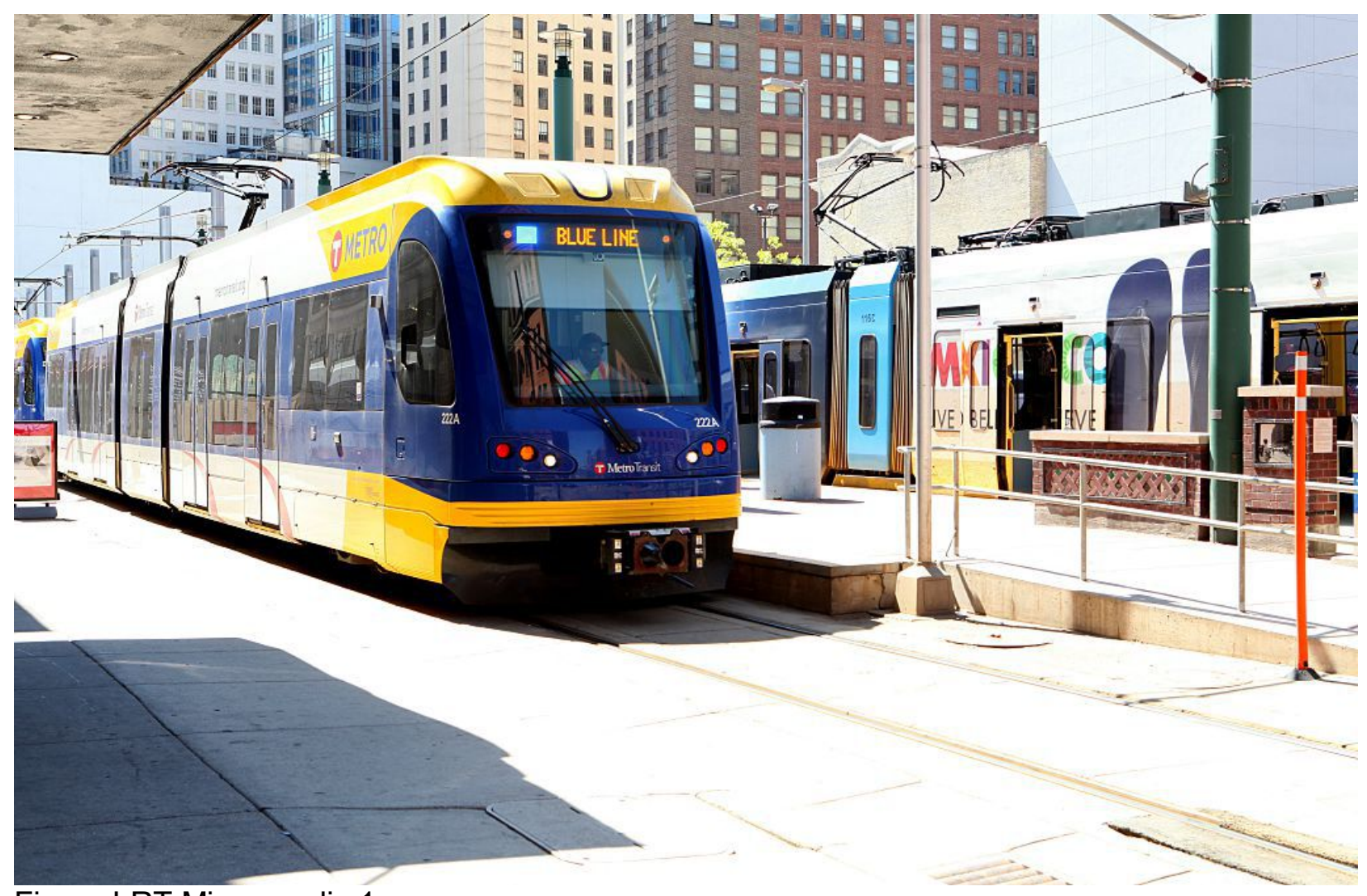

Figure LRT Minneapolis 1

Minneapolis Metro

Source:

https://www.tripsavvy.com/thmb/xCUG_EY8EtIDAAiy8kObdQEEX1o=/1024x665/filters:no_upsc ale():fill(transparent,1)/Gettylmages-476036388-5a578d79da27150037b36fbd.jpg

The Metro Blue Line serves the Minneapolis - St. Paul metro area along its 12-mile route. It runs between the Mall of America to the south and Target Field (Minnesota Twins MLB stadium) to the north. There are 19 stations along the route, and it opened in June of 2004 . There were 10.6 million riders in $2015 .^{10}$

${ }^{10}$ Adapted from: https://en.wikipedia.org/wiki/Metro_Blue_Line_(Minnesota). 


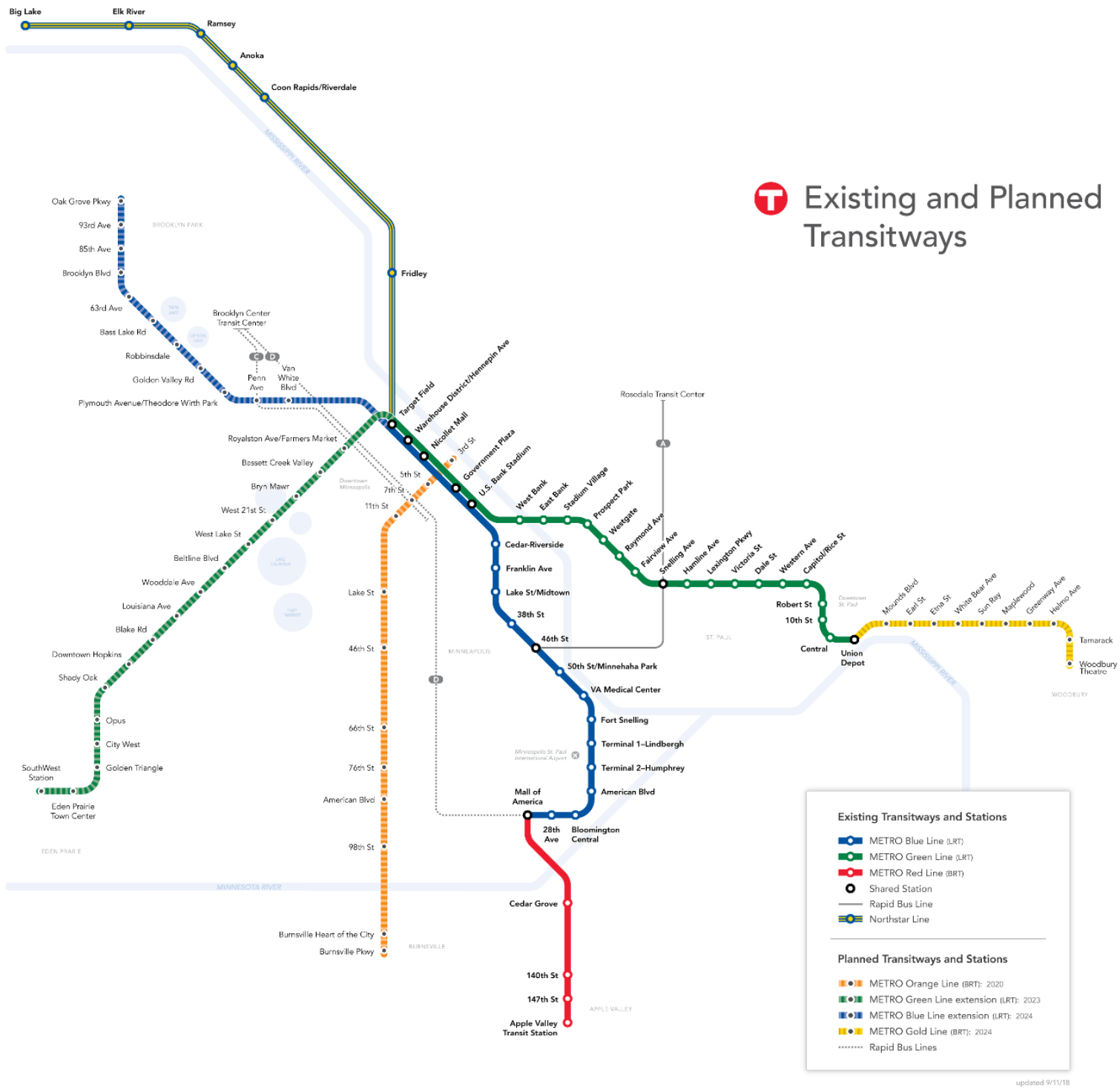

Figure LRT Minneapolis 2

Minneapolis Light Rail Service Map

Source:

https://www.metrotransit.org/Data/Sites/1/media/metro/transitways_diagrammap_2x_11-142018.png 
NORFOLK LIGHT RAIL SYSTEM

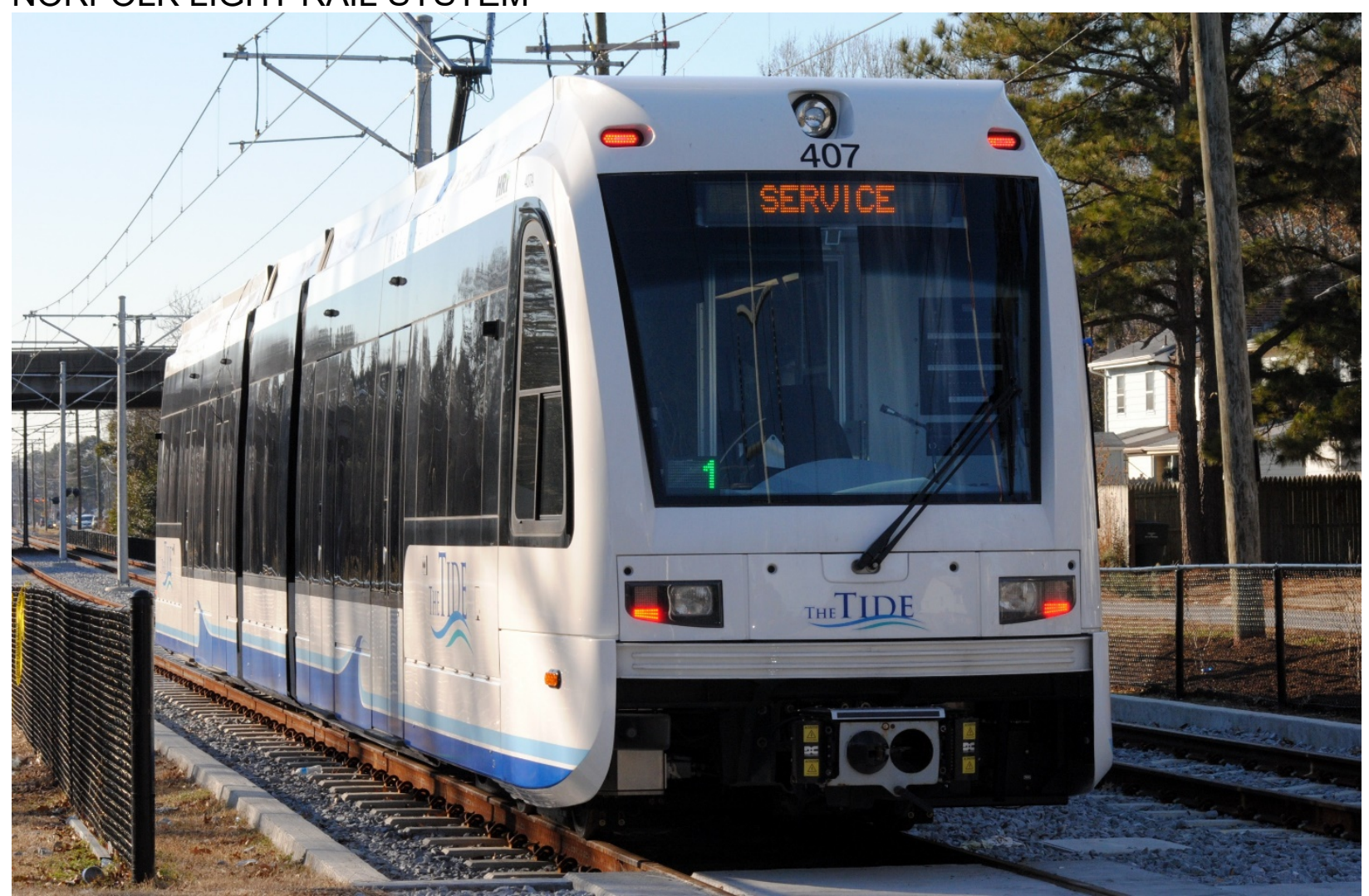

Figure LRT Norfolk 1

The Tide Light Rail System

Source: https://upload.wikimedia.org/wikipedia/commons/b/b6/Tidelrt_01142011.JPG

With 11 stations along one 7.4-mile route, The Tide is a light rail line serving Norfolk, Virginia. It was the first light rail system in Virginia opening on August 19, 2011. As of April 2012, the line was carrying 4,900 passengers per day. ${ }^{11}$

${ }^{11}$ Adapted from: https://en.wikipedia.org/wiki/Tide_Light_Rail. 


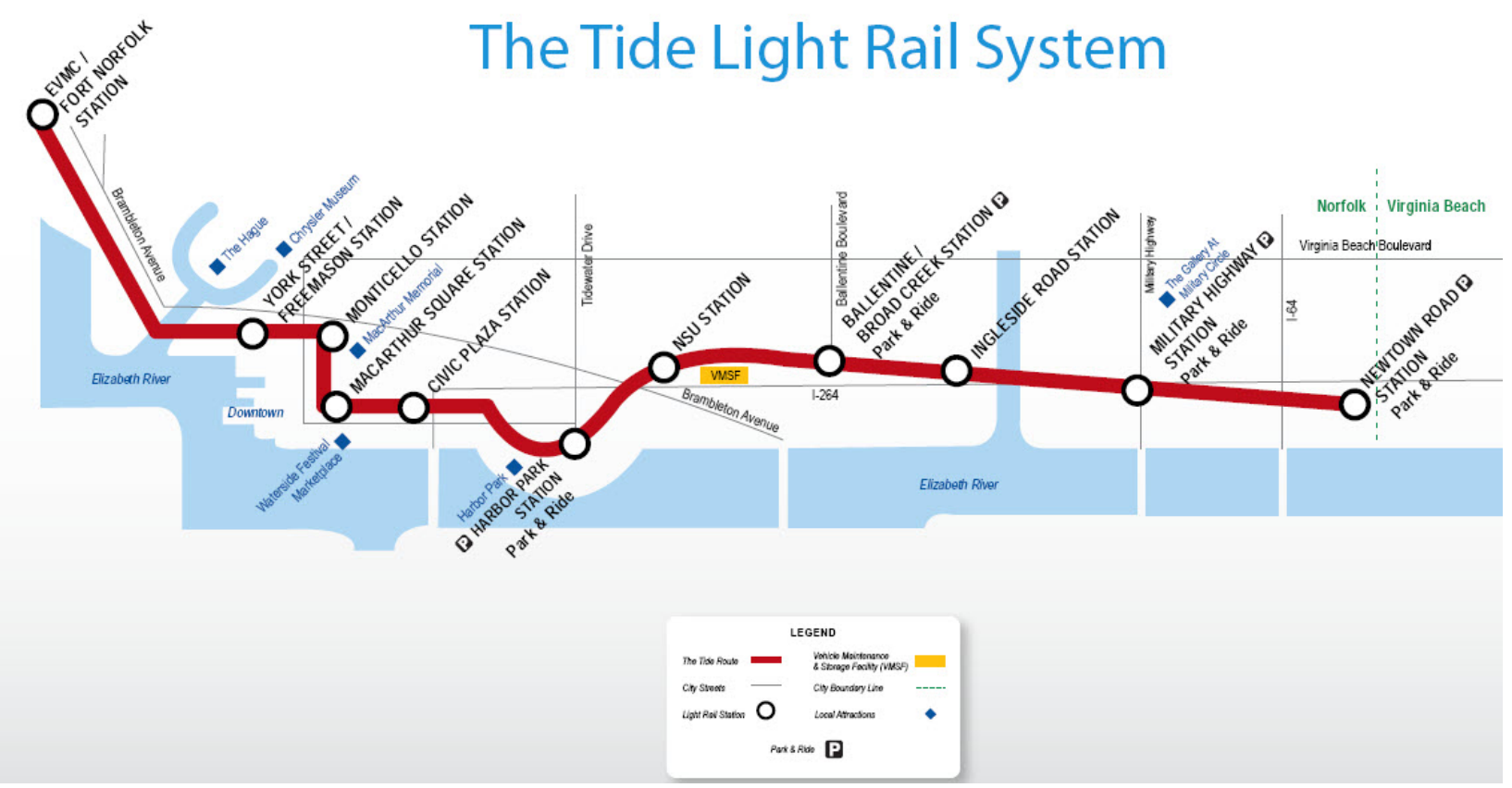

Figure LRT Norfolk 2

The Tide Light Rail Service Map

Source: http://www.railfanguides.us/va/tide/index.htm

PHOENIX LIGHT RAIL SYSTEM 


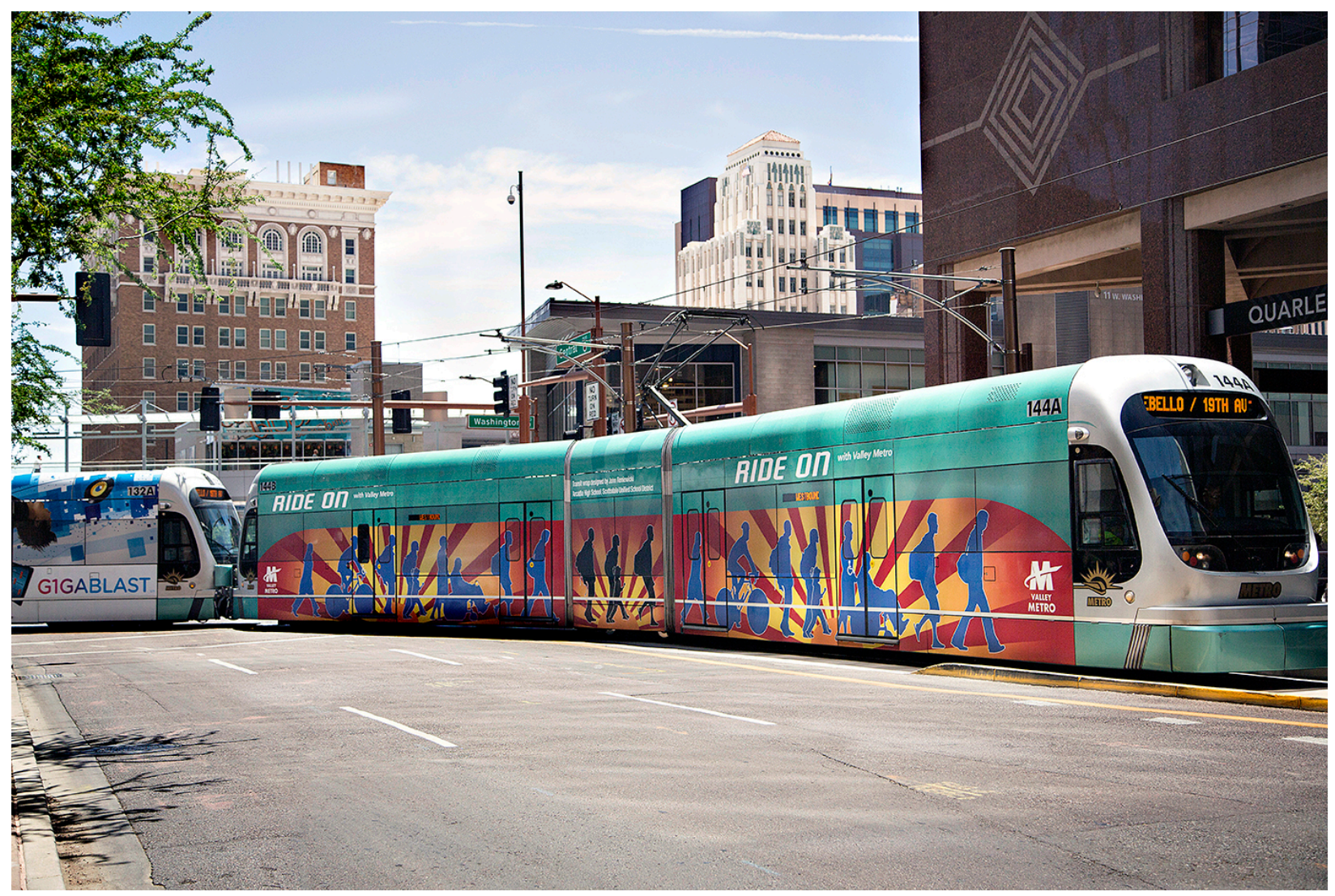

Figure LRT Phoenix 1

Phoenix Valley Metro

Source: https://www.visitphoenix.com/learn-plan/getting-around/public-transportation/ Going between Mesa, Tempe, and Phoenix, the Valley Metro Rail opened in late December of 2008. Valley Metro carries just over 50,000 people per day along a 26.3-mile, 35-station route. It is the $14^{\text {th }}$ busiest light rail system in the nation. ${ }^{12}$

${ }^{12}$ Adapted from: https://en.wikipedia.org/wiki/Valley_Metro_Rail. 


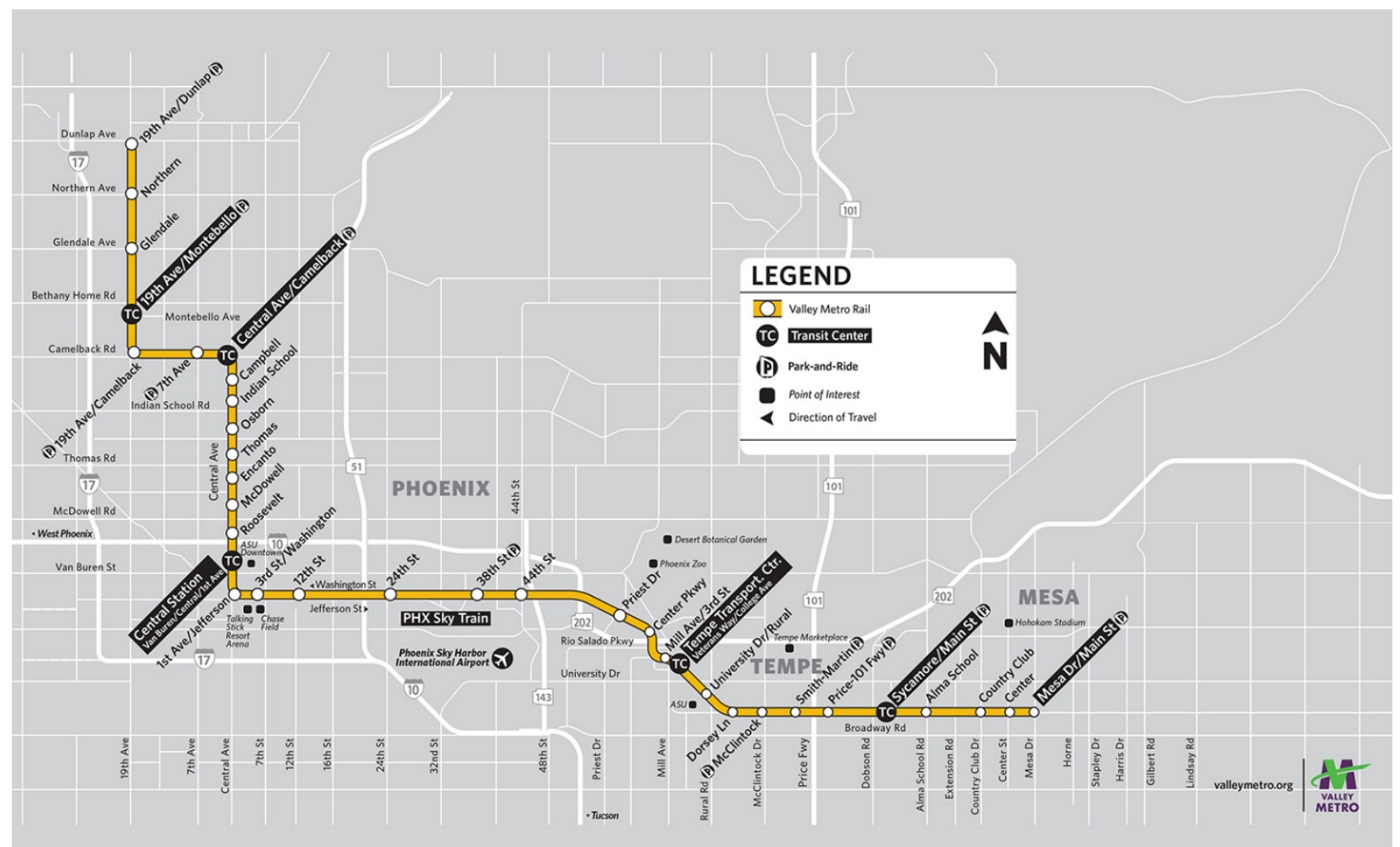

Figure LRT Phoenix 2

Phoenix Valley Metro Rail Service Map

Source: http://azmag.gov/Programs/Transportation/Transit

\section{PITTSBURGH LIGHT RAIL SYSTEM}




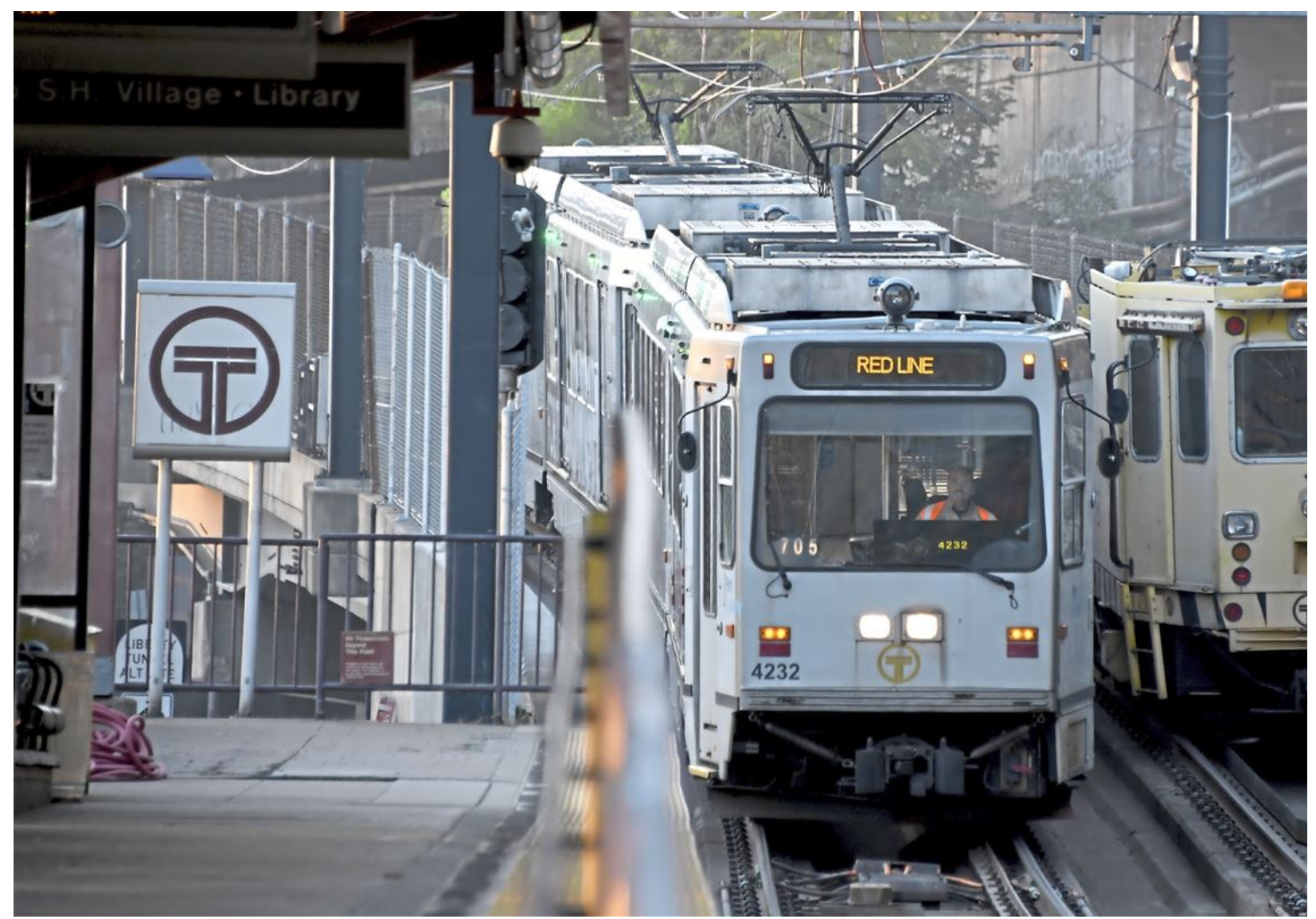

Figure LRT Pittsburgh 1

Pittsburgh Metro

Source: https://www.post-gazette.com/news/transportation/2018/08/23/Port-Authority-StationSquare-light-rail-vehicles-closed-two-hours/stories/201808230159

With 52 stations and a 26.2-mile route, the Pittsburgh Light Rail, commonly known as The T, began operation in 1984. 27,700 passengers ride the system per day, and it operates on lines that date back to $1903 .{ }^{13}$

\footnotetext{
${ }^{13}$ Adapted from:

https://ipfs.io/ipfs/QmXoypizjW3WknFiJnKLwHCnL72vedxjQkDDP1mXWo6uco/wiki/Pittsburgh_light_rai I.html.
} 


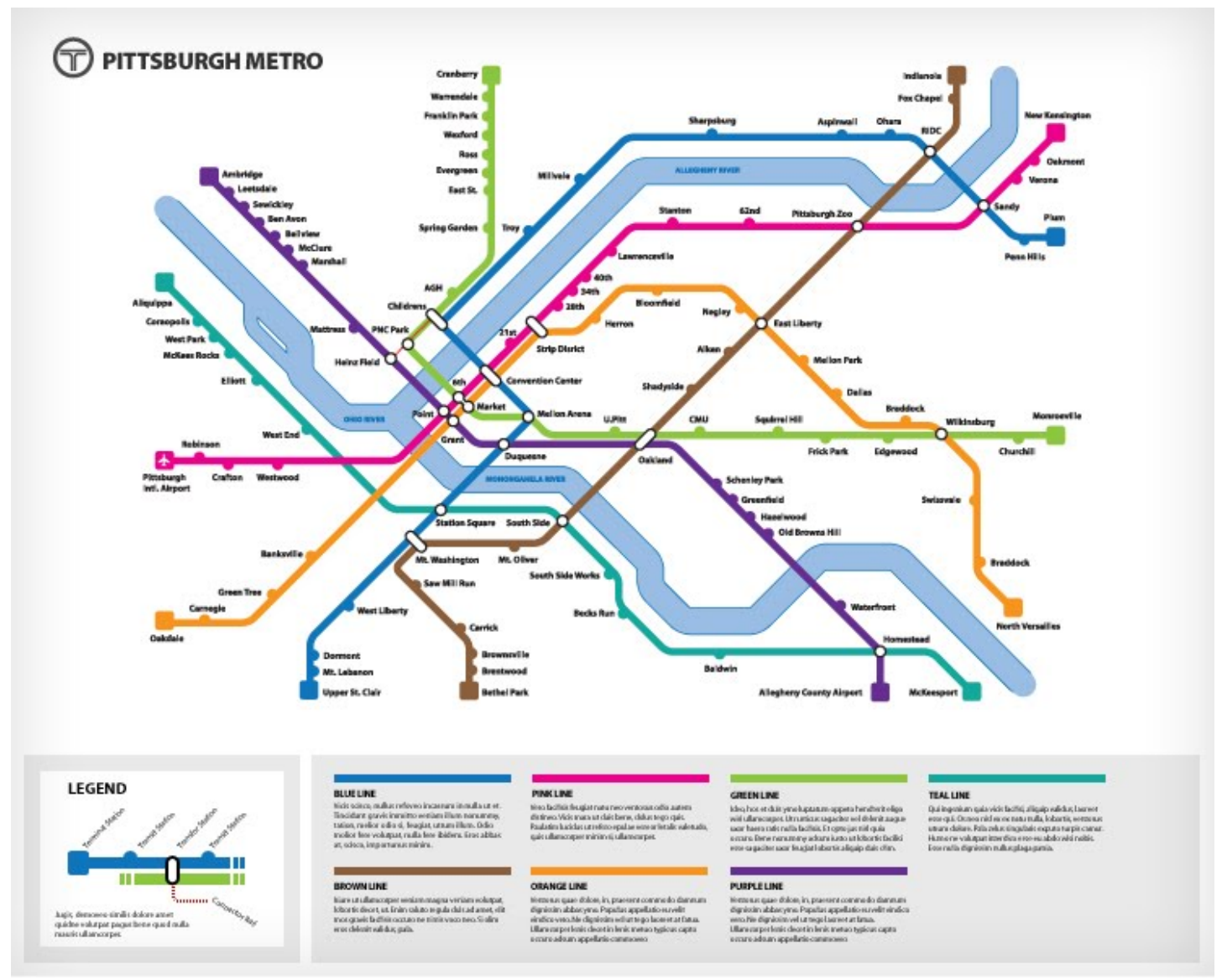

Figure LRT Pittsburgh 2

Pittsburgh Metro Service Map

Source:

https://ipfs.io/ipfs/QmXoypizjW3WknFiJnKLwHCnL72vedxjQkDDP1mXWo6uco/wiki/Pittsburgh_I ight_rail.html 


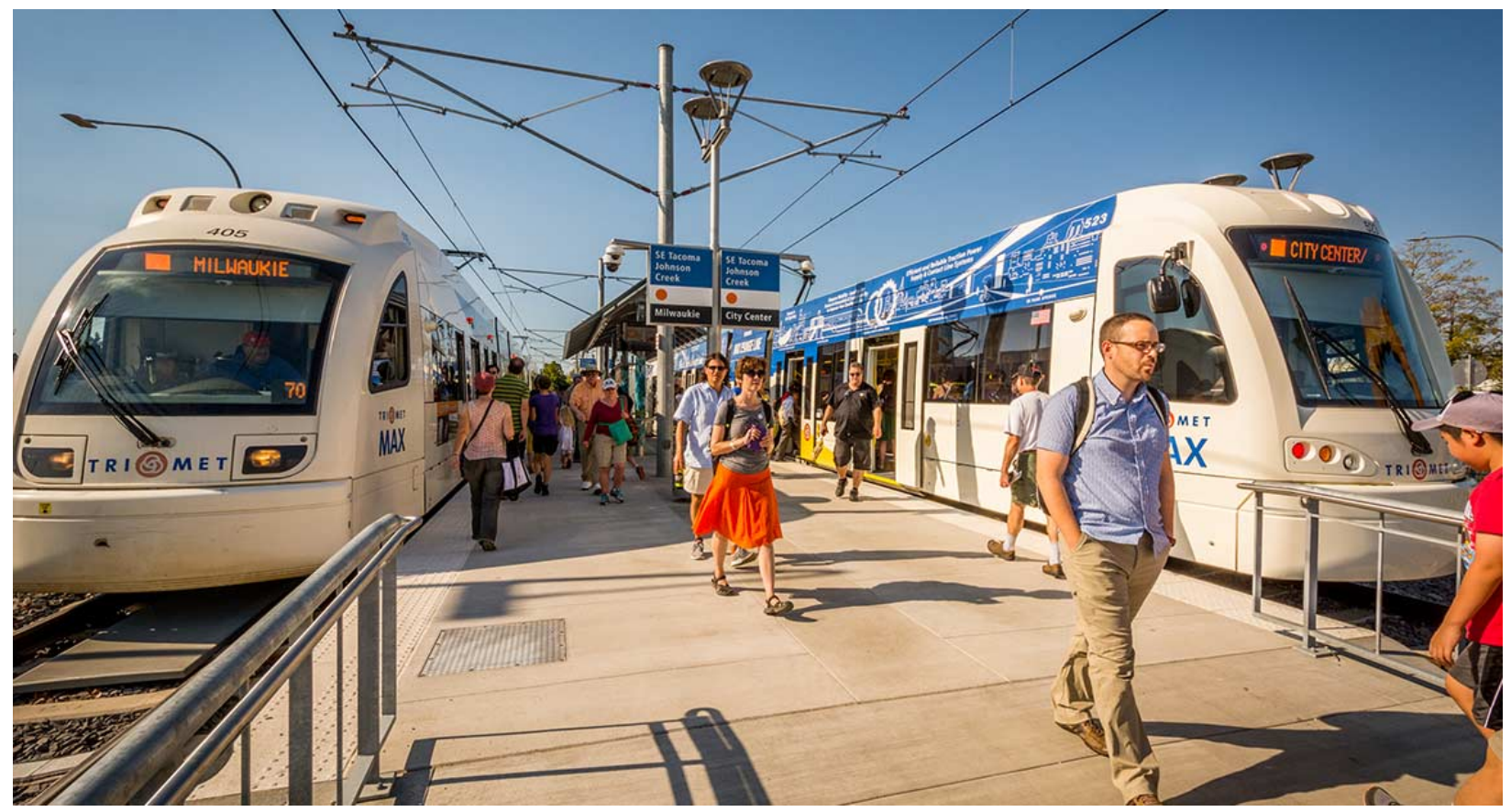

Figure LRT Portland 1

Portland MAX Light Rail System

Source: https://trimet.org/max/

Serving Portland, Oregon, the MAX light rail system has over 121,000 passengers per day. There are five lines stretching to suburbs in all directions with 97 stations. MAX began operation in 1986. There are 86 miles of track in total. ${ }^{14}$

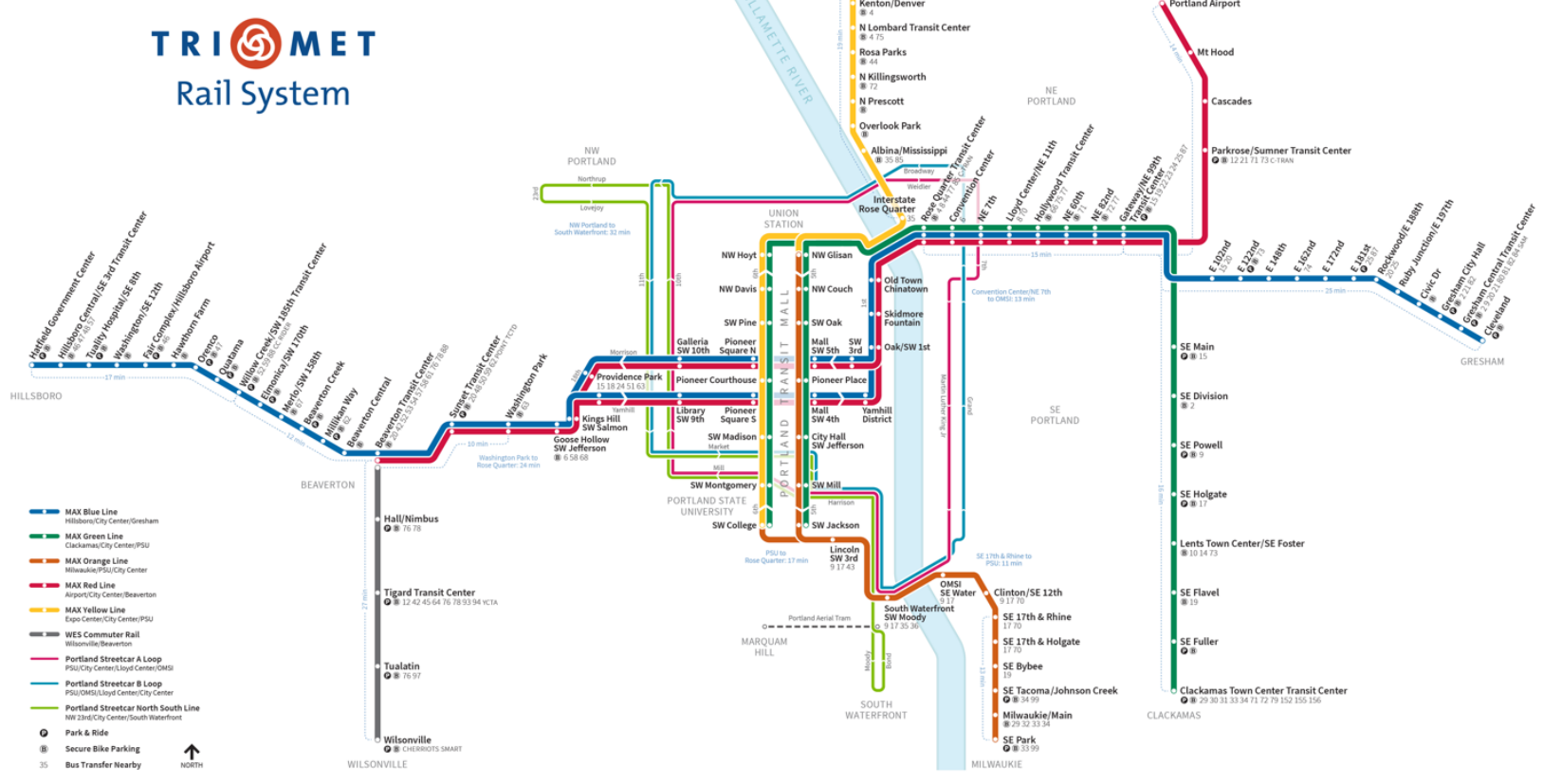

${ }^{14}$ Adapted from: https://en.wikipedia.org/wiki/MAX_Light_Rail. 
Figure LRT Portland 2

MAX Service Map

Source: https://trimet.org/max/

\section{SACRAMENTO LIGHT RAIL SYSTEM}

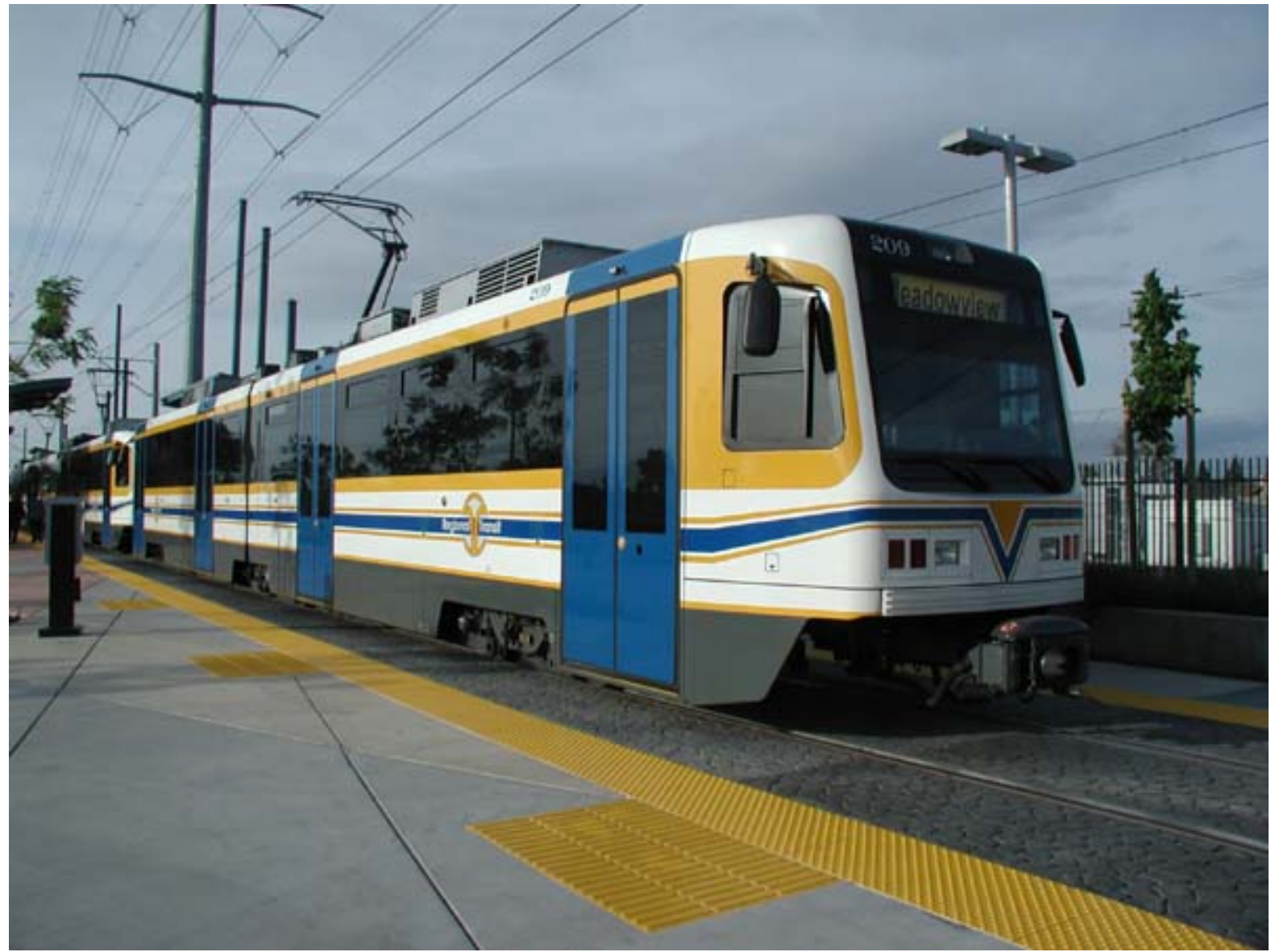

Figure LRT Sacramento 1

Sacramento Light Rail

Source: http://ktransit.com/transit/NAmerica/uscalifornia/sacramento/lightrail/Photos/sac-Irmeadowview-041404-05.jpg

The sixteenth busiest light rail system in the nation, Sacramento's RT system has an average of just under 40,000 passengers riding every weekday. It has 3 lines along 54 stations. All lines, though serving separate suburban areas, go through downtown Sacramento. The line opened on March 12, 1987. 


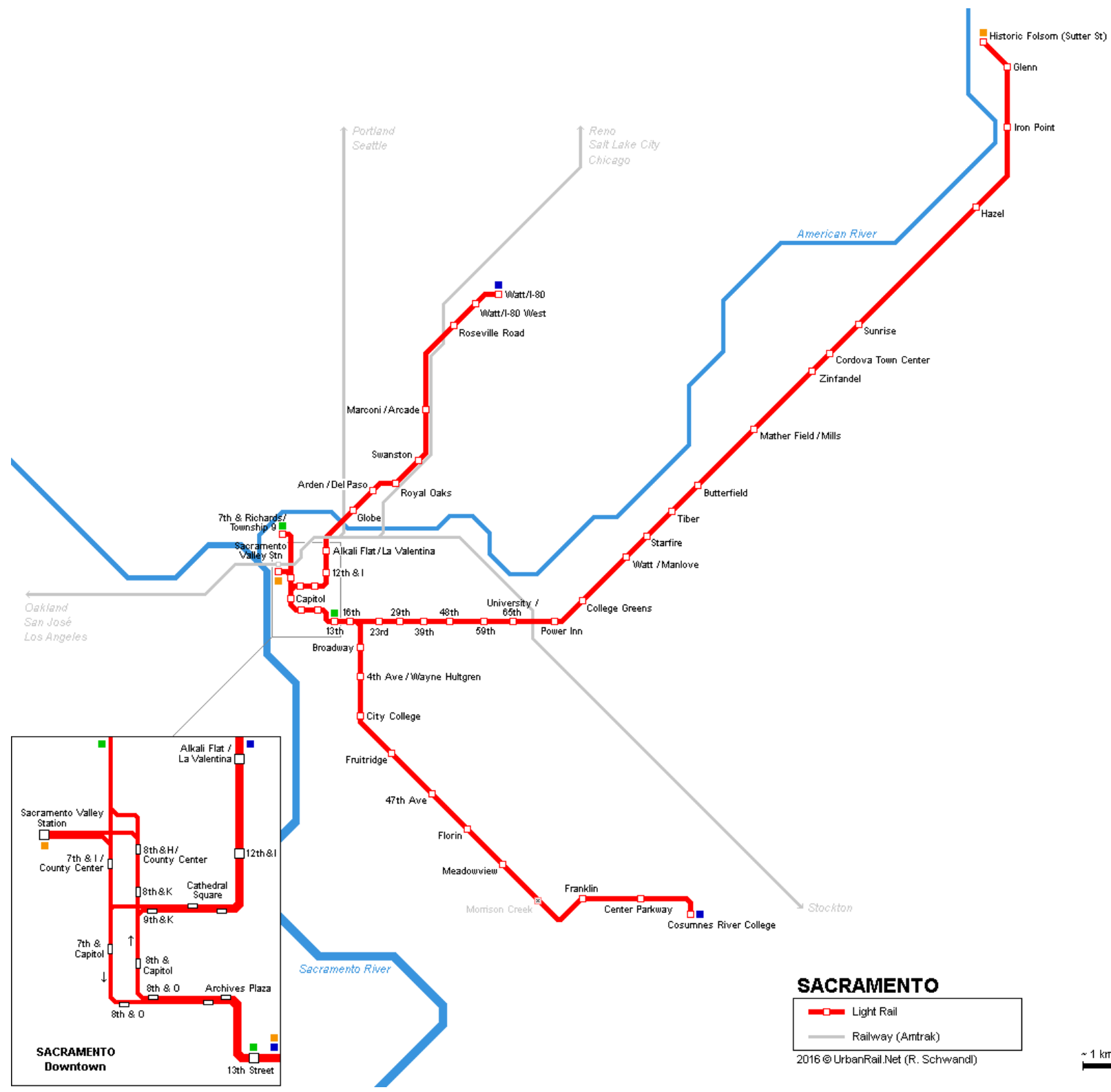

Figure LRT Sacramento 2

Sacramento Light Rail Service Map

Source: http://www.urbanrail.net/am/sacr/sacramento-map.gif

SALT LAKE CITY LIGHT RAIL SYSTEM 


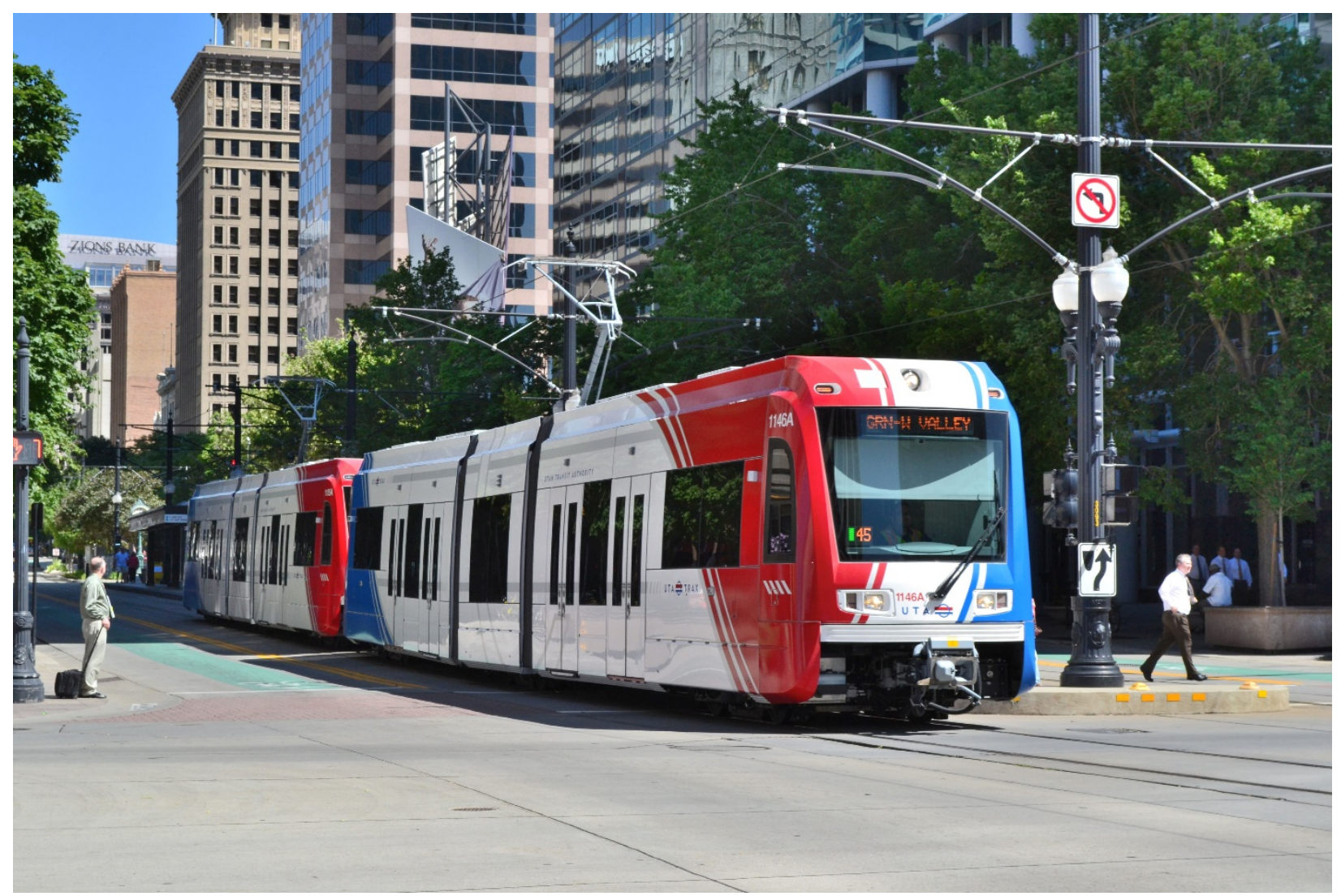

Figure LRT Salt Lake City 1

Salt Lake City Light Rail

Source: https://en.wikipedia.org/wiki/TRAX_(light_rail)

There are three lines which the Transit Express, or TRAX, light rail system serves in the Salt Lake City, Utah metro area. TRAX has a daily ridership of approximately 67,300 people with 50 stations in total. The line was open for operation on December 4, 1999 and has 146 vehicles in total. The system's length is 44.8 miles. $^{15}$

${ }^{15}$ Adapted from: https://en.wikipedia.org/wiki/TRAX_(light_rail). 


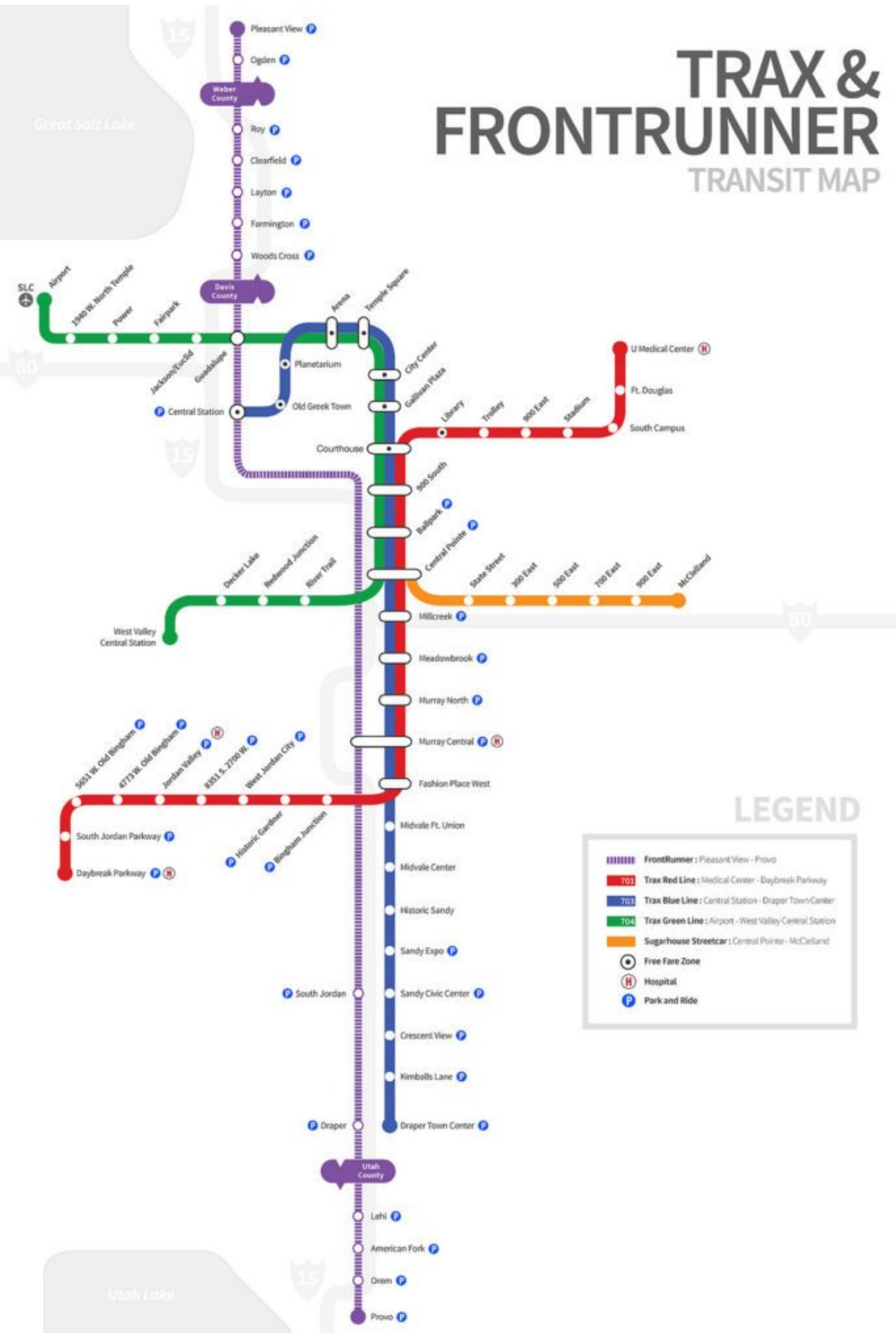

Figure LRT Salt Lake City 2

Salt Lake City Light Rail Service Map

Source: https://i1.wp.com/www.transitmap.net/wp-

content/uploads/2012/12/tumblr_meu9utRQeV1r54c4oo1_1280-699x1024.jpg?ssI=1

SAN DIEGO LIGHT RAIL SYSTEM 


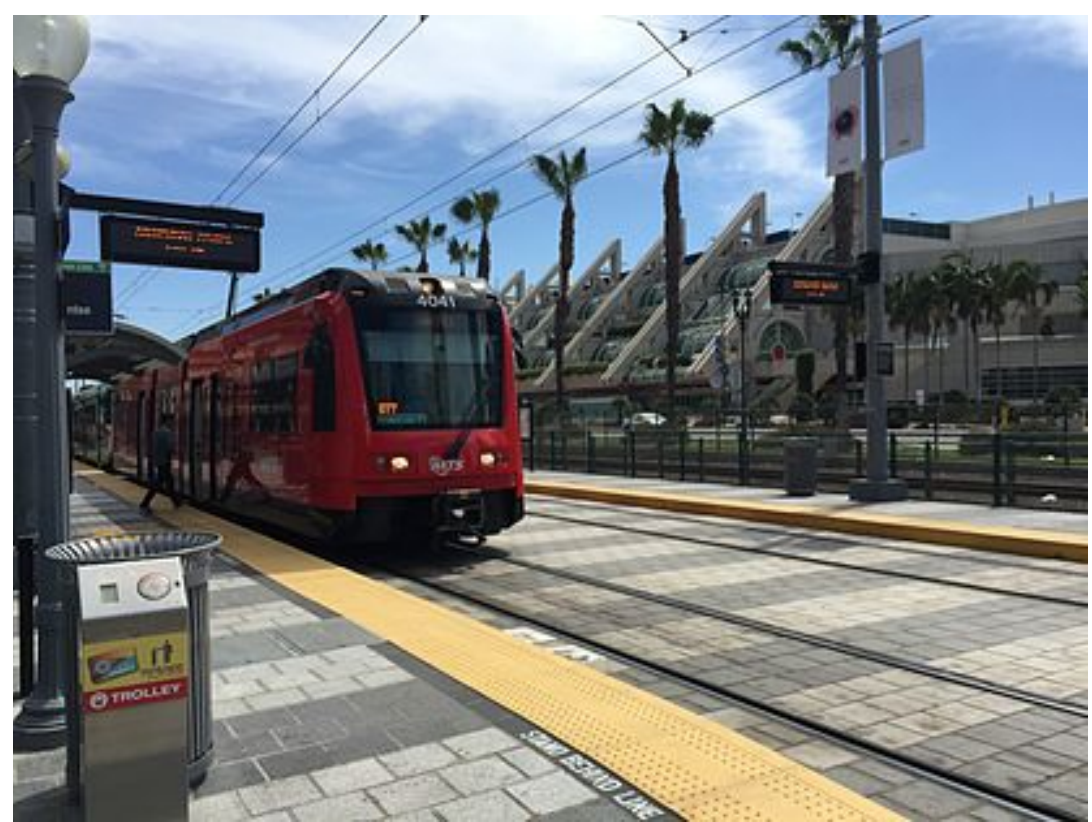

Figure LRT San Diego 1

San Diego Trolley

Source: https://en.wikipedia.org/wiki/San_Diego_Trolley

The San Diego Trolley has 55 stations for its 3 daily lines and serves 119,800 passengers daily. It began operation in 1981, with the system as a whole dating back to the 1880 s. The line is 53.5 miles long and brings passengers from suburbs into the downtown area. ${ }^{16}$

${ }^{16}$ Adapted from: https://en.wikipedia.org/wiki/San_Diego_Trolley. 


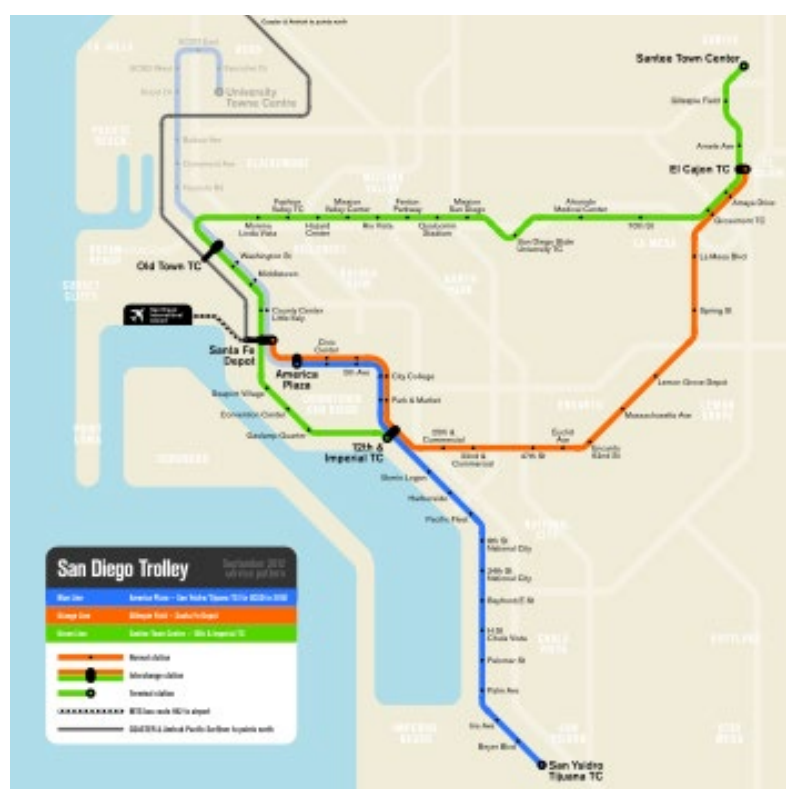

Figure LRT San Diego 2

San Diego Trolley Service Map

Source:

https://upload.wikimedia.org/wikipedia/commons/thumb/8/8a/San_Diego_Trolley_September_2 012.svg/350px-San_Diego_Trolley_September_2012.svg.png 
SAN JOSE LIGHT RAIL SYSTEM

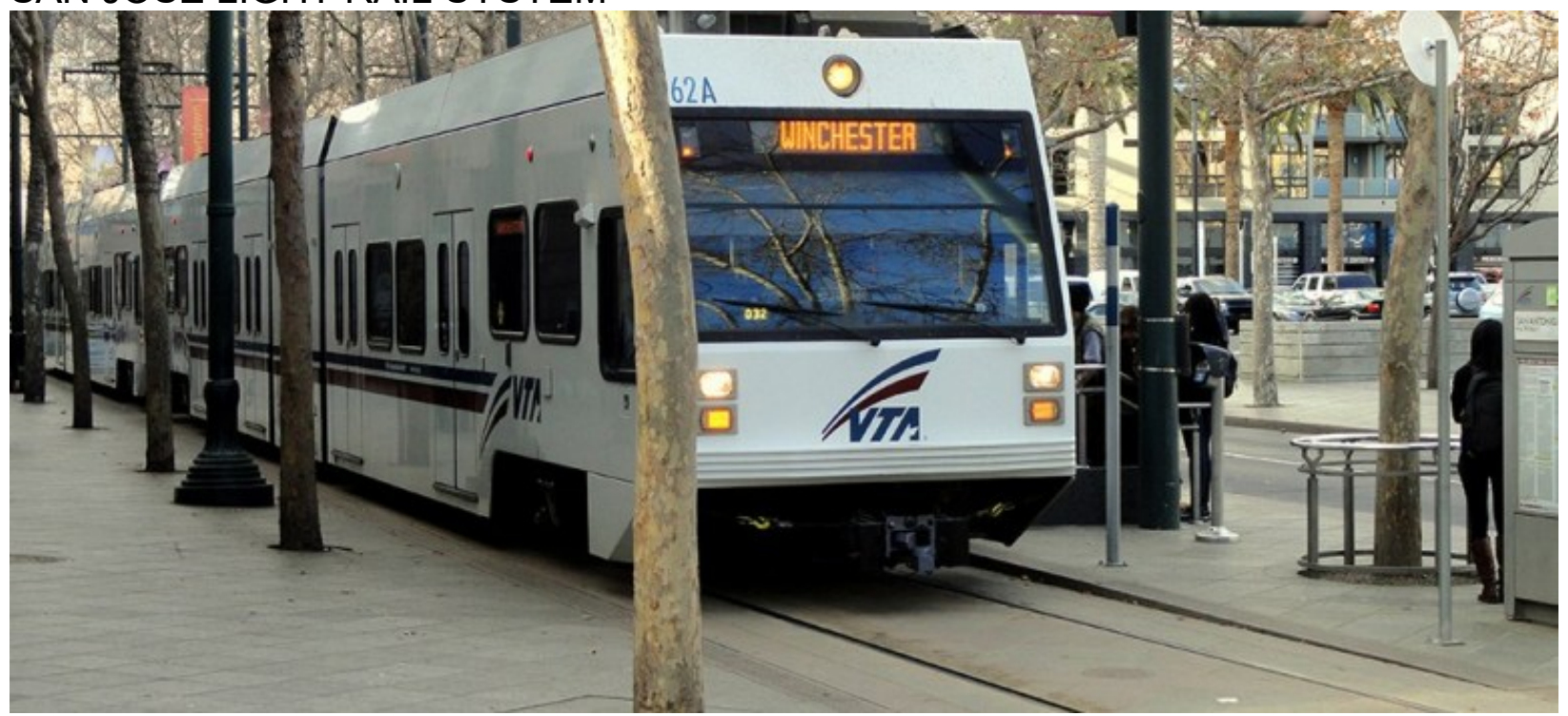

Figure LRT San Jose 1

San Jose Light Rail

Source: https://i2.wp.com/www.sanjoseinside.com/wp-content/uploads/2017/09/VTA-Light-RailWikimedia.jpg?resize $=772 \% 2 \mathrm{C} 350$

Serving the Silicon Valley and San Jose, the VTA Light Rail consists of 3 lines serving 62 stations with an additional four stations planned for development. On an annual basis, the VTA Light Rail carries 11.03 million passengers as of 2015. The system began operation on December 11, 1987, and has 42.2 miles of track. ${ }^{17}$

${ }^{17}$ Adapted from: https://en.wikipedia.org/wiki/Santa_Clara_Valley_Transportation_Authority_light_rail. 


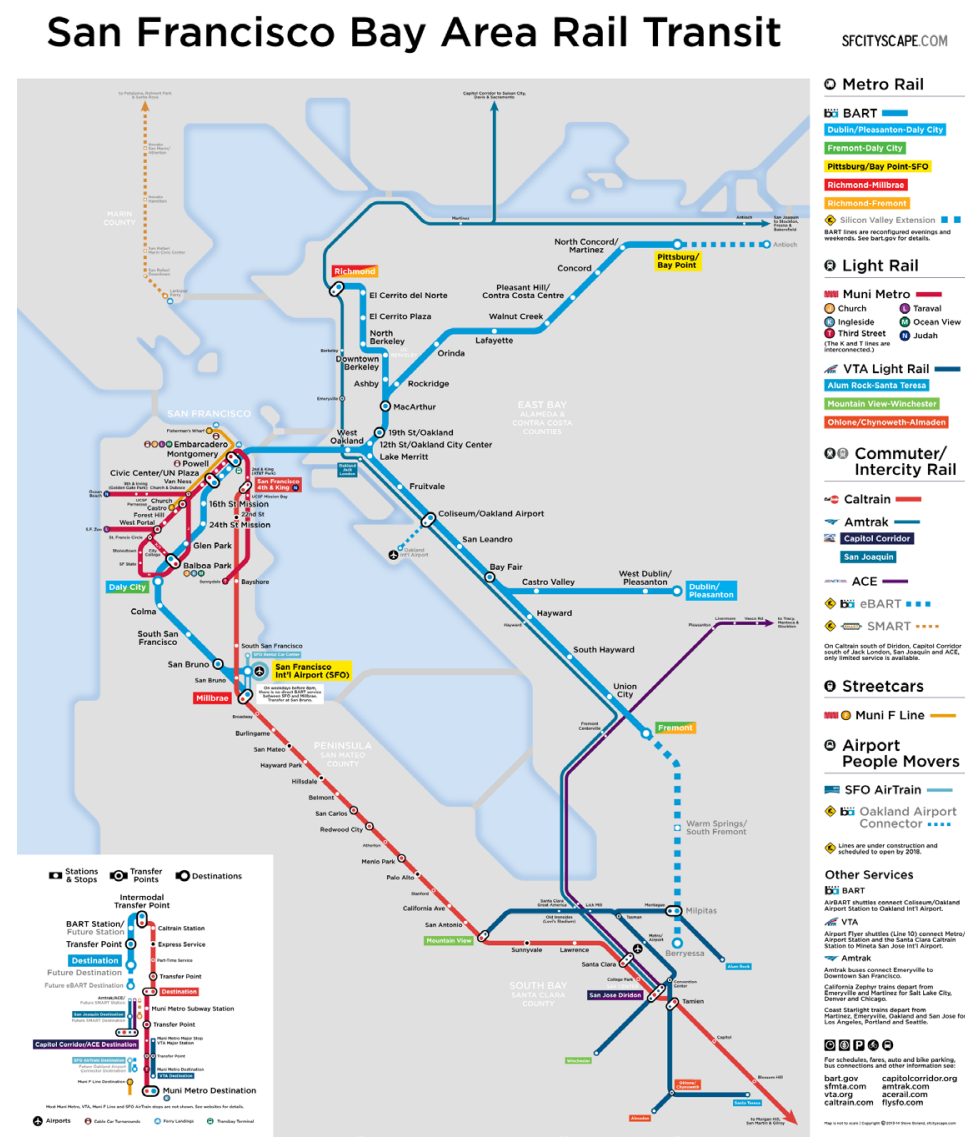

Figure LRT San Jose 2

San Jose VTA Service Map (Denoted in light blue)

Source: https://rsnous.com/posts/my-favorite-regional-transit-maps/ 


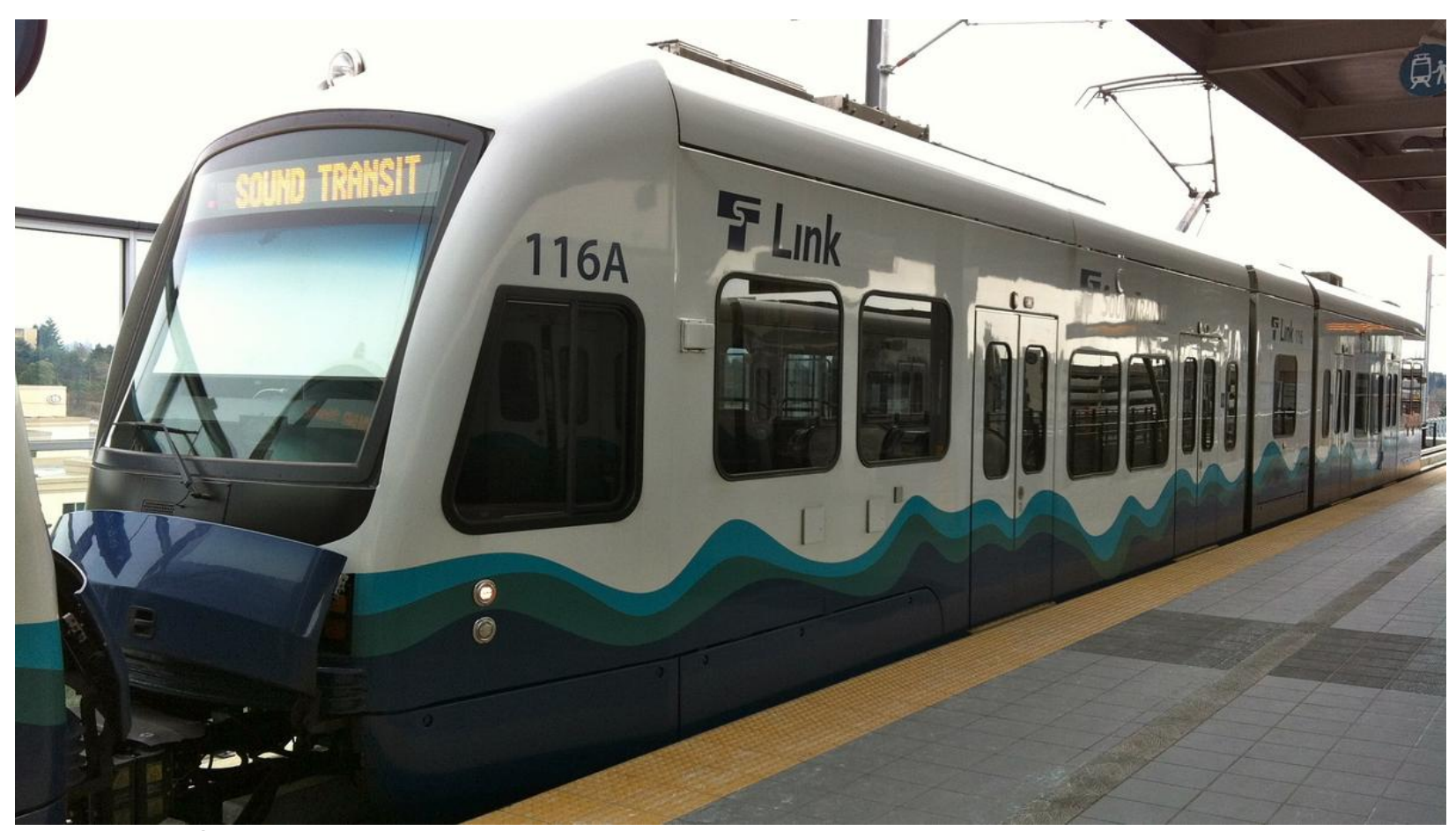

Figure LRT Seattle 1

Link Light Rail

Source: https://www.bizjournals.com/seattle/news/2015/06/05/ballard-to-seattle-heres-whatmay-be-next-for.html

With an annual ridership of over 24 million, the Link Light Rail system began operation in August of 2003. The line consists of two disconnected lines formed by a partnership between regional transit partners - the Central Link in King County and the Tacoma Link in Pierce County. There are 22 stations in total along 21.95 miles of track. The line opened on August 22, 2003. ${ }^{18}$

${ }^{18}$ Adapted from: https://en.wikipedia.org/wiki/Link_light_rail. 


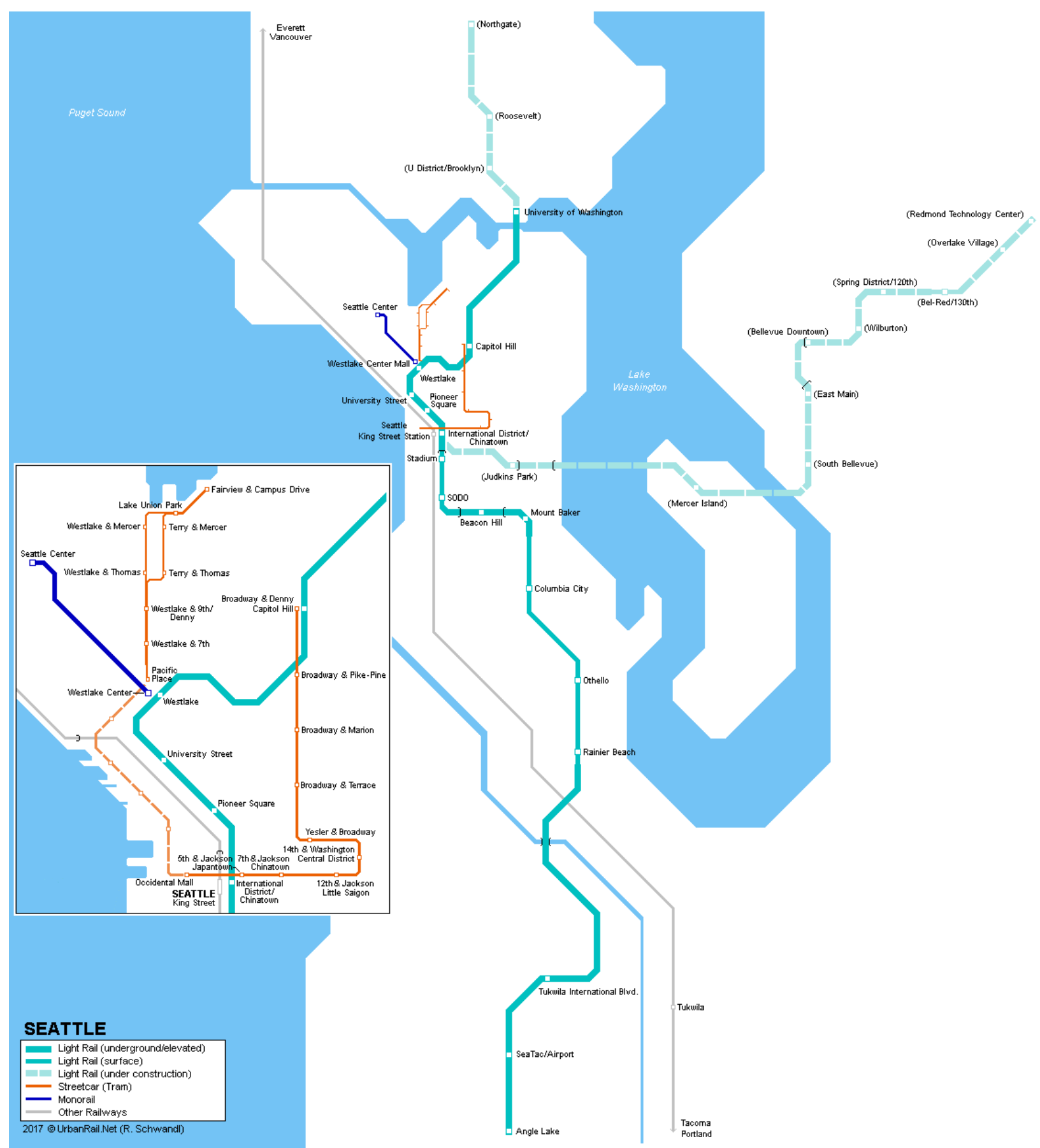

Figure LRT Seattle 2

Seattle Light Rail Service Map

Source: http://www.urbanrail.net/am/seat/seattle-map.png

ST. LOUIS LIGHT RAIL SYSTEM 


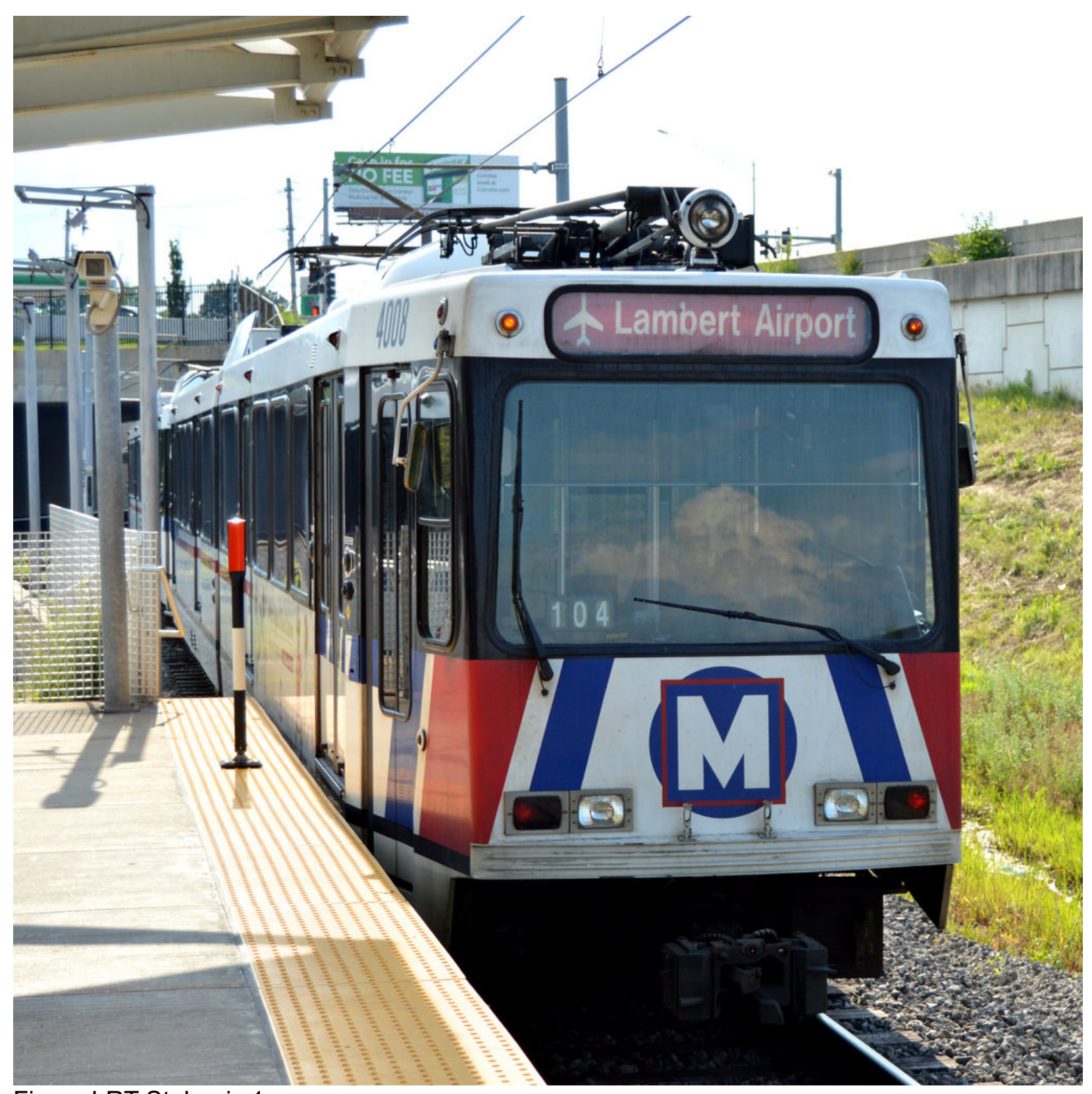

Figure LRT St. Louis 1

St. Louis Metrolink

Source: https://farm1.staticflickr.com/450/18645452774_308f375b90_b.jpg

With two lines, St. Louis' Metrolink opened on July 31, 1993. The system has 38 stations and carries on average 53,123 people per day. The system extends into the suburbs of St. Louis in Missouri and Illinois as well as the airport and the Scott Air Force Base. The line is 46 miles in total length. ${ }^{19}$

${ }^{19}$ Adapted from: https://en.wikipedia.org/wiki/MetroLink_(St._Louis). 


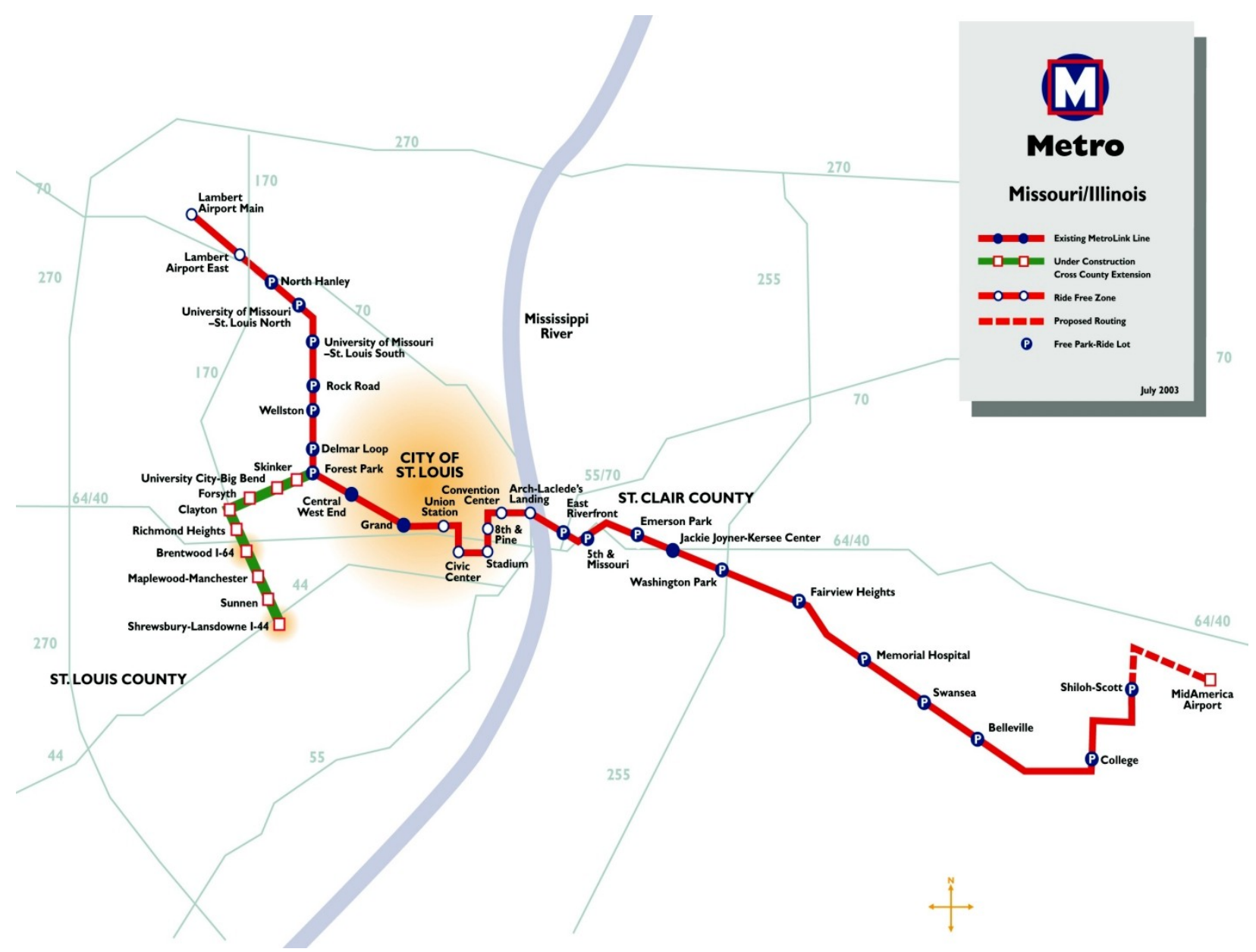

Figure LRT St. Louis 2

St. Louis Metro Service Map

Source: https://www.lightrailnow.org/images/stl-Irt-map-system_cross-county-metro.jpg 


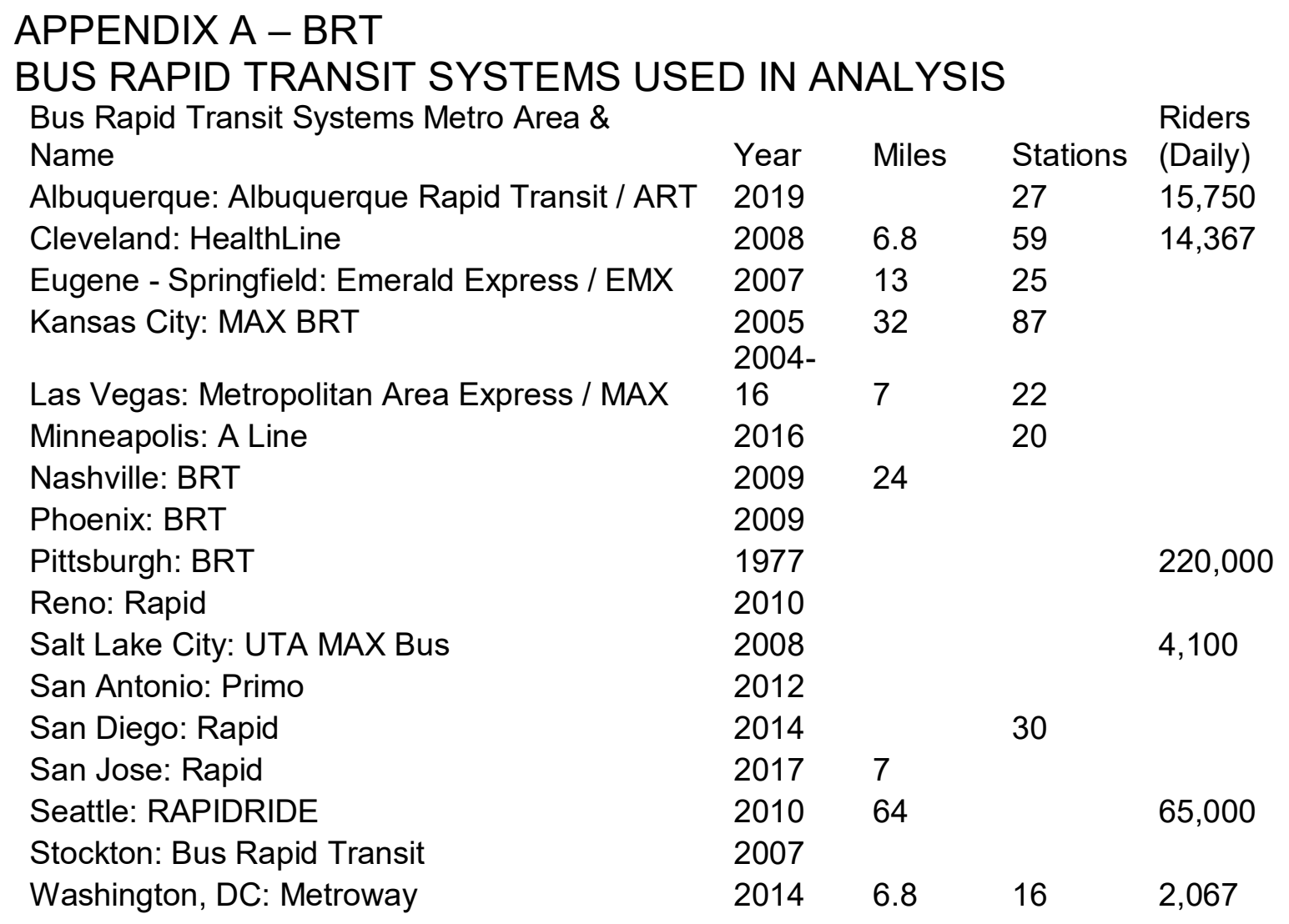




\section{ALBUQUERQUE BUS RAPID TRANSIT SYSTEM}

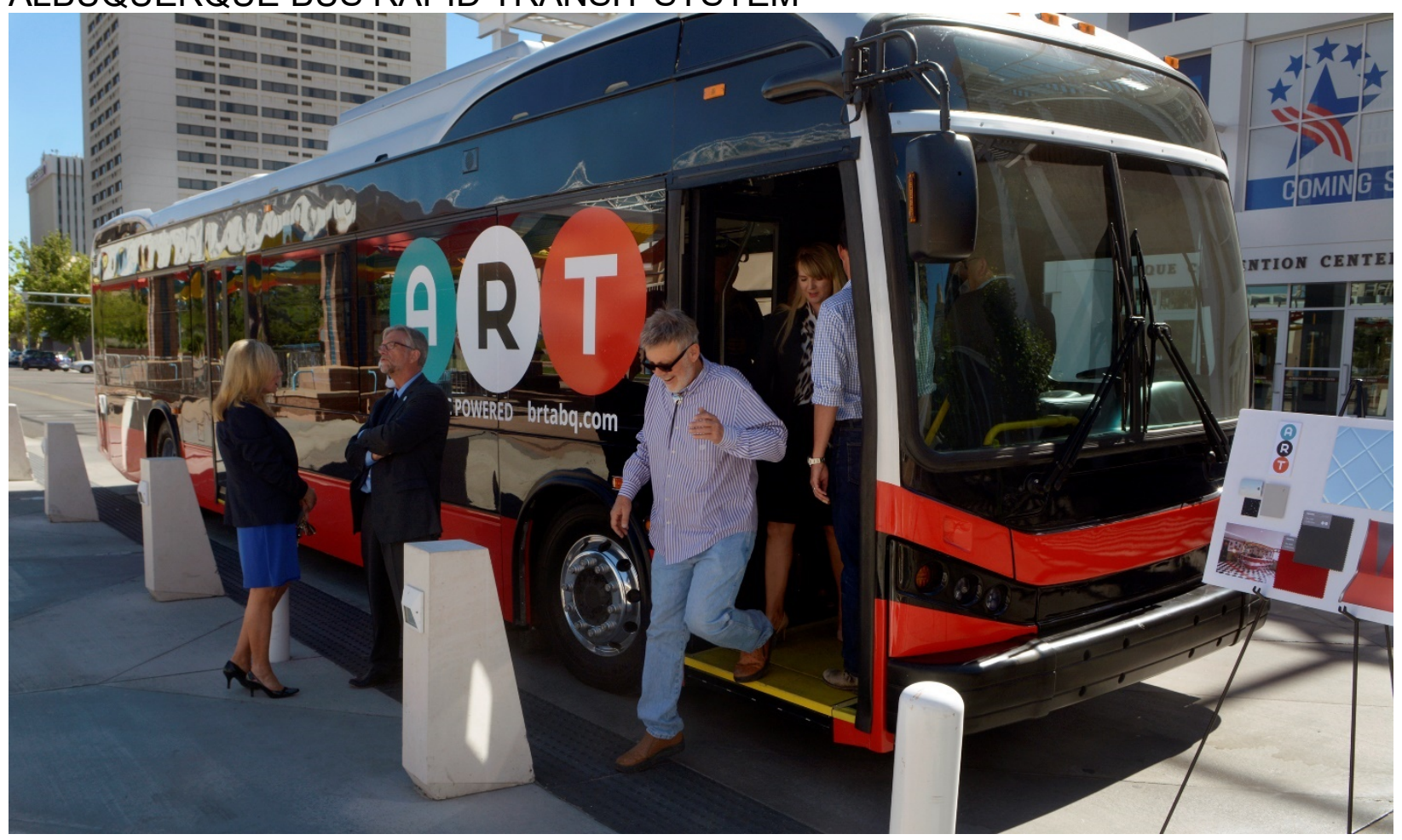

Figure BRT Albuquerque 1

ART Rolling Stock

Source: https://www.abqjournal.com/815792/court-hearing-begins-on-suit-that-could-halt-abqrapid-transit.html

Albuquerque Rapid Transit, abbreviated ART, is a rapid transit line slated to open in 2019. Its route is set to revive parts of historic Route 66 and features 27 stops. $^{20}$

\footnotetext{
${ }^{20}$ Adapted from: http://www.cabq.gov/transit/art-information.
} 


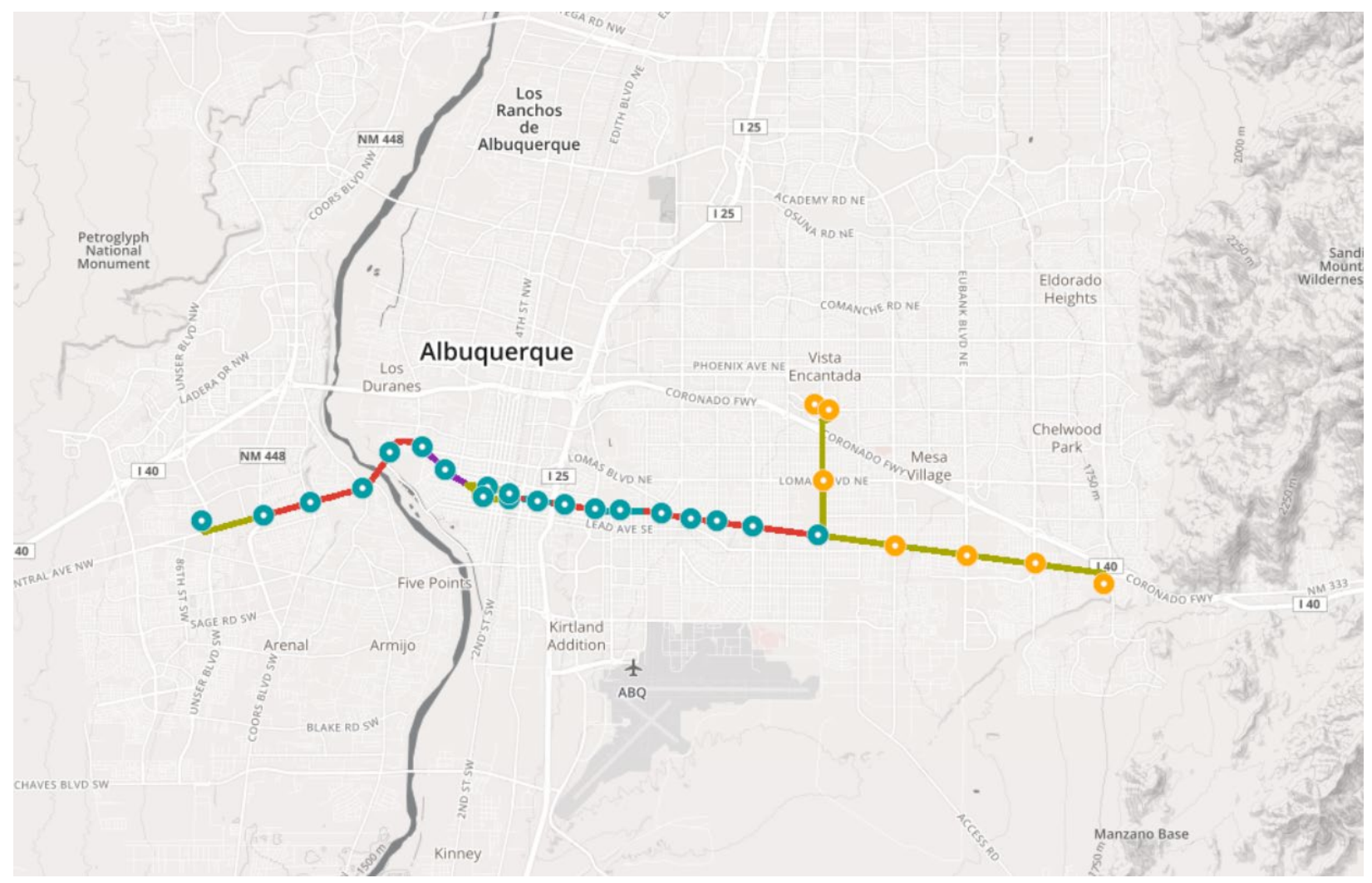

Figure BRT Albuquerque 2

ART System Map

Source: https://www.brtabq.com/Map

CLEVELAND BUS RAPID TRANSIT SYSTEM 


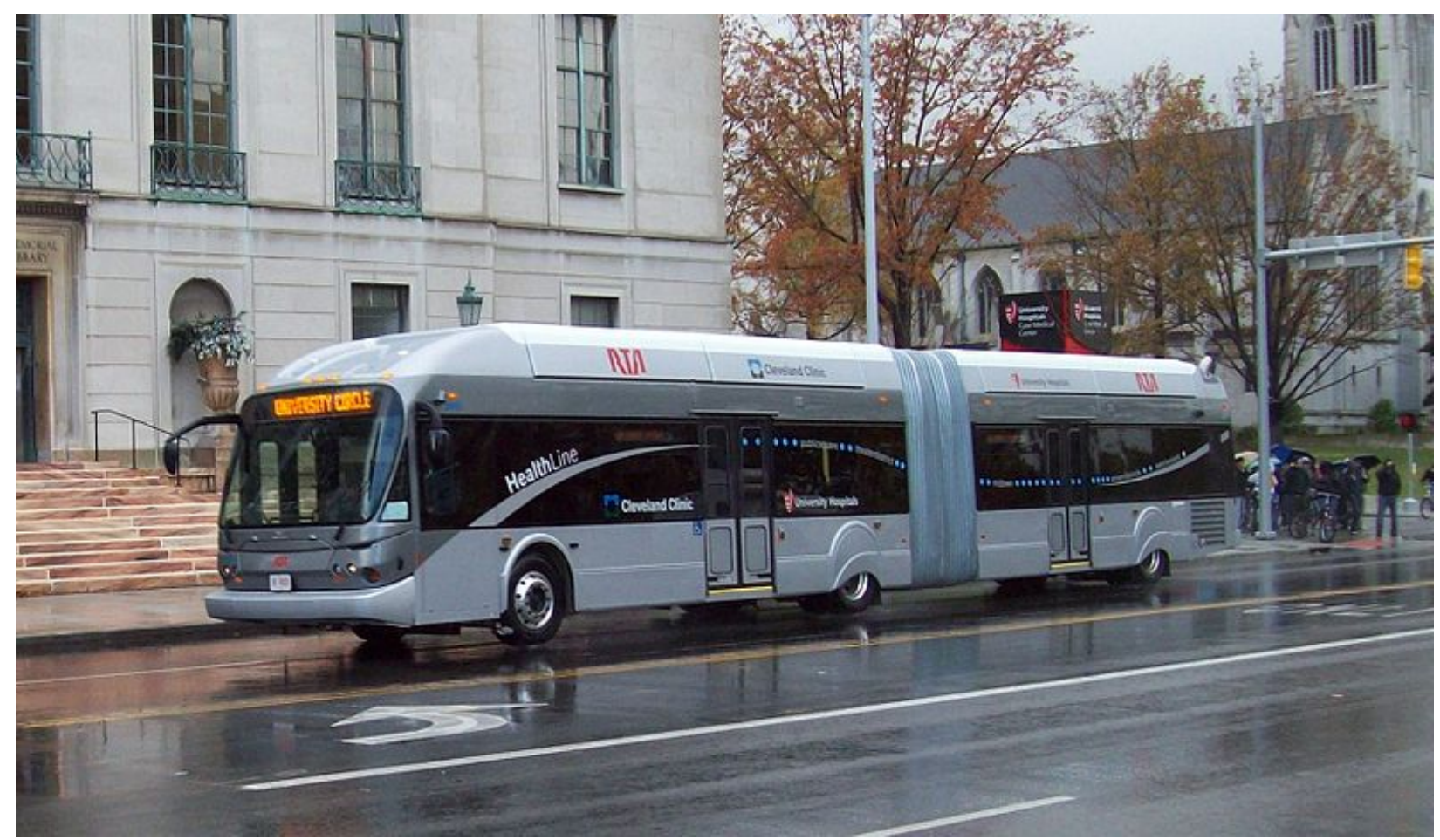

Figure BRT Cleveland 1

HealthLine BRT System

Source: https://en.wikipedia.org/wiki/File:HealthLine_1.jpg

The HealthLine is the bus rapid transit system in Cleveland, Ohio. It is operated by the Greater Cleveland Regional Transit Authority. The line has 59 stations along a 6.8-mile route. Daily, it serves 14,367 passengers. It is a top-rated BRT system according to the BRT Standard. ${ }^{21}$

${ }^{21}$ Adapted from: https://en.wikipedia.org/wiki/HealthLine. 


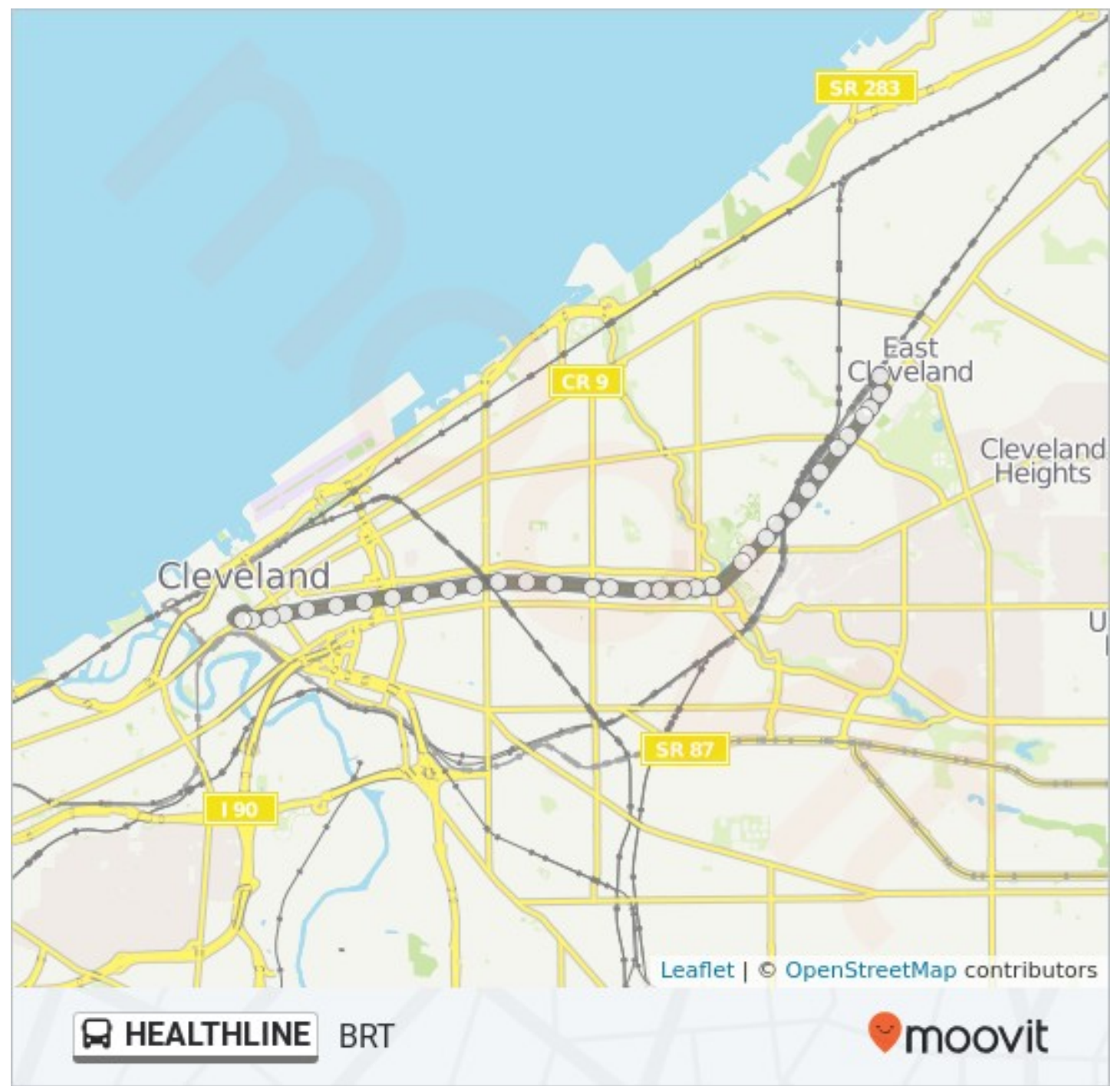

Figure BRT Cleveland 2

HealthLine Map

Source: https://moovitapp.com/index/en/public_transit-line-HEALTHLINE-Cleveland_OH-1362775392-239205-0 


\section{EUGENE - SPRINGFIELD BUS RAPID TRANSIT SYSTEM}

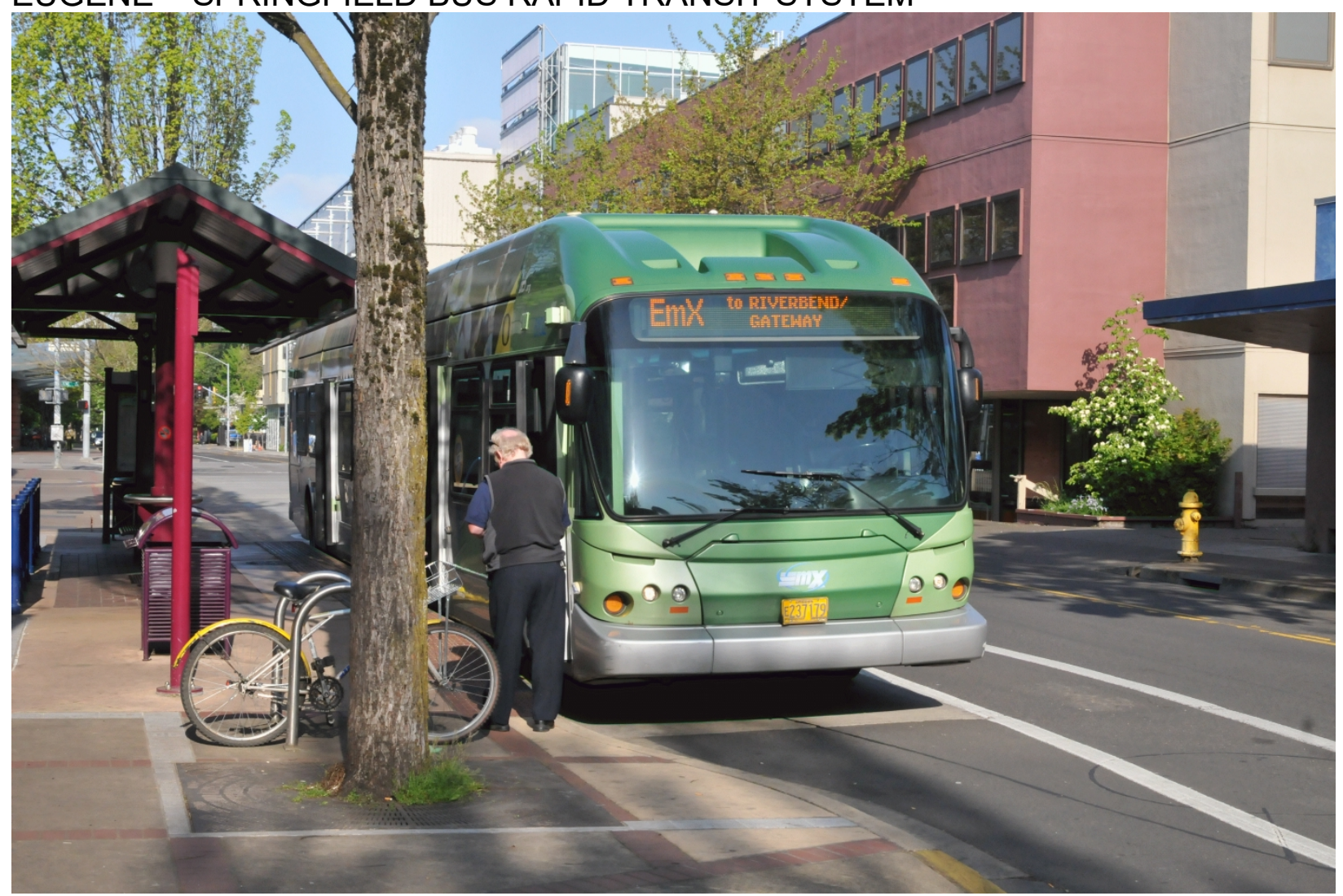

Figure BRT Eugene - Springfield 1

Emerald Express

Source: http://www.bcx.news/photos/transport/public/ltd/emx/bus/

Serving the Eugene-Springfield metro area of Oregon, the Emerald Express (EMX) line was one of the first BRT systems in the country. EMX began service on January 14, 2007 with 25 stations serving a single line. The line received an honorable mention in the Sustainable Transportation Awards in 2008 since ridership had doubled in the year since it opened. ${ }^{22}$

${ }^{22}$ Adapted from: https://en.wikipedia.org/wiki/Emerald_Express. 


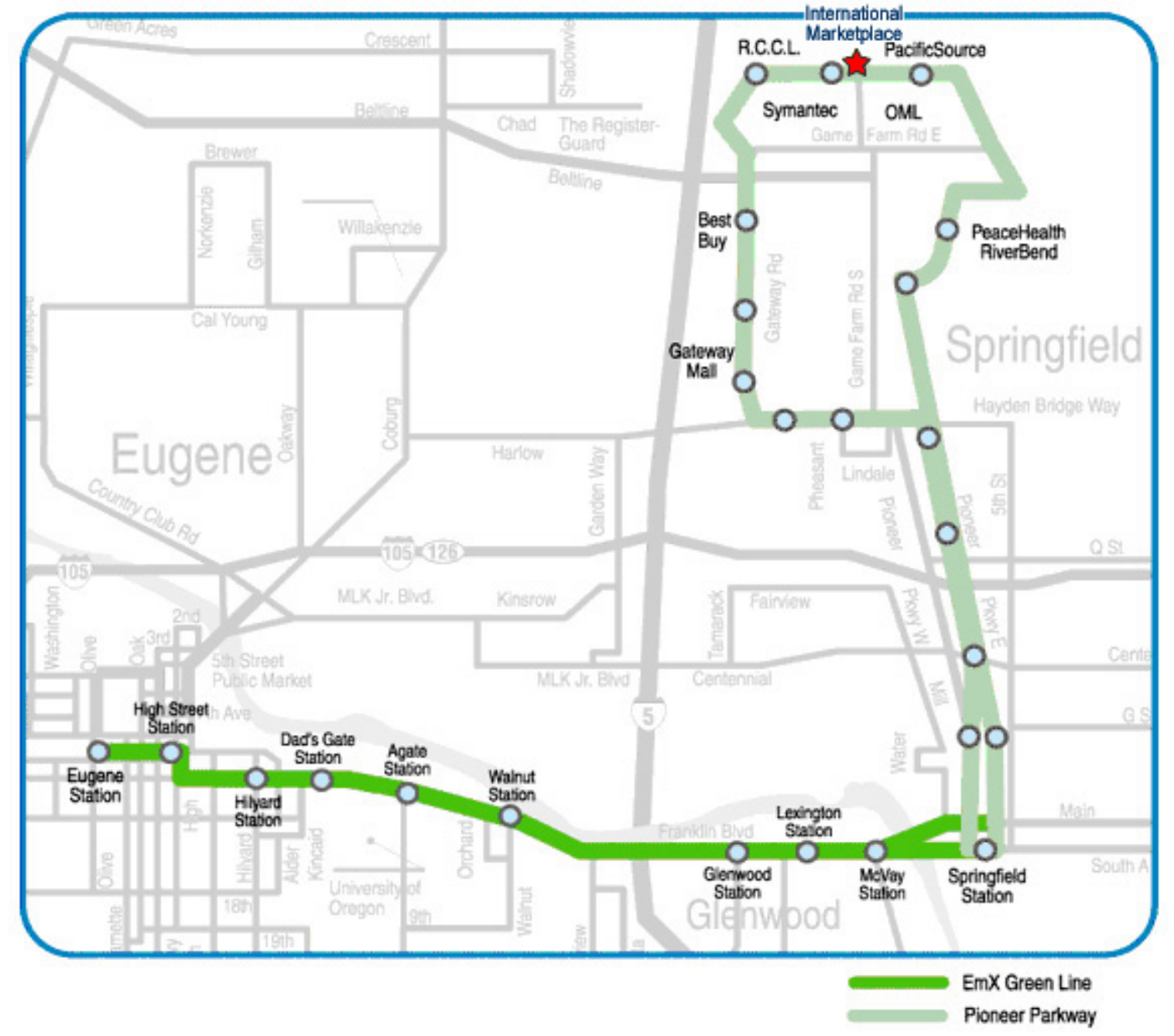

Figure BRT Eugene - Springfield 2

EmX Service Map

Source: http://www.voyentcapital.com/images/emx_map.jpg 


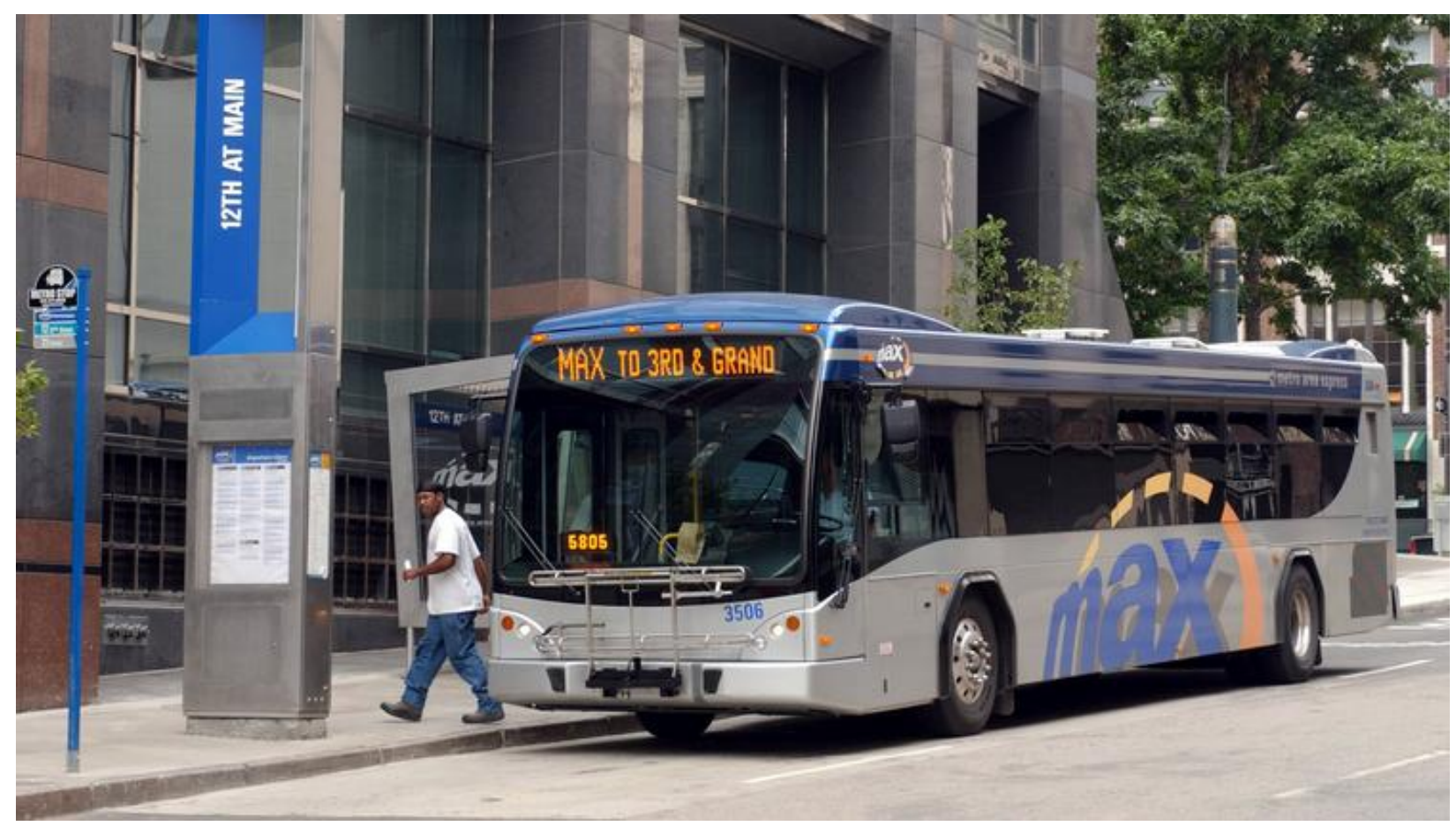

Figure BRT Kansas City 1

Kansas City MAX System

Source: https://www.bizjournals.com/kansascity/news/2016/02/10/kcata-federal-transitadministration-grant.html

Serving areas of concentrated residential and business activity, Kansas City's MAX BRT system debuted in 2005. There are currently 87 stations that are served by MAX. With two routes currently in operation, there are an addition four planned with one now under construction. According to the Federal Transit Administration, it is a model bus rapid transit line. ${ }^{23}$

${ }^{23}$ Adapted from: https://en.wikipedia.org/wiki/Metro_Area_Express. 


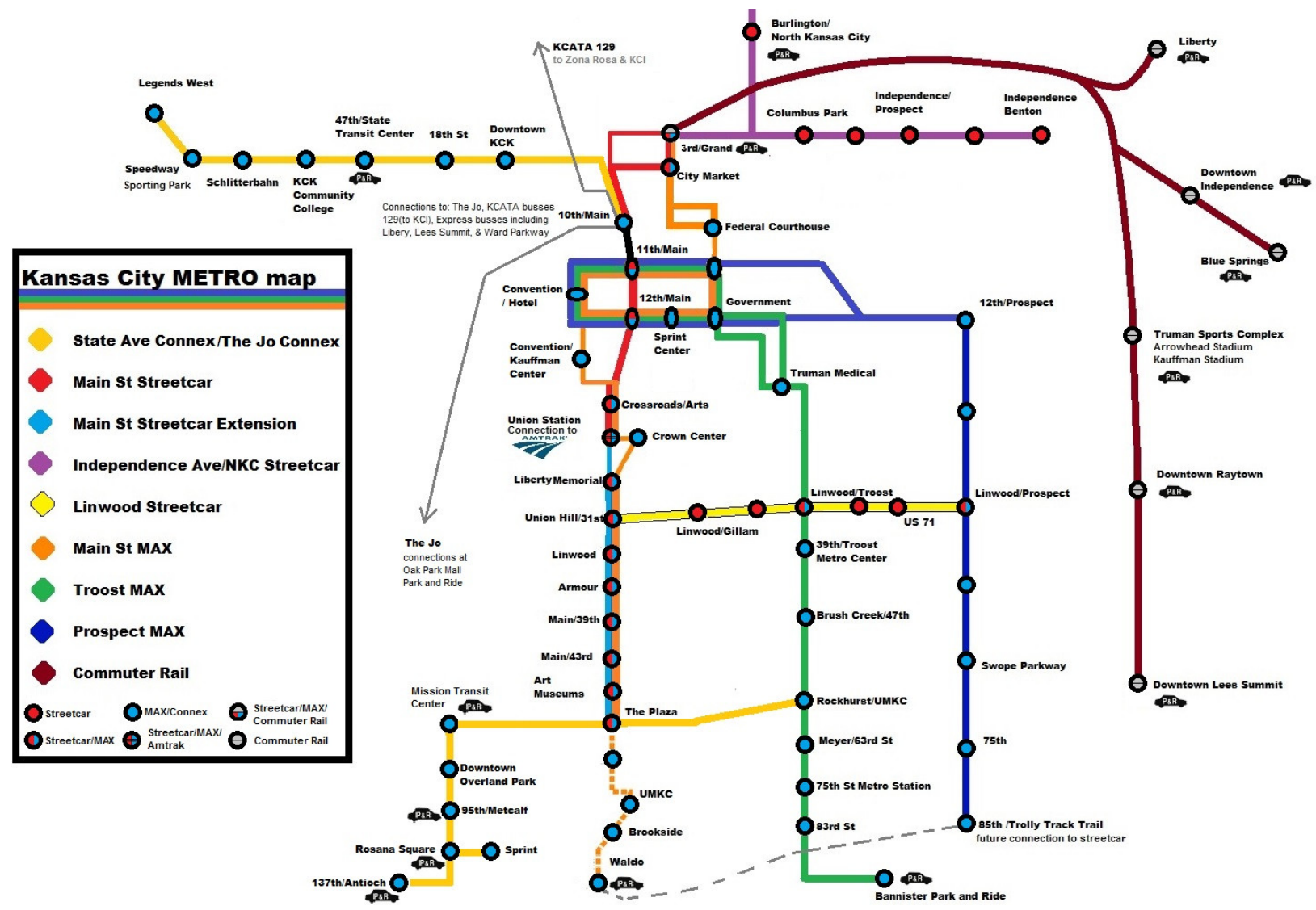

Figure BRT Kansas City 2

Kansas City Transit Service Map

Source: http://kcrag.com/viewtopic.php?t=19518 


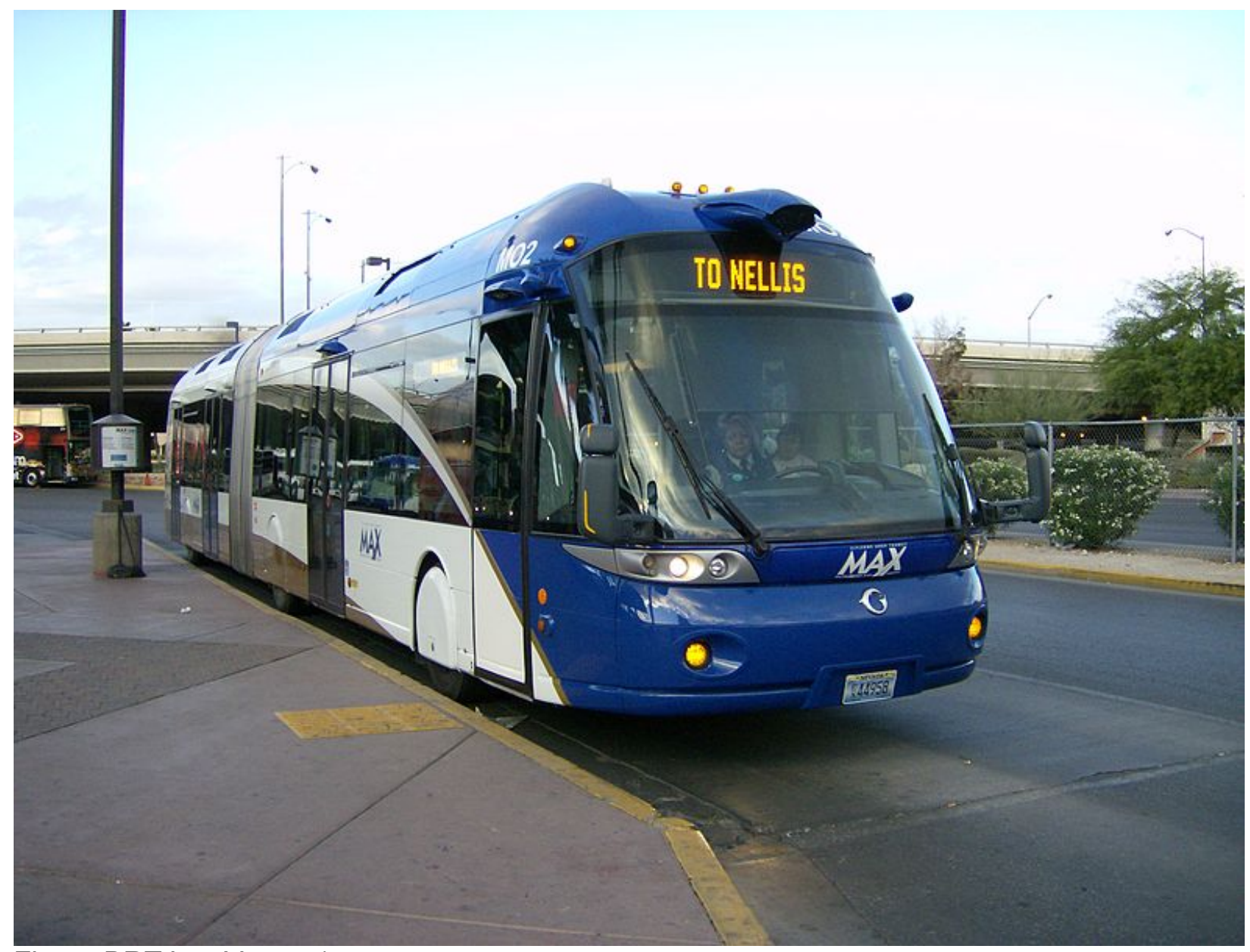

Figure BRT Las Vegas 1

Las Vegas Bus Rapid Transit

Source: https://en.wikipedia.org/wiki/File:CAT_Irisbus_Civis.jpg

The Metropolitan Area Express (MAX) was Las Vegas' bus rapid transit system which operated from June 30, 2004 until February 20, 2016. It ran in 12-minute intervals during the day and 20 minute intervals at night. There were 22 stations along its 7 -mile route. ${ }^{24}$

${ }^{24}$ Adapted from: https://en.wikipedia.org/wiki/Metropolitan_Area_Express_(Las_Vegas). 


\section{Effective: December 2, 2018}

\section{Transit Map \\ Mapa de Transporte Público}
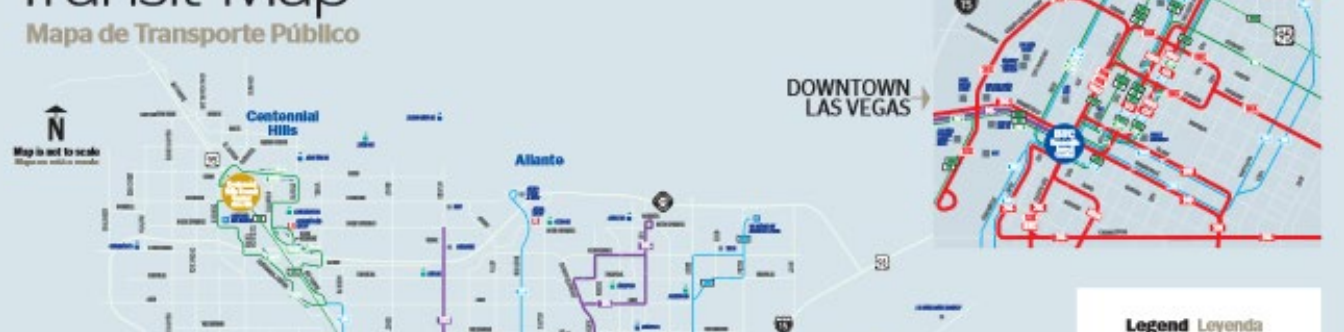

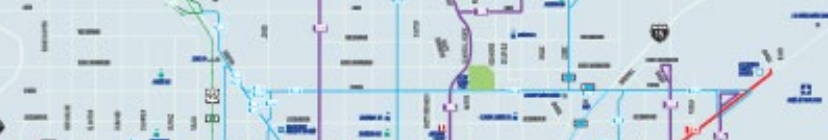

-

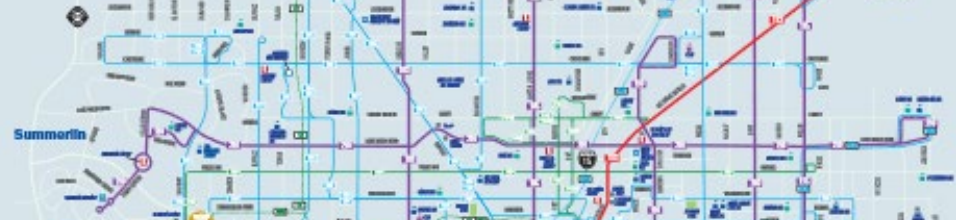

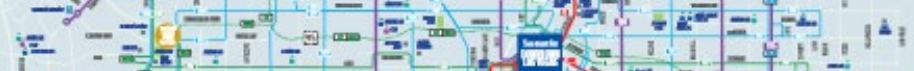

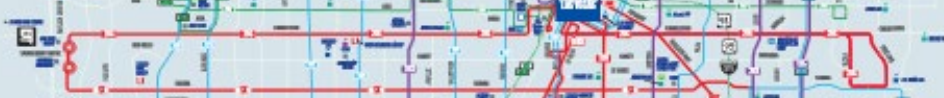

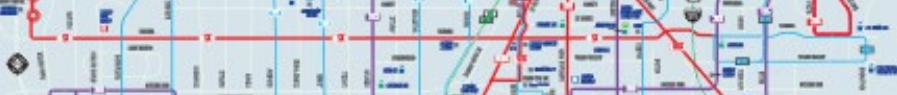

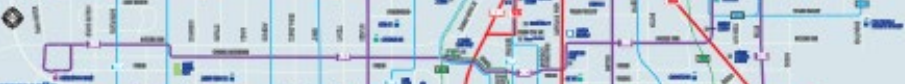

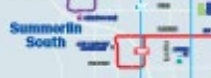
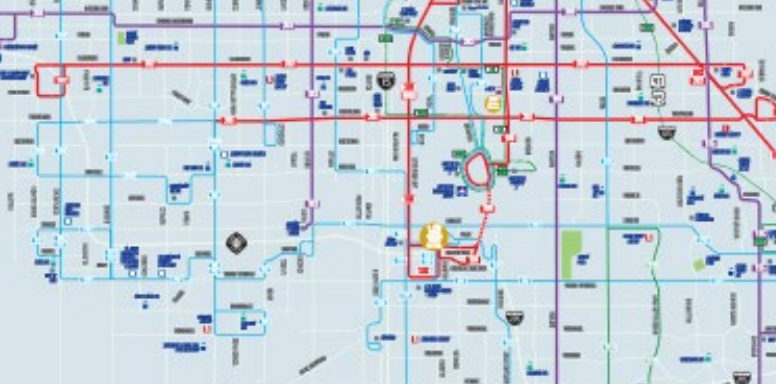

$-1+1$
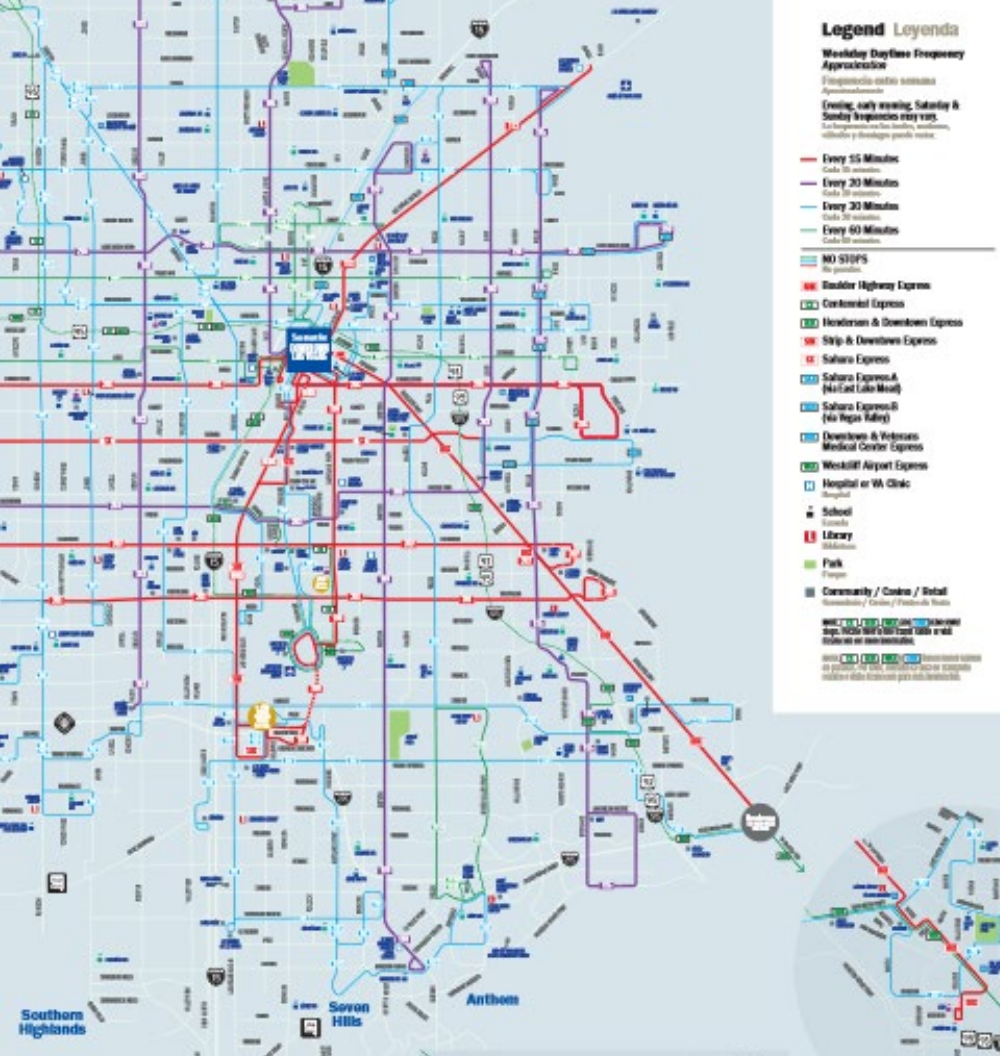

$=-1$
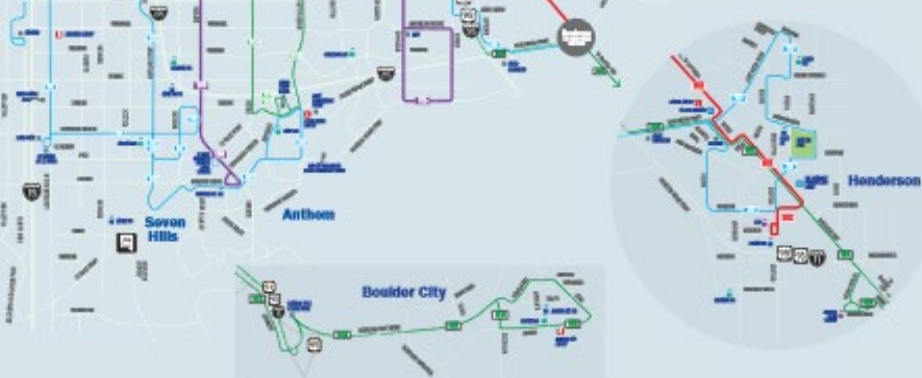

Figure BRT Las Vegas 2

Las Vegas Transit Map (Express Lines)

Source: https://www.rtcsnv.com/wp-content/uploads/2018/11/SystemMap-Dec2018.pdf 


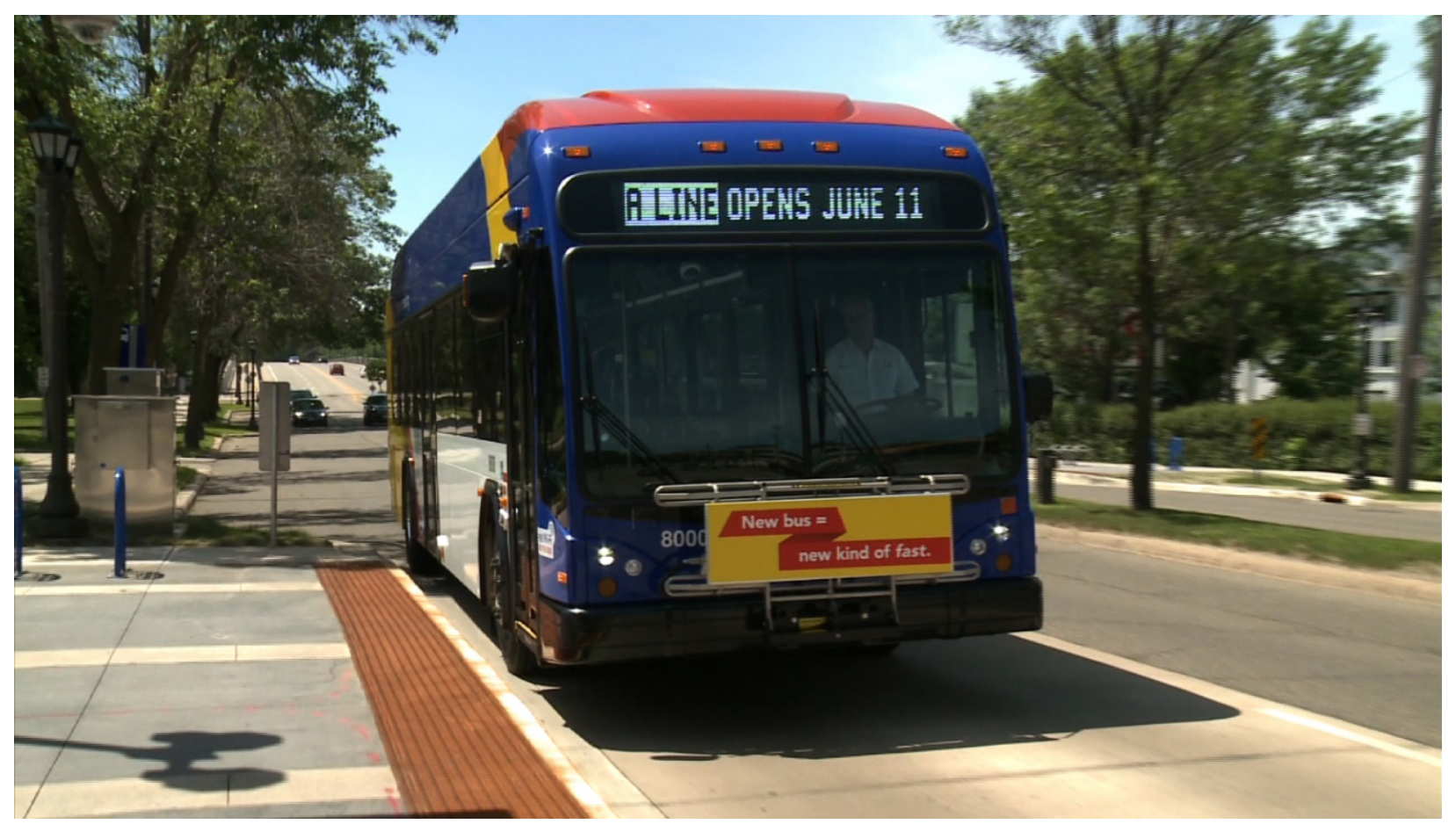

Figure BRT Minneapolis 1

A Line Bus

Source: https://minnesota.cbslocal.com/2016/06/08/brt/

Called the A Line, the Twin Cities' rapid bus service is like conventional buses but operates much quicker and more efficient. Service on the A Line is every ten minutes, and all A Line buses have free onboard $\mathrm{Wi}-\mathrm{Fi}$. It connects passengers from suburbs to the rail station on to Downtown Minneapolis. ${ }^{25}$

\footnotetext{
${ }^{25}$ Adapted from: https://www.metrotransit.org/a-line-now-open.
} 


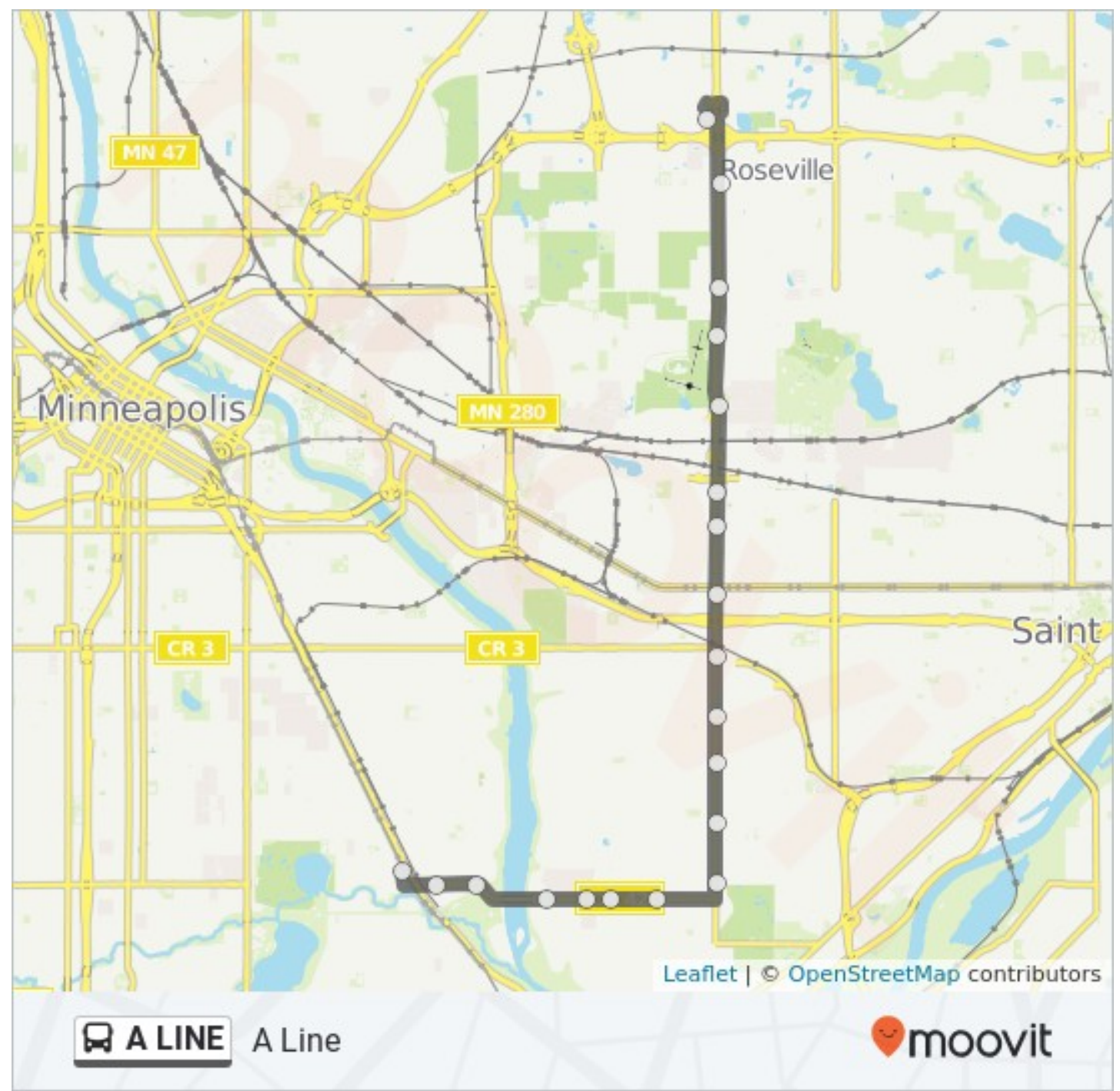

Figure BRT Minneapolis 2

A Line Service Map

Source: https://moovitapp.com/index/en/public_transit-line-A_LINE-MinneapolisSt_Paul_MN1143-10734-455984-0 


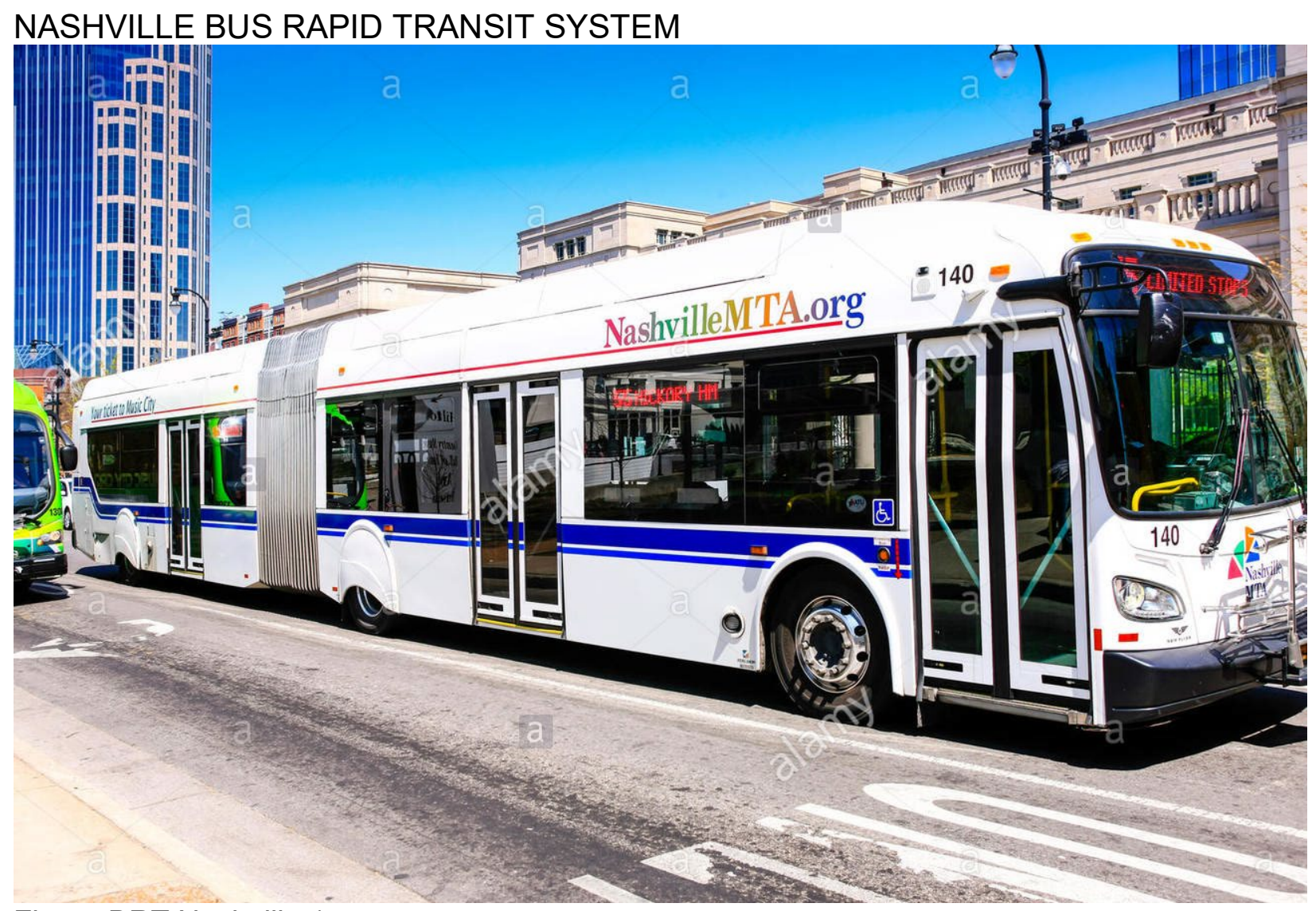

Figure BRT Nashville 1

Nashville BRT

Source: https://www.alamy.com/stock-photo/nashville-mta.html

Operating as lines 50 and 52, Nashville's BRT lines connect Hillwood and Old Hickory with Downtown Nashville. They are called BRT Lite lines since they don't technically fall into a traditional BRT realm, but operate as one for all intents and purposes. ${ }^{26}$

\footnotetext{
${ }^{26}$ Adapted from:

https://en.wikipedia.org/wiki/Nashville_Metropolitan_Transit_Authority\#BRT_(Bus_Rapid_Transit)_Lite.
} 


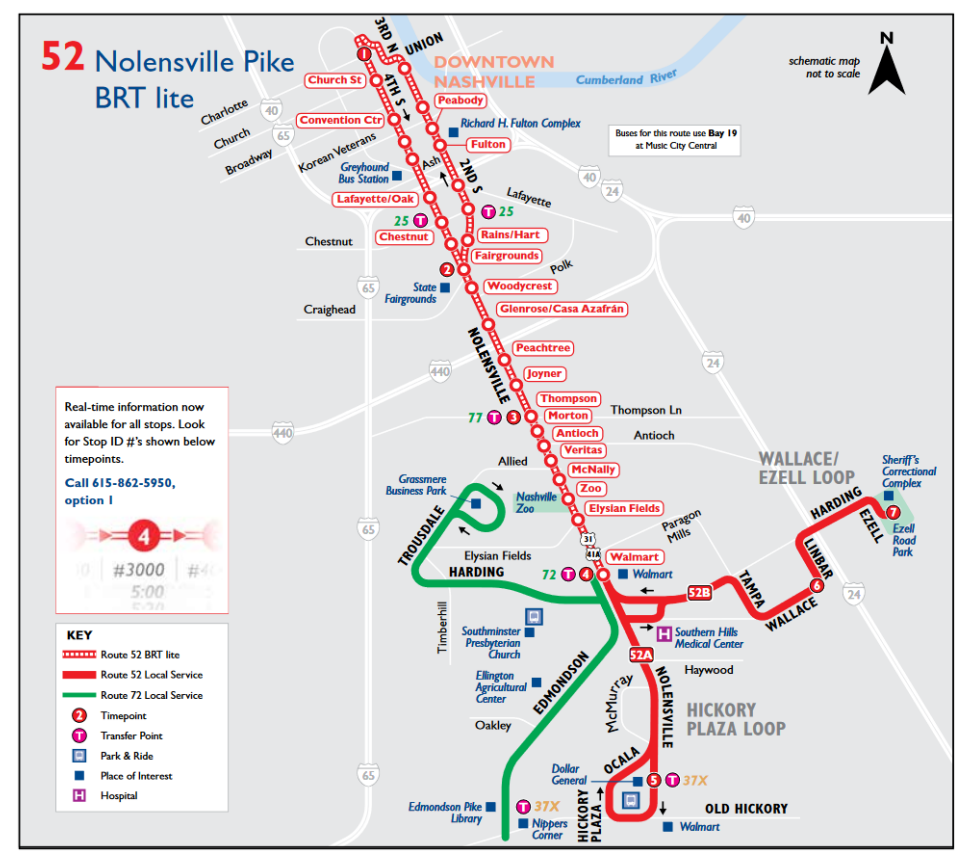

\section{Charlotte Pike BRT lite}

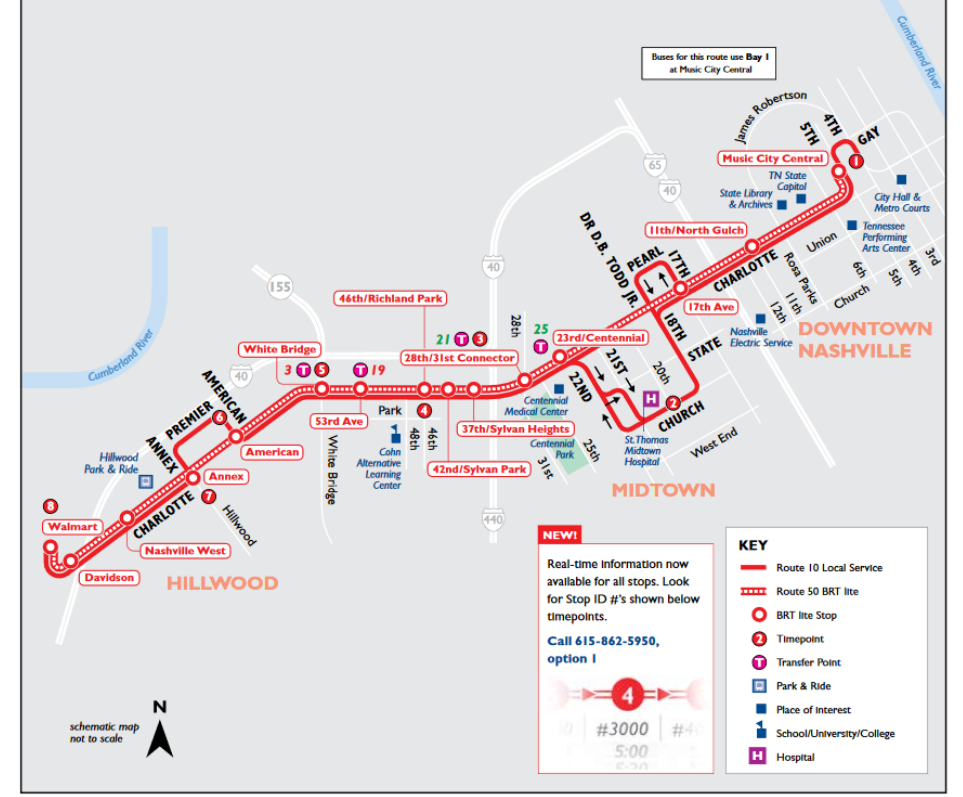

Figure BRT Nashville 2

Nashville BRT Lite Service Maps

Source: http://www.nashvillemta.org/Nashville-MTA-Maps-and-Schedules.asp 


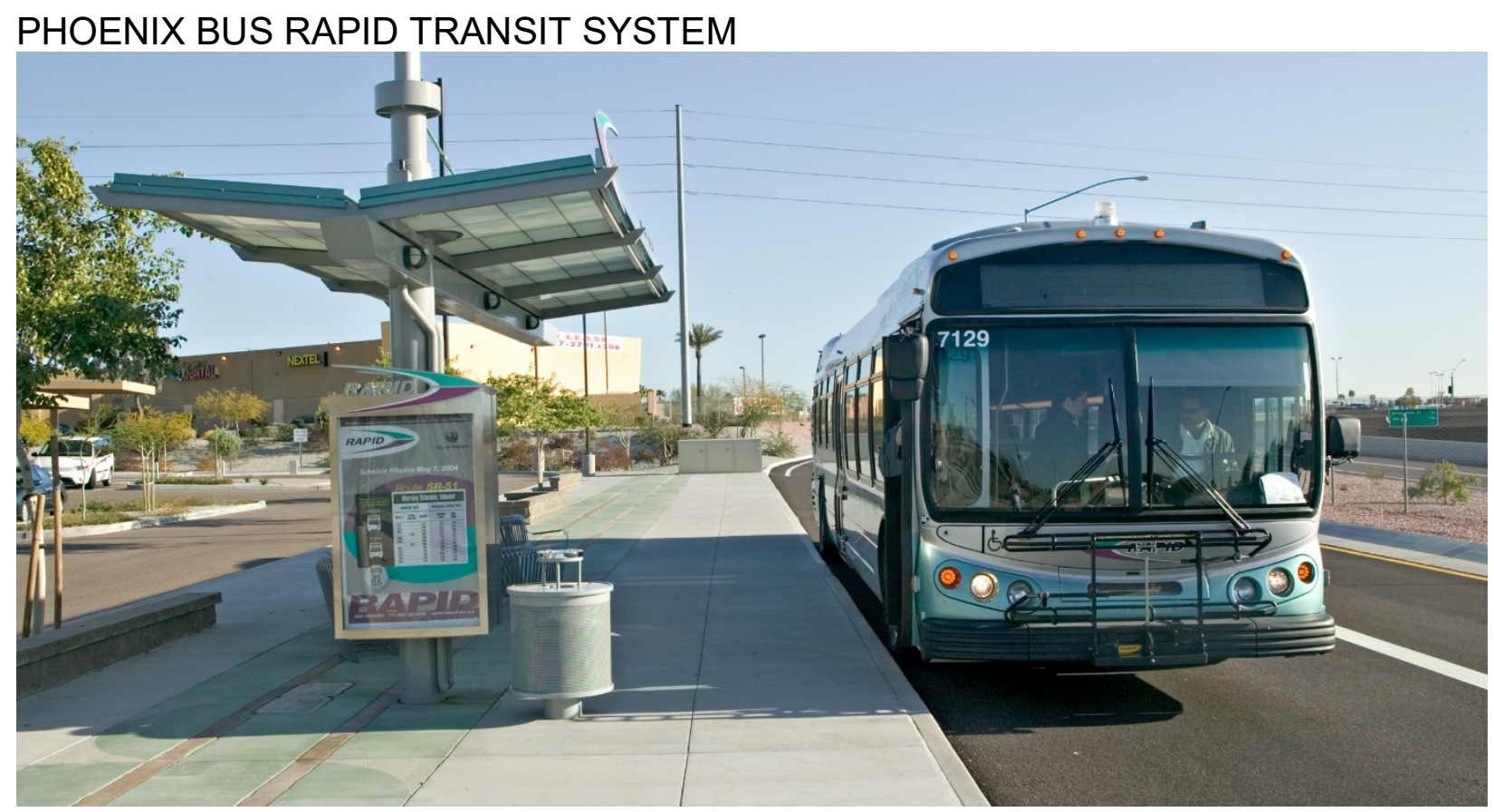

Figure BRT Phoenix 1

Phoenix BRT Rolling Stock

Source: https://www.stvinc.com/project/phoenix-bus-rapid-transit

Valley Metro Transportation Authority operates six rapid bus lines in the Phoenix, Arizona metro area. These lines travel along Interstate 10, Arizona State Road 51, and South Mountain. ${ }^{27}$

${ }^{27}$ Adapted from: https://www.valleymetro.org/maps-schedules. 


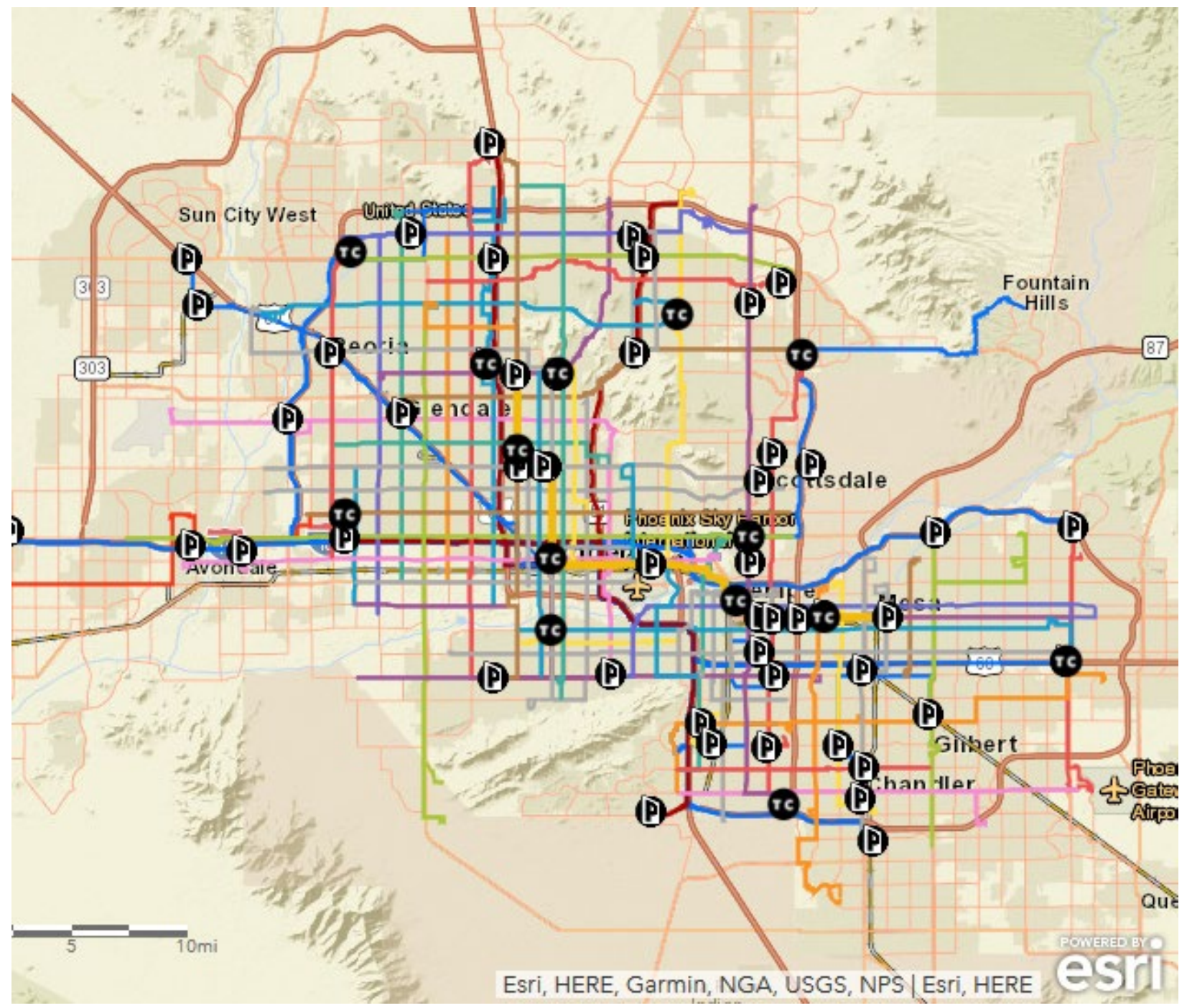

Figure BRT Phoenix 2

Valley Metro Bus Service Map (RAPID lines denoted in deep red)

Source: https://www.valleymetro.org/system-map

PITTSBURGH BUS RAPID TRANSIT SYSTEM 


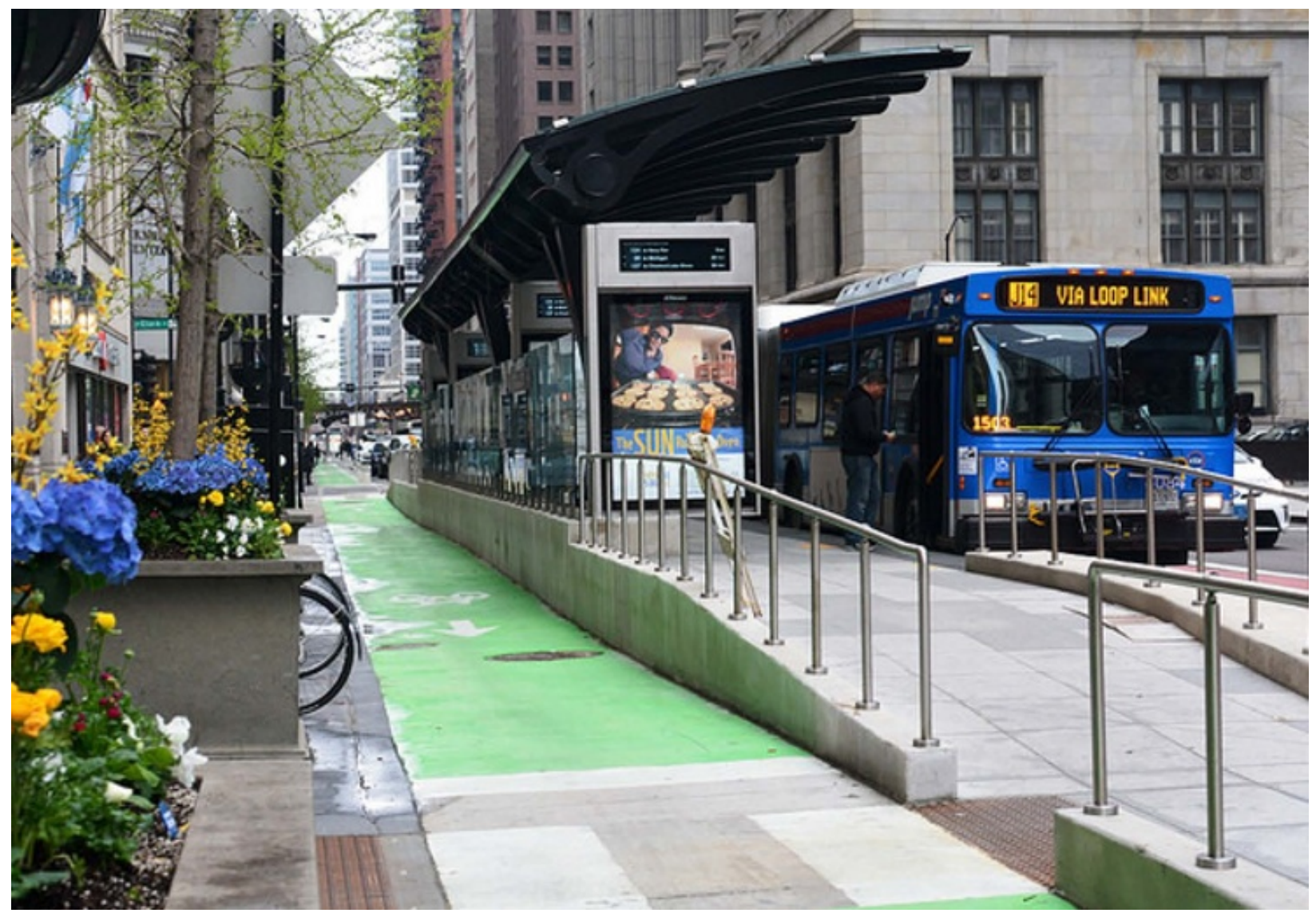

Figure BRT Pittsburgh 1

Pittsburgh Bus Rolling Stock

Source: Source: http://gcapgh.org/wp-content/uploads/2017/03/GCA BRT photo.jpg The Pittsburgh Bus system has a fleet of over 700 buses and averages 220,000 rides every weekday for all public transit services. ${ }^{28}$

${ }^{28}$ Adapted from: https://www.portauthority.org/inside-Port-Authority/about-us/. 


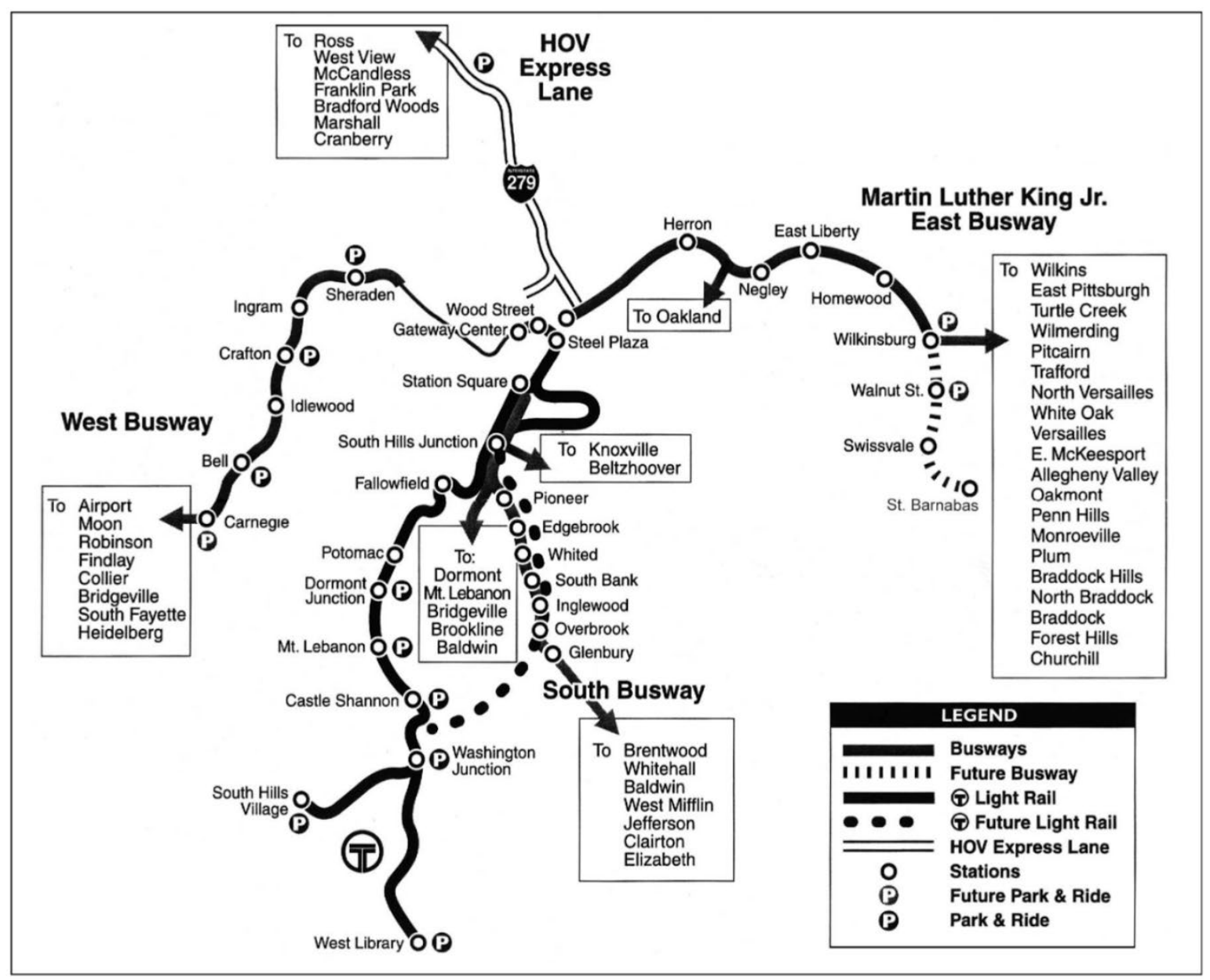

Figure 1: Busway System Map

Figure BRT Pittsburgh 2

Source: https://cdn-images-1.medium.com/max/2600/0*2ni_pbZgl8K_ttba.

\section{RENO BUS RAPID TRANSIT SYSTEM}




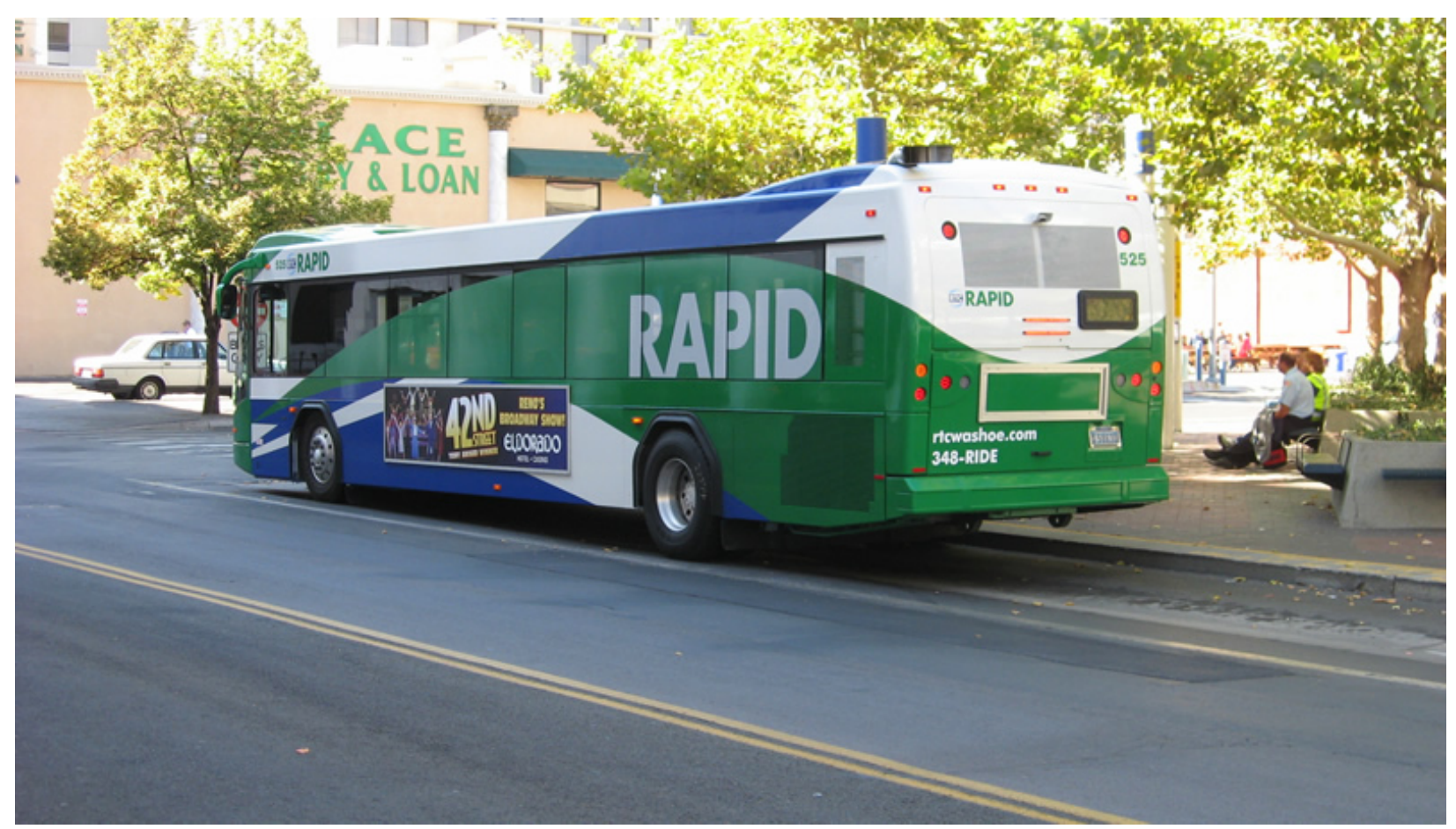

Figure BRT Reno 1

Reno Rapid Bus

Source: http://www.imagemag.org/rtc-bus-reno/

Reno, Nevada's rapid transit bus system operates during most of the day with two separate lines, with reliable and quick transportation between suburban areas and downtown Reno. ${ }^{29}$

${ }^{29}$ Adapted from: https://www.rtcwashoe.com/routes/. 


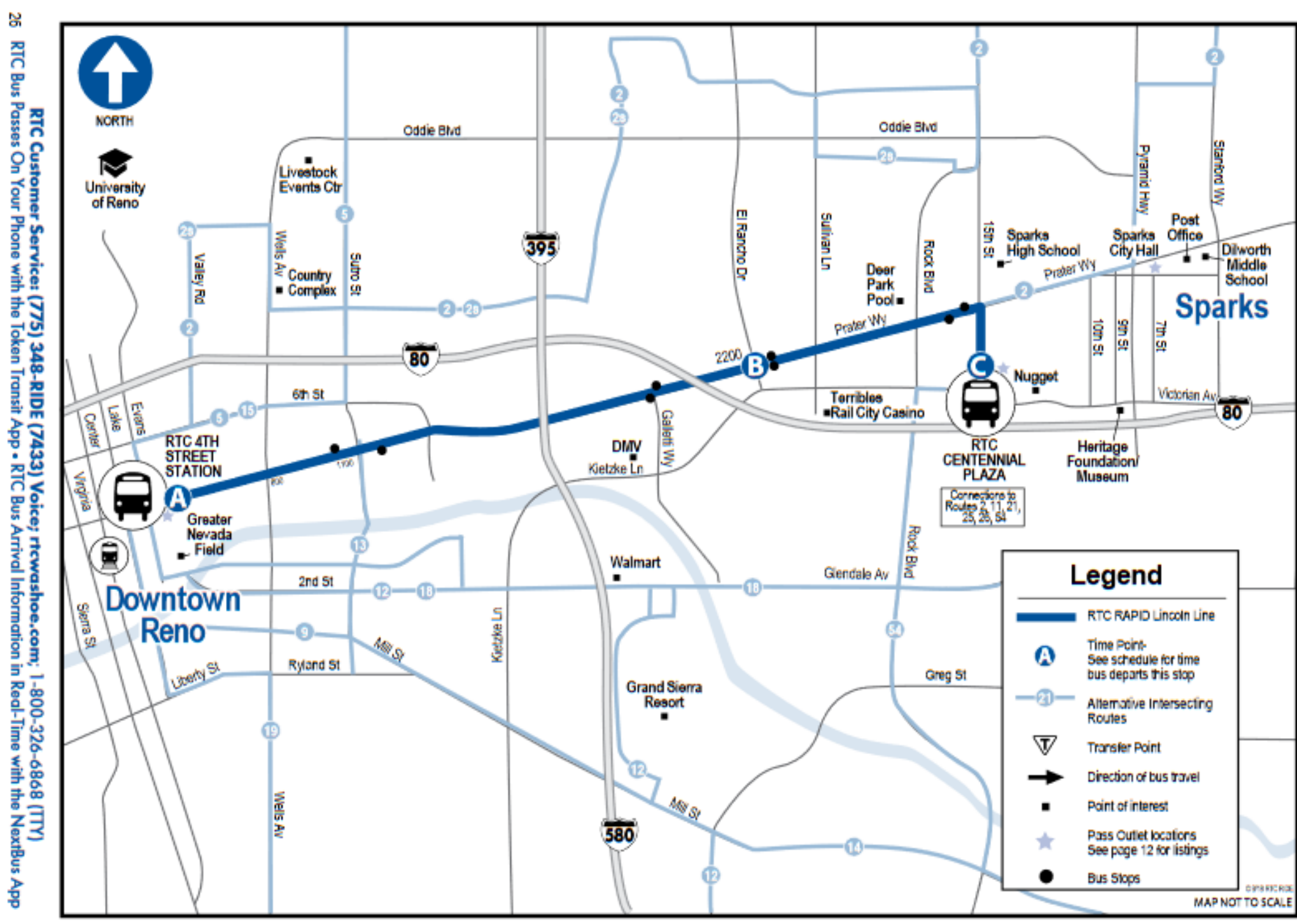

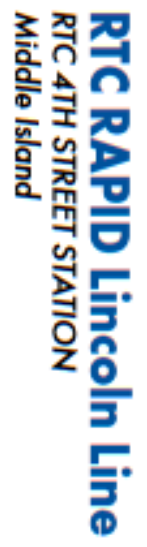




\section{RTC RAPID Virginia Line RTC 4TH STREET STATION

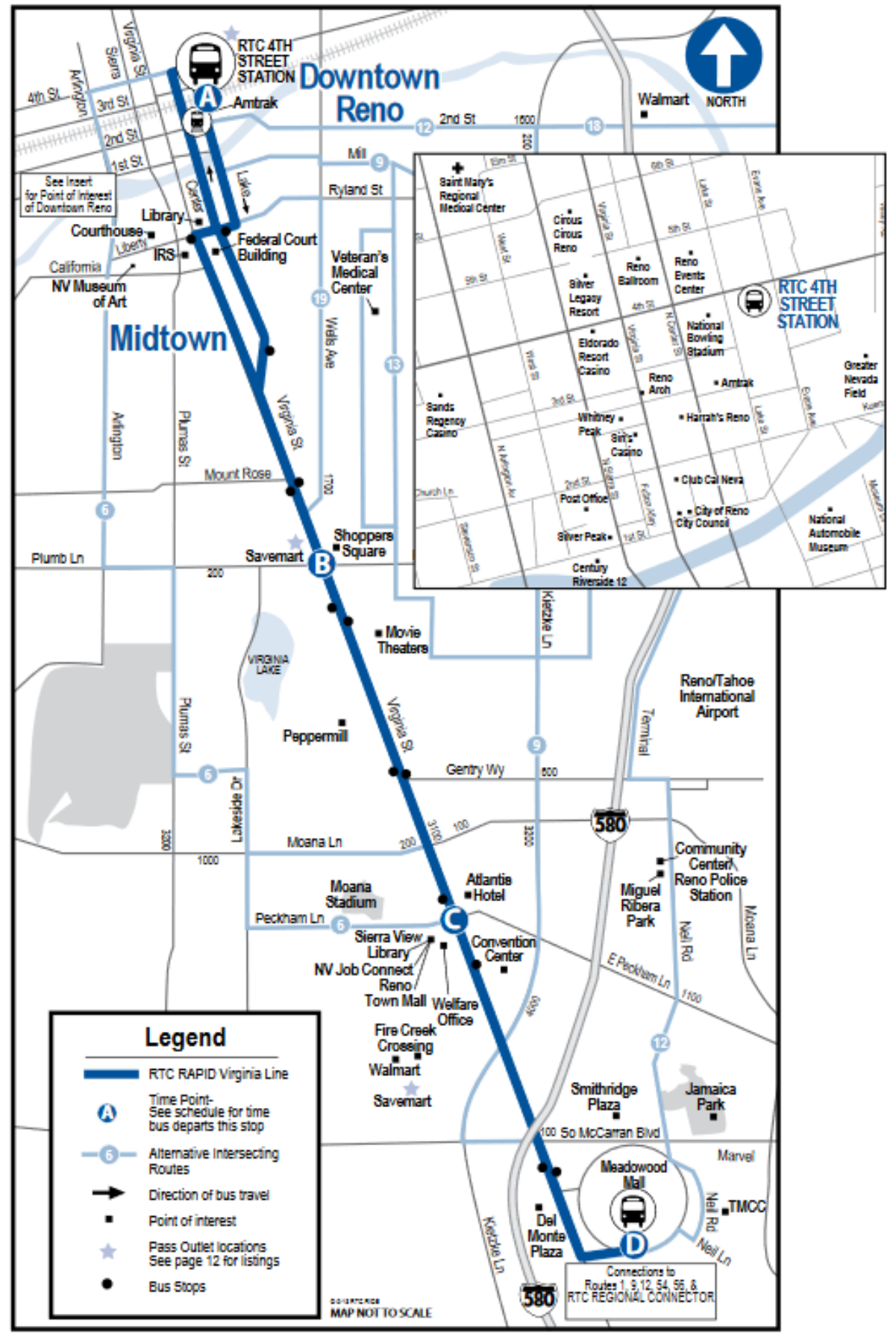

Figure BRT Reno 2 \& 3

Rapid Transit Reno Service Map

Source: https://www.rtcwashoe.com/routes/

SALT LAKE CITY BUS RAPID TRANSIT SYSTEM 


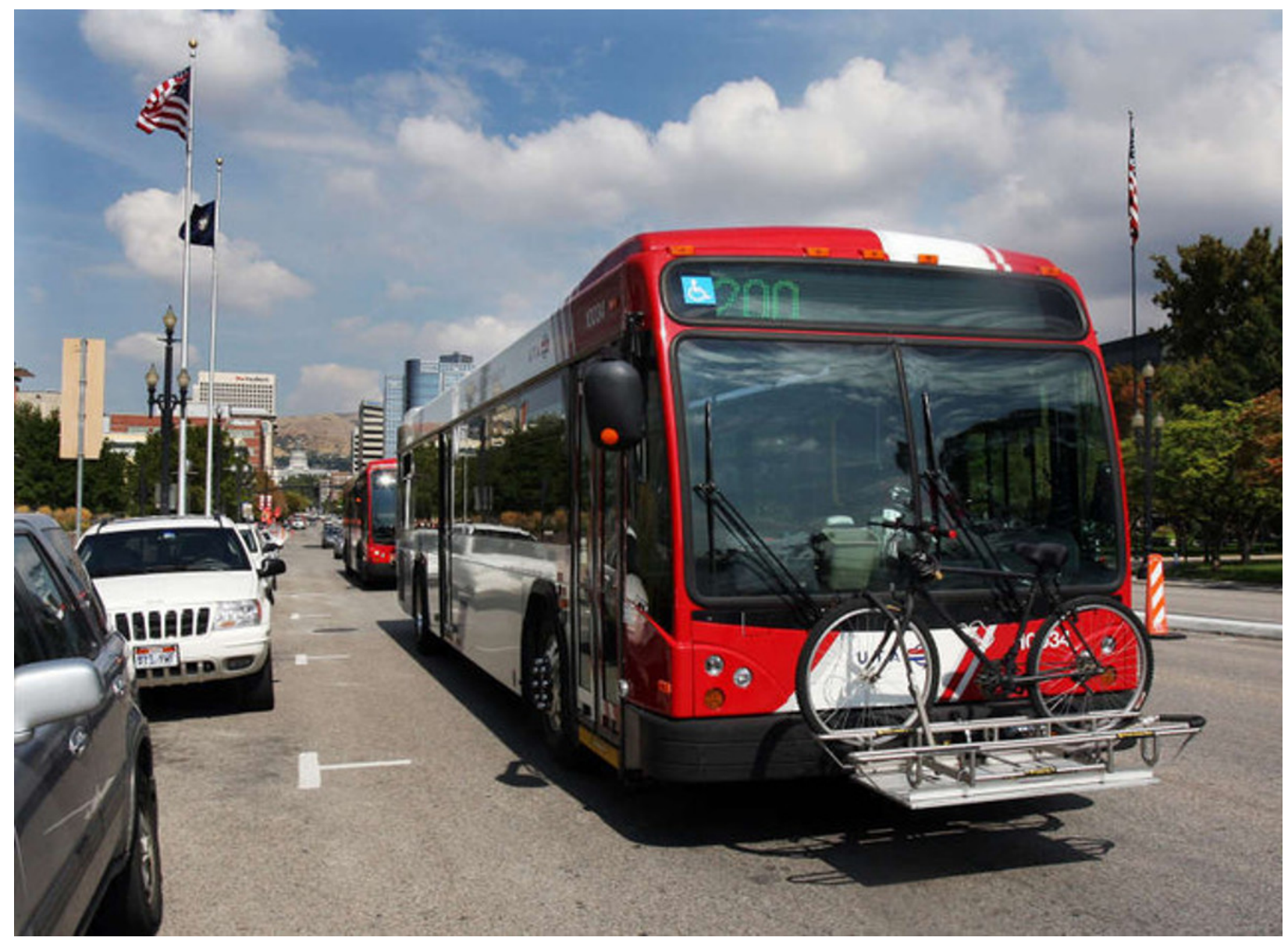

Figure BRT Salt Lake City 1

UTA Bus

Source: https://www.deseretnews.com/article/900053005/uta-offers-extra-service-to-capitol-forlegislative-session.html

The Utah Transit Authority (UTA) operates two bus rapid transit lines - the MAX 3500 South and the Utah Valley Express. The 3500 Line serves the areas just south of Salt Lake City running east and west, and the Valley Express line goes between Orem and Provo with connections to the light rail. ${ }^{30}$

${ }^{30}$ Adapted from: https://www.rideuta.com/Services/Bus-Rapid-Transit. 


\section{UVX Route 830X}

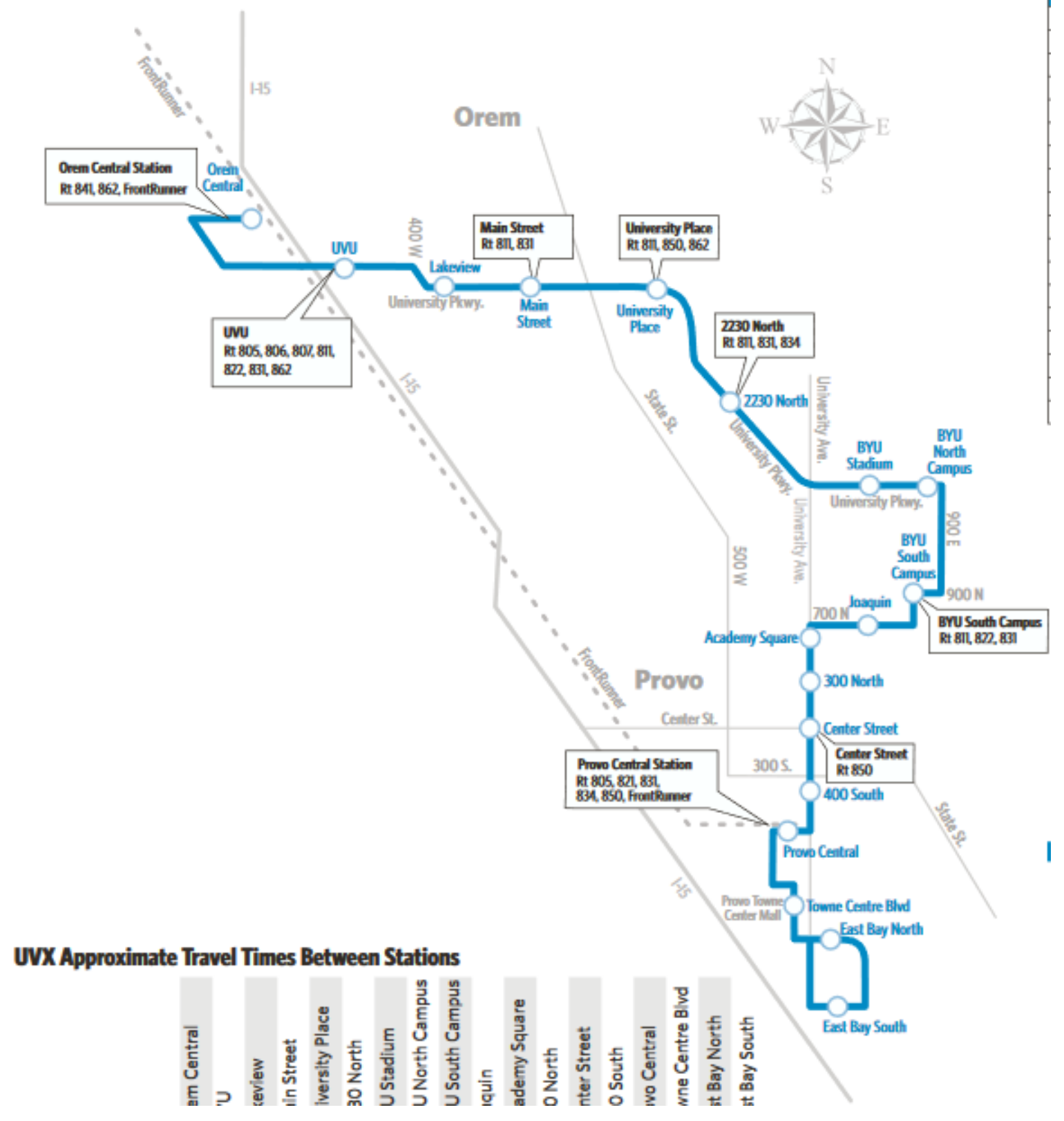




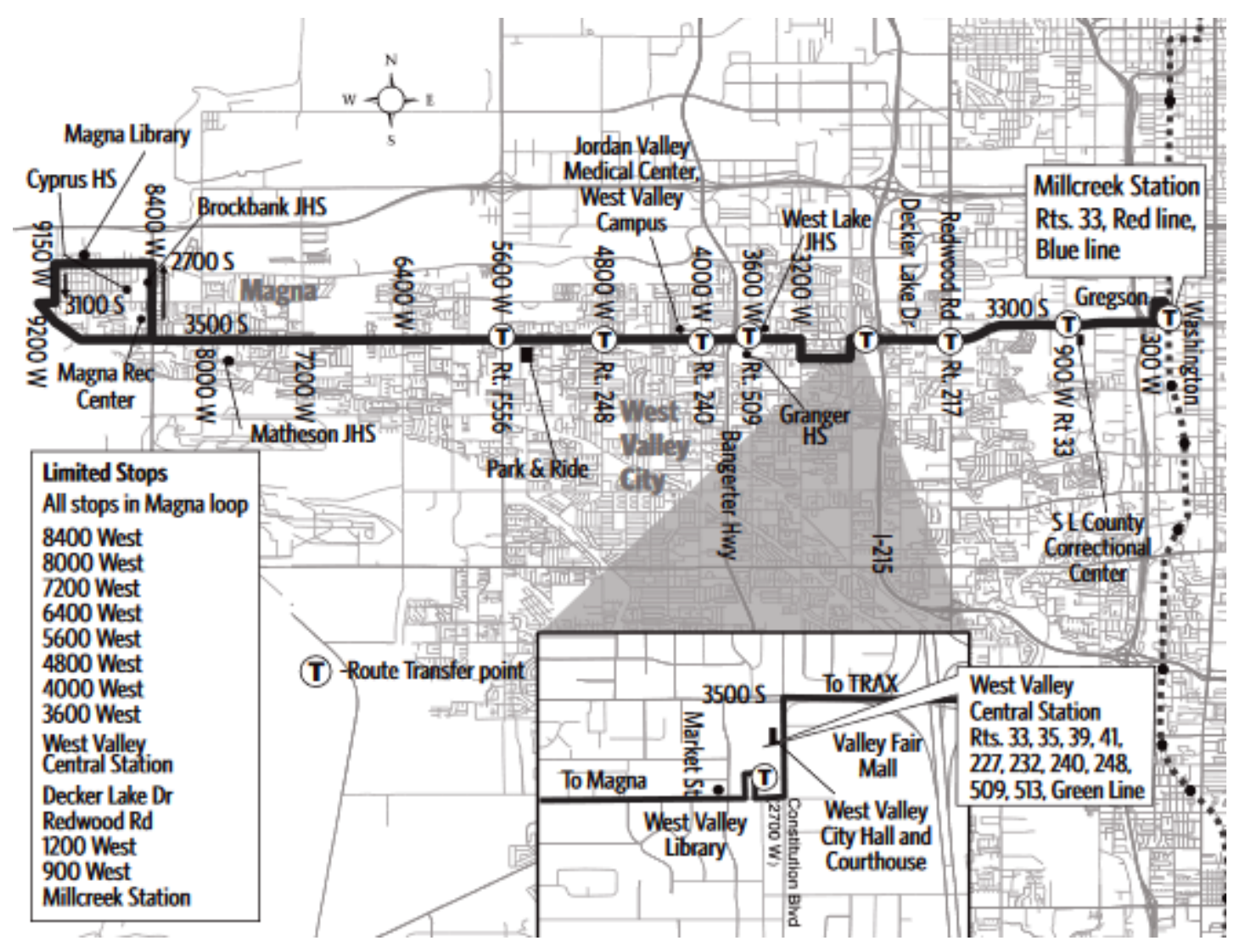

SAN ANTONIO BUS RAPID TRANSIT SYSTEM 


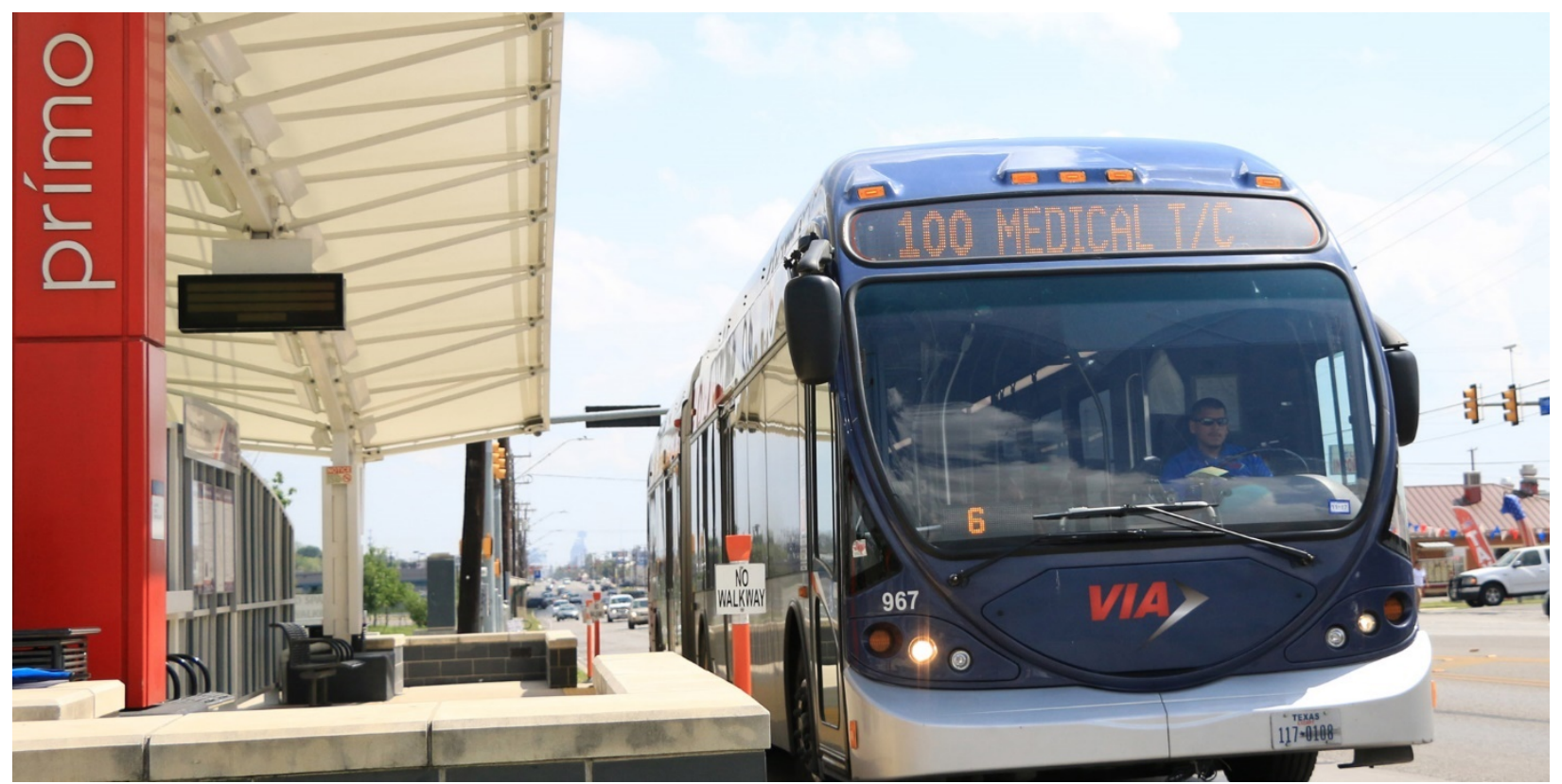

Figure BRT San Antonio 1

San Antonio Primo Bus

Source: https://www.viainfo.net/primo service/

San Antonio's bus rapid transit system is called Primo. Primo buses get traffic signal priority and free high-speed wifi among others. Buses run every 12 minutes along two lines, the 100 and 103, with 102 opening late 2019. ${ }^{31}$

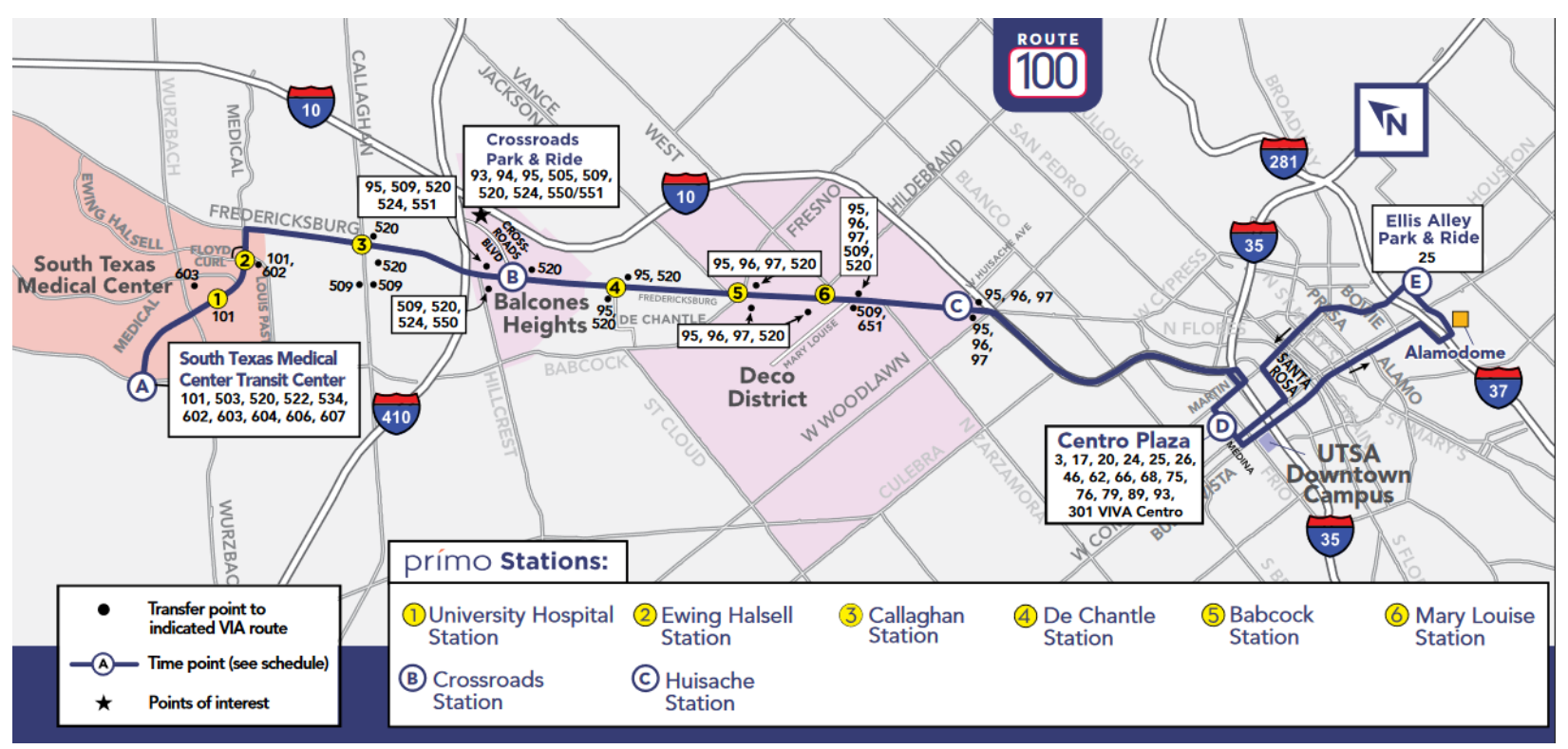

${ }^{31}$ Adapted from: https://www.viainfo.net/primo_service/. 


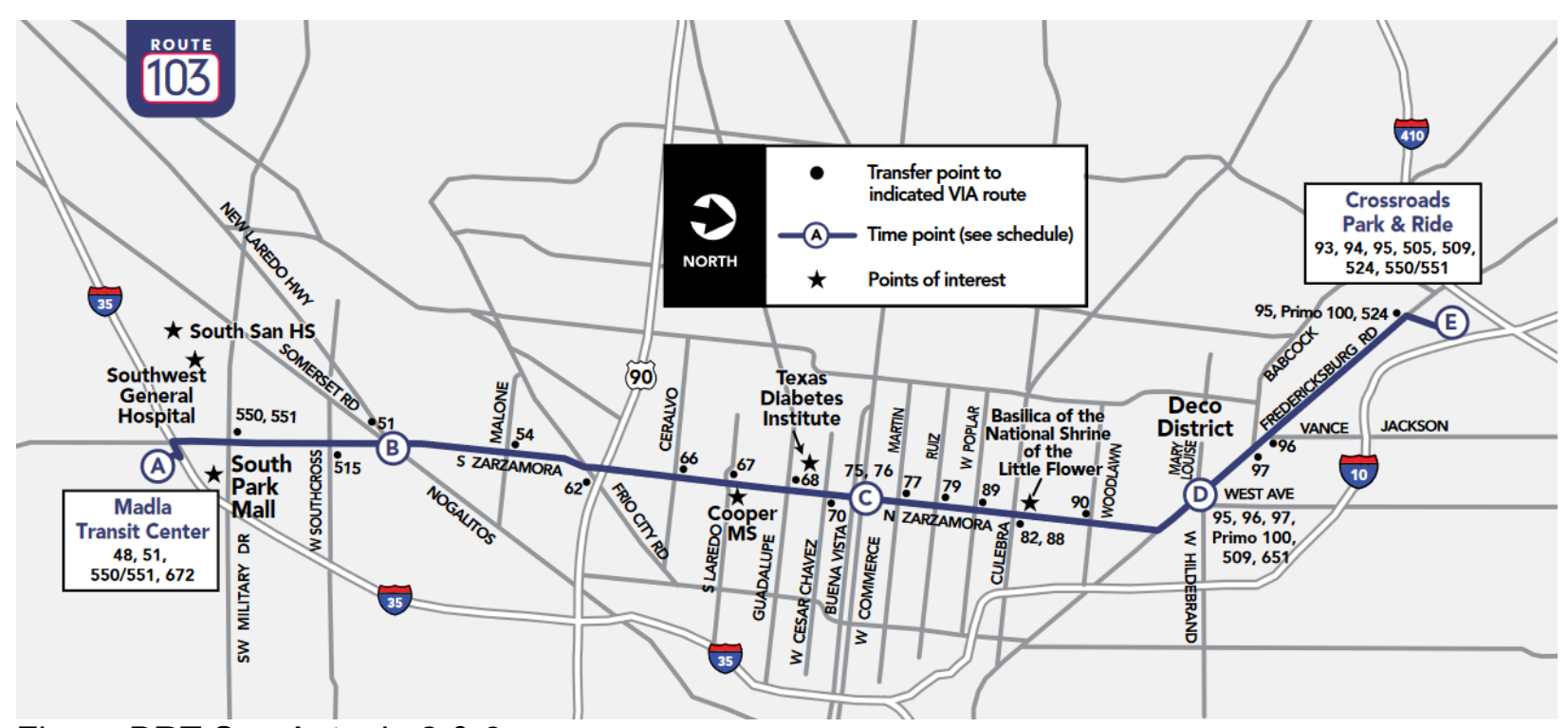

Figure BRT San Antonio 2 \& 3

Primo Routes 100 and 103 Map

Source: Source: https://www.viainfo.net/primo service/

\section{SAN DIEGO BUS RAPID TRANSIT}

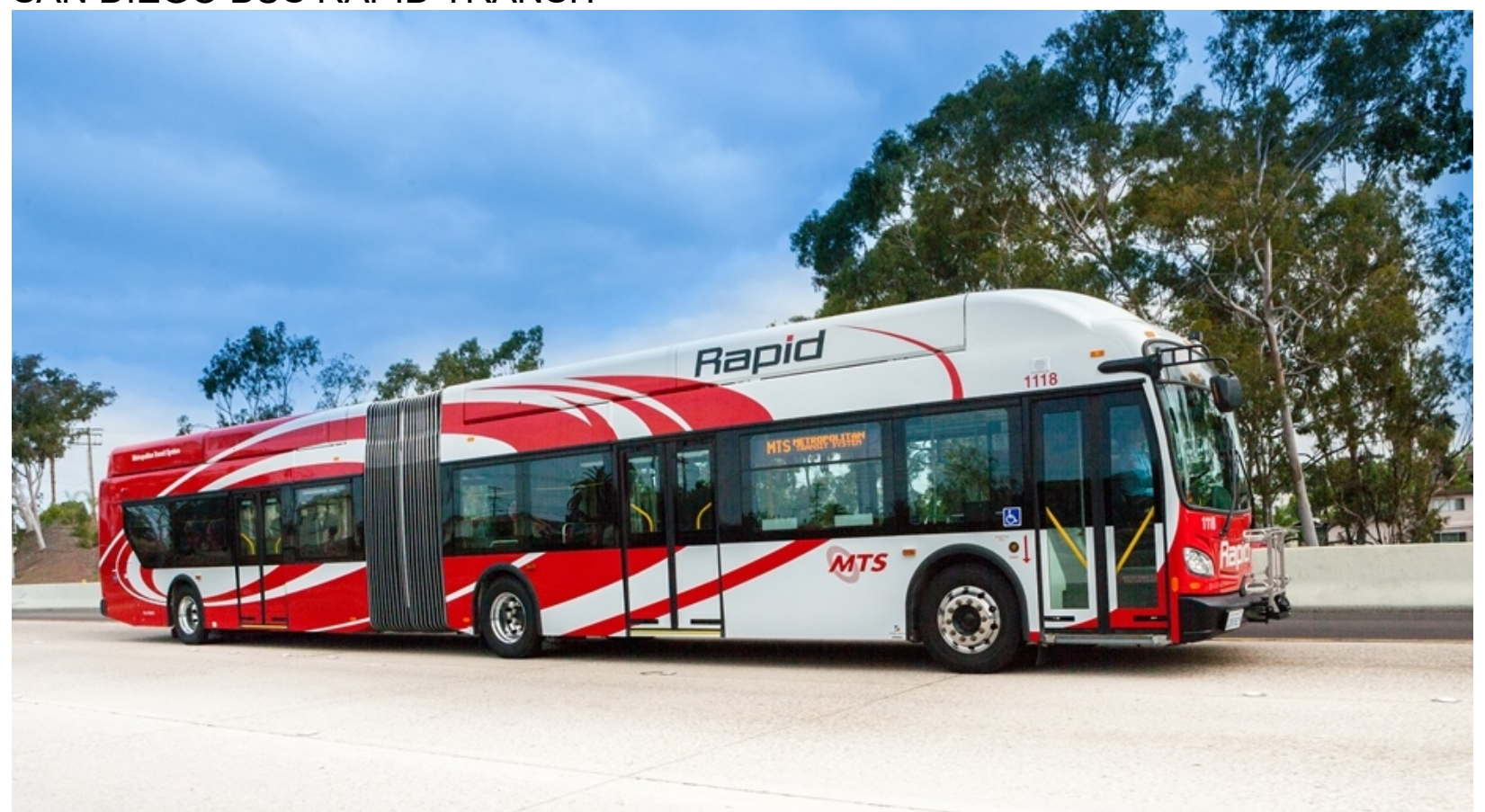

Figure $X$

San Diego Rapid BRT System

Source: https://keepsandiegomoving.com/i-15-corridor/l-15-transit-services.aspx 
Called Rapid, San Diego's bus rapid transit system operated mainly in the HOV lanes of Interstate 15 and Interstate 805 . The system was founded in 2014 with 30 stops along 9 routes. Rapid has 34 stations and runs mainly on compressed natural gas. ${ }^{32}$

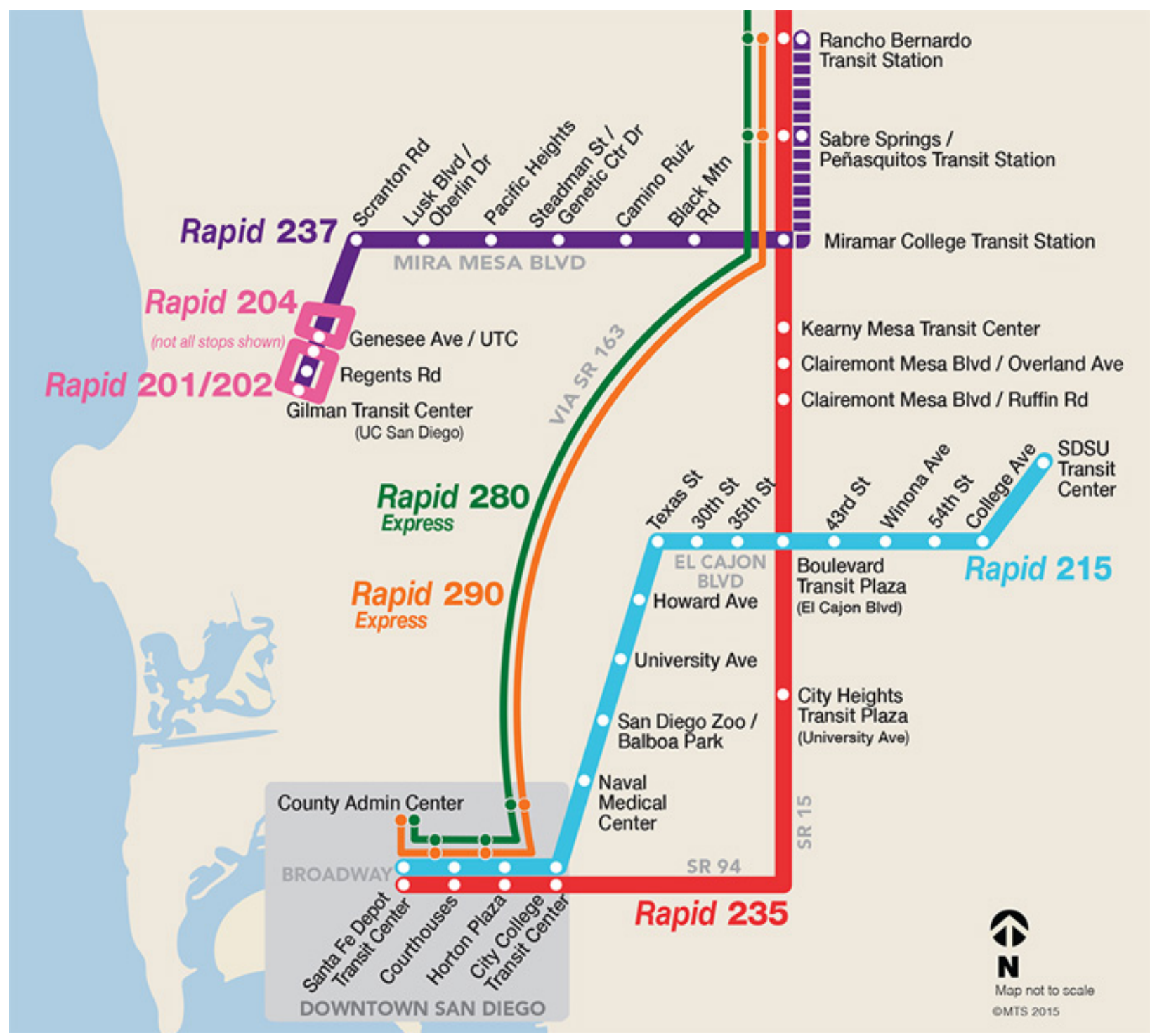

\section{Figure $X$}

San Diego Rapid Service Map

Source: http://theboulevard.org/wp-content/uploads/2017/06/Transit-Mid-City-BRT.jpg

${ }^{32}$ Adapted from: https://en.wikipedia.org/wiki/Rapid_(San_Diego). 
SAN JOSE BUS RAPID TRANSIT

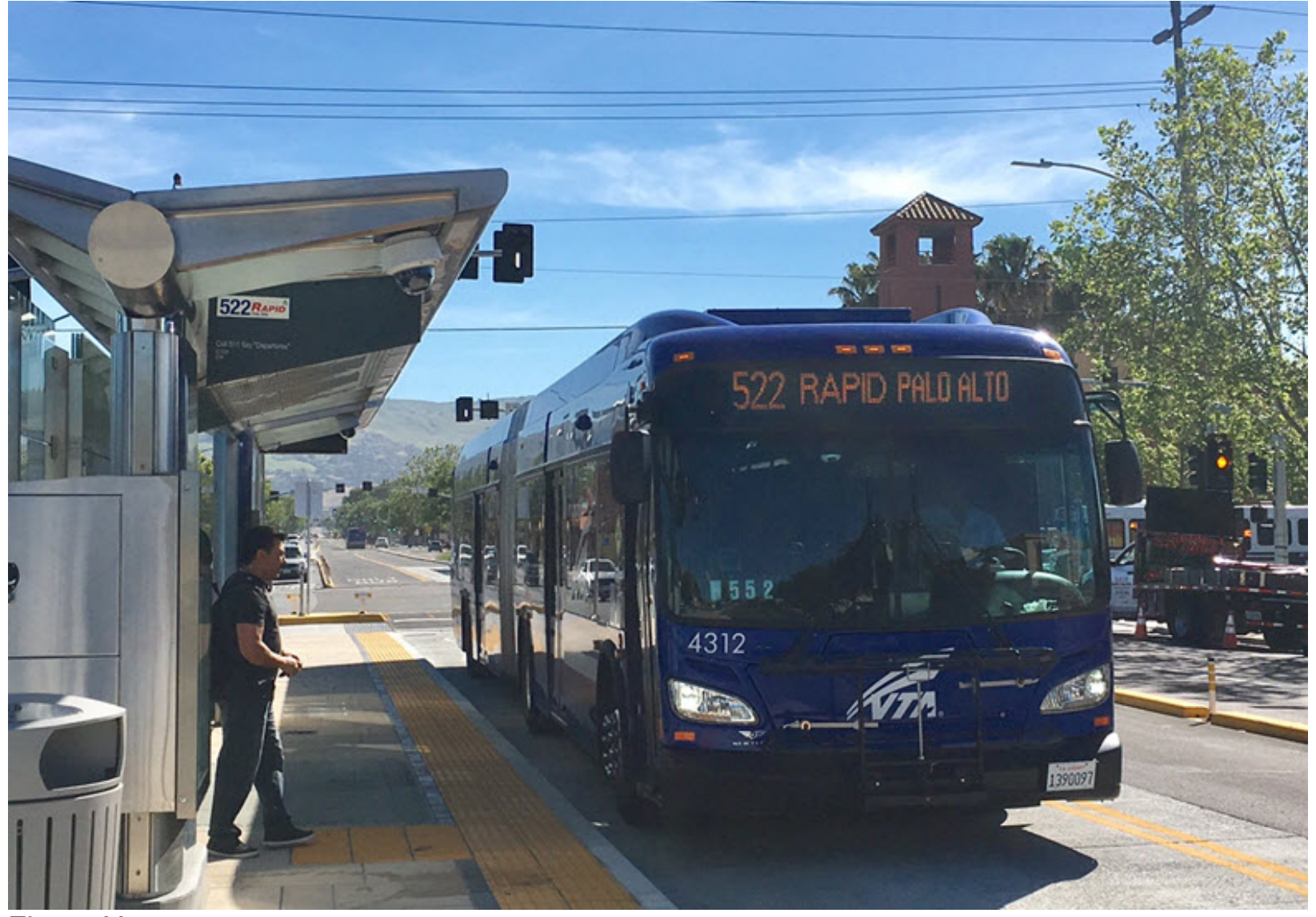

Figure $X$

San Jose BRT

Source: http://www.vta.org/projects-and-programs/transit/alum-rock-santa-clara

The Santa Clara Valley Transportation Authority (VTA) opened the first line of San Jose's bus rapid transit system on May 2, 2017. There are three lines planned in total, and the fleet is hybrid electric. The line is 7 miles in length with limited stops and traffic signal priority. ${ }^{33}$

${ }^{33}$ Adapted from: http://www.vta.org/projects-and-programs/transit/alum-rock-santa-clara. 


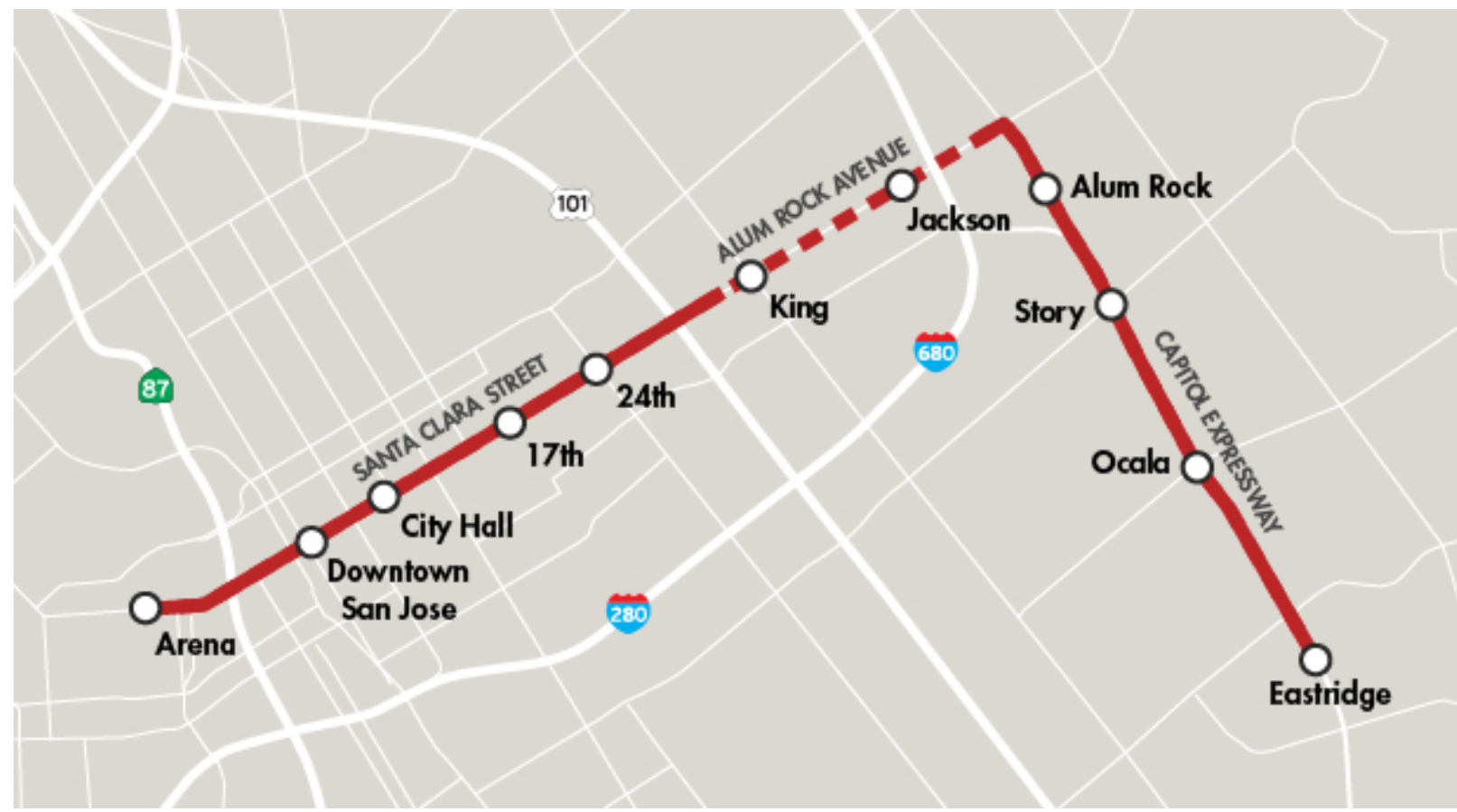

Figure $X$

VTA Alum Rock BRT Route Map

Source: http://www.vta.org/News-and-Media/Connect-with-VTA/Taking-Shape-AlumRockSanta-Clara-Bus-Rapid-Transit-Corridor\#.XJFyhbh7IPY 


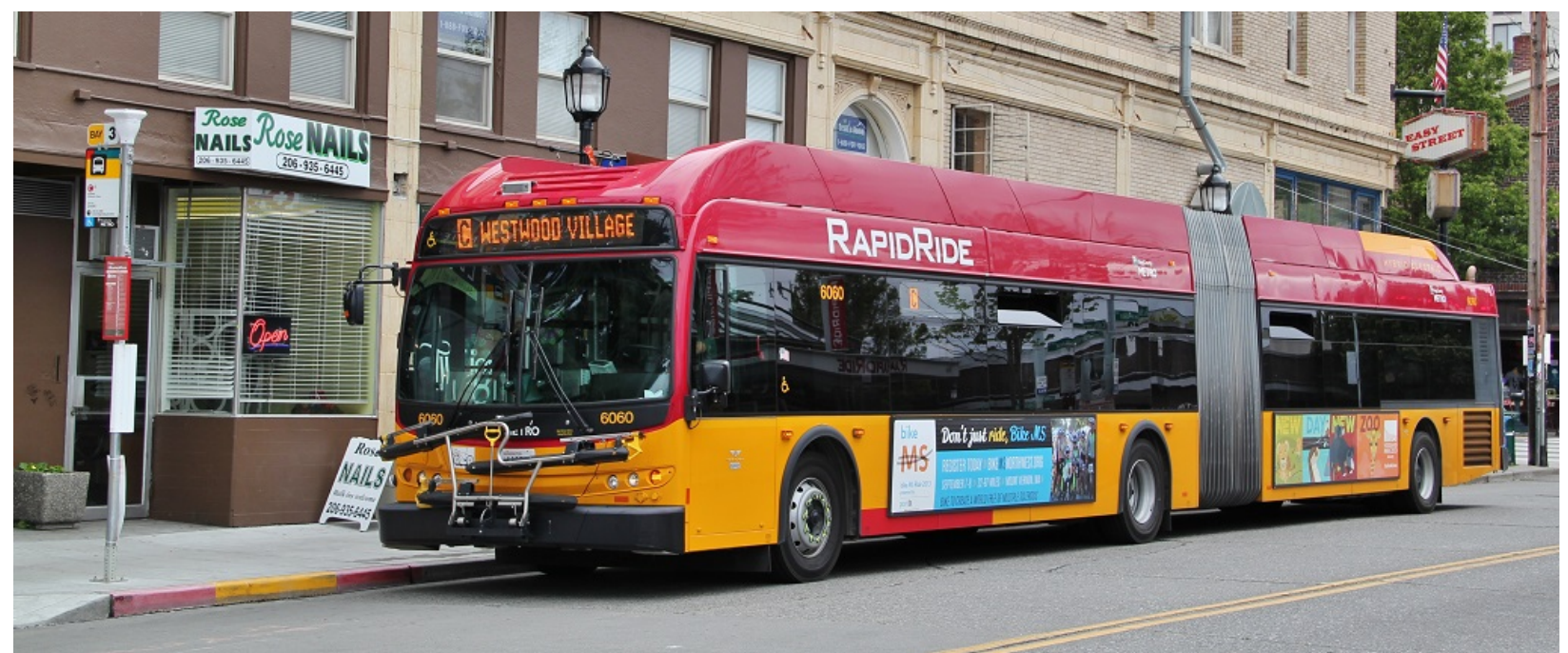

Figure BRT Seattle 1

Seattle RAPIDRIDE BRT

Source:

https://commons.wikimedia.org/wiki/File:King_County_Metro_Rapid_Ride_New_Flyer_DE60LF R_6060.JPG

Operated by King County Metro, RAPIDRIDE is Seattle's transit system with bus rapid transit (BRT) features. This system has six lines totaling 64 miles in and around downtown Seattle. With over 150 buses in the fleet, the RAPIDRIDE system carries nearly 65,000 riders per day. It opened October 2, 2010. ${ }^{34}$

${ }^{34}$ Adapted from: https://en.wikipedia.org/wiki/RapidRide. 


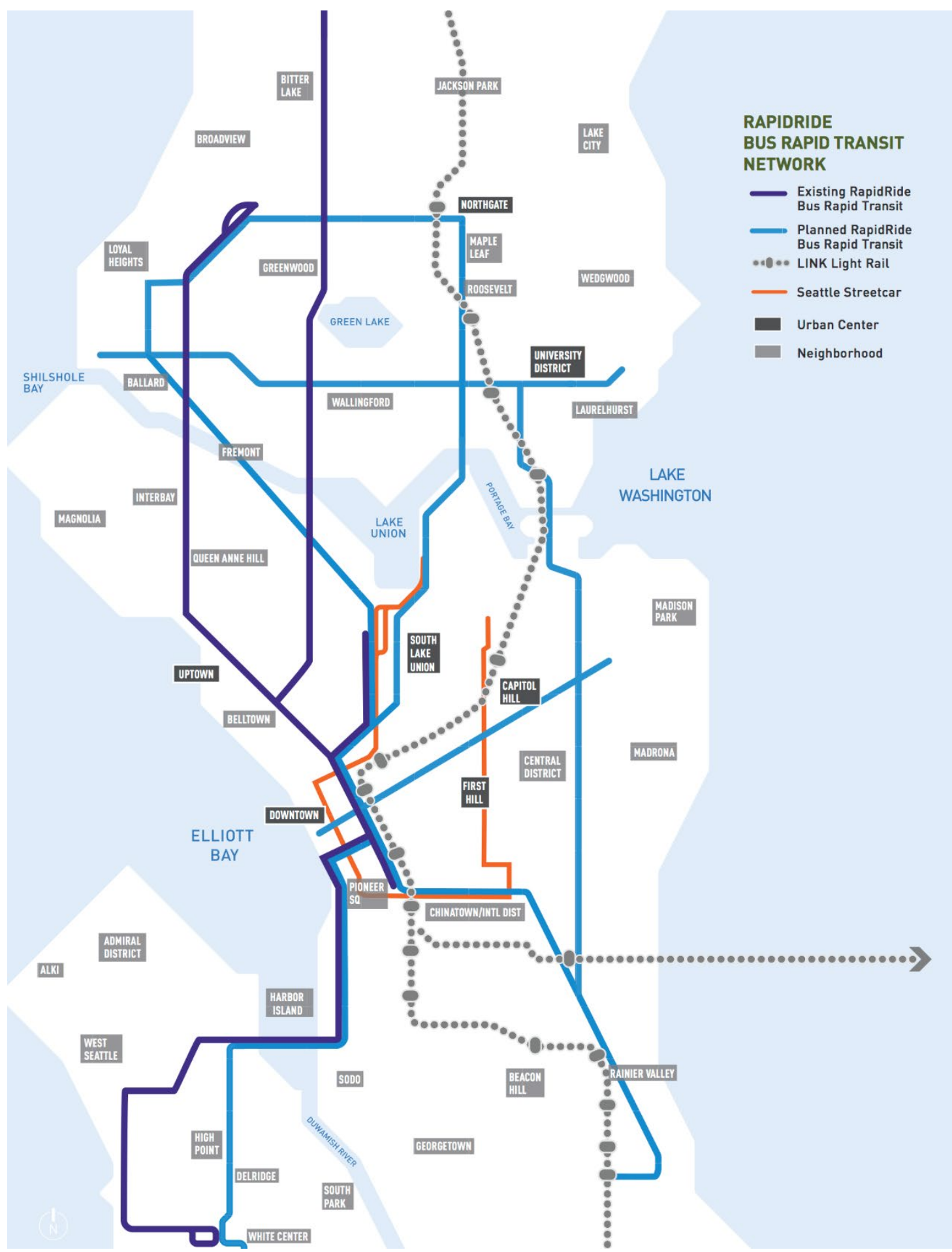

Figure BRT Seattle 1

Current (violet) and Proposed (blue) RAPIDRIDE Map

Source: https://seattletransitblog.com/2015/12/18/an-introduction-to-rapidride/

STOCKTON BUS RAPID TRANSIT SYSTEM 


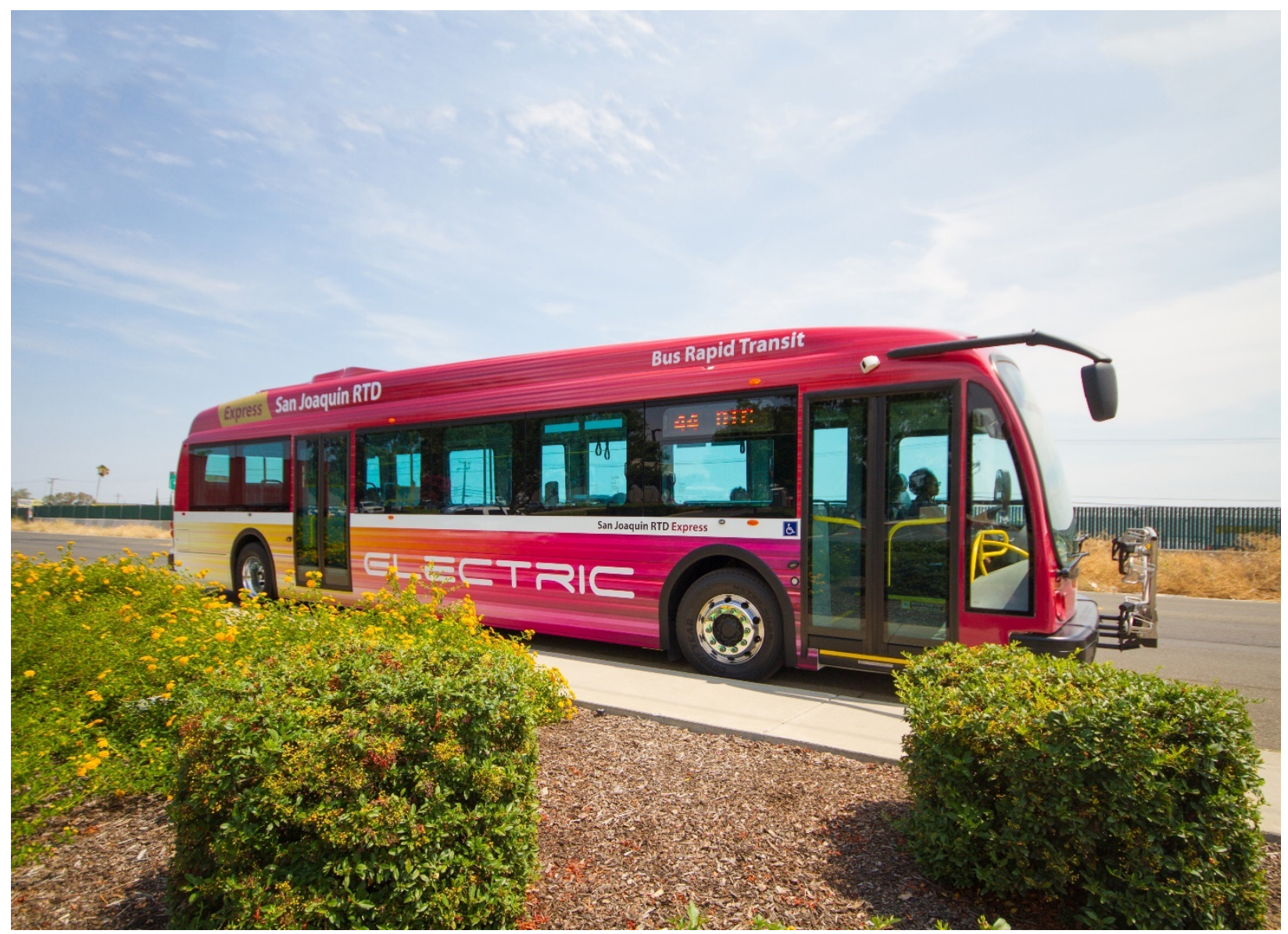

Figure BRT Stockton 1

San Joaquin RTD Bus Rapid Transit Stock

Source: Source: http://sanjoaquinrtd.com/first-in-the-nation-1/

Operated by the San Joaquin Regional Transit District, there are five bus rapid transit lines serving the greater Stockton, California area. ${ }^{35}$

${ }^{35}$ Adapted from: http://sanjoaquinrtd.com/bus-maps-schedules/. 


\section{RE WEEKDAY SYSTEM MAP}

\section{EFFECTIVE: AUGUST 6, 2017}

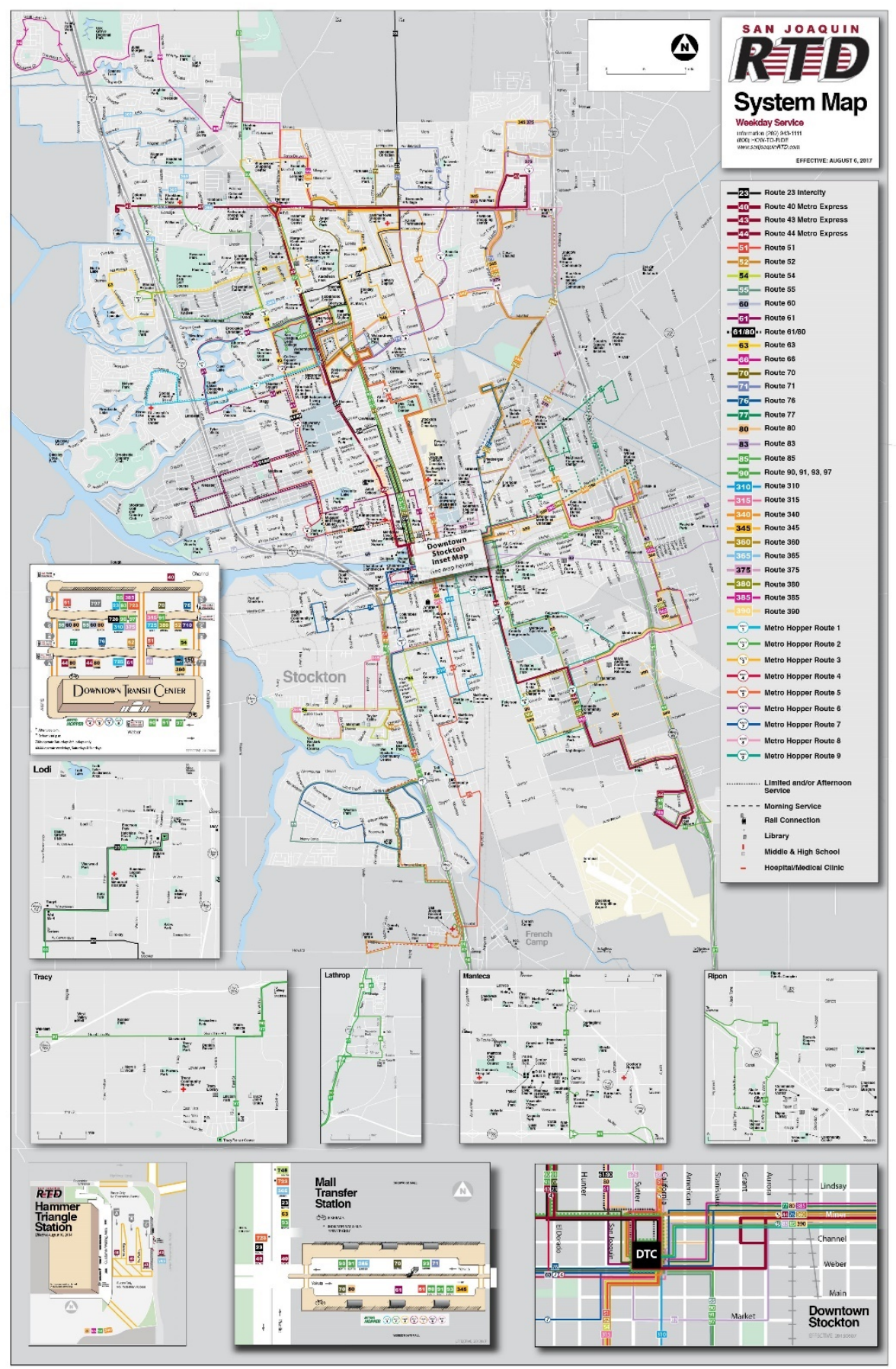




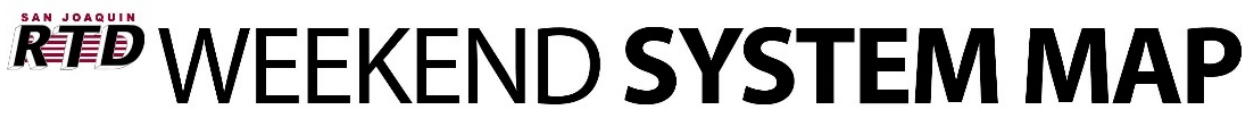

EFFECTIVE: AUGUST 6, 2017

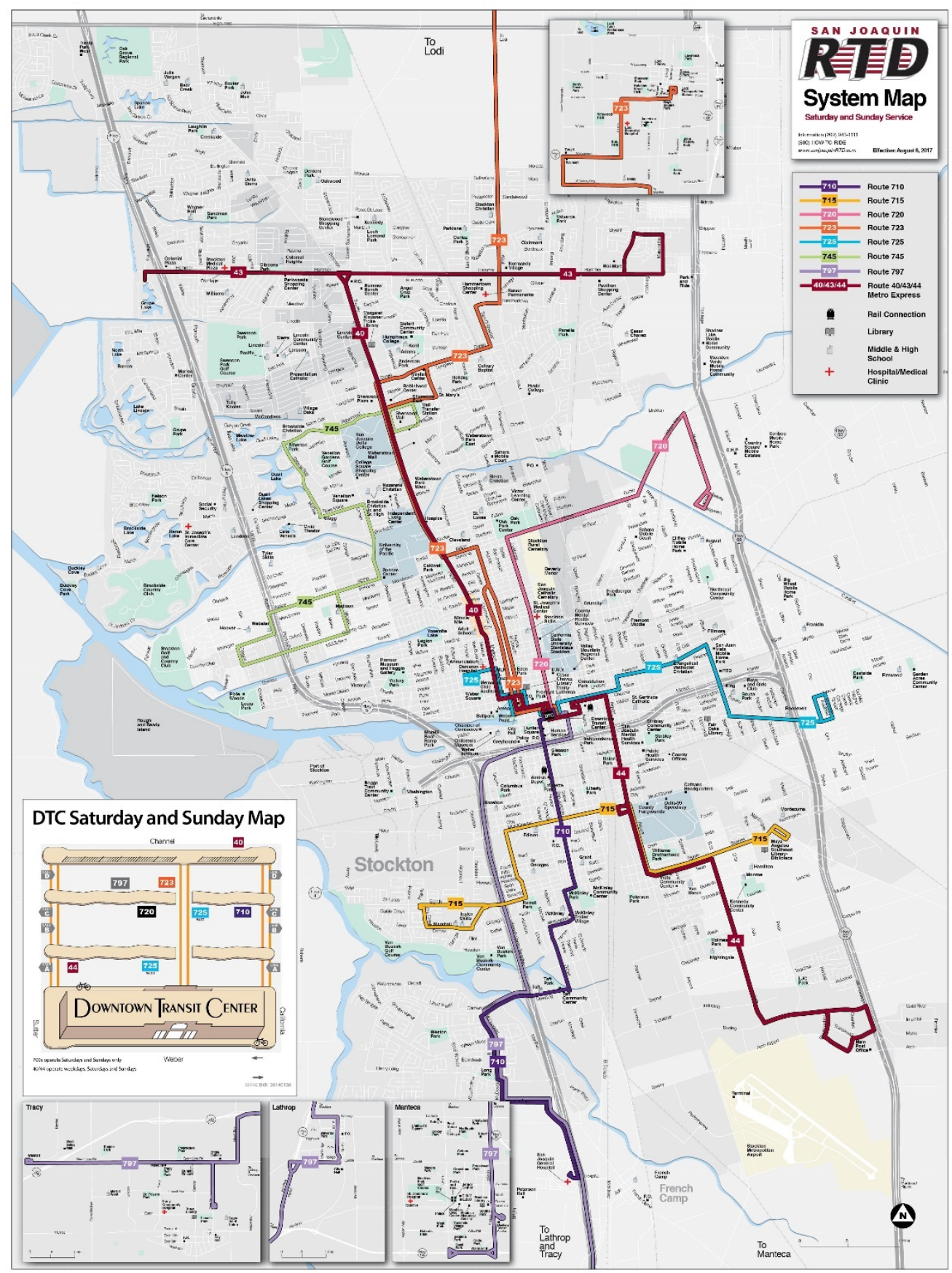

Figure BRT Stockton $2 \& 3$

San Joaquin RTD Transit Map

Source: http://sanjoaquinrtd.com/maps_and_schedules/system_maps.php

WASHINGTON, DC BUS RAPID TRANSIT SYSTEM 


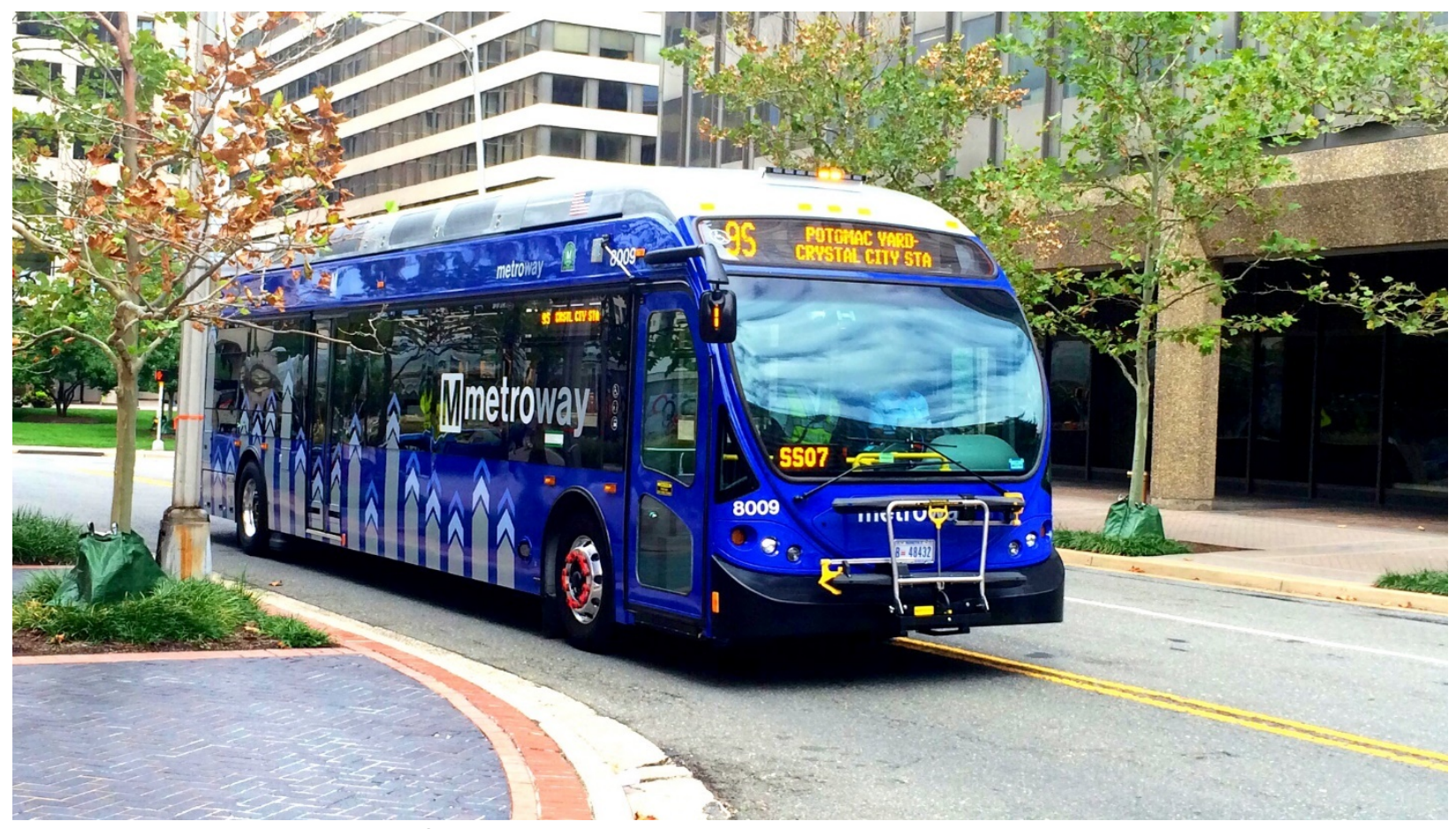

Figure BRT Washington, DC 1

Metroway Rolling Stock

Source: Source: http://www.wikiwand.com/en/Metroway

Operated by the Washington Metro Area Transit Authority, the Metroway is the DC area's first bus rapid transit system. It opened in August 2014, and it has one line in Arlington and Alexandria, Virginia. The line is 6.8 miles long and has 16 stations. $^{36}$

${ }^{36}$ Adapted from: https://en.wikipedia.org/wiki/Metroway. 


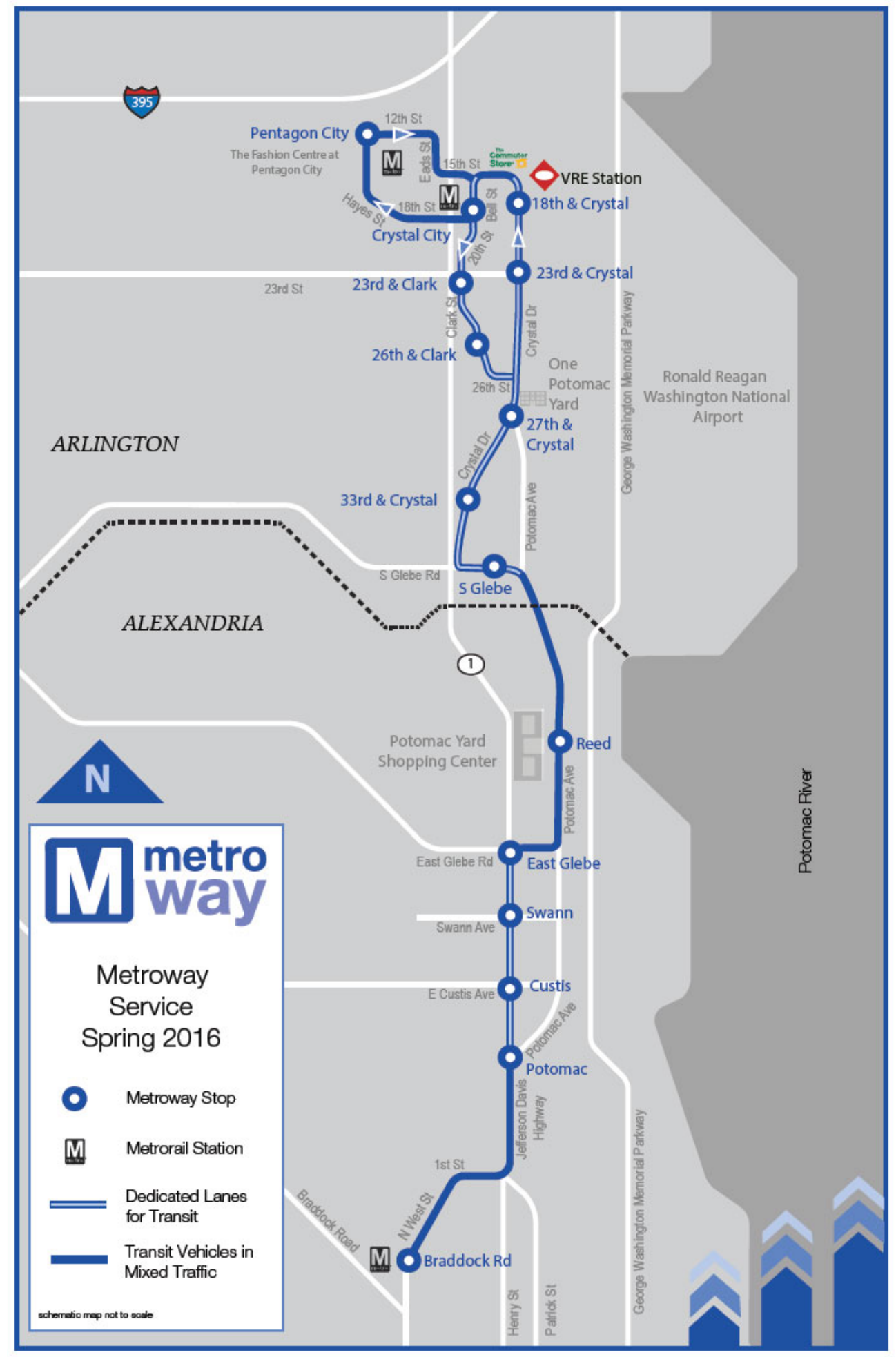

Figure BRT Washington, DC 2

Metroway Map

Source: http://metrowayva.com/route/

APPENDIX A - SCT 


\section{STREETCAR TRANSIT SYSTEMS USED IN ANALYSIS}

$\begin{array}{lllll}\text { Streetcar Transit Systems Metro Area \& Name } & \text { Year } & \text { Miles } & \text { Stations } & \begin{array}{l}\text { Riders } \\ \text { (Daily) }\end{array} \\ \text { Atlanta: Downtown Loop } & 2014 & 2.7 & 12 & 1,500 \\ \text { Cincinnati: Bell Connector } & 2016 & 3.6 & 18 & 1,750 \\ \text { Dallas: Streetcar } & 2015 & 2.45 & 6 & 1,000 \\ \text { Kansas City: Streetcar } & 2016 & 2.2 & 16 & 6,000 \\ \text { Little Rock: Metro Streetcar } & 2004 & 2.4 & 15 & 274 \\ \text { New Orleans: Streetcar } & 1835 & 22.3 & 22.3 & 21,600 \\ \text { Portland: Streetcar } & 2001 & 8.3 & 72 & 16,000 \\ \text { Salt Lake City: S Line } & 2013 & 2 & 7 & 1,000 \\ \text { Seattle: Streetcar } & 2007 & 3.8 & 17 & 5,000 \\ \text { Tacoma: Link } & 2003 & 1.6 & 6 & 2,663 \\ \text { Tampa: TECO } & 2002 & 2.7 & 11 & 783 \\ \text { Tucson: Sun Link } & 2014 & 3.9 & 21 & 3,000 \\ \text { Washington, DC: Streetcar } & 2016 & 2.2 & 8 & 3,014\end{array}$




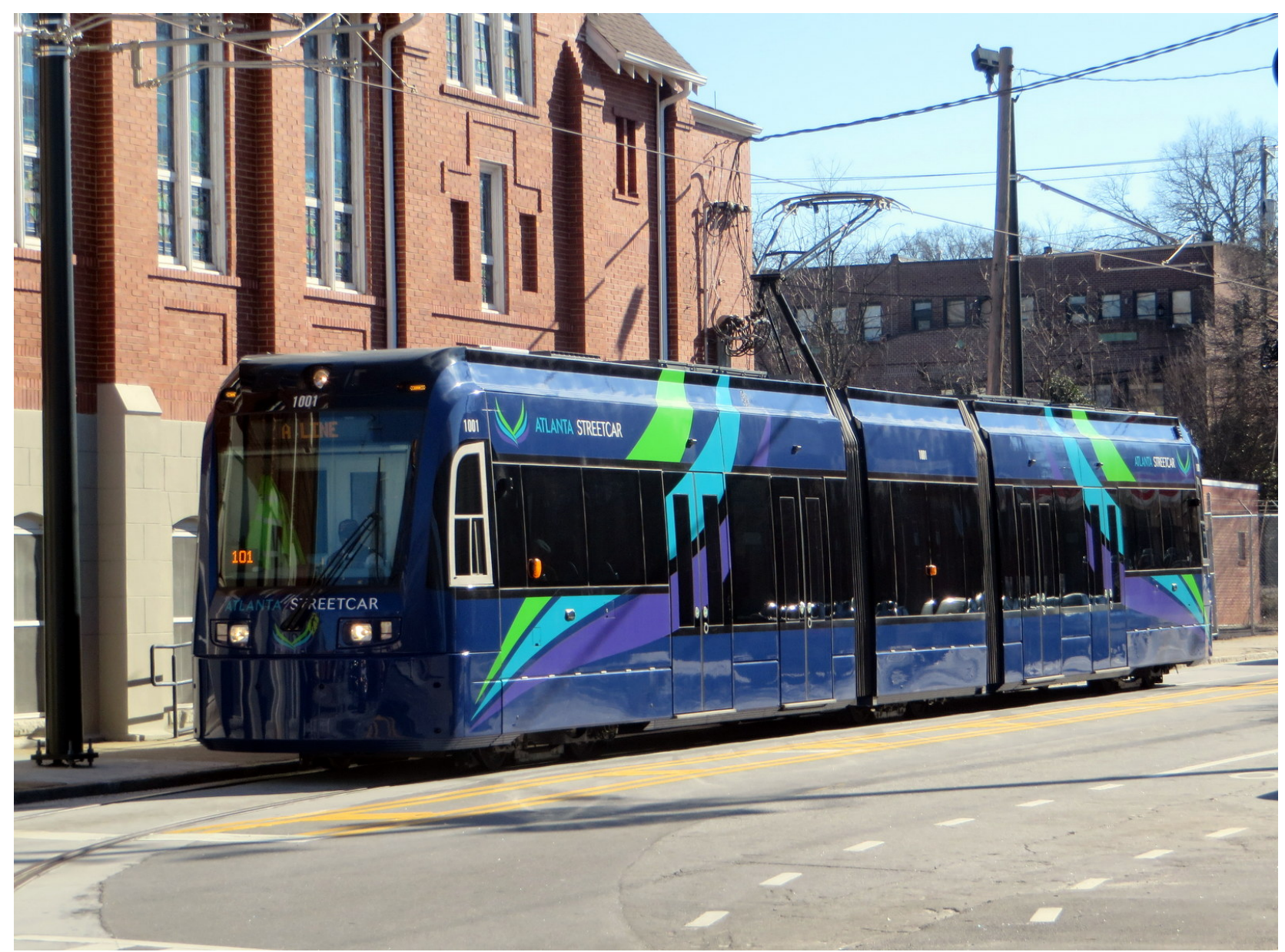

Figure $X$

Atlanta Streetcar

Source: https://upload.wikimedia.org/wikipedia/commons/3/3f/Atlanta_Streetcar.JPG

The Atlanta Streetcar, also known as the Downtown Loop, is a streetcar line serving downtown and nearby areas in Atlanta, Georgia. The Downtown Loop is the Phase 1 of the Atlanta Streetcar project, which is planning to expand onto the Beltline surrounding central Atlanta. The project is the first regular passenger streetcar service in Atlanta since the original Atlanta streetcars were phased out in 1949. ${ }^{37}$

The streetcar is operated by the Metropolitan Atlanta Rapid Transit Authority (MARTA) and is comprised of one line serving 12 stations, as of 2018. Its average daily ridership ranges about 1,500 .

\footnotetext{
${ }^{37}$ Adapted from: https://en.wikipedia.org/wiki/Atlanta_Streetcar
} 


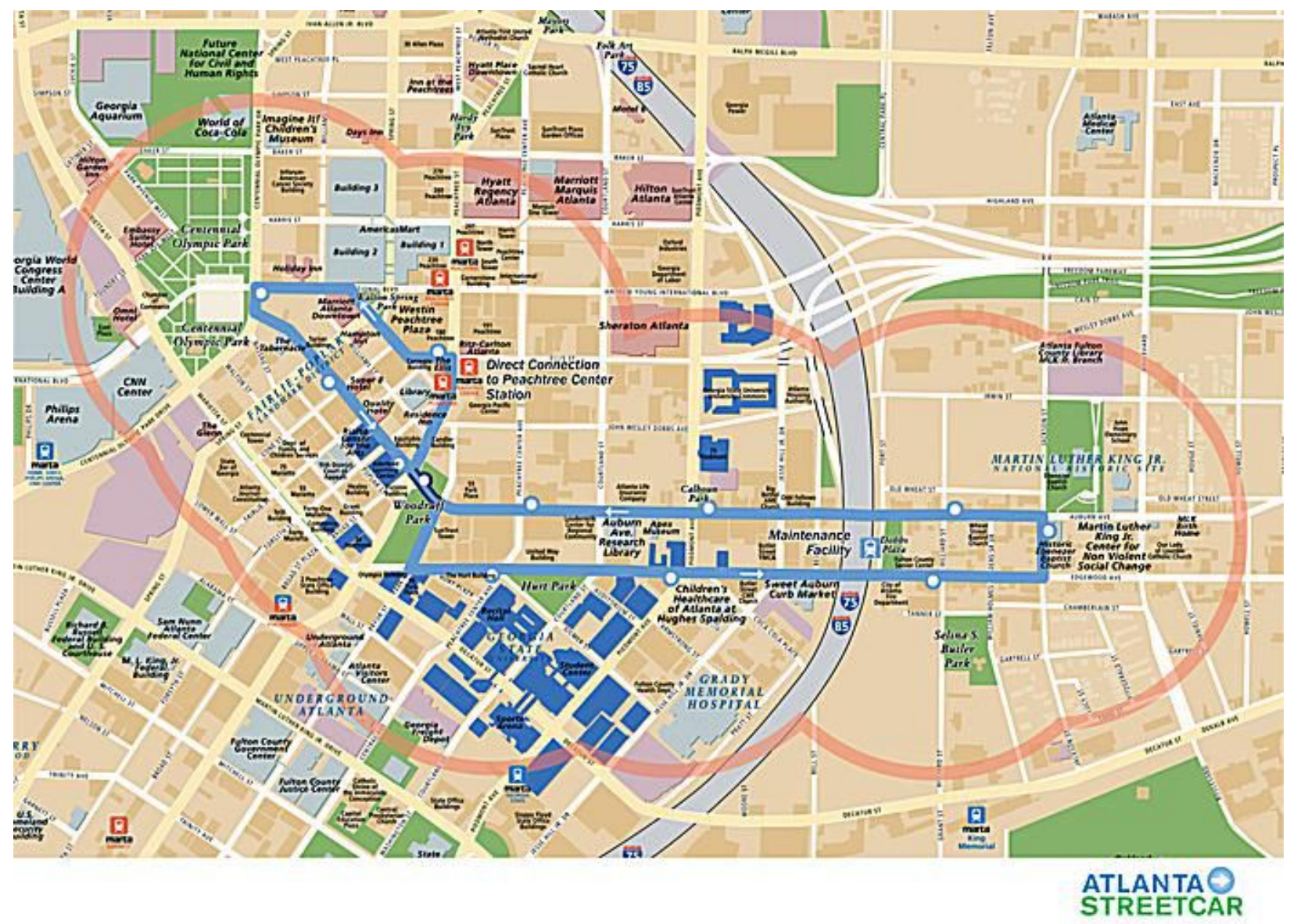

Figure $X$

Atlanta Streetcar route

Source: https://www.tripsavvy.com/thmb/7IV_JpoSPQzbyaEjTvkdkB0y3s=/700x515/filters:fill(auto,1)/Streetcar-2-57a9fb273df78cf4594c0510.jpg 


\section{CINCINNATI STREETCAR SYSTEM}

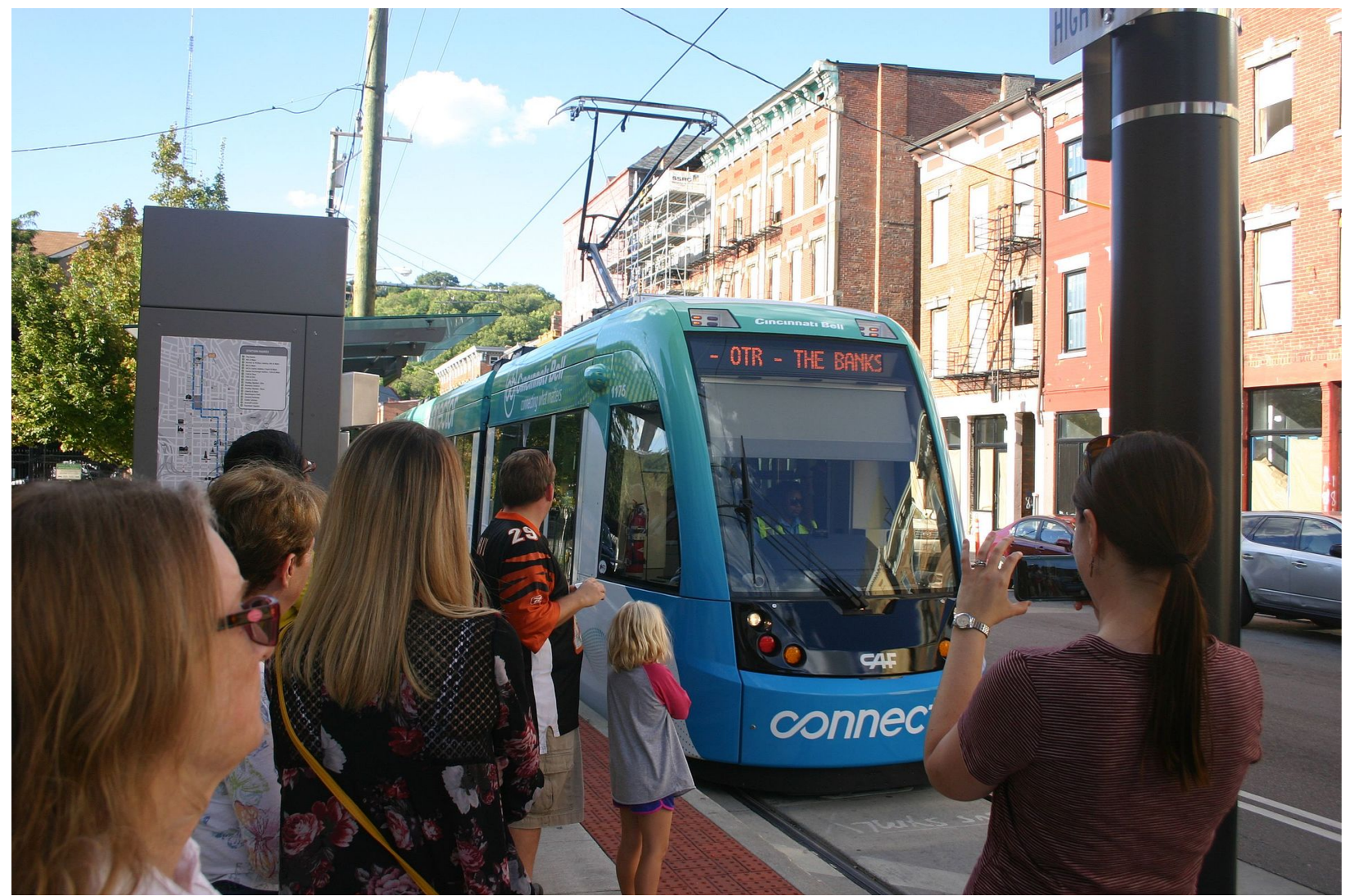

\section{Figure $X$}

Cincinnati Bell Connector

Source: https://upload.wikimedia.org/wikipedia/commons/thumb/e/ec/Cincinnati-bellconnector_station-12-findlay-market-race_09-11-2016.jpg/1920px-Cincinnati-bellconnector_station-12-findlay-market-race_09-11-2016.jpg

The Cincinnati Bell Connector, previously known as the Cincinnati Streetcar, started operations in September 2016. The streetcar operates along on a 3.6-mile $(5.8 \mathrm{~km})$ loop north of downtown through the Over-the-Rhine neighborhood into downtown. As of this report, it serves 18 stations. Ridership ranges from about 1,500 to 2,000 passengers per day. ${ }^{38}$

\footnotetext{
${ }^{38}$ Adapted from: https://en.wikipedia.org/wiki/Cincinnati_Bell_Connector.
} 


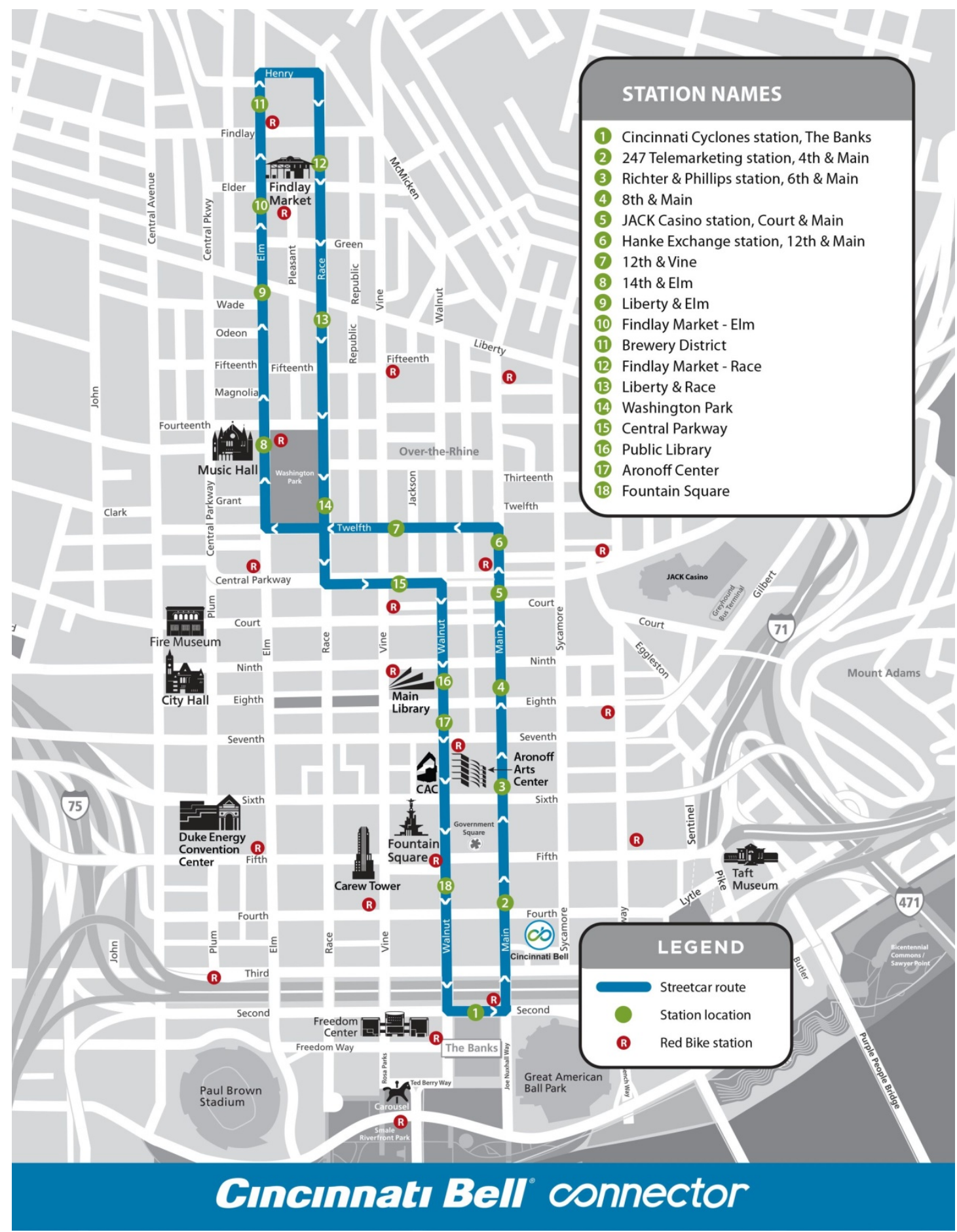

Figure $\mathrm{X}$

Cincinnati Bell Connector route Source: https://www.cincinnatioh.gov/streetcar/assets/File/streetcar\%20map_Decal_OnTVMs_lettersize.jpg

DALLAS STREETCAR SYSTEM 


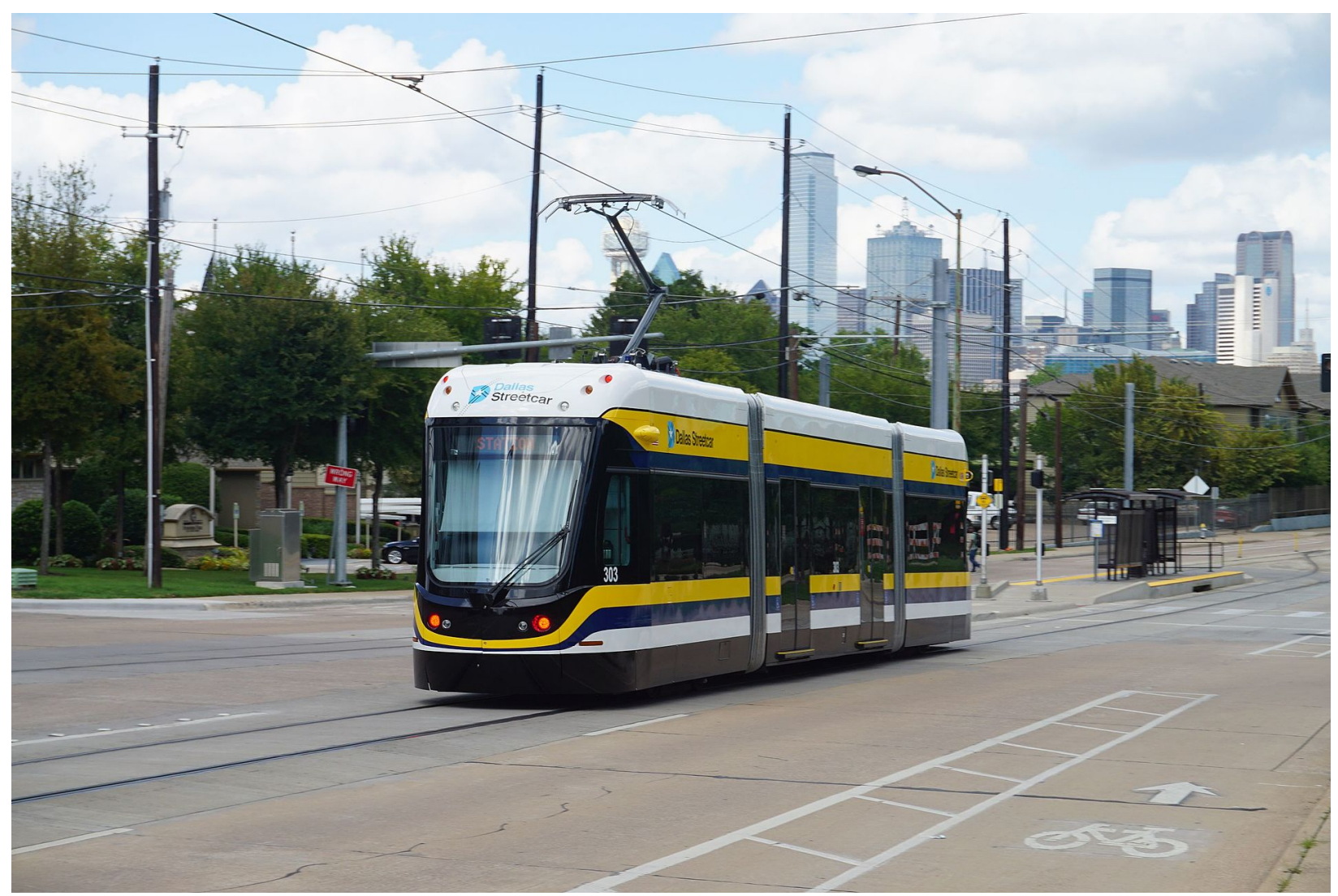

Figure $\mathrm{X}$

Dallas Streetcar

Source:

https://upload.wikimedia.org/wikipedia/commons/thumb/4/44/Oak_Cliff_September_2016_51_\% 28Dallas_Streetcar\%29.jpg/1920px-

Oak_Cliff_September_2016_51_\%28Dallas_Streetcar\%29.jpg

The Dallas Streetcar is a 2.45-mile $(3.94 \mathrm{~km})$ modern streetcar that has operated connecting downtown Dallas to the medical and arts district south, across the Trinity River. It has been operating since 2015 . It serves six stations. ${ }^{39}$ Fewer than 1,000 people use the streetcar on an average daily basis. ${ }^{40}$

\footnotetext{
${ }^{39}$ Adapted from: https://en.wikipedia.org/wiki/Dallas_Streetcar.

${ }^{40}$ Source: https://www.dallasnews.com/opinion/editorials/2018/04/23/city-keep-eye-ridership-weighsadding-1-fare-streetcar.
} 


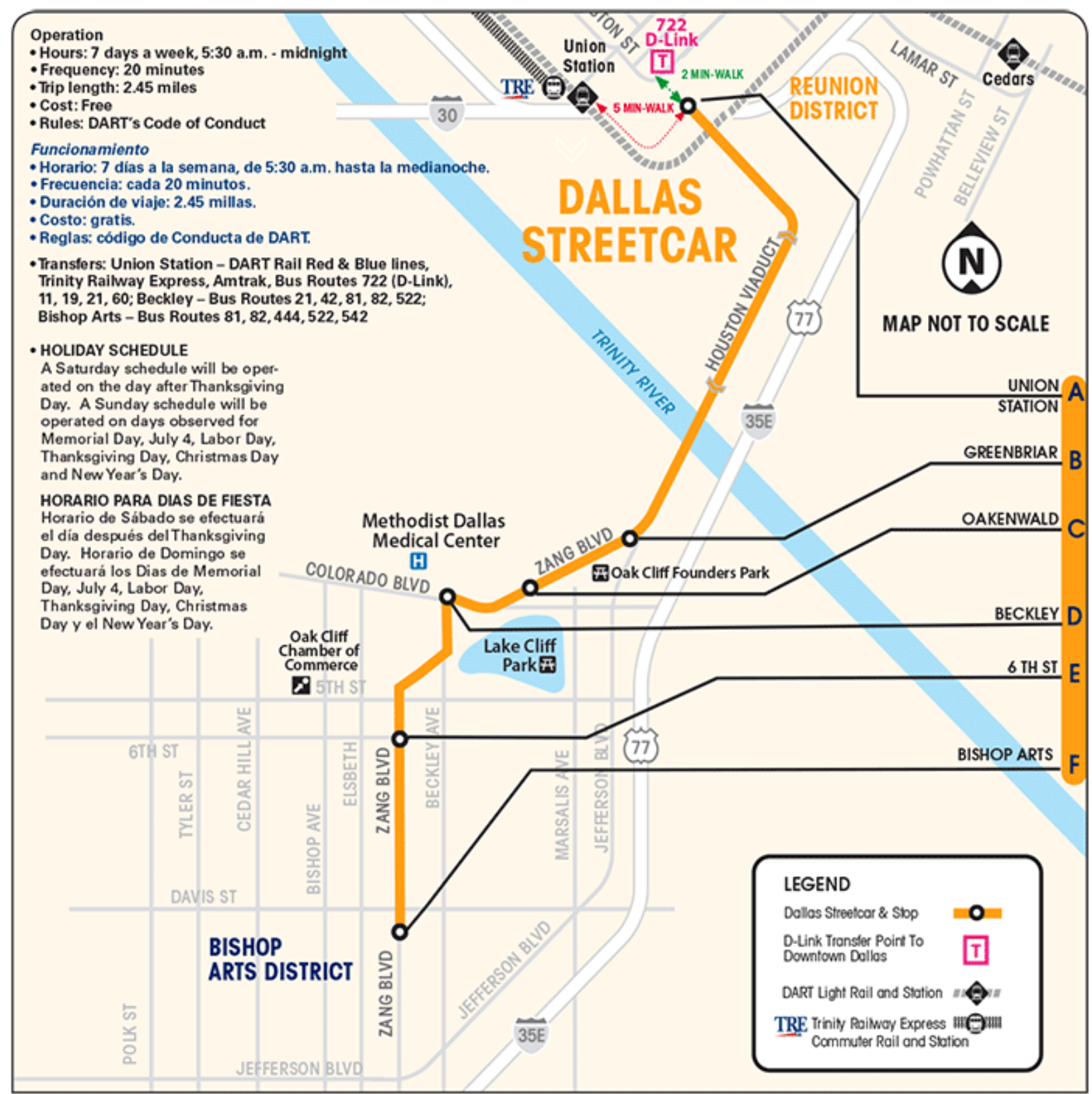

Figure $\mathrm{X}$

Dallas streetcar route

Source: https://www.dart.org/riding/dallasstreetcar.asp 


\section{KANSAS CITY STREETCAR SYSTEM}

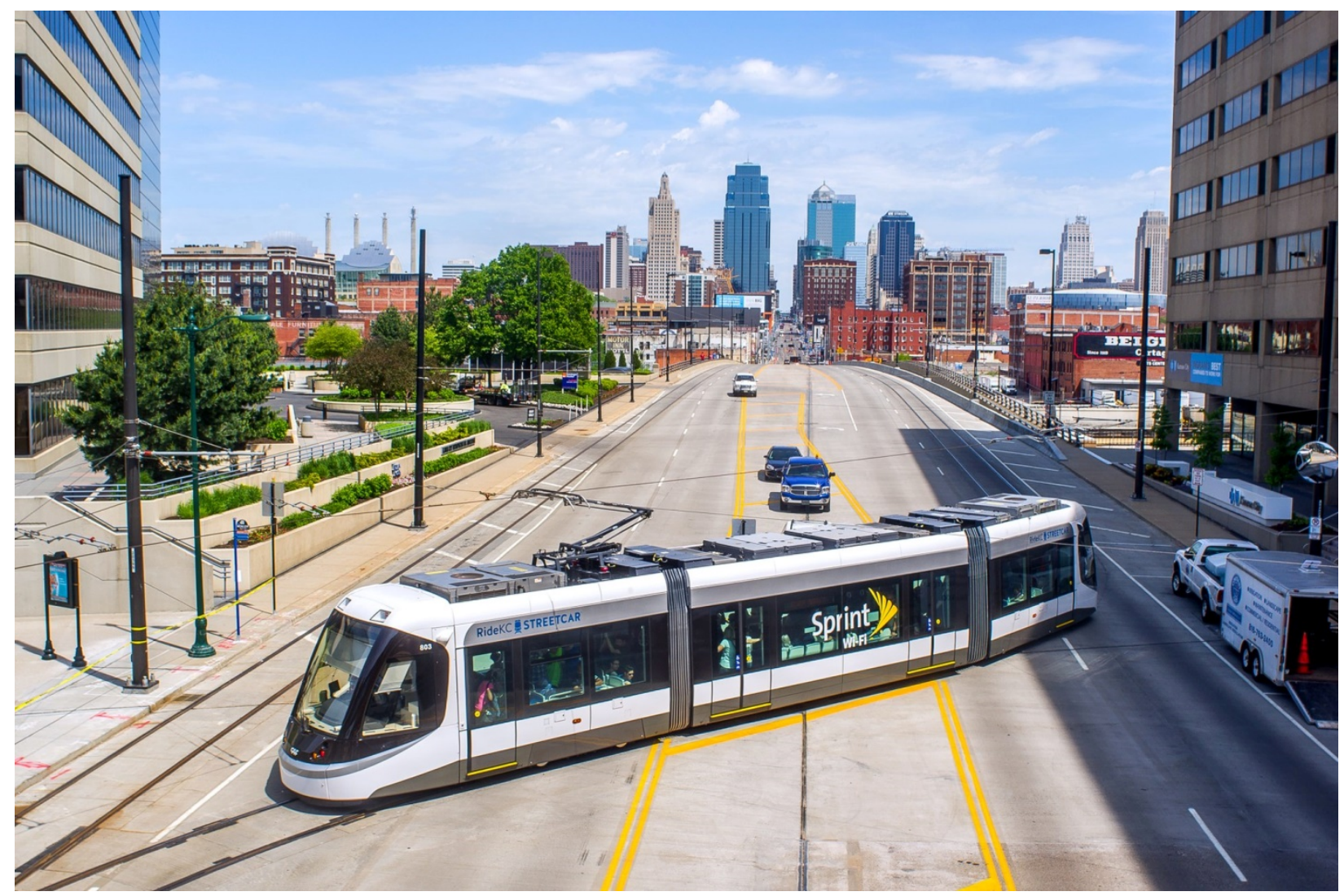

Figure $X$

Kansas City streetcar

Source:

https://upload.wikimedia.org/wikipedia/commons/thumb/6/6a/KC_Streetcar_\%2826813012241\% 29.jpg/1920px-KC_Streetcar_\%2826813012241\%29.jpg

The Kansas City Streetcar, formally known as the RideKC Streetcar, serves downtown Kansas City, Missouri. It started operations in May 2016. Unlike most streetcars, the KC Streetcar is free to ride as costs are borne by a downtown based Transportation Development District. By late fall of 2018 , ridership was averaging nearly 6,000 riders daily. The streetcar line's 2.2 mile route serves 16 stops connecting downtown to the convention center district and Union Station. ${ }^{41}$

\footnotetext{
${ }^{41}$ Adapted from: https://en.wikipedia.org/wiki/KC_Streetcar.
} 


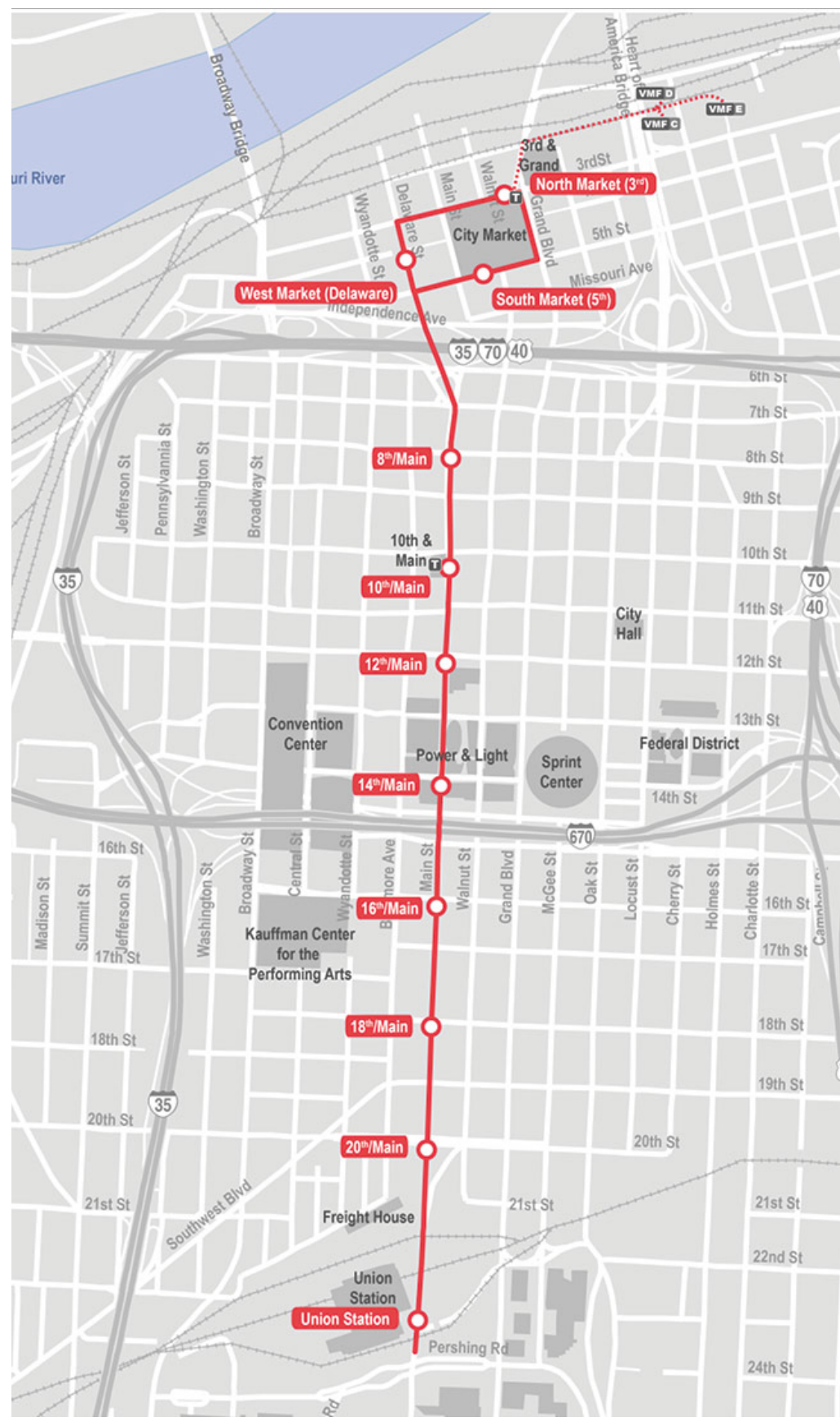

Figure $\mathrm{X}$

Kansas City streetcar route

Source: https://cdn.archpaper.com/wp-content/uploads/2014/01/kc_streetcar_03.jpg 


\section{LITTLE ROCK STREETCAR SYSTEM}

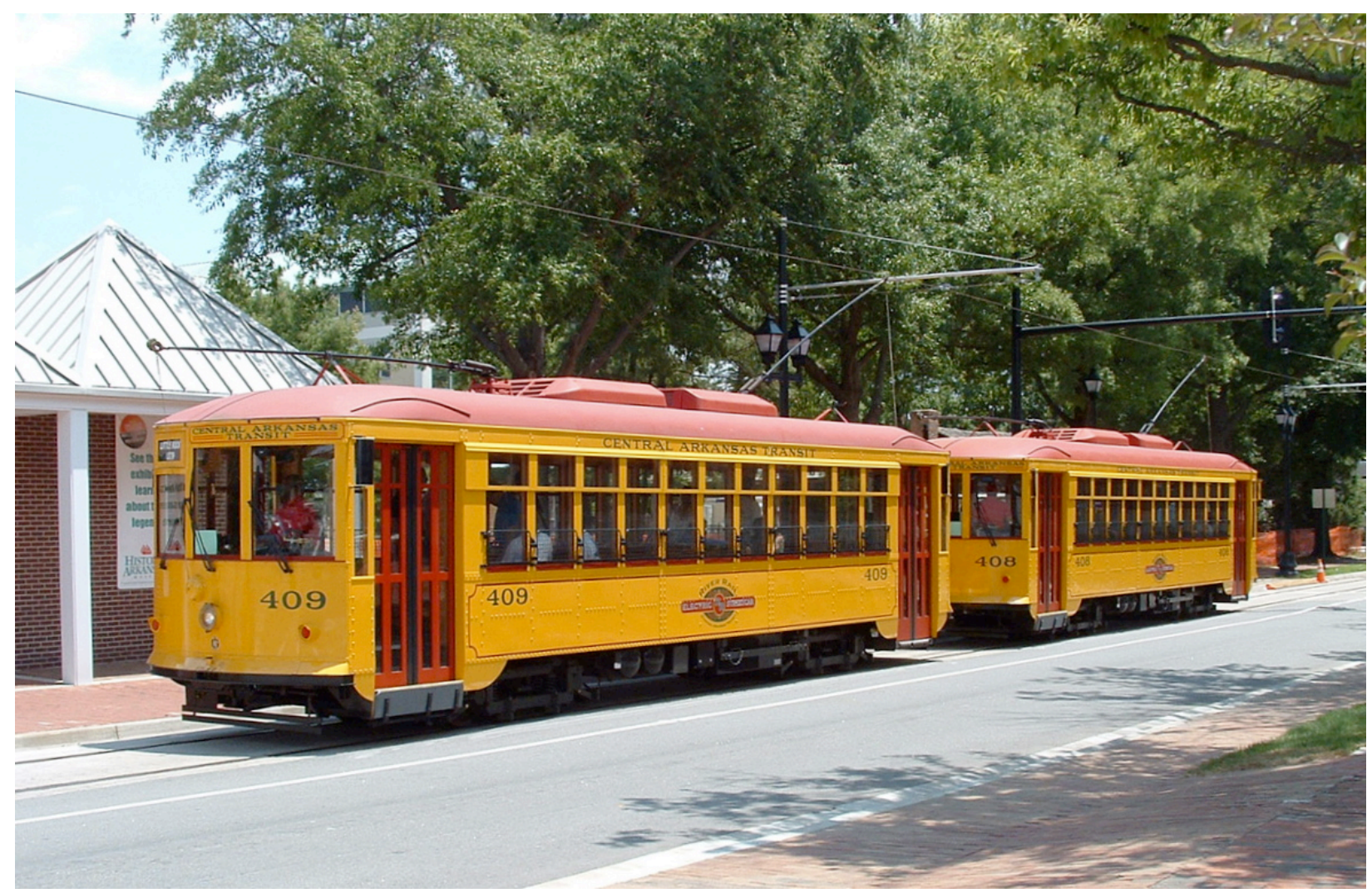

Figure $X$

Little Rock streetcar

Source: https://en.wikipedia.org/wiki/Metro_Streetcar\#/media/File:River_Rail_streetcars.jpg The Metro Streetcar as it's known in metro Little Rock, Arkansas is a streetcar system which has been in operation since November 1, 2004. Spanning between the cities of Little Rock and North Little Rock, the 3.4-mile system serves 100,000 riders annually and covers 1,080 miles every week. Adults can ride the Metro starting at $\$ 1.35$ for a one-way, one-time ride or pay $\$ 36$ for a 31-day pass. There are discounts for students, senior citizens, and others. The Metro has been expanded once in $2007 .{ }^{42}$

\footnotetext{
${ }^{42}$ Adapted from: https://rrmetro.org/services/streetcar/ and Source: https://en.wikipedia.org/wiki/Metro_Streetcar.
} 


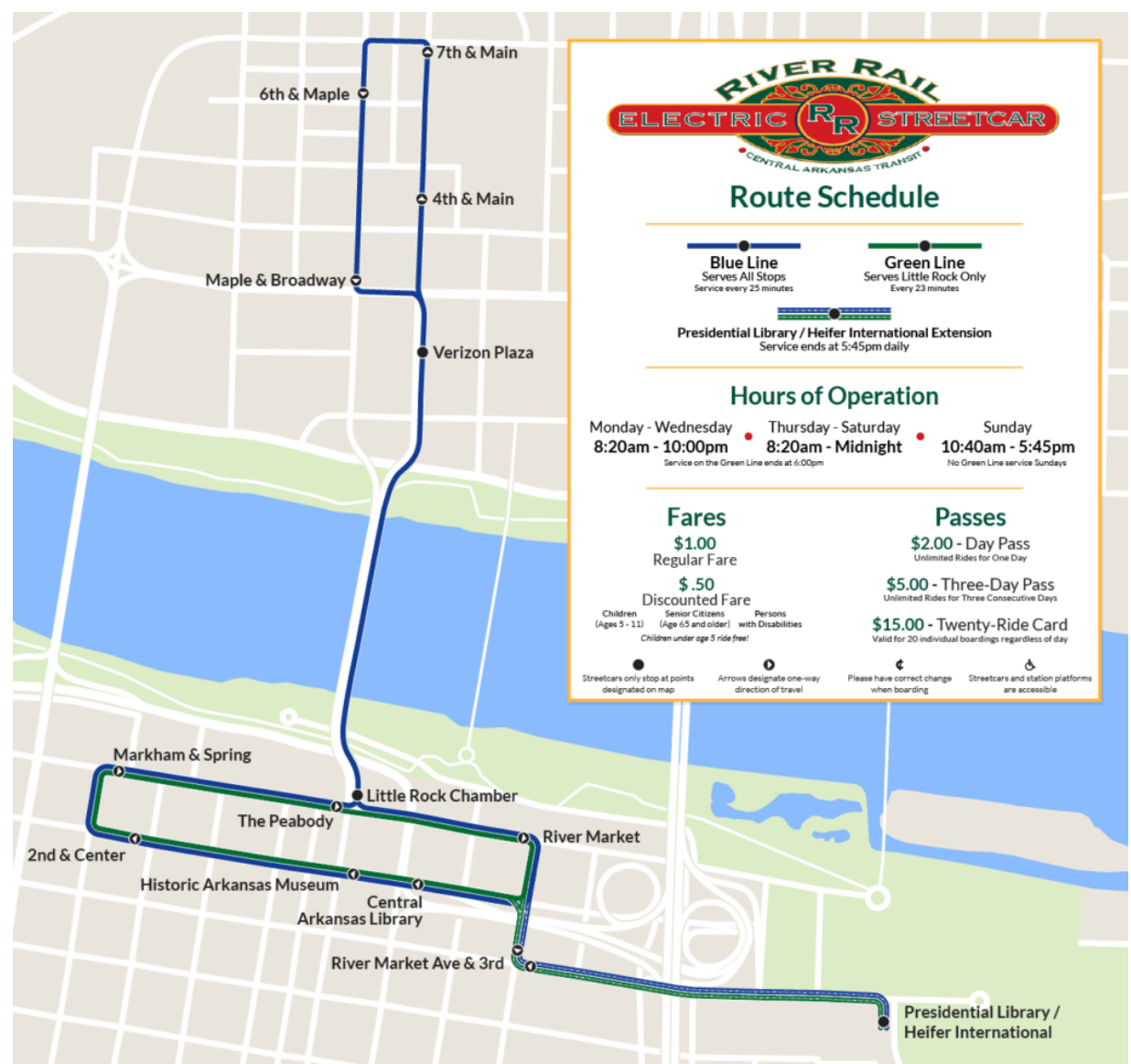

Figure $X$

Little Rock streetcar map

Source: https://www.transitmap.net/little-rock-dovak/

NEW ORLEANS STREETCAR SYSTEM 


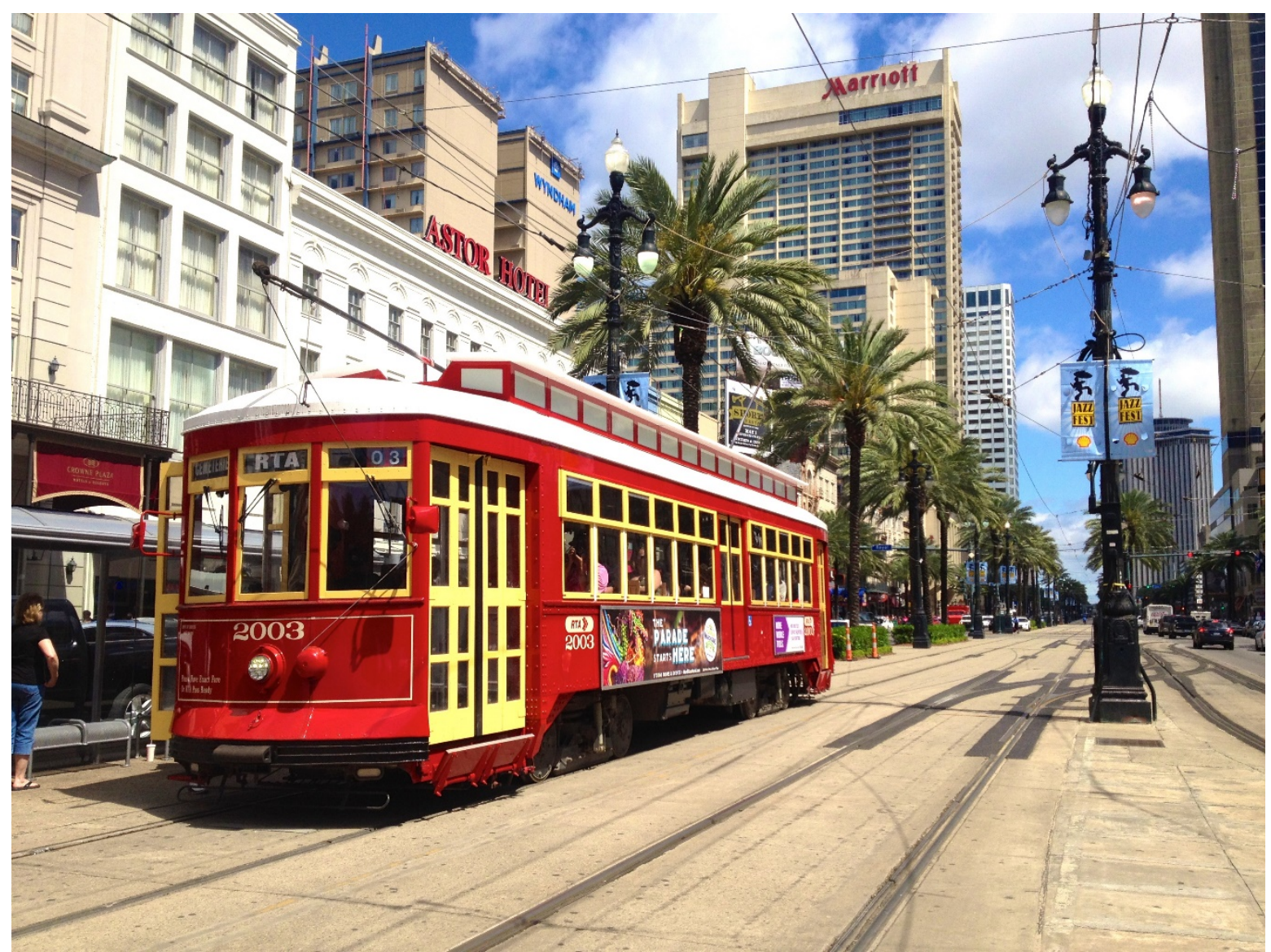

Figure $\mathrm{X}$

New Orleans Canal Line streetcar

Source:

https://en.wikipedia.org/wiki/Canal_Streetcar_Line\#/media/File:Canal_Streetcar_in_New_Orlean s,_Louisiana,_USA.jpg

The New Orleans Regional Transit Authority out of New Orleans, Louisiana operates four streetcar lines in the downtown region all serving different areas and purposes - the historic St. Charles Avenue line, the Canal Street line, the Riverfront line, and the Rampart-St. Claude Avenue line, which is the newest installment.

The oldest continuously operating streetcar line in the world, the St. Charles streetcar line has been running since 1835. Its main passengers are commuters and tourists, making it also the busiest line in the New Orleans System. The St. Charles line is 13.2 miles long with one route. The Canal Street line originally operated between 1861 and 1964, and between 2000 and 2004, the line was redesigned and rebuilt primarily running along its namesake street. The Canal line is 5.5 miles in length and has two routes.

Opened in 1988, the Riverfront streetcar line was the first new line in 62 years. It was opened after a need was identified for tourist transportation, operating along a stretch of the Mississippi River which has plentiful amenities for visitors. It travels 2 miles along an exclusive right of way between the French Quarter and the convention center and has one route. 
The newest line, the Rampart-St. Claude streetcar line, opened on October 2, 2016. It serves as a connection between a large national and regional bus terminal and the rest of the city. The Rampart-St. Claude line is one route at 1.6 miles long. ${ }^{43}$

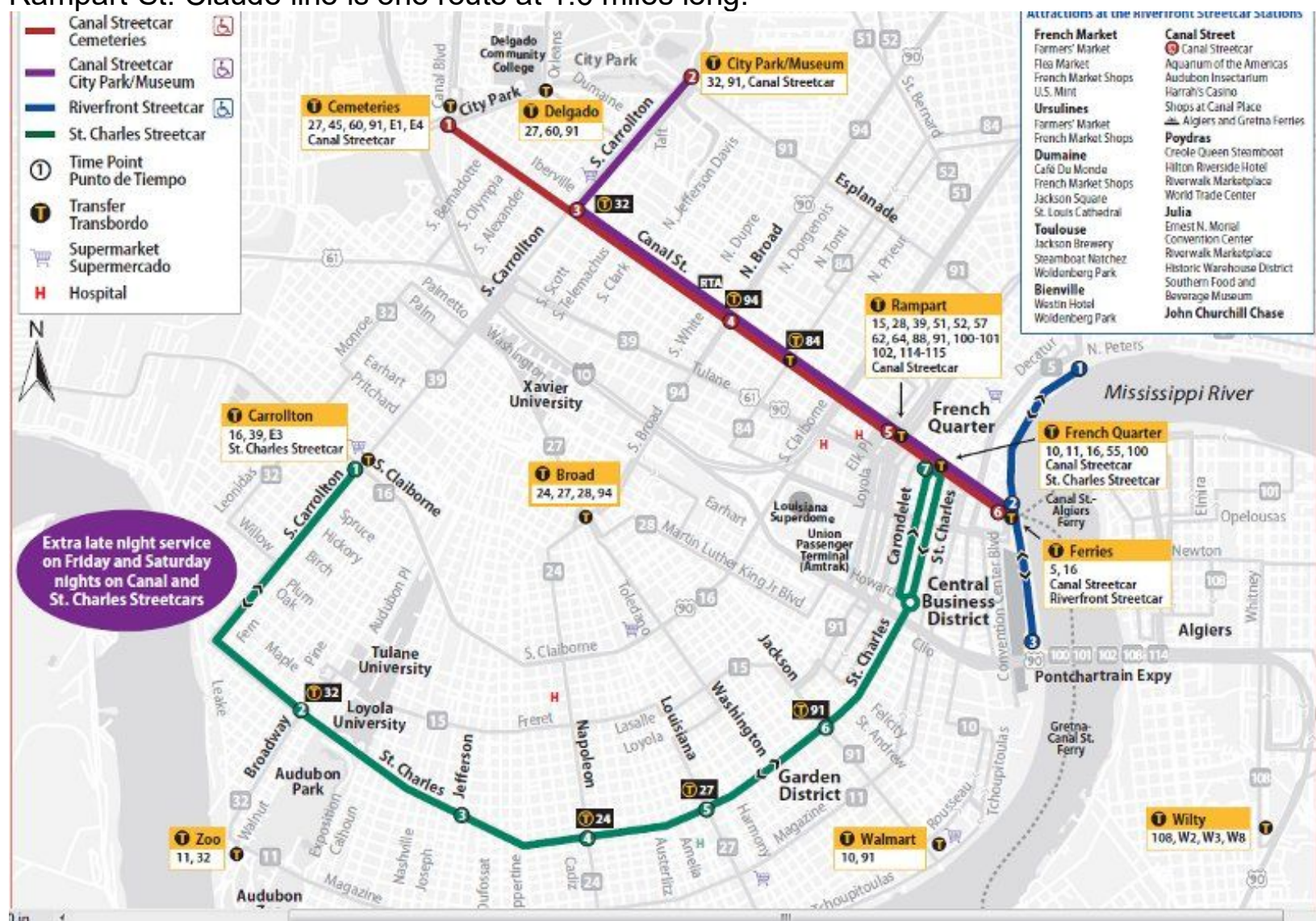

Figure $X$

New Orleans Streetcar Map

Source: https://www.pinterest.com/pin/461267186813387397/

PORTLAND STREETCAR SYSTEM

${ }^{43}$ Adapted from: https://en.wikipedia.org/wiki/St._Charles_Streetcar_Line; Source:

https://en.wikipedia.org/wiki/Canal_Streetcar_Line; Source:

https://en.wikipedia.org/wiki/Riverfront_Streetcar_Line; and Source:

https://en.wikipedia.org/wiki/Rampart\%E2\%80\%93St._Claude_Streetcar_Line. 


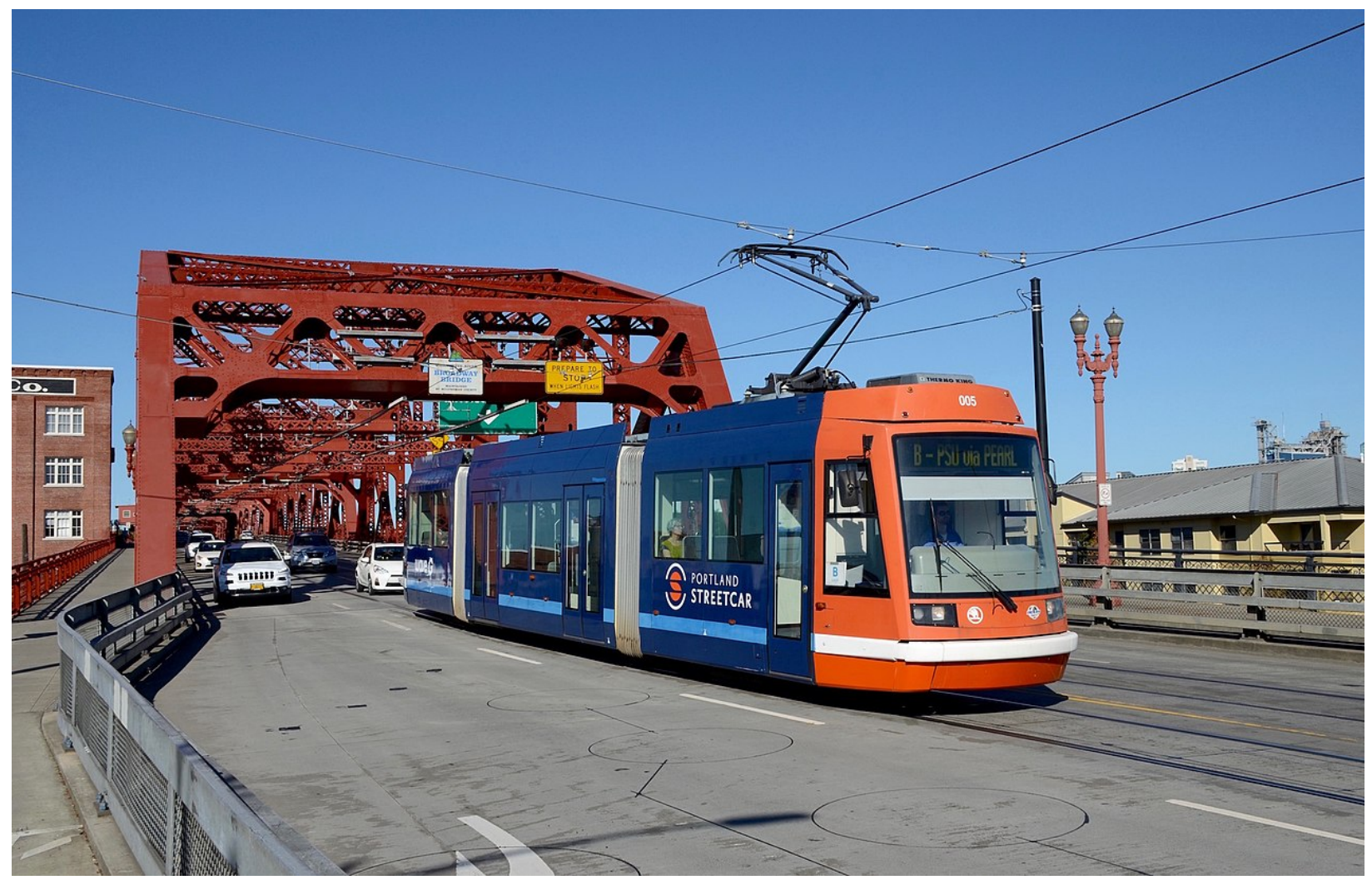

The Portland Streetcar in Portland, Oregon has two lines, a central loop a north-south line, and serves much of the downtown and surrounding areas. The system debuted in 2001 and has a daily ridership of over 16,000 and nearly $5,000,000$ passengers on a yearly basis. The loop line is 4.4 miles long and the north-south line is 3.9 miles long. ${ }^{44}$

${ }^{44}$ Adapted from: https://en.wikipedia.org/wiki/Portland_Streetcar. 


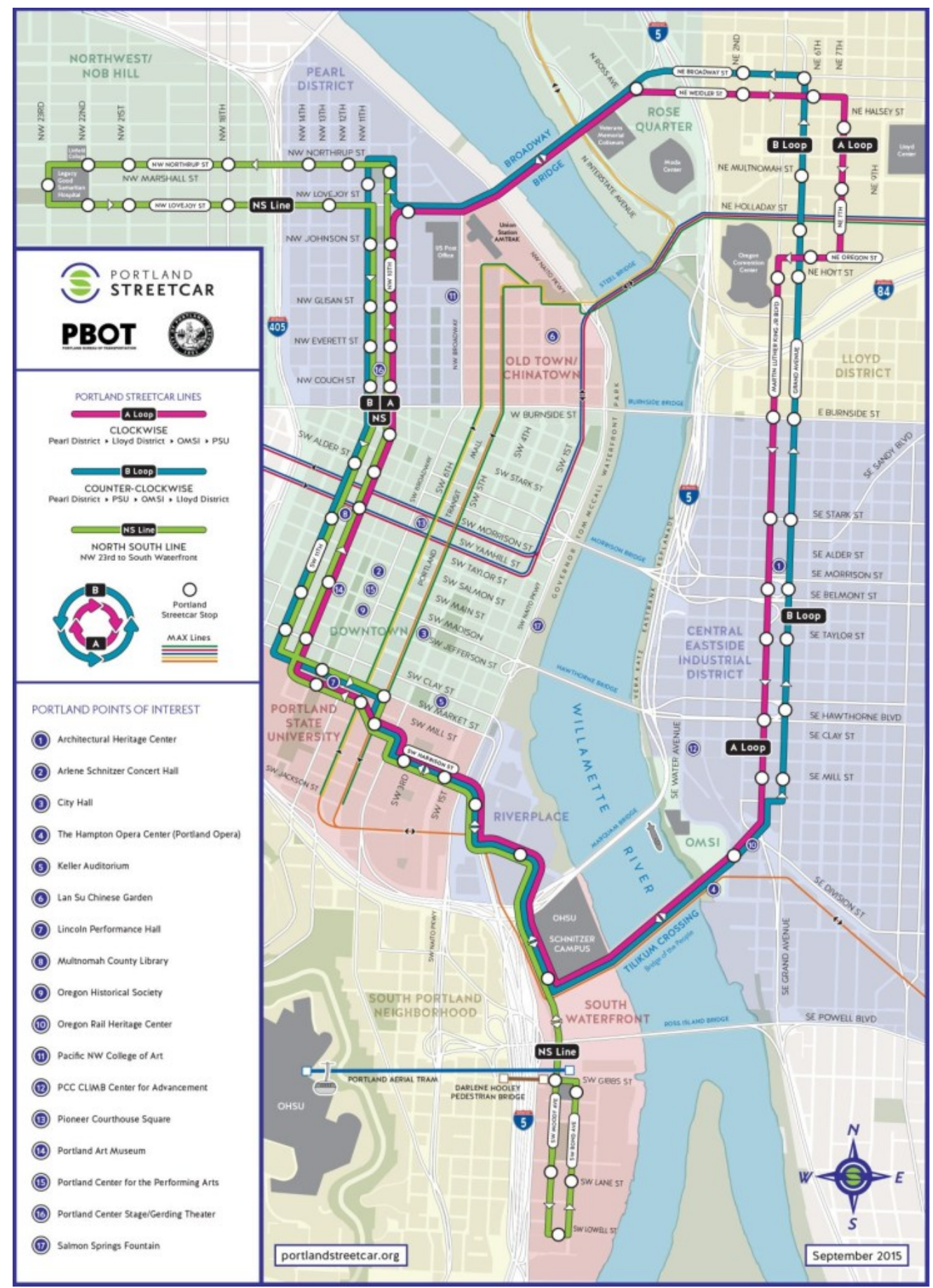

Figure X

Portland Streetcar map

Source: https://www.transitmap.net/portland-streetcar-2015/

SALT LAKE CITY STREETCAR SYSTEM 


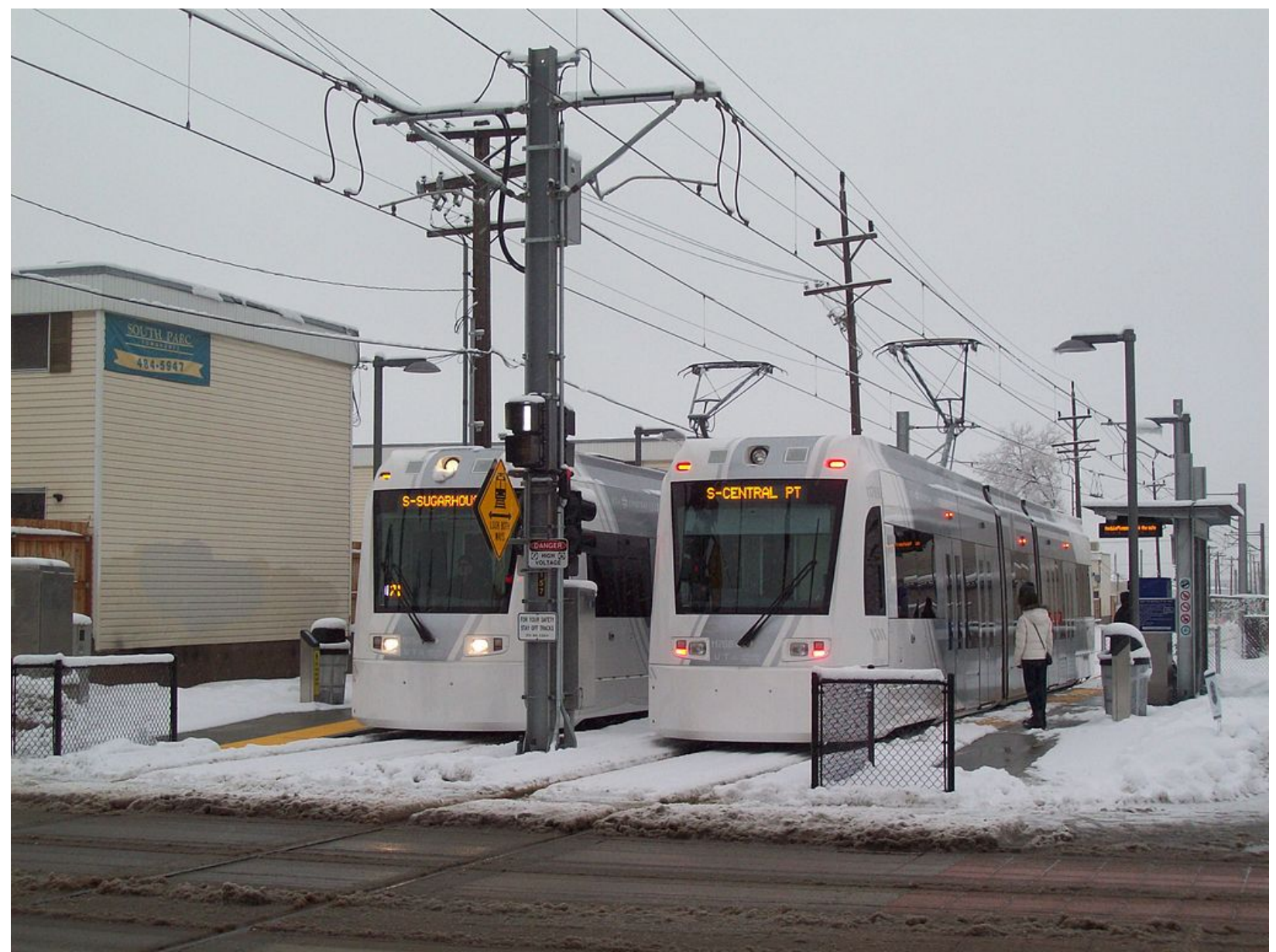

Figure X

Salt Lake City S Line Streetcars

Source:

https://en.wikipedia.org/wiki/S_Line_(Utah_Transit_Authority)\#/media/File:UTA_S_Line_streetca rs_at_500_East.jpg

Connecting the business district with the city of South Salt Lake and the area light rail system, the S Line is a streetcar system in Salt Lake City, Utah. It opened on December 8, 2013 and has 7 stops along one route. It carries just over 1,000 people per day along the 2-mile-long line. An extension of the line beyond the southernmost stop is in the works, but nothing is finalized at this time. ${ }^{45}$

${ }^{45}$ Adapted from: https://en.wikipedia.org/wiki/S_Line_(Utah_Transit_Authority). 


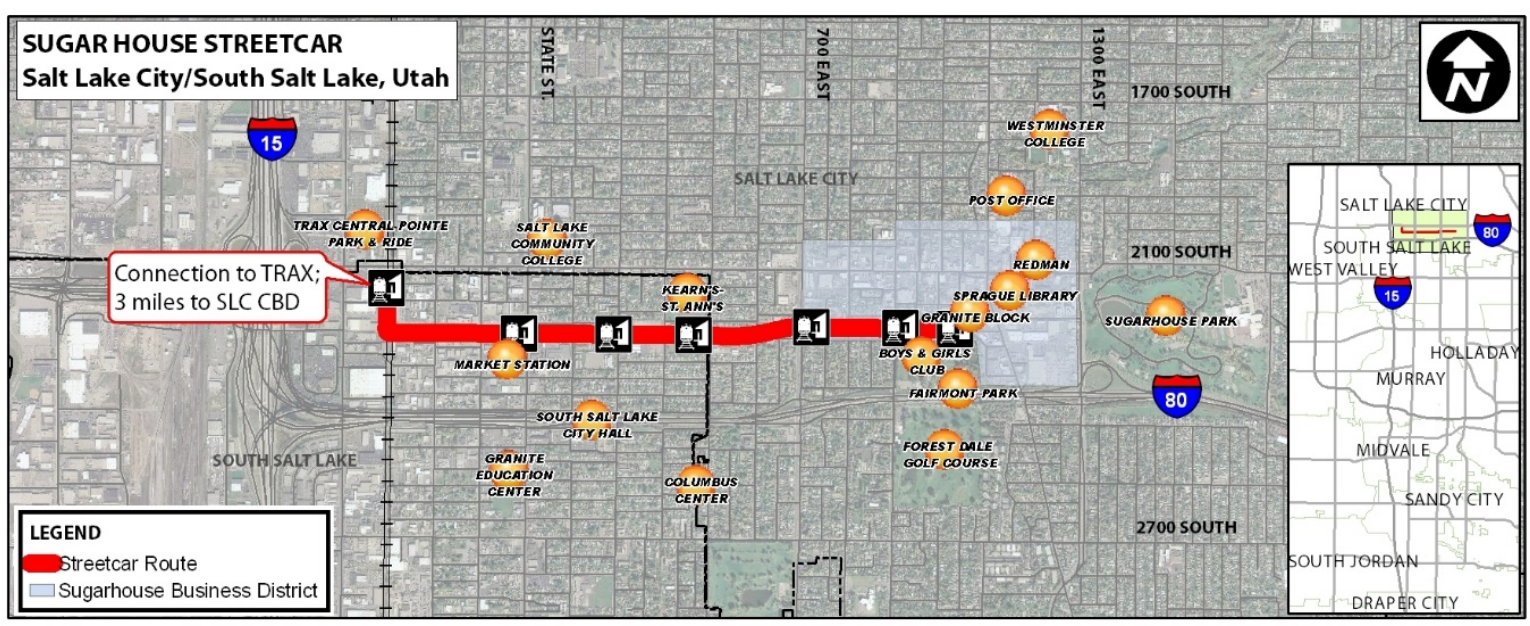

Figure $X$

$S$ Line streetcar map

Source: https://www.ksl.com/article/12896889 


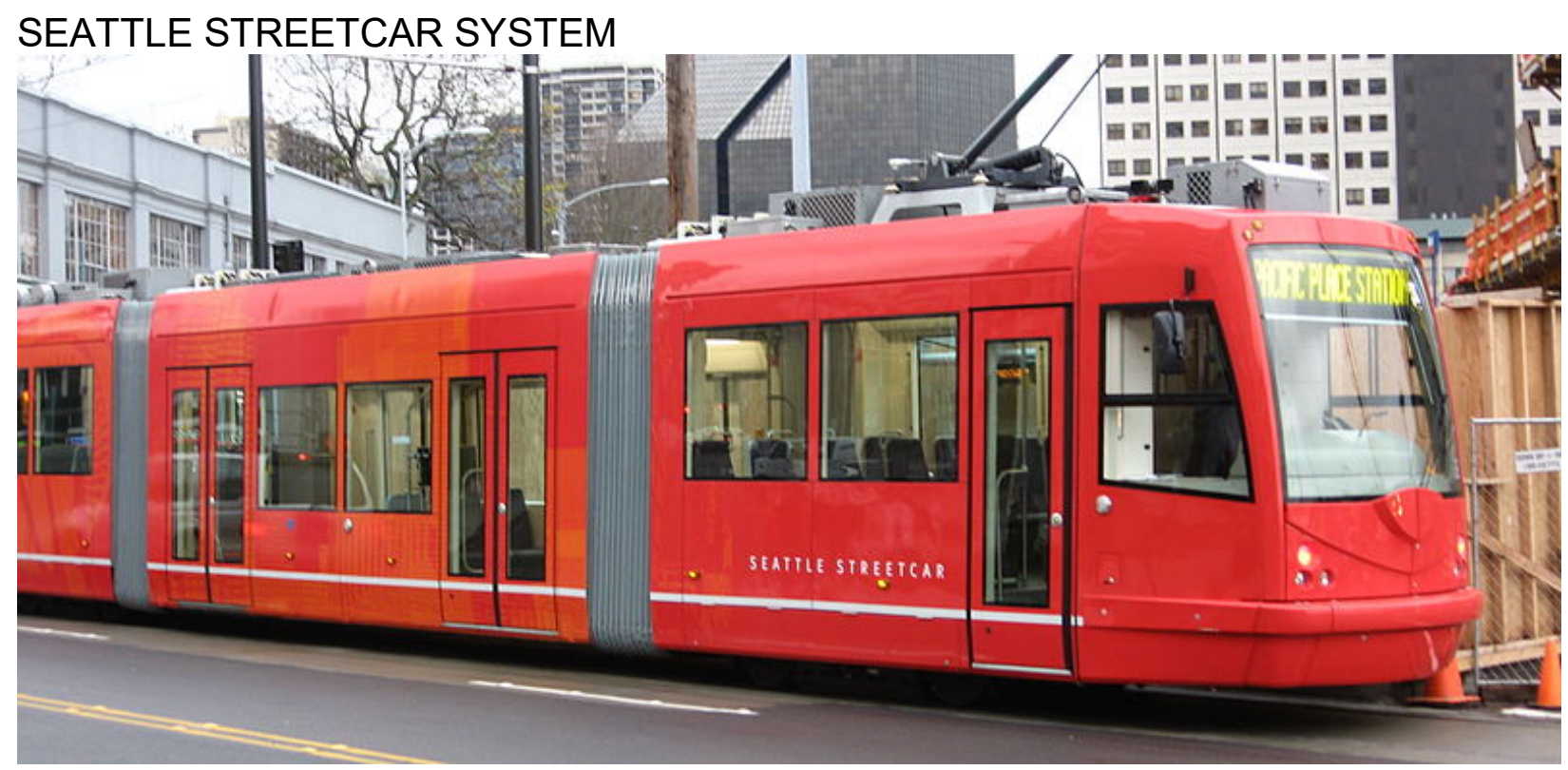

Figure $\mathrm{X}$

Seattle South Lake Union Streetcar

Source: https://commons.wikimedia.org/wiki/File:Seattle streetcar.jpg

First opened in 2007, the Seattle Streetcar is a two-line system serving the downtown area of Seattle, Washington. The South Lake Union line was the first route followed by the addition of the First Hill line in 2016, and, respectively, the lines are 1.3 miles and 2.5 miles in length. The two lines are not connected but share many hardware components and operate similarly. The lines serve approximately 5,000 people daily. ${ }^{46}$

\footnotetext{
${ }^{46}$ Adapted from: https://en.wikipedia.org/wiki/Seattle_Streetcar
} 


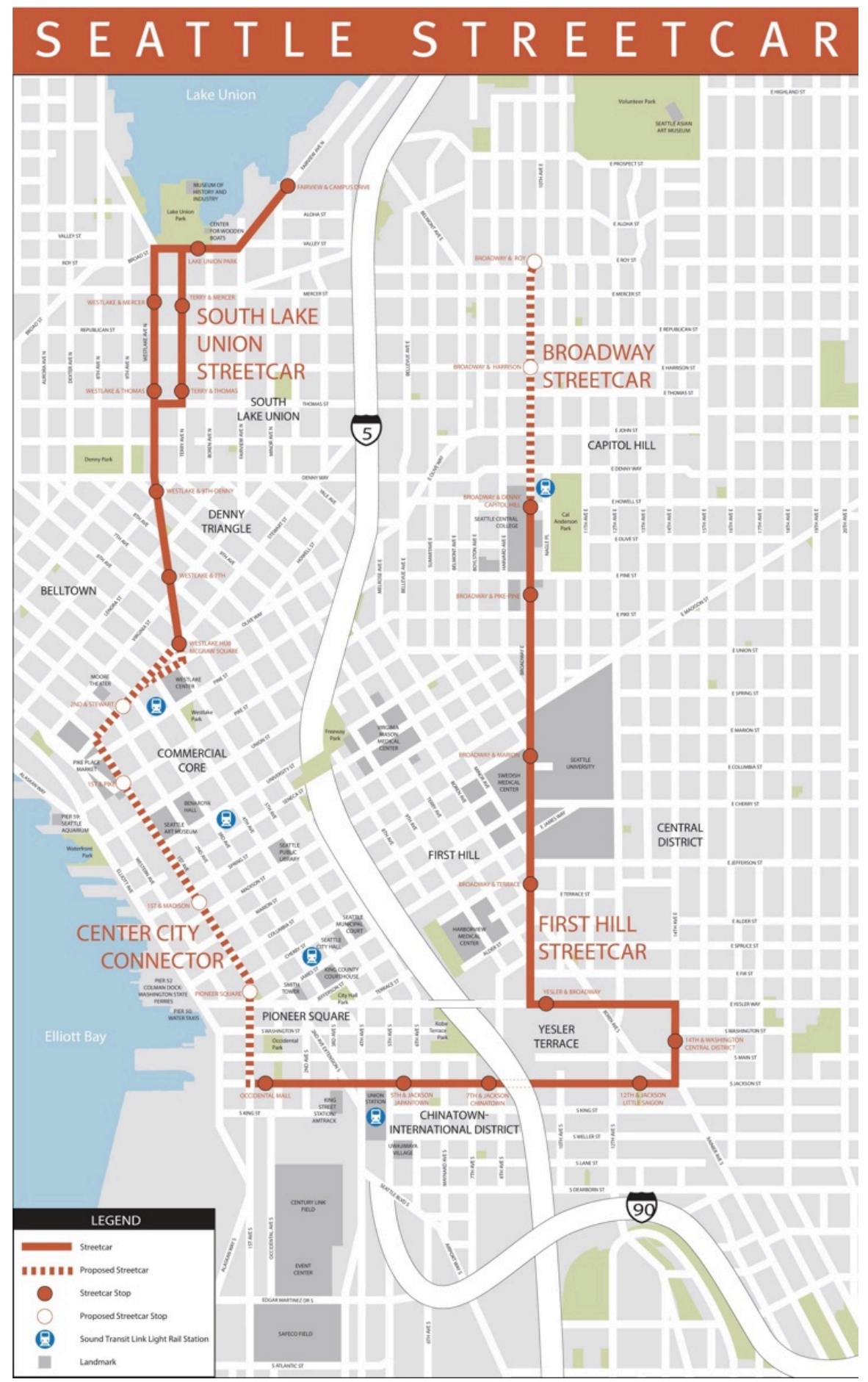

Figure X

Seattle Streetcar Map

Source: http://ontheworldmap.com/usa/city/seattle/seattle-streetcar-map.html

TACOMA STREETCAR SYSTEM 


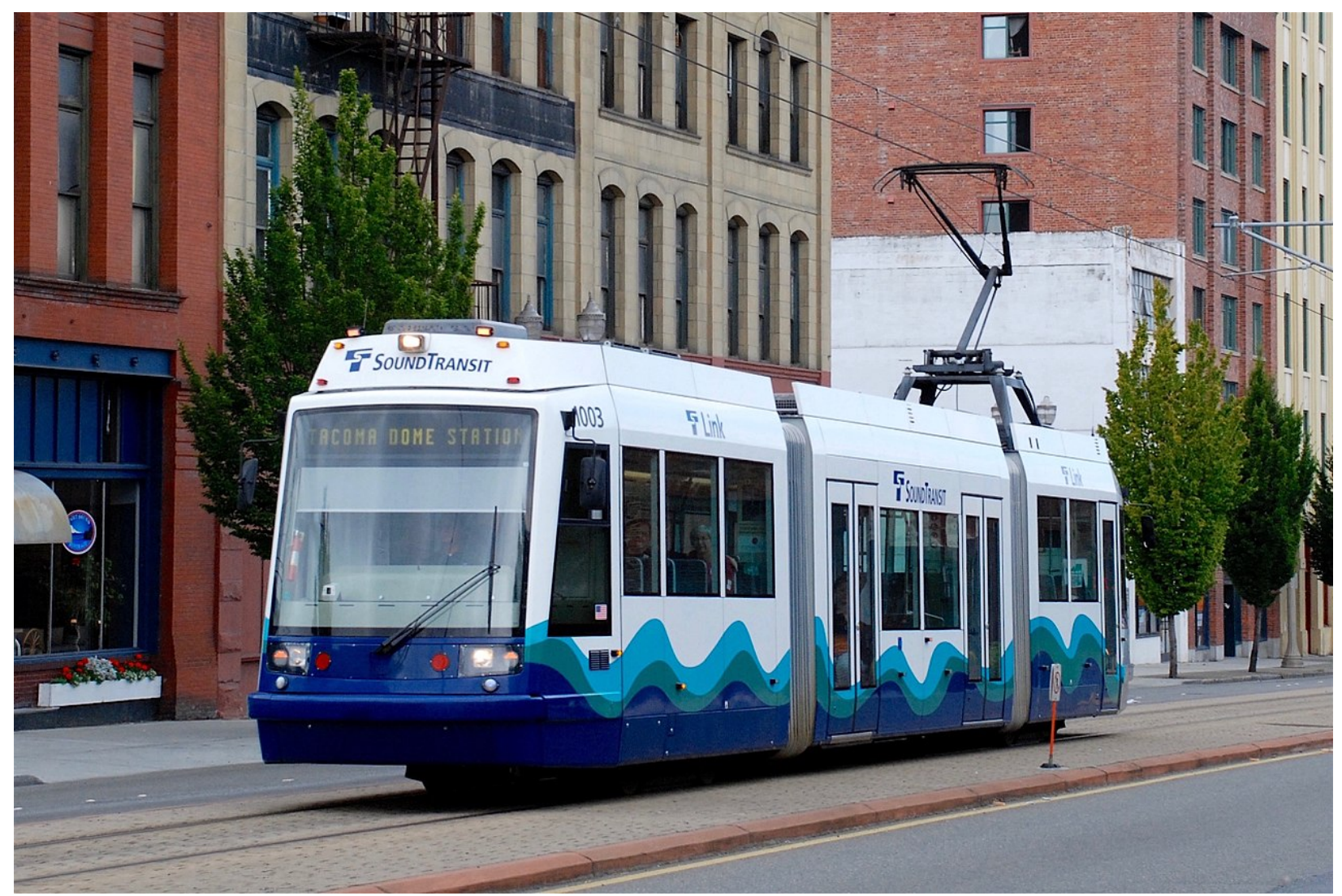

Figure $X$

Tacoma Streetcar

Source:

https://en.wikipedia.org/wiki/Tacoma_Link\#/media/File:Skoda_10T_car_1003_of_Tacoma_Link_ on_Pacific_Ave_(2008).jpg

First approved by a ballot measure in 1996 but opened in 2003, the Tacoma Link serves Tacoma, Washington between the Tacoma Dome and Downtown Tacoma. The line carried approximately 972,000 passengers in 2016 along its 1.6 -mile track. Tacoma Link runs for between 8 and 14 hours a day and is free of charge for passengers. ${ }^{47}$

${ }^{47}$ Adapted from: https://en.wikipedia.org/wiki/Tacoma_Link. 


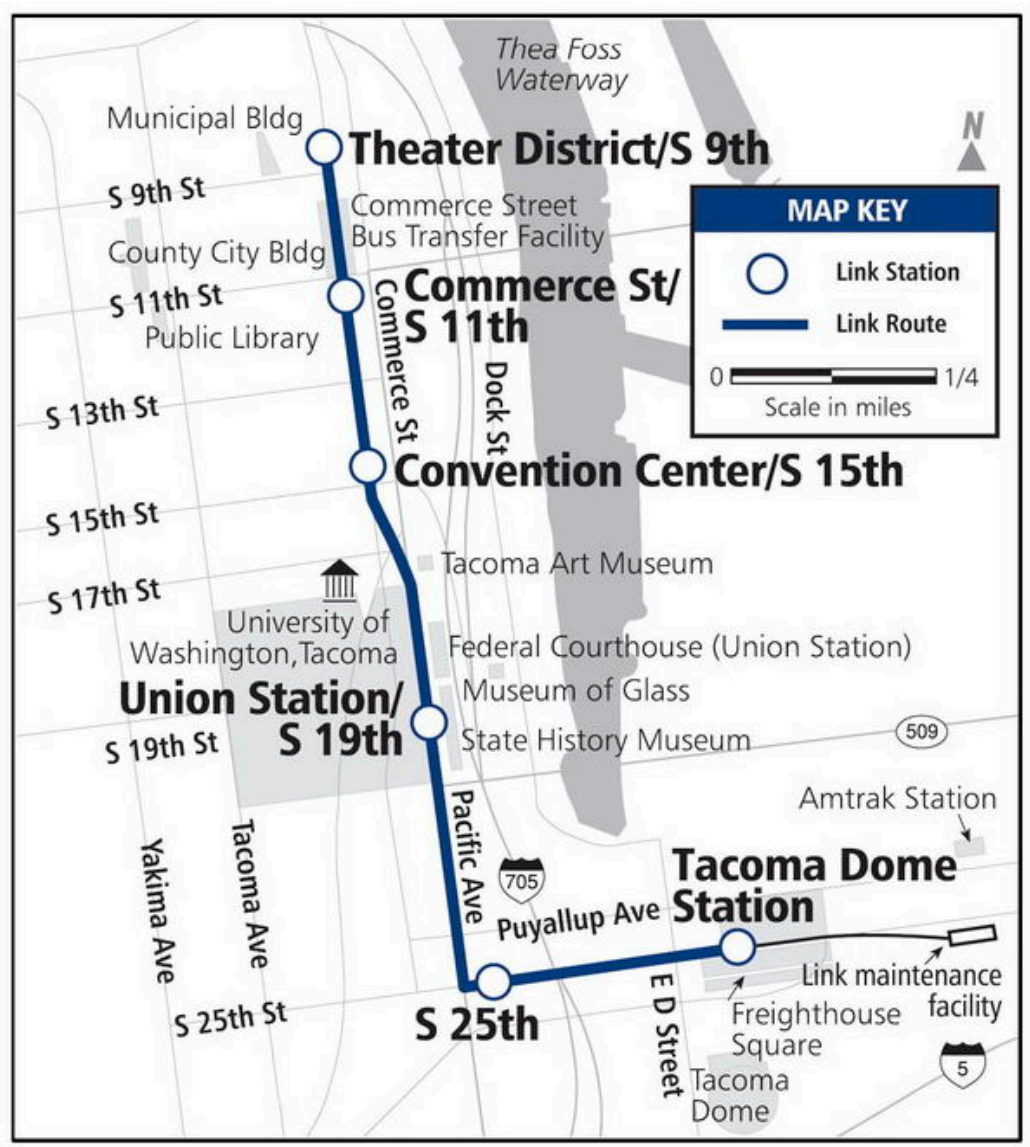

Figure $\mathrm{X}$

Tacoma Link Map

Source: http://sized.us/tacoma-transport-map.html

TAMPA STREETCAR SYSTEM 


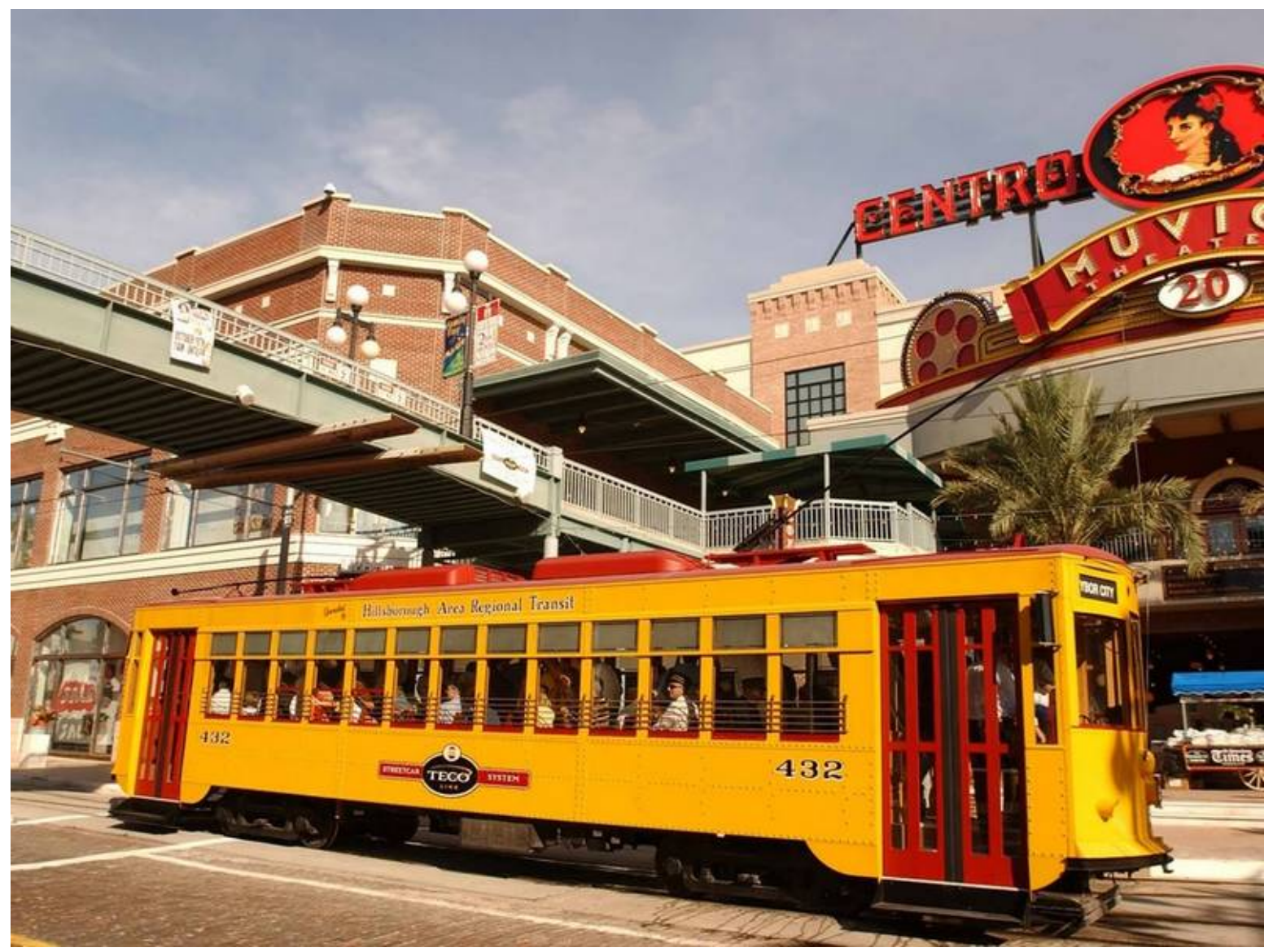

\section{Figure $\mathrm{X}$}

TECO Streetcar

Source: https://patch.com/florida/southtampa/all-aboard-tampa-trolley-will-soon-be-free The TECO Line Streetcar system in Tampa, Florida connects the downtown area to the historic Ybor City district. A three-year grant from the Florida Department of Transportation has allowed the streetcar to be free starting October of 2018. However, a mere 783 people ride the streetcar daily along the 2.7 -mile, 11 -stop track. ${ }^{48}$

\footnotetext{
${ }^{48}$ Source: https://en.wikipedia.org/wiki/TECO_Line_Streetcar_System
} 


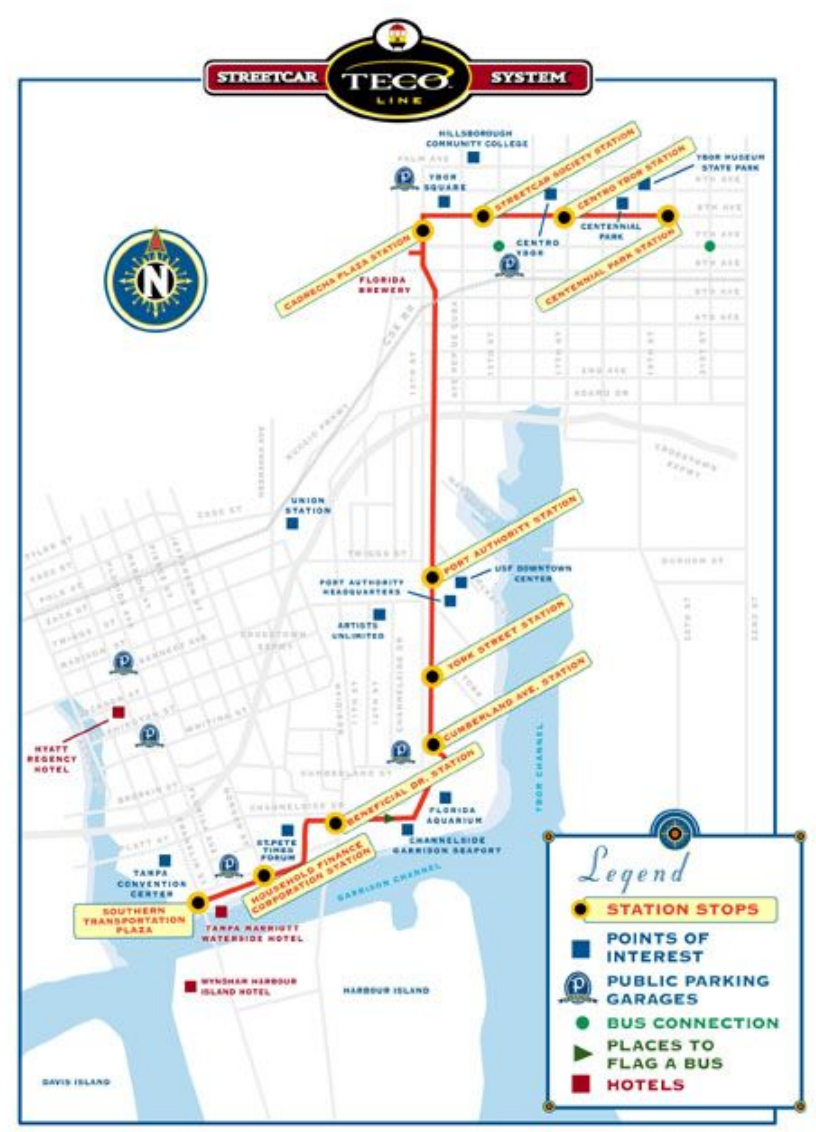

Figure $X$

TECO Streetcar Map

Source: https://www.lightrailnow.org/news/n tam001.htm

172 


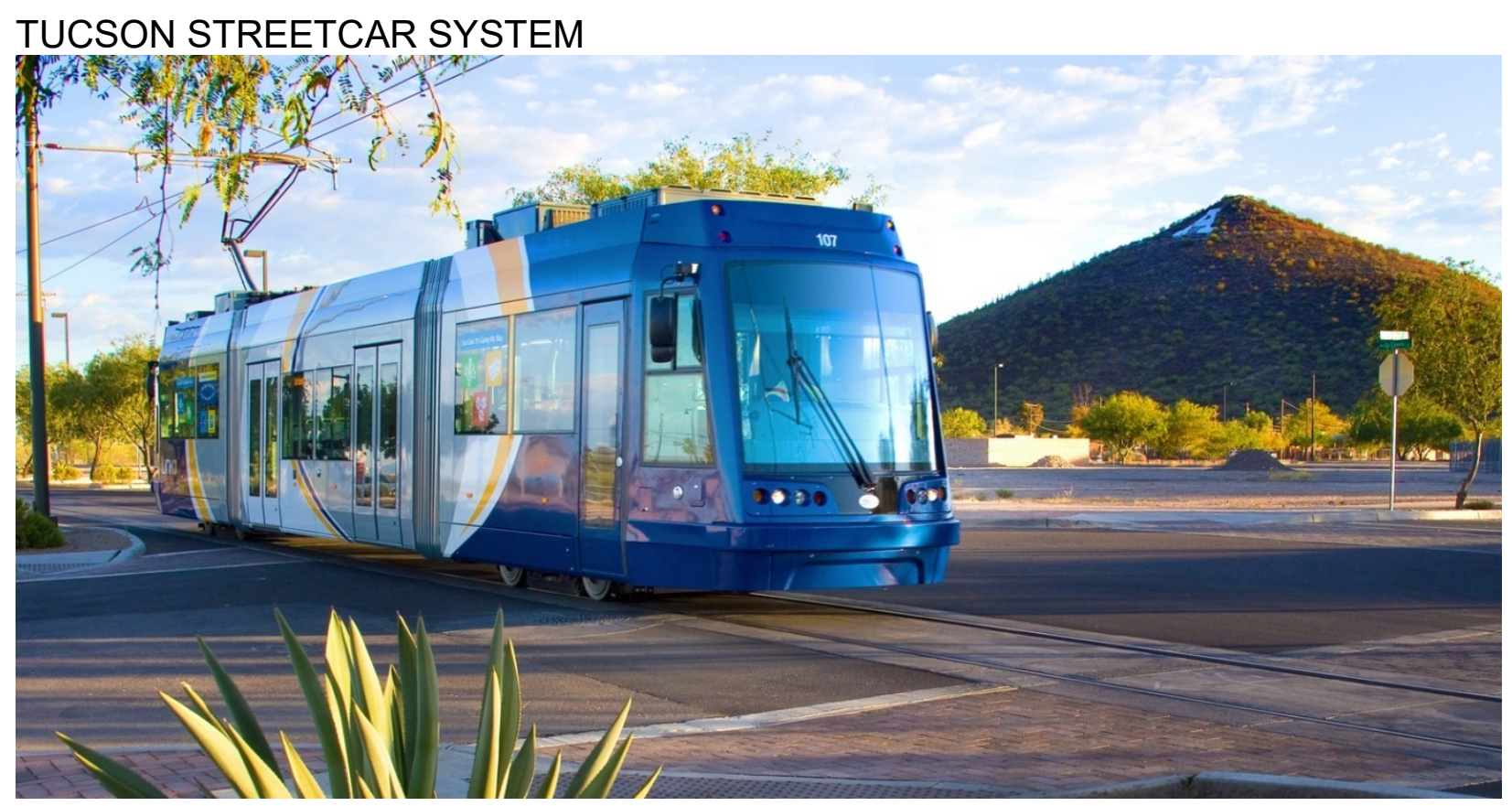

Figure X

Sun Link Streetcar

Source: https://www.tucsontopia.com/tucson-streetcar/

Opening in 2014, the Sun Link streetcar system serves a 3.9-mile stretch of Tucson, Arizona between the Health Sciences Center at the University of Arizona to an area known as Mercado west of downtown. The Sun Link runs between 7am and 2am depending on the day of the week. Nearly 3,000 passengers are served by the Sun Link daily along the 21 -stop line. 49

${ }^{49}$ Adapted from: https://en.wikipedia.org/wiki/Sun_Link. 


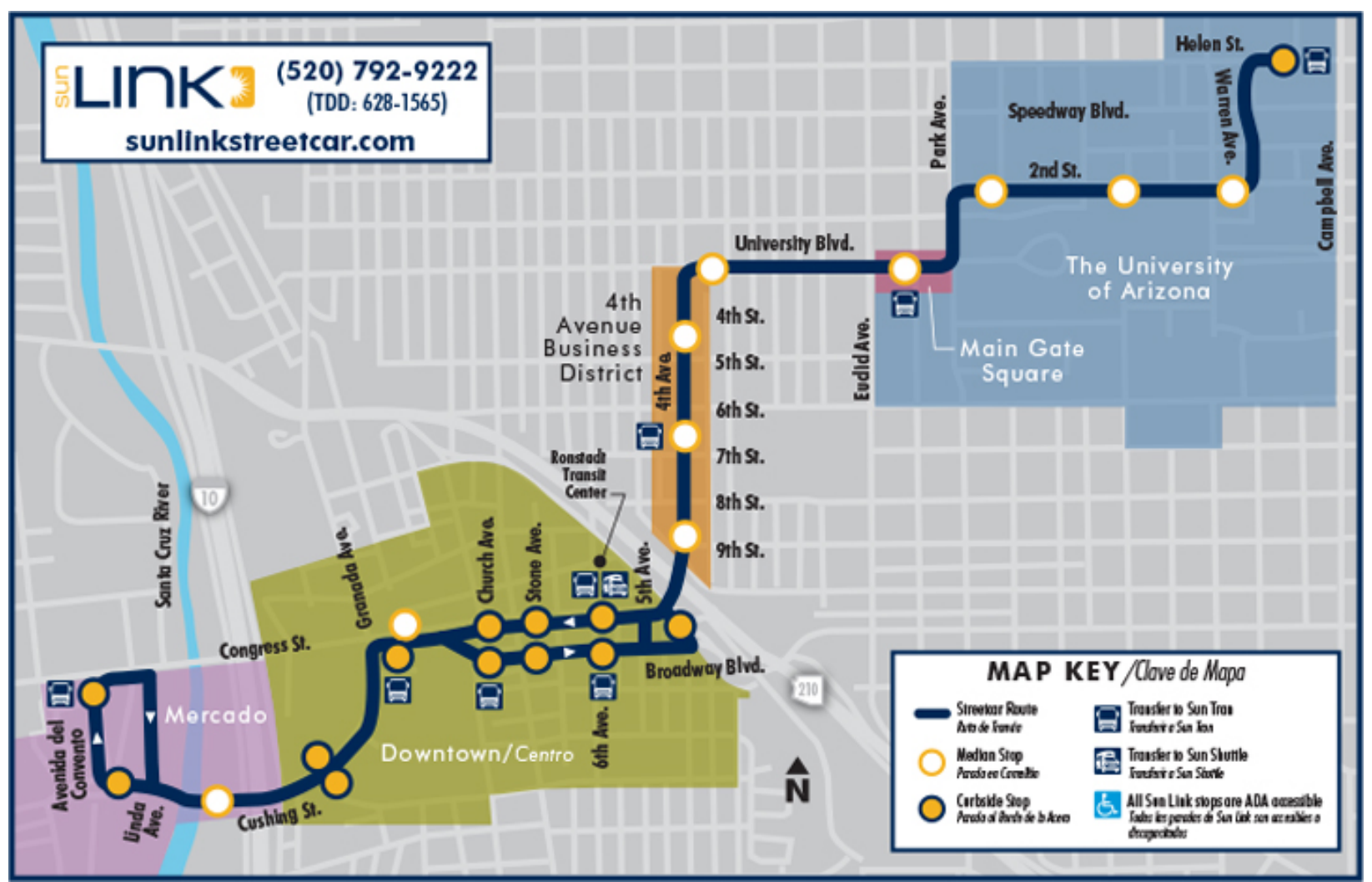

Figure $\mathrm{X}$

Sun Link Map

Source: https://www.sunlinkstreetcar.com/schedule/route

WASHINGTON, DC STREETCAR SYSTEM 


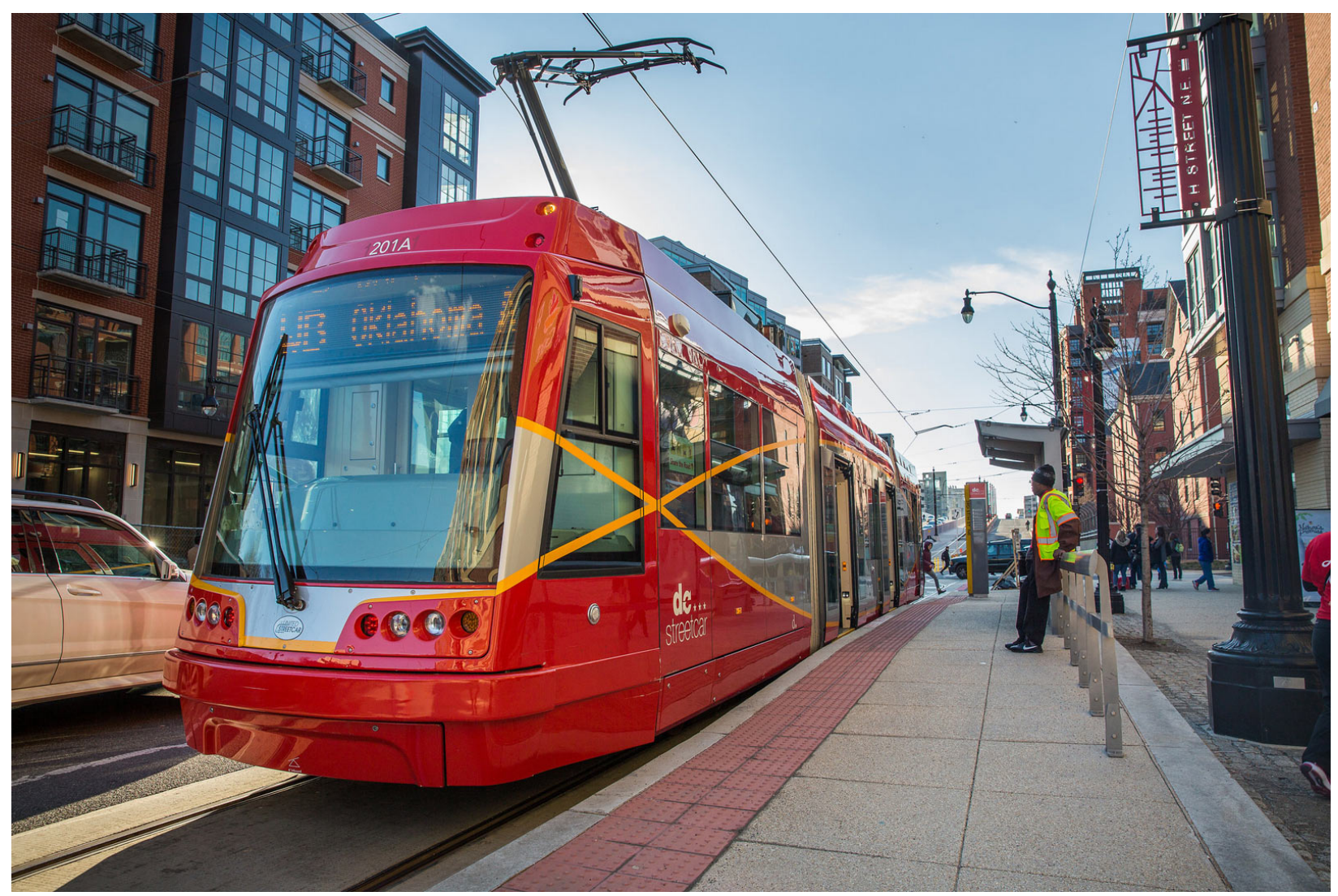

Figure $\mathrm{X}$

DC Streetcar

Source: https://washington.org/dc-guide-to/dc-streetcar

Beginning operation in February 2016, the DC Streetcar consists of a single 2.2-mile line.

Ridership is up nearly $21 \%$ between 2016 and 2017 with an annual ridership of almost

1,100,000. Washington, D.C. previously had a streetcar system which was dismantled in 1962. Though other lines are proposed, the only line operating runs along $\mathrm{H}$ Street and Benning Road in the city's northeastern quadrant. ${ }^{50}$

${ }^{50}$ Adapted from: https://en.wikipedia.org/wiki/DC_Streetcar. 


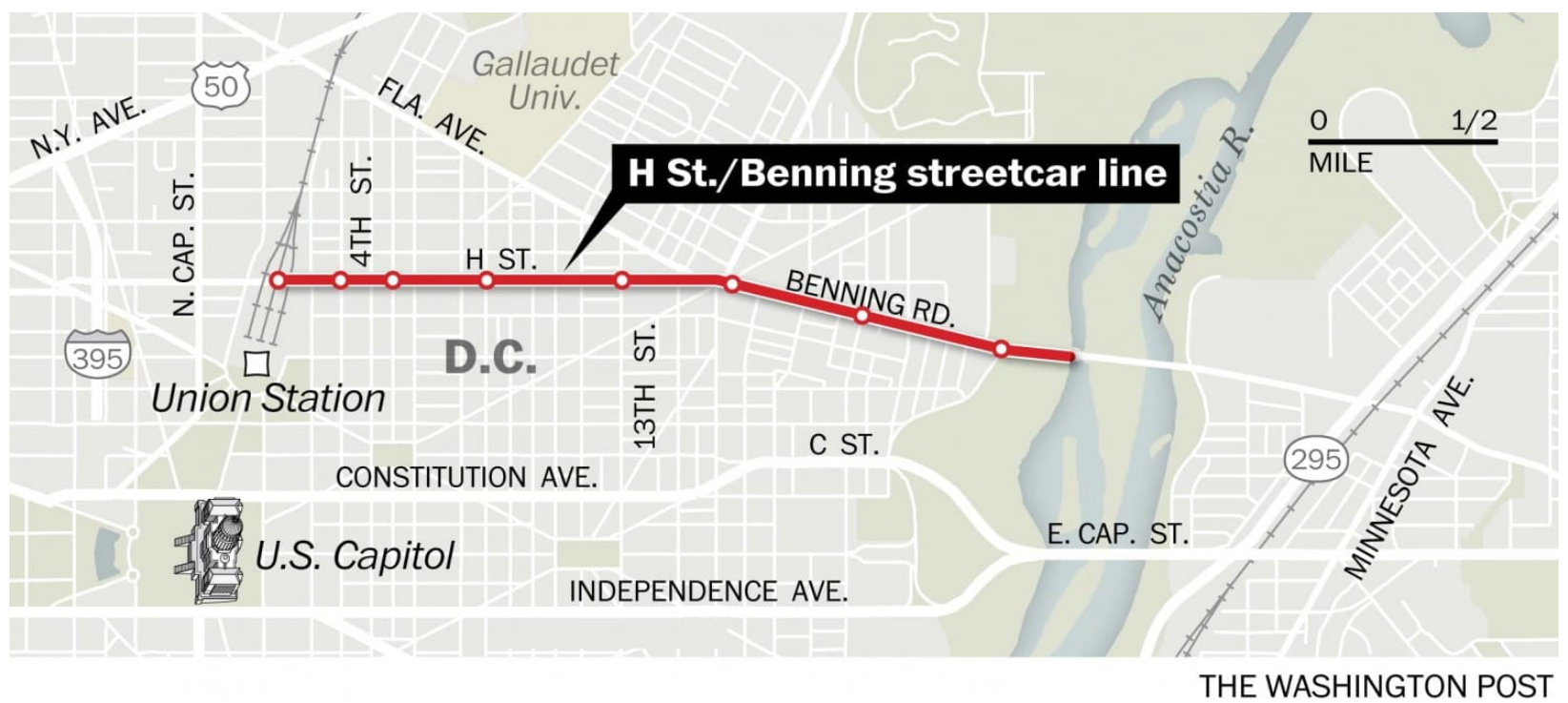

Figure $X$

DC Streetcar Map

Source: https://www.washingtonpost.com/news/dr-gridlock/wp/2016/02/27/want-to-ride-ride-thed-c-streetcar-heres-a-handy-faq/?utm_term=.bb9f6a5caa4b 


\section{APPENDIX A - CRT}

\section{COMMUTER RAIL TRANSIT SYSTEMS USED IN ANALYSIS}

Commuter Rail Transit Systems Metro Area \& Name

Albuquerque - Santa Fe: New Mexico Rail Runner

Austin: Metrorail

Dallas - Fort Worth: Trinity Railway Express

Miami: Tri Rail

Minneapolis: Northstar

Nashville: Music City Star

Orlando: Sunrail

Portland: TriMet WES

Salt Lake City: FrontRunner

San Diego: Coaster

San Jose - Stockton - San Francisco: Altamont Corridor

Express

Seattle - Tacoma: Sounder Commuter Rail

Washington, DC - Baltimore: MARC

Washington, DC - Northern Virginia: VRE

\begin{tabular}{|c|c|c|c|}
\hline Year & Miles & Stations & (Daily) \\
\hline 2006 & 97 & 15 & 2,983 \\
\hline 2010 & 32 & 9 & 2,900 \\
\hline 1996 & 34 & 10 & 8,200 \\
\hline 1989 & 71.2 & 18 & 14,800 \\
\hline 1997 & 40 & 7 & 2,700 \\
\hline 2006 & 32 & 7 & 1,225 \\
\hline 2014 & 49 & 16 & 3,400 \\
\hline 2009 & 14.7 & 5 & 1,600 \\
\hline 2008 & 88 & 17 & 17,600 \\
\hline 1995 & 41 & 8 & 4,384 \\
\hline 1998 & 85 & 10 & 5,900 \\
\hline 2000 & 83 & 12 & 18,314 \\
\hline 1984 & 187 & 42 & 40,000 \\
\hline 1992 & 90 & 19 & 12,830 \\
\hline
\end{tabular}




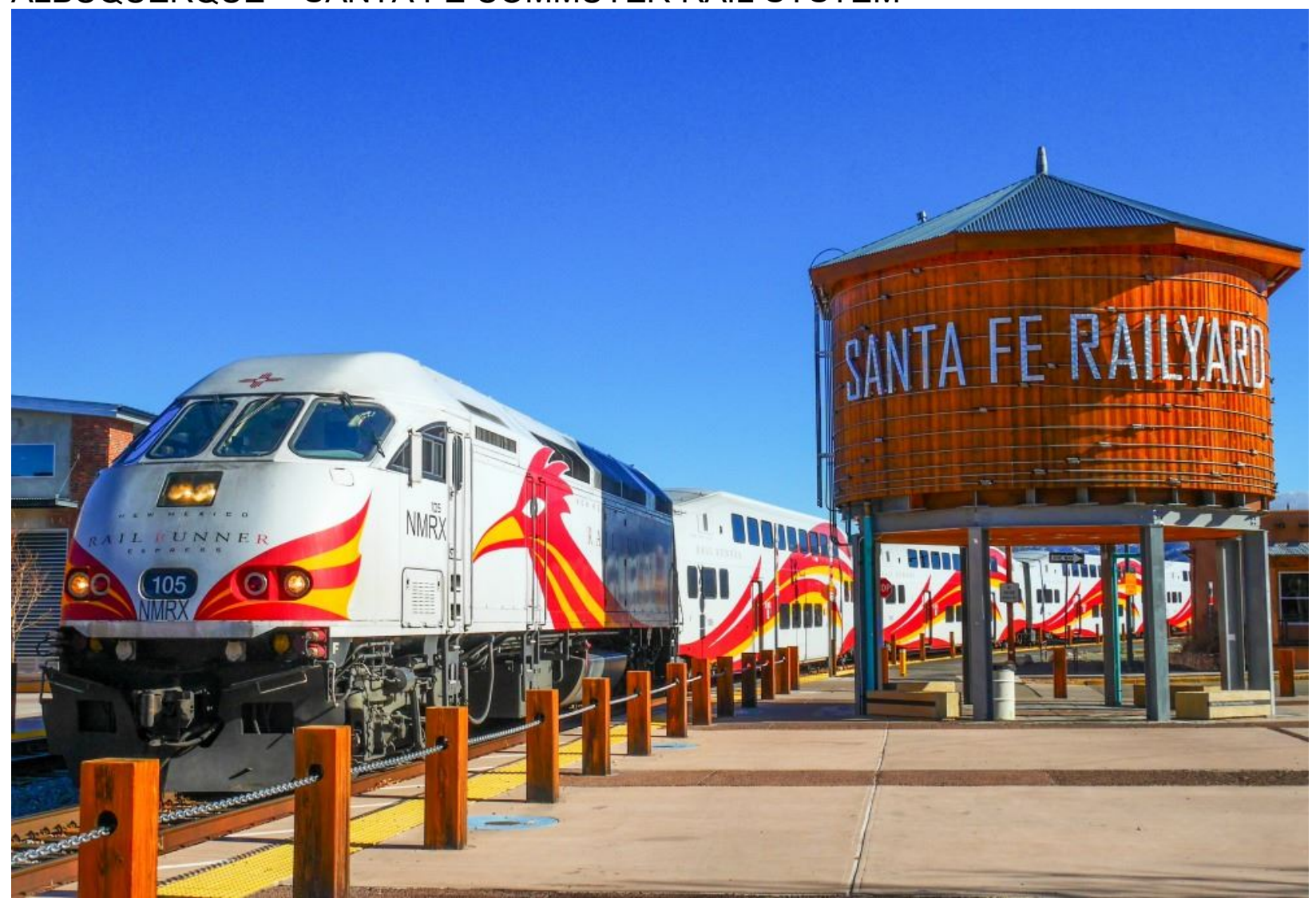

Figure $\mathrm{X}$

New Mexico Rail Runner

Source: https://www.riometro.org/395/New-Mexico-Rail-Runner-Express

Opened on July 14, 2006, the New Mexico Rail Runner is a commuter rail which serves the Albuquerque and Santa Fe areas of New Mexico. The line is 97 miles in length and has a maximum operating speed of 79 miles per hour. There are 15 operational stations along the single line from Belen in the south to Santa Fe in the north. ${ }^{51}$

${ }^{51}$ Adapted from: https://en.wikipedia.org/wiki/New_Mexico_Rail_Runner_Express. 


\section{SYSTEM MAP}
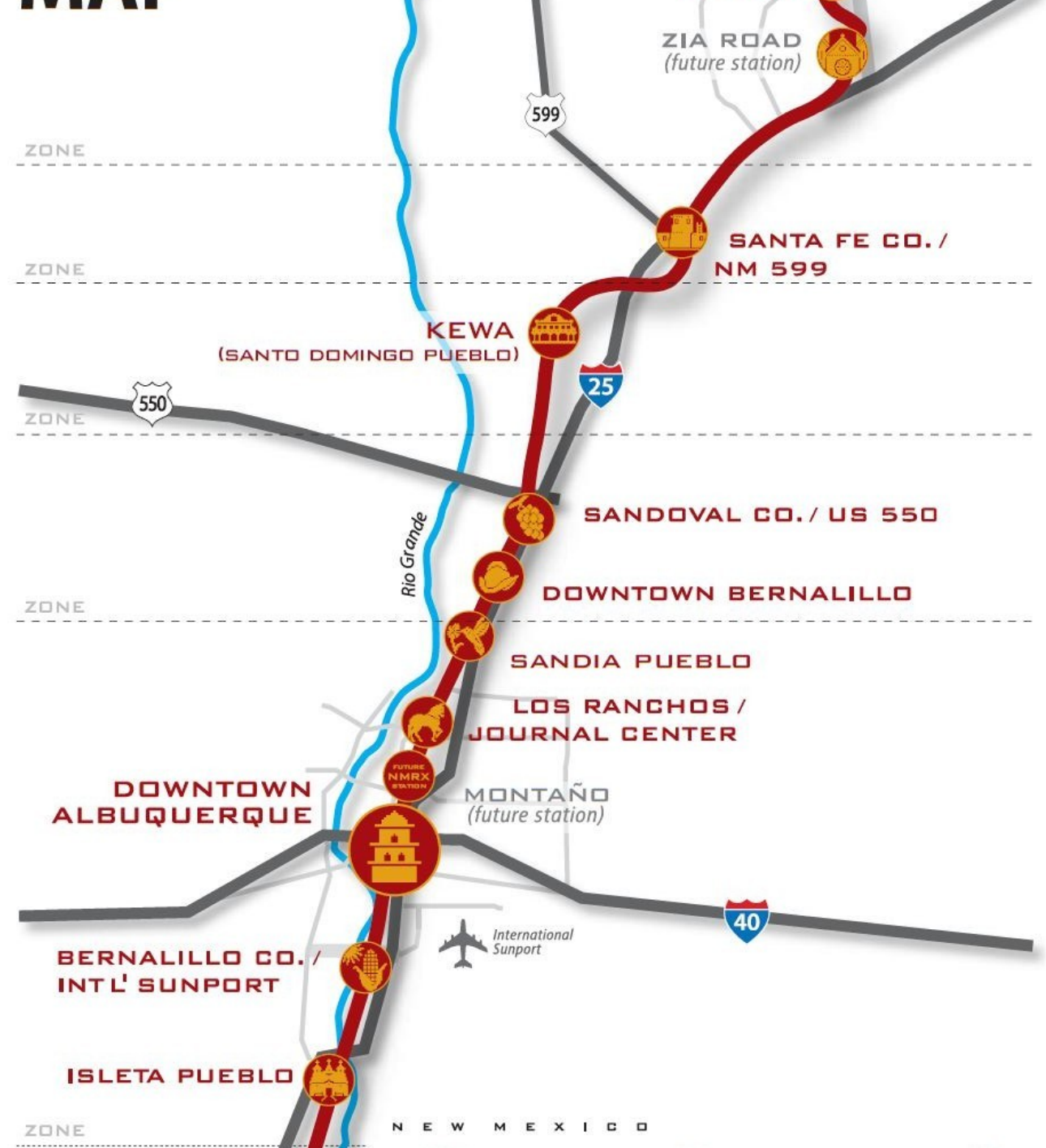

R A I L $R$ U N N E R

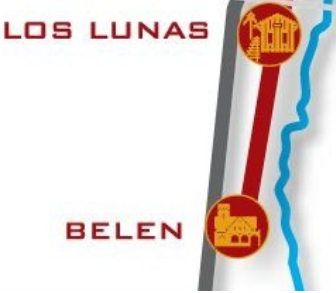

Figure $X$

R A I L R U N N E R

New Mexico Rail Runner Service Map

Source: http://www.santafedia.org/wiki/images/b/b7/Rail_runner_system_map.JPG 


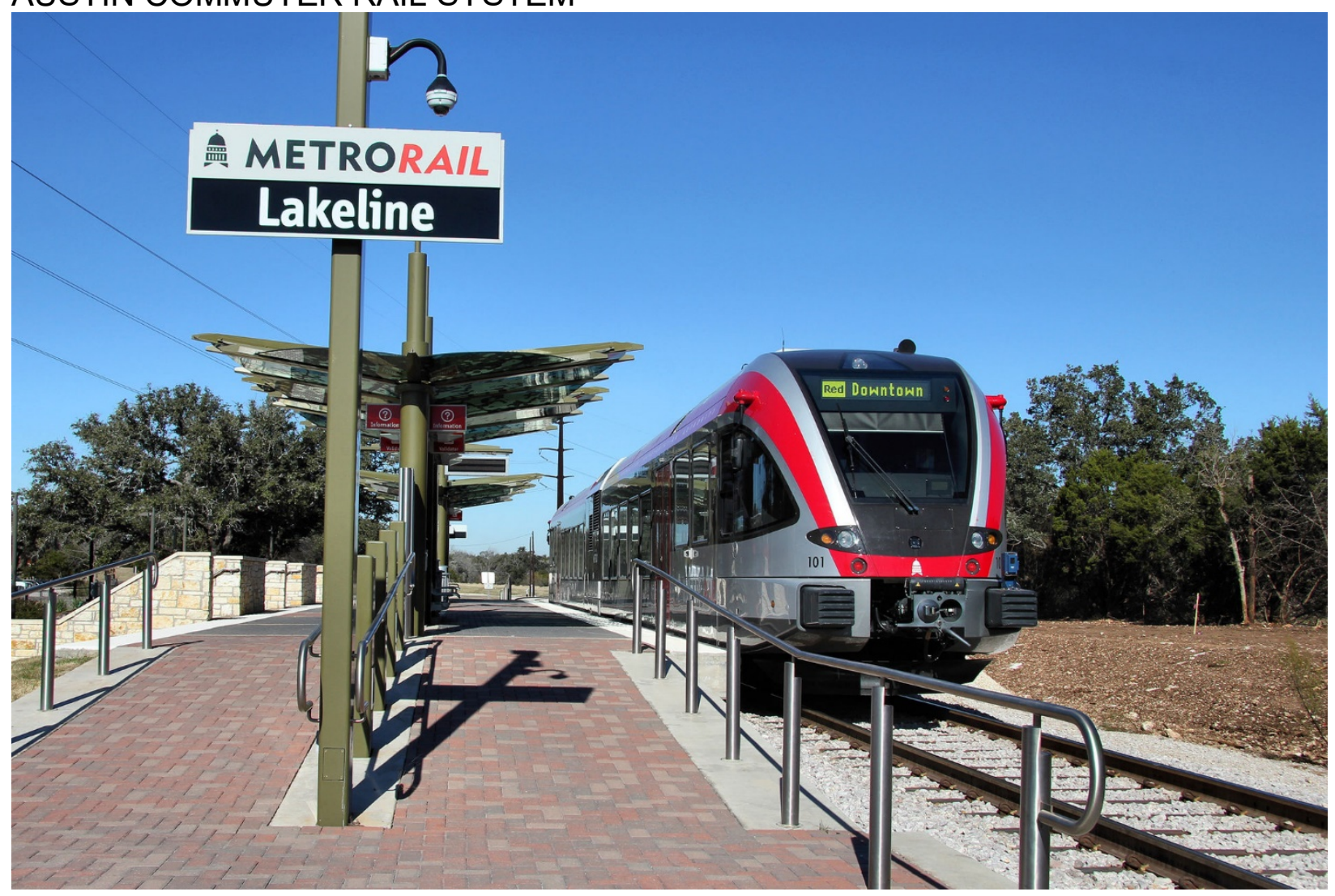

Figure $\mathrm{X}$

Austin MetroRail

Source:

https://en.wikipedia.org/wiki/Capital_MetroRail\#/media/File:Lakeline_metrorail_station_2014.jpg Connecting downtown Austin with its Northern Suburbs, MetroRail is the only rail line in Texas' capital city. As of 2014, the line served about 2,900 commuters each weekday, with an annual ridership of approximately 820,000 . The singular 32-mile line is filled through 9 stations from Leander all the way to downtown Austin. ${ }^{52}$

${ }^{52}$ Adapted from: https://en.wikipedia.org/wiki/Capital_MetroRail. 


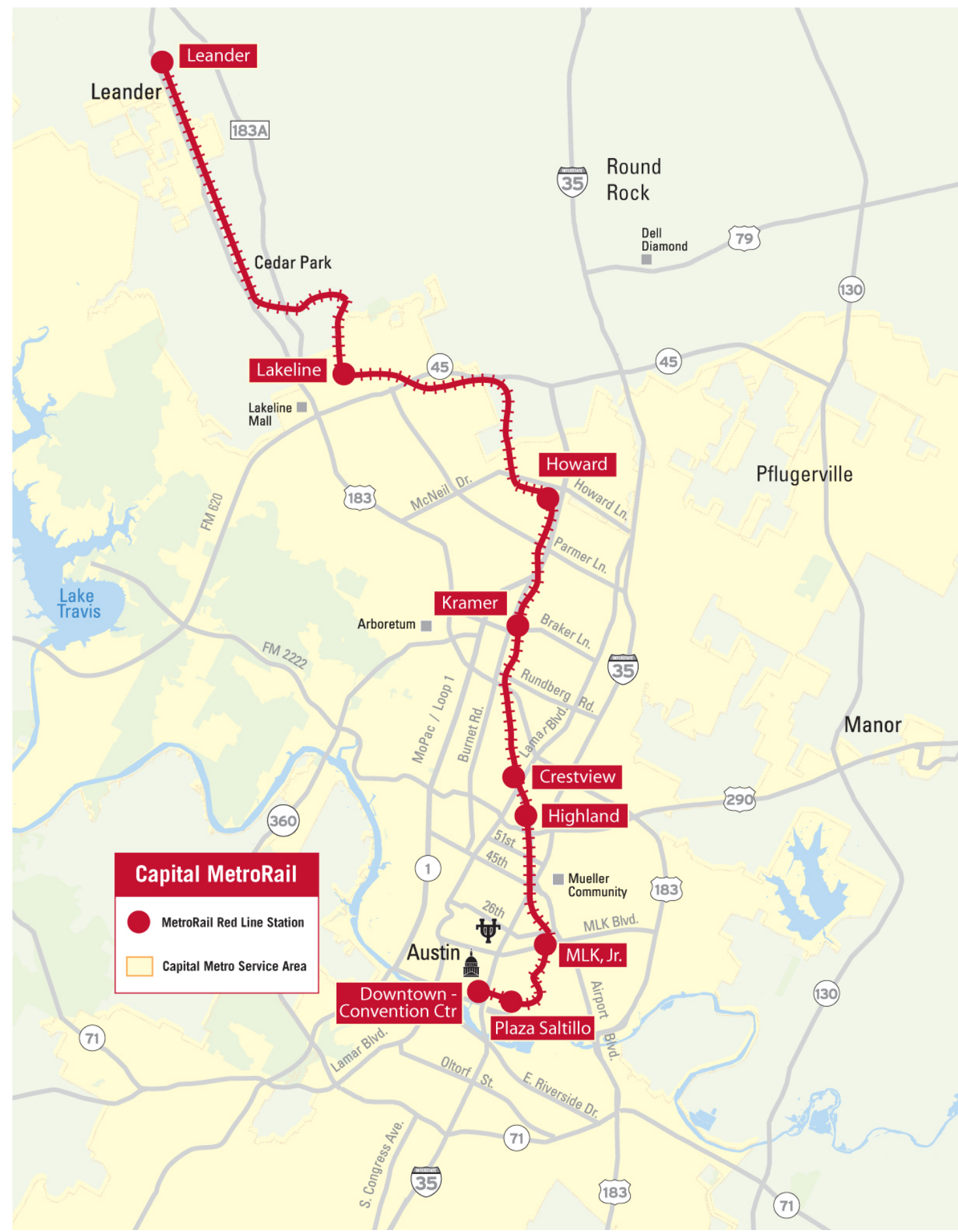

Figure X

MetroRail Map

Source: http://ecohomesaustin.homestead.com/SearchHomesMetroRailStations.html

DALLAS - FORT WORTH COMMUTER RAIL SYSTEM 


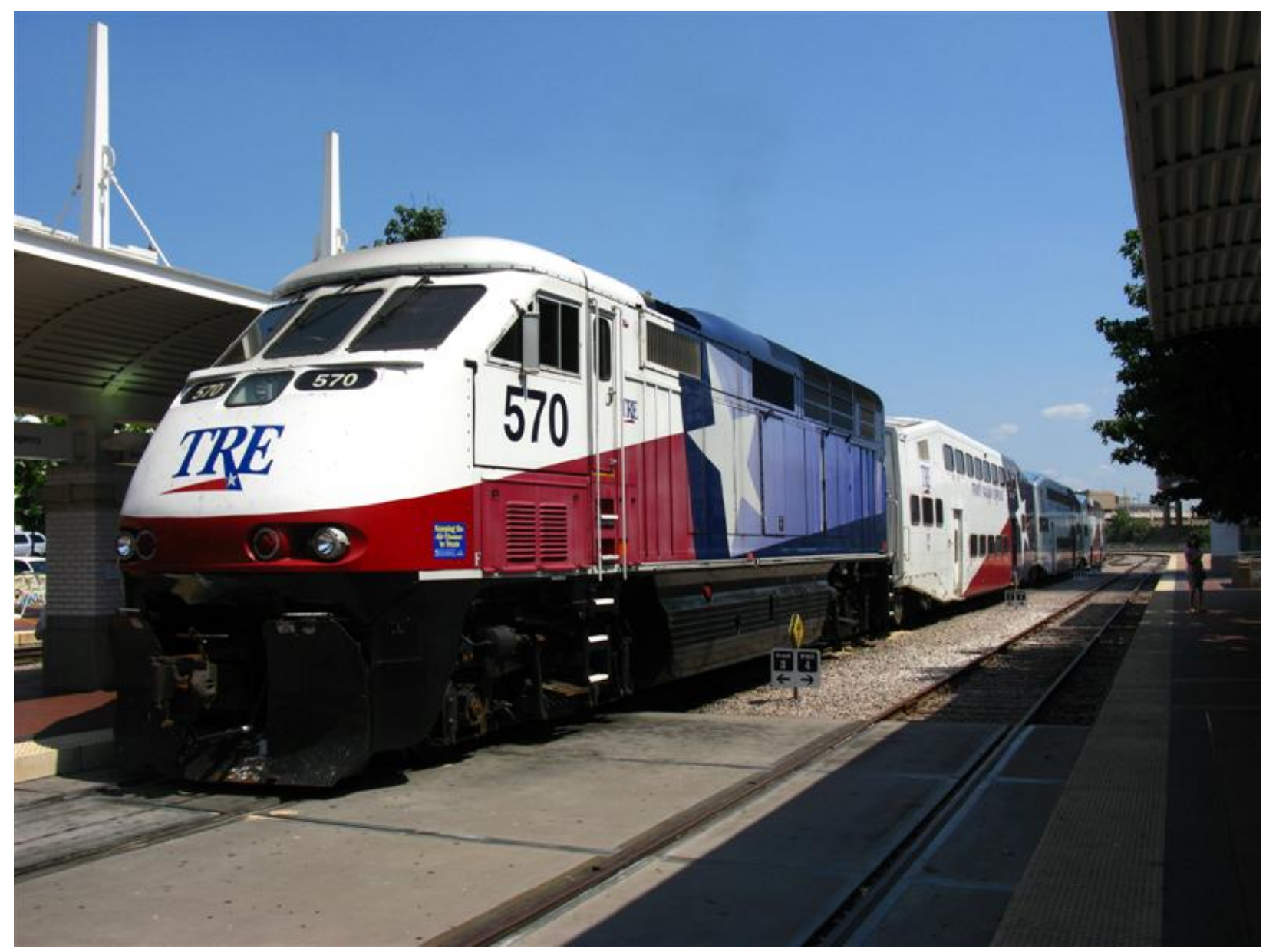

\section{Figure $X$}

Trinity Railway Express

Source: http://trainweb.org/tony/eagletripreport09.htm

The fifteenth most-ridden commuter rail in the country, the Trinity Railway Express (TRE) is the commuter rail system in the Dallas-Fort Worth metro area. The line began operating in late 1996 with 10 stations along its 34-mile route. The TRE goes between Union Station in Dallas and T\&P Station in Fort Worth. ${ }^{53}$

\footnotetext{
${ }^{53}$ Adapted from: https://en.wikipedia.org/wiki/Trinity_Railway_Express.
} 


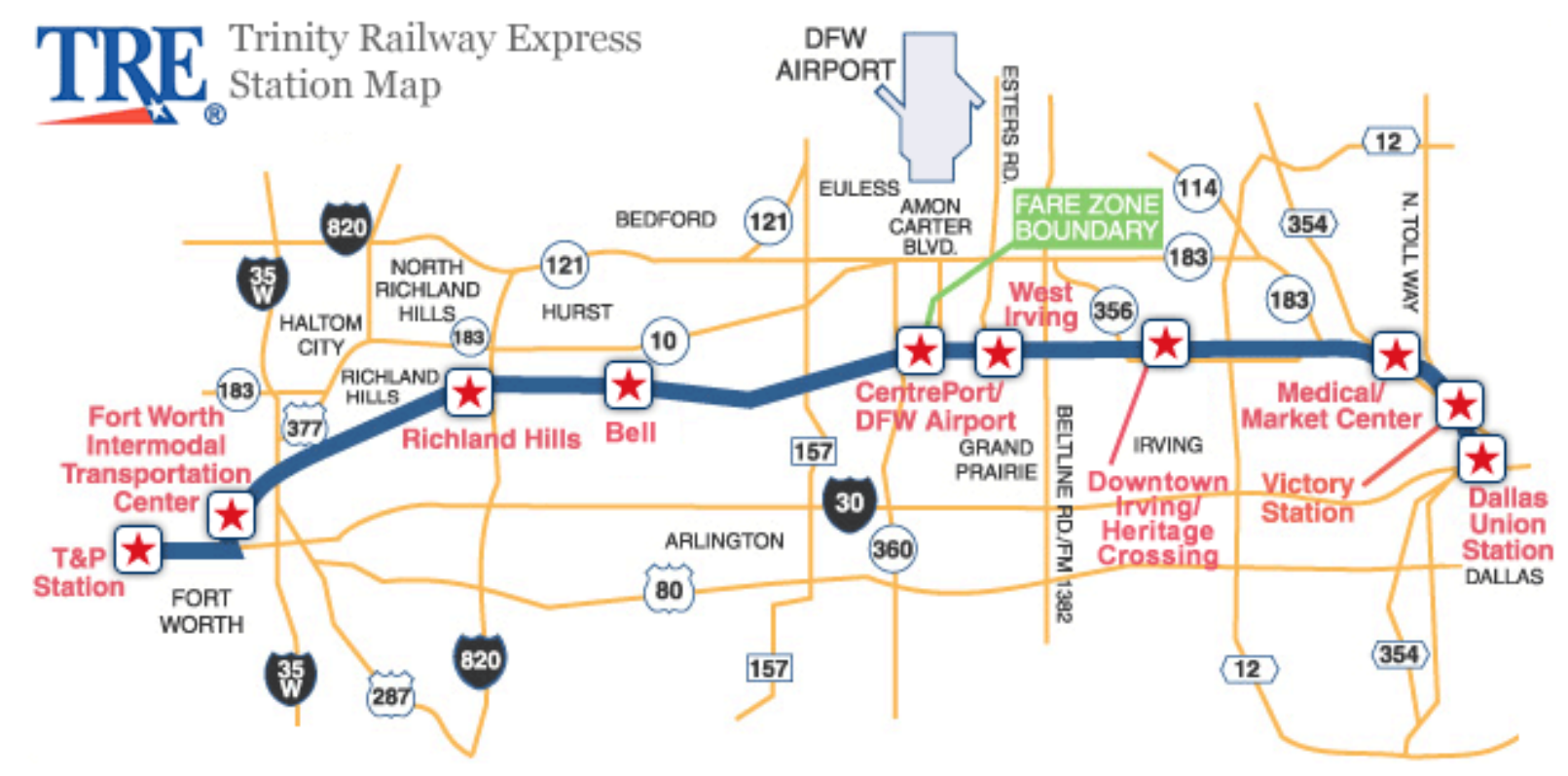

Figure $X$

TRE Service Map

Source: https://trinityrailwayexpress.org/stations/ 


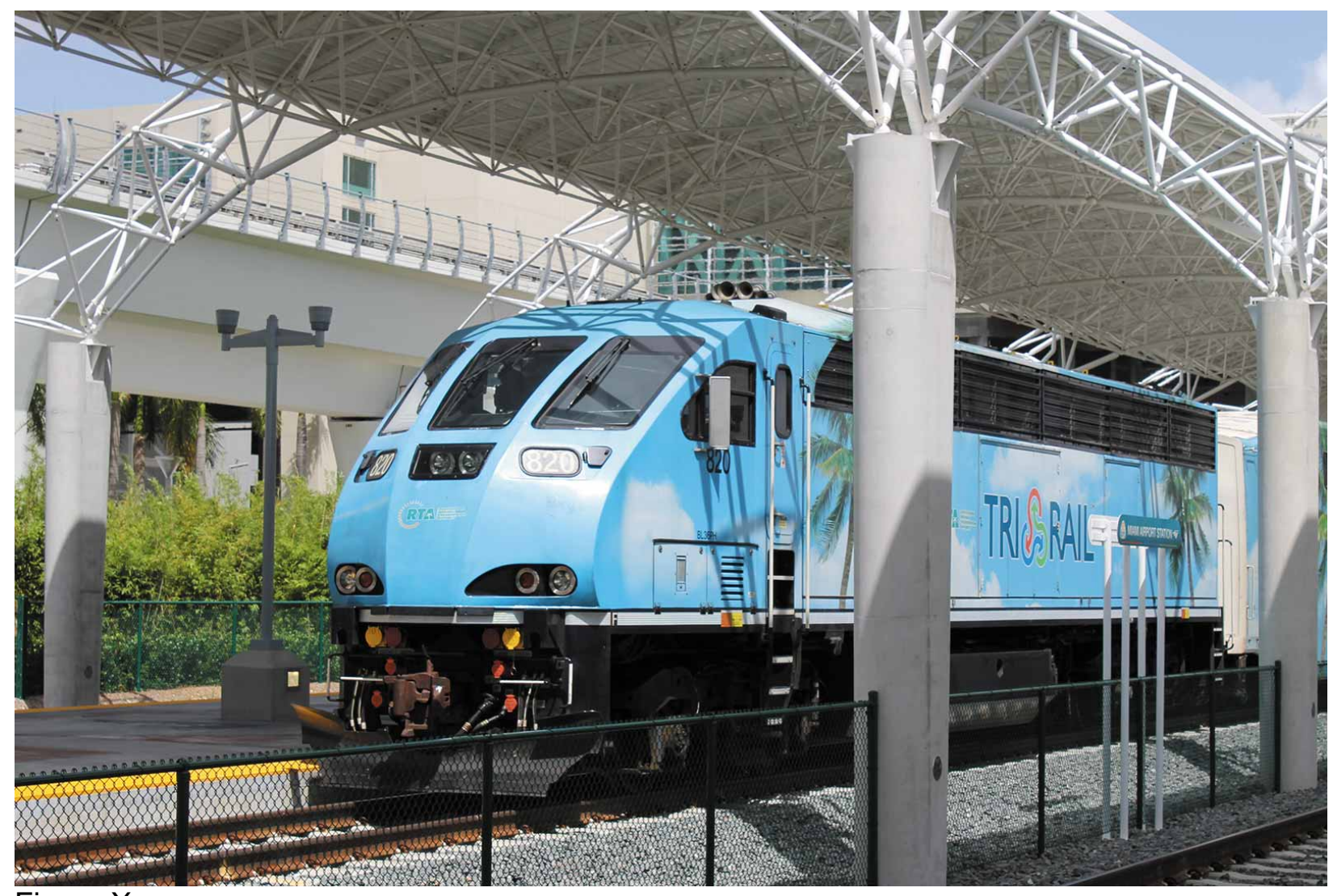

\section{Figure $\mathrm{X}$}

Tri-Rail

Source: https://www.miamitodaynews.com/2017/02/21/tri-rail-roll-commuter-rail-downtownmiami-years-end/

Traveling at speeds of up to 79 miles per hour, the Tri-Rail line in Greater Miami, Florida connects the cities of Miami, Fort Lauderdale, and West Palm Beach. 14,800 passengers ride the line per day and get on and off at 18 stations along the way. The line on which Tri-Rail currently operates was originally built in the 1920s with some of the original stations being utilized as well. ${ }^{54}$

\footnotetext{
${ }^{54}$ Adapted from: https://en.wikipedia.org/wiki/Tri-Rail.
} 


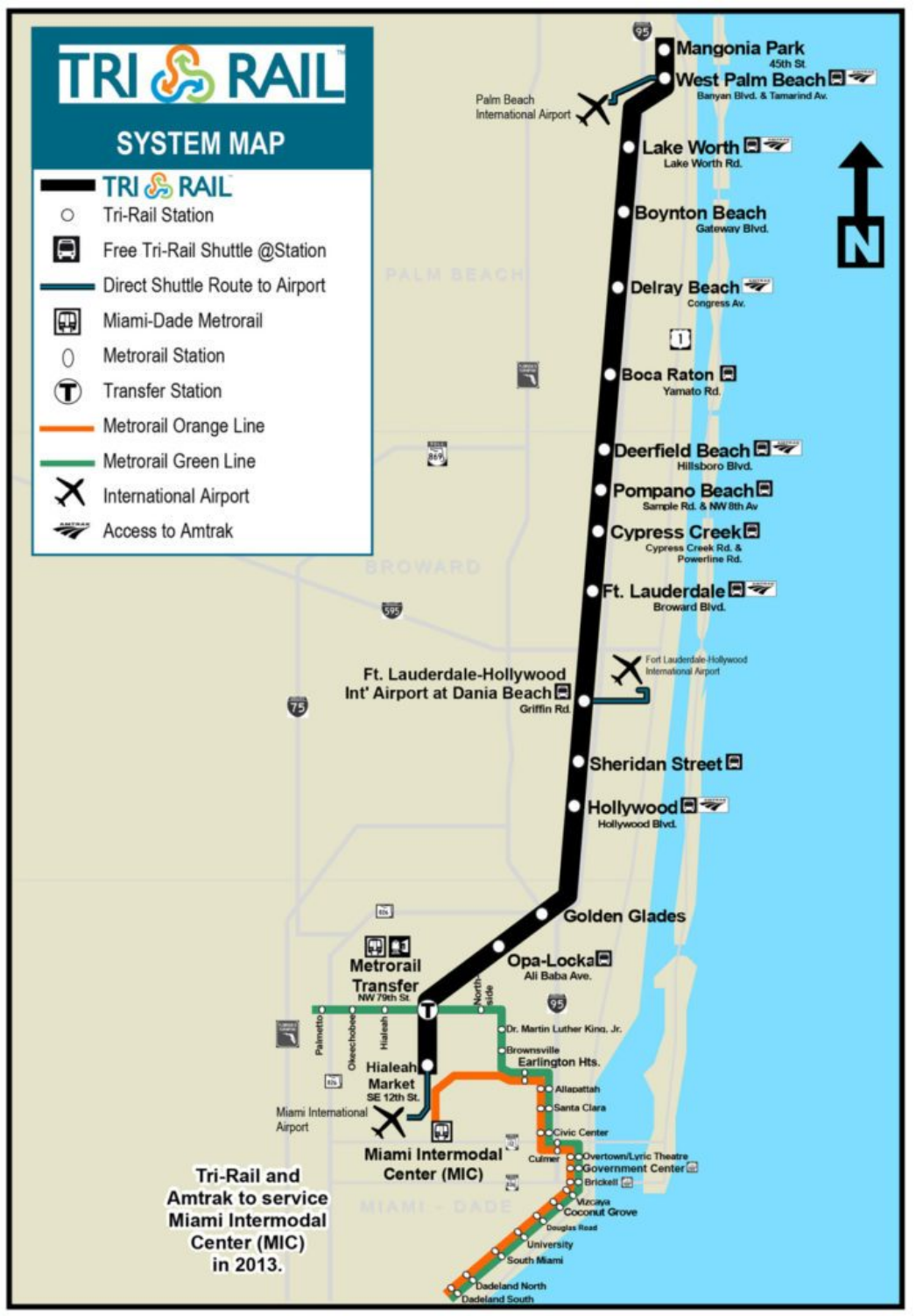

Figure $\mathrm{X}$

Tri-Rail Service Map

Source: https://www.transitmap.net/floida-tri-rail/ 


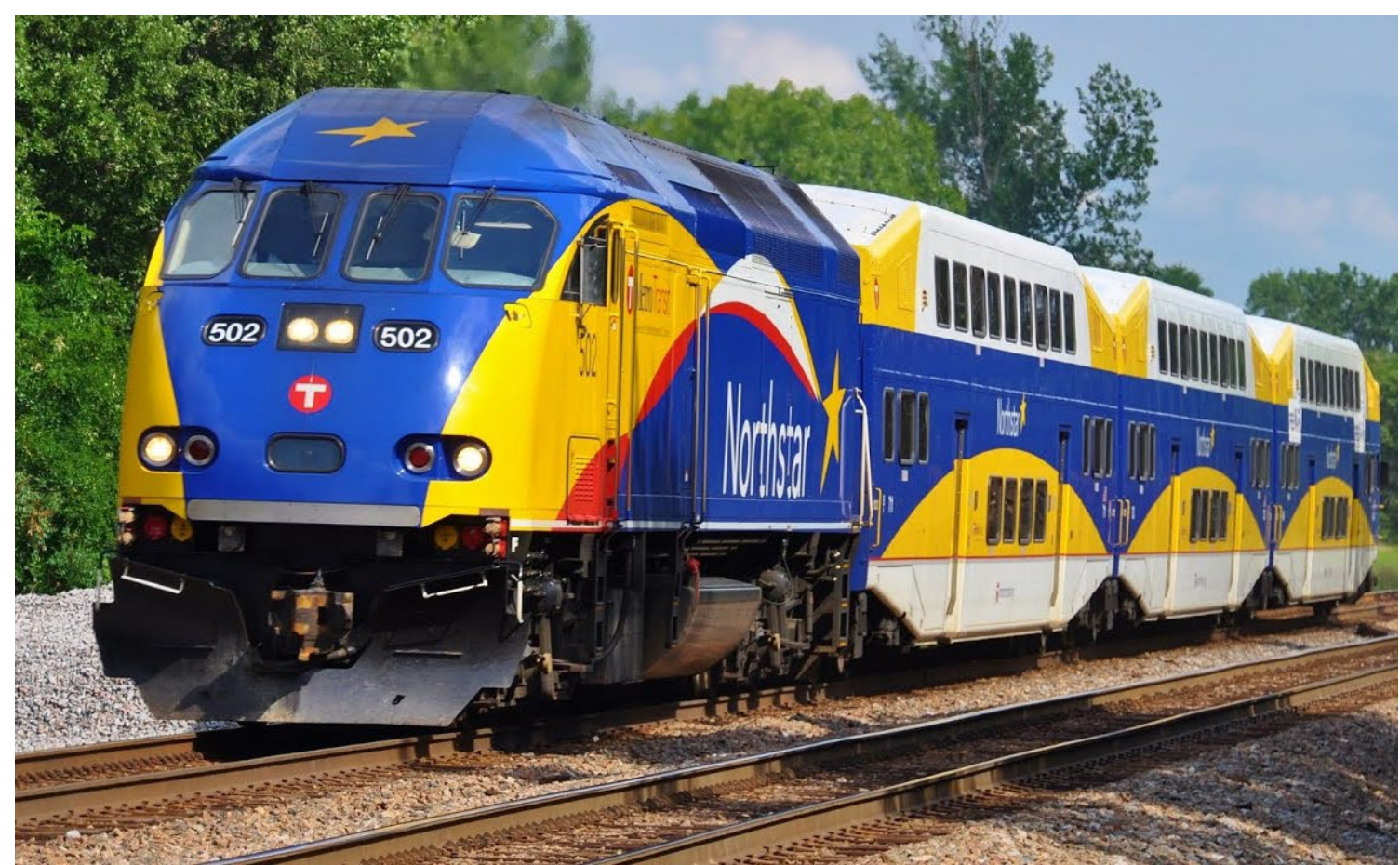

Figure $\mathrm{X}$

Northstar Commuter Rail

Source: https://www.youtube.com/watch?reload=9\&v=ocV_U3kwU6g

With free $\mathrm{Wi}-\mathrm{Fi}$, work stations, and onboard restrooms and bike storage, amenity-rich Northstar Commuter Rail Line serves the capital region of Minnesota between Big Lake and downtown Minneapolis. The line has 7 stations in operation, with another 4 proposed, along its 40-mile route. Planning for the line began in 1997 with the inaugural run commencing November 16, 2009. ${ }^{55}$

\footnotetext{
${ }^{55}$ Adapted from Source: https://www.metrotransit.org/northstar and Source: https://en.wikipedia.org/wiki/Northstar_Line\#Route.
} 


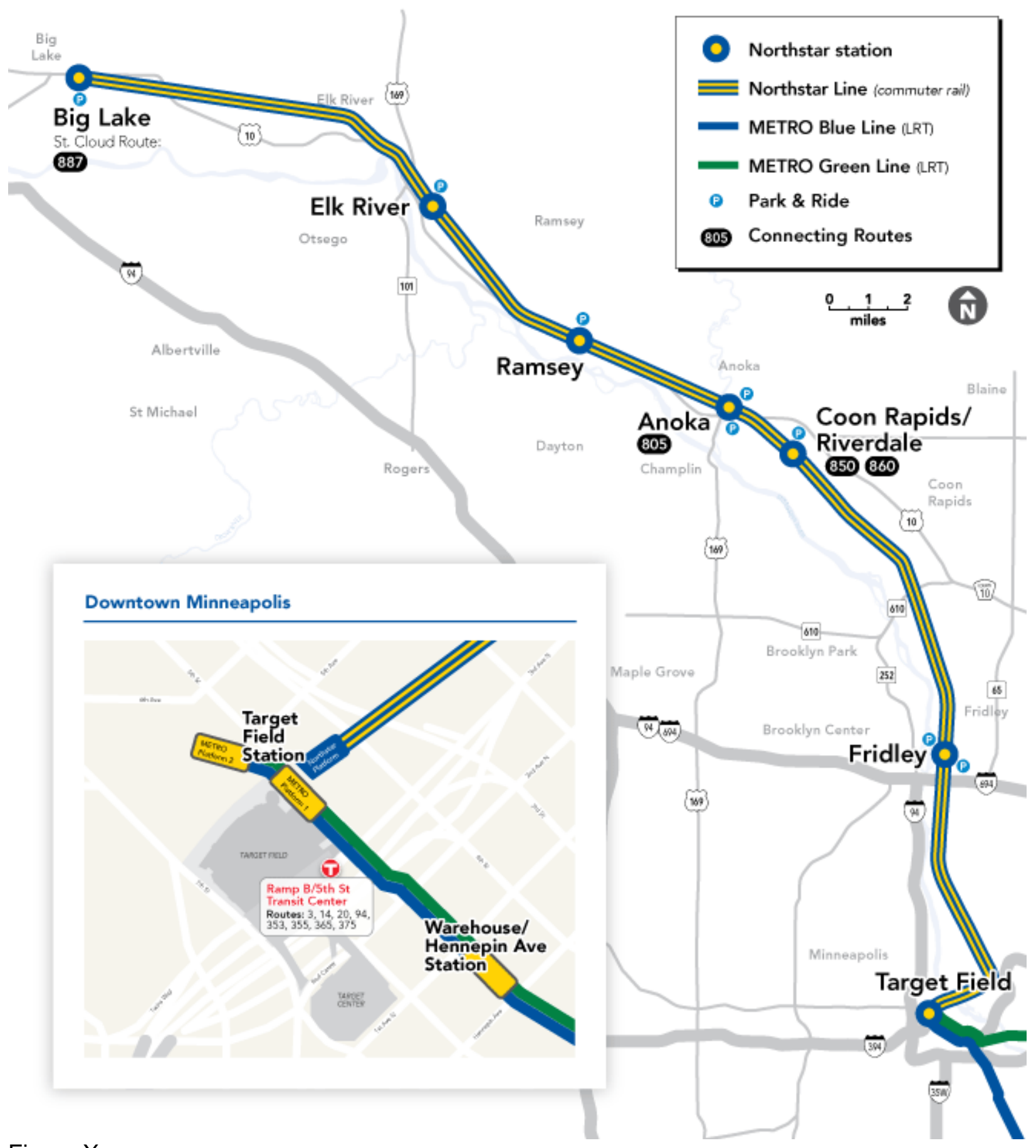

Figure $X$

Northstar Service Map

Source: https://www.metrotransit.org/northstar

NASHVILLE COMMUTER RAIL SYSTEM 


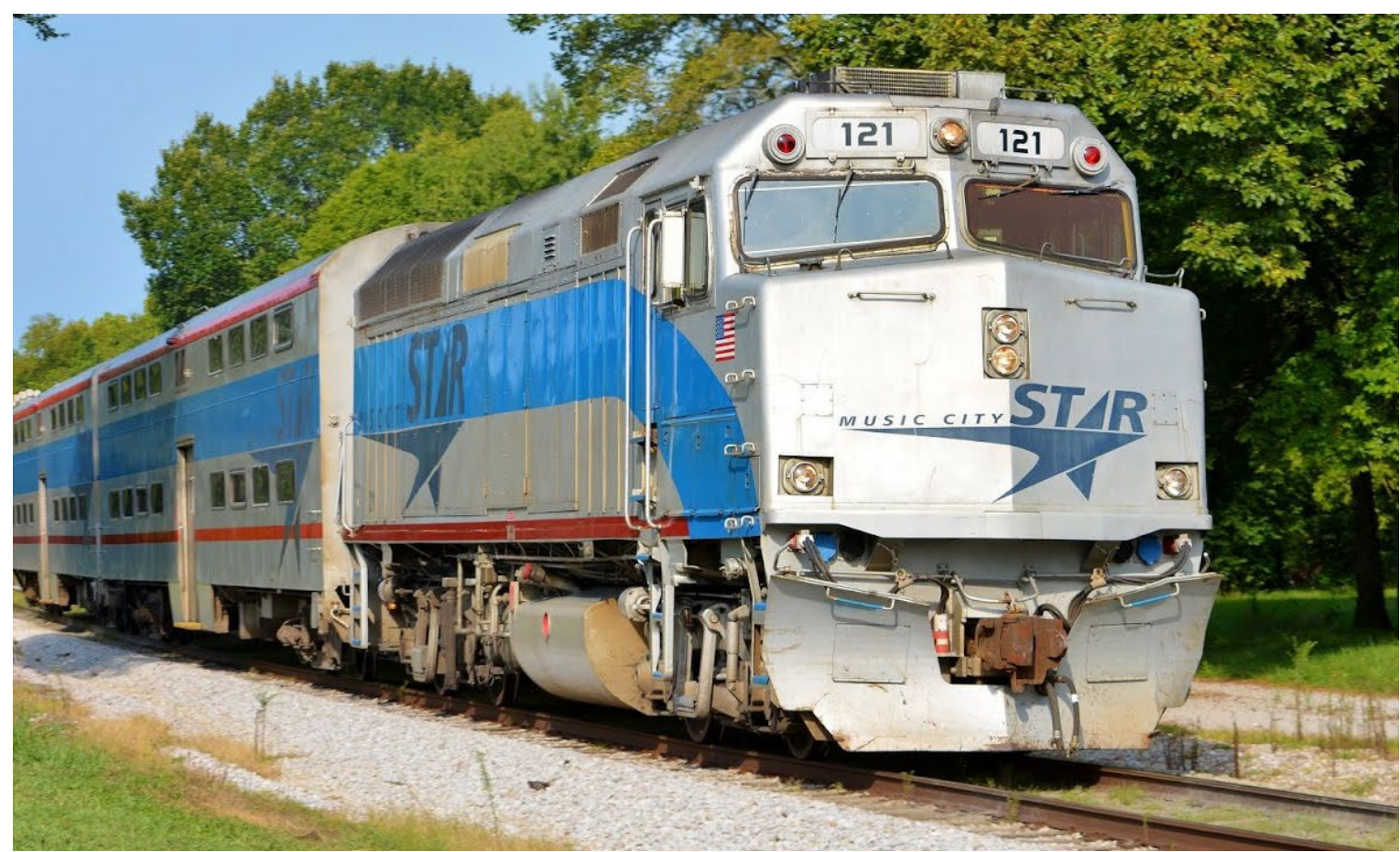

Figure $X$

Music City Star

Source: https://www.youtube.com/watch?v=u8ggFKFOvOc

The Music City Star serves commuters in between Lebanon and Nashville, Tennessee. The line is 32 miles long with stops at seven stations. There is only one operational line now, but there are six more planned to serve other suburbs of Nashville. The line cost just under $\$ 1,300,000$ per mile, which means it is the most cost-efficient development of a commuter line in the nation. 56

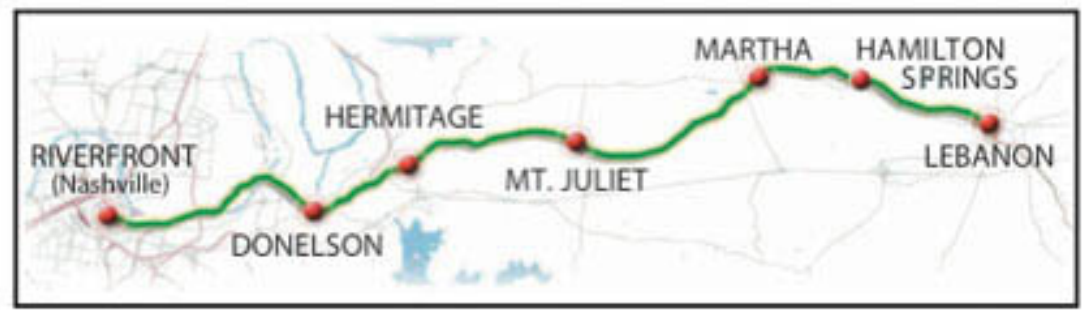

Figure $X$

Music City Star Service Map

Source: http://www.musiccitystar.org/Middle-TN-RTA-stations.asp

${ }^{56}$ Adapted from: https://en.wikipedia.org/wiki/Music_City_Star 


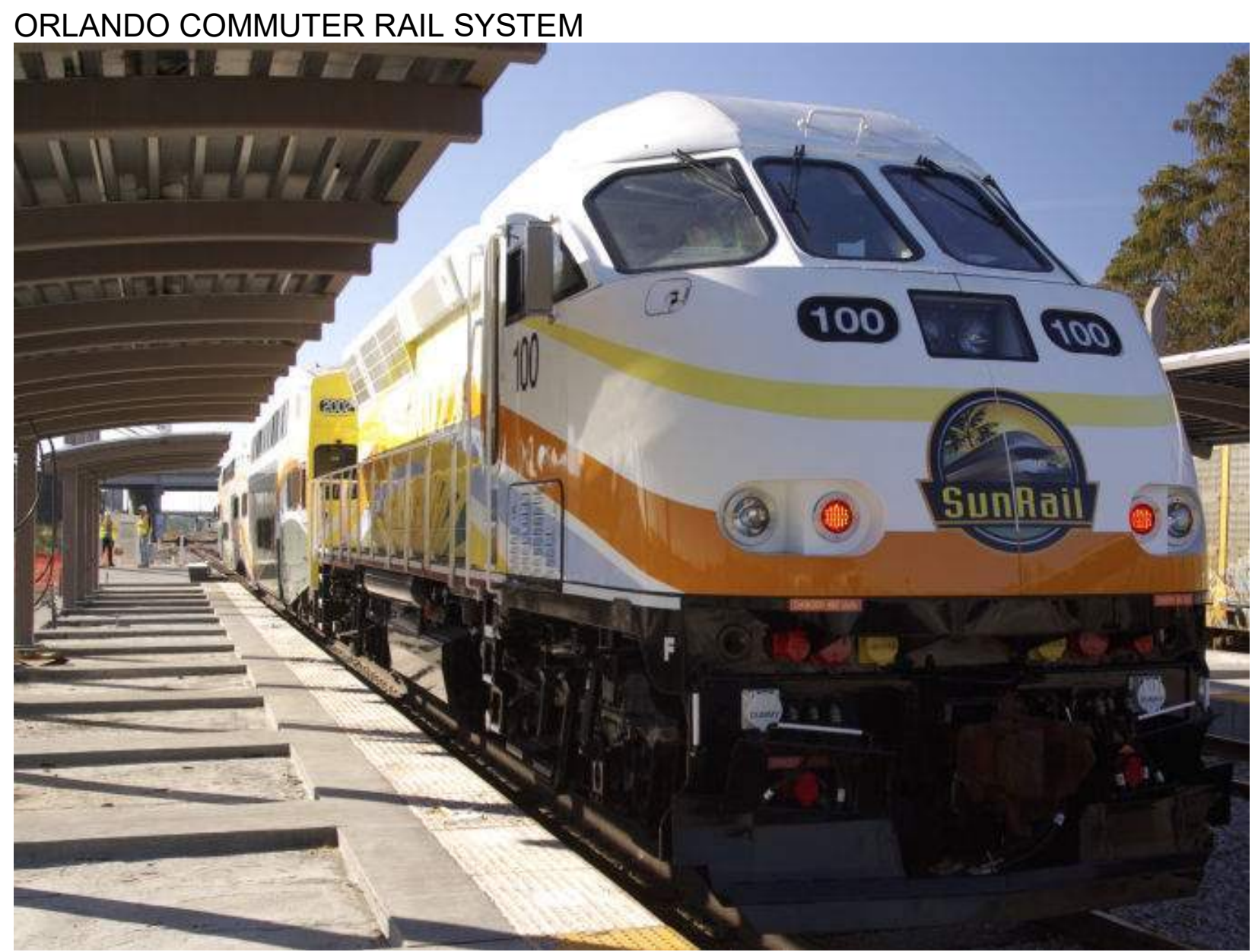

\section{Figure $X$}

SunRail

Source: https://www.tampabay.com/news/Hooper-Wondering-what-could-have-been-forTampa-Orlando_166496888

Service commenced on May 1, 2014 for the Sunrail commuter rail system in the Orlando, Florida area. Operating along a former CSX Transportation line, SunRail serves the counties of Orange, Volusia, and Osceola. The single line system has 16 stations and has about 3,400 riders per day. It travels at an average speed of 30 miles per hour along its nearly 49 -mile-long route. 


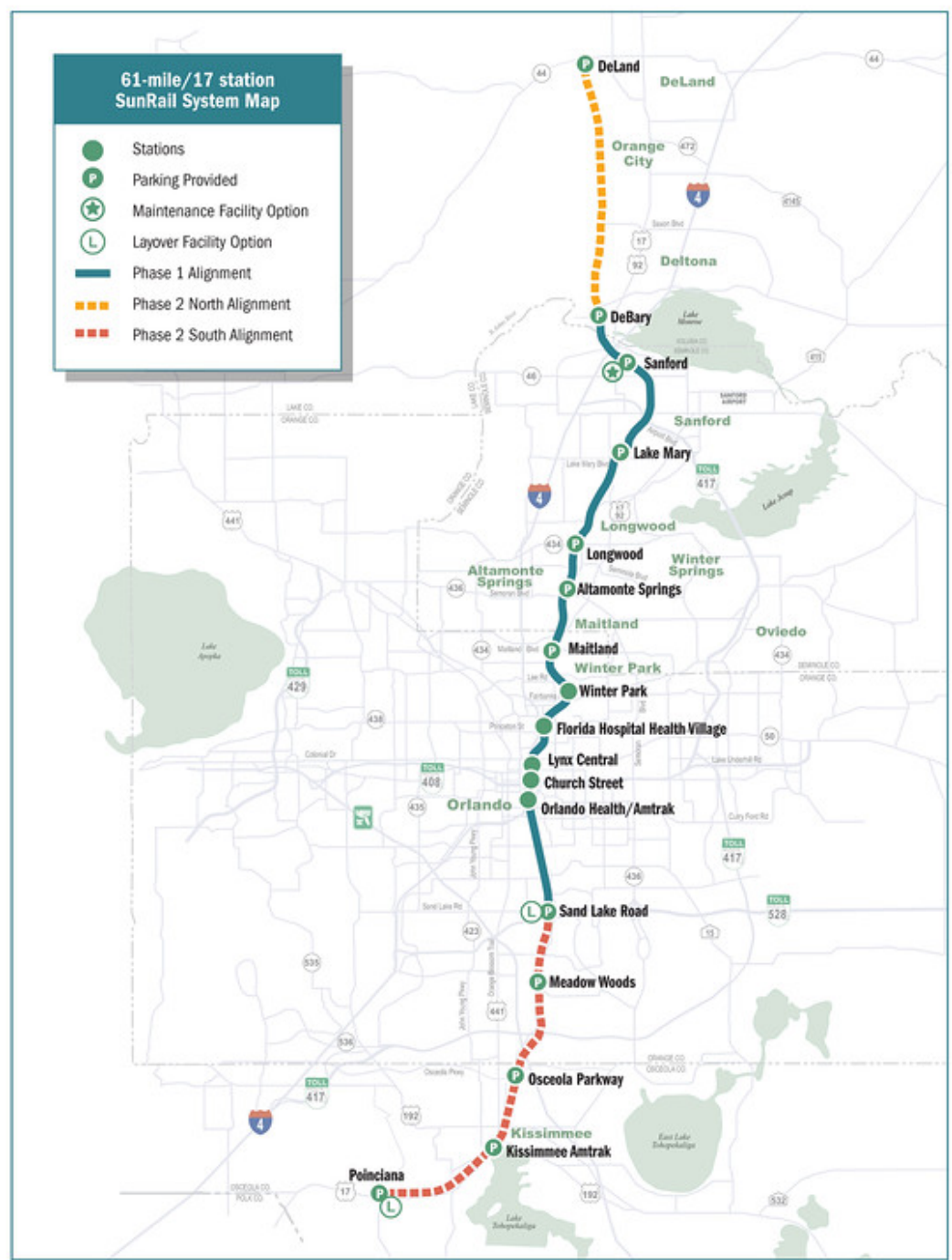

Figure $X$

Sunrail Service Map

Source: https://www.metrojacksonville.com/article/2012-oct-sunrail-redefining-orlando-

ORTLAND COMMUTER RAIL SYSTEM 


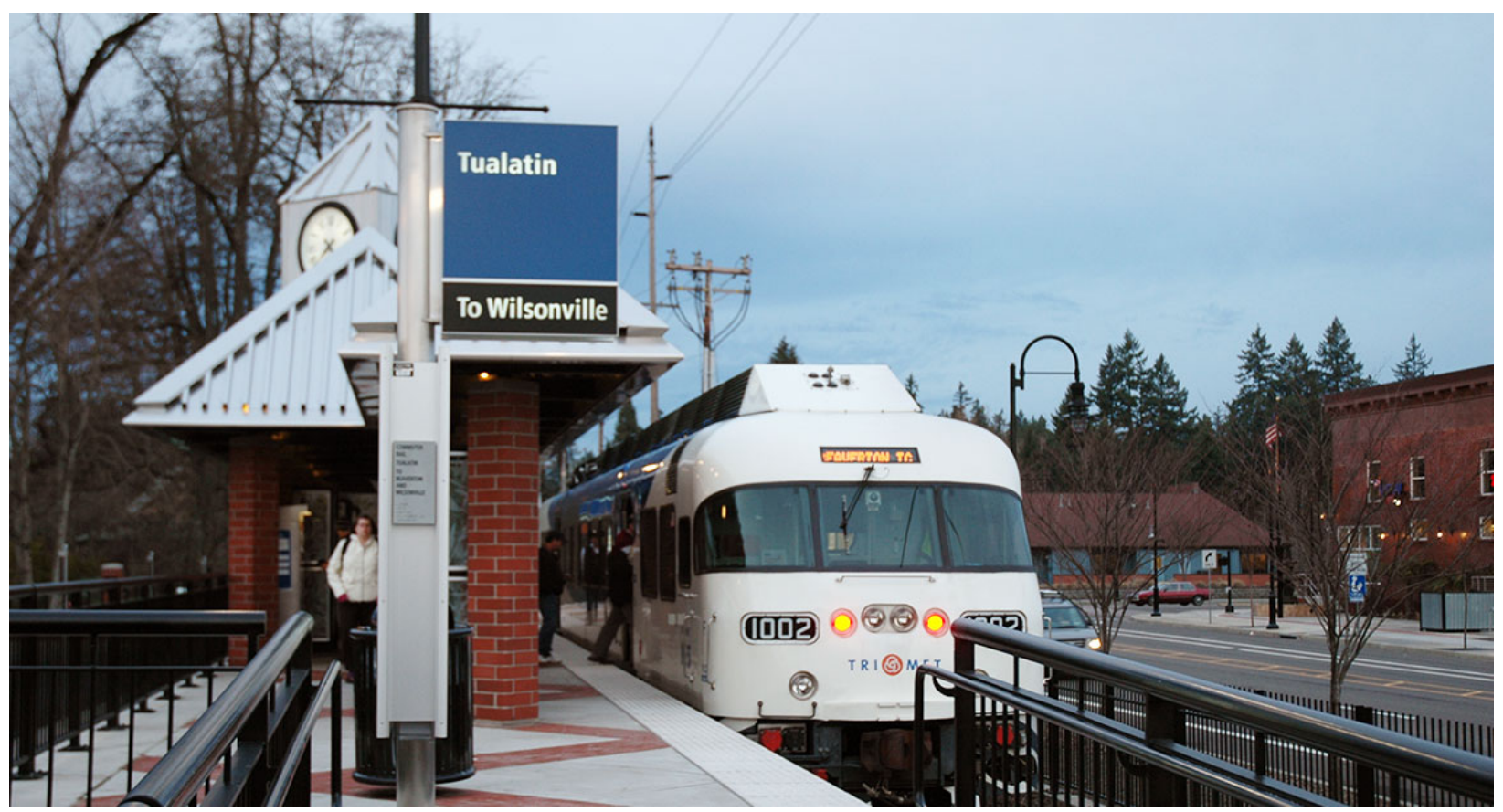

Figure $X$

TriMet WES Commuter Rail

Source: https://trimet.org/wes/index.htm

The commuter rail serving the Portland, Oregon area is called the WES, or Westside Express Service. The line serves Beaverton, Tigard, Tualatin, and Wilsonville, connecting commuters to the light rail line which goes directly downtown. The WES runs every 30 minutes on workdays during morning and evening rush hours. The single-line route has 5 stations and serves approximately 1,600 people per day. ${ }^{57}$

${ }^{57}$ Adapted from: https://trimet.org/wes/index.htm and Source: https://en.wikipedia.org/wiki/WES_Commuter_Rail. 


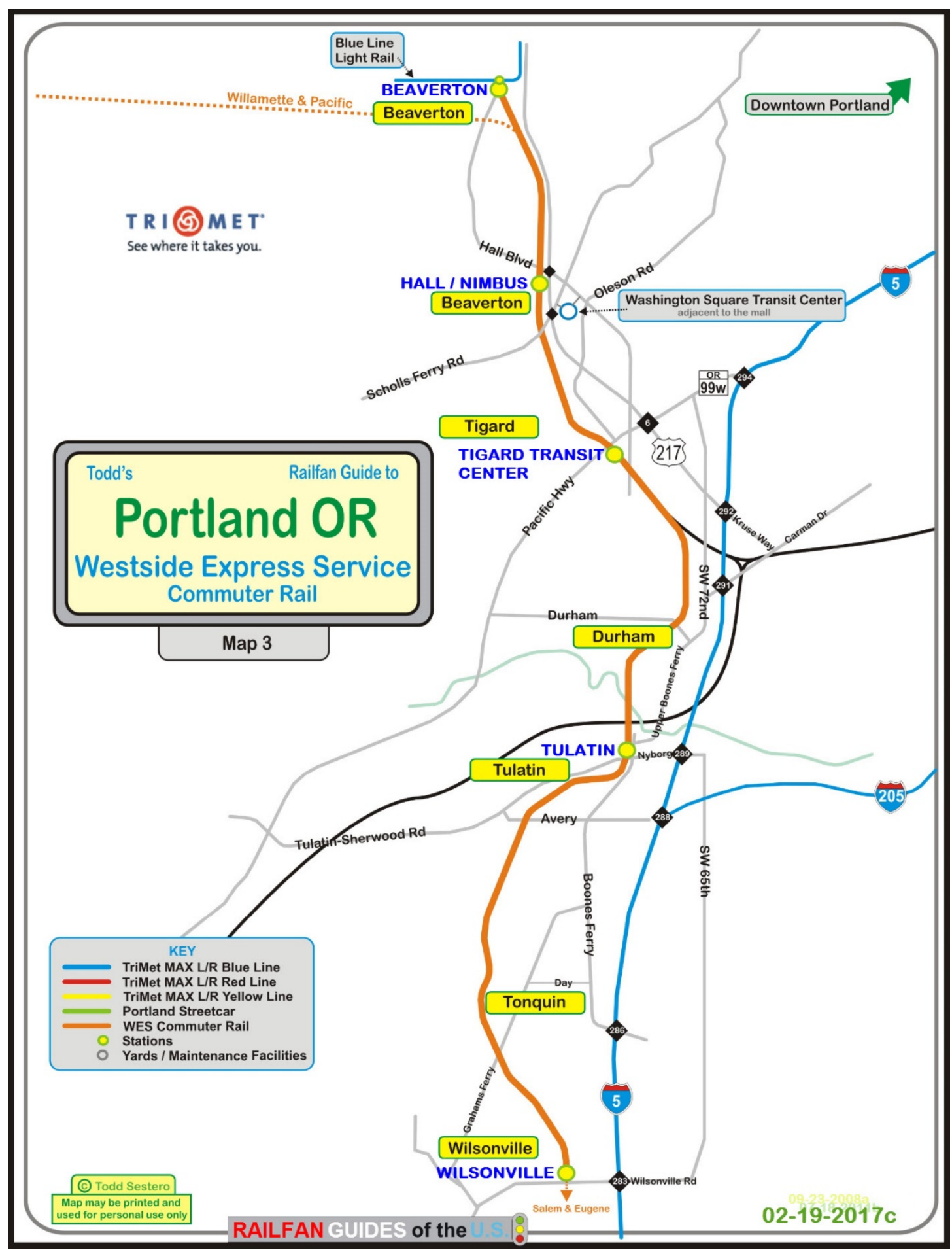

Figure $X$

Trimet WES Service Map

Source: http://www.railfanguides.us/or/trimet/map3/TrimetWESmap2011.jpg

SALT LAKE CITY COMMUTER RAIL SYSTEM 


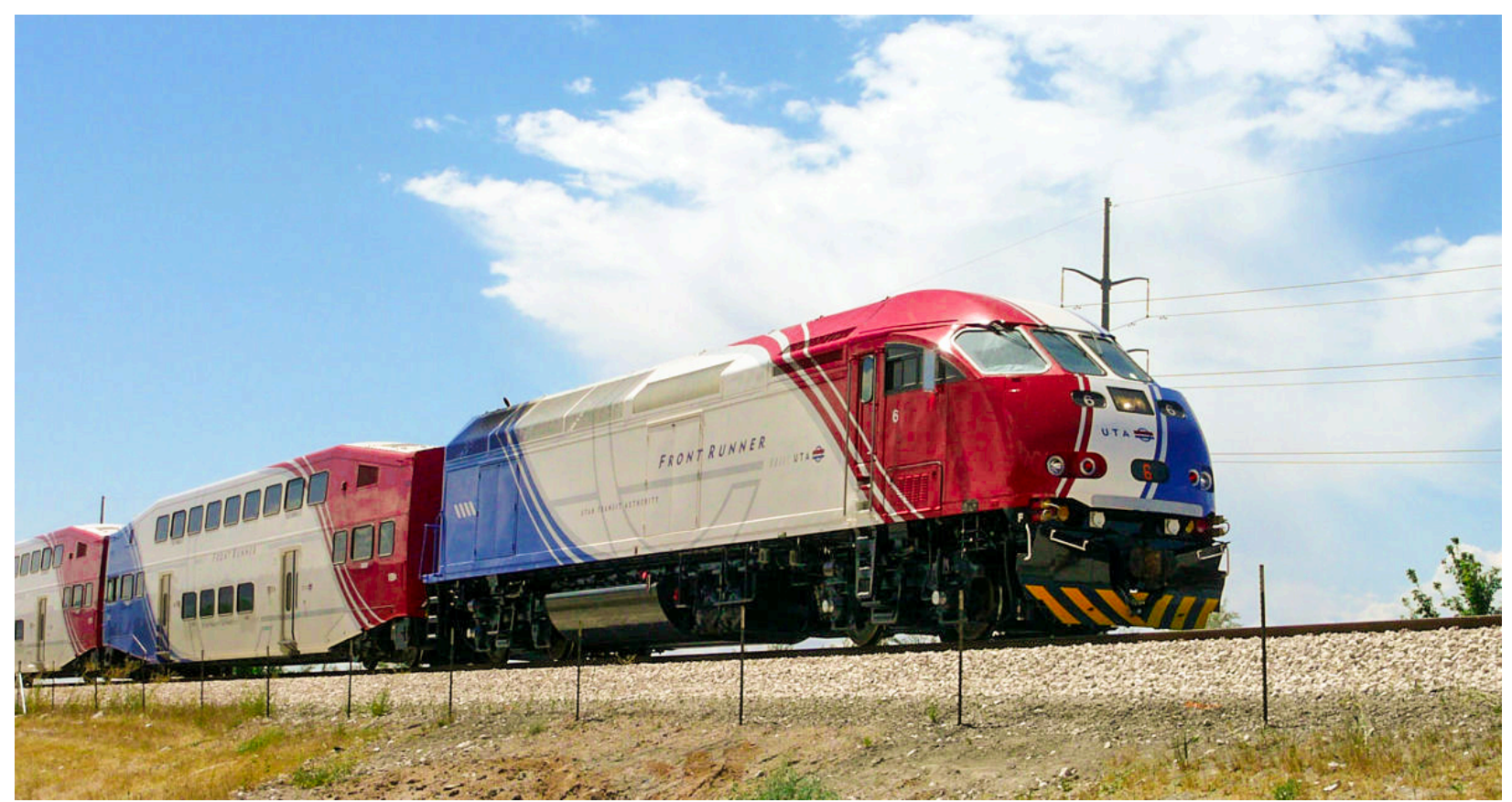

Figure $X$

FrontRunner Commuter Rail

Source: https://en.wikipedia.org/wiki/FrontRunner

The 88-mile system known as the FrontRunner in central Utah began operation in April of 2008. Daily, 17,600 passengers ride the line which goes from Ogden through Salt Lake City to Provo. Annually, the line carries nearly 5,000,000 passengers operating Monday through Saturday along 16 stations every half-hour. ${ }^{58}$

${ }^{58}$ Adapted from Source: https://www.rideuta.com/Services/FrontRunner and Source: https://en.wikipedia.org/wiki/FrontRunner. 


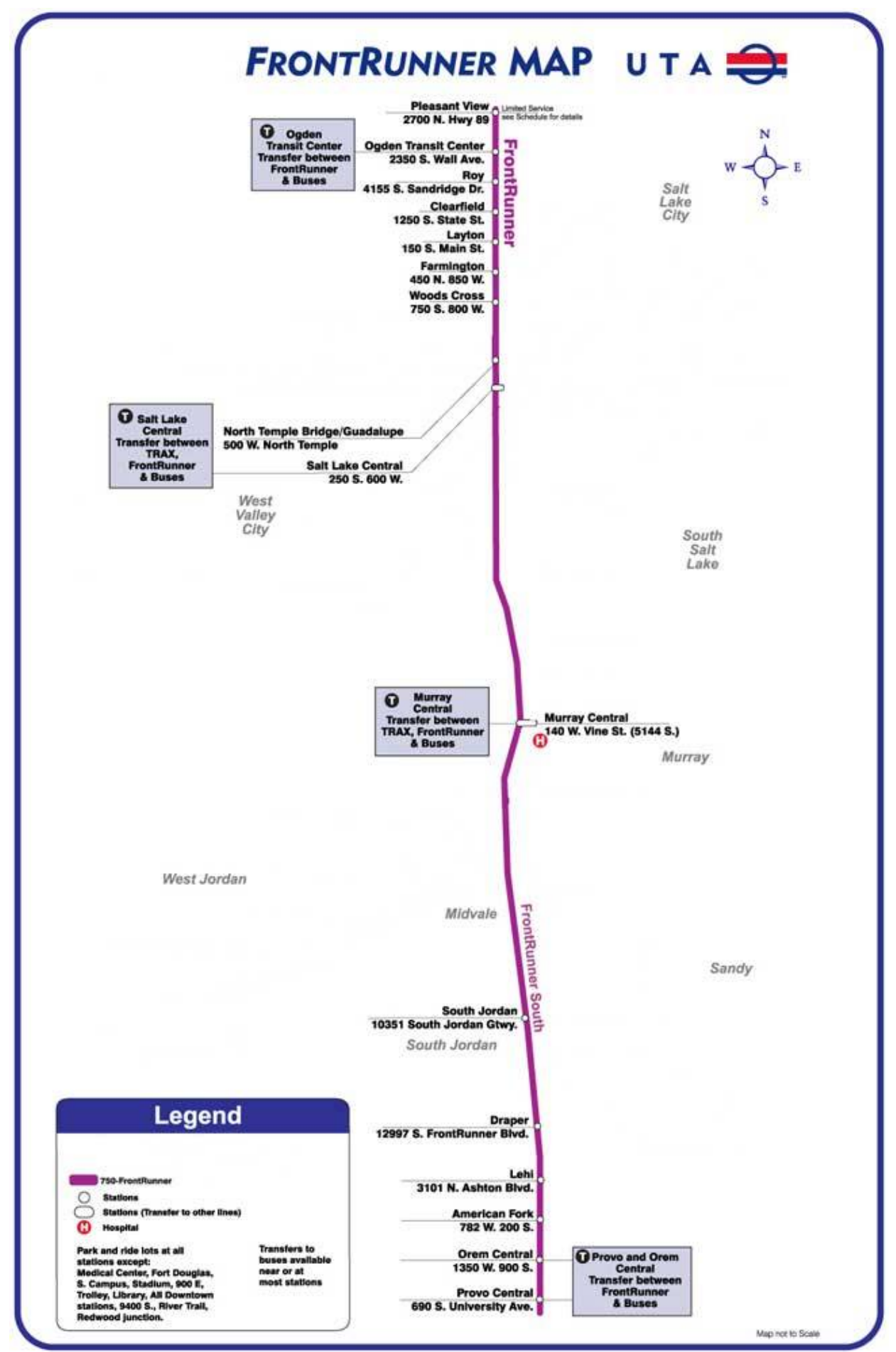

Figure $X$

FrontRunner Service Map

Source:

https://66.media.tumblr.com/7cc4cd6d5b4b3eddb8537361e056deed/tumblr_mlczfqedvs1r54c4o 02_1280.jpg

SAN DIEGO COMMUTER RAIL SYSTEM 


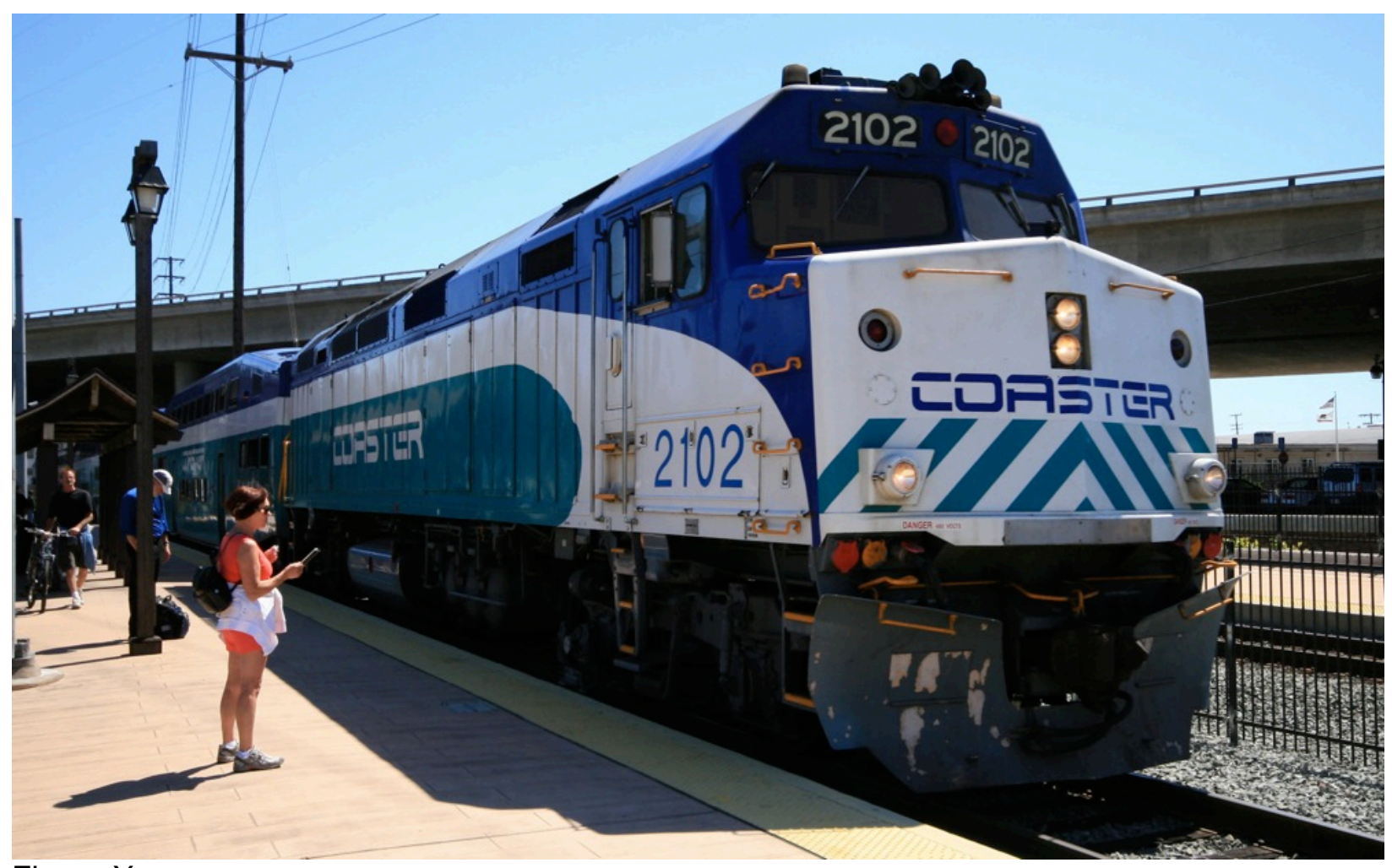

Figure $X$

San Diego Commuter Train

Source: https://chapterscapistrano.com/alcohol-banned-san-diego-coaster-train-step-rightdirection/

The San Diego Coaster commuter train operates mainly on weekdays with limited service on weekends and holidays. The train has eight stops along its 41-mile route between Oceanside and San Diego, California. The operating speed for the rolling stock is 90 miles per hour, and the entire route can be ridden (including stops) in about 55 minutes. On a yearly basis, the ridership is $1,600,000{ }^{59}$

${ }^{59}$ Adapted from: https://en.wikipedia.org/wiki/Coaster_(commuter_rail). 


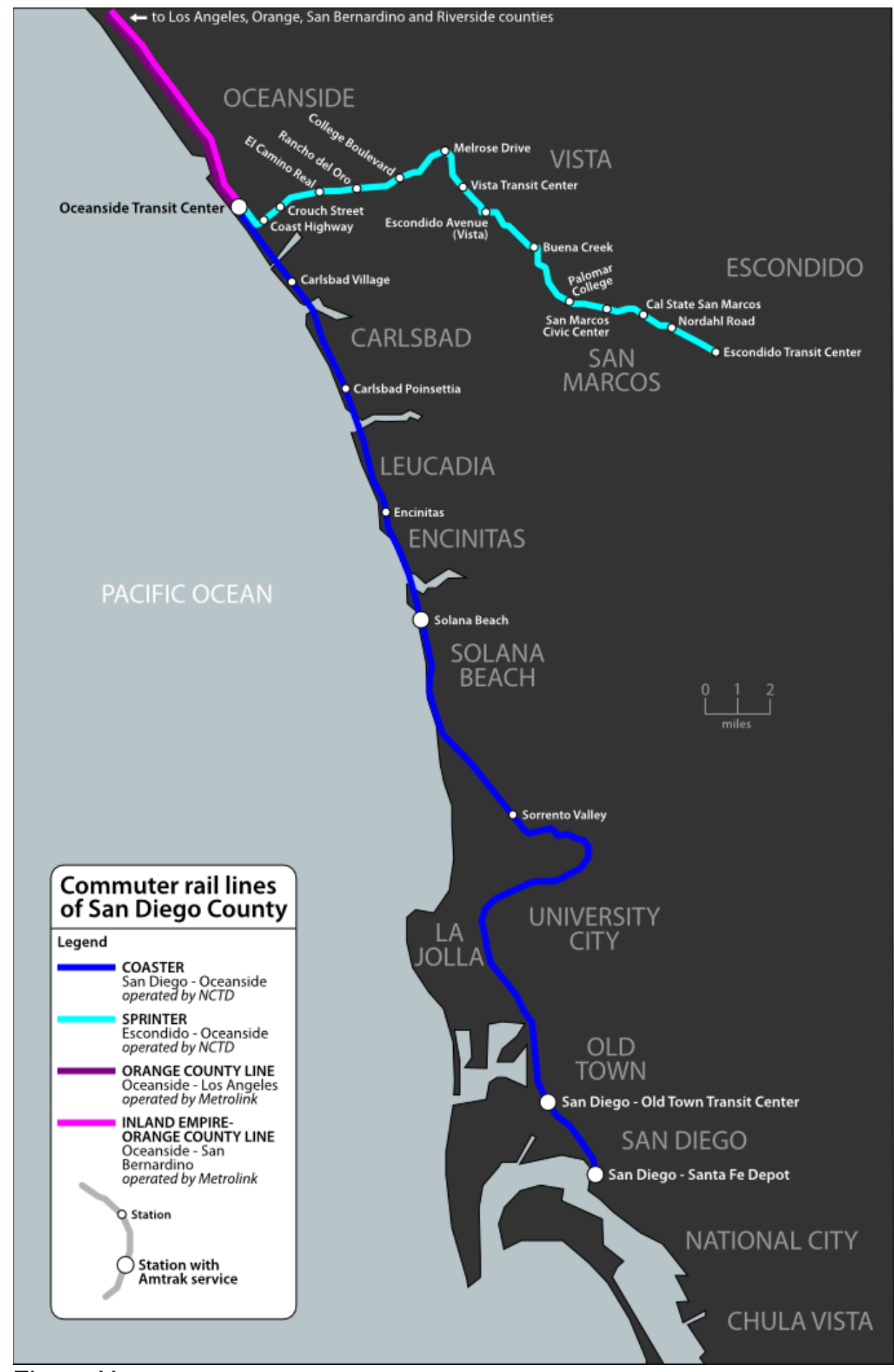

Figure X

Coaster Service Map

Source: http://www.sandiegoasap.com/gfx/san-diego-commuter-rail-map.png

SAN JOSE - STOCKTON - SAN FRANCISCO COMMUTER RAIL SYSTEM 


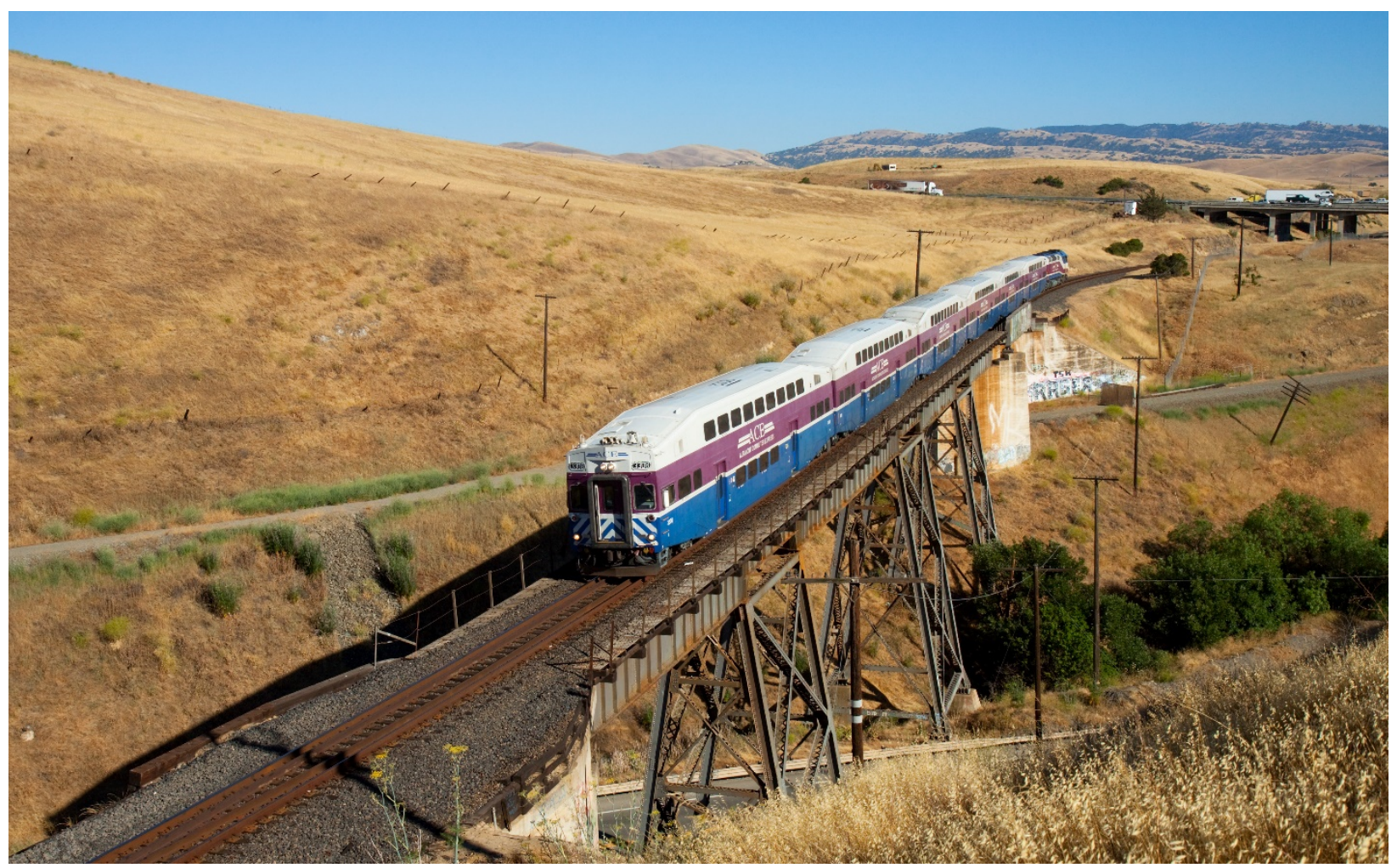

Figure $\mathrm{X}$

Altamont Corridor Express

Source:

https://en.wikipedia.org/wiki/Altamont_Corridor_Express\#/media/File:ACE_Altamont_Pass.jpg The commuter rail linking Stockton and San Jose, California is called the Altamont Corridor Express (ACE). Named after Altamont Pass through which it runs, there is one line with ten stations. The line is 85 miles long and it moves at an average pace of 39 miles per hour. Including stops, the line end-to-end takes about 2.5 hours to ride. Service on the ACE began October 19, 1998. ${ }^{60}$

${ }^{60}$ Adapted from: https://en.wikipedia.org/wiki/Altamont_Corridor_Express. 


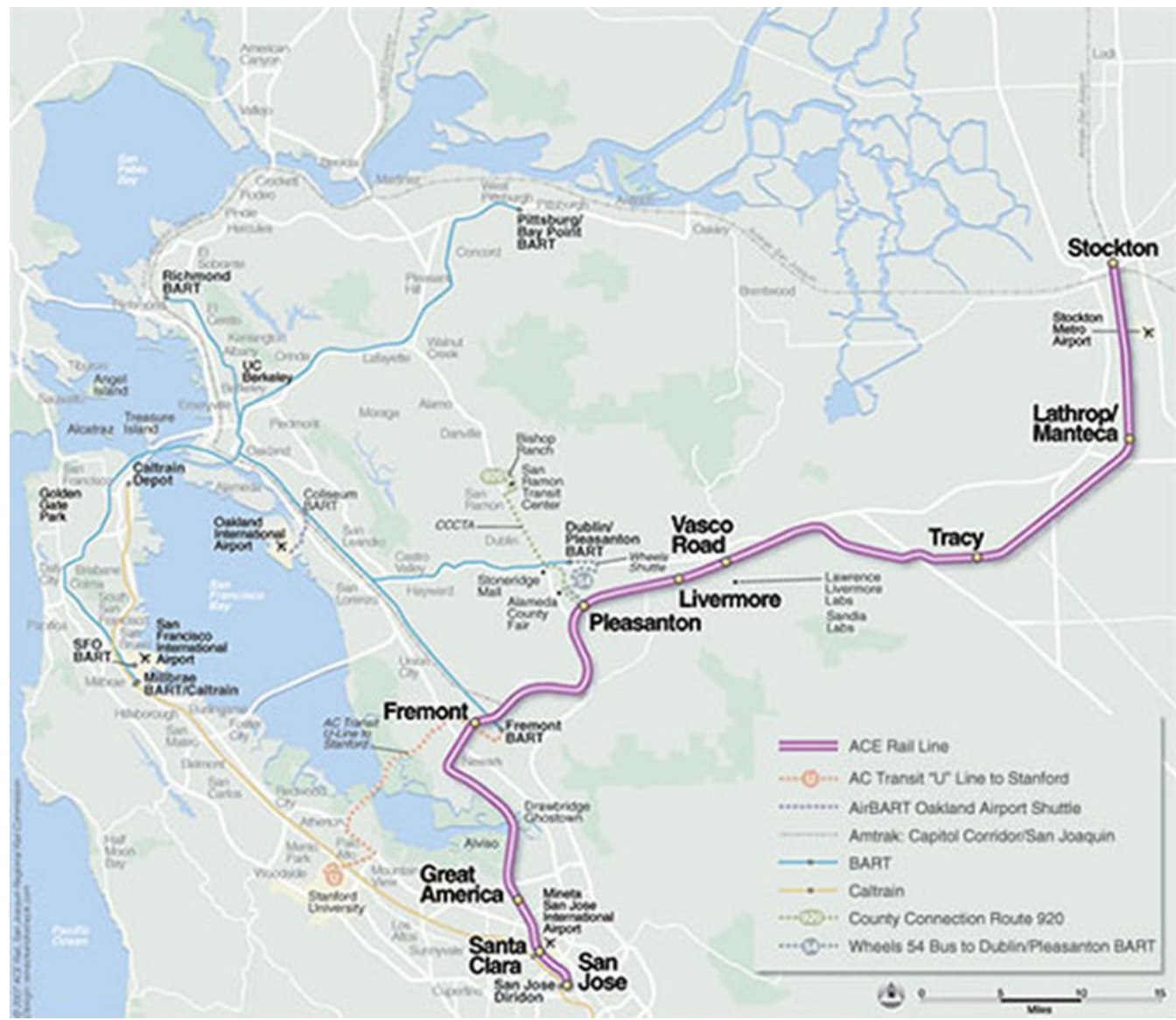

Figure $\mathrm{X}$

Altamont Corridor Express Service Map

Source: https://www.mobilemaplets.com/showplace/6393

SEATTLE - TACOMA COMMUTER RAIL LINE SYSTEM 


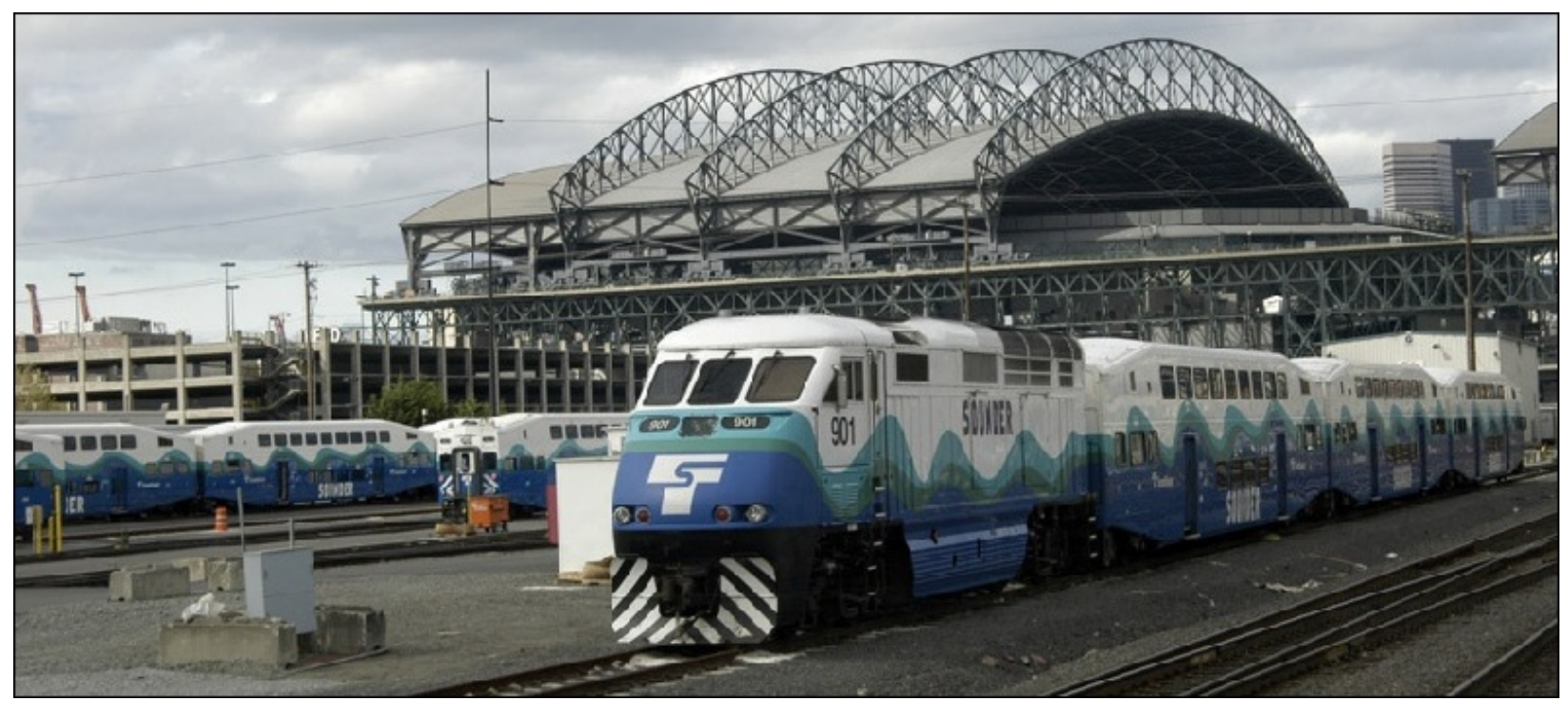

Figure $\mathrm{X}$

Sounder Commuter Rail

Source: https://www.nycsubway.org/wiki/Seattle_Sounder_Commuter_Rail

Operating Monday through Friday during peak commute times, the Sounder Commuter Rail has two lines and twelve stations between southern suburbs of Tacoma and northern suburbs of Seattle, Washington. Daily ridership for Sounder is 18,314, and it opened on September 18, 2000. ${ }^{61}$

${ }^{61}$ Adapted from: https://en.wikipedia.org/wiki/Sounder_commuter_rail. 


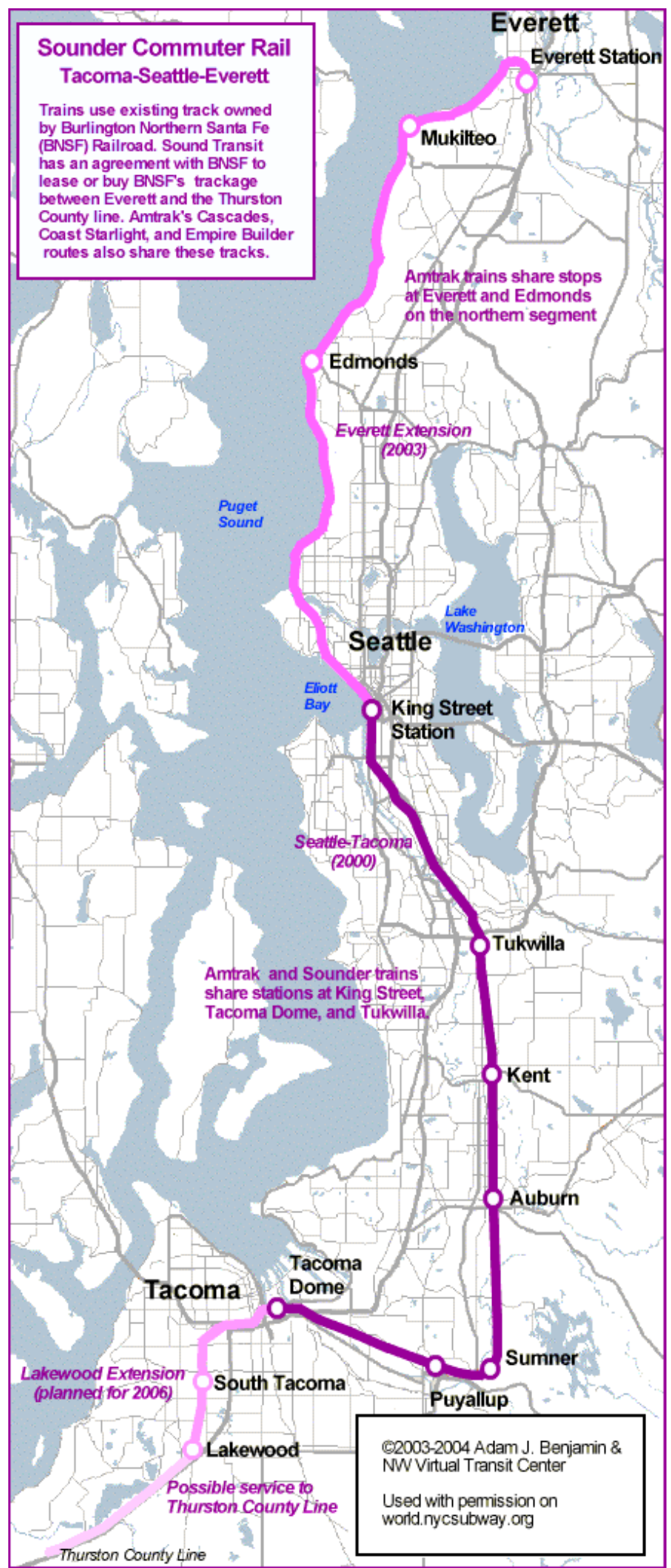

Figure $X$

Sounder Service Map (shown in deep purple)

Source: https://www.nycsubway.org/wiki/Seattle_Sounder_Commuter_Rail WASHINGTON, DC - BALTIMORE COMMUTTER RAIL SYSTEM: MARC 


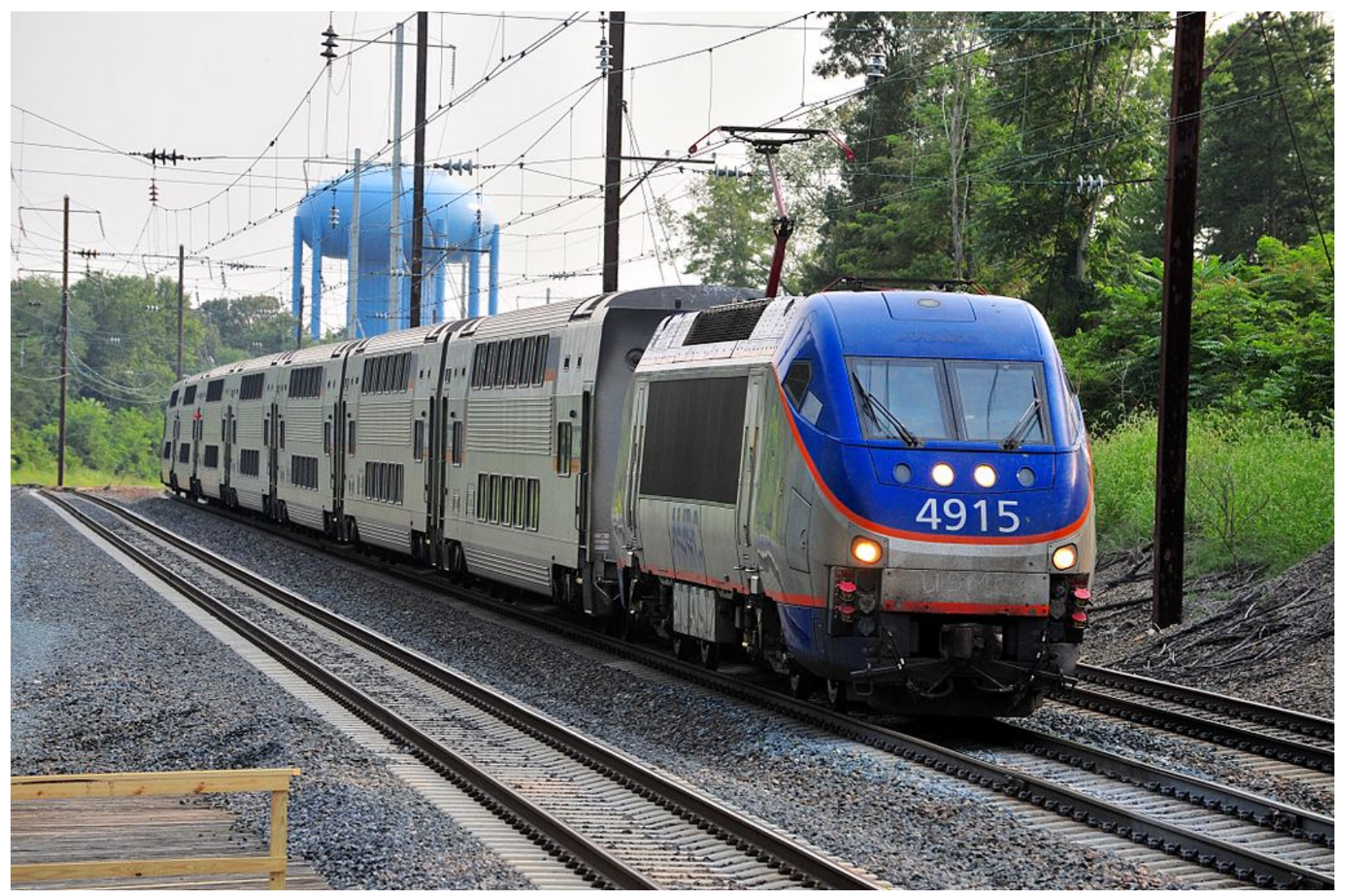

\section{Figure $X$}

MARC Commuter Rail

Source: https://en.wikipedia.org/wiki/MARC_Train\#/media/File:MARC_438_(14833026066).jpg The MARC Commuter Rail is one of two commuter train lines that has service to D.C., and its modern-day operation began in 1984 . Dating back to the 1800 s, the line serves primarily as a connection between Baltimore and D.C. with a daily ridership of over 40,000. The rail system has three lines: Martinsburg, WV to D.C.; Perryville, MD via Baltimore to D.C.; and Baltimore to D.C. ${ }^{62}$

\footnotetext{
${ }^{62}$ Adapted from: https://en.wikipedia.org/wiki/MARC_Train and Source: https://www.mta.maryland.gov/schedule/11080.
} 


\section{MARC TRAIN SERVICE}

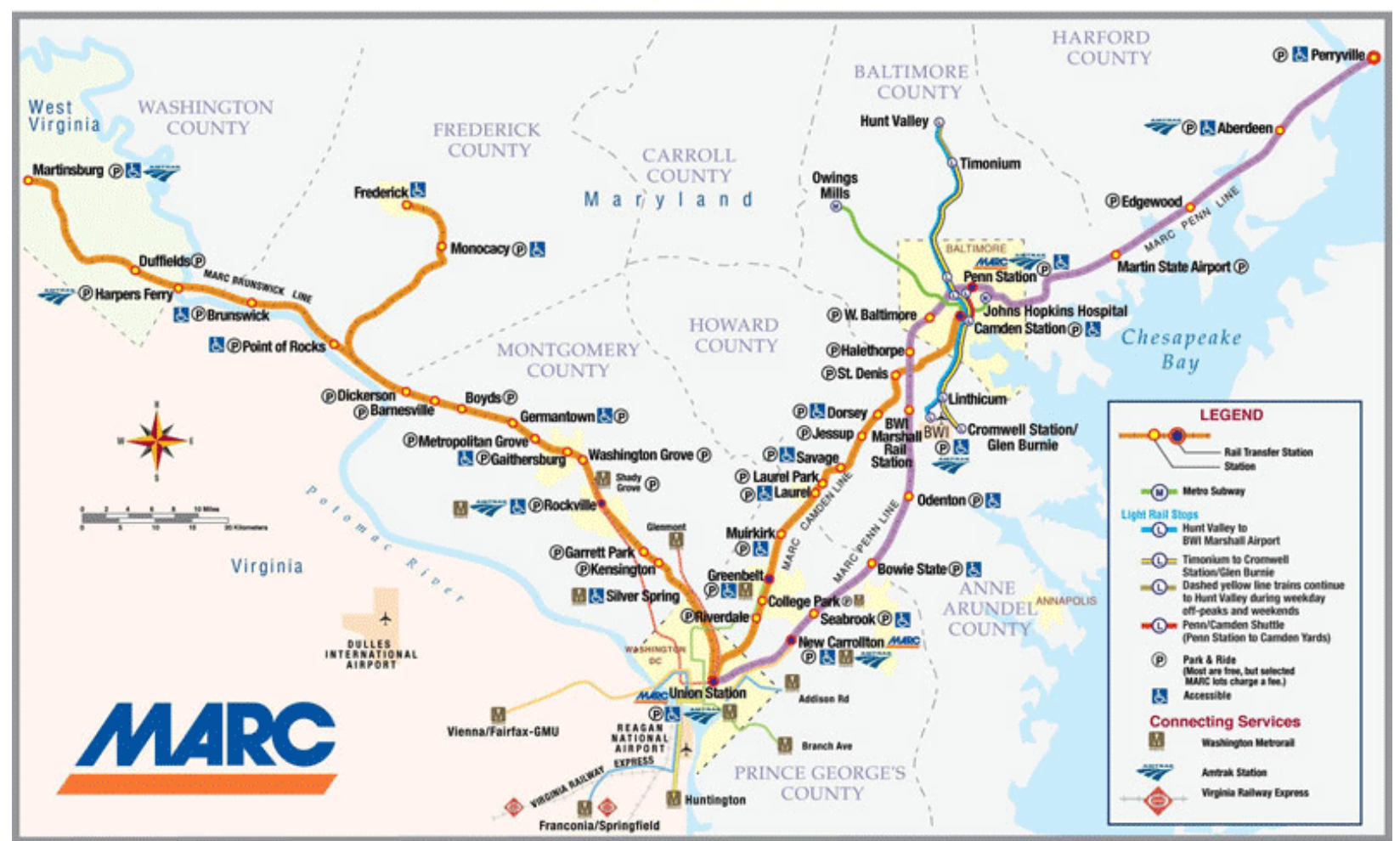

Figure $X$

MARC Service Map

Source: http://www.perryvillemd.org/transportation/pages/marc-train-station

WASHINGTON, DC - NORTHERN VIRGINIA COMMUTER RAIL SYSTEM: VRE 


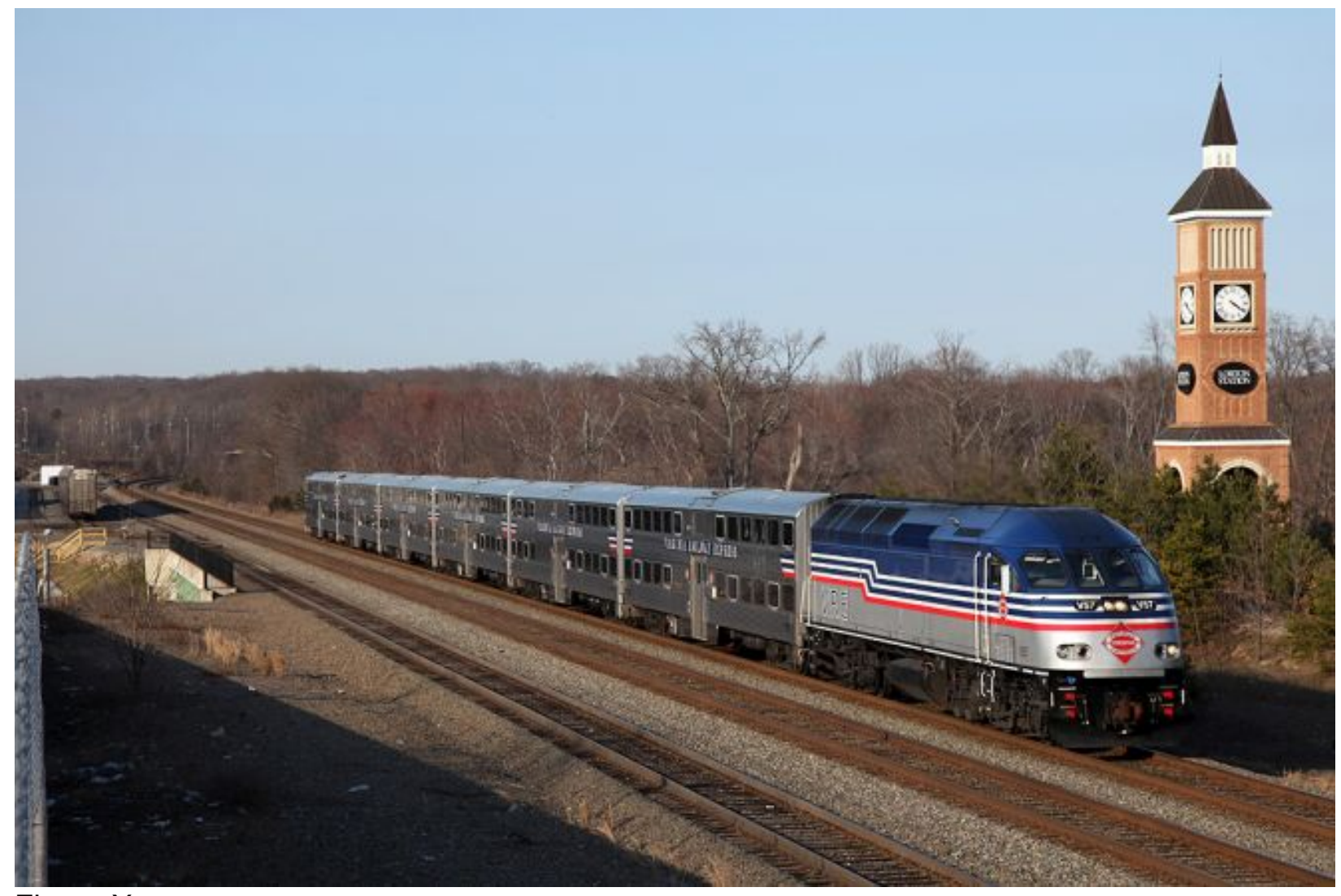

Figure $X$

Virginia Railway Express

Source: https://www.vre.org/development/

Connecting the Northern Virginia suburbs to Union Station in Washington, D.C., the Virginia Railway Express (VRE) operates two lines during peak hours. One line starts from Fredericksburg, Virginia and the other from Bristow, Virginia. The VRE began operations in summer of 1992 with 19 stations serving the two lines. ${ }^{6}$

${ }^{63}$ Adapted from: https://en.wikipedia.org/wiki/Virginia_Railway_Express and Source: https://www.vre.org/. 


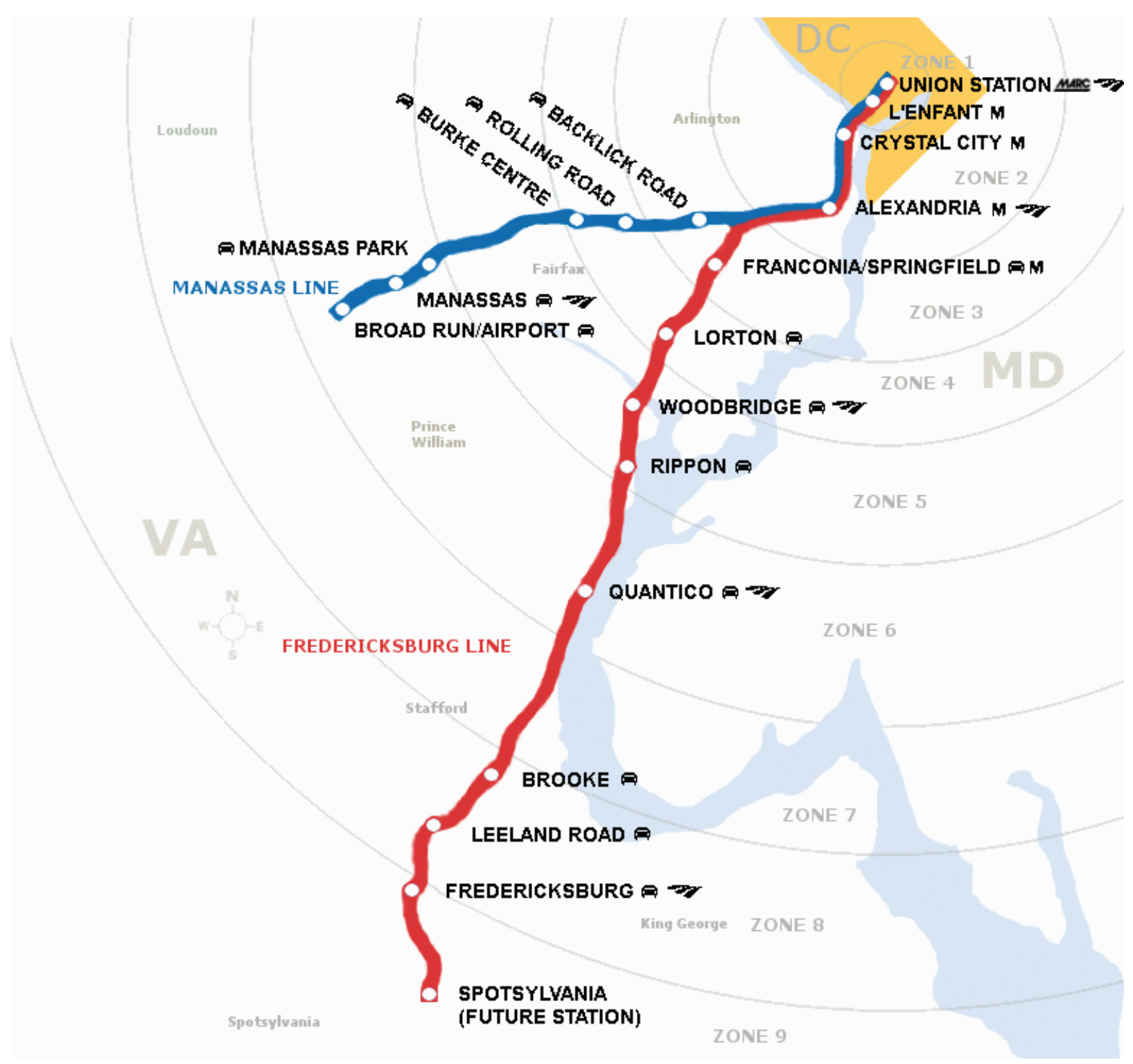

Figure $X$

VRE Service Map

Source: https://map.vre.org/vremap/app?action=ovmap 


\section{APPENDIX A - XBT \\ EXPRESS BUS TRANSIT SYSTEMS USED IN ANALYSIS}

Express Bus Transit Systems Metro Area \&

Name

Albuquerque: Express Lines

Year Miles Stations (Daily)

Atlanta: Xpress

4,932

Austin: MetroExpress

Buffalo: Enhanced Express Bus Service

Charlotte: Express Bus

Cincinnati: Metro Bus Express Lines

Dallas - Fort Worth: DART Express

Denver: Express Bus Lines

Houston: Park and Ride

Kansas City: KC MAX

$2005 \quad 32$

87

Little Rock: Express Routes

Miami: Express Routes

Minneapolis: Express Bus System

Nashville: Express Bus System

New Orleans: Express Lines

Norfolk: Metro Area Express (MAX)

Orlando: Fastlink

Phoenix: MetroExpress

Pittsburgh: Flyer

Portland: Express Lines

Reno: RTC Regional Connector

Sacramento: Express Bus Lines

Salt Lake City: Utah Express Bus Transit

San Antonio: VIA Express

San Jose: VTA Express Bus

Seattle - Tacoma: SoundTransit Express Line

St. Louis: Express Transit Lines

Tacoma: Express Bus Transit

Tucson: SunExpress

Washington, DC: Metrobus Express 


\section{ALBUQUERQUE EXPRESS BUS TRANSIT SYSTEM}

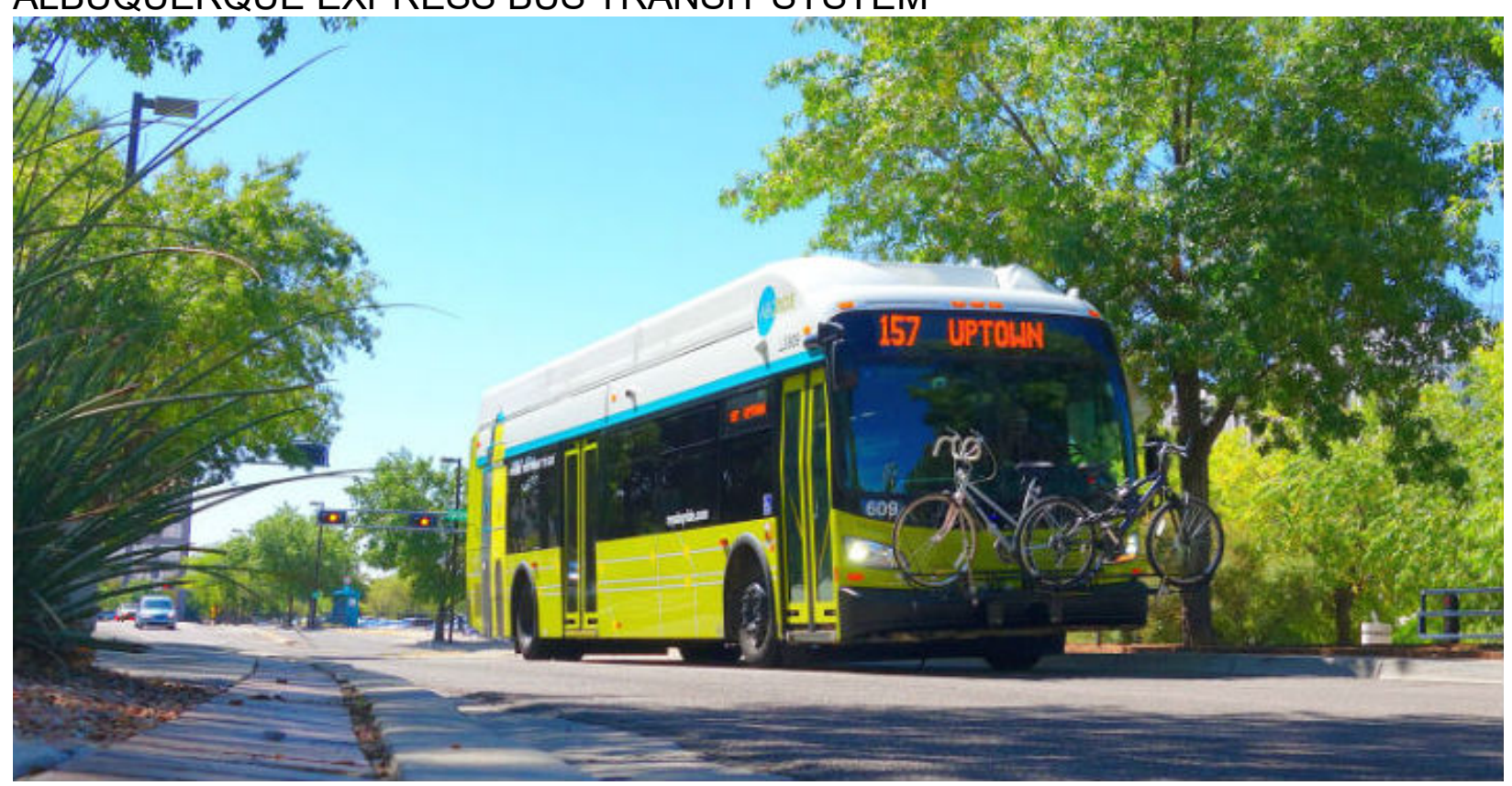

Figure XBT Albuquerque 1

Albuquerque Bus Stock

Source: Source: https://www.cabq.gov/student-guide

The City of Albuquerque, New Mexico operates three express lines. The Taylor Ranch Express line runs from south of Rio Rancho to the University of New Mexico. The Jefferson / Paseo del Norte Express runs from north of Rio Rancho to the University of New Mexico, and there is an additional express line running between the airport and downtown. ${ }^{64}$

${ }^{64}$ Adapted from: https://www.cabq.gov/transit/routes-and-schedules. 


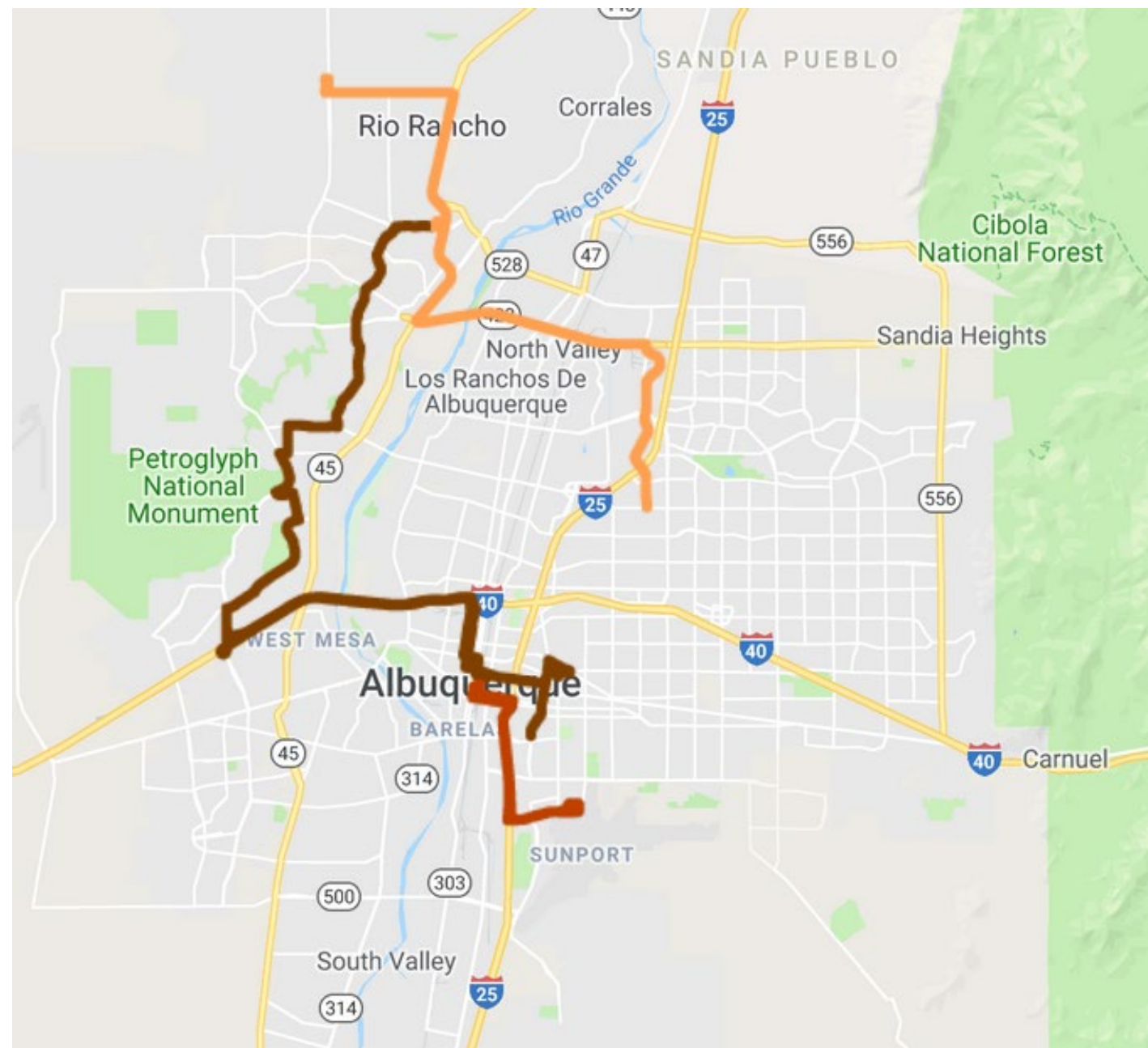

Figure XBT Albuquerque 2

Albuquerque Express Bus Lines

Source: Source: http://wmb.unm.edu/?busid=92 


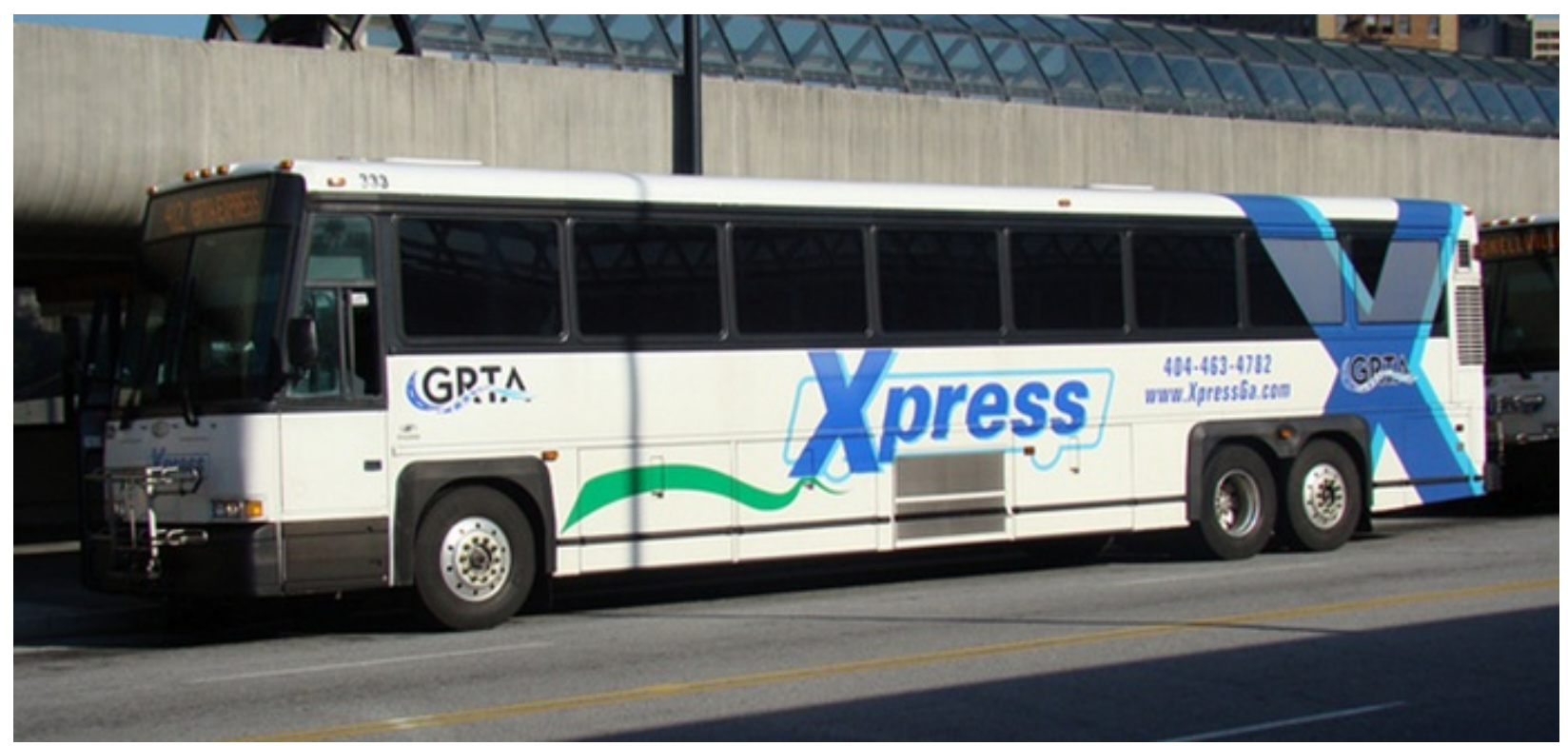

Figure XBT Atlanta 1

Atlanta Xpress

Source: https://dilemma-x.net/2013/02/18/fight-over-atlanta-mass-transit-marta-system-raisesrace-issues/

Operated by the State Road \& Tollway Authority (SRTA), Xpress gives commuters in the metro Atlanta, Georgia area an alternative transportation option to the automobile. The system has 27 routes in 12 metro Atlanta counties, carrying around 1,800,000 passengers on a yearly basis. Annually, Xpress removes 55 million miles of congestion from Atlanta metro highways and interstates. ${ }^{65}$

\footnotetext{
${ }^{65}$ Adapted from: https://www.xpressga.com/about/.
} 


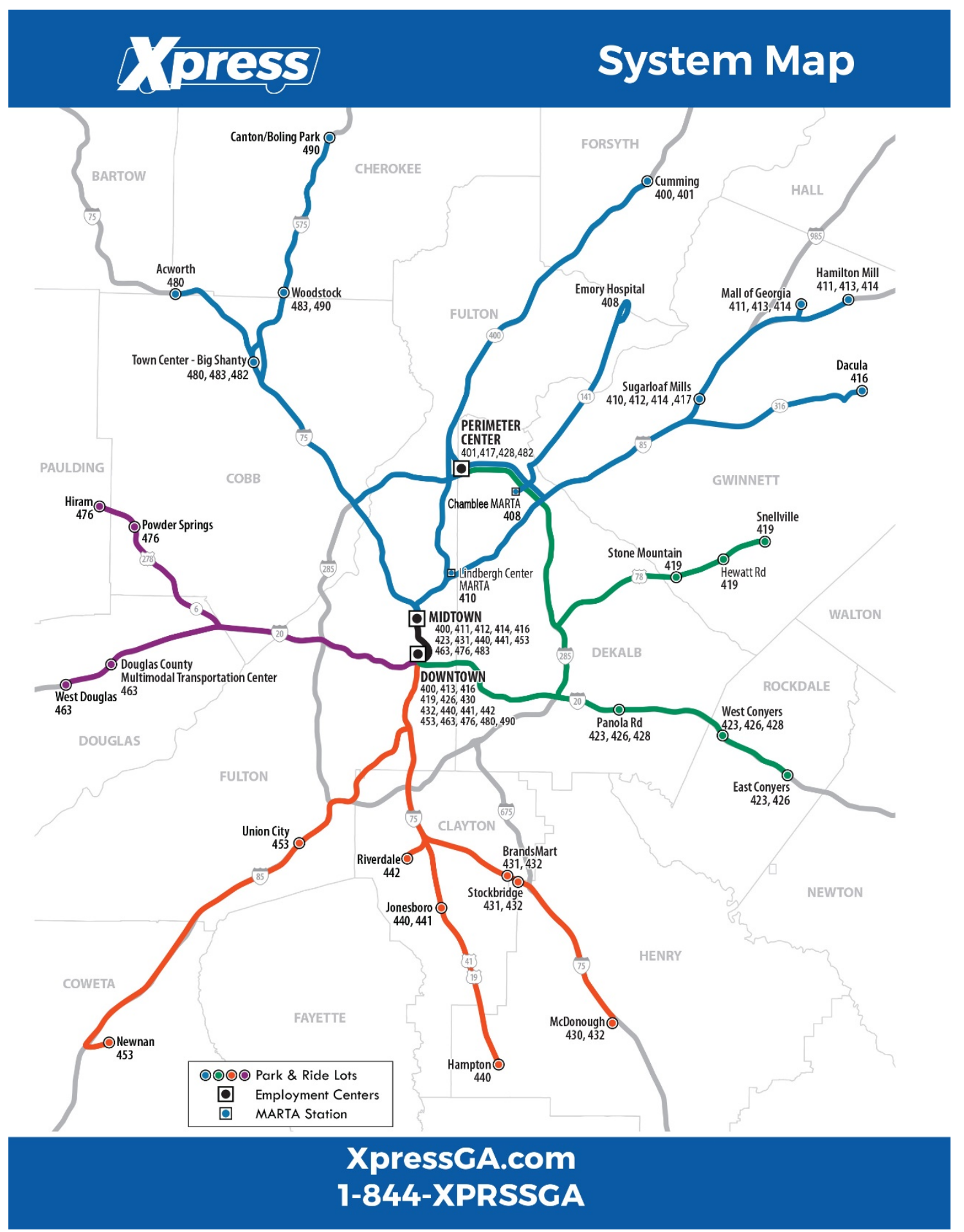

Figure XBT Atlanta 2

Atlanta Xpress Map

Source: https://www.xpressga.com/commutertools/\#maps

AUSTIN EXPRESS BUS TRANSIT SYSTEM 


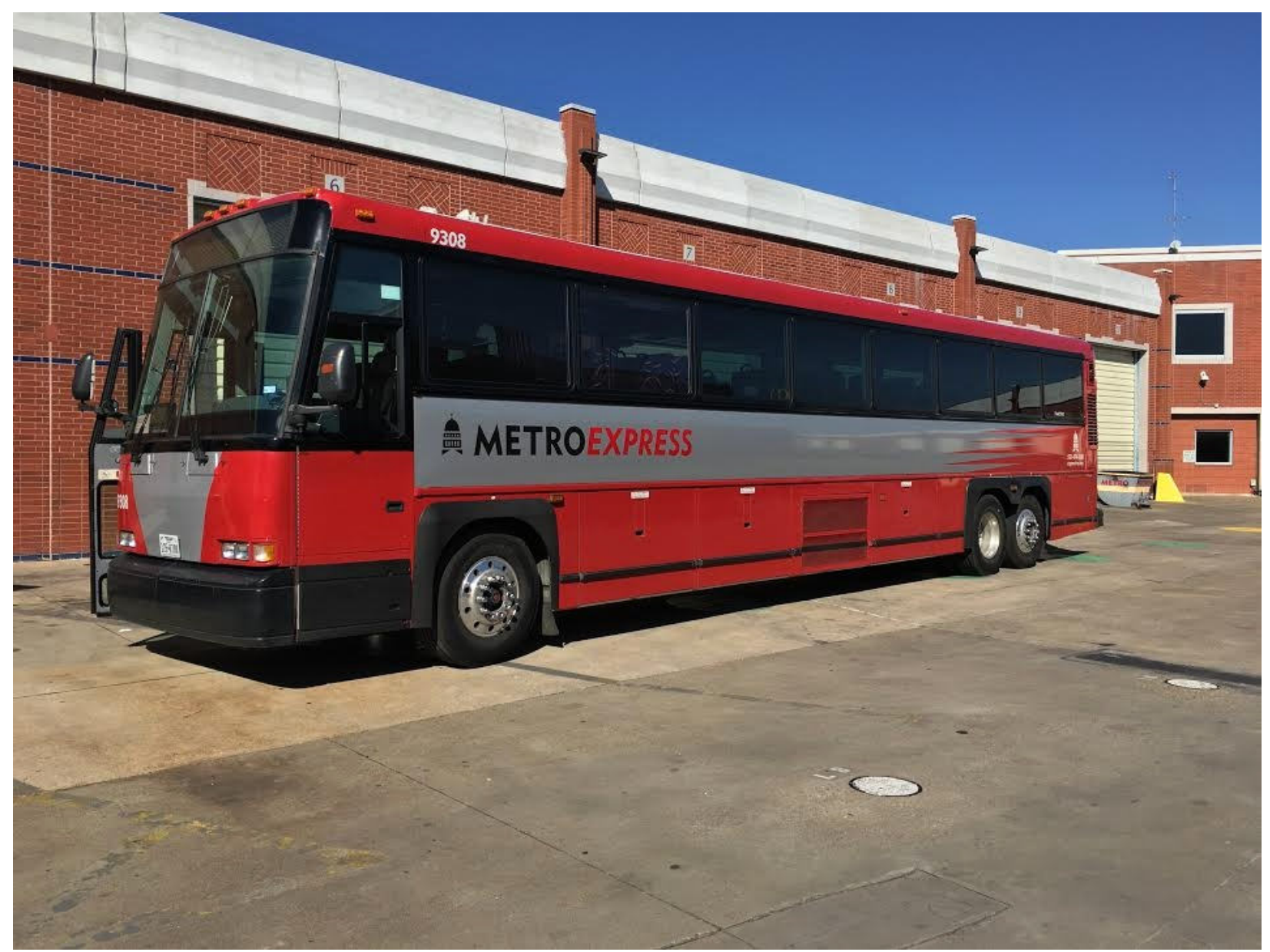

Figure XBT Austin 1

MetroExpress

Source: https://www.flickr.com/photSource:

https://www.flickr.com/photos/27884592@N07/22971129740os/27884592@N07/22971129740

Called MetroExpress, Austin, Texas' express bus transit line operates seven lines directly to downtown and other major employment hubs in Austin from outer suburbs. A monthly pass can be purchased for less than $\$ 100$, and gives riders flexibility with three different departure times each morning. ${ }^{66}$

AUSTIN EXPRESS BUS TRANSIT MAP

${ }^{66}$ Adapted from: https://capmetro.org/metroexpress/\#!. 


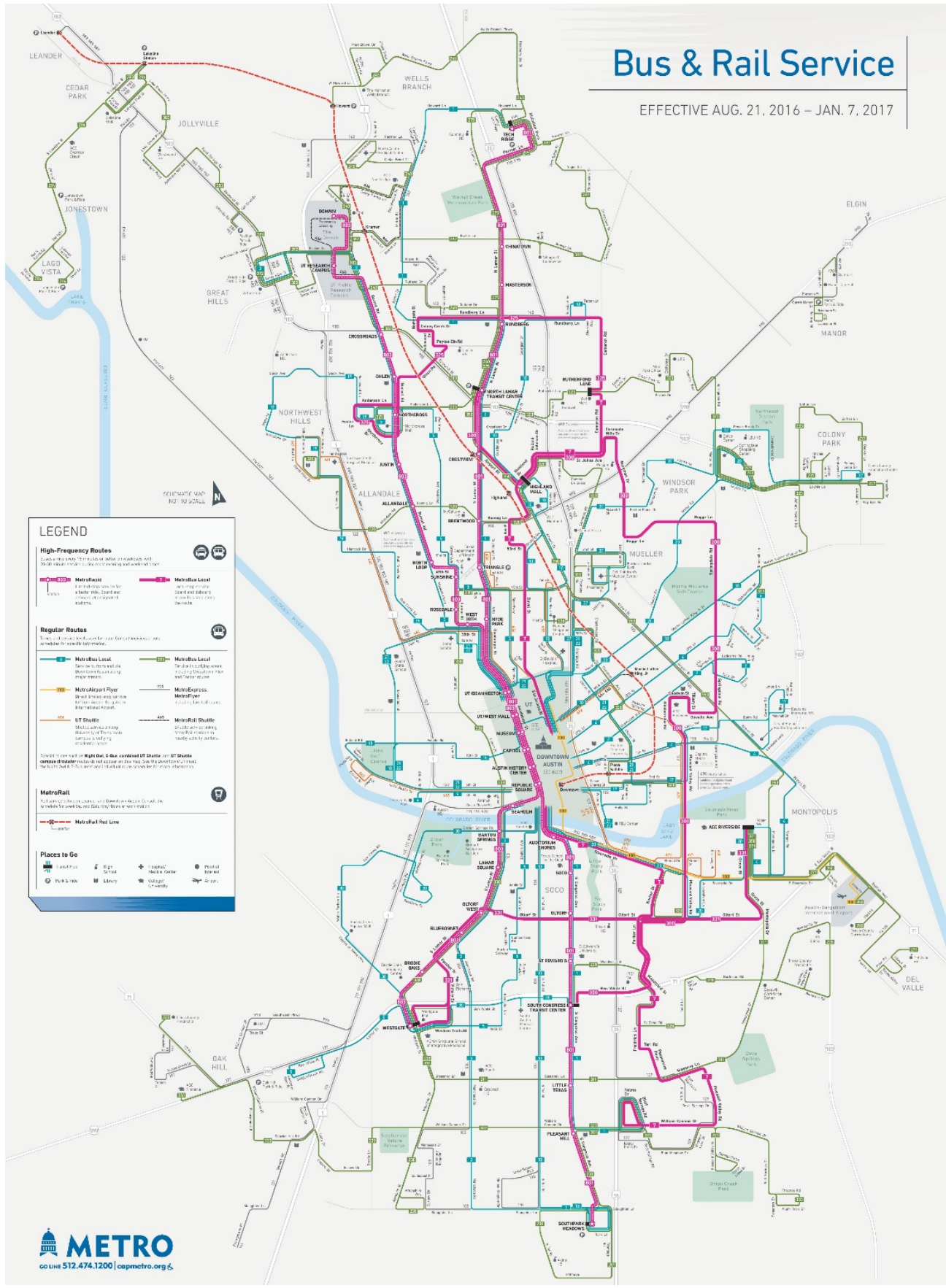

Figure XBT Austin 2

Austin Bus \& Rail Map (Express line denoted in solid gray)

Source: http://ontheworldmap.com/usa/city/austin/austin-bus-and-rail-map.jpg

\section{BUFFALO EXPRESS BUS TRANSIT SYSTEM}




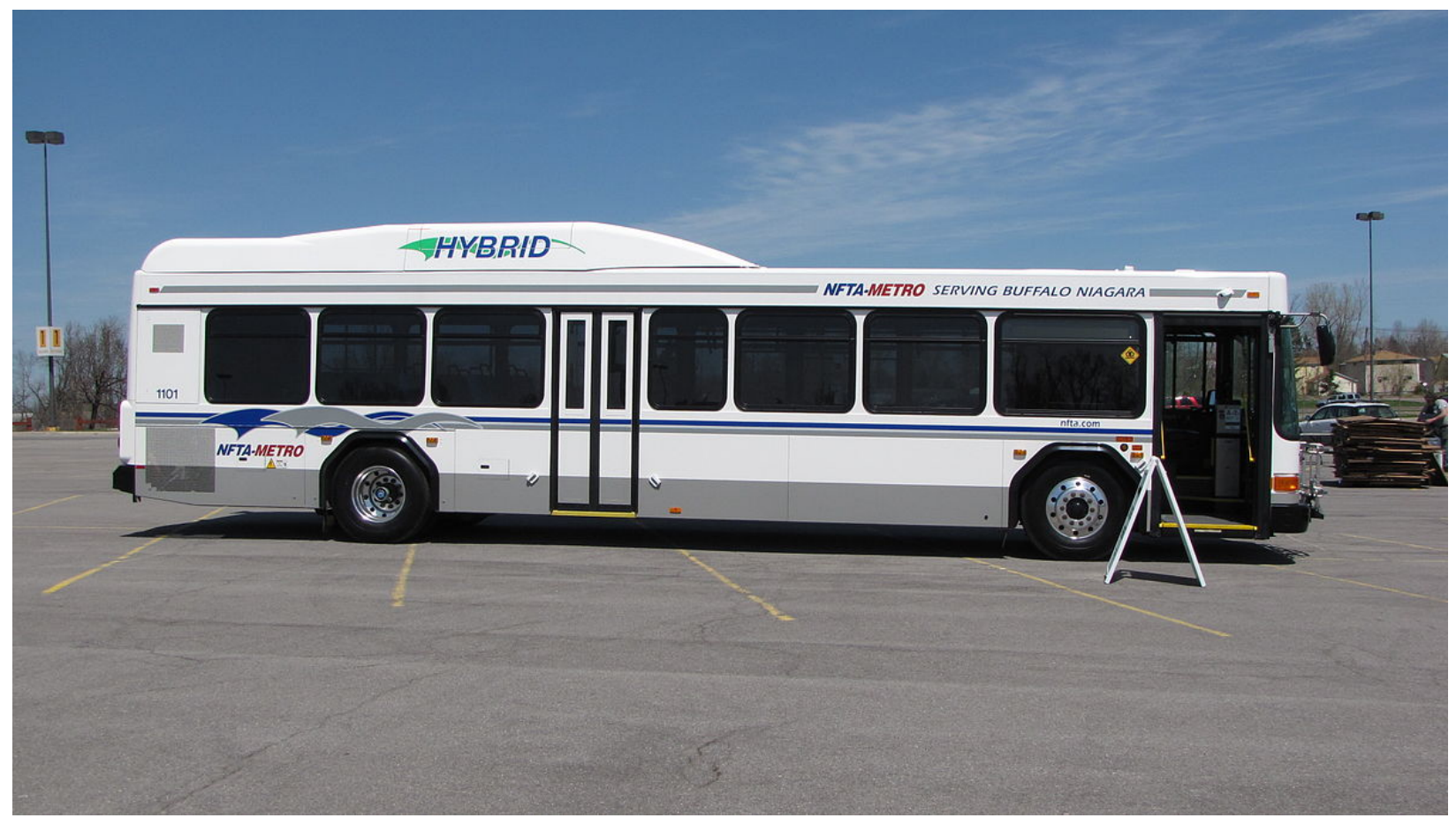

Figure XBT Buffalo 1

Enhanced Express Bus Service

Source: https://en.wikipedia.org/wiki/Niagara_Frontier_Transportation_Authority Operated by the Niagara Frontier Transportation Authority (NFTA), the Enhanced Express Bus serves the metro area of Buffalo, New York. The line operates three routes: a direct route to downtown from the airport, a direct route from downtown Buffalo to Niagara Falls, and a route to downtown from a far suburb called Lockport with stops in other suburbs along the way. These express lines also offer onboard Wi-Fi to enhance rider experience. ${ }^{67}$

${ }^{67}$ Adapted from: http://metro.nfta.com/Routes/express.aspx. 


\section{0 NFTA-METRO}

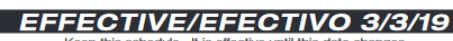

Keep this schedule. It is eflective until this date changes
Siempre mantega este horario. Es efectivo hasta cuando la fechna cambie NIAGARA FALLS

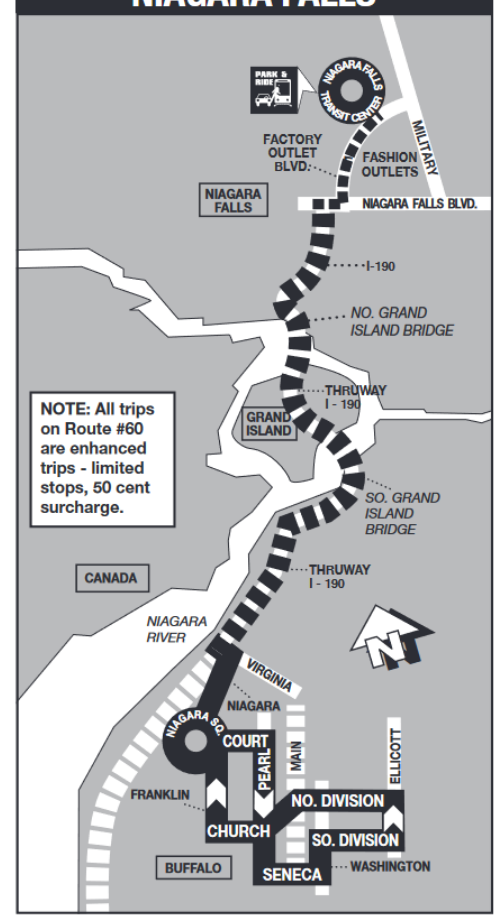

Figure XBT Buffalo 2

NFTA Enhanced Bus Service maps

Source: http://metro.nfta.com/Routes/express.aspx

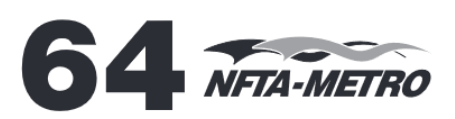

EFFECTIVE/EFECTIVO 12/2/18

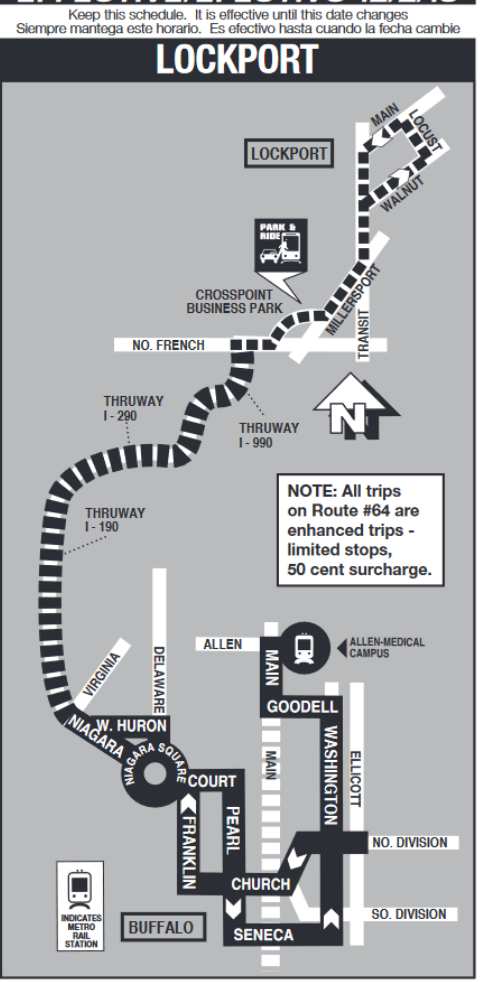

$204 \sqrt{\text { mintand }}$

EFFECTIVE/EFECTIVO 9/2/18

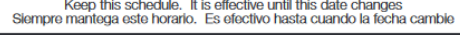

AIRPORT-DOWNTOWNEXPRESS

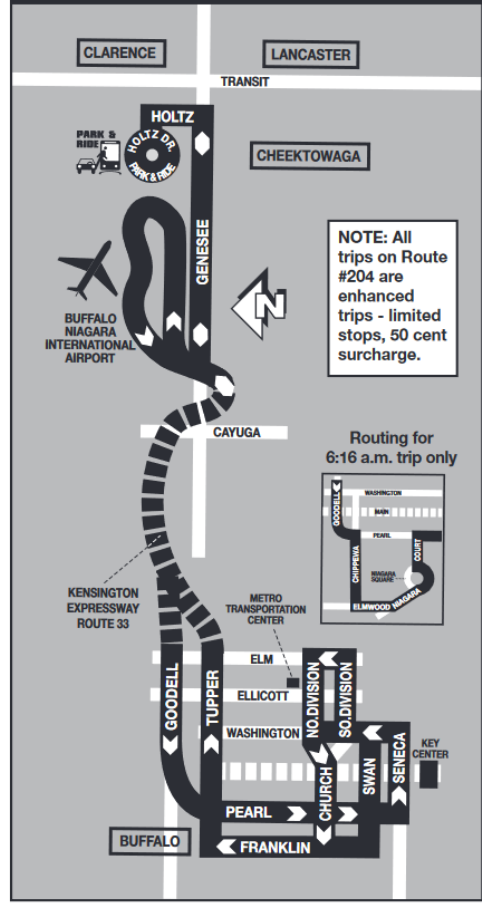




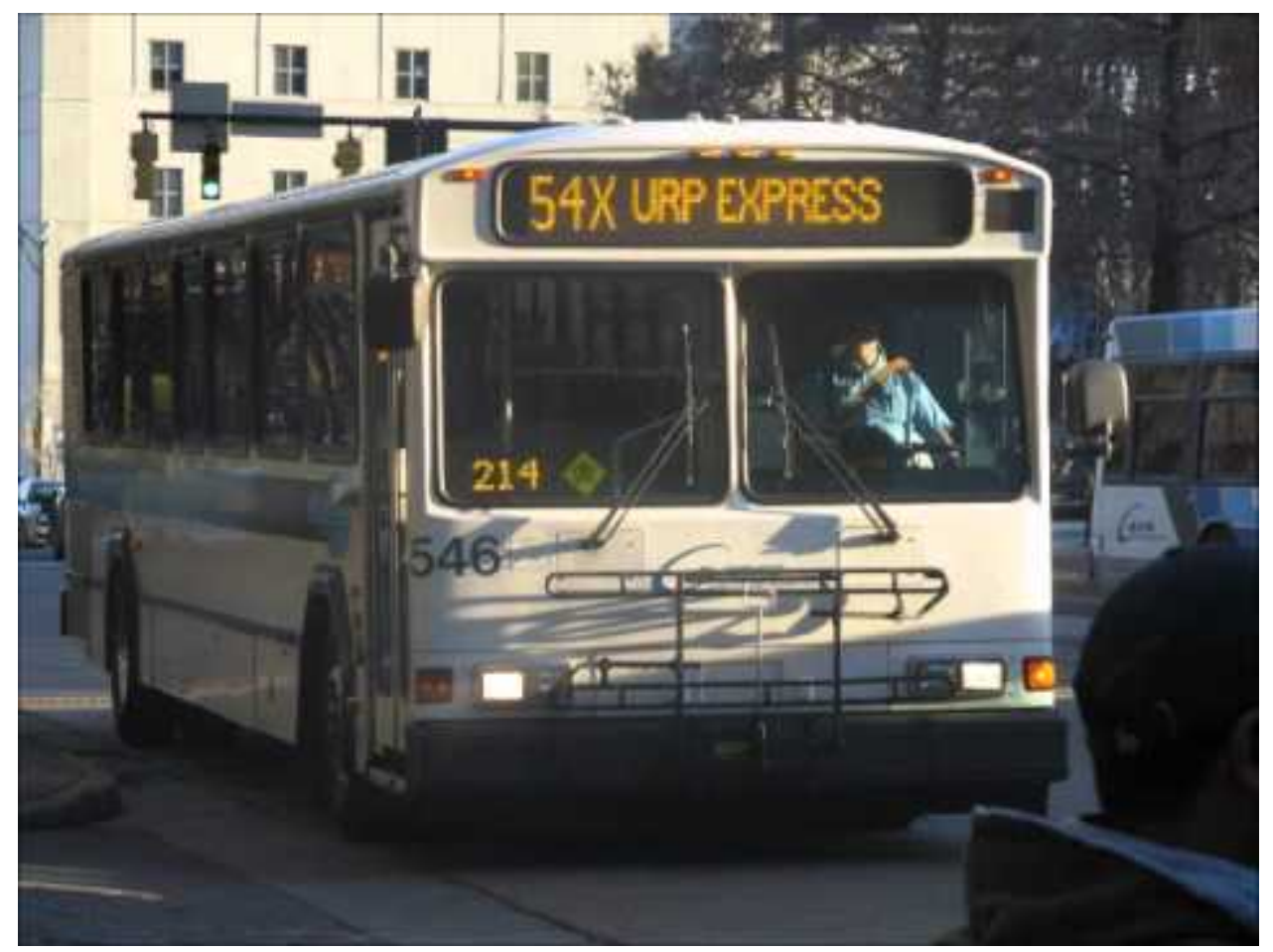

Figure XBT Charlotte 1

Charlotte Express Bus

Source: https://www.youtube.com/watch?v=SpeXLLu6HA8

The Charlotte Area Transit System (CATS) operates 16 express lines, denoted with an ' $X$ ' after the route number. The express systems serve Union, Concord, and Gastonia Counties in North Carolina and Rock Hill County in South Carolina. As a whole, the CATS bus systems transport over 80,000 passengers weekly. ${ }^{68}$

\footnotetext{
${ }^{68}$ Adapted from: https://en.wikipedia.org/wiki/Charlotte_Area_Transit_System and Source: https://charlottenc.gov/cats/bus/routes/Pages/default.aspx.
} 


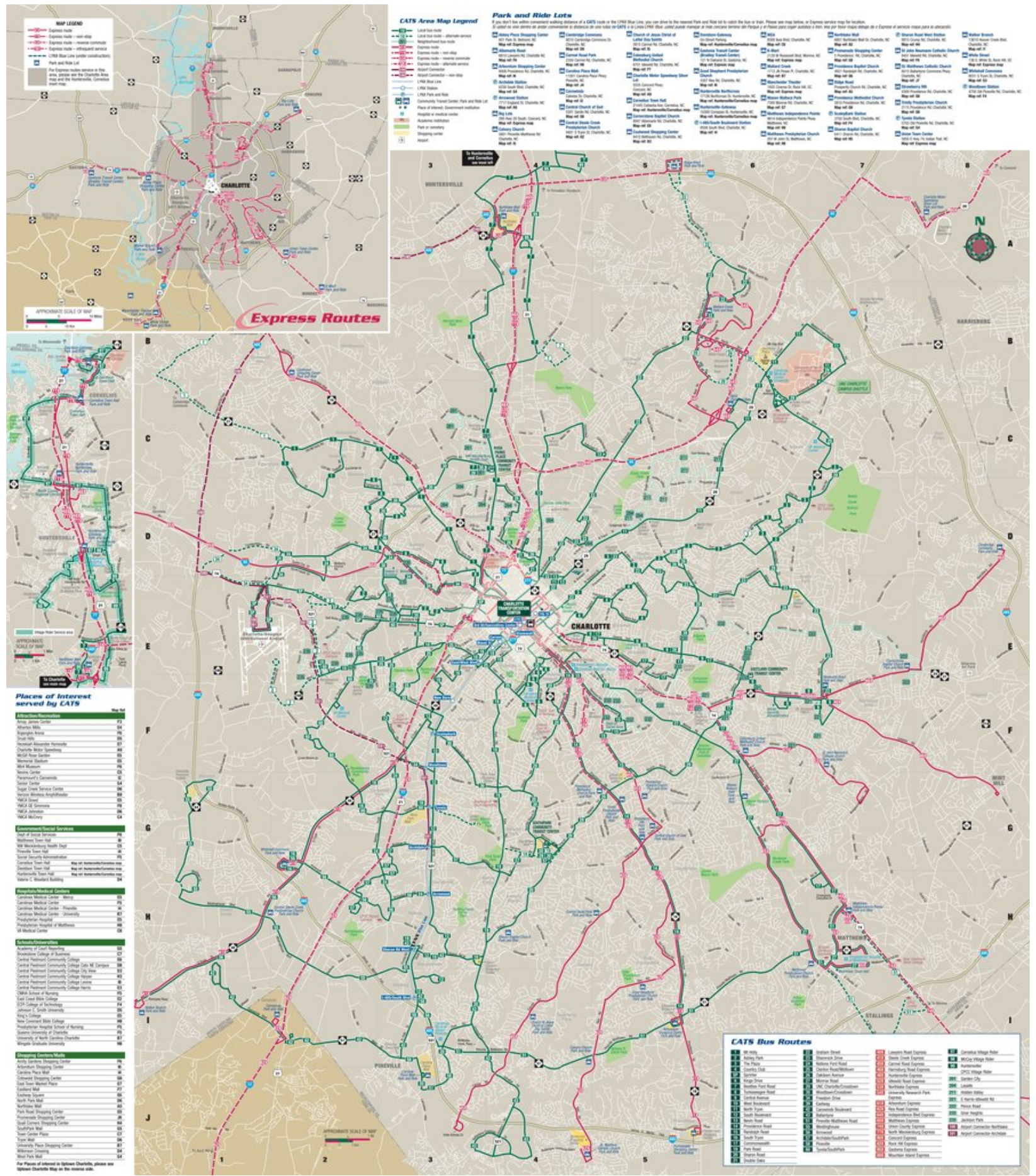

Figure XBT Charlotte 2

Charlotte Bus Map

Source: http://www.mobilemaplets.com/showplace/4331

\section{CINCINNATI EXPRESS BUS TRANSIT SYSTEM}




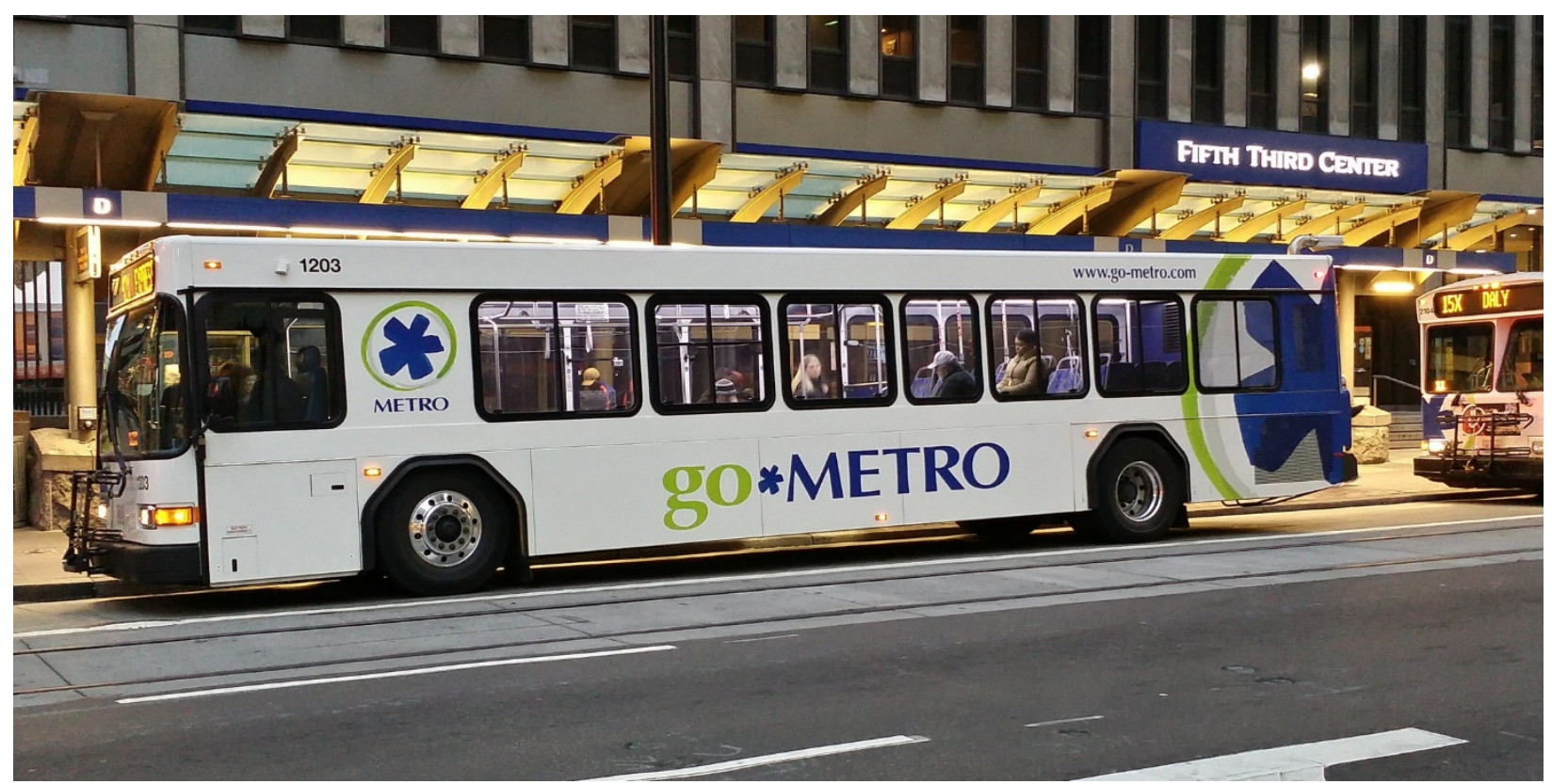

Figure XBT Cincinnati 1

Cincinnati Metro Bus

Source: https://www.urbancincy.com/2016/06/running-time-adjustments-go-into-effect-for-9express-metro-routes-on-monday/cincinnati-metro-bus-10/

The Metro Bus Line has 20 express lines that serve the greater Cincinnati, Ohio metro area. Around $10 \%$ of all daily riders utilize the express lines. The express lines only operate inbound and outbound during rush hour. ${ }^{69}$

${ }^{69}$ Adapted from: https://en.wikipedia.org/wiki/Southwest_Ohio_Regional_Transit_Authority. 


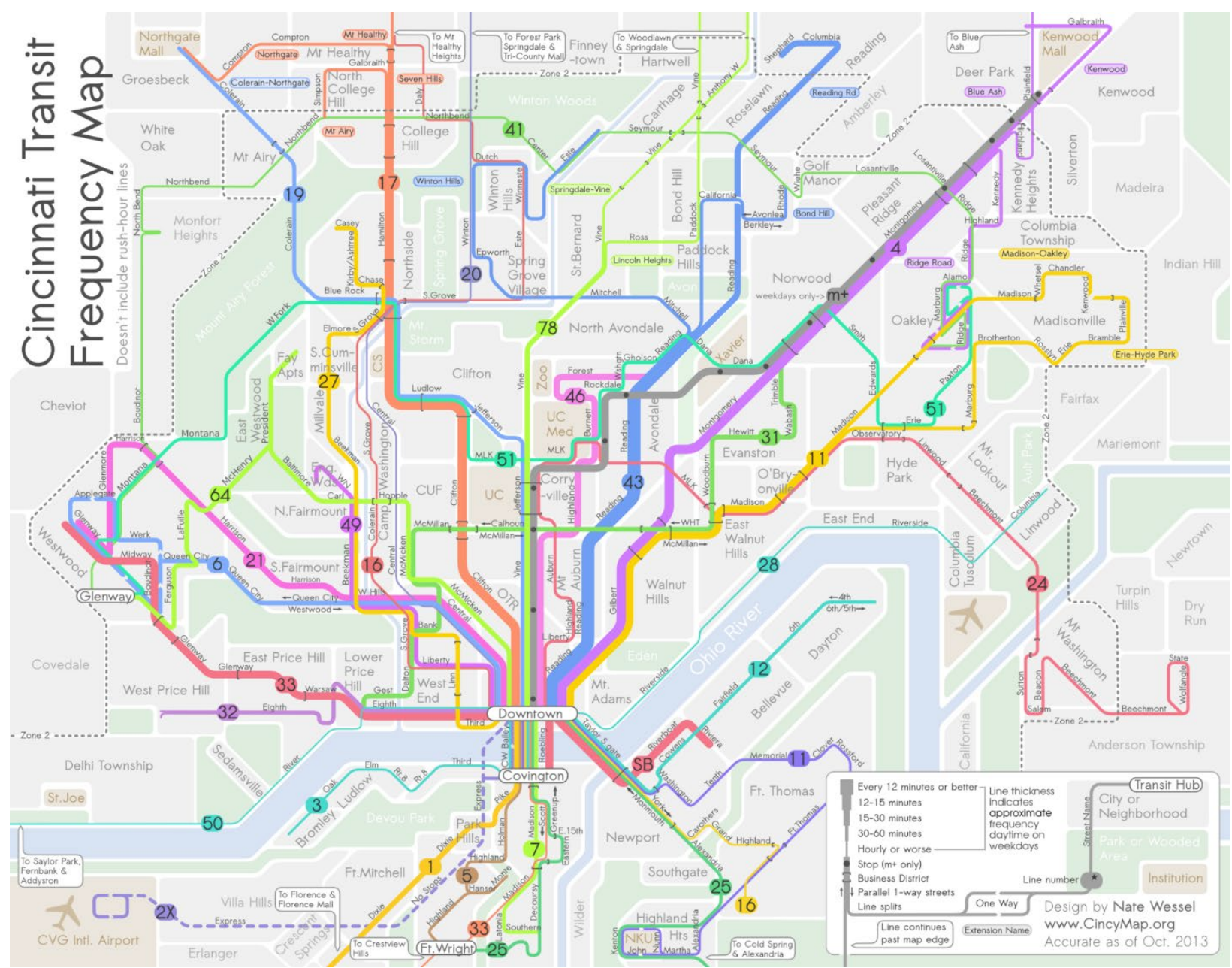

Figure XBT Cincinnati 2

Cincinnati Transit Map

Source:

https://en.wikipedia.org/wiki/Transportation_in_Cincinnati\#/media/File:Cincinnati_Transit_Frequ ency_Map.png

DALLAS - FORT WORTH EXPRESS BUS TRANSIT SYSTEM 


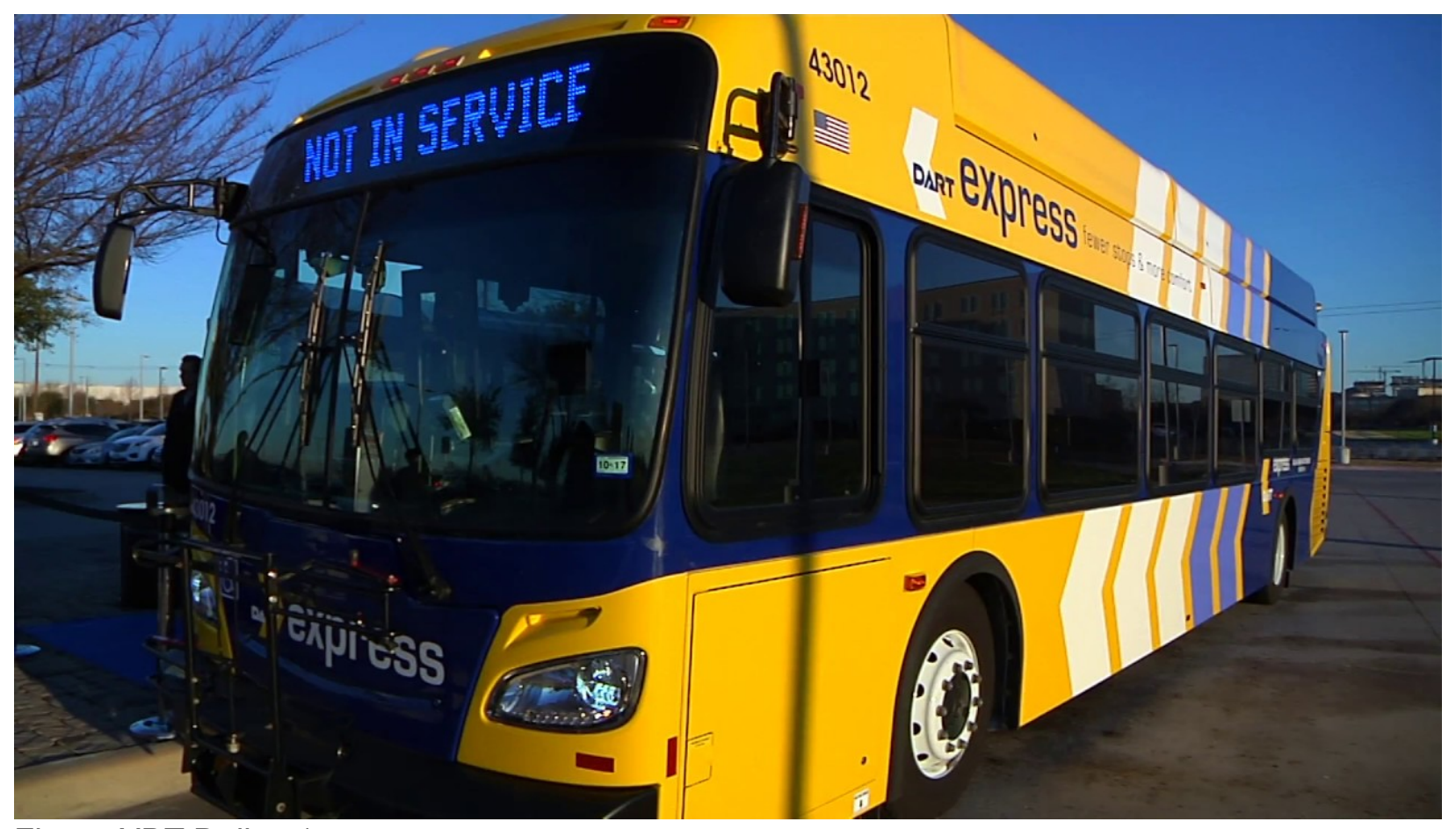

Figure XBT Dallas 1

Dallas Express Bus

Source: Source: https://i.ytimg.com/vi/ws9YFPHs-Ck/maxresdefault.jpg

Operated by Dallas Area Regional Transit (DART), there are eight DART Express lines serving the greater Dallas area. ${ }^{70}$

${ }^{70}$ Adapted from: https://www.dart.org/schedules/busschedules.asp?quicksched=999. 


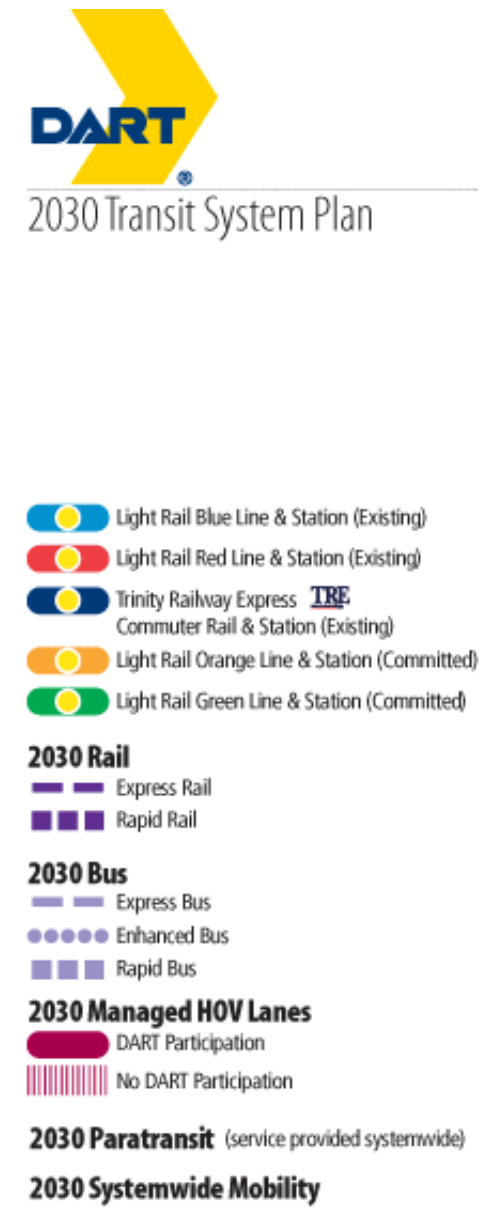

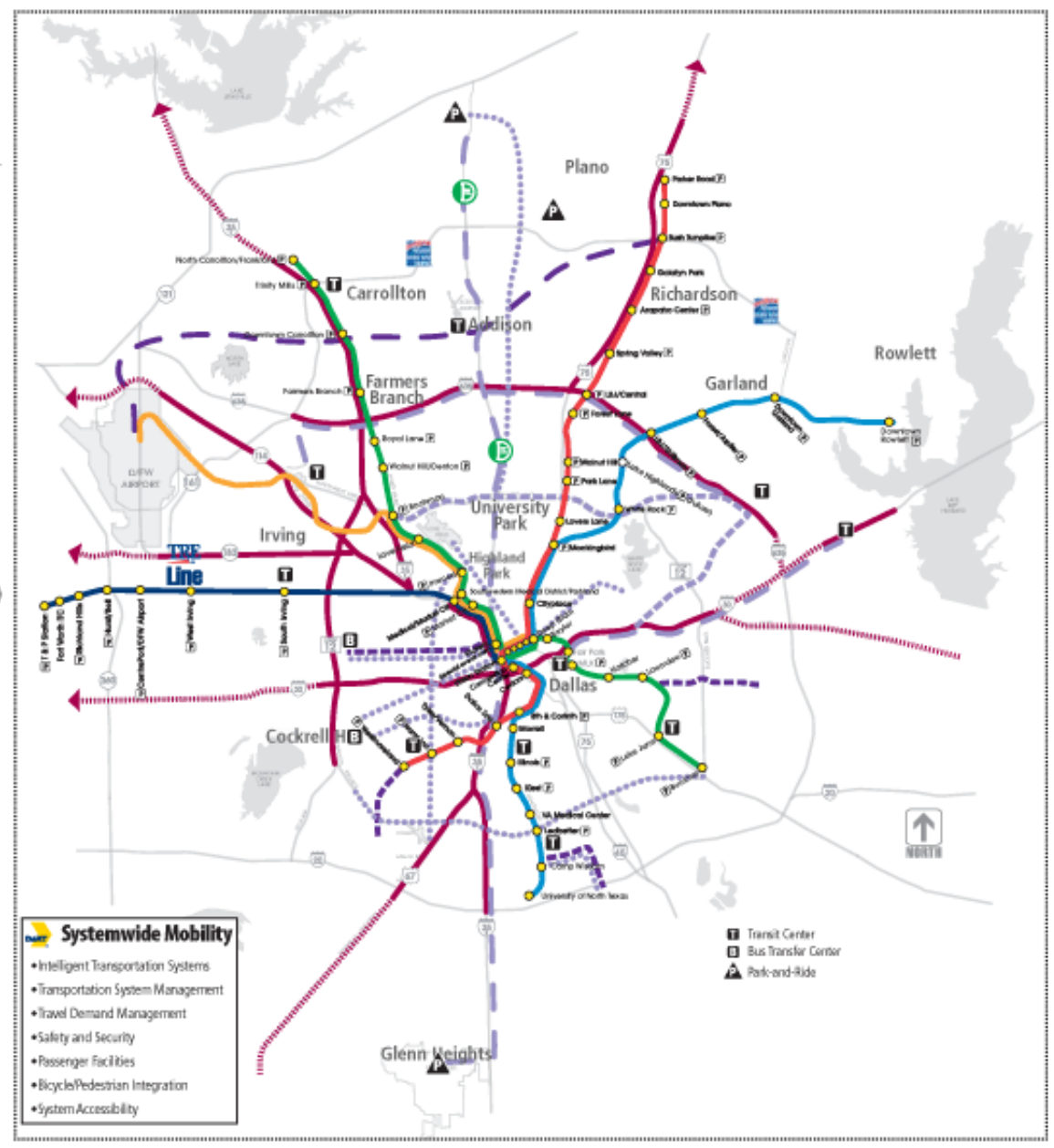

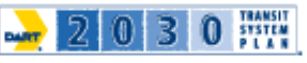

Figure XBT Dallas 2

Dallas Area Regional Transit Plan 2030 (Express in long dash)

Source: https://www.dart.org/maps/DART2030planmap.asp

\section{DENVER EXPRESS BUS TRANSIT SYSTEM}




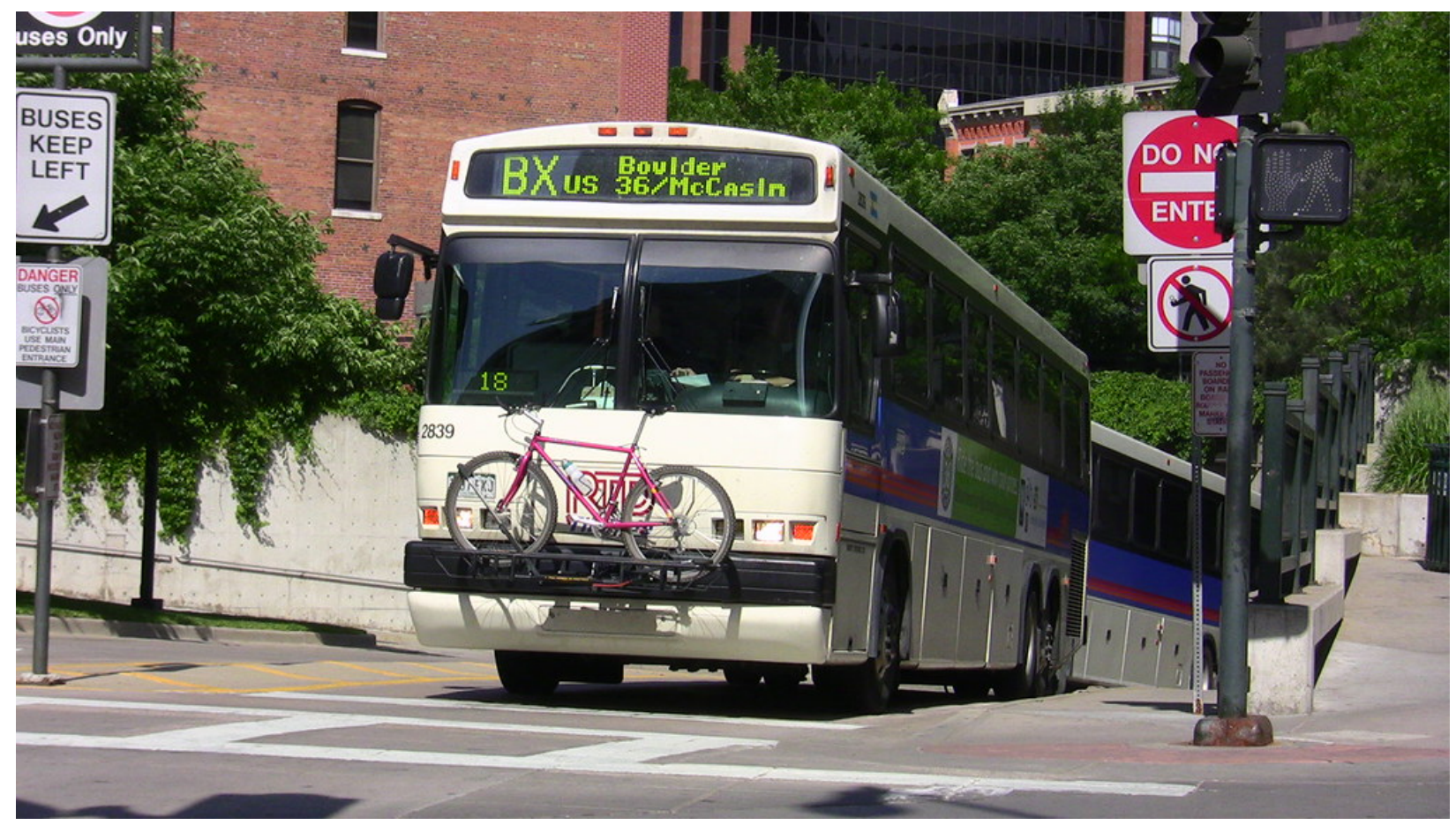

Figure XBT Denver 1

Denver Express Bus

Source: https://www.flickr.com/photos/raythetrain/5843779934

Denoted by an " $X$ " in the route name, Denver has five express bus transit routes. ${ }^{71}$

${ }^{71}$ Adapted from: http://www.rtd-denver.com/Schedules.shtml. 

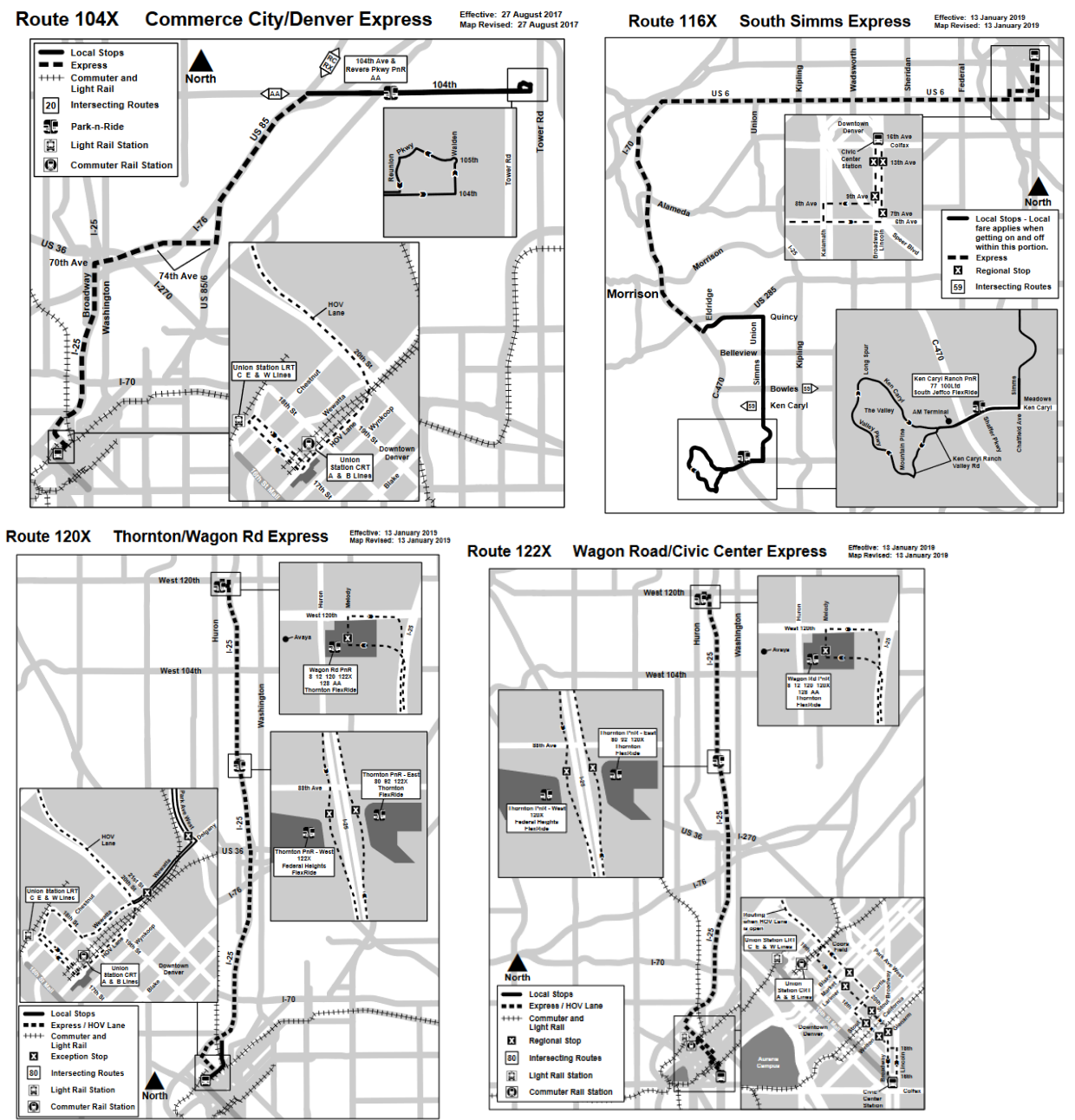

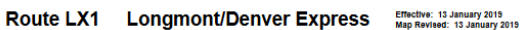

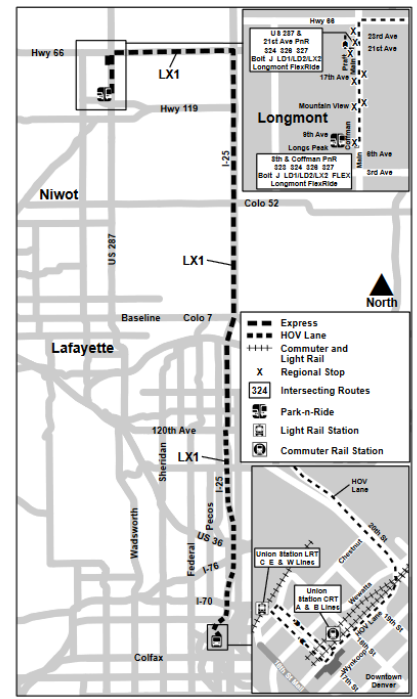

Figure XBT Denver 2-6

Express Bus Maps

Source: http://www.rtd-denver.com/Schedules.shtml HOUSTON EXPRESS BUS TRANSIT SYSTEM 


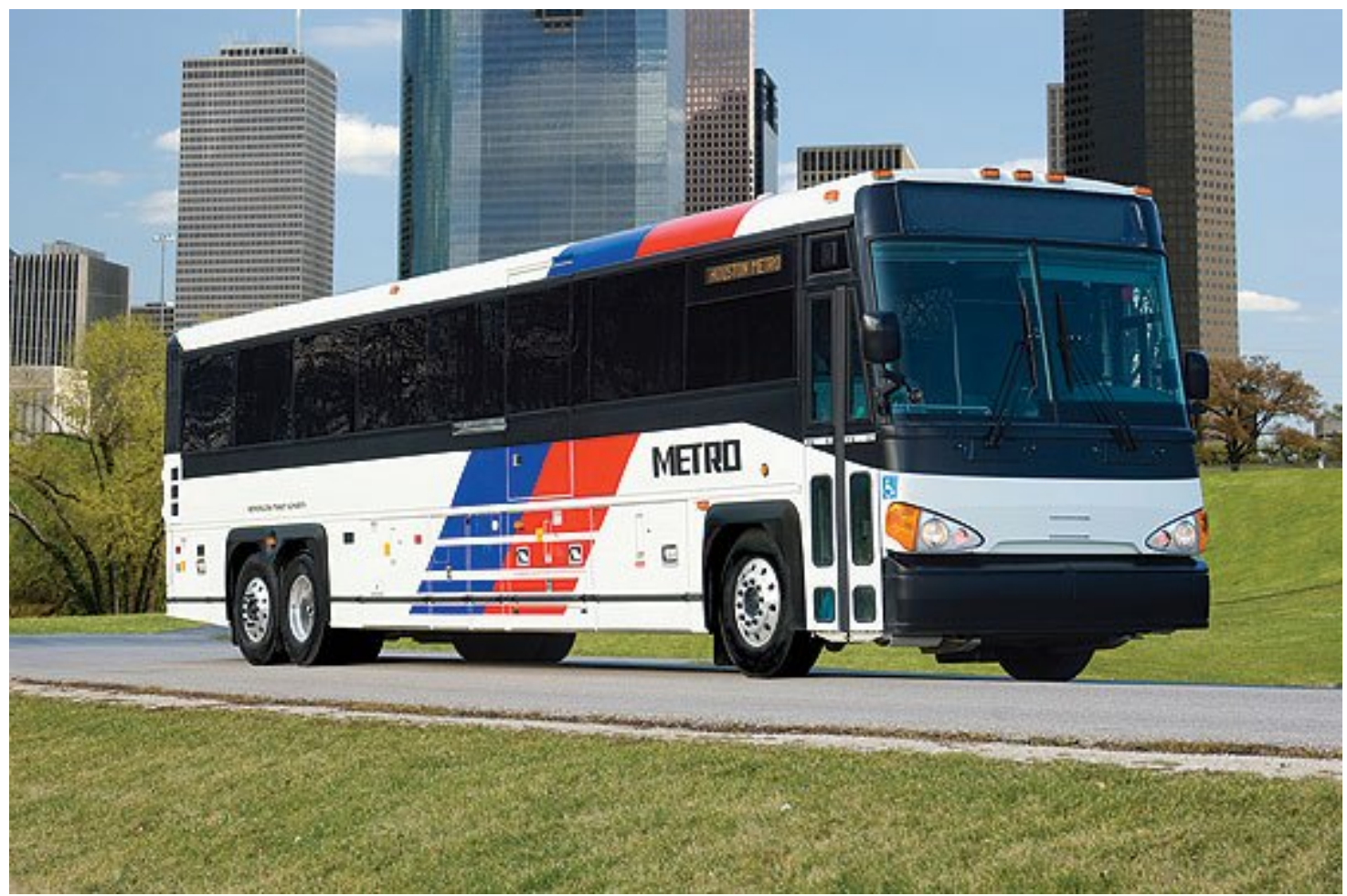

Figure XBT Houston 1

Houston Commuter Bus

Source: https://lastrow.wordpress.com/tag/commuting/

With service at morning, midday, and evening, Houston's Park and Ride commuter bus service serves outlying suburbs with direct routes to downtown, the Texas Medical Center, and other large employment centers in Houston. The system is operated by the Metropolitan Transit Authority of Harris County, and offers discounts to students. ${ }^{72}$

\footnotetext{
${ }^{72}$ Adapted from: https://www.ridemetro.org/Pages/ParkRide.aspx and Source: https://www.ridemetro.org/Pages/PR-BayArea.aspx.
} 


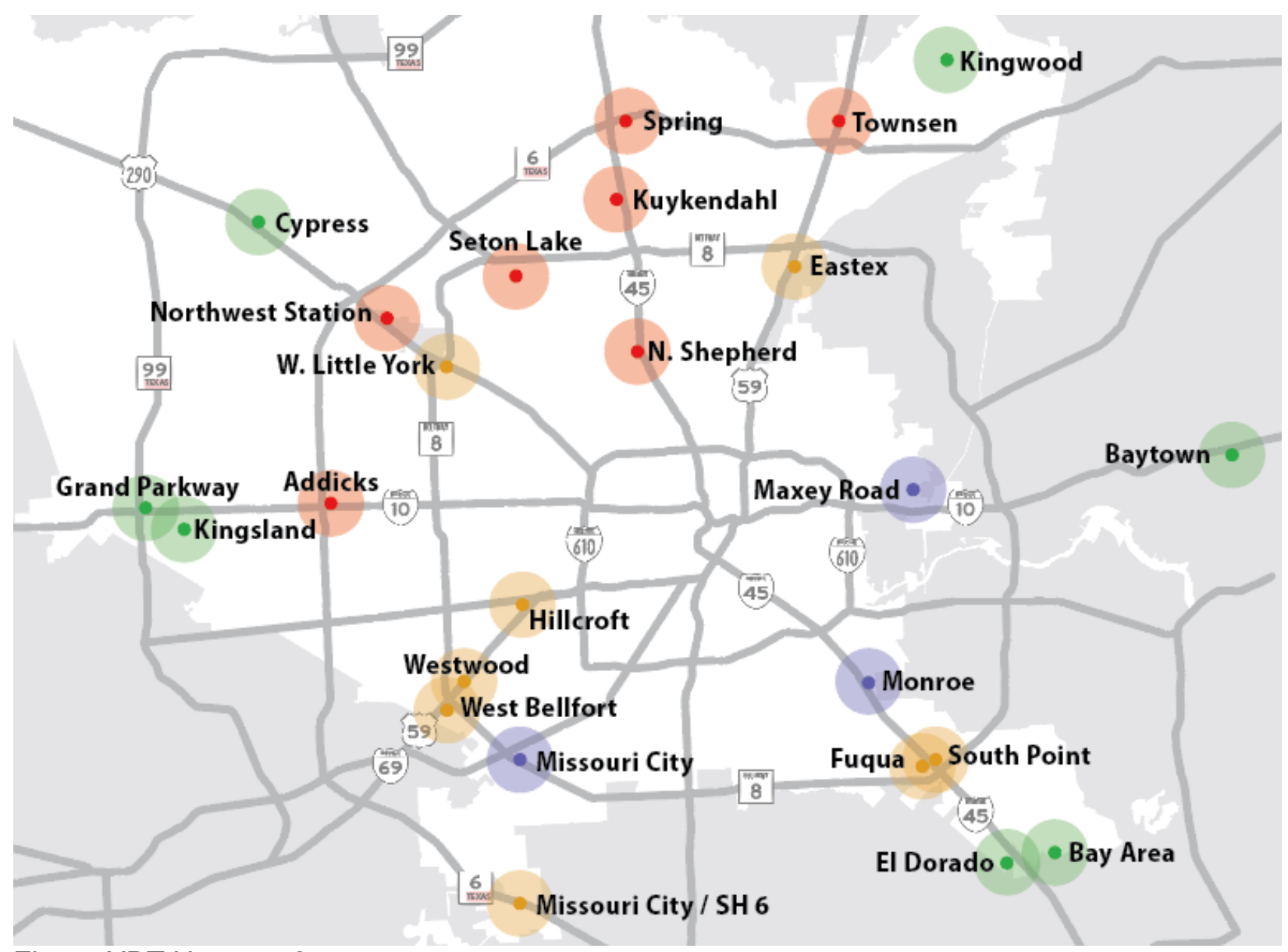

Figure XBT Houston 2

Houston Commuter Bus Service Map

Source: https://www.ridemetro.org/Pages/PR-BayArea.aspx

KANSAS CITY EXPRESS BUS TRANSIT SYSTEM 


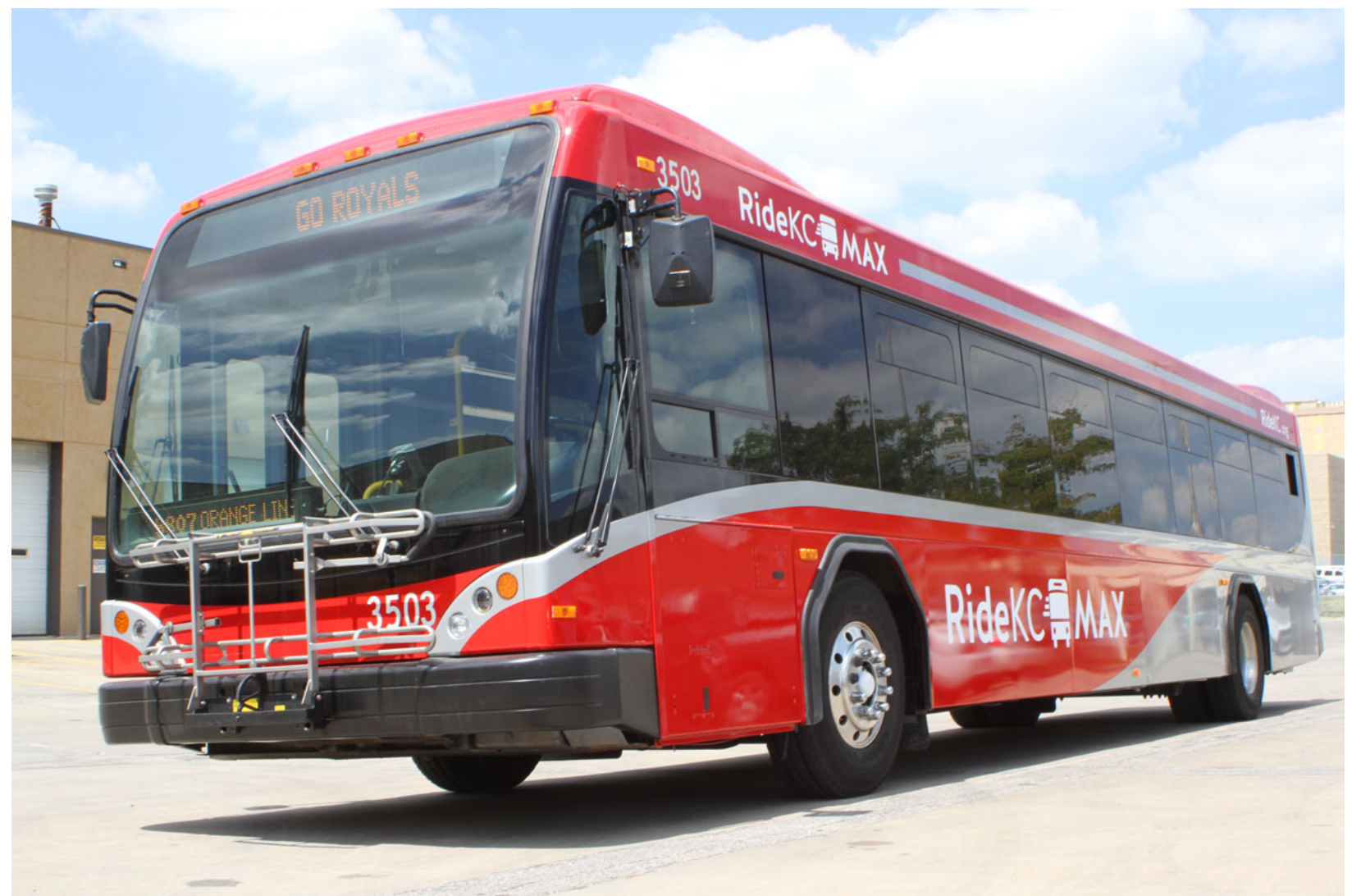

Figure XBT Kansas City 1

KC MAX Express Bus Transit

Source: http://www.kcata.org/transit-initiatives/max_and_bus_rapid_transit

With the first service beginning in July of 2005, the Metro Area Express (MAX) serves Kansas

City, Missouri. The line is 32 miles in length with 87 stations. The line was an "instant success," with ridership 50\% more than expected upon launch. The Federal Transit Administration holds Kansas City's MAX line as a model for other rapid transit services. ${ }^{73}$

${ }^{73}$ Adapted from: https://en.wikipedia.org/wiki/Metro_Area_Express. 


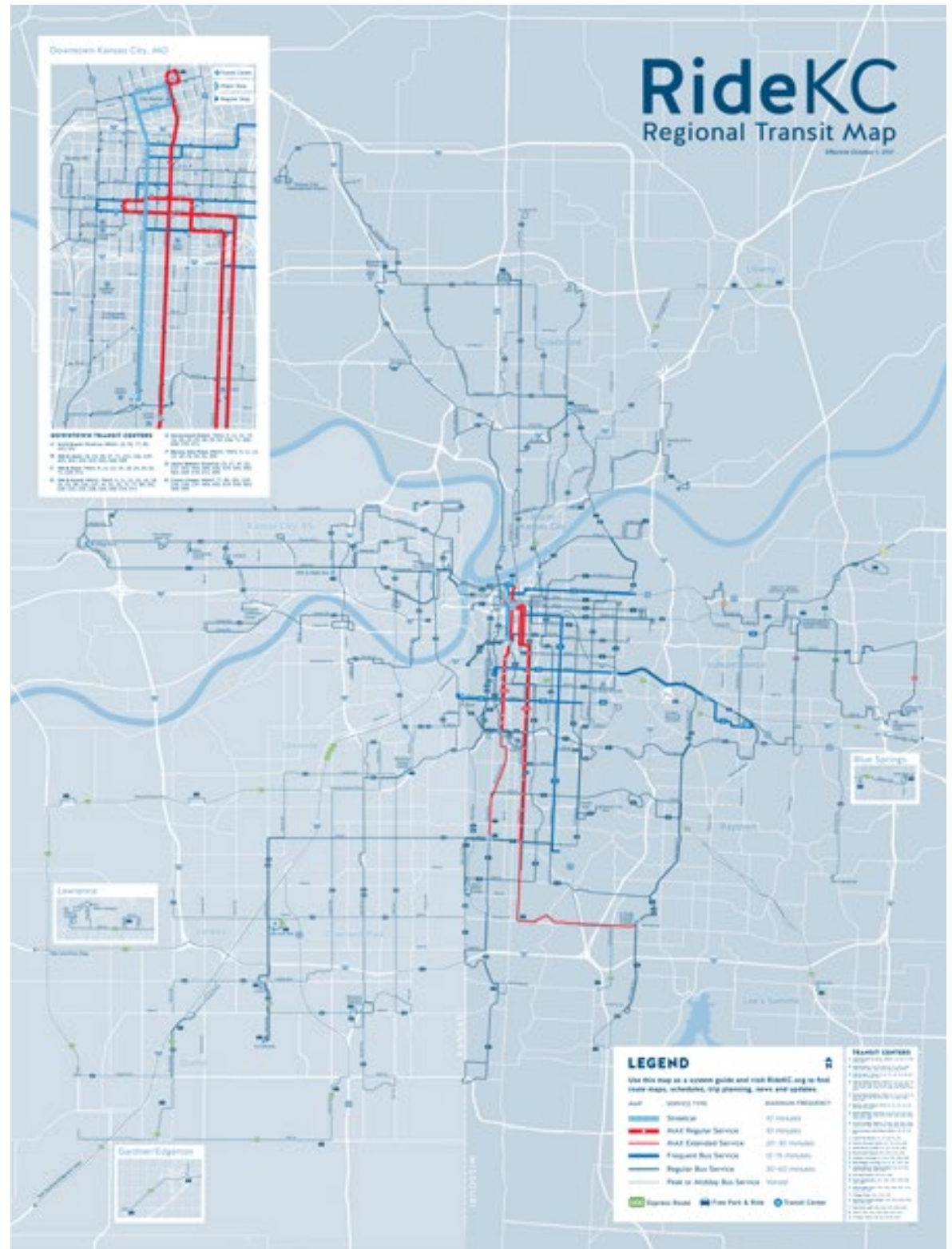

Figure XBT Kansas City 2

MAX Service Map

Source: http://ridekc.org/rider-guide/system-map

\section{LITTLE ROCK EXPRESS BUS TRANSIT SYSTEM}




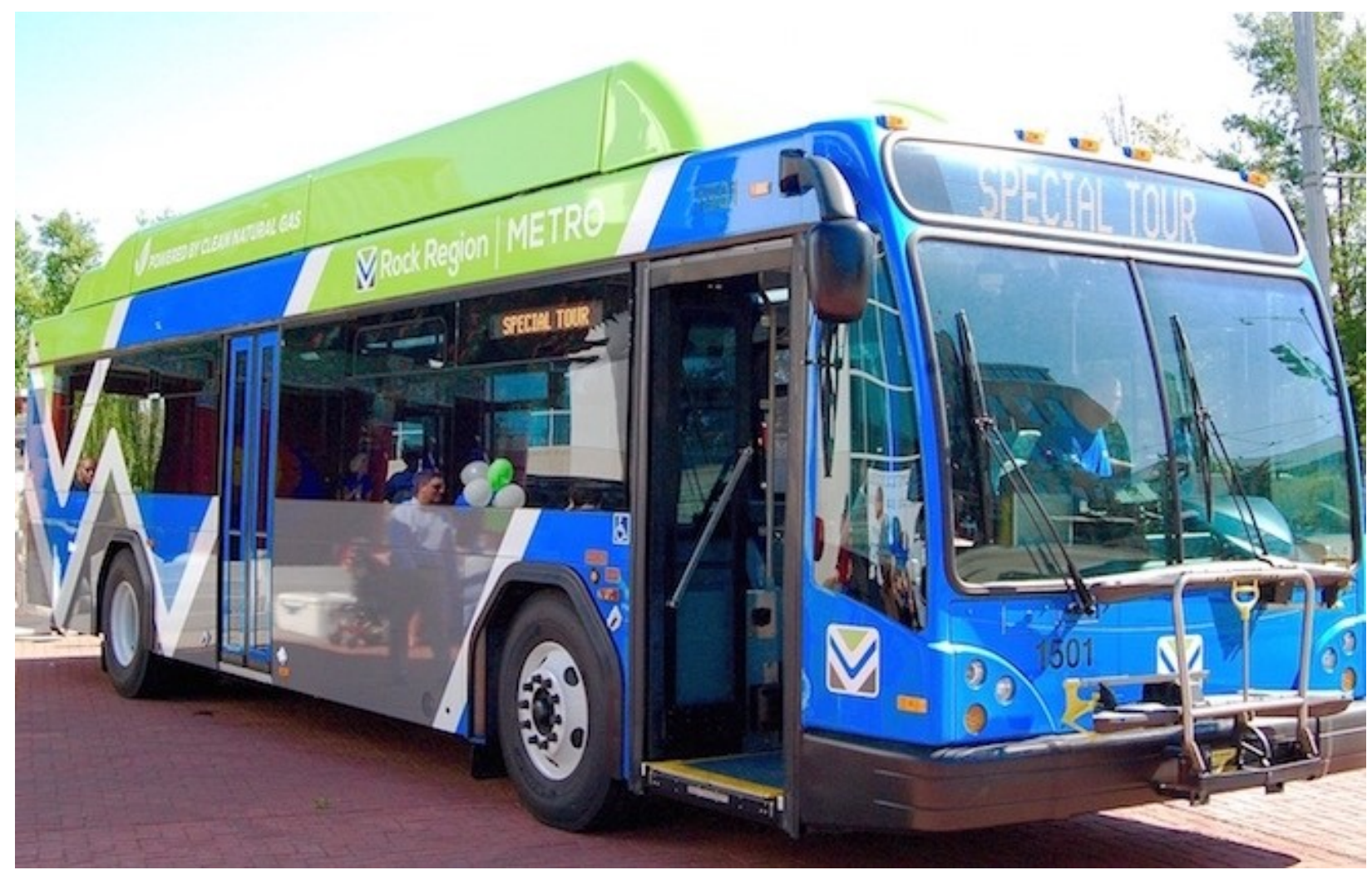

Figure XBT Little Rock 1

Little Rock Express Bus Transit

Source: https://m.arktimes.com/ArkansasBlog/archives/2018/05/15/rock-region-metro-local-andexpress-buses-will-be-fare-free-on-election-day

Rock Region Metro operates four express routes serving the Little Rock, Arkansas region.

These four routes serve Hensley, Pinnacle Mountain, Maumelle/Oak, and Jacksonville/Sherwood all with service to downtown Little Rock. The purpose of these express lanes is to connect far commuters with downtown employment centers. ${ }^{74}$

${ }^{74}$ Adapted from: https://rrmetro.org/services/local/maps-schedules/. 


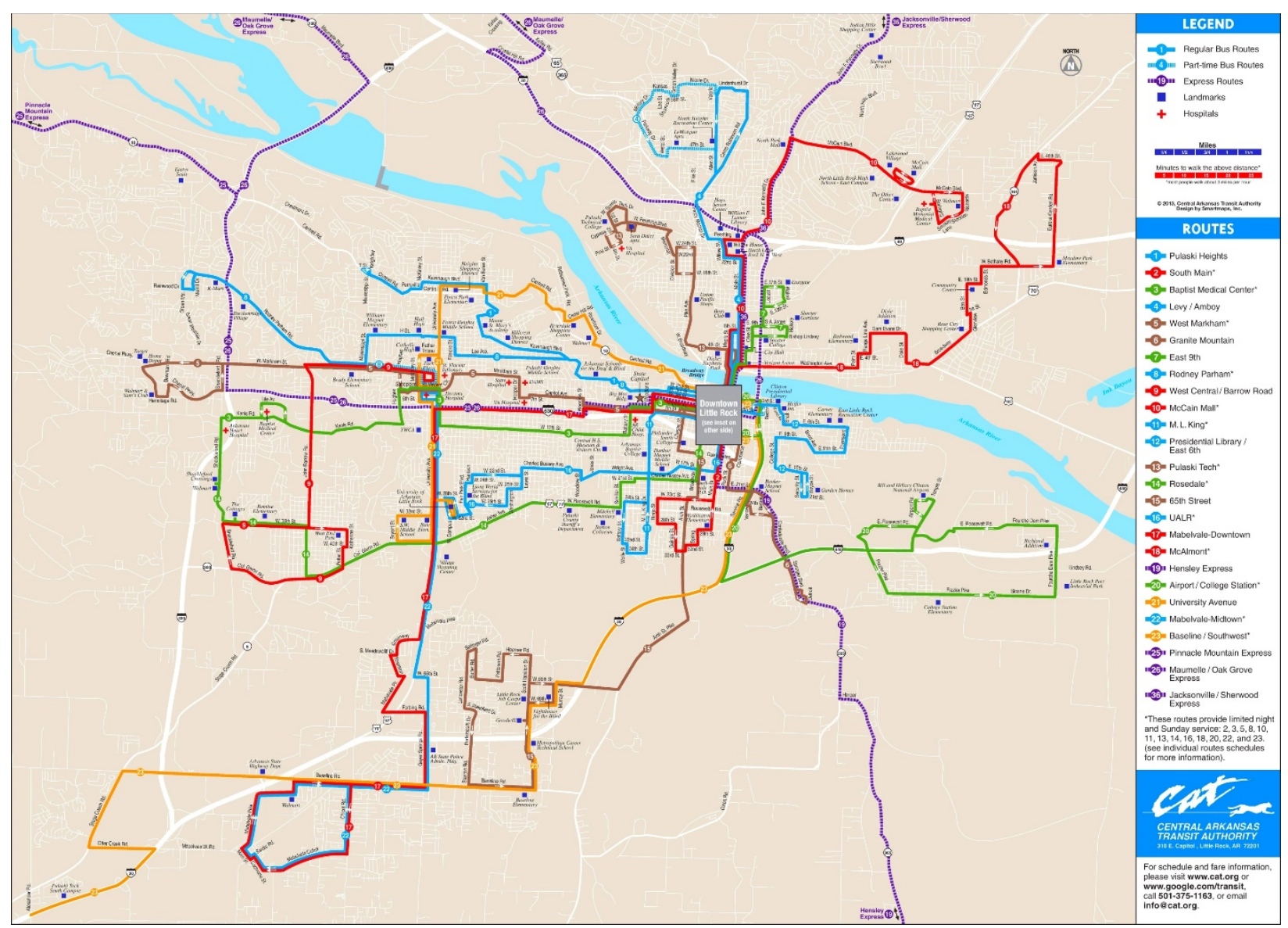

Figure XBT Little Rock 2

Little Rock Transit Service Map (Express lines in violet)

Source: http://ontheworldmap.com/usa/city/little-rock/little-rock-bus-map.html 


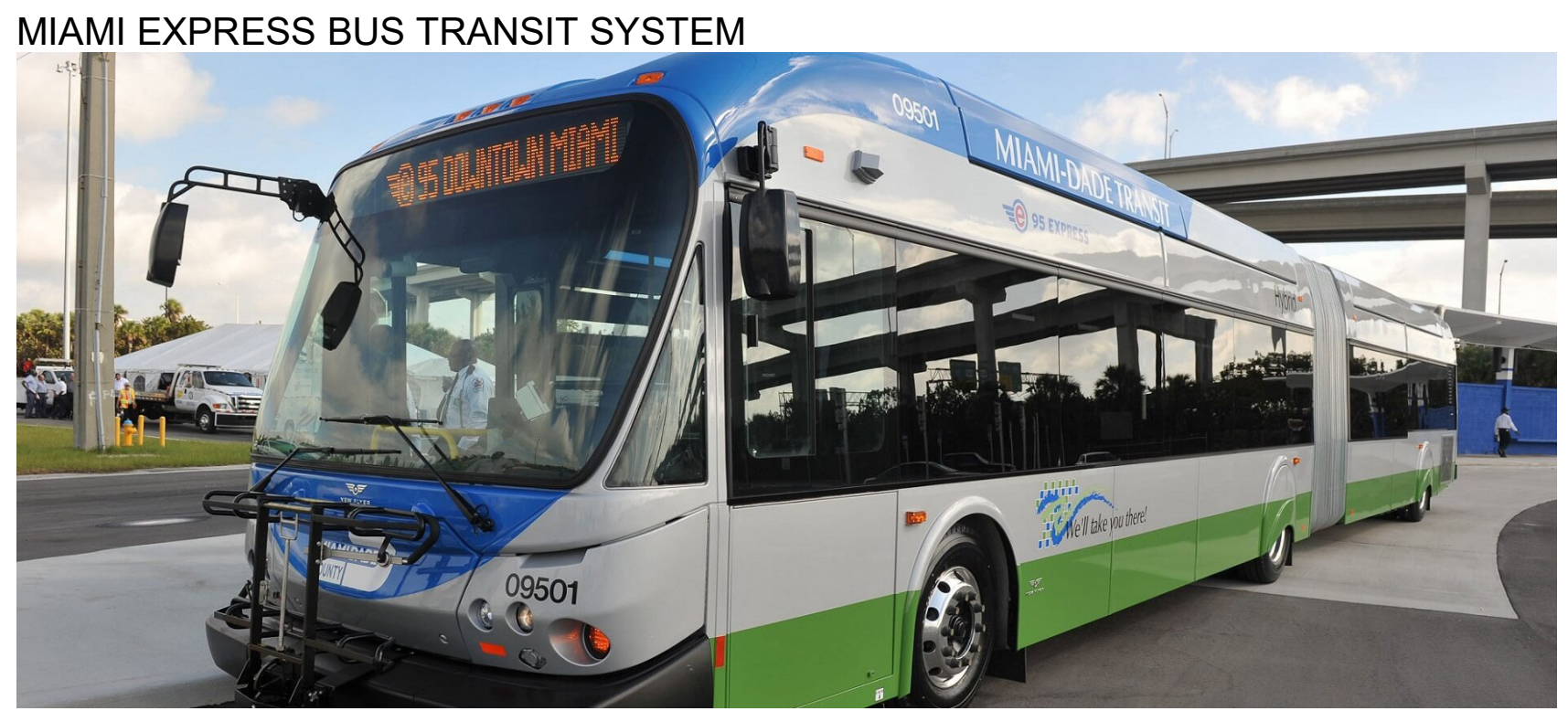

Figure XBT Miami 1

Miami Express Bus

Source: https://www.miamidade.gov/beta/easyperks/attractions.asp

Miami offers two express bus transit lines, the 95 Express and the Miami Beach Airport

Express. The 95 Express offers service during peak weekday travel times. It serves downtown Miami, the Miami Civic center, the Miami Health District, and Doral from many locations in Broward County and the Golden Glades Interchange. The Miami Beach Airport Express runs between 6:00 AM and 11:40 PM every day of the week. Service is every 30 minutes between Miami Beach and the Miami International Airport Metrorail Station. ${ }^{75}$

${ }^{75}$ Adapted from: https://www8.miamidade.gov/global/transportation/metrobus.page. 


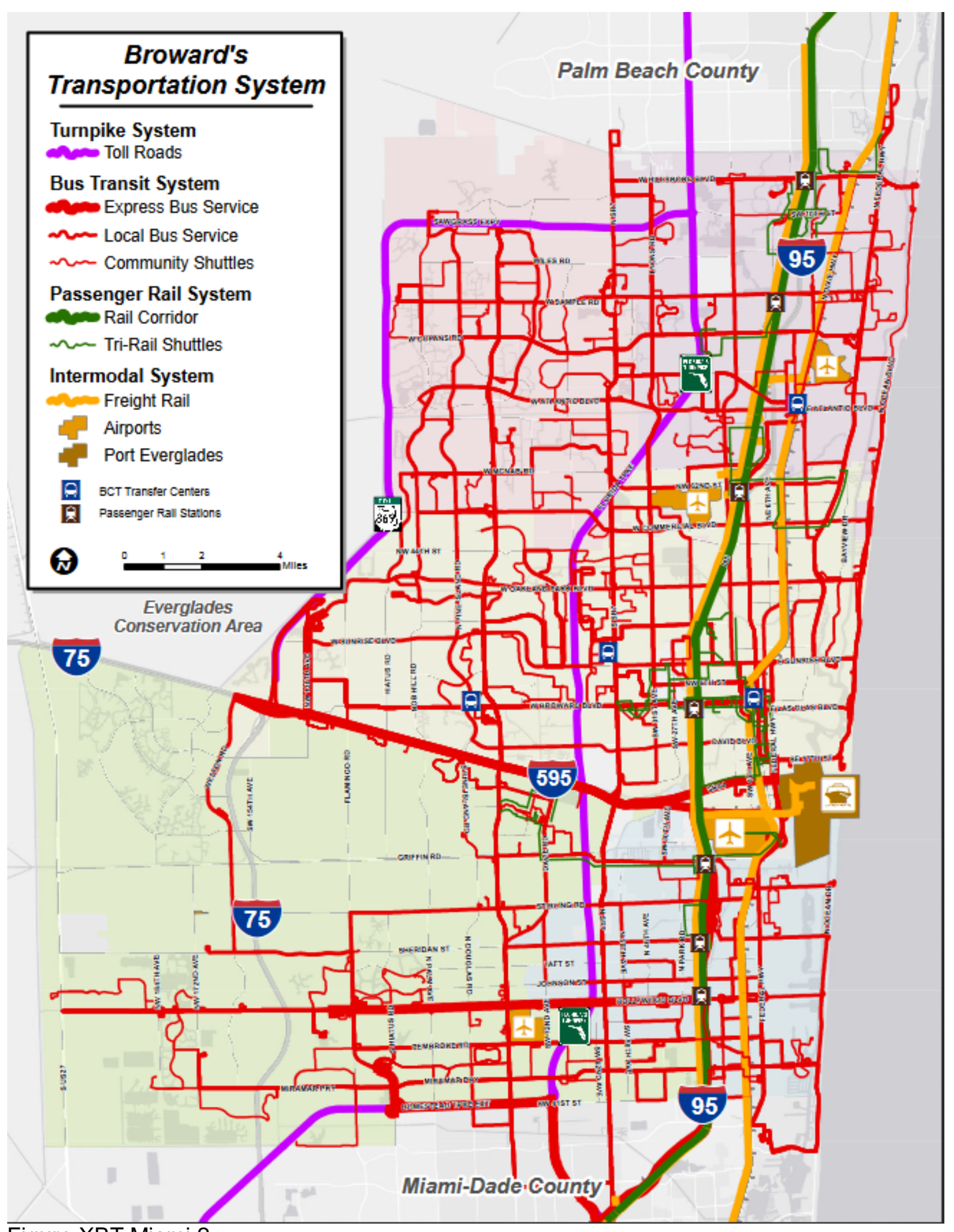

Figure XBT Miami 2

Miami Transit Map

Source: http://www.browardmpo.org/images/SpeakUpBroward/systemmap2.pdf MINNEAPOLIS EXPRESS BUS TRANSIT SYSTEM 


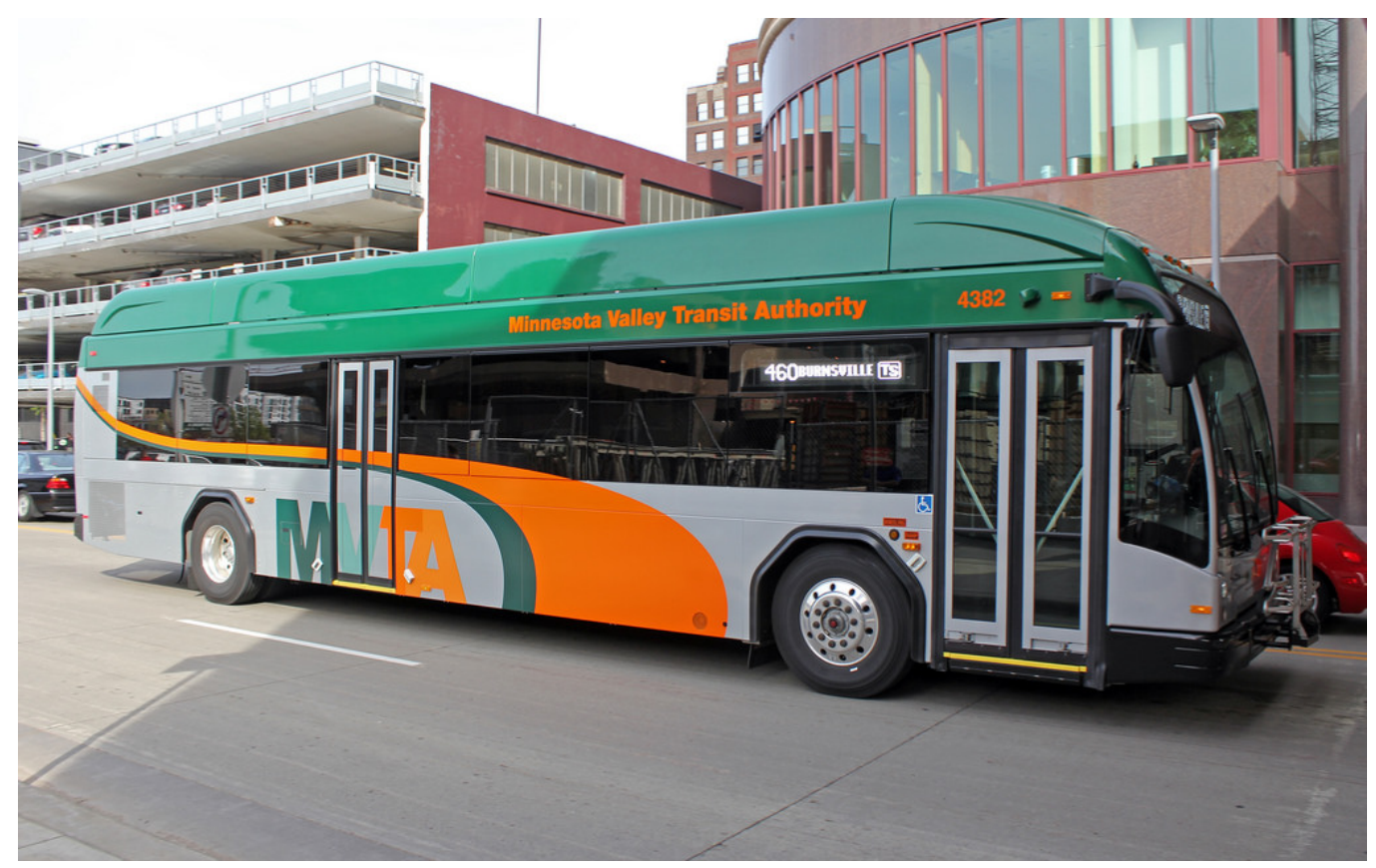

Figure XBT Minneapolis 1

MVTA Bus

Source: https://www.flickr.com/photos/mspdude/8956466254

Operated by the Minnesota Valley Transit Authority, the Express Bus System offers 16 express routes from far-reaching suburbs into the Minneapolis - St. Paul metro area. This system gives commuters an option other than vehicular transit to get to work. Operation is usually confined to commute times and midday during weekdays. ${ }^{76}$

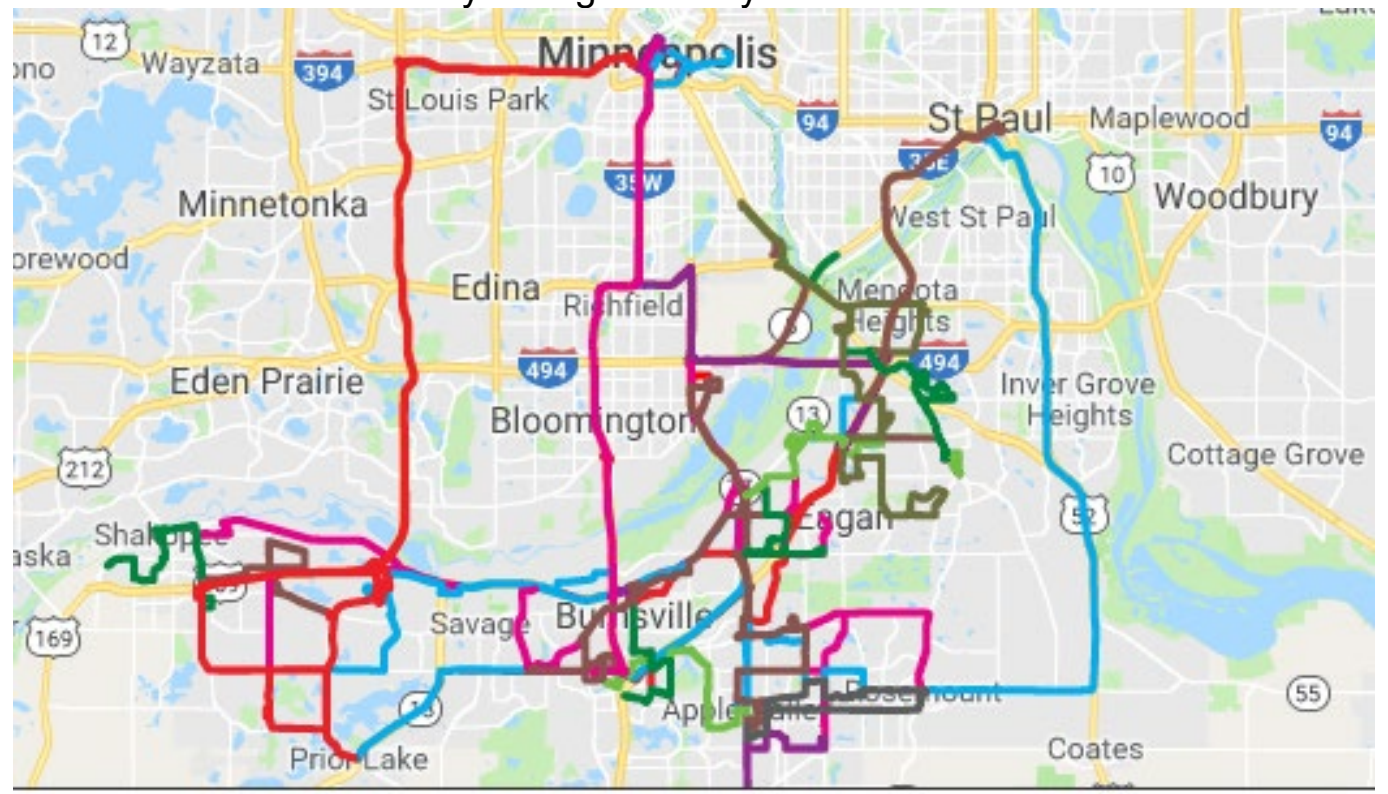

Figure XBT Minneapolis 2

MVTA Bus \& Express Line System Map

Source: https://www.mvta.com/routes/

\footnotetext{
${ }^{76}$ Adapted from: https://www.mvta.com/routes/491/.
} 


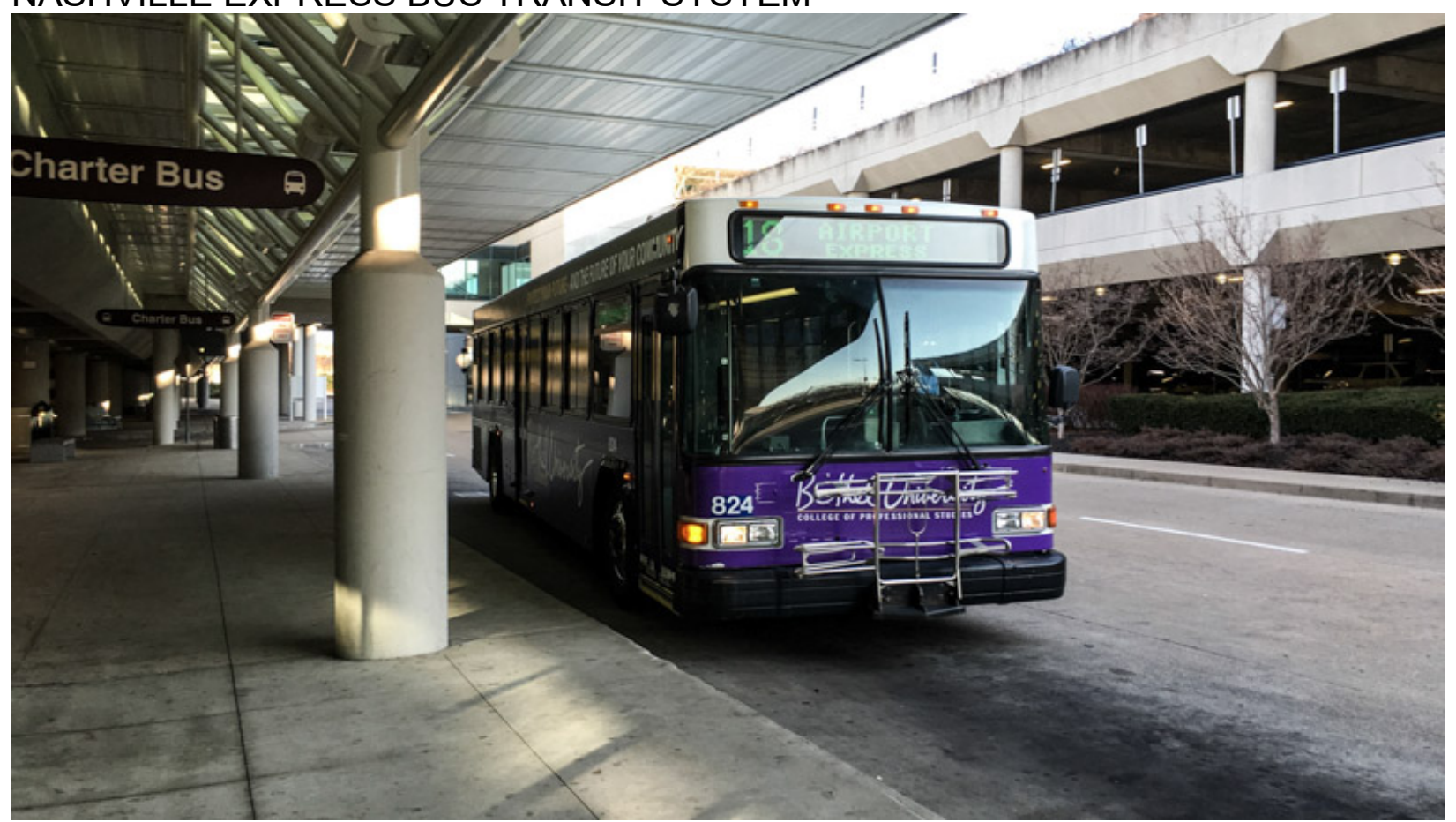

Figure XBT Nashville 1

Nashville MTA Express Bus

Source: https://www.thetravelmentor.com/2016/03/how-to-get-from-bna-airport-to-downtownnashville-on-bus-18/

The Nashville MTA operates 16 express bus services from outer suburbs to downtown Nashville. These lines give commuters an option to avoid driving through traffic and operate during the morning and evening rush as well as midday during weekdays only. ${ }^{77}$

${ }^{77}$ Adapted from: http://www.nashvillemta.org/Nashville-MTA-Maps-and-Schedules.asp. 


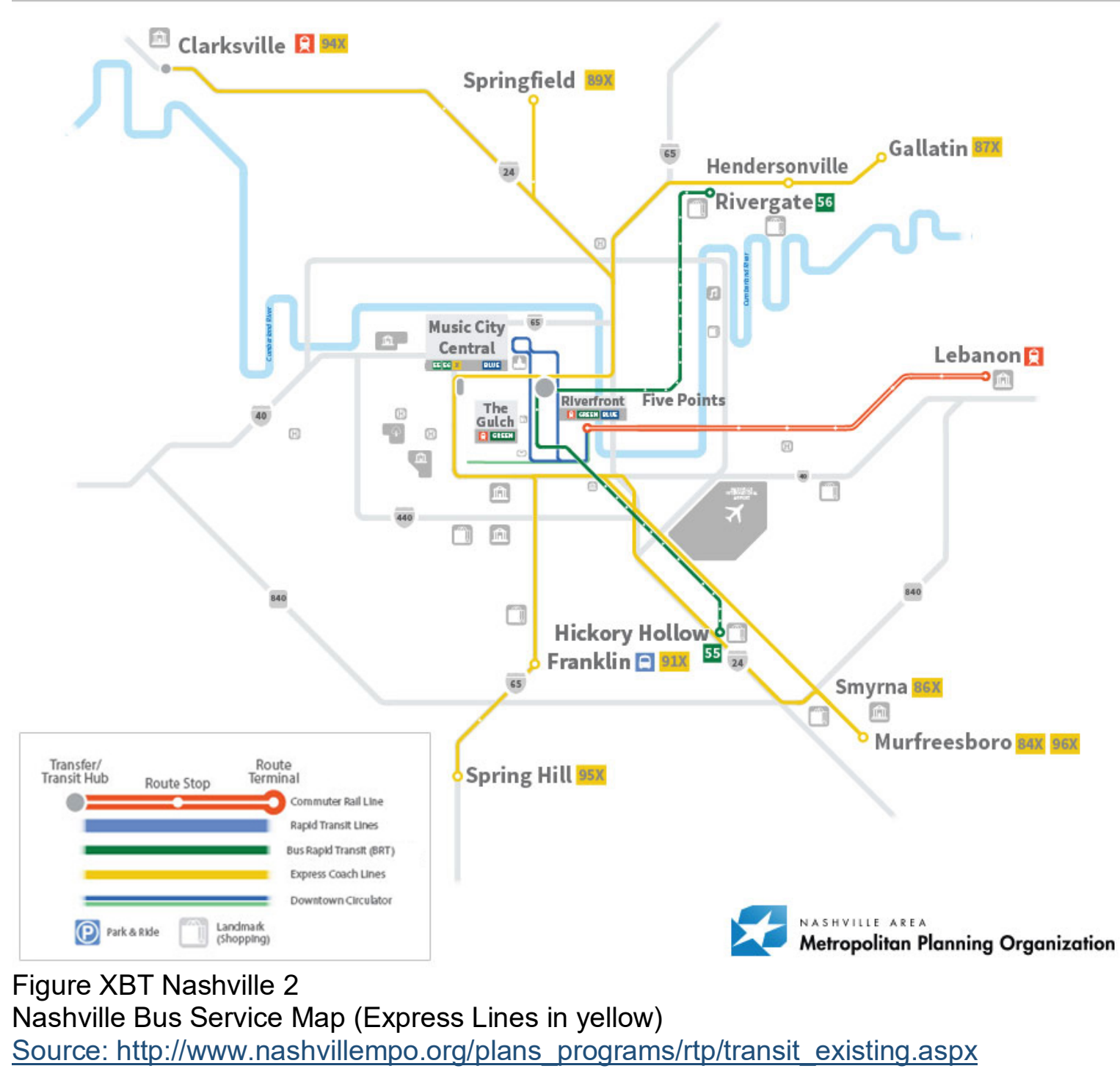

NEW ORLEANS EXPRESS BUS TRANSIT SYSTEM 


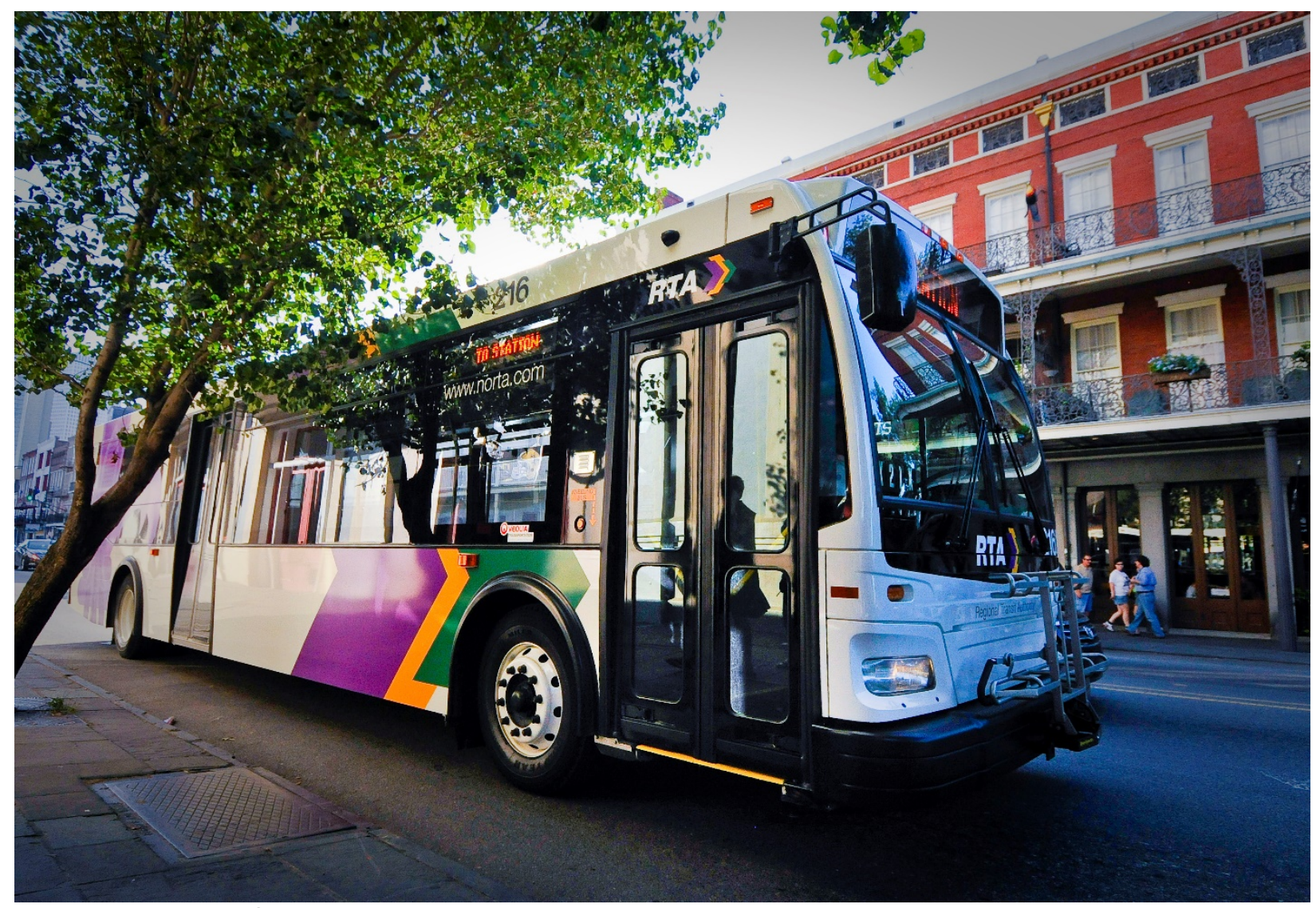

Figure XBT New Orleans 1

NORTA Express Bus

Source: https://www.norta.com/Maps-Schedules/System-Map

The New Orleans Regional Transit Authority operates four express lines serving downtown New Orleans from outer suburbs and the airport. These lines have varying times of operation, but will reliably serve passengers during peak commuting times and midday. ${ }^{78}$

${ }^{78}$ Adapted from: https://www.norta.com/Maps-Schedules/System-Map. 


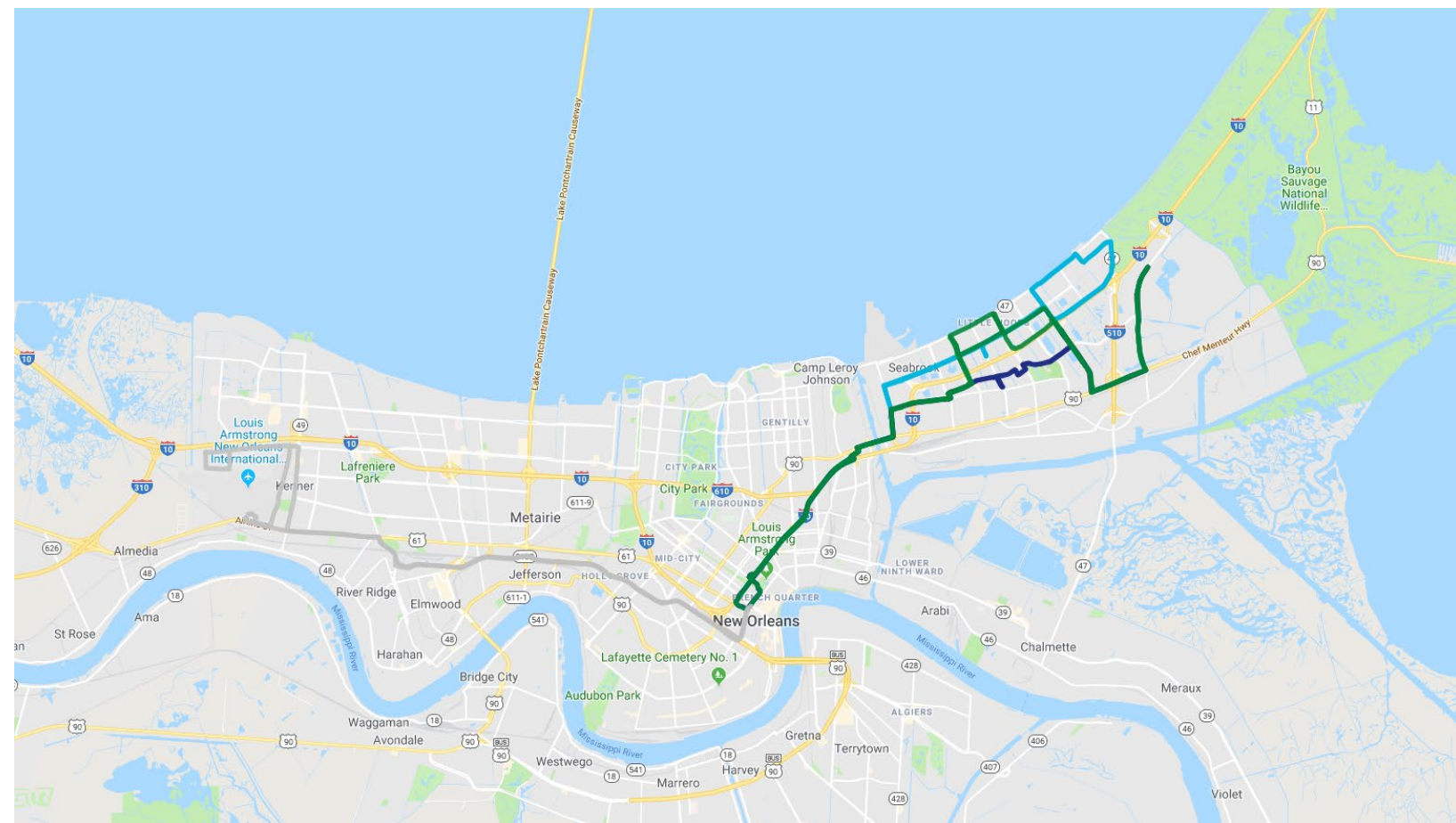

Figure XBT New Orleans 2

NORTA Express Bus Line Service Map (shown in gray, green, navy, and blue)

Source: https://www.norta.com/Maps-Schedules/System-Map

NORFOLK EXPRESS BUS TRANSIT SYSTEM 


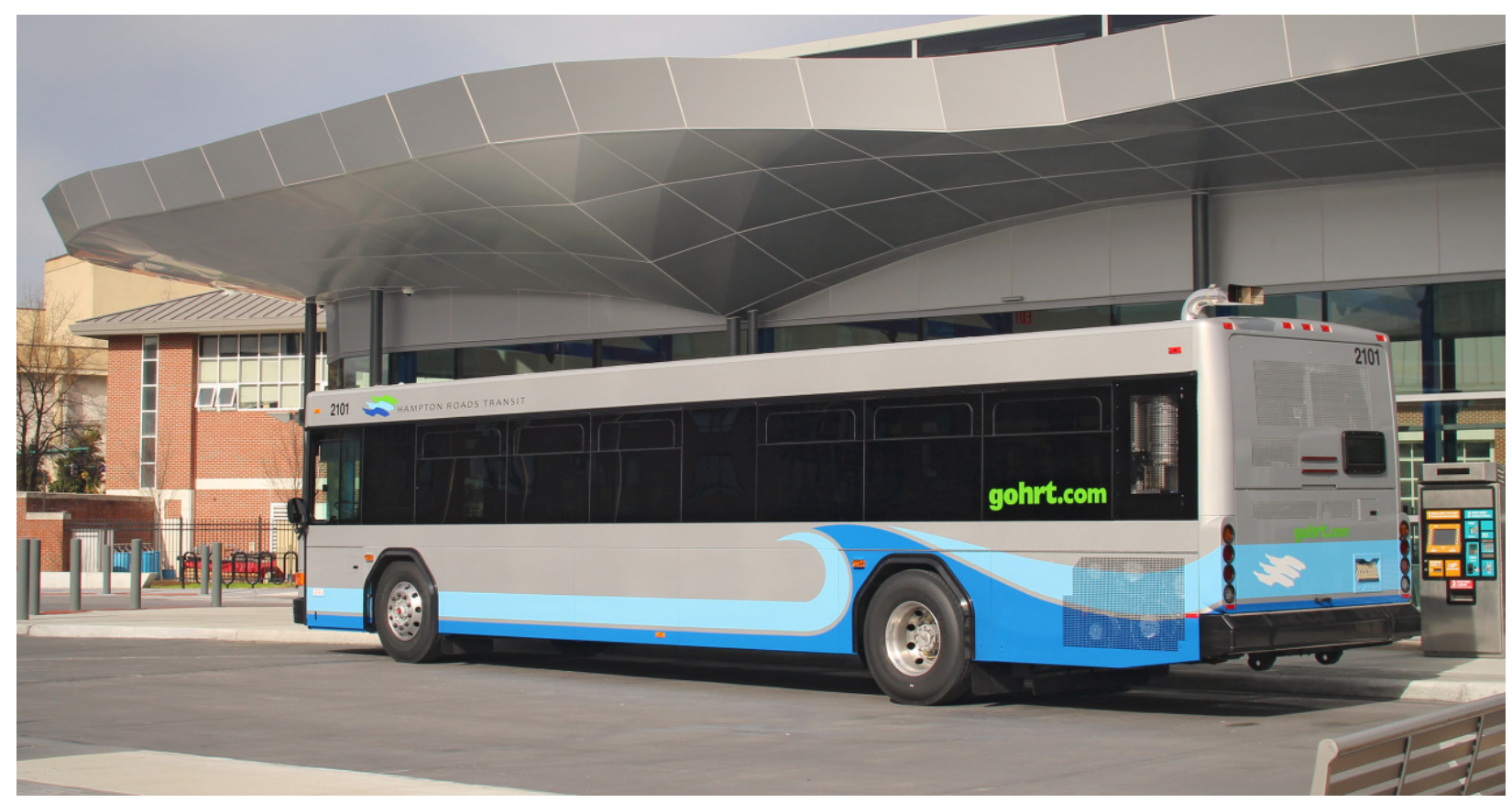

Figure XBT Norfolk 1

HRT Bus

Source: http://thechasfoundation.org/mental-health-awareness-campaigns/

Known as the MAX, Norfolk's metro area express bus system is operated by Hampton Roads Transit (HRT). There are many park-and-ride facilities giving many options to commuters. The buses on this express system offer onboard Wi-Fi to ensure productivity even on the way to work. This system has nine lines. ${ }^{79}$

Maps for all nine routes can be found here: Source: https://gohrt.com/routes/max/ Figures XBT Norfolk 2-10 Metro Area Express Maps

Source: https://gohrt.com/routes/max/

\section{ORLANDO EXPRESS BUS TRANSIT SYSTEM}

\footnotetext{
${ }^{79}$ Adapted from: https://gohrt.com/2019/01/the-max-park-less-text-more/.
} 


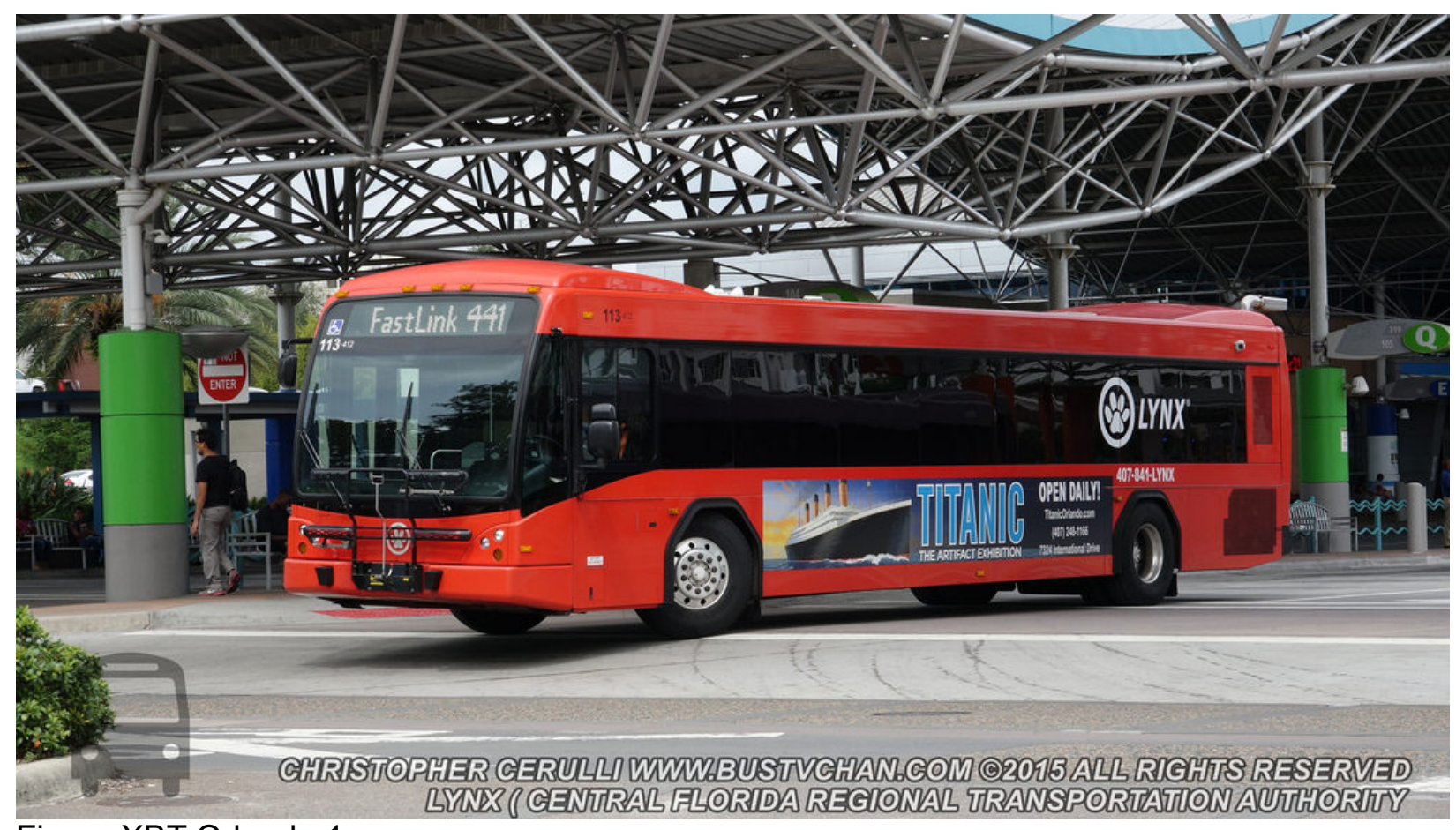

Figure XBT Orlando 1

FastLink Bus

Source: https://www.flickr.com/photos/126261518@N03/21458290146/

Called FastLink, Orlando's express commuter bus system operates similarly to its conventional bus lines only with fewer stops. This saves time for commuters going in and out of Orlando. FastLink has three lines serving Kissimmee, downtown Orlando, Orlando International Airport, the VA Hospital, Lake Nona, Meadow Woods, and Florida Mall. ${ }^{80}$

${ }^{80}$ Adapted from: https://www.golynx.com/plan-trip/riding-lynx/fastlink.stml. 


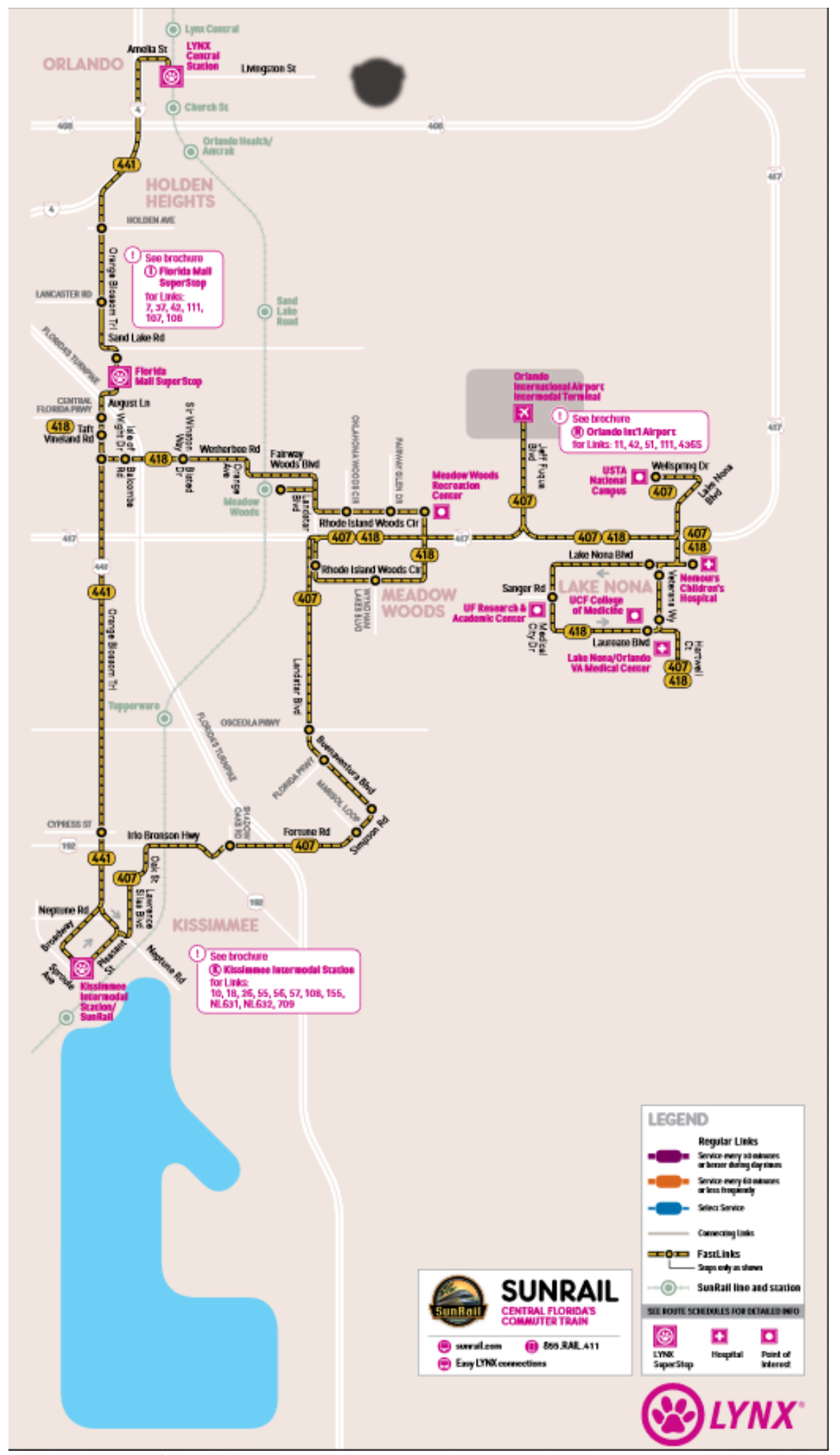

Figure XBT Orlando 2

FastLink Service Map

Source: https://www.golynx.com/core/fileparse.php/97362/urlt/LNX_Lft_FastLink_WEB.pdf PHOENIX EXPRESS BUS TRANSIT SYSTEM 


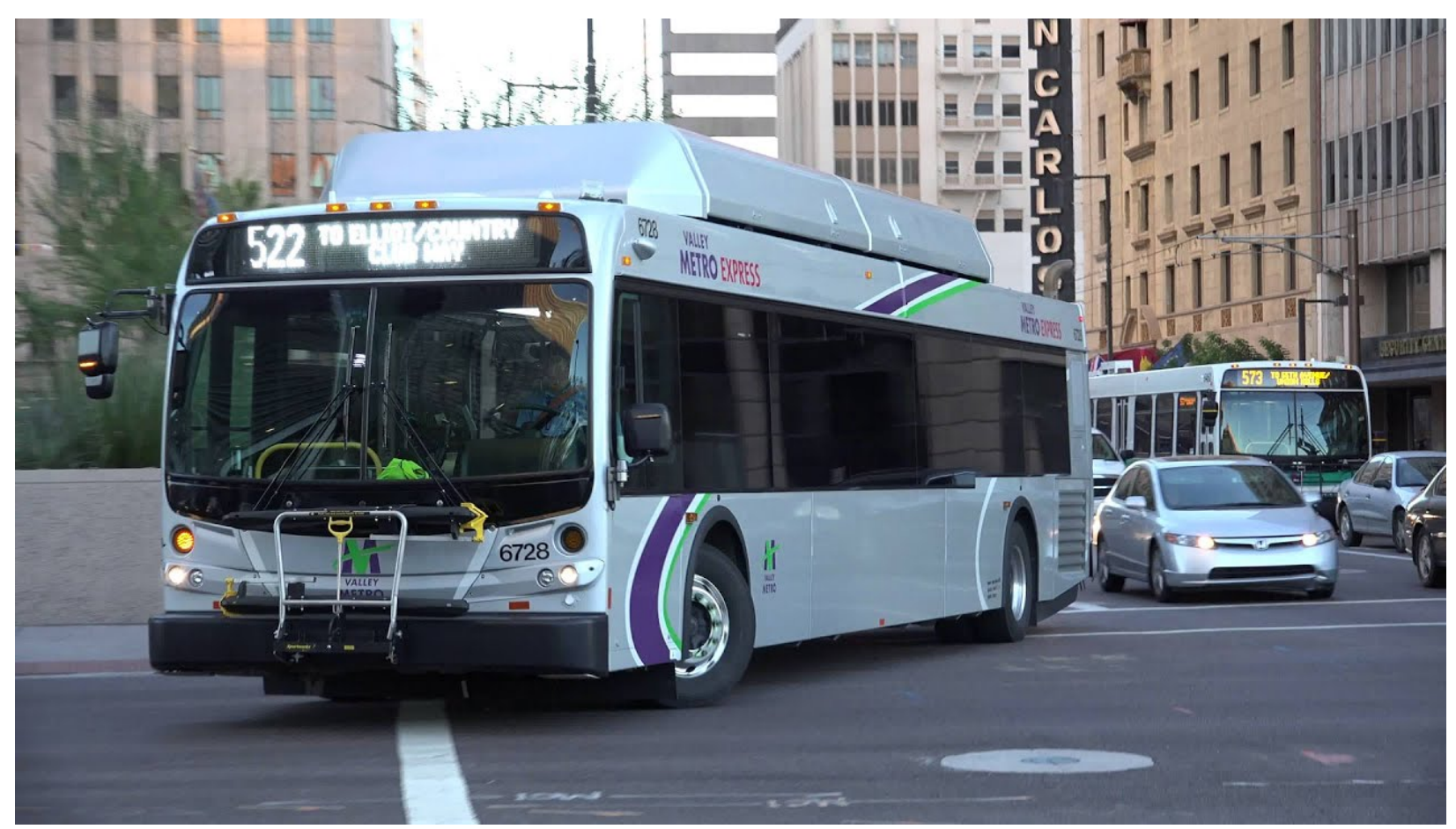

Figure XBT Phoenix 1

MetroExpress Bus

Source: https://www.youtube.com/watch?reload=9\&v=qrCMTaPFKol

Operated by Valley Metro, MetroExpress buses serve Phoenix employment hubs from farreaching suburbs. There are 14 express lines serving Scottsdale, Tempe, Mesa, Gilbert, Chandler, Goodyear, Avondale, Buckeye, Surprise, and Glendale. ${ }^{81}$

${ }^{81}$ Adapted from: https://www.valleymetro.org/maps-schedules. 


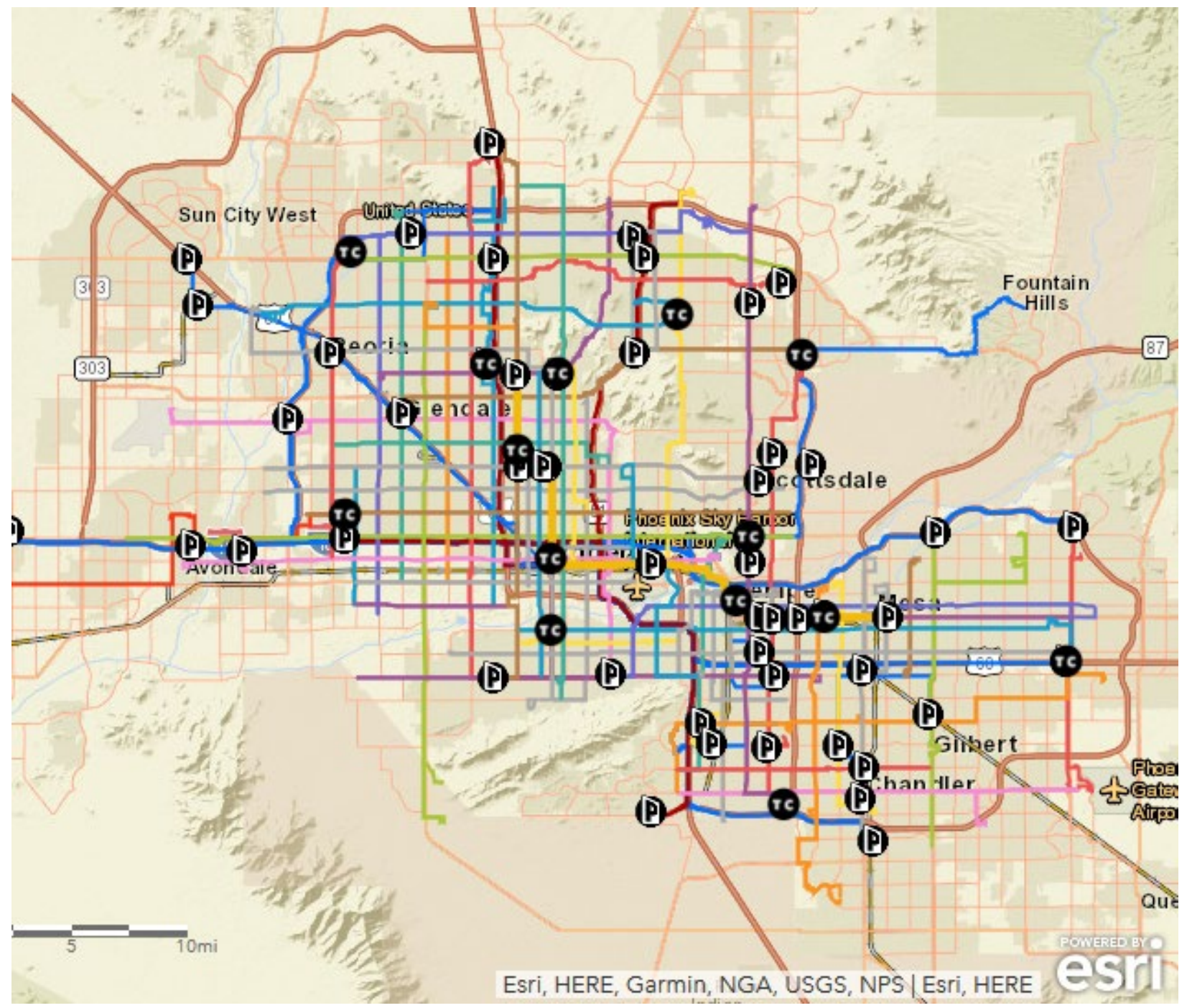

Figure XBT Phoenix 2

Valley Metro Bus System Map (express lines in royal blue) Source: https://www.valleymetro.org/system-map

PITTSBURGH EXPRESS BUS TRANSIT SYSTEM 


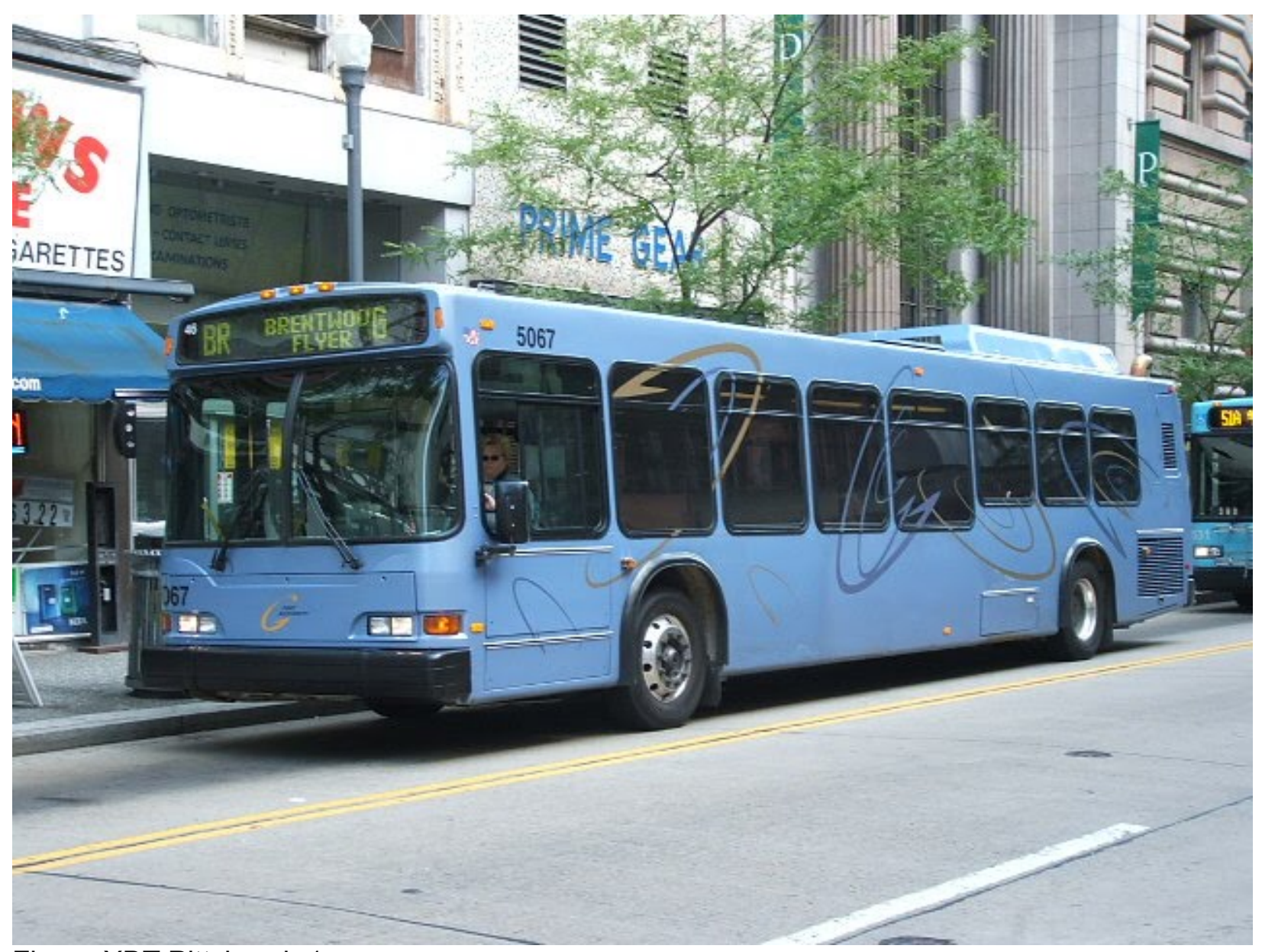

Figure XBT Pittsburgh 1

Flyer

Source: https://sites.google.com/site/patransit/Home

The Flyer lines operated by Pittsburgh's Port Authority give commuters access to downtown Pittsburgh and other employment centers. ${ }^{82}$

${ }^{82}$ Adapted from: https://en.wikipedia.org/wiki/List_of_bus_routes_in_Pittsburgh. 


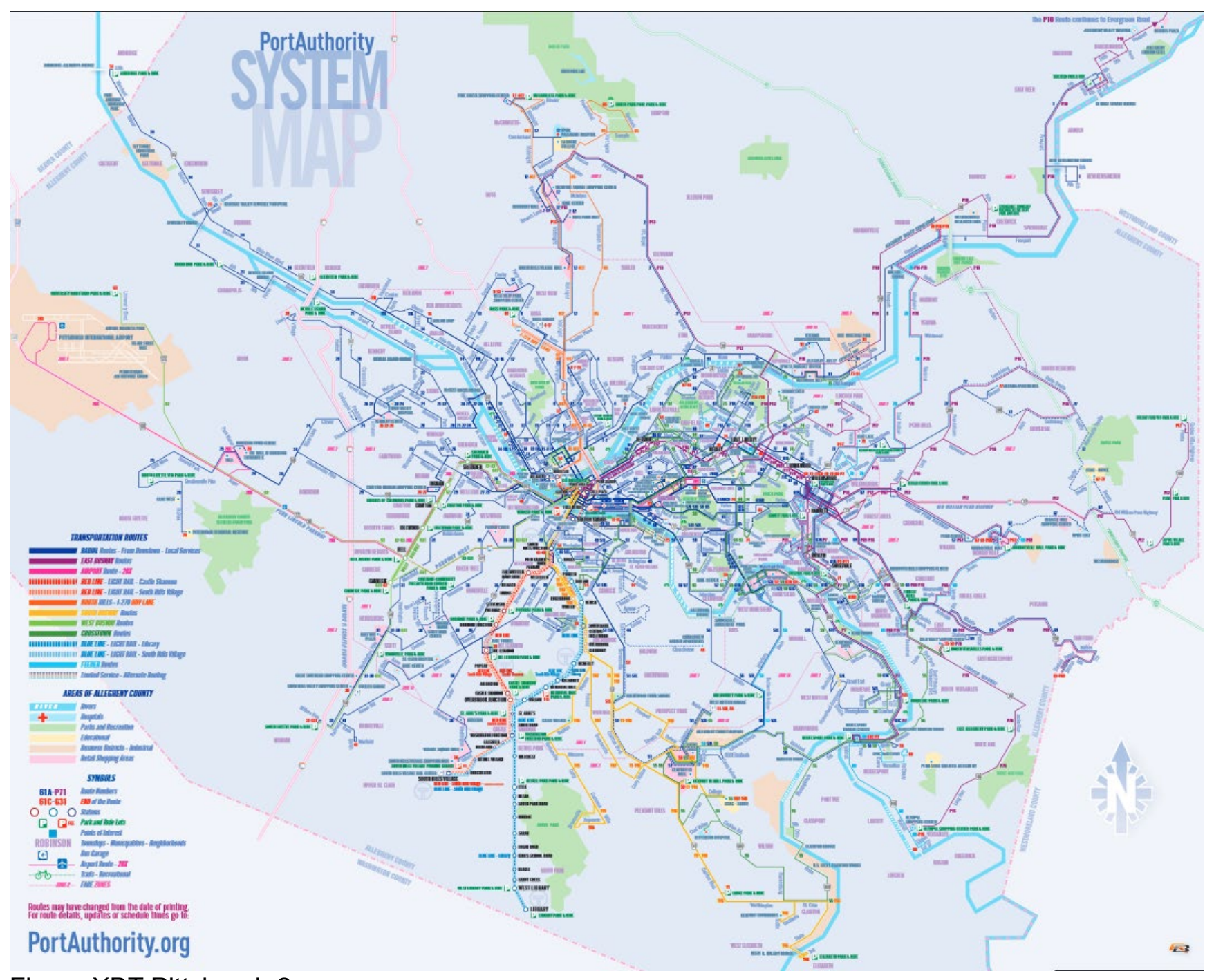

Figure XBT Pittsburgh 2

Flyer Map

Source: http://www.portauthority.org/PAAC/Apps/maps/SystemMap.pdf

PORTLAND EXPRESS BUS TRANSIT SYSTEM 


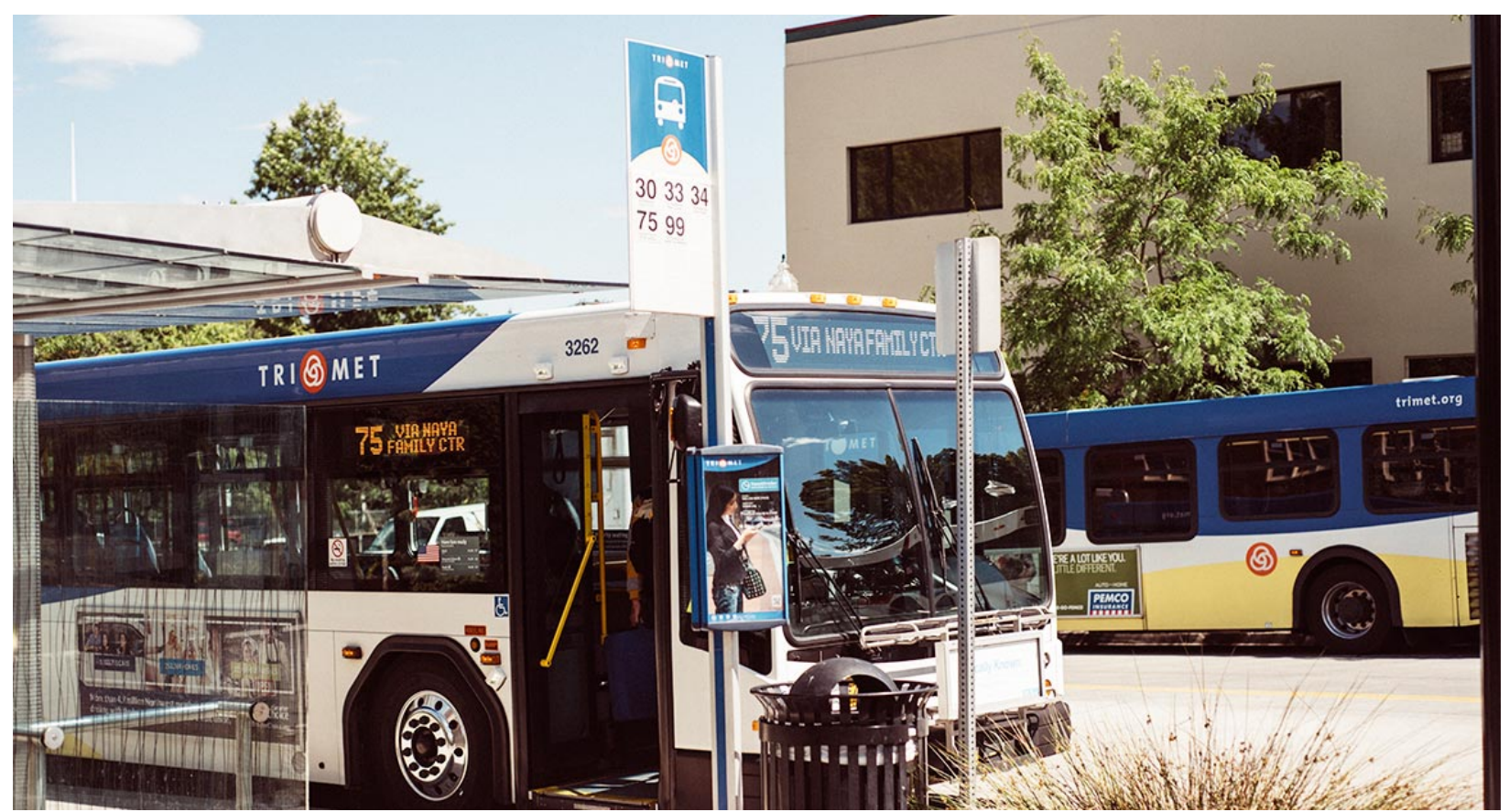

Figure XBT Portland 1

Portland Bus Rolling Stock

Source: Source: https://trimet.org/bus/img/header.jpg

Offering rush hour service between suburban and downtown Portland, the 92-South Beaverton Express bus line offers commuters an alternative way to get to employment hubs in the downtown area. ${ }^{83}$

${ }^{83}$ Adapted from: https://trimet.org/schedules/r092.htm. 


\section{2-South Beaverton Express}

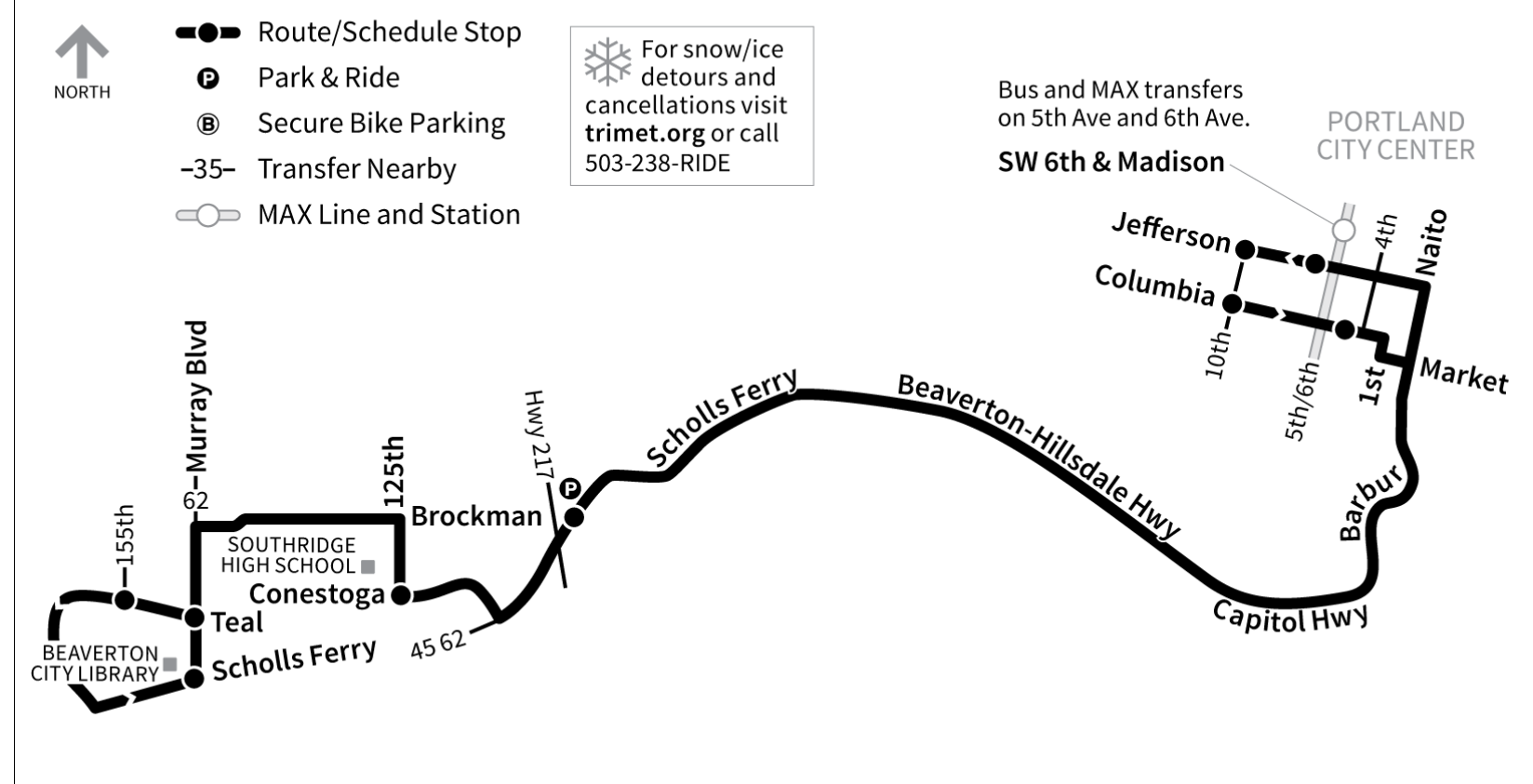

Figure XBT Portland 2

92-South Beaverton Express Map

Source: https://trimet.org/schedules/img/092.png 


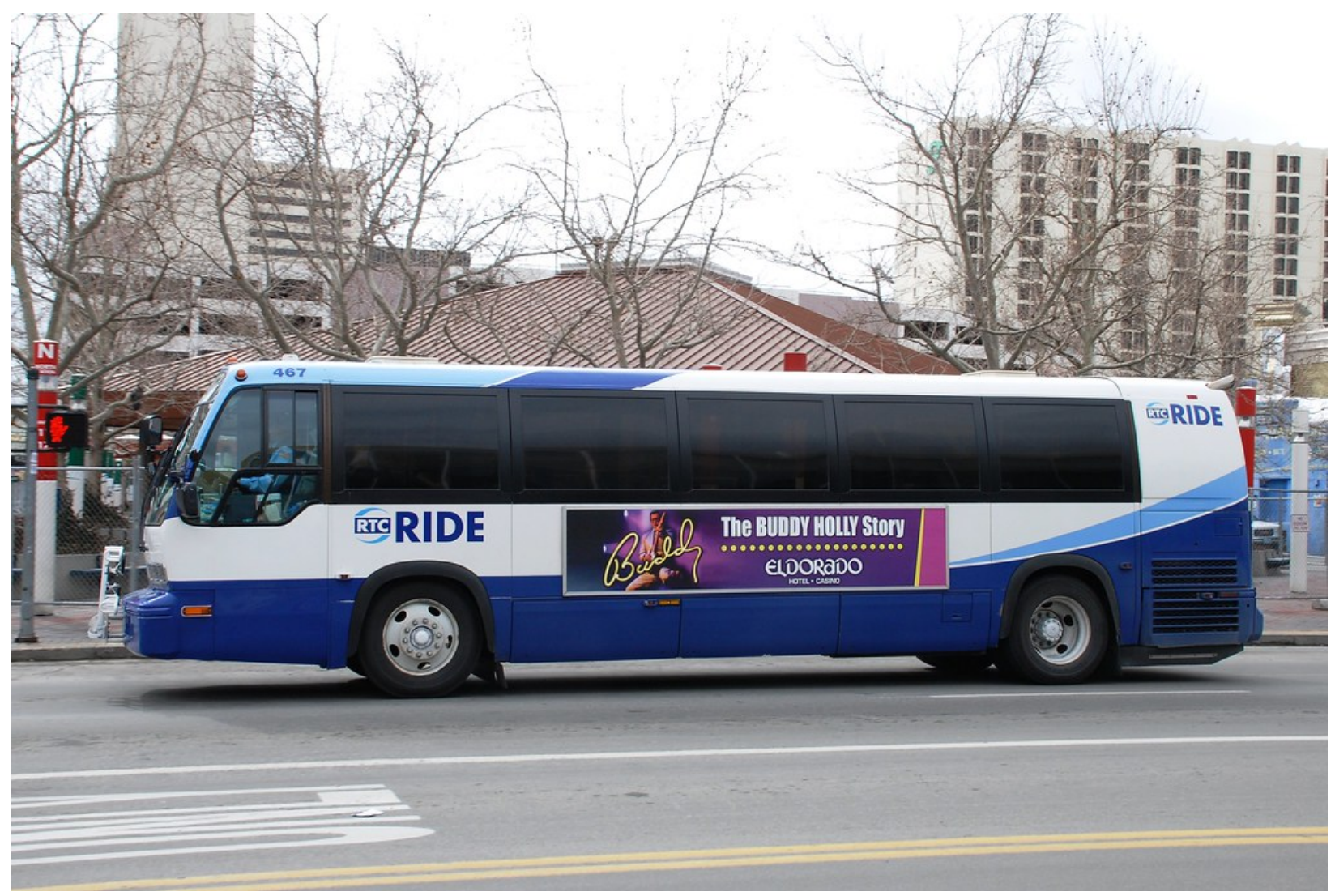

Figure XBT Reno 1

Reno RTC Bus

Source: Source: https://www.flickr.com/photos/southerncalifornian/5507640309

Operating between Reno and Carson City, Nevada, the RTC Regional Connector is operated by the Regional Transportation Commission of Washoe County. ${ }^{84}$

${ }^{84}$ Adapted from: https://www.rtcwashoe.com/public-transportation/. 


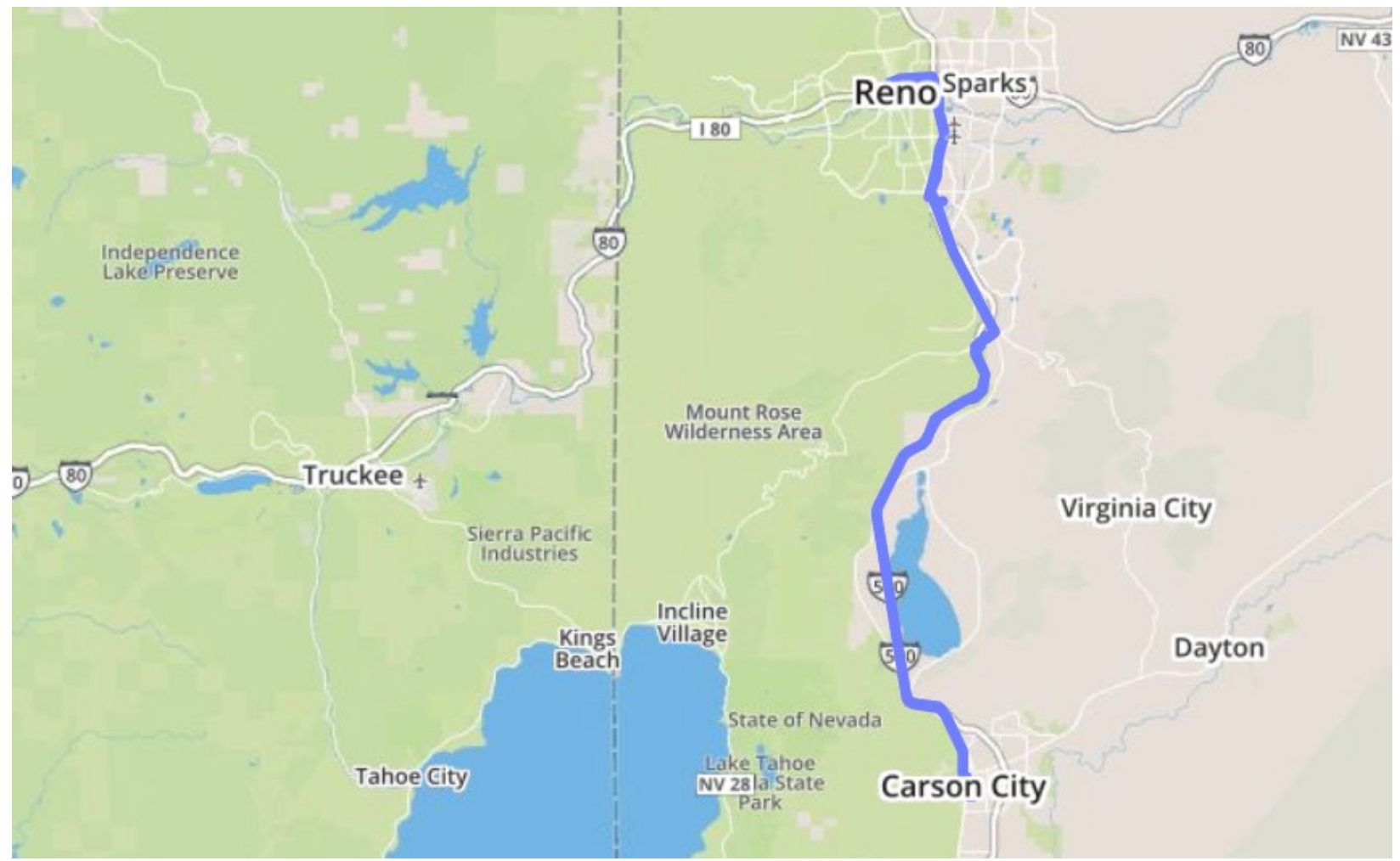

Figure XBT Reno 2

RTC Regional Connector Bus Route

Source: Source: https://www.rtcwashoe.com/routes/rtc-intercity/ 


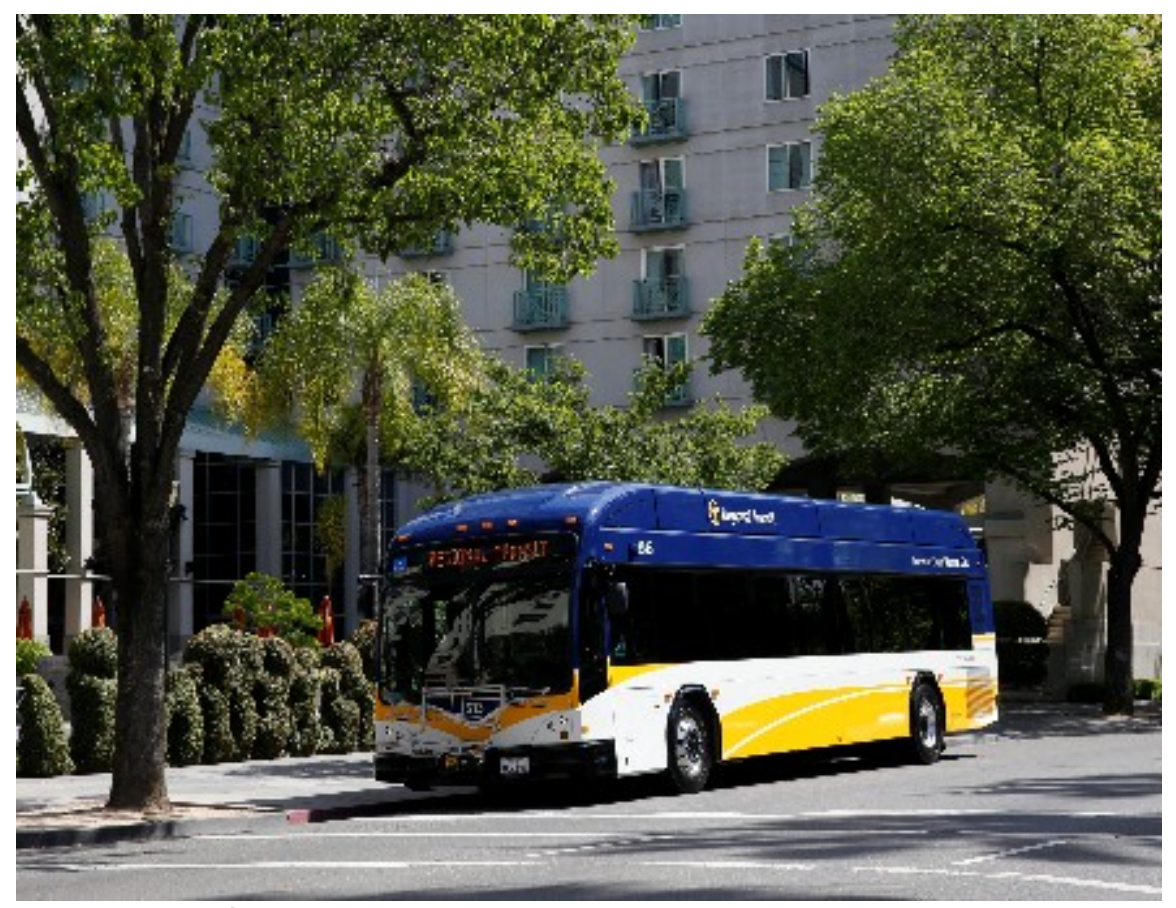

Figure XBT Sacramento 1

SRT Bus

Source: http://www.sacrt.com/services/

Sacramento Regional Transit operates seven express bus lines. Numbered 3, 7, 109, 170, 171, 172 , and 174 , this system gives passengers quicker options when commuting. ${ }^{85}$

${ }^{85}$ Adapted from: http://www.sacrt.com/services/. 


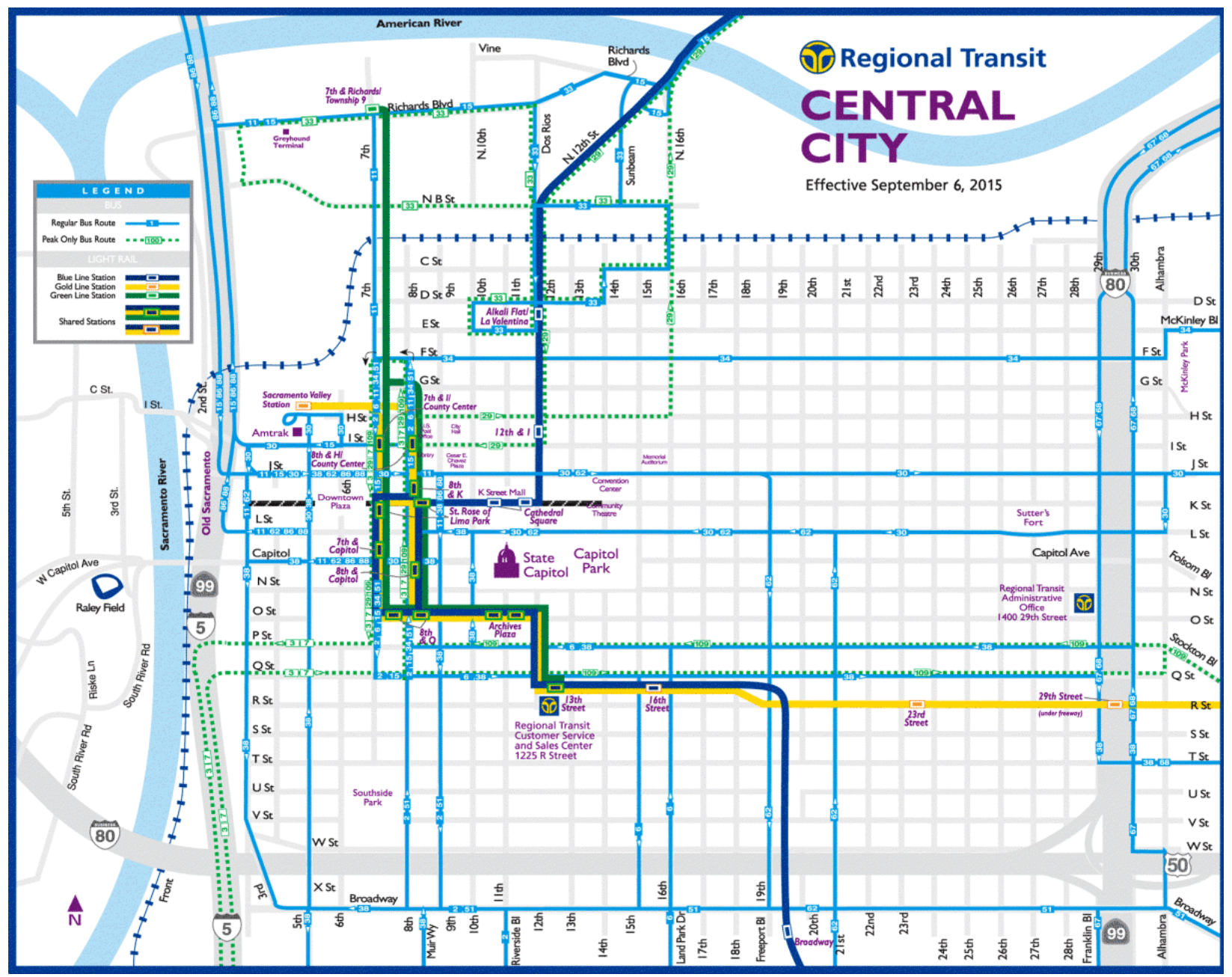

Figure XBT Sacramento 2

Sacramento Regional Transit Bus Service Map (excluding XBT lines 170, 171, and 172)

Source: http://www.sacrt.com/systemmap/central.stm 


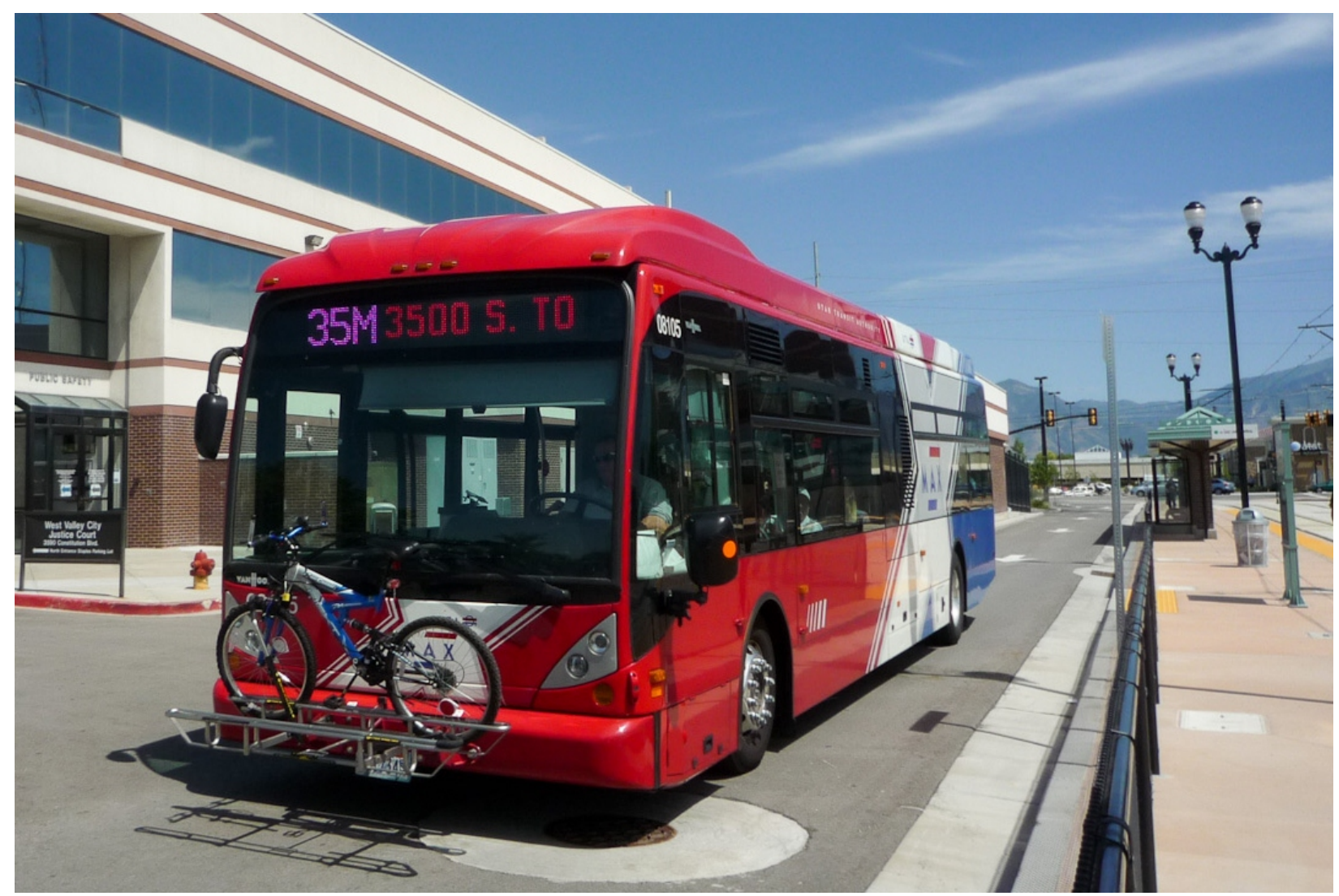

Figure XBT Salt Lake City 1

Utah Express Bus Transit

Source: https://en.wikipedia.org/wiki/MAX_(Utah_Transit_Authority)

Designed specifically for commuters, Utah Transit Authority's express bus transit service operates nine lines. The fleet is comprised of diesel, hybrid electric, and compressed natural gas buses. ${ }^{86}$

${ }^{86}$ Adapted from: http://www.rideuta.com/Services/Bus. 


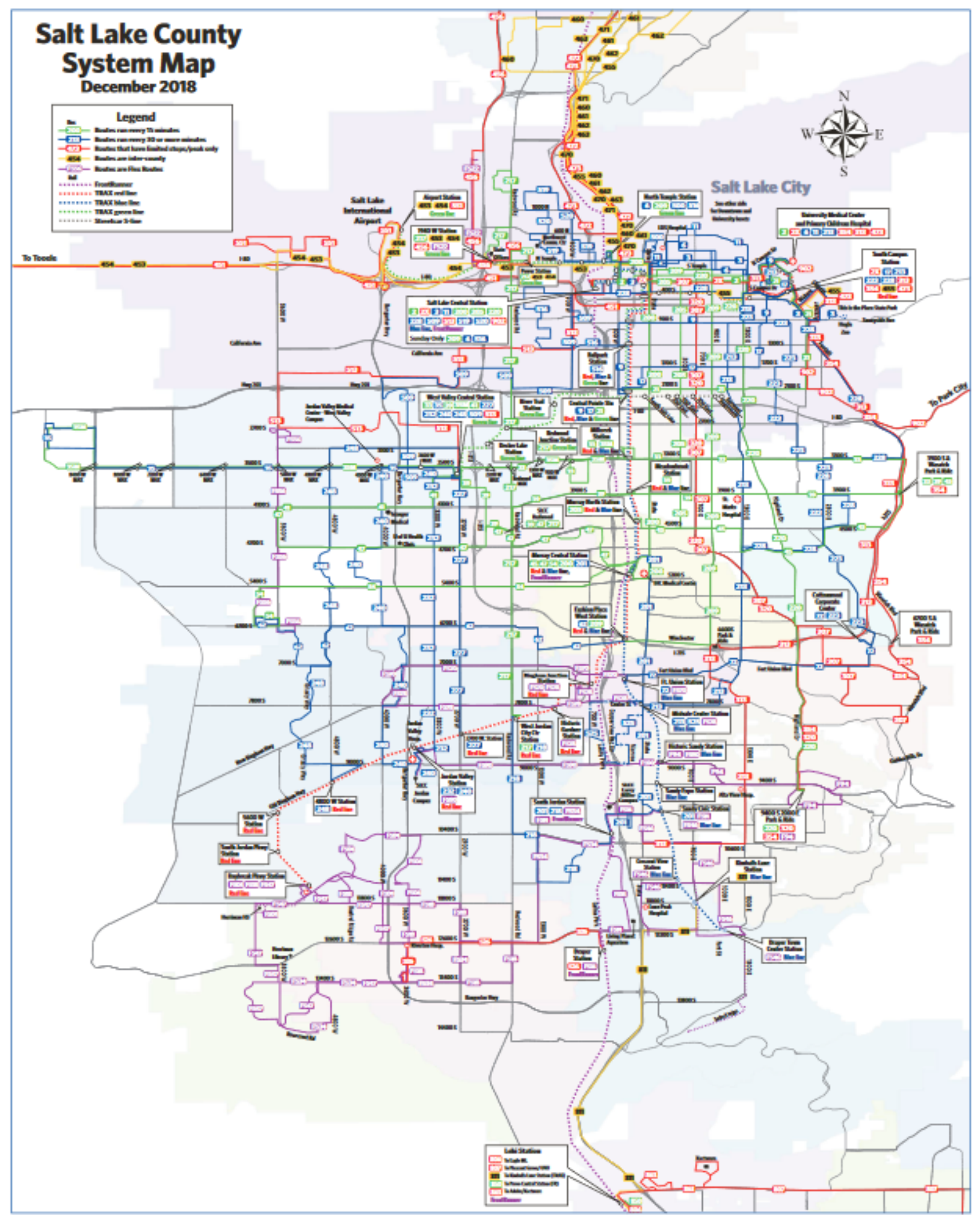

Figure XBT Salt Lake City 2

Salt Lake City Transit Service Map

Source: https://www.rideuta.com/-/media/Files/System-Maps/2018/Salt-Lake-

County/Dec_2018_SL_System_Map.ashx

SAN ANTONIO EXPRESS BUS TRANSIT SYSTEM 


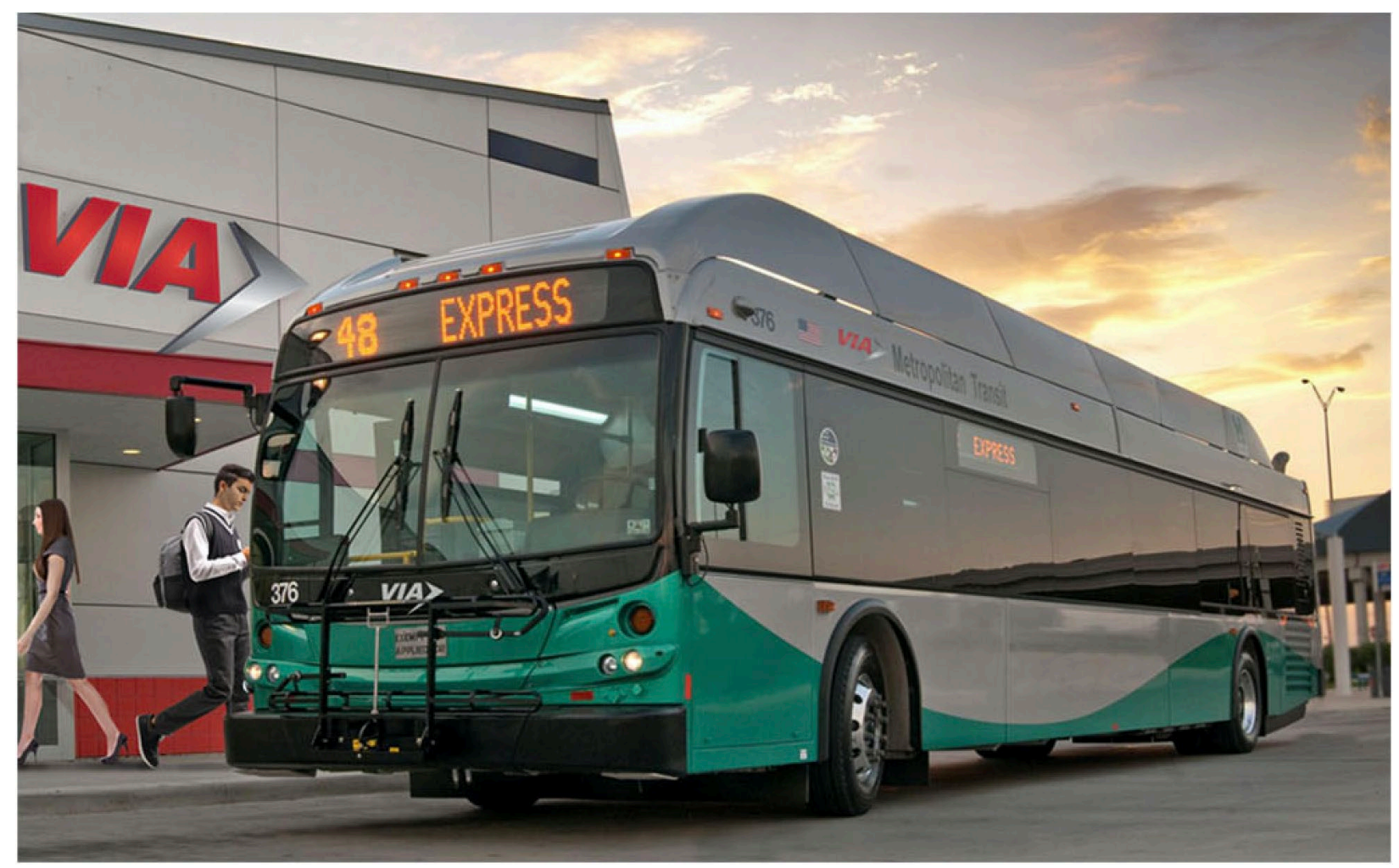

Figure XBT San Antonio 1

VIA Express Bus

Source: Source: https://www.viainfo.net/express/

The VIA Express bus lines cater service direct to downtown with minimal stops in the San Antonio area. The suburban stations offer Park-and-Ride and there are six express bus lines. ${ }^{87}$

${ }^{87}$ Adapted from: https://www.viainfo.net/express/. 


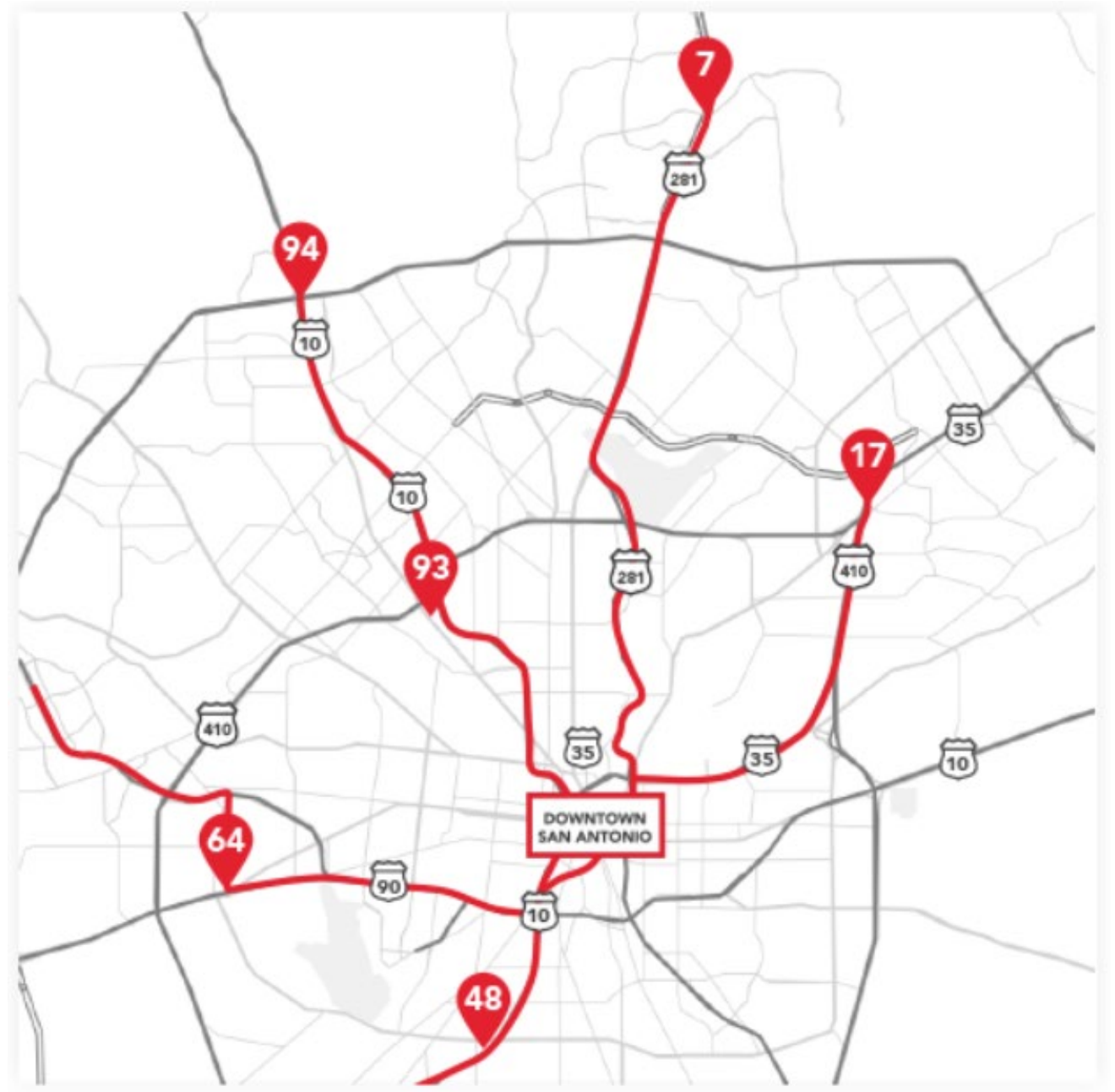

Figure XBT San Antonio 2

Express Bus Service Map

Source: Source: https://www.viainfo.net/express/ 


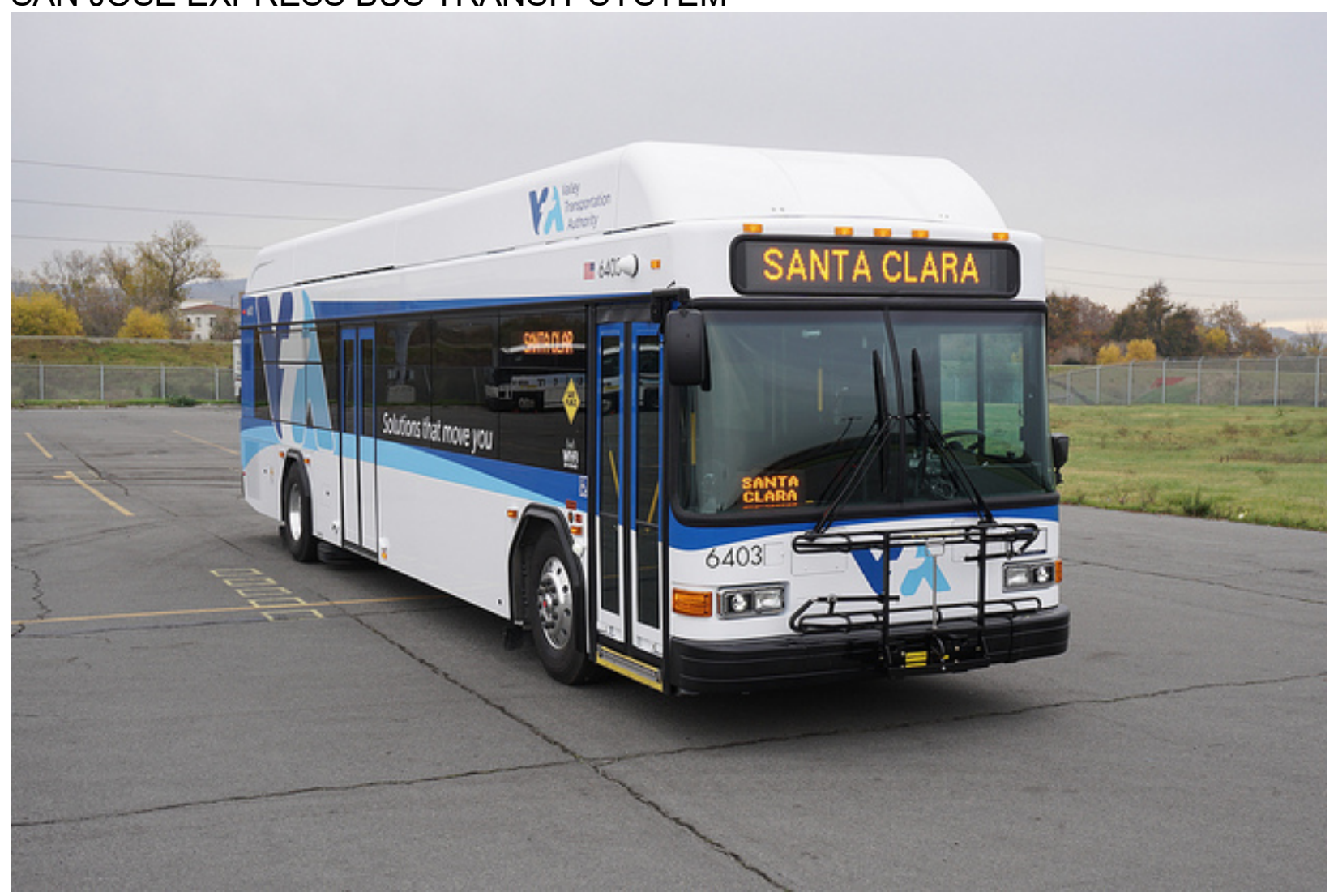

Figure XBT San Jose 1

VTA Express Bus

Source: Source: http://www.vta.org/Getting-Around/Riders-Tips/VTA-Express-Bus-Service Offering free Wi-Fi, reading lights, reclining seats, and footrests, Santa Clara Valley Transit Authority's Express Bus Lines are rapidly expanding to offer alternative commute transportation to many people in the San Jose area. ${ }^{88}$

${ }^{88}$ Adapted from: http://www.vta.org/Getting-Around/Riders-Tips/VTA-Express-Bus-Service. 


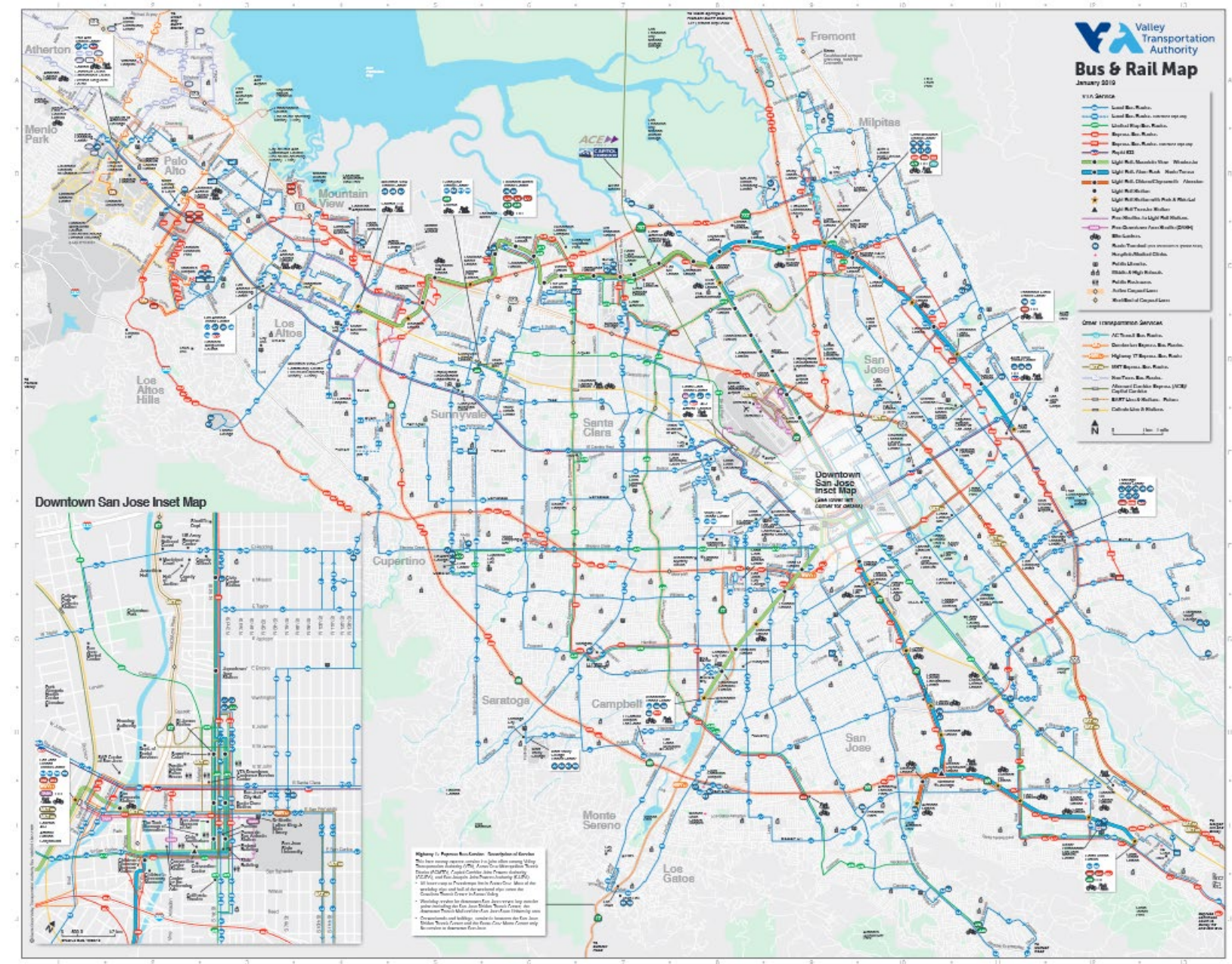

Figure XBT San Jose 2

VTA Bus and Rail Map

Source: http://www.vta.org/sfc/servlet.shepherd/document/download/069A0000001cwcWIAQ

SEATTLE - TACOMA EXPRESS BUS TRANSIT SYSTEM 


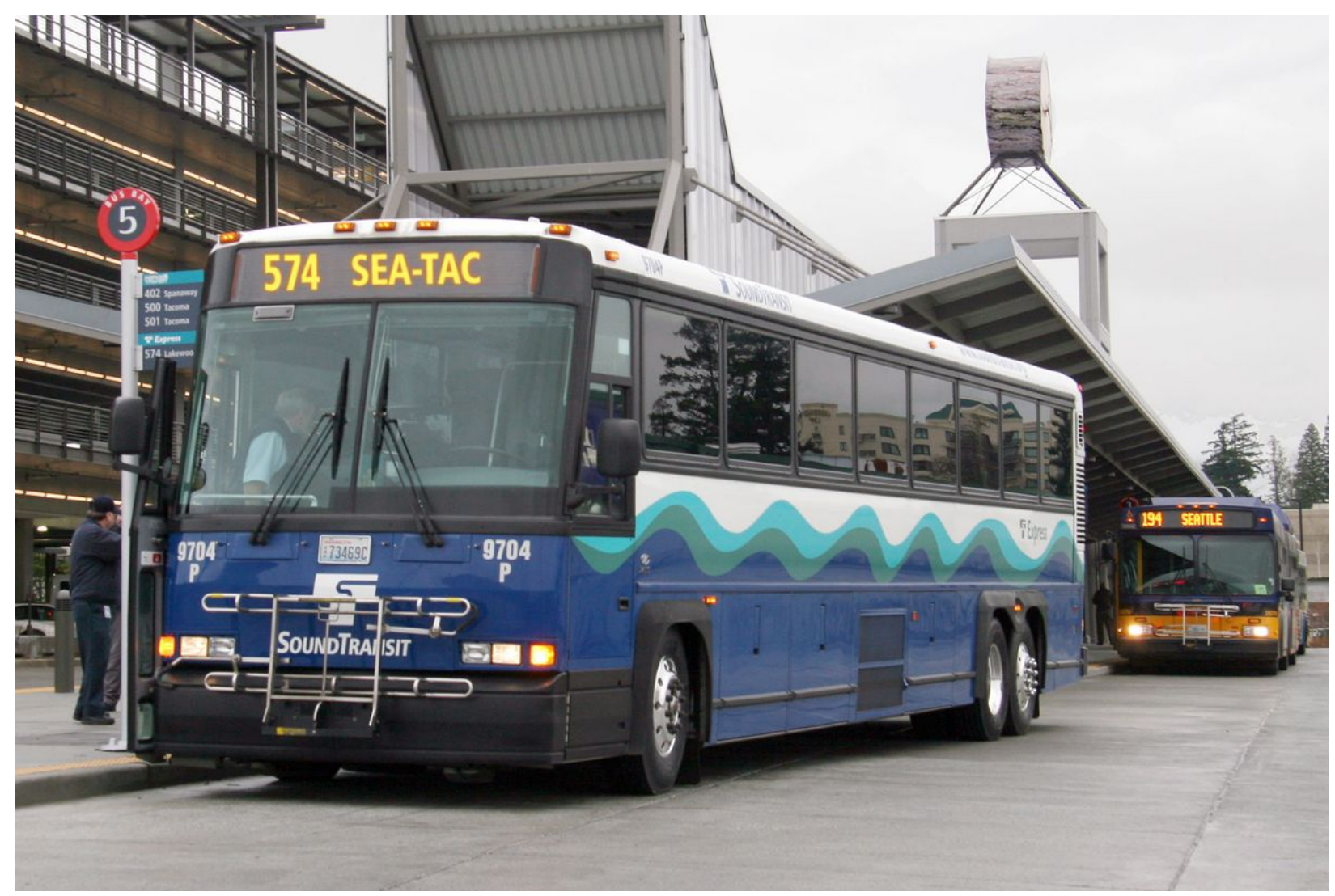

Figure XBT Seattle 1

Seattle - Tacoma XBT

Source: https://seattle.curbed.com/2018/1/17/16902734/sound-transit-express-bus-farechanges

Called route 590, SoundTransit operates an express bus transit line between Seattle and Tacoma. With several stops, it takes approximately 2 hours to travel the entire distance from the north end of Seattle to Tacoma, Washington. ${ }^{89}$

\footnotetext{
${ }^{89}$ Adapted from:

https://www.soundtransit.org/schedules/route/40_590/at/1552945344721/direction/0/from/null.
} 


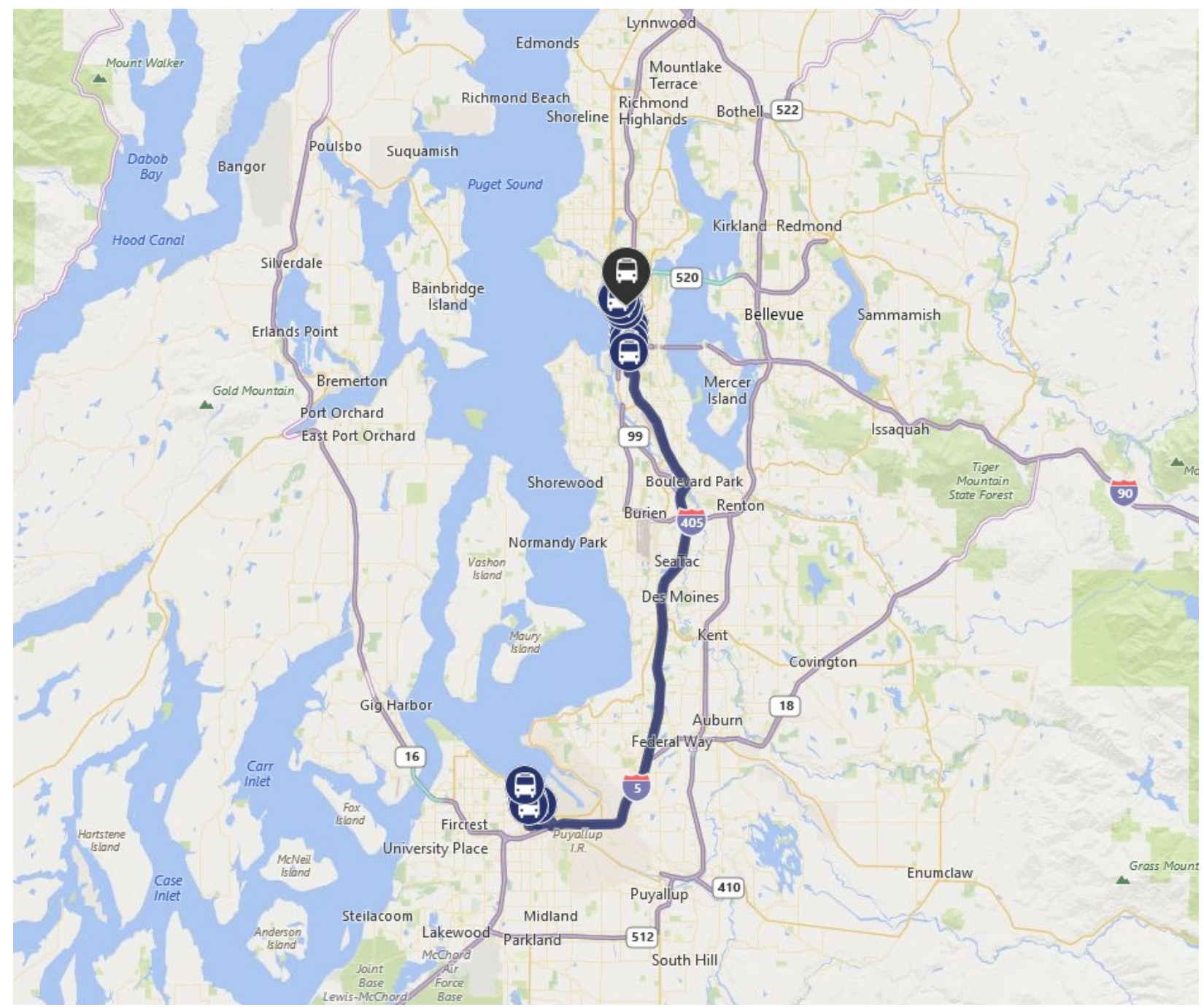

Figure XBT Seattle 2

Route 590 Map

Source:

https://www.soundtransit.org/schedules/route/40_590/at/1552945344721/direction/0/from/null

ST. LOUIS EXPRESS BUS TRANSIT SYSTEM 


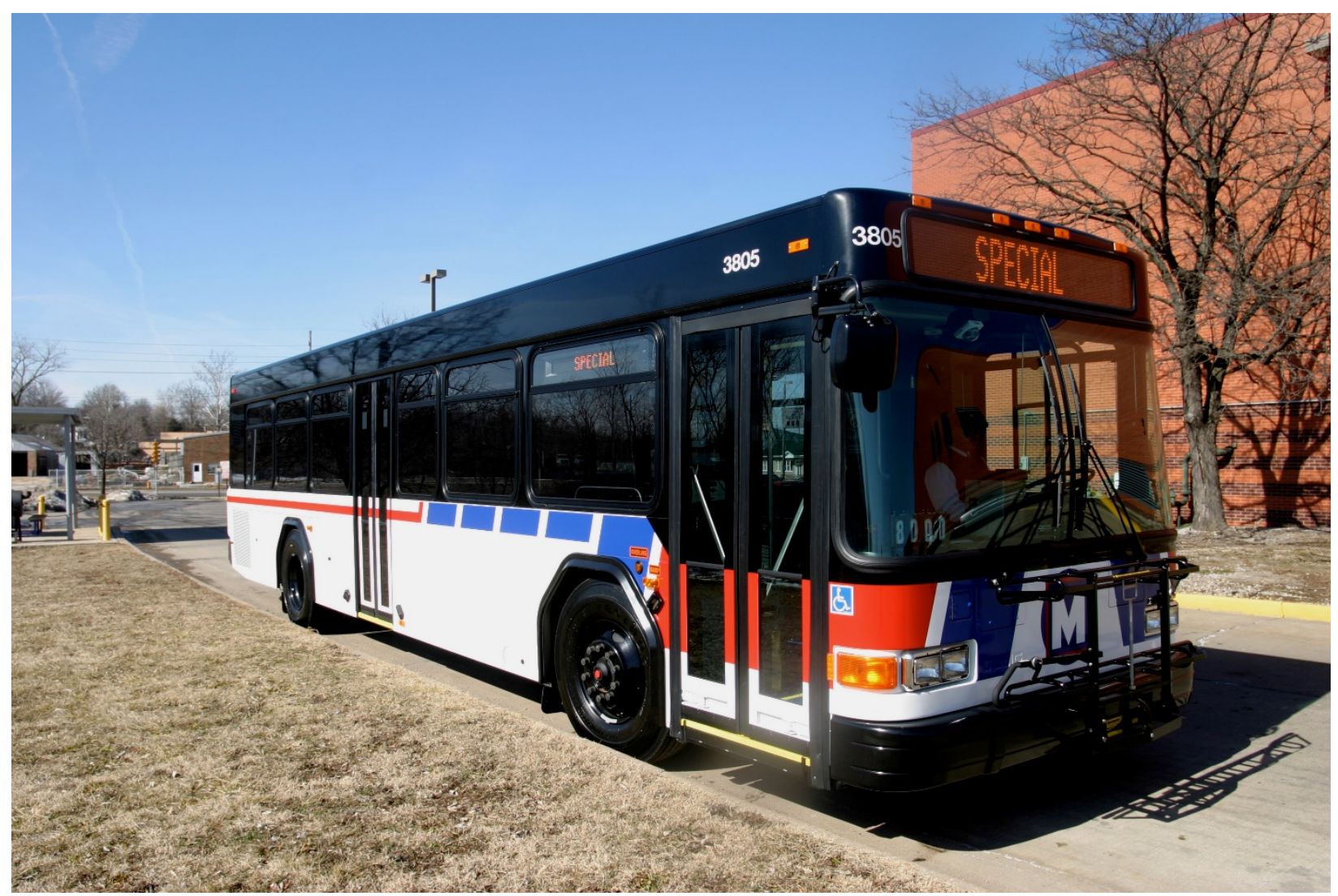

Figure XBT St. Louis 1

St. Louis XBT

Source: https://www.metrostlouis.org/nextstop/metro-transit-records-biggest-bus-ridershipincrease-in-the-nation-among-large-bus-systems/

Metro St. Louis operates four express transit lines in the region: the Interstate 55 Express, Twin Oaks Express, North Express, and Eureka Express. ${ }^{90}$

${ }^{90}$ Adapted from: https://www.metrostlouis.org/metrobus/. 


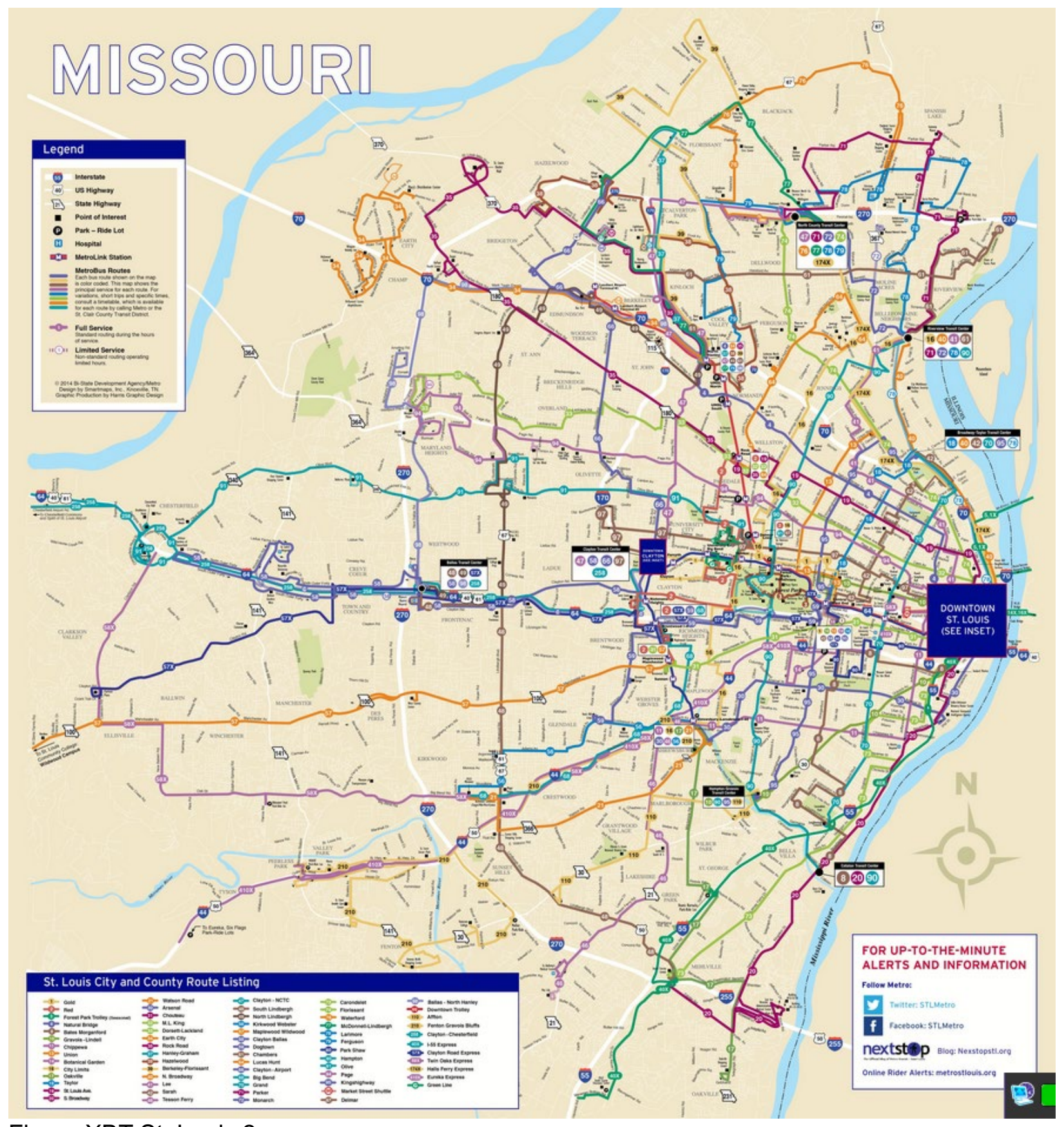

Figure XBT St. Louis 2

St. Louis Transit System Map

Source: https://www.metrostlouis.org/wp-content/uploads/2016/02/SystemMap2017.jpg

TACOMA EXPRESS BUS TRANSIT SYSTEM 


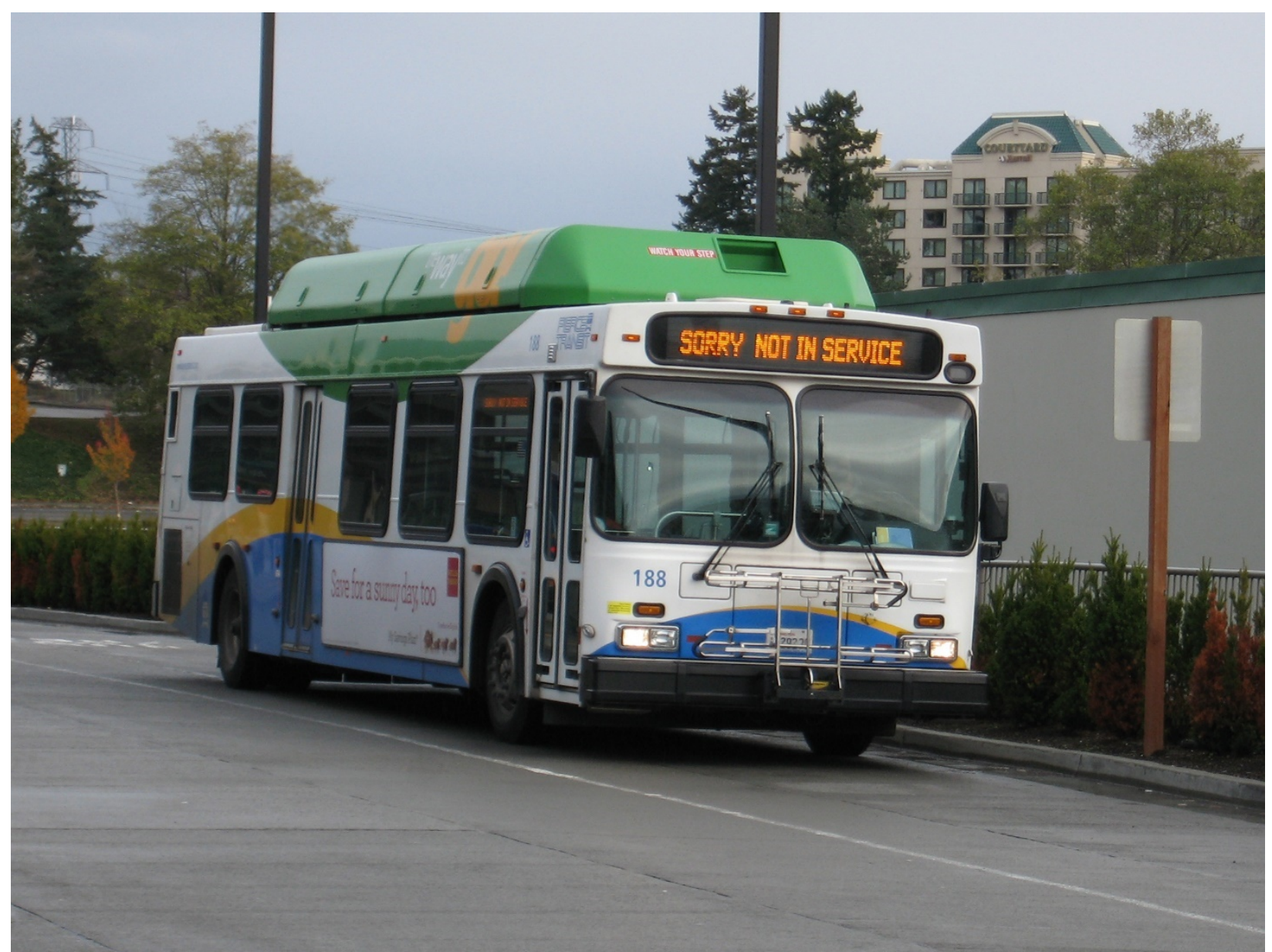

Figure XBT Tacoma 1

Pierce Transit Bus

Source: Source: https://en.wikipedia.org/wiki/Pierce Transit

Serving Pierce County, Washington, which includes the cities of Tacoma and Lakewood, Pierce Transit operates three Express Bus Transit lines. ${ }^{91}$

${ }^{91}$ Adapted from: https://www.piercetransit.org/pierce-transit-routes/. 


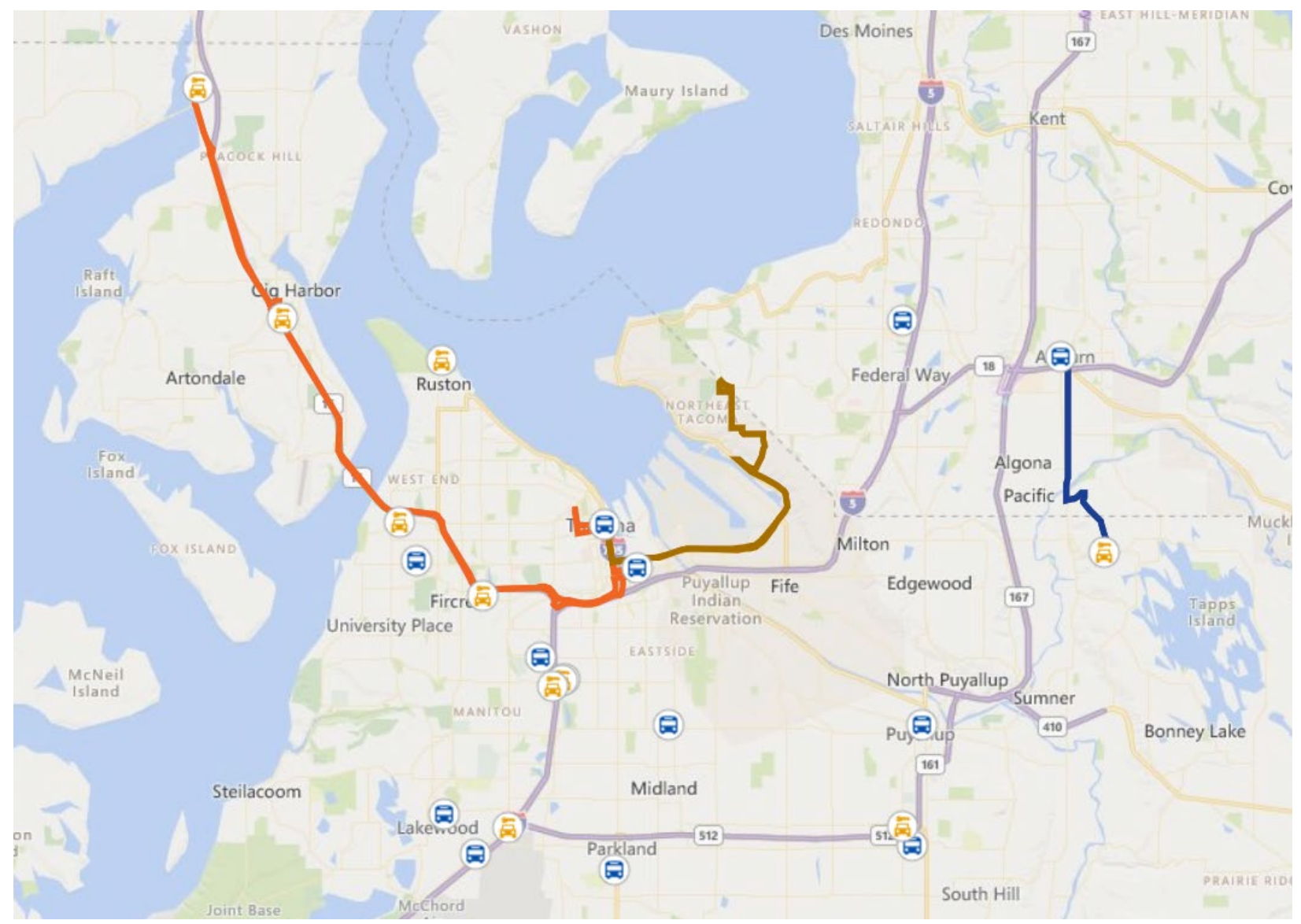

Figure XBT Tacoma 2

Pierce Transit Express Bus Lines

Source: Source:

https://piercetransit.maps.arcgis.com/apps/webappviewer/index.html?id=5e122c82aab449f9acf $\underline{4 c e 14 b 596 d 394}$ 


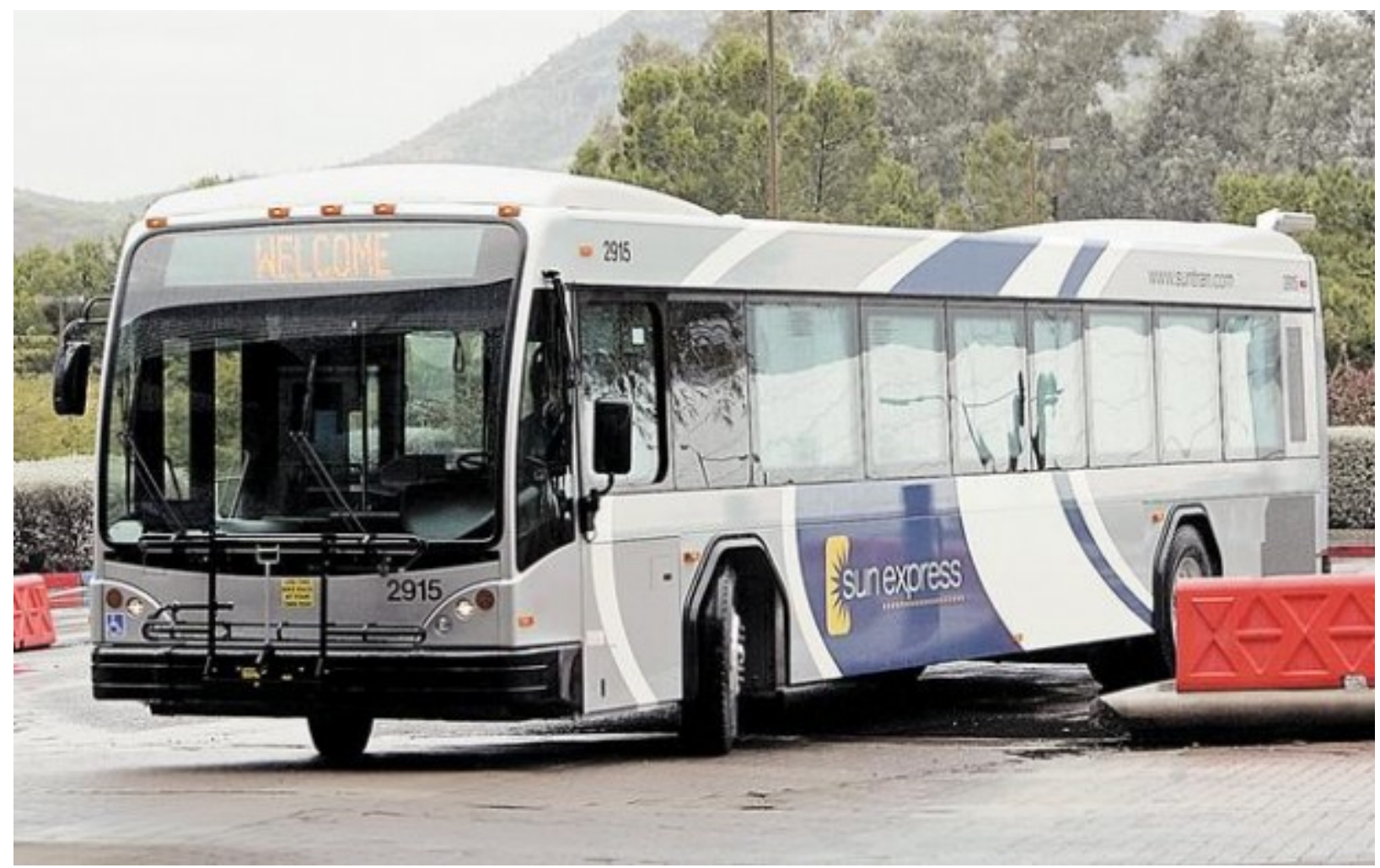

Figure XBT Tucson 1

SunExpress XBT Service

Source: https://tucson.com/news/local/govt-and-politics/sun-tran-introduces-new-lookstrategies-to-make-travel-easier/article_d8ea6d7a-c16d-5b22-b005-dc40fdc79882.html With limited stops from outlying suburbs, SunTran's SunExpress line makes commuting hasslefree for many riders each day. The line has 12 routes with differing destinations and originations. It operates Monday through Friday during peak hours only. ${ }^{92}$

${ }^{92}$ Adapted from: https://www.suntran.com/commuter_express.php. 


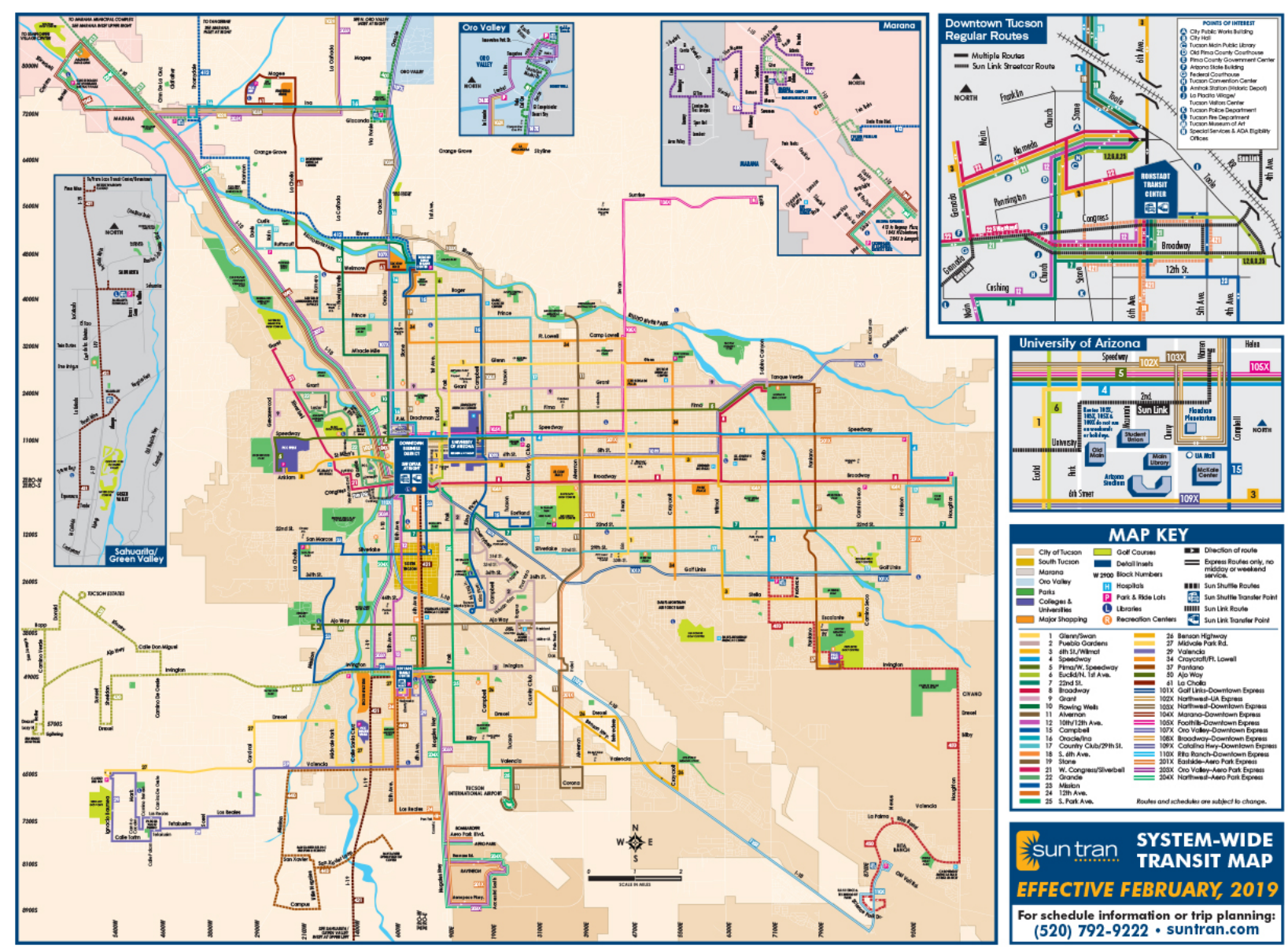

Figure XBT Tucson 2

Tucson Bus Service Map

Source:

https://infoweb.suntran.com/FILE/Apps/FixedRoute/Customerlnfo/images/systemmap.jpg

WASHINGTON, D.C. EXPRESS BUS TRANSIT SYSTEM 


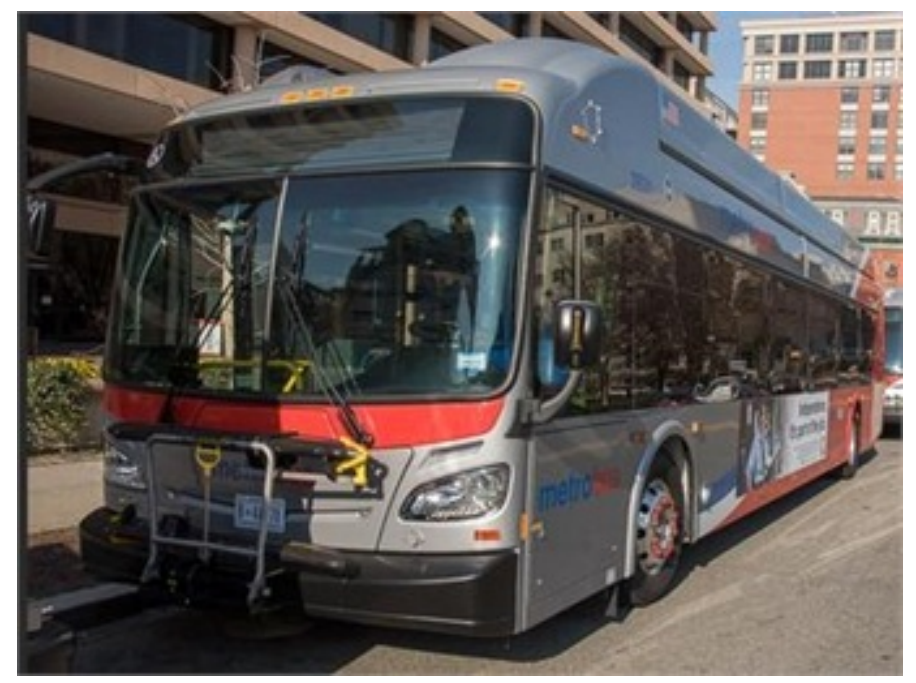

Figure XBT Washington, DC 1

Metro Express XBT

Source: https://www.metro-magazine.com/sustainability/news/411615/d-c-metro-debuts-cngbuses-for-the-holidays

The Metrobus Express service is Washington, D.C.'s express bus system. It provides an estimated time savings of $15-20 \%$ for all riders. Limited stops on the line mean less time spent in traffic. ${ }^{93}$

${ }^{93}$ Adapted from: https://ddot.dc.gov/page/metrobus-express-service. 


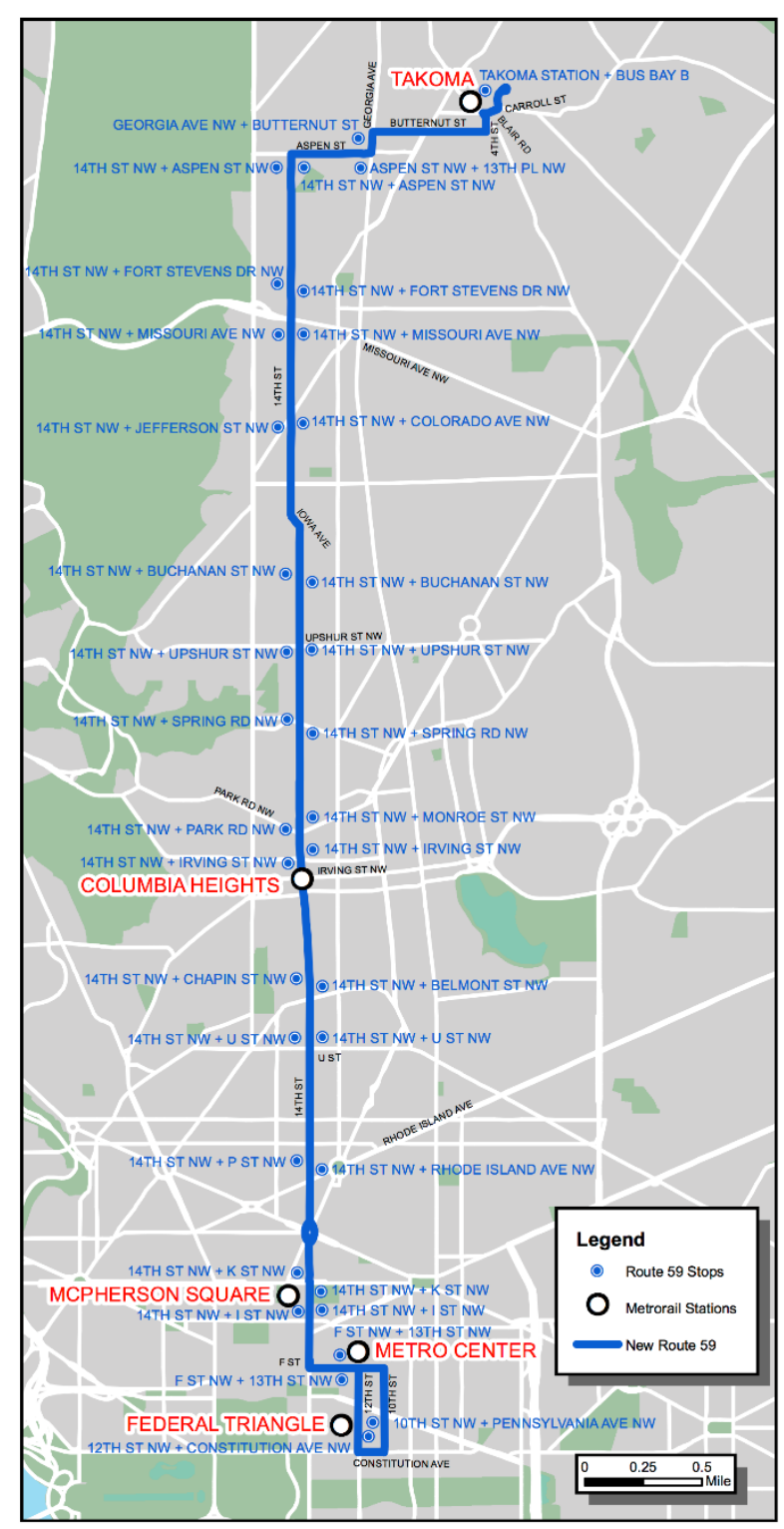

Figure XBT Washington, DC 2

Metro Express Bus Service Map

Source: https://www.wmata.com/service/bus/metroextra.cfm 


APPENDIX A - HRT
HEAVY RAIL TRANSIT SYSTEMS (reserved for future analysis)
\begin{tabular}{llllll} 
Heavy Rail Transit Systems Metro Area \& & & & \multicolumn{3}{l}{ Riders } \\
Name & Year & Miles & Stations & (Daily) \\
Atlanta: MARTA Heavy Rail & 1975 & 48 & 38 & 231,700 \\
Miami: Metrorail & 1984 & 24.4 & 23 & 67,000 \\
Washington, DC: Washington Metro & 1976 & 117 & 91 & 612,652
\end{tabular}


ATLANTA HEAVY RAIL SYSTEM

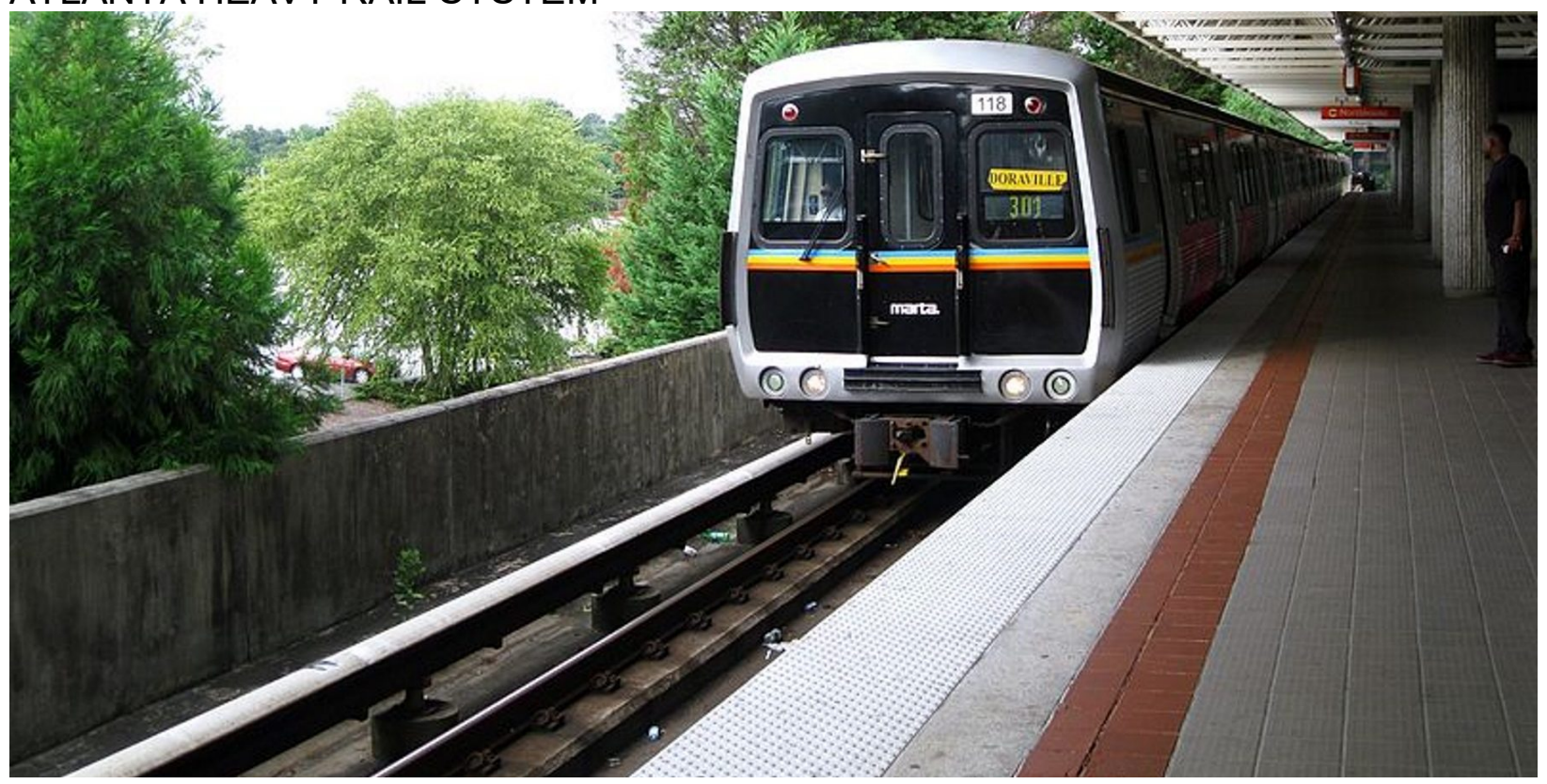

Figure $X$

Atlanta Heavy Rail

Source: https://www.wabe.org/unprecedented-gwinnett-transit-plan-includes-heavy-rail/

The heavy rail system in Atlanta, Georgia consists of 48 miles of track, a fleet of 338 rail cars, and service to 38 stations within Fulton, Dekalb, and Clay counties including the city of Atlanta. The heavy rail system in Atlanta operates at less than or equal to 10 minutes between trains during peak travel times and can take up to 576 passengers in one six-car train. The heavy rail service operates for 21 hours a day every day of the week. ${ }^{94}$

\footnotetext{
${ }^{94}$ Adapted from:

https://www.itsmarta.com/uploadedfiles/10.04.18_ServiceStandardsFY19_BoardApproved.pdf
} 


\section{merta - I METROPOLITAN ATLANTA RAPID TRANSIT AUTHORITY}

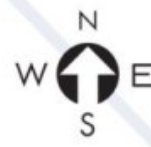
Green Lin Blue Line

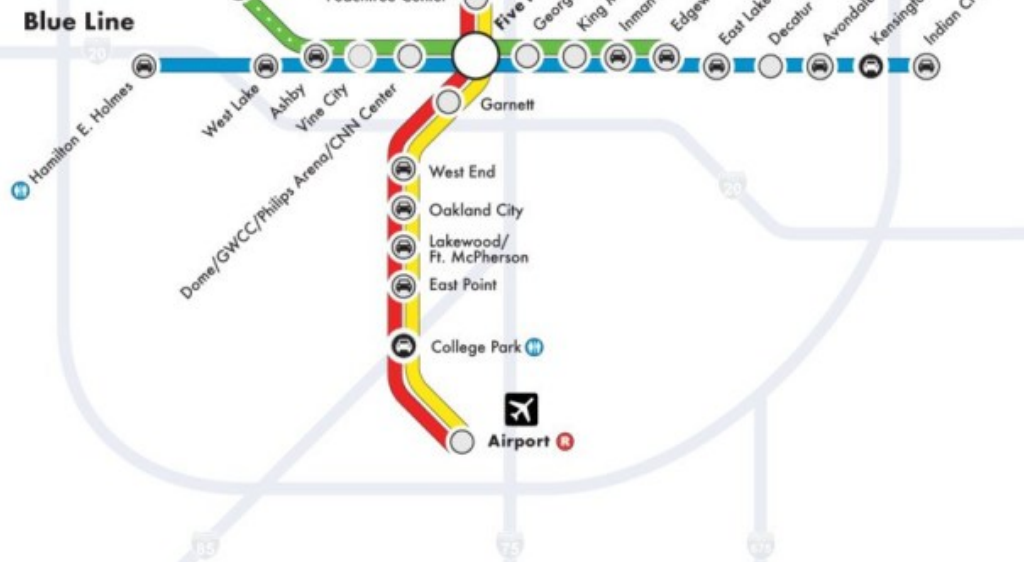

unw.itsmarta.com 404-848-5000 TTY: 404-848-5665 Accessible Format: 404-848-5202

\section{RAILMAP}

\section{Legend}

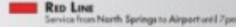

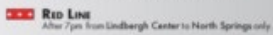

$\square$ Gow Lima

Thus los

$\square$ Intessian Hionwars

- Gank Lag

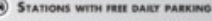

- Stanons wint

(1) Stanions wita astrooms

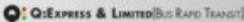

O Marta Riostone
. Aarpon Stanion - Five Porers Stranow.

O Rlovad Fan Oma - Lmosear Canre Siarions Fivi Poners Stancen

O Lost a Founo

- Five Poiness Stration

Regional Connections

7. Coss Communart Teness

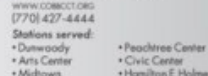

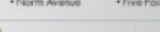

24. Owmoner Counrr Teanser Trobiz2s:on

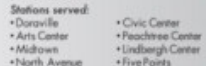

Oom- GRTA Xmess

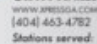

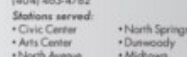

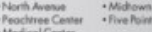

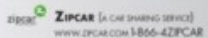

$\Rightarrow$ Antrex

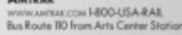

A Garnowno Bus Las/Sounasurnen Sraces

(1) Hearsina-jacrso

Figure $X$

Atlanta Heavy Rail Service Map

Source: https://www.transitmap.net/marta-atlanta/ 


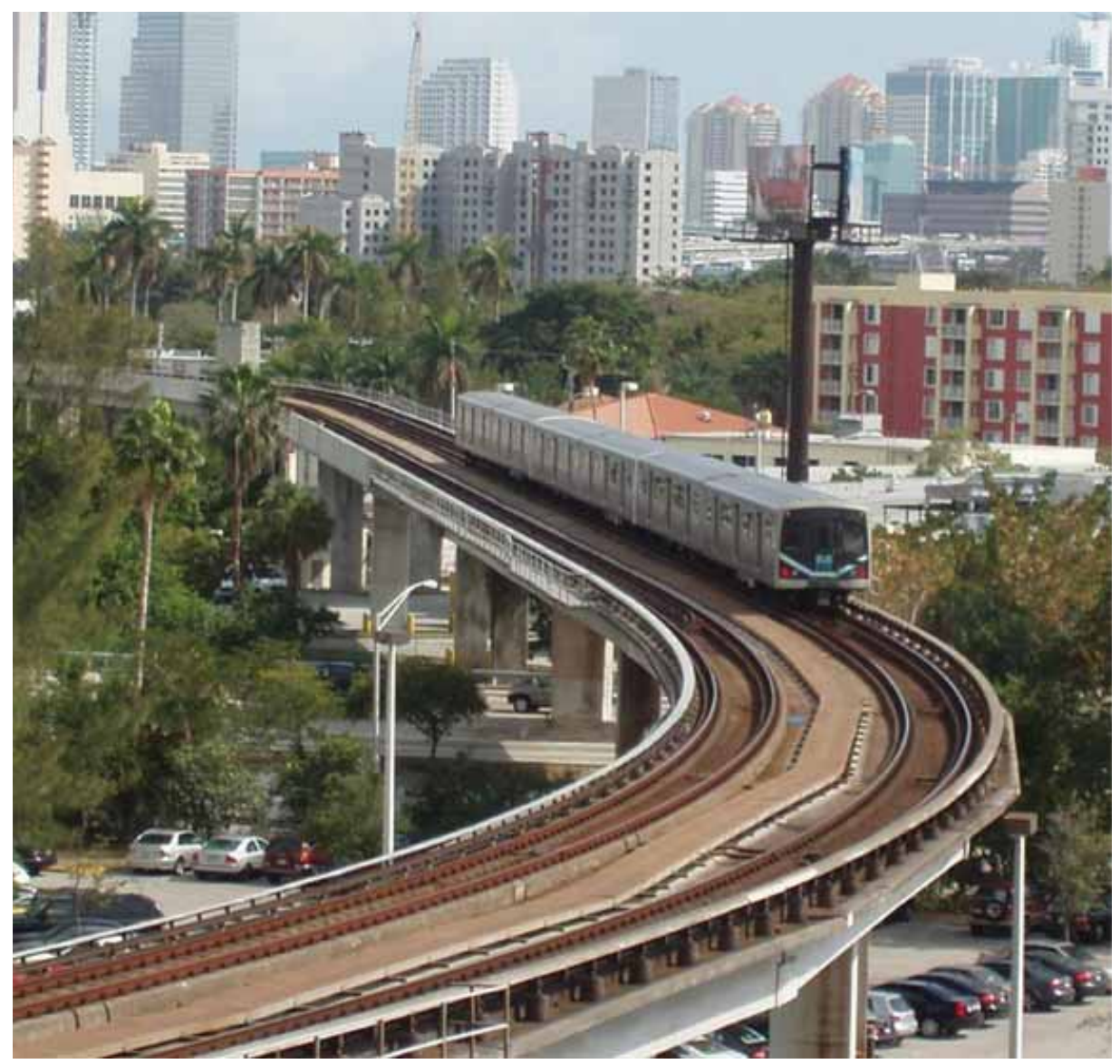

\section{Figure $\mathrm{X}$}

Miami Metrorail

Source: http://www.subways.net/usa/florida/miami.html

The Metrorail, opened in 1984, is Florida's only heavy rail system, and its only rapid rail commuter system. In its 24.4 miles of track, it has 23 stations and serves approximately 67,000 people per day. Metrorail links the Miami International Airport, the Miami Civic Center, Downtown Miami, and Brickell with extensions to northern and southern neighborhoods. With a top speed of 58 miles per hour, the Metrorail typically travels at about $27-31$ miles per hour. ${ }^{95}$

${ }^{95}$ Source: https://en.wikipedia.org/wiki/Metrorail_(Miami-Dade_County) 


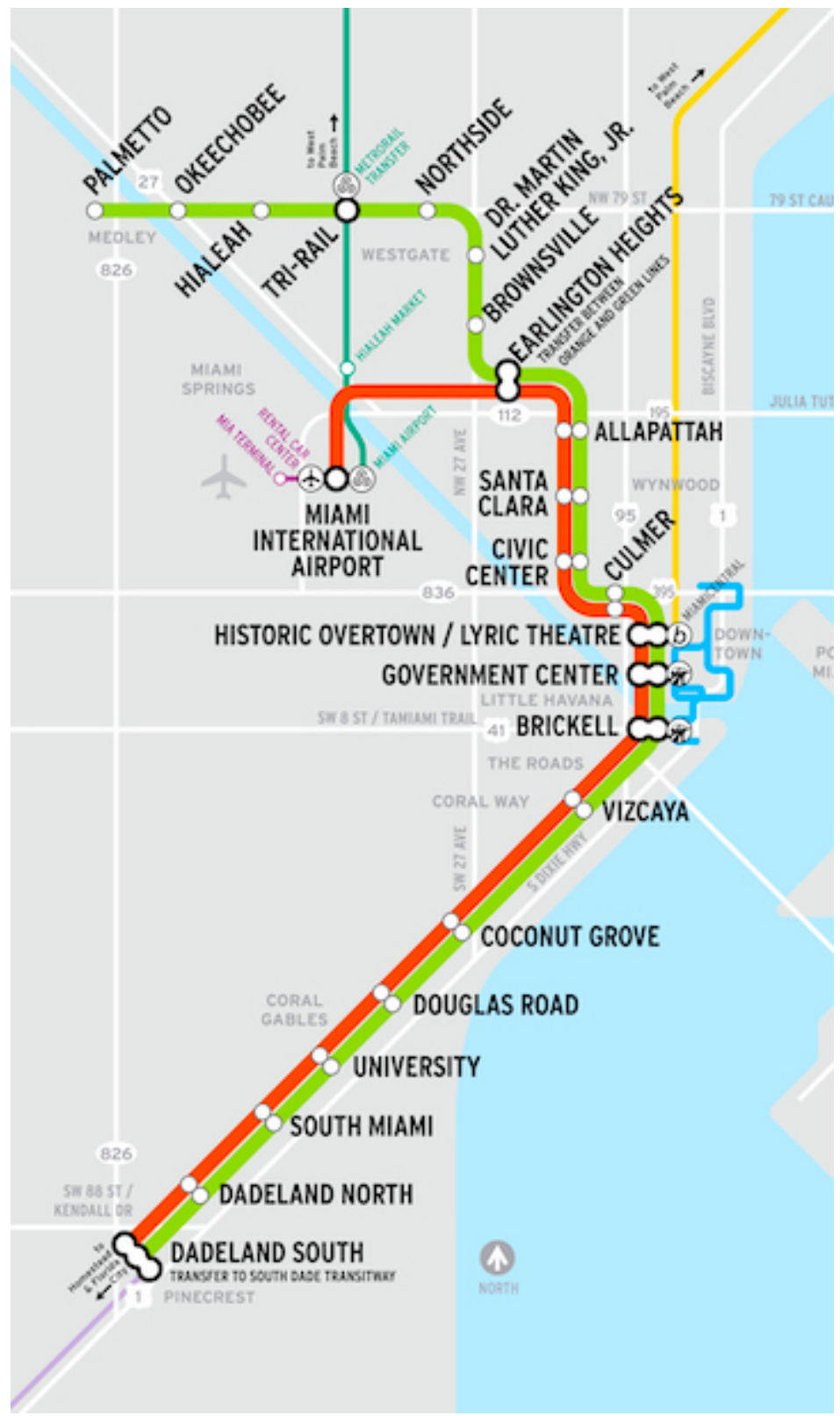

Figure $X$

Metrorail Service Map

Source: https://www8.miamidade.gov/transportation-publicworks/metrorail-stations.asp

WASHINGTON, D.C. HEAVY RAIL SYSTEM 


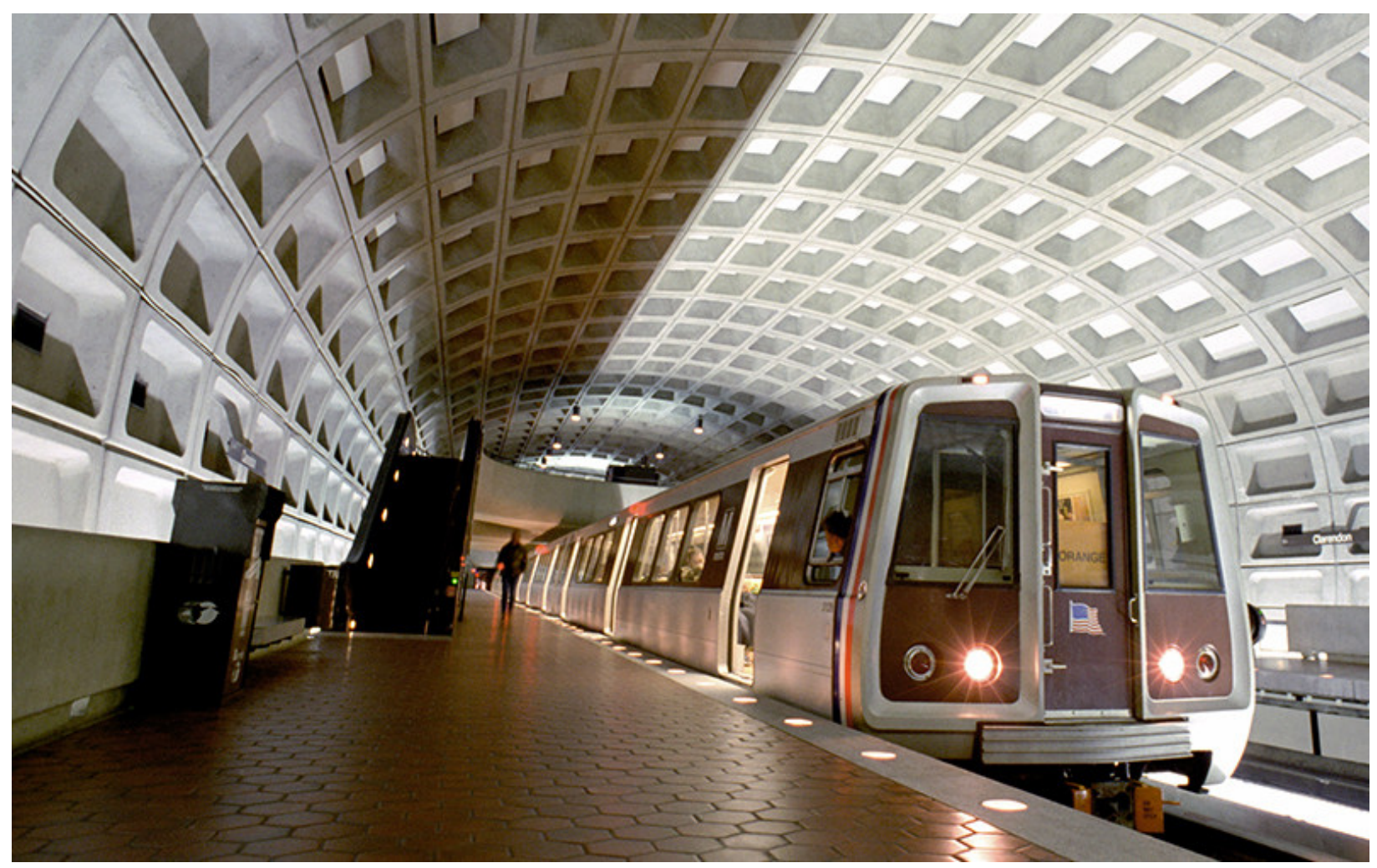

Figure $\mathrm{X}$

Washington Metro

Source: https://washington.org/find-dc-listings/washington-metropolitan-area-transit-authority Cocooned in a series of brutalist stations, Washington D.C.'s Metro serves the D.C. metro area in Maryland, Virginia, and within Washington, D.C. This system carries a staggering 612,652 people on a daily basis, with service from 5:00 AM to 1:00 AM depending on the day. Metro has 6 lines serving 91 stations in the tri-state area, with seven additional stops under construction. Metro began operation in $1976 .{ }^{96}$

${ }^{96}$ Adapted from: https://en.wikipedia.org/wiki/Washington_Metro\#Hours_and_headways. 


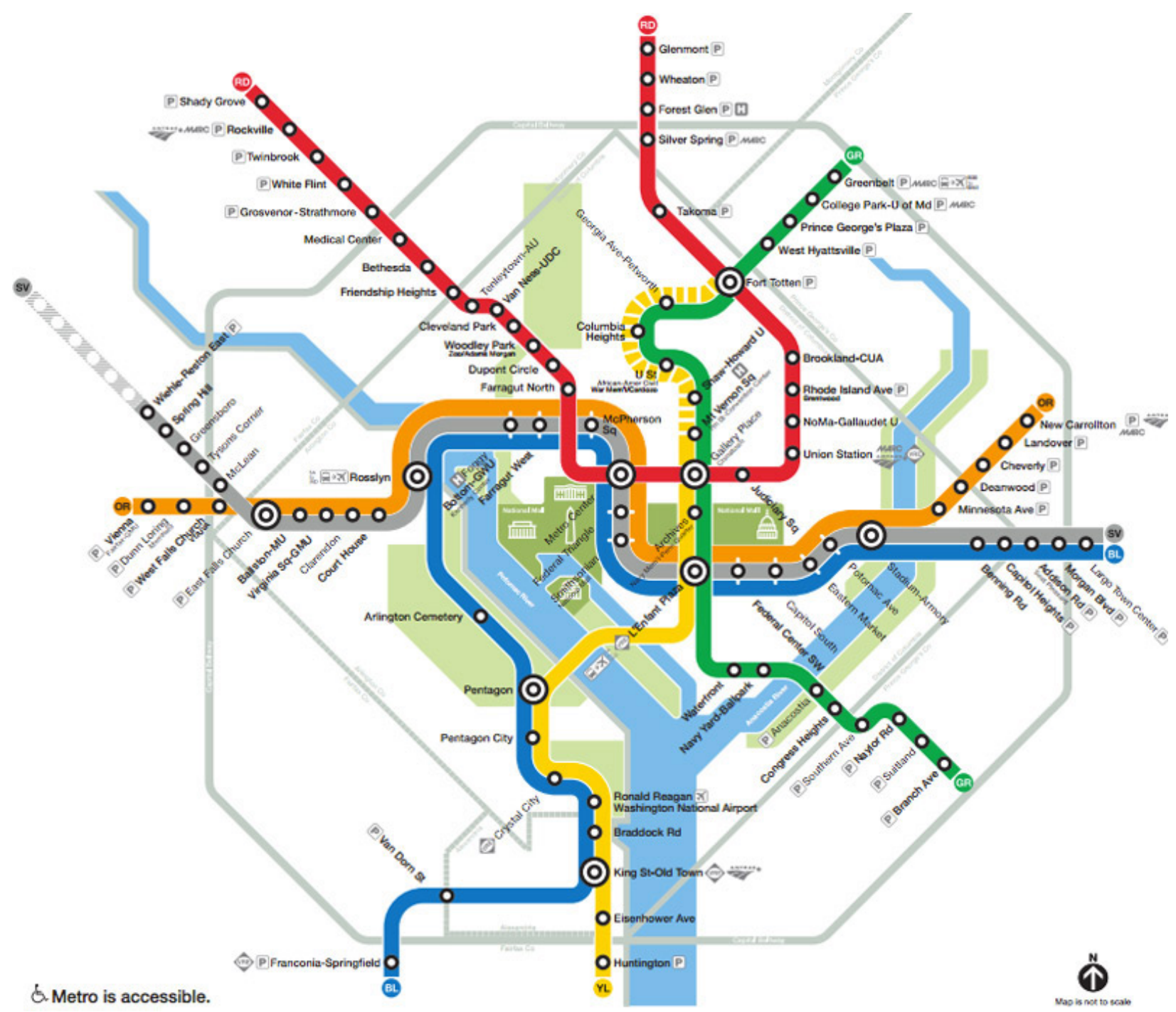

Figure $X$

Washington Metro Service Map

Source: https://washington.org/navigating-dc-met 


\section{APPENDIX B: Developing Place Typologies for Transit Analysis ${ }^{97}$}

Annotated Bibliography

The studies included here incorporate the designation of TOD typologies (or complimentary TOD studies). References from additional studies may be incorporated in the main text even if they are not included in this bibliography. The references are at the end of this appendix.

Agencies

Puget Sound Regional Council, Washington (2013-2014)

References: (Puget Sound Regional Council; City of Bellevue; King County Metro, 2013, 2014;

Sound Transit, 2014)

Transit System: 74 transit communities in Puget Sound including (aggregated) light rail, bus rapid transit and commuter rail (both existing and planned).

Purpose of Typology:

Types of Use: Agency; Strategy Identification \& Implementation; Prioritization; Evaluation; Findings \& Outcomes:

Strategy development using place and people 'screens'

Established to support various 'implementation approaches'-bundled strategies depending on the context of place and people. This approach was developed in recognition of unique needs across different transit communities. The 'toolkit' of strategies that support each of the 8 implementation approaches provide a range of complementary options based on the unique needs and situation of the communities.

Place is a two-dimensional set of categories expressing the Physical Form + Activity/TransitOrientation (lower or higher) and change/market strength (weaker or stronger).

People is a two-dimensional set of categories expressing the social infrastructure/access to opportunity (limited or good) and change/displacement risk (low, potential, immediate).

Note:

The white paper from October 2014 completed for Sound Transit provided an issue paper on regional land use and transit planning. This document did not specify any Puget Sound analysis on station typologies, and in fact referenced the TCRP paper that included such. Instead, this document provides guidance for the ways in which high-capacity transit planning might be integrated with other forms of land use planning at a variety of scales.

\footnotetext{
97 We are pleased to acknowledge invaluable assistance in preparing this appendix as well as Chapter 1 by Nicole Iroz-Elardo.
} 
Method for Aggregating Typology:

The authors developed an equally weighted index for the supporting variables within each category. The index was then split into subcategories (such as 'lower or higher' or 'weaker or stronger') based on a combination of (a) natural breaks in the data distribution and (b) discussions with technical committees and decision-makers who are more familiar with the specific stations and locations. Minor adjustments were made for stations at the border of category thresholds.

Categories \& Supporting Variables or Definitions:

The authors and technical teams recognized that typologies that rely on place alone ignore the broader context of the locations and markets. That's why a 'people' screening was included. The following tables and graphics were pulled from the Appendix D document (Puget Sound Regional Council; City of Bellevue; King County Metro, 2014).

Page 7

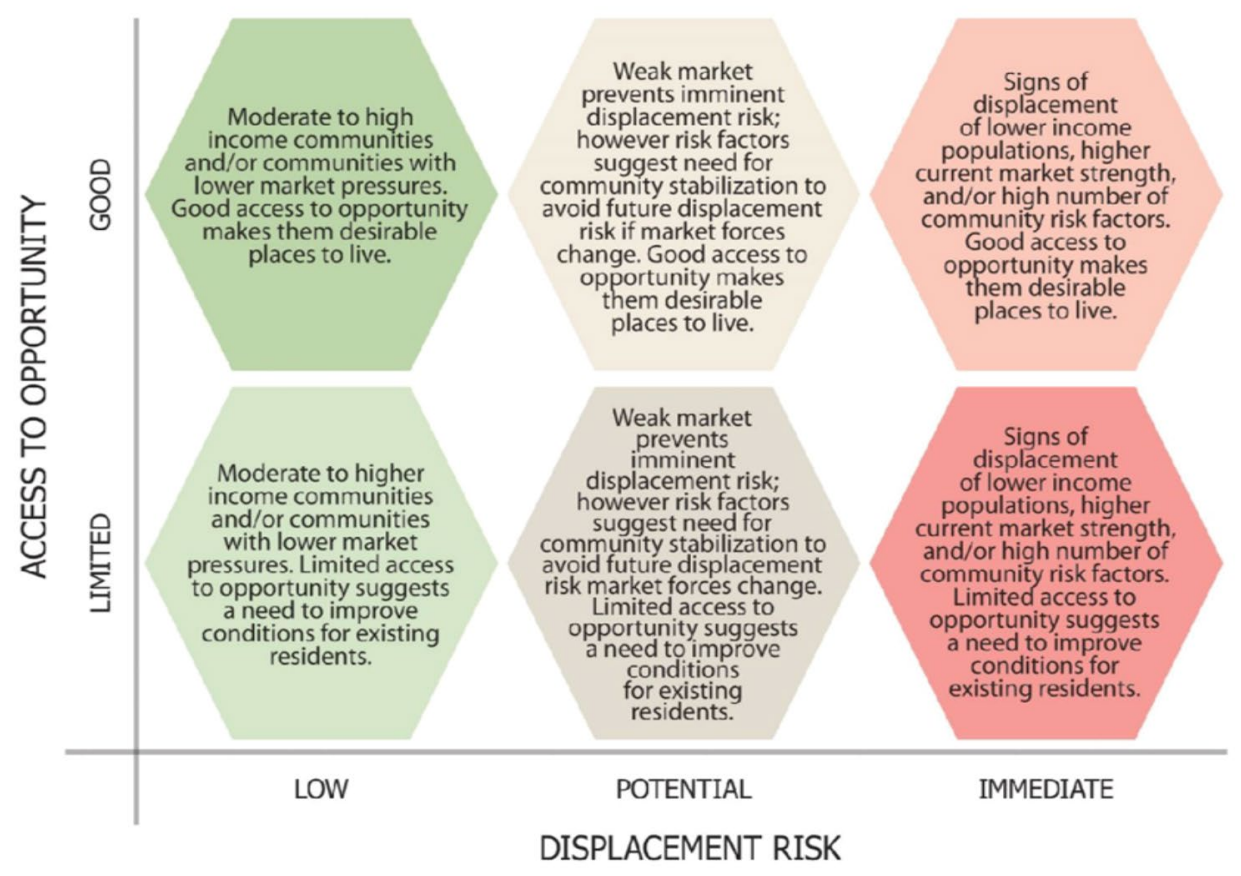

Figure 4: People Profile Community Descriptions

Page 15 


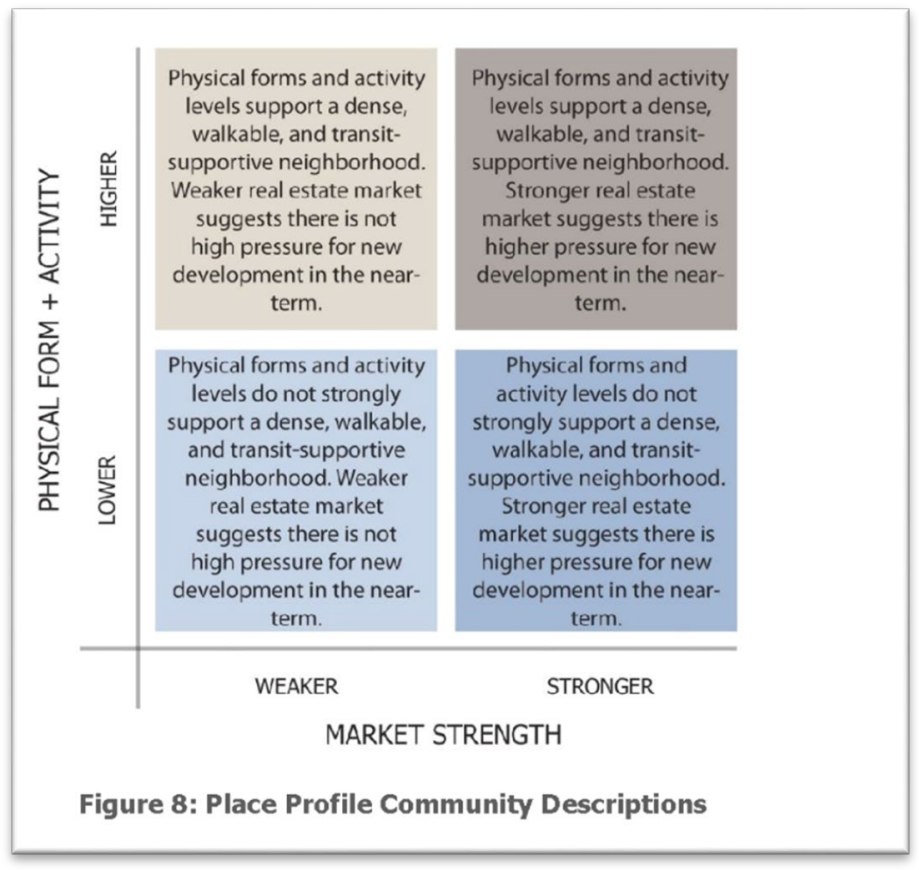

Page 8 access to opportunity 


\begin{tabular}{|c|c|c|}
\hline INDICES & INDICATORS & DATA SOURCES \\
\hline $\begin{array}{l}\text { Access to quality } \\
\text { education measures } \\
\text { the quality of the } \\
\text { elementary and high } \\
\text { school resources } \\
\text { within, or in close } \\
\text { proximity of the study } \\
\text { area }\end{array}$ & $\begin{array}{l}\text { - Fourth grade WASL scores for math } \\
\text { - Fourth grade WASL scores for reading } \\
\text { - Percentage of elementary school students receiving free or } \\
\text { reduced lunch } \\
\text { - Percentage of elementary school teachers with a master's } \\
\text { - } \text { degree or higher } \\
\text { - High school graduation rate }\end{array}$ & $\begin{array}{l}\text { Washington State Report Card, } \\
\text { Office of Superintendent of } \\
\text { Public Instruction (OSPI), 2010- } \\
2011 \text { school year } \\
\text { (Data comes from the } 3 \text { schools } \\
\text { closest to the census tract) }\end{array}$ \\
\hline $\begin{array}{l}\text { Economic health } \\
\text { measures the access } \\
\text { to employment } \\
\text { opportunities for } \\
\text { residents of the study } \\
\text { area }\end{array}$ & $\begin{array}{l}\text { - Number of living wage jobs within a } 15 \text {-minute auto } \\
\text { commute or 30-minute transit commute of the study area } \\
\text { - Unemployment rate }\end{array}$ & $\begin{array}{l}\text { Puget Sound Regional Council } \\
\text { Travel Model (Traffic Analysis Zon€ } \\
\text { (TAZ)) and Covered } \\
\text { Employment Estimates. } \\
\text { "Searching For Work That Pays", } \\
\text { Report from Alliance for a Just } \\
\text { Society, 2008-2010; American } \\
\text { Community Survey, } 2010\end{array}$ \\
\hline $\begin{array}{l}\text { Housing and } \\
\text { neighborhood } \\
\text { quality measures the } \\
\text { condition of housing } \\
\text { and neighborhood } \\
\text { attributes that } \\
\text { contribute to a sense } \\
\text { of safety and security }\end{array}$ & $\begin{array}{l}\text { - Housing vacancy rate } \\
\text { - Estimated housing foreclosure rate } \\
\text { - Estimated rate of subprime mortgages } \\
\text { - Housing conditions regarding overcrowding and presence of } \\
\text { plumbing facilities } \\
\text { - Estimated crime rate based on personal and property crimes } \\
\text { relative to total population }\end{array}$ & $\begin{array}{l}\text { US Census, 2010; HUD, 2010; } \\
\text { Tetrad Computer Applications, } \\
\text { Inc. } 2010\end{array}$ \\
\hline $\begin{array}{l}\text { Mobility and } \\
\text { transportation } \\
\text { measures the access } \\
\text { and availability of } \\
\text { affordable } \\
\text { transportation choices }\end{array}$ & $\begin{array}{l}\text { - Cost of the average auto commute to work from study area } \\
\text { at } \$ 0.50 \text { per mile } \\
\text { - Percentage of study area within } 1 / 4 \text { mile of express bus } \\
\text { stops ( } 15 \text { min headways, peak hours) } \\
\text { - Average transit fare for commute to work from study area } \\
\text { - Percentage of commute trips by walking }\end{array}$ & $\begin{array}{l}\text { Puget Sound Regional Council } \\
\text { Travel Model, 2010; PSRC data } \\
\text { collected from Transit Agencies, } \\
\text { 2008-2010; American } \\
\text { Community Survey, } 2010\end{array}$ \\
\hline $\begin{array}{l}\text { Health and } \\
\text { environment } \\
\text { measures the degree } \\
\text { to which the } \\
\text { community's attributes } \\
\text { promote or diminish } \\
\text { physical health }\end{array}$ & $\begin{array}{l}\text { - Number of acres of parks or open space within the study } \\
\text { area } \\
\text { - Proximity of study area to toxic waste emitting location } \\
\text { - Percentage of the study area that is in a 'food desert' } \\
\text { without access to retail selling fresh and healthy groceries }\end{array}$ & $\begin{array}{l}\text { PSRC, 2006; EPA, 2010; PSRC } \\
\text { Food Policy Council \& UW Report } \\
2011\end{array}$ \\
\hline
\end{tabular}


Page 11 displacement risk data

MEASURES INDICATORS DATASOURCES

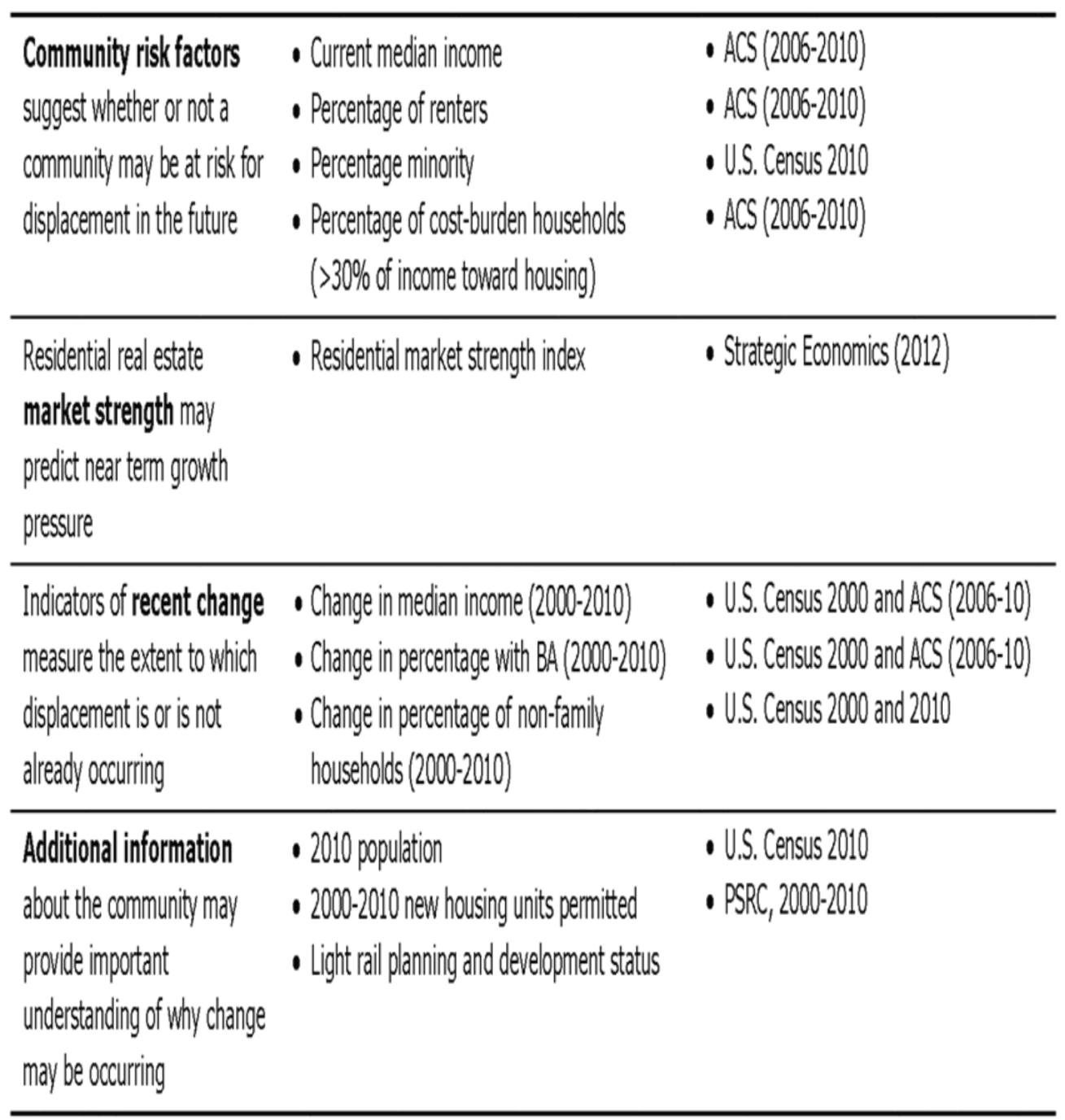

Notes: Recent trends in income, educational attainment, and household status are derved from a comparison of data for selected blocks and block groups that approximate the 74 study areas. Minor differences in geography exist between the 2000 and 2010 Censuls, most recent American Community Sunvey (ACS) data, and block groups. All ACS data represents an average over the $2006-2010$ repoting period, Income figures have been controlled to 2010 dollars. 
Page 16 physical form + activity data

INDICES

INDCATORS

DATASOUREES

Pedestrian connectivity measulues the - Estimated percentage of existing road network PSRC, WSDOT, Community

degree to which the community has

the infrastructure to support high

with sidewalk coverage on at least one side of

the road.

Transit, Cities of Bellevue,

pedestrian activity

Lynnwood, Mountlake

Terrace, Shoreline, Seatlle,

Mercer Island, Bellevue,

Redmond, Tacoma, and

Tukwila.

Transit performance measules the

- Total number of weekday dally core and high

PSRC, Metro, Community

avallability of cove and high capacity capacity transit runs through the study area

Transit, Everett Transit, transit service within the community

- Total number of non-peak (midday, after 7pm, Sound Transit, and Pierce all day Saturday and all day Sunday) runs Transit. through the study area

Physical form measures the degree - Average block size in acres

PSRC, U.S. Census

the physical structure of the street grid - Percentage of study area within the haff-mile

suppots smaller scale land-uses, and wakshed

walking and biking activity

Population measures the level of - Total number of people living in the study area 2010 Census'; PSRC;

activity of people in the study area

- Total number of covered jobs in the study area Washington State

- Total number of full-time students enrolled at Employment Security colleges or universities within the study area Dept: PSRC

Proximity measures the availability of - Total number of retall and food service PSRC; Wastington State

a mix of uses that support a vibrant, workplaces within study area

Employment Security Dept.

wakable community 
Page 18

Table 6: Market Strength Data Measures

\begin{tabular}{lll} 
MEASURES & INDICATORS & DATA SOURCES \\
\hline $\begin{array}{l}\text { Real Estate Market measures } \\
\text { provide insight into existing and } \\
\text { future market strength. }\end{array}$ & $\begin{array}{l}\text { - Planned and proposed new housing } \\
\text { units } \\
\text { - Home sales } \\
\text { - Apartment rents and vacancy rates } \\
\text { - Condominium sales price }\end{array}$ & $\begin{array}{l}\text { Units in pipeline: 2012 - 2014 Dupre and } \\
\text { Scott; Gardner Economics }\end{array}$ \\
$\begin{array}{lll}\text { Home sales: 2005-2012 Dupre and Scott; } \\
\text { Gardner Economics } \\
\text { Rental data: 2012 Dupre and Scott; Gardner } \\
\text { Economics }\end{array}$ \\
\hline $\begin{array}{l}\text { Employment patterns } \\
\text { measures of proximity to } \\
\text { employment as a major factor } \\
\text { influencing residential demand. }\end{array}$ & $\begin{array}{l}\text { - Commute distance to major } \\
\text { employment centers } \\
\text { change over time) }\end{array}$ & $\begin{array}{l}\text { U.S. Census Longitudinal Employer-Household } \\
\text { Dynamics Data (2009) }\end{array}$ \\
\hline $\begin{array}{l}\text { Density measures indicate } \\
\text { market strength for and } \\
\text { community acceptance of } \\
\text { multifamily or compact housing. }\end{array}$ & $\begin{array}{l}\text { - Household density } \\
\text { - Current inventory housing unit } \\
\text { density }\end{array}$ & 2000, 2010 State of Washington; PSRC \\
\hline $\begin{array}{l}\text { Several household } \\
\text { characteristics are correlated } \\
\text { with stronger demand for new } \\
\text { residential development, } \\
\text { especially around transit. }\end{array}$ & - Household income & 2012 Dupre and Scott; Gardner Economics \\
\hline
\end{tabular}

Other Notes:

Page 51 "Many station area typologies developed in other regions have described the current or aspirational physical characteristics of different transit communities. An implementation typology, on the other hand, classifies transit communities according to the types of strategies that will be most meaningful to help achieve desired outcomes."

Implementation approach categories

Emerging or strong real estate demand, capitalize on potential in investing in housing, employment and public amenities, increase equity and opportunity

Protect and grow

Expand housing choices

Improve access

Transform and diversify

Medium- to long-term growth potential based on current market demand, focus on the market catalysts, long-range planning, economic/community development

Stimulate demand

Build urban places

Enhance community

Regional job centers where residential growth is limited, but access for jobs is important Preserve and connect 
St. Louis, Missouri (2013)

References: (Design Workshop, 2013)

Transit System: considers full set of modes from 'high-capacity regional rail and bus', to BRT and local-serving bus. Distinguishes between local and regional; high-capacity; high/low frequency.

Purpose of Typology:

Types of Use: Agency; Design or Land Use; Common Vocabulary; Strategy Identification \& Implementation

Findings \& Outcomes: categories are used to recognize how TODs vary across a region, partially used to categorize design typologies

Method for Aggregating Typology:

Notes: No methodology was discussed. It appears these general descriptions may have been pulled from other network design typologies elsewhere.

Categories \& Supporting Variables or Definitions:

Notes: Categories from top to bottom of the table generally indicate the intensity level from high to low. The following table is from Chapter 4 in the plan (Design Workshop, 2013, p. 63). All serve transit types "Special, LRT, BRT, Commuter rail, express and local bus hub" at varying levels.

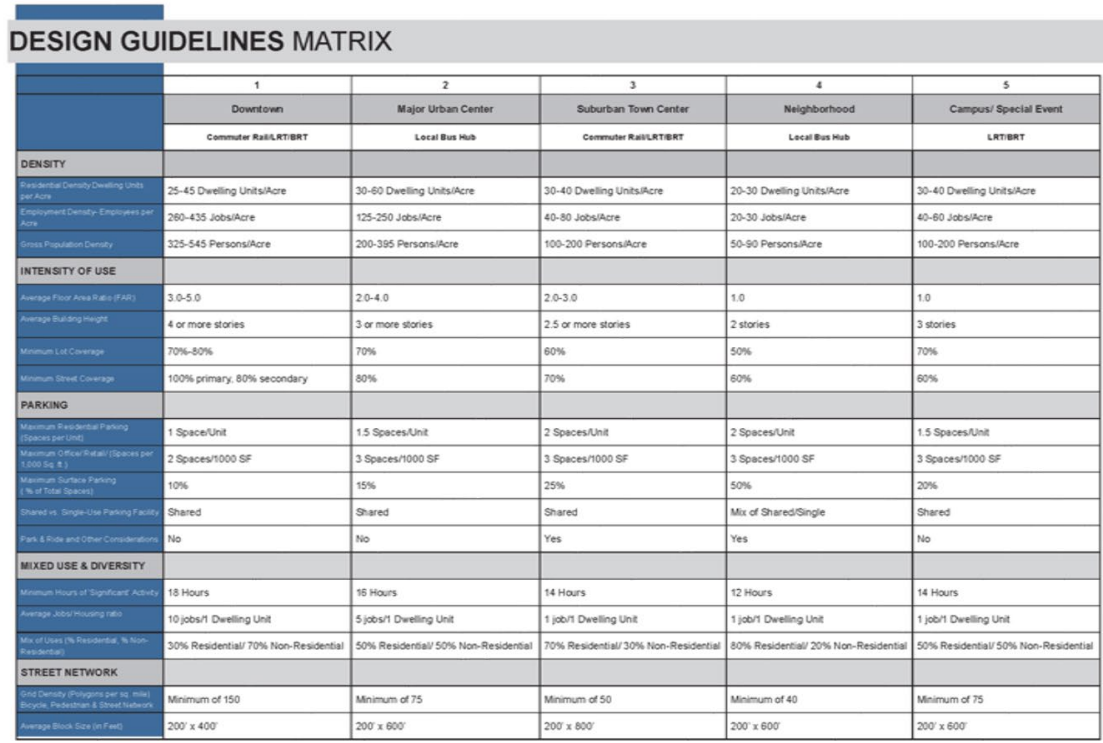

\section{Other Notes:}

This document provides simple descriptions of the typologies and then classifies example stations and provides some similar stations external to St. Louis.

The document also cites Nelson/Nygaard (2013) in 'minimum supportive density thresholds', which may be useful in evaluation.

Maybe this citation? Years don't line up: NelsonlNygaard Consulting Associates. "Rhode Island Avenue Parking Analysis, Technical Memorandum \#1," prepared for the US EPA and DC Office of Planning. 2003. 
(Design Workshop, 2013, p. 57) Chapter 4

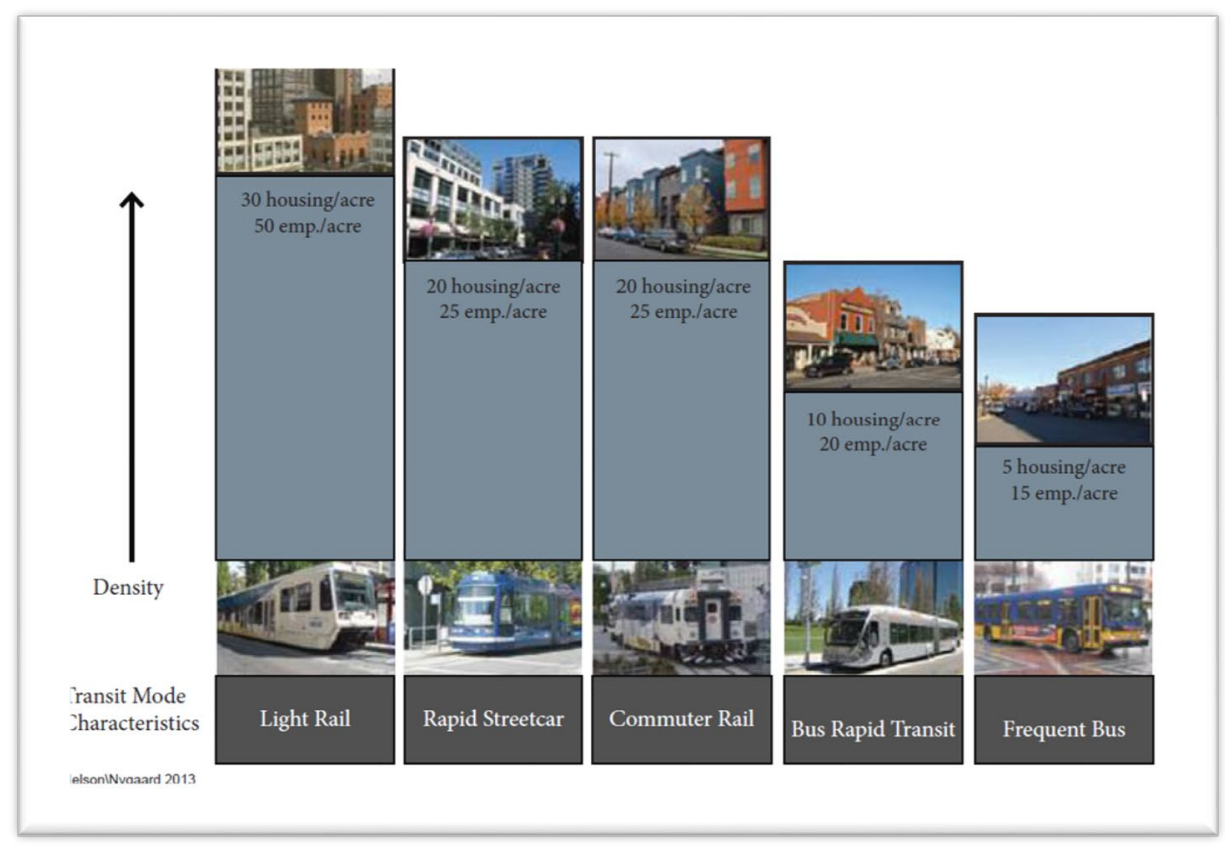

They also include some crosswalks that describe square feet/FAR/acre per employee based on a report by Southern California Council of Governments. This can be used to link employee density with SQFT or acreage per land use type. (Ch. 4; page 58-59)

Reference: Southern California Council of Governments. Employment Density Study. October 2001 


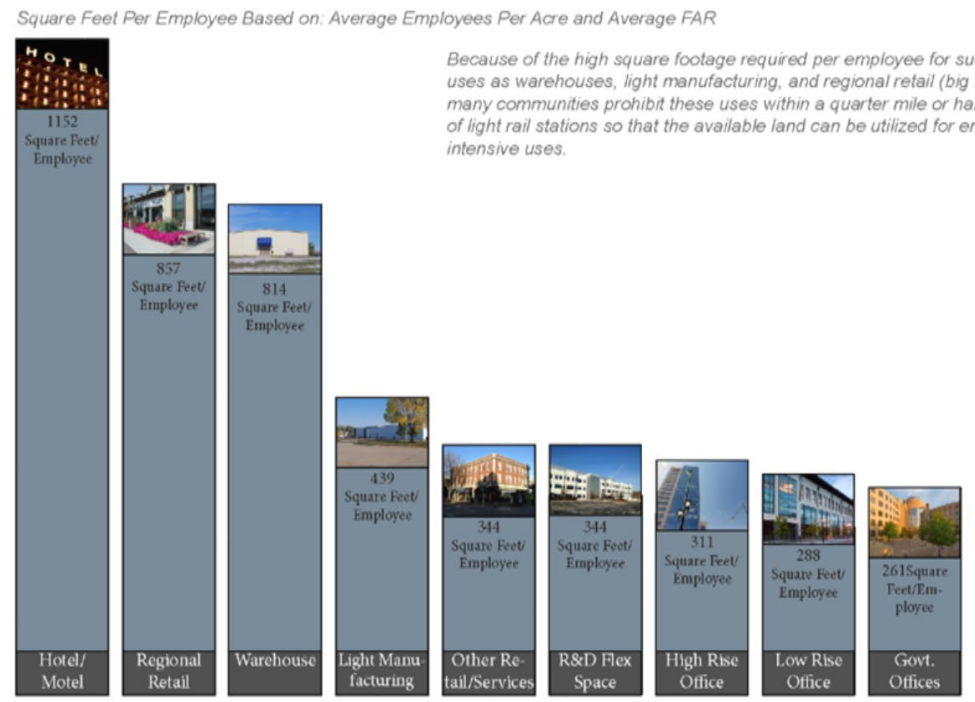

Square Feet Per Employee Based on: Floor Area Ratio

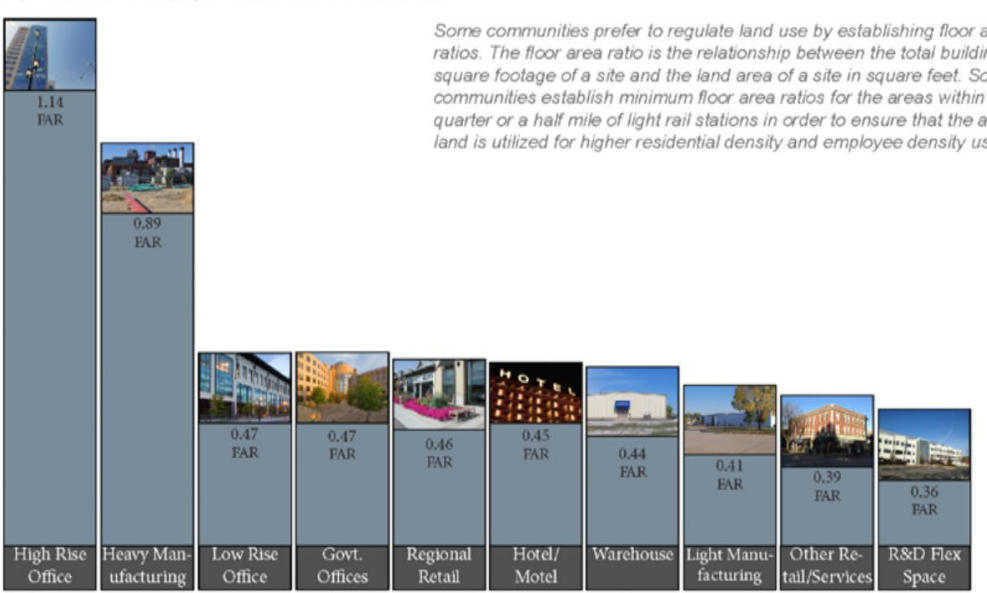




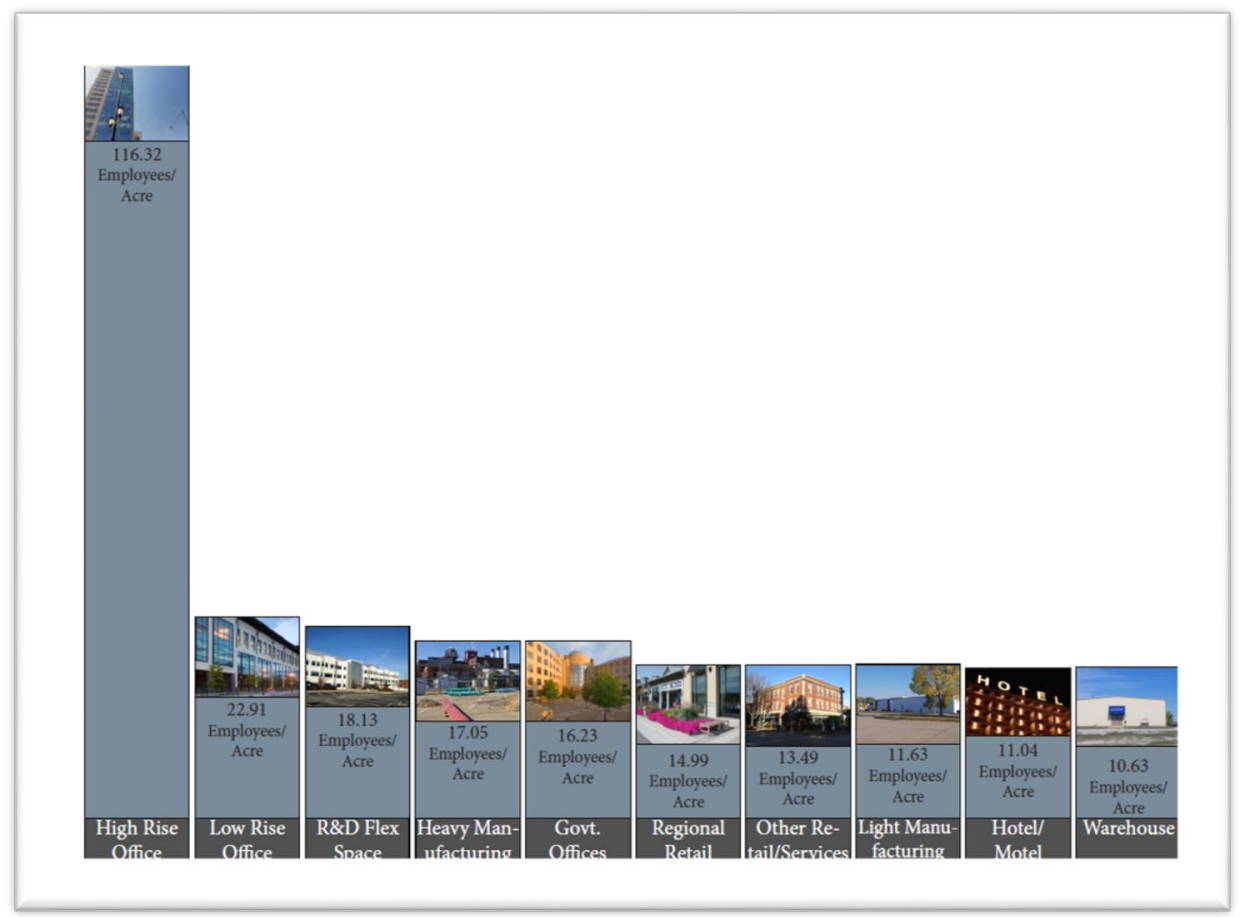


Arizona Department of Transportation (2012)

References: (Arizona Department of Transportation, 2012)

Transit System: Mostly commuter and intercity rail planning with discussion about multimodal supportive infrastructure.

Purpose of Typology:

Types of Use: Agency; Design or Land Use; Common Vocabulary;

Findings \& Outcomes: This is an early-stage typology used for developing and collecting attitudes, concerns, and other initial planning approaches. No existing or planned sites were identified (in general and using this typology).

Method for Aggregating Typology:

Notes: No clear method for distinguishing typology. This appears to be the outcome of a longer process for distinguishing regional passenger rail opportunities/potential (see:

https://www.azdot.gov/planning/transportation-studies/PassengerRail/library).

Categories \& Supporting Variables or Definitions:

Notes: This report identifies the scale of station area orientation as follows (page 1)

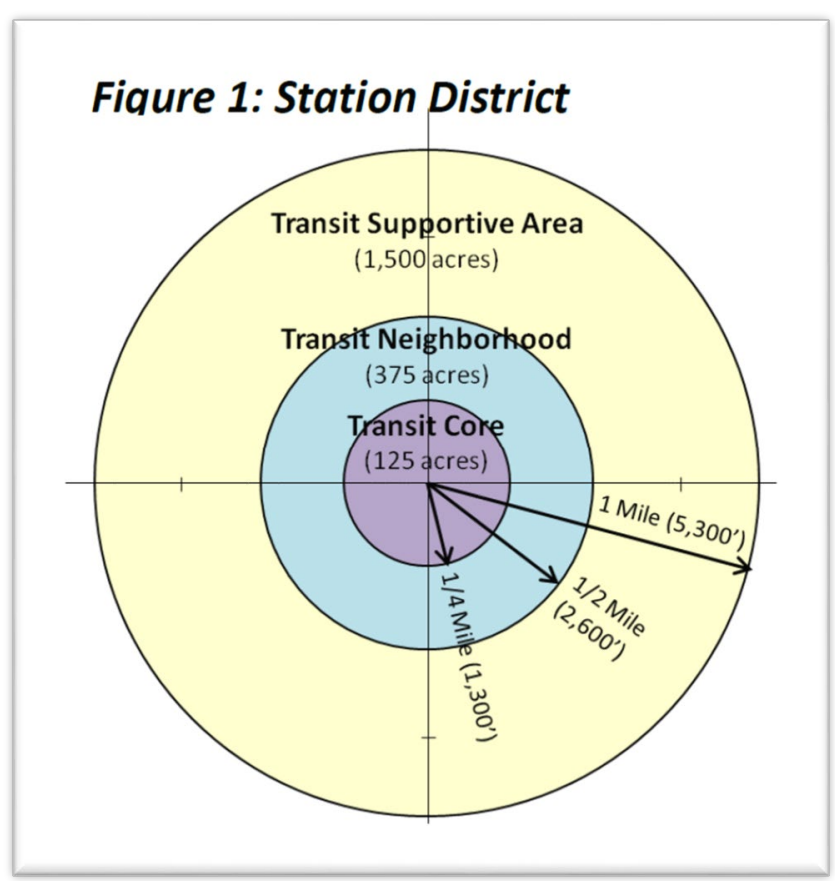

Top to bottom reflects general intensity level spectrum. Below is the general description of each of the four area types in the ADOT report (page 3): 


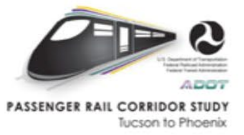

Table 1: Station Area Typology Overview

\begin{tabular}{|c|c|c|c|c|c|}
\hline Station Type & Typical Urban Setting & $\begin{array}{c}\text { Employment/ Commercial } \\
\text { Land Use Types }\end{array}$ & $\begin{array}{c}\text { Residential Land Use } \\
\text { Types }\end{array}$ & $\begin{array}{c}\text { Transit } \\
\text { Patronage Area }\end{array}$ & $\begin{array}{c}\text { Typical Transportation Modes } \\
\text { and Parking Types }\end{array}$ \\
\hline System Hub & $\begin{array}{l}\text { Downtown/ center of } \\
\text { metropolitan area }\end{array}$ & $\begin{array}{l}\text { Primary office, government, } \\
\text { and cultural/sports/ } \\
\text { entertainment center with } \\
\text { supportive retail and } \\
\text { services }\end{array}$ & $\begin{array}{l}\text { High-density, multi- } \\
\text { family housing }\end{array}$ & 15 to 25 miles & $\begin{array}{l}\text { Intermodal facility/transit hub; } \\
\text { Major regional destination with } \\
\text { high- quality feeder transit (light } \\
\text { rail, streetcar, bus, circulator); } \\
\text { Potential park-and-ride location } \\
\text { with structured parking } \\
\text { integrated into mixed use } \\
\text { development. }\end{array}$ \\
\hline Regional Station & $\begin{array}{l}\text { Subregional downtown or } \\
\text { major employment } \\
\text { center }\end{array}$ & $\begin{array}{l}\text { Regional employment hub } \\
\text { and major activity center } \\
\text { (retail, services, education, } \\
\text { medical, entertainment) }\end{array}$ & $\begin{array}{l}\text { Mid-to high-density } \\
\text { residential, often as part } \\
\text { of mixed-use } \\
\text { developments }\end{array}$ & 10 to 15 miles & $\begin{array}{l}\text { May be a subregional destination } \\
\text { on fixed-guideway transit } \\
\text { corridor, or subregional transit } \\
\text { center with high quality feeder } \\
\text { bus service, including local } \\
\text { activity center circulator; } \\
\text { Potential park-and-ride location } \\
\text { with structured parking. }\end{array}$ \\
\hline Local Station & $\begin{array}{l}\text { Suburban town center, } \\
\text { master planned } \\
\text { community commercial } \\
\text { core, or historic } \\
\text { downtown of rural } \\
\text { community }\end{array}$ & $\begin{array}{l}\text { Office/service/retail } \\
\text { economic activity center, } \\
\text { potential regional } \\
\text { government service center }\end{array}$ & $\begin{array}{l}\text { Mid-density multi- } \\
\text { family, and higher } \\
\text { density single family } \\
\text { (e.g., townhouses, row } \\
\text { houses) }\end{array}$ & $\begin{array}{l}5 \text { to } 20 \text { miles } \\
\text { (Suburban) } \\
20 \text { to } 40 \text { miles } \\
\text { (Rural) }\end{array}$ & $\begin{array}{l}\text { Local activity center linked with } \\
\text { high quality feeder bus services } \\
\text { (e.g., express bus, regional fixed- } \\
\text { route bus routes); Potential park- } \\
\text { and-ride location with decked } \\
\text { parking or surface lots. }\end{array}$ \\
\hline $\begin{array}{l}\text { Transit Emergent } \\
\text { Station }\end{array}$ & $\begin{array}{l}\text { Center of a small town } \\
\text { outside a major } \\
\text { metropolitan area with } \\
\text { significant surrounding } \\
\text { growth potential }\end{array}$ & $\begin{array}{l}\text { Office/service/retail center, } \\
\text { potential civic service } \\
\text { center; often a historic } \\
\text { "Main Street" activity node }\end{array}$ & $\begin{array}{l}\text { Medium-density multi- } \\
\text { family, possibly single } \\
\text { family (e.g., row houses, } \\
\text { patio homes) }\end{array}$ & 20 to 40 miles & $\begin{array}{l}\text { Transit station with future } \\
\text { connections to local feeder bus } \\
\text { service, and regional bus transit } \\
\text { with service to adjacent } \\
\text { towns/cities; Potential park-and- } \\
\text { ride location with surface } \\
\text { parking. }\end{array}$ \\
\hline
\end{tabular}

Each category is further segmented by the station district categories:

Transit Core (<1/4 mile and 125 acres): 20 -min. walk or 5 -min. drive

Transit Neighborhoods (1/4-1/2 miles and 375 acres): 10 min. walk

Transit Supportive Area (1/2-1 miles and 1500 acres): 5 min. walk

\begin{tabular}{|c|c|c|c|c|}
\hline & System Hub & Regional Station & Local Station & $\begin{array}{l}\text { Transit Emergent } \\
\text { Station }\end{array}$ \\
\hline \multicolumn{5}{|c|}{ Desired Land Use Mix } \\
\hline Transit Core & $\begin{array}{l}<75 \% \text { emp } \\
<35 \% \text { res } \\
<10 \% \text { other }\end{array}$ & $\begin{array}{l}<70 \% \text { emp } \\
<50 \% \text { res } \\
<15 \% \text { other }\end{array}$ & $\begin{array}{l}<60 \% \text { emp } \\
<50 \% \text { res } \\
>15 \% \text { other }\end{array}$ & $\begin{array}{l}<40 \% \text { emp } \\
>60 \% \text { res } \\
>10 \% \text { other }\end{array}$ \\
\hline $\begin{array}{l}\text { Transit } \\
\text { Neighborhoods }\end{array}$ & $\begin{array}{l}<60 \% \text { emp } \\
<50 \% \text { res } \\
<15 \% \text { other }\end{array}$ & $\begin{array}{l}<60 \% \text { emp } \\
>50 \% \text { res } \\
>15 \% \text { other }\end{array}$ & $\begin{array}{l}<40 \% \text { emp } \\
>50 \% \text { res } \\
<15 \% \text { other }\end{array}$ & $\begin{array}{l}<30 \% \text { emp } \\
<80 \% \text { res } \\
>5 \% \text { other }\end{array}$ \\
\hline $\begin{array}{l}\text { Transit } \\
\text { Supportive Area }\end{array}$ & $\begin{array}{l}<40 \text { emp } \\
>60 \% \text { res } \\
>15 \% \text { other }\end{array}$ & $\begin{array}{l}<40 \% \text { emp } \\
>60 \% \text { res } \\
>15 \% \text { other }\end{array}$ & $\begin{array}{l}<303 \% \text { emp } \\
>70 \% \text { res } \\
>10 \% \text { toher }\end{array}$ & $\begin{array}{l}<20 \% \text { emp } \\
>80 \% \text { res } \\
>5 \% \text { other }\end{array}$ \\
\hline \multicolumn{5}{|c|}{ Typical Land Use Mix } \\
\hline Transit Core & $\begin{array}{l}\text { Corporate offices; gov. } \\
\text { offices; regional sports/ } \\
\text { entertainment; } \\
\text { convention/conference } \\
\text { facilities; high-rise res. }\end{array}$ & $\begin{array}{l}\text { Mid-high rise office } \\
\text { or residential; } \\
\text { gov/educational/ } \\
\text { employment/ }\end{array}$ & $\begin{array}{l}\text { Lofts/condo; mid- } \\
\text { rise res; apart./ } \\
\text { townhouse } \\
\text { complex; 'main } \\
\text { street' }\end{array}$ & $\begin{array}{l}\text { 'main street' } \\
\text { commercial/ mixed } \\
\text { use dev.; apart/ } \\
\text { townhomes; row } \\
\text { houses; gov. }\end{array}$ \\
\hline
\end{tabular}




\begin{tabular}{|c|c|c|c|c|}
\hline & & $\begin{array}{l}\text { research } \\
\text { campuses }\end{array}$ & $\begin{array}{l}\text { commercial/ } \\
\text { mixed-use dev;; } \\
\text { government } \\
\text { service center; } \\
\text { office/research } \\
\text { park }\end{array}$ & $\begin{array}{l}\text { service center; } \\
\text { garden office } \\
\text { buildings }\end{array}$ \\
\hline $\begin{array}{l}\text { Transit } \\
\text { Neighborhoods }\end{array}$ & $\begin{array}{l}\text { Mid-high rise office } \\
\text { towers; mid-high rise res.; } \\
\text { gov/educational/ } \\
\text { employment/ research } \\
\text { campuses }\end{array}$ & $\begin{array}{l}\text { ofts/ condos; mid- } \\
\text { rise res towers; } \\
\text { apart/townhomes; } \\
\text { office/research } \\
\text { park; med. } \\
\text { Facilities; lifestyle } \\
\text { retail; mixed-use } \\
\text { dev. }\end{array}$ & $\begin{array}{l}\text { Apart/townhomes; } \\
\text { row houses; } \\
\text { garden office } \\
\text { buildings; multi- } \\
\text { use developments }\end{array}$ & $\begin{array}{l}\text { Apart/townhomes; } \\
\text { row houses; } \\
\text { garden office } \\
\text { buildings; multi- } \\
\text { use dev. }\end{array}$ \\
\hline $\begin{array}{l}\text { Transit } \\
\text { Supportive Area }\end{array}$ & $\begin{array}{l}\text { Lofts/ condos; mid-rise } \\
\text { res towers; } \\
\text { apart/townhomes; } \\
\text { office/research park; med. } \\
\text { Facilities; lifestyle retail; } \\
\text { mixed-use dev. }\end{array}$ & $\begin{array}{l}\text { Apartments/ } \\
\text { townhomes; row } \\
\text { houses; } \\
\text { office/research } \\
\text { park; garden office } \\
\text { buildings; mixed- } \\
\text { use dev. }\end{array}$ & $\begin{array}{l}\text { Apart/townhomes; } \\
\text { patio home/ zero } \\
\text { lot line residential; } \\
\text { garden office } \\
\text { buildings; multi- } \\
\text { use dev. }\end{array}$ & $\begin{array}{l}\text { Patio home/zero } \\
\text { lot line res.; row } \\
\text { houses; garden } \\
\text { office buildings; } \\
\text { multi-use dev. }\end{array}$ \\
\hline \multicolumn{5}{|c|}{ Typical Building Heights (stories } \\
\hline Transit Core & $10+$ & $5+$ & $4+$ & $2+$ \\
\hline $\begin{array}{l}\text { Transit } \\
\text { Neighborhoods }\end{array}$ & $6+$ & $4+$ & $3+$ & $2+$ \\
\hline $\begin{array}{l}\text { Transit } \\
\text { Supportive Area }\end{array}$ & $4+$ & $2+$ & $2+$ & 1 \\
\hline \multicolumn{5}{|c|}{ Average Employment Density (Floor to Area Ratio; FAR) } \\
\hline Transit Core & $3.0-5.0$ & $1.0-3.0$ & $0.5-1.0$ & $0.5-1.0$ \\
\hline $\begin{array}{l}\text { Transit } \\
\text { Neighborhoods }\end{array}$ & $1.5-3.0$ & $0.5-1.0$ & $0.35-0.5$ & $0.25-0.5$ \\
\hline $\begin{array}{l}\text { Transit } \\
\text { Supportive Area }\end{array}$ & $0.5-1.5$ & $0.35-0.5$ & $0.25-0.35$ & $0.15-0.25$ \\
\hline \multicolumn{5}{|c|}{ Average Residential Density (Dwelling units per acre) } \\
\hline Transit Core & $100+$ & $50-100$ & $25-50$ & $15-35$ \\
\hline $\begin{array}{l}\text { Transit } \\
\text { Neighborhoods }\end{array}$ & $50-100$ & $25-50$ & $18-25$ & $10-25$ \\
\hline $\begin{array}{l}\text { Transit } \\
\text { Supportive Area }\end{array}$ & $25-50$ & $18-25$ & $8-18$ & $8-12$ \\
\hline \multicolumn{5}{|l|}{ Parking Types } \\
\hline Transit Core & Multi-story & Multi-story & $\begin{array}{l}\text { Multi-story or } \\
\text { parking deck }\end{array}$ & $\begin{array}{l}\text { Surface lot with } \\
\text { plans for } \\
\text { structured } \\
\text { parking deck }\end{array}$ \\
\hline $\begin{array}{l}\text { Transit } \\
\text { Neighborhoods }\end{array}$ & Multi-story & $\begin{array}{l}\text { Multi-story or } \\
\text { parking deck }\end{array}$ & Surface Lot & Surface Lot \\
\hline $\begin{array}{l}\text { Transit } \\
\text { Supportive Area }\end{array}$ & $\begin{array}{l}\text { Short term: surface lot } \\
\text { Long term: parking } \\
\text { deck }\end{array}$ & $\begin{array}{l}\text { Short term: } \\
\text { surface lot } \\
\text { Long term: } \\
\text { parking deck }\end{array}$ & Surface Lot & Surface Lot \\
\hline
\end{tabular}

This document also includes some fairly extensive descriptions of 'supportive transit' networks (see image of table below, from page 11 of (Arizona Department of Transportation, 2012)). 


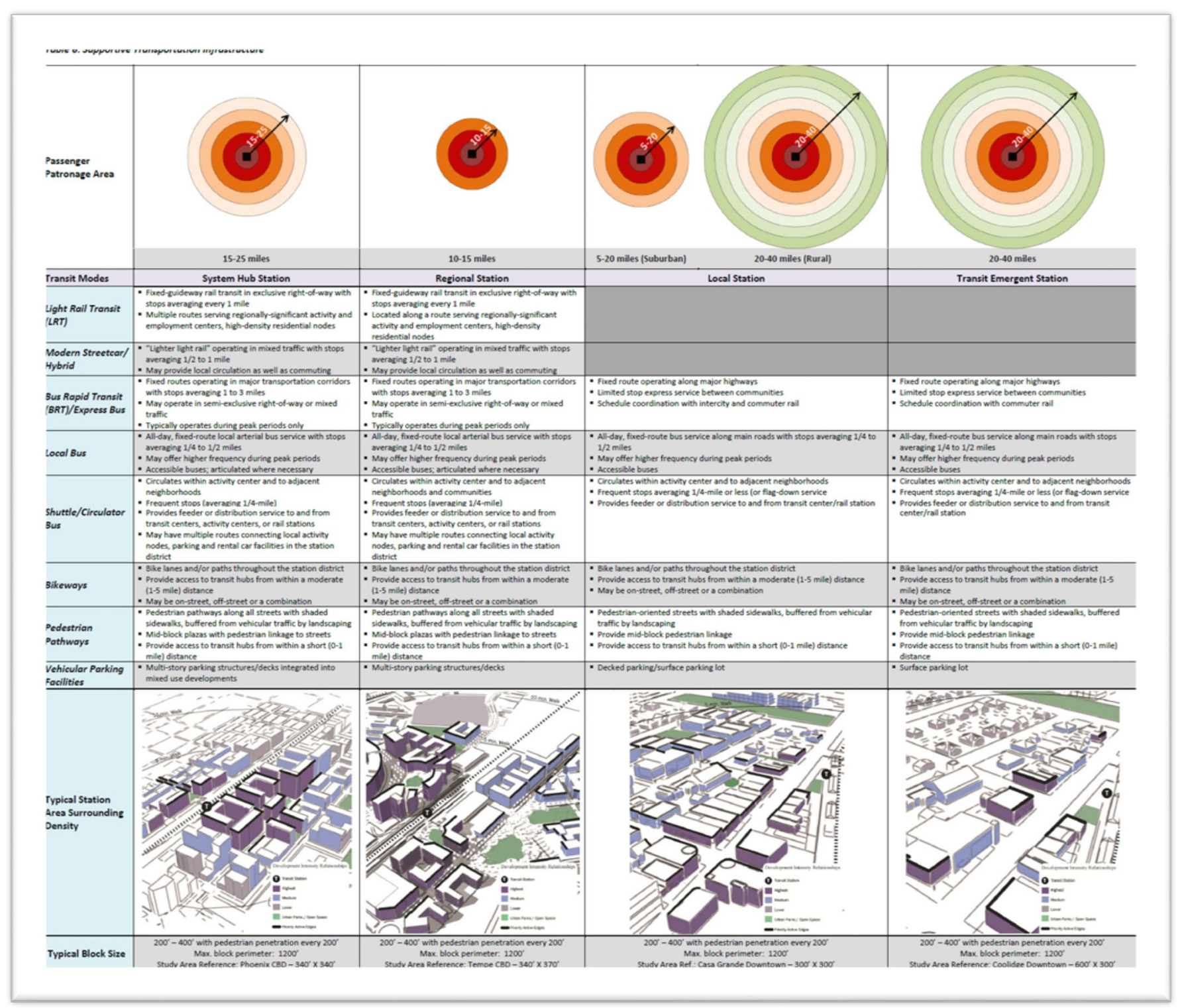


Phoenix, Arizona (2018)

References: (City of Phoenix, 2018; General Plan Amendment, 2018)

Transit System: Mainly light-rail, but conscious of supportive transportation alternatives Purpose of Typology:

Types of Use: Agency; Agency; Design or Land Use; Common Vocabulary; Conceptual Planning;

Findings \& Outcomes: The larger purpose of the report was to describe the outcomes (including benefits) and market for various TOD design, identifying potential opportunities. The area types were mainly used for planning purposes, considered a 'starting point' for plans and interim guidance for rezoning decisions and coordinating T\&LU before any TOD plans can be developed (page 15). The provide some example policies for one example typology, linking the policies (often zoning-specific) with the supporting metrics used to distinguish typologies. As this provides some interim guidance, individual typology plans should be developed following to supplement this document/guidance.

Method for Aggregating Typology:

Notes: The analysts in 'RelnventPHX' worked with the city's Village Planning Committees (VPCs). They analyzed 'land use, zoning, entitlements, destinations, demographics, housing, employment, walkability, market research studies, and existing plans to assess the existing context and susceptibility to future change within $1 / 4$ mile of light-rail stations" (page 14-15). The VPCs then voted to recommend area types for each existing or planned light rail station. The planning model uses a 'connected centers' approach by identifying each area type 'center or core' and linking those areas together. "Center" is a common term they use, defined as "concentration of activities within a city" (page 14).

Categories \& Supporting Variables or Definitions:

Notes: The descriptions here may be pulled directly from the language of the document; for image screenshots (marked with an image shadow), page numbers are either left on the image or embedded in the text directly before the image. The table below from top to bottom represents the spectrum of intensity of development from high to low. These area types apply to all properties within a $1 / 4$ mile with the following exceptions (from page 15):

Historic or historic-eligible (as determined by historic preservation officer);

Single-family zoned;

VPC specifying actions exclusions;

Existing entitlements greater than allowed in each area type;

Incompatible through TOC district planning or rezoning processes.

People is the copied table which describes the quantitative land use and transportation aspects of each area type (page 16): 
TOD Typology Matrix

\begin{tabular}{|c|c|c|c|c|c|c|}
\hline ace Type Image & Place Type & Land Use Mifix & Housing & Commercial & Transit Wode & Intensity \\
\hline & Dom & $\begin{array}{l}\text { - Central Business District } \\
\text { - Entertainment Destination } \\
\text { - Destination Retail } \\
\text { - High \& Mid Rise Uving } \\
\text { - Industry Cluster } \\
\text { - Civic \& College Compuses }\end{array}$ & $\begin{array}{l}\text { - High Rise } \\
\text { Mid Rise } \\
\text { - Loft Comversion }\end{array}$ & $\begin{array}{l}\text { - High Rise Office \& Hotel } \\
\text { - Major } \\
\text { - Under } 40,000 \text { sq, fi. single tenamt } \\
\text { retall footprint }\end{array}$ & $\begin{array}{l}\text { - Central Hub } \\
\text { - Highest Regional } \\
\text { Accessibility }\end{array}$ & $\begin{array}{l}\text { Highess Inten } \\
\text { - } 6+\text { Stories }\end{array}$ \\
\hline & Re & $\begin{array}{l}\text { - Office Employment } \\
\text { - Industry Cluster } \\
\text { - High \& Mid Rise Living } \\
\text { - Supportive Retail }\end{array}$ & $\begin{array}{l}\text { - High Rise } \\
\text { - Mid Rise } \\
\text { - Apartment } \\
\text { - Town house } \\
\text { - Row house }\end{array}$ & $\begin{array}{l}\text { - Mid-High Rise Office \& Hotel } \\
\text { - Under } 40,000 \text { sq, fi. single tencant } \\
\text { retail footprint Incentive. } 60,000 \text { sq. ff. }\end{array}$ & $\begin{array}{l}\text { - Regional Destination } \\
\text { - High Regional } \\
\text { Accessibulity }\end{array}$ & $\begin{array}{l}: \text { High lintensity } \\
: 5-10 \text { Stories } \\
\cdot \text { Incentive: } 20 \\
\text { Stories }\end{array}$ \\
\hline & M & $\begin{array}{l}\text { - Entertoinment Desstination } \\
\text { - Retcil Destination } \\
\text {-Mud Rise Living } \\
\text { - Office Employment }\end{array}$ & $\begin{array}{l}\text { - Mid Rise } \\
\text {-Aparment } \\
\text { - Town house } \\
\text { - Row house }\end{array}$ & 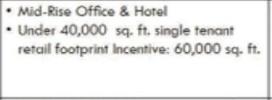 & $\begin{array}{l}\text { - Regional Destination } \\
\text { - High Regional } \\
\text { Accessibility }\end{array}$ & $\begin{array}{l}\cdot \text { Medium-High } \\
\text { Intensity } \\
-4.8 \text { Stories } \\
- \text { Incentive } 15 \\
\text { Stories } \\
\end{array}$ \\
\hline & inter & $\begin{array}{l}\text { - Bolanced Commercial \& } \\
\text { Residential } \\
\text { - Retail Destination } \\
\text { - Entertainment Destination } \\
\text { - Some Employment }\end{array}$ & $\begin{array}{l}\text { - Mid Rise } \\
\text { - Apartment } \\
\text { - - Town house } \\
\text { - Row house } \\
\text { - Live/Work }\end{array}$ & $\begin{array}{l}\text { - Low-Rise Office } \\
\text { - Under } 40,000 \text { sq, ff. single tenant } \\
\text { retall footprint incentive } 80,000 \text { sq. fi. }\end{array}$ & \begin{tabular}{|l} 
- Sub-Regional \\
Destination \\
- Medium Reglonal \\
Accessibility
\end{tabular} & $\begin{array}{l}\cdot \text { Medium } \\
\text { Intensity } \\
\text { - 3-6 Stories } \\
\text { - Incentive: } 10 \\
\text { Stories }\end{array}$ \\
\hline & Minor: & $\begin{array}{l}\text { - Balanced Commercial \& } \\
\text { Residential } \\
\text { - Retail Destination } \\
\text { - Ententainment Destination } \\
\text { - Some Employment }\end{array}$ & $\begin{array}{l}\text { - Mid Rise } \\
\text { - Apartment } \\
\text { - - Town house } \\
\text { - Row house } \\
\text { - Live/ Work }\end{array}$ & $\begin{array}{l}\text { - Low-Rise Office } \\
\text { - Under } 40,000 \text { sq, fit, single tencant } \\
\text { retail footprint incentive: } 60,000 \text { sq, ff. }\end{array}$ & $\begin{array}{l}\text { - Sub-Regional } \\
\text { Destination } \\
\text { - Medium Regional } \\
\text { Accessiblity }\end{array}$ & $\begin{array}{l}\text { - Medium-low } \\
\text { Intensity } \\
\text { - } 2-5 \text { Stories } \\
\text { - Incentive: } 7 \\
\text { Stories }\end{array}$ \\
\hline & $\begin{array}{l}\text { Suburban Commuter } \\
\text { Center }\end{array}$ & $\begin{array}{l}\text { - Office Employment } \\
\text { - Colleges \& Trade Schools } \\
\text { - Hotels } \\
\text { - Commuter serving Retail } \\
\text { - Limited Housing }\end{array}$ & $\begin{array}{l}\text { - Apartment } \\
- \text { - Town/Row Home } \\
\text { - Live/Work }\end{array}$ & $\begin{array}{l}\text { - Mid-Fise Office, Hotel \& Campus } \\
\text { - Under } 80,000 \text { sq.ft. single tenant } \\
\text { footprint. Incentive } 100,000 \text { sq. fit. }\end{array}$ & $\begin{array}{l}\text { - Commuter Intermodal } \\
\text { Destination } \\
\text { - Medium-Low Regional } \\
\text { Accessibility }\end{array}$ & $\begin{array}{l}\text { - Medium-Low } \\
\text { Intensity } \\
\text { - } 2-4 \text { Stories } \\
\text { Incentive: } 7 \\
\text { Stories }\end{array}$ \\
\hline & Neighborthood Center & $\begin{array}{l}\text { - Primarily Residentiol } \\
\text { - Neighborhood serving retail } \\
\text { - Limited employment }\end{array}$ & $\begin{array}{l}- \text { Aportment } \\
- \text { - Town/Row Home } \\
- \text { - Live/Work } \\
-2 \text { or } 3 \text { unit } \\
\text { - Single Unit }\end{array}$ & $\begin{array}{l}\text { - Low-fise office } \\
\text { - Under } 40,000 \text { sq. fit, single tenant } \\
\text { retail footprint Incentive: } 50,000 \text { sq. ft. }\end{array}$ & $\begin{array}{l}- \text { Neighborhood } \\
\text { Destination } \\
\text { - Less Regional } \\
\text { Accessibility }\end{array}$ & $\begin{array}{l}\text { - Low Intensily } \\
-2.4 \text { Stories } \\
\text { - Incentive: } 5 \\
\text { Stories }\end{array}$ \\
\hline & $\begin{array}{l}\text { Historic Neighborhood } \\
\text { Center }\end{array}$ & $\begin{array}{l}\text { - Primarily Residential } \\
\text { - Neighborhood serving retail } \\
\text { - Limited employment }\end{array}$ & $\begin{array}{l}\text { - Apartment } \\
- \text { - Tornt/Row Home } \\
- \text { - Live/ Work } \\
-2 \text { or } 3 \text { unit } \\
- \text { - Single Unit }\end{array}$ & $\begin{array}{l}\text { - Low-Rise office } \\
\text { - Under } 20,000 \text { sq. fi. single tenant } \\
\text { retail footprint }\end{array}$ & $\begin{array}{l}\text { - Noighborhood } \\
\text { Destination } \\
\text { - Less Regional } \\
\text { Accessibility }\end{array}$ & $\begin{array}{l}\text { - Low Intensity } \\
\text {-2.4 Stories } \\
\text { - Incentive: } 5 \\
\text { Stories }\end{array}$ \\
\hline
\end{tabular}


Portland Metro, Oregon (2011)

References: (Center for Transit-Oriented Development \& Nelson/Nygaard, 2011)

Transit System: Considers metro-wide transit, but 'categories' LRT stations specifically.

Purpose of Typology:

Types of Use: Agency; Agency; Strategy Identification \& Implementation; Prioritization;

Evaluation;

Findings \& Outcomes: Similar to the Puget Sound example, these area types were used to develop a sense of variation in transit typology across the region and to package strategies aimed at addressing concerns, growth or funding mechanisms across each typology.

Method for Aggregating Typology:

Notes: The typology separates station areas into 9 categories along two dimensions (each dimension having three sub-categories). For the 'market strength' dimension (one variables), the data were split based on natural breaks in the data (excluding downtown Portland, which tends to skew the data). For 'transit orientation scores', the ' 5 Ps' were each standardized and summed together. The resulting index was then split based on natural breaks into three categories, similar to 'market strength'. This means that the definition of the categories are relative to what is currently available across the region.

Question: It's not clear if the 'natural breaks' were used across station scores or across the region (based on the raster grid 'context tool'. The 'context tool' supportive 5Ps data pulled into this study was reflective of Portland Metro's larger 'context tool' that we used for the site selection and analysis of our 2012 Contextual Influence on Trip Generation study. I'm thinking the market strength may have been 'broken' on the station area information, which the transit orientation data may have been 'broken' at a regional level.

Categories \& Supporting Variables or Definitions:

Notes: The descriptions here may be pulled directly from the language of the document; for image screenshots (marked with an image shadow), page numbers are either left on the image or embedded in the text directly before the image.

\begin{tabular}{|c|c|c|c|}
\hline Dimensions & Category & Description & Supporting variables \\
\hline \multirow[t]{2}{*}{$\begin{array}{l}\text { Market } \\
\text { Strength } \\
\text { (page 33) }\end{array}$} & Limited & $\begin{array}{l}\text { "these areas have weaker market conditions } \\
\text { and lack the sales values necessary to } \\
\text { support new compact and/or mixed use } \\
\text { development. TOD Program investments in } \\
\text { these areas, thus, are less likely to catalyze } \\
\text { additional private development and should be } \\
\text { used only on a limited basis. Emphasis on } \\
\text { visioning and planning is more appropriate to } \\
\text { begin to develop physical and regulatory } \\
\text { conditions that could influence future private } \\
\text { development } \\
\text { interest." }\end{array}$ & \multirow[t]{2}{*}{$\begin{array}{l}\text { Residential (including mixed use) and } \\
\text { commercial real estate sales by square } \\
\text { foot ( } 2000-2010) \text {; split by natural } \\
\text { breaks in the data }\end{array}$} \\
\hline & Emerging & $\begin{array}{l}\text { "these are areas that have limited to moderate } \\
\text { real estate market } \\
\text { conditions and where intensive building types } \\
\text { are generally not supported in the near-term. } \\
\text { Although they may lack immediate market } \\
\text { support for TOD, emerging areas may be } \\
\text { ideally suited for catalytic TOD Program } \\
\text { investments to enhance local market strength. } \\
\text { These areas represent a "sweet spot" for TOD } \\
\text { program investment, since land and } \\
\text { development costs are not elevated (as in } \\
\text { Stronger market areas) and small investments }\end{array}$ & \\
\hline
\end{tabular}




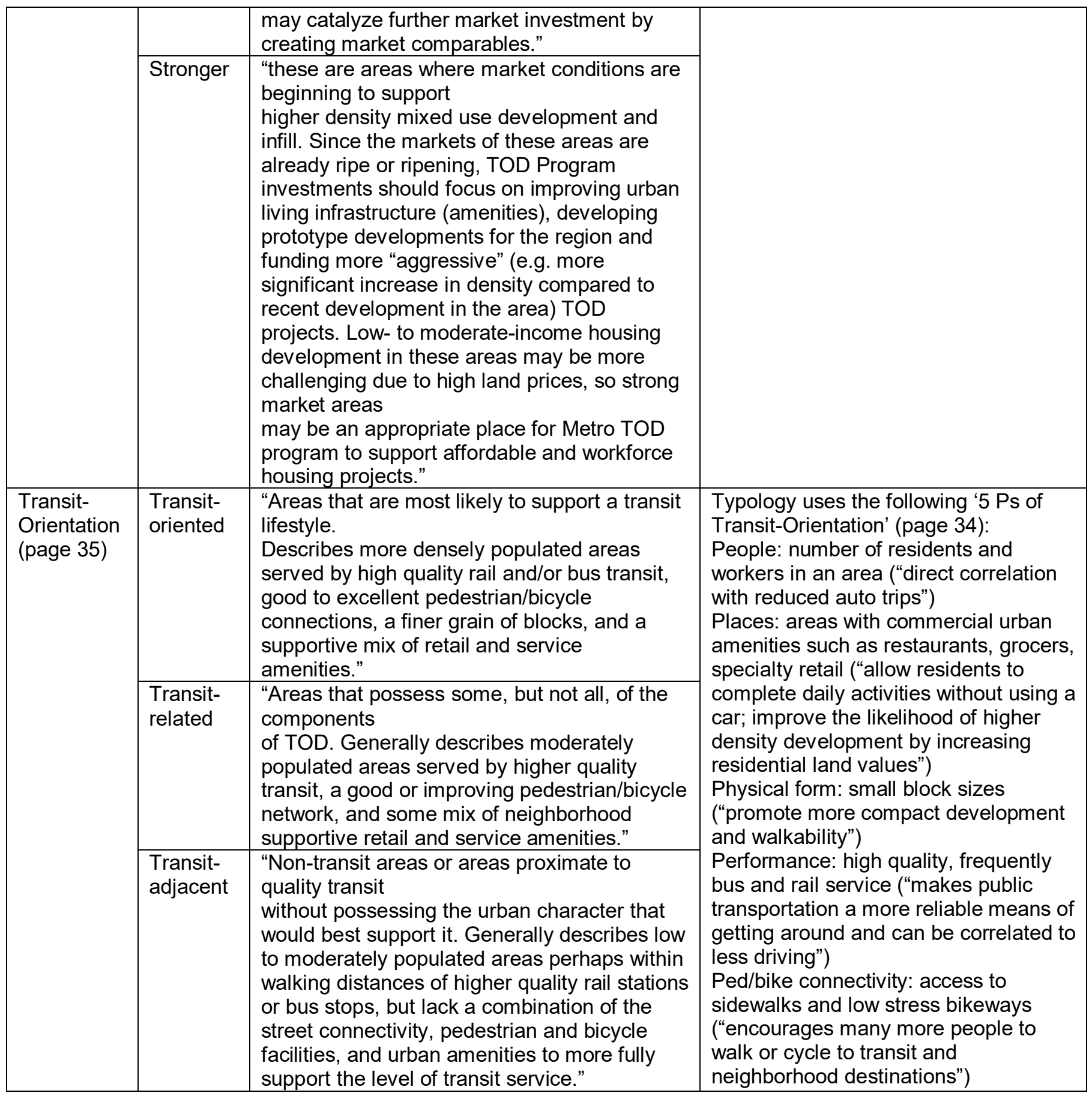

Page 40 - Clustering typologies to define TOD program investments and strategies 


\section{Using the Typology to Define TOD Program Investments}

The nine place types provide the first step in an investment strategy for the Metro TOD Program. Howrever, many of the place types face similar challenges, and clusters of place types would benefit from similar investment strategies. To address this, the place types are grouped in three clusters that are commonly positioned for invest. ments and implementation actions that could be administered by the TOD Program. The place type clusters are described in Figure 22. Each of the clusters is described below and illustrated with case examples from existing stations and corricors in the Portland region.

Figure 22: TOD Place Type Clusters
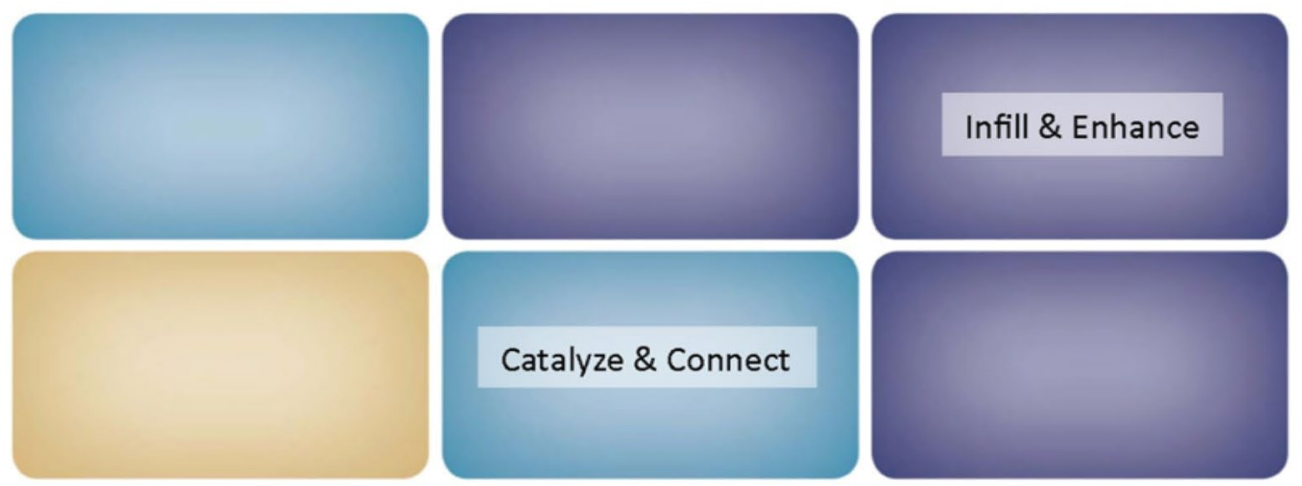

Plan \& Partner
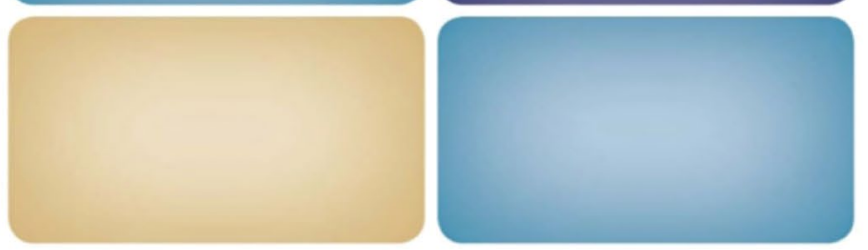
Denver, Colorado (2014)

References: (Buchanan et al., 2014)

Transit System: The focus of this report is at rail stations (possibly LRT and commuter), but the study recognizes the need to consider supportive transit/transportation infrastructure.

Purpose of Typology:

Types of Use: Agency; Design or Land Use; Common Vocabulary; Strategy Identification \& Implementation; Prioritization;

Findings \& Outcomes: There is a major purpose for both typologies. The area type + functional overlay provides guidance for the designation and direction of each station in terms of the built environment. The "TOD Continuum" (market readiness, development potential, and transit readiness) segments stations into areas that help the agency, practitioner, and developer align strategies and mitigations across the stations. It's important to note that some of the information that informs the area types may also inform the Continuum, but the Continuum is designed to align the needs of each station types while the area types are intended to organize the goal built environment or design.

Additional Definitions:

Transit community (page 9): "Denver's transit communities are walkable places that provide destinations like shopping, dining, jobs, parks, and schools - most of ones daily activities easily accessed from home by foot, bicycle, and transit. These communities tend to have a variety of housing types, provide the opportunity for a healthy lifestyle, and are designed to maximize resident access to public transportation by focusing activities on a major transit stop." Transit-oriented development (page 9): "Transit-oriented development in Denver generally describes a development in an existing or planned transit community that adds to the walkable, vibrant, mixed-use environment and is oriented towards frequent, high-quality transit service that connects the community to the rest of the region."

TOD Principles (page 10-11):

Connect: "entry point-access to the regional economy; first/last mile - walk, bike, bus to the station; access to all - connect to new and existing neighborhoods"

Innovate: "sustainable - economic, social, environmental; equitable - opportunities for all; global economy - compete on the world stage"

Efficient: "Location - one place to live, work, and play decreases need for regional trips; Shared Resources - reduce cost of infrastructure per household; Balance - jobs and homes nearby reduce travel times and long commutes"

Place: "Active - promote safety and visual interest; Vibrant - bring together people and activities; Destination - public life happens in the streets and open space"

Mix: "Choice - housing, jobs, shopping, transit options; Diversity - mix of incomes and age groups; Resilient - stands up through changing economic conditions"

Shift: "Car Free/Car Lite - becoming non-/less car dependent for most trips; Public Space more room for pedestrians and bikes, less for cars; Reduce and Energize - carbon emissions go down, healthy living goes up"

Method for Aggregating Typology:

Notes: It is not clear how the five built environment place typologies were created, but five categories of characteristics were included: land use mix; street and block patterns; building placement and location; building heights; mobility. The functional overlays appear to be identified based on major generators (institutional and/or entertainment districts) or anecdotal experiences/expertise. Given the qualitative description of the categories, it appears that this approach was more 'manual' than quantitative.

In addition to the built environment area types, the report considers categorizing 'market readiness' and 'development potential' of each station area called the 'TOD Continuum". The team considered a 10-minute walkshed around the area. This approach is based on three prior resources (Central Maryland; Portland, Metro; and Los Angeles). The 34 stations (not including 
downtown) were plotted on a graph with 'transit readiness' informing the policy implications and recommendations. The outcomes of both market readiness and development potential appear to be standardized on a scale from 1 to 5 . It is likely that this scale is an indication of natural breaks as they cite Portland, LA, and Baltimore.

Categories \& Supporting Variables or Definitions:

Notes: The descriptions here may be pulled directly from the language of the document; for image screenshots (marked with an image shadow), page numbers are either left on the image or embedded in the text directly before the image. Below are tables and descriptions for each of the five main place typologies and overlays. The overlays indicate the aspirational qualities of the given station, which can occur in any typology. 


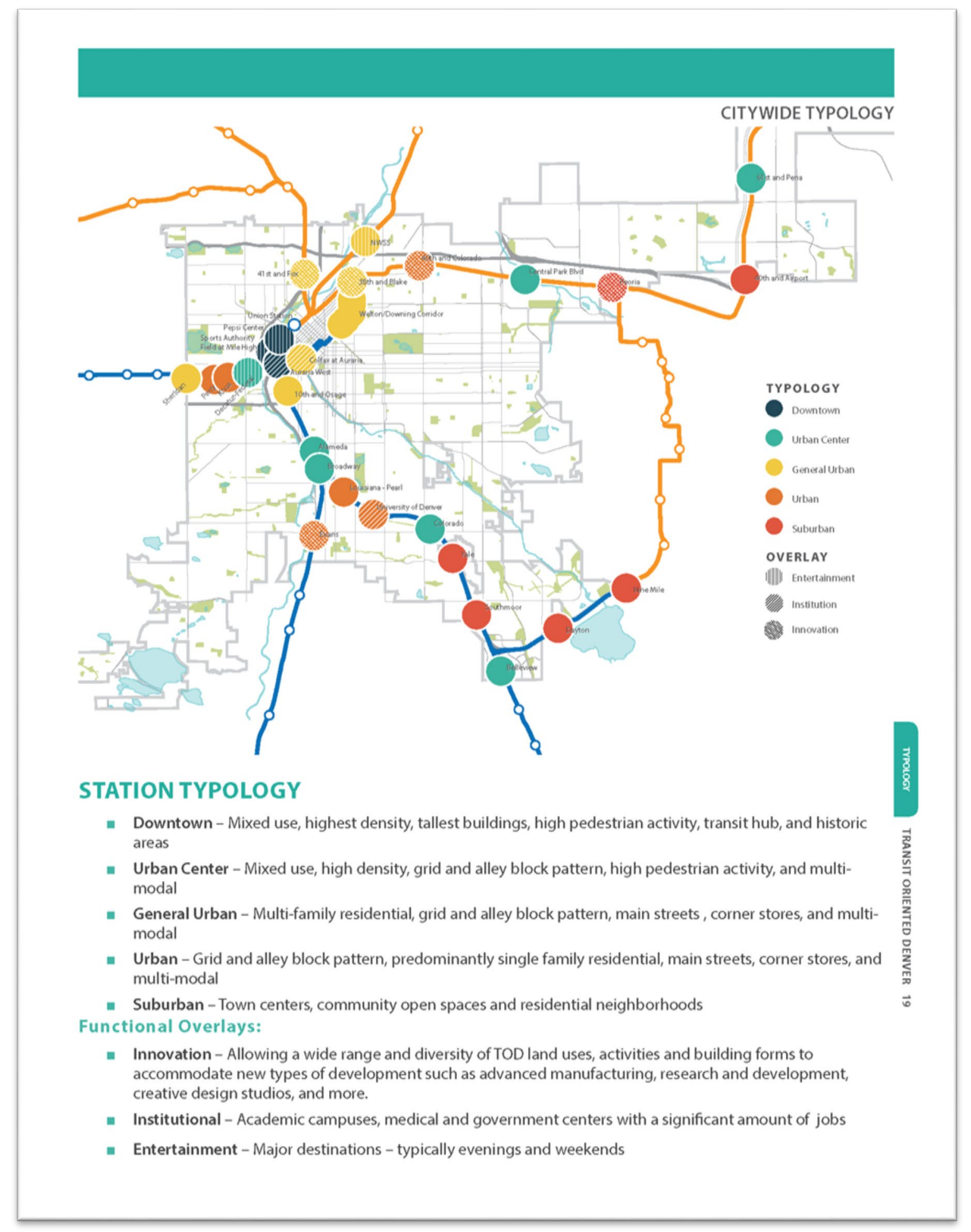




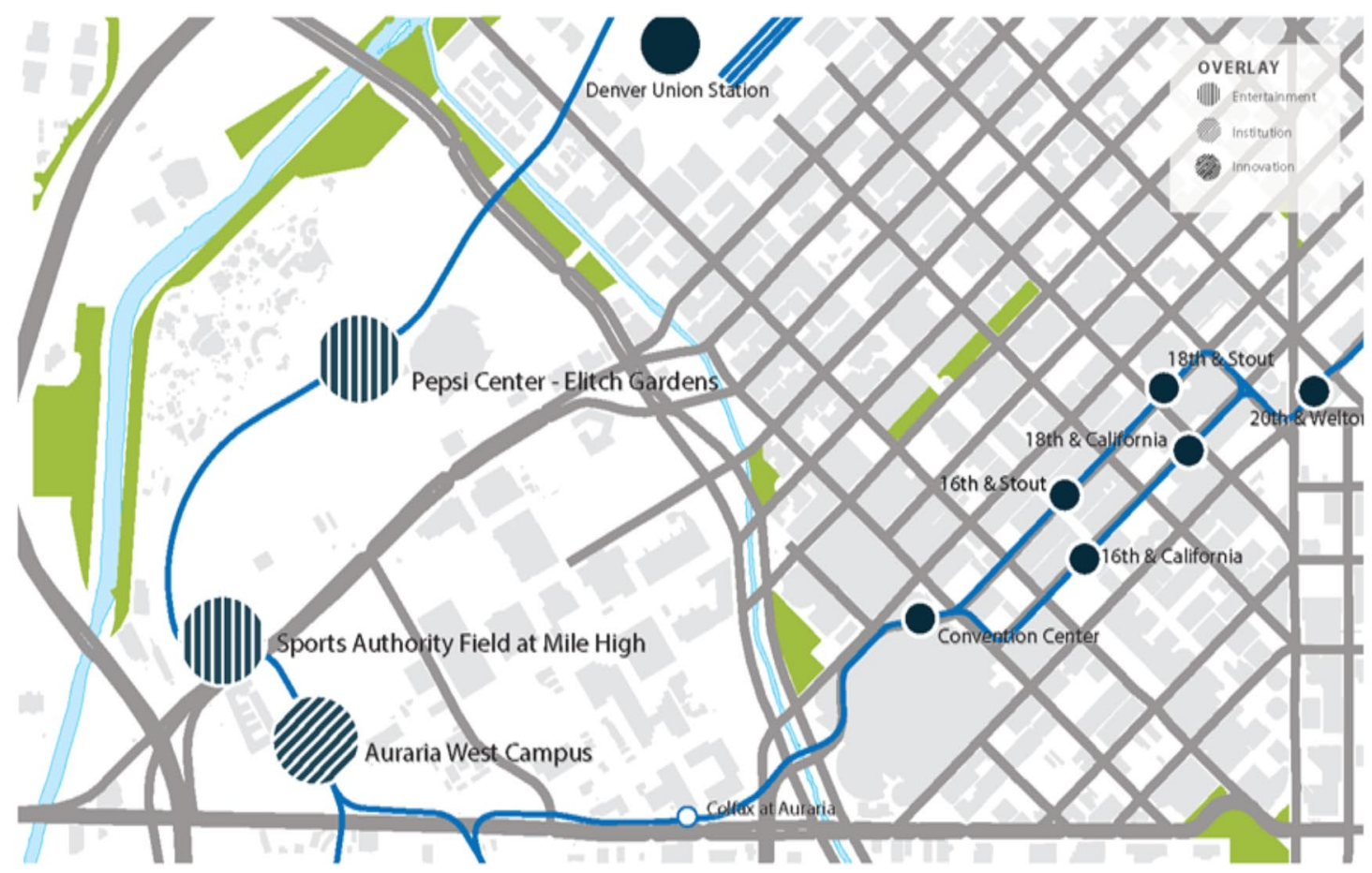

Downtown rail stations are unique as they are located in the most intensely used land in the region, with civic, institutional and entertainment uses sharing the same spaces as high density residential, office and commercial uses. Buildings are mostly mid- to high-rise structures located in a consistent pattern of small blocks and linear streets. Downtown stations have the highest level of use due to downtown being the center of the regional transit

\section{芩 Land Use Mix}

$\sum_{\text {u }}$

Strong mix of uses

$\underset{\sim}{\tilde{\alpha}}$ Mid to high-rise

함 buildings with a

mix of multi-family,

commercial, office,

civic, institutional and entertainment uses

\section{Street and Block Pattern}

Regular, smaller blocks

Regular pattern of pedestrian/vehicle connections

Unique triangular blocks where grids meet

Linear streets

Consistent alleys system. Downtown streets have the most pedestrian activity and extensive set of bicycle facilities of all station types. All downtown rail stations are walk-up stations, but a few stations have specific functions - Pepsi Center and Mile High Station serve as entertainment stations, and Auraria West Station serves as an institutional station.

\section{Building \\ Placement}

Buildings built-to sidewalks

Continuous street wall Consistent orientation

Parking at rear/side or structured

\section{Building Height Mobility}

Context-sensitive heights in historic districts

Consistent mid to high-rise in other districts
Highest priority to pedestrian

High level of bicycle facilities

Center of multi-modal transit system 


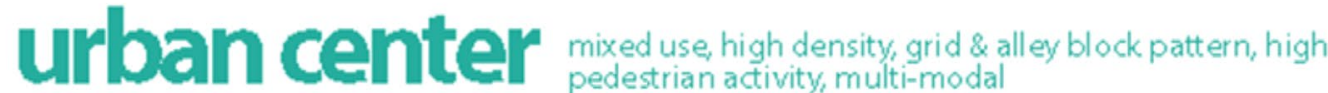

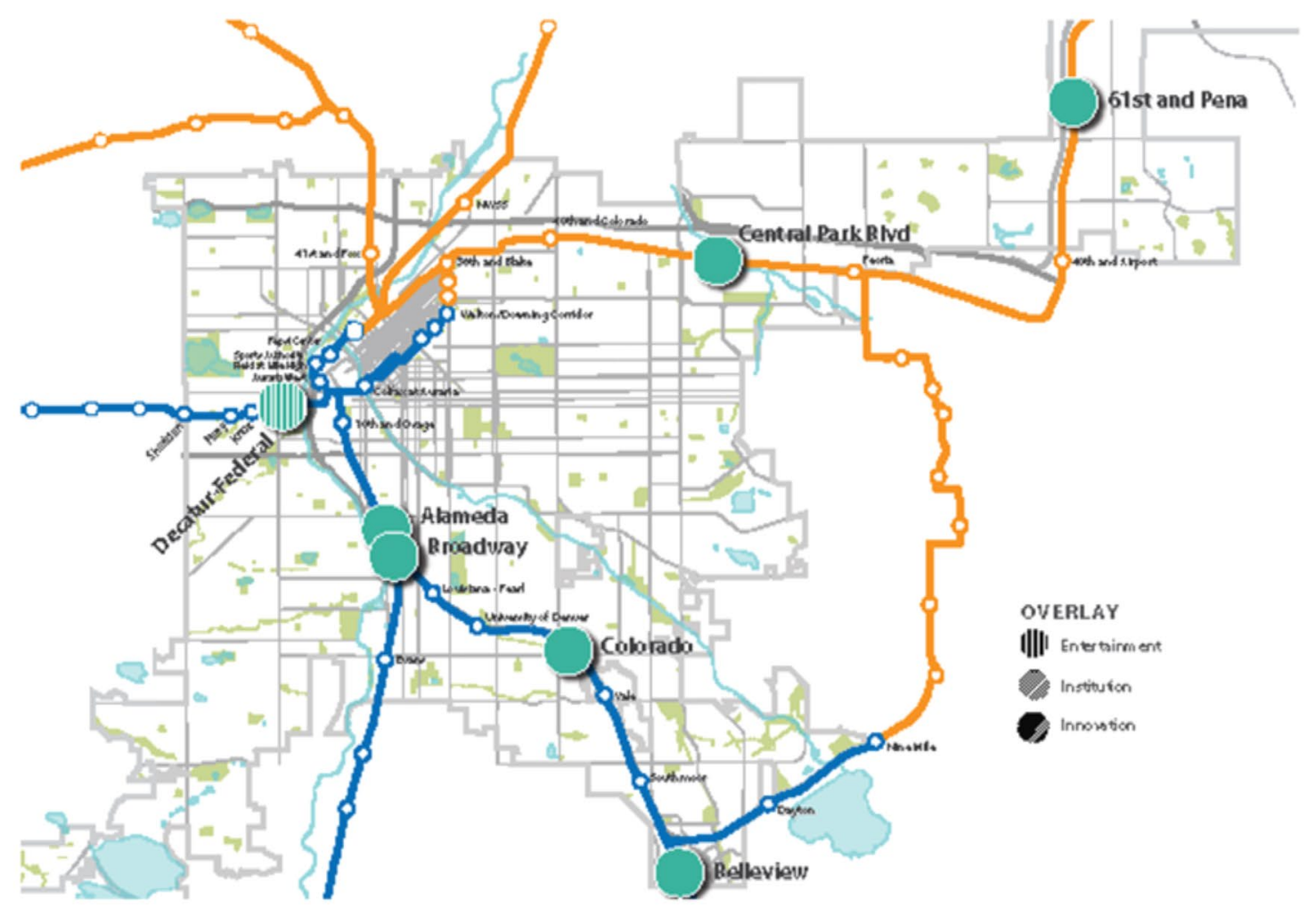

Urban Center rail stations typically serve or are planned to serve as a destination for surrounding neighborhoods with strong transit use and a high level of ped estrian and bicycle activity. Urban Centers have a mix of uses, with mid- to high-rise multi-family residential integrated with mixed-use commercial buildings. The intended high inten sity nature of urban centers positions these stations as regional employment hubs. Buildings front sidewalks with consistent pedestrian entrances and are located within a pattern of regular, smaller blocks and linear streets. Many urban center stations have one or more major land owners.

สี

$\stackrel{\leftrightarrow}{\rightleftarrows}$

쳫

蒫

Street and

o Mid-high rise

产 Multi-family

栗

Mixed-use

commerojal

Destination for

surrounding

neighborhoods

\section{Block Pattern}

Regular, smaller blocks

Regular pattern of ped/vehicle connections

Linear streets

Mostly alleys

\section{Building} Placement

Buildings built to sid ewa lk or very shallow setbacks

Consistent orientation

Parking at rear/side or structured

\section{Building Height Mobility}

Consistent mid- to high-rise residential mixed-use and commerdal structures;

Maximum height at the core is typically 20 stories with transitions
Strong transit use

High level of ped/bike use

Potentialjob center 


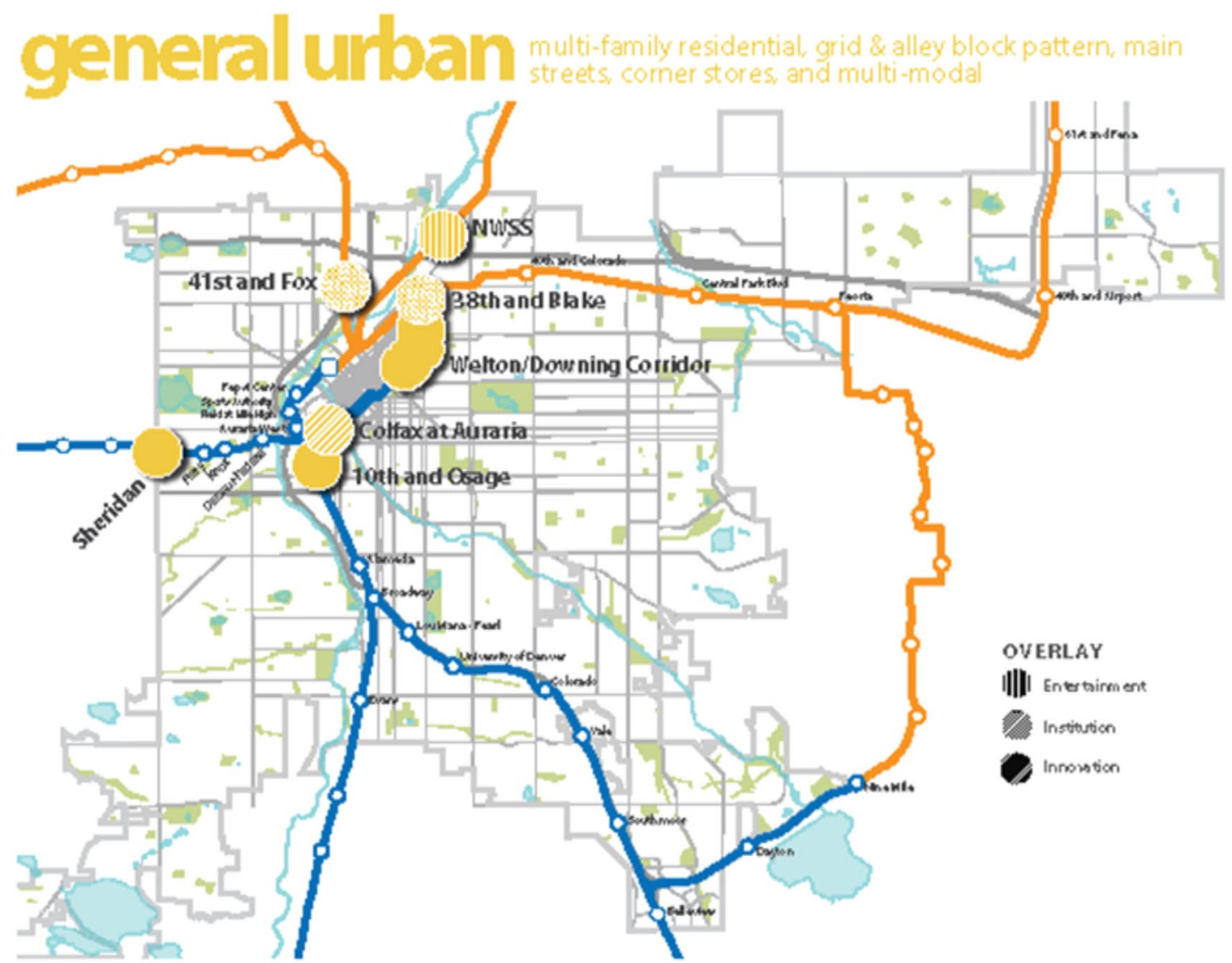

General Urban rail stations arecharacterized by their significant amount of mid to high-density multifamily residential areas. These areas have a variety of building \% form s, such as urban houses, rowhouses, and mid to high-riseapartment and/orcondominium buildings, as well as some limited single family and two family residential uses. Commercial areas, generally consisting in of low to mid rise structures, are bothembedded in the arterials. Buildings have shalbw or moderate setbacks, with consistent pedestrian orientation and parking bcated behind or to the side. Areas around general urban stations have a regular, smaller block pattern with linear streets and alleys. Due to the higher residential densities, transit ure is strong, espexially along high capacity transit corridors. There is a general balance of pedestrian bicycleand vehic le travel modes.

$\stackrel{*}{w}$ neighborhood and located along busier, mixed-use

密

Land Use Mix

Mix of uses with

heavy emphasis on

higher density multi-

family residential

areas with row houses and apartment buildings

Commercial uses bcated on key mixeduse and main streets
Street and Building

\section{Block Pattern}

Regubr, smaller blocks

\section{Placement}

Consistent shallow to moderate setbacks

Regular pattern of pedestrianvehicle connextions

Linear streets

Mostly alkys
Consistententrance street

Parking accessed from the alley or side yard orientation to the

\section{Building Height: Mobility}

Mid- to high-rise Strong transit use residential strux tures especially abng

Low- to mid-rise commercial structures at appropriate locations vehic leuse 


\section{U.}

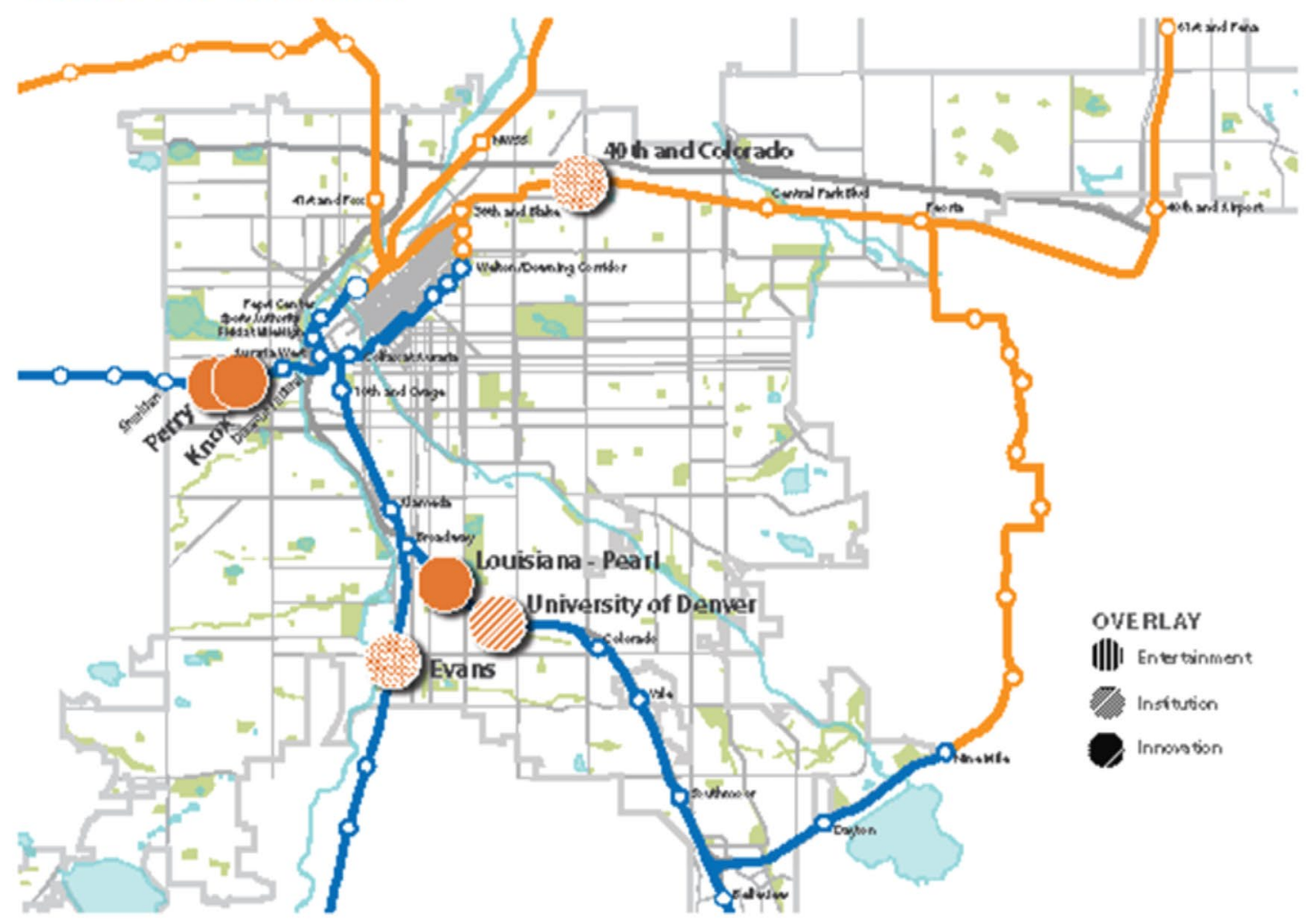

Urban rail stations are lower-scale "walk-up" stations, providing transit access to existing neighborhoods primarily characterized by singk-unit and two-unit \$ residential uses, smal-scak multi-unit residential uses and embeddedcommercial areas. Buildings have shallow or moderate setbacks, with consistent pedestrian $\mathscr{s}$ orientation and parking bcated beh ind or to the side.

A reas around urben stations have a regular, smaller block pattern with linear streets and alleys. Due to the lower residen tial densities but strong street grid, tran sit use is moderate, with higher use abnghigh capacity transit corridors during peak commuting periods. There is a general balance of pedestrian, bicycle and veh icle travel modes.

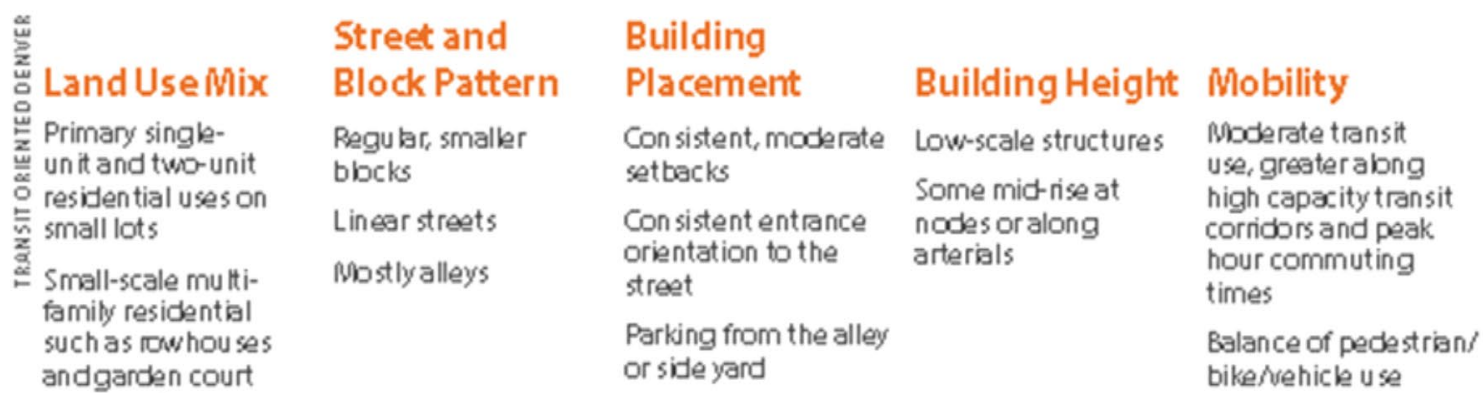

apartments

Embedjed

commerial 


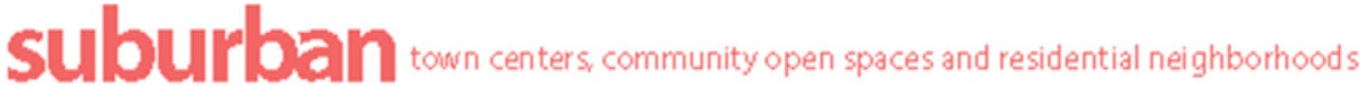

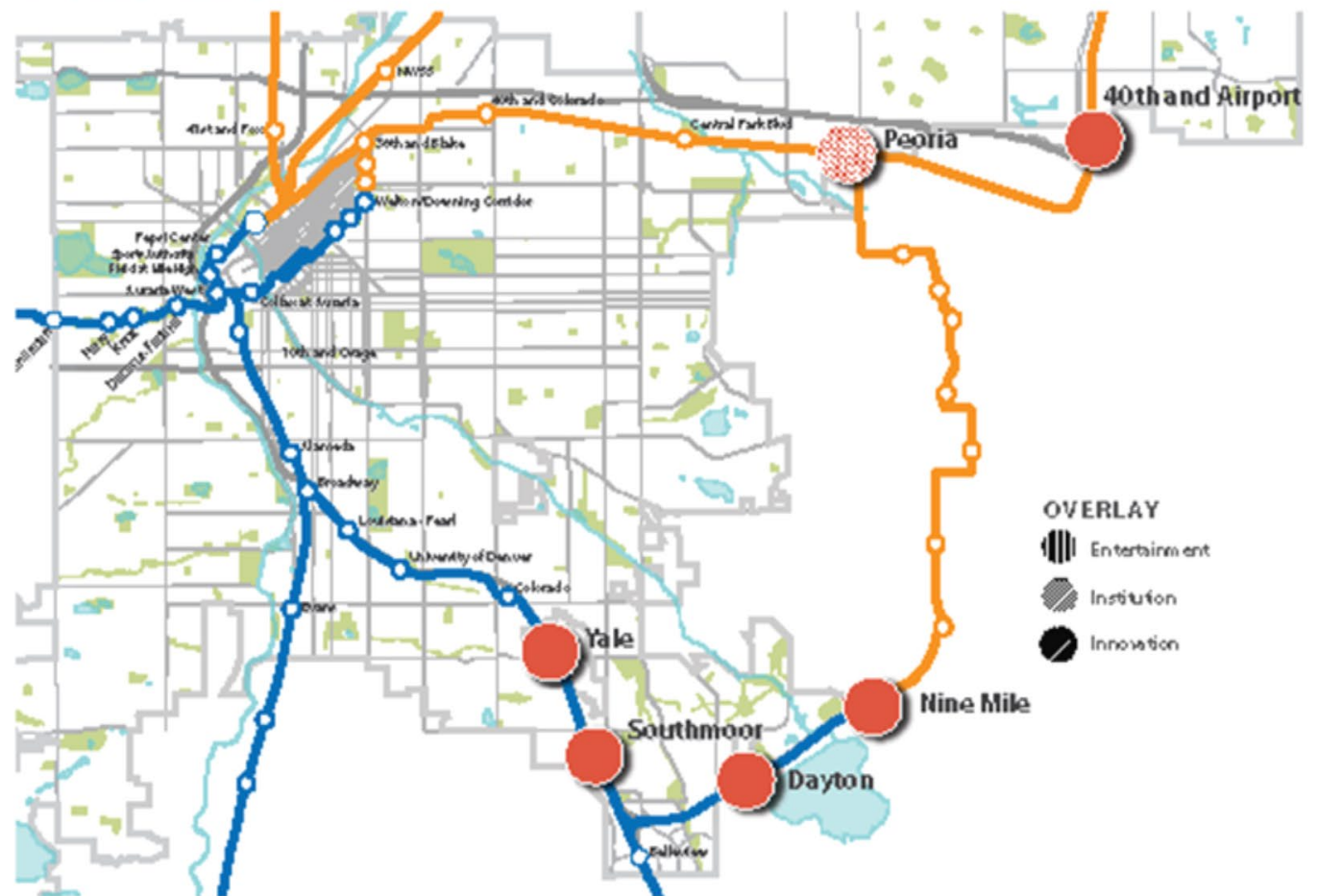

Su burban rail stations are characterized by their higher kvel of transit service and pedestrianorientation than the su mou nding auto-oriented context. These stations may take on the qualities of a town center, having a mix of uses with some mid-to-high-rise bu ildings oriented towards the transit station, but with significant amou nts of surface or structured parking for commuters. A public plaza or open space serving as a community gathering place is a desired amenity. Residential neighborhoods is consisting of single-unit and two-unit residential uses

and small-scale multi-u nit residential uses are found further from the station. Other commercial u ses are found along major arterial streets. Bbck sizes and street types vary greatly, but smalker bbcks and pedestrian friendly streets are fou nd near the station with lager bbcks that provide devebpment flexibility further away. Bu ildings with shallow setbacks are placed in front of parking bts neer the station, with deeper setbacks on arterials and parking infront of buildings further from the station.

\begin{tabular}{|c|c|c|c|c|}
\hline & Street and & Building & & \\
\hline Land Use Mix & Block Pattern & Placement & Building Height & Mobility \\
\hline Mixed of u ses & Mix of block sizes, & Deep setbacks & Low-rise structures & Auto-oriented \\
\hline $\begin{array}{l}\text { Public plaza or open } \\
\text { space as central } \\
\text { gathering place }\end{array}$ & $\begin{array}{l}\text { pedestrian streets } \\
\text { near station, larger } \\
\text { blocks further from } \\
\text { station }\end{array}$ & $\begin{array}{l}\text { Parking in front of } \\
\text { building }\end{array}$ & $\begin{array}{l}\text { Some mid/high-rise } \\
\text { structures }\end{array}$ & Regional bike trails \\
\hline $\begin{array}{l}\text { Primarily 1-u nit, } \\
\text { 2-unit, and small-scale }\end{array}$ & $\begin{array}{l}\text { Best connectivity near } \\
\text { the station }\end{array}$ & & & \\
\hline from station & Large blocks have & & & \\
\hline $\begin{array}{l}\text { Commercial uses } \\
\text { along arterials }\end{array}$ & $\begin{array}{l}\text { mid-block pedestria } \\
\text { passages }\end{array}$ & & & \\
\hline
\end{tabular}




\section{FUNCTIONAL OVERLAYS}

These designations are applied to stations that have a key functional aspect on top of their context type that provides additional context and clarifies future expectations.

INNOVATION
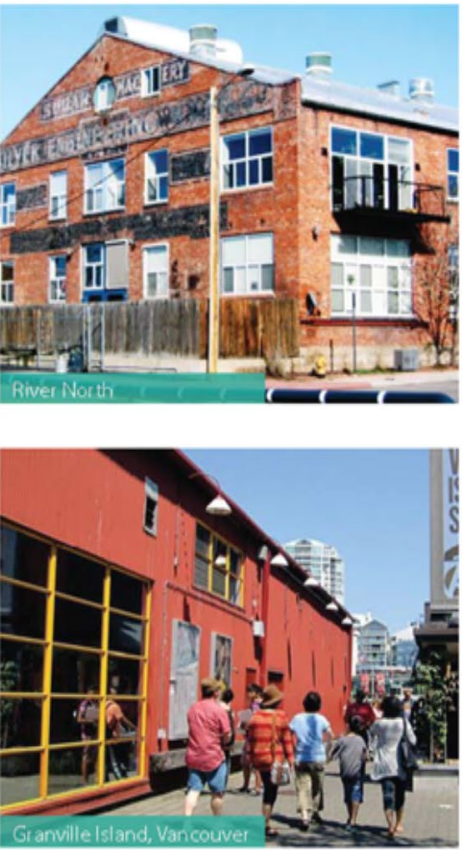

Innovation stations a re characterized by their high degree of mixed use, adaptive reuse of existing structures, and creative approach to business.

i These stations typically are found in existing industrial areas, but may have experienced new housing and retail arriving with the rail station.

o Under-utilized warehouses are being

\% reused by young companies looking

for space, often seeking synergy

ü and cooperation with other like-

minded companies. Many of these

z businesses have corporate cultures

of that emphasize sustainable building

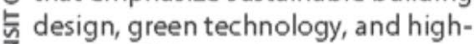

quality of life employee amenities

$\approx$ like transit passes, car-sharing, and bicycle parking. Businesses may include advanced manufacturing, research and development, and creative design studios.

\section{INSTITUTIONAL}
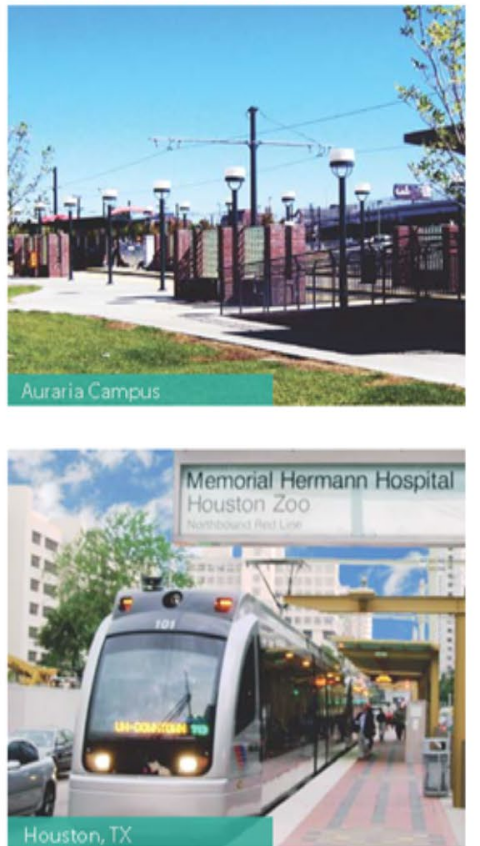

Institutional stations have specific uses that bring unique attributes to station areas. This overlay typically applies to stations with one or more large land owners that have multiple buildings located in a campus setting. Universities, government centers, and medical campuses are typical uses. Stations have a large concentration of jobs and a significant amount of daily visitors, resulting in a high level of transit ridership and internal trip capture via walking and biking.
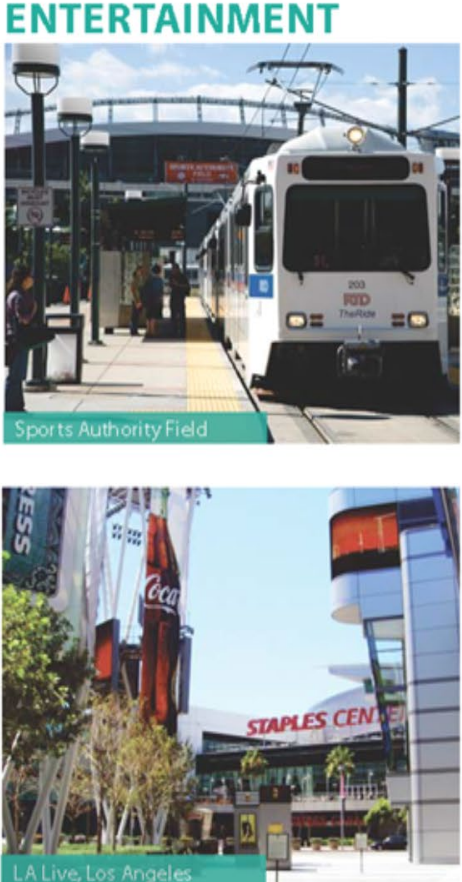

Entertainment stations are designed for accommodating major events when a large amount of passengers arrive and depart during a limited period of time. Ample surface parking is typically located at these sites to serve non-transit users. As the region continues to grow, market demand for reuse of this surface parking into commercial and residential development may present itself. 
Page 31

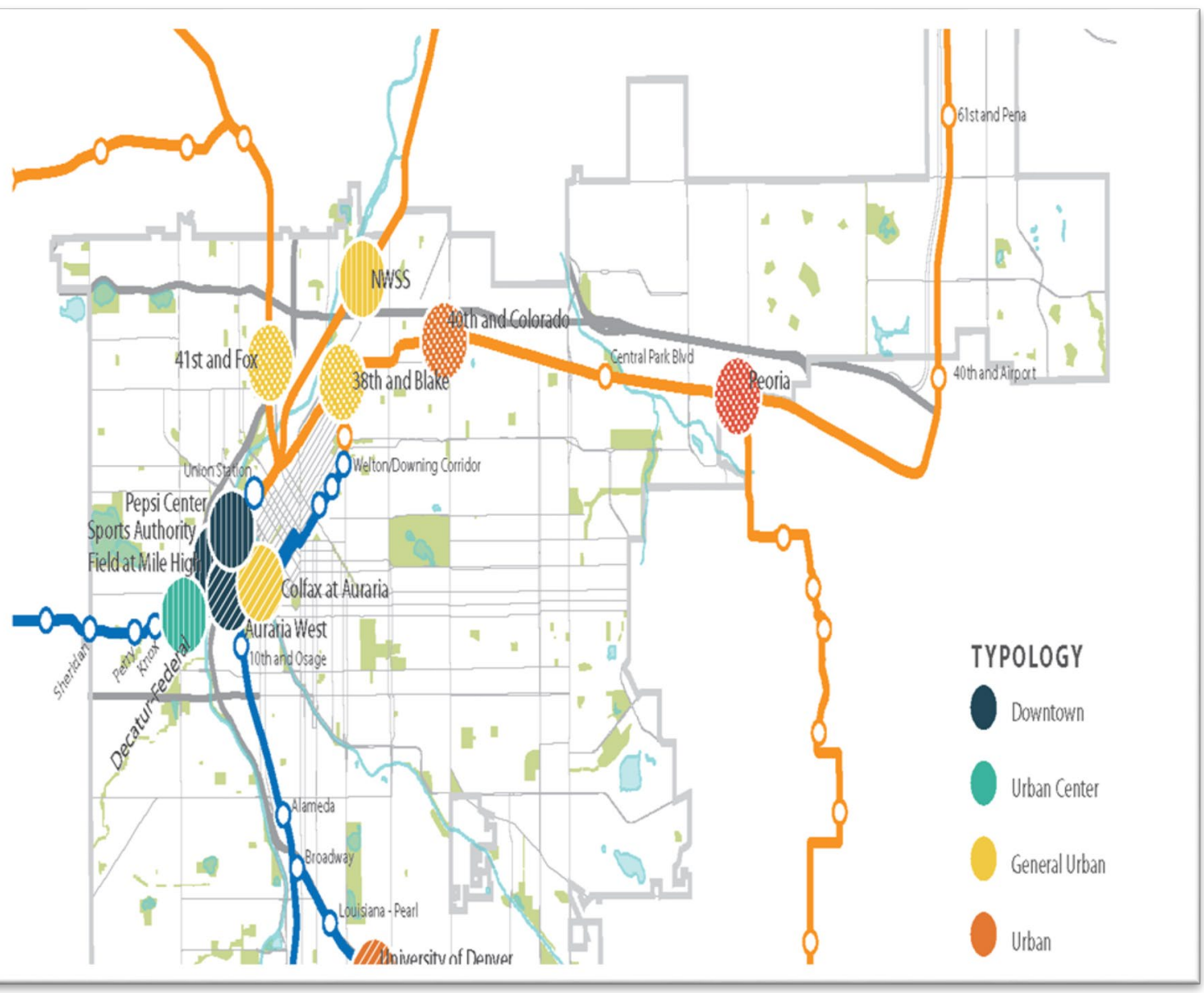

In addition to the area types described above, the following three criteria categories for their continued evaluation of TODs on the 'TOD Continuum' (page 38), evaluating based on a standard ' $1 / 2$ radius station area or a $1 / 2$ mile walk-shed ( 10 -minute walk)'. See table following from page 39 for specific variables.

\begin{tabular}{|l|l|l|}
\hline Type & Description & Supporting variables \\
\hline Rearket & $\begin{array}{l}\text { "helps determine whether the station area real } \\
\text { estate market is capable of supporting new } \\
\text { development by evaluating the strength of } \\
\text { market demand and market timing." }\end{array}$ & $\begin{array}{l}\text { "population density, employment density, TOD } \\
\text { demographics, land values, residential price } \\
\text { appreciation, commercial rents, and market } \\
\text { activity (permit values)." }\end{array}$ \\
\hline $\begin{array}{l}\text { Development } \\
\text { Potential }\end{array}$ & $\begin{array}{l}\text { "evaluates whether the legal, physical, and } \\
\text { infrastructure framework of the station area is } \\
\text { ready to support new development, and } \\
\text { determines the potential capacity for new } \\
\text { development" }\end{array}$ & $\begin{array}{l}\text { "plan in place, transit-supportive zoning, } \\
\text { developable land (vacant + underutilized), } \\
\text { ownership fragmentation, special district (in } \\
\text { place), and cost of infrastructure needed." }\end{array}$ \\
\hline $\begin{array}{l}\text { Transit-Oriented } \\
\text { Characteristics }\end{array}$ & $\begin{array}{l}\text { "evaluates how likely it is that station area } \\
\text { development will be transit-oriented; that is, are } \\
\text { the quantity and quality of access, amenities, } \\
\text { and services in and near a station area } \\
\text { sufficient to support TOD?" }\end{array}$ & $\begin{array}{l}\text { "physical form (block size), pedestrian access } \\
\text { (walk score), bicycle access, number of parks, } \\
\text { and transit service frequency." }\end{array}$ \\
\hline
\end{tabular}


METHODOLOGY

DATA ANALYSIS

Measure

\begin{tabular}{l}
\hline Household Growth $(2000-2010)$ \\
\hline Employment Growth $(2000-2010)$ \\
\hline ToD Demographics
\end{tabular}

TOD Demographics

(Non-Family Households, Households with no Kids,

Householders 25-34 and 55 to 64)

崖 Property Values

Residential Sales Price App. (2000 - 2010)

近

똔

แ

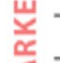

$\sum_{\Sigma}^{\frac{c}{c}}$

Office Rents

Retail Rents

Commercial Development To Date

Residential Development To Date
Variable

Annual Percent Change

Percent of Area with Transit Supportive Zoning

Location Quotient

Dollar Amount of Actual Value (Assessor)

Annual Percentage Change

Average Commercial Rents - Dollar per square foot (Co-Star)

Avgerage Commercial Rents - Dollar per square foot (Co-Star)

Dollar Amount of Permit Value

Dollar Amount of Permit Value

\begin{tabular}{l|l}
\hline Planning Completed to Date & None/ Station Area Plan / GDP \\
\hline Zoning & Percentage of Area with transit supportive zoning \\
\hline Parcelization & Number of Parcels per Acre \\
\hline Vacant Land & Acres of Vacant Land \\
\hline Redevelopment Land & Acres of Improved Value/Land Value < 1.0 \\
\hline Ownership & Number of Owners/ (Acres of Vacant + Acres of \\
\hline $\begin{array}{l}\text { Urban Renewal Area or Special District } \\
\text { Infrastructure Investment }\end{array}$ & Redevelopable Land) \\
\hline Infrastructure Needs & Yes/No \\
\hline
\end{tabular}

\begin{tabular}{|c|c|}
\hline Employment Density & Jobs/Acre \\
\hline Population Density & Population/Acre \\
\hline Physical Form & Percentage of Blocks $=<4.0$ acres \\
\hline Community Amenity Access & Walk Score \\
\hline Park Access & Number of Parks \\
\hline Transit Service & Number of Bus Stops and Peak Hour Train \\
\hline & Frequency Combined Location Quotient \\
\hline Bicycle Access & Linear Feet of Dedicated Bicycle Routes \\
\hline Bike Share & B-Cycle Station \\
\hline Automobile Ownership & Number of Vehicle Households Location Quotient \\
\hline
\end{tabular}

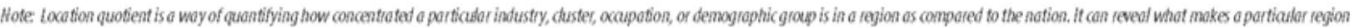
"unizue" in comparison to the nationd overage 
Charlotte Area, North Carolina (2016)

References: (Lynx Rapid Transit Services, 2016)

Transit System: FGT (BRT and LRT)

Purpose of Typology:

Types of Use: Agency; Design or Land Use; Conceptual Planning;

Findings \& Outcomes: The purpose of this typology is to help assist in early-stage planning for an expansion of LRT. The area types were used to develop conceptual station locations and types for the hypothetical expanded line.

Method for Aggregating Typology:

Notes: Supporting variables include factors such as scale, density, population, and land uses. It is not clear how the metrics considered across the five Area types were categorized. It is likely it was 'manual' based on anecdotal variation and local expertise. The typologies are only applied to the conceptual station locations of the hypothetical new rail alignment.

Categories \& Supporting Variables or Definitions:

Notes: The descriptions here may be pulled directly from the language of the document; for image screenshots (marked with an image shadow), page numbers are either left on the image or embedded in the text directly before the image.
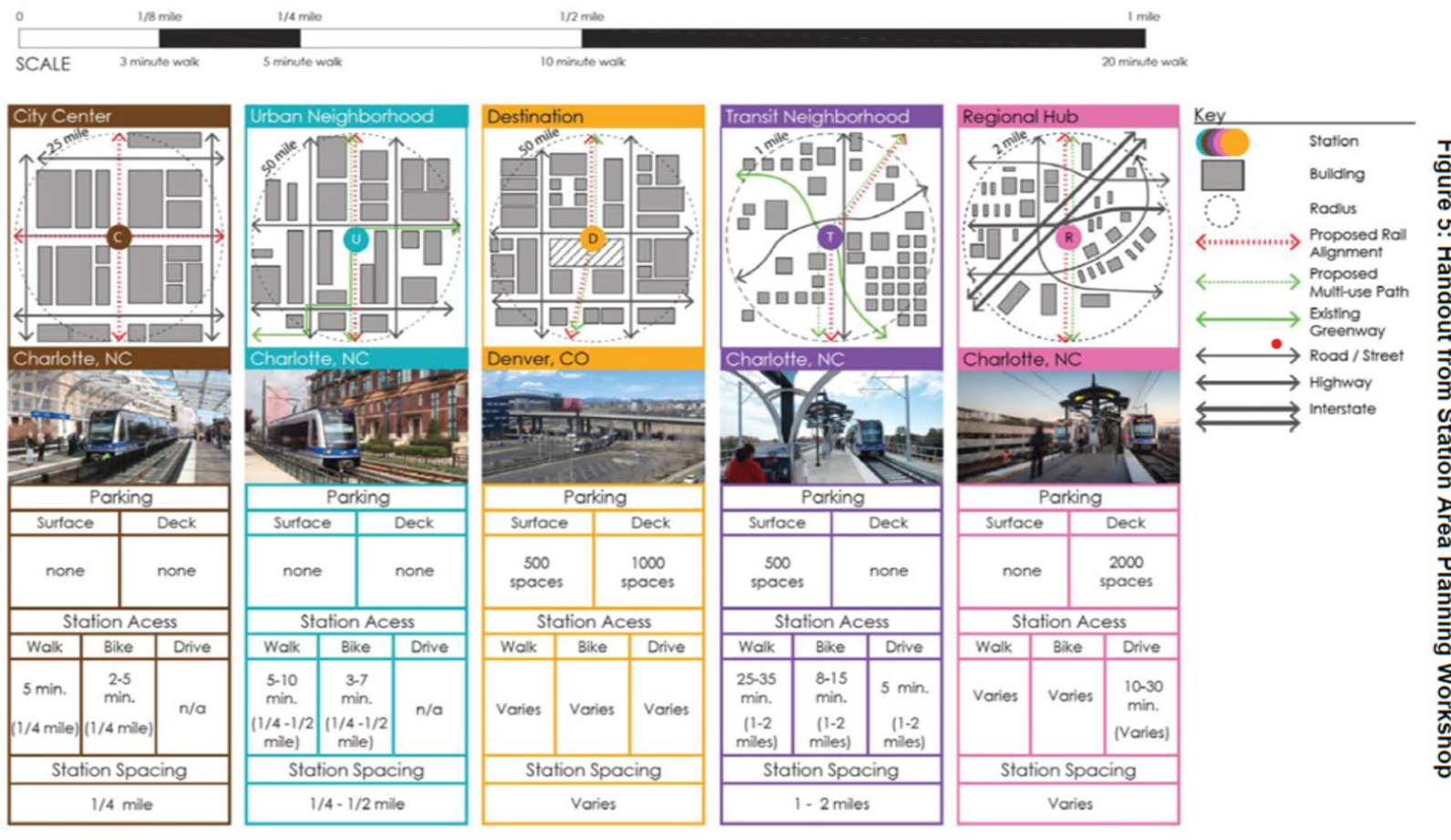

CrRe

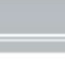




\subsection{Center City}

The Center City station area typology is applicable for stations located within the I-277 Loop. Faced with urban conditions, established infrastructure, and the highest density along the rail alignment, Center City stations are unique and must fit within existing conditions.

\section{Station Area:}

1. Urban

2. High density

3. High to mid-rise development

4. Connectivity to existing pedestrian systems

\section{Station Character:}

1. Architecture: Walk-up

2. Ridership Area: Walking distance (5-10 minutes, $1 / 4$ $-1 / 2$ mile)

3. Parking: None

4. Surrounding Uses: High-rise Office, Commercial, Residential

5. Associated Uses: Mixed-use

6. Rail alignment: Based on city's grid

7. Rail Type: Light Rail, low speed

8. Station spacing: $1 / 2$ mile or less, frequent stops

9. Other: Connections to all modes of transit

Figure 7: Typical Center City Station Area

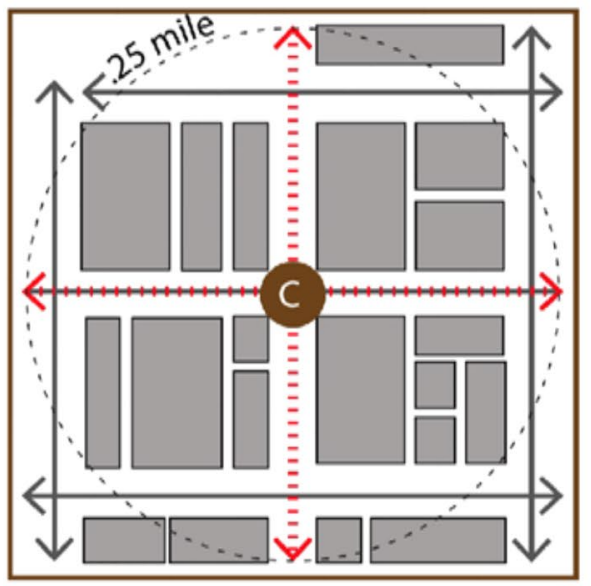

Figure 6: Center City Station Precedents

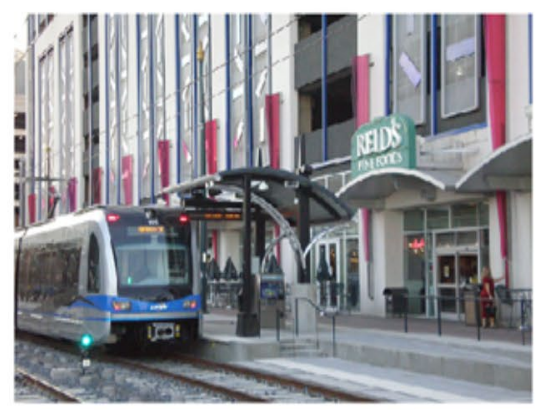

Chariotte, NC ( $7^{\text {th }}$ Street)

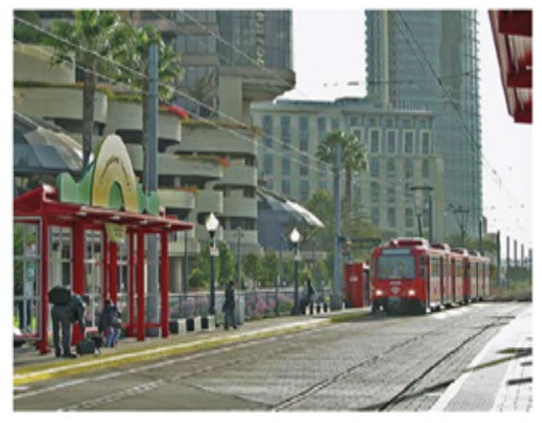

San Diego, CA

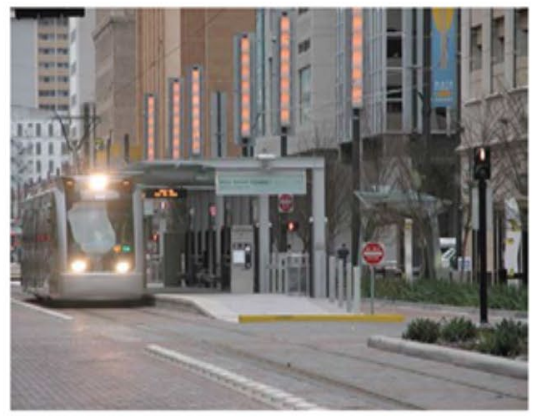

Houston, TX

Southeast Corridor Transit Study

Rail Station Locations and Typologies 


\subsection{Center City}

The Center City station area typology is applicable for stations located within the I-277 Loop. Faced with urban conditions, established infrastructure, and the highest density along the rail alignment, Center City stations are unique and must fit within existing conditions.

\section{Station Area:}

1. Urban

2. High density

3. High to mid-rise development

4. Connectivity to existing pedestrian systems

\section{Station Character:}

1. Architecture: Walk-up

2. Ridership Area: Walking distance (5-10 minutes, $1 / 4$ $-1 / 2$ mile)

3. Parking: None

4. Surrounding Uses: High-rise Office, Commercial, Residential

5. Associated Uses: Mixed-use

6. Rail alignment: Based on city's grid

7. Rail Type: Light Rail, low speed

8. Station spacing: $1 / 2$ mile or less, frequent stops

9. Other: Connections to all modes of transit

Figure 7: Typical Center City Station Area

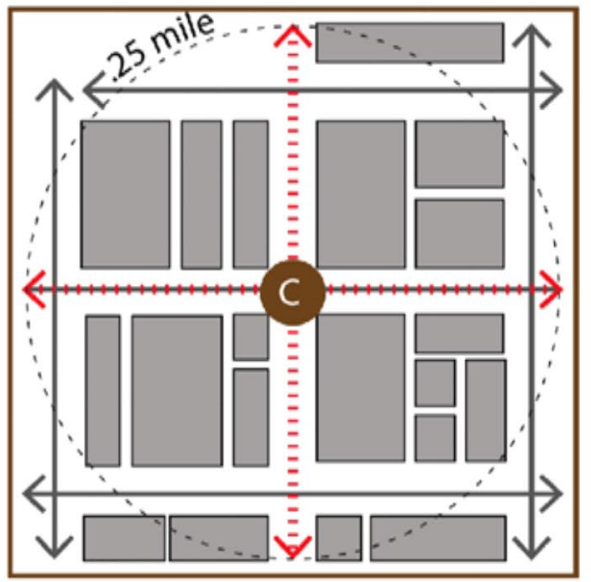

Figure 6: Center City Station Precedents

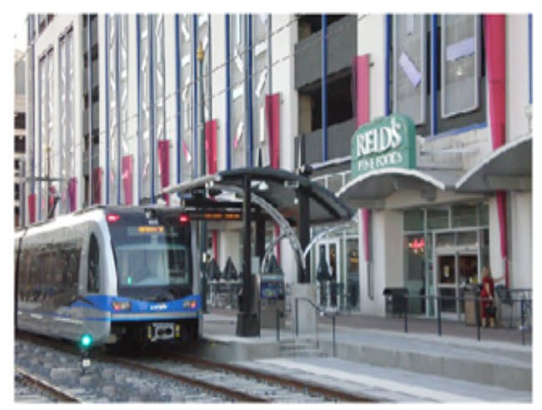

Chariotte, NC ( $7^{\text {th }}$ Street)

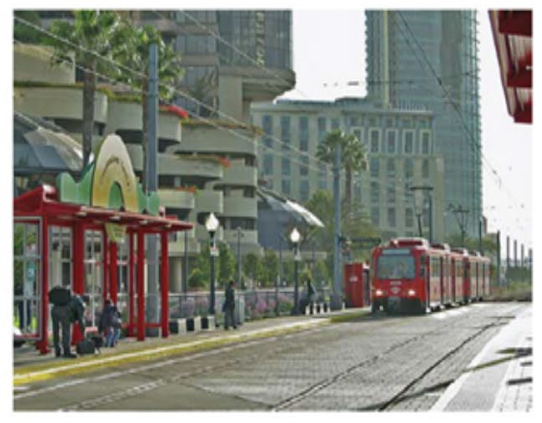

San Diego, CA

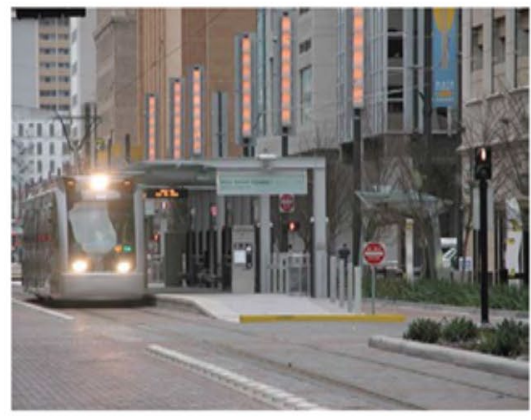

Houston, TX

Southeast Corridor Transit Study

Rail Station Locations and Typologies 


\subsection{Urban Neighborhood}

The Urban Neighborhood station area typology is applicable for stations planned for urban, inner-ring neighborhoods. These neighborhoods are typically dense, walkable, and have considerable existing infrastructure.

\section{Station Area:}

1. Urban

2. High density

3. High to mid-rise development

4. Connectivity to existing pedestrian systems

\section{Station Character:}
1. Architecture: Walk-up
2. Ridership Area: Walking distance (10-15 minutes)
3. Parking: None
4. Surrounding Uses: Mixed-use, Commercial, Multi- family, Single family
5. Associated Uses: None
6. Rail Type: Light Rail, low speed
7. Station Spacing: 1 mile or less, frequent stops
8. Other: Streetcar, bus, and greenway connections

Figure 9: Typical Urban Neighborhood Station Area

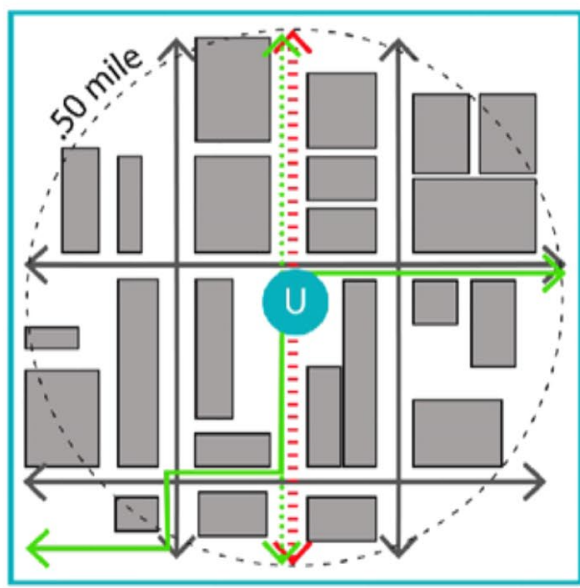

Figure 8: Urban Neighborhood Station Precedents

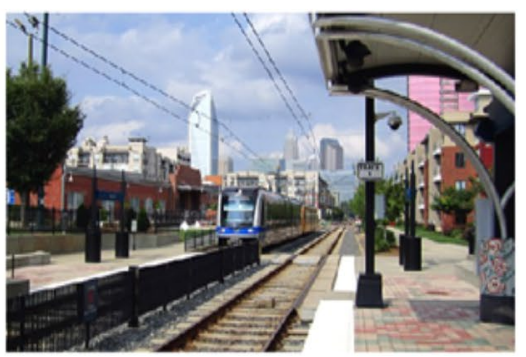

Charlotte, NC (Bland)

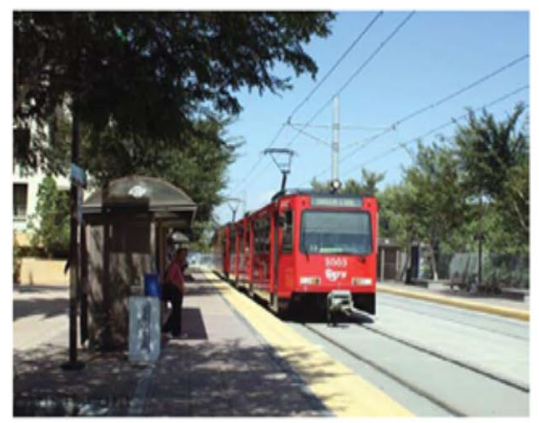

San Diego, CA

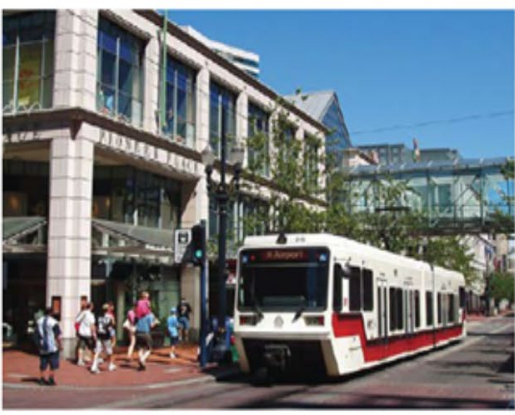

Portland, OR

Southeast Corridor Transit Study

Rail Station Locations and Typologies 


\subsection{Urban Neighborhood}

The Urban Neighborhood station area typology is applicable for stations planned for urban, inner-ring neighborhoods. These neighborhoods are typically dense, walkable, and have considerable existing infrastructure.

\section{Station Area:}

1. Urban

2. High density

3. High to mid-rise development

4. Connectivity to existing pedestrian systems

\section{Station Character:}
1. Architecture: Walk-up
2. Ridership Area: Walking distance (10-15 minutes)
3. Parking: None
4. Surrounding Uses: Mixed-use, Commercial, Multi- family, Single family
5. Associated Uses: None
6. Rail Type: Light Rail, low speed
7. Station Spacing: 1 mile or less, frequent stops
8. Other: Streetcar, bus, and greenway connections

Figure 9: Typical Urban Neighborhood Station Area

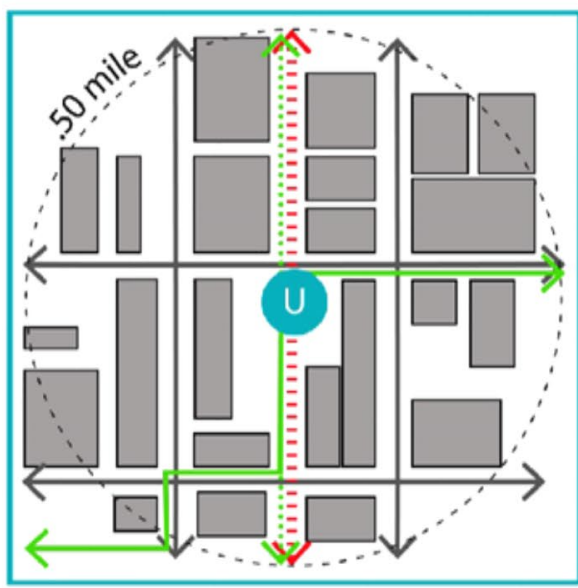

Figure 8: Urban Neighborhood Station Precedents

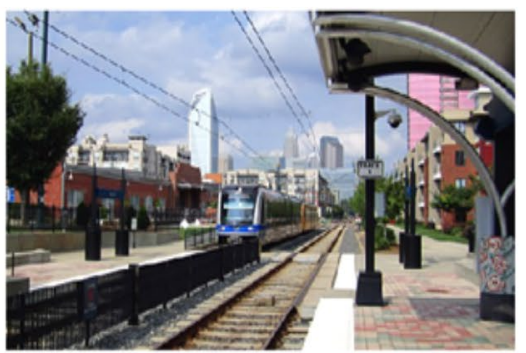

Charlotte, NC (Bland)

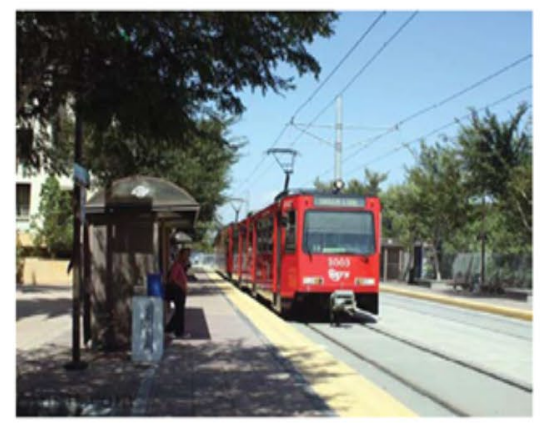

San Diego, CA

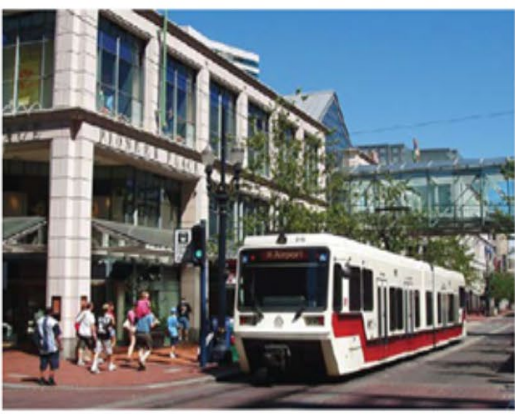

Portland, OR

Southeast Corridor Transit Study

Rail Station Locations and Typologies 


\subsection{Transit Neighborhood}

The Transit Neighborhood station area typology is applicable for stations planned for suburban areas along the corridor. These neighborhoods typically consist of suburban single family developments, dedicated retail centers, and large arterial roads.

\section{Station Area:}

1. Suburban

2. Medium density

3. Low rise to single story development

4. Connectivity to existing/proposed pedestrian systems

\section{Station Character:}

1. Architecture: Commuter

2. Ridership Area: Neighborhood/Local (1-3 miles)

3. Parking: Surface or Deck

4. Surrounding Uses: Small Commercial, Multi-family, Single family

5. Associated Uses: None

6. Rail Type: Light Rail, higher speed

7. Station Spacing: 1-3 miles, infrequent stops

8. Other: Possible express service, connections to bus and greenway

Figure 11: Typical Transit Neighborhood Station Area

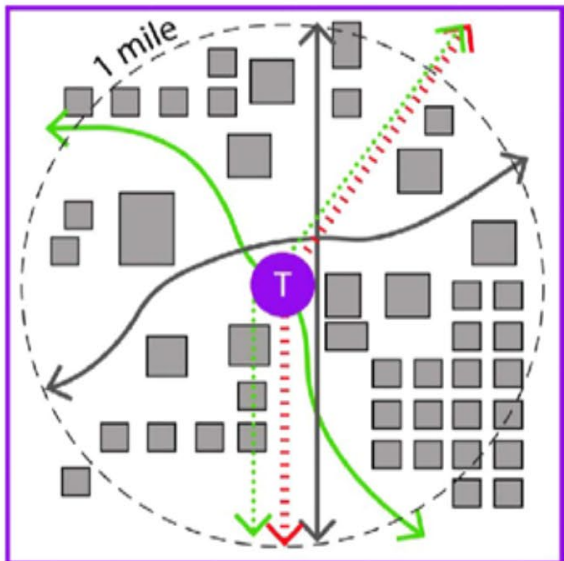

Figure 10: Transit Neighborhood Station Precedents

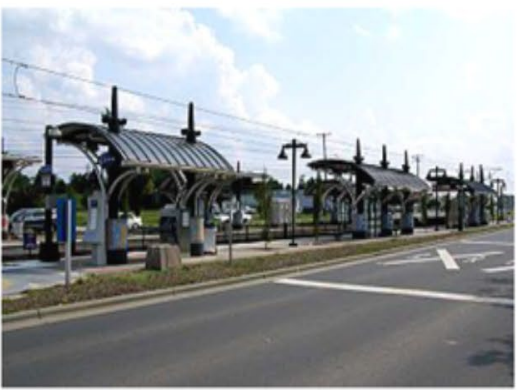

Chariotte, NC (Scaleybark)

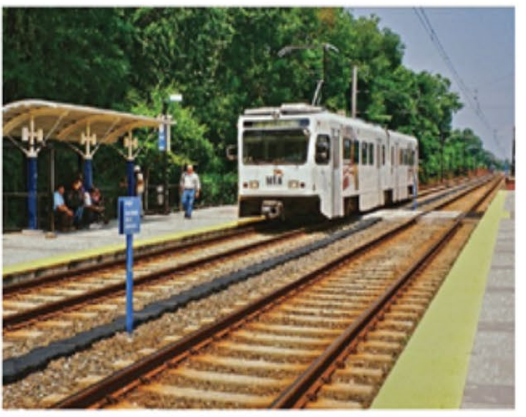

Baltimore, $M D$

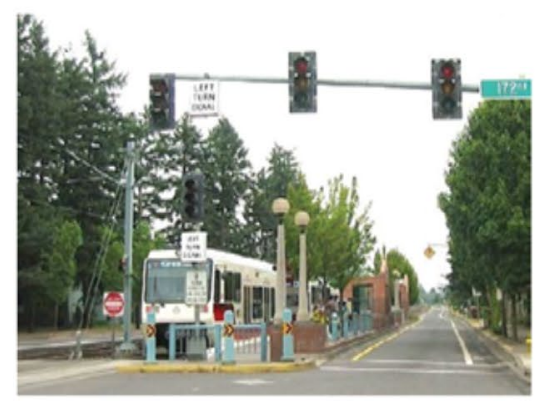

Portland, OR

Southeast Corridor Transit Study

Rail Station Locations and Typologies 
Chicago, Illinois (2009; 2014)

References: (Jones Lang LaSalle et al., 2009; Teska Associates, Inc. et al., 2014)

Note: The information and images come from the 2014 update, unless otherwise noted. The development of the area types was more detailed in the 2009 edition; the 2014 built upon the 2009 version, but they added two new typologies.

Transit System: 77 existing and 2 planned Metra stations, defined as 'commuter rail'. Identifies 11 lines with about a third of the stations (77/241) within the City of Chicago, the focus of this study.

Purpose of Typology:

Types of Use: Agency; Design or Land Use; Strategy Identification \& Implementation (light); Findings \& Outcomes: Among other purposes, these documents aim to differentiating across TOD types in the region. While both reports provide some guidance and recommendations for encouraging development and transitioning TODs into their 'realized' potential, these documents fall short of providing a detailed 'toolkit' of strategies for economic and social development.

Definitions:

"Transit oriented development (TOD) is generally defined as development that is oriented towards and integrated with a nearby transit facility, such as a rail station or bus line. TOD is typically perceived as a means to improve access to the transit facility by building up the station area as a compact, mixed use district that is intended to encourage increased transit ridership." (2014, page 3)

Transit friendly development (TFD): "focuses on multimodal connectivity, appropriately scaled development, and station area improvements that create better access to transit facilities and encourage greater transit ridership." (2014, page 3)

Method for Aggregating Typology:

Notes: The 2014 study uses the prior (2009) 7 CTA typologies and adds 2 new ones. It is still not clear how the typologies were categorized, but it is likely it was a combination of quantitative analysis and local expertise.

Supporting data included: "land use; zoning; density; neighborhood character; Metra ridership data, frequency of service, and fare zones; commuter parking; access to CTA bus and rail; walkability and bikeability scores; nearby employers and business districts; local institutions; and opportunities for development and station area improvements." (Teska Associates, Inc. et al., 2014, p. 3)

Categories \& Supporting Variables or Definitions:

Notes: The descriptions here may be pulled directly from the language of the document; for image screenshots (marked with an image shadow), page numbers are either left on the image or embedded in the text directly before the image. 
(Jones Lang LaSalle et al., 2009, pp. 29-30)

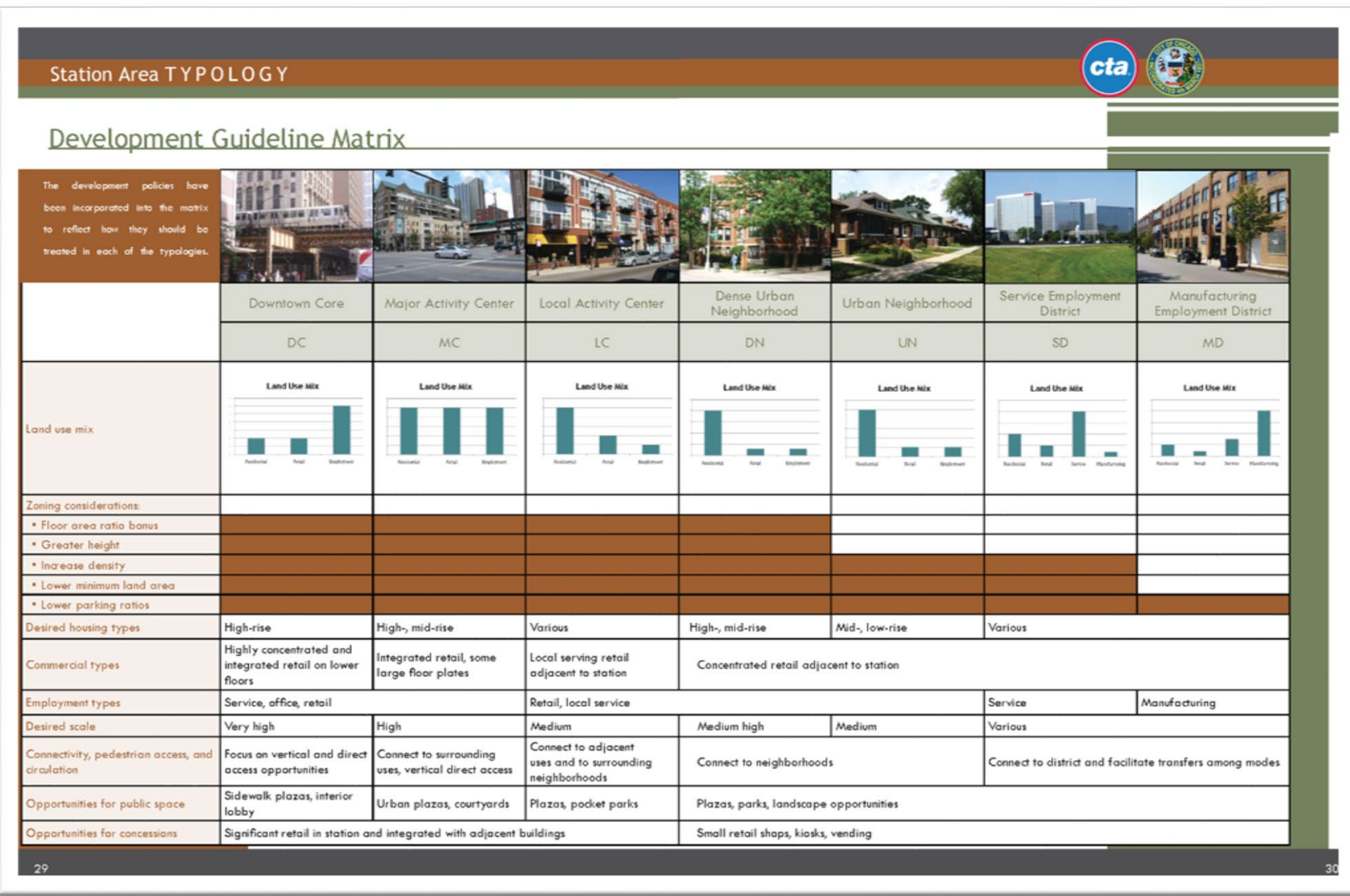


(Teska Associates, Inc. et al., 2014, p. 2)- LN and RI are new; more detailed descriptions of each of these 2014 area types to follow.

Chicago Plan Commission Meeting - October 16, 2014

\section{DC}

\section{DOWNIOWNCORE}

Located in the Loop and adjacent high density areas, Metra service generates highest ridership counts in the system within the City of Chicago Land uses are primarily employment-generating uses within the central business district, with a mix of retail and residential. Residential primarily in high-rise buildings. Superior access to CTA rail and bus.

MC

\section{MORACTMTYCEIIR}

An MC is a major node of activity generally located outside of the downtown core. Metra ridership at the MCs varies, but all station areas are served by CTA rail and bus. They typically have a balanced mix of residential, commercial, and employment-generating uses, with residential development typically provided in mid- to high-rise buildings.

\section{C LCNACTIMTYCENIR}

An LC is primarily characterized by the Metra station being the central focus of a built-up and identifiable neighborhood. An LC typically has the highest density and greatest mix of uses around the station. Infil development and adaptive reuse present opportunities to enhance the vitality of the LC.

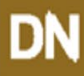

\section{DEISE UREAN NEGFOAHOOD}

A DN serves Chicago neighborhoods with a high concentration of development and a high level of riders who walk to the station. While all stations have access to CTA bus, only Rogers Park has nearby CTA rail access. Land use is composed of a mix of commercial development near the stations surrounded by residential development.

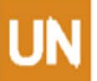

\section{URANNEGH:OPHOOD}

A UN serves an established neighborhood, but ridership varies in intensity and about half of riders walk, bike or take transit to the station. Land use is primarily residential, but many UNs have commercial districts. UN stations generally have CTA or Pace buses with only a few having CTA rail stations nearby

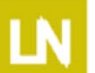

\section{LOWDEYSTYKECHBOPHOOD}

An LN is predominantly residential in nature with modest Metra ridership. LN is one of two new typologies that has been created for Metra stations. With more than three-quarters of the land use devoted to residential, an LN has a strong residential character with minimal retail and employment uses located around the station areas.

\section{SEVMEEPTONETDSTRCT}

An SD is typically identified by a major service use with high employ ment, such as a university or airport. Two of the four SD stations are located next to major universities: Chicago State University and the University of Chicago. The other two serve O'Hare Airport, which is a major multimodal transportation hub with access to various employers

\section{MANUFACTURANG BMPONATT DSTIRCT}

An MD is generally characterized by a significant amount of manufacturing land uses. Over one-quarter of the total land use is devoted to industrial, warehouse, or wholesale trading. Another quarter are for railways and freight use. Residential uses still comprise less than one-third, which contributes to about half of all commuters accessing the MD stations

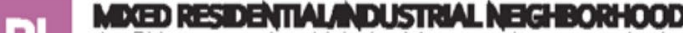

F An Rl is an area in which the Metra station serves both residential and industrial uses. The train tracks often separate these uses which have evolved over time.
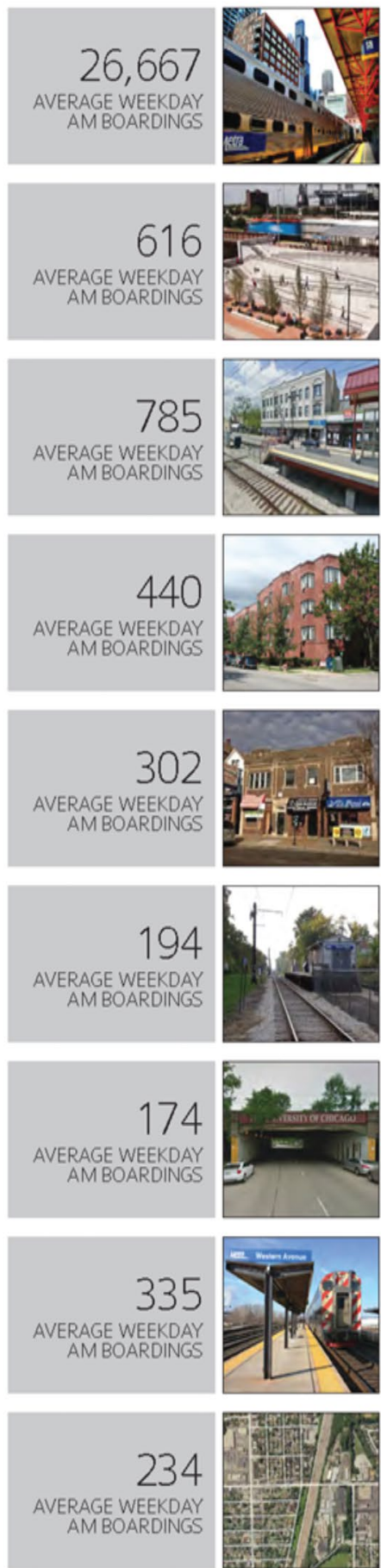


\section{DOWNTOWN CORE}

\section{METRA RIDERSHIP}

Weekday ridership averages more than 26,000 riders, which is the highest in the system.

\section{CTAACCESS}

All five DC station areas have adequate CTA bus and rail access.

\section{PEDESTRIAN B BICYCLEACCESS}

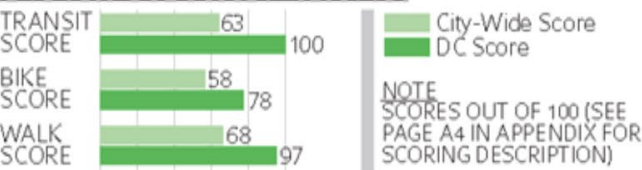

\section{COMMUTER PARKNG}

None of the DCs have access to commuter parking facilities.

\section{MODE OF ACCESS}

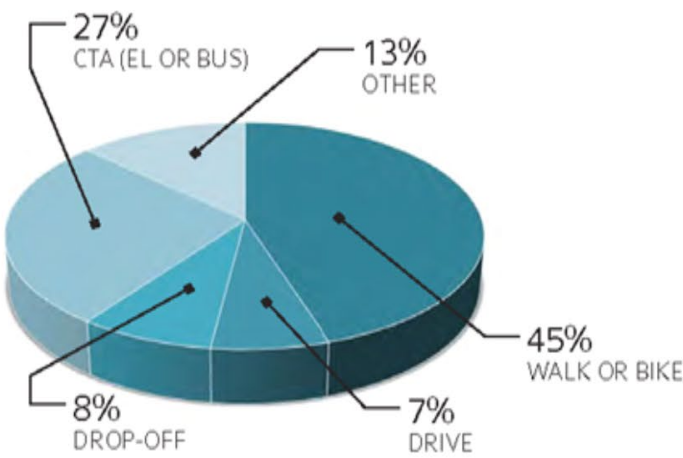

A Data refer to typology averages within $1 / 2$-mile radius of DC stations

\section{The Downtown Core (DC) is located around the Loop and adjacent to high density areas, with stations generating the highest ridership counts in the system.}

Metra weekday ridership averages $26,000+$ riders for the five DCs, with all station areas served by CTA rail and bus. A majority of commuters amive to the DC stations on foot or via CTA. Consistent with the Loop, the average land use makeup of a DC station area is predominantly commercial and service uses, with residential, institutional, and open space components as well. DCs also have the highest walk, bike, and transit scores in the entire system.

\section{LND USE ${ }^{A}$}

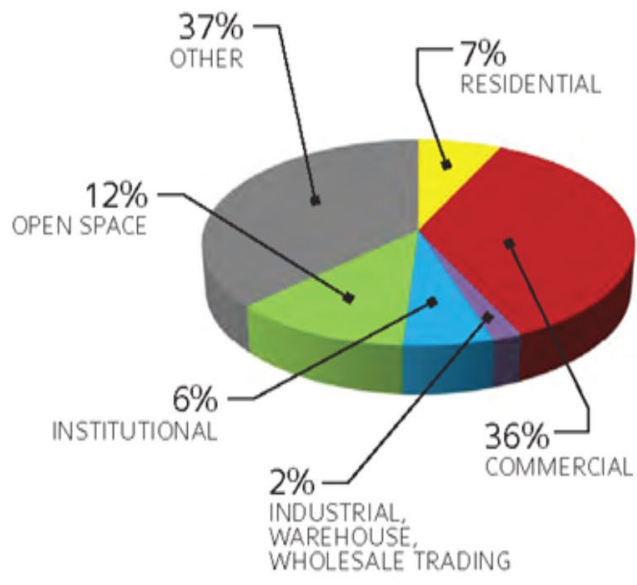

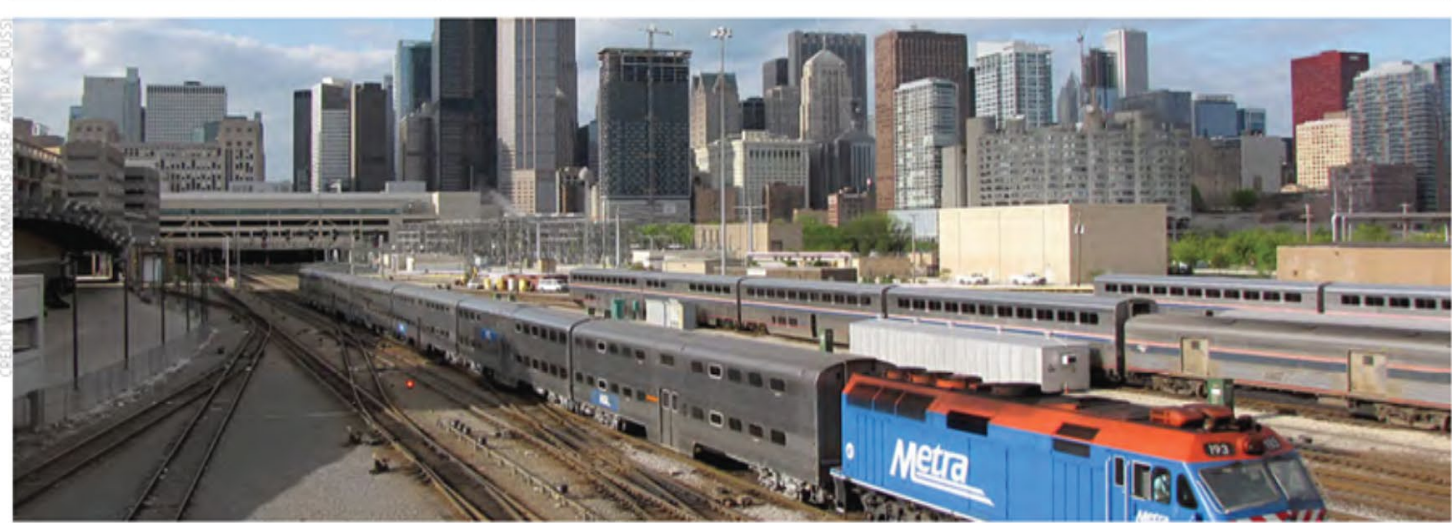




\section{MANOR ACTIVTYY CENTER}

\section{MEIRA RIDERSHIP}

Weekday ridership is a strong attribute of MC. Four of the $7 \mathrm{MC}$ stations attract 500 + riders.

\section{CTAACCESS}

While 3 of the 7 MC stations have nearby CTA rail access, all MCs have strong CTA bus access.

\section{PEDESTRIAN \& BICYCIEACCESS}

\begin{tabular}{|c|c|}
\hline $\begin{array}{lc}\text { TRANSIT } & 63 \\
\text { SCORE } & 77\end{array}$ & $\begin{array}{l}\text { City-Wide Score } \\
\text { MC Score }\end{array}$ \\
\hline $\begin{array}{ll}\text { IKE } & 58 \\
\text { CORE } & \end{array}$ & 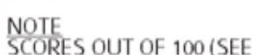 \\
\hline $\begin{array}{ll}\text { ALK } & 68 \\
\text { ORE } & \quad 86\end{array}$ & $\begin{array}{l}\text { PAGE A4 IN APPENDIX FOR } \\
\text { SCORING DESCRIPTION) }\end{array}$ \\
\hline
\end{tabular}

\section{COMMUIER PARKING}

Two of the $7 \mathrm{MC}$ stations have access to commuter parking, with an average of $95 \%$ of available parking spaces being utilized.

\section{MODE OF ACCESS}

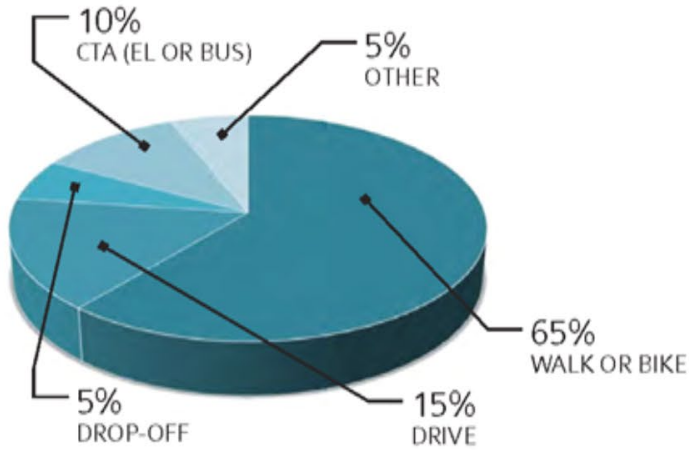

A Data refer to typology averages within $1 / 2$-mile radius of MC stations.

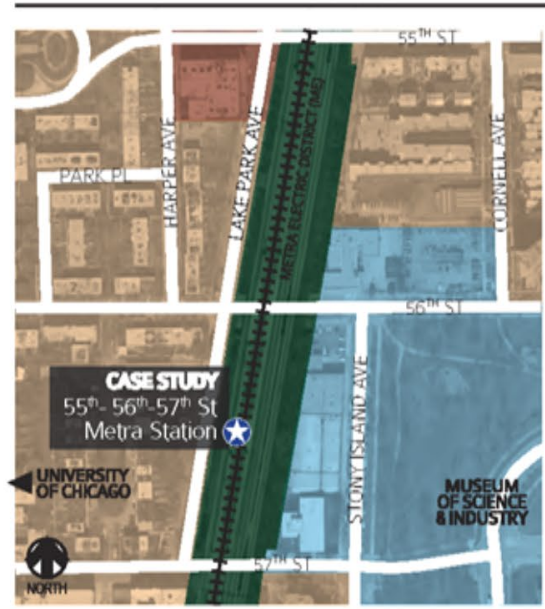

\section{A Major Activity Center (MC) is a major node of activity generally located outside of the downtown core.}

Metra weekday ridership at the MCs varies, but all station areas are served by CTA rail and bus. They typically have a balanced mix of residential, commercial, and employment-generating uses, with residential development typically provided in midto high-rise buildings. Some have major cultural attractions or institutional uses, such as a university, sports facility, convention center, or museum. In addition, the Metra station area at Jefferson Park is one of the City's more prominent transit hubs located beyond the downtown core.

\section{LAND USE ${ }^{A}$}

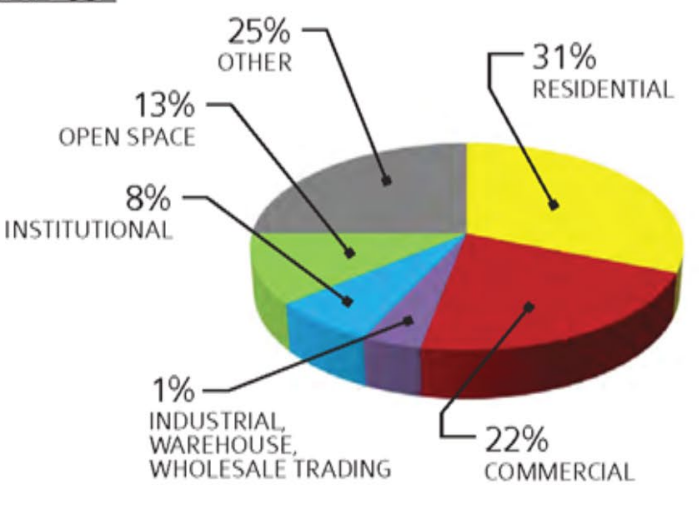

\section{CASE STUDY}

\section{$55^{\mathrm{h}}-56^{\mathrm{h}}-\mathbf{5}^{\mathrm{h}}$ Street}

The $55^{\text {th }}-56^{\text {th }}-57^{\text {th }}$ Street Metra Station, serving Hyde Park, the University of Chicago, and the Museum of Science and Industry, is at the center of a large built-up neighborhood with a mix of land uses, from high rise residential to large retailers and university-related buildings. The station is located above a viaduct with a small retail space at ground level. With 1,500+ riders per day, the station is one of the most heavily used stations - ranking $8^{\text {th }}$ of all 77 existing Metra stations within the City of Chicago - in a neighborhood setting. The pedestrian environment, signage, and linkages to nearby amenities are important aspects of this station area. 


\section{LC LOCALACTIVITY CENTER}

\section{METRA RIDERSHIP}

Weekday ridership is a strong attribute of LC. Seven of the $11 \mathrm{LC}$ stations attract $500+$ riders.

\section{CTAACCESS}

Each LC is defined by a Metra station as its focal point with strong CTA bus access

\section{PEDESTRIAN\& BICYCLEACCESS}

\begin{tabular}{l|l|l} 
TRANSIT & 63 & City-Wide Score \\
\hline SCORE & 60 & LC SCore \\
BIKE & 58 & NOTE \\
\hline SCORE & 63 & SCORES OUT OF 100 (SEE \\
WALK & 68 & PAGE A4 IN APPENDIX FOR \\
SCORE & 73 & SCORING DESCRIPTION)
\end{tabular}

\section{COMMUTER PARKING}

Seven of the 11 LC stations have access to commuter parking, with an average of $67 \%$ of available parking spaces being utilized.

\section{MODE OF ACCESS}

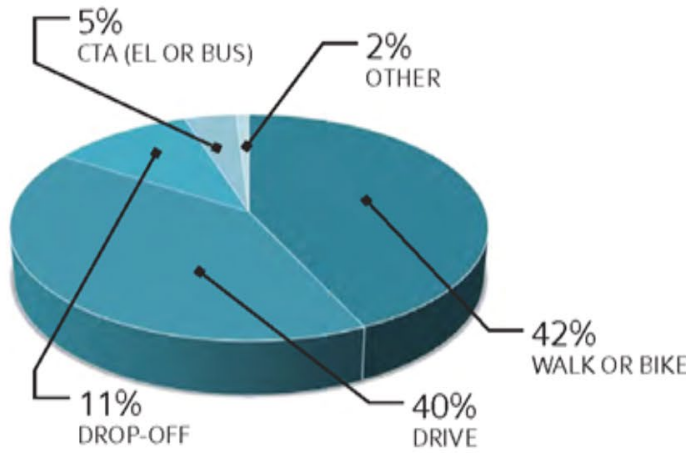

${ }^{A}$ Data refer to typology averages within $1 / 2$-mile radius of LC stations.
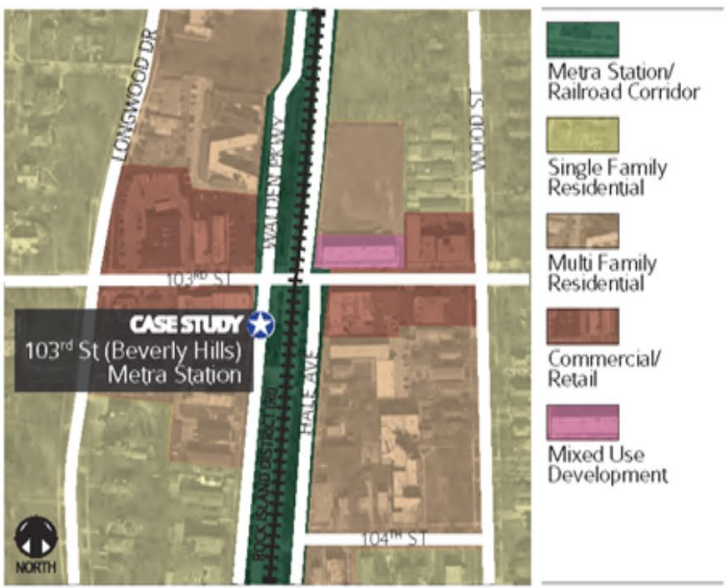

\section{A Local Activity Center (LC) is primarily characterized by the Metra station being the central focus of a built-up and identifiable neighborhood.}

An LC is primarily built up with the highest density and greatest mix of uses around the station. Residential also varies with single- and multi-family uses. Infill development and adaptive reuse present opportunities to enhance the vitality of the LC. Redevelopment opportunities, as well as enhanced connectivity and amenities for pedestrians and bicyclists, will help attract Metra riders. The Metra station will continue to be the central focus of the LC, while also maintaining the pedestrian scale of the surrounding area and providing opportunities for local shopping, dining, and employment.

\section{LAND USE ${ }^{A}$}

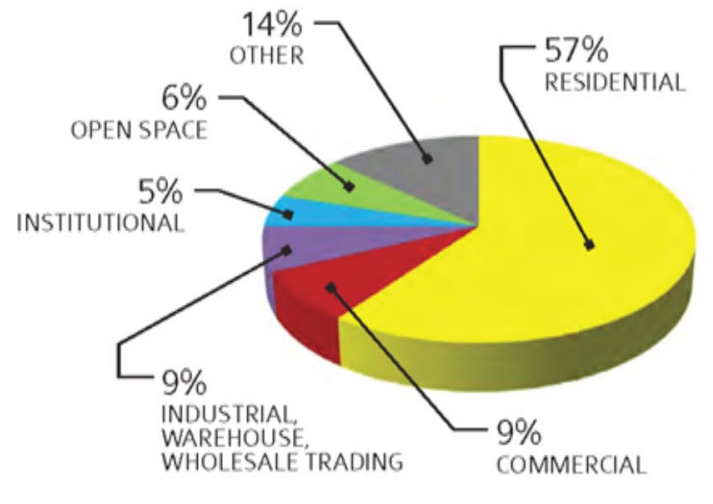

\section{CASE STUDY}

\section{$103^{\text {rd }}$ Street (Beverly Hills)}

The $103^{\text {rd }}$ Street Metra Station is the focal point of the portion of the Beverly Hills community along the $103^{\text {rd }}$ Street corridor. The corridor is presently defined by a strong streetwall of businesses and mixed use buildings that create a pedestrianoriented streetscape that leads to the Metra station. While recent mixed use and residential development have appeared on the north side of $103^{\text {rd }}$ Street across from the station, opportunities exist for infill development and adaptive reuse of a former funeral parlor. As outlined in the case study on the next page, a mix of transit, streetscape, and site improvements are intended to build upon the existing transit friendly elements for this LC. 


\section{DN DENSE URBAN NEIGHBORHOOD}

\section{METRA RIDERSHIP}

Weekday ridership for DN is moderate, averaging 440 riders. Rogers Park attracts 1,176 riders.

\section{CTAACCESS}

Each DN has adequate CTA bus access, with only Rogers Park having nearby CTA rail.

\section{PEDESTRIAN\& BICYCLEACCESS}

\begin{tabular}{l|l|l} 
TRANSIT & 63 & City-Wide Score \\
SCORE & 67 & DN SCore \\
\hline BIKE & 58 & NOTE \\
\hline SCORE & 69 & SCORES OUT OF 100 (SEE \\
\hline WALK & 68 & PAGE A4 IN APPENDIX FOR \\
\hline SCORE & 75 & SCORING DESCRIPTION)
\end{tabular}

\section{COMMUTER PARKING}

Three-fourths of existing DN stations have access to commuter parking, with an average of $80 \%$ of available parking spaces being utilized

\section{MODE OF ACCESS}

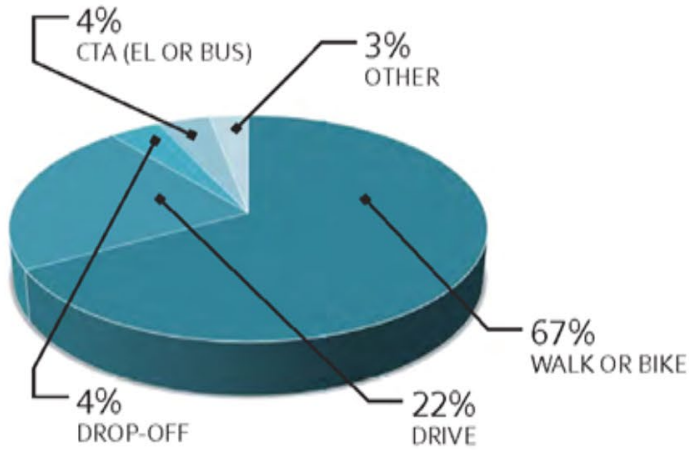

A Data refer to typology averages within $1 / 2$-mile radius of DN stations.
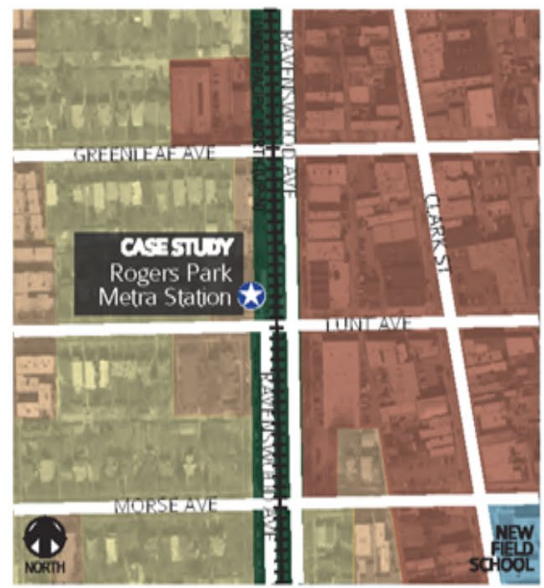

\section{A Dense Urban Neighborhood (DN) serve Chicago neighborhoods with a high concentration of development.}

Four existing Metra station are designated as DN, with the proposed Peterson/Ridge station being the fifth. While all stations have access to CTA bus, only Rogers Park has nearby CTA rail access. The Metra station is not the focal point of a DN like it is for most LCS, despite their similar land use characteristics. For example, the Rogers Park station sits west of the bustling Clark Street corridor. Land use is composed of a mix of commercial development near the stations, surrounded by residential development. Residential uses may include mid-to high-density buildings, although some areas may be primarily composed of single-family two- and threeflats on small lots located near the station.

\section{LAND USE $^{A}$}

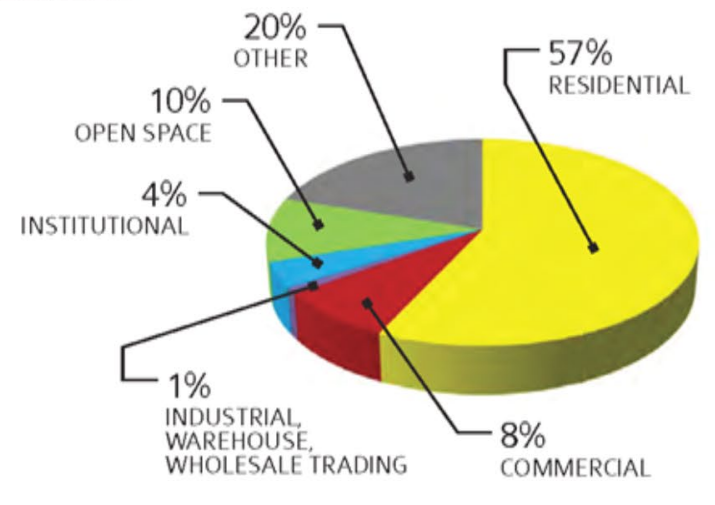

\section{CASE STUDY}

\section{Rogers Park}

The Rogers Park Metra Station serves a vibrant neighborhood with a strong mix of uses, smaller industrial buildings near the railroad tracks to the east, and a major commercial corridor one block to the east. On the west side, most of the neighborhood is residential. With over 1,100 riders per day, the station ranks $11^{\text {th }}$ of all 77 existing Metra stations within the City of Chicago. In addition to having 137 available parking spaces that have a $90 \%$ utilization rate, nearly three-quarters of riders access the station by walking. The station serves both residents and employees who live and work nearby in the neighborhood. 


\section{UN URBAN NEIGHBORHOOD}

\section{METRA RIDERSHIP}

Weekday ridership is moderate with an average of 302 riders. Five of the existing $28 \mathrm{UN}$ stations attract $500+$ riders.

\section{CTAACCESS}

While only a few UN stations have CTA rail access, all have CTA or Pace bus access.

\section{PEDESTRIAN \& BICYCIE ACCESS}

\begin{tabular}{l|l||l} 
IRANSIT & 63 & City-Wide Score \\
\hline SCORE & 61 & UN SCOre \\
\hline BIKE & 58 & NOTE \\
\hline SCORE & 55 & SCORES OUT OF 100 (SEE \\
WALK & 68 & PAGE A4 IN APPENDIXFOR \\
SCORE & 68 & SCORING DESCRIPTION)
\end{tabular}

\section{COMMUTER PARKING}

Twenty-three of 28 existing UN stations have access to commuter parking, which average a $49 \%$ utilization rate of available spaces.

\section{MODE OF ACCESS}

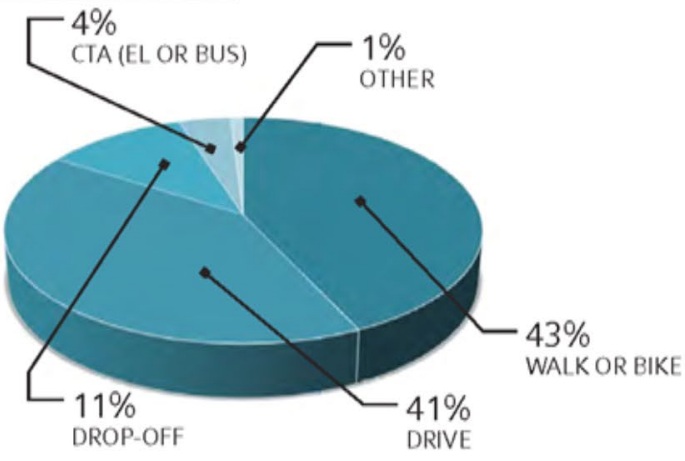

A Data refer to typology averages within $1 / 2$-mile radius of UN stations

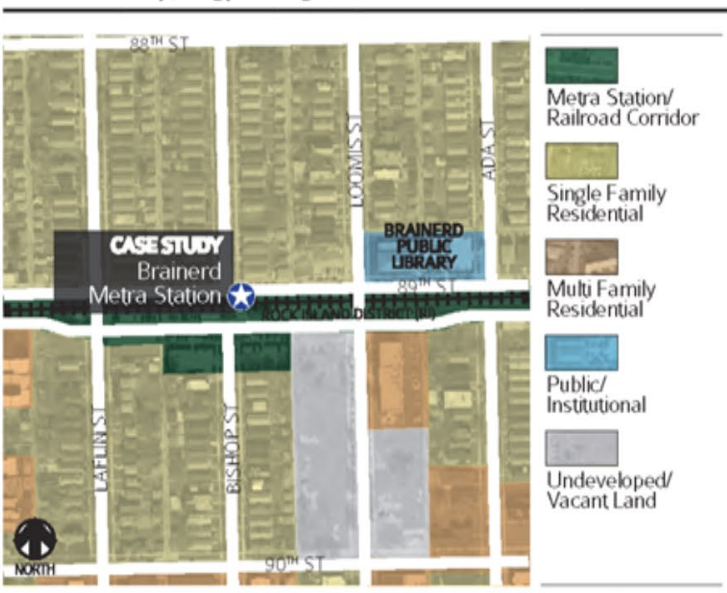

\section{An Urban Neighborhood (UN) serves an established neighborhood, but ridership varies in intensity.}

The UN typology designation is applied to 28 existing Metra stations, with the proposed Auburn Park ( $79^{\text {th }}$ Street) station bringing the total up to 29 Of all nine Metra typologies, the UN designation is applied to the most stations in the City of Chicago (29 out of 79). A UN neighborhood is generally served by CTA or Pace bus, with only a few UNs having CTA rail stations nearby. Land use is primarily residential, but many UNs have commercial districts. About half of riders either walk, bike, or take transit to Metra and the other half drive to the station. Density around a UN station is moderate, then tapers off away from the station, generally to low-density residential.

\section{LAND USE ${ }^{\wedge}$}

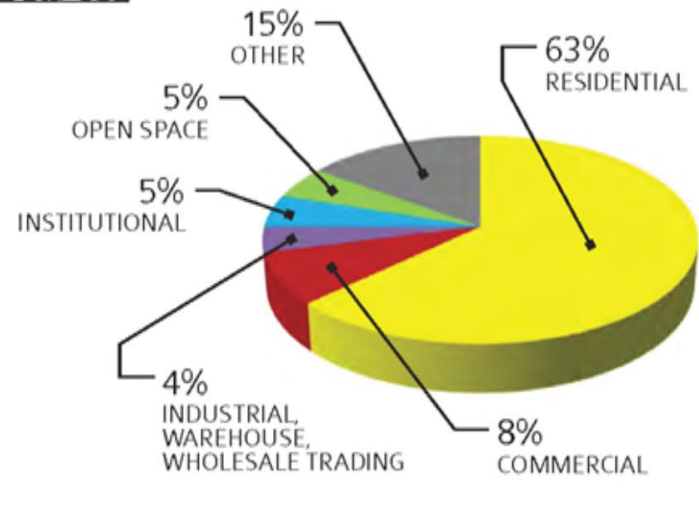

\section{CASE STUDY}

\section{Brainerd}

The Brainerd Metra Station serves a primarily residential area on both sides of the railroad tracks, which run east-west through the neighborhood at surface level. A large senior building was recently built south of the tracks, and additional vacant land could be developed for residential or commercial purposes. Parking lots around the station area make it convenient to drive to the station, but the area is also generally pedestrian-friendly. Additional landscaping and pedestrian improvements could make the station area more attractive to Metra users. 


\section{UN URBAN NEIGHBORHOOD}

\section{METRA RIDERSHIP}

Weekday ridership is moderate with an average of 302 riders. Five of the existing $28 \mathrm{UN}$ stations attract $500+$ riders.

\section{CTAACCESS}

While only a few UN stations have CTA rail access, all have CTA or Pace bus access.

\section{PEDESTRIAN \& BICYCIE ACCESS}

\begin{tabular}{l|l||l} 
IRANSIT & 63 & City-Wide Score \\
\hline SCORE & 61 & UN SCOre \\
\hline BIKE & 58 & NOTE \\
\hline SCORE & 55 & SCORES OUT OF 100 (SEE \\
WALK & 68 & PAGE A4 IN APPENDIXFOR \\
SCORE & 68 & SCORING DESCRIPTION)
\end{tabular}

\section{COMMUTER PARKING}

Twenty-three of 28 existing UN stations have access to commuter parking, which average a $49 \%$ utilization rate of available spaces.

\section{MODE OF ACCESS}

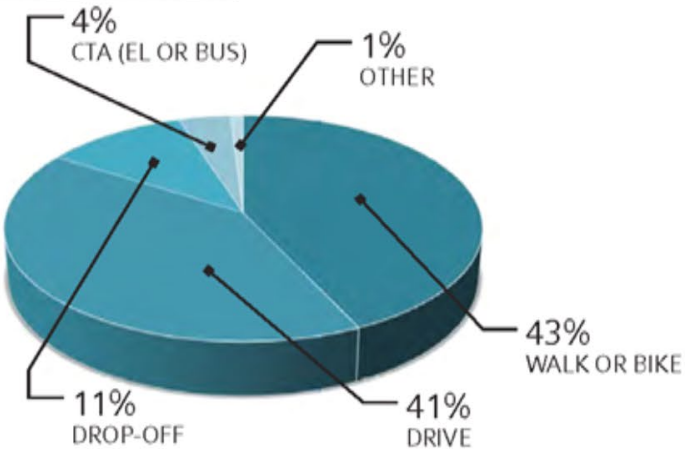

A Data refer to typology averages within $1 / 2$-mile radius of UN stations.

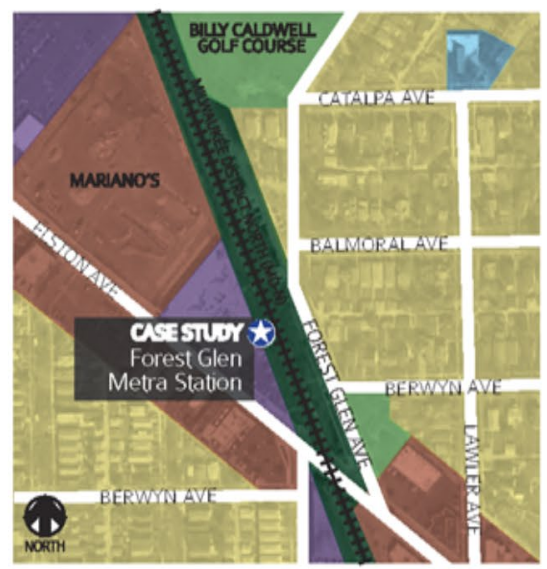

\section{An Urban Neighborhood (UN) serves an established neighborhood, but ridership varies in intensity.}

The UN typology designation is applied to 28 existing Metra stations, with the proposed Auburn Park ( $79^{\text {th }}$ Street) station bringing the total up to 29 Of all nine Metra typologies, the UN designation is applied to the most stations in the City of Chicago (29 out of 79). A UN neighborhood is generally served by CTA or Pace bus, with only a few UNs having CTA rail stations nearby. Land use is primarily residential, but many UNs have commercial districts. About half of riders either walk, bike, or take transit to Metra and the other half drive to the station. Density around a UN station is moderate, then tapers off away from the station, generally to low-density residential.

\section{LAND USE ${ }^{\wedge}$}

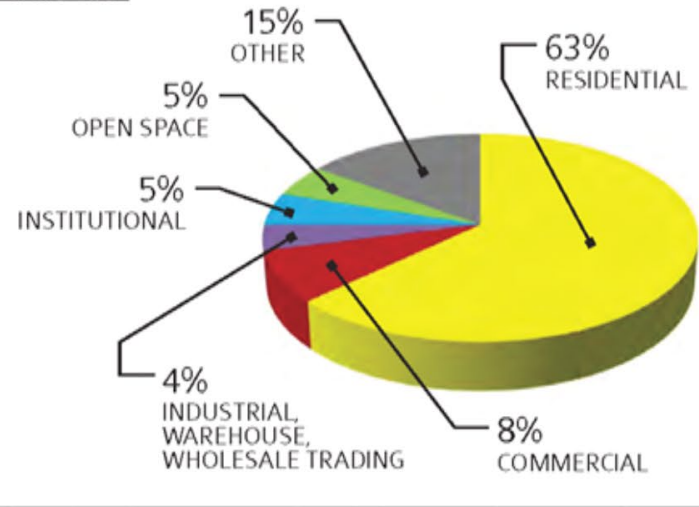

\section{CASE STUDY}

\section{Forest Glen}

The Forest Glen Metra Station serves a residentia neighborhood east and south of the station and a commercial district along N. Elston Avenue west of the station. A new grocery store that recently opened on Elston will be a major retail anchor for the area. Just north of the station, Forest Glen Woods is owned by the Cook County Forest Preserve District. The station serves both riders walking to the station from nearby homes, as well as passengers who drive to the station who either park or are dropped off. While the station is generally favorable to pedestrians and bikes, modest improvements could make the area more pedestrian- and bike-friendly. 


\section{IN LOW DENSTIY NEIGHBORHOOD}

\section{METRARIDERSHIP}

Two of the 3 LN stations attract an average of 85 riders or less on weekdays. The third station at $91^{\text {st }}$ Street (Beverly Hills) attracts 437 riders.

\section{CTAACCESS}

None of the LNs have nearby CTA rail access, but all three have CTA or Pace bus access.

\section{PEDESTRIANBBICYCLEACCESS}
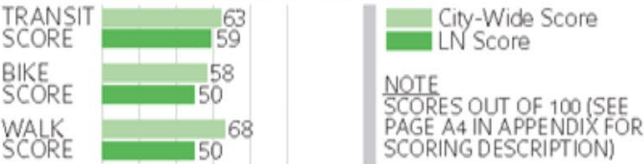

\section{COMMUTER PARKNG}

Only one of the three LNs has access to commuter parking. The $91^{\text {ta }}$ Street (Beverly Hills) Station has 189 parking spaces with a $64 \%$ utilization rate.

\section{MODE OF ACCESS}

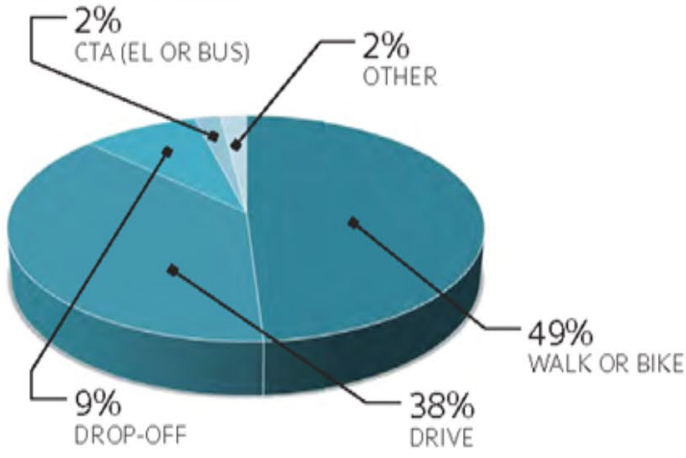

A Data refer to typology averages within $1 / 2$-mile radius of $L N$ stations

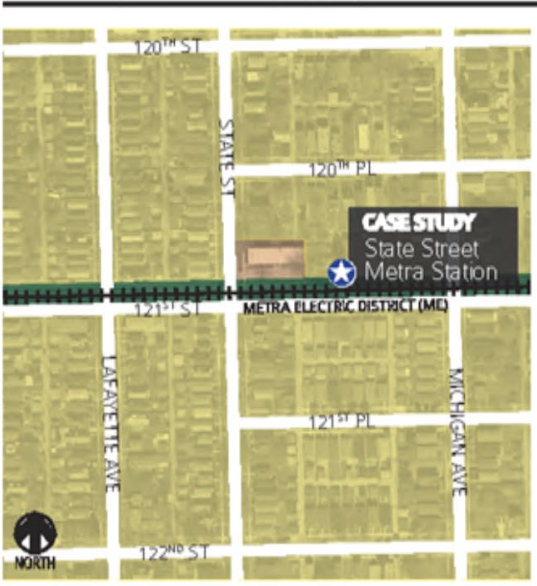

\section{A Low Density Neighborhood (LN) is predominanty resicential in nature with modest Metra ridership.}

$\mathrm{LN}$ is one of two new typologies that has been created for Metra stations. With more than threequarters of the land use devoted to residential, an LN has a strong residential character with minimal retail and employment uses located around the station areas. Metra is often the most visible form of transit, as few station areas have proximate CTA rail, although most are served by CTA or Pace bus. Approximately half of riders walk or bike to the station, with the other half driving or being dropped off at the station. Metra serves to stabilize the LN areas and is a significant amenity for the local housing stock

\section{LAND USE $^{\mathrm{A}}$}

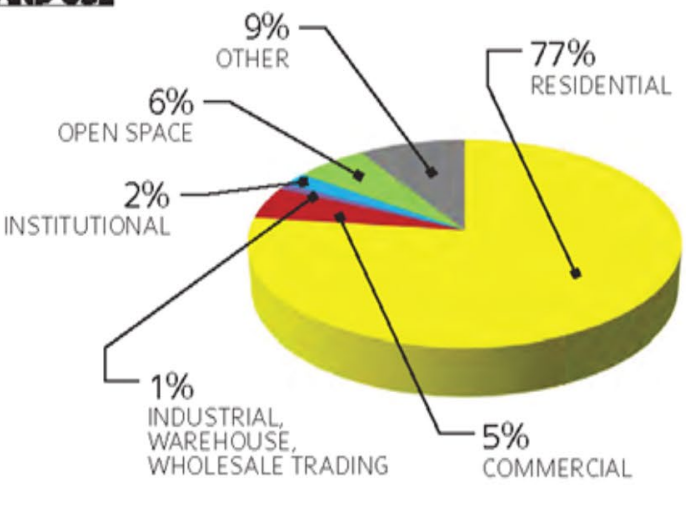

\section{CASE STUDY}

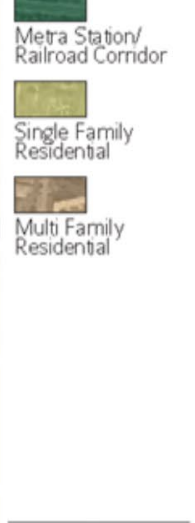

\section{State Street}

The State Street Metra Station, which is located in the West Pullman neighborhood, serves a low density residential base that generally walks to the station. Although some parking is available, none of the parking is designated commuter parking. The station is located on the single-track Blue Island Branch, which is not elevated and has less frequent Metra service than stations on the Main Line of the Metra Electric District. Pedestrian and bike friendliness is due to generally low traffic counts on local streets and the low-density residential nature around the station area. 


\section{SD SERVCE EMPLOYMENT DISTRICT}

\section{METRA RIDERSHIP}

Weekday ridership is moderate with an average of 174 riders. The $59^{\text {th }}$ Street Station at the University of Chicago attracts $500+$ riders.

\section{CTAACCESS}

All 4 SDs are accessible via CTA or Pace bus: however, none have nearby CTA rail stations.

\section{PEDESTRIAN \& BICYCIE ACCESS}

\begin{tabular}{l|l||l} 
TRANSIT & 63 & City-Wide Score \\
\hline SCORE & 61 & SD SCOre \\
\hline BIKE & 58 & NOTE \\
SCORE & 51 & SCORES OUT OF 100 (SEE \\
WALK & 68 & PAGE A4 IN APPENDIX FOR \\
SCORE & 58 & SCORING DESCRIPTION)
\end{tabular}

\section{COMMUTER PARKING}

Two of the 4 SD station areas have access to commuter parking, which average a $71 \%$ utilization rate of available spaces.

\section{MODE OF ACCESS}

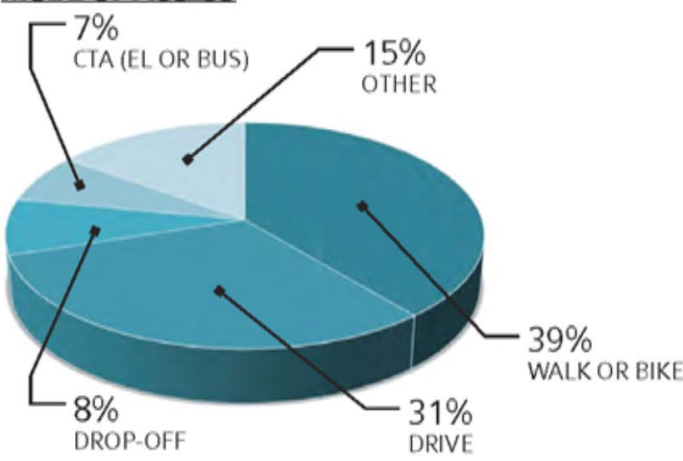

A Data refer to typology averages within $1 / 2$-mile radius of SD stations

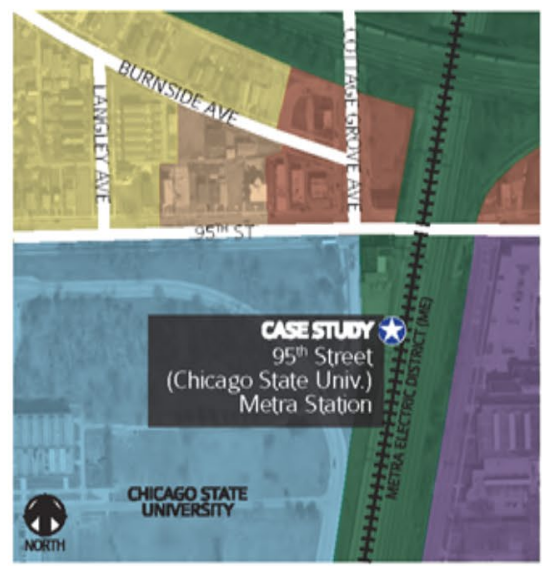

\begin{tabular}{l} 
Metra Station' \\
Railroad Corridor \\
\hline \\
Single Family \\
Residential \\
MultiFamily \\
Residential \\
\hline Commercial \\
Retail \\
\hline \\
Office/ndustriaV \\
Employment \\
\hline \\
Public/ \\
Institutional
\end{tabular}

\section{A Service Employment District (SD) is typically identufied by a major service use with high employment such as a university or O'Hare Airport.}

Two of the four SD stations are located next to major universities: $59^{\text {th }}$ Street next to the University of Chicago and $95^{\text {th }}$ Street adjacent to Chicago State University. The other two serve the O'Hare Airport area, which is a major multimodal transportation hub with access to various employers. An SD also has significantly more riders that view the station as their AM destination, due to employment in the area. Land use distribution is diverse, particularly noting the high percentage of institutional (e.g., schools) and other (e.g., transportation-related) uses. About an even amount of commuters walk or bike to an SD as arrive by car. Another 15\% arrive by other means, including employer or university shuttles.

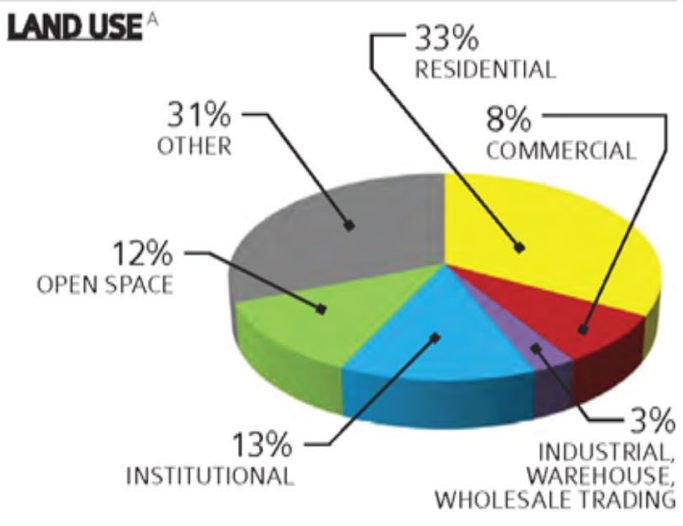

\section{CASE STUDY}

\section{5}

The $95^{\text {th }}$ Street (Chicago State University) Metra Station is located just east of the Chicago State University campus. The CTA $95^{\text {th }}$ Street bus route provides significant connectivity for the campus and Metra station, since the route links to the CTA $95^{\text {th }}$ Dan Ryan Red Line Station -- one of the busiest rail stations in the CTA system and a key CTA/Pace bus terminal. While there are preliminary plans to establish additional commuter parking near the campus, the City, Metra, and university will continue to work together on other mutually beneficial projects to encourage ridership and create improved connectivity between the station and the campus. 


\section{MANUFACTURING EMPLOYMENT DISTRICT}

\section{METRARIDERSHIP}

Weekday ridership averages 335 riders. The Western Avenue station along the MD-N, MD-W, and NCS Lines attracts $800+$ riders.

\section{CTAACCESS}

Two of the three MD stations have nearby CTA rail access. All three have CTA bus access.

\section{PEDESTRIAN B BICYCLEACCESS}
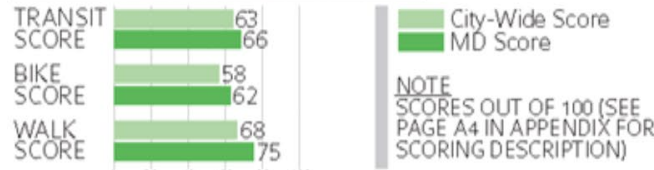

\section{COMMUTER PARKNG}

Two of the three MD stations have access to commuter parking, which average a $94 \%$ utilization rate of available spaces.

\section{MODE OF ACCESS}

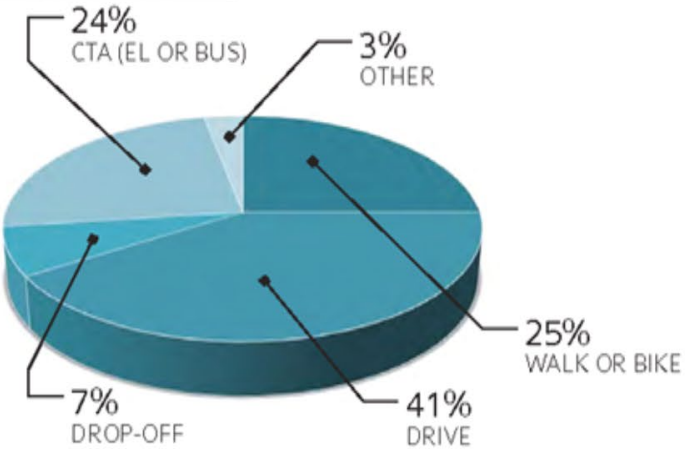

A Data refer to ty pology averages within $1 / 2$-mile radius of MD stations

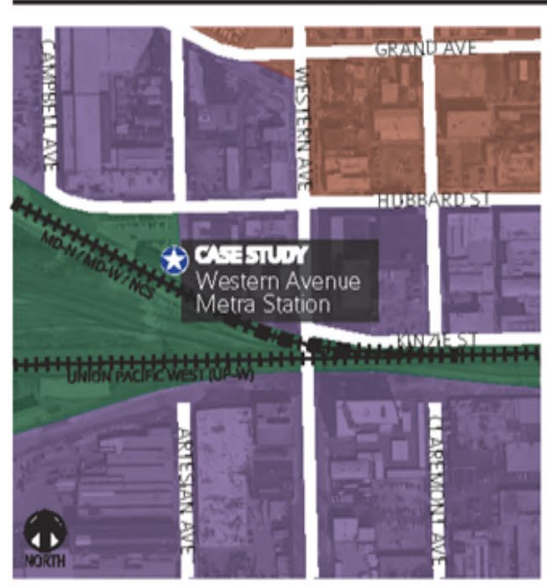

\section{A Manufacturing Employment District (MD) is generally characterized by a sign'ficant amount of manufacturng related land uses.}

About $28 \%$ of the total land use in a typical MD station area is devoted to industrial, warehouse, or wholesale trading. Another $27 \%$ are for other uses, which typically include railways and freight uses relating to manufacturing. Residential uses still comprise a significant amount at 31\%, which contributes to a quarter of all commuters accessing the MD stations by walking or biking, and another quarter by CTA rail or bus. Commuters arriving by car utilize almost all available parking spaces. Similar to SD, an MD has significantly more riders than other typologies that view the station as their $\mathrm{AM}$ destination, due to employment in the area.

\section{LAND USE ${ }^{\mathrm{A}}$}

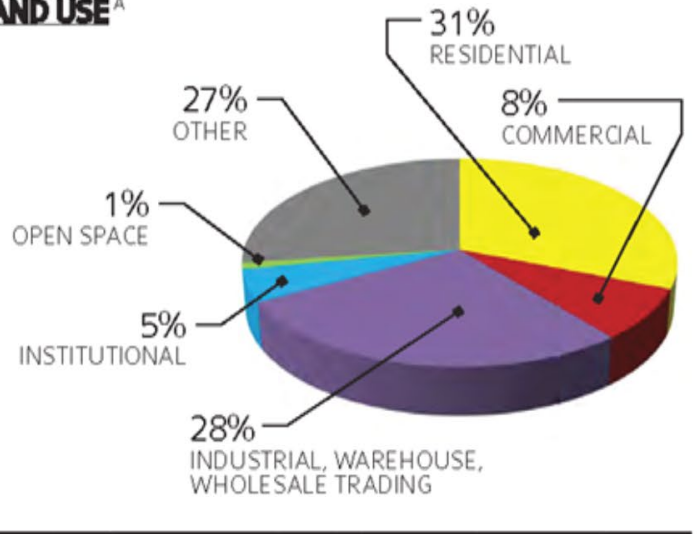

\section{CASE STUDY}

\section{Westem Avenue}

Serving the Milwaukee District North and West Lines, the Western Avenue Metra Station attracts $800+$ daily riders, ranking 14 of 77 existing Metra stations within the City of Chicago. Surrounded by railyards and industrial uses, the station area generates significant employment. Established neighborhoods north of the station enable commuters to access the station conveniently on foot or by bike. The station is accessible via CTA bus, with the CTA California Green Line Station located within a $1 / 2$-mile radius (less than a 1 -mile walk/bike ride). Infill development is encouraged to continue building up the proximity of industrial and commercial uses near the station. 


\section{R MIXED RESIDENTAL/INDUSTRIAL NEIGHBORHOOD}

\section{METRARIDERSHIP}

Weekday ridership is moderate with an average of 234 riders. One-quarter of the 12 RI stations have about $300+$ riders.

\section{CTAACCESS}

Only one RI station has nearby CTA rail access, but all 12 Rls have CTA or Pace bus access.

\section{PEDESTRIAN BBICYCLEACCESS}
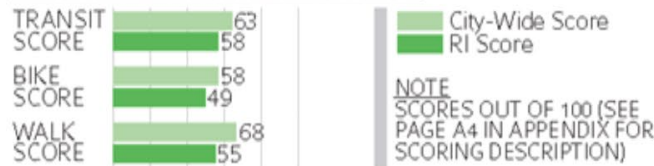

\section{COMMUIER PARK NG}

Two-thirds of the Rl stations have access to commuter parking, which average a 52\% utilization rate of available spaces.

\section{MODE OF ACCESS}

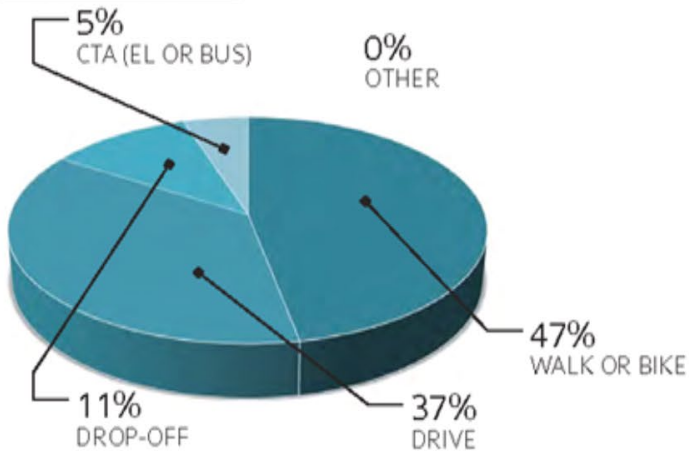

A Data refer to ty pology averages within $1 / 2$-mile radius of $R$ I stations.

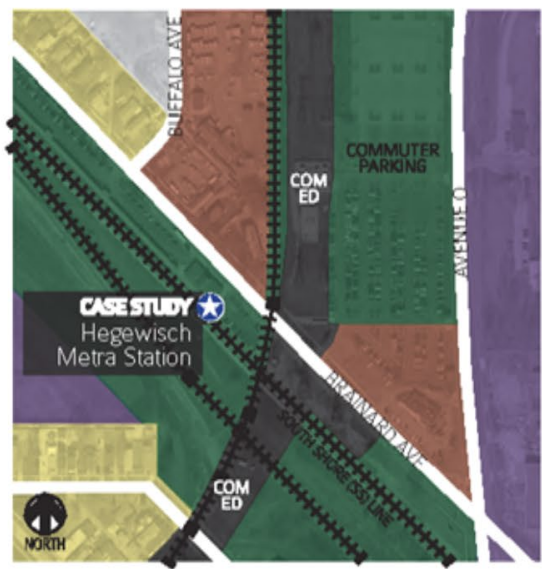

\section{A Mixed Residential / Industrial Neighborhood (R) is an area in which the Metra station serves both residential and industrial uses.}

$\mathrm{Rl}$ is one of two new typologies that has been created for Metra stations. While residential use is usually the predominant land use, industrial related uses are also a significant component of the neighborhood. In particular, about $16 \%$ is devoted to industrial, warehouse, and wholesale trading, with another 19\% covering other uses, which is often railyards or other industrial related uses. The residential aspect plays a major role in the fact that almost half of commuters access RI stations on foot or by bike. The high walk/bike percentage may also be an influential factor on the $52 \%$ utilization rate of available commuter parking spaces.

\section{LAND USE $^{\mathrm{A}}$}

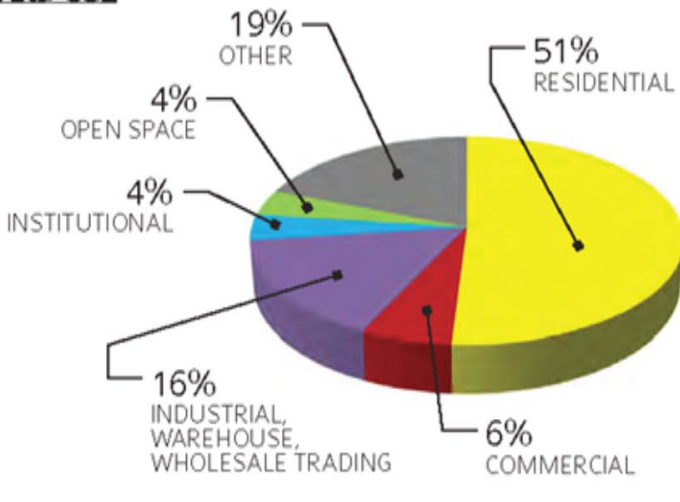

\section{CASE STUDY}

\section{Hegewisch}

The Hegewisch Metra Station, which is located along the South Shore Line managed by NICTD, is a prime example of the RI typology. In particular, major industrial users are located on the eastern and western sections of the $1 / 2$-mile station area, and residential neighborhoods set on the northern and southern sections. Commercial uses are also located near the Metra station and along the Baltimore Avenue corridor. Residential development is encouraged in close proximity to the station. Improvements to pedestrian and bike access and circulation are also recommended. 
Atlanta, Georgia (2014)

References: (Reconnecting America, 2014) - Note: This is a working document and may not reflect the final typologies or strategies.

Transit System: Heavy rail stations, but they consider overlap with alternative/supportive transportation modes.

Purpose of Typology:

Types of Use: Agency; Strategy Identification \& Implementation; Prioritization;

Findings \& Outcomes: The purpose of this typology is to evaluate existing transit with an 'social equity lens' to identify strategies and investments.

Key Findings:

"There is a disconnect between where low-income and communities of color live and where the jobs are." (page 8)

"The real estate market and TOD demand is stronger in more affluent areas, which is also where most jobs are." (page 11)

"The real estate market is weakest in low-income communities to the west and south." (page 12)

"Emerging real estate markets in communities proximate to downtown presents a risk of displacement." (page 12)

"The western and southern communities need better regional access to employment centers via transit." (page 14)

Recommendations:

System wide

"The strength of the market will dictate TOD in certain station areas." (page 15)

"Vulnerability concerns will require equitable TOD strategies in certain station areas." (page 15)

"The region needs to continue pushing for affordable housing strategies for major job centers on the MARTA system and move forward with transportation strategies for those employment centers that are not on the MARTA system." (page 15)

Area type recommendations (page 19)

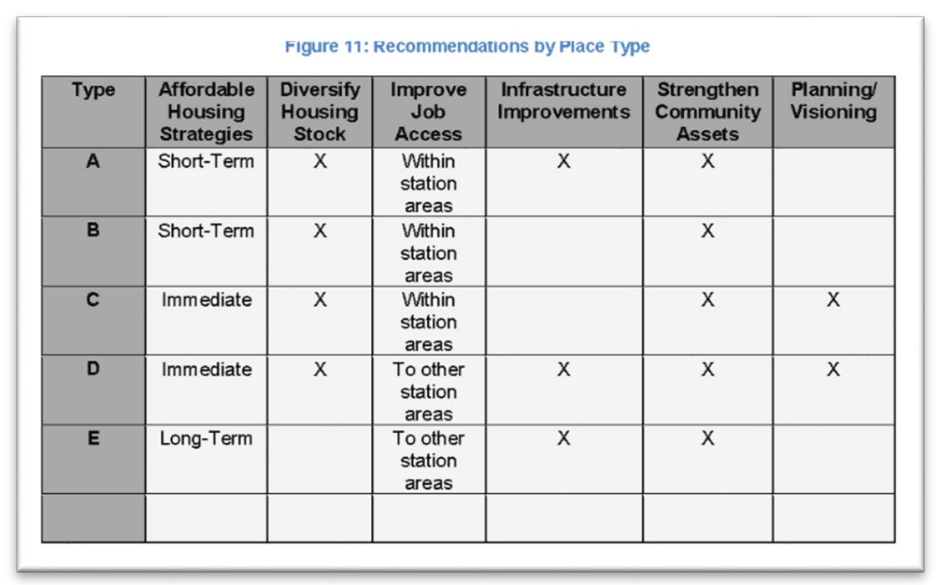

Method for Aggregating Typology:

Notes: Two dimensions (vulnerability and market strength) are developed based relative supporting variables. The variables are 'scored and indexed' into categories. The 'scoring system' is unknown for each variable, but it possible that this is either a 'scaling' or a manual approach.

Categories \& Supporting Variables or Definitions:

Notes: The descriptions here may be pulled directly from the language of the document; for image screenshots (marked with an image shadow), page numbers are either left on the image or embedded in the text directly before the image. 


\begin{tabular}{|c|c|c|}
\hline Vulnerability & $\begin{array}{l}\text { High ("high percentage of low-income and } \\
\text { transit oriented vulnerable populations") } \\
\text { Moderate ("mix of incomes and a moderate } \\
\text { percentage of transit oriented vulnerable } \\
\text { populations") } \\
\text { Low ("low percentage of low-income and } \\
\text { transit oriented vulnerable populations") }\end{array}$ & $\begin{array}{l}\text { Median Household Income } \\
\text { Percentage of Zero-Car Households } \\
\text { Percent Renters } \\
\text { Percent Walk, Bike, and Transit Commuters } \\
\text { (combined) }\end{array}$ \\
\hline $\begin{array}{l}\text { Market } \\
\text { Strength \& } \\
\text { TOD } \\
\text { Suitability }\end{array}$ & $\begin{array}{l}\text { Mature: ("most urban locations, with a wide } \\
\text { range of high-density uses over the decades. } \\
\text { Transit adds to development potential but is } \\
\text { not necessarily a catalyst.") } \\
\text { Emerging: ("developed urban attributes, and } \\
\text { future real estate development will capitalize } \\
\text { on transit access to further aid in urban infill.") } \\
\text { Emerging Potential: ("positioned to benefit } \\
\text { from TOD but are lacking attributes to attract } \\
\text { large amounts of mixed-uses to date.") } \\
\text { Lagging: ("lack the attributes that are likely to } \\
\text { attract developers looking for acceptable } \\
\text { returns in a market-rate environment.") }\end{array}$ & $\begin{array}{l}\text { TOD Demographics } \\
\text { Housing Density per Acre } \\
\text { Percent Population Change, 2000-2012 } \\
\text { Percent of Population aged 18-34 (Generation } \\
\text { Y/Millennial) } \\
\text { Percent of Singles Population } \\
\text { Median Household Income } \\
\text { Employment Characteristics } \\
\text { Employment Density (Jobs per Acre) } \\
\text { Percent of Employees Earning More Than } \\
\text { \$3,333 Per Month } \\
\text { Commercial Characteristics } \\
\text { Total Office Square Feet (Office Inventory) } \\
\text { Average Office Rents (\$) } \\
\text { Total Retail Square Feet (Retail Inventory) } \\
\text { Average Retail Rents (\$) } \\
\text { Residential Characteristics } \\
\text { Percentage of Housing Built Since } 2000 \\
\text { Average Apartment Rents (within } 1 \text { mile) (\$) } \\
2012 \text { Number of New Homes Sold (within } 1 \text { mile) } \\
2012 \text { New Average Sales Price (within } 1 \text { mile) } \\
\text { (\$) } \\
\text { Physical Characteristics } \\
\text { Walk Score } \\
\text { Nearby Barriers } \\
\text { MARTA TOD Land } \\
\text { Nearby Development Land }\end{array}$ \\
\hline
\end{tabular}




\section{Reconnecting America \\ People - Places - Possibility \\ Typology Groupings/Place Types}

Figure 3 shows the combined vulnerability and market data on one graph. The station areas are grouped into five place types based on where they fall on the graph:

- Type A: Affluent + Emerging/Strong Market (dark green): These stations score low on vulnerability and emerging/high on market strength. They are mostly concentrated in the northern suburbs, which are relatively affluent areas with strong real estate markets.

- Type B: Mixed-Income + Strong Market (olive green): These station areas score moderate or high on vulnerability and high on market strength. These station areas are concentrated just north of downtown Atlanta and its northern neighborhoods.

- Type C: Mixed-lncome + Emerging Market (light blue): These areas score moderately on vulnerability and have emerging real estate markets. They are primarily to the east and north of downtown Atlanta.

- Type D: Low Income + Emerging Market (dark blue): These station areas score towards the high side on vulnerability and have emerging markets for TOD. Two of these stations are near downtown Atlanta, while the other one (Chamblee) is in the far north.

- Type E: Low -ncome + Weak Market (red): These station areas score moderate to high on vulnerability but are lagging in market strength. They are concentrated to the west and south.

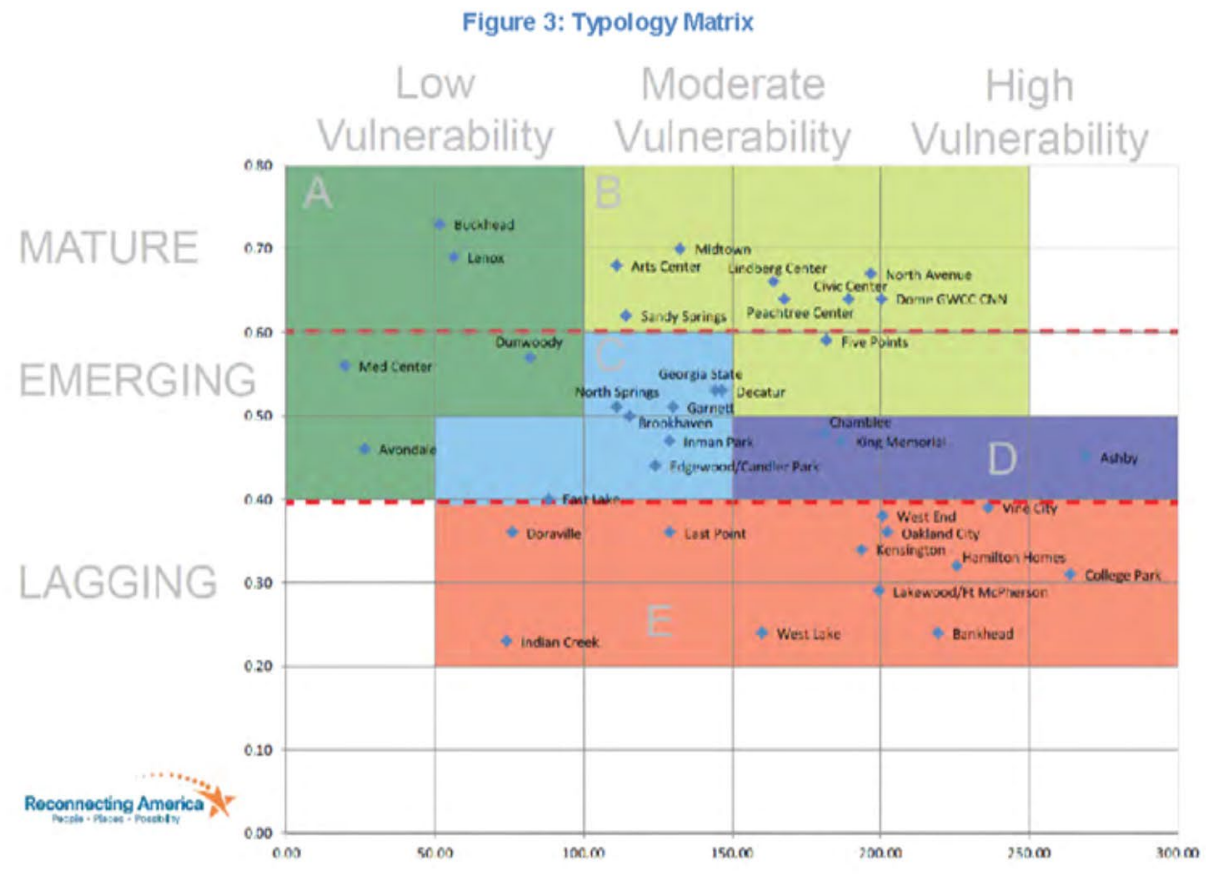

Atlanta Typology Memo 
References: (Renaissance Planning Group, 2011)

Transit System: heavy rail (commuter); light rail; BRT/bus;

Purpose of Typology:

Types of Use: Agency; Design or Land Use;

Findings \& Outcomes: The purpose of this typology is to provide both quantitative and qualitative information to help planners and developers "asses how transit-ready existing development patterns are and help guide decision making in the direction of creating more compact and transit supportive development patterns in the future." (page 2)

Method for Aggregating Typology:

Notes: This report defines station area scales, similar to other reports (page 3)

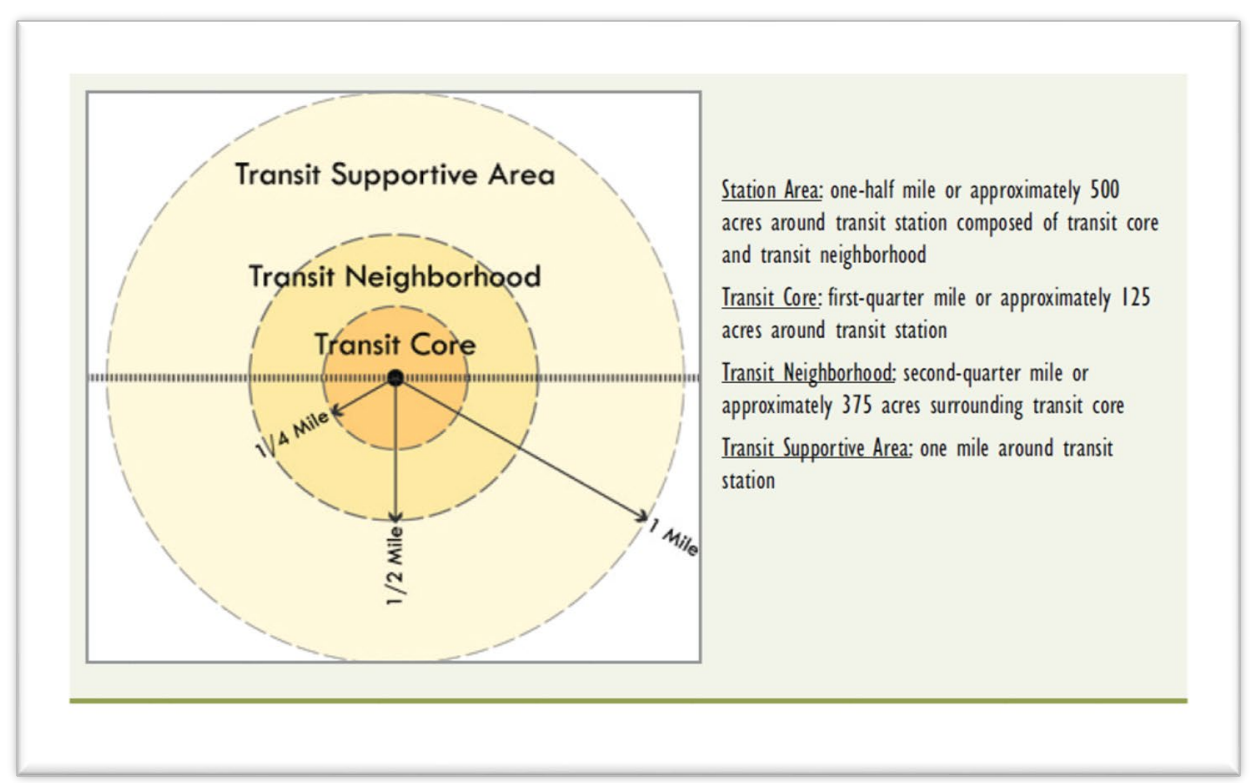

This method uses some initial assumptions about 'target' typology characteristics and relies on a series of assumption to estimate the target indicators for the project. This means that they developed the 'goal' typologies (but did not elaborate) and then 'reverse engineered' target indicators. The following four images (pages 56-59) summarize the process and assumptions linking the inputs and outputs. 


\section{Station Area Measures}

\section{GROSS INTENSITY AND DENSITY MEASURES (FIGURE 25)}

The gross intensity and density measures address population, employment, and the jobs to housing ratio. Mix of uses is a related measure. The targets set for each TOD place type apply to the whole station area and are derived from estimating the residential and employment densities most likely to support specific transit ridership goals at the station and corridor levels.

\section{Station Area Residential and Employ-} ment Densities

These measures identify the targeted number of residential units and jobs for a station area. The assumptions used to derive the values for total residential units and total employment are described below.

- Station Area Total Residential Units and Gross Residential Density - Total residential units are measured as the total number of dwelling units in the station area, and gross residential density is measured as dwelling units per acre. Residential units are computed based on total FAR (gross) and percent of mix of uses allocated

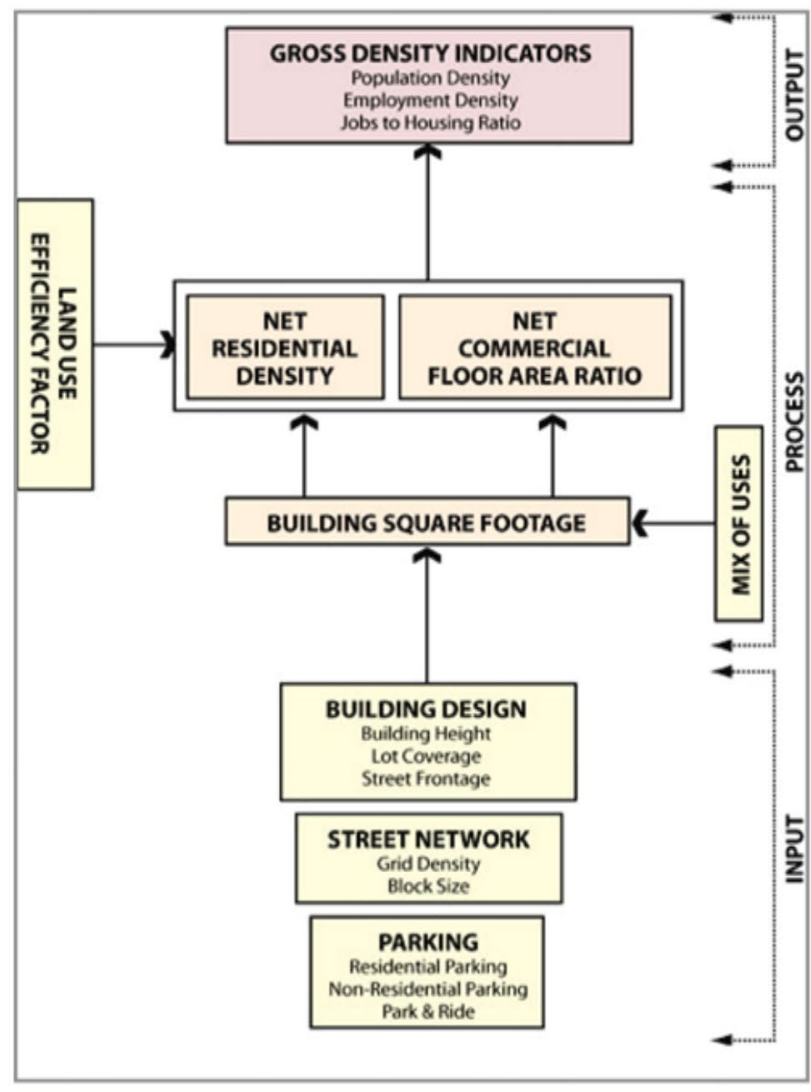

Figure 25: Gross intensity and Density to residential. Dwelling unit square footage is assumed to be 1,200 square feet in Regional Centers, 1,500 square feet in Community Centers, and I,800 square feet in Neighborhood Centers.

- Station Area Total Employment and Gross Employment Density - Total employment is measured as the total number of jobs in the station area, and gross employment density is measured as jobs/employees per acre. Employment is derived from total FAR (gross) and percent mix of uses allocated to non-residential. Employment is calculated based on Planners Estimating Guide standards for square feet per employee for office, retail/services, and industrial uses ( 350 square feet for Regional Centers, 500 square feet for Community Centers, and 750 square feet for Neighborhood Centers). 


\section{Station Area Jobs to Housing Ratio}

The jobs to housing ratio is a measure of the proportion of total employees and total dwelling units within a station area. The jobs to housing ratio helps to estimate the number of trips that can be produced by or attracted to each station area. More jobs rich station areas serve as trip destinations, whereas more housing rich stations serve as trip origins. A balanced jobs to housing ratio within a station area creates efficiencies for transit service and increases the likelihood of people being able to access a range of destinations (retail, employment, cultural facilities, and the like) within the station area walking shed.

Mix of Uses

Mix of uses is measured as the percentage of residential and non-residential uses. The mix of uses ranges from $35 \%$ residential and $65 \%$ non-residential in Regional Centers to $75 \%$ residential and $25 \%$ non-residential in Neighborhood Centers. Best practices research indicates that optimal TODs should contain a minimum of $30 \%$ residential uses.

\section{Site Level Measures \\ NET INTENSITY AND DENSITY MEASURES (FIGURE 26)}

Net intensity and density measures address sitelevel design considerations for development or redevelopment within a station area. The targets set for each TOD place type are intended to encourage context appropriate building massing/ form and a transit supportive mix of uses. Pedestrian-scaled building massing and form, complemented by the appropriate mix of uses (horizontal and vertical), encourage walkability, reduce vehicle trips per person, and enhance transit ridership potential. Intensity (measured by FAR) and density (measured by dwelling units per acre) are critical measures that need to be well coordinated with building design measures such as building height, lot coverage, and street frontage. Optimal TODs contain the highest intensity and density within the transit core (first-quarter mile). As minimums, it is likely that sites within the transit core could well exceed the targets and thereby reduce the intensities or densities needed in the transit neighborhood (second-quarter mile) to achieve the same transit ridership goals. Therefore, planning at the site level for TOD requires consideration of each site relative to meeting targets for the station area as a whole.

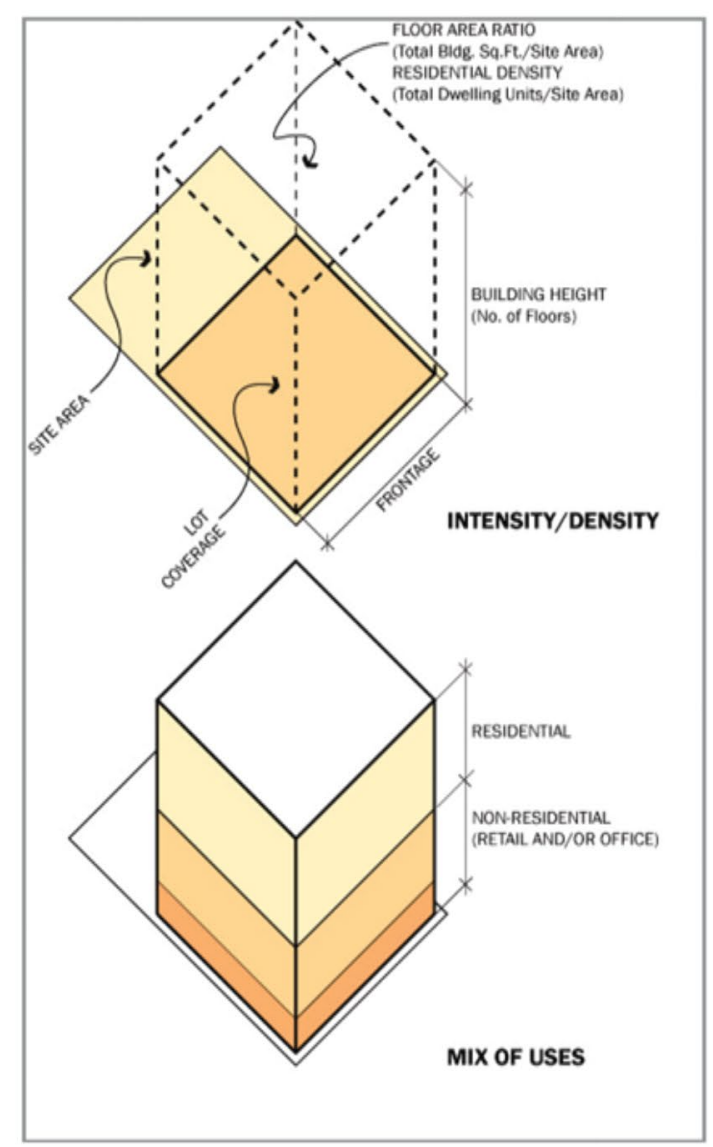

Figure 26: Net Density and Intensity 
- Net Non-Residential Floor Area Ratio - Net Non-residential FAR includes all non-residential building square footage. Distinct from the Gross FAR measure for the station area, it excludes land utilization features (e.g., roadways, open space, stormwater management).

- Net Residential Density - Residential density is measured as dwelling units per net acres and is computed based on net total FAR and percent mix of uses allocated to residential. Dwelling unit square footage is assumed to be 1,200 square feet in Regional Centers, I,500 square feet in Community Centers, and 1,800 square feet in Neighborhood Centers.

\section{NETTO GROSS CONVERSION FACTORS}

The gross intensity and density and mix of use measures for each TOD place type serve as a guide for determining the net intensity and density needed at the site level given existing land use efficiency within station areas. Land use efficiency is the percentage of land available for building square footage after excluding roadways, open space, stormwater management, and so forth. Since the gross measures for the TOD place types do not exclude land utilization features, the net intensity and density targets need to be calibrated to local conditions. This calibration could result in even higher site level targets within the station area. This conversion factor is best addressed by analyzing local conditions.

\section{STREET NETWORK AND BUILDING DESIGN (FIGURE 27)}

Street networks and building design help define the pattern of urban form within each TOD place type. For TOD, the goal is to create the 'bones' of urban form that will support a high concentration of vertically and horizontally mixed uses and walkable public spaces within the station area. Higher street grid density and smaller block sizes, combined with appropriately scaled and permeable building frontages, improve street-level activity, pedestrian connectivity and accessibility.

- Grid Density - Grid density is measured as the number of blocks (polygons) per square mile.A block is defined as a contiguous piece of land bounded by street network connections that include vehicle, bicycle, and pedestrian pathways. Grid density is a proxy measure for connectivity (links/nodes or intersection density) and accessibility (intersection spacing). Grid density ranges from 350 blocks per square mile in Regional Centers to 150 blocks per square mile in Neighborhood Centers.

\section{CONNECTED NETWORKS}

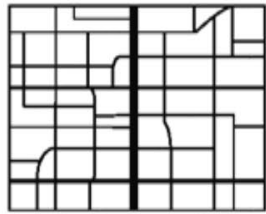

High Connectivity

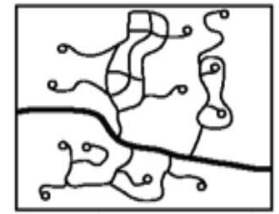

Low Connectivity

\section{TYPES OF CONNECTIVITY}
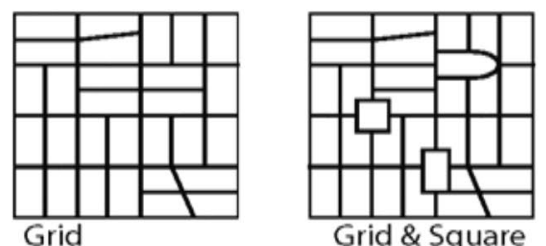

Grid \& Square
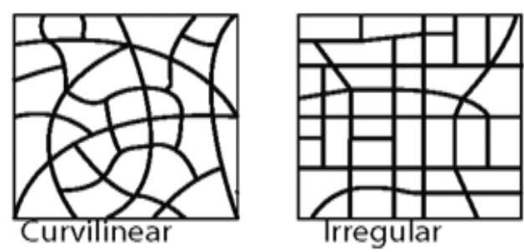

Figure 27: Street Networks and Connectivity 
- Building Height - Building height is measured as the number of floors in a building. Total FAR is a calculated by looking at total building height to lot coverage. Building heights range from four or more floors in Regional Centers to one or more floors in Neighborhood Centers.

- Lot Coverage - Lot coverage is measured as the percentage of a site that can be built on. Computation of lot coverage includes structured parking and other accessory structures, but it does not include open stormwater management or surface parking. Lot coverage targets range from 80 to $90 \%$ in Regional Centers to 40 to $50 \%$ in Neighborhood Centers.

- Street Frontage - Street frontage is measured as the percentage of primary building frontages built to the lot-line or sidewalk. The targets for street frontage within the TOD place types assume a small percentage (25-30\%) of the frontage set back no more than 5'-10' from the parcel line. However, this factor should be calibrated to reflect existing building massing/form and development character. Street frontages range from $80-90 \%$ in Regional Centers to $60-70 \%$ in Neighborhood Centers.

\section{PARKING}

Generally, parking within TODs should be limited. Parking targets by TOD place type establish parking caps for sites within station areas with the intention of discouraging vehicle trips and encouraging walking or transit trips. However, phasing in the parking caps over time should be considered based on the type of transit system implementation and connectivity to more regional systems. Other strategies such as shared parking facilities or utilization of surface parking lots as land banks for future redevelopment should also be considered. Parking caps are limited to on-site parking and public/private parking facilities (surface or structured) and exclude on-street parking.

- Residential Parking - Residential parking is defined as the maximum number of parking spaces per dwelling unit. This number represents an average for single-family and multi-family dwelling units. Residential parking caps range from one space per dwelling unit in Regional Centers to two spaces per dwelling unit in Neighborhood Centers.

- Non-Residential Parking - Non-residential parking is defined as the maximum number of parking spaces per 1,000 square feet of office, retail, or industrial space. Non-residential parking caps range from one space per I,000 square feet in Regional Centers to three spaces per I,000 square feet in Neighborhood Centers.

- Park and Ride - Station areas that include park-and-ride lots to allow for greater drive access to transit will require exemptions from parking caps. Park-and-ride lots are typically located in less densely developed areas where TOD potential is not as strong, or in areas where they can serve as a temporary land bank until development conditions are more conducive to TOD. Generally, park-and-ride lots are not desirable for use in a Regional Center or a Community Center. However, transit system and corridor level planning often involves some level of tradeoff analysis to determine which stations are appropriate for park-and-ride lots and which ones are not. This analysis involves consideration of factors such as the auto-trip and walk-trip access ridership catchment potential, parking fee revenue potential, adjacent development and market conditions, and travel markets to determine the best location for park-and-ride facilities within a larger transit system.

Categories \& Supporting Variables or Definitions: 
Notes: The descriptions here may be pulled directly from the language of the document; for image screenshots (marked with an image shadow), page numbers are either left on the image or embedded in the text directly before the image.

Using the same definitions as (Arizona Department of Transportation, 2012), this study distinguishes each station as having a transit core $(<1 / 4)$; Transit neighborhood $(1 / 4-1 / 2$ mile) and transit supportive area ( $<1$ mile). The transit station makes up both the core and neighborhood (<1/2 mile).

Station Area Targets:

Gross intensity and Density: combined employment/residential units; total residential units; gross residential density (dwelling units per acre); total employment; gross employment density (jobs per acre), and jobs to housing ratio.

Mix of Uses: percentages of residential and non-residential uses.

Site Level Targets:

Net Intensity and Density: net total FAR for non-residential uses and residential density (dwelling units per acre)

Street Network and Building Design: grid density, building height (in floors), maximum lot coverage, and minimum street frontage

Parking: Maximum residential parking, maximum non-residential parking, and park-and-ride The following three images (page $39,41,43$ ) visually describe the differences in each area types typical 'urban form'.

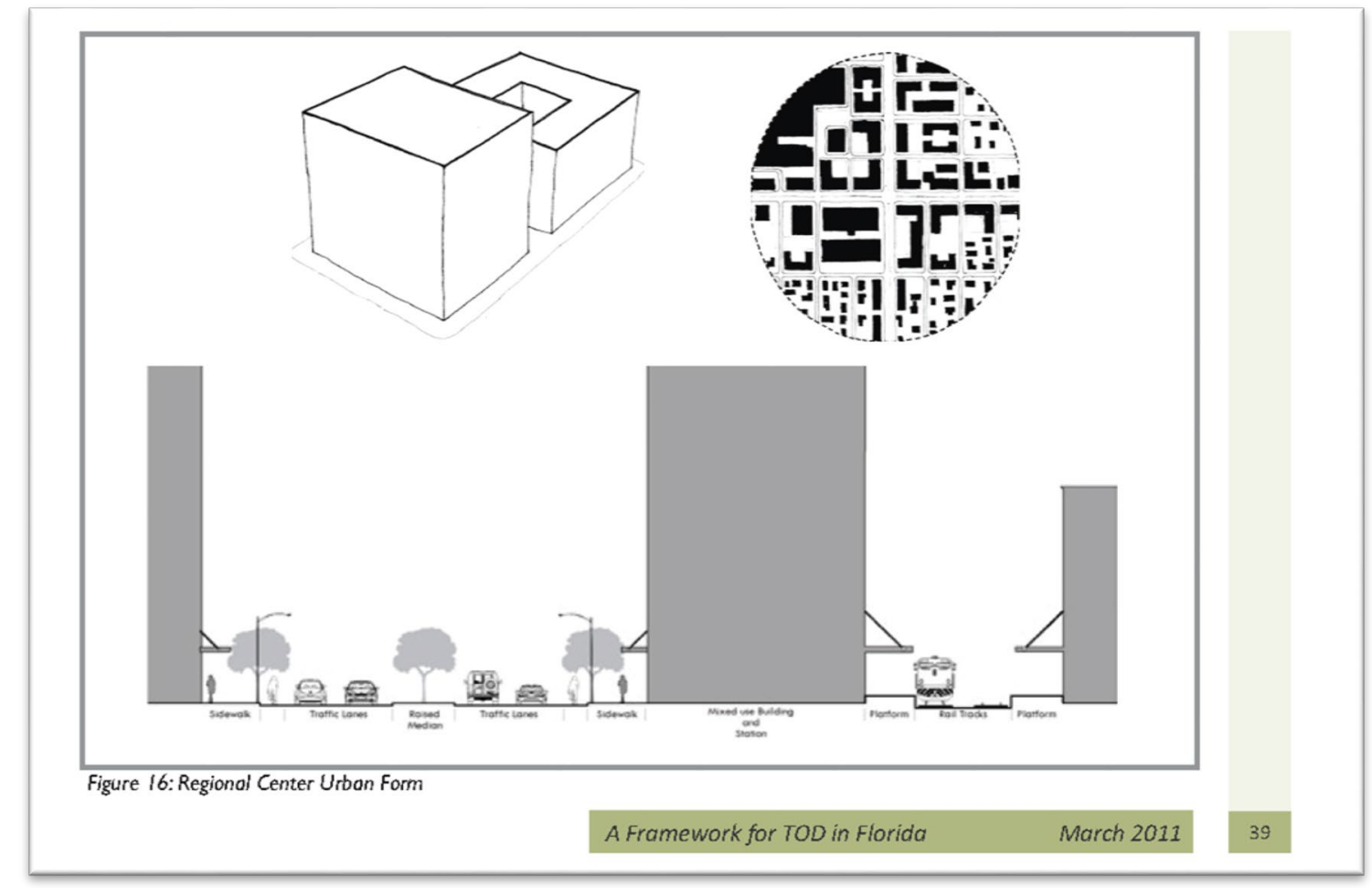




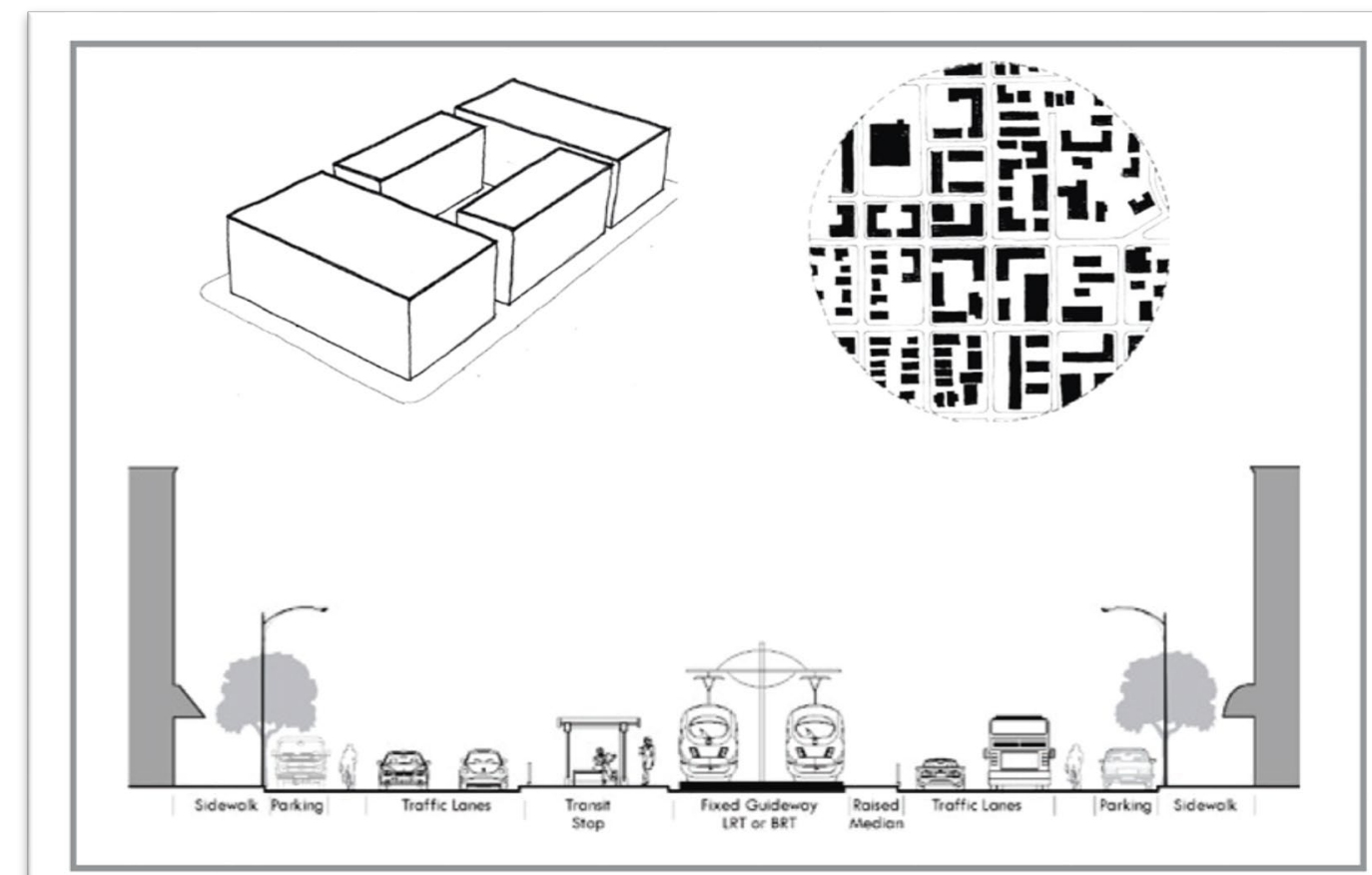

Figure 17: Community Center Urban form

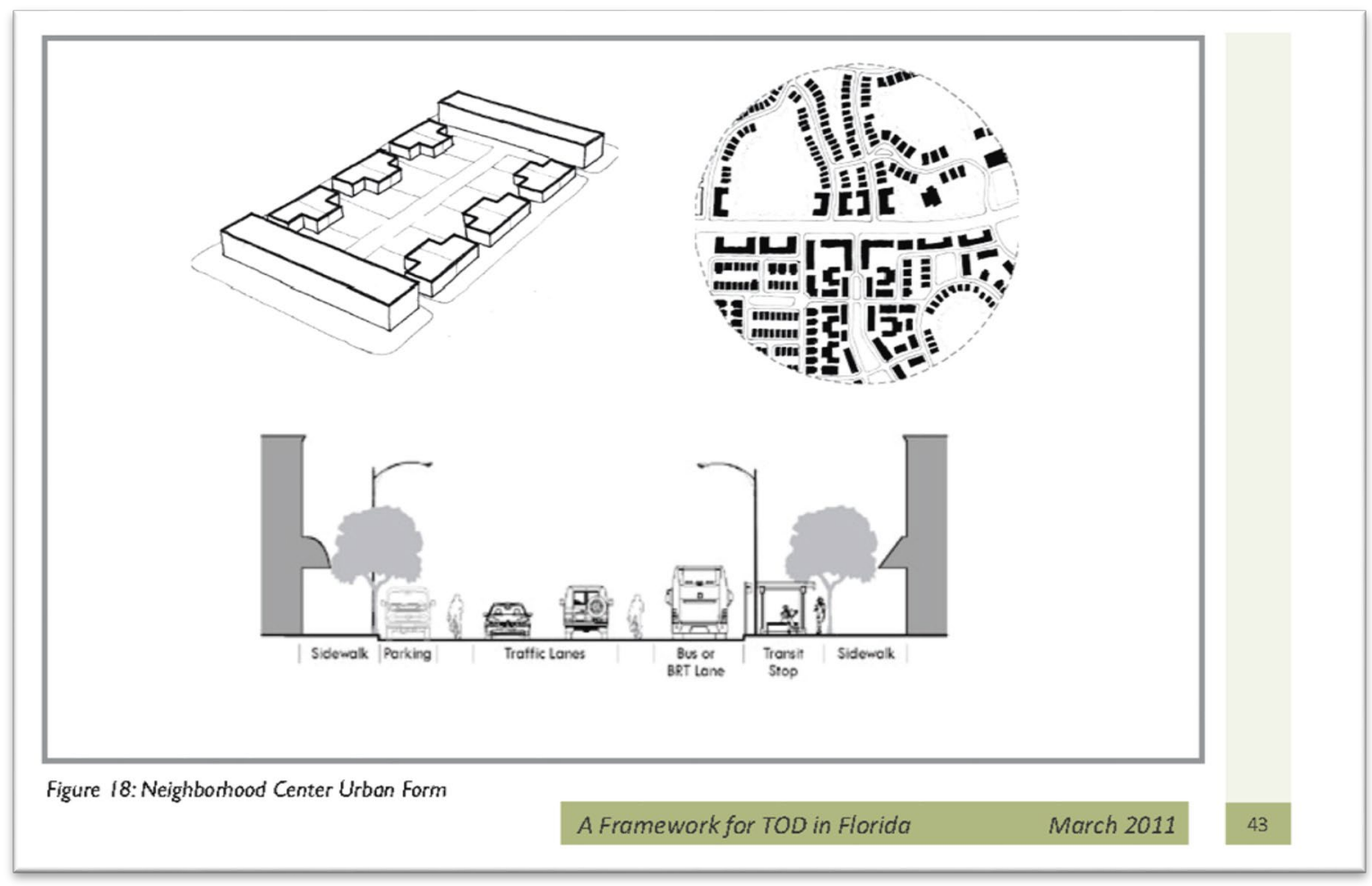

The following three images (page $38,40,42$ ) describe the quantitative descriptors for the station and site area measures. 


\section{REGIONAL CENTER}

Regional Centers are centers of economic and cultural significance, including downtowns and central business districts, which serve a regional travel market and are served by a rich mix of transit types ranging from high speed, heavy or commuter rail to BRT to local bus service. Usually emphasizing employment uses, Regional Centers increasingly are being sought out for residential uses in response to changing demographics and housing preferences. Regional Centers are larger in size than Community Centers or Neighborhood Centers and tend to contain more than one transit station and multiple bus stops. Small block sizes, more lot coverage, higher intensities and densities of development, civic open spaces, and minimal surface parking result in a highly urban development pattern in Regional Centers. Figure 16 illustrates a prototypical Regional Center urban form that reflects application of the station area and site level targets identified for the Regional Center TOD place type (lable 3).

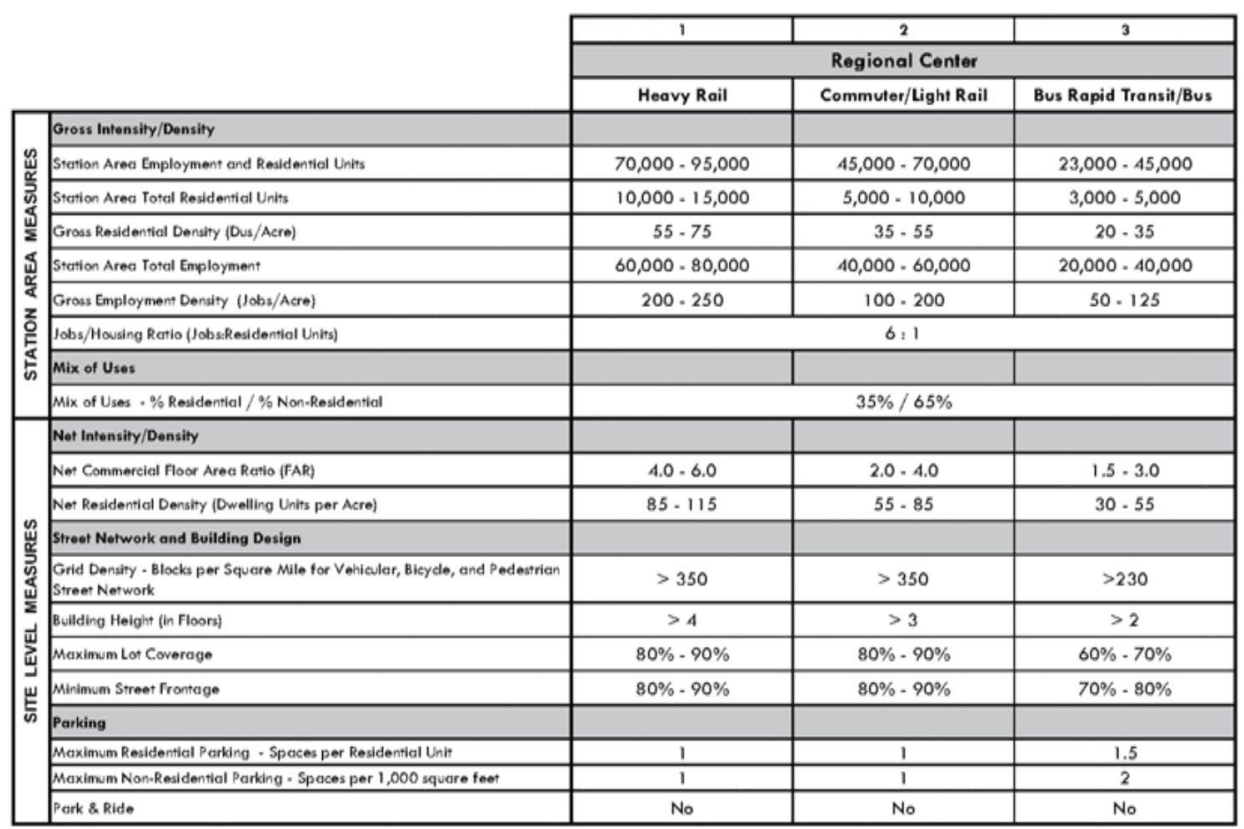

Table 3:TOD Place Type Targets - Regional Center 


\section{COMMUNITY CENTERS}

Community Centers function as sub-regional or local centers of economic and community activity and include urban and town centers served by one or more transit types. Residential densities in Community Centers are typically lower than residential densities in Regional Centers, but the mix of uses in them is more balanced between residential and employment uses. More intense or dense development in Community Centers tends to be concentrated within walking distance of the transit station. The pattern of development in Community Centers ranges from urban to suburban. Block sizes, lot coverage, and development intensities and densities all tend to be moderate. Parking is typically structured and located close to the transit station. Figure 17 illustrates a prototypical Community Center urban form that reflects application of the station area and site level targets identified for the Community Center TOD place type (Table 4).

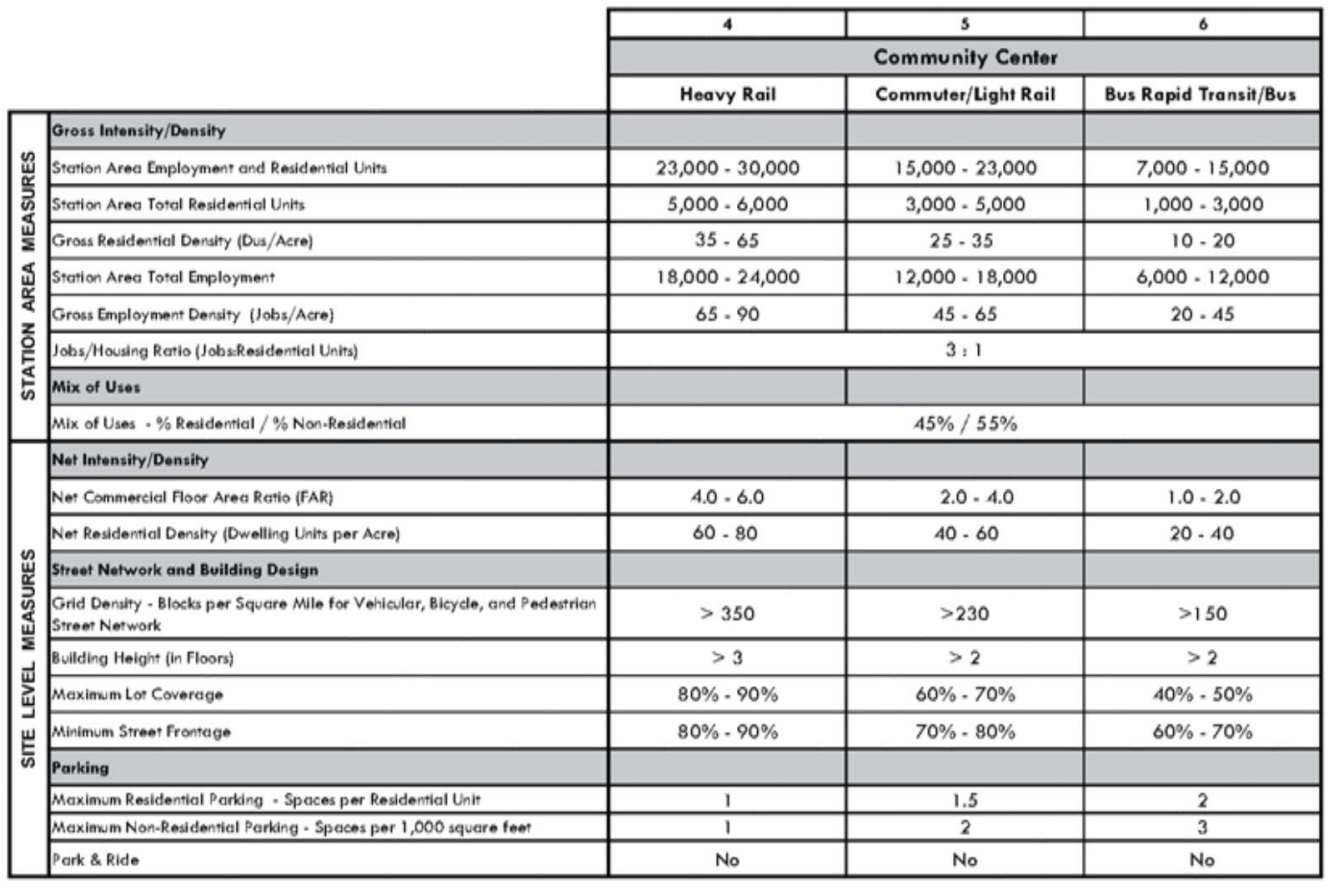

Table 4:TOD Place Type Targets - Community Center 


\section{NEIGHBORHOOD CENTERS}

Neighborhood Centers are dominated by residential uses and are served by some type of premium transit. Non-residential uses in them are limited to local-serving retail and services. Residential densities in Neighborhood Centers tend to be lower than in Community Centers and at their highest within walking distance of the transit station. Neighborhood Centers are found in older urban areas and newer suburban developments. Open space is usually abundant in them, and parking is mostly in surface lots. Figure 18 illustrates a prototypical Neighborhood Center urban form that reflects application of the station area and site level targets identified for the Neighborhood Center TOD place type (Table 5).

\begin{tabular}{|c|c|c|c|c|}
\hline & 7 & 8 & 9 \\
\hline & & \multicolumn{3}{|c|}{ Neighborhood Center } \\
\hline & & Heavy Rail & Commuter/Light Rail & Bus Rapid Transit/Bus \\
\hline \multirow{8}{*}{ 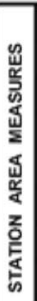 } & Gross Intonsity/Dansity & & & \\
\hline & Stertion Arec Employment and Residentiol Units & $5,000 \cdot 8,000$ & $4,000-6,000$ & $2,000 \cdot 4,000$ \\
\hline & Station Area Total Residenticl Units & $3,000 \cdot 4,500$ & $2,000 \cdot 3,000$ & $1,000 \cdot 2,000$ \\
\hline & Gross Residential Density (Dus/Acre) & $12 \cdot 15$ & 9.12 & 7.9 \\
\hline & Starion Arec Total Employment & $2,000 \cdot 3,500$ & $2,000 \cdot 3,000$ & $1,000 \cdot 2,000$ \\
\hline & Gross Employment Density (Jobs/Acre) & $20 \cdot 30$ & $15 \cdot 20$ & 10.15 \\
\hline & Jobs//Housing Ratio (JobskResidential Units) & \multicolumn{3}{|c|}{$1: 1$} \\
\hline & Mix of Usos & & & \\
\hline & Mix of Uses $=\%$ Residentrial $/ \%$ Non-Resididential & \multicolumn{3}{|c|}{$75 \% / 25 \%$} \\
\hline \multirow{12}{*}{ 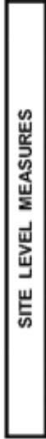 } & Not Intensity/Densily & & & \\
\hline & Ner Commercial Floor Areo Retio (FAR) & $1.5 \cdot 2.0$ & $1.0 \cdot 1.5$ & $0.5 \cdot 1.0$ \\
\hline & Ner Residential Density (Dwelling Units per Acre) & $15 \cdot 20$ & $12 \cdot 15$ & 10.12 \\
\hline & Stroet Notwork and Building Dosign & & & \\
\hline & 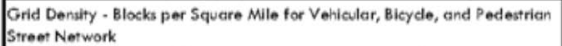 & $>230$ & $>150$ & $>150$ \\
\hline & Bullding Height (in Floors) & $>2$ & $>2$ & $>1$ \\
\hline & Maximum Lot Coverage & $60 \% \cdot 70 \%$ & $40 \% \cdot 50 \%$ & $40 \% \cdot 50 \%$ \\
\hline & Minimum Strees Frontage & $70 \%-80 \%$ & $60 \% \cdot 70 \%$ & $60 \% \cdot 70 \%$ \\
\hline & Parking & & & \\
\hline & Maximum Residentital Parking - Spaces per Residential Unit & 1.5 & 2 & 2 \\
\hline & Mexinum Non-Residential Perking - Spacess per 1,000 square feen & 2 & 3 & 3 \\
\hline & Park \& Ride & Yes & Yes & Yes \\
\hline
\end{tabular}

Table 5:TOD Place Type Targets - Neighborhood Center 
Each of the three area types and transit modes are compared with the Smartcode Transect and the Context Sensitive Solutions (CSS) Zones. (Page 34 \& 35)

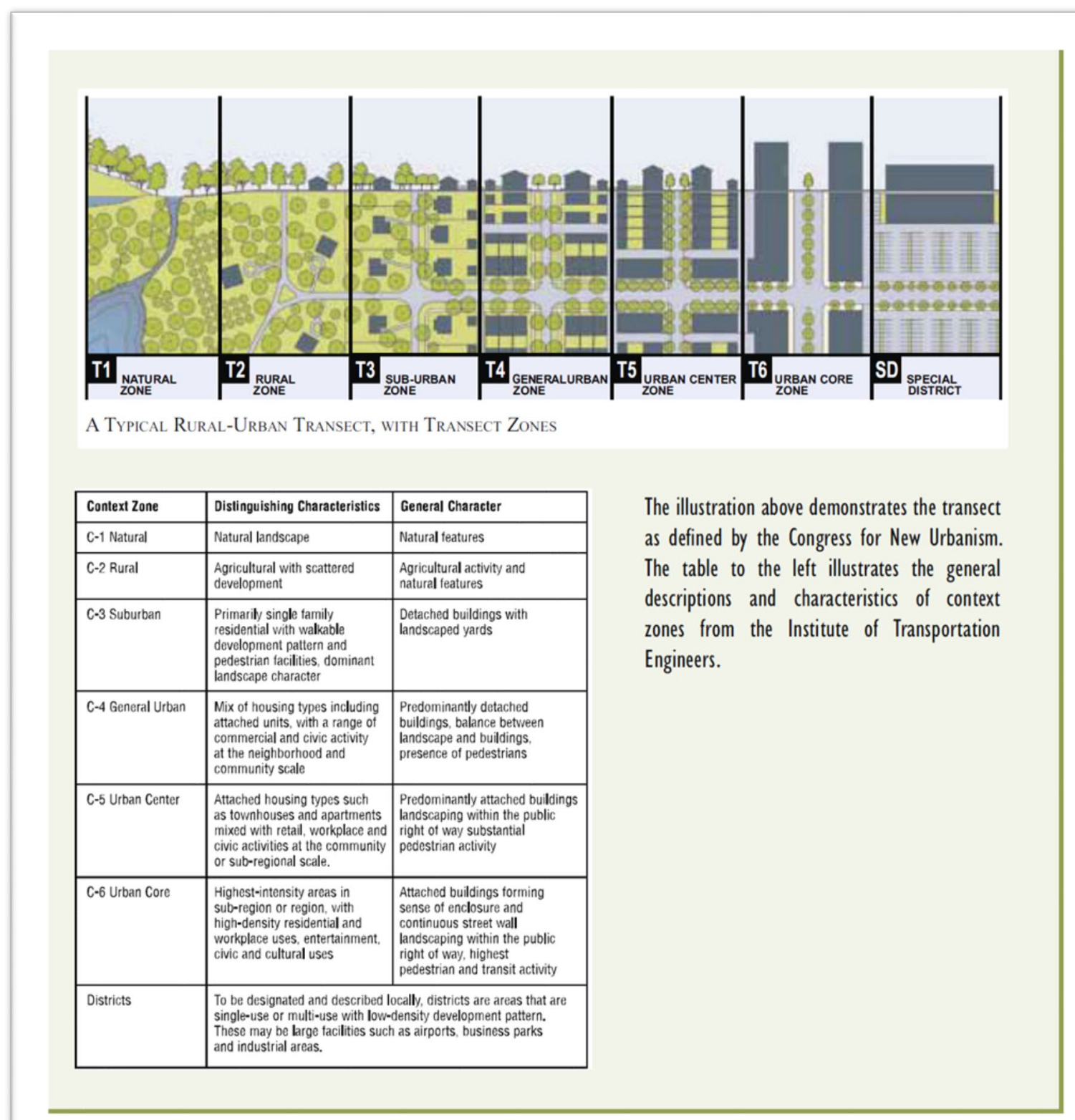

Fiaıre $14 \cdot 5$ martende Trancert and CSS Cnntext 7nnes 


\begin{tabular}{|c|c|c|c|}
\hline TOD PLACE TYPES & $\begin{array}{c}\text { COMMUNITY } \\
\text { CONTEXT }\end{array}$ & $\begin{array}{c}\text { SMARTCODE } \\
\text { TRANSECT ZONE }\end{array}$ & $\begin{array}{c}\text { CSS } \\
\text { CONTEXT ZONES }\end{array}$ \\
\hline Regional Center - Heavy Rail & \multirow{3}{*}{ Urban } & \multirow{3}{*}{$\begin{array}{l}\text { Urban Core (T6) } \\
\text { Urban Center (T5) }\end{array}$} & \multirow{3}{*}{$\begin{array}{l}\text { Urban Core (C6) } \\
\text { Urban Center (C5) }\end{array}$} \\
\hline Regional Center - Light Rail & & & \\
\hline Community Center - Heavy Rail & & & \\
\hline Regional Center - BRT/Bus & \multirow{3}{*}{ Transitional } & \multirow{3}{*}{ Urban General (T4) } & \multirow{3}{*}{ General Urban (C4) } \\
\hline Community Center - Light Rail & & & \\
\hline Neighborhood Center - Heavy Rail & & & \\
\hline Community Center - BRT/Bus & \multirow{3}{*}{ Suburban } & \multirow{3}{*}{ Suburban (T3) } & \multirow{3}{*}{ Suburban (C3) } \\
\hline Neighborhood Center - Light Rail & & & \\
\hline Neighborhood Center - BRT/Bus & & & \\
\hline
\end{tabular}

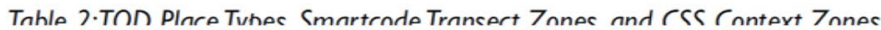


Central Maryland (2009)

References: (Central Maryland Transportation Alliance \& Center for Transit-Oriented

Development, 2009)

Transit System: Light rail, heavy rail, commuter rail

Purpose of Typology:

Types of Use: Agency; Strategy Identification \& Implementation; Prioritization;

Findings \& Outcomes: This study aimed at identifying market potential and corresponding strategies for stations in the Central Maryland area. The goal here was to develop a station-level prioritization of infrastructure needs (including supportive infrastructure) and to encourage

partnerships and development based on both market potential AND market need.

Strategies:

Complete existing projects to demonstrate high-quality TOD in the region

Develop new corridor-level initiatives in key regional locations for TOD

Modify local, regional, and state policies to support TOD

Construct transit and multi-modal transportation systems to support TOD

Foster cross-sector partnerships and build local capacity for TOD implementation

Notes:

There was a prior study by University of Maryland and Baltimore identifying built environment 'area types'. The map of station areas and definitions was included in the location-specific file. Method for Aggregating Typology:

Notes: The authors consider two dimensions: market opportunity and demographic need/stability. In both dimensions, several performance indicators are identified (see images of tables in the next subsection'. The 'market opportunity' indicator captures housing markets and land opportunities, including existing activity and existing transit infrastructure. The 'demographic change' dimension considers the change in home values, incomes (compared with median incomes), and a composite 'drilldown update' (jobs/housing balance, housing type, median income, etc). It is not clear how the 'drilldown' composite factor was developed. Each composite indicator is given a ranking, and each station falls within a set of four tiers for each dimension based on the frequency of 'mid to high' priorities for each of four categories (as well as severity). This was a somewhat manual process. Areas with 'high to mid' categorization on some indicators, but 'low or NA' on others may still fall into 'tier 2'. Priorities fall within tiers 1 and 2, with tiers 3 and 4 indicating low short-term priorities.

Categories \& Supporting Variables or Definitions:

Notes: The descriptions here may be pulled directly from the language of the document; for image screenshots (marked with an image shadow), page numbers are either left on the image or embedded in the text directly before the image.

Factors influencing "Market Opportunity", related to housing, land opportunity, region's employment and whether transit and transportation infrastructure is 'conducive' to supporting a walkable TOD. Factors are summarized on the following image (page 41): 


\begin{tabular}{|c|c|c|c|}
\hline Factor & Indicator & Importance & Priority Thresholds \\
\hline $\begin{array}{l}\text { Housing Market } \\
\text { Condition }\end{array}$ & $\begin{array}{l}\text { Baltimore Housing } \\
\text { Market Typology }\end{array}$ & $\begin{array}{l}\text { Helps determine the potential that an investment will have a positive impact on } \\
\text { the ability to attract new investment in the short term; investments should be } \\
\text { focused on "Stabilization" and "Reinvestment" Neighborhoods }\end{array}$ & $\begin{array}{l}\text { - High: Emerging and Stable } \\
\text { - Mid: Transitional } \\
\text { - Low: Competitive } \\
\text { - None: Distressed } \\
\end{array}$ \\
\hline $\begin{array}{l}\text { Land } \\
\text { Opportunity }\end{array}$ & $\begin{array}{l}\text { Number and Size } \\
\text { of Vacant and } \\
\text { Underutilized Parcels }\end{array}$ & $\begin{array}{l}\text { Helps determine the extent to which market interest in neighborhood } \\
\text { investments can be translated into new development. }\end{array}$ & $\begin{array}{l}\text { - High: }>100 \text { acres or } 400 \text { units } \\
\text { - Mid: } 20-100 \text { acres or } 100-400 \text { units } \\
\text { - Low. }<20 \text { acres or } 100 \text { units }\end{array}$ \\
\hline $\begin{array}{c}\text { Proximity to } \\
\text { Activity Centers }\end{array}$ & $\begin{array}{l}\text { Type of Activity Center } \\
\text { (Density, Dominant } \\
\text { Activity, etc.) }\end{array}$ & $\begin{array}{l}\text { The type of activity center will determine the frequency and timing of trips } \\
\text { from residential neighborhoods. Dense daytime employment centers are the } \\
\text { most likely to be accessed by public transit; thus, transit will have the greatest } \\
\text { impact on land values in residential areas closely linked to these centers. This } \\
\text { is true to a lesser extent of entertainment districts, which may have a lesser } \\
\text { employment base, but still lend themselves to non-automobile-based trips. } \\
\text { Those areas in which this impact is greatest will have the potential response to } \\
\text { TOD investments. }\end{array}$ & $\begin{array}{l}\text { - High: Downtown, Education, or } \\
\text { Entertainment employment clusters } \\
\text { - Mid: Other employment clusters } \\
\text { - Low: Non-employment clusters }\end{array}$ \\
\hline $\begin{array}{c}\text { Proximity to } \\
\text { Activity Centers }\end{array}$ & $\begin{array}{c}\text { Distance from Activity } \\
\text { Center }\end{array}$ & $\begin{array}{l}\text { The land value/TOD potential associated with activity centers (described above) } \\
\text { diminishes with distance. After a certain distance in the transit network, these } \\
\text { connections cease to have an appreciable impact. }\end{array}$ & $\begin{array}{l}\text { - Mid: Adjacent to Downtown, Education, or } \\
\text { Entertainment employment clusters } \\
\text { - High/Low: N.A. }\end{array}$ \\
\hline $\begin{array}{c}\text { Proximity to } \\
\text { Activity Centers }\end{array}$ & $\begin{array}{l}\text { Employment } \\
\text { Dynamics of Activity } \\
\text { Center }\end{array}$ & $\begin{array}{l}\text { The extent to which activity centers have a positive overall rate of jobs growth } \\
\text { and/or include sectors/employers that are growing, plays an important role in } \\
\text { whether households will move to improve their accessibility. This will influence } \\
\text { the attractiveness of new TOD opportunities and, in turn, investment potential. }\end{array}$ & $\begin{array}{l}\text { - Mid: High employment growth rate in } \\
\text { cluster. } \\
\text { - High/Low. N.A. }\end{array}$ \\
\hline $\begin{array}{c}\text { Transit } \\
\text { Infrastructure }\end{array}$ & $\begin{array}{l}\text { Accessibility of } \\
\text { Transit Station } \\
\text { and Connection to } \\
\text { Neighborhood }\end{array}$ & $\begin{array}{l}\text { Transit infrastructure can have a large impact on the potential market for } \\
\text { TOD. Stations that are part of an interconnected street grid provide access } \\
\text { from multiple directions and to many destinations. Elevated transit stations } \\
\text { or stations with limited or poor pedestrian connectivity can dampen the } \\
\text { catalytic potential of investments. }\end{array}$ & $\begin{array}{l}\text { - High: At grade or sub-grade with highly } \\
\text { walkable street pattern } \\
\text { - Mid: At grade or sub-grade with } \\
\text { connected street pattern } \\
\text { - Low: At grade or grade separate d with } \\
\text { disconnected street pattern } \\
\text { - None: Grade separated with limited access } \\
\text { or freeway median. }\end{array}$ \\
\hline
\end{tabular}

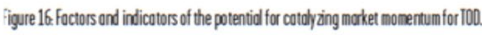

July 2009

Factors related to 'Demographic Change' were also considered. While 'market potential' looks at TODs with the greatest potential, this dimension considers those areas with the greatest need. The four factors in this dimension include: median income; income diversity; family structure; and educational attainment. Station areas were categories as changing or stable, and again within the following subcategories (page 45-46):

Changing neighborhoods

Gentrifying ("increasing number of residents in higher income and educational attainment categories as there are fewer residents in lower income and educational attainment categories." The result of existing patterns or displacement.)

Disinvesting ("increasing number of residents in lower income and education categories as there are fewer residents in higher income and education categories." May be a result of wealthy households leaving or shrinkage of major employers of the residents.)

Polarizing ("increasing number of residents at each end of the income and education spectrum, at the expense of middle class residents." Sensitive to sudden "upward shifts in housing costs or to rapid disinvestment")

Stable Neighborhoods ("may not require short-term intervention") Higher Income ("the median income and educational attainment exceeds the city regional average and has not been shifting significantly") Middle Income ("median income and educational attainment is near the city regional average and has not been shifting significantly") 
Lower Income ("median income and educational attainment is below the city and/or regional average and has not shifted significantly")

Stably Mixed-Income ("median income and educational attainment is not far from the regional average, but there is a high degree of variability.")

\begin{tabular}{|c|c|c|c|}
\hline \multicolumn{4}{|c|}{ Central Maryland Iransit-Oriented Development Strategy / Chapter ?: Priority TOD Investment Locations } \\
\hline Factor & Indicator & Importance & Priority Thresholds \\
\hline $\begin{array}{l}\text { Jobs/Housing } \\
\text { Balance }\end{array}$ & $\begin{array}{l}\text { Ratio of workers to } \\
\text { residents within } 1 / 2 \text {-mile of } \\
\text { station }\end{array}$ & $\begin{array}{l}\text { Places that are predominantly job locations are of less } \\
\text { significance. Predominantly housing locations are places of higher } \\
\text { importance in addressing this goal. }\end{array}$ & $\begin{array}{l}\text { - High: Housing (>0.5 workers/residents) } \\
\text { - Mid: Mixed (0.5-3.0 workers/ } \\
\text { residents) } \\
\text { - Low: Jobs ( }>3.0 \text { workers/residents) } \\
\end{array}$ \\
\hline Household Structure & $\begin{array}{l}\text { Change in share of } \\
\text { households that are not } \\
\text { families }\end{array}$ & $\begin{array}{l}\text { Change in the share of households that are in families can be } \\
\text { indicative of neighborhood change. In gentrifying neighborhoods, } \\
\text { young non-family households may be replacing families; in } \\
\text { disinvesting neighborhoods, family households may be leaving } \\
\text { for more desirable neighborhoods. While rapid decreases in this } \\
\text { indicator show the potential for gentrification and displacement, } \\
\text { rapid decreases show more neighborhood stability. }\end{array}$ & $\begin{array}{l}\text { - High: Rapid Increase }(>+10 \%) \\
\text { - Mid: Increase }(+2.5 \%-+10 \%) \\
\text { - Low. No change }(-2.5 \%-+2.5 \%) \text { or } \\
\text { decrease }(-10 \%--2.5 \%) \\
\text { - None: Rapid Decrease }(<-10 \%)\end{array}$ \\
\hline Education & $\begin{array}{l}\text { Change in \% of households } \\
\text { earning a bachelor's } \\
\text { degree or higher }\end{array}$ & $\begin{array}{l}\text { Whereas income reflects current buying power, education is } \\
\text { a powerful indicator of potential buying power. Thus, even if } \\
\text { incomes remain stable, a significant increase or decrease in } \\
\text { educational attainment can be important indicator of neighborhood } \\
\text { change. }\end{array}$ & $\begin{array}{l}\text { - High: Rapid Increase }(>+10 \%) \text { or } \\
\text { Rapid Decrease }(<-10 \%) \\
\text { - Mid: Increase }(+2.5 \%-+10 \%) \\
\text { - Low. No change }(-2.5 \%-+2.5 \%) \text { or } \\
\text { decrease }(-10 \%--2.5 \%)\end{array}$ \\
\hline Median Income & $\begin{array}{l}\text { Change in median } \\
\text { household income }\end{array}$ & $\begin{array}{l}\text { This reflects the overall change in the wealth of a neighborhood. } \\
\text { While rapid changes in either direction are the most important } \\
\text { indicator, decreases of median income can show signs of } \\
\text { disinvestment, while modest increases show more signs of } \\
\text { underlying stability, and may not signal gentrification. }\end{array}$ & $\begin{array}{l}\text { - High: Rapid increase }(>+15 \%) \text { or } \\
\text { decrease }(<-15 \%) \\
\text { - Mid: Decrease }(-15 \%--5 \%) \\
\text { - Low. Increase }(+5 \%-+15 \%) \\
\text { - None: No change }(-5 \%-+5 \%) \\
\end{array}$ \\
\hline $\begin{array}{c}\text { Change in Income } \\
\text { Distribution }\end{array}$ & $\begin{array}{l}\text { Change in distribution } \\
\text { of household Incomes, } \\
\text { including overall diversity } \\
\text { and change within income } \\
\text { categories }\end{array}$ & $\begin{array}{l}\text { While median income provides a simple measure of the wealth } \\
\text { of residents, the distribution of incomes provides greater insights } \\
\text { into the dynamics of neighborhood change. Specifically, the } \\
\text { change in the relative shares of households in the lower, middle, } \\
\text { and higher income ranges can indicate whether a neighborhood } \\
\text { is stable, gentrifying, disinvesting, or polarizing. When there is } \\
\text { stability in income distribution, there is not a priority on addressing } \\
\text { neighborhood change. }\end{array}$ & $\begin{array}{l}\text { - High: Gentrifying or Disinvesting (rapid } \\
\text { increases or decreases in high and low } \\
\text { incomes) } \\
\text { - Mid: Polarizing (rapid decline in } \\
\text { middle incomes) } \\
\text { - Low: Stable Diverse or Middle-Income } \\
\text { - None: Stable High-Income }\end{array}$ \\
\hline
\end{tabular}




\begin{tabular}{|c|c|c|c|c|}
\hline & Factor & Indicator & Importance & Priority Thresholds \\
\hline \multicolumn{2}{|r|}{ Neighborhood Trend } & $\begin{array}{l}\text { Composite of DrillDown } \\
\text { Comparisons }\end{array}$ & $\begin{array}{l}\text { Because the economic landscape in Central Maryland has shifted } \\
\text { since the } 2000 \text { USCensus, the DrillDown report indicators can be } \\
\text { used to update the other neighborhood indicators and confirm or } \\
\text { refute trends between } 1990 \text { and } 2006 \text {. Rapid increases between } \\
2000 \text { and } 2006 \text { indicate gentrification, while decreases or small } \\
\text { increases indicate disinvestment. Moderate increases indicate } \\
\text { general stability. This analysis is used to flag potential changes } \\
\text { in neighborhood trend since } 2000 \text {. }\end{array}$ & $\begin{array}{l}\text { - High: Confirmation of previous trend } \\
\text { - Mid:Stable or confirmation of } \\
\text { - } \quad \text { Low:Stable or refutation of previous } \\
\text { trend } \\
\text { - None: Continued stability }\end{array}$ \\
\hline \multirow{3}{*}{ 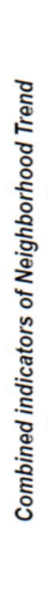 } & $\begin{array}{l}\text { Change in Home } \\
\text { Values }\end{array}$ & $\begin{array}{c}\text { Change in value of housing } \\
\text { units }\end{array}$ & $\begin{array}{l}\text { This reflects the change in aneighborhood real estatemarket from } 2000 \text { - } \\
2006 \text {. This period captures a booming real estate market nationwide, } \\
\text { but very large change in home value is a signal of gentrification and } \\
\text { potential displacement. Small increases in home values can be a sign } \\
\text { of economic distress because of the overall price appreciation during } \\
\text { this period. }\end{array}$ & $\begin{array}{l}\text { - } \quad \text { Very large increase }=>200 \% \\
\text { - } \quad \text { Lodge increase }=100-199 \% \\
\text { - } \quad \text { Small increase }=0-50 \% \\
\text { - } \quad \text { Decrease }=<0 \%\end{array}$ \\
\hline & $\begin{array}{l}\text { Change in Median } \\
\text { Income }\end{array}$ & $\begin{array}{l}\text { Change in median household } \\
\text { income (DrillDown vs Census) }\end{array}$ & $\begin{array}{l}\text { This reflects the overall change in the wealth of a neighborhood from } \\
2000-2006 \text {. While rapid changes in either direction are the most } \\
\text { important indicator, decreases of median income can show signs of } \\
\text { disinvestment, while modest increases show more signs of underlying } \\
\text { stability, and may not signal gentrification. }\end{array}$ & 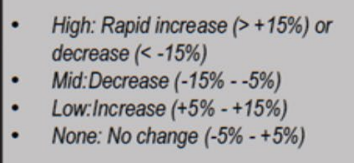 \\
\hline & $\begin{array}{l}\text { Change in Homebuyer } \\
\text { Income }\end{array}$ & $\begin{array}{l}\text { Income of Homebuyers } \\
\text { (HMDA) vs. Overall Income } \\
\text { (Census) }\end{array}$ & $\begin{array}{l}\text { This reflects the change in the income of new residents moving to a } \\
\text { neighborhood. Rapid increases signal gentrification, while declines or } \\
\text { small increases signal economic distress. Moderate increases indicate } \\
\text { general stability. }\end{array}$ & 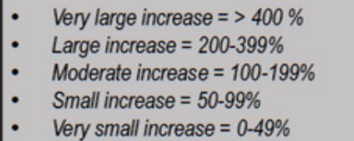 \\
\hline
\end{tabular}

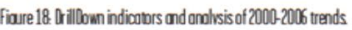


ES-8 Executive Summary: Regional Investments for Transit-Centered Communities / Central Maryland Iransit-Oriented Development Strategy

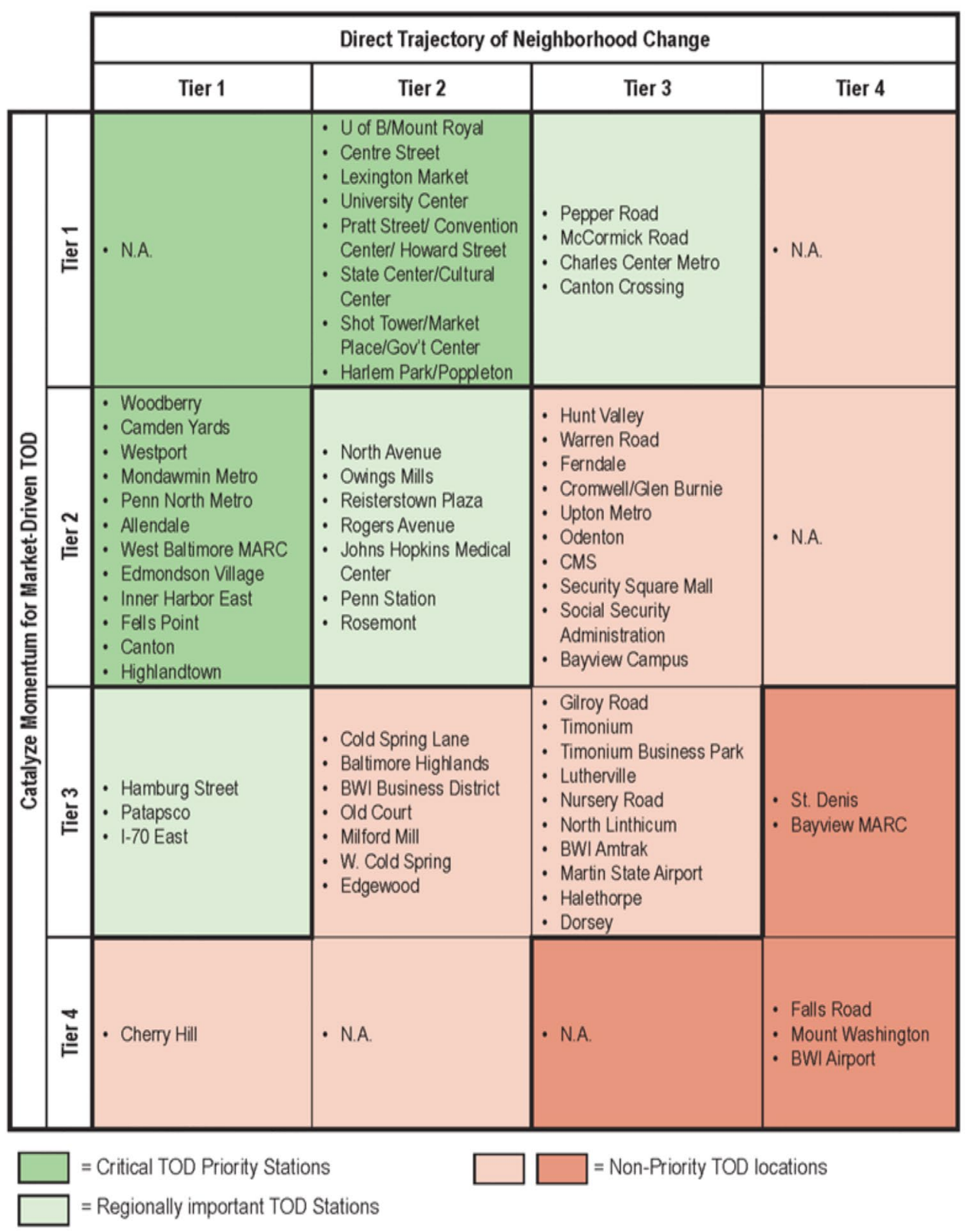

RegionolTo0 Priointy loctions

\section{Other Notes:}


This report also provided 'performance metrics' (shown in the image below) that can be used to monitor the successful implementation of any of the strategies.

\section{Ippendix D: Performance Metrics for Monitoring Implementation}

\begin{tabular}{|c|c|c|c|}
\hline \multicolumn{4}{|c|}{ Performance Metrics for Measuring the Outcomes of TOD Efforts } \\
\hline & Indicator & Metrics & Source \\
\hline \multirow{8}{*}{ 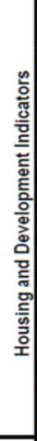 } & Increased housing values in inner-city transit-œentered neighborhoods & Sales data for transit zones œmpared to city and regional data & Baltimore City, Baltimore County, BNIA \\
\hline & $\begin{array}{l}\text { Continued presence of a mix of housing stock around transit, affordable } \\
\text { and market, rental and homeownership }\end{array}$ & $\begin{array}{l}\text { Transit zone data on unit typ, permit data for rehabilitation, subsidized } \\
\text { developments. }\end{array}$ & $\begin{array}{l}\text { Baltimore City, Baltimore County, US } \\
\text { Census, MDP, DHCD }\end{array}$ \\
\hline & Increased income diversity in transit-centered neighborhoods & Composite indicator of income diversity developed by BNIA. & BNIA \\
\hline & Improved housing market stability in transit-centered neighborhoods & Improved HMVA for TOD areas. & BNIA \\
\hline & Expanded homeownership in transit-centered neighborhoods. & Housing tenure & US Census and/or BNIA \\
\hline & Increased regional awareness of transit as an asset & Q3, Q14, and Q21 of the CMTA Culture of Transit telephone survey & CMTA \\
\hline & $\begin{array}{l}\text { Improved development capacity for local and state officials around TOD } \\
\text { projects }\end{array}$ & $\begin{array}{l}\text { Programs and policies that target capital funds, development incentives and other } \\
\text { resources toward TOD projects. }\end{array}$ & $\begin{array}{l}\text { MDOT, Baltimore County, Baltimore } \\
\text { City, CMTA }\end{array}$ \\
\hline & $\begin{array}{l}\text { Increased residential and commercial development near Central Maryland } \\
\text { transit stations }\end{array}$ & Permit data for builting permits $>\$ 50,000$ & Baltimore County, Baltimore City \\
\hline \multirow{6}{*}{ 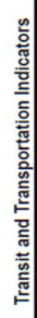 } & Improved transportation savings for residents living in proximity to transit & The Housing plus Transportation $(H+T)$ Affordability Index & Center for Neighborhood Technology \\
\hline & $\begin{array}{l}\text { Funds appropriated by state, federal, and local governments for public } \\
\text { transit and transit-oriented development }\end{array}$ & $\begin{array}{l}\text { Maryland Capital Transportation Program (CTP), Local Capital Improvement } \\
\text { Programs (CIP) }\end{array}$ & MDOT, Baltimore County, Baltimore City \\
\hline & $\begin{array}{l}\text { Increases in ridership on the MARC line, light rail and bus lines serving } \\
\text { Central Maryland, especially walk-access trips }\end{array}$ & APTA quarterly ridership reports (not broken out for Central Maryland); MTA & APTA, MTA \\
\hline & $\begin{array}{l}\text { Poll results through regularly conducted consumer polls on transportation } \\
\text { and transit issues }\end{array}$ & $\begin{array}{l}\text { Improvement on "no transit near where I live" and "transit doesn't go where I need } \\
\text { it to go" reponses to Q13 of Culture of Transit telephone survey }\end{array}$ & CMTA \\
\hline & Reduction in road congestion per capita & $\begin{array}{l}\text { "Annual hours of delay per traveler" from the Texas Transportation Institute's } \\
\text { Annual Urban Mobility Report }\end{array}$ & Texas Transportation Institute \\
\hline & Reduction of carbon emissions in the region & Vehicle Miles Traveled, emissions modeling & Baltimore Metropolitan Council \\
\hline
\end{tabular}


Los Angeles, California (2011)

References: (Office of the Mayor, City of Los Angeles, 2011)

Transit System: 49 stations

Purpose of Typology:

Types of Use: Agency; Prioritization;

Findings \& Outcomes: The purpose of this study was to priority opportunities for

developing/expanding upon 10 stations, as the mayor promised. The prioritization was partially

based on whether sites were suitable for new development, but also whether they are

'Sustainable Transit Community' (STC) ready. The 'STC Readiness analysis' was only

performed on the top 20 stations using the Development Potential analysis. The goal was not

just TOD development, but achieving sustainable transit community goals (related to smart

growth efforts) related to both market potential and multimodal use.

Method for Aggregating Typology:

Notes: The authors analyzed most of the stations using the following criteria. Definitions and scorecard criteria of all used performance indicators are described in the rubrics from following section. Additional information was collected (such as the quality in addition to the quantity of parks and recreation within the area), but not all information as used to prioritize development. Information collected from the urban design, walkability, multimodal transportation system, and sustainability categories were sometimes collected using site visits.

First, the 'Development Potential Analysis' (DPA) included only performance indicators from the Development Opportunity category. The average 'score' of the opportunity site indicators (public/quasi-public sites; total sites'; incentivized sites; large sizes) was averaged and weighted by $40 \%$. The employment potential (high-wage) was scored and weighted by $10 \%$. The sum of these two composite indicators was calculated, and all 49 sites were ranked in order of this score.

Second, for the top 20 sites the DPA process, the Sustainable Transit Communities (STC) Readiness analysis was computed. The analysis was based on the composite average score within each of the following categories: mix and vitality of land use total score (weighted 15\%); urban design total score (weighted $5 \%$ ); walkability total score (weighted $10 \%$ ); multimodal transportation system total score (weighted 15\%); sustainability total score (weighted $5 \%$ ). Third, for the top 20 DPA sites, each of the composite average scores from the DPA and STC were averaged together (with the corresponding weights). A rank was assigned to each site based on the relative total weighted readiness score. This ranking provides prioritization of the sites.

Categories \& Supporting Variables or Definitions:

Notes: The descriptions here may be pulled directly from the language of the document; for image screenshots (marked with an image shadow), page numbers are either left on the image or embedded in the text directly before the image.

The following images the dimensions, performance indicators, and corresponding scoring rubrics. 
(Office of the Mayor, City of Los Angeles, 2011, p. A-1 to A-9)

\begin{tabular}{|c|c|c|c|c|c|c|}
\hline riteria & \multicolumn{4}{|c|}{ Scoring Ranges } & Scoring Explanation & Data Source \\
\hline \multicolumn{7}{|c|}{ IEVELOPMENT OPPORTUNITY } \\
\hline \multirow{6}{*}{$\begin{array}{l}\text { otal Opportunity Site } \\
\text { icreage }\end{array}$} & \multicolumn{4}{|c|}{ Opportunity site acreage: } & \multirow{6}{*}{ Range of acreages divided into 10 equal intervals. } & \multirow{4}{*}{$\begin{array}{l}\text { Acreages represent acreages of specific opportunity sites within } \\
1 / 2 \text { mile of the station. Opportunity sites were identified on a } \\
\text { parcel basis by CTOD for the Los Angeles Transit-Oriented } \\
\text { Development Typology project, and were refined by DC\&E } \\
\text { based on Los Angeles County Assessor data for use in this } \\
\text { project. A more detailed description is included in Appendix B. }\end{array}$} \\
\hline & Value & Score & Value & Score & & \\
\hline & $\begin{array}{c}0-20 \\
20-40\end{array}$ & $\begin{array}{l}1 \\
2\end{array}$ & $\begin{array}{l}100-120 \\
120-140\end{array}$ & $\begin{array}{l}6 \\
7\end{array}$ & & \\
\hline & $40-60$ & 3 & $140-160$ & 8 & & \\
\hline & $60-80$ & 4 & $160-180$ & 9 & & For stations where the $1 / 2$-mile buffer includes areas outside the \\
\hline & $80-100$ & 5 & $180-200$ & 10 & & $\begin{array}{l}\text { city, opportunity site acreage has been divided by the percent- } \\
\text { age of the station area within the city. }\end{array}$ \\
\hline \multirow{6}{*}{$\begin{array}{l}\text { ublic and Quasi- } \\
\text { 'ublic Opportunity } \\
\text { ite Acreage }\end{array}$} & \multicolumn{4}{|c|}{ Public and quasi-public opportunity site acreage: } & \multirow{6}{*}{ Range of values divided into 10 equal intervals. } & \multirow{5}{*}{$\begin{array}{l}\text { Acreages represent acreages of specific opportunity sites within } \\
1 / 2 \text { mile of the station that are owned by public or quasi-public } \\
\text { entities. Opportunity sites were identified on a parcel basis by } \\
\text { CTOD for the Los Angeles Transit-Oriented Development Ty- } \\
\text { pology project, and were refined by DC\&E based on Los Ange- } \\
\text { les County Assessor data for use in this project. A more de- } \\
\text { tailed description is included in Appendix B. }\end{array}$} \\
\hline & Value & Score & Value & Søre & & \\
\hline & $0-14$ & 1 & $70-84$ & 6 & & \\
\hline & $14-28$ & 2 & $84-98$ & 7 & & \\
\hline & $28-42$ & 3 & $98-112$ & 8 & & \\
\hline & $\begin{array}{l}42-56 \\
56-70\end{array}$ & $\begin{array}{l}4 \\
5\end{array}$ & $\begin{array}{r}112-126 \\
126-140\end{array}$ & $\begin{array}{c}9 \\
10\end{array}$ & & $\begin{array}{l}\text { For stations where the } 1 / 2 \text {-mile buffer includes areas outside the } \\
\text { aty, opportunity site acreage has been divided by the percent- } \\
\text { age of the station area within the city. }\end{array}$ \\
\hline \multirow{7}{*}{$\begin{array}{l}\text { icentivized Site } \\
\text { icreage }\end{array}$} & \multicolumn{4}{|c|}{ Incentivized site acreage: } & \multirow{7}{*}{ Range of values divided into 10 equal intervals. } & \multirow{6}{*}{$\begin{array}{l}\text { Acreages represent acreages of specific opportunity sites within } \\
1 / 2 \text { mile of the station that are within a State Enterprise Zone, } \\
\text { Community Redevelopment Agency Project Area, or a Federal } \\
\text { Empowerment Zone. Opportunity sites were identified on a } \\
\text { parcel basis by CTOD for the Los Angeles Transit-Oriented } \\
\text { Development Typology project, and were refined by DC\&E } \\
\text { based on Los Angeles County Assessor data for use in this } \\
\text { project. A more detailed description is included in Appendx B. }\end{array}$} \\
\hline & Value & Score & Value & Søre & & \\
\hline & & & & & & \\
\hline & $\begin{array}{c}0-20 \\
20-40\end{array}$ & $\begin{array}{l}1 \\
2\end{array}$ & $\begin{array}{l}100-120 \\
120-140\end{array}$ & $\begin{array}{l}6 \\
7\end{array}$ & & \\
\hline & $40-60$ & 3 & $140-160$ & 8 & & \\
\hline & $60-80$ & 4 & $160-180$ & 9 & & \\
\hline & $80-100$ & 5 & $180-200$ & 10 & & $\begin{array}{l}\text { For stations where the } 1 / 2 \text {-mile buffer includes areas outside the } \\
\text { city, opportunity site acreage has been divided by the percent- } \\
\text { age of the station area within the city. }\end{array}$ \\
\hline
\end{tabular}

\begin{tabular}{|c|c|c|c|c|c|c|}
\hline riteria & \multicolumn{4}{|c|}{ Scoring Ranges } & Scoring Explanation & \multirow[t]{2}{*}{ Data Source } \\
\hline \multirow[b]{2}{*}{$\begin{array}{l}\text { arge Opportunity } \\
\text { ites }\end{array}$} & \multicolumn{4}{|c|}{ Number of large opportunity sites. } & \multirow[b]{2}{*}{ Range of values divided into 9 equal intervals. } & \\
\hline & $\begin{array}{c}\text { Value } \\
1 \\
2 \\
3 \\
4 \\
5\end{array}$ & $\begin{array}{c}\text { Score } \\
1 \\
2 \\
3 \\
4 \\
5\end{array}$ & $\begin{array}{c}\text { Value } \\
6 \\
7 \\
8 \\
9\end{array}$ & $\begin{array}{c}\text { Score } \\
6 \\
7 \\
8 \\
9\end{array}$ & & $\begin{array}{l}\text { Number represents the number of opportunity site areas that } \\
\text { are greater than } 5 \text { acres within a } 1 / 2 \text { mile of the station. Oppor- } \\
\text { tunity sites may include more than one parcel if they are adja- } \\
\text { cent and have the same owner. }\end{array}$ \\
\hline $\begin{array}{l}\text { ligh-Wage Employ- } \\
\text { nent Potential }\end{array}$ & \multicolumn{3}{|c|}{$\begin{array}{l}\text { Weak }=0 \\
\text { Weak/Moderate }=25 \\
\text { Moderate }=5 \\
\text { Moderate/Strong }=7.5 \\
\text { Strong }=10\end{array}$} & & $\begin{array}{l}\text { Bay Area Economics evaluated the percentage of employment growth } \\
\text { or contraction occurning in each market area in high-wage sectors. } \\
\text { Based on how this percentage compared to the County average, and } \\
\text { on local knowledge of the market area, BAE classified each market area } \\
\text { between weak and strong potential for high-wage employment growth. }\end{array}$ & Provided by Bay Area Economics. \\
\hline \multicolumn{7}{|c|}{ ONCENTRATION, DENSITY AND BALANCE OF USES } \\
\hline \multicolumn{7}{|l|}{ tousing: } \\
\hline \multirow[b]{2}{*}{ 'esidential Density } & \multicolumn{4}{|c|}{ Dwelling units per acre: } & \multirow[b]{2}{*}{ Range of densities divided into 10 equal intervak. } & \multirow[b]{2}{*}{$\begin{array}{l}\text { County Assessor data indicates number of units on each parcel. } \\
\text { The total Number of units is divided by the total acreage within } \\
1 / 2 \text { mile of the station to obtain density. }\end{array}$} \\
\hline & $\begin{array}{c}\text { Value } \\
0-4 \\
4-8 \\
8-12 \\
12-16 \\
16-20\end{array}$ & $\begin{array}{c}\text { Score } \\
0 \\
1 \\
2 \\
3 \\
4\end{array}$ & $\begin{array}{l}\text { Value } \\
20-24 \\
24-28 \\
28-32 \\
32-36 \\
36-40\end{array}$ & $\begin{array}{c}\text { Score } \\
5 \\
6 \\
7 \\
8 \\
9\end{array}$ & & \\
\hline \multirow{4}{*}{$\begin{array}{l}\text { iffordable Housing } \\
\text { leed }\end{array}$} & Percent ho & old incor & spent on $\mathrm{h}$ & & \multirow{4}{*}{ Range of values divided into 10 equal intervals. } & \multirow{3}{*}{$\begin{array}{l}\text { Affordable housing need is measured by the "housing cost } \\
\text { burden", which is the relationship between the amount a } \\
\text { household pays for rent or mortgage costs compared to the } \\
\text { household's income. A household paying more that } 30 \text { per- } \\
\text { cent of their income for housing is considered "cost-burdened." }\end{array}$} \\
\hline & Value & Score & Value & Score & & \\
\hline & $\begin{array}{l}25-28 \% \\
28-31 \%\end{array}$ & $\begin{array}{l}1 \\
2\end{array}$ & $\begin{array}{l}40-43 \% \\
43-46 \%\end{array}$ & $\begin{array}{l}6 \\
7\end{array}$ & & \\
\hline & $\begin{array}{l}31-34 \% \\
34-37 \% \\
37-40 \%\end{array}$ & $\begin{array}{l}3 \\
4 \\
5\end{array}$ & $\begin{array}{l}46-49 \% \\
49-52 \% \\
52-55 \%\end{array}$ & $\begin{array}{c}8 \\
9 \\
10\end{array}$ & & $\begin{array}{l}\text { Bay Area Economics determined the percentage of households } \\
\text { within each station area that are cost-burdened and scores } \\
\text { were assigned based on these percentages. }\end{array}$ \\
\hline
\end{tabular}




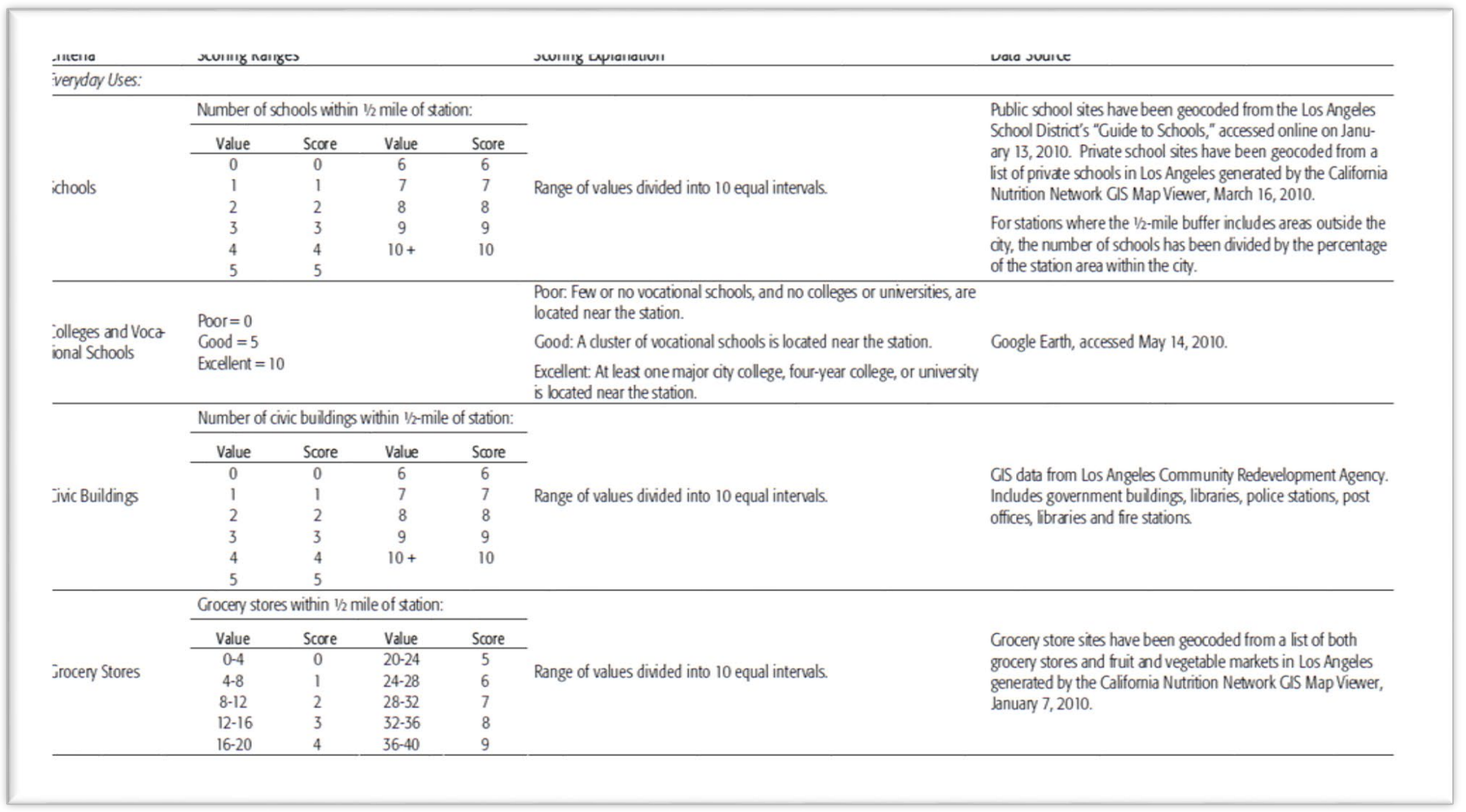

\begin{tabular}{|c|c|c|c|c|c|c|}
\hline ....... & - & & & & מ......... & 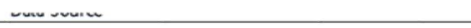 \\
\hline \multirow{7}{*}{ onvenience Stores } & \multicolumn{4}{|c|}{ Convenience stores within $1 / 2$ mile of the station: } & \multirow{7}{*}{ Range of values divided into 10 equal intervals. } & \multirow{7}{*}{$\begin{array}{l}\text { Convenience store sites have been geocoded from a list for Los } \\
\text { Angeles generated by the California Nutrition Network GIS Map } \\
\text { Viewer, January 7, 2010. }\end{array}$} \\
\hline & Value & Score & Value & Score & & \\
\hline & 0 & 0 & 6 & 6 & & \\
\hline & 1 & 1 & 7 & 7 & & \\
\hline & 2 & 2 & 8 & 8 & & \\
\hline & 3 & 3 & 9 & 9 & & \\
\hline & 4 & 4 & $10+$ & 10 & & \\
\hline \multirow{7}{*}{ staurants } & \multicolumn{4}{|c|}{ Number of restaurants within $1 / 2$ mile of station: } & \multirow{7}{*}{ Range of values divided into 10 equal intervals. } & \multirow{7}{*}{$\begin{array}{l}\text { Restaurant sites have been geocoded from a list for Los Ange- } \\
\text { les generated by the Calfomia Nutrition Network GIS Map } \\
\text { Viewer, April 29, } 2010 \text {. }\end{array}$} \\
\hline & Value & Scare & Value & Score & & \\
\hline & $0-15$ & 1 & $75-90$ & 6 & & \\
\hline & $15-30$ & 2 & $90-105$ & 7 & & \\
\hline & $30-45$ & 3 & $105-120$ & 8 & & \\
\hline & $45-60$ & 4 & $120-135$ & 9 & & \\
\hline & $60-75$ & 5 & $135-150$ & 10 & & \\
\hline $\begin{array}{l}\text { snks and Financial } \\
\text { ?vices }\end{array}$ & Present = 10 & & $\mathrm{nt}=0$ & & Presence/absence & Google Earth, accessed May 5, 2010. \\
\hline \multirow{6}{*}{$\begin{array}{l}\text { yrks and Recreation } \\
\text { ıcilities }\end{array}$} & Value & Score & Value & Score & \multirow{6}{*}{ Range of values divided into 10 equal intervals. } & \multirow{6}{*}{$\begin{array}{l}\text { GIS data from Los Angeles Community Redevelopment Agency. } \\
\text { Includes neighborhood and community park acreages only. }\end{array}$} \\
\hline & $0-5$ & 1 & $25 \cdot 30$ & 6 & & \\
\hline & $5-10$ & 2 & $30-35$ & 7 & & \\
\hline & $10-15$ & 3 & $35-40$ & 8 & & \\
\hline & $15-20$ & 4 & $40-45$ & 9 & & \\
\hline & $20-25$ & 5 & $45+$ & 10 & & \\
\hline \multicolumn{7}{|l|}{ tractions: } \\
\hline itertainment Venues & Present $=10$ & \multicolumn{2}{|c|}{ Absent $=0$} & & Presence/absence & Google Earth, accessed May 5, 2010. \\
\hline \multicolumn{7}{|l|}{ arket Outiook: } \\
\hline \multirow{3}{*}{$\begin{array}{l}\text { sail Occupancy } \\
\text { end }\end{array}$} & \multirow{3}{*}{$\begin{array}{l}\text { Poor }=0 \\
\text { Good }=5 \\
\text { Excellent }=10\end{array}$} & & & & Poor. Higher vacancy rate and lower rents than LA County. & \multirow{3}{*}{ Data provided by Bay Area Economics for $4^{\text {th }}$ Quarter of 2009.} \\
\hline & & & & & $\begin{array}{l}\text { Good: Lower vacancy rate and higher rents than LA County, or higher } \\
\text { vacancy rate and lower rents than LA County. }\end{array}$ & \\
\hline & & & & & Fxcellent I ower varannv rate and higher rents than I A Countv. & \\
\hline
\end{tabular}




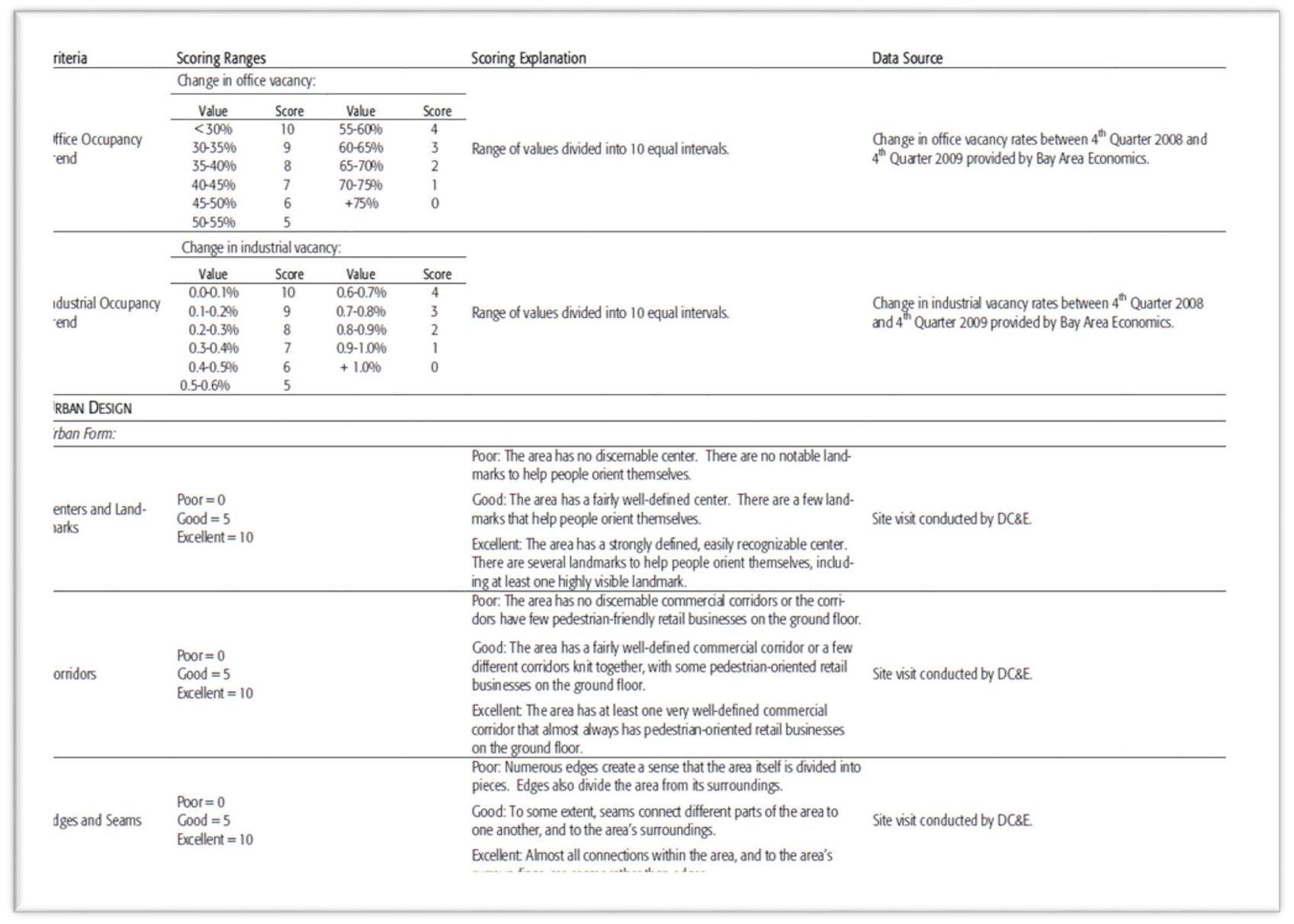




\begin{tabular}{|c|c|c|c|}
\hline imsı & runarg nairges & 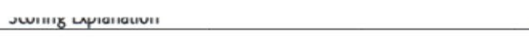 & vara juntue \\
\hline \multicolumn{4}{|c|}{ edestrian-Oriented Architecture: } \\
\hline \multirow[b]{2}{*}{ uilt Edge } & \multirow[b]{2}{*}{$\begin{array}{l}\text { Poor }=0 \\
\text { Good }=5 \\
\text { Excellent }=10\end{array}$} & $\begin{array}{l}\text { Poor: buildings are not oriented toward the street, and widely varying } \\
\text { setbacks create an inconsistent street edge. Frontages are dominated } \\
\text { by parking and/or driveways. }\end{array}$ & \multirow[b]{2}{*}{ Site visit conducted by DC\&E. } \\
\hline & & $\begin{array}{l}\text { Good: buildings are oniented toward the street, and consistent or ap- } \\
\text { propriately varied setbadks ceate a sense of a street edge. Most park- } \\
\text { ing is located behind buildings. }\end{array}$ & \\
\hline \multirow{3}{*}{ cale of Development } & \multirow{3}{*}{$\begin{array}{l}\text { Poor }=0 \\
\text { Cood }=5 \\
\text { Excellent }=10\end{array}$} & $\begin{array}{l}\text { Poor: Most development consists of large-scaled buildings with long, } \\
\text { undifferentiated horizontal surfaces near street level. }\end{array}$ & \multirow{3}{*}{ Site visit conducted by DC\&E. } \\
\hline & & $\begin{array}{l}\text { Good: Some small-scale development is present. Some large-scale } \\
\text { development uses changes in massing and architectural details to } \\
\text { divide façades into smaller horizontal components. }\end{array}$ & \\
\hline & & $\begin{array}{l}\text { Excellent Almost all buildings are either small in scale or incorporate } \\
\text { architectural features that divide their facades into smaller horizontal } \\
\text { components. }\end{array}$ & \\
\hline \multirow[b]{3}{*}{ treet Frontages } & \multirow{3}{*}{$\begin{array}{l}\text { Poor }=0 \\
\text { Cood }=5 \\
\text { Excellent }=10\end{array}$} & $\begin{array}{l}\text { Poor. building frontages are visually monotonous, dominated by } \\
\text { opaque materials, with minimal views into the building. }\end{array}$ & \multirow[b]{3}{*}{ Site visit conducted by DC\&E } \\
\hline & & Good: transparent window openings are provided at the street level. & \\
\hline & & $\begin{array}{l}\text { Excellent building entrances and frontages provide awnings, canopies } \\
\text { or arcades that offer shade and weather protection for pedestrians. } \\
\text { Transparent window opening are provided at the street level. Some } \\
\text { ground-floor frontages allow for outdoor seating. }\end{array}$ & \\
\hline \multirow{3}{*}{$\begin{array}{l}\text { reet Trees and } \\
\text { andscaping }\end{array}$} & \multirow{3}{*}{$\begin{array}{l}\text { Poor }=0 \\
\text { Cood }=5 \\
\text { Excellent }=10\end{array}$} & $\begin{array}{l}\text { Poor: Street trees are sparsely planted, poorly maintained and do not } \\
\text { provide shade for pedestrians. Landscaping is poorly maintained or } \\
\text { consists largely of turf, and it ceates little aesthetic benefit. }\end{array}$ & \multirow{3}{*}{ Site visit conducted by DC\&E. } \\
\hline & & $\begin{array}{l}\text { Good: Street trees are present but could be more consistently planted } \\
\text { or more closely spaced. Trees may provide some shade for pedestri- } \\
\text { ans. Landscaping enhances the site aesthetically. }\end{array}$ & \\
\hline & & $\begin{array}{l}\text { Excellent: Consistently planted, well-maintained street trees provide } \\
\text { shade for pedestrians. Landscaping enhances the site aesthetically and } \\
\text { indudes an appropriately varied plant palette. }\end{array}$ & \\
\hline \multicolumn{4}{|l|}{ VALKABILITY } \\
\hline \multirow[t]{2}{*}{$\begin{array}{l}\text { inear Feet of Walk- } \\
\text { ble Streets }\end{array}$} & $\begin{array}{l}\text { Linear feet of street that are within a } 1 / 2 \text {-mile walk of } \\
\text { the station: }\end{array}$ & \multirow[t]{2}{*}{ Range of values divided into 10 equal intervals. } & \multirow[t]{2}{*}{$\begin{array}{l}\text { Developed by DC\&E using GIS data from the Los Angeles } \\
\text { Community Redevelopment Agency. }\end{array}$} \\
\hline & Srenre & & \\
\hline
\end{tabular}




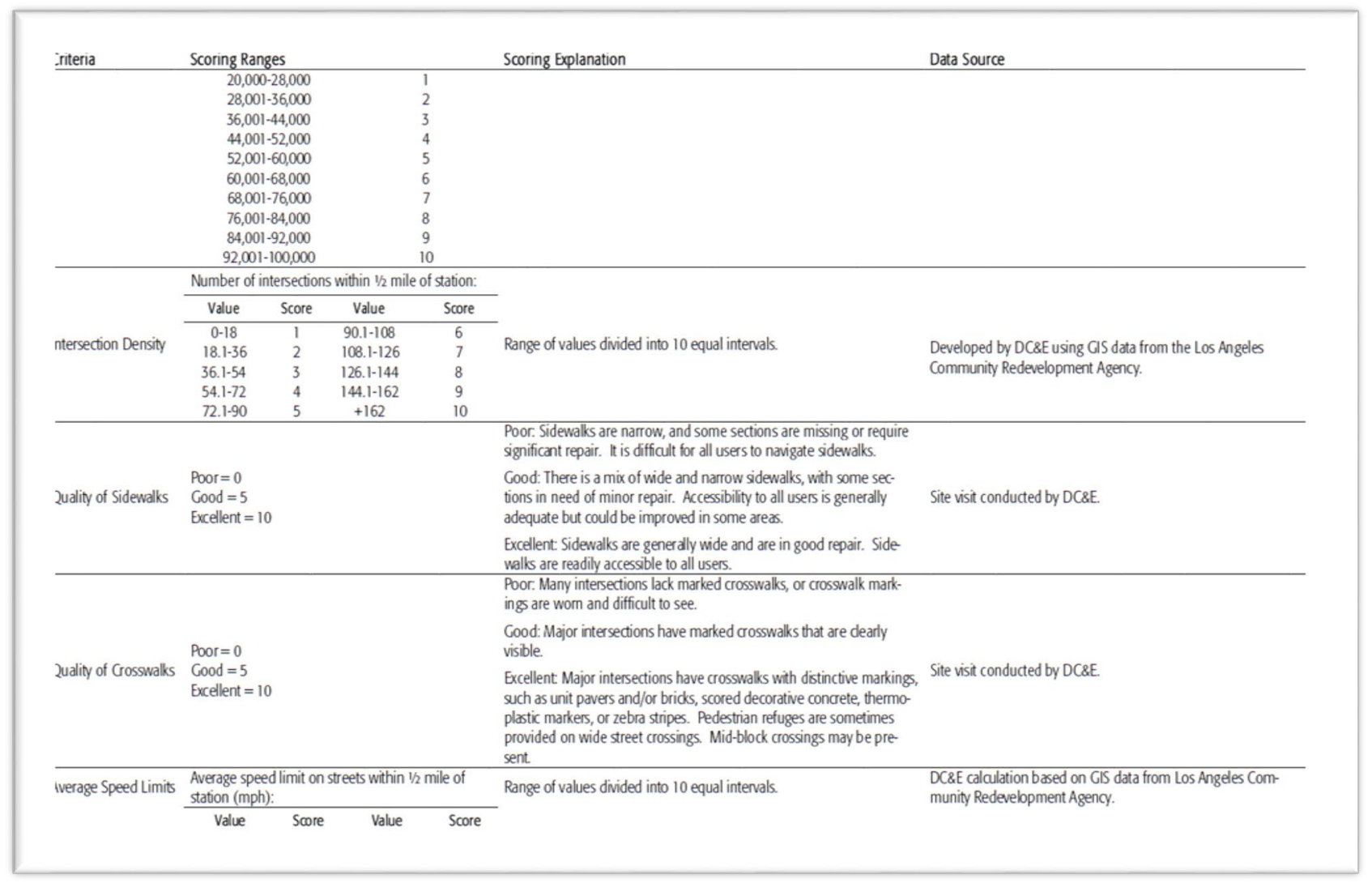

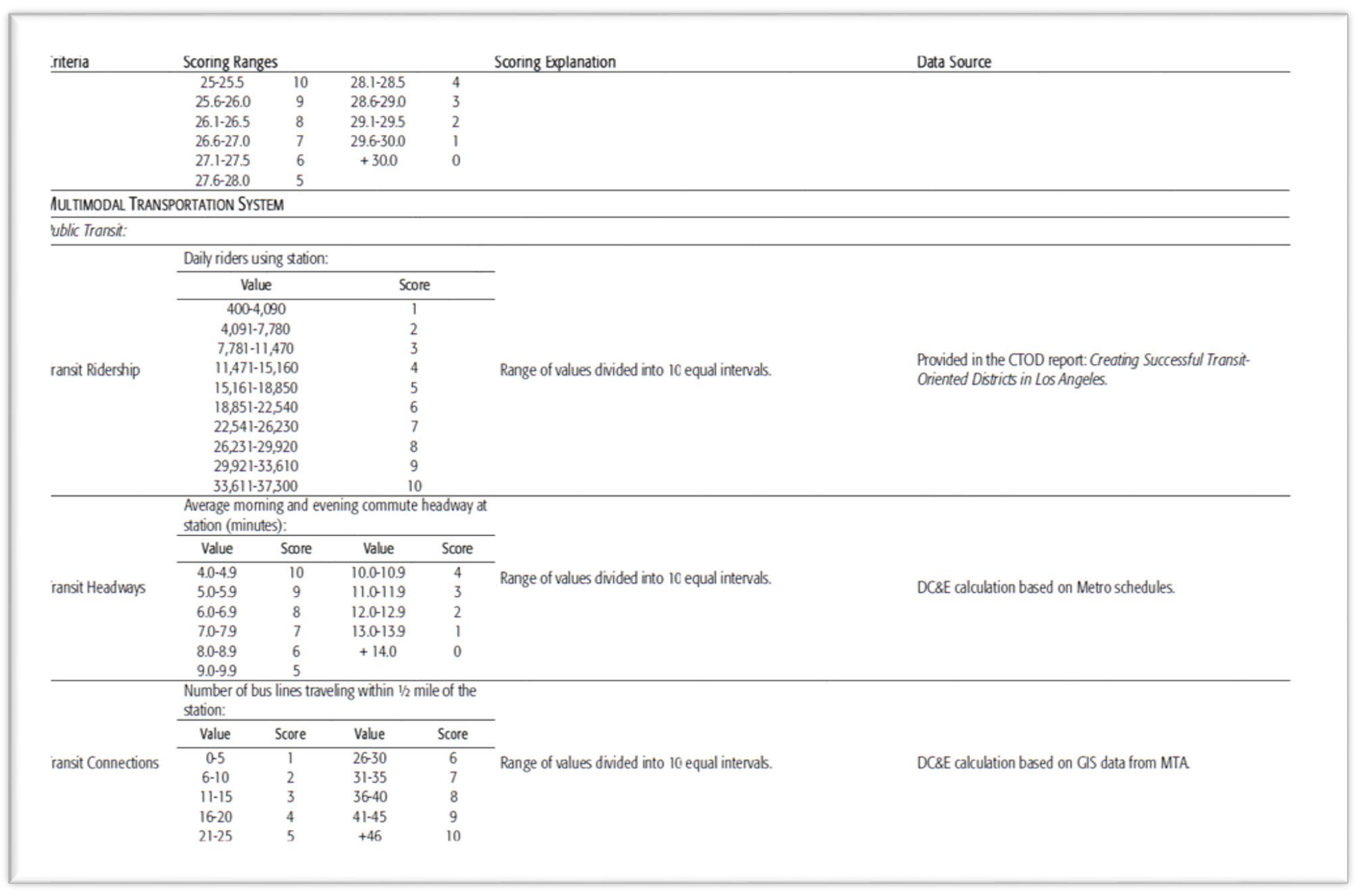




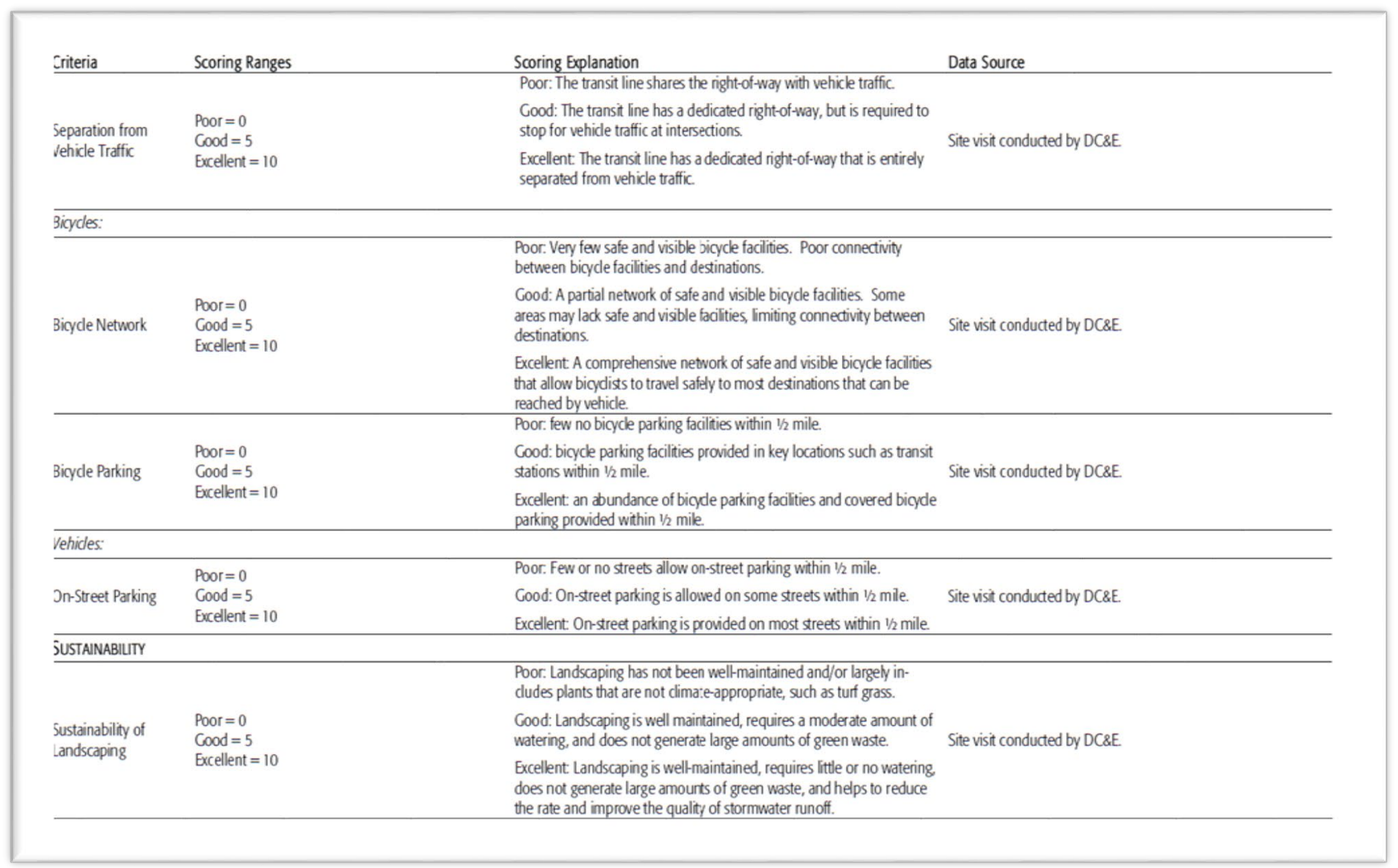


Buffalo, New York (2014)

References: (WSP, 2017) - Note: The document under review was a draft interim report made public in June 2017. Updated guidance or outcomes may vary from the provided summary.

Transit System: Metro Rail

Purpose of Typology:

Types of Use: Agency; Design or Land Use;

Findings \& Outcomes: It is also too early to tell the full use of this typology. This is an interim report, which means that the full potential of these typologies may not have been realized just yet. The types appear to represent mostly area types, not capturing the demographic shifts or market potential of studies aimed at developing strategies that strengthen these neighborhoods or evaluating the success of different policies. However, the interim report does acknowledge the potential for typologies to be used in this way. It's currently too early to tell how these typologies will be used and applied in practice.

Method for Aggregating Typology:

Notes: There is no mention of the methodology that was used to develop the place-type based typology for this report. It was mentioned early in the document that this came out of a workshop, which means that it may have been more anecdotal or manual than quantitative. These typologies communicate area type/land use

Categories \& Supporting Variables or Definitions:

Notes: The descriptions here may be pulled directly from the language of the document; for image screenshots (marked with an image shadow), page numbers are either left on the image or embedded in the text directly before the image.

The following images describe the typologies and the supporting high-level variables. The dimensions of these typologies include: character (such as major attractions or activities); density; mix of uses; pedestrian environments; multimodal connectivity; and parking. 

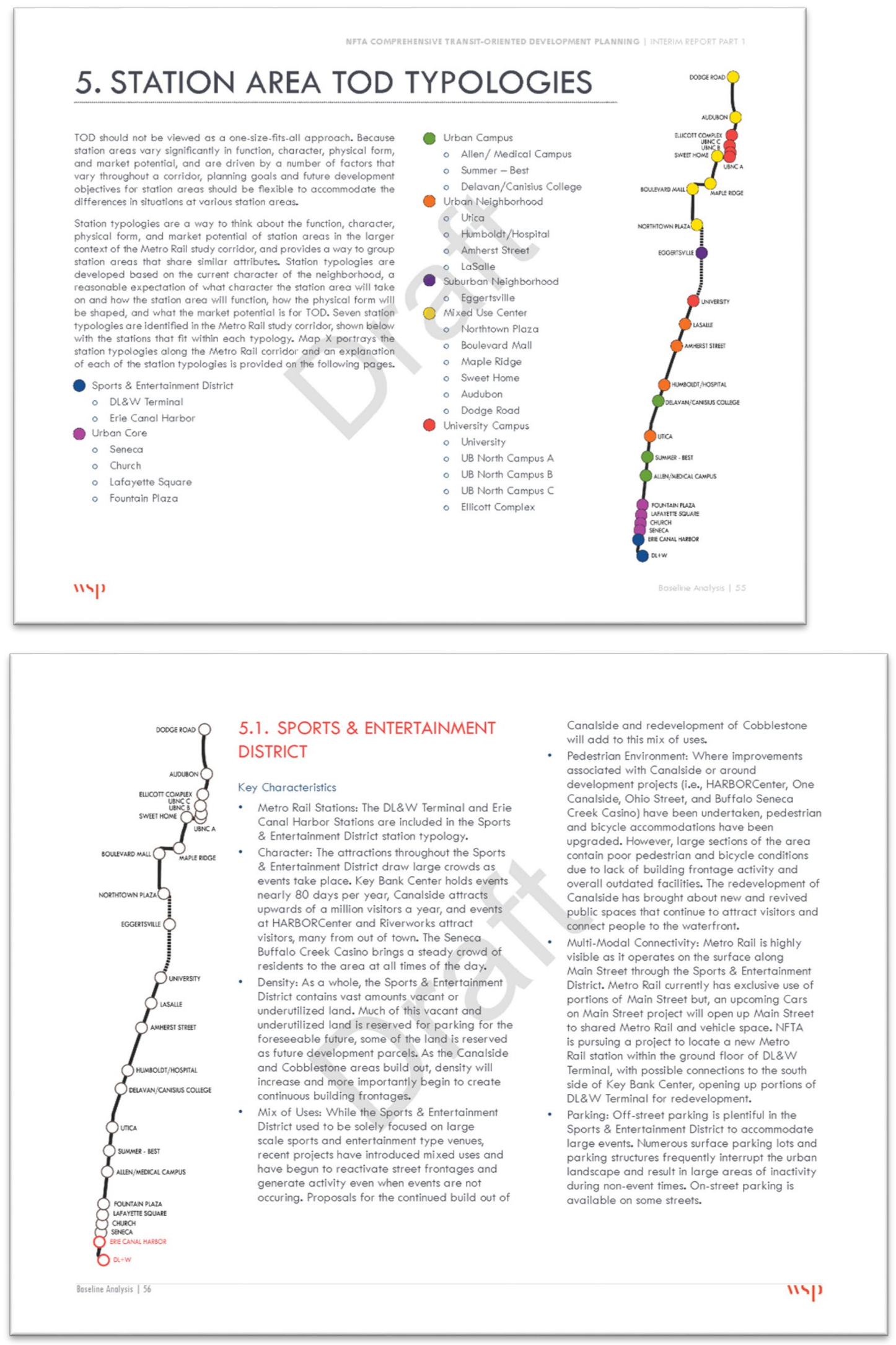


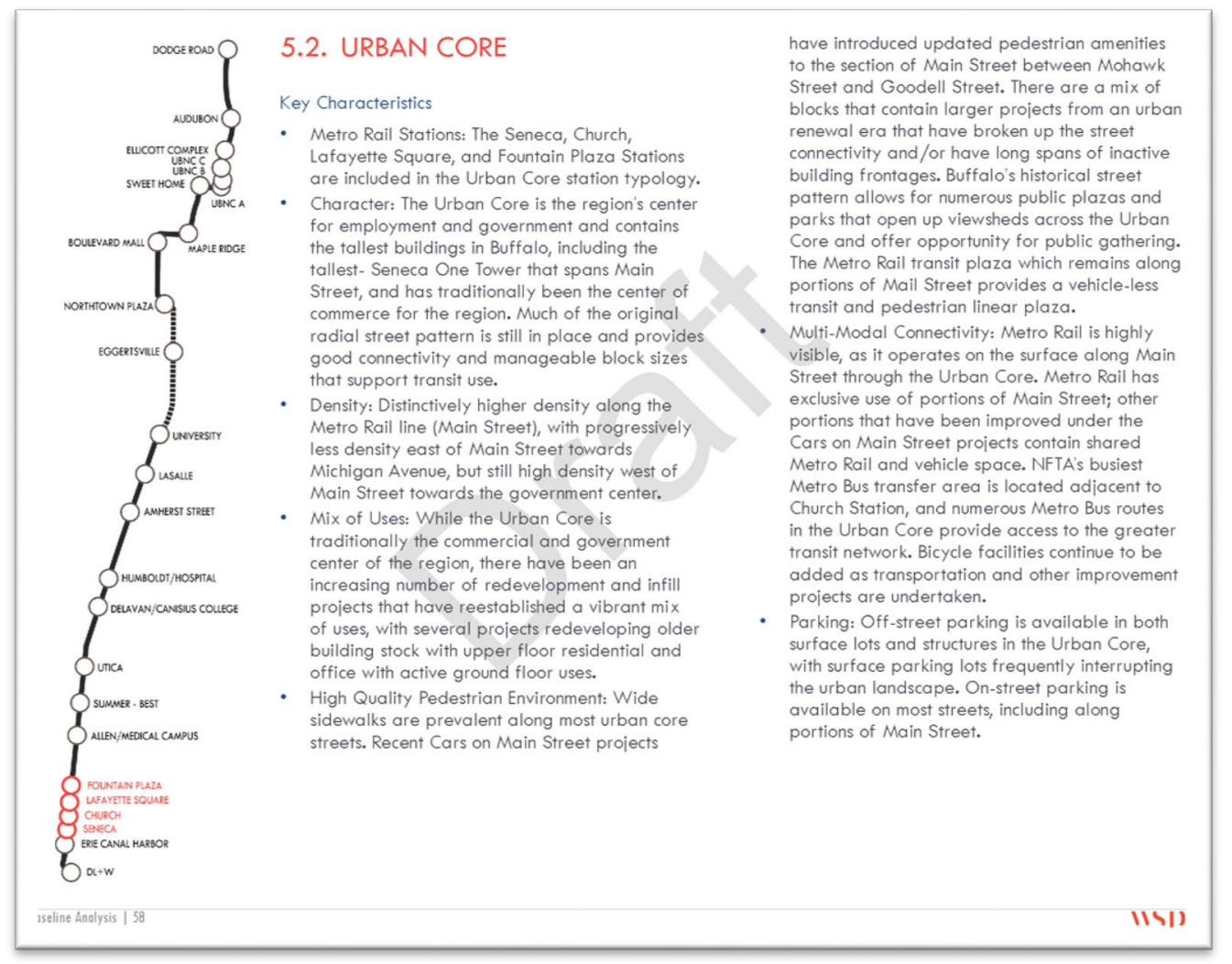

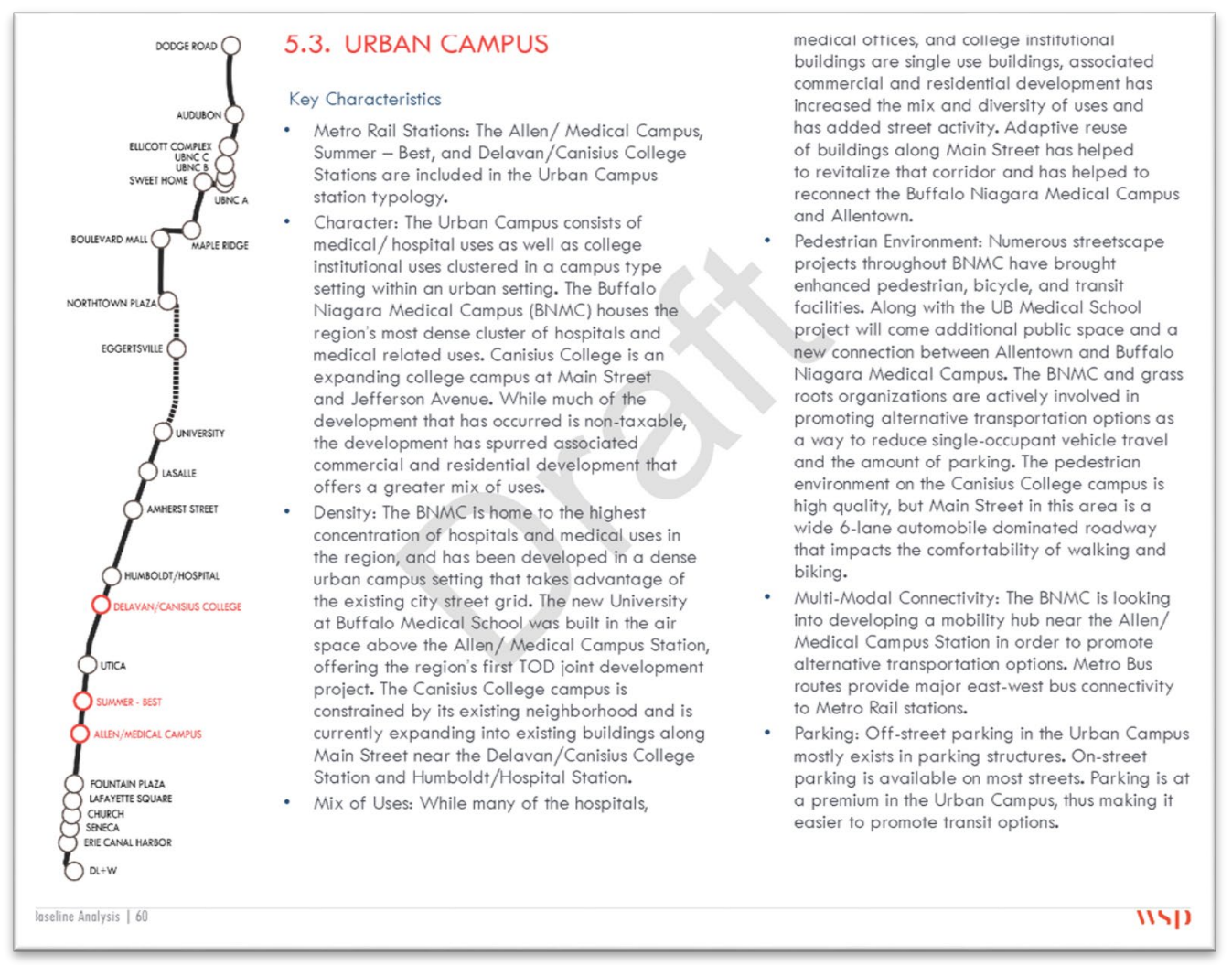




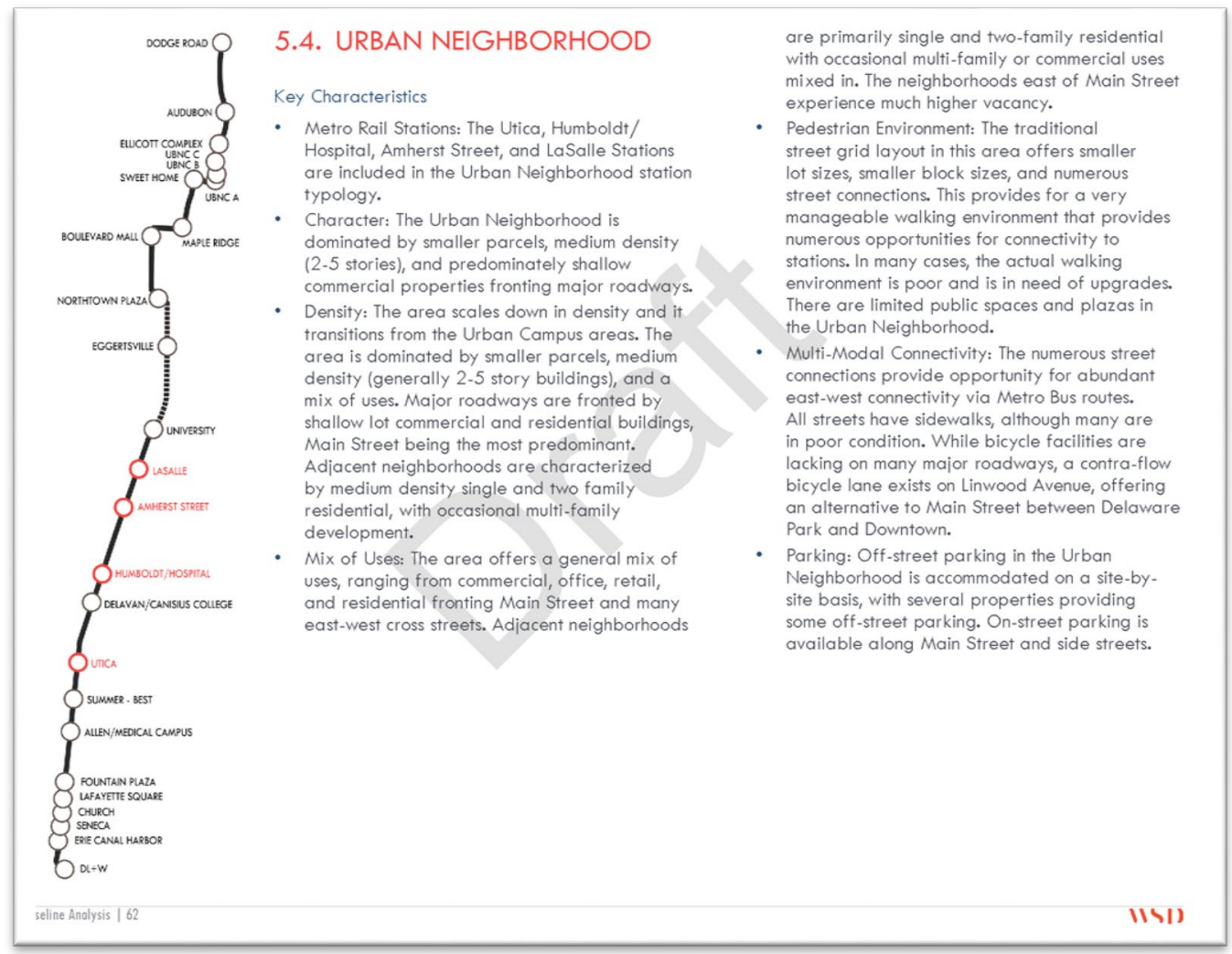

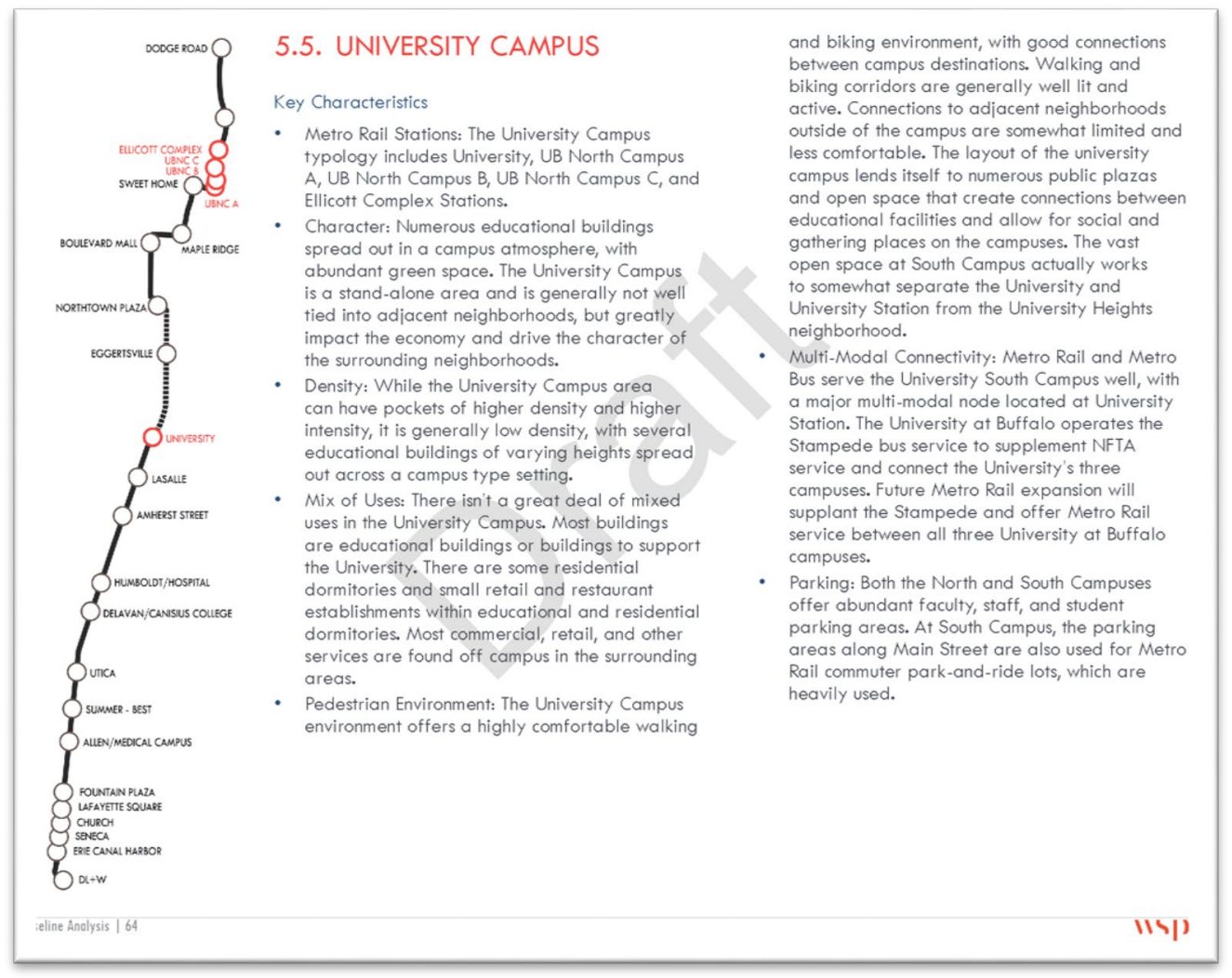




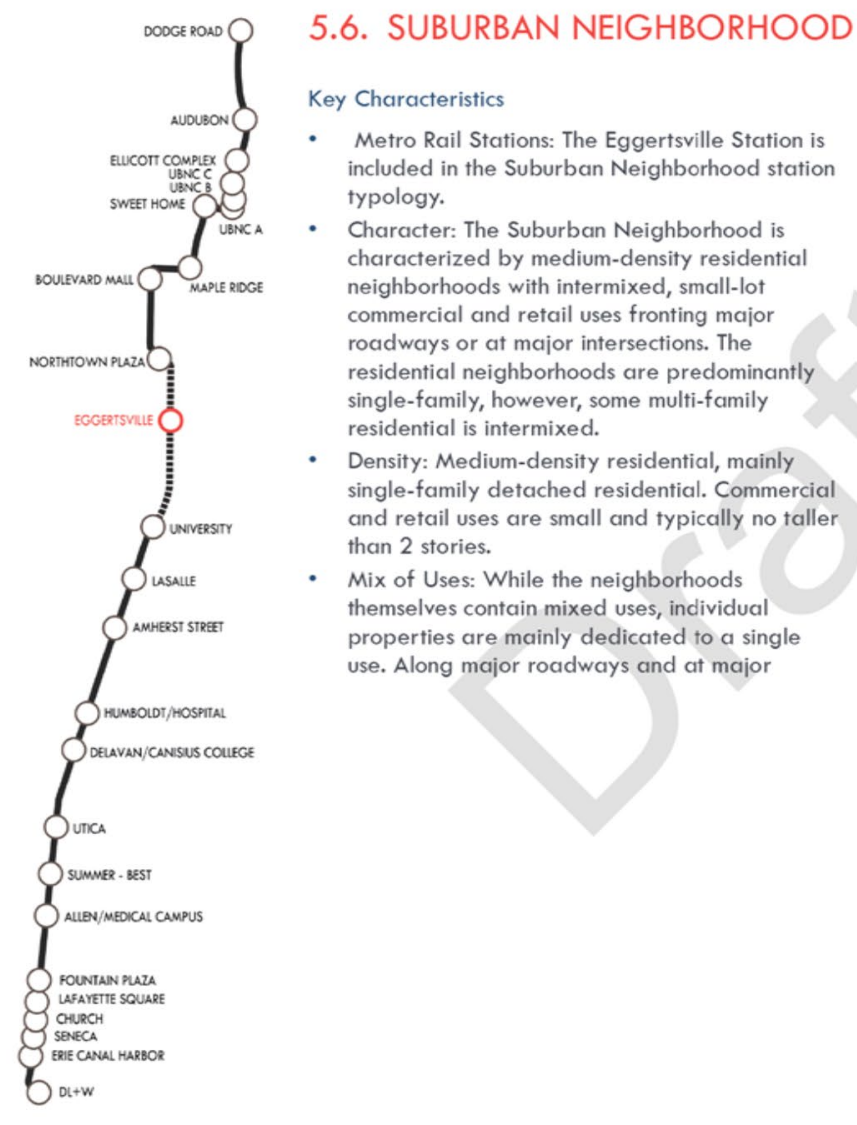

intersections, commercial and retail uses are prevalent and are often adjacent to residential with little buffer.

- Pedestrian Environment: The walking environment is very good, with all streets containing sidewalks and block sizes very manageable. Multiple connections are available between neighborhood commercial areas and residences.

- Multi-Modal Connectivity: Metro Bus operates on major streets. The layout of the street pattern and medium-density makeup of the neighborhood make transit very accessible by a large population. The Inter-Campus bikeway connects the University at Buffalo South and North Campuses.

- Parking: Most commercial and residential properties contain their own off-street parking. On-street parking is available on most streets and supplements off-street parking, especially where commercial properties do not have sufficient off-street parking. 


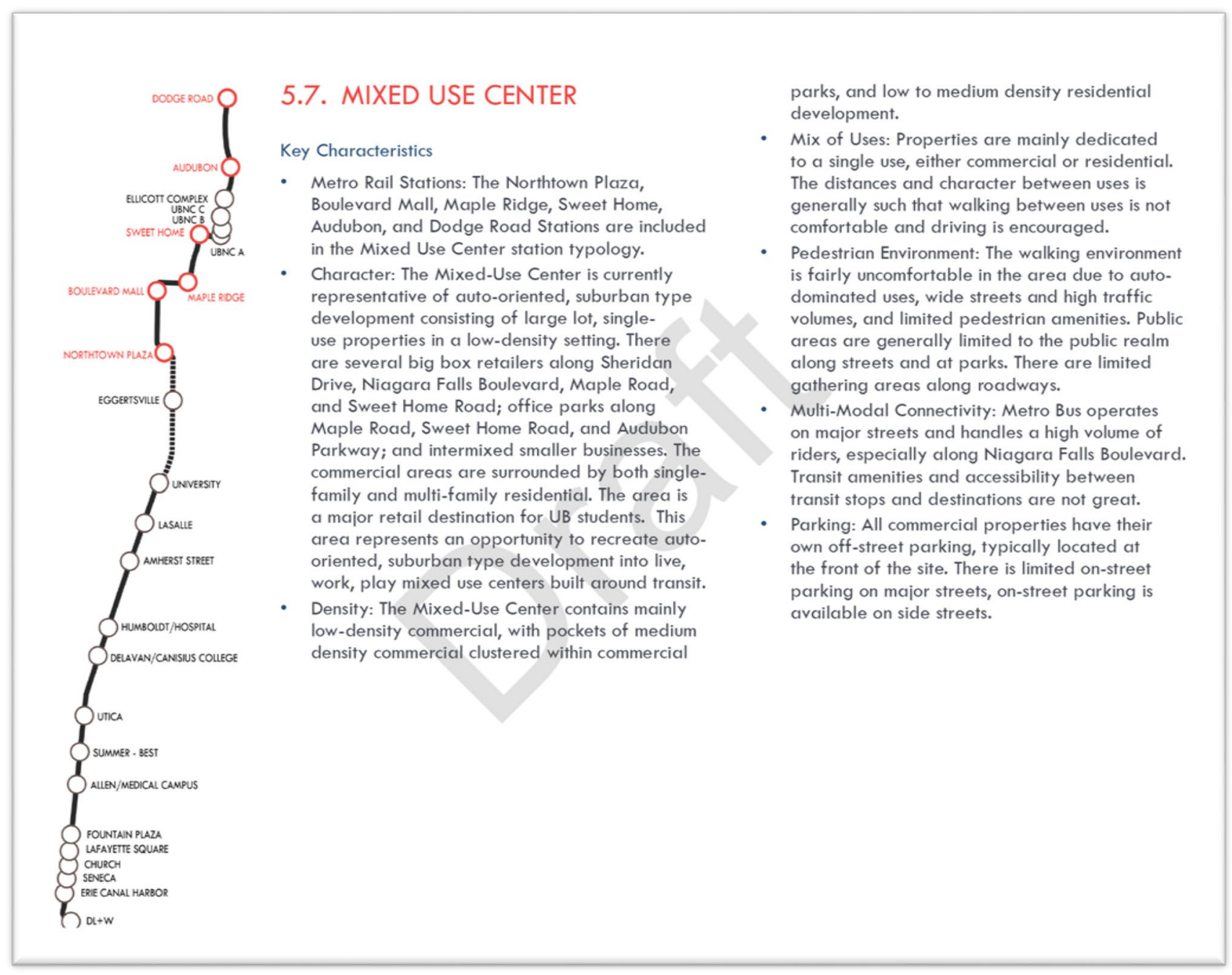


Federal Guidebooks or Reports Directly Related

CTOD - Performance-Based Transit-Oriented Development Typology Guidebook (2010)

Reference: (Center for Transit-Oriented Development, 2010)

Transit System: Any (potentially)

Purpose of Typology:

Types of Use: Agency; Design or Land Use; Evaluation;

Findings \& Outcomes: This typology is for evaluative purposes based on the performance measure: vehicle-miles traveled (VMT) considering land use measures as an input. VMT, however, is a proxy for many other outcomes that correspond with multimodal and livable community goes - such as walkability, transit use, accessibility (and trip length), active travel, or reduced car ownership and use rates. The output of VMT is not a function of only use mix (workers/(workers + residents)), but rather a host of factors related to the built environment, socio-economic demographics and accessibility opportunities. Instead, mixed use is a way of distinguishing the built environment and regional context of the stations, recognizing that the VMT produced of that area is a means of evaluating the status of the area and identifying strategies that may help further achieve performance goals.

Other Notes:

Page 4: "The characteristics that define a typology can differ depending on what outcomes the typology is meant to accomplish, and not every station area in one area type will be exactly the same."

In this study, the users produce a typology to evaluate the sustainability of TODs. Similar types of typologies could be generated to accommodate evaluation of goals on economic or social outcomes.

Method and Outcomes:

Notes: Recognizing that many built environment measures correlate with each other, this study relies on one set of measures - the proximity and mix of residents and workers-to demonstrate the evaluation. VMT is estimated based on a host of social and environmental factors and normalized across national averages based on the VMT-intensity thresholds (page 10, below). Page 10:

mix, or the balance between residential and non-residential uses is a critical determinant of the qualities and characteristics of a place.

Table 2. Use Mix Types

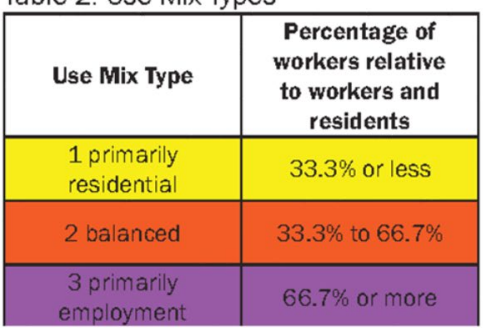

Figure 4: Performance-Based Place Types

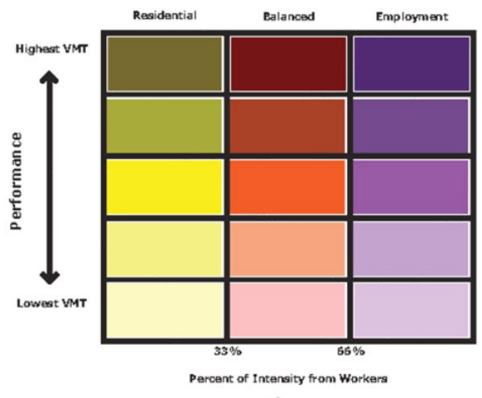

Table 1. VMT Types Household VMT Type

\begin{tabular}{c|c}
\hline Household VMT Type & VMT Range \\
\hline 1 - Low & $<9,100$ \\
\hline 2 - Low-Moderate & 9,100 to 11,600 \\
\hline 3 - Moderate & 11,600 to 14,300 \\
\hline 4 - High-Moderate & 14,300 to 17,200 \\
\hline 5 - High & $>17,200$ \\
\hline
\end{tabular}


Table 4. Normative Metrics

\begin{tabular}{|c|c|c|c|c|c|c|c|c|c|c|c|c|c|c|c|}
\hline \multirow[b]{2}{*}{ Place types } & \multicolumn{5}{|c|}{ Residentlal Places } & \multicolumn{5}{|c|}{ Balanced Places } & \multicolumn{5}{|c|}{ Employment Places } \\
\hline & Low VMT & $\begin{array}{l}\text { Low-Mod } \\
\text { VMT }\end{array}$ & Mod VMT & $\begin{array}{l}\text { Hlgh-Mlod } \\
\text { Vhat }\end{array}$ & Hlgh VMT & Low VMT & $\begin{array}{l}\text { Low-Mod } \\
\text { VMTT }\end{array}$ & Mlod VMT & $\begin{array}{l}\text { Hlgh-Mod } \\
\text { VMT }\end{array}$ & HIgh VMT & Low VMT & $\begin{array}{l}\text { Low-Mod } \\
\text { VMT }\end{array}$ & Mod VMT & $\begin{array}{l}\text { High-Mod } \\
\text { VATT }\end{array}$ & HIgh VMT \\
\hline $\begin{array}{c}\text { Total Intensity } \\
\text { (reslidents + workers) }\end{array}$ & 54,216 & 24,718 & 12,580 & 7,708 & 3,429 & 64,155 & 21,783 & 11,600 & 6,887 & 3,242 & 109,306 & 34,914 & 13,009 & 5,969 & 2,325 \\
\hline Reslclents & 44,293 & 20,106 & 10,229 & 6,292 & 2,716 & 29,875 & 10,732 & 5,884 & 3,695 & 1,764 & 12,581 & 5,103 & 2,065 & 1,154 & 321 \\
\hline Workers & 9,923 & 4,612 & 2,351 & 1,416 & 713 & 34,280 & 11,031 & 5,716 & 3,172 & 1,478 & 96,725 & 29,811 & 10,944 & 4,815 & 2,004 \\
\hline Workers/Reslitents & $18.3 \%$ & $19.5 \%$ & $19.6 \%$ & $20,3 \%$ & $19.6 \%$ & $51.6 \%$ & $49.7 \%$ & $48.2 \%$ & 46.036 & $46.2 \%$ & $86.5 \%$ & $83.9 \%$ & $84.2 \%$ & $83.0 \%$ & $87.1 \%$ \\
\hline Households & 16,214 & 7,684 & 3,906 & 2,253 & 974 & 15,466 & 4,846 & 2,429 & 1,467 & 670 & 6,328 & 2,524 & 861 & 467 & 120 \\
\hline Household Slze & 2.71 & 2.61 & 2.82 & 2.71 & 2.68 & 1.95 & 2.21 & 2.41 & 2.43 & 2.60 & 1.58 & 1.67 & 2.22 & 2.28 & 2.84 \\
\hline $\begin{array}{l}\text { Gross Denslty } \\
\text { (unlts/acre) }\end{array}$ & 50.0 & 21.6 & 10.3 & 5.7 & 2.2 & 48.7 & 16.4 & 7.6 & 4.0 & 1.9 & 28.5 & 10.3 & 4.6 & 2.2 & 0.9 \\
\hline $\begin{array}{c}\text { Residenttal Density } \\
\text { (units/acre) }\end{array}$ & 53.2 & 23.6 & 12.1 & 6.7 & 3.4 & 55.6 & 20.9 & 10.5 & 5.8 & 3.5 & 51.4 & 20.6 & 10.8 & 6.0 & 2.9 \\
\hline Block Slze (acres) & 4.2 & 4.1 & 5.7 & 7.7 & 18.8 & 3.7 & 5.8 & 8.5 & 9.9 & 23.7 & 3.7 & 6.4 & 14.2 & 69.9 & 86.7 \\
\hline Monthly $\boldsymbol{T}$ Cost & $\$ 422$ & $\$ 563$ & $\$ 688$ & $\$ 781$ & $\$ 906$ & $\$ 394$ & $\$ 597$ & $\$ 721$ & $\$ 794$ & $\$ 900$ & $\$ 463$ & 5613 & $\$ 713$ & $\$ 793$ & $\$ 920$ \\
\hline Yearly $T$ cost & $\$ 5,064$ & $\$ 6,756$ & $\$ 8,256$ & $\$ 9,372$ & $\$ 10,872$ & $\$ 4,728$ & $\$ 7,164$ & $\$ 8,652$ & $\$ 9,528$ & $\$ 10,800$ & $\$ 5,556$ & $\$ 7,356$ & $\$ 8,556$ & $\$ 9,516$ & $\$ 11,040$ \\
\hline $\begin{array}{l}\text { Average Metlan } \\
\text { Income (1999) }\end{array}$ & $\$ 31,713$ & $\$ 35,643$ & $\$ 41,344$ & $\$ 53,492$ & $\$ 62,06 t 9$ & $\$ 43,997$ & $\$ 37,364$ & $\$ 43,395$ & $\$ 51,138$ & $\$ 65,544$ & $\$ 41,875$ & $\$ 34,183$ & $\$ 43,935$ & $\$ 40,985$ & $\$ 57,562$ \\
\hline $\begin{array}{c}\text { Travel TIme to Work } \\
\text { (mlnutes) }\end{array}$ & 35.6 & 31.4 & 27.4 & 25.5 & 24.7 & 23.5 & 22.1 & 21.4 & 21.6 & 22.9 & 18.0 & 17.1 & 18.7 & 19.0 & 21.5 \\
\hline $\begin{array}{l}\text { Employment } \\
\text { Proxlmlty }\end{array}$ & 233,890 & 127,448 & 65,640 & 42,260 & 20,788 & 451,725 & 152,310 & 73,393 & 41,335 & 27,131 & 396,277 & 159,118 & 99,648 & 58,747 & 32,167 \\
\hline Transitt Aocess Intex & 31 & 19 & 13 & 10 & 3 & 56 & 28 & 11 & 9 & 4 & 85 & 45 & 19 & 10 & 4 \\
\hline Autos/Household & 0.45 & 0.82 & 1.18 & 1.47 & 1.71 & 0.52 & 0.87 & 122 & 141 & 1.68 & 0.48 & 0.74 & 1.11 & 118 & 1.61 \\
\hline $\begin{array}{l}\text { Home Journey to } \\
\text { Work Translt }\end{array}$ & $58 \%$ & $39 \%$ & $23 \%$ & $15 \%$ & $8 \%$ & $43 \%$ & $25 \%$ & $14 \%$ & $10 \%$ & $8 \%$ & $25 \%$ & $16 \%$ & $13 \%$ & $9 \%$ & $5 \%$ \\
\hline $\begin{array}{c}\text { Home Journey to } \\
\text { Work Walk/Blke/ } \\
\text { Transitt }\end{array}$ & $68 \%$ & $47 \%$ & $27 \%$ & $18 \%$ & $10 \%$ & $64 \%$ & $40 \%$ & $23 \%$ & $15 \%$ & $11 \%$ & $58 \%$ & $37 \%$ & $24 \%$ & $18 \%$ & $9 \%$ \\
\hline $\begin{array}{c}\text { Workplace Journey } \\
\text { to Work Transitt }\end{array}$ & $33 \%$ & $20 \%$ & $11 \%$ & $7 \%$ & $2 \%$ & $38 \%$ & $17 \%$ & $8 \%$ & $5 \%$ & $3 \%$ & $38 \%$ & $16 \%$ & $9 \%$ & $5 \%$ & $3 \%$ \\
\hline $\begin{array}{c}\text { Workplace Journey } \\
\text { to Work Walk/Blke/ } \\
\text { Transitt }\end{array}$ & $47 \%$ & $30 \%$ & $18 \%$ & $12 \%$ & $6 \%$ & $48 \%$ & $23 \%$ & $12 \%$ & $8 \%$ & $5 \%$ & $43 \%$ & 1936 & $11 \%$ & $7 \%$ & $5 \%$ \\
\hline
\end{tabular}

Any one station's location on this typology is a function of not just the mixed-use variable, but the host of variables that go into estimating VMT (see page 15 table above with the normative metrics for each of the VMT threshold categories). The normative metrics allow stations across systems to be compared relative to the national 'universe' on any one variable. When considering strategies to lower VMT, it is the comparison with a station's metrics within any of the 15 VMT/MXD types that provides a direction for which inputs might impact lowering VMT (and increasing active travel or lowering vehicle ownership rates, etc.).

For example, for any one station, one can consider its location relative to the normative metrics to get a sense for which variables might contribute most to VMT, and therefore strategies aimed at improving that corresponding variable/metric. (See right example from page 3 of the appendix; page 60 of the PDF document.)

Similarly, the typology/VMT setup, can be used to assess potential impacts of policies that increase housing (a factor that impacts the mixed-use metric) or any of the VMT inputs to examine the 'direction and scale' of impacts. For examples, Figure 24 (page 31) for example of increasing households (which changes the Use Mix) or see Figure 22 (page 27) for a

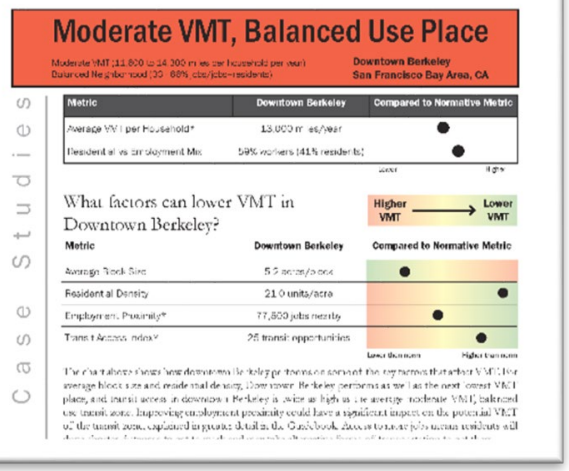


scenario of another VMT input (which does not change the Use Mix).

Figure 24: Increase Households by 2,000

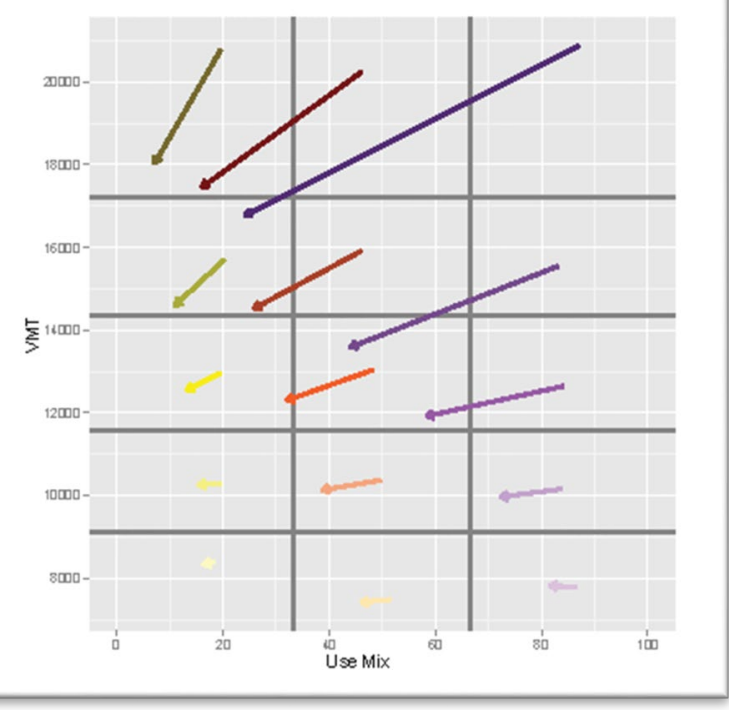

Figure 22: Scenarios A, B, C - Increased Employment Access \& Households by 15,30 , and 50 Percent

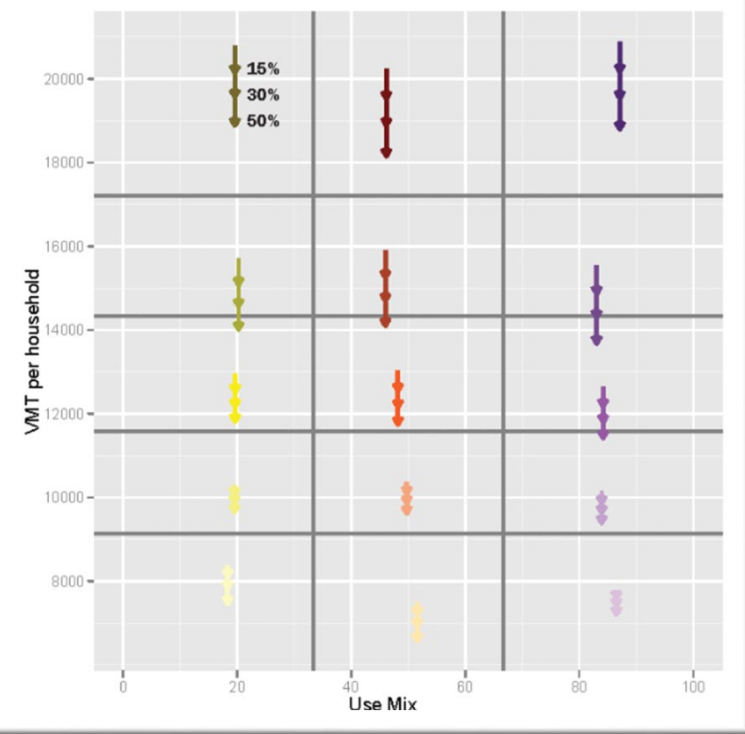


TCRP Report 153: Providing Access to Transit Stations (2012)

Reference: (Levinson et al., 2012)

Transit System: commuter rail, heavy rail, light rail, and BRT lines.

Purpose of Typology:

Types of Use: Design or Land Use; Common Vocabulary; Conceptual Planning; Evaluation;

Findings \& Outcomes:

This report had several purposes. Overall, this report aims to provide comprehensive guidance on the planning of station access-from problem identification to partnerships to solutions. Part of this process includes classifying TODs into different categories or typologies, recognizing that the varying contexts captures the variation in the roles of different types of stations. It also provides a means for understanding, evaluating, and aiming to improve access to and use of stations across different contexts.

The typology might be simplified into five basic types: CBD; urban-medium to high density; suburban low-density; terminal stations; and special conditions.

The typology as proposed was based on the following conceptual illustration, recognizing that as the built environment (here depicted by density) becomes less urban, the typical travel distances increase (making trip length and VMT increase) resulting in more frequent use (and higher proportions) of automobile mode shares (page 34):

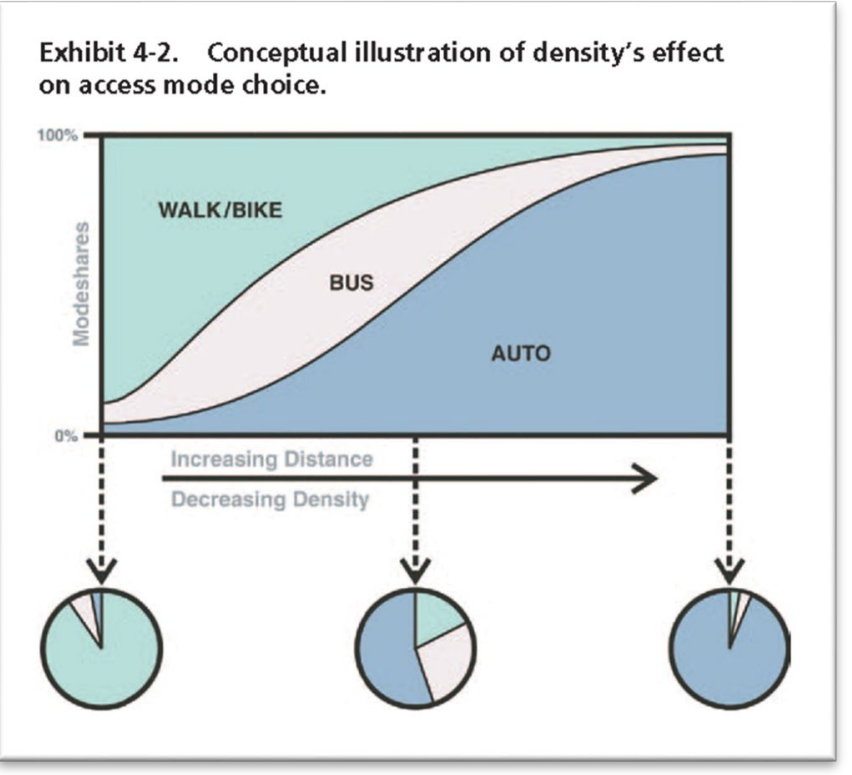

Other Notes:

Method and Outcomes:

Notes:

There is no clear methodology for deriving a 'station access' typology from the following inputs, but the authors provide the typology as an example. The inputs to the typology include the following metrics, indicating that these metrics corresponding with 'station access' performance (in terms of ridership and multimodal access/use): (page 35) 
stations were reviewed according to eignt categories:

- Housing density - a characterization of the housing density in the area around the station. This attribute provides insight into the potential riders that live within walking distance of the station.

- Scale-average building height in the area surrounding the station. Building scale relates to walkability, density, and activity levels, and helps to illustrate the feel of the station area when combined with some of the other categories.

- Distance from CBD - a measure of the typical station type's location within the metro area. Stations further from downtown will tend to serve a different market than those closer to the CBD. Stations closer to the urban core tend to emphasize pedestrian connections while commuter stations focus on providing enough parking to meet demand. These locational attributes will vary according to transit mode and other land use considerations.

- Supporting Transit Network-the level of transit connectivity to other transit services available at the station. This measure identifies how the station operates in the context of the overall transit network and indicates the station's ability to serve a wide-ranging area.

- Pedestrian/Bike Access - a measure of the completeness and attractiveness of the pedestrian and bicycle networks around the station. Well-formed connections for pedestrians and bicycles are important for assuring successful station access.

- Surrounding Land Uses-description of the land use mix in the station area. Stations adjacent to different land use types serve different functions.

- Parking Facilities - the level of off-street parking accommodation provided at the station type.

- Access/Egress - simple classification (Access/Egress/Both) describing the primary role of the station in the transportation system. Some stations are located at the "home" end of the journey for most passengers, while others represent the destination. This distinction is important because passengers are more likely to have access to a private vehicle at the "home," or access station.

Page 36 \& 37 - The following typologies were provided. Although not explicitly mentioned, these appear to be partially developed based manual categorization based on actual stations and contexts. The authors list this as a 'suggested station access typology' (page 35). The table is in two parts and has been aggregated here into one page. 
Exhibit 4-3. Station access typology

\begin{tabular}{|c|c|c|c|c|c|}
\hline $\begin{array}{l}\text { Station Area } \\
\text { Type }\end{array}$ & $\begin{array}{l}\text { Houring } \\
\text { Density }\end{array}$ & $\begin{array}{l}\text { Scale } \\
\text { (H of } \\
\text { stories) }\end{array}$ & $\begin{array}{l}\text { Distance } \\
\text { from CBD }\end{array}$ & $\begin{array}{l}\text { Supporting } \\
\text { Transit } \\
\text { Network }\end{array}$ & Ped/Bike Access \\
\hline $\begin{array}{l}\text { Urtan } \\
\text { Commercial }\end{array}$ & High & 25 & 0.40 miles & $\begin{array}{l}\text { Internodal } \\
\text { facility:transit } \\
\text { hub }\end{array}$ & $\begin{array}{l}\text { High-quality natwork; } \\
\text { good connectivity }\end{array}$ \\
\hline $\begin{array}{l}\text { Highr. Density } \\
\text { Untwan } \\
\text { Neightornood }\end{array}$ & Hight? & 2.5 & 0.10 miles & Subregionat hub & $\begin{array}{l}\text { Hight-quallty network: } \\
\text { goos connectivity }\end{array}$ \\
\hline $\begin{array}{l}\text { Medium. } \\
\text { Density Uirtan } \\
\text { Neighborhood }\end{array}$ & Medium & 2.5 & $\overline{5}-10$ miles & $\begin{array}{l}\text { Soma iccal bus } \\
\text { connections }\end{array}$ & $\begin{array}{l}\text { High-quallty network; } \\
\text { good connectivity }\end{array}$ \\
\hline $\begin{array}{l}\text { Urban } \\
\text { Neighborthood } \\
\text { with Parking }\end{array}$ & Medium & $2 \cdot 5$ & $\overline{5}-10$ miles & Subregionat hut & $\begin{array}{l}\text { High-quality network; } \\
\text { high-yolume padways } \\
\text { may fimit connectivity }\end{array}$ \\
\hline $\begin{array}{l}\text { Historic Transiti } \\
\text { Village }\end{array}$ & $\begin{array}{l}\text { Medium- } \\
\text { Hiligh }\end{array}$ & $2 \cdot 5$ & $\begin{array}{l}10-40 \\
\text { miliss }\end{array}$ & $\begin{array}{l}\text { Some lacal bus } \\
\text { corninetions }\end{array}$ & $\begin{array}{l}\text { High-qually netwolk; } \\
\text { good cennectivity }\end{array}$ \\
\hline Suldubar TOD & $\begin{array}{l}\text { Medsiutr. } \\
\text { Hight }\end{array}$ & 2.8 & $5 \times 15$ miless & $\begin{array}{l}\text { Some iccal bus } \\
\text { connections }\end{array}$ & $\begin{array}{l}\text { Good nitwork wittin } \\
\text { station area, soint } \\
\text { high-yolume roadways }\end{array}$ \\
\hline $\begin{array}{l}\text { Suburtan } \\
\text { Village Cinter }\end{array}$ & $\begin{array}{l}\text { Mediuri. } \\
\text { Higl। }\end{array}$ & $2-5$ & 5.15 roiles & Subregional hub & $\begin{array}{l}\text { Limited ronnectivity. } \\
\text { some highthototurte } \\
\text { road dways }\end{array}$ \\
\hline $\begin{array}{l}\text { Sulututan } \\
\text { Neighborhxid }\end{array}$ & $\begin{array}{l}\text { Lover- } \\
\text { Medium }\end{array}$ & $1-3$ & 5-15 miles & $\begin{array}{l}\text { Soma local bus } \\
\text { semingctions }\end{array}$ & $\begin{array}{l}\text { Limited connrectivity, } \\
\text { some ligh-volume } \\
\text { road'ways }\end{array}$ \\
\hline $\begin{array}{l}\text { Sidurbari } \\
\text { (Free way) }\end{array}$ & Low & 0.2 & $\begin{array}{l}10.20 \\
\text { inilos }\end{array}$ & $\begin{array}{l}\text { Empioyer } \\
\text { shutles, limited } \\
\text { tuis cornections }\end{array}$ & $\begin{array}{l}\text { Isolated afficicult } \\
\text { connections }\end{array}$ \\
\hline $\begin{array}{l}\text { Suturban } \\
\text { Employmentent } \\
\text { Centier }\end{array}$ & LON & $1-3$ & $5.15 \mathrm{miles}$ & $\begin{array}{l}\text { Sorna lical bus } \\
\text { connections. } \\
\text { employer } \\
\text { shuttlas }\end{array}$ & $\begin{array}{l}\text { Poor connectivity, high- } \\
\text { voitume roadways }\end{array}$ \\
\hline $\begin{array}{l}\text { Sutburban } \\
\text { Retail Center }\end{array}$ & Low & $1-3$ & $5-15$ miles & $\begin{array}{l}\text { Soma local bus } \\
\text { connectyons }\end{array}$ & $\begin{array}{l}\text { Poor connactivity, high. } \\
\text { volume roadvays }\end{array}$ \\
\hline $\begin{array}{l}\text { Intarmotal } \\
\text { Transit Center }\end{array}$ & $\begin{array}{l}\text { Los- } \\
\text { Metium }\end{array}$ & 1.3 & 5-15 miles & $\begin{array}{l}\text { Internodai } \\
\text { tacility transit } \\
\text { thitb }\end{array}$ & $\begin{array}{l}\text { Good vonnections } \\
\text { between systerns; } \\
\text { is datated }\end{array}$ \\
\hline $\begin{array}{l}\text { Fraeweyf } \\
\text { Highway Park } \\
\text { \& Fide }\end{array}$ & Low & 0.2 & $\begin{array}{l}15 \cdot 40 \\
\text { miles }\end{array}$ & $\begin{array}{l}\text { Empicyer } \\
\text { shuttles. limited } \\
\text { buls connections }\end{array}$ & $\begin{array}{l}\text { Isolated, dfficult } \\
\text { connestionis }\end{array}$ \\
\hline Busway & Vañas & Varies & $\begin{array}{l}10-30 \\
\text { miles }\end{array}$ & Subregional hub & $\begin{array}{l}\text { Hilgh-wolume roadways, } \\
\text { cifficult connections }\end{array}$ \\
\hline $\begin{array}{l}\text { Specia! Eveltst } \\
\text { Campus }\end{array}$ & $\begin{array}{l}\text { Low } \\
\text { Medium }\end{array}$ & $1 \cdots 3$ & vantes & $\begin{array}{l}\text { Some lacal bus } \\
\text { connentions }\end{array}$ & $\begin{array}{l}\text { Limited coninectivity } \\
\text { vith ernphasis on } \\
\text { special facility }\end{array}$ \\
\hline Shuthe Station & Low & 0.2 & $\begin{array}{l}15-40 \\
\text { milis } \\
\end{array}$ & $\begin{array}{l}\text { Empleye:, } \\
\text { aimort, special } \\
\text { event shustles }\end{array}$ & $\begin{array}{l}\text { Isolated, Itricuit } \\
\text { connestions }\end{array}$ \\
\hline Satblilite city & $\begin{array}{l}\text { Low- } \\
\text { Mestum }\end{array}$ & 13 & 530 miles & Subregional hut & $\begin{array}{l}\text { Hiligh-quality networik; } \\
\text { good commostluty }\end{array}$ \\
\hline Legacy & Low & 0.2 & Vates & $\begin{array}{l}\text { Limited } \\
\text { connections }\end{array}$ & $\begin{array}{l}\text { Isolated, dfficuit } \\
\text { cominestions }\end{array}$ \\
\hline
\end{tabular}

\begin{tabular}{|c|c|c|c|c|}
\hline Surrounding Land Use & $\begin{array}{l}\text { Access/ } \\
\text { Egress }\end{array}$ & $\begin{array}{l}\text { Parking } \\
\text { Facilities }\end{array}$ & Example Stations & $\begin{array}{l}\text { Rapid Transit } \\
\text { Modes }\end{array}$ \\
\hline $\begin{array}{l}\text { Office, residential, institutional, } \\
\text { retail, entertainment, and civic } \\
\text { uses }\end{array}$ & Both & $\begin{array}{l}\text { No off-street } \\
\text { parking }\end{array}$ & $\begin{array}{l}\text { 16th Street/Mission (BART) } \\
\text { Lloyd Center (Trimet) } \\
\text { East Liberty (Port Authority) }\end{array}$ & $\begin{array}{l}\begin{array}{l}\text { Heavy Rail } \\
\text { Light Rail } \\
\text { BRT }\end{array} \\
\end{array}$ \\
\hline $\begin{array}{l}\text { Residential, neighborhood retail, } \\
\text { limited office }\end{array}$ & Access & $\begin{array}{l}\text { No/limited off- } \\
\text { street parking }\end{array}$ & Kingsbridge Road (NYCT) & Heavy Rail \\
\hline Residential, neighborhood retails & Access & $\begin{array}{l}\text { No/limited off- } \\
\text { street parking }\end{array}$ & $\begin{array}{l}\text { Western - Pink Line (CTA) } \\
\text { West Baltimore (MARC) } \\
\text { Othello Station (Sound Transit) } \\
\text { Euclid Ave/71st St (Cleveland RTA) } \\
\text { Hoboken - 14th Street (NY Waterway) }\end{array}$ & $\begin{array}{l}\text { Heavy Rail } \\
\text { Commuter Rail } \\
\text { Light Rail } \\
\text { BRT } \\
\text { Ferry }\end{array}$ \\
\hline Residential, neighborhood retail & Access & $\begin{array}{l}\text { Otf-street } \\
\text { parking } \\
\text { available }\end{array}$ & Anacostia (WMATA) & Heavy Rail \\
\hline $\begin{array}{l}\text { Residential, neighborhood retail, } \\
\text { limited office }\end{array}$ & Access & $\begin{array}{l}\text { Some off-street } \\
\text { parking }\end{array}$ & Greenwich Station (Metro North) & Commuter Rail \\
\hline Residential, neighborhood retail & Both & $\begin{array}{l}\text { Some off-street } \\
\text { parking }\end{array}$ & $\begin{array}{l}\text { Bethesda (WMATA) } \\
\text { Davis Street (Metra) } \\
\text { Orenco Station (Trímet) } \\
\text { Tunney's Pasture (OC Transpo) }\end{array}$ & $\begin{array}{l}\text { Heavy Rail } \\
\text { Commuter Rail } \\
\text { Light Rail } \\
\text { BRT }\end{array}$ \\
\hline $\begin{array}{l}\text { Residential, neighborhood retail, } \\
\text { commercial }\end{array}$ & Access & $\begin{array}{l}\text { Some oft-street } \\
\text { parking } \\
\text { available }\end{array}$ & $\begin{array}{l}\text { Downtown Littleton (RTD) } \\
\text { Van Nuys (LA Metro) }\end{array}$ & $\begin{array}{l}\text { Light Rail } \\
\text { BRT }\end{array}$ \\
\hline Residential, retail, limited office & Access & $\begin{array}{l}\text { Some off-street } \\
\text { parking } \\
\text { available }\end{array}$ & $\begin{array}{l}\text { South Bank (PAT) } \\
\text { Pleasant Park (OC Transpo) } \\
\text { Route 915. Columbia (MTA) } \\
\text { Quincy (MBTA) }\end{array}$ & $\begin{array}{l}\text { Light Rail } \\
\text { BRT } \\
\text { Commuter Bus } \\
\text { Ferry }\end{array}$ \\
\hline Varies & Both & $\begin{array}{l}\text { Park-and-ride } \\
\text { prioritized }\end{array}$ & Owings Mills (MTA) & Heavy Rail \\
\hline $\begin{array}{l}\text { Office, retail and limited } \\
\text { residential }\end{array}$ & Egress & $\begin{array}{l}\text { Park-and-ride } \\
\text { prioritized }\end{array}$ & $\begin{array}{l}\text { McCormick Road (MTA) } \\
\text { Maple Island (Lane Transit) }\end{array}$ & $\begin{array}{l}\text { Light Rail } \\
\text { BRT }\end{array}$ \\
\hline Retail, limited office & Egress & $\begin{array}{l}\text { Park-and-ride } \\
\text { prioritized }\end{array}$ & $\begin{array}{l}\text { Great Mall Transit Center (VTA) } \\
\text { Warner Center (LA Metro) }\end{array}$ & $\begin{array}{l}\text { Light Rail } \\
\text { BRT }\end{array}$ \\
\hline Varies & Both & $\begin{array}{l}\text { Park-and-ride } \\
\text { often prioritized }\end{array}$ & $\begin{array}{l}\text { Forest Hills (MBTA) } \\
\text { Mukilteo (Sound Transit) } \\
\text { Bellevue Transit Center (Sound Transit) } \\
\text { Hoboken Transit Terminal (NY Waterway) }\end{array}$ & $\begin{array}{l}\text { Heavy Rail } \\
\text { Commuter Rail } \\
\text { Commuter Bus } \\
\text { Ferry }\end{array}$ \\
\hline Varies & Both & $\begin{array}{l}\text { Park-and-ride } \\
\text { prioritized }\end{array}$ & $\begin{array}{l}\text { Golden Glades (TriRail) } \\
\text { 1-485/South Blvd (CATS) } \\
\text { Eagleson (OC Transpo) } \\
\text { Sammamish Park \& Ride (Sound Transit) }\end{array}$ & $\begin{array}{l}\text { Commuter Rail } \\
\text { Light Rail } \\
\text { BRT } \\
\text { Commuter Bus }\end{array}$ \\
\hline Varies & Access & $\begin{array}{l}\text { Park-and-ride } \\
\text { prionitized }\end{array}$ & El Monte Bus Station (LA Metro) & Commuter Bus \\
\hline $\begin{array}{l}\text { Entertainment, airport, and/or } \\
\text { civic uses }\end{array}$ & Egress & $\begin{array}{l}\text { Limited off- } \\
\text { street parking } \\
\text { available }\end{array}$ & $\begin{array}{l}\text { Hartsfield Airport (MARTA) } \\
\text { Hamburg Street (MTA) } \\
\text { Airport Station (MBTA) }\end{array}$ & $\begin{array}{l}\text { Heavy Rail } \\
\text { Light Rail } \\
\text { BRT }\end{array}$ \\
\hline Varies & Egress & $\begin{array}{l}\text { Some oft-street } \\
\text { parking }\end{array}$ & Great America (ACE) & Commuter Rail \\
\hline Residential, retail, limited office & Both & $\begin{array}{l}\text { Park-and-ride } \\
\text { prioritized }\end{array}$ & $\begin{array}{l}\text { Elgin (Metra) } \\
\text { Port Townsend (WSDOT Ferry) }\end{array}$ & $\begin{array}{l}\text { Commuter Rail } \\
\text { Ferry }\end{array}$ \\
\hline Varies & Access & $\begin{array}{l}\text { Some oft-street } \\
\text { parking }\end{array}$ & St. Denis (MARC) & Commuter Rail \\
\hline
\end{tabular}


In an analysis of more than 450 rail stations across eight systems, the authors also provide the 'weekday daily average percentage of station users (for all trips) arriving by a particular mode' (page 35, figure on page 38) to demonstrate the relationship between mode share and urban context in the form of their proposed area types.

Exhibit 4-4. Average station access mode share by station type.

\begin{tabular}{|c|c|c|c|c|c|}
\hline \multirow[b]{2}{*}{ Station Type } & \multicolumn{5}{|c|}{ Average Access Mode Percentage } \\
\hline & $\begin{array}{l}\text { Walk } \\
(\%)\end{array}$ & $\begin{array}{c}\text { Bicycie } \\
(\%)\end{array}$ & $\begin{array}{l}\text { Feeder } \\
\text { Bus } \\
(\%)\end{array}$ & $\begin{array}{l}\text { Auto } \\
\text { (Drop- } \\
\text { off) (\%) }\end{array}$ & $\begin{array}{c}\text { Auto } \\
\text { (Park- } \\
\text { and-Rlde) } \\
(\%)\end{array}$ \\
\hline Untban Cornmercial & 82 & 1 & 10 & 2 & 5 \\
\hline $\begin{array}{l}\text { High-Density utran } \\
\text { Neighborhood }\end{array}$ & 72 & 2 & 14 & 4 & 10 \\
\hline $\begin{array}{l}\text { Medium-Density } \\
\text { Urban Neighbornood }\end{array}$ & 80 & 1 & 9 & 4 & 7 \\
\hline $\begin{array}{l}\text { Untan Neightornood } \\
\text { With Farking }\end{array}$ & 35 & 3 & 21 & 10 & 31 \\
\hline $\begin{array}{l}\text { Historic Transit } \\
\text { Village }\end{array}$ & 25 & 1 & 3 & 17 & 53 \\
\hline Suburtan TOD & 32 & 2 & 13 & 14 & 39 \\
\hline $\begin{array}{l}\text { Suburban Village } \\
\text { Center }\end{array}$ & 30 & 2 & 16 & 12 & 40 \\
\hline $\begin{array}{l}\text { Suburban } \\
\text { Neighborthoad }\end{array}$ & 29 & 1 & 11 & 13 & 46 \\
\hline Subuthan Freeway & 10 & 1 & 12 & 12 & 65 \\
\hline $\begin{array}{l}\text { Suburban } \\
\text { Employment Center }\end{array}$ & 29 & 3 & 25 & 9 & 36 \\
\hline $\begin{array}{l}\text { Suburban Fetail } \\
\text { Center }\end{array}$ & 30 & 2 & 19 & 11 & 39 \\
\hline $\begin{array}{l}\text { Intermodal Transit } \\
\text { Center }\end{array}$ & 27 & 1 & 36 & 6 & 30 \\
\hline $\begin{array}{l}\text { Special } \\
\text { Event/Campus }\end{array}$ & 55 & 2 & 24 & 6 & 13 \\
\hline Sate!lite City & 7 & 6 & 12. & 16 & 59 \\
\hline
\end{tabular}


TCRP Report 167: Making Effective FGT Investments (2014)

Reference: (Chatman et al., 2014, p.)

Transit System: 55 projects primarily heavy rail and light rail with some commuter rail and bus rapid transit.

Purpose of Typology:

Types of Use: NA

Findings \& Outcomes:

Other Notes:

Page 2-14 "Suggesting that a one-size-fits-all approach does not match the diversity of local goals and project types, some participants said that projects with different goals and characteristics should be categorized and evaluated under different criteria. One participant suggested that the evaluation process should "put a project into one of a number of categories" (a typology of projects)."

Page 2-24 "The research team deliberately did not establish a typology of indicators according to fixed-guideway transit type (e.g., initial versus expansion project), transit mode (e.g., LRT, HRT, CR, BRT) or by urban setting (e.g., based on surrounding densities or whether location is a CBD, central city, inner suburb, or outer suburb). The approach was instead to run analyses that included appropriate measures to render variables representing type and mode statistically insignificant, given that such measures are imprecise. Other indicators were sufficient to predict ridership according to the statistical tests used, enabling the method to avoid relying on somewhat arbitrary definitions of HRT, LRT, and BRT—categories that have large overlaps in service quality and capital cost."

Method and Outcomes:

Notes: This study considers 55 TOD projects and estimates two measures of 'success' in terms of ridership and use as a function of the built and transportation environment based on factors known for impacting the use of TOD (e.g., densities, congestion, parking).

The measurements of 'success' were based on ridership, not secondary impacts. The metrics include the average weekday ridership measured at a project-level and the change in annual passenger miles traveled (PMT) measured at a metro-area level.

The relevant predictors for ridership were jobs, population, CBD parking rate, percent at-grade, and an interaction between jobs, population, and parking.

The relevant predictors for PMT were high-earning jobs, leisure jobs, congestion score, population, and jobs, and the interaction between jobs, population, and congestion.

All indicators were measured within a $1 / 2$ mile of the station.

This study relies on the 'indicator' method, which associates measures of success (like ridership) with elements that are more readily controlled for in the planned environment (like zoned or actual density). In other words, ridership is taken as a function of the built and transportation environment to provide a means for estimating demand. Other options may include identifying minimum/maximum thresholds for the environmental variables (like densities, floor space requirements, households, parking ratios) for specific transit modes (and or area types) to provide a simple means for ensuring a high-likelihood of success based on previous studies and analysis. The following Table 4 (from page 1-14) describes the criterion indicators that correlate with specific measures of success. Table 5 (below, from page 1-16) describes the main indicators of ridership. 
Table 5: Most Significant Indicators of Project Ridership and System-Wide PMT

\section{Indicators of Project Ridership}

- Employment within one-half-mile of project stations

- Population within one-half-mile of project stations

- Combination of employment and population within one-halfmile of stations and daily parking rate in the CBD

- Percent of the project alignment at grade

\section{Indicators of Change in PMT on System}

- Metropolitan area population

- Employment density within one-half-mile of fixed-guideway stations in the metropolitan area

- Population density within one-half-mile of fixed-guideway stations in the metropolitan area

- Higher wage jobs within one-half-mile of fixed-guideway stations in the metropolitan area

- Average congestion in the metropolitan area (daily vehiclemiles traveled (VMT) per freeway lane-mile)

- Retail, entertainment, and food jobs within one-half-mile of fixed-guideway stations in the metropolitan area

- Interaction of jobs and population within one-half-mile of fixed-guideway stations in the metropolitan area 
Table 4: Success Indicators from TCRP Project H-42 Case Studies

\begin{tabular}{|c|c|c|c|c|c|c|c|}
\hline Criterion (Rule of Thumb) & Measure of Project Success & $\frac{\stackrel{y}{ \pm}}{\frac{0}{2}}$ & $\frac{n}{\overline{0}}$ & 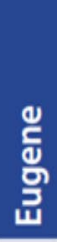 & 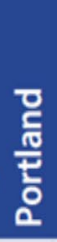 & 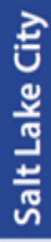 & $\underset{0}{\stackrel{0}{0}}$ \\
\hline Provide fixed-guideway transit where bus ridership is already high & Ridership / Consolidated bus operations & & - & - & - & $\bullet$ & 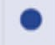 \\
\hline Select high-visibility corridors where patrons will feel safe & Ridership & & & & ○ & & \\
\hline Connect CBD with suburban park-and-rides near a congested belt loop & $\begin{array}{l}\text { Ridership / Sustainability / Congestion relief / } \\
\text { Consolidated bus operations }\end{array}$ & ○ & - & & & & D \\
\hline Minimize stations to maximize speed & Ridership / Sustainability / Congestion relief & - & & - & & & \\
\hline Minimize grade crossings and in-street operations to maximize speed & Ridership / Sustainability / Congestion relief & ○ & - & - & $\bullet$ & & - \\
\hline $\begin{array}{l}\text { Provide fixed-guideway transit in corridors where parallel highway infra- } \\
\text { structure is heavily congested }\end{array}$ & Ridership / Sustainability / Congestion relief & $\bullet$ & - & & • & & \\
\hline Connect multiple employment centers & Ridership / Sustainability / Congestion relief & & - & ○ & & $\bullet$ & • \\
\hline Connect major regional destinations & Ridership / Economic development & & & - & - & - & \\
\hline Place alignment in close proximity to commercial property & Ridership / Economic development & & & & - & $\bullet$ & \\
\hline $\begin{array}{l}\text { Place stations in busy locations where "eyes on the street" provide sense of } \\
\text { safety }\end{array}$ & Ridership & & & & $\bullet$ & & \\
\hline $\begin{array}{l}\text { Provide service that has average travel speeds greater than existing bus } \\
\text { routes }\end{array}$ & Ridership / Consolidated bus operations & ○ & - & & & 0 & 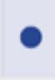 \\
\hline $\begin{array}{l}\text { Provide transit in high-demand travel corridors where alternative capacity } \\
\text { is prohibitively expensive }\end{array}$ & Economic development & • & • & & • & 0 & \\
\hline Maximize the number of stations & Economic development / Real estate values & $\bullet$ & & ○ & ○ & & - \\
\hline $\begin{array}{l}\text { Place alignment along corridors with ample development potential to fa- } \\
\text { cilitate urban growth as described by local land use plans or regional plans }\end{array}$ & Real estate values & $\bullet$ & & • & - & $\bullet$ & \\
\hline $\begin{array}{l}\text { Provide fixed-guideway transit in corridors where inexpensive right-of-way } \\
\text { can be easily accessed }\end{array}$ & Construction completion / Minimized impacts & ○ & - & • & • & $\bullet$ & D \\
\hline $\begin{array}{l}\text { Maximize distance between alignment and single family neighborhoods; } \\
\text { Minimize taking of residential property }\end{array}$ & Minimized impacts / Public support & • & & • & • & & \\
\hline $\begin{array}{l}\text { Identify corridors that can help garner local political support for further } \\
\text { transit system investment }\end{array}$ & Public support & • & & - & & & P \\
\hline Select corridors that garner congressional support & Public support & - & & & $\bullet$ & & 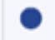 \\
\hline Locate stations in low income areas or in communities of color & Dependent riders / Economic development & & & - & $\bullet$ & & $\bullet$ \\
\hline Provide substantial bus layover facilities at stations & Consolidated bus operations & & 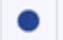 & & & - & • \\
\hline
\end{tabular}


FTA Report no. 0057: Local Planning and Transit-Supportive Development (2014) Reference: (Santasieri, 2014)

Transit System: commuter, light rail, streetcar, heavy rail, bus

Purpose of Typology:

Types of Use: Design or Land Use; Conceptual Planning; Strategy Identification \& Implementation;

Findings \& Outcomes:

This study develops a typology that considers the concurrency of planning and zoned land use as part of the TOD type. This means that this type of typology would not likely be integrated into the kind of analysis we are conducting. However, the success of any one TOD is likely to be driven by the planned efforts in achieving transit-friendly and -supportive environments. At a system level, this type of classification might be an interesting way to assess economic impacts. However, the typology must at least partially be developed with the discussion of local developers and planners to identify the level of 'planned' environment (versus coincidental). The separation within each typology of urban/suburban designation is a recognition of the variation of inputs and outcomes of TOD across a region. There is no clear designation/definition of how 'urban/suburban' were classified.

Although the use of the typology was not to drive the identification of future strategies, instead the use of the typology as a means for qualitatively considering the mechanisms for which the case studies were developed. In other words, patterns and themes in successes/failures across the case studies were organized based on the typologies.

Other Notes:

TOD (page 5-3): "a pedestrian-friendly community that extends for $1 / 4$ to $1 / 2$ mile from a public transit station and includes mixed uses, higher densities, and compact design."

Method and Outcomes:

Notes:

The authors studied a sample (initially 60 and then 25) which met the criteria "contained within a connected, comfortable walking distance of transit, generally $1 / 4$ to $1 / 2$ mile" and "includes a mix of at least three different land uses, including retail, housing, office, entertainment, transit facilities, and/or transit-facility parking". For the filtered 25 sites, addition information was collected for classification and case-study analysis purposes, including the location, transit orientation, land use, density and massing, site and building design, and funding and process.

The authors analyzed the data based on quantitative (mean/median calculations) and qualitative observations, which include interviews (developers and planners) and discussion. In addition to the following typologies, sites were separated by the (community context defined) urban and suburban nature of the location as well as the 'transit-supportive' nature of the development, which includes type and extent of linking the access of rail from development. 


\begin{tabular}{|c|c|}
\hline Typology & Description \\
\hline Transit-ready development & $\begin{array}{l}\text { "... a mixed-use development that is planned and } \\
\text { implemented in concert with, and in anticipation of, future } \\
\text { rail stations and implemented before the station is } \\
\text { constructed ... occur[ing] in conjunction with adopted } \\
\text { corridor plans. They have the advantage of being built } \\
\text { early into the planning process, which means that zoning } \\
\text { and design guidelines or codes can be developed in } \\
\text { advance to accommodate the type of project envisioned." } \\
\text { (page 5-3) }\end{array}$ \\
\hline Transit-integral development & $\begin{array}{l}\text { "...a mixed-use or single-use development that is } \\
\text { implemented in concert with station and corridor } \\
\text { implementation... [with] significant connectivity with the } \\
\text { proposed stations and have no access barriers to } \\
\text { surrounding land uses. They have the advantage of early } \\
\text { planning and are encouraged by zoning, code, and } \\
\text { design controls that support their development." (page 5- } \\
\text { 4) }\end{array}$ \\
\hline Transit-adjacent development & $\begin{array}{l}\text { "... a single-use or mixed-use development that has or is } \\
\text { being implemented adjacent to rail stations and corridors } \\
\text { where significant barriers (e.g., surface highways, arterial } \\
\text { or freight rail corridors, park-and-rides, industrial or big } \\
\text { block retail) separate stations from less intense land use } \\
\text {...[and are] indicative of a lack of coordinated planning } \\
\text { and/or coordinated agency decision making. While such } \\
\text { developments can be made more user-friendly, the } \\
\text { linkages and infrastructure costs are more expensive later } \\
\text { in the development process." (page 5-6) }\end{array}$ \\
\hline $\begin{array}{l}\text { Transit-coincidental } \\
\text { development }\end{array}$ & $\begin{array}{l}\text { "... a mixed-use or single-use development that builds on } \\
\text { the success of previous developments surrounding } \\
\text { stations and corridors ... [which] benefits from the place- } \\
\text { making features that exist in typically successful urban } \\
\text { areas, where zone and code adjustments and financial } \\
\text { investments have already been made." (page 5-6) }\end{array}$ \\
\hline
\end{tabular}


Other Studies about TOD (with typologies)

LSU/UNO UTC: Examination of America's TOD 2000 \& 2010 (2013)

Reference: (J. L. Renne \& Ewing, 2013)

Transit System: appears to be entirely rail, including heavy and light systems

Purpose of Typology:

Types of Use: Conceptual Planning; Prioritization; Evaluation;

Findings \& Outcomes:

TAD-TOD Typology: This study aggregates 1,325 TODS in 2000 and 1,640 TODs in 2010 (about a third of all stations) to categorize sites into adjacent/oriented/hybrid typology using the density, land use diversity, and walkable design. The difference between TADs and TODs in terms of built environment is explored. The typology was then correlated with commute mode share, vehicle ownership, transportation + housing costs, and housing tenure.

Other Notes:

Peter Calthrope in Next American Metropolis (1993) on page 56: "a mixed-use community within an average 2,000-foot walking distance of a transit stop and a core commercial area. TODs mix residential, retail, office, open space, and public uses in a walkable environment, making it convenient for residents and employees to travel by transit, bicycle, foot or car"

Belzer and Autler (2002) Transit Oriented Development: Moving from Rhetoric to Reality on page 3 indicate that definitions should focus on outcomes (not just physical environments), recognize the 'continuum of success', and adapt to different contexts.

Method and Outcomes:

Notes:

The typology for this study uses a point-based system (page 6). Where the points are allocated based on the following criteria:

"Greater than 30 jobs or residents per gross acre $=1$ point"

"Not having $100 \%$ of land uses as either residential or commercial $=1$ point"

"Average block size less than 6.5 acres = 1 point" (footnote: "This threshold was recommended by Reid Ewing based on his knowledge of many studies of which is the minimum average block size for being walkable")

Each station was then assigned according to the following rubric:

TAD $=0$ or 1 points

Hybrid $=2$ points

TOD $=3$ points.

The authors then conducted two types of analysis: Descriptive statistics of transportation, economic (e.g., housing income), and built environment variables across their typology and multivariate statistical analyses of community and built environment variables.

The authors also consider a 'conceptual framework' that estimates transit commute mode share by characteristics of the region (e.g., sprawl, regional jobs within railway stations) and neighborhood (densities, mix, etc.). 
TCRP Report 128: Effects of TOD (2008)

Reference: (Arrington \& Cervero, 2008)

Transit System: light rail

Purpose of Typology:

Types of Use: Design or Land Use; Evaluation;

Findings \& Outcomes:

This study focuses on the travel behavior of employees, employers, and residents of TOD areas. The outcome of this analysis is related to trip and parking generation, factors that play a part in transportation impact analyses. The unit of analysis was behavior measured at a (housing) site level (not a station level). No clear outcomes from this study relate directly to the work proposed in this project.

Other Notes:

Method and Outcomes:

Notes:

This analysis does not consider the TOD type within the analysis of travel behavior outcomes. They are mentioned however throughout the literature review in reference to prior works. The key emphasis here is that the mode share is partly related to the regional location, and typologies tend to capture the hierarchy of locations across a region (basically a proxy for distance to the CBD and/or accessibilities/densities). In the final analyses, densities (such as retail densities) and parking are inputs into the estimates of vehicle trip and parking generation models, suggesting these indicators are the strongest predictors of automobile/non-automobile travel at housing locations with close proximity to light-rail transit. 
NITC: Trip and Parking Generation at TOD (2017)

Reference: (Ewing et al., 2017)

Transit System: light rail

Purpose of Typology:

Types of Use: Study site selection threshold criteria

Findings \& Outcomes:

Seven criteria:

Align with ITE's definition

Dense (mid-rise or higher multifamily housing)

Mixed use (residential, retail, entertainment, and sometimes office uses within one

development)

Pedestrian friendly (streets built for peds as well as cars/transit)

Additional:

Adjacent to transit (literally abutting related)

Built after transit was constructed/proposed (indicates parking supply decisions that took transit access into consideration)

Full developed (or near so)

Self-contained/dedicated parking

Other Notes:

ITE (2004, page 5-7) define TODs as "compact, mixed-use developments with high-quality walking environments near transit facilities" (quote Ewing et al).

Method and Outcomes:

Notes:

Sites were selected first through a professional and local survey administered over the phone with local professions dealing with TODs (often located in public agencies). Following, google street view and secondary (ACS, Census) data analysis were completed to narrow down to 10 study sites, ranging from 2 to 50 gross acres (development only, not including dedicated transit parking, etc.). Five TODs were then studied for the report.

Person trip generation counts (entering/existing developments); intercept surveys (peak periods only); and parking inventory and occupancy (off-street, development dedicated only, but for each 2 hour period) were collected. 
Cervero \& Guerra (2011) - Urban Densities and Transit: A Multi-Dimensional Perspective Reference: (Cervero \& Guerra, 2011)

Transit System: Mainly LRT and HR, but with some BRT.

Purpose of Typology:

Types of Use: Conceptual Planning; Evaluation;

Findings \& Outcomes:

LRT need 30 people per gross acre and HR needs 45 people per gross acre to remain in the top-quartile of cost-effective systems.

The authors are not relying on a typology as much as they are working to define minimum job/residential thresholds around LRT and HR. They also aim to establish guidelines about the catchment areas. All of this analysis is based on providing more cost-effective systems in terms of costs per passenger mile and per passenger.

Other Notes:

Methods and Outcomes:

Notes:

Additional analysis of photo simulation reactions of densities and design were considered, but were determined not to be directly relevant for this analysis.

Minimum density thresholds:

The authors collected information on 33 LRT investments and 23 heavy rail (and 4 BRT). This includes 768 stations and 740 'bidirectional route miles of fixed-guideway service' built for $\$ 68$ billion 2009-USD. The information included investment data, fare revenues, operating costs, passenger trips, and jobs/population in station catchment areas. [ full methods are cited as being presented in the Guerra \& Cervero JAPA article "Cost of a Ride". ]

Costs were annualized to calculate the cost per passenger mile and per passenger of each system. Costs against densities were considered to establish a review of Pushkarev and Zupan's 1977 and re-consider an updated 'recommended minimum threshold'.

When comparing with Pushkarev and Zupan's thresholds, only $26 \%$ of HR and $19 \%$ of LRT meet the recommended thresholds (HR: 12 households per acre for areas with CBD of $>50$ million non-residential square feet; LRT: 9 households per acre with access to a CBD with 2050-million non-residential square feet).

Defining 'cost-effectiveness' as costing less than $\$ 0.58$ per passenger mile (based on average estimated marginal costs, just above the top-quartile of investments), the authors the "minimum threshold population density that an average light-rail and heavy-rail city need in order to achieve a high cost-effectiveness rating at different capital costs per passenger mile".

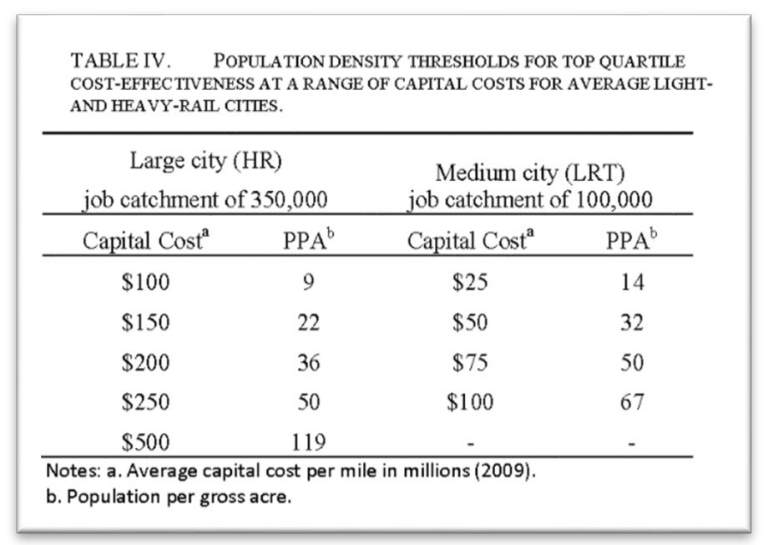

The authors also found that light-rail is more cost effective than heavy rail up to approximately 28 people and jobs per gross acre. This analysis included modeling 'the variation inn cost per passenger mile while adjusting capital costs, based on increasing densities.' By varying 
jobs/populations by $1 \%$, the authors derived the following relationship between costs and densities:

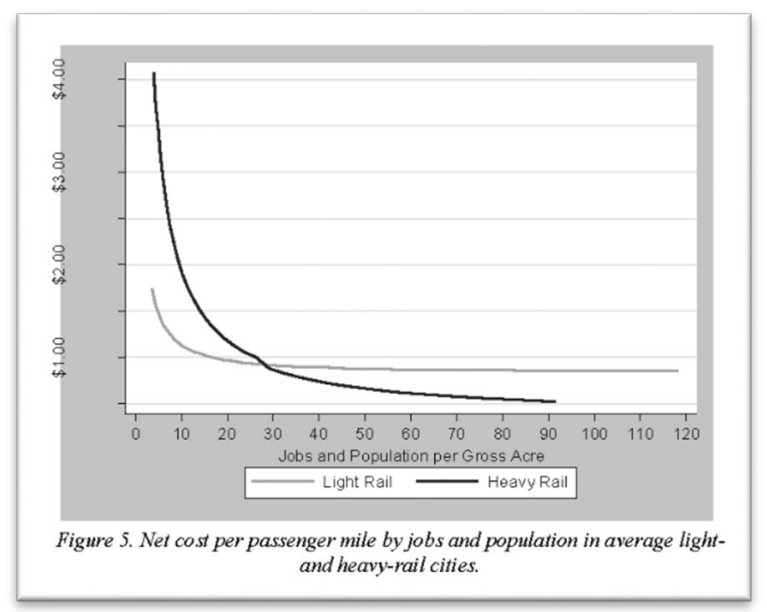

The authors also note that high-cost systems require more densities, needing approximately 45 and 30 people per gross acre to achieve their high 'cost-effectiveness' for HR and LRT, respectively.

Catchment areas:

Using data from $832 \mathrm{HR}, 589 \mathrm{LRT}$, and $36 \mathrm{BRT}$, the author estimates a direct demand model of stations and transit ridership as a function of population within different catchment areas. Each coefficient provides an estimate of the contribution of boardings/alightings based on population for that buffer area. The multivariate analysis parses out the impacts of population from a distance. Although not as robust as a full travel demand model, a direct demand approach can be useful for establishing guidance based on existing contexts at a station (not human) level. The authors found little variation in prediction power when using jobs/population densities for different catchment areas, suggesting catchment areas are irrelevant for ridership. Slight improvements in models using the 0.5 to 0.75 buffer population counts and the 0 to 0.25 buffer for job counts: 


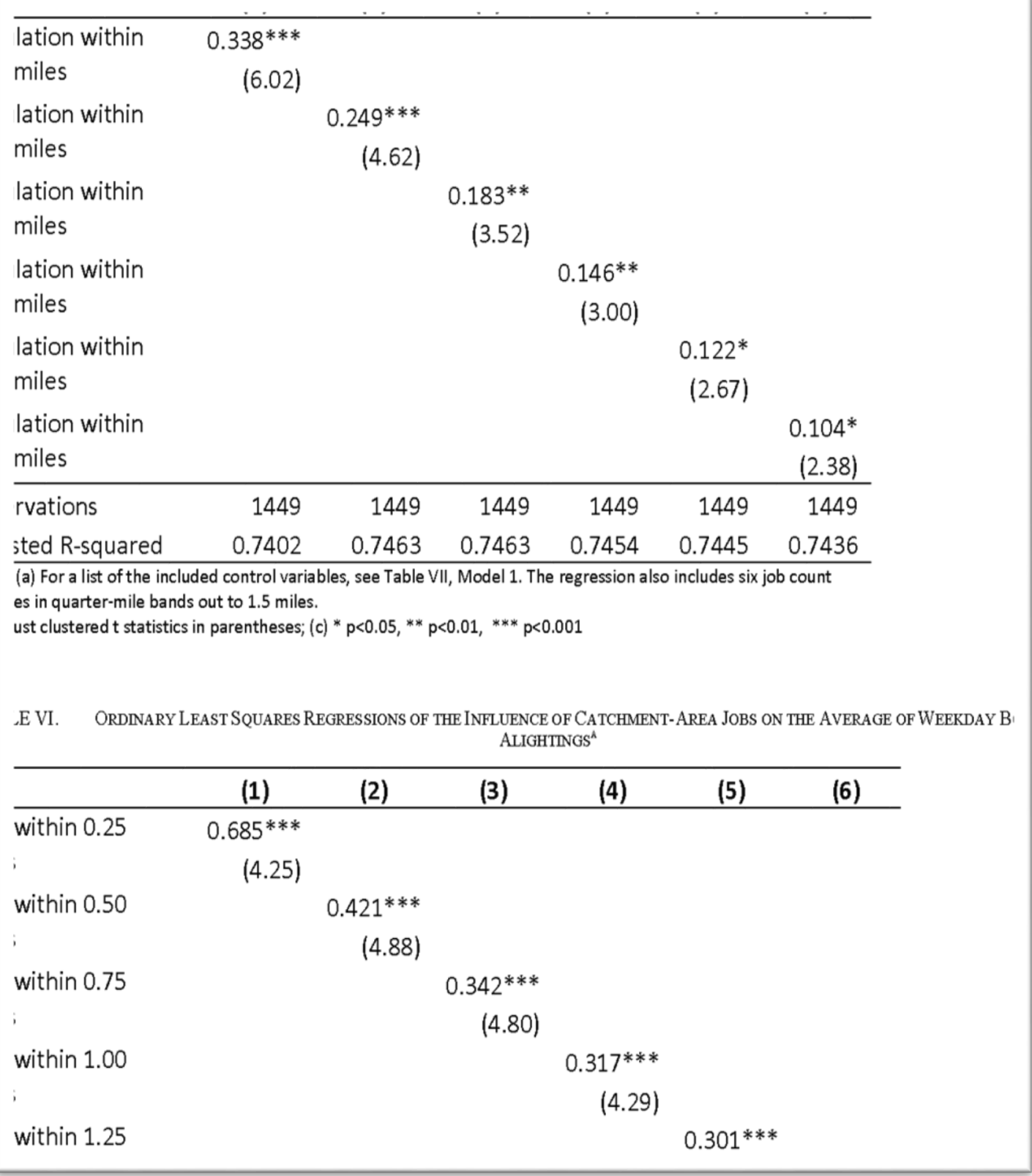

Lastly, the authors also found that population and jobs were significant in contributing to ridership, when controlling for other various contextual information. 
TABLE VII. LOG-LOG ORDINARY LEAST SQUARES DIRECT MODELS OF U.S. TRANSIT RIDERSHIP

\begin{tabular}{|c|c|c|c|c|c|}
\hline & (1) & (2) & (3) & (4) & (5) \\
\hline Population within 0.50 miles & $\begin{array}{c}0.0922^{*} \\
(2.27)\end{array}$ & $\begin{array}{c}0.140^{* *} \\
(2.99)\end{array}$ & $\begin{array}{c}0.137^{* *} \\
(3.15)\end{array}$ & $\begin{array}{c}0.147^{* *} \\
(3.00)\end{array}$ & $\begin{array}{c}0.345^{* * *} \\
(5.18)\end{array}$ \\
\hline Jobs within 0.25 miles & $\begin{array}{c}0.198 * * * \\
(3.88)\end{array}$ & $\begin{array}{c}0.257^{* * *} \\
(3.89)\end{array}$ & $\begin{array}{c}0.374^{* *} \\
(3.73)\end{array}$ & $\begin{array}{c}0.370^{* *} \\
(3.78)\end{array}$ & $\begin{array}{c}0.466 * * * \\
(4.61)\end{array}$ \\
\hline Park-and-ride spaces & $\begin{array}{c}0.0136^{* * * *} \\
(4.20)\end{array}$ & $\begin{array}{c}0.0137^{* * * *} \\
(4.06)\end{array}$ & $\begin{array}{c}0.0145^{* * *} \\
(3.09)\end{array}$ & $\cdot$ & - \\
\hline Regional Rail Connection Dummy & $\begin{array}{c}0.296^{* *} \\
(3.37)\end{array}$ & $\begin{array}{l}0.292^{*} \\
(2.67)\end{array}$ & $\begin{array}{c}0.446^{* *} \\
(3.62)\end{array}$ & - & - \\
\hline Bus lines servings station area & $\begin{array}{c}0.0375^{* * *} \\
(7.79)\end{array}$ & $\begin{array}{c}0.0401^{* * *} \\
(5.68)\end{array}$ & $\begin{array}{c}0.0479 * * * \\
(8.60)\end{array}$ & $\cdot$ & $\cdot$ \\
\hline Terminal station dummy & $\begin{array}{c}0.340^{* *} \\
(3.59)\end{array}$ & $\begin{array}{c}0.359^{* * *} \\
(3.96)\end{array}$ & $\begin{array}{c}0.322^{* * *} \\
(4.26)\end{array}$ & $\cdot$ & - \\
\hline Airport station dummy & $\begin{array}{c}0.755^{* * *} \\
(3.98)\end{array}$ & $\begin{array}{c}0.788^{* * *} \\
(3.90)\end{array}$ & $\begin{array}{c}0.753^{* *} \\
(3.31)\end{array}$ & $\cdot$ & $\cdot$ \\
\hline $\begin{array}{l}\text { Linear distance (yards) to central business } \\
\text { district }\end{array}$ & $\begin{array}{c}-0.0204^{*} \\
(-2.74)\end{array}$ & $\begin{array}{c}-0.0256^{*} \\
(-2.46)\end{array}$ & $\begin{array}{c}-0.0343^{*} \\
(-2.16)\end{array}$ & - & - \\
\hline Linear distance (yards) to nearest station & $\begin{array}{c}0.00971 \\
(0.40)\end{array}$ & $\begin{array}{c}0.0932^{*} \\
(2.47)\end{array}$ & $\begin{array}{l}0.0589 \\
(1.22)\end{array}$ & - & - \\
\hline Frequency (trains during AM peak hour) & $\begin{array}{c}0.875 * * * \\
(17.70)\end{array}$ & $\begin{array}{c}0.817^{* * * *} \\
(13.24)\end{array}$ & - & - & - \\
\hline Light rail dummy (1=LRT) & $\begin{array}{c}-1.098 * * * \\
(-9.69)\end{array}$ & - & - & - & - \\
\hline BRT dummy (1=BRT) & $\begin{array}{c}-1.876^{* * *} \\
(-13.13) \\
\end{array}$ & $\cdot$ & $\cdot$ & $\cdot$ & $\cdot$ \\
\hline \multicolumn{6}{|l|}{ City-level dummy variables } \\
\hline Baltimore & $-0.203^{*}$ & $-0.922^{* * * *}$ & $-1.197^{* * *}$ & $-1.383^{* * *}$ & $\cdot$ \\
\hline Boston & -0.0115 & $-0.629^{* * *}$ & $-0.367^{* * *}$ & $-0.730^{* * *}$ & $\cdot$ \\
\hline Buffalo & $0.388^{* *}$ & $-0.689^{* * *}$ & $-1.044^{* * *}$ & $-1.191^{* * *}$ & - \\
\hline Chicago & $-0.506^{* * *}$ & $-0.491^{* * *}$ & $-0.347^{* * *}$ & $-0.605^{* * *}$ & $\cdot$ \\
\hline Dallas & $0.279^{*}$ & $-0.814^{* * *}$ & $-0.908^{* * *}$ & $-0.961^{* * *}$ & - \\
\hline Denver & -0.0396 & $-1.113^{* * *}$ & $-1.211^{* * *}$ & $-1.271^{* * *}$ & $\cdot$ \\
\hline Los Angeles & $0.303^{* *}$ & $-0.785^{* * *}$ & $-0.695^{* * *}$ & $-0.776^{* * *}$ & - \\
\hline Miami & $-0.765^{* * *}$ & $-0.792^{* * *}$ & $-0.835^{* * *}$ & $-0.747^{* * *}$ & - \\
\hline Minneapolis & $0.432^{* *}$ & $-0.607^{* * *}$ & $-0.733^{* * *}$ & $-1.071^{* * *}$ & - \\
\hline New York & 0.0935 & -0.0107 & $0.289^{*}$ & -0.106 & - \\
\hline Newark/Jersey City & $-0.914^{* * *}$ & $-1.965^{* * *}$ & $-1.970 * * *$ & $-2.197^{* * *}$ & - \\
\hline Phoenix & -0.0278 & $-1.115^{* * *}$ & $-1.303^{* * *}$ & $-1.443^{* * *}$ & - \\
\hline Portland & $0.327^{*}$ & $-0.675 * * *$ & $-0.702^{* * *}$ & $-1.066^{* * *}$ & - \\
\hline Sacramento & $0.635^{* * *}$ & $-0.403^{* * *}$ & $-0.879^{* * *}$ & $-1.352^{* * *}$ & $=$ \\
\hline San Diego & $0.295^{*}$ & $-0.788^{* * *}$ & $-1.004^{* * *}$ & $-1.308^{* * *}$ & - \\
\hline San Francisco & 0.0560 & -0.0151 & $0.157^{*}$ & $0.330^{* * *}$ & $\cdot$ \\
\hline San Jose & $-0.681^{* * *}$ & $-1.751^{* * *}$ & $-2.188^{* * *}$ & $-2.440^{* * *}$ & - \\
\hline St. Louis & $0.557^{* *}$ & $-0.481^{* * *}$ & $-0.737^{* * *}$ & $-0.879^{* * *}$ & - \\
\hline Trenton & $-0.503^{* *}$ & $-1.546^{* * *}$ & $-1.977^{* * *}$ & $-2.156^{* * *}$ & - \\
\hline Washington D.C. & $0.459^{* * *}$ & $0.500^{* * *}$ & $1.026 * * *$ & $0.300^{* * *}$ & - \\
\hline Constant & $3.907^{* * *}$ & $2.750^{* *}$ & $4.606 * * *$ & $4.778^{* * *}$ & 1.812 \\
\hline Observations & 1449 & 1449 & 1449 & 1449 & 1449 \\
\hline Adjusted R-squared & 0.798 & 0.734 & 0.667 & 0.577 & 0.334 \\
\hline
\end{tabular}

Notes: (a)Robust clustered $t$ statistics in parentheses; (b) ${ }^{*} p<0.05,{ }^{* *} p<0.01,{ }^{* * *} p<0.001$ 
Lyu, Bertolini, and Pfeffer (2016) - TOD Typology for Beijing

Reference: (Lyu et al., 2016)

Transit System: Beijing 'metro' (I am assuming this is more like heavy rail, but I'm not sure.) Purpose of Typology:

Types of Use: Agency; Design or Land Use; Common Vocabulary; Strategy Identification \& Implementation; Conceptual Planning; Prioritization; Evaluation;

Findings \& Outcomes:

The authors based their analysis on the node-place theoretical framework. This specific paper extends the node-place framework (applied here as the transit-development relationship) to include 'orientation' which describes the catchment area. Although the authors do not provide enough descriptive information to identify the actual TOD characteristics/indicators, this approach and framing provides support for a T-O-D analysis, at the very least through the selection of important indicators for our 'place typology' based approach.

Other Notes:

The area types were developed in this paper, but no additional analysis was considered. The authors described the ways in which a typology can be useful. In this case, for cost-benefit analysis, cost-effectiveness analysis, and other evaluative approaches for grouping 'similar' stations for evaluation.

The authors reference Bertolini's 1999 node-place model (below, page 41), which aligns transport-note and urban development-place characteristics of location and relationships. Page 41: "Bertolini distinguishes five ideal typical situations in the node-place model (Bertolini, 1999, 2005; see Fig. 1). Along the middle diagonal line are areas in 'Balance' where the node and the place values are equally strong, indicating that the development potential of both has been realized. At the upper right corner of the line are areas under 'Stress', which indicates that the potential for land use development is highest (strong node) and that it has been realized (strong place). The same can be said about the potential for transport development. However, competition for scarce space between node and place functions also produces tensions. At the bottom of the middle line are areas characterized by 'Dependency'. There is no tension here, but demand for both land use and transport development is insufficient to generate an autonomous development dynamics. Areas where transportation facilities are more developed than urban activities are labeled 'Unsustained Nodes' (upper left area of Fig. 1). Conversely, in 'Unsustained Places', at the bottom right of Fig. 1, urban activities are much more developed than transportation facilities. The latter two are the situations where the most development dynamics is to be expected, either positive (upgrading) or negative downgrading)."

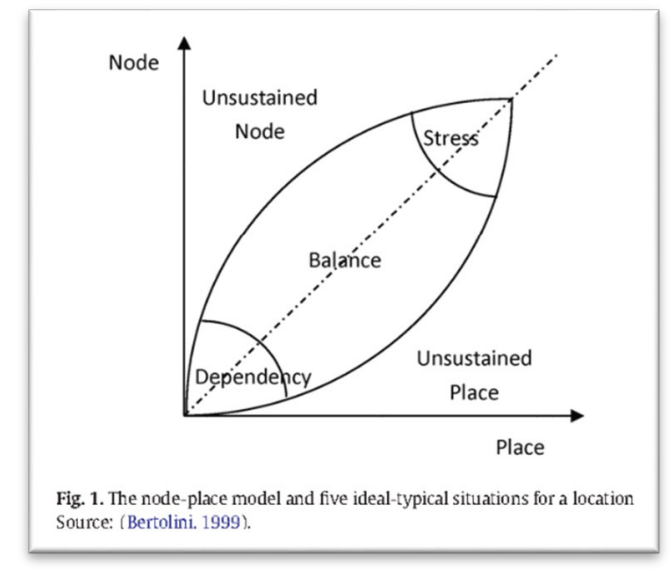

By further elaborating the relationship between the pedestrian catchment area of the surrounding location, analysts can establish a difference between 'adjacent' and 'oriented' 
development. This further establishes the relationships between place and node, but brings in a third dimension or 'functional proximity' of entities to node.

Methods and Outcomes:

Notes:

The authors: (1) identified transit, oriented, and development indicators'; (2) selected indicators; (3) measured indicators for the study area; and (4) applied procedures to identify a typology, including:

Standardized metrics; principal component analysis; hierarchical cluster analysis; duda test (to 'define optimal number of clusters').

Identified 94 indicators (24 on transit dimension, 53 on development, and 17 on oriented).

Two filters were used to reduce the number of metrics: local experts from Beijing and a ranking of indicators based on their presence in the literature. The following five rules were used (quote from page 42):

"(1) For each of the three TOD dimensions, indicators elected in the top five by both local experts and international studies should be selected first.

(2) The remaining indicators in the top five of both rankings should be selected according to their ranked place.

(3) When indicators describe similar characteristics of a location, the lower scoring ones should be removed from the final selection (see details below).

(4) Indicators should be measurable with publicly accessible data (allowing for transparency and applicability in other contexts).

(5) Each TOD dimension should have the same number of indicators."

Selected the following indicators:

Transit: T1 - number of directions service by metro; T5 - daily frequency of metro services; T12

- number of stations within 20 min. of travel by metro; T2 - number of directions served by bus;

T15 - travel times to major employment and activity centers by metro; T19 - car parking capacity.

T8 - number of passengers per day by metro - was determined to be important, but unavailable due to lack of data.

Development: D1 - number of residents; D29 - degree of functional mix; D7 - number of jobs; D9 - number of workers in retail/hotel and catering; D10 - number of workers in education/health/culture; D11 - number of workers in public administration and services. D30 - land-use mix - was determined to be important, but unavailable due to lack of data. Oriented: $\mathrm{O} 14$ - average block size; $\mathrm{O} 1$ - average distance from station to jobs; O9 - length of paved foot-path per acre; $\mathrm{O} 12$ - intersection density; )2 - average distance from station to resident; $\mathrm{O} 17$ - walk scores.

Three dimensions were established (transit, development, oriented), and from that 6 types of metro stations were identified (page 45): 


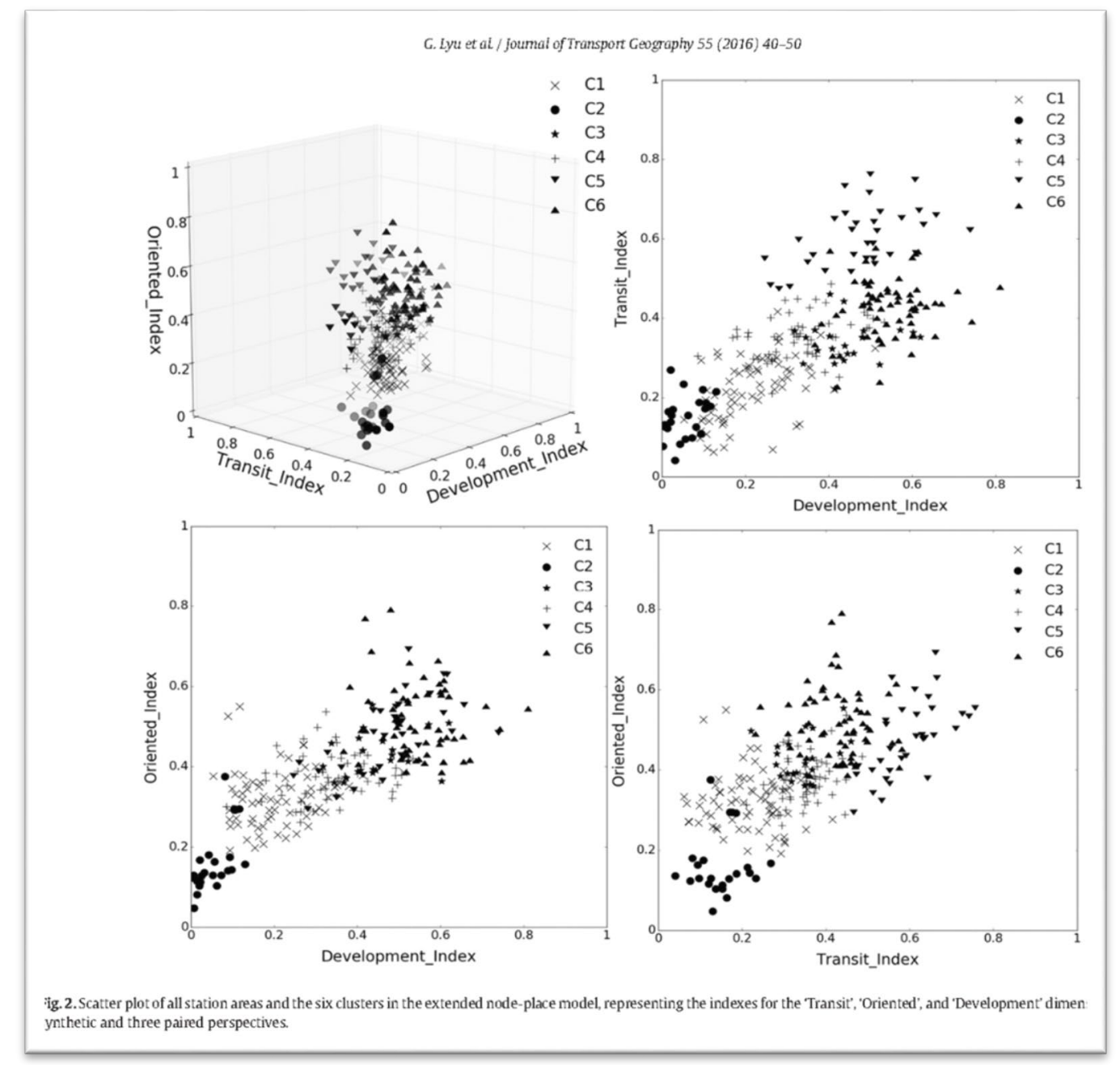

The following table (page 46) depicts the summary of rescaled TOD indicators. Unfortunately, the summary of each indicator used to scale the values was not provided. 
Table 3

Cluster description and summary means on rescaled TOD indicators ${ }^{\mathrm{a}}$ and the T, D, and O index ${ }^{b}$.

\begin{tabular}{|c|c|c|c|c|c|c|c|}
\hline Rescaled & $\begin{array}{l}\mathrm{C} 1 \\
(\mathrm{~N}=72)\end{array}$ & $\begin{array}{l}\mathrm{C} 2 \\
(\mathrm{~N}=23)\end{array}$ & $\begin{array}{l}\mathrm{C} 3 \\
(\mathrm{~N}=22)\end{array}$ & $\begin{array}{l}\mathrm{C} 4 \\
(\mathrm{~N}=55)\end{array}$ & $\begin{array}{l}\mathrm{C} 5 \\
(\mathrm{~N}=33)\end{array}$ & $\begin{array}{l}\mathrm{C6} \\
(\mathrm{N}=63)\end{array}$ & $\begin{array}{l}\text { All } \\
(\mathrm{N}=268)\end{array}$ \\
\hline $\mathrm{T} 1$ & 0.222 & 0.217 & 0.284 & 0.250 & 0.750 & 0.250 & 0.304 \\
\hline $\mathrm{T} 2$ & 0.136 & 0.055 & 0.348 & 0.191 & 0.258 & 0.277 & 0.206 \\
\hline T5 & 0.180 & 0.120 & 0.280 & 0.280 & 0.604 & 0.249 & 0.272 \\
\hline $\mathrm{T} 12$ & 0.137 & 0.067 & 0.202 & 0.314 & 0.591 & 0.444 & 0.301 \\
\hline $\mathrm{T} 15$ & 0.553 & 0.414 & 0.683 & 0.842 & 0.920 & 0.910 & 0.740 \\
\hline $\mathrm{T} 19$ & 0.078 & 0.024 & 0.258 & 0.240 & 0.462 & 0.463 & 0.259 \\
\hline D1 & 0.162 & 0.058 & 0.259 & 0.381 & 0.518 & 0.585 & 0.349 \\
\hline D7 & 0.189 & 0.048 & 0.531 & 0.266 & 0.482 & 0.557 & 0.343 \\
\hline D9 & 0.199 & 0.045 & 0.572 & 0.209 & 0.351 & 0.434 & 0.292 \\
\hline D10 & 0.101 & 0.015 & 0.342 & 0.225 & 0.408 & 0.520 & 0.275 \\
\hline D11 & 0.156 & 0.037 & 0.394 & 0.273 & 0.505 & 0.616 & 0.340 \\
\hline D29 & 0.459 & 0.131 & 0.564 & 0.650 & 0.588 & 0.560 & 0.518 \\
\hline 01 & 0.336 & 0.172 & 0.440 & 0.245 & 0.274 & 0.320 & 0.300 \\
\hline $\mathrm{O} 2$ & 0.586 & 0.246 & 0.610 & 0.498 & 0.521 & 0.540 & 0.522 \\
\hline O9 & 0.131 & 0.101 & 0.229 & 0.250 & 0.382 & 0.450 & 0.267 \\
\hline 012 & 0.093 & 0.056 & 0.152 & 0.170 & 0.311 & 0.381 & 0.205 \\
\hline O14 & 0.249 & 0.186 & 0.362 & 0.357 & 0.508 & 0.570 & 0.382 \\
\hline 017 & 0.530 & 0.208 & 0.769 & 0.729 & 0.833 & 0.861 & 0.678 \\
\hline T_Index & 0.217 & 0.150 & 0.343 & 0.353 & 0.598 & 0.432 & 0.347 \\
\hline D_Index & 0.211 & 0.056 & 0.444 & 0.334 & 0.475 & 0.545 & 0.353 \\
\hline O_Index & 0.321 & 0.162 & 0.427 & 0.375 & 0.472 & 0.520 & 0.392 \\
\hline
\end{tabular}

Attached below is the list of indicators identified in the literature (page 48-49): 


\begin{tabular}{|c|c|}
\hline TOD indicator & Literature source \\
\hline T1 Number of directions served by Metro & $\begin{array}{l}\text { Bertolini (1999), Reusser et al. (2008), Chorus and Bertolini (2011), Zemp et al (2011), } \\
\text { Song and Deguchi (2013), Vale (2015) }\end{array}$ \\
\hline T2 Number of directions served by bus & $\begin{array}{l}\text { Bertolini (1999), Reusser et al. (2008), Chorus and Bertolini (2011), Zemp et al (2011), } \\
\text { Song and Deguchi (2013), Vale (2015) }\end{array}$ \\
\hline T3 Number of metro stations in one TOD & Song and Deguchi (2013) \\
\hline T4 Number of bus stops in one TOD & Song and Deguchi (2013) \\
\hline T5 Daily frequency of Metro services & $\begin{array}{l}\text { Bertolini (1999). Dittmar and Ohland (2004), Reusser et al. (2008), Center for } \\
\text { Transit-Oriented Development (2011). Zemp et al. (2011), Song and Deguchi (2013), } \\
\text { Monajem and Nosratian (2015), Vale (2015) }\end{array}$ \\
\hline T6 Number of other public transport modes (Bus, Tram) departing on a working day & $\begin{array}{l}\text { Bertolini (1999), Reusser et al. (2008), Center for Transit-Oriented Development } \\
\text { (2011), Zemp et al. (2011), Ivan et al. (2012), Vale (2015) }\end{array}$ \\
\hline $\begin{array}{l}\text { T7 Public Transport Accessibility Level (It is calculated by schedule waiting time of bus } \\
\text { and metro, and access (walk) time to stops/stations) }\end{array}$ & Kamruzzaman et al. (2014) \\
\hline T8 Number of passengers per day by Metro & Reusser et al. (2008), Monajem and Nosratian (2015) \\
\hline T9 Ratio of metro passengers on weekends to ones on weekdays & Zemp et al. (2011) \\
\hline T10 Changing rate of Metro passengers in 10 years & Song and Deguchi (2013) \\
\hline T11 Number of stations within $45 \mathrm{~min}$ of travel by Metro & Bertolini (1999), Monajem and Nosratian (2015) \\
\hline T12 Number of stations within 20 min of travel by metro & Reusser et al. (2008), Zemp et al. (2011), Vale (2015) \\
\hline T13 Geographic distance to CBD & Reusser et al. (2008). Chorus and Bertolini (2011). Monajem and Nosratian (2015) \\
\hline T14 Travel time to CBD by Metro & Center for Transit-Oriented Development (2013) \\
\hline T15 Travel times to major employment and activity centres by Metro & Center for Transit-Oriented Development (2013) \\
\hline T16 Type of metro service (e.g. old, new, slow, rapid) & Reusser et al. (2008), Chorus and Bertolini (2011) \\
\hline $\mathrm{T} 17$ Whether station connects to airport directly (no transfer) & Atkinson-Palombo and Kuby (2011) \\
\hline T18 Whether station is a terminal & Atkinson-Palombo and Kuby (2011) \\
\hline T19 Car parking capacity & Bertolini (1999), Atkinson-Palombo and Kuby (2011), Ivan et al. (2012), Vale (2015) \\
\hline T20 Bicycle Parking capacity & Bertolini (1999), Atkinson-Palombo and Kuby (2011) \\
\hline T21 Distance to the closest motorway access by car & Bertolini (1999), Reusser et al. (2008), Vale (2015) \\
\hline T22 Number of free-standing bicycle paths (separated bicycle paths) & Bertolini (1999) \\
\hline T23 Total bike path length within $2 \mathrm{~km}$ around metro station & Reusser et al. (2008) \\
\hline T24 Number of staff in the station & Reusser et al. (2008) \\
\hline D1 Number of residents & $\begin{array}{l}\text { Bertolini (1999), Reusser et al. (2008), Shastry (2010), Atkinson-Palombo and Kuby } \\
\text { (2011), Chorus and Bertolini (2011), Center for Transit-Oriented Development (2011), } \\
\text { Zemp et al. (2011), Ivan et al. (2012), Center for Transit-Oriented Development } \\
\text { (2013), Song and Deguchi (2013), Kamruzzaman et al. (2014), Singh et al. (2014). } \\
\text { Monajem and Nosratian (2015), Vale (2015) }\end{array}$ \\
\hline D2 Percentage of working-age population & $\begin{array}{l}\text { Center for Transit-Oriented Development (2011), Center for Transit-Oriented Devel- } \\
\text { opment (2013) }\end{array}$ \\
\hline D3 Percentage of elderly population (above 65 ) & Song and Deguchi (2013) \\
\hline D4 Changing rate of residential population in 10 years & Song and Deguchi (2013) \\
\hline D5 Changing rate of working-age population in 10 years & Song and Deguchi (2013) \\
\hline D6 Changing rate of elderly population (above 65 ) in 10 years & Song and Deguchi (2013) \\
\hline D7 Number of jobs & $\begin{array}{l}\text { Shastry (2010), Atkinson-Palombo and Kuby (2011), Zemp et al. (2011), } \\
\text { Kamruzzaman et al. (2014), Pollack et al. (2014), Singh et al. (2014) }\end{array}$ \\
\hline D8 Number of jobs per resident & Shastry (2010) \\
\hline D9 Number of workers in retail/hotel and catering & $\begin{array}{l}\text { Bertolini (1999), Reusser et al. (2008), Chorus and Bertolini (2011), Ivan et al. (2012), } \\
\text { Singh et al. (2014), Monajem and Nosratian (2015), Vale (2015) }\end{array}$ \\
\hline D10 Number of workers in education/health/culture & $\begin{array}{l}\text { Bertolini (1999), Reusser et al. (2008), Chorus and Bertolini (2011), Ivan et al. (2012), } \\
\text { Monajem and Nosratian (2015), Vale (2015) }\end{array}$ \\
\hline D11 Number of workers in public administration and services & $\begin{array}{l}\text { Bertolini (1999), Reusser et al. (2008), Chorus and Bertolini (2011), Ivan et al. (2012), } \\
\text { Monajem and Nosratian (2015), Vale (2015) }\end{array}$ \\
\hline D12 Number of workers in industry & $\begin{array}{l}\text { Bertolini (1999), Reusser et al. (2008), Chorus and Bertolini (2011), Ivan et al. (2012), } \\
\text { Singh et al. (2014), Monajem and Nosratian (2015), Vale (2015) }\end{array}$ \\
\hline D13 Housing density (units/acre) & Dittmar and Ohland (2004). Pollack et al. (2014) \\
\hline D14 Number of flats & Ivan et al. (2012) \\
\hline D15 The percentage of public housing above 6 floor & Song and Deguchi (2013) \\
\hline D16 The percentage of private housing & Song and Deguchi (2013) \\
\hline D17 Total gross floor area of development & Cervero and Murakami (2009) \\
\hline $\begin{array}{l}\text { D18 Building floor area by use (residential, office, retail shopping hotel/service } \\
\text { apartments and other) }\end{array}$ & Cervero and Murakami (2009), Ivan et al. (2012) \\
\hline D19 Floor area ratio & Cervero and Murakami (2009), Song and Deguchi (2013) \\
\hline D20 Height of buildings & Cervero and Murakami (2009) \\
\hline D21 The number of neighbourhood retail and service establishments & Center for Transit-Oriented Development (2011) \\
\hline D22 The size of built-up area for housing and services & Ivan et al. (2012) \\
\hline D23 Areas with commercial urban amenities & Shastry (2010). Center for Transit-Oriented Development (2013) \\
\hline D24 Number of massive commercial facilities (above 1000 square meter in areas) & Song and Deguchi (2013) \\
\hline D25 Number of public facilities & Reusser et al. (2008), Song and Deguchi (2013) \\
\hline D26 Average real estate sales per square foot & $\begin{array}{l}\text { Center for Transit-Oriented Development (2011), Center for Transit-Oriented Development } \\
\text { (2013) }\end{array}$ \\
\hline D27 Land prices per square meter & Ivan et al. (2012) \\
\hline D28 Average residential rents & Center for Transit-Oriented Development (2013) \\
\hline $\begin{array}{l}\text { D29 Degree of functional mix (Calculated by numbers of workers from different } \\
\text { economic sections and residents) }\end{array}$ & $\begin{array}{l}\text { Bertolini (1999), Reusser et al. (2008), Chorus and Bertolini (2011), Monajem and } \\
\text { Nosratian (2015), Vale (2015) }\end{array}$ \\
\hline D30 Land-use Mix & Dittmar and Ohland (2004). Kamruzzaman et al. (2014), Singh et al. (2014) \\
\hline D31 The proportion of similar adjacent land use types & Shastry (2010) \\
\hline D32 Mixed-use attributes (Building floor area Mix) & Cervero and Murakami (2009) \\
\hline
\end{tabular}


Appendix A (continued)

\begin{tabular}{|c|c|}
\hline TOD indicator & Literature source \\
\hline D33 Housing types (e.g. multifamily, single family, loft, town-home) & Dittmar and Ohland (2004) \\
\hline D34 Statistical dispersion of different income groups & Shastry (2010) \\
\hline $\begin{array}{l}\text { D35 Geographic position of station area (e.g. urban downtown, urban neighbourhood, } \\
\text { suburban centre, suburban neighbourhood, commuter town centre) }\end{array}$ & Dittmar and Ohland (2004) \\
\hline $\begin{array}{l}\text { D36 Percentage of TOD-compatible land use (A parcel was defined as being } \\
\text { TOD-compatible if it is neither residential nor vacant and its property use code } \\
\text { would be allowed for future development in the overlay zoning ordinances) }\end{array}$ & Atkinson-Palombo and Kuby (2011) \\
\hline D37 Percentage of TOD-incompatible land use (see the definition above (D36)) & Atkinson-Palombo and Kuby (2011) \\
\hline D38 Percentage of vacant land use & Atkinson-Pal ombo and Kuby (2011), Center for Transit-Oriented Development (2013) \\
\hline D39 Areas of green or open space & Shastry (2010) \\
\hline D40 Changing rate of public facility in 15 years & Song and Deguchi (2013) \\
\hline D41 Changing rate of floor area ratio in 10 years & Song and Deguchi (2013) \\
\hline D42 Changing rate of office jobs in 10 years & Song and Deguchi (2013) \\
\hline D43 Qualitative rating of planning initiatives (e.g station area planning or zoning) & Center for Transit-Oriented Development (2013) \\
\hline D44 The Presence of a redevelopment authority & Center for Transit-Oriented Development (2013) \\
\hline D45 Qualitative rating of recent development activity & Center for Transit-Oriented Development (2013) \\
\hline D46 Qualitative rating of securing funding and financing for projects & Center for Transit-Oriented Development (2013) \\
\hline D47 Private investment in the area & Singh et al. (2014) \\
\hline D48 Percentage of people with bachelor's degree & Atkinson-Palombo and Kuby (2011) \\
\hline D49 Household income & Atkinson-Palombo and Kuby (2011) \\
\hline D50 Unemployment levels & Singh et al. (2014) \\
\hline D51 Rate of unemployed with basic education & Ivan et al. (2012) \\
\hline D52 Tax earnings of district & Singh et al. (2014) \\
\hline D53 Arriving tourists per 1000 residents of the district & Zemp et al. (2011) \\
\hline O1 Average distance from station to jobs & Zemp et al. (2011) \\
\hline 02 Average distance from station to residents & Zemp et al. (2011) \\
\hline $\mathrm{O} 3$ Percentage of housing units owner-occupied & Atkinson-Palombo and Kuby (2011), Pollack et al. (2014) \\
\hline O4 Percentage of households with access to one or more private vehicles & Center for Transit-Oriented Development (2013), Pollack et al. (2014) \\
\hline O5 Percentage workers who use non-automobile commuting & Pollack et al. (2014) \\
\hline 06 Percentage of households with low income & Pollack et al. (2014) \\
\hline 07 Percentage of income spent on transportation & Pollack et al. (2014) \\
\hline O8 Walking time to a Metro Station from the centre of each block & Shastry (2010) \\
\hline O9 Length of paved foot-path per acre & Shastry (2010), Pollack et al. (2014), Singh et al. (2014) \\
\hline O10 Length of sidewalks and low-stress bike ways & Center for Transit-Oriented Development (2011) \\
\hline 011 Number of cul-de-sac (dead end road) & Kamruzzaman et al. (2014) \\
\hline 012 Intersection density & Shastry (2010), Kamruzzaman et al. (2014), Singh et al. (2014) \\
\hline 013 Number of entry points into the neighbourhood & Shastry (2010) \\
\hline O1 4 Average block size & $\begin{array}{l}\text { Center for Transit-Oriented Development (2011), Center for Transit-Oriented } \\
\text { Development (2013) }\end{array}$ \\
\hline O15 Closeness index of urban street networks (space-syntax, network structure index) & Monajem and Nosratian (2015) \\
\hline O16 Betweenness index of urban street networks (space-syntax, network structure index) & Monajem and Nosratian (2015) \\
\hline $\begin{array}{l}017 \text { Walk Scores (It is calculated based on distance to various categories of amenities } \\
\text { (e.g., schools, stores, parks and libraries) that are weighted equally and summed) }\end{array}$ & Pollack et al. (2014) \\
\hline
\end{tabular}


Pojani et al (2016) - Critical Deconstruction of the Concept of TOD

Reference: (Pojani \& Stead, 2016)

Methods and Outcomes: This article is a white paper that focuses on three European case studies. Building from the culturized planning model which considers how culture shapes planning systems), this paper describes some context of the three case studies to reflect the relevancy of TOD development, even in areas where the term TOD doesn't come into play. There is no clear information in this paper that corresponds to the delineation of TOD types. For more information about the 'culturized planning model', see KNIELING, Joerg and Frank Othengrafen. 2015. "Planning Culture: A Concept to Explain the Evolution of Planning Policies and Processes in Europe?” European Planning Studies 23(11):2133-2147. 
Rayle (2015) - Connection b/t TOD and Displacement: Four Hypotheses

Reference: (Rayle, 2015)

Methods and Outcomes:

The authors provide only a broad category definition of TOD_-"typically a cluster of relatively dense buildings oriented toward a rail transit station, supported by pedestrian-friendly design" (page 534, referencing Bernick \& Cervero 1997 and Calthorpe 1993). They also note the modern definition is usually within the context of institutionalized practices. The author uses the "term transit-oriented development rather than the more general transit-adjacent development or transit-rich neighborhood (Pollack et al., 2010) so as to focus on the TOD package-that is, the set of policies and the development" (page 534). [ Pollack et al: Pollack, S., Bluestone, B., \& Billingham, C. (2010). Maintaining diversity in America's transit-rich neighborhoods: Tools for equitable neighborhood change. Retrieved from http://nuweb9.neu.edu/dukakiscenter/wpcontent/uploads/TRN Equity final.pdf ]

While the definition of gentrification remains debated, it generally contains the following aspects (quoted from page 532): "transformation in class and, often, racial composition of a neighborhood; an influx of investment to a neighborhood that has previously experienced disinvestment; a process of rehabilitating structures and the built environment; class- or racebased conflict over territory; displacement of original residents".

The authors note that TOD is an effective tool for urban redevelopment in part because it facilitates investment in fixed capital, making it less risky or uncertain for potential real estate investors. The infrastructure is also more concentrated, making it more likely that accessibility will be increased (thus increasing land value). FGT, specifically LRT, has been defined as serving more high-income and white riders, with buses contributing to lower-class and minority connotations. Redevelopment with transit often incurs more political support including support from coalitions aimed at equity (or sustainability) concerns. Additionally, funds for redevelopment in the transportation realm has continued, tying funding more closely to plans that include transportation elements.

Many of the studies examined have found little to no displacement, contradicting more disaggregate, qualitative, or anecdotal evidence of such. The author presents four points/explanation aiming to explain TODs as a form of gentrification leading to displacement. "methodological shortcomings of existing studies may mask the actual extent of displacement caused by gentrification" (quoted from page 532) Meaning areas of analysis larger than the neighborhood scale or measuring too short a temporal period (displacement or out-migration per year instead of per five year or 10 year). Taking into account government intervention (subsidized public housing) allows many residents to stay, which should be controlled for in an analysis. In general, the data used were not intended to measure displacement (too aggregated in space, not enough aggregation across time, no information about household-level reasons for moving).

"even if physical displacement rates are small, social and psychological displacement may have greater effects on residents" (quoted from page 532)

"Empirical studies have operationally defined displacement as the physical movement of households into or out of a neighborhood. According to Wyly et al. (2010), processes of displacement have shifted from direct, visible forms like tenant evictions to more diffuse, less obvious forms, such as gradual economic pressure or the slow erosion of residents' sense of belonging in their neighborhood." (quoted from page 539)

Our study will not consider 'indirect' forms of displacement.

"while TOD may raise housing prices, reduced transportation costs may allow households to remain in place" (quoted from page 532)

"in the face of uncertain outcomes, advocacy groups may use political openings created by TOD plans to claim development benefits for low-income communities" (quoted from page 532) 
Renne (2009) - From TAD to TOD

Reference: (J. L. Renne, 2009)

Methods and Outcomes:

Page 1:

"Both concepts refer to the area within a 10-min walk, or half-mile radius, around a major transit station. While a TOD describes a station-area precinct that is compact, mixed-use, and facilitates transit connectivity through urban design, a TAD is "physically near transit [but] fails to capitalize upon this proximity. . . [It] lacks any functional connectivity to transit - whether in terms of land-use composition, means of station access, or site design" (Cervero et al. 2002, p. 6)."

"A national study here in the USA found that about 100 of the nation's 3300 fixed rail stations are TODs (Cervero et al. 2004). Even many of these may be TAD-like because "TOD designations, of course, are quite subjective: one person's TOD may be viewed by others as little more than an office building with suburban parking ratios that happens to be near a train stop" (Cervero et al. 2004). Based on these numbers, even if all of these stations were TODs, nearly $97 \%$ of rail stations in the USA would be underdeveloped or in other words - a TAD." TOD-TAD Spectrum (page 3):

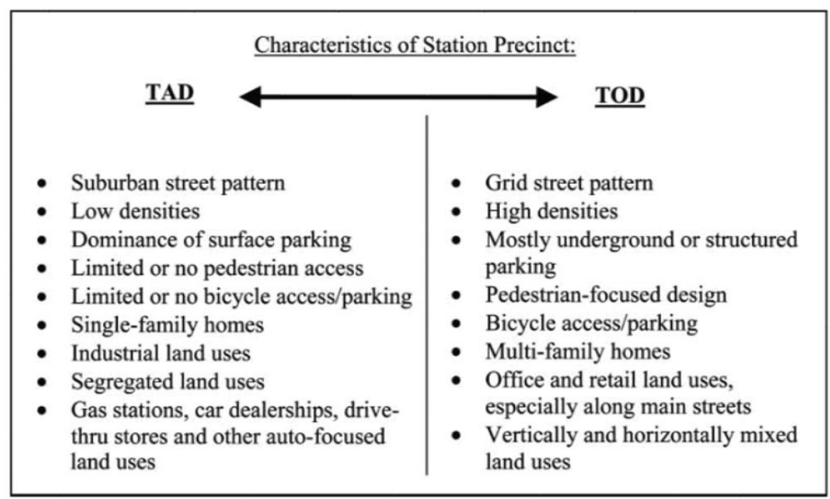

Figure 3. The TAD-TOD spectrum.

The authors consider the characteristics of three case studies in the San Francisco area: Downtown Berkeley (TOD); Hayward (more TAD); and Fremont (TAD). The following characteristics are provided as TAD/TOD indicators (page 8):

Table 3. Built environment indicators.

\begin{tabular}{lcccccc}
\hline Station area & $\begin{array}{c}\text { Number } \\
\text { of street } \\
\text { links }\end{array}$ & $\begin{array}{c}\text { Number of } \\
\text { nodes (three- } \\
\text { way or more } \\
\text { intersections) }\end{array}$ & $\begin{array}{c}\text { Typical block } \\
\text { dimensions } \\
\text { (in ft) }\end{array}$ & $\begin{array}{c}\text { Station } \\
\text { design } \\
\text { rating }\end{array}$ & $\begin{array}{c}\text { Pedestrian } \\
\text { accessibility } \\
\text { rating }\end{array}$ & $\begin{array}{c}\text { Bicycle } \\
\text { accessibility } \\
\text { rating }\end{array}$ \\
\hline $\begin{array}{c}\text { Downtown } \\
\text { Berkeley }\end{array}$ & 184 & 102 & $\begin{array}{c}350 \times 700 \text { or } \\
\text { less }\end{array}$ & 6 of 8 & 3 of 4 & 3 of 4 \\
Hayward & 144 & 80 & $\begin{array}{c}350 \times 700 \text { or } \\
\text { more } \\
\text { No clear } \\
\text { pattern } \\
\text { suburban } \\
\text { street design }\end{array}$ & 5 of 8 & 3 of 4 & 2 of 4 \\
\hline
\end{tabular}

Note: Calculations are based on the half-mile station area taken from the street maps available from the California TOD Database. 
Renne \& Wells (2002) - State of the Literature: TOD

Reference: (J. Renne \& Wells, 2002)

Methods and Outcomes:

This report provides a selected summary of three reports:

Transit Oriented Development: Moving from Rhetoric to Reality (Brookings report: Belzer and Autler 2002)

Transit Oriented Development and Joint Development in the US: A literature review (TCRP report: Cervero, Ferrell, and Murphy 2002).

Statewide Transit Oriented Development Study: Factors for Success in California (Caltrans 2002a)

Although the majority of this report summarizes existing reports, they provide a few conclusions that are relevant to this study (quoted on page 28):

"Collaboration is key - In order to successfully build a TOD, it is vital that not only do public and private sectors need to work together, but also different levels of government and different agencies across government."

"Public policies are lacking - The TCRP report discusses case studies in a best practice manner, but the Brookings report begins to outline necessary goals and objectives for a coherent public vision. The California report takes the Brookings report's recommendations and develops a model of state policy to promote TOD."

"It is necessary to develop a typology and guidelines for success-Although TOD is subject to local market constraints, it is necessary to develop a system for classifying different places and then creating guidelines for success. Future TODs should learn from the successes and/or failures of the past - it is necessary to define obstacles to success, especially in a local context."

"Housing, parking, and financing need special attention- All three of these reports identify the importance of housing, parking, and financing for TODs. These issues need to be worked on in a general sense, again to develop guidelines for success, but they also need to be addressed in a local context for each new project."

"Measuring and evaluating success is necessary- To ensure that TODs are successful, a process of evaluation is important to ensure that goals are being realized. As stated in the TCRP report, most TODs in the United States are so new that adequate data have not yet been collected to evaluate their success." 
Dittmar \& Poticha (2004) - Ch. 2 - Defining TOD: New Regional Building Block

Reference: (Dittmar \& Poticha, 2004)

Methods and Outcomes:

Notes:

This chapter describes the efforts defining a typology of TOD that aligns with planned goals providing elements of livability using performance-based definitions that include:

Location efficiency: "Conscious placement of homes" (page 23)

Density within walking/biking distance

Transit accessibility: stations located with efficiency within the station area to make other destinations accessible

Pedestrian friendliness: interconnected/scaled network of streets for human convenience

Rich mix of choices: "many activities within walking distance for those that do not drive...,

people who cannot afford cars, and people who choose not to rely on cars to get around" (page 25). This is about providing options.

Value capture: reducing transportation costs can provide economic value capture, but requires the following: "frequent, high-quality transit service; good connections between transit and the community; community amenities and a dedication to place making; scorekeeping and attention to financial returns" (page 26). Potential stakeholders are denoted in the following table (Bartlett School of Planning 2001, page 29 qtd. In Dittmar and Poticha 2004, page 27). 


\begin{tabular}{|c|c|c|}
\hline STAKEHOLDERS & SHORT-TERM VALUE & LONG-TERM VALUE \\
\hline Landowners & Potential for increased land values & \\
\hline Funders (short-term) & Potential for greater security of investment & \\
\hline Developers & $\begin{array}{l}\text { Quicker approvals (reduced cost } \\
\text { and uncertainty) } \\
\text { Increased public support } \\
\text { Higher sales values (profitability) } \\
\text { Distinctiveness (greater product differentiation) } \\
\text { Increased funding potential (public/private } \\
\text { partnering) } \\
\text { Allows difficult sites to be tackled }\end{array}$ & $\begin{array}{l}\text { Better reputation } \\
\text { Future collaborations more likely }\end{array}$ \\
\hline Design Professionals & $\begin{array}{l}\text { Increased workload and repeat commissions } \\
\text { from high-quality, stable clients }\end{array}$ & Enhanced professional reputation \\
\hline Investors (long-term) & $\begin{array}{l}\text { Higher rental returns } \\
\text { Increased asset value } \\
\text { Reduced running costs } \\
\text { Competitive investment edge }\end{array}$ & $\begin{array}{l}\text { Maintenance of value/income } \\
\text { Reduced life cycle maintenance costs } \\
\text { Better resale value } \\
\text { Higher quality long-term tenants }\end{array}$ \\
\hline Management Agents & Easy maintenance if high-quality materials & \\
\hline Occupiers (tenants) & & $\begin{array}{l}\text { Happier workforce } \\
\text { Better productivity } \\
\text { Increased client confidence } \\
\text { Reduced running costs }\end{array}$ \\
\hline Public Interests & $\begin{array}{l}\text { Regenerative potential (encouraging } \\
\text { other development) } \\
\text { Reduced public/private discord }\end{array}$ & $\begin{array}{l}\text { Reduced public expenditure (on crime } \\
\text { prevention/urban management/ } \\
\text { urban maintenance/health) } \\
\text { More time for positive planning } \\
\text { Increased economic viability for } \\
\text { neighboring uses } \\
\text { Increased local tax revenue } \\
\text { More sustainable environment }\end{array}$ \\
\hline Community Interests & & $\begin{array}{l}\text { Better security and less crime } \\
\text { Increased cultural viability } \\
\text { Better quality of life } \\
\text { More inclusive public space } \\
\text { A more equitable/accessible environment } \\
\text { Greater civic pride (sense of community) } \\
\text { Reinforced sense of place } \\
\text { Higher property prices }\end{array}$ \\
\hline
\end{tabular}

Place making: "places for people... enrich the existing... make connections... work with the landscape... mix uses and forms... manage the investment... design for change" (page 31-32). Resolution of the tension between node and place: The corresponds with some of Bertonlini's node-place work. Bertolini and Spit (Cities on Rails text) are quoted "the unique challenge of the development of node-places is the need to deal, at the same time, with both transport and urban development issues" (Bertolini and Spit (1998) qtd in Dittmar and Poticha (2004) page 32). The authors then present a typology of six types of stations, with the caution that evaluating TODs and expecting the same returns and observations is exactly why typologies were originally created. Typologies allow for similar sites to be compared. The following is Dittmar and Poticha's typology (page 38): 


\begin{tabular}{|c|c|c|c|c|c|c|c|c|}
\hline TOD TYPE & $\begin{array}{l}\text { LAND-USE } \\
\text { MIX }\end{array}$ & $\begin{array}{l}\text { MINIMUM HOUSING } \\
\text { OENSITY }\end{array}$ & $\begin{array}{l}\text { HOUSING } \\
\text { TYPES }\end{array}$ & SCALE & $\begin{array}{l}\text { REG:ONAL } \\
\text { CONNECTIVITY }\end{array}$ & $\begin{array}{l}\text { TRANSIT } \\
\text { MODES }\end{array}$ & FREQUENCIES & EXAMPLES \\
\hline $\begin{array}{l}\text { Urban } \\
\text { Downtown }\end{array}$ & $\begin{array}{l}\text { Primary } \\
\text { office center } \\
\text { Urban } \\
\text { entertainment } \\
\text { Multifamily } \\
\text { housing } \\
\text { Retail }\end{array}$ & $>50$ units/acre & $\begin{array}{l}\text { Multifamily } \\
\text { Loft }\end{array}$ & $\mathrm{High}$ & $\begin{array}{l}\text { High } \\
\text { Hub of radial } \\
\text { system }\end{array}$ & Ali modes & $<10$ minutes & $\begin{array}{l}\text { Printers Row (Chicago) } \\
\text { LoDo (Denver) } \\
\text { South Beach } \\
\text { (San Francisco) }\end{array}$ \\
\hline $\begin{array}{l}\text { Urban } \\
\text { Neighborhood }\end{array}$ & $\begin{array}{l}\text { Residential } \\
\text { Retail } \\
\text { Class B } \\
\text { commercial }\end{array}$ & $>20$ units/acre & $\begin{array}{l}\text { Multifamily } \\
\text { Loft } \\
\text { Townhome } \\
\text { Single family }\end{array}$ & Medium & $\begin{array}{l}\text { Medium } \\
\text { access to } \\
\text { downtown } \\
\text { Subregional } \\
\text { circulation }\end{array}$ & $\begin{array}{l}\text { Light-rail } \\
\text { Streetcar } \\
\text { Rapid bus } \\
\text { Local bus }\end{array}$ & $\begin{array}{l}10 \text { minutes peak } \\
20 \text { minutes } \\
\text { offpeak }\end{array}$ & $\begin{array}{l}\text { Mockingbird (Dallas) } \\
\text { Fullerton (Chicago) } \\
\text { Barrio Logan (San Diego }\end{array}$ \\
\hline $\begin{array}{l}\text { Suburban } \\
\text { Center }\end{array}$ & $\begin{array}{l}\text { Primary office } \\
\text { center } \\
\text { Urban } \\
\text { entertainment } \\
\text { Multifamily } \\
\text { housing } \\
\text { Retail }\end{array}$ & $>50$ units/acre & $\begin{array}{l}\text { Multifamily } \\
\text { Loft } \\
\text { Townhome }\end{array}$ & High & $\begin{array}{l}\text { High } \\
\text { access to } \\
\text { downtown } \\
\text { Subregional hub }\end{array}$ & $\begin{array}{l}\text { Rail } \\
\text { Streetcar } \\
\text { Rapid bus } \\
\text { Local bus } \\
\text { Paratransit }\end{array}$ & $\begin{array}{l}10 \text { minutes peak } \\
10-15 \text { minutes } \\
\text { offpeak }\end{array}$ & $\begin{array}{l}\text { Arlington County } \\
\text { Nirginia) } \\
\text { Addison Circle (Dallas) } \\
\text { Evanston (Illinois) }\end{array}$ \\
\hline $\begin{array}{l}\text { Suburban } \\
\text { Neighborhood }\end{array}$ & $\begin{array}{l}\text { Residential } \\
\text { Neighborhood } \\
\text { retail } \\
\text { Local office }\end{array}$ & $>12$ units/acre & $\begin{array}{l}\text { Multifamily } \\
\text { Townhome } \\
\text { Single family }\end{array}$ & Moderate & $\begin{array}{l}\text { Medium } \\
\text { access to } \\
\text { suburban } \\
\text { center } \\
\text { Access to } \\
\text { downtown }\end{array}$ & $\begin{array}{l}\text { Light-rail } \\
\text { Rapid bus } \\
\text { Local bus } \\
\text { Paratransit }\end{array}$ & $\begin{array}{l}20 \text { minutes peak } \\
30 \text { minutes } \\
\text { offpeak }\end{array}$ & $\begin{array}{l}\text { Crossings (Mountain } \\
\text { View, CA) } \\
\text { Ohlone-Chynoweth } \\
\text { (San Jose, CA) }\end{array}$ \\
\hline $\begin{array}{l}\text { Neighborhood } \\
\text { Transit Zone }\end{array}$ & $\begin{array}{l}\text { Residential } \\
\text { Neighborhood } \\
\text { retail }\end{array}$ & $>$ T units/acre & $\begin{array}{l}\text { Townhome } \\
\text { Single family }\end{array}$ & $\begin{array}{l}\text { Low } \\
\text { access to } \\
\text { a center }\end{array}$ & Low & $\begin{array}{l}\text { Local bus } \\
\text { Paratransit }\end{array}$ & $\begin{array}{l}25-30 \text { minutes } \\
\text { Demand } \\
\text { responsive }\end{array}$ & \\
\hline $\begin{array}{l}\text { Commuter } \\
\text { Town Center }\end{array}$ & $\begin{array}{l}\text { Retail center } \\
\text { Residential }\end{array}$ & $>12$ units/acre & $\begin{array}{l}\text { Multifamily } \\
\text { Townhome } \\
\text { Single family }\end{array}$ & Low & $\begin{array}{l}\text { Low } \\
\text { access to } \\
\text { downtown }\end{array}$ & $\begin{array}{l}\text { Commuter } \\
\text { rail } \\
\text { Rapid bus }\end{array}$ & $\begin{array}{l}\text { Peak service } \\
\text { Demand } \\
\text { responsive }\end{array}$ & $\begin{array}{l}\text { Prairie Crossing (1!linois) } \\
\text { Suisun City (California) }\end{array}$ \\
\hline
\end{tabular}


Jeihani \& Zhang (2013) - Development of a Framework for TOD

Reference: (Jeihani \& Zhang, 2013)

Methods and Outcomes:

Notes:

The goal of this study was to define a measure of TOD to be incorporated into a four-step transportation demand model (trip generation, distribution, mode choice steps) at a transportation analysis zone (TAZ) level.

The methodology for defining TOD areas is as follows (page 26) at a TAZ level for Washington DC and Baltimore areas separately:

Walkability and high-density; Walking distance to transit station; Collaboration of mixed uses and transit; and Affordable housing available around transit.

The methods of classifying a TAZ as a TOD must meet the following conditions (written originally in math, translated to meaning here):

Residential density (population per acre) must be greater than the average residential density

for the entire metro area (DC and Baltimore considered separately OR employment density (employment population per acre) must be greater than the average employment density for the entire metro area.

Average block size for each TAZ (square miles) should be less than the average block size for the entire metro area.

The entropy of the TAZ (mixed-use measure) falls within the top $30 \%$ (when ranked in decreasing order, meaning it meets the highest entropy/mixed-use scores).

The Housing and transportation affordability (\% of housing/transportation cost of household income) is less than $45 \%$.

The TAZ's "U" (undefined and/or ill-defined in the math, but l'm assuming it's either the centroid of the TAZ or the majority of the area) is within a $1 / 2$ mile of the transit station location.

The authors (page 28) continue to disaggregate the TODs by the following built environment/area type categories by activity density (household + employment + retail employment and divided by area). The thresholds of activity density across the three area types was unclear (rural, suburban, urban), but it relied on existing regional models (MSTM). After aggregating rural and suburban TOD observations, the six categories (TOD/non-TOD across rural/suburban/urban) become five.

Household travel survey data were then geocoded and disaggregated into typical travel purposes, aligned with TAZs, and then modeled to derive typical four-step outcomes and approaches (e.g., trips f(SES + TOD)... or discrete choice models). TDM outcomes were not discussed in this summary of the paper as typology was the focus on this review.

This approach is more aggregated and simplified for application in a regional or statewide model. It relies on data available at more aggregated levels, but may classify appropriate "highquality' TOD locations according to the standards derived from the literature. When modeled, using the thresholds for higher-quality TOD may more accurately reflect travel demand outcomes. Conflating affordability with TOD definitions may make modeling transportation outcomes for affordable-transportation/housing policies more difficult. 


\section{References}

Arizona Department of Transportation. (2012). Station Area Typology Definitions (Passenger Rail Corridor Study: Tucson to Phoenix). Federal Transit Administration.

Arrington, G. B., \& Cervero, R. (2008). Effects of TOD on Housing, Parking, and Travel. TCRP Report, 128. https://trid.trb.org/view/870956

Buchanan, B., Gordon, S., Champine, C., Gaspers, D., Chester, S., Santoro, A., Oss, D., Burns, A., Kennedy, C., Mayor, D., Hollrah, G., Johnston, A., Hambidge, T., Washington, P., Romine, J., Cornejo, J., Fanganello, C., Dannemiller, L., Robertson, G., ... Consulting, O. (2014).

Transit-Oriented Denver: Transit Oriented Development Strategic Plan (p. 83).

Center for Transit-Oriented Development. (2010). Performance-Based Transit-Oriented

Development Typology Guidebook. Center for Transit-Oriented Development.

http://reconnectingamerica.org/assets/Uploads/2010_performancebasedtodtypologyguidebook.

pdf

Center for Transit-Oriented Development, \& Nelson/Nygaard. (2011). Transit-Oriented

Development Strategic Plan. Metro. http://ctod.org/pdfs/2011PortlandTODweb.pdf

Central Maryland Transportation Alliance, \& Center for Transit-Oriented Development. (2009).

Central Maryland TOD Strategy: A Regional Action Plan for Transit-Centered Communities.

http://ctod.org/pdfs/2009CentralMarylandTODStrategy.pdf

Cervero, R., \& Guerra, E. (2011). Urban Densities and Transit: A Multi-dimensional Perspective (Working Paper UCB-ITS-WWP-2011-6; p. 15). Institute of Transportation Studies: University of California, Davis.

Chatman, D. G., Cervero, R., Moylan, E., Carlton, I., Weissman, D., Zissman, J., Guerra, E., Murakami, J., Ikezoe, P., Emerson, D., Tischler, D., Means, D., Winkler, S., Sheu, K., Kwon, S. Y., Transit Cooperative Research Program, Transportation Research Board, \& National Academies of Sciences, Engineering, and Medicine. (2014). Making Effective Fixed-Guideway Transit Investments: Indicators of Success (TCRP No. 167). Transportation Research Board. https://doi.org/10.17226/22355

City of Phoenix. (2018). Reinvent PHX: Transit Oriented Development Strategic Policy Framework. City of Phoenix.

https://www.phoenix.gov/villagessite/Documents/pdd_pz_pdf_00380.pdf

Design Workshop. (2013). St. Louis TOD Framework Plan. East-West Gateway Council of Governments. http://www.onestl.org/resources/reports/transit-oriented-development/119-todframework-master-plan

Dittmar, H., \& Poticha, S. (2004). Ch. 2 Defining Transit-Oriented Development: The New Regional Building Block. In The New Transit Town: Best Practices in Transit-Oriented Development (pp. 18-39). Island Press.

Ewing, R., Tian, G., Lyons, T., Stinger, P., Weinberger, R., Kaufman, B., \& Shivley, K. (2017). Trip and Parking Generation at Transit-Oriented Developments (Research Report NITC-RR767). http://nitc.trec.pdx.edu/research/project/767/Trip_and_Parking_Generation_at_TransitOriented_Developments

Jeihani, M., \& Zhang, L. (2013). Development of a Framework for Transit-Oriented Development (Final Report SP209B4N; p. 100). State Highway Administration; Maryland Department of Transportation.

Jones Lang LaSalle, TRA TR Advisors, \& Kimley-Horn and Associates, Inc. (2009). Transit Friendly Development Guide: Station Area Typology. CTA; City of Chicago.

https://www.chicago.gov/content/dam/city/depts/zlup/Planning_and_Policy/Publications/Transit_ Friendly_Development_Guide/CTA_Typology_Study.pdf

Levinson, H. S., Ryus, P., Schofer, J. L., Semler, C., Parks, J., Coffel, K., Sampson, D., Kachadoorian, C., Transportation Research Board, Transit Cooperative Research Program, \& Transportation Research Board. (2012). Guidelines for Providing Access to Public 
Transportation Stations (Research Report TCRP Report 153; Transit Cooperative Research Program (TCRP)). National Academies Press. https://doi.org/10.17226/14614

Lynx Rapid Transit Services. (2016). Southeast Corridor Transit Study: Rail Station Locations and Typologies. Charlotte Area Transit System.

Lyu, G., Bertolini, L., \& Pfeffer, K. (2016). Developing a TOD typology for Beijing metro station areas. Journal of Transport Geography, 55, 40-50.

https://doi.org/10.1016/j.jtrangeo.2016.07.002

Office of the Mayor, City of Los Angeles. (2011). Sustainable Transit Communities Study:

Scorecard Analysis Summary (p. 54).

General Plan Amendment, no. GPA-3-17, 28 (2018).

Pojani, D., \& Stead, D. (2016). A Critical Deconstruction of the Concept of Transit Oriented

Development (TOD). In M. Schenk, V. V. Popovich, P. Zelle, P. Elisei, \& C. Beyer (Eds.), REAL

CORP 2016 (pp. 829-833). http://pure.tudelft.nl/ws/files/10056669/CORP2016_33.pdf

Puget Sound Regional Council; City of Bellevue; King County Metro. (2013). People + Place

Implementation Typology. https://www.psrc.org/sites/default/files/strategytypology.pdf

Puget Sound Regional Council; City of Bellevue; King County Metro. (2014). Appendix D.

Growing Transit Communities Strategy People + Place Implementation Typology Methods and

Results. https://www.nap.edu/read/23630/chapter/11

Rayle, L. (2015). Investigating the Connection Between Transit-Oriented Development and

Displacement: Four Hypotheses. Housing Policy Debate, 25(3), 531-548.

https://doi.org/10.1080/10511482.2014.951674

Reconnecting America. (2014). An Equitable TOD Typology for the Atlanta Region (DRAFT

MEMO).

Renaissance Planning Group. (2011). A Framework for Transit Oriented Development in

Florida. Florida Department of Transportation and Department of Community Affairs.

http://www.fltod.com/renaissance/docs/Products/FrameworkTOD_0715.pdf

Renne, J. L. (2009). From transit-adjacent to transit-oriented development. Local Environment, 14(1), 1-15. https://doi.org/10.1080/13549830802522376

Renne, J. L., \& Ewing, R. (2013). Transit-Oriented Development: An Examination of America's

Transit Precincts in 2000 \& 2010. University of New Orleans Transportation Institute.

https://scholarworks.uno.edu/cgi/viewcontent.cgi?article=1016\&context=unoti_pubs

Renne, J., \& Wells, J. (2002). State of the literature: Transit-oriented development. Vorhees

Transportation Policy Institute.

Santasieri, C. (2014). Section 5: Local Planning and Transit-Supportive Development (FTA

Report No. 0057; Planning for Transit-Supportive Development: A Practitioner's Guide, p. 106).

Federal Transit Administration Research. https://www.transit.dot.gov/funding/funding-finance-

resources/transit-oriented-development/planning-transit-supportive

Sound Transit. (2014). Regional Transit Long-Range Plan Update: Issue Paper on Regional

Land Use and Transit Planning (DRAFT). Sound Transit.

Teska Associates, Inc., Fish Transportation Group, \& OKW Architects. (2014). City of Chicago \& Metra Station Typology Study. City of Chicago Plan Commission.

WSP. (2017). NFTA Comprehensive Transit-Oriented Development Planning: Interim Report

Part 1 (DRAFT). 


\section{APPENDIX C: Place Typology Maps}

APPENDIX C.1

This section contains maps of Bus Rapid Transit systems for the study.

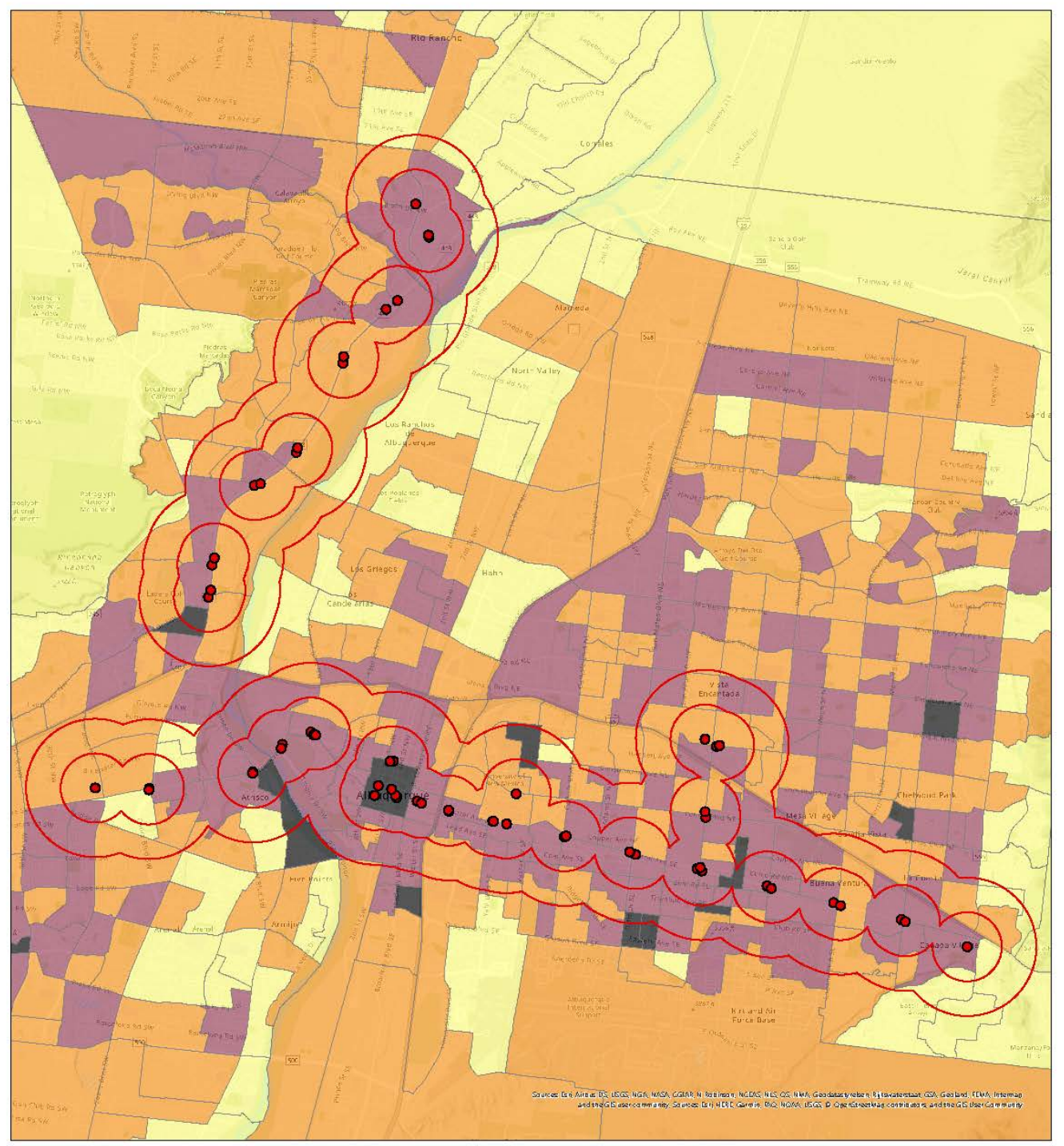

Station Typology for Bus Rapid Transit:

Buffers: Half \& 1 Mile Albuquerque, NM 


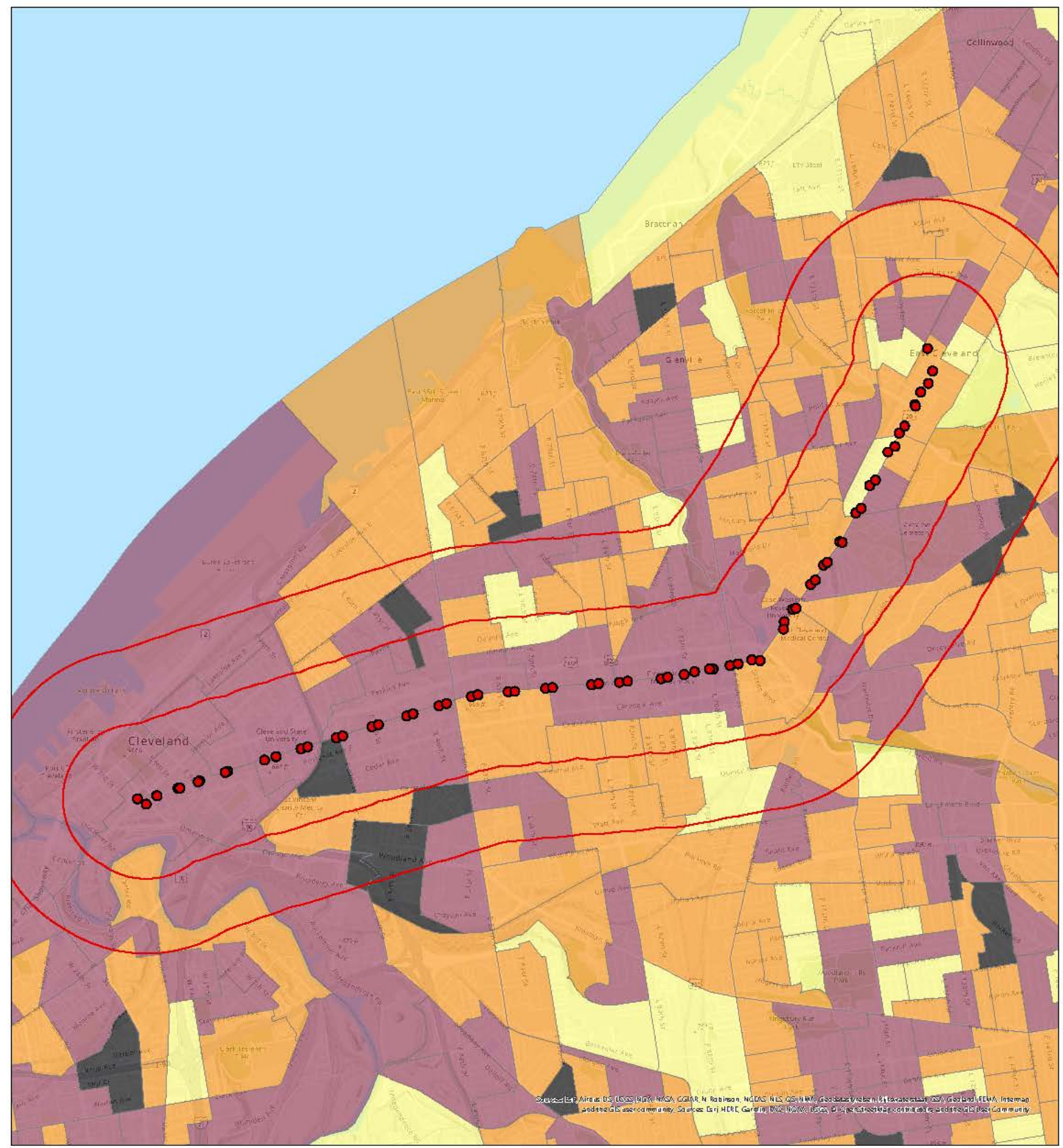

Station Typology for Bus Rapid Transit: Cleveland-Elyria, $\mathrm{OH}$

Buffers: Half \& 1 Mile

Buffers:

Station Types

-High MA

Mod MA

LoW MA

$\square$ Poor MA 


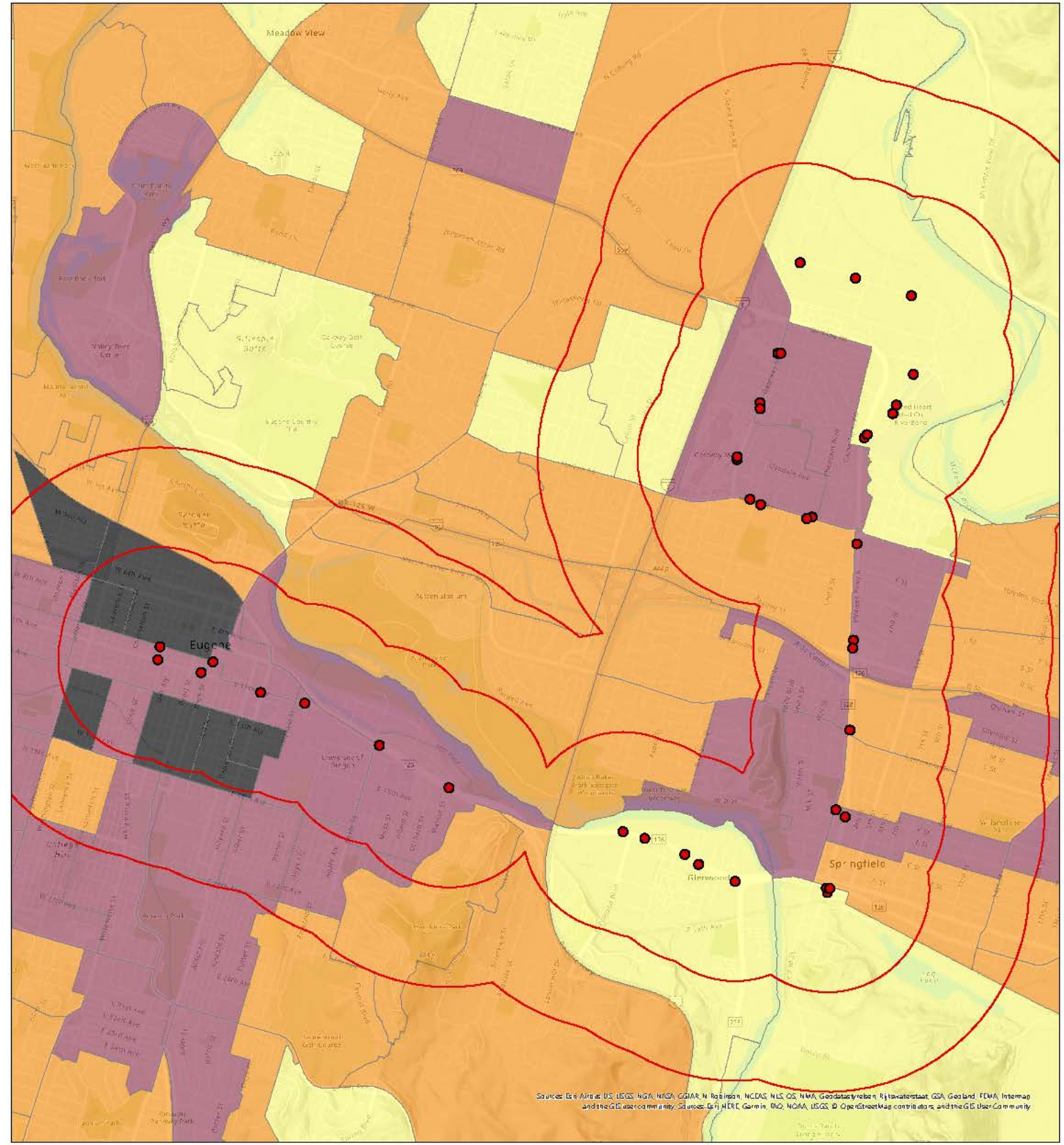

Station Typology for Bus Rapid Transit:

Buffers: Half \& 1 Mile Eugene, OR

\section{$\square$ BRT Buffers}

Station Types

-High MA

Mod MA

$\square$ LOW MA

$\square$ Poor MA

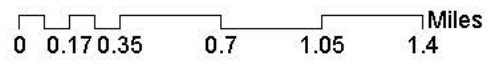




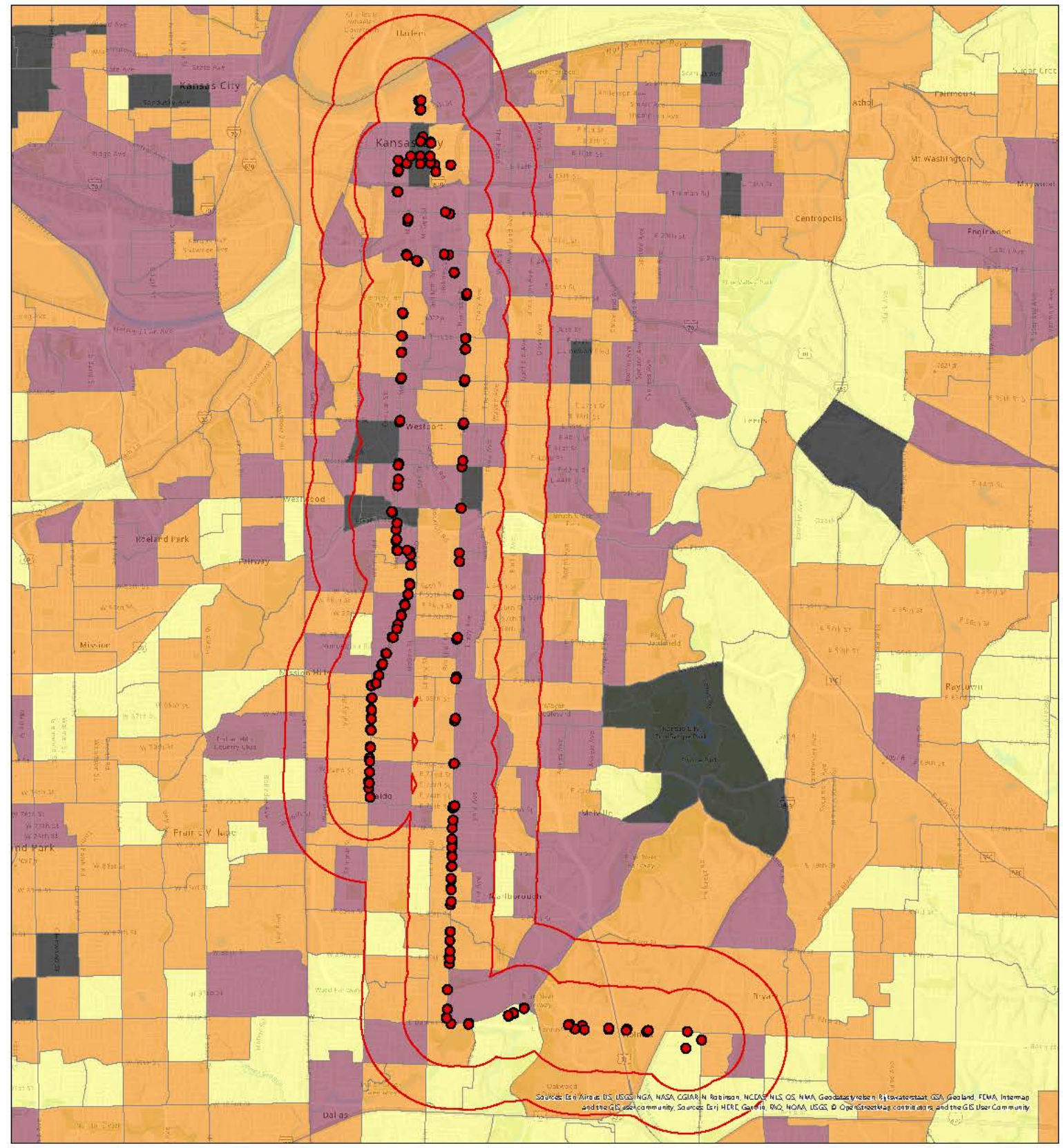

Station Typology for Bus Rapid Transit: Kansas City, MO-KS

$\begin{array}{lllllll}1 & 0.4 & 0.8 & 1.6 & 2.4 & 3.2\end{array}$

Buffers: Half \& 1 Mile

$\square$ BRT Buffers

Station Types

-High MA

Mod MA

$\square$ LW MA
$\square$ Poor MA 


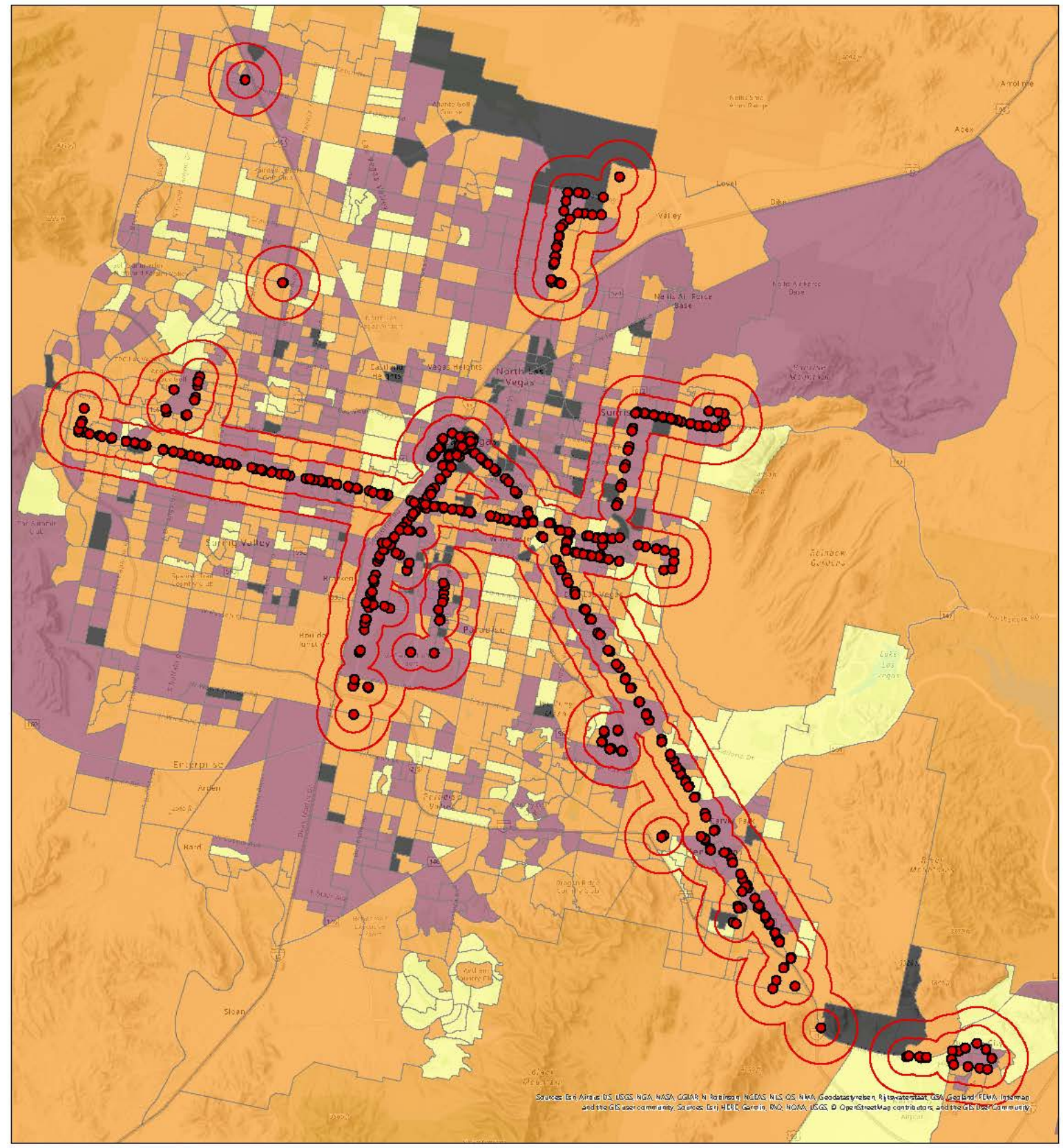

Station Typology for Bus Rapid Transit: Las Vegas-Henderson-Paradise, NV

Buffers: Half \& 1 Mile 口BRT Buffers

Station Types

-High MA

Mod MA

LOW MA

$\square$ Poor MA 


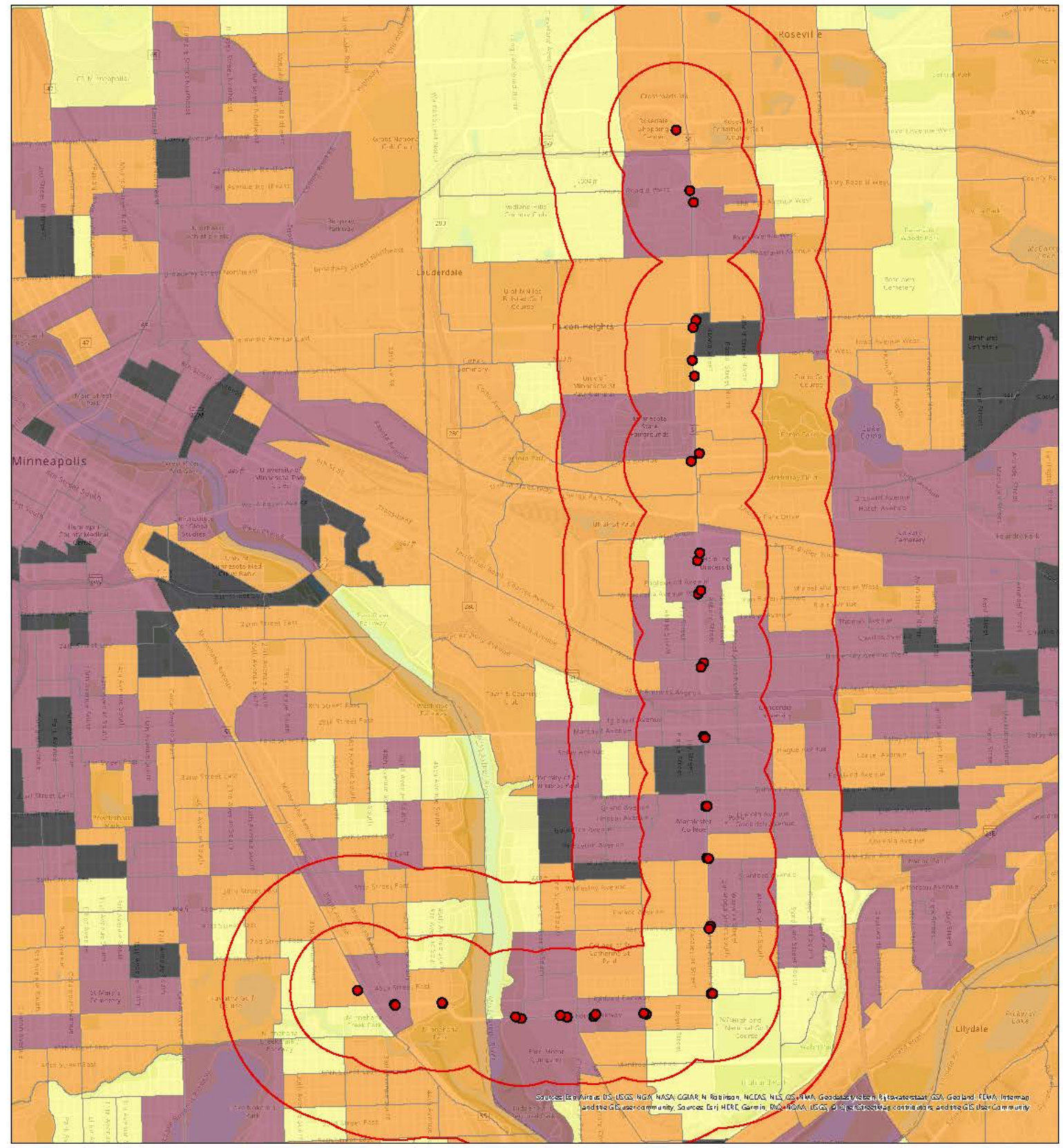

Station Typology for Bus Rapid Transit:

Minneapolis-St. Paul-Bloomington, MN-WI

Buffers: Half \& 1 Mile $\square$ BRT Buffers

Station Types

-High MA

- Mod MA

LOW MA

$\square$ Poor MA

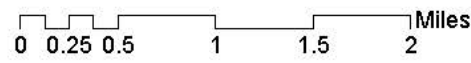




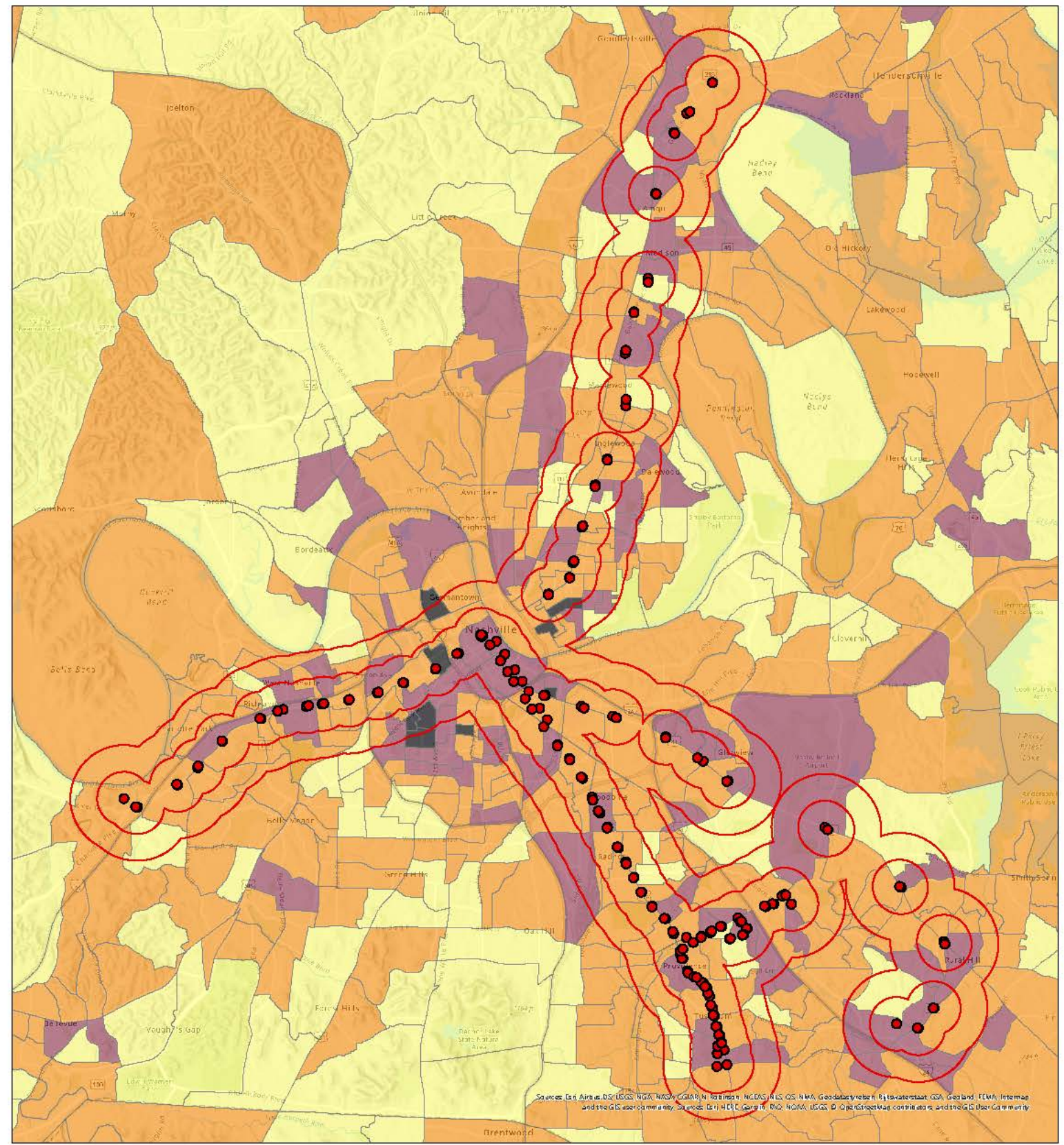

Station Typology for Bus Rapid Transit:

Nashville-Davidson--Murfreesboro--Franklin, TN

Buffers: Half \& 1 Mile

$\square$ BRT Buffers

Station Types

-High MA

Mod MA

$\square$ Low MA
$\square$ Poor MA

$\begin{array}{lllll}0 & 0.5 & 1 & 2 & 3\end{array} 4_{4}^{\text {Miles }}$ 


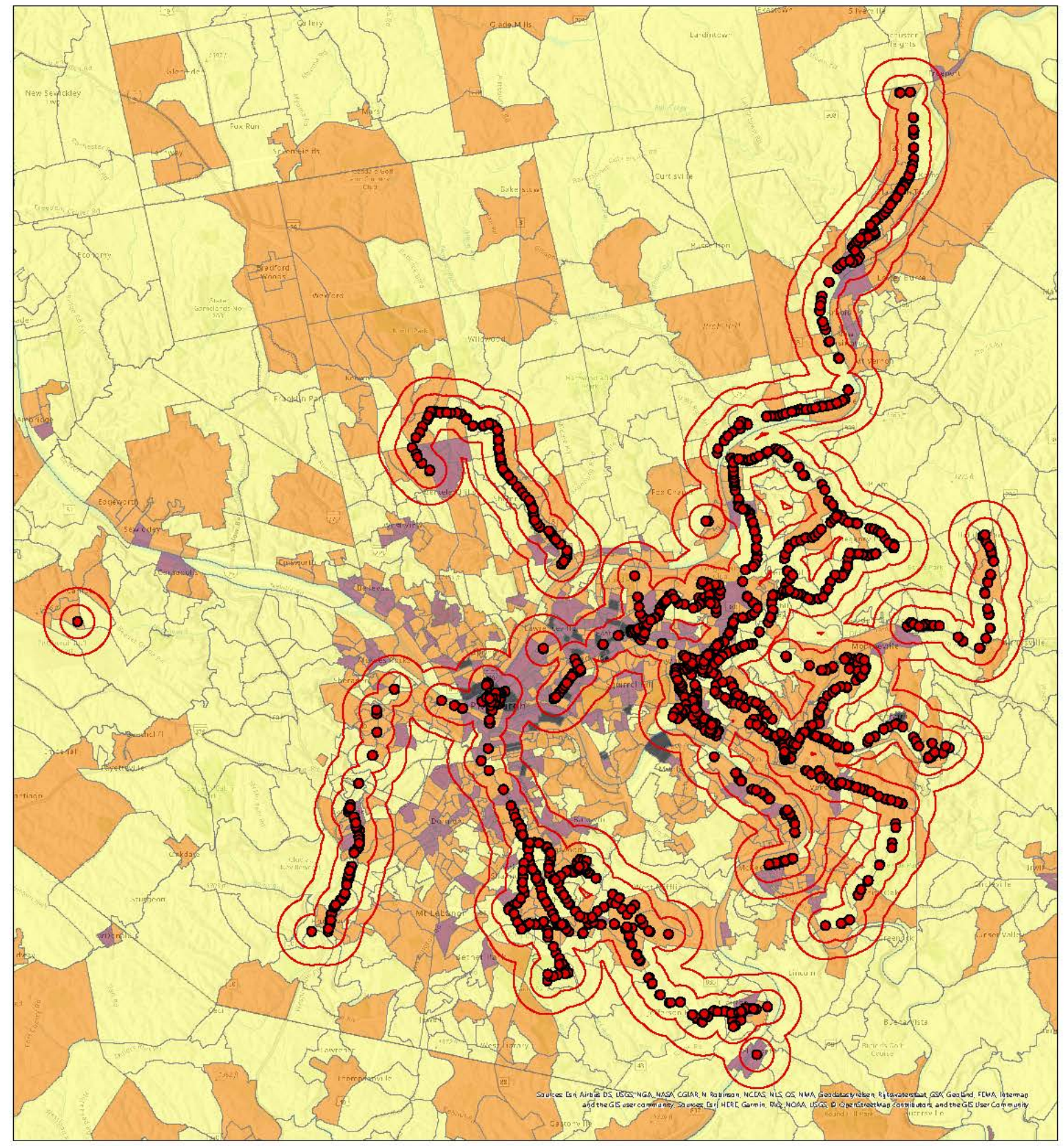

Station Typology for Bus Rapid Transit:

Buffers: Half \& 1 Mile Pittsburgh, PA
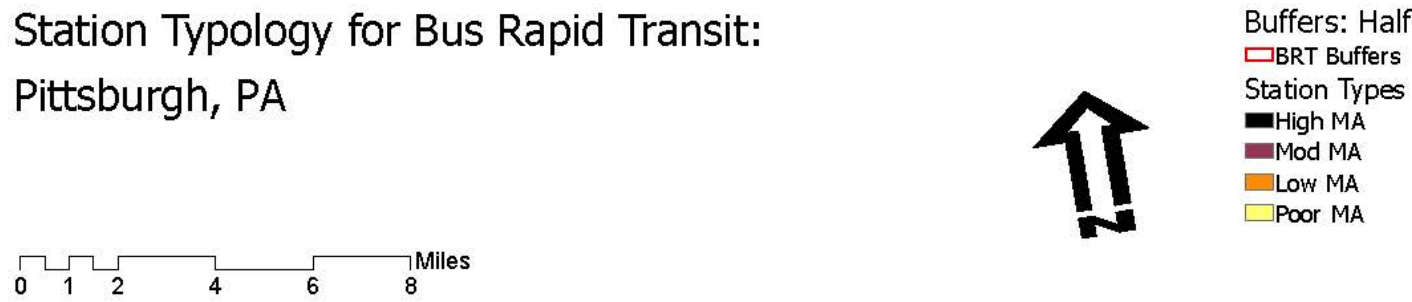


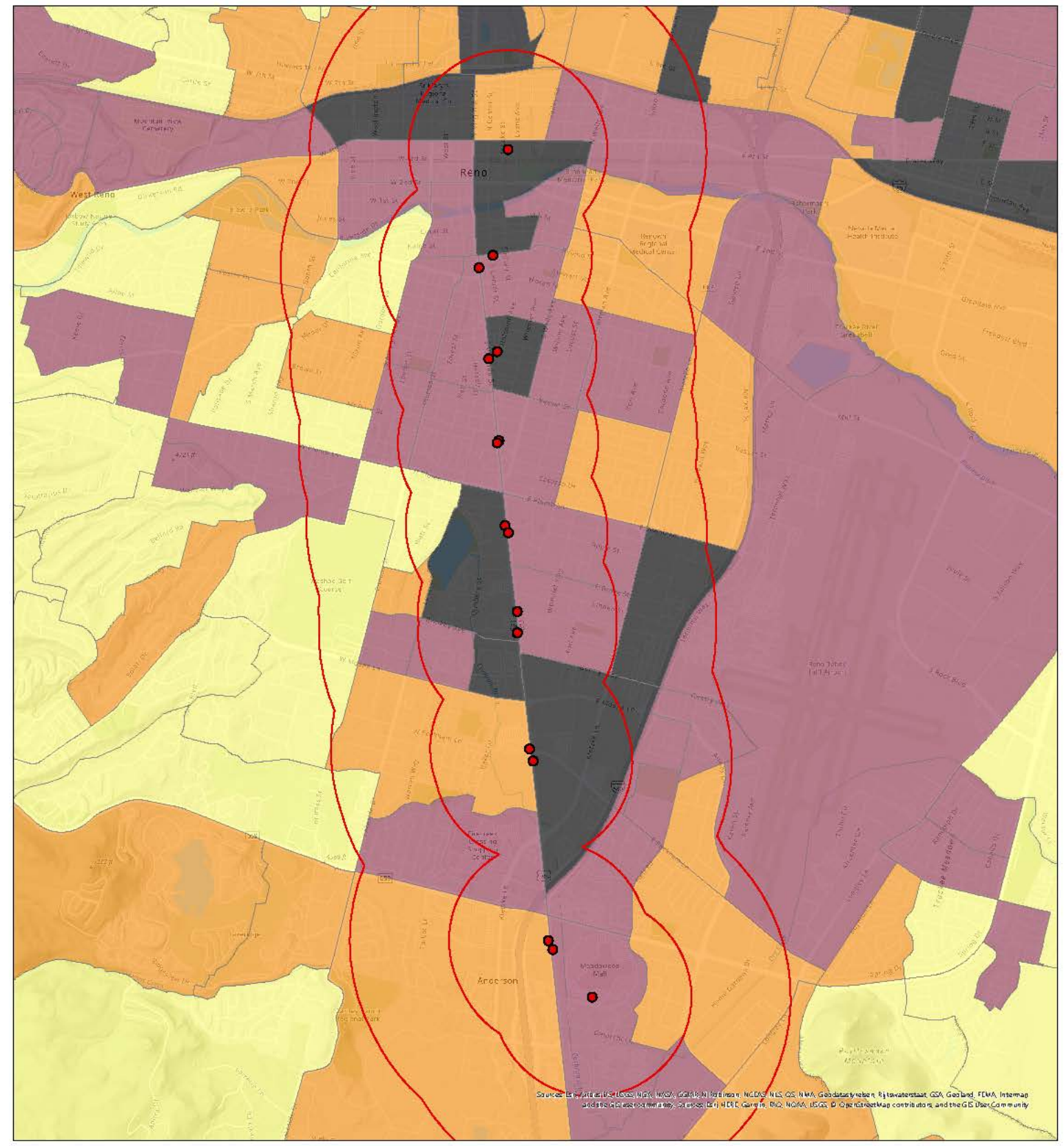

Station Typology for Bus Rapid Transit: Reno, NV

Buffers: Half \& 1 Mile Reno, $N$,

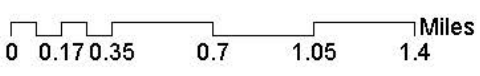




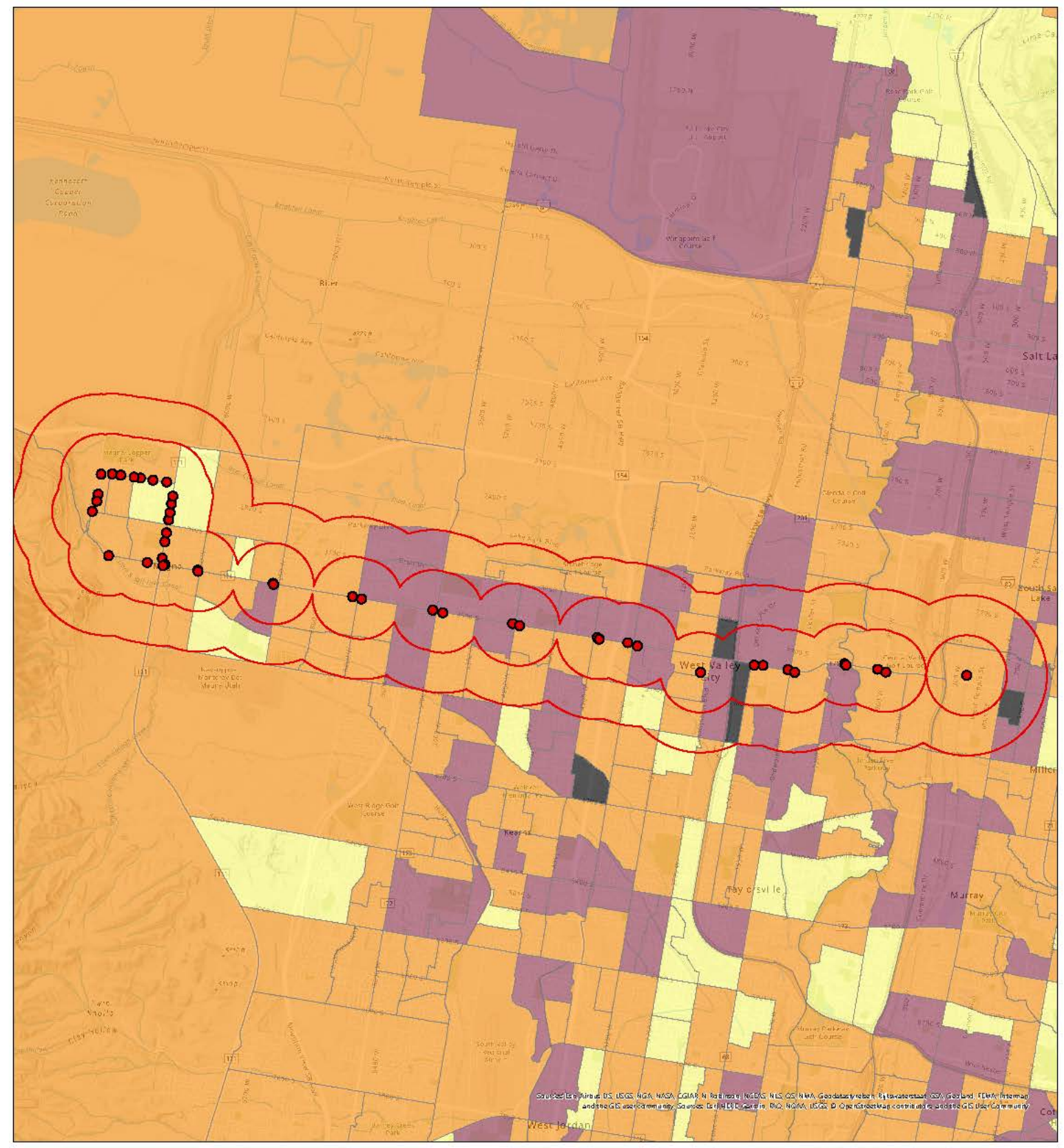

Station Typology for Bus Rapid Transit: Salt Lake City, UT

Buffers: Half \& 1 Mile

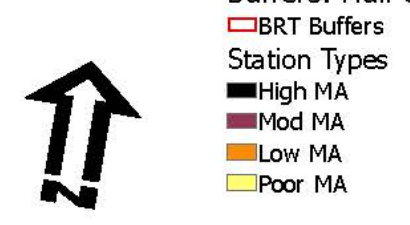




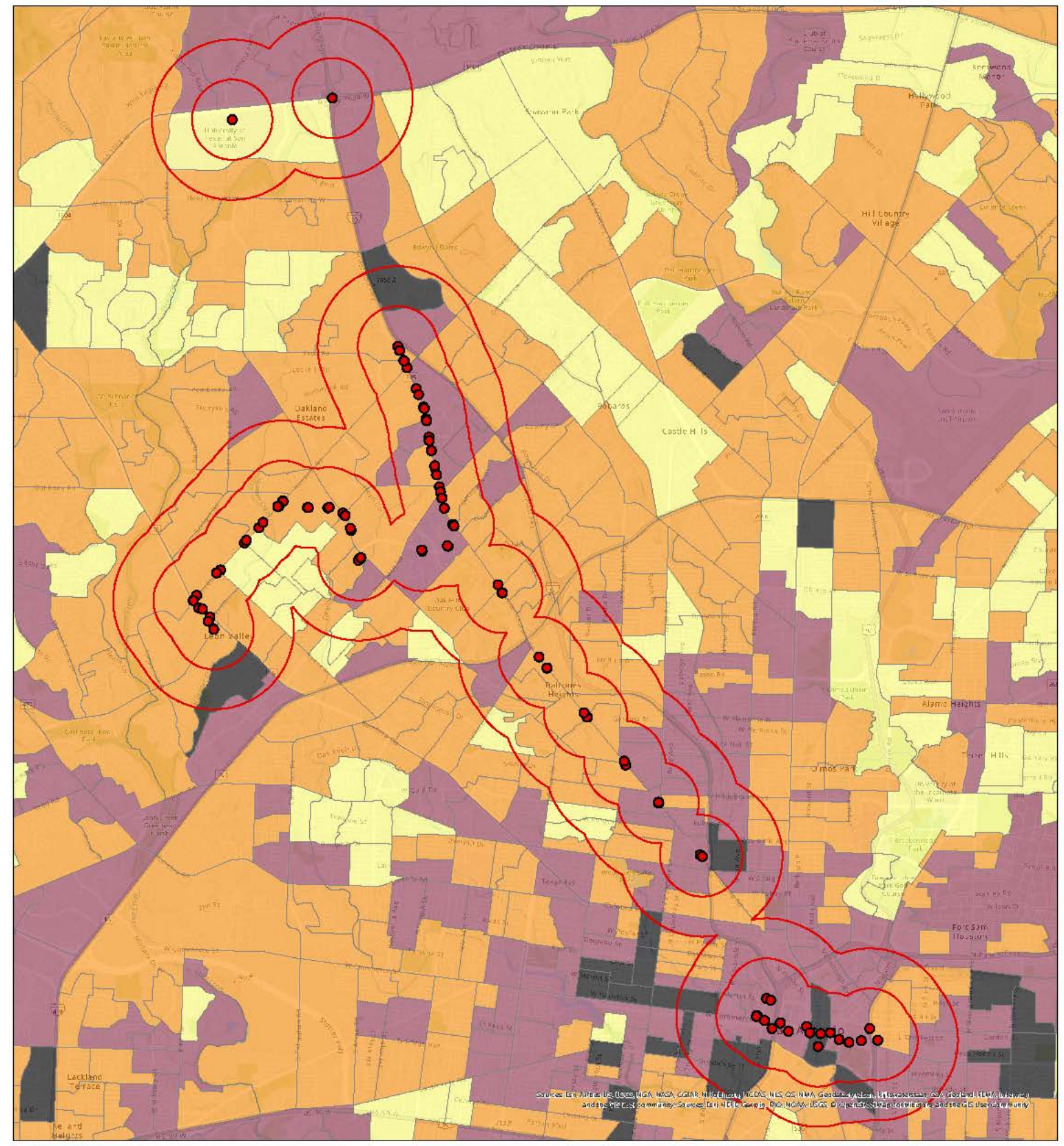

Station Typology for Bus Rapid Transit: San Antonio-New Braunfels, TX

Buffers: Half \& 1 Mile

LOW MA

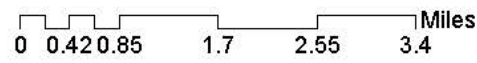




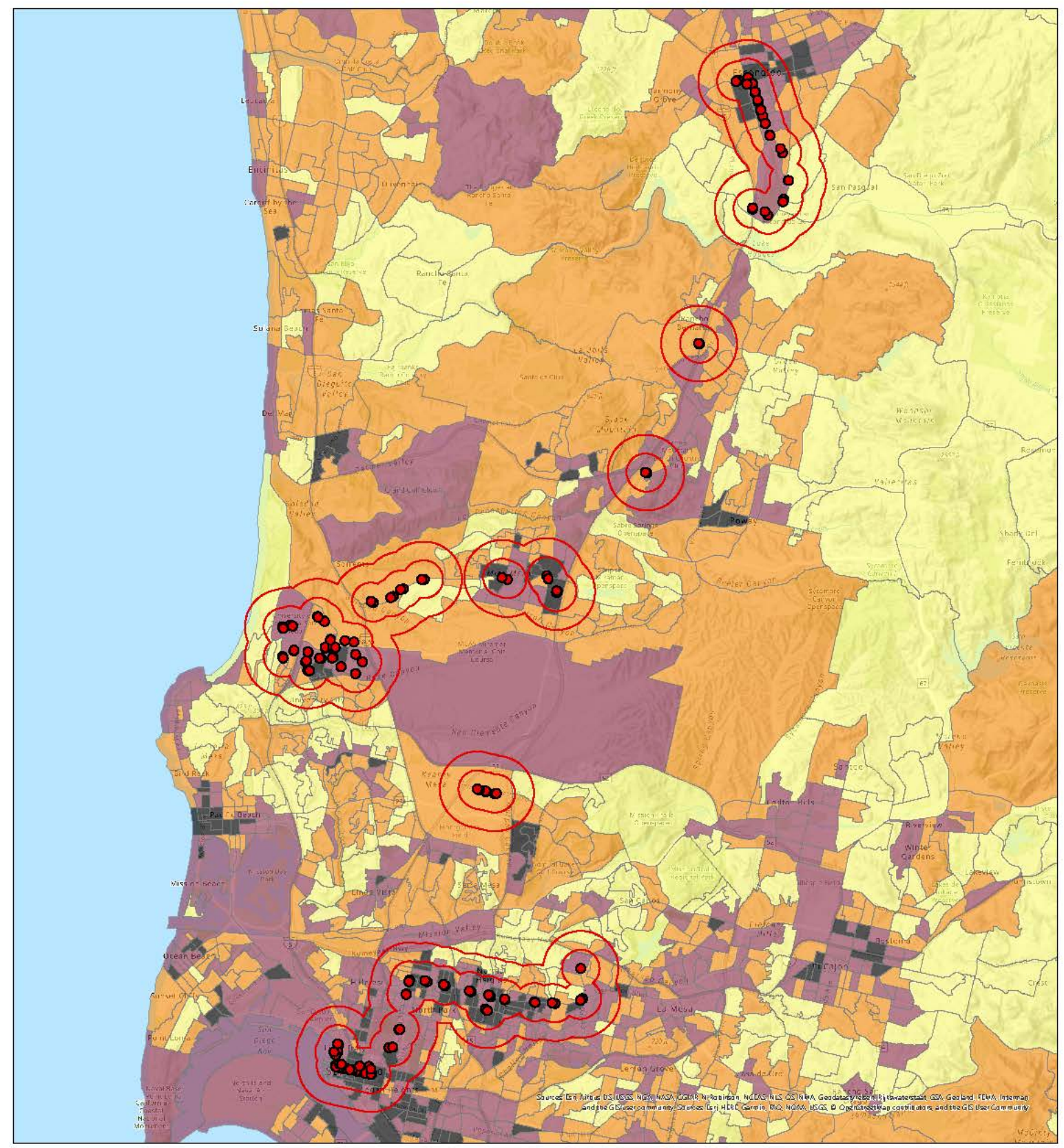

Station Typology for Bus Rapid Transit: San Diego-Carlsbad, CA

Buffers: Half \& 1 Mile

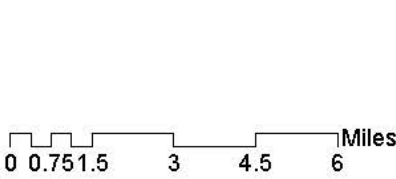




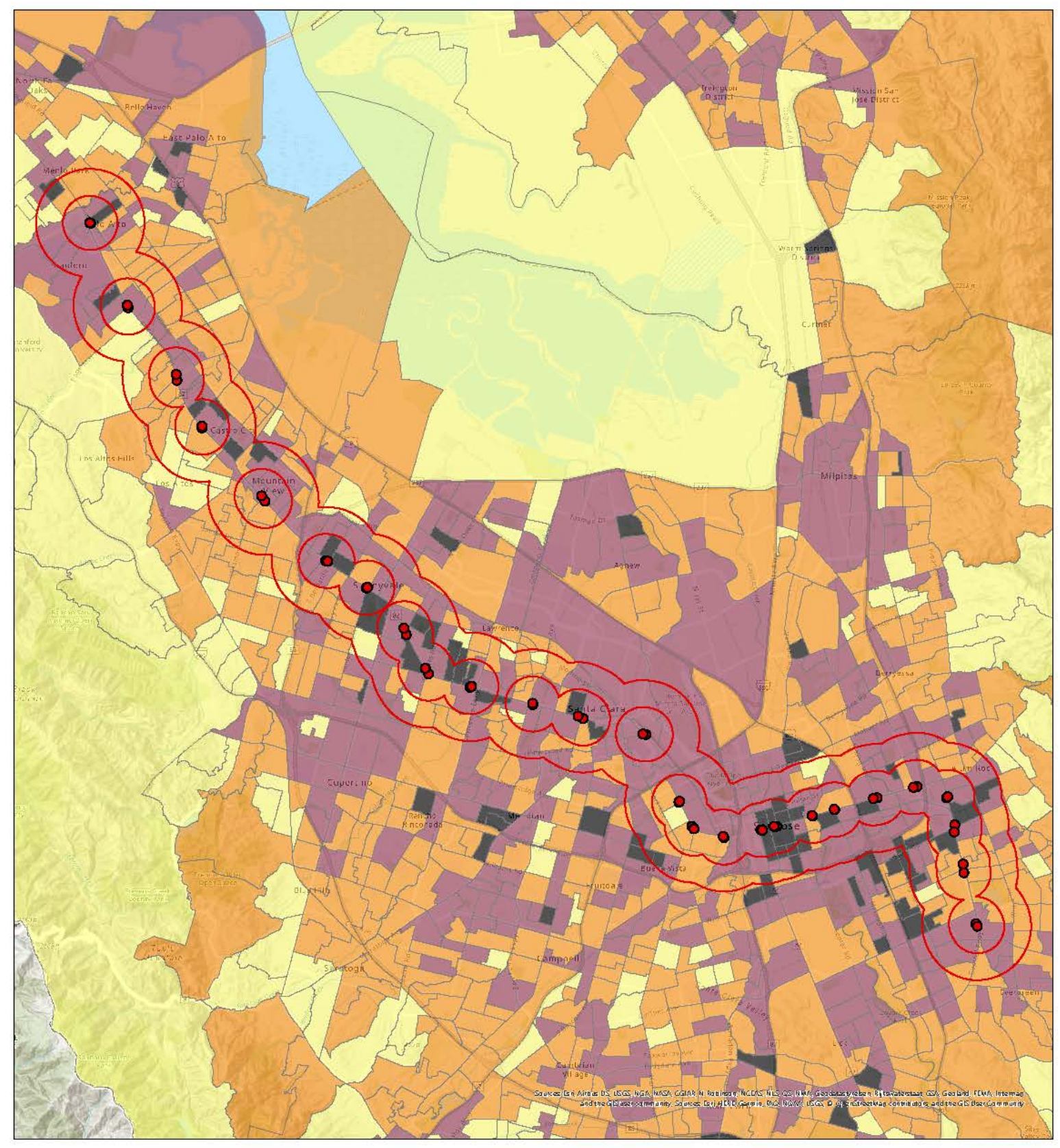

Station Typology for Bus Rapid Transit:

Buffers: Half \& 1 Mile San Jose-Sunnyvale-Santa Clara, CA
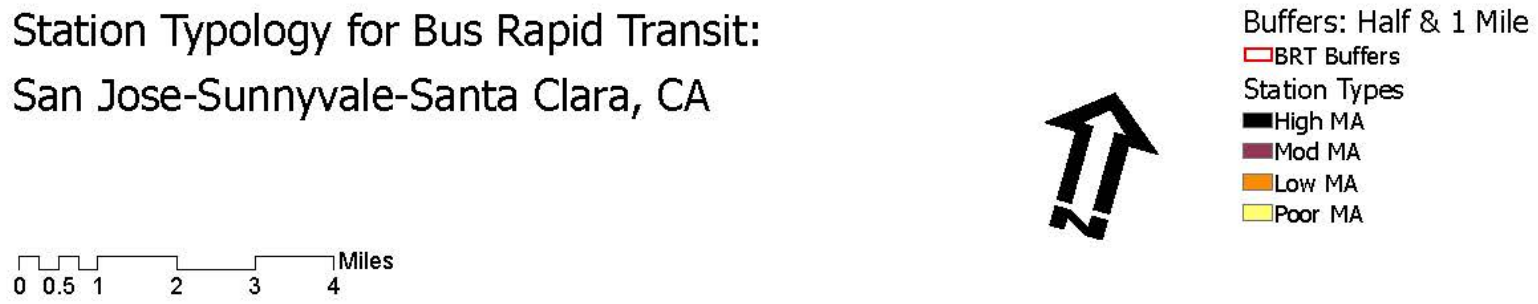


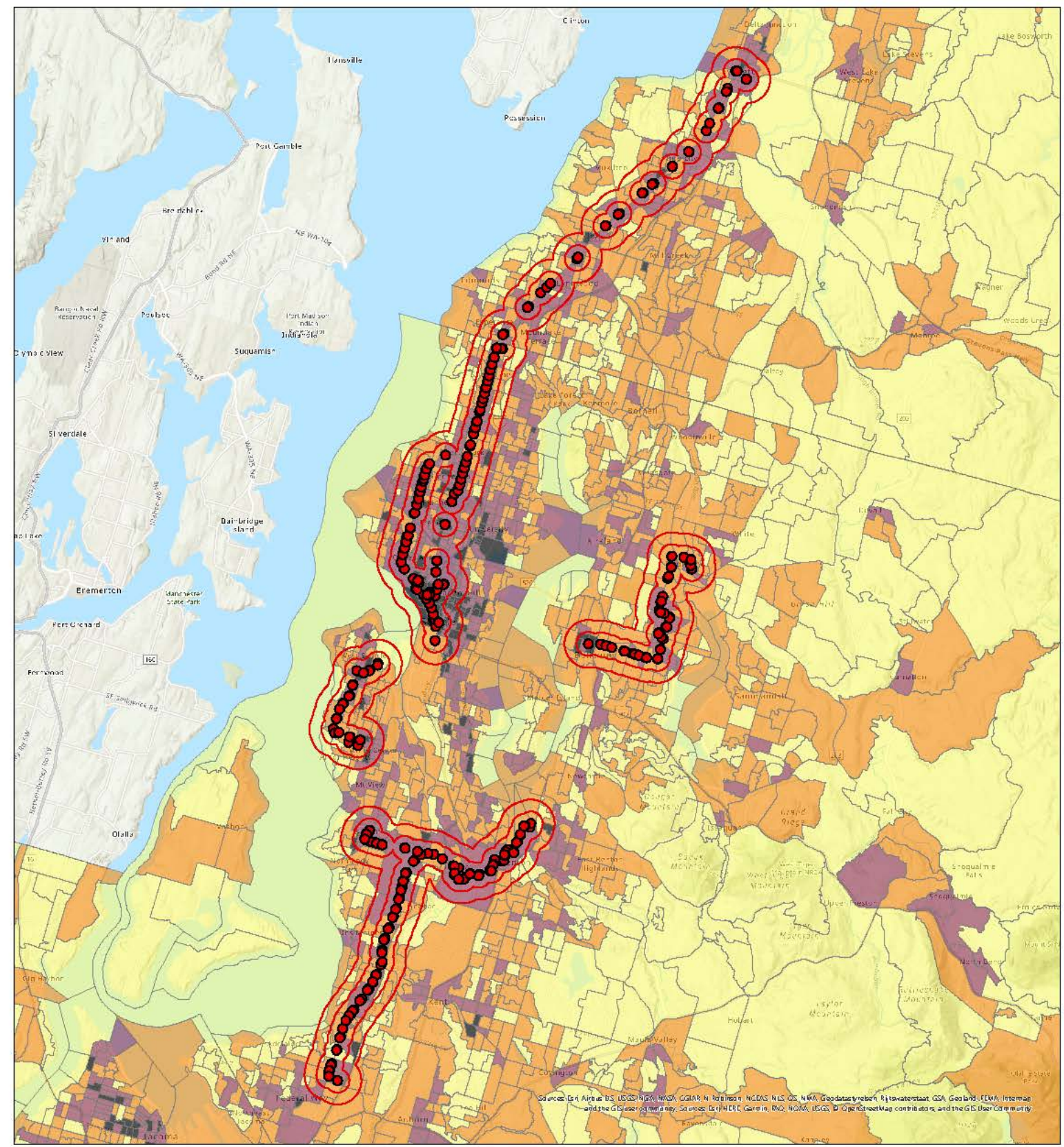

Station Typology for Bus Rapid Transit: Seattle-Tacoma-Bellevue, WA

Buffers: Half \& 1 Mile

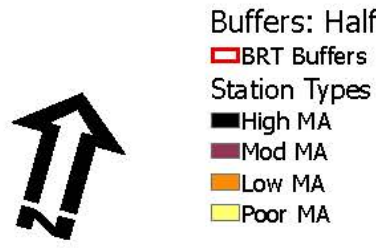

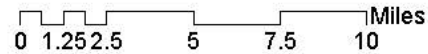




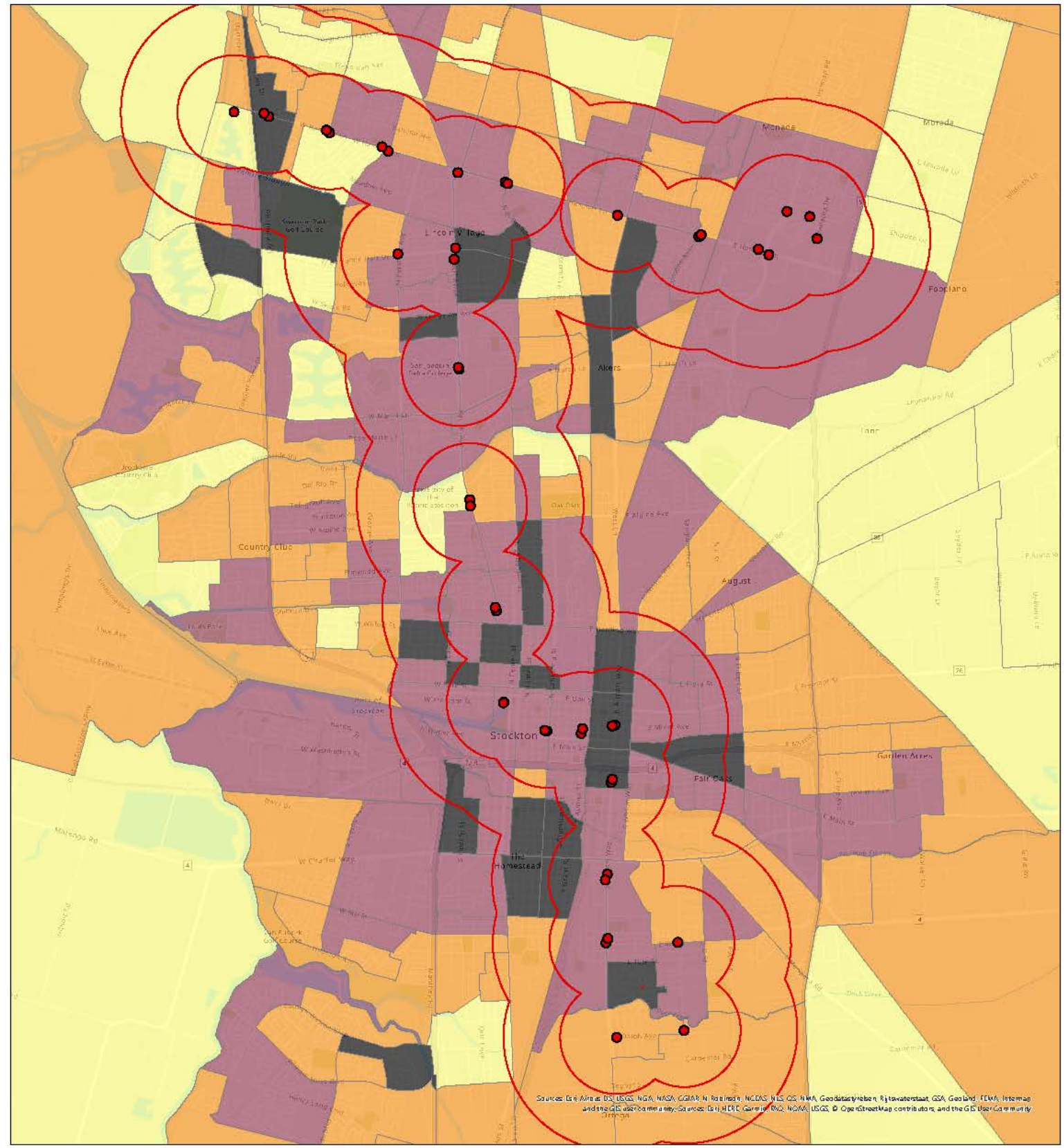

Station Typology for Bus Rapid Transit: Stockton-Lodi, CA

Buffers: Half \& 1 Mile $\square$ BRT Buffers Station Types

-High MA

Mod MA

LOW MA

$\square$ Poor MA 


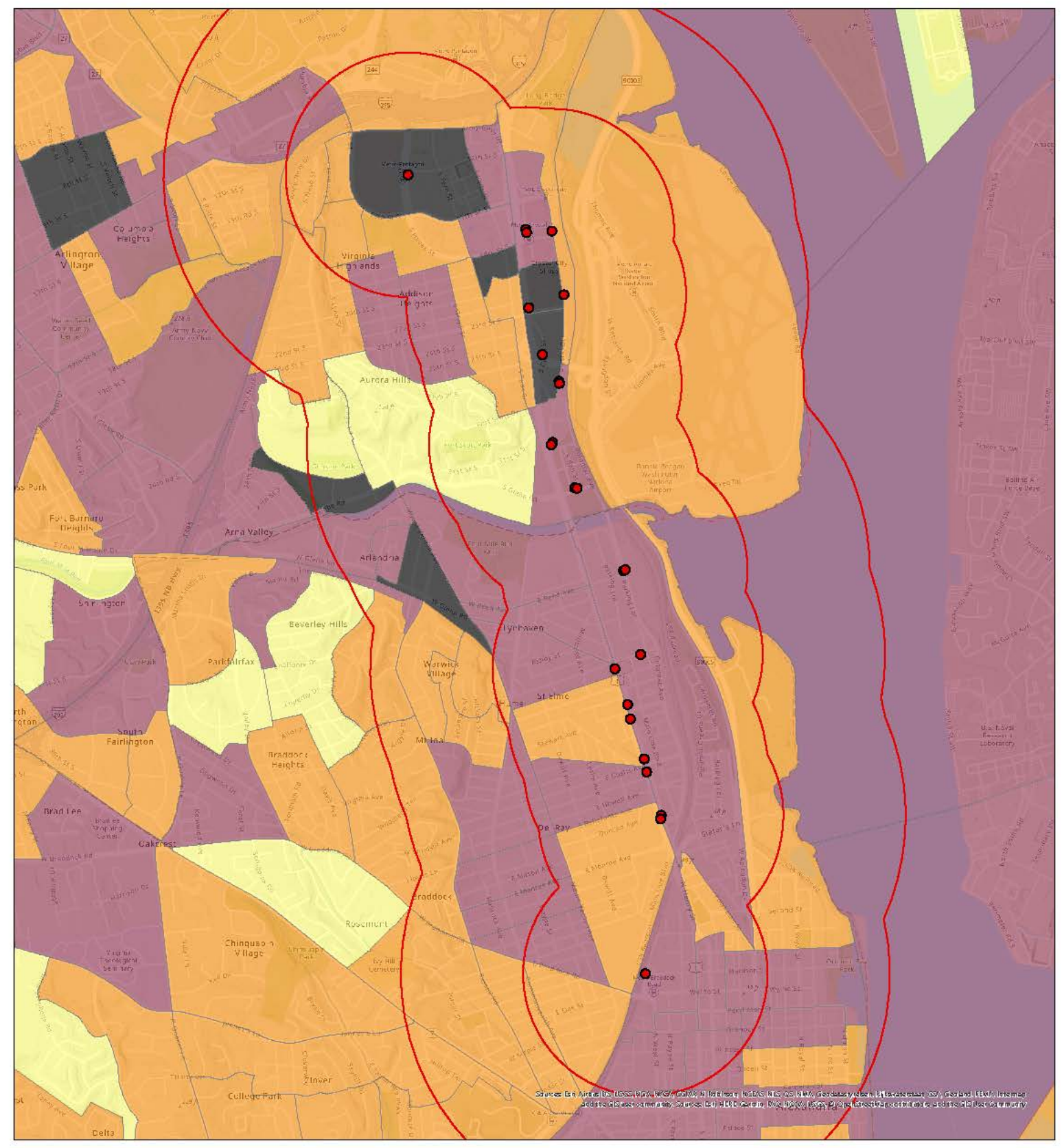

Station Typology for Bus Rapid Transit: Washington-Arlington-Alexandria, DC-VA-MDWV

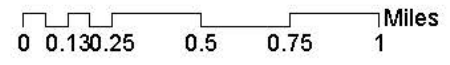

Buffers: Half \& 1 Mile $\square$ BRT Buffers

Station Types

-High MA

Mod MA

LOW MA

$\square$ Poor MA 
This section contains maps for all Streetcar Transit systems in the study.

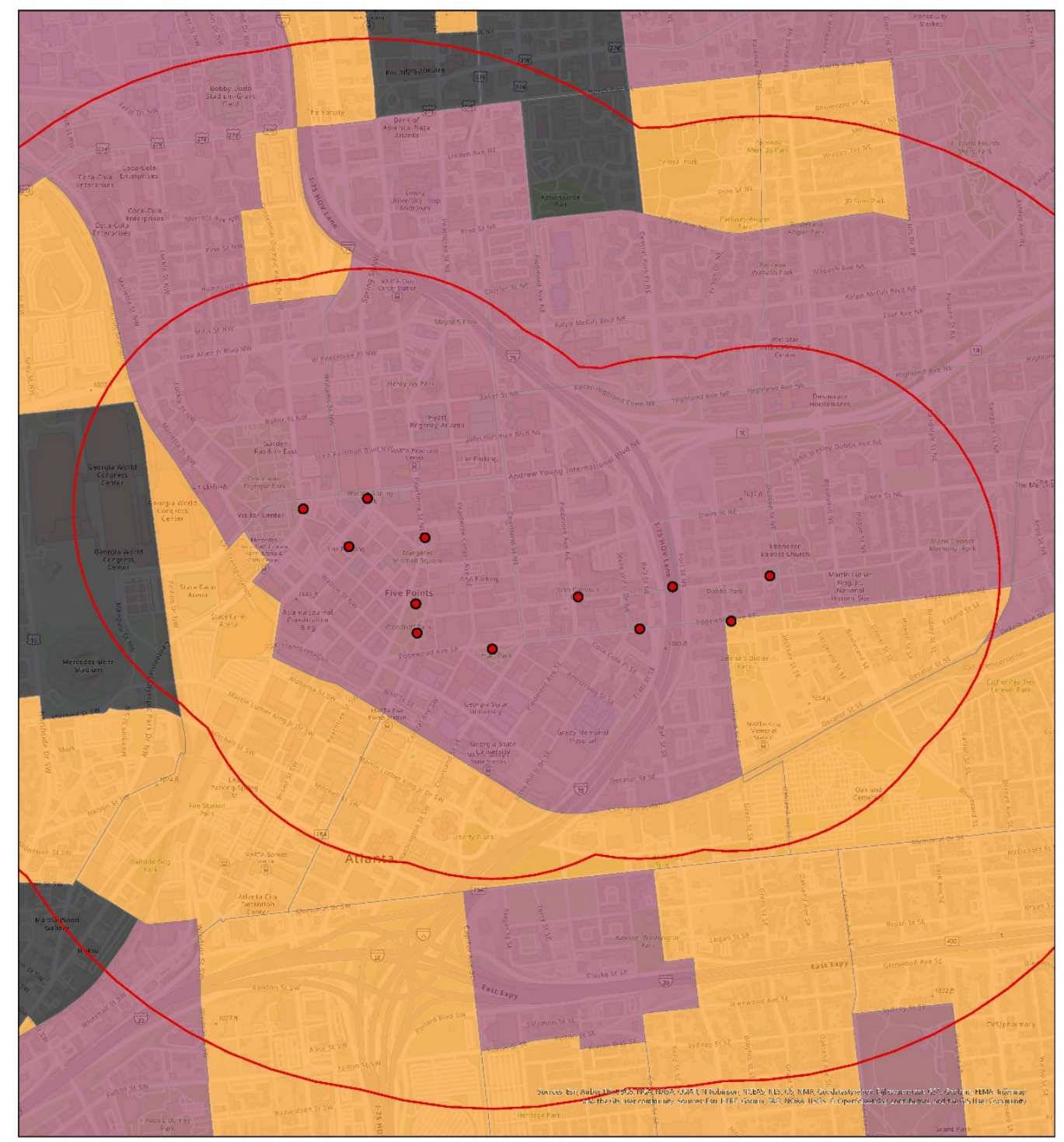

Station Typology for Streetcar Transit: Atlanta-Sandy Springs-Roswell, GA

Buffers: Half \& 1 Mile 口SCT Buffers Station Types

- High MA

Mod MA

Low MA

$\square$ Poor MA

\begin{tabular}{lllll}
$\curvearrowleft$ & \multicolumn{1}{c}{} & \multicolumn{1}{c}{ Miles } \\
0 & 0.070 .15 & 0.3 & 0.45 & 0.6
\end{tabular} 


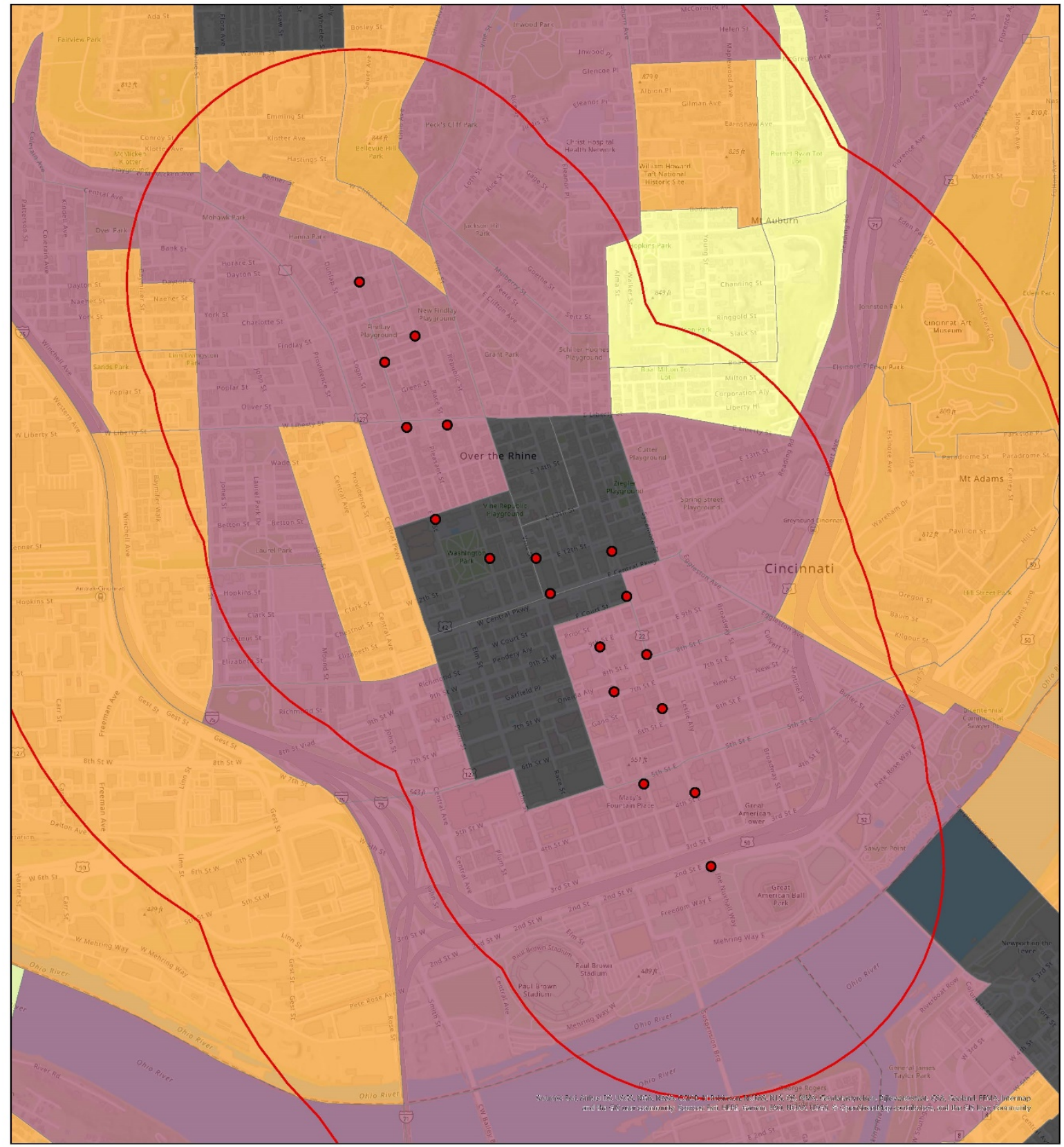

Station Typology for Streetcar Transit: Cincinnati, OH-KY-IN

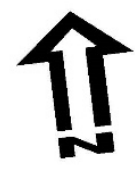

Buffers: Half \& 1 Mile

$\square$ SCT Buffers

Station Types

-High MA

- Mod MA

LoW MA

$\square$ Poor MA

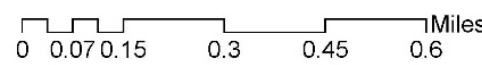




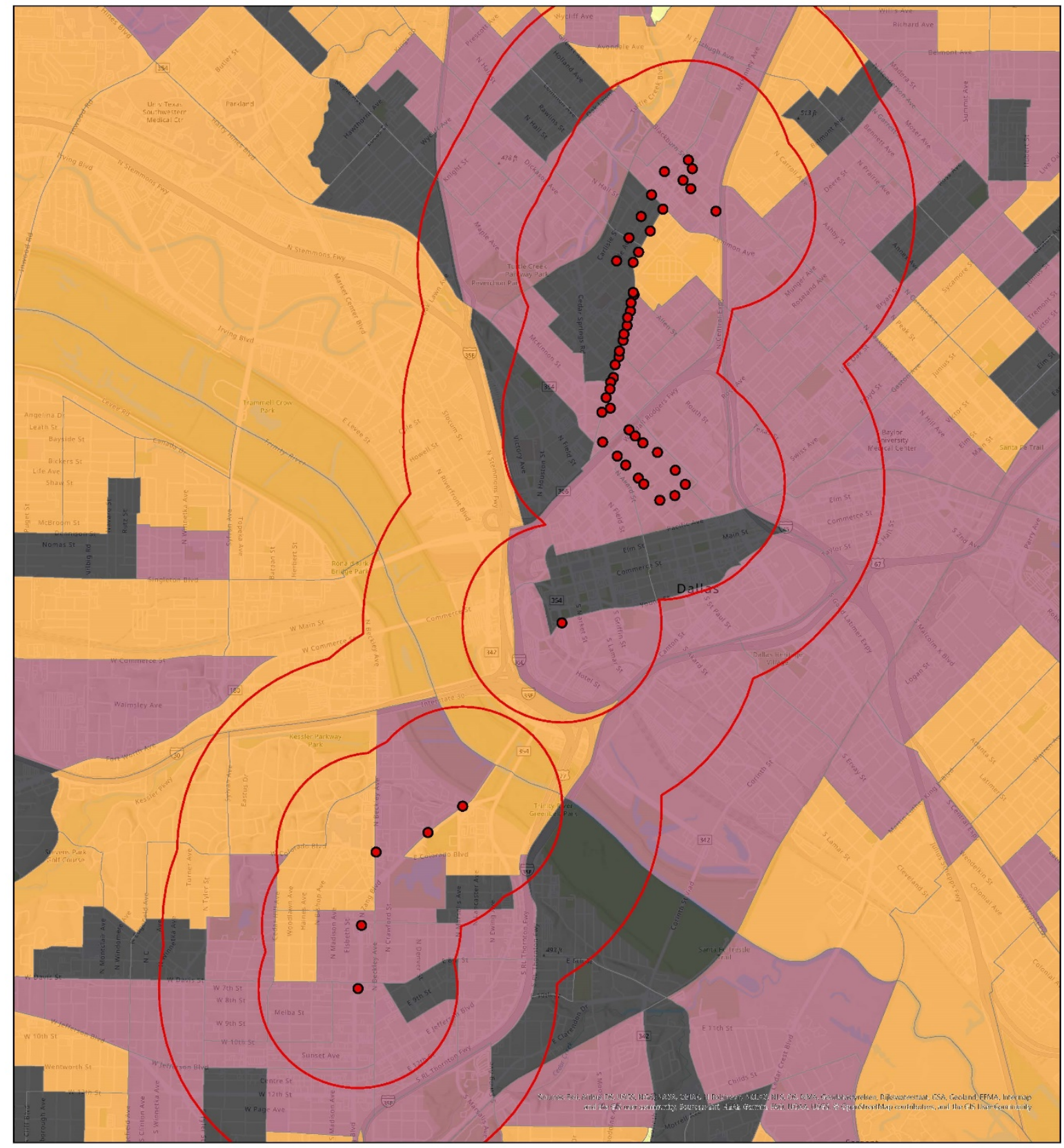

Station Typology for Streetcar Transit:

Dallas-Fort Worth-Arlington, TX

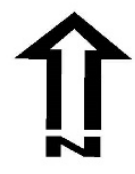

Buffers: Half \& 1 Mile

$\square$ SCT Buffers

Station Types

-High MA

mod MA

Low MA

$\square$ Poor MA

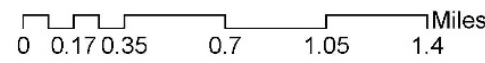




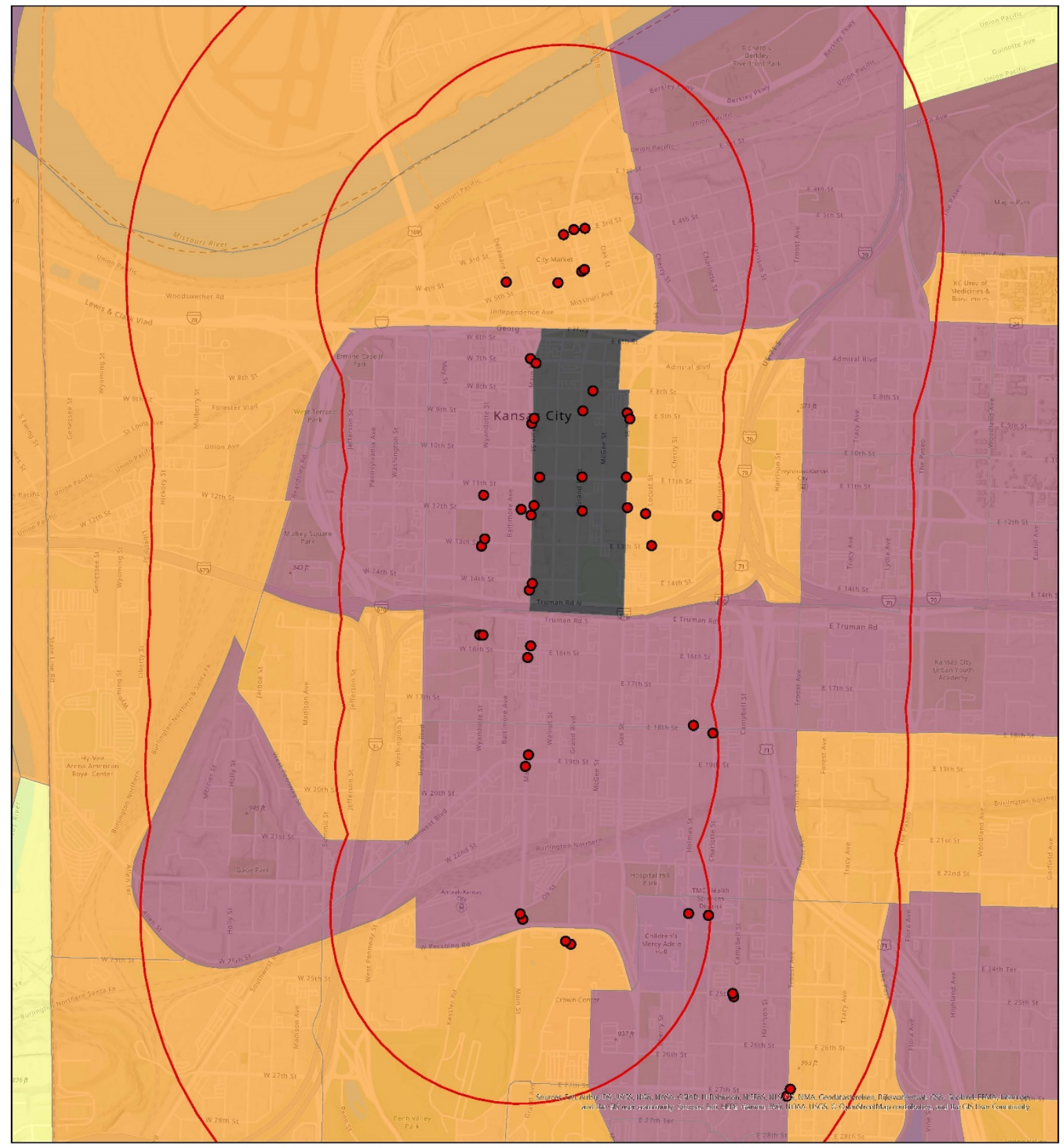

Station Typology for Streetcar Transit: Kansas City, MO-KS

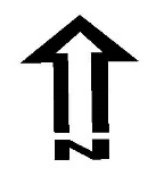

Buffers: Half \& 1 Mile 口SCT Buffers Station Types

- High MA

Mod MA

Low MA

$\square$ Poor MA

\begin{tabular}{lllll}
$\neg$ & \multicolumn{1}{l}{ Miles } \\
0 & 0.070 .15 & 0.3 & 0.45 & 0.6
\end{tabular} 


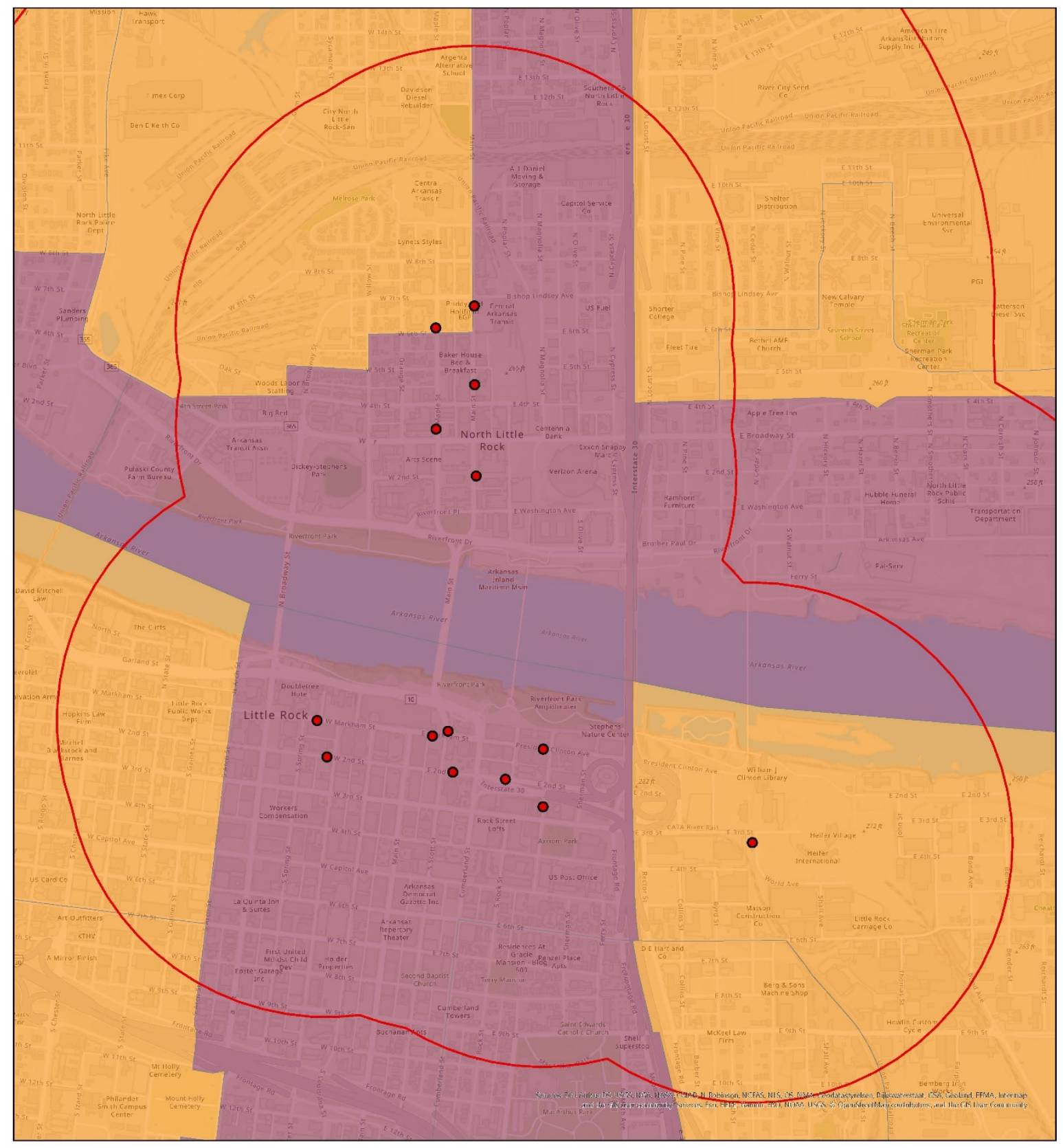

Station Typology for Streetcar Transit: Little Rock-North Little Rock-Conway, AR

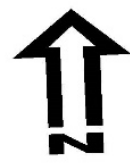

Buffers: Half \& 1 Mile 口SCT Buffers

Station Types

- High MA

- Mod MA

Low MA

$\square$ Poor MA

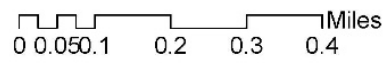




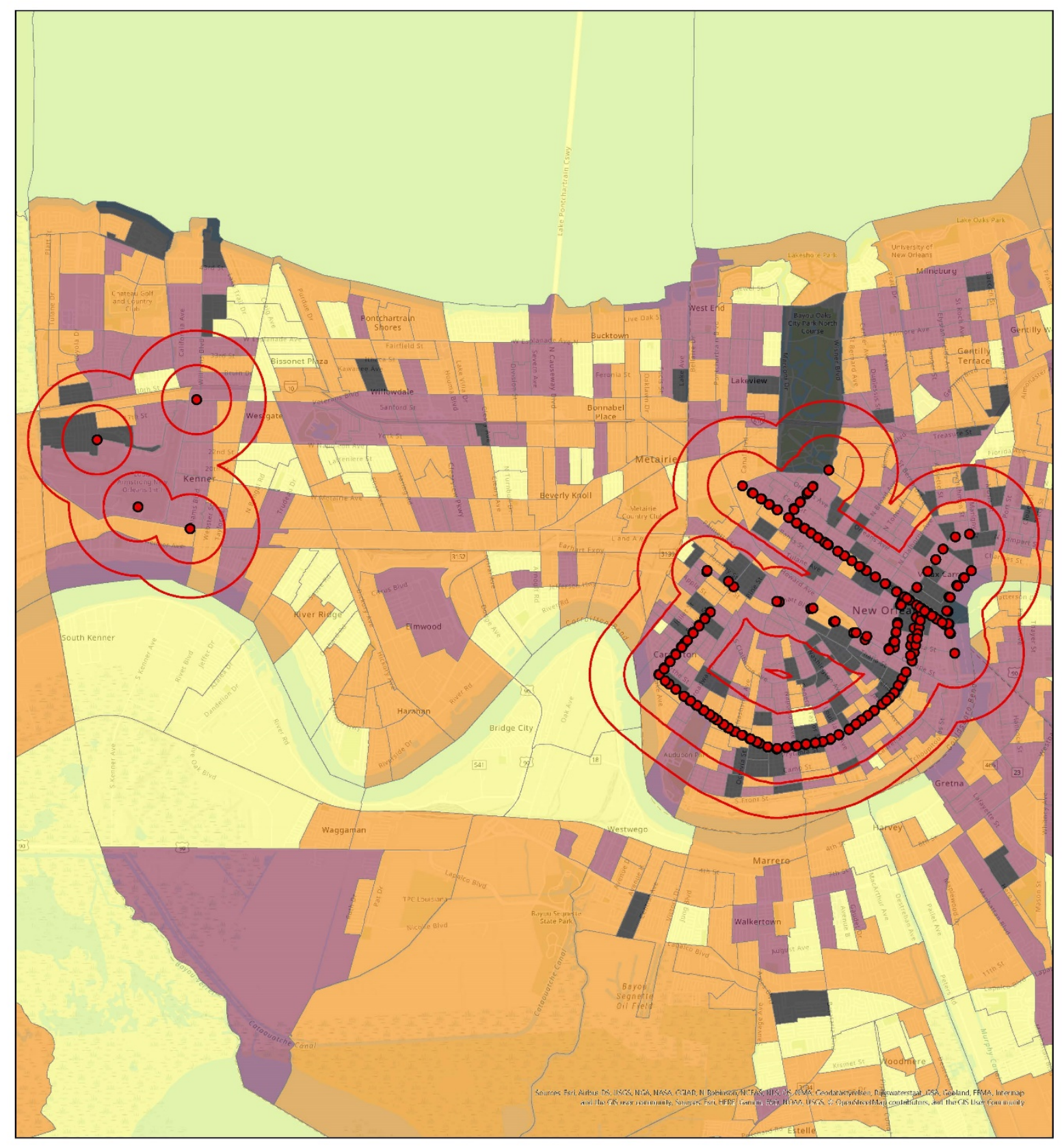

Station Typology for Streetcar Transit: New Orleans-Metairie, LA

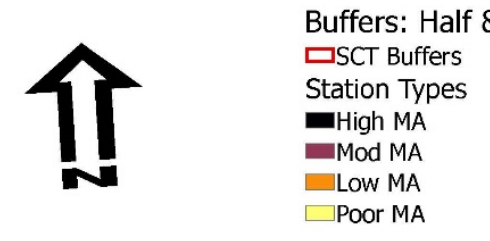

Buffers: Half \& 1 Mile $\square$ SCT Buffers

-High MA

Low MA

Poor MA

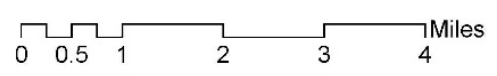




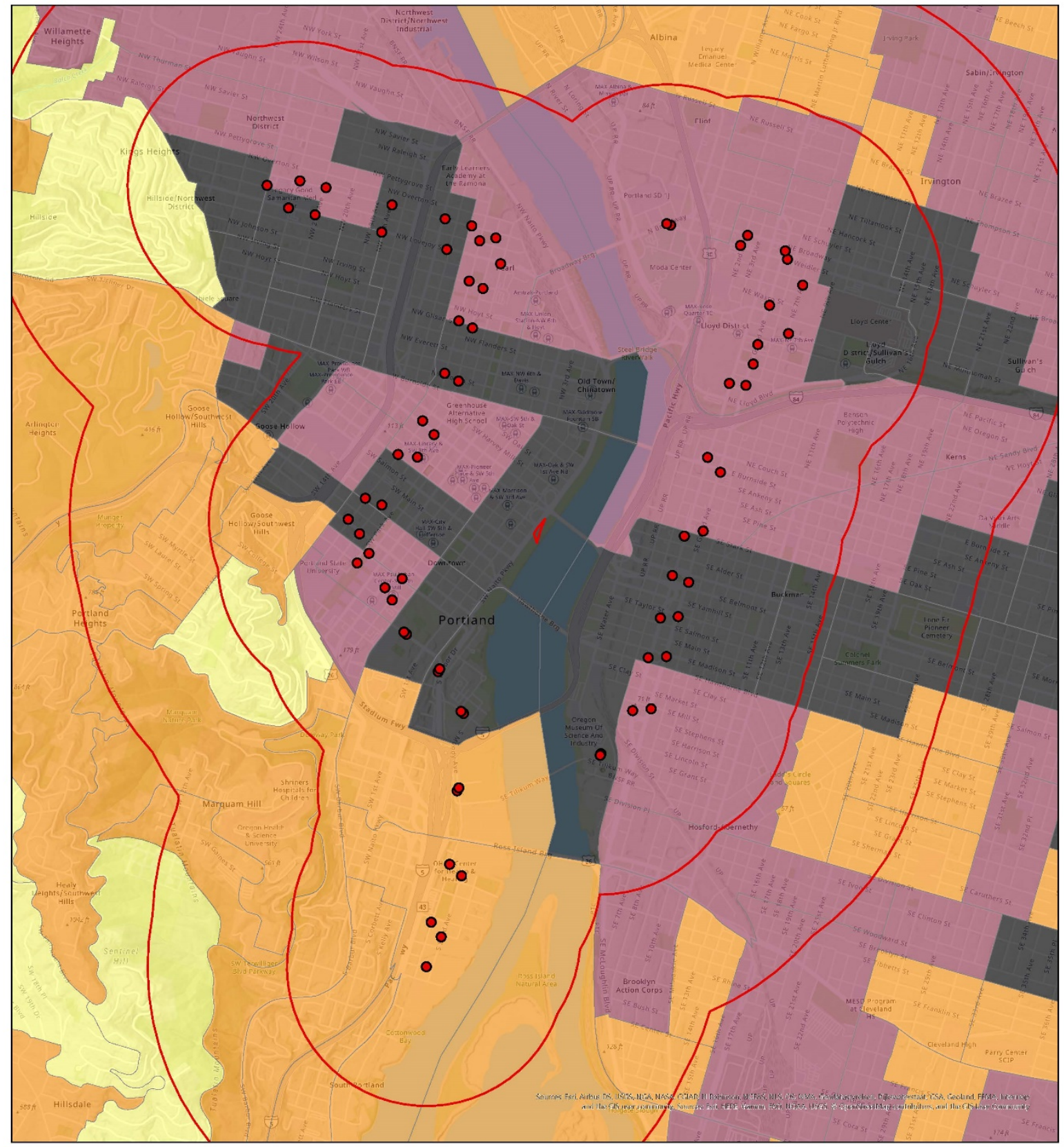

Station Typology for Streetcar Transit: Portland-Vancouver-Hillsboro, OR-WA

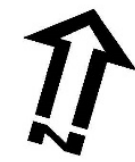

Buffers: Half \& 1 Mile $\square$ SCT Buffers Station Types

- High MA

mod MA

Low MA

$\square$ Poor MA

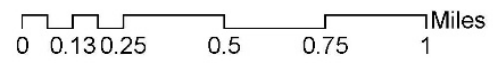




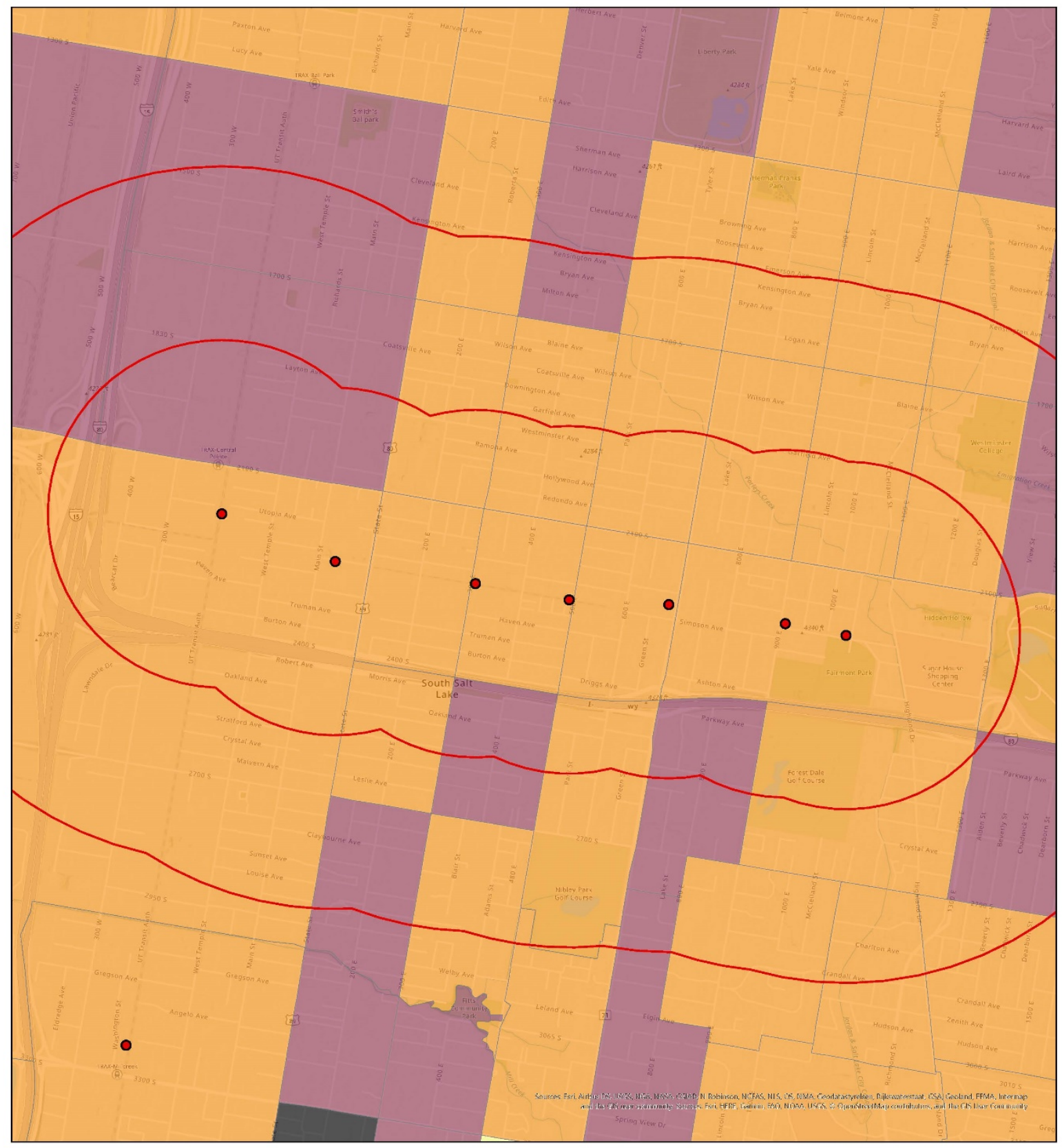

Station Typology for Streetcar Transit: Salt Lake City, UT

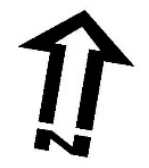

Buffers: Half \& 1 Mile $\square$ SCT Buffers Station Types

- High MA

mod MA

Low MA

$\square$ Poor MA

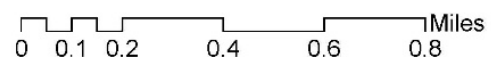




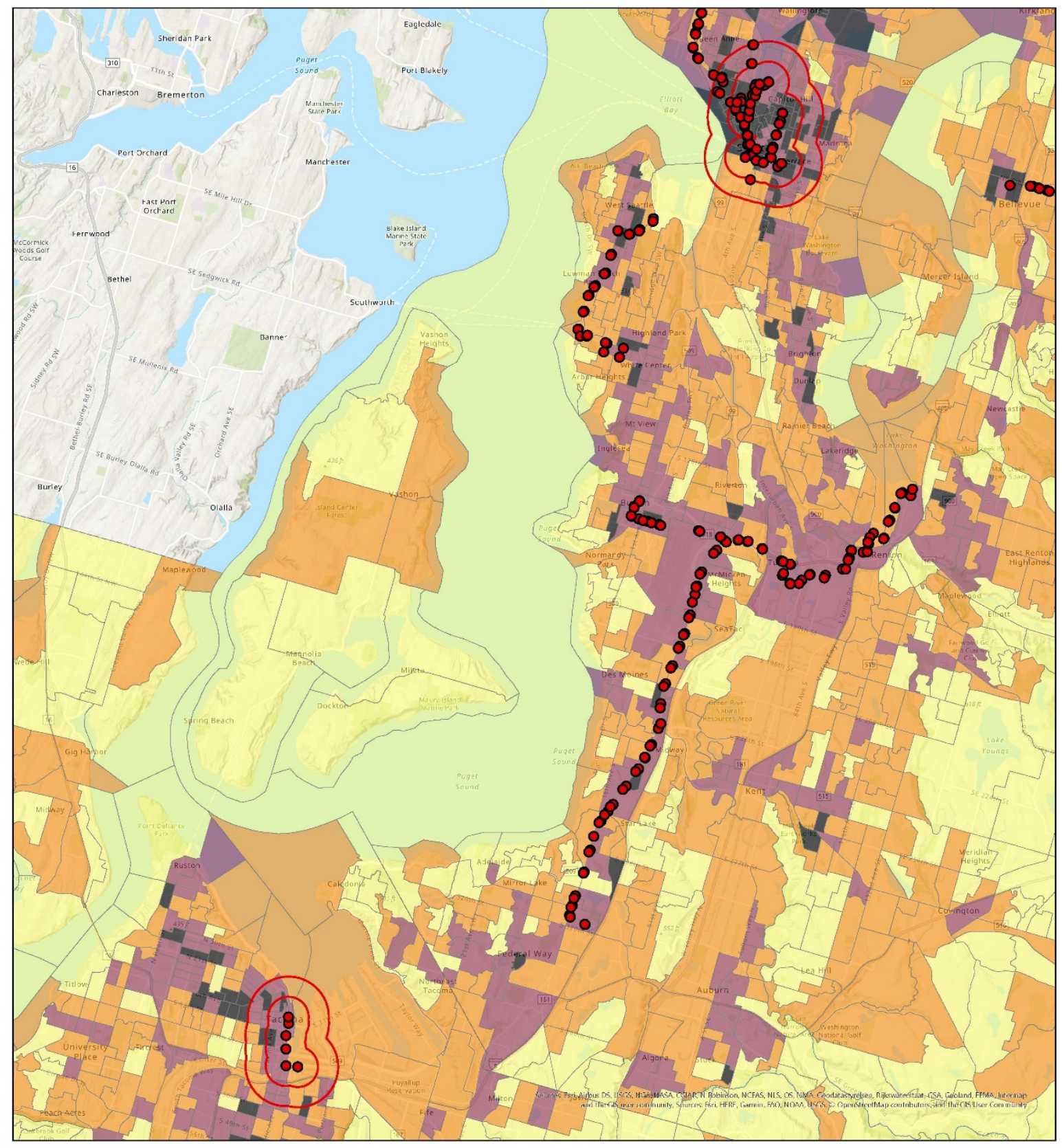

Station Typology for Streetcar Transit: Seattle-Tacoma-Bellevue, WA

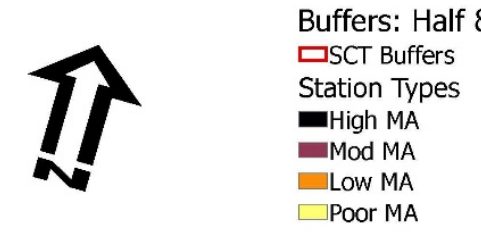

Buffers: Half \& 1 Mile

Station Types

-High MA

Low MA

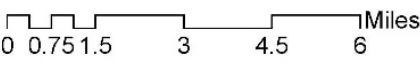




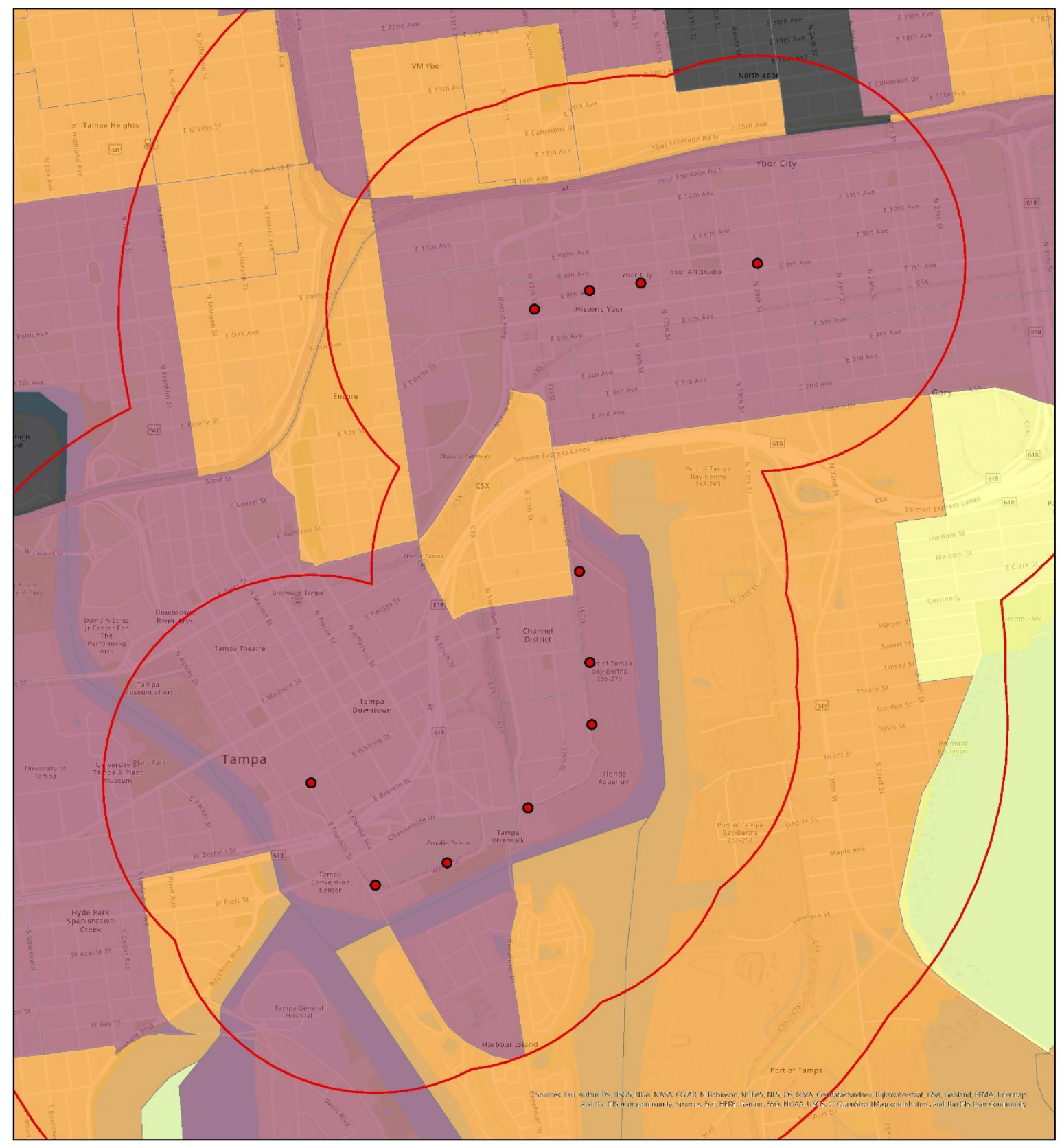

Station Typology for Streetcar Transit: Tampa-St. Petersburg-Clearwater, FL

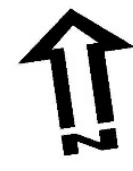

Buffers: Half \& 1 Mile 口SCT Buffers

Station Types

- High MA

$\square$ Mod MA

Low MA

$\square$ Poor MA

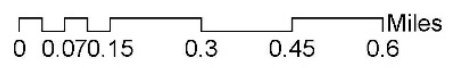




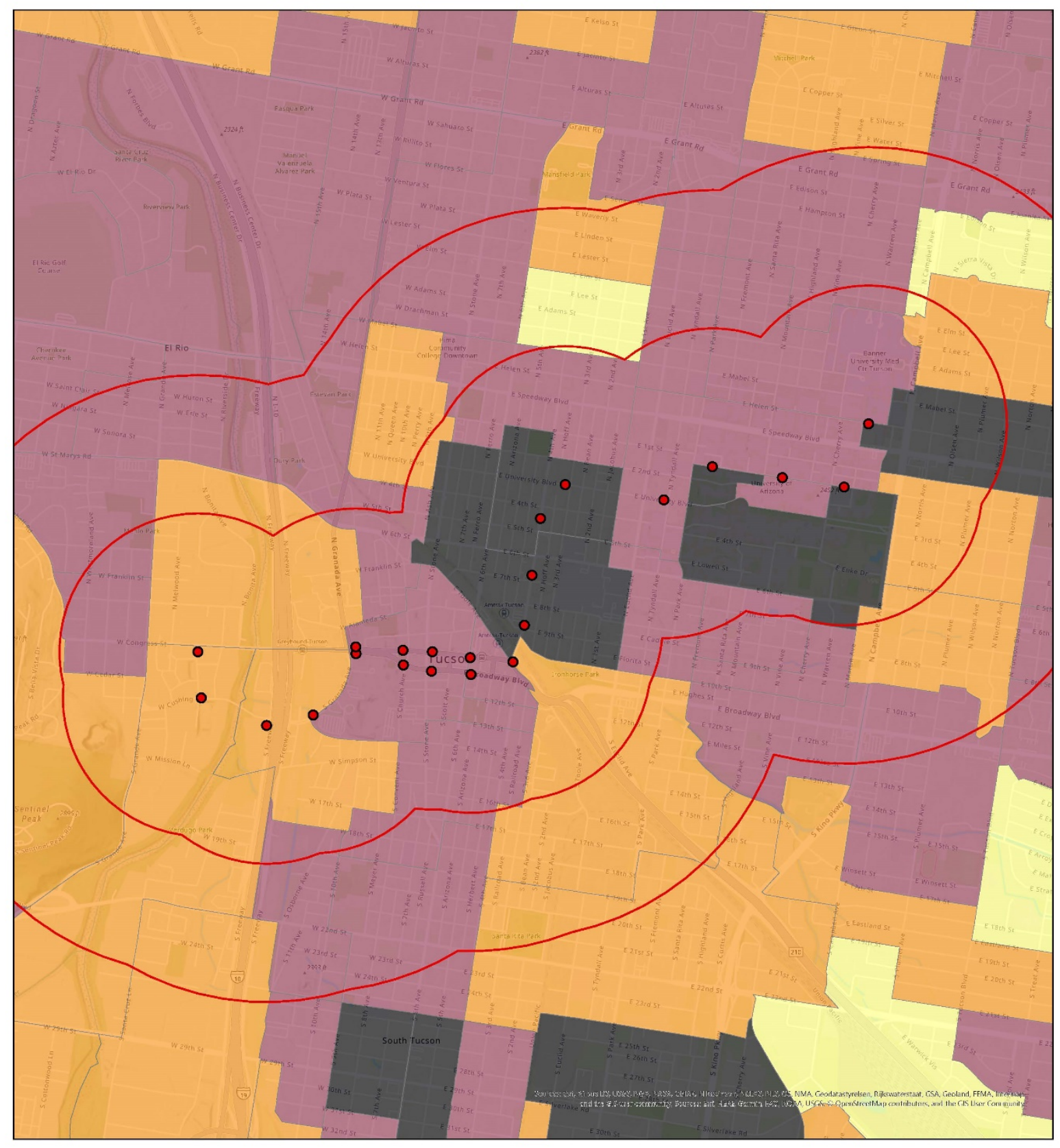

Station Typology for Streetcar Transit: Tucson, AZ

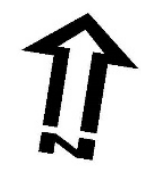

Buffers: Half \& 1 Mile $\square$ SCT Buffers Station Types

-High MA

Mod MA

Low MA

$\square$ Poor MA

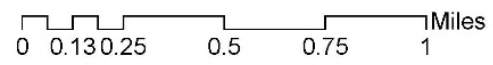




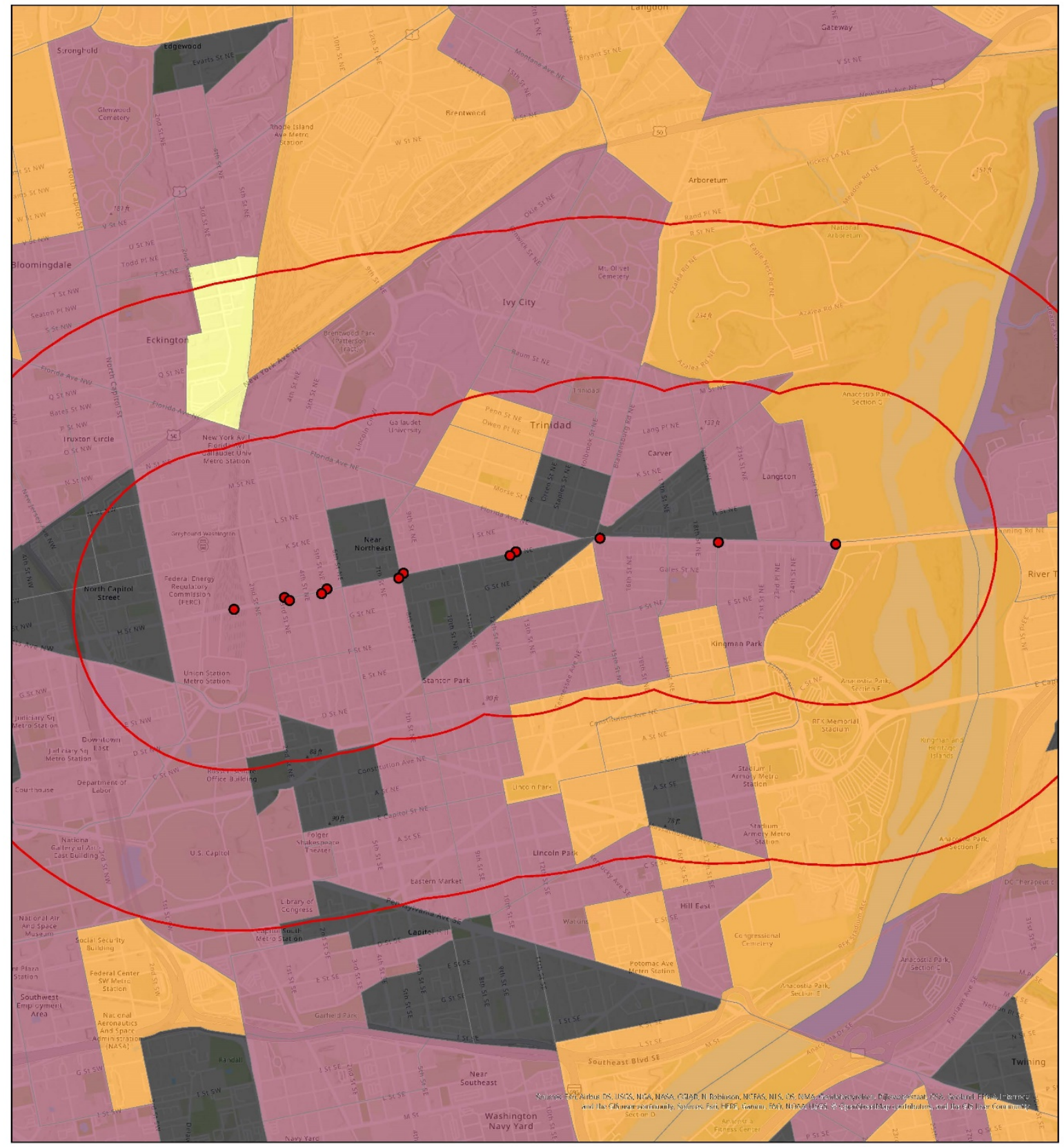

Station Typology for Streetcar Transit: Washington-Arlington-Alexandria, DC-VA-MDWV

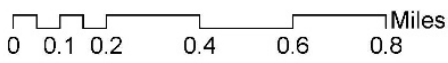

Buffers: Half \& 1 Mile $\square$ SCT Buffers Station Types

- High MA

- Mod MA

Low MA

$\square$ Poor MA 
APPENDIX C.3

This section contains maps for all Commuter Rail Transit systems in the study.

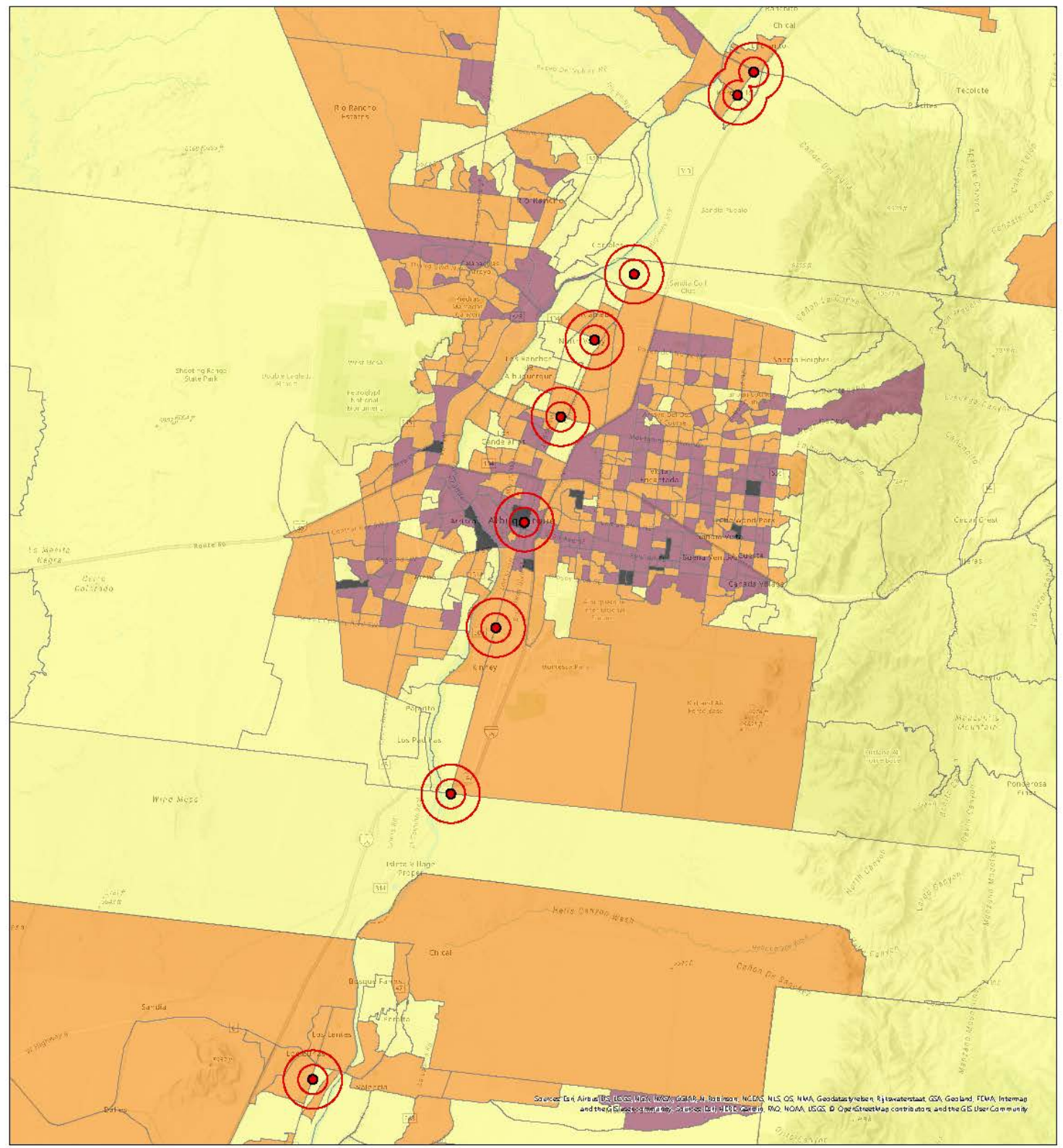

Station Typology for Commuter Rail Transit:

Buffers: Half \& 1 Mile Albuquerque, NM

$\square$ CRT Buffers

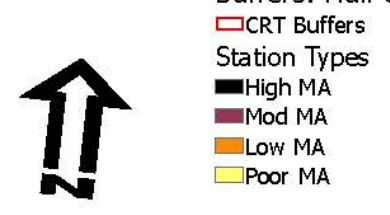

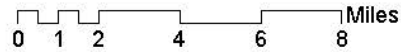




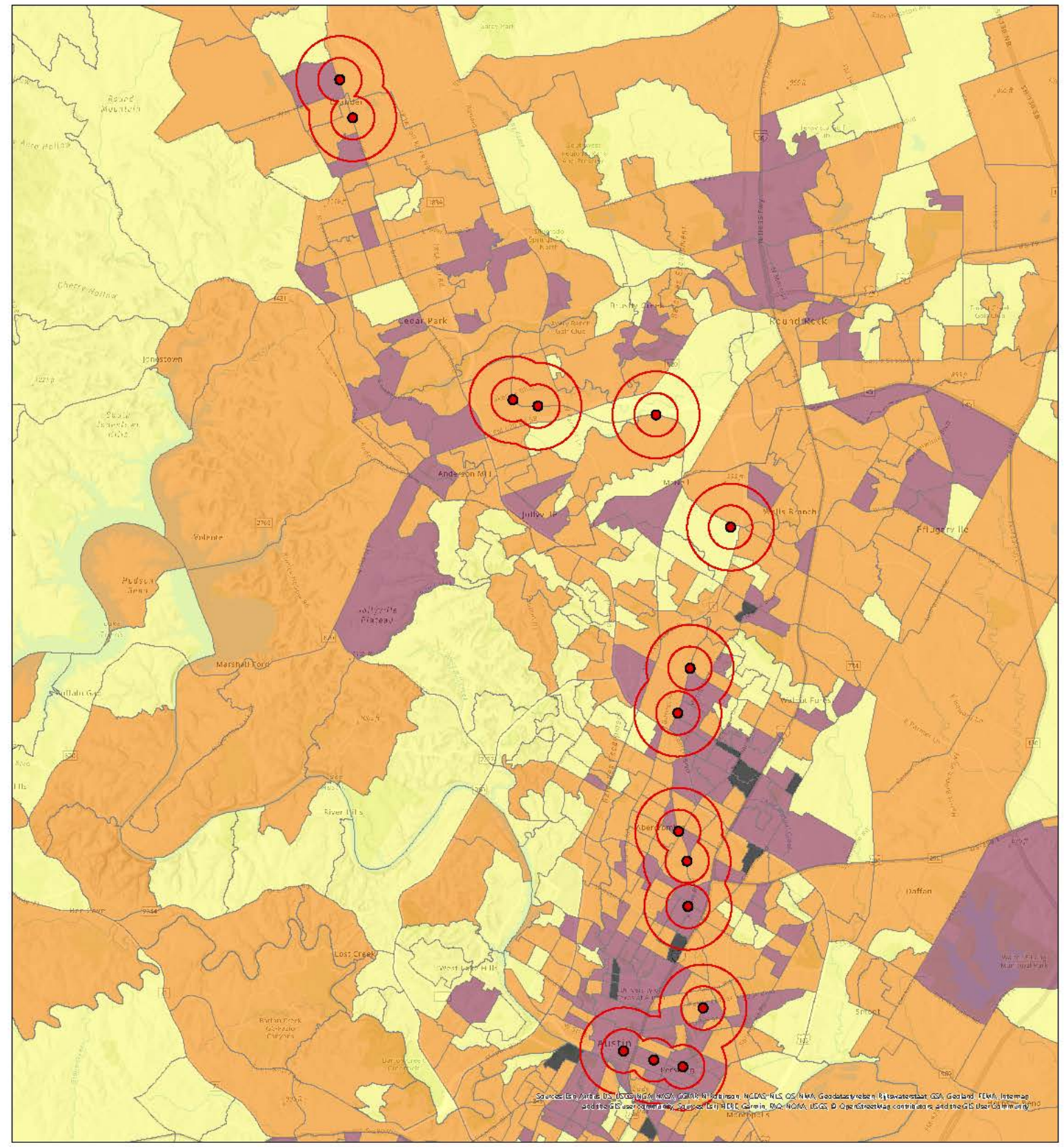

Station Typology for Commuter Rail Transit: Austin-Round Rock, TX

Buffers: Half \& 1 Mile 


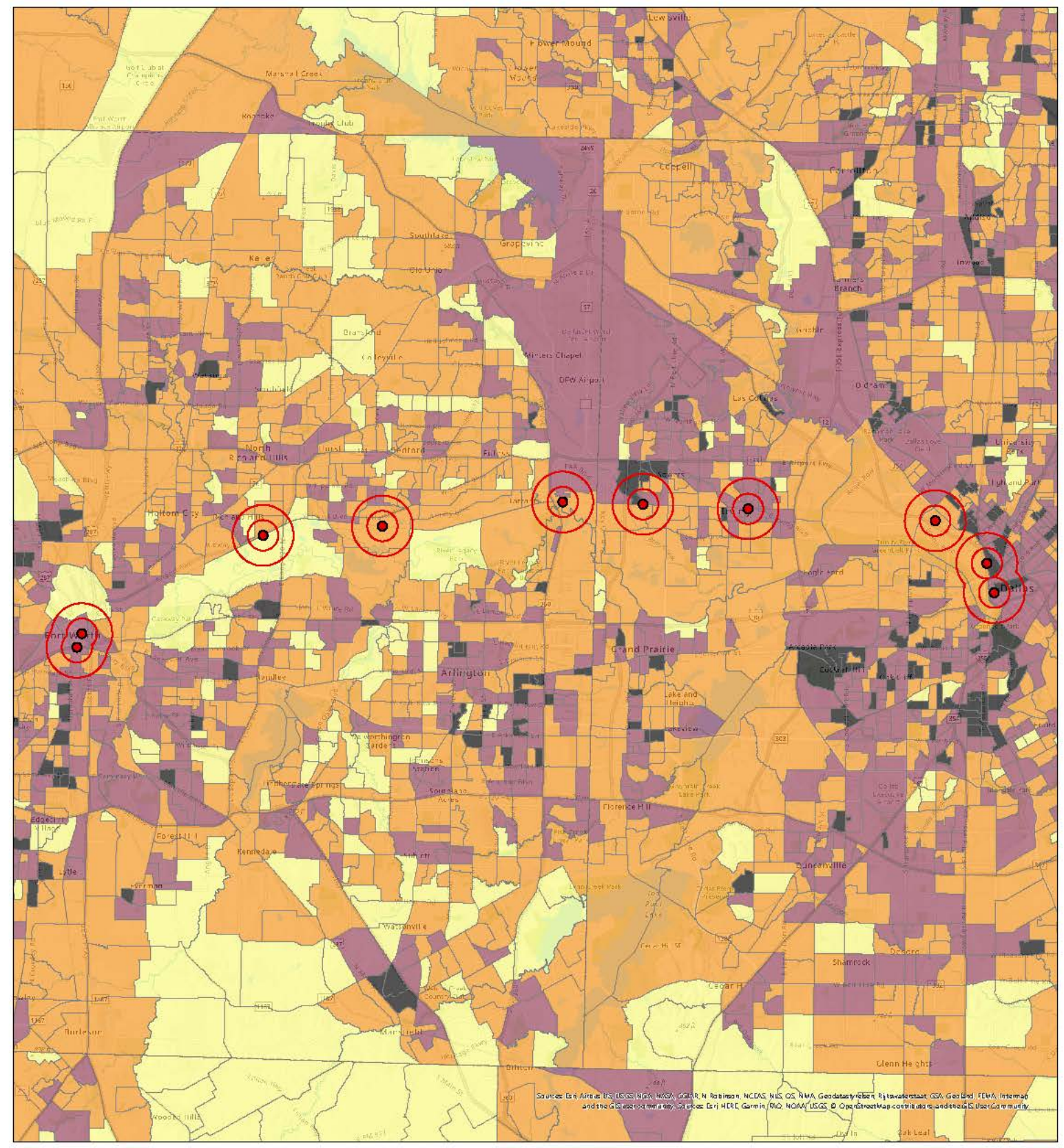

Station Typology for Commuter Rail Transit: Dallas-Fort Worth-Arlington, TX

Buffers: Half \& 1 Mile

$\square$ LoW MA

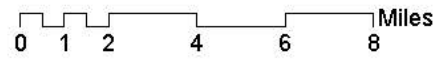




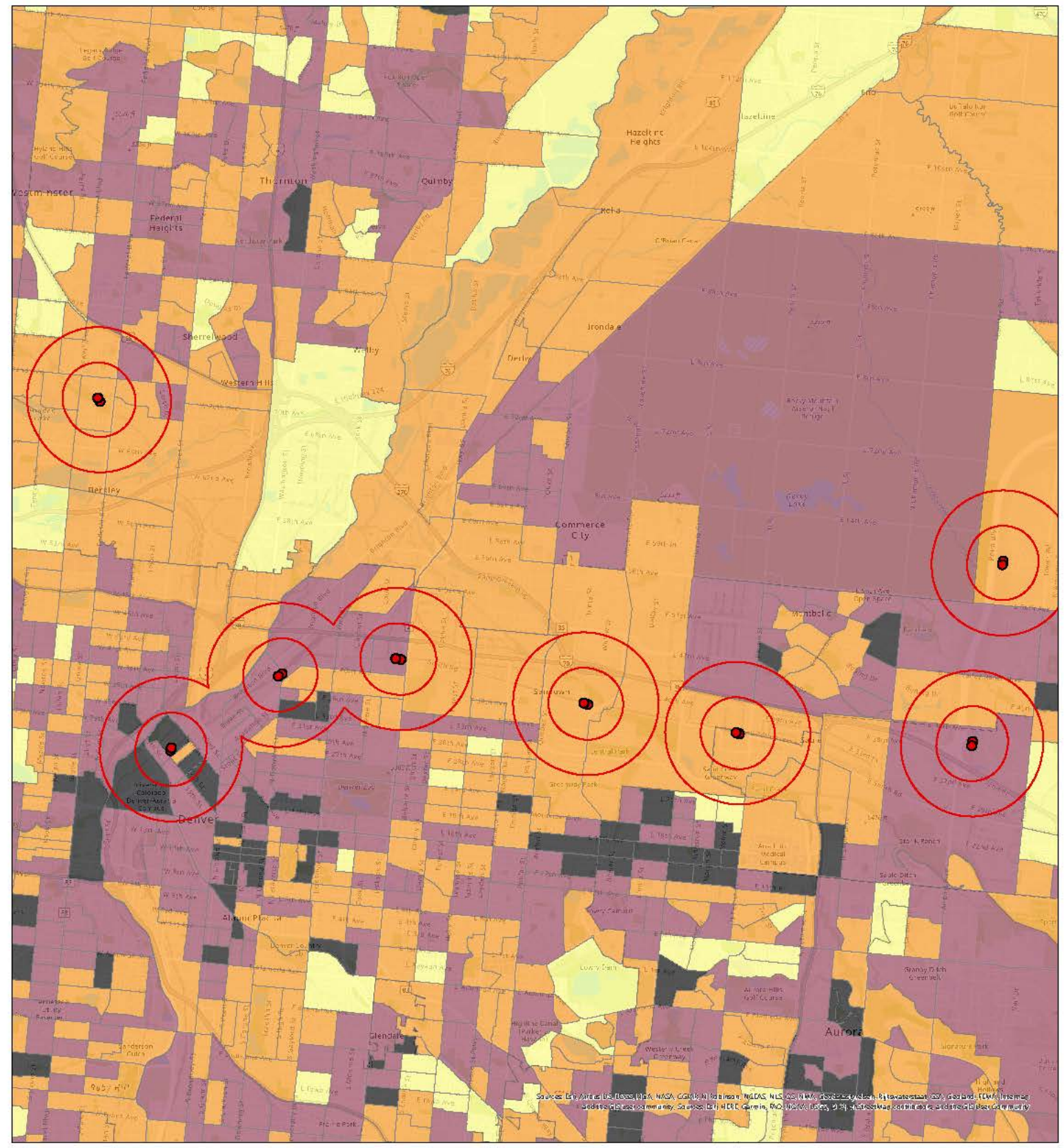

Station Typology for Commuter Rail Transit: Denver-Aurora-Lakewood, CO

Buffers: Half \& 1 Mile $\square$ CRT Buffers

Station Types

-High MA

- Mod MA

$\square$ LoW MA

$\square$ Poor MA

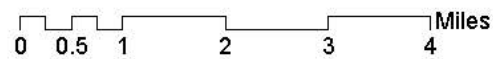




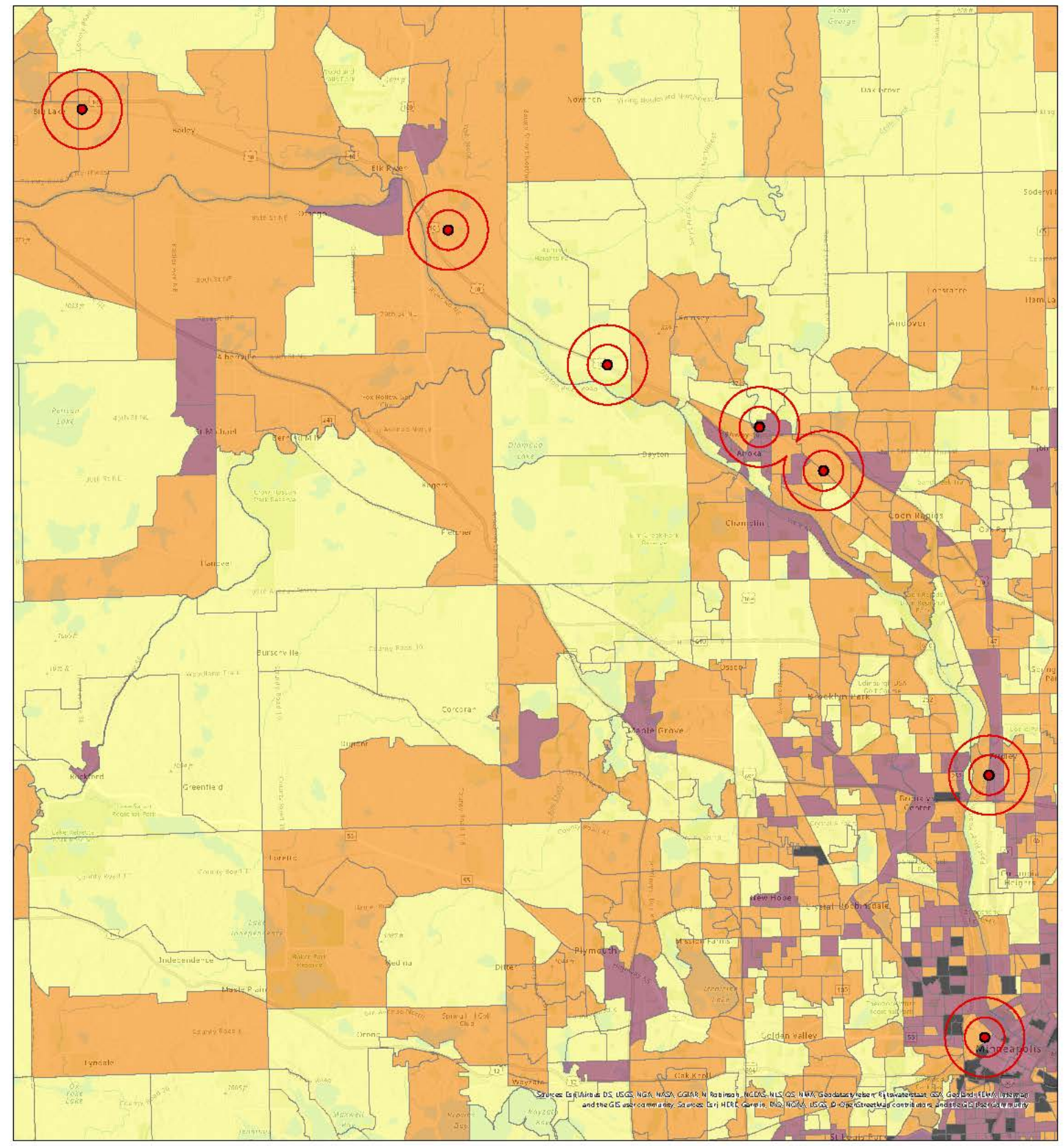

Station Typology for Commuter Rail Transit:

Buffers: Half \& 1 Mile Minneapolis-St. Paul-Bloomington, MN-WI

LOW MA

$\square$ Poor MA

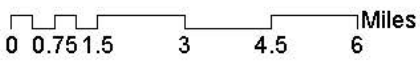




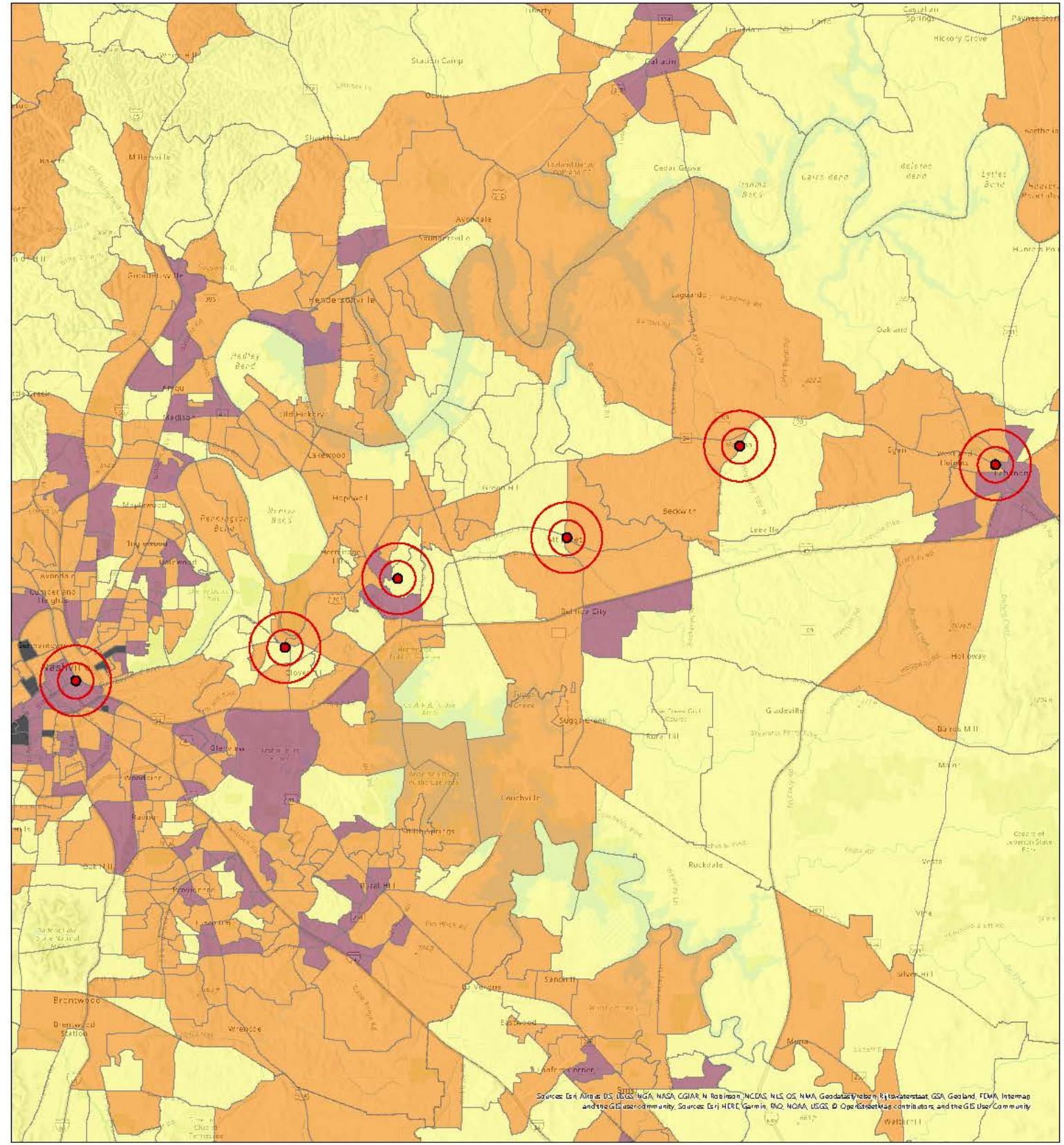

Station Typology for Commuter Rail Transit: Nashville-Davidson--Murfreesboro--Franklin, TN

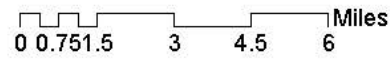

Buffers: Half \& 1 Mile $\square$ CRT Buffers

Station Types

-High MA

Mod MA

$\square$ LOW MA

$\square$ Poor MA 


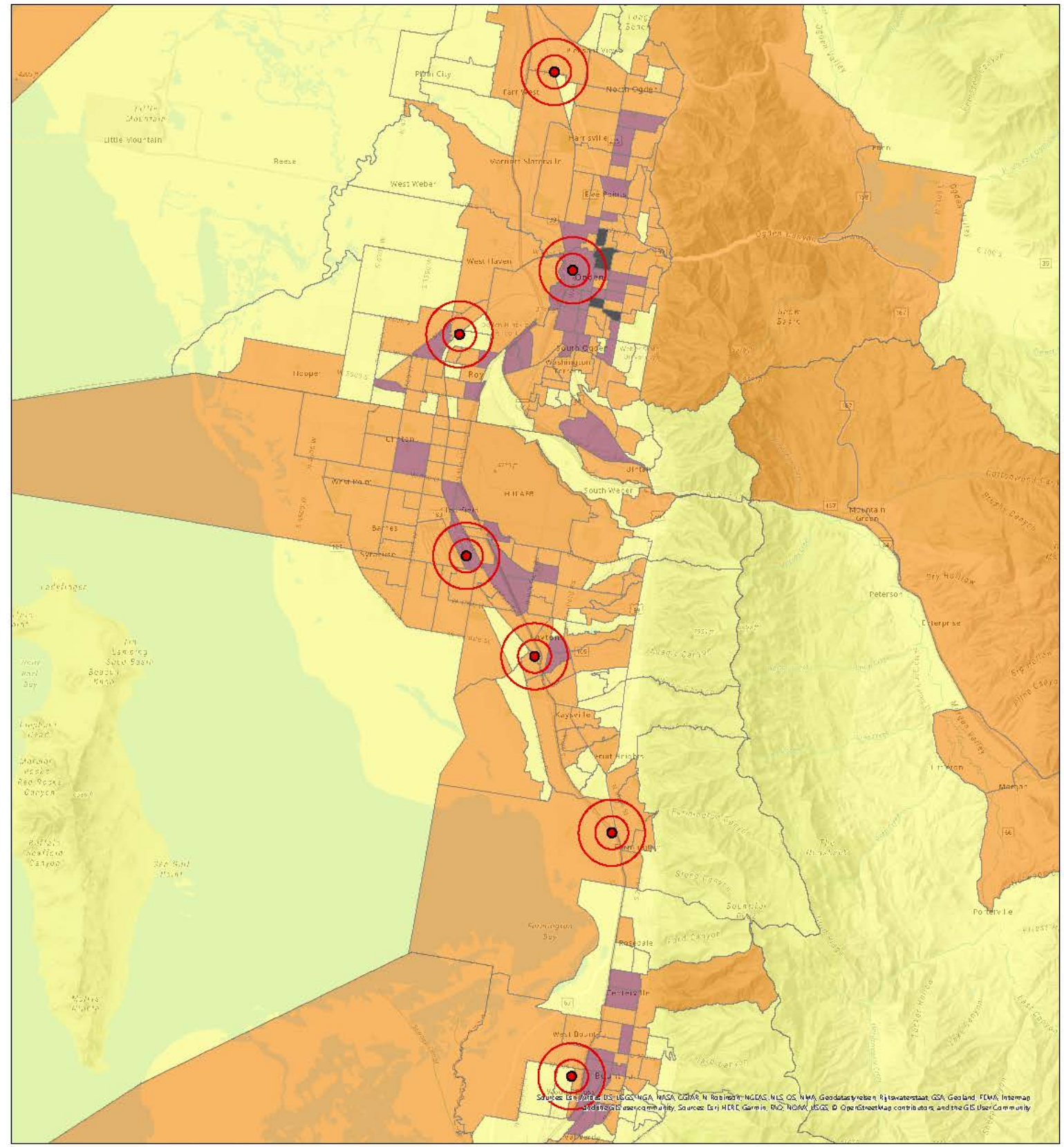

Station Typology for Commuter Rail Transit: Ogden-Clearfield, UT

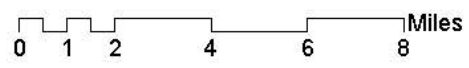

Buffers: Half \& 1 Mile $\square$ CRT Buffers

Station Types

-High MA

Mod MA

LOW MA

$\square$ Poor MA 


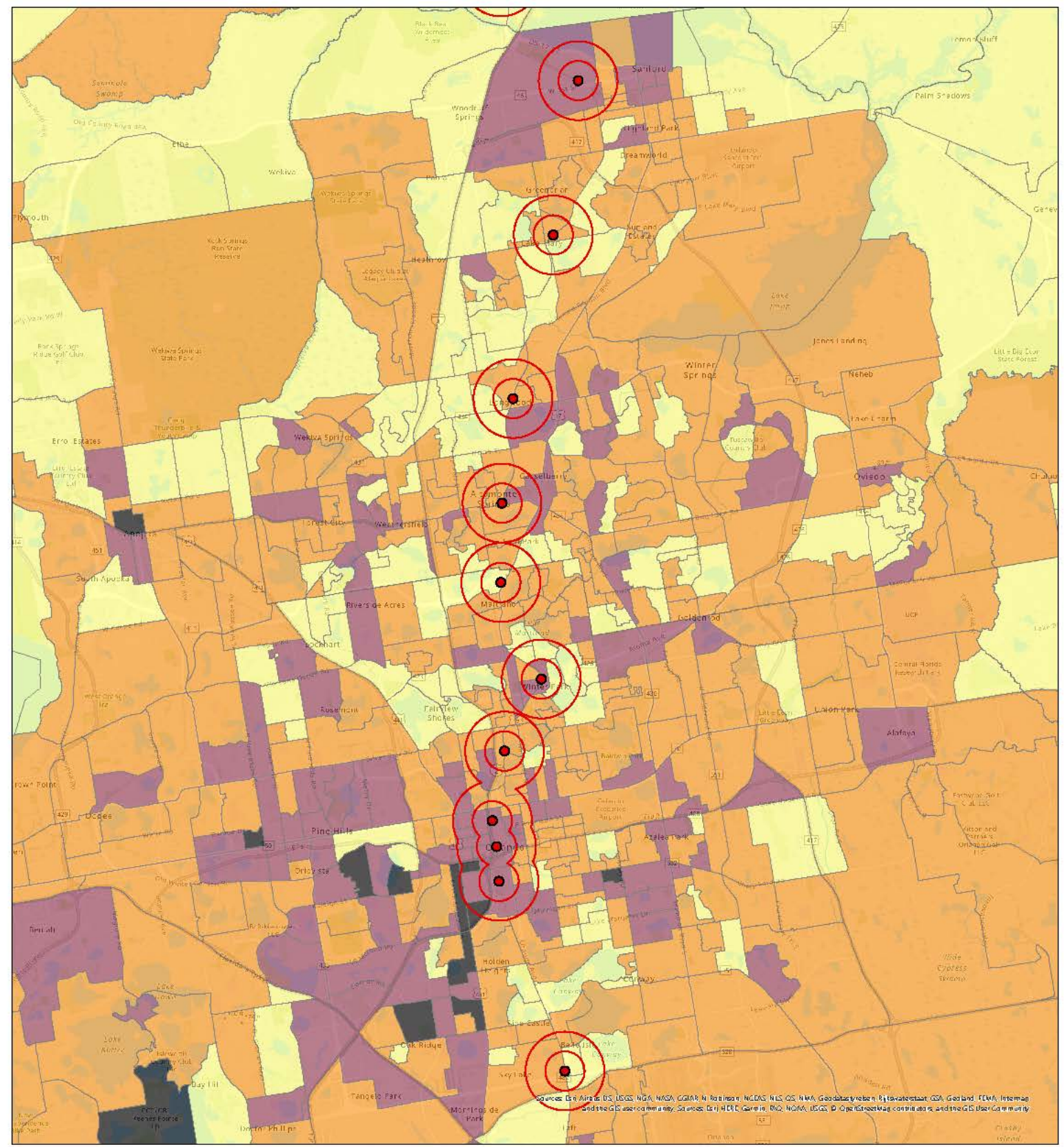

Station Typology for Commuter Rail Transit:

Buffers: Half \& 1 Mile Orlando-Kissimmee-Sanford, FL

Station Types
High MA
Mod MA
Low MA
$\square$ Poor MA

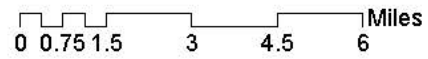




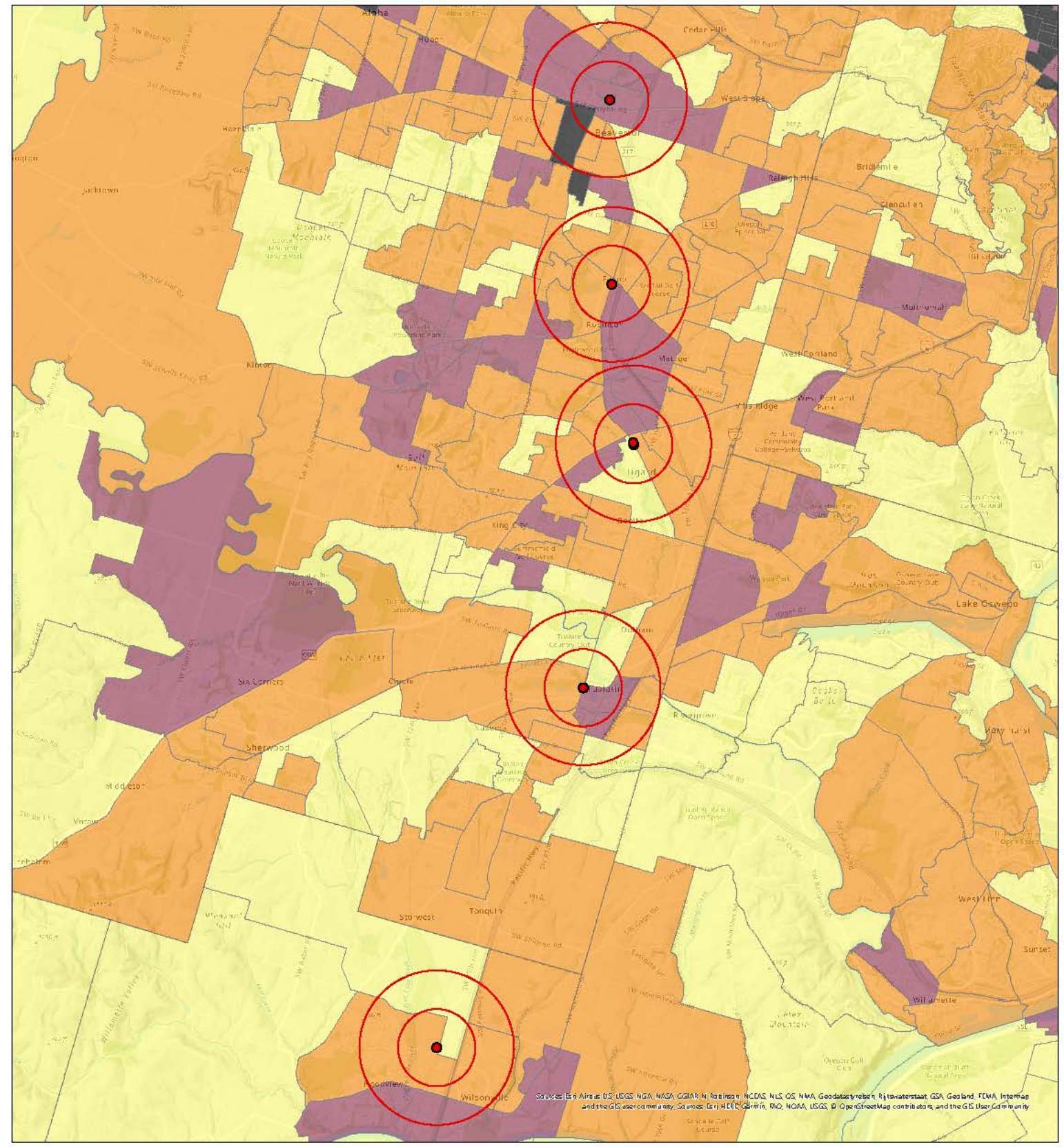

Station Typology for Commuter Rail Transit: Portland-Vancouver-Hillsboro, OR-WA

Buffers: Half \& 1 Mile

LOW MA

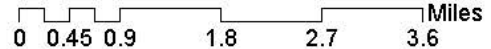




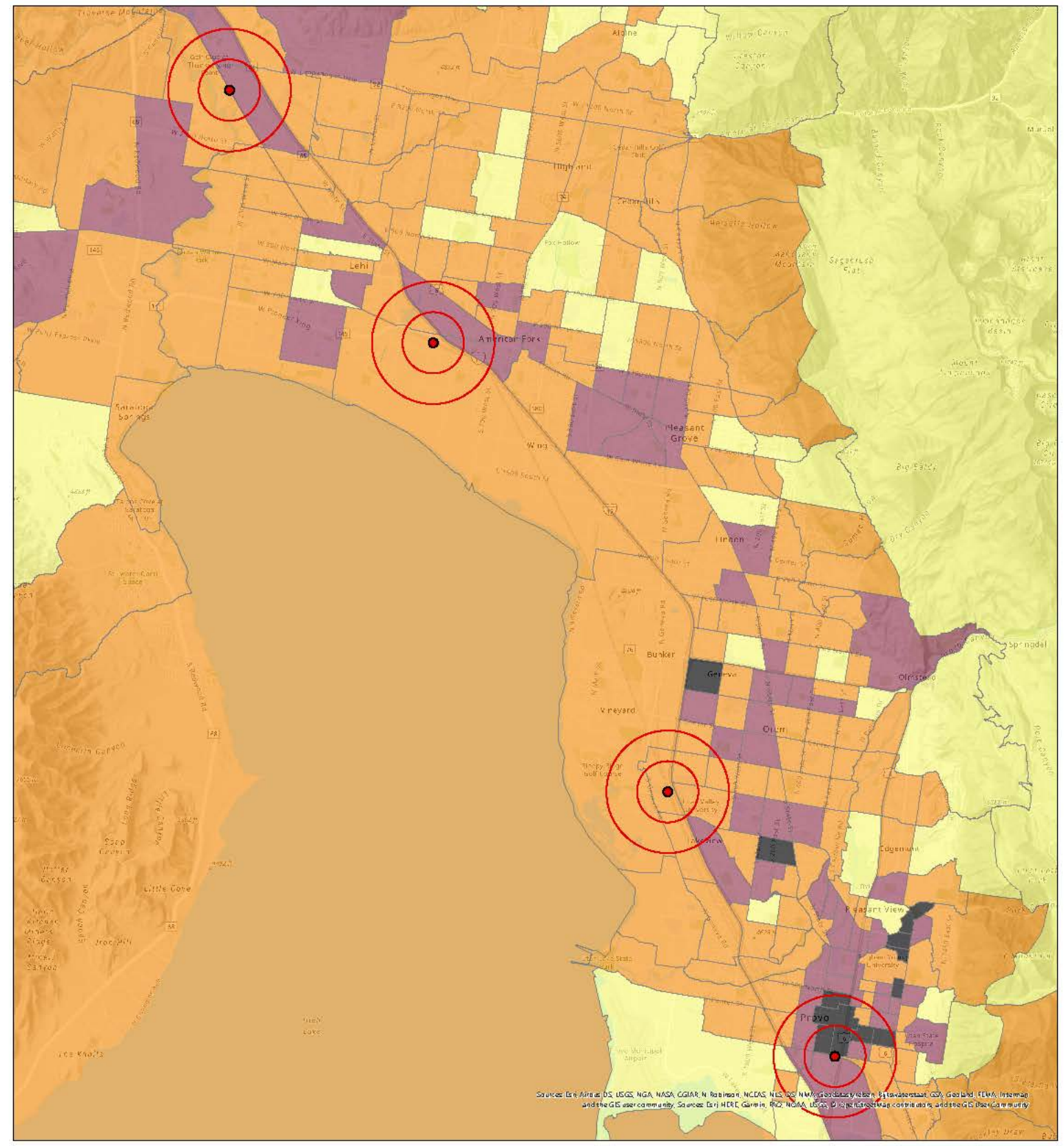

Station Typology for Commuter Rail Transit: Provo-Orem, UT

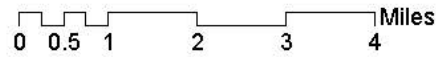

Buffers: Half \& 1 Mile $\square$ CRT Buffers

Station Types

-High MA

- Mod MA

Low MA

$\square$ Poor MA 


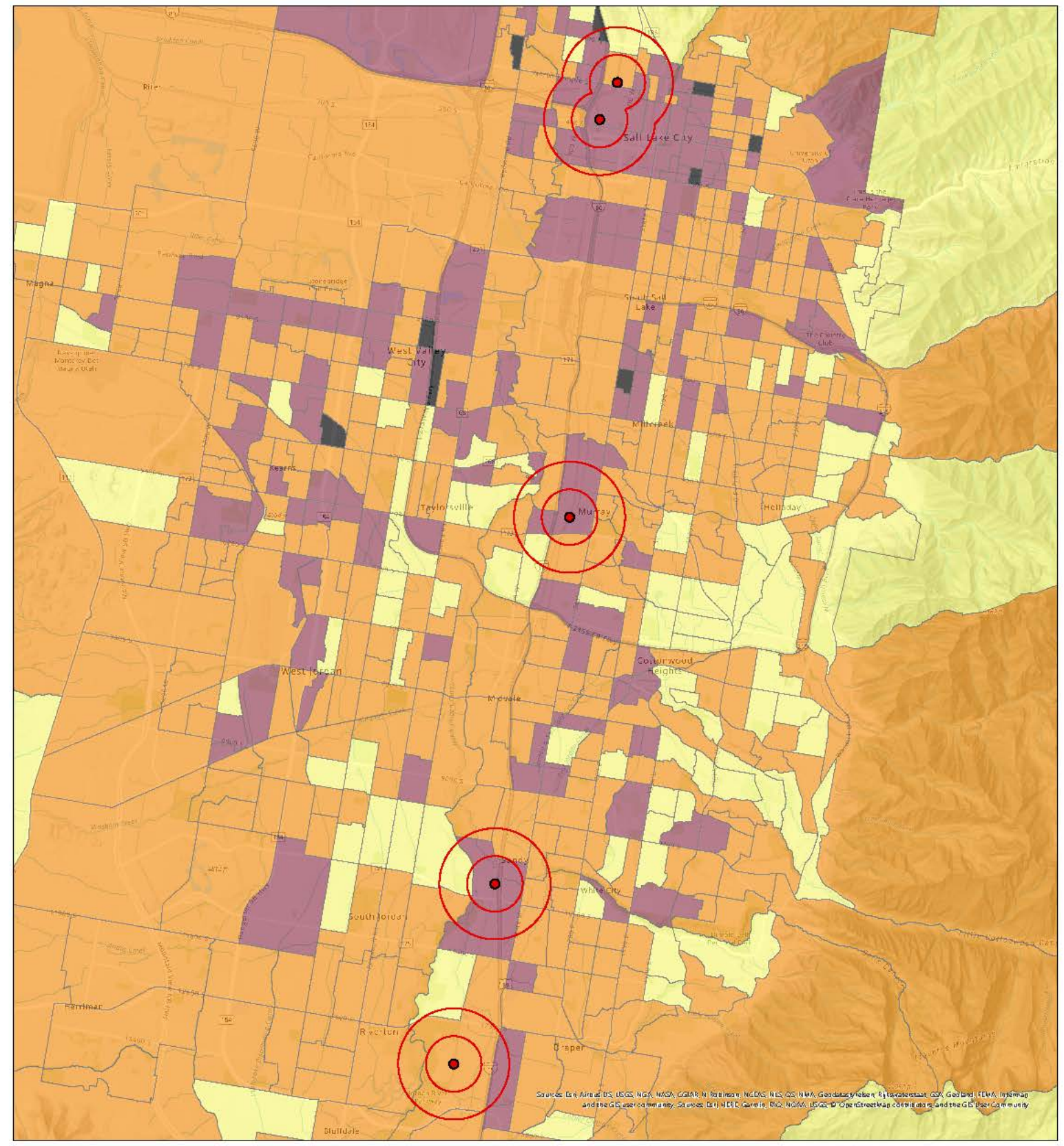

Station Typology for Commuter Rail Transit: Salt Lake City, UT

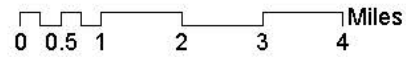

Buffers: Half \& 1 Mile $\square$ CRT Buffers

Station Types

-High MA

Mod MA

Low MA

$\square$ Poor MA 


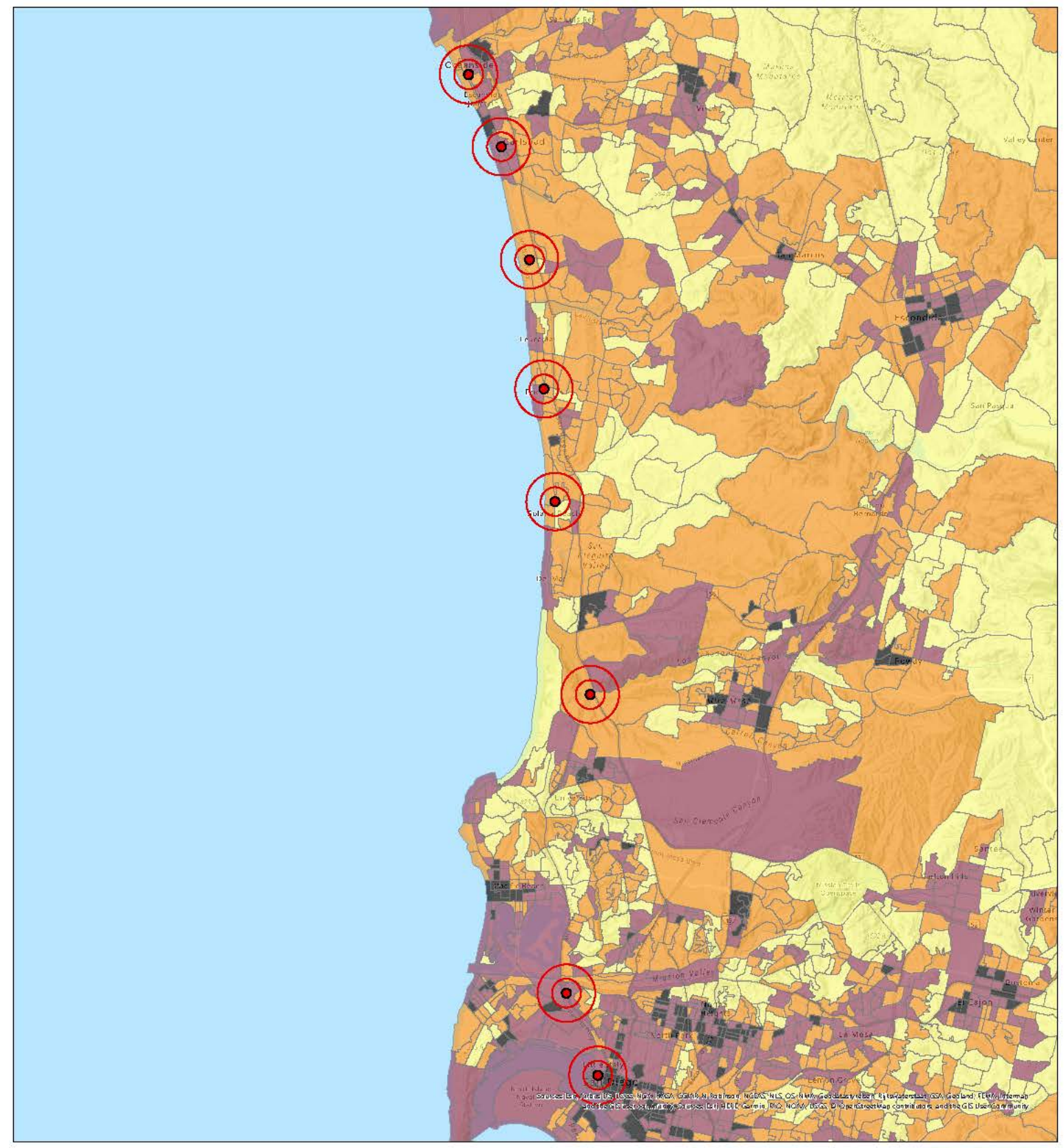

Station Typology for Commuter Rail Transit: San Diego-Carlsbad, CA

Buffers: Half \& 1 Mile
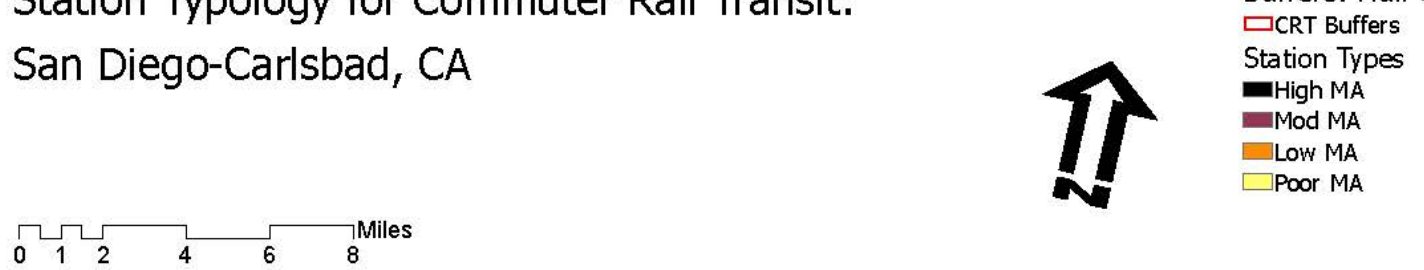


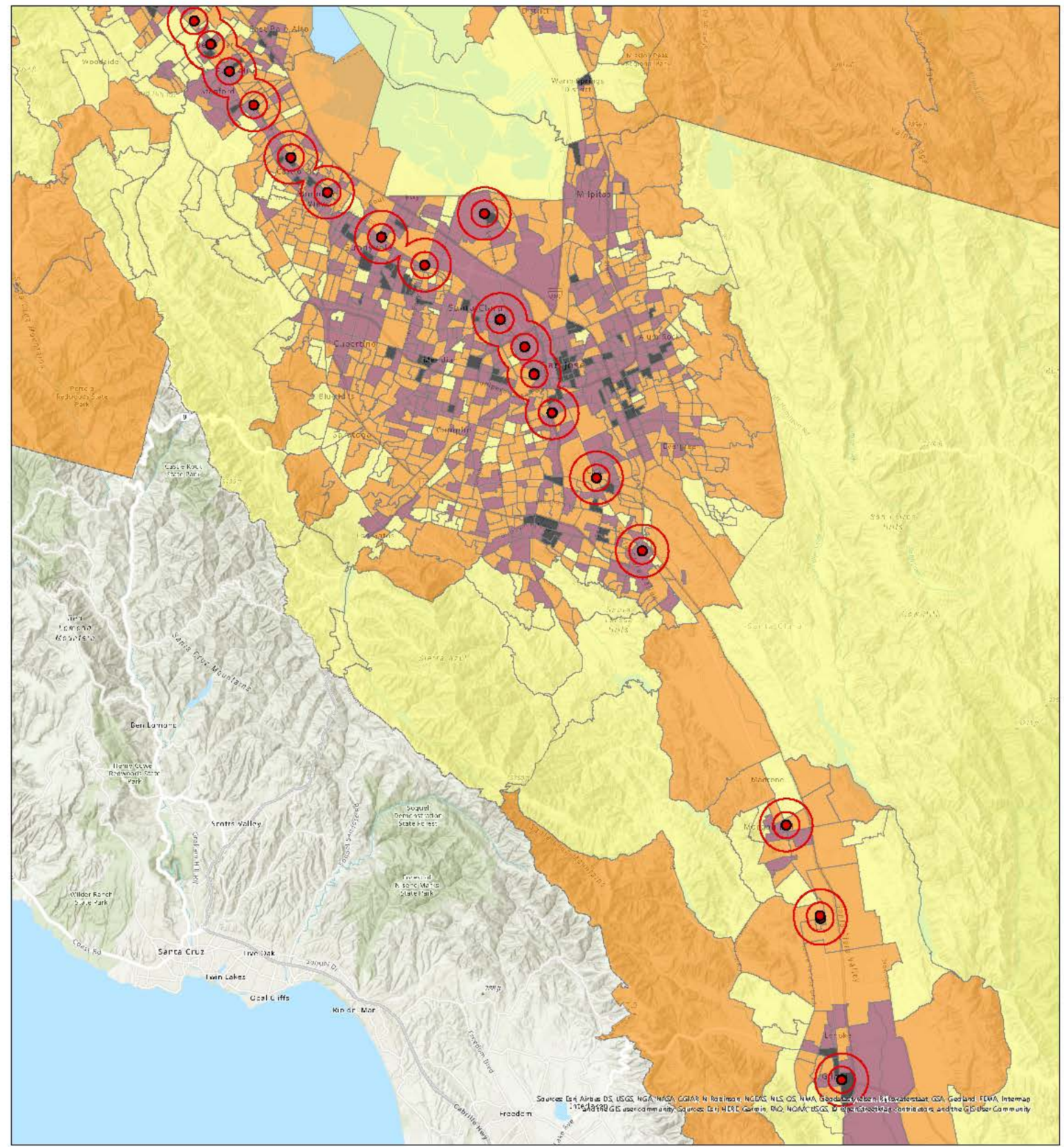

Station Typology for Commuter Rail Transit: San Jose-Sunnyvale-Santa Clara, CA

Buffers: Half \& 1 Mile

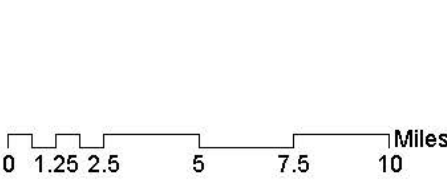




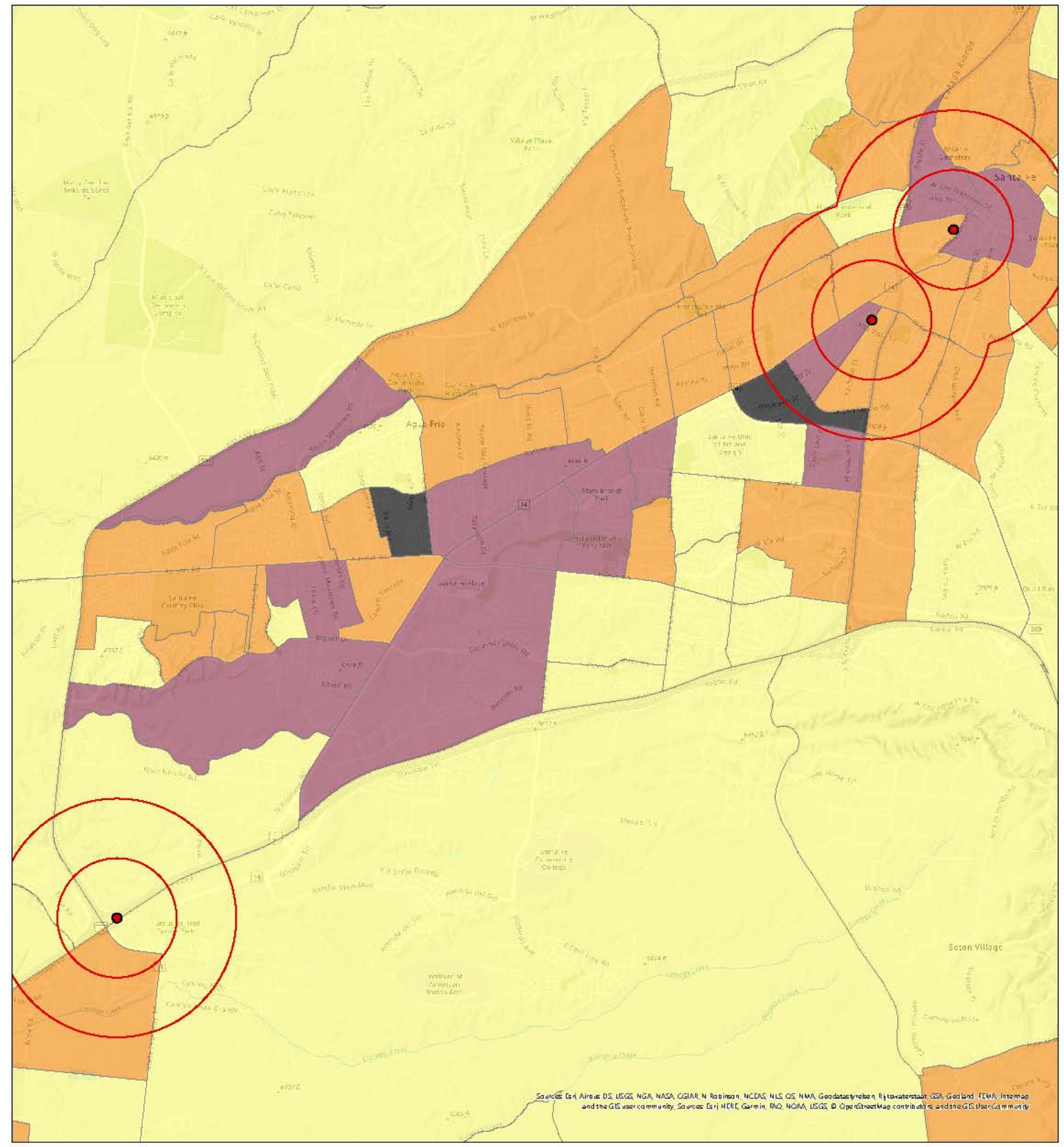

Station Typology for Commuter Rail Transit: Santa Fe, NM

Buffers: Half \& 1 Mile

$\square$ CRT Buffers

Station Types

-High MA

Mod MA

$\square$ LOW MA

$\square$ Poor MA 


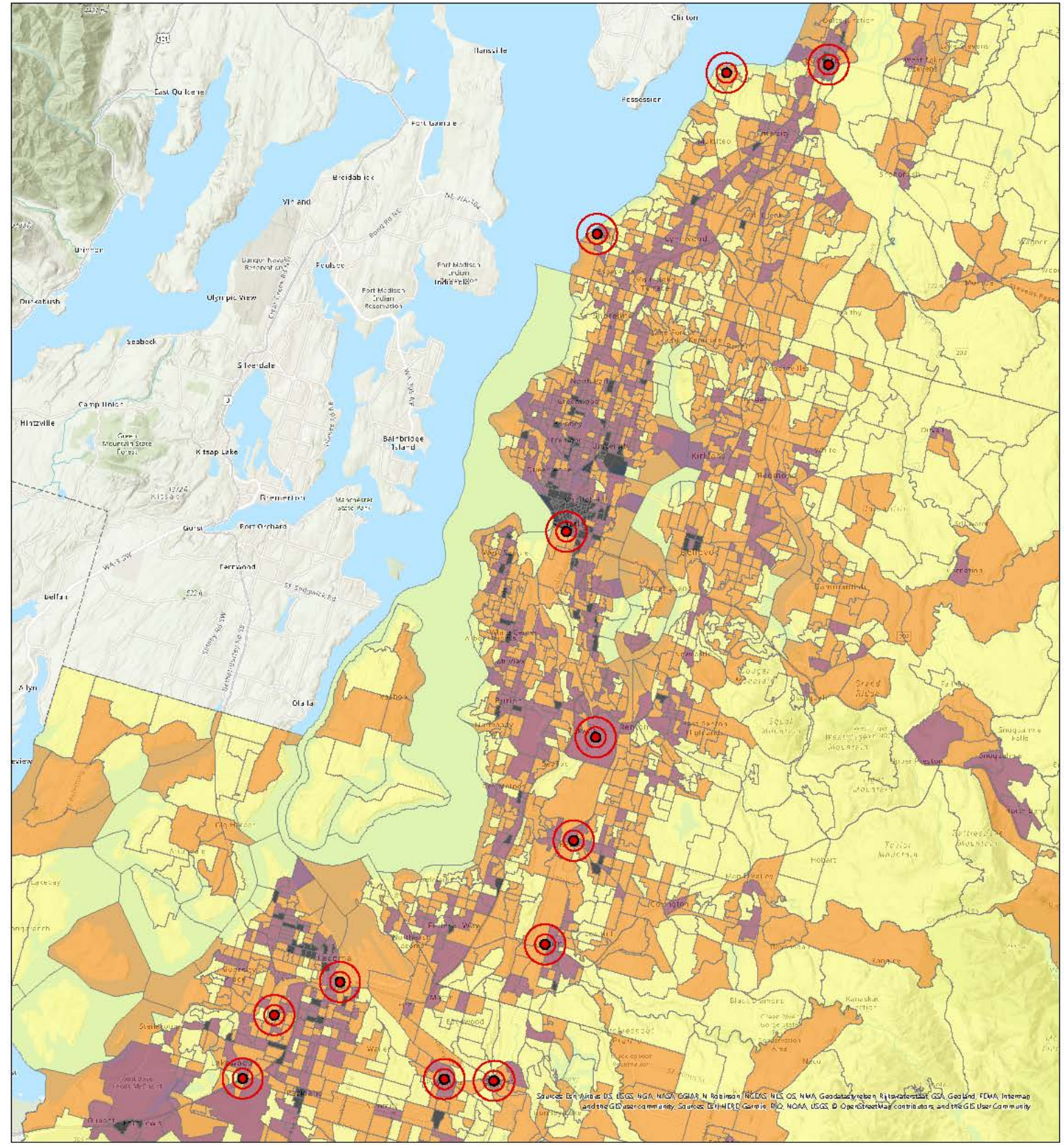

Station Typology for Commuter Rail Transit:

Buffers: Half \& 1 Mile Seattle-Tacoma-Bellevue, WA

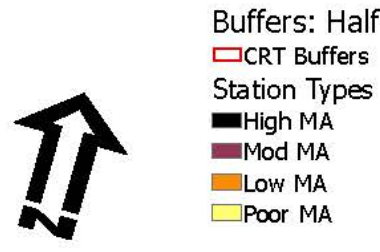




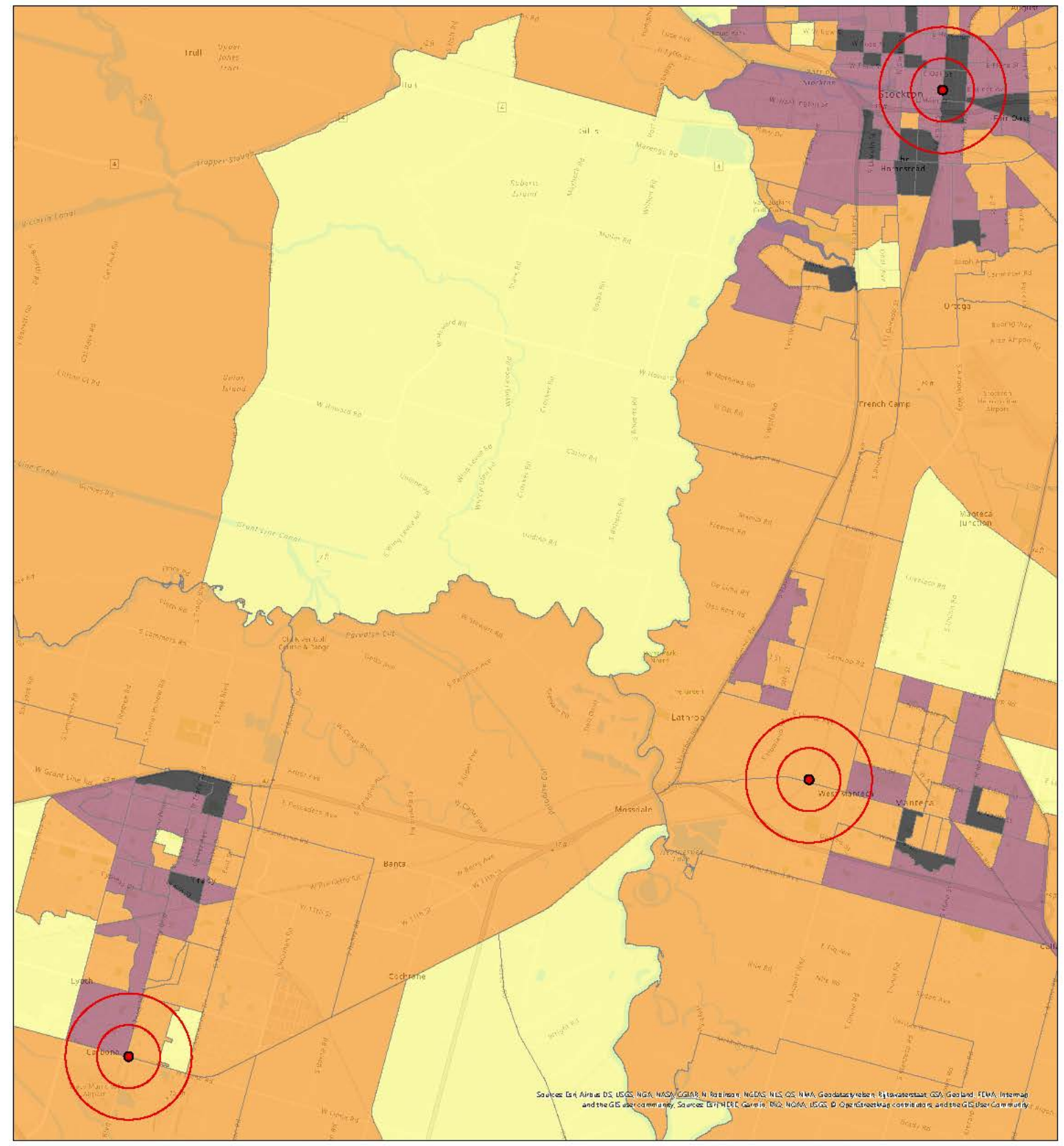

Station Typology for Commuter Rail Transit: Stockton-Lodi, CA

Buffers: Half \& 1 Mile

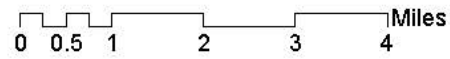




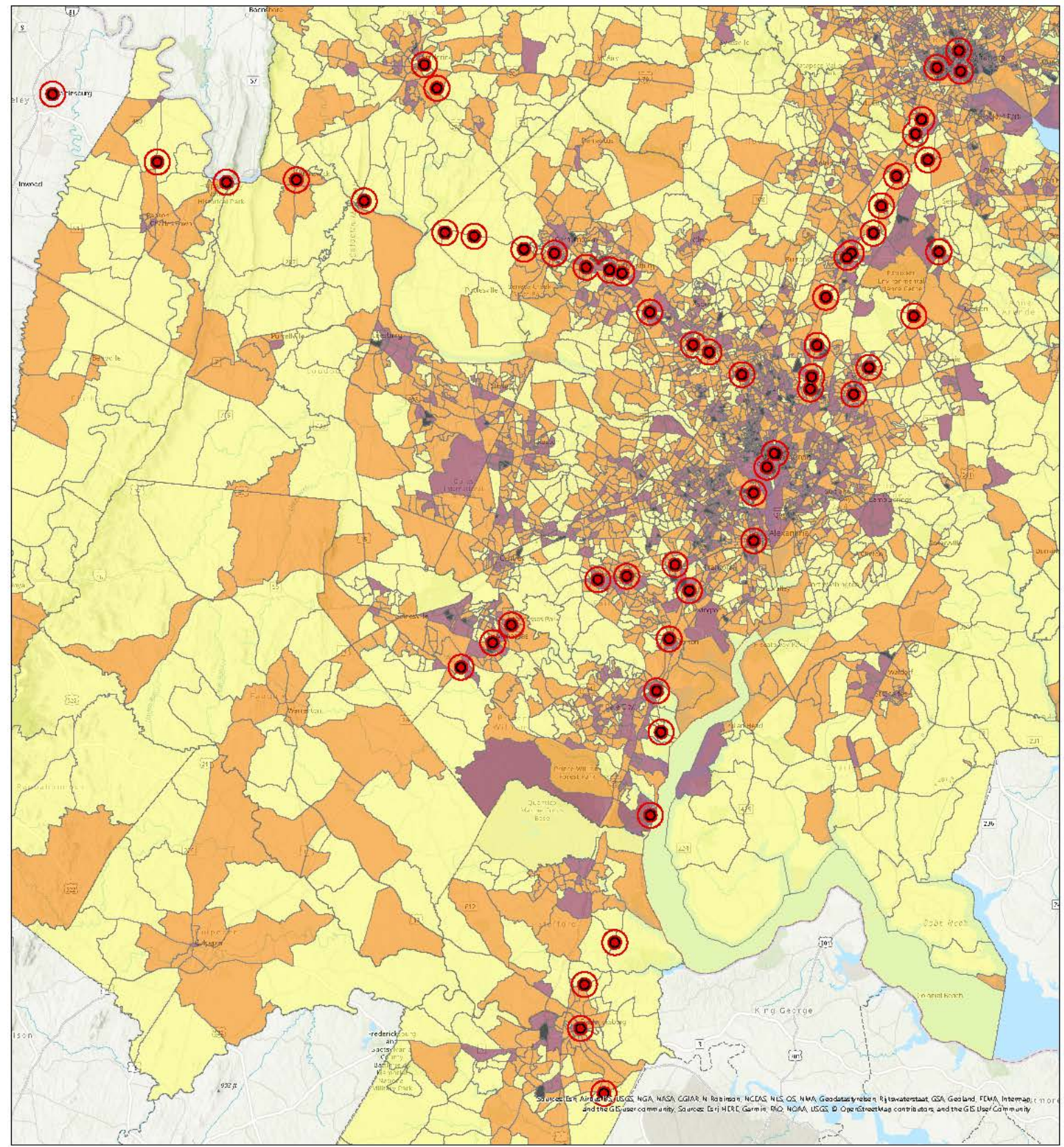

Station Typology for Commuter Rail Transit: Washington-Arlington-Alexandria, DC-VA-MDWV

$\begin{array}{lcccc}0 & 2.75 & & & \\ 5.5 & 11 & & \text { Miles }\end{array}$

Buffers: Half \& 1 Mile $\square$ CRT Buffers

$14 \begin{aligned} & \text { Station Types } \\ & \text { High MA } \\ & \text { Mod MA } \\ & \text { Low MA }\end{aligned}$ 
APPENDIX C.4

This section contains maps for all Light Rail Transit systems in the study.

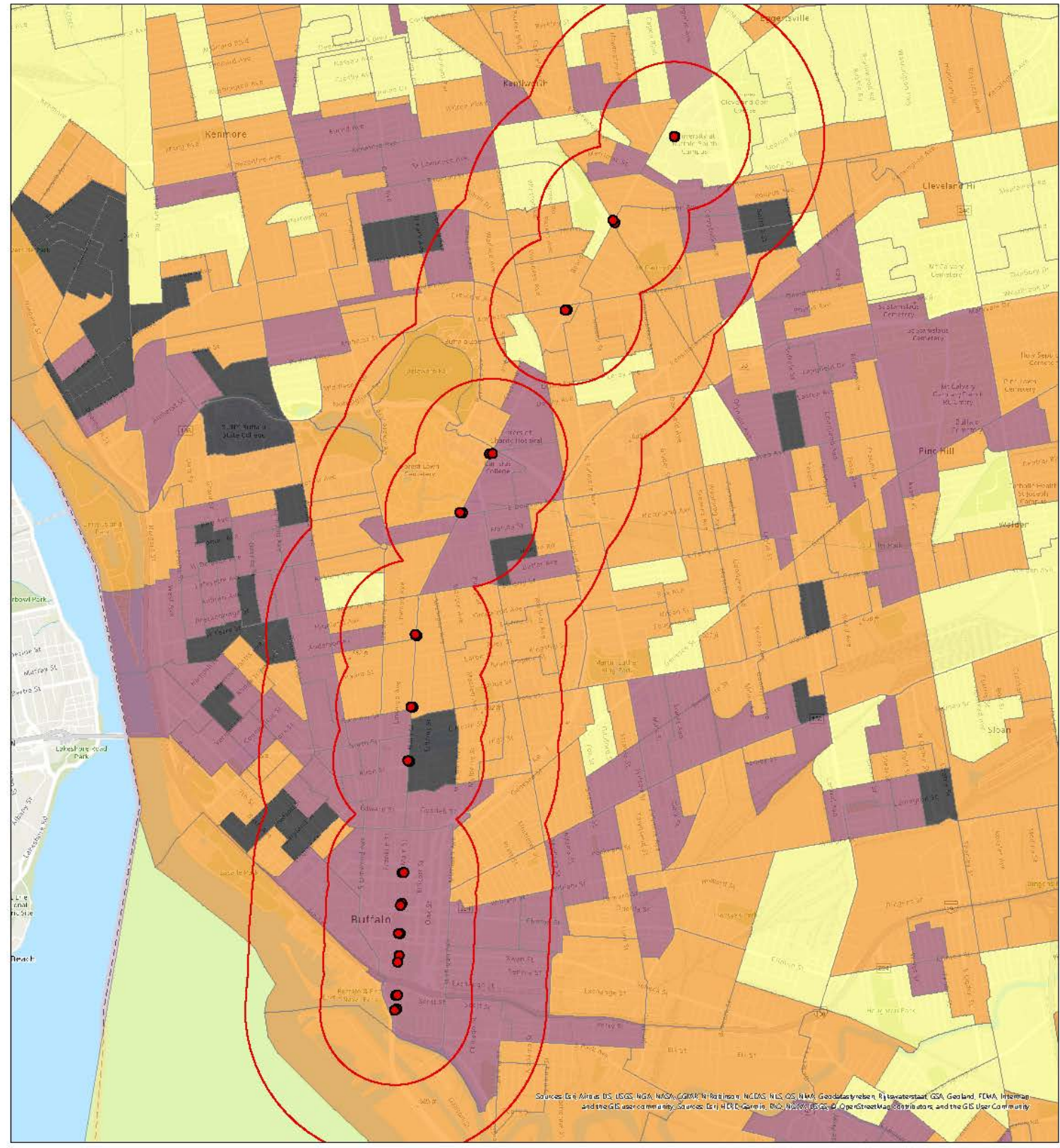

Station Typology for Light Rail Transit: Buffalo-Cheektowaga-Niagara Falls, NY
Buffers: Half \& 1 Mile $\square$ LRT Buffers

Station Types

-High MA

- Mod MA

LOW MA

$\square$ Poor MA 


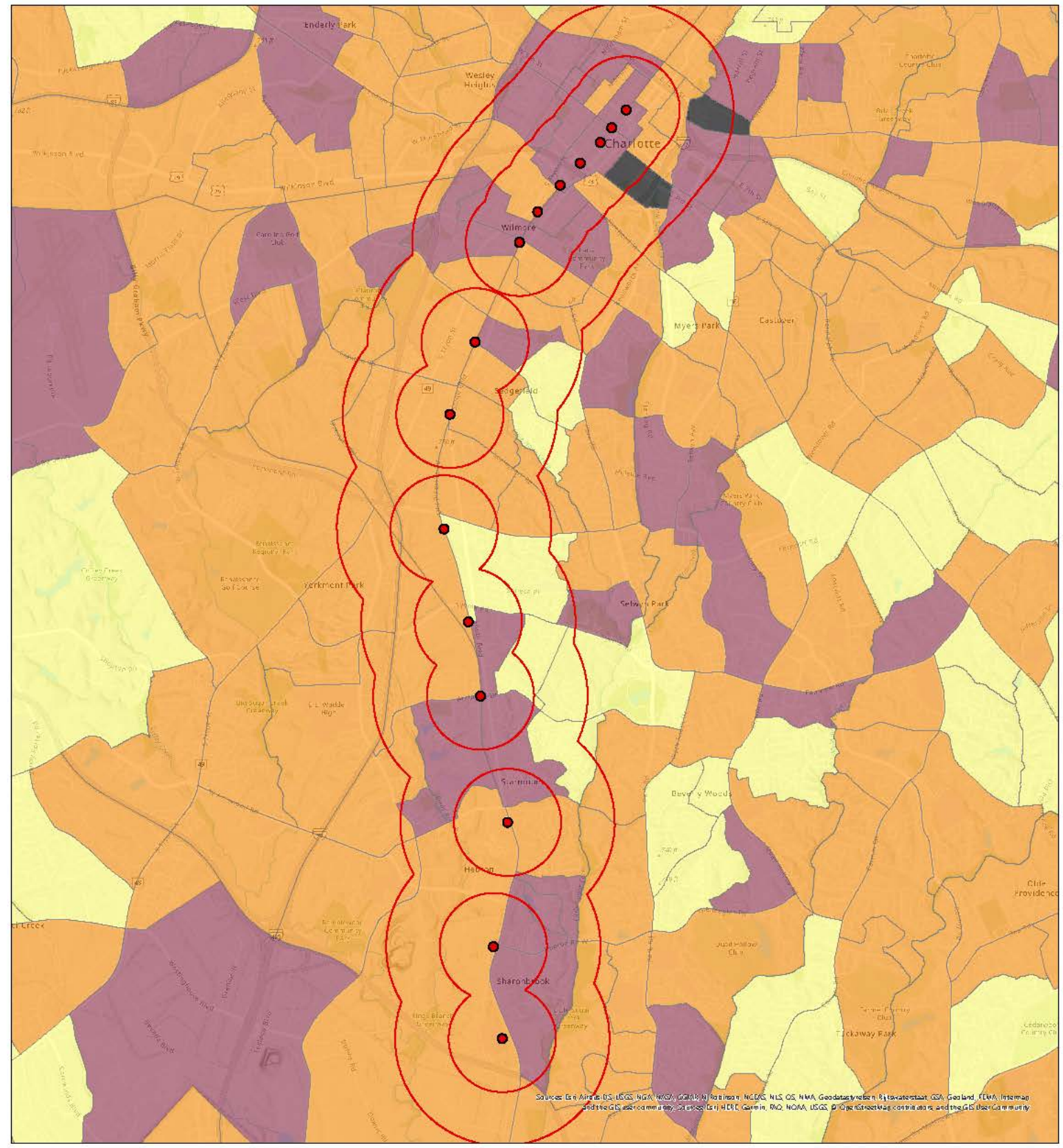

Station Typology for Light Rail Transit:

Buffers: Half \& 1 Mile Charlotte-Concord-Gastonia, NC-SC

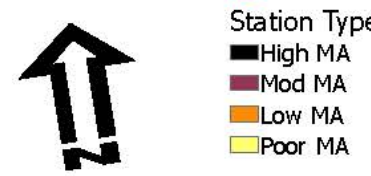

$\begin{array}{lllll}0.330 .65 & 1.3 & 1.95 & 2.6\end{array}$ 


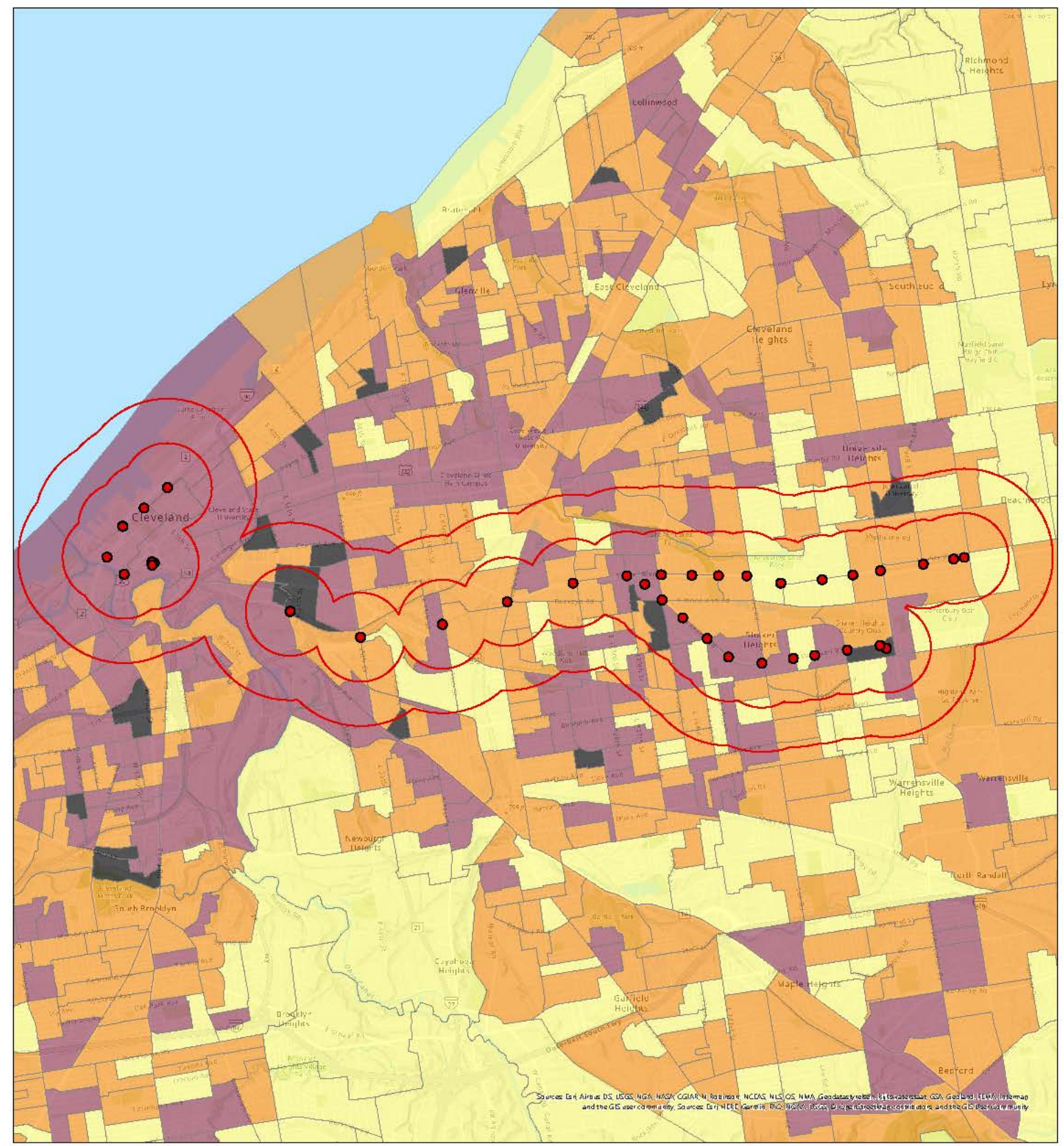

Station Typology for Light Rail Transit:

Buffers: Half \& 1 Mile Cleveland-Elyria, $\mathrm{OH}$

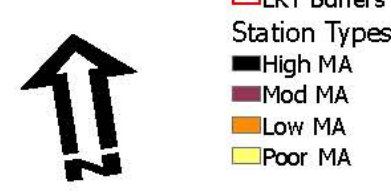

$\begin{array}{lllll}0 & 0.380 .75 & 1.5 & 2.25 & 3\end{array}$ 


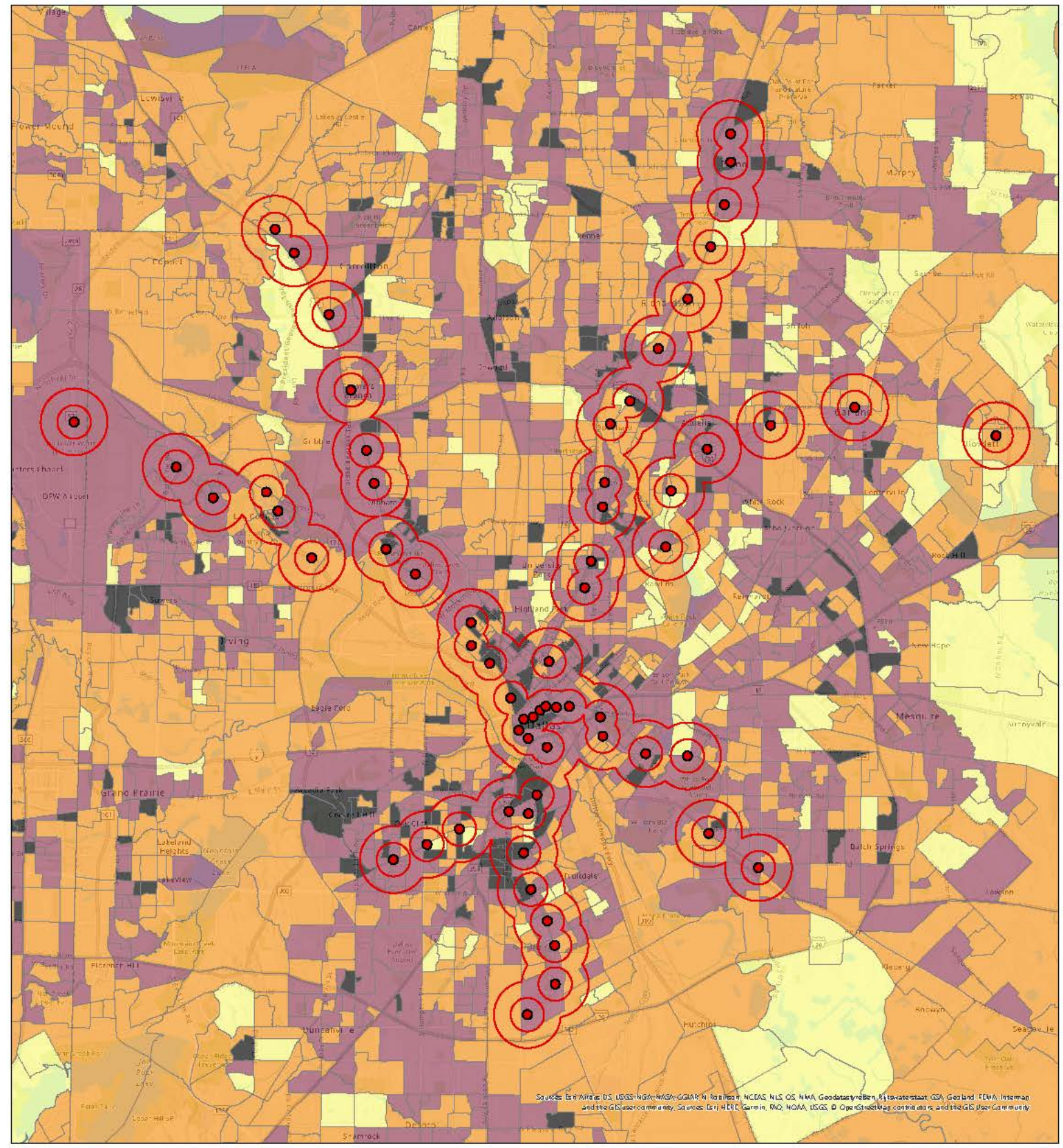

Station Typology for Light Rail Transit: Dallas-Fort Worth-Arlington, TX

Buffers: Half \& 1 Mile

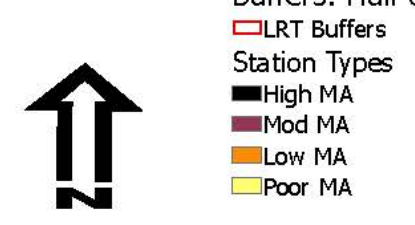




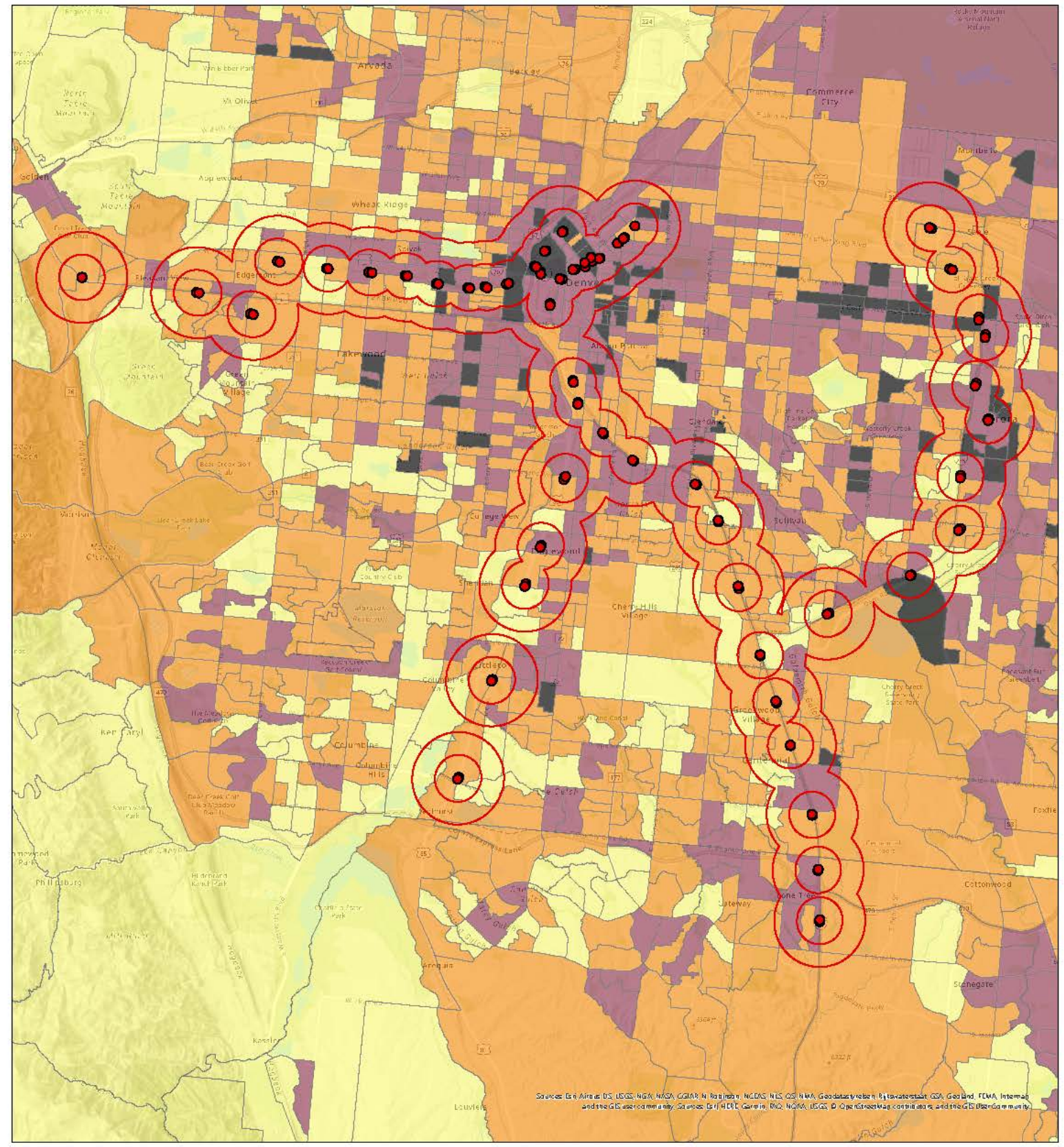

Station Typology for Light Rail Transit:

Buffers: Half \& 1 Mile Denver-Aurora-Lakewood, CO

LOW MA

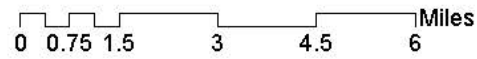




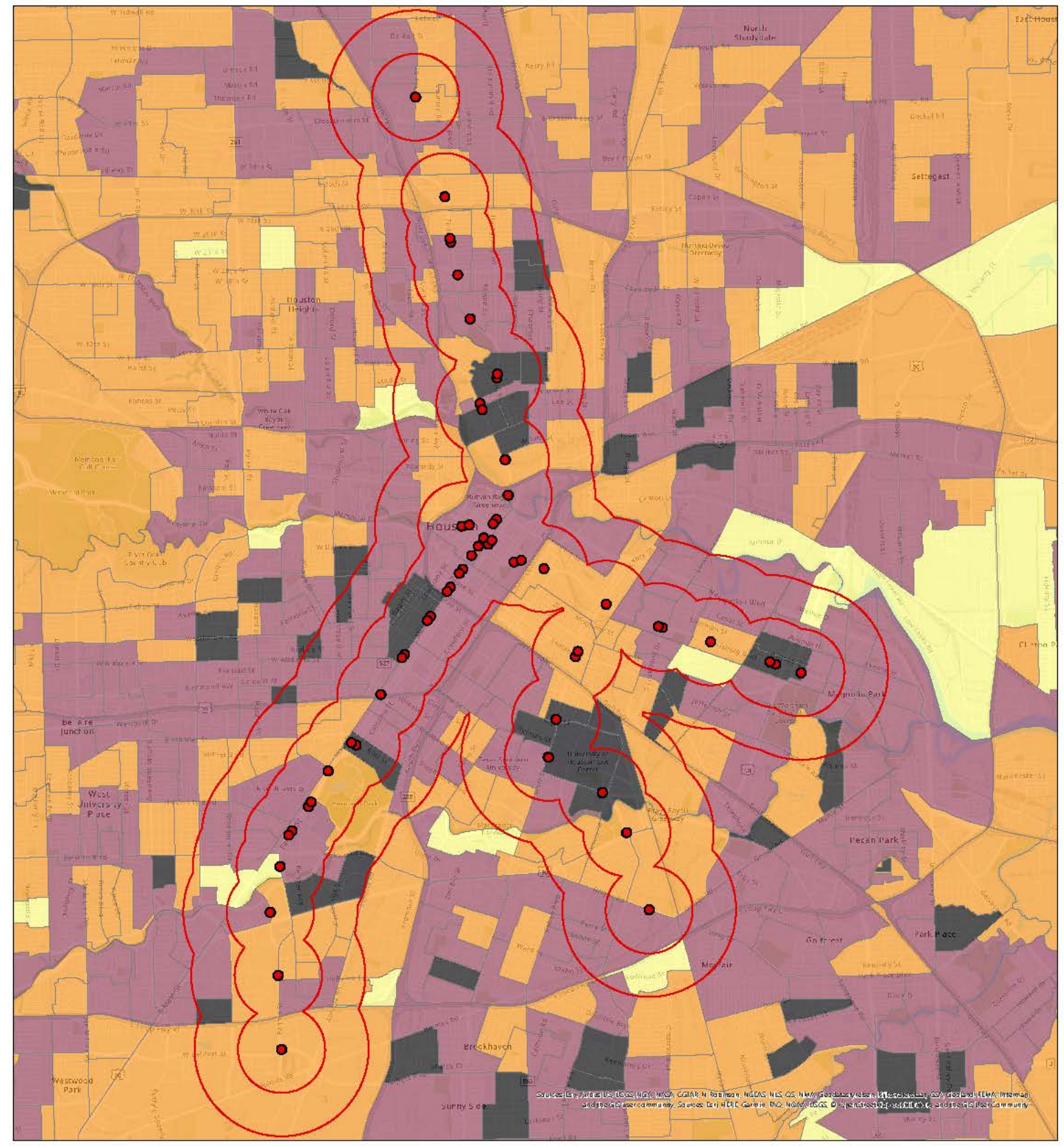

Station Typology for Light Rail Transit:

Buffers: Half \& 1 Mile Houston-The Woodlands-Sugar Land, TX

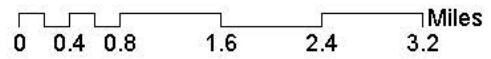




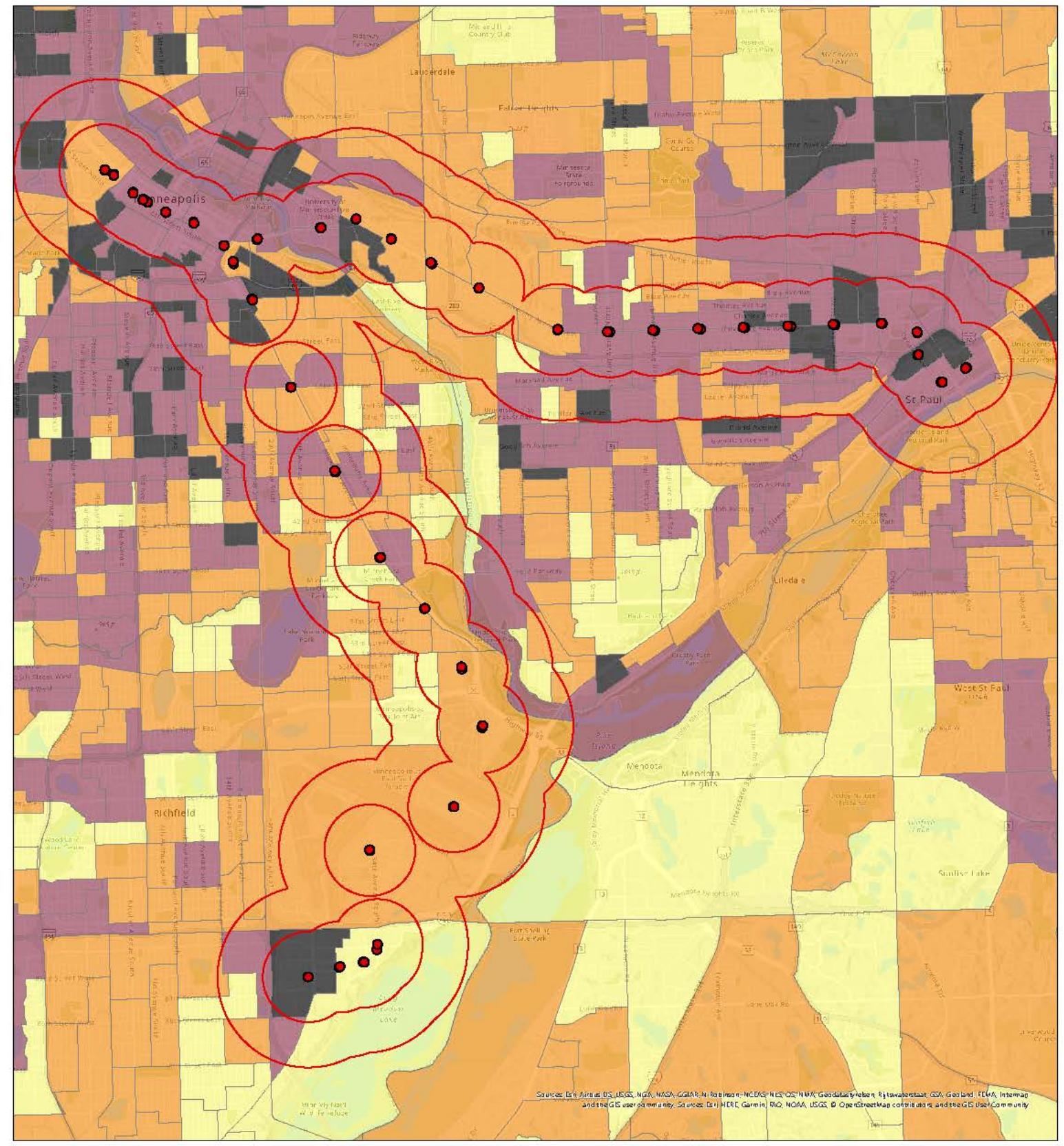

Station Typology for Light Rail Transit: Minneapolis-St. Paul-Bloomington, MN-WI

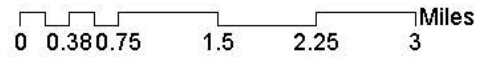

Buffers: Half \& 1 Mile 口LRT Buffers Station Types

-High MA

- Mod MA

$\square$ LOW MA

$\square$ Poor MA 


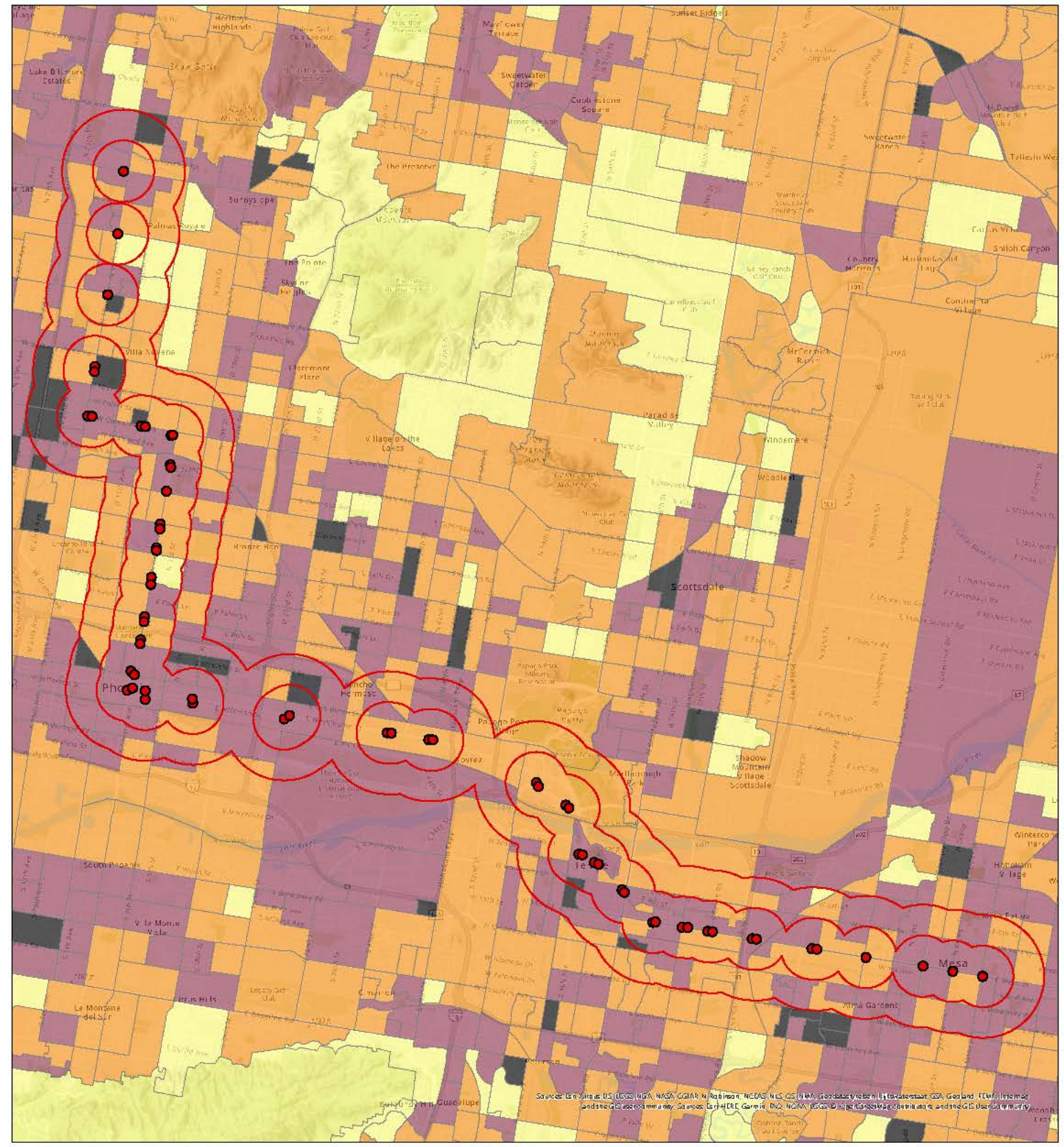

Station Typology for Light Rail Transit: Phoenix-Mesa-Scottsdale, AZ

Buffers: Half \& 1 Mile
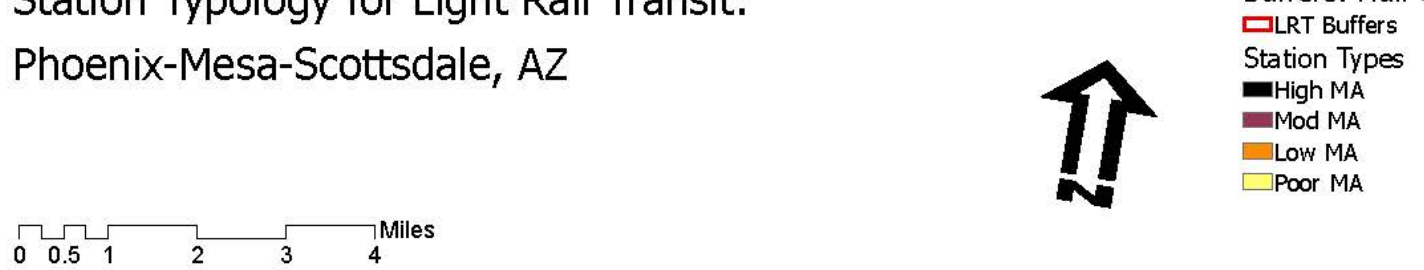


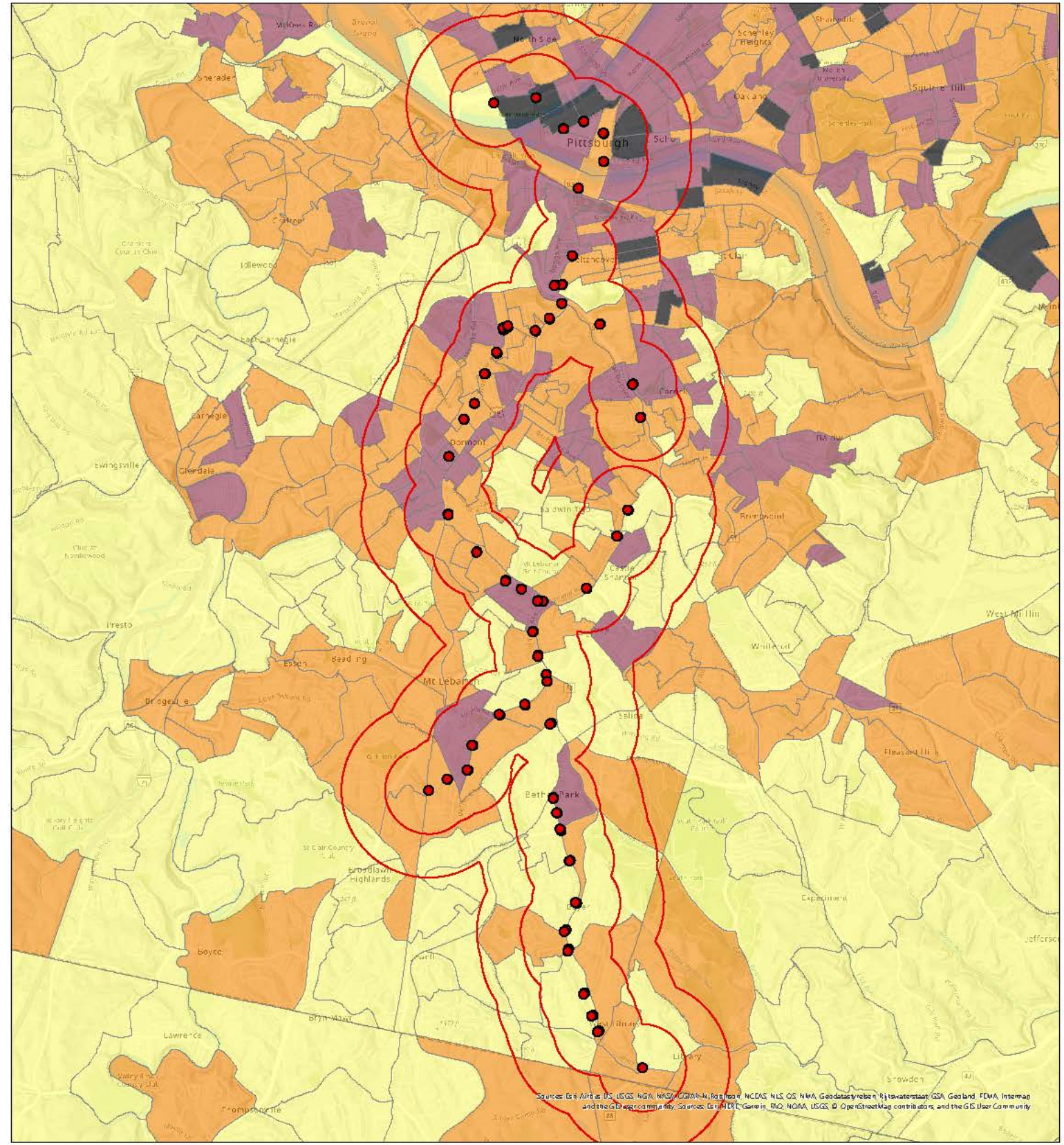

Station Typology for Light Rail Transit:

Buffers: Half \& 1 Mile Pittsburgh, PA

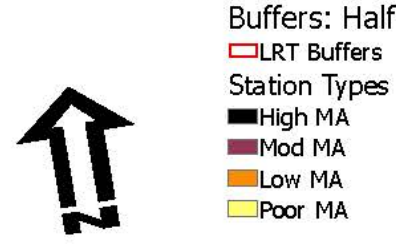

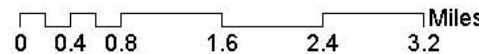




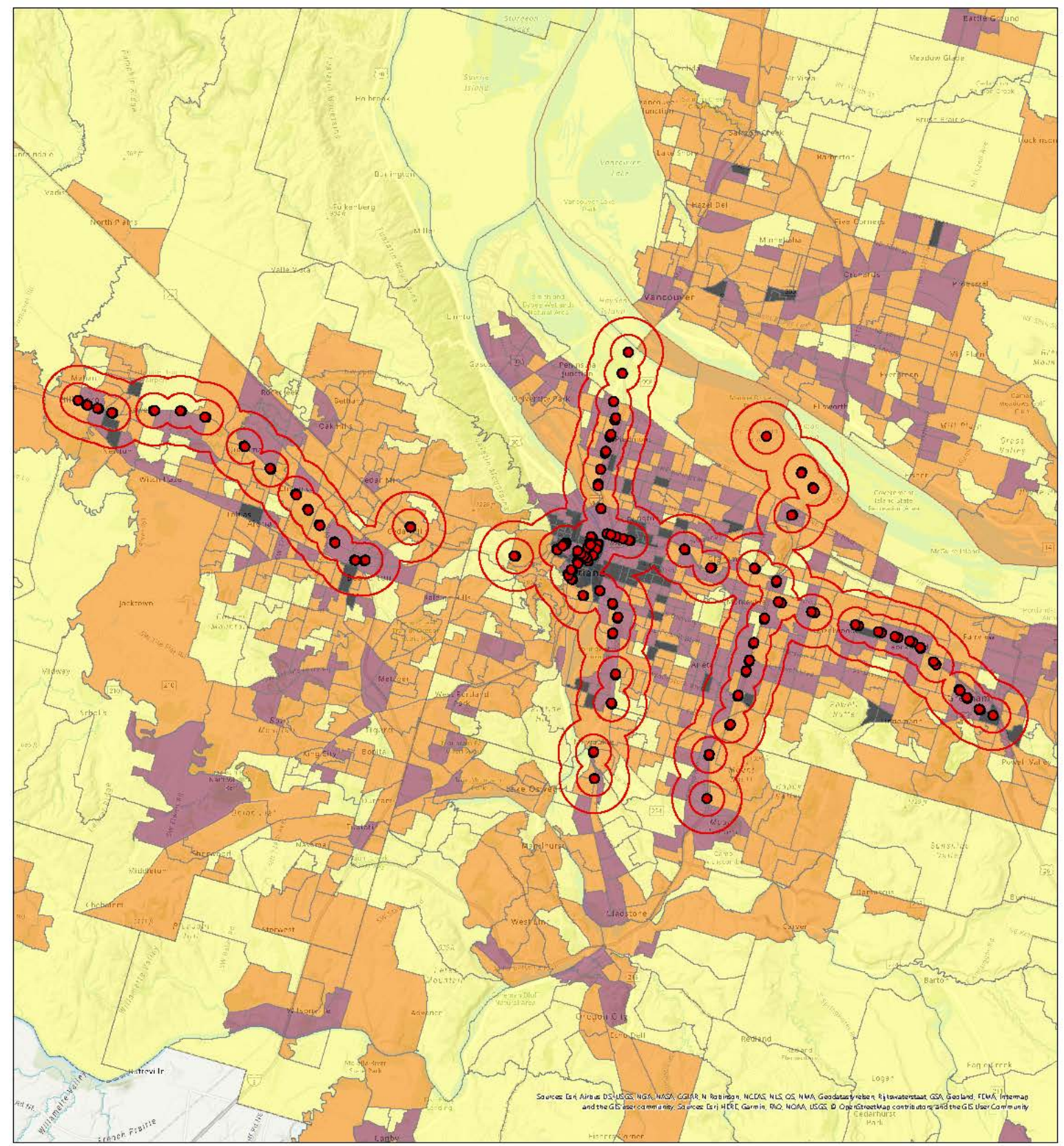

Station Typology for Light Rail Transit:

Buffers: Half \& 1 Mile Portland-Vancouver-Hillsboro, OR-WA

$\square$ LW MA
$\square$ Poor MA 


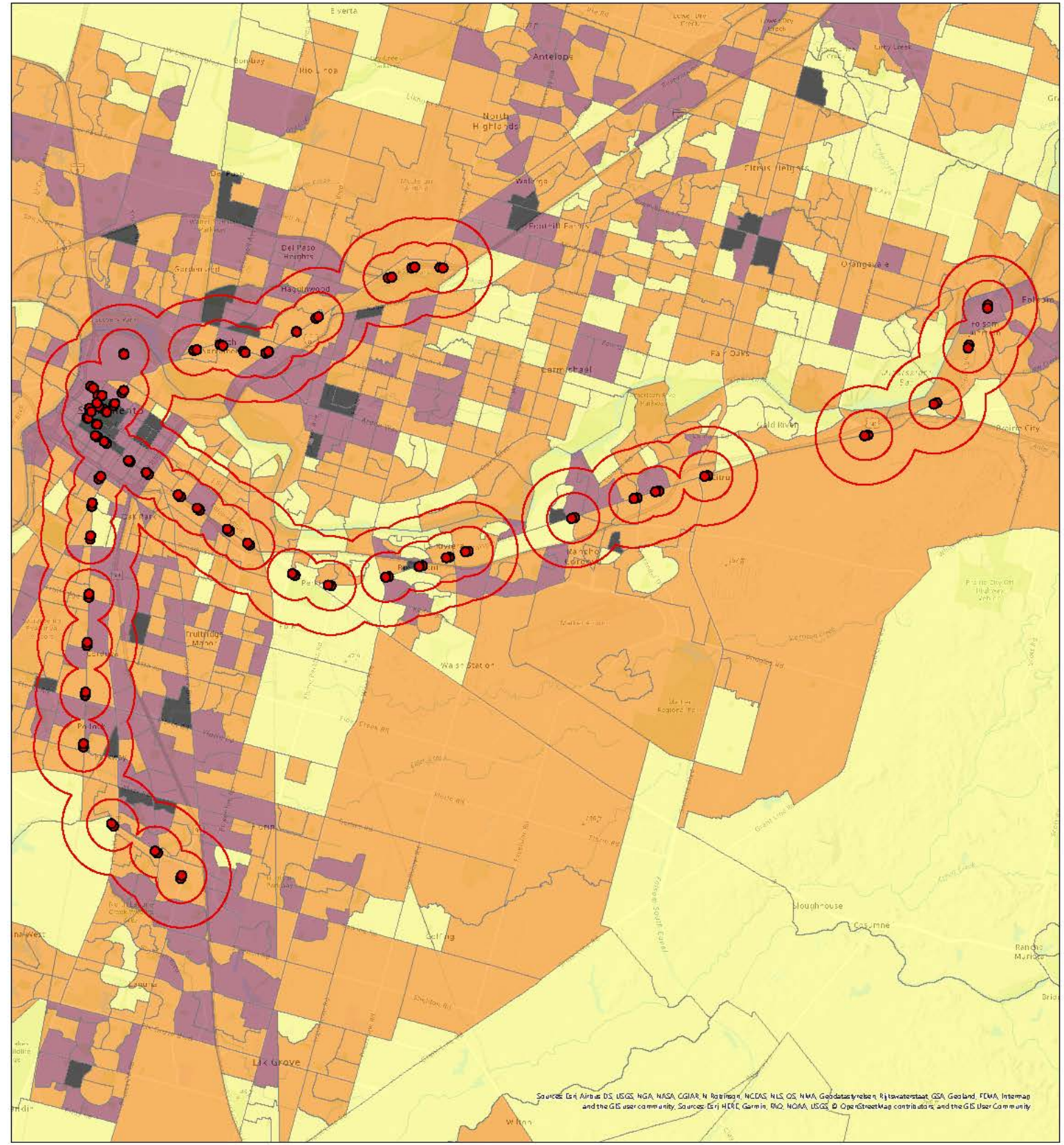

Station Typology for Light Rail Transit: Sacramento--Roseville--Arden-Arcade, CA

Buffers: Half \& 1 Mile $\square$ LRT Buffers

Station Types

-High MA

Mod MA

$\square$ Low MA
$\square$ Poor MA

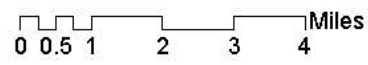




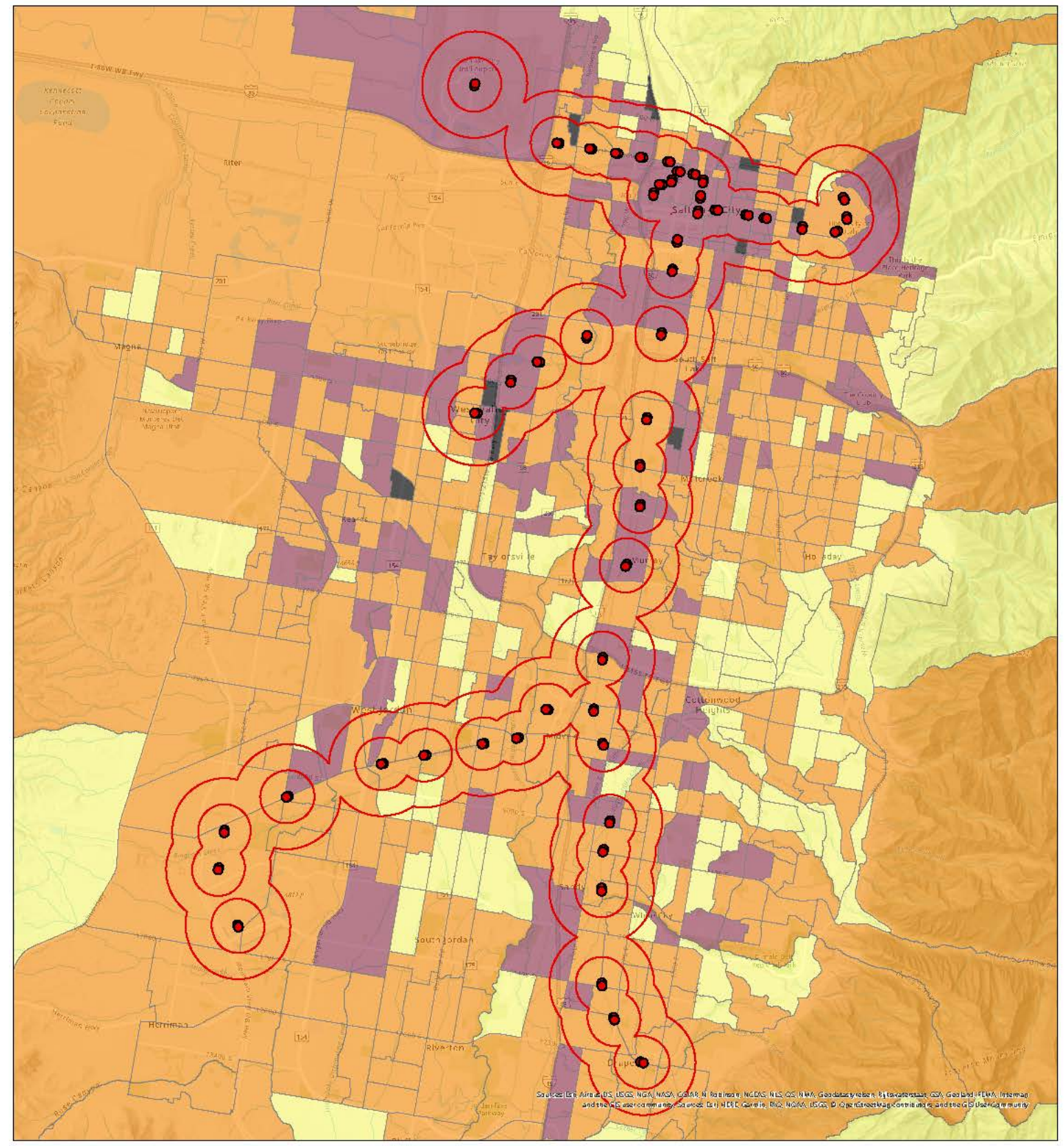

Station Typology for Light Rail Transit: Salt Lake City, UT

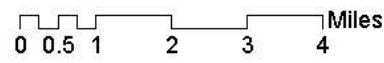

Buffers: Half \& 1 Mile 口LRT Buffers

Station Types

-High MA

-Mod MA

$\square$ LoW MA

$\square$ Poor MA 


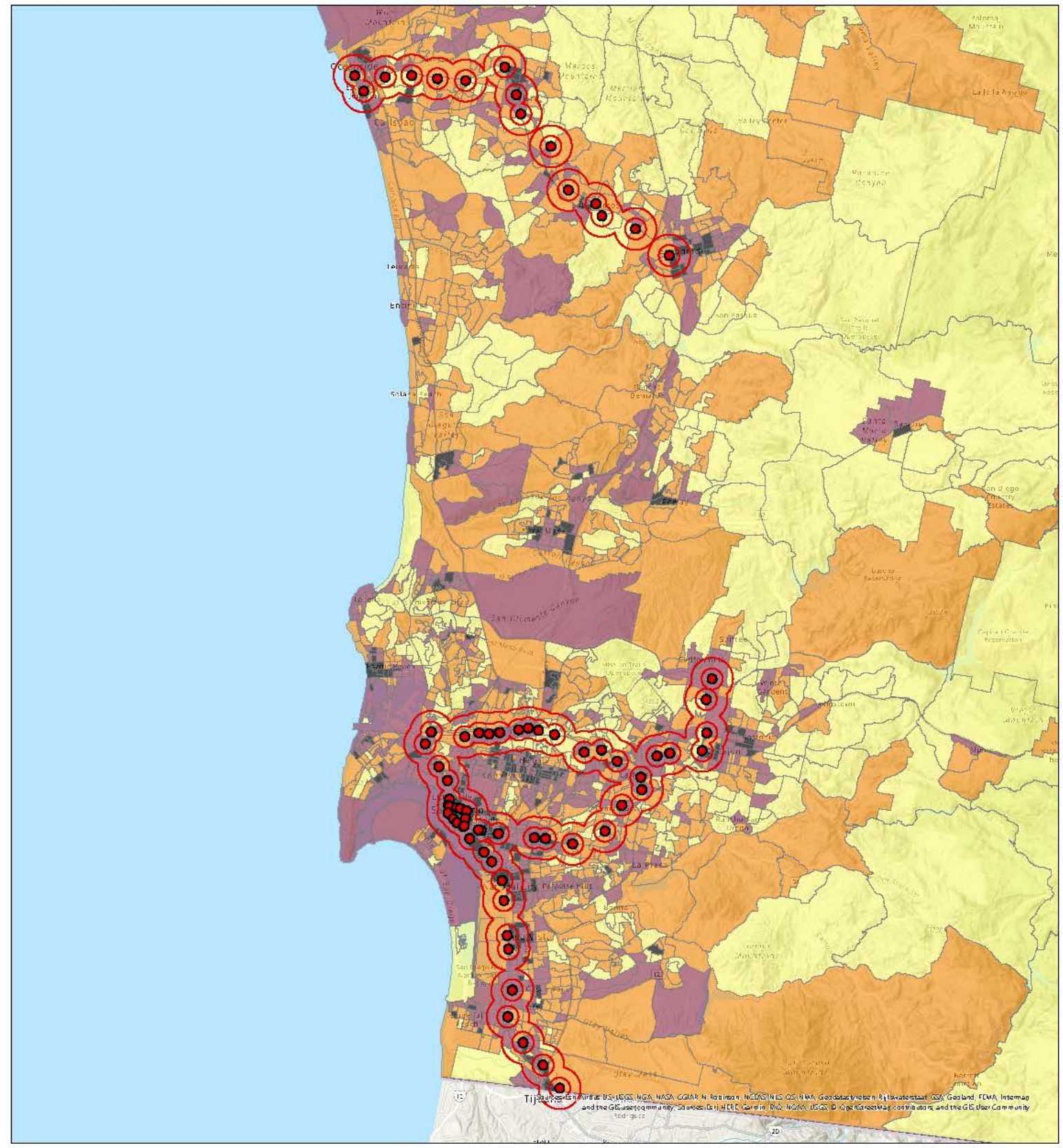

Station Typology for Light Rail Transit: San Diego-Carlsbad, CA

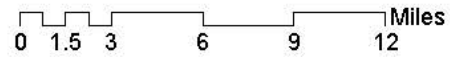

Buffers: Half \& 1 Mile 口LRT Buffers

Station Types

High MA

- Mod MA

$\square$ Low MA

$\square$ Poor MA 


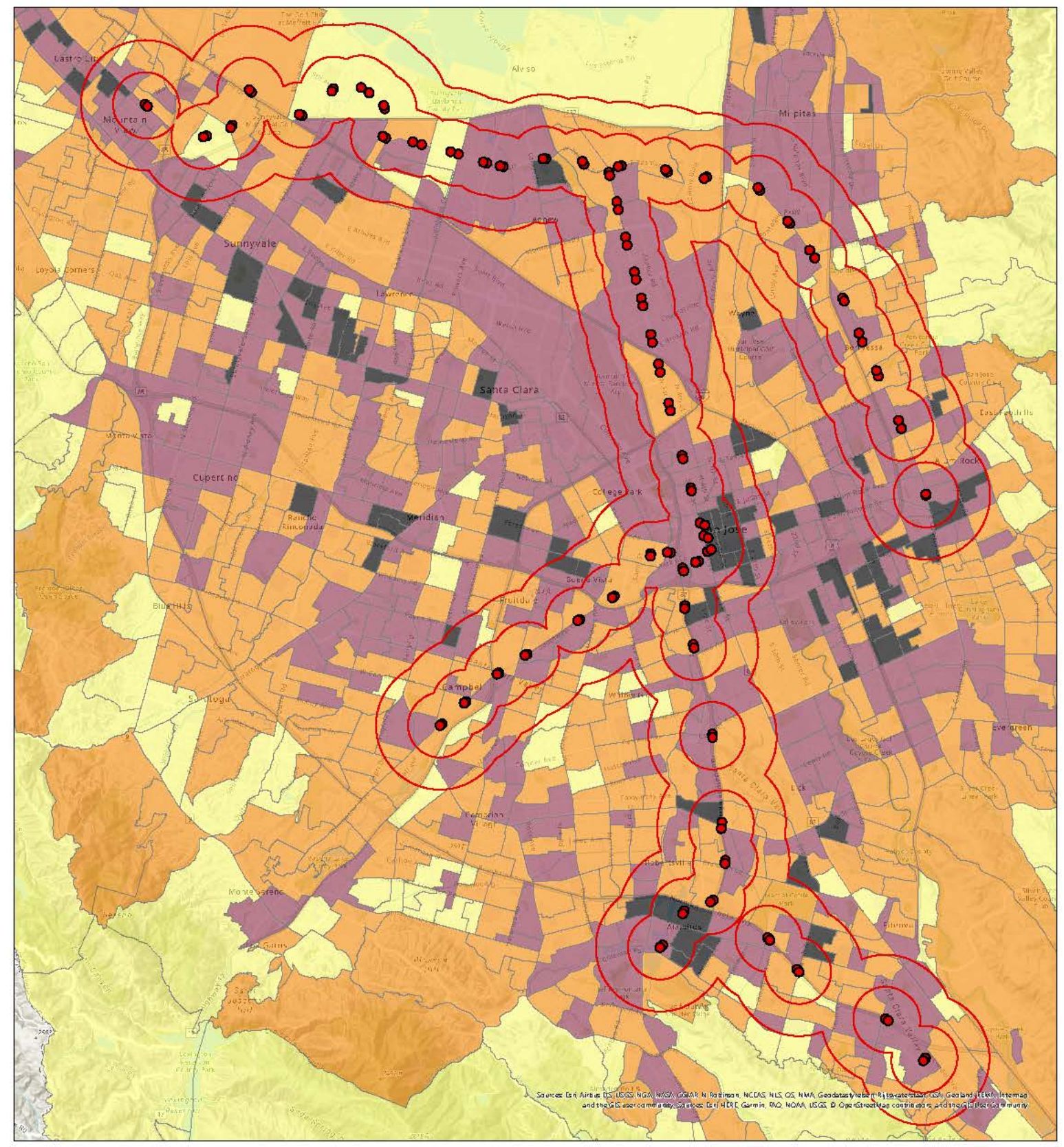

Station Typology for Light Rail Transit:

Buffers: Half \& 1 Mile San Jose-Sunnyvale-Santa Clara, CA

LOW MA

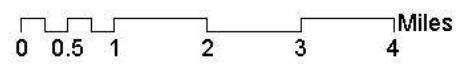




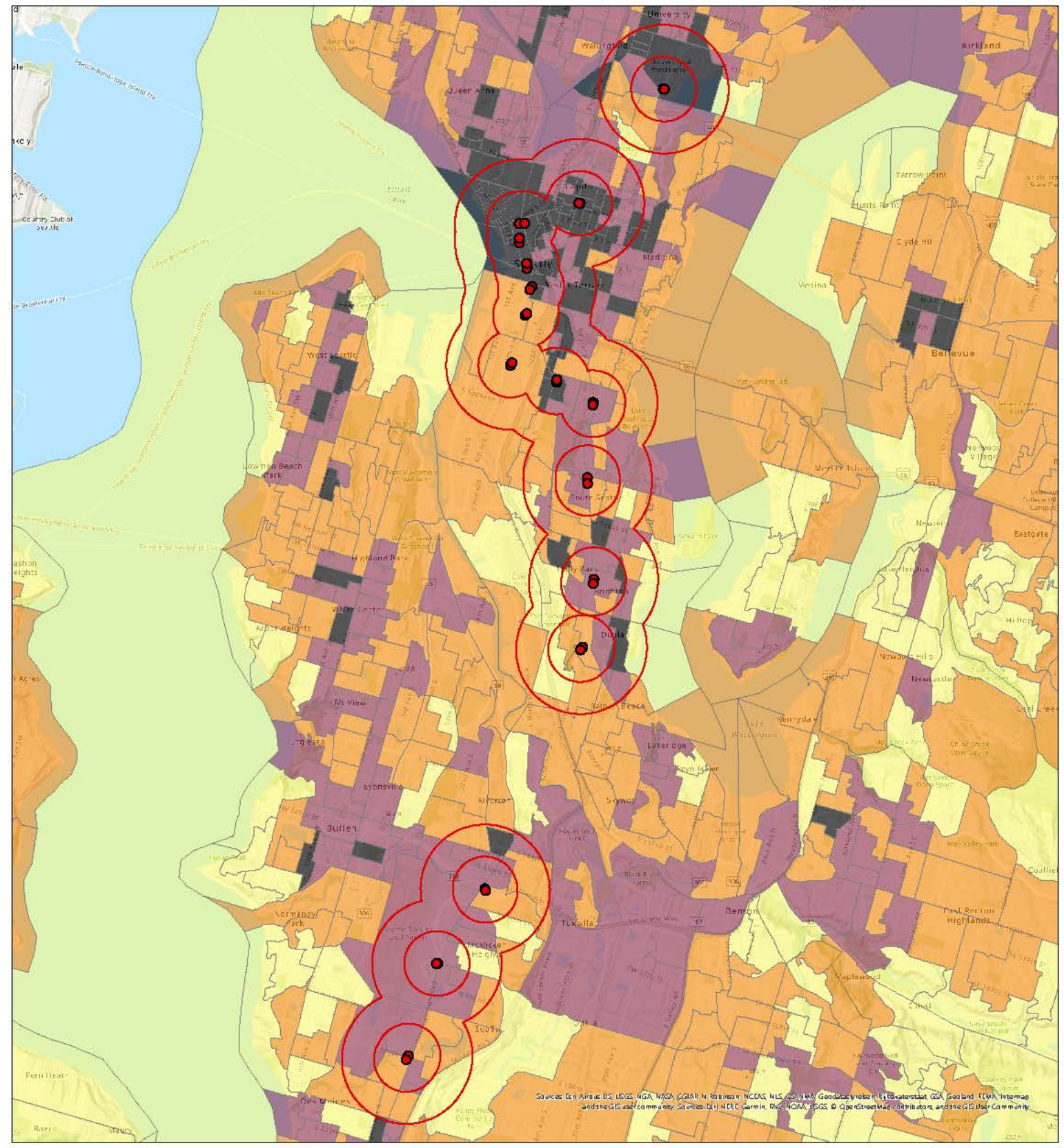

Station Typology for Light Rail Transit: Seattle-Tacoma-Bellevue, WA

Buffers: Half \& 1 Mile

Low MA
$\square$ Poor MA

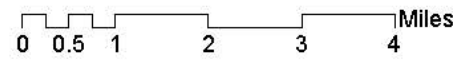




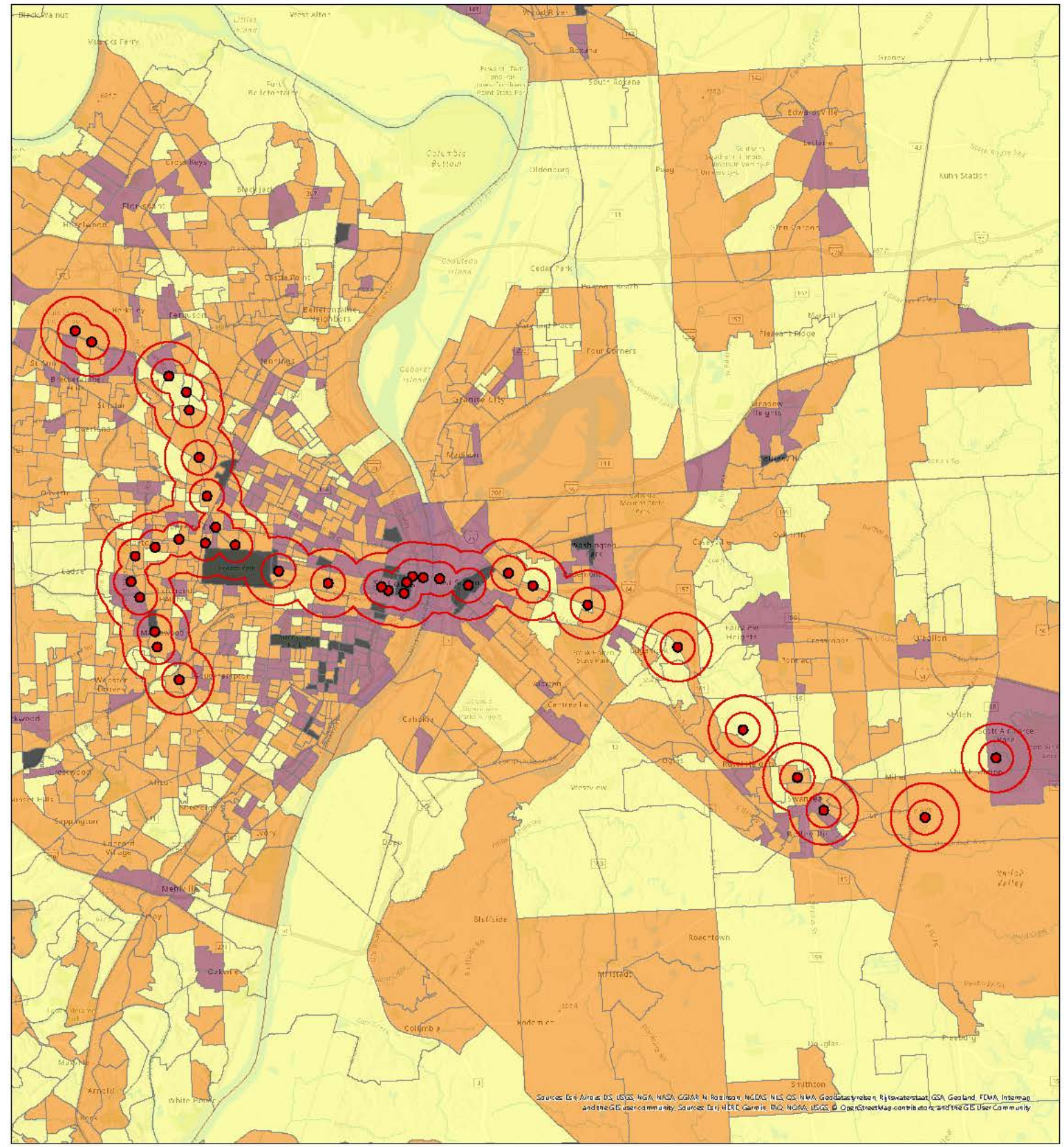

Station Typology for Light Rail Transit:

Buffers: Half \& 1 Mile St. Louis, MO-IL
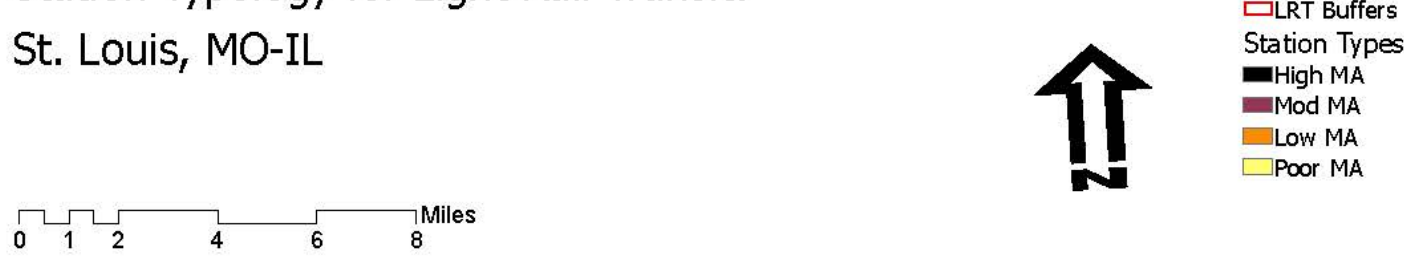


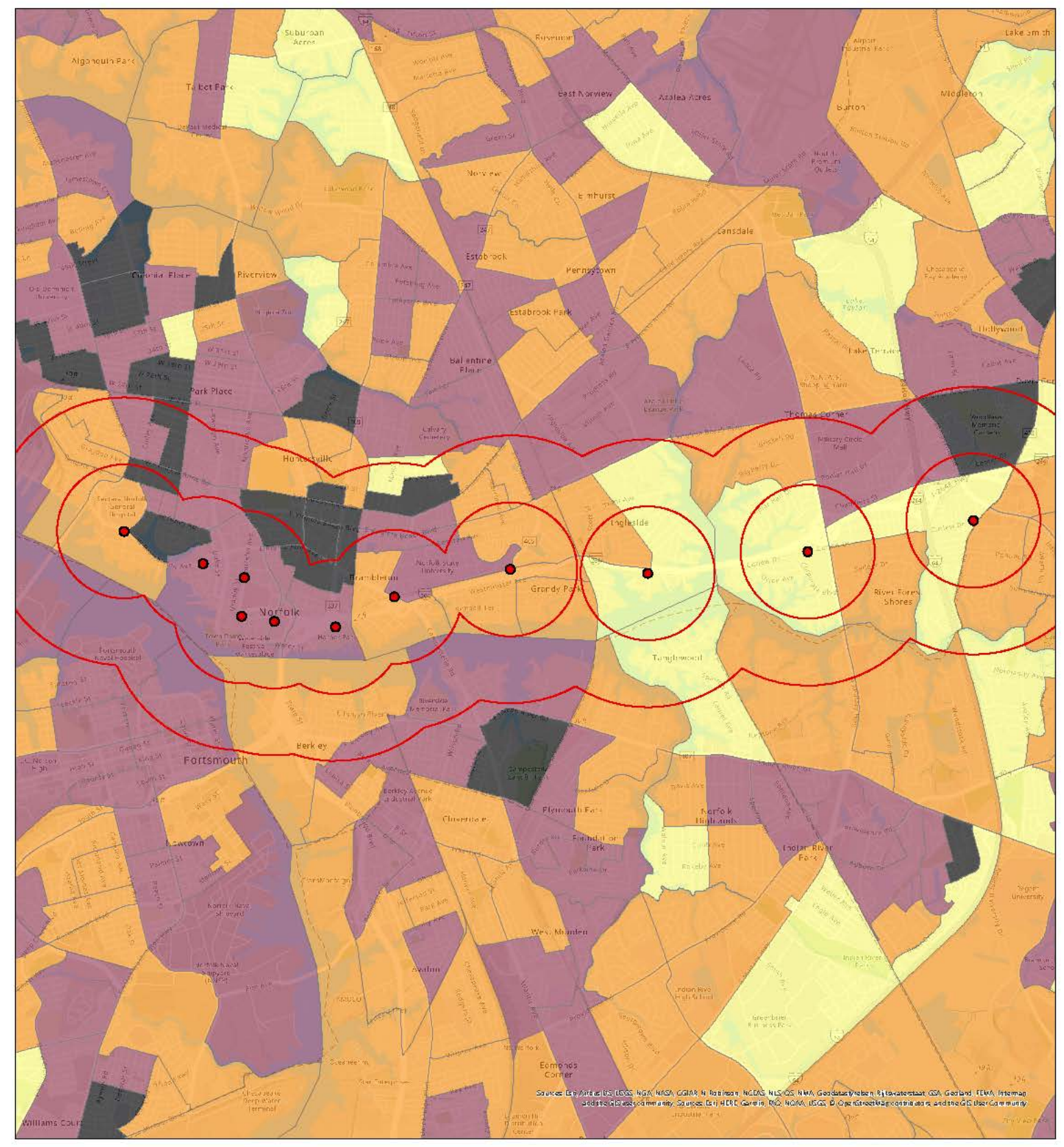

Station Typology for Light Rail Transit:

Buffers: Half \& 1 Mile Virginia Beach-Norfolk-Newport News, VA-NC

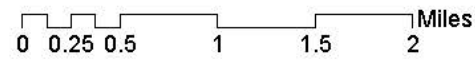




\section{TRANSIT IMPACTS ON JOBS, PEOPLE AND REAL ESTATE}

Volume 2

Impact on Job Location Over Time with Respect to Transit Station Proximity Considering Economic Groups by Transit Mode and Place Typology with Implications for Transit and Land Use Planning
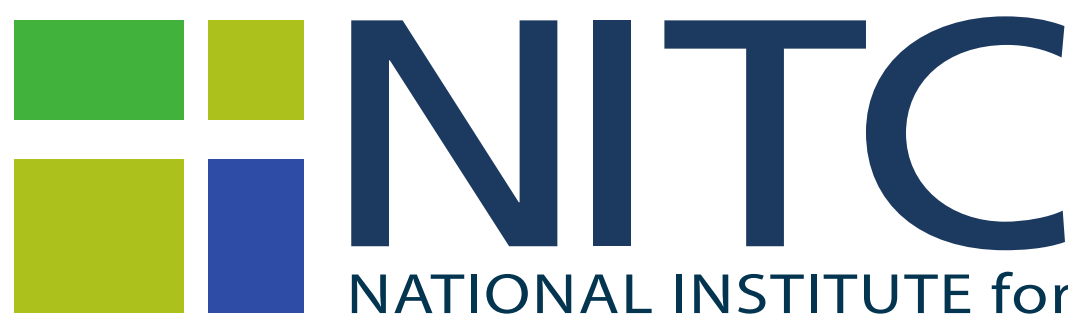

NATIONAL INSTITUTE for TRANSPORTATION and COMMUNITIES 


\section{VOLUME 2 PREFACE}

Transit Impacts on Jobs, People, and Real Estate is the fourth report in a series that started with funding from the National Institute of Transportation and Communities (NITC), a US DOT funded National University Transportation Center. While it completes the "quadrilogy" of work comprising a unique genre of transit and land use planning research it is by no means the last work-it is more likely the foundation for future work.

This document is Volume 2 of five volumes from the full report Transit Impacts on Jobs, People, and Real Estate:

- Volume 1: Orientation, Executive Summary, Context and Place Typologies

- Volume 2: Impact on Job Location Over Time with Respect to Transit Station Proximity Considering Economic Groups by Transit Mode and Place Typology with Implications for Transit and Land Use Planning

- Volume 3: Impact on Where People Live Over Time with Respect to Transit Station Proximity Considering Race/Ethnicity and Household Type and Household Budget by Transit Mode and Place Typology with Implications for Transit and Land Use Planning

- Volume 4: Impact on Real Estate Rents with Respect to Transit Station Proximity Considering Type of Real Estate by Transit Mode and Place with Implications for Transit and Land Use Planning

- Volume 5: Improving Transit Impacts by Reconsidering Design and Broadening Investment Resources

Each of these volumes, and the full report, can be found at https://nitc.trec.pdx.edu/research/project/1253

The genre of research within which four research projects call is grounded in trend that is common throughout all reports: That America is becoming increasingly focused on the need for transit to meet a growing number of social, economic and environmental objectives. But it is also rooted is simple market dynamics.

America will add at least 100 million new residents, 40 million new households, and 60 million new jobs by 2050. We know from demographic analysis and consumer preference surveys that at least a third of America's 150 million households (50+ million) in 2050 will want to live in locations providing them with transit options, in addition to mixed-use and mixed-housing options. We also know from research on firm location behavior that up to 100 million jobs will be attracted to locations with transit options. Indeed, some research has estimated that even if all new development to 2050 occurred within one-half mile of existing and planned transit stations-such as transit oriented development (TOD) planning areas-the market demand for such development would not be met.

Our prior research outlines the extent to which fixed route transit (FRT) systems can meet future demand. But each system has its own niche. Light rail transit (LRT) systems serve metropolitan wide markets, connecting multiple nodes to each other. Bus rapid transit (BRT) systems can accomplish many of the same objectives as LRT systems at lower cost per mile but also lower capacity-which is fine for the Eugene-Springfield metropolitan area though not necessarily the Portland metropolitan area which, being four times larger and more densely settled, relies on LRT. At the lowest scale of operations are street car transit (SCT) systems that serve mostly downtowns such as Seattle or connect employment centers near downtown to downtown such as Portland, Tucson and Dallas. At the other end of the spectrum are commuter rail transit 
(CRT) systems that are intercity systems that connect cities within a metropolitan area to downtown such as San Diego's Coaster, or multiple metropolitan areas such as the SeattleTacoma Sounder or the Albuquerque-Santa Fe Rail Runner or the Utah Transit Authority's FrontRunner connecting three metropolitan areas.

Here we will summarize the purpose and key findings of each of the three prior reports and then frame the role of the fourth report. 


\section{Do TODs Make a Difference?}

The first report in the Quadrilogy was Do TODs Make a Difference? (Nelson et al. 2015). NITC contracts 547 and 650 were used to build station area databases for 12 light rail transit (LRT) systems, nine bus rapid transit (BRT) systems, four streetcar transit (SCT), and five commuter rail transit (CRT) systems. In this report, we presented research that measures the outcomes of TOD areas in relation to their metropolitan area controls with respect to:

- Jobs by sector;

- Housing choice for household types based on key demographic characteristics;

- Housing affordability based on transportation costs; and

- Job-worker balance as a measure of accessibility.

Prior literature has not systematically evaluated TOD outcomes in these respects with respect to light rail transit (LRT), commuter rail transit (CRT), bus rapid transit (BRT), and streetcar transit (SCT) systems. Our analysis helps close some of these gaps. We applied our analysis to 23 fixed guideway transit systems operating in 17 metropolitan areas in the South and West that have one or more of those systems. We found:

- Most TOD areas gained jobs in the office, knowledge, education, health care and entertainment sectors, adding more than $\$ 100$ billion in wages capitalized over time;

- In assessing economic resilience associated with LRT systems, jobs continued to shift away from TOD areas before the Great Recession, the pace slowed during the Recession, but reversed during recovery leading us to speculate that LRT TOD areas may have transformed metropolitan economies served by LRT systems;

- Rents for offices, retail stores and apartments were higher when closer to SCT systems, had mixed results with respect LRT systems, but were mostly lower with respect to CRT systems (our earlier BRT sample size was too small to evaluate);

- SCT systems performed best in terms of increasing their TOD area shares of metropolitan population, households and householders by age, housing units, and renters with BRT systems performing less well while LRT and CRT systems experienced a much smaller shift in the share of growth;

- Household transportation costs as a share of budgets increase with respect to distance from LRT transit stations to seven miles suggesting the proximity to LRT stations reduces total household transportation costs;

- Emerging trends that may favor higher-wage jobs locating in transit TOD areas over time than lower or middle wage jobs perhaps because TOD areas attract more investment which requires more productive, higher-paid labor to justify the investment; and

- The share of workers who commute 10 minutes or less to work increases nearly one-half of one percent for each half-mile their resident block group is to an LRT transit station, capping at a gain of 1.3 percent, which is not a trivial gain.

This work identified a missing element of research relating to one of the fastest growing modes of fixed route transit systems: Bus rapid transit (BRT). That led to a second NITC-funded project. 


\section{National Study of BRT Development Outcomes}

The second report was the nation's largest and most comprehensive assessment of the influence of bus rapid transit (BRT) systems on jobs, people and households, and real estate rents (Nelson and Ganning 2016).

Public transit systems are often promoted as offering a plethora of social, economic and environmental benefits to urban populations by transforming urban forms from auto-centric designs into more sustainable ones. The "next big thing" in public transit is bus rapid transit (BRT) systems. From virtually no systems a generation ago, there are now nearly 20 lines operating with at least seven under construction and more than 20 in the planning stages. Part of this recent popularity in BRT stems from its more affordable capital investment costs and its potential to be utilized by municipal planning organizations as an economic development tool. Yet, research into development outcomes associated with BRT station/stop proximity is small. This study found:

- For metropolitan counties with BRT systems, (0.50-mile) transit corridors increased their share of new office space by a third, from 11.4 percent to 15.2 percent and although new multifamily apartment construction was small, its share more than doubled since 2008;

- BRT station areas gained share of central county jobs at a faster pace or even at the expense of the rest of the central county and that more technologically advanced BRT systems may contribute to positive economic development outcomes;

- However, when disaggregating data to sectors, BRT is found to influence employment change in only one sector-manufacturing though that sector is broad and includes such activities as assembly, food processing (think beer making) and fashion design;

- Evidence of an office rent premium for location within a BRT corridor for most albeit not all of the metropolitan areas studied;

- Household transportation costs as a share of budgets increase with respect to CBD distance to about 19 miles and about eight miles with respect to BRT stations;

- Before the recession, the shift in jobs for all wage groups was about the same between BRT station areas and counterfactual locations but during recovery, BRT station areas saw larger shifts compared to counter-factual locations for lower-wage but upper-wage jobs had the largest change share in BRT station areas during recovery while the share of lower-wage jobs in BRT station areas fell; and

- There is little difference in BRT study area performance compared to their metropolitan areas in terms of influencing population and residential patterns though we did find indirect evidence that BRT systems choosing higher-quality design and technology options tended to enjoy better population and housing outcomes than those that chose lesser options.

We conclude that, on the whole, BRT systems are associated with positive development and job location outcomes, though not necessarily population or housing outcomes. By the time this study was completed more robust data had become available allowing for updates and expansions of prior work, which led to the third grant in this genre. 
The Link between Transit Station Proximity and Real Estate Rents, Jobs, People and Housing with Transit and Land Use Planning Implications

This report updates and expands prior research in the genre of research that has used economic base analysis (especially shift-share) and CoStar commercial rent data to estimate the development outcomes to transit (Nelson and Hibberd 2019). The study period for prior economic base analysis was 2002-2011 and census data for 2000 and 2010, as well as CoStar data for 2013. This report expands the number of systems used in analysis to 17 LRT systems, 14 BRT systems, nine SCT systems and 12 CRT systems. It also expands the period of analysis to 2015 for jobs-related data, 2016 for census data, and 2018 for CoStar data. The expanded and updated databases allow for more comprehensive assessment of their outcomes. Key findings include:

- Market rents increase with respect to Fixed Guideway Transit (FGT) station proximity for nearly all commercial types and for all modes, except there no rent premium for BRT in the closet $(0.125$ mile $)$ distance band and office responds positively only within the closets ( 0.125 mile) distance band from LRT stations, with rent premiums extend one to two miles away from FGT stations for many commercial types;

- On the whole, more mature Fixed Guideway Transit (FGT) system saw gains in regional share of jobs in closer in ( 0.25 mile and 0.50 mile) distance bands if not up to the 1.00 mile distance band from transit stations-BRT being an exception in gaining share only in the nearest ( 0.25 mile) distance band - while ones build during and since the Great Recession saw small or negative shifts in regional share;

- There are only modest gains in the regional share of population and housing before/during the Great Recession (2000-2009) bit somewhat more gains afterward (2010-2016) for all transit types except BRT with larger gains associated with households without children and early/middle aged households (35-49); and

- For the most part for all transit modes saw reductions in regional share of driving alone and carpooling, and increases in regional share of transit, biking, walking, and working at home with respect to FGT station proximity.

The report also featured illustrations of "good, bad and ugly" transit station/stop planning and design, suggesting that systems may be underperforming because of these limitations.

A missing element of prior work was the milieu or type of place within which transit stations are located. Addressing this is the key purpose of this report (Nelson, Hibberd and Currans 2021). 
Transit Impacts on Jobs, People and Real Estate

This is the fourth report in the genre of research supported by NITC. This project entailed updating data and disaggregating it to assess outcomes based on station area types or what we call Place Typologies. This research is guided by two overarching questions and analytic contexts:

\begin{abstract}
How do Transit Development Outcomes Vary by Mode and Place Typology? This analysis includes each transit system for each metropolitan area studied during appropriate time periods for that system, as well as systems combined across metros. Trends that are assessed include: (1) Changes in the number and share of jobs by sector with respect to type of system and distance from stations, by type of station based on Place Typology; (2) Changes in the number and share of jobs by wage category with respect to transit mode and station proximity by Place Typology; and (3) Changes in number and share of population, households, householders by age, and housing by tenure with respect to transit mode, station proximity, and Place Typology.
\end{abstract}

\title{
How does the real estate market for office, retail and apartment properties respond to proximity to transit stations by mode and Place Typology? Our prior
} work pioneered the use of CoStar commercial rental data for very broad assessments of real estate market responsiveness to transit by type but not really by location except for corridor distance bands. The new research conducts more refined relationships in those metropolitan areas based on mode and Place Typology where CoStar data are sufficient for analysis.

In addition, we updated our complete database with a codebook for anyone to access through NITC.

\section{References}

Nelson, Arthur C., Matt Miller, Dejan Eskic, Keuntae Kim, Joanna P. Ganning, Reid Ewing, Jenny Liu, Matt Berggren, Zakari Mumuni (2015). Do TODs Make a Difference? Portland OR: Portland State University, National Institute for Transportation and Communities Final Report NITC-RR-547 and NITC-RR-763. Available along with related materials at https://nitc.trec.pdx.edu/research/project/547/Do_TODs_Make_a_Difference?

Nelson, Arthur C. and Joanna P. Ganning (2016). National Study of BRT Development Outcomes. Portland OR: Portland State University, National Institute for Transportation and Communities Final Report 650. Available along with related materials at http://nitc.trec.pdx.edu/research/project/650

Nelson, Arthur C. and Robert Hibberd (2019). The Link between Transit Station Proximity and Real Estate Rents, Jobs, People and Housing with Transit and Land Use Planning Implications. Portland OR: Portland State University, National Institute for Transportation and Communities Final Report 1103. Available along with related materials at https://nitc.trec.pdx.edu/research/project/1103.

Nelson, Arthur C., Robert Hibberd and Kristian Currans with Nicole Iroz-Elardo (2021). Transit Impacts on Jobs, People and Real Estate, five volumes. Portland OR: Portland State University, National Institute for Transportation and Communities Final Report 1253. Available along with related materials at https://nitc.trec.pdx.edu/research/project/1253. 


\section{SYNOPSIS FOR VOLUME 2}

Three sets of themes emerge from analysis reported in Volume 2. First, although conventional wisdom would have it the High MA (mixed-use/accessible) Places would be more robust in attracting jobs over time than other Place Types, this is not true as our research shows, surprisingly. Second, while one would assume that higher wage jobs might be attracted more so to transit stations than middle or lower wage jobs, this is not the case given considerable variation both by transit mode and Place Typology. Third, a new approach to measuring jobshousing balance may be more informative for planning and policy than conventional measures—namely what we call the Employment-Worker Balance (EWB) metric.

\section{Variation in Transit Station Proximity Job Attractiveness by Mode and Place Typology Over Time (Chapter 2)}

Transit systems vary substantially in their attractiveness to jobs with respect to Place Typology. CRT performs best in the Moderate MA (mixed-use/accessibility) Place Type than others. SCT does better among the Moderate and High Place Types. BRT performed best at the Moderate MA Place Type. LRT did best in the Moderate and Low Place Types. Notably, for each transit mode:

- $\quad$ BRT proved to be quite flexible to the variations of each place type, showing robust growth across three four place types, shining in the two mid-range classes (Moderate and Low MA Places Types), while losing share slightly in the lowest-mix (Poor MA) areas. BRT stations may need to adapt to the context of the outlying areas to better attract firms to them. This may be undermined by the challenges of low-density dispersed land uses, however.

- $\quad$ CRT showed mostly modest gains in job share for the Low MA place type stations. Perhaps firms are opting for locations farther from stations because of externality affects such as noise and air pollution. Newer systems such as that in Salt Lake City, Utah use quieter, less polluting train technology for these commuter-oriented stations. An update may be necessary in other metropolitan areas to attract further job share gain near these stations.

- LRT saw modest growth at the Poor MA station areas but saw great share gains in the Low MA and Mod MA place type areas, with acceptable gains in the High MA areas. This seems reasonable given the scale of the trains, the competition from SCT systems for the most urban land, and the low response to transit proximity in all of the transit mode stations.

- SCT did best in the context for which it was designed, the High MA and Moderate MA Places. It saw a slight loss of job share in the Poor MA place type areas, for reasons that are likely to be similar to the other transit modes. SCT, like LRT, may benefit from efforts at greater integration of BRT and other transport mode to increase the utility of the system for all place types. 


\section{Variation in Transit Station Proximity Job Attractiveness based on Economic Group and Wage Group by Mode and Place Typology Over Time (Chapter 3)}

Each mode has different levels of attractiveness to jobs by economic and wage group, at different distances from transit stations and also depending on the Place Typology. Perhaps this should not be surprising intuitively but our research confirms that adage that "one size does not fit all." For instance, the Poor MA place type struggled with low job numbers, but all transit modes but SCT gained respectable shares of jobs. At the Low MA place type areas, with the exception of CRT, all job groups were repelled from the station. For their part, High MA Places mostly suffered from competition, with most wage and economic groups competing to be near the stations. These are job destinations for those riding CRT and LRT; they are place destinations for SCT riders, while BRT attracts everyone.

Overall, CRT and BRT did the best in the "Poor MA" neighborhoods. Still growth was miniscule for all transit modes in Poor MA. SCT actually declined at the "Poor MA" level. BRT and LRT had significant growth in job share at the "Low MA" neighborhoods. All modes grew, moreover; SCT and CRT showed modest growth, which was nevertheless disproportionate to the land area of the stations, compared to their share of regional urbanized area. BRT and LRT had significant growth at transit typology level 3, "Mod MA." SCT had strong growth. CRT showed very modest growth, almost remaining flat. At the most urban neighborhood type, SCT had robust growth, and BRT grew at a tremendous rate. LRT showed respectable rates of growth, while CRT was again flat in growth.

Trends for individual modes are as follows.

- Bus Rapid Transit performed well across all station types. The Poor MA type performed at the lowest rate of all types, with the land nearest the station declining in share and land in the next distance bands doing well. BRT systems did the best of all modes in the Poor MA category, implying that it may well be the best option for connecting outlying suburbs to more urban locales and rail transit. The implication for the low response of the market to the BRT station at the Poor MA station type is that the relative lack of walkability, as well as the auto-centric nature of transport leads to a poor response nearest the station, but a more robust response further away from the station. The lack of enthusiasm for the area nearest the station reflects the design conflicts that lead to negative spillovers. Examples include poor street connectivity to the station area and low-density development that does not respond to transit proximity as well as higher density areas.

- CRT also did better than LRT and SCT in the Poor MA station type. It reflected the same negative response at the station, with the neighborhoods beyond the station responding very positively to station proximity. CRT's low response to the high and moderate station types but robust response at the Low MA level reflects that its best applicability at present is in lower-density neighborhoods, with riders being most likely commuters for the light industry and other sectors.

- LRT systems as a whole performed best at the middle of the access and land use mix scale. This is likely due to the large size of these systems, which are usually above ground and not as well-connected to the built environment as the heavy rail systems of cities like New York or Washington, D.C. Further, the streetcar systems of many cities likely pull away some of the returns for LRT in High MA Places, as they are smaller and more amenable in design than lower-level places. 
- Streetcar Transit performed well in High MA places. This is due largely to the focus of streetcar systems on the urban core. The scale of the built environment is well-matched to the scale of the SCT system. However, in all but the Office and Education sector groups, the SCT LQ declined at the station, while improving just beyond. 


\section{Improving Jobs-Housing Balance Metrics through the Employment-Worker Balance Metric (Chapter 4)}

A more accessible workplace translates to a more productive and resilient workforce through potential improvements in work-life balance and overall cost of living, which in turn benefits the firm through higher output. Low EWB scores near transit stations reveal low-hanging fruit for planners who wish to increase economic and housing resiliency. Targeted solutions are needed to increase EWB. The EWB metric is consistent with economic development theory whereby regions in which workers have greater TOD-driven access to firms also provide a more business-friendly environment with increased situs via a more accessible, active workforce. When appropriate housing is provided for workers of all sectors of the economy, greater economic diversification is possible.

The policy implications of increasing employment-worker balance depend upon the nature of Place Typology imbalance that needs correction. In neighborhoods that are job-rich and housing poor for a lower- to moderate-income worker, challenges may include potential for local opposition from businesses that benefit from larger numbers of workers than residents, businesses seeking to protect their market share from newcomer firms, or from residents who fear negative externalities of lower or moderate-income housing development in their neighborhoods. Neighborhoods with upper-income jobs that seek to improve EWB may face gentrification pressures. Bedroom communities for blue-collar workers needing more jobs may face challenges from industrial externalities. 


\section{CHAPTER 2: The Link between Transit Station Proximity and Typology and Change in Jobs Over Time}

\section{OVERVIEW}

The research reported in this chapter expands upon previous work by assessing the extent to which jobs by sector are attracted to transit stations over time and across a range of station area intensities. Analysis is given of the land area encompassed by transit systems by mode and station type. Using economic base theory and relying upon shift-share and location quotient analyses, the economic development outcomes of station areas are assessed by transit mode, such as light rail, and by station typology. Transit modes include light rail transit, commuter rail transit, streetcar transit, and bus rapid transit systems. The station area types are characterized as lying somewhere along a continuum of land use mix, intensity, and accessibility. These types are based upon the relative intensity of a combination of characteristics of jobs, households, and the built environment. The analysis will advance the understanding of how transit stations by type effect the economy in a multimodal transportation system context. Case studies comprise metropolitan areas across the United States, in the Urbanized Area of the counties served by the transit systems under study. Each station area is analyzed by distance from the station in eighth-mile distance bands.

\section{Introduction}

Several of our previous studies (Arthur C Nelson 2017b; A. Nelson et al. 2015; Arthur C Nelson and Ganning 2015; A.C. Nelson et al. 2015; A. Nelson et al. 2013; Petheram et al. 2013; Arthur C Nelson 2017a; Arthur C. Nelson and Hibberd 2019; Arthur C Nelson and Hibberd 2019) focused on the economic outcomes of transit station proximity. These studies especially focused on economic base theory, and particularly shift-share analysis. They analyzed economic development, demographic and housing outcomes associated with those transit systems. Many focused on the period before the Great Recession (2000 through 2009) and during recession into and beyond the years of recovery (2010 through 2016).

The present work builds upon those previous studies, extending them to include segmentation of previous variables by transit station typology. The typology is based upon clustering of values in a series of characteristics indicative of the intensity and density of population, jobs, and housing. It also includes density and connectivity of street intersections. Each class (cluster) of station area represents a combination of characteristics that is unique from the other classes. Our methodology focuses on making associations and correlations, rather than causal relationships.

Our study includes transit systems of several different modes in metropolitan areas across the United States. Those modes include Bus Rapid Transit (BRT), Commuter Rail Transit (CRT), Light Rail Transit (LRT), and Streetcar Transit (SCT). These modes present different technologies and intensities of transport. Each mode, as the study will demonstrate, functions differently across the spectrum of land use mix, intensity, and accessibility. 
Table 2.1

Fixed Route Transit (FRT) Systems Studied

\begin{tabular}{|c|c|c|c|c|c|c|c|}
\hline $\begin{array}{l}\text { Light Rail } \\
\text { Transit }\end{array}$ & Year & $\begin{array}{l}\text { Bus Rapid } \\
\text { Transit }\end{array}$ & Year & $\begin{array}{l}\text { Streetcar } \\
\text { Transit }\end{array}$ & Year & $\begin{array}{l}\text { Commuter Rail } \\
\text { Transit }\end{array}$ & Year \\
\hline Buffalo & 1984 & Cleveland & 2008 & Atlanta & 2014 & $\begin{array}{l}\text { Albuquerque- } \\
\text { Santa Fe }\end{array}$ & 2006 \\
\hline Charlotte & 2007 & $\begin{array}{l}\text { Eugene- } \\
\text { Springfield }\end{array}$ & 2007 & Cincinnati & 2016 & Austin & 2010 \\
\hline Cleveland & 1980 & Kansas City & 2005 & Dallas & 2015 & Dallas-Ft. Worth & 1996 \\
\hline Dallas & 1996 & Nashville & 2009 & Kansas City & 2016 & Miami Tri-Rail & 1989 \\
\hline Denver & 1994 & Pittsburgh & 1977 & Little Rock & 2004 & Minneapolis & 1997 \\
\hline Houston & 2004 & Reno & 2010 & New Orleans & 2016 & Nashville & 2006 \\
\hline $\begin{array}{l}\text { Minneapolis-St. } \\
\text { Paul }\end{array}$ & 2004 & Salt Lake City & 2008 & Portland & 2001 & Orlando & 2014 \\
\hline Norfolk & 2011 & San Antonio & 2012 & Salt Lake City & 2013 & Portland & 2009 \\
\hline Phoenix & 2008 & San Diego & 2014 & Seattle & 2007 & Salt Lake City & 2008 \\
\hline Pittsburgh & 1984 & Seattle & 2010 & Tacoma & 2003 & San Diego & 1995 \\
\hline Portland & 1986 & Stockton & 2007 & Tampa & 2002 & $\begin{array}{l}\text { San Jose- } \\
\text { Stockton }\end{array}$ & 1998 \\
\hline Sacramento & 1987 & & & Tucson & 2014 & Seattle-Tacoma & 2000 \\
\hline Salt Lake City & 1999 & & & $\begin{array}{l}\text { Washington, } \\
\text { D.C. }\end{array}$ & 2016 & & \\
\hline San Diego & 1981 & & & & & & \\
\hline San Jose & 1987 & & & & & & \\
\hline Seattle & 2003 & & & & & & \\
\hline St. Louis & 1993 & & & & & & \\
\hline
\end{tabular}


Of the transit modes studied, light rail transit systems have the longest heritage. Several cities opened LRT operation in the early 1980s. Commuter Rail systems began opening in the 1990s. With the exception of Pittsburgh's long-standing BRT system of the late 1970s, SCT and BRT systems began opening only after the turn of the century. The more recent transit systems are BRT and SCT.

The land area encompassed by transit stations varies by transit mode and station type. We measure station area to a distance of one mile (referred to below as a one-mile distance band). Transit stations' square miles within the Urbanized Area are broken down by distance bands. These bands are one-eighth mile bands to half a mile from the stations, then by quarter-mile distances to one mile. Table $X$ sums all stations by mode and type for all metropolitan areas under study.

For all transit system modes, the land area within a mile of the stations increases with land use intensity, with exception of the commuter rail (CRT), which has much more land in the lower half of the land use mix and accessibility scale. CRT has the most land area in the Poor MA and Low MA types, while LRT has the most land area in the Mod MA and High MA station areas. SCT has the smallest spatial footprint, with a maximum of 79 square miles total in the High MA station type for all studied regions.

The Urbanized Area totals for each mode speak to their function within the regional transportation systems of each region. Overall sums for square miles within Urbanized Areas are as follows: SCT and BRT at approximately 14,000 square miles each; LRT at 30,000 and CRT at roughly 42,000 square miles. The limited area encompassed by the first two modes relative to the last two hint at the difference in scope for these modes. Highlighting the individual metropolitan regions' area figures reveals that the variation in scope for each transit mode is significant between each region. BRT ranges from a low 111 square miles in Eugene, OR to 2,700 square miles in the Washington, D.C. region. Only four of the metropolitan regions studied had more a thousand square miles devoted to BRT, while the rest average roughly 500 square miles. Likewise, large-scale regional SCT systems, those of approximately 2,000 square miles each, were limited to four regions, with the remaining regions' systems being much smaller in area, at an average of roughly 600 square miles. CRT and LRT systems for each region averaged a much larger area per region. The largest CRT system, for Washington, D.C., is nearly 17,000 square miles, and the largest LRT system, for Dallas, is nearly 8,000 square miles. Only two of the CRT systems are under 1,000, while LRT systems vary much more in area. A closer look at the number of stations versus the length of the routes would provide further insight on these figures. 
Table 2.2

Square Miles in Urbanized Area by Station Typology for all transit systems to 1 Mile from Station Incremental (Increm.) and Cumulative (Cum.) Square Miles

\begin{tabular}{|c|c|c|c|c|c|c|c|c|c|}
\hline & & $S C T$ & & $L R T$ & & $C R T$ & & $B R T$ & \\
\hline $\begin{array}{l}\text { Station } \\
\text { Types }\end{array}$ & $\begin{array}{l}\text { Distance } \\
\text { Bands }\end{array}$ & $\begin{array}{l}\text { Increm. } \\
\text { Square } \\
\text { Miles }\end{array}$ & $\begin{array}{l}\text { Cum. } \\
\text { Square } \\
\text { Miles } \\
\end{array}$ & $\begin{array}{l}\text { Increm. } \\
\text { Square } \\
\text { Miles } \\
\end{array}$ & $\begin{array}{l}\text { Cum. } \\
\text { Square } \\
\text { Miles } \\
\end{array}$ & $\begin{array}{l}\text { Increm. } \\
\text { Square } \\
\text { Miles }\end{array}$ & $\begin{array}{l}\text { Cum. } \\
\text { Square } \\
\text { Miles }\end{array}$ & $\begin{array}{l}\text { Increm. } \\
\text { Square } \\
\text { Miles }\end{array}$ & $\begin{array}{l}\text { Cum. } \\
\text { Squar } \\
e \\
\text { Miles }\end{array}$ \\
\hline \multirow{6}{*}{$\begin{array}{l}\text { Poor } \\
\text { MA }\end{array}$} & 0.125 & 2 & 2 & 3 & 3 & 10 & 10 & 15 & 15 \\
\hline & 0.25 & 6 & 8 & 19 & 22 & 30 & 40 & 20 & 35 \\
\hline & 0.375 & 10 & 18 & 20 & 42 & 51 & 91 & 22 & 57 \\
\hline & 0.5 & 4 & 22 & 5 & 46 & 71 & 162 & 24 & 81 \\
\hline & 0.75 & 4 & 25 & 8 & 55 & 205 & 367 & 53 & 134 \\
\hline & 1 & 10 & 35 & 48 & 103 & 277 & 644 & 57 & 191 \\
\hline \multirow{6}{*}{ Low MA } & 0.125 & 11 & 11 & 45 & 45 & 17 & 17 & 27 & 27 \\
\hline & 0.25 & 4 & 15 & 9 & 55 & 51 & 68 & 44 & 71 \\
\hline & 0.375 & 5 & 19 & 14 & 68 & 81 & 149 & 49 & 120 \\
\hline & 0.5 & 11 & 30 & 69 & 137 & 105 & 254 & 51 & 171 \\
\hline & 0.75 & 10 & 40 & 56 & 193 & 261 & 515 & 102 & 273 \\
\hline & 1 & 3 & 44 & 10 & 203 & 307 & 822 & 98 & 371 \\
\hline \multirow{6}{*}{$\begin{array}{l}\text { Mod } \\
\text { MA }\end{array}$} & 0.125 & 5 & 5 & 18 & 18 & 9 & 9 & 23 & 23 \\
\hline & 0.25 & 12 & 16 & 80 & 98 & 25 & 33 & 38 & 61 \\
\hline & 0.375 & 10 & 26 & 61 & 159 & 38 & 71 & 39 & 100 \\
\hline & 0.5 & 3 & 29 & 10 & 169 & 47 & 118 & 36 & 136 \\
\hline & 0.75 & 9 & 38 & 46 & 215 & 110 & 229 & 61 & 196 \\
\hline & 1 & 25 & 62 & 172 & 386 & 124 & 352 & 50 & 246 \\
\hline \multirow{6}{*}{$\begin{array}{l}\text { High } \\
\text { MA }\end{array}$} & 0.125 & 19 & 19 & 124 & 124 & 1 & 1 & 4 & 4 \\
\hline & 0.25 & 4 & 23 & 19 & 143 & 3 & 3 & 7 & 11 \\
\hline & 0.375 & 10 & 33 & 56 & 199 & 4 & 7 & 6 & 17 \\
\hline & 0.5 & 24 & 58 & 173 & 372 & 5 & 12 & 5 & 22 \\
\hline & 0.75 & 18 & 75 & 116 & 488 & 12 & 24 & 8 & 30 \\
\hline & 1 & 3 & 79 & 17 & 504 & 14 & 38 & 6 & 36 \\
\hline
\end{tabular}


Table 2.3

BRT Square Miles of Urbanized Area by Region

\begin{tabular}{lr}
\hline \hline & \multicolumn{2}{c}{$\begin{array}{c}\text { Urbanized Area Sq. } \\
\text { Miles for Transit- }\end{array}$} \\
Metropolitan Areas with Bus Rapid Transit & Served Counties \\
\hline Albuquerque, NM & 254.0 \\
Cleveland, OH & 778.4 \\
Eugene, OR & 111.1 \\
Kansas City, MO-KS & 730.2 \\
Minneapolis-St. Paul, MN & $2,225.5$ \\
Nashville, TN & 579.6 \\
Pittsburgh, PA & $1,938.0$ \\
Reno, NV & 180.1 \\
Salt Lake City, UT & 278.1 \\
San Antonio, TX & 608.3 \\
San Diego, CA & 780.6 \\
San Jose, CA & 617.6 \\
Seattle-Tacoma, WA & $2,263.7$ \\
Stockton, CA & 158.1 \\
Washington, DC & $2,697.7$ \\
Grand Total & 14,201 \\
\hline
\end{tabular}


Table 2.4

CRT Square Miles of Urbanized Area by Region

\begin{tabular}{lc}
\hline \hline & $\begin{array}{l}\text { Urbanized Area } \\
\text { Sq. Miles for } \\
\text { Transit-Served } \\
\text { Counties }\end{array}$ \\
\hline Metropolitan Areas with Light Rail & 651.1 \\
Austin, TX & $1,081.7$ \\
Dallas-Fort Worth, TX & $3,932.8$ \\
Denver, CO & $1,362.6$ \\
Miami, FL & $3,960.4$ \\
Minneapolis-St. Paul, MN & $3,376.3$ \\
Nashville, TN & $1,188.2$ \\
Orlando-Deltona, FL & $1,795.8$ \\
Portland, OR & $1,094.6$ \\
Salt Lake City-Ogden-Provo, UT & $1,450.3$ \\
San Diego, CA & 780.6 \\
San Jose-Stockton, CA & $1,061.8$ \\
Seattle-Tacoma, WA & $3,342.6$ \\
Washington, DC & $16,624.4$ \\
Grand Total & $41,703.2$ \\
\hline
\end{tabular}


Table 2.5

LRT Square Miles of Urbanized Area by Region

\begin{tabular}{lc}
\hline \hline & $\begin{array}{c}\text { Urbanized Area Sq. Miles } \\
\text { for Transit-Served } \\
\text { Metropolitan Areas with Light Rail }\end{array}$ \\
\hline Buffalo, NY & 403.55 \\
Charlotte, NC & 957.73 \\
Cleveland, OH & 778.40 \\
Dallas, TX & $7,810.96$ \\
Denver, CO & $3,422.63$ \\
Houston, TX & $1,694.23$ \\
Los Angeles, CA & $2,111.32$ \\
Minneapolis-St. Paul, MN & $2,225.55$ \\
Phoenix, AZ & $1,261.74$ \\
Pittsburgh, PA & 967.62 \\
Portland, OR & $1,645.59$ \\
Sacramento, CA & 488.04 \\
Salt Lake City, UT & 278.08 \\
San Diego, CA & 780.58 \\
San Jose, CA & 331.53 \\
Seattle-Tacoma, WA & $1,089.45$ \\
St. Louis, MO & $2,832.58$ \\
Virginia Beach-Norfolk, VA & 589.08 \\
Grand Total & $29,668.66$ \\
\hline
\end{tabular}


Table 2.6

SCT Square Miles of Urbanized Area by Region

\begin{tabular}{lr}
\hline \hline & $\begin{array}{c}\text { Urbanized Area Sq. } \\
\text { Miles for Transit- } \\
\text { Metropolitan Areas with Light Rail }\end{array}$ \\
\hline Atlanta, GA & $2,681.4$ \\
Cincinnati, OH & 806.3 \\
Dallas, TX & $1,963.5$ \\
Kansas City, MO-KS & 730.2 \\
Little Rock, AR & 262.0 \\
New Orleans, LA & 539.3 \\
Portland, OR & 551.0 \\
Salt Lake City, UT & 278.1 \\
Seattle-Tacoma WA & $2,168.4$ \\
Tampa, FL & $1,038.5$ \\
Tucson, AZ & 402.1 \\
Washington, DC & $1,348.9$ \\
Grand Total & \\
\hline
\end{tabular}


Table 2.7

Sums of Square Miles for 1-Mile Distance Bands for All MSA's

\begin{tabular}{llllllllll} 
& SCT & \multicolumn{2}{c}{ LRT } & \multicolumn{2}{c}{ CRT } & \multicolumn{2}{c}{ BRT } \\
\cline { 2 - 9 } 1-Mile DB & $\begin{array}{l}\text { Increm. } \\
\text { Area }\end{array}$ & $\begin{array}{l}\text { Cum. } \\
\text { Square } \\
\text { Siles }\end{array}$ & $\begin{array}{l}\text { Square } \\
\text { Miles }\end{array}$ & $\begin{array}{l}\text { Square } \\
\text { Siles }\end{array}$ & $\begin{array}{l}\text { Cum. } \\
\text { Square } \\
\text { Miles }\end{array}$ & $\begin{array}{l}\text { Increm. } \\
\text { Square } \\
\text { Miles }\end{array}$ & $\begin{array}{l}\text { Square } \\
\text { Siles }\end{array}$ & $\begin{array}{l}\text { Increm. } \\
\text { Square } \\
\text { Miles }\end{array}$ & $\begin{array}{l}\text { Cum. } \\
\text { Square } \\
\text { Miles }\end{array}$ \\
\hline Poor MA & 10 & 35 & 48 & 103 & 277 & 644 & 57 & 191 \\
Low MA & 3 & 44 & 10 & 203 & 307 & 822 & 98 & 371 \\
Mod MA & 25 & 62 & 172 & 386 & 124 & 352 & 50 & 246 \\
High MA & 3 & 79 & 17 & 504 & 14 & 38 & 6 & 36 \\
\hline Sums & 41 & 220 & 247 & 1,196 & 722 & 1,856 & 211 & 844 \\
\hline
\end{tabular}


The sums for square miles at a one-mile distance band for each station type gives a clearer picture of the extent of the systems across the country by mode. CRT systems had the highest figures in both incremental and cumulative area for each station type (see Table X). SCT had significantly less area than the other modes for all station types. The incremental area by station typology gives a sense for what typology is most prominent for each transit mode. SCT has the most area in the Mod MA type; LRT also has the most area in the Mod MA type. CRT has the most in the Low MA and Poor MA types. BRT is concentrated mainly in the Mod MA station type. Three transit modes have the most area in the Mod MA, while CRT is concentrated more in the Low MA type.

\section{Literature Review and Research Questions}

Studies on outcomes to station proximity that have disaggregated by station mode and typology are non-existent. Also needed is research that provides a way to predict transit station development outcomes based on transit station planning and design. However, what we do know is that ineffective station design and linkage to surrounding neighborhoods significantly impacts, even hinders, station access. The market responds in kind. Were it not for present barriers in design and planning, a substantial portion of urban growth since 2010 could have been absorbed within the first half-mile distance from stations; there yet remains a great deal of room for development within those neighborhoods, much of which are comprised of vacant or dated retail astride vast seas of empty parking lots (Arthur C. Nelson and Hibberd 2019), (Arthur C. Nelson 2013).

Our study focuses on transit-served regions (i.e., counties or multiple counties directly served by transit via the presence of a transit station; hereafter referred to as "Transit Regions"). The Nelson-Stoker-Hibberd Resilience Hypothesis (Arthur C. Nelson, Stoker, and Hibberd 2019) posited that the Great Recession's economic shocks upon Transit Regions lead firms, especially in key economic sectors, to seek to reduce vulnerability to possible subsequent shocks by relocating their firms nearer to transit stations. Our 2019 study on transit systems at a systemwide scale confirmed this hypothesis. For our present study, we will further disaggregate transit systems into a hierarchy of station area types, from low-density suburban to highintensity urban core. More accurately, we will segment land use by relative level and intensity of accessibility and land use mix. We expect that this disaggregation will reveal results that stand counter to our earlier results, which is a common occurrence in studies employing methodological refinements. We will study a range of transit systems (see Table X.1). We are concerned with changes in the number and share of jobs by sector with respect to type of transit system and distance from stations, by type of station. Specifically, we want to know:

\section{Is there a link between transit station proximity and change in workers by economic sector across a hierarchy of station area land use mix and accessibility types from 2010 to 2016 ?}

Our hypothesis is that station proximity will result in a wide variety of outcomes, depending upon the regional economy, the land use intensity of the station area, and the local job sector and income mix. We hypothesize that each transit mode will serve different areas of the region and different sectors of the economy and the worker population. SCT will depend highly upon more urban areas, while CRT and BRT will serve outlying areas. LRT will serve primarily areas in the middle of the urban range. This means further that each mode will serve a particular range of job sectors. 


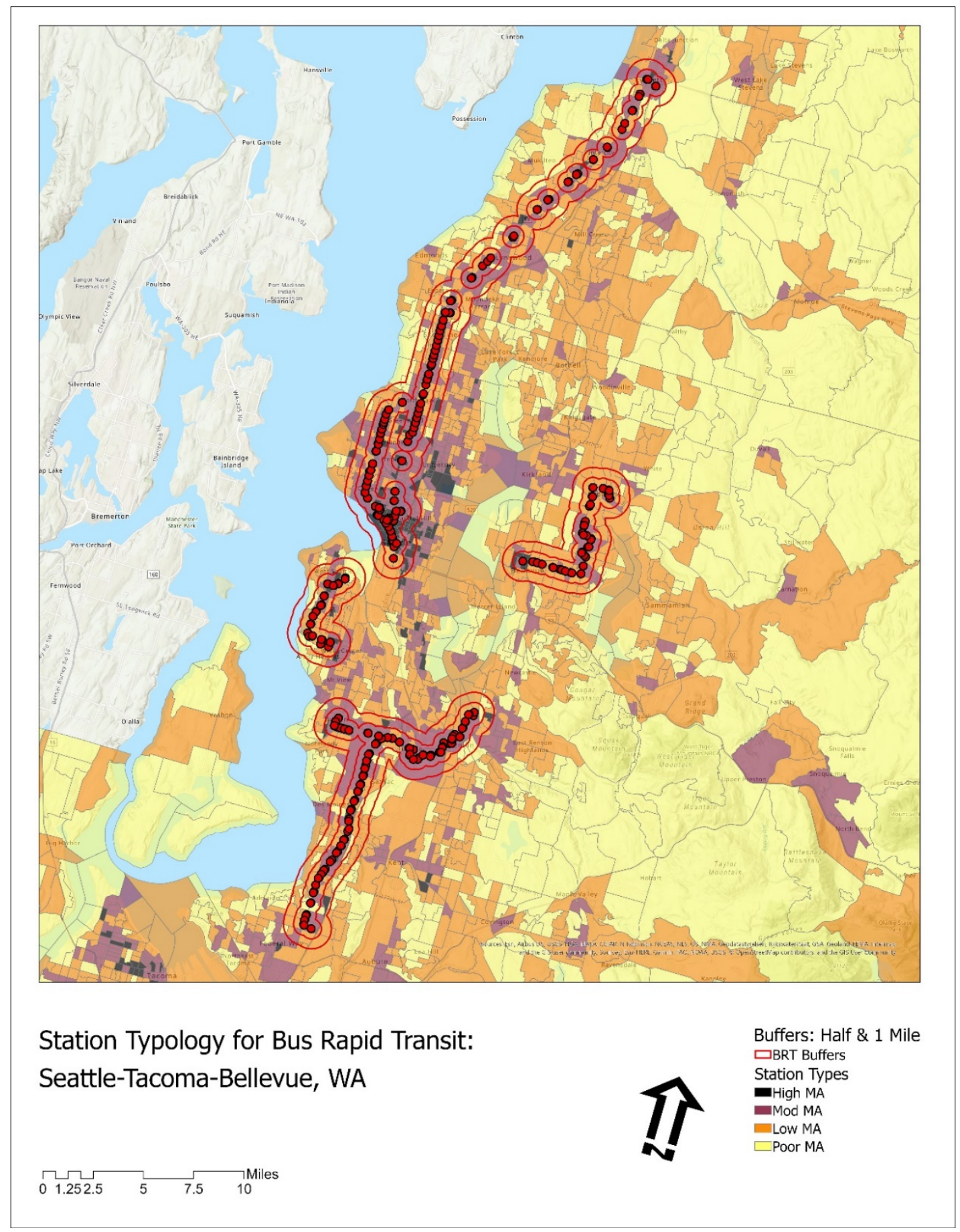

Figure 2.1

Bus Rapid Transit Station Area Typology, with buffers at half-mile and 1-mile distances from the station

Distance bands are based upon Euclidean distance from the edge of the census block group to the transit station centroid. Block groups classified to each distance band may have area that extends into other distance bands. Station Typology is classified by relative scores along continuum from poor to high land use mix / accessibility (seen on map legend as "Poor MA," etc.). Seattle's BRT systems is one of the most extensive in the USA. The typology map shows specific stations that may provide ready opportunities for targeted development. 


\section{Research Design and Plan}

Our research design and plan include using GIS data and analyses to join transit stations and buffers, representing eighth-mile distance bands around each station, to a layer of land use intensity. These data allow the segmentation of the station areas, their environs, and their regions into relative land use mix and intensity. We call these place types. US census data provide job figures over time by sector, income and other categorizations. Economic base analysis is used to analyze the shift in share and relative local concentration of jobs near the station viz-a-vis the transit-served region surrounding the study transit systems.

\section{Data Resources}

The employment data come from the US Census Bureau's Longitudinal Employer-Household Dynamics data (LEHD) for 2010 and 2016. Transit system data come from the General Transit Feed Specification (GTFS). ${ }^{98}$ Census blocks were downloaded from IPUMS HGIS website (\#\#). Station typology data are outlined below.

\section{Transit Station Typology - Place Types}

To evaluate by place types, we aggregate the following built environment variables to the census block group, and then apply a data clustering method:

Longitudinal Employer-Household Dynamics (LEHD, 2017)

- Total jobs per acre

- Proportion of jobs that are retail or entertainment

American Community Survey (ACS, 2017, 5-year)

- Total residential population per acre

- Total households per acre

- Proportion of households with no kids (representing smaller dwelling units)

- Proportion of households that are owner occupied

\section{Smart Location Database ${ }^{99}$}

- Intersection density (an indication of connectivity)

- Proportion of intersections that are three-way to those that are four-way (an indication of connectivity)

We apply Jenks natural breaks to each variable to segment the spectrum of variables. Each "break" is ranked in terms of the urban intensity of the categories. The lowest density category has a score of 1 , while the highest has a 5 . The sum of these rankings, summing all variables together, provides an indication of the level of urban intensity and concentration for each block group. The sum of rankings is then divided into the number of categories of interest. For this study, we aggregated the place types into four categories labeled from $1=$ most suburban to $4=$ highly urban. An iterative verification process rotated between testing variables and groundtruthing them through spatial mapping and observations using Google Streetview. Figure 2 shows a map of LRT stations in the St. Louis metropolitan area. It demonstrates that many stations consist of multiple land use types, indicating that different land use intensities and mixtures occur in different sectors of the station area, even within a 1-mile DB of the station. We calculate each station type separately in our analysis of economic change.

\footnotetext{
${ }^{98}$ See TransitFeeds.com for downloadable tables, which get regular updates.

${ }^{99}$ See https://www.epa.gov/smartgrowth/smart-location-mapping. Accessed 11-25-2020. Note that while this data is older, intersection density is not something that widely changes from decade to decade in most of the areas that are already developed enough to have FRT.
} 


\section{Shift-Share Method}

Economic development is often analyzed using economic base theory and measures spatial concentrations of jobs by sector or other segmentations, as well as their spatial and temporal dynamics. Shift-share analysis compares change of employment concentrations at the "regional" level, which is defined by the analyst at a chosen scale (e.g., national, state, or county), with changes in concentrations at the "local" level, which can also be defined at various scales by the analyst. The study assigns "transit-served" counties as regions (those counties with access to a transit system) and assigns transit neighborhoods as the "local" scale. The transit neighborhoods are further segmented into distance bands away from the station, in increments of one-eighth or one-quarter mile, up to a distance of 1 mile from the transit station centroid. The analytic method isolates the various sources of job change into 3 categories: 1) the Transit Region Share, which references overall economic dynamics at the regional scale 2) the Industry or Job Sector Mix, which accounts for job dynamics as a result of change in a specific industry, and 3) FRT Station Shift, also called the "competitive effect," which measures the degree of change at the local spatial scale of the transit station neighborhood. It measures the station's lagging and leading job sectors by isolating station area economic trends from those at the regional scale. The shift-share formula is as follows (Carnegie Mellon n.d.):

Where

$$
S S_{i}=T R_{i}+S M_{i}+F R T_{i}
$$

$$
\begin{aligned}
& S S_{i}=\text { Shift-Share } \\
& T R_{i}=\text { Transit Region share } \\
& S M_{i}=\text { Sector Mix } \\
& F R T_{i}=\text { FRT Station Shift }
\end{aligned}
$$

Each component is calculated with the following equations:

$T R=\left(\right.$ FRT Station Area $\left.{ }^{\mathrm{t}-1} \times \mathrm{TR}^{\mathrm{t}} / \mathrm{TR}^{\mathrm{t}-1}\right)$

$S M=\left[\left({ }_{i} F R T\right.\right.$ Station Area $\left.\left.{ }^{\mathrm{t}-1} \times \mathrm{iTR}_{\mathrm{T}}{ }^{\mathrm{t}} / \mathrm{TTR}^{\mathrm{t}-1}\right)-\mathrm{TR}\right]$

$F R T=\left[{ }_{i} F R T\right.$ Station Area ${ }^{\mathrm{t}-1} \times\left({ }_{\mathrm{i} F R T}\right.$ Station Area ${ }^{\mathrm{t}} / \mathrm{i}$ FRT Station Area $\left.\left.{ }^{\mathrm{t}-1}-\mathrm{i}_{\mathrm{TR}}{ }^{\mathrm{t}} / \mathrm{iTR}^{\mathrm{t}-1}\right)\right]$

Where:

iFRT Station Area $=$ number of jobs in the FRT Station Area sector (i) at the beginning of the analysis period $(\mathrm{t}-1)$

${ }_{i}$ FRT Station Area ${ }^{t}=$ number of jobs in the FRT Station Area in sector (i) at the end of the analysis period $(t)$

$\mathrm{TR}^{\mathrm{t}-1}=$ total number of jobs in the Transit Region at the beginning of the analysis period(t-1)

$\mathrm{iTR}^{\mathrm{t}}=$ total number of jobs in the Transit Region at the end of the analysis period $(\mathrm{t})$ $\mathrm{iTR}=$ number of jobs in the Transit Region in sector (i) at the beginning of the analysis period (t-1)

$\mathrm{iTR}^{\mathrm{t}}=$ number of jobs in the Transit Region in sector (i) at the end of the analysis period (t) 


\section{Location Quotients}

Location Quotients (LQ) provide a spatial concentration measure that compares local concentrations of phenomena with a regional or global concentration of the same phenomena. For this study, transit station areas by eighth-mile distance bands provide the local context, while "transit-served counties," or counties and groups of counties that are served by transit systems, provide the regional context. LQ metrics, along with shift-share analyses, are a proven methodological staple of economic development studies. The effectiveness of these methodologies at providing evidence of economic development highlight the spatial nature of the economy. Transit systems serve to provide network connectivity across local economies, connecting the geographies highlighted by these methodologies. 


\section{Results and Discussion}

In our 2019 report, we discussed an emerging theme, which follows the Nelson-Hibberd-Stoker Resilience Hypothesis - that neighborhoods proximate to transit stations will attract and absorb many times more workers than the urbanized area of the same Transit Region. This study supports that hypothesis. However, results greatly vary by transit mode (e.g., SCT or LRT) and station type on the continuum from poor to high access and land use mix. BRT is proving to be the most versatile to changes in land use intensity. CRT and LRT are more successful in middle urban intensities, while SCT shines the brightest at the highest level of urban intensity.

The most significant growth in job share within half a mile of the station of all systems and station types occurred in BRT systems at the moderate level of station area accessibility and land use mix. The next-most successful near the station, within a half-mile distance, was LRT at the more moderate levels of station intensity. These also performed best of all the categories at the eighth-mile distance band. SCT outperformed the other modes in the High MA station areas both at the eighth mile and the half-mile distances from the stations. It brought significant gains in share in areas that were already highly developed, suggesting a shift in share of jobs that is not completely dependent upon development.

\section{Station Type 1: Poor Land Use Mix \& Accessibility (Poor MA)}

We shall review total employment growth trends across each transit mode, considering modes in order of highest to lowest growth trends for the study period. In Poor MA BRT station areas across the study regions, the trend of total workers declined for the first half-mile from the station. For CRT and LRT at the distance band just beyond the station, from one-eighth of a mile to one-quarter, the growth was small but positive. The other modes experienced no growth or loss of job share growth at the first DB. These neighborhoods may represent regionally outlying areas, but they often represent neighborhoods just beyond more intensely developed land, with which they are competing for land use intensity.

- CRT: The Poor MA station types for the CRT systems, saw the highest overall growth of the four transit modes, with most one-eighth mile distance bands (DBs) growing by several thousand jobs between 2010 and 2016. While these stations account for half a percent of the regional total Urbanized Area (UA), job growth was slightly higher, at $0.58 \%$. So, CRT remained in positive growth even in outlying areas with very low levels of land use mix and accessibility.

- LRT: The response to LRT station proximity in Poor MA locations was modest but positive overall. These station areas, to the half-mile DB, comprised $0.2 \%$ of their regions' Urbanized Area and gained $0.25 \%$ of the regional growth in total jobs.

- SCT systems in Poor MA station areas comprised a very small percentage of the urbanized land use in their regions. They stayed relatively flat in growth, with a loss of about one-tenth of one percent, which was a loss of 577 jobs in the first half-mile DB.

- BRT: The Poor MA neighborhoods near BRT stations, at a half-mile distance from the stations, accounted for less than 1 percent of the regional Urbanized Area, at 102 square miles. In these neighborhoods, BRT saw a modest loss of regional share of employment growth from 2010 to 2016. 


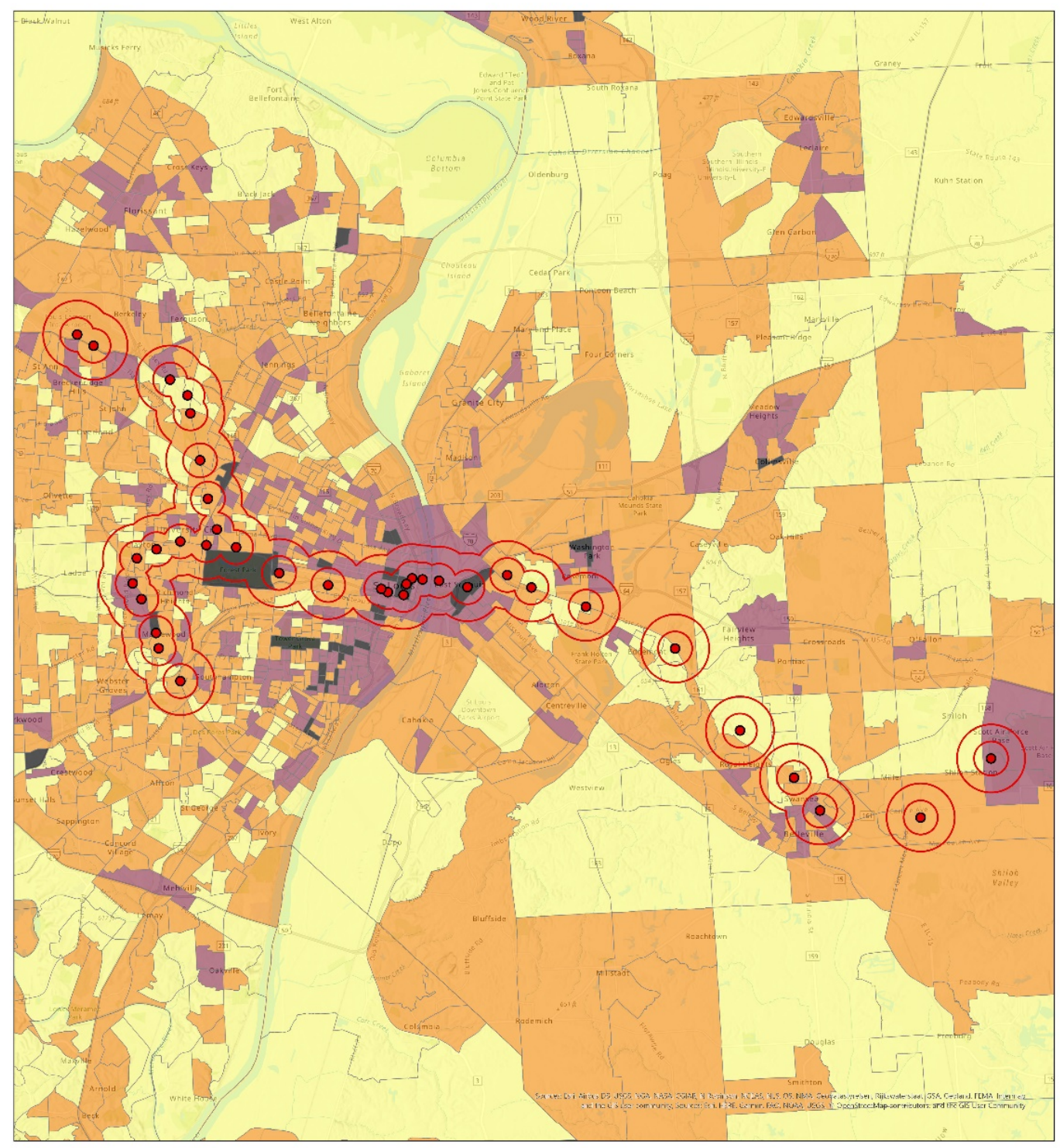

Station Typology for Light Rail Transit:
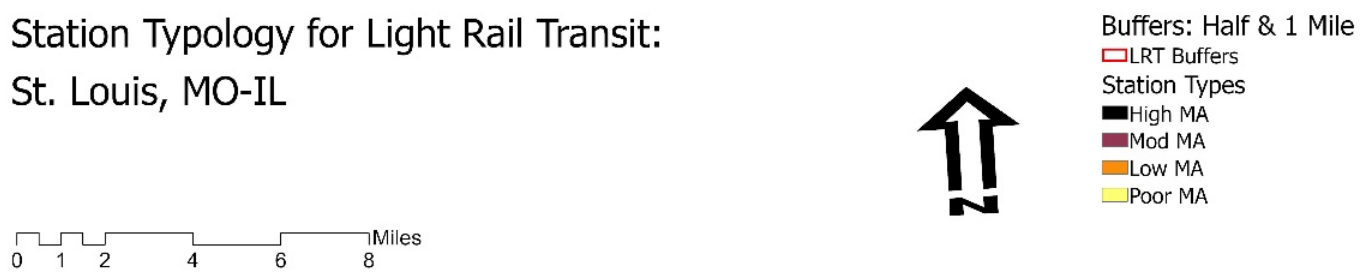

\section{Figure 1.1}

St. Louis LRT stations contain all of the four station types.

Many stations have multiple types. In outlying areas, for example, there are stations that range from Mod MA to Poor MA within the 1-mile distance band around a station. 
The firms in these areas responded to the kind of transit mode at hand. CRT and LRT each picked up thousands of jobs with a half-mile DB of the stations, while BRT and SCT saw mild losses. These results speak partly to the design of the transit modes, but mainly they indicate the challenge that transit has in general of attracting use in dispersed-intensity areas of the region. It also indicates some major opportunities in these neighborhoods to attract further growth very near the transit station (Renne et al. 2016). This kind of growth will increase the economic resilience of more outlying areas. The challenge then becomes to increase these areas' land use mix and accessibility sufficiently to attract viable transit options while maintaining the local populations' desired sense of place. Main Street projects have been occurring around the country in an attempt to retrofit these areas in appropriate ways (DunhamJones and Williamson 2011).

\section{Station Type 2: Low Land Use Mix \& Accessibility (Low MA)}

Growth was much more robust in Low MA station type areas than in Poor MA areas. All four transit modes achieved growth. Those most suited to a lower-intensity land use environment again saw the highest gains in regional job share.

- BRT, at $1.5 \%$ of the regions' UA, achieved $11 \%$ of the regional share of job growth. This is the highest rate of growth for the transit modes in Low MA neighborhoods. It indicates that BRT is capturing far more share of regional job growth than could be indicated by the land area it utilizes.

- LRT, with $0.5 \%$ of the regions' UA, captured the next highest level of growth, which was $6.15 \%$ of regional share of job growth. LRT thrives best, according to the numbers, in mid-level land use intensities. This may be due to the typical size of LRT systems. They are of higher capacity than BRT and SCT, and therefore provide economies of scale in appropriately scaled neighborhoods. They attract less growth in areas that are too dispersed or too concentrated.

- CRT, at $0.7 \%$ of the regions' UA, achieved $2.25 \%$ of regional job growth share, which is near 50,000 total jobs just within the first half-mile DB from these stations, and a rate considerably higher than the station area proportion of the regions.

- SCT only encompassed $0.3 \%$ of UA for its regions but captured $1.6 \%$ of job growth share. The streetcar suburbs of New Orleans provide a great example of areas of relatively modest land use intensity and mix that can still benefit from proximity to SCT stations. Like LRT, SCT does less well in Poor MA than in Low MA neighborhoods.

Even at this relatively low level of land use intensity, all four transit modes absorbed disproportionate numbers of jobs relative to their respective regions. BRT and LRT saw significantly robust growth, while CRT and SCT growth rates were more modest. These percentages represent considerable numbers of jobs. For the first half-mile DB, the figures, were approximately as follows: 73,000 for BRT, 48,700 for CRT, 95,000 for LRT, and 8,400 for SCT. These figures provide a picture of which systems are most suited to a Low MA neighborhood context. SCT grew the least, while LRT and BRT saw notable growth and CRT fared well. 
Table 2.8

Change in Total Workers 2010-2016 for all FRT Modes, Poor MA Station Type

Change in Total Workers by Time Period for BRT

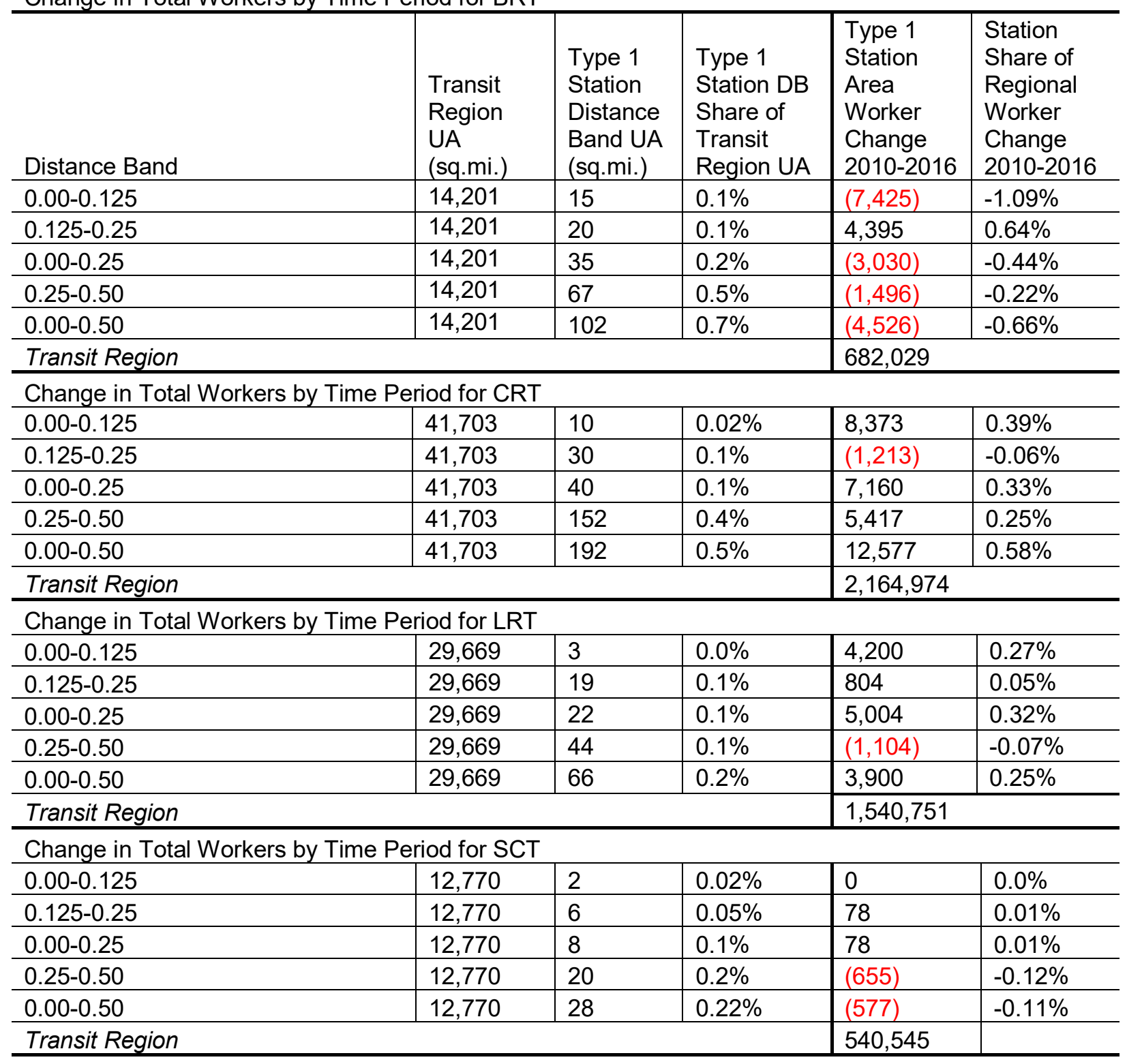


Table 2.9

Change in Total Workers 2010-2016 for all FRT Modes, Low MA Station Type

Change in Total Workers by Time Period for BRT

\begin{tabular}{|c|c|c|c|c|c|}
\hline Distance Band & $\begin{array}{l}\text { Transit } \\
\text { Region UA } \\
\text { (sq.mi.) }\end{array}$ & $\begin{array}{l}\text { Type } 2 \\
\text { Station } \\
\text { Distance } \\
\text { Band UA } \\
\text { (sq.mi.) }\end{array}$ & $\begin{array}{l}\text { Type } 2 \\
\text { Station } \\
\text { DB Share } \\
\text { of Transit } \\
\text { Region } \\
\text { UA }\end{array}$ & $\begin{array}{l}\text { Type } 2 \\
\text { Station } \\
\text { Area } \\
\text { Worker } \\
\text { Change } \\
2010- \\
2016 \\
\end{array}$ & $\begin{array}{l}\text { Station } \\
\text { Share of } \\
\text { Regional } \\
\text { Worker } \\
\text { Change } \\
2010-2016\end{array}$ \\
\hline $0.00-0.125$ & 14,201 & 27 & $0.2 \%$ & 33,253 & $4.88 \%$ \\
\hline $0.125-0.25$ & 14,201 & 44 & $0.3 \%$ & 14,011 & $2.05 \%$ \\
\hline $0.00-0.25$ & 14,201 & 71 & $0.5 \%$ & 47,264 & $6.93 \%$ \\
\hline $0.25-0.50$ & 14,201 & 144 & $1.0 \%$ & 25,654 & $3.76 \%$ \\
\hline $0.00-0.50$ & 14,201 & 215 & $1.5 \%$ & 72,918 & $10.69 \%$ \\
\hline \multicolumn{4}{|l|}{ Transit Region } & 682,029 & \\
\hline \multicolumn{6}{|c|}{ Change in Total Workers by Time Period for CRT } \\
\hline $0.00-0.125$ & 41,703 & 17 & $0.04 \%$ & 30,363 & $1.40 \%$ \\
\hline $0.125-0.25$ & 41,703 & 51 & $0.1 \%$ & 6,006 & $0.28 \%$ \\
\hline $0.00-0.25$ & 41,703 & 68 & $0.2 \%$ & 36,369 & $1.68 \%$ \\
\hline $0.25-0.50$ & 41,703 & 237 & $0.6 \%$ & 12,295 & $0.57 \%$ \\
\hline $0.00-0.50$ & 41,703 & 305 & $0.7 \%$ & 48,664 & $2.25 \%$ \\
\hline \multicolumn{4}{|l|}{ Transit Region } & $2,164,974$ & \\
\hline \multicolumn{6}{|c|}{ Change in Total Workers by Time Period for LRT } \\
\hline $0.00-0.125$ & 29,669 & 45 & $0.2 \%$ & 55,649 & $3.61 \%$ \\
\hline $0.125-0.25$ & 29,669 & 9 & $0.03 \%$ & 15,048 & $0.98 \%$ \\
\hline $0.00-0.25$ & 29,669 & 54 & $0.2 \%$ & 70,697 & $4.59 \%$ \\
\hline $0.25-0.50$ & 29,669 & 92 & $0.3 \%$ & 23,985 & $1.56 \%$ \\
\hline $0.00-0.50$ & 29,669 & 146 & $0.5 \%$ & 94,682 & $6.15 \%$ \\
\hline \multicolumn{4}{|l|}{ Transit Region } & $1,540,757$ & \\
\hline \multicolumn{6}{|c|}{ Change in Total Workers by Time Period for SCT } \\
\hline $0.00-0.125$ & 12,770 & 11 & $0.1 \%$ & 5,561 & $1.03 \%$ \\
\hline $0.125-0.25$ & 12,770 & 4 & $0.03 \%$ & 2,033 & $0.38 \%$ \\
\hline $0.00-0.25$ & 12,770 & 15 & $0.1 \%$ & 7,594 & $1.40 \%$ \\
\hline $0.25-0.50$ & 12,770 & 20 & $0.2 \%$ & 841 & $0.16 \%$ \\
\hline $0.00-0.50$ & 12,770 & 35 & $0.3 \%$ & 8,435 & $1.56 \%$ \\
\hline \multicolumn{4}{|l|}{ Transit Region } & 540,545 & \\
\hline
\end{tabular}




\section{Station Type 3: Moderate Land Use Mix \& Accessibility (Mod MA)}

Firms in Mod MA neighborhoods saw growth; some transit systems had considerable growth, while others were more modest. Neighborhoods near BRT stations saw great gains in total workers, considerably above the percentage of regional UA. The CRT systems in these station areas faired most modestly but saw some growth overall. These results may indicate that the market is drawn towards systems of greater flexibility (LRT and BRT) across the land use continuum. CRT and SCT both may be limited by their size to certain areas of the region, especially as competition from BRT systems grows.

- BRT-proximate neighborhoods saw the highest employment growth, at a very strong $17.6 \%$ of total regional growth share with a half-mile of the station. These station areas accounted for only $1.2 \%$ of total regional urbanized land area. The number of jobs added was $120,117$.

- $\quad$ LRT station areas within a half-mile DB from the station saw the next-highest growth rate, at $8.3 \%$, also a very strong rate of employment growth. Accounting for less than $1 \%$ of the total urbanized land area of their respective regions, these stations attracted jobs at a disproportionate rate compared to the rest of the region.

- SCT: The next-highest rate of growth occurred in the SCT-proximate neighborhoods of their respective regions. At a slightly negative rate of growth, the SCT station areas repelled less than a proportional share of regional employment growth. They comprised $0.2 \%$ of the urbanized area of the regions.

- CRT had flat growth in the moderate-intensity neighborhoods. At $0.6 \%$ growth CRT grew slightly faster than the rest of the region, of which it comprised $0.3 \%$ of the urbanized land area of the respective regions. These results may be indicative of multiple challenges. First, each station usually consists of more than station typology, and the land with the most effective station type (or, in other words, land use type) may be outcompeting the other types. 
Table 2.10

Change in Total Workers 2010-2016 for all FRT Modes, Mod MA Station Type

Change in Total Workers by Time Period for BRT

\begin{tabular}{|c|c|c|c|c|c|}
\hline Distance Band & $\begin{array}{l}\text { Transit } \\
\text { Region UA } \\
\text { (sq.mi.) }\end{array}$ & $\begin{array}{l}\text { Type } 3 \\
\text { Station } \\
\text { Distance } \\
\text { Band UA } \\
\text { (sq.mi.) }\end{array}$ & $\begin{array}{l}\text { Type } 3 \\
\text { Station } \\
\text { DB Share } \\
\text { of Transit } \\
\text { Region } \\
\text { UA }\end{array}$ & $\begin{array}{l}\text { Type } 3 \\
\text { Station } \\
\text { Area } \\
\text { Worker } \\
\text { Change } \\
\text { 2010-2016 }\end{array}$ & $\begin{array}{l}\text { Station } \\
\text { Share of } \\
\text { Regional } \\
\text { Worker } \\
\text { Change } \\
\text { 2010-2016 }\end{array}$ \\
\hline $0.00-0.125$ & 14,201 & 23 & $0.2 \%$ & 75,322 & $11.04 \%$ \\
\hline $0.125-0.25$ & 14,201 & 38 & $0.3 \%$ & 12,950 & $1.90 \%$ \\
\hline $0.00-0.25$ & 14,201 & 61 & $0.4 \%$ & 88,272 & $12.94 \%$ \\
\hline $0.25-0.50$ & 14,201 & 113 & $0.8 \%$ & 31,845 & $4.67 \%$ \\
\hline $0.00-0.50$ & 14,201 & 174 & $1.2 \%$ & 120,117 & $17.6 \%$ \\
\hline \multicolumn{4}{|l|}{ Transit Region } & 682,029 & \\
\hline \multicolumn{6}{|c|}{ Change in Total Workers by Time Period for CRT } \\
\hline $0.00-0.125$ & 41,703 & 9 & $0.02 \%$ & 3,492 & $0.16 \%$ \\
\hline $0.125-0.25$ & 41,703 & 25 & $0.1 \%$ & 890 & $0.04 \%$ \\
\hline $0.00-0.25$ & 41,703 & 34 & $0.1 \%$ & 4,382 & $0.20 \%$ \\
\hline $0.25-0.50$ & 41,703 & 110 & $0.3 \%$ & 8,004 & $0.37 \%$ \\
\hline $0.00-0.50$ & 41,703 & 144 & $0.3 \%$ & 12,386 & $0.57 \%$ \\
\hline \multicolumn{4}{|l|}{ Transit Region } & $2,164,974$ & \\
\hline \multicolumn{6}{|c|}{ Change in Total Workers by Time Period for LRT } \\
\hline $0.00-0.125$ & 29,669 & 18 & $0.1 \%$ & 64,225 & $4.17 \%$ \\
\hline $0.125-0.25$ & 29,669 & 80 & $0.3 \%$ & 21,360 & $1.39 \%$ \\
\hline $0.00-0.25$ & 29,669 & 98 & $0.3 \%$ & 85,585 & $5.55 \%$ \\
\hline $0.25-0.50$ & 29,669 & 151 & $0.5 \%$ & 41,995 & $2.73 \%$ \\
\hline $0.00-0.50$ & 29,669 & 249 & $0.8 \%$ & 127,580 & $8.28 \%$ \\
\hline \multicolumn{4}{|l|}{ Transit Region } & $1,540,757$ & \\
\hline \multicolumn{6}{|c|}{ Change in Total Workers by Time Period for SCT } \\
\hline $0.00-0.125$ & 12,770 & 5 & $0.04 \%$ & 16,194 & $3.00 \%$ \\
\hline $0.125-0.25$ & 12,770 & 12 & $0.1 \%$ & 6,786 & $1.26 \%$ \\
\hline $0.00-0.25$ & 12,770 & 17 & $0.1 \%$ & 22,980 & $4.25 \%$ \\
\hline $0.25-0.50$ & 12,770 & 25 & $0.2 \%$ & 5,144 & $0.95 \%$ \\
\hline $0.00-0.50$ & 12,770 & 42 & $0.3 \%$ & 28,124 & $5.20 \%$ \\
\hline \multicolumn{4}{|l|}{ Transit Region } & 540,545 & \\
\hline
\end{tabular}




\section{Station Type 4: High Land Use Mix \& Accessibility (High MA)}

At the highest level of land use mix, intensity and accessibility, growth tapered off while continuing at a good clip for most modes. The land use intensity and the related constraints can be seen in the results: BRT and SCT grew the most, while LRT grew modestly, and CRT remained flat. Still, growth in the High MA neighborhoods near transit stations was at a much larger scale than in the Poor MA in outlying or underdeveloped neighborhoods. While some cities such as Denver and Salt Lake City bring LRT directly into the CBD, others have opted to build SCT systems in the High MA neighborhoods, which provide the kind of land use from which SCT systems most greatly benefit. CRT faces challenges from the scale of the trains and therefore the stations, as well as noise and air pollution disamenities. BRT has begun competing well with SCT but has to contend for space on congested streets in the urban core.

- BRT also grew significantly at a rate of $6.1 \%$ at the half-mile DB from the station. It captured more regional share of growth than its land area, $0.2 \%$, would indicate. It more modest growth relative to SCT may indicate some competition between the two for routes in the CBD.

- LRT: Light rail stations in high mix and accessibility areas comprised 1.3 percent of the urbanized land area in metropolitan areas served by LRT systems. At the same time, the employment growth in those areas represented 1.8 percent of the total regional employment growth. Most of that growth occurred within a quarter mile of those transit stations, 1.24 percent, while the land area only consisted of $0.5 \%$ of the regional land area.

- CRT saw flat growth in the highest intensity land use neighborhoods of the CRT-served regions. At the same time, CRT has long been oriented toward taking commuters from outlying areas and delivering them to jobs at the CBD in the urban core of the region. While the highest intensity areas saw flat growth, this may be due to the fact that the $\mathrm{CBD}$ is much more built out than the areas from which commuters usually travel to work.

- SCT: Cumulatively at the half-mile distance band, SCT type 4 accounted for $0.5 \%$ of the Urbanized Area of the streetcar-served counties in metropolitan areas of the study. While these transit regions increased total workers by 540,545 the half-mile DB obtained 27,251 jobs, or 5 percent of the job growth in these regions. 
Table 2.11

Change in Total Workers 2010-2016 for all FRT Modes, High MA Station Type

Change in Total Workers by Time Period for BRT

\begin{tabular}{|c|c|c|c|c|c|}
\hline Distance Band & $\begin{array}{l}\text { Transit } \\
\text { Region } \\
\text { UA } \\
\text { (sq.mi.) }\end{array}$ & $\begin{array}{l}\text { Type } 4 \\
\text { Station } \\
\text { Distance } \\
\text { Band UA } \\
\text { (sq.mi.) }\end{array}$ & $\begin{array}{l}\text { Type } 4 \\
\text { Station } \\
\text { DB Share } \\
\text { of Transit } \\
\text { Region } \\
\text { UA }\end{array}$ & $\begin{array}{l}\text { Type } 4 \\
\text { Station } \\
\text { Area } \\
\text { Worker } \\
\text { Change } \\
\text { 2010-2016 } \\
\end{array}$ & $\begin{array}{l}\text { Station } \\
\text { Share of } \\
\text { Regional } \\
\text { Worker } \\
\text { Change } \\
2010-2016 \\
\end{array}$ \\
\hline $0.00-0.125$ & 14,201 & 4 & $0.03 \%$ & 24,773 & $3.63 \%$ \\
\hline $0.125-0.25$ & 14,201 & 7 & $0.05 \%$ & 7,966 & $1.17 \%$ \\
\hline $0.00-0.25$ & 14,201 & 11 & $0.1 \%$ & 32,739 & $4.80 \%$ \\
\hline $0.25-0.50$ & 14,201 & 18 & $0.1 \%$ & 8,846 & $1.30 \%$ \\
\hline $0.00-0.50$ & 14,201 & 29 & $0.2 \%$ & 41,585 & $6.10 \%$ \\
\hline \multicolumn{4}{|l|}{ Transit Region } & 682,029 & \\
\hline
\end{tabular}

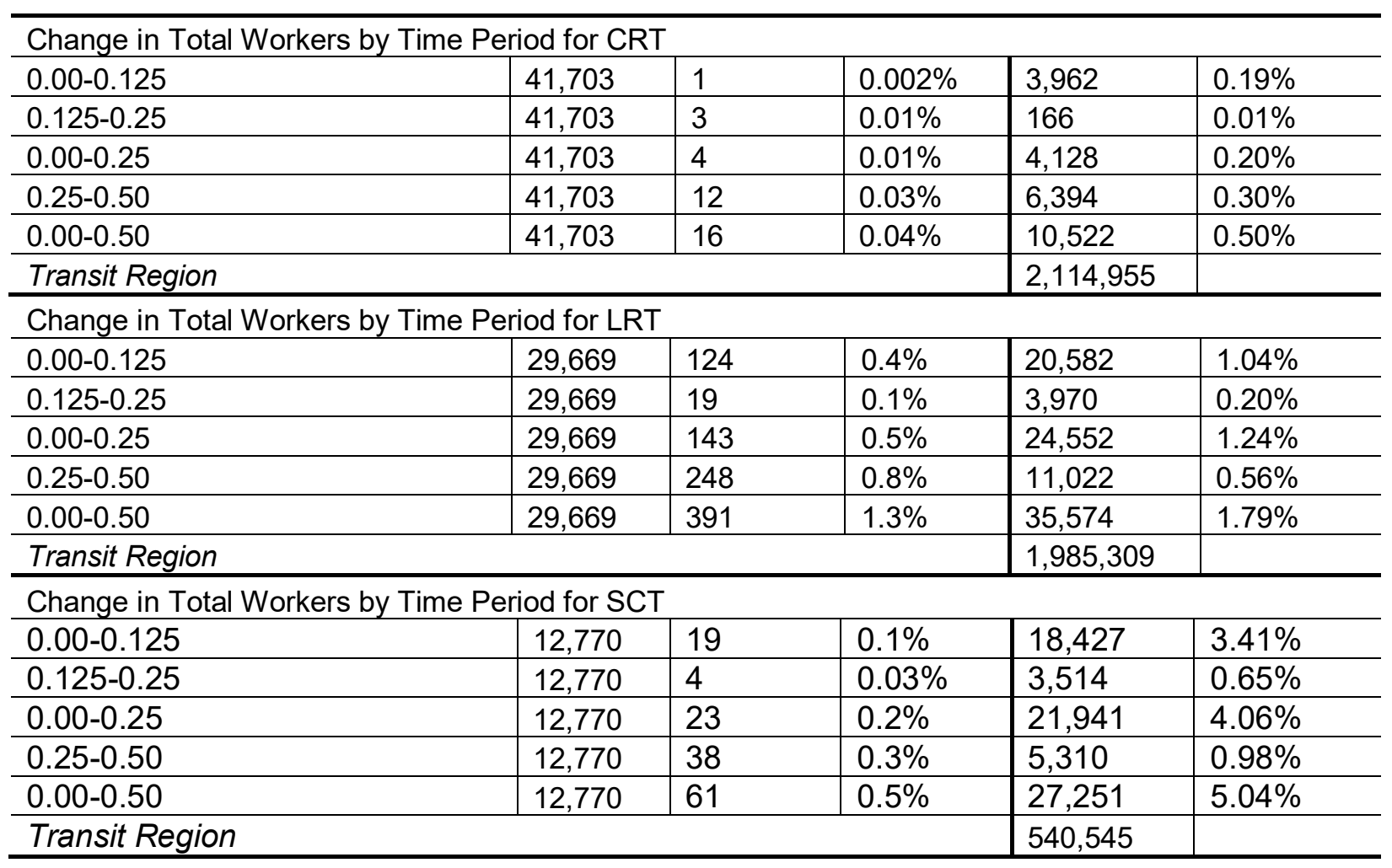




\section{Implications for Transit and Land Use Planning}

Decomposing transit mode results by land use place types has revealed a considerable range of variation within each transit mode, based upon the place type context of the station area. Each transit mode has its own areas of triumph and challenge.

It seems clear that there are multiple acting forces affecting each other in the shift of employment share and growth near the transit stations of our study. First, the transit station and vehicle design, which is both attracting and obstructing development depending on the context. Second, the nature of the surrounding neighborhood: how well-connected the streets, and the degree of access and land use mix. This factor includes, but also depends upon, the job sector groups that operate in the vicinity of the station, and their relative health over time. The land use mix that is most viable and effective at each station-the job sector mix that functions bestdepends to a significant degree upon the accessibility and land use mix existing at the station and its immediate neighborhood. The intensity of development affects what job sectors and transit mode types will be most effective in any area.

In general, returns on transit station proximity correlated positively with the level of land use mix and accessibility. However, transit systems substantially vary in their response to level of mix and accessibility. CRT is more aimed at moderate levels of mix and accessibility. SCT performed best at moderate and high levels. BRT performed best at the "Mod MA" neighborhood level. LRT did best in the mid-range mix and accessibility levels. For each transit mode:

- BRT proved to be quite flexible to the variations of each place type, showing robust growth across three four place types, shining in the two mid-range classes, while losing share slightly in the lowest-mix areas. This indicates, first, that BRT stations and technology need to adapt to the context of the outlying areas to better attract firms to these station areas. Second, it also may indicate that the challenges from low-density dispersed land use impede the efficient use of these stations, just as is the case for most other transit modes.

- CRT showed mostly modest gains in job share for the Low MA place type stations, to the first half mile. It had flat share gains or slight declines in three of the four place type stations. This might indicate that in these stations the firms are opting for locations farther from the station due to the disamenities involved in this large-scale transit mode, such as noise and air pollution. Newer systems such as that in Salt Lake City, Utah use quieter, less polluting train technology for these commuter-oriented stations. This update may be necessary in other metropolitan areas to attract further job share gain near these stations.

- $\quad$ LRT saw modest growth at the Poor MA station areas but saw great share gains in the Low MA and Mod MA place type areas, with acceptable gains in the High MA areas. This seems reasonable given the scale of the trains, the competition from SCT systems for the most urban land, and the low response to transit proximity in all of the transit mode stations. A great deal of focus could shift to the Poor MA station areas, to increase accessibility in the most outlying areas. This will provide gains across all segments of the transit network. The challenge of cost structures for providing greater-quality LRT may impede gains for the lowest-intensity place type. One option is to consider ways to 
increase integration of LRT and BRT systems to provide higher-quality transit connections to outlying areas.

- SCT did best in the context for which it was designed, the High MA and Mod MA areas. It did reasonably well in Low MA areas, which may include the streetcar suburbs of New Orleans. It saw a slight loss of job share in the Poor MA place type areas, for reasons that are likely to be similar to the other transit modes. However, the scale of the streetcar transit system, and the capacity of the trains may impact its utility in the most outlying areas. SCT, like LRT, may benefit from efforts at greater integration of BRT and other transport mode to increase the utility of the system for all place types.

We will apply shift share analysis by Place Typology to economic sectors and workers by wage groups in the next chapter. 


\section{References}

Alonso, William. 1964. Location and Land Use. Cambridge, MA: Harvard University Press.

Bertolini, L. 1999. "Spatial Development Patterns and Public Transport: The Application of an Analytical Model in the Netherlands Spatial Development Patterns and Public Transport: The Application of an Analytical Model in the Netherlands." Planning Practice \& Research 14 (2): 199-210. https://doi.org/10.1080/02697459915724.

Chapple, Karen, and Anastasia Loukaitou-Sideris. 2019. Transit-Oriented Displacement or Community Dividends? Understanding the Effects of Smarter Growth on Communities. Cambridge, MA: The MIT Press.

Dittmar, Hank, and Gloria Ohland. 2004. The New Transit Town: Best Practices In TransitOriented Development. Washington, DC: Island Press.

Dunham-Jones, Ellen, and June Williamson. 2011. Retrofitting Suburbia: Urban Design Solutions for Redesigning Suburbs. Hoboken, NJ: John Wiley \& Sons.

Kain, John F. 1992. "The Spatial Mismatch Hypothesis: Three Decades Later." Housing Policy Debate 3 (2): 371-460. https://doi.org/10.1080/10511482.1992.9521100.

Levinson, David M B T - The 30-Minute City: Designing for Access. 2019. The 30-Minute City: Designing for Access. Network Design Lab. https://hdl.handle.net/2123/21630.

Mills, Edwin S. 1967. "American Economic Association An Aggregative Model of Resource Allocation in a Metropolitan Area." The American Economic Review 57 (2): 197-210.

Muth, Richard F. 1969. Cities and Housing: The Spatial Pattern of Urban Residential Land Use. Chicago: University of Chicago Press.

Nelson, A.C., D. Eskic, S. Hamidi, S.J. Petheram, R. Ewing, and J.H. Liu. 2015. Office Rent Premiums with Respect to Light Rail Transit Stations: Case Study of Dallas, Texas, with Implications for Planning of Transit-Oriented Development. Transportation Research Record. https://doi.org/10.3141/2500-13.

Nelson, Arthur, Bruce Appleyard, Shyam Kannan, Reid Ewing, Matt Miller, and Dejan Eskic. 2013. "Bus Rapid Transit and Economic Development: Case Study of the EugeneSpringfield BRT System.” Journal of Public Transportation 16 (3): 41-57. https://doi.org/10.5038/2375-0901.16.3.3.

Nelson, Arthur C. 2013. Reshaping Metropolitan America: Development Trends and Opportunities to 2030. Washington, DC: Island Press.

Nelson, Arthur C., and Robert Hibberd. 2019. "The Link between Transit Station Proximity and Real Estate Rents , Jobs , People and Housing with Transit and Land Use Planning Implications The Link between Transit Station Proximity and Real Estate Rents , Jobs , People and Housing with Transit and Land." Portland, OR.

Nelson, Arthur C., Philip Stoker, and Robert Hibberd. 2019. "Light Rail Transit and Economic Recovery: A Case of Resilience or Transformation?" Research in Transportation Economics 74 (November 2018): 2-9. https://doi.org/10.1016/j.retrec.2018.11.003.

Nelson, Arthur C. 2017a. "Transit-Oriented Developments Make a Difference in Job Location." Fordham Urban Law Journal 44 (4). https://ir.lawnet.fordham.edu/cgi/viewcontent.cgi?article=2705\&context=ulj. 2017b. "Transit and Real Estate Rents." Portland, OR. https://ppms.trec.pdx.edu/media/project_files/Transit_and_Real_Estate_Rents.pdf. 
Nelson, Arthur C, and Joanna Ganning. 2015. "National Study of BRT Development Outcomes." Portland, OR. https://nitc.trec.pdx.edu/research/project/650.

Nelson, Arthur C, and Robert Hibberd. 2019. "Streetcars and Real Estate Rents with Implications for Transit and Land Use Planning." Transportation Research Record 00 (0): 1-12. https://doi.org/10.1177/0361198119849916.

Nelson, Arthur, Matt Miller, Dejan Eskic, Keuntae Kim, Reid Ewing, Jenny Liu, Matt Berggren, and Zakari Mumuni. 2015. "Do TODs Make a Difference?" http://pdxscholar.library.pdx.edu/trec_reports/7.

Petheram, Susan J., Arthur C. Nelson, Matt Miller, and Reid Ewing. 2013. "Use of the Real Estate Market to Establish Light Rail Station Catchment Areas." Transportation Research Record: Journal of the Transportation Research Board 2357 (1): 95-99. https://doi.org/10.3141/2357-11.

Renne, John L, Tara Tolford, Shima Hamidi, and Reid Ewing. 2016. "The Cost and Affordability Paradox of Transit- Oriented Development : A Comparison of Housing and Transportation Costs Across Transit-Oriented Development , Hybrid and TransitAdjacent Development Station Typologies." Housing Policy Debate 26 (4-5): 819-34. https://doi.org/10.1080/10511482.2016.1193038.

Sanchez, By Thomas W, Rich Stolz, and Jacinta S Ma. 2003. "MOVING TO EQUITY: Addressing Inequitable Effects of Transportation Policies on Minorities." Cambridge, MA.

Scheer, Brenda. 2017. "TOD Beats TAD in Affordability Showdown." Transportation Research and Education Center, no. August.

Steven Manson, Jonathan Schroeder, David Van Riper, and Steven Ruggles. 2018. "IPUMS National Historical Geographic Information System: Version 12.0 [Database]."

Minneapolis: University of Minnesota. 2018. https://doi.org/http://doi.org/10.18128/D050.V12.0. 


\section{CHAPTER 3: The Link between Transit Station Proximity and Typology and Change in Jobs by Economic Groups and Wage Categories Over Time}

\section{OVERVIEW}

Our research expands upon previous work by assessing the extent to which jobs by wage and economic group are attracted to transit stations over time. Station areas are assessed by transit mode, such as light rail, and by station typology. The types are characterized as lying somewhere along a continuum from low to high land use mix and accessibility. These types are based upon the relative intensity a combination of jobs, households, and the built environment. The analysis will advance the understanding of how transit stations effect the economy in a multimodal transportation system context. It will highlight these trends by wage and economic group stratifications. We allocate jobs by economic sector groups based upon NAICS classifications, and group jobs by wage based upon the salary levels of each sector. This chapter focuses on economic development outcomes first by job sector groups, then by job wage groupings. It follows up with summary findings, implications and recommendations.

\section{Introduction and Literature Review}

Agglomeration economies, according to extant research, accrue over time to transit stations. Such economies accrued to ports and railway stations prior to the widespread use of the automobile but were reduced by the automobile's massive and precipitous growth in the early and mid-twentieth century. Urban sprawl was "driven" by the automobile, but as planners and economists have come to realize the negative impacts of sprawling development, efforts have grown to draw back on this trend and return to more efficient, transit-friendly land use patterns. From 2000 to 2010, U.S. metropolitan areas urbanized land area disproportionate to urban population growth (Wilson et al. 2012). Glaeser and Kahn (Glaeser, Edward and Kahn, 2004) argue that while agglomeration economies were dispersed and enervated in part by sprawl, it produced some social benefits, such as reduced travel times and larger homes. As cities have grown, moreover, many population segments have opted out of the larger regions, heading to smaller metropolitan and micropolitan areas, usually in a stepwise pattern down the urban hierarchy to enjoy the benefits of not-too-strong urbanization and its congestion and price disamenities, which have overcome the earlier benefits of automobile-oriented sprawl (D. A. Plane, Henrie, and Perry 2005; David A. Plane 1984). In terms of transit systems, this migration and transfer of population seems to have corresponded with a growth of smaller-scale FixedRoute Transit (FRT) systems, such as Tucson's streetcar transit system and West Valley City, Utah's Bus Rapid Transit system, both having recently been constructed.

This migration pattern has its impact upon firm location, as well. A variant of this larger-scale pattern has played out within metropolitan regions as firms have followed large segments of the population out of the urban core as they have moved outward from the CBD over the autocentric decades of the twentieth century, first to the inner-ring suburbs, then the outer suburbs, and then on to the exurbs (the suburbs of the suburbs), with land use and travel time growing in kind. The result is a range of metropolitan region sizes, and a range of neighborhood-scale levels of land use intensity and mix, which affects relative accessibility. Transportation technology and infrastructure in turn influences accessibility by imposing various systemic limitations or failures upon the local and regional land use regime. Congestion caused by excessive reliance upon the automobile is accompanied by a mismatch in most places between 
land use and fixed-route transit systems, which rely upon the presence of a minimum level of land use efficiency and its concomitant density and intensity.

The urban picture across the United States is a multifarious and dynamic one, with economic, demographic and technological changes all influencing each other. Glaeser et al. (2008) posited that the poor live in cities because of the higher income elasticity of demand for transport relative to elasticity of demand for land: in accordance with the Alonso-Mills-Muth (AMM) urban land use theory, richer consumers will move further from the city in order to gain more land at a cheaper price per area. The model assumes one mode of transport for everyone and that the main cost is travel time (Alonso 1964; Mills 1972; Muth 1969). While of ongoing relevance, this theory has its limitations in application to current urban morphology. Land use regimes are of a wide variety across the metropolitan region. Such variety also exists in the urban economy, and the spatial location of firms, many of which no longer inhabit the CBD. We relax the AMM assumption that all jobs are concentrated in the CBD, and apply the attractive force of the CBD to the transit station areas, theorizing that firms will compete for land near stations in order to benefit from access to the regional transit system.

As research continues to gather evidence, we find economic benefits from urban design that focuses on providing a range of options in land use and transportation infrastructure and technology. Complete Streets projects urge engineering, design, and policies to create streets that serve a multimodal transportation regime. ${ }^{100} \mathrm{~A}$ complete street optimizes all modes of transport together, from walking and bicycling for all segments of the population, including the elderly and those with ADA requirements, to automobiles of all kinds, and increasingly, fixedroute transit systems of a wide range of capacities. Housing markets reap benefits when the Missing Middle housing types (e.g., townhomes and quadplexes) are placed near more traditional single-family homes and high-density apartments (Parolek 2020). These land use and transportation systems interweave and influence each other to create a wide variety of place types and land use intensities across the built environment.

The urban economy should benefit from such an infusion of variety, but we need more evidence of the response of economic groups to the different combinations of transit modes and land use types. Different economic sector groups may benefit from transit proximity differently, and in a range that varies across the transit system modes and transit station typology.

Our research question is as follows:

\section{Is there a link between transit station proximity and change in workers by economic group, and does it vary across the range of transit station area land use mix and accessibility typology between the years of 2010 and 2016?}

We hypothesize that each economic sector group will respond differently to different combinations of land use intensity and transit mode. Some sector groups will prefer smallerscale transit in highly intense land use areas while others will respond better-by locating disproportionately near transit stations-to heavier, higher capacity transit in areas with more dispersed land use intensities.

\section{Research Design and Plan}

\footnotetext{
${ }^{100}$ See Smart Growth America's National Complete Streets Coalition website: https://smartgrowthamerica.org/program/national-complete-streets-coalition/. Accessed 11/21/2020.
} 
We apply economic base theory to test our hypothesis through shift-share and location quotient analyses. We ascertain trends in concentration of jobs by sector group and wage group between the years 2010 and 2016 in urban areas across the United States.

\section{Data Resources}

The employment data come from the US Census Bureau's Longitudinal Employer-Household Dynamics data (LEHD) for 2010 and 2016. Transit system data come from the General Transit Feed Specification (GTFS). ${ }^{101}$ Census blocks were downloaded from IPUMS HGIS website (Steven Manson, Jonathan Schroeder, David Van Riper 2018). Station typology data are outlined below.

\section{Transit Station Typology - Place Types}

To evaluate by place types, we aggregate the following built environment variables to the census block group, and then apply a data clustering method:

Longitudinal Employer-Household Survey (LEHD, 2017):

- Total jobs per acre

- Proportion of jobs that are retail or entertainment

American Community Survey (ACS, 2017, 5-year):

- Total residential population per acre

- Total households per acre

- Proportion of households with no kids (representing smaller dwelling units)

- Proportion of households that are owner occupied

Smart Location Database ${ }^{102}$

- Intersection density (an indication of connectivity)

- Proportion of intersections that are three-way to those that are four-way (an indication of connectivity)

We apply Jenks natural breaks to each variable to segment the spectrum of variables. Each "break" is ranked in terms of the urban intensity of the categories. The lowest density category has a score of 1 , while the highest has a 5 . The sum of these rankings, summing all variables together, provides an indication of the level of urban intensity and concentration for each block group. The sum of rankings is then divided into the number of categories of interest. For this study, we aggregated the place types into four categories labeled from $1=$ most suburban to $4=$ highly urban. An iterative verification process rotated between testing variables and groundtruthing them through spatial mapping and observations using Google Streetview.

The transit station areas usually contain multiple station place types. As seen in the maps below (Figures X), Austin's CRT stations and Denver's LRT stations consist of multiple land use intensities in different sectors around the transit stations.

\section{Shift-Share Method}

\footnotetext{
${ }^{101}$ See TransitFeeds.com for downloadable

${ }^{102}$ See https://www.epa.gov/smartgrowth/smart-location-mapping. Accessed 11-25-2020. Note that while this data is older, intersection density is not something that widely changes from decade to decade in most of the areas that are already developed enough to have FRT.
} 
Economic development is often analyzed using economic base theory and measures spatial concentrations of jobs by sector or other segmentations, as well as their spatial and temporal dynamics. Shift-share analysis compares change of employment concentrations at the "regional" level, which is defined by the analyst at a chosen scale (e.g., national, state, or county), with changes in concentrations at the "local" level, which can also be defined at various scales by the analyst. The study assigns "transit-served" counties as regions (those counties with access to a transit system) and assigns transit neighborhoods as the "local" scale. The transit neighborhoods are further segmented into distance bands away from the station, in increments of one-eighth or one-quarter mile, up to a distance of 1 mile from the transit station centroid. The analytic method isolates the various sources of job change into 3 categories: 1) the Transit Region share, which references overall economic dynamics at the regional scale 2) the industry or job sector mix, which accounts for job dynamics as a result of change in a specific industry, and 3) FRT Station Shift, also called the "competitive effect," which measures the degree of change at the local spatial scale of the transit station neighborhood. It is a measure of the station's lagging and leading job sectors by isolating station area economic trends from those at the regional scale. The shift-share formula is as follows (Carnegie Mellon n.d.):

Where:

$$
S S_{i}=T R_{i}+S M_{i}+F R T_{i}
$$

$$
\begin{aligned}
& S S_{i}=\text { Shift-Share } \\
& \\
& T R_{i}=\text { Transit Region share } \\
& S M_{i}=\text { Sector Mix } \\
& F R T_{i}=\text { FRT Station Shift }
\end{aligned}
$$

Each component is calculated with the following equations:

$T R=\left({ }_{\mathrm{i}} \mathrm{FRT}\right.$ Station Area $\left.^{\mathrm{t}-1} \times \mathrm{TR}^{\mathrm{t}} / \mathrm{TR}^{\mathrm{t}-1}\right)$

$S M=\left[\left({ }_{i} F R T\right.\right.$ Station Area $\left.\left.{ }^{\mathrm{t}-1} \times \mathrm{iTR}_{\mathrm{T}}{ }^{\mathrm{t}} / \mathrm{TTR}^{\mathrm{t}-1}\right)-\mathrm{TR}\right]$

$F R T=\left[{ }_{i} F R T\right.$ Station Area ${ }^{\mathrm{t}-1} \times\left({ }_{\mathrm{i} F R T}\right.$ Station Area ${ }^{\mathrm{t}} / \mathrm{i}$ FRT Station Area $\left.\left.{ }^{\mathrm{t}-1}-\mathrm{i}_{\mathrm{TR}}{ }^{\mathrm{t}} / \mathrm{iTR}^{\mathrm{t}-1}\right)\right]$

Where:

¡FRT Station Area $=$ number of jobs in the FRT Station Area sector (i) at the beginning of the analysis period $(\mathrm{t}-1)$

${ }_{i}$ FRT Station Area ${ }^{t}=$ number of jobs in the FRT Station Area in sector (i) at the end of the analysis period $(\mathrm{t})$

$\mathrm{TR}^{\mathrm{t}-1}=$ total number of jobs in the Transit Region at the beginning of the analysis period(t-1)

$\mathrm{iTR}^{\mathrm{t}}=$ total number of jobs in the Transit Region at the end of the analysis period $(\mathrm{t})$ $\mathrm{iTR}=$ number of jobs in the Transit Region in sector (i) at the beginning of the analysis period $(\mathrm{t}-1)$

$\mathrm{iTR}^{\mathrm{t}}=$ number of jobs in the Transit Region in sector (i) at the end of the analysis period (t) 


\section{Location Quotients}

Location Quotients (LQ) provide a spatial concentration measure that compares local concentrations of phenomena with a regional or global concentration of the same phenomena. For this study, transit station areas by eighth-mile distance bands provide the local context, while "transit-served counties," or counties and groups of counties that are served by transit systems, provide the regional context. LQ metrics, along with shift-share analyses, are a proven methodological staple of economic development studies. The effectiveness of these methodologies at providing evidence of economic development highlight the spatial nature of the economy. Transit systems serve to provide network connectivity across local economies, connecting the geographies highlighted by these methodologies.

\section{Results and Discussion}

We first present the results of the analysis of job sector groups, followed by wage groupings, and discuss the findings, first referring to summed figures, and then by discussing key metropolitan areas.

\section{Jobs by Sector, Selected Transit Systems and Station Types: Under-performers and Over-performers}

This section will outline growth and spatial concentration trends of jobs by economic sector group for a sample of key transit mode-station typology combinations. Each combination will be summarized by 1) a table containing FRT Station Shift figures from the shift-share analysis results from each $\mathrm{DB}, 2$ ) the rate of change for jobs at each $\mathrm{DB}$, and 3) Location Quotient trends for the period, with scores above 1 denoting increases in spatial concentrations at the station relative to the regions ("Transit County") served by the transit systems. Each table also contains a measure of the square miles each transit mode-station type contains, in incremental ("increm.") and cumulative ("cum") measures, which clearly demonstrate the disproportionate shift in job share toward the transit stations.

The North American Industry Classification System (NAICS) classifies job sectors. The study classifies job sectors into broad economic groups such as industrial, office, knowledge, and retail jobs. This section reviews the economic trends for separate sector groups. We indicate which transit modes and station types specific sector groups prefer by analyzing their trends in job share capture between 2010 and 2016. These trends are segmented by DB, up to 1 mile from the transit station.

For Poor MA, CRT lost concentration at the station in all economic groups except Knowledge and Light Industry. The latter gained significant spatial concentration at the station, or the first DB. Major gains were seen in most DB's for Knowledge, Light Industry, and Office job groups. Education and Arts-Entertainment-Recreation jobs declined in many DB's. Very close to the station, in the first quarter mile, Manufacturing, Light Industry, Retail-Lodging-Food, and Office gained substantial job share. Health did well at the station but declined just beyond the station. Overall, the job numbers were fairly small, especially relative to the region totals. It appears that Light Industry and economic groups that synergize with it outcompeted all other economic groups for a location at the station, providing these upper-income workers with easy access to transit. While job share declined strongly at the 1-mile DB, these station areas mostly gained share up to the 1-mile $\mathrm{DB}$, demonstrating a market response to transit proximity beyond the common half-mile threshold. 
Table 3.1

Combinations of NAICS Sectors into Economic Groups for Analysis

$\begin{array}{ll}\text { NAICS Code } & \begin{array}{l}\text { NAICS Sector Title and Economic Group Name } \\ \text { Industrial }\end{array} \\ 31-33 & \text { Manufacturing } \\ 22 & \text { Utilities } \\ & \text { Light Industrial } \\ 42 & \text { Wholesale Trade } \\ 48-49 & \text { Transportation and Warehousing } \\ & \text { Retail-Lodging-Food ("Retail-Lodging") } \\ 44-45 & \text { Retail Trade } \\ 72 & \text { Accommodation and Food Services } \\ 51 & \text { Knowledge } \\ 54 & \text { Information } \\ 52 & \text { Professional, Scientific, and Technical Services } \\ 53 & \text { Office } \\ 55 & \text { Finance and Insurance } \\ 56 & \text { Real Estate and Rental and Leasing } \\ 81 & \text { Management of Companies and Enterprises } \\ 92 & \text { Administrative and Support, Waste Management, Remediation } \\ 61 & \text { Other Services (except Public Administration) } \\ 62 & \text { Public Administration } \\ & \text { Education } \\ 71 & \text { Educational Services } \\ 504 & \text { Health } \\ \text { Health Care and Social Assistance }\end{array}$

Source: Adapted from the North American Industrial Classification System by Arthur C. Nelson and Robert Hibberd, University of Arizona.

Note: Phrases in quotations and italics labels for the respective economic groups. 
Table 3.2 CRT Poor MA Transit Station Type Job Dynamics by Economic Group 20102016

Station Share of Shift 2010-2016

\begin{tabular}{|c|c|c|c|c|c|c|c|c|}
\hline Sector Groups & 0.125 & 0.25 & 0.375 & 0.5 & 0.75 & 1 & \multicolumn{2}{|c|}{$\begin{array}{l}\text { Transit } \\
\text { County } \\
\text { Sum } \\
2016\end{array}$} \\
\hline $\begin{array}{l}\text { Urban Square Miles - } \\
\text { Increm. }\end{array}$ & 10 & 30 & 51 & 71 & 205 & 277 & \multicolumn{2}{|c|}{41,703} \\
\hline $\begin{array}{l}\text { Urban Square Miles - } \\
\text { Cum. }\end{array}$ & 10 & 40 & 91 & 162 & 367 & 644 & \multicolumn{2}{|c|}{41,703} \\
\hline Manufacturing & 8,661 & 5,591 & 4,029 & 5,481 & 3,408 & 1,068 & & $1,238,634$ \\
\hline Light Industry & 18,548 & 7,562 & 4,915 & 4,690 & 5,056 & 1,129 & & $1,621,064$ \\
\hline Retail-Lodging-Food & 11,961 & 5,510 & 2,531 & 2,220 & 1,461 & 1,447 & & $3,809,507$ \\
\hline Knowledge & 15,462 & 1,506 & 18,475 & 3,863 & 3,117 & 1,647 & & $2,408,601$ \\
\hline Office & 32,893 & 4,993 & 7,223 & 8,398 & 3,187 & 4,935 & & $4,199,409$ \\
\hline Education & 41,219 & 1,131 & 17,358 & 1,128 & 3,501 & 3,666 & & $1,565,704$ \\
\hline Health & 11,215 & 545 & 3,967 & 2,874 & 4,304 & 1,925 & & $2,328,226$ \\
\hline Arts-Ent-Rec & 2,668 & 156 & 313 & 577 & 1,164 & 407 & & 382,686 \\
\hline$\underline{\text { Total Jobs }}$ & $\begin{array}{l}142,63 \\
4\end{array}$ & 27,001 & 58,818 & 29,238 & 25,205 & 16,23 & & \begin{tabular}{|l|}
$17,553,83$ \\
1
\end{tabular} \\
\hline \multicolumn{9}{|c|}{ Poor MA: CRT. Economic Change 2010-2016 } \\
\hline Sector Groups & 0.125 & 0.25 & 0.375 & 0.5 & 0.75 & 1 & \multicolumn{2}{|c|}{$\begin{array}{l}\text { Transit } \\
\text { County }\end{array}$} \\
\hline Manufacturing & 1,712 & 2,595 & $(1,473)$ & $(742)$ & 845 & $(1,251)$ & \multicolumn{2}{|c|}{$(199,595)$} \\
\hline Light Industry & 5,618 & 1,268 & 2,066 & $(3,369)$ & 3,598 & $(1,986)$ & \multicolumn{2}{|c|}{$3,183,866$} \\
\hline Retail-Lodging-Food & 2,573 & 3,173 & $(398)$ & $(4,215)$ & 381 & $(898)$ & \multicolumn{2}{|c|}{415,822} \\
\hline Knowledge & $(447)$ & 167 & 2,971 & 1,290 & 1,351 & $(1,762)$ & \multicolumn{2}{|c|}{543,440} \\
\hline Office & 4,869 & 930 & $(185)$ & 2,562 & 445 & $(1,003)$ & \multicolumn{2}{|c|}{331,340} \\
\hline Education & 2,888 & $(70)$ & 2,785 & $(232)$ & $(283)$ & $(17,076)$ & \multicolumn{2}{|c|}{179,340} \\
\hline Health & 5,198 & $(284)$ & $(2,186)$ & 1,315 & 1,565 & $(1,780)$ & \multicolumn{2}{|c|}{319,634} \\
\hline Arts-Ent-Rec & 1,370 & $(42)$ & $(120)$ & 337 & 159 & (9) & \multicolumn{2}{|c|}{304,931} \\
\hline$\underline{\text { Total Jobs }}$ & 23,781 & 7,737 & 3,460 & $(3,054)$ & 8,061 & $(25,765)$ & \multicolumn{2}{|c|}{$5,078,778$} \\
\hline Poor MA: CRT. Percen & Economic & Change 2 & $010-2016$ & & & & & \\
\hline Sector Groups & 0.125 & 0.25 & 0.375 & 0.5 & 0.75 & 1 & $\begin{array}{l}\text { Trans } \\
\text { Count }\end{array}$ & \\
\hline Manufacturing & $24.6 \%$ & $86.6 \%$ & $-26.8 \%$ & $-11.9 \%$ & $33.0 \%$ & $-53.9 \%$ & $8.1 \%$ & \\
\hline Light Industry & $43.4 \%$ & $20.1 \%$ & $72.5 \%$ & $-41.8 \%$ & $246.6 \%$ & $-63.7 \%$ & $17.2 \%$ & \\
\hline Retail-Lodging-Food & $27.4 \%$ & $\begin{array}{l}135.7 \\
\%\end{array}$ & $-13.6 \%$ & $-65.5 \%$ & $35.2 \%$ & $-38.3 \%$ & $23.5 \%$ & \\
\hline Knowledge & $-2.8 \%$ & $12.5 \%$ & $19.2 \%$ & $50.1 \%$ & $76.5 \%$ & $-51.7 \%$ & $21.8 \%$ & \\
\hline Office & $17.4 \%$ & $22.9 \%$ & $-2.5 \%$ & $43.9 \%$ & $16.2 \%$ & $-16.9 \%$ & $4.8 \%$ & \\
\hline Education & $7.5 \%$ & $-5.8 \%$ & $19.1 \%$ & $-17.0 \%$ & $-7.5 \%$ & $-82.3 \%$ & $4.8 \%$ & \\
\hline Health & $86.4 \%$ & $\begin{array}{l}- \\
34.2 \% \\
\end{array}$ & $-35.5 \%$ & $84.3 \%$ & $57.1 \%$ & $-48.0 \%$ & $19.8 \%$ & \\
\hline Arts-Ent-Rec & $\begin{array}{l}105.5 \\
\%\end{array}$ & $21.1 \%$ & $-27.6 \%$ & $139.8 \%$ & $15.8 \%$ & $-2.2 \%$ & $11.2 \%$ & \\
\hline$\underline{\text { Total Jobs }}$ & $20.0 \%$ & $40.2 \%$ & $6.3 \%$ & $-9.5 \%$ & $47.0 \%$ & $-61.3 \%$ & $14.2 \%$ & \\
\hline Poor MA: CRT. LQ & $2010-201$ & (LQ 20 & $16 / L Q 20$ & 010) & & & & \\
\hline Sector Groups & 0.125 & 0.25 & 0.375 & 0.5 & 0.625 & 0.75 & 0.875 & 1 \\
\hline Manufacturing & 0.58 & 0.45 & 0.87 & 0.62 & 0.61 & 0.67 & 0.62 & 0.51 \\
\hline Light Industry & 2.02 & 2.82 & 1.49 & 3.76 & 0.72 & 1.02 & 1.83 & 2.57 \\
\hline Retail-Lodging-Food & 0.78 & 0.49 & 1.01 & 2.16 & 0.97 & 0.90 & 1.20 & 0.52 \\
\hline
\end{tabular}




\begin{tabular}{lllll|l|l|l|l|l} 
Knowledge & 1.21 & 1.22 & 0.87 & 0.59 & 1.23 & 0.82 & 0.93 & 0.78 \\
\hline Office & 0.80 & 0.90 & 0.86 & 0.49 & 0.82 & 0.99 & 0.89 & 0.37 \\
\hline Education & 0.92 & 1.22 & 0.73 & 0.90 & 1.34 & 1.31 & 0.83 & 1.80 \\
\hline Health & 0.57 & 1.87 & 1.45 & 0.43 & 1.52 & 0.82 & 1.02 & 0.65 \\
\hline Arts-Ent-Rec & 0.87 & 2.63 & 2.18 & 0.56 & 1.63 & 1.88 & 0.59 & 0.59 \\
\hline
\end{tabular}

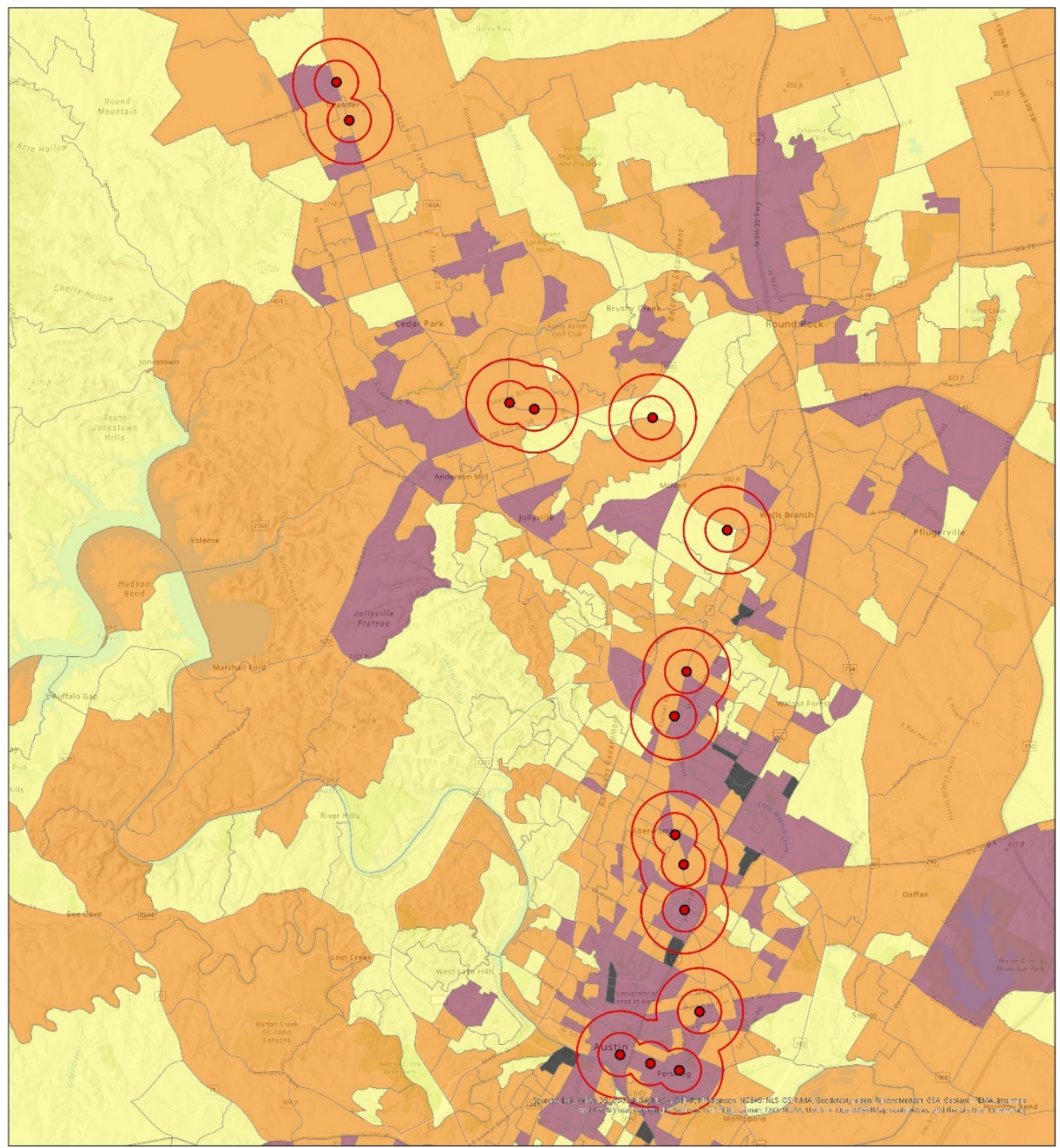

Station Typology for Commuter Rail Transit:

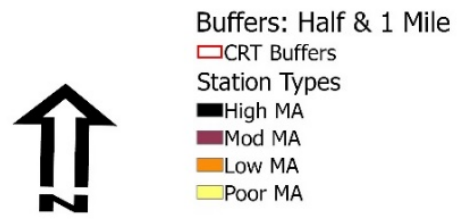

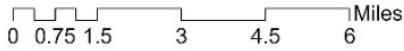

Figure 2. Austin CRT system covers an area of relatively low to moderate land use intensity, but connects the suburbs to the downtown. 
Table 3.3 BRT Low MA Transit Station Type Job Dynamics by Economic Group 2010-2016 Station Share of Shift 2010-2016

\begin{tabular}{|c|c|c|c|c|c|c|c|}
\hline Sector Groups & 0.125 & 0.25 & 0.375 & 0.5 & 0.75 & 1 & $\begin{array}{l}\text { Transit } \\
\text { County } \\
\text { Sum } \\
2016\end{array}$ \\
\hline $\begin{array}{l}\text { Urban Square Miles - } \\
\text { Increm. }\end{array}$ & 27 & 44 & 49 & 51 & 102 & 98 & 14,201 \\
\hline Urban Square Miles - Cum. & 27 & 71 & 120 & 171 & 273 & 371 & 14,201 \\
\hline Manufacturing & 60,886 & 4,894 & 6,143 & 18,473 & 6,154 & 25,779 & 830,769 \\
\hline Light Industry & 75,070 & 10,730 & 8,743 & 29,346 & $\begin{array}{l}10,84 \\
1\end{array}$ & 21,435 & 818,346 \\
\hline Retail-Lodging-Food & $\begin{array}{l}130,37 \\
6\end{array}$ & 11,904 & $\begin{array}{l}10,28 \\
4\end{array}$ & 16,133 & $\begin{array}{l}13,86 \\
5\end{array}$ & 13,781 & $\begin{array}{l}1,970,97 \\
5\end{array}$ \\
\hline Knowledge & $\begin{array}{l}112,22 \\
7\end{array}$ & 17,101 & 9,238 & 10,169 & 3,900 & 15,298 & $\begin{array}{l}1,309,01 \\
3\end{array}$ \\
\hline Office & $\begin{array}{l}233,56 \\
5\end{array}$ & 34,800 & $\begin{array}{l}19,00 \\
8\end{array}$ & 30,670 & $\begin{array}{l}10,92 \\
4\end{array}$ & 21,142 & $\begin{array}{l}2,247,69 \\
3\end{array}$ \\
\hline Education & 58,304 & 21,997 & 5,909 & 21,942 & $\begin{array}{l}20,41 \\
1\end{array}$ & 2,939 & 863,140 \\
\hline Health & $\begin{array}{l}120,66 \\
7\end{array}$ & 22,138 & $\begin{array}{l}12,46 \\
2\end{array}$ & 14,993 & 6,093 & 22,746 & $\begin{array}{l}1,464,16 \\
8\end{array}$ \\
\hline Arts-Ent-Rec & 11,195 & 771 & 2,241 & 1,200 & 864 & 1,323 & 197,902 \\
\hline Total Jobs & $\begin{array}{l}802,29 \\
7\end{array}$ & $\begin{array}{l}124,34 \\
2\end{array}$ & $\begin{array}{l}74,03 \\
5\end{array}$ & $\begin{array}{l}142,93 \\
3\end{array}$ & $\begin{array}{l}73,05 \\
9\end{array}$ & $\begin{array}{l}124,45 \\
0\end{array}$ & $\begin{array}{l}9,702,00 \\
6\end{array}$ \\
\hline
\end{tabular}

Economic Change 2010-2016

\begin{tabular}{l|l|l|l|l|l|l|l}
\hline Sector Groups & 0.125 & 0.25 & 0.375 & 0.5 & 0.75 & 1 & \multicolumn{1}{l}{ Transit County } \\
\hline Manufacturing & $(124,133)$ & $(40,453)$ & $(7,574)$ & $(22,179)$ & $(8,051)$ & $(1,560)$ & $(145,037)$ \\
\hline Light Industry & $(190,532)$ & $(39,737)$ & $(9,647)$ & $(27,102)$ & $(33,215)$ & $(7,307)$ & $(31,845)$ \\
\hline Retail-Lodging-Food & 69,422 & 3,343 & 8,000 & $(3,510)$ & 7,492 & $(16,307)$ & $(9,243)$ \\
\hline Knowledge & 50,490 & 4,356 & 4,695 & $(14,824)$ & $(5,447)$ & $(5,401)$ & 40,655 \\
\hline Office & 125,609 & 21,475 & 9,841 & 15,134 & $(913)$ & 6,317 & 34,291 \\
\hline Education & $(36,297)$ & 12,972 & 267 & 8,302 & 16,450 & $(10,679)$ & 70,350 \\
\hline Health & $(74,010)$ & $(22,361)$ & 1,262 & $(23,352)$ & $(7,267)$ & 4,481 & 194,081 \\
\hline Arts-Ent-Rec & $(60,969)$ & $(21,450)$ & $(1,166)$ & $(19,242)$ & $(23,757)$ & $(1,966)$ & 6,694 \\
\hline Total Jobs & $(240,420)$ & $(81,855)$ & 5,678 & $(86,773)$ & $(54,708)$ & $(32,422)$ & 159,946 \\
\hline
\end{tabular}

Percent Economic Change 2010-2016

\begin{tabular}{l|l|l|l|l|l|l|l}
\hline Sector Groups & 0.125 & 0.25 & 0.375 & 0.5 & 0.75 & 1 & \multicolumn{1}{l}{ Transit County } \\
\hline Manufacturing & $-67.1 \%$ & $-89.2 \%$ & $-55.2 \%$ & $-54.6 \%$ & $-56.7 \%$ & $-5.7 \%$ & $-62.2 \%$ \\
\hline Light Industry & $-71.7 \%$ & $-78.7 \%$ & $-52.5 \%$ & $-48.0 \%$ & $-75.4 \%$ & $-25.4 \%$ & $-76.6 \%$ \\
\hline Retail-Lodging-Food & $113.9 \%$ & $39.0 \%$ & $349.8 \%$ & $-17.9 \%$ & $117.5 \%$ & $-54.2 \%$ & $153.0 \%$ \\
\hline Knowledge & $81.8 \%$ & $34.2 \%$ & $103.3 \%$ & $-59.3 \%$ & $-58.3 \%$ & $-26.1 \%$ & $79.0 \%$ \\
\hline Office & $116.4 \%$ & $161.2 \%$ & $107.3 \%$ & $97.4 \%$ & $-7.7 \%$ & $42.6 \%$ & $34.0 \%$ \\
\hline Education & $-38.4 \%$ & $143.7 \%$ & $4.7 \%$ & $60.9 \%$ & $415.2 \%$ & $-78.4 \%$ & $-18.3 \%$ \\
\hline Health & $-38.0 \%$ & $-50.2 \%$ & $11.3 \%$ & $-60.9 \%$ & $-54.4 \%$ & $24.5 \%$ & $-33.2 \%$ \\
\hline Arts-Ent-Rec & $-84.5 \%$ & $-96.5 \%$ & $-34.2 \%$ & $-94.1 \%$ & $-96.5 \%$ & $-59.8 \%$ & $-76.2 \%$ \\
\hline Total Jobs & $-23.1 \%$ & $-39.7 \%$ & $8.3 \%$ & $-37.8 \%$ & $-42.8 \%$ & $-20.7 \%$ & $-25.2 \%$ \\
\hline
\end{tabular}

LQ Trend 2010-2016 (LQ 2016 / LQ 2010)

\begin{tabular}{lllllllll}
\hline Sector Groups & 0.125 & 0.25 & 0.375 & 0.5 & 0.625 & 0.75 & 0.875 & 1 \\
\hline Manufacturing & 1.95 & 4.66 & 2.02 & 1.14 & 2.05 & 1.10 & 2.28 & 0.70 \\
\hline
\end{tabular}




\begin{tabular}{|c|c|c|c|c|c|c|c|c|}
\hline Light Industry & 2.56 & 2.67 & 2.14 & 1.13 & 3.20 & 2.19 & 1.66 & 1.00 \\
\hline Retail-Lodging-Food & 0.35 & 0.42 & 0.23 & 0.74 & 0.17 & 0.26 & 0.45 & 1.69 \\
\hline Knowledge & 0.43 & 0.46 & 0.54 & 1.56 & 0.31 & 1.40 & 0.42 & 1.10 \\
\hline Office & 0.35 & 0.23 & 0.52 & 0.31 & 1.08 & 0.62 & 0.34 & 0.56 \\
\hline Education & 1.34 & 0.27 & 1.11 & 0.42 & 1.07 & 0.12 & 1.21 & 3.95 \\
\hline Health & 1.46 & 1.43 & 1.15 & 1.88 & 0.78 & 1.48 & 1.31 & 0.75 \\
\hline Arts-Ent-Rec & 5.07 & 17.78 & 1.68 & 10.84 & 3.20 & 16.67 & 6.19 & 2.02 \\
\hline
\end{tabular}

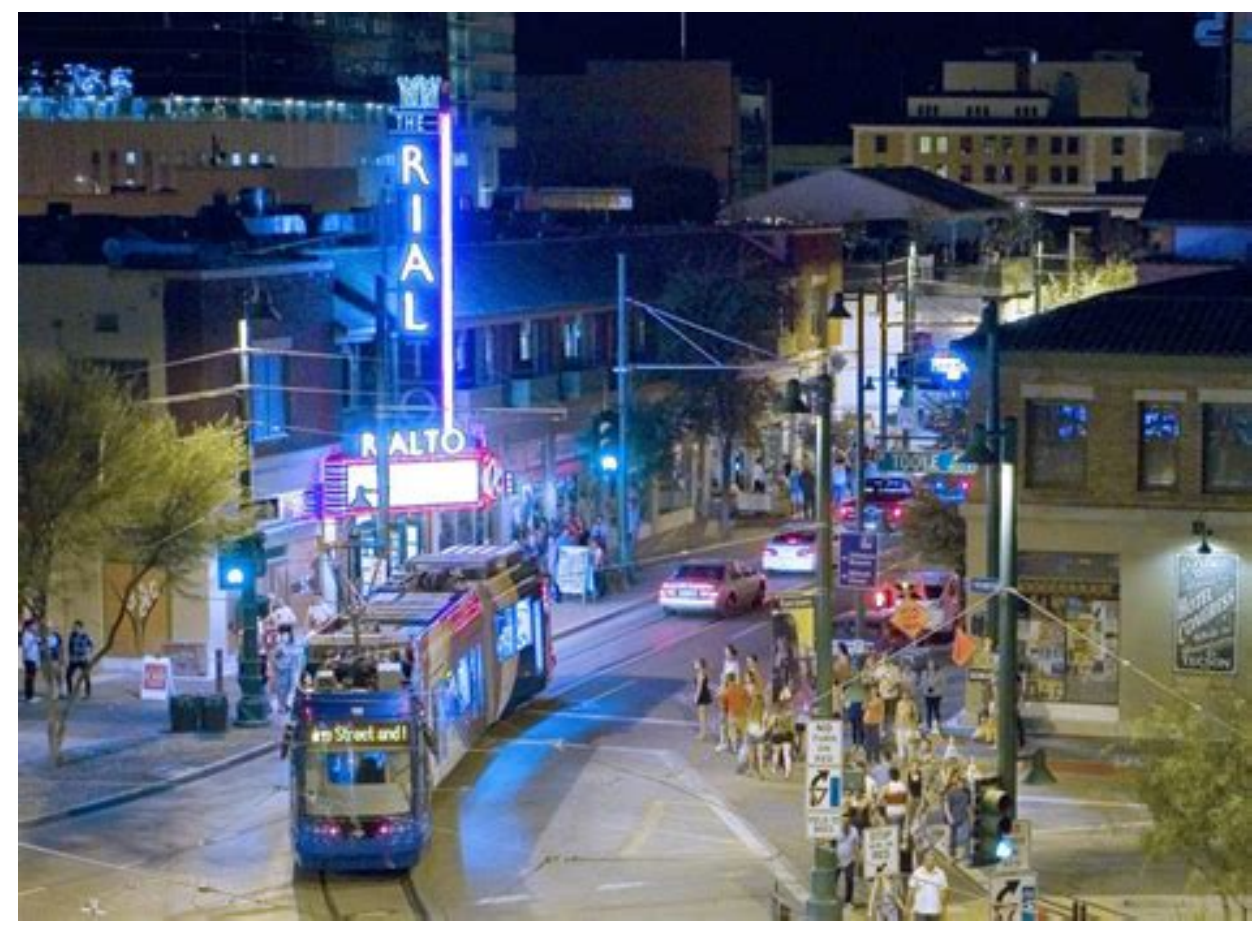

Figure 3. Tucson SunLink Streetcar. Source: hereandnow.wbur.org 
For Low MA BRT station areas, Manufacturing and Retail-Lodging-Food, and Education declined near the station, across the first 1-mile range. Near the half-mile range, all economic groups but Retail saw large rates of job share gain. Knowledge and Health jobs exerted major competitive efforts to gain job share near the station, in the first and second DB's from the station. Light Industry jobs also gained share in large rates from 0.375 -mile DB to the 0.75 -mile $\mathrm{DB}$. Beyond the half-mile $\mathrm{DB}$, Health job increased substantially in concentrations relative to the regions, although rates of growth in Health dropped in the half-mile and 0.75-mile DB's. This is due to larger declines in the rest of the regions than those occurring at these DB's from the stations.

For Mod MA BRT station areas, response was quite negative, with most economic groups showing major negative growth rates. Growth rates turned very positive just beyond the station, however, with Manufacturing approaching a 50\% growth rate. The LQ scores highlight that this high Manufacturing growth was also occurring at high rates across the whole of the region. Not so with Education, which saw a very high rate of growth at the quarter-mile DB (with mildly declining rates to 1-mile DB), as well as major increases in spatial concentration within the station neighborhood, with LQ scores such as 1.40 at the 0.375 -mile DB being indicative. Unlike Low MA BRT stations, Retail-Lodging-Food jobs picked up steam with large rates of growth in job share to the 1-mile DB, with the exception of the 0.75 -mile DB, which had a declining rate of growth. However, of importance to notice is that Retail did not enjoy at the same an increase in spatial concentration; its LQ scores were basically flat.

For High MA SCT stations, competition between economic groups is causing sorting of the land uses. Retail-Lodging-Food gained job share at the station to a distance of 0.75 miles, with some decline at the 1-mile DB. Office and Education declined in rates but gained spatial concentrations near the stations, due to larger declines at the regional scale. For many economic groups, this was the story: either growth rates were positive while LQ trends were negative, or vice-versa. These areas represent small proportions of the overall regional urbanized land, so a major shift in concentration may represent a small number of jobs. Two economic groups that gained in concentration, as well as rate of growth were Health and ArtsEntertainment-Recreation jobs. These economic groups valued being close to the station in a hotly competitive land market. 
Table 3.4 LRT Mod MA Transit Station Type Job Dynamics by Economic Group 2010-2016 Mod MA: LRT. Station Share of Job Shift 2010-2016

\begin{tabular}{|c|c|c|c|c|c|c|c|c|}
\hline Sector Groups & 0.125 & 0.25 & 0.375 & 0.5 & 0.75 & 1 & \multicolumn{2}{|c|}{$\begin{array}{l}\text { County Sums } \\
2016\end{array}$} \\
\hline Urban Square Miles - Increm. & 18 & 80 & 61 & 10 & 46 & 172 & \multicolumn{2}{|c|}{29,669} \\
\hline Urban Square Miles - Cum. & 18 & 98 & 159 & 169 & 215 & 386 & \multicolumn{2}{|c|}{29,669} \\
\hline Manufacturing & 72,185 & 14,839 & 9,509 & 9,184 & 4,140 & 4,070 & \multicolumn{2}{|c|}{$1,504,975$} \\
\hline Light Industry & 104,258 & 36,949 & 11,079 & 11,060 & 4,763 & 8,270 & \multicolumn{2}{|c|}{$1,842,851$} \\
\hline Retail-Lodging-Food & 263,058 & 46,184 & 48,807 & 37,360 & 18,289 & 34,042 & \multicolumn{2}{|c|}{$3,800,602$} \\
\hline Knowledge & 251,268 & 39,222 & 22,809 & 17,123 & 5,400 & 9,988 & \multicolumn{2}{|c|}{$2,242,526$} \\
\hline Office & 556,074 & 78,022 & 62,169 & 55,012 & 29,933 & 20,464 & \multicolumn{2}{|c|}{$4,609,558$} \\
\hline Education & 141,032 & 33,520 & 11,206 & 10,233 & 11,715 & 13,969 & \multicolumn{2}{|c|}{$1,608,044$} \\
\hline Health & 192,496 & 28,976 & 40,490 & 56,838 & 18,227 & 16,582 & \multicolumn{2}{|c|}{$2,630,962$} \\
\hline Arts-Ent-Rec & 46,901 & 5,855 & 3,504 & 5,083 & 800 & 3,836 & \multicolumn{2}{|c|}{353,302} \\
\hline Total Jobs & $1,627,279$ & 283,574 & 209,580 & 201,900 & 93,274 & 111,228 & \multicolumn{2}{|c|}{$18,592,820$} \\
\hline \multicolumn{9}{|c|}{ Mod MA: LRT. Economic Change 2010-2016 } \\
\hline Sector Groups & 0.125 & 0.25 & 0.375 & 0.5 & 0.75 & 1 & \multicolumn{2}{|c|}{ Transit County } \\
\hline Manufacturing & $(27,144)$ & 4,782 & 2,239 & $(1,303)$ & 371 & $(763)$ & \multicolumn{2}{|c|}{$(247,069)$} \\
\hline Light Industry & $(83,660)$ & 3,960 & 769 & 252 & $(660)$ & 892 & \multicolumn{2}{|c|}{$(26,098)$} \\
\hline Retail-Lodging-Food & 6,184 & 3,440 & 13,992 & 8,299 & $(2,591)$ & 6,749 & \multicolumn{2}{|l|}{64,894} \\
\hline Knowledge & $(7,340)$ & 7,196 & 1,480 & 1,067 & 293 & 1,854 & \multicolumn{2}{|c|}{104,140} \\
\hline Office & $(54,259)$ & 5,489 & 11,382 & 3,512 & 10,611 & 768 & \multicolumn{2}{|c|}{152,352} \\
\hline Education & 11,863 & 22,770 & $(994)$ & $(1,344)$ & $(1,692)$ & 2,846 & \multicolumn{2}{|c|}{137,537} \\
\hline Health & $(12,563)$ & $(1,934$ & 6,477 & 6,162 & 3,268 & 7,455 & \multicolumn{2}{|c|}{378,107} \\
\hline Arts-Ent-Rec & 1,655 & $(1,813$ & 693 & $(282)$ & $(128)$ & 2,188 & \multicolumn{2}{|l|}{25,271} \\
\hline Total Jobs & $(165,264)$ & 43,890 & 36,038 & 16,363 & 9,472 & 21,989 & 589,13 & \\
\hline Mod MA: LRT. Percent Econ & ic Change & $010-2016$ & & & & & & \\
\hline Sector Groups & 0.125 & 0.25 & 0.375 & 0.5 & 0.75 & 1 & Transit & Jounty \\
\hline Manufacturing & $-27.3 \%$ & $47.5 \%$ & $30.8 \%$ & $-12.4 \%$ & $9.8 \%$ & $-15.8 \%$ & $6.2 \%$ & \\
\hline Light Industry & $-44.5 \%$ & $12.0 \%$ & $7.5 \%$ & $2.3 \%$ & $-12.2 \%$ & $12.1 \%$ & $13.2 \%$ & \\
\hline Retail-Lodging-Food & $2.4 \%$ & $8.0 \%$ & $40.2 \%$ & $28.6 \%$ & $-12.4 \%$ & $24.7 \%$ & $19.2 \%$ & \\
\hline Knowledge & $-2.8 \%$ & $22.5 \%$ & $6.9 \%$ & $6.6 \%$ & $5.7 \%$ & $22.8 \%$ & $21.8 \%$ & \\
\hline Office & $-8.9 \%$ & $7.6 \%$ & $22.4 \%$ & $6.8 \%$ & $54.9 \%$ & $3.9 \%$ & $10.6 \%$ & \\
\hline Education & $9.2 \%$ & $211.8 \%$ & $-8.1 \%$ & $-11.6 \%$ & $-12.6 \%$ & $25.6 \%$ & $4.1 \%$ & \\
\hline Health & $-6.1 \%$ & $-6.3 \%$ & $19.0 \%$ & $12.2 \%$ & $21.8 \%$ & $81.7 \%$ & $18.7 \%$ & \\
\hline Arts-Ent-Rec & $3.7 \%$ & $-23.6 \%$ & $24.6 \%$ & $-5.3 \%$ & $-13.8 \%$ & $132.7 \%$ & $17.5 \%$ & \\
\hline Total Jobs & $-9.2 \%$ & $18.3 \%$ & $20.8 \%$ & $8.8 \%$ & $11.3 \%$ & $24.6 \%$ & $14.0 \%$ & \\
\hline Mod MA: LRT. LQ Trend 20 & $016(L Q$ & $16 / L Q 201$ & & & & & & \\
\hline Sector Groups & 0.125 & 0.25 & 0.375 & 0.5 & 0.625 & 0.75 & 0.875 & 1 \\
\hline Manufacturing & 1.03 & 0.66 & 0.76 & 1.02 & 0.82 & 0.84 & 1.10 & 1.22 \\
\hline Light Industry & 1.55 & 1.00 & 1.07 & 1.01 & 1.24 & 1.20 & 1.06 & 1.05 \\
\hline Retail-Lodging-Food & 0.87 & 1.08 & 0.85 & 0.83 & 0.91 & 1.25 & 0.95 & 0.98 \\
\hline Knowledge & 0.95 & 0.99 & 1.15 & 1.04 & 1.05 & 1.07 & 1.10 & 1.04 \\
\hline Office & 1.00 & 1.10 & 0.99 & 1.02 & 1.06 & 0.72 & 1.27 & 1.20 \\
\hline Education & 0.88 & 0.40 & 1.40 & 1.31 & 1.84 & 1.35 & 0.70 & 1.05 \\
\hline Health & 1.14 & 1.49 & 1.20 & 1.14 & 0.91 & 1.08 & 0.99 & 0.81 \\
\hline Arts-Ent-Rec & 0.92 & 1.63 & 1.02 & 1.21 & 0.80 & 1.36 & 1.29 & 0.56 \\
\hline
\end{tabular}




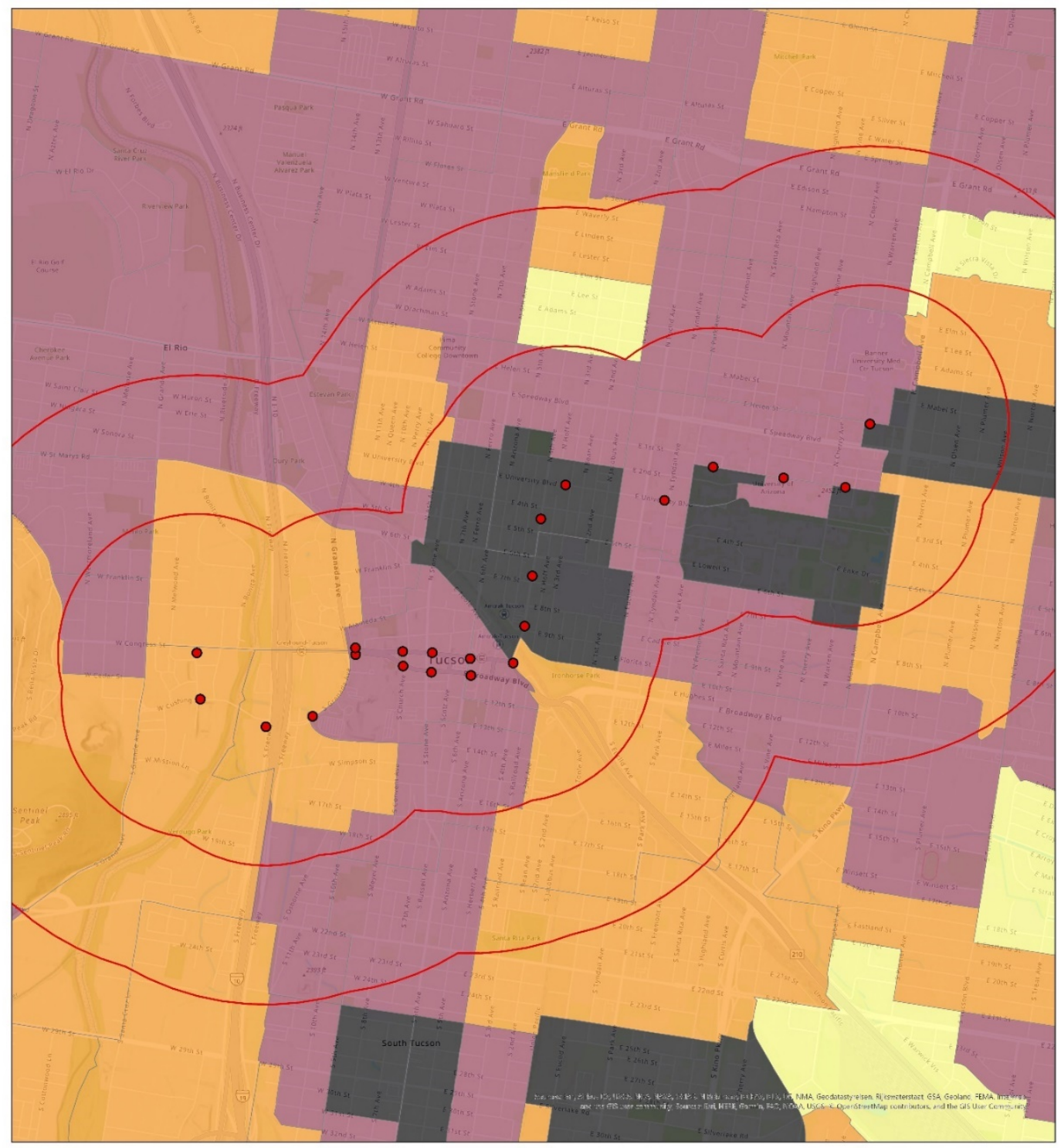

Station Typology for Streetcar Transit:

Tucson, AZ

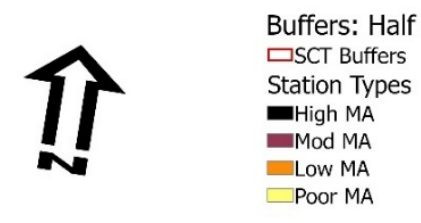

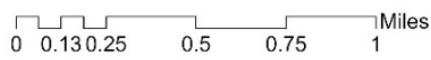

Figure 4. Map of Streetcar Transit system in downtown Tucson, AZ. The majority of the place types are in the Mod MA and the High MA. 
Table 3.5 SCT High MA Transit Station Type Job Dynamics by Economic Group 2010-2016 Mod High MA: SCT. Station Share of Shift 2010-2016

\begin{tabular}{|c|c|c|c|c|c|c|c|c|}
\hline Sector Groups & 0.125 & 0.25 & 0.375 & 0.5 & 0.75 & 1 & \multicolumn{2}{|c|}{$\begin{array}{l}\text { Transit } \\
\text { County Sum } \\
2016\end{array}$} \\
\hline Urban Square Miles - Increm. & 19 & 4 & 10 & 24 & 18 & 3 & \multicolumn{2}{|c|}{12,770} \\
\hline Urban Square Miles - Cum. & 19 & 23 & 33 & 58 & 75 & 79 & \multicolumn{2}{|c|}{12,770} \\
\hline Manufacturing & 3,446 & 1,392 & 125 & 1,355 & 492 & 39 & \multicolumn{2}{|c|}{524,288} \\
\hline Light Industry & 18,911 & 2,645 & 392 & 3,000 & 405 & 49 & \multirow{2}{*}{\multicolumn{2}{|c|}{$\frac{825,910}{1507012}$}} \\
\hline Retail-Lodging-Food & 66,304 & 10,444 & 26,442 & 6,359 & 1,658 & 3,561 & \multirow{2}{*}{\multicolumn{2}{|c|}{$\begin{array}{l}1,597,042 \\
1,101,103\end{array}$}} \\
\hline Knowledge & 87,348 & 14,051 & 3,075 & 3,114 & 991 & 673 & & \\
\hline Office & 107,562 & 18,331 & 2,837 & 5,798 & 822 & 1,715 & \multicolumn{2}{|c|}{$1,981,603$} \\
\hline Education & 14,962 & 1,034 & 435 & 253 & 258 & 332 & \multicolumn{2}{|c|}{689,431} \\
\hline Health & 33,059 & 10,618 & 1,897 & 6,126 & 268 & 762 & \multicolumn{2}{|c|}{$1,035,329$} \\
\hline Arts-Ent-Rec & 9,063 & 1,062 & 1,080 & 1,648 & 27 & 113 & \multicolumn{2}{|c|}{185,019} \\
\hline Total Jobs & 340,662 & 59,584 & 36,290 & 27,660 & 4,928 & 7,251 & \multicolumn{2}{|c|}{$7,939,725$} \\
\hline \multicolumn{9}{|l|}{ Economic Change 2010-2016 } \\
\hline Sector Groups & 0.125 & 0.25 & 0.375 & 0.5 & 0.75 & \multirow[t]{2}{*}{1} & \multicolumn{2}{|c|}{ Transit County } \\
\hline Manufacturing & $(78)$ & 193 & (78) & 766 & 47 & & \multicolumn{2}{|c|}{$(76,872)$} \\
\hline Light Industry & $(1,060)$ & $(444)$ & (27) & 36 & 194 & (61) & \multicolumn{2}{|c|}{$(30,086)$} \\
\hline Retail-Lodging-Food & 9,750 & 842 & 18,103 & 2,363 & 617 & $(828)$ & \multicolumn{2}{|c|}{$(16,664)$} \\
\hline Knowledge & 21,873 & $(1,775)$ & 145 & (397) & 155 & $(324)$ & \multicolumn{2}{|c|}{34,442} \\
\hline Office & $(35,890)$ & $(6,759)$ & 218 & 53 & 75 & 89 & \multicolumn{2}{|c|}{$(35,118)$} \\
\hline Education & $(7,035)$ & $(71)$ & 3 & (208) & 97 & 25 & \multicolumn{2}{|c|}{46,586} \\
\hline Health & 5,186 & $(264)$ & 139 & 1,497 & (27) & $(412)$ & \multicolumn{2}{|c|}{105,773} \\
\hline Arts-Ent-Rec & 2,869 & 142 & 483 & 299 & (31) & 4 & \multicolumn{2}{|l|}{3,632} \\
\hline Total Jobs & $(4,385)$ & $(8,136)$ & 18,986 & 4,409 & 1,127 & $(1,496)$ & 31,69 & \\
\hline rer & $70-2076$ & & & & & & & \\
\hline Sector Groups & 0.125 & 0.25 & 0.375 & 0.5 & 0.75 & 1 & Transit & County \\
\hline Manufacturing & $-2.2 \%$ & $16.1 \%$ & $-38.2 \%$ & $129.8 \%$ & $10.5 \%$ & $37.9 \%$ & $7.5 \%$ & \\
\hline Light Industry & $-5.3 \%$ & $-14.4 \%$ & $-6.4 \%$ & $1.2 \%$ & $91.5 \%$ & $-55.0 \%$ & $19.9 \%$ & \\
\hline Retail-Lodging-Food & $17.2 \%$ & $8.8 \%$ & $217.1 \%$ & $59.1 \%$ & $59.2 \%$ & $-18.9 \%$ & $21.0 \%$ & \\
\hline Knowledge & $33.4 \%$ & $-11.2 \%$ & $4.9 \%$ & $-11.3 \%$ & $18.5 \%$ & $-32.5 \%$ & $17.1 \%$ & \\
\hline Office & $-25.0 \%$ & $-26.9 \%$ & $8.3 \%$ & $0.9 \%$ & $10.0 \%$ & $5.5 \%$ & $0.1 \%$ & \\
\hline Education & $-32.0 \%$ & $-6.4 \%$ & $0.7 \%$ & $-45.0 \%$ & $59.9 \%$ & $8.1 \%$ & $13.7 \%$ & \\
\hline Health & $18.6 \%$ & $-2.4 \%$ & $7.9 \%$ & $32.3 \%$ & $-9.1 \%$ & $-35.1 \%$ & $8.3 \%$ & \\
\hline Arts-Ent-Rec & $46.3 \%$ & $15.4 \%$ & $80.8 \%$ & $22.1 \%$ & $-52.5 \%$ & $3.6 \%$ & $39.9 \%$ & \\
\hline Total Jobs & $-1.3 \%$ & $-12.0 \%$ & $109.7 \%$ & $19.0 \%$ & $29.6 \%$ & $-17.1 \%$ & $11.7 \%$ & \\
\hline LQ Trend 2010-2016 (LQ 2 & $16 / L Q 2010$ & & & & & & & \\
\hline Sector Groups & 0.125 & 0.25 & 0.375 & 0.5 & 0.625 & 0.75 & 0.875 & 1 \\
\hline Manufacturing & 0.87 & 0.66 & 2.94 & 0.45 & 2.67 & 1.02 & 1.72 & 0.52 \\
\hline Light Industry & 0.99 & 0.98 & 2.14 & 1.12 & 1.61 & 0.65 & 0.68 & 1.76 \\
\hline Retail-Lodging-Food & 0.83 & 0.79 & 0.65 & 0.73 & 0.79 & 0.80 & 0.53 & 1.00 \\
\hline Knowledge & 0.77 & 1.03 & 2.08 & 1.39 & 1.15 & 1.14 & 0.93 & 1.28 \\
\hline Office & 1.28 & 1.17 & 1.89 & 1.15 & 1.32 & 1.15 & 1.68 & 0.77 \\
\hline Education & 1.58 & 1.03 & 2.27 & 2.36 & 1.33 & 0.88 & 8.78 & 0.84 \\
\hline Health & 0.95 & 1.03 & 2.22 & 1.02 & 0.80 & 1.63 & 1.34 & 1.46 \\
\hline Arts-Ent-Rec & 0.69 & 0.78 & 1.19 & 1.00 & 1.75 & 2.80 & 0.82 & 0.82 \\
\hline
\end{tabular}




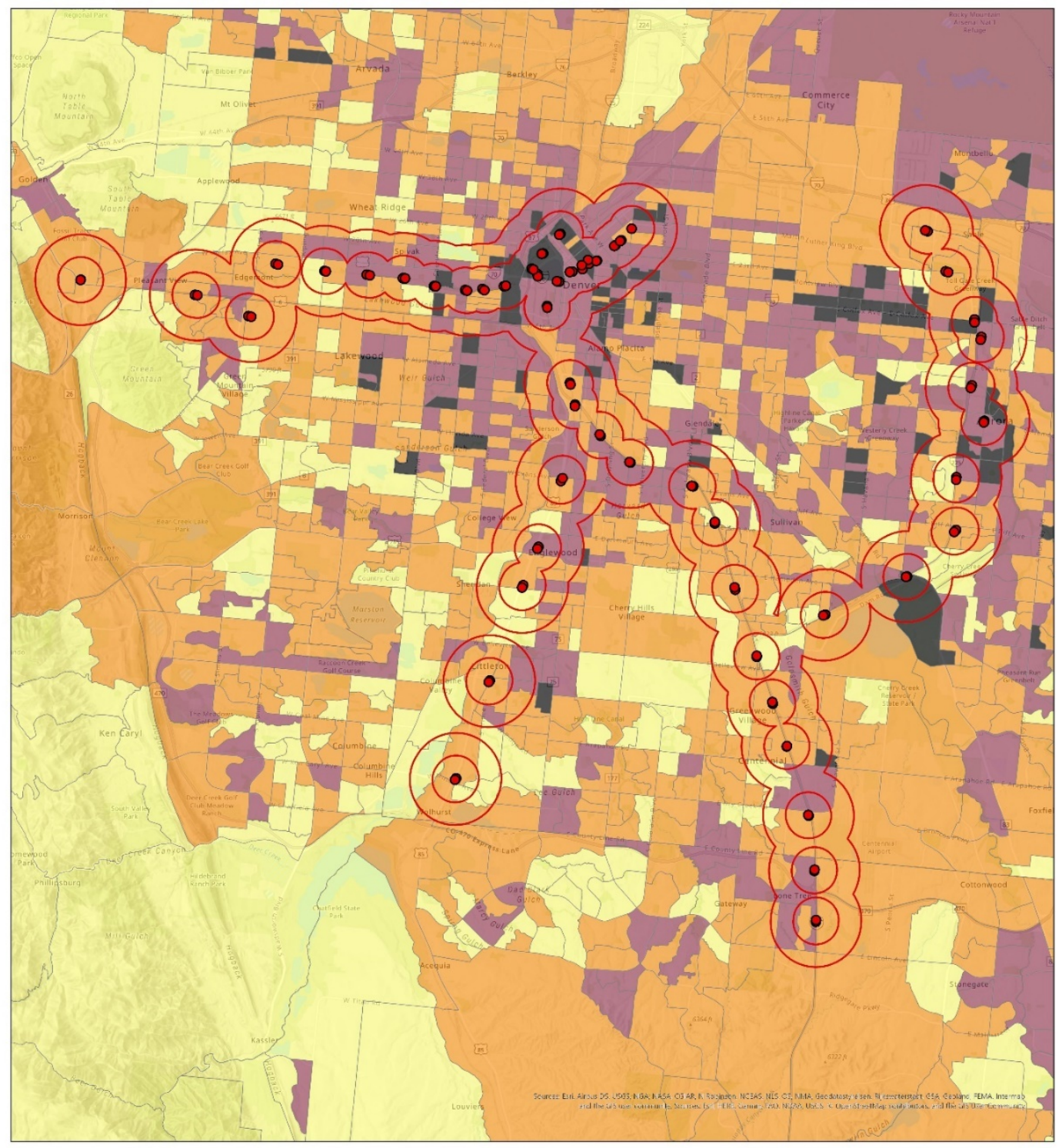

Station Typology for Light Rail Transit:
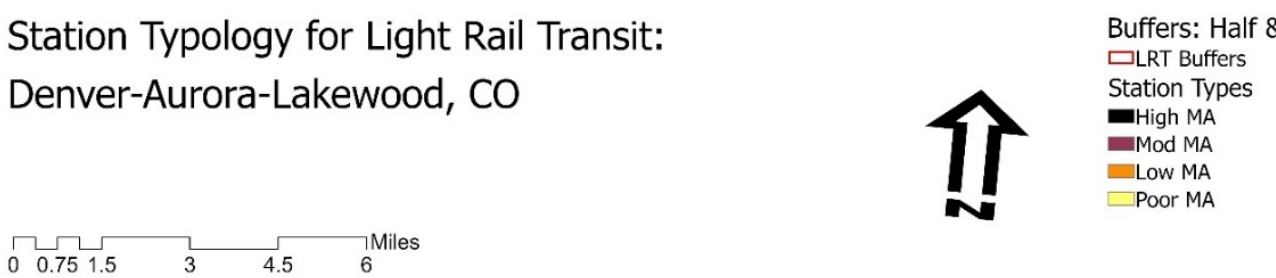

Figure 5. Light Rail Transit in Denver, Colorado show a wide variety of station place types. A brief visual inspection of the map implies that Low MA and Mod MA are the most prevalent station place types. Further, the map demonstrates the wide variety of place types at each individual transit station. Competition for revenue-generating land uses may be drawn into those higher-intensity areas, with a concomitant loss of land uses in less intense locations. 
Jobs by Wage Group for Transit Systems and Station Types: Under-performers and Over-performers

The North American Industry Classification System (NAICS) classifies job sectors. The study further classified jobs by income based on NAICS wage averages. Lower-income job sectors consist mainly of retail and food service jobs. Middle-income jobs consist mainly of health care, real estate, transport, and mid-level public administration jobs. Upper-income jobs focus on industrial, professional, and management positions.

Table 3.6 Allocation of Workers by Lower-, Middle- and Upper-Wage Category

\begin{tabular}{|c|c|c|c|c|}
\hline NAICS & Description & $\begin{array}{l}\text { Mean Annual } \\
\text { Wages, } 2013\end{array}$ & $\begin{array}{l}\text { Wage } \\
\text { Category }\end{array}$ & $\begin{array}{l}\text { Share } \\
\text { of } \\
\text { Workers }\end{array}$ \\
\hline 44 & Retail Trade & $\$ 25,779$ & Lower & \\
\hline 56 & $\begin{array}{l}\text { Administrative, Support, Waste Mgmt., } \\
\text { Remediation }\end{array}$ & $\$ 35,931$ & Lower & \\
\hline 61 & Educational Services & $\$ 35,427$ & Lower & \\
\hline 71 & Arts, Entertainment and Recreation & $\$ 32,188$ & Lower & \\
\hline 72 & Accommodation and Food Services & $\$ 17,453$ & Lower & \\
\hline \multirow[t]{2}{*}{81} & Other Services (except Public Administration) & $\$ 29,021$ & Lower & \\
\hline & \multicolumn{2}{|c|}{ Weighted Mean Wages and National Share of Workers } & $\sim \$ 30,000$ & $\sim 33 \%$ \\
\hline 48 & Transportation and Warehousing & $\$ 45,171$ & Middle & \\
\hline 53 & Real Estate and Rental and Leasing & $\$ 46,813$ & Middle & \\
\hline 62 & Health Care and Social Assistance & $\$ 44,751$ & Middle & \\
\hline \multirow[t]{2}{*}{92} & Public Administration & $\$ 51,340$ & Middle & \\
\hline & \multicolumn{2}{|c|}{ Weighted Mean Wages and National Share of Workers } & $\sim \$ 50,000$ & $\sim 33 \%$ \\
\hline 22 & Utilities & $\$ 94,239$ & Upper & \\
\hline 31 & Manufacturing & $\$ 54,258$ & Upper & \\
\hline 42 & Wholesale Trade & $\$ 65,385$ & Upper & \\
\hline 51 & Information & $\$ 83,677$ & Upper & \\
\hline 52 & Finance and Insurance & $\$ 88,677$ & Upper & \\
\hline 54 & Professional, Scientific and Technical Services & $\$ 75,890$ & Upper & \\
\hline \multirow[t]{2}{*}{55} & Management of Companies and Enterprises & $\$ 105,138$ & Upper & \\
\hline & \multicolumn{2}{|c|}{ Weighted Mean Wages and National Share of Workers } & $\sim \$ 70,000$ & $34 \%$ \\
\hline
\end{tabular}

Source: Adapted from County Business Patterns, 2013 by Arthur C. Nelson and Robert Hibberd, University of Arizona. 
This section will outline growth and spatial concentration trends of jobs by wage group for the full set of transit mode-station typology combinations. Each combination will be summarized by 1) a table containing FRT Station Shift figures from the shift-share analysis results from each $D B, 2$ ) the rate of change for jobs at each DB, and 3) Location Quotient trends for the period, with scores above 1 denoting increases in spatial concentrations at the station relative to the regions ("Transit County") served by the transit systems.

Table 3.7. Poor MA BRT

Station Share of Job Shift 2010-2016

\begin{tabular}{|c|c|c|c|c|c|c|c|}
\hline Income Groups & 0.125 & 0.25 & 0.375 & 0.5 & 0.75 & 1 & $\begin{array}{l}\text { Transit } \\
\text { County } \\
\text { Sum } 2016\end{array}$ \\
\hline Urban Square Miles - Increm. & 15 & 20 & 22 & 24 & 53 & 57 & 14,201 \\
\hline Urban Square Miles - Cum. & 15 & 35 & 57 & 81 & 134 & 191 & 14,201 \\
\hline Upper Income Jobs & 44,327 & 13,073 & 16,096 & 12,971 & 10,135 & 15,359 & $3,335,487$ \\
\hline Middle Income Jobs & 6,203 & 8,295 & 8,449 & 5,716 & 6,508 & 8,677 & $2,289,894$ \\
\hline Lower Income Jobs & 31,250 & 10,316 & 8,977 & 8,702 & 7,683 & 9,612 & $4,010,614$ \\
\hline Total Jobs & 81,782 & 31,686 & 33,524 & 27,391 & 24,328 & 33,650 & $9,635,995$ \\
\hline
\end{tabular}

Economic Change 2010-2016

\begin{tabular}{|c|c|c|c|c|c|c|c|}
\hline Income Groups & 0.125 & 0.25 & 0.375 & 0.5 & 0.75 & 1 & $\begin{array}{l}\text { Transit } \\
\text { County }\end{array}$ \\
\hline Upper Income Jobs & 27,390 & 9,254 & 10,331 & $\begin{array}{l}7,85 \\
0\end{array}$ & 4,995 & 10,623 & $(68,521)$ \\
\hline Middle Income Jobs & $(167,859)$ & $\begin{array}{l}(25,558 \\
)^{2}\end{array}$ & $(33,512)$ & $\begin{array}{l}(23,1 \\
85)\end{array}$ & )$^{(11,676}$ & $\begin{array}{l}(25,295 \\
)^{2}\end{array}$ & 169,035 \\
\hline Lower Income Jobs & $(36,797)$ & 610 & $(9,594)$ & $\begin{array}{l}(2,68 \\
4)\end{array}$ & 503 & $(5,810)$ & 61,107 \\
\hline Total Jobs & $(177,266)$ & $\begin{array}{l}(15,694 \\
)^{2}\end{array}$ & $(32,775)$ & $\begin{array}{l}(18,0 \\
19)\end{array}$ & $(6,178)$ & $\begin{array}{l}(20,482 \\
)^{(20}\end{array}$ & 161,621 \\
\hline
\end{tabular}

Percent Economic Change 2010-2016

\begin{tabular}{|c|c|c|c|c|c|c|c|}
\hline Income Groups & 0.125 & 0.25 & 0.375 & 0.5 & 0.75 & 1 & $\begin{array}{l}\text { Transit } \\
\text { County }\end{array}$ \\
\hline Upper Income Jobs & $161.7 \%$ & $242.2 \%$ & $179.1 \%$ & $\begin{array}{l}153 . \\
2 \% \\
\end{array}$ & $97.1 \%$ & $224.2 \%$ & $50.9 \%$ \\
\hline Middle Income Jobs & $-96.4 \%$ & $-75.5 \%$ & $-79.9 \%$ & $\begin{array}{l}- \\
80.2 \\
\% \\
\end{array}$ & $-64.2 \%$ & $-74.5 \%$ & $-74.8 \%$ \\
\hline Lower Income Jobs & $-54.1 \%$ & $6.3 \%$ & $-51.7 \%$ & $\begin{array}{l}- \\
23.6 \\
\% \\
\end{array}$ & $7.0 \%$ & $-37.7 \%$ & $34.6 \%$ \\
\hline$\underline{\text { Total Jobs }}$ & $-68.4 \%$ & $-33.1 \%$ & $-49.4 \%$ & $\begin{array}{l}- \\
39.7 \\
\%\end{array}$ & $-20.3 \%$ & $-37.8 \%$ & $-32.5 \%$ \\
\hline
\end{tabular}

LQ Trend 2010-2016 (LQ 2016 / LQ 2010)

\begin{tabular}{llllll|l|l|l}
\hline Income Groups & 0.125 & 0.25 & 0.375 & 0.5 & 0.625 & 0.75 & 0.875 & 1 \\
\hline Upper Income Jobs & 3.70 & 2.29 & 2.47 & 1.88 & 1.68 & 1.10 & 1.26 & 2.33 \\
\hline Middle Income Jobs & 0.30 & 0.98 & 1.07 & 0.88 & 1.31 & 1.20 & 1.30 & 1.10 \\
\hline Lower Income Jobs & 0.73 & 0.80 & 0.48 & 0.63 & 0.49 & 0.67 & 0.56 & 0.50 \\
\hline
\end{tabular}



Station areas for BRT systems in Poor MA land types responded to proximity to the station by a reduction of job share in the first one-eighth mile DB from the station, which has direct access to the station and includes the station itself. All jobs together took a massive loss of $46 \%$. Middleincome jobs dropped at a precipitous $74 \%$ during the study period. Only low-wage jobs responded positively to station proximity in the first quarter mile. Upper and lower-income jobs responded positively at a half mile from the station. Growth was considerably positive within the 0.75 and 1-mile DB's from the station. This indicates that firms chose against locations with direct access to the stations but opted for locations within an easy walk from those stations. The dispersed nature of the land uses may have caused this negative response.

At the same time that jobs moved away from the immediate neighborhood of Poor MA BRT stations, they gained in concentration near the stations relative to the remainder of the region, as evinced in the LQ score trends from 2010 to 2016. Middle income jobs lost concentrations while upper- and lower-income jobs increased. All job types gained growth at the half-mile to 1mile distance band increments.

Table 3.7. Low MA BRT

Station Share of Job Shift 20102016

\begin{tabular}{|c|c|c|c|c|c|c|c|}
\hline Income Groups & 0.125 & 0.25 & 0.375 & 0.5 & 0.75 & 1 & $\begin{array}{l}\text { Transit } \\
\text { County Sum } \\
2016\end{array}$ \\
\hline $\begin{array}{l}\text { Urban Square Miles - } \\
\text { Increm. }\end{array}$ & 27 & 44 & 49 & 51 & 102 & 98 & 14,201 \\
\hline $\begin{array}{l}\text { Urban Square Miles - } \\
\text { Cum. }\end{array}$ & 27 & 71 & 120 & 171 & 273 & 371 & 14,201 \\
\hline Upper Income Jobs & 304,281 & 33,923 & $\begin{array}{l}27,91 \\
8\end{array}$ & 50,054 & $\begin{array}{l}17,65 \\
6\end{array}$ & 59,948 & $3,335,487$ \\
\hline Middle Income Jobs & 208,321 & 40,874 & $\begin{array}{l}16,98 \\
9\end{array}$ & 36,568 & $\begin{array}{l}14,39 \\
4\end{array}$ & 32,707 & $2,289,894$ \\
\hline Lower Income Jobs & 289,693 & 49,543 & $\begin{array}{l}29,12 \\
6\end{array}$ & 56,309 & $\begin{array}{l}41,00 \\
7\end{array}$ & 31,793 & $4,010,614$ \\
\hline Total Jobs & 802,297 & $\begin{array}{l}124,34 \\
2\end{array}$ & $\begin{array}{l}74,03 \\
5\end{array}$ & $\begin{array}{l}142,93 \\
3\end{array}$ & $\begin{array}{l}73,05 \\
9\end{array}$ & 124,450 & $9,635,995$ \\
\hline
\end{tabular}

Economic Change 2010-

2016

\begin{tabular}{|c|c|c|c|c|c|c|c|}
\hline Income Groups & 0.125 & 0.25 & 0.375 & 0.5 & 0.75 & 1 & $\begin{array}{l}\text { Transit } \\
\text { County }\end{array}$ \\
\hline Upper Income Jobs & 201,025 & 10,785 & 3,434 & 21,308 & 466 & 36,471 & $(68,521)$ \\
\hline Middle Income Jobs & $\begin{array}{l}(548,02 \\
5)\end{array}$ & $\begin{array}{l}(95,05 \\
7)\end{array}$ & $\begin{array}{l}(32,34 \\
2)\end{array}$ & $\begin{array}{l}(128,32 \\
8)\end{array}$ & $\begin{array}{l}(67,22 \\
2)\end{array}$ & $\begin{array}{l}(91,00 \\
9)\end{array}$ & 169,035 \\
\hline Lower Income Jobs & 23,953 & 17,596 & 14,158 & 284 & 21,408 & $\begin{array}{l}(30,10 \\
5)\end{array}$ & 61,107 \\
\hline Total Jobs & $\begin{array}{l}(323,04 \\
7)\end{array}$ & $\begin{array}{l}(66,67 \\
6)\end{array}$ & $\begin{array}{l}(14,75 \\
0)\end{array}$ & $\begin{array}{l}(106,73 \\
6)\end{array}$ & $\begin{array}{l}(45,34 \\
8)\end{array}$ & $\begin{array}{l}\text { (84,64 } \\
3)\end{array}$ & 161,621 \\
\hline
\end{tabular}

Percent Economic Change 20102016

Income Groups

0.125

0.25

0.375

0.5

0.75

1

Transit 


\begin{tabular}{|c|c|c|c|c|c|c|c|}
\hline Upper Income Jobs & $194.7 \%$ & $46.6 \%$ & $14.0 \%$ & $74.1 \%$ & $2.7 \%$ & $\begin{array}{l}155.3 \\
\%\end{array}$ & $50.9 \%$ \\
\hline Middle Income Jobs & $-72.5 \%$ & $-69.9 \%$ & $-65.6 \%$ & $77.8 \%$ & $-82.4 \%$ & $-73.6 \%$ & $-74.8 \%$ \\
\hline Lower Income Jobs & $9.0 \%$ & $55.1 \%$ & $94.6 \%$ & $0.5 \%$ & $\begin{array}{l}109.2 \\
\%\end{array}$ & $-48.6 \%$ & $34.6 \%$ \\
\hline Total Jobs & $-28.7 \%$ & $-34.9 \%$ & $\begin{array}{l}- \\
16.6 \%\end{array}$ & $\begin{array}{l} \\
42.8 \%\end{array}$ & $-38.3 \%$ & $-40.5 \%$ & $-32.5 \%$ \\
\hline
\end{tabular}

LQ Trend 2010-2016 (LQ 2016 / LQ 2010)

\begin{tabular}{ll|lllll|l|l}
\hline Income Groups & 0.125 & 0.25 & 0.375 & 0.5 & 0.625 & 0.75 & 0.875 & 1 \\
\hline Upper Income Jobs & 1.85 & 1.01 & 0.61 & 1.36 & 0.57 & 0.74 & 0.88 & 1.92 \\
\hline Middle Income Jobs & 1.04 & 1.24 & 1.11 & 1.04 & 1.13 & 0.77 & 1.21 & 1.19 \\
\hline Lower Income Jobs & 0.77 & 1.19 & 1.17 & 0.88 & 1.34 & 1.70 & 0.95 & 0.43 \\
\hline
\end{tabular}


Firms near Low MA BRT stations responded fairly tepidly to BRT station proximity, with losses at the station for low-income jobs, losses for middle-income jobs just beyond the station at the quarter-mile DB, considerable growth in job share at the 0.375 -mile DB, but mostly loss of job share to the 1 mile DB. This may indicate a negative response to the low-intensity land use in the local area beyond the station, as well as to the transit connection itself. While these transit counties mostly lost jobs, LQ trends were positive for upper and middle-income job groups near the station. Lower-income jobs had a negative LQ trend, denoting loss of local concentration of these jobs relative to the regional concentrations. This may indicate that much of the reduction of transit area job share was in hospitality, entertainment, and other retail services.

Table 3.8. Mod MA: BRT

Station Share of Job Shift 2010-2016

\begin{tabular}{|c|c|c|c|c|c|c|c|}
\hline Income Groups & 0.125 & 0.25 & 0.375 & 0.5 & 0.75 & 1 & $\begin{array}{l}\text { Transit } \\
\text { County } \\
\text { Sum } \\
2016\end{array}$ \\
\hline Urban Square Miles - Increm. & 23 & 38 & 39 & 36 & 61 & 50 & 14,201 \\
\hline Urban Square Miles - Cum. & 23 & 61 & 100 & 136 & 196 & 246 & 14,201 \\
\hline Upper Income Jobs & 293,352 & 23,759 & 26,643 & 19,165 & 21,890 & 8,713 & $3,335,487$ \\
\hline Middle Income Jobs & 215,707 & 19,605 & 22,042 & 25,236 & 18,375 & 35,867 & $2,289,894$ \\
\hline Lower Income Jobs & 316,532 & 43,805 & 29,498 & 36,780 & 33,892 & 20,470 & $4,010,614$ \\
\hline Total Jobs & 825,593 & 87,171 & 78,185 & 81,183 & 74,159 & 65,052 & $9,635,995$ \\
\hline
\end{tabular}

Economic Change 2010-2016

\begin{tabular}{l|l|l|l|l|l|l|l}
\hline Income Groups & 0.125 & 0.25 & 0.375 & 0.5 & 0.75 & 1 & Transit County \\
\hline Upper Income Jobs & 143,537 & $(3,477)$ & $(2,450)$ & $(15,444)$ & 3,196 & $(11,472)$ & $(68,521)$ \\
\hline Middle Income Jobs & $(886,237)$ & $(63,132)$ & $(36,900)$ & $(57,810)$ & $(68,378)$ & $(68,541)$ & 169,035 \\
\hline Lower Income Jobs & $(31,913)$ & 17,666 & 17,335 & 19,348 & 14,101 & 9,850 & 61,107 \\
\hline Total Jobs & $(774,613)$ & $(48,943)$ & $(22,015)$ & $(53,906)$ & $(51,081)$ & $(70,163)$ & 161,621 \\
\hline
\end{tabular}

Percent Economic Change 2010-2016

\begin{tabular}{l|l|l|l|l|l|l|l}
\hline Income Groups & 0.125 & 0.25 & 0.375 & 0.5 & 0.75 & 1 & Transit County \\
\hline Upper Income Jobs & $95.8 \%$ & $-12.8 \%$ & $-8.4 \%$ & $-44.6 \%$ & $17.1 \%$ & $-56.8 \%$ & $50.9 \%$ \\
\hline Middle Income Jobs & $-80.4 \%$ & $-76.3 \%$ & $-62.6 \%$ & $-69.6 \%$ & $-78.8 \%$ & $-65.6 \%$ & $-74.8 \%$ \\
\hline Lower Income Jobs & $-9.2 \%$ & $67.6 \%$ & $142.5 \%$ & $111.0 \%$ & $71.2 \%$ & $92.7 \%$ & $34.6 \%$ \\
\hline Total Jobs & $-48.4 \%$ & $-36.0 \%$ & $-22.0 \%$ & $-39.9 \%$ & $-40.8 \%$ & $-51.9 \%$ & $-32.5 \%$ \\
\hline
\end{tabular}

LQ Percent Change 2010-2016

\begin{tabular}{llllllll|l|l}
\hline Income Groups & 0.125 & 0.25 & 0.375 & 0.5 & 0.625 & 0.75 & 0.875 & 1 \\
\hline Upper Income Jobs & 1.70 & 0.61 & 0.52 & 0.41 & 1.22 & 0.88 & 0.26 & 0.40 \\
\hline Middle Income Jobs & 1.02 & 0.99 & 1.28 & 1.36 & 1.11 & 0.96 & 1.18 & 1.91 \\
\hline Lower Income Jobs & 0.88 & 1.31 & 1.56 & 1.76 & 0.61 & 1.45 & 2.75 & 2.01 \\
\hline
\end{tabular}


Firms responded to BRT near Mod MA stations by distancing themselves from the immediate vicinity of the stations themselves, while growing in job share just beyond the station. Lowerincome jobs grew in the quarter-mile DB, while upper and lower-income jobs had considerable growth to the 0.75 DB. Middle-income jobs declined in most DB's, with mild growth in the 0.375 DB. This indicates that Mod MA neighborhoods attract mainly upper-income jobs; lower-income jobs are attracted at a lesser rate, while middle-income jobs are moving away, perhaps as a result of competition from firms in the other income groups. LQ trends were mostly flat for middle-income groups, indicating that they did not increase in concentration near BRT stations relative to their concentrations in the broader regions. Job share rates indicate that jobs can be too close or too far from the station. Direct proximity results in negative change, as does the 1mile DB. The Mod MA land use type may therefore respond best to walkable and bikeable spaces and distances. Distances beyond the half-mile DB seem too far from the station for middle-income jobs, while the upper-and lower-income jobs seemed to respond negatively to distances farther than the 0.75 -mile DB.

Table 3.9. High MA: BRT

Station Share of Job Shift 2010-2016

\begin{tabular}{l|l|l|l|l|l|l|l|l}
\hline & \multicolumn{1}{l}{0.5} & & & & Transit \\
County \\
Income Groups & 0.125 & 0.25 & 0.375 & 0.5 & 0.75 & 1 & Sum 2016 \\
\hline Urban Square Miles - Increm. & 4 & 7 & 6 & 5 & 8 & 6 & 14,201 \\
\hline Urban Square Miles - Cum. & 4 & 11 & 17 & 22 & 30 & 36 & 14,201 \\
\hline Upper Income Jobs & 166,902 & 10,060 & 7,799 & 5,084 & 1,722 & 553 & $3,335,487$ \\
\hline Middle Income Jobs & 82,712 & 17,212 & 4,273 & 3,017 & 1,482 & 674 & $2,289,894$ \\
\hline Lower Income Jobs & 164,399 & 16,125 & 24,874 & 40,512 & 7,980 & 6,671 & $4,010,614$ \\
\hline Total Jobs & 414,015 & 43,399 & 36,948 & 48,615 & 11,186 & 7,900 & $9,635,995$ \\
\hline
\end{tabular}

Economic Change 2010-

2016

\begin{tabular}{|c|c|c|c|c|c|c|c|}
\hline Income Groups & 0.125 & 0.25 & 0.375 & 0.5 & 0.75 & 1 & $\begin{array}{l}\text { Transit } \\
\text { County }\end{array}$ \\
\hline Upper Income Jobs & 120,582 & $(4,073)$ & $(464)$ & $(4,379)$ & $\begin{array}{l}(2,423 \\
)\end{array}$ & $\begin{array}{l}(3,057 \\
)\end{array}$ & $(68,521)$ \\
\hline Middle Income Jobs & $\begin{array}{l}(335,825 \\
\end{array}$ & )$^{(21,085}$ & )$^{(28,036}$ & )$^{(24,313}$ & $\begin{array}{l}(8,439 \\
\end{array}$ & $\begin{array}{l}(3,807 \\
{ }^{\prime}\end{array}$ & 169,035 \\
\hline Lower Income Jobs & 19,041 & 7,895 & 18,820 & 36,067 & 5,933 & 5,985 & 61,107 \\
\hline$\underline{\text { Total Jobs }}$ & )$^{(196,202}$ & )$^{(17,263}$ & $(9,680)$ & 7,375 & $\begin{array}{l}(4,929 \\
)^{2}\end{array}$ & $(879)$ & 161,621 \\
\hline
\end{tabular}

Percent Economic Change 2010-2016

\begin{tabular}{l|l|l|l|l|l|l|l}
\hline Income Groups & 0.125 & 0.25 & 0.375 & 0.5 & 0.75 & 1 & Transit County \\
\hline Upper Income Jobs & $260.3 \%$ & $-28.8 \%$ & $-5.6 \%$ & $-46.3 \%$ & $-58.4 \%$ & $-84.6 \%$ & $50.9 \%$ \\
\hline Middle Income Jobs & $-80.2 \%$ & $-55.1 \%$ & $-86.8 \%$ & $-89.0 \%$ & $-85.1 \%$ & $-85.0 \%$ & $-74.8 \%$ \\
\hline Lower Income Jobs & $13.1 \%$ & $95.9 \%$ & $310.8 \%$ & $811.2 \%$ & $289.7 \%$ & $871.2 \%$ & $34.6 \%$ \\
\hline Total Jobs & $-32.2 \%$ & $-28.5 \%$ & $-20.8 \%$ & $17.9 \%$ & $-30.6 \%$ & $-10.0 \%$ & $-32.5 \%$ \\
\hline
\end{tabular}

LQ Trend 2010-2016 (LQ 2016 / LQ 2010)

\begin{tabular}{lllllll|l|l|l}
\hline Income Groups & 0.125 & 0.25 & 0.375 & 0.5 & 0.625 & 0.75 & 0.875 & 1 \\
\hline Upper Income Jobs & 2.37 & 0.44 & 0.53 & 0.20 & 0.17 & 0.27 & 0.06 & 0.08 \\
\hline Middle Income Jobs & 0.78 & 1.68 & 0.45 & 0.25 & 0.86 & 0.58 & 2.74 & 0.45 \\
\hline Lower Income Jobs & 0.84 & 1.37 & 2.60 & 3.87 & 3.22 & 2.81 & 2.10 & 5.41 \\
\hline
\end{tabular}


High MA BRT stations attracted upper-income jobs at the station, which may have pushed middle and especially lower-income jobs further away from the stations. All income groups had robust percent economic change within most DB's to 1 mile from the stations. Upper and middle-income jobs gained the greatest share in the closest DB's, while lower-income jobs grew substantially in share from the half-mile to the 1-mile DB. The LQ trends show strong growth in concentration for upper-income jobs nearest the stations, while lower-income jobs gained very significantly in concentrations in the half-mile and 0.624-mile DB's. Overall, these station areas attracted jobs at high rates to the 1-mile DB, much higher than the regional growth rates. Growth remained strong at the 1-mile DB for lower-and middle-income jobs, and the latter grew in concentration considerably from the half-mile DB to the 1-mile DB.

Table 3.10. Poor MA: CRT

Station Share of Job Shift 2010-2016

\begin{tabular}{|c|c|c|c|c|c|c|c|}
\hline Income Groups & 0.125 & 0.25 & 0.375 & 0.5 & 0.75 & 1 & $\begin{array}{l}\text { Transit } \\
\text { County } \\
\text { Sum } 2016\end{array}$ \\
\hline Urban Square Miles - Increm. & 10 & 30 & 51 & 71 & 205 & 277 & 41,703 \\
\hline Urban Square Miles - Cum. & 10 & 40 & 91 & 162 & 367 & 644 & 41,703 \\
\hline Upper Income Jobs & 44,914 & 10,563 & 28,796 & 15,617 & 9,409 & 4,662 & $5,695,896$ \\
\hline Middle Income Jobs & 25,600 & 7,257 & 5,589 & 5,835 & 7,794 & 3,084 & $4,003,309$ \\
\hline Lower Income Jobs & 72,118 & 9,179 & 24,431 & 7,784 & 8,000 & 8,483 & $7,817,123$ \\
\hline Total Jobs & 142,634 & 27,001 & 58,818 & 29,238 & 25,205 & 16,231 & $17,516,328$ \\
\hline
\end{tabular}

Economic Change 2010-2016

\begin{tabular}{l|ll|l|l|l|l|l}
\hline Income Groups & 0.125 & 0.25 & 0.375 & 0.5 & 0.75 & 1 & \multicolumn{1}{l}{ Transit County } \\
\hline Upper Income Jobs & 4,778 & 2,481 & 2,949 & 1,691 & 4,061 & $(3,754)$ & $(62,703)$ \\
\hline Middle Income Jobs & 8,420 & 1,693 & $(2,376)$ & $(639)$ & 3,101 & $(3,791)$ & 299,555 \\
\hline Lower Income Jobs & 10,583 & 3,563 & 2,887 & $(4,106)$ & 899 & $(18,220)$ & 256,188 \\
\hline Total Jobs & 23,781 & 7,737 & 3,460 & $(3,054)$ & 8,061 & $(25,765)$ & 493,040 \\
\hline
\end{tabular}

Percent Economic Change 2010-2016

\begin{tabular}{l|l|l|l|l|l|l|l}
\hline Income Groups & 0.125 & 0.25 & 0.375 & 0.5 & 0.75 & 1 & Transit County \\
\hline Upper Income Jobs & $11.9 \%$ & $30.7 \%$ & $11.4 \%$ & $12.1 \%$ & $75.9 \%$ & $-44.6 \%$ & $14.6 \%$ \\
\hline Middle Income Jobs & $49.0 \%$ & $30.4 \%$ & $-29.8 \%$ & $-9.9 \%$ & $66.1 \%$ & $-55.1 \%$ & $5.2 \%$ \\
\hline Lower Income Jobs & $17.2 \%$ & $63.4 \%$ & $13.4 \%$ & $-34.5 \%$ & $12.7 \%$ & $-68.2 \%$ & $18.9 \%$ \\
\hline Total Jobs & $20.0 \%$ & $40.2 \%$ & $6.3 \%$ & $-9.5 \%$ & $47.0 \%$ & $-61.3 \%$ & $14.1 \%$ \\
\hline
\end{tabular}

LQ Trend 2010-2016 (LQ 2016 / LQ 2010)

\begin{tabular}{l|lllll|l|l|l|l}
\hline Income Groups & 0.125 & 0.25 & 0.375 & 0.5 & 0.625 & 0.75 & \multicolumn{1}{l}{0.875} & 1 \\
\hline Upper Income Jobs & 0.93 & 0.93 & 1.04 & 1.23 & 1.01 & 1.19 & 1.05 & 1.43 \\
\hline Middle Income Jobs & 1.35 & 1.01 & 0.72 & 1.08 & 1.17 & 1.23 & 0.93 & 1.26 \\
\hline Lower Income Jobs & 0.94 & 1.12 & 1.02 & 0.69 & 0.85 & 0.74 & 0.82 & 0.79 \\
\hline
\end{tabular}


CRT stations in the Poor MA transit station type neighborhoods saw robust rates of job growth for all income levels. Middle-income jobs grew at a considerable $49 \%$ at the station (the 0.125 DB). The other income groups also grew substantially at the station, and just beyond, in the quarter-mile DB. It fell off for middle and lower-income groups at approximately the half-mile DB, then grew considerably for upper and middle-income groups at the 0.75 -mile DB, then declined significantly at the 1-mile DB. These figures indicate that all job groups see a benefit in direct access to the station in outlying areas but prefer overall to be just beyond the station. LQ trends show greater concentrations at the station of middle-income jobs relative to the regions as a whole, with both upper and lower-income groups gaining concentrations at the quarter and halfmile DB, and also at the 0.75-mile and 1-mile DB's. Lower-income jobs are gaining concentration near the station but are being outcompeted in the other DBs to one mile from the station. While these regions lost upper-income jobs as a whole, transit stations in lower-intensity areas gained considerably in job share over the time period.

Table 3.11. Low MA: CRT

Station Share of Job Shift 2010-2016

\begin{tabular}{l|l|l|l|l|l|l|l}
\hline \\
Income Groups & 0.125 & 0.25 & \multicolumn{1}{l}{0.375} & 0.5 & \multicolumn{1}{c}{0.75} & \multicolumn{1}{c}{$\begin{array}{l}\text { Transit } \\
\text { County } \\
\text { Sum 2016 }\end{array}$} \\
\hline Urban Square Miles - Increm. & 17 & 51 & 81 & 105 & 261 & 307 & 41,703 \\
\hline Urban Square Miles - Cum. & 17 & 68 & 149 & 254 & 515 & 822 & 41,703 \\
\hline Upper Income Jobs & 215,824 & 82,035 & 45,133 & 96,343 & 54,561 & 65,232 & $5,695,896$ \\
\hline Middle Income Jobs & 145,142 & 24,166 & 35,777 & 42,975 & 20,819 & 63,831 & $4,003,309$ \\
\hline Lower Income Jobs & 225,585 & 57,995 & 37,538 & 77,521 & 54,739 & 71,614 & $7,817,123$ \\
\hline Total Jobs & 586,553 & 164,198 & 118,450 & 216,841 & 130,121 & 200,679 & $17,516,328$ \\
\hline
\end{tabular}

Economic Change 2010-2016

\begin{tabular}{l|l|l|l|l|l|l|l}
\hline Income Groups & 0.125 & 0.25 & 0.375 & 0.5 & 0.75 & 1 & Transit County \\
\hline Upper Income Jobs & 24,958 & 21,928 & 5,480 & 11,512 & 5,734 & 8,437 & $(62,703)$ \\
\hline Middle Income Jobs & 6,692 & 1,511 & 2,532 & 3,619 & $(808)$ & 14,205 & 299,555 \\
\hline Lower Income Jobs & 28,123 & 9,259 & 2,715 & 14,780 & $(1,189)$ & 13,164 & 256,188 \\
\hline Total Jobs & 59,773 & 32,698 & 10,727 & 29,911 & 3,737 & 35,806 & 493,040 \\
\hline
\end{tabular}

Percent Economic Change 2010-2016

\begin{tabular}{l|l|l|l|l|l|l|l}
\hline Income Groups & 0.125 & 0.25 & 0.375 & 0.5 & 0.75 & 1 & \multicolumn{1}{l}{ Transit County } \\
\hline Upper Income Jobs & $13.1 \%$ & $36.5 \%$ & $13.8 \%$ & $13.6 \%$ & $11.7 \%$ & $14.9 \%$ & $14.6 \%$ \\
\hline Middle Income Jobs & $4.8 \%$ & $6.7 \%$ & $7.6 \%$ & $9.2 \%$ & $-3.7 \%$ & $28.6 \%$ & $5.2 \%$ \\
\hline Lower Income Jobs & $14.2 \%$ & $19.0 \%$ & $7.8 \%$ & $23.6 \%$ & $-2.1 \%$ & $22.5 \%$ & $18.9 \%$ \\
\hline Total Jobs & $11.3 \%$ & $24.9 \%$ & $10.0 \%$ & $16.0 \%$ & $3.0 \%$ & $21.7 \%$ & $14.1 \%$ \\
\hline
\end{tabular}

LQ Percent Change 2010-2016

\begin{tabular}{llllll|l|l|l}
\hline Income Groups & 0.125 & 0.25 & 0.375 & 0.5 & 0.625 & 0.75 & 0.875 & 1 \\
\hline Upper Income Jobs & 1.01 & 1.09 & 1.03 & 0.97 & 0.95 & 1.08 & 1.12 & 0.94 \\
\hline Middle Income Jobs & 1.02 & 0.93 & 1.06 & 1.02 & 1.09 & 1.01 & 0.74 & 1.15 \\
\hline Lower Income Jobs & 0.98 & 0.91 & 0.94 & 1.02 & 1.02 & 0.91 & 1.16 & 0.97 \\
\hline
\end{tabular}


CRT stations in Low MA station type neighborhoods attracted jobs, gaining share of jobs mostly in the upper-income group, with middle-income jobs being outcompeted from both upper and lower-income jobs groups. All groups saw positive trends in job share to the 1-mile DB, aside from a small decline in middle-income jobs at the 0.75 -mile DB. Middle-income jobs relatively modest growth rates compared to the other wage groups to the 1-mile DB, at which it gained employment share at the highest rate of growth of all groups, at a very strong $28 \%$. Location Quotients indicate that lower-income jobs lost concentrations in most of the DB's, with an exception at the 0.875 -mile DB. Lower-income jobs were likely attracted to these areas as a secondary effect of upper-income jobs being attracted to these stations. Retail and food services are often attracted by office workers and management. These CRT stations gained shares overall in jobs well above the rates of regional growth.

Table 3.12. Mod MA: CRT

Station Share of Job Shift 2010-

2016

\begin{tabular}{|c|c|c|c|c|c|c|c|c|}
\hline Income Groups & 0.125 & 0.25 & 0.375 & 0.5 & 0.75 & 1 & \multicolumn{2}{|c|}{$\begin{array}{l}\text { Transit } \\
\text { County Sum } \\
2016\end{array}$} \\
\hline $\begin{array}{l}\text { Urban Square Miles - } \\
\text { Increm. }\end{array}$ & 9 & 25 & 38 & 47 & 110 & 124 & \multicolumn{2}{|c|}{41,703} \\
\hline $\begin{array}{l}\text { Urban Square Miles - } \\
\text { Cum. }\end{array}$ & 9 & 33 & 71 & 118 & 229 & 352 & \multicolumn{2}{|c|}{41,703} \\
\hline Upper Income Jobs & $\begin{array}{l}365,33 \\
3\end{array}$ & 43,638 & 29,105 & 86,526 & 34,768 & 32,054 & \multicolumn{2}{|c|}{$5,695,896$} \\
\hline Middle Income Jobs & $\begin{array}{l}238,94 \\
3\end{array}$ & 30,006 & 39,896 & 76,269 & 35,558 & 24,093 & \multicolumn{2}{|c|}{$4,003,309$} \\
\hline Lower Income Jobs & $\begin{array}{l}359,80 \\
6\end{array}$ & 63,802 & 32,535 & 90,111 & 64,731 & 54,135 & \multicolumn{2}{|c|}{$7,817,123$} \\
\hline$\underline{\text { Total Jobs }}$ & \begin{tabular}{|l|l|}
964,08 \\
4
\end{tabular} & $\begin{array}{l}137,44 \\
8\end{array}$ & $\begin{array}{l}101,53 \\
8\end{array}$ & $\begin{array}{l}252,90 \\
8\end{array}$ & $\begin{array}{l}135,05 \\
9\end{array}$ & $\begin{array}{l}110,28 \\
4\end{array}$ & \multicolumn{2}{|c|}{$17,516,328$} \\
\hline \multicolumn{9}{|c|}{ Economic Change 2010-2016 } \\
\hline Income Groups & 0.125 & 0.25 & 0.375 & 0.5 & 0.75 & 1 & \multicolumn{2}{|c|}{ Transit County } \\
\hline Upper Income Jobs & 45,452 & $(4,205)$ & $(463)$ & 17,144 & 3,094 & 6,858 & \multicolumn{2}{|c|}{$(62,703)$} \\
\hline Middle Income Jobs & $\begin{array}{l}(82,656 \\
\end{array}$ & )$^{(29,049}$ & 7,002 & 5,528 & )$^{(12,355}$ & $\begin{array}{l}(5,830 \\
\end{array}$ & \multicolumn{2}{|c|}{299,555} \\
\hline Lower Income Jobs & )$^{(10,000}$ & $(4,149)$ & )$^{(1,612}$ & 26,481 & 6,616 & 17,710 & \multicolumn{2}{|c|}{256,188} \\
\hline$\underline{\text { Total Jobs }}$ & $(47,204$ & $\begin{array}{l}(37,403 \\
\end{array}$ & 4,927 & 49,153 & $(2,645)$ & 18,738 & \multicolumn{2}{|c|}{493,040} \\
\hline \multicolumn{9}{|c|}{ Percent Economic Change 2010-2016 } \\
\hline Income Groups & 0.125 & 0.25 & 0.375 & 0.5 & 0.75 & 1 & \multicolumn{2}{|c|}{ Transit County } \\
\hline Upper Income Jobs & $14.2 \%$ & $-8.8 \%$ & $-1.6 \%$ & $24.7 \%$ & $9.8 \%$ & $27.2 \%$ & \multicolumn{2}{|c|}{$14.6 \%$} \\
\hline Middle Income Jobs & $-25.7 \%$ & $-49.2 \%$ & $21.3 \%$ & $7.8 \%$ & $-25.8 \%$ & $-\overline{19.5 \%}$ & \multicolumn{2}{|l|}{$5.2 \%$} \\
\hline Lower Income Jobs & $-2.7 \%$ & $-6.1 \%$ & $-4.7 \%$ & $41.6 \%$ & $11.4 \%$ & $48.6 \%$ & \multicolumn{2}{|c|}{$18.9 \%$} \\
\hline Total Jobs & $-4.7 \%$ & $-21.4 \%$ & $5.1 \%$ & $24.1 \%$ & $-1.9 \%$ & $20.5 \%$ & \multicolumn{2}{|l|}{$14.1 \%$} \\
\hline \multicolumn{9}{|c|}{ LQ Trend 2010-2016 (LQ 2016 / LQ 2010) } \\
\hline Income Groups & 0.125 & 0.25 & 0.375 & 0.5 & 0.625 & 0.75 & \multicolumn{2}{|l|}{0.875} \\
\hline Upper Income Jobs & 1.19 & 1.16 & 0.93 & 1.00 & 1.01 & 1.11 & 0.99 & 1.05 \\
\hline Middle Income Jobs & 0.85 & 0.70 & 1.25 & 0.94 & 1.10 & 0.82 & 0.88 & 0.73 \\
\hline Lower Income Jobs & 0.98 & 1.15 & 0.87 & 1.10 & 0.94 & 1.09 & 1.16 & 1.18 \\
\hline
\end{tabular}



In Mod MA station areas, CRT stations attracted upper-income jobs to the station area. Middleincome jobs declined in concentrations and saw negative job share change in most DB's.

Upper-income jobs grew significantly in concentration in the first two DB's and grew at a rate of $14 \%$ at the station. Job figures declined in the first quarter-mile DB for middle and lower-income jobs. Mild upper-income job losses occurred in the quarter-mile and 0.375-mile DB's, but were otherwise positive. Both middle and lower-income jobs lost concentrations at the station, being outcompeted by upper-income jobs. Lower-income jobs gained in concentration from 0.75-mile $\mathrm{DB}$ to the 1-mile DB, also gaining share at very strong rates the half-mile DB to the 1-mile DB.

Table 3.13. High MA: CRT

Station Share of Job Shift 2010-2016

\begin{tabular}{|c|c|c|c|c|c|c|c|}
\hline Income Groups & 0.125 & 0.25 & 0.375 & 0.5 & 0.75 & 1 & $\begin{array}{l}\text { Transit } \\
\text { County Sum } \\
2016\end{array}$ \\
\hline Urban Square Miles - Increm. & 1 & 3 & 4 & 5 & 12 & 14 & 41,703 \\
\hline Urban Square Miles - Cum. & 1 & 3 & 7 & 12 & 24 & 38 & 41,703 \\
\hline Upper Income Jobs & 40,863 & 10,980 & 37,661 & 31,643 & 1,526 & 10,746 & $5,711,287$ \\
\hline Middle Income Jobs & 19,455 & 13,751 & 23,037 & 12,877 & 11,197 & 4,219 & $4,082,268$ \\
\hline Lower Income Jobs & 32,607 & 12,753 & 25,496 & 18,145 & 8,875 & 21,879 & $7,639,070$ \\
\hline Total Jobs & 92,927 & 37,486 & 86,196 & 62,667 & 21,600 & 36,846 & $17,432,625$ \\
\hline
\end{tabular}

Economic Change 2010-2016

\begin{tabular}{l|l|l|l|l|l|l|l}
\hline Income Groups & 0.125 & 0.25 & \multicolumn{1}{l}{0.375} & \multicolumn{1}{l}{0.5} & \multicolumn{1}{l}{0.75} & \multicolumn{1}{l}{ Transit County } \\
\hline Upper Income Jobs & 4,004 & 1,402 & 6,134 & $(1,079)$ & $(734)$ & $(692)$ & $3,894,354$ \\
\hline Middle Income Jobs & $(14,418)$ & $(1,946)$ & $(3,679)$ & $(1,696)$ & 1,491 & 421 & $2,816,473$ \\
\hline Lower Income Jobs & 941 & 1,997 & 2,783 & 1,107 & 722 & 4,031 & $5,264,279$ \\
\hline Total Jobs & $(9,473)$ & 1,453 & 5,238 & $(1,668)$ & 1,479 & 3,760 & $11,975,106$ \\
\hline
\end{tabular}

Percent Economic Change 2010-2016

\begin{tabular}{l|l|l|l|l|l|l|l}
\hline Income Groups & 0.125 & 0.25 & 0.375 & \multicolumn{1}{l}{0.5} & 0.75 & 1 & \multicolumn{1}{l}{ Transit County } \\
\hline Upper Income Jobs & $10.9 \%$ & $14.6 \%$ & $19.5 \%$ & $-3.3 \%$ & $-32.5 \%$ & $-6.0 \%$ & $14.9 \%$ \\
\hline Middle Income Jobs & $-42.6 \%$ & $-12.4 \%$ & $-13.8 \%$ & $-11.6 \%$ & $15.4 \%$ & $11.1 \%$ & $7.2 \%$ \\
\hline Lower Income Jobs & $3.0 \%$ & $18.6 \%$ & $12.3 \%$ & $6.5 \%$ & $8.9 \%$ & $22.6 \%$ & $16.2 \%$ \\
\hline Total Jobs & $-9.3 \%$ & $4.0 \%$ & $6.5 \%$ & $-2.6 \%$ & $7.4 \%$ & $11.4 \%$ & $13.6 \%$ \\
\hline
\end{tabular}

LQ Trend 2010-2016 (LQ 2016 / LQ 2010)

\begin{tabular}{lllllll|l|l}
\hline Income Groups & 0.125 & 0.25 & 0.375 & 0.5 & 0.625 & 0.75 & 0.875 & 1 \\
\hline Upper Income Jobs & 1.21 & 1.09 & 1.11 & 0.98 & 1.08 & 0.62 & 1.07 & 0.83 \\
\hline Middle Income Jobs & 0.67 & 0.89 & 0.86 & 0.96 & 0.65 & 1.14 & 1.13 & 1.06 \\
\hline Lower Income Jobs & 1.11 & 1.11 & 1.03 & 1.07 & 1.04 & 0.99 & 0.93 & 1.08 \\
\hline
\end{tabular}


Competition for urban land is evident in the High MA land areas of CRT stations. Jobs mostly declined for middle-income jobs at the stations. Upper and lower-income jobs outcompeted middle-income jobs for scarce land in the urban core. It appears that upper-income jobs also outcompeted lower-income jobs for land, as well. Concentrations of jobs at the station relative to the region as a whole icnreased up to the 0.625 -mile DB. After that DB, middle-income jobs gained positive trends in percent change, as well as LQ concentrations. The numbers of jobs at these stations changed in small numbers of jobs relative to other transit modes and station types. This may suggest, along with the evident competition for land, that many CRT stations in the urban core are approaching full capacity. This may result in further competition for space between job sectors within each income group.

Table 3.14. Poor MA: LRT

Station Share of Job Shift 2010-2016

\begin{tabular}{|c|c|c|c|c|c|c|c|}
\hline Income Groups & 0.125 & 0.25 & 0.375 & 0.5 & 0.75 & 1 & $\begin{array}{l}\text { Transit } \\
\text { County Sum } \\
2016\end{array}$ \\
\hline Urban Square Miles - Increm. & 3 & 19 & 20 & 5 & 8 & 48 & 29,669 \\
\hline Urban Square Miles - Cum. & 3 & 22 & 42 & 46 & 55 & 103 & 29,669 \\
\hline Upper Income Jobs & 104,283 & 13,830 & 9,943 & 11,998 & 49,185 & 8,781 & $6,348,275$ \\
\hline Middle Income Jobs & 26,590 & 4,244 & 5,671 & 6,198 & 12,757 & 5,013 & $4,376,463$ \\
\hline Lower Income Jobs & 46,774 & 9,993 & 21,179 & 8,310 & 14,198 & 5,017 & $7,795,428$ \\
\hline Total Jobs & 177,649 & 28,069 & 36,795 & 26,508 & 76,142 & 18,813 & $18,520,166$ \\
\hline
\end{tabular}

Economic Change 2010-2016

\begin{tabular}{l|lll|l|l|l|l|l}
\hline Income Groups & 0.125 & 0.25 & \multicolumn{1}{l}{0.375} & \multicolumn{1}{l}{0.5} & 0.75 & 1 & Transit County \\
\hline Upper Income Jobs & 23,963 & 1,877 & $(272)$ & 1,162 & 4,944 & 1,225 & $(26,908)$ \\
\hline Middle Income Jobs & $(812)$ & 941 & 1,427 & 1,404 & 3,167 & 678 & 347,957 \\
\hline Lower Income Jobs & 1,056 & 3,403 & 1,864 & 555 & 2,023 & $(10)$ & 269,224 \\
\hline Total Jobs & 24,207 & 6,221 & 3,019 & 3,121 & 10,134 & 1,893 & 590,273 \\
\hline
\end{tabular}

Percent Economic Change 2010-2016

\begin{tabular}{|c|c|c|c|c|c|c|c|c|}
\hline Income Groups & 0.125 & 0.25 & 0.375 & 0.5 & 0.75 & 1 & \multirow{2}{*}{\multicolumn{2}{|c|}{$\begin{array}{l}\text { Transit County } \\
13.7 \%\end{array}$}} \\
\hline Upper Income Jobs & $29.8 \%$ & $15.7 \%$ & $-2.7 \%$ & $10.7 \%$ & $11.2 \%$ & $16.2 \%$ & & \\
\hline Middle Income Jobs & $-3.0 \%$ & $28.5 \%$ & $33.6 \%$ & $29.3 \%$ & $33.0 \%$ & $15.6 \%$ & \multicolumn{2}{|l|}{$9.6 \%$} \\
\hline Lower Income Jobs & $2.3 \%$ & $51.6 \%$ & $9.7 \%$ & $7.2 \%$ & $16.6 \%$ & $-0.2 \%$ & \multicolumn{2}{|l|}{$16.1 \%$} \\
\hline Total Jobs & $15.8 \%$ & $28.5 \%$ & $8.9 \%$ & $13.3 \%$ & $15.4 \%$ & $11.2 \%$ & \multicolumn{2}{|l|}{$13.7 \%$} \\
\hline \multicolumn{9}{|c|}{ LQ Trend 2010-2016 (LQ 2016 / LQ 2010) } \\
\hline Income Groups & 0.125 & 0.25 & 0.375 & 0.5 & 0.625 & 0.75 & 0.875 & 1 \\
\hline Upper Income Jobs & 1.12 & 0.90 & 0.89 & 0.98 & 1.01 & 0.96 & 1.00 & 1.04 \\
\hline Middle Income Jobs & 0.87 & 1.04 & 1.27 & 1.18 & 1.06 & 1.20 & 1.08 & 1.08 \\
\hline Lower Income Jobs & 0.87 & 1.16 & 0.99 & 0.93 & 0.92 & 0.99 & 0.94 & 0.88 \\
\hline
\end{tabular}


Middle-income jobs dominated LRT stations at the Poor MA station type neighborhoods in terms of percent change and LQ concentration trends, but upper-income jobs gained more job share in terms of raw change figures. Growth was most substantial at the station for upper-income jobs, while all jobs gained significant share at the quarter-mile DB. Considerable growth in upper-income jobs occurred at the station. All wage groups grew substantially just beyond the station across all DB's to the 1 mile DB. Small job declines occurred for middle-income group at the station, while upper-income jobs declined in small numbers at the $0.375 \mathrm{DB}$. Lower-income jobs showed a negligible job loss at the 1-mile DB.

The market responded well to LRT in the lowest-intensity land use areas of the served regions. Overall, the increase in job numbers was modest. On the other hand, the numbers represent significant rates of growth, especially in the middle-income level, which saw approximately $30 \%$ rate for all DB's from 0.25 to 0.75 , and $15 \%$ growth at the 1-mile DB. Overall, growth at the station grew at rates higher than that of the respective regions.

Table 3.15. Low MA: LRT

Station Share of Job Shift 2010-2016

\begin{tabular}{|c|c|c|c|c|c|c|c|}
\hline Income Groups & 0.125 & 0.25 & 0.375 & 0.5 & 0.75 & 1 & $\begin{array}{l}\text { Transit } \\
\text { County } \\
\text { Sum } 2016\end{array}$ \\
\hline Urban Square Miles - Increm. & 45 & 9 & 14 & 69 & 56 & 10 & 29,669 \\
\hline Urban Square Miles - Cum. & 45 & 55 & 68 & 137 & 193 & 203 & 29,669 \\
\hline Upper Income Jobs & 462,323 & 61,804 & 35,922 & 84,031 & 55,551 & 81,993 & $6,348,275$ \\
\hline Middle Income Jobs & 309,124 & 42,802 & 43,330 & 54,894 & 40,316 & 57,046 & $4,376,463$ \\
\hline Lower Income Jobs & 396,017 & 61,198 & 50,160 & 91,115 & 49,784 & 77,584 & $7,795,428$ \\
\hline Total Jobs & $1,167,466$ & 165,806 & 129,414 & 230,042 & 145,653 & 216,625 & $18,520,166$ \\
\hline
\end{tabular}

Economic Change 2010-2016

\begin{tabular}{l|l|l|l|l|l|l|l}
\hline Income Groups & 0.125 & 0.25 & 0.375 & 0.5 & 0.75 & 1 & Transit County \\
\hline Upper Income Jobs & 5,071 & $(5,369)$ & $(19,891)$ & 2,277 & 8,973 & $(4,876)$ & $(26,908)$ \\
\hline Middle Income Jobs & $(2,510)$ & $(190)$ & $(7,546)$ & $(5,118)$ & 774 & 2,978 & 347,957 \\
\hline Lower Income Jobs & $(12,000)$ & $(9,114)$ & $(2,020)$ & 17,831 & 380 & $(9,984)$ & 269,224 \\
\hline Total Jobs & $(9,439)$ & $(14,673)$ & $(29,457)$ & 14,990 & 10,127 & $(11,882)$ & 590,273 \\
\hline
\end{tabular}

Percent Economic Change 2010-2016

\begin{tabular}{l|l|l|l|l|l|l|l}
\hline Income Groups & 0.125 & \multicolumn{1}{l}{0.25} & \multicolumn{1}{l}{0.375} & \multicolumn{1}{l}{0.5} & \multicolumn{1}{l}{0.75} & \multicolumn{1}{l}{ Transit County } \\
\hline Upper Income Jobs & $1.1 \%$ & $-8.0 \%$ & $-35.6 \%$ & $2.8 \%$ & $19.3 \%$ & $-5.6 \%$ & $13.7 \%$ \\
\hline Middle Income Jobs & $-0.8 \%$ & $-0.4 \%$ & $-14.8 \%$ & $-8.5 \%$ & $2.0 \%$ & $5.5 \%$ & $9.6 \%$ \\
\hline Lower Income Jobs & $-2.9 \%$ & $-13.0 \%$ & $-3.9 \%$ & $24.3 \%$ & $0.8 \%$ & $-11.4 \%$ & $16.1 \%$ \\
\hline Total Jobs & $-0.8 \%$ & $-8.1 \%$ & $-18.5 \%$ & $7.0 \%$ & $7.5 \%$ & $-5.2 \%$ & $13.7 \%$ \\
\hline
\end{tabular}

LQ Trend 2010-2016 (LQ 2016 / LQ 2010)

\begin{tabular}{llllll|l|l|l}
\hline Income Groups & 0.125 & 0.25 & 0.375 & 0.5 & 0.625 & 0.75 & 0.875 & 1 \\
\hline Upper Income Jobs & 1.02 & 1.00 & 0.79 & 0.96 & 1.05 & 1.11 & 0.95 & 1.00 \\
\hline Middle Income Jobs & 1.04 & 1.12 & 1.08 & 0.89 & 1.03 & 0.98 & 1.09 & 1.15 \\
\hline Lower Income Jobs & 0.96 & 0.93 & 1.16 & 1.14 & 0.95 & 0.92 & 0.98 & 0.92 \\
\hline
\end{tabular}


LRT stations in Low MA areas declined in jobs overall within the first half-mile neighborhood. At the Low MA stations, LRT attracted 5,000 upper-income jobs at the station. Otherwise, all income groups lost job share to the half-mile DB. Upper and lower-income jobs grew at the halfmile and 0.75-mile DB's, while middle-income jobs mostly declined at these distances. Lowerincome jobs gained share substantially at the half-mile DB, while upper-income jobs gained substantially at the 0.75 -mile DB. Middle-income jobs then gained job share at the 1-mile DB. LQ trends reveal modest growth in concentration of upper and middle-income jobs at the station, while lower-income jobs slightly declined in concentration relative to the included regions. Overall, growth appears to have been stronger at the regional scale than at these LRT stations.

Table 3.16. Mod MA: LRT

Station Share of Job Shift 2010-2016

\begin{tabular}{|c|c|c|c|c|c|c|c|}
\hline Income Groups & 0.125 & 0.25 & 0.375 & 0.5 & 0.75 & 1 & $\begin{array}{l}\text { Transit } \\
\text { County } \\
\text { Sum } 2016 \\
\end{array}$ \\
\hline $\begin{array}{l}\text { Urban Square Miles - } \\
\text { Increm. }\end{array}$ & 18 & 80 & 61 & 10 & 46 & 172 & 29,669 \\
\hline Urban Square Miles - Cum. & 18 & 98 & 159 & 169 & 215 & 386 & 29,669 \\
\hline Upper Income Jobs & 588,572 & 97,163 & 60,159 & 49,511 & $\begin{array}{l}32,25 \\
2\end{array}$ & 26,591 & $6,348,275$ \\
\hline Middle Income Jobs & 425,961 & 68,051 & 62,335 & 84,109 & $\begin{array}{l}21,54 \\
6\end{array}$ & 21,876 & $4,376,463$ \\
\hline Lower Income Jobs & 612,744 & $\begin{array}{l}118,35 \\
8\end{array}$ & 87,084 & 68,278 & $\begin{array}{l}39,47 \\
4\end{array}$ & 62,759 & $7,795,428$ \\
\hline Total Jobs & $\begin{array}{l}1,627,27 \\
9\end{array}$ & $\begin{array}{l}283,57 \\
4\end{array}$ & $\begin{array}{l}209,58 \\
0\end{array}$ & $\begin{array}{l}201,90 \\
0\end{array}$ & $\begin{array}{l}93,27 \\
4\end{array}$ & $\begin{array}{l}111,22 \\
8\end{array}$ & $\begin{array}{l}18,520,16 \\
6\end{array}$ \\
\hline
\end{tabular}

Economic Change 2010-

2016

\begin{tabular}{|c|c|c|c|c|c|c|c|}
\hline Income Groups & 0.125 & 0.25 & 0.375 & 0.5 & 0.75 & 1 & $\begin{array}{l}\text { Transit } \\
\text { County }\end{array}$ \\
\hline Upper Income Jobs & $(61,228)$ & 16,973 & 10,920 & 3,924 & 15,068 & 2,156 & $(26,908)$ \\
\hline Middle Income Jobs & $\begin{array}{l}(108,788 \\
)\end{array}$ & )$^{(2,466}$ & 7,580 & 6,736 & 1,984 & 8,476 & 347,957 \\
\hline Lower Income Jobs & 4,752 & 29,383 & 17,538 & 5,703 & $(7,580$ & 11,357 & 269,224 \\
\hline Total Jobs & $\begin{array}{l}(165,264 \\
)^{2}\end{array}$ & 43,890 & 36,038 & 16,363 & 9,472 & 21,989 & 590,273 \\
\hline
\end{tabular}

Percent Economic Change 2010-2016

\begin{tabular}{l|l|l|l|l|l|l|l}
\hline Income Groups & 0.125 & 0.25 & 0.375 & 0.5 & 0.75 & 1 & \multicolumn{1}{l}{ Transit County } \\
\hline Upper Income Jobs & $-9.4 \%$ & $21.2 \%$ & $22.2 \%$ & $8.6 \%$ & $87.7 \%$ & $8.8 \%$ & $13.7 \%$ \\
\hline Middle Income Jobs & $-20.3 \%$ & $-3.5 \%$ & $13.8 \%$ & $8.7 \%$ & $10.1 \%$ & $63.2 \%$ & $9.6 \%$ \\
\hline Lower Income Jobs & $0.8 \%$ & $33.0 \%$ & $25.2 \%$ & $9.1 \%$ & $-16.1 \%$ & $22.1 \%$ & $16.1 \%$ \\
\hline Total Jobs & $-9.2 \%$ & $18.3 \%$ & $20.8 \%$ & $8.8 \%$ & $11.3 \%$ & $24.6 \%$ & $13.7 \%$ \\
\hline
\end{tabular}

LQ Trend 2010-2016 (LQ 2016 / LQ 2010)

\begin{tabular}{llllll|l|l|l}
\hline Income Groups & 0.125 & 0.25 & 0.375 & 0.5 & \multicolumn{1}{l}{0.625} & 0.75 & 0.875 & 1 \\
\hline Upper Income Jobs & 1.00 & 1.02 & 1.01 & 1.00 & 0.96 & 1.69 & 0.84 & 0.87 \\
\hline Middle Income Jobs & 0.91 & 0.85 & 0.98 & 1.04 & 1.17 & 1.03 & 1.23 & 1.36 \\
\hline Lower Income Jobs & 1.09 & 1.10 & 1.02 & 0.98 & 0.94 & 0.74 & 1.01 & 0.96 \\
\hline
\end{tabular}



LRT stations gained very significant share of jobs, especially of upper-income sectors overall for the first mile from the stations. The station area lost share of jobs for all but lower-income jobs. Middle-income jobs lost spatial concentration from the station to a half-mile distance. Only lower-income jobs saw a notable increase in LQ scores near the station, and only for the first two DB's from the station. Middle-income jobs trended very positively from the half-mile to 1mile DB. Upper-income jobs increased in LQ score considerably at the 0.75 -mile DB. All income groups grew at the 0.375 and half-mile DB's. In these trends competition among the income levels appears evident. Strong growth rates and increases in concentration occurred at the 0.75-mile and 1-mile DB's. Each income group, however had its largest growth rates and concentrations at different DB's, evidence of a competitive sorting process at the station. Overall, these station areas gained job share at much higher rates than their respective regions.

Table 3.17. High MA: LRT

Station Share of Job Shift 2010-2016

\begin{tabular}{l|l|l|l|l|l|l|l}
\hline \\
Income Groups & 0.125 & 0.25 & 0.375 & 0.5 & 0.75 & 1 & $\begin{array}{l}\text { Transit } \\
\text { County Sum } \\
2016\end{array}$ \\
\hline Urban Square Miles - Increm. & 124 & 19 & 56 & 173 & 116 & 17 & 29,669 \\
\hline Urban Square Miles - Cum. & 124 & 143 & 199 & 372 & 488 & 504 & 29,669 \\
\hline Upper Income Jobs & 239,859 & 10,248 & 30,745 & 18,420 & 2,607 & 7,045 & $6,348,275$ \\
\hline Middle Income Jobs & 162,373 & 28,058 & 21,683 & 19,080 & 3,141 & 6,823 & $4,376,463$ \\
\hline Lower Income Jobs & 211,838 & 31,482 & 54,918 & 29,057 & 13,624 & 11,809 & $7,795,428$ \\
\hline Total Jobs & 614,072 & 69,790 & 107,348 & 66,559 & 19,374 & 25,679 & $18,520,166$ \\
\hline
\end{tabular}

Economic Change 2010-2016

\begin{tabular}{l|l|l|l|l|l|l|l}
\hline Income Groups & 0.125 & 0.25 & 0.375 & 0.5 & 0.75 & 1 & Transit County \\
\hline Upper Income Jobs & 28,299 & $(131)$ & 14,272 & 1,174 & $(328)$ & 3,246 & $(26,908)$ \\
\hline Middle Income Jobs & $(21,544)$ & 10,893 & 3,151 & 2,733 & $(783)$ & 721 & 347,957 \\
\hline Lower Income Jobs & $(13,667)$ & 5,562 & 29,232 & 5,977 & 2,282 & 3,571 & 269,224 \\
\hline Total Jobs & $(6,912)$ & 16,324 & 46,655 & 9,884 & 1,171 & 7,538 & 590,273 \\
\hline
\end{tabular}

Percent Economic Change 2010-2016

\begin{tabular}{l|l|l|l|l|l|l|l}
\hline Income Groups & 0.125 & 0.25 & \multicolumn{1}{l}{0.375} & \multicolumn{1}{l}{0.5} & \multicolumn{1}{l}{0.75} & 1 & \multicolumn{1}{l}{ Transit County } \\
\hline Upper Income Jobs & $13.4 \%$ & $-1.3 \%$ & $86.6 \%$ & $6.8 \%$ & $-11.2 \%$ & $85.4 \%$ & $17.8 \%$ \\
\hline Middle Income Jobs & $-11.7 \%$ & $63.5 \%$ & $17.0 \%$ & $16.7 \%$ & $-19.9 \%$ & $11.8 \%$ & $12.7 \%$ \\
\hline Lower Income Jobs & $-6.1 \%$ & $21.5 \%$ & $113.8 \%$ & $25.9 \%$ & $20.1 \%$ & $43.3 \%$ & $19.3 \%$ \\
\hline Total Jobs & $-1.1 \%$ & $30.5 \%$ & $76.9 \%$ & $17.4 \%$ & $6.4 \%$ & $41.5 \%$ & $17.2 \%$ \\
\hline
\end{tabular}

LQ Trend 2010-2016 (LQ 2016 / LQ 2010)

\begin{tabular}{|c|c|c|c|c|c|c|c|c|}
\hline Income Groups & 0.125 & 0.25 & 0.375 & 0.5 & 0.625 & 0.75 & 0.875 & 1 \\
\hline Upper Income Jobs & 1.14 & 0.75 & 1.05 & 0.90 & 0.87 & 0.83 & 1.17 & 1.30 \\
\hline Middle Income Jobs & 0.93 & 1.30 & 0.69 & 1.03 & 1.07 & 0.78 & 0.83 & 0.82 \\
\hline Lower Income Jobs & 0.93 & 0.91 & 1.19 & 1.05 & 1.01 & 1.11 & 1.01 & 0.99 \\
\hline
\end{tabular}


LRT stations grew in job share considerably in High MA locations, with competitive sorting evident at many DB's. At the station, upper-income jobs gained share while middle and lowerincome jobs declined in growth rate and concentrations. Middle-income jobs outcompeted the other wage categories at the quarter-mile DB; upper- and lower-income jobs gained substantially at the 0.375 -mile DB; then, lower-income jobs gained share most prominently at the half-mile DB. Low-income jobs gained substantial share from the quarter-mile to the 1-mile DB. Upper-income jobs gained concentration at the 0.875-mile and 1-mile DB's. Upper and lower-income jobs gained share at rates much higher overall than the regions.

Table 3.18. Poor MA: SCT

Station Share of Job Shift 2010-2016

\begin{tabular}{|c|c|c|c|c|c|c|c|}
\hline Income Groups & 0.125 & 0.25 & 0.375 & 0.5 & 0.75 & 1 & $\begin{array}{l}\text { Transit } \\
\text { County Sum } \\
2016\end{array}$ \\
\hline Urban Square Miles - Increm. & 2 & 6 & 10 & 4 & 4 & 10 & 12,770 \\
\hline Urban Square Miles - Cum. & 2 & 8 & 18 & 22 & 25 & 35 & 12,770 \\
\hline Upper Income Jobs & $\mathrm{NA}$ & 212 & 237 & 18 & 7,597 & 6,172 & $2,711,230$ \\
\hline Middle Income Jobs & NA & 3,234 & 13 & 82 & 2,703 & 3,757 & $1,866,830$ \\
\hline Lower Income Jobs & NA & 369 & 144 & NA & 1,920 & 2,792 & $3,363,486$ \\
\hline Total Jobs & $\mathrm{NA}$ & 3,817 & 396 & 205 & 12,222 & 12,723 & $7,941,546$ \\
\hline
\end{tabular}

Economic Change 2010-2016

\begin{tabular}{|c|c|c|c|c|c|c|c|c|}
\hline Income Groups & 0.125 & 0.25 & 0.375 & 0.5 & 0.75 & 1 & \multicolumn{2}{|c|}{ Transit County } \\
\hline Upper Income Jobs & NA & $(163)$ & (26) & 5 & 371 & (927) & \multicolumn{2}{|c|}{$(35,061)$} \\
\hline Middle Income Jobs & NA & 3,051 & $(185)$ & 10 & 584 & 1,332 & \multicolumn{2}{|c|}{56,941} \\
\hline Lower Income Jobs & NA & $(10)$ & $(196)$ & 104 & $(102)$ & $(707)$ & \multicolumn{2}{|c|}{23,518} \\
\hline Total Jobs & NA & 2,878 & $(407)$ & 119 & 853 & $(302)$ & \multicolumn{2}{|c|}{45,398} \\
\hline \multicolumn{9}{|c|}{ Percent Economic Change 2010-2016 } \\
\hline Income Groups & 0.125 & 0.25 & 0.375 & 0.5 & 0.75 & 1 & \multicolumn{2}{|c|}{ Transit County } \\
\hline Upper Income Jobs & NA & $-43.4 \%$ & $-9.8 \%$ & $35.7 \%$ & $5.1 \%$ & $-13.1 \%$ & \multicolumn{2}{|c|}{$12.3 \%$} \\
\hline Middle Income Jobs & NA & $1658.2 \%$ & $-93.0 \%$ & $13.7 \%$ & $27.5 \%$ & $54.9 \%$ & \multicolumn{2}{|c|}{$3.0 \%$} \\
\hline Lower Income Jobs & NA & $-2.6 \%$ & $-57.5 \%$ & NA & $-5.0 \%$ & $-20.2 \%$ & \multicolumn{2}{|c|}{$16.5 \%$} \\
\hline Total Jobs & NA & $306.2 \%$ & $-50.6 \%$ & $136.8 \%$ & $7.5 \%$ & $-2.3 \%$ & \multicolumn{2}{|c|}{$11.6 \%$} \\
\hline \multicolumn{9}{|c|}{ LQ Trend 2010-2016 (LQ 2016 / LQ 2010) } \\
\hline Income Groups & 0.125 & 0.25 & 0.375 & 0.5 & 0.625 & 0.75 & \multicolumn{2}{|l|}{0.875} \\
\hline Upper Income Jobs & NA & 0.14 & 1.82 & 0.57 & 0.97 & 0.97 & 1.19 & 0.88 \\
\hline Middle Income Jobs & NA & 4.69 & 0.15 & 0.52 & 3.19 & 1.29 & 0.94 & 1.72 \\
\hline Lower Income Jobs & NA & 0.23 & 0.83 & NA & 0.37 & 0.85 & 0.57 & 0.78 \\
\hline
\end{tabular}


Table 3.19 indicates that SCT stations did not contain the Poor MA land use type at the first DB from the station. It indicates that middle-income jobs gained tremendously in share of jobs at the quarter-mile DB, lost at $0.375 \mathrm{DB}$, and gained robust share to 1 mile DB. Lower-income jobs lost share across all DB's for this station type, suggesting that firms providing these jobs prefer to disperse more broadly in outlying areas than to concentrate near SCT stations. Middle-income jobs competed most strongly for position near these stations. Upper-income jobs gained share at the half-mile DB, then dropped off. Middle-income jobs continued to grow at significant rates and concentrations from the half-mile to the 1-mile DB.

Table 3.19. Low MA: SCT

Station Share of Job Shift 2010-2016

\begin{tabular}{|c|c|c|c|c|c|c|c|}
\hline Income Groups & 0.125 & 0.25 & 0.375 & 0.5 & 0.75 & 1 & $\begin{array}{l}\text { Transit } \\
\text { County Sum } \\
2016\end{array}$ \\
\hline Urban Square Miles - Increm. & 11 & 4 & 5 & 11 & 10 & 3 & 12,770 \\
\hline Urban Square Miles - Cum. & 11 & 15 & 19 & 30 & 40 & 44 & 12,770 \\
\hline Upper Income Jobs & 39,532 & 22,378 & 11,356 & 12,323 & 7,268 & 12,890 & $2,711,230$ \\
\hline Middle Income Jobs & 19,030 & 58,391 & 4,269 & 20,279 & 3,330 & 6,389 & $1,866,830$ \\
\hline Lower Income Jobs & 28,025 & 46,487 & 25,894 & 12,426 & 6,652 & 12,851 & $3,363,486$ \\
\hline Total Jobs & 86,589 & 127,258 & 41,521 & 45,030 & 17,252 & 32,132 & $7,941,546$ \\
\hline
\end{tabular}

Economic Change 2010-2016

\begin{tabular}{|c|c|c|c|c|c|c|c|c|}
\hline Income Groups & 0.125 & 0.25 & 0.375 & 0.5 & 0.75 & 1 & \multirow{2}{*}{\multicolumn{2}{|c|}{$\begin{array}{l}\text { Transit County } \\
(35,061)\end{array}$}} \\
\hline Upper Income Jobs & 4,717 & $(4,982)$ & 7,863 & 318 & 1,654 & 617 & & \\
\hline Middle Income Jobs & 1,593 & $(31,152$ & $(1,337)$ & 8,603 & $(2,573)$ & 380 & \multicolumn{2}{|c|}{56,941} \\
\hline Lower Income Jobs & $(4,944)$ & $(3,151)$ & 7,739 & 2,889 & $(243)$ & 929 & \multicolumn{2}{|c|}{23,518} \\
\hline$\underline{\text { Total Jobs }}$ & 1,366 & $\begin{array}{l}(39,285 \\
)^{2}\end{array}$ & 14,265 & 11,810 & $(1,162)$ & 1,926 & \multicolumn{2}{|c|}{45,398} \\
\hline \multicolumn{9}{|c|}{ Percent Economic Change 2010-2016 } \\
\hline Income Groups & 0.125 & 0.25 & 0.375 & 0.5 & 0.75 & 1 & \multicolumn{2}{|c|}{ Transit County } \\
\hline Upper Income Jobs & $13.5 \%$ & $-18.2 \%$ & $225.0 \%$ & $2.6 \%$ & $29.5 \%$ & $5.0 \%$ & \multicolumn{2}{|l|}{$12.3 \%$} \\
\hline Middle Income Jobs & $9.1 \%$ & $-34.8 \%$ & $-23.8 \%$ & $73.7 \%$ & $-43.6 \%$ & $6.3 \%$ & \multicolumn{2}{|l|}{$3.0 \%$} \\
\hline Lower Income Jobs & $-15.0 \%$ & $-6.3 \%$ & $42.6 \%$ & $30.3 \%$ & $-3.5 \%$ & $7.8 \%$ & \multicolumn{2}{|l|}{$16.5 \%$} \\
\hline Total Jobs & $1.6 \%$ & $-23.6 \%$ & $52.3 \%$ & $35.5 \%$ & $-6.3 \%$ & $6.4 \%$ & \multicolumn{2}{|l|}{$11.6 \%$} \\
\hline \multicolumn{9}{|c|}{ 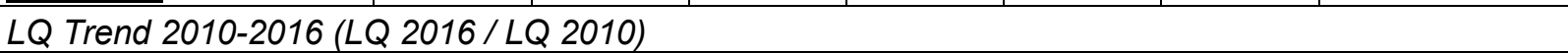 } \\
\hline Income Groups & 0.125 & 0.25 & 0.375 & 0.5 & 0.625 & 0.75 & \multicolumn{2}{|l|}{0.875} \\
\hline Upper Income Jobs & 1.11 & 1.06 & 2.12 & 0.75 & 1.06 & 1.37 & 0.99 & 0.98 \\
\hline Middle Income Jobs & 1.16 & 0.92 & 0.54 & 1.39 & 1.00 & 0.65 & \multirow{2}{*}{$\begin{array}{l}1.20 \\
0.88\end{array}$} & 1.08 \\
\hline Lower Income Jobs & 0.80 & 1.17 & 0.90 & 0.92 & 0.95 & 0.99 & & 0.97 \\
\hline
\end{tabular}


SCT stations in Low MA station areas saw robust growth for upper- and middle-income jobs. The responses to proximity varied broadly between DB's. Upper- and middle-income groups gained share at the stations, while lower-income groups declined. The most significant growth occurred in the 0.375-mile and half-mile DB's, with upper-income jobs gaining shares at a very high rate of $225 \%$, and with middle-income jobs gaining shares at a strong $74 \%$ rate. All jobs lost share at the quarter-mile DB.

Table 3.20. Mod MA: SCT

Station Share of Job Shift 2010-2016

\begin{tabular}{|c|c|c|c|c|c|c|c|}
\hline Income Groups & 0.125 & 0.25 & 0.375 & 0.5 & 0.75 & 1 & $\begin{array}{l}\text { Transit } \\
\text { County Sum } \\
2016\end{array}$ \\
\hline Urban Square Miles - Increm. & 5 & 12 & 10 & 3 & 9 & 25 & 12,770 \\
\hline Urban Square Miles - Cum. & 5 & 16 & 26 & 29 & 38 & 62 & 12,770 \\
\hline Upper Income Jobs & 236,738 & 24,291 & 18,226 & 6,613 & 6,754 & 31,027 & $2,711,230$ \\
\hline Middle Income Jobs & 145,471 & 39,678 & 20,722 & 15,176 & 5,496 & 19,425 & $1,866,830$ \\
\hline Lower Income Jobs & 217,857 & 31,790 & 42,752 & 9,854 & 12,783 & 32,523 & $3,363,486$ \\
\hline Total Jobs & 600,068 & 95,761 & 81,702 & 31,645 & 25,035 & 82,977 & $7,941,546$ \\
\hline
\end{tabular}

Economic Change 2010-2016

\begin{tabular}{l|l|l|l|l|l|l|l}
\hline Income Groups & 0.125 & 0.25 & 0.375 & \multicolumn{1}{l}{0.5} & \multicolumn{1}{l}{0.75} & \multicolumn{1}{c}{ Transit County } \\
\hline Upper Income Jobs & 589 & $(2,686)$ & $(1,497)$ & $(22)$ & $(806)$ & 883 & $(35,061)$ \\
\hline Middle Income Jobs & $(31,123)$ & $(36,267)$ & $(2,058)$ & $(2,096)$ & $(14)$ & $(11,214)$ & 56,941 \\
\hline Lower Income Jobs & $(24,224)$ & 4,229 & 24,225 & $(887)$ & 1,683 & 5,376 & 23,518 \\
\hline Total Jobs & $(54,758)$ & $(34,724)$ & 20,670 & $(3,005)$ & 863 & $(4,955)$ & 45,398 \\
\hline
\end{tabular}

Percent Economic Change 2010-2016

\begin{tabular}{l|l|l|l|l|l|l|l}
\hline Income Groups & 0.125 & 0.25 & \multicolumn{1}{l}{0.375} & \multicolumn{1}{l}{0.5} & 0.75 & 1 & Transit County \\
\hline Upper Income Jobs & $0.2 \%$ & $-10.0 \%$ & $-7.6 \%$ & $-0.3 \%$ & $-10.7 \%$ & $2.9 \%$ & $12.3 \%$ \\
\hline Middle Income Jobs & $-17.6 \%$ & $-47.8 \%$ & $-9.0 \%$ & $-12.1 \%$ & $-0.3 \%$ & $-36.6 \%$ & $3.0 \%$ \\
\hline Lower Income Jobs & $-10.0 \%$ & $15.3 \%$ & $130.7 \%$ & $-8.3 \%$ & $15.2 \%$ & $19.8 \%$ & $16.5 \%$ \\
\hline Total Jobs & $-8.4 \%$ & $-26.6 \%$ & $33.9 \%$ & $-8.7 \%$ & $3.6 \%$ & $-5.6 \%$ & $11.6 \%$ \\
\hline
\end{tabular}

LQ Percent Change 2010-2016

\begin{tabular}{llllll|l|l|l}
\hline Income Groups & 0.125 & 0.25 & 0.375 & 0.5 & 0.625 & 0.75 & 0.875 & 1 \\
\hline Upper Income Jobs & 1.09 & 1.22 & 0.69 & 1.08 & 1.20 & 0.86 & 1.03 & 1.08 \\
\hline Middle Income Jobs & 0.97 & 0.77 & 0.74 & 1.04 & 1.06 & 1.04 & 1.75 & 0.73 \\
\hline Lower Income Jobs & 0.94 & 1.51 & 1.65 & 0.96 & 0.88 & 1.07 & 0.91 & 1.22 \\
\hline
\end{tabular}


Lower-income jobs grew the most at the Mod MA SCT stations. Middle and lower-income jobs declined at large rates and lost spatial concentration at the stations, while upper-income jobs gained share at the station, to the quarter-mile DB, and then declined in most DB's to 1 mile. Middle-income jobs declined at significant rates in all but the 0.75 -mile DB. Station areas gained lower-income job share for most DB's. These jobs gained in concentrations in the quarter-mile and 0.375-mile DB's to a substantial degree. These figures and trends suggest that SCT is most suitable for lower-income jobs in Mod MA place type station areas.

Table 3.21. High MA: SCT

Station Share of Job Shift 20102016

\begin{tabular}{|c|c|c|c|c|c|c|c|}
\hline Income Groups & 0.125 & 0.25 & 0.375 & 0.5 & 0.75 & 1 & $\begin{array}{l}\text { Transit County } \\
\text { Sum } 2016\end{array}$ \\
\hline $\begin{array}{l}\text { Urban Square Miles - } \\
\text { Increm. }\end{array}$ & 19 & 4 & 10 & 24 & 18 & 3 & 12,770 \\
\hline $\begin{array}{l}\text { Urban Square Miles - } \\
\text { Cum. }\end{array}$ & 19 & 23 & 33 & 58 & 75 & 79 & 12,770 \\
\hline Upper Income Jobs & $\begin{array}{l}149,76 \\
0\end{array}$ & 23,483 & 4,338 & 5,834 & 1,910 & 905 & $2,711,230$ \\
\hline Middle Income Jobs & 65,691 & 20,433 & 2,546 & 10,026 & 495 & 980 & $1,866,830$ \\
\hline Lower Income Jobs & $\begin{array}{l}125,20 \\
9\end{array}$ & 15,666 & 29,404 & 11,798 & 2,521 & 5,364 & $3,363,486$ \\
\hline Total Jobs & $\begin{array}{l}340,66 \\
2\end{array}$ & 59,584 & 36,290 & 27,660 & 4,928 & 7,251 & $7,941,546$ \\
\hline
\end{tabular}

Economic Change 2010-2016

\begin{tabular}{l|l|l|l|l|l|l|l}
\hline Income Groups & 0.125 & 0.25 & 0.375 & 0.5 & 0.75 & 1 & Transit County \\
\hline Upper Income Jobs & 12,505 & $(1,444)$ & 116 & 380 & 321 & $(506)$ & $(35,061)$ \\
\hline Middle Income Jobs & $(3,373)$ & $(6,238)$ & 91 & 504 & 5 & $(479)$ & 56,941 \\
\hline Lower Income Jobs & $(13,517)$ & $(454)$ & 18,779 & 3,525 & 801 & $(511)$ & 23,518 \\
\hline Total Jobs & $(4,385)$ & $(8,136)$ & 18,986 & 4,409 & 1,127 & $(1,496)$ & 45,398 \\
\hline
\end{tabular}

Percent Economic Change 2010-2016

\begin{tabular}{l|l|l|l|l|l|l|l}
\hline Income Groups & 0.125 & \multicolumn{1}{l}{0.25} & \multicolumn{1}{l}{0.375} & \multicolumn{1}{l}{0.5} & 0.75 & 1 & Transit County \\
\hline Upper Income Jobs & $9.1 \%$ & $-5.8 \%$ & $2.7 \%$ & $7.0 \%$ & $20.2 \%$ & $-35.8 \%$ & $12.3 \%$ \\
\hline Middle Income Jobs & $-4.9 \%$ & $-23.4 \%$ & $3.7 \%$ & $5.3 \%$ & $1.0 \%$ & $-32.8 \%$ & $3.0 \%$ \\
\hline Lower Income Jobs & $-9.7 \%$ & $-2.8 \%$ & $176.7 \%$ & $42.6 \%$ & $46.5 \%$ & $-8.7 \%$ & $16.5 \%$ \\
\hline Total Jobs & $-1.3 \%$ & $-12.0 \%$ & $109.7 \%$ & $19.0 \%$ & $29.6 \%$ & $-17.1 \%$ & $11.6 \%$ \\
\hline
\end{tabular}

LQ Trend 2010-2016 (LQ 2016 / LQ 2010)

\begin{tabular}{lllll|l|l|l|l}
\hline Income Groups & 0.125 & 0.25 & 0.375 & 0.5 & 0.625 & 0.75 & 0.875 & 1 \\
\hline Upper Income Jobs & 1.10 & 1.06 & 0.49 & 0.89 & 0.68 & 0.92 & 1.13 & 0.77 \\
\hline Middle Income Jobs & 1.04 & 0.94 & 0.54 & 0.96 & 1.50 & 0.84 & 0.53 & 0.88 \\
\hline Lower Income Jobs & 0.88 & 1.06 & 1.26 & 1.15 & 0.94 & 1.08 & 1.33 & 1.06 \\
\hline
\end{tabular}


Upper-income jobs displaced other income groups at the station, but lower-income jobs were dominant in the distance from 0.375 to 0.75 miles from the station. All wage groups lost share at significant rates at a mile from the station, but these rates represent only a small number of jobs. This may indicate that these station areas are reaching build-out. This can be further intimated from the declines at the station concomitant to the upper-income job growth there, as upper-income jobs outcompeted the other wage groups. The transit regions as a whole saw modest growth in this period, as well. SCT station areas gained significant share of jobs, nonetheless, as the economy continued its shift towards station areas, a move shown to increase resiliency to economic downturns.

\section{Summary of Results}

Variations are widespread between transit mode-station typology combinations. A brief summary follows that reiterates key findings for each combination above, for wage groups and economic groups.

BRT stations across station place types responded as follows:

- Poor MA: upper-income jobs are attracted to the station (one-eighth DB), and lowincome jobs are attracted to the station across all bands to 1-mile DB. Retail, Knowledge and Office showed high rates of growth at the first two DB's, while other sectors declined. Manufacturing and Light Industry gained concentrations at the station relative to the regional trends.

- Low MA: lower-income jobs are repelled by proximity to the station. All wage levels respond tepidly to the direct vicinity of the station, with substantial growth in the mid DB's, and mixed results beyond, to one mile. Knowledge, Education, Health and Arts economic groups had the most overall growth at these stations to 1 mile.

- Mod MA: just as in the case of Low MA, BRT repelled all wage groups at the station. Upper and lower-income jobs competed for land beyond, to 0.75-mile DB, while middleincome jobs mostly declined from the station to the 1-mile DB. Knowledge, Office, and especially Retail grew at high rates at the station. While these had the highest gains in LQ scores, as well, Education, Health and Arts-Entertainment-Recreation also gained in concentration just beyond the first quarter-mile DB.

- High MA: this station place type grew in job share substantially for all wage groups. Upper-income jobs dominated the station area, while it shared growth with middleincome jobs to half a mile, upon which lower-income jobs dominated the growth trend. High rates of growth occurred for all wage groups at different DB's to 1 mile from the station. Retail, Knowledge, Office, and Arts grew at the highest rates and spatial concentrations at this place type.

CRT stations across station place types responded as follows:

- Poor MA: Middle-income jobs grew at a considerable $49 \%$ at the station (the 0.125 DB). The other income groups also grew substantially at the station, and just beyond, in the quarter-mile DB. The 1-mile DB saw declining rates for all wage groups. Light Industry and Knowledge jobs had the most significant portion of the growth. Office also had positive rates across most DB's. Light Industry, Knowledge, Arts and Health jobs gained in spatial concentration; the latter two declined in concentration at the station but gained just beyond the station.

- Low MA: Upper and lower-income wage groups grew at large rates up to the 0.75-mile DB. Middle-income groups saw tepid growth or decline throughout. Education declined, while Light Industry and the Arts gained in growth rate and concentration. 
- Mod MA: Upper-income jobs dominated at the station area, while lower-income grew most substantially from half-mile to the 1-mile DB. Upper-income jobs also saw notable growth at the half-mile to 1-mile DB. Competition between sector groups was quite evident at the station. Manufacturing, Light Industry, Retail and Knowledge gained at the station, while Office, Education, and Health declined in first quarter and then mostly gained between 0.375 and 1 -mile DB's.

- High MA: Competition for urban land is evident in the High MA land areas of CRT stations. Jobs mostly declined for middle-income jobs at the stations. Upper and lowerincome jobs outcompeted middle-income jobs for scarce land very near the station, while dominating the growth rates farther out to 1 mile from the station. Retail and Knowledge had positive growth rates at the station, while Office declined. Health did well just beyond the station.

LRT stations across station place types responded as follows:

- Poor MA: Middle-income jobs dominated LRT stations at the Poor MA station type neighborhoods in terms of percent change and LQ concentration trends, but upperincome jobs gained more job share in terms of raw job figures. Knowledge, Office and Health did gained the highest share at the station, while Manufacturing and Industry also gained share at the station. Knowledge, Office, and Health gained most in spatial concentration near the station.

- Low MA: Job growth rates and figures were flat or in decline at or near the station. Some growth occurred in upper- and lower-income jobs at half a mile and 0.75 miles from the station. Retail, Knowledge, Health and Arts grew at the station, while the quarter-and 0.375-mile DB's declined in most industry groups.

- Mod MA: Jobs for all wage groups were repelled from the station, while growing at high rates of job share growth from the 0.25 -mile DB to 1 mile from the station. Light Industry, Office, and Health job groups dominated the growth in the overall station area to 1 mile.

- High MA: LRT did exceptionally well at all distances to 1 mile from the station, except at the station, where upper-income jobs pushed out the other wage groups, which declined in growth rates. Retail, Knowledge, Health, and Arts showed positive rates of growth and spatial concentration near the station. Light Industry gained at positive rates in the 0.375-mile and 0.5-mile DB's. At the same time, Light Industry, Office and Education lost concentration at the station.

SCT stations across station place types responded as follows:

- Poor MA: these station areas had no land area of this place type at the station, and rates of growth declined until the half-mile DB, with some growth thereafter to 1 mile from the station. Health, Knowledge, and Office jobs saw notable positive outcomes in growth rates.

- Low MA: Upper- and middle-income jobs had healthy growth at the station, pushing lower-income to decline. All groups declined at the quarter-mile DB. High rates of growth, with competitive sorting occurred from the 0.375 to the 0.75 -mile DB. All declined at the 1-mile DB. All industries saw gains in share at the station, except Manufacturing and Education. Office jobs gained the most share and concentration at the station.

- Mod MA: Growth mostly occurred in lower-income jobs. Upper-and lower-income jobs were repelled by the station in the first quarter mile from the station. Lower-income jobs grew across most DB's to 1 mile. Middle-income jobs mostly declined. Light Industry, Retail, Knowledge, and Arts did well at the first DB (at the station). Office declined in all DB's to 1 mile. Education and Health declined at the first DB. 
- High MA: Upper-income jobs were attracted to the station area, but jobs were repelled from the quarter-mile DB, with considerable growth mostly in lower-income jobs. Upperincome jobs also grew in share at the half-mile and substantially at the 0.75 -mile DB. Rates went into decline for all wage groups at the 1-mile DB. There was considerable competition at the first two DB's from the station. Retail, Knowledge, Health, and ArtsEntertainment-Recreation did the best at this highly competitive urban station type.

Office, Education and Light Industry declined at these distances. 


\section{Implications for Transit and Land Use Planning}

\section{Overall Trends}

These figures reveal important context for these transit modes. CRT's performance at the lower levels of land use mix and accessibility shows its utility to the suburban commuter. LRT's highest performance in the middle ranges of the mix and accessibility continuum (Moderate and Low MA) may be due to the size and capacity of this mode. BRT did very well at all levels, showing exceptional adaptability to the land use context. BRT was the best-performing at the Poor MA Place Type. SCT clearly demonstrates its urban configuration, being the most successful at High MA places or urban core level.

Each transit mode has its most useful application, which is true of the transit place types, as well. The winning combinations are all of a minimum threshold of land use efficiency. The Poor MA place type struggled with low job numbers, but all transit modes but SCT gained respectable shares of jobs. At the Low MA place type areas, with the exception of CRT, job groups were repelled from the station. This could be due to the larger scale of parcels and the higher degree of automobile dependency at this place level. Stations of the Mod MA type repelled jobs from the station, with exception of upper-wage jobs at CRT stations. High MA areas mostly suffered from competition, with most wage and economic groups competing to be near the stations. These are job destinations for those riding CRT and LRT; they are place destinations for SCT riders, while BRT attracts everyone.

CRT and BRT did the best in the "Poor MA" neighborhoods. Still growth was miniscule for all transit modes in Poor MA. SCT actually declined at the "Poor MA" level. BRT and LRT had significant growth in job share at the "Low MA" neighborhoods. All modes grew, moreover; SCT and CRT showed modest growth, which was nevertheless disproportionate to the land area of the stations, compared to their share of regional urbanized area. BRT and LRT had significant growth at transit typology level 3, "Mod MA." SCT had strong growth. CRT showed very modest growth, almost remaining flat. At the most urban neighborhood type, SCT had robust growth, and BRT grew at a tremendous rate. LRT showed respectable rates of growth, while CRT was again flat in growth.

Bus Rapid Transit performed well across all station types. The Poor MA type performed at the lowest rate of all types, with the land nearest the station declining in share and land in the next distance bands doing well. BRT systems did the best of all modes in the Poor MA category, implying that it may well be the best option for connecting outlying suburbs to more urban locales and rail transit. The implication for the low response of the market to the BRT station at the Poor MA station type is that the relative lack of walkability, as well as the auto-centric nature of transport leads to a poor response nearest the station, but a more robust response further away from the station. The lack of enthusiasm for the area nearest the station reflects the design conflicts that lead to negative spillovers. Examples include poor street connectivity to the station area and low-density development that does not respond to transit proximity as well as higher density areas. The introduction of gentle density increases and "missing middle" housing in these areas could be combined with more street and sidewalk network connections between residential and station areas to increase the response to and use of the station (Arthur C. Nelson 2013; Dunham-Jones and Williamson 2011; Parolek 2020).

CRT also did better than LRT and SCT in the Poor MA station type. It reflected the same negative response at the station, with the neighborhoods beyond the station responding very positively to station proximity. CRT's low response to the high and moderate station types but robust response at the Low MA level reflects that its best applicability at present is in lower- 
density neighborhoods, with riders being most likely commuters for the light industry and other sectors. The example of Austin, Texas points out, however, that the CRT systems may be relying considerably upon their regional connection to the CBD. While many stations along the CRT systems are of lower-intensity development, they are typically connecting to an endpoint within an urban core with high intensity access and land use mix.

The LRT system as a whole performed best at the middle of the access and land use mix scale. This is likely due to the large size of these systems, which are usually above ground and not as well-connected to the built environment as the heavy rail systems of cities like New York or Washington, D.C. Further, the streetcar systems of many cities likely pull away some of the returns for LRT in the High MA category, as they are smaller and more amenable in design to the urban core. Notable exceptions include Salt Lake City's TRAX and Denver's LRT system. This may be due to a largely nonexistent SCT presence in the vicinity of these cities' LRT systems.

Streetcar Transit performed well in the highest station type, High MA, and poorest in the "Poor MA" areas. This is due largely to the focus of streetcar systems on the urban core. The example of Tucson, Arizona is the quintessential example of a successful SCT system. The high performance of Tucson's streetcar is partly due to the planning policies involved, such as the City of Tucson's Rio Nuevo District, a tax-increment financing (TIF) district. However, the most important characteristic of the Tucson streetcar is its placement along the city's most walkable, most accessible, and highest land use mix blocks. These areas include the downtown, the $4^{\text {th }}$ Avenue shopping district, and the University of Arizona campus, including its flagship hospital. The scale of the built environment is well-matched to the scale of the SCT system. However, in all but the Office and Education sector groups, the SCT LQ declined at the station, while improving just beyond.

For all but CRT stations, the stations themselves are mostly seen as a disamenity from which to escape. Station areas are mostly unpopular, with the exception of low-density CRT stations at the Poor MA and Low MA levels; and, for LRT at the Low MA level. For those who are attracted to the station for upper-income jobs, the distances just beyond the station are not attractive enough to draw upon that enthusiasm. Even SCT stations in the urban core are unpopular except to upper-income jobs. This may be due, however, to the competitive sorting process.

\section{Trends by Job Economic and Wage Groupings}

Competition between economic sector groups and wage groups is evident at stations for many transit mode-place type combinations. Also very evident is a trend away from the DB closest to the station, or the station area itself, for many transit modes at many station place types. In highly competitive station areas, land use policy may be of help in improving the utility of underutilized land parcels, to bring them into alignment with the most productive level of mix and intensity for the context. Also true is that many stations repelled firms away from the first DB, at the station itself.

In many station areas, upper and lower-income jobs are partners in growth trends, co-locating in the same DB or nearby. This has left many stations with relatively low growth rates in the middle-income jobs. This is also in part due to the nature of those sector groups, which include such occupations as transport and warehousing. They often require an inordinate land area for the first mile from a station.

For BRT, CRT and LRT, transit share of job shift in this time period was most pronounced at the Low MA and Mod MA place types. For SCT, that trend was most pronounced at the Mod MA and High MA place types. This highlights the urban orientation of the SCT systems. 
For SCT, job growth and concentration at the station (the 0.125-mile DB) was the highest at the Low MA place type, possibly due to the built-out nature of the more intensely developed locations. For CRT and LRT, growth at the station was highest at the Poor MA place type. For BRT, growth was quite pronounced at all stations for the upper-income jobs. The rest mostly declined at the BRT station. CRT saw upper-income jobs grow at the Mod MA type, while both upper and lower-income jobs grew at the High MA type. This indicates that upper-income jobs pushed away other jobs at the Mod MA level while lower-income jobs supported upper-income jobs at the High MA level where low-income jobs can support upper-income jobs. This phenomenon is present at the Mod MA LRT, as well, with middle-income jobs declining seemingly as a result of significant growth of the upper and lower-income jobs in the same locations.

For some place types, industries gained spatial concentration at a lower rate than the region as a whole, which resulted in negative $L Q$ trends at the station. This occurred for Education, Office and Light Industry at the High MA LRT stations. This may point to these industries losing the competition for transit-proximate land to those who gained in concentration such as Retail and the Arts-Entertainment-Recreation groups. This also happened in the Poor MA SCT stations, as Health and Knowledge outcompeted Retail and Light Industry.

These results indicate the market responses to transit proximity across a range of place types and transit modes. Various policy approaches could be taken in these areas, including 1) encouraging the most competitive land uses to increase their presence at a given station place type and transit mode, 2) increasing the land use mix, intensity and accessibility at specific stations by place type and transit mode by encouraging target land uses to the stations to fill the gaps needed for mixed-use development, and 3) make modifications to the local built environment and zoning code that will support the desired targets. 


\section{References}

Alonso, William. 1964. Location and Land Use. Cambridge, MA: Harvard University Press.

Bertolini, L. 1999. "Spatial Development Patterns and Public Transport: The Application of an Analytical Model in the Netherlands Spatial Development Patterns and Public Transport: The Application of an Analytical Model in the Netherlands." Planning Practice \& Research 14 (2): 199-210. https://doi.org/10.1080/02697459915724.

Chapple, Karen, and Anastasia Loukaitou-Sideris. 2019. Transit-Oriented Displacement or Community Dividends? Understanding the Effects of Smarter Growth on Communities. Cambridge, MA: The MIT Press.

Dittmar, Hank, and Gloria Ohland. 2004. The New Transit Town: Best Practices In TransitOriented Development. Washington, DC: Island Press.

Dunham-Jones, Ellen, and June Williamson. 2011. Retrofitting Suburbia: Urban Design Solutions for Redesigning Suburbs. Hoboken, NJ: John Wiley \& Sons.

Glaeser, Edward and Kahn, Matthew. n.d. "Decentralized Employment and Transofmration of the American City" 3.

Glaeser, Edward L., Matthew E. Kahn, and Jordan Rappaport. 2008. "Why Do the Poor Live in Cities? The Role of Public Transportation." Journal of Urban Economics 63 (1): 1-24. https://doi.org/10.1016/j.jue.2006.12.004.

Kain, John F. 1992. "The Spatial Mismatch Hypothesis : Three Decades Later." Housing Policy Debate 3 (2): 371-460. https://doi.org/10.1080/10511482.1992.9521100.

Levinson, David M B T - The 30-Minute City: Designing for Access. 2019. The 30-Minute City: Designing for Access. Network Design Lab. https://hdl.handle.net/2123/21630.

Mills, Edwin S. 1967. "American Economic Association An Aggregative Model of Resource Allocation in a Metropolitan Area." The American Economic Review 57 (2): 197-210.

1972. "Markets and Efficient Resource Allocation in Urban Areas." The Swedish Journal of Economics 74 (1): 100-113. http://www.jstor.org/stable/3439012.

Muth, Richard F. 1969. Cities and Housing: The Spatial Pattern of Urban Residential Land Use. Chicago: University of Chicago Press.

Nelson, A.C., D. Eskic, S. Hamidi, S.J. Petheram, R. Ewing, and J.H. Liu. 2015. Office Rent Premiums with Respect to Light Rail Transit Stations: Case Study of Dallas, Texas, with Implications for Planning of Transit-Oriented Development. Transportation Research Record. https://doi.org/10.3141/2500-13.

Nelson, Arthur, Bruce Appleyard, Shyam Kannan, Reid Ewing, Matt Miller, and Dejan Eskic. 2013. "Bus Rapid Transit and Economic Development: Case Study of the EugeneSpringfield BRT System." Journal of Public Transportation 16 (3): 41-57. https://doi.org/10.5038/2375-0901.16.3.3.

Nelson, Arthur C. 2013. Reshaping Metropolitan America: Development Trends and Opportunities to 2030. Washington, DC: Island Press.

Nelson, Arthur C., and Robert Hibberd. 2019. "The Link between Transit Station Proximity and Real Estate Rents, Jobs, People and Housing with Transit and Land Use Planning Implications The Link between Transit Station Proximity and Real Estate Rents , Jobs , People and Housing with Transit and Land." Portland, OR. 
Nelson, Arthur C., Philip Stoker, and Robert Hibberd. 2019. "Light Rail Transit and Economic Recovery: A Case of Resilience or Transformation?" Research in Transportation Economics 74 (November 2018): 2-9. https://doi.org/10.1016/j.retrec.2018.11.003.

Nelson, Arthur C. 2017a. "Transit-Oriented Developments Make a Difference in Job Location." Fordham Urban Law Journal 44 (4). https://ir.lawnet.fordham.edu/cgi/viewcontent.cgi?article=2705\&context=ulj. 2017b. "Transit and Real Estate Rents." Portland, OR. https://ppms.trec.pdx.edu/media/project_files/Transit_and_Real_Estate_Rents.pdf.

Nelson, Arthur C, and Joanna Ganning. 2015. "National Study of BRT Development Outcomes." Portland, OR. https://nitc.trec.pdx.edu/research/project/650.

Nelson, Arthur C, and Robert Hibberd. 2019. "Streetcars and Real Estate Rents with Implications for Transit and Land Use Planning." Transportation Research Record 00 (0): 1-12. https://doi.org/10.1177/0361198119849916.

Nelson, Arthur, Matt Miller, Dejan Eskic, Keuntae Kim, Reid Ewing, Jenny Liu, Matt Berggren, and Zakari Mumuni. 2015. "Do TODs Make a Difference?" http://pdxscholar.library.pdx.edu/trec_reports/7.

Parolek, Daniel. 2020. Missing Middle Housing. Thinking Big and Building Small to Respond to Today's Housing Crisis. Washington: Island Press.

Petheram, Susan J., Arthur C. Nelson, Matt Miller, and Reid Ewing. 2013. "Use of the Real Estate Market to Establish Light Rail Station Catchment Areas." Transportation Research Record: Journal of the Transportation Research Board 2357 (1): 95-99. https://doi.org/10.3141/2357-11.

Plane, D. A., C. J. Henrie, and M. J. Perry. 2005. "Migration up and down the Urban Hierarchy and across the Life Course." Proceedings of the National Academy of Sciences 102 (43): 15313-18. https://doi.org/10.1073/pnas.0507312102.

Plane, David A. 1984. "Migration Space: Doubly Constrained Gravity Model Mapping of Relative Interstate Separation." Annals of the Association of American Geographers 74 (2): 24456. https://doi.org/10.1111/j.1467-8306.1984.tb01451.x.

Renne, John L, Tara Tolford, Shima Hamidi, and Reid Ewing. 2016. "The Cost and Affordability Paradox of Transit- Oriented Development : A Comparison of Housing and Transportation Costs Across Transit-Oriented Development, Hybrid and TransitAdjacent Development Station Typologies." Housing Policy Debate 26 (4-5): 819-34. https://doi.org/10.1080/10511482.2016.1193038.

Sanchez, By Thomas W, Rich Stolz, and Jacinta S Ma. 2003. "MOVING TO EQUITY: Addressing Inequitable Effects of Transportation Policies on Minorities." Cambridge, MA.

Scheer, Brenda. 2017. "TOD Beats TAD in Affordability Showdown.” Transportation Research and Education Center, no. August.

Steven Manson, Jonathan Schroeder, David Van Riper, and Steven Ruggles. 2018. "IPUMS National Historical Geographic Information System: Version 12.0 [Database]." Minneapolis: University of Minnesota. 2018. https://doi.org/http://doi.org/10.18128/D050.V12.0.

Wilson, Steven G, David a Plane, Paul J Mackun, Thomas R Fischetti, Justyna Goworowska, Darryl T. Cohen, Marc J Perry, and Geoffrey W Hatchard. 2012. "Patterns of 
Metropolitan and Micropolitan Population Change : 2000 to 2010." 2010 Census Special Reports, no. September: 1-102. https://doi.org/C2010SR-01. 


\section{CHAPTER 4: Toward an Index of Employment-Worker Balance by Transit Station Mode}

\section{OVERVIEW}

An "Employment-Worker Balance" (EWB) is created. It is viewed as a key to economic growth through agglomeration economies is also a key to social equity. This is due to its ability to both increase workers' access to employment and firms' access to a strong, diverse, and resilient workforce. Smart Growth advocates frequently identify Employment-Worker Balance as a key metric in compact urban design. Because of its potential synergistic effects with EWB, another key element of Smart Growth, Fixed-Rail Transit systems (FRT), needs to be studied for its effects on EWB: is the latter improved by the former, and for which job sectors and which workers? Principle Component Analysis will be used to produce a EWB Index that is able to map EWB across multifarious spatial contexts across the U.S., taking into its scope the multiple types of transit system modes, real estate types, and the many sectors of the economy that surround FRT stations. The EWB Index will provide a tool for practitioners and researchers to utilize in regression analysis, and policy and decision support. This chapter follows up on this significant increase of available evidence to work towards further theoretical refinement of EWB.

\section{Introduction}

There has been a long-standing and continuous debate regarding the relative merits of accessibility and mobility as separate paradigms of human flows. The EWB inherently is built upon a measure of access; however, the mode of travel between places changes the salient components of access. The built environment must support whatever transportation technology is chosen to reach one's destination. Some researchers assert the lack of a strong connection between accessibility and the built environment, citing instead the importance of individual behavior and constraints placed upon individuals by social structures(1,2). However, mobility is one way to increase accessibility. It is most available and enjoyed by those who can pay to use mobilizing infrastructures and technologies. These, moreover, are ever-costlier to jurisdictions as they are required to support the transport of ever-larger magnitudes of people across everlonger distances. Sprawling development necessitates the near-complete human reliance upon the automobile-as-prosthetic-device, and thus the infrastructure to facilitate its use. The continuance of sprawling development will exacerbate financial excesses in real estate development and public infrastructure spending (3). Others emphasize the need to balance mobility and accessibility. The former is the ability to move about the region in order to access needed land uses; the latter is "the relative connectedness of an area" (4). Paez et al. (5) provide clarification in their definition, describing accessibility as "the joint result of a transportation network and the geographical distribution of activities." Regianni et al. (6) describe accessibility as "the potential of opportunity for interaction," which aids in economic growth. Mode of transportation is also critical. The empirical data measured by studies such as Ewing \& Hamidi (7) and Levin (8) demonstrate the importance of the built environment to accessibility. Relative accessibility is measured by one's ability to utilize needed land uses. 


\section{Questions \& Hypotheses}

Can we directly measure the effect on EWB from transit stations via an index that is sensitive to different kinds and levels of transit across metros?

- Hypothesis 1: Different combinations of economic sectors and transit modes will load on different PCs

- Hypothesis 2: Different modes of travel will load differently on the Employment-Worker Balance Index (EWBI).

- Hypothesis 3: These differential loadings will produce a variety of EWB regimes or clusters.

\section{Literature Review}

Graaskamp (9) emphasized the value (situs) of a site as "related to the functional needs of the activity and not the site." Linkages between a site and the surrounding region facilitate accessibility, and the "costs of friction" are those of the stress, time, and costs accruing to each of the needed linkages for a specific activity (9). Employment-worker balance enhances those linkages between sites, both for the workforce and for the workplace, easing the costs of friction through greater accessibility. TOD enhances the EWB inasmuch as it is relevant, through built environment characteristics and transit node interconnectivity that draws people to utilize the site for both land uses and access to the regional transit network. Levine (8) argued that while "commute time remains a strong determinate of residential location at the regional scale," the salient improvement in accessibility accruing from an employment-worker balance derives from the increased match between workplace and residential location due to a greater range of options from which to choose in both housing and transportation. This principle is consistent with the theory of the gravity model, as a multitude of land uses in close proximity will increase the pull effect of a location. Relaxing zoning regulations that promote and subsidize spatially separated, single-use and lower-density development may promote better EWB, as demonstrated by Levine's (8) discrete choice model.

Worker accessibility is of significant value to both worker and employer. The "drive till you qualify" crowd living out in the suburbs or exurbs pay thousands of dollars more annually for transportation costs, when considering both monetary cost and time spent, and many choose to live nearer to work when given the option. The positive market response to development of residences nearer employment clusters negates the argument that a regulatory promotion of EWB is an interference with the market (8). Moreover, firms regularly demonstrate the importance of workforce accessibility to the health of the firm. Employers regularly place firms on the basis of an analysis of local workforce educational attainment and spatial concentration (10). 


\section{Data \& Methods}

The quantitative analysis of multivariate processes and phenomena in the social sciences requires the combination of many indicators of these phenomena, which further requires a structured paradigm or theory to both formulate and to interpret the analysis. A common definition of an index is informative: it is a measure of an abstract theory that combines multiple indicators.

Method examples for creation of indices in the literature include both Factor or Principal Component Analysis (PCA) and multiple regression. In the PCA realm, Ewing \& Hamidi (7) use the Census Tract to provide local "sprawl-like" measures, applying their PCA methodology, which was originally used at the metropolitan area scale. The PCA combines many correlated covariates in vector space to reveal the latent processes jointly explained by the correlated variables. In the realm of regression, the U.S. Department of Housing and Urban Development's (HUD) Location Affordability Index (LAI) relies upon a complex Structural Equation model (SEM), which maps out direct and indirect causal pathways between endogenous variables.

The choice of either method requires weighing the tradeoffs of positive and negative aspects of each, given the unique requirements of each study undertaken. PCA is non-parametric, a probable source of advantage over regression. Regression modeling with fixed effects may provide some advantages over PCA, as it can control for noisy differences between unique places using various fixed effects (11).

Transit systems for this study were derived from General Transit Feed Specification (GTFS) static files, which most transit authorities across the United States provide in accordance with the Google GTFS data standard. Transit authorities prepare their data about stops and routes along the various modes of public transportation available in their communities, including local, express, and rapid bus routes, commuter rail transit, light rail, streetcar rail, and heavy rail subway-metro systems. The GTFS standard tables were processed through ArcGIS Model Builder.

The study will review transit systems for the year 2016 in the cities of Atlanta, Cleveland, Eugene, and Minneapolis. These cases represent a wide variety in terms of region, population size, economy, transit modes (e.g., streetcar or bus rapid transit), and urban form. The study area is restricted to the U.S. Census Urbanized Area of the counties of the metropolitan area that are served by transit systems. The transit system modes for each city are as follows:

- Atlanta: streetcar (SCT), heavy rail transit (HRT)

- Cleveland: light rail (LRT), bus rapid transit (BRT)

- Eugene: bus rapid transit (BRT)

- $\quad$ Minneapolis: LRT, BRT \& commuter rail (CRT) 


\section{Commutesheds from LEHD Origin-Destination Tables}

The data tables for jobs and workers were gathered from the U.S. Census Bureau's Longitudinal Employment-Housing Database (LEHD) job data tables for census blocks were downloaded from the U.S. Census Bureau's On the Map website in shapefile format. The LEHD Origin- Destination Employment Statistics (LODES) tables provide full counts, rather than samples, of wage and salary jobs covered by unemployment insurance, with strict enforcement of privacy for individual respondents. These tables provided the variables for study about the location of jobs and their pay level, as well as workers and their pay scale. The former are found in the Work Area Characteristics (WAC) files, detailing the workplace location and other data for the employees that are enumerated in the file. Jobs totals are provided, along with a breakout of jobs by age of employee, by pay ranges, and by jobs according to the North American Industry Classification System (NAICS) job sector categorization. The Residence Area Characteristics (RAC) file provides data on the residence location of workers, including the same variables as the WAC file, but from the basis of the residence location of the enumerated workers, which may or may not include the residence census block. Benner \& Karner (12) point out the limitations of the LEHD earnings classification, including the lack of an index to inflation and the significant variation in the number of workers who fall into each category as one controls for metropolitan statistical area. This study will utilize a classification of income based on NAICS job sectors, following Nelson and Ganning (13). Street and intersection data will come from the U.S. Census Bureau's TIGER Line data set, with post-processing done in GIS.

Commuteshed sums of workers for a dissimilarity index and internal capture ("residence ratio" in Kain (14)) is measured using an origin-destination cost matrix, which maps the Euclidean distance from each origin to each destination to which it is connected. The distance method is a 3-mile cutoff.

The commuteshed is derived in GIS by a search from each origin census block group to all CBGs listed as destinations. An origin-destination cost matrix selects all destinations within the 3-mile Euclidean distance threshold. A one-to-many relationship exists between origins and destination. Therefore, the cost matrix provided the required lookup table between origins and destinations. Summing the workers in the commuteshed of each CBG was calculated as follows:

workers in CBG commuteshed $=\sum_{i}^{n} \sum_{j}^{m} C_{i j}$

Where the total number of workers commuting from an origin $i$, to a destination, $j$, or $C_{i j}$, within the 3-mile range is considered part of the commuteshed. The number of origins, $i$, is denoted by $n$, and $m$ is the number of destinations $j$ per origin, $i$. This calculation is done by summing each origin-destination CBG pair, and then again for the origin CBG. The origin census block group ID provided the basis for summing those workers working at job sites within about 3 miles from home. This method was used for both the numerator and the denominator in the internal capture equation. Each census block group gets evaluated for the number of workers at each destination, and a sum is made of workers who live or work and who both live and work in the commute shed. This enables use of the equation for internal capture in each cluster:

internal capture $=\frac{2 * \text { workers living \& working }}{\text { workers living }+ \text { workers working }}$

Commuteshed sums for the dissimilarity index were calculated with the same method. The dissimilarity index gives a measure of distribution or concentration of subsets of a data 
population. This study applies it to the level of "income match" in a CBG commuteshed. Income match (15) determines the relative balance in a location of workers and relevant housing by income. The dissimilarity index is computed thusly:

$D I=0.5 \sum_{i=3}^{N}\left|\frac{r_{i}}{R}-\frac{w_{i}}{W}\right|$

Where $r_{i}$ is the number of workers of a given income level subset residing in the commuteshed, $R$ is the number of all workers residing in the commuteshed, $w_{i}$ is the number of workers of a given income level subset working in the commuteshed, and $W$ is the number of all workers working in the commuteshed.

\section{Spatial Cluster Analysis - Identifying Centers \& Sub-Centers}

Centers of employment and residential land use will be identified through spatial cluster analysis, which relies upon spatial dependency or autocorrelation between objects in terms of one measured variable. Moran's I, a global measure of spatial autocorrelation, a spatiallyweighted version of the Pearson correlation coefficient (16), is the most appropriate analysis to begin with, as it determines overall levels of spatial clustering in a given region or total study area. Then, if it identifies statistically significant clustering, this finding indicates that more neighborhood-level measures can be used (and at what distance band), such as the Getis \& Ord $\mathrm{Gi}^{*}$ statistic, which identifies neighborhood-level hot or cold spots of a given variable, assigning $z$ scores and $p$ values for quantification. The most intense employment cluster in the region is the CBD (17).

Moran's I is defined as

$I=\left(\frac{1}{s_{y}^{2}}\right) \frac{\sum_{i}^{N} \sum_{\{j: i \neq j\}}^{N} w_{i j}\left(y_{i}-\bar{y}\right)\left(y_{j}-\bar{y}\right)}{\sum_{i}^{N} \sum_{\{j: i \neq j\}}^{N} w_{i j}}$

Where $\bar{y}=\sum_{i} y_{i} /{ }_{N}, s_{y}^{2}=\frac{1}{N} \sum_{i=1}^{N}\left(y_{i}-\bar{y}\right)^{2} \cdot y_{i}$ are counts, although alternative versions of Moran's I utilize continuous values (16). The metric provides a cross-product, as it sums the covariance between each point and each of its neighbors, providing the sum of covariance (deviation from the mean at $y_{i}$ multiplied by the deviation from the mean at $y_{j}$ ) for all sets of adjacent neighbors, and then it divides it by the global variance, $s_{y}^{2}$. The resulting index ranges between -1 and 1 , from a spatially dispersed pattern, to a spatially clustered one. This metric can be used at various distance bands, defined in the equation by assigning all features within the desired distance band a value of 1 in the matrix, $w_{i j}$. The various peaks in the score can represent neighborhoods in which the underlying spatial associations are strongest, and it is not necessarily true that each phenomenon has only one peak. ${ }^{103}$ The researcher may then choose the peak distance band at which the phenomenon being studied is operative (Figure 4.1).

The Getis and Ord $\mathrm{Gi}^{*}$ metric measures the degree of association resulting from the concentration of weighted points or areas and the other weighted points or areas within a given neighborhood, which is defined by distance $d$ from the origin $i$. The $\mathrm{Gi}^{\star}$ metric is defined as follows,

$G i^{*}(d)=\frac{\sum_{i=1}^{n} \sum_{j=1}^{n} w_{i j}(d) x_{i} x_{j}}{\sum_{i=1}^{n} \sum_{j=1}^{n} x_{i} x_{j}}$

${ }^{103}$ ESRI ArcGIS Desktop Help. “Incremental Spatial Autocorrelation.” Accessed 7-25-2017. http://desktop.arcgis.com/en/arcmap/10.4/tools/spatial-statistics-toolbox/incremental-spatialautocorrelation.htm. 
Where $w_{i j}$ is the matrix of weighted points within each neighborhood, $w_{i j}(d)$. The matrix is a set of binary values designating whether each location $j$ is within distance $d$ of the origin location $i$. Each weighted point has the attribute value, $x_{i}$ or $x_{j}$. The metric has a null hypothesis of spatial independence (18). Moran's I is a useful starting point for using local-scaled metrics of spatial association, by defining distance bands at which association may be strongest. This distance then becomes the definition for the neighborhoods in the $\mathrm{Gi}^{*}$ statistic (distance $d$ in equation 2 above).

Centering is evaluated using non-parametric global and local spatial autocorrelation metrics, and sub-centering is evaluated using non-parametric geographically weighted regression (GWR). It fits a separate regression model to each observation according to a sample of observations taken from a neighborhood kernel centered on the observation. The kernel can be fixed in size or adjusted at each observation for size to capture $k$ observations to make the sample sufficiently large. The result is a set of unique coefficients and error terms associated with each observation in the study sample. This produces a local statistic that answers for a lack of structural integrity in some explanatory variables that vary significantly across space. It is specified thusly:

$$
Y_{i}=\beta_{0}\left(u_{i}, v_{i}\right)+\sum_{k} \beta_{k}\left(u_{i}, v_{i}\right) X_{i k}+\varepsilon_{i} \quad i=1, \ldots, n
$$

It answers for spatial non-stationarity by fitting a regression to each observation, $i$, estimating the dependent variable by estimating a constant, $\beta_{0}$, and a vector of parameters, $\beta_{k}$, at each spatial location designated by the coordinates of $i,\left(u_{i}, v_{i}\right)$. The error term is also determined for each location, $i$. The parameters $\beta_{k}\left(u_{i}, v_{i}\right)$ are estimated by adding a spatial weights matrix, $W\left(u_{i}, v_{i}\right)$ to the traditional OLS parameter estimation equation. The $\mathrm{W}$ matrix models spatial relationships using either a fixed or adaptive continuous kernel, with a distance decay function estimating the spatial relationship. Common forms are a Gaussian distance decay or bisquare weighting function. The adaptive kernel chooses a varying distance bandwidth in order to capture the same number of nonzero weights per observation $i$ (19).

To evaluate centering, one identifies and culls those centers with employment that consist of more than $75 \%$ of all jobs in one single economic sector (20). This eliminates large single-sector land uses. Standard deviations of the $\mathrm{Gi}^{*}$ statistic will be used to evaluate the magnitude of centering. Positive residuals from GWR regression of employment density on distance from CBD represent sub-centers. One threshold employment density for sub-centers is 20 jobs per acre. Alternatively, the magnitude of the positive residuals, proxies for the intensity of centering, with 2.5 standard errors being used in the literature as a cutoff $(17,20)$. The study will use the latter approach to generalize the results to multiple levels of density across the urban hierarchy. 
TABLE 4.1. Place-Based Job Sectors in the Study Allocated by Wage Category

\begin{tabular}{|c|c|c|c|c|}
\hline NAICS & Description & $\begin{array}{l}\text { Mean Annual } \\
\text { Wages, } 2013\end{array}$ & $\begin{array}{l}\text { Wage } \\
\text { Category }\end{array}$ & $\begin{array}{l}\text { Share } \\
\text { of Jobs }\end{array}$ \\
\hline 44 & Retail Trade & $\$ 25,779$ & Lower & \\
\hline 56 & $\begin{array}{l}\text { Administrative, Support, Waste Mgmt., } \\
\text { Remediation }\end{array}$ & $\$ 35,931$ & Lower & \\
\hline 61 & Educational Services & $\$ 35,427$ & Lower & \\
\hline 71 & Arts, Entertainment and Recreation & $\$ 32,188$ & Lower & \\
\hline 72 & Accommodation and Food Services & $\$ 17,453$ & Lower & \\
\hline \multirow[t]{2}{*}{81} & $\begin{array}{l}\text { Other Services (except Public } \\
\text { Administration) }\end{array}$ & $\$ 29,021$ & Lower & \\
\hline & \multicolumn{2}{|c|}{ Weighted Mean Wages and National Share of Jobs } & $\sim \$ 30,000$ & $\sim 33 \%$ \\
\hline 48 & Transportation and Warehousing & $\$ 45,171$ & Middle & \\
\hline 53 & Real Estate and Rental and Leasing & $\$ 46,813$ & Middle & \\
\hline 62 & Health Care and Social Assistance & $\$ 44,751$ & Middle & \\
\hline \multirow[t]{2}{*}{92} & Public Administration & $\$ 51,340$ & Middle & \\
\hline & \multicolumn{2}{|c|}{ Weighted Mean Wages and National Share of Jobs } & $\sim \$ 50,000$ & $\sim 33 \%$ \\
\hline 22 & Utilities & $\$ 94,239$ & Upper & \\
\hline 31 & Manufacturing & $\$ 54,258$ & Upper & \\
\hline 42 & Wholesale Trade & $\$ 65,385$ & Upper & \\
\hline 51 & Information & $\$ 83,677$ & Upper & \\
\hline 52 & Finance and Insurance & $\$ 88,677$ & Upper & \\
\hline 54 & $\begin{array}{l}\text { Professional, Scientific and Technical } \\
\text { Services }\end{array}$ & $\$ 75,890$ & Upper & \\
\hline \multirow[t]{2}{*}{55} & $\begin{array}{l}\text { Management of Companies and } \\
\text { Enterprises }\end{array}$ & $\$ 105,138$ & Upper & \\
\hline & \multicolumn{2}{|c|}{ Weighted Mean Wages and National Share of Jobs } & $\sim \$ 70,000$ & $34 \%$ \\
\hline
\end{tabular}

Source: Adapted from (13). 


\section{Principal Component Analysis}

Factor analysis reveals latent variables from a series of highly correlated observed variables. One major variant, Principal Component Analysis (PCA), reduces the noise in a set of correlated variables, revealing with greater clarity the underlying signal of the phenomena being explained by the variables by highlighting their shared variance and removing white noise. Each component is a group of correlated variables that load highly on the component, meaning they are closely related to it. It is also known as Empirical Orthogonal Functions (EOF) due to nonparametric fitting of eigenvectors to highly correlated covariates. Each EOF is orthogonal to the others.

The two most common applications of PCA involve explaining the variance across 1) a time series (21), or 2) a set of variables (22). The first approach reduces the noise in a single variable across many time periods, while the second approach reduces noise for many variables for a single-year cross-sectional data set. The study relies upon PCA to reveal job growth dynamics in redlined zones and nearby transit stations, hypothesizing that transit proximity increased job growth over the years of the study, but did not provide this benefit to all segments of the population.

Table 4.2 lists the variables to be used in the PCA, with justifications from the literature. The variables' data sources include the US Census Bureau's ACS and LEHD data sets, the GTFS transit data format, and various GIS and R-derived spatial processes.

The method consists of taking four matrices to translate from variables to component scores for each observation in space. The process begins with a) the base matrix of $N$ observations by $M$ variables translated into standardized z-score format, also known as a centered matrix, and next, b) the correlation coefficient matrix is taken, producing a square matrix of $M$ dimensions. Then, c) the singular value decomposition method (SVD) creates matrices of eigenvectors (as wells as eigenvalues in a separate matrix). The eigenvalues are presented as the diagonal of the S matrix in SVD, and the proportion between each value of the diagonal and the trace (the sum of the diagonal) provides the explained variance of each eigenvector. Finally, d) the eigenvectors, found in the U matrix of the SVD output, are used as weights in linear combination with the original data values to produce the components (i.e., signals or scores). The individual elements of the components in (d) are also known as score coefficients.

The literature cites four reasons to rotate the vector space (a linear transformation process). Rotation provides such advantages as insensitivity to the shape of the spatial domain and subdomains underlying the data, no trouble with sampling error, and an accurate picture of physical relationships within the original data (23). Also, rotated space typically increases the explained variance and the loadings of each component on the relevant original variables, by better fitting the components to the data (24). Further, rotating and gaining a better fit of the components to the variable vectors also reduces secondary loadings of the variable vectors on the components, in effect causing each factor to represent one process captured by the clustering (i.e., correlated) variable vectors $(22,23)$. 
TABLE 4.2

Variables Included in EWBI, Justification \& Literature Sources

\author{
Variables \\ Distance to nearest FRT \\ stations by mode and \\ station's centering \\ intensity (GWR score) \\ Place-Based Employment \\ by sector group, age, and \\ income \\ Place-Based Workers by \\ sector group, age, and \\ income \\ Housing by tenure and \\ quality
}

Commuting mode, time

Vehicles per Household

Intersection density

Road network density

Strength of employment density; centering/subcentering

Strength of housing density

Distance to CBD

Dissimilarity Index of income match for placebased jobs Internal capture
Description \& Justification

Vector of measures of node and place attributes of neighborhood transit stations.

Categorized vectors of employment, they are a necessary input to capture demographic interactions. Firms compete for location.

Vector of workers. Worker demographics greatly affects commute.

Vector of housing. Renters can move residences easier than owners. Housing quality increases in newer development, with fewer vacancies.

EWB highly dependent upon commute mode and shed, a vector measured in time or distance. Link between station proximity and mode choice to work.

Vector proxy for automobile dependency

A measure of urban compactness and walkability.

A measure of urban compactness and walkability.

Higher EWB results in lower VMT and VHT and facilitates substitution of other travel modes for the automobile.

Higher EWB results in lower VMT\& VHT and facilitates substitution of other travel modes for the automobile. Clustering of housing should increase EWB.

Regional context of the neighborhood

Degree to which the neighborhood employment sectors is matched with workers' job sectors Workers living and working in the same commute shed as \% of total
Selected Literature

(25), $(17,20,26)$

$(13,14,27)$ 
Diagnostic tests for the PCA include Kaiser's Criterion, which calls for keeping only those components that have an eigenvalue of 1 or higher, due to lower eigenvalues providing insufficient information to retain. The Broken Stick test employs a line above which the components are considered significant, by applying a random component distribution, above which the eigenvalues of the components should fall to be retained.

Mapping the EWBI to the underlying census enumeration units will be done following the method in Plane \& Rogerson (22). Each component of interest to the study will be mapped onto the underlying block groups. This is done by a linear combination of the vector of weighted normalized variables used in each component. Each component produces a "component score coefficient" for each variable. This coefficient is used to weight a vector for each variable. Then the weighted vectors are linearly combined and the resulting component scores can be mapped in GIS to visualize the spatial distribution of each component, classified by component score ranges (less than $-1,-1$ to 0,0 to 1 , and greater than 1 ). These maps will reveal spatial concentrations of high or low values of EWB, with multiple compound characteristic regimes, denoting various types or varieties of what may be considered EWB. These types may be delineated by various demographics groups or employment sectors, or other heretofore unconsidered subgroups.

Analysis outputs will include:

- Global Moran's / plots

- tables of loadings and explained variance

- scree plots showing variance for each PC

- component significance tests

- thematic maps of component scores

\section{Results \& Discussion}

The Moran's I results show significant variation in spatial autocorrelation intensity and scale across the four metropolitan areas of the study. Figure 3 shows z-scores at 2,000-meter intervals. Atlanta shows a major peak at approximately four kilometers, with a precipitous drop in intensity thereafter. Cleveland's intensity is high at two kilometers, also dropping precipitously thereafter. Eugene shows a markedly different pattern, with a peak at approximately three kilometers, and two thereafter. Its highest z-score is about 2, considerably lower than the other metropolitan areas. Minneapolis demonstrates larger-scale land use concentrations than the other metropolitan areas in the study. It has relatively low intensity at the local scale and begins a sharp climb to its peak at five kilometers, drops until ten kilometers, and then climbs considerably to sixteen kilometers. Its intensity of concentration is high.

The results for the varimax rotation were unsuitable, as most of the loadings were near zero. Therefore, the rotated components were dropped from the study. The original PCA results are utilized for the study. The Broken Stick test indicated that the following PCs were retainable, as they were above the expected component value in the case of a random component distribution. For Atlanta, the first 3; for Cleveland, 3; for Eugene, 4; and, for Minneapolis, 3. 
Only significant components with $9 \%$ or more variance explained were retained, the first two for Atlanta and Cleveland, and the first 3 for Eugene and Minneapolis. The strength of the loadings are modest for all components, but the expected patterns emerge, with multiple regimes displayed across the different components. All loadings will be evaluted in this context. Each city shows varying intensity of response to transit by mode, and to jobs by sector and income.

The loadings (Table 4.3) show, most saliently, that in the study cities the location of jobs and residences are not loading on the same components. In Atlanta, the places with jobs also have the strongest access to transit, but the spatial relationship between workers' residences and transit stations is weak. Atlanta's jobs load on the same PC across various income levels and sector groups. Retail, Lodging and Food jobs load on the same PC as Office and Knowledge jobs. The same is the case in Cleveland. For all of the study cities, the jobs and worker residences load on different PCs, indicating that their locations are not highly correlated. In Minneapolis, jobs and residences do not load highly on any PCs, which may indicate a lack of strong spatial concentration of these variables. Eugene's loadings suggest that it is mainly a suburb for workers in Portland, as residences load highly but jobs load negatively. Atlanta and Cleveland show residents loading highly on PC1 and jobs loading highly on PC2. Minneapolis residents load highly on PC1 and jobs load negatively on PC2 and somewhat highly on PC3. This suggests that Minneapolis consists of more complex spatial regimes than the other cities. As Atlanta is also a large and complex city, the results also demonstrate the explanatory limitations of the study methods, and the need to further the scale effects of these cities' spatial regimes.

The commuting modes show the ongoing dominance of the automobile. All cities show a dominant pattern of commuters driving alone to work, followed by carpooling. Work from home loaded more highly for all cities than did transit use. For Eugene, walking to work loaded highly on the same PC as proximity to BRT. Transit proximity loaded in varying ways across the cities, and all but Minneapolis responded positively to proximity to transit stations, with modestly negative loadings on the distance to the transit station. As stated above, a negative loading on distance indicates a positive loading on transit station proximity, which may be interpreted as a positive response to station proximity by the surrounding land uses. In Atlanta and Cleveland, job locations and transit station proximity loaded highly on the same PC, suggesting that job locations are more highly served than residential neighborhoods. Eugene responded well to proximity to BRT stations, but its job variables loaded negatively on all components, which further supports the interpretation of Eugene as a suburb of Portland.

Households with no vehicle loaded weakly on the components all cities, and households with 2 or more loaded most highly. Longer commute times loaded most highly across all the cities. Density and distance to CBD varied in relevance across the cities. Job density loaded positively in Atlanta and Cleveland, but negatively in Eugene and Minneapolis. Population density loaded positively in Eugene, but elsewhere was weak or negative. Total occupied housing was most relevant in all cities, with owners being more relevant than renters in most contexts, but renters loaded more highly than owners in Eugene. Centering and subcentering (polycentric development) loaded positively in Atlanta, Cleveland, and Eugene, but loaded negatively in Minneapolis. This suggests a more polycentric development in the first 3 cities, but a more dispersed development in Minneapolis. The built environment appears to be less walkable in all of these cities but Eugene, as the road network and intersection densities loaded weakly or negatively in all but Eugene, which had positive loadings on PC3, which also has high loadings from proximity to BRT. 

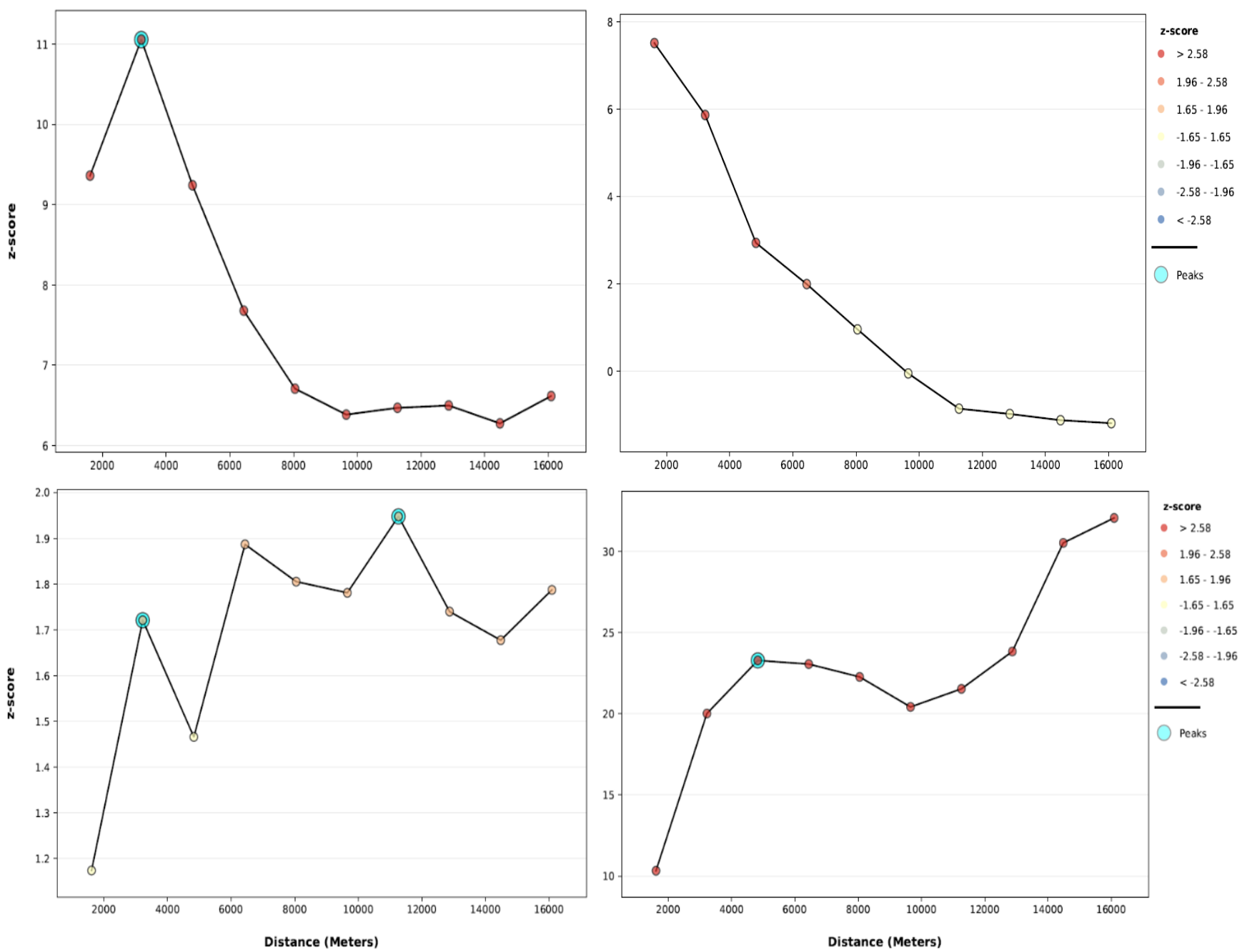

Figure 4.1 Results of Global Moran's I at various scales. 
TABLE 4.3

Loadings \& Explained Variance

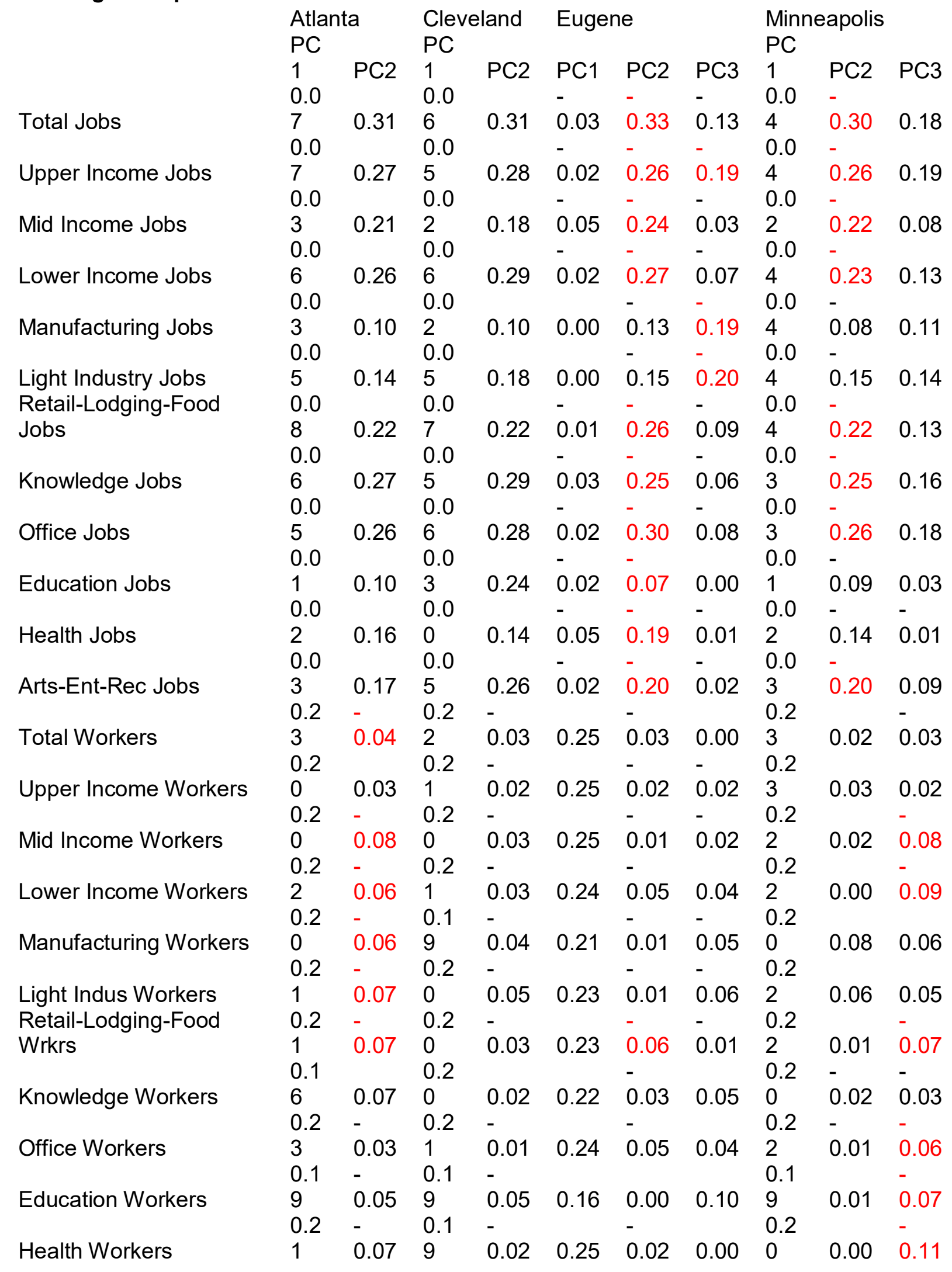




$\begin{array}{lllllllllll} & 0.1 & - & 0.1 & & & - & & 0.2 & - & - \\ \text { Arts-Ent-Rec Workers } & 9 & 0.01 & 9 & 0.02 & 0.19 & 0.03 & 0.04 & 1 & 0.03 & 0.10 \\ & 4.2 & & 4.5 & & & & & 4.1 & & \\ \text { Standard deviation } & 1 & 2.90 & 2 & 2.97 & 3.88 & 2.78 & 2.23 & 9 & 2.95 & 2.29 \\ & 33 & & 38 & & & & & 32 & & \\ \text { Proportion of Variance } & \% & 16 \% & \% & 16 \% & 28 \% & 15 \% & 9 \% & \% & 16 \% & 10 \% \\ & 33 & & 38 & & & & & 32 & & \\ \text { Cumulative Proportion } & \% & 48 \% & \% & 54 \% & 28 \% & 43 \% & 52 \% & \% & 48 \% & 57 \% \\ & \text { ATL: 3 } & \text { CLV: } 3 & & & & & & & & \\ \text { Broken Stick Sig. Test } & \text { PCs } & \text { PCs } & \text { EUG: 4 PCs } & & \text { MINN: 3 PCs }\end{array}$


TABLE 4.3 (Continued) Loadings \& Explained Variance

\begin{tabular}{|c|c|c|c|c|c|c|c|c|c|}
\hline & Atlan & & Cleve & eland & $\mathrm{Eu}$ & & $\mathrm{Mi}$ & polis & \\
\hline & PC1 & PC2 & PC1 & PC2 & PC1 & PC2 PC3 & PC1 & PC2 & $\mathrm{PC} 3$ \\
\hline Drove Alone to work & 0.22 & -0.02 & 0.21 & -0.05 & 0.24 & -0.010 .00 & 0.22 & 0.03 & -0.02 \\
\hline arpooled to work & .11 & -0.03 & 0.10 & -0.01 & 0.13 & $-0.01-0.03$ & 30.11 & -0.01 & -0.10 \\
\hline Transit to work & .03 & 0.04 & 0.01 & 0.07 & 0.05 & -0.070 .18 & 0.03 & -0.12 & -0.25 \\
\hline Walked to work & 0.03 & 0.15 & 0.04 & 0.15 & -0.05 & -0.110 .22 & 0.02 & -0.20 & -0.11 \\
\hline Nork at Home & 0.13 & 0.03 & 0.11 & -0.02 & 0.07 & $0.02 \quad 0.03$ & 0.11 & 0.00 & -0.01 \\
\hline Distance to LRT & & & 0.12 & -0.09 & & & 0.11 & 0.13 & 0.25 \\
\hline Distance to HRT & 0.11 & -0.13 & & & & & & & \\
\hline Distance to BRT & & & 0.14 & -0.10 & -0.02 & $0.08-0.21$ & 10.10 & 0.11 & 0.23 \\
\hline istance to SCT & 0.11 & -0.12 & & & & & & & \\
\hline Distance to CRT & & & & & & & 0.02 & 0.07 & 0. \\
\hline o Vehicle & 0.03 & 0.07 & 0.01 & 0.09 & 0.00 & -0.170 .18 & 0.02 & -0.17 & -0.21 \\
\hline ol & 0.17 & 0.08 & 0.13 & 0.05 & 0.13 & -0.110 .13 & 0.11 & -0.14 & -0.18 \\
\hline olds - 2+ Vehicles & 0.20 & -0.08 & 0.20 & -0.08 & 0.22 & $0.04-0.07$ & 70.21 & 0.08 & 0.0 \\
\hline omr & 0.07 & 0.06 & 0.08 & 0.04 & 0.02 & $-0.06-0.03$ & 30.07 & -0.07 & $7-0.02$ \\
\hline on & 0.15 & 0.11 & 0.16 & 0.03 & 0.13 & -0.110 .14 & 0.16 & -0.10 & -0.1 \\
\hline Comr & 0.18 & 0.04 & 0.18 & -0.02 & 0.21 & $0.00 \quad 0.09$ & 0.18 & -0.04 & $4-0.14$ \\
\hline ne 30 to 44 & 0.17 & -0.06 & 0.19 & -0.05 & 0.13 & $-0.01-0.01$ & 10.19 & 0.03 & -0.03 \\
\hline on & 0.17 & -0.10 & 0.15 & -0.04 & 0.11 & $0.02-0.01$ & 10.17 & 0.05 & 0.00 \\
\hline Dista & 0.11 & -0.12 & 0.12 & -0.10 & -0.03 & $\begin{array}{lll}3 & 0.08 & -0.23\end{array}$ & B 0.10 & 0.14 & 0.25 \\
\hline sity / mile & 0.00 & 0.08 & -0.06 & -0.01 & -0.03 & $3-0.040 .33$ & -0.04 & $4-0.09$ & -0.28 \\
\hline Nor & 0.03 & 0.27 & 0.01 & 0.25 & -0.07 & -0.220 .02 & 0.01 & -0.29 & 0.09 \\
\hline Tot & 0.22 & 0.01 & 0.19 & 0.01 & 0.21 & -0.080 .07 & 0.21 & -0.06 & -0.12 \\
\hline Own & 0.17 & -0.08 & 0.18 & -0.09 & 0.19 & $\begin{array}{lll}0.08 & -0.17\end{array}$ & 70.19 & 0.09 & 0.07 \\
\hline & .13 & 0.09 & 0.07 & 0.10 & 0.07 & -0.170 .24 & 0.06 & -0.17 & -0.23 \\
\hline & -0.07 & 0.05 & -0.11 & 0.05 & -0.08 & $3-0.10-0.05$ & $5-0.03$ & $3-0.06$ & -0.03 \\
\hline Medi & 0.14 & -0.01 & 0.14 & -0.04 & 0.10 & $-0.04-0.16$ & 0.13 & 0.02 & 0.1 \\
\hline Diss & -0.04 & -0.02 & -0.05 & -0.02 & -0.01 & $0.03-0.03$ & $3-0.04$ & 0.03 & -0.02 \\
\hline & 0.16 & -0.05 & 0.18 & -0.05 & -0 & $0.06-0.19$ & 90.1 & 0.03 & 0.03 \\
\hline GW & 0.07 & 0.29 & 0.06 & 0.31 & -0.03 & $3-0.32-0.18$ & 30.05 & -0.29 & 0.19 \\
\hline Score & 0.03 & 0.20 & 0.06 & 0.17 & -0.07 & $\begin{array}{lll}-0.16 & 0.22\end{array}$ & 0.02 & -0.12 & -0.0 \\
\hline & -0.05 & 0.16 & -0.12 & 0.07 & -0.07 & -0.050 .31 & -0.09 & & $1-0.2$ \\
\hline & -0.06 & 0.16 & -0.13 & 0.07 & -0.08 & $3-0.070 .33$ & -0.10 & -0.14 & $4-0.25$ \\
\hline Stand & 4.21 & 2.90 & 4.52 & 2.97 & 3.88 & $2.78 \quad 2.23$ & 4.19 & 2.95 & 2.29 \\
\hline Prop & $33 \%$ & $16 \%$ & $38 \%$ & $16 \%$ & $28 \%$ & $15 \% 9 \%$ & $32 \%$ & $16 \%$ & $10 \%$ \\
\hline Cum & $\begin{array}{l}33 \% \\
\text { ATL: }\end{array}$ & $\begin{array}{l}48 \% \\
3\end{array}$ & $\begin{array}{l}38 \% \\
\text { CLV: }\end{array}$ & $54 \%$ & $28 \%$ & $43 \% 52 \%$ & $32 \%$ & $48 \%$ & 57 \\
\hline & PCs & & PCs & & & & & & \\
\hline
\end{tabular}



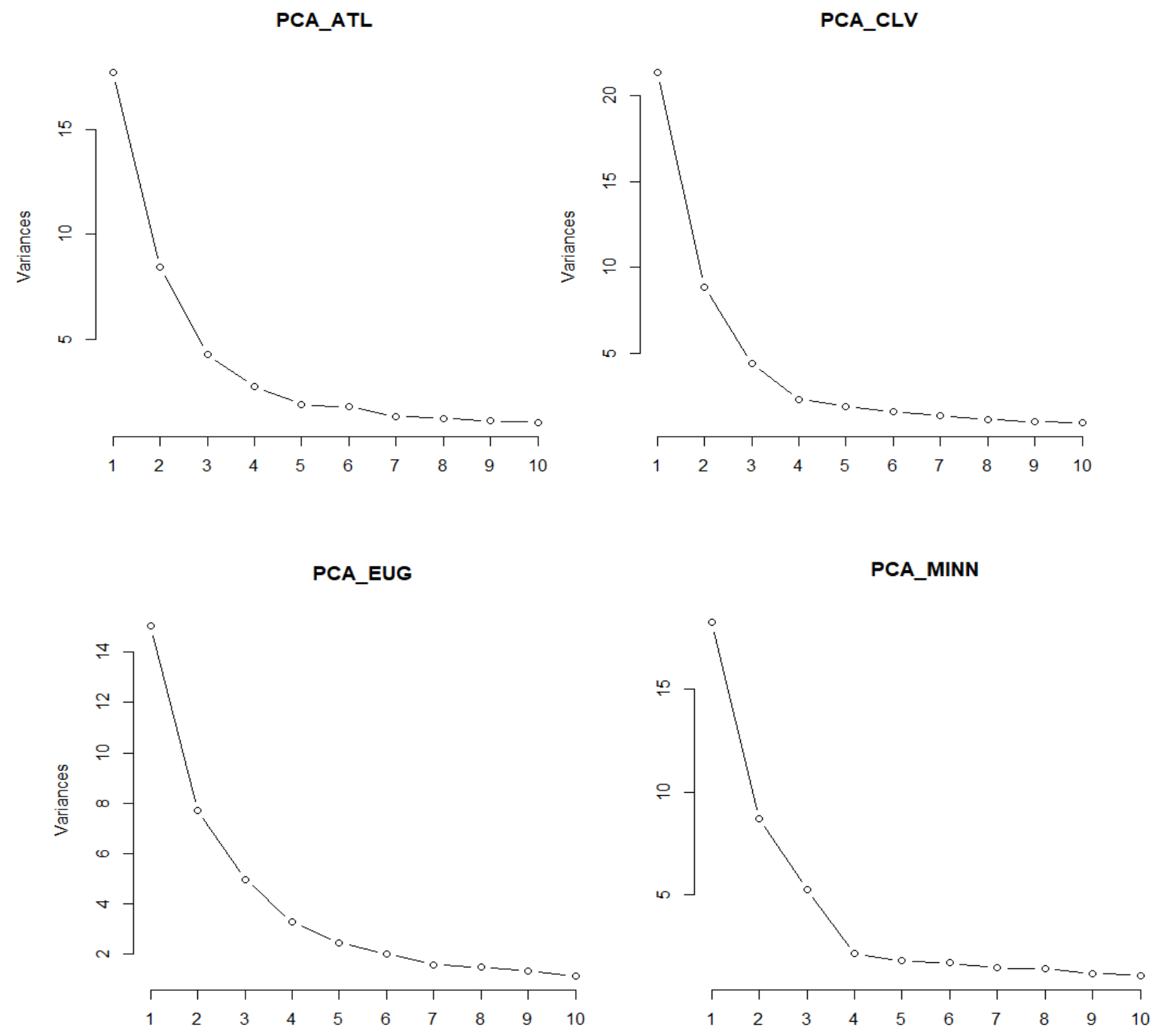

Figure 4.2

PCA Scree plots, showing PCs by variance 
All study cities demonstrated weak loadings from income match and internal capture measures. This is an expected outcome, with a manifest need in most US cities for a greater emphasis on employment-worker balance.

Maps of PC1 scores (Figure 4.3) reveal a wide variation in the index across the study cities. Each city shows some degree of high intensity along road networks. This is quite pronounced in Cleveland and seen in a radial pattern of low intensity in Atlanta, and in the north region of Minneapolis.

\section{Conclusions and Implications for Transit and Land Use Planning}

Theoretical implications of the employment-worker balance phenomenon are drawn from the spatial and attribute clusters revealed by the EWBI. A more accessible workplace translates to a more productive and resilient workforce through potential improvements in work-life balance and overall cost of living, which in turn benefits the firm through higher output. Additionally, existing discrepancies in EWB near transit stations reveal low-hanging fruit for planners who wish to increase economic and housing resiliency. The employment-worker spatial regimes identified in this study through PCA may require targeted solutions to increase EWB. This may reveal some significant patterns of outcomes to transit development. One main implication is that there is a great deal of potential to develop spatial balance between employment and worker residence. The built environment in Eugene far better supports walkability than in the other larger cities of the study. The built environment also plays a role in a positive response to transit proximity. Road and intersection densities seem to correlate well with a positive response to transit.

Workers remain separated from their workplaces. This may be seen by a portion of the population as a significant benefit, but many are paying excessive transportation costs, spending excessive time to commute, and high municipal taxes to support this separation of land uses. These results have significant workforce as well as workplace implications, as accessibility outcomes provide agglomeration economies. The regions in which workers have greater TOD-driven access to firms also provide a more business-friendly environment with increased situs via a more accessible, active workforce. When appropriate housing is provided for workers of all sectors of the economy, greater economic diversification is possible.

The results indicate a modestly positive response to TOD. The political implications of increasing employment-worker balance depend upon the local typology of imbalance needing correction. In neighborhoods that are job-rich and housing poor for a lower- to moderate-income worker, challenges may include potential for local opposition from businesses that benefit from larger numbers of workers than residents, businesses seeking to protect their market share from newcomer firms, or from residents who fear negative externalities of lower or moderate-income housing development in their neighborhoods. Neighborhoods with upper-income jobs that seek to improve EWB may face gentrification pressures. Bedroom communities for blue-collar workers needing more jobs may face challenges from industrial externalities (10). 


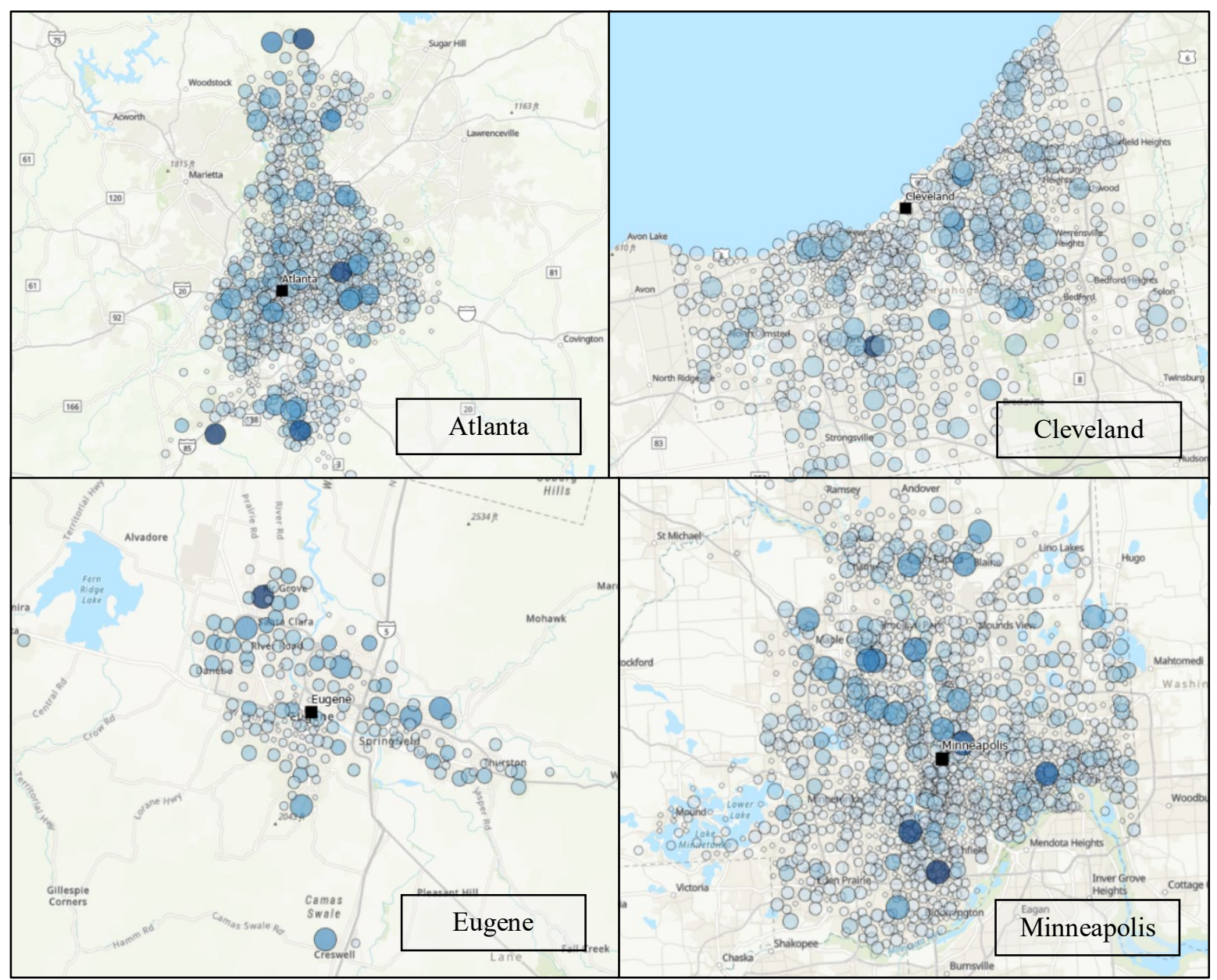

Figure 4.3

PC1 Scores for Atlanta, Cleveland, Eugene, And Minneapolis.

Graduated symbols range from small to large circles in light to dark blue, and high to low transparency to denote score magnitude. Atlanta's scores range from -2.3 to 27 . Cleveland's scores range from -3.2 to 35.6. Eugene's scores range from -3.3 to 19.8. Scores range from 1.7 to 31.4 for Minneapolis. Base Map Sources: Esri, HERE, Garmin, FAO, NOAA, USGS, (C) OpenStreetMap contributors and the GIS User Community 


\section{REFERENCES}

1. Weber J, Kwan M-P. Evaluating the Effects of Geographic Contexts on Individual Accessibility: A Multilevel Approach ${ }^{1}$. Urban Geogr [Internet]. 2003;24(8):647-71. Available from: http://www.tandfonline.com/doi/abs/10.2747/0272-3638.24.8.647

2. Schwanen T, Dijst M. Travel-time ratios for visits to the workplace: The relationship between commuting time and work duration. Transp Res Part A Policy Pract. 2002;36(7):573-92.

3. Nelson AC, Marshall JT, Juergensmeyer JC, Nicholas JC. Market Demand-based Planning and Permitting. Chicago: American Bar Association Press; 2017.

4. Sanchez TW. The Connection Between Public Transit and Employment. 2007;4363.

5. Paez, Antonio., Scott, Darren., Morency C. Measuring Accessibility: Positive and Normative Implementation of Various Accessibility Indicators. J Transp Geogr [Internet]. 2012;25:141-53. Available from: http://journals1.scholarsportal.info/details.xqy?uri=/09666923/v25inone_c/141_mapaniov ai.xml

6. Reggiani A, Bucci P, Russo G, Haas A, Nijkamp P. Regional labour markets and job accessibility in City Network systems in Germany. J Transp Geogr [Internet]. 2011;19(4):528-36. Available from: http://dx.doi.org/10.1016/j.jtrangeo.2010.05.008

7. Ewing, Reid, and Hamidi S. Measuring Urban Sprawl and Validating Sprawl Measures [Internet]. Washington, D.C.; 2014. Available from: https://gis.cancer.gov/tools/urbansprawl/

8. Levine J. Rethinking Accessibility and Jobs-Housing Balance. J Am Plan Assoc. 1998;64(2):133-49.

9. Graaskamp JA. Fundamentals of Real Estate Development. ULI-The Urban Land Institute. Washington, DC; 1981.

10. Weitz J. Jobs-Housing Balance. Chicago, III.; 2003.

11. Sommervoll $\AA$, Sommervoll DE. Learning from man or machine: Spatial fixed effects in urban econometrics. Reg Sci Urban Econ. 2019;

12. Benner $C$, Karner A. Low-wage jobs-housing fit: identifying locations of affordable housing shortages. Urban Geogr [Internet]. 2016;37(6):883-903. Available from: http://dx.doi.org/10.1080/02723638.2015.1112565

13. Nelson AC, Ganning J. National Study of BRT Development Outcomes [Internet]. Portland, OR; 2015. Available from: https://nitc.trec.pdx.edu/research/project/650

14. Kain JF. Housing Segregation, Negro Employment, and Metropolitan Decentralization. Q J Econ [Internet]. 1968;82(2):175-97. Available from: http://www.jstor.org/stable/1885893

15. Stoker P, Ewing R. Job - Worker Balance and Income Match in the United States. Hous Policy Debate [Internet]. 2014;24(2). Available from: http://dx.doi.org/10.1080/10511482.2013.852604

16. Jackson MC, Huang L, Xie Q, Tiwari RC. A modified version of Moran's I. Int J Health Geogr [Internet]. 2010;9:33. Available from:

http://www.pubmedcentral.nih.gov/articlerender.fcgi?artid=2903534\&tool=pmcentrez\&re ndertype $=$ abstract

17. Hajrasouliha $\mathrm{AH}$, Hamidi S. The typology of the American metropolis: monocentricity, polycentricity, or generalized dispersion? Urban Geogr [Internet]. 2016;3638(April):1-25. Available from: http://www.tandfonline.com/doi/full/10.1080/02723638.2016.1165386

18. Getis A, Ord JK. The Analysis of Spatial Association. Geogr Anal. 1992;24(3):189-206.

19. Huang B, Wu B, Barry M. Geographically and temporally weighted regression for modeling spatio-temporal variation in house prices. Int J Geogr Inf Sci. 2010;24(3):383401. 
20. Park K, Ewing R, Sabouri S, Choi D, Hamidi S, Tian G. Guidelines for a Polycentric Region to Reduce Vehicle Use and Increase Walking and Transit Use. J Am Plan Assoc [Internet]. 2020;0(0):1-14. Available from: https://doi.org/10.1080/01944363.2019.1692690

21. Behera SK, Rao SA, Saji HN, Yamagata T. Comments on "A cautionary note on the interpretation of EOFs." J Clim. 2003;16(2):1087-93.

22. Plane DA, Rogerson PA. The Geographical Analysis of Population with Applications to Planning and Business. New York: John Wiley \& Sons; 1994.

23. Richman MB. Rotation of Principle Components. J Climatol. 1986;6:292-335.

24. Cadwallader MT. Migration and residential mobility: Macro and micro approaches. Madison, Wis.: Univ of Wisconsin Press; 1992.

25. Nelson AC, Hibberd R. The Link between Transit Station Proximity and Real Estate Rents, Jobs, People and Housing with Transit and Land Use Planning Implications The Link between Transit Station Proximity and Real Estate Rents , Jobs, People and Housing with Transit and Land. Portland, OR; 2019.

26. Bertolini L. Nodes and places: Complexities of railway station redevelopment. Eur Plan Stud. 1996;4(3):331-45.

27. Ewing R, Cervero R. Travel and the built environment: a synthesis. Transp Res Rec [Internet]. 2001;1780(Paper No. 01-3515):87-114. Available from: http://mrc.cap.utah.edu/wp-content/uploads/sites/8/2015/04/fulltext.pdf

28. Cervero R, Duncan M. Jobs-Housing Balauce or Retail-Housing Mixing ? J Am Plan Assoc. 2008;74(2):475-90. 


\section{APPENDIX D}

All study tables are significance tested. All z scores denote significance at the .10 level for 2tailed test.

Appendix $D$ is for chapter 3 tables.

Table 3A.1 BRT Poor MA Transit Station Type Job Dynamics by Economic Group 20102016

Station Share of Shift 2010-2016

\begin{tabular}{|c|c|c|c|c|c|c|c|}
\hline Sector Groups & 0.125 & 0.25 & 0.375 & 0.5 & 0.75 & 1 & $\begin{array}{l}\text { Transit County } \\
\text { Sum } 2016\end{array}$ \\
\hline $\begin{array}{l}\text { Urban Square Miles - } \\
\text { Increm. }\end{array}$ & 15 & 20 & 22 & 24 & 53 & 57 & 14,201 \\
\hline $\begin{array}{l}\text { Urban Square Miles - } \\
\text { Cum. }\end{array}$ & 15 & 35 & 57 & 81 & 134 & 191 & 14,201 \\
\hline Manufacturing & 6,194 & 1,091 & 3,036 & 3,320 & 2,768 & 2,353 & 830,769 \\
\hline Light Industry & 6,207 & 3,460 & 3,884 & 3,270 & 1,695 & 8,169 & 818,346 \\
\hline Retail-Lodging-Food & 2,928 & 2,031 & 2,268 & 3,699 & 1,780 & 2,473 & $1,970,975$ \\
\hline Knowledge & 29,975 & 6,383 & 7,038 & 6,161 & 4,693 & 6,194 & $1,309,013$ \\
\hline Office & 12,400 & 9,609 & 7,974 & 4,316 & 6,679 & 8,042 & $2,247,693$ \\
\hline Education & 20,194 & 1,735 & 2,067 & 2,160 & 1,768 & 2,131 & 863,140 \\
\hline Health & 3,468 & 5,575 & 7,027 & 4,086 & 4,692 & 3,400 & $1,464,168$ \\
\hline Arts-Ent-Rec & 409 & 1,795 & 223 & 372 & 246 & 881 & 197,902 \\
\hline$\underline{\text { Total Jobs }}$ & 81,782 & 31,686 & 33,524 & $\begin{array}{l}27,39 \\
1 \\
\end{array}$ & $\begin{array}{l}24,32 \\
8\end{array}$ & 33,650 & $9,702,006$ \\
\hline \multicolumn{8}{|c|}{ Economic Change 2010-2016 } \\
\hline Sector Groups & 0.125 & 0.25 & 0.375 & 0.5 & 0.75 & 1 & Transit County \\
\hline Manufacturing & )$^{(26,398}$ & $\begin{array}{l}(12,69 \\
8)\end{array}$ & $(5,689)$ & $\begin{array}{l}(3,49 \\
8)\end{array}$ & $\begin{array}{l}(1,81 \\
3)\end{array}$ & $(3,497)$ & $(145,037)$ \\
\hline Light Industry & $\begin{array}{l}(58,456 \\
{ }^{2}\end{array}$ & $(5,431)$ & $(9,515)$ & $\begin{array}{l}(5,05 \\
5)\end{array}$ & $\begin{array}{l}(3,61 \\
3)\end{array}$ & $(2,327)$ & $(31,845)$ \\
\hline Retail-Lodging-Food & $(17,180$ & 1,269 & $(2,124)$ & 821 & $\begin{array}{l}(1,83 \\
0)\end{array}$ & $(1,017)$ & $(9,243)$ \\
\hline Knowledge & 16,250 & $(1,266)$ & 2,476 & 2,647 & 3,636 & $(1,101)$ & 40,655 \\
\hline Office & $(9,188)$ & 6,962 & 3,151 & 714 & 5,168 & 4,418 & 34,291 \\
\hline Education & $(11,483$ & $(2,646)$ & $(6,092)$ & $\begin{array}{l}(3,46 \\
7)\end{array}$ & (286) & $(1,694)$ & 70,350 \\
\hline Health & )$^{(27,460}$ & $(1,721)$ & $(2,681)$ & $(231)$ & 805 & $(4,835)$ & 194,081 \\
\hline Arts-Ent-Rec & $\begin{array}{l}(24,706 \\
{ }^{2}\end{array}$ & (39) & $(2,195)$ & $\begin{array}{l}(1,70 \\
1)\end{array}$ & $(818)$ & $(1,114)$ & 6,694 \\
\hline$\underline{\text { Total Jobs }}$ & $\begin{array}{l}(158,62 \\
1)\end{array}$ & $\begin{array}{l}(15,57 \\
0)\end{array}$ & $\begin{array}{l}(22,66 \\
9)\end{array}$ & $\begin{array}{l}(9,77 \\
0) \\
\end{array}$ & 1,249 & $\begin{array}{l}(11,16 \\
7)\end{array}$ & 159,946 \\
\hline
\end{tabular}




\begin{tabular}{|c|c|c|c|c|c|c|c|c|}
\hline Income Groups & 0.125 & 0.25 & 0.375 & 0.5 & 0.75 & 1 & \multicolumn{2}{|c|}{ Transit County } \\
\hline Manufacturing & $-81.0 \%$ & $-92.1 \%$ & $65.2 \%$ & $51.3 \%$ & $-39.6 \%$ & $-59.8 \%$ & \multicolumn{2}{|l|}{$-62.2 \%$} \\
\hline Light Industry & $-90.4 \%$ & $-61.1 \%$ & $\overline{71.0 \%}$ & $\overline{-} 60.7 \%$ & $-68.1 \%$ & $-22.2 \%$ & \multicolumn{2}{|l|}{$-76.6 \%$} \\
\hline Retail-Lodging-Food & $-85.4 \%$ & $\begin{array}{l}165.9 \\
\% \\
\end{array}$ & $\begin{array}{l} \\
48.3 \% \\
\end{array}$ & $28.5 \%$ & $-50.7 \%$ & $-29.1 \%$ & \multicolumn{2}{|l|}{$153.0 \%$} \\
\hline Knowledge & $\begin{array}{l}118.4 \\
\%\end{array}$ & $-16.5 \%$ & $54.3 \%$ & $75.3 \%$ & $\begin{array}{l}343.3 \\
\%\end{array}$ & $-15.1 \%$ & \multicolumn{2}{|l|}{$79.0 \%$} \\
\hline Office & $-42.6 \%$ & $\begin{array}{l}262.9 \\
\%\end{array}$ & $65.3 \%$ & $19.8 \%$ & $\begin{array}{l}341.8 \\
\%\end{array}$ & $\begin{array}{l}121.9 \\
\%\end{array}$ & \multicolumn{2}{|l|}{$34.0 \%$} \\
\hline Education & $-36.2 \%$ & $-60.4 \%$ & $\begin{array}{l}- \\
74.7 \% \\
\end{array}$ & $\begin{array}{l}- \\
61.6 \% \\
\end{array}$ & $-13.9 \%$ & $-44.3 \%$ & \multicolumn{2}{|l|}{$-18.3 \%$} \\
\hline Health & $-88.8 \%$ & $-23.6 \%$ & $27.6 \%$ & $-5.3 \%$ & $20.7 \%$ & $-58.7 \%$ & \multicolumn{2}{|l|}{$-33.2 \%$} \\
\hline Arts-Ent-Rec & $-98.4 \%$ & $-2.1 \%$ & $\begin{array}{l}- \\
90.8 \% \\
\end{array}$ & $-\overline{82.1 \%}$ & $-76.9 \%$ & $-55.8 \%$ & \multicolumn{2}{|l|}{$-76.2 \%$} \\
\hline Total Jobs & $-66.0 \%$ & $-32.9 \%$ & $40.3 \%$ & $\overline{2}-3 \%$ & $5.4 \%$ & $-24.9 \%$ & \multicolumn{2}{|l|}{$-25.2 \%$} \\
\hline \multicolumn{9}{|c|}{ LQ Trend 2010-2016 (LQ 2016 / LQ 2010) } \\
\hline Sector Groups & 0.125 & 0.25 & 0.375 & 0.50 & 0.625 & 0.75 & 0.875 & 1.00 \\
\hline Manufacturing & 1.11 & 0.23 & 1.15 & 1.31 & 2.50 & 1.13 & 0.54 & 1.06 \\
\hline Light Industry & 0.90 & 1.86 & 1.55 & 1.71 & 3.40 & 0.97 & 4.83 & 3.32 \\
\hline Retail-Lodging-Food & 0.13 & 1.17 & 0.26 & 0.52 & 0.10 & 0.14 & 0.22 & 0.28 \\
\hline Knowledge & 2.68 & 0.52 & 1.08 & 0.99 & 0.29 & 1.76 & 0.70 & 0.47 \\
\hline Office & 0.94 & 3.02 & 1.55 & 0.91 & 2.14 & 2.34 & 1.33 & 1.65 \\
\hline Education & 1.72 & 0.54 & 0.39 & 0.48 & 1.68 & 0.75 & 0.69 & 0.68 \\
\hline Health & 0.37 & 1.28 & 1.36 & 1.44 & 0.77 & 1.28 & 2.07 & 0.62 \\
\hline Arts-Ent-Rec & 0.15 & 4.59 & 0.49 & 0.76 & 0.39 & 0.69 & 0.63 & 1.85 \\
\hline Total Jobs & 1.00 & 1.00 & 1.00 & 1.00 & 1.00 & 1.00 & 1.00 & 1.00 \\
\hline
\end{tabular}


Table 3A.2 CRT Poor MA Transit Station Type Job Dynamics by Economic Group 20102016

Station Share of Shift 2010-2016

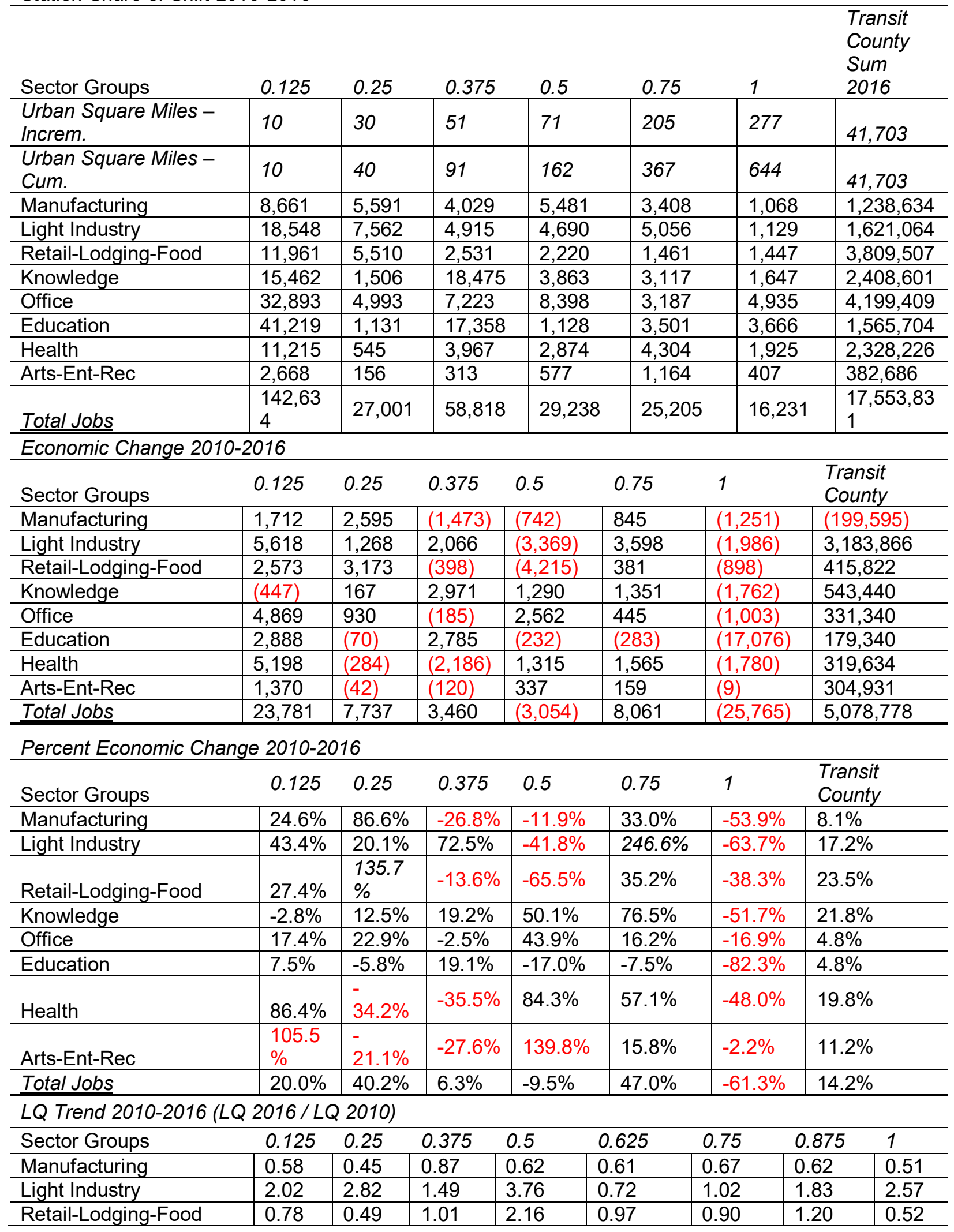




\begin{tabular}{l|l|l|l|l|l|l|l|l} 
Knowledge & 1.21 & 1.22 & 0.87 & 0.59 & 1.23 & 0.82 & 0.93 & 0.78 \\
\hline Office & 0.80 & 0.90 & 0.86 & 0.49 & 0.82 & 0.99 & 0.89 & 0.37 \\
\hline Education & 0.92 & 1.22 & 0.73 & 0.90 & 1.34 & 1.31 & 0.83 & 1.80 \\
\hline Health & 0.57 & 1.87 & 1.45 & 0.43 & 1.52 & 0.82 & 1.02 & 0.65 \\
\hline Arts-Ent-Rec & 0.87 & 2.63 & 2.18 & 0.56 & 1.63 & 1.88 & 0.59 & 0.59 \\
\hline
\end{tabular}


Table 3A.3 LRT Poor MA Transit Station Type Job Dynamics by Economic Group 2010-2016

Station Share of Shift 2010-2016

\begin{tabular}{|c|c|c|c|c|c|c|c|c|}
\hline Sector Groups & 0.125 & 0.25 & 0.375 & 0.5 & 0.75 & 1 & \multicolumn{2}{|c|}{$\begin{array}{l}\text { Transit County } \\
\text { Sum } 2016\end{array}$} \\
\hline Urban Square Miles - Increm. & 3 & 19 & 20 & 5 & 8 & 48 & \multicolumn{2}{|l|}{29,669} \\
\hline Urban Square Miles - Cum. & 3 & 22 & 42 & 46 & 55 & 103 & \multicolumn{2}{|l|}{29,669} \\
\hline Manufacturing & 29,701 & 5,567 & 2,379 & 2,689 & 7,412 & 763 & \multicolumn{2}{|l|}{$1,504,975$} \\
\hline Light Industry & 23,489 & 6,959 & 1,948 & 3,376 & 5,344 & 4,835 & \multicolumn{2}{|l|}{$1,842,851$} \\
\hline Retail-Lodging-Food & 12,756 & 1,493 & 3,742 & 2,934 & 5,392 & 578 & \multicolumn{2}{|l|}{$3,800,602$} \\
\hline Knowledge & 42,352 & 2,149 & 2,475 & 5,123 & 35,918 & 1,725 & \multicolumn{2}{|l|}{$2,242,526$} \\
\hline Office & 46,574 & 8,704 & 7,516 & 6,506 & 10,853 & 7,223 & \multicolumn{2}{|l|}{$4,609,558$} \\
\hline Education & 9,177 & 1,191 & 14,366 & 1,282 & 2,762 & 1,515 & \multicolumn{2}{|l|}{$1,608,044$} \\
\hline Health & 10,941 & 1,903 & 3,932 & 4,307 & 7,956 & 1,870 & \multicolumn{2}{|l|}{$2,630,962$} \\
\hline Arts-Ent-Rec & 2,652 & 96 & 430 & 284 & 498 & 297 & \multicolumn{2}{|l|}{353,302} \\
\hline Total Jobs & 177,649 & 28,069 & 36,795 & 26,508 & 76,142 & 18,813 & \multicolumn{2}{|c|}{$18,592,820$} \\
\hline \multicolumn{9}{|l|}{ Economic Change 2010-2016 } \\
\hline Sector Groups & 0.125 & 0.25 & 0.375 & 0.5 & 0.75 & 1 & \multicolumn{2}{|c|}{ Transit County } \\
\hline Manufacturing & 3,867 & 828 & $(673)$ & $(1,162)$ & $(5,107)$ & $(350)$ & \multirow{2}{*}{\multicolumn{2}{|c|}{$\begin{array}{l}(247,069) \\
(26,098)\end{array}$}} \\
\hline Light Industry & 5,054 & 1,050 & $(147)$ & 602 & $(821)$ & 1,257 & & \\
\hline Retail-Lodging-Food & $(1,203)$ & $(313)$ & (345) & 586 & 1,396 & $(165)$ & \multicolumn{2}{|l|}{$\frac{(26,098)}{64,894}$} \\
\hline Knowledge & 12,965 & 311 & (185) & 1,464 & 11,591 & 2 & \multicolumn{2}{|l|}{104,140} \\
\hline Office & 10,362 & 4,013 & 1,875 & 202 & 1,274 & 1,016 & \multicolumn{2}{|l|}{152,352} \\
\hline Education & $(4,766)$ & $(227)$ & 1,719 & (105) & $(272)$ & $(96)$ & \multicolumn{2}{|l|}{137,537} \\
\hline Health & $(2,417)$ & 522 & 829 & 1,589 & 1,900 & 182 & \multicolumn{2}{|l|}{378,107} \\
\hline Arts-Ent-Rec & 345 & 37 & (54) & (55) & 173 & 47 & \multicolumn{2}{|l|}{25,271} \\
\hline$\underline{\underline{T o t a l} \text { Jobs }}$ & 24,207 & 6,221 & 3,019 & 3,121 & 10,134 & 1,893 & \multicolumn{2}{|l|}{589,134} \\
\hline Percent Economic Change 201 & & & & & & & & \\
\hline Income Groups & 0.125 & 0.25 & 0.375 & 0.5 & 0.75 & 1 & Transit Co & unty \\
\hline Manufacturing & $15.0 \%$ & $17.5 \%$ & $-22.0 \%$ & $-30.2 \%$ & $-40.8 \%$ & $-31.4 \%$ & $6.2 \%$ & \\
\hline Light Industry & $27.4 \%$ & $17.8 \%$ & $-7.0 \%$ & $21.7 \%$ & $-13.3 \%$ & $35.1 \%$ & $13.2 \%$ & \\
\hline Retail-Lodging-Food & $-8.6 \%$ & $-17.3 \%$ & $-8.4 \%$ & $24.9 \%$ & $34.9 \%$ & $-22.2 \%$ & $19.2 \%$ & \\
\hline Knowledge & $44.1 \%$ & $16.9 \%$ & $-7.0 \%$ & $40.0 \%$ & $47.6 \%$ & $0.1 \%$ & $21.8 \%$ & \\
\hline Office & $28.6 \%$ & $85.5 \%$ & $33.2 \%$ & $3.2 \%$ & $13.3 \%$ & $16.4 \%$ & $10.6 \%$ & \\
\hline Education & $-34.2 \%$ & $-16.0 \%$ & $13.6 \%$ & $-7.6 \%$ & $-9.0 \%$ & $-6.0 \%$ & $4.1 \%$ & \\
\hline Health & $-18.1 \%$ & $37.8 \%$ & $26.7 \%$ & $58.4 \%$ & $31.4 \%$ & $10.8 \%$ & $18.7 \%$ & \\
\hline Arts-Ent-Rec & $14.9 \%$ & $61.7 \%$ & $-11.1 \%$ & $-16.2 \%$ & $53.1 \%$ & $18.7 \%$ & $17.5 \%$ & \\
\hline Total Jobs & $15.8 \%$ & $28.5 \%$ & $8.9 \%$ & $13.3 \%$ & $15.4 \%$ & $11.2 \%$ & $14.0 \%$ & \\
\hline LQ Trend 2010-2016 (LQ 20 & & & & & & & & \\
\hline Sector Groups & 0.125 & 0.25 & 0.375 & 0.50 & 0.625 & 0.75 & 0.875 & 1.00 \\
\hline Manufacturing & 1.07 & 0.98 & 0.77 & 0.66 & 1.00 & 0.55 & 0.92 & 0.66 \\
\hline Light Industry & 1.11 & 0.92 & 0.86 & 1.08 & 0.93 & 0.76 & 1.36 & 1.22 \\
\hline Retail-Lodging-Food & 0.75 & 0.62 & 0.80 & 1.05 & 0.95 & 1.12 & 0.69 & 0.67 \\
\hline Knowledge & 1.17 & 0.85 & 0.80 & 1.16 & 1.54 & 1.20 & 1.26 & 0.84 \\
\hline Office & 1.15 & 1.49 & 1.26 & 0.94 & 0.83 & 1.01 & 0.89 & 1.08 \\
\hline Education & 0.62 & 0.72 & 1.14 & 0.89 & 1.29 & 0.86 & 1.28 & 0.93 \\
\hline Health & 0.68 & 1.03 & 1.12 & 1.34 & 1.08 & 1.09 & 0.89 & 0.96 \\
\hline Arts-Ent-Rec & 0.96 & 1.22 & 0.79 & 0.72 & 1.22 & 1.29 & 1.12 & 1.04 \\
\hline Total Jobs & 1.00 & 1.00 & 1.00 & 1.00 & 1.00 & 1.00 & 1.00 & 1.00 \\
\hline
\end{tabular}


Table 3A.4 SCT Poor MA Transit Station Type Job Dynamics by Economic Group 20102016

Station Share of Shift 2010-2016

\begin{tabular}{|c|c|c|c|c|c|c|c|}
\hline Sector Groups & 0.125 & 0.25 & 0.375 & 0.5 & 0.75 & 1 & $\begin{array}{l}\text { Transit } \\
\text { County Sum } \\
2016\end{array}$ \\
\hline $\begin{array}{l}\text { Urban Square Miles - } \\
\text { Increm. }\end{array}$ & 2 & 6 & 10 & 4 & 4 & 10 & 12770 \\
\hline $\begin{array}{l}\text { Urban Square Miles - } \\
\text { Cum. }\end{array}$ & 2 & 8 & 18 & 22 & 25 & 35 & 12770 \\
\hline Manufacturing & 0 & 43 & 1 & NA & 3,764 & $\begin{array}{l}1,90 \\
3\end{array}$ & 524,288 \\
\hline Light Industry & 0 & 33 & 38 & 1 & 5,187 & $\begin{array}{l}6,95 \\
3\end{array}$ & 825,910 \\
\hline Retail-Lodging-Food & 0 & 143 & 12 & NA & 606 & 619 & $1,597,042$ \\
\hline Knowledge & 0 & 51 & 164 & 16 & 337 & 242 & $1,101,103$ \\
\hline Office & 0 & 295 & 58 & 116 & 2,103 & $\begin{array}{l}2,12 \\
6\end{array}$ & $1,981,603$ \\
\hline Education & 0 & NA & 118 & NA & 46 & 313 & 689,431 \\
\hline Health & 0 & 3,214 & (1) & 69 & 122 & 106 & $1,035,329$ \\
\hline Arts-Ent-Rec & 0 & 32 & (1) & NA & 50 & 454 & 185,019 \\
\hline$\underline{\text { Total Jobs }}$ & 0 & 3,817 & 396 & 205 & 12,222 & $\begin{array}{l}12,7 \\
23\end{array}$ & $7,939,725$ \\
\hline \multicolumn{8}{|c|}{ Economic Change 2010-2016 } \\
\hline Sector Groups & 0.125 & 0.25 & 0.375 & 0.5 & 0.75 & 1 & $\begin{array}{l}\text { Transit } \\
\text { County }\end{array}$ \\
\hline Manufacturing & 0 & 5 & $(15)$ & 0 & $(153)$ & $(623$ & $(76,872)$ \\
\hline Light Industry & 0 & $(13)$ & $(81)$ & (3) & 836 & 806 & $(30,086)$ \\
\hline Retail-Lodging-Food & 0 & (131) & $(38)$ & 0 & $(604)$ & (318 & $(16,664)$ \\
\hline Knowledge & 0 & 17 & (76) & 9 & 22 & )$^{(125}$ & 34,442 \\
\hline Office & 0 & $(45)$ & $(37)$ & 108 & 668 & $(43)$ & $(35,118)$ \\
\hline Education & 0 & 0 & $(79)$ & 0 & 2 & 29 & 46,586 \\
\hline Health & 0 & 3,051 & $(76)$ & 5 & 54 & 68 & 105,773 \\
\hline Arts-Ent-Rec & 0 & (6) & (5) & 0 & 28 & (96) & 3,632 \\
\hline Total Jobs & 0 & 2,878 & $(407)$ & 119 & 853 & $(302$ & 31,693 \\
\hline \multicolumn{8}{|c|}{$\begin{array}{l}\text { Percent Economic Change 2010- } \\
2016\end{array}$} \\
\hline Income Groups & 0.125 & 0.25 & 0.375 & 0.5 & 0.75 & 1 & $\begin{array}{l}\text { Transit } \\
\text { County }\end{array}$ \\
\hline Manufacturing & 0 & $12.8 \%$ & $-88.2 \%$ & NA & $-3.9 \%$ & $\begin{array}{l} \\
24.7 \\
\%\end{array}$ & $7.5 \%$ \\
\hline Light Industry & 0 & $-27.7 \%$ & $-67.5 \%$ & $-60.0 \%$ & $19.2 \%$ & $\begin{array}{l}13.1 \\
\%\end{array}$ & $19.9 \%$ \\
\hline Retail-Lodging-Food & 0 & $-47.6 \%$ & $-74.5 \%$ & NA & $-49.9 \%$ & $\begin{array}{l}- \\
33.9 \\
\%\end{array}$ & $21.0 \%$ \\
\hline Knowledge & 0 & $48.6 \%$ & $-31.5 \%$ & $\begin{array}{l}112.5 \\
\%\end{array}$ & $7.0 \%$ & $\begin{array}{l}- \\
34.0 \\
\%\end{array}$ & $17.1 \%$ \\
\hline
\end{tabular}




\begin{tabular}{|c|c|c|c|c|c|c|c|c|}
\hline Office & 0 & $-13.2 \%$ & $-38.5 \%$ & $\begin{array}{l}1200.0 \\
\%\end{array}$ & $46.5 \%$ & $\begin{array}{l}- \\
2.0 \\
\%\end{array}$ & $0.1 \%$ & \\
\hline Education & 0 & NA & $-39.9 \%$ & NA & $4.4 \%$ & $\begin{array}{l}10.2 \\
\%\end{array}$ & $13.7 \%$ & \\
\hline Health & 0 & $\begin{array}{l}1860.4 \\
\% \\
\end{array}$ & $-100.0 \%$ & $7.7 \%$ & $78.3 \%$ & $\begin{array}{l}174 . \\
4 \% \\
\end{array}$ & $8.3 \%$ & \\
\hline Arts-Ent-Rec & 0 & $-15.4 \%$ & $-100.0 \%$ & NA & $\begin{array}{l}121.7 \\
\%\end{array}$ & $\begin{array}{l}- \\
17.4 \\
\% \\
\end{array}$ & $39.9 \%$ & \\
\hline$\underline{\text { Total Jobs }}$ & 0 & $306.2 \%$ & $-50.6 \%$ & $\begin{array}{l}136.8 \\
\% \\
\end{array}$ & $7.5 \%$ & $\begin{array}{l}2.3 \\
\% \\
\end{array}$ & $11.7 \%$ & \\
\hline \multicolumn{9}{|c|}{ LQ Trend 2010-2016 (LQ 2016 / LQ 2010) } \\
\hline Sector Groups & 0.125 & 0.25 & 0.375 & 0.50 & 0.625 & 0.75 & $\begin{array}{l}0.87 \\
5 \\
\end{array}$ & 1.00 \\
\hline Manufacturing & 0 & 0.17 & 0.14 & 0.00 & 3.26 & 4.66 & 6.71 & 2.27 \\
\hline Light Industry & 0 & 0.09 & 1.20 & 0.09 & 3.52 & 4.08 & 0.89 & 5.25 \\
\hline Retail-Lodging-Food & 0 & 0.19 & 1.17 & 0.00 & 0.27 & 0.25 & 0.07 & 0.24 \\
\hline Knowledge & 0 & 0.10 & 0.03 & 0.60 & 0.79 & 0.20 & 0.62 & 0.14 \\
\hline Office & 0 & 0.31 & 0.46 & 2.28 & 0.77 & 0.69 & 0.56 & 0.67 \\
\hline Education & 0 & 0.00 & 0.06 & 0.00 & 0.00 & 0.04 & 0.00 & 0.28 \\
\hline Health & 0 & 6.46 & 0.17 & 2.61 & 0.33 & 0.08 & 1.62 & 0.06 \\
\hline Arts-Ent-Rec & 0 & 0.37 & 0.21 & 0.00 & 0.83 & 0.18 & 0.60 & 1.53 \\
\hline Total Jobs & 0 & 1.00 & 1.00 & 1.00 & 1.00 & 1.00 & 1.00 & 1.00 \\
\hline
\end{tabular}


Table 3A.5 BRT Low MA Transit Station Type Job Dynamics by Economic Group 20102016

Station Share of Shift 2010-2016

\begin{tabular}{|c|c|c|c|c|c|c|c|}
\hline Sector Groups & 0.125 & 0.25 & 0.375 & 0.5 & 0.75 & 1 & $\begin{array}{l}\text { Transit } \\
\text { County Sum } \\
2016\end{array}$ \\
\hline Urban Square Miles - Increm. & 27 & 44 & 49 & 51 & 102 & 98 & 14,201 \\
\hline Urban Square Miles - Cum. & 27 & 71 & 120 & 171 & 273 & 371 & 14,201 \\
\hline Manufacturing & 60,886 & 4,894 & 6,143 & 18,473 & 6,154 & 25,779 & 830,769 \\
\hline Light Industry & 75,070 & 10,730 & 8,743 & 29,346 & 10,841 & 21,435 & 818,346 \\
\hline Retail-Lodging-Food & 130,376 & 11,904 & 10,284 & 16,133 & 13,865 & 13,781 & $1,970,975$ \\
\hline Knowledge & 112,227 & 17,101 & 9,238 & 10,169 & 3,900 & 15,298 & $1,309,013$ \\
\hline Office & 233,565 & 34,800 & 19,008 & 30,670 & 10,924 & 21,142 & $2,247,693$ \\
\hline Education & 58,304 & 21,997 & 5,909 & 21,942 & 20,411 & 2,939 & 863,140 \\
\hline Health & 120,667 & 22,138 & 12,462 & 14,993 & 6,093 & 22,746 & $1,464,168$ \\
\hline Arts-Ent-Rec & 11,195 & 771 & 2,241 & 1,200 & 864 & 1,323 & 197,902 \\
\hline Total Jobs & 802,297 & 124,342 & 74,035 & 142,933 & 73,059 & 124,450 & $9,702,006$ \\
\hline
\end{tabular}

Economic Change 2010-2016

\begin{tabular}{l|l|l|l|l|l|l|l}
\hline Sector Groups & 0.125 & 0.25 & 0.375 & 0.5 & 0.75 & 1 & \multicolumn{1}{l}{ Transit County } \\
\hline Manufacturing & $(124,133)$ & $(40,453)$ & $(7,574)$ & $(22,179)$ & $(8,051)$ & $(1,560)$ & $(145,037)$ \\
\hline Light Industry & $(190,532)$ & $(39,737)$ & $(9,647)$ & $(27,102)$ & $(33,215)$ & $(7,307)$ & $(31,845)$ \\
\hline Retail-Lodging-Food & 69,422 & 3,343 & 8,000 & $(3,510)$ & 7,492 & $(16,307)$ & $(9,243)$ \\
\hline Knowledge & 50,490 & 4,356 & 4,695 & $(14,824)$ & $(5,447)$ & $(5,401)$ & 40,655 \\
\hline Office & 125,609 & 21,475 & 9,841 & 15,134 & $(913)$ & 6,317 & 34,291 \\
\hline Education & $(36,297)$ & 12,972 & 267 & 8,302 & 16,450 & $(10,679)$ & 70,350 \\
\hline Health & $(74,010)$ & $(22,361)$ & 1,262 & $(23,352)$ & $(7,267)$ & 4,481 & 194,081 \\
\hline Arts-Ent-Rec & $(60,969)$ & $(21,450)$ & $(1,166)$ & $(19,242)$ & $(23,757)$ & $(1,966)$ & 6,694 \\
\hline Total Jobs & $(240,420)$ & $(81,855)$ & 5,678 & $(86,773)$ & $(54,708)$ & $(32,422)$ & 159,946 \\
\hline
\end{tabular}

Percent Economic Change 2010-2016

\begin{tabular}{|c|c|c|c|c|c|c|c|}
\hline Sector Groups & 0.125 & 0.25 & 0.375 & 0.5 & 0.75 & 1 & Transit County \\
\hline Manufacturing & $-67.1 \%$ & $-89.2 \%$ & $-55.2 \%$ & $-54.6 \%$ & $-56.7 \%$ & $-5.7 \%$ & $-62.2 \%$ \\
\hline Light Industry & $-71.7 \%$ & $-78.7 \%$ & $-52.5 \%$ & $-48.0 \%$ & $-75.4 \%$ & $-25.4 \%$ & $-76.6 \%$ \\
\hline Retail-Lodging-Food & $113.9 \%$ & $39.0 \%$ & $349.8 \%$ & $-17.9 \%$ & $117.5 \%$ & $-54.2 \%$ & $153.0 \%$ \\
\hline Knowledge & $81.8 \%$ & $34.2 \%$ & $103.3 \%$ & $-59.3 \%$ & $-58.3 \%$ & $-26.1 \%$ & $79.0 \%$ \\
\hline Office & $116.4 \%$ & $161.2 \%$ & $107.3 \%$ & $97.4 \%$ & $-7.7 \%$ & $42.6 \%$ & $34.0 \%$ \\
\hline Education & $-38.4 \%$ & $143.7 \%$ & $4.7 \%$ & $60.9 \%$ & $415.2 \%$ & $-78.4 \%$ & $-18.3 \%$ \\
\hline Health & $-38.0 \%$ & $-50.2 \%$ & $11.3 \%$ & $-60.9 \%$ & $-54.4 \%$ & $24.5 \%$ & $-33.2 \%$ \\
\hline Arts-Ent-Rec & $-84.5 \%$ & $-96.5 \%$ & $-34.2 \%$ & $-94.1 \%$ & $-96.5 \%$ & $-59.8 \%$ & $-76.2 \%$ \\
\hline Total Jobs & $-23.1 \%$ & $-39.7 \%$ & $8.3 \%$ & $-37.8 \%$ & $-42.8 \%$ & $-20.7 \%$ & $-25.2 \%$ \\
\hline
\end{tabular}

\begin{tabular}{l|l|l|l|l|l|l|l|l} 
LQ Trend 2010-2016 (LQ $2016 / L Q ~ 2010)$ \\
\hline Sector Groups & 0.125 & \multicolumn{1}{l}{0.25} & \multicolumn{1}{l}{0.375} & \multicolumn{1}{l}{0.5} & 0.625 & 0.75 & 0.875 & 1 \\
\hline Manufacturing & 1.95 & 4.66 & 2.02 & 1.14 & 2.05 & 1.10 & 2.28 & 0.70 \\
\hline Light Industry & 2.56 & 2.67 & 2.14 & 1.13 & 3.20 & 2.19 & 1.66 & 1.00 \\
\hline Retail-Lodging-Food & 0.35 & 0.42 & 0.23 & 0.74 & 0.17 & 0.26 & 0.45 & 1.69 \\
\hline Knowledge & 0.43 & 0.46 & 0.54 & 1.56 & 0.31 & 1.40 & 0.42 & 1.10 \\
\hline Office & 0.35 & 0.23 & 0.52 & 0.31 & 1.08 & 0.62 & 0.34 & 0.56 \\
\hline Education & 1.34 & 0.27 & 1.11 & 0.42 & 1.07 & 0.12 & 1.21 & 3.95 \\
\hline Health & 1.46 & 1.43 & 1.15 & 1.88 & 0.78 & 1.48 & 1.31 & 0.75 \\
\hline Arts-Ent-Rec & 5.07 & 17.78 & 1.68 & 10.84 & 3.20 & 16.67 & 6.19 & 2.02 \\
\hline
\end{tabular}


Table 3A.6 CRT Low MA Transit Station Type Job Dynamics by Economic Group 20102016

Station Share of Shift 2010-2016

\begin{tabular}{|c|c|c|c|c|c|c|c|}
\hline Sector Groups & 0.125 & 0.25 & 0.375 & 0.5 & 0.75 & 1 & $\begin{array}{l}\text { Transit } \\
\text { County Sum } \\
2016\end{array}$ \\
\hline $\begin{array}{l}\text { Urban Square Miles - } \\
\text { Increm. }\end{array}$ & 17 & 51 & 81 & 105 & 261 & 307 & 41703 \\
\hline $\begin{array}{l}\text { Urban Square Miles - } \\
\text { Cum. }\end{array}$ & 17 & 68 & 149 & 254 & 515 & 822 & 41703 \\
\hline Manufacturing & 55,517 & 26,333 & 18,869 & 29,459 & 10,373 & 17,045 & $1,238,634$ \\
\hline Light Industry & 94,796 & 23,904 & 16,107 & 30,271 & 9,165 & 28,948 & $1,621,064$ \\
\hline Retail-Lodging-Food & 92,744 & 21,644 & 14,049 & 28,244 & 15,645 & 31,044 & $3,809,507$ \\
\hline Knowledge & 75,477 & 32,165 & 10,847 & 27,922 & 20,544 & 27,174 & $2,408,601$ \\
\hline Office & $\begin{array}{l}142,85 \\
3\end{array}$ & 34,513 & 26,310 & 67,651 & 33,850 & 40,797 & $4,199,409$ \\
\hline Education & 57,462 & 12,069 & 4,549 & 5,030 & 24,685 & 14,627 & $1,565,704$ \\
\hline Health & 58,376 & 11,499 & 25,808 & 25,517 & 14,411 & 35,356 & $2,328,226$ \\
\hline Arts-Ent-Rec & 9,321 & 2,064 & 1,904 & 2,740 & 1,441 & 5,681 & 382,686 \\
\hline$\underline{\text { Total Jobs }}$ & $\begin{array}{l}586,55 \\
3 \\
\end{array}$ & \begin{tabular}{|l|}
164,19 \\
8 \\
\end{tabular} & $\begin{array}{l}118,45 \\
0\end{array}$ & $\begin{array}{l}216,84 \\
1\end{array}$ & $\begin{array}{l}130,12 \\
1 \\
\end{array}$ & $\begin{array}{l}200,67 \\
9\end{array}$ & $17,553,831$ \\
\hline \multicolumn{8}{|c|}{ Economic Change 2010-2016 } \\
\hline Sector Groups & 0.125 & 0.25 & 0.375 & 0.5 & 0.75 & 1 & $\begin{array}{l}\text { Transit } \\
\text { County }\end{array}$ \\
\hline Manufacturing & )$^{(5,255}$ & 3,712 & 990 & $(6,137)$ & $(5,847)$ & 714 & $(199,595)$ \\
\hline Light Industry & 22,890 & 3,099 & 5,891 & 5,945 & $(5,992)$ & 7,206 & $3,183,866$ \\
\hline Retail-Lodging-Food & 14,487 & 5,120 & 418 & 3,084 & $(1,005)$ & 4,658 & 415,822 \\
\hline Knowledge & 13,104 & 13,046 & 659 & 3,994 & 4,881 & 6,584 & 543,440 \\
\hline Office & 16,165 & 5,268 & 2,390 & 19,885 & 9,829 & 526 & 331,340 \\
\hline Education & $(6,872$ & $(1,268)$ & (375) & $(2,390)$ & (37) & 5,814 & 179,340 \\
\hline Health & 1,916 & 3,422 & 836 & 4,931 & 1,870 & 8,250 & 319,634 \\
\hline Arts-Ent-Rec & 3,338 & 299 & (82) & 599 & 38 & 2,054 & 304,931 \\
\hline Total Jobs & 59,773 & 32,698 & 10,727 & 29,911 & 3,737 & 35,806 & $5,078,778$ \\
\hline \multicolumn{8}{|c|}{$\begin{array}{l}\text { Percent Economic Change 2010- } \\
2016\end{array}$} \\
\hline Income Groups & 0.125 & 0.25 & 0.375 & 0.5 & 0.75 & 1 & $\begin{array}{l}\text { Transit } \\
\text { County }\end{array}$ \\
\hline Manufacturing & $-8.6 \%$ & $16.4 \%$ & $5.5 \%$ & $-17.2 \%$ & $-36.0 \%$ & $4.4 \%$ & $8.1 \%$ \\
\hline Light Industry & $31.8 \%$ & $14.9 \%$ & $57.7 \%$ & $24.4 \%$ & $-39.5 \%$ & $33.1 \%$ & $17.2 \%$ \\
\hline Retail-Lodging-Food & $18.5 \%$ & $31.0 \%$ & $3.1 \%$ & $12.3 \%$ & $-6.0 \%$ & $17.7 \%$ & $23.5 \%$ \\
\hline Knowledge & $21.0 \%$ & $68.2 \%$ & $6.5 \%$ & $16.7 \%$ & $31.2 \%$ & $32.0 \%$ & $21.8 \%$ \\
\hline Office & $12.8 \%$ & $18.0 \%$ & $10.0 \%$ & $41.6 \%$ & $40.9 \%$ & $1.3 \%$ & $4.8 \%$ \\
\hline Education & $-\overline{10.7 \%}$ & $-9.5 \%$ & $-7.6 \%$ & $-32.2 \%$ & $-0.1 \%$ & $66.0 \%$ & $4.8 \%$ \\
\hline Health & $3.4 \%$ & $42.4 \%$ & $3.3 \%$ & $24.0 \%$ & $14.9 \%$ & $30.4 \%$ & $19.8 \%$ \\
\hline Arts-Ent-Rec & $55.8 \%$ & $16.9 \%$ & $-4.1 \%$ & $28.0 \%$ & $2.7 \%$ & $56.6 \%$ & $11.2 \%$ \\
\hline Total Jobs & $11.3 \%$ & $24.9 \%$ & $10.0 \%$ & $16.0 \%$ & $3.0 \%$ & $21.7 \%$ & $14.2 \%$ \\
\hline \multicolumn{8}{|c|}{ LQ Trend 2010-2016 (LQ 2016 / LQ 2010) } \\
\hline Sector Groups & 0.125 & 0.25 & 0.375 & 0.50 & 0.625 & 0.75 & 0.875 \\
\hline
\end{tabular}




\begin{tabular}{l|l|l|l|l|l|l|l|l}
\hline Manufacturing & 0.87 & 0.98 & 1.01 & 0.75 & 1.05 & 0.66 & 0.99 & $\begin{array}{l}0.9 \\
1\end{array}$ \\
\hline Light Industry & 1.15 & 0.90 & 1.40 & 1.05 & 1.04 & 0.57 & 1.08 & $\begin{array}{l}1.0 \\
7\end{array}$ \\
\hline Retail-Lodging-Food & 0.98 & 0.97 & 0.87 & 0.89 & 0.92 & 0.84 & 1.16 & $\begin{array}{l}0.8 \\
9\end{array}$ \\
\hline Knowledge & 1.02 & 1.26 & 0.91 & 0.94 & 0.82 & 1.19 & 1.27 & $\begin{array}{l}1.0 \\
2\end{array}$ \\
\hline Office & 1.10 & 1.03 & 1.09 & 1.33 & 1.09 & 1.49 & 0.76 & $\begin{array}{l}1.9 \\
1\end{array}$ \\
\hline Education & 0.87 & 0.79 & 0.92 & 0.64 & 1.25 & 1.06 & 1.24 & $\begin{array}{l}1.4 \\
9\end{array}$ \\
\hline Health & 0.88 & 1.09 & 0.90 & 1.02 & 0.90 & 1.06 & 0.91 & $\begin{array}{l}1.0 \\
2\end{array}$ \\
\hline Arts-Ent-Rec & 1.44 & 0.96 & 0.90 & 1.13 & 1.50 & 1.02 & 2.97 & $\begin{array}{l}1.3 \\
2\end{array}$ \\
\hline Total Jobs & 1.00 & 1.00 & 1.00 & 1.00 & 1.00 & 1.00 & 1.00 & $\begin{array}{l}1.0 \\
0\end{array}$ \\
\hline
\end{tabular}


Table 3A.7 LRT Low MA Transit Station Type Job Dynamics by Economic Group 20102016

Station Share of Shift 2010-2016

\begin{tabular}{|c|c|c|c|c|c|c|c|}
\hline Sector Groups & 0.125 & 0.25 & 0.375 & 0.5 & 0.75 & 1 & $\begin{array}{l}\text { Transit } \\
\text { County Sum } \\
2016\end{array}$ \\
\hline $\begin{array}{l}\text { Urban Square Miles - } \\
\text { Increm. }\end{array}$ & 45 & 9 & 14 & 69 & 56 & 10 & 29,669 \\
\hline $\begin{array}{l}\text { Urban Square Miles - } \\
\text { Cum. }\end{array}$ & 45 & 55 & 68 & 137 & 193 & 203 & 29,669 \\
\hline Manufacturing & 121,939 & 15,017 & 13,114 & 25,105 & $\begin{array}{l}10,95 \\
2\end{array}$ & 27,840 & $1,504,975$ \\
\hline Light Industry & 134,821 & 13,214 & 9,758 & 33,984 & $\begin{array}{l}18,42 \\
6\end{array}$ & 16,463 & $1,842,851$ \\
\hline Retail-Lodging-Food & 139,259 & 21,952 & 23,005 & 25,210 & $\begin{array}{l}18,52 \\
1\end{array}$ & 18,844 & $3,800,602$ \\
\hline Knowledge & 143,697 & 24,077 & 9,814 & 15,270 & $\begin{array}{l}16,01 \\
8\end{array}$ & 30,214 & $2,242,526$ \\
\hline Office & 321,977 & 54,720 & 32,385 & 68,144 & $\begin{array}{l}44,94 \\
1\end{array}$ & 41,618 & $4,609,558$ \\
\hline Education & 108,468 & 10,235 & 6,857 & 35,109 & 8,187 & 33,151 & $1,608,044$ \\
\hline Health & 181,892 & 24,043 & 32,860 & 25,041 & $\begin{array}{l}27,34 \\
2\end{array}$ & 46,912 & $2,630,962$ \\
\hline Arts-Ent-Rec & \begin{tabular}{|l|}
15,406 \\
\end{tabular} & 2,541 & 1,614 & 2,172 & 1,259 & 1,576 & 353,302 \\
\hline Total Jobs & \begin{tabular}{|l}
$1,167,4$ \\
66 \\
\end{tabular} & $\begin{array}{l}165,80 \\
6 \\
\end{array}$ & $\begin{array}{l}129,41 \\
4 \\
\end{array}$ & $\begin{array}{l}230,04 \\
2\end{array}$ & $\begin{array}{l}145,6 \\
53 \\
\end{array}$ & $\begin{array}{l}216,62 \\
5 \\
\end{array}$ & $18,592,820$ \\
\hline \multicolumn{8}{|c|}{ Economic Change 2010-2016 } \\
\hline Sector Groups & 0.125 & 0.25 & 0.375 & 0.5 & 0.75 & 1 & $\begin{array}{l}\text { Transit } \\
\text { County }\end{array}$ \\
\hline Manufacturing & 1,059 & $(83)$ & $(7,265)$ & 887 & $(721)$ & $\begin{array}{l}(11,72 \\
0)\end{array}$ & $(247,069)$ \\
\hline Light Industry & $(5,691)$ & $(1,069)$ & $\begin{array}{l}(12,12 \\
1)\end{array}$ & 1,980 & 1,229 & $(665)$ & $(26,098)$ \\
\hline Retail-Lodging-Food & 6,561 & $(5,307)$ & $(906)$ & 510 & $(603)$ & 1,054 & 64,894 \\
\hline Knowledge & 7,455 & $(648)$ & $(858)$ & $(1,502)$ & 2,403 & 6,420 & 104,140 \\
\hline Office & $(506)$ & $(4,545)$ & $(5,639)$ & 8,663 & 7,085 & 3,508 & 152,352 \\
\hline Education & $(27,175)$ & $(4,716)$ & $(1,533)$ & 12,324 & $(628)$ & $\begin{array}{l}(14,28 \\
0)\end{array}$ & 137,537 \\
\hline Health & 6,613 & 1,492 & $(1,202)$ & $(8,595)$ & 2,234 & 3,184 & 378,107 \\
\hline Arts-Ent-Rec & 2,245 & 203 & 67 & 723 & $(872)$ & 617 & 25,271 \\
\hline Total Jobs & $(9,439)$ & $\begin{array}{l}(14,67 \\
3) \\
\end{array}$ & $\begin{array}{l}(29,45 \\
7)\end{array}$ & 14,990 & $\begin{array}{l}10,12 \\
7\end{array}$ & $\begin{array}{l}(11,88 \\
2)\end{array}$ & 589,134 \\
\hline \multicolumn{8}{|c|}{ Percent Economic Change 2010-2016 } \\
\hline Income Groups & 0.125 & 0.25 & 0.375 & 0.5 & 0.75 & 1 & $\begin{array}{l}\text { Transit } \\
\text { County }\end{array}$ \\
\hline Manufacturing & $0.9 \%$ & $-0.5 \%$ & $-35.6 \%$ & $3.7 \%$ & $-6.2 \%$ & $-29.6 \%$ & $6.2 \%$ \\
\hline Light Industry & $-4.1 \%$ & $-7.5 \%$ & $-55.4 \%$ & $6.2 \%$ & $7.1 \%$ & $-3.9 \%$ & $13.2 \%$ \\
\hline Retail-Lodging-Food & $4.9 \%$ & $-19.5 \%$ & $-3.8 \%$ & $2.1 \%$ & $-3.2 \%$ & $5.9 \%$ & $19.2 \%$ \\
\hline Knowledge & $5.5 \%$ & $-2.6 \%$ & $-8.0 \%$ & $-9.0 \%$ & $17.6 \%$ & $27.0 \%$ & $21.8 \%$ \\
\hline Office & $-0.2 \%$ & $-7.7 \%$ & $-14.8 \%$ & $14.6 \%$ & $18.7 \%$ & $9.2 \%$ & $10.6 \%$ \\
\hline Education & $-20.0 \%$ & $-31.5 \%$ & $-18.3 \%$ & $54.1 \%$ & $-7.1 \%$ & $-30.1 \%$ & $4.1 \%$ \\
\hline Health & $3.8 \%$ & $6.6 \%$ & $-3.5 \%$ & $-25.6 \%$ & $8.9 \%$ & $7.3 \%$ & $18.7 \%$ \\
\hline Arts-Ent-Rec & $17.1 \%$ & $8.7 \%$ & $4.3 \%$ & $49.9 \%$ & $40.9 \%$ & $64.3 \%$ & $17.5 \%$ \\
\hline
\end{tabular}




\begin{tabular}{|c|c|c|c|c|c|c|c|c|}
\hline Total Jobs & $-0.8 \%$ & $-8.1 \%$ & $-18.5 \%$ & $7.0 \%$ & $7.5 \%$ & $-5.2 \%$ & \multicolumn{2}{|l|}{$14.0 \%$} \\
\hline \multicolumn{9}{|c|}{$\begin{array}{l}\text { LQ Trend 2010-2016 (LQ 2016 / LQ } \\
\text { 2010) }\end{array}$} \\
\hline Sector Groups & 0.125 & 0.25 & 0.375 & 0.50 & 0.625 & 0.75 & 0.875 & 1.00 \\
\hline Manufacturing & 1.09 & 1.16 & 0.85 & 1.04 & 1.24 & 0.94 & 0.98 & 0.80 \\
\hline Light Industry & 0.97 & 1.01 & 0.55 & 1.00 & 0.66 & 1.00 & 0.70 & 1.02 \\
\hline Retail-Lodging-Food & 1.01 & 0.84 & 1.13 & 0.91 & 0.97 & 0.86 & 0.90 & 1.07 \\
\hline Knowledge & 1.00 & 0.99 & 1.06 & 0.80 & 1.21 & 1.02 & 1.08 & 1.25 \\
\hline Office & 1.04 & 1.04 & 1.08 & 1.10 & 0.98 & 1.14 & 1.00 & 1.19 \\
\hline Education & 0.88 & 0.82 & 1.10 & 1.58 & 0.92 & 0.95 & 1.14 & 0.81 \\
\hline Health & 1.01 & 1.12 & 1.14 & 0.67 & 1.08 & 0.97 & 1.14 & 1.09 \\
\hline Arts-Ent-Rec & 1.14 & 1.15 & 1.24 & 1.36 & 1.34 & 0.53 & 1.42 & 1.68 \\
\hline Total Jobs & 1.00 & 1.00 & 1.00 & 1.00 & 1.00 & 1.00 & 1.00 & 1.00 \\
\hline
\end{tabular}


Table 3A.8 SCT Low MA Transit Station Type Job Dynamics by Economic Group 20102016

Station Share of Shift 2010-2016

\begin{tabular}{|c|c|c|c|c|c|c|c|}
\hline Sector Groups & 0.125 & 0.25 & 0.375 & 0.5 & 0.75 & 1 & $\begin{array}{l}\text { Transit } \\
\text { County Sum } \\
2016\end{array}$ \\
\hline $\begin{array}{l}\text { Urban Square Miles - } \\
\text { Increm. }\end{array}$ & 11 & 4 & 5 & 11 & 10 & 3 & 13727 \\
\hline $\begin{array}{l}\text { Urban Square Miles - } \\
\text { Cum. }\end{array}$ & 11 & 15 & 19 & 30 & 40 & 44 & 13727 \\
\hline Manufacturing & 7,905 & 3,028 & 3,957 & 4,311 & 661 & 3,125 & 524,288 \\
\hline Light Industry & $\begin{array}{l}12,51 \\
9\end{array}$ & 10,147 & 4,119 & 7,199 & 1,877 & 7,862 & 825,910 \\
\hline Retail-Lodging-Food & $\begin{array}{l}12,07 \\
4\end{array}$ & 9,005 & 2,105 & 3,799 & 1,721 & 5,940 & $1,597,042$ \\
\hline Knowledge & $\begin{array}{l}12,15 \\
6 \\
\end{array}$ & 7,733 & 3,232 & 1,796 & 2,209 & 2,677 & $1,101,103$ \\
\hline Office & $\begin{array}{l}27,39 \\
2\end{array}$ & 48,196 & 6,039 & 11,077 & 6,396 & 7,748 & $1,981,603$ \\
\hline Education & 1,867 & 25,572 & 18,483 & 1,015 & 461 & 2,367 & 689,431 \\
\hline Health & 8,773 & 22,471 & 2,347 & 14,854 & 2,371 & 2,234 & $1,035,329$ \\
\hline Arts-Ent-Rec & 3,896 & 1,099 & 1,232 & 972 & 1,549 & 172 & 185,019 \\
\hline$\underline{\text { Total Jobs }}$ & $\begin{array}{l}86,58 \\
9 \\
\end{array}$ & $\begin{array}{l}127,25 \\
8 \\
\end{array}$ & 41,521 & 45,030 & $\begin{array}{l}17,25 \\
2 \\
\end{array}$ & $\begin{array}{l}32,13 \\
2 \\
\end{array}$ & $7,939,725$ \\
\hline \multicolumn{8}{|c|}{ Economic Change 2010-2016 } \\
\hline Sector Groups & 0.125 & 0.25 & 0.375 & 0.5 & 0.75 & 1 & $\begin{array}{l}\text { Transit } \\
\text { County }\end{array}$ \\
\hline Manufacturing & $(423)$ & $(354)$ & 3,280 & 681 & $(71)$ & 521 & $(76,872)$ \\
\hline Light Industry & 1,067 & $(4,647)$ & 3,436 & 94 & $(578)$ & 931 & $(30,086)$ \\
\hline Retail-Lodging-Food & 756 & $(3,601)$ & 251 & 653 & $(601)$ & 648 & $(16,664)$ \\
\hline Knowledge & 1,017 & $(3,455)$ & 1,062 & $(702)$ & 984 & $(122)$ & 34,442 \\
\hline Office & 4,607 & )$^{(28,264}$ & 3,599 & 3,201 & 700 & 776 & $(35,118)$ \\
\hline Education & $\begin{array}{l}(7,56 \\
8)\end{array}$ & $(886)$ & 3,671 & $(181)$ & 11 & )$^{(1,029}$ & 46,586 \\
\hline Health & 858 & 1,805 & )$^{(2,035}$ & 7,850 & )$^{(2,151}$ & 177 & 105,773 \\
\hline Arts-Ent-Rec & 1,052 & 117 & 1,001 & 214 & 544 & 24 & 3,632 \\
\hline$\underline{\text { Total Jobs }}$ & 1,366 & )$^{(39,285}$ & 14,265 & 11,810 & )$^{(1,162}$ & 1,926 & 31,693 \\
\hline \multicolumn{8}{|c|}{$\begin{array}{l}\text { Percent Economic Change 2010- } \\
2016\end{array}$} \\
\hline Income Groups & 0.125 & 0.25 & 0.375 & 0.5 & 0.75 & 1 & $\begin{array}{l}\text { Transit } \\
\text { County }\end{array}$ \\
\hline Manufacturing & $-5.1 \%$ & $-10.5 \%$ & $\begin{array}{l}483.8 \\
\%\end{array}$ & $18.8 \%$ & $-9.7 \%$ & $20.0 \%$ & $7.5 \%$ \\
\hline Light Industry & $9.3 \%$ & $-31.4 \%$ & $\begin{array}{l}502.3 \\
\%\end{array}$ & $1.3 \%$ & $23.5 \%$ & $13.4 \%$ & $19.9 \%$ \\
\hline Retail-Lodging-Food & $6.7 \%$ & $-28.6 \%$ & $13.5 \%$ & $20.7 \%$ & $-\overline{25.9 \%}$ & $12.2 \%$ & $21.0 \%$ \\
\hline Knowledge & $9.1 \%$ & $-30.9 \%$ & $48.9 \%$ & $-\overline{28.1 \%}$ & $80.3 \%$ & $-4.4 \%$ & $17.1 \%$ \\
\hline Office & $\begin{array}{l}20.2 \\
\%\end{array}$ & $-37.0 \%$ & $\begin{array}{l}147.4 \\
\% \\
\end{array}$ & $40.6 \%$ & $12.3 \%$ & $11.1 \%$ & $0.1 \%$ \\
\hline
\end{tabular}




\begin{tabular}{|c|c|c|c|c|c|c|c|c|}
\hline Education & $\begin{array}{l}- \\
80.2 \\
\%\end{array}$ & $-3.3 \%$ & $24.8 \%$ & $15.1 \%$ & $2.4 \%$ & $30.3 \%$ & \multicolumn{2}{|l|}{$13.7 \%$} \\
\hline Health & $\begin{array}{l}10.8 \\
\%\end{array}$ & $8.7 \%$ & $\begin{array}{l} \\
46.4 \%\end{array}$ & $\begin{array}{l}112.1 \\
\%\end{array}$ & $-\overline{47.6 \%}$ & $8.6 \%$ & \multicolumn{2}{|l|}{$8.3 \%$} \\
\hline Arts-Ent-Rec & $\begin{array}{l}37.0 \\
\% \\
\end{array}$ & $11.9 \%$ & $\begin{array}{l}431.5 \\
\%\end{array}$ & $28.2 \%$ & $54.1 \%$ & $16.1 \%$ & \multicolumn{2}{|l|}{$39.9 \%$} \\
\hline Total Jobs & $1.6 \%$ & $-23.6 \%$ & $52.3 \%$ & $35.5 \%$ & $-6.3 \%$ & $6.4 \%$ & \multicolumn{2}{|l|}{$11.7 \%$} \\
\hline \multicolumn{9}{|c|}{ LQ Trend 2010-2016 (LQ 2016 / LQ 2010) } \\
\hline Sector Groups & 0.125 & 0.25 & 0.375 & 0.50 & 0.625 & 0.75 & 0.875 & 1.00 \\
\hline Manufacturing & 0.97 & 1.22 & 3.98 & 0.91 & 0.94 & 1.00 & 1.89 & 1.17 \\
\hline Light Industry & 1.00 & 0.84 & 3.68 & 0.70 & 0.98 & 0.76 & 0.86 & 0.99 \\
\hline Retail-Lodging-Food & 0.97 & 0.86 & 0.69 & 0.82 & 1.09 & 0.73 & 0.85 & 0.97 \\
\hline Knowledge & 1.02 & 0.86 & 0.93 & 0.51 & 0.78 & 1.84 & 0.76 & 0.86 \\
\hline Office & 1.32 & 0.92 & 1.81 & 1.16 & 1.33 & 1.34 & 0.76 & 1.16 \\
\hline Education & 0.19 & 1.24 & 0.80 & 0.62 & 0.72 & 1.07 & 1.04 & 0.64 \\
\hline Health & 1.12 & 1.47 & 0.36 & 1.61 & 0.75 & 0.58 & 1.44 & 1.05 \\
\hline Arts-Ent-Rec & 1.08 & 1.17 & 2.79 & 0.76 & 0.81 & 1.31 & 0.35 & 0.87 \\
\hline Total Jobs & 1.00 & 1.00 & 1.00 & 1.00 & 1.00 & 1.00 & 1.00 & 1.00 \\
\hline
\end{tabular}

Table 3A.9 BRT Mod MA Transit Station Type Job Dynamics by Economic Group 20102016

Station Share of Shift 2010-2016

\begin{tabular}{|c|c|c|c|c|c|c|c|}
\hline Sector Groups & 0.125 & 0.25 & 0.375 & 0.5 & 0.75 & 1 & $\begin{array}{l}\text { Transit County } \\
\text { Sum } 2016\end{array}$ \\
\hline Urban Square Miles - Increm. & 23 & 38 & 39 & 36 & 61 & 50 & 14201 \\
\hline Urban Square Miles - Cum. & 23 & 61 & 100 & 136 & 196 & 246 & 14201 \\
\hline Manufacturing & 51,349 & 1,867 & 3,492 & 2,849 & 3,617 & 1,374 & 830,769 \\
\hline Light Industry & 51,591 & 6,180 & 7,325 & 5,884 & 6,283 & 1,481 & 818,346 \\
\hline Retail-Lodging-Food & 180,124 & 21,199 & 18,828 & 18,907 & 15,633 & 13,758 & $1,970,975$ \\
\hline Knowledge & 143,145 & 11,936 & 18,985 & 11,360 & 10,612 & 4,580 & $1,309,013$ \\
\hline Office & 198,473 & 18,233 & 9,607 & 16,401 & 20,538 & 17,824 & $2,247,693$ \\
\hline Education & 45,852 & 13,065 & 2,597 & 5,492 & 1,881 & 2,852 & 863,140 \\
\hline Health & 139,041 & 13,094 & 14,562 & 19,393 & 13,687 & 22,467 & $1,464,168$ \\
\hline Arts-Ent-Rec & 16,011 & 1,590 & 2,782 & 890 & 1,901 & 709 & 197,902 \\
\hline Total Jobs & 825,593 & 87,171 & 78,185 & 81,183 & 74,159 & 65,052 & $9,702,006$ \\
\hline \multicolumn{8}{|l|}{ Economic Change 2010-2016 } \\
\hline Sector Groups & 0.125 & 0.25 & 0.375 & 0.5 & 0.75 & 1 & Transit County \\
\hline Manufacturing & $(276,551)$ & $(14,751)$ & $(17,771)$ & $(32,429)$ & $(29,955)$ & $(63,350)$ & $(145,037)$ \\
\hline Light Industry & $(352,266)$ & $(30,361)$ & $(15,256)$ & $(22,252)$ & $(24,641)$ & $(25,580)$ & $(31,845)$ \\
\hline Retail-Lodging-Food & 128,046 & 18,963 & 14,990 & 16,045 & 12,832 & 12,973 & $(9,243)$ \\
\hline Knowledge & 89,196 & 5,904 & 11,387 & 5,261 & 4,555 & 2,638 & 40,655 \\
\hline Office & 19,477 & $(390)$ & $(2,506)$ & 2,243 & 7,043 & 6,379 & 34,291 \\
\hline Education & $(120,853)$ & 949 & $(1,159)$ & $(2,294)$ & $(7,237)$ & $(3,808)$ & 70,350 \\
\hline Health & $(180,593)$ & $(10,213)$ & 2,838 & $(8,911)$ & $(14,998)$ & $(39,558)$ & 194,081 \\
\hline Arts-Ent-Rec & $(92,589)$ & $(3,571)$ & 1,039 & $(3,327)$ & $(2,922)$ & $(4,209)$ & 6,694 \\
\hline Total Jobs & $(786,133)$ & $(33,470)$ & $(6,438)$ & $(45,664)$ & $(55,323)$ & $(114,515)$ & 159,946 \\
\hline \multicolumn{8}{|c|}{ Percent Economic Change 2010-2016 } \\
\hline Income Groups & 0.125 & 0.25 & 0.375 & 0.5 & 0.75 & 1 & Transit County \\
\hline Manufacturing & $-84.3 \%$ & $-88.8 \%$ & $-83.6 \%$ & $-91.9 \%$ & $-89.2 \%$ & $-97.9 \%$ & $-62.2 \%$ \\
\hline Light Industry & $-87.2 \%$ & $-83.1 \%$ & $-67.6 \%$ & $-79.1 \%$ & $-79.7 \%$ & $-94.5 \%$ & $-76.6 \%$ \\
\hline Retail-Lodging-Food & $245.9 \%$ & $846.9 \%$ & $390.3 \%$ & $560.0 \%$ & $457.6 \%$ & $1646.3 \%$ & $153.0 \%$ \\
\hline
\end{tabular}




\begin{tabular}{|c|c|c|c|c|c|c|c|c|}
\hline Knowledge & $165.3 \%$ & $97.8 \%$ & $149.8 \%$ & $86.2 \%$ & $75.2 \%$ & $135.7 \%$ & \multicolumn{2}{|l|}{$79.0 \%$} \\
\hline Office & $10.9 \%$ & $-2.1 \%$ & $-20.7 \%$ & $15.8 \%$ & $52.2 \%$ & $55.7 \%$ & \multicolumn{2}{|l|}{$34.0 \%$} \\
\hline Education & $-72.5 \%$ & $7.8 \%$ & $-30.8 \%$ & $-29.5 \%$ & $-79.4 \%$ & $-57.2 \%$ & \multicolumn{2}{|l|}{$-18.3 \%$} \\
\hline Health & $-56.5 \%$ & $-43.8 \%$ & $24.2 \%$ & $-31.5 \%$ & $-52.3 \%$ & $-63.8 \%$ & \multicolumn{2}{|l|}{$-33.2 \%$} \\
\hline Arts-Ent-Rec & $-85.3 \%$ & $-69.2 \%$ & $59.6 \%$ & $-78.9 \%$ & $-60.6 \%$ & $-85.6 \%$ & \multicolumn{2}{|l|}{$-76.2 \%$} \\
\hline Total Jobs & $-48.8 \%$ & $-27.7 \%$ & $-7.6 \%$ & $-36.0 \%$ & $-42.7 \%$ & $-63.8 \%$ & \multicolumn{2}{|l|}{$-25.2 \%$} \\
\hline \multicolumn{9}{|c|}{ LQ Trend 2010-2016 (LQ 2016 / LQ 2010) } \\
\hline Sector Groups & 0.125 & 0.25 & 0.375 & 0.50 & 0.625 & 0.75 & 0.875 & 1.00 \\
\hline Manufacturing & 0.61 & 0.31 & 0.35 & 0.25 & 2.80 & 0.37 & 0.60 & 0.12 \\
\hline Light Industry & 0.80 & 0.75 & 1.12 & 1.05 & 0.82 & 1.14 & 0.71 & 0.48 \\
\hline Retail-Lodging-Food & 2.00 & 3.88 & 1.57 & 3.05 & 0.20 & 2.88 & 7.53 & 14.26 \\
\hline Knowledge & 2.16 & 1.14 & 1.13 & 1.22 & 0.90 & 1.28 & 0.74 & 2.72 \\
\hline Office & 1.21 & 0.76 & 0.48 & 1.01 & 0.98 & 1.48 & 0.29 & 2.40 \\
\hline Education & 0.49 & 1.37 & 0.69 & 1.01 & 0.53 & 0.33 & 1.69 & 1.08 \\
\hline Health & 0.95 & 0.87 & 1.51 & 1.20 & 1.85 & 0.93 & 1.97 & 1.12 \\
\hline Arts-Ent-Rec & 0.90 & 1.34 & 5.43 & 1.04 & 0.56 & 2.16 & 0.49 & 1.25 \\
\hline Total Jobs & 1.00 & 1.00 & 1.00 & 1.00 & 1.00 & 1.00 & 1.00 & 1.00 \\
\hline
\end{tabular}

Table 3A.10 CRT Mod MA Transit Station Type Job Dynamics by Economic Group 2010-2016 Station Share of Shift 2010-2016

\begin{tabular}{|c|c|c|c|c|c|c|c|}
\hline Sector Groups & 0.125 & 0.25 & 0.375 & 0.5 & 0.75 & 1 & $\begin{array}{l}\text { Transit } \\
\text { County Sum } \\
2016\end{array}$ \\
\hline $\begin{array}{l}\text { Urban Square Miles - } \\
\text { Increm. }\end{array}$ & 9 & 25 & 38 & 47 & 110 & 124 & 41,703 \\
\hline $\begin{array}{l}\text { Urban Square Miles - } \\
\text { Cum. }\end{array}$ & 9 & 33 & 71 & 118 & 229 & 352 & 41,703 \\
\hline Manufacturing & 56,280 & 4,529 & 2,670 & 9,027 & 6,568 & 4,847 & $1,238,634$ \\
\hline Light Industry & 98,084 & 15,083 & 8,152 & 14,963 & 4,444 & 7,566 & $1,621,064$ \\
\hline Retail-Lodging-Food & $\begin{array}{l}177,74 \\
8\end{array}$ & 32,957 & 18,341 & 42,194 & 37,395 & 24,695 & $3,809,507$ \\
\hline Knowledge & $\begin{array}{l}177,44 \\
4\end{array}$ & 23,657 & 11,022 & 41,357 & 15,400 & 18,052 & $2,408,601$ \\
\hline Office & $\begin{array}{l}287,20 \\
8\end{array}$ & 39,049 & 42,845 & 99,171 & 35,839 & 18,951 & $4,199,409$ \\
\hline Education & 62,813 & 8,527 & 4,150 & 19,058 & 7,172 & 14,386 & $1,565,704$ \\
\hline Health & 86,509 & 9,435 & 12,549 & 20,331 & 23,072 & 15,351 & $2,328,226$ \\
\hline Arts-Ent-Rec & 17,991 & 4,204 & 1,802 & 6,800 & 5,162 & 6,429 & 382,686 \\
\hline$\underline{\text { Total Jobs }}$ & $\begin{array}{l}964,08 \\
4 \\
\end{array}$ & $\begin{array}{l}137,44 \\
8\end{array}$ & $\begin{array}{l}101,53 \\
8\end{array}$ & $\begin{array}{l}252,90 \\
8\end{array}$ & \begin{tabular}{|l|}
135,05 \\
9 \\
\end{tabular} & $\begin{array}{l}110,28 \\
4 \\
\end{array}$ & $17,553,831$ \\
\hline \multicolumn{8}{|c|}{ Economic Change 2010-2016 } \\
\hline Sector Groups & 0.125 & 0.25 & 0.375 & 0.5 & 0.75 & 1 & $\begin{array}{l}\text { Transit } \\
\text { County }\end{array}$ \\
\hline Manufacturing & 2,513 & $(1,788)$ & $(372)$ & $(331)$ & 2,092 & $(586)$ & $(199,595)$ \\
\hline Light Industry & 15,577 & $(717)$ & 3,095 & 1,602 & $(200)$ & 780 & $3,183,866$ \\
\hline Retail-Lodging-Food & 19,963 & 1,625 & $(345)$ & 8,939 & 7,720 & 8,019 & 415,822 \\
\hline Knowledge & 32,940 & 701 & $(4,205)$ & 14,219 & 431 & 5,834 & 543,440 \\
\hline Office & $\begin{array}{l}(86,93 \\
5) \\
\end{array}$ & $\begin{array}{l}(32,81 \\
7)\end{array}$ & 1,448 & 10,839 & $(9,414)$ & $(8,409)$ & 331,340 \\
\hline Education & $\begin{array}{l}(41,02 \\
5)\end{array}$ & $(1,257)$ & 219 & 13,279 & $(507)$ & 7,626 & 179,340 \\
\hline Health & 9,792 & $(2,240)$ & 4,891 & 426 & $(2,587)$ & 3,860 & 319,634 \\
\hline Arts-Ent-Rec & (29) & (910) & 196 & 180 & $(180)$ & 1,614 & 304,931 \\
\hline
\end{tabular}




\begin{tabular}{|c|c|c|c|c|c|c|c|}
\hline Total Jobs & $\begin{array}{l}(47,20 \\
4)\end{array}$ & $\begin{array}{l}(37,40 \\
3)\end{array}$ & 4,927 & 49,153 & $(2,645)$ & 18,738 & $5,078,778$ \\
\hline \multicolumn{8}{|c|}{$\begin{array}{l}\text { Percent Economic Change 2010- } \\
2016\end{array}$} \\
\hline Income Groups & 0.125 & 0.25 & 0.375 & 0.5 & 0.75 & 1 & $\begin{array}{l}\text { Transit } \\
\text { County }\end{array}$ \\
\hline Manufacturing & $4.7 \%$ & $-28.3 \%$ & $-12.2 \%$ & $-3.5 \%$ & $46.7 \%$ & $-10.8 \%$ & $8.1 \%$ \\
\hline Light Industry & $18.9 \%$ & $-4.5 \%$ & $61.2 \%$ & $12.0 \%$ & $-4.3 \%$ & $11.5 \%$ & $17.2 \%$ \\
\hline Retail-Lodging-Food & $12.7 \%$ & $5.2 \%$ & $-1.8 \%$ & $26.9 \%$ & $26.0 \%$ & $48.1 \%$ & $23.5 \%$ \\
\hline Knowledge & $22.8 \%$ & $3.1 \%$ & $-27.6 \%$ & $52.4 \%$ & $2.9 \%$ & $47.7 \%$ & $21.8 \%$ \\
\hline Office & $-23.2 \%$ & $-45.7 \%$ & $3.5 \%$ & $12.3 \%$ & $-20.8 \%$ & $-30.7 \%$ & $4.8 \%$ \\
\hline Education & $-39.5 \%$ & $-12.8 \%$ & $5.6 \%$ & $\begin{array}{l}229.7 \\
\%\end{array}$ & $-6.6 \%$ & $\begin{array}{l}112.8 \\
\%\end{array}$ & $4.8 \%$ \\
\hline Health & $12.8 \%$ & $-19.2 \%$ & $63.9 \%$ & $2.1 \%$ & $-10.1 \%$ & $33.6 \%$ & $19.8 \%$ \\
\hline Arts-Ent-Rec & $-0.2 \%$ & $-17.8 \%$ & $12.2 \%$ & $2.7 \%$ & $-3.4 \%$ & $33.5 \%$ & $11.2 \%$ \\
\hline Total Jobs & $-4.7 \%$ & $-21.4 \%$ & $5.1 \%$ & $24.1 \%$ & $-1.9 \%$ & $20.5 \%$ & $14.2 \%$ \\
\hline
\end{tabular}

LQ Trend 2010-2016 (LQ 2016 / LQ 2010)

\begin{tabular}{l|l|l|l|l|l|l|l|l}
\hline Sector Groups & 0.125 & 0.25 & 0.375 & 0.50 & 0.625 & 0.75 & 0.875 & 1.00 \\
\hline Manufacturing & 1.16 & 0.96 & 0.88 & 0.82 & 1.42 & 1.58 & 1.01 & 0.78 \\
\hline Light Industry & 1.22 & 1.18 & 1.49 & 0.88 & 0.79 & 0.95 & 1.24 & 0.90 \\
\hline Retail-Lodging-Food & 1.09 & 1.24 & 0.86 & 0.94 & 1.05 & 1.19 & 1.18 & 1.14 \\
\hline Knowledge & 1.21 & 1.23 & 0.65 & 1.15 & 0.94 & 0.98 & 0.98 & 1.15 \\
\hline Office & 0.88 & 0.75 & 1.07 & 0.98 & 0.86 & 0.88 & 0.98 & 0.63 \\
\hline Education & 0.69 & 1.21 & 1.09 & 2.90 & 0.97 & 1.04 & 0.98 & 1.92 \\
\hline Health & 1.13 & 0.98 & 1.49 & 0.78 & 1.86 & 0.87 & 0.73 & 1.06 \\
\hline Arts-Ent-Rec & 1.08 & 1.07 & 1.10 & 0.85 & 0.67 & 1.01 & 1.15 & 1.14 \\
\hline Total Jobs & 1.00 & 1.00 & 1.00 & 1.00 & 1.00 & 1.00 & 1.00 & 1.00 \\
\hline
\end{tabular}


Table 3A.11 LRT Mod MA Transit Station Type Job Dynamics by Economic Group 20102016

Station Share of Job Shift 2010-2016

\begin{tabular}{|c|c|c|c|c|c|c|c|}
\hline Sector Groups & 0.125 & 0.25 & 0.375 & 0.5 & 0.75 & 1 & $\begin{array}{l}\text { Transit } \\
\text { County Sums } \\
2016\end{array}$ \\
\hline Urban Square Miles - Increm. & 18 & 80 & 61 & 10 & 46 & 172 & 29,669 \\
\hline Urban Square Miles - Cum. & 18 & 98 & 159 & 169 & 215 & 386 & 29,669 \\
\hline Manufacturing & 72,185 & 14,839 & 9,509 & 9,184 & 4,140 & 4,070 & $1,504,975$ \\
\hline Light Industry & 104,258 & 36,949 & 11,079 & 11,060 & 4,763 & 8,270 & $1,842,851$ \\
\hline Retail-Lodging-Food & 263,058 & 46,184 & 48,807 & 37,360 & 18,289 & 34,042 & $3,800,602$ \\
\hline Knowledge & 251,268 & 39,222 & 22,809 & 17,123 & 5,400 & 9,988 & $2,242,526$ \\
\hline Office & 556,074 & 78,022 & 62,169 & 55,012 & 29,933 & 20,464 & $4,609,558$ \\
\hline Education & 141,032 & 33,520 & 11,206 & 10,233 & 11,715 & 13,969 & $1,608,044$ \\
\hline Health & 192,496 & 28,976 & 40,490 & 56,838 & 18,227 & 16,582 & $2,630,962$ \\
\hline Arts-Ent-Rec & 46,901 & 5,855 & 3,504 & 5,083 & 800 & 3,836 & 353,302 \\
\hline Total Jobs & $1,627,279$ & \begin{tabular}{l|l}
283,574 & \\
\end{tabular} & 209,580 & 201,900 & 93,274 & 111,228 & $18,592,820$ \\
\hline \multicolumn{8}{|l|}{ Economic Change 2010-2016 } \\
\hline Sector Groups & 0.125 & 0.25 & 0.375 & 0.5 & 0.75 & 1 & Transit County \\
\hline Manufacturing & $(27,144)$ & 4,782 & 2,239 & $(1,303)$ & 371 & $(763)$ & $(247,069)$ \\
\hline Light Industry & $(83,660)$ & 3,960 & 769 & 252 & $(660)$ & 892 & $(26,098)$ \\
\hline Retail-Lodging-Food & 6,184 & 3,440 & 13,992 & ? 8,299 & $(2,591)$ & 6,749 & 64,894 \\
\hline Knowledge & $(7,340)$ & 7,196 & 1,480 & 1,067 & 293 & 1,854 & 104,140 \\
\hline Office & $(54,259)$ & 5,489 & 11,382 & 3,512 & 10,611 & 768 & 152,352 \\
\hline Education & 11,863 & 22,770 & $(994)$ & $(1,344)$ & $(1,692)$ & 2,846 & 137,537 \\
\hline Health & $(12,563)$ & $(1,934)$ & 6,477 & 6,162 & 3,268 & 7,455 & 378,107 \\
\hline Arts-Ent-Rec & 1,655 & $(1,813)$ & 693 & $(282)$ & $(128)$ & 2,188 & 25,271 \\
\hline Total Jobs & $(165,264)$ & 43,890 & 36,038 & 16,363 & 9,472 & 21,989 & 589,134 \\
\hline \multicolumn{8}{|c|}{ Percent Economic Change 2010-2016 } \\
\hline Sector Groups & 0.125 & 0.25 & 0.375 & 0.5 & 0.75 & 1 & Transit County \\
\hline Manufacturing & $-27.3 \%$ & $47.5 \%$ & $30.8 \%$ & $-12.4 \%$ & $9.8 \%$ & $-15.8 \%$ & $6.2 \%$ \\
\hline Light Industry & $-44.5 \%$ & $12.0 \%$ & $7.5 \%$ & $2.3 \%$ & $-12.2 \%$ & $12.1 \%$ & $13.2 \%$ \\
\hline Retail-Lodging-Food & $2.4 \%$ & $8.0 \%$ & $40.2 \%$ & $28.6 \%$ & $-12.4 \%$ & $24.7 \%$ & $19.2 \%$ \\
\hline Knowledge & $-2.8 \%$ & $22.5 \%$ & $6.9 \%$ & $6.6 \%$ & $5.7 \%$ & $22.8 \%$ & $21.8 \%$ \\
\hline Office & $-8.9 \%$ & $7.6 \%$ & $22.4 \%$ & $6.8 \%$ & $54.9 \%$ & $3.9 \%$ & $10.6 \%$ \\
\hline Education & $9.2 \%$ & $211.8 \%$ & $-8.1 \%$ & $-11.6 \%$ & $-12.6 \%$ & $25.6 \%$ & $4.1 \%$ \\
\hline Health & $-6.1 \%$ & $-6.3 \%$ & $19.0 \%$ & $12.2 \%$ & $21.8 \%$ & $81.7 \%$ & $18.7 \%$ \\
\hline Arts-Ent-Rec & $3.7 \%$ & $-23.6 \%$ & $24.6 \%$ & $-5.3 \%$ & $-13.8 \%$ & $132.7 \%$ & $17.5 \%$ \\
\hline Total Jobs & $-9.2 \%$ & $18.3 \%$ & $20.8 \%$ & $8.8 \%$ & $11.3 \%$ & $24.6 \%$ & $14.0 \%$ \\
\hline
\end{tabular}

\begin{tabular}{|c|c|c|c|c|c|c|c|c|}
\hline Sector Groups & 0.125 & 0.25 & 0.375 & 0.5 & 0.625 & 0.75 & 0.875 & 1 \\
\hline Manufacturing & 1.03 & 0.66 & 0.76 & 1.02 & 0.82 & 0.84 & 1.10 & 1.22 \\
\hline Light Industry & 1.55 & 1.00 & 1.07 & 1.01 & 1.24 & 1.20 & 1.06 & 1.05 \\
\hline Retail-Lodging-Food & 0.87 & 1.08 & 0.85 & 0.83 & 0.91 & 1.25 & 0.95 & 0.98 \\
\hline Knowledge & 0.95 & 0.99 & 1.15 & 1.04 & 1.05 & 1.07 & 1.10 & 1.04 \\
\hline Office & 1.00 & 1.10 & 0.99 & 1.02 & 1.06 & 0.72 & 1.27 & 1.20 \\
\hline Education & 0.88 & 0.40 & 1.40 & 1.31 & 1.84 & 1.35 & 0.70 & 1.05 \\
\hline Health & 1.14 & 1.49 & 1.20 & 1.14 & 0.91 & 1.08 & 0.99 & 0.81 \\
\hline Arts-Ent-Rec & 0.92 & 1.63 & 1.02 & 1.21 & 0.80 & 1.36 & 1.29 & 0.56 \\
\hline
\end{tabular}


Table 3A.12 SCT Mod MA Transit Station Type Job Dynamics by Economic Group 20102016

Station Share of Shift 2010-2016

\begin{tabular}{|c|c|c|c|c|c|c|c|}
\hline Sector Groups & 0.125 & 0.25 & 0.375 & 0.5 & 0.75 & 1 & $\begin{array}{l}\text { Transit County } \\
\text { Sum } 2016\end{array}$ \\
\hline Urban Square Miles - Increm. & 5 & 12 & 10 & 3 & 9 & 25 & 13,727 \\
\hline Urban Square Miles - Cum. & 5 & 16 & 26 & 29 & 38 & 62 & 13,727 \\
\hline Manufacturing & 14,710 & 1,968 & 3,302 & 1,149 & 781 & 1,024 & 524,288 \\
\hline Light Industry & 32,836 & 3,618 & 4,847 & 3,571 & 3,025 & 4,007 & 825,910 \\
\hline Retail-Lodging-Food & 77,747 & 9,509 & 6,223 & 4,672 & 6,580 & 17,658 & $1,597,042$ \\
\hline Knowledge & 123,693 & 13,440 & 9,268 & 2,438 & 3,574 & 24,115 & $1,101,103$ \\
\hline Office & 202,501 & 29,399 & 11,730 & 5,458 & 6,517 & 23,864 & $1,981,603$ \\
\hline Education & 70,981 & 10,458 & 28,729 & 1,404 & 1,029 & 2,140 & 689,431 \\
\hline Health & 57,470 & 26,575 & 16,636 & 12,592 & 2,806 & 8,798 & $1,035,329$ \\
\hline Arts-Ent-Rec & 20,123 & 787 & 960 & 354 & 716 & 1,364 & 185,019 \\
\hline Total Jobs & 600,068 & 95,761 & 81,702 & 31,645 & 25,035 & 82,977 & $7,939,725$ \\
\hline \multicolumn{8}{|c|}{ Economic Change 2010-2016 } \\
\hline Sector Groups & 0.125 & 0.25 & 0.375 & 0.5 & 0.75 & 1 & Transit County \\
\hline Manu & $(3,512)$ & $(2,193)$ & $(1,395)$ & 197 & $(134)$ & 54 & $(76,872)$ \\
\hline dustry & 3,612 & 836 & $(1,497)$ & 1,002 & 95 & $(88)$ & $(30,086)$ \\
\hline odging-Food & 2,143 & 2,265 & 1,394 & $(5)$ & 1,211 & 4,875 & $(16,664)$ \\
\hline ledge & 1,607 & 473 & 1,345 & $(445)$ & 351 & $(175)$ & 34,442 \\
\hline Offi & $(25,139)$ & $(47,050)$ & $(7,680)$ & $(977)$ & $(1,161)$ & $(11,561)$ & $(35,118)$ \\
\hline Ed & $(17,608)$ & 2,903 & 23,687 & $(379)$ & 334 & 1,452 & 46,586 \\
\hline Health & $(17,117)$ & 9,203 & 4,396 & $(2,454)$ & $(75)$ & 550 & 105,773 \\
\hline Arts-Ent-Rec & 1,256 & $(1,161)$ & 420 & 56 & 242 & $(62)$ & 3,632 \\
\hline$\underline{\text { Total Jobs }}$ & $(54,758)$ & $(34,724)$ & 20,670 & $(3,005)$ & 863 & $(4,955)$ & 31,693 \\
\hline \multicolumn{8}{|c|}{ Percent Economic Change 2010-2016 } \\
\hline Income Groups & 0.125 & 0.25 & 0.375 & 0.5 & 0.75 & 1 & Transit County \\
\hline Manufacturing & $-19.3 \%$ & $-52.7 \%$ & $-29.7 \%$ & $20.7 \%$ & $-14.6 \%$ & $5.6 \%$ & $7.5 \%$ \\
\hline Light Industry & $12.4 \%$ & $30.0 \%$ & $-23.6 \%$ & $39.0 \%$ & $3.2 \%$ & $-2.1 \%$ & $19.9 \%$ \\
\hline Retail-Lodging-Food & $2.8 \%$ & $31.3 \%$ & $28.9 \%$ & $-0.1 \%$ & $22.6 \%$ & $38.1 \%$ & $21.0 \%$ \\
\hline Knowledge & $1.3 \%$ & $3.6 \%$ & $17.0 \%$ & $-15.4 \%$ & $10.9 \%$ & $-0.7 \%$ & $17.1 \%$ \\
\hline Office & $-11.0 \%$ & $-61.5 \%$ & $-39.6 \%$ & $-15.2 \%$ & $-15.1 \%$ & $-32.6 \%$ & $0.1 \%$ \\
\hline Educati & $-19.9 \%$ & $38.4 \%$ & $469.7 \%$ & $-21.2 \%$ & $48.0 \%$ & $210.7 \%$ & $13.7 \%$ \\
\hline Health & $-22.9 \%$ & $53.0 \%$ & $35.9 \%$ & $-16.3 \%$ & $-2.6 \%$ & $6.7 \%$ & $8.3 \%$ \\
\hline Arts-Ent-Re & $6.7 \%$ & $-59.6 \%$ & $77.6 \%$ & $18.7 \%$ & $50.9 \%$ & $-4.3 \%$ & $39.9 \%$ \\
\hline Total Jobs & $-8.4 \%$ & $-26.6 \%$ & $33.9 \%$ & $-8.7 \%$ & $3.6 \%$ & $-5.6 \%$ & $11.7 \%$ \\
\hline
\end{tabular}

\begin{tabular}{|c|c|c|c|c|c|c|c|c|}
\hline Sector Groups & 0.125 & 0.25 & 0.375 & 0.50 & 0.625 & 0.75 & 0.875 & 1 \\
\hline Manufacturing & 0.92 & 0.67 & 0.55 & 1.37 & 1.06 & 0.86 & 2.17 & 1.16 \\
\hline Light Industry & 1.14 & 1.65 & 0.53 & 1.42 & 0.58 & 0.93 & 0.97 & 0.97 \\
\hline Retail-Lodging-Food & 1.04 & 1.65 & 0.89 & 1.01 & 0.71 & 1.09 & 1.01 & 1.35 \\
\hline Knowledge & 1.05 & 1.35 & 0.83 & 0.88 & 1.41 & 1.02 & 1.10 & 1.00 \\
\hline Office & 1.08 & 0.58 & 0.50 & 1.04 & 1.27 & 0.91 & 2.08 & 0.80 \\
\hline Education & 0.86 & 1.85 & 4.18 & 0.85 & 1.06 & 1.40 & 0.68 & 3.24 \\
\hline Health & 0.87 & 2.15 & 1.05 & 0.94 & 1.10 & 0.97 & 1.59 & 1.17 \\
\hline Arts-Ent-Rec & 0.93 & 0.44 & 1.06 & 1.04 & 1.05 & 1.16 & 1.54 & 0.81 \\
\hline Total Jobs & 1.00 & 1.00 & 1.00 & 1.00 & 1.00 & 1.00 & 1.00 & 1.00 \\
\hline
\end{tabular}


Table 3A.13 BRT High MA Transit Station Type Job Dynamics by Economic Group 20102016

Station Share of Shift 2010-2016

\begin{tabular}{|c|c|c|c|c|c|c|c|c|c|}
\hline \multicolumn{2}{|l|}{ Sector Groups } & \multicolumn{2}{|c|}{0.125} & 0.25 & 0.375 & 0.5 & 0.75 & 1 & $\begin{array}{l}\text { Transit } \\
\text { County Sum } \\
2016\end{array}$ \\
\hline \multicolumn{2}{|c|}{$\begin{array}{l}\text { Urban Square Miles - } \\
\text { Increm. }\end{array}$} & \multicolumn{2}{|l|}{4} & 7 & 6 & 5 & 8 & 6 & 14,201 \\
\hline \multicolumn{2}{|c|}{$\begin{array}{l}\text { Urban Square Miles - } \\
\text { Cum. }\end{array}$} & \multicolumn{2}{|l|}{4} & 11 & 17 & 22 & 30 & 36 & 14,201 \\
\hline \multicolumn{2}{|l|}{ Manufacturing } & \multicolumn{2}{|c|}{4,986} & 309 & 633 & 1,007 & 196 & 292 & 830,769 \\
\hline \multicolumn{2}{|l|}{ Light Industry } & \multicolumn{2}{|c|}{23,047} & 529 & 3,362 & 296 & 212 & 89 & 818,346 \\
\hline \multicolumn{2}{|c|}{ Retail-Lodging-Food } & \multicolumn{2}{|c|}{93,809} & 11,358 & 13,557 & \begin{tabular}{|l|l|}
57 & 32,258 \\
\end{tabular} & 6,480 & 4,815 & $1,970,975$ \\
\hline \multicolumn{2}{|l|}{ Knowledge } & \multicolumn{2}{|c|}{$\begin{array}{l}101,33 \\
9\end{array}$} & 6,615 & 4,952 & 2,612 & 1,204 & 86 & $1,309,013$ \\
\hline Office & & $\begin{array}{l}131,0 \\
2\end{array}$ & & 7,073 & 3,80 & 4,360 & 1,577 & 1,077 & $2,247,693$ \\
\hline Education & & 15,82 & & 1,128 & 8,206 & 5,883 & 241 & 1,132 & 863,140 \\
\hline Health & & 32,03 & & 15,96 & \begin{tabular}{|l|l}
67 & $1,98 \varepsilon$ \\
\end{tabular} & 1,934 & 865 & 375 & $1,464,168$ \\
\hline Arts-Ent-Rec & & 11,90 & & 413 & \begin{tabular}{|l|l|}
443 \\
\end{tabular} & 258 & 404 & 27 & 197,902 \\
\hline$\underline{\text { Total Jobs }}$ & & $\begin{array}{l}414,0 \\
5 \\
\end{array}$ & & 43,39 & \begin{tabular}{l|l}
99 & 36,9
\end{tabular} & \begin{tabular}{l|l}
48 & 48,615
\end{tabular} & 11,186 & 7,900 & $9,702,006$ \\
\hline Economic Chans & 201 & -2016 & & & & & & & \\
\hline Sector Groups & 0.1 & & 0.2 & 25 & 0.375 & 0.5 & 0.75 & 1 & $\begin{array}{l}\text { Transit } \\
\text { County }\end{array}$ \\
\hline Manufacturing & $(89$ & 048) & \begin{tabular}{|l}
$(14$ \\
$0)$ \\
\end{tabular} & 4,33 & $(2,600)$ & $(2,830)$ & $(1,587)$ & $(211)$ & $(145,037)$ \\
\hline Light Industry & )$^{(15}$ & 311 & & 4,46 & $\begin{array}{l}(19,09 \\
0)\end{array}$ & $(18,300)$ & $(5,578)$ & $(3,158)$ & $(31,845)$ \\
\hline $\begin{array}{l}\text { Retail-Lodging- } \\
\text { Food }\end{array}$ & 89, & & & ,078 & 12,739 & 31,350 & 6,221 & 4,467 & $(9,243)$ \\
\hline Knowledge & 71 & & 5,9 & 969 & 3,354 & 1,387 & 919 & $(129)$ & 40,655 \\
\hline Office & 52 & & & ,040) & $(7,163)$ & $(8,039)$ & $(2,559)$ & $(1,445)$ & 34,291 \\
\hline Education & $(61$ & 299) & & 166) & 4,372 & 3,925 & $(910)$ & 999 & 70,350 \\
\hline Health & $(13$ & 845 & 8,8 & 831 & $(2,596)$ & $(2,124)$ & $(1,219)$ & $(340)$ & 194,081 \\
\hline Arts-Ent-Rec & $(7,5$ & & $(26$ & & $(7,175)$ & $(4,584)$ & 63 & (231) & 6,694 \\
\hline Total Jobs & )$^{(23}$ & 657 & $\begin{array}{l}(10 \\
9)\end{array}$ & & $\begin{array}{l}(18,15 \\
9)\end{array}$ & 785 & $(4,650)$ & $(48)$ & 159,946 \\
\hline Percent Econon & Cha & e 20 & $10-2$ & 2016 & & & & & \\
\hline Income Groups & 0.1 & & 0.2 & & 0.375 & 0.5 & 0.75 & 1 & $\begin{array}{l}\text { Transit } \\
\text { County }\end{array}$ \\
\hline Manufacturing & -94 & & & $7.9 \%$ & $-80.4 \%$ & $-73.8 \%$ & $-89.0 \%$ & $-41.9 \%$ & $-62.2 \%$ \\
\hline Light Industry & -86 & & & $6.5 \%$ & $-85.0 \%$ & $-98.4 \%$ & $-96.3 \%$ & $-97.3 \%$ & $-76.6 \%$ \\
\hline $\begin{array}{l}\text { Retail-Lodging- } \\
\text { Food }\end{array}$ & 200 & $9.1 \%$ & & $14 \%$ & $1551 \%$ & $3441.3 \%$ & $2374.4 \%$ & $1272.6 \%$ & $153.0 \%$ \\
\hline Knowledge & 234 & $6 \%$ & $\begin{array}{l}92 \\
\%\end{array}$ & & $\begin{array}{l}209.6 \\
\%\end{array}$ & $113.0 \%$ & $320.2 \%$ & $-59.4 \%$ & $79.0 \%$ \\
\hline Office & 67. & & & $0.1 \%$ & $-65.3 \%$ & $-64.8 \%$ & $-61.9 \%$ & $-57.3 \%$ & $34.0 \%$ \\
\hline Education & -79 & & & $8.7 \%$ & $\begin{array}{l}114.0 \\
\%\end{array}$ & $200.4 \%$ & $-79.0 \%$ & $745.5 \%$ & $-18.3 \%$ \\
\hline Health & -81 & & $\begin{array}{l}12 \\
\%\end{array}$ & & $-56.6 \%$ & $-52.3 \%$ & $-58.5 \%$ & $-47.5 \%$ & $-33.2 \%$ \\
\hline Arts-Ent-Rec & -38 & & & $8.8 \%$ & $-94.2 \%$ & $-94.7 \%$ & $18.5 \%$ & $-89.5 \%$ & $-76.2 \%$ \\
\hline
\end{tabular}




\begin{tabular}{|c|c|c|c|c|c|c|c|c|}
\hline Total Jobs & $-35.9 \%$ & $-19.3 \%$ & $-33.0 \%$ & $1.6 \%$ & $-29.4 \%$ & $-0.6 \%$ & \multicolumn{2}{|c|}{$-25.2 \%$} \\
\hline \multicolumn{9}{|c|}{ LQ Trend 2010-2016 (LQ 2016 / LQ 2010) } \\
\hline Sector Groups & 0.125 & 0.25 & 0.375 & 0.50 & 0.625 & 0.75 & 0.875 & 1.00 \\
\hline Manufacturing & 0.16 & 0.05 & 0.58 & 0.51 & 0.03 & 0.31 & 0.01 & 1.16 \\
\hline Light Industry & 0.66 & 0.14 & 0.71 & 0.05 & 0.25 & 0.17 & 0.05 & 0.09 \\
\hline $\begin{array}{l}\text { Retail-Lodging- } \\
\text { Food }\end{array}$ & 9.73 & 14.71 & 7.29 & 10.30 & 10.19 & 10.36 & 11.73 & 4.08 \\
\hline Knowledge & 2.18 & 5.29 & 1.93 & 0.88 & 1.13 & 2.49 & 0.93 & 0.17 \\
\hline Office & 1.46 & 0.48 & 0.29 & 0.19 & 0.29 & 0.30 & 0.24 & 0.24 \\
\hline Education & 0.29 & 0.24 & 2.92 & 2.71 & 4.90 & 0.27 & 0.51 & 7.79 \\
\hline Health & 0.33 & 3.11 & 0.73 & 0.53 & 1.75 & 0.66 & 16.34 & 0.59 \\
\hline Arts-Ent-Rec & 3.00 & 2.38 & 0.27 & 0.16 & 0.24 & 5.27 & 0.99 & 0.33 \\
\hline Total Jobs & 1.00 & 1.00 & 1.00 & 1.00 & 1.00 & 1.00 & 1.00 & 1.00 \\
\hline
\end{tabular}

Table 3A.14 CRT High MA Transit Station Type Job Dynamics by Economic Group 20102016

Station Share of Shift 2010-2016

\begin{tabular}{|c|c|c|c|c|c|c|c|}
\hline Sector Groups & 0.125 & 0.25 & 0.375 & 0.5 & 0.75 & 1 & $\begin{array}{l}\text { Transit } \\
\text { County Sum } \\
2016\end{array}$ \\
\hline $\begin{array}{l}\text { Urban Square Miles - } \\
\text { Increm. }\end{array}$ & 1 & 3 & 4 & 5 & 12 & 14 & 41,703 \\
\hline Urban Square Miles - Cum. & 1 & 3 & 7 & 12 & 24 & 38 & 41,703 \\
\hline Manufacturing & 1,297 & 87 & 575 & 625 & 491 & 144 & $1,247,240$ \\
\hline Light Industry & 5,204 & 2,346 & 5,543 & 2,469 & 864 & 627 & $1,699,290$ \\
\hline Retail-Lodging-Food & 15,941 & 6,992 & $\begin{array}{l}16,22 \\
5\end{array}$ & $\begin{array}{l}12,05 \\
1\end{array}$ & 6,361 & 9,170 & $3,752,570$ \\
\hline Knowledge & 32,909 & 6,551 & $\begin{array}{l}24,81 \\
6\end{array}$ & $\begin{array}{l}18,39 \\
1\end{array}$ & 961 & 8,410 & $2,451,350$ \\
\hline Office & 26,550 & 17,445 & $\begin{array}{l}24,94 \\
1\end{array}$ & $\begin{array}{l}18,56 \\
9\end{array}$ & 2,323 & $\begin{array}{l}12,85 \\
1\end{array}$ & $4,147,638$ \\
\hline Education & 10,864 & 700 & 946 & 587 & 616 & 644 & $1,603,407$ \\
\hline Health & 2,913 & 1,484 & $\begin{array}{l}12,16 \\
0\end{array}$ & 9,410 & 9,509 & 2,474 & $2,261,704$ \\
\hline Arts-Ent-Rec & 1,733 & 1,874 & 983 & 558 & 760 & 2,519 & 386,885 \\
\hline Total Jobs & 97,418 & 37,486 & $\begin{array}{l}86,19 \\
6 \\
\end{array}$ & $\begin{array}{l}62,66 \\
7 \\
\end{array}$ & $\begin{array}{l}21,89 \\
2\end{array}$ & $\begin{array}{l}36,84 \\
6 \\
\end{array}$ & $17,550,084$ \\
\hline \multicolumn{8}{|c|}{ Economic Change 2010-2016 } \\
\hline Sector Groups & 0.125 & 0.25 & 0.375 & 0.5 & 0.75 & 1 & $\begin{array}{l}\text { Transit } \\
\text { County }\end{array}$ \\
\hline Manufacturing & 629 & $(57)$ & 37 & 243 & $(140)$ & $(199)$ & 957,803 \\
\hline Light Industry & $(241)$ & 1,642 & $(1,332$ & 703 & 373 & $(476)$ & $4,446,116$ \\
\hline Retail-Lodging-Food & 4,636 & 1,191 & 2,129 & 1,775 & 1,012 & 2,099 & $2,813,637$ \\
\hline Knowledge & 8,123 & 400 & 6,603 & $(220)$ & 194 & $(338)$ & $1,806,586$ \\
\hline Office & $(16,772$ & $(2,649$ & $(5,559$ & $(6,046$ & $(551)$ & 247 & $3,176,861$ \\
\hline Education & $(1,135)$ & 63 & 350 & $(40)$ & (15) & $(301)$ & $1,224,061$ \\
\hline Health & (90) & $(248)$ & 3,152 & 1,795 & 593 & 520 & $1,565,297$ \\
\hline Arts-Ent-Rec & $(132)$ & 1,111 & $(142)$ & 122 & 305 & 2,208 & 570,440 \\
\hline Total Jobs & $(4,982)$ & 1,453 & 5,238 & $(1,668$ & 1,771 & 3,760 & $16,560,801$ \\
\hline
\end{tabular}

Percent Economic Change 2010-2016 


\begin{tabular}{|c|c|c|c|c|c|c|c|}
\hline Income Groups & 0.125 & 0.25 & 0.375 & 0.5 & 0.75 & 1 & $\begin{array}{l}\text { Transit } \\
\text { County }\end{array}$ \\
\hline Manufacturing & $94.0 \%$ & $39.3 \%$ & $6.9 \%$ & $63.4 \%$ & $\begin{array}{l}- \\
22.2 \%\end{array}$ & $-\overline{57.8 \%}$ & $8.9 \%$ \\
\hline Light Industry & $-4.4 \%$ & $232 \%$ & $19.4 \%$ & $39.8 \%$ & $75.8 \%$ & - & $22.8 \%$ \\
\hline Retail-Lodging-Food & $41.0 \%$ & $20.5 \%$ & $15.1 \%$ & $17.3 \%$ & $18.9 \%$ & $29.7 \%$ & $21.7 \%$ \\
\hline Knowledge & $32.8 \%$ & $6.5 \%$ & $36.3 \%$ & $-1.2 \%$ & $25.3 \%$ & $-3.9 \%$ & $24.0 \%$ \\
\hline Office & $-38.7 \%$ & $\begin{array}{l}- \\
13.2 \%\end{array}$ & $\begin{array}{l}- \\
18.2 \%\end{array}$ & $-\overline{24.6 \%}$ & $\begin{array}{l}- \\
19.2 \%\end{array}$ & $2.0 \%$ & $3.5 \%$ \\
\hline Education & $-9.5 \%$ & $9.9 \%$ & $58.6 \%$ & $-6.4 \%$ & $-2.4 \%$ & $\begin{array}{l}- \\
31.8 \%\end{array}$ & $7.3 \%$ \\
\hline Health & $-3.0 \%$ & - & $35.0 \%$ & $23.6 \%$ & $6.7 \%$ & $26.6 \%$ & $16.4 \%$ \\
\hline Arts-Ent-Rec & $-7.1 \%$ & $145 \%$ & $\begin{array}{l}- \\
12.6 \%\end{array}$ & $27.9 \%$ & $66.9 \%$ & $707 \%$ & $12.4 \%$ \\
\hline Total Jobs & $-4.9 \%$ & $4.0 \%$ & $6.5 \%$ & $-2.6 \%$ & $8.8 \%$ & $11.4 \%$ & $14.1 \%$ \\
\hline
\end{tabular}

LQ Trend 2010-2016 (LQ 2016 / LQ 2010)

\begin{tabular}{l|l|l|l|l|l|l|l|l}
\hline Sector Groups & 0.125 & 0.25 & \multicolumn{1}{c}{0.375} & 0.50 & 0.625 & 0.75 & 0.875 & 1.00 \\
\hline Manufacturing & 2.14 & 0.61 & 1.05 & 1.76 & 0.45 & 0.75 & 1.49 & 0.40 \\
\hline Light Industry & 0.93 & 2.97 & 0.70 & 1.33 & 1.02 & 1.50 & 1.96 & 0.47 \\
\hline Retail-Lodging-Food & 1.39 & 1.09 & 1.01 & 1.13 & 2.15 & 1.03 & 0.91 & 1.09 \\
\hline Knowledge & 1.28 & 0.94 & 1.18 & 0.93 & 1.01 & 1.06 & 1.01 & 0.79 \\
\hline Office & 0.71 & 0.92 & 0.85 & 0.85 & 0.57 & 0.82 & 0.98 & 1.01 \\
\hline Education & 1.01 & 1.12 & 1.59 & 1.02 & 1.02 & 0.95 & 1.00 & 0.65 \\
\hline Health & 1.00 & 0.81 & 1.24 & 1.24 & 1.00 & 0.96 & 1.04 & 1.11 \\
\hline Arts-Ent-Rec & 0.99 & 2.40 & 0.83 & 1.33 & 1.22 & 1.56 & 0.44 & 7.36 \\
\hline Total Jobs & 1.00 & 1.00 & 1.00 & 1.00 & 1.00 & 1.00 & 1.00 & 1.00 \\
\hline
\end{tabular}


Table 3A.15 LRT High MA Transit Station Type Job Dynamics by Economic Group 2010-2016

Station Share of Shift 2010-2016

\begin{tabular}{|c|c|c|c|c|c|c|c|}
\hline Sector Groups & 0.125 & 0.25 & 0.375 & 0.5 & 0.75 & 1 & $\begin{array}{l}\text { Transit County Sum } \\
2016\end{array}$ \\
\hline Urban Square Miles - Increm. & 124 & 19 & 56 & 173 & 116 & 17 & 29,669 \\
\hline Urban Square Miles - Cum. & 124 & 143 & 199 & 372 & 488 & 504 & 29,669 \\
\hline Manufacturing & 11,094 & 370 & 842 & 2,704 & 380 & 115 & $1,504,975$ \\
\hline Light Industry & 34,099 & 564 & 8,268 & 5,168 & 367 & 298 & $1,842,851$ \\
\hline Retail-Lodging-Food & 105,545 & 14,973 & 38,251 & 19,669 & 9,839 & 8,616 & $3,800,602$ \\
\hline Knowledge & 134,855 & 7,456 & 13,258 & 7,070 & 1,464 & 1,692 & $2,242,526$ \\
\hline Office & 218,912 & 26,014 & 26,314 & 16,104 & 2,817 & 6,468 & $4,609,558$ \\
\hline Education & 32,000 & 11,428 & 2,332 & 2,968 & 532 & 1,519 & $1,608,044$ \\
\hline Health & 59,060 & 6,969 & 16,947 & 12,297 & 2,627 & 6,408 & $2,630,962$ \\
\hline Arts-Ent-Rec & 18,500 & 2,009 & 1,129 & 572 & 1,341 & 556 & 353,302 \\
\hline Total Jobs & 614,072 & 69,790 & 107,348 & 66,559 & 19,374 & 25,679 & $18,592,820$ \\
\hline \multicolumn{8}{|l|}{ Economic Change 2010-2016 } \\
\hline Sector Groups & 0.125 & 0.25 & 0.375 & 0.5 & 0.75 & 1 & Transit County \\
\hline Manufacturing & $(659)$ & $(14)$ & 71 & 42 & $(110)$ & (993) & $(247,069)$ \\
\hline Light Industry & $(5,376)$ & (29) & 5,707 & 1,578 & $(153)$ & $(75)$ & $(26,098)$ \\
\hline Retail-Lodging-Food & 20,438 & 4,850 & 22,856 & 4,626 & 2,570 & 2,379 & 64,894 \\
\hline Knowledge & 27,572 & 3,095 & 5,630 & $(737)$ & $(10)$ & 935 & 104,140 \\
\hline Office & $(47,363)$ & 6,018 & 8,996 & $(220)$ & $(1,579)$ & 3,278 & 152,352 \\
\hline Education & $(15,499)$ & 655 & 507 & 894 & 197 & 683 & 137,537 \\
\hline Health & 8,709 & 654 & 2,786 & 3,617 & 104 & 790 & 378,107 \\
\hline Arts-Ent-Rec & 5,266 & 1,095 & 102 & 84 & 152 & 541 & 25,271 \\
\hline Total Jobs & $(6,912)$ & 16,324 & 46,655 & 9,884 & 1,171 & 7,538 & 589,134 \\
\hline \multicolumn{8}{|c|}{ Percent Economic Change 2010-2016 } \\
\hline Income Groups & 0.125 & 0.25 & 0.375 & 0.5 & 0.75 & 1 & Transit County \\
\hline Manufacturing & $-5.6 \%$ & $-3.6 \%$ & $9.2 \%$ & $1.6 \%$ & $-22.4 \%$ & $-89.5 \%$ & $8.6 \%$ \\
\hline Light Industry & $-13.6 \%$ & $-4.9 \%$ & $222.8 \%$ & $43.9 \%$ & $-29.4 \%$ & $-20.1 \%$ & $17.8 \%$ \\
\hline Retail-Lodging-Food & $24.0 \%$ & $47.9 \%$ & $148.5 \%$ & $30.7 \%$ & $35.4 \%$ & $38.1 \%$ & $23.0 \%$ \\
\hline Knowledge & $25.7 \%$ & $71.0 \%$ & $73.8 \%$ & $-9.4 \%$ & $-0.7 \%$ & $123.4 \%$ & $26.0 \%$ \\
\hline Office & $-17.8 \%$ & $30.1 \%$ & $51.9 \%$ & $-1.3 \%$ & $-35.9 \%$ & $102.7 \%$ & $14.2 \%$ \\
\hline Education & $-32.6 \%$ & $6.1 \%$ & $27.8 \%$ & $43.1 \%$ & $58.6 \%$ & $81.6 \%$ & $5.2 \%$ \\
\hline Health & $17.3 \%$ & $10.4 \%$ & $19.7 \%$ & $41.7 \%$ & $4.1 \%$ & $14.1 \%$ & $22.3 \%$ \\
\hline Arts-Ent-Rec & $39.8 \%$ & $119.7 \%$ & $9.9 \%$ & $17.2 \%$ & $12.8 \%$ & $3381.3 \%$ & $22.3 \%$ \\
\hline Total Jobs & $-1.1 \%$ & $30.5 \%$ & $76.9 \%$ & $17.4 \%$ & $6.4 \%$ & $41.5 \%$ & $17.5 \%$ \\
\hline
\end{tabular}


LQ Trend 2010-2016 (LQ 2016 / LQ 2010)

\begin{tabular}{l|l|l|l|l|l|l|l|l}
\hline Sector Groups & 0.125 & 0.25 & 0.375 & 0.50 & 0.625 & 0.75 & 0.875 & 1.00 \\
\hline Manufacturing & 1.03 & 0.80 & 0.67 & 0.94 & 0.61 & 0.79 & 2.17 & 0.08 \\
\hline Light Industry & 0.87 & 0.73 & 1.82 & 1.22 & 0.69 & 0.66 & 1.14 & 0.56 \\
\hline Retail-Lodging-Food & 1.20 & 1.08 & 1.34 & 1.06 & 1.08 & 1.21 & 1.06 & 0.93 \\
\hline Knowledge & 1.19 & 1.22 & 0.92 & 0.72 & 0.98 & 0.87 & 1.22 & 1.47 \\
\hline Office & 0.86 & 1.03 & 0.88 & 0.86 & 0.77 & 0.62 & 0.97 & 1.47 \\
\hline Education & 0.76 & 0.91 & 0.81 & 1.36 & 1.20 & 1.66 & 0.68 & 1.43 \\
\hline Health & 1.14 & 0.81 & 0.65 & 1.16 & 1.23 & 0.94 & 0.60 & 0.77 \\
\hline Arts-Ent-Rec & 1.36 & 1.62 & 0.60 & 0.96 & 2.03 & 1.02 & 1.15 & 23.62 \\
\hline Total Jobs & 1.00 & 1.00 & 1.00 & 1.00 & 1.00 & 1.00 & 1.00 & 1.00 \\
\hline
\end{tabular}


Table 3A.16 SCT High MA Transit Station Type Job Dynamics by Economic Group 20102016

Station Share of Shift 2010-2016

\begin{tabular}{|c|c|c|c|c|c|c|c|}
\hline Sector Groups & 0.125 & 0.25 & 0.375 & 0.5 & 0.75 & 1 & $\begin{array}{l}\text { Transit } \\
\text { County Sum } \\
2016\end{array}$ \\
\hline $\begin{array}{l}\text { Urban Square Miles - } \\
\text { Increm. }\end{array}$ & 19 & 4 & 10 & 24 & 18 & 3 & 12,770 \\
\hline $\begin{array}{l}\text { Urban Square Miles - } \\
\text { Cum. }\end{array}$ & 19 & 23 & 33 & 58 & 75 & 79 & 12,770 \\
\hline Manufacturing & 3,446 & 1,392 & 125 & 1,355 & 492 & 39 & 524,288 \\
\hline Light Industry & 18,911 & 2,645 & 392 & 3,000 & 405 & 49 & 825,910 \\
\hline Retail-Lodging-Food & 66,304 & 10,444 & 26,442 & 6,359 & 1,658 & 3,561 & $1,597,042$ \\
\hline Knowledge & 87,348 & 14,051 & 3,075 & 3,114 & 991 & 673 & $1,101,103$ \\
\hline Office & $\begin{array}{l}107,56 \\
2\end{array}$ & 18,331 & 2,837 & 5,798 & 822 & 1,715 & $1,981,603$ \\
\hline Education & 14,962 & 1,034 & 435 & 253 & 258 & 332 & 689,431 \\
\hline Health & 33,059 & $\begin{array}{l}10,61 \\
8\end{array}$ & 1,897 & 6,126 & 268 & 762 & $1,035,329$ \\
\hline Arts-Ent-Rec & 9,063 & 1,062 & 1,080 & 1,648 & 27 & 113 & 185,019 \\
\hline Total Jobs & $\begin{array}{l}340,66 \\
2 \\
\end{array}$ & $\begin{array}{l}59,58 \\
4 \\
\end{array}$ & 36,290 & 27,660 & 4,928 & 7,251 & $7,939,725$ \\
\hline \multicolumn{8}{|c|}{ Economic Change 2010-2016 } \\
\hline Sector Groups & 0.125 & 0.25 & 0.375 & 0.5 & 0.75 & 1 & $\begin{array}{l}\text { Transit } \\
\text { County }\end{array}$ \\
\hline Manufacturing & $(78)$ & 193 & $(78)$ & 766 & 47 & 11 & $(76,872)$ \\
\hline Light Industry & $(1,060)$ & $(444)$ & $(27)$ & 36 & 194 & (61) & $(30,086)$ \\
\hline Retail-Lodging-Food & 9,750 & 842 & 18,103 & 2,363 & 617 & $(828)$ & $(16,664)$ \\
\hline Knowledge & 21,873 & )$^{(1,775}$ & 145 & $(397)$ & 155 & $(324)$ & 34,442 \\
\hline Office & )$^{(35,890}$ & $(6,759$ & 218 & 53 & 75 & 89 & $(35,118)$ \\
\hline Education & $(7,035)$ & (71) & 3 & $(208)$ & 97 & 25 & 46,586 \\
\hline Health & 5,186 & $(264)$ & 139 & 1,497 & $(27)$ & $(412)$ & 105,773 \\
\hline Arts-Ent-Rec & 2,869 & 142 & 483 & 299 & (31) & 4 & 3,632 \\
\hline Total Jobs & $(4,385)$ & )$^{(8,136}$ & 18,986 & 4,409 & 1,127 & )$^{(1,496}$ & 31,693 \\
\hline \multicolumn{8}{|c|}{$\begin{array}{l}\text { Percent Economic Change 2010- } \\
2016\end{array}$} \\
\hline Income Groups & 0.125 & 0.25 & 0.375 & 0.5 & 0.75 & 1 & $\begin{array}{l}\text { Transit } \\
\text { County }\end{array}$ \\
\hline Manufacturing & $-2.2 \%$ & $16.1 \%$ & $-38.2 \%$ & $\begin{array}{l}129.8 \\
\% \\
\end{array}$ & $10.5 \%$ & $37.9 \%$ & $7.5 \%$ \\
\hline Light Industry & $-5.3 \%$ & $-\overline{14.4 \%}$ & $-6.4 \%$ & $1.2 \%$ & $91.5 \%$ & $55.0 \%$ & $19.9 \%$ \\
\hline Retail-Lodging-Food & $17.2 \%$ & $8.8 \%$ & $\begin{array}{l}217.1 \\
\%\end{array}$ & $59.1 \%$ & $59.2 \%$ & $-\overline{18.9 \%}$ & $21.0 \%$ \\
\hline Knowledge & $33.4 \%$ & $-\overline{11.2 \%}$ & $4.9 \%$ & $-11.3 \%$ & $18.5 \%$ & $-\overline{32.5 \%}$ & $17.1 \%$ \\
\hline Office & $-25.0 \%$ & $-\overline{26.9 \%}$ & $8.3 \%$ & $0.9 \%$ & $10.0 \%$ & $5.5 \%$ & $0.1 \%$ \\
\hline Education & $-32.0 \%$ & $-6.4 \%$ & $0.7 \%$ & $-45.0 \%$ & $59.9 \%$ & $8.1 \%$ & $13.7 \%$ \\
\hline Health & $18.6 \%$ & $-2.4 \%$ & $7.9 \%$ & $32.3 \%$ & $-9.1 \%$ & - & $8.3 \%$ \\
\hline
\end{tabular}




\begin{tabular}{l|l|l|l|l|l|l|l}
\cline { 3 - 7 } Arts-Ent-Rec & & & & - & & \\
& $46.3 \%$ & $15.4 \%$ & $80.8 \%$ & $22.1 \%$ & $52.5 \%$ & $3.6 \%$ & $39.9 \%$ \\
\hline Total Jobs & & - & 109.7 & & & - & \\
\hline
\end{tabular}

LQ Trend 2010-2016 (LQ 2016 / LQ 2010)

\begin{tabular}{l|l|l|l|l|l|l|l|l}
\hline Sector Groups & 0.125 & 0.25 & \multicolumn{1}{l}{0.375} & \multicolumn{1}{l}{0.50} & \multicolumn{1}{l}{0.625} & 0.75 & 0.875 & 1.00 \\
\hline Manufacturing & 0.87 & 0.66 & 2.94 & 0.45 & 2.67 & 1.02 & 1.72 & 0.52 \\
\hline Light Industry & 0.99 & 0.98 & 2.14 & 1.12 & 1.61 & 0.65 & 0.68 & 1.76 \\
\hline Retail-Lodging-Food & 0.83 & 0.79 & 0.65 & 0.73 & 0.79 & 0.80 & 0.53 & 1.00 \\
\hline Knowledge & 0.77 & 1.03 & 2.08 & 1.39 & 1.15 & 1.14 & 0.93 & 1.28 \\
\hline Office & 1.28 & 1.17 & 1.89 & 1.15 & 1.32 & 1.15 & 1.68 & 0.77 \\
\hline Education & 1.58 & 1.03 & 2.27 & 2.36 & 1.33 & 0.88 & 8.78 & 0.84 \\
\hline Health & 0.95 & 1.03 & 2.22 & 1.02 & 0.80 & 1.63 & 1.34 & 1.46 \\
\hline Arts-Ent-Rec & 0.69 & 0.78 & 1.19 & 1.00 & 1.75 & 2.80 & 0.82 & 0.82 \\
\hline Total Jobs & 1.00 & 1.00 & 1.00 & 1.00 & 1.00 & 1.00 & 1.00 & 1.00 \\
\hline
\end{tabular}




\section{TRANSIT IMPACTS ON JOBS, PEOPLE AND REAL ESTATE}

Volume 3

Impact on Where People Live Over Time with Respect to Transit Station Proximity Considering Race/Ethnicity and Household Type, and Household Budget by Transit Mode and Place Typology with Implications for Transit and Land Use Planning
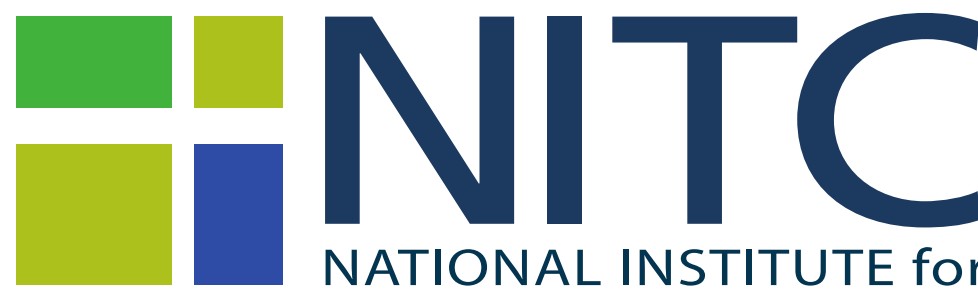

NATIONAL INSTITUTE for TRANSPORTATION and COMMUNITIES 


\section{VOLUME 3 PREFACE}

Transit Impacts on Jobs, People, and Real Estate is the fourth report in a series that started with funding from the National Institute of Transportation and Communities (NITC), a US DOT funded National University Transportation Center. While it completes the "quadrilogy" of work comprising a unique genre of transit and land use planning research it is by no means the last work-it is more likely the foundation for future work.

This document is Volume 3 of five volumes from the full report Transit Impacts on Jobs, People, and Real Estate:

- Volume 1: Orientation, Executive Summary, Context and Place Typologies

- Volume 2: Impact on Job Location Over Time with Respect to Transit Station Proximity Considering Economic Groups by Transit Mode and Place Typology with Implications for Transit and Land Use Planning

- Volume 3: Impact on Where People Live Over Time with Respect to Transit Station Proximity Considering Race/Ethnicity and Household Type and Household Budget by Transit Mode and Place Typology with Implications for Transit and Land Use Planning

- Volume 4: Impact on Real Estate Rents with Respect to Transit Station Proximity Considering Type of Real Estate by Transit Mode and Place with Implications for Transit and Land Use Planning

- Volume 5: Improving Transit Impacts by Reconsidering Design and Broadening Investment Resources

Each of these volumes, and the full report, can be found at https://nitc.trec.pdx.edu/research/project/1253

The genre of research within which four research projects call is grounded in trend that is common throughout all reports: That America is becoming increasingly focused on the need for transit to meet a growing number of social, economic and environmental objectives. But it is also rooted is simple market dynamics.

America will add at least 100 million new residents, 40 million new households, and 60 million new jobs by 2050 . We know from demographic analysis and consumer preference surveys that at least a third of America's 150 million households (50+ million) in 2050 will want to live in locations providing them with transit options, in addition to mixed-use and mixed-housing options. We also know from research on firm location behavior that up to 100 million jobs will be attracted to locations with transit options. Indeed, some research has estimated that even if all new development to 2050 occurred within one-half mile of existing and planned transit stations-such as transit oriented development (TOD) planning areas-the market demand for such development would not be met.

Our prior research outlines the extent to which fixed route transit (FRT) systems can meet future demand. But each system has its own niche. Light rail transit (LRT) systems serve metropolitan wide markets, connecting multiple nodes to each other. Bus rapid transit (BRT) systems can accomplish many of the same objectives as LRT systems at lower cost per mile but also lower capacity-which is fine for the Eugene-Springfield metropolitan area though not necessarily the Portland metropolitan area which, being four times larger and more densely settled, relies on 
LRT. At the lowest scale of operations are street car transit (SCT) systems that serve mostly downtowns such as Seattle or connect employment centers near downtown to downtown such as Portland, Tucson and Dallas. At the other end of the spectrum are commuter rail transit (CRT) systems that are intercity systems that connect cities within a metropolitan area to downtown such as San Diego's Coaster, or multiple metropolitan areas such as the SeattleTacoma Sounder or the Albuquerque-Santa Fe Rail Runner or the Utah Transit Authority's FrontRunner connecting three metropolitan areas.

Here we will summarize the purpose and key findings of each of the three prior reports and then frame the role of the fourth report. 


\section{Do TODs Make a Difference?}

The first report in the Quadrilogy was Do TODs Make a Difference? (Nelson et al. 2015). NITC contracts 547 and 650 were used to build station area databases for 12 light rail transit (LRT) systems, nine bus rapid transit (BRT) systems, four streetcar transit (SCT), and five commuter rail transit (CRT) systems. In this report, we presented research that measures the outcomes of TOD areas in relation to their metropolitan area controls with respect to:

Jobs by sector;

- Housing choice for household types based on key demographic characteristics;

- Housing affordability based on transportation costs; and

- Job-worker balance as a measure of accessibility.

Prior literature has not systematically evaluated TOD outcomes in these respects with respect to light rail transit (LRT), commuter rail transit (CRT), bus rapid transit (BRT), and streetcar transit (SCT) systems. Our analysis helps close some of these gaps. We applied our analysis to 23 fixed guideway transit systems operating in 17 metropolitan areas in the South and West that have one or more of those systems. We found:

- Most TOD areas gained jobs in the office, knowledge, education, health care and entertainment sectors, adding more than $\$ 100$ billion in wages capitalized over time;

- In assessing economic resilience associated with LRT systems, jobs continued to shift away from TOD areas before the Great Recession, the pace slowed during the Recession, but reversed during recovery leading us to speculate that LRT TOD areas may have transformed metropolitan economies served by LRT systems;

- Rents for offices, retail stores and apartments were higher when closer to SCT systems, had mixed results with respect LRT systems, but were mostly lower with respect to CRT systems (our earlier BRT sample size was too small to evaluate);

- SCT systems performed best in terms of increasing their TOD area shares of metropolitan population, households and householders by age, housing units, and renters with BRT systems performing less well while LRT and CRT systems experienced a much smaller shift in the share of growth;

- Household transportation costs as a share of budgets increase with respect to distance from LRT transit stations to seven miles suggesting the proximity to LRT stations reduces total household transportation costs;

- Emerging trends that may favor higher-wage jobs locating in transit TOD areas over time than lower or middle wage jobs perhaps because TOD areas attract more investment which requires more productive, higher-paid labor to justify the investment; and

- The share of workers who commute 10 minutes or less to work increases nearly one-half of one percent for each half-mile their resident block group is to an LRT transit station, capping at a gain of 1.3 percent, which is not a trivial gain.

This work identified a missing element of research relating to one of the fastest growing modes of fixed route transit systems: Bus rapid transit (BRT). That led to a second NITC-funded project. 


\section{National Study of BRT Development Outcomes}

The second report was the nation's largest and most comprehensive assessment of the influence of bus rapid transit (BRT) systems on jobs, people and households, and real estate rents (Nelson and Ganning 2016).

Public transit systems are often promoted as offering a plethora of social, economic and environmental benefits to urban populations by transforming urban forms from auto-centric designs into more sustainable ones. The "next big thing" in public transit is bus rapid transit (BRT) systems. From virtually no systems a generation ago, there are now nearly 20 lines operating with at least seven under construction and more than 20 in the planning stages. Part of this recent popularity in BRT stems from its more affordable capital investment costs and its potential to be utilized by municipal planning organizations as an economic development tool. Yet, research into development outcomes associated with BRT station/stop proximity is small. This study found:

- For metropolitan counties with BRT systems, (0.50-mile) transit corridors increased their share of new office space by a third, from 11.4 percent to 15.2 percent and although new multifamily apartment construction was small, its share more than doubled since 2008;

- BRT station areas gained share of central county jobs at a faster pace or even at the expense of the rest of the central county and that more technologically advanced BRT systems may contribute to positive economic development outcomes;

- However, when disaggregating data to sectors, BRT is found to influence employment change in only one sector-manufacturing though that sector is broad and includes such activities as assembly, food processing (think beer making) and fashion design;

- Evidence of an office rent premium for location within a BRT corridor for most albeit not all of the metropolitan areas studied;

- Household transportation costs as a share of budgets increase with respect to CBD distance to about 19 miles and about eight miles with respect to BRT stations;

- Before the recession, the shift in jobs for all wage groups was about the same between BRT station areas and counterfactual locations but during recovery, BRT station areas saw larger shifts compared to counter-factual locations for lower-wage but upper-wage jobs had the largest change share in BRT station areas during recovery while the share of lower-wage jobs in BRT station areas fell; and

- There is little difference in BRT study area performance compared to their metropolitan areas in terms of influencing population and residential patterns though we did find indirect evidence that BRT systems choosing higher-quality design and technology options tended to enjoy better population and housing outcomes than those that chose lesser options.

We conclude that, on the whole, BRT systems are associated with positive development and job location outcomes, though not necessarily population or housing outcomes. By the time this study was completed more robust data had become available allowing for updates and expansions of prior work, which led to the third grant in this genre. 
The Link between Transit Station Proximity and Real Estate Rents, Jobs, People and Housing with Transit and Land Use Planning Implications

This report updates and expands prior research in the genre of research that has used economic base analysis (especially shift-share) and CoStar commercial rent data to estimate the development outcomes to transit (Nelson and Hibberd 2019). The study period for prior economic base analysis was 2002-2011 and census data for 2000 and 2010, as well as CoStar data for 2013. This report expands the number of systems used in analysis to 17 LRT systems, 14 BRT systems, nine SCT systems and 12 CRT systems. It also expands the period of analysis to 2015 for jobs-related data, 2016 for census data, and 2018 for CoStar data. The expanded and updated databases allow for more comprehensive assessment of their outcomes. Key findings include:

- Market rents increase with respect to Fixed Guideway Transit (FGT) station proximity for nearly all commercial types and for all modes, except there no rent premium for BRT in the closet $(0.125$ mile $)$ distance band and office responds positively only within the closets ( 0.125 mile) distance band from LRT stations, with rent premiums extend one to two miles away from FGT stations for many commercial types;

- On the whole, more mature Fixed Guideway Transit (FGT) system saw gains in regional share of jobs in closer in ( 0.25 mile and 0.50 mile) distance bands if not up to the 1.00 mile distance band from transit stations-BRT being an exception in gaining share only in the nearest ( 0.25 mile) distance band- while ones build during and since the Great Recession saw small or negative shifts in regional share;

- There are only modest gains in the regional share of population and housing before/during the Great Recession (2000-2009) bit somewhat more gains afterward (2010-2016) for all transit types except BRT with larger gains associated with households without children and early/middle aged households (35-49); and

- For the most part for all transit modes saw reductions in regional share of driving alone and carpooling, and increases in regional share of transit, biking, walking, and working at home with respect to FGT station proximity.

The report also featured illustrations of "good, bad and ugly" transit station/stop planning and design, suggesting that systems may be underperforming because of these limitations.

A missing element of prior work was the milieu or type of place within which transit stations are located. Addressing this is the key purpose of this report (Nelson, Hibberd and Currans 2021). 
Transit Impacts on Jobs, People and Real Estate

This is the fourth report in the genre of research supported by NITC. This project entailed updating data and disaggregating it to assess outcomes based on station area types or what we call Place Typologies. This research is guided by two overarching questions and analytic contexts:

\begin{abstract}
How do Transit Development Outcomes Vary by Mode and Place Typology? This analysis includes each transit system for each metropolitan area studied during appropriate time periods for that system, as well as systems combined across metros. Trends that are assessed include: (1) Changes in the number and share of jobs by sector with respect to type of system and distance from stations, by type of station based on Place Typology; (2) Changes in the number and share of jobs by wage category with respect to transit mode and station proximity by Place Typology; and (3) Changes in number and share of population, households, householders by age, and housing by tenure with respect to transit mode, station proximity, and Place Typology.
\end{abstract}

\title{
How does the real estate market for office, retail and apartment properties respond to proximity to transit stations by mode and Place Typology? Our prior
} work pioneered the use of CoStar commercial rental data for very broad assessments of real estate market responsiveness to transit by type but not really by location except for corridor distance bands. The new research conducts more refined relationships in those metropolitan areas based on mode and Place Typology where CoStar data are sufficient for analysis.

In addition, we updated our complete database with a codebook for anyone to access through NITC.

\section{References}

Nelson, Arthur C., Matt Miller, Dejan Eskic, Keuntae Kim, Joanna P. Ganning, Reid Ewing, Jenny Liu, Matt Berggren, Zakari Mumuni (2015). Do TODs Make a Difference? Portland OR: Portland State University, National Institute for Transportation and Communities Final Report NITC-RR-547 and NITC-RR-763. Available along with related materials at https://nitc.trec.pdx.edu/research/project/547/Do_TODs_Make_a_Difference?

Nelson, Arthur C. and Joanna P. Ganning (2016). National Study of BRT Development Outcomes. Portland OR: Portland State University, National Institute for Transportation and Communities Final Report 650. Available along with related materials at http://nitc.trec.pdx.edu/research/project/650

Nelson, Arthur C. and Robert Hibberd (2019). The Link between Transit Station Proximity and Real Estate Rents, Jobs, People and Housing with Transit and Land Use Planning Implications. Portland OR: Portland State University, National Institute for Transportation and Communities Final Report 1103. Available along with related materials at https://nitc.trec.pdx.edu/research/project/1103.

Nelson, Arthur C., Robert Hibberd and Kristian Currans with Nicole Iroz-Elardo (2021). Transit Impacts on Jobs, People and Real Estate, five volumes. Portland OR: Portland State University, National Institute for Transportation and Communities Final Report 1253. Available along with related materials at https://nitc.trec.pdx.edu/research/project/1253. 


\section{SYNOPSIS FOR VOLUME 3}

This Volume explores numerous ways in which transit station proximity affects the location of people and households over time based on their race/ethnicity, householder age, household type, and commute mode. Analyses are reported by mode and Place Typology. It also includes analysis of the extent to which household transportation costs are reduced with respect to LRT station proximity and the nature of cost change over time.

\section{Households by Type-HHs with children, 2 or more adult HHs without children, single person households (Chapter 5)}

LRT station areas accounted for more than 10 percent of their transit region's growth in households with nearly all of that occurring in Moderate and Low MA places. We surmise High MA places are dominated by high rent office and residential real estate. One important surprise is that households with children accounted for nearly 30 percent of the change in total households within one-half mile of LRT transit stations. Planners and real estate developers may have unwittingly underestimated this niche of demand for LRT station proximity. In contrast, households with children were clearly not attracted to SCT station proximity and to some extent have been repelled, while nearly all the change occurred among households without children with about half of them being single person households. However, BRT stations attracted the largest number of total households and more than a third of their combined transit regions' share of all household change, occurring in High-, Moderate- and Low-MA places with the largest share among them being in Moderate-MA places. For their part, CRT station proximity within one-half mile repelled households in Moderate-MA places with only weak changes among the others, though individual metropolitan areas gained considerable share, such as San Diego.

\section{Households by Householder Age-under 25, 25-44, 45-65, 65 or more (Chapter 5)}

Across all Place Typologies, the number of households with householders under 25 years of age fell within one-half mile of LRT, SCT and BRT stations. This is consistent with overall trends on those transit regions. Likewise, householders under 25 years of age fell within one-half mile of CRT stations despite substantial growth in that age group. The middle age groups (25-44 and 45-64) added a total of nearly 200,000 households living within one-half mile of LRT and BRT stations among High-, Moderate- and Low-MA places in the transit regions we studied; however, the share of such households relative to their regions fell. Conventional wisdom suggests that middle aged households prefer larger homes and yards, and places to raise children over transit station proximity. On the other hand, we know from survey research by credible real estate organizations that about half of those households prefer to live near transit stations even if that means trading off house and lot size. The implication for planners and real estate developers is that demand among middle aged households for locations near transit stations is not being met.

\section{Transit Proximity and Transportation Mode Choice for Commuting (Chapter 5)}

Between 2010 and 2016 there was an increase among households living near transit stations to drive to work along with a decrease among those who carpooled. That can be considered bad news. However, for most transit modes in most places within one-half mile, the share of workers using transit, walking or biking to work or working at home soared relative to their 2010 base. 
The exceptions to this trend are BRT systems in all but High-MA places and CRT systems for High- and Moderate-MA places.

\section{The Link between Transit Station Proximity and Typology and Change in People by Demographic Groups Over Time (Chapter 6)}

Chapter 5 shows that while householders between 25-44 years of age dominated the change in households near most transit stations for most modes and in most places. Chapter 6 shows that White-Alone (those who self-designate as White on census forms) and White Non-Hispanic (those Whites who do not also self-designate as Hispanic or Latino on census forms) tend to dominate the race/ethnicity of those who locate near transit stations for nearly all modes and especially in High- and Moderate-MA places. This may be evidence of gentrification as older householders tend to have higher incomes than younger ones, as well as displacement if total population declines near stations especially among non-White persons. Our research thus suggests new avenues of exploration.

\section{The Link between Transit Station Proximity, Place Typology and Transportation Costs Incurred by Household Types (Chapter 7)}

Without evidence, there is the assumption that transportation costs as a share of household budgets increases with respect to distance from downtowns, freeway interchanges, and transit such as light rail transit (LRT) stations. We evaluate the association between median household transportation costs and distance from stations using the 2008-2012 and 2012-2016 American Community Survey (ACS). We find clear associations between LRT station proximity and lower household transportation costs for both periods suggesting increasing transportation savings over time. We also find important differences in transportation costs incurred by different households with respect to the type of urban place in which they live and proximity to LRT stations. While not surprising intuitively, social equity issues arise especially with respect to higher income households better more able than lower income ones to compete for locations near transit stations because they are better able to afford housing prices and rents that capitalize transportation costs savings into higher prices and rents. 


\section{CHAPTER 5: The Link between Transit Station Proximity and Place Typology with Change in Households, Housing tenure and commuting choice Over Time}

\section{OVERVIEW}

Our research expands upon previous work by assessing the extent to which households are attracted to transit stations over time. Households are classified by several salient characteristics, including household type, householder age, and housing tenure. Station areas are assessed by transit mode, such as light rail, and by station typology. The types are characterized as lying somewhere along a continuum from urban core to suburban. These types are based upon the relative intensity a combination of jobs, households, and the built environment. The analysis will advance the understanding of how transit stations effect the pattern of household residence in a multimodal transportation system context, how commuters respond to transit proximity, what transportation modes seem to complement each other, and what demographics may be in competition for transit station proximity. Also evident from the study will be which transit modes in which place types (from low to high land use intensity, mix, and accessibility) are repelling or attracting population to the transit station and beyond to 1 mile.

\section{Introduction}

People respond to transit proximity in their housing and commuting choices very differently depending upon the local context. Transit expansion in the United States is limited by the scant funding assigned to it as a percentage of total transportation infrastructure outlays. Meanwhile, the gas tax, a main source of transportation infrastructure funding, has not been raised for many years, even as the need to fix old bridges and other infrastructure continues with insufficient attention from policymakers (Sanchez, Shen, and Peng 2004; Sanchez 2007). Congestion grows apace in the urban core as many commuters put up obstructions to the needed funding for maintenance and updating of our transportation infrastructure. This underscores the limits of the "mobility turn" as an answer to society's need for access to needed land uses, as well as the growing need for a "proximity turn," in which more theorists and decision makers will advocate for increased land use efficiency and multimodal transportation infrastructure (Sheller and Urry 2006; Ewing 1997).

Transit infrastructure is at the theoretical center of the "proximity turn," as it facilitates and supports more efficient land uses connected by more multimodal transportation infrastructure. Increases in efficiency may result in benefits such as the reduction of the "spatial mismatch" between suburban jobs and urban housing (Kain 1992), decreases greenhouse gases emissions and automobile exhaust pollution in the city (Calthorpe 2011), increases public space in which people can interact with their communities (Calthorpe and Fulton 2001), and provides more opportunities for people to use active transportation (Moniruzzaman et al. 2013). The Missing Middle housing has advocates that argue that the overlooked condominiums and quadplexes of the residential real estate market would make a ready contribution to efforts at greater land use and transportation efficiency (e.g., reduction of vehicle miles traveled), as well as affordability and climate health (Parolek 2020).

Land use efficiency is a central focus of current planning literature. Transit systems allow much more efficient land use for transportation infrastructure and support the expansion of 
agglomeration economies that strengthen city business networks and provide innovation and job opportunities (Spieler 2018; Nelson et al. 2015; Meijers, Burger, and Hoogerbrugge 2015). The Alonso-Mills-Muth urban land use model (AMM) postulates that the CBD contains all jobs while all residents live outside the CBD and commute into the center of the region (Alonso 1964; Mills 1972; Muth 1969). Transit systems can be modeled similarly by relaxing the assumption that all jobs are at the center, and by treating each transit station as itself a miniature center of economic gravity to which the market will respond by competing for scarce land resources at or near the station to capture the benefit of greater local and regional accessibility, on which agglomeration economies - the benefits the economy gains in lower transportation costs and other related efficiencies-thrive.

\section{Research Question and Design}

This chapter's research will be guided by the following research question:

\section{Relative to the counties within which transit systems operate ("transit counties"), are there shifts in the regional share of people and housing over time with respect to FRT station proximity, particularly with respect to change in: Households by age, Households by commuting choice, Households by type and tenure?}

\section{Research Design and Plan}

Our research design and plan include using GIS data and analyses to join transit stations and buffers, representing eighth-mile distance bands around each station, to a layer of land use intensity. These data allow the segmentation of the station areas, their environs, and their regions into relative land use mix and intensity. We call these place types. US census data provide job figures over time by sector, income, and other categorizations. Economic base analysis is used to analyze the shift in share and relative local concentration of jobs near the station viz-a-vis the transit-served region surrounding the study transit systems.

\section{Data Resources}

The employment data come from the US Census Bureau's Longitudinal Employer-Household Dynamics data (LEHD) for 2010 and 2016. Transit system data come from the General Transit Feed Specification (GTFS). ${ }^{104}$ Census blocks were downloaded from IPUMS HGIS website (\#\#). Station typology data are outlined below.

\section{Shift-Share Method}

Economic development is often analyzed using economic base theory and measures spatial concentrations of jobs by sector or other segmentations, as well as their spatial and temporal dynamics. Shift-share analysis compares change of employment concentrations at the "regional" level, which is defined by the analyst at a chosen scale (e.g., national, state, or county), with changes in concentrations at the "local" level, which can also be defined at various scales by the analyst. The study assigns "transit-served" counties as regions (those counties with access to a transit system) and assigns transit neighborhoods as the "local" scale. The transit neighborhoods are further segmented into distance bands away from the station, in increments of one-eighth or one-quarter mile, up to a distance of 1 mile from the transit station

${ }^{104}$ See TransitFeeds.com for downloadable data sets. 
centroid. The analytic method isolates the various sources of job change into 3 categories: 1) the Transit Region share, which references overall economic dynamics at the regional scale 2) the Demographic Mix, which accounts for job dynamics as a result of change in a specific industry, and 3) FRT Station Shift, also called the "competitive effect," which measures the degree of change at the local spatial scale of the transit station neighborhood. It is a measure of the station's lagging and leading job sectors by isolating station area economic trends from those at the regional scale, and from other factors. The shift-share formula is as follows (Carnegie Mellon n.d.):

Where:

$$
S S_{i}=T R_{i}+D M_{i}+F R T_{i}
$$

$$
\begin{aligned}
& S S_{i}=\text { Shift-Share } \\
& T R_{i}=\text { Transit Region share } \\
& D M_{i}=\text { Demographic Mix } \\
& F R T_{i}=\text { FRT Station Shift }
\end{aligned}
$$

Each component is calculated with the following equations:

$T R=\left({ }_{\mathrm{i}} \mathrm{FRT}\right.$ Station Area $\left.{ }^{\mathrm{t}-1} \times \mathrm{TR}^{\mathrm{t}} / \mathrm{TR}^{\mathrm{t}-1}\right)$

$D M=\left[\left(\mathrm{i} F R T\right.\right.$ Station Area $\left.\left.{ }^{\mathrm{t}-1} \mathrm{x}_{\mathrm{i}} \mathrm{TR}^{\mathrm{t}} \mathrm{i}_{\mathrm{i}} \mathrm{TR}^{\mathrm{t}-1}\right)-\mathrm{TR}\right]$

$F R T=\left[{ }_{i}\right.$ FRT Station Area ${ }^{\mathrm{t}-1} \times\left({ }_{\mathrm{i} F R T}\right.$ Station Area ${ }^{\mathrm{t}} / \mathrm{i}$ FRT Station Area $\left.\left.{ }^{\mathrm{t}-1}-\mathrm{i}_{\mathrm{i}} \mathrm{R}^{\mathrm{t}} / \mathrm{iTR}^{\mathrm{t}-1}\right)\right]$

Where:

iFRT Station Area $=$ number of jobs in the FRT Station Area sector (i) at the beginning of the analysis period $(\mathrm{t}-1)$

${ }_{\text {iFRT Station Area }}{ }^{\mathrm{t}}=$ number of jobs in the FRT Station Area in sector (i) at the end of the analysis period $(\mathrm{t})$

$\mathrm{TR}^{\mathrm{t}-1}=$ total number of jobs in the Transit Region at the beginning of the analysis period(t-1)

${ }_{i T R}{ }^{t}=$ total number of jobs in the Transit Region at the end of the analysis period (t)

$\mathrm{iTR}=$ number of jobs in the Transit Region in sector (i) at the beginning of the analysis period (t-1)

$\mathrm{iTR}^{\mathrm{t}}=$ number of jobs in the Transit Region in sector (i) at the end of the analysis period $(\mathrm{t})$

\section{Location Quotients}

Location Quotients (LQ) provide a spatial concentration measure that compares local concentrations of phenomena with a regional or global concentration of the same phenomena. For this study, transit station areas by eighth-mile distance bands provide the local context, while "transit-served counties," or counties and groups of counties that are served by transit systems, provide the regional context. LQ metrics, along with shift-share analyses, are a proven methodological staple of economic development studies. The effectiveness of these methodologies at providing evidence of economic development highlight the spatial nature of the economy. Transit systems serve to provide network connectivity across local economies, connecting the geographies highlighted by these methodologies. 


\section{Transit Station Typology - Place Types}

To evaluate by place types, we aggregate the following built environment variables to the census block group, and then apply a data clustering method:

Longitudinal Employer-Household Dynamics (LEHD, 2017)

- Total jobs per acre

- Proportion of jobs that are retail or entertainment

American Community Survey (ACS, 2017, 5-year)

- Total residential population per acre

- Total households per acre

- Proportion of households with no kids (representing smaller dwelling units)

- Proportion of households that are owner occupied

Smart Location Database ${ }^{105}$

- Intersection density (an indication of connectivity)

- Proportion of intersections that are three-way to those that are four-way (an indication of connectivity)

We apply Jenks natural breaks to each variable to segment the spectrum of variables. Each "break" is ranked in terms of the urban intensity of the categories. The lowest density category has a score of 1 , while the highest has a 5 . The sum of these rankings, summing all variables together, provides an indication of the level of urban intensity and concentration for each block group. The sum of rankings is then divided into the number of categories of interest. For this study, we aggregated the place types into four categories labeled from $1=$ most suburban to $4=$ highly urban. An iterative verification process rotated between testing variables and groundtruthing them through spatial mapping and observations using Google Streetview.

We allocate jobs by sector groups based upon NAICS classifications, and group jobs by wage based upon the salary levels of each sector. This current chapter focuses on economic development outcomes by job sector groups, while a subsequent chapter will consider outcomes by job wage groupings.

${ }^{105}$ See https://www.epa.gov/smartgrowth/smart-location-mapping. Accessed 11-25-2020. Note that while this data is older, intersection density is not something that widely changes from decade to decade in most of the areas that are already developed enough to have FRT. 


\section{Results and Discussion}

Three sections comprise the results below: 1) the household type, including age and household size, 2) housing tenure by vehicle presence, and 3) commuting choice. Each population segment responded differently at different transit stops by transit mode and place type. Most of the growth occurred at the station, but some stations repelled certain population segments.

Tables provide summed data for all "transit-served" counties of MSAs, summed into a group for each transit mode and place type. Appendix F includes results for individual MSAs by transit mode and place type.

\section{Households by Type and Householder Age}

\section{For BRT}

- Poor MA place types incurred declines in growth at each DB from the station to a halfmile distance. Total household trend was a cumulative loss of 9,000 . Households with Children declined in growth by $82 \%$ at the half-mile DB but gained the largest share for this household type at the station. Households with householders of age 25 to 44 also experienced large rates of decline, at $63 \%$ cumulative at the half-mile DB.

- Low MA place types, total households gained nearly 21,000. Cumulative growth of Householders age 25 to 44 was significant, capturing $57 \%$ of total household growth. Householders under 25 declined nearly 5,000 , at a rate of $11 \%$ of total decline at the half-mile DB.

- Mod MA place types, 62,000 households moved to the cumulative half-mile DB while Householders age 25 to 44 declined by $15.5 \%$ relative to the regional trend but at the same time capturing $59.2 \%$ of the station-area growth. While the transit region lost population in the 64-plus age group, the transit station cumulatively gained, and captured $23 \%$ of station-area growth.

- High MA place types gained 13,000 households. Households with children gained 5,450 households, a $6.8 \%$ rate of capture of the regional growth. This increase accounted for $40.6 \%$ of the growth cumulatively at the half-mile DB. Householders under 25 declined while Householders 25-44 gained considerable share.

\section{For CRT}

- Poor MA place type stations gained nearly 10,000 households to the half-mile radius from the station. At the same time, they elicited declines in growth at each DB from the station to a half-mile distance. Households with Children declined in growth by $82 \%$ at the half-mile DB. Households with householders of age 25 to 44 also experienced large rates of decline, at $63 \%$ cumulative at the half-mile DB.

- Low MA place types added nearly 8,000 households. They gained households with children at the half-mile radius. They gained 4,000 householders under 25 . One-person households and householders age 65 or above gained considerable share at the cumulative half-mile radius.

- Mod MA place types declined in total households by 27,000 which is a $5 \%$ share of the transit counties. Every household type lost numbers at the half-mile radius. This suggests a strong competitive edge held by non-housing land uses, which may be outcompeting households for space near these stations.

- High MA place types gained 2,400 households. Household types that gained share did so with very modest rates. Householders age 25-44 gained at the highest rate. 


\section{For LRT}

- Poor MA place types lost share of population. Growth at each DB from the station to a half-mile distance. Households with Children declined at the highest rate of $-2 \%$. Householders age 65 or above gained $3.8 \%$ of regional share.

- Low MA place types had a 4\% increase in households $(31,000)$. Growth for the various household types was robust at this place type. Householders age 65 and over gained at the largest rate, $17 \%$, growing at a rate $43 \%$ that of total households.

- Mod MA place types gained total households at $5 \%$ rate, capturing 41,400 of the region's 841,000 -strong household increase.

- High MA place types grew by $2 \%$ to capture 15,600 households of the 841,000 total households. Householders age $25-44$ grew significantly at the station while these households declined at the regional level. Householders under 25 lost significant population share while all other household types gained share at this station place type.

\section{For SCT}

- Poor MA place types did not occur for SCT transit stations in the first DB (0.125 mile). Change at this place type was miniscule for SCT systems.

- Low MA place types gained modest additional numbers of households, at less than $1 \%$ growth. Households with children took advantage of this place type, with a growth rate of $10 \%$ of regional share. Householders age 65 and over also grew at a rate of $9 \%$ of regional growth of this household type. Incremental rates of growth were small.

- Mod MA place types gained 2.2\% rate growth for the total population. Households with children and householders under 25 moved away while still gaining regional share of their household type at the station area. Two-plus adult households with no children captured $5 \%$ of the regional share in growth while growing at a rate of $77 \%$.

- High MA place types grew nearly 11,000 households, which is $5 \%$ of 225,000 at the regional level. One-person households captured $3 \%$ of the regional growth in that household type, $47 \%$ as fast as the total population. Householders 25 to 44 declined significantly at the cumulative half-mile DB. This occurred while all other household types gained from 3 to $6 \%$ of their regional shares of the population. 


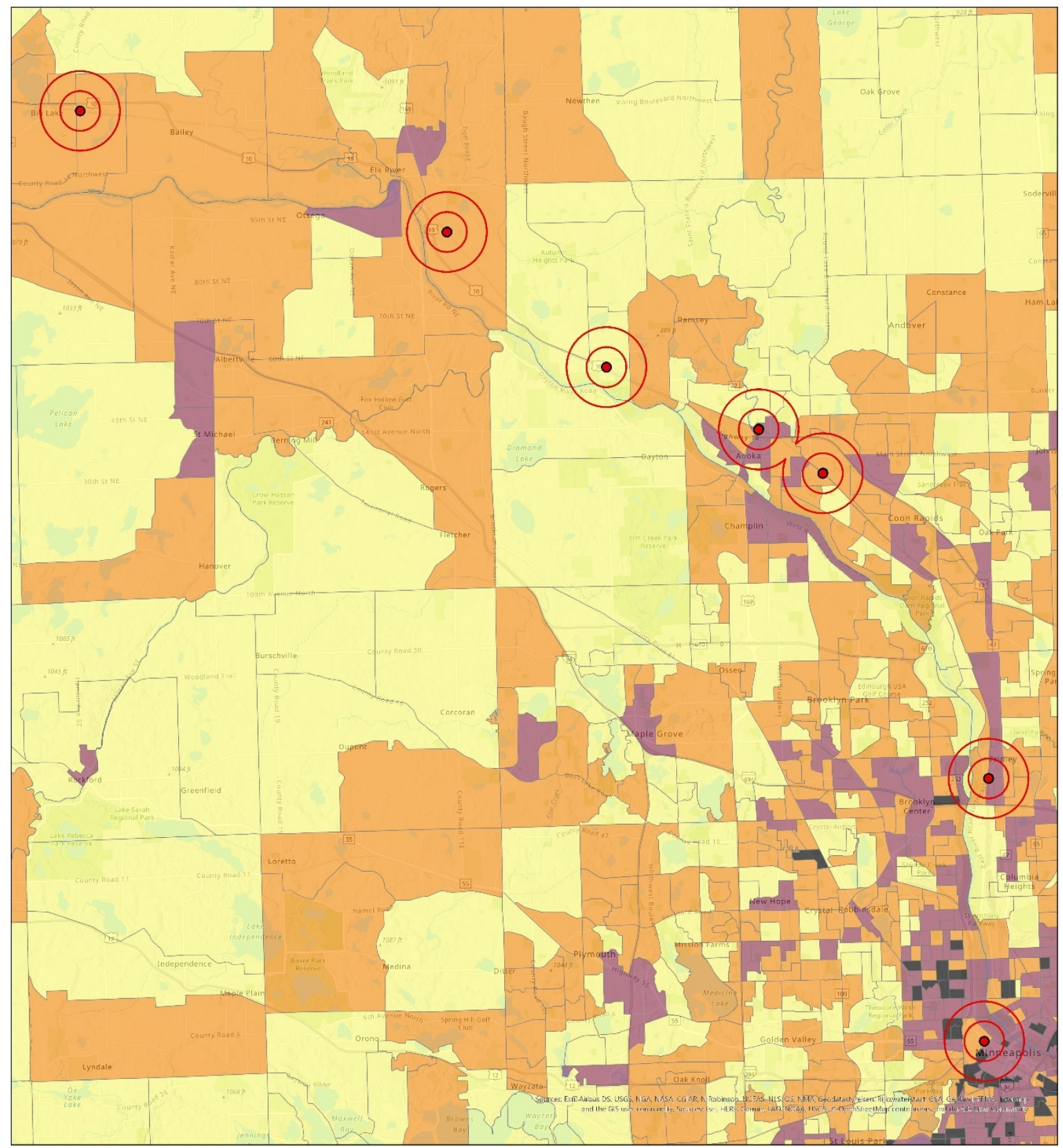

Station Typology for Commuter Rail Transit: Minneapolis-St. Paul-Bloomington, MN-WI

Buffers: Half \& 1 Mile $\square$ CRT Buffers

Station Types

- High MA

Mod MA

Low MA

$\square$ Poor MA

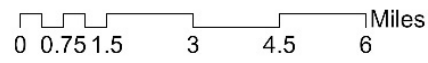

Figure 6. Minneapolis commuter rail serves outlying areas of the region. 
Table 5.1. Poor MA: BRT Households by Type and Householder Age

\begin{tabular}{|c|c|c|c|c|c|c|c|}
\hline \multirow[b]{2}{*}{$\begin{array}{l}\text { Demographic Share-- } \\
\text { Distance Band } \\
\text { Change }\end{array}$} & \multirow[b]{2}{*}{$\begin{array}{l}\text { Transit } \\
\text { Region } \\
\text { Change } \\
2010- \\
2016\end{array}$} & \multicolumn{3}{|c|}{ Incremental Analysis } & \multicolumn{3}{|c|}{ Cumulative Analysis } \\
\hline & & $\begin{array}{l}\text { Distance } \\
\text { Band } \\
\text { Change } \\
2010- \\
2016\end{array}$ & $\begin{array}{l}\text { Share of } \\
\text { Transit } \\
\text { Counties }\end{array}$ & $\begin{array}{l}\text { Share of } \\
\text { Distance } \\
\text { Band } \\
\text { Change }\end{array}$ & $\begin{array}{l}\text { Distance } \\
\text { Band } \\
\text { Change } \\
2010- \\
2016\end{array}$ & $\begin{array}{l}\text { Share of } \\
\text { Transit } \\
\text { Counties }\end{array}$ & $\begin{array}{l}\text { Share of } \\
\text { Distance } \\
\text { Band } \\
\text { Change }\end{array}$ \\
\hline \multicolumn{8}{|c|}{ Basic Demographics--0.125 Mile Distance Band } \\
\hline Total Households & 269,730 & $-8,064$ & $-3.0 \%$ & & $-8,064$ & $-3.0 \%$ & \\
\hline $\mathrm{HH}$ with Children & 80,558 & $-4,654$ & $-5.8 \%$ & $57.7 \%$ & $-4,654$ & $-5.8 \%$ & $57.7 \%$ \\
\hline 2+ Adult HH no Child & 59,245 & $-1,555$ & $-2.6 \%$ & $19.3 \%$ & $-1,555$ & $-2.6 \%$ & $19.3 \%$ \\
\hline One Person HH & 129,927 & $-1,855$ & $-1.4 \%$ & $23.0 \%$ & $-1,855$ & $-1.4 \%$ & $23.0 \%$ \\
\hline Householder under 25 & $-43,227$ & -622 & $1.4 \%$ & $7.7 \%$ & -622 & $1.4 \%$ & $7.7 \%$ \\
\hline Householder 25 to 44 & $-150,588$ & $-3,193$ & $2.1 \%$ & $39.6 \%$ & $-3,193$ & $2.1 \%$ & $39.6 \%$ \\
\hline Householder 45 to 64 & 385,369 & $-3,543$ & $-0.9 \%$ & $43.9 \%$ & $-3,543$ & $-0.9 \%$ & $43.9 \%$ \\
\hline Householder 65+ & $-12,518$ & -645 & $5.2 \%$ & $8.0 \%$ & -645 & $5.2 \%$ & $8.0 \%$ \\
\hline \multicolumn{8}{|c|}{ Basic Demographics--0.25 Mile Distance Band } \\
\hline Total Households & 269,730 & 2,091 & $0.8 \%$ & & $-5,973$ & $-2.2 \%$ & \\
\hline $\mathrm{HH}$ with Children & 80,558 & -31 & $0.0 \%$ & $-1.5 \%$ & $-4,685$ & $-5.8 \%$ & $78.4 \%$ \\
\hline 2+ Adult HH no Child & 59,245 & 1,358 & $2.3 \%$ & $64.9 \%$ & -197 & $-0.3 \%$ & $3.3 \%$ \\
\hline One Person $\mathrm{HH}$ & 129,927 & 764 & $0.6 \%$ & $36.5 \%$ & $-1,091$ & $-0.8 \%$ & $18.3 \%$ \\
\hline Householder under 25 & $-43,227$ & -11 & $0.0 \%$ & $-0.5 \%$ & -633 & $1.5 \%$ & $10.6 \%$ \\
\hline Householder 25 to 44 & $-150,588$ & 351 & $-0.2 \%$ & $16.8 \%$ & $-2,842$ & $1.9 \%$ & $47.6 \%$ \\
\hline Householder 45 to 64 & 385,369 & 273 & $0.1 \%$ & $13.1 \%$ & $-3,270$ & $-0.8 \%$ & $54.7 \%$ \\
\hline Householder 65+ & $-12,518$ & 1,442 & $-11.5 \%$ & $69.0 \%$ & 797 & $-6.4 \%$ & $-13.3 \%$ \\
\hline \multicolumn{8}{|c|}{ Basic Demographics--0.50 Mile Distance Band } \\
\hline Total Households & 269,730 & $-2,537$ & $-0.9 \%$ & & $-9,080$ & $-3.4 \%$ & \\
\hline $\mathrm{HH}$ with Children & 80,558 & $-1,967$ & $-2.4 \%$ & $77.5 \%$ & $-7,423$ & $-9.2 \%$ & $81.8 \%$ \\
\hline 2+ Adult HH no Child & 59,245 & -398 & $-0.7 \%$ & $15.7 \%$ & $-1,257$ & $-2.1 \%$ & $13.8 \%$ \\
\hline One Person $\mathrm{HH}$ & 129,927 & -172 & $-0.1 \%$ & $6.8 \%$ & -400 & $-0.3 \%$ & $4.4 \%$ \\
\hline Householder under 25 & $-43,227$ & -231 & $0.5 \%$ & $9.1 \%$ & -865 & $2.0 \%$ & $9.5 \%$ \\
\hline Householder 25 to 44 & $-150,588$ & $-1,094$ & $0.7 \%$ & $43.1 \%$ & $-4,302$ & $2.9 \%$ & $47.4 \%$ \\
\hline Householder 45 to 64 & 385,369 & $-1,545$ & $-0.4 \%$ & $60.9 \%$ & $-5,743$ & $-1.5 \%$ & $63.2 \%$ \\
\hline Householder 65+ & $-12,518$ & 312 & $-2.5 \%$ & $-12.3 \%$ & 1,822 & $-14.6 \%$ & $-20.1 \%$ \\
\hline
\end{tabular}


Table 5.2. Low MA: BRT. Households by Type and Householder Age

\begin{tabular}{|c|c|c|c|c|c|c|c|}
\hline \multirow[b]{2}{*}{$\begin{array}{l}\text { Demographic } \\
\text { Share-- Distance } \\
\text { Band Change }\end{array}$} & \multirow[b]{2}{*}{$\begin{array}{l}\text { Transit } \\
\text { Region } \\
\text { Change } \\
\text { 2010-2016 }\end{array}$} & \multicolumn{3}{|c|}{ Incremental Analysis } & \multicolumn{3}{|c|}{ Cumulative Analysis } \\
\hline & & $\begin{array}{l}\text { Distanc } \\
\text { e Band } \\
\text { Change } \\
2010- \\
2016\end{array}$ & $\begin{array}{l}\text { Share } \\
\text { of } \\
\text { Transit } \\
\text { Countie } \\
\text { s }\end{array}$ & $\begin{array}{l}\text { Share } \\
\text { of } \\
\text { Distanc } \\
\text { e Band } \\
\text { Change }\end{array}$ & $\begin{array}{l}\text { Distanc } \\
\text { e Band } \\
\text { Change } \\
2010- \\
2016\end{array}$ & $\begin{array}{l}\text { Share } \\
\text { of } \\
\text { Transit } \\
\text { Countie } \\
\text { s }\end{array}$ & $\begin{array}{l}\text { Share } \\
\text { of } \\
\text { Distanc } \\
\text { e Band } \\
\text { Change }\end{array}$ \\
\hline \multicolumn{8}{|c|}{$\begin{array}{l}\text { Basic Demographics--0.125 Mile Distance } \\
\text { Band }\end{array}$} \\
\hline Total Households & 269,730 & 7,519 & $2.8 \%$ & & 7,519 & $2.8 \%$ & \\
\hline $\begin{array}{l}\mathrm{HH} \text { with Children } \\
2+\text { Adult } \mathrm{HH} \text { no }\end{array}$ & 80,558 & 771 & $1.0 \%$ & $10.3 \%$ & 771 & $1.0 \%$ & $10.3 \%$ \\
\hline Child & 59,246 & 2,831 & $4.8 \%$ & $37.7 \%$ & 2,831 & $4.8 \%$ & $37.7 \%$ \\
\hline $\begin{array}{l}\text { One Person } \mathrm{HH} \\
\text { Householder under }\end{array}$ & 129,927 & 3,917 & $3.0 \%$ & $52.1 \%$ & 3,917 & $3.0 \%$ & $52.1 \%$ \\
\hline $\begin{array}{l}25 \\
\text { Householder } 25 \text { to }\end{array}$ & $-43,227$ & $-3,914$ & $9.1 \%$ & $-52.1 \%$ & $-3,914$ & $9.1 \%$ & $-52.1 \%$ \\
\hline & $-150,588$ & 6,160 & $-4.1 \%$ & $81.9 \%$ & 6,160 & $-4.1 \%$ & $81.9 \%$ \\
\hline 64 & 385,369 & 2,401 & $0.6 \%$ & $31.9 \%$ & 2,401 & $0.6 \%$ & $31.9 \%$ \\
\hline Householder 65+ & $-12,518$ & 3,526 & $-28.2 \%$ & $46.9 \%$ & 3,526 & $-28.2 \%$ & $46.9 \%$ \\
\hline \multicolumn{8}{|c|}{ Basic Demographics--0.25 Mile Distance Band } \\
\hline Total Households & 269,730 & 2,038 & $0.8 \%$ & & 9,557 & $3.5 \%$ & \\
\hline $\begin{array}{l}\mathrm{HH} \text { with Children } \\
2+\text { Adult } \mathrm{HH} \text { no }\end{array}$ & 80,558 & 439 & $0.5 \%$ & $21.5 \%$ & 1,210 & $1.5 \%$ & $12.7 \%$ \\
\hline Child & 59,246 & 2,337 & $3.9 \%$ & $114.7 \%$ & 5,168 & $8.7 \%$ & $54.1 \%$ \\
\hline $\begin{array}{l}\text { One Person } \mathrm{HH} \\
\text { Householder under }\end{array}$ & 129,927 & -738 & $-0.6 \%$ & $-36.2 \%$ & 3,179 & $2.4 \%$ & $33.3 \%$ \\
\hline $\begin{array}{l}25 \\
\text { Householder } 25 \text { to }\end{array}$ & $-43,227$ & -436 & $1.0 \%$ & $-21.4 \%$ & $-4,350$ & $10.1 \%$ & $-45.5 \%$ \\
\hline $\begin{array}{l}44 \\
\text { Householder } 45 \text { to }\end{array}$ & $-150,588$ & 741 & $-0.5 \%$ & $36.4 \%$ & 6,901 & $-4.6 \%$ & $72.2 \%$ \\
\hline 64 & 385,369 & 1,147 & $0.3 \%$ & $56.3 \%$ & 3,548 & $0.9 \%$ & $37.1 \%$ \\
\hline Householder 65+ & $-12,518$ & 439 & $-3.5 \%$ & $21.5 \%$ & 3,965 & $-31.7 \%$ & $41.5 \%$ \\
\hline \multicolumn{8}{|c|}{ Basic Demographics--0.50 Mile Distance Band } \\
\hline Total Households & 269,730 & 4,393 & $1.6 \%$ & & 20,772 & $7.7 \%$ & \\
\hline $\begin{array}{l}\mathrm{HH} \text { with Children } \\
\text { 2+ Adult } \mathrm{HH} \text { no }\end{array}$ & 80,558 & 435 & $0.5 \%$ & $9.9 \%$ & 3,578 & $4.4 \%$ & $17.2 \%$ \\
\hline Child & 59,246 & 1,935 & $3.3 \%$ & $44.0 \%$ & 9,691 & $16.4 \%$ & $46.7 \%$ \\
\hline $\begin{array}{l}\text { One Person } \mathrm{HH} \\
\text { Householder under }\end{array}$ & 129,927 & 2,023 & $1.6 \%$ & $46.1 \%$ & 7,503 & $5.8 \%$ & $36.1 \%$ \\
\hline $\begin{array}{l}25 \\
\text { Householder } 25 \text { to }\end{array}$ & $-43,227$ & -268 & $0.6 \%$ & $-6.1 \%$ & $-4,835$ & $11.2 \%$ & $-23.3 \%$ \\
\hline $\begin{array}{l}44 \\
\text { Householder } 45 \text { to }\end{array}$ & $-150,588$ & 1,328 & $-0.9 \%$ & $30.2 \%$ & 11,856 & $-7.9 \%$ & $57.1 \%$ \\
\hline 64 & 385,369 & 1,843 & $0.5 \%$ & $42.0 \%$ & 6,722 & $1.7 \%$ & $32.4 \%$ \\
\hline Householder 65+ & $-12,518$ & 1,215 & $-9.7 \%$ & $27.7 \%$ & 7,127 & $-56.9 \%$ & $34.3 \%$ \\
\hline
\end{tabular}


Table 5.3. Mod MA: BRT Households by Type and Householder Age

\begin{tabular}{|c|c|c|c|c|c|c|c|}
\hline \multirow[b]{2}{*}{$\begin{array}{l}\text { Demographic } \\
\text { Share-- Distance } \\
\text { Band Change }\end{array}$} & \multirow[b]{2}{*}{$\begin{array}{l}\text { Transit } \\
\text { Region } \\
\text { Change } \\
\text { 2010-2016 }\end{array}$} & \multicolumn{3}{|c|}{ Incremental Analysis } & \multicolumn{3}{|c|}{ Cumulative Analysis } \\
\hline & & $\begin{array}{l}\text { Distanc } \\
\text { e Band } \\
\text { Change } \\
2010- \\
2016 \\
\end{array}$ & $\begin{array}{l}\text { Share } \\
\text { of } \\
\text { Transit } \\
\text { Countie } \\
\text { s }\end{array}$ & $\begin{array}{l}\text { Share } \\
\text { of } \\
\text { Distanc } \\
\text { e Band } \\
\text { Change }\end{array}$ & $\begin{array}{l}\text { Distanc } \\
\text { e Band } \\
\text { Change } \\
2010- \\
2016 \\
\end{array}$ & $\begin{array}{l}\text { Share } \\
\text { of } \\
\text { Transit } \\
\text { Countie } \\
\text { S }\end{array}$ & $\begin{array}{l}\text { Share } \\
\text { of } \\
\text { Distanc } \\
\text { e Band } \\
\text { Change }\end{array}$ \\
\hline \multicolumn{8}{|c|}{$\begin{array}{l}\text { Basic Demographics--0.125 Mile Distance } \\
\text { Band }\end{array}$} \\
\hline Total Households & 269,730 & 39,406 & $14.6 \%$ & & 39,406 & $14.6 \%$ & \\
\hline $\begin{array}{l}\mathrm{HH} \text { with Children } \\
2+\text { Adult } \mathrm{HH} \text { no }\end{array}$ & 80,558 & 10,871 & $13.5 \%$ & $27.6 \%$ & 10,871 & $13.5 \%$ & $27.6 \%$ \\
\hline Child & 59,246 & 15,401 & $26.0 \%$ & $39.1 \%$ & 15,401 & $26.0 \%$ & $39.1 \%$ \\
\hline $\begin{array}{l}\text { One Person } \mathrm{HH} \\
\text { Householder under }\end{array}$ & 129,927 & 13,134 & $10.1 \%$ & $33.3 \%$ & 13,134 & $10.1 \%$ & $33.3 \%$ \\
\hline $\begin{array}{l}25 \\
\text { Householder } 25 \text { to }\end{array}$ & $-43,227$ & $-2,289$ & $5.3 \%$ & $-5.8 \%$ & $-2,289$ & $5.3 \%$ & $-5.8 \%$ \\
\hline & $-150,588$ & 23,346 & $-15.5 \%$ & $59.2 \%$ & 23,346 & $-15.5 \%$ & $59.2 \%$ \\
\hline 64 & 385,369 & 10,462 & $2.7 \%$ & $26.5 \%$ & 10,462 & $2.7 \%$ & $26.5 \%$ \\
\hline Householder 65+ & $-12,518$ & 9,185 & $-73.4 \%$ & $23.3 \%$ & 9,185 & $-73.4 \%$ & $23.3 \%$ \\
\hline \multicolumn{8}{|c|}{ Basic Demographics--0.25 Mile Distance Band } \\
\hline Total Households & 269,730 & 6,639 & $2.5 \%$ & & 46,045 & $17.1 \%$ & \\
\hline $\begin{array}{l}\mathrm{HH} \text { with Children } \\
\text { 2+ Adult } \mathrm{HH} \text { no }\end{array}$ & 80,558 & 2,715 & $3.4 \%$ & $40.9 \%$ & 13,586 & $16.9 \%$ & $29.5 \%$ \\
\hline Child & 59,246 & 1,684 & $2.8 \%$ & $25.4 \%$ & 17,085 & $28.8 \%$ & $37.1 \%$ \\
\hline $\begin{array}{l}\text { One Person } \mathrm{HH} \\
\text { Householder under }\end{array}$ & 129,927 & 2,240 & $1.7 \%$ & $33.7 \%$ & 15,374 & $11.8 \%$ & $33.4 \%$ \\
\hline $\begin{array}{l}25 \\
\text { Householder } 25 \text { to }\end{array}$ & $-43,227$ & -272 & $0.6 \%$ & $-4.1 \%$ & $-2,561$ & $5.9 \%$ & $-5.6 \%$ \\
\hline $\begin{array}{l}44 \\
\text { Householder } 45 \text { to }\end{array}$ & $-150,588$ & 3,173 & $-2.1 \%$ & $47.8 \%$ & 26,519 & $-17.6 \%$ & $57.6 \%$ \\
\hline 64 & 385,369 & 2,221 & $0.6 \%$ & $33.5 \%$ & 12,683 & $3.3 \%$ & $27.5 \%$ \\
\hline & $\begin{array}{l}-12,518 \\
0.50 \text { Mile Dis }\end{array}$ & \multicolumn{5}{|c|}{ Basic Demographics--0.50 Mile Distance Band } & $23.4 \%$ \\
\hline Total Households & 269,730 & 6,460 & $2.4 \%$ & & 61,964 & $23.0 \%$ & \\
\hline $\begin{array}{l}\mathrm{HH} \text { with Children } \\
2+\text { Adult } \mathrm{HH} \text { no }\end{array}$ & 80,558 & 2,075 & $2.6 \%$ & $32.1 \%$ & 18,847 & $23.4 \%$ & $30.4 \%$ \\
\hline Child & 59,246 & 2,165 & $3.7 \%$ & $33.5 \%$ & 22,588 & $38.1 \%$ & $36.5 \%$ \\
\hline $\begin{array}{l}\text { One Person } \mathrm{HH} \\
\text { Householder under }\end{array}$ & 129,927 & 2,220 & $1.7 \%$ & $34.4 \%$ & 20,529 & $15.8 \%$ & $33.1 \%$ \\
\hline $\begin{array}{l}25 \\
\text { Householder } 25 \text { to }\end{array}$ & $-43,227$ & -961 & $2.2 \%$ & $-14.9 \%$ & $-3,717$ & $8.6 \%$ & $-6.0 \%$ \\
\hline 44 & $-150,588$ & 3,414 & $-2.3 \%$ & $52.8 \%$ & 36,103 & $-24.0 \%$ & $58.3 \%$ \\
\hline
\end{tabular}




\begin{tabular}{lccccccc}
$\begin{array}{l}\text { Householder 45 to } \\
64\end{array}$ & 385,369 & 2,295 & $0.6 \%$ & $35.5 \%$ & 17,006 & $4.4 \%$ & $27.4 \%$ \\
& & & & & & - & \\
Householder 65+ & $-12,518$ & 1,968 & $-15.7 \%$ & $30.5 \%$ & 14,266 & $114.0 \%$ & $23.0 \%$ \\
\hline \hline
\end{tabular}


Table 5.4. High MA: BRT Households by Type and Householder Age

\begin{tabular}{|c|c|c|c|c|c|c|c|}
\hline \multirow[b]{2}{*}{$\begin{array}{l}\text { Demographic Share- } \\
\text { - Distance Band } \\
\text { Change }\end{array}$} & \multirow[b]{2}{*}{$\begin{array}{l}\text { Transit } \\
\text { Region } \\
\text { Change } \\
\text { 2010-2016 } \\
\end{array}$} & \multicolumn{3}{|c|}{ Incremental Analysis } & \multicolumn{3}{|c|}{ Cumulative Analysis } \\
\hline & & $\begin{array}{l}\text { Distanc } \\
\text { e Band } \\
\text { Change } \\
2010- \\
2016\end{array}$ & $\begin{array}{l}\text { Share } \\
\text { of } \\
\text { Transit } \\
\text { Countie } \\
\text { s }\end{array}$ & $\begin{array}{l}\text { Share } \\
\text { of } \\
\text { Distanc } \\
\text { e Band } \\
\text { Change }\end{array}$ & $\begin{array}{l}\text { Distanc } \\
\text { e Band } \\
\text { Change } \\
2010- \\
2016\end{array}$ & $\begin{array}{l}\text { Share } \\
\text { of } \\
\text { Transit } \\
\text { Countie } \\
\text { s }\end{array}$ & $\begin{array}{l}\text { Share } \\
\text { of } \\
\text { Distanc } \\
\text { e Band } \\
\text { Change } \\
\end{array}$ \\
\hline \multicolumn{8}{|c|}{ Basic Demographics--0.125 Mile Distance Band } \\
\hline Total Households & 269,730 & 7,977 & $3.0 \%$ & & 7,977 & $3.0 \%$ & \\
\hline $\begin{array}{l}\mathrm{HH} \text { with Children } \\
2+\text { Adult } \mathrm{HH} \text { no }\end{array}$ & 80,558 & 2,441 & $3.0 \%$ & $30.6 \%$ & 2,441 & $3.0 \%$ & $30.6 \%$ \\
\hline Child & 59,246 & 3,079 & $5.2 \%$ & $38.6 \%$ & 3,079 & $5.2 \%$ & $38.6 \%$ \\
\hline $\begin{array}{l}\text { One Person } \mathrm{HH} \\
\text { Householder under }\end{array}$ & 129,927 & 2,457 & $1.9 \%$ & $30.8 \%$ & 2,457 & $1.9 \%$ & $30.8 \%$ \\
\hline $\begin{array}{l}25 \\
\text { Householder } 25 \text { to }\end{array}$ & $-43,227$ & $-1,118$ & $2.6 \%$ & $-14.0 \%$ & $-1,118$ & $2.6 \%$ & $-14.0 \%$ \\
\hline $\begin{array}{l}44 \\
\text { Householder } 45 \text { to }\end{array}$ & $-150,588$ & 7,801 & $-5.2 \%$ & $97.8 \%$ & 7,801 & $-5.2 \%$ & $97.8 \%$ \\
\hline 64 & 385,369 & 1,215 & $0.3 \%$ & $15.2 \%$ & 1,215 & $0.3 \%$ & $15.2 \%$ \\
\hline $\begin{array}{l}\text { Householder 65+ } \\
\text { Basic Demographics-- } \\
\text { Band }\end{array}$ & $\begin{array}{l}-12,518 \\
0.25 \text { Mile Dis }\end{array}$ & $\begin{array}{l}770 \\
n c e\end{array}$ & $-6.2 \%$ & $9.7 \%$ & 770 & $-6.2 \%$ & $9.7 \%$ \\
\hline Total Households & 269,730 & 2,843 & $1.1 \%$ & & 10,820 & $4.0 \%$ & \\
\hline $\begin{array}{l}\mathrm{HH} \text { with Children } \\
2+\text { Adult } \mathrm{HH} \text { no }\end{array}$ & 80,558 & 707 & $0.9 \%$ & $24.9 \%$ & 3,148 & $3.9 \%$ & $29.1 \%$ \\
\hline Child & 59,246 & 1,780 & $3.0 \%$ & $62.6 \%$ & 4,859 & $8.2 \%$ & $44.9 \%$ \\
\hline $\begin{array}{l}\text { One Person } \mathrm{HH} \\
\text { Householder under }\end{array}$ & 129,927 & 356 & $0.3 \%$ & $12.5 \%$ & 2,813 & $2.2 \%$ & $26.0 \%$ \\
\hline $\begin{array}{l}25 \\
\text { Householder } 25 \text { to }\end{array}$ & $-43,227$ & -249 & $0.6 \%$ & $-8.8 \%$ & $-1,367$ & $3.2 \%$ & $-12.6 \%$ \\
\hline $\begin{array}{l}44 \\
\text { Householder } 45 \text { to }\end{array}$ & $-150,588$ & 2,283 & $-1.5 \%$ & $80.3 \%$ & 10,084 & $-6.7 \%$ & $93.2 \%$ \\
\hline 64 & 385,369 & 287 & $0.1 \%$ & $10.1 \%$ & 1,502 & $0.4 \%$ & $13.9 \%$ \\
\hline $\begin{array}{l}\text { Householder 65+ } \\
\text { Basic Demographics-- } \\
\text { Band }\end{array}$ & $\begin{array}{l}-12,518 \\
0.50 \text { Mile Dis }\end{array}$ & $\begin{array}{l}700 \\
n c e\end{array}$ & $-5.6 \%$ & $24.6 \%$ & 1,470 & $-11.7 \%$ & $13.6 \%$ \\
\hline Total Households & 269,730 & 1,211 & $0.4 \%$ & & 13,434 & $5.0 \%$ & \\
\hline $\begin{array}{l}\mathrm{HH} \text { with Children } \\
2+\text { Adult } \mathrm{HH} \text { no }\end{array}$ & 80,558 & 1,448 & $1.8 \%$ & $119.6 \%$ & 5,450 & $6.8 \%$ & $40.6 \%$ \\
\hline Child & 59,246 & 600 & $1.0 \%$ & $49.5 \%$ & 5,594 & $9.4 \%$ & $41.6 \%$ \\
\hline $\begin{array}{l}\text { One Person } \mathrm{HH} \\
\text { Householder under }\end{array}$ & 129,927 & -837 & $-0.6 \%$ & $-69.1 \%$ & 2,390 & $1.8 \%$ & $17.8 \%$ \\
\hline $\begin{array}{l}25 \\
\text { Householder } 25 \text { to }\end{array}$ & $-43,227$ & -58 & $0.1 \%$ & $-4.8 \%$ & $-1,995$ & $4.6 \%$ & $-14.9 \%$ \\
\hline $\begin{array}{l}44 \\
\text { Householder } 45 \text { to }\end{array}$ & $-150,588$ & 1,068 & $-0.7 \%$ & $88.2 \%$ & 12,873 & $-8.5 \%$ & $95.8 \%$ \\
\hline 64 & 385,369 & 205 & $0.1 \%$ & $16.9 \%$ & 1,790 & $0.5 \%$ & $13.3 \%$ \\
\hline Householder 65+ & $-12,518$ & -4 & $0.0 \%$ & $-0.3 \%$ & 1,635 & $-13.1 \%$ & $12.2 \%$ \\
\hline
\end{tabular}


Table 5.5. Poor MA: CRT Households by Type and Householder Age

\begin{tabular}{|c|c|c|c|c|c|c|c|}
\hline \multirow[b]{2}{*}{$\begin{array}{l} \\
\text { Demographic Share- } \\
\text { - Distance Band } \\
\text { Change }\end{array}$} & \multirow[b]{2}{*}{$\begin{array}{l}\text { Transit } \\
\text { Region } \\
\text { Change } \\
2010- \\
2016 \\
\end{array}$} & \multicolumn{3}{|c|}{ Incremental Analysis } & \multicolumn{3}{|c|}{ Cumulative Analysis } \\
\hline & & $\begin{array}{l}\text { Distanc } \\
\text { e Band } \\
\text { Change } \\
2010- \\
2016\end{array}$ & $\begin{array}{l}\text { Share of } \\
\text { Transit } \\
\text { Countie } \\
\mathrm{s}\end{array}$ & $\begin{array}{l}\text { Share } \\
\text { of } \\
\text { Distanc } \\
\text { e Band } \\
\text { Change }\end{array}$ & $\begin{array}{l}\text { Distanc } \\
\text { e Band } \\
\text { Change } \\
2010- \\
2016\end{array}$ & $\begin{array}{l}\text { Share of } \\
\text { Transit } \\
\text { Countie } \\
\text { s }\end{array}$ & $\begin{array}{l}\text { Share } \\
\text { of } \\
\text { Distanc } \\
\text { e Band } \\
\text { Change }\end{array}$ \\
\hline \multicolumn{8}{|c|}{ Basic Demographics--0.125 Mile Distance Band } \\
\hline Total Households & $-520,022$ & 6,280 & $-1.2 \%$ & & 6,280 & $-1.2 \%$ & \\
\hline $\mathrm{HH}$ with Children & $\begin{array}{l}-285,718 \\
-\end{array}$ & 1,328 & $-0.5 \%$ & $21.1 \%$ & 1,328 & $-0.5 \%$ & $21.1 \%$ \\
\hline 2+ Adult HH no Child & $1,264,926$ & 3,301 & $-0.3 \%$ & $52.6 \%$ & 3,301 & $-0.3 \%$ & $52.6 \%$ \\
\hline $\begin{array}{l}\text { One Person } \mathrm{HH} \\
\text { Householder under }\end{array}$ & $1,030,622$ & 1,651 & $0.2 \%$ & $26.3 \%$ & 1,651 & $0.2 \%$ & $26.3 \%$ \\
\hline $\begin{array}{l}25 \\
\text { Householder } 25 \text { to }\end{array}$ & 381,392 & 37 & $0.0 \%$ & $0.6 \%$ & 37 & $0.0 \%$ & $0.6 \%$ \\
\hline $\begin{array}{l}44 \\
\text { Householder } 45 \text { to }\end{array}$ & $-666,950$ & 1,634 & $-0.2 \%$ & $26.0 \%$ & 1,634 & $-0.2 \%$ & $26.0 \%$ \\
\hline 64 & 858,641 & 2,239 & $0.3 \%$ & $35.7 \%$ & 2,239 & $0.3 \%$ & $35.7 \%$ \\
\hline \multicolumn{8}{|c|}{$\begin{array}{l}\text { Basic Demographics--0.25 Mile Distance } \\
\text { Band }\end{array}$} \\
\hline Total Households & $-520,022$ & -967 & $0.2 \%$ & & 5,313 & $-1.0 \%$ & \\
\hline $\mathrm{HH}$ with Children & $\begin{array}{l}-285,718 \\
-\end{array}$ & -389 & $0.1 \%$ & $40.2 \%$ & 939 & $-0.3 \%$ & $17.7 \%$ \\
\hline 2+ Adult HH no Child & $1,264,926$ & -194 & $0.0 \%$ & $20.1 \%$ & 3,107 & $-0.2 \%$ & $58.5 \%$ \\
\hline $\begin{array}{l}\text { One Person } \mathrm{HH} \\
\text { Householder under }\end{array}$ & $1,030,622$ & -384 & $0.0 \%$ & $39.7 \%$ & 1,267 & $0.1 \%$ & $23.8 \%$ \\
\hline $\begin{array}{l}25 \\
\text { Householder } 25 \text { to }\end{array}$ & 381,392 & -91 & $0.0 \%$ & $9.4 \%$ & -54 & $0.0 \%$ & $-1.0 \%$ \\
\hline $\begin{array}{l}44 \\
\text { Householder } 45 \text { to }\end{array}$ & $-666,950$ & -275 & $0.0 \%$ & $28.4 \%$ & 1,359 & $-0.2 \%$ & $25.6 \%$ \\
\hline 64 & 858,641 & -363 & $0.0 \%$ & $37.5 \%$ & 1,876 & $0.2 \%$ & $35.3 \%$ \\
\hline $\begin{array}{l}\text { Householder 65+ } \\
\text { Basic Demographics--- } \\
\text { Band }\end{array}$ & $\begin{array}{l}542,133 \\
.50 \text { Mile Dis }\end{array}$ & $\begin{array}{l}-238 \\
\text { ance }\end{array}$ & $0.0 \%$ & $24.6 \%$ & 2,132 & $0.4 \%$ & $40.1 \%$ \\
\hline Total Households & $-520,022$ & 4,022 & $-0.8 \%$ & & 9,992 & $-1.9 \%$ & \\
\hline $\mathrm{HH}$ with Children & $-285,718$ & -496 & $0.2 \%$ & $-12.3 \%$ & -128 & $0.0 \%$ & $-1.3 \%$ \\
\hline 2+ Adult HH no Child & $1,264,926$ & 2,478 & $-0.2 \%$ & $61.6 \%$ & 6,520 & $-0.5 \%$ & $65.3 \%$ \\
\hline $\begin{array}{l}\text { One Person } \mathrm{HH} \\
\text { Householder under }\end{array}$ & $1,030,622$ & 2,040 & $0.2 \%$ & $50.7 \%$ & 3,600 & $0.3 \%$ & $36.0 \%$ \\
\hline $\begin{array}{l}25 \\
\text { Householder } 25 \text { to }\end{array}$ & 381,392 & -171 & $0.0 \%$ & $-4.3 \%$ & -621 & $-0.2 \%$ & $-6.2 \%$ \\
\hline $\begin{array}{l}44 \\
\text { Householder } 45 \text { to }\end{array}$ & $-666,950$ & 957 & $-0.1 \%$ & $23.8 \%$ & 1,151 & $-0.2 \%$ & $11.5 \%$ \\
\hline 64 & 858,641 & 1,592 & $0.2 \%$ & $39.6 \%$ & 4,351 & $0.5 \%$ & $43.5 \%$ \\
\hline Householder 65+ & 542,133 & 1,644 & $0.3 \%$ & $40.9 \%$ & 5,111 & $0.9 \%$ & $51.2 \%$ \\
\hline
\end{tabular}


Table 5.6. Low MA: CRT Households by Type and Householder Age

\begin{tabular}{|c|c|c|c|c|c|c|c|}
\hline & & Increment & Analysis & & Cumulat & e Analysi & \\
\hline $\begin{array}{l}\text { Demographic } \\
\text { Share-- Distance } \\
\text { Band Change }\end{array}$ & $\begin{array}{l}\text { Transit } \\
\text { Region } \\
\text { Change } \\
2010- \\
2016\end{array}$ & $\begin{array}{l}\text { Distance } \\
\text { Band } \\
\text { Change } \\
2010- \\
2016\end{array}$ & $\begin{array}{l}\text { Share } \\
\text { of } \\
\text { Transit } \\
\text { Countie } \\
\text { s }\end{array}$ & $\begin{array}{l}\text { Share } \\
\text { of } \\
\text { Distanc } \\
\text { e Band } \\
\text { Change }\end{array}$ & $\begin{array}{l}\text { Distanc } \\
\text { e Band } \\
\text { Change } \\
2010- \\
2016\end{array}$ & $\begin{array}{l}\text { Share } \\
\text { of } \\
\text { Transit } \\
\text { Countie } \\
\text { s }\end{array}$ & $\begin{array}{l}\text { Share } \\
\text { of } \\
\text { Distanc } \\
\text { e Band } \\
\text { Change }\end{array}$ \\
\hline $\begin{array}{l}\text { Basic Demographic } \\
\text { Band }\end{array}$ & 0.125 Mile $L$ & stance & & & & & \\
\hline Total Households & $-520,022$ & 8,709 & $-1.7 \%$ & & 8,709 & $-1.7 \%$ & \\
\hline $\begin{array}{l}\mathrm{HH} \text { with Children } \\
2+\text { Adult } \mathrm{HH} \text { no }\end{array}$ & $\begin{array}{l}-285,718 \\
-\end{array}$ & 2,027 & $-0.7 \%$ & $23.3 \%$ & 2,027 & $-0.7 \%$ & $23.3 \%$ \\
\hline Child & $1,264,926$ & 3,122 & $-0.2 \%$ & $35.8 \%$ & 3,122 & $-0.2 \%$ & $35.8 \%$ \\
\hline $\begin{array}{l}\text { One Person } \mathrm{HH} \\
\text { Householder under }\end{array}$ & $1,030,622$ & 3,560 & $0.3 \%$ & $40.9 \%$ & 3,560 & $0.3 \%$ & $40.9 \%$ \\
\hline $\begin{array}{l}25 \\
\text { Householder } 25 \text { to }\end{array}$ & 381,392 & $-1,410$ & $-0.4 \%$ & $-16.2 \%$ & $-1,410$ & $-0.4 \%$ & $-16.2 \%$ \\
\hline $\begin{array}{l}44 \\
\text { Householder } 45 \text { to }\end{array}$ & $-666,950$ & 3,734 & $-0.6 \%$ & $42.9 \%$ & 3,734 & $-0.6 \%$ & $42.9 \%$ \\
\hline 64 & 858,641 & 3,116 & $0.4 \%$ & $35.8 \%$ & 3,116 & $0.4 \%$ & $35.8 \%$ \\
\hline Householder 65+ & 542,133 & 3,269 & $0.6 \%$ & $37.5 \%$ & 3,269 & $0.6 \%$ & $37.5 \%$ \\
\hline Basic Demographic & 0.25 Mile Di & tance Bano & & & & & \\
\hline Total Households & $-520,022$ & 1,171 & $-0.2 \%$ & & 9,880 & $-1.9 \%$ & \\
\hline $\begin{array}{l}\mathrm{HH} \text { with Children } \\
2+\text { Adult } \mathrm{HH} \text { no }\end{array}$ & $\begin{array}{l}-285,718 \\
-\end{array}$ & -541 & $0.2 \%$ & $-46.2 \%$ & 1,486 & $-0.5 \%$ & $15.0 \%$ \\
\hline Child & $1,264,926$ & 612 & $0.0 \%$ & $52.3 \%$ & 3,734 & $-0.3 \%$ & $37.8 \%$ \\
\hline $\begin{array}{l}\text { One Person } \mathrm{HH} \\
\text { Householder under }\end{array}$ & $1,030,622$ & 1,100 & $0.1 \%$ & $93.9 \%$ & 4,660 & $0.5 \%$ & $47.2 \%$ \\
\hline $\begin{array}{l}25 \\
\text { Householder } 25 \text { to }\end{array}$ & 381,392 & -379 & $-0.1 \%$ & $-32.4 \%$ & $-1,789$ & $-0.5 \%$ & $-18.1 \%$ \\
\hline $\begin{array}{l}44 \\
\text { Householder } 45 \text { to }\end{array}$ & $-666,950$ & -255 & $0.0 \%$ & $-21.8 \%$ & 3,479 & $-0.5 \%$ & $35.2 \%$ \\
\hline 64 & 858,641 & 836 & $0.1 \%$ & $71.4 \%$ & 3,952 & $0.5 \%$ & $40.0 \%$ \\
\hline Householder 65+ & 542,133 & 969 & $0.2 \%$ & $82.7 \%$ & 4,238 & $0.8 \%$ & $42.9 \%$ \\
\hline Basic Demographic & 0.50 Mile Di & tance Bano & & & & & \\
\hline Total Households & $-520,022$ & $-2,098$ & $0.4 \%$ & & 7,910 & $-1.5 \%$ & \\
\hline $\begin{array}{l}\mathrm{HH} \text { with Children } \\
2+\text { Adult } \mathrm{HH} \text { no }\end{array}$ & $\begin{array}{l}-285,718 \\
-\end{array}$ & $-1,532$ & $0.5 \%$ & $73.0 \%$ & -725 & $0.3 \%$ & $-9.2 \%$ \\
\hline Child & $1,264,926$ & -440 & $0.0 \%$ & $21.0 \%$ & 3,130 & $-0.2 \%$ & $39.6 \%$ \\
\hline $\begin{array}{l}\text { One Person } \mathrm{HH} \\
\text { Householder under }\end{array}$ & $1,030,622$ & -126 & $0.0 \%$ & $6.0 \%$ & 5,505 & $0.5 \%$ & $69.6 \%$ \\
\hline $\begin{array}{l}25 \\
\text { Householder } 25 \text { to }\end{array}$ & 381,392 & $-1,270$ & $-0.3 \%$ & $60.5 \%$ & $-3,971$ & $-1.0 \%$ & $-50.2 \%$ \\
\hline $\begin{array}{l}44 \\
\text { Householder } 45 \text { to }\end{array}$ & $-666,950$ & -915 & $0.1 \%$ & $43.6 \%$ & 3,049 & $-0.5 \%$ & $38.5 \%$ \\
\hline 64 & 858,641 & -773 & $-0.1 \%$ & $36.8 \%$ & 2,611 & $0.3 \%$ & $33.0 \%$ \\
\hline Householder 65+ & 542,133 & 860 & $0.2 \%$ & $-41.0 \%$ & 6,221 & $1.1 \%$ & $78.6 \%$ \\
\hline
\end{tabular}


Table 5.7. Mod MA: CRT Households by Type and Householder Age

\begin{tabular}{|c|c|c|c|c|c|c|c|}
\hline \multirow[b]{2}{*}{$\begin{array}{l}\text { Demographic } \\
\text { Share-- Distance } \\
\text { Band Change }\end{array}$} & \multirow[b]{2}{*}{$\begin{array}{l}\text { Transit } \\
\text { Region } \\
\text { Change } \\
\text { 2010-2016 }\end{array}$} & \multicolumn{3}{|c|}{ Incremental Analysis } & \multicolumn{3}{|c|}{ Cumulative Analysis } \\
\hline & & $\begin{array}{l}\text { Distanc } \\
\text { e Band } \\
\text { Change } \\
2010- \\
2016\end{array}$ & $\begin{array}{l}\text { Share } \\
\text { of } \\
\text { Transit } \\
\text { Countie } \\
\text { s }\end{array}$ & $\begin{array}{l}\text { Share } \\
\text { of } \\
\text { Distanc } \\
\text { e Band } \\
\text { Change }\end{array}$ & $\begin{array}{l}\text { Distanc } \\
\text { e Band } \\
\text { Change } \\
2010- \\
2016\end{array}$ & $\begin{array}{l}\text { Share } \\
\text { of } \\
\text { Transit } \\
\text { Countie } \\
\mathrm{s}\end{array}$ & $\begin{array}{l}\text { Share } \\
\text { of } \\
\text { Distanc } \\
\text { e Band } \\
\text { Change }\end{array}$ \\
\hline \multicolumn{8}{|c|}{$\begin{array}{l}\text { Basic Demographics--0.125 Mile Distance } \\
\text { Band }\end{array}$} \\
\hline Total Households & $-520,022$ & $-18,481$ & $3.6 \%$ & & $-18,481$ & $3.6 \%$ & \\
\hline $\begin{array}{l}\mathrm{HH} \text { with Children } \\
2+\text { Adult } \mathrm{HH} \text { no }\end{array}$ & $-285,718$ & $-5,026$ & $1.8 \%$ & $27.2 \%$ & $-5,026$ & $1.8 \%$ & $27.2 \%$ \\
\hline Child & $-1,264,926$ & $-5,298$ & $0.4 \%$ & $28.7 \%$ & $-5,298$ & $0.4 \%$ & $28.7 \%$ \\
\hline $\begin{array}{l}\text { One Person HH } \\
\text { Householder under }\end{array}$ & $1,030,622$ & $-8,157$ & $-0.8 \%$ & $44.1 \%$ & $-8,157$ & $-0.8 \%$ & $44.1 \%$ \\
\hline $\begin{array}{l}25 \\
\text { Householder } 25 \text { to }\end{array}$ & 381,392 & $-3,792$ & $-1.0 \%$ & $20.5 \%$ & $-3,792$ & $-1.0 \%$ & $20.5 \%$ \\
\hline & $-666,950$ & $-4,171$ & $0.6 \%$ & $22.6 \%$ & $-4,171$ & $0.6 \%$ & $22.6 \%$ \\
\hline 64 & 858,641 & $-8,026$ & $-0.9 \%$ & $43.4 \%$ & $-8,026$ & $-0.9 \%$ & $43.4 \%$ \\
\hline Householder 65+ & 542,133 & $-2,492$ & $-0.5 \%$ & $13.5 \%$ & $-2,492$ & $-0.5 \%$ & $13.5 \%$ \\
\hline \multicolumn{8}{|c|}{ Basic Demographics--0.25 Mile Distance Band } \\
\hline Total Households & $-520,022$ & $-4,175$ & $0.8 \%$ & & $-22,656$ & $4.4 \%$ & \\
\hline $\begin{array}{l}\mathrm{HH} \text { with Children } \\
2+\text { Adult } \mathrm{HH} \text { no }\end{array}$ & $-285,718$ & 87 & $0.0 \%$ & $-2.1 \%$ & $-4,939$ & $1.7 \%$ & $21.8 \%$ \\
\hline Child & $-1,264,926$ & $-1,863$ & $0.1 \%$ & $44.6 \%$ & $-7,161$ & $0.6 \%$ & $31.6 \%$ \\
\hline $\begin{array}{l}\text { One Person } \mathrm{HH} \\
\text { Householder under }\end{array}$ & $1,030,622$ & $-2,399$ & $-0.2 \%$ & $57.5 \%$ & $-10,556$ & $-1.0 \%$ & $46.6 \%$ \\
\hline $\begin{array}{l}25 \\
\text { Householder } 25 \text { to }\end{array}$ & 381,392 & $-1,936$ & $-0.5 \%$ & $46.4 \%$ & $-5,728$ & $-1.5 \%$ & $25.3 \%$ \\
\hline $\begin{array}{l}44 \\
\text { Householder } 45 \text { to }\end{array}$ & $-666,950$ & -952 & $0.1 \%$ & $22.8 \%$ & $-5,123$ & $0.8 \%$ & $22.6 \%$ \\
\hline 64 & 858,641 & -534 & $-0.1 \%$ & $12.8 \%$ & $-8,560$ & $-1.0 \%$ & $37.8 \%$ \\
\hline Householder 65+ & 542,133 & -753 & $-0.1 \%$ & $18.0 \%$ & $-3,245$ & $-0.6 \%$ & $14.3 \%$ \\
\hline \multicolumn{8}{|c|}{ Basic Demographics--0.50 Mile Distance Band } \\
\hline Total Households & $-520,022$ & $-1,862$ & $0.4 \%$ & & $-27,043$ & $5.2 \%$ & \\
\hline $\begin{array}{l}\mathrm{HH} \text { with Children } \\
\text { 2+ Adult } \mathrm{HH} \text { no }\end{array}$ & $-285,718$ & -745 & $0.3 \%$ & $40.0 \%$ & $-6,273$ & $2.2 \%$ & $23.2 \%$ \\
\hline Child & $-1,264,926$ & -760 & $0.1 \%$ & $40.8 \%$ & $-8,034$ & $0.6 \%$ & $29.7 \%$ \\
\hline $\begin{array}{l}\text { One Person } \mathrm{HH} \\
\text { Householder under }\end{array}$ & $1,030,622$ & -357 & $0.0 \%$ & $19.2 \%$ & $-12,736$ & $-1.2 \%$ & $47.1 \%$ \\
\hline $\begin{array}{l}25 \\
\text { Householder } 25 \text { to }\end{array}$ & 381,392 & $-1,182$ & $-0.3 \%$ & $63.5 \%$ & $-7,762$ & $-2.0 \%$ & $28.7 \%$ \\
\hline $\begin{array}{l}44 \\
\text { Householder } 45 \text { to }\end{array}$ & $-666,950$ & -542 & $0.1 \%$ & $29.1 \%$ & $-6,456$ & $1.0 \%$ & $23.9 \%$ \\
\hline 64 & 858,641 & -552 & $-0.1 \%$ & $29.6 \%$ & $-9,923$ & $-1.2 \%$ & $36.7 \%$ \\
\hline Householder $65+$ & 542,133 & 414 & $0.1 \%$ & $-22.2 \%$ & $-2,902$ & $-0.5 \%$ & $10.7 \%$ \\
\hline
\end{tabular}


Table 5.8. High MA: CRT Households by Type and Householder Age

\begin{tabular}{|c|c|c|c|c|c|c|c|}
\hline \multirow[b]{2}{*}{$\begin{array}{l}\text { Demographic Share- } \\
\text { - Distance Band } \\
\text { Change }\end{array}$} & \multirow[b]{2}{*}{$\begin{array}{l}\text { Transit } \\
\text { Region } \\
\text { Change } \\
2010-2016\end{array}$} & \multicolumn{3}{|c|}{ Incremental Analysis } & \multicolumn{3}{|c|}{ Cumulative Analysis } \\
\hline & & $\begin{array}{l}\text { Distanc } \\
\text { e Band } \\
\text { Change } \\
2010- \\
2016\end{array}$ & $\begin{array}{l}\text { Share of } \\
\text { Transit } \\
\text { Countie } \\
\text { s }\end{array}$ & $\begin{array}{l}\text { Share } \\
\text { of } \\
\text { Distanc } \\
\text { e Band } \\
\text { Change }\end{array}$ & $\begin{array}{l}\text { Distanc } \\
\text { e Band } \\
\text { Change } \\
2010- \\
2016\end{array}$ & $\begin{array}{l}\text { Share of } \\
\text { Transit } \\
\text { Countie } \\
\mathrm{s}\end{array}$ & $\begin{array}{l}\text { Share } \\
\text { of } \\
\text { Distanc } \\
\text { e Band } \\
\text { Change }\end{array}$ \\
\hline \multicolumn{8}{|c|}{$\begin{array}{c}\text { Basic Demographics--0.125 Mile Distance Band } \\
10,206,45\end{array}$} \\
\hline Total Households & 8 & 1,952 & $0.019 \%$ & & 1,952 & $0.02 \%$ & \\
\hline $\mathrm{HH}$ with Children & $3,553,464$ & 764 & $0.022 \%$ & $39.1 \%$ & 764 & $0.02 \%$ & $39.1 \%$ \\
\hline 2+ Adult HH no Child & $2,728,201$ & 765 & $0.028 \%$ & $39.2 \%$ & 765 & $0.03 \%$ & $39.2 \%$ \\
\hline $\begin{array}{l}\text { One Person } \mathrm{HH} \\
\text { Householder under }\end{array}$ & $3,924,793$ & 423 & $0.011 \%$ & $21.7 \%$ & 423 & $0.01 \%$ & $21.7 \%$ \\
\hline $\begin{array}{l}25 \\
\text { Householder } 25 \text { to }\end{array}$ & 995,014 & 128 & $0.013 \%$ & $6.6 \%$ & 128 & $0.01 \%$ & $6.6 \%$ \\
\hline $\begin{array}{l}44 \\
\text { Householder } 45 \text { to }\end{array}$ & $4,049,688$ & 895 & $0.022 \%$ & $45.9 \%$ & 895 & $0.02 \%$ & $45.9 \%$ \\
\hline 64 & $4,348,615$ & 364 & $0.008 \%$ & $18.6 \%$ & 364 & $0.01 \%$ & $18.6 \%$ \\
\hline $\begin{array}{l}\text { Householder 65+ } \\
\text { Basic Demographics-- } \\
\text { Band }\end{array}$ & $\begin{array}{l}2,500,007 \\
\text { o.25 Mile Dist }\end{array}$ & $\begin{array}{r}164 \\
\text { ance }\end{array}$ & $0.007 \%$ & $8.4 \%$ & 164 & $0.01 \%$ & $8.4 \%$ \\
\hline Total Households & $\begin{array}{l}10,206,45 \\
8\end{array}$ & -828 & $-0.008 \%$ & & 1,124 & $0.01 \%$ & \\
\hline $\mathrm{HH}$ with Children & $3,553,464$ & -236 & $-0.007 \%$ & $28.5 \%$ & 528 & $0.01 \%$ & $47.0 \%$ \\
\hline 2+ Adult HH no Child & $2,728,201$ & -188 & $-0.007 \%$ & $22.7 \%$ & 577 & $0.02 \%$ & $51.3 \%$ \\
\hline $\begin{array}{l}\text { One Person } \mathrm{HH} \\
\text { Householder under }\end{array}$ & $3,924,793$ & -404 & $-0.010 \%$ & $48.8 \%$ & 19 & $0.00 \%$ & $1.7 \%$ \\
\hline $\begin{array}{l}25 \\
\text { Householder } 25 \text { to }\end{array}$ & 995,014 & -211 & $-0.021 \%$ & $25.5 \%$ & -83 & $-0.01 \%$ & $-7.4 \%$ \\
\hline $\begin{array}{l}44 \\
\text { Householder } 45 \text { to }\end{array}$ & $4,049,688$ & 79 & $0.002 \%$ & $-9.5 \%$ & 974 & $0.02 \%$ & $86.7 \%$ \\
\hline 64 & $4,348,615$ & -366 & $-0.008 \%$ & $44.2 \%$ & -2 & $0.00 \%$ & $-0.2 \%$ \\
\hline $\begin{array}{l}\text { Householder 65+ } \\
\text { Basic Demographics--- } \\
\text { Band }\end{array}$ & $\begin{array}{l}2,500,007 \\
.50 \text { Mile Dist }\end{array}$ & $\begin{array}{l}-330 \\
\text { ance }\end{array}$ & $-0.013 \%$ & $39.9 \%$ & -166 & $-0.01 \%$ & $-14.8 \%$ \\
\hline Total Households & $\begin{array}{l}10,206,45 \\
8\end{array}$ & 380 & $0.004 \%$ & & 2,413 & $0.02 \%$ & \\
\hline $\mathrm{HH}$ with Children & $3,553,464$ & 217 & $0.006 \%$ & $57.1 \%$ & 1,007 & $0.03 \%$ & $41.7 \%$ \\
\hline 2+ Adult HH no Child & $2,728,201$ & 413 & $0.015 \%$ & $108.7 \%$ & 1,238 & $0.05 \%$ & $51.3 \%$ \\
\hline $\begin{array}{l}\text { One Person } \mathrm{HH} \\
\text { Householder under }\end{array}$ & $3,924,793$ & -250 & $-0.006 \%$ & $-65.8 \%$ & 168 & $0.00 \%$ & $7.0 \%$ \\
\hline $\begin{array}{l}25 \\
\text { Householder } 25 \text { to }\end{array}$ & 995,014 & -82 & $-0.008 \%$ & $-21.6 \%$ & -423 & $-0.04 \%$ & $-17.5 \%$ \\
\hline $\begin{array}{l}44 \\
\text { Householder } 45 \text { to }\end{array}$ & $4,049,688$ & 743 & $0.018 \%$ & $195.5 \%$ & 2,742 & $0.07 \%$ & $113.6 \%$ \\
\hline 64 & $4,348,615$ & -269 & $-0.006 \%$ & $-70.8 \%$ & -483 & $-0.01 \%$ & $-20.0 \%$ \\
\hline Householder 65+ & $2,500,007$ & -12 & $0.000 \%$ & $-3.2 \%$ & 176 & $0.01 \%$ & $7.3 \%$ \\
\hline
\end{tabular}


Table 5.9. Poor MA: LRT Households by Type and Householder Age

\begin{tabular}{|c|c|c|c|c|c|c|c|}
\hline \multirow[b]{2}{*}{$\begin{array}{l}\text { Demographic } \\
\text { Share-- Distance } \\
\text { Band Change }\end{array}$} & \multirow[b]{2}{*}{$\begin{array}{l}\text { Transit } \\
\text { Region } \\
\text { Change } \\
2010-2016\end{array}$} & \multicolumn{3}{|c|}{ Incremental Analysis } & \multicolumn{3}{|c|}{ Cumulative Analysis } \\
\hline & & $\begin{array}{l}\text { Distanc } \\
\text { e Band } \\
\text { Change } \\
2010- \\
2016 \\
\end{array}$ & $\begin{array}{l}\text { Share } \\
\text { of } \\
\text { Transit } \\
\text { Countie } \\
\text { s }\end{array}$ & $\begin{array}{l}\text { Share of } \\
\text { Distance } \\
\text { Band } \\
\text { Change }\end{array}$ & $\begin{array}{l}\text { Distanc } \\
\text { e Band } \\
\text { Change } \\
2010- \\
2016 \\
\end{array}$ & $\begin{array}{l}\text { Share } \\
\text { of } \\
\text { Transit } \\
\text { Countie } \\
\text { s }\end{array}$ & $\begin{array}{l}\text { Share of } \\
\text { Distance } \\
\text { Band } \\
\text { Change }\end{array}$ \\
\hline \multicolumn{8}{|c|}{$\begin{array}{l}\text { Basic Demographics--0.125 Mile Distance } \\
\text { Band }\end{array}$} \\
\hline Total Households & 841,178 & -73 & $0.0 \%$ & 2290.4 & -73 & $0.0 \%$ & 2290.4 \\
\hline $\mathrm{HH}$ with Children & 227,689 & $-1,672$ & $-0.7 \%$ & & $-1,672$ & $-0.7 \%$ & \\
\hline $\begin{array}{l}2+\text { Adult } \mathrm{HH} \text { no } \\
\text { Child }\end{array}$ & 253,075 & 1,440 & $0.6 \%$ & $\begin{array}{l}1972.6 \\
\%\end{array}$ & 1,440 & $0.6 \%$ & $\begin{array}{l}1972.6 \\
\%\end{array}$ \\
\hline $\begin{array}{l}\text { One Person } \mathrm{HH} \\
\text { Householder under }\end{array}$ & 360,414 & 159 & $0.0 \%$ & $-217.8 \%$ & 159 & $0.0 \%$ & $-217.8 \%$ \\
\hline $\begin{array}{l}25 \\
\text { Householder } 25 \text { to }\end{array}$ & $-74,731$ & -711 & $1.0 \%$ & $974.0 \%$ & -711 & $1.0 \%$ & $974.0 \%$ \\
\hline $\begin{array}{l}44 \\
\text { Householder } 45 \text { to }\end{array}$ & $-31,610$ & 30 & $-0.1 \%$ & $-41.1 \%$ & 30 & $-0.1 \%$ & $-41.1 \%$ \\
\hline 64 & 850,264 & -329 & $0.0 \%$ & $\begin{array}{l}450.7 \% \\
- \\
1283.6\end{array}$ & -329 & $0.0 \%$ & $\begin{array}{l}450.7 \% \\
- \\
1283.6\end{array}$ \\
\hline \multicolumn{8}{|c|}{$\begin{array}{l}\text { Basic Demographics--0.25 Mile Distance } \\
\text { Band }\end{array}$} \\
\hline Total Households & 841,178 & -381 & $0.0 \%$ & & -454 & $-0.1 \%$ & \\
\hline $\begin{array}{l}\mathrm{HH} \text { with Children } \\
\text { 2+ Adult } \mathrm{HH} \text { no }\end{array}$ & 227,689 & -848 & $-0.4 \%$ & $222.6 \%$ & $-2,520$ & $-1.1 \%$ & $555.1 \%$ \\
\hline Child & 253,075 & 712 & $0.3 \%$ & $-186.9 \%$ & 2,152 & $0.9 \%$ & $-474.0 \%$ \\
\hline $\begin{array}{l}\text { One Person } \mathrm{HH} \\
\text { Householder under }\end{array}$ & 360,414 & -245 & $-0.1 \%$ & $64.3 \%$ & -86 & $0.0 \%$ & $18.9 \%$ \\
\hline & $-74,731$ & -72 & $0.1 \%$ & $18.9 \%$ & -783 & $1.0 \%$ & $172.5 \%$ \\
\hline $\begin{array}{l}44 \\
\text { Householder } 45 \text { to }\end{array}$ & $-31,610$ & 189 & $-0.6 \%$ & $-49.6 \%$ & 219 & $-0.7 \%$ & $-48.2 \%$ \\
\hline 64 & 850,264 & -795 & $-0.1 \%$ & $208.7 \%$ & $-1,124$ & $-0.1 \%$ & $247.6 \%$ \\
\hline Householder 65+ & 80,041 & 297 & $0.4 \%$ & $-78.0 \%$ & 1,234 & $1.5 \%$ & $-271.8 \%$ \\
\hline \multicolumn{8}{|c|}{ Basic Demographics--0.50 Mile Distance Band } \\
\hline Total Households & 841,178 & -779 & $-0.1 \%$ & & -744 & $-0.1 \%$ & \\
\hline $\begin{array}{l}\mathrm{HH} \text { with Children } \\
2+\text { Adult } \mathrm{HH} \text { no }\end{array}$ & 227,689 & $-1,744$ & $-0.8 \%$ & $223.9 \%$ & $-5,105$ & $-2.2 \%$ & $686.2 \%$ \\
\hline Child & 253,075 & 686 & $0.3 \%$ & $-88.1 \%$ & 3,768 & $1.5 \%$ & $-506.5 \%$ \\
\hline $\begin{array}{l}\text { One Person } \mathrm{HH} \\
\text { Householder under }\end{array}$ & 360,414 & 279 & $0.1 \%$ & $-35.8 \%$ & 593 & $0.2 \%$ & $-79.7 \%$ \\
\hline $\begin{array}{l}25 \\
\text { Householder } 25 \text { to }\end{array}$ & $-74,731$ & -339 & $0.5 \%$ & $43.5 \%$ & $-1,446$ & $1.9 \%$ & $194.4 \%$ \\
\hline $\begin{array}{l}44 \\
\text { Householder } 45 \text { to }\end{array}$ & $-31,610$ & -710 & $2.2 \%$ & $91.1 \%$ & -841 & $2.7 \%$ & $113.0 \%$ \\
\hline 64 & 850,264 & -893 & $-0.1 \%$ & $114.6 \%$ & $-1,466$ & $-0.2 \%$ & $197.0 \%$ \\
\hline Householder 65+ & 80,041 & 1,163 & $1.5 \%$ & $-149.3 \%$ & 3,009 & $3.8 \%$ & $-404.4 \%$ \\
\hline
\end{tabular}


Table 5.10. Low MA: LRT Households by Type and Householder Age

\begin{tabular}{|c|c|c|c|c|c|c|c|}
\hline \multirow[b]{2}{*}{$\begin{array}{l}\text { Demographic } \\
\text { Share-- Distance } \\
\text { Band Change }\end{array}$} & \multirow[b]{2}{*}{$\begin{array}{l}\text { Transit } \\
\text { Region } \\
\text { Change } \\
\text { 2010-2016 }\end{array}$} & \multicolumn{3}{|c|}{ Incremental Analysis } & \multicolumn{3}{|c|}{ Cumulative Analysis } \\
\hline & & $\begin{array}{l}\text { Distanc } \\
\text { e Band } \\
\text { Change } \\
2010- \\
2016\end{array}$ & $\begin{array}{l}\text { Share } \\
\text { of } \\
\text { Transit } \\
\text { Countie } \\
\text { s }\end{array}$ & $\begin{array}{l}\text { Share } \\
\text { of } \\
\text { Distanc } \\
\text { e Band } \\
\text { Change }\end{array}$ & $\begin{array}{l}\text { Distanc } \\
\text { e Band } \\
\text { Change } \\
2010- \\
2016\end{array}$ & $\begin{array}{l}\text { Share } \\
\text { of } \\
\text { Transit } \\
\text { Countie } \\
\text { s }\end{array}$ & $\begin{array}{l}\text { Share } \\
\text { of } \\
\text { Distanc } \\
\text { e Band } \\
\text { Change }\end{array}$ \\
\hline \multicolumn{8}{|c|}{$\begin{array}{l}\text { Basic Demographics--0.125 Mile Distance } \\
\text { Band }\end{array}$} \\
\hline Total Households & 841,178 & 19,386 & $2.3 \%$ & & 19,386 & $2.3 \%$ & \\
\hline $\begin{array}{l}\mathrm{HH} \text { with Children } \\
2+\text { Adult } \mathrm{HH} \text { no }\end{array}$ & 227,689 & -496 & $-0.2 \%$ & $-2.6 \%$ & -496 & $-0.2 \%$ & $-2.6 \%$ \\
\hline Child & 253,075 & 11,389 & $4.5 \%$ & $58.7 \%$ & 11,389 & $4.5 \%$ & $58.7 \%$ \\
\hline $\begin{array}{l}\text { One Person } \mathrm{HH} \\
\text { Householder under }\end{array}$ & 360,414 & 8,493 & $2.4 \%$ & $43.8 \%$ & 8,493 & $2.4 \%$ & $43.8 \%$ \\
\hline $\begin{array}{l}25 \\
\text { Householder } 25 \text { to }\end{array}$ & $-74,731$ & $-3,333$ & $4.5 \%$ & $-17.2 \%$ & $-3,333$ & $4.5 \%$ & $-17.2 \%$ \\
\hline $\begin{array}{l}44 \\
\text { Householder } 45 \text { to }\end{array}$ & $-31,610$ & 10,622 & $-33.6 \%$ & $54.8 \%$ & 10,622 & $-33.6 \%$ & $54.8 \%$ \\
\hline $\begin{array}{l}64 \\
\text { Householder } 65+\end{array}$ & $\begin{array}{l}850,264 \\
80,041\end{array}$ & $\begin{array}{l}5,611 \\
6,480\end{array}$ & $\begin{array}{l}0.7 \% \\
8.1 \%\end{array}$ & $\begin{array}{l}29.0 \% \\
33.4 \%\end{array}$ & 6,480 & $\begin{array}{l}0.1 \% \\
8.1 \%\end{array}$ & $\begin{array}{l}29.0 \% \\
33.4 \%\end{array}$ \\
\hline \multicolumn{8}{|c|}{ Basic Demographics--0.25 Mile Distance Band } \\
\hline Total Households & 841,178 & 4,591 & $0.5 \%$ & & 23,977 & $2.9 \%$ & \\
\hline $\begin{array}{l}\mathrm{HH} \text { with Children } \\
\text { 2+ Adult } \mathrm{HH} \text { no }\end{array}$ & 227,689 & $-1,508$ & $-0.7 \%$ & $-32.8 \%$ & $-2,004$ & $-0.9 \%$ & $-8.4 \%$ \\
\hline Child & 253,075 & 4,318 & $1.7 \%$ & $94.1 \%$ & 15,707 & $6.2 \%$ & $65.5 \%$ \\
\hline $\begin{array}{l}\text { One Person } \mathrm{HH} \\
\text { Householder under }\end{array}$ & 360,414 & 1,781 & $0.5 \%$ & $38.8 \%$ & 10,274 & $2.9 \%$ & $42.8 \%$ \\
\hline $\begin{array}{l}25 \\
\text { Householder } 25 \text { to }\end{array}$ & $-74,731$ & $-1,216$ & $1.6 \%$ & $-26.5 \%$ & $-4,549$ & $6.1 \%$ & $-19.0 \%$ \\
\hline $\begin{array}{l}44 \\
\text { Householder } 45 \text { to }\end{array}$ & $-31,610$ & 473 & $-1.5 \%$ & $10.3 \%$ & 11,095 & $-35.1 \%$ & $46.3 \%$ \\
\hline 64 & 850,264 & 2,720 & $0.3 \%$ & $59.2 \%$ & 8,337 & $1.0 \%$ & $34.8 \%$ \\
\hline Householder 65+ & 80,041 & 2,614 & $3.3 \%$ & $56.9 \%$ & 9,094 & $11.4 \%$ & $37.9 \%$ \\
\hline \multicolumn{8}{|c|}{ Basic Demographics--0.50 Mile Distance Band } \\
\hline Total Households & 841,178 & 4,885 & $0.6 \%$ & & 30,740 & $3.7 \%$ & \\
\hline $\begin{array}{l}\mathrm{HH} \text { with Children } \\
\text { 2+ Adult } \mathrm{HH} \text { no }\end{array}$ & 227,689 & $-1,427$ & $-0.6 \%$ & $-29.2 \%$ & $-4,050$ & $-1.8 \%$ & $-13.2 \%$ \\
\hline Child & 253,075 & 3,463 & $1.4 \%$ & $70.9 \%$ & 20,311 & $8.0 \%$ & $66.1 \%$ \\
\hline $\begin{array}{l}\text { One Person } \mathrm{HH} \\
\text { Householder under }\end{array}$ & 360,414 & 2,849 & $0.8 \%$ & $58.3 \%$ & 14,479 & $4.0 \%$ & $47.1 \%$ \\
\hline $\begin{array}{l}25 \\
\text { Householder } 25 \text { to }\end{array}$ & $-74,731$ & -950 & $1.3 \%$ & $-19.4 \%$ & $-6,837$ & $9.1 \%$ & $-22.2 \%$ \\
\hline $\begin{array}{l}44 \\
\text { Householder } 45 \text { to }\end{array}$ & $-31,610$ & 1,759 & $-5.6 \%$ & $36.0 \%$ & 13,553 & $-42.9 \%$ & $44.1 \%$ \\
\hline 64 & 850,264 & 1,413 & $0.2 \%$ & $28.9 \%$ & 10,612 & $1.2 \%$ & $34.5 \%$ \\
\hline Householder 65+ & 80,041 & 2,663 & $3.3 \%$ & $54.5 \%$ & 13,412 & $16.8 \%$ & $43.6 \%$ \\
\hline
\end{tabular}


Table 5.11. Mod MA: LRT Households by Type and Householder Age

\begin{tabular}{|c|c|c|c|c|c|c|c|}
\hline \multirow[b]{2}{*}{$\begin{array}{l}\text { Demographic Share- } \\
\text { - Distance Band } \\
\text { Change }\end{array}$} & \multirow[b]{2}{*}{$\begin{array}{l}\text { Transit } \\
\text { Region } \\
\text { Change } \\
\text { 2010-2016 }\end{array}$} & \multicolumn{3}{|c|}{ Incremental Analysis } & \multicolumn{3}{|c|}{ Cumulative Analysis } \\
\hline & & $\begin{array}{l}\text { Distanc } \\
\text { e Band } \\
\text { Change } \\
2010- \\
2016\end{array}$ & $\begin{array}{l}\text { Share } \\
\text { of } \\
\text { Transit } \\
\text { Countie } \\
\mathrm{s}\end{array}$ & $\begin{array}{l}\text { Share } \\
\text { of } \\
\text { Distanc } \\
\text { e Band } \\
\text { Change }\end{array}$ & $\begin{array}{l}\text { Distanc } \\
\text { e Band } \\
\text { Change } \\
2010- \\
2016\end{array}$ & $\begin{array}{l}\text { Share } \\
\text { of } \\
\text { Transit } \\
\text { Countie } \\
\mathrm{s}\end{array}$ & $\begin{array}{l}\text { Share } \\
\text { of } \\
\text { Distanc } \\
\text { e Band } \\
\text { Change }\end{array}$ \\
\hline \multicolumn{8}{|c|}{ Basic Demographics--0.125 Mile Distance Band } \\
\hline Total Households & 841,178 & 24,663 & $2.9 \%$ & & 24,663 & $2.9 \%$ & \\
\hline $\begin{array}{l}\mathrm{HH} \text { with Children } \\
2+\text { Adult } \mathrm{HH} \text { no }\end{array}$ & 227,689 & 7,405 & $3.3 \%$ & $30.0 \%$ & 7,405 & $3.3 \%$ & $30.0 \%$ \\
\hline Child & 253,075 & 9,727 & $3.8 \%$ & $39.4 \%$ & 9,727 & $3.8 \%$ & $39.4 \%$ \\
\hline $\begin{array}{l}\text { One Person } \mathrm{HH} \\
\text { Householder under }\end{array}$ & 360,414 & 7,531 & $2.1 \%$ & $30.5 \%$ & 7,531 & $2.1 \%$ & $30.5 \%$ \\
\hline $\begin{array}{l}25 \\
\text { Householder } 25 \text { to }\end{array}$ & $-74,731$ & $-1,949$ & $2.6 \%$ & $-7.9 \%$ & $-1,949$ & $2.6 \%$ & $-7.9 \%$ \\
\hline $\begin{array}{l}44 \\
\text { Householder } 45 \text { to }\end{array}$ & $-31,610$ & 16,693 & $-52.8 \%$ & $67.7 \%$ & 16,693 & $-52.8 \%$ & $67.7 \%$ \\
\hline & 850,264 & 4,752 & $0.6 \%$ & $19.3 \%$ & 4,752 & $0.6 \%$ & $19.3 \%$ \\
\hline Householder 65+ & 80,041 & 5,167 & $6.5 \%$ & $21.0 \%$ & 5,167 & $6.5 \%$ & $21.0 \%$ \\
\hline \multicolumn{8}{|c|}{ Basic Demographics--0.25 Mile Distance Band } \\
\hline Total Households & 841,178 & 5,933 & $0.7 \%$ & & 30,596 & $3.6 \%$ & \\
\hline $\begin{array}{l}\mathrm{HH} \text { with Children } \\
2+\text { Adult } \mathrm{HH} \text { no }\end{array}$ & 227,689 & 2,003 & $0.9 \%$ & $33.8 \%$ & 9,408 & $4.1 \%$ & $30.7 \%$ \\
\hline Child & 253,075 & 3,553 & $1.4 \%$ & $59.9 \%$ & 13,280 & $5.2 \%$ & $43.4 \%$ \\
\hline $\begin{array}{l}\text { One Person } \mathrm{HH} \\
\text { Householder under }\end{array}$ & 360,414 & 377 & $0.1 \%$ & $6.4 \%$ & 7,908 & $2.2 \%$ & $25.8 \%$ \\
\hline $\begin{array}{l}25 \\
\text { Householder } 25 \text { to }\end{array}$ & $-74,731$ & -495 & $0.7 \%$ & $-8.3 \%$ & $-2,444$ & $3.3 \%$ & $-8.0 \%$ \\
\hline $\begin{array}{l}44 \\
\text { Householder } 45 \text { to }\end{array}$ & $-31,610$ & 3,522 & $-11.1 \%$ & $59.4 \%$ & 20,215 & $-64.0 \%$ & $66.1 \%$ \\
\hline 64 & 850,264 & 2,115 & $0.2 \%$ & $35.6 \%$ & 6,867 & $0.8 \%$ & $22.4 \%$ \\
\hline Householder 65+ & 80,041 & 791 & $1.0 \%$ & $13.3 \%$ & 5,958 & $7.4 \%$ & $19.5 \%$ \\
\hline \multicolumn{8}{|c|}{ Basic Demographics--0.50 Mile Distance Band } \\
\hline Total Households & 841,178 & 5,863 & $0.7 \%$ & & 41,403 & $4.9 \%$ & \\
\hline $\begin{array}{l}\mathrm{HH} \text { with Children } \\
2+\text { Adult } \mathrm{HH} \text { no }\end{array}$ & 227,689 & 1,430 & $0.6 \%$ & $24.4 \%$ & 11,763 & $5.2 \%$ & $28.4 \%$ \\
\hline Child & 253,075 & 1,883 & $0.7 \%$ & $32.1 \%$ & 17,215 & $6.8 \%$ & $41.6 \%$ \\
\hline $\begin{array}{l}\text { One Person } \mathrm{HH} \\
\text { Householder under }\end{array}$ & 360,414 & 2,550 & $0.7 \%$ & $43.5 \%$ & 12,425 & $3.4 \%$ & $30.0 \%$ \\
\hline $\begin{array}{l}25 \\
\text { Householder } 25 \text { to }\end{array}$ & $-74,731$ & $-1,227$ & $1.6 \%$ & $-20.9 \%$ & $-4,806$ & $6.4 \%$ & $-11.6 \%$ \\
\hline 44 & $-31,610$ & 3,938 & $-12.5 \%$ & $67.2 \%$ & 27,964 & $-88.5 \%$ & $67.5 \%$ \\
\hline
\end{tabular}




\begin{tabular}{llllllll} 
Householder 45 to & & & & & & & \\
64 & 850,264 & 559 & $0.1 \%$ & $9.5 \%$ & 9,212 & $1.1 \%$ & $22.2 \%$ \\
Householder 65+ & 80,041 & 2,593 & $3.2 \%$ & $44.2 \%$ & 9,033 & $11.3 \%$ & $21.8 \%$ \\
\hline \hline
\end{tabular}


Table 5.12. High MA: LRT Households by Type and Householder Age

\begin{tabular}{|c|c|c|c|c|c|c|c|}
\hline \multirow[b]{2}{*}{$\begin{array}{l}\text { Demographic Share- } \\
\text { - Distance Band } \\
\text { Change }\end{array}$} & \multirow[b]{2}{*}{$\begin{array}{l}\text { Transit } \\
\text { Region } \\
\text { Change } \\
\text { 2010-2016 }\end{array}$} & \multicolumn{3}{|c|}{ Incremental Analysis } & \multicolumn{3}{|c|}{ Cumulative Analysis } \\
\hline & & $\begin{array}{l}\text { Distanc } \\
\text { e Band } \\
\text { Change } \\
2010- \\
2016 \\
\end{array}$ & $\begin{array}{l}\text { Share } \\
\text { of } \\
\text { Transit } \\
\text { Countie } \\
\mathrm{s}\end{array}$ & $\begin{array}{l}\text { Share } \\
\text { of } \\
\text { Distanc } \\
\text { e Band } \\
\text { Change }\end{array}$ & $\begin{array}{l}\text { Distanc } \\
\text { e Band } \\
\text { Change } \\
2010- \\
2016\end{array}$ & $\begin{array}{l}\text { Share } \\
\text { of } \\
\text { Transit } \\
\text { Countie } \\
\text { s }\end{array}$ & $\begin{array}{l}\text { Share } \\
\text { of } \\
\text { Distanc } \\
\text { e Band } \\
\text { Change }\end{array}$ \\
\hline \multicolumn{8}{|c|}{ Basic Demographics--0.125 Mile Distance Band } \\
\hline Total Households & 841,178 & 9,118 & $1.1 \%$ & & 9,118 & $1.1 \%$ & \\
\hline $\begin{array}{l}\mathrm{HH} \text { with Children } \\
2+\text { Adult } \mathrm{HH} \text { no }\end{array}$ & 227,689 & 1,924 & $0.8 \%$ & $21.1 \%$ & 1,924 & $0.8 \%$ & $21.1 \%$ \\
\hline Child & 253,075 & 2,891 & $1.1 \%$ & $31.7 \%$ & 2,891 & $1.1 \%$ & $31.7 \%$ \\
\hline $\begin{array}{l}\text { One Person } \mathrm{HH} \\
\text { Householder under }\end{array}$ & 360,414 & 4,303 & $1.2 \%$ & $47.2 \%$ & 4,303 & $1.2 \%$ & $47.2 \%$ \\
\hline $\begin{array}{l}25 \\
\text { Householder } 25 \text { to }\end{array}$ & $-74,731$ & $-1,895$ & $2.5 \%$ & $-20.8 \%$ & $-1,895$ & $2.5 \%$ & $-20.8 \%$ \\
\hline $\begin{array}{l}44 \\
\text { Householder } 45 \text { to }\end{array}$ & $-31,610$ & 8,294 & $-26.2 \%$ & $91.0 \%$ & 8,294 & $-26.2 \%$ & $91.0 \%$ \\
\hline 64 & 850,264 & 1,298 & $0.2 \%$ & $14.2 \%$ & 1,298 & $0.2 \%$ & $14.2 \%$ \\
\hline Householder 65+ & 80,041 & 1,421 & $1.8 \%$ & $15.6 \%$ & 1,421 & $1.8 \%$ & $15.6 \%$ \\
\hline \multicolumn{8}{|c|}{ Basic Demographics--0.25 Mile Distance Band } \\
\hline Total Households & 841,178 & 1,805 & $0.2 \%$ & & 10,923 & $1.3 \%$ & \\
\hline $\begin{array}{l}\mathrm{HH} \text { with Children } \\
2+\text { Adult } \mathrm{HH} \text { no }\end{array}$ & 227,689 & 590 & $0.3 \%$ & $32.7 \%$ & 2,514 & $1.1 \%$ & $23.0 \%$ \\
\hline Child & 253,075 & 861 & $0.3 \%$ & $47.7 \%$ & 3,752 & $1.5 \%$ & $34.3 \%$ \\
\hline $\begin{array}{l}\text { One Person HH } \\
\text { Householder under }\end{array}$ & 360,414 & 354 & $0.1 \%$ & $19.6 \%$ & 4,657 & $1.3 \%$ & $42.6 \%$ \\
\hline $\begin{array}{l}25 \\
\text { Householder } 25 \text { to }\end{array}$ & $-74,731$ & -341 & $0.5 \%$ & $-18.9 \%$ & $-2,236$ & $3.0 \%$ & $-20.5 \%$ \\
\hline $\begin{array}{l}44 \\
\text { Householder } 45 \text { to }\end{array}$ & $-31,610$ & 1,044 & $-3.3 \%$ & $57.8 \%$ & 9,338 & $-29.5 \%$ & $85.5 \%$ \\
\hline 64 & 850,264 & 585 & $0.1 \%$ & $32.4 \%$ & 1,883 & $0.2 \%$ & $17.2 \%$ \\
\hline Householder 65+ & 80,041 & 517 & $0.6 \%$ & $28.6 \%$ & 1,938 & $2.4 \%$ & $17.7 \%$ \\
\hline \multicolumn{8}{|c|}{ Basic Demographics--0.50 Mile Distance Band } \\
\hline Total Households & 841,178 & 1,587 & $0.2 \%$ & & 15,617 & $1.9 \%$ & \\
\hline $\begin{array}{l}\mathrm{HH} \text { with Children } \\
2+\text { Adult } \mathrm{HH} \text { no }\end{array}$ & 227,689 & 864 & $0.4 \%$ & $54.4 \%$ & 4,268 & $1.9 \%$ & $27.3 \%$ \\
\hline Child & 253,075 & 684 & $0.3 \%$ & $43.1 \%$ & 5,830 & $2.3 \%$ & $37.3 \%$ \\
\hline $\begin{array}{l}\text { One Person } \mathrm{HH} \\
\text { Householder under }\end{array}$ & 360,414 & 39 & $0.0 \%$ & $2.5 \%$ & 5,519 & $1.5 \%$ & $35.3 \%$ \\
\hline $\begin{array}{l}25 \\
\text { Householder } 25 \text { to }\end{array}$ & $-74,731$ & -911 & $1.2 \%$ & $-57.4 \%$ & $-3,998$ & $5.3 \%$ & $-25.6 \%$ \\
\hline $\begin{array}{l}44 \\
\text { Householder } 45 \text { to }\end{array}$ & $-31,610$ & 1,504 & $-4.8 \%$ & $94.8 \%$ & 13,725 & $-43.4 \%$ & $87.9 \%$ \\
\hline 64 & 850,264 & 70 & $0.0 \%$ & $4.4 \%$ & 2,462 & $0.3 \%$ & $15.8 \%$ \\
\hline Householder 65+ & 80,041 & 924 & $1.2 \%$ & $58.2 \%$ & 3,428 & $4.3 \%$ & $22.0 \%$ \\
\hline
\end{tabular}


Table 5.13. Poor MA: SCT Households by Type and Householder Age

\begin{tabular}{|c|c|c|c|c|c|c|c|}
\hline \multirow[b]{2}{*}{$\begin{array}{l}\text { Demographic } \\
\text { Share-- Distance } \\
\text { Band Change }\end{array}$} & \multirow[b]{2}{*}{$\begin{array}{l}\text { Transit } \\
\text { Region } \\
\text { Change } \\
\text { 2010-2016 }\end{array}$} & \multicolumn{3}{|c|}{ Incremental Analysis } & \multicolumn{3}{|c|}{ Cumulative Analysis } \\
\hline & & $\begin{array}{l}\text { Distanc } \\
\text { e Band } \\
\text { Change } \\
2010- \\
2016\end{array}$ & $\begin{array}{l}\text { Share } \\
\text { of } \\
\text { Transit } \\
\text { Countie } \\
\text { s }\end{array}$ & $\begin{array}{l}\text { Share } \\
\text { of } \\
\text { Distanc } \\
\text { e Band } \\
\text { Change }\end{array}$ & $\begin{array}{l}\text { Distanc } \\
\text { e Band } \\
\text { Change } \\
2010- \\
2016\end{array}$ & $\begin{array}{l}\text { Share } \\
\text { of } \\
\text { Transit } \\
\text { Countie } \\
\text { s }\end{array}$ & $\begin{array}{l}\text { Share } \\
\text { of } \\
\text { Distanc } \\
\text { e Band } \\
\text { Change }\end{array}$ \\
\hline \multicolumn{8}{|c|}{$\begin{array}{l}\text { Basic Demographics--0.125 Mile Distance } \\
\text { Band }\end{array}$} \\
\hline Total Households & 224,479 & 0 & $0.0 \%$ & & 0 & $0.0 \%$ & \\
\hline \multirow{2}{*}{$\begin{array}{l}\mathrm{HH} \text { with Children } \\
2+\text { Adult } \mathrm{HH} \text { no } \\
\text { Child }\end{array}$} & $-16,532$ & 0 & $0.0 \%$ & NA & 0 & $0.0 \%$ & NA \\
\hline & 70,287 & 0 & $0.0 \%$ & NA & 0 & $0.0 \%$ & NA \\
\hline \multirow{4}{*}{$\begin{array}{l}\text { One Person } \mathrm{HH} \\
\text { Householder under } \\
25 \\
\text { Householder } 25 \text { to } \\
44 \\
\text { Householder } 45 \text { to } \\
64\end{array}$} & 170,723 & 0 & $0.0 \%$ & NA & 0 & $0.0 \%$ & NA \\
\hline & $-56,320$ & 0 & $0.0 \%$ & NA & 0 & $0.0 \%$ & NA \\
\hline & $-45,744$ & 0 & $0.0 \%$ & NA & 0 & $0.0 \%$ & NA \\
\hline & 298,042 & 0 & $0.0 \%$ & NA & 0 & $0.0 \%$ & NA \\
\hline Householder 65+ & 25,889 & 0 & $0.0 \%$ & NA & 0 & $0.0 \%$ & NA \\
\hline \multicolumn{8}{|c|}{ Basic Demographics--0.25 Mile Distance Band } \\
\hline Total Households & 224,479 & -48 & $-0.02 \%$ & & -48 & $-0.02 \%$ & \\
\hline $\begin{array}{l}\mathrm{HH} \text { with Children } \\
2+\text { Adult } \mathrm{HH} \text { no }\end{array}$ & $-16,532$ & -57 & $0.3 \%$ & $118.8 \%$ & -57 & $0.34 \%$ & $118.8 \%$ \\
\hline $\begin{array}{l}\text { Child } \\
\text { One Person HH } \\
\text { Householder under }\end{array}$ & $\begin{array}{l}70,287 \\
170,723\end{array}$ & $\begin{array}{l}-33 \\
42\end{array}$ & $\begin{array}{l}-0.05 \% \\
0.02 \%\end{array}$ & $\begin{array}{l}68.8 \% \\
-87.5 \% \\
-\end{array}$ & $\begin{array}{l}-33 \\
42\end{array}$ & $\begin{array}{l}-0.05 \% \\
0.02 \%\end{array}$ & $\begin{array}{l}68.8 \% \\
-87.5 \% \\
-\end{array}$ \\
\hline $\begin{array}{l}25 \\
\text { Householder } 25 \text { to }\end{array}$ & $-56,320$ & 75 & $-0.1 \%$ & $156.3 \%$ & 75 & $-0.1 \%$ & $156.3 \%$ \\
\hline & $-45,744$ & -7 & $0.02 \%$ & $14.6 \%$ & -7 & $0.02 \%$ & $14.6 \%$ \\
\hline 64 & 298,042 & -196 & $-0.1 \%$ & $\begin{array}{l}408.3 \% \\
-\end{array}$ & -196 & $-0.1 \%$ & $\begin{array}{l}408.3 \% \\
-\end{array}$ \\
\hline Householder 65+ & 25,889 & 80 & $0.3 \%$ & $166.7 \%$ & 80 & $0.3 \%$ & $166.7 \%$ \\
\hline \multicolumn{8}{|c|}{ Basic Demographics--0.50 Mile Distance Band } \\
\hline Total Households & 224,479 & -116 & $-0.1 \%$ & & -553 & $-0.2 \%$ & \\
\hline $\begin{array}{l}\mathrm{HH} \text { with Children } \\
2+\text { Adult } \mathrm{HH} \text { no }\end{array}$ & $-16,532$ & -1 & $0.01 \%$ & $0.9 \%$ & -374 & $2.3 \%$ & $67.6 \%$ \\
\hline Child & 70,287 & -121 & $-0.2 \%$ & $104.3 \%$ & -199 & $-0.3 \%$ & $36.0 \%$ \\
\hline $\begin{array}{l}\text { One Person } \mathrm{HH} \\
\text { Householder under }\end{array}$ & 170,723 & 6 & $0.00 \%$ & $-5.2 \%$ & 20 & $0.01 \%$ & $-3.6 \%$ \\
\hline $\begin{array}{l}25 \\
\text { Householder } 25 \text { to }\end{array}$ & $-56,320$ & -136 & $0.2 \%$ & $117.2 \%$ & -82 & $0.1 \%$ & $14.8 \%$ \\
\hline $\begin{array}{l}44 \\
\text { Householder } 45 \text { to }\end{array}$ & $-45,744$ & -47 & $0.1 \%$ & $40.5 \%$ & -228 & $0.5 \%$ & $41.2 \%$ \\
\hline 64 & 298,042 & 72 & $0.02 \%$ & $-62.1 \%$ & -228 & $-0.1 \%$ & $41.2 \%$ \\
\hline Householder 65+ & 25,889 & -5 & $-0.02 \%$ & $4.3 \%$ & -15 & $-0.1 \%$ & $2.7 \%$ \\
\hline
\end{tabular}


Table 5.14. Low MA: SCT Households by Type and Householder Age

\begin{tabular}{|c|c|c|c|c|c|c|c|}
\hline \multirow[b]{2}{*}{$\begin{array}{l}\text { Demographic } \\
\text { Share-- Distance } \\
\text { Band Change }\end{array}$} & \multirow[b]{2}{*}{$\begin{array}{l}\text { Transit } \\
\text { Region } \\
\text { Change } \\
\text { 2010-2016 }\end{array}$} & \multicolumn{3}{|c|}{ Incremental Analysis } & \multicolumn{3}{|c|}{ Cumulative Analysis } \\
\hline & & $\begin{array}{l}\text { Distanc } \\
\text { e Band } \\
\text { Change } \\
2010- \\
2016\end{array}$ & $\begin{array}{l}\text { Share } \\
\text { of } \\
\text { Transit } \\
\text { Countie } \\
\text { s }\end{array}$ & $\begin{array}{l}\text { Share } \\
\text { of } \\
\text { Distanc } \\
\text { e Band } \\
\text { Change }\end{array}$ & $\begin{array}{l}\text { Distanc } \\
\text { e Band } \\
\text { Change } \\
2010- \\
2016\end{array}$ & $\begin{array}{l}\text { Share } \\
\text { of } \\
\text { Transit } \\
\text { Countie } \\
\text { s }\end{array}$ & $\begin{array}{l}\text { Share } \\
\text { of } \\
\text { Distanc } \\
\text { e Band } \\
\text { Change }\end{array}$ \\
\hline \multicolumn{8}{|c|}{$\begin{array}{l}\text { Basic Demographics--0.125 Mile Distance } \\
\text { Band }\end{array}$} \\
\hline Total Households & 224,479 & 2,961 & $1.3 \%$ & & 2,961 & $1.3 \%$ & \\
\hline $\begin{array}{l}\mathrm{HH} \text { with Children } \\
2+\text { Adult } \mathrm{HH} \text { no }\end{array}$ & $-16,532$ & -471 & $2.8 \%$ & $-15.9 \%$ & -471 & $2.8 \%$ & $-15.9 \%$ \\
\hline Child & 70,287 & 755 & $1.1 \%$ & $25.5 \%$ & 755 & $1.1 \%$ & $25.5 \%$ \\
\hline $\begin{array}{l}\text { One Person } \mathrm{HH} \\
\text { Householder under }\end{array}$ & 170,723 & 2,677 & $1.6 \%$ & $90.4 \%$ & 2,677 & $1.6 \%$ & $90.4 \%$ \\
\hline $\begin{array}{l}25 \\
\text { Householder } 25 \text { to }\end{array}$ & $-56,320$ & -355 & $0.6 \%$ & $-12.0 \%$ & -355 & $0.6 \%$ & $-12.0 \%$ \\
\hline $\begin{array}{l}44 \\
\text { Householder } 45 \text { to }\end{array}$ & $-45,744$ & 1,392 & $-3.0 \%$ & $47.0 \%$ & 1,392 & $-3.0 \%$ & $47.0 \%$ \\
\hline 64 & 298,042 & 1,028 & $0.3 \%$ & $34.7 \%$ & 1,028 & $0.3 \%$ & $34.7 \%$ \\
\hline Householder 65+ & 25,889 & 1,394 & $5.4 \%$ & $47.1 \%$ & 1,394 & $5.4 \%$ & $47.1 \%$ \\
\hline \multicolumn{8}{|c|}{ Basic Demographics--0.25 Mile Distance Band } \\
\hline Total Households & 224,479 & -194 & $-0.1 \%$ & & 2,767 & $1.2 \%$ & \\
\hline $\begin{array}{l}\mathrm{HH} \text { with Children } \\
2+\text { Adult } \mathrm{HH} \text { no }\end{array}$ & $-16,532$ & -451 & $2.7 \%$ & $232.5 \%$ & -922 & $5.6 \%$ & $-33.3 \%$ \\
\hline Child & 70,287 & -82 & $-0.1 \%$ & $\begin{array}{l}42.3 \% \\
-\end{array}$ & 673 & $1.0 \%$ & $24.3 \%$ \\
\hline $\begin{array}{l}\text { One Person } \mathrm{HH} \\
\text { Householder under }\end{array}$ & 170,723 & 339 & $0.2 \%$ & $174.7 \%$ & 3,016 & $1.8 \%$ & $109.0 \%$ \\
\hline $\begin{array}{l}25 \\
\text { Householder } 25 \text { to }\end{array}$ & $-56,320$ & -320 & $0.6 \%$ & $\begin{array}{l}164.9 \% \\
-\end{array}$ & -675 & $1.2 \%$ & $-24.4 \%$ \\
\hline $\begin{array}{l}44 \\
\text { Householder } 45 \text { to }\end{array}$ & $-45,744$ & 420 & $-0.9 \%$ & $216.5 \%$ & 1,812 & $-4.0 \%$ & $65.5 \%$ \\
\hline 64 & 298,042 & -480 & $-0.2 \%$ & $\begin{array}{l}247.4 \% \\
-\end{array}$ & 548 & $0.2 \%$ & $19.8 \%$ \\
\hline Householder 65+ & 25,889 & 399 & $1.5 \%$ & $205.7 \%$ & 1,793 & $6.9 \%$ & $64.8 \%$ \\
\hline \multicolumn{8}{|c|}{ Basic Demographics--0.50 Mile Distance Band } \\
\hline Total Households & 224,479 & -148 & $-0.1 \%$ & & 1,707 & $0.8 \%$ & \\
\hline $\begin{array}{l}\mathrm{HH} \text { with Children } \\
2+\text { Adult } \mathrm{HH} \text { no }\end{array}$ & $-16,532$ & -278 & $1.7 \%$ & $187.8 \%$ & $-1,666$ & $10.1 \%$ & $-97.6 \%$ \\
\hline Child & 70,287 & -325 & $-0.5 \%$ & $\begin{array}{l}219.6 \% \\
-\end{array}$ & 156 & $0.2 \%$ & $9.1 \%$ \\
\hline $\begin{array}{l}\text { One Person } \mathrm{HH} \\
\text { Householder under }\end{array}$ & 170,723 & 455 & $0.3 \%$ & $307.4 \%$ & 3,217 & $1.9 \%$ & $188.5 \%$ \\
\hline $\begin{array}{l}25 \\
\text { Householder } 25 \text { to }\end{array}$ & $-56,320$ & -344 & $0.6 \%$ & $232.4 \%$ & $-1,151$ & $2.0 \%$ & $-67.4 \%$ \\
\hline $\begin{array}{l}44 \\
\text { Householder } 45 \text { to }\end{array}$ & $-45,744$ & -27 & $0.1 \%$ & $18.2 \%$ & 824 & $-1.8 \%$ & $48.3 \%$ \\
\hline 64 & 298,042 & 17 & $0.0 \%$ & $\begin{array}{l}-11.5 \% \\
-\end{array}$ & 629 & $0.2 \%$ & $36.8 \%$ \\
\hline Householder 65+ & 25,889 & 300 & $1.2 \%$ & $202.7 \%$ & 2,214 & $8.6 \%$ & $129.7 \%$ \\
\hline
\end{tabular}


Table 5.15. Mod MA: SCT Households by Type and Householder Age

\begin{tabular}{|c|c|c|c|c|c|c|c|}
\hline \multirow[b]{2}{*}{$\begin{array}{l}\text { Demographic } \\
\text { Share-- Distance } \\
\text { Band Change }\end{array}$} & \multirow[b]{2}{*}{$\begin{array}{l}\text { Transit } \\
\text { Region } \\
\text { Change } \\
\text { 2010-2016 }\end{array}$} & \multicolumn{3}{|c|}{ Incremental Analysis } & \multicolumn{3}{|c|}{ Cumulative Analysis } \\
\hline & & $\begin{array}{l}\text { Distanc } \\
\text { e Band } \\
\text { Change } \\
2010- \\
2016 \\
\end{array}$ & $\begin{array}{l}\text { Share } \\
\text { of } \\
\text { Transit } \\
\text { Countie } \\
\text { s }\end{array}$ & $\begin{array}{l}\text { Share } \\
\text { of } \\
\text { Distanc } \\
\text { e Band } \\
\text { Change }\end{array}$ & $\begin{array}{l}\text { Distanc } \\
\text { e Band } \\
\text { Change } \\
2010- \\
2016\end{array}$ & $\begin{array}{l}\text { Share } \\
\text { of } \\
\text { Transit } \\
\text { Countie } \\
\text { s }\end{array}$ & $\begin{array}{l}\text { Share } \\
\text { of } \\
\text { Distanc } \\
\text { e Band } \\
\text { Change }\end{array}$ \\
\hline \multicolumn{8}{|c|}{$\begin{array}{l}\text { Basic Demographics--0.125 Mile Distance } \\
\text { Band }\end{array}$} \\
\hline Total Households & 224,479 & -630 & $-0.3 \%$ & & -630 & $-0.3 \%$ & \\
\hline $\begin{array}{l}\mathrm{HH} \text { with Children } \\
2+\text { Adult } \mathrm{HH} \text { no }\end{array}$ & $-16,532$ & $-1,173$ & $7.1 \%$ & $186.2 \%$ & $-1,173$ & $7.1 \%$ & $186.2 \%$ \\
\hline Child & 70,287 & 1,506 & $2.1 \%$ & $239.0 \%$ & 1,506 & $2.1 \%$ & $239.0 \%$ \\
\hline $\begin{array}{l}\text { One Person } \mathrm{HH} \\
\text { Householder under }\end{array}$ & 170,723 & -963 & $-0.6 \%$ & $152.9 \%$ & -963 & $-0.6 \%$ & $152.9 \%$ \\
\hline $\begin{array}{l}25 \\
\text { Householder } 25 \text { to }\end{array}$ & $-56,320$ & $-2,432$ & $4.3 \%$ & $386.0 \%$ & $-2,432$ & $4.3 \%$ & $386.0 \%$ \\
\hline & $-45,744$ & 1,703 & $-3.7 \%$ & $270.3 \%$ & 1,703 & $-3.7 \%$ & $270.3 \%$ \\
\hline 64 & 298,042 & 106 & $0.0 \%$ & $\begin{array}{l}-16.8 \% \\
-\end{array}$ & 106 & $0.0 \%$ & $\begin{array}{l}-16.8 \% \\
-\end{array}$ \\
\hline Householder 65+ & 25,889 & 781 & $3.0 \%$ & $124.0 \%$ & 781 & $3.0 \%$ & $124.0 \%$ \\
\hline \multicolumn{8}{|c|}{ Basic Demographics--0.25 Mile Distance Band } \\
\hline Total Households & 224,479 & 3,118 & $1.4 \%$ & & 2,488 & $1.1 \%$ & \\
\hline $\begin{array}{l}\mathrm{HH} \text { with Children } \\
2+\text { Adult } \mathrm{HH} \text { no }\end{array}$ & $-16,532$ & -51 & $0.3 \%$ & $-1.6 \%$ & $-1,224$ & $7.4 \%$ & $-49.2 \%$ \\
\hline Child & 70,287 & 1,211 & $1.7 \%$ & $38.8 \%$ & 2,717 & $3.9 \%$ & $109.2 \%$ \\
\hline $\begin{array}{l}\text { One Person } \mathrm{HH} \\
\text { Householder under }\end{array}$ & 170,723 & 1,958 & $1.1 \%$ & $62.8 \%$ & 995 & $0.6 \%$ & $40.0 \%$ \\
\hline $\begin{array}{l}25 \\
\text { Householder } 25 \text { to }\end{array}$ & $-56,320$ & -88 & $0.2 \%$ & $-2.8 \%$ & $-2,520$ & $4.5 \%$ & $101.3 \%$ \\
\hline $\begin{array}{l}44 \\
\text { Householder } 45 \text { to }\end{array}$ & $-45,744$ & 1,546 & $-3.4 \%$ & $49.6 \%$ & 3,249 & $-7.1 \%$ & $130.6 \%$ \\
\hline 64 & 298,042 & 484 & $0.2 \%$ & $15.5 \%$ & 590 & $0.2 \%$ & $23.7 \%$ \\
\hline Householder 65+ & 25,889 & 1,396 & $5.4 \%$ & $44.8 \%$ & 2,177 & $8.4 \%$ & $87.5 \%$ \\
\hline \multicolumn{8}{|c|}{ Basic Demographics--0.50 Mile Distance Band } \\
\hline Total Households & 224,479 & 772 & $0.3 \%$ & & 4,841 & $2.2 \%$ & \\
\hline $\begin{array}{l}\mathrm{HH} \text { with Children } \\
2+\text { Adult } \mathrm{HH} \text { no }\end{array}$ & $-16,532$ & 204 & $-1.2 \%$ & $26.4 \%$ & $-1,227$ & $7.4 \%$ & $-25.3 \%$ \\
\hline Child & 70,287 & 258 & $0.4 \%$ & $33.4 \%$ & 3,706 & $5.3 \%$ & $76.6 \%$ \\
\hline One Person $\mathrm{HH}$ & 170,723 & 310 & $0.2 \%$ & $40.2 \%$ & 2,362 & $1.4 \%$ & $48.8 \%$ \\
\hline
\end{tabular}




\begin{tabular}{llllllll} 
Householder under & & & & & & & \\
25 & $-56,320$ & -510 & $0.9 \%$ & $-66.1 \%$ & $-2,909$ & $5.2 \%$ & $-60.1 \%$ \\
Householder 25 to & & & & & & & \\
44 & $-45,744$ & 724 & $-1.6 \%$ & $93.8 \%$ & 5,090 & $-11.1 \%$ & $105.1 \%$ \\
Householder 45 to & & & & & & & \\
64 & 298,042 & -27 & $0.0 \%$ & $-3.5 \%$ & 640 & $0.2 \%$ & $13.2 \%$ \\
Householder 65+ & 25,889 & 585 & $2.3 \%$ & $75.8 \%$ & 3,173 & $12.3 \%$ & $65.5 \%$ \\
\hline \hline
\end{tabular}

Table 5.16. High MA: SCT Households by Type and Householder Age

\begin{tabular}{|c|c|c|c|c|c|c|c|}
\hline \multirow[b]{2}{*}{$\begin{array}{l}\text { Demographic Share- } \\
\text { - Distance Band } \\
\text { Change }\end{array}$} & \multirow[b]{2}{*}{$\begin{array}{l}\text { Transit } \\
\text { Region } \\
\text { Change } \\
\text { 2010-2016 }\end{array}$} & \multicolumn{3}{|c|}{ Incremental Analysis } & \multicolumn{3}{|c|}{ Cumulative Analysis } \\
\hline & & $\begin{array}{l}\text { Distanc } \\
\text { e Band } \\
\text { Change } \\
2010- \\
2016\end{array}$ & $\begin{array}{l}\text { Share } \\
\text { of } \\
\text { Transit } \\
\text { Countie } \\
\text { s }\end{array}$ & $\begin{array}{l}\text { Share } \\
\text { of } \\
\text { Distanc } \\
\text { e Band } \\
\text { Change }\end{array}$ & $\begin{array}{l}\text { Distanc } \\
\text { e Band } \\
\text { Change } \\
2010- \\
2016\end{array}$ & $\begin{array}{l}\text { Share } \\
\text { of } \\
\text { Transit } \\
\text { Countie } \\
\text { S }\end{array}$ & $\begin{array}{l}\text { Share } \\
\text { of } \\
\text { Distanc } \\
\text { e Band } \\
\text { Change }\end{array}$ \\
\hline \multicolumn{8}{|c|}{ Basic Demographics--0.125 Mile Distance Band } \\
\hline Total Households & 224,479 & 6,927 & $3.1 \%$ & & 6,927 & $3.1 \%$ & \\
\hline $\begin{array}{l}\mathrm{HH} \text { with Children } \\
2+\text { Adult } \mathrm{HH} \text { no }\end{array}$ & $-16,532$ & 701 & $-4.2 \%$ & $10.1 \%$ & 701 & $-4.2 \%$ & $10.1 \%$ \\
\hline Child & 70,287 & 2,903 & $4.1 \%$ & $41.9 \%$ & 2,903 & $4.1 \%$ & $41.9 \%$ \\
\hline $\begin{array}{l}\text { One Person } \mathrm{HH} \\
\text { Householder under }\end{array}$ & 170,723 & 3,323 & $1.9 \%$ & $48.0 \%$ & 3,323 & $1.9 \%$ & $48.0 \%$ \\
\hline $\begin{array}{l}25 \\
\text { Householder } 25 \text { to }\end{array}$ & $-56,320$ & -845 & $1.5 \%$ & $-12.2 \%$ & -845 & $1.5 \%$ & $-12.2 \%$ \\
\hline $\begin{array}{l}44 \\
\text { Householder } 45 \text { to }\end{array}$ & $-45,744$ & 6,889 & $-15.1 \%$ & $99.5 \%$ & 6,889 & $-15.1 \%$ & $99.5 \%$ \\
\hline 64 & 298,042 & 379 & $0.1 \%$ & $5.5 \%$ & 379 & $0.1 \%$ & $5.5 \%$ \\
\hline \multicolumn{8}{|c|}{$\begin{array}{l}\text { Basic Demographics--0.25 Mile Distance } \\
\text { Band }\end{array}$} \\
\hline Total Households & 224,479 & 1,547 & $0.7 \%$ & & 8,474 & $3.8 \%$ & \\
\hline $\begin{array}{l}\mathrm{HH} \text { with Children } \\
2+\text { Adult } \mathrm{HH} \text { no }\end{array}$ & $-16,532$ & 281 & $-1.7 \%$ & $18.2 \%$ & 982 & $-5.9 \%$ & $11.6 \%$ \\
\hline Child & 70,287 & 632 & $0.9 \%$ & $40.9 \%$ & 3,535 & $5.0 \%$ & $41.7 \%$ \\
\hline $\begin{array}{l}\text { One Person } \mathrm{HH} \\
\text { Householder under }\end{array}$ & 170,723 & 634 & $0.4 \%$ & $41.0 \%$ & 3,957 & $2.3 \%$ & $46.7 \%$ \\
\hline $\begin{array}{l}25 \\
\text { Householder } 25 \text { to } \\
44\end{array}$ & $-56,320$ & -350 & $0.6 \%$ & $-22.6 \%$ & $-1,195$ & $2.1 \%$ & $-14.1 \%$ \\
\hline 44 & $-45,744$ & 1,345 & $-2.9 \%$ & $86.9 \%$ & 8,234 & $-18.0 \%$ & $97.2 \%$ \\
\hline
\end{tabular}




\begin{tabular}{|c|c|c|c|c|c|c|c|}
\hline \multicolumn{8}{|l|}{ Householder 45 to } \\
\hline Householder 65+ & 25,889 & 292 & $1.1 \%$ & $18.9 \%$ & 1,038 & $4.0 \%$ & $12.2 \%$ \\
\hline \multicolumn{8}{|c|}{ Basic Demographics--0.50 Mile Distance Band } \\
\hline Total Households & 224,479 & 1,320 & $0.6 \%$ & & 10,766 & $4.8 \%$ & \\
\hline $\begin{array}{l}\mathrm{HH} \text { with Children } \\
2+\text { Adult } \mathrm{HH} \text { no }\end{array}$ & $-16,532$ & 141 & $-0.9 \%$ & $10.7 \%$ & 1,232 & $-7.5 \%$ & $11.4 \%$ \\
\hline Child & 70,287 & 675 & $1.0 \%$ & $51.1 \%$ & 4,481 & $6.4 \%$ & $41.6 \%$ \\
\hline $\begin{array}{l}\text { One Person } \mathrm{HH} \\
\text { Householder under }\end{array}$ & 170,723 & 504 & $0.3 \%$ & $38.2 \%$ & 5,053 & $3.0 \%$ & $46.9 \%$ \\
\hline $\begin{array}{l}25 \\
\text { Householder } 25 \text { to }\end{array}$ & $-56,320$ & -120 & $0.2 \%$ & $-9.1 \%$ & $-1,774$ & $3.1 \%$ & $-16.5 \%$ \\
\hline $\begin{array}{l}44 \\
\text { Householder } 45 \text { to }\end{array}$ & $-45,744$ & 644 & $-1.4 \%$ & $48.8 \%$ & 9,410 & $-20.6 \%$ & $87.4 \%$ \\
\hline 64 & 298,042 & 690 & $0.2 \%$ & $52.3 \%$ & 1,929 & $0.6 \%$ & $17.9 \%$ \\
\hline Householder 65+ & 25,889 & 106 & $0.4 \%$ & $8.0 \%$ & 1,443 & $5.6 \%$ & $13.4 \%$ \\
\hline
\end{tabular}




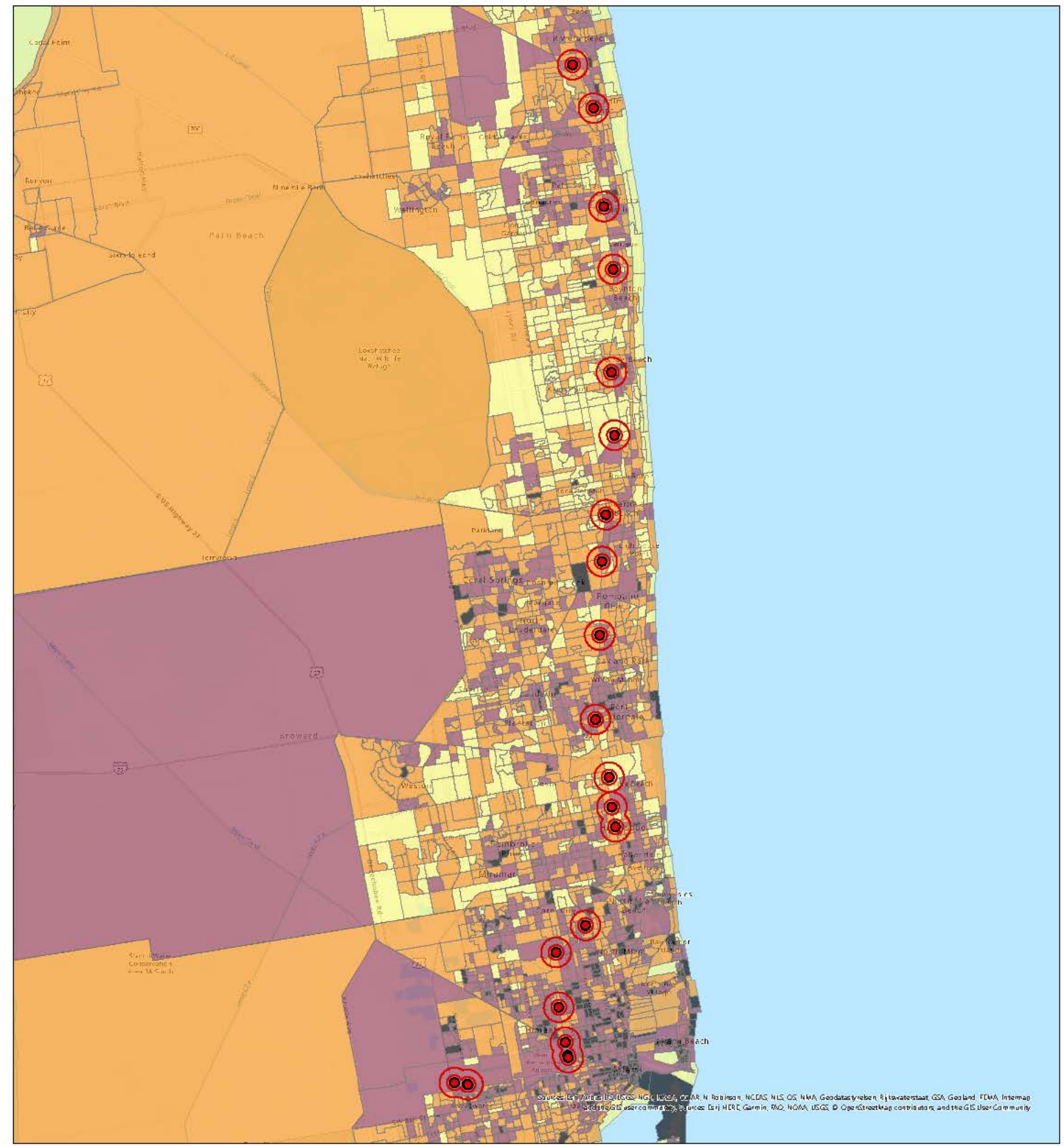

Station Typology for Commuter Rail Transit:

Buffers: Half \& 1 Mile Miami-Fort Lauderdale-West Palm Beach, FL

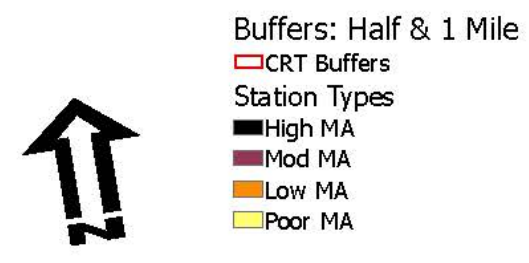

Figure 7. Miami to West Palm Beach CRT - stations vary in place type; however, the image gives evidence of significant land use intensification around rail stations, but with room for further growth. 


\section{Tenure by Vehicle Presence}

\section{For BRT}

- Poor MA growth rates were mostly negative at the station. Owner-occupied housing with vehicles saw robust growth. Households with vehicles increased in spatial concentration (LQ scores) at the station. Owner occupied with no vehicle increased concentration across all DB's to 1 mile. Overall, growth bands occurred at the quarter-mile and 0.75mile DB's.

- Low MA growth rates were strongest in the owner-occupied with vehicle category. Concentrations were positive for renters without vehicles. Households with vehicles saw negative rates of growth.

- Mod MA place types grew most for renter-occupied households. Households with vehicles grew much more than those with no vehicles. Spatial concentrations increase at a moderate level for renters with no vehicles from the station to the 1-mile DB.

- High MA place types experienced major concentrations and rates of growth of owneroccupied households with vehicles, and modest concentration growth for renteroccupied, which saw robust rates of growth at the station. Renter-occupied with vehicles, however, saw strong declines in spatial concentrations at all distances from the station. Renters without vehicles increase robustly in rates of growth, while those with vehicles dramatically declined in rates of growth.

\section{For CRT}

- Poor MA place types elicited declines in growth at each DB from the station to a halfmile distance. Owner-occupied households with vehicles gained concentration at the station (0.125-mile DB), along with renter-occupied households without vehicles, which grew $65 \%$ at the station. Renter-occupied households with vehicles declined in regional concentration while at positive rates of growth at the station.

- Low MA place types gained share at the station across virtually all categories. Owneroccupied without vehicles declined $18 \%$, while renter-occupied with vehicles gained $30 \%$. Owner-occupied with vehicles saw substantial gains across all DB's to 1 mile. Households overall gained the most in the category of those with vehicles. Owneroccupied with vehicles gained LQ scores, denoting spatial concentrations, substantially from the first to the third DB's.

- Mod MA place types lost share of households at the station. Significant losses occurred for owner-occupied households without vehicles, which did rebound from the half-mile to the 1-mile DB. The change in spatial concentration was mostly flat for all categories.

- High MA place types saw major gains at the station in households with no vehicle, renters and owners both separately and in combined figures. Those households with vehicles gained greater spatial concentrations at the station, while owner-occupied with no vehicle lost spatial concentration relative to the region as a whole. 


\section{For LRT}

- Poor MA place types saw flat levels of growth across all DB's from the station to a halfmile distance. Households of all types did see growth at the station (0.125), with flat change in spatial concentrations.

- Low MA place types experienced major growth in all household types except for renteroccupied households with no vehicle. Households with vehicles grew the most, particularly at the station (0.125). Renter-occupied with vehicles grew at the highest rate, $23 \%$. Increases in spatial concentrations (LQ scores) were mostly flat, except at the station, at which they gained modest levels of concentration.

- Mod MA place types overall saw some minor declines in renter-occupied with vehicles. Households as a whole grew significantly at the station, while maintaining robust growth to 1 mile. Spatial concentrations (changes over time in LQ scores) were mostly flat.

- High MA place types saw the most growth in households with vehicles, while those without vehicle also saw notable growth. Renter-occupied households with vehicles gained notable LQ score increases across most DB's from the station to 1 mile away. Owner-occupied with vehicles actually lost modest amounts of concentrations just beyond the station.

\section{For SCT}

- Poor MA place types did not experience much growth. Rates and figures were near zero for most DB's and tenure types. Some spatial concentrations increased, particularly for owner-occupied without vehicles.

- Low MA place types grew in all household categories at the station, and then quickly declined in modest numbers. Spatial concentrations grew somewhat at the station for owner-occupied without vehicles. Renter-occupied with vehicles grew in concentration at the station, while renter-occupied without vehicles grew just beyond the immediate station area at the quarter-mile DB. Subsequent drops in spatial concentration occurred in modest trends.

- Mod MA place types increased in renter-occupied households with no vehicles at the station. Most of the growth was in the owner-occupied households in the first half-mile cumulative distance from the station. Growth rates near the station, however, were highest for renter-occupied households with vehicles. In other words, in raw figures owner-occupied households grew the most, but in terms of rates of growth, renteroccupied households grew most. In terms of spatial concentrations, owner-occupied households without vehicles gained the most.

- High MA place types had strong growth trends for all housing and tenure types up to the half-mile DB. Spatial concentrations increased mostly for both kinds of owner-occupied households. Growth rates were highest for households with vehicles at the station, and at the quarter-mile DB. Negative rates of growth occurred from 0.375 -mile DB to the 1mile DB. These were interspersed with some positive rates, perhaps indicating some competition for space, or perhaps an indication of heterogeneity in the quality of land around the station. 
Table 5.17. Poor MA: CRT, Tenure by Vehicle Presence

Demographic Change 2010-2016 - Incremental

\begin{tabular}{llllllll}
\hline Tenure by Vehicle Presence & 0.125 & 0.25 & 0.375 & 0.5 & 0.125 & 0.25 & 0.5 \\
\hline Owner Occupied & 4,930 & $(686)$ & 1,327 & 2,171 & 4,930 & 4,244 & 7,742 \\
Renter Occupied & 1,350 & $(281)$ & $(670)$ & 1,851 & 1,350 & 1,069 & 2,250 \\
Total Housing Units & 6,280 & $(967)$ & 657 & 4,022 & 6,280 & 5,313 & 9,992 \\
\hline Owner Occ No Veh & 111 & 12 & 53 & $(93)$ & 111 & 123 & 83 \\
Owner Occupied Veh & 4,500 & $(1,365)$ & 1,660 & 1,965 & 4,500 & 3,135 & 6,760 \\
Renter Occ No Veh & 236 & 19 & $(18)$ & 110 & 236 & 255 & 347 \\
Renter Occupied Veh & 1,604 & 62 & $(772)$ & 2,386 & 1,604 & 1,666 & 3,280 \\
Total Housing Units & 6,451 & $(1,272)$ & 923 & 4,368 & 6,451 & 5,179 & 10,470 \\
Households No Veh & 347 & 31 & 35 & 17 & 347 & 378 & 430 \\
Households with Veh & 6,104 & $(1,303)$ & 888 & 4,351 & 6,104 & 4,801 & 10,040 \\
Total Housing Units & 6,451 & $(1,272)$ & 923 & 4,368 & 6,451 & 5,179 & 10,470 \\
\hline Percent Demographic Change & $2010-2016-$ Incremental & & Cumulative & \\
\hline Tenure by Vehicle Presence & 0.125 & 0.25 & 0.375 & 0.5 & 0.125 & 0.25 & 0.5 \\
\hline Owner Occupied & $21 \%$ & $-7 \%$ & $11 \%$ & $11 \%$ & $21 \%$ & $13 \%$ & $12 \%$ \\
Renter Occupied & $28 \%$ & $-13 \%$ & $-13 \%$ & $40 \%$ & $28 \%$ & $15 \%$ & $13 \%$ \\
Total Housing Units & $23 \%$ & $-8 \%$ & $4 \%$ & $17 \%$ & $23 \%$ & $13 \%$ & $12 \%$ \\
Owner Occ No Veh & $17 \%$ & $4 \%$ & $23 \%$ & $-22 \%$ & $17 \%$ & $13 \%$ & $5 \%$ \\
Owner Occupied Veh & $20 \%$ & $-13 \%$ & $14 \%$ & $10 \%$ & $20 \%$ & $9 \%$ & $11 \%$ \\
Renter Occ No Veh & $65 \%$ & $11 \%$ & $-3 \%$ & $34 \%$ & $65 \%$ & $15 \%$ & $13 \%$ \\
Renter Occupied Veh & $41 \%$ & $4 \%$ & $-17 \%$ & $65 \%$ & $41 \%$ & $30 \%$ & $24 \%$ \\
Total Housing Units & $23 \%$ & $-10 \%$ & $5 \%$ & $19 \%$ & $23 \%$ & $15 \%$ & $13 \%$ \\
Households No Veh & $34 \%$ & $6 \%$ & $4 \%$ & $2 \%$ & $34 \%$ & $25 \%$ & $14 \%$ \\
Households with Veh & $23 \%$ & $-11 \%$ & $5 \%$ & $19 \%$ & $23 \%$ & $12 \%$ & $13 \%$ \\
Total Housing Units & $23 \%$ & $-10 \%$ & $5 \%$ & $19 \%$ & $23 \%$ & $15 \%$ & $13 \%$ \\
\hline
\end{tabular}

\begin{tabular}{lllllll|l|l}
\hline LQ Trend 2010-2016 (LQ 2016/LQ 2010) & \multicolumn{2}{c}{ - Incremental } & \multicolumn{5}{c}{ Cumulative } \\
\hline Tenure by Vehicle Presence & 0.125 & 0.25 & 0.375 & 0.5 & 0.125 & 0.25 & 0.5 \\
\hline Owner Occupied & 1.02 & 1.04 & 1.10 & 0.98 & 1.02 & 1.03 & 1.03 \\
Renter Occupied & 1.00 & 0.90 & 0.80 & 1.14 & 1.00 & 0.97 & 0.96 \\
Owner Occ No Veh & 0.98 & 1.15 & 1.21 & 0.68 & 0.98 & 1.02 & 0.96 \\
\hline Owner Occupied Veh & 0.94 & 0.90 & 1.05 & 0.90 & 0.94 & 0.92 & 0.94 \\
Renter Occ No Veh & 1.25 & 1.12 & 0.87 & 1.06 & 1.25 & 1.21 & 1.02 \\
Renter Occupied Veh & 1.19 & 1.16 & 0.83 & 1.46 & 1.19 & 1.19 & 1.14 \\
Households No Veh & 1.04 & 1.09 & 0.95 & 0.83 & 1.04 & 1.07 & 0.97 \\
Households with Veh & 0.99 & 0.95 & 1.00 & 1.00 & 0.99 & 1.00 & 1.00 \\
\hline
\end{tabular}


Table 5.18. Mod MA: CRT, Tenure by Vehicle Presence

Demographic Change 2010-2016 - Incremental

\begin{tabular}{llllllll}
\hline Tenure by Vehicle Presence & 0.125 & 0.25 & 0.375 & 0.5 & 0.125 & 0.25 & 0.5 \\
\hline Owner Occupied & $(10,181)$ & $(1,130)$ & $(2,196)$ & $(2,863)$ & $(10,181)$ & $(11,311)$ & $(16,370)$ \\
Renter Occupied & $(8,300)$ & $(3,045)$ & $(329)$ & 1,001 & $(8,300)$ & $(11,345)$ & $(10,673)$ \\
Total Housing Units & $(18,481)$ & $(4,175)$ & $(2,525)$ & $(1,862)$ & $(18,481)$ & $(22,656)$ & $(27,043)$ \\
\hline Owner Occ No Veh & $(232)$ & $(328)$ & $(612)$ & 150 & $(232)$ & $(560)$ & $(1,022)$ \\
Owner Occupied Veh & $(9,268)$ & $(1,139)$ & $(2,603)$ & $(3,738)$ & $(9,268)$ & $(10,407)$ & $(16,748)$ \\
Renter Occ No Veh & $(35)$ & $(423)$ & 274 & $(191)$ & $(35)$ & $(458)$ & $(375)$ \\
Renter Occupied Veh & $(1,107)$ & $(705)$ & 1,493 & 2,874 & $(1,107)$ & $(1,812)$ & 2,555 \\
Total Housing Units & $(10,642)$ & $(2,595)$ & $(1,448)$ & $(905)$ & $(10,642)$ & $(13,237)$ & $(15,590)$ \\
Households No Veh & $(267)$ & $(751)$ & $(338)$ & $(41)$ & $(267)$ & $(1,018)$ & $(1,397)$ \\
Households with Veh & $(10,375)$ & $(1,844)$ & $(1,110)$ & $(864)$ & $(10,375)$ & $(12,219)$ & $(14,193)$ \\
Total Housing Units & $(10,642)$ & $(2,595)$ & $(1,448)$ & $(905)$ & $(10,642)$ & $(13,237)$ & $(15,590)$ \\
\hline Percent Demographic Change & $2010-2016-I n c r e m e n t a l$ & \multicolumn{3}{c}{ Cumulative } & \\
\hline Tenure by Vehicle Presence & 0.125 & 0.25 & 0.375 & 0.5 & 0.125 & 0.25 & 0.5 \\
\hline Owner Occupied & $-21 \%$ & $-6 \%$ & $-12 \%$ & $-13 \%$ & $-21 \%$ & $-17 \%$ & $-15 \%$ \\
Renter Occupied & $-10 \%$ & $-9 \%$ & $-1 \%$ & $3 \%$ & $-10 \%$ & $-10 \%$ & $-6 \%$ \\
Total Housing Units & $-14 \%$ & $-8 \%$ & $-5 \%$ & $-3 \%$ & $-14 \%$ & $-12 \%$ & $-9 \%$ \\
Owner Occ No Veh & $-11 \%$ & $-42 \%$ & $-47 \%$ & $18 \%$ & $-11 \%$ & $-19 \%$ & $-20 \%$ \\
Owner Occupied Veh & $-20 \%$ & $-7 \%$ & $-14 \%$ & $-17 \%$ & $-20 \%$ & $-17 \%$ & $-16 \%$ \\
Renter Occ No Veh & $0 \%$ & $-7 \%$ & $5 \%$ & $-3 \%$ & $0 \%$ & $-10 \%$ & $-6 \%$ \\
Renter Occupied Veh & $-2 \%$ & $-3 \%$ & $6 \%$ & $9 \%$ & $-2 \%$ & $-2 \%$ & $2 \%$ \\
Total Housing Units & $-9 \%$ & $-5 \%$ & $-3 \%$ & $-2 \%$ & $-9 \%$ & $-10 \%$ & $-6 \%$ \\
Households No Veh & $-2 \%$ & $-11 \%$ & $-5 \%$ & $-1 \%$ & $-2 \%$ & $-5 \%$ & $-4 \%$ \\
Households with Veh & $-10 \%$ & $-4 \%$ & $-3 \%$ & $-2 \%$ & $-10 \%$ & $-8 \%$ & $-6 \%$ \\
Total Housing Units & $-9 \%$ & $-5 \%$ & $-3 \%$ & $-2 \%$ & $-9 \%$ & $-10 \%$ & $-6 \%$ \\
\hline
\end{tabular}

\begin{tabular}{l|lllll|l|l|}
\hline LQ Trend 2010-2016 (LQ 2016 / LQ 2010) & \multicolumn{1}{l}{ Incremental } & \multicolumn{5}{c}{ Cumulative } \\
\hline Tenure by Vehicle Presence & 0.125 & 0.25 & 0.375 & 0.5 & 0.125 & 0.25 & 0.5 \\
\hline Owner Occupied & 0.95 & 1.05 & 0.96 & 0.92 & 0.95 & 0.98 & 0.96 \\
Renter Occupied & 1.00 & 0.94 & 0.99 & 1.01 & 1.00 & 0.98 & 0.99 \\
Owner Occ No Veh & 1.06 & 0.65 & 0.57 & 1.24 & 1.06 & 0.94 & 0.90 \\
Owner Occupied Veh & 0.92 & 1.01 & 0.90 & 0.85 & 0.92 & 0.95 & 0.92 \\
Renter Occ No Veh & 1.08 & 0.94 & 1.03 & 0.93 & 1.08 & 1.04 & 1.01 \\
Renter Occupied Veh & 0.99 & 0.92 & 0.97 & 0.97 & 0.99 & 0.97 & 0.97 \\
Households No Veh & 1.09 & 0.92 & 0.95 & 0.97 & 1.09 & 1.04 & 1.02 \\
Households with Veh & 1.00 & 0.99 & 0.97 & 0.96 & 1.00 & 1.00 & 1.00 \\
\hline
\end{tabular}


Table 5.19. High MA: CRT, Tenure by Vehicle Presence

\begin{tabular}{llllllll} 
Demographic Change 2010-2016 - Incremental & \multicolumn{4}{c}{ Cumulative } \\
\hline Tenure by Vehicle Presence & 0.125 & 0.25 & 0.375 & 0.5 & 0.125 & 0.25 & 0.5 \\
\hline Owner Occupied & 203 & $(459)$ & $(296)$ & $(547)$ & 203 & $(256)$ & $(1,099)$ \\
Renter Occupied & 1,313 & $(369)$ & 1,205 & 927 & 1,313 & 944 & 3,076 \\
Total Housing Units & 1,516 & $(828)$ & 909 & 380 & 1,516 & 688 & 1,977 \\
\hline Owner Occ No Veh & 94 & $(46)$ & 44 & 107 & 94 & 48 & 199 \\
Owner Occupied Veh & $(117)$ & $(447)$ & $(194)$ & 132 & $(117)$ & $(564)$ & $(626)$ \\
Renter Occ No Veh & 17,405 & 735 & 423 & 90 & 17,405 & 18,140 & 18,653 \\
Renter Occupied Veh & 2,414 & $(492)$ & 1,181 & 2,104 & 2,414 & 1,922 & 5,207 \\
Total Housing Units & 19,796 & $(250)$ & 1,454 & 2,433 & 19,796 & 19,546 & 23,433 \\
Households No Veh & 17,499 & 689 & 467 & 197 & 17,499 & 18,188 & 18,852 \\
Households with Veh & 2,297 & $(939)$ & 987 & 2,236 & 2,297 & 1,358 & 4,581 \\
Total Housing Units & 19,796 & $(250)$ & 1,454 & 2,433 & 19,796 & 19,546 & 23,433 \\
\hline Percent Demographic Change & $2010-2016-I n c r e m e n t a l$ & \multicolumn{4}{c}{ Cumulative } \\
\hline Tenure by Vehicle Presence & 0.125 & 0.25 & 0.375 & 0.5 & 0.125 & 0.25 & 0.5 \\
\hline Owner Occupied & $7 \%$ & $-37 \%$ & $-12 \%$ & $-17 \%$ & $7 \%$ & $-6 \%$ & $-11 \%$ \\
Renter Occupied & $12 \%$ & $-5 \%$ & $12 \%$ & $7 \%$ & $12 \%$ & $5 \%$ & $8 \%$ \\
Total Housing Units & $11 \%$ & $-10 \%$ & $7 \%$ & $2 \%$ & $11 \%$ & $3 \%$ & $4 \%$ \\
Owner Occ No Veh & $44 \%$ & $-29 \%$ & $17 \%$ & $50 \%$ & $44 \%$ & $13 \%$ & $24 \%$ \\
Owner Occupied Veh & $-4 \%$ & $-40 \%$ & $-9 \%$ & $6 \%$ & $-4 \%$ & $-15 \%$ & $-8 \%$ \\
Renter Occ No Veh & $604 \%$ & $38 \%$ & $14 \%$ & $3 \%$ & $604 \%$ & $5 \%$ & $8 \%$ \\
Renter Occupied Veh & $37 \%$ & $-10 \%$ & $18 \%$ & $26 \%$ & $37 \%$ & $17 \%$ & $20 \%$ \\
Total Housing Units & $161 \%$ & $-3 \%$ & $12 \%$ & $18 \%$ & $161 \%$ & $5 \%$ & $8 \%$ \\
Households No Veh & $565 \%$ & $33 \%$ & $14 \%$ & $6 \%$ & $565 \%$ & $351 \%$ & $158 \%$ \\
Households with Veh & $25 \%$ & $-16 \%$ & $11 \%$ & $22 \%$ & $25 \%$ & $9 \%$ & $14 \%$ \\
Total Housing Units & $161 \%$ & $-3 \%$ & $12 \%$ & $18 \%$ & $161 \%$ & $5 \%$ & $8 \%$ \\
\hline
\end{tabular}

\begin{tabular}{|c|c|c|c|c|c|c|c|}
\hline \multicolumn{5}{|c|}{ LQ Trend 2010-2016 (LQ 2016 / LQ 2010) - Incremental } & \multicolumn{3}{|c|}{ Cumulative } \\
\hline Tenure by Vehicle Presence & 0.125 & 0.25 & 0.375 & 0.5 & 0.125 & 0.25 & 0.5 \\
\hline Owner Occupied & 0.99 & 0.72 & 0.85 & 0.83 & 0.99 & 0.94 & 0.88 \\
\hline Renter Occupied & 0.96 & 1.01 & 1.00 & 1.00 & 0.96 & 0.98 & 0.99 \\
\hline Owner Occ No Veh & 1.24 & 0.75 & 1.04 & 1.40 & 1.24 & 1.05 & 1.14 \\
\hline Occupied Veh & 0.84 & 0.65 & 0.83 & 1.01 & 0.84 & 0.81 & 0.87 \\
\hline Occ No Veh & 3.71 & 0.90 & 0.62 & 0.59 & 3.71 & 2.71 & 1.51 \\
\hline Occupied Veh & 1.06 & 0.85 & 0.95 & 1.06 & 1.06 & 0.98 & 0.99 \\
\hline Veh & 3.85 & 0.95 & 0.68 & 0.66 & 3.85 & 1.63 & 1.22 \\
\hline Households with Veh & 1.05 & 0.87 & 0.97 & 1.11 & 1.05 & 0.57 & 0.78 \\
\hline
\end{tabular}


Table 5.20. Poor MA: LRT, Tenure by Vehicle Presence

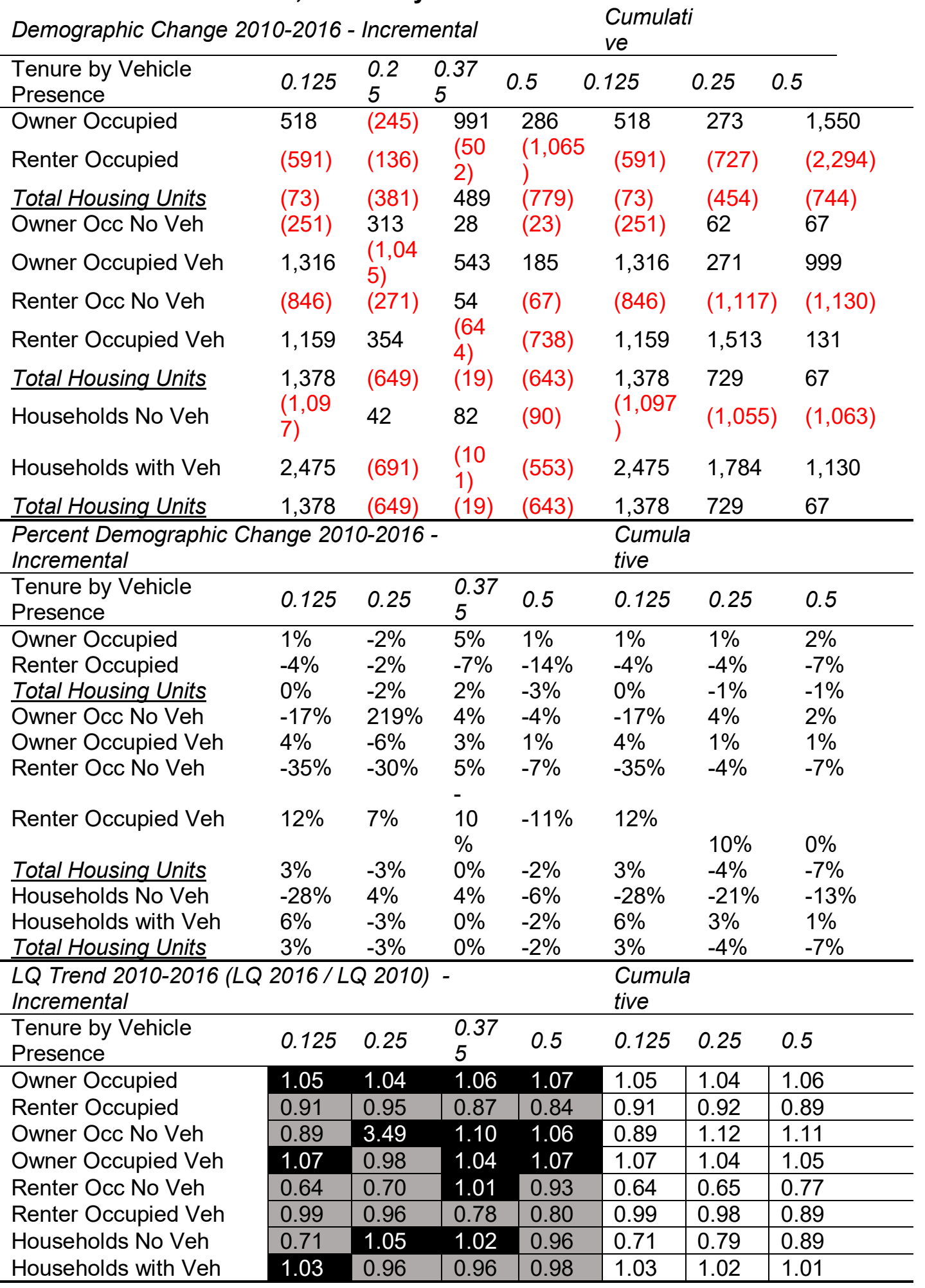

Table 5.21. Poor MA: SCT, Tenure by Vehicle Presence 
Demographic Change 2010-2016 - Incremental

\begin{tabular}{|c|c|c|c|c|c|c|c|}
\hline Tenure by Vehicle Presence & 0.125 & 0.25 & 0.375 & 0.5 & 0.125 & 0.25 & 0.5 \\
\hline Owner Occupied & 0 & (39) & $(128)$ & 82 & 0 & (39) & (85) \\
\hline Renter Occupied & 0 & (9) & (261) & (198) & 0 & (9) & $(468)$ \\
\hline Total Housing Units & 0 & $(48)$ & (389) & (116) & 0 & (48) & (553) \\
\hline Owner Occ No Veh & 0 & 25 & (63) & 11 & 0 & 25 & (27) \\
\hline Owner Occupied Veh & 0 & 152 & $(263)$ & 61 & 0 & 152 & $(50)$ \\
\hline Renter Occ No Veh & 0 & 58 & (55) & (5) & 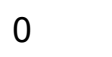 & 58 & (2) \\
\hline Renter Occupied Veh & 0 & $(107)$ & 8 & (51) & 0 & $(107)$ & (150) \\
\hline Total Housing Units & 0 & 128 & $(373)$ & 16 & 0 & 128 & (229) \\
\hline Households No Veh & 0 & 83 & $(118)$ & 6 & 0 & 83 & (29) \\
\hline Househ & 0 & 45 & $(255)$ & 10 & 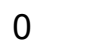 & 45 & (200) \\
\hline Total Housing Units & 0 & 128 & (373) & 16 & 0 & 128 & $(229)$ \\
\hline \multicolumn{5}{|c|}{$\overline{P \text { Percent Demographic Change 2010-2016 - Incremental }}$} & \multicolumn{3}{|c|}{ Cumulative } \\
\hline Tenure by Vehicle Presence & 0.125 & 0.25 & 0.375 & 0.5 & 0.125 & 0.25 & 0.5 \\
\hline Owner Occupied & 0 & $-3 \%$ & $-9 \%$ & $27 \%$ & 0 & $-3 \%$ & $-3 \%$ \\
\hline Renter Occ & 0 & $-1 \%$ & $-25 \%$ & $-45 \%$ & 0 & $-1 \%$ & $-22 \%$ \\
\hline Total Hous & 0 & $-2 \%$ & $-16 \%$ & $-16 \%$ & 0 & $-2 \%$ & $-11 \%$ \\
\hline Owner Occ & 0 & 0 & $-67 \%$ & $61 \%$ & 0 & 0 & $-24 \%$ \\
\hline d Veh & 0 & $14 \%$ & $-17 \%$ & $21 \%$ & 0 & $14 \%$ & $-2 \%$ \\
\hline Ren & 0 & $116 \%$ & $-33 \%$ & $-8 \%$ & u & $-1 \%$ & $-22 \%$ \\
\hline Renter Occupied Veh & 0 & $-18 \%$ & $1 \%$ & $-22 \%$ & 0 & $-18 \%$ & $-10 \%$ \\
\hline Total Housing Units & 0 & $7 \%$ & $-15 \%$ & $3 \%$ & 0 & $-1 \%$ & $-22 \%$ \\
\hline Households No Veh & 0 & $166 \%$ & $-45 \%$ & $7 \%$ & 0 & $166 \%$ & $-7 \%$ \\
\hline Household & 0 & $3 \%$ & $-12 \%$ & $2 \%$ & 0 & $3 \%$ & $-4 \%$ \\
\hline$\underline{\text { Total Housing Units }}$ & 0 & $7 \%$ & $-15 \%$ & $3 \%$ & 0 & $-1 \%$ & $-22 \%$ \\
\hline \multicolumn{5}{|c|}{$\overline{L Q Q}$ Trend 2010-2016 (LQ 2016 / LQ 2010) - Incremental } & \multicolumn{3}{|c|}{ Cumulative } \\
\hline Tenure by Vehicle Presence & 0.125 & 0.25 & 0.375 & 0.5 & 0.125 & 0.25 & 0.5 \\
\hline \multirow{8}{*}{$\begin{array}{l}\text { Owner Occupied } \\
\text { Renter Occupied } \\
\text { Owner Occ No Veh } \\
\text { Owner Occupied Veh } \\
\text { Renter Occ No Veh } \\
\text { Renter Occupied Veh } \\
\text { Households No Veh } \\
\text { Households with Veh }\end{array}$} & 0 & 1.03 & 1.12 & 1.56 & 0 & 1.03 & 1.13 \\
\hline & 0 & 0.96 & 0.85 & 0.62 & 0 & 0.96 & 0.83 \\
\hline & 0 & 0 & 0.39 & 1.92 & 0 & 0 & 0.85 \\
\hline & 0 & 1.21 & 1.02 & 1.48 & 0 & 1.21 & 1.14 \\
\hline & 0 & 2.06 & 0.74 & 1.02 & 0 & 2.06 & 1.03 \\
\hline & 0 & 0.74 & 1.06 & 0.82 & 0 & 0.74 & 0.89 \\
\hline & 0 & 2.57 & 0.62 & 1.20 & 0 & 2.40 & 0.94 \\
\hline & 0 & 1.03 & 1.02 & 1.18 & 0 & 0.96 & 1.01 \\
\hline
\end{tabular}


Table 5.22. Low MA: SCT, Tenure by Vehicle Presence

\begin{tabular}{|c|c|c|c|c|c|c|c|}
\hline \multicolumn{5}{|c|}{ Demographic Change 2010-2016 - Incremental } & \multicolumn{3}{|c|}{ Cumulative } \\
\hline Tenure by Vehicle Presence & 0.125 & 0.25 & 0.375 & 0.5 & 0.125 & 0.25 & 0.5 \\
\hline Owner Occupied & 1,576 & $(277)$ & $(571)$ & 168 & 1,576 & 1,299 & 896 \\
\hline Renter Occupied & 1,385 & 83 & (341) & (316) & 1,385 & 1,468 & 811 \\
\hline Total Housing Units & 2,961 & (194) & (912) & (148) & 2,961 & 2,767 & 1,707 \\
\hline Owner Occ No Veh & 139 & (80) & (74) & (322) & 139 & 59 & (337) \\
\hline Owner Occupied Veh & 2,165 & (603) & (275) & (110) & 2,165 & 1,562 & 1,177 \\
\hline Renter Occ No Veh & 368 & (142) & (72) & (478) & 368 & 226 & (324) \\
\hline Renter Occupied Veh & 2,599 & 1,523 & (666) & 283 & 2,599 & 4,122 & 3,739 \\
\hline Total Housing Units & 5,271 & 698 & $(1,087)$ & (627) & 5,271 & 5,969 & 4,255 \\
\hline Households No Veh & 507 & (222) & (146) & $(800)$ & 507 & 285 & (661) \\
\hline Households with Veh & 4,764 & 920 & (941) & 173 & 4,764 & 5,684 & 4,916 \\
\hline Total Housing Units & 5,271 & 698 & $(1,087)$ & $(627)$ & 5,271 & 5,969 & 4,255 \\
\hline \multicolumn{5}{|c|}{ Percent Demographic Change 2010-2016 - Incremental } & \multicolumn{3}{|c|}{ Cumulative } \\
\hline Tenure by Vehicle Presence & 0.125 & 0.25 & 0.375 & 0.5 & 0.125 & 0.25 & 0.5 \\
\hline Owner Occupied & $17 \%$ & $-4 \%$ & $-9 \%$ & $2 \%$ & $17 \%$ & $8 \%$ & $3 \%$ \\
\hline Renter Occupied & $10 \%$ & $1 \%$ & $-6 \%$ & $-3 \%$ & $10 \%$ & $6 \%$ & $2 \%$ \\
\hline Total Housing Units & $13 \%$ & $-1 \%$ & $-7 \%$ & $-1 \%$ & $13 \%$ & $7 \%$ & $2 \%$ \\
\hline$\overline{\text { Owner Occ No Veh }}$ & $27 \%$ & $-22 \%$ & $-16 \%$ & $-44 \%$ & $27 \%$ & $7 \%$ & $-16 \%$ \\
\hline Owner Occupied Veh & $27 \%$ & $-9 \%$ & $-5 \%$ & $-1 \%$ & $27 \%$ & $10 \%$ & $4 \%$ \\
\hline Renter Occ No Veh & $13 \%$ & $-8 \%$ & $-5 \%$ & $-16 \%$ & $13 \%$ & $6 \%$ & $2 \%$ \\
\hline Renter Occupied Veh & $27 \%$ & $24 \%$ & $-13 \%$ & $5 \%$ & $27 \%$ & $26 \%$ & $14 \%$ \\
\hline Total Housing Units & $25 \%$ & $5 \%$ & $-8 \%$ & $-4 \%$ & $25 \%$ & $6 \%$ & $2 \%$ \\
\hline Households No Veh & $15 \%$ & $-11 \%$ & $-8 \%$ & $-21 \%$ & $15 \%$ & $5 \%$ & $-6 \%$ \\
\hline Households with Veh & $27 \%$ & $7 \%$ & $-9 \%$ & $1 \%$ & $27 \%$ & $18 \%$ & $9 \%$ \\
\hline Total Housing Units & $25 \%$ & $5 \%$ & $-8 \%$ & $-4 \%$ & $25 \%$ & $6 \%$ & $2 \%$ \\
\hline \multicolumn{5}{|c|}{ LQ Trend 2010-2016 (LQ 2016 / LQ 2010) - Incremental } & \multicolumn{3}{|c|}{ Cumulative } \\
\hline Tenure by Vehicle Presence & 0.125 & 0.25 & 0.375 & 0.5 & 0.125 & 0.25 & 0.5 \\
\hline Owner Occupied & 1.08 & 1.01 & 1.02 & 1.07 & 1.08 & 1.05 & 1.04 \\
\hline Renter Occupied & 0.93 & 0.97 & 0.97 & 0.93 & 0.93 & 0.95 & 0.95 \\
\hline Owner Occ No Veh & 1.14 & 0.80 & 0.91 & 0.57 & 1.14 & 1.00 & 0.82 \\
\hline Owner Occupied Veh & 1.17 & 0.96 & 1.06 & 1.03 & 1.17 & 1.07 & 1.05 \\
\hline Renter Occ No Veh & 0.93 & 0.86 & 0.95 & 0.79 & 0.93 & 0.91 & 0.88 \\
\hline Renter Occupied Veh & 1.00 & 1.11 & 0.83 & 0.94 & 1.00 & 1.04 & 0.98 \\
\hline Households No Veh & 0.96 & 0.85 & 0.93 & 0.75 & 0.96 & 0.88 & 0.86 \\
\hline Households with Veh & 1.10 & 1.06 & 0.96 & 1.00 & 1.10 & 1.02 & 1.03 \\
\hline
\end{tabular}


Table 5.23. Mod MA: SCT, Tenure by Vehicle Presence

\begin{tabular}{|c|c|c|c|c|c|c|c|}
\hline \multicolumn{3}{|c|}{ Demographic Change 2010-2016 - Incremental } & \multicolumn{5}{|c|}{ Cumulative } \\
\hline Tenure by Vehicle Presence & 0.125 & 0.25 & 0.375 & 0.5 & 0.125 & 0.25 & 0.5 \\
\hline Owner Occupied & $(316)$ & 302 & (80) & (67) & (316) & (14) & $(161)$ \\
\hline Renter Occupied & (314) & 2,816 & 1,661 & 839 & (314) & 2,502 & 5,002 \\
\hline Total Housing Units & $(630)$ & 3,118 & 1,581 & 772 & (630) & 2,488 & 4,841 \\
\hline Owner Occ No Veh & (198) & (209) & 7 & (37) & (198) & $(407)$ & $(437)$ \\
\hline Owner Occupied Veh & 2,091 & 703 & (257) & (117) & 2,091 & 2,794 & 2,420 \\
\hline Renter Occ No Veh & $(1,009)$ & 963 & 0 & (143) & $(1,009)$ & $(46)$ & (189) \\
\hline Renter Occupied Veh & 7,548 & 2,511 & 1,833 & 1,630 & 7,548 & 10,059 & 13,522 \\
\hline Total Housing Units & 8,432 & 3,968 & 1,583 & 1,333 & 8,432 & 12,400 & 15,316 \\
\hline Households No Veh & $(1,207)$ & 754 & 7 & (180) & $(1,207)$ & $(453)$ & $(626)$ \\
\hline Households with Veh & 9,639 & 3,214 & 1,576 & 1,513 & 9,639 & 12,853 & 15,942 \\
\hline Total Housing Units & 8,432 & 3,968 & 1,583 & 1,333 & 8,432 & 12,400 & 15,316 \\
\hline \multicolumn{5}{|c|}{ Percent Demographic Change 2010-2016 - Incremental } & \multicolumn{3}{|l|}{ Cumulative } \\
\hline Tenure by Vehicle Presence & 0.125 & 0.25 & 0.375 & 0.5 & 0.125 & 0.25 & 0.5 \\
\hline Owner Occupied & $-1 \%$ & $3 \%$ & $-1 \%$ & $-1 \%$ & $-1 \%$ & $0 \%$ & $0 \%$ \\
\hline Renter Occupied & $-1 \%$ & $17 \%$ & $10 \%$ & $6 \%$ & $-1 \%$ & $3 \%$ & $5 \%$ \\
\hline Total Housing Units & $-1 \%$ & $12 \%$ & $7 \%$ & $4 \%$ & $-1 \%$ & $2 \%$ & $3 \%$ \\
\hline$\overline{\text { Owner Occ No Veh }}$ & $-11 \%$ & $-22 \%$ & $1 \%$ & $-7 \%$ & $-11 \%$ & $-15 \%$ & $-11 \%$ \\
\hline Owner Occupied Veh & $12 \%$ & $9 \%$ & $-4 \%$ & $-1 \%$ & $12 \%$ & $11 \%$ & $6 \%$ \\
\hline Renter Occ No Veh & $-6 \%$ & $17 \%$ & $0 \%$ & $-4 \%$ & $-6 \%$ & $3 \%$ & $5 \%$ \\
\hline Renter Occupied Veh & $22 \%$ & $23 \%$ & $18 \%$ & $18 \%$ & $22 \%$ & $22 \%$ & $21 \%$ \\
\hline Total Housing Units & $12 \%$ & $16 \%$ & $7 \%$ & $6 \%$ & $12 \%$ & $3 \%$ & $5 \%$ \\
\hline$\overline{\text { Households No Veh }}$ & $-6 \%$ & $11 \%$ & $0 \%$ & $-5 \%$ & $-6 \%$ & $-2 \%$ & $-2 \%$ \\
\hline Households with Veh & $18 \%$ & $17 \%$ & $9 \%$ & $9 \%$ & $18 \%$ & $18 \%$ & $15 \%$ \\
\hline Total Housing Units & $12 \%$ & $16 \%$ & $7 \%$ & $6 \%$ & $12 \%$ & $3 \%$ & $5 \%$ \\
\hline \multicolumn{5}{|c|}{ LQ Trend 2010-2016 (LQ 2016 / LQ 2010) - Incremental } & \multicolumn{3}{|l|}{ Cumulative } \\
\hline Tenure by Vehicle Presence & 0.125 & 0.25 & 0.375 & 0.5 & 0.125 & 0.25 & 0.5 \\
\hline Owner Occupied & 1.03 & 0.96 & 0.96 & 0.99 & 1.03 & 1.01 & 1.00 \\
\hline Renter Occupied & 0.95 & 0.99 & 0.98 & 0.98 & 0.95 & 0.96 & 0.97 \\
\hline Owner Occ No Veh & 0.90 & 0.70 & 0.96 & 0.90 & 0.90 & 0.84 & 0.86 \\
\hline Owner Occupied Veh & 1.17 & 1.01 & 0.94 & 0.98 & 1.17 & 1.12 & 1.06 \\
\hline Renter Occ No Veh & 0.88 & 0.97 & 0.87 & 0.86 & 0.88 & 0.91 & 0.90 \\
\hline Renter Occupied Veh & 1.09 & 0.97 & 0.98 & 1.01 & 1.09 & 1.06 & 1.04 \\
\hline Households No Veh & 0.89 & 0.94 & 0.89 & 0.87 & 0.89 & 0.84 & 0.86 \\
\hline Households with Veh & 1.16 & 1.02 & 1.00 & 1.03 & 1.16 & 1.05 & 1.04 \\
\hline
\end{tabular}


Table 5.24. High MA: SCT, Tenure by Vehicle Presence

\begin{tabular}{llllllll} 
Demographic Change 2010-2016 - Incremental & \multicolumn{7}{l}{ Cumulative } \\
\hline Tenure by Vehicle Presence & 0.125 & 0.25 & 0.375 & 0.5 & 0.125 & 0.25 & 0.5 \\
\hline Owner Occupied & 1,618 & 389 & $(368)$ & $(29)$ & 1,618 & 2,007 & 1,610 \\
Renter Occupied & 5,309 & 1,158 & 1,340 & 1,349 & 5,309 & 6,467 & 9,156 \\
Total Housing Units & 6,927 & 1,547 & 972 & 1,320 & 6,927 & 8,474 & 10,766 \\
\hline Owner Occ No Veh & 357 & 54 & $(49)$ & $(58)$ & 357 & 411 & 304 \\
Owner Occupied Veh & 2,605 & 286 & $(440)$ & 654 & 2,605 & 2,891 & 3,105 \\
Renter Occ No Veh & 2,436 & 511 & 645 & 471 & 2,436 & 2,947 & 4,063 \\
Renter Occupied Veh & 7,335 & 1,673 & 1,050 & 1,313 & 7,335 & 9,008 & 11,371 \\
Total Housing Units & 12,733 & 2,524 & 1,206 & 2,380 & 12,733 & 15,257 & 18,843 \\
\hline Households No Veh & 2,793 & 565 & 596 & 413 & 2,793 & 3,358 & 4,367 \\
Households with Veh & 9,940 & 1,959 & 610 & 1,967 & 9,940 & 11,899 & 14,476 \\
Total Housing Units & 12,733 & 2,524 & 1,206 & 2,380 & 12,733 & 15,257 & 18,843 \\
\hline Percent Demographic Change & $2010-2016-I n c r e m e n t a l$ \\
\hline
\end{tabular}




\section{Transit Proximity and Transportation Mode Choice for Commuting}

\section{For BRT}

- Poor MA - Growth at the station was mostly limited to those working at home. This and Other Transportation gained concentration in the first quarter mile. Transit was negative or neutral for the first quarter mile. Walking gained higher rates, admittedly with small figures, at the quarter and 0.375-mile DB's. Carpooling, bicycling and transit grew at the half-mile DB. Overall, most transportation modes, even transit, was repelled by the station. This implies that those who take transit still prefer to live some distance away from the station. Or perhaps the surrounding land uses are not conducive to increased growth at the station.

- Low MA - this area grew in large rates but at small numbers in most of the station area. Other Transportation saw some decline. Concentrations increased for carpooling and walking in some areas. Transit, bicycling, and walking gained the most spatial concentrations relative to the whole region. Bicycling, walking and carpooling gained concentration at the stations. Transit had very strong growth rates across all DB's. Working at home did just as well as transit.

- Mod MA - this area grew substantially, both in terms of numbers and growth rates. Transit, bicycling, and working from home grew substantially at the station and for all DB's. Bicycling saw the highest rates of concentration growth, which occurred just beyond the station.

- High MA - This area saw high rates of growth throughout the first mile from the station, but the figures were small except at the station. Bicycling, walking, and other transportation types saw the most concentration growth. Transit saw mostly very positive rates of growth, but for small numbers of people beyond the station area. In this case, the station is attracting riders to the station more than the distances beyond the station.

The numbers suggest that while people are still repelled somewhat by the station area itself, people are drawn to the area within a mile of the station and are increasingly utilizing transit, bikes, walking, and alternatives such as e-scooters. A good number are increasingly working from near the BRT stations.

\section{For CRT}

- Poor MA - The overall story for this place type is one of robust gains at the station, but small numbers just beyond that area, to 1 mile. Many of the rates of growth are strong but built from small numbers of additional people in the time period. Transit, bicycling, and walking gained the most robust spatial concentrations. Transit saw strong rates of growth.

- Low MA - At this place type most gains were in driving alone, transit, and working at home. The total workers increased substantially, especially at the station, but also all across the distances to 1 mile from the station. The strongest gains in concentration were in transit and bicycling.

- Mod MA - this place type gained the most share in transit, bicycling, walking, and working at home. Driving alone also gained, except at the station where it declined in growth rate and concentration.

- High MA - at this place type, transit did very well. Biking did phenomenally well, with $355 \%$ growth and major gains in spatial concentrations (LQ scores). Driving alone did 
well, while carpooling declined at the station but gained at the quarter-mile DB. Walking, bicycling, and transit gained in spatial concentrations.

\section{For LRT}

- Poor MA - driving alone, bicycling, and working at home gained share at the station. No major declines occurred, but the figures were small throughout the station to the 1-mile distance. Transit grew in concentrations but declined in growth rate at the station.

- Low MA - these place types gained the largest numbers at the station but gained share in terms of rate of growth in all but a couple DB's to the 1-mile DB. Transit gained at major growth rates. Other transportation had the highest rates of growth. Working at home and bicycling likewise gained substantially in the entire distance from the station to one mile.

- Mod MA - growth was strong in this place type, with transit, walking, bicycling and working at home enjoyed high rates. Walking, transit, and working at home had the highest number of growth in people. Carpooling declined somewhat. Walking, transit, and other transportation gained somewhat in spatial concentration at the station, relative to the regional growth trend.

- High MA - Driving alone, transit and walking gained the highest number of people. Working at home gained most in rate of growth. Walking, bicycling and grew significantly at the station. Carpooling and other transportation declined at the station.

\section{For SCT}

- Poor MA - this place type begins at a quarter-mile distance from the station. Bicycling, carpooling, driving alone, and other transportation declined, while transit saw mixed results by distance from the station. Numbers of people involved in the rates of change were very small.

- Low MA - Most growth was at the station, with small numbers at the other distances from the station. Driving, transit, and working at home gained the most in concentrations.

- Mod MA - Driving, bicycling, walking, and working at home saw the most growth. Transit grew up to the quarter mile. Working at home had high rates reflected by relatively larger numbers of people than the other modes of travel. Bicycling grew the most in concentrations.

- High MA - Walking and transit use gained rates and concentrations of growth. Only walking gained rates of growth at the station itself. Working at home had major rates of growth. Carpool and other transportation modes slightly declined. 
Table 5.25. Poor MA:

BRT

Demographic Change 2010-2016

\begin{tabular}{llllllll}
\hline Commuting Mode & 0.125 & 0.25 & 0.375 & 0.5 & 0.75 & 1 & County \\
\hline Auto Drove Alone & $(5,628)$ & 3,098 & $(742)$ & $(1,122)$ & 6,757 & $(2,836)$ & 264,402 \\
Carpool & $(1,114)$ & 91 & $(281)$ & 338 & $(97)$ & $(101)$ & $(108,055)$ \\
Transit & $(567)$ & 1 & 235 & 34 & 529 & $(222)$ & 34,862 \\
Bike & $(59)$ & $(13)$ & 74 & 71 & 154 & $(7)$ & 17,950 \\
Walked & $(751)$ & 96 & 123 & $(102)$ & $(7)$ & 39 & 5,911 \\
Other Transportation & 504 & 135 & $(165)$ & $(29)$ & 55 & 85 & 10,810 \\
Worked at Home & 456 & 964 & 267 & $(217)$ & 744 & 79 & 85,093 \\
Total Workers & $(7,425)$ & 4,395 & $(487)$ & $(1,009)$ & 8,149 & $(3,003)$ & 329,658 \\
Total Labor Force & 123,477 & 32,660 & 46,522 & 42,684 & 57,437 & $(1,765)$ & $(1,460,89$ \\
\hline
\end{tabular}

Percent Demographic Change 20102016

\begin{tabular}{|c|c|c|c|c|c|c|c|}
\hline Commuting Mode & 0.125 & 0.25 & 0.375 & 0.5 & 0.75 & 1 & $\begin{array}{l}\text { Transit } \\
\text { County }\end{array}$ \\
\hline Auto Drove Alone & $-6.09 \%$ & $14.68 \%$ & $-2.31 \%$ & $-3.75 \%$ & $23.45 \%$ & $\begin{array}{l}11.92 \\
\%\end{array}$ & $7.43 \%$ \\
\hline Carpool & $-10.35 \%$ & $3.63 \%$ & $-7.16 \%$ & $9.61 \%$ & $-2.54 \%$ & $\begin{array}{l}-3.41 \% \\
-\end{array}$ & $0.02 \%$ \\
\hline Transit & $-8.16 \%$ & $0.06 \%$ & $12.72 \%$ & $3.10 \%$ & $36.99 \%$ & $\begin{array}{l}14.75 \\
\%\end{array}$ & $9.47 \%$ \\
\hline Bike & $-14.32 \%$ & $11.02 \%$ & $26.43 \%$ & $94.67 \%$ & $78.17 \%$ & $-5.34 \%$ & $31.31 \%$ \\
\hline Walked & $-28.13 \%$ & $27.20 \%$ & $19.77 \%$ & $-13.92 \%$ & $-1.58 \%$ & $\begin{array}{l}13.40 \\
\%\end{array}$ & $7.95 \%$ \\
\hline Other Transportation & $141.57 \%$ & $\begin{array}{l}117.39 \\
\%\end{array}$ & - & $-13.88 \%$ & $21.48 \%$ & $\begin{array}{l}36.80 \\
\%\end{array}$ & $9.51 \%$ \\
\hline Worked at Home & $9.22 \%$ & $\begin{array}{l}102.88 \\
\%\end{array}$ & $15.94 \%$ & $-11.12 \%$ & $39.30 \%$ & $5.70 \%$ & $24.92 \%$ \\
\hline$\underline{\text { Total Workers }}$ & $-6.24 \%$ & $16.31 \%$ & $-1.19 \%$ & $-2.68 \%$ & $22.04 \%$ & $-9.88 \%$ & $7.80 \%$ \\
\hline Jobs Per Labor Force & $-47.27 \%$ & $10.53 \%$ & $-\overline{15.58 \%}$ & $14.04 \%$ & $22.86 \%$ & $\begin{array}{l}- \\
91.00 \\
\%\end{array}$ & $5.41 \%$ \\
\hline Total Labor Force & $605.40 \%$ & $\begin{array}{l}476.23 \\
\%\end{array}$ & $\begin{array}{l}715.83 \\
\%\end{array}$ & $\begin{array}{l}1019.44 \\
\%\end{array}$ & $\begin{array}{l}1618.40 \\
\%\end{array}$ & $-4.63 \%$ & $936.13 \%$ \\
\hline \multicolumn{8}{|c|}{$\begin{array}{l}\text { LQ Trend 2010-2016 (LQ } 2016 \text { / LQ } \\
\text { 2010) }\end{array}$} \\
\hline Commuting Mode & 0.125 & 0.25 & 0.375 & 0.5 & 0.75 & 1 & $\begin{array}{l}\text { Trst Cty } \\
\text { Change } \\
\text { Ratio }\end{array}$ \\
\hline Auto Drove Alone & 1.01 & 0.99 & 0.99 & 0.99 & 1.02 & 0.98 & 1.07 \\
\hline Carpool & 1.03 & 0.96 & 1.01 & 1.21 & 0.86 & 1.16 & 1.00 \\
\hline Transit & 0.96 & 0.85 & 1.12 & 1.04 & 1.11 & 0.93 & 1.09 \\
\hline Bike & 0.75 & 0.63 & 1.05 & 1.64 & 1.20 & 0.86 & 1.31 \\
\hline
\end{tabular}




\begin{tabular}{l|lllll|l|l} 
Walked & 0.77 & 1.09 & 1.21 & 0.88 & 0.81 & 1.26 & 1.08 \\
\hline Other Transportation & 2.54 & 1.84 & 0.63 & 0.87 & 0.98 & 1.49 & 1.10 \\
\hline Worked at Home & 1.01 & 1.51 & 1.01 & 0.79 & 0.99 & 1.01 & 1.25 \\
\hline
\end{tabular}

\section{Table 54.26. Low MA:}

BRT

Demographic Change 2010-2016

\begin{tabular}{llllllll}
\hline Commuting Mode & 0.125 & 0.25 & 0.375 & 0.5 & 0.75 & 1 & $\begin{array}{l}\text { Transit } \\
\text { County }\end{array}$ \\
\hline Auto Drove Alone & 24,827 & 9,898 & 11,780 & 7,705 & 4,618 & 6,584 & 264,402 \\
Carpool & $(1,908)$ & 1,458 & 1,412 & 255 & 883 & 721 & $(108,055)$ \\
Transit & 4,218 & 576 & $(169)$ & 675 & 815 & 1,104 & 34,862 \\
Bike & 620 & 302 & 419 & 251 & 247 & 447 & 17,949 \\
Walked & 1,060 & 870 & $(129)$ & 623 & $(786)$ & 64 & 5,911 \\
Other Transportation & $(253)$ & $(105)$ & 349 & $(192)$ & $(348)$ & 364 & 10,811 \\
Worked at Home & 4,657 & 1,253 & 865 & 1,864 & 524 & 918 & 85,093 \\
Total Workers & 33,253 & 14,011 & 14,508 & 11,146 & 5,839 & 10,353 & 329,658 \\
Total Labor Force & 373,61 & 103,13 & 128,767 & 131,48 & 98,196 & 7,971 & $(1,460,89$ \\
\hline
\end{tabular}

Percent Demographic Change 2010-

2016

\begin{tabular}{|c|c|c|c|c|c|c|c|}
\hline Commuting Mode & 0.125 & 0.25 & 0.375 & 0.5 & 0.75 & 1 & $\begin{array}{l}\text { Transit } \\
\text { County }\end{array}$ \\
\hline Auto Drove Alone & $10.60 \%$ & $19.08 \%$ & $18.71 \%$ & $10.80 \%$ & $9.21 \%$ & $\begin{array}{l}10.41 \\
\%\end{array}$ & $7.43 \%$ \\
\hline Carpool & $-5.32 \%$ & $20.37 \%$ & $16.05 \%$ & $2.31 \%$ & $11.98 \%$ & $7.91 \%$ & $0.02 \%$ \\
\hline Transit & $18.00 \%$ & $9.68 \%$ & $-2.60 \%$ & $9.02 \%$ & $19.54 \%$ & $\begin{array}{l}24.01 \\
\%\end{array}$ & $9.47 \%$ \\
\hline Bike & $32.14 \%$ & $35.16 \%$ & $33.65 \%$ & $17.80 \%$ & $27.88 \%$ & $\begin{array}{l}56.87 \\
\%\end{array}$ & $31.31 \%$ \\
\hline Walked & $10.14 \%$ & $39.08 \%$ & $-4.99 \%$ & $18.88 \%$ & $-29.25 \%$ & $4.07 \%$ & $7.95 \%$ \\
\hline Other Transportation & $-9.02 \%$ & $\begin{array}{l}- \\
13.91 \%\end{array}$ & $60.59 \%$ & $-\overline{28.92 \%}$ & $-47.54 \%$ & $\begin{array}{l}95.79 \\
\%\end{array}$ & $9.51 \%$ \\
\hline Worked at Home & $38.00 \%$ & $45.43 \%$ & $23.79 \%$ & $46.72 \%$ & $17.28 \%$ & $\begin{array}{l}27.57 \\
\%\end{array}$ & $24.92 \%$ \\
\hline Total Workers & $10.33 \%$ & $19.46 \%$ & $16.72 \%$ & $11.18 \%$ & $8.41 \%$ & $\begin{array}{l}12.41 \\
\%\end{array}$ & $7.80 \%$ \\
\hline Jobs Per Labor Force & $5.45 \%$ & $-\overline{16.79 \%}$ & $36.59 \%$ & $-\overline{14.29 \%}$ & $-9.88 \%$ & $\begin{array}{l}- \\
78.35 \\
\%\end{array}$ & $5.41 \%$ \\
\hline Total Labor Force & $\begin{array}{l}324.21 \\
\%\end{array}$ & $\begin{array}{l}648.85 \\
\%\end{array}$ & $\begin{array}{l}1243.89 \\
\%\end{array}$ & $\begin{array}{l}676.83 \\
\%\end{array}$ & $\begin{array}{l}1323.57 \\
\%\end{array}$ & $6.87 \%$ & $936.13 \%$ \\
\hline
\end{tabular}

LQ Trend 2010-2016 (LQ 2016 / LQ 2010)

$\begin{array}{lllllllll} & & & & & \begin{array}{l}\text { Trst Cty } \\ \text { Change } \\ \text { Catio }\end{array} \\ \text { Commuting Mode } & 0.125 & 0.25 & 0.375 & 0.5 & 0.75 & 1 & \text { Ration }\end{array}$




\begin{tabular}{llllllll|l}
\hline Auto Drove Alone & 1.01 & 1.00 & 1.02 & 1.00 & 1.01 & 0.99 & 1.07 \\
\hline Carpool & 0.92 & 1.09 & 1.07 & 0.99 & 1.11 & 1.03 & 1.00 \\
\hline Transit & 1.05 & 0.90 & 0.82 & 0.97 & 1.09 & 1.09 & 1.09 \\
\hline Bike & 0.98 & 0.93 & 0.94 & 0.87 & 0.97 & 1.15 & 1.31 \\
\hline Walked & 1.00 & 1.16 & 0.81 & 1.07 & 0.65 & 0.92 & 1.08 \\
\hline Other Transportation & 0.81 & 0.71 & 1.35 & 0.63 & 0.48 & 1.71 & 1.10 \\
\hline Worked at Home & 1.08 & 1.05 & 0.92 & 1.14 & 0.93 & 0.98 & 1.25 \\
\hline
\end{tabular}


Table 5.27. Mod MA:

BRT

Demographic Change 2010-2016

\begin{tabular}{llllllll}
\hline Commuting Mode & 0.125 & 0.25 & 0.375 & 0.5 & 0.75 & 1 & County \\
\hline Auto Drove Alone & 45,441 & 8,490 & 11,576 & 8,038 & 2,828 & 4,750 & 264,402 \\
Carpool & 5,733 & 42 & 59 & 1,012 & 228 & $(253)$ & $(108,055)$ \\
Transit & 7,266 & 1,335 & 2,591 & 2,305 & 1,019 & 484 & 34,862 \\
Bike & 3,185 & 553 & 1,198 & 1,726 & 424 & 175 & 17,949 \\
Walked & 6,038 & 2,054 & 179 & $(436)$ & 879 & 375 & 5,911 \\
Other Transportation & 260 & 360 & $(100)$ & $(232)$ & 345 & 136 & 10,811 \\
Worked at Home & 7,014 & 7 & 1,851 & 1,872 & 1,013 & 1,017 & 85,093 \\
Total Workers & 75,322 & 12,950 & 17,575 & 14,270 & 6,660 & 6,414 & 329,658 \\
Total Labor Force & 419,651 & 113,010 & 109,19 & 124,15 & 66,916 & 9,416 & $(1,460,89$ \\
\hline
\end{tabular}

Percent Demographic Change 20102016

\begin{tabular}{|c|c|c|c|c|c|c|c|}
\hline Commuting Mode & 0.125 & 0.25 & 0.375 & 0.5 & 0.75 & 1 & $\begin{array}{l}\text { Transit } \\
\text { County }\end{array}$ \\
\hline Auto Drove Alone & $19.87 \%$ & $19.53 \%$ & $23.75 \%$ & $14.33 \%$ & $8.31 \%$ & $\begin{array}{l}12.88 \\
\%\end{array}$ & $7.43 \%$ \\
\hline Carpool & $16.27 \%$ & $0.50 \%$ & $0.67 \%$ & $11.20 \%$ & $3.77 \%$ & $-3.99 \%$ & $0.02 \%$ \\
\hline Transit & $20.56 \%$ & $17.03 \%$ & $41.38 \%$ & $30.48 \%$ & $16.17 \%$ & $8.07 \%$ & $9.47 \%$ \\
\hline Bike & $67.67 \%$ & $31.97 \%$ & $99.01 \%$ & $\begin{array}{l}139.31 \\
\%\end{array}$ & $45.49 \%$ & $\begin{array}{l}12.04 \\
\%\end{array}$ & $31.31 \%$ \\
\hline Walked & $27.03 \%$ & $52.46 \%$ & $4.30 \%$ & $-7.46 \%$ & $41.44 \%$ & $\begin{array}{l}18.88 \\
\%\end{array}$ & $7.95 \%$ \\
\hline Other Transportation & $8.84 \%$ & $42.76 \%$ & $-\overline{15.13 \%}$ & $-\overline{22.33 \%}$ & $89.15 \%$ & $\begin{array}{l}34.61 \\
\%\end{array}$ & $9.51 \%$ \\
\hline Worked at Home & $52.32 \%$ & $0.13 \%$ & $78.00 \%$ & $55.85 \%$ & $48.15 \%$ & $\begin{array}{l}44.20 \\
\%\end{array}$ & $24.92 \%$ \\
\hline Total Workers & $21.90 \%$ & $18.04 \%$ & $24.23 \%$ & $16.84 \%$ & $12.79 \%$ & $\begin{array}{l}11.51 \\
\%\end{array}$ & $7.80 \%$ \\
\hline Jobs Per Labor Force & $-33.49 \%$ & $-6.33 \%$ & $17.54 \%$ & $-9.09 \%$ & $21.55 \%$ & $\begin{array}{l}- \\
71.97 \\
\%\end{array}$ & $5.41 \%$ \\
\hline Total Labor Force & $238.20 \%$ & $\begin{array}{l}1104.04 \\
\%\end{array}$ & $\begin{array}{l}807.66 \\
\% \\
\end{array}$ & $\begin{array}{l}756.48 \\
\% \\
\end{array}$ & $\begin{array}{l}376.52 \\
\% \\
\end{array}$ & $\begin{array}{l}12.06 \\
\%\end{array}$ & $936.13 \%$ \\
\hline
\end{tabular}

LQ Trend 2010-2016 (LQ 2016 / LQ 2010)

\begin{tabular}{llllll|l|l} 
Commuting Mode & 0.125 & 0.25 & 0.375 & 0.5 & 0.75 & 1 & $\begin{array}{l}\text { Change } \\
\text { Ratio }\end{array}$ \\
\hline Auto Drove Alone & 0.99 & 1.02 & 1.00 & 0.98 & 0.96 & 1.02 & 1.07 \\
\hline Carpool & 1.03 & 0.92 & 0.87 & 1.03 & 0.99 & 0.93 & 1.00 \\
\hline Transit & 0.97 & 0.98 & 1.12 & 1.10 & 1.01 & 0.95 & 1.09 \\
\hline Bike & 1.13 & 0.92 & 1.32 & 1.68 & 1.06 & 0.82 & 1.31 \\
\hline Walked & 1.04 & 1.29 & 0.84 & 0.79 & 1.25 & 1.06 & 1.08 \\
\hline
\end{tabular}




\begin{tabular}{l|l|l|l|l|l|l|l} 
Other Transportation & 0.88 & 1.19 & 0.67 & 0.65 & 1.65 & 1.19 & 1.10 \\
\hline Worked at Home & 1.08 & 0.73 & 1.24 & 1.15 & 1.13 & 1.12 & 1.25 \\
\hline
\end{tabular}


Table 5.28. High MA:

BRT

Demographic Change 2010-2016

\begin{tabular}{|c|c|c|c|c|c|c|c|}
\hline Commuting Mode & 0.125 & 0.25 & 0.375 & 0.5 & 0.75 & 1 & $\begin{array}{l}\text { Transit } \\
\text { County }\end{array}$ \\
\hline Auto Drove Alone & 12,508 & 4,490 & 2,701 & 1,862 & 1,083 & 1,845 & 264,402 \\
\hline Carpool & 345 & 53 & 578 & 290 & $(254)$ & 379 & $(108,055)$ \\
\hline Transit & 3,478 & 619 & (135) & 483 & 650 & $(444)$ & 34,862 \\
\hline Bike & 1,040 & 574 & 223 & 300 & 136 & 233 & 17,949 \\
\hline Walked & 4,706 & 1,676 & 546 & 761 & 769 & 200 & 5,911 \\
\hline Other Transportation & 730 & $(56)$ & (24) & 201 & 58 & (6) & 10,811 \\
\hline Worked at Home & 1,805 & 549 & 605 & 462 & 192 & 187 & 85,093 \\
\hline Total Workers & 24,773 & 7,966 & 4,507 & 4,339 & 2,773 & 2,471 & 329,658 \\
\hline Total Labor Force & 141,674 & 33,138 & 29,724 & 42,033 & 15,515 & 2,614 & $\begin{array}{l}(1,460,89 \\
4)\end{array}$ \\
\hline \multicolumn{8}{|c|}{$\begin{array}{l}\text { Percent Demographic Change 2010- } \\
2016\end{array}$} \\
\hline Commuting Mode & 0.125 & 0.25 & 0.375 & 0.5 & 0.75 & 1 & $\begin{array}{l}\text { Transit } \\
\text { County }\end{array}$ \\
\hline Auto Drove Alone & $24.21 \%$ & $\begin{array}{l}33.33 \\
\%\end{array}$ & $28.65 \%$ & $13.97 \%$ & $21.92 \%$ & 39.41 & $7.43 \%$ \\
\hline Carpool & $3.88 \%$ & $2.12 \%$ & $32.97 \%$ & $13.96 \%$ & $-20.91 \%$ & $\begin{array}{l}54.45 \\
\%\end{array}$ & $0.02 \%$ \\
\hline Transit & $26.66 \%$ & $\begin{array}{l}26.10 \\
\%\end{array}$ & $-5.52 \%$ & $13.79 \%$ & $40.88 \%$ & $\begin{array}{l}- \\
25.18 \\
\%\end{array}$ & $9.47 \%$ \\
\hline Bike & $85.46 \%$ & $\begin{array}{l}52.95 \\
\%\end{array}$ & $77.97 \%$ & $64.38 \%$ & $91.89 \%$ & $\begin{array}{l}173.88 \\
\%\end{array}$ & $31.31 \%$ \\
\hline Walked & $41.04 \%$ & $\begin{array}{l}51.63 \\
\%\end{array}$ & $19.64 \%$ & $24.66 \%$ & $\begin{array}{l}129.68 \\
\%\end{array}$ & $\begin{array}{l}32.47 \\
\%\end{array}$ & $7.95 \%$ \\
\hline Other Transportation & $100.97 \%$ & $\begin{array}{l}- \\
22.13 \\
\%\end{array}$ & $-8.36 \%$ & $\begin{array}{l}120.36 \\
\%\end{array}$ & $70.73 \%$ & $-4.08 \%$ & $9.51 \%$ \\
\hline Worked at Home & $49.79 \%$ & $\begin{array}{l}61.55 \\
\%\end{array}$ & $91.25 \%$ & $48.28 \%$ & $51.61 \%$ & $\begin{array}{l}46.17 \\
\%\end{array}$ & $24.92 \%$ \\
\hline Total Workers & $27.21 \%$ & $\begin{array}{l}33.28 \\
\% \\
-\end{array}$ & $25.45 \%$ & $18.30 \%$ & $30.82 \%$ & $\begin{array}{l}29.19 \\
\%\end{array}$ & $7.80 \%$ \\
\hline Jobs Per Labor Force & $-12.97 \%$ & $\begin{array}{l}16.81 \\
\%\end{array}$ & $-7.03 \%$ & $48.68 \%$ & $-7.89 \%$ & $\begin{array}{l}66.26 \\
\%\end{array}$ & $5.41 \%$ \\
\hline Total Labor Force & $578.31 \%$ & $\begin{array}{l}247.13 \\
\%\end{array}$ & $\begin{array}{l}1629.61 \\
\%\end{array}$ & $\begin{array}{l}3032.68 \\
\%\end{array}$ & $\begin{array}{l}1423.39 \\
\%\end{array}$ & $\begin{array}{l}20.62 \\
\%\end{array}$ & $936.13 \%$ \\
\hline
\end{tabular}
2010)

\begin{tabular}{l|lllll|l|l} 
Commuting Mode & 0.125 & 0.25 & 0.375 & 0.5 & 0.75 & 1 & \begin{tabular}{l} 
Ratio \\
\hline Auto Drove Alone
\end{tabular} \\
\hline Carpool & 0.98 & 1.00 & 1.03 & 0.97 & 0.94 & 1.08 & 1.07 \\
\hline Transit & 0.88 & 0.83 & 1.14 & 1.04 & 0.65 & 1.29 & 1.00 \\
\hline Bike & 0.98 & 0.93 & 0.74 & 0.95 & 1.06 & 0.57 & 1.09 \\
\hline
\end{tabular}




\begin{tabular}{llllll|l|l} 
Walked & 1.11 & 1.14 & 0.95 & 1.05 & 1.75 & 1.02 & 1.08 \\
\hline Other Transportation & 1.56 & 0.58 & 0.72 & 1.83 & 1.28 & 0.73 & 1.10 \\
\hline Worked at Home & 1.02 & 1.05 & 1.32 & 1.08 & 1.00 & 0.98 & 1.25 \\
\hline
\end{tabular}


Table 5.29. Poor MA: CRT

Demographic Change 2010-

2016

\begin{tabular}{llllllll}
\hline Commuting Mode & 0.125 & 0.25 & 0.375 & 0.5 & 0.75 & 1 & $\begin{array}{l}\text { Transit } \\
\text { County }\end{array}$ \\
\hline Auto Drove Alone & 5,049 & $(1,126)$ & $(29)$ & 3,412 & 2,856 & 201 & $(7,770,835)$ \\
Carpool & 1,242 & $(153)$ & $(839)$ & 473 & 11 & $(552)$ & $(1,111,478)$ \\
Transit & 452 & 54 & 421 & 266 & $(115)$ & $(651)$ & $(318,698)$ \\
Bike & 109 & $(31)$ & $(187)$ & 300 & $(14)$ & 127 & 19,300 \\
Walked & 305 & $(90)$ & 241 & 334 & 409 & 121 & $(30,993)$ \\
Other & 116 & $(94)$ & 20 & 75 & 14 & 422 & 105,526 \\
Transportation & 1,023 & 242 & 151 & 643 & 976 & 973 & 117,832 \\
Worked at Home & 8,373 & $(1,213)$ & $(237)$ & 5,654 & 4,040 & 572 & $(121,001)$ \\
Total Workers & 12,252 & $(1,759)$ & 1,000 & 6,353 & 3,246 & $(1,888)$ & $(4,177,082)$ \\
Total Labor Force & & & & & & &
\end{tabular}

Percent Demographic Change 2010-2016

\begin{tabular}{|c|c|c|c|c|c|c|c|}
\hline Commuting Mode & 0.125 & 0.25 & 0.375 & 0.5 & 0.75 & 1 & $\begin{array}{l}\text { Transit } \\
\text { County }\end{array}$ \\
\hline Auto Drove Alone & $17.66 \%$ & $-8.88 \%$ & $-0.17 \%$ & $13.21 \%$ & $13.15 \%$ & $0.70 \%$ & $13.47 \%$ \\
\hline Carpool & $37.04 \%$ & $-9.58 \%$ & $-34.91 \%$ & $17.53 \%$ & $0.34 \%$ & $-15.42 \%$ & $3.53 \%$ \\
\hline Transit & $22.69 \%$ & $6.74 \%$ & $47.20 \%$ & $25.53 \%$ & $-7.97 \%$ & $-27.84 \%$ & $19.38 \%$ \\
\hline Bike & $363.33 \%$ & $45.59 \%$ & $-59.74 \%$ & $245.90 \%$ & $-7.18 \%$ & $122.12 \%$ & $42.98 \%$ \\
\hline Walked & $60.16 \%$ & $-\overline{25.79 \%}$ & $152.53 \%$ & $161.35 \%$ & $78.96 \%$ & $13.96 \%$ & $13.13 \%$ \\
\hline $\begin{array}{l}\text { Other } \\
\text { Transportation }\end{array}$ & $49.79 \%$ & $50.00 \%$ & $18.02 \%$ & $31.65 \%$ & $6.54 \%$ & $435.05 \%$ & $10.77 \%$ \\
\hline Worked at Home & $50.42 \%$ & $27.88 \%$ & $11.04 \%$ & $46.49 \%$ & $54.99 \%$ & $49.22 \%$ & $32.18 \%$ \\
\hline Total Workers & $22.75 \%$ & $-7.29 \%$ & $-1.06 \%$ & $17.91 \%$ & $13.81 \%$ & $1.51 \%$ & $13.75 \%$ \\
\hline $\begin{array}{l}\text { Jobs Per Labor } \\
\text { Force }\end{array}$ & $-1.59 \%$ & $46.07 \%$ & $4.98 \%$ & $-20.48 \%$ & $39.13 \%$ & $0.86 \%$ & $-2.56 \%$ \\
\hline Total Labor Force & $24.49 \%$ & $-6.99 \%$ & $3.51 \%$ & $14.99 \%$ & $8.27 \%$ & $-3.55 \%$ & $17.43 \%$ \\
\hline \multicolumn{8}{|c|}{ LQ Trend 2010-2016 (LQ 2016 / LQ 2010) } \\
\hline Commuting Mode & 0.125 & 0.25 & 0.375 & 0.5 & 0.75 & 1 & $\begin{array}{l}\text { Trst Cty } \\
\text { Change Ratio }\end{array}$ \\
\hline Auto Drove Alone & 0.96 & 0.99 & 1.01 & 0.96 & 1.00 & 0.99 & 1.13 \\
\hline Carpool & 1.23 & 1.07 & 0.72 & 1.10 & 0.97 & 0.92 & 1.04 \\
\hline Transit & 0.95 & 1.10 & 1.42 & 1.01 & 0.77 & 0.68 & 1.19 \\
\hline Bike & 3.00 & 0.47 & 0.32 & 2.33 & 0.65 & 1.74 & 1.43 \\
\hline Walked & 1.31 & 0.80 & 2.57 & 2.23 & 1.58 & 1.13 & 1.13 \\
\hline $\begin{array}{l}\text { Other } \\
\text { Transportation }\end{array}$ & 1.25 & 0.55 & 1.22 & 1.15 & 0.96 & 5.41 & 1.11 \\
\hline Worked at Home & 1.05 & 1.19 & 0.97 & 1.07 & 1.17 & 1.26 & 1.32 \\
\hline
\end{tabular}


Table 5.30. Low MA: CRT

Demographic Change 2010-

2016

\begin{tabular}{|c|c|c|c|c|c|c|c|}
\hline Commuting Mode & 0.125 & 0.25 & 0.375 & 0.5 & 0.75 & 1 & $\begin{array}{l}\text { Transit } \\
\text { County }\end{array}$ \\
\hline Auto Drove Alone & 19,268 & 4,698 & 4,306 & 4,236 & 7,049 & 12,857 & $(7,770,835)$ \\
\hline Carpool & 1,137 & 21 & 10 & $(220)$ & (731) & $(1,383)$ & $(1,111,478)$ \\
\hline Transit & 3,384 & 976 & 1,424 & 444 & 320 & 42 & $(318,698)$ \\
\hline Bike & 1,054 & 255 & $(322)$ & 76 & 354 & 133 & 19,300 \\
\hline Walked & 319 & $(274)$ & 359 & $(100)$ & 689 & $(521)$ & $(30,993)$ \\
\hline $\begin{array}{l}\text { Other } \\
\text { Transportation }\end{array}$ & 309 & 203 & (124) & $(422)$ & $(251)$ & 158 & 105,526 \\
\hline Worked at Home & 4,908 & 240 & 1,654 & 836 & 721 & 1,965 & 117,832 \\
\hline Total Workers & 30,363 & 6,006 & 7,391 & 4,904 & 8,032 & 12,967 & $(121,001)$ \\
\hline Total Labor Force & 32,056 & 5,588 & 7,370 & 1,650 & 4,719 & 11,477 & $(4,177,082)$ \\
\hline \multicolumn{8}{|c|}{ Percent Demographic Change 2010-2016 } \\
\hline Commuting Mode & 0.125 & 0.25 & 0.375 & 0.5 & 0.75 & 1 & $\begin{array}{l}\text { Transit } \\
\text { County }\end{array}$ \\
\hline Auto Drove Alone & $15.34 \%$ & $10.84 \%$ & $6.72 \%$ & $6.61 \%$ & $8.95 \%$ & $14.01 \%$ & $13.47 \%$ \\
\hline Carpool & $6.17 \%$ & $0.31 \%$ & $0.11 \%$ & $-2.25 \%$ & $-5.80 \%$ & $-9.28 \%$ & $3.53 \%$ \\
\hline Transit & $36.34 \%$ & $29.87 \%$ & $27.37 \%$ & $8.53 \%$ & $3.99 \%$ & $0.59 \%$ & $19.38 \%$ \\
\hline Bike & $91.33 \%$ & $57.17 \%$ & $36.43 \%$ & $6.88 \%$ & $30.36 \%$ & $11.10 \%$ & $42.98 \%$ \\
\hline Walked & $7.60 \%$ & $-\overline{15.43 \%}$ & $18.68 \%$ & $-4.98 \%$ & $26.78 \%$ & $-17.29 \%$ & $13.13 \%$ \\
\hline $\begin{array}{l}\text { Other } \\
\text { Transportation }\end{array}$ & $23.13 \%$ & $75.46 \%$ & $-\overline{17.79 \%}$ & $-\overline{37.31 \%}$ & $-\overline{24.27 \%}$ & $15.57 \%$ & $10.77 \%$ \\
\hline Worked at Home & $67.45 \%$ & $10.68 \%$ & $48.25 \%$ & $25.21 \%$ & $13.37 \%$ & $37.94 \%$ & $32.18 \%$ \\
\hline Total Workers & $18.06 \%$ & $10.31 \%$ & $8.62 \%$ & $5.64 \%$ & $7.29 \%$ & $10.39 \%$ & $13.75 \%$ \\
\hline $\begin{array}{l}\text { Jobs Per Labor } \\
\text { Force }\end{array}$ & $0.87 \%$ & $18.29 \%$ & $4.00 \%$ & $13.17 \%$ & $-1.15 \%$ & $21.63 \%$ & $2.70 \%$ \\
\hline Total Labor Force & $13.33 \%$ & $7.08 \%$ & $6.30 \%$ & $1.36 \%$ & $3.10 \%$ & $6.62 \%$ & $12.28 \%$ \\
\hline \multicolumn{8}{|c|}{$\begin{array}{l}\text { LQ Trend 2010-2016 (LQ 2016 / LQ } \\
\text { 2010) }\end{array}$} \\
\hline Commuting Mode & 0.125 & 0.25 & 0.375 & 0.5 & 0.75 & 1 & $\begin{array}{l}\text { Trst Cty } \\
\text { Change Ratio }\end{array}$ \\
\hline Auto Drove Alone & 0.98 & 1.01 & 0.98 & 1.01 & 1.02 & 1.04 & 1.13 \\
\hline Carpool & 0.99 & 1.00 & 1.01 & 1.02 & 0.96 & 0.90 & 1.04 \\
\hline Transit & 1.10 & 1.12 & 1.12 & 0.98 & 0.92 & 0.87 & 1.19 \\
\hline Bike & 1.29 & 1.13 & 0.47 & 0.80 & 0.97 & 0.80 & 1.43 \\
\hline Walked & 0.92 & 0.77 & 1.10 & 0.90 & 1.19 & 0.75 & 1.13 \\
\hline $\begin{array}{l}\text { Other } \\
\text { Transportation }\end{array}$ & 1.07 & 1.63 & 0.78 & 0.61 & 0.72 & 1.07 & 1.11 \\
\hline Worked at Home & 1.22 & 0.86 & 1.17 & 1.02 & 0.91 & 1.08 & 1.32 \\
\hline
\end{tabular}


Table 5.31. Mod MA: CRT

Demographic Change 2010-

2016

\begin{tabular}{llllllll}
\hline Commuting Mode & 0.125 & 0.25 & 0.375 & 0.5 & 0.75 & 1 & Transit \\
\hline Auto Drove Alone & $(3,776)$ & 1,530 & 1,666 & 2,663 & 4,859 & 6,231 & $(7,770,835)$ \\
Carpool & $(1,046)$ & $(264)$ & $(256)$ & $(2,056)$ & $(832)$ & $(337)$ & $(1,111,478)$ \\
Transit & 3,370 & 168 & 1,368 & 777 & 1,172 & 1,684 & $(318,698)$ \\
Bike & 1,105 & $(604)$ & 324 & 483 & 468 & 418 & 19,300 \\
Walked & 2,299 & $(149)$ & 508 & 1,337 & 1,593 & 335 & $(30,993)$ \\
Other & $(183)$ & 24 & $(114)$ & $(689)$ & $(108)$ & $(643)$ & 105,526 \\
Transportation & 1,675 & 193 & 963 & 943 & 2,311 & $(381)$ & 117,832 \\
Worked at Home & 3,492 & 890 & 4,534 & 3,470 & 9,697 & 7,352 & $(121,001)$ \\
Total Workers & $(2,672)$ & $(1,982)$ & 4,703 & 946 & 8,655 & 14,114 & $(4,177,082)$ \\
\hline Total Labor Force & & & & & & &
\end{tabular}

Percent Demographic Change 2010-2016

\begin{tabular}{|c|c|c|c|c|c|c|c|}
\hline Commuting Mode & 0.125 & 0.25 & 0.375 & 0.5 & 0.75 & 1 & $\begin{array}{l}\text { Transit } \\
\text { County }\end{array}$ \\
\hline Auto Drove Alone & $-3.75 \%$ & $3.81 \%$ & $4.03 \%$ & $5.21 \%$ & $8.30 \%$ & $11.36 \%$ & $13.47 \%$ \\
\hline Carpool & $-6.92 \%$ & $-3.96 \%$ & $-3.07 \%$ & $\overline{2}-72 \%$ & $-8.36 \%$ & $-4.20 \%$ & $3.53 \%$ \\
\hline Transit & $25.30 \%$ & $2.74 \%$ & $25.65 \%$ & $12.74 \%$ & $14.87 \%$ & $29.30 \%$ & $19.38 \%$ \\
\hline Bike & $36.76 \%$ & $35.24 \%$ & $27.74 \%$ & $38.03 \%$ & $40.10 \%$ & $48.44 \%$ & $42.98 \%$ \\
\hline Walked & $27.87 \%$ & $-3.01 \%$ & $17.95 \%$ & $25.26 \%$ & $40.65 \%$ & $7.95 \%$ & $13.13 \%$ \\
\hline $\begin{array}{l}\text { Other } \\
\text { Transportation }\end{array}$ & $-9.98 \%$ & $4.24 \%$ & - & $\begin{array}{l}- \\
53.74 \%\end{array}$ & $-\overline{14.52 \%}$ & $-48.97 \%$ & $10.77 \%$ \\
\hline Worked at Home & $28.27 \%$ & $7.12 \%$ & $43.30 \%$ & $38.41 \%$ & $76.20 \%$ & $-8.01 \%$ & $32.18 \%$ \\
\hline Total Workers & $2.35 \%$ & $1.41 \%$ & $7.27 \%$ & $4.46 \%$ & $11.33 \%$ & $9.16 \%$ & $13.75 \%$ \\
\hline $\begin{array}{l}\text { Jobs Per Labor } \\
\text { Force }\end{array}$ & $-2.46 \%$ & $\begin{array}{l}- \\
18.42 \%\end{array}$ & $0.88 \%$ & $23.66 \%$ & $-9.24 \%$ & $19.53 \%$ & $2.70 \%$ \\
\hline Total Labor Force & $-1.24 \%$ & $-2.10 \%$ & $5.33 \%$ & $0.84 \%$ & $7.15 \%$ & $12.59 \%$ & $12.28 \%$ \\
\hline \multicolumn{8}{|c|}{$\begin{array}{l}\text { LQ Trend 2010-2016 (LQ } 2016 \text { / LQ } \\
\text { 2010) }\end{array}$} \\
\hline Commuting Mode & 0.125 & 0.25 & 0.375 & 0.5 & 0.75 & 1 & $\begin{array}{l}\text { Trst Cty } \\
\text { Change Ratio }\end{array}$ \\
\hline Auto Drove Alone & 0.94 & 1.03 & 0.97 & 1.01 & 0.98 & 1.02 & 1.13 \\
\hline Carpool & 1.00 & 1.04 & 0.99 & 0.83 & 0.90 & 0.96 & 1.04 \\
\hline Transit & 1.17 & 0.97 & 1.12 & 1.03 & 0.98 & 1.13 & 1.19 \\
\hline Bike & 1.06 & 0.51 & 0.95 & 1.05 & 1.00 & 1.08 & 1.43 \\
\hline Walked & 1.26 & 0.96 & 1.11 & 1.21 & 1.27 & 0.99 & 1.13 \\
\hline $\begin{array}{l}\text { Other } \\
\text { Transportation }\end{array}$ & 0.90 & 1.06 & 0.84 & 0.45 & 0.79 & 0.48 & 1.11 \\
\hline Worked at Home & 1.08 & 0.91 & 1.15 & 1.14 & 1.36 & 0.73 & 1.32 \\
\hline
\end{tabular}


Table 5.32. High MA: CRT

Demographic Change 2010-

2016

\begin{tabular}{llllllll}
\hline Commuting Mode & 0.125 & 0.25 & 0.375 & 0.5 & 0.75 & 1 & County \\
\hline Auto Drove Alone & 1,101 & $(404)$ & 520 & 2,383 & 3,067 & 1,563 & $2,451,866$ \\
Carpool & $(187)$ & 115 & $(313)$ & $(43)$ & $(485)$ & 10 & 697,414 \\
Transit & 1,140 & 306 & 348 & $(453)$ & 95 & $(226)$ & 389,113 \\
Bike & 423 & 165 & 400 & 449 & 384 & 104 & 80,724 \\
Walked & 815 & 121 & 701 & 1,505 & 391 & 216 & 303,564 \\
Other & 88 & $(147)$ & $(81)$ & 58 & 36 & 100 & 206,191 \\
Transportation & 569 & 49 & 208 & 565 & 411 & 240 & 611,622 \\
Worked at Home & 3,962 & 166 & 1,848 & 4,546 & 3,936 & 2,077 & $13,629,359$ \\
Total Workers & 1,449 & 521 & 1,683 & 4,648 & 3,684 & 4,482 & $17,925,615$ \\
Total Labor Force
\end{tabular}

Percent Demographic Change 2010-2016

\begin{tabular}{|c|c|c|c|c|c|c|c|}
\hline Commuting Mode & 0.125 & 0.25 & 0.375 & 0.5 & 0.75 & 1 & $\begin{array}{l}\text { Transit } \\
\text { County }\end{array}$ \\
\hline Auto Drove Alone & $14.52 \%$ & $-11.53 \%$ & $7.71 \%$ & $27.41 \%$ & $26.25 \%$ & $14.42 \%$ & $10.69 \%$ \\
\hline Carpool & $-15.35 \%$ & $32.58 \%$ & $-24.45 \%$ & $-2.17 \%$ & $-14.97 \%$ & $0.50 \%$ & $1.45 \%$ \\
\hline Transit & $72.02 \%$ & $13.21 \%$ & $12.86 \%$ & - $19.36 \%$ & $3.54 \%$ & $-11.78 \%$ & $19.00 \%$ \\
\hline Bike & $355.46 \%$ & $214.29 \%$ & $701.75 \%$ & $64.79 \%$ & $159.34 \%$ & $49.29 \%$ & $46.57 \%$ \\
\hline Walked & $58.68 \%$ & $10.74 \%$ & $51.28 \%$ & $98.75 \%$ & $29.78 \%$ & $10.70 \%$ & $12.08 \%$ \\
\hline $\begin{array}{l}\text { Other } \\
\text { Transportation }\end{array}$ & $51.16 \%$ & $-88.02 \%$ & $-44.02 \%$ & $22.39 \%$ & $19.78 \%$ & $73.53 \%$ & $23.81 \%$ \\
\hline Worked at Home & $91.04 \%$ & $19.44 \%$ & $42.80 \%$ & $84.71 \%$ & $75.69 \%$ & $31.75 \%$ & $45.60 \%$ \\
\hline Total Workers & $31.08 \%$ & $2.11 \%$ & $14.39 \%$ & $28.09 \%$ & $19.74 \%$ & $11.61 \%$ & $13.43 \%$ \\
\hline $\begin{array}{l}\text { Jobs Per Labor } \\
\text { Force }\end{array}$ & $-21.97 \%$ & $0.00 \%$ & $-1.71 \%$ & - & $-7.04 \%$ & $11.44 \%$ & $4.05 \%$ \\
\hline Total Labor Force & $7.27 \%$ & $3.95 \%$ & $8.36 \%$ & $20.19 \%$ & $12.83 \%$ & $18.98 \%$ & $9.43 \%$ \\
\hline
\end{tabular}

LQ Trend 2010-2016 (LQ 2016 / LQ 2010)

\begin{tabular}{lllllll|l|l}
\hline Commuting Mode & 0.125 & 0.25 & 0.375 & 0.5 & 0.75 & 1 & \multicolumn{1}{c}{$\begin{array}{l}\text { Trst Cty } \\
\text { Change Ratio }\end{array}$} \\
\hline Auto Drove Alone & 0.90 & 0.89 & 0.96 & 1.02 & 1.08 & 1.05 & 1.11 \\
\hline Carpool & 0.72 & 1.45 & 0.74 & 0.85 & 0.79 & 1.01 & 1.01 \\
\hline Transit & 1.25 & 1.06 & 0.94 & 0.60 & 0.82 & 0.75 & 1.19 \\
\hline Bike & 2.69 & 2.38 & 5.42 & 1.00 & 1.68 & 1.04 & 1.47 \\
\hline Walked & 1.23 & 1.10 & 1.34 & 1.57 & 1.10 & 1.00 & 1.12 \\
\hline Other & 1.06 & 0.11 & 0.45 & 0.88 & 0.92 & 1.42 & 1.24 \\
\hline Transportation & 1.14 & 0.91 & 0.97 & 1.12 & 1.14 & 0.92 & 1.46 \\
\hline Worked at Home & 1.14 & & & & & &
\end{tabular}


Table 5.33. Poor MA: LRT

Demographic Change 2010-

2016

\begin{tabular}{llllllll}
\hline Commuting Mode & 0.125 & 0.25 & 0.375 & 0.5 & 0.75 & 1 & $\begin{array}{l}\text { Transit } \\
\text { County }\end{array}$ \\
\hline Auto Drove Alone & 3,665 & 510 & $(180)$ & $(848)$ & 3,338 & $(212)$ & $1,070,528$ \\
Carpool & $(686)$ & 129 & $(155)$ & $(557)$ & $(390)$ & $(45)$ & $(76,905)$ \\
Transit & 33 & $(205)$ & 111 & $(30)$ & 455 & 146 & 46,462 \\
Bike & 272 & $(1)$ & 57 & 106 & 87 & 104 & 36,529 \\
Walked & 54 & 4 & 3 & $(177)$ & 206 & $(143)$ & 27,988 \\
Other & $(105)$ & 33 & 77 & 57 & $(153)$ & 96 & 37,723 \\
Transportation & 780 & 408 & 366 & 58 & $(657)$ & 114 & 207,348 \\
Worked at Home & 4,200 & 804 & 331 & $(1,435)$ & 2,881 & $(31)$ & $1,380,111$ \\
Total Workers & 5,144 & 2,087 & 294 & $(3,391)$ & 1,792 & $(4,774)$ & $(1,257,490)$ \\
\hline Total Labor Force & & & & & & &
\end{tabular}

Percent Demographic Change 2010-2016

\begin{tabular}{|c|c|c|c|c|c|c|c|}
\hline Commuting Mode & 0.125 & 0.25 & 0.375 & 0.5 & 0.75 & 1 & $\begin{array}{l}\text { Transit } \\
\text { County }\end{array}$ \\
\hline Auto Drove Alone & $8.81 \%$ & $2.41 \%$ & $-0.67 \%$ & $-2.84 \%$ & $11.32 \%$ & $-0.71 \%$ & $9.73 \%$ \\
\hline Carpool & $-\overline{13.13 \%}$ & $5.15 \%$ & $-5.01 \%$ & $-\overline{16.25 \%}$ & $-\overline{10.48 \%}$ & $-1.36 \%$ & $-1.45 \%$ \\
\hline Transit & $0.91 \%$ & $13.08 \%$ & $5.71 \%$ & $-2.04 \%$ & $27.54 \%$ & $10.52 \%$ & $7.68 \%$ \\
\hline Bike & $68.00 \%$ & $-0.46 \%$ & $16.86 \%$ & $26.17 \%$ & $20.67 \%$ & $40.31 \%$ & $30.02 \%$ \\
\hline Walked & $4.87 \%$ & $1.09 \%$ & $0.26 \%$ & $\overline{23.17 \%}$ & $22.64 \%$ & $-26.05 \%$ & $8.28 \%$ \\
\hline $\begin{array}{l}\text { Other } \\
\text { Transportation }\end{array}$ & $-\overline{22.98 \%}$ & $18.03 \%$ & $31.69 \%$ & $23.95 \%$ & $-\overline{6} .96 \%$ & $49.48 \%$ & $16.67 \%$ \\
\hline Worked at Home & $28.78 \%$ & $33.53 \%$ & $17.46 \%$ & $2.55 \%$ & $\overline{21.59 \%}$ & $5.75 \%$ & $26.90 \%$ \\
\hline Total Workers & $7.60 \%$ & $2.94 \%$ & $0.93 \%$ & $-3.72 \%$ & $7.27 \%$ & $-0.08 \%$ & $9.40 \%$ \\
\hline $\begin{array}{l}\text { Jobs Per Labor } \\
\text { Force }\end{array}$ & $9.48 \%$ & $37.88 \%$ & $8.33 \%$ & $22.45 \%$ & $12.80 \%$ & $0.57 \%$ & $6.67 \%$ \\
\hline$\underline{\text { Total Labor Force }}$ & $6.67 \%$ & $5.80 \%$ & $0.60 \%$ & $-6.63 \%$ & $3.27 \%$ & $-8.71 \%$ & $7.50 \%$ \\
\hline \multicolumn{8}{|c|}{$\begin{array}{l}\text { LQ Trend 2010-2016 (LQ 2016 / LQ } \\
\text { 2010) }\end{array}$} \\
\hline Commuting Mode & 0.125 & 0.25 & 0.375 & 0.5 & 0.75 & 1 & $\begin{array}{l}\text { Trst Cty } \\
\text { Change Ratio }\end{array}$ \\
\hline Auto Drove Alone & 1.01 & 0.99 & 0.98 & 1.01 & 1.03 & 0.99 & 1.10 \\
\hline Carpool & 0.90 & 1.13 & 1.04 & 0.97 & 0.93 & 1.10 & 0.99 \\
\hline Transit & 0.95 & 0.86 & 1.06 & 1.03 & 1.21 & 1.12 & 1.08 \\
\hline Bike & 1.31 & 0.81 & 0.97 & 1.10 & 0.95 & 1.18 & 1.30 \\
\hline Walked & 0.98 & 0.99 & 1.00 & 0.81 & 1.16 & 0.75 & 1.08 \\
\hline $\begin{array}{l}\text { Other } \\
\text { Transportation }\end{array}$ & 0.67 & 1.08 & 1.22 & 1.21 & 0.32 & 1.40 & 1.17 \\
\hline Worked at Home & 1.03 & 1.12 & 1.00 & 0.92 & 0.63 & 0.91 & 1.27 \\
\hline
\end{tabular}


Table 5.34. Low MA: LRT

Demographic Change 2010-

2016

\begin{tabular}{llllllll}
\hline Commuting Mode & 0.125 & 0.25 & 0.375 & 0.5 & 0.75 & 1 & $\begin{array}{l}\text { Transit } \\
\text { County }\end{array}$ \\
\hline Auto Drove Alone & 41,180 & 9,696 & 4,582 & 10,741 & 6,397 & 8,959 & $1,070,528$ \\
Carpool & $(1,662)$ & $(585)$ & 231 & 2,378 & $(1,387)$ & 860 & $(76,905)$ \\
Transit & 5,398 & 710 & 797 & 590 & 461 & $(113)$ & 46,462 \\
Bike & 1,344 & 1,125 & 534 & 409 & 938 & 595 & 36,529 \\
Walked & 1,860 & 1,283 & 261 & 335 & 152 & 26 & 27,988 \\
Other & 884 & 710 & 580 & 284 & 331 & 165 & 37,723 \\
Transportation & 6,311 & 1,948 & 1,339 & 897 & 2,142 & 2,460 & 207,348 \\
Worked at Home & 55,649 & 15,048 & 8,500 & 15,485 & 9,020 & 13,229 & $1,380,111$ \\
Total Workers & 54,781 & 18,573 & 8,165 & 14,998 & 8,304 & 8,282 & $(1,257,490)$ \\
\hline Total Labor Force & & & & & & &
\end{tabular}

Percent Demographic Change 2010-2016

\begin{tabular}{|c|c|c|c|c|c|c|c|}
\hline Commuting Mode & 0.125 & 0.25 & 0.375 & 0.5 & 0.75 & 1 & $\begin{array}{l}\text { Transit } \\
\text { County }\end{array}$ \\
\hline Auto Drove Alone & $15.79 \%$ & $11.44 \%$ & $4.22 \%$ & $10.96 \%$ & $6.06 \%$ & $9.79 \%$ & $9.73 \%$ \\
\hline Carpool & $-4.05 \%$ & $-4.55 \%$ & $1.47 \%$ & $17.62 \%$ & $-8.21 \%$ & $6.39 \%$ & $-1.45 \%$ \\
\hline Transit & $20.95 \%$ & $8.27 \%$ & $9.09 \%$ & $7.40 \%$ & $5.49 \%$ & $-1.36 \%$ & $7.68 \%$ \\
\hline Bike & $30.40 \%$ & $84.52 \%$ & $32.68 \%$ & $32.62 \%$ & $51.97 \%$ & $36.50 \%$ & $30.02 \%$ \\
\hline Walked & $14.42 \%$ & $31.37 \%$ & $6.43 \%$ & $11.62 \%$ & $4.51 \%$ & $0.89 \%$ & $8.28 \%$ \\
\hline $\begin{array}{l}\text { Other } \\
\text { Transportation }\end{array}$ & $34.37 \%$ & $76.84 \%$ & $52.39 \%$ & $26.30 \%$ & $33.71 \%$ & $18.17 \%$ & $16.67 \%$ \\
\hline Worked at Home & $36.94 \%$ & $38.11 \%$ & $18.85 \%$ & $15.78 \%$ & $37.22 \%$ & $44.28 \%$ & $26.90 \%$ \\
\hline Total Workers & $15.20 \%$ & $12.75 \%$ & $5.76 \%$ & $11.83 \%$ & $6.29 \%$ & $10.61 \%$ & $9.40 \%$ \\
\hline $\begin{array}{l}\text { Jobs Per Labor } \\
\text { Force }\end{array}$ & $-9.25 \%$ & $-\overline{15.45 \%}$ & $-\overline{20.73 \%}$ & $0.00 \%$ & $4.17 \%$ & $13.52 \%$ & $6.67 \%$ \\
\hline Total Labor Force & $10.04 \%$ & $10.82 \%$ & $3.93 \%$ & $8.09 \%$ & $4.12 \%$ & $4.60 \%$ & $7.50 \%$ \\
\hline
\end{tabular}

LQ Trend 2010-2016 (LQ 2016 / LQ 2010)

\begin{tabular}{llllll|l|l}
\hline & & & & & & \multicolumn{2}{c}{ Trst Cty } \\
Commuting Mode & 0.125 & 0.25 & 0.375 & 0.5 & 0.75 & 1 & \multicolumn{1}{c}{ Change Ratio } \\
\hline Auto Drove Alone & 0.92 & 0.94 & 1.07 & 1.17 & 0.96 & 1.07 & 1.10 \\
\hline Carpool & 1.07 & 0.98 & 1.05 & 0.98 & 1.01 & 0.91 & 0.99 \\
\hline Transit & 0.95 & 1.38 & 1.06 & 1.00 & 1.20 & 1.04 & 1.08 \\
\hline Bike & 1.00 & 1.18 & 1.02 & 1.01 & 0.99 & 0.92 & 1.30 \\
\hline Walked & 1.09 & 1.47 & 1.35 & 1.06 & 1.18 & 1.00 & 1.08 \\
\hline Other & 1.02 & 1.06 & 0.97 & 0.89 & 1.11 & 1.12 & 1.17 \\
\hline Transportation & 1.00 & 1.00 & 1.00 & 1.00 & 1.00 & 1.00 & 1.27 \\
\hline Worked at Home & 1.00
\end{tabular}


Table 5.35. Mod MA: LRT Commuting Mode Demographic Change 2010-

2016

\begin{tabular}{llllllll}
\hline Commuting Mode & 0.125 & 0.25 & 0.375 & 0.5 & 0.75 & 1 & $\begin{array}{l}\text { Transit } \\
\text { County }\end{array}$ \\
\hline Auto Drove Alone & 41,794 & 11,866 & 15,597 & 11,629 & 11,011 & 10,439 & $1,070,528$ \\
Carpool & $(507)$ & 2,843 & $(170)$ & 2,156 & $(1,824)$ & $(780)$ & $(76,905)$ \\
Transit & 6,878 & 1,810 & 1,578 & 1,773 & 354 & 716 & 46,462 \\
Bike & 2,308 & 1,052 & 973 & 1,447 & 677 & 840 & 36,529 \\
Walked & 8,007 & 1,261 & 3,004 & 276 & $(413)$ & 2,616 & 27,988 \\
Other & 407 & 376 & $(91)$ & 390 & 46 & 102 & 37,723 \\
Transportation & 4,700 & 2,049 & 807 & 2,481 & 1,199 & 3,082 & 207,348 \\
Worked at Home & 64,225 & 21,360 & 21,669 & 20,326 & 11,212 & 17,039 & $1,380,111$ \\
Total Workers & 78,992 & 25,322 & 21,244 & 18,927 & 10,496 & 13,784 & $(1,257,490)$ \\
\hline Total Labor Force & 78,240 & & & &
\end{tabular}

Percent Demographic Change 2010-2016

\begin{tabular}{|c|c|c|c|c|c|c|c|}
\hline Commuting Mode & 0.125 & 0.25 & 0.375 & 0.5 & 0.75 & 1 & $\begin{array}{l}\text { Transit } \\
\text { County }\end{array}$ \\
\hline Auto Drove Alone & $19.27 \%$ & $14.86 \%$ & $19.86 \%$ & $12.16 \%$ & $14.61 \%$ & $12.25 \%$ & $9.73 \%$ \\
\hline Carpool & $-1.31 \%$ & $24.99 \%$ & $-1.32 \%$ & $14.30 \%$ & $\overline{13.01 \%}$ & $-5.14 \%$ & $-1.45 \%$ \\
\hline Transit & $22.33 \%$ & $17.59 \%$ & $16.39 \%$ & $16.09 \%$ & $4.62 \%$ & $7.59 \%$ & $7.68 \%$ \\
\hline Bike & $35.64 \%$ & $61.88 \%$ & $45.64 \%$ & $61.05 \%$ & $42.18 \%$ & $50.03 \%$ & $30.02 \%$ \\
\hline Walked & $33.28 \%$ & $18.85 \%$ & $45.36 \%$ & $3.40 \%$ & $\begin{array}{l}- \\
10.58 \%\end{array}$ & $78.42 \%$ & $8.28 \%$ \\
\hline $\begin{array}{l}\text { Other } \\
\text { Transportation }\end{array}$ & $11.98 \%$ & $32.78 \%$ & $-6.45 \%$ & $26.55 \%$ & $4.10 \%$ & $7.57 \%$ & $16.67 \%$ \\
\hline Worked at Home & $25.87 \%$ & $44.55 \%$ & $14.94 \%$ & $45.66 \%$ & $25.65 \%$ & $57.28 \%$ & $26.90 \%$ \\
\hline Total Workers & $18.92 \%$ & $18.40 \%$ & $18.51 \%$ & $14.56 \%$ & $10.32 \%$ & $13.94 \%$ & $9.40 \%$ \\
\hline $\begin{array}{l}\text { Jobs Per Labor } \\
\text { Force }\end{array}$ & $-\overline{22.13 \%}$ & $3.47 \%$ & $8.82 \%$ & $0.00 \%$ & $3.64 \%$ & $15.92 \%$ & $6.67 \%$ \\
\hline Total Labor Force & $15.38 \%$ & $14.72 \%$ & $12.12 \%$ & $9.17 \%$ & $6.60 \%$ & $7.67 \%$ & $7.50 \%$ \\
\hline \multicolumn{8}{|c|}{$\begin{array}{l}\text { LQ Trend 2010-2016 (LQ 2016 / LQ } \\
\text { 2010) }\end{array}$} \\
\hline Commuting Mode & 0.125 & 0.25 & 0.375 & 0.5 & 0.75 & 1 & $\begin{array}{l}\text { Trst Cty } \\
\text { Change Ratio }\end{array}$ \\
\hline Auto Drove Alone & 0.13 & 0.25 & 0.38 & 0.50 & 0.75 & 1.00 & 1.10 \\
\hline Carpool & 1.00 & 0.97 & 1.01 & 0.98 & 1.04 & 0.98 & 0.99 \\
\hline Transit & 0.92 & 1.17 & 0.92 & 1.11 & 0.88 & 0.92 & 1.08 \\
\hline Bike & 1.05 & 1.01 & 1.00 & 1.03 & 0.96 & 0.96 & 1.30 \\
\hline Walked & 0.96 & 1.15 & 1.03 & 1.18 & 1.08 & 1.11 & 1.08 \\
\hline $\begin{array}{l}\text { Other } \\
\text { Transportation }\end{array}$ & 1.13 & 1.01 & 1.24 & 0.91 & 0.82 & 1.58 & 1.17 \\
\hline Worked at Home & 0.88 & 1.05 & 0.74 & 1.04 & 0.88 & 0.89 & 1.27 \\
\hline
\end{tabular}


Table 5.36. High MA: LRT Commuting Mode

Demographic Change 2010-

2016

\begin{tabular}{llllllll}
\hline Commuting Mode & 0.125 & 0.25 & 0.375 & 0.5 & 0.75 & 1 & $\begin{array}{l}\text { Transit } \\
\text { County }\end{array}$ \\
\hline Auto Drove Alone & 11,055 & 1,626 & 2,976 & 3,347 & 4,058 & 5,305 & $1,070,528$ \\
Carpool & $(220)$ & 72 & $(530)$ & 18 & $(1,503)$ & $(553)$ & $(76,905)$ \\
Transit & 1,163 & 757 & 367 & $(353)$ & $(72)$ & 417 & 46,462 \\
Bike & 525 & $(98)$ & 587 & 156 & 91 & 10 & 36,529 \\
Walked & 5,206 & 1,633 & 1,634 & 1,779 & 63 & 371 & 27,988 \\
Other & $(150)$ & $(134)$ & 228 & $(78)$ & $(405)$ & 9 & 37,723 \\
Transportation & 2,652 & 41 & 786 & 143 & 693 & 475 & 207,348 \\
Worked at Home & 20,582 & 3,970 & 6,010 & 5,012 & 3,009 & 6,215 & $1,380,111$ \\
Total Workers & 24,304 & 4,973 & 8,238 & 8,077 & 2,745 & 9,259 & $(1,257,490)$ \\
\hline Total Labor Force & & & & & & &
\end{tabular}

Percent Demographic Change 2010-2016

\begin{tabular}{|c|c|c|c|c|c|c|c|}
\hline Commuting Mode & 0.125 & 0.25 & 0.375 & 0.5 & 0.75 & 1 & $\begin{array}{l}\text { Transit } \\
\text { County }\end{array}$ \\
\hline Auto Drove Alone & $23.51 \%$ & $11.50 \%$ & $11.01 \%$ & $14.12 \%$ & $21.18 \%$ & $28.37 \%$ & $12.82 \%$ \\
\hline Carpool & $-2.39 \%$ & $2.38 \%$ & $-9.20 \%$ & $0.45 \%$ & $\overline{26.98 \%}$ & $-10.78 \%$ & $1.63 \%$ \\
\hline Transit & $8.55 \%$ & $19.42 \%$ & $7.17 \%$ & $-7.61 \%$ & $-2.43 \%$ & $14.15 \%$ & $9.97 \%$ \\
\hline Bike & $30.10 \%$ & $12.34 \%$ & $59.96 \%$ & $16.74 \%$ & $9.21 \%$ & $1.80 \%$ & $30.84 \%$ \\
\hline Walked & $33.21 \%$ & $34.72 \%$ & $39.81 \%$ & $53.89 \%$ & $3.14 \%$ & $26.16 \%$ & $10.59 \%$ \\
\hline $\begin{array}{l}\text { Other } \\
\text { Transportation }\end{array}$ & - & $39.76 \%$ & $36.31 \%$ & $-\overline{17.53 \%}$ & $\begin{array}{l}- \\
54.14 \%\end{array}$ & $1.40 \%$ & $19.42 \%$ \\
\hline Worked at Home & $65.37 \%$ & $2.55 \%$ & $62.63 \%$ & $7.61 \%$ & $70.00 \%$ & $63.76 \%$ & $30.68 \%$ \\
\hline Total Workers & $22.10 \%$ & $13.88 \%$ & $13.35 \%$ & $12.82 \%$ & $9.24 \%$ & $20.58 \%$ & $12.45 \%$ \\
\hline $\begin{array}{l}\text { Jobs Per Labor } \\
\text { Force }\end{array}$ & $-\overline{13.77 \%}$ & $17.83 \%$ & $54.26 \%$ & $3.92 \%$ & $2.50 \%$ & $11.04 \%$ & $6.67 \%$ \\
\hline Total Labor Force & $15.78 \%$ & $11.91 \%$ & $12.23 \%$ & $14.22 \%$ & $6.00 \%$ & $22.84 \%$ & $10.41 \%$ \\
\hline \multicolumn{8}{|c|}{$\begin{array}{l}\text { LQ Trend 2010-2016 (LQ } 2016 \text { / LQ } \\
\text { 2010) }\end{array}$} \\
\hline Commuting Mode & 0.125 & 0.25 & 0.375 & 0.5 & 0.75 & 1 & $\begin{array}{l}\text { Trst Cty } \\
\text { Change Ratio }\end{array}$ \\
\hline Auto Drove Alone & 0.13 & 0.25 & 0.38 & 0.50 & 0.63 & 0.75 & 1.13 \\
\hline Carpool & 1.01 & 0.98 & 0.98 & 1.01 & 0.97 & 1.11 & 1.02 \\
\hline Transit & 0.88 & 0.99 & 0.89 & 0.99 & 0.94 & 0.74 & 1.10 \\
\hline Bike & 0.91 & 1.07 & 0.97 & 0.84 & 1.14 & 0.91 & 1.31 \\
\hline Walked & 0.92 & 0.66 & 1.21 & 0.89 & 0.93 & 0.86 & 1.11 \\
\hline $\begin{array}{l}\text { Other } \\
\text { Transportation }\end{array}$ & 1.11 & 1.20 & 1.25 & 1.39 & 1.18 & 0.96 & 1.19 \\
\hline Worked at Home & 0.69 & 0.50 & 1.13 & 0.69 & 0.97 & 0.40 & 1.31 \\
\hline
\end{tabular}


Table 5.37. Poor MA: SCT Commuting Mode

Demographic Change 2010-

2016

\begin{tabular}{llllllll}
\hline Commuting Mode & 0.125 & 0.25 & 0.375 & 0.5 & 0.75 & 1 & Cransit \\
\hline Auto Drove Alone & NA & $(86)$ & $(697)$ & 76 & $(117)$ & 56 & 395,315 \\
Carpool & NA & $(62)$ & 40 & $(25)$ & $(323)$ & $(144)$ & $(76,927)$ \\
Transit & NA & 50 & $(141)$ & 33 & 85 & $(51)$ & 37,266 \\
Bike & NA & $(12)$ & $(98)$ & $(16)$ & 26 & 67 & 19,348 \\
Walked & NA & 75 & 82 & 0 & $(19)$ & 23 & 22,484 \\
Other & NA & $(14)$ & $(34)$ & 10 & 15 & 7 & 11,059 \\
Transportation & NA & 127 & 118 & $(35)$ & 88 & $(52)$ & 77,325 \\
Worked at Home & NA & 78 & $(697)$ & 42 & $(231)$ & $(90)$ & 501,623 \\
Total Workers & NA & 174 & $(858)$ & 45 & $(436)$ & $(596)$ & $(595,230)$ \\
\hline Total Labor Force & Naty
\end{tabular}

Percent Demographic Change 2010-2016

\begin{tabular}{|c|c|c|c|c|c|c|c|}
\hline Commuting Mode & 0.125 & 0.25 & 0.375 & 0.5 & 0.75 & 1 & $\begin{array}{l}\text { Transit } \\
\text { County }\end{array}$ \\
\hline Auto Drove Alone & NA & $-7.47 \%$ & $-30.15 \%$ & $20.21 \%$ & $-4.49 \%$ & $2.84 \%$ & $14.53 \%$ \\
\hline Carpool & NA & $-35.43 \%$ & $16.53 \%$ & $-24.51 \%$ & $-51.27 \%$ & $-43.50 \%$ & $-1.38 \%$ \\
\hline Transit & NA & $45.87 \%$ & $-57.79 \%$ & NA & $134.92 \%$ & $-21.79 \%$ & $23.94 \%$ \\
\hline Bike & NA & $-17.39 \%$ & $\begin{array}{l}- \\
100.00 \%\end{array}$ & $-28.57 \%$ & $216.67 \%$ & $93.06 \%$ & $27.47 \%$ \\
\hline Walked & NA & $42.13 \%$ & $66.13 \%$ & $0.00 \%$ & $-31.67 \%$ & $54.76 \%$ & $19.24 \%$ \\
\hline $\begin{array}{l}\text { Other } \\
\text { Transportation }\end{array}$ & NA & $-31.11 \%$ & $-91.89 \%$ & NA & $166.67 \%$ & NA & $-12.21 \%$ \\
\hline Worked at Home & NA & $106.72 \%$ & $168.57 \%$ & $-64.81 \%$ & $53.33 \%$ & $-24.88 \%$ & $-3.59 \%$ \\
\hline Total Workers & NA & $4.22 \%$ & $-22.29 \%$ & $6.72 \%$ & $-6.52 \%$ & $-3.12 \%$ & $10.18 \%$ \\
\hline $\begin{array}{l}\text { Jobs Per Labor } \\
\text { Force }\end{array}$ & NA & $278.95 \%$ & $-38.89 \%$ & $111.11 \%$ & $21.34 \%$ & $10.30 \%$ & $2.30 \%$ \\
\hline Total Labor Force & NA & $6.95 \%$ & $-18.84 \%$ & $4.36 \%$ & $-8.71 \%$ & $-13.62 \%$ & $15.28 \%$ \\
\hline
\end{tabular}

LQ Trend 2010-2016 (LQ 2016 / LQ 2010)

\begin{tabular}{|c|c|c|c|c|c|c|c|}
\hline Commuting Mode & 0.125 & 0.25 & 0.375 & 0.5 & 0.75 & 1 & $\begin{array}{l}\text { Trst Cty } \\
\text { Change Ratio }\end{array}$ \\
\hline Auto Drove Alone & NA & 0.90 & 0.91 & 1.14 & 1.03 & 1.07 & 1.08 \\
\hline Carpool & NA & 0.68 & 1.66 & 0.78 & 0.58 & 0.64 & 0.98 \\
\hline Transit & NA & 1.33 & 0.52 & NA & 2.40 & 0.77 & 1.14 \\
\hline Bike & NA & 0.57 & 0.00 & 0.48 & 2.44 & 1.44 & 1.51 \\
\hline Walked & NA & 1.29 & 2.03 & 0.89 & 0.69 & 1.52 & 1.15 \\
\hline $\begin{array}{l}\text { Other } \\
\text { Transportation }\end{array}$ & NA & 0.54 & 0.09 & NA & 2.33 & NA & 1.33 \\
\hline Worked at Home & NA & 1.71 & 2.98 & 0.28 & 1.41 & 0.67 & 1.26 \\
\hline
\end{tabular}


Table 5.38. Low MA: SCT Commuting Mode

Demographic Change 2010-

2016

\begin{tabular}{llllllll}
\hline Commuting Mode & 0.125 & 0.25 & 0.375 & 0.5 & 0.75 & 1 & $\begin{array}{l}\text { Transit } \\
\text { County }\end{array}$ \\
\hline Auto Drove Alone & 2,953 & 3,309 & 1,020 & 2,454 & 352 & 297 & 395,315 \\
Carpool & $(315)$ & $(356)$ & 175 & $(682)$ & $(228)$ & $(1,100)$ & $(76,927)$ \\
Transit & 972 & 88 & 327 & 53 & 672 & $(128)$ & 37,266 \\
Bike & 556 & 182 & 301 & 36 & 42 & $(771)$ & 19,348 \\
Walked & 452 & 7 & $(182)$ & 472 & $(121)$ & 648 & 22,484 \\
Other & $(70)$ & $(343)$ & $(229)$ & $(185)$ & $(106)$ & $(222)$ & 11,059 \\
Transportation & 1,023 & 34 & $(132)$ & 171 & $(121)$ & 198 & 77,325 \\
Worked at Home & 5,561 & 2,737 & $(583)$ & 2,346 & 703 & 242 & 501,623 \\
Total Workers & 6,755 & 870 & 2,030 & 4,903 & $(102)$ & $(2,097)$ & $(595,230)$ \\
Total Labor Force & & & & & & &
\end{tabular}

Percent Demographic Change 2010-2016

\begin{tabular}{|c|c|c|c|c|c|c|c|}
\hline Commuting Mode & 0.125 & 0.25 & 0.375 & 0.5 & 0.75 & 1 & $\begin{array}{l}\text { Transit } \\
\text { County }\end{array}$ \\
\hline Auto Drove Alone & $19.27 \%$ & $21.76 \%$ & $-12.20 \%$ & $13.26 \%$ & $0.86 \%$ & $-1.52 \%$ & $7.61 \%$ \\
\hline Carpool & $-9.66 \%$ & $\begin{array}{l}- \\
23.91 \%\end{array}$ & $8.42 \%$ & $-\overline{18.44 \%}$ & $-3.70 \%$ & $-22.69 \%$ & $-1.61 \%$ \\
\hline Transit & $44.40 \%$ & $-1.35 \%$ & $31.52 \%$ & $-\overline{15.86 \%}$ & $32.58 \%$ & $-37.56 \%$ & $14.06 \%$ \\
\hline Bike & $94.72 \%$ & $90.55 \%$ & $122.61 \%$ & $56.51 \%$ & $14.83 \%$ & $-7.51 \%$ & $50.90 \%$ \\
\hline Walked & $25.35 \%$ & $-9.15 \%$ & $-19.36 \%$ & $32.13 \%$ & $-\overline{28.32 \%}$ & $-2.06 \%$ & $14.53 \%$ \\
\hline $\begin{array}{l}\text { Other } \\
\text { Transportation }\end{array}$ & $-21.47 \%$ & - & $-56.44 \%$ & - & $36.11 \%$ & $-38.57 \%$ & $33.24 \%$ \\
\hline Worked at Home & $113.67 \%$ & - & $-1.65 \%$ & $46.36 \%$ & $-5.56 \%$ & $17.49 \%$ & $26.10 \%$ \\
\hline Total Workers & $22.69 \%$ & $11.38 \%$ & $-6.13 \%$ & $9.50 \%$ & $2.89 \%$ & $-8.00 \%$ & $8.72 \%$ \\
\hline $\begin{array}{l}\text { Jobs Per Labor } \\
\text { Force }\end{array}$ & $-13.22 \%$ & $-17.17 \%$ & $60.58 \%$ & $28.13 \%$ & $-1.30 \%$ & $-5.07 \%$ & $4.71 \%$ \\
\hline Total Labor Force & $16.88 \%$ & $-7.56 \%$ & $-5.50 \%$ & $7.58 \%$ & $-5.19 \%$ & $-6.88 \%$ & $7.10 \%$ \\
\hline
\end{tabular}

LQ Trend 2010-2016 (LQ 2016 / LQ 2010)

\begin{tabular}{llllll|l|l} 
Commuting Mode & 0.125 & 0.25 & 0.375 & 0.5 & 0.75 & 1 & \multicolumn{2}{c}{ Change Ratio } \\
\hline Auto Drove Alone & 0.98 & 1.10 & 0.94 & 1.04 & 0.99 & 1.08 & 1.08 \\
\hline Carpool & 0.81 & 0.75 & 1.28 & 0.82 & 1.03 & 0.93 & 0.98 \\
\hline Transit & 1.12 & 0.84 & 1.34 & 0.73 & 1.23 & 0.65 & 1.14 \\
\hline Bike & 1.14 & 1.23 & 1.71 & 1.03 & 0.80 & 0.72 & 1.51 \\
\hline Walked & 0.97 & 0.77 & 0.82 & 1.15 & 0.66 & 1.01 & 1.15 \\
\hline Other & 0.52 & 0.64 & 0.38 & 0.40 & 0.51 & 0.54 & 1.33 \\
\hline Transportation & 1.50 & 0.62 & 0.90 & 1.15 & 0.79 & 1.10 & 1.26 \\
\hline Worked at Home & & & & & & & \\
\hline
\end{tabular}


Table 5.39. Mod MA: SCT Commuting Mode Demographic Change 2010-

2016

\begin{tabular}{llllllll}
\hline Commuting Mode & 0.125 & 0.25 & 0.375 & 0.5 & 0.75 & 1 & Transit \\
\hline Auto Drove Alone & 9,040 & 2,865 & 1,718 & 642 & 1,962 & 2,001 & 395,315 \\
Carpool & $(36)$ & $(278)$ & 250 & $(373)$ & $(368)$ & 44 & $(76,927)$ \\
Transit & 531 & 1,391 & $(229)$ & $(456)$ & 942 & $(601)$ & 37,266 \\
Bike & 2,249 & 285 & 935 & 770 & 219 & 403 & 19,348 \\
Walked & 2,248 & 1,540 & 332 & 110 & $(40)$ & 315 & 22,484 \\
Other & 292 & 215 & 150 & $(23)$ & $(98)$ & $(126)$ & 11,059 \\
Transportation & 1,814 & 674 & 447 & 706 & 214 & 2 & 77,325 \\
Worked at Home & 16,194 & 6,786 & 3,708 & 1,436 & 2,809 & 2,068 & 501,623 \\
Total Workers & 12,434 & 6,183 & 2,398 & 1,337 & 1,930 & 2,176 & $(595,230)$ \\
Total Labor Force
\end{tabular}

Percent Demographic Change 2010-2016

\begin{tabular}{|c|c|c|c|c|c|c|c|}
\hline Commuting Mode & 0.125 & 0.25 & 0.375 & 0.5 & 0.75 & 1 & $\begin{array}{l}\text { Transit } \\
\text { County }\end{array}$ \\
\hline Auto Drove Alone & $20.81 \%$ & $20.60 \%$ & $13.28 \%$ & $4.21 \%$ & $15.68 \%$ & $13.82 \%$ & $7.61 \%$ \\
\hline Carpool & $-0.68 \%$ & $-12.20 \%$ & $13.74 \%$ & $-13.20 \%$ & $-\overline{15.90 \%}$ & $1.60 \%$ & $-1.61 \%$ \\
\hline Transit & $5.28 \%$ & $40.54 \%$ & $-5.02 \%$ & $-11.76 \%$ & $29.37 \%$ & $-15.05 \%$ & $14.06 \%$ \\
\hline Bike & $115.27 \%$ & $26.69 \%$ & $164.61 \%$ & $138.49 \%$ & $23.25 \%$ & $54.46 \%$ & $50.90 \%$ \\
\hline Walked & $23.16 \%$ & $42.25 \%$ & $9.83 \%$ & $5.60 \%$ & $-2.98 \%$ & $21.49 \%$ & $14.53 \%$ \\
\hline $\begin{array}{l}\text { Other } \\
\text { Transportation }\end{array}$ & $53.78 \%$ & $148.28 \%$ & $90.91 \%$ & $-7.26 \%$ & $-43.36 \%$ & $-36.10 \%$ & $33.24 \%$ \\
\hline Worked at Home & $45.67 \%$ & $53.96 \%$ & $53.79 \%$ & $63.21 \%$ & $22.41 \%$ & $0.14 \%$ & $26.10 \%$ \\
\hline Total Workers & $21.47 \%$ & $26.23 \%$ & $15.15 \%$ & $5.52 \%$ & $13.00 \%$ & $8.16 \%$ & $8.72 \%$ \\
\hline $\begin{array}{l}\text { Jobs Per Labor } \\
\text { Force }\end{array}$ & $-16.97 \%$ & $-35.57 \%$ & $26.14 \%$ & $-12.24 \%$ & $-3.80 \%$ & $13.18 \%$ & $4.71 \%$ \\
\hline Total Labor Force & $11.03 \%$ & $15.79 \%$ & $5.85 \%$ & $3.65 \%$ & $5.94 \%$ & $5.96 \%$ & $7.10 \%$ \\
\hline
\end{tabular}

LQ Trend 2010-2016 (LQ 2016 / LQ 2010)

\begin{tabular}{lllll|l|l|l}
\hline Commuting Mode & 0.125 & 0.25 & \multicolumn{1}{l}{0.375} & \multicolumn{1}{l}{0.5} & 0.75 & 1 & \multicolumn{1}{c}{ Trst Cty } \\
Change Ratio
\end{tabular}


Table 5.40. High MA: SCT Commuting Mode

Demographic Change 2010-

2016

\begin{tabular}{llllllll}
\hline Commuting Mode & 0.125 & 0.25 & 0.375 & 0.5 & 0.75 & 1 & $\begin{array}{l}\text { Transit } \\
\text { County }\end{array}$ \\
\hline Auto Drove Alone & 5,930 & 1,344 & 846 & 1,456 & 604 & 1,140 & 395,315 \\
Carpool & 631 & $(387)$ & $(208)$ & 30 & $(632)$ & 11 & $(76,927)$ \\
Transit & 2,269 & 238 & 7 & 709 & 453 & 207 & 37,266 \\
Bike & 824 & 477 & 165 & 40 & $(172)$ & $(85)$ & 19,348 \\
Walked & 6,769 & 1,392 & 1,207 & 979 & 115 & 296 & 22,484 \\
Other & 64 & 1 & 177 & $(9)$ & $(125)$ & $(95)$ & 11,059 \\
Transportation & 1,872 & 327 & $(64)$ & 230 & 135 & 65 & 77,325 \\
Worked at Home & 18,427 & 3,514 & 2,213 & 3,357 & $(693)$ & 1,215 & 501,623 \\
Total Workers & 22,560 & 3,679 & 3,500 & 5,231 & 1,349 & 991 & $(595,230)$ \\
\hline Total Labor Force
\end{tabular}

Percent Demographic Change 2010-2016

\begin{tabular}{|c|c|c|c|c|c|c|c|}
\hline Commuting Mode & 0.125 & 0.25 & 0.375 & 0.5 & 0.75 & 1 & $\begin{array}{l}\text { Transit } \\
\text { County }\end{array}$ \\
\hline Auto Drove Alone & $32.27 \%$ & $19.20 \%$ & $8.25 \%$ & $41.34 \%$ & $\overline{18.09 \%}$ & $2.55 \%$ & $7.61 \%$ \\
\hline Carpool & $28.71 \%$ & $-22.45 \%$ & $2.38 \%$ & $6.34 \%$ & $-\overline{67.03 \%}$ & $16.64 \%$ & $-1.61 \%$ \\
\hline Transit & $29.48 \%$ & $7.11 \%$ & $-6.31 \%$ & $62.47 \%$ & $22.64 \%$ & $2.45 \%$ & $14.06 \%$ \\
\hline Bike & $59.54 \%$ & $133.99 \%$ & $22.21 \%$ & $23.12 \%$ & $1.53 \%$ & $79.28 \%$ & $50.90 \%$ \\
\hline Walked & $74.59 \%$ & $40.87 \%$ & $30.50 \%$ & $71.04 \%$ & $-8.29 \%$ & $-0.87 \%$ & $14.53 \%$ \\
\hline $\begin{array}{l}\text { Other } \\
\text { Transportation }\end{array}$ & $15.92 \%$ & $1.12 \%$ & $301.67 \%$ & - & $-\overline{81.82 \%}$ & $40.54 \%$ & $33.24 \%$ \\
\hline Worked at Home & $93.32 \%$ & $28.91 \%$ & $15.07 \%$ & $38.40 \%$ & $28.86 \%$ & $17.87 \%$ & $26.10 \%$ \\
\hline Total Workers & $44.45 \%$ & $20.48 \%$ & $11.71 \%$ & $45.07 \%$ & $-\overline{15.23 \%}$ & $5.66 \%$ & $8.72 \%$ \\
\hline $\begin{array}{l}\text { Jobs Per Labor } \\
\text { Force }\end{array}$ & - & $-22.99 \%$ & $92.96 \%$ & - & $57.89 \%$ & $15.00 \%$ & $4.71 \%$ \\
\hline Total Labor Force & $35.17 \%$ & $13.91 \%$ & $10.36 \%$ & $51.53 \%$ & $-\overline{18.73 \%}$ & $8.27 \%$ & $7.10 \%$ \\
\hline
\end{tabular}

LQ Trend 2010-2016 (LQ 2016 / LQ 2010)

\begin{tabular}{l|llll|l|l|l}
\hline Commuting Mode & 0.125 & 0.25 & 0.375 & \multicolumn{1}{l}{0.5} & 0.75 & 1 & \multicolumn{2}{c}{ Trst Cty } \\
\hline Auto Drove Alone & 0.93 & 1.00 & 0.98 & 0.98 & 0.98 & 0.98 & 1.08 \\
\hline Carpool & 0.98 & 0.71 & 1.01 & 0.81 & 0.43 & 1.22 & 0.98 \\
\hline Transit & 0.85 & 0.85 & 0.80 & 1.07 & 1.38 & 0.92 & 1.14 \\
\hline Bike & 0.80 & 1.40 & 0.79 & 0.61 & 0.86 & 1.22 & 1.51 \\
\hline Walked & 1.15 & 1.11 & 1.11 & 1.12 & 1.03 & 0.89 & 1.15 \\
\hline Other & 0.65 & 0.68 & 2.93 & 0.49 & 0.17 & 1.09 & 1.33 \\
\hline Transportation & 1.15 & 0.92 & 0.89 & 0.82 & 1.31 & 0.96 & 1.26 \\
\hline Worked at Home & & & & & & & \\
\hline
\end{tabular}




\section{Implications for Transit and Land Use Planning}

The shifts in the regional populations of this study were measured in terms of household by age, type, tenure, and commuting choice. Variations in demographic response to transit proximity are broad across transit modes (e.g., LRT or SCT) and place types from low to high degrees of land use mix, intensity and accessibility.

There are results that hold true across most of the mode-place type categories. For example, walking, biking, transit use, and working from home gained share in most of these locations and categories, in the aggregate. On the other hand, some categories repelled certain groups while others attracted them. Further, some categories attracted people to the station while other categories repelled them.

At the station, the market was attracted or repelled dependent upon the transit mode as well as the place type. For most transit modes, the Poor MA place type repelled the market, in varying degrees, from the direct vicinity of the station. In many cases, growth was evident just beyond the station, mostly within the first half-mile radius of distance from the station. In many cases, growth occurred at the station while the regional figures declined, or vice-versa. Those demographic segments that grew faster than the regional trend, or faster than the station area total population highlight important market responses to transit proximity and help policy makers determine the relative change in importance over time of being connected to transit stations for those specific segments of the population.

One important takeaway from this study for planners is the classification of the stations into attractors and repellants, by what transit mode and place type, and for whom, and at what distance from the transit station. There are indications of competition and synergy between the measured households by size and age, housing tenure and commuting choice. It also increases the evidence that households with children are being attracted to many transit station by mode and place type. This is contrary to the traditional wisdom. It gives evidence as well of the consistent increases in positive market response to the presence of transit, but the ongoing concurrent problem of many households being repelled from the station at the first distance band (0.125-mile) away.

For Household by type and age, Poor MA BRT stations lost total population both at the station and cumulatively at the half-mile distance away. These losses occurred for virtually all population segments but were of particular strength among households with children. This is of further importance when the numbers of households involved in the rates of change are considered. Far more householders of age 45 to 64 left the station area than did householders under age 25, for example. For Mod MA LRT stations, households with children were attracted to the direct station area at a $3 \%$ increase over the whole region while this change represented a full $30 \%$ of the overall population change. The cumulative half-mile DB captured $5 \%$ of that same demographic. Householders under 25 actually left these LRT stations at roughly $6 \%$ at the cumulative half-mile DB. This occurred at the same time these younger householders were attracted to the Poor MA BRT stations.

Implications for planners from these results mainly consist of a clear set of evidence of which transit mode and place type needs to address challenges or unfavorable characteristics of station areas, the larger neighborhood context, or transit systems that need to be overcome to increase the favorable response of target demographic groups, such as a certain segment of the worker population that is needed in greater numbers along CRT lines. 
An unexpected trend in these data include the rising popularity of "other" transportation modes at the stations. This indicates that the market is indeed responding in significant ways to these new forms of transport that may include bike shares and e-scooters.

\section{REFERENCES}

Alonso, William. 1964. Location and Land Use. Cambridge, MA: Harvard University Press.

Calthorpe, Peter. 2011. Urbanism in the Age of Climate Change. Washington, DC: Island Press.

Calthorpe, Peter., and William B. Fulton. 2001. The Regional City: Planning for the End of Sprawl. Island Press.

https://books.google.com/books?hl=en\&lr=\&id=42OhoBidTkIC\&oi=fnd\&pg=PR4\&dq=calt horpe+and+fulton+2001\&ots=ZolBNVBAsE\&sig=6vL5KItuXPLxRnjfu3-

D7ejPL1Q\#v=onepage \&q=calthorpe and fulton $2001 \& f=$ false.

Ewing, Reid. 1997. "Is Los Angeles-Style Sprawl Desirable?" Journal of the American Planning Association 63 (1): 107-26. https://doi.org/10.1080/01944369708975728.

Kain, John F. 1992. "The Spatial Mismatch Hypothesis : Three Decades Later." Housing Policy Debate 3 (2): 371-460. https://doi.org/10.1080/10511482.1992.9521100.

Meijers, Evert J, Martijn J Burger, and Marloes M Hoogerbrugge. 2015. "Borrowing Size in Networks of Cities : City Size, Network Connectivity and Metropolitan Functions in Europe *" 95 (1). https://doi.org/10.1111/pirs.12181.

Mills, Edwin S. 1972. "Markets and Efficient Resource Allocation in Urban Areas." The Swedish Journal of Economics 74 (1): 100-113. http://www.jstor.org/stable/3439012.

Moniruzzaman, Md, Antonio Páez, Khandker M. Nurul Habib, and Catherine Morency. 2013. "Mode Use and Trip Length of Seniors in Montreal." Journal of Transport Geography 30: 89-99. https://doi.org/10.1016/j.jtrangeo.2013.03.007.

Muth, Richard F. 1969. Cities and Housing: The Spatial Pattern of Urban Residential Land Use. Chicago: University of Chicago Press.

Nelson, Arthur, Matt Miller, Dejan Eskic, Keuntae Kim, Reid Ewing, Jenny Liu, Matt Berggren, and Zakari Mumuni. 2015. "Do TODs Make a Difference?" http://pdxscholar.library.pdx.edu/trec_reports/7.

Parolek, Daniel. 2020. Missing Middle Housing. Thinking Big and Building Small to Respond to Today's Housing Crisis. Washington: Island Press.

Sanchez, Thomas W. 2007. "The Connection Between Public Transit and Employment" 4363. https://doi.org/10.1080/01944369908976058.

Sanchez, Thomas W, Qing Shen, and Zhong-ren Peng. 2004. “Transit Mobility , Jobs Access and Low-Income Labour Participation in US Metropolitan Areas" 41 (7): 1313-31. https://doi.org/10.1080/0042098042000214815.

Sheller, Mimi, and John Urry. 2006. "The New Mobilities Paradigm." Environment and Planning A 38 (2): 207-26. https://doi.org/10.1068/a37268.

Spieler, Christof. 2018. Trains, Buses, People: An Opinionated Atlas of US Transit. Washington, D.C.: Island Press. https://ebookcentral.proquest.com/lib/umontrealebooks/detail.action?doclD=5589345. 


\section{CHAPTER 6: The Link between Transit Station Proximity and Typology and Change in People by Demographic Groups Over Time}

\section{OVERVIEW}

Our research reported in this chapter expands upon previous work by assessing the extent to which jobs by sector are attracted to transit stations over time and across a range of station area intensities. Analysis is given of the land area encompassed by transit systems by mode and station type. Using economic base theory and relying upon shift-share and location quotient analyses, the demographic dynamics of station areas are assessed by transit mode, such as light rail, and by station area "place" typology. Transit modes include light rail transit, commuter rail transit, streetcar transit, and bus rapid transit systems. The station area place types are characterized as lying somewhere along a continuum of land use mix, intensity, and accessibility. These types are based upon the relative intensity of a combination of characteristics of jobs, households, and the built environment. The analysis will advance the understanding of how transit stations by type effect the spatial dynamics in a multimodal transportation system context. Demographic change is evaluated as an important result of the makeup of the transportation system, and particularly the effects of transit stations on the changing aspects of demographic concentrations across the landscape. Case studies comprise aggregations of multiple metropolitan areas across the United States, in the Urbanized Area of the counties served by the transit systems under study, grouped by place type. Each station area is analyzed by distance from the station in eighth-mile distance bands.

\section{Introduction}

"Modern people care about access to jobs and schools and stores and shopping centres and healthcare and amenities, like the [Sydney] Opera House or Big Fiddle, and the outside world through ports and airports, and so on, Similarly, organizsations care about access to labour and customers and suppliers and competitors and complementors and the outside world. Access is multidimensional" (Levinson 2019). These considerations play a major role in the agglomeration economies of the metropolitan areas under study. Spatial concentrations provide advantages such that they have driven the creation of cities across human history. Congestion becomes an agglomeration diseconomy as a city grows, which impels firms and policymakers to focus on ways to decrease congestion. Transit has been shown to increase accessibility and agglomeration economies (Arthur C. Nelson and Hibberd 2019).

Transit station neighborhoods come in a variety of types (i.e., "places"), from low-intensity dispersed development with isolated land uses, to neighborhoods with high degrees of land use mix, intensity, and accessibility. Accessibility can be quantified as the number of destinations reachable within a distance or time limit from a given origin. Each type along this transit station "place typology" can provide accessibility in a range of methods, from walking or biking in an urban place, to taking transit or car to work from an first-ring suburb, and finally to using an automobile to get everywhere beyond one's morning walk. Different place types will attract different demographic segments and different sectors of the economy. In all cases, however, higher accessibility is always a preferable outcome. Many scholars today assert the utility of Fixed-Route Transit (FRT) systems, such as the commuter rail lines of San Diego, the light rail lines in Denver and Salt Lake City, or the streetcar routes in the highly urban cores of Portland, Seattle, and New Orleans. Bus Rapid Transit is being constructed across the country, in every 
kind of place from Milwaukee to Albuquerque. Many of these systems are of very recent vintage, having been constructed within the last 20 years.

According to the oft-cited Alonso-Mills-Muth (AMM) urban land use theory, richer consumers will move further from the city in order to gain more land at a cheaper price per area, while jobs concentrate in the Central Business District (CBD). The model assumes one mode of transport for everyone and that the main cost is travel time (Alonso 1964; Mills 1967; Muth 1969). While the auto-centric city fits quite well to this theory in terms of transportation, for today's city the model assumption of one mode of transport needs to be relaxed somewhat, as many US cities attempt to transition to a fully multimodal approach to transportation infrastructure and technology. Bikeshares and e-scooters provide solutions for the First-Mile/Last-Mile challenge, which make an effort to get potential transit users seamlessly to and from the transit station. While cities work to expand such multimodal transport networks, planners and policymakers seek to do so in a way that furthers access to all demographic segments of the population. Many ask the question, who benefits from increased transit access? The response to transit station proximity also varies according to place typology, but the literature lacks sufficient evidence of this response. This chapter will utilize shift-share and location quotient analysis to ascertain the changes in population near the station by demographic makeup, and how this varies across the typology of station "place types." 


\section{Literature Review and Research Questions}

Transport scholars have highlighted the need to focus policies in connection with the development of transit-oriented development that will take into account the impacts on the existing land uses and populations, which vary by demographic subsets. Some scholars fear that smarter development patterns are lagging in implementation due to fears of the negative impacts, while protective policies are slow to implementation (Chapple and Loukaitou-Sideris 2019; Sanchez, Stolz, and Ma 2003).

Further complicating the issue is the variable impacts transportation infrastructure policies have on populations by demographic segment. Sanchez et al. (2003) highlighted the unintended negative outcomes of auto-centric transportation infrastructure and supporting land uses (i.e., sprawl), which are more dispersed than the traditional "walkable" city. These include reduction of access to needed land uses among "transit dependent" populations, higher tax outlays required in funding dispersed public facilities (water and energy facilities) and transportation infrastructure, increases in residential segregation and "spatial mismatch," or the lack of access to jobs for urban populations geographically separated from needed job opportunities (Sanchez, Stolz, and Ma 2003; Kain 1992).

Recent literature has distinguished between "transit-oriented" and "transit-adjacent" developments (TOD and TAD) (Renne et al. 2016; Scheer 2017). Dittmar et al. (2004) posited that TOD "should be reserved to refer to projects that achieve five main goals: location efficiency, rich mix of choices, value capture, place making, [and] resolution of the tension between node and place" (Renne et al. 2016). The elements of density, land use diversity, and intersection density are measured as indicators of the relative level of accessibility and efficiency of the surrounding built environment. These are the indicators that distinguish TOD from TAD. Essentially, TAD denotes transit station areas that do not optimize land use through density, land use mix, and interconnections between the station and the surrounding vicinity through direct links to the transportation infrastructure: road intersections and sidewalks, etc., that connect directly to the station area. These interconnections help in the effort to balance node and place characteristics of a transit station area (Bertolini 1999). A "node" is a connection to the regional transportation network, while a "place" comprises an attraction to local land uses. 


\section{Research Design and Plan}

Our research design and plan include using GIS data and analyses to join transit stations and buffers, representing eighth-mile distance bands around each station, to a layer of land use intensity. These data allow the segmentation of the station areas, their environs, and their regions into relative land use mix and intensity. We call these place types. US census data provide job figures over time by sector, income and other categorizations. Economic base analysis is used to analyze the shift in share and relative local concentration of jobs near the station viz-a-vis the transit-served region surrounding the study transit systems.

\section{Data Resources}

The employment data come from the US Census Bureau's Longitudinal Employer-Household Dynamics data (LEHD) for 2010 and 2016. Transit system data come from the General Transit Feed Specification (GTFS). ${ }^{106}$ Census blocks were downloaded from IPUMS HGIS website (Steven Manson, Jonathan Schroeder, David Van Riper 2018). Station typology data are outlined below.

\section{Shift-Share Method}

Economic development is often analyzed using economic base theory and measures spatial concentrations of jobs by sector or other segmentations, as well as their spatial and temporal dynamics. Shift-share analysis compares change of employment concentrations at the "regional" level, which is defined by the analyst at a chosen scale (e.g., national, state, or county), with changes in concentrations at the "local" level, which can also be defined at various scales by the analyst. The study assigns "transit-served" counties as regions (those counties with access to a transit system) and assigns transit neighborhoods as the "local" scale. The transit neighborhoods are further segmented into distance bands away from the station, in increments of one-eighth or one-quarter mile, up to a distance of 1 mile from the transit station centroid. The analytic method isolates the various sources of job change into 3 categories: 1) the Transit Region share, which references overall economic dynamics at the regional scale 2) the Demograhic Mix, which accounts for job dynamics as a result of change for the whole region in a specific industry, and 3) FRT Station Shift, also called the "competitive effect," which measures the degree of change at the local spatial scale of the transit station neighborhood. It is a measure of the station's lagging and leading job sectors by isolating station area economic trends from those at the regional scale, and from other factors. The shift-share formula is as follows (Carnegie Mellon n.d.):

\footnotetext{
${ }^{106}$ See TransitFeeds.com for downloadable GTFS data tables. These are frequently updated.
} 
Where:

$$
S S_{i}=T R_{i}+D M_{i}+F R T_{i}
$$

$$
\begin{aligned}
S S_{i}=\text { Shift-Share } \\
\\
T R_{i}=\text { Transit Region share } \\
D M_{i}=\text { Demographic Mix } \\
F R T_{i}=\text { FRT Station Shift }
\end{aligned}
$$

Each component is calculated with the following equations:

$T R=\left(\right.$ iFRT Station Area $\left.{ }^{\mathrm{t}-1} \times \mathrm{TR}^{\mathrm{t}} / \mathrm{TR}^{\mathrm{t}-1}\right)$

$D M=\left[\left(\mathrm{i}_{\mathrm{F} R T}\right.\right.$ Station Area $\left.\left.{ }^{\mathrm{t}-1} \mathrm{x}_{\mathrm{i}} \mathrm{TR}^{\mathrm{t}} / \mathrm{iTR} \mathrm{R}^{\mathrm{t}-1}\right)-\mathrm{TR}\right] \quad(5-3)$

$F R T=\left[{ }_{i} F R T\right.$ Station Area ${ }^{t-1} \times\left({ }_{i} F R T\right.$ Station Area ${ }^{t} / \mathrm{F} F T$ Station Area $\left.\left.{ }^{\mathrm{t}-1}-\mathrm{iTR}^{\mathrm{t}} / \mathrm{iTR}^{\mathrm{t}-1}\right)\right]$

Where:

iFRT Station Area = number of jobs in the FRT Station Area sector (i) at the beginning of the analysis period (t-1)

${ }_{i}$ FRT Station Area ${ }^{\mathrm{t}}=$ number of jobs in the FRT Station Area in sector (i) at the end of the analysis period $(\mathrm{t})$

$\mathrm{TR}^{\mathrm{t}-1}=$ total number of jobs in the Transit Region at the beginning of the analysis period(t-1)

$\mathrm{TR}^{\mathrm{t}}=$ total number of jobs in the Transit Region at the end of the analysis period ( $t$ )

ITR = number of jobs in the Transit Region in sector (i) at the beginning of the analysis period (t-1)

$\mathrm{TR}^{\mathrm{t}}=$ number of jobs in the Transit Region in sector (i) at the end of the analysis period $(\mathrm{t})$

\section{Location Quotients}

Location Quotients (LQ) provide a spatial concentration measure that compares local concentrations of phenomena with a regional or global concentration of the same phenomena. For this study, transit station areas by eighth-mile distance bands provide the local context, while "transit-served counties," or counties and groups of counties that are served by transit systems, provide the regional context. LQ metrics, along with shift-share analyses, are a proven methodological staple of economic development studies. The effectiveness of these methodologies at providing evidence of economic development highlight the spatial nature of the economy. Transit systems serve to provide network connectivity across local economies, connecting the geographies highlighted by these methodologies.

The tables in the section below provide an analysis of transit station share of population change for certain demographic segments, in the general categories of race and ethnicity, from 2010 to 2016. An incremental analysis is given, followed by a cumulative analysis for each eighth-mile DB from the station to the first half-mile DB. More detailed results are available in Appendix G. The Location Quotient trends in our time period of 2010 to 2016 will identify changes in spatial concentration at the station relative to the region as a whole.

The tables below can be interpreted as follows: the "Region Change 2010-2016" and "DB Change 2010-2016" fields are presented as the ratio of current jobs to base time jobs at the region and transit station distance band (DB), respectively. A score of 1 denotes no change, above 1 denotes growth, while below 1 identifies decline in jobs. The "Share of Transit Counties" field gives the percentage of the transit region change at the distance band. Or, in 
other words, it provides the transit station's DB share by percentage of transit county demographic change. It answers the question,

"how much regional change over time occurred for a specific variable at the station $D B$ ?"

The "Share of Distance Band Change" provides a Location Quotient (LQ) score as a percentage to represent demographic change over time captured by the DB. It divides the change of the segment of the population at the transit station DB to the change of the total population at the DB. It answers the question,

"how much of the total demographic change at the station did a variable's share of transit county change represent?"

An example from this study is thus: the share of change at the streetcar station DB of White Non-Latino population between 2010 and 2016 was 0.18 , a low ratio, meaning that the station modestly increased concentration of the population of White Non-Latinos between 2010 and 2016. That station-level ratio of change is then divided by the ratio of change at the regional scale, giving us an LQ score (as a percentage) of $103.3 \%$. That percentage represents the difference in change of the White Non-Latino population at the local scale and the regional scale. 


\section{Results and Discussion}

The following section displays and discusses the results of a subset of the population's demographic segments. The Appendix contains a full set of tables for the studied variables. We here discuss the growth and decline rates of White Non-Latino, Hispanic, and Black populations at each of the transit station-place type combinations, such as the Poor MA place type for BRT stations.

\section{Poor MA: BRT}

For White Non-Latino population at the Poor MA BRT stations,

- At the station (from the station to 0.125 -mile distance), share decreased modestly at $-4 \%$ of the regional change and half the rate of change for the total population at the distance band.

- At the quarter-mile DB, share gained $7 \%$, representing $77 \%$ of the DB change of total population at the station area. Cumulatively, the first quarter mile from the station saw a $75 \%$ of the change rate for the total population.

- The half-mile DB lost share of total regional growth of White Non-Latino population by $9 \%$ at the increment of the DB, but for the total half-mile radius around the station, the share dropped by $5 \%$. The decline of this population at the station represented a change rate of $59 \%$ of the total station population change.

For Hispanic population at the Poor MA BRT stations,

- At the station DB, share of station population change from the regional Hispanic population dropped slightly, while the rate of decline at the station for Hispanics was 5 times the rate of the total population change.

- At the quarter-mile DB, the station area's rate of growth in Hispanic population was $62 \%$ as fast as Hispanic regional growth. Station-area Hispanics declined 3 times as fast as the total population decline at the DB.

- At the half-mile DB, the Hispanic population cumulative change was $-20 \%$ relative to regional Hispanic population change. Station-area Hispanic population decline twice as fast as the total population.

For Black population at the Poor MA BRT stations,

- At the station DB, station share of regional change in Black population declined by $5 \%$, while Black population declined at $70 \%$ of the rate of the total population at the station.

- At the quarter-mile DB, station-area share of the regional Black population dropped $11 \%$. For the station-area population, Black population declined at a slightly higher rate than the total population.

- At the half-mile DB, station share of regional change in Black population declined by $6 \%$. The station area Black population remained approximately the same, while the total station population declined slightly. 


\section{Low MA: BRT}

For White Non-Latino population at the Low MA BRT stations,

- At the station, share of the regional growth in the population segment was a small $1.5 \%$. The station-area change in this population segment was $35 \%$ as fast as the whole population at the station.

- At the quarter-mile DB, station-area share of regional White population change was negligible. Cumulatively, at the first quarter mile from the station this population changed at a negligible rate of comparison with the total population change at the station.

- At the half-mile DB, this population increased at $7 \%$ the rate of change at the increment of the DB, but for the total half-mile radius around the station, the share dropped slightly. For the station area change, the White population declined at a very small rate while the total population grew slightly.

For Hispanic population at the Low MA BRT stations,

- At the station DB, share of station population change from the Hispanic population increased as a small portion of the regional Hispanic change rate. The station-area change of Hispanic population was $50 \%$ as fast as change for the total population at the station.

- At the quarter-mile DB, share of the regional Hispanic change was negligible. The Hispanic station population change declined $18 \%$ faster than the total population.

- At the half-mile DB, the Hispanic population change was a small fraction of its regional change. Hispanic population change at the station grew half as fast as the total station population.

For Black population at the Low MA BRT stations,

- At the station, population share rose very little, while Black population growth at the station was nearly as fast as the rate of the total population.

- At the quarter-mile DB, share of Black regional change was negligible. Black share of station population declined slightly while total population rates grew slightly.

- At the half-mile DB, station share of Black regional population change was miniscule. At the station, Black population declined slightly while total population grew slightly.

\section{Mod MA: BRT}

For White Non-Latino population at the Mod MA BRT stations,

- At the station, share increased modestly, representing $8 \%$ of the regional change of the White population and $60 \%$ the rate of change of the total population at the station distance band.

- At the quarter-mile DB, share decreased modestly, representing $48 \%$ of the DB change of total population at the station area. Cumulatively, the first quarter mile from the station saw a $43 \%$ decline of White Non-Latino population.

- At the half-mile DB, this population declined slightly, both as a percent of the regional White population, but as a portion of the station-area total population.

For Hispanic population at the Mod MA BRT stations,

- At the station DB, the station share of regional Hispanic population change was $27 \%$ The Hispanic share of the station-area population change was twice the rate of change as the total station population.

- At the quarter-mile DB, share of the regional Hispanic population change grew cumulatively by $8 \%$. The station-area Hispanic population grew nearly as fast as the total population. 
- At the half-mile DB, station-area Hispanic population captured $5 \%$ of the regional Hispanic growth. Hispanic rate of growth at the station was $50 \%$ as fast as the total station population.

For Black population at the Mod MA BRT stations,

- At the station, population share of regional growth of the Black population was $5 \%$. At the station, the Black population grew at $40 \%$ of the rate of growth for the total population.

- At the quarter-mile DB, incremental growth was $12 \%$ of regional Black growth. The cumulative station-area Black population was in slight decline while the total population grew slightly.

- At the half-mile DB, the station-area rate relative to the regional was in slight decline. Black growth was in decline while the total population rate was $8 \%$ growth.

High MA: BRT

For White Non-Latino population:

- At the station, share increased modestly, representing $6 \%$ of the regional change and a rate of $60 \%$ as fast as the total station population.

- At the quarter-mile DB, share of the regional White population increased by $17 \%$. Cumulatively, the first quarter mile from the station saw a $9 \%$ increase of White NonLatino population growth relative to total station growth.

- At the half-mile DB, this population grew at $9 \%$ of Hispanic regional growth, at the increment of the $\mathrm{DB}$, but for the total half-mile radius around the station, the share stayed at a flat rate of growth. Cumulatively, the station area White growth was negligible, as was the total population growth rate.

For Hispanic population:

- At the station DB, share of station population change from the Hispanic population increased $8.5 \%$. The station population grew at near the rate of the total population at the station.

- At the quarter-mile $\mathrm{DB}$, regional share of the station population change grew incrementally at $18 \%$ and declined cumulatively by $3 \%$. The station-area share of declined while total population grew at a modest rate.

- At the half-mile DB, incrementally the station area captured $22 \%$ of the regional Hispanic population growth. The cumulative growth was flat. The station-area trend grew $50 \%$ faster incrementally than the station population but declined slightly by the cumulative figure.

For Black population:

- At the station, population share was flat, both in terms of the regional share and the station share of population change.

- At the quarter-mile DB, the regional share fell, and the station area share of the Black population fell $80 \%$ faster than the total population.

- At the half-mile DB, the Black population captured $3 \%$ of the regional Black growth. At the station, Blacks captured $24 \%$, incrementally, of the station area growth. However, the cumulative scores were negative. 
Table 6.1 Poor MA:

BRT

\begin{tabular}{|c|c|c|c|c|c|c|c|}
\hline \multirow[t]{2}{*}{ BRT } & & \multicolumn{3}{|c|}{ Incremental Analysis } & \multicolumn{3}{|c|}{ Cumulative Analysis } \\
\hline & $\begin{array}{l}\text { Region } \\
\text { Chang } \\
\mathrm{e}\end{array}$ & $\begin{array}{l}\text { DB } \\
\text { Chang } \\
\text { e }\end{array}$ & $\begin{array}{l}\text { Share } \\
\text { of } \\
\text { Transit }\end{array}$ & $\begin{array}{l}\text { Share of } \\
\text { Distance }\end{array}$ & $\begin{array}{l}\text { DB } \\
\text { Chang } \\
\mathrm{e}\end{array}$ & $\begin{array}{l}\text { Share } \\
\text { of } \\
\text { Transit }\end{array}$ & $\begin{array}{l}\text { Share of } \\
\text { Distance }\end{array}$ \\
\hline $\begin{array}{l}\text { Transit Region LQ of } \\
\text { Demographic Change }\end{array}$ & $\begin{array}{l}2010- \\
2016\end{array}$ & $\begin{array}{l}2010- \\
2016\end{array}$ & $\begin{array}{l}\text { Countie } \\
\mathrm{s}\end{array}$ & $\begin{array}{l}\text { Band } \\
\text { Change }\end{array}$ & $\begin{array}{l}2010- \\
2016\end{array}$ & $\begin{array}{l}\text { Countie } \\
\mathrm{s}\end{array}$ & $\begin{array}{l}\text { Band } \\
\text { Change }\end{array}$ \\
\hline
\end{tabular}

Demographic Group--0.125 Mile Distance

Band

White Non Latino

$\begin{array}{lllllll}1.01 & -0.04 & -3.7 \% & 47.6 \% & -0.04 & -3.7 \% & 47.6 \% \\ 1.09 & -0.14 & -13.1 \% & 179.7 \% & -0.14 & -13.1 \% & 179.7 \% \\ 1.10 & -0.30 & -27.2 \% & 375.7 \% & -0.30 & -27.2 \% & 375.7 \% \\ 1.05 & -0.08 & -7.6 \% & & -0.08 & -7.6 \% & \end{array}$

Othon Latino

$1.01-0.04-3.7 \%$

TotalPopulation

White Non Latino

1.08

$-0.40$

$-37.1 \%$

$47.6 \%$

Other Non Latino

$1.09 \quad-0.14 \quad-13.1 \%$

$507.4 \%$

1.21

0.29

$23.7 \%$

$179.7 \%$

Other Groups

1.05

$-0.08 \quad-7.6 \%$

$-360.8 \%$

TotalPopulation

$1.07-0.05$

White Alone

1.03

$-0.06$

$-4.9 \%$

$65.8 \%$

Black Alone

$-5.4 \% \quad 70.4 \%$

$\begin{array}{llll}1.14 & 0.00 & 0.2 \% & -3.5 \%\end{array}$

$-0.04$

$-3.7 \%$

$47.6 \%$

Asian \& Pacif Islander

Aln

$\begin{array}{ll}1.14 & 0.00\end{array}$

Native American Alone

$0.86-0.93$

$-$

All Other Races Alone

$0.84-0.31$

$107.3 \%$

$-37.0 \%$

$1169.1 \%$

$-0.40$

$-37.1 \%$

$507.4 \%$

$-0.14$

$-13.1 \%$

$179.7 \%$

0.29

$23.7 \%$

$-360.8 \%$

TotalPopulation

$\begin{array}{ll}1.05 & -0.08\end{array}$

$-7.6 \%$

$392.9 \%$

Demographic Group--0.25 Mile Distance

Band

White Non Latino

$1.01 \quad 0.07$

$7.3 \%$

$77.4 \%$

Other Non Latino

1.09

$-0.03$

1.10

0.54

$-3.0 \%$

$49.3 \%$

TotalPopulation

1.05

0.10

$9.2 \%$

White Non Latino

1.01

0.07

$7.3 \%$

1.08

0.67

$61.9 \%$

$-34.4 \%$

$563.0 \%$

Hispanic

1.09

$-0.03$

Other Non Latino

1.21

0.23

$-3.0 \%$

$19.2 \%$

1.05

0.10

$9.2 \%$

TotalPopulation

1.07

$-0.87$

$-81.4 \%$

$-0.08$

$-7.6 \%$

$-0.05$

$-4.9 \%$

$65.8 \%$

$-0.06$

$-5.4 \%$

$70.4 \%$

Black Alone

1.03

$-0.11$

$-11.0 \%$

$77.4 \%$

0.00

$0.2 \%$

$-3.5 \%$

Asian \& Pacif Islander

Aln

1.14

0.10

$9.0 \%$

$107.3 \%$

$-0.93$

$-$

$-0.31$

$107.3 \%$

$1169.1 \%$

$-0.08$

$-37.0 \%$

$392.9 \%$

Native American Alone

0.86

1.44

$166.0 \%$

$1494.6 \%$

$1729.3 \quad 15196.2$

All Other Races Alone

0.84

14.59

$\%$

1.05

0.10

$9.2 \%$

$\%$

0.07

$6.6 \%$

$-74.6 \%$

$103.6 \%$

$1263.3 \%$

$-0.17 \quad-15.4 \% \quad 189.7 \%$

$-0.09-8.5 \%$

$0.07 \quad 6.6 \%$

$-0.25$

$-23.0 \%$

$-74.6 \%$

$279.5 \%$

$1.13 \quad 103.6 \% \quad 1263.3 \%$

$-0.17 \quad-14.0 \% \quad 189.7 \%$

$-0.09-8.5 \%$

$0.00-0.2 \%$

$2.9 \%$

$\begin{array}{lll}-0.01 & -0.7 \% & 8.3 \%\end{array}$

Demographic Group--0.5 Mile Distance Band

White Non Latino

$1.01 \quad-0.09$

Other Non Latino

1.09

$-9.2 \%$

0.08

$7.7 \%$

$-19.4 \%$

1.10

$-0.21$

TotalPopulation

1.05

$-0.08$

$-8.0 \%$

1.01

Hispanic

1.08

$-0.09$

$-9.2 \%$

$-0.33$

Other Non Latino

1.09

0.08

$-30.3 \%$

$7.7 \%$

$110.7 \%$
$-100.2 \%$
$253.9 \%$
$110.7 \%$
$392.2 \%$
$-100.2 \%$

0.00

$0.0 \%$

$0.0 \%$

$-0.93 \quad 107.4 \% \quad 1041.0 \%$

$-0.17 \quad-20.0 \% \quad 189.7 \%$

$-0.09-8.5 \%$

$\begin{array}{lll}0.05 & 5.3 \% & -59.0 \% \\ 0.02 & 1.8 \% & -21.1 \% \\ -0.08 & -7.6 \% & 90.4 \% \\ -0.09 & -8.8 \% & \\ 0.05 & 5.3 \% & -59.0 \% \\ -0.22 & -20.4 \% & 240.9 \% \\ 0.02 & 1.8 \% & -21.1 \%\end{array}$




$\begin{array}{llllllll}\text { Other Groups } & 1.21 & 0.41 & 33.9 \% & -489.8 \% & -0.08 & -6.9 \% & 90.4 \% \\ \text { TotalPopulation } & 1.05 & -0.08 & -8.0 \% & & -0.09 & -8.8 \% & \\ \text { White Alone } & 1.07 & -0.10 & -9.7 \% & 124.0 \% & -0.01 & -1.1 \% & 13.2 \% \\ \text { Black Alone } & 1.03 & -0.06 & -5.9 \% & 73.2 \% & 0.00 & 0.2 \% & -1.9 \% \\ \text { Asian \& Pacif Islander Aln } & 1.14 & 0.22 & 18.9 \% & -257.9 \% & 0.00 & 0.0 \% & 0.0 \% \\ & & & & & & - & \\ \text { Native American Alone } & 0.86 & -0.05 & -6.1 \% & 63.4 \% & -0.91 & 105.4 \% & 992.5 \% \\ \text { All Other Races Alone } & 0.84 & -0.19 & -22.9 \% & 230.8 \% & -0.08 & -9.8 \% & 90.4 \% \\ \text { TotalPopulation } & 1.05 & -0.08 & -8.0 \% & & -0.09 & -8.8 \% & \end{array}$

Table 6.2 Mod MA:

BRT.

Transit Region LQ of

Demographic Change

Demographic Group--0.125 M

White Non Latino

Other Non Latino

Other Groups

TotalPopulation

White Non Latino

Hispanic

Other Non Latino

Other Groups

TotalPopulation

White Alone

Black Alone

Asian \& Pacif Islander Aln

Native American Alone

All Other Races Alone

TotalPopulation

Demographic Group--0.25 Mile Distance Band

White Non Latino $\quad 1.01 \quad 0.10$

Other Non Latino

Other Groups

TotalPopulation

White Non Latino

Hispanic

Other Non Latino

Other Groups

TotalPopulation

White Alone

Black Alone

Asian \& Pacif Islander Aln

Native American Alone

All Other Races Alone

TotalPopulation

Demographic Group--0.5 Mile

White Non Latino

Other Non Latino

Other Groups

TotalPopulation

White Non Latino

Hispanic

Other Non Latino

Other Groups

TotalPopulation

White Alone

Black Alone

Asian \& Pacif Islander Aln
$1.09 \quad 0.13$

$1.10 \quad 0.23$

$1.05 \quad 0.14$

$1.01 \quad 0.10$

$1.08 \quad 0.21$

$1.09 \quad 0.13$

$1.21 \quad 0.36$

$1.05 \quad 0.14$

$1.07-0.50$

$1.03 \quad 0.13$

$1.14 \quad 0.11$

$0.86 \quad 0.16$

$0.84 \quad 2.83$

$1.05 \quad 0.14$

0.14

$\begin{array}{ll}\text { Distance } & \text { Band } \\ 1.01 & 0.11 \\ 1.09 & 0.09\end{array}$

$\begin{array}{ll}1.09 & 0.09\end{array}$

1.10

1.05

1.01

1.08

1.09

1.21

1.05

1.07

1.03

1.14
0.13

0.11

0.11

0.11

0.09

0.27

0.11

0.20

0.03

0.13 ental Analysis

$\begin{array}{ll}\text { Share of } & \text { Share of } \\ \text { Distance } \\ \text { Transit } & \text { Band }\end{array}$

Counties Change

$8.1 \%$

$8.9 \%$

$27.5 \%$

$13.2 \%$

$8.1 \%$

$27.0 \%$

$8.9 \%$

$30.1 \%$

$13.2 \%$

$16.4 \%$

$5.4 \%$

$9.7 \%$

$48.2 \%$

$9.0 \%$

$13.2 \%$

$10.0 \%$

$12.1 \%$

$20.8 \%$

$13.7 \%$

$10.0 \%$

$19.4 \%$

$12.1 \%$

$30.1 \%$

$13.7 \%$

$-47.0 \%$

$12.5 \%$

$9.3 \%$

$19.0 \%$

$335.7 \%$

$13.7 \%$

$11.0 \%$

$8.1 \%$

$11.4 \%$

$10.5 \%$

$11.0 \%$

$10.1 \%$

$8.1 \%$

$22.0 \%$

$10.5 \%$

$18.7 \%$

$2.6 \%$

$11.7 \%$
$59.3 \%$

$70.2 \%$

$218.1 \%$

$59.3 \%$

$211.6 \%$

$70.2 \%$

$262.5 \%$

$127.1 \%$

$40.5 \%$

$80.2 \%$

$300.9 \%$

$55.1 \%$

$70.6 \%$

$91.2 \%$

$159.2 \%$

$70.6 \%$

$146.2 \%$

$91.2 \%$

$253.4 \%$

$-350.7 \%$

$89.5 \%$

$73.6 \%$

$114.4 \%$

$1970.4 \%$

$101.9 \%$

$80.6 \%$

$114.4 \%$

$101.9 \%$

$100.0 \%$

$80.6 \%$

$242.9 \%$

$183.1 \%$

$24.8 \%$

$121.5 \%$
Cumulative Analysis

\begin{tabular}{lll} 
DB & Share of & Share of \\
Change & Transit & Distance Band \\
2010-2016 & Counties & Change \\
\hline
\end{tabular}

$0.08 \quad 8.1 \% \quad 59.3 \%$

$0.10 \quad 8.9 \% \quad 70.2 \%$

$0.30 \quad 27.5 \% \quad 218.1 \%$

$0.14 \quad 13.2 \%$

$0.08 \quad 8.1 \%$

0.29

0.10

0.36

0.14

0.18

0.06

0.11

0.42

0.08

0.14

$27.0 \%$

$8.9 \%$

$30.1 \%$

$13.2 \%$

$16.4 \%$

$5.4 \%$

$9.7 \%$

$48.2 \%$

$9.0 \%$

$13.2 \%$

$59.3 \%$

$211.6 \%$

$70.2 \%$

$262.5 \%$

$127.1 \%$

$40.5 \%$

$80.2 \%$

$300.9 \%$

$55.1 \%$

$-0.01-1.5 \% \quad-16.7 \%$

$\begin{array}{lll}-0.07 & -6.7 \% & -82.9 \%\end{array}$

$0.21 \quad 19.0 \% \quad 235.7 \%$

$0.09 \quad 8.4 \%$

$-0.01 \quad-1.5 \%$

0.08

$-0.07$

$7.6 \%$

$-6.7 \%$

$17.2 \%$

$8.4 \%$

0.09

0.01

$-0.05$

0.00

$0.8 \%$

$-4.6 \%$

$0.0 \%$

$88.1 \%$

0.21

$24.7 \%$

$-16.7 \%$

$93.5 \%$

$-82.9 \%$

$235.7 \%$

$9.5 \%$

$-54.0 \%$

$0.0 \%$

$862.8 \%$

$235.7 \%$

$-0.01$

$-0.8 \%$

$-9.2 \%$

$-0.07$

$-6.0 \%$

$-71.4 \%$

$0.18 \quad 16.5 \%$

$197.9 \%$

0.09

$8.7 \%$

$-0.8 \%$

0.05

$-0.07$

$4.6 \%$

$-9.2 \%$

$54.4 \%$

$-6.0 \%$

$15.0 \%$

$-71.4 \%$

$197.9 \%$

0.09

$8.7 \%$

0.01

$1.1 \%$

$-3.6 \%$

$13.4 \%$

$-40.6 \%$ 
Native American Alone All Other Races Alone TotalPopulation

$$
\begin{aligned}
& 0.86 \\
& 0.84
\end{aligned}
$$

1.05
0.10
-0.14

0.11

\begin{abstract}
$11.7 \%$
$-16.9 \%$

$10.5 \%$
\end{abstract}

$92.5 \%$
$-130.3 \%$
$0.0 \%$

$78.1 \%$

$21.5 \%$
$0.0 \%$

$737.4 \%$

$197.9 \%$

\section{Poor MA: CRT}

For White Non-Latino population at the Poor MA CRT stations,

- At the station, share increased modestly, representing $11.7 \%$ of the regional White population change and $44.6 \%$ of the change at the distance band, as a percentage of total population change at the station.

- At the quarter-mile DB, share decreased modestly, representing $48 \%$ of the DB change of total population at the station area. Cumulatively, the first quarter mile from the station saw a $43 \%$ decline of White Non-Latino population.

- At the half-mile $\mathrm{DB}$, this population increased at the increment of the $\mathrm{DB}$, but for the total half-mile radius around the station, the share dropped by $21 \%$.

For Hispanic population at the Poor MA CRT stations,

- At the station DB, station-area Hispanic population growth grew at roughly the same rate as the region. The Hispanic station population change increased $400 \%$ faster than the total population.

- At the quarter-mile DB, Hispanic population captured $24 \%$ of regional Hispanic growth. The Hispanic share of the station population change grew cumulatively by $258 \%$.

- At the half-mile DB, Hispanic growth captured $25 \%$ of regional Hispanic growth and grew at the station $75 \%$ faster than the station population as a whole.

For Black population at the Poor MA CRT stations,

- At the station, the share of regional Black population rose $4 \%$. Black population at the station grew $16 \%$ as fast as the total station population.

- At the quarter-mile DB, the cumulative rate of growth was $-10 \%$ for local share of regional Black population growth. At the same time that population grew at the station, Black population declined at $106 \%$.

- At the half-mile DB, incrementally growth was a strong $20 \%$ for regional share of Black population. Cumulatively, it represented $-4 \%$ of growth. At the station, Black share of the station population was $-65 \%$ of growth, which was positive for total population.

\section{Low MA: CRT}

For White Non-Latino population at the Low MA CRT stations,

- At the station, share increased modestly, representing $7 \%$ of the regional change and $86 \%$ of the change at the distance band, as a percentage of total population change at the station.

- At the quarter-mile $\mathrm{DB}$, share increased modestly, cumulatively representing 8 times the rate of $\mathrm{DB}$ change of total population at the station area.

- At the half-mile DB, this population increased share at less than $1 \%$ for the increment of the $\mathrm{DB}$, but for the total half-mile radius around the station, the share increased while the total population declined slightly.

For Hispanic population at the Low MA CRT stations,

- At the station DB, station share of regional Hispanic population change from the regional total increased $11 \%$. For the station area, Hispanic population grew $45 \%$ faster than the total population of the station. 
- At the quarter-mile DB, share of the station population change was fairly flat.

- At the half-mile DB, the cumulative change in Hispanic population was a $4 \%$ decline in regional share, and a decline at the station 3 times faster than the total population change.

For Black population at the Low MA CRT stations,

- At the station, population share rose $2 \%$, and the station area Black population one-third as fast as the total population of the station area.

- At the quarter-mile DB, incremental growth in share was at $5 \%$, but cumulatively the station share dropped $4 \%$ and the Black population share declined while the total population stayed flat.

- At the half-mile DB, the station lost $3 \%$ of Black population share, while the Black population declined 3 times as fast as the rest of the station population.

\section{Mod MA: CRT}

For White Non-Latino population,

- At the station, share of regional White population decreased modestly at $-4 \%$ of the regional change and $57 \%$ of the change at the distance band, as a percentage of total population change at the station, which declined slightly as a whole.

- At the half-mile DB, share increased $5 \%$ modestly, representing a positive rate of growth of the station total population DB change, which itself was in decline. This population declined at a slightly faster rate than the overall population of the station area.

For Hispanic population at the Mod MA CRT stations,

- At the station DB, share of station population change from the Hispanic population was $5 \%$ incrementally and $-9 \%$ cumulatively as share of regional Hispanic population.

- At the quarter-mile DB, regional capture was $-13 \%$, while share of the station population change grew cumulatively by $126 \%$.

- At the half-mile DB, regional capture was $-6 \%$. The share of the station Hispanic population change grew slightly faster than the whole population at the station.

For Black population,

- At the station, population share was $-2.3 \%$, while station population share changed at a rate $31 \%$ of the total population rate of growth.

- At the quarter-mile DB, Blacks captured $7 \%$ of regional Black growth, while Black population at the station grew at the same time the total population declined.

- At the half-mile DB, the station area captured $2 \%$ less of the regional population. The Black share of the station population grew at $6 \%$ while the total population declined by $10 \%$. 


\section{High MA: CRT}

For White Non-Latino population at the High MA CRT stations,

- At the station, share increased, representing $18 \%$ of the regional change and 4 times faster than the station total population.

- At the quarter-mile DB, share decreased incrementally by $15 \%$, but cumulatively grew at $10 \%$. Cumulatively, the White population grew modestly while the rest of the station population declined by $10 \%$

- At the half-mile DB, this population captured $11 \%$ share of regional White growth, but for the total half-mile radius around the station, the White population grew while the remainder slightly declined.

For Hispanic population at the High MA CRT stations,

- At the station DB, share of station population change declined in share by $20 \%$, and Hispanic share of station population declined while the total population grew.

- At the quarter-mile DB, share of the station population change declined by $19 \%$. Hispanic share declined twice as fast as the total population.

- At the half-mile DB, incremental growth was $16 \%$, while cumulatively it was $-9 \%$. Hispanic share dropped twice as fast as the decline in total population growth rate.

For Black population at the High MA CRT stations,

- At the station, population share rose $11 \%$, while Black population grew at the station 3 times faster than the total population.

- At the quarter-mile DB, the share dropped by $15 \%$ incrementally and grew $5 \%$ cumulatively, while the Black population grew at the station as the station population declined.

- At the half-mile DB, cumulative share fell by $4 \%$ but Black population declined at the same rate as the total population. 
Table 6.3 Poor MA:

CRT.

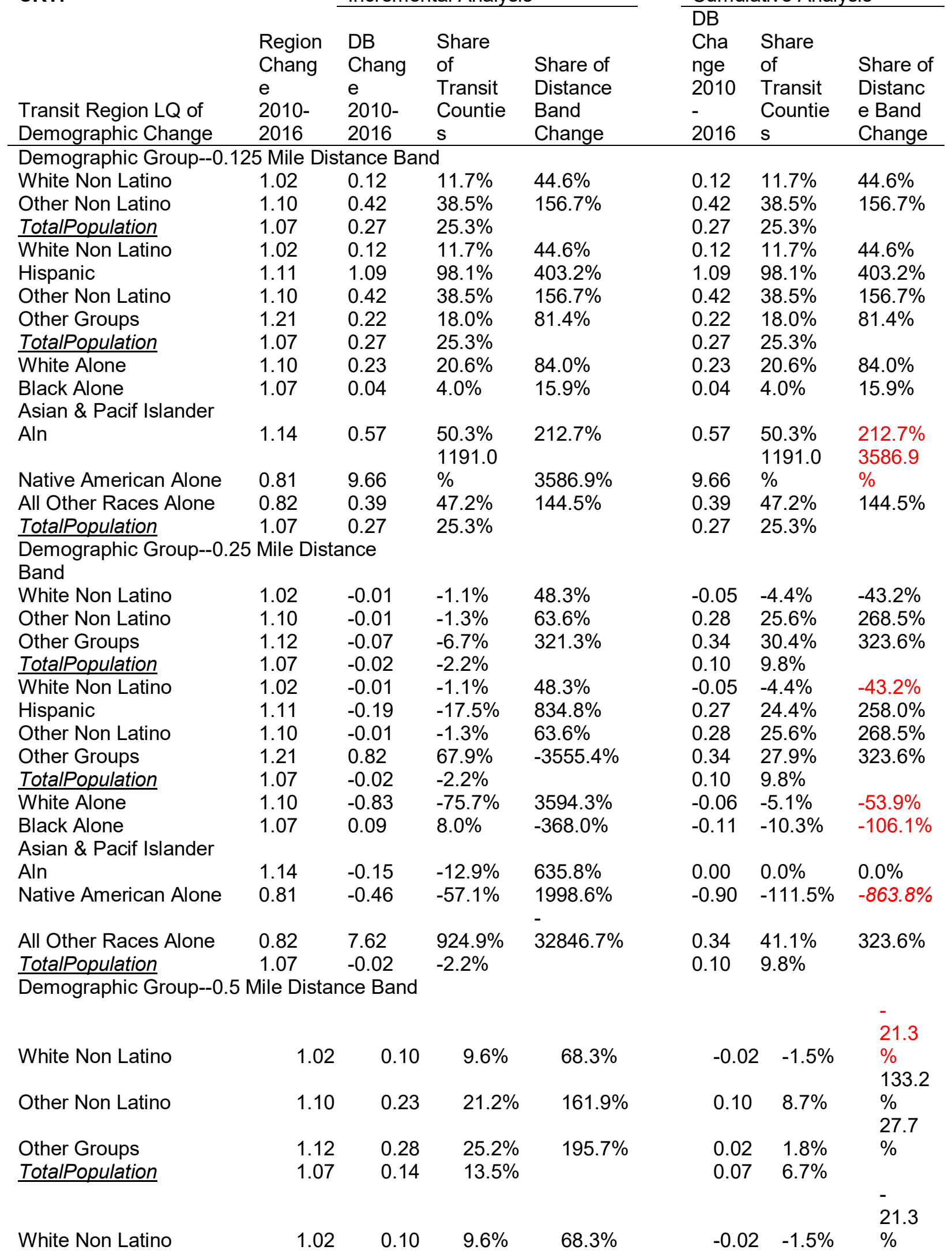




\begin{tabular}{|c|c|c|c|c|c|c|c|}
\hline Hispanic & 1.11 & 0.28 & $25.0 \%$ & $192.2 \%$ & 0.13 & $11.5 \%$ & $\begin{array}{l}176.6 \\
\% \\
133.2\end{array}$ \\
\hline Other Non Latino & 1.10 & 0.23 & $21.2 \%$ & $161.9 \%$ & 0.10 & $8.7 \%$ & $\begin{array}{l}\% \\
27.7\end{array}$ \\
\hline Other Groups & 1.21 & 0.32 & $26.4 \%$ & $222.7 \%$ & 0.02 & $1.6 \%$ & $\%$ \\
\hline TotalPopulation & 1.07 & 0.14 & $13.5 \%$ & & 0.07 & $6.7 \%$ & \\
\hline White Alone & 1.10 & 0.17 & $15.6 \%$ & $119.1 \%$ & -0.03 & $-2.8 \%$ & $\begin{array}{l}42.3 \\
\%\end{array}$ \\
\hline Black Alone & 1.07 & 0.22 & $20.2 \%$ & $150.6 \%$ & -0.05 & $-4.4 \%$ & $\begin{array}{l}65.2 \\
\%\end{array}$ \\
\hline Asian \& Pacif Islander Aln & 1.14 & 0.28 & $24.2 \%$ & $191.7 \%$ & 0.00 & $0.0 \%$ & $\begin{array}{l}0.0 \% \\
-\end{array}$ \\
\hline Native American Alone & 0.81 & -0.09 & $-10.5 \%$ & $-59.5 \%$ & -0.70 & $-86.2 \%$ & $\begin{array}{l}973.4 \\
\% \\
27.7\end{array}$ \\
\hline All Other Races Alone & 0.82 & -0.24 & $-28.7 \%$ & $-164.5 \%$ & 0.02 & $2.4 \%$ & $\%$ \\
\hline TotalPopulation & 1.07 & 0.14 & $13.5 \%$ & & 0.07 & $6.7 \%$ & \\
\hline
\end{tabular}

Table 6.4 High MA:

\begin{tabular}{|c|c|c|c|c|c|c|c|}
\hline \multirow[t]{2}{*}{ CRT } & \multicolumn{4}{|c|}{ Incremental Analysis } & \multicolumn{3}{|c|}{ Cumulative Analysis } \\
\hline & $\begin{array}{l}\text { Region } \\
\text { Change }\end{array}$ & $\begin{array}{l}\text { DB } \\
\text { Change }\end{array}$ & $\begin{array}{l}\text { Share } \\
\text { of } \\
\text { Transit }\end{array}$ & $\begin{array}{l}\text { Share } \\
\text { of } \\
\text { Distanc }\end{array}$ & $\begin{array}{l}\text { DB } \\
\text { Chang } \\
\text { e }\end{array}$ & $\begin{array}{l}\text { Share } \\
\text { of } \\
\text { Transit }\end{array}$ & $\begin{array}{l}\text { Share } \\
\text { of } \\
\text { Distanc }\end{array}$ \\
\hline $\begin{array}{l}\text { Transit Region LQ of } \\
\text { Demographic Change }\end{array}$ & $\begin{array}{l}2010- \\
2016\end{array}$ & $\begin{array}{l}2010- \\
2016\end{array}$ & $\begin{array}{l}\text { Countie } \\
\mathrm{s}\end{array}$ & $\begin{array}{l}\text { e Band } \\
\text { Change }\end{array}$ & $\begin{array}{l}2010- \\
2016\end{array}$ & $\begin{array}{l}\text { Countie } \\
\mathrm{s}\end{array}$ & $\begin{array}{l}\text { e Band } \\
\text { Change }\end{array}$ \\
\hline \multicolumn{8}{|c|}{$\begin{array}{l}\text { Demographic Group--0.125 Mile Distance Band } \\
\text { Only }\end{array}$} \\
\hline White Non Latino & 1.02 & 0.18 & $18 \%$ & $459 \%$ & 0.18 & $18 \%$ & $459 \%$ \\
\hline Other Non Latino & 1.20 & 0.16 & $13 \%$ & $392 \%$ & 0.16 & $13 \%$ & $392 \%$ \\
\hline TotalPopulation & 1.07 & 0.04 & $4 \%$ & & 0.04 & $4 \%$ & \\
\hline White Non Latino & 1.02 & 0.18 & $18 \%$ & $459 \%$ & 0.18 & $18 \%$ & $459 \%$ \\
\hline Hispanic & 1.11 & -0.22 & $-20 \%$ & $-569 \%$ & -0.22 & $-20 \%$ & $-569 \%$ \\
\hline Other Non Latino & 1.20 & 0.16 & $13 \%$ & $392 \%$ & 0.16 & $13 \%$ & $392 \%$ \\
\hline Other Groups & 0.25 & -0.07 & $-28 \%$ & $-172 \%$ & -0.07 & $-28 \%$ & $-172 \%$ \\
\hline TotalPopulation & 1.07 & 0.04 & $4 \%$ & & 0.04 & $4 \%$ & \\
\hline White Alone & 1.07 & 0.06 & $5 \%$ & $142 \%$ & 0.06 & $5 \%$ & $142 \%$ \\
\hline $\begin{array}{l}\text { Black Alone } \\
\text { Asian \& Pacif Islander }\end{array}$ & \multicolumn{6}{|c|}{ Asian \& Pacif Islander } & $290 \%$ \\
\hline Aln & 1.18 & 0.22 & $18 \%$ & $551 \%$ & 0.22 & $18 \%$ & $551 \%$ \\
\hline Native American Alone & 0.68 & -0.63 & $-93 \%$ & $-1593 \%$ & -0.63 & $-93 \%$ & $-1593 \%$ \\
\hline All Other Races Alone & 0.98 & -0.10 & $-10 \%$ & $-244 \%$ & -0.10 & $-10 \%$ & $-244 \%$ \\
\hline TotalPopulation & 1.07 & 0.04 & $4 \%$ & & 0.04 & $4 \%$ & \\
\hline \multicolumn{8}{|c|}{$\begin{array}{l}\text { Demographic Group--0.25 Mile Distance Band } \\
\text { Only }\end{array}$} \\
\hline White Non Latino & 1.02 & -0.15 & $-15 \%$ & $105 \%$ & 0.10 & $10 \%$ & $-107 \%$ \\
\hline Other Non Latino & 1.20 & -0.06 & $-5 \%$ & $44 \%$ & 1.87 & $156 \%$ & $-1920 \%$ \\
\hline TotalPopulation & 1.07 & -0.15 & $-14 \%$ & & -0.10 & $-9 \%$ & \\
\hline White Non Latino & 1.02 & -0.15 & $-15 \%$ & $105 \%$ & 0.10 & $10 \%$ & $-107 \%$ \\
\hline Hispanic & 1.11 & -0.19 & $-17 \%$ & $130 \%$ & -0.21 & $-19 \%$ & $216 \%$ \\
\hline Other Non Latino & 1.20 & -0.06 & $-5 \%$ & $44 \%$ & 1.87 & $156 \%$ & $-1920 \%$ \\
\hline Other Groups & 0.25 & -0.20 & $-83 \%$ & $138 \%$ & -0.17 & $-70 \%$ & $178 \%$ \\
\hline TotalPopulation & 1.07 & -0.15 & $-14 \%$ & & -0.10 & $-9 \%$ & \\
\hline White Alone & 1.07 & -0.61 & $-57 \%$ & $410 \%$ & 0.05 & $4 \%$ & $-47 \%$ \\
\hline
\end{tabular}




\begin{tabular}{llllllll} 
Black Alone & 1.08 & -0.17 & $-15 \%$ & $112 \%$ & 0.06 & $5 \%$ & $-59 \%$ \\
Asian \& Pacif Islander & & & & & & & \\
Aln & 1.18 & 0.17 & $15 \%$ & $-118 \%$ & 0.00 & $0 \%$ & $0 \%$ \\
Native American Alone & 0.68 & -0.67 & $-98 \%$ & $452 \%$ & -0.67 & $-99 \%$ & $688 \%$ \\
All Other Races Alone & 0.98 & 1.19 & $121 \%$ & $-801 \%$ & -0.17 & $-18 \%$ & $178 \%$ \\
TotalPopulation & 1.07 & -0.15 & $-14 \%$ & & -0.10 & $-9 \%$ & \\
\hline $\begin{array}{l}\text { Demographic Group--0.5 Mile Distance Band } \\
\text { Only }\end{array}$ & & & & & & \\
White Non Latino & 1.02 & 0.11 & $11 \%$ & $126 \%$ & 0.06 & $6 \%$ & $-168 \%$ \\
Other Non Latino & 1.20 & -0.05 & $-4 \%$ & $-52 \%$ & 1.37 & $114 \%$ & $-3551 \%$ \\
TotalPopulation & 1.07 & 0.09 & $8 \%$ & & -0.04 & $-4 \%$ & $-168 \%$ \\
White Non Latino & 1.02 & 0.11 & $11 \%$ & $126 \%$ & 0.06 & $6 \%$ & $265 \%$ \\
Hispanic & 1.11 & 0.18 & $16 \%$ & $201 \%$ & -0.10 & $-9 \%$ & $-3551 \%$ \\
Other Non Latino & 1.20 & -0.05 & $-4 \%$ & $-52 \%$ & 1.37 & $114 \%$ & $-37 \%$ \\
Other Groups & 0.25 & 0.10 & $40 \%$ & $112 \%$ & -0.19 & $-77 \%$ & $490 \%$ \\
TotalPopulation & 1.07 & 0.09 & $8 \%$ & & -0.04 & $-4 \%$ & \\
$\begin{array}{l}\text { White Alone } \\
\text { Black Alone }\end{array}$ & 1.07 & 0.33 & $31 \%$ & $374 \%$ & 0.08 & $8 \%$ & $-208 \%$ \\
Asian \& Pacific Islander & 1.08 & -0.16 & $-15 \%$ & $-178 \%$ & -0.04 & $-4 \%$ & $104 \%$ \\
Aln & 1.18 & 0.12 & $11 \%$ & $141 \%$ & 0.00 & $0 \%$ & $0 \%$ \\
Native American Alone & 0.68 & -0.73 & $-107 \%$ & $-821 \%$ & -0.55 & $-81 \%$ & $1436 \%$ \\
All Other Races Alone & 0.98 & -0.32 & $-33 \%$ & $-367 \%$ & -0.19 & $-19 \%$ & $490 \%$ \\
TotalPopulation & 1.07 & 0.09 & $8 \%$ & & -0.04 & $-4 \%$ &
\end{tabular}




\section{Poor MA: LRT}

For White Non-Latino population at the Poor MA LRT stations,

- At the station, share decreased somewhat, at $-1 \%$ of the regional change and lost share of the change at the distance band, as a $-107 \%$ percentage of total population change at the station.

- At the quarter-mile DB, share decreased modestly, representing $-2 \%$ of the DB change of total population at the station area.

- At the half-mile DB, the station area White population grew at $4 \%$ while the total population declined by $6 \%$. This represents a small percentage of the regional White population growth

For Hispanic population at the Poor MA LRT stations,

- At the station DB, station capture of regional population was $11 \%$. Station share of total population change was many times faster than the total population trend.

- At the quarter-mile DB, share of the station population change grew incrementally at $13 \%$, and many times faster than the total population growth trend at the station. Cumulatively, the trend was positive while the total population declined.

- At the half-mile DB, the overall trend declined slightly, but at a slower rate than the total population.

For Black Alone population at the Poor MA LRT stations,

- At the station, Black population lost share of regional Black growth, at $-9 \%$ while also declining at the station during an overall growth trend.

- At the quarter-mile DB, Black population declined at the station slightly faster than the overall decline trend, while total population grew $9 \%$.

- At the half-mile DB, this trend continued. Cumulative share was $-9 \%$, while station rate of decline was $76 \%$ faster than total population decline.

\section{Low MA: LRT}

For White Non-Latino population at the Low MA LRT stations,

- At the station, share grew at $7 \%$ of the regional change and station share of the change grew at a $110 \%$ rate.

- At the quarter-mile DB, share of regional White population was $4 \%$ cumulatively, and station share grew faster than the total population.

- At the half-mile DB, the regional share captured at the station was $4.5 \%$, and the station area White population grew while the remaining segments declined in growth rates.

For Hispanic population at the Low MA LRT stations,

- At the station DB, share of regional Hispanic population change was $7 \%$, but Hispanic share of station growth was $30 \%$ as fast as total population growth.

- At the quarter-mile DB, capture of regional share dropped slightly, and share of the station population change declined twice as fast as the total population.

- At the half-mile DB, share of regional growth dropped $6 \%$ but cumulatively declined 4 times faster than the total station population.

For Black population at the Low MA LRT stations,

- At the station, share of regional Black population declined 3\%. Station area Black population declined slightly, while total population grew $6 \%$.

- At the quarter-mile DB, black population capture of regional population dropped $8 \%$. Black population declined $9 \%$ while the remainder of the total population stayed stable. 
- At the half-mile DB, station capture of the regional Black population declined $9 \%$ while the Black population declined 6 times faster than the rest of the station population.

\section{Mod MA: LRT}

For White Non-Latino population at the Mod MA LRT stations,

- At the station, share increased modestly, representing $8 \%$ of the regional change and $87 \%$ of the change at the distance band, as a percentage of total population change at the station.

- At the quarter-mile DB, share also increased modestly, cumulatively representing $3 \%$ of the regional growth. Cumulative growth at the station was about as fast as the total station growth.

- At the half-mile $\mathrm{DB}$, this population increased at $6 \%$ for the increment of the $\mathrm{DB}$, but for the total half-mile radius around the station, the White population grew $45 \%$ faster than the total population.

For Hispanic population at the Mod MA LRT stations,

- At the station DB, share of station population change from the Hispanic population was at $7 \%$. It grew $80 \%$ as fast as the station total population.

- At the quarter-mile DB, share of the regional Hispanic population change grew incrementally at $6 \%$ but declined cumulatively by $5 \%$. Hispanics declined at $5 \%$ while the station population as a whole grew by $3 \%$.

- At the half-mile DB, capture of the regional Hispanic population was cumulatively $-4 \%$. It declined $5 \%$ while the station population total grew by $2 \%$.

For Black Alone population at the Mod MA LRT stations,

- At the station, population share gained $5 \%$. Station share grew $60 \%$ as fast as the total population.

- At the quarter-mile DB, Black population shares of regional and station areas slightly declined.

- At the half-mile DB, this trend continued. 


\section{High MA: LRT}

For White Non-Latino population:

- At the station, share increased at $9 \%$ of the regional change and $112 \%$ of the change at the distance band, as a percentage of total population change at the station.

- At the quarter-mile DB, share decreased 4\% cumulatively, the White Non-Latino population gaining $4 \%$ while the total population stayed flat in growth.

- At the half-mile DB, this population increased $11 \%$ at the increment of the DB, but for the total half-mile radius around the station, the share increased by $5 \%$. It grew at $5 \%$ at the station, while the total saw no growth.

For Hispanic population at High MA LRT stations:

- At the station DB, share of regional Hispanic population was captured at the rate of $4 \%$. The Hispanic portion of station increased half as fast as the total population.

- At the quarter-mile DB, share of the station population change grew incrementally but declined cumulatively by $5 \%$.

- At the half-mile DB, population declined at the cumulative level, in terms of both regional percent of Hispanic population and station-area population.

For Black population:

- At the station, share of regional Black population rose $5 \%$, while it grew at $63 \%$ of the total population's rate of growth at the station.

- At the quarter-mile DB, it declined while the total population grew.

- At the half-mile DB, share of regional Black population incrementally grew at $14 \%$, while it cumulatively declined $4 \%$. Station growth declined $5 \%$ while the whole of the population stayed flat. 
Table 6.5 Poor MA:

LRT

\begin{tabular}{|c|c|c|c|c|c|c|c|}
\hline & \multirow[b]{2}{*}{$\begin{array}{l}\text { Region } \\
\text { Chang } \\
\text { e } \\
2010- \\
2016 \\
\end{array}$} & & \\
\hline & & $\begin{array}{l}\text { DB } \\
\text { Chang } \\
\text { e } \\
2010- \\
2016 \\
\end{array}$ & $\begin{array}{l}\text { Share } \\
\text { of } \\
\text { Transit } \\
\text { Countie } \\
\text { s }\end{array}$ & $\begin{array}{l}\text { Share of } \\
\text { Distance } \\
\text { Band } \\
\text { Change }\end{array}$ & $\begin{array}{l}\text { Chang } \\
\text { e } \\
2010- \\
2016 \\
\end{array}$ & $\begin{array}{l}\text { Share } \\
\text { of } \\
\text { Transit } \\
\text { Countie } \\
\mathrm{s}\end{array}$ & $\begin{array}{l}\text { Share of } \\
\text { Distance } \\
\text { Band } \\
\text { Change }\end{array}$ \\
\hline \multicolumn{8}{|c|}{ Demographic Group--0.125 Mile Distance Band Only } \\
\hline White Non Latino & 1.02 & -0.01 & $-0.8 \%$ & $-107.2 \%$ & -0.01 & $-0.8 \%$ & $-107.2 \%$ \\
\hline Other Non Latino & 1.10 & -0.04 & $-3.3 \%$ & $-489.9 \%$ & -0.04 & $-3.3 \%$ & $-489.9 \%$ \\
\hline TotalPopulation & 1.06 & 0.01 & $0.7 \%$ & & 0.01 & $0.7 \%$ & \\
\hline White Non Latino & 1.02 & -0.01 & $-0.8 \%$ & $-107.2 \%$ & -0.01 & $-0.8 \%$ & $-107.2 \%$ \\
\hline Hispanic & 1.10 & 0.12 & $10.8 \%$ & $1591.2 \%$ & 0.12 & $10.8 \%$ & $1591.2 \%$ \\
\hline Other Non Latino & 1.10 & -0.04 & $-3.3 \%$ & $-489.9 \%$ & -0.04 & $-3.3 \%$ & $-489.9 \%$ \\
\hline Other Groups & 1.24 & 0.24 & $19.5 \%$ & $3233.5 \%$ & 0.24 & $19.5 \%$ & $3233.5 \%$ \\
\hline TotalPopulation & 1.06 & 0.01 & $0.7 \%$ & & 0.01 & $0.7 \%$ & \\
\hline White Alone & 1.11 & 0.04 & $3.7 \%$ & $549.1 \%$ & 0.04 & $3.7 \%$ & $\begin{array}{l}549.1 \% \\
-\end{array}$ \\
\hline $\begin{array}{l}\text { Black Alone } \\
\text { Asian \& Pacif Islander }\end{array}$ & 1.06 & -0.09 & $-8.9 \%$ & $-1253.0 \%$ & -0.09 & $-8.9 \%$ & $1253.0 \%$ \\
\hline Aln & 1.16 & 0.09 & $7.6 \%$ & $1174.2 \%$ & 0.09 & $7.6 \%$ & $1174.2 \%$ \\
\hline Native American Alone & 0.83 & 0.05 & $6.4 \%$ & $713.0 \%$ & 0.05 & $6.4 \%$ & $\begin{array}{l}713.0 \% \\
-\end{array}$ \\
\hline All Other Races Alone & 0.76 & -0.18 & $-22.9 \%$ & $-2339.7 \%$ & -0.18 & $-22.9 \%$ & $2339.7 \%$ \\
\hline TotalPopulation & 1.06 & 0.01 & $0.7 \%$ & & 0.01 & $0.7 \%$ & \\
\hline \multicolumn{8}{|c|}{ Demographic Group--0.25 Mile Distance Band Only } \\
\hline White Non Latino & 1.02 & -0.02 & $-2.4 \%$ & $-156.5 \%$ & 0.01 & $1.3 \%$ & $\begin{array}{l}-27.7 \% \\
-\end{array}$ \\
\hline Other Non Latino & 1.10 & 0.00 & $-0.4 \%$ & $-28.6 \%$ & 0.92 & $83.9 \%$ & $1986.7 \%$ \\
\hline TotalPopulation & 1.06 & 0.02 & $1.5 \%$ & & -0.05 & $-4.4 \%$ & \\
\hline White Non Latino & 1.02 & -0.02 & $-2.4 \%$ & $-156.5 \%$ & 0.01 & $1.3 \%$ & $-27.7 \%$ \\
\hline Hispanic & 1.10 & 0.15 & $13.3 \%$ & $937.8 \%$ & 0.08 & $7.0 \%$ & $\begin{array}{l}-166.8 \% \\
-\end{array}$ \\
\hline Other Non Latino & 1.10 & 0.00 & $-0.4 \%$ & $-28.6 \%$ & 0.92 & $83.9 \%$ & $1986.7 \%$ \\
\hline Other Groups & 1.24 & 0.44 & $35.3 \%$ & $2806.9 \%$ & 0.15 & $11.8 \%$ & $-314.9 \%$ \\
\hline TotalPopulation & 1.06 & 0.02 & $1.5 \%$ & & -0.05 & $-4.4 \%$ & \\
\hline White Alone & 1.11 & -0.77 & $-69.5 \%$ & $-4922.8 \%$ & -0.02 & $-1.7 \%$ & $39.6 \%$ \\
\hline $\begin{array}{l}\text { Black Alone } \\
\text { Asian \& Pacif Islander }\end{array}$ & 1.06 & -0.03 & $-2.6 \%$ & $-173.8 \%$ & -0.08 & $-7.8 \%$ & $177.4 \%$ \\
\hline Aln & 1.16 & 0.04 & $3.3 \%$ & $248.1 \%$ & 0.00 & $0.0 \%$ & $0.0 \%$ \\
\hline Native American Alone & 0.83 & -0.36 & $-42.8 \%$ & $\begin{array}{l}-2285 \% \\
40120.8\end{array}$ & 1.02 & $123.0 \%$ & $-2207 \%$ \\
\hline All Other Races Alone & 0.76 & 6.26 & $819.7 \%$ & $\%$ & 0.15 & $19.1 \%$ & $-314.9 \%$ \\
\hline TotalPopulation & 1.06 & 0.02 & $1.5 \%$ & & -0.05 & $-4.4 \%$ & \\
\hline \multicolumn{8}{|c|}{ Demographic Group--0.5 Mile Distance Band Only } \\
\hline White Non Latino & 1.02 & 0.00 & $0.1 \%$ & $-2.5 \%$ & 0.04 & $3.5 \%$ & $-62.4 \%$ \\
\hline Other Non Latino & 1.10 & -0.14 & $-13.1 \%$ & $274.7 \%$ & 0.10 & $8.8 \%$ & $-170.0 \%$ \\
\hline TotalPopulation & 1.06 & -0.05 & $-4.9 \%$ & & -0.06 & $-5.4 \%$ & \\
\hline White Non Latino & 1.02 & 0.00 & $0.1 \%$ & $-2.5 \%$ & 0.04 & $3.5 \%$ & $-62.4 \%$ \\
\hline Hispanic & 1.10 & -0.21 & $-19.0 \%$ & $399.0 \%$ & -0.01 & $-0.7 \%$ & $13.2 \%$ \\
\hline Other Non Latino & 1.10 & -0.14 & $-13.1 \%$ & $274.7 \%$ & 0.10 & $8.8 \%$ & $-170.0 \%$ \\
\hline Other Groups & 1.24 & 0.15 & $12.2 \%$ & $-290.8 \%$ & 0.07 & $5.4 \%$ & $-117.1 \%$ \\
\hline TotalPopulation & 1.06 & -0.05 & $-4.9 \%$ & & -0.06 & $-5.4 \%$ & \\
\hline White Alone & 1.11 & 0.00 & $0.3 \%$ & $-5.8 \%$ & -0.01 & $-1.1 \%$ & $21.4 \%$ \\
\hline Black Alone & 1.06 & -0.24 & $-22.3 \%$ & $452.4 \%$ & -0.10 & $-9.5 \%$ & $176.7 \%$ \\
\hline
\end{tabular}


Asian \& Pacif Islander

Aln

Native American Alone

All Other Races Alone

TotalPopulation

$\begin{array}{lllllll}1.16 & -0.03 & -2.7 \% & 59.9 \% & 0.00 & 0.0 \% & 0.0 \% \\ 0.83 & -0.52 & -62.4 \% & 993.6 \% & 0.41 & 49.2 \% & -720.0 \% \\ 0.76 & -0.24 & -31.8 \% & 464.5 \% & 0.07 & 8.7 \% & -117.1 \% \\ 1.06 & -0.05 & -4.9 \% & & -0.06 & -5.4 \% & \end{array}$


Table 6.6 Mod MA: LRT.

\begin{tabular}{|c|c|c|c|c|c|c|}
\hline \multirow{6}{*}{$\begin{array}{l}\text { Region } \\
\text { Chang } \\
\text { e } \\
2010- \\
2016\end{array}$} & \multicolumn{3}{|c|}{ Incremental Analysis } & \multicolumn{3}{|c|}{ Cumulative Analysis } \\
\hline & DB & Share & Share & $\mathrm{DB}$ & Share & Share \\
\hline & Chang & & & $\mathrm{Cr}$ & & \\
\hline & & $\operatorname{Tr}$ & $\mathrm{Di}$ & & Trá & Dis \\
\hline & 2010- & Cour & e Band & 2010- & Cou & e Band \\
\hline & 2016 & $\mathrm{~s}$ & Chan & 2016 & $\mathrm{~s}$ & Cha \\
\hline
\end{tabular}

Transit Region LQ of

Distance Band Only

Demographic Group--0.125 Mile

White Non Latino

$\begin{array}{lll}1.02 & 0.08 \quad 7.9 \%\end{array}$

Other Non Latino

$1.10 \quad 0.11$

TotalPopulation

1.06

0.09

$9.8 \%$

$86.8 \%$

0.08

$7.9 \%$

$86.8 \%$

White Non Latino

1.02

$8.7 \%$

Hispanic

1.10

0.08

$7.9 \%$

$116.0 \%$

0.11

$9.8 \%$

0.09

$8.7 \%$

Other Non Latino

$7.1 \%$

$86.8 \%$

0.08

$7.9 \%$

$116.0 \%$

Other Groups

$1.10 \quad 0.11$

$1.24 \quad 0.28$

TotalPopulation

1.06

$9.8 \%$

$84.4 \%$

0.08

$7.1 \%$

$86.8 \%$

White Alone

1.11

0.09

0.11

$9.8 \%$

$84.4 \%$

Black Alone

1.06

0.18

$8.7 \%$

$299.4 \%$

0.28

$22.3 \%$

0.09

$8.7 \%$

$16.6 \% \quad 197.9 \%$

0.18

$16.6 \%$

0.05

$5.1 \%$

$116.0 \%$

Asian and Pacific Islander

Alone

1.16

0.19

$5.1 \%$

$58.0 \%$

0.19

$16.3 \%$

$299.4 \%$

Native American Alone

$0.83-0.21$

$16.3 \% \quad 203.6 \%$

0.19

$16.3 \%$

$197.9 \%$

All Other Races Alone

TotalPopulation

0.76

$-0.24$

$-25.2 \%$

$226.2 \%$

$-0.21$

$-25.2 \%$

$203.6 \%$

Demographic Group--0.25 Mile Distance Band

Only

White Non Latino

Other Non Latino

1.02

0.12

1.10

0.08

1.06

0.10

TotalPopulation

1.02

0.12

$-31.0 \% \quad 255.5 \%$

$8.7 \%$

$-0.24$

0.09

$-31.0 \%$

$8.7 \%$

$226.2 \%$

White Non Latino

$1.10 \quad 0.06$

Hispanic

1.10

0.08

1.24

0.36

Other Groups

TotalPopulation

1.06

0.10

$11.9 \% \quad 125.8 \%$

0.03

0.12

$3.3 \%$

$7.1 \%$

$80.3 \%$

0.03

$10.7 \%$

$9.1 \%$

$11.9 \%$

$125.8 \%$

0.03

$3.1 \%$

$3.3 \%$

$5.9 \% \quad 66.6 \%$

$-0.05$

$-4.8 \%$

$0.12 \quad 10.7 \%$

$7.1 \%$

$80.3 \%$

$28.7 \% \quad 367.9 \%$

$-0.03$

$-2.6 \%$

0.03

$3.1 \%$

$255.5 \%$

White Alone

$1.11-0.35$

$-31.7 \% \quad 361.7 \%$

0.05

$4.4 \%$

$149.0 \%$

Black Alone

Asian and Pacific Islander

$1.06 \quad 0.04$

$3.6 \% \quad 39.9 \%$

$-0.04$

$-3.8 \%$

$122.0 \%$

Alone

$1.16 \quad 0.11$

$9.2 \% \quad 110.8 \%$

0.00

$0.0 \%$

$0.0 \%$

Native American Alone

$0.83-0.27$

$-32.8 \%$

$282.5 \%$

$0.01 \quad 1.0 \%$

$24.3 \%$

All Other Races Alone

$0.76 \quad 1.45$ 1503.1

TotalPopulation

$1.06 \quad 0.10$

$190.2 \% \quad \%$

$-0.03-4.2 \%$

$-98.8 \%$

Demographic Group--0.5 Mile Distance Band

Only

White Non Latino

$1.02 \quad 0.06$

$\begin{array}{ll}1.10 & 0.07\end{array}$

$9.1 \%$

0.03

$3.1 \%$

$6.0 \% \quad 87.9 \%$

0.03

$3.2 \%$

$0.2 \%$

$6.6 \%$

$97.6 \%$

0.00

$2.1 \%$

$1.02 \quad 0.06$

$6.0 \%$

$87.9 \%$

0.02

$3.2 \%$

$145.8 \%$

$8.1 \%$

White Non Latino

$\begin{array}{ll}1.10 \quad 0.07 \\ 1.10 & 0.07\end{array}$

1.10

$6.6 \%$

$6.2 \%$

$102.9 \%$

$97.6 \%$

0.03

$145.8 \%$

Hispanic

1.24

0.19

$15.7 \%$

$-0.05$

0.00

$-4.2 \%$

$0.2 \%$

$205.7 \%$

$277.0 \%$

0.02

$1.4 \%$

$8.1 \%$

$78.1 \%$ 


$\begin{array}{lccccccc}\text { TotalPopulation } & 1.06 & 0.07 & 6.6 \% & & 0.02 & 2.1 \% & \\ \text { White Alone } & 1.11 & 0.18 & 16.3 \% & 256.6 \% & 0.05 & 4.5 \% & 223.8 \% \\ \begin{array}{l}\text { Black Alone } \\ \text { Asian and Pacific Islander }\end{array} & 1.06 & 0.03 & 3.2 \% & 47.7 \% & -0.04 & -3.7 \% & 177.3 \% \\ \text { Alone } & 1.16 & 0.11 & 9.7 \% & 160.1 \% & 0.00 & 0.0 \% & 0.0 \% \\ & & & & - & & & \\ \text { Native American Alone } & 0.83 & -0.32 & -38.6 \% & 457.5 \% & 0.13 & 15.8 \% & 592.3 \% \\ \text { All Other Races Alone } & 0.76 & -0.23 & -30.2 \% & -328.7 \% & 0.02 & 2.3 \% & 78.1 \% \\ \text { TotalPopulation } & 1.06 & 0.07 & 6.6 \% & & 0.02 & 2.1 \% & \end{array}$

\section{Poor MA: SCT}

For White Non-Latino population at the Poor MA SCT stations,

- At the station, the Poor MA place type was not found.

- At the quarter-mile DB, station capture of regional share decreased modestly, representing $-6 \%$ of regional White population change.

- At the half-mile DB, this population capture $15 \%$ of growth at the increment of the DB, but for the total half-mile radius around the station, the share increased by $2 \%$.

For Hispanic population at the Poor MA SCT stations,

- At the station, the Poor MA place type was not found.

- At the quarter-mile DB, share of the station population change grew $22 \%$. It grew at the station while the whole station population declined $8 \%$.

- At the half-mile DB, cumulative growth was $13 \%$ of regional Hispanic population. The station area Hispanic population grew while the rest of the station population declined $16 \%$.

For Black Alone population at the Poor MA SCT stations,

- At the station, the Poor MA place type was not found.

- At the quarter-mile DB, the capture rate declined significantly at $-35 \%$. Cumulatively, Black population declined 4 times faster than total population at the station.

- At the half-mile DB, incremental growth of station capture was $18.5 \%$ of regional growth. Cumulatively, it was $-9.6 \%$ of that growth. Black share of station population growth was $60 \%$ as fast a decline as that of the whole station population.

\section{Low MA: SCT}

For White Non-Latino population at the Low MA SCT stations,

- At the station, share increased at a capture rate of $15 \%$ of the regional change and grew at twice the rate of total population change at the station.

- At the half-mile DB, this population increased at the increment of the DB, but for the total half-mile radius around the station, the share dropped $40 \%$ faster than the whole population.

For Hispanic population at the Low MA SCT stations, 
- At the station DB, share of station population change from the Hispanic population at $8 \%$. The station population declined faster than the whole population at the same location.

- At the half-mile DB, the Hispanic population declined in regional share at $7 \%$. The station population declined faster than the whole population at the same location. The station area population grew at $7 \%$ while Hispanic declined at $8 \%$.

For Black population at the Low MA SCT stations,

- At the station, station share of regional Black population declined at $8 \%$.

- At a quarter-mile from the station, the trend was approximately the same as the station area.

- At the half-mile DB, cumulative share at the station of the regional Black population declined by $9 \%$. The cumulative share of Black population declined faster than the whole of the population at the transit station.

\section{Mod MA: SCT}

For White Non-Latino population at the Mod MA SCT stations,

- At the station, share increased modestly, representing $4.7 \%$ of the regional change and growing at $5 \%$ of the change at the distance band, as a percentage of total population change at the station, which declined for the whole population.

- At the quarter-mile DB, share of regional White population gained $12 \%$ while the total population declined at the station.

- At the half-mile DB, this population increased at the increment of the $\mathrm{DB}$, but for the total half-mile radius around the station, the share rose by $21 \%$ while total population declined at the station by $3 \%$.

For Hispanic population at the Mod MA SCT stations,

- At the station DB, station share of regional Hispanic population change increased $3 \%$. At the station, Hispanic share grew while the total population declined in growth by $4 \%$.

- At the quarter-mile DB, cumulative station share of the regional Hispanic station population change grew incrementally by $8 \%$ as fast as the total station population, with roughly the same rate of growth in the Hispanic station population and the whole station population.

- At the half-mile DB, the population change was flat, with Hispanic growth remaining steady while the whole of the population declined somewhat in growth rate.

For Black population at the Mod MA SCT stations,

- At the station, share of regional Black population share declined significantly as a share of regional Black population, $-5 \%$. It declined 6 times faster than the total station population change.

- At the quarter-mile DB, cumulative figures showed a $19 \%$ loss of regional share, with losses occurring 3 times faster than the station population totals.

- At the half-mile DB, cumulative figures show a loss of regional share of growth at $16 \%$. Black population continued to decline at 5 times the rate of the whole of the population at the station. 
High MA: SCT

For White Non-Latino population:

- At the station, share increased moderately at $17.7 \%$ of the regional White population change and $103 \%$ of the change at the distance band, as a percentage of total population change at the station.

- At the quarter-mile DB, incremental share increased moderately, representing $12 \%$ of the DB change of total population at the station area. Cumulatively, the first quarter mile from the station saw a $5 \%$ gain of White Non-Latino population. White population at the station grew $65 \%$ as fast as the total population.

- At the half-mile DB, the cumulative rate of growth was $3 \%$ of the regional growth. Station White population grew a third as fast as the total population.

For Hispanic population:

- At the station $\mathrm{DB}$, share of station population change from the Hispanic population at a resounding rate of $46 \%$ incrementally, while the Hispanic population grew nearly 3 times faster than the total station population.

- At the quarter-mile DB, share of the station population change grew cumulatively by $8 \%$. Station Hispanic population grew at $112 \%$ of the growth of the station total population.

- At the half-mile DB, incremental rate of growth was a resounding rate of $67 \%$. Cumulative growth was $8 \%$ and station-level growth was roughly equal between Hispanic and total population.

For Black Alone population:

- At the station, population share declined $5 \%$ and station-level growth of the Hispanic population declined at a ratio of -0.05 while the total population grew at 0.18 .

- At the quarter-mile DB, cumulative growth was at $18 \%$ while Hispanic population declined at $5 \%$ while the main population had an overall positive rate of growth.

- At the half-mile DB, the rate of regional capture was $7 \%$ incrementally, but declined $13 \%$ as a cumulative figure. Black population declined while the total population grew in this period. 
Table 6.7 Low MA: SCT.

\begin{tabular}{|c|c|c|c|c|c|c|c|}
\hline & & \\
\hline $\begin{array}{l}\text { Transit Region LQ of } \\
\text { Demographic Change }\end{array}$ & $\begin{array}{l}\text { Region } \\
\text { Chang } \\
\text { e } \\
2010- \\
2016\end{array}$ & $\begin{array}{l}\text { DB } \\
\text { Chang } \\
\text { e } \\
2010- \\
2016\end{array}$ & $\begin{array}{l}\text { Share } \\
\text { of } \\
\text { Transit } \\
\text { Countie } \\
\text { s }\end{array}$ & $\begin{array}{l}\text { Share of } \\
\text { Distanc } \\
\text { e Band } \\
\text { Change }\end{array}$ & $\begin{array}{l}\text { DB } \\
\text { Chang } \\
\text { e } \\
2010- \\
2016\end{array}$ & $\begin{array}{l}\text { Share } \\
\text { of } \\
\text { Transit } \\
\text { Countie } \\
\text { s }\end{array}$ & $\begin{array}{l}\text { Share } \\
\text { of } \\
\text { Distanc } \\
\text { e Band } \\
\text { Change }\end{array}$ \\
\hline \multicolumn{8}{|c|}{ Demographic Group--0.125 Mile Distance Band Only } \\
\hline White Non Latino & 1.02 & 0.16 & $15.4 \%$ & $239.2 \%$ & 0.16 & $15.4 \%$ & $239.2 \%$ \\
\hline Other Non Latino & 1.08 & -0.03 & $-2.3 \%$ & $-38.1 \%$ & -0.03 & $-2.3 \%$ & $-38.1 \%$ \\
\hline TotalPopulation & 1.06 & 0.07 & $6.2 \%$ & & 0.07 & $6.2 \%$ & \\
\hline White Non Latino & 1.02 & 0.16 & $15.4 \%$ & $239.2 \%$ & 0.16 & $15.4 \%$ & $239.2 \%$ \\
\hline Hispanic & 1.10 & -0.08 & $-7.4 \%$ & $-124.0 \%$ & -0.08 & $-7.4 \%$ & $124.0 \%$ \\
\hline Other Non Latino & 1.08 & -0.03 & $-2.3 \%$ & $-38.1 \%$ & -0.03 & $-2.3 \%$ & $-38.1 \%$ \\
\hline Other Groups & 1.26 & 0.43 & $34.2 \%$ & $652.8 \%$ & 0.43 & $34.2 \%$ & $652.8 \%$ \\
\hline TotalPopulation & 1.06 & 0.07 & $6.2 \%$ & & 0.07 & $6.2 \%$ & \\
\hline White Alone & 1.08 & 0.15 & $13.8 \%$ & $226.3 \%$ & 0.15 & $13.8 \%$ & $226.3 \%$ \\
\hline $\begin{array}{l}\text { Black Alone } \\
\text { Asian and Pacific Islander }\end{array}$ & 1.06 & -0.08 & $-7.8 \%$ & $-124.7 \%$ & -0.08 & $-7.8 \%$ & $124.7 \%$ \\
\hline Alone & 1.16 & 0.35 & $29.8 \%$ & $527.4 \%$ & 0.35 & $29.8 \%$ & $527.4 \%$ \\
\hline Native American Alone & 0.88 & 0.06 & $7.4 \%$ & $98.1 \%$ & 0.06 & $7.4 \%$ & $98.1 \%$ \\
\hline All Other Races Alone & 0.87 & -0.12 & $-13.5 \%$ & $-177.3 \%$ & -0.12 & $-13.5 \%$ & $177.3 \%$ \\
\hline TotalPopulation & 1.06 & 0.07 & $6.2 \%$ & & 0.07 & $6.2 \%$ & \\
\hline \multicolumn{8}{|c|}{$\begin{array}{l}\text { Demographic Group--0.25 Mile Distance Band } \\
\text { Only }\end{array}$} \\
\hline White Non Latino & 1.02 & -0.06 & $-5.6 \%$ & $81.5 \%$ & 0.09 & $9.1 \%$ & $190.6 \%$ \\
\hline Other Non Latino & 1.08 & -0.10 & $-9.1 \%$ & $138.4 \%$ & 0.12 & $10.9 \%$ & $242.0 \%$ \\
\hline TotalPopulation & 1.06 & -0.07 & $-6.7 \%$ & & -0.05 & $-4.6 \%$ & \\
\hline White Non Latino & 1.02 & -0.06 & $-5.6 \%$ & $81.5 \%$ & 0.09 & $9.1 \%$ & $190.6 \%$ \\
\hline Hispanic & 1.10 & -0.09 & $-8.3 \%$ & $129.3 \%$ & -0.13 & $-11.6 \%$ & $262.1 \%$ \\
\hline Other Non Latino & 1.08 & -0.10 & $-9.1 \%$ & $138.4 \%$ & 0.12 & $10.9 \%$ & $242.0 \%$ \\
\hline Other Groups & 1.26 & 0.35 & $27.8 \%$ & $-493.7 \%$ & 0.02 & $1.6 \%$ & $-40.4 \%$ \\
\hline TotalPopulation & 1.06 & -0.07 & $-6.7 \%$ & 1098.5 & -0.05 & $-4.6 \%$ & \\
\hline White Alone & 1.08 & -0.78 & $-71.9 \%$ & & 0.04 & $3.4 \%$ & $-75.2 \%$ \\
\hline $\begin{array}{l}\text { Black Alone } \\
\text { Asian and Pacific Islander }\end{array}$ & 1.06 & -0.10 & $-9.1 \%$ & $135.9 \%$ & -0.09 & $-8.8 \%$ & $191.3 \%$ \\
\hline Alone & 1.16 & -0.03 & $-2.3 \%$ & $37.9 \%$ & 0.00 & $0.0 \%$ & $\begin{array}{l}0.0 \% \\
1177.7\end{array}$ \\
\hline Native American Alone & 0.88 & -0.32 & $-36.6 \%$ & $\begin{array}{l}453.8 \% \\
-\end{array}$ & -0.57 & $-65.6 \%$ & $\%$ \\
\hline $\begin{array}{l}\text { All Other Races Alone } \\
\text { TotalPopulation }\end{array}$ & $\begin{array}{l}0.87 \\
1.06\end{array}$ & $\begin{array}{l}6.71 \\
-0.07\end{array}$ & $\begin{array}{l}774.9 \% \\
-6.7 \%\end{array}$ & $\begin{array}{l}9497.6 \\
\%\end{array}$ & $\begin{array}{l}0.02 \\
-0.05\end{array}$ & $\begin{array}{l}2.3 \% \\
-4.6 \%\end{array}$ & $-40.4 \%$ \\
\hline \multicolumn{8}{|c|}{$\begin{array}{l}\text { Demographic Group--0.5 Mile Distance Band } \\
\text { Only }\end{array}$} \\
\hline White Non Latino & 1.02 & 0.02 & $1.8 \%$ & $-101.0 \%$ & 0.08 & $8.2 \%$ & $140.5 \%$ \\
\hline Other Non Latino & 1.08 & -0.10 & $-9.7 \%$ & $588.2 \%$ & 0.04 & $4.0 \%$ & $-72.1 \%$ \\
\hline$\underline{\text { TotalPopulation }}$ & 1.06 & -0.02 & $-1.7 \%$ & & -0.06 & $-5.6 \%$ & \\
\hline
\end{tabular}


White Non Latino

Hispanic

Other Non Latino

Other Groups

TotalPopulation

White Alone

Black Alone

Asian and Pacific Islander

Alone

Native American Alone

All Other Races Alone

$\underline{\text { TotalPopulation }}$

$\begin{array}{lllllll}1.02 & 0.02 & 1.8 \% & -101.0 \% & 0.08 & 8.2 \% & 140.5 \% \\ 1.10 & 0.12 & 11.3 \% & -700.3 \% & -0.09 & -7.9 \% & 146.2 \% \\ 1.08 & -0.10 & -9.7 \% & 588.2 \% & 0.04 & 4.0 \% & -72.1 \% \\ 1.26 & 0.16 & 12.4 \% & -876.3 \% & 0.00 & -0.1 \% & 2.9 \% \\ 1.06 & -0.02 & -1.7 \% & & -0.06 & -5.6 \% & \\ 1.08 & 0.05 & 5.0 \% & -300.8 \% & 0.04 & 3.6 \% & -65.5 \% \\ 1.06 & -0.15 & -14.0 \% & 830.4 \% & -0.10 & -9.1 \% & 161.5 \% \\ & & & - & & & \\ 1.16 & 0.20 & 16.8 \% & \% & 0.00 & 0.0 \% & 0.0 \% \\ 0.88 & -0.10 & -11.7 \% & 575.6 \% & -0.19 & -21.3 \% & 313.0 \% \\ 0.87 & -0.10 & -11.9 \% & 577.4 \% & 0.00 & -0.2 \% & 2.9 \% \\ 1.06 & -0.02 & -1.7 \% & & -0.06 & -5.6 \% & \end{array}$


Table 6.8 Mod MA: SCT.

\begin{tabular}{|c|c|c|c|c|c|c|c|}
\hline \multirow[t]{2}{*}{ 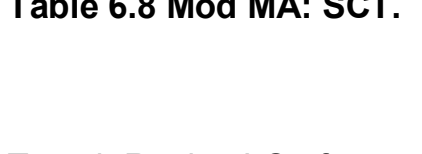 } & \multirow[b]{2}{*}{$\begin{array}{l}\text { Region } \\
\text { Chang } \\
\text { e } \\
2010- \\
2016 \\
\end{array}$} & \multicolumn{3}{|c|}{ mivererroricar riseryoro } & \multicolumn{3}{|c|}{ Cumulative Analysis } \\
\hline & & $\begin{array}{l}\text { DB } \\
\text { Chang } \\
\text { e } \\
2010- \\
2016 \\
\end{array}$ & $\begin{array}{l}\text { Share } \\
\text { of } \\
\text { Transit } \\
\text { Countie } \\
\text { s }\end{array}$ & $\begin{array}{l}\text { Share } \\
\text { of } \\
\text { Distanc } \\
\text { e Band } \\
\text { Change }\end{array}$ & $\begin{array}{l}\text { DB } \\
\text { Chang } \\
\text { e } \\
2010- \\
2016\end{array}$ & $\begin{array}{l}\text { Share } \\
\text { of } \\
\text { Transit } \\
\text { Countie } \\
\text { s }\end{array}$ & $\begin{array}{l}\text { Share of } \\
\text { Distanc } \\
\text { e Band } \\
\text { Change }\end{array}$ \\
\hline \multicolumn{8}{|c|}{ Demographic Group--0.125 Mile Distance Band Only } \\
\hline $\begin{array}{l}\text { White Non Latino } \\
\text { Other Non Latino } \\
\text { TotalPopulation } \\
\end{array}$ & $\begin{array}{l}1.02 \\
1.08 \\
1.06\end{array}$ & $\begin{array}{l}0.05 \\
-0.20 \\
-0.04\end{array}$ & $\begin{array}{l}4.7 \% \\
-18.6 \% \\
-3.9 \%\end{array}$ & $\begin{array}{l}116.6 \% \\
485.6 \%\end{array}$ & $\begin{array}{l}0.05 \\
-0.20 \\
-0.04\end{array}$ & $\begin{array}{l}4.7 \% \\
-18.6 \% \\
-3.9 \%\end{array}$ & $\begin{array}{l}-116.6 \% \\
485.6 \%\end{array}$ \\
\hline $\begin{array}{l}\text { White Non Latino } \\
\text { Hispanic } \\
\text { Other Non Latino }\end{array}$ & $\begin{array}{l}1.02 \\
1.10 \\
1.08\end{array}$ & $\begin{array}{l}0.05 \\
0.03 \\
-0.20\end{array}$ & $\begin{array}{l}4.7 \% \\
3.0 \% \\
-18.6 \%\end{array}$ & $\begin{array}{l}- \\
116.6 \% \\
-79.0 \% \\
485.6 \% \\
-\end{array}$ & $\begin{array}{l}0.05 \\
0.03 \\
-0.20\end{array}$ & $\begin{array}{l}4.7 \% \\
3.0 \% \\
-18.6 \%\end{array}$ & $\begin{array}{l}-116.6 \% \\
-79.0 \% \\
485.6 \%\end{array}$ \\
\hline $\begin{array}{l}\text { Other Groups } \\
\text { TotalPopulation } \\
\end{array}$ & $\begin{array}{l}1.26 \\
1.06\end{array}$ & $\begin{array}{l}0.28 \\
-0.04\end{array}$ & $\begin{array}{l}22.5 \% \\
-3.9 \%\end{array}$ & $683.3 \%$ & $\begin{array}{l}0.28 \\
-0.04\end{array}$ & $\begin{array}{l}22.5 \% \\
-3.9 \%\end{array}$ & $-683.3 \%$ \\
\hline $\begin{array}{l}\text { White Alone } \\
\text { Black Alone } \\
\text { Asian and Pacific Islander }\end{array}$ & $\begin{array}{l}1.08 \\
1.06\end{array}$ & $\begin{array}{l}0.08 \\
-0.25\end{array}$ & $\begin{array}{l}7.4 \% \\
-24.1 \%\end{array}$ & $\begin{array}{l}192.3 \% \\
614.1 \% \\
-\end{array}$ & $\begin{array}{l}0.08 \\
-0.25\end{array}$ & $\begin{array}{l}7.4 \% \\
-24.1 \%\end{array}$ & $\begin{array}{l}-192.3 \% \\
614.1 \%\end{array}$ \\
\hline $\begin{array}{l}\text { Alone } \\
\text { Native American Alone } \\
\text { All Other Races Alone } \\
\text { TotalPopulation } \\
\text { Demographic Group--0.25 } \\
\text { Only }\end{array}$ & $\begin{array}{l}1.16 \\
0.88 \\
0.87 \\
1.06 \\
\text { Distance }\end{array}$ & $\begin{array}{l}0.19 \\
-0.27 \\
-0.17 \\
-0.04 \\
\text { Band }\end{array}$ & $\begin{array}{l}15.9 \% \\
-31.3 \% \\
-19.5 \% \\
-3.9 \%\end{array}$ & $\begin{array}{l}448.3 \% \\
663.0 \% \\
409.2 \%\end{array}$ & $\begin{array}{l}0.19 \\
-0.27 \\
-0.17 \\
-0.04\end{array}$ & $\begin{array}{l}15.9 \% \\
-31.3 \% \\
-19.5 \% \\
-3.9 \%\end{array}$ & $\begin{array}{l}-448.3 \% \\
663.0 \% \\
409.2 \%\end{array}$ \\
\hline White Non Latino & 1.02 & 0.15 & $15.0 \%$ & $183.1 \%$ & 0.12 & $12.1 \%$ & $\begin{array}{l}-197.0 \% \\
- \\
1144.1\end{array}$ \\
\hline $\begin{array}{l}\text { Other Non Latino } \\
\text { TotalPopulation }\end{array}$ & $\begin{array}{l}1.08 \\
1.06\end{array}$ & $\begin{array}{l}-0.02 \\
0.08\end{array}$ & $\begin{array}{l}-1.6 \% \\
7.9 \%\end{array}$ & $-20.2 \%$ & $\begin{array}{l}0.72 \\
-0.06\end{array}$ & $\begin{array}{l}66.3 \% \\
-5.9 \%\end{array}$ & $\%$ \\
\hline White Non Latino & 1.02 & 0.15 & $15.0 \%$ & $183.1 \%$ & 0.12 & $12.1 \%$ & $-197.0 \%$ \\
\hline Hispanic & 1.10 & 0.02 & $2.0 \%$ & $26.0 \%$ & 0.00 & $-0.3 \%$ & $\begin{array}{l}5.4 \% \\
- \\
1144.1\end{array}$ \\
\hline $\begin{array}{l}\text { Other Non Latino } \\
\text { Other Groups } \\
\text { TotalPopulation } \\
\end{array}$ & $\begin{array}{l}1.08 \\
1.26 \\
1.06\end{array}$ & $\begin{array}{l}-0.02 \\
0.25 \\
0.08\end{array}$ & $\begin{array}{l}-1.6 \% \\
20.2 \% \\
7.9 \%\end{array}$ & $\begin{array}{l}-20.2 \% \\
303.1 \%\end{array}$ & $\begin{array}{l}0.72 \\
-0.15 \\
-0.06\end{array}$ & $\begin{array}{l}66.3 \% \\
-12.3 \% \\
-5.9 \%\end{array}$ & $\begin{array}{l}\% \\
246.7 \%\end{array}$ \\
\hline $\begin{array}{l}\text { White Alone } \\
\text { Black Alone } \\
\text { Asian and Pacific Islander }\end{array}$ & $\begin{array}{l}1.08 \\
1.06\end{array}$ & $\begin{array}{l}-0.80 \\
-0.06\end{array}$ & $\begin{array}{l}-73.9 \% \\
-5.2 \%\end{array}$ & $\begin{array}{l}951.0 \% \\
-65.8 \%\end{array}$ & $\begin{array}{l}0.09 \\
-0.20\end{array}$ & $\begin{array}{l}8.4 \% \\
-19.0 \%\end{array}$ & $\begin{array}{l}-144.8 \% \\
320.4 \%\end{array}$ \\
\hline Alone & 1.16 & 0.31 & $26.7 \%$ & $\begin{array}{l}370.5 \% \\
-\end{array}$ & 0.00 & $0.0 \%$ & $0.0 \%$ \\
\hline Native American Alone & 0.88 & -0.73 & $-83.5 \%$ & $\begin{array}{l}871.4 \% \\
9272.7\end{array}$ & -0.47 & $-54.1 \%$ & $757.0 \%$ \\
\hline $\begin{array}{l}\text { All Other Races Alone } \\
\text { TotalPopulation }\end{array}$ & $\begin{array}{l}0.87 \\
1.06\end{array}$ & $\begin{array}{l}7.79 \\
0.08\end{array}$ & $\begin{array}{l}898.8 \% \\
7.9 \%\end{array}$ & $\%$ & $\begin{array}{l}-0.15 \\
-0.06\end{array}$ & $\begin{array}{l}-17.8 \% \\
-5.9 \%\end{array}$ & $246.7 \%$ \\
\hline $\begin{array}{l}\text { Demographic Group--0.5 } \\
\text { Only }\end{array}$ & Distanc & Band & & & & & \\
\hline White Non Latino & 1.02 & 0.13 & $12.6 \%$ & $148.3 \%$ & 0.11 & $10.3 \%$ & $-314.4 \%$ \\
\hline
\end{tabular}


Other Non Latino

TotalPopulation

White Non Latino

Hispanic

Other Non Latino

Other Groups

TotalPopulation

White Alone

Black Alone

Asian and Pacific Islander

Alone

Native American Alone

All Other Races Alone

$\underline{\text { TotalPopulation }}$
1.08

1.06

1.02

1.10

0.09

0.13

0.07

$2.2 \%$

$8.2 \%$

$12.6 \%$

$6.0 \%$

$27.4 \%$

$148.3 \%$

$75.4 \%$

1.08

1.26

1.06

1.08

1.06

0.02

0.20

0.09

0.21

$-0.02$

$1.16 \quad 0.49$

$2.2 \%$

$16.3 \%$

$8.2 \%$

$19.1 \%$

$-2.0 \%$

1.16

0.88

0.87

1.06

$41.8 \% \quad 559.5 \%$

$-73.2 \% \quad 737.5 \%$

$-46.1 \% \quad 459.3 \%$

$8.2 \%$

$\begin{array}{ll}-0.40 & -46.1 \% \\ 0.09 & 8.2 \%\end{array}$

(59.3\%

0.00

$-0.5$

$-0.51$

$-0.18 \quad-20.2 \%$

$-0.03-3.2 \%$

1705.3

$\%$

$-314.4 \%$

$14.1 \%$

1705.3

$\%$

$523.3 \%$

$-242.8 \%$

$500.4 \%$

$-0.03$

$0.0 \%$

1533.5

$\%$

$523.3 \%$

$523.3 \%$ 
Table 6.9 High MA: SCT.

\begin{tabular}{|c|c|c|c|c|c|c|c|}
\hline \multirow[t]{4}{*}{ Table 6.9 High MA: SCT. } & \multirow{6}{*}{$\begin{array}{l}\text { Region } \\
\text { Chang } \\
\text { e } \\
2010- \\
2016\end{array}$} & \multicolumn{3}{|c|}{ Incremental Analysis } & \multicolumn{3}{|c|}{ Cumulative Analysis } \\
\hline & & DB & Share & & \multirow{5}{*}{$\begin{array}{l}\text { DB } \\
\text { Chang } \\
\text { e } \\
2010- \\
2016\end{array}$} & \multirow{5}{*}{$\begin{array}{l}\text { Share } \\
\text { of } \\
\text { Transit } \\
\text { Countie } \\
\text { s }\end{array}$} & \multirow{5}{*}{$\begin{array}{l}\text { Share } \\
\text { of } \\
\text { Distanc } \\
\text { e Band } \\
\text { Change }\end{array}$} \\
\hline & & Chang & & Share of & & & \\
\hline & & & Transit & Distanc & & & \\
\hline Transit Region LQ of & & $2010-$ & Countie & e Band & & & \\
\hline Demographic Change & & 2016 & $\mathrm{~s}$ & Change & & & \\
\hline \multicolumn{8}{|c|}{ Demographic Group--0.125 Mile Distance Band Only } \\
\hline White Non Latino & 1.02 & 0.18 & $17.7 \%$ & $103.3 \%$ & 0.18 & $17.7 \%$ & $103.3 \%$ \\
\hline Other Non Latino & 1.08 & 0.03 & $2.6 \%$ & $15.9 \%$ & 0.03 & $2.6 \%$ & $15.9 \%$ \\
\hline TotalPopulation & 1.06 & 0.18 & $16.6 \%$ & & 0.18 & $16.6 \%$ & \\
\hline White Non Latino & 1.02 & 0.18 & $17.7 \%$ & $103.3 \%$ & 0.18 & $17.7 \%$ & $103.3 \%$ \\
\hline Hispanic & 1.10 & 0.50 & $45.6 \%$ & $286.9 \%$ & 0.50 & $45.6 \%$ & $286.9 \%$ \\
\hline Other Non Latino & 1.08 & 0.03 & $2.6 \%$ & $15.9 \%$ & 0.03 & $2.6 \%$ & $15.9 \%$ \\
\hline Other Groups & 1.26 & 0.80 & $64.0 \%$ & $459.7 \%$ & 0.80 & $64.0 \%$ & $459.7 \%$ \\
\hline TotalPopulation & 1.06 & 0.18 & $16.6 \%$ & & 0.18 & $16.6 \%$ & \\
\hline White Alone & 1.08 & 0.21 & $19.6 \%$ & $121.1 \%$ & 0.21 & $19.6 \%$ & $121.1 \%$ \\
\hline Black Alone & 1.06 & -0.05 & $-5.0 \%$ & $-30.3 \%$ & -0.05 & $-5.0 \%$ & $-30.3 \%$ \\
\hline \multicolumn{8}{|l|}{ Asian and Pacific Islander } \\
\hline Alone & 1.16 & 0.24 & $20.9 \%$ & $139.0 \%$ & 0.24 & $20.9 \%$ & $139.0 \%$ \\
\hline Native American Alone & 0.88 & -0.05 & $-5.7 \%$ & $-28.7 \%$ & -0.05 & $-5.7 \%$ & $-28.7 \%$ \\
\hline All Other Races Alone & 0.87 & 0.55 & $63.0 \%$ & $311.6 \%$ & 0.55 & $63.0 \%$ & $311.6 \%$ \\
\hline TotalPopulation & 1.06 & 0.18 & $16.6 \%$ & & 0.18 & $16.6 \%$ & \\
\hline \multirow{2}{*}{\multicolumn{8}{|c|}{ Demographic Group--0.25 Mile Distance Band }} \\
\hline & & & & & & & \\
\hline White Non Latino & 1.02 & 0.12 & $12.1 \%$ & $190.2 \%$ & 0.05 & $5.3 \%$ & $65.5 \%$ \\
\hline Other Non Latino & 1.08 & -0.06 & $-5.4 \%$ & $-89.0 \%$ & 0.00 & $-0.2 \%$ & $-3.3 \%$ \\
\hline TotalPopulation & 1.06 & 0.07 & $6.2 \%$ & & 0.08 & $7.8 \%$ & \\
\hline White Non Latino & 1.02 & 0.12 & $12.1 \%$ & $190.2 \%$ & 0.05 & $5.3 \%$ & $65.5 \%$ \\
\hline Hispanic & 1.10 & 0.07 & $6.8 \%$ & $114.5 \%$ & 0.09 & $8.4 \%$ & $112.5 \%$ \\
\hline Other Non Latino & 1.08 & -0.06 & $-5.4 \%$ & $-89.0 \%$ & 0.00 & $-0.2 \%$ & $-3.3 \%$ \\
\hline Other Groups & 1.26 & 0.19 & $14.8 \%$ & $284.5 \%$ & 0.25 & $19.7 \%$ & $299.9 \%$ \\
\hline \multirow[t]{2}{*}{ TotalPopulation } & 1.06 & 0.07 & $6.2 \%$ & & 0.08 & $7.8 \%$ & \\
\hline & & & & - & & & \\
\hline White Alone & 1.08 & -0.72 & $-66.8 \%$ & $\%$ & 0.03 & $2.5 \%$ & $32.6 \%$ \\
\hline Black Alone & 1.06 & -0.11 & $-10.5 \%$ & $-169.9 \%$ & -0.19 & $-17.7 \%$ & $226.6 \%$ \\
\hline Asian and Pacific Islander & & & & & & & \\
\hline Alone & 1.16 & 0.11 & $9.5 \%$ & $168.8 \%$ & 0.00 & $0.0 \%$ & $0.0 \%$ \\
\hline Native American Alone & 0.88 & -0.22 & $-24.5 \%$ & $\begin{array}{l}-330.0 \% \\
7945.6\end{array}$ & -0.79 & $-89.9 \%$ & $955.0 \%$ \\
\hline All Other Races Alone & 0.87 & 5.18 & $598.0 \%$ & $\%$ & 0.25 & $28.6 \%$ & $299.9 \%$ \\
\hline TotalPopulation & 1.06 & 0.07 & $6.2 \%$ & & 0.08 & $7.8 \%$ & \\
\hline \multirow{2}{*}{\multicolumn{8}{|c|}{ Demographic Group--0.5 Mile Distance Band }} \\
\hline & & & & & & & \\
\hline White Non Latino & 1.02 & 0.21 & $20.4 \%$ & $81.4 \%$ & 0.03 & $3.2 \%$ & $38.1 \%$ \\
\hline Other Non Latino & 1.08 & 0.18 & $17.1 \%$ & $72.1 \%$ & -0.15 & $-14.2 \%$ & $-\overline{178.6 \%}$ \\
\hline TotalPopulation & 1.06 & 0.26 & $24.2 \%$ & & 0.09 & $8.1 \%$ & \\
\hline White Non Latino & 1.02 & 0.21 & $20.4 \%$ & $81.4 \%$ & 0.03 & $3.2 \%$ & $38.1 \%$ \\
\hline Hispanic & 1.10 & 0.74 & $67.2 \%$ & $289.3 \%$ & 0.09 & $8.4 \%$ & $107.9 \%$ \\
\hline Other Non Latino & 1.08 & 0.18 & $17.1 \%$ & $72.1 \%$ & -0.15 & $-14.2 \%$ & $178.6 \%$ \\
\hline Other Groups & 1.26 & 0.76 & $60.3 \%$ & $296.0 \%$ & 0.17 & $13.7 \%$ & $200.5 \%$ \\
\hline TotalPopulation & 1.06 & 0.26 & $24.2 \%$ & & 0.09 & $8.1 \%$ & \\
\hline
\end{tabular}




$\begin{array}{lccccccc}\text { White Alone } & 1.08 & 0.30 & 28.0 \% & 118.1 \% & 0.01 & 0.8 \% & \begin{array}{l}9.9 \% \\ \text { Black Alone }\end{array} \\ \begin{array}{l}\text { Asian and Pacific Islander } \\ \text { Alone }\end{array} & 1.06 & 0.08 & 7.4 \% & 30.4 \% & -0.13 & -12.6 \% & 154.7 \% \\ & 1.16 & 0.56 & 48.0 \% & 218.3 \% & 0.00 & 0.0 \% & 0.0 \% \\ \begin{array}{l}\text { Native American Alone } \\ \text { All Other Races Alone }\end{array} & 0.88 & -0.72 & -82.1 \% & -281.2 \% & -0.82 & -93.7 \% & 956.1 \% \\ \begin{array}{l}\text { TotalPopulation } \\ \hline\end{array} & 0.87 & 0.25 & 29.3 \% & 99.0 \% & 0.17 & 19.9 \% & 200.5 \% \\ & 1.06 & 0.26 & 24.2 \% & & 0.09 & 8.1 \% & \end{array}$




\section{Summary of Results}

$B R T$ results are as follows:

At Poor MA BRT: Whites declined at the station, grew at the quarter-mile DB, and declined at the half-mile DB. Hispanics saw station DB major decline at the station to the half-mile DB. Blacks saw negligible change in the time period.

Low MA BRT: White population saw negligible growth to the half-mile $\mathrm{DB}$, which had a robust incremental rate of growth. Hispanics saw a small rate of growth or some decline at this place type. Blacks had a negligible rate of growth at this place type.

Mod MA BRT: Whites saw modest growth at the station, then modest declines. Hispanics captured a third of the regional population at the stations, growing at a much faster rate than the whole population, to the half-mile DB at which growth tapered off to a more modest rate. Blacks saw robust growth at the station, with minor declines to the half-mile DB.

High MA BRT: Whites saw modest growth, Hispanics had modest gains at the station, followed by a flat trend. Blacks mostly declined at this place type.

CRT results are as follows:

Poor MA CRT: White population increased at the station and then declined. Hispanics saw very significant growth at this place type. Blacks experienced a net cumulative loss of population share.

Low MA CRT: Whites saw modest growth at the station with significant increase in concentration.

Hispanics strong growth at the station, with subsequent declines. Blacks experienced modest growth at the station followed by subsequent loss of population and a fast decrease in population concentration relative to the rest of the population at the station.

Mod MA CRT: White and Hispanics populations mostly decreased in population growth rates, while Black populations gained population concentration at the station and the quarter mile DB, while declining at half a mile.

High MA CRT: White population experienced robust growth and increased concentration. Hispanics declined in moderate rates across the half-mile from the stations. Black populations saw robust growth at the first and second DB's, with slight declines at the half-mile DB.

$L R T$ results are as follows:

Poor MA LRT: Whites saw a modest decline, Hispanics at $11 \%$ and $13 \%$, then had a modestly positive rate of growth thereafter. Blacks experienced an overall moderate decline at this place type.

Low MA LRT: Whites grew at modest rates. Hispanics gained at the station, but declined thereafter. Blacks saw moderate decline in shares at this place type.

Mod MA LRT: Whites increased at modest rates, but gained some concentrations at the halfmile DB. Hispanics experienced growth rates and concentrations in the first two DB's, while losing share somewhat in the final DB. 
High MA LRT: Whites experienced robust growth at the station, with milder growth to the halfmile DB. Hispanics experienced modest growth at the station, with declines thereafter. Blacks also experienced fair growth rates at the station, with declines overall thereafter. Incrementally, Blacks grew at a robust level at the half-mile DB.

SCT results are as follows:

Poor MA SCT: This place type did not exist at the station area for SCT systems in the study. Whites grew moderately at the quarter-mile $\mathrm{DB}$, with strong incremental growth at the half-mile DB. Hispanics grew at robust levels. Blacks declined at these place type stations.

Low MA SCT: Whites experienced moderate growth at the station but dropped thereafter. Hispanics had an $8 \%$ growth at the station but declined faster than the whole population thereafter. Blacks declined in population at these place type stations.

Mod MA: Whites experienced mild to moderate growth rates across the station DB's, growing at the same time that the whole population was declining. Hispanics grew at modest to moderate rates while the population was declining somewhat. Blacks experienced major declines at this station and place type.

High MA: Whites saw moderate growth at this station area. Hispanics enjoyed a resoundingly high rate of growth at this station and place type. Blacks declined overall in cumulative figures but increased in the incremental rate measures at the quarter- and half-mile DB's. 


\section{Implications for Transit and Land Use Planning}

A good deal of sorting occurs across the various place type-transit mode combinations. However, some basic trends are evident: White populations increased presence at varying rates: modest for BRT, and mostly at the higher-intensity places. Whites saw modest increases at CRT stations in lower-intensity land uses; and declines in growth at higher-intensity stations. For LRT, Whites declined at low intensities, then gradually increased growth at the stations, ending finally with robust growth at the High MA stations. For SCT, Whites saw moderate growth rates at all land use intensities.

For Hispanics, growth was present but mostly modest, with the strongest rates at Mod MA place types. For CRT, Hispanics experienced strong growth rates at Poor and Low MA place type stations but declines at the Mod and High MA station areas. Hispanics grew at the first DB, at the station, and then declined in growth thereafter. For SCT, Hispanics grew at modest to moderate rates at the station with the exception of the High MA station areas, at which they saw very strong growth.

Blacks at BRT stations had negligible growth at the Poor and Low MA station areas, with robust growth at the station for Mod MA place types, and then mostly declined at High MA stations. Blacks at CRT stations saw modest to moderate growth at the first DB of the station, but mostly declines between a quarter and half-mile DB from the stations. Blacks at LRT stations saw declines at the Poor and Low MA stations, experienced modest gains at the Mod MA stations while seeing decline at subsequent DB's, and then saw robust growth at the half-mile DB. Blacks at SCT stations saw, surprisingly, declines at all place types.

These results strongly suggest further research to determine the impetus for such consistent rates of decline, overall, for Black populations near most stations by transit mode and place type. White populations saw mostly modest to robust growth in most stations by mode and place type. Hispanics saw a range of growth and decline, with many examples of growth being confined mainly to the station area. There appear to be some hints at competitive sorting between these population segments, but perhaps the strongest influence on these patterns is the underlying locations of jobs most held by each group, the part of the city most inhabited by each group, and the kind of housing each group usually occupies. These elements vary greatly between metropolitan areas.

These findings may be considered a preliminary search of these patterns, with some important hints at policy directions to improve these patterns, such as zoning for a wider range of housing across the metropolitan area, and provision of transit system extensions into less-served areas of regions.

Regression and spatial regression may improve the clarity of these outcomes through hypothesis testing and significance levels. 


\section{References}

Alonso, William. 1964. Location and Land Use. Cambridge, MA: Harvard University Press.

Bertolini, L. 1999. "Spatial Development Patterns and Public Transport : The Application of an Analytical Model in the Netherlands Spatial Development Patterns and Public Transport: The Application of an Analytical Model in the Netherlands." Planning Practice \& Research 14 (2): 199-210. https://doi.org/10.1080/02697459915724.

Chapple, Karen, and Anastasia Loukaitou-Sideris. 2019. Transit-Oriented Displacement or Community Dividends? Understanding the Effects of Smarter Growth on Communities. Cambridge, MA: The MIT Press.

Dittmar, Hank, and Gloria Ohland. 2004. The New Transit Town: Best Practices In TransitOriented Development. Washington, DC: Island Press.

Dunham-Jones, Ellen, and June Williamson. 2011. Retrofitting Suburbia: Urban Design Solutions for Redesigning Suburbs. Hoboken, NJ: John Wiley \& Sons.

Glaeser, Edward and Kahn, Matthew. n.d. "Decentralized Employment and Transofmration of the American City" 3.

Glaeser, Edward L., Matthew E. Kahn, and Jordan Rappaport. 2008. "Why Do the Poor Live in Cities? The Role of Public Transportation." Journal of Urban Economics 63 (1): 1-24. https://doi.org/10.1016/j.jue.2006.12.004.

Kain, John F. 1992. "The Spatial Mismatch Hypothesis: Three Decades Later." Housing Policy Debate 3 (2): 371-460. https://doi.org/10.1080/10511482.1992.9521100.

Levinson, David M B T - The 30-Minute City: Designing for Access. 2019. The 30-Minute City: Designing for Access. Network Design Lab. https://hdl.handle.net/2123/21630.

Mills, Edwin S. 1967. "American Economic Association An Aggregative Model of Resource Allocation in a Metropolitan Area." The American Economic Review 57 (2): 197-210.

1972. "Markets and Efficient Resource Allocation in Urban Areas." The Swedish Journal of Economics 74 (1): 100-113. http://www.jstor.org/stable/3439012.

Muth, Richard F. 1969. Cities and Housing: The Spatial Pattern of Urban Residential Land Use. Chicago: University of Chicago Press.

Nelson, A.C., D. Eskic, S. Hamidi, S.J. Petheram, R. Ewing, and J.H. Liu. 2015. Office Rent Premiums with Respect to Light Rail Transit Stations: Case Study of Dallas, Texas, with Implications for Planning of Transit-Oriented Development. Transportation Research Record. https://doi.org/10.3141/2500-13.

Nelson, Arthur, Bruce Appleyard, Shyam Kannan, Reid Ewing, Matt Miller, and Dejan Eskic. 2013. "Bus Rapid Transit and Economic Development: Case Study of the EugeneSpringfield BRT System.” Journal of Public Transportation 16 (3): 41-57. https://doi.org/10.5038/2375-0901.16.3.3.

Nelson, Arthur C. 2013. Reshaping Metropolitan America: Development Trends and Opportunities to 2030. Washington, DC: Island Press.

Nelson, Arthur C., and Robert Hibberd. 2019. "The Link between Transit Station Proximity and Real Estate Rents , Jobs , People and Housing with Transit and Land Use Planning Implications The Link between Transit Station Proximity and Real Estate Rents , Jobs , People and Housing with Transit and Land." Portland, OR. 
Nelson, Arthur C., Philip Stoker, and Robert Hibberd. 2019. "Light Rail Transit and Economic Recovery: A Case of Resilience or Transformation?" Research in Transportation Economics 74 (November 2018): 2-9. https://doi.org/10.1016/j.retrec.2018.11.003.

Nelson, Arthur C. 2017a. "Transit-Oriented Developments Make a Difference in Job Location." Fordham Urban Law Journal 44 (4). https://ir.lawnet.fordham.edu/cgi/viewcontent.cgi?article=2705\&context=ulj. 2017b. "Transit and Real Estate Rents." Portland, OR. https://ppms.trec.pdx.edu/media/project_files/Transit_and_Real_Estate_Rents.pdf.

Nelson, Arthur C, and Joanna Ganning. 2015. "National Study of BRT Development Outcomes." Portland, OR. https://nitc.trec.pdx.edu/research/project/650.

Nelson, Arthur C, and Robert Hibberd. 2019. "Streetcars and Real Estate Rents with Implications for Transit and Land Use Planning." Transportation Research Record 00 (0): 1-12. https://doi.org/10.1177/0361198119849916.

Nelson, Arthur, Matt Miller, Dejan Eskic, Keuntae Kim, Reid Ewing, Jenny Liu, Matt Berggren, and Zakari Mumuni. 2015. "Do TODs Make a Difference?" http://pdxscholar.library.pdx.edu/trec_reports/7.

Parolek, Daniel. 2020. Missing Middle Housing. Thinking Big and Building Small to Respond to Today's Housing Crisis. Washington: Island Press.

Petheram, Susan J., Arthur C. Nelson, Matt Miller, and Reid Ewing. 2013. "Use of the Real Estate Market to Establish Light Rail Station Catchment Areas." Transportation Research Record: Journal of the Transportation Research Board 2357 (1): 95-99. https://doi.org/10.3141/2357-11.

Plane, D. A., C. J. Henrie, and M. J. Perry. 2005. "Migration up and down the Urban Hierarchy and across the Life Course." Proceedings of the National Academy of Sciences 102 (43): 15313-18. https://doi.org/10.1073/pnas.0507312102.

Plane, David A. 1984. "Migration Space: Doubly Constrained Gravity Model Mapping of Relative Interstate Separation." Annals of the Association of American Geographers 74 (2): 24456. https://doi.org/10.1111/j.1467-8306.1984.tb01451.x.

Renne, John L, Tara Tolford, Shima Hamidi, and Reid Ewing. 2016. "The Cost and Affordability Paradox of Transit- Oriented Development : A Comparison of Housing and Transportation Costs Across Transit-Oriented Development, Hybrid and TransitAdjacent Development Station Typologies." Housing Policy Debate 26 (4-5): 819-34. https://doi.org/10.1080/10511482.2016.1193038.

Sanchez, By Thomas W, Rich Stolz, and Jacinta S Ma. 2003. "MOVING TO EQUITY: Addressing Inequitable Effects of Transportation Policies on Minorities." Cambridge, MA.

Scheer, Brenda. 2017. "TOD Beats TAD in Affordability Showdown." Transportation Research and Education Center, no. August.

Steven Manson, Jonathan Schroeder, David Van Riper, and Steven Ruggles. 2018. "IPUMS National Historical Geographic Information System: Version 12.0 [Database]." Minneapolis: University of Minnesota. 2018. https://doi.org/http://doi.org/10.18128/D050.V12.0.

Wilson, Steven G, David a Plane, Paul J Mackun, Thomas R Fischetti, Justyna Goworowska, Darryl T. Cohen, Marc J Perry, and Geoffrey W Hatchard. 2012. "Patterns of 
Metropolitan and Micropolitan Population Change : 2000 to 2010." 2010 Census Special Reports, no. September: 1-102. https://doi.org/C2010SR-01. 


\section{CHAPTER 7: The Link between Transit Station Proximity, Place Typology and Transportation Costs Incurred by Household Types}

\section{OVERVIEW}

It seems an article of faith that transportation costs as a share of household income increase with respect to distance from downtowns, freeway interchanges, and light rail transit stations. Considerable literature reports price effects of these points on residential property values but none measure explicitly differences in household transportation costs as a share of household budgets. Our study helps close this gap in literature. Using the U.S. Department of Housing and Urban Development's (HUD) Location Affordability Index (LAI) database, which estimates the share of household budgets consumed by transportation at the block group level based on the 2012 5-year American Community Survey (ACS) and census tracts based on the 2016 5-year ACS. We evaluate the association between median household transportation costs and distance from light rail transit (LRT) stations using both ACS data sets. We find clear associations between transit station proximity and lower household transportation costs for both periods suggesting increasing transportation savings over time. We also find important differences in transportation costs incurred by different households with respect to the type of urban place in which they live and proximity to LRT stations. While not surprising intuitively, social equity issues arise. We offer implications for transit and land use planning and housing, as well as for future research.

\section{Introduction and Literature Review}

Conventional theory of location and land-use, especially residential location, in post-World War II, automobile dominant American metropolitan areas show that household demand for location as a function of income, household size, and location costs - that is, the transportation costs associated with accessing work, shopping, services, recreation and other purposes from a prospective home. House and lot size increased the farther from centers one went. At some point, a household achieved equilibrium where preference for housing and neighborhood attributes were maximized given location costs. Conventional models of location and land-use decisions (see Alonso (1964), Mills (1967) and Muth (1969)), however, did not consider lenders' underwriting standards which often capped principal-interest-taxes-insurance payments at a range of about 28 to 40 percent of the household's income available to service a mortgage.

By failing to consider location costs in the mortgage underwriting decision, lenders induce households to purchase homes farther away from centers than they may have chosen otherwise, resulting in more land-extensive development patterns across America's metropolitan landscapes. Combined with the ability to deduct mortgage interest against taxable income, the practice in most states to under-value owner-occupied homes for property tax assessment purposes, average-cost pricing of utility services resulting in high-cost areas paying less than their costs with low-cost areas paying more, and heavily subsidized highway investments among other actions (Blais 2010) led to inefficient land-use patterns. Some call it "sprawl."

In recent years a growing body of literature has argued that housing and transportation costs need to be considered together when considering housing affordability. ${ }^{107}$ Ewing and Hamidi

\footnotetext{
${ }^{107}$ We refer readers to HUD's Location Affordability Portal for literature and other materials on the concept of housing plus transportation (" $\mathrm{H}+\mathrm{T}$ ") costs (see http://www.locationaffordability.info/).
} 
(2015) note that HUD's definition of affordability—where no more than 30 percent of a household's income would be spent on housing - along with indexes of others are "structurally flawed in that they only consider costs directly related to housing, ignoring those related to utilities and transportation" (Ewing and Hamidi: 5). The 2013 Consumer Expenditure Survey, for instance, reports that total housing costs consume 33.6 percent of income ${ }^{108}$ while transportation costs consume another 17.6 percent for a total $\mathrm{H}+\mathrm{T}$ of 51.2 percent. If a household's transportation costs could be reduced by half, however, it would not able to acquire a home mortgage for a more expensive home in a more efficient location that capitalizes the savings even though it would not be economically worse off.

Conceptually, transportation cost savings are realized by locating in or near such places as downtowns, mixed-use developments, and transit stations. Studies only estimate these savings in two ways. First, a suite of studies based on work by the Center for Neighborhood Technology uses secondary data to estimate the share of trips by mode and household type at the block group, and then derive vehicle miles traveled through inferences based on other secondary data. The actual distance from block groups to such points as downtowns and transit is not estimated directly. ${ }^{109}$ For several household types, CNT's studies estimate housing costs that are constant across large geographies such as counties while transportation costs vary by block group.

Another set of studies use hedonic regression analysis to estimate the variation in real estate values with respect to distance from such points as the downtown center and transit stations. Higgins' and Kanaroglou's (2016) review of 40 years of literature on market responsiveness to transit investment provide a thorough review of the models, methods, and outcomes using this technique. Transportation costs per se are not included in any of those studies.

We know of no research that estimates variation in transportation costs spatially. ${ }^{110}$ Our study helps close this gap. Our particular interest is in knowing whether and the extent to which proximity to transit stations affects the share of transportation costs incurred by households, and whether those savings increase over time. If so, the finding may help explain part of the capitalization effect numerous studies find with respect to residential property values and rents. It may also add new information to the discussion on the relationship between housing affordability and transportation costs as a function of transit station proximity. In establishing this relationship, we will also explore similar relationships with respect to distance from downtown and freeway interchanges.

We are also interested in the changes in the variation of transportation costs by different kinds of households over time. This helps lead to social equity insights.

\footnotetext{
108 These costs include "shelter" components such as rent and mortgage, utilities, insurance, maintenance and repairs, and several other expenditures. See http://www.bls.gov/cex/2013/combined/income.pdf.
}

${ }^{109}$ CNT has produced two significant generations of these studies. The first is reported in http://htaindex.cnt.org/map/ and the second in http://www.locationaffordability.info/default.aspx.

${ }^{110}$ Specifically, we do not know of any study that estimates the slope of change in the share of $\mathrm{HH}$ income consumed by transportation with respect to downtown or transit stations. 
We begin with a discussion of our analytic approach, model, data, and analytic strategy. This is followed by results and interpretations. We finish this chapter with implications for transit and land use planning, with special reference to social equity.

\section{Research Question and Design, and Model}

Our research question is:

\section{Do transportation costs as a share of median household incline decline generally and over time with respect to light rail transit station proximity controlling for other factors?}

The research question lends itself to quasi-experimental, cross-section analysis at a given point in time. Our aim is to measure the variation in household transportation costs with respect to distance from LRT stations. Fortunately, HUD's Location Affordability Index (LAI) includes data we need for this analysis. The LAl estimates household housing and transportation costs at the neighborhood level based on eight household prototypes. HUD's motivation for advancing discussion of location affordability is summarized as follows:

The prevailing standard of affordability in the United States is paying 30 percent or less of your family's income on housing, but this fails to account for transportation costs. One reason is that transportation costs have grown significantly as a proportion of household income since this standard was established. According to the Bureau of Labor Statistics, in the 1930's American households spent just 8 percent of their income on transportation. Since then, as a substantial proportion of the U.S. population has migrated from center cities to surrounding suburbs and exurbs and come to rely more heavily (or exclusively) on cars, that percentage has steadily increased, peaking at 19.1 percent in 2003. As of 2013, households spent on average about 17 percent of their annual income on transportation, second only to housing costs in terms of budget impact. And for many working-class and rural households, transportation costs actually exceed housing costs. ${ }^{111}$

HUD has produced three versions though Version 2 and Version 3 are considered the most compatible. Version 2 is based on census block groups applied to the 2012 5-year ACS while Version 3 is based on census tracts applied to the 2016 5-year ACS. Among the eight household types for which estimates are provided, we use figures for the "regional typical" household. ${ }^{112}$ In effect, each of the household types is a composite of all households in the census block group (CBG) in Version 2 and central tract (CT) in Version 3. As such, these composite or index measures inherently include income, race/ethnicity, education, and other socioeconomic constructs. These household prototypes vary based on transportation costs as a share of median regional household income for the regional typical household by CBG or CT. In turn, these household transportation costs are based on simultaneous equation models using a variety of federal data sources.

\section{${ }^{111}$ https://www.hudexchange.info/programs/location-affordability-index/about/}

${ }^{112}$ For details of both versions, see https://www.hudexchange.info/programs/location-affordabilityindex/ 
As no database provides estimates of household transportation costs disaggregated to the CBG or CT levels, and as disaggregation is needed to address the research question, we choose to use the LAl for our analysis. We apply our analysis to 17 LRT systems used in other analyses for this report (see Table 7.1). All these systems were operating at the time of the 2016 5-year ACS while nearly all were operating concurrent with the 2012 5-year ACS.

\section{Model and Specification}

We use the standard-form ordinary least squares regression model adapted for our purposes:

Household Transportation Cost Share $=f$ (Households, Location, Metropolitan Area, Place Typology, LRT Station proximity)

Where

Household Transportation Cost Share is the dependent variable. It is defined as the median household transportation cost divided by median household income at the CBG or CT for the 2012 5-year ACS or 2016 5-year ACS, respectively. We actually run six regression equations, one for each type of household specified in HUD's LAI documentation (HUDF ca 2015). These household types are:

Median-Income Family comprised of four persons with two commuters where the household earning the national median household income (MHHII);

Working Individual being a single person earning 50 percent of the $\mathrm{MHHI}$;

Single Professional being also a single person though earning 135 percent of the $\mathrm{MHHI}$

Single-Parent Family being one adult with two dependents earning 50 percent of the $\mathrm{MHHI}$;

Moderate-Income Family being comprised of a family of three with one worker earning 80 percent of the $\mathrm{MHHI}$; and

Dual-Professional Family comprised of four persons with two who together earn 150 percent of the $\mathrm{MHHI}$;

Table 7.2 summarizes key features of these household type. Because these household types are themselves an index, they inherently include socioeconomic and demographic factors.

The dependent variable is specifically the household vehicle miles traveled (VMT) annually, as estimated by the HUD LAI, which is used later to estimate the transportation costs share based on household location. 
Table 7.1

Light Rail Transit Systems Used in Analysis

$\begin{array}{ll}\text { Light Rail Transit } & \text { Year } \\ \text { Buffalo } & 1984 \\ \text { Charlotte } & 2007 \\ \text { Cleveland } & 1980 \\ \text { Dallas } & 1996 \\ \text { Denver } & 1994 \\ \text { Houston } & 2004 \\ \text { Minn.-St. Paul } & 2004 \\ \text { Phoenix } & 2008 \\ \text { Pittsburgh } & 1984 \\ \text { Portland } & 1986 \\ \text { Sacramento } & 1987 \\ \text { Salt Lake City } & 1999 \\ \text { San Diego } & 1981 \\ \text { San Jose } & 1987 \\ \text { Seattle } & 2003 \\ \text { St. Louis } & 1993 \\ \text { Virginia Beach } & 2011\end{array}$


Table 7.2

HUD LAI Household Types

Household Type

Median-Income Family

Working Individual

Single Professional

Single-Parent Family

Moderate-Income Family

Dual-Professional Family

Source: HUD (ca 2015).
Income

$\mathrm{MHHI}$

$50 \%$ of $\mathrm{MHHI}$

$135 \%$ of $\mathrm{MHHI}$

$50 \%$ of $\mathrm{MHHI}$

$80 \%$ of $\mathrm{MHHI}$

$150 \%$ of $\mathrm{MHHI}$

$\begin{array}{ll}\text { Size } & \begin{array}{l}\text { Number of } \\ \text { Commuters }\end{array} \\ 4 & 2 \\ 1 & 1 \\ 1 & 1 \\ 3 & 1 \\ 3 & 1 \\ 4 & 2\end{array}$


Households is simply the number of households in the CBG or CT, logged, to help control for the variability of households occupying census geographic units. There is no a priori expectation for association between households in a CBT or CT and VMT.

Location means distance to the nearest freeway ramp (freeway distance). Other location controls are embedded in our Place Typology construct described below. Because freeways enable longer commutes (see Angle and Blei 2015), we hypothesize a positive association between freeway distance and VMT.

Metropolitan controls are simply the location of the CBG or CT in a given metropolitan area where an LRT system operates. (We use Virginia Beach as the referent as it is the smallest in terms of stations and track distance.) This variable is effectively a composite index of attributes unique to each metropolitan area and as such there are no a priori directions of association.

Place Typology was constructed in Chapter 1. It is comprised of variables reflecting distance to downtown, land use mix, density, street network density and other factors. Compared to PoorMixed Use/Accessibility (MA) areas, we hypothesize that household VMT will decrease successively from Low- to Moderate- to High-MA areas.

The experimental variable is the distance from the nearest transit station to the CBG or CT. For reasons explained in Chapter 7 , we use 0.125 -mile distance bands to 2.00 miles; thus, all coefficients are interpreted in comparison to all cases beyond 2 miles.

We next outline our analytic strategy.

\section{Analytic Strategy}

We will first present overall regression results for each of the six household types, for each of the 2008-2012 and 2012-2016 ACS-based LAI data. This will include interpretations of those results that will lead to more detailed discussions of implications. 


\section{Results and Interpretations}

Tables 7.3 and 7.4 report our regression results for the ACS 2008-2012 and 2012-2016 periods, respectively. They also report, at the bottom, the mean household income and the share of that income used for transportation based on HUD's LAI data for the respective ACS periods.

We focus on results first for Place Typologies and then for distance bands, for each household type. Our focus is also on just differences in VMT among household types and over time. We will apply transportation cost insights in the concluding section since it is derived from the regression analysis.

These tables show for two important outcomes:

First, compared to Poor-Mixed Use/Accessibility areas, households in census block groups (CBGs) and census tracts (CTs) located in High-, Moderate- and Low-MA areas incurred fewer vehicles miles traveled (VMT) during both periods. Moreover, the higher the degree of mixed use and accessibility, the lower the VMT. This was a trend seen across all household types.

Second, compared to households in CBGs and CTs that are more than 2.00-miles from the nearest light rail transit (LRT) station, VMT is lower. Moreover, in nearly every distance band, VMT is lower successively the closer a CBG or CT is the LRT station. This again applied to all household types.

While these results may seem correct a priori, they are nonetheless the first time these expectations have been confirmed. In other words, popular perceptions are supported by the evidence. That is a good thing. But there are subtleties worth exploring.

Consider the change in VMT over time with respect to Place Typology and household type, as shown in Table 7.5. We see that compared to Poor-MA areas, nearly all household types saw reduced VMT per household between the ACS time periods. The only outliers were SingleParent and Moderate Income households in the High-MA places where their mean household VMT increased by about 11 percent and 14 percent respectively. ${ }^{113}$ In other words, for some reason, these households increased their VMT even while livening in High MA places.

Table 7.6 allows us to drill further down into change in VMT by household type with respect to LRT station proximity, holding such things as Place Typology constant. Here we see that, by and large and certainly within 1.00-mile of LRT stations, Median-Income, Working Individual and Single Professional households enjoyed falling VMT between the study periods. In contrast, the other three household types-Single-Parent, Moderate-Income and Dual-Professional—all saw their VMT increase across nearly all distance bands. Why is this? We offer some insights in the last section of this chapter, which is next.

\footnotetext{
${ }^{113}$ Calculated as one minus the mean VMT for the period 2012-2016 divided by the mean VMT for the period 2008-2012.
} 
Table 7.3

Association between Place Typology and Light Rail Transit Station Proximity with Respect to Vehicle Miles Traveled by Household Type, HUD's Location Affordability Index based on American Community Survey for 2008-2012

\begin{tabular}{|c|c|c|c|c|c|c|}
\hline Variable & $\begin{array}{l}\text { Median- } \\
\text { Income } \mathrm{HH}\end{array}$ & $\begin{array}{l}\text { Working } \\
\text { Individual } \mathrm{HH}\end{array}$ & $\begin{array}{l}\text { Single } \\
\text { Professional } \mathrm{HH}\end{array}$ & $\begin{array}{l}\text { Single- } \\
\text { Parent } \mathrm{HH}\end{array}$ & $\begin{array}{l}\text { Moderate- } \\
\text { Income } \mathrm{HH}\end{array}$ & $\begin{array}{l}\text { Dual- } \\
\text { Professional HH }\end{array}$ \\
\hline Constant & 10.29 & 9.79 & 9.86 & 9.98 & 10.01 & 10.33 \\
\hline \multicolumn{7}{|l|}{ Household Control } \\
\hline Households (log) & $-2.3 \%$ & $-1.6 \%$ & $-2.1 \%$ & $-2.8 \%$ & $-2.9 \%$ & $-2.3 \%$ \\
\hline \multicolumn{7}{|l|}{ Location Control } \\
\hline $\begin{array}{l}\text { Freeway Distance } \\
\text { (miles) }\end{array}$ & $2.7 \%$ & $3.6 \%$ & $3.5 \%$ & $3.5 \%$ & $3.4 \%$ & $2.7 \%$ \\
\hline \multicolumn{7}{|l|}{ Metropolitan Control } \\
\hline Buffalo & $-2.1 \%$ & $-2.4 \%$ & $-2.9 \%$ & $-2.9 \%$ & $-2.9 \%$ & $-2.2 \%$ \\
\hline Charlotte & $3.4 \%$ & $3.6 \%$ & $4.7 \%$ & $3.1 \%$ & $3.5 \%$ & $3.6 \%$ \\
\hline Cleveland & $-3.0 \%$ & $-4.2 \%$ & $-5.1 \%$ & $-3.9 \%$ & $-4.1 \%$ & $-3.2 \%$ \\
\hline Dallas & $5.7 \%$ & $6.4 \%$ & $6.2 \%$ & $6.6 \%$ & $6.5 \%$ & $5.5 \%$ \\
\hline Denver & $3.6 \%$ & $4.1 \%$ & $3.2 \%$ & $4.2 \%$ & $3.9 \%$ & $3.3 \%$ \\
\hline Houston & $1.4 \%$ & $0.4 \%$ & $0.6 \%$ & $0.9 \%$ & $1.0 \%$ & $1.4 \%$ \\
\hline Minneapolis-St. Paul & $-0.1 \%$ & $-1.1 \%$ & $-2.1 \%$ & $-0.9 \%$ & $-1.2 \%$ & $-0.4 \%$ \\
\hline Phoenix & $1.6 \%$ & $1.5 \%$ & $1.2 \%$ & $1.8 \%$ & $1.7 \%$ & $1.5 \%$ \\
\hline Pittsburgh & $-4.3 \%$ & $-5.9 \%$ & $-6.4 \%$ & $-5.3 \%$ & $-5.4 \%$ & $-4.3 \%$ \\
\hline Portland & $2.6 \%$ & $2.2 \%$ & $1.8 \%$ & $3.1 \%$ & $2.9 \%$ & $2.4 \%$ \\
\hline Sacramento & $5.7 \%$ & $6.3 \%$ & $5.9 \%$ & $6.7 \%$ & $6.5 \%$ & $5.4 \%$ \\
\hline Salt Lake City & $4.7 \%$ & $5.2 \%$ & $4.3 \%$ & $5.7 \%$ & $5.3 \%$ & $4.3 \%$ \\
\hline San Diego & $5.0 \%$ & $6.5 \%$ & $6.0 \%$ & $6.0 \%$ & $5.7 \%$ & $4.7 \%$ \\
\hline San Jose & $7.2 \%$ & $8.4 \%$ & $6.7 \%$ & $8.6 \%$ & $7.8 \%$ & $6.6 \%$ \\
\hline Seattle & $-0.2 \%$ & $-1.5 \%$ & $-2.4 \%$ & $-1.0 \%$ & $-1.2 \%$ & $-0.4 \%$ \\
\hline St. Louis & $1.1 \%$ & $1.0 \%$ & $0.7 \%$ & $1.4 \%$ & $1.3 \%$ & $1.0 \%$ \\
\hline
\end{tabular}

Table 7.3 
Association between Place Typology and Light Rail Transit Station Proximity with Respect to Vehicle Miles Traveled by Household Type, HUD's Location Affordability Index based on American Community Survey for 2008-2012—continued

\begin{tabular}{|c|c|c|c|c|c|c|}
\hline Variable & $\begin{array}{l}\text { Median- } \\
\text { Income } \mathrm{HH}\end{array}$ & $\begin{array}{l}\text { Working } \\
\text { Individual } \mathrm{HH}\end{array}$ & $\begin{array}{l}\text { Single } \\
\text { Professional } \mathrm{HH}\end{array}$ & $\begin{array}{l}\text { Single- } \\
\text { Parent HH }\end{array}$ & $\begin{array}{l}\text { Moderate- } \\
\text { Income HH }\end{array}$ & $\begin{array}{l}\text { Dual- } \\
\text { Professional } \mathrm{HH}\end{array}$ \\
\hline \multicolumn{7}{|c|}{ Place Typology Control } \\
\hline Low MA & $-7.8 \%$ & $-9.5 \%$ & $-9.3 \%$ & $-9.7 \%$ & $-9.4 \%$ & $-7.6 \%$ \\
\hline Moderate MA & $-16.8 \%$ & $-20.5 \%$ & $-19.6 \%$ & $-21.4 \%$ & $-20.6 \%$ & $-16.2 \%$ \\
\hline High MA & $-29.2 \%$ & $-36.2 \%$ & $-34.8 \%$ & $-37.9 \%$ & $-36.5 \%$ & $-28.1 \%$ \\
\hline \multicolumn{7}{|c|}{ LRT Distance Band } \\
\hline LRT 0.125 & $-10.7 \%$ & $-14.4 \%$ & $-12.5 \%$ & $-14.8 \%$ & $-13.8 \%$ & $-10.0 \%$ \\
\hline LRT 0.250 & $-12.4 \%$ & $-16.7 \%$ & $-16.0 \%$ & $-16.7 \%$ & $-16.1 \%$ & $-11.9 \%$ \\
\hline LRT 0.375 & $-11.5 \%$ & $-15.5 \%$ & $-15.3 \%$ & $-15.2 \%$ & $-14.8 \%$ & $-11.1 \%$ \\
\hline LRT 0.500 & $-10.6 \%$ & $-14.6 \%$ & $-14.3 \%$ & $-14.2 \%$ & $-13.8 \%$ & $-10.3 \%$ \\
\hline LRT 0.625 & $-10.2 \%$ & $-14.0 \%$ & $-14.2 \%$ & $-13.5 \%$ & $-13.2 \%$ & $-10.0 \%$ \\
\hline LRT 0.750 & $-9.4 \%$ & $-13.0 \%$ & $-12.9 \%$ & $-12.5 \%$ & $-12.2 \%$ & $-9.2 \%$ \\
\hline LRT 0.875 & $-8.9 \%$ & $-12.5 \%$ & $-12.7 \%$ & $-11.8 \%$ & $-11.7 \%$ & $-8.8 \%$ \\
\hline LRT 1.000 & $-8.2 \%$ & $-11.5 \%$ & $-11.6 \%$ & $-11.0 \%$ & $-10.8 \%$ & $-8.1 \%$ \\
\hline LRT 1.125 & $-7.7 \%$ & $-11.0 \%$ & $-11.2 \%$ & $-10.2 \%$ & $-10.1 \%$ & $-7.6 \%$ \\
\hline LRT 1.250 & $-7.3 \%$ & $-10.3 \%$ & $-10.7 \%$ & $-9.5 \%$ & $-9.5 \%$ & $-7.3 \%$ \\
\hline LRT 1.375 & $-6.9 \%$ & $-9.9 \%$ & $-10.1 \%$ & $-9.1 \%$ & $-9.0 \%$ & $-6.8 \%$ \\
\hline LRT 1.500 & $-6.3 \%$ & $-9.1 \%$ & $-9.2 \%$ & $-8.5 \%$ & $-8.4 \%$ & $-6.2 \%$ \\
\hline LRT 1.625 & $-6.1 \%$ & $-8.8 \%$ & $-9.2 \%$ & $-7.9 \%$ & $-7.9 \%$ & $-6.1 \%$ \\
\hline LRT 1.750 & $-5.9 \%$ & $-8.2 \%$ & $-8.2 \%$ & $-7.8 \%$ & $-7.7 \%$ & $-5.8 \%$ \\
\hline LRT 1.875 & $-6.2 \%$ & $-8.7 \%$ & $-9.0 \%$ & $-8.0 \%$ & $-8.0 \%$ & $-6.2 \%$ \\
\hline LRT 2.000 & $-6.7 \%$ & $-9.1 \%$ & $-9.5 \%$ & $-8.6 \%$ & $-8.5 \%$ & $-6.6 \%$ \\
\hline
\end{tabular}

Table 7.3

Association between Place Typology and Light Rail Transit Station Proximity with Respect to Vehicle Miles Traveled by Household Type, HUD's Location Affordability Index based on American Community Survey for 2008-2012—continued 


\begin{tabular}{|c|c|c|c|c|c|c|}
\hline Variable & $\begin{array}{l}\text { Median- } \\
\text { Income HH }\end{array}$ & $\begin{array}{l}\text { Working } \\
\text { Individual } \mathrm{HH}\end{array}$ & $\begin{array}{l}\text { Single } \\
\text { Professional } \mathrm{HH}\end{array}$ & $\begin{array}{l}\text { Single- } \\
\text { Parent HH }\end{array}$ & $\begin{array}{l}\text { Moderate- } \\
\text { Income HH }\end{array}$ & $\begin{array}{l}\text { Dual- } \\
\text { Professio }\end{array}$ \\
\hline \multicolumn{7}{|l|}{ Performance Metrics } \\
\hline Mean Annual VMT & 24,120 & 14,993 & 15,508 & 16,775 & 17,303 & 24,962 \\
\hline Cases & 22,961 & 22,961 & 22,961 & 22,961 & 22,961 & 22,961 \\
\hline $\mathrm{R} 2$ adjusted & 0.474 & 0.489 & 0.476 & 0.473 & 0.474 & 0.472 \\
\hline Standard Error of Estimate & 0.117 & 0.145 & 0.144 & 0.152 & 0.147 & 0.113 \\
\hline F-ratio & 560.852 & 593.813 & 565.078 & 559.055 & 560.808 & 554.642 \\
\hline \multicolumn{7}{|l|}{ Household Metrics } \\
\hline Mean Household Income & $\$ 59,730$ & $\$ 29,865$ & $\$ 80,636$ & $\$ 29,865$ & $\$ 47,784$ & $\$ 85,996$ \\
\hline Mean Annual Trans. Percen & it $21.6 \%$ & $23.2 \%$ & $10.2 \%$ & $29.1 \%$ & $20.0 \%$ & $14.7 \%$ \\
\hline
\end{tabular}

Note: Coefficients in bold are significant at $p<0.10$ of the one-tailed since the direction of association is predicted. 
Table 7.4

Association between Place Typology and Light Rail Transit Station Proximity with Respect to Vehicle Miles Traveled by Household Type, HUD's Location Affordability Index based on American Community Survey for 2012-2016

\begin{tabular}{|c|c|c|c|c|c|c|}
\hline Variable & $\begin{array}{l}\text { Median- } \\
\text { Income HH }\end{array}$ & $\begin{array}{l}\text { Working } \\
\text { Individual } \mathrm{HH}\end{array}$ & $\begin{array}{l}\text { Single } \\
\text { Professional HH }\end{array}$ & $\begin{array}{l}\text { Single- } \\
\text { Parent } \mathrm{HH}\end{array}$ & $\begin{array}{l}\text { Moderate- } \\
\text { Income HH }\end{array}$ & $\begin{array}{l}\text { Dual- } \\
\text { Professional HH }\end{array}$ \\
\hline Constant & 10.29 & 9.73 & 9.85 & 9.93 & 9.97 & 10.30 \\
\hline \multicolumn{7}{|l|}{ Household Control } \\
\hline Households (log) & $0.9 \%$ & $1.7 \%$ & $0.7 \%$ & $0.6 \%$ & $0.6 \%$ & $1.0 \%$ \\
\hline \multicolumn{7}{|l|}{ Location Control } \\
\hline $\begin{array}{l}\text { Freeway Distance } \\
\text { (miles) }\end{array}$ & $2.7 \%$ & $4.2 \%$ & $3.4 \%$ & $2.7 \%$ & $2.5 \%$ & $2.6 \%$ \\
\hline \multicolumn{7}{|l|}{ Metropolitan Control } \\
\hline Buffalo & $-3.0 \%$ & $-4.9 \%$ & $-5.0 \%$ & $-3.7 \%$ & $-3.5 \%$ & $-2.9 \%$ \\
\hline Charlotte & $-3.5 \%$ & $-1.6 \%$ & $-1.0 \%$ & $-0.2 \%$ & $-0.1 \%$ & $-3.4 \%$ \\
\hline Cleveland & $-5.8 \%$ & $-5.7 \%$ & $-5.9 \%$ & $-4.9 \%$ & $-4.6 \%$ & $-5.7 \%$ \\
\hline Dallas & $-1.1 \%$ & $2.0 \%$ & $1.7 \%$ & $2.0 \%$ & $1.9 \%$ & $-1.1 \%$ \\
\hline Denver & $0.4 \%$ & $-1.3 \%$ & $0.1 \%$ & $0.9 \%$ & $0.9 \%$ & $0.4 \%$ \\
\hline Houston & $-7.1 \%$ & $-7.2 \%$ & $-6.2 \%$ & $-3.7 \%$ & $-3.4 \%$ & $-6.9 \%$ \\
\hline Minneapolis-St. Paul & $-5.0 \%$ & $-6.2 \%$ & $-6.5 \%$ & $-3.6 \%$ & $-3.3 \%$ & $-4.8 \%$ \\
\hline Phoenix & $-5.9 \%$ & $-5.3 \%$ & $-4.6 \%$ & $-2.8 \%$ & $-2.5 \%$ & $-5.8 \%$ \\
\hline Pittsburgh & $-9.7 \%$ & $-19.2 \%$ & $-13.5 \%$ & $-10.0 \%$ & $-9.4 \%$ & $-9.5 \%$ \\
\hline Portland & $-2.0 \%$ & $0.5 \%$ & $-1.9 \%$ & $-0.4 \%$ & $-0.3 \%$ & $-2.0 \%$ \\
\hline Sacramento & $1.3 \%$ & $8.5 \%$ & $5.5 \%$ & $5.6 \%$ & $5.2 \%$ & $1.3 \%$ \\
\hline Salt Lake City & $1.9 \%$ & $3.0 \%$ & $0.2 \%$ & $1.3 \%$ & $1.3 \%$ & $1.9 \%$ \\
\hline San Diego & $2.8 \%$ & $11.0 \%$ & $6.8 \%$ & $5.4 \%$ & $5.0 \%$ & $2.8 \%$ \\
\hline San Jose & $3.6 \%$ & $10.4 \%$ & $5.7 \%$ & $5.6 \%$ & $5.4 \%$ & $3.6 \%$ \\
\hline Seattle & $-2.7 \%$ & $-16.4 \%$ & $-3.8 \%$ & $-0.3 \%$ & $-0.1 \%$ & $-2.6 \%$ \\
\hline St. Louis & $-1.2 \%$ & $0.9 \%$ & $-0.6 \%$ & $0.3 \%$ & $0.3 \%$ & $-1.2 \%$ \\
\hline
\end{tabular}


Table 7.4

Association between Place Typology and Light Rail Transit Station Proximity with Respect to Vehicle Miles Traveled by Household Type, HUD's Location Affordability Index based on American Community Survey for 2012-2016—continued

\begin{tabular}{|c|c|c|c|c|c|c|}
\hline Variable & $\begin{array}{l}\text { Median- } \\
\text { Income HH }\end{array}$ & $\begin{array}{l}\text { Working } \\
\text { Individual HH }\end{array}$ & $\begin{array}{l}\text { Single } \\
\text { Professional } \mathrm{HH}\end{array}$ & $\begin{array}{l}\text { Single- } \\
\text { Parent } \mathrm{HH}\end{array}$ & $\begin{array}{l}\text { Moderate- } \\
\text { Income HH }\end{array}$ & $\begin{array}{l}\text { Dual- } \\
\text { Professional HH }\end{array}$ \\
\hline \multicolumn{7}{|c|}{ Place Typology Control } \\
\hline Low MA & $-9.6 \%$ & $-12.9 \%$ & $-11.8 \%$ & $-10.4 \%$ & $-9.8 \%$ & $-9.5 \%$ \\
\hline Moderate MA & $-19.7 \%$ & $-26.4 \%$ & $-23.7 \%$ & $-20.6 \%$ & $-19.4 \%$ & $-19.4 \%$ \\
\hline High MA & $-30.7 \%$ & $-54.4 \%$ & $-38.1 \%$ & $-31.4 \%$ & $-29.4 \%$ & $-30.1 \%$ \\
\hline \multicolumn{7}{|c|}{ LRT Distance Band } \\
\hline LRT 0.125 & $-14.5 \%$ & $-41.8 \%$ & $-22.8 \%$ & $-13.7 \%$ & $-12.3 \%$ & $-13.9 \%$ \\
\hline LRT 0.250 & $-14.1 \%$ & $-32.0 \%$ & $-17.8 \%$ & $-12.9 \%$ & $-11.9 \%$ & $-13.7 \%$ \\
\hline LRT 0.375 & $-14.7 \%$ & $-21.2 \%$ & $-18.0 \%$ & $-13.6 \%$ & $-12.5 \%$ & $-14.3 \%$ \\
\hline LRT 0.500 & $-14.7 \%$ & $-20.9 \%$ & $-17.7 \%$ & $-13.1 \%$ & $-12.1 \%$ & $-14.3 \%$ \\
\hline LRT 0.625 & $-12.6 \%$ & $-15.9 \%$ & $-14.4 \%$ & $-12.0 \%$ & $-11.2 \%$ & $-12.3 \%$ \\
\hline LRT 0.750 & $-11.4 \%$ & $-15.8 \%$ & $-13.5 \%$ & $-10.9 \%$ & $-10.2 \%$ & $-11.2 \%$ \\
\hline LRT 0.875 & $-12.2 \%$ & $-14.8 \%$ & $-13.0 \%$ & $-11.3 \%$ & $-10.5 \%$ & $-12.0 \%$ \\
\hline LRT 1.000 & $-9.9 \%$ & $-15.2 \%$ & $-12.3 \%$ & $-8.8 \%$ & $-8.2 \%$ & $-9.6 \%$ \\
\hline LRT 1.125 & $-9.5 \%$ & $-11.5 \%$ & $-10.4 \%$ & $-8.3 \%$ & $-7.8 \%$ & $-9.3 \%$ \\
\hline LRT 1.250 & $-10.8 \%$ & $-12.4 \%$ & $-11.4 \%$ & $-10.0 \%$ & $-9.5 \%$ & $-10.7 \%$ \\
\hline LRT 1.375 & $-9.0 \%$ & $-12.5 \%$ & $-10.3 \%$ & $-8.4 \%$ & $-8.0 \%$ & $-8.9 \%$ \\
\hline LRT 1.500 & $-7.0 \%$ & $-8.3 \%$ & $-7.4 \%$ & $-6.5 \%$ & $-6.1 \%$ & $-6.9 \%$ \\
\hline LRT 1.625 & $-8.0 \%$ & $-9.5 \%$ & $-8.7 \%$ & $-7.3 \%$ & $-7.0 \%$ & $-7.9 \%$ \\
\hline LRT 1.750 & $-7.2 \%$ & $-23.8 \%$ & $-8.8 \%$ & $-6.8 \%$ & $-6.4 \%$ & $-7.1 \%$ \\
\hline LRT 1.875 & $-7.1 \%$ & $-10.8 \%$ & $-9.7 \%$ & $-7.4 \%$ & $-7.0 \%$ & $-6.9 \%$ \\
\hline LRT 2.000 & $-7.0 \%$ & $-9.4 \%$ & $-7.7 \%$ & $-6.6 \%$ & $-6.3 \%$ & $-6.9 \%$ \\
\hline
\end{tabular}

\section{Table 7.4}


Association between Place Typology and Light Rail Transit Station Proximity with Respect to Vehicle Miles Traveled by Household Type, HUD's Location Affordability Index based on American Community Survey for 2012-2016—continued

\begin{tabular}{|c|c|c|c|c|c|c|}
\hline Variable & $\begin{array}{l}\text { Median- } \\
\text { Income } \mathrm{HH}\end{array}$ & $\begin{array}{l}\text { Working } \\
\text { Individual HH }\end{array}$ & $\begin{array}{l}\text { Single } \\
\text { Professional } \mathrm{HH}\end{array}$ & $\begin{array}{l}\text { Single- } \\
\text { Parent } \mathrm{HH}\end{array}$ & $\begin{array}{l}\text { Moderate- } \\
\text { Income HH }\end{array}$ & $\begin{array}{l}\text { Dual- } \\
\text { Professional HH }\end{array}$ \\
\hline \multicolumn{7}{|l|}{ Performance Metrics } \\
\hline Mean Annual VMT & 26,260 & 14,972 & 16,227 & 18,274 & 19,199 & 26,539 \\
\hline Cases & 8,557 & 8,557 & 8,557 & 8,557 & 8,557 & 8,557 \\
\hline R2 adjusted & 0.514 & 0.633 & 0.425 & 0.468 & 0.468 & 0.515 \\
\hline Standard Error of Estimate & 0.122 & 0.394 & 0.186 & 0.132 & 0.123 & 0.119 \\
\hline F-ratio & 245.959 & 379.498 & 172.074 & 204.543 & 204.493 & 246.256 \\
\hline \multicolumn{7}{|l|}{ Household Metrics } \\
\hline Mean Household Income & $\$ 68,658$ & $\$ 31,829$ & $\$ 85,939$ & $\$ 31,829$ & $\$ 50,927$ & $\$ 95,488$ \\
\hline Mean Annual Trans. Percent & $23.0 \%$ & $27.2 \%$ & $12.1 \%$ & $31.2 \%$ & $21.4 \%$ & $16.1 \%$ \\
\hline
\end{tabular}

Note: Coefficients in bold are significant at $p<0.10$ of the one-tailed since the direction of association is predicted. 
Table 7.5

Ratio of Change in VMT by Place Typology and Household Type between ACS 2008-2012 and ACS 2012-2016

Household Type

Median-Income Family

Working Individual @ 50\% MHHI

Single Professional @ 135\% MHHI

Single Parent Family @ 50\% MHHI

Moderate-Income Family @ 80\%

$\mathrm{MHHI}$

Dual-Professional Family @ 150\%

$\mathrm{MHHI}$

Household Type

Median-Income Family

Working Individual @ 50\% MHHI

Single Professional @ 135\% MHHI

Single Parent Family @ 50\% MHHI

Moderate-Income Family @ 80\%

$\mathrm{MHHI}$

Dual-Professional Family @ 150\%

$\mathrm{MHHI}$

Household Type

Median-Income Family

Working Individual @ 50\% MHHI

Single Professional @ 135\% MHHI

Single Parent Family @ 50\% MHHI

Moderate-Income Family @ 80\%

$\mathrm{MHHI}$

Dual-Professional Family @ 150\%

$\mathrm{MHHI}$
High-Mixed Use/Accessibility Areas

ACS 2008-2012 ACS 2012-2016

$-6.3 \%$

$-7.1 \%$

Change Ratio

$-8.4 \%$

$-14.8 \%$

1.12

$-3.5 \%$

$-4.6 \%$

1.76

$-11.0 \%$

$-9.8 \%$

1.30

0.89

$\begin{array}{lll}-7.3 \% & -6.3 \% & 0.86\end{array}$

$-4.1 \%$

$-4.8 \%$

1.17

Moderate-Mixed Use/Accessibility Areas

ACS 2008-2012 ACS 2012-2016 Change Ratio

$-3.6 \% \quad-4.5 \% \quad 1.25$

$-4.8 \% \quad-7.2 \% \quad 1.51$

$\begin{array}{lll}-2.0 \% & -2.9 \% & 1.43\end{array}$

$\begin{array}{lll}-6.2 \% & -6.4 \% & 1.03\end{array}$

$\begin{array}{lll}-4.1 \% & -4.2 \% & 1.01\end{array}$

$\begin{array}{lll}-2.4 \% & -3.1 \% & 1.31\end{array}$

Low-Mixed Use/Accessibility Areas

ACS 2008-2012 ACS 2012-2016 Change Ratio

$-1.7 \% \quad-2.2 \% \quad 1.31$

$\begin{array}{lll}-2.2 \% & -3.5 \% & 1.59\end{array}$

$-0.9 \% \quad-1.4 \% \quad 1.51$

$-2.8 \% \quad-3.2 \% \quad 1.15$

$-1.9 \% \quad-2.1 \% \quad 1.12$

$\begin{array}{lll}-1.1 \% & -1.5 \% & 1.37\end{array}$

Note: In this context, since all figures are coefficients from the above tables and all are negative meaning vehicle miles traveled (VMT) is below the mean, bold means VMT for the respective household type fell within the Place Typology from the ACS 2008-2012 to ACS 2012-2016 periods while bold red means VMT increased. 
Table 7.6

Ratio of Change in VMT by Light Rail Transit Station Distance Band and by Household Metrics by Household Type between ACS 2008-2012 and ACS 2012-2016 


\section{Implications for Transit and Land Use Planning}

We conclude this chapter by creating graphics derived from other tables to illustrate the differences in the share of income devoted to transportation and how that share has changed over time, by household type, and with respect to LRT distance band. This will lead to implications for transit and land use planning with special reference to social equity.

We divide this part of the chapter into two subsections. The first draws implications for locations near LRT transit stations as well as the kind of place on chooses to live. The second examines implications for households that may be displaced by those who are able to locate where savings are the largest.

\section{Light Rail Transit Station Proximity and Place Typology}

Here is how the calculations are done. We adjust the regression coefficients to reflect the share of the regional typical household budget savings with respect to transit station proximity. This is simply the coefficient for a given distance band multiplied by the mean household transportation cost for those households as a whole. For instance, for LRT systems in the ACS 2008-2012 table (6.3) in the first (0.125-mile) distance band for the mean income household, the coefficient is $-10.7 \%$. Multiplying this by the mean household transportation budget of $21.6 \%$ means that there is an overall savings of 2.3 percent for mean income households living in this distance band. For the ACS 2012-2016 table 6.4, the coefficient is 14.5 percent so with a budget share of 23.0 percent the distance band-related savings are 3.3 percent or nearly 50 percent higher.

While a 3.3 percent savings in the total household budget if one lives in the first (0.125-mile) distance band from an LRT station, it is not trivial. And, it is added to the Place Typology. Suppose this household lived in a High MA place. The incremental savings would be 30.7 percent based on the place times the median income transportation budget, being 23.0 percent times $\$ 68,658$. Together, the transportation cost savings to the Median Income household would be 14.5 percent for living in the first $(0.125$-mile) distance band plus 30.7 percent for living in a High MA place, for a total of 45.2 percent times the 23.0 percent is spends on transportation times its budget of $\$ 68,658$ for a total savings of:

$$
[(14.5 \%+30.7 \%) \times(23 \% \times \$ 68,658)]=\$ 7,138 / \text { year }
$$

Assuming about a third of these savings can be used to support a mortgage at the 2020 rate of 2.25 percent, this household could add $\$ 100,000$ to their mortgage and be no worse off financially.

Figures 7.1 through 7.6 illustrate the effect of LRT station distance on only the transportation share of the household budget regardless of their Place Typology, for the ACS 2008-2012 and ACS 2012-2016 periods. We offer interpretations and implications for each here.

\section{Median-Income Household}

Figure 6.1 shows that these households enjoy lower VMT and lower transportation costs the closer they are to LRT stations. And their savings has increased between the two time periods with savings accelerating near LRT stations - this is shown as the bold line for ACS 2012-2016 is lower than that for the lighter line for ACS 2008-2012. 


\section{Working Individual @ 50\% MHHI}

As shown in Figure 6.2, these households have gained considerable transportation cost savings between ACS 2008-2012 and ACS 2012-2016 in the first three distance bands, to 0.375-mile from LRT stations. Thereafter, the gain in savings between the two study periods is modest though not trivial. (We cannot explain the anomalous dip at the 0.175 -mile distance band.) Combined with being in High MA places, these households save the most in transportation costs being close to LRT stations. It is also remarkable that this is the lowest income group studied. It is also likely they are predominantly renters occupying small units close to transit and high activity centers.

\section{Single Professionals @ 135\% MHHI}

In a sense, these are households with the most choices because of their higher incomes and presumably fewer household obligations than other household types. Then would be expected to gravitate to transit stations as well as locate in High MAS areas. This is borne out by tables 6.3 and 6.4 above, and by Figure 6.3 below. Although ostensibly their transportation costs savings might be the most modest because such accounts for only 12.1 percent of their total budget, in the ACS 2012-2016 period, they still realize more than 60 percent savings when living in the first (0.125-mile) distance band and High MA places. Given their higher incomes, total household savings would be in the range of $\$ 11,000$, the most of any household group. Allocating one third of that to a mortgaged based on 2020 rates could increase the mortgage by nearly $\$ 150,000$.

\section{Single Parent Family @ 50\% MHHI}

These are perhaps the most challenged households as they have the lowest budgets with the highest transportation cost share at $\$ 31,829$ and 31.2 percent in the ACS 2012-2016, respectively. Table 6.6 also shows that their VMT has also increased between the study periods. Figure 6.4 also shows the trend where transportation cost savings with respect to LRT station proximity has eroded compared to the first three groups. We surmise that these households are being displaced from locations with lower transportation costs, which is also suggested in Table 6.5 .

\section{Moderate-Income Family @ 80\% MHHI}

With the second lowest income of the household types included in this study, these households may be nearly as challenged as single parent households, although their transportation cost share is about in the middle of the five other groups. Nonetheless, Tables 6.5 and 6.6 show they are similar to single parent households. While Figure 6.5 is not as pronounced as that for single parent households, it would seem that perhaps moderate income households are also being displaced from locations near LRT transit as well as in High MA areas.

\section{Dual-Professional Family @ 150\% MHHI}

While these households have the highest incomes of the types we used in this analysis, their transportation costs are nearly the highest as well. One challenge these households may face is finding a location that meets the needs of both professionals. Although Table 6.6 shows that their annual VMT increased between the study periods, Figure 6.6 nonetheless shows that they gain considerable savings when locating near LRT transit stations, and especially if they also live in High MA areas.

Our analysis reveals that there can be considerable transportation cost savings when locating near LRT stations and especially when also locating in High MA areas but only to some households and notably not to others. We discuss these implications next. 


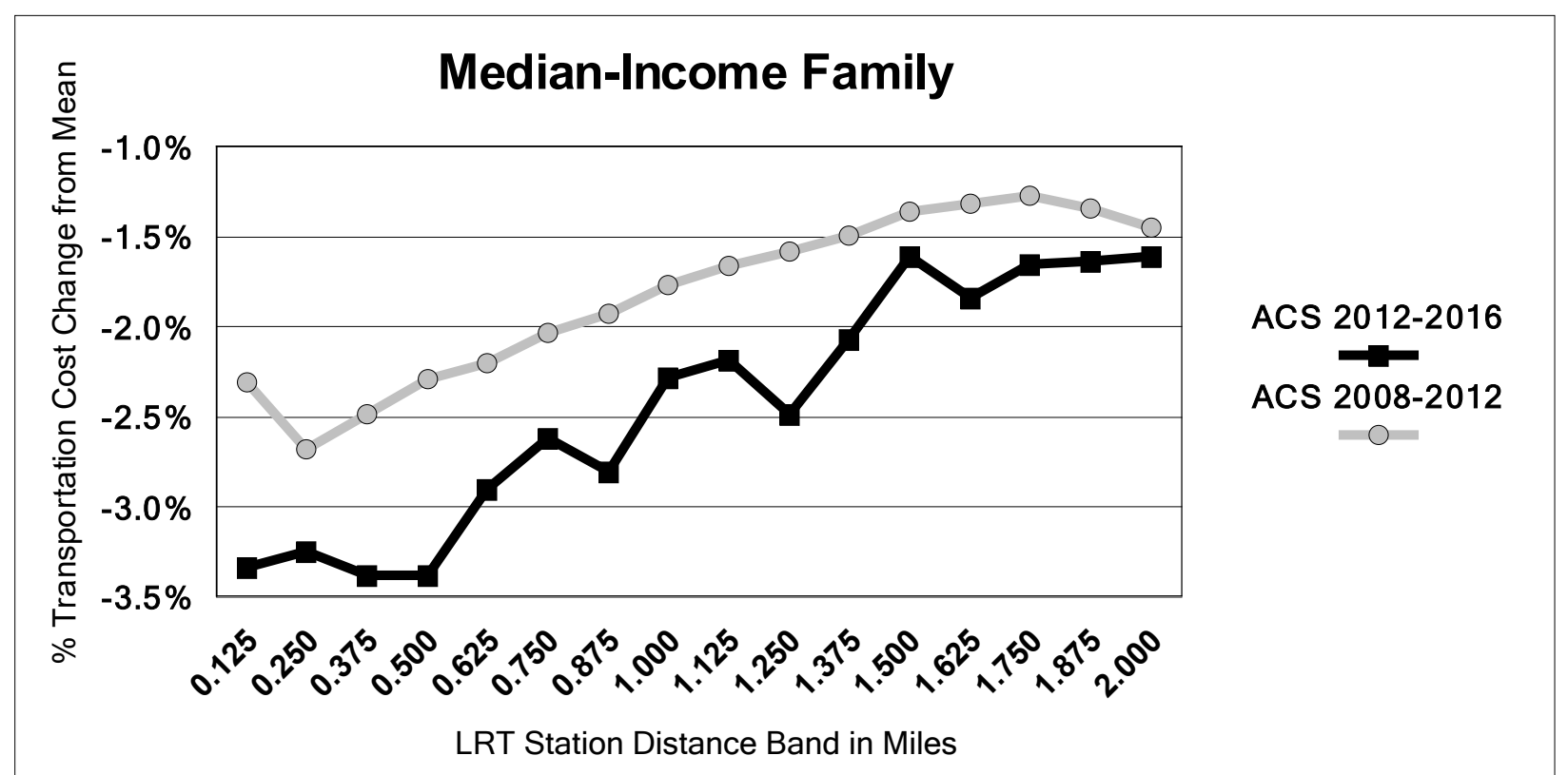

Figure 7.1

Median-Income family household budget savings attributable to transportation cost savings by location in LRT distance band by between ACS 2008-2012 and ACS 2012-2016 


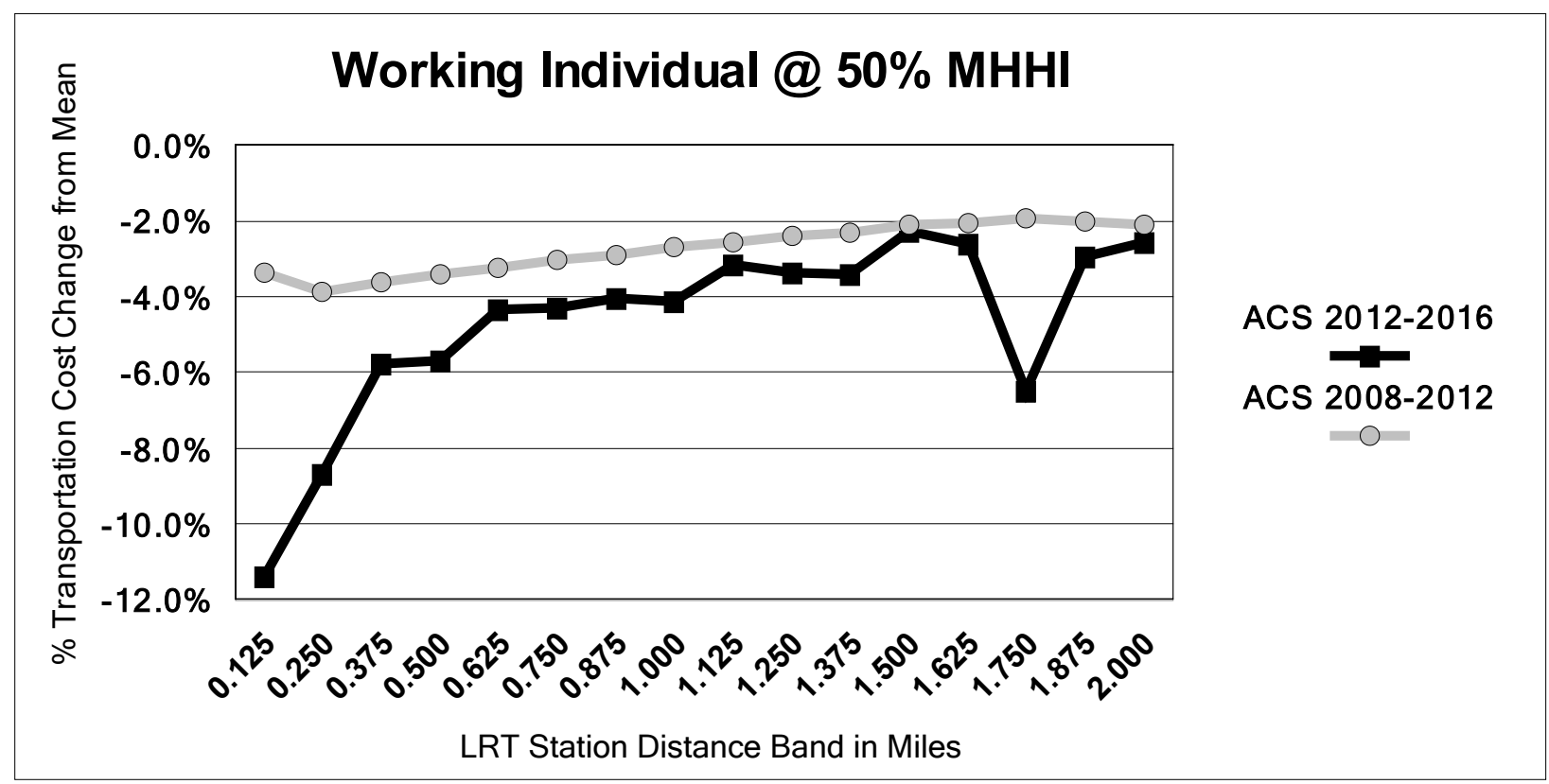

Figure 7.2

Working Individual household budget savings attributable to transportation cost savings by location in LRT distance band by between ACS 2008-2012 and ACS 2012-2016 


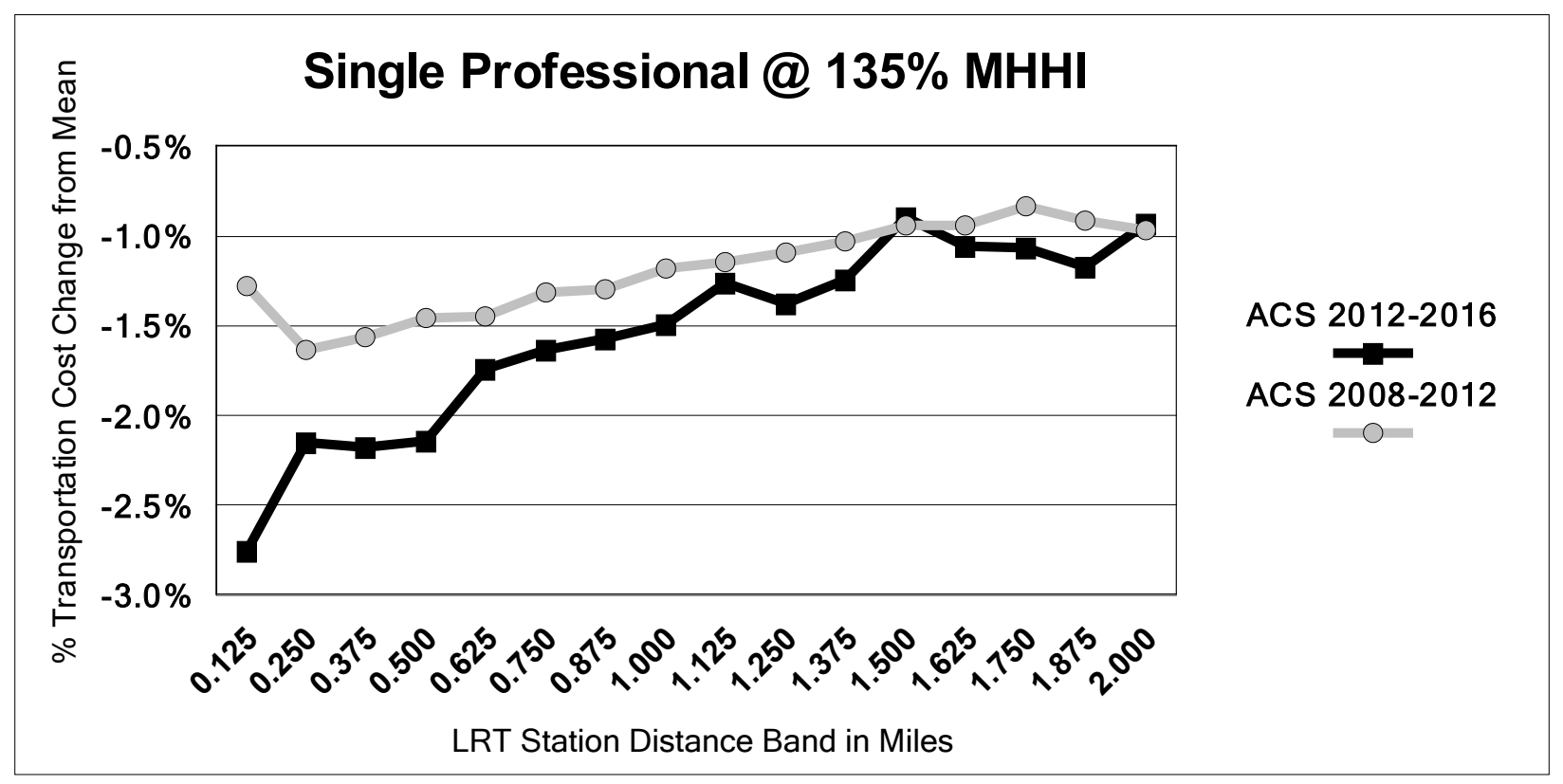

Figure 7.3

Single Professional household budget savings attributable to transportation cost savings by location in LRT distance band by between ACS 2008-2012 and ACS 2012-2016 


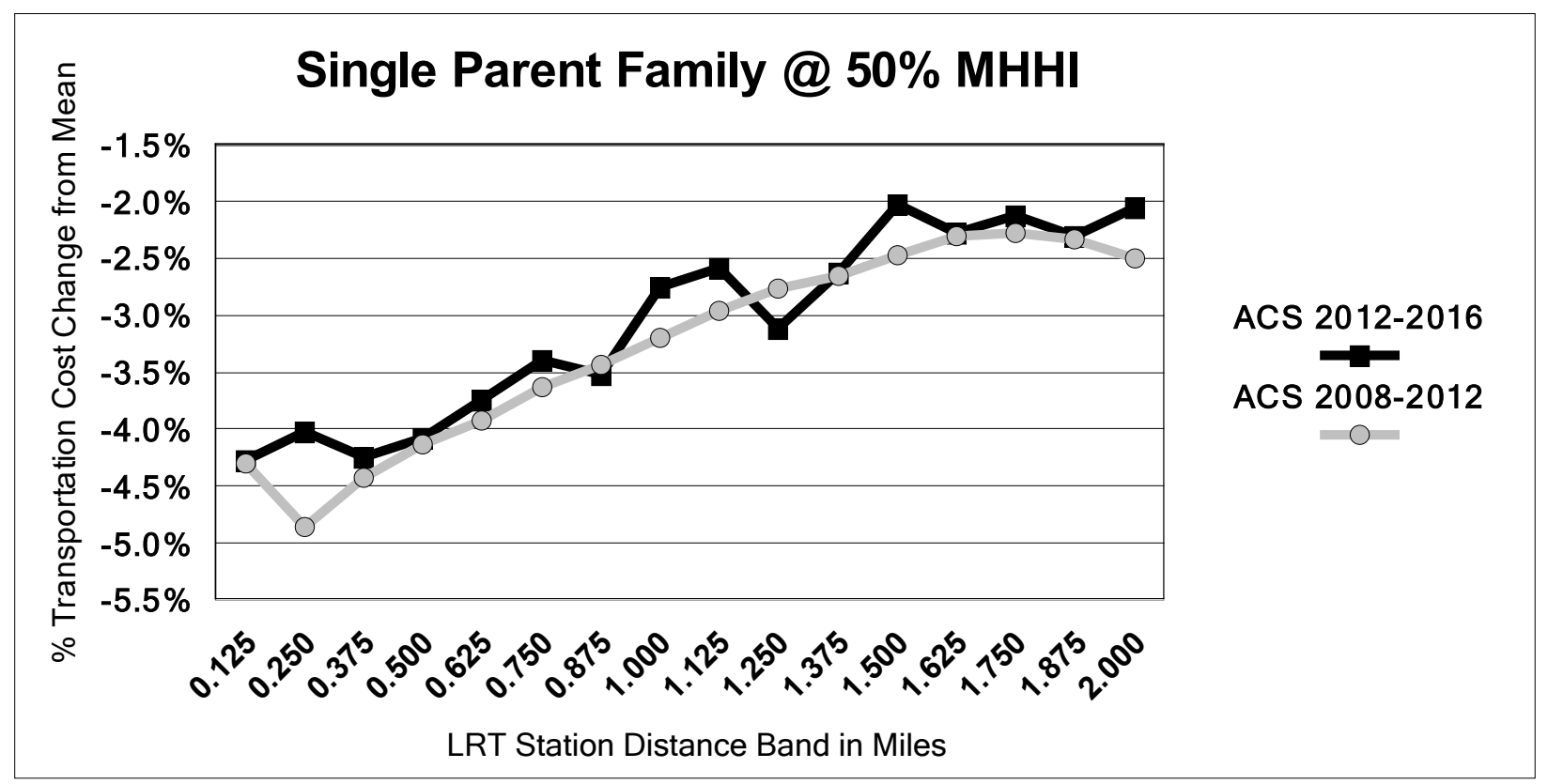

Figure 7.4

Single Parent family household budget savings attributable to transportation cost savings by location in LRT distance band by between ACS 2008-2012 and ACS 2012-2016 


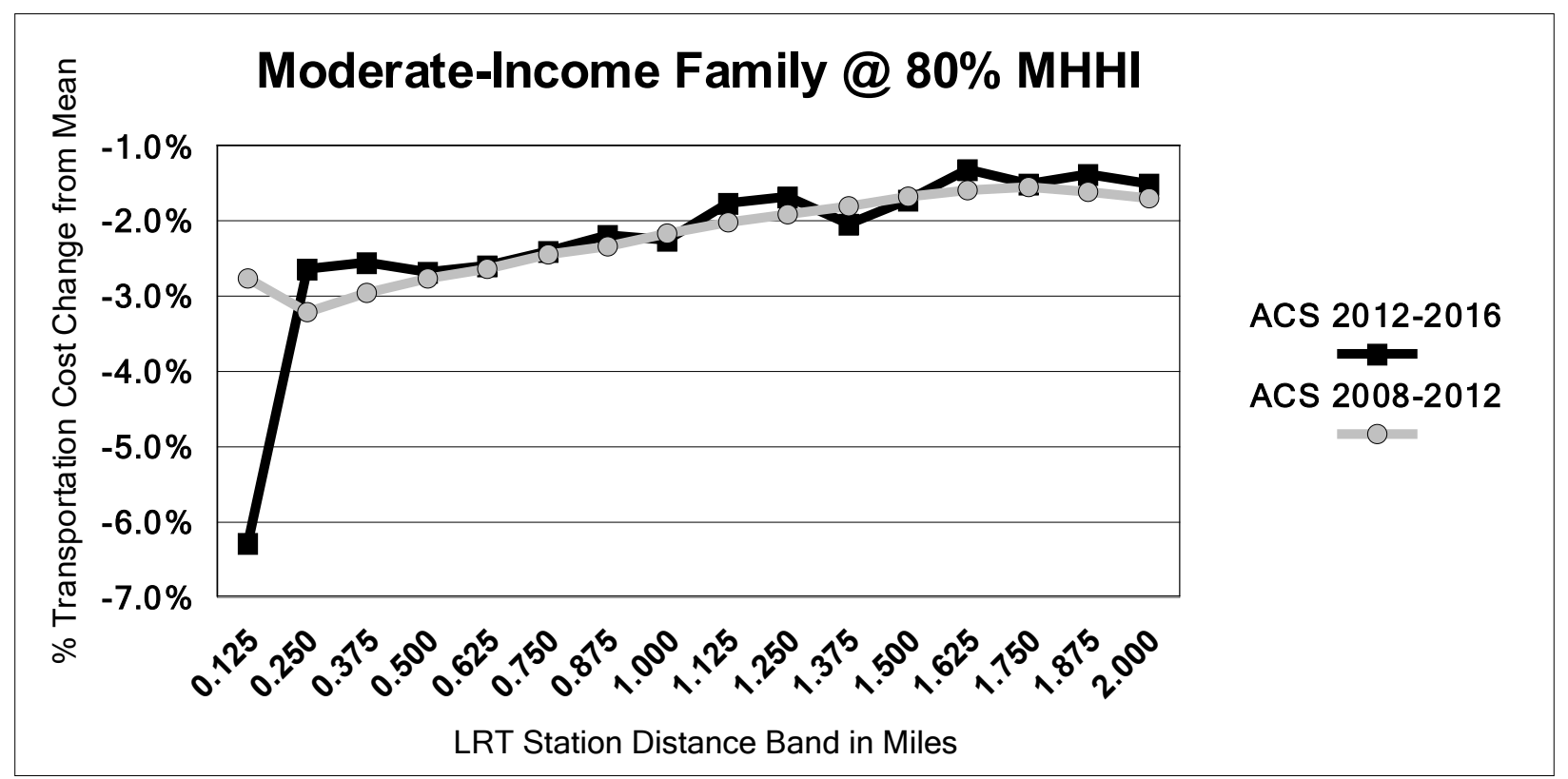

Figure 7.5

Moderate-Income family household budget savings attributable to transportation cost savings by location in LRT distance band by between ACS 2008-2012 and ACS 2012-2016 


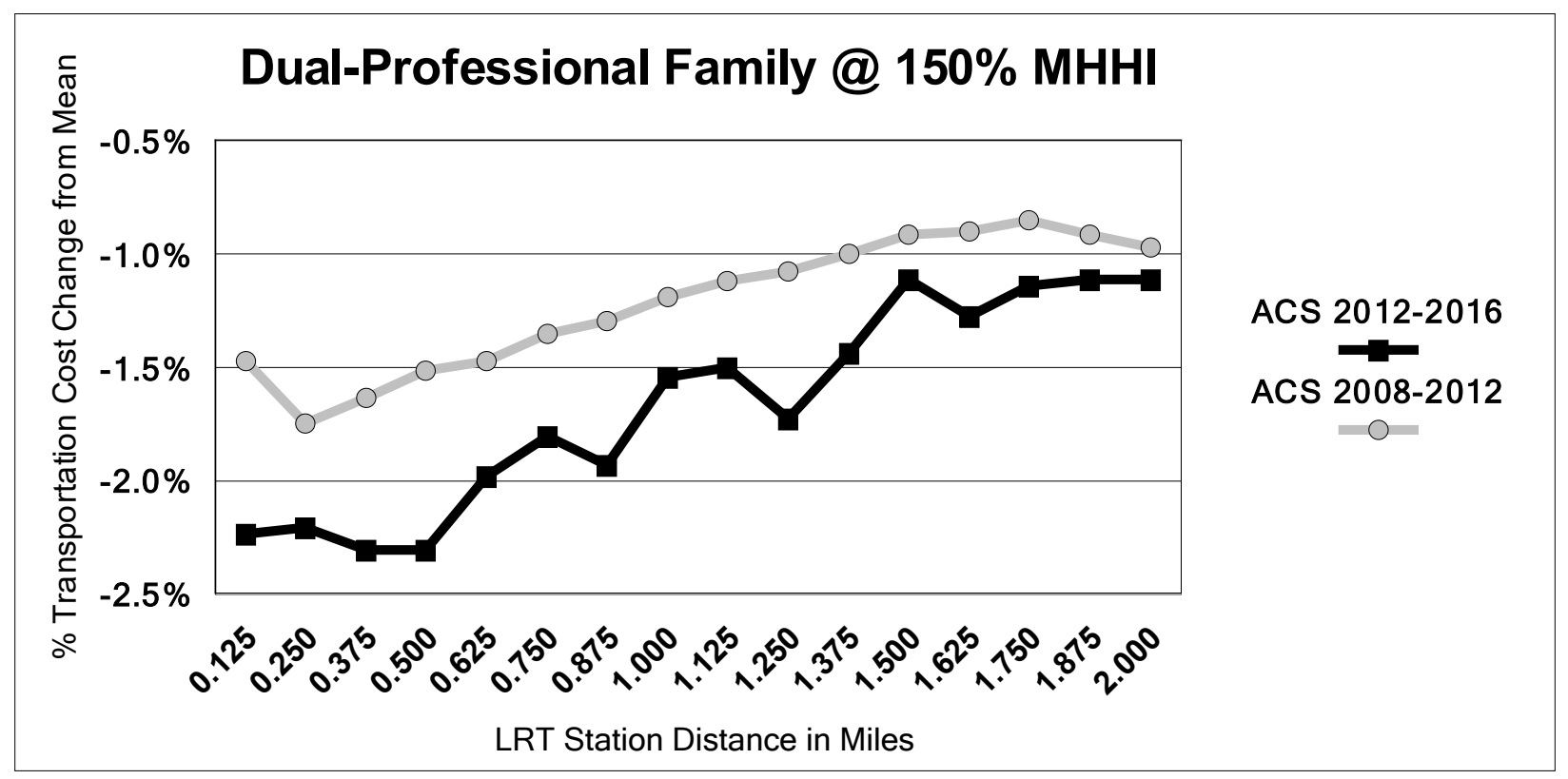

Figure 7.6

Dual-Professional amily household budget savings attributable to transportation cost savings by location in LRT distance band by between ACS 2008-2012 and ACS 2012-2016 


\section{Implications for Selected Households}

First of all, our findings may be used to relax early efforts to calibrate location-efficient mortgages (LEM). For the most part, the LEM calculations were weighted substantially toward the central business district. Considering just this limitation, research by Blackman and Krupnick (2001) conclude that LEMs do not raise mortgage default rates and should be weighed against anti-sprawl benefits they may offer. We suspect default rates will be lower the closer properties are to LRT stations. Further research may explore the relationship between proximity to LRT stations if not all fixed guideway transit stations and foreclosure rates. ${ }^{114}$

Secondly, assumptions about planning land uses around FRT stations may need to be relaxed. The so-called half-mile circle planning area has coming under increasing challenge with studies_including our own (see also Petheram 2013, Nelson et al. 2015, Nelson and Hibberd 2019) - showing market responsiveness transit station proximity up to 2 miles. Our empirical analysis suggests that FRT station planning protocols may need to extend many miles from stations.

These improvements aside, it may be the case that interventions are needed to make it possible for some households who wish to locate near transit and in higher MA areas but cannot compete with other households. They could be made financially and socially worse off as a consequence.

As Makarewicz, Dantzler and Adkins (2020) admonish, it may be (past) time to accelerate efforts to improve inclusionary housing especially near transit and in higher mixeduse/accessibility areas. But how? Their review of literature offers selected approaches we elaborate on here.

A simple(-minded?) approach is to increase the supply of housing, especially accessory dwelling units and other forms of "missing middle housing" (Parolek with Nelson 2020). We note that several cities (notably Minneapolis, Portland and Seattle) have expanded the range of residential options in formerly single-family residential districts, and one entire state (Oregon) has essentially banned exclusive single-family zoning.

An oft overlooked opportunity to increase density is simple to rebalance population especially near transit and other service amenities. The population in Minneapolis, for instance, has stayed about the same between 1970 and 2020 at about 440,000 residents. Yet it added nearly 30,000 housing units. The reason is declining household size. Most mature urban areas have fewer people living in them now than a generation ago. The creates excessive infrastructure capacity that is expensive to maintain. And economic development opportunities are lost. Part of Portland's middle housing objective is to repopulate mature neighborhoods to their former levels through a range of middle housing options, especially near transit stations. Salt Lake City's accessory dwelling unit policy also favors ADUs near transit.

Local and state governments may also need to expand the supply of deeply subsidized affordable housing in location efficient areas. This achieves two objectives: reduces density-

\footnotetext{
${ }^{114}$ We conducted an indirect test of this is using our data through a bivariate regression where Vacancy Rate (VR) as a proxy for foreclosure potential is a function of LRT station distance: VR $=10.344+$ LRTStation-Distance*-0.626, $\mathrm{p}<0.001$.
} 
based public costs-indeed cost savings might be a source of subsidies and diversifies the community-based labor force.

We note that the nation will add about 100 million people between now and mid-century. One of us (Nelson 2013) has estimated that about a quarter of American households want to live near fixed guideway transit opportunities though less than 10 percent have those options now. Perhaps one reason is that Americans understand the cost savings associated with living near transit stations. Yet, even if all new homes built between now and mid-century were located near existing or planned fixed-guideway transit stations the demand for living near those stations would still not be met. 


\section{REFERENCES}

Alonso, William (1964). Location and Land Use: Toward a General Theory of Land Rent. Cambridge, MA: Harvard University Press.

Angel, Shlomo and Alejandro M. Blei (2015). Commuting and the Productivity of American Cities. New York: New York University, Marron Institute of Urban Management.

Blackman, Allen and Alan Krupnick (2001). Location Efficient Mortgages: Is the Rationale Sound? Baltimore, MD: Resources for the Future.

Blais, Pamela (2010). Perverse Cities: Hidden Subsidies, Wonky Policy, and Urban Sprawl. Vancouver, BC: University of British Columbia.

Center for Housing Policy (2006). A Heavy Load: The Combined Housing and Transportation Burdens of Working Families. Washington, DC: Center for Housing Policy

Emrath, Paul and Natalia Siniavskaia (2009). Household Type, Housing Choice, and Commuting Behavior. Washington, DC: National Association of Home Builders.

Ewing, Reid and Shima Hamidi (2015). How Affordable is HUD Affordable Housing? Portland, OR: Portland State University, National Institute for Transportation and Communities.

Fan, Yingling and Arthur Huang (2012). How Affordable is Transportation? A Context-Sensitive Framework. Minneapolis, MN: University of Minnesota, Humphrey School of Public Affairs.

Gallagher, Leigh (2014). The End of the Suburbs. New York, NY: Portfolio

Galster, George and Jackie Cutsinger (2007). Racial Settlement and Metropolitan Land Use Patterns:

Does Sprawl Abet Black-White Segregation? Urban Geography 28(6): 515-553.

Haas, Peter M., Carrie Makarewicz, Albert Benedict, and Scott Bernstein (2008). Estimating Transportation Costs by Characteristics of Neighborhood and Household. Transportation Research Record: Journal of the Transportation Research Board, 2077: 62-70.

Hicky, Robert, Jeffrey Lubell, Peter Haas, Stephanie Morse (2012). Losing Ground: The Struggle of Moderate-Income Households to Afford the Rising Costs of Housing and Transportation. Washington, DC: Center for Housing Policy and Chicago, IL: Center for Neighborhood Technology.

Higgins, C. D. and P. S. Kanaroglou (2016). Forty years of modelling rapid transit's land value uplift in North America: moving beyond the tip of the iceberg, Transport Reviews, 36:5, 610-634, DOI: $\underline{10.1080 / 01441647.2016 .1174748 .}$

Housing and Urban Development, Department of (ca 2015). Data and Methodology: Location Affordability Index Version 2.0. Washington DC: Office of Policy Development and Research, USHUD.

Makarewicz, Carrie, Prentiss Dantzler \& Arlie Adkins (2020) Another Look at Location Affordability: Understanding the Detailed Effects of Income and Urban Form on Housing and Transportation Expenditures, Housing Policy Debate, 30:6, 1033-1055, DOI: 10.1080/10511482.2020.1792528 
Mills, Edwin S. (1967). An Aggregative Model of Resource Allocation in a Metropolitan Area. American Economic Review (Papers and Proceedings) 57(2):197-210.

Muth, Richard F. 1969. Cities and Housing. Chicago: University of Chicago Press.

Nelson, Arthur C., Dejan Eskic, Shima Hamidi, Susan J. Petheram, Reid Ewing, Jenny H. Liu (2015). Office Rent Premiums with Respect to Light Rail Transit Stations: Case Study of Dallas with Implications for TOD Planning. Transportation Research Record: Journal of the Transportation Research Board (forthcoming).

Nelson, Arthur C., Gail Meakins, Deanne Eeber, Shyam Kannan, Reid Ewing (2013). The Tragedy of the Unmet Demand for Walking and Biking. The Urban Lawyer. 45(3): 615-630.

Parolek, Dan with Arthur C. Nelson (2020) Missing Middle Housing. Washington, DC: Island Press.

Petheram, Susan J., Arthur C. Nelson, Matt Miller, and Reid Ewing (2013). Use of the Real Estate Market to Establish Light Rail Station Catchment Areas Case Study of Attached Residential Property Values in Salt Lake County, Utah, by Light Rail Station Distance. Transportation Research Record: Journal of the Transportation Research Board, 2357: 95-99.

Redding, Stephen J. and Matthew A. Turner (2014). Transportation Costs and the Spatial Organization of Economic Activity. National Bureau of Economic Research Work Paper 20235. Cambridge, MA: National Bureau of Economic Research.

Reichenberger, Adam (2012). A comparison of 25 years of consumer expenditures by homeowners and renters. Beyond the Numbers 1(15): 1-8.

Stoker, Philip and Reid Ewing (2014). Job-Worker Balance and Income Match in the United States. Housing Policy Debate 24 (2): 485-497. 


\section{APPENDIX F: Supplemental Tables for Chapter 5}

Appendix $F$ is for chapter 5 . All study tables are significance tested. All z scores denote significance at the .10 level for 2-tailed test.

Table 5A.1. Poor MA: BRT, Tenure by Vehicle Presence

\begin{tabular}{|c|c|c|c|c|c|c|c|c|c|c|c|c|}
\hline $\begin{array}{l}\text { Demographic } \\
\text { Incremental }\end{array}$ & e & 2-2 & & & & & $\begin{array}{l}\text { Cumu } \\
\text { lative }\end{array}$ & & & & & \\
\hline Tenure by & & & & & & & & & & & & \\
\hline $\begin{array}{l}\text { Vehicle } \\
\text { Presence }\end{array}$ & $\begin{array}{l}0.12 \\
5\end{array}$ & 0.25 & $\begin{array}{l}0.37 \\
5\end{array}$ & 0.5 & 0.75 & 1 & 0.125 & 0.25 & $\begin{array}{l}0.37 \\
5\end{array}$ & 0.5 & 0.75 & 1 \\
\hline $\begin{array}{l}\text { Owner } \\
\text { Occupied }\end{array}$ & $\begin{array}{l}(6,10 \\
4)\end{array}$ & $\begin{array}{l}1,98 \\
0\end{array}$ & $(721$ & $\begin{array}{l}(1,7 \\
76)\end{array}$ & $\begin{array}{l}4,93 \\
0\end{array}$ & $\begin{array}{l}(1,5 \\
74)\end{array}$ & $\begin{array}{l}(6,10 \\
4)\end{array}$ & $\begin{array}{l}(4,12 \\
4)\end{array}$ & $\begin{array}{l}(4,84 \\
5)\end{array}$ & $\begin{array}{l}\text { (6,62 } \\
1)\end{array}$ & $\begin{array}{l}(1,69 \\
1)\end{array}$ & $\begin{array}{l}(3,26 \\
5)\end{array}$ \\
\hline $\begin{array}{l}\text { Renter } \\
\text { Occupied }\end{array}$ & $\begin{array}{l}1,96 \\
0)\end{array}$ & 111 & 151 & )$^{(761}$ & 419 & $\begin{array}{l}(2,9 \\
49)\end{array}$ & $\begin{array}{l}(1,96 \\
0)\end{array}$ & $\begin{array}{l}(1,84 \\
9)\end{array}$ & $\begin{array}{l}(1,69 \\
8)\end{array}$ & $\begin{array}{l}\text { (2,45 } \\
9)\end{array}$ & $\begin{array}{l}(2,04 \\
0)\end{array}$ & $\begin{array}{l}(4,98 \\
9)\end{array}$ \\
\hline $\begin{array}{l}\text { Total Housing } \\
\text { Units }\end{array}$ & $\begin{array}{l}(8,06 \\
4)\end{array}$ & $\begin{array}{l}2,09 \\
1\end{array}$ & )$^{(570}$ & $\begin{array}{l}(2,5 \\
37)\end{array}$ & $\begin{array}{l}5,34 \\
9\end{array}$ & $\begin{array}{l}(1,5 \\
74)\end{array}$ & $\begin{array}{l}(8,06 \\
4)\end{array}$ & $\begin{array}{l}(5,97 \\
3)\end{array}$ & $\begin{array}{l}(6,54 \\
3)\end{array}$ & $\begin{array}{l}(9,08 \\
0)\end{array}$ & $\begin{array}{l}(3,73 \\
1)\end{array}$ & $\begin{array}{l}(5,30 \\
5)\end{array}$ \\
\hline $\begin{array}{l}\text { Owner Occ No } \\
\text { Veh }\end{array}$ & (229) & 4 & 124 & (13) & 24 & $\begin{array}{l}(1,2 \\
90)\end{array}$ & (229) & (225) & (101) & (114) & (90) & $\begin{array}{l}(1,38 \\
0)\end{array}$ \\
\hline $\begin{array}{l}\text { Owner } \\
\text { Occupied Veh }\end{array}$ & $\begin{array}{l}67,7 \\
28\end{array}$ & $\begin{array}{l}18,3 \\
88\end{array}$ & $\begin{array}{l}25,7 \\
87\end{array}$ & $\begin{array}{l}21,7 \\
93\end{array}$ & $\begin{array}{l}27,7 \\
28\end{array}$ & $\begin{array}{l}(2,8 \\
64) \\
\end{array}$ & $\begin{array}{l}67,72 \\
8\end{array}$ & $\begin{array}{l}86,1 \\
16\end{array}$ & $\begin{array}{l}111 \\
903\end{array}$ & $\begin{array}{l}133 \\
696\end{array}$ & $\begin{array}{l}161 \\
424\end{array}$ & $\begin{array}{l}158 \\
560\end{array}$ \\
\hline $\begin{array}{l}\text { Renter Occ No } \\
\text { Veh }\end{array}$ & 408 & 232 & 385 & 579 & )$^{(246}$ & )$^{(170}$ & 408 & 640 & $\begin{array}{l}1,02 \\
5\end{array}$ & $\begin{array}{l}1,60 \\
4\end{array}$ & $\begin{array}{l}1,35 \\
8\end{array}$ & $\begin{array}{l}1,18 \\
8\end{array}$ \\
\hline $\begin{array}{l}\text { Renter } \\
\text { Occupied Veh }\end{array}$ & $\begin{array}{l}(141, \\
908)\end{array}$ & $\begin{array}{l}31, \\
003)\end{array}$ & $\begin{array}{l}48, \\
011) \\
\end{array}$ & $\begin{array}{l}(46, \\
133) \\
\end{array}$ & $\begin{array}{l}45 \\
062) \\
\end{array}$ & $\begin{array}{l}16,6 \\
91 \\
\end{array}$ & $\begin{array}{l}(141, \\
908)\end{array}$ & $\begin{array}{l}(172, \\
911)\end{array}$ & $\begin{array}{l}(220, \\
922)\end{array}$ & $\begin{array}{l}(267, \\
055)\end{array}$ & $\begin{array}{l}(312, \\
117)\end{array}$ & $\begin{array}{l}(295, \\
426)\end{array}$ \\
\hline $\begin{array}{l}\text { Total Housing } \\
\text { Units }\end{array}$ & $\begin{array}{l}74,0 \\
01) \\
\end{array}$ & $\begin{array}{l}(12, \\
379)\end{array}$ & $\begin{array}{l}(21 \\
715) \\
\end{array}$ & $\begin{array}{l}(23 \\
774) \\
\end{array}$ & $\begin{array}{l}(17, \\
556)\end{array}$ & (89) & $\begin{array}{l}(74,0 \\
01)\end{array}$ & $\begin{array}{l}(86,3 \\
80)\end{array}$ & $\begin{array}{l}(108, \\
095)\end{array}$ & $\begin{array}{l}(131, \\
869)\end{array}$ & $\begin{array}{l}(149, \\
425)\end{array}$ & $\begin{array}{l}(149, \\
514)\end{array}$ \\
\hline $\begin{array}{l}\text { Households No } \\
\text { Veh }\end{array}$ & 179 & 236 & 509 & 566 & )$^{(222}$ & $\begin{array}{l}(37 \\
721)\end{array}$ & 179 & 415 & 924 & $\begin{array}{l}1,49 \\
0\end{array}$ & $\begin{array}{l}1,26 \\
8\end{array}$ & $\begin{array}{l}(36,4 \\
53)\end{array}$ \\
\hline $\begin{array}{l}\text { Households } \\
\text { with Veh }\end{array}$ & $\begin{array}{l}(74,1 \\
80)\end{array}$ & $\begin{array}{l}12, \\
615) \\
\end{array}$ & $\begin{array}{l}(22, \\
224) \\
\end{array}$ & $\begin{array}{l}24 \\
340) \\
\end{array}$ & $\begin{array}{l}117 \\
334) \\
\end{array}$ & $\begin{array}{l}(21, \\
289) \\
\end{array}$ & $\begin{array}{l}(74,1 \\
80) \\
\end{array}$ & $\begin{array}{l}(86,7 \\
95) \\
\end{array}$ & $\begin{array}{l}109, \\
019)\end{array}$ & $\begin{array}{l}133, \\
359)\end{array}$ & $\begin{array}{l}(150, \\
693)\end{array}$ & $\begin{array}{l}171, \\
982)\end{array}$ \\
\hline$\frac{\text { Total Housing }}{\text { Units }}$ & $\begin{array}{l}(74,0 \\
01)\end{array}$ & $\begin{array}{l}(12, \\
379)\end{array}$ & $\begin{array}{l}(21 \\
715)\end{array}$ & $\begin{array}{l}(23 \\
774)\end{array}$ & $\begin{array}{l}(17, \\
556)\end{array}$ & $(259$ & $\begin{array}{l}(74,0 \\
01)\end{array}$ & $\begin{array}{l}(86,3 \\
80)\end{array}$ & $\begin{array}{l}(108, \\
095)\end{array}$ & $\begin{array}{l}(131, \\
869)\end{array}$ & $\begin{array}{l}(149, \\
425)\end{array}$ & $\begin{array}{l}(149, \\
684)\end{array}$ \\
\hline $\begin{array}{l}\text { Percent Demos } \\
2016 \text { - Increme }\end{array}$ & 1 & 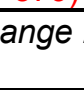 & 010 & & & & $\begin{array}{l}\text { Cumu } \\
\text { lative }\end{array}$ & & & & & \\
\hline $\begin{array}{l}\text { Tenure by } \\
\text { Vehicle } \\
\text { Presence }\end{array}$ & $\begin{array}{l}0.12 \\
5\end{array}$ & 0.25 & $\begin{array}{l}0.37 \\
5\end{array}$ & 0.5 & 0.75 & 1 & 25 & 5 & $\begin{array}{l}0.37 \\
5\end{array}$ & & 75 & 1 \\
\hline $\begin{array}{l}\text { Owner } \\
\text { Occupied }\end{array}$ & $-8 \%$ & $11 \%$ & $-3 \%$ & $-7 \%$ & $21 \%$ & $-8 \%$ & $-8 \%$ & $-4 \%$ & $-4 \%$ & $-4 \%$ & $0 \%$ & $0 \%$ \\
\hline $\begin{array}{l}\text { Renter } \\
\text { Occupied }\end{array}$ & $-9 \%$ & $2 \%$ & $2 \%$ & $-\overline{11 \%}$ & $6 \%$ & $-\overline{23 \%}$ & $-9 \%$ & $-7 \%$ & $-5 \%$ & $-6 \%$ & $-4 \%$ & $-5 \%$ \\
\hline $\begin{array}{l}\text { Total Housing } \\
\text { Units }\end{array}$ & $-8 \%$ & $9 \%$ & $-2 \%$ & $-8 \%$ & $18 \%$ & $-\overline{11 \%}$ & $-8 \%$ & $-5 \%$ & $-4 \%$ & $-5 \%$ & $-1 \%$ & $-1 \%$ \\
\hline $\begin{array}{l}\overline{\text { Owner Occ No }} \\
\text { Veh }\end{array}$ & $-9 \%$ & $1^{c}$ & $16 \%$ & $3 \%$ & $4 \%$ & $\begin{array}{l}- \\
27 \%\end{array}$ & $c_{0}$ & $-7 \%$ & $-3 \%$ & $3 \%$ & $0 \%$ & $-8 \%$ \\
\hline $\begin{array}{l}\text { Owner } \\
\text { Occupied Veh }\end{array}$ & $\begin{array}{l}3853 \\
\%\end{array}$ & $\begin{array}{l}193 \\
2 \%\end{array}$ & $\begin{array}{l}203 \\
05 \%\end{array}$ & $\begin{array}{l}672 \\
6 \%\end{array}$ & $\begin{array}{l}840 \\
2 \%\end{array}$ & $\begin{array}{l}156 \\
3 \%\end{array}$ & $\begin{array}{l}3853 \\
\%\end{array}$ & $\begin{array}{l}3178 \\
\%\end{array}$ & $\begin{array}{l}3944 \\
\%\end{array}$ & $\begin{array}{l}4230 \\
\%\end{array}$ & $\begin{array}{l}4722 \\
\%\end{array}$ & $\begin{array}{l}4277 \\
\%\end{array}$ \\
\hline $\begin{array}{l}\text { Renter Occ No } \\
\text { Veh }\end{array}$ & $12 \%$ & $24 \%$ & $60 \%$ & $75 \%$ & $28 \%$ & $15 \%$ & $12 \%$ & $7 \%$ & $-5 \%$ & $-6 \%$ & $-4 \%$ & $-5 \%$ \\
\hline $\begin{array}{l}\text { Renter } \\
\text { Occupied Veh }\end{array}$ & $-89 \%$ & $-\overline{87 \%}$ & $\overline{8} \%$ & $\overline{9} \%$ & $\overline{8} \%$ & $\overline{9}-\overline{0}$ & $-89 \%$ & $-89 \%$ & $-89 \%$ & $-89 \%$ & $-89 \%$ & $-89 \%$ \\
\hline $\begin{array}{l}\text { Total Housing } \\
\text { Units }\end{array}$ & $-44 \%$ & $33 \%$ & - & - & $33 \%$ & - & $-44 \%$ & $-7 \%$ & $-5 \%$ & $-6 \%$ & $-4 \%$ & $-5 \%$ \\
\hline $\begin{array}{l}\text { Households No } \\
\text { Veh }\end{array}$ & $3 \%$ & $16 \%$ & $35 \%$ & $47 \%$ & $\begin{array}{l}- \\
15 \% \\
\end{array}$ & $-\overline{21 \%}$ & $3 \%$ & $6 \%$ & $10 \%$ & $15 \%$ & $12 \%$ & $6 \%$ \\
\hline
\end{tabular}




\begin{tabular}{|c|c|c|c|c|c|c|c|c|c|c|c|c|}
\hline $\begin{array}{l}\text { Households } \\
\text { with Veh }\end{array}$ & $-46 \%$ & $-\overline{35 \%}$ & - & $\begin{array}{l}- \\
47 \%\end{array}$ & $\overline{34 \%}$ & - & $-46 \%$ & $-44 \%$ & $57 \%$ & $-44 \%$ & $-42 \%$ & $-42 \%$ \\
\hline $\begin{array}{l}\text { Total Housing } \\
\text { Units }\end{array}$ & $-44 \%$ & $-\overline{33 \%}$ & $-39 \%$ & - & - & - & $-44 \%$ & $-7 \%$ & $-5 \%$ & $-6 \%$ & $-4 \%$ & $-5 \%$ \\
\hline \multicolumn{7}{|c|}{$\begin{array}{l}\text { LQ Trend 2010-2016 (LQ 2016/LQ } \\
\text { 2010) - Incremental }\end{array}$} & \multicolumn{6}{|l|}{$\begin{array}{l}\text { Cumu } \\
\text { lative }\end{array}$} \\
\hline $\begin{array}{l}\text { Tenure by } \\
\text { Vehicle } \\
\text { Presence }\end{array}$ & $\begin{array}{l}0.12 \\
5\end{array}$ & 0.25 & $\begin{array}{l}0.37 \\
5\end{array}$ & 0.5 & 0.75 & 1 & 0.125 & 0.25 & $\begin{array}{l}0.37 \\
5\end{array}$ & 0.5 & 0.75 & 1 \\
\hline $\begin{array}{l}\text { Owner } \\
\text { Occupied }\end{array}$ & 0.96 & 0.90 & 1.00 & 0.93 & 0.87 & 0.87 & 0.96 & 1.03 & 1.03 & 1.03 & 1.04 & 1.04 \\
\hline $\begin{array}{l}\text { Renter } \\
\text { Occupied }\end{array}$ & 1.00 & 1.00 & 1.00 & 1.00 & 1.00 & 1.00 & 1.00 & 0.94 & 0.96 & 0.95 & 0.93 & 0.93 \\
\hline $\begin{array}{l}\text { Owner Occ No } \\
\text { Veh }\end{array}$ & 1.83 & 0.79 & 8.84 & 3.16 & 2.26 & 3.08 & 1.83 & 1.05 & 1.10 & 1.11 & 1.10 & 1.01 \\
\hline $\begin{array}{l}\text { Owner } \\
\text { Occupied Veh }\end{array}$ & 1.17 & 1.09 & 1.55 & 1.83 & 1.04 & 0.59 & .17 & 47 & 1.80 & .94 & 2.07 & 1.89 \\
\hline $\begin{array}{l}\text { Renter Occ No } \\
\text { Veh }\end{array}$ & 0.57 & 0.59 & 0.58 & 0.52 & 0.64 & 0.52 & 0.57 & 1.15 & 1.20 & 1.28 & 1.16 & 1.13 \\
\hline $\begin{array}{l}\text { Renter } \\
\text { Occupied Veh }\end{array}$ & 1.11 & 1.13 & 1.14 & 1.09 & 1.10 & 1.04 & 1.11 & 0.57 & 0.57 & 0.57 & 0.57 & 0.57 \\
\hline $\begin{array}{l}\text { Households No } \\
\text { Veh }\end{array}$ & 1.12 & 1.15 & 1.15 & 1.09 & 1.12 & 1.08 & 1.12 & 0.98 & 1.01 & 1.06 & 1.00 & 0.96 \\
\hline $\begin{array}{l}\text { Households } \\
\text { with Veh }\end{array}$ & 1.11 & 1.13 & 1.14 & 1.09 & 1.10 & 1.04 & 1.11 & 1.01 & 1.01 & 1.01 & 1.01 & 1.02 \\
\hline
\end{tabular}

Table 5A.2. Poor MA: CRT, Tenure by Vehicle Presence

Demographic Change 2010-2016 - Incremental

Cumul

\begin{tabular}{|c|c|c|c|c|c|c|c|c|c|c|c|c|}
\hline Tenure by Vehicle & 0.1 & & 0.3 & & 0.7 & & & 0.2 & 0.3 & & & \\
\hline Presence & 25 & 0.25 & 75 & 0.5 & 5 & 1 & 0.125 & 5 & 75 & 0.5 & 0.75 & 1 \\
\hline Owner Occupied & $\begin{array}{l}4,9 \\
30 \\
\end{array}$ & )$^{6866}$ & $\begin{array}{l}1,3 \\
27\end{array}$ & $\begin{array}{l}2,1 \\
71\end{array}$ & $\begin{array}{l}29 \\
3\end{array}$ & $\begin{array}{l}87 \\
0 \\
\end{array}$ & 4,930 & $\begin{array}{l}4,2 \\
44 \\
\end{array}$ & $\begin{array}{l}5,5 \\
71\end{array}$ & $\begin{array}{l}7,74 \\
2\end{array}$ & $\begin{array}{l}8,03 \\
5\end{array}$ & $\begin{array}{l}8,90 \\
5\end{array}$ \\
\hline Renter Occupied & $\begin{array}{l}1,3 \\
50\end{array}$ & (281 & $\begin{array}{l}\text { (67 } \\
0)\end{array}$ & $\begin{array}{l}1,8 \\
51\end{array}$ & $\begin{array}{l}16 \\
9\end{array}$ & $\begin{array}{l}1,0 \\
46\end{array}$ & 1,350 & $\begin{array}{l}1,0 \\
69\end{array}$ & 399 & $\begin{array}{l}2,25 \\
0\end{array}$ & $\begin{array}{l}2,41 \\
9\end{array}$ & $\begin{array}{l}3,46 \\
5\end{array}$ \\
\hline Total Housing Units & $\begin{array}{l}6,2 \\
80 \\
\end{array}$ & )$^{(967}$ & $\begin{array}{l}65 \\
7 \\
\end{array}$ & $\begin{array}{l}4,0 \\
22 \\
\end{array}$ & $\begin{array}{l}46 \\
2 \\
\end{array}$ & $\begin{array}{l}87 \\
0 \\
\end{array}$ & 6,280 & $\begin{array}{l}5,3 \\
13 \\
\end{array}$ & $\begin{array}{l}5,9 \\
70 \\
\end{array}$ & $\begin{array}{l}9,99 \\
2\end{array}$ & $\begin{array}{l}10,4 \\
54 \\
\end{array}$ & $\begin{array}{l}11,3 \\
24 \\
\end{array}$ \\
\hline Owner Occ No Veh & 111 & 12 & 53 & $\begin{array}{l}(93 \\
\end{array}$ & $\begin{array}{l}(26 \\
3) \\
\end{array}$ & $\begin{array}{l}17 \\
6 \\
\end{array}$ & 111 & $\begin{array}{l}12 \\
3 \\
\end{array}$ & 176 & 83 & $\begin{array}{l}180 \\
\end{array}$ & (4) \\
\hline Owner Occupied Veh & $\begin{array}{l}4,5 \\
00 \\
\end{array}$ & $\begin{array}{l}(1,3 \\
65)\end{array}$ & $\begin{array}{l}1,6 \\
60\end{array}$ & $\begin{array}{l}1,9 \\
65\end{array}$ & (3) & $\begin{array}{l}1,0 \\
46\end{array}$ & 4,500 & $\begin{array}{l}3,1 \\
35\end{array}$ & $\begin{array}{l}4,7 \\
95\end{array}$ & $\begin{array}{l}6,76 \\
0\end{array}$ & $\begin{array}{l}6,75 \\
7\end{array}$ & $\begin{array}{l}7,80 \\
3\end{array}$ \\
\hline Renter Occ No Veh & 236 & 19 & (18 & $\begin{array}{l}11 \\
0\end{array}$ & 3 & (16 & 236 & $\begin{array}{l}25 \\
5\end{array}$ & 237 & 347 & 350 & 334 \\
\hline Renter Occupied Veh & $\begin{array}{l}1,6 \\
04\end{array}$ & 62 & $\begin{array}{l}(77 \\
2) \\
\end{array}$ & $\begin{array}{l}2,3 \\
86 \\
\end{array}$ & $\begin{array}{l}77 \\
8\end{array}$ & $\begin{array}{l}45 \\
8\end{array}$ & 1,604 & $\begin{array}{l}1,6 \\
66\end{array}$ & 894 & $\begin{array}{l}3,28 \\
0\end{array}$ & $\begin{array}{l}4,05 \\
8\end{array}$ & $\begin{array}{l}4,51 \\
6\end{array}$ \\
\hline Total Housing Units & $\begin{array}{l}6,4 \\
51 \\
\end{array}$ & $\begin{array}{l}(1,2 \\
72)\end{array}$ & $\begin{array}{l}92 \\
3 \\
\end{array}$ & $\begin{array}{l}4,3 \\
68 \\
\end{array}$ & $\begin{array}{l}51 \\
5 \\
\end{array}$ & $\begin{array}{l}(28 \\
1) \\
\end{array}$ & 6,451 & $\begin{array}{l}5,1 \\
79 \\
\end{array}$ & $\begin{array}{l}6,1 \\
02 \\
\end{array}$ & $\begin{array}{l}10,4 \\
70 \\
\end{array}$ & $\begin{array}{l}10,9 \\
85\end{array}$ & $\begin{array}{l}10,7 \\
04\end{array}$ \\
\hline Households No Veh & 347 & 31 & 35 & 17 & $\begin{array}{l}26 \\
0)\end{array}$ & 45 & 347 & $\begin{array}{l}37 \\
8\end{array}$ & 413 & 430 & 170 & 215 \\
\hline Households with Veh & $\begin{array}{l}6,1 \\
04\end{array}$ & $\begin{array}{l}(1,3 \\
03)\end{array}$ & $\begin{array}{l}88 \\
8\end{array}$ & $\begin{array}{l}4,3 \\
51\end{array}$ & $\begin{array}{l}77 \\
5\end{array}$ & $\begin{array}{l}20 \\
6\end{array}$ & 6,104 & $\begin{array}{l}4,8 \\
01\end{array}$ & $\begin{array}{l}5,6 \\
89\end{array}$ & $\begin{array}{l}10,0 \\
40\end{array}$ & $\begin{array}{l}10,8 \\
15\end{array}$ & $\begin{array}{l}11,0 \\
21\end{array}$ \\
\hline Total Housing Units & $\begin{array}{l}6,4 \\
51 \\
\end{array}$ & $\begin{array}{l}(1,2 \\
72) \\
\end{array}$ & $\begin{array}{l}92 \\
3 \\
\end{array}$ & $\begin{array}{l}4,3 \\
68 \\
\end{array}$ & $\begin{array}{l}51 \\
5 \\
\end{array}$ & $\begin{array}{l}(29 \\
7) \\
\end{array}$ & 6,451 & $\begin{array}{l}5,1 \\
79 \\
\end{array}$ & $\begin{array}{l}6,1 \\
02\end{array}$ & $\begin{array}{l}10,4 \\
70\end{array}$ & $\begin{array}{l}10,9 \\
85\end{array}$ & $\begin{array}{l}10,6 \\
88\end{array}$ \\
\hline \multicolumn{7}{|c|}{$\begin{array}{l}\text { Percent Demographic Change 2010- } \\
2016 \text { - Incremental }\end{array}$} & \multicolumn{6}{|l|}{$\begin{array}{l}\text { Cumul } \\
\text { ative }\end{array}$} \\
\hline $\begin{array}{l}\text { Tenure by Vehicle } \\
\text { Presence }\end{array}$ & $\begin{array}{l}0.1 \\
25\end{array}$ & 0.25 & $\begin{array}{l}0.3 \\
75\end{array}$ & 0.5 & $\begin{array}{l}0.7 \\
5\end{array}$ & 1 & 0.125 & $\begin{array}{l}0.2 \\
5\end{array}$ & $\begin{array}{l}0.3 \\
75\end{array}$ & 0.5 & 0.75 & 1 \\
\hline
\end{tabular}




\begin{tabular}{|c|c|c|c|c|c|c|c|c|c|c|c|c|}
\hline Owner Occupied & $\begin{array}{l}21 \\
\% \\
\end{array}$ & $-7 \%$ & $\begin{array}{l}11 \\
\%\end{array}$ & $\begin{array}{l}11 \\
\%\end{array}$ & $2 \%$ & $4 \%$ & $21 \%$ & $\begin{array}{l}13 \\
\%\end{array}$ & $\begin{array}{l}12 \\
\%\end{array}$ & $12 \%$ & $8 \%$ & $5 \%$ \\
\hline Renter Occupied & $\begin{array}{l}28 \\
\% \\
\end{array}$ & $\begin{array}{l}- \\
13 \% \\
\end{array}$ & $\begin{array}{l}13 \\
\% \\
\end{array}$ & $\begin{array}{l}40 \\
\% \\
\end{array}$ & $4 \%$ & $3 \%$ & $28 \%$ & $\begin{array}{l}15 \\
\%\end{array}$ & $3 \%$ & $13 \%$ & $9 \%$ & $6 \%$ \\
\hline Total Housing Units & \begin{tabular}{|l|}
23 \\
$\%$ \\
\end{tabular} & $-8 \%$ & $4 \%$ & $\begin{array}{l}17 \\
\%\end{array}$ & $2 \%$ & $4 \%$ & $23 \%$ & $\begin{array}{l}13 \\
\%\end{array}$ & $\begin{array}{l}10 \\
\%\end{array}$ & $12 \%$ & $8 \%$ & $5 \%$ \\
\hline Owner Occ No Veh & $\begin{array}{l}17 \\
\% \\
\end{array}$ & $4 \%$ & $\begin{array}{l}23 \\
\%\end{array}$ & $\begin{array}{l}- \\
22 \\
\%\end{array}$ & $\begin{array}{l}- \\
37 \\
\% \\
\end{array}$ & $-\overline{2 \%}$ & $17 \%$ & $\begin{array}{l}13 \\
\%\end{array}$ & $\begin{array}{l}15 \\
\%\end{array}$ & $5 \%$ & $-4 \%$ & $1 \%$ \\
\hline Owner Occupied Veh & \begin{tabular}{|l|}
20 \\
$\%$ \\
\end{tabular} & $\begin{array}{l}- \\
13 \% \\
\end{array}$ & $\begin{array}{l}14 \\
\% \\
\end{array}$ & $\begin{array}{l}10 \\
\% \\
\end{array}$ & $0 \%$ & $2 \%$ & $20 \%$ & $9 \%$ & $\begin{array}{l}11 \\
\%\end{array}$ & $11 \%$ & $7 \%$ & $4 \%$ \\
\hline Renter Occ No Veh & $\begin{array}{l}65 \\
\% \\
\end{array}$ & $11 \%$ & $\begin{array}{l}- \\
3 \%\end{array}$ & $\begin{array}{l}34 \\
\%\end{array}$ & $1 \%$ & $\begin{array}{l}- \\
38 \\
\%\end{array}$ & $65 \%$ & $\begin{array}{l}15 \\
\% \\
\end{array}$ & $3 \%$ & $13 \%$ & $9 \%$ & $6 \%$ \\
\hline Renter Occupied Veh & $\begin{array}{l}41 \\
\%\end{array}$ & $4 \%$ & $\begin{array}{l}- \\
17 \\
\%\end{array}$ & $\begin{array}{l}65 \\
\%\end{array}$ & $\begin{array}{l}22 \\
\%\end{array}$ & $1 \%$ & $41 \%$ & $\begin{array}{l}30 \\
\%\end{array}$ & $9 \%$ & $24 \%$ & $21 \%$ & $14 \%$ \\
\hline Total Housing Units & $\begin{array}{l}23 \\
\% \\
\end{array}$ & $-\overline{10 \%}$ & $5 \%$ & $\begin{array}{l}19 \\
\%\end{array}$ & $2 \%$ & $1 \%$ & $23 \%$ & $\begin{array}{l}15 \\
\%\end{array}$ & $3 \%$ & $13 \%$ & $9 \%$ & $6 \%$ \\
\hline Households No Veh & $\begin{array}{l}34 \\
\% \\
\end{array}$ & $6 \%$ & $4 \%$ & $2 \%$ & $\begin{array}{l}- \\
26 \\
\%\end{array}$ & $\begin{array}{l} \\
21 \\
\%\end{array}$ & $34 \%$ & $\begin{array}{l}25 \\
\%\end{array}$ & $\begin{array}{l}17 \\
\%\end{array}$ & $14 \%$ & $4 \%$ & $-3 \%$ \\
\hline Households with Veh & \begin{tabular}{|l|}
23 \\
$\%$ \\
\end{tabular} & $\begin{array}{l}- \\
11 \% \\
\end{array}$ & $5 \%$ & $\begin{array}{l}19 \\
\%\end{array}$ & $4 \%$ & $2 \%$ & $23 \%$ & $\begin{array}{l}12 \\
\%\end{array}$ & $\begin{array}{l}110 \\
\%\end{array}$ & $13 \%$ & $9 \%$ & $6 \%$ \\
\hline Total Housing Units & \begin{tabular}{|l|}
23 \\
$\%$ \\
\end{tabular} & $\begin{array}{l}- \\
10 \% \\
\end{array}$ & $5 \%$ & $\begin{array}{l}19 \\
\%\end{array}$ & $2 \%$ & $1 \%$ & $23 \%$ & $\begin{array}{l}15 \\
\%\end{array}$ & $3 \%$ & $13 \%$ & $9 \%$ & $6 \%$ \\
\hline $\begin{array}{l}\text { LQ Trend 2010-2016 ( } \\
\text { 2010) - Incremental }\end{array}$ & $Q 2$ & $\overline{16 / L Q}$ & & & & & $\begin{array}{l}\text { Cumu } \\
\text { ative }\end{array}$ & & & & & \\
\hline $\begin{array}{l}\text { Tenure by Vehicle } \\
\text { Presence }\end{array}$ & $\begin{array}{l}0.1 \\
25\end{array}$ & 0.25 & $\begin{array}{l}0.3 \\
75\end{array}$ & 0.5 & $\begin{array}{l}0.7 \\
5\end{array}$ & 1 & 0.125 & $\begin{array}{l}0.2 \\
5\end{array}$ & $\begin{array}{l}0.3 \\
75\end{array}$ & 0.5 & 0.75 & $T$ \\
\hline Owner Occupied & \begin{tabular}{|l|}
1.0 \\
0 \\
\end{tabular} & 0.90 & $\begin{array}{l}0.8 \\
0 \\
\end{array}$ & $\begin{array}{l}1.1 \\
4 \\
\end{array}$ & $\begin{array}{l}0.9 \\
2 \\
\end{array}$ & $\begin{array}{l}0.9 \\
7 \\
\end{array}$ & 1.00 & $\begin{array}{l}1.0 \\
3 \\
\end{array}$ & $\begin{array}{l}1.0 \\
5 \\
\end{array}$ & 1.03 & 1.03 & 1.03 \\
\hline Renter Occupied & \begin{tabular}{|l|}
1.0 \\
0 \\
\end{tabular} & 1.00 & $\begin{array}{l}1.0 \\
0 \\
\end{array}$ & $\begin{array}{l}1.0 \\
0 \\
\end{array}$ & $\begin{array}{l}1.0 \\
0 \\
\end{array}$ & $\begin{array}{l}1.0 \\
0 \\
\end{array}$ & 1.00 & $\begin{array}{l}0.9 \\
7 \\
\end{array}$ & $\begin{array}{l}0.8 \\
9 \\
\end{array}$ & 0.96 & 0.96 & 0.95 \\
\hline Owner Occ No Veh & \begin{tabular}{|l|}
0.9 \\
4 \\
\end{tabular} & 0.90 & $\begin{array}{l}1.0 \\
5\end{array}$ & $\begin{array}{l}0.9 \\
0\end{array}$ & $\begin{array}{l}0.9 \\
6 \\
\end{array}$ & $\begin{array}{l}0.9 \\
4\end{array}$ & 0.94 & $\begin{array}{l}1.0 \\
2\end{array}$ & $\begin{array}{l}1.0 \\
6 \\
\end{array}$ & 0.96 & 0.91 & 0.98 \\
\hline Owner Occupied Veh & $\begin{array}{l}1.2 \\
5\end{array}$ & 1.12 & $\begin{array}{l}0.8 \\
7\end{array}$ & $\begin{array}{l}1.0 \\
6\end{array}$ & $\begin{array}{l}0.7 \\
8\end{array}$ & $\begin{array}{l}0.9 \\
2\end{array}$ & 1.25 & $\begin{array}{l}0.9 \\
2\end{array}$ & $\begin{array}{l}0.9 \\
6\end{array}$ & 0.94 & 0.94 & 0.95 \\
\hline Renter Occ No Veh & $\begin{array}{l}1.1 \\
9\end{array}$ & 1.16 & $\begin{array}{l}0.8 \\
3\end{array}$ & $\begin{array}{l}1.4 \\
6\end{array}$ & $\begin{array}{l}1.1 \\
2\end{array}$ & $\begin{array}{l}1.2 \\
4\end{array}$ & 1.19 & $\begin{array}{l}1.2 \\
1\end{array}$ & $\begin{array}{l}1.0 \\
1\end{array}$ & 1.02 & 0.98 & 0.82 \\
\hline Renter Occupied Veh & $\begin{array}{l}0.9 \\
9 \\
\end{array}$ & 0.96 & $\begin{array}{l}1.0 \\
0\end{array}$ & $\begin{array}{l}1.0 \\
0\end{array}$ & $\begin{array}{l}1.0 \\
0\end{array}$ & $\begin{array}{l}0.9 \\
9\end{array}$ & 0.99 & $\begin{array}{l}1.1 \\
9\end{array}$ & $\begin{array}{l}1.0 \\
2\end{array}$ & 1.14 & 1.15 & 1.12 \\
\hline Households No Veh & $\begin{array}{l}0.9 \\
9\end{array}$ & 0.95 & $\begin{array}{l}1.0 \\
0\end{array}$ & $\begin{array}{l}1.0 \\
0\end{array}$ & $\begin{array}{l}1.0 \\
1\end{array}$ & $\begin{array}{l}1.0 \\
0\end{array}$ & 0.99 & $\begin{array}{l}1.0 \\
7\end{array}$ & $\begin{array}{l}1.0 \\
2\end{array}$ & 0.97 & 0.92 & 0.89 \\
\hline Households with Veh & $\begin{array}{l}0.9 \\
9 \\
\end{array}$ & 0.96 & $\begin{array}{l}1.0 \\
0 \\
\end{array}$ & $\begin{array}{l}1.0 \\
0 \\
\end{array}$ & $\begin{array}{l}1.0 \\
0 \\
\end{array}$ & $\begin{array}{l}0.9 \\
9 \\
\end{array}$ & 0.99 & $\begin{array}{l}1.0 \\
0\end{array}$ & $\begin{array}{l}1.0 \\
0 \\
\end{array}$ & 1.00 & 1.00 & 1.01 \\
\hline
\end{tabular}

Table 5A.3. Poor MA: LRT, Tenure by Vehicle Presence

Demographic Change 2010-2016 -

Incremental

Cumul

\begin{tabular}{|c|c|c|c|c|c|c|c|c|c|c|c|c|}
\hline Tenure by Vehicle & 0.12 & & 0.3 & & 0.7 & & & & 0.37 & & & \\
\hline Presence & 5 & 0.25 & 75 & 0.5 & 5 & 1 & 0.125 & 0.25 & 5 & 0.5 & 0.75 & 1 \\
\hline Owner Occupied & 518 & (245 & $\begin{array}{l}99 \\
1\end{array}$ & 286 & \begin{tabular}{l|}
29 \\
6
\end{tabular} & $\begin{array}{l}(15 \\
8)\end{array}$ & 518 & 273 & $\begin{array}{l}1,26 \\
4\end{array}$ & $\begin{array}{l}1,55 \\
0\end{array}$ & $\begin{array}{l}1,84 \\
6\end{array}$ & $\begin{array}{l}1,68 \\
8\end{array}$ \\
\hline
\end{tabular}




\begin{tabular}{|c|c|c|c|c|c|c|c|c|c|c|c|c|}
\hline Renter Occupied & )$^{(591}$ & )$^{(136}$ & $\begin{array}{l}(50 \\
2)\end{array}$ & $\begin{array}{l}(1,0 \\
65)\end{array}$ & $\begin{array}{l}(18 \\
6)\end{array}$ & )$^{(80}$ & (591) & )$^{(727}$ & $\begin{array}{l}(1,2 \\
29)\end{array}$ & $\begin{array}{l}(2,2 \\
94)\end{array}$ & $\begin{array}{l}(2,4 \\
80)\end{array}$ & $\begin{array}{l}(2,5 \\
60)\end{array}$ \\
\hline Total Housing Units & (73) & )$^{(381}$ & $\begin{array}{l}48 \\
9\end{array}$ & )$^{(779}$ & $\begin{array}{l}11 \\
0\end{array}$ & $\begin{array}{l}(15 \\
8)\end{array}$ & $(73)$ & )$^{(454}$ & 35 & )$^{(744}$ & )$^{(634}$ & )$^{(792}$ \\
\hline Owner Occ No Veh & )$^{(251}$ & 313 & 28 & (23) & $\begin{array}{l}18 \\
1\end{array}$ & 78 & $(251)$ & 62 & 90 & 67 & 248 & 326 \\
\hline $\begin{array}{l}\text { Owner Occupied } \\
\text { Veh }\end{array}$ & $\begin{array}{l}1,31 \\
6\end{array}$ & $\begin{array}{l}(1,0 \\
45) \\
\end{array}$ & $\begin{array}{l}54 \\
3 \\
\end{array}$ & 185 & $\begin{array}{l}16 \\
8\end{array}$ & )$^{(80}$ & 1,316 & 271 & 814 & 999 & $\begin{array}{l}1,16 \\
7\end{array}$ & $\begin{array}{l}1,08 \\
7\end{array}$ \\
\hline Renter Occ No Veh & )$^{(846}$ & )$^{(271}$ & 54 & $(67)$ & $\begin{array}{l}(21 \\
7) \\
\end{array}$ & $\begin{array}{l}(12 \\
8)\end{array}$ & $(846)$ & $\begin{array}{l}(1,1 \\
17) \\
\end{array}$ & $\begin{array}{l}(1,0 \\
63)\end{array}$ & $\begin{array}{l}(1,1 \\
30)\end{array}$ & $\begin{array}{l}(1,3 \\
47) \\
\end{array}$ & $\begin{array}{l}(1,4 \\
75) \\
\end{array}$ \\
\hline $\begin{array}{l}\text { Renter Occupied } \\
\text { Veh }\end{array}$ & $\begin{array}{l}1,15 \\
9\end{array}$ & 354 & $\begin{array}{l}64 \\
4) \\
\end{array}$ & )$^{(738}$ & $\begin{array}{l}55 \\
8\end{array}$ & $\begin{array}{l}(21 \\
7) \\
\end{array}$ & 1,159 & $\begin{array}{l}1,51 \\
3\end{array}$ & 869 & 131 & 689 & 472 \\
\hline Total Housing Units & $\begin{array}{l}1,37 \\
8\end{array}$ & )$^{(649}$ & )$^{(19}$ & )$^{(643}$ & $\begin{array}{l}69 \\
0 \\
\end{array}$ & 99 & 1,378 & 729 & 710 & 67 & 757 & 856 \\
\hline Households No Veh & $\begin{array}{l}(1,0 \\
97)\end{array}$ & 42 & 82 & $(90)$ & )$^{(36}$ & 29 & $(1,097)$ & $\begin{array}{l}(1,0 \\
55)\end{array}$ & )$^{(973}$ & $\begin{array}{l}(1,0 \\
63)\end{array}$ & $\begin{array}{l}(1,0 \\
99)\end{array}$ & $\begin{array}{l}(1,0 \\
70)\end{array}$ \\
\hline $\begin{array}{l}\text { Households with } \\
\text { Veh }\end{array}$ & $\begin{array}{l}2,47 \\
5\end{array}$ & )$^{691}$ & $\begin{array}{l}(10 \\
1) \\
\end{array}$ & )$^{(553}$ & $\begin{array}{l}72 \\
6 \\
\end{array}$ & $\begin{array}{l}(21 \\
7)\end{array}$ & 2,475 & $\begin{array}{l}1,78 \\
4 \\
\end{array}$ & $\begin{array}{l}1,68 \\
3\end{array}$ & $\begin{array}{l}1,13 \\
0\end{array}$ & $\begin{array}{l}1,85 \\
6 \\
\end{array}$ & $\begin{array}{l}1,63 \\
9\end{array}$ \\
\hline Total Housing Units & $\begin{array}{l}1,37 \\
8 \\
\end{array}$ & )$^{(649}$ & )$^{(19}$ & )$^{(643}$ & $\begin{array}{l}69 \\
0 \\
\end{array}$ & )$^{(29}$ & 1,378 & 729 & 710 & 67 & 757 & 728 \\
\hline $\begin{array}{l}\text { Percent Demographic } \\
2016 \text { - Incremental }\end{array}$ & Chan & e 201C & & & & & $\begin{array}{l}\text { Cumul } \\
\text { ative }\end{array}$ & & & & & \\
\hline $\begin{array}{l}\text { Tenure by Vehicle } \\
\text { Presence }\end{array}$ & $\begin{array}{l}0.12 \\
5 \\
\end{array}$ & 0.25 & $\begin{array}{l}0.3 \\
75 \\
\end{array}$ & 0.5 & $\begin{array}{l}0.7 \\
5 \\
\end{array}$ & 1 & 0.125 & 0.25 & $\begin{array}{l}0.37 \\
5 \\
\end{array}$ & 0.5 & 0.75 & 1 \\
\hline Owner Occupied & $1 \%$ & $-2 \%$ & $5 \%$ & $1 \%$ & $1 \%$ & $\begin{array}{l}- \\
1 \% \\
\end{array}$ & $1 \%$ & $1 \%$ & $2 \%$ & $2 \%$ & $2 \%$ & $1 \%$ \\
\hline Renter Occupied & $-4 \%$ & $-2 \%$ & $7 \%$ & $-\overline{14 \%}$ & $2 \%$ & $1 \%$ & $-4 \%$ & $-4 \%$ & $-5 \%$ & $-7 \%$ & $-5 \%$ & $-4 \%$ \\
\hline Total Housing Units & $0 \%$ & $-2 \%$ & $2 \%$ & $-3 \%$ & $0 \%$ & $0 \%$ & $0 \%$ & $-1 \%$ & $0 \%$ & $-1 \%$ & $0 \%$ & $0 \%$ \\
\hline Owner Occ No Veh & $-17 \%$ & $\begin{array}{l}219 \\
\%\end{array}$ & $4 \%$ & $-4 \%$ & $\begin{array}{l}34 \\
\%\end{array}$ & $\begin{array}{l}16 \\
\% \\
\end{array}$ & $-17 \%$ & $4 \%$ & $4 \%$ & $2 \%$ & $1 \%$ & $-2 \%$ \\
\hline $\begin{array}{l}\text { Owner Occupied } \\
\text { Veh }\end{array}$ & $4 \%$ & $-6 \%$ & $3 \%$ & $1 \%$ & $1 \%$ & $\begin{array}{l}- \\
\end{array}$ & $4 \%$ & $1 \%$ & $1 \%$ & $1 \%$ & $0 \%$ & $0 \%$ \\
\hline Renter Occ No Veh & $\begin{array}{l}- \\
35 \% \\
\end{array}$ & $\begin{array}{l}- \\
30 \% \\
\end{array}$ & $5 \%$ & $-7 \%$ & $\begin{array}{l}- \\
23 \\
\%\end{array}$ & $\begin{array}{l}11 \\
\% \\
\end{array}$ & $55 \%$ & $-4 \%$ & $-5 \%$ & $-7 \%$ & $-5 \%$ & $-4 \%$ \\
\hline $\begin{array}{l}\text { Renter Occupied } \\
\text { Veh }\end{array}$ & $12 \%$ & $7 \%$ & $\begin{array}{l}- \\
10 \\
\% \\
\end{array}$ & $\begin{array}{l}- \\
11 \% \\
\end{array}$ & $9 \%$ & $1 \%$ & $2 \%$ & $10 \%$ & $4 \%$ & $0 \%$ & $2 \%$ & $2 \%$ \\
\hline Total Housing Units & $3 \%$ & $-3 \%$ & $0 \%$ & $-2 \%$ & $2 \%$ & $\begin{array}{l}- \\
1 \% \\
\end{array}$ & $3 \%$ & $-4 \%$ & $-5 \%$ & $-7 \%$ & $-5 \%$ & $-4 \%$ \\
\hline Households No Veh & $-\overline{28 \%}$ & $4 \%$ & $4 \%$ & $-6 \%$ & $\begin{array}{l}- \\
2 \%\end{array}$ & $\begin{array}{l}- \\
2 \% \\
\end{array}$ & $-28 \%$ & $-\overline{21 \%}$ & $-\overline{14 \%}$ & $\begin{array}{l}- \\
13 \% \\
\end{array}$ & $\begin{array}{l}- \\
11 \% \\
\end{array}$ & $-8 \%$ \\
\hline $\begin{array}{l}\text { Households with } \\
\text { Veh }\end{array}$ & $6 \%$ & $-3 \%$ & $0 \%$ & $-2 \%$ & $2 \%$ & $\begin{array}{l}- \\
1 \% \\
\end{array}$ & $6 \%$ & $3 \%$ & $\begin{array}{l}102 \\
\% \\
\end{array}$ & $1 \%$ & $1 \%$ & $0 \%$ \\
\hline Total Housing Units & $3 \%$ & $-3 \%$ & $0 \%$ & $-2 \%$ & $2 \%$ & $\overline{1} \%$ & $3 \%$ & $-4 \%$ & $-5 \%$ & $-7 \%$ & $-5 \%$ & $-4 \%$ \\
\hline \multicolumn{7}{|c|}{$\begin{array}{l}\text { LQ Trend 2010-2016 (LQ } 2016 / L Q \\
\text { 2010) - Incremental }\end{array}$} & \multicolumn{6}{|l|}{$\begin{array}{l}\text { Cumul } \\
\text { ative }\end{array}$} \\
\hline Tenure by Vehicle & 0.12 & & 0.3 & & 0.7 & & & & 0.37 & & & \\
\hline Presence & 5 & 0.25 & 75 & 0.5 & 5 & 1 & 0.125 & 0.25 & 5 & 0.5 & 0.75 & 1 \\
\hline Owner Occupied & 0.91 & 0.95 & $\begin{array}{l}0.8 \\
7\end{array}$ & 0.84 & $\begin{array}{l}0.9 \\
3\end{array}$ & $\begin{array}{l}0.9 \\
3\end{array}$ & 0.91 & 1.04 & 1.05 & 1.06 & 1.05 & 1.05 \\
\hline
\end{tabular}




\begin{tabular}{|c|c|c|c|c|c|c|c|c|c|c|c|c|}
\hline ied & .00 & 1.00 & $\begin{array}{l}1.0 \\
0\end{array}$ & 1.00 & $\begin{array}{l}1.0 \\
0\end{array}$ & $\begin{array}{l}1.0 \\
0\end{array}$ & 1.00 & 0.92 & 0.91 & 0.89 & 0.90 & 0.91 \\
\hline Owner Occ No Veh & 1.07 & .98 & $\begin{array}{l}1.0 \\
4\end{array}$ & 1.07 & $\begin{array}{l}0.9 \\
7\end{array}$ & $\begin{array}{l}1.0 \\
4\end{array}$ & 1.07 & 1.12 & .12 & 1.11 & .09 & 1.05 \\
\hline $\begin{array}{l}\text { Owner Occupied } \\
\text { Veh }\end{array}$ & 0.64 & 0.70 & $\begin{array}{l}1.0 \\
1\end{array}$ & 0.93 & $\begin{array}{l}0.9 \\
7\end{array}$ & $\begin{array}{l}0.7 \\
5\end{array}$ & 0.64 & 1.04 & 1.04 & 1.05 & 1.03 & 1.03 \\
\hline Renter Occ No Veh & 0.99 & 0.96 & $\begin{array}{l}0.7 \\
8\end{array}$ & 0.80 & $\begin{array}{l}0.9 \\
1\end{array}$ & $\begin{array}{l}0.9 \\
6\end{array}$ & 090 & 0.65 & 0.74 & 0.77 & 0.80 & 0.87 \\
\hline $\begin{array}{l}\text { Renter Occupied } \\
\text { Veh }\end{array}$ & 1.01 & 0.97 & $\begin{array}{l}0.9 \\
6\end{array}$ & 0.98 & $\begin{array}{l}0.9 \\
3\end{array}$ & $\begin{array}{l}1.0 \\
0\end{array}$ & 1.01 & 0.98 & 0.92 & 0.89 & 0.90 & 0.90 \\
\hline olds No Veh & 1.03 & 0.96 & $\begin{array}{l}0.9 \\
6\end{array}$ & 0.98 & $\begin{array}{l}0.9 \\
3\end{array}$ & $\begin{array}{l}1.0 \\
0\end{array}$ & 1.03 & 0.79 & 0.86 & 0.89 & 0.91 & 0.94 \\
\hline $\begin{array}{l}\text { Households with } \\
\text { Veh }\end{array}$ & 1.01 & 0.97 & $\begin{array}{l}0.9 \\
6\end{array}$ & 0.98 & $\begin{array}{l}0.9 \\
3\end{array}$ & $\begin{array}{l}1.0 \\
0\end{array}$ & 1.01 & 1.02 & 1.01 & 1.01 & 1.01 & 1.00 \\
\hline
\end{tabular}

Table 5A.4. Poor MA: SCT, Tenure by Vehicle Presence

\begin{tabular}{|c|c|c|c|c|c|c|c|c|c|c|c|c|}
\hline Demographic Change & $010-2$ & $16-1$ & $\mathrm{crem}$ & ntal & & & $\begin{array}{l}\text { Cum } \\
\text { tive }\end{array}$ & & & & & \\
\hline Tenure by Vehicle & 0.12 & & 0.3 & & 0.7 & & & 0.2 & 0.3 & & 0.7 & \\
\hline Presence & 5 & 0.25 & 75 & 0.5 & 5 & 1 & 0.125 & 5 & 75 & 0.5 & 5 & 1 \\
\hline Owner Occupied & 0 & (39) & $\begin{array}{l}12 \\
8)\end{array}$ & 82 & $\begin{array}{l}(11 \\
5)\end{array}$ & 173 & 0 & (39) & $\begin{array}{l}16 \\
7) \\
\end{array}$ & $\begin{array}{l}\text { (85 } \\
\end{array}$ & $\begin{array}{l}\text { (20 } \\
0)\end{array}$ & )$^{(27}$ \\
\hline Renter Occupied & 0 & (9) & $\begin{array}{l}\text { (26 } \\
1)\end{array}$ & $\begin{array}{l}\text { (19 } \\
8)\end{array}$ & 54 & 74 & 0 & (9) & $\begin{array}{l}(27 \\
0)\end{array}$ & $\begin{array}{l}(46 \\
8)\end{array}$ & $\begin{array}{l}(41 \\
4)\end{array}$ & $\begin{array}{l}\text { (34 } \\
0)\end{array}$ \\
\hline Total Housing Units & 0 & $(48)$ & $\begin{array}{l}\text { (38 } \\
9)\end{array}$ & $\begin{array}{l}\text { (11 } \\
6)\end{array}$ & (61) & 173 & 0 & $(48)$ & $\begin{array}{l}\text { (43 } \\
7)\end{array}$ & $\begin{array}{l}\text { (55 } \\
3)\end{array}$ & $\begin{array}{l}\text { (61 } \\
4) \\
\end{array}$ & $\begin{array}{l}\text { (44 } \\
\text { 1) }\end{array}$ \\
\hline Owner Occ No Veh & 0 & 25 & (63 & 11 & 31 & (63) & 0 & 25 & (38 & (27 & 4 & (59 \\
\hline Owner Occupied Veh & 0 & 152 & $\begin{array}{l}\text { (26 } \\
3)\end{array}$ & 61 & $\begin{array}{l}\text { (13 } \\
9)\end{array}$ & 110 & 0 & 152 & $\begin{array}{l}\text { (11 } \\
1)\end{array}$ & (50 & $\begin{array}{l}\text { (18 } \\
9)\end{array}$ & (79 \\
\hline Renter Occ No Veh & 0 & 58 & (55 & (5) & 95 & 56 & 0 & 58 & 3 & (2) & 93 & $\begin{array}{l}14 \\
9\end{array}$ \\
\hline Renter Occupied Veh & 0 & $\begin{array}{l}(10 \\
7) \\
\end{array}$ & 8 & $\begin{array}{l}(51 \\
\end{array}$ & 135 & 12 & 0 & $\begin{array}{l}(10 \\
7) \\
\end{array}$ & $\begin{array}{l}(99 \\
\end{array}$ & $\begin{array}{l}(15 \\
0) \\
\end{array}$ & )$^{(15}$ & (3) \\
\hline Total Housing Units & 0 & 128 & $\begin{array}{l}(37 \\
3)\end{array}$ & 16 & 122 & $\begin{array}{l}\text { (18 } \\
2)\end{array}$ & 0 & 128 & $\begin{array}{l}(24 \\
5)\end{array}$ & $\begin{array}{l}(22 \\
9)\end{array}$ & $\begin{array}{l}\text { (10 } \\
7)\end{array}$ & $\begin{array}{l}\text { (28 } \\
9)\end{array}$ \\
\hline Households No Veh & 0 & 83 & $\begin{array}{l}(11 \\
8) \\
\end{array}$ & 6 & 126 & 48 & 0 & 83 & $\begin{array}{l}(35 \\
\end{array}$ & $\begin{array}{l}(29 \\
)^{2}\end{array}$ & 97 & $\begin{array}{l}14 \\
5 \\
\end{array}$ \\
\hline Households with Veh & 0 & 45 & $\begin{array}{l}(25 \\
5)\end{array}$ & 10 & (4) & (66) & 0 & 45 & $\begin{array}{l}(21 \\
0)\end{array}$ & $\begin{array}{l}(20 \\
0)\end{array}$ & $\begin{array}{l}(20 \\
4)\end{array}$ & $\begin{array}{l}\text { (27 } \\
0)\end{array}$ \\
\hline Total Housing Units & 0 & 128 & $\begin{array}{l}\text { (37 } \\
3) \\
\end{array}$ & 16 & 122 & $\begin{array}{l}(12 \\
6) \\
\end{array}$ & 0 & 128 & $\begin{array}{l}\text { (24 } \\
5) \\
\end{array}$ & $\begin{array}{l}\text { (22 } \\
9) \\
\end{array}$ & $\begin{array}{l}110 \\
7) \\
\end{array}$ & $\begin{array}{l}(23 \\
3) \\
\end{array}$ \\
\hline $\begin{array}{l}\text { Percent Demographic } \\
\text { - Incremental }\end{array}$ & hange & 2010 & 2016 & & & & $\begin{array}{l}\text { Cumı } \\
\text { tive }\end{array}$ & & & & & \\
\hline Tenure by Vehicle & 0.12 & & 0.3 & & 0.7 & & & 0.2 & 0.3 & & 0.7 & \\
\hline Presence & 5 & 0.25 & 75 & 0.5 & 5 & 1 & 0.125 & 5 & 75 & 0.5 & 5 & 1 \\
\hline Owner Occupied & 0 & $-3 \%$ & $\overline{9} \%$ & $\begin{array}{l}27 \\
\%\end{array}$ & $-5 \%$ & $\begin{array}{l}11 \\
\%\end{array}$ & 0 & $-3 \%$ & $-6 \%$ & $3 \%$ & $1 \%$ & $0 \%$ \\
\hline Renter Occupied & 0 & $-1 \%$ & $\begin{array}{l}- \\
25 \\
\%\end{array}$ & $\begin{array}{l}- \\
45 \\
\%\end{array}$ & $8 \%$ & $-9 \%$ & 0 & $-1 \%$ & $\begin{array}{l}- \\
16 \\
\%\end{array}$ & $\begin{array}{l}- \\
22 \\
\%\end{array}$ & $8 \%$ & - \\
\hline Total Housing Units & 0 & $-2 \%$ & $\begin{array}{l}- \\
16 \\
\%\end{array}$ & $\begin{array}{l}- \\
16 \\
\%\end{array}$ & $-2 \%$ & $5 \%$ & 0 & $-2 \%$ & $\begin{array}{l}- \\
10 \\
\%\end{array}$ & $\begin{array}{l}- \\
11 \\
\%\end{array}$ & - & - \\
\hline
\end{tabular}




\begin{tabular}{|c|c|c|c|c|c|c|c|c|c|c|c|c|}
\hline Owner Occ No Veh & 0 & 0 & $\begin{array}{l}- \\
67 \\
\% \\
\end{array}$ & $\begin{array}{l}61 \\
\%\end{array}$ & $\begin{array}{l}207 \\
\%\end{array}$ & $\begin{array}{l}295 \\
\%\end{array}$ & 0 & 0 & $\begin{array}{l}- \\
40 \\
\%\end{array}$ & $\begin{array}{l}- \\
24 \\
\%\end{array}$ & $\begin{array}{l}30 \\
\%\end{array}$ & $6 \%$ \\
\hline Owner Occupied Veh & 0 & $\begin{array}{l}14 \\
\%\end{array}$ & $\begin{array}{l}- \\
17 \\
\%\end{array}$ & $\begin{array}{l}21 \\
\%\end{array}$ & $-7 \%$ & $1 \%$ & 0 & $\begin{array}{l}14 \\
\%\end{array}$ & - & - & $1 \%$ & - \\
\hline Renter Occ No Veh & 0 & $\begin{array}{l}116 \\
\%\end{array}$ & $\begin{array}{l}- \\
33 \\
\%\end{array}$ & $\overline{8 \%}$ & $\begin{array}{l}106 \\
\%\end{array}$ & $\begin{array}{l}-\overline{61} \\
\%\end{array}$ & 0 & $-1 \%$ & $\begin{array}{l}- \\
16 \\
\%\end{array}$ & $\begin{array}{l}- \\
22 \\
\%\end{array}$ & $\overline{8 \%}$ & - \\
\hline Renter Occupied Veh & 0 & $\begin{array}{l}- \\
18 \\
\% \\
\end{array}$ & $1 \%$ & $\begin{array}{l}- \\
22 \\
\% \\
\end{array}$ & $\begin{array}{l}33 \\
\%\end{array}$ & $\begin{array}{l}10 \\
\%\end{array}$ & 0 & $\begin{array}{l}- \\
18 \\
\%\end{array}$ & - & $\begin{array}{l}- \\
10 \\
\%\end{array}$ & $5 \%$ & $7 \%$ \\
\hline Total Housing Units & 0 & $7 \%$ & $\begin{array}{l}- \\
15 \\
\% \\
\end{array}$ & $3 \%$ & $5 \%$ & $-3 \%$ & 0 & $-1 \%$ & $\begin{array}{l}- \\
16 \\
\%\end{array}$ & $\begin{array}{l}- \\
22 \\
\%\end{array}$ & - & - \\
\hline Households No Veh & 0 & $\begin{array}{l}166 \\
\%\end{array}$ & $\begin{array}{l}- \\
45 \\
\%\end{array}$ & $7 \%$ & $\begin{array}{l}120 \\
\%\end{array}$ & $\begin{array}{l}- \\
39 \\
\%\end{array}$ & 0 & $\begin{array}{l}166 \\
\%\end{array}$ & $\begin{array}{l}- \\
11 \\
\%\end{array}$ & 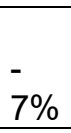 & $\begin{array}{l}30 \\
\%\end{array}$ & - \\
\hline Households with Veh & 0 & $3 \%$ & $\begin{array}{l}- \\
12 \\
\%\end{array}$ & $2 \%$ & $0 \%$ & $3 \%$ & 0 & $3 \%$ & $\begin{array}{l}95 \\
\%\end{array}$ & - & $2 \%$ & $0 \%$ \\
\hline Total Housing Units & 0 & $7 \%$ & $\begin{array}{l}- \\
15 \\
\% \\
\end{array}$ & $3 \%$ & $5 \%$ & $-3 \%$ & 0 & $-1 \%$ & $\begin{array}{l}- \\
16 \\
\%\end{array}$ & $\begin{array}{l}- \\
22 \\
\%\end{array}$ & $-\overline{8 \%}$ & - \\
\hline $\begin{array}{l}\text { LQ Trend 2010-2016 ( } \\
\text { 2010) - Incremental }\end{array}$ & $Q 201$ & $6 / L Q$ & & & & & $\begin{array}{l}\text { Cum } \\
\text { tive }\end{array}$ & & & & & \\
\hline $\begin{array}{l}\text { Tenure by Vehicle } \\
\text { Presence }\end{array}$ & $\begin{array}{l}0.12 \\
5 \\
\end{array}$ & 0.25 & $\begin{array}{l}0.3 \\
75 \\
\end{array}$ & 0.5 & $\begin{array}{l}0.7 \\
5 \\
\end{array}$ & 1 & 0.125 & $\begin{array}{l}0.2 \\
5 \\
\end{array}$ & $\begin{array}{l}0.3 \\
75 \\
\end{array}$ & 0.5 & $\begin{array}{l}0.7 \\
5 \\
\end{array}$ & 1 \\
\hline Owner Occupied & 0 & 0.96 & $\begin{array}{l}0.8 \\
5\end{array}$ & $\begin{array}{l}0.6 \\
2\end{array}$ & $\begin{array}{l}0.9 \\
0\end{array}$ & $\begin{array}{l}1.0 \\
5\end{array}$ & 0 & $\begin{array}{l}1.0 \\
3\end{array}$ & $\begin{array}{l}1.0 \\
8\end{array}$ & $\begin{array}{l}1.1 \\
3\end{array}$ & $\begin{array}{l}1.0 \\
7\end{array}$ & $\begin{array}{l}1.0 \\
6\end{array}$ \\
\hline Renter Occupied & 0 & 1.00 & $\begin{array}{l}1.0 \\
0\end{array}$ & $\begin{array}{l}1.0 \\
0\end{array}$ & $\begin{array}{l}1.0 \\
0\end{array}$ & $\begin{array}{l}1.0 \\
0\end{array}$ & 0 & $\begin{array}{l}0.9 \\
6\end{array}$ & $\begin{array}{l}0.8 \\
8\end{array}$ & $\begin{array}{l}0.8 \\
3\end{array}$ & $\begin{array}{l}0.8 \\
9\end{array}$ & $\begin{array}{l}0.9 \\
2\end{array}$ \\
\hline Owner Occ No Veh & 0 & 1.21 & $\begin{array}{l}1.0 \\
2 \\
\end{array}$ & $\begin{array}{l}1.4 \\
8 \\
\end{array}$ & $\begin{array}{l}0.9 \\
9 \\
\end{array}$ & $\begin{array}{l}0.9 \\
9 \\
\end{array}$ & 0 & 0 & $\begin{array}{l}0.6 \\
6 \\
\end{array}$ & $\begin{array}{l}0.8 \\
5 \\
\end{array}$ & $\begin{array}{l}1.3 \\
4 \\
\end{array}$ & $\begin{array}{l}1.0 \\
9 \\
\end{array}$ \\
\hline Owner Occupied Veh & 0 & 2.06 & $\begin{array}{l}0.7 \\
4\end{array}$ & $\begin{array}{l}1.0 \\
2\end{array}$ & $\begin{array}{l}0.9 \\
1\end{array}$ & $\begin{array}{l}1.9 \\
5\end{array}$ & 0 & $\begin{array}{l}1.2 \\
1\end{array}$ & $\begin{array}{l}1.1 \\
0\end{array}$ & $\begin{array}{l}1.1 \\
4\end{array}$ & $\begin{array}{l}1.0 \\
6\end{array}$ & $\begin{array}{l}1.0 \\
3\end{array}$ \\
\hline Renter Occ No Veh & 0 & 0.74 & $\begin{array}{l}1.0 \\
6 \\
\end{array}$ & $\begin{array}{l}0.8 \\
2 \\
\end{array}$ & $\begin{array}{l}0.7 \\
5 \\
\end{array}$ & $\begin{array}{l}1.2 \\
0 \\
\end{array}$ & 0 & $\begin{array}{l}2.0 \\
6 \\
\end{array}$ & $\begin{array}{l}1.0 \\
5 \\
\end{array}$ & $\begin{array}{l}1.0 \\
3 \\
\end{array}$ & $\begin{array}{l}1.2 \\
3 \\
\end{array}$ & $\begin{array}{l}0.9 \\
1 \\
\end{array}$ \\
\hline Renter Occupied Veh & 0 & 1.07 & $\begin{array}{l}0.9 \\
8\end{array}$ & $\begin{array}{l}1.1 \\
8\end{array}$ & $\begin{array}{l}0.9 \\
2\end{array}$ & $\begin{array}{l}1.0 \\
4\end{array}$ & 0 & $\begin{array}{l}0.7 \\
4\end{array}$ & $\begin{array}{l}0.9 \\
1\end{array}$ & $\begin{array}{l}0.8 \\
9\end{array}$ & $\begin{array}{l}0.9 \\
5\end{array}$ & $\begin{array}{l}0.9 \\
6\end{array}$ \\
\hline Households No Veh & 0 & 1.03 & $\begin{array}{l}1.0 \\
2\end{array}$ & $\begin{array}{l}1.1 \\
8\end{array}$ & $\begin{array}{l}0.8 \\
9\end{array}$ & $\begin{array}{l}1.0 \\
0\end{array}$ & 0 & $\begin{array}{l}2.4 \\
0\end{array}$ & $\begin{array}{l}0.9 \\
1\end{array}$ & $\begin{array}{l}0.9 \\
4\end{array}$ & $\begin{array}{l}1.2 \\
1\end{array}$ & $\begin{array}{l}0.9 \\
5\end{array}$ \\
\hline Households with Veh & 0 & 1.07 & $\begin{array}{l}0.9 \\
8 \\
\end{array}$ & $\begin{array}{l}1.1 \\
8 \\
\end{array}$ & $\begin{array}{l}0.9 \\
2 \\
\end{array}$ & $\begin{array}{l}1.0 \\
4 \\
\end{array}$ & 0 & $\begin{array}{l}0.9 \\
6 \\
\end{array}$ & $\begin{array}{l}1.0 \\
1 \\
\end{array}$ & $\begin{array}{l}1.0 \\
1 \\
\end{array}$ & $\begin{array}{l}0.9 \\
9 \\
\end{array}$ & $\begin{array}{l}1.0 \\
0 \\
\end{array}$ \\
\hline
\end{tabular}

Table 5A.5. Low MA: BRT, Tenure by Vehicle Presence

\begin{tabular}{|c|c|c|c|c|c|c|c|c|c|c|c|c|}
\hline $\begin{array}{l}\text { Demograph } \\
\text { Incrementa }\end{array}$ & ge & $0-2$ & & & & & $\begin{array}{l}\text { Cumu } \\
\text { lative }\end{array}$ & & & & & \\
\hline Tenure by & & & & & & & & & & & & \\
\hline $\begin{array}{l}\text { Vehicle } \\
\text { Presence }\end{array}$ & $\begin{array}{l}0.12 \\
5\end{array}$ & 0.25 & $\begin{array}{l}0.37 \\
5\end{array}$ & 0.5 & 0.75 & 1 & 0.125 & 0.25 & $\begin{array}{l}0.37 \\
5\end{array}$ & 0.5 & 0.75 & 1 \\
\hline $\begin{array}{l}\text { Owner } \\
\text { Occupied }\end{array}$ & 908 & 789 & $\begin{array}{l}2,63 \\
6\end{array}$ & $\begin{array}{l}2,74 \\
9\end{array}$ & $\begin{array}{l}2,22 \\
8\end{array}$ & $\begin{array}{l}1,36 \\
4\end{array}$ & 908 & $\begin{array}{l}1,69 \\
7\end{array}$ & $\begin{array}{l}4,33 \\
3 \\
\end{array}$ & $\begin{array}{l}7,08 \\
2\end{array}$ & $\begin{array}{l}9,31 \\
0\end{array}$ & $\begin{array}{l}10,6 \\
74\end{array}$ \\
\hline $\begin{array}{l}\text { Renter } \\
\text { Occupied }\end{array}$ & $\begin{array}{l}6,61 \\
1\end{array}$ & $\begin{array}{l}1,24 \\
9\end{array}$ & $\begin{array}{l}4,18 \\
6\end{array}$ & $\begin{array}{l}1,64 \\
4\end{array}$ & $\begin{array}{l}(923 \\
)^{2}\end{array}$ & $\begin{array}{l}1,64 \\
0\end{array}$ & 6,611 & $\begin{array}{l}7,86 \\
0\end{array}$ & $\begin{array}{l}12,0 \\
46\end{array}$ & $\begin{array}{l}13,6 \\
90\end{array}$ & $\begin{array}{l}12,7 \\
67\end{array}$ & $\begin{array}{l}14,4 \\
07\end{array}$ \\
\hline
\end{tabular}




\begin{tabular}{|c|c|c|c|c|c|c|c|c|c|c|c|c|}
\hline $\begin{array}{l}\text { Total Housing } \\
\text { Units }\end{array}$ & $\begin{array}{l}7,51 \\
9\end{array}$ & $\begin{array}{l}2,03 \\
8\end{array}$ & $\begin{array}{l}6,82 \\
2\end{array}$ & $\begin{array}{l}4,39 \\
3\end{array}$ & $\begin{array}{l}1,30 \\
5\end{array}$ & $\begin{array}{l}1,36 \\
4\end{array}$ & 7,519 & $\begin{array}{l}9,55 \\
7\end{array}$ & $\begin{array}{l}16,3 \\
79\end{array}$ & $\begin{array}{l}20,7 \\
72\end{array}$ & $\begin{array}{l}22,0 \\
77\end{array}$ & $\begin{array}{l}23,4 \\
41\end{array}$ \\
\hline $\begin{array}{l}\overline{\text { Owner Occ No }} \\
\text { Veh }\end{array}$ & (103) & )$^{(382}$ & )$^{(259}$ & (373) & $\begin{array}{l}(359 \\
)\end{array}$ & 360 & (103) & (485) & (744) & $\begin{array}{l}(1,11 \\
7)\end{array}$ & $\begin{array}{l}(1,47 \\
6) \\
\end{array}$ & $\begin{array}{l}(1,11 \\
6)\end{array}$ \\
\hline $\begin{array}{l}\text { Owner } \\
\text { Occupied Veh }\end{array}$ & $\begin{array}{l}133 \\
110 \\
\end{array}$ & $\begin{array}{l}32,4 \\
00\end{array}$ & $\begin{array}{l}42,3 \\
13 \\
\end{array}$ & $\begin{array}{l}44,7 \\
71\end{array}$ & $\begin{array}{l}31,6 \\
90\end{array}$ & $\begin{array}{l}1,72 \\
4\end{array}$ & $\begin{array}{l}133,1 \\
10\end{array}$ & $\begin{array}{l}165 \\
510\end{array}$ & $\begin{array}{l}207 \\
823\end{array}$ & $\begin{array}{l}252 \\
594\end{array}$ & $\begin{array}{l}284 \\
284\end{array}$ & $\begin{array}{l}286 \\
008\end{array}$ \\
\hline $\begin{array}{l}\text { Renter Occ No } \\
\text { Veh }\end{array}$ & $\begin{array}{l}1,98 \\
5\end{array}$ & 143 & 771 & (545) & )$^{(894}$ & (98) & 1,985 & $\begin{array}{l}2,12 \\
8 \\
\end{array}$ & $\begin{array}{l}2,89 \\
9\end{array}$ & $\begin{array}{l}2,35 \\
4 \\
\end{array}$ & $\begin{array}{l}1,46 \\
0\end{array}$ & $\begin{array}{l}1,36 \\
2\end{array}$ \\
\hline $\begin{array}{l}\text { Renter } \\
\text { Occupied Veh }\end{array}$ & $\begin{array}{l}(342, \\
723)\end{array}$ & $\begin{array}{l}(76, \\
347)\end{array}$ & $\begin{array}{l}(91, \\
541)\end{array}$ & $\begin{array}{l}(106, \\
259)\end{array}$ & $\begin{array}{l}(82, \\
364)\end{array}$ & $\begin{array}{l}39,8 \\
24\end{array}$ & $\begin{array}{l}(342, \\
723)\end{array}$ & $\begin{array}{l}(419, \\
070)\end{array}$ & $\begin{array}{l}510, \\
611)\end{array}$ & $\begin{array}{l}616, \\
870)\end{array}$ & $\begin{array}{l}699, \\
234)\end{array}$ & $\begin{array}{l}(659, \\
410)\end{array}$ \\
\hline $\begin{array}{l}\text { Total Housing } \\
\text { Units }\end{array}$ & $\begin{array}{l}(207 \\
731)\end{array}$ & $\begin{array}{l}(44, \\
186)\end{array}$ & $\begin{array}{l}(48, \\
716)\end{array}$ & $\begin{array}{l}(62,4 \\
06)\end{array}$ & $\begin{array}{l}(51, \\
927)\end{array}$ & 554 & $\begin{array}{l}(207 \\
731)\end{array}$ & $\begin{array}{l}(251, \\
917)\end{array}$ & $\begin{array}{l}(300, \\
633)\end{array}$ & $\begin{array}{l}(363, \\
039)\end{array}$ & $\begin{array}{l}(414, \\
966)\end{array}$ & $\begin{array}{l}(414, \\
412)\end{array}$ \\
\hline $\begin{array}{l}\text { Households No } \\
\text { Veh }\end{array}$ & $\begin{array}{l}1,88 \\
2\end{array}$ & )$^{(239}$ & 512 & (918) & $\begin{array}{l}(1,2 \\
53)\end{array}$ & $\begin{array}{l}(90 \\
604)\end{array}$ & 1,882 & $\begin{array}{l}1,64 \\
3 \\
\end{array}$ & $\begin{array}{l}2,15 \\
5\end{array}$ & $\begin{array}{l}1,23 \\
7 \\
\end{array}$ & (16) & $\begin{array}{l}(90,6 \\
20)\end{array}$ \\
\hline $\begin{array}{l}\text { Households } \\
\text { with Veh }\end{array}$ & $\begin{array}{l}(209) \\
613)\end{array}$ & $\begin{array}{l}(43, \\
947)\end{array}$ & $\begin{array}{l}(49, \\
228)\end{array}$ & $\begin{array}{l}(61,4 \\
88)\end{array}$ & $\begin{array}{l}(50 \\
674)\end{array}$ & $\begin{array}{l}(50, \\
324)\end{array}$ & $\begin{array}{l}(209 \\
613)\end{array}$ & $\begin{array}{l}(253, \\
560)\end{array}$ & $\begin{array}{l}(302, \\
788)\end{array}$ & $\begin{array}{l}(364, \\
276)\end{array}$ & $\begin{array}{l}(414 \\
950)\end{array}$ & $\begin{array}{l}(465, \\
274)\end{array}$ \\
\hline $\begin{array}{l}\text { Total Housing } \\
\text { Units }\end{array}$ & $\begin{array}{l}207 \\
731) \\
\end{array}$ & $\begin{array}{l}44, \\
186)\end{array}$ & $\begin{array}{l}(48, \\
716) \\
\end{array}$ & $\begin{array}{l}(62,4 \\
06) \\
\end{array}$ & $\begin{array}{l}51 \\
927)\end{array}$ & 456 & $\begin{array}{l}(207 \\
731) \\
\end{array}$ & $\begin{array}{l}(251, \\
917)\end{array}$ & $\begin{array}{l}(300, \\
633)\end{array}$ & $\begin{array}{l}363, \\
039)\end{array}$ & $\begin{array}{l}(414, \\
966)\end{array}$ & $\begin{array}{l}(414, \\
510)\end{array}$ \\
\hline \multicolumn{7}{|c|}{$\begin{array}{l}\text { Percent Demographic Change 2010- } \\
2016 \text { - Incremental }\end{array}$} & \multicolumn{6}{|l|}{$\begin{array}{l}\text { Cumu } \\
\text { lative }\end{array}$} \\
\hline $\begin{array}{l}\text { Tenure by } \\
\text { Vehicle } \\
\text { Presence }\end{array}$ & $\begin{array}{l}0.12 \\
5\end{array}$ & & $\begin{array}{l}0.37 \\
5\end{array}$ & & & & & & 0.37 & & & \\
\hline $\begin{array}{l}\text { Presence } \\
\text { Owner } \\
\text { Occupied }\end{array}$ & $1 \%$ & 0.25 & $6 \%$ & $6 \%$ & 0.75 & $3 \%$ & 0.125 & 0.25 & $2 \%$ & 0.5 & 0.75 & $3 \%$ \\
\hline $\begin{array}{l}\text { Renter } \\
\text { Occupied }\end{array}$ & $5 \%$ & $4 \%$ & $13 \%$ & $4 \%$ & $-4 \%$ & $1 \%$ & $5 \%$ & $5 \%$ & $6 \%$ & $6 \%$ & $5 \%$ & $6 \%$ \\
\hline $\begin{array}{l}\text { Total Housing } \\
\text { Units }\end{array}$ & $3 \%$ & $3 \%$ & $9 \%$ & $5 \%$ & $2 \%$ & $2 \%$ & $3 \%$ & $3 \%$ & $4 \%$ & $4 \%$ & $3 \%$ & $4 \%$ \\
\hline $\begin{array}{l}\text { Owner Occ No } \\
\text { Veh }\end{array}$ & $-2 \%$ & $22 \%$ & $15 \%$ & $-19 \%$ & $27 \%$ & $-6 \%$ & $-2 \%$ & $-6 \%$ & $-8 \%$ & $-10 \%$ & $-14 \%$ & $-14 \%$ \\
\hline $\begin{array}{l}\text { Owner } \\
\text { Occupied Veh }\end{array}$ & $\begin{array}{l}1475 \\
\%\end{array}$ & $\begin{array}{l}218 \\
5 \%\end{array}$ & $\begin{array}{l}894 \\
6 \% \\
\end{array}$ & $\begin{array}{l}4100 \\
\%\end{array}$ & $\begin{array}{l}338 \\
9 \%\end{array}$ & $\begin{array}{l}402 \\
7 \%\end{array}$ & $\begin{array}{l}1475 \\
\%\end{array}$ & $\begin{array}{l}1575 \\
\%\end{array}$ & $\begin{array}{l}1892 \\
\%\end{array}$ & $\begin{array}{l}2092 \\
\%\end{array}$ & $\begin{array}{l}2380 \\
\%\end{array}$ & $\begin{array}{l}2618 \\
\%\end{array}$ \\
\hline $\begin{array}{l}\text { Renter Occ No } \\
\text { Veh }\end{array}$ & $7 \%$ & $2 \%$ & $15 \%$ & $-8 \%$ & $\begin{array}{l}- \\
19 \%\end{array}$ & $14 \%$ & $7 \%$ & $5 \%$ & $6 \%$ & $\%$ & $5 \%$ & $6 \%$ \\
\hline $\begin{array}{l}\text { Renter } \\
\text { Occupied Veh }\end{array}$ & $-75 \%$ & $74 \%$ & $75 \%$ & $-77 \%$ & $81 \%$ & $78 \%$ & $75 \%$ & $-75 \%$ & $-75 \%$ & $75 \%$ & $-76 \%$ & $-76 \%$ \\
\hline $\begin{array}{l}\text { Total Housing } \\
\text { Units } \\
\end{array}$ & $-42 \%$ & $39 \%$ & $38 \%$ & $2 \%$ & $48 \%$ & $41 \%$ & $42 \%$ & $5 \%$ & $6 \%$ & $6 \%$ & $5 \%$ & $6 \%$ \\
\hline $\begin{array}{l}\text { Households No } \\
\text { Veh }\end{array}$ & $6 \%$ & $-3 \%$ & $7 \%$ & $-11 \%$ & $21 \%$ & $8 \%$ & $6 \%$ & $4 \%$ & $5 \%$ & $\%$ & $0 \%$ & $1 \%$ \\
\hline $\begin{array}{l}\text { Households } \\
\text { with Veh }\end{array}$ & $-45 \%$ & $-\overline{42 \%}$ & $-\overline{40 \%}$ & $-44 \%$ & $-\overline{50 \%}$ & - & $-45 \%$ & $-44 \%$ & $56 \%$ & $-44 \%$ & $-44 \%$ & $-44 \%$ \\
\hline $\begin{array}{l}\text { Total Housing } \\
\text { Units }\end{array}$ & $-42 \%$ & $39 \%$ & $38 \%$ & $-42 \%$ & - & $41 \%$ & $-42 \%$ & $5 \%$ & $6 \%$ & $5 \%$ & $5 \%$ & $6 \%$ \\
\hline \multicolumn{7}{|c|}{$\begin{array}{l}\text { LQ Trend 2010-2016 (LQ 2016 / LQ } \\
\text { 2010) - Incremental }\end{array}$} & \multicolumn{6}{|l|}{$\begin{array}{l}\text { Cumu } \\
\text { lative }\end{array}$} \\
\hline $\begin{array}{l}\text { Tenure by } \\
\text { Vehicle } \\
\text { Presence }\end{array}$ & $\begin{array}{l}0.12 \\
5\end{array}$ & 0.25 & $\begin{array}{l}0.37 \\
5 \\
\end{array}$ & 0.5 & 0.75 & 1 & 0.125 & 0.25 & $\begin{array}{l}0.37 \\
5 \\
\end{array}$ & 0.5 & 0.75 & 1 \\
\hline $\begin{array}{l}\text { Owner } \\
\text { Occupied }\end{array}$ & 0.98 & 0.97 & 1.00 & 0.95 & 1.00 & 0.90 & 0.98 & 1.01 & 1.01 & 1.01 & 1.02 & 1.01 \\
\hline $\begin{array}{l}\text { Renter } \\
\text { Occupied }\end{array}$ & 1.00 & 1.00 & 1.00 & 1.00 & 1.00 & 1.00 & 1.00 & 0.98 & 0.98 & 0.98 & 0.97 & 0.98 \\
\hline $\begin{array}{l}\text { Owner Occ No } \\
\text { Veh }\end{array}$ & 0.65 & 0.94 & 3.52 & 1.70 & 2.49 & 1.45 & 0.65 & 0.99 & 0.96 & 0.94 & 0.90 & 0.90 \\
\hline
\end{tabular}




\begin{tabular}{l|l|l|l|l|l|l|l|l|l|l|l|l}
$\begin{array}{l}\text { Owner } \\
\text { Occupied Veh }\end{array}$ & 1.00 & 0.95 & 1.00 & 0.83 & 1.05 & 0.76 & 1.00 & 0.69 & 0.82 & 0.90 & 1.02 & 1.11 \\
\hline $\begin{array}{l}\text { Renter Occ No } \\
\text { Veh }\end{array}$ & 1.22 & 1.27 & 1.12 & 1.10 & 1.01 & 0.91 & 1.22 & 0.99 & 0.99 & 0.97 & 0.96 & 0.96 \\
\hline $\begin{array}{l}\text { Renter } \\
\text { Occupied Veh }\end{array}$ & 1.04 & 1.08 & 1.04 & 1.01 & 1.04 & 0.93 & 1.04 & 1.23 & 1.21 & 1.19 & 1.14 & 1.13 \\
\hline $\begin{array}{l}\text { Households No } \\
\text { Veh }\end{array}$ & 1.02 & 1.08 & 1.04 & 1.01 & 1.04 & 0.94 & 1.02 & 0.95 & 0.94 & 0.93 & 0.92 & 0.92 \\
\hline $\begin{array}{l}\text { Households } \\
\text { with Veh }\end{array}$ & 1.04 & 1.08 & 1.04 & 1.01 & 1.04 & 0.93 & 1.04 & 0.99 & 0.99 & 0.99 & 0.99 & 1.00 \\
\hline
\end{tabular}

Table 5A.6. Low MA: CRT, Tenure by Vehicle Presence

\begin{tabular}{|c|c|c|c|c|c|c|c|c|c|c|c|c|}
\hline $\begin{array}{l}\text { Demographic Ch } \\
\text { Incremental }\end{array}$ & e 2 & 20 & & & & & $\begin{array}{l}\text { Cumul } \\
\text { ative }\end{array}$ & & & & & \\
\hline Tenure by & 0.1 & & 0.37 & & & & & 0.2 & 0.37 & & & \\
\hline Vehicle Presence & 25 & 0.25 & 5 & 0.5 & 0.75 & 1 & 0.125 & 5 & 5 & 0.5 & 0.75 & 1 \\
\hline Owner Occupied & $\begin{array}{l}1,3 \\
13\end{array}$ & $(578$ & $\begin{array}{l}(1,6 \\
97)\end{array}$ & $\begin{array}{l}(3,4 \\
36)\end{array}$ & $\begin{array}{l}(1,7 \\
13)\end{array}$ & $\begin{array}{l}(81 \\
7)\end{array}$ & 1,313 & 735 & (962 & $\begin{array}{l}(4,3 \\
98)\end{array}$ & $\begin{array}{l}(6,1 \\
11)\end{array}$ & $\begin{array}{l}(6,9 \\
28)\end{array}$ \\
\hline Renter Occupied & $\begin{array}{l}7,3 \\
96 \\
\end{array}$ & $\begin{array}{l}1,74 \\
9\end{array}$ & $\begin{array}{l}1,82 \\
5\end{array}$ & $\begin{array}{l}1,33 \\
8\end{array}$ & 418 & $\begin{array}{l}1,7 \\
22 \\
\end{array}$ & 7,396 & $\begin{array}{l}9,1 \\
45\end{array}$ & $\begin{array}{l}10,9 \\
70\end{array}$ & $\begin{array}{l}12,3 \\
08\end{array}$ & $\begin{array}{l}12,7 \\
26\end{array}$ & $\begin{array}{l}14,4 \\
48\end{array}$ \\
\hline $\begin{array}{l}\text { Total Housing } \\
\text { Units }\end{array}$ & $\begin{array}{l}8,7 \\
09 \\
\end{array}$ & $\begin{array}{l}1,17 \\
1\end{array}$ & 128 & $\begin{array}{l}(2,0 \\
98)\end{array}$ & $\begin{array}{l}(1,2 \\
95)\end{array}$ & $\begin{array}{l}(81 \\
7)\end{array}$ & 8,709 & $\begin{array}{l}9,8 \\
80\end{array}$ & $\begin{array}{l}10,0 \\
08\end{array}$ & $\begin{array}{l}7,91 \\
0\end{array}$ & $\begin{array}{l}6,61 \\
5\end{array}$ & $\begin{array}{l}5,79 \\
8\end{array}$ \\
\hline $\begin{array}{l}\text { Owner Occ No } \\
\text { Veh }\end{array}$ & $\begin{array}{l}(37 \\
8)\end{array}$ & 292 & $(219$ & $(222$ & (85) & $\begin{array}{l}2,5 \\
39\end{array}$ & $(378)$ & $(86)$ & (305 & (527 & (612 & $\begin{array}{l}1,92 \\
7\end{array}$ \\
\hline $\begin{array}{l}\text { Owner Occupied } \\
\text { Veh }\end{array}$ & $\begin{array}{l}1,9 \\
09\end{array}$ & $\begin{array}{l}(1,1 \\
16)\end{array}$ & $\begin{array}{l}(1,8 \\
40)\end{array}$ & $\begin{array}{l}(3,8 \\
85)\end{array}$ & $\begin{array}{l}(2,7 \\
49)\end{array}$ & $\begin{array}{l}1,7 \\
22\end{array}$ & 1,909 & 793 & $\begin{array}{l}(1,0 \\
47)\end{array}$ & $\begin{array}{l}(4,9 \\
32)\end{array}$ & $\begin{array}{l}(7,6 \\
81)\end{array}$ & $\begin{array}{l}(5,9 \\
59)\end{array}$ \\
\hline $\begin{array}{l}\text { Renter Occ No } \\
\text { Veh }\end{array}$ & $\begin{array}{l}1,2 \\
99\end{array}$ & 831 & 510 & )$^{(135}$ & $\begin{array}{l}(1,3 \\
41)\end{array}$ & $\begin{array}{l}(16 \\
9)\end{array}$ & 1,299 & $\begin{array}{l}2,1 \\
30\end{array}$ & $\begin{array}{l}2,64 \\
0\end{array}$ & $\begin{array}{l}2,50 \\
5\end{array}$ & $\begin{array}{l}1,16 \\
4\end{array}$ & 995 \\
\hline $\begin{array}{l}\text { Renter Occupied } \\
\text { Veh }\end{array}$ & $\begin{array}{l}12 \\
822 \\
\end{array}$ & $\begin{array}{l}1,99 \\
0\end{array}$ & $\begin{array}{l}3,69 \\
9\end{array}$ & $\begin{array}{l}4,19 \\
0\end{array}$ & $\begin{array}{l}4,97 \\
7\end{array}$ & $\begin{array}{l}(41 \\
3) \\
\end{array}$ & 12,822 & $\begin{array}{l}14 \\
812 \\
\end{array}$ & $\begin{array}{l}18,5 \\
11 \\
\end{array}$ & $\begin{array}{l}22,7 \\
01\end{array}$ & $\begin{array}{l}27,6 \\
78\end{array}$ & $\begin{array}{l}27,2 \\
65\end{array}$ \\
\hline $\begin{array}{l}\text { Total Housing } \\
\text { Units }\end{array}$ & $\begin{array}{l}15 \\
652\end{array}$ & $\begin{array}{l}1,99 \\
7\end{array}$ & $\begin{array}{l}2,15 \\
0\end{array}$ & (52) & 802 & $\begin{array}{l}\text { (55 } \\
1)\end{array}$ & 15,652 & $\begin{array}{l}17 \\
649\end{array}$ & $\begin{array}{l}19,7 \\
99\end{array}$ & $\begin{array}{l}19,7 \\
47\end{array}$ & $\begin{array}{l}20,5 \\
49\end{array}$ & $\begin{array}{l}19,9 \\
98\end{array}$ \\
\hline $\begin{array}{l}\text { Households No } \\
\text { Veh }\end{array}$ & 921 & $\begin{array}{l}1,12 \\
3\end{array}$ & 291 & (357 & $\begin{array}{l}(1,4 \\
26)\end{array}$ & $\begin{array}{l}6,7 \\
48\end{array}$ & 921 & $\begin{array}{l}2,0 \\
44\end{array}$ & $\begin{array}{l}2,33 \\
5\end{array}$ & $\begin{array}{l}1,97 \\
8\end{array}$ & 552 & $\begin{array}{l}7,30 \\
0\end{array}$ \\
\hline $\begin{array}{l}\text { Households with } \\
\text { Veh }\end{array}$ & $\begin{array}{l}14 \\
731\end{array}$ & 874 & $\begin{array}{l}1,85 \\
9\end{array}$ & 305 & $\begin{array}{l}2,22 \\
8\end{array}$ & $\begin{array}{l}5,6 \\
15\end{array}$ & 14,731 & $\begin{array}{l}15 \\
605\end{array}$ & $\begin{array}{l}17,4 \\
64\end{array}$ & $\begin{array}{l}17,7 \\
69\end{array}$ & $\begin{array}{l}19,9 \\
97\end{array}$ & $\begin{array}{l}25,6 \\
12\end{array}$ \\
\hline $\begin{array}{l}\text { Total Housing } \\
\text { Units } \\
\end{array}$ & $\begin{array}{l}15 \\
652 \\
\end{array}$ & $\begin{array}{l}1,99 \\
7 \\
\end{array}$ & $\begin{array}{l}2,15 \\
0\end{array}$ & (52) & 802 & $\begin{array}{l}72 \\
0)\end{array}$ & 15,652 & $\begin{array}{l}17 \\
649 \\
\end{array}$ & $\begin{array}{l}19,7 \\
99\end{array}$ & $\begin{array}{l}19,7 \\
47\end{array}$ & $\begin{array}{l}20,5 \\
49\end{array}$ & $\begin{array}{l}19,8 \\
29 \\
\end{array}$ \\
\hline $\begin{array}{l}\text { Percent Demogr } \\
2016 \text { - Incremen }\end{array}$ & & 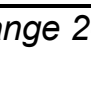 & & & & & $\begin{array}{l}\text { Cumul } \\
\text { ative }\end{array}$ & & & & & \\
\hline $\begin{array}{l}\text { Tenure by } \\
\text { Vehicle Presence }\end{array}$ & $\begin{array}{l}0.1 \\
25 \\
\end{array}$ & 0.25 & $\begin{array}{l}0.37 \\
5 \\
\end{array}$ & 0.5 & 0.75 & 1 & 125 & $\begin{array}{l}0.2 \\
5 \\
\end{array}$ & $\begin{array}{l}0.37 \\
5 \\
\end{array}$ & 0.5 & 0.75 & 1 \\
\hline Owner Occupied & $2 \%$ & $-2 \%$ & $-4 \%$ & $-9 \%$ & $-3 \%$ & $\begin{array}{l}- \\
1 \%\end{array}$ & $\%$ & $1 \%$ & $-1 \%$ & $-2 \%$ & $-1 \%$ & $2 \%$ \\
\hline Renter Occupied & $\begin{array}{l}13 \\
\%\end{array}$ & $9 \%$ & $6 \%$ & $4 \%$ & $\%$ & $\%$ & $3 \%$ & $\begin{array}{l}12 \\
\%\end{array}$ & $10 \%$ & $9 \%$ & $\%$ & $\%$ \\
\hline $\begin{array}{l}\text { Total Housing } \\
\text { Units } \\
\end{array}$ & $6 \%$ & $3 \%$ & $0 \%$ & $-3 \%$ & $-1 \%$ & $2 \%$ & $6 \%$ & $6 \%$ & $4 \%$ & $2 \%$ & $2 \%$ & $1 \%$ \\
\hline $\begin{array}{l}\text { Owner Occ No } \\
\text { Veh }\end{array}$ & $\begin{array}{l}- \\
18 \\
\%\end{array}$ & $53 \%$ & $\overline{20 \%}$ & $\begin{array}{l}- \\
18 \% \\
\end{array}$ & $-5 \%$ & $\begin{array}{l}- \\
10 \\
\%\end{array}$ & $-18 \%$ & $-3 \%$ & $-8 \%$ & $\overline{-}$ & $-7 \%$ & $-8 \%$ \\
\hline $\begin{array}{l}\text { Owner Occupied } \\
\text { Veh }\end{array}$ & $2 \%$ & $-4 \%$ & $-5 \%$ & - & $-5 \%$ & $\begin{array}{l}- \\
1 \% \\
\end{array}$ & $2 \%$ & $1 \%$ & $-1 \%$ & $-3 \%$ & $-2 \%$ & $-2 \%$ \\
\hline
\end{tabular}




\begin{tabular}{|c|c|c|c|c|c|c|c|c|c|c|c|c|c|}
\hline $\begin{array}{l}\text { Renter Occ No } \\
\text { Veh }\end{array}$ & $\begin{array}{l}21 \\
\%\end{array}$ & 40 & $\%$ & $14 \%$ & $3 \%$ & $\overline{2}-\overline{2} \%$ & $\begin{array}{l}10 \\
\%\end{array}$ & $21 \%$ & $\begin{array}{l}12 \\
\%\end{array}$ & $10 \%$ & $9 \%$ & $7 \%$ & $6 \%$ \\
\hline $\begin{array}{l}\text { Renter Occupied } \\
\text { Veh }\end{array}$ & $\begin{array}{l}30 \\
\%\end{array}$ & 12 & & $15 \%$ & $7 \%$ & $18 \%$ & $\begin{array}{l}22 \\
\%\end{array}$ & $30 \%$ & $\begin{array}{l}25 \\
\%\end{array}$ & $22 \%$ & $21 \%$ & $19 \%$ & $18 \%$ \\
\hline $\begin{array}{l}\text { Total Housing } \\
\text { Units }\end{array}$ & $\begin{array}{l}12 \\
\%\end{array}$ & $4 \%$ & & $3 \%$ & $0 \%$ & $1 \%$ & $6 \%$ & $12 \%$ & $\begin{array}{l}12 \\
\%\end{array}$ & $10 \%$ & $9 \%$ & $7 \%$ & $6 \%$ \\
\hline $\begin{array}{l}\text { Households No } \\
\text { Veh }\end{array}$ & $\begin{array}{l}11 \\
\%\end{array}$ & 43 & & $6 \%$ & $-6 \%$ & $\overline{-}$ & $\begin{array}{l}10 \\
\%\end{array}$ & $11 \%$ & $\begin{array}{l}19 \\
\%\end{array}$ & $15 \%$ & $9 \%$ & $1 \%$ & $0 \%$ \\
\hline $\begin{array}{l}\text { Households with } \\
\text { Veh }\end{array}$ & $\begin{array}{l}12 \\
\%\end{array}$ & $2 \%$ & & $3 \%$ & $0 \%$ & $3 \%$ & $7 \%$ & $12 \%$ & $\begin{array}{l}10 \\
\%\end{array}$ & $\begin{array}{l}108 \\
\%\end{array}$ & $6 \%$ & $6 \%$ & $5 \%$ \\
\hline$\frac{\text { Total Housing }}{\text { Units }}$ & $\begin{array}{l}12 \\
\%\end{array}$ & $4 \%$ & & $3 \%$ & $0 \%$ & $1 \%$ & $6 \%$ & $12 \%$ & $\begin{array}{l}12 \\
\%\end{array}$ & $10 \%$ & $9 \%$ & $7 \%$ & $6 \%$ \\
\hline \multicolumn{8}{|c|}{$\begin{array}{l}\text { LQ Trend 2010-2016 (LQ 2016 / LQ } \\
\text { 2010) - Incremental }\end{array}$} & \multicolumn{6}{|l|}{$\begin{array}{l}\text { Cumul } \\
\text { ative }\end{array}$} \\
\hline $\begin{array}{l}\text { Tenure by } \\
\text { Vehicle Presence }\end{array}$ & $\begin{array}{l}0.1 \\
25\end{array}$ & 0.2 & & $\begin{array}{l}0.37 \\
5\end{array}$ & 0.5 & 0.75 & 1 & 0.125 & $\begin{array}{l}0.2 \\
5\end{array}$ & $\begin{array}{l}0.37 \\
5\end{array}$ & 0.5 & 0.75 & 1 \\
\hline Owner Occupied & $\begin{array}{l}1.0 \\
1\end{array}$ & 1.0 & & 1.01 & 1.02 & 0.93 & $\begin{array}{l}0.9 \\
8\end{array}$ & 1.01 & $\begin{array}{l}0.9 \\
9\end{array}$ & 0.99 & 0.98 & 1.00 & 1.00 \\
\hline Renter Occupied & $\begin{array}{l}1.0 \\
0\end{array}$ & 1.0 & & 1.00 & 1.00 & 1.00 & $\begin{array}{l}1.0 \\
0\end{array}$ & 0 & $\begin{array}{l}1.0 \\
1\end{array}$ & .01 & 1.01 & 1.00 & 0.99 \\
\hline $\begin{array}{l}\text { Owner Occ No } \\
\text { Veh }\end{array}$ & $\begin{array}{l}0.9 \\
6\end{array}$ & 0.5 & & 0.95 & 0.93 & 1.01 & $\begin{array}{l}0.9 \\
6\end{array}$ & 0.96 & $\begin{array}{l}0.9 \\
4\end{array}$ & 0.90 & 0.89 & 0.93 & 0.93 \\
\hline $\begin{array}{l}\text { Owner Occupied } \\
\text { Veh }\end{array}$ & $\begin{array}{l}1.0 \\
6\end{array}$ & 1.2 & & 1.06 & 0.93 & 0.80 & $\begin{array}{l}0.7 \\
2\end{array}$ & 1.06 & $\begin{array}{l}0.9 \\
5\end{array}$ & 0.95 & 0.95 & .96 & 0.96 \\
\hline $\begin{array}{l}\text { Renter Occ No } \\
\text { Veh }\end{array}$ & $\begin{array}{l}1.0 \\
6\end{array}$ & 0.9 & & 0.99 & 1.05 & 0.91 & $\begin{array}{l}1.0 \\
3\end{array}$ & 1.06 & $\begin{array}{l}1.1 \\
1\end{array}$ & 1.09 & 1.04 & 0.94 & 0.93 \\
\hline $\begin{array}{l}\text { Renter Occupied } \\
\text { Veh }\end{array}$ & $\begin{array}{l}1.0 \\
0\end{array}$ & 0.9 & & 0.98 & 0.98 & 0.96 & $\begin{array}{l}0.9 \\
7\end{array}$ & 0 & $\begin{array}{l}1.0 \\
3\end{array}$ & 1.02 & 1.02 & 1.01 & 1.00 \\
\hline $\begin{array}{l}\text { Households No } \\
\text { Veh }\end{array}$ & $\begin{array}{l}1.0 \\
0\end{array}$ & $0 . s$ & & 0.97 & 98 & 97 & $\begin{array}{l}0.9 \\
9\end{array}$ & & $\begin{array}{l}1.0 \\
8\end{array}$ & 1.06 & 1.03 & 0.96 & 0.95 \\
\hline $\begin{array}{l}\text { Households with } \\
\text { Veh }\end{array}$ & $\begin{array}{l}1.0 \\
0 \\
\end{array}$ & 0.9 & & 0.98 & 0.98 & 0.96 & $\begin{array}{l}0.9 \\
7 \\
\end{array}$ & 0 & $\begin{array}{l}0.9 \\
9 \\
\end{array}$ & 1.00 & 1.00 & 1.00 & 1.00 \\
\hline $\begin{array}{l}\text { Table 5A.7. Low M } \\
\text { Demographic Chan } \\
\text { Incremental }\end{array}$ & $\begin{array}{l}\text { A: LF } \\
\text { ge } 20\end{array}$ & $\begin{array}{l}\text { RT, T } \\
10-2\end{array}$ & $\begin{array}{l}\text { Tenul } \\
016 \text { - }\end{array}$ & re by & Vehic & e Pres & ence & $\begin{array}{l}\text { umul } \\
\text { tive }\end{array}$ & & & & & \\
\hline $\begin{array}{l}\text { Tenure by Vehicle } \\
\text { Presence }\end{array}$ & & 1 & $\begin{array}{l}0.2 \\
5\end{array}$ & $\begin{array}{l}0.3 \\
75\end{array}$ & 0.5 & 75 & 1 & $1 \angle 0$ & 0.25 & $\begin{array}{l}0.37 \\
5\end{array}$ & .5 & 0.75 & $T$ \\
\hline Owne & & 90 & $\begin{array}{l}2,6 \\
73\end{array}$ & $\begin{array}{l}1,6 \\
54\end{array}$ & 98 & 412 & $\begin{array}{l}93 \\
8\end{array}$ & 905 & $\begin{array}{l}6,57 \\
8\end{array}$ & $\begin{array}{l}8,23 \\
2\end{array}$ & $\begin{array}{l}8,33 \\
0\end{array}$ & \begin{tabular}{|l|}
8,74 \\
2
\end{tabular} & $\begin{array}{l}9,68 \\
0\end{array}$ \\
\hline Renter Occupied & & 4 & $\begin{array}{l}1,9 \\
18\end{array}$ & $\begin{array}{l}22 \\
4\end{array}$ & $\begin{array}{l}4,7 \\
87\end{array}$ & $\begin{array}{l}3,39 \\
8\end{array}$ & $\begin{array}{l}3,0 \\
36\end{array}$ & 0,4 & $\begin{array}{l}17,3 \\
99\end{array}$ & $\begin{array}{l}17,6 \\
23\end{array}$ & $\begin{array}{l}22,4 \\
10\end{array}$ & $\begin{array}{l}25,8 \\
08\end{array}$ & $\begin{array}{l}28,8 \\
44\end{array}$ \\
\hline Ising Units & & 9,3 & $\begin{array}{l}4,5 \\
91 \\
\end{array}$ & $\begin{array}{l}1,8 \\
78\end{array}$ & $\begin{array}{l}4,8 \\
85\end{array}$ & 3,81 & $\begin{array}{l}93 \\
8 \\
\end{array}$ & 19,386 & $\begin{array}{l}23,9 \\
77 \\
\end{array}$ & $\begin{array}{l}25,8 \\
55 \\
\end{array}$ & $\begin{array}{l}30,7 \\
40 \\
\end{array}$ & $\begin{array}{l}34,5 \\
50 \\
\end{array}$ & $\begin{array}{l}35,4 \\
88 \\
\end{array}$ \\
\hline Owner Occ No Veh & 5 & & $\begin{array}{l}(14 \\
1)\end{array}$ & 66 & $\begin{array}{l}(31 \\
7)\end{array}$ & 31 & $\begin{array}{l}2,0 \\
98\end{array}$ & 5 & $\begin{array}{l}(13 \\
6)\end{array}$ & (70) & $\begin{array}{l}(38 \\
7)\end{array}$ & $\begin{array}{l}35 \\
6)\end{array}$ & $\begin{array}{l}1,74 \\
2\end{array}$ \\
\hline $\begin{array}{l}\text { Owner Occupied } \\
\text { Veh }\end{array}$ & & 74 & $\begin{array}{l}2,9 \\
72\end{array}$ & (33 & $\begin{array}{l}137 \\
1)\end{array}$ & $\begin{array}{l}(1,7 \\
18)\end{array}$ & $\begin{array}{l}3,0 \\
36\end{array}$ & 743 & $\begin{array}{l}6,71 \\
5\end{array}$ & $\begin{array}{l}6,68 \\
2\end{array}$ & $\begin{array}{l}6,31 \\
1\end{array}$ & $\begin{array}{l}4,59 \\
3\end{array}$ & $\begin{array}{l}7,62 \\
9\end{array}$ \\
\hline Ren & & 9 & (14 & $\begin{array}{l}26 \\
8\end{array}$ & $\begin{array}{l}(26 \\
7)\end{array}$ & 454 & 17 & 98 & $\begin{array}{l}1,98 \\
4\end{array}$ & $\begin{array}{l}2,25 \\
2\end{array}$ & $\begin{array}{l}1,98 \\
5\end{array}$ & $\begin{array}{l}2,43 \\
9\end{array}$ & $\begin{array}{l}2,45 \\
6\end{array}$ \\
\hline $\begin{array}{l}\text { Renter Occupied } \\
\text { Veh }\end{array}$ & & 6,3 & $\begin{array}{l}3,6 \\
43\end{array}$ & $\begin{array}{l}3,4 \\
06\end{array}$ & $\begin{array}{l}5,9 \\
02\end{array}$ & $\begin{array}{l}6,47 \\
1\end{array}$ & $\begin{array}{l}11 \\
8\end{array}$ & 26,347 & $\begin{array}{l}29,9 \\
90\end{array}$ & $\begin{array}{l}33,3 \\
96\end{array}$ & $\begin{array}{l}39,2 \\
98\end{array}$ & \begin{tabular}{|l|}
45,7 \\
69
\end{tabular} & $\begin{array}{l}45,8 \\
87\end{array}$ \\
\hline Total Housing Units & & 0 & $\begin{array}{l}6,4 \\
60\end{array}$ & $\begin{array}{l}3,7 \\
07\end{array}$ & $\begin{array}{l}4,9 \\
47\end{array}$ & \begin{tabular}{|l|}
5,23 \\
8
\end{tabular} & 71 & 32,093 & $\begin{array}{l}38,5 \\
53\end{array}$ & $\begin{array}{l}42,2 \\
60\end{array}$ & $\begin{array}{l}47,2 \\
07\end{array}$ & \begin{tabular}{|l|}
52,4 \\
45
\end{tabular} & $\begin{array}{l}52,5 \\
16\end{array}$ \\
\hline
\end{tabular}




\begin{tabular}{|c|c|c|c|c|c|c|c|c|c|c|c|c|}
\hline Households No Veh & $\begin{array}{l}2,00 \\
3\end{array}$ & $\begin{array}{l}(15 \\
5)\end{array}$ & $\begin{array}{l}33 \\
4\end{array}$ & $\begin{array}{l}(58 \\
4)\end{array}$ & 485 & $\begin{array}{l}4,6 \\
26\end{array}$ & 2,003 & $\begin{array}{l}1,84 \\
8\end{array}$ & $\begin{array}{l}2,18 \\
2\end{array}$ & $\begin{array}{l}1,59 \\
8\end{array}$ & $\begin{array}{l}2,08 \\
3\end{array}$ & $\begin{array}{l}6,70 \\
9\end{array}$ \\
\hline $\begin{array}{l}\text { Households with } \\
\text { Veh }\end{array}$ & $\begin{array}{l}30,0 \\
90\end{array}$ & $\begin{array}{l}6,6 \\
15\end{array}$ & $\begin{array}{l}3,3 \\
73\end{array}$ & $\begin{array}{l}5,5 \\
31\end{array}$ & $\begin{array}{l}4,75 \\
3\end{array}$ & $\begin{array}{l}4,8 \\
32\end{array}$ & 30,090 & $\begin{array}{l}36,7 \\
05\end{array}$ & $\begin{array}{l}40,0 \\
78\end{array}$ & $\begin{array}{l}45,6 \\
09\end{array}$ & $\begin{array}{l}50,3 \\
62\end{array}$ & $\begin{array}{l}55,1 \\
94\end{array}$ \\
\hline Total Housing Units & $\begin{array}{l}32,0 \\
93\end{array}$ & $\begin{array}{l}6,4 \\
60\end{array}$ & $\begin{array}{l}3,7 \\
07\end{array}$ & $\begin{array}{l}4,9 \\
47\end{array}$ & $\begin{array}{l}5,23 \\
8\end{array}$ & 88 & 32,093 & $\begin{array}{l}38,5 \\
53\end{array}$ & $\begin{array}{l}42,2 \\
60\end{array}$ & $\begin{array}{l}47,2 \\
07\end{array}$ & $\begin{array}{l}52,4 \\
45\end{array}$ & $\begin{array}{l}52,5 \\
33\end{array}$ \\
\hline \multicolumn{7}{|c|}{$\begin{array}{l}\text { Percent Demographic Change 2010- } \\
2016 \text { - Incremental }\end{array}$} & \multicolumn{6}{|l|}{$\begin{array}{l}\text { Cumul } \\
\text { ative }\end{array}$} \\
\hline $\begin{array}{l}\text { Tenure by Vehicle } \\
\text { Presence }\end{array}$ & $\begin{array}{l}0.12 \\
5\end{array}$ & $\begin{array}{l}0.2 \\
5\end{array}$ & $\begin{array}{l}0.3 \\
75\end{array}$ & 0.5 & 0.75 & 1 & 0.125 & 0.25 & $\begin{array}{l}0.37 \\
5\end{array}$ & 0.5 & 0.75 & 1 \\
\hline Owner Occupied & $3 \%$ & $5 \%$ & $2 \%$ & $0 \%$ & $1 \%$ & $2 \%$ & $3 \%$ & $3 \%$ & $3 \%$ & $3 \%$ & $3 \%$ & $2 \%$ \\
\hline Renter Occupied & $\begin{array}{l}10 \\
\%\end{array}$ & $4 \%$ & $0 \%$ & $\begin{array}{l}10 \\
\%\end{array}$ & $7 \%$ & $5 \%$ & $10 \%$ & $9 \%$ & $7 \%$ & $7 \%$ & $7 \%$ & $7 \%$ \\
\hline Total Housing Units & $6 \%$ & $5 \%$ & $2 \%$ & $5 \%$ & $3 \%$ & $3 \%$ & $6 \%$ & $6 \%$ & $5 \%$ & $5 \%$ & $5 \%$ & $4 \%$ \\
\hline Owner Occ No Veh & $0 \%$ & $8 \%$ & $3 \%$ & $\begin{array}{l}- \\
16 \\
\%\end{array}$ & $1 \%$ & $1 \%$ & $0 \%$ & $-2 \%$ & $-1 \%$ & $-3 \%$ & $-2 \%$ & $-4 \%$ \\
\hline $\begin{array}{l}\text { Owner Occupied } \\
\text { Veh }\end{array}$ & $2 \%$ & $6 \%$ & $0 \%$ & $-\overline{1 \%}$ & $-3 \%$ & $0 \%$ & $2 \%$ & $3 \%$ & $3 \%$ & $2 \%$ & $1 \%$ & $1 \%$ \\
\hline Renter Occ I & $8 \%$ & $0 \%$ & $3 \%$ & $-\overline{3 \%}$ & $6 \%$ & $1 \%$ & $8 \%$ & $9 \%$ & $7 \%$ & $7 \%$ & $7 \%$ & $7 \%$ \\
\hline $\begin{array}{l}\text { Renter Occupied } \\
\text { Veh }\end{array}$ & $\begin{array}{l}23 \\
\%\end{array}$ & $9 \%$ & $9 \%$ & $\begin{array}{l}15 \\
\%\end{array}$ & $18 \%$ & $\begin{array}{l}14 \\
\%\end{array}$ & $23 \%$ & $\begin{array}{l}20 \\
\%\end{array}$ & $\begin{array}{l}17 \\
\%\end{array}$ & $\begin{array}{l}17 \\
\%\end{array}$ & $\begin{array}{l}17 \\
\%\end{array}$ & $\begin{array}{l}16 \\
\%\end{array}$ \\
\hline Total Housing Units & $\begin{array}{l}11 \\
\%\end{array}$ & $7 \%$ & $3 \%$ & $5 \%$ & $5 \%$ & $5 \%$ & $11 \%$ & $9 \%$ & $7 \%$ & $7 \%$ & $7 \%$ & $7 \%$ \\
\hline Households No Veh & $7 \%$ & $-\overline{1 \%}$ & $3 \%$ & $-\overline{6 \%}$ & $5 \%$ & $1 \%$ & $7 \%$ & $4 \%$ & $4 \%$ & $3 \%$ & $3 \%$ & $1 \%$ \\
\hline $\begin{array}{l}\text { Households with } \\
\text { Veh }\end{array}$ & $\begin{array}{l}11 \\
\%\end{array}$ & $8 \%$ & $3 \%$ & $6 \%$ & $5 \%$ & $5 \%$ & $11 \%$ & $\begin{array}{l}10 \\
\%\end{array}$ & $\begin{array}{l}109 \\
\%\end{array}$ & $8 \%$ & $7 \%$ & $7 \%$ \\
\hline$\underline{\text { Total Housing Units }}$ & $\begin{array}{l}11 \\
\% \\
\end{array}$ & $7 \%$ & $3 \%$ & $5 \%$ & $5 \%$ & $5 \%$ & $11 \%$ & $9 \%$ & $7 \%$ & $7 \%$ & $7 \%$ & $7 \%$ \\
\hline \multicolumn{7}{|c|}{$\begin{array}{l}\text { LQ Trend 2010-2016 (LQ 2016 / LQ } \\
\text { 2010) - Incremental }\end{array}$} & \multicolumn{6}{|l|}{$\begin{array}{l}\text { Cumul } \\
\text { ative }\end{array}$} \\
\hline $\begin{array}{l}\text { Tenure by Vehicle } \\
\text { Presence }\end{array}$ & $\begin{array}{l}0.12 \\
5\end{array}$ & $\begin{array}{l}0.2 \\
5\end{array}$ & $\begin{array}{l}0.3 \\
75\end{array}$ & 0.5 & 0.75 & 1 & 0.125 & 0.25 & $\begin{array}{l}0.37 \\
5\end{array}$ & 0.5 & 0.75 & 1 \\
\hline Owr & 0.99 & $\begin{array}{l}0.9 \\
5\end{array}$ & $\begin{array}{l}0.9 \\
4\end{array}$ & $\begin{array}{l}1.0 \\
0\end{array}$ & 0.95 & $\begin{array}{l}0.9 \\
9\end{array}$ & 0.99 & 1.01 & 1.01 & 1.01 & 1.01 & 1.01 \\
\hline Renter Occ & 1.00 & $\begin{array}{l}1.0 \\
0\end{array}$ & $\begin{array}{l}1.0 \\
0\end{array}$ & $\begin{array}{l}1.0 \\
0\end{array}$ & 1.00 & $\begin{array}{l}1.0 \\
0\end{array}$ & 1.00 & 0.98 & 0.97 & 0.98 & 0.98 & 0.98 \\
\hline o Veh & 1.00 & $\begin{array}{l}1.0 \\
5\end{array}$ & $\begin{array}{l}1.0 \\
2\end{array}$ & $\begin{array}{l}0.9 \\
8\end{array}$ & 1.00 & $\begin{array}{l}0.9 \\
7\end{array}$ & 1.00 & 1.00 & 1.02 & 0.99 & 1.01 & 0.99 \\
\hline $\begin{array}{l}\text { Owner Occupied } \\
\text { Veh }\end{array}$ & 0.99 & $\begin{array}{l}0.9 \\
3\end{array}$ & $\begin{array}{l}0.9 \\
9\end{array}$ & $\begin{array}{l}0.9 \\
0\end{array}$ & 0.98 & $\begin{array}{l}1.0 \\
0\end{array}$ & 0.99 & 1.01 & 1.01 & 1.00 & 1.00 & 1.00 \\
\hline r Occ No Veh & 1.02 & $\begin{array}{l}0.9 \\
2 \\
\end{array}$ & $\begin{array}{l}0.9 \\
4 \\
\end{array}$ & $\begin{array}{l}0.9 \\
7 \\
\end{array}$ & 0.95 & $\begin{array}{l}1.0 \\
1 \\
\end{array}$ & 1.02 & 0.97 & 0.98 & 0.96 & 0.97 & 0.96 \\
\hline $\begin{array}{l}\text { Renter Occupied } \\
\text { Veh }\end{array}$ & 1.02 & $\begin{array}{l}1.0 \\
0 \\
\end{array}$ & $\begin{array}{l}0.9 \\
9 \\
\end{array}$ & $\begin{array}{l}0.9 \\
8 \\
\end{array}$ & 0.99 & $\begin{array}{l}0.9 \\
9 \\
\end{array}$ & 1.02 & 1.00 & 0.99 & 0.98 & 0.98 & 0.99 \\
\hline Hou & 1.02 & $\begin{array}{l}1.0 \\
0\end{array}$ & $\begin{array}{l}0.9 \\
9\end{array}$ & $\begin{array}{l}0.9 \\
9\end{array}$ & 0.99 & $\begin{array}{l}0.9 \\
9\end{array}$ & 1.02 & 0.97 & 0.98 & 0.97 & 0.98 & 0.97 \\
\hline $\begin{array}{l}\text { Households with } \\
\text { Veh }\end{array}$ & 1.02 & $\begin{array}{l}1.0 \\
0\end{array}$ & $\begin{array}{l}0.9 \\
9\end{array}$ & $\begin{array}{l}0.9 \\
8\end{array}$ & 0.99 & $\begin{array}{l}0.9 \\
9\end{array}$ & 1.02 & 1.00 & 1.00 & 1.00 & 1.00 & 1.00 \\
\hline
\end{tabular}

Table 5A.8. Low MA: SCT, Tenure by Vehicle Presence 


\begin{tabular}{|c|c|c|c|c|c|c|c|c|c|c|c|c|}
\hline $\begin{array}{l}\text { Tenure by Vehicle } \\
\text { Presence }\end{array}$ & $\begin{array}{l}0.1 \\
25\end{array}$ & $\begin{array}{l}0.2 \\
5\end{array}$ & $\begin{array}{l}0.37 \\
5\end{array}$ & 0.5 & $\begin{array}{l}0.7 \\
5\end{array}$ & 1 & 0.125 & $\begin{array}{l}0.2 \\
5\end{array}$ & $\begin{array}{l}0.3 \\
75\end{array}$ & 0.5 & $\begin{array}{l}0.7 \\
5\end{array}$ & 1 \\
\hline Owner Occupied & $\begin{array}{l}1,5 \\
76\end{array}$ & $\begin{array}{l}(27 \\
7)\end{array}$ & )$^{(571}$ & $\begin{array}{l}16 \\
8\end{array}$ & $\begin{array}{l}(17 \\
0)\end{array}$ & )$^{(588}$ & 1,576 & $\begin{array}{l}1,2 \\
99\end{array}$ & 728 & 896 & 726 & 138 \\
\hline Renter Occupied & $\begin{array}{l}1,3 \\
85 \\
\end{array}$ & 83 & )$^{(341}$ & $\begin{array}{l}(31 \\
6)\end{array}$ & $\begin{array}{l}(23 \\
4)\end{array}$ & $\begin{array}{l}(1,2 \\
92)\end{array}$ & 1,385 & $\begin{array}{l}1,4 \\
68\end{array}$ & $\begin{array}{l}1,1 \\
27\end{array}$ & 811 & 577 & (715 \\
\hline Total Housing Units & $\begin{array}{l}2,9 \\
61 \\
\end{array}$ & $\begin{array}{l}(19 \\
4)\end{array}$ & )$^{(912}$ & $\begin{array}{l}114 \\
8)\end{array}$ & $\begin{array}{l}(40 \\
4)\end{array}$ & )$^{(588}$ & 2,961 & $\begin{array}{l}2,7 \\
67\end{array}$ & $\begin{array}{l}1,8 \\
55\end{array}$ & $\begin{array}{l}1,7 \\
07\end{array}$ & $\begin{array}{l}1,3 \\
03\end{array}$ & 715 \\
\hline Owner Occ No Veh & 139 & $(80$ & (74) & $\begin{array}{l}(32 \\
2)\end{array}$ & $\begin{array}{l}(11 \\
0)\end{array}$ & )$^{(810}$ & 139 & 59 & (15 & $\begin{array}{l}(33 \\
7)\end{array}$ & $\begin{array}{l}(44 \\
7)\end{array}$ & $\begin{array}{l}(1,2 \\
57)\end{array}$ \\
\hline Owner Occupied Veh & $\begin{array}{l}2,1 \\
65 \\
\end{array}$ & $\begin{array}{l}(60 \\
3)\end{array}$ & )$^{(275}$ & $\begin{array}{l}111 \\
0) \\
\end{array}$ & $\begin{array}{l}(47 \\
6) \\
\end{array}$ & $\begin{array}{l}(1,3 \\
98) \\
\end{array}$ & 2,165 & $\begin{array}{l}1,5 \\
62 \\
\end{array}$ & $\begin{array}{l}1,2 \\
87\end{array}$ & $\begin{array}{l}1,1 \\
77\end{array}$ & 701 & )$^{697}$ \\
\hline Renter Occ No Veh & 368 & $\begin{array}{l}114 \\
2) \\
\end{array}$ & $(72)$ & $\begin{array}{l}(47 \\
8)\end{array}$ & $\begin{array}{l}30 \\
4 \\
\end{array}$ & )$^{(149}$ & 368 & 226 & 154 & $\begin{array}{l}(32 \\
4) \\
\end{array}$ & )$^{(20}$ & )$^{(169}$ \\
\hline Renter Occupied Veh & $\begin{array}{l}2,5 \\
99\end{array}$ & $\begin{array}{l}1,5 \\
23\end{array}$ & )$^{(666}$ & $\begin{array}{l}28 \\
3\end{array}$ & $\begin{array}{l}(18 \\
7)\end{array}$ & $(248$ & 2,599 & $\begin{array}{l}4,1 \\
22\end{array}$ & $\begin{array}{l}3,4 \\
56\end{array}$ & $\begin{array}{l}3,7 \\
39\end{array}$ & $\begin{array}{l}3,5 \\
52\end{array}$ & $\begin{array}{l}3,30 \\
4\end{array}$ \\
\hline Total Housing Units & $\begin{array}{l}5,2 \\
71 \\
\end{array}$ & 698 & $\begin{array}{l}(1,0 \\
87)\end{array}$ & $\begin{array}{l}(62 \\
7)\end{array}$ & $\begin{array}{l}146 \\
9)\end{array}$ & )$^{(431}$ & 5,271 & $\begin{array}{l}5,9 \\
69\end{array}$ & $\begin{array}{l}4,8 \\
82\end{array}$ & $\begin{array}{l}4,2 \\
55\end{array}$ & $\begin{array}{l}3,7 \\
86\end{array}$ & $\begin{array}{l}3,35 \\
5\end{array}$ \\
\hline Households No Veh & 507 & $\begin{array}{l}(22 \\
2)\end{array}$ & )$^{146}$ & $\begin{array}{l}(80 \\
0) \\
\end{array}$ & $\begin{array}{l}19 \\
4 \\
\end{array}$ & )$^{(282}$ & 507 & 285 & 139 & $\begin{array}{l}66 \\
1)\end{array}$ & $\begin{array}{l}46 \\
7) \\
\end{array}$ & )$^{(749}$ \\
\hline Households with Veh & $\begin{array}{l}4,7 \\
64 \\
\end{array}$ & 920 & )$^{(941}$ & $\begin{array}{l}17 \\
3 \\
\end{array}$ & $\begin{array}{l}(66 \\
3)\end{array}$ & $\begin{array}{l}(1,1 \\
10)\end{array}$ & 4,764 & $\begin{array}{l}5,6 \\
84 \\
\end{array}$ & $\begin{array}{l}4,7 \\
43 \\
\end{array}$ & $\begin{array}{l}4,9 \\
16 \\
\end{array}$ & $\begin{array}{l}4,2 \\
53 \\
\end{array}$ & $\begin{array}{l}3,14 \\
3 \\
\end{array}$ \\
\hline Total Housing Units & $\begin{array}{l}5,2 \\
71 \\
\end{array}$ & 698 & $\begin{array}{l}(1,0 \\
87)\end{array}$ & $\begin{array}{l}62 \\
7) \\
\end{array}$ & $\begin{array}{l}\text { (46 } \\
9)\end{array}$ & )$^{(580}$ & 5,271 & $\begin{array}{l}5,9 \\
69 \\
\end{array}$ & $\begin{array}{l}4,8 \\
82\end{array}$ & $\begin{array}{l}4,2 \\
55 \\
\end{array}$ & $\begin{array}{l}3,7 \\
86 \\
\end{array}$ & $\begin{array}{l}3,20 \\
6 \\
\end{array}$ \\
\hline $\begin{array}{l}\text { Percent Demographic } \\
2016 \text { - Incremental }\end{array}$ & Chang & 2010 & & & & & $\begin{array}{l}\text { Cumul } \\
\text { ative }\end{array}$ & & & & & \\
\hline $\begin{array}{l}\text { Tenure by Vehicle } \\
\text { Presence }\end{array}$ & $\begin{array}{l}0.1 \\
25 \\
\end{array}$ & $\begin{array}{l}0.2 \\
5 \\
\end{array}$ & $\begin{array}{l}0.37 \\
5\end{array}$ & 0.5 & $\begin{array}{l}0.7 \\
5 \\
\end{array}$ & 1 & 0.125 & $\begin{array}{l}0.2 \\
5 \\
\end{array}$ & $\begin{array}{l}0.3 \\
75 \\
\end{array}$ & 0.5 & $\begin{array}{l}0.7 \\
5 \\
\end{array}$ & 1 \\
\hline Dccu & $\begin{array}{l}17 \\
\%\end{array}$ & - & $-9 \%$ & $2 \%$ & $\begin{array}{l}- \\
2 \%\end{array}$ & $-7 \%$ & $17 \%$ & $8 \%$ & $3 \%$ & $3 \%$ & $2 \%$ & $1 \%$ \\
\hline Renter Occu & $\begin{array}{l}10 \\
\%\end{array}$ & $1 \%$ & $-6 \%$ & $3 \%$ & $\begin{array}{l}- \\
3 \%\end{array}$ & $-\overline{11 \%}$ & $10 \%$ & $6 \%$ & $4 \%$ & $2 \%$ & $2 \%$ & $-2 \%$ \\
\hline Units & $\begin{array}{l}13 \\
\%\end{array}$ & $-\overline{1 \%}$ & $-7 \%$ & - & $-3 \%$ & $-9 \%$ & $13 \%$ & $7 \%$ & $4 \%$ & $2 \%$ & $0 \%$ & $-1 \%$ \\
\hline Occ & $\begin{array}{l}27 \\
\%\end{array}$ & $\begin{array}{l}- \\
22 \\
\%\end{array}$ & $\begin{array}{l}- \\
16 \% \\
\end{array}$ & $\begin{array}{l}- \\
44 \\
\%\end{array}$ & $\begin{array}{l} \\
20 \\
\%\end{array}$ & - & $27 \%$ & $7 \%$ & - & $\begin{array}{l}- \\
16 \\
\%\end{array}$ & $\begin{array}{l}- \\
17 \\
\%\end{array}$ & - \\
\hline Owner Occupied Veh & $\begin{array}{l}27 \\
\%\end{array}$ & $9 \%$ & $-5 \%$ & $-\overline{1 \%}$ & $-6 \%$ & $-3 \%$ & $27 \%$ & $\begin{array}{l}10 \\
\%\end{array}$ & $6 \%$ & $4 \%$ & $2 \%$ & $1 \%$ \\
\hline Veh & $\begin{array}{l}13 \\
\%\end{array}$ & - & $-5 \%$ & $\begin{array}{l}- \\
16 \\
\%\end{array}$ & $\begin{array}{l}13 \\
\%\end{array}$ & $-\overline{25 \%}$ & $3 \%$ & $6 \%$ & $4 \%$ & $2 \%$ & $-\overline{2 \%}$ & $-2 \%$ \\
\hline Renter Occupied Veh & $\begin{array}{l}27 \\
\%\end{array}$ & $\begin{array}{l}24 \\
\%\end{array}$ & $-13 \%$ & $5 \%$ & $-\overline{4 \%}$ & $-5 \%$ & $7 \%$ & $\begin{array}{l}26 \\
\%\end{array}$ & $\begin{array}{l}16 \\
\%\end{array}$ & $\begin{array}{l}14 \\
\%\end{array}$ & $9 \%$ & $8 \%$ \\
\hline Total Housing Units & $\begin{array}{l}25 \\
\%\end{array}$ & $5 \%$ & $-8 \%$ & - & $3 \%$ & $-7 \%$ & $25 \%$ & $6 \%$ & $4 \%$ & $2 \%$ & $\overline{2} \%$ & $-2 \%$ \\
\hline Households No Veh & $\begin{array}{l}15 \\
\%\end{array}$ & $\begin{array}{l}- \\
11 \\
\%\end{array}$ & $-8 \%$ & $\begin{array}{l}- \\
21 \\
\%\end{array}$ & $7 \%$ & $\overline{2}-\overline{2} \%$ & $15 \%$ & $5 \%$ & $2 \%$ & $-\overline{6 \%}$ & $-\overline{7 \%}$ & - \\
\hline Households with Veh & $\begin{array}{l}27 \\
\%\end{array}$ & $7 \%$ & $-9 \%$ & $1 \%$ & $\begin{array}{l}- \\
5 \%\end{array}$ & $-4 \%$ & $27 \%$ & $\begin{array}{l}18 \\
\%\end{array}$ & $\begin{array}{l}111 \\
\%\end{array}$ & $9 \%$ & $5 \%$ & $4 \%$ \\
\hline Total Housing Units & $\begin{array}{l}25 \\
\%\end{array}$ & $5 \%$ & $-8 \%$ & $4 \%$ & $\overline{3} \%$ & $-7 \%$ & $25 \%$ & $6 \%$ & $4 \%$ & $2 \%$ & $-\overline{2 \%}$ & $-2 \%$ \\
\hline \multicolumn{5}{|c|}{$\begin{array}{l}\text { LQ Trend 2010-2016 (LQ 2016 / LQ } \\
\text { 2010) - Incremental }\end{array}$} & & & $\begin{array}{l}\text { Cumb } \\
\text { ative }\end{array}$ & & & & & \\
\hline
\end{tabular}




\begin{tabular}{|c|c|c|c|c|c|c|c|c|c|c|c|c|}
\hline $\begin{array}{l}\text { Tenure by Vehicle } \\
\text { Presence }\end{array}$ & $\begin{array}{l}0.1 \\
25\end{array}$ & $\begin{array}{l}0.2 \\
5\end{array}$ & $\begin{array}{l}0.37 \\
5\end{array}$ & 0.5 & $\begin{array}{l}0.7 \\
5\end{array}$ & 1 & 0.125 & $\begin{array}{l}0.2 \\
5\end{array}$ & $\begin{array}{l}0.3 \\
75\end{array}$ & 0.5 & $\begin{array}{l}0.7 \\
5\end{array}$ & 1 \\
\hline Owner Occupied & $\begin{array}{l}0.9 \\
3\end{array}$ & $\begin{array}{l}0.9 \\
7\end{array}$ & 0.97 & $\begin{array}{l}0.9 \\
3\end{array}$ & $\begin{array}{l}0.8 \\
5\end{array}$ & 0.95 & 0.93 & $\begin{array}{l}1.0 \\
5\end{array}$ & $\begin{array}{l}1.0 \\
4\end{array}$ & $\begin{array}{l}1.0 \\
4\end{array}$ & $\begin{array}{l}1.0 \\
6\end{array}$ & 1.06 \\
\hline Renter Occupied & $\begin{array}{l}1.0 \\
0\end{array}$ & $\begin{array}{l}1.0 \\
0\end{array}$ & 1.00 & $\begin{array}{l}1.0 \\
0\end{array}$ & $\begin{array}{l}1.0 \\
0 \\
\end{array}$ & 1.00 & 1.00 & $\begin{array}{l}0.9 \\
5\end{array}$ & $\begin{array}{l}0.9 \\
5\end{array}$ & $\begin{array}{l}0.9 \\
5\end{array}$ & $\begin{array}{l}0.9 \\
4 \\
\end{array}$ & 0.93 \\
\hline Owner Occ 1 & $\begin{array}{l}1.1 \\
7\end{array}$ & $\begin{array}{l}0.9 \\
6 \\
\end{array}$ & 1.06 & $\begin{array}{l}1.0 \\
3\end{array}$ & $\begin{array}{l}1.1 \\
9\end{array}$ & 0.99 & 1.17 & $\begin{array}{l}1.0 \\
0\end{array}$ & $\begin{array}{l}0.9 \\
6 \\
\end{array}$ & $\begin{array}{l}0.8 \\
2\end{array}$ & $\begin{array}{l}0.8 \\
3 \\
\end{array}$ & 0.82 \\
\hline Owner Occupied Veh & $\begin{array}{l}0.9 \\
3 \\
\end{array}$ & $\begin{array}{l}0.8 \\
6 \\
\end{array}$ & 0.95 & $\begin{array}{l}0.7 \\
9 \\
\end{array}$ & $\begin{array}{l}0.7 \\
5\end{array}$ & 1.08 & 0.93 & $\begin{array}{l}1.0 \\
7 \\
\end{array}$ & $\begin{array}{l}1.0 \\
6 \\
\end{array}$ & $\begin{array}{l}1.0 \\
5 \\
\end{array}$ & $\begin{array}{l}1.0 \\
6 \\
\end{array}$ & 1.06 \\
\hline Renter Occ & $\begin{array}{l}1.0 \\
0\end{array}$ & $\begin{array}{l}1.1 \\
1\end{array}$ & 0.83 & $\begin{array}{l}0.9 \\
4\end{array}$ & $\begin{array}{l}0.9 \\
1\end{array}$ & 0.88 & 1.00 & $\begin{array}{l}0.9 \\
1\end{array}$ & $\begin{array}{l}0.9 \\
2\end{array}$ & $\begin{array}{l}0.8 \\
8\end{array}$ & $\begin{array}{l}0.8 \\
9\end{array}$ & 0.84 \\
\hline Renter Occl & $\begin{array}{l}1.0 \\
8\end{array}$ & $\begin{array}{l}1.0 \\
3\end{array}$ & 0.96 & $\begin{array}{l}0.9 \\
5\end{array}$ & $\begin{array}{l}1.0 \\
1\end{array}$ & 0.97 & 1.08 & $\begin{array}{l}1.0 \\
4\end{array}$ & $\begin{array}{l}0.9 \\
9\end{array}$ & $\begin{array}{l}0.9 \\
8\end{array}$ & $\begin{array}{l}0.9 \\
6\end{array}$ & 0.97 \\
\hline Households & $\begin{array}{l}1.1 \\
0\end{array}$ & $\begin{array}{l}1.0 \\
6\end{array}$ & 0.96 & $\begin{array}{l}1.0 \\
0\end{array}$ & $\begin{array}{l}1.0 \\
7\end{array}$ & 0.95 & 1.10 & $\begin{array}{l}0.8 \\
8\end{array}$ & $\begin{array}{l}0.9 \\
0\end{array}$ & $\begin{array}{l}0.8 \\
6\end{array}$ & $\begin{array}{l}0.8 \\
7\end{array}$ & 0.84 \\
\hline Households with Veh & $\begin{array}{l}1.0 \\
8\end{array}$ & $\begin{array}{l}1.0 \\
3\end{array}$ & 0.96 & $\begin{array}{l}0.9 \\
5\end{array}$ & $\begin{array}{l}1.0 \\
1\end{array}$ & 0.97 & 1.08 & $\begin{array}{l}1.0 \\
2\end{array}$ & $\begin{array}{l}1.0 \\
2\end{array}$ & $\begin{array}{l}1.0 \\
3\end{array}$ & $\begin{array}{l}1.0 \\
2\end{array}$ & 1.03 \\
\hline
\end{tabular}

Table 5A.9. Mod MA: BRT, Tenure by Vehicle Presence

\begin{tabular}{|c|c|c|c|c|c|c|c|c|c|c|c|c|}
\hline $\begin{array}{l}\text { Demographic } \\
\text { Incremental }\end{array}$ & $y$ & $0-20$ & & & & & $\begin{array}{l}\text { Cumu } \\
\text { lative }\end{array}$ & & & & & \\
\hline Tenure by & & & & & & & & & & & & \\
\hline Vehicle & 0.12 & & 0.37 & & & & & & 0.37 & & & \\
\hline Presence & 5 & 0.25 & 5 & 0.5 & 0.75 & 1 & 0.125 & 0.25 & 5 & 0.5 & 0.75 & 1 \\
\hline $\begin{array}{l}\text { Owner } \\
\text { Occupied }\end{array}$ & $\begin{array}{l}6,97 \\
9\end{array}$ & $\begin{array}{l}1,48 \\
6\end{array}$ & $\begin{array}{l}2,42 \\
2\end{array}$ & $\begin{array}{l}1,70 \\
7\end{array}$ & (99) & )$^{(276}$ & 6,979 & $\begin{array}{l}8,46 \\
5 \\
\end{array}$ & $\begin{array}{l}10,8 \\
87 \\
\end{array}$ & $\begin{array}{l}12,5 \\
94 \\
\end{array}$ & $\begin{array}{l}12,4 \\
95 \\
\end{array}$ & $\begin{array}{l}12,2 \\
19 \\
\end{array}$ \\
\hline $\begin{array}{l}\text { Renter } \\
\text { Occupied }\end{array}$ & $\begin{array}{l}32,4 \\
27 \\
\end{array}$ & $\begin{array}{l}5,15 \\
3 \\
\end{array}$ & $\begin{array}{l}7,03 \\
7\end{array}$ & $\begin{array}{l}4,75 \\
3 \\
\end{array}$ & $\begin{array}{l}2,54 \\
8 \\
\end{array}$ & $\begin{array}{l}1,78 \\
2\end{array}$ & $\begin{array}{l}32,42 \\
7 \\
\end{array}$ & $\begin{array}{l}37,5 \\
80 \\
\end{array}$ & $\begin{array}{l}44,6 \\
17 \\
\end{array}$ & $\begin{array}{l}49,3 \\
70 \\
\end{array}$ & $\begin{array}{l}51,9 \\
18 \\
\end{array}$ & $\begin{array}{l}53,7 \\
00 \\
\end{array}$ \\
\hline $\begin{array}{l}\text { Total Housing } \\
\text { Units }\end{array}$ & $\begin{array}{l}39,4 \\
06 \\
\end{array}$ & $\begin{array}{l}6,63 \\
9\end{array}$ & $\begin{array}{l}9,45 \\
9\end{array}$ & $\begin{array}{l}6,46 \\
0 \\
\end{array}$ & $\begin{array}{l}2,44 \\
9\end{array}$ & )$^{(276}$ & $\begin{array}{l}39,40 \\
6\end{array}$ & $\begin{array}{l}46,0 \\
45\end{array}$ & $\begin{array}{l}55,5 \\
04 \\
\end{array}$ & $\begin{array}{l}61,9 \\
64 \\
\end{array}$ & $\begin{array}{l}64,4 \\
13 \\
\end{array}$ & $\begin{array}{l}64,1 \\
37 \\
\end{array}$ \\
\hline $\begin{array}{l}\text { Owner Occ No } \\
\text { Veh }\end{array}$ & (320) & )$^{(272}$ & 108 & )$^{(373}$ & )$^{(250}$ & $\begin{array}{l}2,32 \\
3\end{array}$ & (320) & (592) & (484) & (857) & $\begin{array}{l}(1,10 \\
7)\end{array}$ & $\begin{array}{l}1,21 \\
6\end{array}$ \\
\hline $\begin{array}{l}\text { Owner } \\
\text { Occupied Veh }\end{array}$ & $\begin{array}{l}87,1 \\
91 \\
\end{array}$ & $\begin{array}{l}21,1 \\
36\end{array}$ & $\begin{array}{l}22,6 \\
92 \\
\end{array}$ & $\begin{array}{l}26,1 \\
63\end{array}$ & $\begin{array}{l}15,7 \\
82 \\
\end{array}$ & $\begin{array}{l}2,04 \\
7\end{array}$ & $\begin{array}{l}87,19 \\
1\end{array}$ & $\begin{array}{l}108 \\
327\end{array}$ & $\begin{array}{l}131 \\
019\end{array}$ & $\begin{array}{l}157 \\
182 \\
\end{array}$ & $\begin{array}{l}172 \\
964\end{array}$ & $\begin{array}{l}175 \\
011\end{array}$ \\
\hline $\begin{array}{l}\text { Renter Occ No } \\
\text { Veh }\end{array}$ & $\begin{array}{l}7,89 \\
6 \\
\end{array}$ & $\begin{array}{l}1,54 \\
2\end{array}$ & 788 & $\begin{array}{l}2,08 \\
8\end{array}$ & 604 & )$^{(579}$ & 7,896 & $\begin{array}{l}9,43 \\
8 \\
\end{array}$ & $\begin{array}{l}10,2 \\
26 \\
\end{array}$ & $\begin{array}{l}12,3 \\
14 \\
\end{array}$ & $\begin{array}{l}12,9 \\
18 \\
\end{array}$ & $\begin{array}{l}12,3 \\
39\end{array}$ \\
\hline $\begin{array}{l}\text { Renter } \\
\text { Occupied Veh }\end{array}$ & $\begin{array}{l}(330, \\
767)\end{array}$ & $\begin{array}{l}71 \\
232) \\
\end{array}$ & $\begin{array}{l}(67 \\
576) \\
\end{array}$ & $\begin{array}{l}(85, \\
163) \\
\end{array}$ & $\begin{array}{l}52 \\
872) \\
\end{array}$ & $\begin{array}{l}18,5 \\
26 \\
\end{array}$ & $\begin{array}{l}(330, \\
767) \\
\end{array}$ & $\begin{array}{l}(401, \\
999)\end{array}$ & $\begin{array}{l}(469, \\
575)\end{array}$ & $\begin{array}{l}(554, \\
738)\end{array}$ & $\begin{array}{l}(607, \\
610)\end{array}$ & $\begin{array}{l}589, \\
084)\end{array}$ \\
\hline $\begin{array}{l}\text { Total Housing } \\
\text { Units }\end{array}$ & $\begin{array}{l}(236, \\
000)\end{array}$ & $\begin{array}{l}(48, \\
826)\end{array}$ & $\begin{array}{l}43 \\
988)\end{array}$ & $\begin{array}{l}(57, \\
285)\end{array}$ & $\begin{array}{l}(36, \\
736)\end{array}$ & 746 & $\begin{array}{l}(236, \\
000)\end{array}$ & $\begin{array}{l}(284, \\
826)\end{array}$ & $\begin{array}{l}328, \\
814)\end{array}$ & $\begin{array}{l}386, \\
099)\end{array}$ & $\begin{array}{l}(422, \\
835)\end{array}$ & $\begin{array}{l}(422, \\
089)\end{array}$ \\
\hline $\begin{array}{l}\text { Households No } \\
\text { Veh }\end{array}$ & $\begin{array}{l}7,57 \\
6\end{array}$ & $\begin{array}{l}1,27 \\
0\end{array}$ & 896 & $\begin{array}{l}1,71 \\
5\end{array}$ & 354 & $\begin{array}{l}(57 \\
400)\end{array}$ & 7,576 & $\begin{array}{l}8,84 \\
6 \\
\end{array}$ & $\begin{array}{l}9,74 \\
2 \\
\end{array}$ & $\begin{array}{l}11,4 \\
57\end{array}$ & $\begin{array}{l}11,8 \\
11\end{array}$ & $\begin{array}{l}(45,5 \\
89)\end{array}$ \\
\hline $\begin{array}{l}\text { Households } \\
\text { with Veh }\end{array}$ & $\begin{array}{l}(243, \\
576)\end{array}$ & $\begin{array}{l}50 \\
096)\end{array}$ & $\begin{array}{l}(44, \\
884)\end{array}$ & $\begin{array}{l}(59, \\
000)\end{array}$ & $\begin{array}{l}37 \\
090)\end{array}$ & $\begin{array}{l}(38, \\
707)\end{array}$ & $\begin{array}{l}(243, \\
576)\end{array}$ & $\begin{array}{l}(293, \\
672)\end{array}$ & $\begin{array}{l}(338, \\
556)\end{array}$ & $\begin{array}{l}397, \\
556)\end{array}$ & $\begin{array}{l}(434, \\
646)\end{array}$ & $\begin{array}{l}(473, \\
353)\end{array}$ \\
\hline $\begin{array}{l}\text { Total Housing } \\
\text { Units }\end{array}$ & $\begin{array}{l}(236, \\
000)\end{array}$ & $\begin{array}{l}(48, \\
826) \\
\end{array}$ & $\begin{array}{l}(43, \\
988) \\
\end{array}$ & $\begin{array}{l}(57, \\
285) \\
\end{array}$ & $\begin{array}{l}(36, \\
736) \\
\end{array}$ & 167 & $\begin{array}{l}(236, \\
000)\end{array}$ & $\begin{array}{l}(284, \\
826)\end{array}$ & $\begin{array}{l}(328, \\
814)\end{array}$ & $\begin{array}{l}(386, \\
099)\end{array}$ & $\begin{array}{l}(422, \\
835)\end{array}$ & $\begin{array}{l}(422, \\
668) \\
\end{array}$ \\
\hline $\begin{array}{l}\text { Percent Demos } \\
2016 \text { - Increme }\end{array}$ & 70 & - & & & & & $\begin{array}{l}\text { Cumu } \\
\text { lative }\end{array}$ & & & & & \\
\hline Tenure by & & & & & & & & & & & & \\
\hline Vehicle & 0.12 & 025 & 0.37 & & 75 & & 25 & & $\begin{array}{l}0.37 \\
5\end{array}$ & & & \\
\hline Owner & & & & & 0.10 & & $1 \angle 0$ & 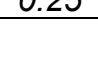 & & & 110 & \\
\hline Occupied & $6 \%$ & $7 \%$ & $10 \%$ & $6 \%$ & $-1 \%$ & $-1 \%$ & $6 \%$ & $6 \%$ & $7 \%$ & $7 \%$ & $5 \%$ & $5 \%$ \\
\hline $\begin{array}{l}\text { Renter } \\
\text { Occupied }\end{array}$ & $17 \%$ & $13 \%$ & $20 \%$ & $11 \%$ & $10 \%$ & $9 \%$ & $17 \%$ & $16 \%$ & $16 \%$ & $16 \%$ & $14 \%$ & $14 \%$ \\
\hline
\end{tabular}




\begin{tabular}{|c|c|c|c|c|c|c|c|c|c|c|c|c|}
\hline $\begin{array}{l}\text { Total Housing } \\
\text { Units }\end{array}$ & $13 \%$ & $11 \%$ & $16 \%$ & $9 \%$ & $6 \%$ & $4 \%$ & $13 \%$ & $13 \%$ & $13 \%$ & $12 \%$ & $11 \%$ & $10 \%$ \\
\hline $\begin{array}{l}\text { Owner Occ No } \\
\text { Veh }\end{array}$ & $-6 \%$ & $21 \%$ & $10 \%$ & $22 \%$ & $-\overline{20 \%}$ & - & $-6 \%$ & $-9 \%$ & $-6 \%$ & $-9 \%$ & $-8 \%$ & $-13 \%$ \\
\hline $\begin{array}{l}\text { Owner } \\
\text { Occupied Veh }\end{array}$ & $\begin{array}{l}362 \\
\% \\
\end{array}$ & $\begin{array}{l}133 \\
8 \%\end{array}$ & $\begin{array}{l}132 \\
9 \% \\
\end{array}$ & $\begin{array}{l}261 \\
4 \% \\
\end{array}$ & $\begin{array}{l}103 \\
2 \%\end{array}$ & $\begin{array}{l}839 \\
\%\end{array}$ & $362 \%$ & $\begin{array}{l}423 \\
\%\end{array}$ & $\begin{array}{l}479 \\
\%\end{array}$ & $\begin{array}{l}555 \\
\%\end{array}$ & $\begin{array}{l}647 \\
\%\end{array}$ & $\begin{array}{l}691 \\
\%\end{array}$ \\
\hline $\begin{array}{l}\text { Renter Occ No } \\
\text { Veh }\end{array}$ & $20 \%$ & $17 \%$ & $13 \%$ & $27 \%$ & $12 \%$ & $18 \%$ & $20 \%$ & $16 \%$ & $16 \%$ & $16 \%$ & $14 \%$ & $14 \%$ \\
\hline $\begin{array}{l}\text { Renter } \\
\text { Occupied Veh }\end{array}$ & $-64 \%$ & $68 \%$ & $\begin{array}{l}- \\
65 \% \\
\end{array}$ & $-68 \%$ & $71 \%$ & $72 \%$ & $-64 \%$ & $-65 \%$ & $-65 \%$ & $-66 \%$ & $-67 \%$ & $-67 \%$ \\
\hline $\begin{array}{l}\text { Total Housing } \\
\text { Units }\end{array}$ & $-41 \%$ & $-\overline{42 \%}$ & $\begin{array}{l}- \\
39 \% \\
\end{array}$ & $-\overline{42 \%}$ & - & - & $41 \%$ & $16 \%$ & $16 \%$ & $16 \%$ & $14 \%$ & $14 \%$ \\
\hline $\begin{array}{l}\text { Households No } \\
\text { Veh }\end{array}$ & $17 \%$ & $12 \%$ & $13 \%$ & $18 \%$ & $6 \%$ & $3 \%$ & $17 \%$ & $16 \%$ & $16 \%$ & $16 \%$ & $14 \%$ & $12 \%$ \\
\hline $\begin{array}{l}\text { Households } \\
\text { with Veh }\end{array}$ & $-45 \%$ & $-\overline{47 \%}$ & $-\overline{43 \%}$ & $-\overline{47 \%}$ & - & - & $-45 \%$ & $-46 \%$ & $55 \%$ & $-45 \%$ & $-46 \%$ & $-46 \%$ \\
\hline $\begin{array}{l}\text { Total Housing } \\
\text { Units }\end{array}$ & $-41 \%$ & $-\overline{42 \%}$ & $\begin{array}{l}- \\
39 \%\end{array}$ & $-\overline{42 \%}$ & $\begin{array}{l}- \\
45 \%\end{array}$ & - & $-41 \%$ & $16 \%$ & $16 \%$ & $16 \%$ & $14 \%$ & $14 \%$ \\
\hline \multicolumn{7}{|c|}{$\begin{array}{l}\text { LQ Trend 2010-2016 (LQ 2016 / LQ } \\
\text { 2010) - Incremental }\end{array}$} & \multicolumn{6}{|l|}{$\begin{array}{l}\text { Cumu } \\
\text { lative }\end{array}$} \\
\hline $\begin{array}{l}\text { Tenure by } \\
\text { Vehicle } \\
\text { Presence }\end{array}$ & $\begin{array}{l}0.12 \\
5\end{array}$ & 0.25 & $\begin{array}{l}0.37 \\
5\end{array}$ & 0.5 & 75 & 1 & 125 & 0.25 & $\begin{array}{l}0.37 \\
5\end{array}$ & 0.5 & 75 & 1 \\
\hline $\begin{array}{l}\text { Owner } \\
\text { Occupied }\end{array}$ & 0.99 & 0.98 & 0.99 & 0.98 & 0.97 & 1.00 & 0.99 & 0.97 & 0.97 & 0.98 & 0.98 & 0.97 \\
\hline $\begin{array}{l}\text { Renter } \\
\text { Occupied }\end{array}$ & 1.00 & 1.00 & 1.00 & 1.00 & 00 & 1.00 & 00 & 0.99 & .99 & 0.99 & .99 & 0.99 \\
\hline $\begin{array}{l}\text { Owner Occ No } \\
\text { Veh }\end{array}$ & 0.17 & 0.55 & 0.52 & 1.06 & 1.56 & 0.46 & 0.17 & 0.87 & 0.90 & 0.87 & 0.90 & 0.86 \\
\hline $\begin{array}{l}\text { Owner } \\
\text { Occupied Veh }\end{array}$ & 1.02 & 1.01 & 0.93 & 1.11 & 0.93 & 1.01 & 1.02 & 0.20 & 0.22 & 0.25 & 0.29 & 0.31 \\
\hline $\begin{array}{l}\text { Renter Occ No } \\
\text { Veh }\end{array}$ & 1.57 & 1.45 & 1.48 & 1.46 & 1.38 & 1.37 & 1.57 & 1.02 & 1.01 & 1.02 & 1.01 & 1.01 \\
\hline $\begin{array}{l}\text { Renter } \\
\text { Occupied Veh }\end{array}$ & 0.96 & 0.96 & 0.96 & 0.97 & 1.00 & 0.96 & 0.96 & 1.55 & 1.54 & 1.53 & 1.50 & 1.49 \\
\hline $\begin{array}{l}\text { Households No } \\
\text { Veh }\end{array}$ & 0.92 & 0.91 & 0.94 & 0.93 & 0.98 & 0.93 & 0.92 & 1.05 & 1.05 & 1.05 & 1.04 & 1.03 \\
\hline $\begin{array}{l}\text { Households } \\
\text { with Veh }\end{array}$ & 0.96 & 0.96 & 0.96 & 0.97 & 1.00 & 0.96 & 0.96 & 0.96 & 0.96 & 0.96 & 0.96 & 0.97 \\
\hline
\end{tabular}

Table 5A.10. Mod MA: CRT, Tenure by Vehicle Presence

\begin{tabular}{|c|c|c|c|c|c|c|c|c|c|c|c|c|}
\hline \multicolumn{7}{|c|}{$\begin{array}{l}\text { Demographic Change 2010-2016 - } \\
\text { Incremental }\end{array}$} & \multicolumn{6}{|l|}{$\begin{array}{l}\text { Cumul } \\
\text { ative }\end{array}$} \\
\hline Tenure by & & & & & & & & & & & & \\
\hline Vehicle & 0.12 & 0.2 & 0.3 & & 0.7 & & & & 0.37 & & & \\
\hline Presence & 5 & 5 & 75 & 0.5 & 5 & 1 & 0.125 & 0.25 & 5 & 0.5 & 0.75 & 1 \\
\hline $\begin{array}{l}\text { Owner } \\
\text { Occupied }\end{array}$ & $\begin{array}{l}(10, \\
181)\end{array}$ & $\begin{array}{l}(1,1 \\
30)\end{array}$ & $\begin{array}{l}(2,1 \\
96)\end{array}$ & $\begin{array}{l}(2,8 \\
63)\end{array}$ & $\begin{array}{l}(1,4 \\
65)\end{array}$ & $\begin{array}{l}(17 \\
4)\end{array}$ & $\begin{array}{l}(10,18 \\
1)\end{array}$ & $\begin{array}{l}(11 \\
311)\end{array}$ & $\begin{array}{l}(13, \\
507)\end{array}$ & $\begin{array}{l}(16, \\
370)\end{array}$ & $\begin{array}{l}(17 \\
835)\end{array}$ & $\begin{array}{l}(18, \\
009)\end{array}$ \\
\hline $\begin{array}{l}\text { Renter } \\
\text { Occupied }\end{array}$ & $\begin{array}{l}(8,3 \\
00)\end{array}$ & $\begin{array}{l}(3,0 \\
45)\end{array}$ & $\begin{array}{l}\text { (32 } \\
9)\end{array}$ & $\begin{array}{l}1,0 \\
01\end{array}$ & $\begin{array}{l}1,1 \\
19\end{array}$ & $\begin{array}{l}3,1 \\
58\end{array}$ & $(8,300$ & $\begin{array}{l}(11 \\
345)\end{array}$ & $\begin{array}{l}(11 \\
674)\end{array}$ & $\begin{array}{l}(10, \\
673)\end{array}$ & $\begin{array}{l}(9,5 \\
54)\end{array}$ & $\begin{array}{l}(6,3 \\
96)\end{array}$ \\
\hline$\frac{\text { Total Housing }}{\text { Units }}$ & $\begin{array}{l}(18 \\
481)\end{array}$ & $\begin{array}{l}(4,1 \\
75)\end{array}$ & $\begin{array}{l}(2,5 \\
25)\end{array}$ & $\begin{array}{l}(1,8 \\
62)\end{array}$ & $\begin{array}{l}(34 \\
6)\end{array}$ & $\begin{array}{l}(17 \\
4)\end{array}$ & $\begin{array}{l}(18,48 \\
1)\end{array}$ & $\begin{array}{l}(22, \\
656)\end{array}$ & $\begin{array}{l}(25, \\
181)\end{array}$ & $\begin{array}{l}(27, \\
043)\end{array}$ & $\begin{array}{l}(27 \\
389)\end{array}$ & $\begin{array}{l}(27 \\
563)\end{array}$ \\
\hline $\begin{array}{l}\text { Owner Occ No } \\
\text { Veh }\end{array}$ & $(232$ & $\begin{array}{l}(32 \\
8)\end{array}$ & $\begin{array}{l}(61 \\
2)\end{array}$ & 150 & $\begin{array}{l}(33 \\
5)\end{array}$ & $\begin{array}{l}3,3 \\
32\end{array}$ & (232) & )$^{(560}$ & \begin{tabular}{|l}
$(1,1$ \\
$72)$
\end{tabular} & $\begin{array}{l}(1,0 \\
22)\end{array}$ & $\begin{array}{l}(1,3 \\
57)\end{array}$ & $\begin{array}{l}1,97 \\
5\end{array}$ \\
\hline $\begin{array}{l}\text { Owner } \\
\text { Occupied Veh }\end{array}$ & $\begin{array}{l}(9,2 \\
68)\end{array}$ & $\begin{array}{l}(1,1 \\
39)\end{array}$ & $\begin{array}{l}(2,6 \\
03) \\
\end{array}$ & $\begin{array}{l}(3,7 \\
38) \\
\end{array}$ & $\begin{array}{l}(1,9 \\
80)\end{array}$ & $\begin{array}{l}3,1 \\
58\end{array}$ & $\begin{array}{l}(9,268 \\
{ }^{\prime}\end{array}$ & $\begin{array}{l}(10, \\
407)\end{array}$ & $\begin{array}{l}(13 \\
010) \\
\end{array}$ & $\begin{array}{l}16 \\
748)\end{array}$ & $\begin{array}{l}18, \\
728)\end{array}$ & $\begin{array}{l}15 \\
570)\end{array}$ \\
\hline
\end{tabular}




\begin{tabular}{|c|c|c|c|c|c|c|c|c|c|c|c|c|}
\hline $\begin{array}{l}\text { Renter Occ No } \\
\text { Veh }\end{array}$ & (35) & $\begin{array}{l}(42 \\
3)\end{array}$ & 274 & $\begin{array}{l}(19 \\
1)\end{array}$ & 93 & 69 & (35) & )$^{(458}$ & )$^{(184}$ & )$^{(375}$ & )$^{(282}$ & )$^{(213}$ \\
\hline $\begin{array}{l}\text { Renter } \\
\text { Occupied Veh }\end{array}$ & $\begin{array}{l}(1,1 \\
07)\end{array}$ & $\begin{array}{l}170 \\
5)\end{array}$ & $\begin{array}{l}1,4 \\
93\end{array}$ & $\begin{array}{l}2,8 \\
74\end{array}$ & $\begin{array}{l}4,6 \\
19\end{array}$ & $\begin{array}{l}(1,8 \\
73)\end{array}$ & $(1,107$ & $\begin{array}{l}(1,8 \\
12)\end{array}$ & (319 & $\begin{array}{l}2,55 \\
5\end{array}$ & $\begin{array}{l}7,17 \\
4\end{array}$ & $\begin{array}{l}5,30 \\
1\end{array}$ \\
\hline $\begin{array}{l}\text { Total Housing } \\
\text { Units }\end{array}$ & $\begin{array}{l}(10, \\
642)\end{array}$ & $\begin{array}{l}(2,5 \\
95)\end{array}$ & $\begin{array}{l}(1,4 \\
48)\end{array}$ & $\begin{array}{l}(90 \\
5)\end{array}$ & $\begin{array}{l}2,3 \\
97\end{array}$ & 134 & $\begin{array}{l}(10,64 \\
2)\end{array}$ & $\begin{array}{l}(13, \\
237)\end{array}$ & $\begin{array}{l}(14, \\
685)\end{array}$ & $\begin{array}{l}(15 \\
590)\end{array}$ & $\begin{array}{l}(13, \\
193)\end{array}$ & $\begin{array}{l}(13, \\
059)\end{array}$ \\
\hline $\begin{array}{l}\text { Households No } \\
\text { Veh }\end{array}$ & )$^{(267}$ & $\begin{array}{l}75 \\
1) \\
\end{array}$ & $\begin{array}{l}33 \\
8) \\
\end{array}$ & (41) & $\begin{array}{l}(24 \\
2) \\
\end{array}$ & $\begin{array}{l}5,2 \\
38 \\
\end{array}$ & (267) & $\begin{array}{l}(1,0 \\
18)\end{array}$ & $\begin{array}{l}(1,3 \\
56)\end{array}$ & $\begin{array}{l}(1,3 \\
97) \\
\end{array}$ & $\begin{array}{l}(1,6 \\
39) \\
\end{array}$ & $\begin{array}{l}3,59 \\
9\end{array}$ \\
\hline $\begin{array}{l}\text { Households with } \\
\text { Veh }\end{array}$ & $\begin{array}{l}(10, \\
375)\end{array}$ & $\begin{array}{l}(1,8 \\
44)\end{array}$ & $\begin{array}{l}(1,1 \\
10)\end{array}$ & $\begin{array}{l}(86 \\
4)\end{array}$ & $\begin{array}{l}2,6 \\
39\end{array}$ & $\begin{array}{l}3,5 \\
68\end{array}$ & $\begin{array}{l}(10,37 \\
5)\end{array}$ & $\begin{array}{l}12 \\
219)\end{array}$ & $\begin{array}{l}13 \\
329)\end{array}$ & $\begin{array}{l}(14, \\
193)\end{array}$ & $\begin{array}{l}11 \\
554)\end{array}$ & $\begin{array}{l}(7,9 \\
86)\end{array}$ \\
\hline $\begin{array}{l}\text { Total Housing } \\
\text { Units }\end{array}$ & $\begin{array}{l}10 \\
642) \\
\end{array}$ & $\begin{array}{l}(2,5 \\
95) \\
\end{array}$ & $\begin{array}{l}(1,4 \\
48) \\
\end{array}$ & $\begin{array}{l}190 \\
5) \\
\end{array}$ & $\begin{array}{l}2,3 \\
97 \\
\end{array}$ & 203 & $\begin{array}{l}(10,64 \\
2)\end{array}$ & $\begin{array}{l}13 \\
237) \\
\end{array}$ & $\begin{array}{l}(14, \\
685)\end{array}$ & $\begin{array}{l}15 \\
590) \\
\end{array}$ & $\begin{array}{l}13 \\
193) \\
\end{array}$ & $\begin{array}{l}12 \\
990)\end{array}$ \\
\hline \multicolumn{7}{|c|}{$\begin{array}{l}\text { Percent Demographic Change 2010- } \\
2016 \text { - Incremental }\end{array}$} & \multicolumn{6}{|l|}{$\begin{array}{l}\text { Cumul } \\
\text { ative }\end{array}$} \\
\hline $\begin{array}{l}\text { Tenure by } \\
\text { Vehicle } \\
\text { Presence }\end{array}$ & $\begin{array}{l}0.12 \\
5\end{array}$ & $\begin{array}{l}0.2 \\
5\end{array}$ & $\begin{array}{l}0.3 \\
75\end{array}$ & 0.5 & $\begin{array}{l}0.7 \\
5\end{array}$ & 1 & 0.125 & 0.25 & $\begin{array}{l}0.37 \\
5\end{array}$ & 0.5 & 0.75 & 1 \\
\hline $\begin{array}{l}\text { Owner } \\
\text { Occupied }\end{array}$ & $-\overline{21 \%}$ & $-6 \%$ & $\begin{array}{l}- \\
12 \\
\%\end{array}$ & $\begin{array}{l}- \\
13 \\
\%\end{array}$ & $-5 \%$ & $-1 \%$ & $-21 \%$ & - & - & - & - & $-9 \%$ \\
\hline $\begin{array}{l}\text { Renter } \\
\text { Occupied }\end{array}$ & $-\overline{10 \%}$ & $-9 \%$ & $-1 \%$ & $3 \%$ & $3 \%$ & $9 \%$ & $-10 \%$ & $-\overline{10 \%}$ & $-8 \%$ & $-6 \%$ & $-2 \%$ & $1 \%$ \\
\hline $\begin{array}{l}\text { Total Housing } \\
\text { Units }\end{array}$ & $-\overline{14 \%}$ & $-8 \%$ & $-5 \%$ & $-3 \%$ & $0 \%$ & $5 \%$ & $-14 \%$ & $-\overline{12 \%}$ & $-\overline{11 \%}$ & $-9 \%$ & $-5 \%$ & $-3 \%$ \\
\hline $\begin{array}{l}\text { Owner Occ No } \\
\text { Veh }\end{array}$ & - & $\begin{array}{l}- \\
42 \\
\%\end{array}$ & $\begin{array}{l}- \\
47 \\
\%\end{array}$ & $\begin{array}{l}18 \\
\%\end{array}$ & $\begin{array}{l}- \\
27 \\
\%\end{array}$ & $7 \%$ & $-11 \%$ & $-\overline{19 \%}$ & $-\overline{28 \%}$ & - & - & - \\
\hline $\begin{array}{l}\text { Owner } \\
\text { Occupied Veh }\end{array}$ & $-\overline{20 \%}$ & $-7 \%$ & $\begin{array}{l}- \\
14 \\
\%\end{array}$ & $\begin{array}{l}- \\
17 \\
\%\end{array}$ & $-7 \%$ & $-7 \%$ & $-20 \%$ & $-\overline{17 \%}$ & $-\overline{16 \%}$ & $-\overline{16 \%}$ & $\overline{-}$ & $-\overline{10 \%}$ \\
\hline $\begin{array}{l}\text { Renter Occ No } \\
\text { Veh }\end{array}$ & $0 \%$ & $-7 \%$ & $5 \%$ & $-3 \%$ & $1 \%$ & $2 \%$ & $0 \%$ & $-10 \%$ & $-8 \%$ & $-6 \%$ & $-2 \%$ & $1 \%$ \\
\hline $\begin{array}{l}\text { Renter } \\
\text { Occupied Veh }\end{array}$ & $-2 \%$ & $-3 \%$ & $6 \%$ & $9 \%$ & $\begin{array}{l}14 \\
\%\end{array}$ & $\begin{array}{l}20 \\
\%\end{array}$ & $-2 \%$ & $-2 \%$ & $0 \%$ & $2 \%$ & $7 \%$ & $9 \%$ \\
\hline $\begin{array}{l}\text { Total Housing } \\
\text { Units }\end{array}$ & $-9 \%$ & $-5 \%$ & $-3 \%$ & $-2 \%$ & $3 \%$ & $6 \%$ & $-9 \%$ & $-\overline{10 \%}$ & $-8 \%$ & $-6 \%$ & $-2 \%$ & $1 \%$ \\
\hline $\begin{array}{l}\text { Households No } \\
\text { Veh }\end{array}$ & $-2 \%$ & $\begin{array}{l}- \\
11 \\
\%\end{array}$ & $-5 \%$ & $-1 \%$ & $-3 \%$ & $3 \%$ & $-2 \%$ & $-5 \%$ & $-5 \%$ & $-4 \%$ & $-1 \%$ & $-1 \%$ \\
\hline $\begin{array}{l}\text { Households with } \\
\text { Veh }\end{array}$ & $-\overline{10 \%}$ & $-4 \%$ & $-3 \%$ & $-2 \%$ & $4 \%$ & $6 \%$ & $-10 \%$ & $-8 \%$ & $93 \%$ & $-6 \%$ & $-1 \%$ & $1 \%$ \\
\hline $\begin{array}{l}\text { Total Housing } \\
\text { Units }\end{array}$ & $-9 \%$ & $-5 \%$ & $-3 \%$ & $-2 \%$ & $3 \%$ & $6 \%$ & $-9 \%$ & $-\overline{10 \%}$ & $-8 \%$ & $-6 \%$ & $-2 \%$ & $1 \%$ \\
\hline \multicolumn{7}{|c|}{$\begin{array}{l}\text { LQ Trend 2010-2016 (LQ 2016 / LQ } \\
\text { 2010) - Incremental }\end{array}$} & \multicolumn{6}{|l|}{$\begin{array}{l}\text { Cumul } \\
\text { ative }\end{array}$} \\
\hline $\begin{array}{l}\text { Tenure by } \\
\text { Vehicle } \\
\text { Presence }\end{array}$ & $\begin{array}{l}0.12 \\
5\end{array}$ & $\begin{array}{l}0.2 \\
5\end{array}$ & $\begin{array}{l}0.3 \\
75\end{array}$ & 0.5 & $\begin{array}{l}0.7 \\
5\end{array}$ & 1 & 0.125 & 0.25 & $\begin{array}{l}0.37 \\
5\end{array}$ & 0.5 & 0.75 & 1 \\
\hline $\begin{array}{l}\text { Owner } \\
\text { Occupied }\end{array}$ & 1.00 & $\begin{array}{l}0.9 \\
4\end{array}$ & $\begin{array}{l}0.9 \\
9\end{array}$ & $\begin{array}{l}1.0 \\
1\end{array}$ & $\begin{array}{l}1.0 \\
1\end{array}$ & $\begin{array}{l}0.9 \\
8\end{array}$ & 1.00 & 0.98 & 0.97 & 0.96 & 0.97 & 0.97 \\
\hline $\begin{array}{l}\text { Renter } \\
\text { Occupied }\end{array}$ & 1.00 & $\begin{array}{l}1.0 \\
0\end{array}$ & $\begin{array}{l}1.0 \\
0\end{array}$ & $\begin{array}{l}1.0 \\
0\end{array}$ & $\begin{array}{l}1.0 \\
0\end{array}$ & $\begin{array}{l}1.0 \\
0\end{array}$ & 1.00 & 0.98 & 0.98 & 0.99 & 0.99 & 0.99 \\
\hline $\begin{array}{l}\text { Owner Occ No } \\
\text { Veh }\end{array}$ & 0.92 & $\begin{array}{l}1.0 \\
1\end{array}$ & $\begin{array}{l}0.9 \\
0\end{array}$ & $\begin{array}{l}0.8 \\
5\end{array}$ & $\begin{array}{l}0.9 \\
5\end{array}$ & $\begin{array}{l}0.9 \\
3\end{array}$ & 0.92 & 0.94 & 0.83 & 0.90 & 0.89 & 0.88 \\
\hline
\end{tabular}




\begin{tabular}{|c|c|c|c|c|c|c|c|c|c|c|c|c|c|}
\hline $\begin{array}{l}\text { Owner } \\
\text { Occupied Veh }\end{array}$ & 1.08 & & & $\begin{array}{l}1.0 \\
3\end{array}$ & $\begin{array}{l}0.9 \\
3\end{array}$ & $\begin{array}{l}1.0 \\
1\end{array}$ & $\begin{array}{l}0.9 \\
5\end{array}$ & 1.08 & 0.95 & 0.94 & 0.92 & .93 & 0.92 \\
\hline $\begin{array}{l}\text { Renter Occ No } \\
\text { Veh }\end{array}$ & 0.99 & & & $\begin{array}{l}0.9 \\
7\end{array}$ & $\begin{array}{l}0.9 \\
7\end{array}$ & $\begin{array}{l}0.9 \\
8\end{array}$ & $\begin{array}{l}0.9 \\
9\end{array}$ & 0.99 & 1.04 & 1.03 & 1.01 & 1.00 & 0.97 \\
\hline $\begin{array}{l}\text { Renter } \\
\text { Occupied Veh }\end{array}$ & 1.01 & $\begin{array}{l}0 \\
8\end{array}$ & 9 & $\begin{array}{l}0.9 \\
7\end{array}$ & $\begin{array}{l}0.9 \\
6\end{array}$ & $\begin{array}{l}0.9 \\
9\end{array}$ & $\begin{array}{l}0.9 \\
9\end{array}$ & 1.01 & 0.97 & 0.97 & 0.97 & 0.97 & 0.98 \\
\hline $\begin{array}{l}\text { Households No } \\
\text { Veh }\end{array}$ & 1.00 & 9 & 9 & $\begin{array}{l}0.9 \\
7\end{array}$ & $\begin{array}{l}0.9 \\
6 \\
\end{array}$ & $\begin{array}{l}0.9 \\
9\end{array}$ & $\begin{array}{l}0.9 \\
9\end{array}$ & 1.00 & 1.04 & 1.02 & 1.02 & 1.01 & 0.99 \\
\hline $\begin{array}{l}\text { Households with } \\
\text { Veh }\end{array}$ & 1.01 & & & $\begin{array}{l}0.9 \\
7 \\
\end{array}$ & $\begin{array}{l}0.9 \\
6 \\
\end{array}$ & $\begin{array}{l}0.9 \\
9\end{array}$ & $\begin{array}{l}0.9 \\
9\end{array}$ & 1.01 & 1.00 & 1.00 & 1.00 & 1.00 & 1.00 \\
\hline \multicolumn{14}{|c|}{ 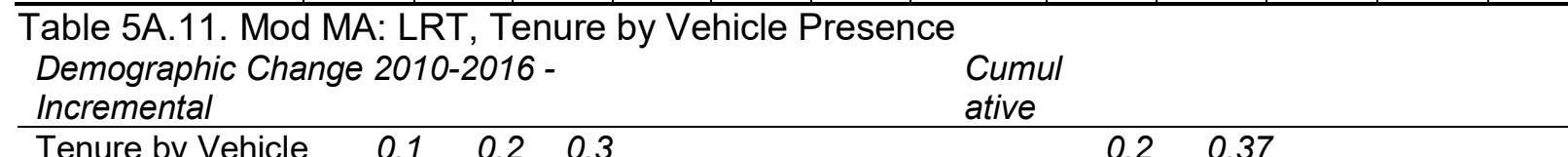 } \\
\hline $\begin{array}{l}\text { Tenure by Vehicle } \\
\text { Presence }\end{array}$ & & $\begin{array}{l}0.1 \\
25\end{array}$ & & $\begin{array}{l}0.3 \\
75\end{array}$ & 0.5 & 0.75 & 1 & 0.125 & $\begin{array}{l}0.2 \\
5\end{array}$ & $\begin{array}{l}0.37 \\
5 \\
\end{array}$ & 0.5 & 0.75 & 1 \\
\hline Owner Occupied & & 740 & \begin{tabular}{|l|}
33 \\
5 \\
\end{tabular} & 43 & $\begin{array}{l}76 \\
4)\end{array}$ & $\begin{array}{l}40 \\
0)\end{array}$ & $\begin{array}{l}(29 \\
8)\end{array}$ & 740 & $\begin{array}{l}1,0 \\
75\end{array}$ & $\begin{array}{l}1,11 \\
8\end{array}$ & 354 & $(46)$ & \begin{tabular}{|l|}
$(34$ \\
$4)$ \\
\end{tabular} \\
\hline Renter Occupied & & $\begin{array}{l}23, \\
923\end{array}$ & $\begin{array}{l}5,5 \\
98\end{array}$ & $\begin{array}{l}4,9 \\
01\end{array}$ & $\begin{array}{l}6,62 \\
7\end{array}$ & $\begin{array}{l}4,86 \\
4\end{array}$ & $\begin{array}{l}3,42 \\
6\end{array}$ & 23,923 & \begin{tabular}{l|l}
3 & 29 \\
3 & 521
\end{tabular} & $\begin{array}{l}34,4 \\
22\end{array}$ & $\begin{array}{l}41,0 \\
49\end{array}$ & $\begin{array}{l}45,9 \\
13\end{array}$ & $\begin{array}{l}49 \\
339\end{array}$ \\
\hline Total Housing Units & & $\begin{array}{l}24, \\
663\end{array}$ & \begin{tabular}{|l|}
5,9 \\
33 \\
\end{tabular} & $\begin{array}{l}4,9 \\
44 \\
\end{array}$ & $\begin{array}{l}5,86 \\
3 \\
\end{array}$ & $\begin{array}{l}4,46 \\
4 \\
\end{array}$ & $\begin{array}{l}(29 \\
8)\end{array}$ & 24,663 & \begin{tabular}{|l|l|}
30 \\
3596 \\
\end{tabular} & $\begin{array}{l}35,5 \\
40 \\
\end{array}$ & $\begin{array}{l}41,4 \\
03\end{array}$ & $\begin{array}{l}45,8 \\
67 \\
\end{array}$ & $\begin{array}{l}45 \\
569 \\
\end{array}$ \\
\hline Owner Occ No Veh & & $\begin{array}{l}(82 \\
4)\end{array}$ & 49 & $\begin{array}{l}(26 \\
9)\end{array}$ & $\begin{array}{l}(15 \\
9)\end{array}$ & (69) & $\begin{array}{l}3,72 \\
4\end{array}$ & (824) & $\begin{array}{l}(77 \\
5)\end{array}$ & $\begin{array}{l}(1,0 \\
44)\end{array}$ & $\begin{array}{l}(1,2 \\
03)\end{array}$ & $\begin{array}{l}(1,2 \\
72)\end{array}$ & $\begin{array}{l}2,4 \\
52 \\
\end{array}$ \\
\hline $\begin{array}{l}\text { Owner Occupied } \\
\text { Veh }\end{array}$ & & $\begin{array}{l}1,8 \\
45\end{array}$ & $\begin{array}{l}(35 \\
4)\end{array}$ & $(98$ & $\begin{array}{l}(1,0 \\
06)\end{array}$ & $\begin{array}{l}(1,2 \\
14)\end{array}$ & $\begin{array}{l}3,42 \\
6\end{array}$ & 1,845 & $\begin{array}{l}1,4 \\
91\end{array}$ & $\begin{array}{l}1,39 \\
3\end{array}$ & 387 & $\begin{array}{l}(82 \\
7)\end{array}$ & $\begin{array}{l}2,5 \\
99\end{array}$ \\
\hline Renter Occ No Veh & & $\begin{array}{l}5,3 \\
33 \\
\end{array}$ & \begin{tabular}{|l|}
40 \\
6 \\
\end{tabular} & $\begin{array}{l}14 \\
8\end{array}$ & 938 & 71 & (18) & 5,333 & $\begin{array}{l}5,7 \\
39\end{array}$ & $\begin{array}{l}5,88 \\
7\end{array}$ & $\begin{array}{l}6,82 \\
5 \\
\end{array}$ & $\begin{array}{l}6,89 \\
6 \\
\end{array}$ & \begin{tabular}{|l|}
6,8 \\
78 \\
\end{tabular} \\
\hline $\begin{array}{l}\text { Renter Occupied } \\
\text { Veh }\end{array}$ & & $\begin{array}{l}30 \\
853\end{array}$ & \begin{tabular}{|l|}
8,1 \\
21 \\
\end{tabular} & $\begin{array}{l}8,7 \\
05 \\
\end{array}$ & $\begin{array}{l}9,19 \\
1\end{array}$ & $\begin{array}{l}7,03 \\
8\end{array}$ & $\begin{array}{l}(1,3 \\
73) \\
\end{array}$ & 30,853 & $\begin{array}{l}38 \\
974 \\
\end{array}$ & $\begin{array}{l}47,6 \\
79 \\
\end{array}$ & $\begin{array}{l}56,8 \\
70 \\
\end{array}$ & $\begin{array}{l}63,9 \\
08 \\
\end{array}$ & $\begin{array}{l}62 \\
535 \\
\end{array}$ \\
\hline Total Housing Units & & $\begin{array}{l}37 \\
207\end{array}$ & \begin{tabular}{|l|}
8,2 \\
22 \\
\end{tabular} & $\begin{array}{l}8,4 \\
86\end{array}$ & $\begin{array}{l}8,96 \\
4\end{array}$ & $\begin{array}{l}5,82 \\
6\end{array}$ & $\begin{array}{l}1,34 \\
9\end{array}$ & 37,207 & \begin{tabular}{l|l}
75 \\
729 \\
\end{tabular} & $\begin{array}{l}53,9 \\
15 \\
\end{array}$ & $\begin{array}{l}62,8 \\
79 \\
\end{array}$ & $\begin{array}{l}68,7 \\
05\end{array}$ & $\begin{array}{l}70 \\
054 \\
\end{array}$ \\
\hline Households No Vel & & $\begin{array}{l}4,5 \\
09\end{array}$ & $\begin{array}{l}45 \\
5\end{array}$ & $\begin{array}{l}(12 \\
1)\end{array}$ & 779 & 2 & $\begin{array}{l}6,73 \\
1\end{array}$ & 4,509 & $\begin{array}{l}4,9 \\
64\end{array}$ & $\begin{array}{l}4,84 \\
3\end{array}$ & $\begin{array}{l}5,62 \\
2\end{array}$ & $\begin{array}{l}5,62 \\
4\end{array}$ & $\begin{array}{l}12 \\
355\end{array}$ \\
\hline $\begin{array}{l}\text { Households with } \\
\text { Veh }\end{array}$ & & $\begin{array}{l}32 \\
698 \\
\end{array}$ & \begin{tabular}{|l|}
7,7 \\
67 \\
\end{tabular} & $\begin{array}{l}8,6 \\
07 \\
\end{array}$ & $\begin{array}{l}8,18 \\
5 \\
\end{array}$ & $\begin{array}{l}, 82 \\
4 \\
\end{array}$ & $\begin{array}{l}6,68 \\
9 \\
\end{array}$ & \begin{tabular}{|l|l|}
32,698 \\
\end{tabular} & \begin{tabular}{l|l}
80 \\
8 & 465 \\
\end{tabular} & $\begin{array}{l}49,0 \\
72 \\
\end{array}$ & $\begin{array}{l}57,2 \\
57 \\
\end{array}$ & $\begin{array}{l}63,0 \\
81 \\
\end{array}$ & \begin{tabular}{|l|}
69 \\
770 \\
\end{tabular} \\
\hline Total Housing Units & & $\begin{array}{l}37 \\
207\end{array}$ & $\begin{array}{l}8,2 \\
22 \\
\end{array}$ & $\begin{array}{l}8,4 \\
86\end{array}$ & $\begin{array}{l}8,96 \\
4\end{array}$ & $\begin{array}{l}5,82 \\
6\end{array}$ & $\begin{array}{l}1,33 \\
1\end{array}$ & 37,207 & \begin{tabular}{l|l}
75 \\
729
\end{tabular} & $\begin{array}{l}53,9 \\
15\end{array}$ & $\begin{array}{l}62,8 \\
79\end{array}$ & $\begin{array}{l}68,7 \\
05\end{array}$ & $\begin{array}{l}70 \\
036 \\
\end{array}$ \\
\hline $\begin{array}{l}\text { Percent Demograp } \\
2016 \text { - Incremental }\end{array}$ & ohic C & $\mathrm{Ch}$ & 20 & 010 & & & & $\begin{array}{l}\text { Cumul } \\
\text { ative }\end{array}$ & & & & & \\
\hline $\begin{array}{l}\text { Tenure by Vehicle } \\
\text { Presence }\end{array}$ & & $\begin{array}{l}0.1 \\
25\end{array}$ & $\begin{array}{l}0.2 \\
5\end{array}$ & $\begin{array}{l}0.3 \\
75\end{array}$ & 0.5 & 0.75 & 1 & 0.125 & $\begin{array}{l}0.2 \\
5\end{array}$ & $\begin{array}{l}0.37 \\
5\end{array}$ & 0.5 & 0.75 & 1 \\
\hline Owner Occupied & & $1 \%$ & $1 \%$ & $0 \%$ & $-2 \%$ & $-1 \%$ & $-1 \%$ & $1 \%$ & $1 \%$ & $1 \%$ & $0 \%$ & $0 \%$ & $-1 \%$ \\
\hline Renter C & & $\begin{array}{l}12 \\
\%\end{array}$ & $9 \%$ & $7 \%$ & $9 \%$ & $9 \%$ & $7 \%$ & $12 \%$ & $\begin{array}{l}11 \\
\% \\
\end{array}$ & $\begin{array}{l}11 \\
\% \\
\end{array}$ & $\begin{array}{l}10 \\
\% \\
\end{array}$ & $9 \%$ & $9 \%$ \\
\hline Total Housing Units & & $8 \%$ & $6 \%$ & $5 \%$ & $5 \%$ & $5 \%$ & $3 \%$ & $8 \%$ & $8 \%$ & $7 \%$ & $7 \%$ & $6 \%$ & $6 \%$ \\
\hline Owner Occ & & $\begin{array}{l}- \\
17 \\
\%\end{array}$ & $3 \%$ & $\begin{array}{l}- \\
13 \\
\%\end{array}$ & $-8 \%$ & $-5 \%$ & $-1 \%$ & $-17 \%$ & $\begin{array}{l}12 \\
\%\end{array}$ & $\begin{array}{l}- \\
12 \\
\%\end{array}$ & $\begin{array}{l}11 \\
\%\end{array}$ & $\begin{array}{l}13 \\
\%\end{array}$ & $\begin{array}{l}- \\
14 \\
\% \\
\end{array}$ \\
\hline $\begin{array}{l}\text { Owner Occupied } \\
\text { Veh }\end{array}$ & & $2 \%$ & $\begin{array}{l}- \\
1 \% \\
\end{array}$ & $0 \%$ & $-2 \%$ & $-3 \%$ & $-3 \%$ & $2 \%$ & $1 \%$ & $1 \%$ & $0 \%$ & $-1 \%$ & $-2 \%$ \\
\hline Renter Occ No Veh & & $\begin{array}{l}13 \\
\%\end{array}$ & $3 \%$ & $1 \%$ & $6 \%$ & $1 \%$ & $\begin{array}{l}14 \\
\%\end{array}$ & $13 \%$ & $\begin{array}{l}11 \\
\%\end{array}$ & $\begin{array}{l}11 \\
\%\end{array}$ & $\begin{array}{l}10 \\
\%\end{array}$ & $9 \%$ & $9 \%$ \\
\hline $\begin{array}{l}\text { Renter Occupied } \\
\text { Veh }\end{array}$ & & $\begin{array}{l}22 \\
\%\end{array}$ & $\begin{array}{l}17 \\
\%\end{array}$ & $\begin{array}{l}18 \\
\%\end{array}$ & $\begin{array}{l}16 \\
\%\end{array}$ & $\begin{array}{l}18 \\
\%\end{array}$ & $\begin{array}{l}16 \\
\%\end{array}$ & $22 \%$ & $\begin{array}{l}21 \\
\%\end{array}$ & $\begin{array}{l}20 \\
\%\end{array}$ & $\begin{array}{l}19 \\
\%\end{array}$ & $\begin{array}{l}18 \\
\%\end{array}$ & $\begin{array}{l}18 \\
\%\end{array}$ \\
\hline
\end{tabular}




\begin{tabular}{|c|c|c|c|c|c|c|c|c|c|c|c|c|}
\hline Total Housing Units & $\begin{array}{l}13 \\
\% \\
\end{array}$ & $8 \%$ & $8 \%$ & $8 \%$ & $7 \%$ & $7 \%$ & $13 \%$ & $\begin{array}{l}11 \\
\% \\
\end{array}$ & $\begin{array}{l}11 \\
\%\end{array}$ & $\begin{array}{l}10 \\
\%\end{array}$ & $9 \%$ & $9 \%$ \\
\hline Households No Veh & $\begin{array}{l}10 \\
\%\end{array}$ & $3 \%$ & $\begin{array}{l}- \\
1 \%\end{array}$ & $5 \%$ & $0 \%$ & $\begin{array}{l}12 \\
\%\end{array}$ & $10 \%$ & $8 \%$ & $6 \%$ & $6 \%$ & $3 \%$ & $3 \%$ \\
\hline $\begin{array}{l}\text { Households with } \\
\text { Veh }\end{array}$ & $\begin{array}{l}14 \\
\%\end{array}$ & $9 \%$ & $\begin{array}{l}10 \\
\%\end{array}$ & $8 \%$ & $8 \%$ & $6 \%$ & $14 \%$ & $\begin{array}{l}13 \\
\%\end{array}$ & $\begin{array}{l}112 \\
\%\end{array}$ & $\begin{array}{l}11 \\
\%\end{array}$ & $\begin{array}{l}10 \\
\%\end{array}$ & $\%$ \\
\hline Total Housing Units & $\begin{array}{l}13 \\
\%\end{array}$ & $8 \%$ & $8 \%$ & $8 \%$ & $7 \%$ & $7 \%$ & $13 \%$ & $\begin{array}{l}11 \\
\% \\
\end{array}$ & $\begin{array}{l}11 \\
\% \\
\end{array}$ & $\begin{array}{l}10 \\
\%\end{array}$ & $9 \%$ & $9 \%$ \\
\hline \multicolumn{7}{|c|}{$\begin{array}{l}\text { LQ Trend 2010-2016 (LQ } 2016 / L Q \\
2010) \text { - Incremental }\end{array}$} & \multicolumn{6}{|l|}{$\begin{array}{l}\text { Cumul } \\
\text { ative }\end{array}$} \\
\hline $\begin{array}{l}\text { Tenure by Vehicle } \\
\text { Presence }\end{array}$ & $\begin{array}{l}0.1 \\
25\end{array}$ & $\begin{array}{l}0.2 \\
5\end{array}$ & $\begin{array}{l}0.3 \\
75\end{array}$ & 0.5 & 0.75 & 1 & 0.125 & $\begin{array}{l}0.2 \\
5\end{array}$ & $\begin{array}{l}0.37 \\
5\end{array}$ & 0.5 & 0.75 & 1 \\
\hline Owner Occupied & $\begin{array}{l}0.9 \\
9\end{array}$ & $\begin{array}{ll}0.9 \\
8 \\
\end{array}$ & $\begin{array}{l}0.9 \\
8 \\
\end{array}$ & 0.99 & 0.97 & 0.99 & 0.99 & $\begin{array}{l}0.9 \\
7 \\
\end{array}$ & 0.97 & 0.97 & 0.97 & $\begin{array}{l}0.9 \\
7 \\
\end{array}$ \\
\hline Renter Occupied & $\begin{array}{l}1.0 \\
0\end{array}$ & $\begin{array}{l}1.0 \\
0\end{array}$ & $\begin{array}{l}1.0 \\
0 \\
\end{array}$ & 1.00 & 1.00 & 1.00 & 1.00 & $\begin{array}{l}0.9 \\
8 \\
\end{array}$ & 0.98 & 0.98 & 0.98 & $\begin{array}{l}0.9 \\
9 \\
\end{array}$ \\
\hline Owner Occ No Veh & $\begin{array}{l}0.9 \\
7 \\
\end{array}$ & $\begin{array}{ll}0.9 \\
7 \\
\end{array}$ & $\begin{array}{l}0.9 \\
8 \\
\end{array}$ & 0.96 & 0.94 & 0.95 & 0.97 & $\begin{array}{ll}0.8 \\
8 \\
\end{array}$ & 0.88 & 0.89 & 0.88 & $\begin{array}{l}0.8 \\
8 \\
\end{array}$ \\
\hline $\begin{array}{l}\text { Owner Occupied } \\
\text { Veh }\end{array}$ & $\begin{array}{l}1.0 \\
1\end{array}$ & $\begin{array}{l}0.9 \\
5\end{array}$ & $\begin{array}{l}0.9 \\
4\end{array}$ & 0.99 & 0.89 & 0.93 & 1.01 & $\begin{array}{l}0.9 \\
7\end{array}$ & 0.97 & 0.97 & 0.96 & $\begin{array}{l}0.9 \\
6\end{array}$ \\
\hline Rente & $\begin{array}{l}0.9 \\
9 \\
\end{array}$ & $\begin{array}{l}0.9 \\
8\end{array}$ & $\begin{array}{l}1.0 \\
0\end{array}$ & 0.98 & 0.95 & .99 & 0.99 & $\begin{array}{l}1.0 \\
0\end{array}$ & .99 & 0.99 & 0.97 & $\begin{array}{l}0.9 \\
7\end{array}$ \\
\hline $\begin{array}{l}\text { Renter Occupied } \\
\text { Veh }\end{array}$ & $\begin{array}{l}1.0 \\
2 \\
\end{array}$ & $\begin{array}{l}1.0 \\
0 \\
\end{array}$ & $\begin{array}{l}1.0 \\
1 \\
\end{array}$ & 1.00 & 0.96 & 0.99 & 1.02 & $\begin{array}{l}0.9 \\
9 \\
\end{array}$ & 0.99 & 0.99 & .98 & $\begin{array}{l}0.9 \\
9 \\
\end{array}$ \\
\hline Households No Veh & $\begin{array}{l}1.0 \\
3\end{array}$ & $\begin{array}{l}1.0 \\
1\end{array}$ & $\begin{array}{l}1.0 \\
3\end{array}$ & 1.01 & 0.97 & 1.00 & 03 & $\begin{array}{l}0.9 \\
8\end{array}$ & 0.97 & 0.97 & 0.97 & $\begin{array}{l}0.9 \\
7\end{array}$ \\
\hline $\begin{array}{l}\text { Households with } \\
\text { Veh }\end{array}$ & $\begin{array}{l}1.0 \\
2 \\
\end{array}$ & $\begin{array}{l}1.0 \\
0\end{array}$ & $\begin{array}{l}1.0 \\
1 \\
\end{array}$ & 1.00 & 0.96 & 0.99 & 1.02 & $\begin{array}{l}1.0 \\
1 \\
\end{array}$ & 1.01 & 1.01 & 1.01 & $\begin{array}{l}1.0 \\
1 \\
\end{array}$ \\
\hline $\begin{array}{l}\text { Table 5A.12. Mod N } \\
\text { Demographic Chang } \\
\text { Incremental }\end{array}$ & A: SC & , Ter & iure $b$ & y Veh & cle $\mathrm{Pr}$ & esenc & $\begin{array}{l}\text { Cumul } \\
\text { ative }\end{array}$ & & & & & \\
\hline $\begin{array}{l}\text { Tenu } \\
\text { Prese }\end{array}$ & $\begin{array}{l}0.12 \\
5 \\
\end{array}$ & $\begin{array}{l}0.2 \\
5 \\
\end{array}$ & $\begin{array}{l}0.3 \\
75\end{array}$ & 0.5 & 0.75 & 1 & 0.125 & 0.25 & $\begin{array}{l}0.37 \\
5 \\
\end{array}$ & 0.5 & 0.75 & 1 \\
\hline Owner Occ & )$^{(316}$ & $\begin{array}{l}30 \\
2\end{array}$ & )$^{(80}$ & )$^{(67}$ & 17 & \begin{tabular}{|l|}
32 \\
9 \\
\end{tabular} & $(316)$ & $(14)$ & $(94)$ & $\begin{array}{l}\text { (16 } \\
1)\end{array}$ & $\begin{array}{l}(14 \\
4)\end{array}$ & 185 \\
\hline Rent & )$^{(314}$ & $\begin{array}{l}2,8 \\
16 \\
\end{array}$ & $\begin{array}{l}1,6 \\
61\end{array}$ & $\begin{array}{l}83 \\
9 \\
\end{array}$ & \begin{tabular}{|l|}
$(1,4$ \\
$32)$ \\
\end{tabular} & \begin{tabular}{|l|}
$(30$ \\
$2)$ \\
\end{tabular} & $(314)$ & $\begin{array}{l}2,50 \\
2\end{array}$ & $\begin{array}{l}4,16 \\
3\end{array}$ & $\begin{array}{l}5,00 \\
2\end{array}$ & $\begin{array}{l}3,57 \\
0\end{array}$ & $\begin{array}{l}3,26 \\
8\end{array}$ \\
\hline$\underline{\text { Total Housing Units }}$ & )$^{(630}$ & $\begin{array}{l}3,1 \\
18 \\
\end{array}$ & $\begin{array}{l}1,5 \\
81 \\
\end{array}$ & $\begin{array}{l}77 \\
2 \\
\end{array}$ & \begin{tabular}{|l|}
$(1,4$ \\
$15)$ \\
\end{tabular} & \begin{tabular}{|l|}
32 \\
9 \\
\end{tabular} & 30) & $\begin{array}{l}2,48 \\
8 \\
\end{array}$ & $\begin{array}{l}4,06 \\
9\end{array}$ & $\begin{array}{l}4,84 \\
1 \\
\end{array}$ & $\begin{array}{ll}3,42 \\
6 \\
\end{array}$ & $\begin{array}{l}3,75 \\
5 \\
\end{array}$ \\
\hline Owr & )$^{(198}$ & $\begin{array}{l}(20 \\
9)\end{array}$ & 7 & )$^{(37}$ & 58 & $\begin{array}{l}(67 \\
2)\end{array}$ & (198) & $\begin{array}{l}40 \\
7)\end{array}$ & $\begin{array}{l}\text { (40 } \\
0)\end{array}$ & $\begin{array}{l}\text { (43 } \\
7)\end{array}$ & $\begin{array}{l}\text { (37 } \\
9)\end{array}$ & $\begin{array}{l}(1,0 \\
51)\end{array}$ \\
\hline $\begin{array}{l}\text { Owner Occupied } \\
\text { Veh }\end{array}$ & $\begin{array}{l}2,09 \\
1 \\
\end{array}$ & $\begin{array}{l}70 \\
3 \\
\end{array}$ & $\begin{array}{l}(25 \\
7)\end{array}$ & $\begin{array}{l}(11 \\
7)\end{array}$ & 348 & \begin{tabular}{|l|}
34 \\
$3)$ \\
\end{tabular} & 11 & $\begin{array}{l}2,79 \\
4\end{array}$ & $\begin{array}{l}2,53 \\
7\end{array}$ & $\begin{array}{l}2,42 \\
0 \\
\end{array}$ & $\begin{array}{l}2,76 \\
8 \\
\end{array}$ & $\begin{array}{l}2,42 \\
5\end{array}$ \\
\hline Ren & $\begin{array}{l}(1,0 \\
09)\end{array}$ & $\begin{array}{l}96 \\
3\end{array}$ & 0 & $\begin{array}{l}(14 \\
3)\end{array}$ & 61) & 19 & ,009) & $(46)$ & $(46)$ & $\begin{array}{l}(18 \\
9)\end{array}$ & $\begin{array}{l}(25 \\
0)\end{array}$ & )$^{(231}$ \\
\hline $\begin{array}{l}\text { Renter Occupied } \\
\text { Veh }\end{array}$ & $\begin{array}{l}7,54 \\
8\end{array}$ & $\begin{array}{l}2,5 \\
11 \\
\end{array}$ & $\begin{array}{l}1,8 \\
33\end{array}$ & $\begin{array}{l}1,6 \\
30\end{array}$ & 997 & \begin{tabular}{|l|}
98 \\
8 \\
\end{tabular} & 7,548 & $\begin{array}{l}10,0 \\
59\end{array}$ & $\begin{array}{l}11,8 \\
92\end{array}$ & $\begin{array}{l}13,5 \\
22\end{array}$ & $\begin{array}{l}4,5 \\
19\end{array}$ & $\begin{array}{l}15,5 \\
07\end{array}$ \\
\hline$\underline{\text { Total Housing Units }}$ & $\begin{array}{l}8,43 \\
2 \\
\end{array}$ & $\begin{array}{l}3,9 \\
68 \\
\end{array}$ & $\begin{array}{l}1,5 \\
83\end{array}$ & $\begin{array}{l}1,3 \\
33 \\
\end{array}$ & $\begin{array}{l}1,34 \\
2 \\
\end{array}$ & $\begin{array}{l}15 \\
7 \\
\end{array}$ & 8,432 & $\begin{array}{l}12,4 \\
00\end{array}$ & $\begin{array}{l}13,9 \\
83\end{array}$ & $\begin{array}{l}15,3 \\
16 \\
\end{array}$ & $\begin{array}{l}16,6 \\
58 \\
\end{array}$ & $\begin{array}{l}16,8 \\
15 \\
\end{array}$ \\
\hline Households No Veh & \begin{tabular}{|l}
$(1,2$ \\
$07)$ \\
\end{tabular} & $\begin{array}{l}75 \\
4 \\
\end{array}$ & 7 & $\begin{array}{l}(18 \\
0)\end{array}$ & $(3)$ & $\begin{array}{l}1,2 \\
20 \\
\end{array}$ & $(1,207)$ & $\begin{array}{l}(45 \\
3)\end{array}$ & $\begin{array}{l}(44 \\
6) \\
\end{array}$ & $\begin{array}{l}(62 \\
6)\end{array}$ & $\begin{array}{l}(62 \\
9)\end{array}$ & 591 \\
\hline $\begin{array}{l}\text { Households with } \\
\text { Veh }\end{array}$ & $\begin{array}{l}9,63 \\
9\end{array}$ & $\begin{array}{l}3,2 \\
14\end{array}$ & $\begin{array}{l}1,5 \\
76\end{array}$ & $\begin{array}{l}1,5 \\
13\end{array}$ & $\begin{array}{l}1,34 \\
5\end{array}$ & \begin{tabular}{|l|}
2,3 \\
84 \\
\end{tabular} & 9,639 & $\begin{array}{l}12,8 \\
53\end{array}$ & $\begin{array}{l}14,4 \\
29\end{array}$ & $\begin{array}{l}15,9 \\
42\end{array}$ & $\begin{array}{l}17,2 \\
87\end{array}$ & $\begin{array}{l}19,6 \\
71\end{array}$ \\
\hline
\end{tabular}




\begin{tabular}{|c|c|c|c|c|c|c|c|c|c|c|c|c|}
\hline$\underline{\text { Total Housing Units }}$ & $\begin{array}{l}8,43 \\
2\end{array}$ & $\begin{array}{l}3,9 \\
68 \\
\end{array}$ & $\begin{array}{l}1,5 \\
83 \\
\end{array}$ & $\begin{array}{l}1,3 \\
33\end{array}$ & $\begin{array}{l}1,34 \\
2\end{array}$ & $\begin{array}{l}17 \\
6 \\
\end{array}$ & 8,432 & $\begin{array}{l}12,4 \\
00\end{array}$ & $\begin{array}{l}13,9 \\
83 \\
\end{array}$ & $\begin{array}{l}15,3 \\
16\end{array}$ & $\begin{array}{l}16,6 \\
58\end{array}$ & $\begin{array}{l}16,8 \\
34 \\
\end{array}$ \\
\hline \multicolumn{7}{|c|}{$\begin{array}{l}\text { Percent Demographic Change 2010- } \\
2016 \text { - Incremental }\end{array}$} & \multicolumn{6}{|l|}{$\begin{array}{l}\text { Cumul } \\
\text { ative }\end{array}$} \\
\hline Tenure by Vehicle & 0.12 & 0.2 & 0.3 & & & & & & 0.37 & & & \\
\hline Presence & 5 & 5 & 75 & 0.5 & 0.75 & 1 & 0.125 & 0.25 & 5 & 0.5 & 0.75 & 1 \\
\hline Owner Occupied & $-1 \%$ & $3 \%$ & $1 \%$ & $1 \%$ & $0 \%$ & $3 \%$ & $-1 \%$ & $0 \%$ & $0 \%$ & $0 \%$ & $-1 \%$ & $0 \%$ \\
\hline Renter Occupied & $-1 \%$ & $\begin{array}{l}17 \\
\%\end{array}$ & $\begin{array}{l}10 \\
\%\end{array}$ & $6 \%$ & $\begin{array}{l}- \\
10 \%\end{array}$ & $4 \%$ & $-1 \%$ & $3 \%$ & $4 \%$ & $5 \%$ & $3 \%$ & $4 \%$ \\
\hline Total Housing Units & $-1 \%$ & $\begin{array}{l}12 \\
\%\end{array}$ & $7 \%$ & $4 \%$ & $-6 \%$ & - & $-1 \%$ & $2 \%$ & $3 \%$ & $3 \%$ & $2 \%$ & $3 \%$ \\
\hline Owner Occ No Veh & - & $\begin{array}{l}- \\
22 \\
\%\end{array}$ & $1 \%$ & $\begin{array}{l}- \\
7 \% \\
\end{array}$ & $9 \%$ & $3 \%$ & $-11 \%$ & $\begin{array}{l}- \\
15 \\
\%\end{array}$ & $\begin{array}{l}- \\
12 \\
\%\end{array}$ & $\begin{array}{l}- \\
11 \\
\%\end{array}$ & $-8 \%$ & $-5 \%$ \\
\hline $\begin{array}{l}\text { Owner Occupied } \\
\text { Veh }\end{array}$ & $12 \%$ & $9 \%$ & - & $\begin{array}{l}- \\
1 \%\end{array}$ & $5 \%$ & $\begin{array}{l}11 \\
\%\end{array}$ & $12 \%$ & $\begin{array}{l}11 \\
\%\end{array}$ & $8 \%$ & $6 \%$ & $4 \%$ & $4 \%$ \\
\hline Renter Occ No Veh & $-6 \%$ & $\begin{array}{l}17 \\
\%\end{array}$ & $0 \%$ & - & $-2 \%$ & $4 \%$ & $-6 \%$ & $3 \%$ & $4 \%$ & $5 \%$ & $3 \%$ & $4 \%$ \\
\hline $\begin{array}{l}\text { Renter Occupied } \\
\text { Veh }\end{array}$ & $22 \%$ & $\begin{array}{l}23 \\
\%\end{array}$ & $\begin{array}{l}18 \\
\%\end{array}$ & $\begin{array}{l}18 \\
\%\end{array}$ & $12 \%$ & $\begin{array}{l}13 \\
\%\end{array}$ & $22 \%$ & $\begin{array}{l}22 \\
\%\end{array}$ & $\begin{array}{l}21 \\
\%\end{array}$ & $\begin{array}{l}21 \\
\%\end{array}$ & $\begin{array}{l}21 \\
\%\end{array}$ & $22 \%$ \\
\hline Total Housing Units & $12 \%$ & $\begin{array}{l}16 \\
\%\end{array}$ & $7 \%$ & $6 \%$ & $7 \%$ & $\begin{array}{l}11 \\
\%\end{array}$ & $12 \%$ & $3 \%$ & $4 \%$ & $5 \%$ & $3 \%$ & $4 \%$ \\
\hline Households No Veh & $-6 \%$ & $\begin{array}{l}11 \\
\%\end{array}$ & $0 \%$ & $5 \%$ & $0 \%$ & $4 \%$ & $-6 \%$ & $-2 \%$ & $-1 \%$ & $-2 \%$ & $0 \%$ & $3 \%$ \\
\hline $\begin{array}{l}\text { Households with } \\
\text { Veh }\end{array}$ & $18 \%$ & $\begin{array}{l}17 \\
\%\end{array}$ & $9 \%$ & $9 \%$ & $9 \%$ & $\begin{array}{l}12 \\
\%\end{array}$ & $18 \%$ & $\begin{array}{l}18 \\
\%\end{array}$ & $\begin{array}{l}116 \\
\%\end{array}$ & $\begin{array}{l}15 \\
\%\end{array}$ & $\begin{array}{l}14 \\
\%\end{array}$ & $15 \%$ \\
\hline Total Housing Units & $12 \%$ & $\begin{array}{l}16 \\
\% \\
\end{array}$ & $7 \%$ & $6 \%$ & $7 \%$ & $\begin{array}{l}11 \\
\% \\
\end{array}$ & $12 \%$ & $3 \%$ & $4 \%$ & $5 \%$ & $3 \%$ & $4 \%$ \\
\hline $\begin{array}{l}\text { LQ Trend 2010-2016 } \\
\text { 2010) - Incremental }\end{array}$ & $\angle Q 20$ & $6 / L$ & & & & & $\begin{array}{l}\text { Cumul } \\
\text { ative }\end{array}$ & & & & & \\
\hline $\begin{array}{l}\text { Tenure by Vehicle } \\
\text { Presence }\end{array}$ & $\begin{array}{l}0.12 \\
5\end{array}$ & $\begin{array}{l}0.2 \\
5\end{array}$ & $\begin{array}{l}0.3 \\
75\end{array}$ & 0.5 & 0.75 & 1 & 0.125 & 0.25 & $\begin{array}{l}0.37 \\
5\end{array}$ & 0.5 & 0.75 & 1 \\
\hline Owner Occupied & 0.95 & $\begin{array}{l}0.9 \\
9 \\
\end{array}$ & $\begin{array}{l}0.9 \\
8 \\
\end{array}$ & $\begin{array}{l}0.9 \\
8 \\
\end{array}$ & 1.00 & $\begin{array}{l}0.9 \\
1\end{array}$ & 0.95 & 1.01 & 1.00 & 1.00 & 1.01 & 1.01 \\
\hline Renter Occupied & 1.00 & $\begin{array}{l}1.0 \\
0\end{array}$ & $\begin{array}{l}1.0 \\
0\end{array}$ & $\begin{array}{l}1.0 \\
0\end{array}$ & 1.00 & $\begin{array}{l}1.0 \\
0\end{array}$ & 1.00 & 0.96 & 0.96 & 0.97 & 0.96 & 0.97 \\
\hline Owner Occ No Veh & 1.17 & $\begin{array}{l}1.0 \\
1 \\
\end{array}$ & $\begin{array}{l}0.9 \\
4\end{array}$ & $\begin{array}{l}0.9 \\
8\end{array}$ & 0.97 & $\begin{array}{l}1.1 \\
6\end{array}$ & 1.17 & 0.84 & 0.86 & 0.86 & 0.91 & 0.93 \\
\hline $\begin{array}{l}\text { Owner Occupied } \\
\text { Veh }\end{array}$ & 0.88 & $\begin{array}{l}0.9 \\
7 \\
\end{array}$ & $\begin{array}{l}0.8 \\
7 \\
\end{array}$ & $\begin{array}{l}0.8 \\
6 \\
\end{array}$ & 1.18 & $\begin{array}{l}0.9 \\
7 \\
\end{array}$ & 0.88 & 1.12 & 1.08 & 1.06 & 1.06 & 1.05 \\
\hline Renter Occ No Veh & 1.09 & $\begin{array}{l}0.9 \\
7 \\
\end{array}$ & $\begin{array}{l}0.9 \\
8\end{array}$ & $\begin{array}{l}1.0 \\
1\end{array}$ & 1.21 & $\begin{array}{l}1.0 \\
6\end{array}$ & 1.09 & 0.91 & 0.90 & 0.90 & 0.92 & 0.94 \\
\hline $\begin{array}{l}\text { Renter Occupied } \\
\text { Veh }\end{array}$ & 1.10 & $\begin{array}{l}1.0 \\
1 \\
\end{array}$ & $\begin{array}{l}0.9 \\
7 \\
\end{array}$ & $\begin{array}{l}1.0 \\
0 \\
\end{array}$ & 1.12 & $\begin{array}{l}1.1 \\
1 \\
\end{array}$ & 1.10 & 1.06 & 1.04 & 1.04 & 1.06 & 1.06 \\
\hline Households No Veh & 1.16 & $\begin{array}{l}1.0 \\
2 \\
\end{array}$ & $\begin{array}{l}1.0 \\
0\end{array}$ & $\begin{array}{l}1.0 \\
3\end{array}$ & 1.11 & $\begin{array}{l}1.1 \\
3\end{array}$ & 1.16 & 0.84 & 0.86 & 0.86 & 0.88 & 0.89 \\
\hline $\begin{array}{l}\text { Households with } \\
\text { Veh }\end{array}$ & 1.10 & $\begin{array}{l}1.0 \\
1 \\
\end{array}$ & $\begin{array}{l}0.9 \\
7 \\
\end{array}$ & $\begin{array}{l}1.0 \\
0 \\
\end{array}$ & 1.12 & $\begin{array}{l}1.1 \\
1 \\
\end{array}$ & 1.10 & 1.05 & 1.05 & 1.04 & 1.03 & 1.03 \\
\hline
\end{tabular}

Table 5A.13. High MA: BRT, Tenure by Vehicle Presence

Demographic Change 2010-2016 - Cumu Incremental

lative 


\begin{tabular}{|c|c|c|c|c|c|c|c|c|c|c|c|c|}
\hline \multirow{3}{*}{$\begin{array}{l}\text { Tenure by } \\
\text { Vehicle } \\
\text { Presence }\end{array}$} & \multirow[b]{2}{*}{0.12} & \multirow[b]{3}{*}{0.25} & \multirow[b]{2}{*}{0.37} & \multirow[b]{3}{*}{0.5} & \multirow{3}{*}{$\begin{array}{l}0.7 \\
5\end{array}$} & & & & & & & \\
\hline & & & & & & & & & 0.37 & & & \\
\hline & 5 & & 5 & & & 1 & 0.125 & 0.25 & 5 & 0.5 & 0.75 & 1 \\
\hline $\begin{array}{l}\text { Owner } \\
\text { Occupied }\end{array}$ & 214 & 118 & (65) & (33) & 284 & 343 & 214 & 332 & 267 & 234 & 518 & 861 \\
\hline $\begin{array}{l}\text { Renter } \\
\text { Occupied }\end{array}$ & $\begin{array}{l}7,76 \\
3\end{array}$ & $\begin{array}{l}2,72 \\
5\end{array}$ & $\begin{array}{l}1,46 \\
8 \\
\end{array}$ & $\begin{array}{l}1,24 \\
4 \\
\end{array}$ & 852 & 584 & 7,763 & $\begin{array}{l}10,4 \\
88\end{array}$ & $\begin{array}{l}11,9 \\
56 \\
\end{array}$ & $\begin{array}{l}13,2 \\
00\end{array}$ & $\begin{array}{l}14,0 \\
52 \\
\end{array}$ & $\begin{array}{l}14,6 \\
36 \\
\end{array}$ \\
\hline $\begin{array}{l}\text { Total Housing } \\
\text { Units }\end{array}$ & $\begin{array}{l}7,97 \\
7\end{array}$ & $\begin{array}{l}2,84 \\
3\end{array}$ & $\begin{array}{l}1,40 \\
3\end{array}$ & $\begin{array}{l}1,21 \\
1\end{array}$ & $\begin{array}{l}1,1 \\
36\end{array}$ & 343 & 7,977 & $\begin{array}{l}10,8 \\
20\end{array}$ & $\begin{array}{l}12,2 \\
23\end{array}$ & $\begin{array}{l}13,4 \\
34\end{array}$ & $\begin{array}{l}14,5 \\
70\end{array}$ & $\begin{array}{l}14,9 \\
13\end{array}$ \\
\hline $\begin{array}{l}\text { Owner Occ No } \\
\text { Veh }\end{array}$ & (55) & 29 & 38 & 13 & 112 & 241 & (55) & (26) & 12 & 25 & 137 & 378 \\
\hline $\begin{array}{l}\text { Owner } \\
\text { Occupied Veh }\end{array}$ & $\begin{array}{l}6,03 \\
3\end{array}$ & $\begin{array}{l}3,83 \\
8\end{array}$ & $\begin{array}{l}3,23 \\
9\end{array}$ & $\begin{array}{l}4,94 \\
2\end{array}$ & $\begin{array}{l}1,9 \\
78\end{array}$ & 584 & 6,033 & $\begin{array}{l}9,87 \\
1\end{array}$ & $\begin{array}{l}13,1 \\
10\end{array}$ & $\begin{array}{l}18,0 \\
52\end{array}$ & $\begin{array}{l}20,0 \\
30\end{array}$ & $\begin{array}{l}20,6 \\
14\end{array}$ \\
\hline $\begin{array}{l}\text { Renter Occ No } \\
\text { Veh }\end{array}$ & $\begin{array}{l}2,01 \\
8\end{array}$ & 505 & 112 & 59 & 411 & 59 & 2,018 & $\begin{array}{l}2,52 \\
3\end{array}$ & $\begin{array}{l}2,63 \\
5\end{array}$ & $\begin{array}{l}2,69 \\
4\end{array}$ & $\begin{array}{l}3,10 \\
5\end{array}$ & $\begin{array}{l}3,16 \\
4\end{array}$ \\
\hline $\begin{array}{l}\text { Renter } \\
\text { Occupied Veh }\end{array}$ & $\begin{array}{l}(86, \\
415)\end{array}$ & $\begin{array}{l}(16, \\
601) \\
\end{array}$ & $\begin{array}{l}(14, \\
629)\end{array}$ & $\begin{array}{l}(25 \\
529)\end{array}$ & $\begin{array}{l}(7 \\
955 \\
1\end{array}$ & $\begin{array}{l}2,05 \\
2\end{array}$ & $\begin{array}{l}(86,4 \\
15) \\
\end{array}$ & $\begin{array}{l}(103, \\
016)\end{array}$ & $\begin{array}{l}(117, \\
645)\end{array}$ & $\begin{array}{l}(143, \\
174)\end{array}$ & $\begin{array}{l}(151, \\
129)\end{array}$ & $\begin{array}{l}(149, \\
077)\end{array}$ \\
\hline $\begin{array}{l}\text { Total Housing } \\
\text { Units }\end{array}$ & $\begin{array}{l}(78, \\
419)\end{array}$ & $\begin{array}{l}(12 \\
229)\end{array}$ & $\begin{array}{l}(11, \\
240)\end{array}$ & $\begin{array}{l}(20 \\
515)\end{array}$ & $\begin{array}{l}(5 \\
454 \\
)\end{array}$ & $\begin{array}{l}(15 \\
8)\end{array}$ & $\begin{array}{l}(78,4 \\
19)\end{array}$ & $\begin{array}{l}(90,6 \\
48)\end{array}$ & $\begin{array}{l}(101, \\
888)\end{array}$ & $\begin{array}{l}(122, \\
403)\end{array}$ & $\begin{array}{l}(127, \\
857)\end{array}$ & $\begin{array}{l}(128, \\
015)\end{array}$ \\
\hline $\begin{array}{l}\text { Households } \\
\text { No Veh }\end{array}$ & $\begin{array}{l}1,96 \\
3 \\
\end{array}$ & 534 & 150 & 72 & 523 & $\begin{array}{l}(7,9 \\
75) \\
\end{array}$ & 1,963 & $\begin{array}{l}2,49 \\
7 \\
\end{array}$ & $\begin{array}{l}2,64 \\
7 \\
\end{array}$ & $\begin{array}{l}2,71 \\
9 \\
\end{array}$ & $\begin{array}{l}3,24 \\
2 \\
\end{array}$ & $\begin{array}{l}(4,73 \\
3)\end{array}$ \\
\hline $\begin{array}{l}\text { Households } \\
\text { with Veh }\end{array}$ & $\begin{array}{l}(80, \\
382)\end{array}$ & $\begin{array}{l}(12, \\
763)\end{array}$ & $\begin{array}{l}(11, \\
390)\end{array}$ & $\begin{array}{l}(20 \\
587)\end{array}$ & $\begin{array}{l}(5 \\
977 \\
)\end{array}$ & $\begin{array}{l}(6,0 \\
22)\end{array}$ & $\begin{array}{l}(80,3 \\
82)\end{array}$ & $\begin{array}{l}(93,1 \\
45)\end{array}$ & $\begin{array}{l}(104, \\
535)\end{array}$ & $\begin{array}{l}(125, \\
122)\end{array}$ & $\begin{array}{l}(131, \\
099)\end{array}$ & $\begin{array}{l}(137, \\
121)\end{array}$ \\
\hline $\begin{array}{l}\text { Total Housing } \\
\underline{\text { Units }}\end{array}$ & $\begin{array}{l}(78, \\
419)\end{array}$ & $\begin{array}{l}(12, \\
229) \\
\end{array}$ & $\begin{array}{l}(11, \\
240) \\
\end{array}$ & $\begin{array}{l}(20, \\
515) \\
\end{array}$ & $\begin{array}{l}(5, \\
454 \\
)\end{array}$ & $(99)$ & $\begin{array}{l}(78,4 \\
19) \\
\end{array}$ & $\begin{array}{l}(90,6 \\
48) \\
\end{array}$ & $\begin{array}{l}(101, \\
888)\end{array}$ & $\begin{array}{l}(122, \\
403)\end{array}$ & $\begin{array}{l}(127, \\
857)\end{array}$ & $\begin{array}{l}(127, \\
956)\end{array}$ \\
\hline \multicolumn{7}{|c|}{$\begin{array}{l}\text { Percent Demographic Change } \\
\text { 2010-2016 - Incremental }\end{array}$} & \multicolumn{6}{|l|}{$\begin{array}{l}\text { Cumu } \\
\text { lative }\end{array}$} \\
\hline $\begin{array}{l}\text { Tenure by } \\
\text { Vehicle } \\
\text { Presence }\end{array}$ & $\begin{array}{l}0.12 \\
5\end{array}$ & & $\begin{array}{l}0.37 \\
5\end{array}$ & & $\begin{array}{l}0.7 \\
5\end{array}$ & 1 & & & 0.37 & 5 & 75 & \\
\hline $\begin{array}{l}\text { Owner } \\
\text { Occupied }\end{array}$ & $1 \%$ & $3 \%$ & $-2 \%$ & $-1 \%$ & $\begin{array}{l}13 \\
\%\end{array}$ & $\begin{array}{l}19 \\
\%\end{array}$ & $1 \%$ & $2 \%$ & $1 \%$ & $1 \%$ & $0 \%$ & $1 \%$ \\
\hline $\begin{array}{l}\text { Renter } \\
\text { Occupied }\end{array}$ & $11 \%$ & $13 \%$ & $12 \%$ & $9 \%$ & $\begin{array}{l}14 \\
\% \\
\end{array}$ & $5 \%$ & $11 \%$ & $11 \%$ & $11 \%$ & $11 \%$ & $11 \%$ & $11 \%$ \\
\hline $\begin{array}{l}\text { Total Housing } \\
\text { Units }\end{array}$ & $9 \%$ & $11 \%$ & $8 \%$ & $6 \%$ & $\begin{array}{l}13 \\
\%\end{array}$ & $9 \%$ & $9 \%$ & $10 \%$ & $9 \%$ & $9 \%$ & $9 \%$ & $9 \%$ \\
\hline $\begin{array}{l}\text { Owner Occ No } \\
\text { Veh }\end{array}$ & $-4 \%$ & $8 \%$ & $12 \%$ & $4 \%$ & $\begin{array}{l}67 \\
\% \\
\end{array}$ & $\begin{array}{l}80 \\
\% \\
\end{array}$ & $-4 \%$ & $-2 \%$ & $1 \%$ & $1 \%$ & $-3 \%$ & $0 \%$ \\
\hline $\begin{array}{l}\text { Owner } \\
\text { Occupied Veh }\end{array}$ & $60 \%$ & $\begin{array}{l}125 \\
0 \%\end{array}$ & $\begin{array}{l}657 \\
\% \\
\end{array}$ & $\begin{array}{l}520 \\
2 \%\end{array}$ & $\begin{array}{l}741 \\
\%\end{array}$ & $\begin{array}{l}513 \\
00 \\
\%\end{array}$ & $60 \%$ & $96 \%$ & $\begin{array}{l}122 \\
\%\end{array}$ & $\begin{array}{l}166 \\
\%\end{array}$ & $\begin{array}{l}206 \\
\%\end{array}$ & $\begin{array}{l}244 \\
\%\end{array}$ \\
\hline $\begin{array}{l}\text { Renter Occ No } \\
\text { Veh }\end{array}$ & $10 \%$ & $9 \%$ & $3 \%$ & $1 \%$ & $\begin{array}{l}25 \\
\% \\
\end{array}$ & $\begin{array}{l}- \\
17 \\
\%\end{array}$ & $10 \%$ & $11 \%$ & $11 \%$ & $11 \%$ & $11 \%$ & $11 \%$ \\
\hline $\begin{array}{l}\text { Renter } \\
\text { Occupied Veh }\end{array}$ & $\begin{array}{l}- \\
61 \% \\
\end{array}$ & $\begin{array}{l}- \\
49 \% \\
\end{array}$ & - & $\begin{array}{l}- \\
71 \% \\
\end{array}$ & $\begin{array}{l}- \\
61 \\
\%\end{array}$ & $\begin{array}{l}- \\
66 \\
\%\end{array}$ & $-61 \%$ & - & - & $-60 \%$ & $-\overline{61 \%}$ & $-\overline{62 \%}$ \\
\hline $\begin{array}{l}\text { Total Housing } \\
\text { Units }\end{array}$ & - & $-\overline{30 \%}$ & - & - & $\begin{array}{l}- \\
36 \\
\%\end{array}$ & $\begin{array}{l}- \\
46 \\
\%\end{array}$ & $-45 \%$ & $11 \%$ & $11 \%$ & $11 \%$ & $11 \%$ & $11 \%$ \\
\hline
\end{tabular}




\begin{tabular}{|c|c|c|c|c|c|c|c|c|c|c|c|c|}
\hline $\begin{array}{l}\text { Households } \\
\text { No Veh }\end{array}$ & $9 \%$ & $9 \%$ & $4 \%$ & $2 \%$ & $\begin{array}{l}28 \\
\%\end{array}$ & $\begin{array}{l}10 \\
\%\end{array}$ & $9 \%$ & $9 \%$ & $9 \%$ & $8 \%$ & $7 \%$ & $7 \%$ \\
\hline $\begin{array}{l}\text { Households } \\
\text { with Veh }\end{array}$ & - & - & - & - & $\begin{array}{l}- \\
45 \\
\%\end{array}$ & $\begin{array}{l}- \\
49 \\
\%\end{array}$ & $-53 \%$ & $\overline{50 \%}$ & $51 \%$ & 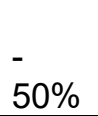 & $\begin{array}{l}- \\
51 \%\end{array}$ & - \\
\hline$\frac{\text { Total Housing }}{\text { Units }}$ & - & - & $-\overline{38 \%}$ & - & $\begin{array}{l}- \\
36 \\
\%\end{array}$ & $\begin{array}{l}- \\
46 \\
\%\end{array}$ & $-45 \%$ & $11 \%$ & $11 \%$ & $11 \%$ & $11 \%$ & $11 \%$ \\
\hline \multicolumn{7}{|c|}{$\begin{array}{l}\text { LQ Trend 2010-2016 (LQ } 2016 / L Q \\
\text { 2010) - Incremental }\end{array}$} & \multicolumn{6}{|l|}{$\begin{array}{l}\text { Cumu } \\
\text { lative }\end{array}$} \\
\hline $\begin{array}{l}\text { Tenure by } \\
\text { Vehicle } \\
\text { Presence }\end{array}$ & $\begin{array}{l}0.12 \\
5\end{array}$ & 0.25 & $\begin{array}{l}0.37 \\
5\end{array}$ & 0.5 & $\begin{array}{l}0.7 \\
5\end{array}$ & 1 & 0.125 & 0.25 & $\begin{array}{l}0.37 \\
5\end{array}$ & 0.5 & 0.75 & 1 \\
\hline $\begin{array}{l}\text { Owner } \\
\text { Occupied }\end{array}$ & 0.98 & 0.98 & 0.99 & 0.99 & $\begin{array}{l}1.0 \\
1\end{array}$ & 0.96 & 0.98 & 0.95 & 0.95 & 0.95 & 0.95 & 0.95 \\
\hline $\begin{array}{l}\text { Renter } \\
\text { Occupied }\end{array}$ & 1.00 & 1.00 & 1.00 & 1.00 & $\begin{array}{l}1.0 \\
0\end{array}$ & 1.00 & 1.00 & 0.98 & 0.98 & 0.98 & 0.98 & 0.98 \\
\hline $\begin{array}{l}\text { Owner Occ No } \\
\text { Veh }\end{array}$ & 0.06 & 0.52 & 0.30 & 2.12 & $\begin{array}{l}0.8 \\
8\end{array}$ & 0.32 & 0.06 & 0.97 & 1.00 & 1.00 & 0.97 & 0.99 \\
\hline $\begin{array}{l}\text { Owner } \\
\text { Occupied Veh }\end{array}$ & 0.96 & 0.94 & 0.91 & 0.91 & $\begin{array}{l}0.9 \\
2\end{array}$ & 1.05 & 0.96 & 0.08 & 0.09 & 0.10 & 0.12 & 0.13 \\
\hline $\begin{array}{l}\text { Renter Occ No } \\
\text { Veh }\end{array}$ & 1.80 & 2.29 & 1.92 & 1.37 & $\begin{array}{l}1.4 \\
7\end{array}$ & 1.71 & 1.80 & 0.96 & 0.95 & 0.95 & 0.95 & 0.95 \\
\hline $\begin{array}{l}\text { Renter } \\
\text { Occupied Veh }\end{array}$ & 0.92 & 1.15 & 1.04 & 0.85 & $\begin{array}{l}0.8 \\
3\end{array}$ & 1.03 & 0.92 & 1.90 & 1.90 & 1.82 & 1.78 & 1.74 \\
\hline $\begin{array}{l}\text { Households } \\
\text { No Veh }\end{array}$ & 0.83 & 1.08 & 0.98 & 0.77 & $\begin{array}{l}0.7 \\
5\end{array}$ & 0.93 & 0.83 & 1.01 & 1.00 & 1.01 & 1.02 & 1.03 \\
\hline $\begin{array}{l}\text { Households } \\
\text { with Veh }\end{array}$ & 0.92 & 1.15 & 1.04 & 0.85 & $\begin{array}{l}0.8 \\
3\end{array}$ & 1.03 & 0.92 & 0.91 & 0.91 & 0.91 & 0.91 & 0.91 \\
\hline
\end{tabular}

Table 5A.14. High MA: CRT, Tenure by Vehicle Presence

\begin{tabular}{|c|c|c|c|c|c|c|c|c|c|c|c|c|}
\hline $\begin{array}{l}\text { Demographic Cha } \\
\text { Incremental }\end{array}$ & 20 & 01 & & & & & $\begin{array}{l}\text { nul } \\
e\end{array}$ & & & & & \\
\hline Tenure by & & & & & & & & 0. & & & & \\
\hline Vehicle & & & 0.37 & & 0.7 & & & 2 & 0.37 & & & \\
\hline Presence & 0.125 & 0.25 & 5 & 0.5 & 5 & 1 & 0.125 & 5 & 5 & 0.5 & 0.75 & 1 \\
\hline Owner Occupied & 203 & )$^{(459}$ & (296) & $\begin{array}{l}\text { (54 } \\
7)\end{array}$ & (15) & $\begin{array}{l}(12 \\
8)\end{array}$ & 203 & $\begin{array}{l}(2 \\
5 \\
6)\end{array}$ & )$^{(552}$ & $\begin{array}{l}(1,0 \\
99)\end{array}$ & $\begin{array}{l}(1,1 \\
14)\end{array}$ & $\begin{array}{l}(1,2 \\
42)\end{array}$ \\
\hline Renter Occupied & 1,313 & )$^{(369}$ & $\begin{array}{l}1,20 \\
5\end{array}$ & 927 & $\begin{array}{l}1,1 \\
38\end{array}$ & 319 & 1,313 & $\begin{array}{l}9 \\
4 \\
4 \\
\end{array}$ & $\begin{array}{l}2,14 \\
9\end{array}$ & $\begin{array}{l}3,07 \\
6\end{array}$ & $\begin{array}{l}4,21 \\
4\end{array}$ & $\begin{array}{l}4,53 \\
3\end{array}$ \\
\hline $\begin{array}{l}\text { Total Housing } \\
\text { Units }\end{array}$ & 1,516 & )$^{(828}$ & 909 & 380 & $\begin{array}{l}1,1 \\
23\end{array}$ & $\begin{array}{l}(12 \\
8)\end{array}$ & 1,516 & $\begin{array}{l}6 \\
8 \\
8\end{array}$ & $\begin{array}{l}1,59 \\
7\end{array}$ & $\begin{array}{l}1,97 \\
7\end{array}$ & $\begin{array}{l}3,10 \\
0\end{array}$ & $\begin{array}{l}2,97 \\
2\end{array}$ \\
\hline $\begin{array}{l}\text { Owner Occ No } \\
\text { Veh }\end{array}$ & 94 & (46) & 44 & 107 & 119 & 447 & 94 & $\begin{array}{l}4 \\
8\end{array}$ & 92 & 199 & 318 & 765 \\
\hline $\begin{array}{l}\text { Owner Occupied } \\
\text { Veh }\end{array}$ & $(117)$ & )$^{(447}$ & (194) & 132 & 198 & 319 & $(117)$ & $\begin{array}{l}5 \\
6 \\
4) \\
\end{array}$ & )$^{(758}$ & )$^{(626}$ & )$^{(428}$ & )$^{(109}$ \\
\hline $\begin{array}{l}\text { Renter Occ No } \\
\text { Veh }\end{array}$ & $\begin{array}{l}17,40 \\
5\end{array}$ & 735 & 423 & 90 & $\begin{array}{l}2,0 \\
66\end{array}$ & 110 & $\begin{array}{l}17,40 \\
5\end{array}$ & $\begin{array}{l}1 \\
4 \\
0\end{array}$ & $\begin{array}{l}18,5 \\
63\end{array}$ & $\begin{array}{l}18,6 \\
53\end{array}$ & $\begin{array}{l}20,7 \\
19\end{array}$ & $\begin{array}{l}20,8 \\
29\end{array}$ \\
\hline
\end{tabular}




\begin{tabular}{|c|c|c|c|c|c|c|c|c|c|c|c|c|c|}
\hline $\begin{array}{l}\text { Renter Occupied } \\
\text { Veh }\end{array}$ & 2,414 & )$^{(492}$ & & $\begin{array}{l}1,18 \\
1\end{array}$ & $\begin{array}{l}2,1 \\
04\end{array}$ & 909 & 33 & 2,414 & $\begin{array}{l}2 \\
2\end{array}$ & $\begin{array}{l}3,10 \\
3\end{array}$ & $\begin{array}{l}5,20 \\
7\end{array}$ & $\begin{array}{l}6,11 \\
6 \\
\end{array}$ & $\begin{array}{l}6,14 \\
9\end{array}$ \\
\hline $\begin{array}{l}\text { Total Housing } \\
\text { Units }\end{array}$ & $\begin{array}{l}19,79 \\
6 \\
\end{array}$ & )$^{(250}$ & & $\begin{array}{l}1,45 \\
4\end{array}$ & $\begin{array}{l}2,4 \\
33\end{array}$ & $\begin{array}{l}3,2 \\
92\end{array}$ & (79) & $\begin{array}{l}19,79 \\
6\end{array}$ & \begin{tabular}{|l}
1 \\
9 \\
5 \\
4 \\
6 \\
\end{tabular} & $\begin{array}{l}21,0 \\
00\end{array}$ & $\begin{array}{l}23,4 \\
33\end{array}$ & $\begin{array}{l}26,7 \\
25\end{array}$ & $\begin{array}{l}26,6 \\
46\end{array}$ \\
\hline $\begin{array}{l}\text { Households No } \\
\text { Veh }\end{array}$ & $\begin{array}{l}17,49 \\
9 \\
\end{array}$ & 689 & & 467 & 197 & $\begin{array}{l}2,1 \\
85\end{array}$ & $\begin{array}{l}1,0 \\
03\end{array}$ & $\begin{array}{l}17,49 \\
9\end{array}$ & \begin{tabular}{|l}
1 \\
8 \\
1 \\
8 \\
8
\end{tabular} & $\begin{array}{l}18,6 \\
55\end{array}$ & $\begin{array}{l}18,8 \\
52\end{array}$ & $\begin{array}{l}21,0 \\
37\end{array}$ & $\begin{array}{l}22,0 \\
40\end{array}$ \\
\hline $\begin{array}{l}\text { Households with } \\
\text { Veh }\end{array}$ & 2,297 & )$^{(935}$ & & 987 & $\begin{array}{l}2,2 \\
36\end{array}$ & $\begin{array}{l}1,1 \\
07\end{array}$ & $\begin{array}{l}1,0 \\
67\end{array}$ & 2,297 & $\begin{array}{l}1 \\
3 \\
5 \\
8\end{array}$ & $\begin{array}{l}2,34 \\
5\end{array}$ & $\begin{array}{l}4,58 \\
1\end{array}$ & $\begin{array}{l}5,68 \\
8\end{array}$ & $\begin{array}{l}6,75 \\
5\end{array}$ \\
\hline $\begin{array}{l}\text { Total Housing } \\
\text { Units }\end{array}$ & \begin{tabular}{|l|}
19 \\
79 \\
6 \\
\end{tabular} & $\begin{array}{l}(25 \\
0)\end{array}$ & $\begin{array}{l}1,4 \\
54\end{array}$ & $\begin{array}{l}2,43 \\
3\end{array}$ & $\begin{array}{ll}3,2 \\
92\end{array}$ & 31 & & ,796 & 19,546 & \begin{tabular}{l|l}
21,0 \\
00
\end{tabular} & $\begin{array}{l}23,4 \\
33\end{array}$ & $\begin{array}{l}26,7 \\
25\end{array}$ & \begin{tabular}{l|l}
26 \\
7 \\
56
\end{tabular} \\
\hline \multicolumn{7}{|c|}{$\begin{array}{l}\text { Percent Demographic Change } \\
\text { 2010-2016 - Incremental }\end{array}$} & \multicolumn{2}{|c|}{$\begin{array}{l}\text { Cumul } \\
\text { ative }\end{array}$} & & & & & \\
\hline $\begin{array}{l}\text { Tenure by } \\
\text { Vehicle } \\
\text { Presence }\end{array}$ & 0.125 & 0.2 & & $\begin{array}{l}0.37 \\
5\end{array}$ & 0.5 & $\begin{array}{l}0.7 \\
5 \\
\end{array}$ & 1 & 0.125 & $\begin{array}{l}0 . \\
2 \\
5\end{array}$ & $\begin{array}{l}0.37 \\
5\end{array}$ & 0.5 & 0.75 & 1 \\
\hline Own & $7 \%$ & $\begin{array}{l}- \\
37 \%\end{array}$ & & $-12 \%$ & $\begin{array}{l}- \\
17 \\
\%\end{array}$ & $0 \%$ & $-3 \%$ & $7 \%$ & $\begin{array}{l}- \\
6 \\
\%\end{array}$ & $-8 \%$ & $\begin{array}{l}- \\
11 \%\end{array}$ & $-7 \%$ & $-6 \%$ \\
\hline Occupied & $12 \%$ & $-5 \%$ & & $12 \%$ & $7 \%$ & $9 \%$ & $4 \%$ & $12 \%$ & $\begin{array}{l}5 \\
\% \\
\end{array}$ & $8 \%$ & $8 \%$ & $8 \%$ & $5 \%$ \\
\hline $\begin{array}{l}\text { Total Housing } \\
\text { Units }\end{array}$ & $11 \%$ & $-\overline{10 \%}$ & & $7 \%$ & $2 \%$ & $7 \%$ & $2 \%$ & $11 \%$ & $\begin{array}{l}3 \\
\% \\
\end{array}$ & $5 \%$ & $4 \%$ & $4 \%$ & $3 \%$ \\
\hline $\begin{array}{l}\text { Owner } \\
\text { Veh }\end{array}$ & $44 \%$ & $\begin{array}{l}- \\
29 \%\end{array}$ & & $17 \%$ & $\begin{array}{l}50 \\
\%\end{array}$ & $\begin{array}{l}52 \\
\% \\
\end{array}$ & $\begin{array}{l}43 \\
\%\end{array}$ & $44 \%$ & $\begin{array}{l}1 \\
3 \\
\% \\
\end{array}$ & $15 \%$ & $24 \%$ & $19 \%$ & $27 \%$ \\
\hline $\begin{array}{l}\text { Owner Occupied } \\
\text { Veh }\end{array}$ & $-4 \%$ & - & & $-9 \%$ & $6 \%$ & $5 \%$ & $1 \%$ & $-4 \%$ & $\begin{array}{l}- \\
1 \\
5 \\
\%\end{array}$ & - & $-8 \%$ & $-1 \%$ & $0 \%$ \\
\hline $\begin{array}{l}\text { Renter Occ No } \\
\text { Veh }\end{array}$ & $604 \%$ & $38 \%$ & & $14 \%$ & $3 \%$ & \begin{tabular}{|l|}
78 \\
$\%$ \\
\end{tabular} & $-3 \%$ & $604 \%$ & $\begin{array}{l}5 \\
\% \\
\end{array}$ & $8 \%$ & $\%$ & $\%$ & $5 \%$ \\
\hline $\begin{array}{l}\text { Renter Occupied } \\
\text { Veh }\end{array}$ & $37 \%$ & $\begin{array}{l}- \\
10 \%\end{array}$ & & $18 \%$ & $\begin{array}{l}26 \\
\%\end{array}$ & $\begin{array}{l}10 \\
\%\end{array}$ & $\begin{array}{l}11 \\
\%\end{array}$ & $37 \%$ & $\begin{array}{l}1 \\
7 \\
\%\end{array}$ & $18 \%$ & $0 \%$ & $16 \%$ & $13 \%$ \\
\hline $\begin{array}{l}\text { Total Housing } \\
\underline{\text { Units }}\end{array}$ & $161 \%$ & $-3 \%$ & & $12 \%$ & $\begin{array}{l}18 \\
\%\end{array}$ & $\begin{array}{l}20 \\
\% \\
\end{array}$ & $7 \%$ & $161 \%$ & $\begin{array}{l}5 \\
\% \\
\end{array}$ & $8 \%$ & $8 \%$ & $8 \%$ & $5 \%$ \\
\hline $\begin{array}{l}\text { Households No } \\
\text { Veh }\end{array}$ & $565 \%$ & $33 \%$ & & $14 \%$ & $6 \%$ & $\begin{array}{l}76 \\
\%\end{array}$ & $1 \%$ & $565 \%$ & $\begin{array}{l}3 \\
5 \\
1 \\
\% \\
\end{array}$ & $\begin{array}{l}218 \\
\%\end{array}$ & $\begin{array}{l}158 \\
\%\end{array}$ & $\begin{array}{l}104 \\
\% \\
\end{array}$ & $77 \%$ \\
\hline $\begin{array}{l}\text { Households with } \\
\text { Veh }\end{array}$ & $25 \%$ & $\begin{array}{l}- \\
16 \%\end{array}$ & & $11 \%$ & $\begin{array}{l}22 \\
\%\end{array}$ & $8 \%$ & $9 \%$ & $25 \%$ & $\begin{array}{l}9 \\
\%\end{array}$ & $\begin{array}{l}110 \\
\%\end{array}$ & $14 \%$ & $11 \%$ & $9 \%$ \\
\hline $\begin{array}{l}\text { Total Housing } \\
\text { Units }\end{array}$ & \begin{tabular}{|l|}
16 \\
$1 \%$
\end{tabular} & $3 \%$ & $\begin{array}{l}12 \\
\%\end{array}$ & $18 \%$ & \begin{tabular}{|l|l|} 
& 20 \\
$\%$
\end{tabular} & $7 \%$ & & $1 \%$ & $5 \%$ & $8 \%$ & $8 \%$ & $8 \%$ & $\begin{array}{l}5 \\
\%\end{array}$ \\
\hline
\end{tabular}




\begin{tabular}{|c|c|c|c|c|c|c|c|c|c|c|c|c|c|}
\hline \multicolumn{8}{|c|}{$\begin{array}{l}\text { LQ Trend 2010-2016 (LQ } 2016 \text { / LQ } \\
\text { 2010) - Incremental }\end{array}$} & \multicolumn{6}{|l|}{$\begin{array}{l}\text { Cumul } \\
\text { ative }\end{array}$} \\
\hline \multicolumn{14}{|l|}{ Tenure by } \\
\hline Vehicle & 0.1 & 0.2 & 0.3 & & 0. & 7 & & & & 0.37 & & & \\
\hline Presence & 25 & 5 & 75 & 0.5 & - & L & 1 & 0.125 & 0.25 & 5 & 0.5 & 0.75 & 1 \\
\hline Owner Occupied & $\begin{array}{ll}0.9 \\
6\end{array}$ & $\begin{array}{l}1.0 \\
1\end{array}$ & $\begin{array}{l}1.0 \\
0\end{array}$ & 1.0 & $\begin{array}{l}0 . \\
7\end{array}$ & 9 & 0.98 & 0.96 & 0.94 & 0.90 & 0.88 & 0.92 & $\begin{array}{l}0 . \\
95\end{array}$ \\
\hline Renter Occupied & $\begin{array}{l}1.0 \\
0 \\
\end{array}$ & $\begin{array}{l}1.0 \\
0\end{array}$ & $\begin{array}{l}1.0 \\
0\end{array}$ & 1.0 & $\begin{array}{l}1 . \\
0\end{array}$ & 0 & 1.00 & 1.00 & 0.98 & 0.98 & 0.99 & 0.98 & $\begin{array}{l}0 . \\
98\end{array}$ \\
\hline $\begin{array}{l}\text { Owner Occ No } \\
\text { Veh }\end{array}$ & $\begin{array}{l}0.8 \\
4 \\
\end{array}$ & $\begin{array}{l}0.6 \\
5\end{array}$ & $\begin{array}{l}0.8 \\
3\end{array}$ & 1.0 & $\begin{array}{l}1 . \\
2\end{array}$ & 0 & 0.96 & 0.84 & 1.05 & 1.05 & 1.14 & 1.09 & $\begin{array}{l}1 . \\
18\end{array}$ \\
\hline $\begin{array}{l}\text { Owner Occupied } \\
\text { Veh }\end{array}$ & $\begin{array}{l}3.7 \\
1\end{array}$ & $\begin{array}{l}0.9 \\
0\end{array}$ & $\begin{array}{l}0.6 \\
2\end{array}$ & 0.5 & $\begin{array}{l}0 . \\
9\end{array}$ & 4 & 0.98 & 3.71 & 0.81 & 0.82 & 0.87 & 0.92 & $\begin{array}{l}0 . \\
95\end{array}$ \\
\hline $\begin{array}{l}\text { Renter Occ No } \\
\text { Veh }\end{array}$ & $\begin{array}{l}1.0 \\
6\end{array}$ & $\begin{array}{l}0.8 \\
5\end{array}$ & $\begin{array}{l}0.9 \\
5\end{array}$ & 1.0 & $\begin{array}{l}0 . \\
0\end{array}$ & 9 & 0.88 & 1.06 & 2.71 & 1.87 & .51 & 1.18 & $\begin{array}{l}1 . \\
03\end{array}$ \\
\hline $\begin{array}{l}\text { Renter Occupied } \\
\text { Veh }\end{array}$ & $\begin{array}{l}2.1 \\
2\end{array}$ & $\begin{array}{l}0.9 \\
7\end{array}$ & $\begin{array}{l}0.9 \\
4\end{array}$ & 1.0 & $\begin{array}{l}0 . \\
9\end{array}$ & 8 & 1.02 & 2.12 & 0.98 & 0.97 & 0.99 & 0.95 & $\begin{array}{l}0 . \\
95\end{array}$ \\
\hline $\begin{array}{l}\text { Households No } \\
\text { Veh }\end{array}$ & $\begin{array}{l}1.0 \\
5 \\
\end{array}$ & $\begin{array}{ll}0.8 \\
7\end{array}$ & $\begin{array}{ll}0.9 \\
7\end{array}$ & 1.1 & $\begin{array}{l}0 . \\
8\end{array}$ & 9 & 0.95 & 1.05 & 1.63 & 1.37 & 1.22 & 1.08 & $\begin{array}{l}1 . \\
00\end{array}$ \\
\hline $\begin{array}{l}\text { Households with } \\
\text { Veh } \\
\end{array}$ & $\begin{array}{l}2.1 \\
2 \\
\end{array}$ & \begin{tabular}{|l|}
0.9 \\
7 \\
\end{tabular} & \begin{tabular}{|l|}
0.9 \\
4 \\
\end{tabular} & 1.0 & \begin{tabular}{l|l} 
& 0. \\
4 & 9 \\
\end{tabular} & 8 & 1.02 & 2.12 & 0.57 & 0.69 & 0.78 & 0.85 & $\begin{array}{l}0 . \\
90 \\
\end{array}$ \\
\hline \multicolumn{14}{|c|}{ Table 5A.15. High MA: LRT, Tenure by Vehicle Presence } \\
\hline \multicolumn{8}{|c|}{$\begin{array}{l}\text { Demographic Change 2010-2016 - } \\
\text { Incremental }\end{array}$} & \multicolumn{6}{|l|}{$\begin{array}{l}\text { Cumul } \\
\text { ative }\end{array}$} \\
\hline \multirow{2}{*}{\multicolumn{2}{|c|}{$\begin{array}{l}\text { Tenure by Vehicle } \\
\text { Presence }\end{array}$}} & 0.12 & 0.2 & 0.3 & & 0.7 & 7 & \multicolumn{6}{|c|}{0.37} \\
\hline & & 5 & 5 & 75 & 0.5 & 5 & 1 & 0.125 & 0.25 & 5 & 0.5 & 0.75 & 1 \\
\hline \multicolumn{2}{|l|}{ Owner Occupied } & 71 & )$^{(76}$ & $\begin{array}{l}(62 \\
7) \\
\end{array}$ & $\begin{array}{l}(41 \\
8)\end{array}$ & 36 & 24 & 71 & (5) & $\begin{array}{l}(63 \\
2) \\
\end{array}$ & $\begin{array}{l}(1,0 \\
50)\end{array}$ & $\begin{array}{l}(1,0 \\
14) \\
\end{array}$ & $\begin{array}{l}(99 \\
0)\end{array}$ \\
\hline \multicolumn{2}{|l|}{ Renter Occupied } & $\begin{array}{l}9,04 \\
7 \\
\end{array}$ & $\begin{array}{l}1,8 \\
81\end{array}$ & $\begin{array}{l}3,7 \\
34\end{array}$ & $\begin{array}{l}2,0 \\
05\end{array}$ & $\begin{array}{l}1,5 \\
62\end{array}$ & $\begin{array}{l}1,4 \\
13 \\
\end{array}$ & 9,047 & $\begin{array}{l}10,9 \\
28\end{array}$ & $\begin{array}{l}14,6 \\
62 \\
\end{array}$ & $\begin{array}{l}16,6 \\
67 \\
\end{array}$ & $\begin{array}{l}18,2 \\
29\end{array}$ & $\begin{array}{l}19,6 \\
42\end{array}$ \\
\hline \multicolumn{2}{|c|}{$\underline{\text { Total Housing Units }}$} & $\begin{array}{l}9,11 \\
8\end{array}$ & $\begin{array}{l}1,8 \\
05 \\
\end{array}$ & $\begin{array}{l}3,1 \\
07\end{array}$ & $\begin{array}{l}1,5 \\
87 \\
\end{array}$ & $\begin{array}{l}1,5 \\
98\end{array}$ & 24 & 9,118 & $\begin{array}{l}10,9 \\
23 \\
\end{array}$ & $\begin{array}{l}14,0 \\
30 \\
\end{array}$ & $\begin{array}{l}15,6 \\
17 \\
\end{array}$ & $\begin{array}{l}17,2 \\
15 \\
\end{array}$ & $\begin{array}{l}17,2 \\
39 \\
\end{array}$ \\
\hline \multicolumn{2}{|l|}{ Owner Occ No Veh } & 197 & $\begin{array}{l}17 \\
4\end{array}$ & $\begin{array}{l}(25 \\
4)\end{array}$ & )$^{(83}$ & )$^{(71}$ & $\begin{array}{l}1,3 \\
89\end{array}$ & 197 & 37 & 117 & 34 & 37) & $\begin{array}{l}1,35 \\
2\end{array}$ \\
\hline \multicolumn{2}{|l|}{$\begin{array}{l}\text { Owner Occupied } \\
\text { Veh }\end{array}$} & 782 & $\begin{array}{l}(50 \\
6)\end{array}$ & $\begin{array}{l}(93 \\
0)\end{array}$ & $\begin{array}{l}(39 \\
1)\end{array}$ & $\begin{array}{l}(21 \\
6) \\
\end{array}$ & $\begin{array}{l}1,4 \\
13\end{array}$ & 782 & 2 & $\begin{array}{l}(65 \\
4)\end{array}$ & $\begin{array}{l}(1,0 \\
45)\end{array}$ & $\begin{array}{l}(1,2 \\
61)\end{array}$ & 152 \\
\hline \multicolumn{2}{|l|}{ Renter Occ No Veh } & $\begin{array}{l}1,88 \\
7\end{array}$ & $\begin{array}{l}58 \\
4\end{array}$ & $\begin{array}{l}62 \\
8\end{array}$ & (53 & $(55$ & (62 & 1,887 & $\begin{array}{l}2,47 \\
1\end{array}$ & $\begin{array}{l}3,09 \\
9\end{array}$ & $\begin{array}{l}3,04 \\
6\end{array}$ & $\begin{array}{l}2,99 \\
1\end{array}$ & $\begin{array}{l}2,92 \\
9\end{array}$ \\
\hline \multicolumn{2}{|l|}{$\begin{array}{l}\text { Renter Occupied } \\
\text { Veh }\end{array}$} & $\begin{array}{l}10,9 \\
63\end{array}$ & $\begin{array}{l}2,6 \\
41\end{array}$ & $\begin{array}{l}3,1 \\
57\end{array}$ & $\begin{array}{l}3,2 \\
04\end{array}$ & $\begin{array}{l}1,7 \\
82\end{array}$ & $\begin{array}{l}(16 \\
1)\end{array}$ & 63 & $\begin{array}{l}13,6 \\
04\end{array}$ & $\begin{array}{l}16,7 \\
61\end{array}$ & $\begin{array}{l}19,9 \\
65\end{array}$ & $\begin{array}{l}21,7 \\
47\end{array}$ & $\begin{array}{l}21,5 \\
86\end{array}$ \\
\hline \multicolumn{2}{|l|}{$\underline{\text { Total Housing Units }}$} & $\begin{array}{l}13,8 \\
29\end{array}$ & $\begin{array}{l}2,8 \\
93 \\
\end{array}$ & $\begin{array}{l}2,6 \\
01 \\
\end{array}$ & $\begin{array}{l}2,6 \\
77 \\
\end{array}$ & $\begin{array}{l}1,4 \\
40 \\
\end{array}$ & $\begin{array}{l}(10 \\
2) \\
\end{array}$ & 3,829 & $\begin{array}{l}16,7 \\
22\end{array}$ & \begin{tabular}{|l|}
19,3 \\
23 \\
\end{tabular} & $\begin{array}{l}22,0 \\
00 \\
\end{array}$ & $\begin{array}{l}23,4 \\
40\end{array}$ & $\begin{array}{l}23,3 \\
38 \\
\end{array}$ \\
\hline \multicolumn{2}{|c|}{ Households No Veh } & $\begin{array}{l}2,08 \\
4 \\
\end{array}$ & $\begin{array}{l}75 \\
8 \\
\end{array}$ & $\begin{array}{l}37 \\
4 \\
\end{array}$ & $\begin{array}{l}(13 \\
6) \\
\end{array}$ & $\begin{array}{l}12 \\
6) \\
\end{array}$ & $\begin{array}{l}1,6 \\
04 \\
\end{array}$ & 4 & $\begin{array}{l}2,84 \\
2 \\
\end{array}$ & \begin{tabular}{|l|}
3,21 \\
6 \\
\end{tabular} & $\begin{array}{l}3,08 \\
0\end{array}$ & $\begin{array}{l}2,95 \\
4 \\
\end{array}$ & $\begin{array}{l}4,55 \\
8 \\
\end{array}$ \\
\hline \multicolumn{2}{|c|}{ Households with Veh } & $\begin{array}{l}11,7 \\
45\end{array}$ & $\begin{array}{l}2,1 \\
35\end{array}$ & $\begin{array}{l}2,2 \\
27\end{array}$ & $\begin{array}{l}2,8 \\
13 \\
\end{array}$ & $\begin{array}{l}1,5 \\
66\end{array}$ & $\begin{array}{l}1,2 \\
79 \\
\end{array}$ & 11,745 & $\begin{array}{l}13,8 \\
80\end{array}$ & $\begin{array}{l}16,1 \\
07 \\
\end{array}$ & $\begin{array}{l}18,9 \\
20\end{array}$ & $\begin{array}{l}20,4 \\
86\end{array}$ & $\begin{array}{l}21,7 \\
65 \\
\end{array}$ \\
\hline Total Housing Uni & & $\begin{array}{l}13,8 \\
29\end{array}$ & $\begin{array}{l}2,8 \\
93\end{array}$ & $\begin{array}{l}2,6 \\
01\end{array}$ & $\begin{array}{l}2,6 \\
77\end{array}$ & $\begin{array}{l}1,4 \\
40\end{array}$ & $\begin{array}{l}(16 \\
4)\end{array}$ & 13,829 & $\begin{array}{l}16,7 \\
22\end{array}$ & $\begin{array}{l}19,3 \\
23\end{array}$ & $\begin{array}{l}22,0 \\
00\end{array}$ & $\begin{array}{l}23,4 \\
40\end{array}$ & $\begin{array}{l}23,2 \\
76\end{array}$ \\
\hline $\begin{array}{l}\text { Percent Demogra } \\
2016 \text { - Incrementa }\end{array}$ & & Chang & 201 & & & & & Cumul & & & & & \\
\hline Tenure by Vehicle & & 0.12 & 0.2 & 0.3 & & 0.7 & & & & 0.37 & & & \\
\hline Presence & & 5 & 5 & 75 & 0.5 & 5 & 1 & 0.125 & 0.25 & & 0.5 & 0.75 & 1 \\
\hline Owner Occupied & & $0 \%$ & - & $9 \%$ & $6 \%$ & $1 \%$ & $0 \%$ & $0 \%$ & $0 \%$ & $-2 \%$ & $-3 \%$ & $-4 \%$ & $-3 \%$ \\
\hline
\end{tabular}




\begin{tabular}{|c|c|c|c|c|c|c|c|c|c|c|c|c|}
\hline Renter Occupied & $\begin{array}{l}12 \\
\%\end{array}$ & $9 \%$ & $\begin{array}{l}13 \\
\%\end{array}$ & $7 \%$ & $8 \%$ & $7 \%$ & $12 \%$ & $\begin{array}{l}11 \\
\%\end{array}$ & $\begin{array}{l}12 \\
\%\end{array}$ & $11 \%$ & $10 \%$ & $\begin{array}{l}10 \\
\%\end{array}$ \\
\hline$\underline{\text { Total Housing Units }}$ & $\begin{array}{l}10 \\
\%\end{array}$ & $7 \%$ & $9 \%$ & $5 \%$ & $6 \%$ & $6 \%$ & $10 \%$ & $9 \%$ & $9 \%$ & $8 \%$ & $7 \%$ & $7 \%$ \\
\hline Owner Occ No Veh & $\begin{array}{l}12 \\
\% \\
\end{array}$ & $\begin{array}{l}45 \\
\% \\
\end{array}$ & $\begin{array}{l}- \\
36 \\
\%\end{array}$ & $\begin{array}{l}- \\
20 \\
\%\end{array}$ & $\begin{array}{l}- \\
23 \\
\% \\
\end{array}$ & $\begin{array}{l}- \\
17 \\
\% \\
\end{array}$ & $12 \%$ & $\begin{array}{l}19 \\
\% \\
\end{array}$ & $4 \%$ & $1 \%$ & $-1 \%$ & $-7 \%$ \\
\hline $\begin{array}{l}\text { Owner Occupied } \\
\text { Veh }\end{array}$ & $5 \%$ & $-\overline{9} \%$ & $\begin{array}{l}14 \\
\% \\
\end{array}$ & $-\overline{6 \%}$ & - & - & $5 \%$ & $1 \%$ & $-2 \%$ & $-3 \%$ & $-4 \%$ & $-3 \%$ \\
\hline Renter Occ No Veh & $7 \%$ & $8 \%$ & $9 \%$ & - & - & $2 \%$ & $7 \%$ & $\begin{array}{l}11 \\
\%\end{array}$ & $\begin{array}{l}12 \\
\%\end{array}$ & $11 \%$ & $10 \%$ & $\begin{array}{l}10 \\
\%\end{array}$ \\
\hline $\begin{array}{l}\text { Renter Occupied } \\
\text { Veh }\end{array}$ & $\begin{array}{l}24 \\
\%\end{array}$ & $\begin{array}{l}23 \\
\%\end{array}$ & $\begin{array}{l}14 \\
\% \\
\end{array}$ & $\begin{array}{l}17 \\
\% \\
\end{array}$ & $\begin{array}{l}11 \\
\% \\
\end{array}$ & $\begin{array}{l}11 \\
\%\end{array}$ & $24 \%$ & $\begin{array}{l}24 \\
\%\end{array}$ & $\begin{array}{l}21 \\
\%\end{array}$ & $20 \%$ & $17 \%$ & $\begin{array}{l}17 \\
\%\end{array}$ \\
\hline Total Housing Units & $\begin{array}{l}16 \\
\%\end{array}$ & $\begin{array}{l}11 \\
\%\end{array}$ & $7 \%$ & $8 \%$ & $6 \%$ & $5 \%$ & $16 \%$ & $\begin{array}{l}11 \\
\%\end{array}$ & $\begin{array}{l}12 \\
\% \\
\end{array}$ & $11 \%$ & $10 \%$ & $\begin{array}{l}10 \\
\%\end{array}$ \\
\hline Households No Veh & $8 \%$ & $\begin{array}{l}10 \\
\%\end{array}$ & $5 \%$ & $2 \%$ & $3 \%$ & $4 \%$ & $8 \%$ & $8 \%$ & $7 \%$ & $6 \%$ & $7 \%$ & $5 \%$ \\
\hline Households with Veh & $\begin{array}{l}19 \\
\%\end{array}$ & $\begin{array}{l}12 \\
\%\end{array}$ & $8 \%$ & $\begin{array}{l}11 \\
\%\end{array}$ & $7 \%$ & $7 \%$ & $19 \%$ & $\begin{array}{l}18 \\
\%\end{array}$ & $\begin{array}{l}115 \\
\%\end{array}$ & $14 \%$ & $11 \%$ & $\begin{array}{l}11 \\
\%\end{array}$ \\
\hline Total Housing Units & $\begin{array}{l}16 \\
\% \\
\end{array}$ & $\begin{array}{l}11 \\
\% \\
\end{array}$ & $7 \%$ & $8 \%$ & $6 \%$ & $5 \%$ & $16 \%$ & $\begin{array}{l}11 \\
\%\end{array}$ & $\begin{array}{l}12 \\
\% \\
\end{array}$ & $11 \%$ & $10 \%$ & $\begin{array}{l}10 \\
\%\end{array}$ \\
\hline \multicolumn{7}{|c|}{$\begin{array}{l}\text { LQ Trend 2010-2016 (LQ 2016/LQ } \\
\text { 2010) - Incremental }\end{array}$} & \multicolumn{6}{|c|}{$\begin{array}{l}\text { Cumul } \\
\text { ative }\end{array}$} \\
\hline Tenure by Vehicle & 0.12 & 0.2 & 0.3 & & 0.7 & & & & 0.37 & & & \\
\hline Presence & 5 & 5 & 75 & 0.5 & 5 & 1 & 0.125 & 0.25 & 5 & 0.5 & 0.75 & 1 \\
\hline Owner Occupied & 0.97 & $\begin{array}{l}0.9 \\
7 \\
\end{array}$ & $\begin{array}{l}0.9 \\
9\end{array}$ & $\begin{array}{l}0.9 \\
8\end{array}$ & $\begin{array}{l}0.9 \\
9\end{array}$ & $\begin{array}{l}0.9 \\
7 \\
\end{array}$ & 0.97 & 0.95 & 0.93 & 0.93 & 0.93 & 0.93 \\
\hline Renter Occupied & 1.00 & $\begin{array}{l}1.0 \\
0\end{array}$ & $\begin{array}{l}1.0 \\
0\end{array}$ & $\begin{array}{l}1.0 \\
0\end{array}$ & $\begin{array}{l}1.0 \\
0\end{array}$ & $\begin{array}{l}1.0 \\
0\end{array}$ & 1.00 & 0.97 & 0.98 & 0.98 & 0.98 & 0.98 \\
\hline Owner Occ No Veh & 0.99 & $\begin{array}{l}0.8 \\
8\end{array}$ & $\begin{array}{l}0.8 \\
2 \\
\end{array}$ & $\begin{array}{l}0.9 \\
3 \\
\end{array}$ & $\begin{array}{l}0.9 \\
4 \\
\end{array}$ & $\begin{array}{l}0.9 \\
4\end{array}$ & 0.99 & 1.17 & 1.04 & 1.01 & 1.00 & 0.94 \\
\hline $\begin{array}{l}\text { Owner Occupied } \\
\text { Veh }\end{array}$ & 0.95 & $\begin{array}{l}0.9 \\
9 \\
\end{array}$ & $\begin{array}{l}0.9 \\
8\end{array}$ & $\begin{array}{l}0.9 \\
3 \\
\end{array}$ & $\begin{array}{l}1.1 \\
2\end{array}$ & $\begin{array}{l}0.9 \\
1\end{array}$ & 0.95 & 0.96 & 0.93 & 0.93 & 0.93 & 0.93 \\
\hline Renter Occ No Veh & 1.00 & $\begin{array}{l}1.0 \\
1\end{array}$ & $\begin{array}{l}0.9 \\
3\end{array}$ & $\begin{array}{l}0.9 \\
8\end{array}$ & $\begin{array}{l}0.9 \\
1\end{array}$ & $\begin{array}{l}0.9 \\
3\end{array}$ & 1.00 & 0.96 & 0.97 & 0.96 & 0.98 & 0.97 \\
\hline $\begin{array}{l}\text { Renter Occupied } \\
\text { Veh }\end{array}$ & 1.03 & $\begin{array}{l}1.0 \\
2\end{array}$ & $\begin{array}{l}0.9 \\
6 \\
\end{array}$ & $\begin{array}{l}1.0 \\
1 \\
\end{array}$ & $\begin{array}{l}1.0 \\
0\end{array}$ & $\begin{array}{l}0.9 \\
7\end{array}$ & 1.03 & 1.00 & 0.98 & 0.98 & 0.97 & 0.97 \\
\hline Households No Veh & 1.06 & $\begin{array}{l}1.0 \\
2\end{array}$ & $\begin{array}{l}0.9 \\
7 \\
\end{array}$ & $\begin{array}{l}1.0 \\
3\end{array}$ & $\begin{array}{l}0.9 \\
7 \\
\end{array}$ & $\begin{array}{l}0.9 \\
9 \\
\end{array}$ & 1.06 & 0.96 & 0.97 & 0.97 & 0.99 & 0.98 \\
\hline Households with Veh & 1.03 & $\begin{array}{l}1.0 \\
2\end{array}$ & $\begin{array}{l}0.9 \\
6 \\
\end{array}$ & $\begin{array}{l}1.0 \\
1\end{array}$ & $\begin{array}{l}1.0 \\
0\end{array}$ & $\begin{array}{l}0.9 \\
7\end{array}$ & 1.03 & 1.02 & 1.02 & 1.02 & 1.01 & 1.01 \\
\hline
\end{tabular}

Table 5A.16. High MA: SCT, Tenure by Vehicle Presence

\begin{tabular}{ll|l|l|l|l|l|l|l|l|l|l|l|l|l|l} 
Cumula \\
tive
\end{tabular}




\begin{tabular}{|c|c|c|c|c|c|c|c|c|c|c|c|c|}
\hline Owner Occ No Veh & 357 & 54 & $(49)$ & (58) & 22 & $\begin{array}{l}(32 \\
5)\end{array}$ & 357 & 411 & 362 & 304 & 326 & 1 \\
\hline Owner Occupied Veh & $\begin{array}{l}2,60 \\
5 \\
\end{array}$ & 286 & $\begin{array}{l}(44 \\
0) \\
\end{array}$ & 654 & $\begin{array}{l}37 \\
0) \\
\end{array}$ & $\begin{array}{l}(41 \\
2) \\
\end{array}$ & 2,605 & $\begin{array}{l}2,89 \\
1\end{array}$ & $\begin{array}{l}2,45 \\
1 \\
\end{array}$ & $\begin{array}{l}3,10 \\
5 \\
\end{array}$ & $\begin{array}{l}2,73 \\
5 \\
\end{array}$ & $\begin{array}{l}2,32 \\
3 \\
\end{array}$ \\
\hline Renter Occ No Veh & $\begin{array}{l}2,43 \\
6 \\
\end{array}$ & 511 & 645 & 471 & $\begin{array}{l}132 \\
)^{1}\end{array}$ & 40 & 2,436 & $\begin{array}{l}2,94 \\
7 \\
\end{array}$ & $\begin{array}{l}3,59 \\
2\end{array}$ & $\begin{array}{l}4,06 \\
3 \\
\end{array}$ & $\begin{array}{l}4,03 \\
1\end{array}$ & $\begin{array}{l}4,07 \\
1\end{array}$ \\
\hline Renter Occupied Veh & $\begin{array}{l}7,33 \\
5 \\
\end{array}$ & $\begin{array}{l}1,6 \\
73 \\
\end{array}$ & $\begin{array}{l}1,0 \\
50 \\
\end{array}$ & $\begin{array}{l}1,3 \\
13 \\
\end{array}$ & $\begin{array}{l}\text { (56 } \\
2)\end{array}$ & $\begin{array}{l}40 \\
0) \\
\end{array}$ & 7,335 & $\begin{array}{l}9,00 \\
8\end{array}$ & $\begin{array}{l}10,0 \\
58 \\
\end{array}$ & $\begin{array}{l}11,3 \\
71 \\
\end{array}$ & $\begin{array}{l}10,8 \\
09 \\
\end{array}$ & $\begin{array}{l}10,4 \\
09\end{array}$ \\
\hline Total Housing Units & $\begin{array}{l}12,7 \\
33\end{array}$ & $\begin{array}{l}2,5 \\
24 \\
\end{array}$ & $\begin{array}{l}1,2 \\
06\end{array}$ & $\begin{array}{l}2,3 \\
80\end{array}$ & $\begin{array}{l}\text { (94 } \\
2)\end{array}$ & 124 & 12,733 & $\begin{array}{l}15,2 \\
57\end{array}$ & $\begin{array}{l}16,4 \\
63\end{array}$ & $\begin{array}{l}18,8 \\
43\end{array}$ & $\begin{array}{l}17,9 \\
01\end{array}$ & $\begin{array}{l}18,0 \\
25\end{array}$ \\
\hline Households No Veh & $\begin{array}{l}2,79 \\
3\end{array}$ & 565 & 596 & 413 & )$^{(10}$ & 458 & 2,793 & $\begin{array}{l}3,35 \\
8\end{array}$ & $\begin{array}{l}3,95 \\
4\end{array}$ & $\begin{array}{l}4,36 \\
7\end{array}$ & $\begin{array}{l}4,35 \\
7\end{array}$ & $\begin{array}{l}4,81 \\
5 \\
\end{array}$ \\
\hline Households with Veh & $\begin{array}{l}9,94 \\
0\end{array}$ & $\begin{array}{l}1,9 \\
59\end{array}$ & 610 & $\begin{array}{l}1,9 \\
67\end{array}$ & $\begin{array}{l}(93 \\
2)\end{array}$ & 222 & 9,940 & $\begin{array}{l}11,8 \\
99\end{array}$ & $\begin{array}{l}12,5 \\
09\end{array}$ & $\begin{array}{l}14,4 \\
76\end{array}$ & $\begin{array}{l}13,5 \\
44\end{array}$ & $\begin{array}{l}13,7 \\
66\end{array}$ \\
\hline Total Housing Units & $\begin{array}{l}12,7 \\
33\end{array}$ & $\begin{array}{l}2,5 \\
24 \\
\end{array}$ & $\begin{array}{l}1,2 \\
06\end{array}$ & $\begin{array}{l}2,3 \\
80\end{array}$ & $\begin{array}{l}(94 \\
2)\end{array}$ & 164 & 12,733 & $\begin{array}{l}15,2 \\
57\end{array}$ & $\begin{array}{l}16,4 \\
63\end{array}$ & $\begin{array}{l}18,8 \\
43\end{array}$ & $\begin{array}{l}17,9 \\
01\end{array}$ & $\begin{array}{l}18,0 \\
65\end{array}$ \\
\hline \multicolumn{7}{|c|}{ Percent Demographic Change 2010-2016 - Incremental } & \multicolumn{6}{|l|}{$\begin{array}{l}\text { Cumula } \\
\text { tive }\end{array}$} \\
\hline Tenure by Vehicle Presence & $\begin{array}{l}0.12 \\
5 \\
\end{array}$ & $\begin{array}{l}0.2 \\
5 \\
\end{array}$ & $\begin{array}{l}0.3 \\
75 \\
\end{array}$ & 0.5 & $\begin{array}{l}0.7 \\
5 \\
\end{array}$ & 1 & 0.125 & 0.25 & $\begin{array}{l}0.37 \\
5 \\
\end{array}$ & 0.5 & 0.75 & 1 \\
\hline Owner Occupied & $18 \%$ & $\begin{array}{l}12 \\
\% \\
\end{array}$ & $\begin{array}{l}- \\
10 \\
\%\end{array}$ & $-1 \%$ & $\begin{array}{l}- \\
16 \\
\%\end{array}$ & - & $18 \%$ & $16 \%$ & $10 \%$ & $9 \%$ & $4 \%$ & $1 \%$ \\
\hline Renter Occupied & $14 \%$ & $8 \%$ & $\begin{array}{l}10 \\
\%\end{array}$ & $\begin{array}{l}21 \\
\%\end{array}$ & $\begin{array}{l}- \\
13 \\
\%\end{array}$ & $\overline{6 \%}$ & $14 \%$ & $12 \%$ & $12 \%$ & $13 \%$ & $11 \%$ & $9 \%$ \\
\hline Total Housing Units & $15 \%$ & $9 \%$ & $6 \%$ & $\begin{array}{l}15 \\
\% \\
\end{array}$ & $\begin{array}{l}- \\
14 \\
\% \\
\end{array}$ & $\begin{array}{l}- \\
5 \% \\
\end{array}$ & $15 \%$ & $13 \%$ & $11 \%$ & $12 \%$ & $10 \%$ & $7 \%$ \\
\hline Owner Occ No Veh & $41 \%$ & $\begin{array}{l}16 \\
\%\end{array}$ & $\begin{array}{l} \\
10 \\
\%\end{array}$ & $\begin{array}{l}- \\
24 \\
\%\end{array}$ & $\begin{array}{l}19 \\
\%\end{array}$ & $\begin{array}{l}23 \\
\%\end{array}$ & $41 \%$ & $34 \%$ & $21 \%$ & $16 \%$ & $17 \%$ & $14 \%$ \\
\hline Owner Occupied Veh & $38 \%$ & $\begin{array}{l}10 \\
\%\end{array}$ & $\begin{array}{l}- \\
14 \\
\%\end{array}$ & $\begin{array}{l}37 \\
\%\end{array}$ & $\begin{array}{l}- \\
21 \\
\%\end{array}$ & $\begin{array}{l}- \\
16 \\
\%\end{array}$ & $38 \%$ & $30 \%$ & $19 \%$ & $21 \%$ & $13 \%$ & $7 \%$ \\
\hline Renter Occ No Veh & $16 \%$ & $9 \%$ & $\begin{array}{l}11 \\
\% \\
\end{array}$ & $\begin{array}{l}22 \\
\% \\
\end{array}$ & $\begin{array}{l}- \\
3 \% \\
\end{array}$ & $7 \%$ & $16 \%$ & $12 \%$ & $12 \%$ & $13 \%$ & $11 \%$ & $9 \%$ \\
\hline Renter Occupied Veh & $39 \%$ & $\begin{array}{l}22 \\
\% \\
\end{array}$ & $\begin{array}{l}14 \\
\%\end{array}$ & $\begin{array}{l}34 \\
\%\end{array}$ & $\begin{array}{l}- \\
17 \\
\%\end{array}$ & $\begin{array}{l}15 \\
\%\end{array}$ & $39 \%$ & $34 \%$ & $30 \%$ & $30 \%$ & $25 \%$ & $22 \%$ \\
\hline Total Housing Units & $31 \%$ & $\begin{array}{l}15 \\
\% \\
\end{array}$ & $7 \%$ & $\begin{array}{l}30 \\
\%\end{array}$ & $\begin{array}{l} \\
15 \\
\% \\
\end{array}$ & $3 \%$ & $31 \%$ & $12 \%$ & $12 \%$ & $13 \%$ & $11 \%$ & $9 \%$ \\
\hline Households No Veh & $18 \%$ & $9 \%$ & $9 \%$ & $\begin{array}{l}18 \\
\%\end{array}$ & $\begin{array}{l} \\
1 \% \\
\end{array}$ & $8 \%$ & $18 \%$ & $15 \%$ & $14 \%$ & $14 \%$ & $14 \%$ & $13 \%$ \\
\hline Households with Veh & $38 \%$ & $\begin{array}{l}18 \\
\% \\
\end{array}$ & $6 \%$ & $\begin{array}{l}35 \\
\%\end{array}$ & $\begin{array}{l}- \\
19 \\
\%\end{array}$ & $1 \%$ & $38 \%$ & $33 \%$ & $\begin{array}{l}127 \\
\% \\
\end{array}$ & $28 \%$ & $22 \%$ & $17 \%$ \\
\hline Total Housing Units & $31 \%$ & $\begin{array}{l}15 \\
\%\end{array}$ & $7 \%$ & $\begin{array}{l}30 \\
\%\end{array}$ & $\begin{array}{l}- \\
15 \\
\%\end{array}$ & $3 \%$ & $31 \%$ & $12 \%$ & $12 \%$ & $13 \%$ & $11 \%$ & $9 \%$ \\
\hline LQ Trend 2010-2016 (LQ 201 & 2010) & Increr & ental & & & & $\begin{array}{l}\text { Cumula } \\
\text { tive }\end{array}$ & & & & & \\
\hline Tenure by Vehicle Presence & $\begin{array}{l}0.12 \\
5\end{array}$ & $\begin{array}{l}0.2 \\
5 \\
\end{array}$ & $\begin{array}{l}0.3 \\
75\end{array}$ & 0.5 & $\begin{array}{l}0.7 \\
5 \\
\end{array}$ & 1 & 0.125 & 0.25 & $\begin{array}{l}0.37 \\
5\end{array}$ & 0.5 & 0.75 & 1 \\
\hline Owner Occupied & 0.94 & $\begin{array}{l}0.9 \\
5\end{array}$ & $\begin{array}{l}0.9 \\
9\end{array}$ & $\begin{array}{l}1.0 \\
1\end{array}$ & $\begin{array}{l}1.0 \\
3\end{array}$ & $\begin{array}{l}0.9 \\
6\end{array}$ & 0.94 & 1.07 & 1.03 & 1.01 & 0.98 & 0.98 \\
\hline Renter Occupied & 1.00 & $\begin{array}{l}1.0 \\
0\end{array}$ & $\begin{array}{l}1.0 \\
0\end{array}$ & $\begin{array}{l}1.0 \\
0\end{array}$ & $\begin{array}{l}1.0 \\
0\end{array}$ & $\begin{array}{l}1.0 \\
0\end{array}$ & 1.00 & 0.94 & 0.95 & 0.96 & 0.97 & 0.97 \\
\hline Owner Occ No Veh & 1.25 & $\begin{array}{l}1.0 \\
4 \\
\end{array}$ & $\begin{array}{l}0.8 \\
5 \\
\end{array}$ & $\begin{array}{l}1.2 \\
4 \\
\end{array}$ & $\begin{array}{l}0.8 \\
3 \\
\end{array}$ & $\begin{array}{l}0.9 \\
6 \\
\end{array}$ & 1.25 & 1.19 & 1.09 & 1.04 & 1.08 & 1.07 \\
\hline Owner Occupied Veh & 0.94 & $\begin{array}{l}0.9 \\
3\end{array}$ & $\begin{array}{l}0.9 \\
8\end{array}$ & $\begin{array}{l}0.9 \\
9\end{array}$ & $\begin{array}{l}1.1 \\
1\end{array}$ & $\begin{array}{l}1.0 \\
5\end{array}$ & 0.94 & 1.19 & 1.10 & 1.12 & 1.06 & 1.03 \\
\hline Renter Occ No Veh & 1.07 & $\begin{array}{l}0.9 \\
9 \\
\end{array}$ & $\begin{array}{l}0.9 \\
6 \\
\end{array}$ & $\begin{array}{l}1.0 \\
4 \\
\end{array}$ & $\begin{array}{l}0.9 \\
8\end{array}$ & $\begin{array}{l}0.8 \\
5\end{array}$ & 1.07 & 0.94 & 0.95 & 0.95 & 0.97 & 0.98 \\
\hline Renter Occupied Veh & 1.11 & $\begin{array}{l}1.0 \\
3\end{array}$ & $\begin{array}{l}0.9 \\
9\end{array}$ & $\begin{array}{l}1.1 \\
0\end{array}$ & $\begin{array}{l}1.0 \\
2\end{array}$ & $\begin{array}{l}0.9 \\
6\end{array}$ & 1.11 & 1.05 & 1.03 & 1.03 & 1.01 & 1.01 \\
\hline
\end{tabular}




\begin{tabular}{l|l|l|l|l|l|l|l|l|l|l|l|l} 
Households No Veh & 1.18 & $\begin{array}{l}1.0 \\
6\end{array}$ & $\begin{array}{l}0.9 \\
8\end{array}$ & $\begin{array}{l}1.1 \\
5\end{array}$ & $\begin{array}{l}0.9 \\
9\end{array}$ & $\begin{array}{l}0.9 \\
3\end{array}$ & 1.18 & 0.89 & 0.91 & 0.90 & 0.93 & 0.95 \\
\hline Households with Veh & 1.11 & $\begin{array}{l}1.0 \\
3\end{array}$ & $\begin{array}{l}0.9 \\
9\end{array}$ & $\begin{array}{l}1.1 \\
0\end{array}$ & $\begin{array}{l}1.0 \\
2\end{array}$ & $\begin{array}{l}0.9 \\
6\end{array}$ & 1.11 & 1.06 & 1.04 & 1.04 & 1.02 & 1.02 \\
\hline
\end{tabular}




\section{APPENDIX G: Supplemental Tables for Chapter 6}

This appendix is for chapter 6 . All study tables are significance tested. All z scores denote significance at the .10 level for 2-tailed test.

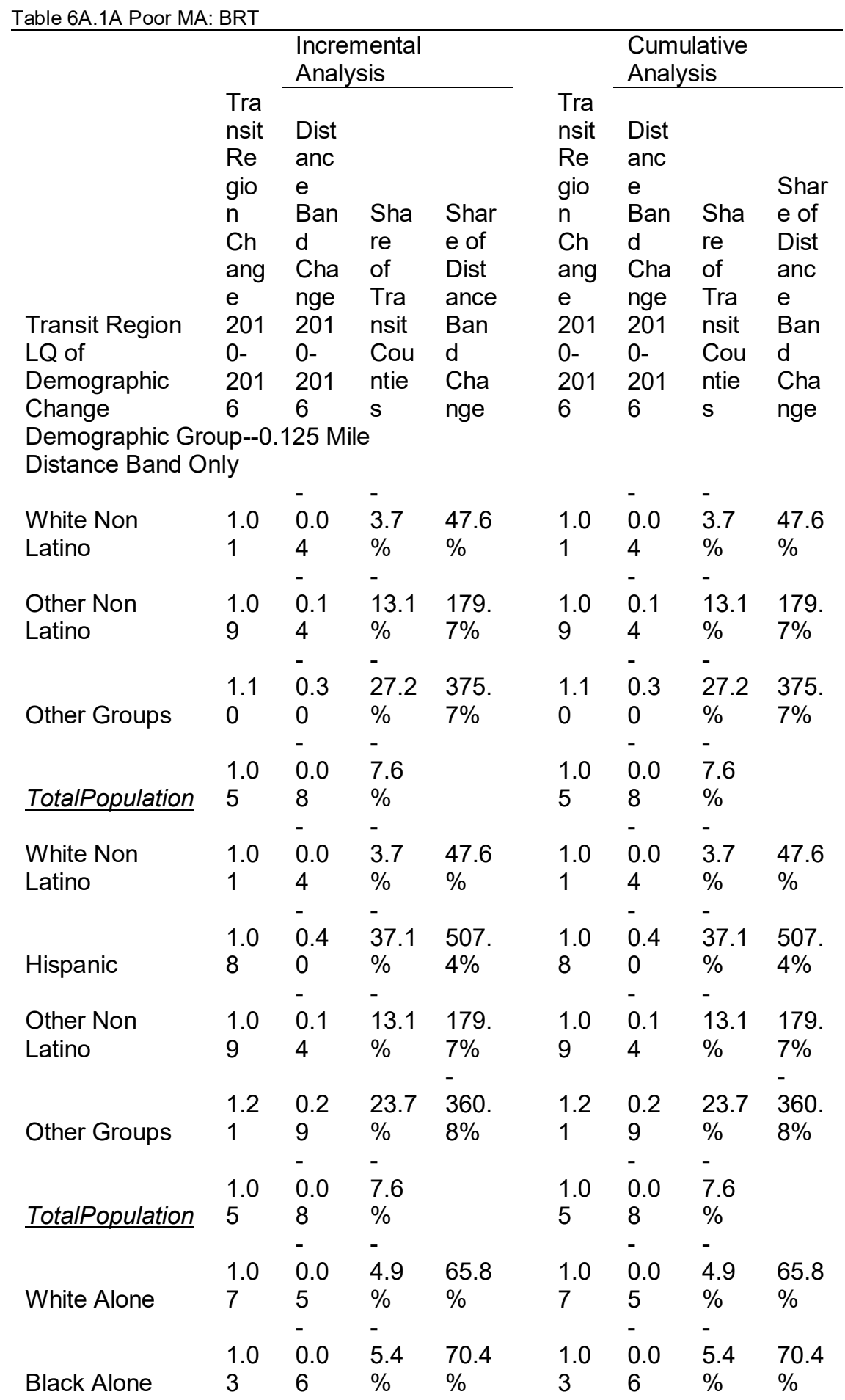




\begin{tabular}{|c|c|c|c|c|c|c|c|c|}
\hline \multicolumn{8}{|l|}{ Asian and } & \multirow[b]{2}{*}{3.5} \\
\hline Pacific Islander & 1.1 & 0.0 & 0.2 & 3.5 & 1.1 & 0.0 & 0.2 & \\
\hline \multirow[t]{2}{*}{ Alone } & 4 & 0 & $\%$ & $\%$ & 4 & 0 & $\%$ & $\%$ \\
\hline & & - & - & & & - & - & 116 \\
\hline Native & 0.8 & 0.9 & 107. & 1169 & 0.8 & 0.9 & 107. & 9.1 \\
\hline American Alone & 6 & 3 & $3 \%$ & $.1 \%$ & 6 & 3 & $3 \%$ & $\%$ \\
\hline All Other Races & 0.8 & 0.3 & 37.0 & 392. & 0.8 & 0.3 & 37.0 & 392. \\
\hline \multirow[t]{2}{*}{ Alone } & 4 & $\begin{array}{l}1 \\
-\end{array}$ & $\begin{array}{l}\% \\
-\end{array}$ & $9 \%$ & 4 & $\begin{array}{l}1 \\
-\end{array}$ & $\%$ & $9 \%$ \\
\hline & 1.0 & 0.0 & 7.6 & & 1.0 & 0.0 & 7.6 & \\
\hline \multirow{2}{*}{\multicolumn{9}{|c|}{$\begin{array}{l}\text { Demographic Group--0.25 } \\
\text { Mile Distance Band Only }\end{array}$}} \\
\hline & & & & & & & & \\
\hline White Non & 1.0 & 0.0 & 7.3 & 77.4 & 1.0 & 0.0 & 6.6 & 74.6 \\
\hline \multirow[t]{2}{*}{ Latino } & 1 & 7 & $\%$ & $\%$ & 1 & 7 & $\%$ & $\begin{array}{l}\% \\
-\end{array}$ \\
\hline & & - & 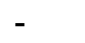 & - & & & & 126 \\
\hline Other Non & 1.0 & 0.0 & 3.0 & 34.4 & 1.0 & 1.1 & 103. & 3.3 \\
\hline \multirow[t]{2}{*}{ Latino } & 9 & 3 & $\%$ & $\%$ & 9 & $\begin{array}{l}3 \\
-\end{array}$ & $\begin{array}{l}6 \% \\
-\end{array}$ & $\%$ \\
\hline & 1.1 & 0.5 & 49.3 & 563. & 1.1 & 0.1 & 15.4 & 189. \\
\hline \multirow[t]{2}{*}{ Other Groups } & 0 & 4 & $\%$ & $0 \%$ & 0 & 7 & $\%$ & $7 \%$ \\
\hline & 1.0 & 0.1 & 9.2 & & 1.0 & 0.0 & 8.5 & \\
\hline TotalPopulation & 5 & 0 & $\%$ & & 5 & 9 & $\%$ & \\
\hline White Non & 1.0 & 0.0 & 7.3 & 77.4 & 1.0 & 0.0 & 6.6 & 74.6 \\
\hline Latino & 1 & 7 & $\%$ & $\%$ & 1 & $\begin{array}{l}7 \\
-\end{array}$ & $\%$ & $\%$ \\
\hline \multirow{3}{*}{ Hispanic } & 1.0 & 0.6 & 61.9 & 698. & 1.0 & 0.2 & 23.0 & 279. \\
\hline & 8 & 7 & $\%$ & $6 \%$ & 8 & 5 & $\%$ & $5 \%$ \\
\hline & & - & - & - & & & & 126 \\
\hline Other Non & 1.0 & 0.0 & 3.0 & 34.4 & 1.0 & 1.1 & 103. & 3.3 \\
\hline \multirow[t]{2}{*}{ Latino } & 9 & 3 & $\%$ & $\%$ & 9 & $\begin{array}{l}3 \\
-\end{array}$ & $\begin{array}{l}6 \% \\
-\end{array}$ & $\%$ \\
\hline & 1.2 & 0.2 & 19.2 & 241. & 1.2 & 0.1 & 14.0 & 189. \\
\hline \multirow[t]{2}{*}{ Other Groups } & 1 & 3 & $\%$ & $2 \%$ & 1 & $\begin{array}{l}7 \\
-\end{array}$ & & $7 \%$ \\
\hline & 1.0 & 0.1 & 9.2 & & 1.0 & 0.0 & 8.5 & \\
\hline \multirow[t]{2}{*}{ TotalPopulation } & 5 & 0 & $\%$ & & 5 & 9 & $\%$ & \\
\hline & & - & 01 & - & & & 0 & \\
\hline \multirow[t]{3}{*}{ White Alone } & 7 & 7 & $\begin{array}{l}81.4 \\
\%\end{array}$ & $\begin{array}{l}909 . \\
9 \%\end{array}$ & $\begin{array}{l}1.0 \\
7\end{array}$ & $\begin{array}{l}0.0 \\
0\end{array}$ & $\begin{array}{l}0.2 \\
\%\end{array}$ & $\begin{array}{l}2.9 \\
\%\end{array}$ \\
\hline & & - & - & - & & - & - & \\
\hline & 1.0 & 0.1 & 11.0 & 117. & 1.0 & 0.0 & 0.7 & 8.3 \\
\hline \multicolumn{9}{|l|}{ Asian and } \\
\hline Pacific Islander & 1.1 & 0.1 & 9.0 & 107. & 1.1 & 0.0 & 0.0 & 0.0 \\
\hline Alone & 4 & 0 & $\%$ & $3 \%$ & 4 & 0 & $\%$ & $\%$ \\
\hline Native & 0.8 & 14 & 166 & 1494 & 0.8 & 0.9 & 107. & $\begin{array}{l}104 \\
1.0\end{array}$ \\
\hline \multirow{2}{*}{$\begin{array}{l}\text { Native } \\
\text { American Alone }\end{array}$} & 6 & 4 & $0 \%$ & $.6 \%$ & 6 & 3 & $4 \%$ & $\%$ \\
\hline & & & 172 & 1519 & & - & - & \\
\hline All Other Races & 0.8 & 14. & 9.3 & 6.2 & 0.8 & 0.1 & 20.0 & 189. \\
\hline Alone & 4 & 59 & $\%$ & $\%$ & 4 & 7 & $\%$ & $7 \%$ \\
\hline
\end{tabular}




\begin{tabular}{|c|c|c|c|c|c|c|c|c|}
\hline \multirow{3}{*}{$\begin{array}{l}\text { TotalPopulation } \\
\text { Demographic Grol } \\
\text { Distance Band On }\end{array}$} & $\begin{array}{l}1.0 \\
5\end{array}$ & $\begin{array}{l}0.1 \\
0\end{array}$ & 9.2 & & $\begin{array}{l}1.0 \\
5\end{array}$ & \multirow[t]{2}{*}{$\begin{array}{l}0.0 \\
9\end{array}$} & 8.5 & \\
\hline & up--0 & $375 \mathrm{M}$ & & & & & & \\
\hline & & - & - & & & & & - \\
\hline White Non & 1.0 & 0.0 & 2.6 & 101. & 1.0 & 0.0 & 5.8 & 69.7 \\
\hline Latino & 1 & 3 & $\%$ & $9 \%$ & 1 & 6 & $\%$ & $\%$ \\
\hline Other Non & 1.0 & 0.0 & 7.4 & 309. & 1.0 & 0.3 & 33.1 & 424. \\
\hline Latino & 9 & 8 & $\%$ & $\begin{array}{l}0 \% \\
-\end{array}$ & 9 & $\begin{array}{l}6 \\
-\end{array}$ & & $0 \%$ \\
\hline & 1.1 & 0.1 & 8.7 & 365. & 1.1 & 0.0 & 5.5 & 70.7 \\
\hline Other Groups & 0 & 0 & $\%$ & $7 \%$ & 0 & 6 & $\%$ & $\%$ \\
\hline & 1.0 & $\overline{0} .0$ & $\overline{2} .5$ & & 1.0 & $\overline{0} .0$ & $\overline{8.1}$ & \\
\hline TotalPopulation & 5 & 3 & $\%$ & & 5 & 8 & $\%$ & \\
\hline & & - & - & & & & & - \\
\hline White Non & 1.0 & 0.0 & 2.6 & 101. & 1.0 & 0.0 & 5.8 & 69.7 \\
\hline Latino & 1 & 3 & $\%$ & $\begin{array}{l}9 \% \\
-\end{array}$ & 1 & $\begin{array}{l}6 \\
-\end{array}$ & $\begin{array}{l}\% \\
-\end{array}$ & $\%$ \\
\hline & 1.0 & 0.1 & 9.8 & 407. & 1.0 & 0.2 & 18.0 & 230. \\
\hline Hispanic & 8 & 1 & $\%$ & $3 \%$ & 8 & 0 & $\%$ & $2 \%$ \\
\hline Other Non & 1.0 & 0.0 & 7.4 & 309. & 1.0 & 0.3 & 33.1 & 424. \\
\hline Latino & 9 & 8 & $\%$ & $0 \%$ & 9 & 6 & $\%$ & $0 \%$ \\
\hline & 1.2 & 0.0 & 5.5 & 252. & 1.2 & 0.0 & 5.0 & 70.7 \\
\hline Other Groups & 1 & 7 & $\%$ & $9 \%$ & 1 & 6 & $\%$ & $\%$ \\
\hline & & - & - & & & - & - & \\
\hline & 1.0 & 0.0 & 2.5 & & 1.0 & 0.0 & 8.1 & \\
\hline TotalPopulation & 5 & 3 & $\%$ & & 5 & 8 & $\%$ & \\
\hline & & - & - & & & - & - & \\
\hline & 1.0 & 0.0 & 1.7 & 69.2 & 1.0 & 0.0 & 0.5 & 6.8 \\
\hline White Alone & 7 & 2 & $\%$ & $\%$ & 7 & 1 & $\%$ & $\%$ \\
\hline & 1.0 & 0.0 & 3.8 & 149. & 1.0 & 0.0 & 0.5 & 6.6 \\
\hline $\begin{array}{l}\text { Black Alone } \\
\text { Asian and }\end{array}$ & 3 & 4 & $\%$ & $0 \%$ & 3 & 1 & $\%$ & $\%$ \\
\hline Pacific Islander & 1.1 & 0.0 & 6.0 & 263. & 1.1 & 0.0 & 0.0 & 0.0 \\
\hline Alone & 4 & $\begin{array}{l}7 \\
-\end{array}$ & $\begin{array}{l}\% \\
-\end{array}$ & $6 \%$ & 4 & $\begin{array}{l}0 \\
-\end{array}$ & $\begin{array}{l}\% \\
-\end{array}$ & $\begin{array}{l}\% \\
108\end{array}$ \\
\hline Native & 0.8 & 0.8 & 94.1 & 3113 & 0.8 & 0.9 & 106. & 8.4 \\
\hline American Alone & 6 & 1 & $\%$ & $\begin{array}{l}.3 \% \\
-\end{array}$ & 6 & 2 & $\begin{array}{l}9 \% \\
-\end{array}$ & $\%$ \\
\hline All Other Races & 0.8 & 0.0 & 2.1 & 66.3 & 0.8 & 0.0 & 7.1 & 70.7 \\
\hline Alone & 4 & 2 & $\%$ & $\%$ & 4 & 6 & $\%$ & $\%$ \\
\hline & 1.0 & 0.0 & 2.5 & & 1.0 & 0.0 & 8.1 & \\
\hline TotalPopulation & 5 & 3 & $\%$ & & 5 & 8 & $\%$ & \\
\hline Demographic Grc & up--0 & & & & & & & \\
\hline IVIIIE & Id & - & - & & & & & - \\
\hline White Non & 1.0 & 0.0 & 9.2 & 110. & 1.0 & 0.0 & 5.3 & 59.0 \\
\hline Latino & 1 & 9 & $\%$ & $7 \%$ & 1 & 5 & $\%$ & $\%$ \\
\hline Other Non & 1.0 & 0.0 & 7.7 & 100. & 1.0 & 0.0 & 1.8 & 21.1 \\
\hline Latino & 9 & 8 & $\%$ & $2 \%$ & 9 & 2 & $\%$ & $\%$ \\
\hline
\end{tabular}




\begin{tabular}{|c|c|c|c|c|c|c|c|c|}
\hline & & & & & & & & \\
\hline & 1.1 & 0.2 & 19.4 & 253. & 1.1 & 0.0 & 7.6 & 90.4 \\
\hline Other Groups & 0 & 1 & $\%$ & $9 \%$ & 0 & 8 & $\%$ & $\%$ \\
\hline & 1.0 & 0.0 & 8.0 & & 1.0 & 0.0 & 8.8 & \\
\hline TotalPopulation & 5 & 8 & $\%$ & & 5 & 9 & $\%$ & \\
\hline White Non & 1.0 & 0.0 & 9.2 & 110. & 1.0 & 0.0 & 5.3 & 59.0 \\
\hline Latino & 1 & 9 & $\%$ & $7 \%$ & 1 & 5 & $\%$ & $\%$ \\
\hline & & - & - & & & - & - & \\
\hline & 1.0 & 0.3 & 30.3 & 392. & 1.0 & 0.2 & 20.4 & 240. \\
\hline Hispanic & 8 & 3 & $\%$ & $2 \%$ & 8 & 2 & $\%$ & $9 \%$ \\
\hline Other Non & 1.0 & 0.0 & 7.7 & 100. & 1.0 & 0.0 & 1.8 & 21.1 \\
\hline Latino & 9 & 8 & $\%$ & $2 \%$ & 9 & 2 & $\%$ & $\%$ \\
\hline & & & & - & & - & - & \\
\hline & 1.2 & 0.4 & 33.9 & 489. & 1.2 & 0.0 & 6.9 & 90.4 \\
\hline Other Groups & 1 & 1 & $\%$ & $8 \%$ & 1 & 8 & $\%$ & $\%$ \\
\hline & & - & - & & & - & - & \\
\hline & 1.0 & 0.0 & 8.0 & & 1.0 & 0.0 & 8.8 & \\
\hline TotalPopulation & 5 & 8 & $\%$ & & 5 & 9 & $\%$ & \\
\hline & 10 & $\overline{0} 1$ & $\overline{9} .7$ & 124 & 10 & $\overline{0} .0$ & $\overline{11}$ & 13.2 \\
\hline White Alone & 7 & 0 & $\%$ & $0 \%$ & 7 & 1 & $\%$ & $\%$ \\
\hline & 1.0 & 0.0 & 5.9 & 73.2 & 1.0 & 0.0 & 0.2 & 1.9 \\
\hline $\begin{array}{l}\text { Black Alone } \\
\text { Asian and }\end{array}$ & 3 & 6 & $\%$ & $\%$ & 3 & 0 & $\%$ & $\%$ \\
\hline Pacific Islander & 1.1 & 0.2 & 18.9 & 257. & 1.1 & 0.0 & 0.0 & 0.0 \\
\hline Alone & 4 & 2 & $\%$ & $9 \%$ & 4 & 0 & $\%$ & $\%$ \\
\hline Native & 0.8 & 0.0 & 6.1 & 63.4 & 0.8 & 0.9 & 105. & 992. \\
\hline American Alone & 6 & 5 & $\%$ & $\%$ & 6 & 1 & $4 \%$ & $5 \%$ \\
\hline All Other Races & 0.8 & 0.1 & 22.9 & 230. & 0.8 & 0.0 & 9.8 & 90.4 \\
\hline Alone & 4 & 9 & $\%$ & $8 \%$ & 4 & $\begin{array}{l}8 \\
-\end{array}$ & $\%$ & $\%$ \\
\hline & 1.0 & 0.0 & 8.0 & & 1.0 & 0.0 & 8.8 & \\
\hline TotalPopulation & 5 & 8 & $\%$ & & 5 & 9 & $\%$ & \\
\hline Demographic Grs & up--0.7 & & & & & & & \\
\hline Mile Distance Ba & nd Only & & & & & & & \\
\hline White Non & 1.0 & 0.1 & 17.3 & 82.3 & 1.0 & 0.0 & 4.0 & 88.4 \\
\hline Latino & 1 & 8 & $\%$ & $\%$ & 1 & 4 & $\%$ & $\%$ \\
\hline Other Non & 1.0 & 0.2 & 21.0 & 107. & 1.0 & 0.2 & 18.2 & 428. \\
\hline Latino & 9 & 3 & $\%$ & $2 \%$ & 9 & 0 & $\%$ & $5 \%$ \\
\hline & 1.1 & 0.3 & 32.6 & 168. & 1.1 & 0.1 & 9.3 & 222. \\
\hline Other Groups & 0 & 6 & $\%$ & $4 \%$ & 0 & 0 & $\%$ & $2 \%$ \\
\hline & 1.0 & 0.2 & 20.3 & & 1.0 & 0.0 & 4.4 & \\
\hline TotalPopulation & 5 & 1 & $\%$ & & 5 & 5 & $\%$ & \\
\hline White Non & 1.0 & 0.1 & 17.3 & 82.3 & 1.0 & 0.0 & 4.0 & 88.4 \\
\hline Latino & 1 & 8 & $\%$ & $\%$ & 1 & 4 & $\%$ & $\%$ \\
\hline & 1.0 & 0.3 & 34.1 & 173. & 1.0 & 0.1 & 9.5 & 222. \\
\hline Hispanic & 8 & 7 & $\%$ & $8 \%$ & 8 & 0 & $\%$ & $3 \%$ \\
\hline
\end{tabular}




\begin{tabular}{|c|c|c|c|c|c|c|c|c|}
\hline Other Non & 1.0 & 0.2 & 21.0 & 107. & 1.0 & 0.2 & 18.2 & 428. \\
\hline Latino & 9 & 3 & $\%$ & $2 \%$ & 9 & 0 & $\%$ & $5 \%$ \\
\hline Other Groups & $\begin{array}{l}1.2 \\
1\end{array}$ & $\begin{array}{l}0.3 \\
0\end{array}$ & $\begin{array}{l}24.8 \\
\%\end{array}$ & $\begin{array}{l}140 . \\
8 \%\end{array}$ & $\begin{array}{l}1.2 \\
1\end{array}$ & $\begin{array}{l}0.1 \\
0\end{array}$ & $\begin{array}{l}8.5 \\
\%\end{array}$ & $\begin{array}{l}222 . \\
2 \%\end{array}$ \\
\hline & 1.0 & 0.2 & 20.3 & & 1.0 & 0.0 & 4.4 & \\
\hline TotalPopulation & 5 & 1 & $\%$ & & 5 & 5 & $\%$ & \\
\hline White Alone & $\begin{array}{l}1.0 \\
7\end{array}$ & $\begin{array}{l}0.2 \\
3\end{array}$ & $\begin{array}{l}21.6 \\
\%\end{array}$ & $\begin{array}{l}109 . \\
0 \%\end{array}$ & $\begin{array}{l}1.0 \\
7\end{array}$ & $\begin{array}{l}0.0 \\
1\end{array}$ & $\begin{array}{l}1.1 \\
\%\end{array}$ & $\begin{array}{l}25.6 \\
\%\end{array}$ \\
\hline $\begin{array}{l}\text { Black Alone } \\
\text { Asian and }\end{array}$ & $\begin{array}{l}1.0 \\
3\end{array}$ & $\begin{array}{l}0.4 \\
9\end{array}$ & $\begin{array}{l}47.6 \\
\%\end{array}$ & $\begin{array}{l}231 . \\
2 \%\end{array}$ & $\begin{array}{l}1.0 \\
3\end{array}$ & $\begin{array}{l}0.0 \\
1\end{array}$ & $\begin{array}{l}1.1 \\
\%\end{array}$ & $\begin{array}{l}23.6 \\
\%\end{array}$ \\
\hline $\begin{array}{l}\text { Pacific Islander } \\
\text { Alone }\end{array}$ & $\begin{array}{l}1.1 \\
4\end{array}$ & $\begin{array}{l}0.1 \\
4\end{array}$ & $\begin{array}{l}12.5 \\
\%\end{array}$ & $\begin{array}{l}67.1 \\
\%\end{array}$ & $\begin{array}{l}1.1 \\
4\end{array}$ & $\begin{array}{l}0.0 \\
0\end{array}$ & $\begin{array}{l}0.0 \\
\%\end{array}$ & $\begin{array}{l}0.0 \\
\%\end{array}$ \\
\hline $\begin{array}{l}\text { Native } \\
\text { American Alone }\end{array}$ & $\begin{array}{l}0.8 \\
6\end{array}$ & $\begin{array}{l}0.3 \\
2 \\
-\end{array}$ & $\begin{array}{l}36.5 \\
\% \\
-\end{array}$ & $\begin{array}{l}148 . \\
5 \% \\
-\end{array}$ & $\begin{array}{l}0.8 \\
6\end{array}$ & $\begin{array}{l}- \\
0.7 \\
4 \\
-\end{array}$ & $\begin{array}{l}- \\
86.2 \\
\% \\
-\end{array}$ & $\begin{array}{l}161 \\
5.0 \\
\%\end{array}$ \\
\hline $\begin{array}{l}\text { All Other Races } \\
\text { Alone }\end{array}$ & $\begin{array}{l}0.8 \\
4\end{array}$ & $\begin{array}{l}0.0 \\
2\end{array}$ & $\begin{array}{l}2.1 \\
\%\end{array}$ & $\begin{array}{l}8.5 \\
\%\end{array}$ & $\begin{array}{l}0.8 \\
4\end{array}$ & $\begin{array}{l}0.1 \\
0 \\
-\end{array}$ & $\begin{array}{l}12.1 \\
\%\end{array}$ & $\begin{array}{l}222 . \\
2 \%\end{array}$ \\
\hline $\begin{array}{l}\text { TotalPopulation } \\
\text { Demographic Gro } \\
\text { Mile Distance Ba }\end{array}$ & $\begin{array}{l}1.0 \\
5 \\
\text { up--1. } \\
\text { d Onl }\end{array}$ & $\begin{array}{l}0.2 \\
1 \\
0 \\
0\end{array}$ & $\begin{array}{l}20.3 \\
\%\end{array}$ & & $\begin{array}{l}1.0 \\
5\end{array}$ & $\begin{array}{l}0.0 \\
5\end{array}$ & $\begin{array}{l}4.4 \\
\%\end{array}$ & \\
\hline $\begin{array}{l}\text { White Non } \\
\text { Latino }\end{array}$ & $\begin{array}{l}1.0 \\
1\end{array}$ & $\begin{array}{l}- \\
0.0 \\
7 \\
-\end{array}$ & $\begin{array}{l}- \\
6.5 \\
\% \\
-\end{array}$ & $\begin{array}{l}55.0 \\
\%\end{array}$ & $\begin{array}{l}1.0 \\
1\end{array}$ & $\begin{array}{l}0.0 \\
4 \\
-\end{array}$ & $\begin{array}{l}3.8 \\
\% \\
-\end{array}$ & $\begin{array}{l}- \\
76.2 \\
\%\end{array}$ \\
\hline $\begin{array}{l}\text { Other Non } \\
\text { Latino }\end{array}$ & $\begin{array}{l}1.0 \\
9\end{array}$ & $\begin{array}{l}0.0 \\
9 \\
-\end{array}$ & $\begin{array}{l}7.9 \\
\%\end{array}$ & $\begin{array}{l}72.1 \\
\%\end{array}$ & $\begin{array}{l}1.0 \\
9\end{array}$ & $\begin{array}{l}0.1 \\
7 \\
-\end{array}$ & $\begin{array}{l}16.1 \\
\%\end{array}$ & $\begin{array}{l}342 \\
7 \%\end{array}$ \\
\hline Other Groups & $\begin{array}{l}1.1 \\
0\end{array}$ & $\begin{array}{l}0.3 \\
8 \\
-\end{array}$ & $\begin{array}{l}34.2 \\
\% \\
-\end{array}$ & $\begin{array}{l}314 . \\
2 \%\end{array}$ & $\begin{array}{l}1.1 \\
0\end{array}$ & $\begin{array}{l}0.0 \\
9 \\
-\end{array}$ & $\begin{array}{l}7.8 \\
\% \\
-\end{array}$ & $\begin{array}{l}168 . \\
1 \%\end{array}$ \\
\hline TotalPopulation & $\begin{array}{l}1.0 \\
5\end{array}$ & $\begin{array}{l}0.1 \\
2 \\
-\end{array}$ & $\begin{array}{l}11.4 \\
\% \\
-\end{array}$ & & $\begin{array}{l}1.0 \\
5\end{array}$ & $\begin{array}{l}0.0 \\
5\end{array}$ & $\begin{array}{l}4.9 \\
\%\end{array}$ & - \\
\hline $\begin{array}{l}\text { White Non } \\
\text { Latino }\end{array}$ & $\begin{array}{l}1.0 \\
1\end{array}$ & $\begin{array}{l}0.0 \\
7\end{array}$ & $\begin{array}{l}6.5 \\
\%\end{array}$ & $\begin{array}{l}55.0 \\
\%\end{array}$ & $\begin{array}{l}1.0 \\
1\end{array}$ & $\begin{array}{l}0.0 \\
4\end{array}$ & $\begin{array}{l}3.8 \\
\%\end{array}$ & $\begin{array}{l}76.2 \\
\%\end{array}$ \\
\hline Hispanic & $\begin{array}{l}1.0 \\
8\end{array}$ & $\begin{array}{l}0.4 \\
3 \\
-\end{array}$ & $\begin{array}{l}39.6 \\
\% \\
-\end{array}$ & $\begin{array}{l}359 . \\
8 \%\end{array}$ & $\begin{array}{l}1.0 \\
8\end{array}$ & $\begin{array}{l}0.1 \\
0 \\
-\end{array}$ & $\begin{array}{l}9.3 \\
\% \\
-\end{array}$ & $\begin{array}{l}198 . \\
3 \%\end{array}$ \\
\hline $\begin{array}{l}\text { Other Non } \\
\text { Latino }\end{array}$ & $\begin{array}{l}1.0 \\
9\end{array}$ & $\begin{array}{l}0.0 \\
9\end{array}$ & $\begin{array}{l}7.9 \\
\% \\
-\end{array}$ & $\begin{array}{l}72.1 \\
\%\end{array}$ & $\begin{array}{l}1.0 \\
9\end{array}$ & $\begin{array}{l}0.1 \\
7 \\
-\end{array}$ & $\begin{array}{l}16.1 \\
\% \\
-\end{array}$ & $\begin{array}{l}342 . \\
7 \%\end{array}$ \\
\hline Other Groups & $\begin{array}{l}1.2 \\
1\end{array}$ & $\begin{array}{l}0.0 \\
0 \\
-\end{array}$ & $\begin{array}{l}0.1 \\
\% \\
-\end{array}$ & $\begin{array}{l}0.6 \\
\%\end{array}$ & $\begin{array}{l}1.2 \\
1\end{array}$ & $\begin{array}{l}0.0 \\
9\end{array}$ & $\begin{array}{l}7.1 \\
\% \\
-\end{array}$ & $\begin{array}{l}168 . \\
1 \%\end{array}$ \\
\hline TotalPopulation & $\begin{array}{l}1.0 \\
5\end{array}$ & $\begin{array}{l}0.1 \\
2 \\
-\end{array}$ & $\begin{array}{l}11.4 \\
\%\end{array}$ & & $\begin{array}{l}1.0 \\
5\end{array}$ & $\begin{array}{l}0.0 \\
5 \\
-\end{array}$ & $\begin{array}{l}4.9 \\
\% \\
-\end{array}$ & \\
\hline White Alone & $\begin{array}{l}1.0 \\
7\end{array}$ & $\begin{array}{l}0.0 \\
8\end{array}$ & $\begin{array}{l}7.7 \\
\%\end{array}$ & $\begin{array}{l}69.7 \\
\%\end{array}$ & $\begin{array}{l}1.0 \\
7\end{array}$ & $\begin{array}{l}0.0 \\
1\end{array}$ & $\begin{array}{l}1.1 \\
\%\end{array}$ & $\begin{array}{l}24.2 \\
\%\end{array}$ \\
\hline
\end{tabular}




\begin{tabular}{|c|c|c|c|c|c|c|c|c|}
\hline & & & & & & & & \\
\hline & 1.0 & 0.1 & 17.3 & 149. & 1.0 & 0.0 & 2.1 & 42.2 \\
\hline $\begin{array}{l}\text { Black Alone } \\
\text { Asian and }\end{array}$ & 3 & 8 & $\%$ & $4 \%$ & 3 & 2 & $\%$ & \\
\hline Pacific Islander & 1.1 & 0.0 & 4.7 & 44.6 & 1.1 & 0.0 & 0.0 & 0.0 \\
\hline Alone & 4 & 5 & $\%$ & $\%$ & 4 & 0 & $\%$ & \\
\hline & & & 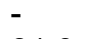 & & & & & 13 \\
\hline Native & 0.8 & 0.7 & 81.9 & 593. & 0.8 & 0.5 & 67.2 & 1 \\
\hline American Alone & 6 & 1 & $\%$ & $2 \%$ & 6 & 8 & $\%$ & $\%$ \\
\hline All Other Races & 08 & 0.4 & 49.4 & 349 & 08 & 0.0 & 10.2 & \\
\hline Alone & 4 & 2 & $\%$ & $0 \%$ & 4 & 9 & $\%$ & $1 \%$ \\
\hline & & - & - & & & & 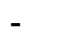 & \\
\hline & 1.0 & 0.1 & 11.4 & & 1.0 & 0.0 & 4.9 & \\
\hline TotalPopulation & 5 & 2 & $\%$ & & 5 & 5 & $\%$ & \\
\hline
\end{tabular}

Table 6A.1B Poor MA: BRT

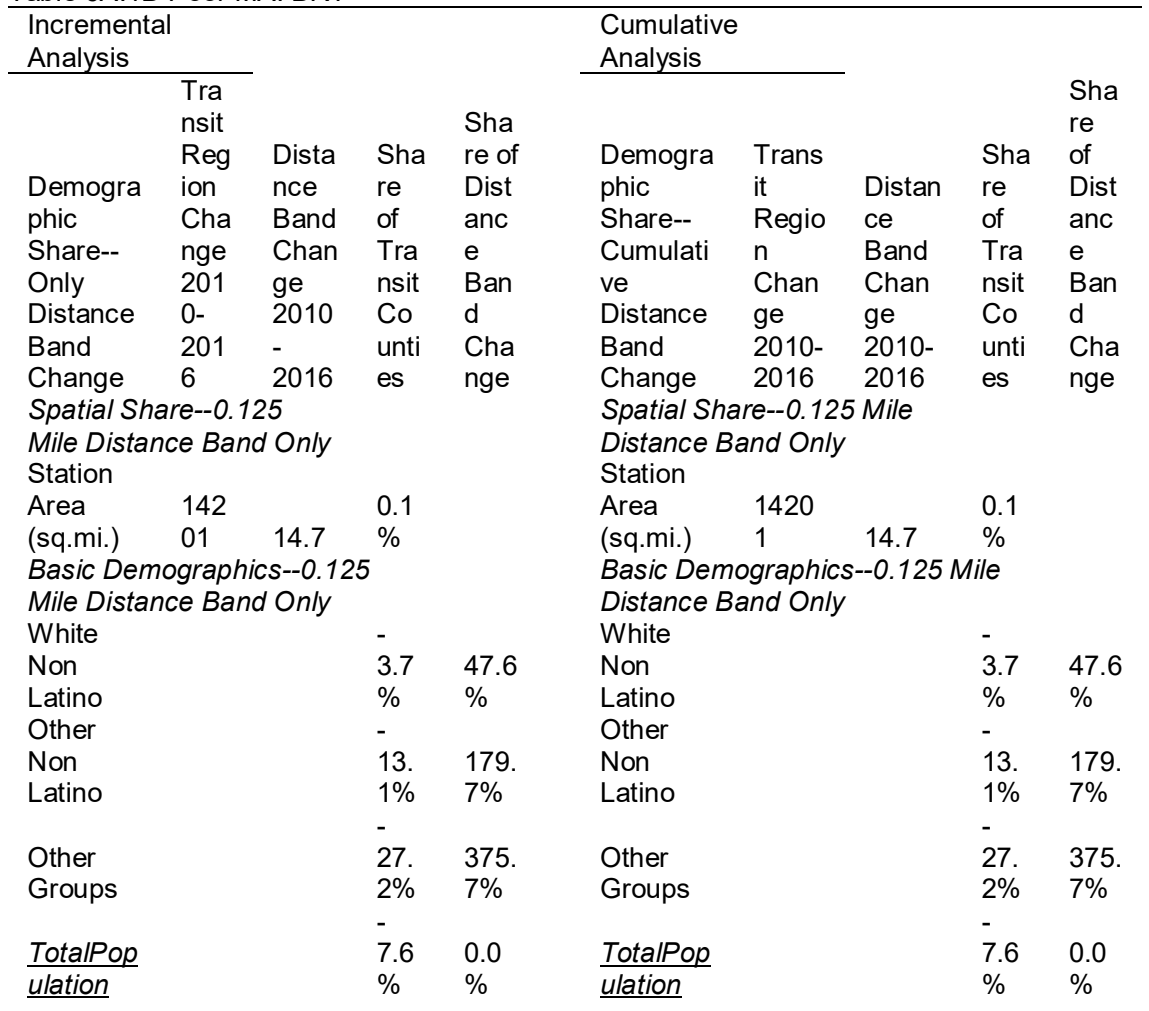




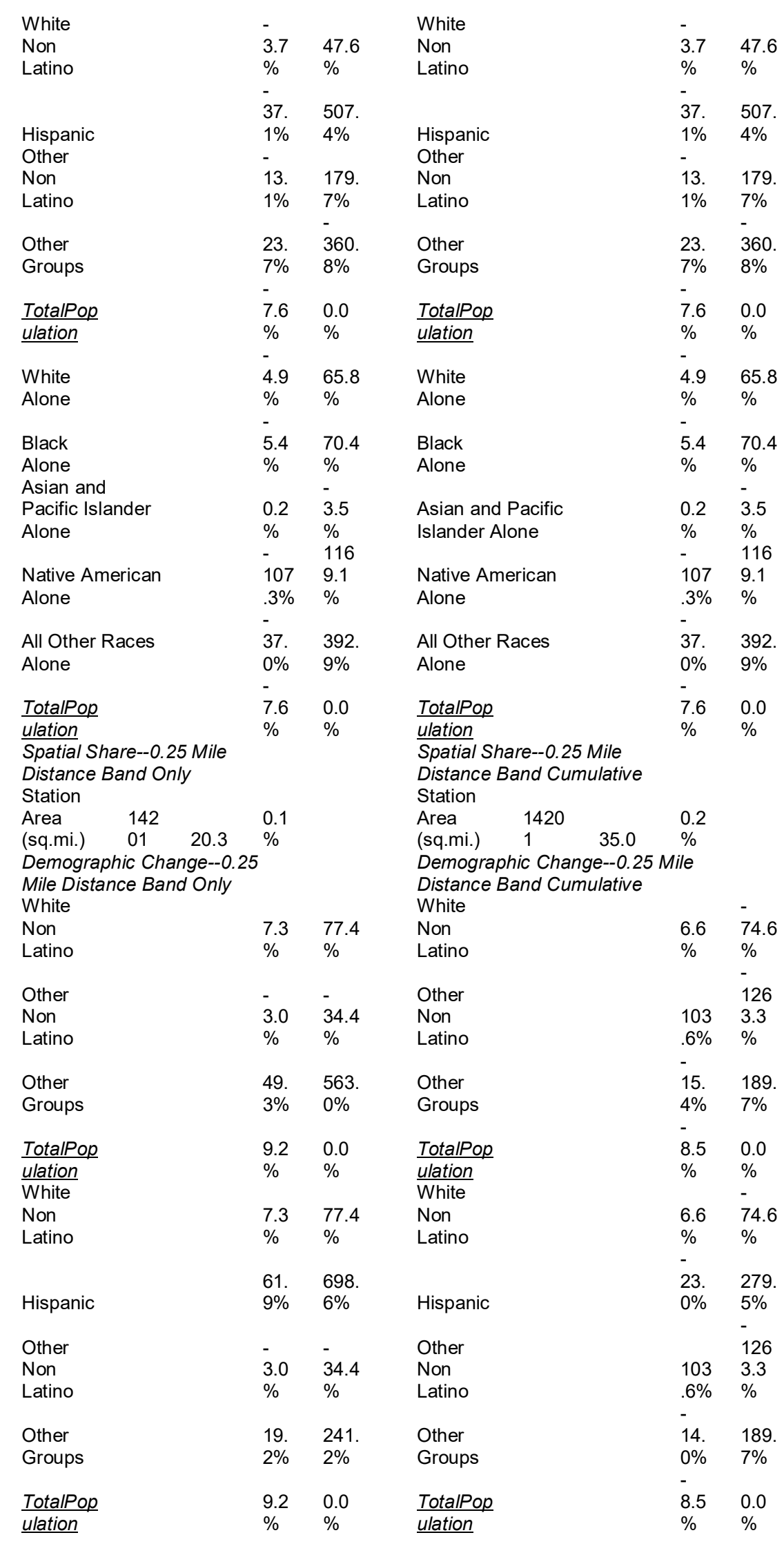




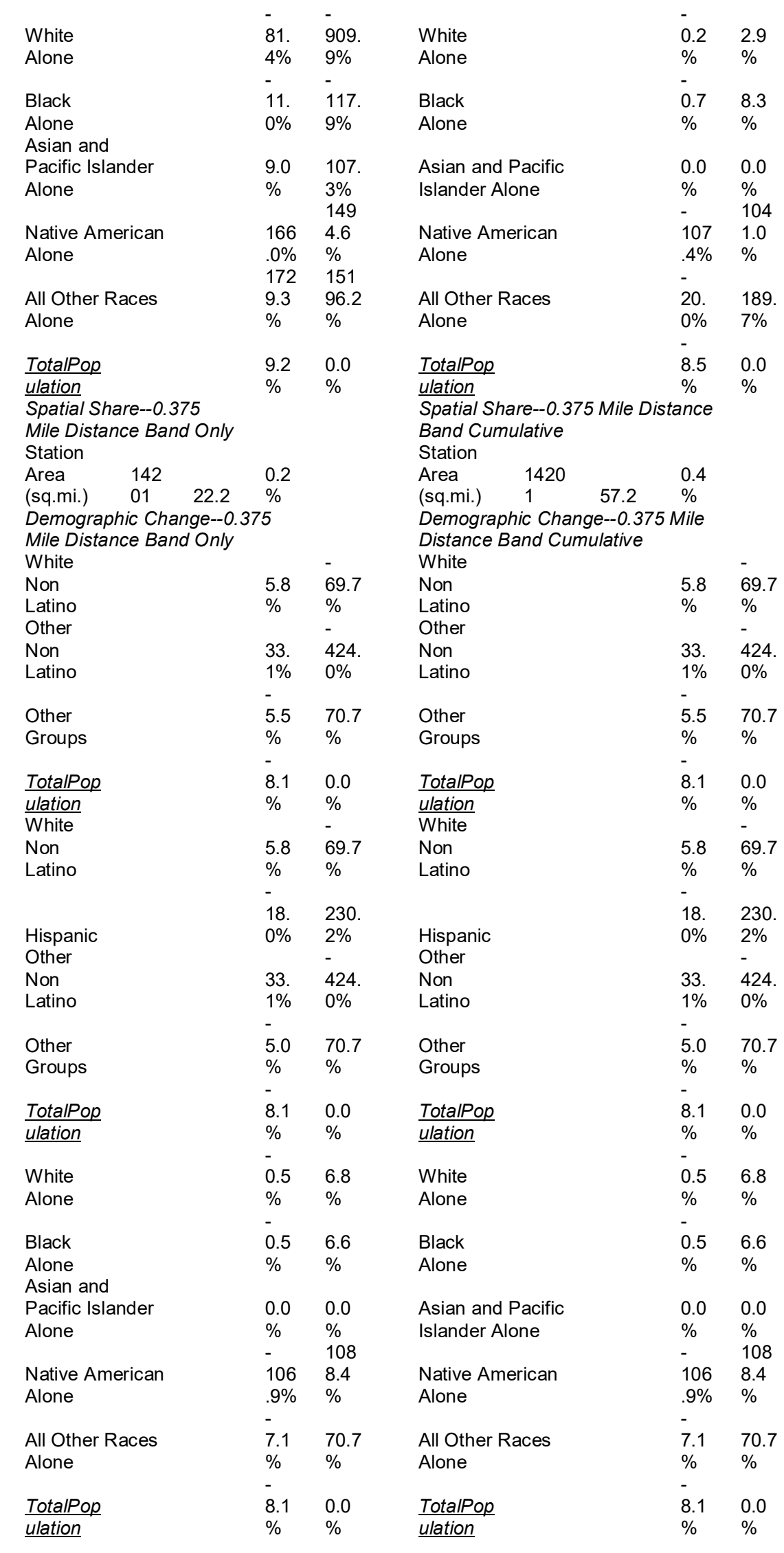




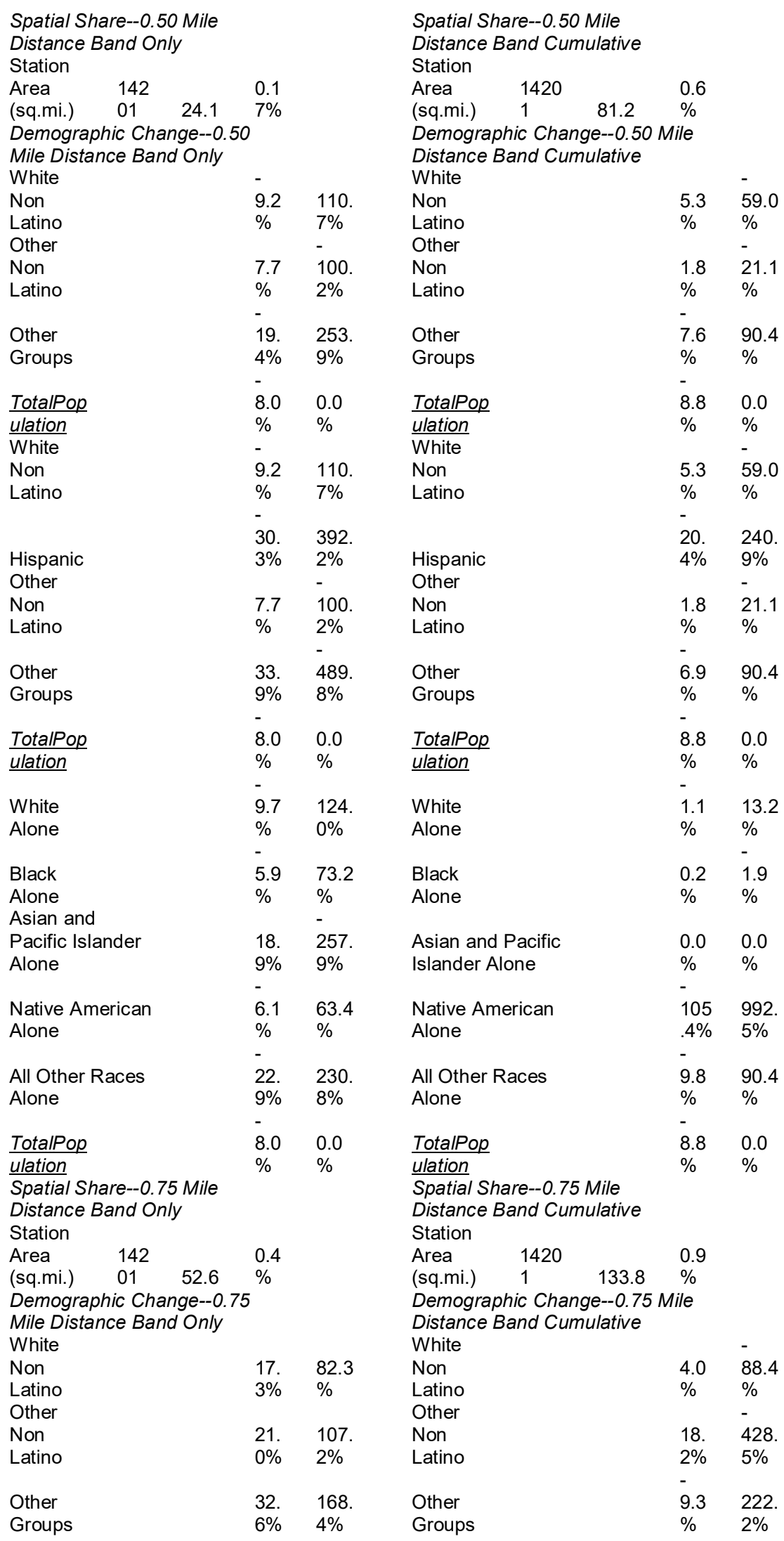




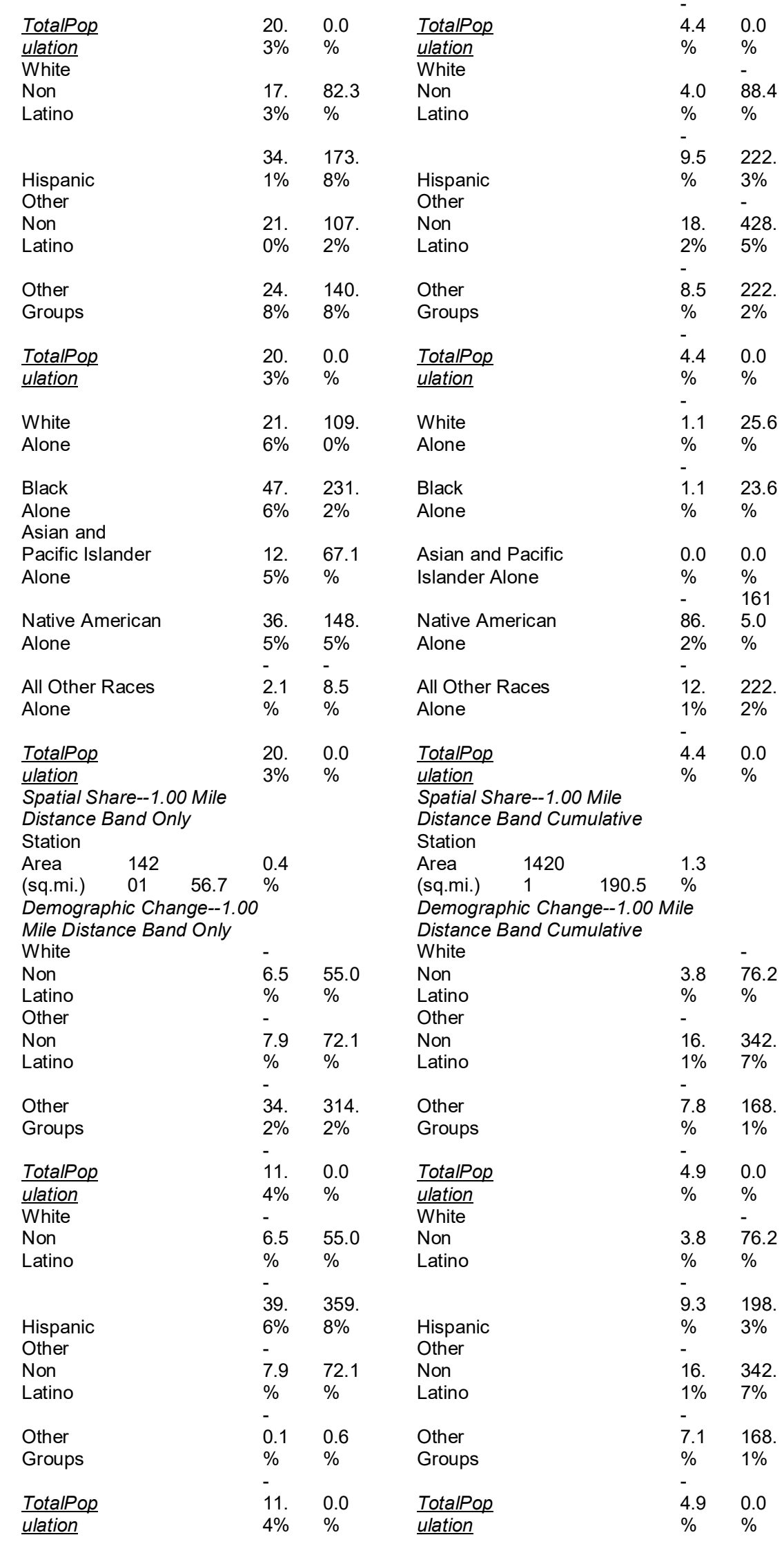




\begin{tabular}{|c|c|c|c|c|}
\hline White & 7.7 & 69.7 & White & 1.1 \\
\hline Alone & $\%$ & $\%$ & Alone & $\%$ \\
\hline Black & 17. & 149. & Black & 2.1 \\
\hline Alone & $3 \%$ & $4 \%$ & Alone & $\%$ \\
\hline Asian and & & - & & \\
\hline $\begin{array}{l}\text { Pacific Islander } \\
\text { Alone }\end{array}$ & $\begin{array}{l}4.7 \\
\%\end{array}$ & $\begin{array}{l}44.6 \\
\%\end{array}$ & $\begin{array}{l}\text { Asian and Pacific } \\
\text { Islander Alone }\end{array}$ & $\begin{array}{l}0.0 \\
\%\end{array}$ \\
\hline Native American & 81. & 593. & Native American & - \\
\hline Alone & $\begin{array}{l}9 \% \\
-\end{array}$ & $2 \%$ & Alone & $\begin{array}{l}2 \% \\
-\end{array}$ \\
\hline All Other Races & 49. & 349. & All Other Races & 10. \\
\hline Alone & $\begin{array}{l}4 \% \\
-\end{array}$ & $0 \%$ & Alone & $\begin{array}{l}2 \% \\
-\end{array}$ \\
\hline TotalPop & 11. & 0.0 & TotalPop & 4.9 \\
\hline ulation & $4 \%$ & $\%$ & ulation & $\%$ \\
\hline
\end{tabular}

Table 6A.2A Low

MA: BRT.

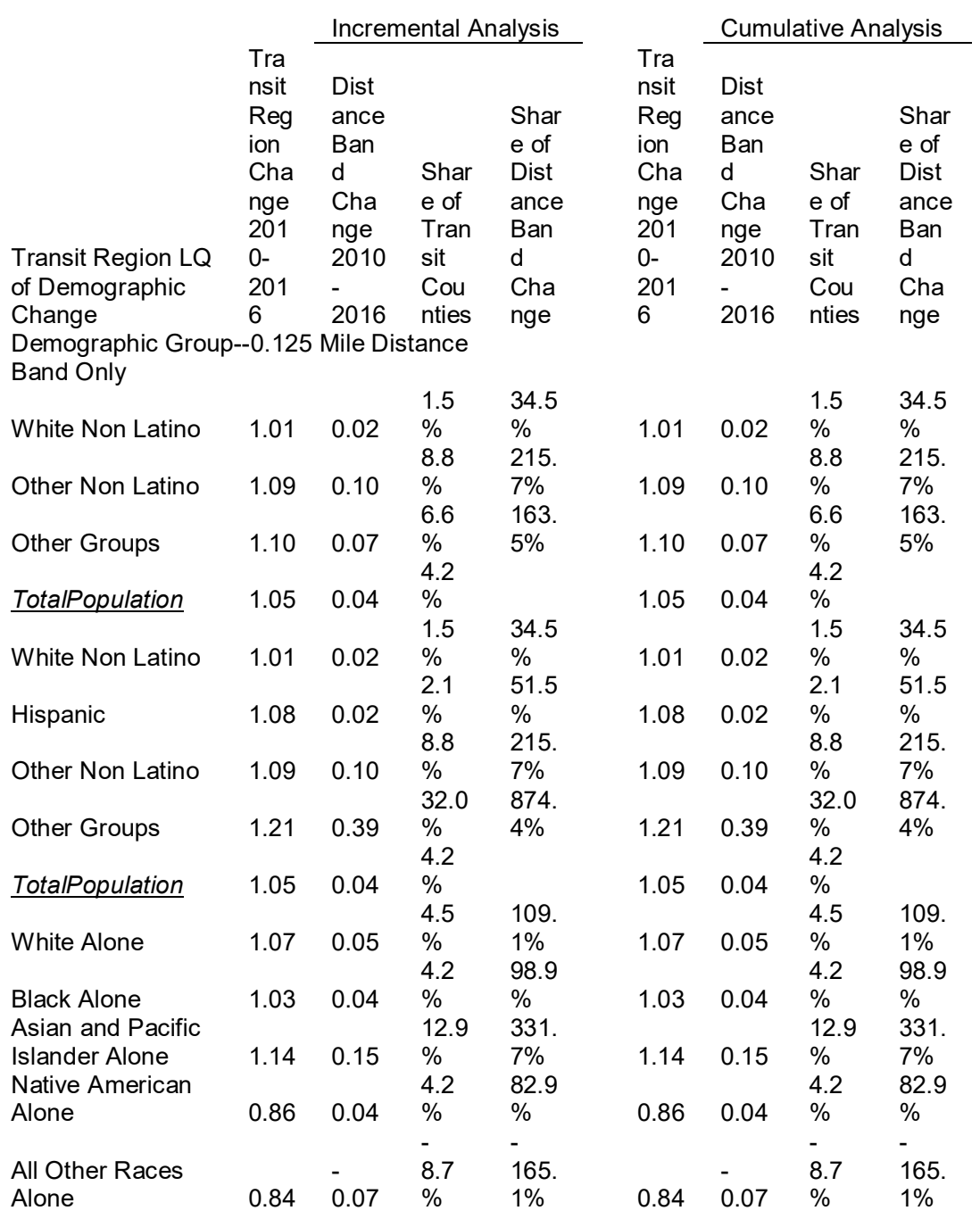




\begin{tabular}{|c|c|c|c|c|c|c|c|c|}
\hline TotalPopulation & 1.05 & 0.04 & $\begin{array}{l}4.2 \\
\%\end{array}$ & & 1.05 & 0.04 & $\begin{array}{l}4.2 \\
\%\end{array}$ & \\
\hline \multicolumn{9}{|c|}{$\begin{array}{l}\text { Demographic Group--0.25 Mile } \\
\text { Distance Band Only }\end{array}$} \\
\hline White Non Latino & 1.01 & 0.04 & $\begin{array}{l}3.6 \\
\% \\
6.6\end{array}$ & $\begin{array}{l}37.0 \\
\% \\
72.3\end{array}$ & 1.01 & 0.00 & $\begin{array}{l}0.0 \\
\% \\
17.9\end{array}$ & $\begin{array}{l}5.4 \\
\% \\
2665\end{array}$ \\
\hline Other Non Latino & 1.09 & 0.07 & $\begin{array}{l}\% \\
29.4\end{array}$ & $\begin{array}{l}\% \\
324 .\end{array}$ & 1.09 & 0.19 & $\begin{array}{l}\% \\
6.2\end{array}$ & $\begin{array}{l}.7 \% \\
931\end{array}$ \\
\hline Other Groups & 1.10 & 0.32 & $\begin{array}{l}\% \\
9.5\end{array}$ & $0 \%$ & 1.10 & 0.07 & $\begin{array}{l}\% \\
0.7\end{array}$ & $0 \%$ \\
\hline TotalPopulation & 1.05 & 0.10 & $\%$ & & 1.05 & 0.01 & $\%$ & - \\
\hline White Non Latino & 1.01 & 0.04 & $\begin{array}{l}3.6 \\
\%\end{array}$ & $\begin{array}{l}37.0 \\
\%\end{array}$ & 1.01 & 0.00 & $\begin{array}{l}0.0 \\
\% \\
-\end{array}$ & $\begin{array}{l}5.4 \\
\% \\
-\end{array}$ \\
\hline Hispanic & 1.08 & 0.34 & $\begin{array}{l}31.8 \\
\% \\
6.6\end{array}$ & $\begin{array}{l}346 . \\
4 \% \\
72.3\end{array}$ & 1.08 & $\overline{-} 0.01$ & $\begin{array}{l}0.8 \\
\% \\
17.9\end{array}$ & $\begin{array}{l}118 . \\
5 \% \\
2665\end{array}$ \\
\hline Other Non Latino & 1.09 & 0.07 & $\begin{array}{l}\% \\
15.7\end{array}$ & $\begin{array}{l}\% \\
190 .\end{array}$ & 1.09 & 0.19 & $\begin{array}{l}\% \\
5.6\end{array}$ & $\begin{array}{l}.7 \% \\
931\end{array}$ \\
\hline Other Groups & 1.21 & 0.19 & $\begin{array}{l}\% \\
9.5\end{array}$ & $7 \%$ & 1.21 & 0.07 & $\begin{array}{l}\% \\
0.7\end{array}$ & $0 \%$ \\
\hline TotalPopulation & 1.05 & 0.10 & $\begin{array}{l}\% \\
-\end{array}$ & - & 1.05 & 0.01 & $\begin{array}{l}\% \\
-\end{array}$ & - \\
\hline White Alone & 1.07 & $\begin{array}{l}- \\
0.66\end{array}$ & $\begin{array}{l}61.5 \\
\% \\
- \\
6.2\end{array}$ & $\begin{array}{l}663 . \\
5 \% \\
- \\
64.1\end{array}$ & 1.07 & $\overline{-}-02$ & $\begin{array}{l}1.6 \\
\% \\
- \\
1.8\end{array}$ & $\begin{array}{l}228 . \\
9 \% \\
- \\
249 .\end{array}$ \\
\hline $\begin{array}{l}\text { Black Alone } \\
\text { Asian and Pacific }\end{array}$ & 1.03 & 0.06 & $\begin{array}{l}0.2 \\
\% \\
24.2\end{array}$ & $\begin{array}{l}\% \\
\% \\
277 .\end{array}$ & 1.03 & 0.02 & $\begin{array}{l}1.0 \\
\% \\
0.0\end{array}$ & $\begin{array}{l}24 \% \\
3 \% \\
0.0\end{array}$ \\
\hline $\begin{array}{l}\text { Islander Alone } \\
\text { Native American }\end{array}$ & 1.14 & 0.28 & $\begin{array}{l}\% \\
28.4\end{array}$ & $\begin{array}{l}5 \% \\
246 .\end{array}$ & 1.14 & 0.00 & $\begin{array}{l}\% \\
4.9\end{array}$ & $\begin{array}{l}\% \\
575 .\end{array}$ \\
\hline $\begin{array}{l}\text { Alone } \\
\text { All Other Races }\end{array}$ & 0.86 & 0.25 & $\begin{array}{l}\% \\
567 .\end{array}$ & $\begin{array}{l}6 \% \\
4810\end{array}$ & 0.86 & 0.04 & $\begin{array}{l}\% \\
8.0\end{array}$ & $\begin{array}{l}6 \% \\
931 .\end{array}$ \\
\hline Alone & 0.84 & 4.78 & $\begin{array}{l}0 \% \\
9.5\end{array}$ & $.0 \%$ & 0.84 & 0.07 & $\begin{array}{l}\% \\
0.7\end{array}$ & $0 \%$ \\
\hline $\begin{array}{l}\text { TotalPopulation } \\
\text { Demographic Group } \\
\text { Band Only }\end{array}$ & $\begin{array}{c}1.05 \\
-0.375\end{array}$ & $\begin{array}{l}0.10 \\
\text { Mile Dis }\end{array}$ & $\begin{array}{l}\% \\
\text { tance }\end{array}$ & & 1.05 & 0.01 & $\%$ & \\
\hline & & & 6.1 & 47.5 & & - & $\overline{0}-6$ & $\overline{2}-9$ \\
\hline White Non Latino & 1.01 & 0.06 & $\begin{array}{l}\% \\
18.5\end{array}$ & $\begin{array}{l}\% \\
154 .\end{array}$ & 1.01 & 0.01 & $\begin{array}{l}\% \\
13.4\end{array}$ & $\begin{array}{l}\% \\
724 .\end{array}$ \\
\hline Other Non Latino & 1.09 & 0.20 & $\begin{array}{l}\% \\
20.3\end{array}$ & $\begin{array}{l}4 \% \\
171 .\end{array}$ & 1.09 & 0.15 & $\begin{array}{l}\% \\
7.1\end{array}$ & $\begin{array}{l}0 \% \\
386 .\end{array}$ \\
\hline Other Groups & 1.10 & 0.22 & $\%$ & $5 \%$ & 1.10 & 0.08 & $\%$ & $1 \%$ \\
\hline TotalPopulation & 1.05 & 0.13 & $\begin{array}{l}12.4 \\
\%\end{array}$ & & 1.05 & 0.02 & $\begin{array}{l}1.9 \\
\% \\
-\end{array}$ & - \\
\hline White Non Latino & 1.01 & 0.06 & $\begin{array}{l}6.1 \\
\%\end{array}$ & $\begin{array}{l}47.5 \\
\%\end{array}$ & 1.01 & $\overline{-} .01$ & $\begin{array}{l}0.6 \\
\% \\
-\end{array}$ & $\begin{array}{l}29.9 \\
\% \\
-\end{array}$ \\
\hline Hispanic & 1.08 & 0.20 & $\begin{array}{l}18.3 \\
\% \\
18.5\end{array}$ & $\begin{array}{l}152 . \\
7 \% \\
154\end{array}$ & 1.08 & 0.00 & $\begin{array}{l}0.2 \\
\% \\
13.4\end{array}$ & $\begin{array}{l}8.2 \\
\% \\
724\end{array}$ \\
\hline Other Non Latino & 1.09 & 0.20 & $\begin{array}{l}\% \\
30.8\end{array}$ & $\begin{array}{l}4 \% \\
286 .\end{array}$ & 1.09 & 0.15 & $\begin{array}{l}\% \\
6.4\end{array}$ & $\begin{array}{l}0 \% \\
386 .\end{array}$ \\
\hline Other Groups & 1.21 & 0.37 & $\begin{array}{l}\% \\
12.4\end{array}$ & $8 \%$ & 1.21 & 0.08 & $\begin{array}{l}\% \\
1.9\end{array}$ & $1 \%$ \\
\hline TotalPopulation & 1.05 & 0.13 & $\%$ & & 1.05 & 0.02 & $\begin{array}{l}\% \\
-\end{array}$ & - \\
\hline White Alone & 1.07 & 0.12 & $\begin{array}{l}10.8 \\
\%\end{array}$ & $\begin{array}{l}89.1 \\
\%\end{array}$ & 1.07 & $\overline{-} .02$ & $\begin{array}{l}1.9 \\
\% \\
-\end{array}$ & $\begin{array}{l}104 . \\
0 \% \\
-\end{array}$ \\
\hline Black Alone & 1.03 & 0.10 & $\begin{array}{l}9.3 \\
\%\end{array}$ & $\begin{array}{l}74.2 \\
\%\end{array}$ & 1.03 & $\overline{-} .02$ & $\begin{array}{l}1.9 \\
\%\end{array}$ & $\begin{array}{l}95.4 \\
\%\end{array}$ \\
\hline
\end{tabular}




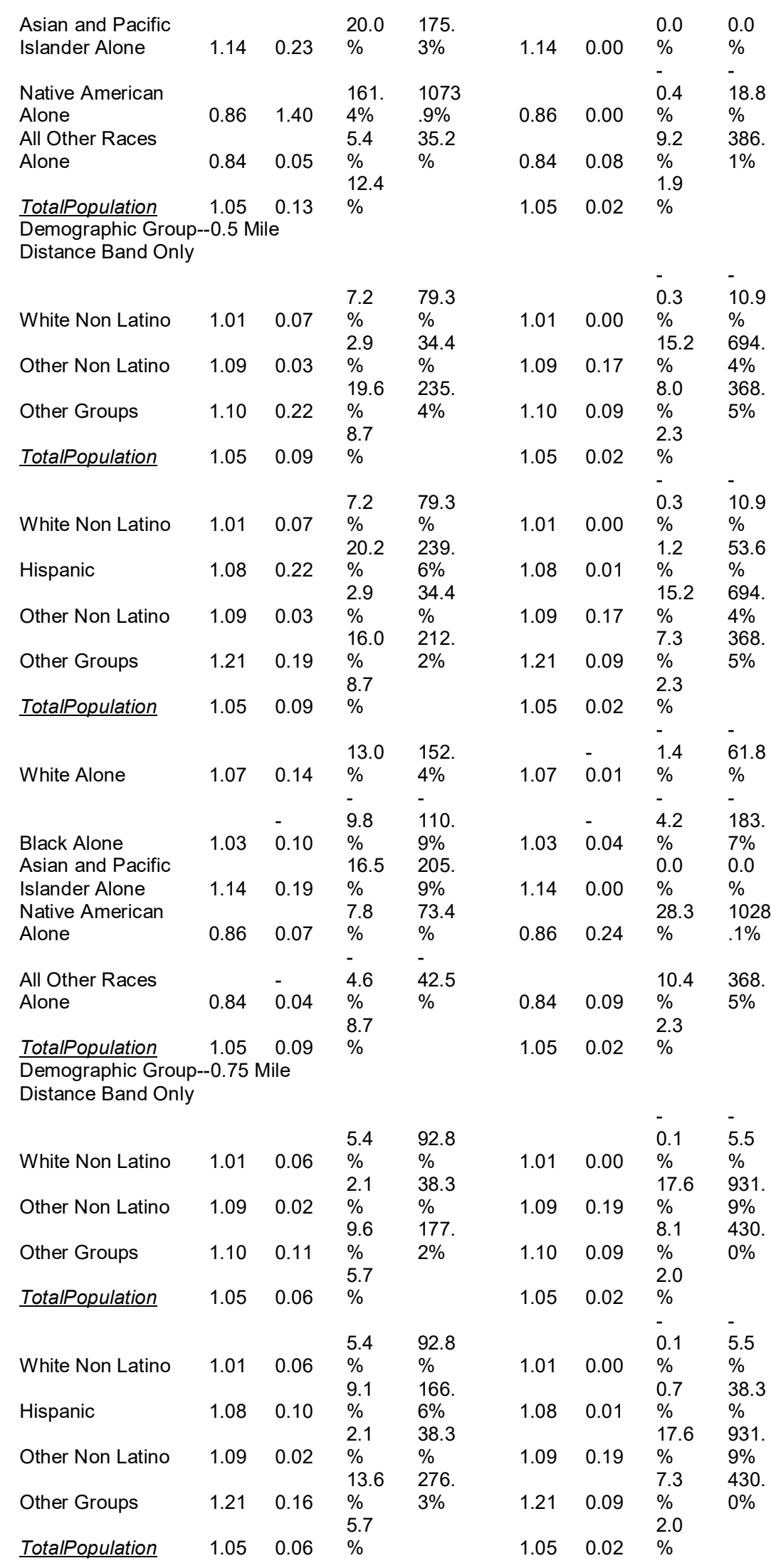




\begin{tabular}{|c|c|c|c|c|c|c|c|c|}
\hline & & & & & & & & \\
\hline & & & 11.0 & 199. & & - & 1.1 & 56.8 \\
\hline White Alone & 1.07 & 0.12 & $\%$ & $5 \%$ & 1.07 & 0.01 & $\%$ & $\%$ \\
\hline & & _ & $\overline{5}$ & $\overline{100}$ & & - & $-\overline{4.8}$ & $\overline{2}-\overline{.}$ \\
\hline Black Alone & 1.03 & 0.06 & $\%$ & $1 \%$ & 1.03 & 0.05 & $\%$ & $2 \%$ \\
\hline Asian and Pacific & & & 9.6 & 183. & & & 0.0 & 0.0 \\
\hline Islander Alone & 1.14 & 0.11 & $\%$ & $7 \%$ & 1.14 & 0.00 & $\%$ & $\%$ \\
\hline Native American & & & 12.7 & 185. & & & 34.2 & 1438 \\
\hline Alone & 0.86 & 0.11 & $\%$ & $2 \%$ & 0.86 & 0.30 & $\%$ & $.6 \%$ \\
\hline & & & - & - & & & & \\
\hline All Other Races & & - & 18.2 & 258. & & & 10.5 & 430. \\
\hline Alone & 0.84 & 0.15 & $\begin{array}{l}\% \\
5.7\end{array}$ & $9 \%$ & 0.84 & 0.09 & $\begin{array}{l}\% \\
2.0\end{array}$ & $0 \%$ \\
\hline TotalPopulation & 1.05 & 0.06 & $\%$ & & 1.05 & 0.02 & $\%$ & \\
\hline $\begin{array}{l}\text { Demographic Group } \\
\text { Distance Band Only }\end{array}$ & --1.00 & Mile & & & & & & \\
\hline & & & 3.7 & 78.3 & & & 0.0 & $\overline{1.8}$ \\
\hline White Non Latino & 1.01 & 0.04 & $\begin{array}{l}\% \\
5.0\end{array}$ & $\begin{array}{l}\% \\
114 .\end{array}$ & 1.01 & 0.00 & $\begin{array}{l}\% \\
11.4\end{array}$ & $\begin{array}{l}\% \\
499 .\end{array}$ \\
\hline Other Non Latino & 1.09 & 0.05 & $\begin{array}{l}\% \\
5.8\end{array}$ & $\begin{array}{l}0 \% \\
133 .\end{array}$ & 1.09 & 0.12 & $\begin{array}{l}\% \\
4.6\end{array}$ & $\begin{array}{l}8 \% \\
204 .\end{array}$ \\
\hline Other Groups & 1.10 & 0.06 & $\begin{array}{l}\% \\
4.6\end{array}$ & $0 \%$ & 1.10 & 0.05 & $\begin{array}{l}\% \\
2.4\end{array}$ & $9 \%$ \\
\hline TotalPopulation & 1.05 & 0.05 & $\%$ & & 1.05 & 0.02 & $\%$ & \\
\hline White Non Latino & 1.01 & 0.04 & $\begin{array}{l}3.7 \\
\% \\
5.0\end{array}$ & $\begin{array}{l}78.3 \\
\% \\
113 .\end{array}$ & 1.01 & 0.00 & $\begin{array}{l}0.0 \\
\% \\
0.5\end{array}$ & $\begin{array}{l}1.8 \\
\% \\
21.9\end{array}$ \\
\hline Hispanic & 1.08 & 0.05 & $\begin{array}{l}\% \\
5.0\end{array}$ & $\begin{array}{l}8 \% \\
114 .\end{array}$ & 1.08 & 0.01 & $\begin{array}{l}\% \\
11.4\end{array}$ & $\begin{array}{l}\% \\
499 .\end{array}$ \\
\hline Other Non Latino & 1.09 & 0.05 & $\begin{array}{l}\% \\
11.0\end{array}$ & $\begin{array}{l}0 \% \\
278 .\end{array}$ & 1.09 & 0.12 & $\begin{array}{l}\% \\
4.2\end{array}$ & $\begin{array}{l}8 \% \\
204 .\end{array}$ \\
\hline Other Groups & 1.21 & 0.13 & $\begin{array}{l}\% \\
4.6\end{array}$ & $8 \%$ & 1.21 & 0.05 & $\begin{array}{l}\% \\
2.4\end{array}$ & $9 \%$ \\
\hline TotalPopulation & 1.05 & 0.05 & $\%$ & & 1.05 & 0.02 & $\%$ & \\
\hline White Alone & 1.07 & 0.10 & $\begin{array}{l}9.0 \\
\%\end{array}$ & $\begin{array}{l}202 . \\
5 \%\end{array}$ & 1.07 & $\overline{0} .01$ & $\begin{array}{l}0.7 \\
\% \\
-\end{array}$ & $\begin{array}{l}29.3 \\
\% \\
-\end{array}$ \\
\hline & & & 2.2 & 47.8 & & - & 3.9 & 164. \\
\hline Black Alone & 1.03 & 0.02 & $\%$ & $\%$ & 1.03 & 0.04 & $\%$ & $6 \%$ \\
\hline Asian and Pacific & & & 7.4 & 175. & & & 0.0 & 0.0 \\
\hline Islander Alone & 1.14 & 0.08 & $\%$ & $7 \%$ & 1.14 & 0.00 & $\%$ & $\%$ \\
\hline Native American & & - & 9.4 & 170. & & & 29.6 & 1034 \\
\hline Alone & 0.86 & 0.08 & $\%$ & $9 \%$ & 0.86 & 0.26 & $\%$ & $.1 \%$ \\
\hline All Other Races & & - & 24.2 & 428. & & & 6.0 & 204. \\
\hline Alone & 0.84 & 0.20 & $\begin{array}{l}\% \\
4.6\end{array}$ & $5 \%$ & 0.84 & 0.05 & $\begin{array}{l}\% \\
2.4\end{array}$ & $9 \%$ \\
\hline TotalPopulation & 1.05 & 0.05 & $\%$ & & 1.05 & 0.02 & $\%$ & \\
\hline
\end{tabular}


Table 6A.2B Low MA: BRT.

\begin{tabular}{|c|c|c|c|c|c|c|c|c|c|}
\hline \multicolumn{2}{|c|}{$\begin{array}{l}\text { Incremental } \\
\text { Analysis }\end{array}$} & \multirow[b]{2}{*}{$\begin{array}{l}\text { Dist } \\
\text { ance }\end{array}$} & \multirow[b]{3}{*}{ Sha } & \multirow[b]{2}{*}{$\begin{array}{l}\text { Sha } \\
\text { re }\end{array}$} & \multicolumn{2}{|c|}{$\begin{array}{l}\text { Cumulative } \\
\text { Analysis }\end{array}$} & & & \multirow[b]{2}{*}{$\begin{array}{l}\text { Sha } \\
\text { re }\end{array}$} \\
\hline & $\begin{array}{l}\text { Tran } \\
\text { sit }\end{array}$ & & & & & & & & \\
\hline & Regi & Ban & & of & Demogra & Trans & & Sha & of \\
\hline Demogra & on & d & re & Dist & phic & & Dista & re & Dist \\
\hline phic & Cha & Cha & of & anc & Share-- & Regio & nce & of & anc \\
\hline Share-- & nge & nge & Tra & e & Cumulati & & Band & Tra & e \\
\hline Only & 201 & 201 & nsit & Ban & ve & Chan & Chan & nsit & Ban \\
\hline Distance & $0-$ & $0-$ & Cou & d & Distance & ge & ge & $\mathrm{Cou}$ & d \\
\hline Band & 201 & 201 & ntie & Cha & Band & $2010-$ & $2010-$ & ntie & Cha \\
\hline Change & 6 & 6 & $\mathrm{~s}$ & nge & Change & 2016 & 2016 & $\mathrm{~s}$ & nge \\
\hline \multicolumn{5}{|c|}{ Spatial Share--0.125 Mile } & \multicolumn{5}{|c|}{ Spatial Share--0.125 Mile } \\
\hline \multicolumn{5}{|c|}{ Distance Band Only } & \multicolumn{5}{|c|}{ Distance Band Only } \\
\hline \multicolumn{5}{|l|}{ Station } & \multicolumn{5}{|l|}{ Station } \\
\hline Area & 142 & 27.4 & 0.2 & & Area & 1420 & & 0.2 & \\
\hline (sq.mi.) & & 6 & $\%$ & & (sq.mi.) & & 27.46 & $\%$ & \\
\hline \multirow{2}{*}{\multicolumn{5}{|c|}{$\begin{array}{l}\text { Basic Demographics--0.125 Mile } \\
\text { Distance Band Only }\end{array}$}} & Basic Den & graphic & -0.125 & & \\
\hline & & & & & Distance $E$ & and Only & & & \\
\hline White & & & & & White & & & & \\
\hline Non & & & 1.5 & 34. & Non & & & 1.5 & 34. \\
\hline Latino & & & $\%$ & $5 \%$ & Latino & & & $\%$ & $5 \%$ \\
\hline Other & & & & & Other & & & & \\
\hline Non & & & 8.8 & 215 & Non & & & 8.8 & 215 \\
\hline Latino & & & $\%$ & $.7 \%$ & Latino & & & $\%$ & $.7 \%$ \\
\hline Other & & & 6.6 & 163 & Other & & & 6.6 & 163 \\
\hline Groups & & & $\%$ & $.5 \%$ & Groups & & & $\%$ & $.5 \%$ \\
\hline TotalPop & & & 4.2 & 0.0 & TotalPop & & & 4.2 & 0.0 \\
\hline ulation & & & $\%$ & $\%$ & ulation & & & $\%$ & $\%$ \\
\hline$\overline{\text { White }}$ & & & & & $\overline{\text { White }}$ & & & & \\
\hline Non & & & 1.5 & 34. & Non & & & 1.5 & 34. \\
\hline Latino & & & $\%$ & $5 \%$ & Latino & & & $\%$ & $5 \%$ \\
\hline & & & 2.1 & 51. & & & & 2.1 & 51. \\
\hline Hispanic & & & $\%$ & $5 \%$ & Hispanic & & & $\%$ & $5 \%$ \\
\hline Other & & & & & Other & & & & \\
\hline Non & & & 8.8 & 215 & Non & & & 8.8 & 215 \\
\hline Latino & & & $\%$ & $.7 \%$ & Latino & & & $\%$ & $.7 \%$ \\
\hline Other & & & 32. & 874 & Other & & & 32. & 874 \\
\hline Groups & & & $0 \%$ & $.4 \%$ & Groups & & & $0 \%$ & $.4 \%$ \\
\hline TotalPop & & & 4.2 & 0.0 & TotalPop & & & 4.2 & 0.0 \\
\hline ulation & & & $\%$ & $\%$ & ulation & & & $\%$ & $\%$ \\
\hline White & & & 4.5 & 109 & White & & & 4.5 & 109 \\
\hline Alone & & & $\%$ & $.1 \%$ & Alone & & & $\%$ & $.1 \%$ \\
\hline Black & & & 4.2 & 98. & Black & & & 4.2 & 98. \\
\hline Alone & & & $\%$ & $9 \%$ & Alone & & & $\%$ & $9 \%$ \\
\hline Asian and & acific & & 12. & 331 & Asian and & acific & & 12. & 331 \\
\hline Islander A & & & $9 \%$ & $.7 \%$ & Islander A & ne & & $9 \%$ & $.7 \%$ \\
\hline Native Am & ican & & 4.2 & 82. & Native Am & rican & & 4.2 & 82. \\
\hline Alone & & & $\%$ & $9 \%$ & Alone & & & $\%$ & $9 \%$ \\
\hline & & & - & - & & & & - & - \\
\hline All Other $\mathrm{F}$ & ices & & 8.7 & 165 & All Other $\mathrm{F}$ & aces & & 8.7 & 165 \\
\hline Alone & & & $\%$ & $.1 \%$ & Alone & & & $\%$ & $.1 \%$ \\
\hline TotalPop & & & 4.2 & 0.0 & TotalPop & & & 4.2 & 0.0 \\
\hline ulation & & & $\%$ & $\%$ & ulation & & & $\%$ & $\%$ \\
\hline Spatial Sh & $e--0.2$ & Mile & & & Spatial Sh & re--0.25 & Mile & & \\
\hline Distance & nd On & & & & Distance & and Cum & lative & & \\
\hline Station & & & & & Station & & & & \\
\hline Area & 142 & & 0.3 & & Area & 1420 & & 0.5 & \\
\hline (sq.mi.) & 01 & 43.8 & $\%$ & & (sq.mi.) & 1 & 71.3 & $\%$ & \\
\hline Demograp & ic Cha & $g e--0.2$ & Mile & & Demograp & ic Chan & e--0.25 & & \\
\hline Distance & nd On & & & & Distance & and Cum & lative & & \\
\hline White & & & & & White & & & & - \\
\hline Non & & & 3.6 & 37. & Non & & & 0.0 & 5.4 \\
\hline Latino & & & $\%$ & $0 \%$ & Latino & & & $\%$ & $\%$ \\
\hline
\end{tabular}




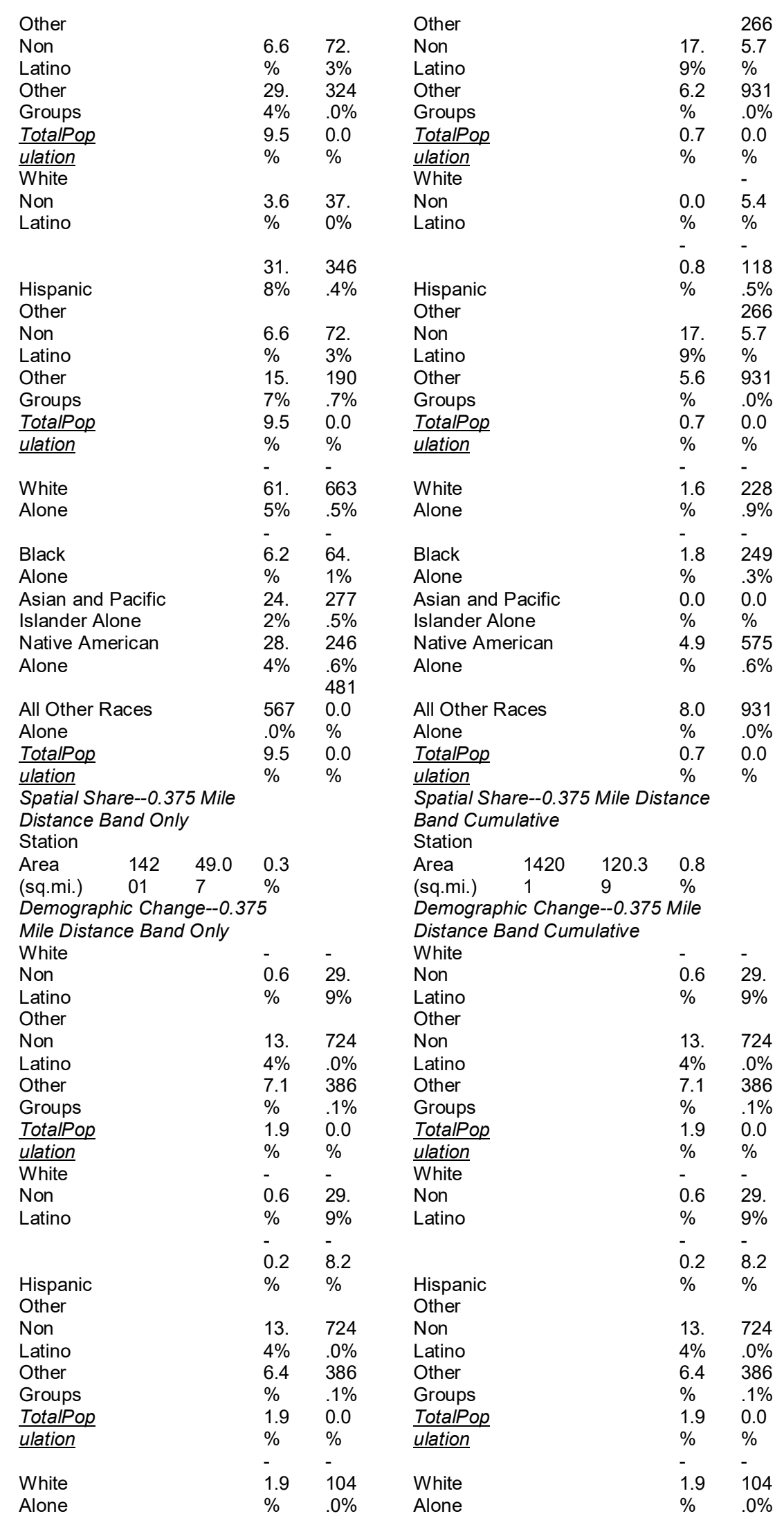




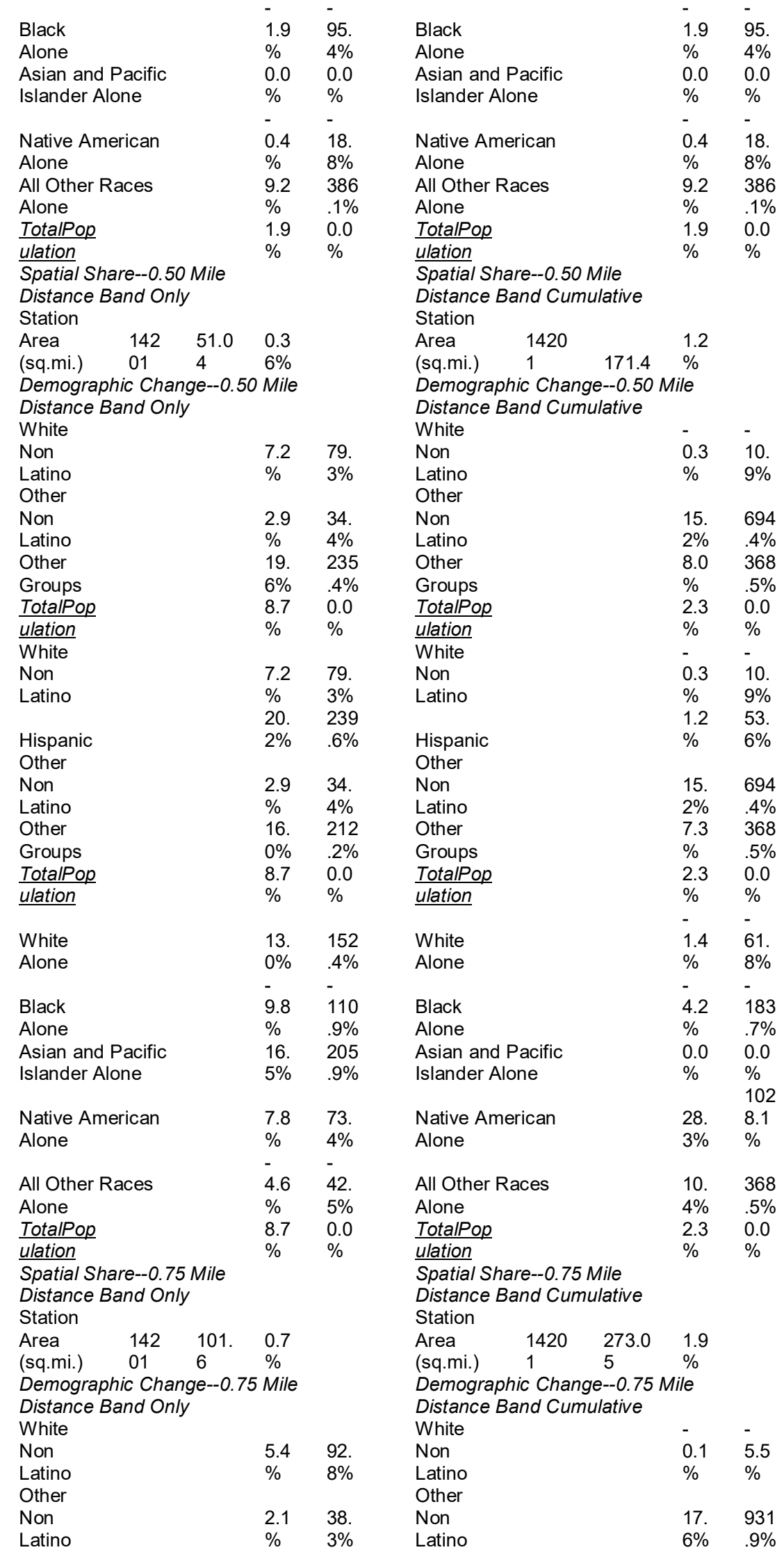




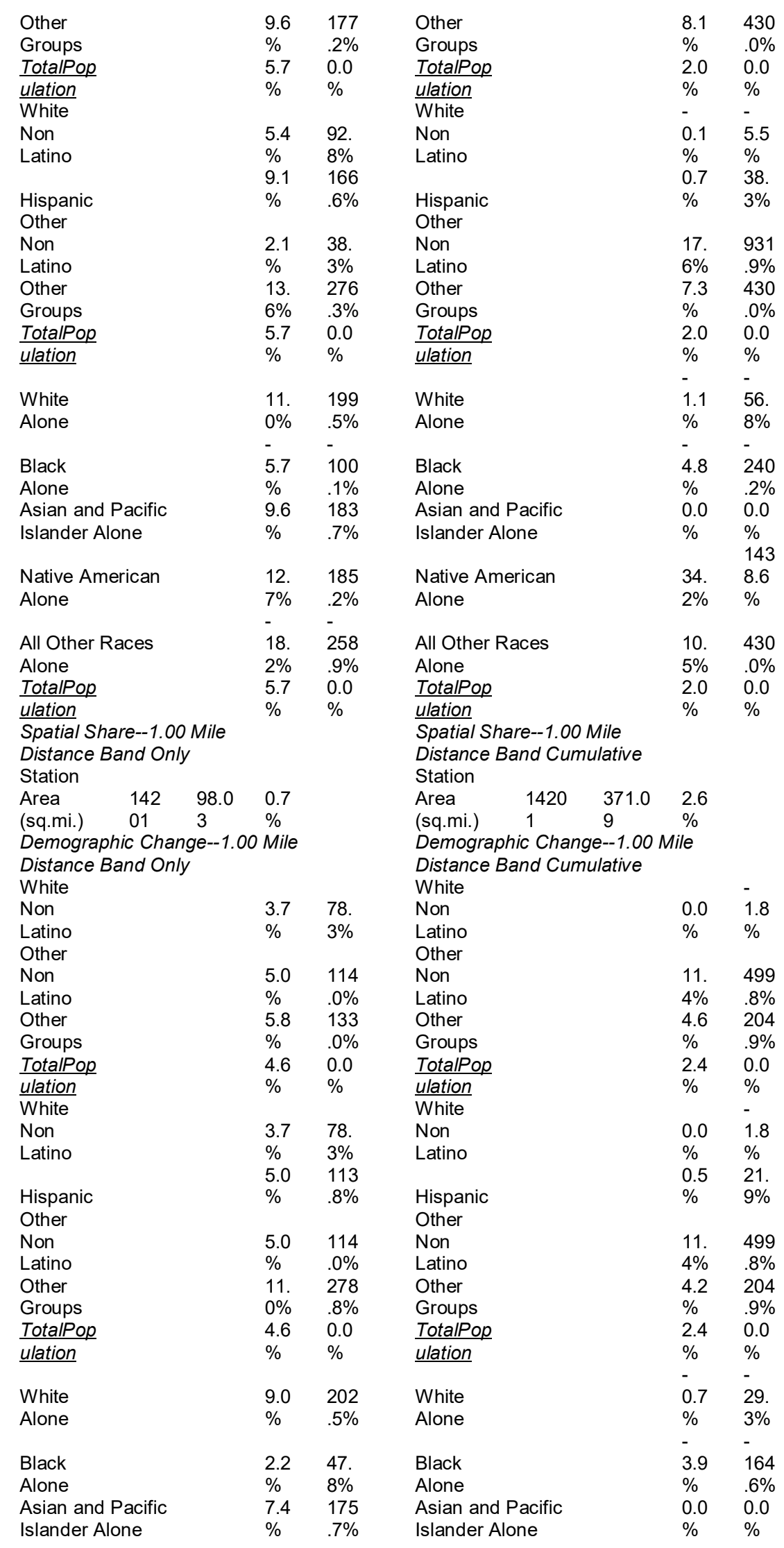




$\begin{array}{llllll}\text { Native American } & - & - & & & 103 \\ \text { Alone } & 9.4 & 170 & \text { Native American } & 29 . & 4.1 \\ & \% & .9 \% & \text { Alone } & 6 \% & \% \\ \text { All Other Races } & - & - & & 6.0 & 204 \\ \text { Alone } & 24 . & 428 & \text { All Other Races } & \% & .9 \% \\ \text { TotalPop } & 2 \% & .5 \% & \text { Alone } & 2.4 & 0.0 \\ \underline{\text { ulation }} & 4.6 & 0.0 & \underline{\text { TotalPop }} & \% & \%\end{array}$

Table 6A.3A Mod MA:

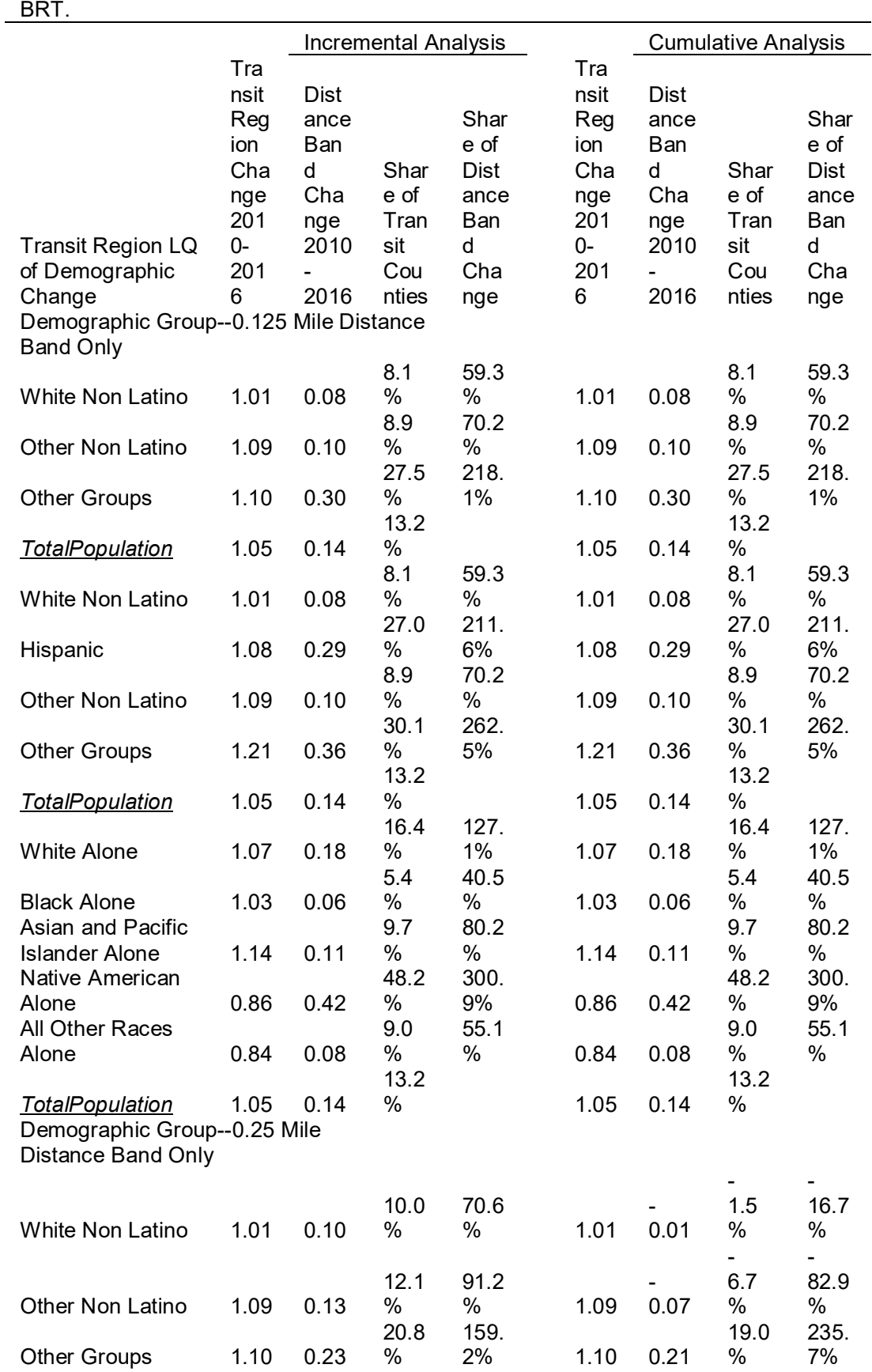




\begin{tabular}{|c|c|c|c|c|c|c|c|c|}
\hline TotalPopulation & 1.05 & 0.14 & $\begin{array}{l}13.7 \\
\%\end{array}$ & & 1.05 & 0.09 & $\begin{array}{l}8.4 \\
\%\end{array}$ & \\
\hline & & & 10.0 & 70.6 & & - & 1.5 & 16.7 \\
\hline White Non Latino & 1.01 & 0.10 & $\begin{array}{l}\% \\
19.4\end{array}$ & $\begin{array}{l}\% \\
146 .\end{array}$ & 1.01 & 0.01 & $\begin{array}{l}\% \\
7.6\end{array}$ & $\begin{array}{l}\% \\
93.5\end{array}$ \\
\hline Hispanic & 1.08 & 0.21 & $\%$ & $2 \%$ & 1.08 & 0.08 & $\%$ & $\begin{array}{l}\% \\
-\end{array}$ \\
\hline Other Non Latino & 1.09 & 0.13 & $\begin{array}{l}12.1 \\
\% \\
30.1\end{array}$ & $\begin{array}{l}91.2 \\
\% \\
253 .\end{array}$ & 1.09 & $\overline{0}-07$ & $\begin{array}{l}6.7 \\
\% \\
17.2\end{array}$ & $\begin{array}{l}82.9 \\
\% \\
235 .\end{array}$ \\
\hline Other Groups & 1.21 & 0.36 & $\begin{array}{l}\% \\
13.7\end{array}$ & $4 \%$ & 1.21 & 0.21 & $\begin{array}{l}\% \\
8.4\end{array}$ & $7 \%$ \\
\hline$\underline{\text { TotalPopulation }}$ & 1.05 & 0.14 & $\begin{array}{l}\% \\
-\end{array}$ & - & 1.05 & 0.09 & $\%$ & \\
\hline White Alone & 1.07 & $\overline{-}-50$ & $\begin{array}{l}47.0 \\
\%\end{array}$ & $\begin{array}{l}350 . \\
7 \%\end{array}$ & 1.07 & 0.01 & $\begin{array}{l}0.8 \\
\% \\
-\end{array}$ & $\begin{array}{l}9.5 \\
\% \\
-\end{array}$ \\
\hline Black Alone & 1.03 & 0.13 & & $\begin{array}{l}89.5 \\
\% \\
736\end{array}$ & 1.03 & $\overline{0.05}$ & $\begin{array}{l}4.6 \\
\%\end{array}$ & $\begin{array}{l}54.0 \\
\%\end{array}$ \\
\hline $\begin{array}{l}\text { Asian and Pacific } \\
\text { Islander Alone } \\
\text { Native American }\end{array}$ & 1.14 & 0.11 & $\begin{array}{l}9.3 \\
\% \\
19.0\end{array}$ & $\begin{array}{l}73.6 \\
\% \\
114 .\end{array}$ & 1.14 & 0.00 & $\begin{array}{l}0.0 \\
\% \\
88.1\end{array}$ & $\begin{array}{l}0.0 \\
\% \\
862 .\end{array}$ \\
\hline $\begin{array}{l}\text { Alone } \\
\text { All Other Races }\end{array}$ & 0.86 & 0.16 & $\begin{array}{l}\% \\
335 .\end{array}$ & $\begin{array}{l}4 \% \\
1970\end{array}$ & 0.86 & 0.76 & $\begin{array}{l}\% \\
24.7\end{array}$ & $\begin{array}{l}8 \% \\
235 .\end{array}$ \\
\hline Alone & 0.84 & 2.83 & $\begin{array}{l}7 \% \\
13.7\end{array}$ & $.4 \%$ & 0.84 & 0.21 & $\begin{array}{l}\% \\
8.4\end{array}$ & $7 \%$ \\
\hline TotalPopulation & 1.05 & 0.14 & $\%$ & & 1.05 & 0.09 & $\%$ & \\
\hline
\end{tabular}

Demographic Group--0.375 Mile Distance

Band Only

\begin{tabular}{|c|c|c|c|c|c|c|c|c|}
\hline & 1.0 & & 14.1 & 69.3 & 1. & 0.0 & 1.6 & 16.4 \\
\hline \multirow[t]{2}{*}{ White Non Latino } & 1 & 0.14 & $\%$ & $\%$ & 01 & 2 & $\%$ & $\%$ \\
\hline & 1.0 & & 23.9 & 125. & 1. & 0.0 & 8.5 & 94.8 \\
\hline Other Non Latino & 9 & 0.26 & $\%$ & $9 \%$ & 09 & 9 & $\%$ & \\
\hline \multirow[t]{2}{*}{ Other Groups } & $\begin{array}{l}1.1 \\
0\end{array}$ & 0.25 & $\begin{array}{l}23.1 \\
\%\end{array}$ & $\begin{array}{l}123 . \\
2 \%\end{array}$ & $\begin{array}{l}1 . \\
10\end{array}$ & $\begin{array}{l}0.2 \\
2\end{array}$ & $\begin{array}{l}20 . \\
2 \%\end{array}$ & $\begin{array}{l}228 . \\
6 \%\end{array}$ \\
\hline & 1.0 & & 19.7 & & 1. & 0.1 & 9.3 & \\
\hline \multirow[t]{2}{*}{ TotalPopulation } & 5 & 0.21 & $\%$ & & 05 & 0 & $\%$ & \\
\hline & 1.0 & & 14.1 & 69.3 & 1. & 0.0 & 1.6 & 16.4 \\
\hline \multirow{2}{*}{ White Non Latino } & 1 & 0.14 & $\%$ & $\%$ & 01 & 2 & $\%$ & \\
\hline & 1.0 & & 21.7 & 114. & 1. & 0.0 & 6.3 & 70.0 \\
\hline \multirow[t]{3}{*}{ Hispanic } & 8 & 0.24 & $\%$ & $3 \%$ & 08 & 7 & $\%$ & $\%$ \\
\hline & & & & & & O & $e^{-1}$ & \\
\hline & 1.0 & & 23.9 & 125. & 1. & 0.0 & 8.5 & 94.8 \\
\hline \multirow[t]{2}{*}{ Other Non Latino } & 9 & 0.26 & $\%$ & $9 \%$ & 09 & 9 & $\%$ & $\%$ \\
\hline & 1.2 & & 35.2 & 206. & 1. & 0.2 & 18. & 228. \\
\hline \multirow{2}{*}{ Other Groups } & 1 & 0.43 & $\%$ & $6 \%$ & 21 & 2 & $4 \%$ & $6 \%$ \\
\hline & 1.0 & & 19.7 & & 1. & 0.1 & 9.3 & \\
\hline \multirow{2}{*}{ TotalPopulation } & 5 & 0.21 & $\%$ & & 05 & 0 & $\%$ & \\
\hline & 1.0 & & 20.3 & 105. & 1. & 0.0 & 0.5 & 5.1 \\
\hline \multirow[t]{2}{*}{ White Alone } & 7 & 0.22 & $\%$ & $7 \%$ & 07 & 0 & $\%$ & $\%$ \\
\hline & 1.0 & & 28.6 & 143. & 1. & 0.0 & 3.3 & 34.8 \\
\hline Black Alone & 3 & 0.30 & $\%$ & $4 \%$ & 03 & 3 & $\%$ & $\%$ \\
\hline Asian and Pacific & 1.1 & & 16.6 & 91.9 & 1. & 0.0 & 0.0 & 0.0 \\
\hline Islander Alone & 4 & 0.19 & $\%$ & $\%$ & 14 & 0 & $\%$ & $\%$ \\
\hline Native American & 0.8 & & 22.6 & 95.0 & 0. & 0.7 & 86. & 769. \\
\hline Alone & 6 & 0.20 & $\%$ & $\%$ & 86 & 5 & $4 \%$ & $4 \%$ \\
\hline All Other Races & 0.8 & & 14.7 & 60.1 & 0. & 0.2 & 26. & 228. \\
\hline \multirow{2}{*}{ Alone } & 4 & 0.12 & $\%$ & $\%$ & 84 & 2 & $3 \%$ & $6 \%$ \\
\hline & 1.0 & & 19.7 & & 1. & 0.1 & 9.3 & \\
\hline TotalPopulation & 5 & 0.21 & $\%$ & & 05 & 0 & $\%$ & \\
\hline
\end{tabular}




\begin{tabular}{|c|c|c|c|c|c|c|c|c|}
\hline \multirow{2}{*}{\multicolumn{9}{|c|}{$\begin{array}{l}\text { Demographic Group--0.5 Mile } \\
\text { Distance Band Only }\end{array}$}} \\
\hline & & & & & & - & - & - \\
\hline & 1.0 & & 11.0 & 101. & 1. & 0.0 & 0.8 & 9.2 \\
\hline \multirow{3}{*}{ White Non Latino } & 1 & 0.11 & $\%$ & $9 \%$ & 01 & 1 & $\%$ & $\%$ \\
\hline & & & & & 1 & $\bar{s}^{-}$ & - & $\overline{714}$ \\
\hline & 1.0 & & 8.1 & 80.6 & 1. & 0.0 & 6.0 & \\
\hline \multirow[t]{2}{*}{ Other Non Latino } & 9 & 0.09 & $\%$ & $\%$ & 09 & 7 & $\%$ & $\%$ \\
\hline & 1.1 & & 11.4 & 114. & 1. & 0.1 & 16. & 197. \\
\hline \multirow[t]{2}{*}{ Other Groups } & 0 & 0.13 & $\%$ & $4 \%$ & 10 & 8 & $5 \%$ & $9 \%$ \\
\hline & 1.0 & & 10.5 & & 1. & 0.0 & 8.7 & \\
\hline \multirow[t]{2}{*}{$\underline{\text { TotalPopulation }}$} & 5 & 0.11 & $\%$ & & 05 & 9 & $\%$ & \\
\hline & 10 & & 110 & & 1 & مיم & $\bar{n}_{8}$ & $\overline{9} .2$ \\
\hline \multirow{2}{*}{ White Non Latino } & 1 & 0.11 & $\%$ & $9 \%$ & 01 & 1 & $\%$ & $\%$ \\
\hline & 1.0 & & 10.1 & 100. & 1. & 0.0 & 4.6 & 54.4 \\
\hline \multirow[t]{3}{*}{ Hispanic } & 8 & 0.11 & $\%$ & $0 \%$ & 08 & 5 & $\%$ & $\%$ \\
\hline & & & & & & - & - & - \\
\hline & 1.0 & & 8.1 & 80.6 & 1. & 0.0 & 6.0 & 71.4 \\
\hline \multirow[t]{2}{*}{ Other Non Latino } & 9 & 0.09 & $\%$ & $\%$ & 09 & 7 & $\%$ & $\%$ \\
\hline & 1.2 & & 22.0 & 242. & 1. & 0.1 & 15. & 197. \\
\hline \multirow[t]{2}{*}{ Other Groups } & 1 & 0.27 & $\%$ & $9 \%$ & 21 & 8 & $0 \%$ & $9 \%$ \\
\hline & 1.0 & & 10.5 & & 1. & 0.0 & 8.7 & \\
\hline \multirow[t]{2}{*}{$\underline{\text { TotalPopulation }}$} & 5 & 0.11 & $\%$ & & 05 & 9 & $\%$ & \\
\hline & 1.0 & & 18.7 & 183. & 1. & 0.0 & 1.1 & 13.4 \\
\hline \multirow[t]{3}{*}{ White Alone } & 7 & 0.20 & $\%$ & $1 \%$ & 07 & 1 & $\%$ & $\%$ \\
\hline & & & & & & - & - & - \\
\hline & 1.0 & & 2.6 & 24.8 & 1. & 0.0 & 3.6 & 40.6 \\
\hline Black Alone & 3 & 0.03 & $\%$ & & 03 & 4 & $\%$ & $\%$ \\
\hline Asian and Pacific & 1.1 & & 11.7 & 121. & 1. & 0.0 & 0.0 & 0.0 \\
\hline Islander Alone & 4 & 0.13 & $\%$ & $5 \%$ & 14 & 0 & $\%$ & $\%$ \\
\hline Native American & 0.8 & & 11.7 & 92.5 & 0. & 0.6 & 78. & 737. \\
\hline \multirow[t]{2}{*}{ Alone } & 6 & 0.10 & $\%$ & $\%$ & 86 & 7 & $1 \%$ & $4 \%$ \\
\hline & & & - & - & & & & \\
\hline All Other Races & 0.8 & & 16.9 & 130. & 0. & 0.1 & 21. & 197. \\
\hline \multirow[t]{2}{*}{ Alone } & 4 & -0.14 & $\%$ & $3 \%$ & 84 & 8 & $5 \%$ & $9 \%$ \\
\hline & 1.0 & & 10.5 & & 1. & 0.0 & 8.7 & \\
\hline$\underline{\text { TotalPopulation }}$ & 5 & 0.11 & $\%$ & & 05 & 9 & $\%$ & \\
\hline Demographic Gro & $75 \mathrm{~N}$ & & & & & & & \\
\hline & & & & & & & - & - \\
\hline & 1.0 & & 6.7 & 70.7 & 1. & 0.0 & 0.5 & 5.9 \\
\hline White Non Latino & 1 & 0.07 & $\%$ & $\%$ & 01 & 0 & $\%$ & $\%$ \\
\hline & & & & & & - & - & - \\
\hline & 1.0 & & 6.7 & 75.8 & 1. & 0.0 & 4.8 & 64.2 \\
\hline Other Non Latino & 9 & 0.07 & $\%$ & & 09 & 5 & $\%$ & $\%$ \\
\hline & 1.1 & & 14.2 & 162. & 1. & 0.1 & 15. & 217. \\
\hline Other Groups & 0 & 0.16 & $\%$ & $5 \%$ & 10 & 7 & $9 \%$ & $2 \%$ \\
\hline & 1.0 & & 9.1 & & 1. & 0.0 & 7.7 & \\
\hline$\underline{\text { TotalPopulation }}$ & 5 & 0.10 & $\%$ & & 05 & 8 & $\%$ & \\
\hline & 1.0 & & & & 1. & 0 & - & 5.9 \\
\hline White Non Latino & 1 & 0.07 & $\%$ & & 01 & 0 & $\%$ & $\%$ \\
\hline & 1.0 & & 13.9 & 157. & 1. & 0.0 & 2.8 & 38.1 \\
\hline Hispanic & 8 & 0.15 & $\%$ & $8 \%$ & 08 & 3 & $\%$ & $\%$ \\
\hline & & & & & & - & - & - \\
\hline & 1.0 & & 6.7 & 75.8 & 1. & 0.0 & 4.8 & 64.2 \\
\hline Other Non Latino & 9 & 0.07 & $\%$ & $\%$ & 09 & 5 & $\%$ & $\%$ \\
\hline & 1.2 & & 16.8 & 211. & 1. & 0.1 & 14. & 217. \\
\hline Other Groups & 1 & 0.20 & $\%$ & $9 \%$ & 21 & 7 & $5 \%$ & $2 \%$ \\
\hline & 1.0 & & 9.1 & & 1. & 0.0 & 7.7 & \\
\hline TotalPopulation & 5 & 0.10 & $\%$ & & 05 & 8 & $\%$ & \\
\hline & 1.0 & & 16.9 & 189. & 1. & 0.0 & 1.2 & 16.0 \\
\hline White Alone & 7 & 0.18 & $\%$ & $8 \%$ & 07 & 1 & $\%$ & $\%$ \\
\hline & 1.0 & & & & 1. & $\overline{0} 0$ & $\overline{26}$ & $\overline{33.6}$ \\
\hline Black Alone & 3 & 0.04 & $\%$ & $\%$ & 03 & 3 & $\%$ & $\%$ \\
\hline Asian and Pacific & 1.1 & & 11.0 & 130. & 1. & 0.0 & 0.0 & 0.0 \\
\hline Islander Alone & 4 & 0.13 & $\%$ & $9 \%$ & 14 & 0 & $\%$ & $\%$ \\
\hline
\end{tabular}




\begin{tabular}{|c|c|c|c|c|c|c|c|c|}
\hline & & & & & & & & \\
\hline Native American & 0.8 & & 37.8 & 340. & 0. & 0.7 & 87. & 936. \\
\hline Alone & 6 & -0.33 & $\begin{array}{l}\% \\
-\end{array}$ & $\begin{array}{l}9 \% \\
-\end{array}$ & 86 & 5 & $2 \%$ & $7 \%$ \\
\hline All Other Races & 0.8 & & 14.6 & 129. & 0. & 0.1 & 20. & 217. \\
\hline Alone & 4 & -0.12 & $\%$ & $0 \%$ & 84 & 7 & $7 \%$ & $2 \%$ \\
\hline & 1.0 & & 9.1 & & 1. & 0.0 & 7.7 & \\
\hline TotalPopulation & 5 & 0.10 & $\%$ & & 05 & 8 & $\%$ & \\
\hline $\begin{array}{l}\text { Demographic Gro } \\
\text { Distance Band On }\end{array}$ & $.00 \mathrm{Mi}$ & & & & & & & \\
\hline & & & & & & & - & - \\
\hline & 1.0 & & 7.8 & 76.3 & 1. & 0.0 & 0.3 & 3.4 \\
\hline White Non Latino & 1 & 0.08 & $\%$ & $\%$ & 01 & $\begin{array}{l}0 \\
-\end{array}$ & $\%$ & $\begin{array}{l}\% \\
-\end{array}$ \\
\hline & 1.0 & & 11.1 & 115. & 1. & 0.0 & 6.1 & 87.4 \\
\hline Other Non Latino & 9 & 0.12 & $\%$ & $5 \%$ & 09 & 7 & $\%$ & $\%$ \\
\hline & 1.1 & & 11.8 & 124. & 1. & 0.1 & 13. & 187. \\
\hline Other Groups & 0 & 0.13 & $\%$ & $5 \%$ & 10 & 4 & $0 \%$ & $5 \%$ \\
\hline & 1.0 & & 9.9 & & 1. & 0.0 & 7.3 & \\
\hline TotalPopulation & 5 & 0.10 & $\%$ & & 05 & 8 & $\%$ & \\
\hline & 1.0 & & 7.8 & 76.3 & 1. & 0.0 & 0.3 & 3.4 \\
\hline White Non Latino & 1 & 0.08 & $\%$ & $\%$ & 01 & 0 & $\%$ & $\%$ \\
\hline & 1.0 & & 10.7 & 111. & 1. & 0.0 & 1.9 & 26.9 \\
\hline Hispanic & 8 & 0.12 & $\%$ & $9 \%$ & 08 & 2 & $\%$ & $\%$ \\
\hline & & & & & & - & - & - \\
\hline & 1.0 & & 11.1 & 115. & 1. & 0.0 & 6.1 & 87.4 \\
\hline Other Non Latino & 9 & 0.12 & $\%$ & $5 \%$ & 09 & 7 & $\%$ & $\%$ \\
\hline & 1.2 & & 20.2 & 235. & 1. & 0.1 & 11. & 187. \\
\hline Other Groups & 1 & 0.24 & $\%$ & $0 \%$ & 21 & 4 & $8 \%$ & $5 \%$ \\
\hline & 1.0 & & 9.9 & & 1. & 0.0 & 7.3 & \\
\hline TotalPopulation & 5 & 0.10 & $\%$ & & 05 & 8 & $\%$ & \\
\hline & 1.0 & & 16.4 & 169. & 1. & 0.0 & 1.5 & 21.1 \\
\hline White Alone & 7 & 0.18 & $\%$ & $0 \%$ & 07 & 2 & $\%$ & $\%$ \\
\hline & & & & & & - & - & - \\
\hline & 1.0 & & 2.3 & 22.4 & 1. & 0.0 & 3.0 & 41.2 \\
\hline Black Alone & 3 & 0.02 & $\%$ & $\%$ & 03 & 3 & $\%$ & $\%$ \\
\hline Asian and Pacific & 1.1 & & 20.2 & 221. & 1. & 0.0 & 0.0 & 0.0 \\
\hline Islander Alone & 4 & 0.23 & $\%$ & $5 \%$ & 14 & 0 & $\%$ & $\%$ \\
\hline & & & - & - & & & & \\
\hline Native American & 0.8 & & 14.1 & 117. & 0. & 0.6 & 74. & 841. \\
\hline Alone & 6 & -0.12 & $\%$ & $0 \%$ & 86 & 4 & $2 \%$ & $6 \%$ \\
\hline All Other Races & 0.8 & & 21.3 & 172. & 0. & 0.1 & 16. & 187. \\
\hline Alone & 4 & -0.18 & $\%$ & $4 \%$ & 84 & 4 & $9 \%$ & $5 \%$ \\
\hline & 1.0 & & 9.9 & & 1. & 0.0 & 7.3 & \\
\hline TotalPopulation & 5 & 0.10 & $\%$ & & 05 & 8 & $\%$ & \\
\hline
\end{tabular}

Table 6A.3B Mod MA:

BRT.

\begin{tabular}{ll}
\hline Incremental & Cumulative \\
Analysis & Analysis
\end{tabular}




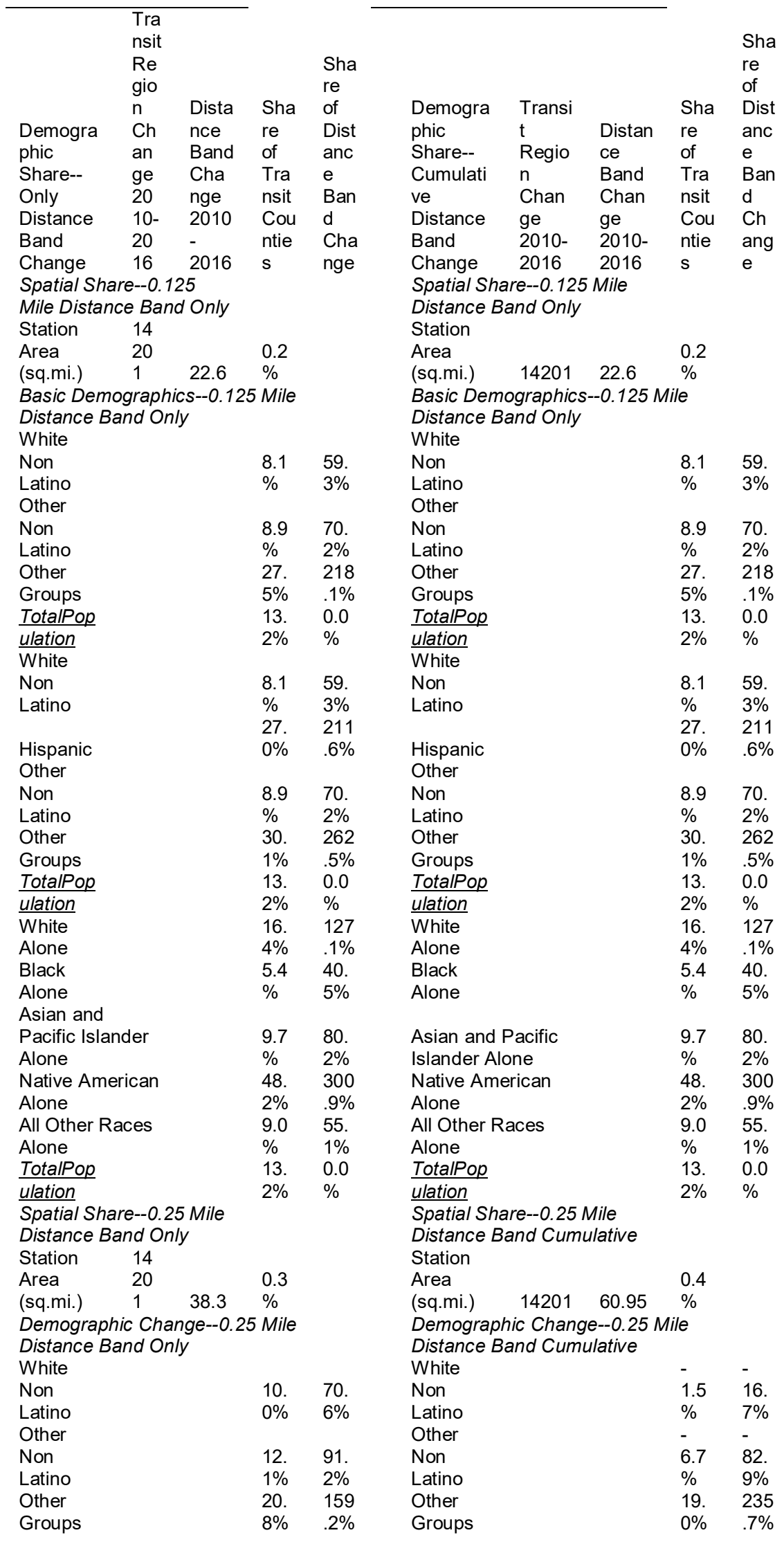




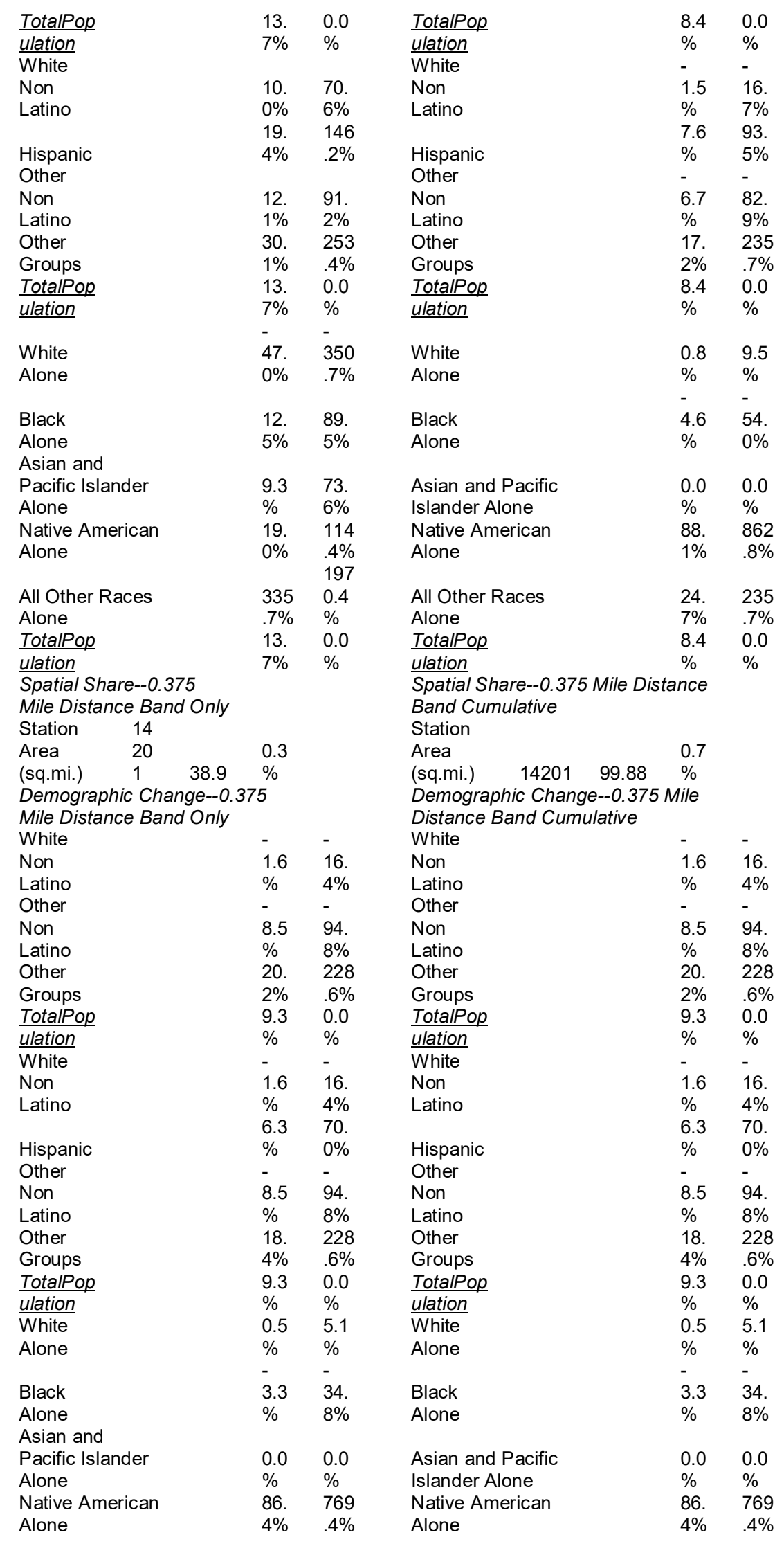




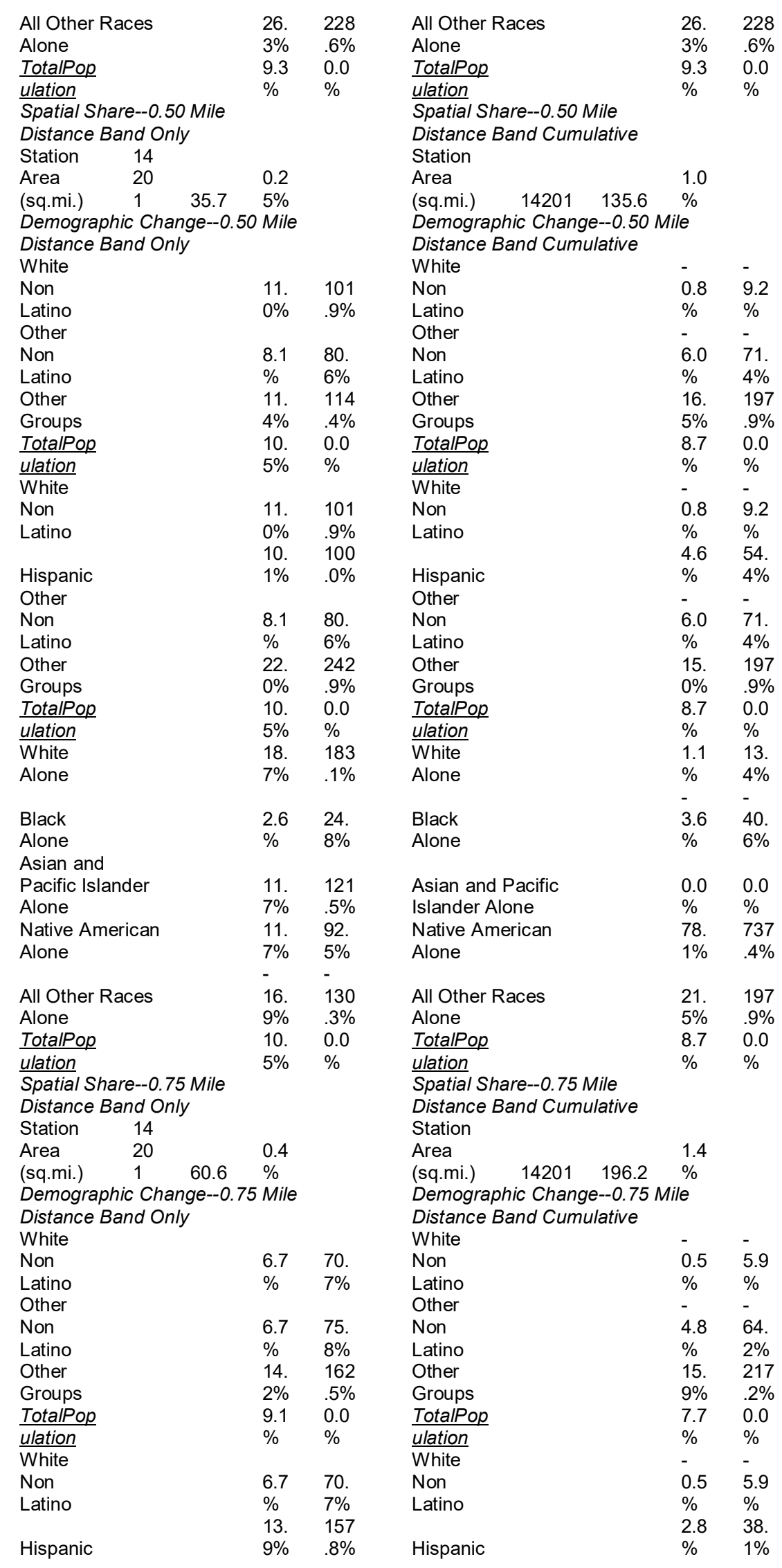




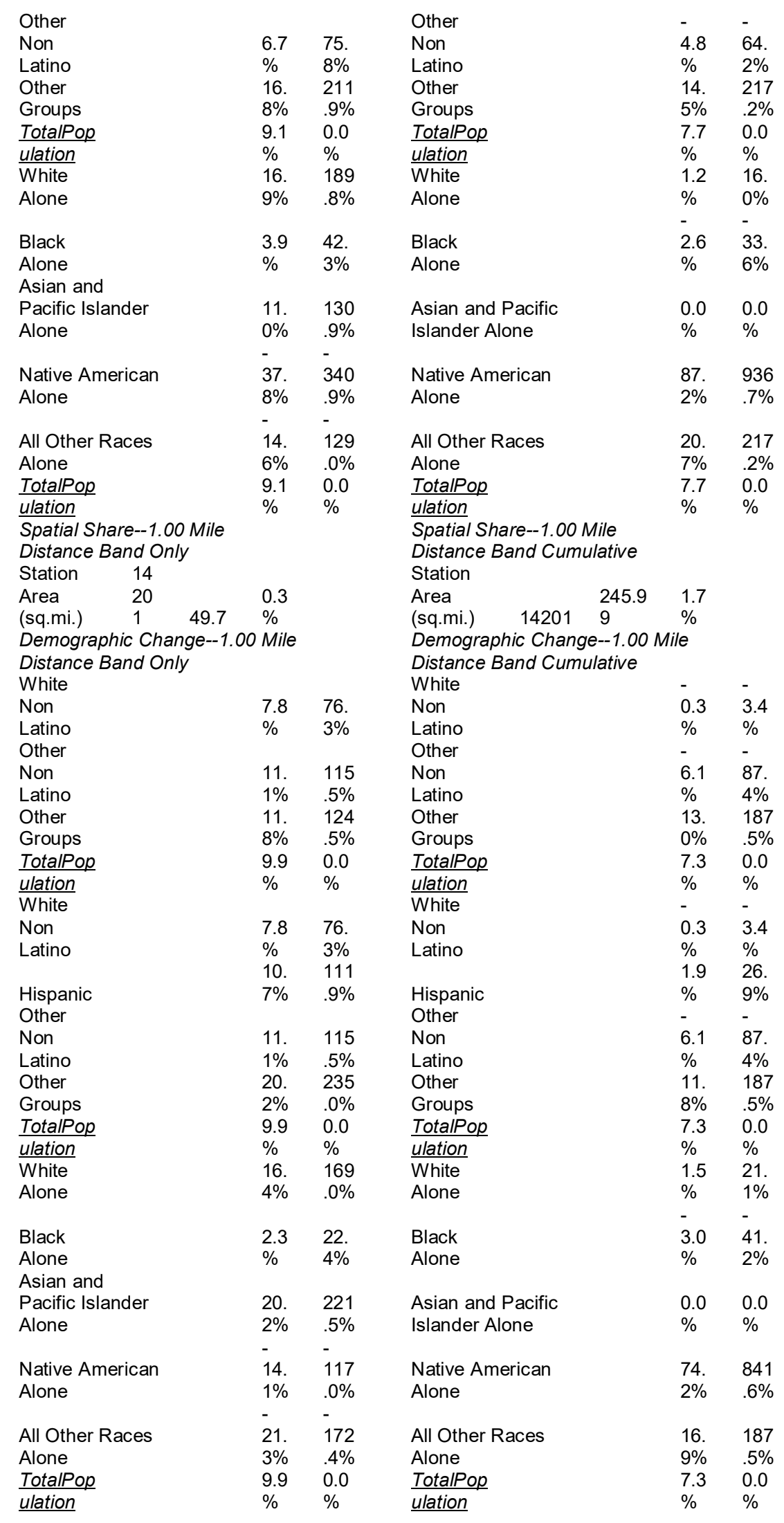




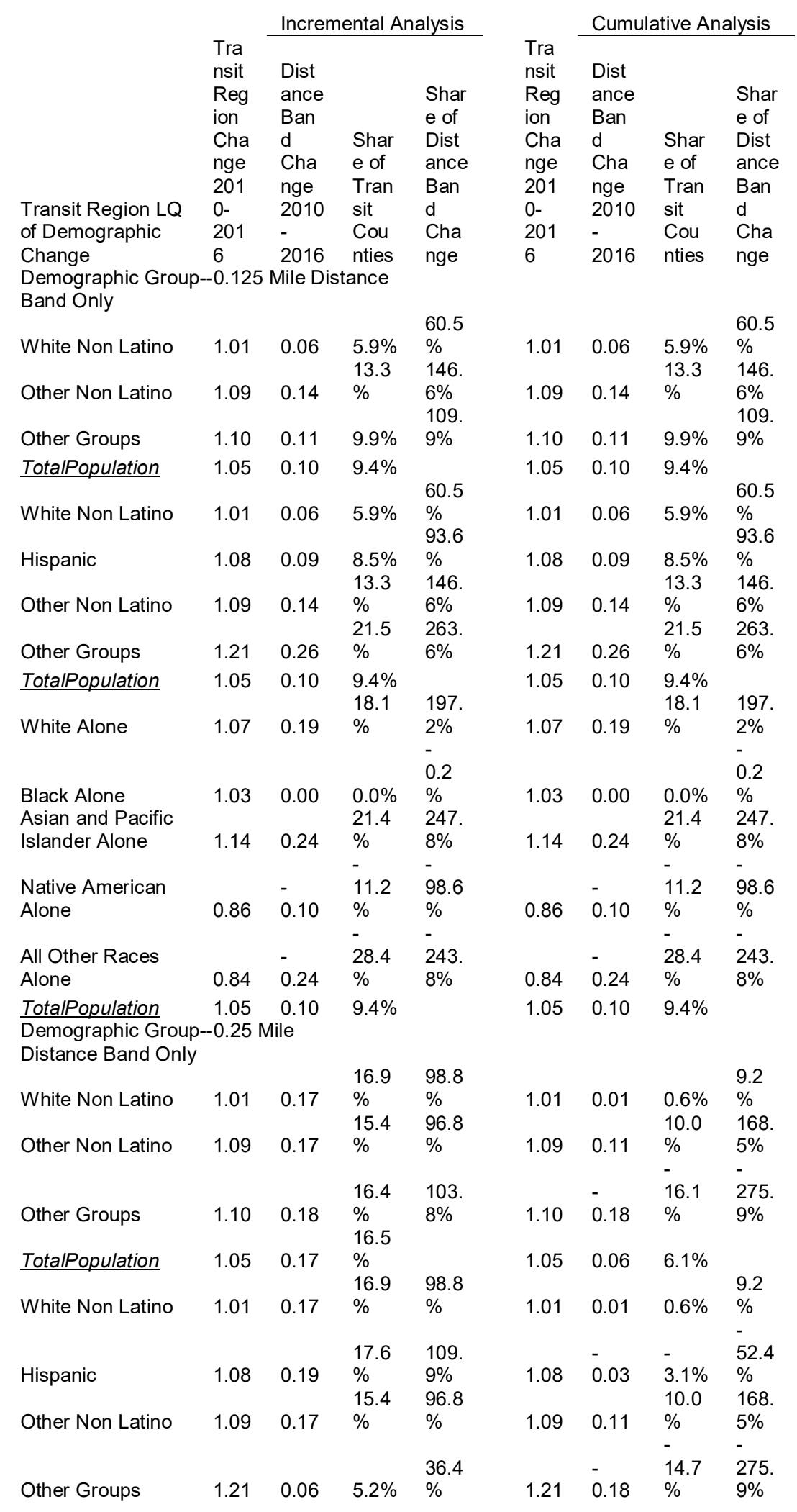




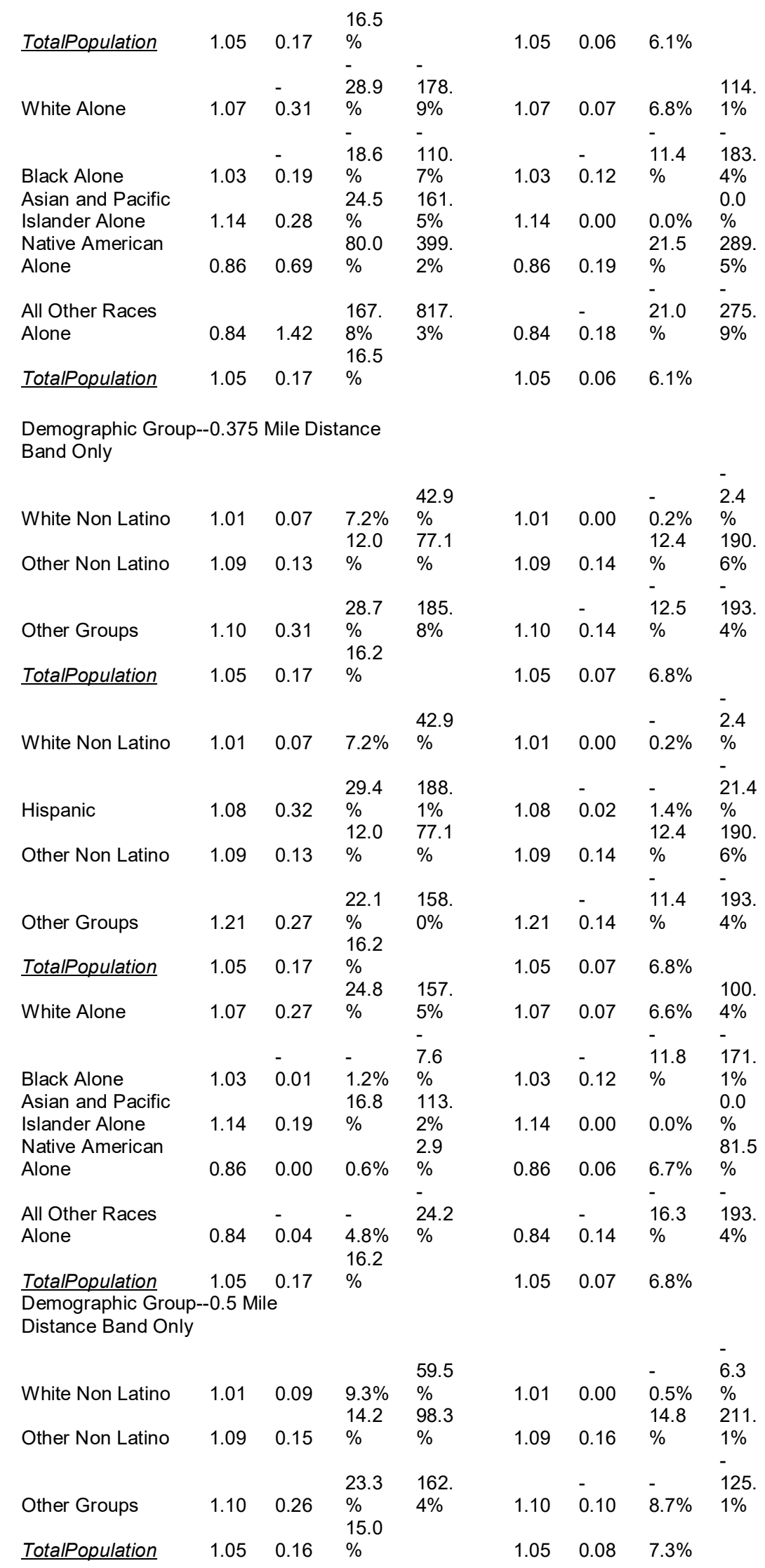




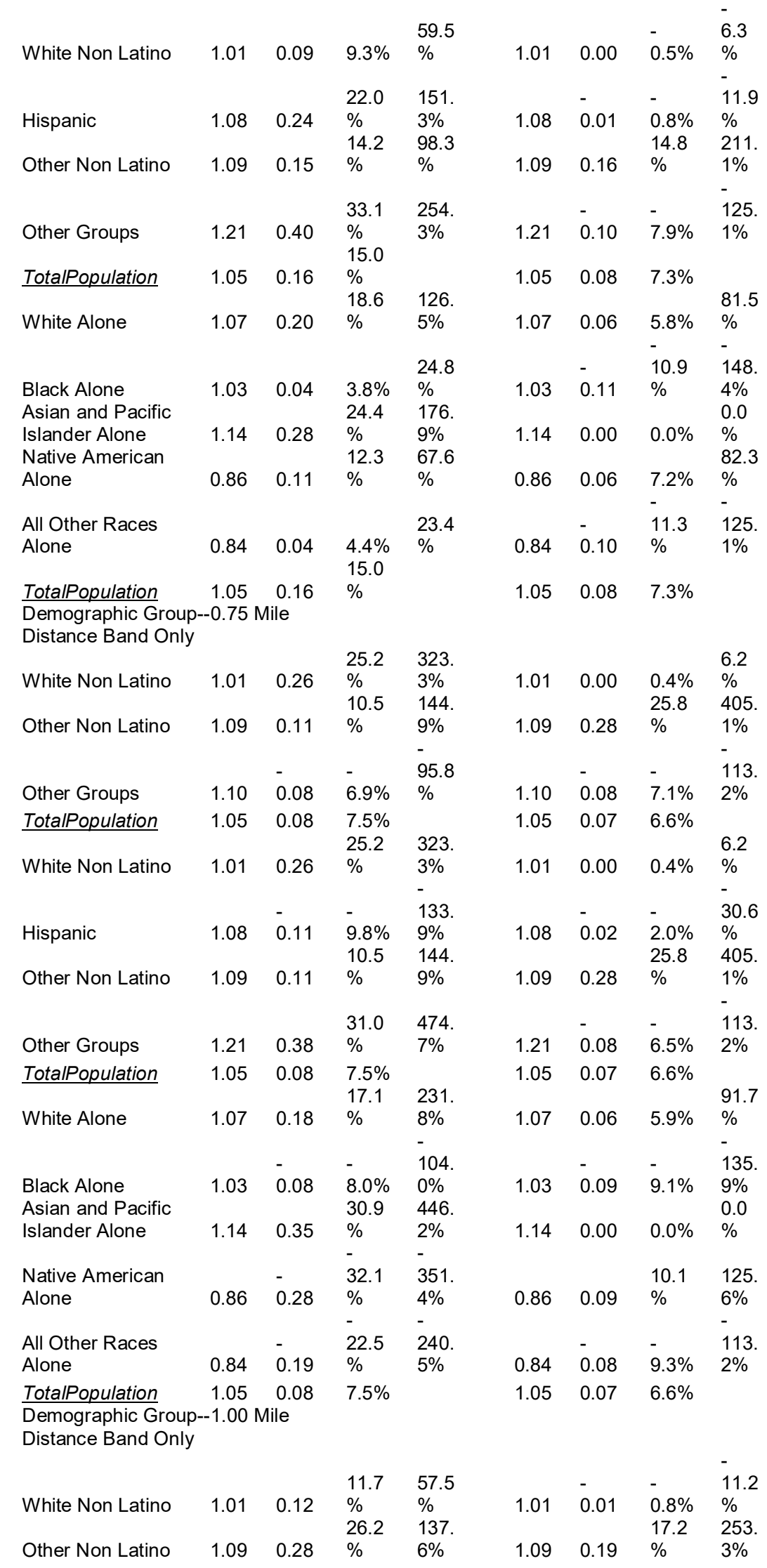




\begin{tabular}{|c|c|c|c|c|c|c|c|c|}
\hline & & & 21.4 & 113 & & _ & _ & 63.4 \\
\hline Other Groups & 1.10 & 0.24 & $\begin{array}{l}\% \\
19.8\end{array}$ & $7 \%$ & 1.10 & 0.05 & $4.3 \%$ & $\%$ \\
\hline TotalPopulation & 1.05 & 0.21 & $\%$ & & 1.05 & 0.07 & $7.0 \%$ & \\
\hline White Non Latino & 1.01 & 0.12 & $\begin{array}{l}11.7 \\
\%\end{array}$ & $\begin{array}{l}57.5 \\
\%\end{array}$ & 1.01 & $\overline{-} .01$ & $\overline{-}-8 \%$ & $\begin{array}{l}11.2 \\
\%\end{array}$ \\
\hline & & & 24.7 & 129. & & - & - & 20.3 \\
\hline Hispanic & 1.08 & 0.27 & $\begin{array}{l}\% \\
26.2\end{array}$ & $\begin{array}{l}3 \% \\
137\end{array}$ & 1.08 & 0.01 & $\begin{array}{l}1.4 \% \\
17.2\end{array}$ & $\begin{array}{l}\% \\
253\end{array}$ \\
\hline Other Non Latino & 1.09 & 0.28 & $\%$ & $6 \%$ & 1.09 & 0.19 & $\%$ & $3 \%$ \\
\hline & & - & 24.6 & 143. & & - & - & 63.4 \\
\hline Other Groups & 1.21 & 0.30 & $\begin{array}{l}\% \\
19.8\end{array}$ & $8 \%$ & 1.21 & 0.05 & $3.9 \%$ & $\%$ \\
\hline TotalPopulation & 1.05 & 0.21 & $\begin{array}{l}\% \\
28.1\end{array}$ & 145. & 1.05 & 0.07 & $7.0 \%$ & 80.6 \\
\hline White Alone & 1.07 & 0.30 & $\%$ & $6 \%$ & 1.07 & 0.06 & $5.5 \%$ & $\begin{array}{l}\% \\
-\end{array}$ \\
\hline $\begin{array}{l}\text { Black Alone } \\
\text { Asian and Pacific }\end{array}$ & 1.03 & 0.26 & $\begin{array}{l}25.1 \\
\% \\
25.8\end{array}$ & $\begin{array}{l}125 . \\
5 \% \\
142 .\end{array}$ & 1.03 & $\overline{-} 0.08$ & $\overline{7}-8 \%$ & $\begin{array}{l}109 . \\
3 \% \\
0.0\end{array}$ \\
\hline Islander Alone & 1.14 & 0.29 & $\%$ & $1 \%$ & 1.14 & 0.00 & $0.0 \%$ & $\begin{array}{l}\% \\
-\end{array}$ \\
\hline Native American & & & 58.4 & 244. & & - & - & 10.5 \\
\hline Alone & 0.86 & 0.50 & $\%$ & $\begin{array}{l}0 \% \\
-\end{array}$ & 0.86 & 0.01 & $0.9 \%$ & $\begin{array}{l}\% \\
-\end{array}$ \\
\hline All Other Races & & - & - & 21.8 & & - & - & 63.4 \\
\hline Alone & 0.84 & 0.05 & $\begin{array}{l}5.3 \% \\
19.8\end{array}$ & $\%$ & 0.84 & 0.05 & $5.5 \%$ & $\%$ \\
\hline TotalPopulation & 1.05 & 0.21 & $\%$ & & 1.05 & 0.07 & $7.0 \%$ & \\
\hline
\end{tabular}

Table 6A.4B High MA: BRT.

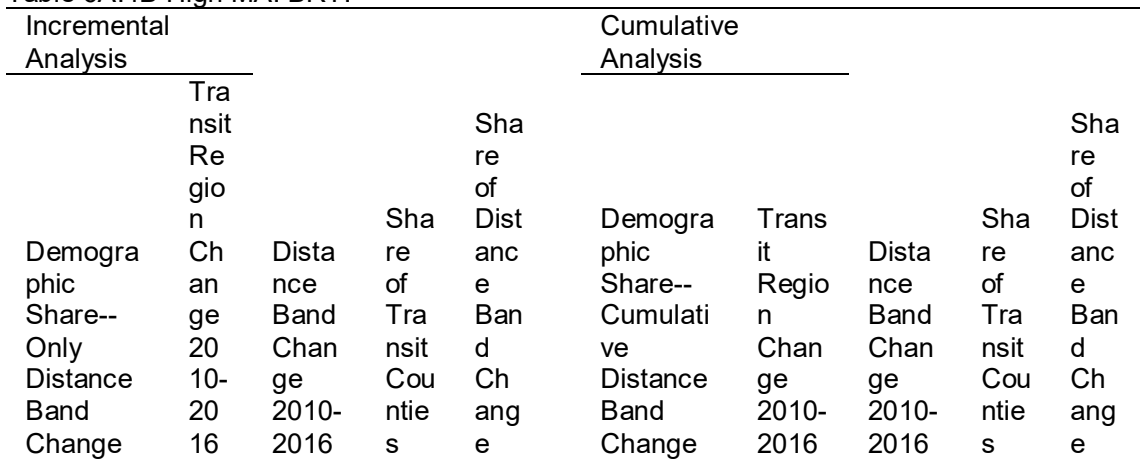




\begin{tabular}{|c|c|c|c|c|c|c|c|c|c|}
\hline \multirow{2}{*}{\multicolumn{5}{|c|}{$\begin{array}{l}\text { Spatial Share--0.125 Mile } \\
\text { Distance Band Only }\end{array}$}} & \\
\hline & & & & & & & \multicolumn{3}{|c|}{$\begin{array}{l}\text { Spatial Share--0.125 Mile } \\
\text { Distance Band Only }\end{array}$} \\
\hline Station & 14 & 4.422 & & & Station & & 4.422 & & \\
\hline Area & 20 & 1530 & 0.0 & & Area & 1420 & 1530 & 0.0 & \\
\hline (sq.mi.) & 1 & 15 & $\%$ & & (sq.mi.) & 1 & 15 & $\%$ & \\
\hline \multicolumn{5}{|c|}{ Basic Demographics--0.125 Mile } & \multicolumn{5}{|c|}{ Basic Demographics--0.125 Mile } \\
\hline \multicolumn{5}{|c|}{ Distance Band Only } & \multicolumn{5}{|c|}{ Distance Band Only } \\
\hline \multicolumn{5}{|l|}{ White } & \multicolumn{5}{|l|}{ White } \\
\hline Non & & & 5.9 & 60. & Non & & & 5.9 & 60. \\
\hline Latino & & & $\%$ & $5 \%$ & Latino & & & $\%$ & $5 \%$ \\
\hline Other & & & & & Other & & & & \\
\hline Non & & & 13. & 146 & Non & & & 13. & 146 \\
\hline Latino & & & $3 \%$ & $.6 \%$ & Latino & & & $3 \%$ & $.6 \%$ \\
\hline Other & & & 9.9 & 109 & Other & & & 9.9 & 109 \\
\hline Groups & & & $\%$ & $.9 \%$ & Groups & & & $\%$ & $.9 \%$ \\
\hline TotalPop & & & 9.4 & 0.0 & TotalPop & & & 9.4 & 0.0 \\
\hline ulation & & & $\%$ & $\%$ & ulation & & & $\%$ & $\%$ \\
\hline White & & & & & White & & & & \\
\hline Non & & & 5.9 & 60. & Non & & & 5.9 & 60. \\
\hline Latino & & & $\%$ & $5 \%$ & Latino & & & $\%$ & $5 \%$ \\
\hline & & & 8.5 & 93. & & & & 8.5 & 93. \\
\hline Hispanic & & & $\%$ & $6 \%$ & Hispanic & & & $\%$ & $6 \%$ \\
\hline Other & & & & & Other & & & & \\
\hline Non & & & 13. & 146 & Non & & & 13. & 146 \\
\hline Latino & & & $3 \%$ & $.6 \%$ & Latino & & & $3 \%$ & $.6 \%$ \\
\hline Other & & & 21. & 263 & Other & & & 21. & 263 \\
\hline Groups & & & $5 \%$ & $.6 \%$ & Groups & & & $5 \%$ & $.6 \%$ \\
\hline TotalPop & & & 9.4 & 0.0 & TotalPop & & & 9.4 & 0.0 \\
\hline ulation & & & $\%$ & $\%$ & ulation & & & $\%$ & $\%$ \\
\hline White & & & 18. & 197 & White & & & 18. & 197 \\
\hline Alone & & & $1 \%$ & $.2 \%$ & Alone & & & $1 \%$ & $.2 \%$ \\
\hline Black & & & 0.0 & 0.2 & Black & & & 0.0 & 0.2 \\
\hline Alone & & & $\%$ & $\%$ & Alone & & & $\%$ & $\%$ \\
\hline Asian an & & & & & & & & & \\
\hline Pacific Is & der & & 21. & 247 & Asian anc & Pacific & & 21. & 247 \\
\hline Alone & & & $4 \%$ & $.8 \%$ & Islander $A$ & & & $4 \%$ & $.8 \%$ \\
\hline & & & - & - & & & & - & - \\
\hline Native $\mathrm{Ar}$ & ican & & 11. & 98. & Native An & rican & & 11. & 98. \\
\hline Alone & & & $2 \%$ & $6 \%$ & Alone & & & $2 \%$ & $6 \%$ \\
\hline & & & - & - & & & & - & - \\
\hline All Other & ces & & 28. & 243 & All Other & aces & & 28. & 243 \\
\hline Alone & & & $4 \%$ & $.8 \%$ & Alone & & & $4 \%$ & $.8 \%$ \\
\hline TotalPop & & & 9.4 & 0.0 & TotalPop & & & 9.4 & 0.0 \\
\hline ulation & & & $\%$ & $\%$ & ulation & & & $\%$ & $\%$ \\
\hline$\overline{\text { Spatial S }}$ & $e-0$ & 5 Mile & & & Spatial SI & re--0.2 & Mile & & \\
\hline Distance & nd $\mathrm{C}$ & & & & Distance & and Cur & ılative & & \\
\hline Station & 14 & 6.762 & & & Station & & 11.18 & & \\
\hline Area & 20 & 7159 & 0.0 & & Area & 1420 & 4868 & 0.1 & \\
\hline (sq.mi.) & 1 & 07 & $\%$ & & (sq.mi.) & & 92 & $\%$ & \\
\hline Demogra & ${ }_{C} \mathrm{Ch}$ & ge--0.2 & Mile & & Demogra & ic Char & $e--0.25$ & iile & \\
\hline Distance & nd $\mathrm{C}$ & & & & Distance & and Cur & ulative & & \\
\hline White & & & & & White & & & & \\
\hline Non & & & 16. & 98. & Non & & & 0.6 & 9.2 \\
\hline Latino & & & $9 \%$ & $8 \%$ & Latino & & & $\%$ & $\%$ \\
\hline Other & & & & & Other & & & & \\
\hline Non & & & 15. & 96. & Non & & & 10. & 168 \\
\hline Latino & & & $4 \%$ & $8 \%$ & Latino & & & $0 \%$ & $.5 \%$ \\
\hline & & & & & & & & - & - \\
\hline Other & & & 16. & 103 & Other & & & 16. & 275 \\
\hline Groups & & & $4 \%$ & $.8 \%$ & Groups & & & $1 \%$ & $.9 \%$ \\
\hline TotalPop & & & 16. & 0.0 & TotalPop & & & 6.1 & 0.0 \\
\hline ulation & & & $5 \%$ & $\%$ & ulation & & & $\%$ & $\%$ \\
\hline White & & & & & White & & & & \\
\hline Non & & & 16. & 98. & Non & & & 0.6 & 9.2 \\
\hline Latino & & & $9 \%$ & $8 \%$ & Latino & & & $\%$ & $\%$ \\
\hline & & & & & & & & - & - \\
\hline & & & 17. & 109 & & & & 3.1 & 52. \\
\hline Hispanic & & & $6 \%$ & $.9 \%$ & Hispanic & & & $\%$ & $4 \%$ \\
\hline
\end{tabular}




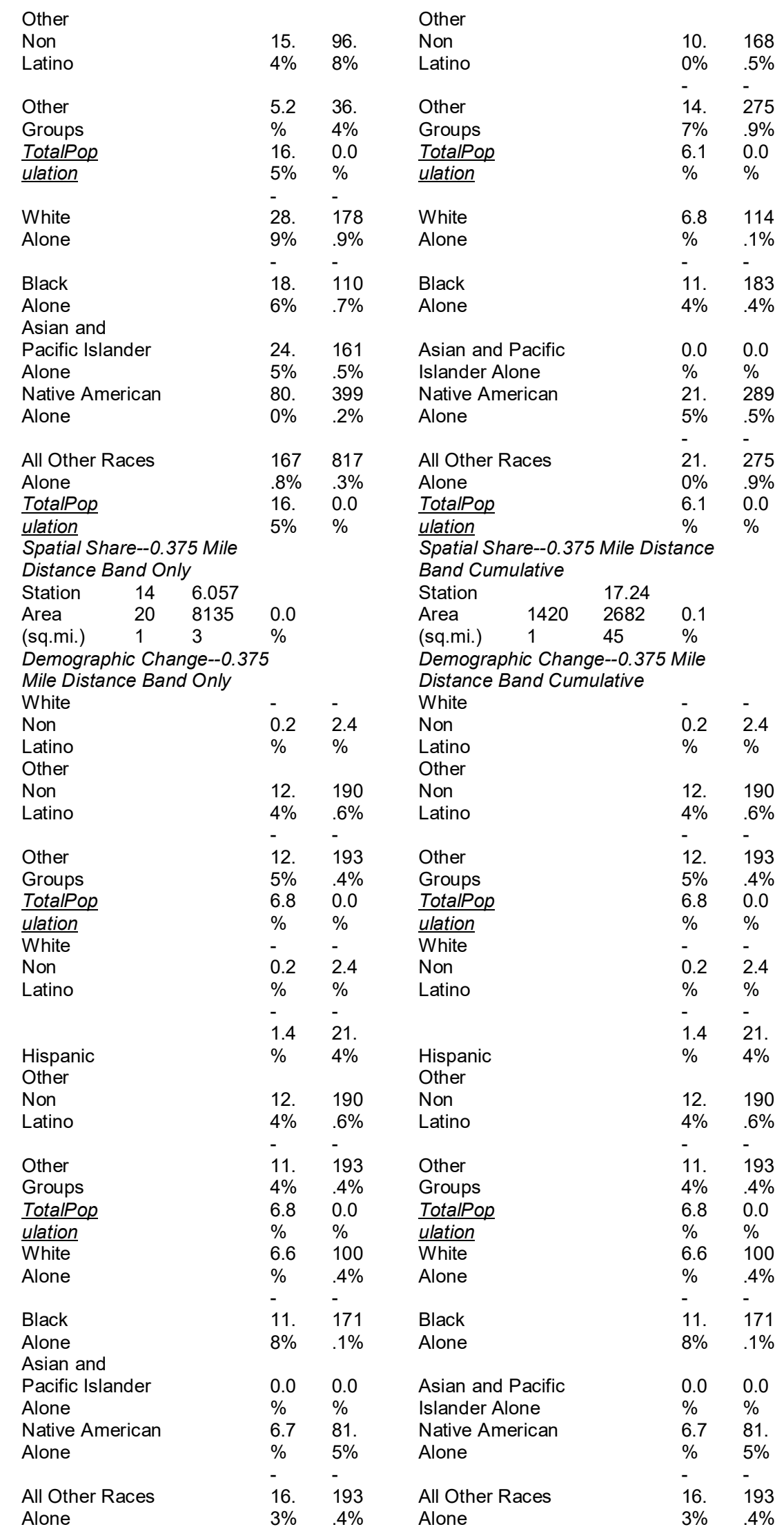




\begin{tabular}{|c|c|c|c|c|c|c|c|c|c|}
\hline TotalPop & & & 6.8 & 0.0 & TotalPop & & & 6.8 & 0.0 \\
\hline ulation & & & $\%$ & $\%$ & ulation & & & $\%$ & $\%$ \\
\hline$\overline{\text { Spatial S }}$ & re--o & Mile & & & $\overline{\text { Spatial S }}$ & re--0.5 & Mile & & \\
\hline Distance & and $C$ & & & & Distance & and $\mathrm{Cu}$ & llative & & \\
\hline Station & 14 & 5.012 & & & Station & & 22.25 & & \\
\hline Area & 20 & 4486 & 0.0 & & Area & 1420 & 5131 & 0.2 & \\
\hline (sq.mi.) & 1 & 75 & $4 \%$ & & (sq.mi.) & & 13 & $\%$ & \\
\hline Demogra & ic $\mathrm{Cl}$ & $g e--0.5$ & Mile & & Demogra & ic Cha & $e--0.50$ & & \\
\hline Distance & and $C$ & & & & Distance & and $\mathrm{Cu}$ & llative & & \\
\hline White & & & & & White & & & - & - \\
\hline Non & & & 9.3 & 59. & Non & & & 0.5 & 6.3 \\
\hline Latino & & & $\%$ & $5 \%$ & Latino & & & $\%$ & $\%$ \\
\hline Other & & & & & Other & & & & \\
\hline Non & & & 14. & 98. & Non & & & 14. & 211 \\
\hline Latino & & & $2 \%$ & $3 \%$ & Latino & & & $8 \%$ & $.1 \%$ \\
\hline & & & & & & & & $\overline{0}$ & \\
\hline Other & & & 23. & 162 & Other & & & 8.7 & 125 \\
\hline Groups & & & $3 \%$ & $.4 \%$ & Groups & & & $\%$ & $.1 \%$ \\
\hline TotalPop & & & 15. & 0.0 & TotalPop & & & 7.3 & 0.0 \\
\hline ulation & & & $0 \%$ & $\%$ & ulation & & & $\%$ & $\%$ \\
\hline White & & & & & White & & & - & - \\
\hline Non & & & 9.3 & 59. & Non & & & 0.5 & 6.3 \\
\hline Latino & & & $\%$ & $5 \%$ & Latino & & & $\%$ & $\%$ \\
\hline & & & 22. & 151 & & & & 0.8 & 11. \\
\hline Hispanic & & & $0 \%$ & $.3 \%$ & Hispanic & & & $\%$ & $9 \%$ \\
\hline Other & & & & & Other & & & & \\
\hline Non & & & 14. & 98. & Non & & & 14. & 211 \\
\hline Latino & & & $2 \%$ & $3 \%$ & Latino & & & $8 \%$ & $.1 \%$ \\
\hline & & & & & & & & - & - \\
\hline Other & & & 33. & 254 & Other & & & 7.9 & 125 \\
\hline Groups & & & $1 \%$ & $.3 \%$ & Groups & & & $\%$ & $.1 \%$ \\
\hline TotalPop & & & 15. & 0.0 & TotalPop & & & 7.3 & 0.0 \\
\hline ulation & & & $0 \%$ & $\%$ & ulation & & & $\%$ & $\%$ \\
\hline White & & & 18. & 126 & White & & & 5.8 & 81. \\
\hline Alone & & & $6 \%$ & $.5 \%$ & Alone & & & $\%$ & $5 \%$ \\
\hline Black & & & 3.8 & 24. & Black & & & 10. & 148 \\
\hline Alone & & & $\%$ & $8 \%$ & Alone & & & $9 \%$ & $.4 \%$ \\
\hline Asian an & & & & & & & & & \\
\hline Pacific Is & der & & 24. & 176 & Asian an & Pacific & & 0.0 & 0.0 \\
\hline Alone & & & $4 \%$ & $.9 \%$ & Islander & ne & & $\%$ & $\%$ \\
\hline Native $A_{1}$ & rican & & 12. & 67. & Native $A$ & rican & & 7.2 & 82. \\
\hline Alone & & & $3 \%$ & $6 \%$ & Alone & & & $\%$ & $3 \%$ \\
\hline & & & & & & & & - & - \\
\hline All Other & aces & & 4.4 & 23. & All Other & aces & & 11. & 125 \\
\hline Alone & & & $\%$ & $4 \%$ & Alone & & & $3 \%$ & $.1 \%$ \\
\hline TotalPop & & & 15. & 0.0 & TotalPop & & & 7.3 & 0.0 \\
\hline ulation & & & $0 \%$ & $\%$ & ulation & & & $\%$ & $\%$ \\
\hline Spatial S & re--o & Mile & & & $\overline{\text { Spatial S }}$ & re--0.7 & Mile & & \\
\hline Distance & and $C$ & & & & Distance & and $\mathrm{Cu}$ & llative & & \\
\hline Station & 14 & 7.590 & & & Station & & 29.84 & & \\
\hline Area & & 4574 & 0.1 & & Area & 1420 & 5588 & 0.2 & \\
\hline (sq.mi.) & 1 & 78 & $\%$ & & (sq.mi.) & & 61 & $\%$ & \\
\hline Demogra & ic $\mathrm{Cl}$ & $g e--0.7$ & Mile & & Demogra & ic Cha & $e--0.75$ & & \\
\hline Distance & and $C$ & & & & Distance & and $\mathrm{Cu}$ & llative & & \\
\hline White & & & & & White & & & & \\
\hline Non & & & 25. & 323 & Non & & & 0.4 & 6.2 \\
\hline Latino & & & $2 \%$ & $.3 \%$ & Latino & & & $\%$ & $\%$ \\
\hline Other & & & & & Other & & & & \\
\hline Non & & & 10. & 144 & Non & & & 25. & 405 \\
\hline Latino & & & $5 \%$ & $.9 \%$ & Latino & & & $8 \%$ & $.1 \%$ \\
\hline & & & - & - & & & & - & - \\
\hline Other & & & 6.9 & 95. & Other & & & 7.1 & 113 \\
\hline Groups & & & $\%$ & $8 \%$ & Groups & & & $\%$ & $.2 \%$ \\
\hline TotalPop & & & 7.5 & 0.0 & TotalPop & & & 6.6 & 0.0 \\
\hline ulation & & & $\%$ & $\%$ & ulation & & & $\%$ & $\%$ \\
\hline White & & & & & White & & & & \\
\hline Non & & & 25. & 323 & Non & & & 0.4 & 6.2 \\
\hline Latino & & & $2 \%$ & $.3 \%$ & Latino & & & $\%$ & $\%$ \\
\hline
\end{tabular}




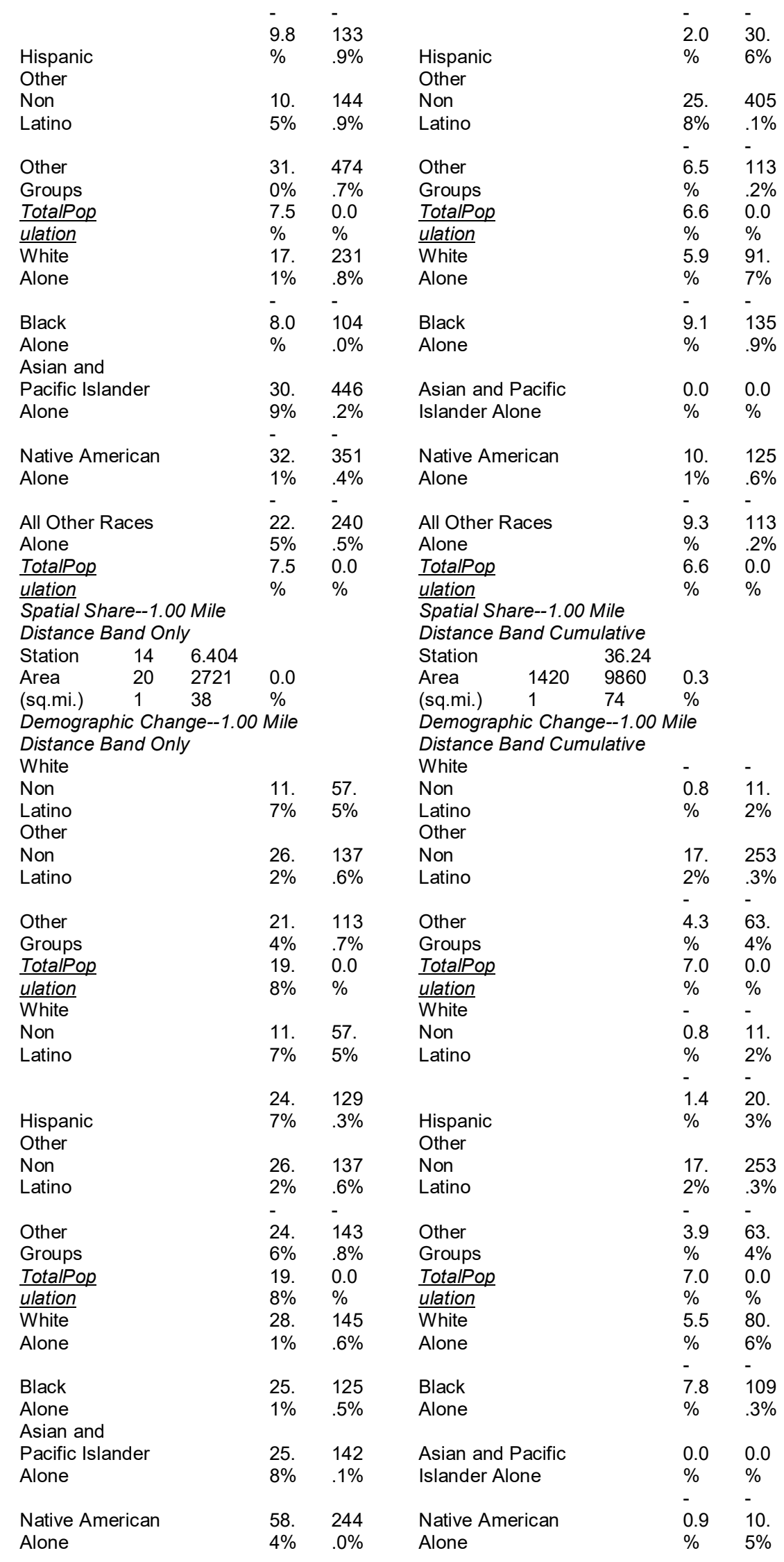




\begin{tabular}{llllll} 
All Other Races & - & - & & - & - \\
Alone & 5.3 & 21. & All Other Races & 5.5 & 63. \\
TotalPop & $\%$ & $8 \%$ & Alone & $\%$ & $4 \%$ \\
ulation & 19. & 0.0 & $\underline{\text { TotalPop }}$ & 7.0 & 0.0 \\
\hline
\end{tabular}

Table 6A.5A Poor

MA: CRT.

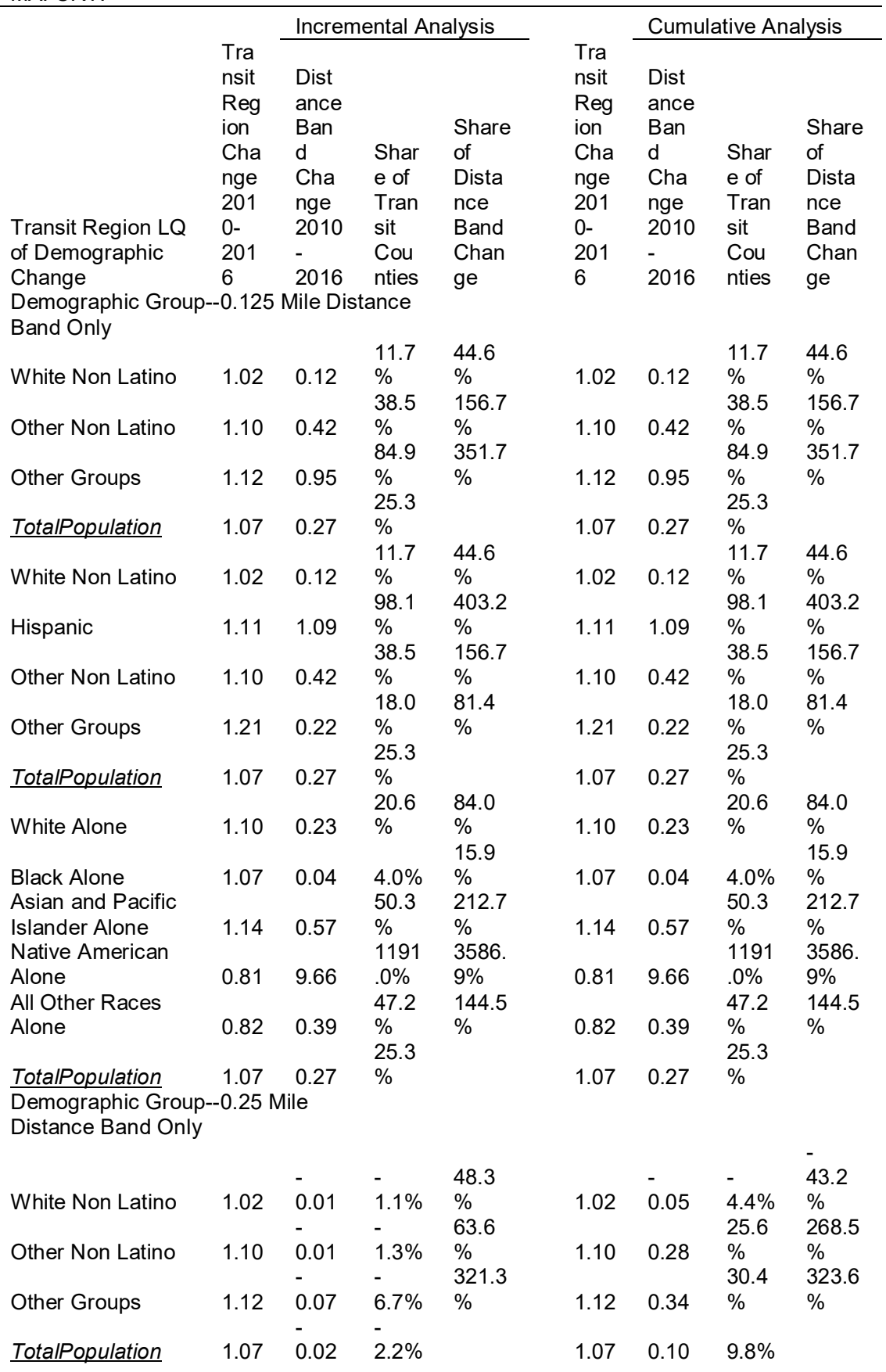




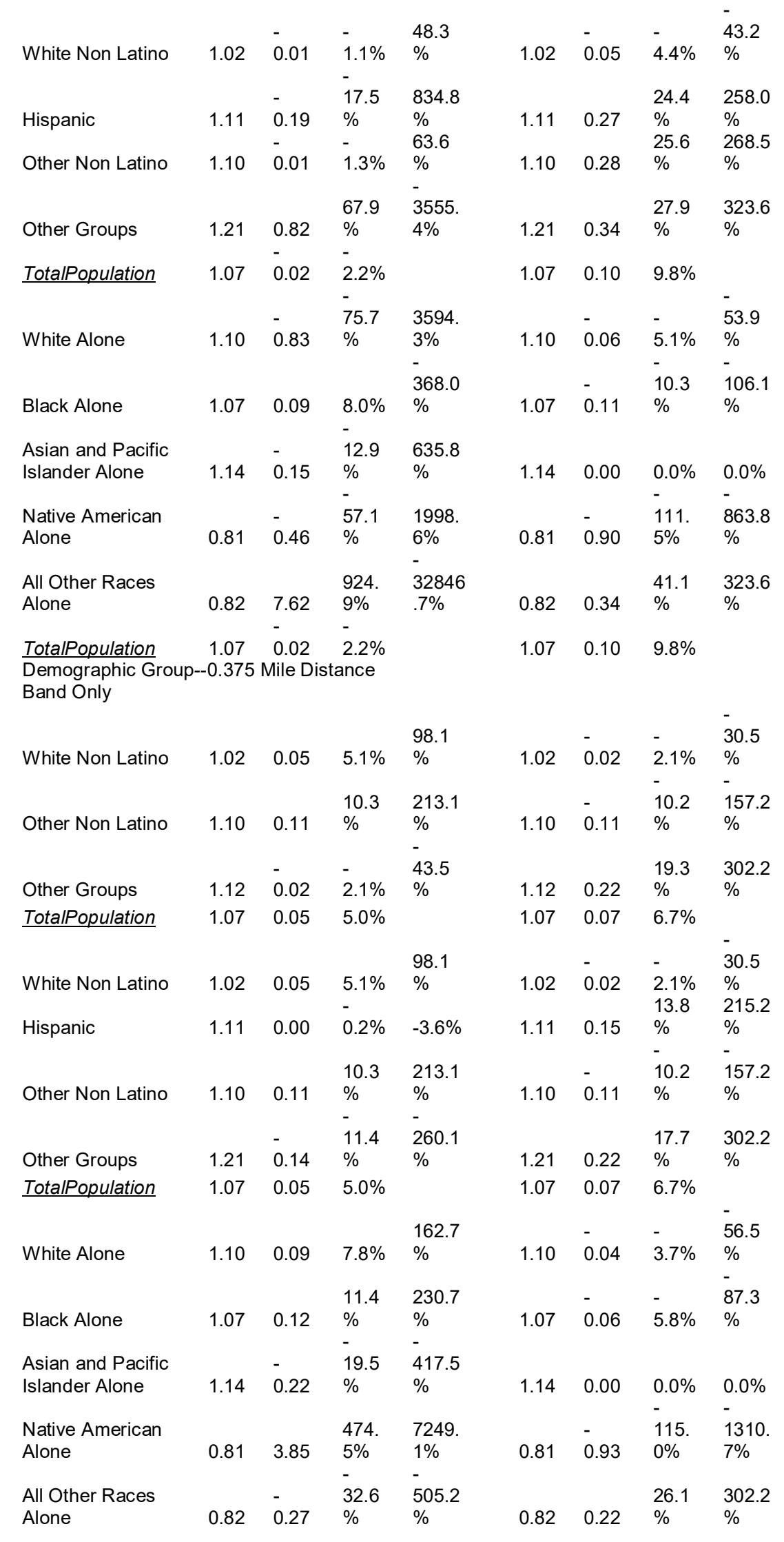




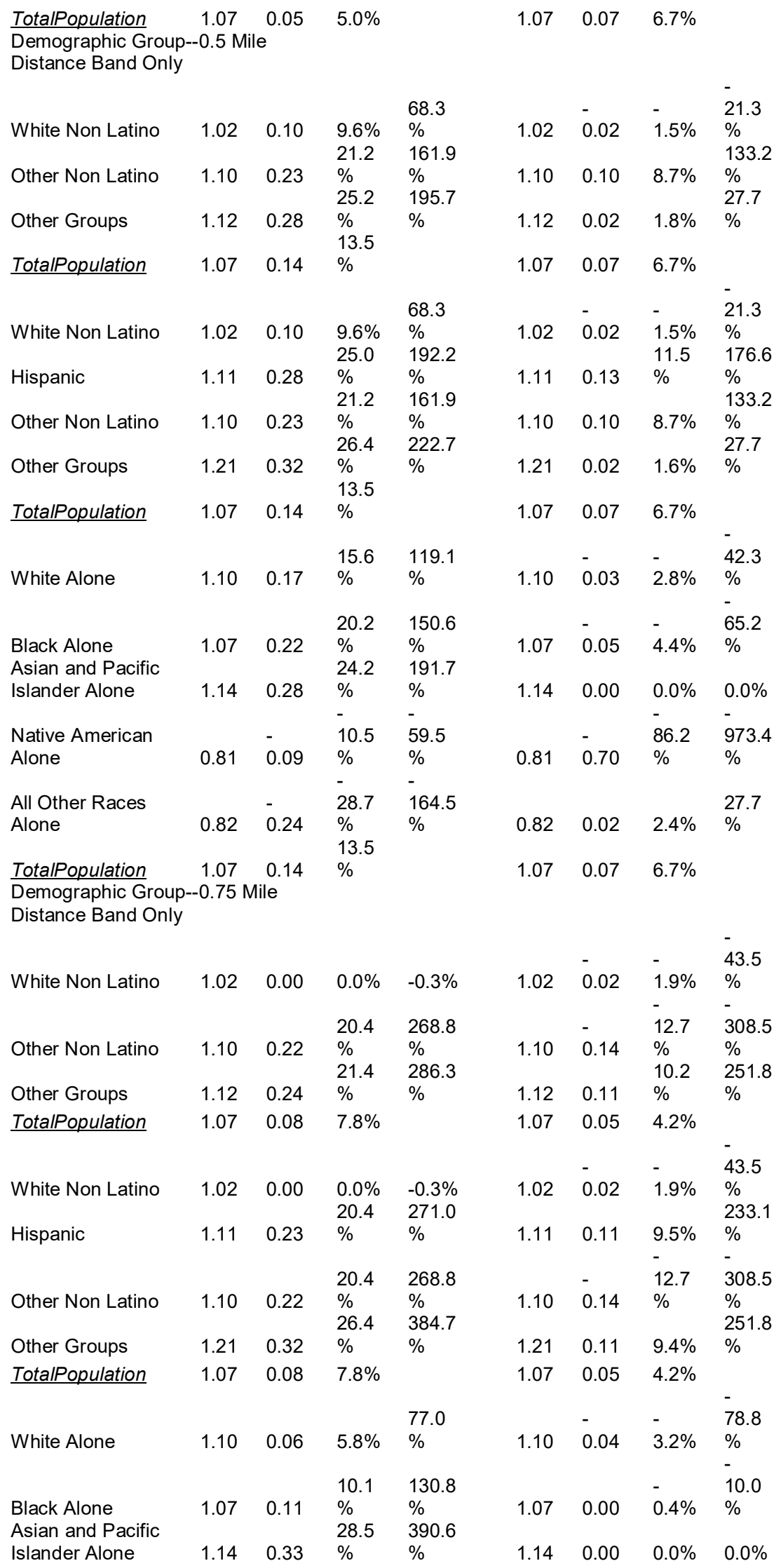




\begin{tabular}{|c|c|c|c|c|c|c|c|c|}
\hline & & & - & - & & & - & - \\
\hline Native American & & - & 57.4 & 559.8 & & - & 13.8 & 247.3 \\
\hline $\begin{array}{l}\text { Alone } \\
\text { All Other Races }\end{array}$ & 0.81 & 0.47 & $\%$ & $\begin{array}{l}\% \\
44.5\end{array}$ & 0.81 & 0.11 & $\begin{array}{l}\% \\
13.8\end{array}$ & $\begin{array}{l}\% \\
251.8\end{array}$ \\
\hline Alone & 0.82 & 0.04 & $4.5 \%$ & $\%$ & 0.82 & 0.11 & $\%$ & $\%$ \\
\hline TotalPopulation & 1.07 & 0.08 & $7.8 \%$ & & 1.07 & 0.05 & $4.2 \%$ & \\
\hline $\begin{array}{l}\text { Demographic Group } \\
\text { Distance Band Only }\end{array}$ & -1.00 I & ile & & & & & & \\
\hline White Non Latino & 1.02 & 0.01 & $1.0 \%$ & $\begin{array}{l}11.4 \\
\%\end{array}$ & 1.02 & $\overline{-}-01$ & $-\overline{0} \%$ & $\begin{array}{l}789.4 \\
\%\end{array}$ \\
\hline Other Non Latino & 1.10 & 0.10 & $9.0 \%$ & $\begin{array}{l}110.8 \\
\%\end{array}$ & 1.10 & $-\overline{0}$ & $\begin{array}{l}18.4 \\
\%\end{array}$ & $\begin{array}{l}30479 \\
.0 \% \\
-\end{array}$ \\
\hline Other Groups & 1.12 & 0.40 & $\begin{array}{l}36.1 \\
\%\end{array}$ & $\begin{array}{l}452.7 \\
\%\end{array}$ & 1.12 & 0.15 & $\begin{array}{l}13.1 \\
\% \\
-\end{array}$ & $\begin{array}{l}22121 \\
.4 \%\end{array}$ \\
\hline TotalPopulation & 1.07 & 0.09 & $8.4 \%$ & & 1.07 & 0.00 & $0.1 \%$ & \\
\hline White Non Latino & 1.02 & 0.01 & $1.0 \%$ & $\begin{array}{l}11.4 \\
\%\end{array}$ & 1.02 & $\overline{0} 0.01$ & $\overline{0} .5 \%$ & $\begin{array}{l}789.4 \\
\% \\
-\end{array}$ \\
\hline Hispanic & 1.11 & 0.44 & $\begin{array}{l}39.7 \\
\%\end{array}$ & $\begin{array}{l}493.7 \\
\%\end{array}$ & 1.11 & 0.06 & $\begin{array}{l}5.1 \% \\
-\end{array}$ & $\begin{array}{l}8509 . \\
0 \%\end{array}$ \\
\hline Other Non Latino & 1.10 & 0.10 & $9.0 \%$ & $\begin{array}{l}110.8 \\
\%\end{array}$ & 1.10 & $\overline{-}-20$ & $\begin{array}{l}18.4 \\
\%\end{array}$ & $\begin{array}{l}30479 \\
.0 \% \\
-\end{array}$ \\
\hline Other Groups & 1.21 & 0.18 & $\begin{array}{l}14.4 \\
\%\end{array}$ & $\begin{array}{l}196.6 \\
\%\end{array}$ & 1.21 & 0.15 & $\begin{array}{l}12.1 \\
\% \\
-\end{array}$ & $\begin{array}{l}22121 \\
.4 \%\end{array}$ \\
\hline$\underline{\text { TotalPopulation }}$ & 1.07 & 0.09 & $8.4 \%$ & 90.4 & 1.07 & 0.00 & $0.1 \%$ & 4640. \\
\hline White Alone & 1.10 & 0.08 & $7.3 \%$ & $\%$ & 1.10 & 0.03 & $2.8 \%$ & $\begin{array}{l}7 \% \\
-\end{array}$ \\
\hline $\begin{array}{l}\text { Black Alone } \\
\text { Asian and Pacific }\end{array}$ & 1.07 & 0.13 & $\begin{array}{l}12.6 \\
\%\end{array}$ & $\begin{array}{l}151.5 \\
\% \\
27.5\end{array}$ & 1.07 & 0.01 & $0.5 \%$ & $\begin{array}{l}766.1 \\
\%\end{array}$ \\
\hline Islander Alone & 1.14 & 0.02 & $\begin{array}{l}2.1 \% \\
-\end{array}$ & $\%$ & 1.14 & 0.00 & $0.0 \%$ & $0.0 \%$ \\
\hline Native American & & - & 45.8 & 417.3 & & - & 42.3 & 51809 \\
\hline Alone & 0.81 & 0.37 & $\%$ & $\%$ & 0.81 & 0.34 & $\%$ & $\begin{array}{l}.9 \% \\
-\end{array}$ \\
\hline $\begin{array}{l}\text { All Other Races } \\
\text { Alone }\end{array}$ & 0.82 & 0.18 & $\begin{array}{l}21.8 \\
\%\end{array}$ & $\begin{array}{l}201.9 \\
\%\end{array}$ & 0.82 & 0.15 & $\begin{array}{l}17.8 \\
\%\end{array}$ & $\begin{array}{l}22121 \\
.4 \%\end{array}$ \\
\hline TotalPopulation & 1.07 & 0.09 & $8.4 \%$ & & 1.07 & 0.00 & $0.1 \%$ & \\
\hline
\end{tabular}


Table 6A.5B Poor MA: CRT.

\begin{tabular}{|c|c|c|c|c|c|c|c|c|c|}
\hline \multicolumn{2}{|c|}{$\begin{array}{l}\text { Incremental } \\
\text { Analysis }\end{array}$} & & & & \multicolumn{4}{|c|}{$\begin{array}{l}\text { Cumulative } \\
\text { Analvsis }\end{array}$} & \multirow{3}{*}{$\begin{array}{l}\text { Shar } \\
\text { e of }\end{array}$} \\
\hline & \multirow{2}{*}{\multicolumn{2}{|c|}{$\begin{array}{l}\text { Tran } \\
\text { sit }\end{array}$}} & & Shar & & Tran & \multirow[b]{3}{*}{$\begin{array}{l}\text { Dista } \\
\text { nce }\end{array}$} & \multirow[b]{2}{*}{ Sh } & \\
\hline & & & Sh & e of & Demogr & sit & & & \\
\hline $\begin{array}{l}\text { Demogr } \\
\text { aphic }\end{array}$ & $\begin{array}{l}\text { Regi } \\
\text { on }\end{array}$ & $\begin{array}{l}\text { Dista } \\
\text { nce }\end{array}$ & $\begin{array}{l}\text { are } \\
\text { of }\end{array}$ & $\begin{array}{l}\text { Dist } \\
\text { anc }\end{array}$ & $\begin{array}{l}\text { aphic } \\
\text { Share-- }\end{array}$ & $\begin{array}{l}\text { Regi } \\
\text { on }\end{array}$ & & $\begin{array}{l}\text { are } \\
\text { of }\end{array}$ & $\begin{array}{l}\text { Dist } \\
\text { anc }\end{array}$ \\
\hline Share-- & Cha & Band & Tra & $\mathrm{e}$ & Cumulati & Cha & Band & Tra & $\mathrm{e}$ \\
\hline Only & nge & Chan & nsit & Ban & ve & nge & Chan & nsit & Ban \\
\hline Distance & 2010 & ge & Co & $d$ & Distance & 2010 & ge & Co & $d$ \\
\hline Band & - & $2010-$ & unti & Cha & Band & - & $2010-$ & unti & Cha \\
\hline ChangB & 2016 & 2016 & es & nge & Change & 2016 & 2016 & es & nge \\
\hline \multicolumn{5}{|c|}{ Spatial Share--0.125 Mile } & \multicolumn{5}{|c|}{ Spatial Share--0.125 Mile } \\
\hline \multicolumn{5}{|c|}{ Distance Band Only } & \multicolumn{5}{|c|}{ Distance Band Only } \\
\hline \multicolumn{5}{|l|}{ Station } & \multicolumn{5}{|c|}{ Station } \\
\hline Area & 4170 & & 0.0 & & Area & 4170 & & 0.0 & \\
\hline (sq.mi.) & & 10 & $2 \%$ & & (sq.mi.) & & 10 & $2 \%$ & \\
\hline Basic Der & & & Mile & & Basic De & ograph & $s-0.12$ & Mile & \\
\hline Distance & and Or & & & & Distance & and On & & & \\
\hline White & & & & & White & & & & \\
\hline Non & & & 11. & 44.6 & Non & & & 11. & 44.6 \\
\hline Latino & & & $7 \%$ & $\%$ & Latino & & & $7 \%$ & $\%$ \\
\hline Other & & & & & Other & & & & \\
\hline Non & & & 38. & 156. & Non & & & 38. & 156. \\
\hline Latino & & & $5 \%$ & $7 \%$ & Latino & & & $5 \%$ & $7 \%$ \\
\hline Other & & & 84. & 351. & Other & & & 84. & 351. \\
\hline Groups & & & $9 \%$ & $7 \%$ & Groups & & & $9 \%$ & $7 \%$ \\
\hline TotalPop & & & 25. & 0.0 & TotalPop & & & 25. & 0.0 \\
\hline$\overline{\text { ulation }}$ & & & $3 \%$ & $\%$ & $\overline{\text { ulation }}$ & & & $3 \%$ & $\%$ \\
\hline$\overline{\text { White }}$ & & & & & $\overline{\text { White }}$ & & & & \\
\hline Non & & & 11. & 44.6 & Non & & & 11. & 44.6 \\
\hline Latino & & & $7 \%$ & $\%$ & Latino & & & $7 \%$ & $\%$ \\
\hline & & & 98. & 403. & & & & 98. & 403. \\
\hline Hispanic & & & $1 \%$ & $2 \%$ & Hispanic & & & $1 \%$ & $2 \%$ \\
\hline Other & & & & & Other & & & & \\
\hline Non & & & 38. & 156. & Non & & & 38. & 156. \\
\hline Latino & & & $5 \%$ & $7 \%$ & Latino & & & $5 \%$ & $7 \%$ \\
\hline Other & & & 18. & 81.4 & Other & & & 18. & 81.4 \\
\hline Groups & & & $0 \%$ & $\%$ & Groups & & & $0 \%$ & $\%$ \\
\hline TotalPop & & & 25. & 0.0 & TotalPop & & & 25. & 0.0 \\
\hline ulation & & & $3 \%$ & $\%$ & ulation & & & $3 \%$ & $\%$ \\
\hline White & & & 20. & 84.0 & $\overline{\text { White }}$ & & & 20. & 84.0 \\
\hline Alone & & & $6 \%$ & $\%$ & Alone & & & $6 \%$ & $\%$ \\
\hline Black & & & 4.0 & 15.9 & Black & & & 4.0 & 15.9 \\
\hline Alone & & & $\%$ & $\%$ & Alone & & & $\%$ & $\%$ \\
\hline Asian anc & Dacific & & 50. & 212. & Asian an & Pacific & & 50. & 212. \\
\hline Islander $A$ & one & & $3 \%$ & $7 \%$ & Islander & one & & $3 \%$ & $7 \%$ \\
\hline & & & 119 & 358 & & & & 119 & 358 \\
\hline Native An & erican & & 1.0 & 6.9 & Native $\mathrm{Ar}$ & erican & & 1.0 & 6.9 \\
\hline Alone & & & $\%$ & $\%$ & Alone & & & $\%$ & $\%$ \\
\hline All Other & aces & & 47. & 144. & All Other & aces & & 47. & 144. \\
\hline Alone & & & $2 \%$ & $5 \%$ & Alone & & & $2 \%$ & $5 \%$ \\
\hline TotalPop & & & 25. & 0.0 & TotalPop & & & 25. & 0.0 \\
\hline ulation & & & $3 \%$ & $\%$ & ulation & & & $3 \%$ & $\%$ \\
\hline & & & & & Spatial S & are--0.2 & Mile & & \\
\hline Spatial SI & are-- 0.2 & Mile & & & Distance & and & & & \\
\hline Distance & and $\mathrm{Or}$ & & & & Cumulati & & & & \\
\hline Station & & & & & Station & & & & \\
\hline Area & 4170 & & 0.1 & & Area & 4170 & & 0.1 & \\
\hline (sq.mi.) & 3 & 30 & $\%$ & & (sq.mi.) & & 40 & $\%$ & \\
\hline Demogra & hic Cha & $g e--0.2$ & Mile & & Demogra & hic Cha & $g e--0.2$ & Mile & \\
\hline Distance & and $\mathrm{Or}$ & & & & Distance & and $\mathrm{Cu}$ & nulative & & \\
\hline White & & & - & & White & & & - & - \\
\hline Non & & & 1.1 & 48.3 & Non & & & 4.4 & 43.2 \\
\hline Latino & & & $\%$ & $\%$ & Latino & & & $\%$ & $\%$ \\
\hline Other & & & - & & Other & & & & \\
\hline Non & & & 1.3 & 63.6 & Non & & & 25. & 268. \\
\hline Latino & & & $\%$ & $\%$ & Latino & & & $6 \%$ & $5 \%$ \\
\hline
\end{tabular}




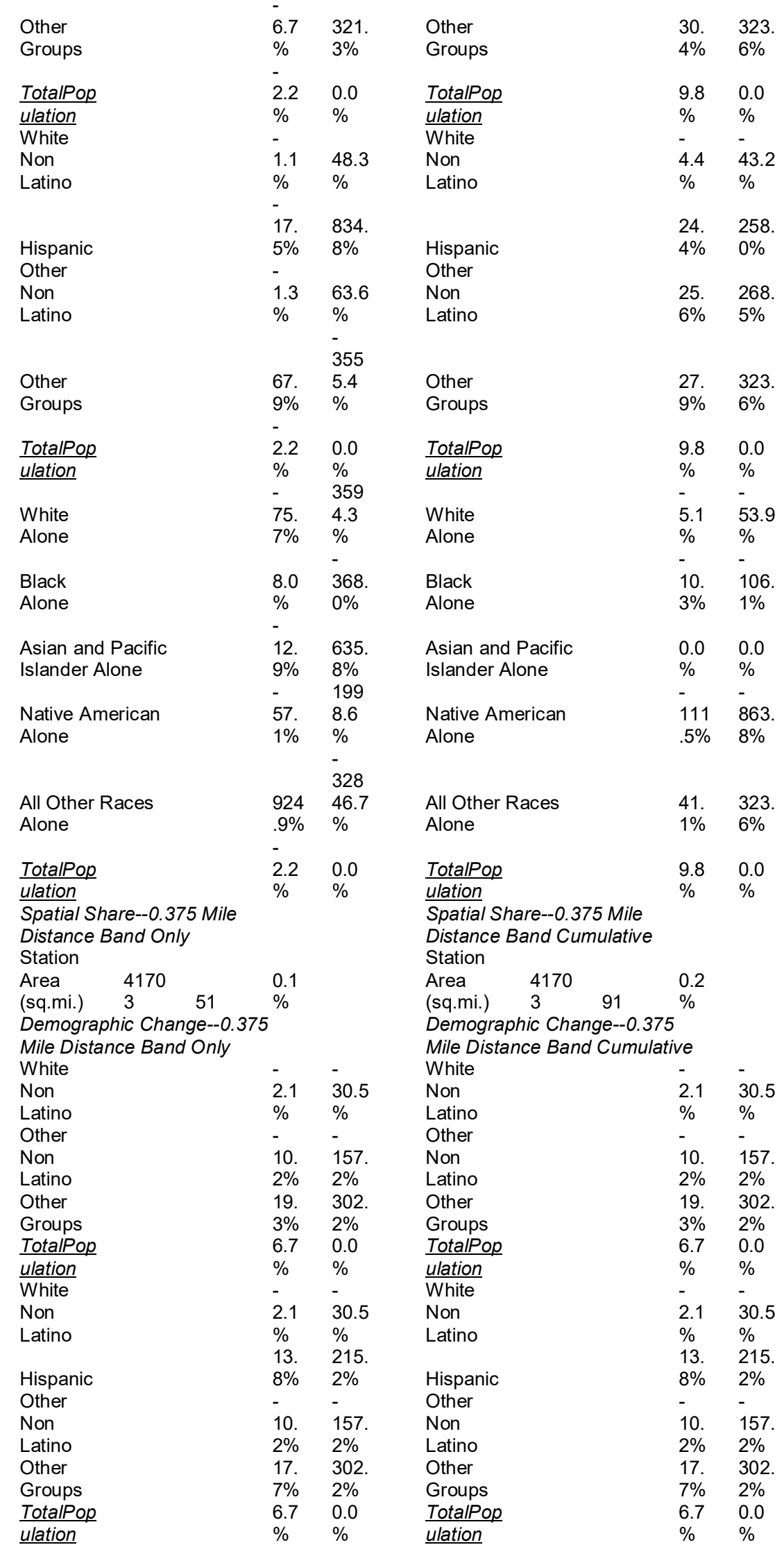




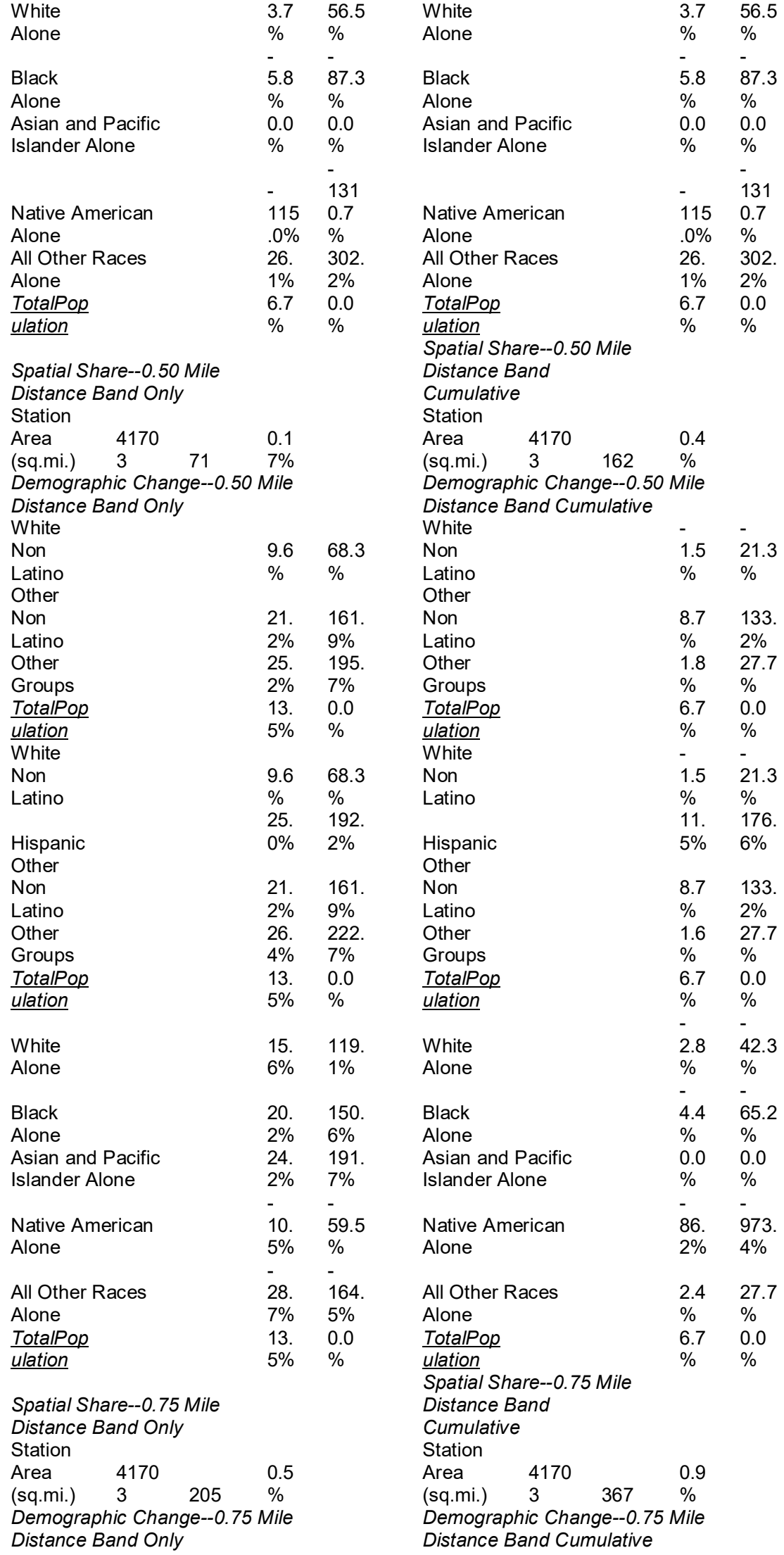




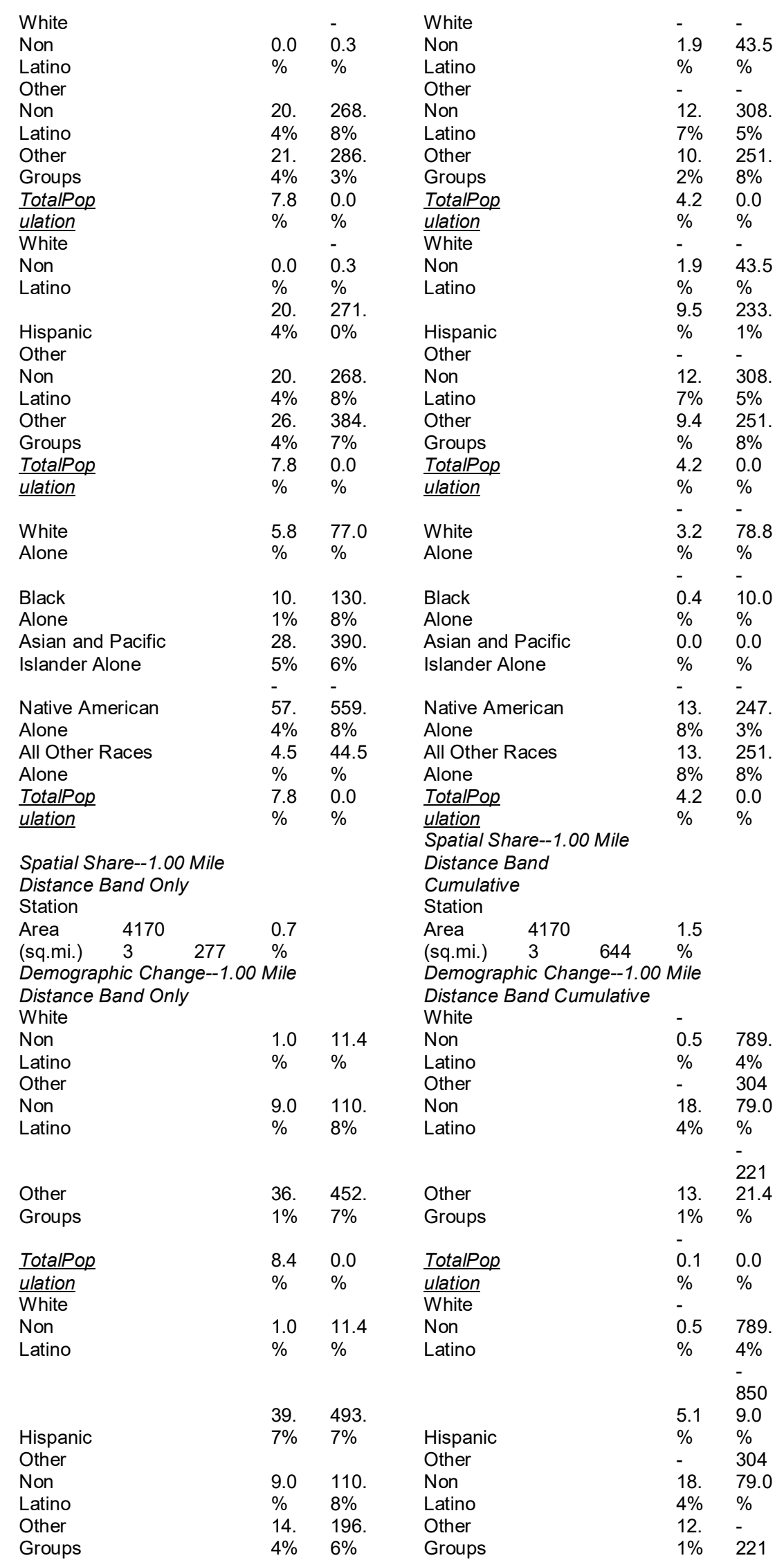




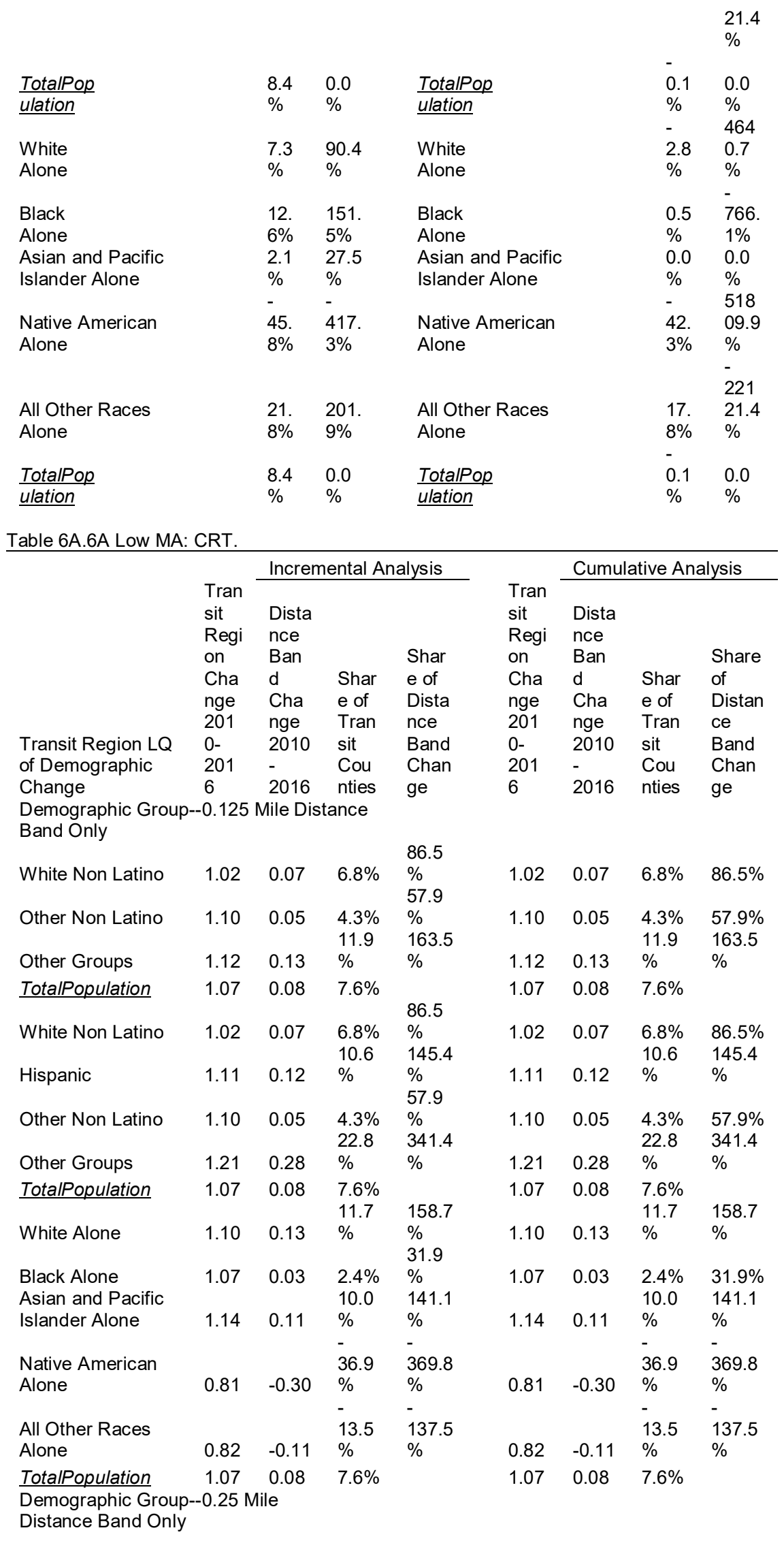




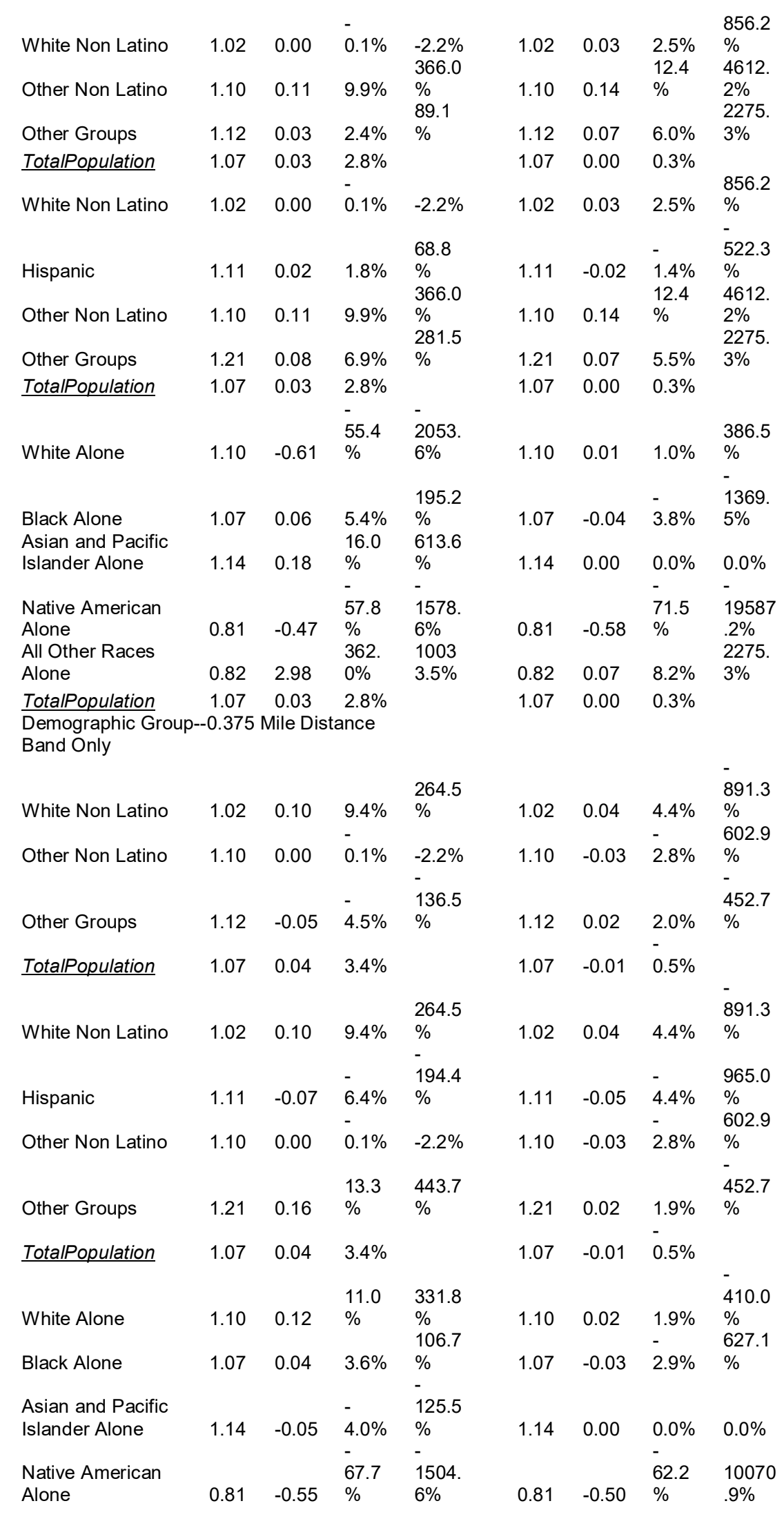




\begin{tabular}{|c|c|c|c|c|c|c|c|c|}
\hline & & & & & & & & \\
\hline All Other Races & & & 33.2 & 748.8 & & & & 452.7 \\
\hline Alone & 0.82 & -0.27 & $\%$ & $\%$ & 0.82 & 0.02 & $2.8 \%$ & $\%$ \\
\hline TotalPopulation & 1.07 & 0.04 & $3.4 \%$ & & 1.07 & -0.01 & $0.5 \%$ & \\
\hline $\begin{array}{l}\text { Demographic Group } \\
\text { Distance Band Only }\end{array}$ & -0.5 Mile & & & & & & & \\
\hline White Non Latino & 1.02 & 0.00 & $0.4 \%$ & $\begin{array}{l}29.3 \\
\% \\
90.9\end{array}$ & 1.02 & 0.04 & $\begin{array}{l}4.1 \% \\
-\end{array}$ & $\begin{array}{l}284.4 \\
\% \\
136.0\end{array}$ \\
\hline Other Non Latino & 1.10 & 0.01 & $1.0 \%$ & $\%$ & 1.10 & -0.02 & $1.8 \%$ & $\%$ \\
\hline Other Groups & 1.12 & 0.03 & $2.8 \%$ & $\begin{array}{l}254.3 \\
\%\end{array}$ & 1.12 & 0.02 & $\begin{array}{l}2.1 \% \\
-\end{array}$ & $\begin{array}{l}159.0 \\
\%\end{array}$ \\
\hline TotalPopulation & 1.07 & 0.01 & $1.2 \%$ & & 1.07 & -0.01 & $1.4 \%$ & \\
\hline White Non Latino & 1.02 & 0.00 & $0.4 \%$ & $\begin{array}{l}29.3 \\
\% \\
114.1\end{array}$ & 1.02 & 0.04 & $\begin{array}{l}4.1 \% \\
-\end{array}$ & $\begin{array}{l}284.4 \\
\% \\
310.4\end{array}$ \\
\hline Hispanic & 1.11 & 0.01 & $1.3 \%$ & $\begin{array}{l}\% \\
90.9\end{array}$ & 1.11 & -0.05 & $\begin{array}{l}4.1 \% \\
-\end{array}$ & $\begin{array}{l}\% \\
136.0\end{array}$ \\
\hline Other Non Latino & 1.10 & 0.01 & $1.0 \%$ & $\%$ & 1.10 & -0.02 & $1.8 \%$ & $\begin{array}{l}\% \\
-\end{array}$ \\
\hline Other Groups & 1.21 & 0.20 & $\begin{array}{l}16.5 \\
\%\end{array}$ & $\begin{array}{l}1608 . \\
8 \%\end{array}$ & 1.21 & 0.02 & $1.9 \%$ & $\begin{array}{l}159.0 \\
\%\end{array}$ \\
\hline TotalPopulation & 1.07 & 0.01 & $1.2 \%$ & & 1.07 & -0.01 & $1.4 \%$ & \\
\hline White Alone & 1.10 & 0.06 & $5.0 \%$ & $\begin{array}{l}446.9 \\
\% \\
-\end{array}$ & 1.10 & 0.02 & $1.6 \%$ & $\begin{array}{l}122.5 \\
\%\end{array}$ \\
\hline $\begin{array}{l}\text { Black Alone } \\
\text { Asian and Pacific }\end{array}$ & 1.07 & -0.04 & $-\overline{3.4 \%}$ & $\begin{array}{l}292.5 \\
\% \\
679.5\end{array}$ & 1.07 & -0.04 & $-3.5 \%$ & $\begin{array}{l}258.3 \\
\%\end{array}$ \\
\hline Islander Alone & 1.14 & 0.08 & $\begin{array}{l}7.4 \% \\
-\end{array}$ & $\begin{array}{l}\% \\
-\end{array}$ & 1.14 & 0.00 & $\begin{array}{l}0.0 \% \\
-\end{array}$ & $0.0 \%$ \\
\hline $\begin{array}{l}\text { Native American } \\
\text { Alone }\end{array}$ & 0.81 & -0.45 & $\begin{array}{l}55.3 \\
\% \\
-\end{array}$ & $\begin{array}{l}3605 . \\
0 \% \\
-\end{array}$ & 0.81 & -0.39 & $\begin{array}{l}48.3 \\
\%\end{array}$ & $\begin{array}{l}2665 \\
2 \% \\
-\end{array}$ \\
\hline $\begin{array}{l}\text { All Other Races } \\
\text { Alone }\end{array}$ & 0.82 & -0.19 & $\begin{array}{l}22.6 \\
\%\end{array}$ & $\begin{array}{l}1494 . \\
0 \%\end{array}$ & 0.82 & 0.02 & $\begin{array}{l}2.8 \% \\
-\end{array}$ & $\begin{array}{l}159.0 \\
\%\end{array}$ \\
\hline $\begin{array}{l}\text { TotalPopulation } \\
\text { Demographic Group } \\
\text { Distance Band Only }\end{array}$ & $\begin{array}{l}1.07 \\
-0.75 \mathrm{Mi}\end{array}$ & 0.01 & $1.2 \%$ & & 1.07 & -0.01 & $1.4 \%$ & \\
\hline White Non Latino & 1.02 & 0.00 & $0.5 \%$ & $\begin{array}{l}18.5 \\
\%\end{array}$ & 1.02 & 0.04 & $\begin{array}{l}4.4 \% \\
-\end{array}$ & $\begin{array}{l}287.6 \\
\%\end{array}$ \\
\hline Other Non Latino & 1.10 & 0.09 & $8.0 \%$ & $\begin{array}{l}328.7 \\
\% \\
76.4\end{array}$ & 1.10 & -0.11 & $\begin{array}{l}10.4 \\
\% \\
-\end{array}$ & $\begin{array}{l}735.5 \\
\% \\
170.5\end{array}$ \\
\hline Other Groups & 1.12 & 0.02 & $1.8 \%$ & $\%$ & 1.12 & -0.03 & $\begin{array}{l}2.4 \% \\
-\end{array}$ & $\%$ \\
\hline TotalPopulation & 1.07 & 0.03 & $2.5 \%$ & & 1.07 & -0.02 & $1.5 \%$ & \\
\hline White Non Latino & 1.02 & 0.00 & $0.5 \%$ & $\begin{array}{l}18.5 \\
\% \\
35.5\end{array}$ & 1.02 & 0.04 & $\begin{array}{l}4.4 \% \\
-\end{array}$ & $\begin{array}{l}287.6 \\
\% \\
442.8\end{array}$ \\
\hline Hispanic & 1.11 & 0.01 & $0.9 \%$ & $\%$ & 1.11 & -0.07 & $\begin{array}{l}6.2 \% \\
-\end{array}$ & $\%$ \\
\hline Other Non Latino & 1.10 & 0.09 & $\begin{array}{l}8.0 \% \\
10.1\end{array}$ & $\begin{array}{l}328.7 \\
\% \\
459.4\end{array}$ & 1.10 & -0.11 & $\begin{array}{l}10.4 \\
\% \\
-\end{array}$ & $\begin{array}{l}735.5 \\
\% \\
170.5\end{array}$ \\
\hline Other Groups & 1.21 & 0.12 & $\%$ & $\%$ & 1.21 & -0.03 & $\begin{array}{l}2.2 \% \\
-\end{array}$ & $\%$ \\
\hline TotalPopulation & 1.07 & 0.03 & $2.5 \%$ & & 1.07 & -0.02 & $1.5 \%$ & \\
\hline
\end{tabular}




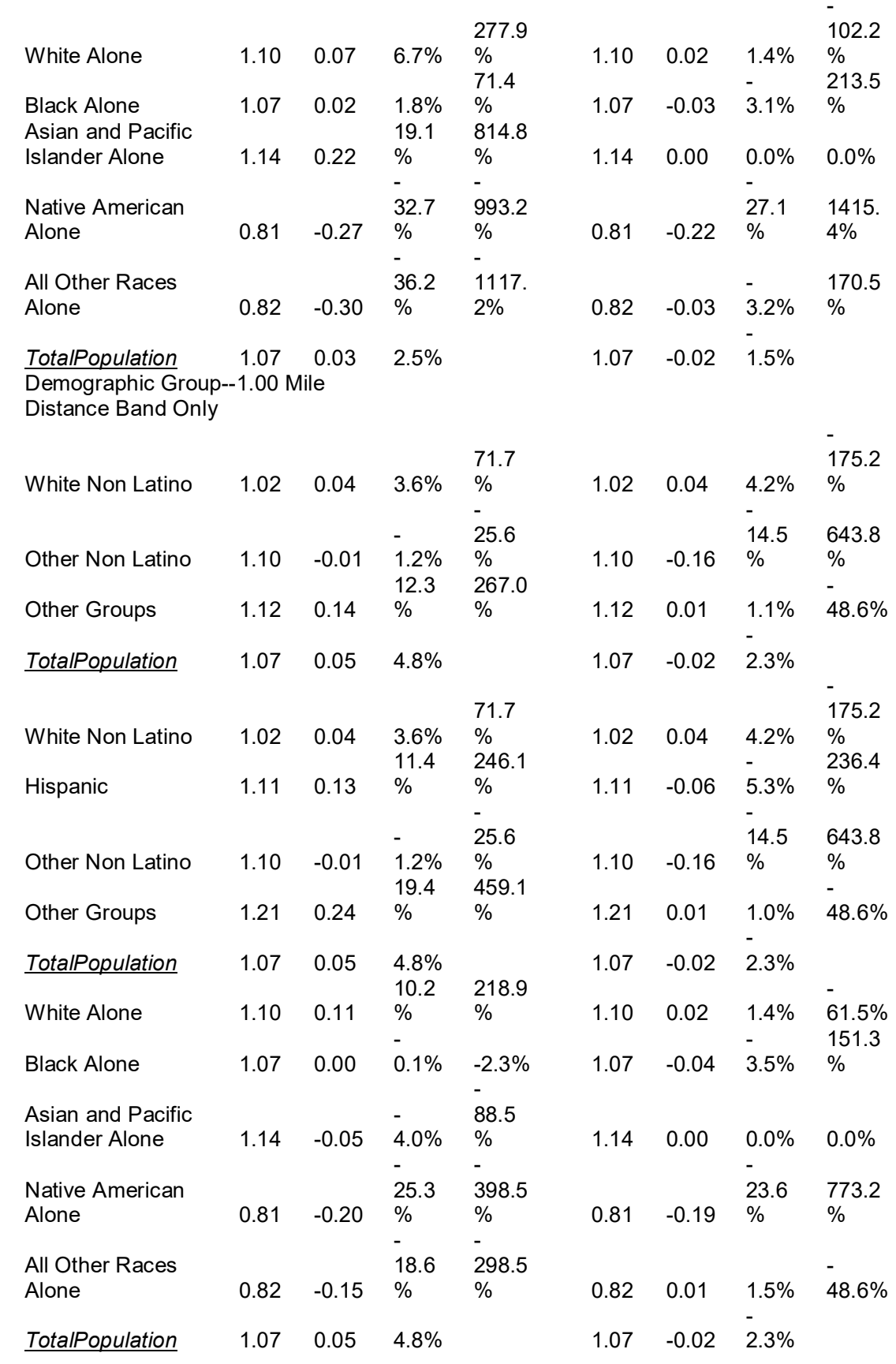


Table 6A.6B Low MA: CRT.

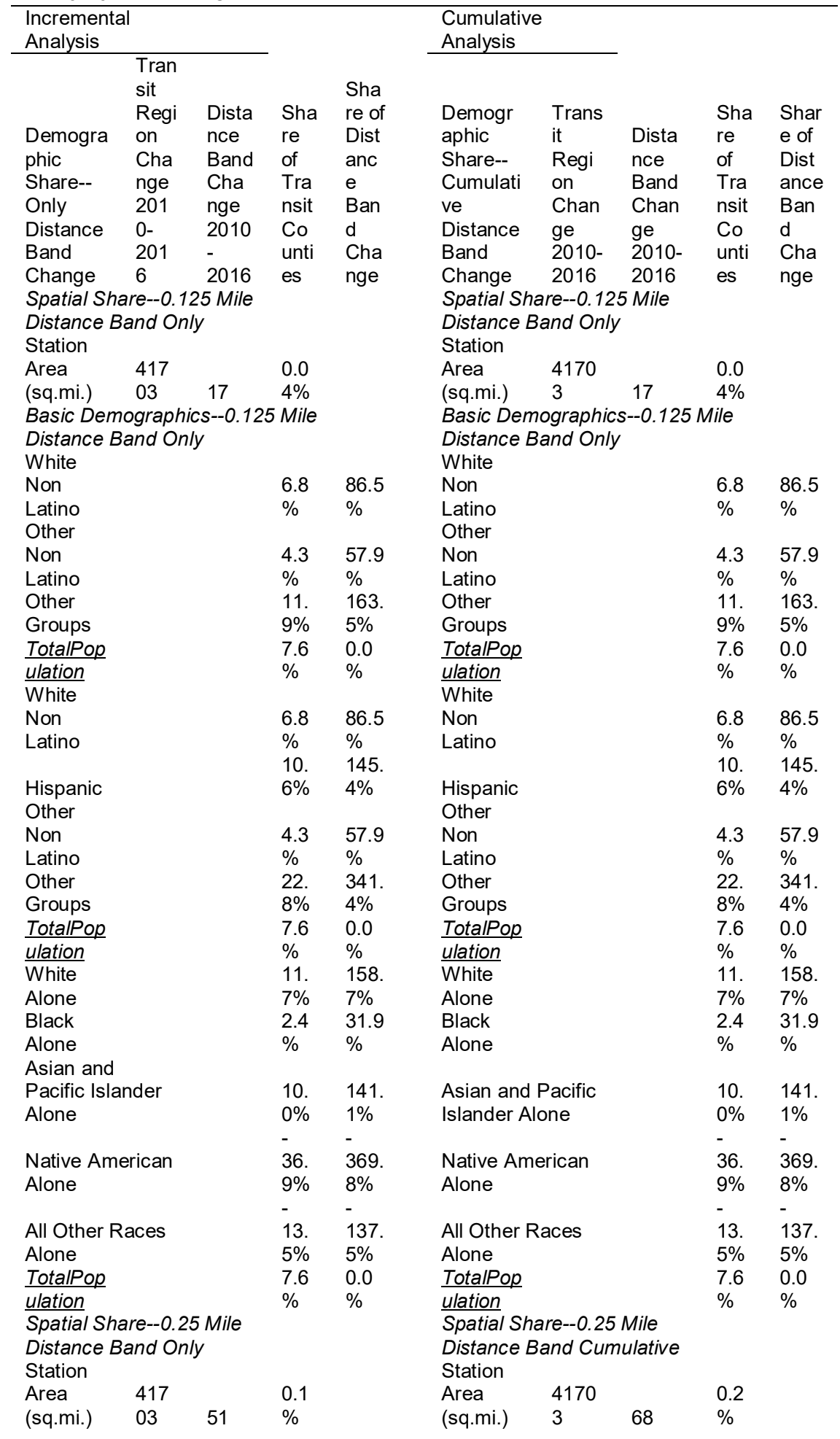




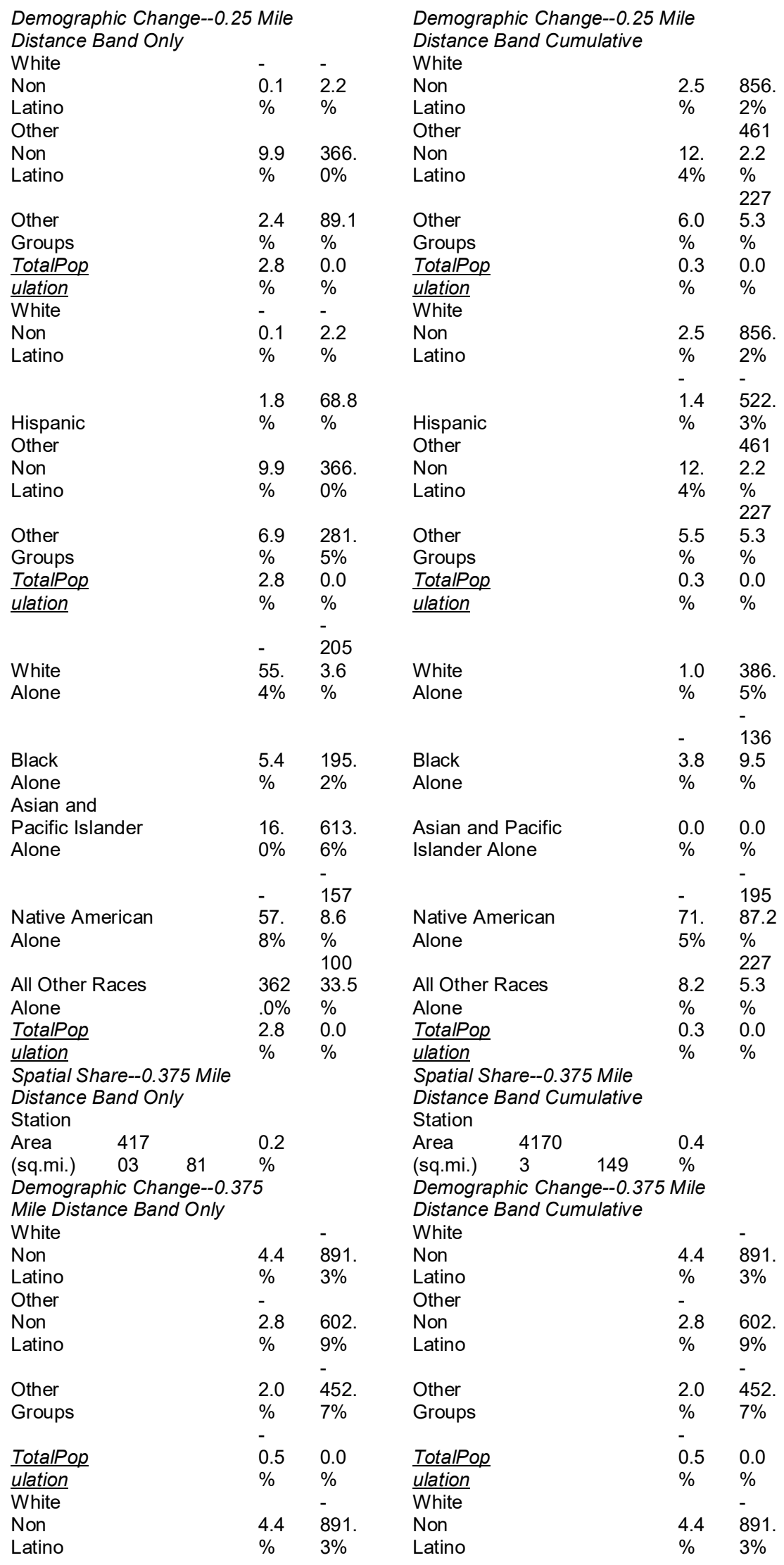




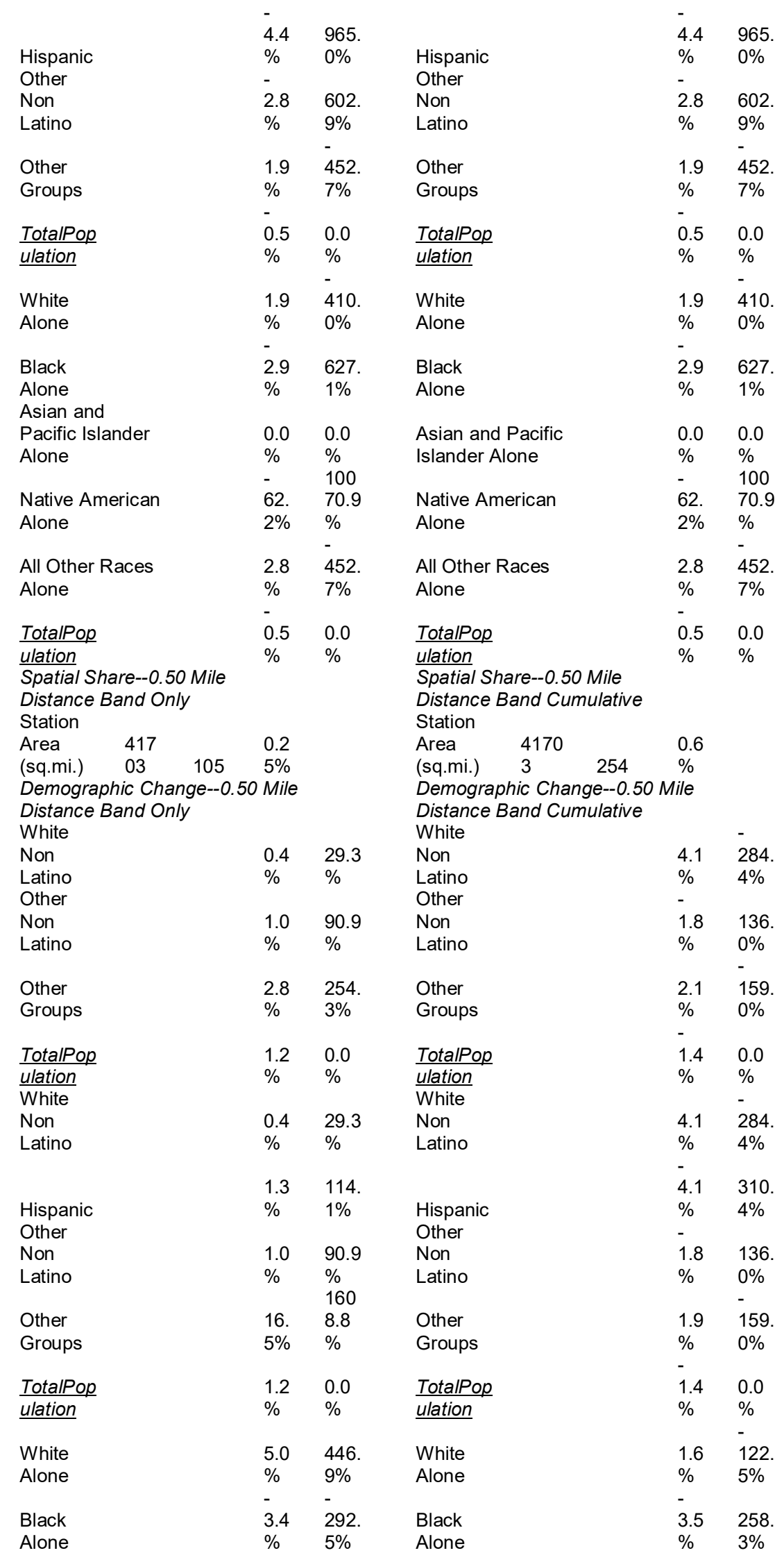




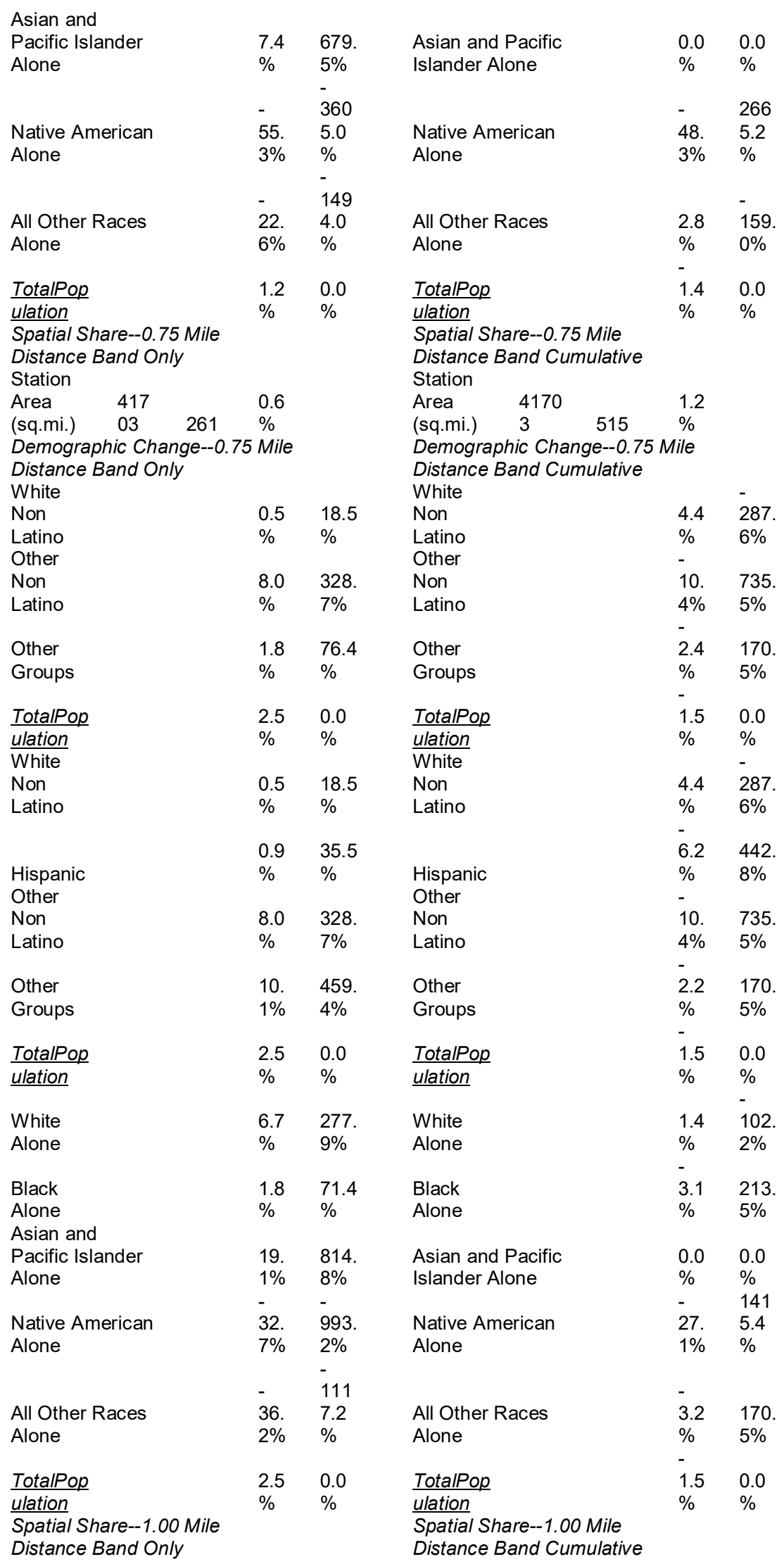




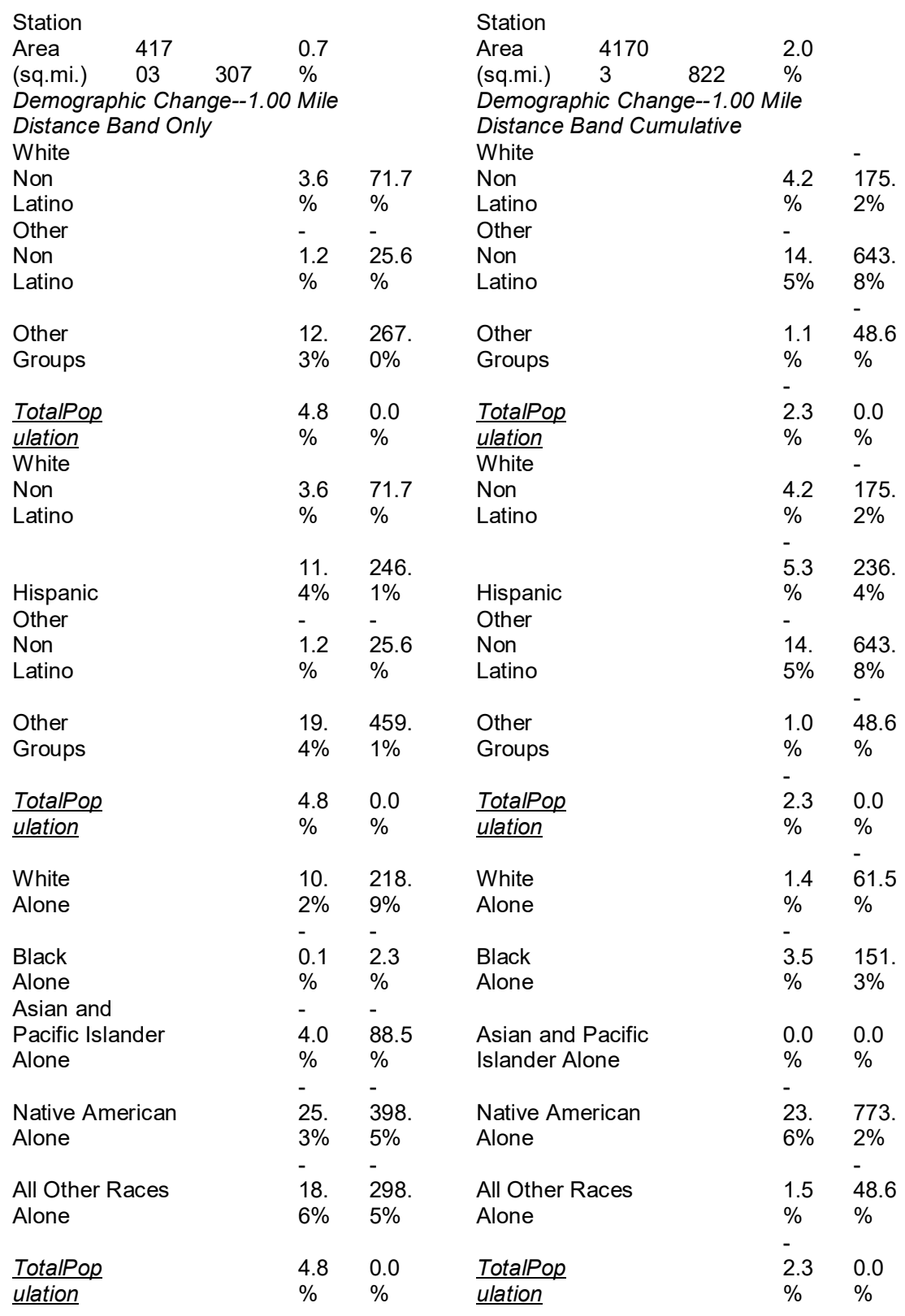

Table 6A.7A Mod MA: CRT.

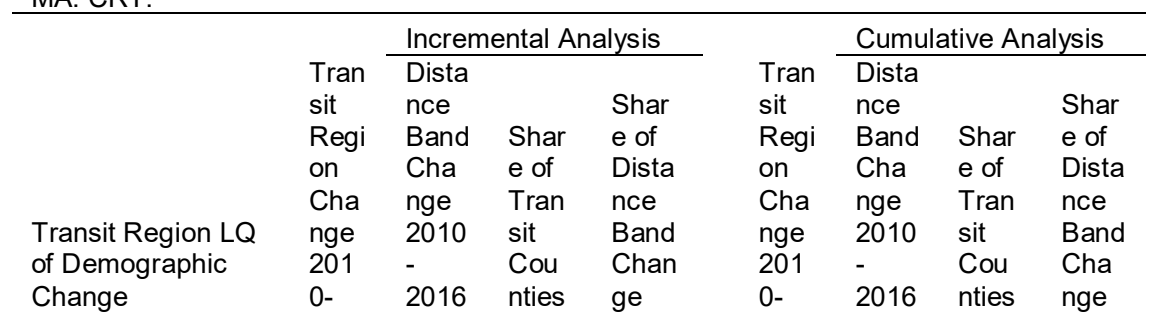




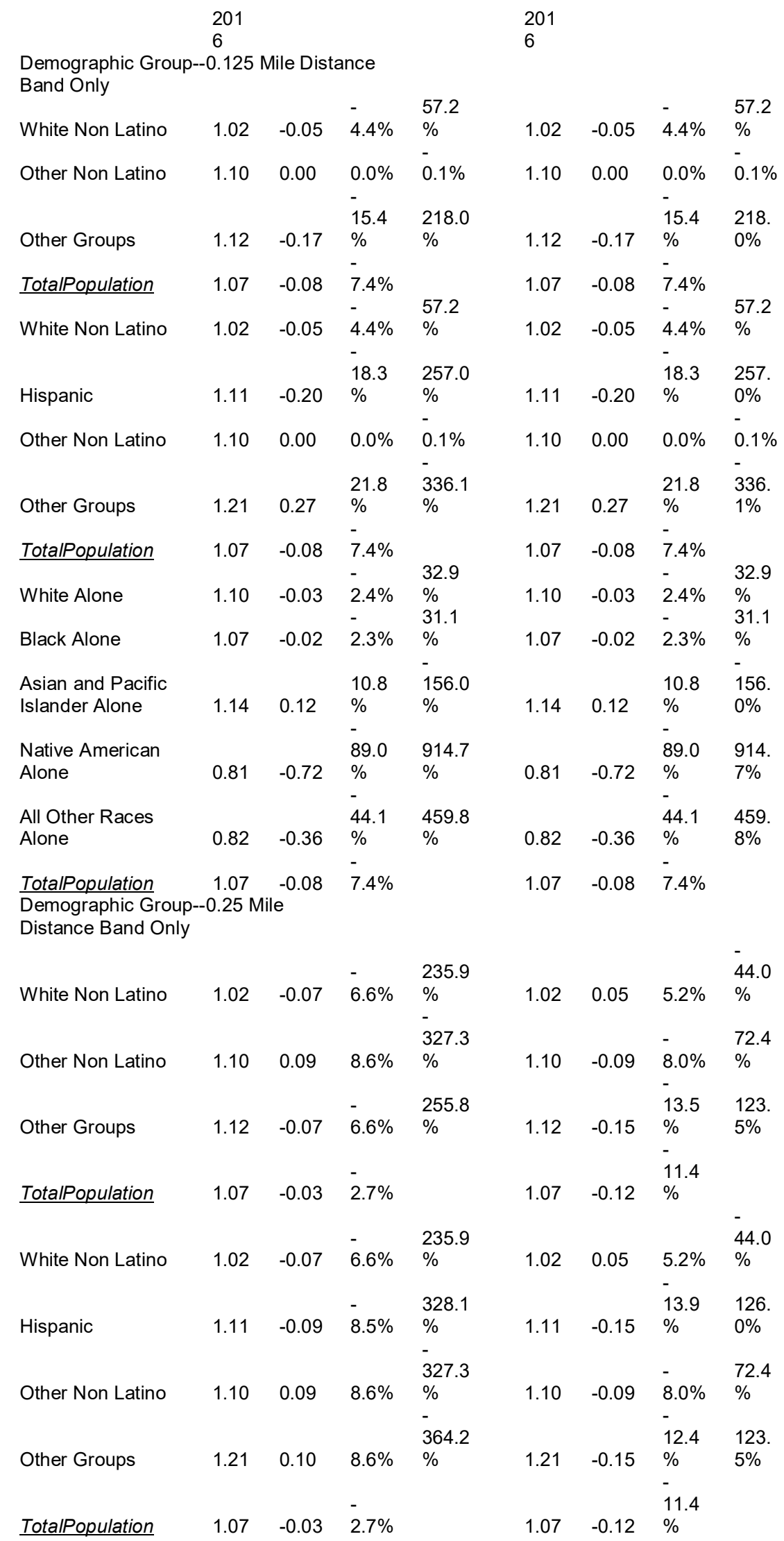




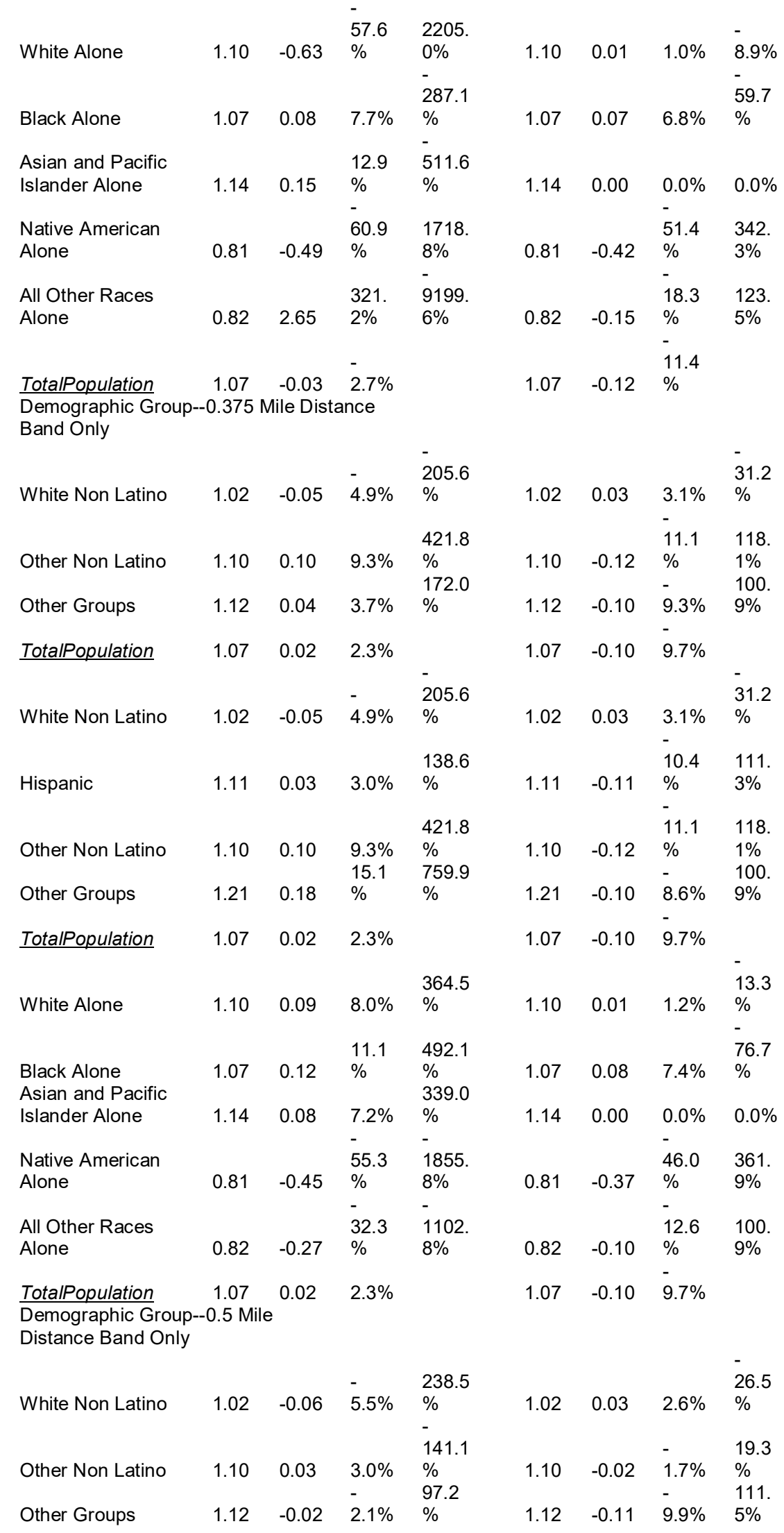




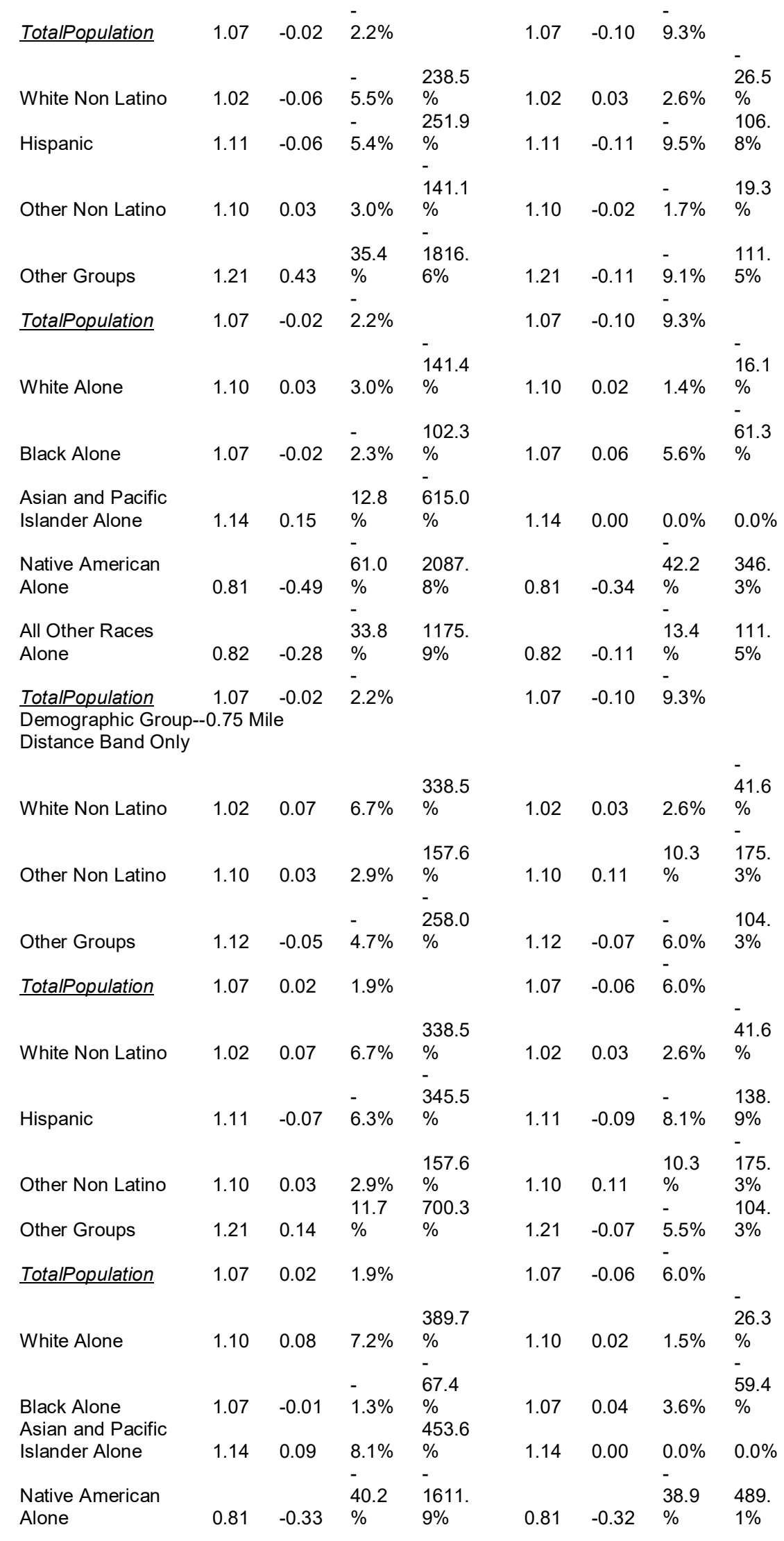




\begin{tabular}{|c|c|c|c|c|c|c|c|c|}
\hline \multicolumn{3}{|l|}{ All Other Races } & 26.9 & 1094. & \multirow[b]{2}{*}{0.82} & \multirow[b]{2}{*}{-0.07} & - & \multirow{2}{*}{$\begin{array}{l}104 . \\
3 \%\end{array}$} \\
\hline Alone & 0.82 & -0.22 & $\%$ & $0 \%$ & & & $\begin{array}{l}8.2 \% \\
-\end{array}$ & \\
\hline TotalPopulation & 1.07 & 0.02 & $1.9 \%$ & & 1.07 & -0.06 & $6.0 \%$ & \\
\hline \multicolumn{9}{|c|}{$\begin{array}{l}\text { Demographic Group--1.00 Mile } \\
\text { Distance Band Only }\end{array}$} \\
\hline White Non Latino & 1.02 & 0.06 & $6.1 \%$ & $\begin{array}{l}76.1 \\
\%\end{array}$ & 1.02 & 0.03 & $2.7 \%$ & $\begin{array}{l}58.7 \\
\%\end{array}$ \\
\hline & & & 16.2 & 216.8 & 110 & 011 & $07 \%$ & 226. \\
\hline Other Non Latino & 1.10 & 0.18 & $\%$ & & 1.10 & 0.11 & $9.1 \%$ & - \\
\hline Other Groups & 1.12 & 0.04 & $3.5 \%$ & $\begin{array}{l}48.3 \\
\%\end{array}$ & 1.12 & 0.01 & $\begin{array}{l}1.3 \% \\
-\end{array}$ & $\begin{array}{l}30.7 \\
\%\end{array}$ \\
\hline TotalPopulation & 1.07 & 0.08 & $7.7 \%$ & & 1.07 & -0.05 & $4.4 \%$ & \\
\hline White Non Latino & 1.02 & 0.06 & $6.1 \%$ & $\begin{array}{l}76.1 \\
\% \\
38.4\end{array}$ & 1.02 & 0.03 & $\begin{array}{l}2.7 \% \\
-\end{array}$ & $\begin{array}{l}58.7 \\
\% \\
175 .\end{array}$ \\
\hline Hispanic & 1.11 & 0.03 & $2.8 \%$ & $\%$ & 1.11 & -0.08 & $7.4 \%$ & $1 \%$ \\
\hline Other Non Latino & 1.10 & 0.18 & $\begin{array}{l}16.2 \\
\%\end{array}$ & $\begin{array}{l}216.8 \\
\%\end{array}$ & 1.10 & 0.11 & $9.7 \%$ & $\begin{array}{l}226 . \\
7 \% \\
-\end{array}$ \\
\hline Other Groups & 1.21 & 0.14 & $\begin{array}{l}11.5 \\
\%\end{array}$ & $\begin{array}{l}169.9 \\
\%\end{array}$ & 1.21 & 0.01 & $\begin{array}{l}1.2 \% \\
-\end{array}$ & $\begin{array}{l}30.7 \\
\%\end{array}$ \\
\hline TotalPopulation & 1.07 & 0.08 & $7.7 \%$ & & 1.07 & -0.05 & $4.4 \%$ & - \\
\hline White Alone & 1.10 & 0.10 & $8.7 \%$ & $\begin{array}{l}117.5 \\
\%\end{array}$ & 1.10 & 0.01 & $1.0 \%$ & $\begin{array}{l}23.2 \\
\% \\
-\end{array}$ \\
\hline $\begin{array}{l}\text { Black Alone } \\
\text { Asian and Pacific }\end{array}$ & 1.07 & 0.11 & $\begin{array}{l}10.4 \\
\% \\
22.7\end{array}$ & $\begin{array}{l}136.4 \\
\% \\
315.9\end{array}$ & 1.07 & 0.03 & $2.9 \%$ & $\begin{array}{l}66.3 \\
\%\end{array}$ \\
\hline Islander Alone & 1.14 & 0.26 & $\%$ & $\%$ & 1.14 & 0.00 & $0.0 \%$ & $0.0 \%$ \\
\hline Native American & & & 13.8 & 136.4 & & & 42.6 & 739. \\
\hline Alone & 0.81 & 0.11 & & & 0.81 & -0.35 & $\%$ & $1 \%$ \\
\hline All Other Races & & & 12.2 & 122.2 & & & & 30.7 \\
\hline Alone & 0.82 & -0.10 & $\%$ & $\%$ & 0.82 & 0.01 & $\begin{array}{l}1.7 \% \\
-\end{array}$ & $\%$ \\
\hline TotalPopulation & 1.07 & 0.08 & $7.7 \%$ & & 1.07 & -0.05 & $4.4 \%$ & \\
\hline
\end{tabular}


Table 6A.7B Mod MA: CRT.

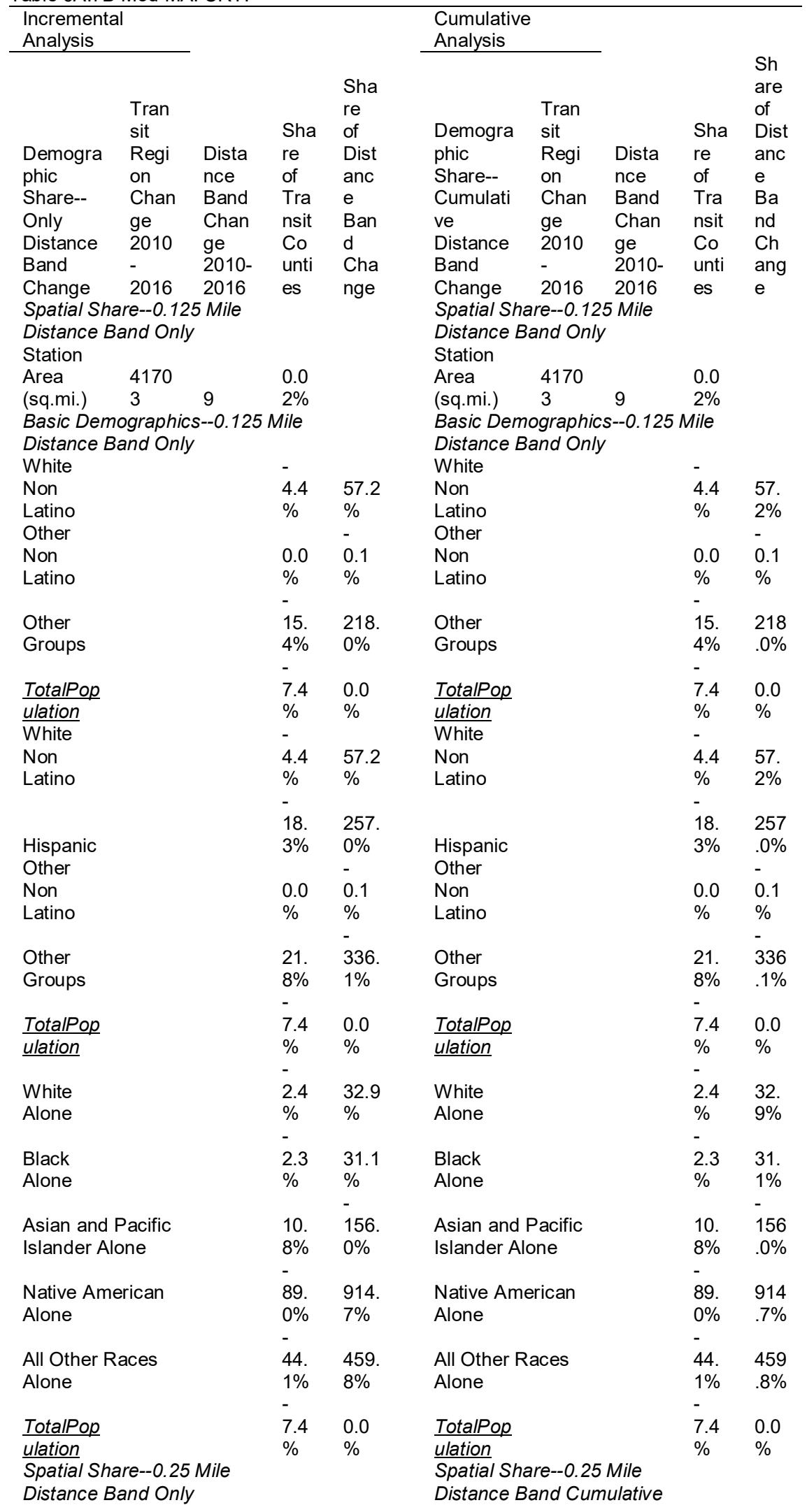




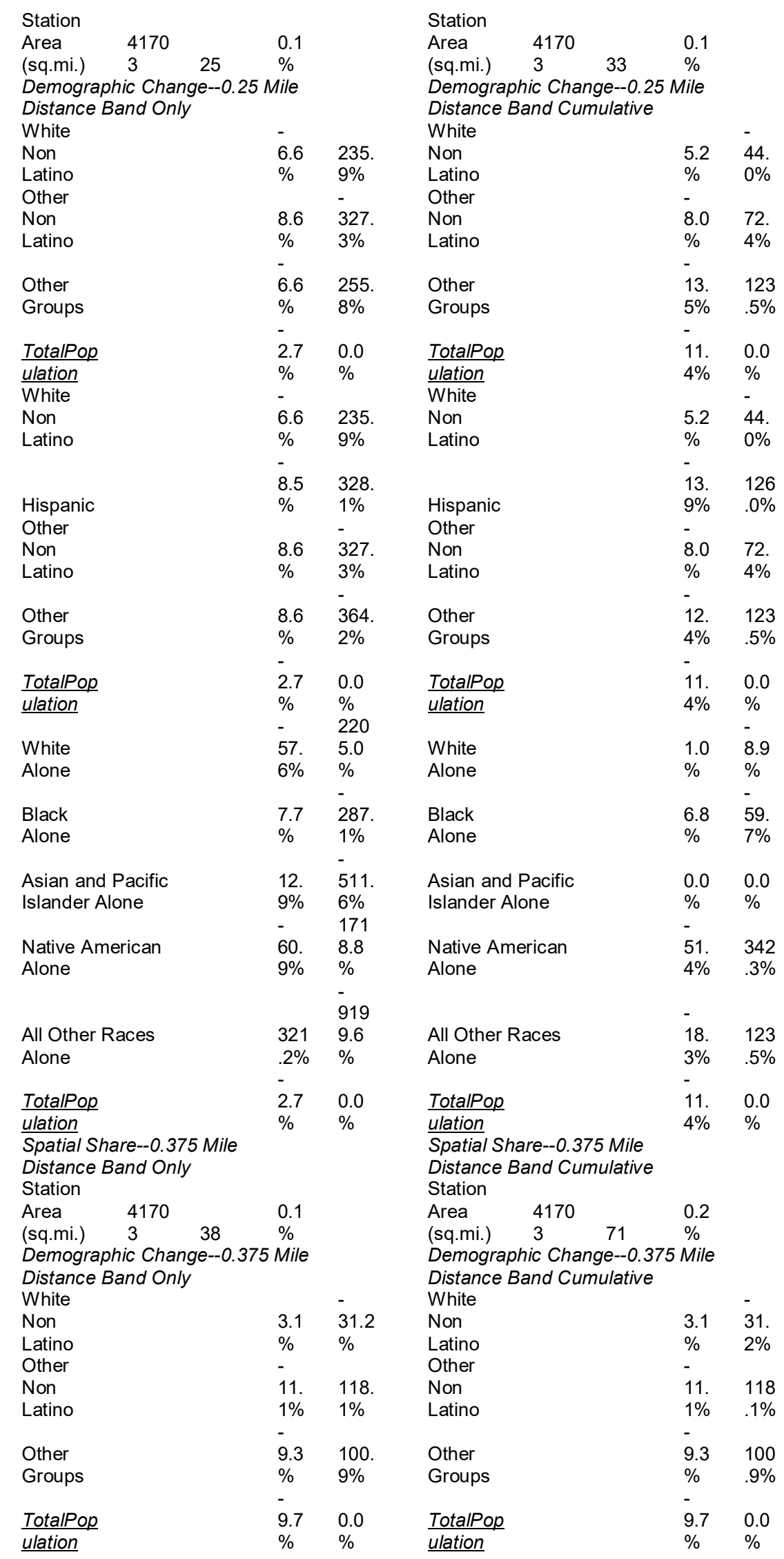




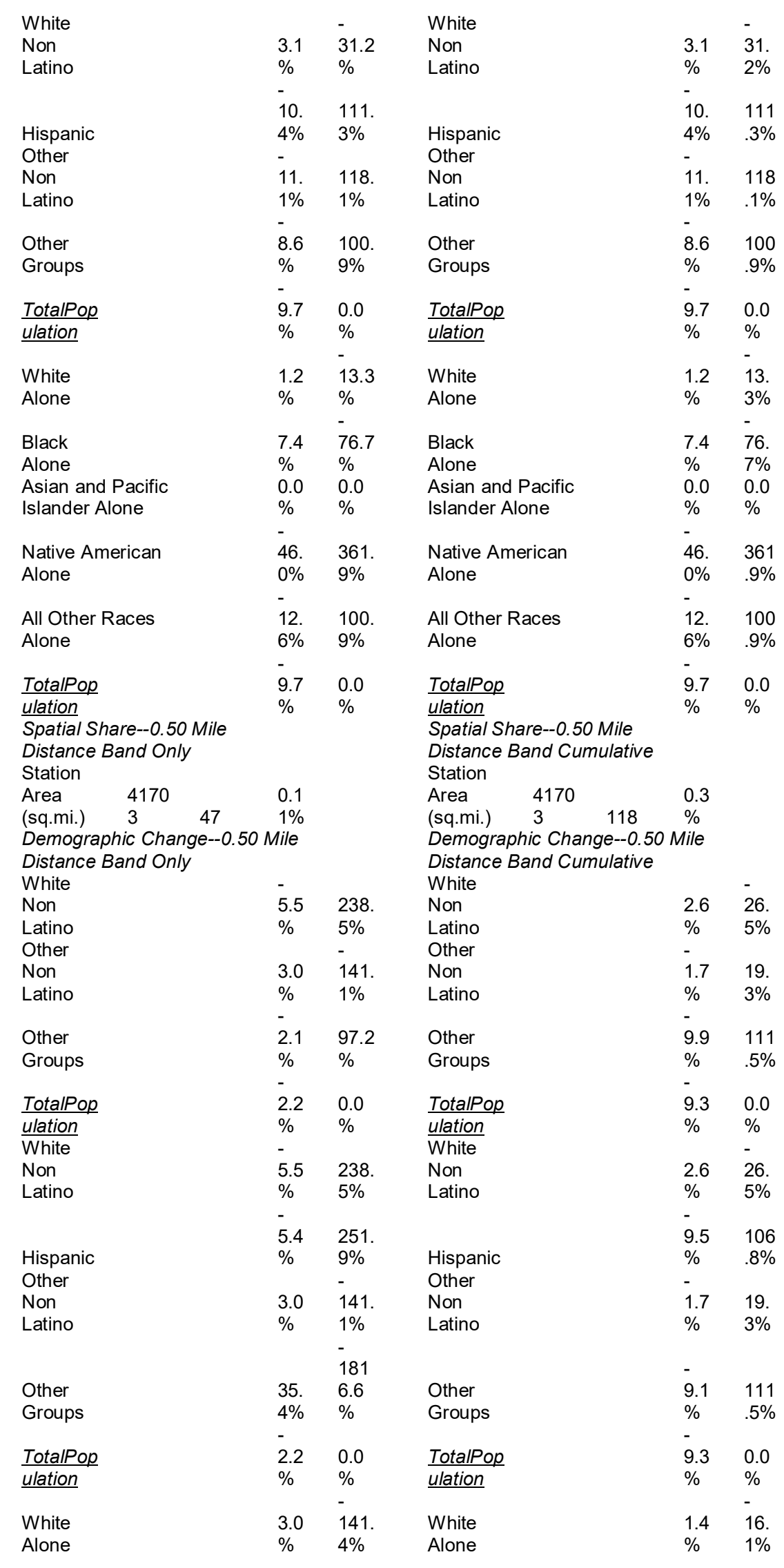




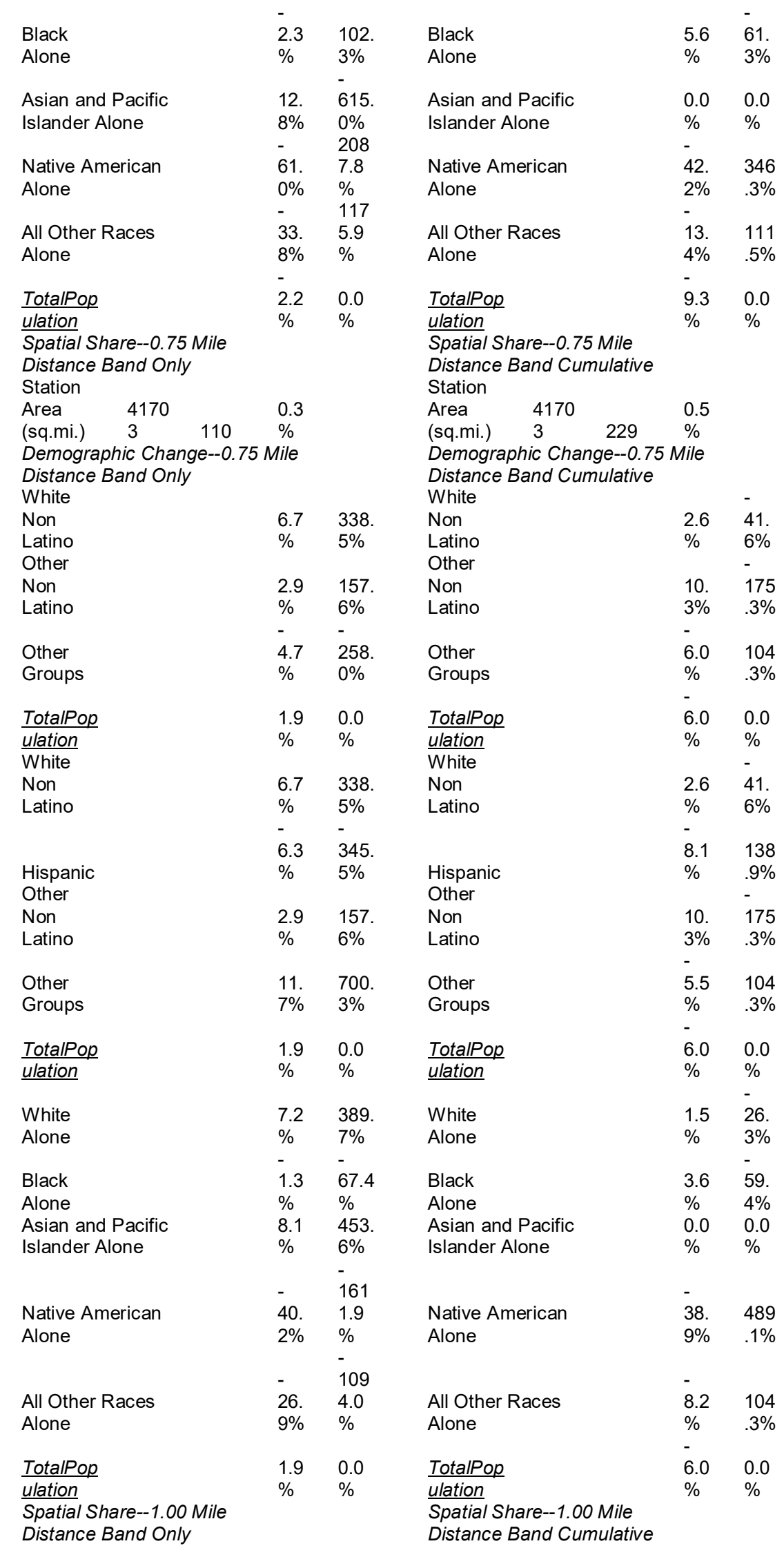




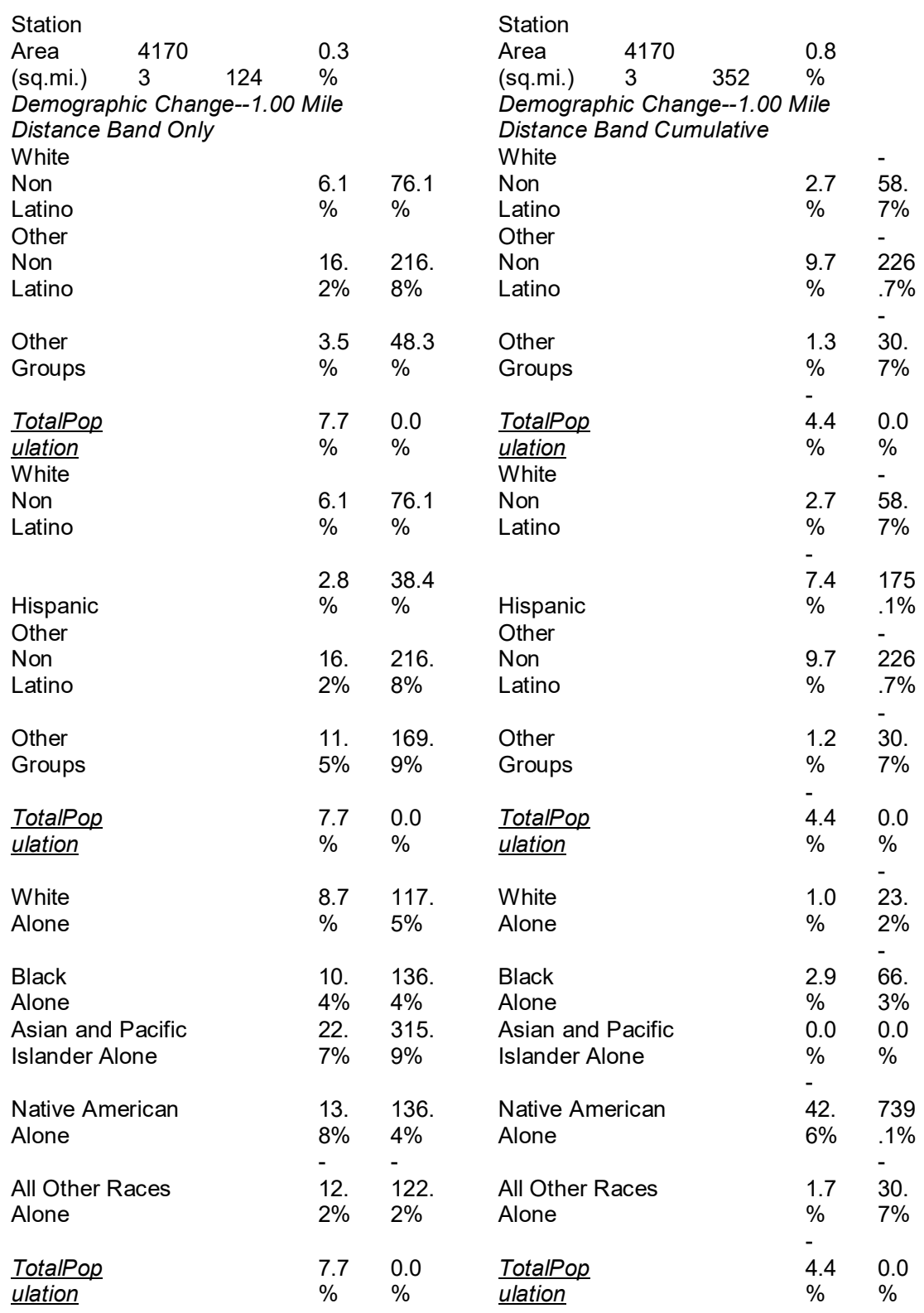

Table 6A.8A High

MA: CRT.

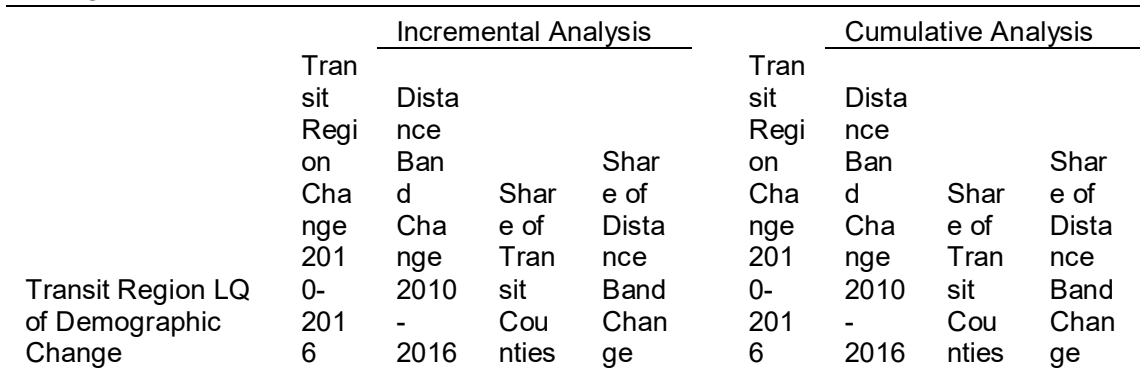




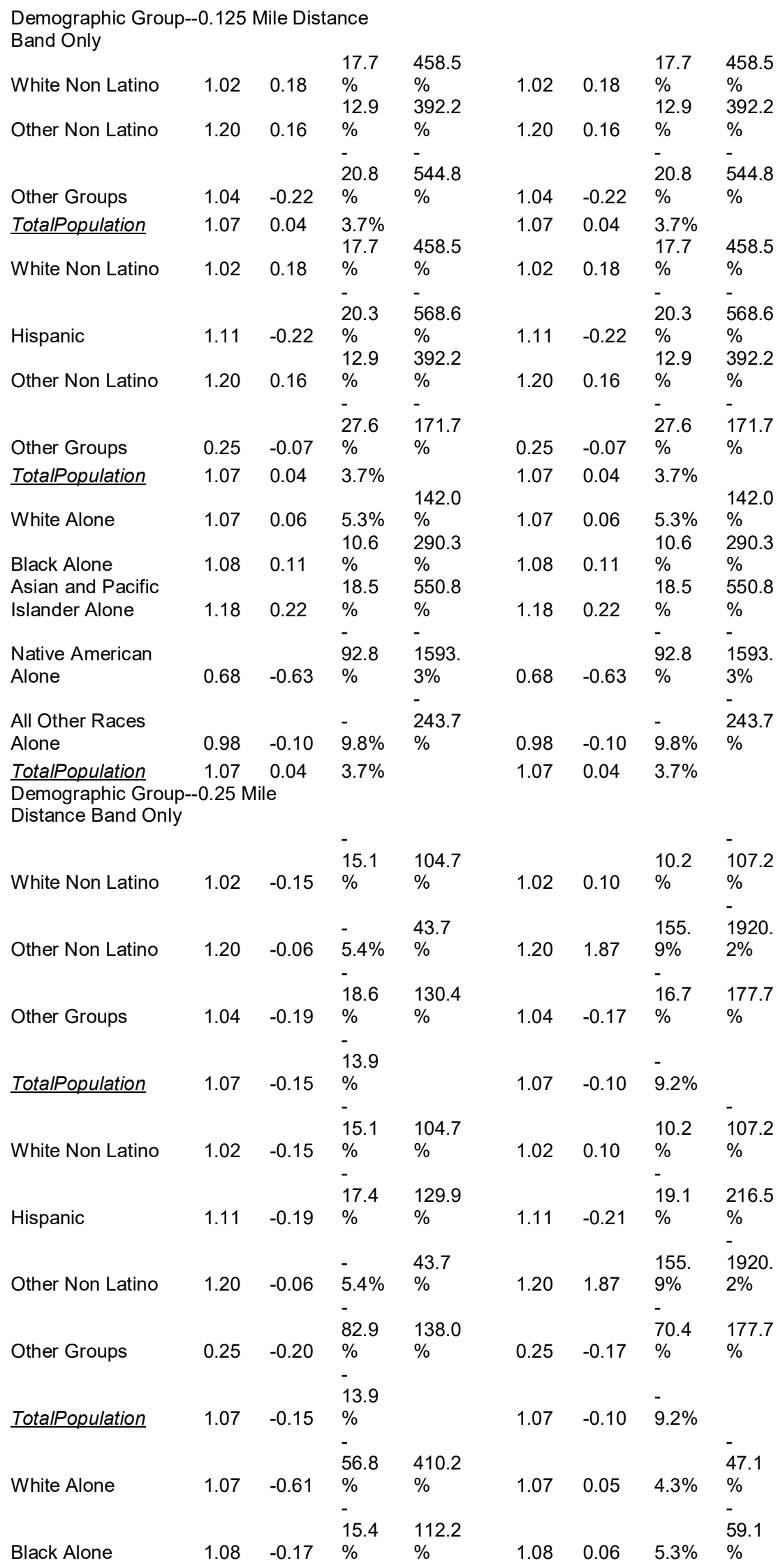




\begin{tabular}{|c|c|c|c|c|c|c|c|c|}
\hline $\begin{array}{l}\text { Asian and Pacific } \\
\text { Islander Alone }\end{array}$ & 1.18 & 0.17 & $\begin{array}{l}14.8 \\
\% \\
-\end{array}$ & $\begin{array}{l}118.2 \\
\%\end{array}$ & 1.18 & 0.00 & $\begin{array}{l}0.0 \% \\
-\end{array}$ & $0.0 \%$ \\
\hline $\begin{array}{l}\text { Native American } \\
\text { Alone }\end{array}$ & 0.68 & -0.67 & $\begin{array}{l}98.5 \\
\%\end{array}$ & $\begin{array}{l}452.4 \\
\% \\
-\end{array}$ & 0.68 & -0.67 & $\begin{array}{l}98.8 \\
\% \\
-\end{array}$ & $\begin{array}{l}688.3 \\
\%\end{array}$ \\
\hline $\begin{array}{l}\text { All Other Races } \\
\text { Alone }\end{array}$ & 0.98 & 1.19 & $\begin{array}{l}120 . \\
8 \% \\
- \\
13.9\end{array}$ & $\begin{array}{l}801.2 \\
\%\end{array}$ & 0.98 & -0.17 & $\begin{array}{l}17.7 \\
\% \\
-\end{array}$ & $\begin{array}{l}177.7 \\
\%\end{array}$ \\
\hline \multicolumn{9}{|c|}{$\begin{array}{l}\text { Demographic Group--0.375 Mile Distance } \\
\text { Band Only }\end{array}$} \\
\hline White Non Latino & 1.02 & 0.04 & $3.6 \%$ & $\begin{array}{l}66.6 \\
\%\end{array}$ & 1.02 & 0.07 & $7.1 \%$ & $\begin{array}{l}110.9 \\
\%\end{array}$ \\
\hline Other Non Latino & 1.20 & 0.15 & $\begin{array}{l}12.1 \\
\%\end{array}$ & $\begin{array}{l}265.7 \\
\%\end{array}$ & 1.20 & 0.70 & $\begin{array}{l}58.2 \\
\% \\
-\end{array}$ & $\begin{array}{l}1064 . \\
2 \%\end{array}$ \\
\hline Other Groups & 1.04 & 0.00 & $0.2 \%$ & $4.4 \%$ & 1.04 & -0.15 & $\begin{array}{l}14.4 \\
\%\end{array}$ & $\begin{array}{l}227.4 \\
\%\end{array}$ \\
\hline TotalPopulation & 1.07 & 0.05 & $5.2 \%$ & & 1.07 & -0.07 & $6.2 \%$ & \\
\hline White Non Latino & 1.02 & 0.04 & $3.6 \%$ & $\begin{array}{l}66.6 \\
\% \\
-\end{array}$ & 1.02 & 0.07 & $\begin{array}{l}7.1 \% \\
-\end{array}$ & $\begin{array}{l}110.9 \\
\%\end{array}$ \\
\hline Hispanic & 1.11 & -0.08 & $-\overline{6} .9 \%$ & $\begin{array}{l}138.5 \\
\%\end{array}$ & 1.11 & -0.19 & $\begin{array}{l}17.4 \\
\%\end{array}$ & $\begin{array}{l}292.7 \\
\%\end{array}$ \\
\hline Other Non Latino & 1.20 & 0.15 & $\begin{array}{l}12.1 \\
\%\end{array}$ & $\begin{array}{l}265.7 \\
\%\end{array}$ & 1.20 & 0.70 & $\begin{array}{l}58.2 \\
\% \\
-\end{array}$ & $\begin{array}{l}1064 . \\
2 \%\end{array}$ \\
\hline Other Groups & 0.25 & 0.80 & $\begin{array}{l}326 . \\
1 \%\end{array}$ & $\begin{array}{l}1462 . \\
2 \%\end{array}$ & 0.25 & -0.15 & $\begin{array}{l}60.6 \\
\% \\
-\end{array}$ & $\begin{array}{l}227.4 \\
\%\end{array}$ \\
\hline TotalPopulation & 1.07 & 0.05 & $5.2 \%$ & & 1.07 & -0.07 & $6.2 \%$ & \\
\hline White Alone & 1.07 & 0.03 & $3.1 \%$ & $\begin{array}{l}59.8 \\
\%\end{array}$ & 1.07 & 0.02 & $1.8 \%$ & $\begin{array}{l}28.8 \\
\% \\
- \\
1112\end{array}$ \\
\hline $\begin{array}{l}\text { Black Alone } \\
\text { Asian and Pacific }\end{array}$ & 1.08 & 0.17 & $\begin{array}{l}15.8 \\
\%\end{array}$ & $\begin{array}{l}309.8 \\
\% \\
110.8\end{array}$ & 1.08 & 0.07 & $6.8 \%$ & $\begin{array}{l}111.3 \\
\%\end{array}$ \\
\hline Islander Alone & 1.18 & 0.06 & $\begin{array}{l}5.2 \% \\
-\end{array}$ & $\begin{array}{l}\% \\
-\end{array}$ & 1.18 & 0.00 & $0.0 \%$ & $0.0 \%$ \\
\hline $\begin{array}{l}\text { Native American } \\
\text { Alone }\end{array}$ & 0.68 & -0.13 & $\begin{array}{l}19.0 \\
\%\end{array}$ & $\begin{array}{l}234.9 \\
\%\end{array}$ & 0.68 & -0.40 & $\begin{array}{l}58.5 \\
\% \\
-\end{array}$ & $\begin{array}{l}605.7 \\
\%\end{array}$ \\
\hline $\begin{array}{l}\text { All Other Races } \\
\text { Alone }\end{array}$ & 0.98 & 0.04 & $4.0 \%$ & $\begin{array}{l}71.3 \\
\%\end{array}$ & 0.98 & -0.15 & $\begin{array}{l}15.2 \\
\% \\
-\end{array}$ & $\begin{array}{l}227.4 \\
\%\end{array}$ \\
\hline $\begin{array}{l}\text { TotalPopulation } \\
\text { Demographic Gro } \\
\text { Distance Band On }\end{array}$ & $\begin{array}{c}1.07 \\
-0.5 \mathrm{Mi}\end{array}$ & 0.05 & $5.2 \%$ & & 1.07 & -0.07 & $6.2 \%$ & \\
\hline White Non Latino & 1.02 & 0.11 & $\begin{array}{l}10.9 \\
\%\end{array}$ & $\begin{array}{l}126.3 \\
\% \\
-\end{array}$ & 1.02 & 0.06 & $6.3 \%$ & $\begin{array}{l}167.6 \\
\% \\
-\end{array}$ \\
\hline Other Non Latino & 1.20 & -0.05 & $-\overline{3.8 \%}$ & $\begin{array}{l}51.7 \\
\%\end{array}$ & 1.20 & 1.37 & $\begin{array}{l}113 . \\
9 \% \\
-\end{array}$ & $\begin{array}{l}3550 . \\
6 \%\end{array}$ \\
\hline Other Groups & 1.04 & 0.17 & $\begin{array}{l}16.6 \\
\%\end{array}$ & $\begin{array}{l}194.8 \\
\%\end{array}$ & 1.04 & -0.19 & $\begin{array}{l}18.2 \\
\% \\
-\end{array}$ & $\begin{array}{l}489.6 \\
\%\end{array}$ \\
\hline TotalPopulation & 1.07 & 0.09 & $8.3 \%$ & & 1.07 & -0.04 & $3.6 \%$ & \\
\hline
\end{tabular}




\begin{tabular}{|c|c|c|c|c|c|c|c|c|}
\hline White Non Latino & 1.02 & 0.11 & $\begin{array}{l}10.9 \\
\% \\
16.0\end{array}$ & $\begin{array}{l}126.3 \\
\% \\
200.7\end{array}$ & 1.02 & 0.06 & $\begin{array}{l}6.3 \% \\
-\end{array}$ & $\begin{array}{l}167.6 \\
\% \\
264.7\end{array}$ \\
\hline Hispanic & 1.11 & 0.18 & $\%$ & $\begin{array}{l}\% \\
-\end{array}$ & 1.11 & -0.10 & $9.2 \%$ & $\%$ \\
\hline Other Non Latino & 1.20 & -0.05 & $-3.8 \%$ & $\begin{array}{l}51.7 \\
\%\end{array}$ & 1.20 & 1.37 & $\begin{array}{l}113 . \\
9 \% \\
-\end{array}$ & $\begin{array}{l}3550 . \\
6 \%\end{array}$ \\
\hline Other Groups & 0.25 & 0.10 & $\begin{array}{l}40.0 \\
\%\end{array}$ & $\begin{array}{l}111.6 \\
\%\end{array}$ & 0.25 & -0.19 & $\begin{array}{l}76.6 \\
\% \\
-\end{array}$ & $\begin{array}{l}489.6 \\
\%\end{array}$ \\
\hline TotalPopulation & 1.07 & 0.09 & $8.3 \%$ & & 1.07 & -0.04 & $3.6 \%$ & - \\
\hline White Alone & 1.07 & 0.33 & $\begin{array}{l}30.9 \\
\% \\
- \\
14\end{array}$ & $\begin{array}{l}373.6 \\
\% \\
- \\
1781\end{array}$ & 1.07 & 0.08 & $7.5 \%$ & $\begin{array}{l}208.4 \\
\%\end{array}$ \\
\hline $\begin{array}{l}\text { Black Alone } \\
\text { Asian and Pacific }\end{array}$ & 1.08 & -0.16 & $\begin{array}{l}14.6 \\
\% \\
10.6\end{array}$ & $\begin{array}{l}178.1 \\
\% \\
141.0\end{array}$ & 1.08 & -0.04 & $-\overline{3}$ & $\begin{array}{l}104.2 \\
\%\end{array}$ \\
\hline Islander Alone & 1.18 & 0.12 & $\begin{array}{l}\% \\
-\end{array}$ & $\begin{array}{l}\% \\
-\end{array}$ & 1.18 & 0.00 & $\begin{array}{l}0.0 \% \\
-\end{array}$ & $0.0 \%$ \\
\hline $\begin{array}{l}\text { Native American } \\
\text { Alone }\end{array}$ & 0.68 & -0.73 & $\begin{array}{l}106 . \\
7 \% \\
-\end{array}$ & $\begin{array}{l}821.2 \\
\% \\
-\end{array}$ & 0.68 & -0.55 & $\begin{array}{l}81.4 \\
\% \\
-\end{array}$ & $\begin{array}{l}1435 . \\
5 \%\end{array}$ \\
\hline $\begin{array}{l}\text { All Other Races } \\
\text { Alone }\end{array}$ & 0.98 & -0.32 & $\begin{array}{l}33.0 \\
\%\end{array}$ & $\begin{array}{l}366.9 \\
\%\end{array}$ & 0.98 & -0.19 & $\begin{array}{l}19.2 \\
\% \\
-\end{array}$ & $\begin{array}{l}489.6 \\
\%\end{array}$ \\
\hline \multicolumn{9}{|c|}{$\begin{array}{l}\text { Demographic Group--0.75 Mile } \\
\text { Distance Band Only }\end{array}$} \\
\hline White Non Latino & 1.02 & 0.12 & $\begin{array}{l}11.5 \\
\%\end{array}$ & $\begin{array}{l}106.0 \\
\%\end{array}$ & 1.02 & 0.04 & $4.3 \%$ & $\begin{array}{l}481.5 \\
\%\end{array}$ \\
\hline Other Non Latino & 1.20 & 0.21 & $\begin{array}{l}17.1 \\
\%\end{array}$ & $\begin{array}{l}185.7 \\
\% \\
16.3\end{array}$ & 1.20 & 0.86 & $\begin{array}{l}71.7 \\
\% \\
-\end{array}$ & $\begin{array}{l}9337 . \\
8 \% \\
370.0\end{array}$ \\
\hline Other Groups & 1.04 & 0.02 & $\begin{array}{l}1.7 \% \\
10.4\end{array}$ & $\%$ & 1.04 & -0.03 & $\begin{array}{l}3.3 \% \\
-\end{array}$ & $\%$ \\
\hline TotalPopulation & 1.07 & 0.11 & $\%$ & & 1.07 & -0.01 & $0.9 \%$ & \\
\hline White Non Latino & 1.02 & 0.12 & $\begin{array}{l}11.5 \\
\%\end{array}$ & $\begin{array}{l}99.5 \\
\% \\
91.0\end{array}$ & 1.02 & 0.04 & $\begin{array}{l}4.3 \% \\
-\end{array}$ & $\begin{array}{l}481.5 \\
\% \\
786.5\end{array}$ \\
\hline Hispanic & 1.11 & 0.11 & $9.7 \%$ & $\%$ & 1.11 & -0.07 & $6.6 \%$ & $\begin{array}{l}\% \\
-\end{array}$ \\
\hline Other Non Latino & 1.20 & 0.21 & $\begin{array}{l}17.1 \\
\% \\
-\end{array}$ & $\begin{array}{l}174.2 \\
\% \\
-\end{array}$ & 1.20 & 0.86 & $\begin{array}{l}71.7 \\
\% \\
-\end{array}$ & $\begin{array}{l}9337 . \\
8 \%\end{array}$ \\
\hline Other Groups & 0.25 & -1.00 & $\begin{array}{l}405 . \\
9 \% \\
11.1\end{array}$ & $\begin{array}{l}848.0 \\
\%\end{array}$ & 0.25 & -0.03 & $\begin{array}{l}13.9 \\
\% \\
-\end{array}$ & $\begin{array}{l}370.0 \\
\%\end{array}$ \\
\hline TotalPopulation & 1.07 & 0.12 & $\%$ & & 1.07 & -0.01 & $0.9 \%$ & - \\
\hline White Alone & 1.07 & 0.07 & $\begin{array}{l}6.2 \% \\
10.4\end{array}$ & $\begin{array}{l}60.2 \\
\% \\
101.1\end{array}$ & 1.07 & 0.05 & $\begin{array}{l}4.4 \% \\
-\end{array}$ & $\begin{array}{l}506.4 \\
\% \\
142.2\end{array}$ \\
\hline $\begin{array}{l}\text { Black Alone } \\
\text { Asian and Pacific }\end{array}$ & 1.08 & 0.11 & $\begin{array}{l}\% \\
11.7\end{array}$ & $\begin{array}{l}\% \\
124.4\end{array}$ & 1.08 & -0.01 & $1.2 \%$ & $\%$ \\
\hline Islander Alone & 1.18 & 0.14 & $\begin{array}{l}\% \\
-\end{array}$ & $\begin{array}{l}\% \\
-\end{array}$ & 1.18 & 0.00 & $\begin{array}{l}0.0 \% \\
-\end{array}$ & $0.0 \%$ \\
\hline Native American & & & 82.2 & 505.0 & & & 82.3 & 6066. \\
\hline $\begin{array}{l}\text { Alone } \\
\text { All Other Races }\end{array}$ & 0.68 & -0.56 & $\begin{array}{l}\% \\
23.9\end{array}$ & $\begin{array}{l}\% \\
211.9\end{array}$ & 0.68 & -0.56 & $\begin{array}{l}\% \\
-\end{array}$ & $\begin{array}{l}3 \% \\
370.0\end{array}$ \\
\hline Alone & 0.98 & 0.23 & $\begin{array}{l}\% \\
10.4\end{array}$ & $\%$ & 0.98 & -0.03 & $3.5 \%$ & $\%$ \\
\hline $\begin{array}{l}\text { TotalPopulation } \\
\text { Demographic Grol } \\
\text { Distance Band On }\end{array}$ & $\begin{array}{l}1.07 \\
1.00 \mathrm{~N}\end{array}$ & 0.11 & $\%$ & & 1.07 & -0.01 & $0.9 \%$ & \\
\hline
\end{tabular}




\begin{tabular}{|c|c|c|c|c|c|c|c|c|}
\hline White Non Latino & 1.02 & 0.02 & $2.1 \%$ & $\begin{array}{l}36.8 \\
\%\end{array}$ & 1.02 & 0.03 & $3.4 \%$ & $\begin{array}{l}250.9 \\
\%\end{array}$ \\
\hline Other Non Latino & 1.20 & 0.08 & $6.7 \%$ & $\begin{array}{l}139.5 \\
\% \\
108.8\end{array}$ & 1.20 & 0.60 & $\begin{array}{l}50.1 \\
\% \\
-\end{array}$ & $\begin{array}{l}4333 . \\
8 \% \\
636.1\end{array}$ \\
\hline Other Groups & 1.04 & 0.06 & $6.0 \%$ & $\%$ & 1.04 & -0.09 & $8.5 \%$ & $\%$ \\
\hline TotalPopulation & 1.07 & 0.06 & $5.4 \%$ & & 1.07 & -0.01 & $1.3 \%$ & \\
\hline White Non Latino & 1.02 & 0.02 & $2.1 \%$ & $\begin{array}{l}36.8 \\
\% \\
98.6\end{array}$ & 1.02 & 0.03 & $\begin{array}{l}3.4 \% \\
-\end{array}$ & $\begin{array}{l}250.9 \\
\% \\
435.3\end{array}$ \\
\hline Hispanic & 1.11 & 0.06 & $5.1 \%$ & $\%$ & 1.11 & -0.06 & $5.5 \%$ & $\%$ \\
\hline Other Non Latino & 1.20 & 0.08 & $6.7 \%$ & $\begin{array}{l}139.5 \\
\%\end{array}$ & 1.20 & 0.60 & $\begin{array}{l}50.1 \\
\% \\
-\end{array}$ & $\begin{array}{l}4333 . \\
8 \%\end{array}$ \\
\hline Other Groups & 0.25 & 0.18 & $\begin{array}{l}73.4 \\
\%\end{array}$ & $\begin{array}{l}314.7 \\
\%\end{array}$ & 0.25 & -0.09 & $\begin{array}{l}35.9 \\
\%\end{array}$ & $\begin{array}{l}636.1 \\
\%\end{array}$ \\
\hline TotalPopulation & 1.07 & 0.06 & $5.4 \%$ & & 1.07 & -0.01 & $1.3 \%$ & \\
\hline White Alone & 1.07 & 0.18 & $\begin{array}{l}16.4 \\
\%\end{array}$ & $\begin{array}{l}305.4 \\
\%\end{array}$ & 1.07 & 0.07 & $\begin{array}{l}6.3 \% \\
-\end{array}$ & $\begin{array}{l}487.1 \\
\% \\
300.3\end{array}$ \\
\hline $\begin{array}{l}\text { Black Alone } \\
\text { Asian and Pacific }\end{array}$ & 1.08 & 0.01 & $\begin{array}{l}0.5 \% \\
18.3\end{array}$ & $\begin{array}{l}9.2 \% \\
375.9\end{array}$ & 1.08 & -0.04 & $3.9 \%$ & $\%$ \\
\hline Islander Alone & 1.18 & 0.22 & $\%$ & $\%$ & 1.18 & 0.00 & $0.0 \%$ & $0.0 \%$ \\
\hline $\begin{array}{l}\text { Native American } \\
\text { Alone }\end{array}$ & 0.68 & -0.14 & $\begin{array}{l}21.3 \\
\%\end{array}$ & $\begin{array}{l}252.1 \\
\%\end{array}$ & 0.68 & -0.62 & $\begin{array}{l}90.5 \\
\%\end{array}$ & $\begin{array}{l}4427 . \\
3 \%\end{array}$ \\
\hline All Other Races & & & - & $\begin{array}{l}- \\
537.1\end{array}$ & & & - & 636.1 \\
\hline Alone & 0.98 & -0.31 & $\%$ & $\%$ & 0.98 & -0.09 & $9.0 \%$ & $\%$ \\
\hline TotalPopulation & 1.07 & 0.06 & $5.4 \%$ & & 1.07 & -0.01 & $1.3 \%$ & \\
\hline
\end{tabular}

Table 6A.8B High

MA: CRT.

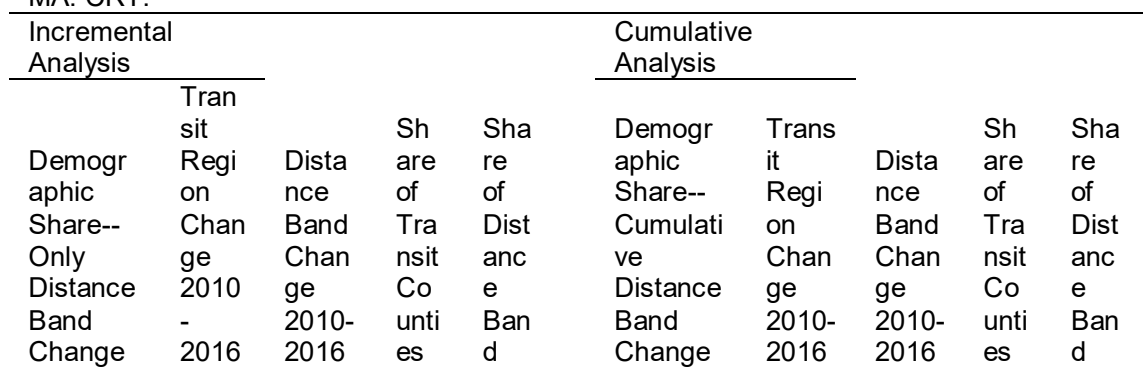




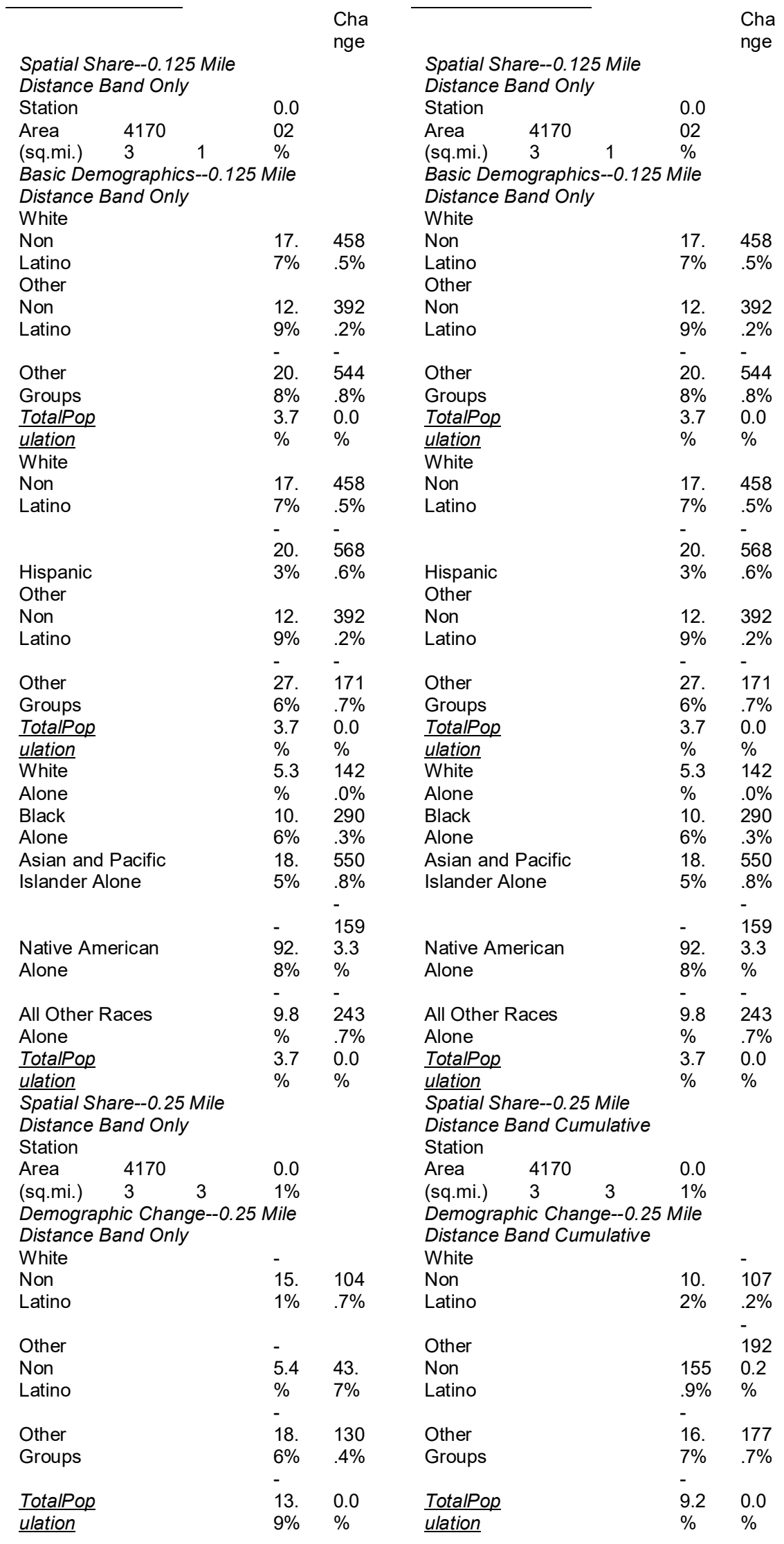




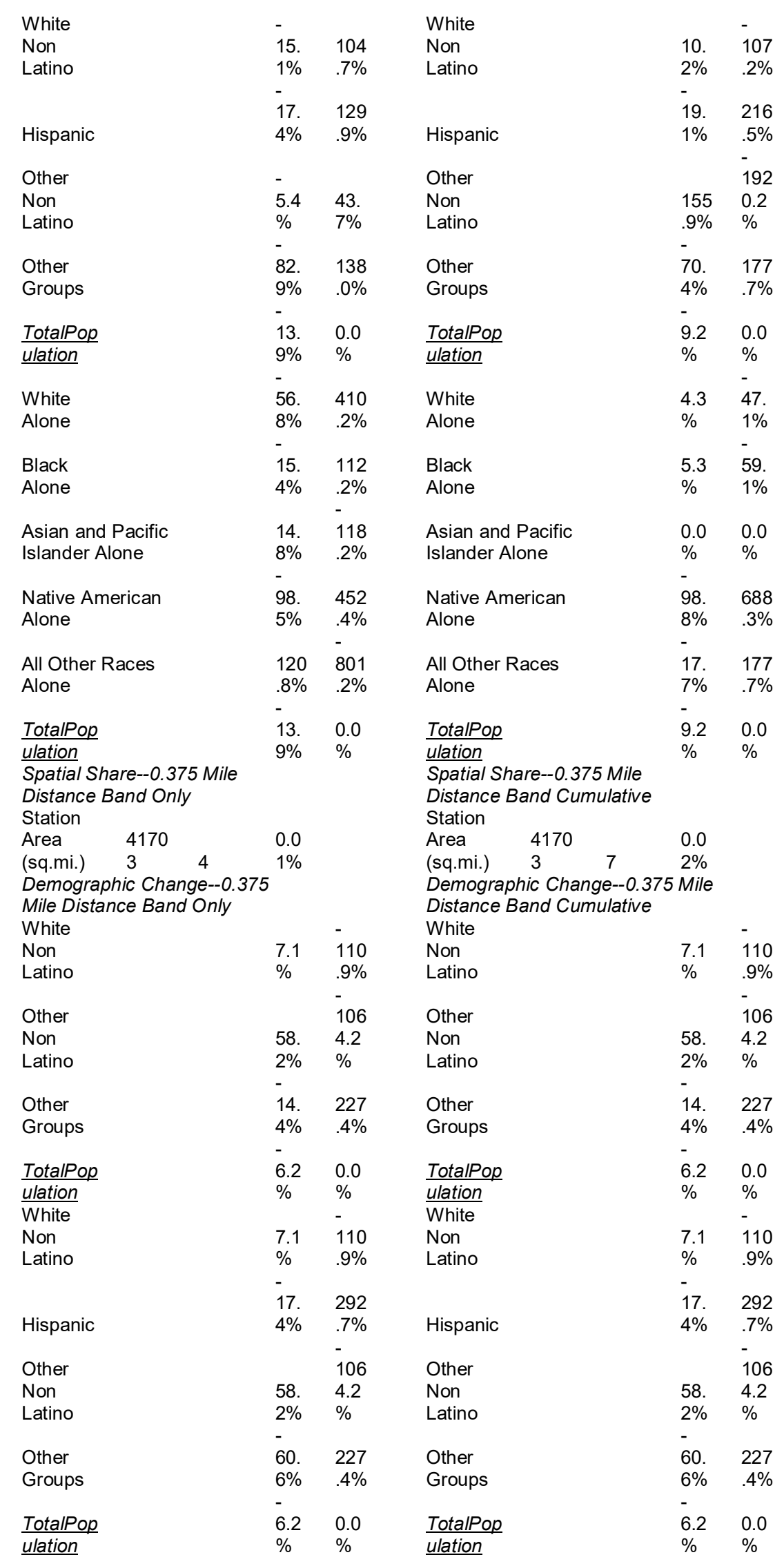




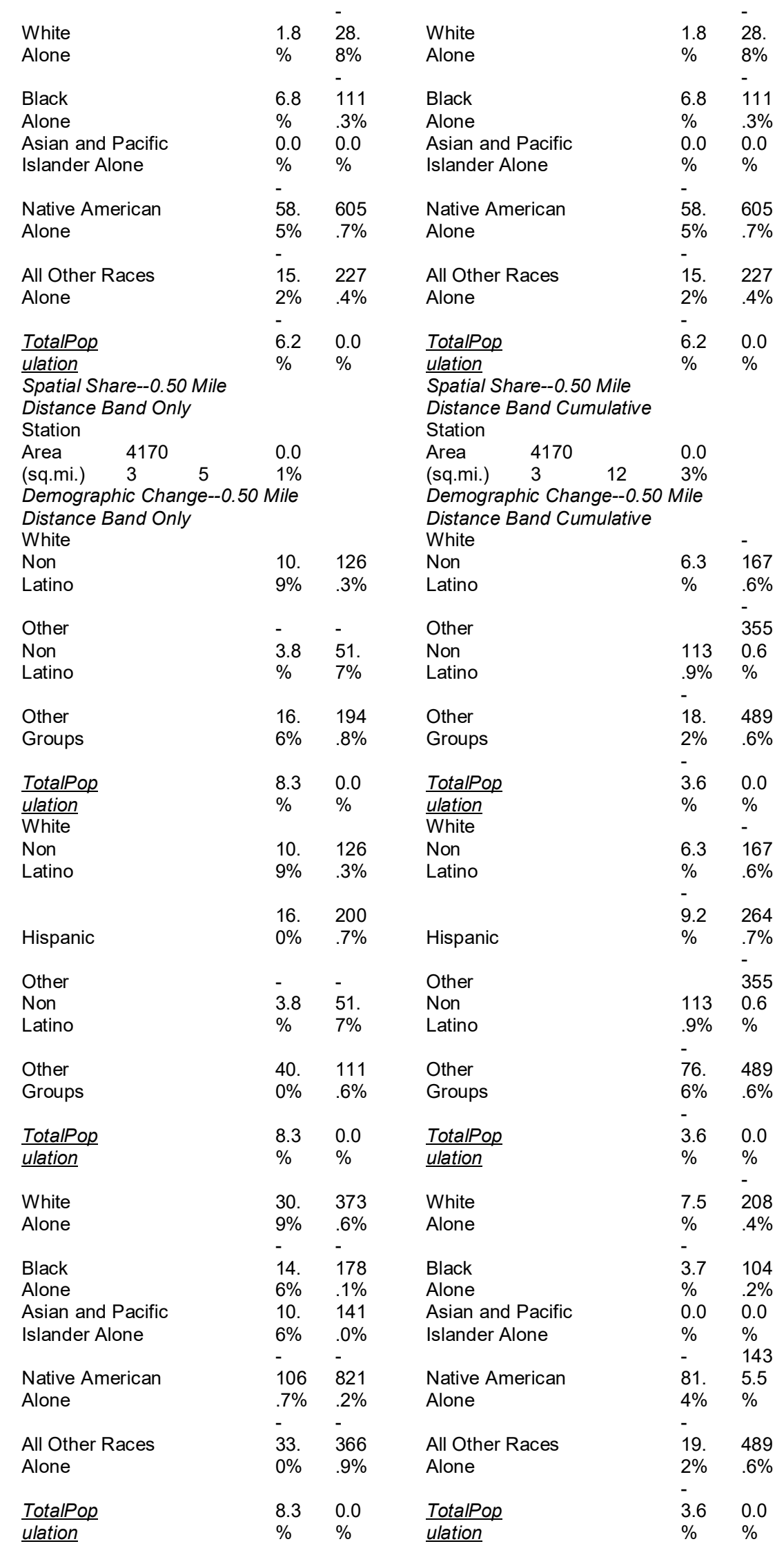




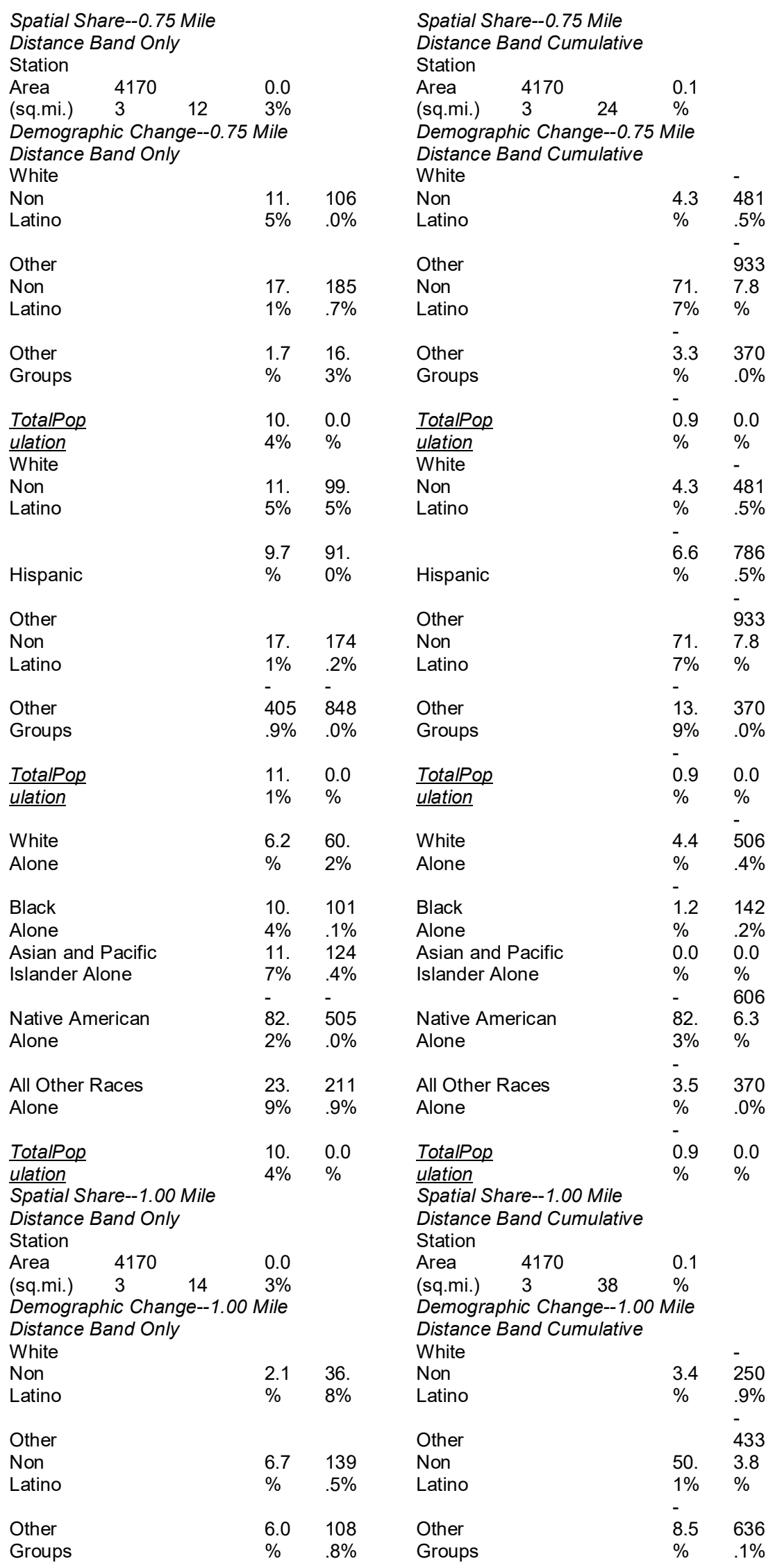




\begin{tabular}{|c|c|c|c|c|c|}
\hline TotalPop & 5.4 & 0.0 & TotalPop & 1.3 & 0.0 \\
\hline ulation & $\%$ & $\%$ & ulation & $\%$ & $\%$ \\
\hline White & & & White & & - \\
\hline Non & 2.1 & 36. & Non & 3.4 & 250 \\
\hline Latino & $\%$ & $8 \%$ & Latino & $\%$ & $.9 \%$ \\
\hline & 5.1 & 98. & & 5.5 & 435 \\
\hline Hispanic & $\%$ & $6 \%$ & Hispanic & $\%$ & $\begin{array}{l}.3 \% \\
-\end{array}$ \\
\hline Other & & & Other & & 433 \\
\hline Non & 6.7 & 139 & Non & 50. & 3.8 \\
\hline Latino & $\%$ & $.5 \%$ & Latino & $1 \%$ & $\%$ \\
\hline Other & 73. & 314 & Other & 35. & 636 \\
\hline Groups & $4 \%$ & $.7 \%$ & Groups & $\begin{array}{l}9 \% \\
-\end{array}$ & $.1 \%$ \\
\hline TotalPop & 5.4 & 0.0 & TotalPop & 1.3 & 0.0 \\
\hline ulation & $\%$ & $\%$ & ulation & $\%$ & $\%$ \\
\hline White & 16. & 305 & White & 6.3 & 487 \\
\hline Alone & $4 \%$ & $.4 \%$ & Alone & $\begin{array}{l}\% \\
-\end{array}$ & $.1 \%$ \\
\hline Black & 0.5 & 9.2 & Black & 3.9 & 300 \\
\hline Alone & $\%$ & $\%$ & Alone & $\%$ & $.3 \%$ \\
\hline Asian and Pacific & 18. & 375 & Asian and Pacific & 0.0 & 0.0 \\
\hline Islander Alone & $3 \%$ & $.9 \%$ & Islander Alone & $\%$ & $\begin{array}{l}\% \\
442\end{array}$ \\
\hline Native American & 21. & 252 & Native American & 90. & 7.3 \\
\hline Alone & $\begin{array}{l}3 \% \\
-\end{array}$ & $\begin{array}{l}.1 \% \\
-\end{array}$ & Alone & $\begin{array}{l}5 \% \\
-\end{array}$ & $\%$ \\
\hline All Other Races & 31. & 537 & All Other Races & 9.0 & 636 \\
\hline Alone & $5 \%$ & $.1 \%$ & Alone & $\begin{array}{l}\% \\
-\end{array}$ & $.1 \%$ \\
\hline TotalPop & 5.4 & 0.0 & TotalPop & 1.3 & 0.0 \\
\hline ulation & $\%$ & $\%$ & ulation & $\%$ & $\%$ \\
\hline
\end{tabular}

Table 6A.9A Poor

MA: LRT.

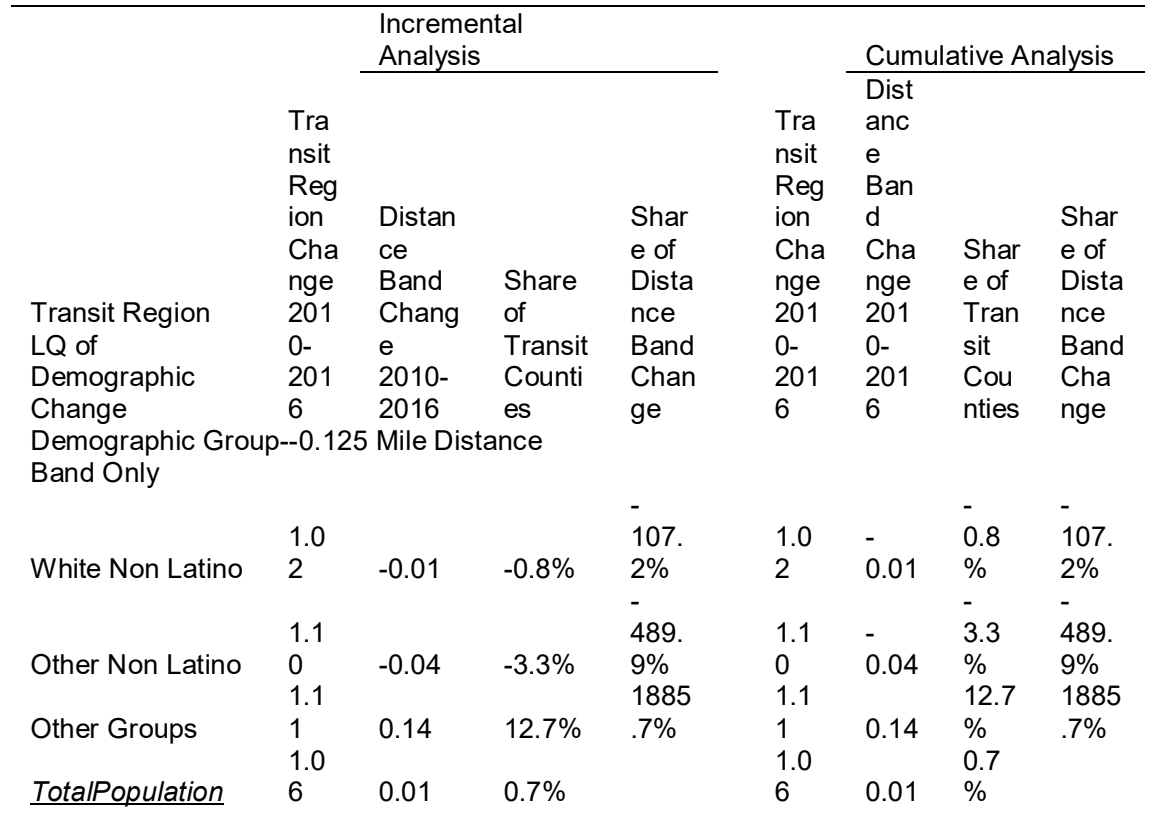




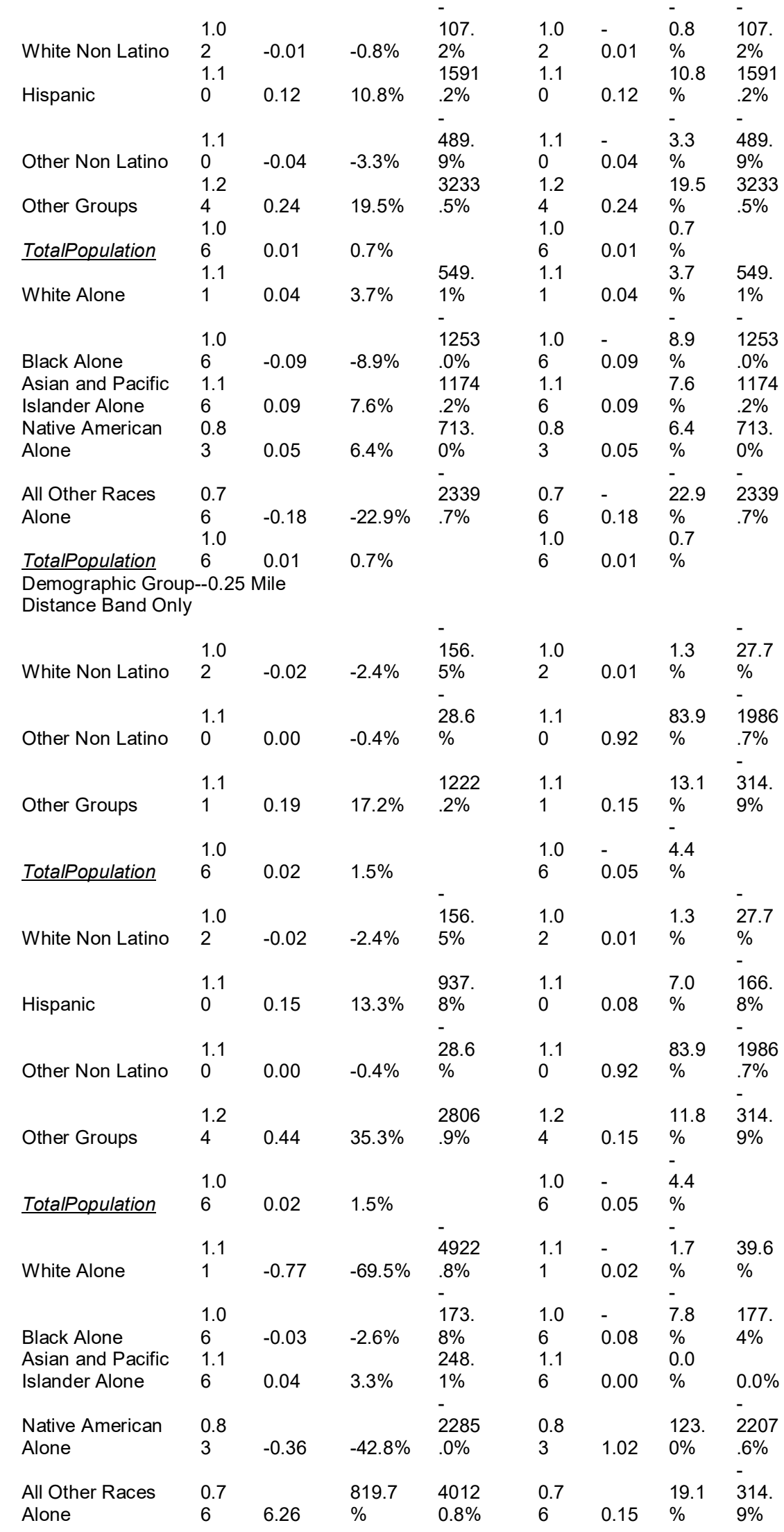




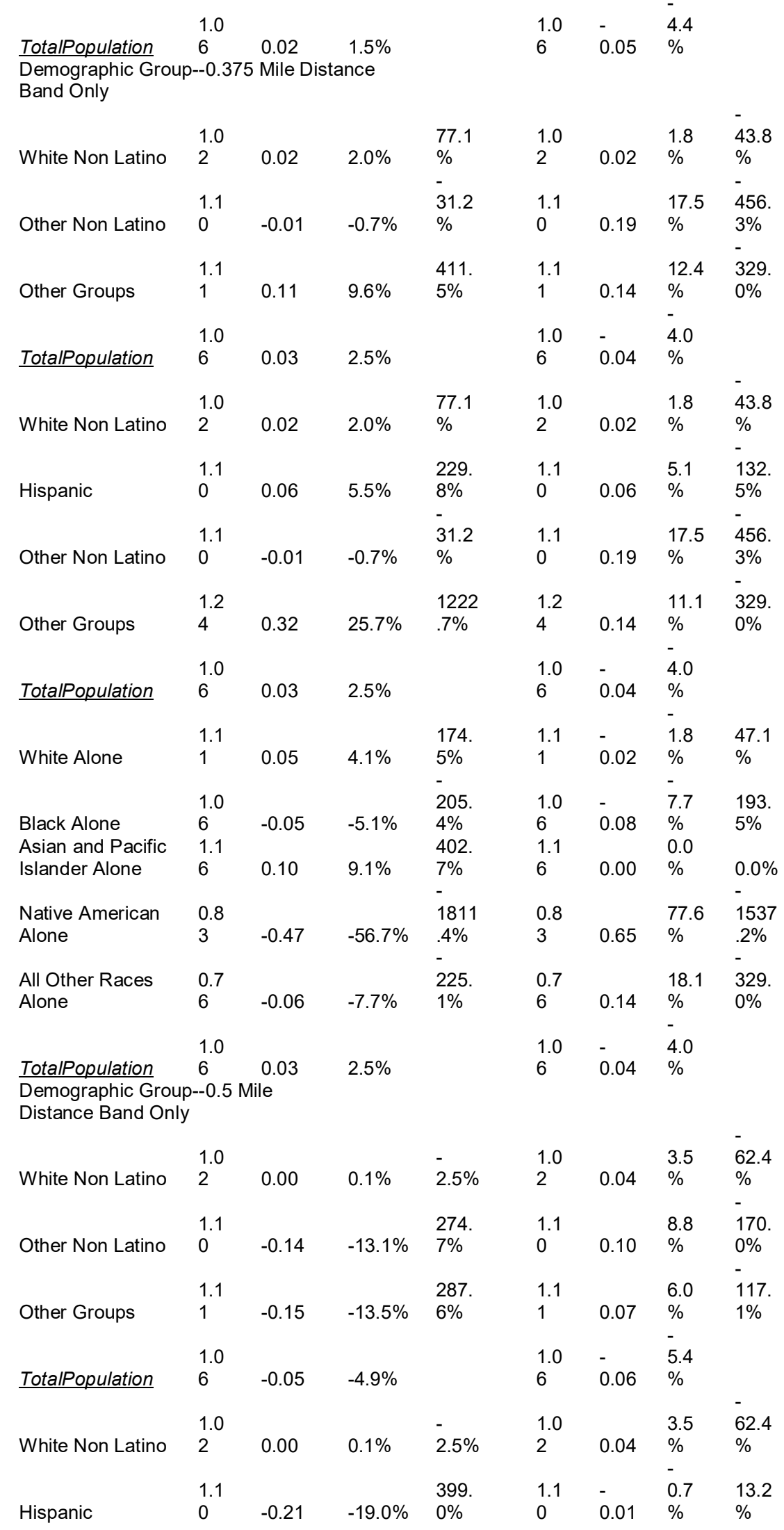




\begin{tabular}{|c|c|c|c|c|c|c|c|c|}
\hline \multirow[b]{2}{*}{ Other Non Latino } & \multicolumn{3}{|l|}{1.1} & \multicolumn{2}{|c|}{$274 . \quad 1.1$} & & \multirow{2}{*}{$\begin{array}{l}8.8 \\
\%\end{array}$} & 170. \\
\hline & 0 & -0.14 & $-13.1 \%$ & $\begin{array}{l}7 \% \\
-\end{array}$ & 0 & 0.10 & & $\begin{array}{l}0 \% \\
-\end{array}$ \\
\hline & 1.2 & & & 290. & 1.2 & & 5.4 & 117. \\
\hline Other Groups & 4 & 0.15 & $12.2 \%$ & $8 \%$ & 4 & 0.07 & $\begin{array}{l}\% \\
-\end{array}$ & $1 \%$ \\
\hline & 1.0 & & & & 1.0 & - & 5.4 & \\
\hline TotalPopulation & 6 & -0.05 & $-4.9 \%$ & & 6 & 0.06 & $\%$ & \\
\hline & 1.1 & & & - & 1.1 & - & 1.1 & 21.4 \\
\hline White Alone & 1 & 0.00 & $0.3 \%$ & $5.8 \%$ & 1 & 0.01 & $\begin{array}{l}\% \\
-\end{array}$ & $\%$ \\
\hline & 1.0 & & & 452. & 1.0 & - & 9.5 & 176. \\
\hline Black Alone & 6 & -0.24 & $-22.3 \%$ & $4 \%$ & 6 & 0.10 & $\%$ & $7 \%$ \\
\hline Asian and Pacific & 1.1 & & & 59.9 & 1.1 & & 0.0 & \\
\hline Islander Alone & 6 & -0.03 & $-2.7 \%$ & $\%$ & 6 & 0.00 & $\%$ & $\begin{array}{l}0.0 \% \\
-\end{array}$ \\
\hline Native American & 0.8 & & & 993. & 0.8 & & 49.2 & 720. \\
\hline Alone & 3 & -0.52 & $-62.4 \%$ & $6 \%$ & 3 & 0.41 & $\%$ & $\begin{array}{l}0 \% \\
-\end{array}$ \\
\hline All Other Races & 0.7 & & & 464. & 0.7 & & 8.7 & 117. \\
\hline Alone & 6 & -0.24 & $-31.8 \%$ & $5 \%$ & 6 & 0.07 & $\begin{array}{l}\% \\
-\end{array}$ & $1 \%$ \\
\hline TotalPopulation & $\begin{array}{l}1.0 \\
6\end{array}$ & -0.05 & $-4.9 \%$ & & $\begin{array}{l}1.0 \\
6\end{array}$ & $\overline{0}-06$ & $\begin{array}{l}5.4 \\
\%\end{array}$ & \\
\hline $\begin{array}{l}\text { Demographic Grou } \\
\text { Distance Band Only }\end{array}$ & -0.75 & Mile & & & & & & \\
\hline White Non Latino & $\begin{array}{l}1.0 \\
2\end{array}$ & 0.02 & $2.2 \%$ & $\begin{array}{l}426 . \\
7 \% \\
-\end{array}$ & $\begin{array}{l}1.0 \\
2\end{array}$ & 0.04 & $\begin{array}{l}4.4 \\
\%\end{array}$ & $\begin{array}{l}76.3 \\
\% \\
-\end{array}$ \\
\hline Other Non Latino & $\begin{array}{l}1.1 \\
0\end{array}$ & -0.06 & $-5.2 \%$ & $\begin{array}{l}1099 \\
.0 \%\end{array}$ & $\begin{array}{l}1.1 \\
0\end{array}$ & 0.01 & $\begin{array}{l}0.7 \\
\%\end{array}$ & $\begin{array}{l}12.4 \\
\% \\
-\end{array}$ \\
\hline Other Groups & $\begin{array}{l}1.1 \\
1\end{array}$ & 0.01 & $0.5 \%$ & $\begin{array}{l}116 . \\
0 \%\end{array}$ & $\begin{array}{l}1.1 \\
1\end{array}$ & 0.06 & $\begin{array}{l}5.3 \\
\% \\
-\end{array}$ & $\begin{array}{l}101 . \\
5 \%\end{array}$ \\
\hline TotalPopulation & $\begin{array}{l}1.0 \\
6\end{array}$ & 0.01 & $0.5 \%$ & & $\begin{array}{l}1.0 \\
6\end{array}$ & $\overline{0} .06$ & $\begin{array}{l}5.5 \\
\%\end{array}$ & \\
\hline & 1.0 & & & 426. & 1.0 & & 4.4 & 76.3 \\
\hline White Non Latino & 2 & 0.02 & $2.2 \%$ & $\begin{array}{l}7 \% \\
-\end{array}$ & 2 & 0.04 & $\begin{array}{l}\% \\
-\end{array}$ & $\%$ \\
\hline & 1.1 & & & 134. & 1.1 & - & 3.0 & 56.0 \\
\hline Hispanic & 0 & -0.01 & $-0.6 \%$ & $\begin{array}{l}8 \% \\
-\end{array}$ & 0 & 0.03 & $\%$ & $\begin{array}{l}\% \\
-\end{array}$ \\
\hline & 1.1 & & & 1099 & 1.1 & & 0.7 & 12.4 \\
\hline Other Non Latino & 0 & -0.06 & $-5.2 \%$ & $.0 \%$ & 0 & 0.01 & $\%$ & $\begin{array}{l}\% \\
-\end{array}$ \\
\hline Other Groups & $\begin{array}{l}1.2 \\
4\end{array}$ & 0.07 & $6.0 \%$ & $\begin{array}{l}1441 \\
.8 \%\end{array}$ & $\begin{array}{l}1.2 \\
4\end{array}$ & 0.06 & $\begin{array}{l}4.8 \\
\% \\
-\end{array}$ & $\begin{array}{l}101 . \\
5 \%\end{array}$ \\
\hline & 1.0 & & & & 1.0 & - & 5.5 & \\
\hline TotalPopulation & 6 & 0.01 & $0.5 \%$ & & 6 & 0.06 & $\begin{array}{l}\% \\
-\end{array}$ & \\
\hline White Alone & $\begin{array}{l}1.1 \\
1\end{array}$ & 0.04 & $4.0 \%$ & $\begin{array}{l}855 . \\
2 \% \\
-\end{array}$ & $\begin{array}{l}1.1 \\
1\end{array}$ & $\overline{-}-01$ & $\begin{array}{l}0.7 \\
\% \\
-\end{array}$ & $\begin{array}{l}13.5 \\
\%\end{array}$ \\
\hline Black Alone & $\begin{array}{l}1.0 \\
6\end{array}$ & -0.05 & $-4.9 \%$ & $\begin{array}{l}999 . \\
0 \% \\
-\end{array}$ & $\begin{array}{l}1.0 \\
6\end{array}$ & $\overline{-} .09$ & $\begin{array}{l}8.9 \\
\%\end{array}$ & $\begin{array}{l}162 . \\
2 \%\end{array}$ \\
\hline Asian and Pacific & 1.1 & & & 1124 & 1.1 & & 0.0 & \\
\hline Islander Alone & 6 & -0.06 & $-5.0 \%$ & $\begin{array}{l}.2 \% \\
-\end{array}$ & 6 & 0.00 & $\%$ & $\begin{array}{l}0.0 \% \\
-\end{array}$ \\
\hline Native American & 0.8 & & & 4341 & 0.8 & & 28.5 & 407. \\
\hline Alone & 3 & -0.22 & $-27.0 \%$ & $\begin{array}{l}.3 \% \\
-\end{array}$ & 3 & 0.24 & $\%$ & $\begin{array}{l}2 \% \\
-\end{array}$ \\
\hline All Other Races & 0.7 & & & 3385 & 0.7 & & 7.8 & 101. \\
\hline Alone & 6 & -0.18 & $-23.0 \%$ & $.5 \%$ & 6 & 0.06 & $\%$ & $5 \%$ \\
\hline
\end{tabular}




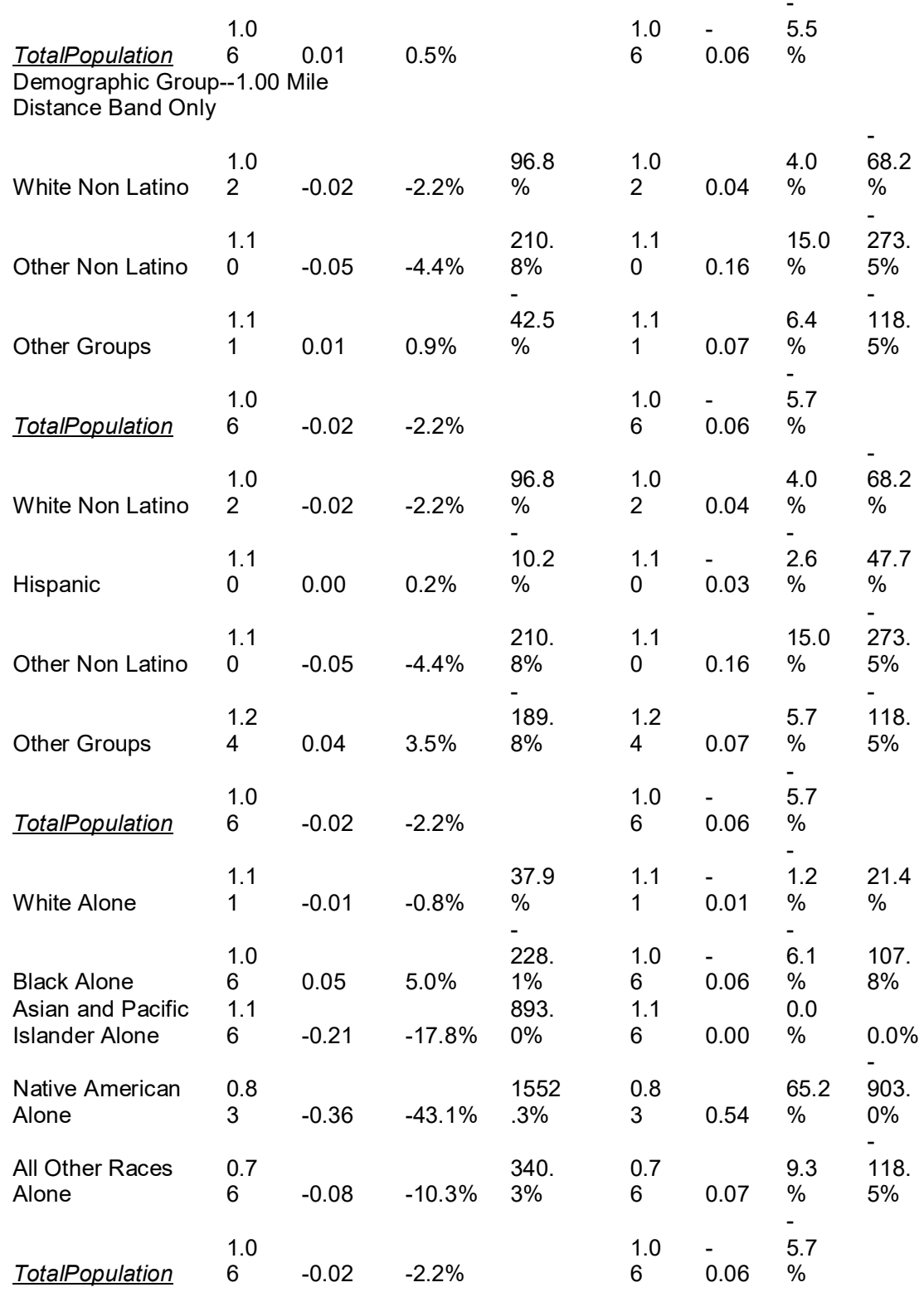

Table 6A.9B Poor MA: LRT

Incremental Cumulative

Analysis Analysis 


\begin{tabular}{|c|c|c|c|c|c|c|c|c|c|}
\hline & & \multirow{2}{*}{$\begin{array}{l}\text { Sha } \\
\text { re of }\end{array}$} & & & & & $\begin{array}{l}\text { Sha } \\
\text { re }\end{array}$ \\
\hline & sit & & Sha & & Demogra & $\begin{array}{l}\text { Tran } \\
\text { sit }\end{array}$ & & Sha & $\begin{array}{l}\text { re } \\
\text { of }\end{array}$ \\
\hline $\begin{array}{l}\text { Demogra } \\
\text { phic }\end{array}$ & $\begin{array}{l}\text { Regi } \\
\text { on }\end{array}$ & $\begin{array}{l}\text { Dista } \\
\text { nce }\end{array}$ & $\begin{array}{l}\text { re } \\
\text { of }\end{array}$ & $\begin{array}{l}\text { Dist } \\
\text { anc }\end{array}$ & $\begin{array}{l}\text { phic } \\
\text { Share-- }\end{array}$ & $\begin{array}{l}\text { Regi } \\
\text { on }\end{array}$ & $\begin{array}{l}\text { Dista } \\
\text { nce }\end{array}$ & $\begin{array}{l}\text { re } \\
\text { of }\end{array}$ & $\begin{array}{l}\text { Dist } \\
\text { anc }\end{array}$ \\
\hline Share-- & Chan & Band & Tra & $\mathrm{e}$ & Cumulati & Chan & Band & Tra & $\mathrm{e}$ \\
\hline Only & ge & Chan & nsit & Ban & & ge & Chan & nsit & Ban \\
\hline Distance & 2010 & ge & Co & $d$ & Distance & 2010 & ge & Co & $d$ \\
\hline Band & - & $2010-$ & unti & Cha & Band & - & $2010-$ & unti & Cha \\
\hline Change & 2016 & 2016 & es & nge & Change & 2016 & 2016 & es & nge \\
\hline \multicolumn{5}{|c|}{ Spatial Share--0.125 Mile } & \multicolumn{5}{|c|}{ Spatial Share--0.125 Mile } \\
\hline \multicolumn{5}{|c|}{ Distance Band Only } & \multicolumn{5}{|c|}{ Distance Band Only } \\
\hline \multicolumn{5}{|l|}{ Station } & \multicolumn{5}{|l|}{ Station } \\
\hline Area & 2966 & & 0.0 & & Area & 2966 & & 0.0 & \\
\hline (sq.mi.) & 9 & 3 & $1 \%$ & & (sq.mi.) & & 3 & $1 \%$ & \\
\hline \multicolumn{5}{|c|}{ Basic Demographics--0.125 Mile } & \multirow{2}{*}{\multicolumn{5}{|c|}{ Basic Demographics--0.125 Mile }} \\
\hline \multicolumn{5}{|c|}{ Distance Band Only } & Distance $E$ & and $\mathrm{On}$ & & & \\
\hline White & & & - & - & White & & & - & - \\
\hline Non & & & 0.8 & 107. & Non & & & 0.8 & 107 \\
\hline Latino & & & $\%$ & $2 \%$ & Latino & & & $\%$ & $.2 \%$ \\
\hline Other & & & - & - & Other & & & - & - \\
\hline Non & & & 3.3 & 489. & Non & & & 3.3 & 489 \\
\hline Latino & & & $\%$ & $9 \%$ & Latino & & & $\%$ & \\
\hline Other & & & & $\begin{array}{l}188 \\
57\end{array}$ & Other & & & & $\begin{array}{l}188 \\
57\end{array}$ \\
\hline Groups & & & $\begin{array}{l}12 . \\
7 \%\end{array}$ & $\begin{array}{l}5.1 \\
\%\end{array}$ & $\begin{array}{l}\text { Other } \\
\text { Groups }\end{array}$ & & & $\begin{array}{l}12 . \\
7 \%\end{array}$ & $\begin{array}{l}5.7 \\
\%\end{array}$ \\
\hline TotalPop & & & 0.7 & 0.0 & TotalPop & & & 0.7 & 0.0 \\
\hline ulation & & & $\%$ & $\%$ & ulation & & & $\%$ & $\%$ \\
\hline White & & & - & - & White & & & - & - \\
\hline Non & & & 0.8 & 107. & Non & & & 0.8 & 107 \\
\hline Latino & & & $\%$ & $2 \%$ & Latino & & & $\%$ & $\begin{array}{l}.2 \% \\
159\end{array}$ \\
\hline & & & & $\begin{array}{l}159 \\
1.2\end{array}$ & & & & & $\begin{array}{l}159 \\
1.2\end{array}$ \\
\hline Hispanic & & & $8 \%$ & $\%$ & Hispanic & & & $8 \%$ & $\%$ \\
\hline Other & & & - & - & Other & & & - & - \\
\hline Non & & & 3.3 & 489. & Non & & & 3.3 & 489 \\
\hline Latino & & & $\%$ & $\begin{array}{l}9 \% \\
323\end{array}$ & Latino & & & $\%$ & $\begin{array}{l}.9 \% \\
323\end{array}$ \\
\hline Other & & & 19. & 3.5 & Other & & & 19. & 3.5 \\
\hline Groups & & & $5 \%$ & $\%$ & Groups & & & $5 \%$ & $\%$ \\
\hline TotalPop & & & 0.7 & 0.0 & TotalPop & & & 0.7 & 0.0 \\
\hline ulation & & & $\%$ & $\%$ & ulation & & & $\%$ & $\%$ \\
\hline$\overline{\text { White }}$ & & & 3.7 & 549. & White & & & 3.7 & 549 \\
\hline Alone & & & $\%$ & $1 \%$ & Alone & & & $\%$ & $.1 \%$ \\
\hline & & & & - & & & & & - \\
\hline & & & - & 125 & & & & - & 125 \\
\hline Black & & & 8.9 & 3.0 & Black & & & 8.9 & 3.0 \\
\hline Alone & & & $\%$ & $\begin{array}{l}\% \\
117\end{array}$ & Alone & & & $\%$ & $\begin{array}{l}\% \\
117\end{array}$ \\
\hline Asian and & Pacific & & 7.6 & 4.2 & Asian and & Pacific & & 7.6 & 4.2 \\
\hline Islander A & one & & $\%$ & $\%$ & Islander A & one & & $\%$ & $\%$ \\
\hline Native Am & erican & & 6.4 & 713. & Native Am & rican & & 6.4 & 713 \\
\hline Alone & & & $\%$ & $0 \%$ & Alone & & & $\%$ & $.0 \%$ \\
\hline & & & - & $\overline{2} 33$ & & & & - & $-\overline{233}$ \\
\hline All Other & aces & & 22. & 9.7 & All Other $\mathrm{F}$ & aces & & 22. & 9.7 \\
\hline Alone & & & $9 \%$ & $\%$ & Alone & & & $9 \%$ & $\%$ \\
\hline TotalPop & & & 0.7 & 0.0 & TotalPop & & & 0.7 & 0.0 \\
\hline ulation & & & $\%$ & $\%$ & ulation & & & $\%$ & $\%$ \\
\hline Spatial Sh & re--0.2 & Mile & & & Spatial Sh & $r e--0.2$ & Mile & & \\
\hline Distance & and On & & & & Distance & and $\mathrm{Cu}$ & ulative & & \\
\hline Station & & & & & Station & & & & \\
\hline Area & 2966 & & 0.1 & & Area & 2966 & & 0.1 & \\
\hline (sq.mi.) & 9 & 19 & $\%$ & & (sq.mi.) & & 22 & $\%$ & \\
\hline Demograp & hic Cha & $g e--0.25$ & Mile & & Demograp & nic Cha & $g e--0.25$ & Mile & \\
\hline Distance & and On & & & & Distance & and $\mathrm{Cu}$ & ulative & & \\
\hline White & & & - & - & White & & & & - \\
\hline Non & & & 2.4 & 156. & Non & & & 1.3 & 27. \\
\hline Latino & & & $\%$ & $5 \%$ & Latino & & & $\%$ & $7 \%$ \\
\hline
\end{tabular}




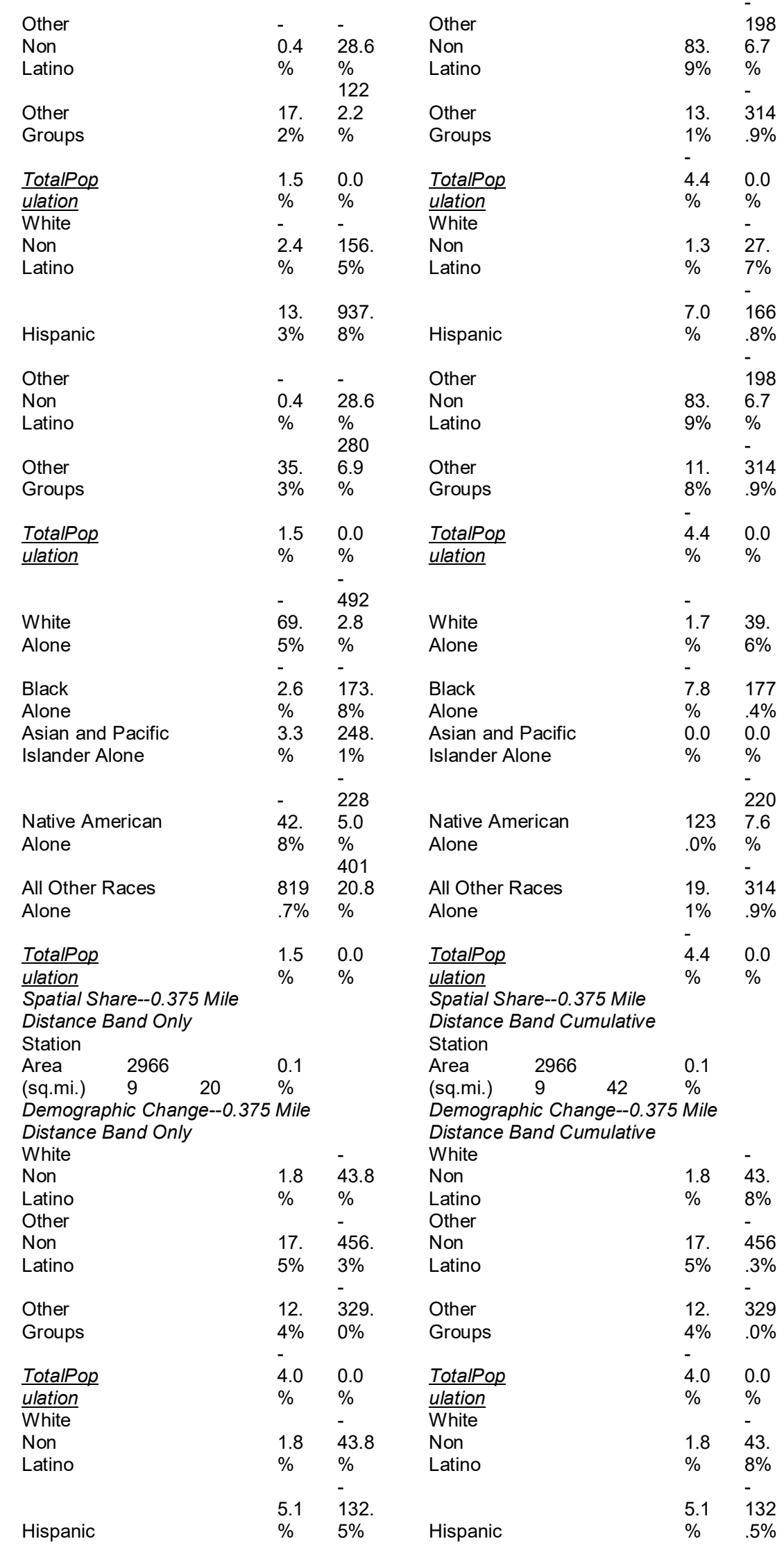




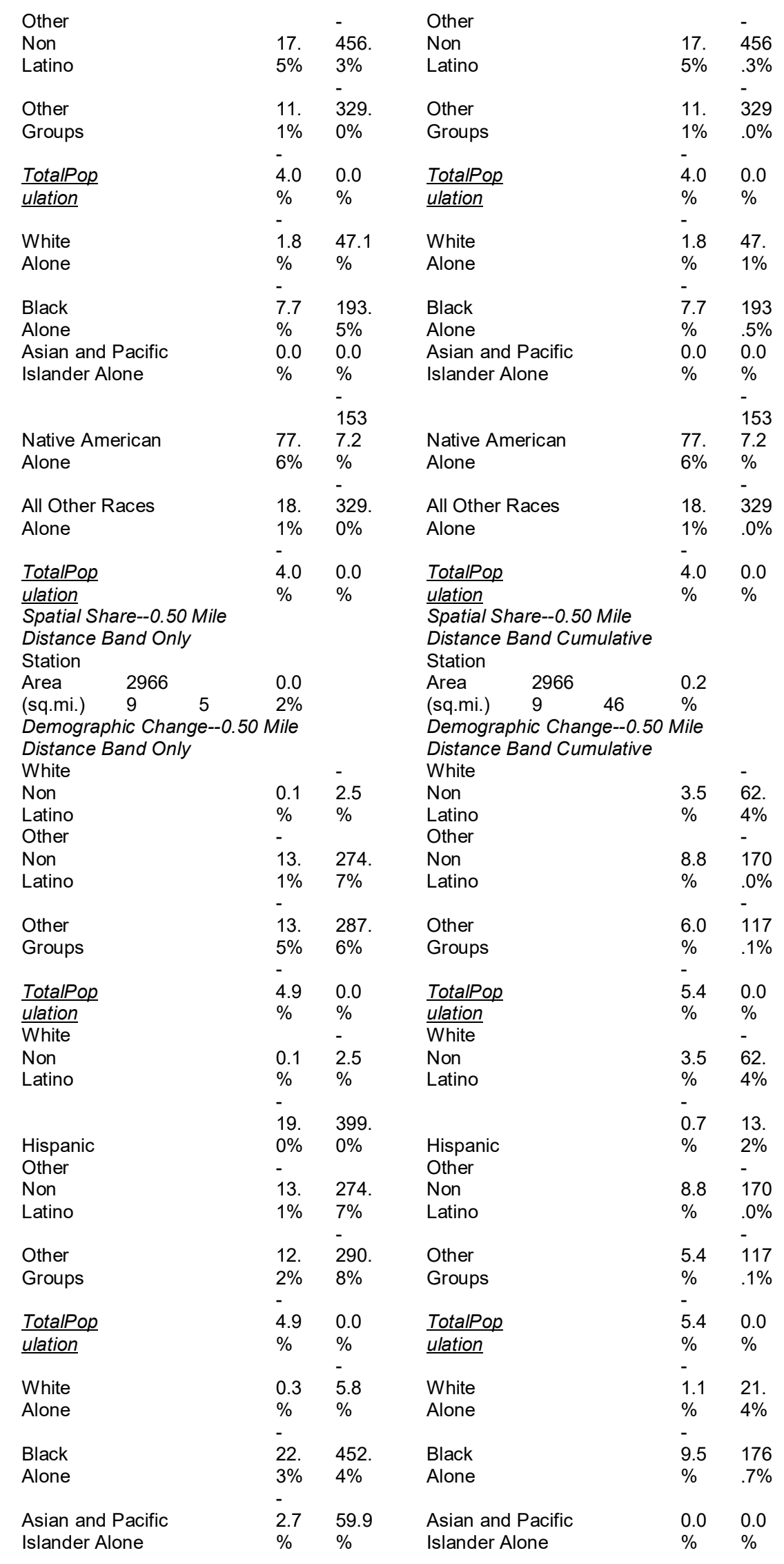




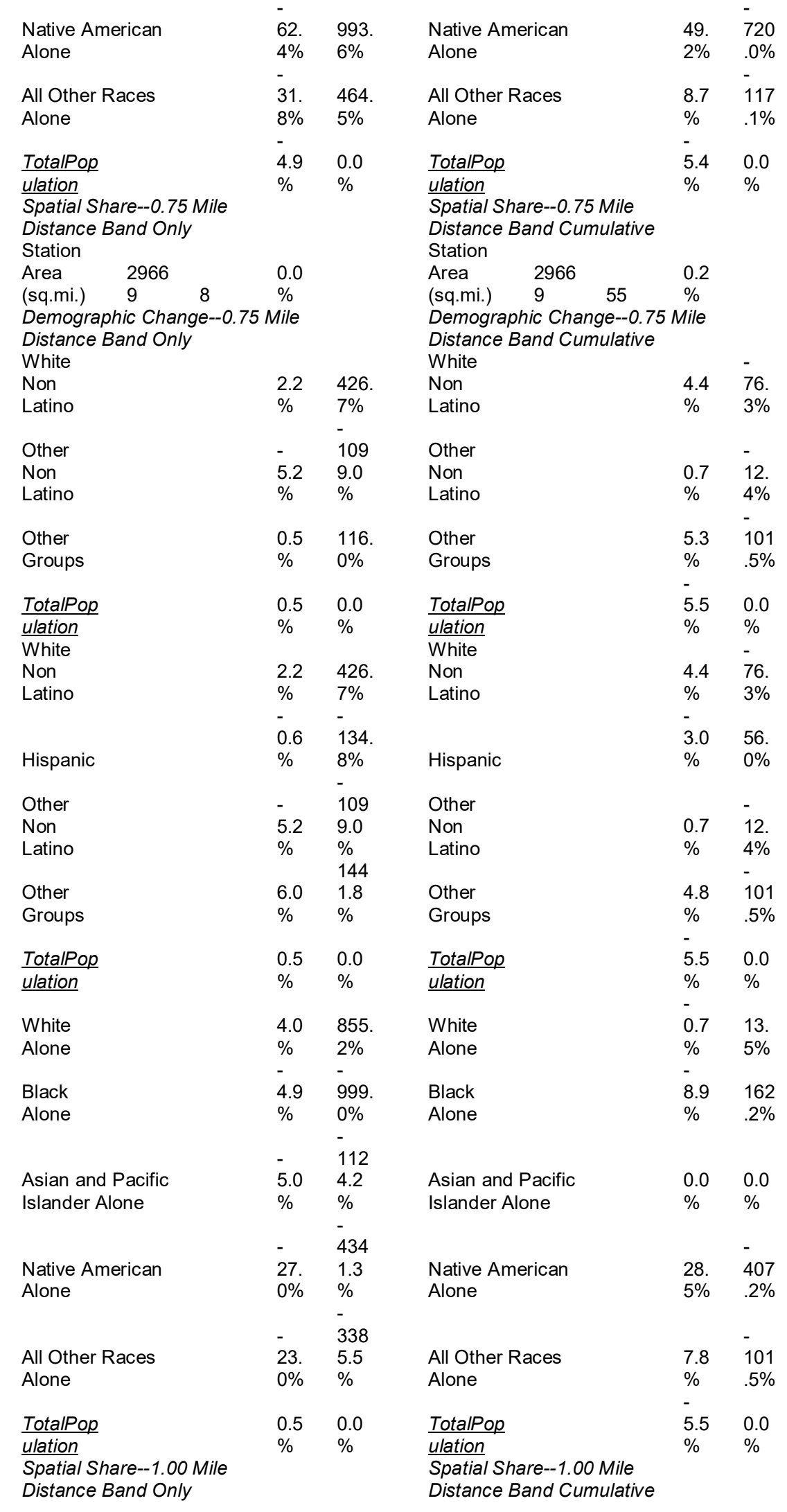




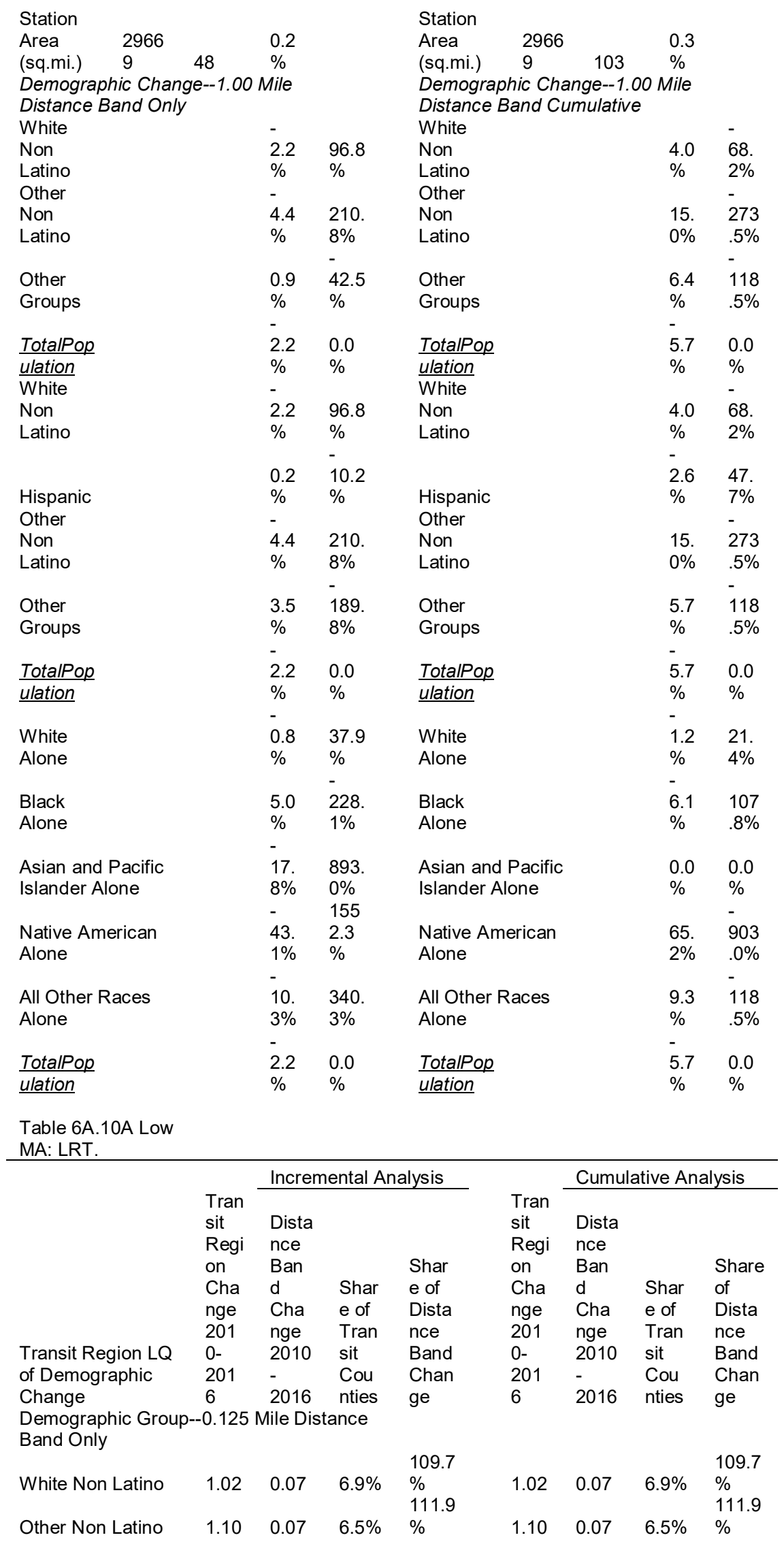




\begin{tabular}{|c|c|c|c|c|c|c|c|c|}
\hline Other Groups & 1.11 & 0.04 & $3.9 \%$ & $\begin{array}{l}68.4 \\
\%\end{array}$ & 1.11 & 0.04 & $3.9 \%$ & $\begin{array}{l}68.4 \\
\%\end{array}$ \\
\hline TotalPopulation & 1.06 & 0.06 & $6.0 \%$ & & 1.06 & 0.06 & $6.0 \%$ & \\
\hline White Non Latino & 1.02 & 0.07 & $6.9 \%$ & $\begin{array}{l}109.7 \\
\% \\
34.2\end{array}$ & 1.02 & 0.07 & $6.9 \%$ & $\begin{array}{l}109.7 \\
\% \\
34.2\end{array}$ \\
\hline Hispanic & 1.10 & 0.02 & $2.0 \%$ & $\begin{array}{l}\% \\
111.9\end{array}$ & 1.10 & 0.02 & $2.0 \%$ & $\begin{array}{l}\% \\
111.9\end{array}$ \\
\hline Other Non Latino & 1.10 & 0.07 & $\begin{array}{l}6.5 \% \\
17.9\end{array}$ & $\begin{array}{l}\% \\
347.4\end{array}$ & 1.10 & 0.07 & $\begin{array}{l}6.5 \% \\
17.9\end{array}$ & $\begin{array}{l}\% \\
347.4\end{array}$ \\
\hline Other Groups & 1.24 & 0.22 & $\%$ & $\%$ & 1.24 & 0.22 & $\%$ & $\%$ \\
\hline TotalPopulation & 1.06 & 0.06 & $\begin{array}{l}6.0 \% \\
10.7\end{array}$ & 184.7 & 1.06 & 0.06 & $\begin{array}{l}6.0 \% \\
10.7\end{array}$ & 184.7 \\
\hline White Alone & 1.11 & 0.12 & $\%$ & $\begin{array}{l}\% \\
- \\
49.9\end{array}$ & 1.11 & 0.12 & $\%$ & $\begin{array}{l}\% \\
- \\
49.9\end{array}$ \\
\hline $\begin{array}{l}\text { Black Alone } \\
\text { Asian and Pacific } \\
\text { Islander Alone }\end{array}$ & 1.06 & $\begin{array}{l}-0.03 \\
0.20\end{array}$ & $\begin{array}{l}3.0 \% \\
17.4 \\
\% \\
-\end{array}$ & $\begin{array}{l}\% \\
315.0 \\
\% \\
-\end{array}$ & 1.06 & $\begin{array}{l}-0.03 \\
0.20\end{array}$ & $\begin{array}{l}3.0 \% \\
17.4 \\
\% \\
-\end{array}$ & $\begin{array}{l}\% \\
315.0 \\
\% \\
-\end{array}$ \\
\hline $\begin{array}{l}\text { Native American } \\
\text { Alone }\end{array}$ & 0.83 & -0.20 & $\begin{array}{l}23.7 \\
\% \\
-\end{array}$ & $\begin{array}{l}308.1 \\
\% \\
-\end{array}$ & 0.83 & -0.20 & $\begin{array}{l}23.7 \\
\% \\
-\end{array}$ & $\begin{array}{l}308.1 \\
\% \\
-\end{array}$ \\
\hline $\begin{array}{l}\text { All Other Races } \\
\text { Alone }\end{array}$ & 0.76 & -0.19 & $\begin{array}{l}24.2 \\
\%\end{array}$ & $\begin{array}{l}289.0 \\
\%\end{array}$ & 0.76 & -0.19 & $\begin{array}{l}24.2 \\
\%\end{array}$ & $\begin{array}{l}289.0 \\
\%\end{array}$ \\
\hline $\begin{array}{l}\text { TotalPopulation } \\
\text { Demographic Gro } \\
\text { Distance Band On }\end{array}$ & $\begin{array}{c}1.06 \\
-0.25 !\end{array}$ & 0.06 & $6.0 \%$ & & 1.06 & 0.06 & $6.0 \%$ & \\
\hline White Non Latino & 1.02 & 0.07 & $7.0 \%$ & $\begin{array}{l}118.8 \\
\%\end{array}$ & 1.02 & 0.04 & $\begin{array}{l}4.3 \% \\
-\end{array}$ & $\begin{array}{l}1155 . \\
2 \% \\
-\end{array}$ \\
\hline Other Non Latino & 1.10 & 0.04 & $3.3 \%$ & $\begin{array}{l}60.1 \\
\% \\
106.5\end{array}$ & 1.10 & -0.21 & $\begin{array}{l}18.9 \\
\%\end{array}$ & $\begin{array}{l}5476 . \\
2 \% \\
2909 .\end{array}$ \\
\hline Other Groups & 1.11 & 0.06 & $5.8 \%$ & $\%$ & 1.11 & 0.11 & $9.9 \%$ & $0 \%$ \\
\hline TotalPopulation & 1.06 & 0.06 & $5.7 \%$ & 118.8 & 1.06 & 0.00 & $0.4 \%$ & 1155. \\
\hline White Non Latino & 1.02 & 0.07 & $7.0 \%$ & $\%$ & 1.02 & 0.04 & $4.3 \%$ & \\
\hline Hispanic & 1.10 & 0.04 & $3.7 \%$ & $\begin{array}{l}68.0 \\
\%\end{array}$ & 1.10 & -0.07 & $-6.3 \%$ & $\begin{array}{l}1822 . \\
4 \% \\
-\end{array}$ \\
\hline Other Non Latino & 1.10 & 0.04 & $\begin{array}{l}3.3 \% \\
20.7\end{array}$ & $\begin{array}{l}60.1 \\
\% \\
425.2\end{array}$ & 1.10 & -0.21 & $\begin{array}{l}18.9 \\
\%\end{array}$ & $\begin{array}{l}5476 . \\
2 \% \\
2909 .\end{array}$ \\
\hline Other Groups & 1.24 & 0.26 & $\%$ & $\%$ & 1.24 & 0.11 & $8.9 \%$ & $0 \%$ \\
\hline TotalPopulation & 1.06 & 0.06 & $\begin{array}{l}5.7 \% \\
-\end{array}$ & - & 1.06 & 0.00 & $0.4 \%$ & \\
\hline White Alone & 1.11 & -0.61 & $\begin{array}{l}55.3 \\
\%\end{array}$ & $\begin{array}{l}1011 . \\
8 \% \\
-\end{array}$ & 1.11 & 0.01 & $0.9 \%$ & $\begin{array}{l}264.5 \\
\% \\
-\end{array}$ \\
\hline $\begin{array}{l}\text { Black Alone } \\
\text { Asian and Pacific }\end{array}$ & 1.06 & -0.03 & $-\overline{2.8 \%}$ & $\begin{array}{l}48.7 \\
\% \\
186.8\end{array}$ & 1.06 & -0.09 & $-8.4 \%$ & $\begin{array}{l}2343 . \\
3 \%\end{array}$ \\
\hline Islander Alone & 1.16 & 0.11 & $\begin{array}{l}9.7 \% \\
-\end{array}$ & $\begin{array}{l}\% \\
-\end{array}$ & 1.16 & 0.00 & $0.0 \%$ & $0.0 \%$ \\
\hline $\begin{array}{l}\text { Native American } \\
\text { Alone } \\
\text { All Other Races } \\
\text { Alone }\end{array}$ & 0.83 & $\begin{array}{l}-0.34 \\
3.01\end{array}$ & $\begin{array}{l}40.6 \\
\% \\
393 . \\
6 \%\end{array}$ & $\begin{array}{l}560.3 \\
\% \\
4981 . \\
2 \%\end{array}$ & 0.83 & $\begin{array}{l}0.59 \\
0.11\end{array}$ & $\begin{array}{l}70.9 \\
\% \\
14.4 \\
\%\end{array}$ & $\begin{array}{l}1556 \\
9.9 \% \\
2909 . \\
0 \%\end{array}$ \\
\hline TotalPopulation & 1.06 & 0.06 & $5.7 \%$ & & 1.06 & 0.00 & $0.4 \%$ & \\
\hline \multicolumn{9}{|c|}{$\begin{array}{l}\text { Demographic Group--0.375 Mile Distance } \\
\text { Band Only }\end{array}$} \\
\hline White Non Latino & 1.02 & -0.02 & $-\overline{2} \%$ & $\begin{array}{l}88.6 \\
\%\end{array}$ & 1.02 & 0.04 & $4.1 \%$ & $\begin{array}{l}258.9 \\
\%\end{array}$ \\
\hline
\end{tabular}




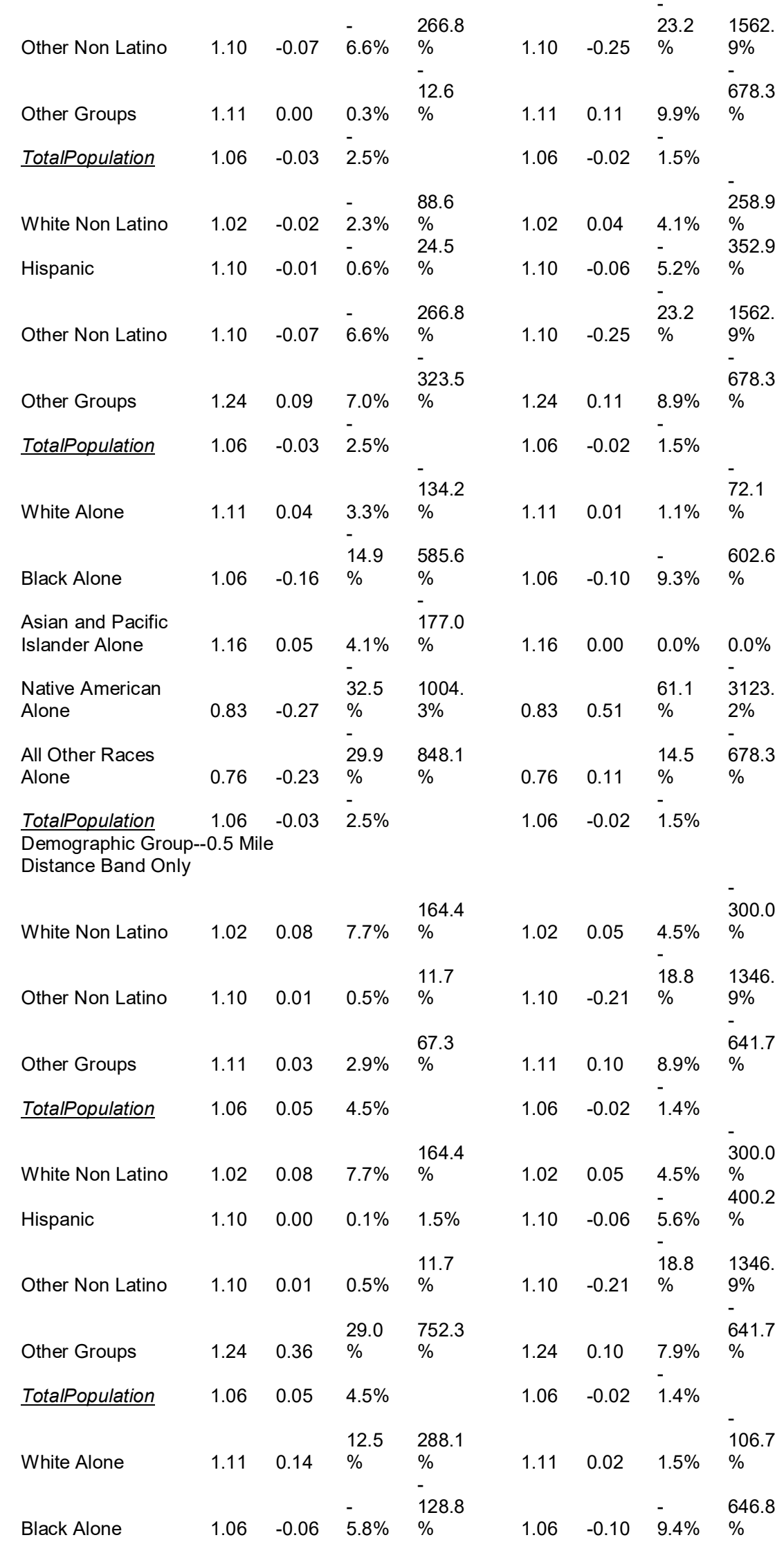




\begin{tabular}{|c|c|c|c|c|c|c|c|c|}
\hline $\begin{array}{l}\text { Asian and Pacific } \\
\text { Islander Alone }\end{array}$ & 1.16 & 0.12 & $\begin{array}{l}10.4 \\
\%\end{array}$ & $\begin{array}{l}253.2 \\
\% \\
-\end{array}$ & 1.16 & 0.00 & $0.0 \%$ & $\begin{array}{l}0.0 \% \\
-\end{array}$ \\
\hline \multirow{2}{*}{$\begin{array}{l}\text { Native American } \\
\text { Alone }\end{array}$} & & & - & 106.0 & & & 65.9 & 3574. \\
\hline & 0.83 & -0.05 & $\begin{array}{l}6.1 \% \\
-\end{array}$ & $\%$ & 0.83 & 0.55 & $\%$ & $4 \%$ \\
\hline \multirow{2}{*}{$\begin{array}{l}\text { All Other Races } \\
\text { Alone }\end{array}$} & & & 29.5 & 471.8 & & & 12.9 & 641.7 \\
\hline & 0.76 & -0.23 & $\%$ & $\%$ & 0.76 & 0.10 & $\begin{array}{l}\% \\
-\end{array}$ & $\%$ \\
\hline \multirow{2}{*}{$\begin{array}{l}\text { TotalPopulation } \\
\text { Demographic Grou } \\
\text { Distance Band Onl }\end{array}$} & 1.06 & 0.05 & $4.5 \%$ & & 1.06 & -0.02 & $1.4 \%$ & \\
\hline & $-0.75 \wedge$ & & & & & & & \\
\hline White Non Latino & 1.02 & 0.05 & $4.7 \%$ & $\begin{array}{l}101.2 \\
\%\end{array}$ & 1.02 & 0.04 & $\begin{array}{l}4.3 \% \\
-\end{array}$ & $\begin{array}{l}382.2 \\
\%\end{array}$ \\
\hline Other Non Latino & 1.10 & 0.05 & $4.9 \%$ & $\begin{array}{l}113.5 \\
\%\end{array}$ & 1.10 & -0.25 & $\begin{array}{l}22.6 \\
\%\end{array}$ & $\begin{array}{l}2145 . \\
1 \% \\
-\end{array}$ \\
\hline Other Groups & 1.11 & 0.04 & $3.6 \%$ & $\begin{array}{l}83.9 \\
\%\end{array}$ & 1.11 & 0.08 & $\begin{array}{l}7.6 \% \\
-\end{array}$ & $\begin{array}{l}734.0 \\
\%\end{array}$ \\
\hline TotalPopulation & 1.06 & 0.05 & $4.5 \%$ & & 1.06 & -0.01 & $1.1 \%$ & - \\
\hline White Non Latino & 1.02 & 0.05 & $4.7 \%$ & $\begin{array}{l}101.2 \\
\% \\
24.5\end{array}$ & 1.02 & 0.04 & $\begin{array}{l}4.3 \% \\
-\end{array}$ & $\begin{array}{l}382.2 \\
\% \\
577.2\end{array}$ \\
\hline Hispanic & 1.10 & 0.01 & $1.1 \%$ & $\%$ & 1.10 & -0.07 & $\begin{array}{l}6.1 \% \\
-\end{array}$ & $\%$ \\
\hline Other Non Latino & 1.10 & 0.05 & $4.9 \%$ & $\begin{array}{l}113.5 \\
\%\end{array}$ & 1.10 & -0.25 & $\begin{array}{l}22.6 \\
\%\end{array}$ & $\begin{array}{l}2145 . \\
1 \% \\
-\end{array}$ \\
\hline Other Groups & 1.24 & 0.30 & $\begin{array}{l}23.8 \\
\%\end{array}$ & $\begin{array}{l}625.3 \\
\%\end{array}$ & 1.24 & 0.08 & $\begin{array}{l}6.8 \% \\
-\end{array}$ & $\begin{array}{l}734.0 \\
\%\end{array}$ \\
\hline TotalPopulation & 1.06 & 0.05 & $4.5 \%$ & & 1.06 & -0.01 & $1.1 \%$ & \\
\hline White Alone & 1.11 & 0.09 & $8.5 \%$ & $\begin{array}{l}198.7 \\
\% \\
-\end{array}$ & 1.11 & 0.01 & $1.3 \%$ & $\begin{array}{l}123.4 \\
\%\end{array}$ \\
\hline \multirow{2}{*}{$\begin{array}{l}\text { Black Alone } \\
\text { Asian and Pacific } \\
\text { Islander Alone }\end{array}$} & 1.06 & -0.02 & $\begin{array}{l}- \\
1.7 \% \\
13.8\end{array}$ & $\begin{array}{l}37.7 \\
\% \\
337.7\end{array}$ & 1.06 & -0.08 & $-7.8 \%$ & $\begin{array}{l}712.0 \\
\%\end{array}$ \\
\hline & 1.16 & 0.16 & $\%$ & $\%$ & 1.16 & 0.00 & $0.0 \%$ & $0.0 \%$ \\
\hline \multirow{2}{*}{$\begin{array}{l}\text { Native American } \\
\text { Alone }\end{array}$} & & & 28.6 & 504.8 & & & 70.3 & 5059. \\
\hline & 0.83 & -0.24 & $\begin{array}{l}\% \\
-\end{array}$ & $\begin{array}{l}\% \\
-\end{array}$ & 0.83 & 0.59 & $\%$ & $\begin{array}{l}7 \% \\
-\end{array}$ \\
\hline $\begin{array}{l}\text { All Other Races } \\
\text { Alone }\end{array}$ & 0.76 & -0.16 & $\begin{array}{l}20.7 \\
\%\end{array}$ & $\begin{array}{l}335.9 \\
\%\end{array}$ & 0.76 & 0.08 & $\begin{array}{l}11.1 \\
\% \\
-\end{array}$ & $\begin{array}{l}734.0 \\
\%\end{array}$ \\
\hline $\begin{array}{l}\text { TotalPopulation } \\
\text { Demographic Grour } \\
\text { Distance Band Only }\end{array}$ & $\begin{array}{l}1.06 \\
-1.00 \wedge\end{array}$ & ile $^{0.05}$ & $4.5 \%$ & & 1.06 & -0.01 & $1.1 \%$ & \\
\hline White Non Latino & 1.02 & 0.03 & $2.8 \%$ & $\begin{array}{l}61.1 \\
\%\end{array}$ & 1.02 & 0.04 & $\begin{array}{l}3.8 \% \\
-\end{array}$ & $\begin{array}{l}- \\
333.1 \\
\%\end{array}$ \\
\hline Other Non Latino & 1.10 & 0.04 & $3.5 \%$ & $\begin{array}{l}82.7 \\
\%\end{array}$ & 1.10 & -0.16 & $\begin{array}{l}14.1 \\
\%\end{array}$ & $\begin{array}{l}1349 . \\
6 \% \\
-\end{array}$ \\
\hline Other Groups & 1.11 & 0.09 & $8.3 \%$ & $\begin{array}{l}195.6 \\
\%\end{array}$ & 1.11 & 0.07 & $\begin{array}{l}6.1 \% \\
-\end{array}$ & $\begin{array}{l}592.4 \\
\%\end{array}$ \\
\hline TotalPopulation & 1.06 & 0.05 & $4.5 \%$ & & 1.06 & -0.01 & $1.1 \%$ & - \\
\hline White Non Latino & 1.02 & 0.03 & $2.8 \%$ & $\begin{array}{l}61.1 \\
\% \\
127.2\end{array}$ & 1.02 & 0.04 & $\begin{array}{l}3.8 \% \\
-\end{array}$ & $\begin{array}{l}333.1 \\
\% \\
483.4\end{array}$ \\
\hline Hispanic & 1.10 & 0.06 & $5.5 \%$ & $\%$ & 1.10 & -0.06 & $5.1 \%$ & $\%$ \\
\hline
\end{tabular}




\begin{tabular}{|c|c|c|c|c|c|c|c|c|}
\hline & & & & & & & & \\
\hline Other Non Latino & 1.10 & 0.04 & $3.5 \%$ & $\begin{array}{l}82.7 \\
\%\end{array}$ & 1.10 & -0.16 & $\begin{array}{l}14.1 \\
\%\end{array}$ & $\begin{array}{l}1349 . \\
6 \% \\
-\end{array}$ \\
\hline Other Groups & 1.24 & 0.39 & $\begin{array}{l}31.0 \\
\%\end{array}$ & $\begin{array}{l}817.5 \\
\%\end{array}$ & 1.24 & 0.07 & $\begin{array}{l}5.5 \% \\
-\end{array}$ & $\begin{array}{l}592.4 \\
\%\end{array}$ \\
\hline TotalPopulation & 1.06 & 0.05 & $4.5 \%$ & & 1.06 & -0.01 & $1.1 \%$ & \\
\hline White Alone & 1.11 & 0.12 & $\begin{array}{l}10.4 \\
\%\end{array}$ & $\begin{array}{l}244.3 \\
\% \\
-\end{array}$ & 1.11 & 0.01 & $1.2 \%$ & $\begin{array}{l}119.8 \\
\%\end{array}$ \\
\hline $\begin{array}{l}\text { Black Alone } \\
\text { Asian and Pacific }\end{array}$ & 1.06 & -0.01 & $\begin{array}{l}- \\
0.7 \% \\
12.2\end{array}$ & $\begin{array}{l}16.4 \\
\% \\
300.7\end{array}$ & 1.06 & -0.08 & $-7.4 \%$ & $\begin{array}{l}682.5 \\
\%\end{array}$ \\
\hline Islander Alone & 1.16 & 0.14 & $\%$ & $\%$ & 1.16 & 0.00 & $0.0 \%$ & $0.0 \%$ \\
\hline $\begin{array}{l}\text { Native American } \\
\text { Alone }\end{array}$ & 0.83 & -0.31 & $\begin{array}{l}37.0 \\
\% \\
-\end{array}$ & $\begin{array}{l}653.4 \\
\% \\
-\end{array}$ & 0.83 & 0.49 & $\begin{array}{l}58.5 \\
\%\end{array}$ & $\begin{array}{l}4234 . \\
0 \% \\
-\end{array}$ \\
\hline $\begin{array}{l}\text { All Other Races } \\
\text { Alone }\end{array}$ & 0.76 & -0.24 & $\begin{array}{l}31.3 \\
\%\end{array}$ & $\begin{array}{l}507.8 \\
\%\end{array}$ & 0.76 & 0.07 & $8.9 \%$ & $\begin{array}{l}592.4 \\
\%\end{array}$ \\
\hline TotalPopulation & 1.06 & 0.05 & $4.5 \%$ & & 1.06 & -0.01 & $1.1 \%$ & \\
\hline
\end{tabular}

Table 6A.10B Low MA:

LRT

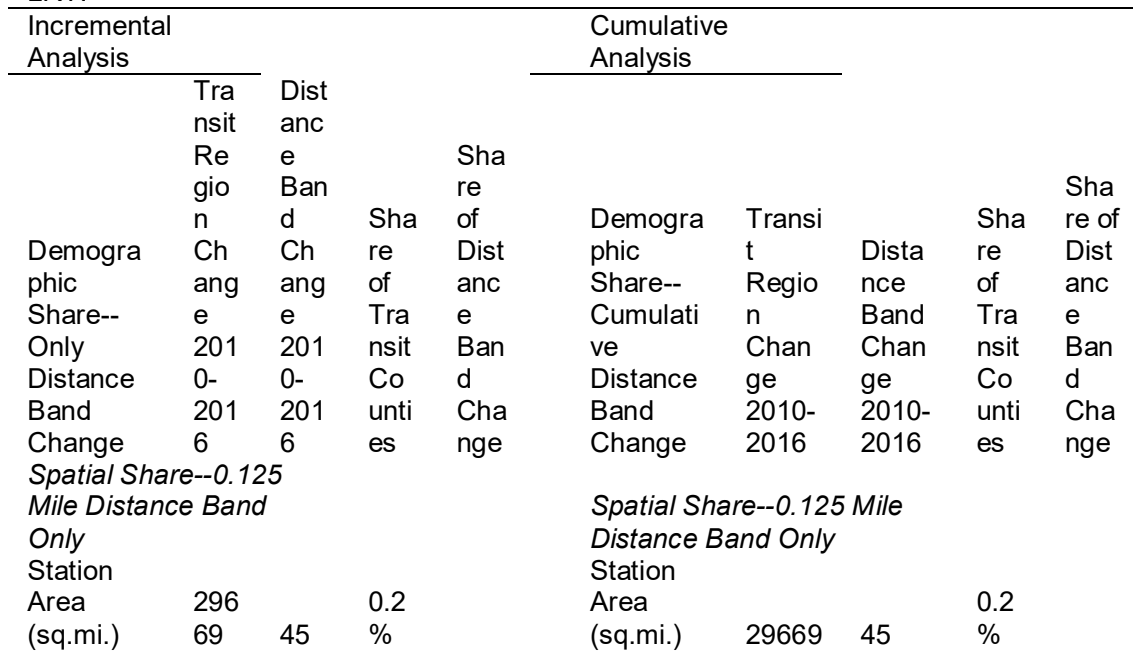




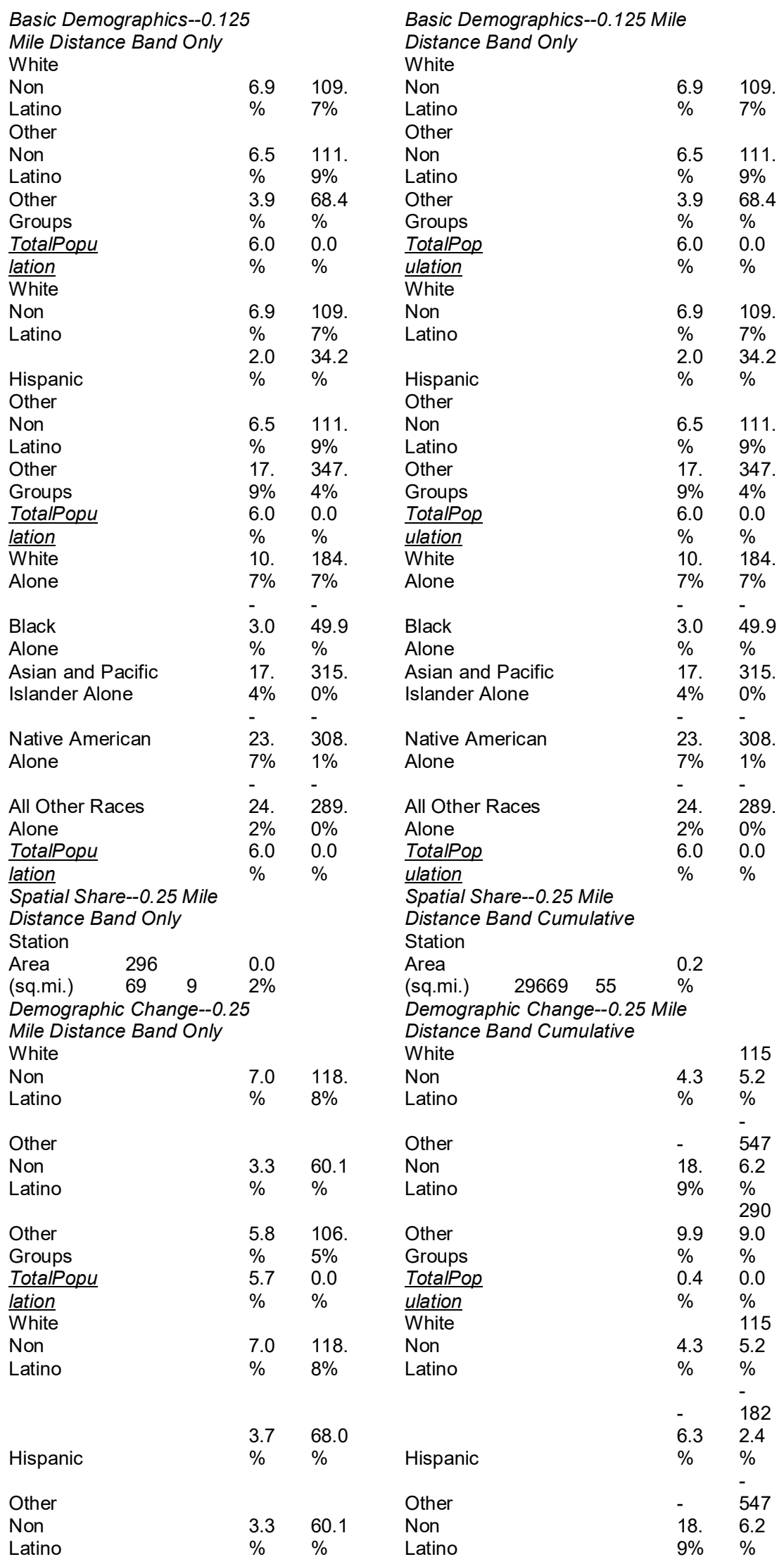




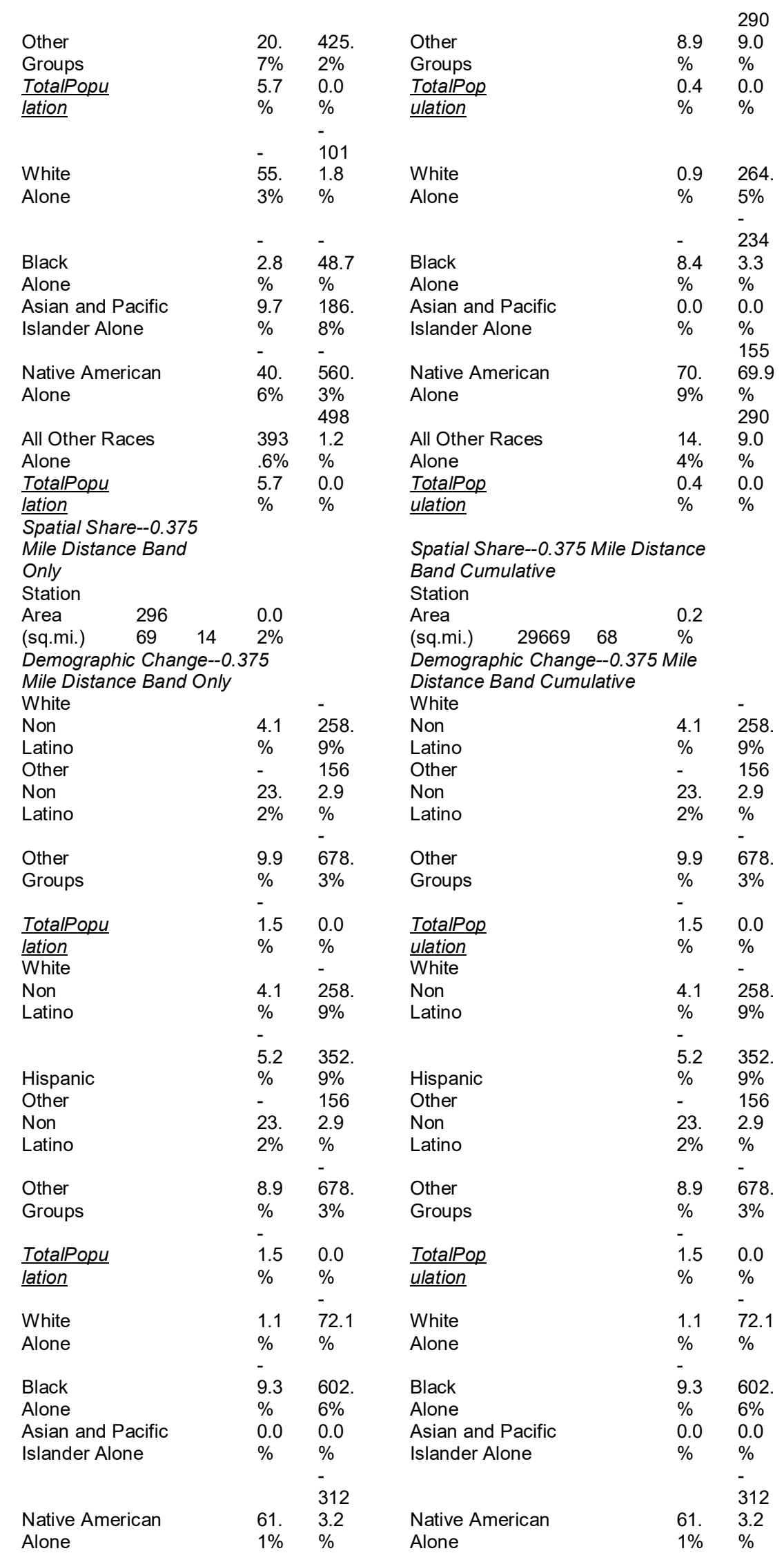




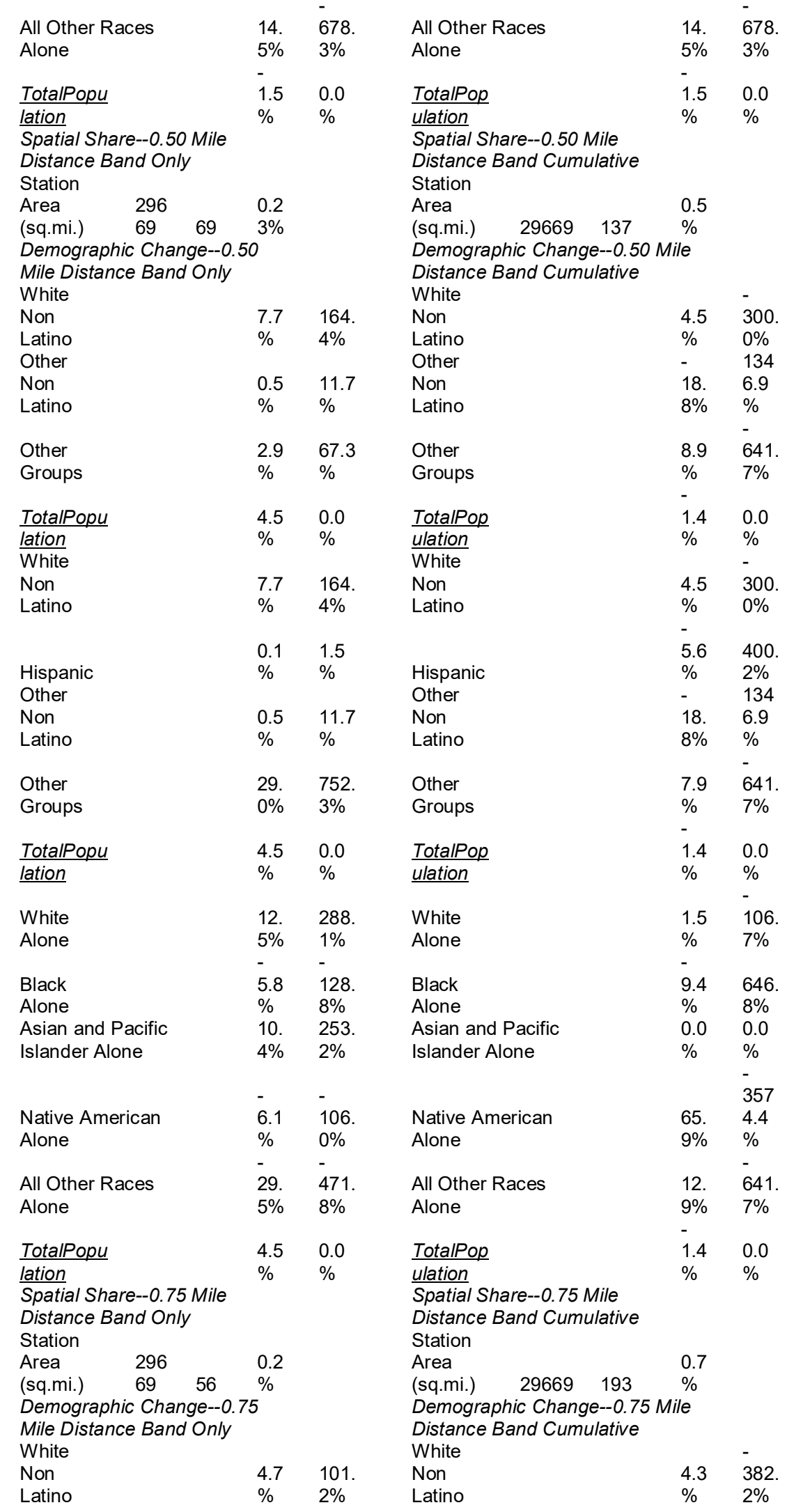




\begin{tabular}{|c|c|c|c|c|c|}
\hline \multirow{3}{*}{$\begin{array}{l}\text { Other } \\
\text { Non } \\
\text { Latino }\end{array}$} & \multirow{3}{*}{$\begin{array}{l}4.9 \\
\%\end{array}$} & \multirow{3}{*}{$\begin{array}{l}113 . \\
5 \%\end{array}$} & \multirow{3}{*}{$\begin{array}{l}\text { Other } \\
\text { Non } \\
\text { Latino }\end{array}$} & \multirow{2}{*}{-} & \multirow{3}{*}{$\begin{array}{l}214 \\
5.1 \\
\%\end{array}$} \\
\hline & & & & & \\
\hline & & & & $6 \%$ & \\
\hline Other & 3.6 & 83.9 & Other & 7.6 & 734. \\
\hline Groups & $\%$ & $\%$ & Groups & $\begin{array}{l}\% \\
-\end{array}$ & $0 \%$ \\
\hline TotalPopu & 4.5 & 0.0 & TotalPop & 1.1 & 0.0 \\
\hline lation & $\%$ & $\%$ & ulation & $\%$ & $\%$ \\
\hline$\overline{\text { White }}$ & & & $\overline{\text { White }}$ & & - \\
\hline Non & 4.7 & 101. & Non & 4.3 & 382. \\
\hline \multirow[t]{2}{*}{ Latino } & $\%$ & $2 \%$ & Latino & $\begin{array}{l}\% \\
-\end{array}$ & $2 \%$ \\
\hline & 1.1 & 24.5 & & 6.1 & 577. \\
\hline Hispanic & $\%$ & $\%$ & Hispanic & $\%$ & $2 \%$ \\
\hline Other & & & Other & - & 214 \\
\hline Non & 4.9 & 113. & Non & 22. & 5.1 \\
\hline Latino & $\%$ & $5 \%$ & Latino & $6 \%$ & $\%$ \\
\hline Other & 23. & 625. & Other & 6.8 & 734 \\
\hline Groups & $8 \%$ & $3 \%$ & Groups & $\begin{array}{l}\% \\
-\end{array}$ & $0 \%$ \\
\hline TotalPopu & 4.5 & 0.0 & TotalPop & 1.1 & 0.0 \\
\hline lation & $\%$ & $\%$ & ulation & $\%$ & $\begin{array}{l}\% \\
-\end{array}$ \\
\hline White & 8.5 & 198. & White & 1.3 & 123. \\
\hline Alone & $\begin{array}{l}\% \\
-\end{array}$ & $\begin{array}{l}7 \% \\
-\end{array}$ & Alone & $\begin{array}{l}\% \\
-\end{array}$ & $4 \%$ \\
\hline Black & 1.7 & 37.7 & Black & 7.8 & 712. \\
\hline Alone & $\%$ & $\%$ & Alone & $\%$ & $0 \%$ \\
\hline \multirow[t]{2}{*}{$\begin{array}{l}\text { Asian and Pacific } \\
\text { Islander Alone }\end{array}$} & $\begin{array}{l}13 . \\
8 \%\end{array}$ & $\begin{array}{l}337 . \\
7 \%\end{array}$ & $\begin{array}{l}\text { Asian and Pacific } \\
\text { Islander Alone }\end{array}$ & $\begin{array}{l}0.0 \\
\%\end{array}$ & $\begin{array}{l}0.0 \\
\%\end{array}$ \\
\hline & - & - & & & 505 \\
\hline Native American & 28. & 504. & Native American & 70. & 9.7 \\
\hline Alone & $\begin{array}{l}6 \% \\
-\end{array}$ & $\begin{array}{l}8 \% \\
-\end{array}$ & Alone & $3 \%$ & $\%$ \\
\hline All Other Races & 20. & 335. & All Other Races & 11. & 734. \\
\hline Alone & $7 \%$ & $9 \%$ & Alone & $\begin{array}{l}1 \% \\
-\end{array}$ & $0 \%$ \\
\hline TotalPopu & 4.5 & 0.0 & $\underline{\text { TotalPop }}$ & 1.1 & 0.0 \\
\hline lation & $\%$ & $\%$ & ulation & $\%$ & $\%$ \\
\hline \multirow{2}{*}{\multicolumn{3}{|c|}{$\begin{array}{l}\text { Spatial Share--1.00 Mile } \\
\text { Distance Band Only }\end{array}$}} & Spatial Share--1.00 Mile & & \\
\hline & & & Distance Band Cumulative & & \\
\hline \multicolumn{3}{|l|}{ Station } & Station & & \\
\hline Area & 0.0 & & Area & 0.7 & \\
\hline $69 \quad 10$ & $2 \%$ & & 29669203 & $\%$ & \\
\hline \multirow{2}{*}{\multicolumn{3}{|c|}{$\begin{array}{l}\text { Demographic Change--1.00 } \\
\text { Mile Distance Band Only }\end{array}$}} & \multirow{2}{*}{\multicolumn{3}{|c|}{ Demographic Change--1.00 Mile }} \\
\hline & & & Distance Band Cumulative & & \\
\hline \multicolumn{2}{|l|}{ White } & & White & & - \\
\hline Non & 2.8 & 61.1 & Non & 3.8 & 333. \\
\hline Latino & $\%$ & $\%$ & Latino & $\%$ & $1 \%$ \\
\hline Other & & & Other & - & 134 \\
\hline Non & 3.5 & 82.7 & Non & 14. & 9.6 \\
\hline Latino & $\%$ & $\%$ & Latino & $1 \%$ & $\%$ \\
\hline Other & 8.3 & 195. & Other & 6.1 & 592. \\
\hline Groups & $\%$ & $6 \%$ & Groups & $\begin{array}{l}\% \\
-\end{array}$ & $4 \%$ \\
\hline TotalPopu & 4.5 & 0.0 & TotalPop & 1.1 & 0.0 \\
\hline Iation & $\%$ & $\%$ & ulation & $\%$ & $\%$ \\
\hline White & & & White & & - \\
\hline Non & 2.8 & 61.1 & Non & 3.8 & 333. \\
\hline Latino & $\%$ & $\%$ & Latino & $\begin{array}{l}\% \\
-\end{array}$ & $1 \%$ \\
\hline & 5.5 & 127. & & 5.1 & 483. \\
\hline Hispanic & $\%$ & $2 \%$ & Hispanic & $\%$ & $4 \%$ \\
\hline Other & & & Other & - & 134 \\
\hline Non & 3.5 & 82.7 & Non & 14. & 9.6 \\
\hline Latino & $\%$ & $\%$ & Latino & $1 \%$ & $\%$ \\
\hline
\end{tabular}




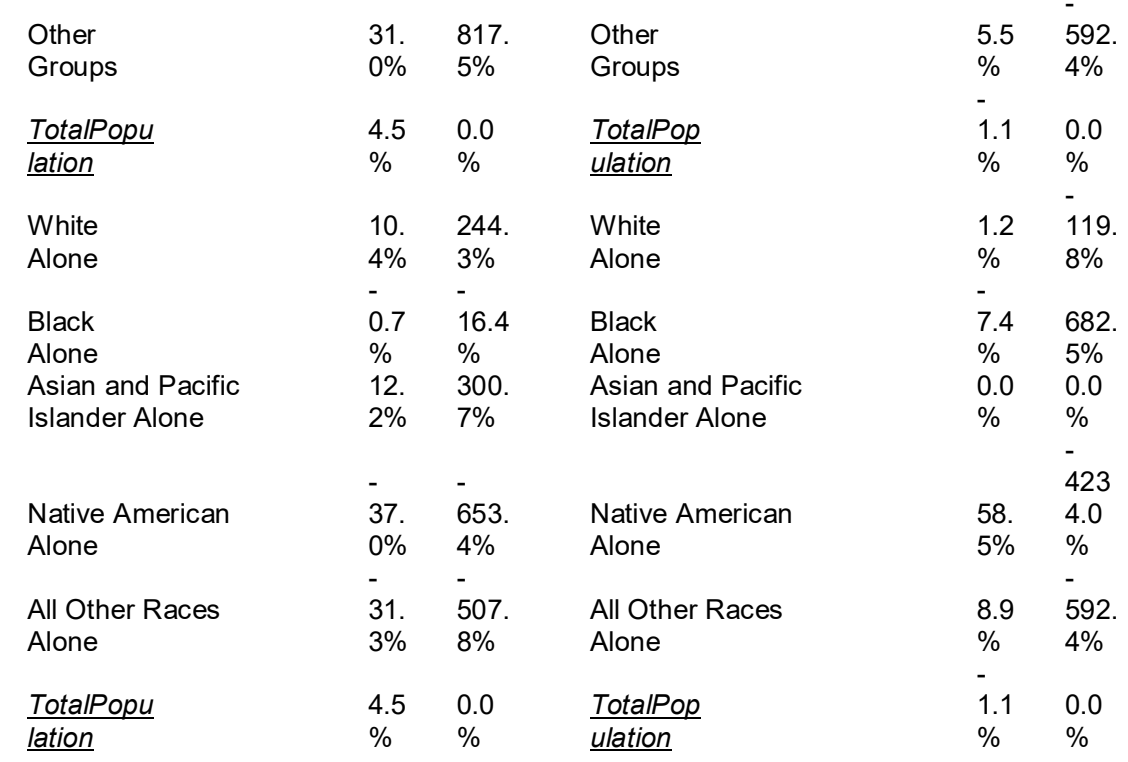

Table 6A.11A. Mod

MA: LRT.

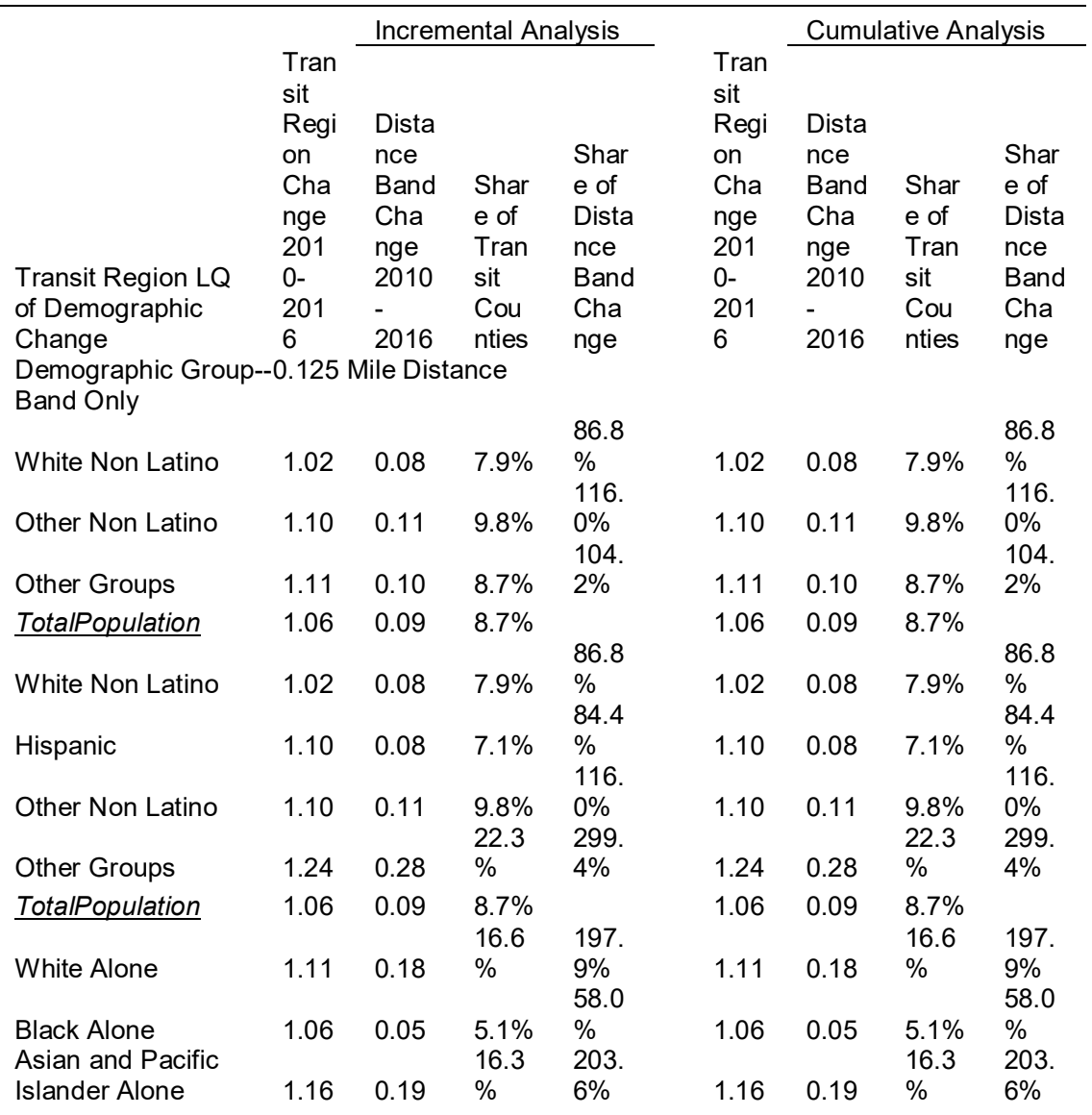




\begin{tabular}{|c|c|c|c|c|c|c|c|c|}
\hline & & & & & & & & \\
\hline Native American & & & 25.2 & 226. & & & 25.2 & 226. \\
\hline Alone & 0.83 & -0.21 & $\begin{array}{l}\% \\
-\end{array}$ & $2 \%$ & 0.83 & -0.21 & $\begin{array}{l}\% \\
-\end{array}$ & $\begin{array}{l}2 \% \\
-\end{array}$ \\
\hline $\begin{array}{l}\text { All Other Races } \\
\text { Alone }\end{array}$ & 0.76 & -0.24 & $\begin{array}{l}31.0 \\
\%\end{array}$ & $\begin{array}{l}255 . \\
5 \%\end{array}$ & 0.76 & -0.24 & $\begin{array}{l}31.0 \\
\%\end{array}$ & $\begin{array}{l}255 . \\
5 \%\end{array}$ \\
\hline $\begin{array}{l}\text { TotalPopulation } \\
\text { Demographic Grou } \\
\text { Distance Band Onl }\end{array}$ & $\begin{array}{l}1.06 \\
0.25 \mathrm{M}\end{array}$ & $e^{0.09}$ & $8.7 \%$ & & 1.06 & 0.09 & $8.7 \%$ & \\
\hline White Non Latino & 1.02 & 0.12 & $\begin{array}{l}11.9 \\
\%\end{array}$ & $\begin{array}{l}125 . \\
8 \% \\
80.3\end{array}$ & 1.02 & 0.03 & $\begin{array}{l}3.3 \% \\
10.7\end{array}$ & $\begin{array}{l}101 . \\
9 \% \\
360 .\end{array}$ \\
\hline Other Non Latino & 1.10 & 0.08 & $7.1 \%$ & $\%$ & 1.10 & 0.12 & $\%$ & $\begin{array}{l}7 \% \\
-\end{array}$ \\
\hline Other Groups & 1.11 & 0.08 & $7.5 \%$ & $\begin{array}{l}86.4 \\
\%\end{array}$ & 1.11 & -0.03 & - & $\begin{array}{l}98.8 \\
\%\end{array}$ \\
\hline TotalPopulation & 1.06 & 0.10 & $\begin{array}{l}9.1 \% \\
11.9\end{array}$ & 125. & 1.06 & 0.03 & $3.1 \%$ & 101. \\
\hline White Non Latino & 1.02 & 0.12 & $\%$ & $8 \%$ & 1.02 & 0.03 & $3.3 \%$ & $\begin{array}{l}9 \% \\
-\end{array}$ \\
\hline Hispanic & 1.10 & 0.06 & $5.9 \%$ & $\begin{array}{l}66.6 \\
\% \\
80.3\end{array}$ & 1.10 & -0.05 & $\begin{array}{l}- \\
4.8 \% \\
10.7\end{array}$ & $\begin{array}{l}163 . \\
2 \% \\
360 .\end{array}$ \\
\hline Other Non Latino & 1.10 & 0.08 & $7.1 \%$ & $\%$ & 1.10 & 0.12 & $\%$ & $\begin{array}{l}7 \% \\
-\end{array}$ \\
\hline Other Groups & 1.24 & 0.36 & $\begin{array}{l}28.7 \\
\%\end{array}$ & $\begin{array}{l}367 . \\
9 \%\end{array}$ & 1.24 & -0.03 & $-\overline{2.6 \%}$ & $\begin{array}{l}98.8 \\
\%\end{array}$ \\
\hline TotalPopulation & 1.06 & 0.10 & $\begin{array}{l}9.1 \% \\
-\end{array}$ & - & 1.06 & 0.03 & $3.1 \%$ & \\
\hline White Alone & 1.11 & -0.35 & $\begin{array}{l}31.7 \\
\%\end{array}$ & $\begin{array}{l}361 . \\
7 \%\end{array}$ & 1.11 & 0.05 & $4.4 \%$ & $\begin{array}{l}149 . \\
0 \% \\
-\end{array}$ \\
\hline $\begin{array}{l}\text { Black Alone } \\
\text { Asian and Pacific }\end{array}$ & 1.06 & 0.04 & $3.6 \%$ & $\begin{array}{l}39.9 \\
\% \\
110 .\end{array}$ & 1.06 & -0.04 & $-3.8 \%$ & $\begin{array}{l}122 . \\
0 \%\end{array}$ \\
\hline Islander Alone & 1.16 & 0.11 & $\begin{array}{l}9.2 \% \\
-\end{array}$ & $\begin{array}{l}8 \% \\
-\end{array}$ & 1.16 & 0.00 & $0.0 \%$ & $0.0 \%$ \\
\hline $\begin{array}{l}\text { Native American } \\
\text { Alone }\end{array}$ & 0.83 & -0.27 & $\begin{array}{l}32.8 \\
\%\end{array}$ & $\begin{array}{l}282 . \\
5 \%\end{array}$ & 0.83 & 0.01 & $1.0 \%$ & $\begin{array}{l}24.3 \\
\% \\
-\end{array}$ \\
\hline $\begin{array}{l}\text { All Other Races } \\
\text { Alone }\end{array}$ & 0.76 & 1.45 & $\begin{array}{l}190 . \\
2 \%\end{array}$ & $\begin{array}{l}1503 \\
.1 \%\end{array}$ & 0.76 & -0.03 & - & $\begin{array}{l}98.8 \\
\%\end{array}$ \\
\hline $\begin{array}{l}\text { TotalPopulation } \\
\text { Demographic Grou } \\
\text { Band Only }\end{array}$ & $\begin{array}{l}1.06 \\
0.375\end{array}$ & $\begin{array}{l}0.10 \\
\text { Iile Dist }\end{array}$ & $\begin{array}{l}9.1 \% \\
\text { ance }\end{array}$ & & 1.06 & 0.03 & $3.1 \%$ & \\
\hline White Non Latino & 1.02 & 0.05 & $5.2 \%$ & $\begin{array}{l}95.5 \\
\%\end{array}$ & 1.02 & 0.03 & $3.3 \%$ & $\begin{array}{l}132 . \\
8 \% \\
-\end{array}$ \\
\hline Other Non Latino & 1.10 & 0.06 & $5.1 \%$ & $\begin{array}{l}100 . \\
6 \% \\
105 .\end{array}$ & 1.10 & -0.04 & - & $\begin{array}{l}176 . \\
6 \% \\
10.7\end{array}$ \\
\hline Other Groups & 1.11 & 0.06 & $5.3 \%$ & $4 \%$ & 1.11 & 0.00 & $0.2 \%$ & $\%$ \\
\hline TotalPopulation & 1.06 & 0.06 & $5.3 \%$ & & 1.06 & 0.03 & $2.4 \%$ & \\
\hline White Non Latino & 1.02 & 0.05 & $5.2 \%$ & $\begin{array}{l}95.5 \\
\%\end{array}$ & 1.02 & 0.03 & $3.3 \%$ & $\begin{array}{l}132 . \\
8 \% \\
-\end{array}$ \\
\hline Hispanic & 1.10 & 0.06 & $5.6 \%$ & $\begin{array}{l}111 . \\
0 \%\end{array}$ & 1.10 & -0.05 & $-4.4 \%$ & $\begin{array}{l}193 . \\
8 \% \\
-\end{array}$ \\
\hline Other Non Latino & 1.10 & 0.06 & $5.1 \%$ & $\begin{array}{l}100 . \\
6 \% \\
32.9\end{array}$ & 1.10 & -0.04 & - & $\begin{array}{l}176 . \\
6 \% \\
10.7\end{array}$ \\
\hline Other Groups & 1.24 & 0.02 & $1.5 \%$ & $\%$ & 1.24 & 0.00 & $0.2 \%$ & $\%$ \\
\hline TotalPopulation & 1.06 & 0.06 & $\begin{array}{l}5.3 \% \\
13.9\end{array}$ & 276. & 1.06 & 0.03 & $2.4 \%$ & 192. \\
\hline White Alone & 1.11 & 0.15 & $\%$ & $6 \%$ & 1.11 & 0.05 & $4.4 \%$ & $1 \%$ \\
\hline
\end{tabular}




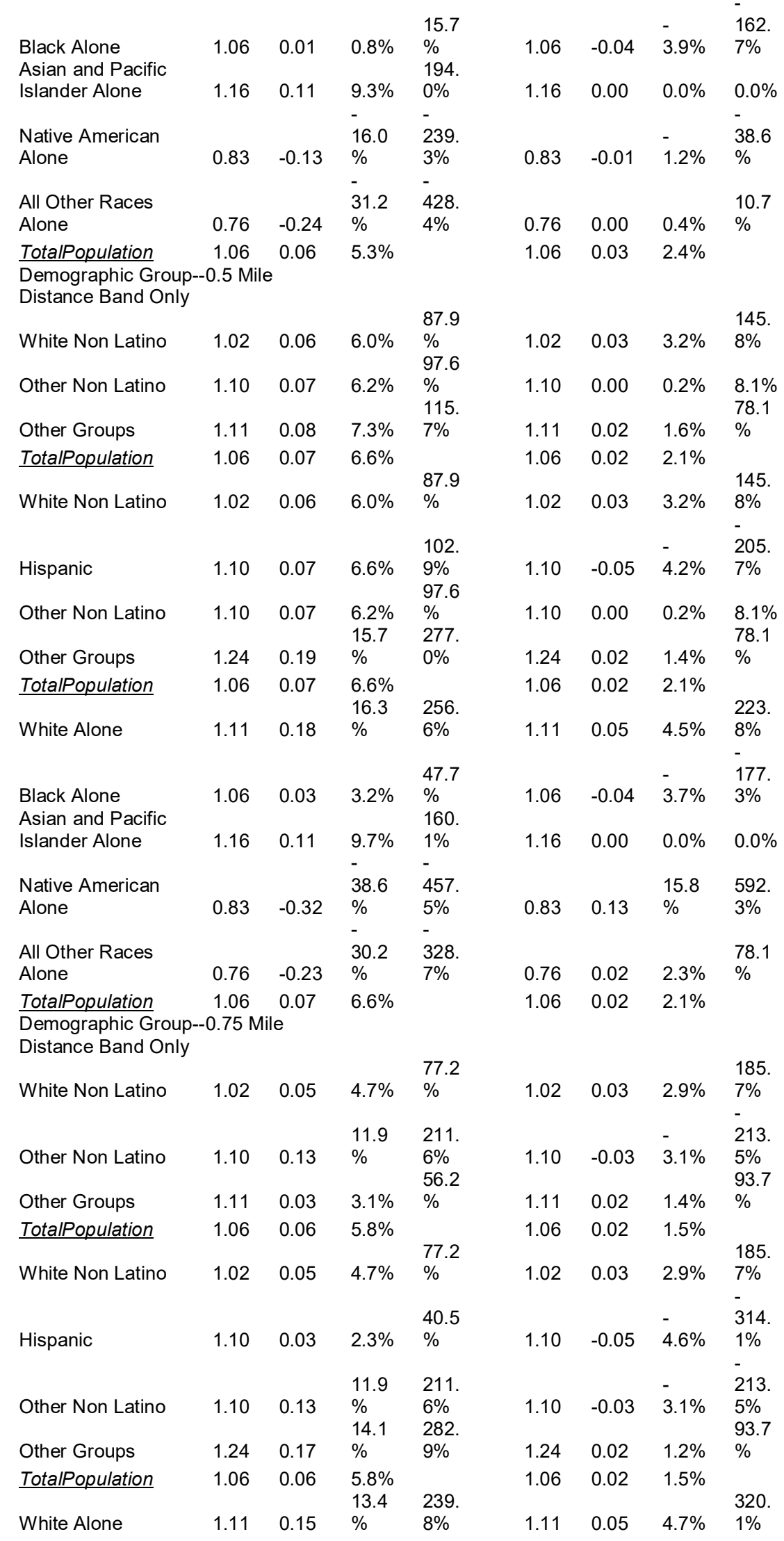




\begin{tabular}{|c|c|c|c|c|c|c|c|c|}
\hline Black Alone & 1.06 & 0.10 & $9.0 \%$ & $\begin{array}{l}154 . \\
7 \%\end{array}$ & 1.06 & -0.03 & $-\overline{2}$ & $\begin{array}{l}181 . \\
5 \%\end{array}$ \\
\hline $\begin{array}{l}\text { Asian and Pacific } \\
\text { Islander Alone } \\
\text { Native American }\end{array}$ & 1.16 & 0.15 & $\begin{array}{l}13.3 \\
\%\end{array}$ & $\begin{array}{l}249 . \\
0 \%\end{array}$ & 1.16 & 0.00 & $0.0 \%$ & $0.0 \%$ \\
\hline Alone & 0.83 & 0.00 & $0.3 \%$ & $\begin{array}{l}3.6 \% \\
-\end{array}$ & 0.83 & 0.09 & $\%$ & $7 \%$ \\
\hline $\begin{array}{l}\text { All Other Races } \\
\text { Alone }\end{array}$ & 0.76 & -0.24 & $\begin{array}{l}31.9 \\
\%\end{array}$ & $\begin{array}{l}394 . \\
6 \%\end{array}$ & 0.76 & 0.02 & $2.0 \%$ & $\begin{array}{l}93.7 \\
\%\end{array}$ \\
\hline \multicolumn{9}{|c|}{$\begin{array}{l}\text { Demographic Group--1.00 Mile } \\
\text { Distance Band Only }\end{array}$} \\
\hline White Non Latino & 1.02 & 0.03 & $2.5 \%$ & $\begin{array}{l}43.3 \\
\%\end{array}$ & 1.02 & 0.03 & $2.5 \%$ & $\begin{array}{l}150 . \\
0 \% \\
- \\
-\end{array}$ \\
\hline Other Non Latino & 1.10 & 0.07 & $6.7 \%$ & $\begin{array}{l}124 . \\
3 \% \\
154\end{array}$ & 1.10 & -0.01 & $-1.2 \%$ & $\begin{array}{l}77.5 \\
\% \\
220 .\end{array}$ \\
\hline Other Groups & 1.11 & 0.09 & $8.2 \%$ & $1 \%$ & 1.11 & 0.04 & $3.3 \%$ & $0 \%$ \\
\hline TotalPopulation & 1.06 & 0.06 & $5.6 \%$ & & 1.06 & 0.02 & $1.6 \%$ & \\
\hline White Non Latino & 1.02 & 0.03 & $2.5 \%$ & $\begin{array}{l}43.3 \\
\%\end{array}$ & 1.02 & 0.03 & $2.5 \%$ & $\begin{array}{l}150 . \\
0 \%\end{array}$ \\
\hline Hispanic & 1.10 & 0.09 & $8.2 \%$ & $\begin{array}{l}151 . \\
3 \%\end{array}$ & 1.10 & -0.04 & $-\overline{3}$ & $\begin{array}{l}235 . \\
8 \% \\
-\end{array}$ \\
\hline Other Non Latino & 1.10 & 0.07 & $6.7 \%$ & $\begin{array}{l}124 . \\
3 \% \\
189 .\end{array}$ & 1.10 & -0.01 & $-1.2 \%$ & $\begin{array}{l}77.5 \\
\% \\
220 .\end{array}$ \\
\hline Other Groups & 1.24 & 0.11 & $9.1 \%$ & $5 \%$ & 1.24 & 0.04 & $3.0 \%$ & $0 \%$ \\
\hline TotalPopulation & 1.06 & 0.06 & $\begin{array}{l}5.6 \% \\
14.1\end{array}$ & 262. & 1.06 & 0.02 & $1.6 \%$ & 307. \\
\hline White Alone & 1.11 & 0.16 & $\%$ & $5 \%$ & 1.11 & 0.05 & $4.7 \%$ & $\begin{array}{l}3 \% \\
- \\
230 .\end{array}$ \\
\hline $\begin{array}{l}\text { Black Alone } \\
\text { Asian and Pacific }\end{array}$ & 1.06 & 0.00 & $\begin{array}{l}0.3 \% \\
16.5\end{array}$ & $\begin{array}{l}5.0 \% \\
323 .\end{array}$ & 1.06 & -0.04 & $3.7 \%$ & $6 \%$ \\
\hline Islander Alone & 1.16 & 0.19 & $\begin{array}{l}\% \\
-\end{array}$ & $\begin{array}{l}0 \% \\
-\end{array}$ & 1.16 & 0.00 & $0.0 \%$ & $0.0 \%$ \\
\hline $\begin{array}{l}\text { Native American } \\
\text { Alone }\end{array}$ & 0.83 & -0.41 & $\begin{array}{l}49.5 \\
\% \\
-\end{array}$ & $\begin{array}{l}695 . \\
2 \% \\
-\end{array}$ & 0.83 & 0.23 & $\begin{array}{l}27.6 \\
\%\end{array}$ & $\begin{array}{l}1357 \\
.6 \%\end{array}$ \\
\hline $\begin{array}{l}\text { All Other Races } \\
\text { Alone }\end{array}$ & 0.76 & -0.23 & $\begin{array}{l}30.0 \\
\%\end{array}$ & $\begin{array}{l}386 . \\
8 \%\end{array}$ & 0.76 & 0.04 & $4.9 \%$ & $\begin{array}{l}220 . \\
0 \%\end{array}$ \\
\hline TotalPopulation & 1.06 & 0.06 & $5.6 \%$ & & 1.06 & 0.02 & $1.6 \%$ & \\
\hline
\end{tabular}


Table 6A.11B. Mod MA: LRT.

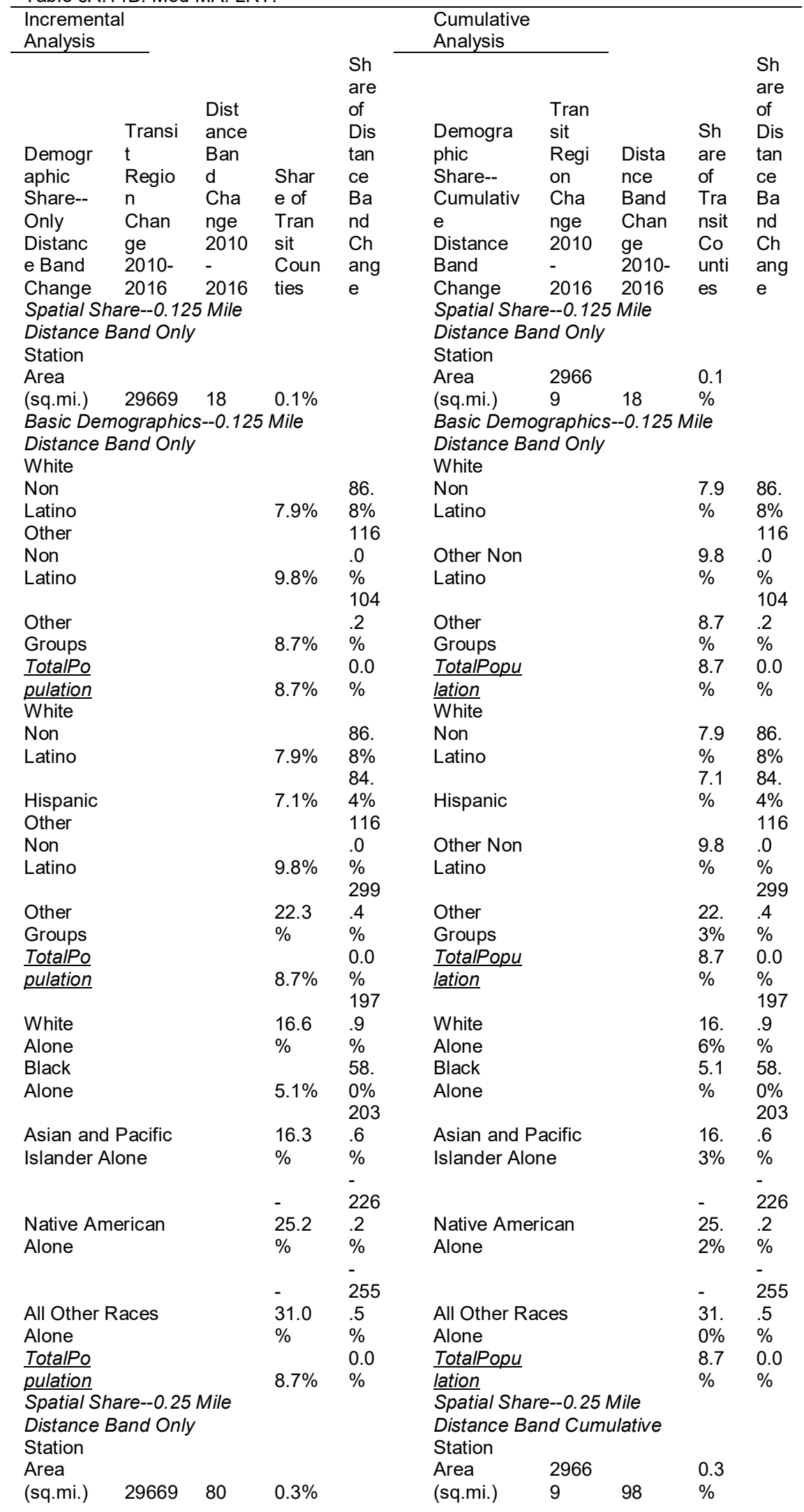




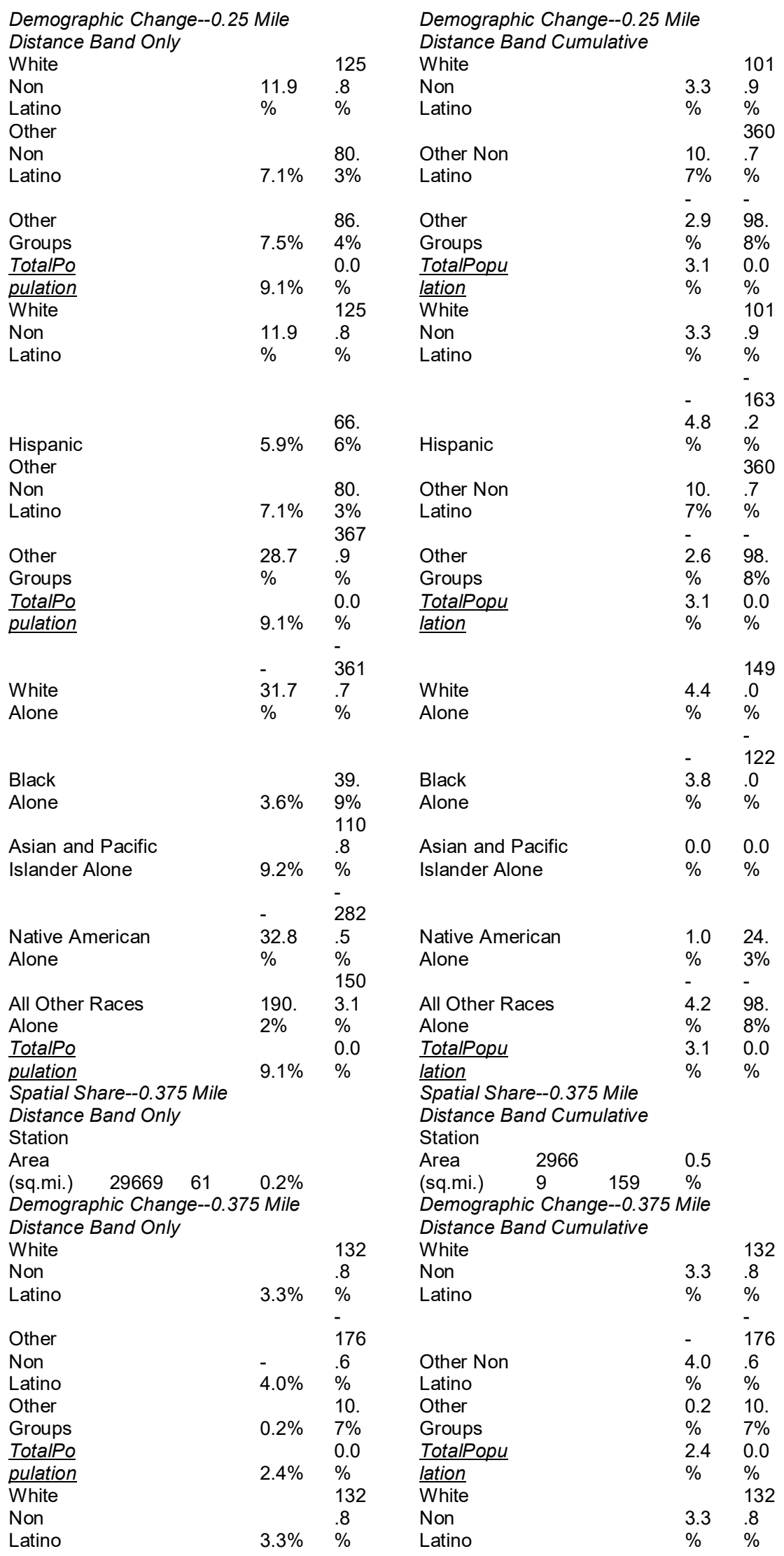




\begin{tabular}{|c|c|c|c|c|c|}
\hline \multirow[b]{3}{*}{ Hispanic } & \multicolumn{3}{|c|}{193} & \multicolumn{2}{|r|}{193} \\
\hline & - & .8 & & 4.4 & .8 \\
\hline & $4.4 \%$ & $\%$ & Hispanic & $\%$ & $\%$ \\
\hline \multicolumn{2}{|l|}{ Other } & \multicolumn{2}{|l|}{$\begin{array}{l}- \\
176\end{array}$} & - & 176 \\
\hline Non & - & .6 & Other Non & 4.0 & .6 \\
\hline Latino & $4.0 \%$ & $\%$ & Latino & $\%$ & $\%$ \\
\hline Other & & 10. & Other & 0.2 & 10. \\
\hline Groups & $0.2 \%$ & $7 \%$ & Groups & $\%$ & $7 \%$ \\
\hline TotalPo & & 0.0 & TotalPopu & 2.4 & 0.0 \\
\hline pulation & $2.4 \%$ & $\begin{array}{l}\% \\
192\end{array}$ & Iation & $\%$ & $\begin{array}{l}\% \\
192\end{array}$ \\
\hline White & & .1 & White & 4.4 & .1 \\
\hline Alone & $4.4 \%$ & $\begin{array}{l}\% \\
- \\
162\end{array}$ & Alone & $\%$ & $\begin{array}{l}\% \\
- \\
162\end{array}$ \\
\hline Black & - & .7 & Black & 3.9 & .7 \\
\hline Alone & $3.9 \%$ & $\%$ & Alone & $\%$ & $\%$ \\
\hline Asian and Pacific & & 0.0 & Asian and Pacific & 0.0 & 0.0 \\
\hline Islander Alone & $0.0 \%$ & $\begin{array}{l}\% \\
-\end{array}$ & Islander Alone & $\begin{array}{l}\% \\
-\end{array}$ & $\begin{array}{l}\% \\
-\end{array}$ \\
\hline Native American & - & 38. & Native American & 1.2 & 38. \\
\hline Alone & $1.2 \%$ & $6 \%$ & Alone & $\%$ & $6 \%$ \\
\hline All Other Races & & 10. & All Other Races & 0.4 & 10. \\
\hline Alone & $0.4 \%$ & $7 \%$ & Alone & $\%$ & $7 \%$ \\
\hline TotalPo & & 0.0 & TotalPopu & 2.4 & 0.0 \\
\hline$\overline{\text { pulation }}$ & $2.4 \%$ & $\%$ & lation & $\%$ & $\%$ \\
\hline \multirow{3}{*}{\multicolumn{3}{|c|}{$\begin{array}{l}\text { Spatial Share--0.50 Mile } \\
\text { Distance Band Only } \\
\text { Station }\end{array}$}} & \multirow{3}{*}{\multicolumn{3}{|c|}{$\begin{array}{l}\text { Spatial Share--0.50 Mile } \\
\text { Distance Band Cumulative } \\
\text { Station }\end{array}$}} \\
\hline & & & & & \\
\hline & & & & & \\
\hline Area & 0.03 & & Area & 0.6 & \\
\hline 2966910 & $\%$ & & (sq.mi.) & $\%$ & \\
\hline \multirow{2}{*}{\multicolumn{3}{|c|}{$\begin{array}{l}\text { Demographic Change--0.50 Mile } \\
\text { Distance Band Only }\end{array}$}} & \multirow{2}{*}{\multicolumn{3}{|c|}{$\begin{array}{l}\text { Demographic Change--0.50 Mile } \\
\text { Distance Band Cumulative }\end{array}$}} \\
\hline & & & & & \\
\hline White & & & White & & 145 \\
\hline Non & & 87. & Non & 3.2 & .8 \\
\hline Latino & $6.0 \%$ & $9 \%$ & Latino & $\%$ & $\%$ \\
\hline \multicolumn{6}{|l|}{ Other } \\
\hline Non & & 97. & Other Non & 0.2 & 8.1 \\
\hline Latino & $6.2 \%$ & $\begin{array}{l}6 \% \\
115\end{array}$ & Latino & $\%$ & $\%$ \\
\hline Other & & .7 & Other & 1.6 & 78. \\
\hline Groups & $7.3 \%$ & $\%$ & Groups & $\%$ & $1 \%$ \\
\hline TotalPo & & 0.0 & TotalPopu & 2.1 & 0.0 \\
\hline$\overline{\text { pulation }}$ & $6.6 \%$ & $\%$ & lation & $\%$ & $\%$ \\
\hline White & & & White & & 145 \\
\hline Non & & 87. & Non & 3.2 & .8 \\
\hline \multirow[t]{3}{*}{ Latino } & $6.0 \%$ & $9 \%$ & Latino & $\%$ & $\%$ \\
\hline & & 102 & & - & 205 \\
\hline & & .9 & & 4.2 & .7 \\
\hline \multicolumn{6}{|l|}{ Other } \\
\hline Non & & 97. & Other Non & 0.2 & 8.1 \\
\hline Latino & $6.2 \%$ & $\begin{array}{l}6 \% \\
277\end{array}$ & Latino & $\%$ & $\%$ \\
\hline Other & 15.7 & .0 & Other & 1.4 & 78. \\
\hline Groups & $\%$ & $\%$ & Groups & $\%$ & $1 \%$ \\
\hline TotalPo & & 0.0 & TotalPopu & 2.1 & 0.0 \\
\hline pulation & $6.6 \%$ & $\begin{array}{l}\% \\
256\end{array}$ & lation & $\%$ & $\begin{array}{l}\% \\
223\end{array}$ \\
\hline White & 16.3 & .6 & White & 4.5 & .8 \\
\hline Alone & $\%$ & $\%$ & Alone & $\%$ & $\%$ \\
\hline & & & & - & 177 \\
\hline Black & & 47. & Black & 3.7 & .3 \\
\hline Alone & $3.2 \%$ & $7 \%$ & Alone & $\%$ & $\%$ \\
\hline
\end{tabular}




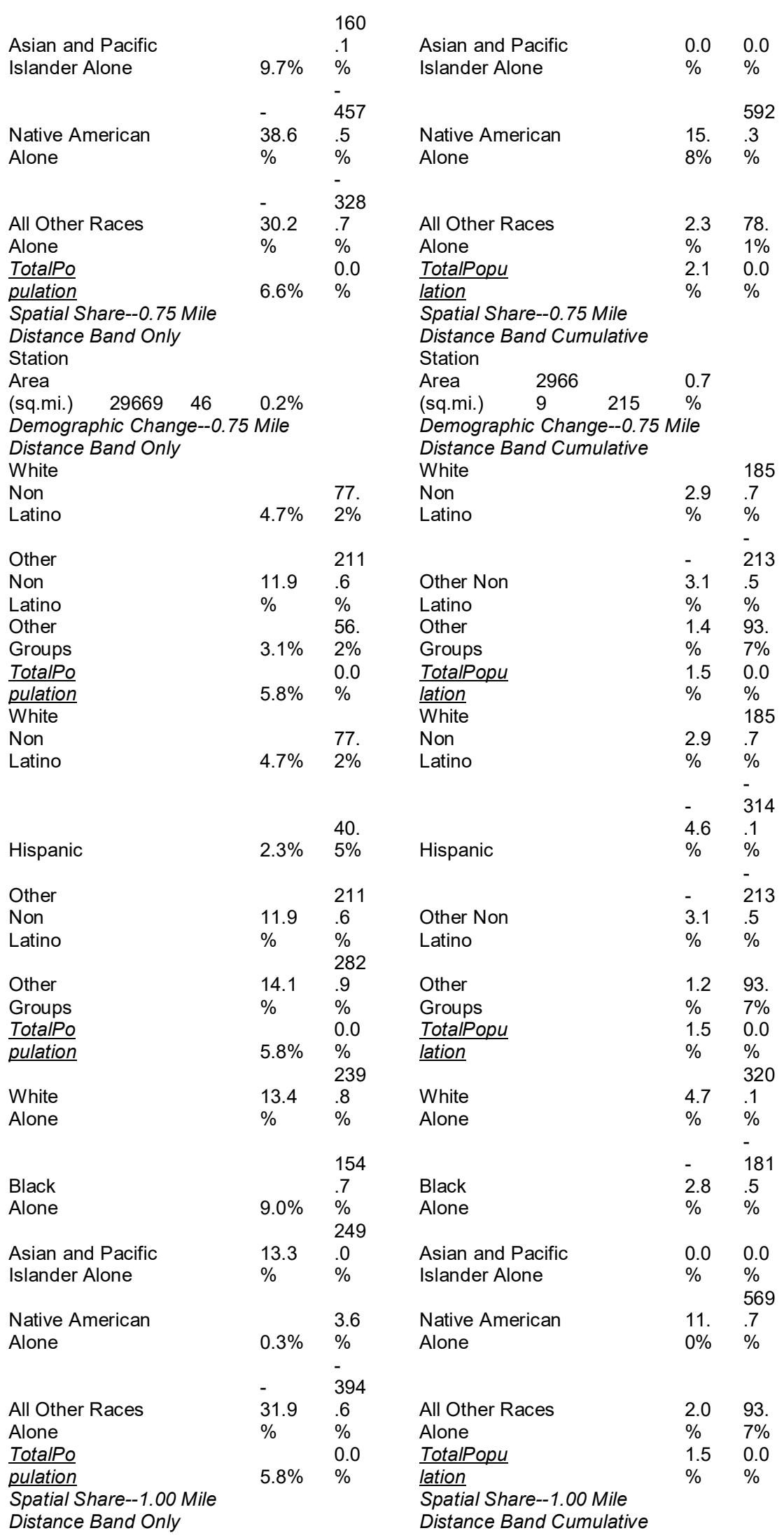




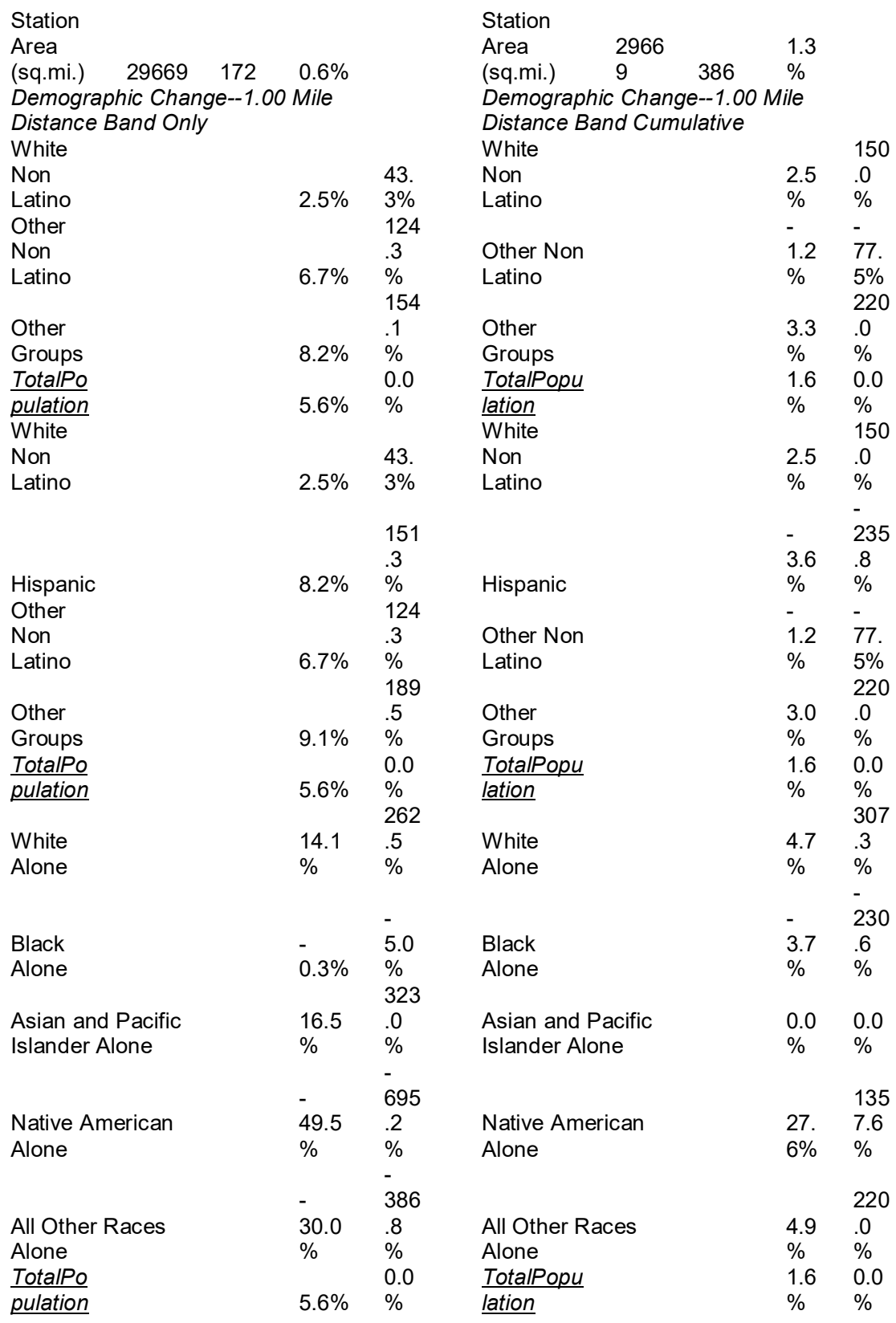

Table 6A.12A

High MA:LRT

\begin{tabular}{|c|c|c|c|c|c|c|c|c|}
\hline \multirow{5}{*}{$\begin{array}{l}\text { Transit Region } \\
\text { LQ of } \\
\text { Demographic } \\
\text { Change }\end{array}$} & \multirow[b]{2}{*}{$\begin{array}{l}\text { Tra } \\
\text { nsit } \\
\text { Reg } \\
\text { ion }\end{array}$} & \multicolumn{3}{|c|}{ Incremental Analysis } & \multirow{3}{*}{$\begin{array}{l}\text { Tra } \\
\text { nsit } \\
\text { Reg } \\
\text { ion }\end{array}$} & \multicolumn{3}{|c|}{ Cumulative Analysis } \\
\hline & & $\begin{array}{l}\text { Dist } \\
\text { ance } \\
\text { Ban }\end{array}$ & $\begin{array}{l}\text { Shar } \\
\text { e of }\end{array}$ & $\begin{array}{l}\text { Shar } \\
\text { e of } \\
\text { Dict }\end{array}$ & & $\begin{array}{l}\text { Dist } \\
\text { ance } \\
\text { Ban }\end{array}$ & $\begin{array}{l}\text { Shar } \\
\text { e of }\end{array}$ & $\begin{array}{l}\text { Share } \\
\text { of } \\
\text { Dista }\end{array}$ \\
\hline & $\begin{array}{l}\text { ion } \\
\text { Cha }\end{array}$ & & $\begin{array}{l}\text { Tran } \\
\text { sit }\end{array}$ & $\begin{array}{l}\text { Dist } \\
\text { ance }\end{array}$ & & $\begin{array}{l}\text { d } \\
\text { Cha }\end{array}$ & $\begin{array}{l}\text { Tran } \\
\text { sit }\end{array}$ & $\begin{array}{l}\text { nce } \\
\text { Band }\end{array}$ \\
\hline & nge & nge & Cou & Ban & nge & nge & Cou & Chan \\
\hline & 201 & 201 & nties & d & 201 & 201 & nties & ge \\
\hline
\end{tabular}




\begin{tabular}{|c|c|c|c|c|c|c|c|c|}
\hline \multirow{2}{*}{\multicolumn{9}{|c|}{$\begin{array}{cl}0- & 0- \\
201 & 201 \\
6 & 6 \\
\text { Demographic Group--0.125 } & \text { Mile Distance }\end{array}$}} \\
\hline & & & & & & & & \\
\hline Band Only & & & & & & & & \\
\hline White Non Latino & 1.05 & 0.10 & $\begin{array}{l}9.4 \\
\% \\
8.6\end{array}$ & $\begin{array}{l}112 . \\
9 \% \\
113 .\end{array}$ & 1.05 & 0.10 & $\begin{array}{l}9.4 \\
\% \\
8.6\end{array}$ & $\begin{array}{l}112.9 \\
\% \\
113.4\end{array}$ \\
\hline Other Non Latino & 1.15 & 0.10 & $\begin{array}{l}\% \\
5.8\end{array}$ & $\begin{array}{l}4 \% \\
74.7\end{array}$ & 1.15 & 0.10 & $\begin{array}{l}\% \\
5.8\end{array}$ & $\begin{array}{l}\% \\
74.7\end{array}$ \\
\hline Other Groups & 1.13 & 0.07 & $\begin{array}{l}\% \\
8.0\end{array}$ & $\%$ & 1.13 & 0.07 & $\begin{array}{l}\% \\
8.0\end{array}$ & $\%$ \\
\hline TotalPopulation & 1.09 & 0.09 & $\begin{array}{l}\% \\
9.4\end{array}$ & 112. & 1.09 & 0.09 & $\begin{array}{l}\% \\
9.4\end{array}$ & 112.9 \\
\hline White Non Latino & 1.05 & 0.10 & $\begin{array}{l}\% \\
3.6\end{array}$ & $\begin{array}{l}9 \% \\
46.5\end{array}$ & 1.05 & 0.10 & $\begin{array}{l}\% \\
3.6\end{array}$ & $\begin{array}{l}\% \\
46.5\end{array}$ \\
\hline Hispanic & 1.11 & 0.04 & $\begin{array}{l}\% \\
8.6\end{array}$ & $\begin{array}{l}\% \\
113 .\end{array}$ & 1.11 & 0.04 & $\begin{array}{l}\% \\
8.6\end{array}$ & $\begin{array}{l}\% \\
113.4\end{array}$ \\
\hline Other Non Latino & 1.15 & 0.10 & $\begin{array}{l}\% \\
29.1\end{array}$ & $\begin{array}{l}4 \% \\
424 .\end{array}$ & 1.15 & 0.10 & $\begin{array}{l}\% \\
29.1\end{array}$ & $\begin{array}{l}\% \\
424.3\end{array}$ \\
\hline Other Groups & 1.27 & 0.37 & $\begin{array}{l}\% \\
8.0\end{array}$ & $3 \%$ & 1.27 & 0.37 & $\begin{array}{l}\% \\
8.0\end{array}$ & $\%$ \\
\hline TotalPopulation & 1.09 & 0.09 & $\begin{array}{l}\% \\
19.0\end{array}$ & 246. & 1.09 & 0.09 & $\begin{array}{l}\% \\
19.0\end{array}$ & 246.9 \\
\hline White Alone & 1.13 & 0.21 & $\begin{array}{l}\% \\
4.9\end{array}$ & $\begin{array}{l}9 \% \\
63.4\end{array}$ & 1.13 & 0.21 & $\begin{array}{l}\% \\
4.9\end{array}$ & $\begin{array}{l}\% \\
63.4\end{array}$ \\
\hline $\begin{array}{l}\text { Black Alone } \\
\text { Asian and Pacific }\end{array}$ & 1.13 & 0.06 & $\begin{array}{l}\% \\
18.4\end{array}$ & $\begin{array}{l}\% \\
249 .\end{array}$ & 1.13 & 0.06 & $\begin{array}{l}\% \\
18.4\end{array}$ & $\begin{array}{l}\% \\
249.1\end{array}$ \\
\hline Islander Alone & 1.18 & 0.22 & $\begin{array}{l}\% \\
-\end{array}$ & $\begin{array}{l}1 \% \\
-\end{array}$ & 1.18 & 0.22 & $\begin{array}{l}\% \\
-\end{array}$ & $\begin{array}{l}\% \\
-\end{array}$ \\
\hline Native American & & - & 32.2 & 312. & & - & 32.2 & 312.7 \\
\hline Alone & 0.84 & 0.27 & $\begin{array}{l}\% \\
-\end{array}$ & $\begin{array}{l}7 \% \\
-\end{array}$ & 0.84 & 0.27 & $\begin{array}{l}\% \\
-\end{array}$ & $\begin{array}{l}\% \\
-\end{array}$ \\
\hline $\begin{array}{l}\text { All Other Races } \\
\text { Alone }\end{array}$ & 0.78 & $\overline{0}-31$ & $\begin{array}{l}39.9 \\
\% \\
8.0\end{array}$ & $\begin{array}{l}357 . \\
0 \%\end{array}$ & 0.78 & $\overline{0}-31$ & $\begin{array}{l}39.9 \\
\% \\
8.0\end{array}$ & $\begin{array}{l}357.0 \\
\%\end{array}$ \\
\hline $\begin{array}{l}\text { TotalPopulation } \\
\text { Demographic Group } \\
\text { Distance Band Only }\end{array}$ & $\begin{array}{c}1.09 \\
-0.25\end{array}$ & $\begin{array}{l}0.09 \\
\text { Aile }\end{array}$ & $\%$ & & 1.09 & 0.09 & $\%$ & \\
\hline White Non Latino & 1.05 & 0.06 & $\begin{array}{l}5.4 \\
\% \\
10.4\end{array}$ & $\begin{array}{l}56.3 \\
\% \\
119 .\end{array}$ & 1.05 & 0.04 & $\begin{array}{l}3.7 \\
\% \\
36.3\end{array}$ & $\begin{array}{l}1874 . \\
6 \% \\
2043\end{array}$ \\
\hline Other Non Latino & 1.15 & 0.12 & $\%$ & $1 \%$ & 1.15 & 0.42 & $\begin{array}{l}\% \\
-\end{array}$ & $\begin{array}{l}0.9 \% \\
-\end{array}$ \\
\hline Other Groups & 1.13 & 0.13 & $\begin{array}{l}11.7 \\
\% \\
9.2\end{array}$ & $\begin{array}{l}132 . \\
1 \%\end{array}$ & 1.13 & $\overline{-}-01$ & $\begin{array}{l}0.8 \\
\% \\
0.2\end{array}$ & $\begin{array}{l}463.8 \\
\%\end{array}$ \\
\hline$\underline{\text { TotalPopulation }}$ & 1.09 & 0.10 & $\begin{array}{l}\% \\
54\end{array}$ & 563 & 1.09 & 0.00 & $\%$ & 1874 \\
\hline White Non Latino & 1.05 & 0.06 & $\%$ & $\%$ & 1.05 & 0.04 & $\begin{array}{l}\% \\
-\end{array}$ & $6 \%$ \\
\hline Hispanic & 1.11 & 0.13 & $\begin{array}{l}11.9 \\
\% \\
10.4\end{array}$ & $\begin{array}{l}131 . \\
8 \% \\
119 .\end{array}$ & 1.11 & $\overline{-} .05$ & $\begin{array}{l}4.2 \\
\% \\
36.3\end{array}$ & $\begin{array}{l}2284 . \\
8 \% \\
2043\end{array}$ \\
\hline Other Non Latino & 1.15 & 0.12 & $\%$ & $1 \%$ & 1.15 & 0.42 & $\begin{array}{l}\% \\
-\end{array}$ & $\begin{array}{l}0.9 \% \\
-\end{array}$ \\
\hline Other Groups & 1.27 & 0.14 & $\begin{array}{l}10.9 \\
\% \\
9.2\end{array}$ & $\begin{array}{l}137 . \\
9 \%\end{array}$ & 1.27 & $\overline{0}-01$ & $\begin{array}{l}0.7 \\
\% \\
0.2\end{array}$ & $\begin{array}{l}463.8 \\
\%\end{array}$ \\
\hline TotalPopulation & 1.09 & 0.10 & $\%$ & - & 1.09 & 0.00 & $\%$ & \\
\hline White Alone & 1.13 & $\overline{0}-19$ & $\begin{array}{l}16.8 \\
\%\end{array}$ & $\begin{array}{l}189 . \\
5 \%\end{array}$ & 1.13 & 0.07 & $\begin{array}{l}6.1 \\
\% \\
-\end{array}$ & $\begin{array}{l}3400 . \\
2 \% \\
-\end{array}$ \\
\hline $\begin{array}{l}\text { Black Alone } \\
\text { Asian and Pacific }\end{array}$ & 1.13 & 0.03 & $\begin{array}{l}3.0 \\
\% \\
13.0\end{array}$ & $\begin{array}{l}34.0 \\
\% \\
153 .\end{array}$ & 1.13 & $\overline{-} .07$ & $\begin{array}{l}6.5 \\
\% \\
0.0\end{array}$ & $\begin{array}{l}3589 . \\
1 \%\end{array}$ \\
\hline Islander Alone & 1.18 & 0.15 & & $1 \%$ & 1.18 & 0.00 & $\%$ & $0.0 \%$ \\
\hline
\end{tabular}




\begin{tabular}{|c|c|c|c|c|c|c|c|c|}
\hline & & & & & & & & \\
\hline Native American & & _ & 26.5 & 223. & & - & 57.5 & 2379 \\
\hline Alone & 0.84 & 0.22 & $\%$ & $0 \%$ & 0.84 & 0.49 & $\%$ & $2.3 \%$ \\
\hline All Other Races & & & 104. & 808. & & - & 1.2 & 463.8 \\
\hline Alone & 0.78 & 0.81 & $\begin{array}{l}1 \% \\
9.2\end{array}$ & $5 \%$ & 0.78 & 0.01 & $\begin{array}{l}\% \\
0.2\end{array}$ & $\%$ \\
\hline TotalPopulation & 1.09 & 0.10 & $\%$ & & 1.09 & 0.00 & $\%$ & \\
\hline $\begin{array}{l}\text { Demographic Group } \\
\text { Band Only }\end{array}$ & -0.375 & Mile Di & tance & & & & & \\
\hline White Non Latino & 1.05 & 0.14 & $\begin{array}{l}13.6 \\
\% \\
13.3\end{array}$ & $\begin{array}{l}151 . \\
0 \% \\
161 .\end{array}$ & 1.05 & 0.05 & $\begin{array}{l}4.5 \\
\% \\
68.5\end{array}$ & $\begin{array}{l}1518 . \\
6 \% \\
2513\end{array}$ \\
\hline Other Non Latino & 1.15 & 0.15 & $\%$ & $3 \%$ & 1.15 & 0.79 & $\begin{array}{l}\% \\
-\end{array}$ & $\begin{array}{l}6.7 \% \\
-\end{array}$ \\
\hline Other Groups & 1.13 & 0.04 & $\begin{array}{l}3.5 \\
\% \\
8.7\end{array}$ & $\begin{array}{l}41.7 \\
\%\end{array}$ & 1.13 & $\overline{0}-06$ & $\begin{array}{l}5.3 \\
\% \\
0.3\end{array}$ & $\begin{array}{l}1891 . \\
3 \%\end{array}$ \\
\hline TotalPopulation & 1.09 & 0.09 & $\begin{array}{l}\% \\
13.6\end{array}$ & 151. & 1.09 & 0.00 & $\begin{array}{l}\% \\
4.5\end{array}$ & 1518. \\
\hline White Non Latino & 1.05 & 0.14 & $\%$ & $0 \%$ & 1.05 & 0.05 & $\begin{array}{l}\% \\
-\end{array}$ & $\begin{array}{l}6 \% \\
-\end{array}$ \\
\hline Hispanic & 1.11 & 0.02 & $\begin{array}{l}1.9 \\
\% \\
13.3\end{array}$ & $\begin{array}{l}22.3 \\
\% \\
161 .\end{array}$ & 1.11 & $\overline{0}-06$ & $\begin{array}{l}5.4 \\
\% \\
68.5\end{array}$ & $\begin{array}{l}1917 . \\
3 \% \\
2513\end{array}$ \\
\hline Other Non Latino & 1.15 & 0.15 & $\%$ & $3 \%$ & 1.15 & 0.79 & $\%$ & $\begin{array}{l}6.7 \% \\
-\end{array}$ \\
\hline Other Groups & 1.27 & 0.46 & $\begin{array}{l}36.7 \\
\% \\
8.7\end{array}$ & $\begin{array}{l}491 . \\
2 \%\end{array}$ & 1.27 & $\overline{0}-06$ & $\begin{array}{l}4.7 \\
\% \\
0.3\end{array}$ & $\begin{array}{l}1891 . \\
3 \%\end{array}$ \\
\hline TotalPopulation & 1.09 & 0.09 & $\begin{array}{l}\% \\
26.1\end{array}$ & 311. & 1.09 & 0.00 & $\begin{array}{l}\% \\
7.6\end{array}$ & 2749 . \\
\hline White Alone & 1.13 & 0.29 & $\%$ & $4 \%$ & 1.13 & 0.09 & $\begin{array}{l}\% \\
-\end{array}$ & $\begin{array}{l}9 \% \\
-\end{array}$ \\
\hline $\begin{array}{l}\text { Black Alone } \\
\text { Asian and Pacific }\end{array}$ & 1.13 & 0.09 & $\begin{array}{l}8.1 \\
\% \\
22.4\end{array}$ & $\begin{array}{l}97.0 \\
\% \\
278 .\end{array}$ & 1.13 & $\overline{-}-07$ & $\begin{array}{l}5.8 \\
\% \\
0.0\end{array}$ & $\begin{array}{l}2114 . \\
1 \%\end{array}$ \\
\hline Islander Alone & 1.18 & 0.26 & $\begin{array}{l}\% \\
-\end{array}$ & $\begin{array}{l}6 \% \\
-\end{array}$ & 1.18 & 0.00 & $\begin{array}{l}\% \\
-\end{array}$ & $\begin{array}{l}0.0 \% \\
-\end{array}$ \\
\hline Native American & & - & 21.2 & 188. & & - & 63.8 & 1718 \\
\hline Alone & 0.84 & 0.18 & $\%$ & $9 \%$ & 0.84 & 0.54 & $\begin{array}{l}\% \\
-\end{array}$ & $\begin{array}{l}4.3 \% \\
-\end{array}$ \\
\hline All Other Races & & - & 46.7 & 384. & & - & 7.6 & 1891. \\
\hline Alone & 0.78 & 0.36 & & $6 \%$ & 0.78 & 0.06 & $\begin{array}{l}\% \\
0.3\end{array}$ & $3 \%$ \\
\hline TotalPopulation & 1.09 & 0.09 & $\%$ & & 1.09 & 0.00 & $\%$ & \\
\hline $\begin{array}{l}\text { Demographic Group } \\
\text { Distance Band Only }\end{array}$ & --0.5 Mil & & & & & & & \\
\hline White Non Latino & 1.05 & 0.11 & $\begin{array}{l}10.9 \\
\% \\
11.9\end{array}$ & $\begin{array}{l}128 . \\
5 \% \\
154 .\end{array}$ & 1.05 & 0.05 & $\begin{array}{l}4.8 \\
\% \\
51.7\end{array}$ & $\begin{array}{l}1826 . \\
8 \% \\
2157\end{array}$ \\
\hline Other Non Latino & 1.15 & 0.14 & $\%$ & $4 \%$ & 1.15 & 0.60 & $\%$ & $\begin{array}{l}4.8 \% \\
-\end{array}$ \\
\hline Other Groups & 1.13 & 0.03 & $\begin{array}{l}2.7 \\
\% \\
8.2\end{array}$ & $\begin{array}{l}34.2 \\
\%\end{array}$ & 1.13 & $\overline{-}-07$ & $\begin{array}{l}6.4 \\
\% \\
0.3\end{array}$ & $\begin{array}{l}2606 . \\
0 \%\end{array}$ \\
\hline TotalPopulation & 1.09 & 0.09 & $\begin{array}{l}\% \\
10.9\end{array}$ & 128. & 1.09 & 0.00 & $\begin{array}{l}\% \\
4.8\end{array}$ & 1826. \\
\hline White Non Latino & 1.05 & 0.11 & $\begin{array}{l}\% \\
-\end{array}$ & $5 \%$ & 1.05 & 0.05 & $\%$ & $\begin{array}{l}8 \% \\
-\end{array}$ \\
\hline Hispanic & 1.11 & $\overline{-}$ & $\begin{array}{l}0.7 \\
\% \\
11.9\end{array}$ & $\begin{array}{l}8.3 \\
\% \\
154 .\end{array}$ & 1.11 & $\overline{-}-07$ & $\begin{array}{l}6.2 \\
\% \\
51.7\end{array}$ & $\begin{array}{l}2502 . \\
1 \% \\
2157\end{array}$ \\
\hline Other Non Latino & 1.15 & 0.14 & $\%$ & $4 \%$ & 1.15 & 0.60 & $\%$ & $\begin{array}{l}4.8 \% \\
-\end{array}$ \\
\hline Other Groups & 1.27 & 0.55 & $\begin{array}{l}43.6 \\
\% \\
8.2\end{array}$ & $\begin{array}{l}621 . \\
7 \%\end{array}$ & 1.27 & $\overline{-}-07$ & $\begin{array}{l}5.7 \\
\% \\
0.3\end{array}$ & $\begin{array}{l}2606 . \\
0 \%\end{array}$ \\
\hline TotalPopulation & 1.09 & 0.09 & $\%$ & & 1.09 & 0.00 & $\%$ & \\
\hline
\end{tabular}




\begin{tabular}{|c|c|c|c|c|c|c|c|c|}
\hline \multirow[t]{3}{*}{ White Alone } & 1.13 & 0.23 & $\begin{array}{l}20.0 \\
\%\end{array}$ & $\begin{array}{l}253 . \\
8 \%\end{array}$ & 1.13 & 0.09 & $\begin{array}{l}7.6 \\
\%\end{array}$ & $\begin{array}{l}3109 . \\
9 \%\end{array}$ \\
\hline & & & & & & & - & - \\
\hline & & & 14.0 & 179. & & - & 4.3 & 1763. \\
\hline \multirow{3}{*}{$\begin{array}{l}\text { Black Alone } \\
\text { Asian and Pacific } \\
\text { Islander Alone }\end{array}$} & 1.13 & 0.16 & $\%$ & $2 \%$ & 1.13 & 0.05 & $\%$ & $7 \%$ \\
\hline & 1.18 & 0.07 & $\begin{array}{l}6.3 \\
\%\end{array}$ & $\begin{array}{l}83.0 \\
\%\end{array}$ & 1.18 & 0.00 & $\%$ & $0.0 \%$ \\
\hline & & & - & - & & & - & \\
\hline \multirow{3}{*}{$\begin{array}{l}\text { Native American } \\
\text { Alone }\end{array}$} & & - & 17.1 & 162. & & - & 62.9 & 1927 \\
\hline & 0.84 & 0.14 & $\%$ & $6 \%$ & 0.84 & 0.53 & $\%$ & $2.1 \%$ \\
\hline & & & - & - & & & - & - \\
\hline \multirow{2}{*}{$\begin{array}{l}\text { All Other Races } \\
\text { Alone }\end{array}$} & & - & 39.1 & 342. & & - & 9.2 & 2606. \\
\hline & 0.78 & 0.30 & $\begin{array}{l}\% \\
8.2\end{array}$ & $6 \%$ & 0.78 & 0.07 & $\begin{array}{l}\% \\
0.3\end{array}$ & $0 \%$ \\
\hline \multirow{3}{*}{$\begin{array}{l}\text { TotalPopulation } \\
\text { Demographic Group } \\
\text { Distance Band Only }\end{array}$} & 1.09 & 0.09 & $\%$ & & 1.09 & 0.00 & $\%$ & \\
\hline & -0.75 & Mile & & & & & & \\
\hline & & & 19.8 & 260. & & & 5.7 & $\overline{1} 1498$. \\
\hline White Non Latino & 1.05 & 0.21 & $\%$ & $9 \%$ & 1.05 & 0.06 & $\%$ & $3 \%$ \\
\hline \multirow[t]{2}{*}{ Other Non Latino } & 1.15 & 0.17 & $\begin{array}{l}15.1 \\
\%\end{array}$ & $\begin{array}{l}218 . \\
9 \%\end{array}$ & 1.15 & 0.15 & $\begin{array}{l}13.3 \\
\%\end{array}$ & $\begin{array}{l}3824 . \\
3 \%\end{array}$ \\
\hline & & - & $\overline{4} .2$ & $-\overline{60.2}$ & & - & $\overline{5} .6$ & 1564. \\
\hline \multirow[t]{2}{*}{ Other Groups } & 1.13 & 0.05 & $\%$ & $\%$ & 1.13 & 0.06 & $\%$ & $8 \%$ \\
\hline & & & 7.3 & & & & 0.4 & \\
\hline \multirow[t]{2}{*}{ TotalPopulation } & 1.09 & 0.08 & $\%$ & & 1.09 & 0.00 & $\%$ & \\
\hline & & & 19.8 & 260. & & & 5.7 & 1498. \\
\hline \multirow[t]{2}{*}{ White Non Latino } & 1.05 & 0.21 & $\%$ & $9 \%$ & 1.05 & 0.06 & $\%$ & \\
\hline & & & $\overline{6}-3$ & $-\overline{88.9}$ & & - & $\overline{71}$ & 1981. \\
\hline \multirow[t]{2}{*}{ Hispanic } & 1.11 & 0.07 & $\%$ & $\%$ & 1.11 & 0.08 & $\%$ & $3 \%$ \\
\hline & 1.15 & 0.17 & $\begin{array}{l}15.1 \\
\%\end{array}$ & $\begin{array}{l}218 . \\
9 \%\end{array}$ & 1.15 & 0.15 & $\begin{array}{l}13.3 \\
\%\end{array}$ & $\begin{array}{l}3824 . \\
3 \%\end{array}$ \\
\hline Other Non Latino & & & & & & & - & \\
\hline \multirow{3}{*}{ Other Groups } & & & 36.2 & 578. & & - & 4.9 & 1564. \\
\hline & 1.27 & 0.46 & $\%$ & $1 \%$ & 1.27 & 0.06 & $\begin{array}{l}\% \\
-\end{array}$ & $8 \%$ \\
\hline & & & 7.3 & & & & 0.4 & \\
\hline \multirow{2}{*}{ TotalPopulation } & 1.09 & 0.08 & $\%$ & & 1.09 & 0.00 & $\%$ & \\
\hline & & & 23.7 & 337. & & & 8.1 & 2279. \\
\hline \multirow[t]{2}{*}{ White Alone } & 1.13 & 0.27 & $\%$ & $8 \%$ & 1.13 & 0.09 & $\%$ & $1 \%$ \\
\hline & & & 2.9 & 40.9 & & - & 5.2 & 1476. \\
\hline \multirow{3}{*}{$\begin{array}{l}\text { Black Alone } \\
\text { Asian and Pacific } \\
\text { Islander Alone }\end{array}$} & 1.13 & 0.03 & $\%$ & $\%$ & 1.13 & 0.06 & $\%$ & $6 \%$ \\
\hline & & & 30.4 & 450. & & & 0.0 & \\
\hline & 1.18 & 0.36 & $\%$ & $7 \%$ & 1.18 & 0.00 & $\begin{array}{l}\% \\
-\end{array}$ & $0.0 \%$ \\
\hline Native American & & & 1.0 & 10.1 & & - & 56.5 & 1191 \\
\hline Alone & 0.84 & 0.01 & $\%$ & $\begin{array}{l}\% \\
-\end{array}$ & 0.84 & 0.48 & $\begin{array}{l}\% \\
-\end{array}$ & $0.2 \%$ \\
\hline \multirow{3}{*}{$\begin{array}{l}\text { All Other Races } \\
\text { Alone }\end{array}$} & & - & 51.4 & 504. & & - & 8.1 & 1564. \\
\hline & 0.78 & 0.40 & $\%$ & $3 \%$ & 0.78 & 0.06 & $\%$ & $8 \%$ \\
\hline & & & 7.3 & & & & 0.4 & \\
\hline TotalPopulation & 1.09 & 0.08 & $\%$ & & 1.09 & 0.00 & $\%$ & \\
\hline \multicolumn{9}{|c|}{$\begin{array}{l}\text { Demographic Group--1.00 Mile } \\
\text { Distance Band Only }\end{array}$} \\
\hline & & & 11.6 & 108. & & & 5.1 & 2718. \\
\hline White Non Latino & 1.05 & 0.12 & $\begin{array}{l}\% \\
14.3\end{array}$ & $\begin{array}{l}1 \% \\
146 .\end{array}$ & 1.05 & 0.05 & $\begin{array}{l}\% \\
6.0\end{array}$ & $\begin{array}{l}7 \% \\
3487 .\end{array}$ \\
\hline \multirow[t]{2}{*}{ Other Non Latino } & 1.15 & 0.16 & $\%$ & $0 \%$ & 1.15 & 0.07 & $\%$ & $0 \%$ \\
\hline & & & 7.5 & 75.1 & & - & $\overline{2} .6$ & 1496. \\
\hline Other Groups & 1.13 & 0.08 & $\%$ & $\%$ & 1.13 & 0.03 & $\%$ & $9 \%$ \\
\hline
\end{tabular}




\begin{tabular}{|c|c|c|c|c|c|c|c|c|}
\hline TotalPopulation & 1.09 & 0.11 & $\begin{array}{l}10.4 \\
\% \\
116\end{array}$ & & 1.09 & 0.00 & $\begin{array}{l}0.2 \\
\% \\
51\end{array}$ & \\
\hline White Non Latino & 1.05 & 0.12 & $\begin{array}{l}11.6 \\
\%\end{array}$ & $\begin{array}{l}108 . \\
1 \%\end{array}$ & 1.05 & 0.05 & $\begin{array}{l}5.1 \\
\% \\
-\end{array}$ & $\begin{array}{l}2718 . \\
7 \% \\
-\end{array}$ \\
\hline Hispanic & 1.11 & 0.07 & $\begin{array}{l}6.2 \\
\% \\
14.3\end{array}$ & $\begin{array}{l}61.5 \\
\% \\
146 .\end{array}$ & 1.11 & $-\overline{0.07}$ & $\begin{array}{l}6.3 \\
\% \\
6.0\end{array}$ & $\begin{array}{l}3549 . \\
4 \% \\
3487 .\end{array}$ \\
\hline Other Non Latino & 1.15 & 0.16 & $\%$ & $0 \%$ & 1.15 & 0.07 & $\begin{array}{l}\% \\
-\end{array}$ & $\begin{array}{l}0 \% \\
-\end{array}$ \\
\hline Other Groups & 1.27 & 0.41 & $\begin{array}{l}32.2 \\
\% \\
10.4 \\
\%\end{array}$ & $\begin{array}{l}362 . \\
7 \%\end{array}$ & 1.27 & $\overline{-}-03$ & $\begin{array}{l}2.3 \\
\% \\
0.2 \\
0\end{array}$ & $\begin{array}{l}1496 . \\
9 \%\end{array}$ \\
\hline TotalPopulation & 1.09 & 0.11 & $\begin{array}{l}\% \\
28.0\end{array}$ & 280. & 1.09 & 0.00 & $\begin{array}{l}\% \\
8.1\end{array}$ & 4610. \\
\hline White Alone & 1.13 & 0.32 & $\%$ & $8 \%$ & 1.13 & 0.09 & $\begin{array}{l}\% \\
-\end{array}$ & $\begin{array}{l}3 \% \\
-\end{array}$ \\
\hline Black Alone & 1.13 & 0.09 & $\begin{array}{l}7.7 \\
\% \\
30.3\end{array}$ & $\begin{array}{l}77.1 \\
\% \\
316 .\end{array}$ & 1.13 & $\overline{-}-07$ & $\begin{array}{l}6.1 \\
\% \\
0.0 \\
0\end{array}$ & $\begin{array}{l}3504 \\
9 \%\end{array}$ \\
\hline Islander Alone & 1.18 & 0.36 & $\begin{array}{l}\% \\
-\end{array}$ & $\begin{array}{l}5 \% \\
-\end{array}$ & 1.18 & 0.00 & $\begin{array}{l}\% \\
-\end{array}$ & $\begin{array}{l}0.0 \% \\
-\end{array}$ \\
\hline Native American & & - & 52.7 & 395. & & - & 52.3 & 2234 \\
\hline Alone & 0.84 & 0.45 & $\begin{array}{l}\% \\
-\end{array}$ & $\begin{array}{l}3 \% \\
-\end{array}$ & 0.84 & 0.44 & $\begin{array}{l}\% \\
-\end{array}$ & $\begin{array}{l}4.8 \% \\
-\end{array}$ \\
\hline All Other Races & & - & 42.1 & 290. & & - & 3.8 & 1496. \\
\hline Alone & 0.78 & 0.33 & $\begin{array}{l}\% \\
10.4\end{array}$ & $8 \%$ & 0.78 & 0.03 & $\begin{array}{l}\% \\
0.2\end{array}$ & $9 \%$ \\
\hline TotalPopulation & 1.09 & 0.11 & $\%$ & & 1.09 & 0.00 & $\%$ & \\
\hline
\end{tabular}

Table 6A.12B High MA: LRT.

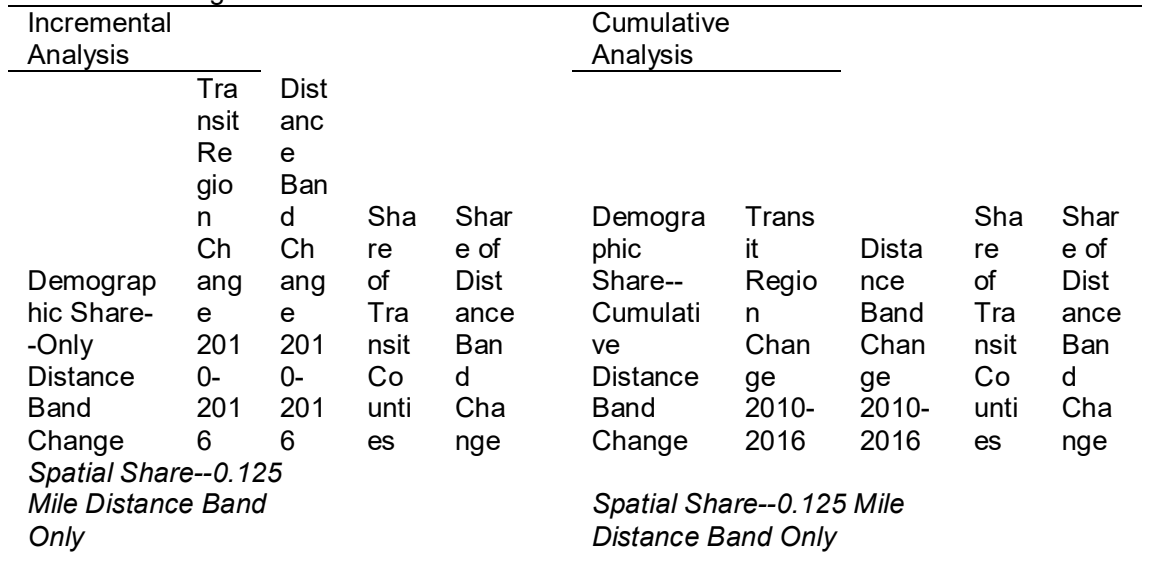




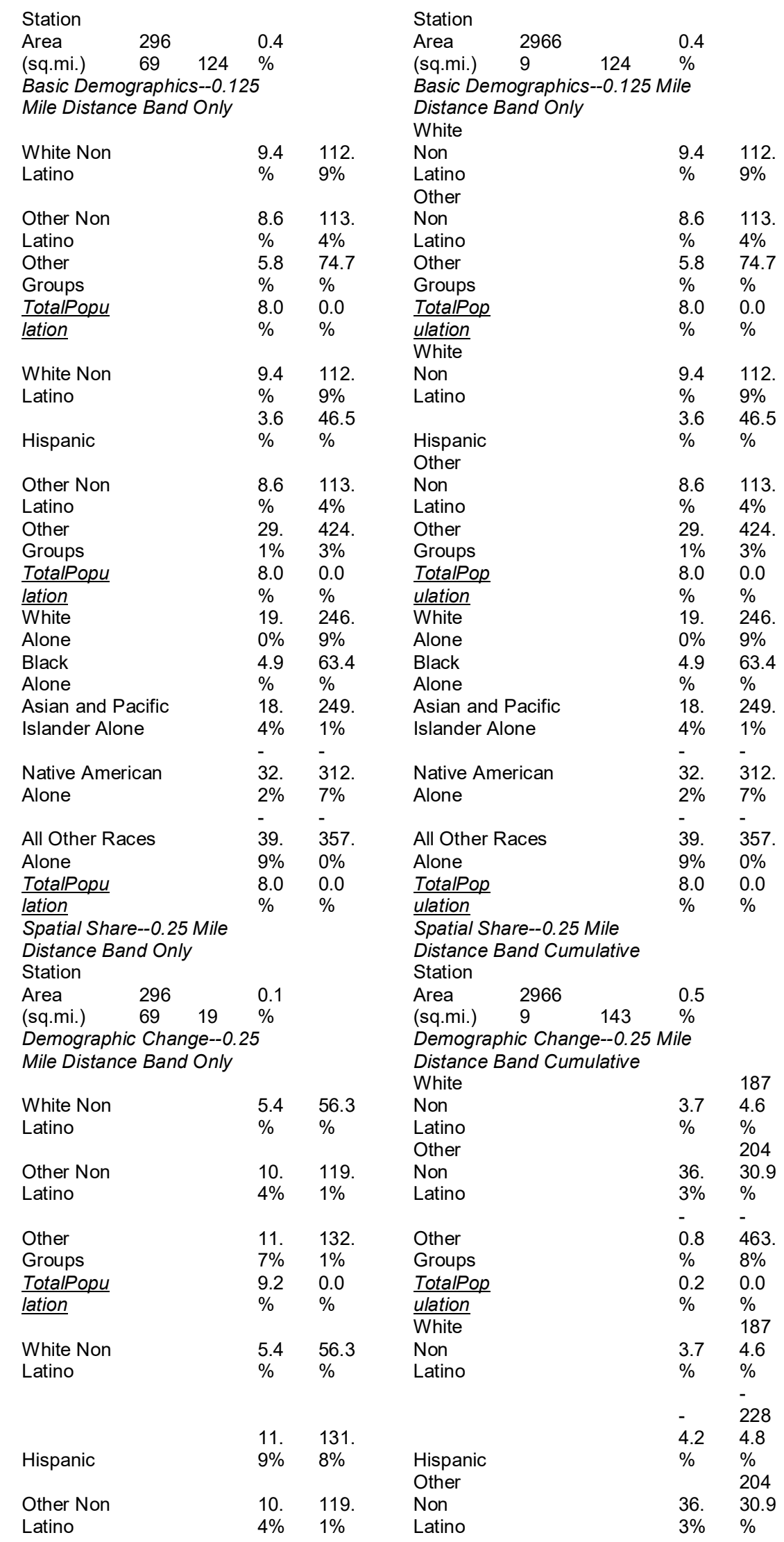




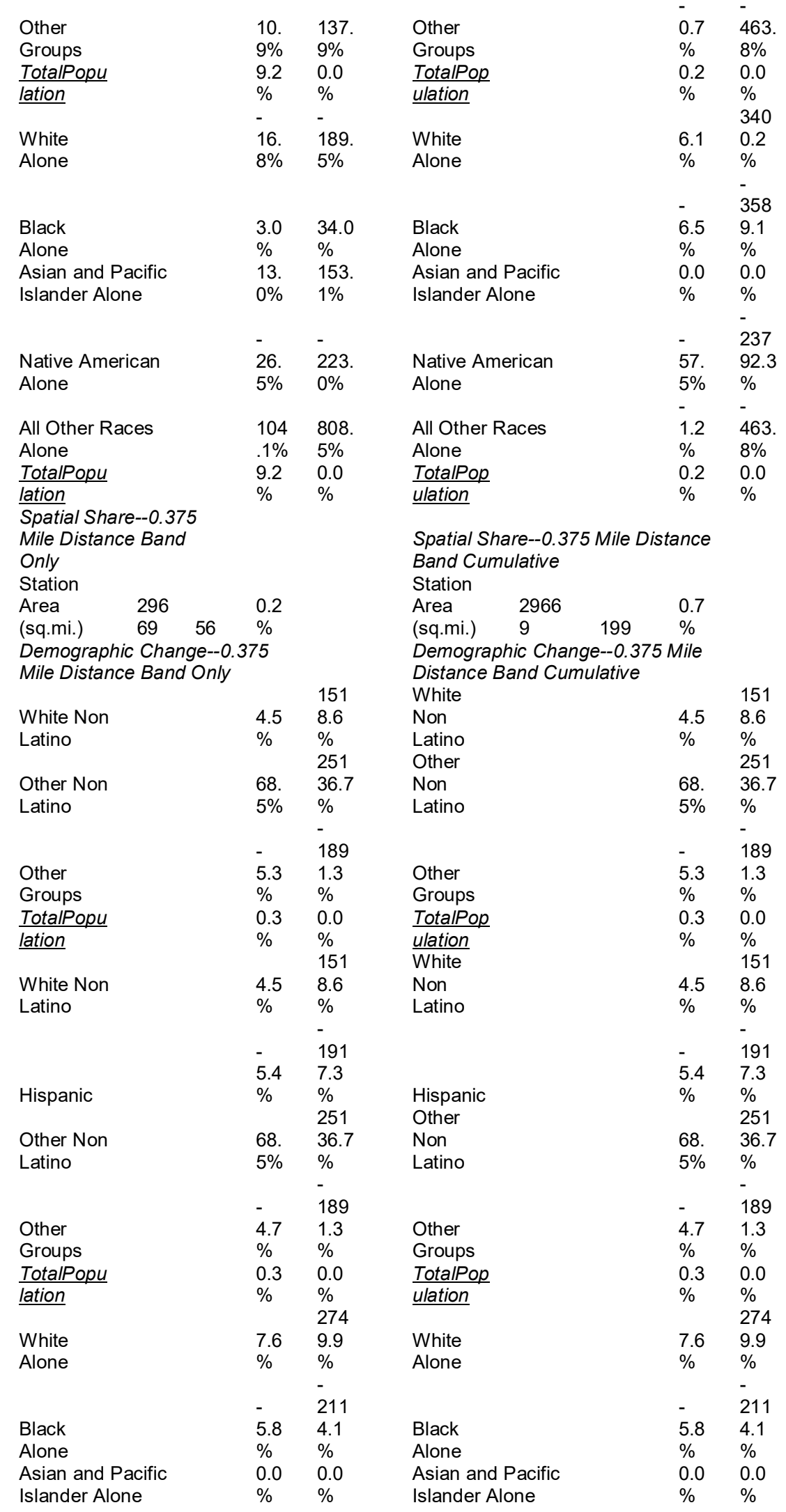




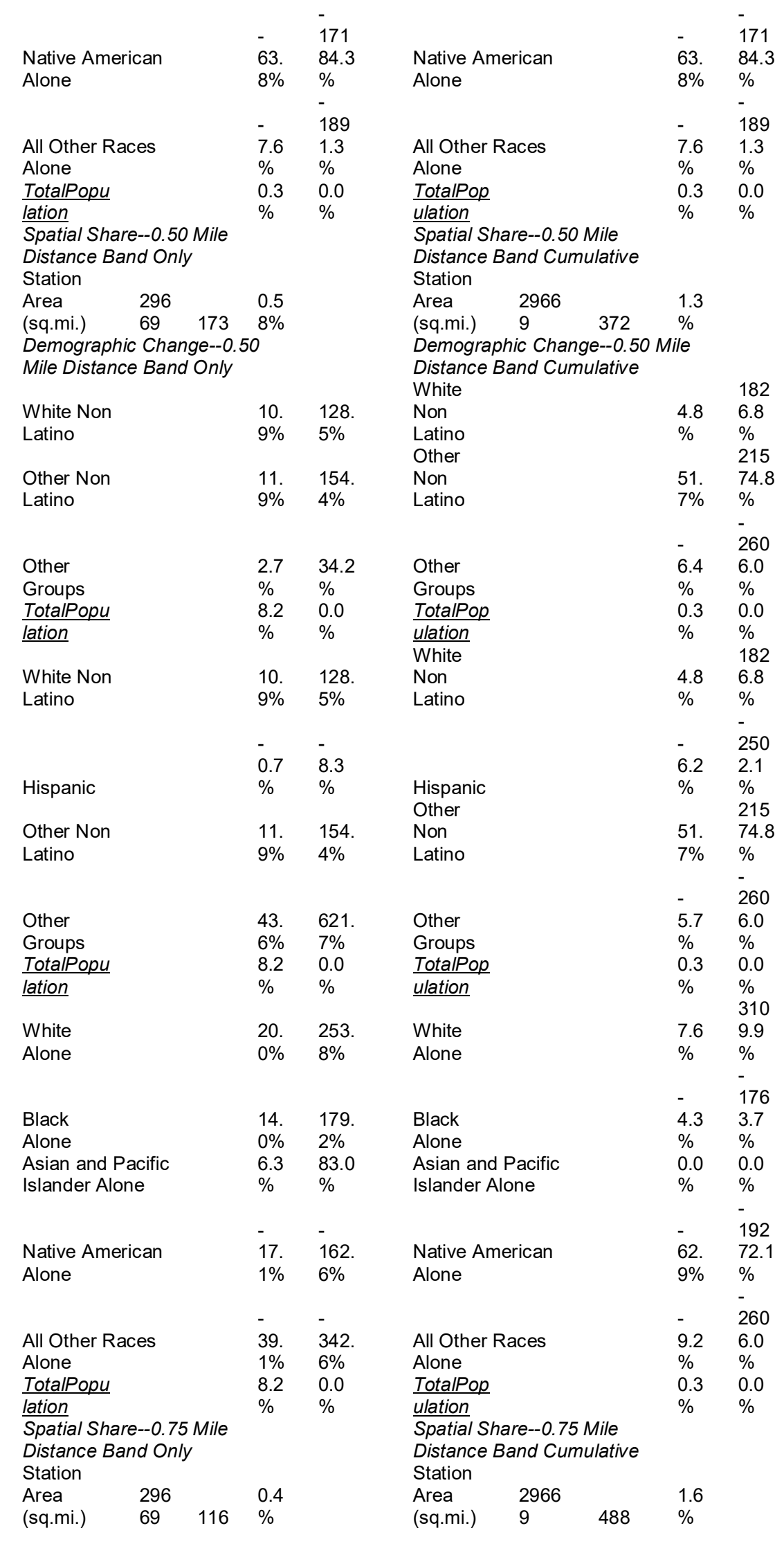




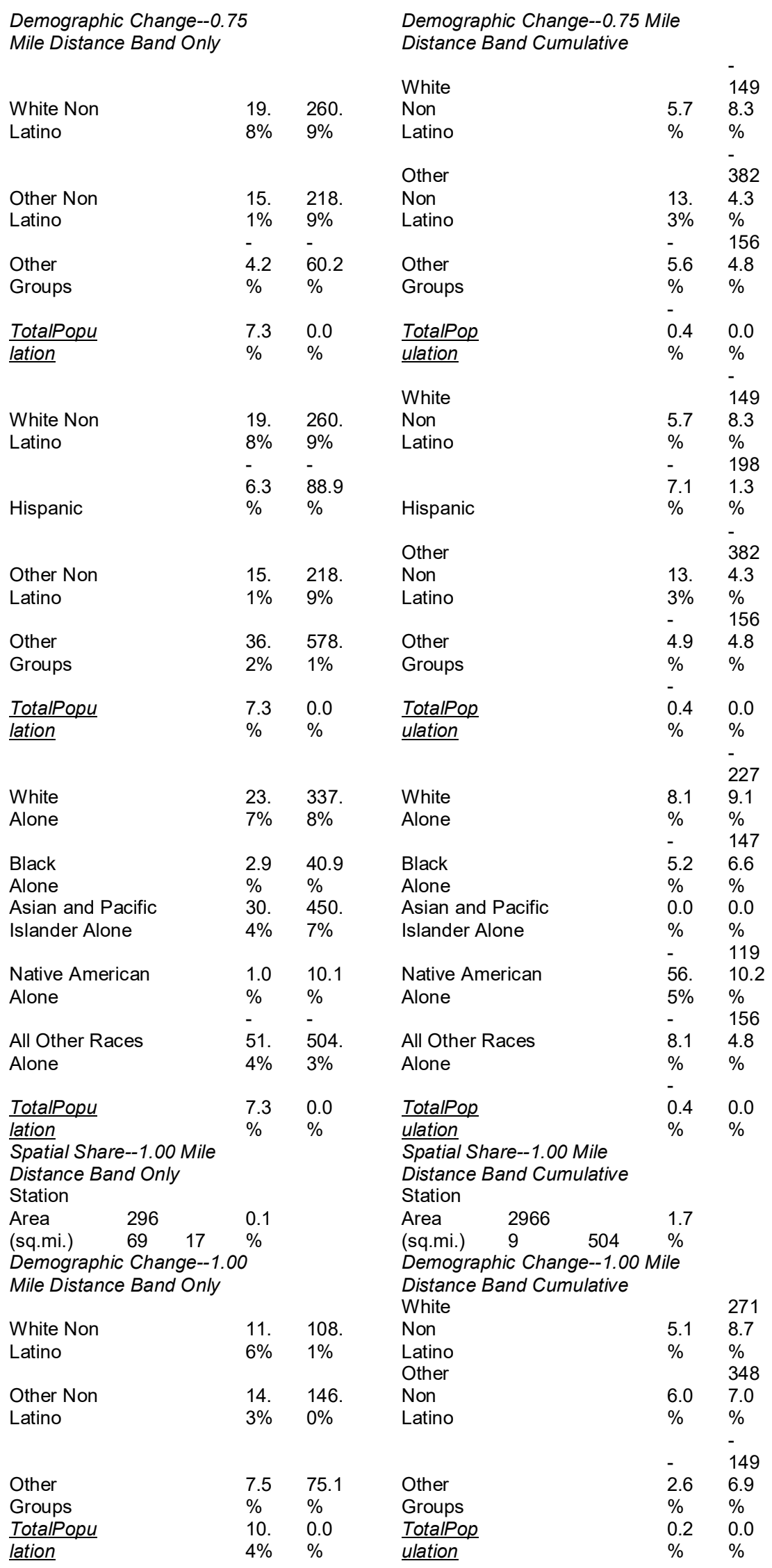




\begin{tabular}{|c|c|c|c|c|c|}
\hline & & & White & & 271 \\
\hline White Non & 11. & 108. & Non & 5.1 & 8.7 \\
\hline \multirow[t]{3}{*}{ Latino } & $6 \%$ & $1 \%$ & Latino & $\%$ & $\%$ \\
\hline & & & & - & 354 \\
\hline & 6.2 & 61.5 & & 6.3 & 9.4 \\
\hline \multirow[t]{2}{*}{ Hispanic } & $\%$ & $\%$ & Hispanic & $\%$ & $\%$ \\
\hline & & & Other & & 348 \\
\hline Other Non & 14. & 146. & Non & 6.0 & 7.0 \\
\hline \multirow[t]{2}{*}{ Latino } & $3 \%$ & $0 \%$ & Latino & $\%$ & $\%$ \\
\hline & & & & - & 149 \\
\hline Other & 32. & 362. & Other & 2.3 & 6.9 \\
\hline Groups & $2 \%$ & $7 \%$ & Groups & $\%$ & $\%$ \\
\hline TotalPopu & 10. & 0.0 & TotalPop & 0.2 & 0.0 \\
\hline lation & $4 \%$ & $\%$ & ulation & $\%$ & $\begin{array}{l}\% \\
461\end{array}$ \\
\hline White & 28. & 280. & White & 8.1 & 0.3 \\
\hline \multirow[t]{2}{*}{ Alone } & $0 \%$ & $8 \%$ & Alone & $\%$ & $\%$ \\
\hline & & & & - & $\begin{array}{l}- \\
350\end{array}$ \\
\hline Black & 7.7 & 77.1 & Black & 6.1 & 4.9 \\
\hline Alone & $\%$ & $\%$ & Alone & $\%$ & $\%$ \\
\hline Asian and Pacific & 30. & 316. & Asian and Pacific & 0.0 & 0.0 \\
\hline \multirow[t]{2}{*}{ Islander Alone } & $3 \%$ & $5 \%$ & Islander Alone & $\%$ & $\%$ \\
\hline & _ & - & & - & $\overline{223}$ \\
\hline Native American & 52. & 395. & Native American & 52. & 44.8 \\
\hline \multirow[t]{2}{*}{ Alone } & $7 \%$ & $3 \%$ & Alone & $3 \%$ & $\%$ \\
\hline & & & & & - \\
\hline All Other Races & 42. & 290. & All Other Races & 3.8 & 6.9 \\
\hline Alone & $1 \%$ & $8 \%$ & Alone & $\%$ & $\%$ \\
\hline TotalPopu & 10. & 0.0 & TotalPop & 0.2 & 0.0 \\
\hline lation & $4 \%$ & $\%$ & ulation & $\%$ & $\%$ \\
\hline
\end{tabular}

Table 6A.13A Poor MA:

SCT.

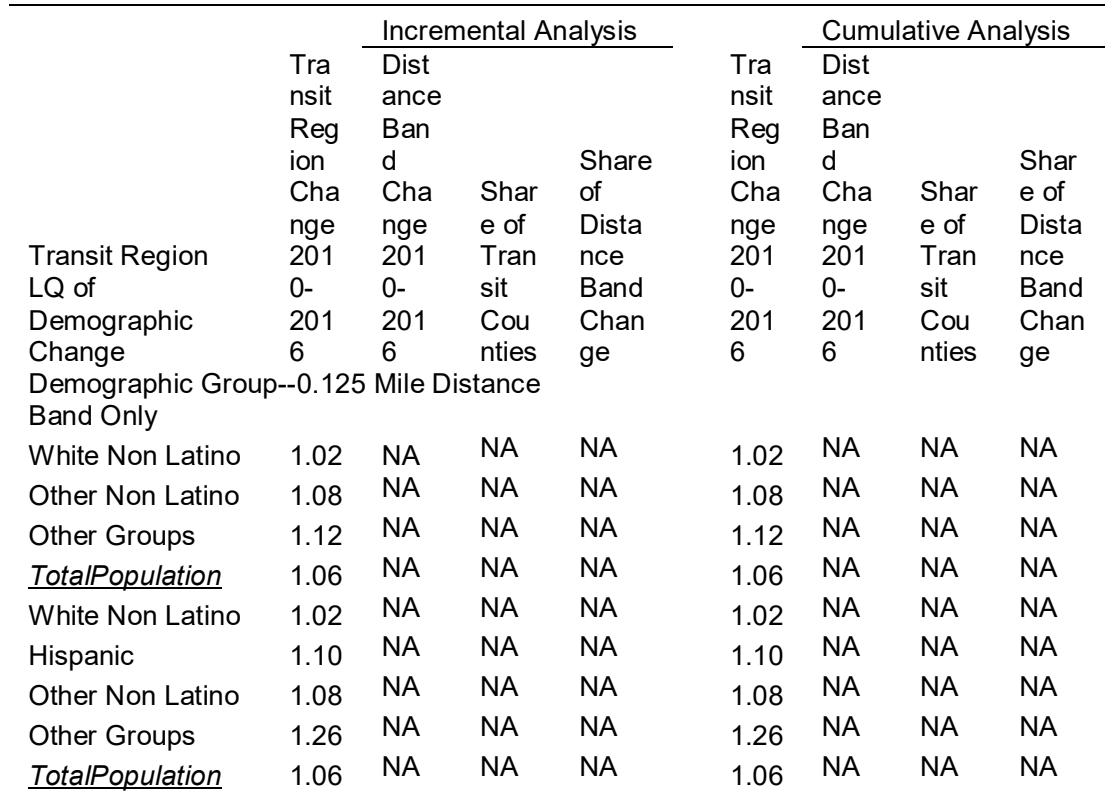




\begin{tabular}{|c|c|c|c|c|c|c|c|c|}
\hline White Alone & 1.08 & NA & NA & NA & 1.08 & NA & NA & NA \\
\hline Black Alone & 1.06 & NA & NA & NA & 1.06 & NA & NA & NA \\
\hline Asian and Pacific & & NA & NA & NA & & NA & NA & NA \\
\hline Islander Alone & 1.16 & & & & 1.16 & & & \\
\hline Native American & & NA & NA & NA & & NA & NA & NA \\
\hline $\begin{array}{l}\text { Alone } \\
\text { All Other Races }\end{array}$ & 0.88 & & & & 0.88 & NA & NA & NA \\
\hline Alone & 0.87 & רת טו & רתטו & הת & 0.87 & 4 & הת & הת \\
\hline TotalPopulation & 1.06 & NA & NA & & 1.06 & NA & NA & \\
\hline \multicolumn{9}{|c|}{$\begin{array}{l}\text { Demographic Group--0.25 Mile } \\
\text { Distance Band Only }\end{array}$} \\
\hline & & & - & & & & - & \\
\hline & & - & 6.8 & 213.2 & & - & 0.5 & \\
\hline \multirow[t]{2}{*}{ White Non Latino } & 1.02 & 0.07 & $\begin{array}{l}\% \\
-\end{array}$ & $\%$ & 1.02 & 0.01 & $\begin{array}{l}\% \\
-\end{array}$ & $6.2 \%$ \\
\hline & & - & 15.5 & 517.5 & & - & 79.9 & 1022 \\
\hline \multirow[t]{2}{*}{ Other Non Latino } & 1.08 & 0.17 & $\%$ & $\begin{array}{l}\% \\
-\end{array}$ & 1.08 & 0.86 & $\%$ & $.9 \%$ \\
\hline & & & 21.9 & 758.0 & & & 213. & 2832 \\
\hline \multirow[t]{2}{*}{ Other Groups } & 1.12 & 0.25 & $\begin{array}{l}\% \\
-\end{array}$ & $\%$ & 1.12 & 2.39 & $\begin{array}{l}4 \% \\
-\end{array}$ & $.3 \%$ \\
\hline & & - & 3.1 & & & - & 8.0 & \\
\hline \multirow[t]{2}{*}{ TotalPopulation } & 1.06 & 0.03 & $\begin{array}{l}\% \\
-\end{array}$ & & 1.06 & 0.08 & $\begin{array}{l}\% \\
-\end{array}$ & \\
\hline & & - & 6.8 & 213.2 & & - & 0.5 & \\
\hline \multirow[t]{2}{*}{ White Non Latino } & 1.02 & 0.07 & $\%$ & & 1.02 & 0.01 & $\%$ & $\begin{array}{l}6.2 \% \\
-\end{array}$ \\
\hline & & & 21.7 & 736.4 & & & 20.7 & 269. \\
\hline \multirow[t]{2}{*}{ Hispanic } & 1.10 & 0.24 & $\begin{array}{l}\% \\
-\end{array}$ & $\%$ & 1.10 & 0.23 & $\begin{array}{l}\% \\
-\end{array}$ & $7 \%$ \\
\hline & & - & 15.5 & 517.5 & & - & 79.9 & 1022 \\
\hline Other Non Latino & 1.08 & 0.17 & $\%$ & $\%$ & 1.08 & 0.86 & $\%$ & $.9 \%$ \\
\hline \multirow[t]{2}{*}{ Other Groups } & 1.26 & 0.29 & $\begin{array}{l}22.9 \\
\% \\
-\end{array}$ & $\begin{array}{l}886.2 \\
\%\end{array}$ & 1.26 & 2.39 & $\begin{array}{l}190 . \\
2 \% \\
-\end{array}$ & $\begin{array}{l}2832 \\
.3 \%\end{array}$ \\
\hline & & - & 3.1 & & & - & 8.0 & \\
\hline \multirow[t]{2}{*}{ TotalPopulation } & 1.06 & 0.03 & $\begin{array}{l}\% \\
-\end{array}$ & & 1.06 & 0.08 & $\begin{array}{l}\% \\
-\end{array}$ & \\
\hline & & - & 77.0 & 2562. & & - & 5.2 & 66.9 \\
\hline \multirow[t]{2}{*}{ White Alone } & 1.08 & 0.83 & $\begin{array}{l}\% \\
-\end{array}$ & $2 \%$ & 1.08 & 0.06 & $\begin{array}{l}\% \\
-\end{array}$ & $\%$ \\
\hline & & - & 34.7 & 1131. & & - & 32.7 & 409. \\
\hline Black Alone & 1.06 & 0.37 & $\begin{array}{l}\% \\
-\end{array}$ & $1 \%$ & 1.06 & 0.35 & $\%$ & $5 \%$ \\
\hline $\begin{array}{l}\text { Asian and Pacific } \\
\text { Islander Alone }\end{array}$ & 1.16 & $-\overline{0}$ & $\begin{array}{l}19.5 \\
\% \\
-\end{array}$ & $\begin{array}{l}701.5 \\
\%\end{array}$ & 1.16 & 0.00 & $\begin{array}{l}0.0 \\
\% \\
-\end{array}$ & $0.0 \%$ \\
\hline \multirow{2}{*}{$\begin{array}{l}\text { Native American } \\
\text { Alone }\end{array}$} & & - & 90.5 & 2444. & & - & 114. & 1184 \\
\hline & 0.88 & 0.79 & $\begin{array}{l}\% \\
131\end{array}$ & & 0.88 & 1.00 & $1 \%$ & $\begin{array}{l}.6 \% \\
-\end{array}$ \\
\hline \multirow{3}{*}{ Alone } & & 11.3 & 2.1 & 3503 & & & 276. & 2832 \\
\hline & 0.87 & 7 & $\begin{array}{l}\% \\
-\end{array}$ & $5.2 \%$ & 0.87 & 2.39 & $\begin{array}{l}0 \% \\
-\end{array}$ & $.3 \%$ \\
\hline & & - & 3.1 & & & - & 8.0 & \\
\hline TotalPopulation & 1.06 & 0.03 & $\%$ & & 1.06 & 0.08 & $\%$ & \\
\hline \multicolumn{9}{|c|}{$\begin{array}{l}\text { Demographic Group--0.375 Mile Distance } \\
\text { Band Only }\end{array}$} \\
\hline & & & - & & & & & - \\
\hline & & - & 17.5 & 116.4 & & & 2.0 & 13.3 \\
\hline \multirow[t]{2}{*}{ White Non Latino } & 1.02 & 0.18 & $\begin{array}{l}\% \\
-\end{array}$ & $\%$ & 1.02 & 0.02 & $\begin{array}{l}\% \\
-\end{array}$ & $\%$ \\
\hline & & - & 18.0 & 126.9 & & - & 74.2 & 524. \\
\hline \multirow[t]{2}{*}{ Other Non Latino } & 1.08 & 0.19 & $\%$ & $\%$ & 1.08 & 0.80 & $\%$ & $\begin{array}{l}4 \% \\
-\end{array}$ \\
\hline & 1.12 & 0.24 & $\begin{array}{l}21.6 \\
\%\end{array}$ & $\begin{array}{l}157.7 \\
\%\end{array}$ & 1.12 & 2.11 & $\begin{array}{l}187 . \\
9 \%\end{array}$ & $\begin{array}{l}1376 \\
.0 \%\end{array}$ \\
\hline
\end{tabular}




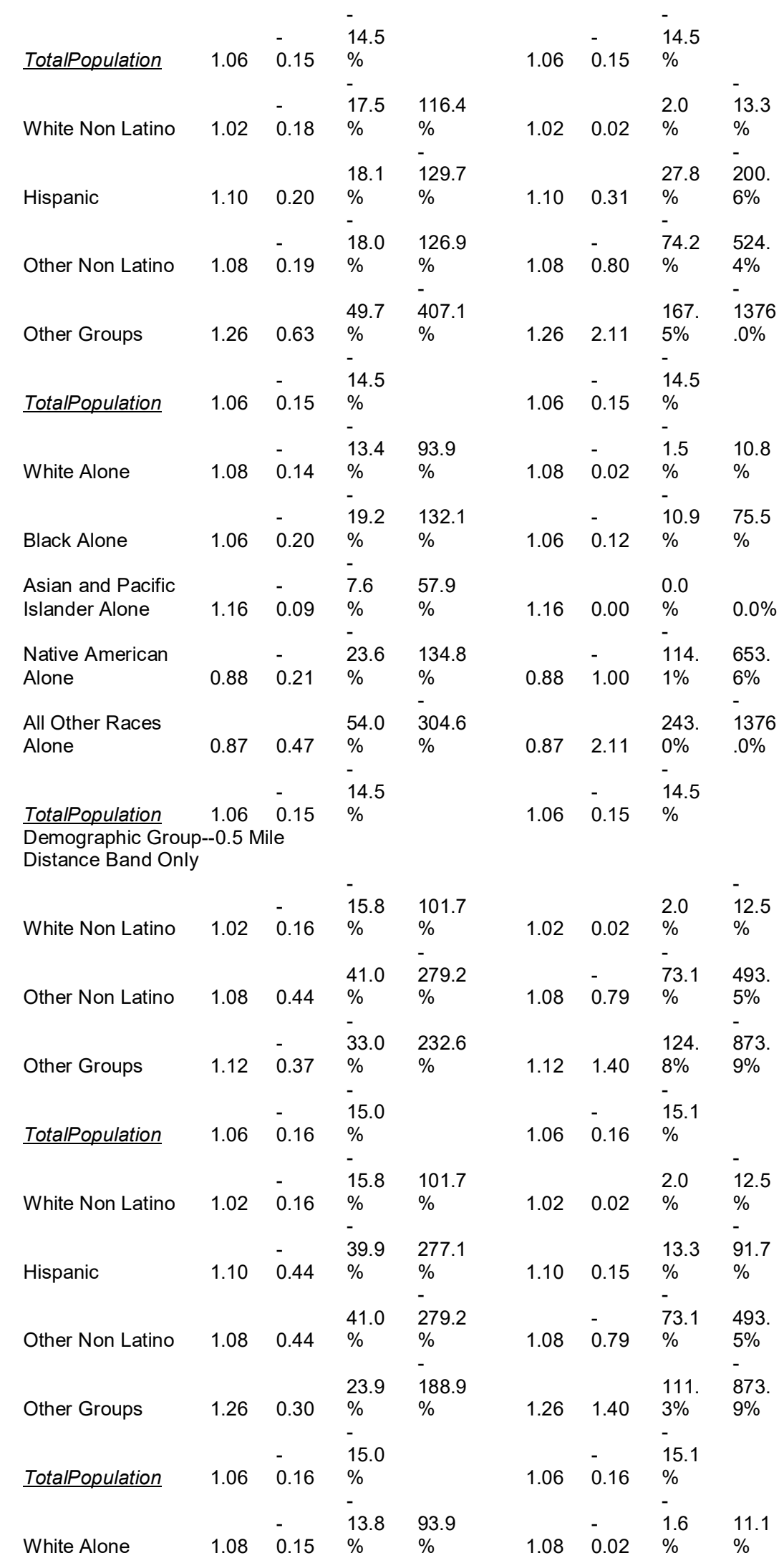




\begin{tabular}{|c|c|c|c|c|c|c|c|c|}
\hline & & & & & & & & \\
\hline & & & 18.5 & 123.2 & & - & 9.6 & 63.5 \\
\hline Black Alone & 1.06 & 0.20 & $\begin{array}{l}\% \\
-\end{array}$ & $\%$ & 1.06 & 0.10 & $\%$ & $\%$ \\
\hline Asian and Pacific & & - & 38.6 & 283.3 & & & 0.0 & \\
\hline Islander Alone & 1.16 & 0.45 & $\%$ & $\%$ & 1.16 & 0.00 & $\%$ & $0.0 \%$ \\
\hline Native American & & & 256. & 1416. & & - & 114. & 624. \\
\hline Alone & 0.88 & 2.25 & $\begin{array}{l}8 \% \\
-\end{array}$ & $4 \%$ & 0.88 & 1.00 & $1 \%$ & $\begin{array}{l}8 \% \\
-\end{array}$ \\
\hline All Other Races & & - & 70.0 & 381.8 & & & 161. & 873. \\
\hline Alone & 0.87 & 0.61 & $\begin{array}{l}\% \\
-\end{array}$ & $\%$ & 0.87 & 1.40 & $\begin{array}{l}4 \% \\
-\end{array}$ & $9 \%$ \\
\hline & & - & 15.0 & & & - & 15.1 & \\
\hline TotalPopulation & 1.06 & 0.16 & $\%$ & & 1.06 & 0.16 & $\%$ & \\
\hline $\begin{array}{l}\text { Demographic Grour } \\
\text { Distance Band Only }\end{array}$ & --0.75 & Mile & & & & & & \\
\hline & & & - & & & & & - \\
\hline & & - & 7.2 & 97.9 & & & 4.7 & 44.4 \\
\hline White Non Latino & 1.02 & 0.07 & $\begin{array}{l}\% \\
-\end{array}$ & $\%$ & 1.02 & 0.05 & $\begin{array}{l}\% \\
-\end{array}$ & $\%$ \\
\hline & & - & 6.7 & 96.0 & & - & 57.0 & 565. \\
\hline Other Non Latino & 1.08 & 0.07 & $\begin{array}{l}\% \\
-\end{array}$ & $\%$ & 1.08 & 0.62 & $\%$ & $\begin{array}{l}6 \% \\
-\end{array}$ \\
\hline & & - & 8.4 & 126.0 & & & 27.1 & 279. \\
\hline Other Groups & 1.12 & 0.09 & $\%$ & $\%$ & 1.12 & 0.30 & $\%$ & $2 \%$ \\
\hline & & - & 7.1 & & & - & 10.3 & \\
\hline TotalPopulation & 1.06 & 0.08 & $\begin{array}{l}\% \\
-\end{array}$ & & 1.06 & 0.11 & $\%$ & - \\
\hline & & - & 7.2 & 97.9 & & & 4.7 & 44.4 \\
\hline White Non Latino & 1.02 & 0.07 & $\%$ & $\%$ & 1.02 & 0.05 & $\%$ & $\%$ \\
\hline & & - & 47.8 & 702.2 & & - & 7.5 & 75.4 \\
\hline Hispanic & 1.10 & 0.53 & $\begin{array}{l}\% \\
-\end{array}$ & $\%$ & 1.10 & 0.08 & $\begin{array}{l}\% \\
-\end{array}$ & $\%$ \\
\hline & & - & 6.7 & 96.0 & & - & 57.0 & 565. \\
\hline Other Non Latino & 1.08 & 0.07 & $\%$ & $\begin{array}{l}\% \\
-\end{array}$ & 1.08 & 0.62 & $\%$ & $\begin{array}{l}6 \% \\
-\end{array}$ \\
\hline Other Groups & 1.26 & 1.37 & $\begin{array}{l}108 . \\
9 \% \\
-\end{array}$ & $\begin{array}{l}1822 . \\
6 \%\end{array}$ & 1.26 & 0.30 & $\begin{array}{l}24.2 \\
\% \\
-\end{array}$ & $\begin{array}{l}279 . \\
2 \%\end{array}$ \\
\hline & & - & 7.1 & & & - & 10.3 & \\
\hline TotalPopulation & 1.06 & 0.08 & $\begin{array}{l}\% \\
-\end{array}$ & & 1.06 & 0.11 & $\begin{array}{l}\% \\
-\end{array}$ & \\
\hline & & - & 7.3 & 105.4 & & & 0.1 & \\
\hline White Alone & 1.08 & 0.08 & $\begin{array}{l}\% \\
-\end{array}$ & $\%$ & 1.08 & 0.00 & $\begin{array}{l}\% \\
-\end{array}$ & $0.9 \%$ \\
\hline & & - & 22.4 & 315.4 & & - & 17.5 & 169. \\
\hline Black Alone & 1.06 & 0.24 & $\%$ & & 1.06 & 0.19 & $\%$ & $9 \%$ \\
\hline $\begin{array}{l}\text { Asian and Pacific } \\
\text { Islander Alone }\end{array}$ & 1.16 & 0.31 & $\begin{array}{l}26.7 \\
\% \\
-\end{array}$ & $\begin{array}{l}414.1 \\
\%\end{array}$ & 1.16 & 0.00 & $\begin{array}{l}0.0 \\
\% \\
-\end{array}$ & $0.0 \%$ \\
\hline Native American & & - & 58.9 & 687.4 & & - & 114. & 918. \\
\hline Alone & 0.88 & 0.52 & $\begin{array}{l}\% \\
-\end{array}$ & $\%$ & 0.88 & 1.00 & $1 \%$ & $0 \%$ \\
\hline All Other Races & & - & 4.6 & 53.4 & & & 35.1 & 279. \\
\hline Alone & 0.87 & 0.04 & $\begin{array}{l}\% \\
-\end{array}$ & $\%$ & 0.87 & 0.30 & & $2 \%$ \\
\hline & & - & 7.1 & & & - & 10.3 & \\
\hline TotalPopulation & 1.06 & 0.08 & $\%$ & & 1.06 & 0.11 & $\%$ & \\
\hline $\begin{array}{l}\text { Demographic Group } \\
\text { Distance Band Only }\end{array}$ & --1.00 & Mile & & & & & & \\
\hline & & & 10.6 & 325.5 & & & 0.9 & $\overline{12.0}$ \\
\hline White Non Latino & 1.02 & 0.11 & $\begin{array}{l}\% \\
-\end{array}$ & $\begin{array}{l}\% \\
-\end{array}$ & 1.02 & 0.01 & $\begin{array}{l}\% \\
-\end{array}$ & $\%$ \\
\hline & & - & 7.7 & 251.2 & & - & 59.2 & 812. \\
\hline Other Non Latino & 1.08 & 0.08 & $\%$ & $\%$ & 1.08 & 0.64 & $\%$ & $0 \%$ \\
\hline
\end{tabular}




\begin{tabular}{|c|c|c|c|c|c|c|c|c|}
\hline & & - & - & $\begin{array}{l}- \\
678.9\end{array}$ & & & 25.0 & - \\
\hline Other Groups & 1.12 & 0.23 & $\%$ & $\%$ & 1.12 & 0.28 & $\%$ & $7 \%$ \\
\hline$\underline{\text { TotalPopulation }}$ & 1.06 & 0.03 & $\begin{array}{l}3.1 \\
\%\end{array}$ & & 1.06 & $\overline{0}-08$ & $\begin{array}{l}7.5 \\
\%\end{array}$ & \\
\hline White Non Latino & 1.02 & 0.11 & $\begin{array}{l}10.6 \\
\% \\
-\end{array}$ & $\begin{array}{l}325.5 \\
\% \\
-\end{array}$ & 1.02 & 0.01 & $\begin{array}{l}0.9 \\
\% \\
-\end{array}$ & $\begin{array}{l}12.0 \\
\%\end{array}$ \\
\hline Hispanic & 1.10 & $\begin{array}{l}- \\
0.17\end{array}$ & $\begin{array}{l}15.5 \\
\% \\
-\end{array}$ & $\begin{array}{l}514.9 \\
\% \\
-\end{array}$ & 1.10 & $\begin{array}{l}- \\
0.17\end{array}$ & $\begin{array}{l}15.8 \\
\% \\
-\end{array}$ & $\begin{array}{l}221 . \\
4 \%\end{array}$ \\
\hline & & - & 7.7 & 251.2 & & - & 59.2 & 812. \\
\hline Other Non Latino & 1.08 & 0.08 & $\%$ & $\begin{array}{l}\% \\
-\end{array}$ & 1.08 & 0.64 & $\%$ & $\begin{array}{l}0 \% \\
-\end{array}$ \\
\hline Other Groups & 1.26 & $\begin{array}{l}- \\
0.54\end{array}$ & $\begin{array}{l}42.8 \\
\%\end{array}$ & $\begin{array}{l}1615 . \\
4 \%\end{array}$ & 1.26 & 0.28 & $\begin{array}{l}22.3 \\
\% \\
-\end{array}$ & $\begin{array}{l}355 . \\
7 \%\end{array}$ \\
\hline TotalPopulation & 1.06 & 0.03 & $\begin{array}{l}3.1 \\
\%\end{array}$ & & 1.06 & $\overline{-}-08$ & $\begin{array}{l}7.5 \\
\% \\
-\end{array}$ & \\
\hline White Alone & 1.08 & 0.11 & $\begin{array}{l}10.0 \\
\%\end{array}$ & $\begin{array}{l}324.7 \\
\%\end{array}$ & 1.08 & $\overline{-} .04$ & $\begin{array}{l}4.1 \\
\%\end{array}$ & $\begin{array}{l}56.1 \\
\% \\
-\end{array}$ \\
\hline Black Alone & 1.06 & 0.01 & $\begin{array}{l}0.9 \\
\% \\
-\end{array}$ & $\begin{array}{l}27.2 \\
\% \\
-\end{array}$ & 1.06 & 0.06 & $\begin{array}{l}6.0 \\
\%\end{array}$ & $\begin{array}{l}80.0 \\
\%\end{array}$ \\
\hline Asian and Pacific & & - & 64.2 & 2245 . & & & 0.0 & \\
\hline Islander Alone & 1.16 & 0.75 & $\begin{array}{l}\% \\
-\end{array}$ & & 1.16 & 0.00 & $\begin{array}{l}\% \\
-\end{array}$ & $0.0 \%$ \\
\hline Native American & & - & 88.8 & 2336. & & - & 49.3 & 548. \\
\hline Alone & 0.88 & 0.78 & $\%$ & & 0.88 & 0.43 & $\%$ & $5 \%$ \\
\hline All Other Races & & - & 44.3 & 1152. & & & 32.3 & 355. \\
\hline Alone & 0.87 & 0.38 & $\%$ & $3 \%$ & 0.87 & 0.28 & $\%$ & $7 \%$ \\
\hline TotalPopulation & 1.06 & 0.03 & $\begin{array}{l}3.1 \\
\%\end{array}$ & & 1.06 & $\begin{array}{l}- \\
0.08\end{array}$ & $\begin{array}{l}7.5 \\
\%\end{array}$ & \\
\hline
\end{tabular}

Table 6A.13B Poor MA: SCT.

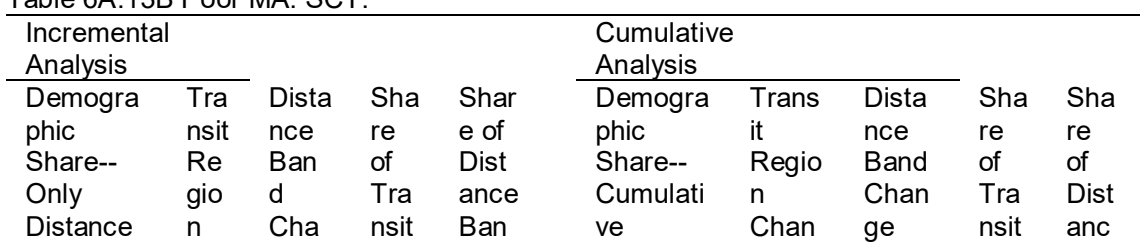




\begin{tabular}{|c|c|c|c|c|c|c|c|c|c|}
\hline & & \multirow[b]{2}{*}{$\begin{array}{l}\text { nge } \\
2010 \\
- \\
2016\end{array}$} & \multirow[b]{2}{*}{$\begin{array}{l}\text { Co } \\
\text { unti } \\
\text { es }\end{array}$} & \multirow[b]{2}{*}{$\begin{array}{l}\text { d } \\
\text { Cha } \\
\text { nge }\end{array}$} & & \multirow[b]{2}{*}{$\begin{array}{l}\text { Co } \\
\text { unti } \\
\text { es }\end{array}$} & \multirow[b]{2}{*}{$\begin{array}{l}\mathrm{e} \\
\text { Ban } \\
\mathrm{d} \\
\text { Cha } \\
\text { nge }\end{array}$} \\
\hline $\begin{array}{l}\text { Band } \\
\text { Change }\end{array}$ & $\begin{array}{l}\text { Ch } \\
\text { an } \\
\text { ge } \\
20 \\
10- \\
20 \\
16\end{array}$ & & & & $\begin{array}{l}\text { Distance } \\
\text { Band } \\
\text { Change }\end{array}$ & $\begin{array}{l}\text { ge } \\
2010- \\
2016\end{array}$ & $\begin{array}{l}2010- \\
2016\end{array}$ & & \\
\hline \multicolumn{5}{|c|}{ Spatial Share--0.125 } & \multicolumn{5}{|c|}{ Spatial Share--0.125 Mile } \\
\hline \multicolumn{5}{|c|}{ Mile Distance Band Only } & \multicolumn{5}{|c|}{ Distance Band Only } \\
\hline Station & 12 & & & & Station & & & & \\
\hline Area & 77 & & 0.0 & & Area & 1277 & & 0.0 & \\
\hline (sq.mi.) & 0 & 2 & $\%$ & & (sq.mi.) & 0 & 2 & $\%$ & \\
\hline \multirow{2}{*}{\multicolumn{5}{|c|}{$\begin{array}{l}\text { Basic Demographics--0.125 } \\
\text { Mile Distance Band Only }\end{array}$}} & \multirow{2}{*}{\multicolumn{5}{|c|}{$\begin{array}{l}\text { Basic Demographics--0.125 Mile } \\
\text { Distance Band Only }\end{array}$}} \\
\hline & Mile Distance Band Only & & & & & & & Distance Band Only & \\
\hline \multicolumn{4}{|l|}{ White } & NA & White & & & NA & NA \\
\hline Non & & & & & Non & & & & \\
\hline Latino & & & NA & & Latino & & & & \\
\hline Other & & & NA & NA & Other & & & NA & NA \\
\hline Non & & & & & Non & & & & \\
\hline Latino & & & & & Latino & & & & \\
\hline Other & & & NA & NA & Other & & & NA & NA \\
\hline Groups & & & & & Groups & & & & \\
\hline TotalPop & & & NA & 0.0 & TotalPop & & & NA & 0.0 \\
\hline ulation & & & & $\%$ & ulation & & & & $\%$ \\
\hline$\overline{\text { White }}$ & & & NA & NA & $\overline{\text { White }}$ & & & NA & NA \\
\hline Non & & & & & Non & & & & \\
\hline Latino & & & & & Latino & & & & \\
\hline Hispanic & & & NA & NA & Hispanic & & & NA & NA \\
\hline Other & & & NA & NA & Other & & & NA & NA \\
\hline Non & & & & & Non & & & & \\
\hline Latino & & & & & Latino & & & & \\
\hline Other & & & NA & NA & Other & & & NA & NA \\
\hline Groups & & & & & Groups & & & & \\
\hline TotalPop & & & NA & 0.0 & TotalPop & & & NA & 0.0 \\
\hline ulation & & & & $\%$ & ulation & & & & $\%$ \\
\hline$\overline{\text { White }}$ & & & NA & NA & $\overline{\text { White }}$ & & & NA & NA \\
\hline Alone & & & & & Alone & & & & \\
\hline Black & & & NA & NA & Black & & & NA & NA \\
\hline Alone & & & & & Alone & & & & \\
\hline Asian and & & & NA & NA & & & & NA & NA \\
\hline $\begin{array}{l}\text { Pacific IsI } \\
\text { Alone }\end{array}$ & der & & & & $\begin{array}{l}\text { Asian and } \\
\text { Islander A }\end{array}$ & $\begin{array}{l}\text { Dacific } \\
\text { ne }\end{array}$ & & & \\
\hline $\begin{array}{l}\text { Native Am } \\
\text { Alone }\end{array}$ & ican & & NA & NA & $\begin{array}{l}\text { Native Am } \\
\text { Alone }\end{array}$ & rican & & NA & NA \\
\hline $\begin{array}{l}\text { All Other } \\
\text { Alone }\end{array}$ & ices & & NA & NA & $\begin{array}{l}\text { All Other } \\
\text { Alone }\end{array}$ & aces & & NA & NA \\
\hline TotalPop & & & NA & 0.0 & TotalPop & & & NA & 0.0 \\
\hline ulation & & & & $\%$ & ulation & & & & $\%$ \\
\hline $\begin{array}{l}\text { Spatial St } \\
\text { Distance }\end{array}$ & $\begin{array}{l}e--0 . \\
\text { nd } O\end{array}$ & 5 Mile & & & $\begin{array}{l}\text { Spatial Sh } \\
\text { Distance }\end{array}$ & $\begin{array}{l}\text { re--0.25 } \\
\text { and Cum }\end{array}$ & $\begin{array}{l}\text { Mile } \\
\text { ulative }\end{array}$ & & \\
\hline Station & 12 & & & & Station & & & & \\
\hline Area & 77 & & 0.0 & & Area & 1277 & & 0.1 & \\
\hline (sq.mi.) & 0 & 6 & $\%$ & & (sq.mi.) & 0 & 8 & $\%$ & \\
\hline Demogra & ic $\mathrm{Ch}$ & $7 g e--0.2$ & & & Demograp & nic Chan & $y e--0.25$ & & \\
\hline Mile Dista & $\mathrm{Ba}$ & d Only & & & Distance & and Cun & ulative & & \\
\hline White & & & - & & White & & & - & \\
\hline Non & & & 6.8 & 213. & Non & & & 0.5 & 6.2 \\
\hline Latino & & & $\%$ & $2 \%$ & Latino & & & $\%$ & $\%$ \\
\hline Other & & & - & & Other & & & - & 102 \\
\hline Non & & & 15. & 517. & Non & & & 79. & 2.9 \\
\hline Latino & & & $5 \%$ & $5 \%$ & Latino & & & $9 \%$ & $\%$ \\
\hline & & & & - & & & & & 283 \\
\hline Other & & & 21. & 758. & Other & & & 213 & 2.3 \\
\hline Groups & & & $9 \%$ & $0 \%$ & Groups & & & $\begin{array}{l}.4 \% \\
-\end{array}$ & $\%$ \\
\hline TotalPop & & & 3.1 & 0.0 & TotalPop & & & 8.0 & 0.0 \\
\hline ulation & & & $\%$ & $\%$ & ulation & & & $\%$ & $\%$ \\
\hline
\end{tabular}




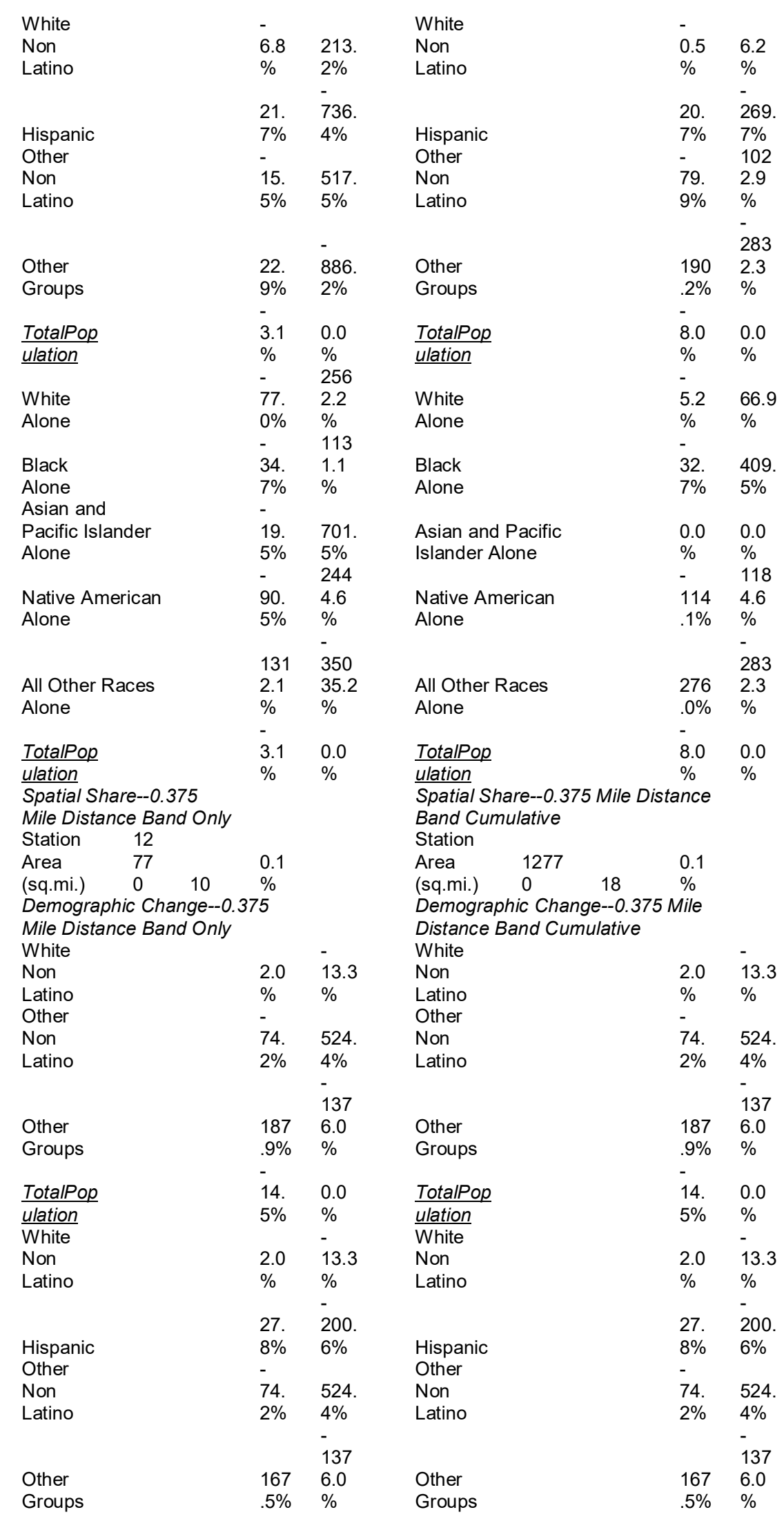




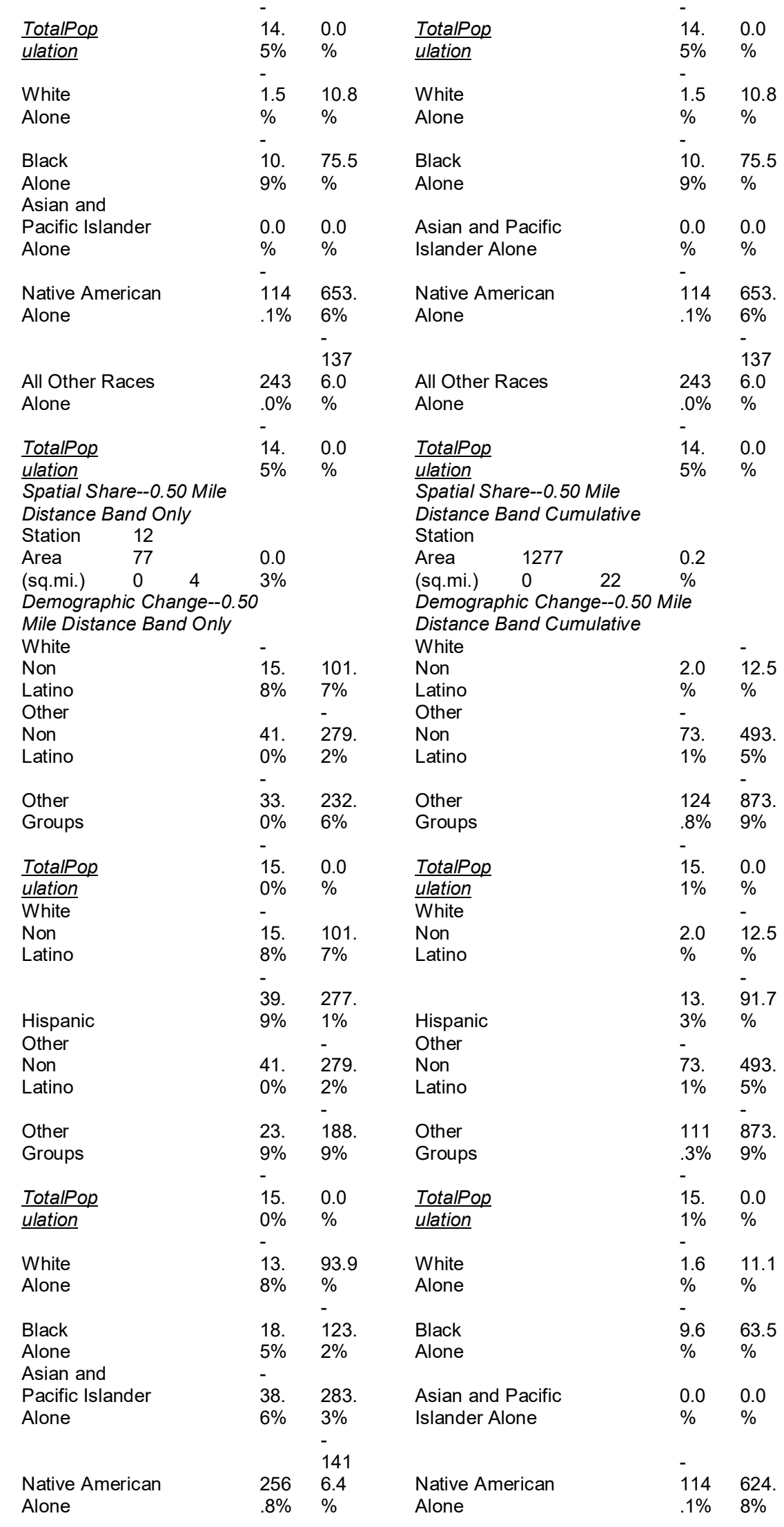




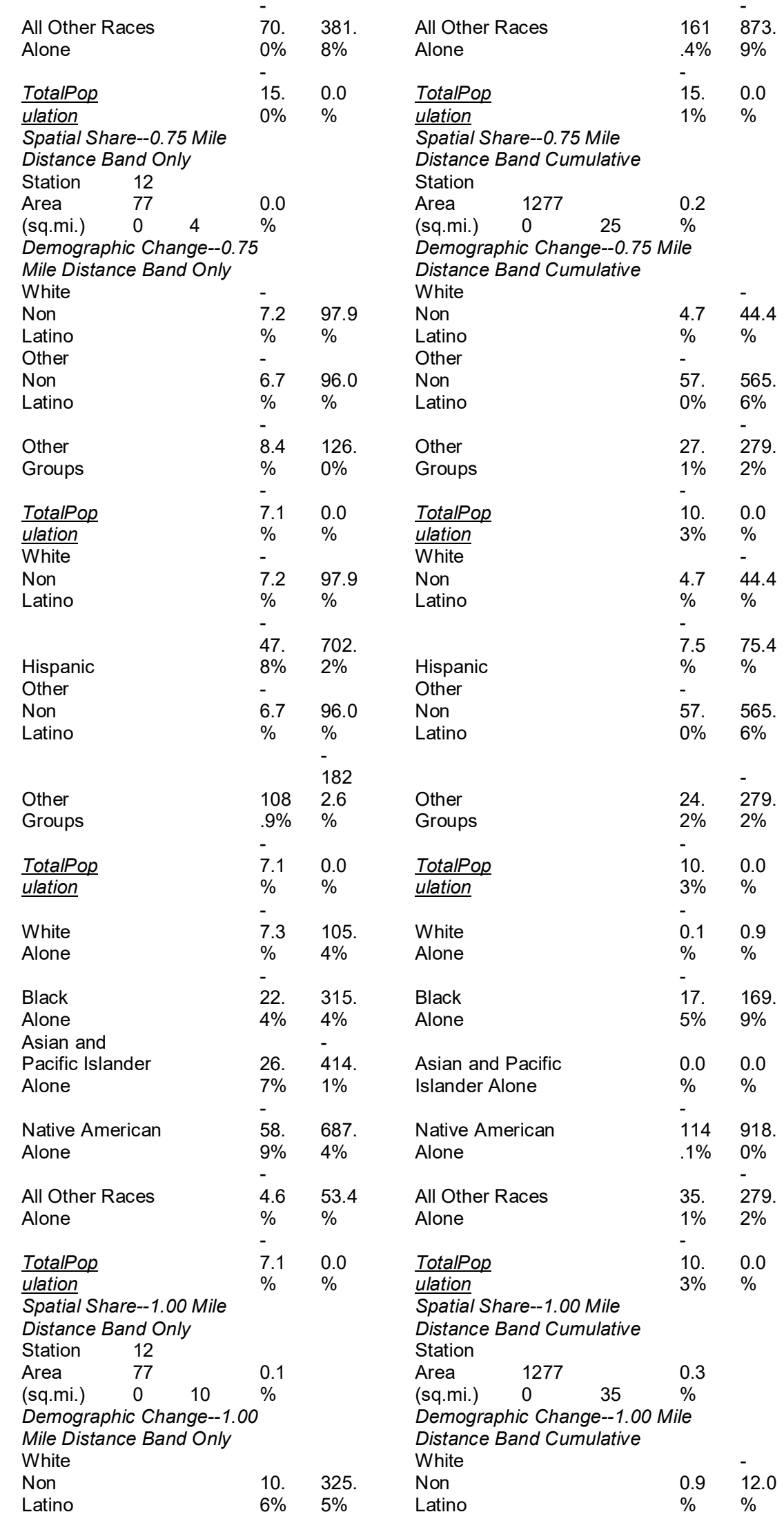




\begin{tabular}{|c|c|c|c|c|c|}
\hline Other & - & - & Other & - & \\
\hline Non & 7.7 & 251. & Non & 59. & 812. \\
\hline Latino & $\begin{array}{l}\% \\
-\end{array}$ & $\begin{array}{l}2 \% \\
-\end{array}$ & Latino & $2 \%$ & $0 \%$ \\
\hline Other & 20. & 678. & Other & 25. & 355. \\
\hline Groups & $2 \%$ & $9 \%$ & Groups & $\begin{array}{l}0 \% \\
-\end{array}$ & $7 \%$ \\
\hline TotalPop & 3.1 & 0.0 & TotalPop & 7.5 & 0.0 \\
\hline ulation & $\%$ & $\%$ & ulation & $\%$ & $\%$ \\
\hline White & & & White & & - \\
\hline Non & 10. & 325. & Non & 0.9 & 12.0 \\
\hline Latino & $\begin{array}{l}6 \% \\
-\end{array}$ & $\begin{array}{l}5 \% \\
-\end{array}$ & Latino & $\begin{array}{l}\% \\
-\end{array}$ & $\%$ \\
\hline & 15. & 514. & & 15. & 221. \\
\hline $\begin{array}{l}\text { Hispanic } \\
\text { Other }\end{array}$ & $\begin{array}{l}5 \% \\
-\end{array}$ & $\begin{array}{l}9 \% \\
-\end{array}$ & $\begin{array}{l}\text { Hispanic } \\
\text { Other }\end{array}$ & $\begin{array}{l}8 \% \\
-\end{array}$ & $4 \%$ \\
\hline Non & 7.7 & 251. & Non & 59. & 812. \\
\hline Latino & $\%$ & $\begin{array}{l}2 \% \\
-\end{array}$ & Latino & $2 \%$ & $0 \%$ \\
\hline & - & 161 & & & - \\
\hline Other & 42. & 5.4 & Other & 22. & 355. \\
\hline Groups & $8 \%$ & $\%$ & Groups & $\begin{array}{l}3 \% \\
-\end{array}$ & $7 \%$ \\
\hline TotalPop & 3.1 & 0.0 & TotalPop & 7.5 & 0.0 \\
\hline ulation & $\%$ & $\%$ & ulation & $\begin{array}{l}\% \\
-\end{array}$ & $\%$ \\
\hline $\begin{array}{l}\text { White } \\
\text { Alone }\end{array}$ & $\begin{array}{l}10 . \\
0 \%\end{array}$ & $\begin{array}{l}324 . \\
7 \%\end{array}$ & $\begin{array}{l}\text { White } \\
\text { Alone }\end{array}$ & $\begin{array}{l}4.1 \\
\%\end{array}$ & $\begin{array}{l}56.1 \\
\%\end{array}$ \\
\hline Black & 0.9 & 27.2 & Black & 6.0 & 80.0 \\
\hline Alone & $\%$ & $\begin{array}{l}\% \\
-\end{array}$ & Alone & $\%$ & $\%$ \\
\hline Asian and & - & 224 & & & \\
\hline Pacific Islander & 64. & 5.2 & Asian and Pacific & 0.0 & 0.0 \\
\hline Alone & $2 \%$ & $\%$ & Islander Alone & $\%$ & $\%$ \\
\hline Native American & $\overline{8}$. & $\begin{array}{l}233 \\
6.9\end{array}$ & Native American & $-\overline{49 .}$ & 548. \\
\hline Alone & $8 \%$ & $\%$ & Alone & $3 \%$ & $5 \%$ \\
\hline & - & 115 & & & - \\
\hline All Other Races & 44. & 2.3 & All Other Races & 32. & 355. \\
\hline Alone & $3 \%$ & $\%$ & Alone & $3 \%$ & $7 \%$ \\
\hline TotalPop & 3.1 & 0.0 & TotalPop & 7.5 & 0.0 \\
\hline ulation & $\%$ & $\%$ & ulation & $\%$ & $\%$ \\
\hline
\end{tabular}

Table 6A.14A Low MA:

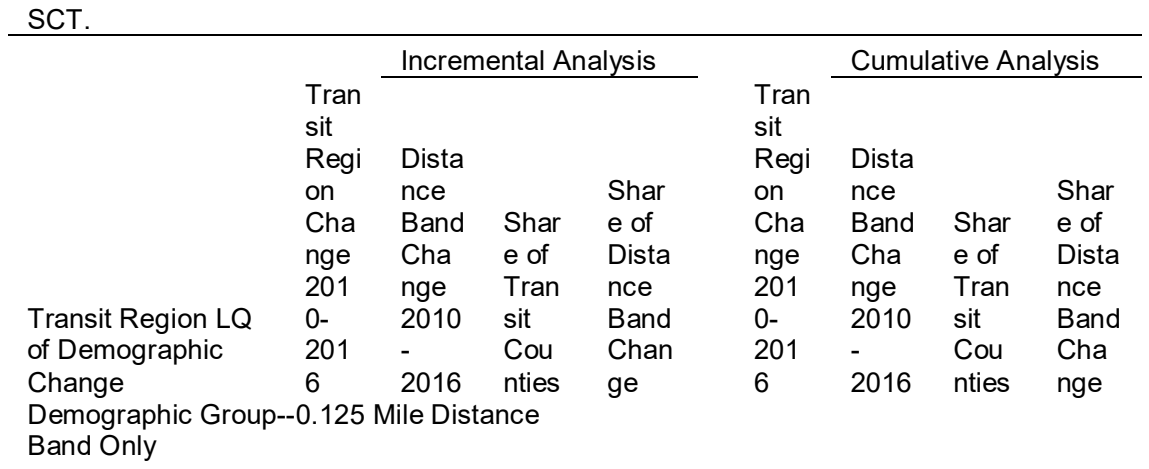




\begin{tabular}{|c|c|c|c|c|c|c|c|c|}
\hline White Non Latino & 1.02 & 0.16 & $\begin{array}{l}15.4 \\
\%\end{array}$ & $\begin{array}{l}239.2 \\
\% \\
-\end{array}$ & 1.02 & 0.16 & $\begin{array}{l}15.4 \\
\%\end{array}$ & $\begin{array}{l}239 . \\
2 \% \\
-\end{array}$ \\
\hline \multirow{3}{*}{ Other Non Latino } & & & - & 38.1 & & & - & 38.1 \\
\hline & 1.08 & -0.03 & $2.3 \%$ & $\%$ & 1.08 & -0.03 & $2.3 \%$ & $\%$ \\
\hline & & & - & 42.4 & & & - & 42.4 \\
\hline Other Groups & 1.12 & -0.03 & $2.5 \%$ & $\%$ & 1.12 & -0.03 & $2.5 \%$ & $\%$ \\
\hline TotalPopulation & 1.06 & 0.07 & $\begin{array}{l}6.2 \% \\
15.4\end{array}$ & 239.2 & 1.06 & 0.07 & $\begin{array}{l}6.2 \% \\
15.4\end{array}$ & 239. \\
\hline White Non Latino & 1.02 & 0.16 & $\%$ & $\%$ & 1.02 & 0.16 & $\%$ & $2 \%$ \\
\hline \multirow[t]{2}{*}{ Hispanic } & 1.10 & -0.08 & $-7.4 \%$ & $\begin{array}{l}124.0 \\
\% \\
-\end{array}$ & 1.10 & -0.08 & $-\overline{7.4 \%}$ & $\begin{array}{l}124 . \\
0 \% \\
-\end{array}$ \\
\hline & & & - & 38.1 & & & - & 38.1 \\
\hline Other Non Latino & 1.08 & -0.03 & $\begin{array}{l}2.3 \% \\
34.2\end{array}$ & $\begin{array}{l}\% \\
652.8\end{array}$ & 1.08 & -0.03 & $\begin{array}{l}2.3 \% \\
34.2\end{array}$ & $\begin{array}{l}\% \\
652 .\end{array}$ \\
\hline Other Groups & 1.26 & 0.43 & $\%$ & $\%$ & 1.26 & 0.43 & $\%$ & $8 \%$ \\
\hline TotalPopulation & 1.06 & 0.07 & $\begin{array}{l}6.2 \% \\
13.8\end{array}$ & 226.3 & 1.06 & 0.07 & $\begin{array}{l}6.2 \% \\
13.8\end{array}$ & 226. \\
\hline \multirow[t]{2}{*}{ White Alone } & 1.08 & 0.15 & $\%$ & $\%$ & 1.08 & 0.15 & $\%$ & $3 \%$ \\
\hline & & & - & 124.7 & & & - & 124. \\
\hline \multirow{3}{*}{$\begin{array}{l}\text { Black Alone } \\
\text { Asian and Pacific } \\
\text { Islander Alone } \\
\text { Native American } \\
\text { Alone }\end{array}$} & 1.06 & -0.08 & $\begin{array}{l}7.8 \% \\
29.8\end{array}$ & $\begin{array}{l}\% \\
527.4\end{array}$ & 1.06 & -0.08 & $\begin{array}{l}7.8 \% \\
29.8\end{array}$ & $\begin{array}{l}7 \% \\
527\end{array}$ \\
\hline & 1.16 & 0.35 & $\%$ & $\begin{array}{l}\% \\
98.1\end{array}$ & 1.16 & 0.35 & $\%$ & $\begin{array}{l}4 \% \\
98.1\end{array}$ \\
\hline & 0.88 & 0.06 & $\begin{array}{l}7.4 \% \\
-\end{array}$ & $\%$ & 0.88 & 0.06 & $\begin{array}{l}7.4 \% \\
-\end{array}$ & $\%$ \\
\hline $\begin{array}{l}\text { All Other Races } \\
\text { Alone }\end{array}$ & 0.87 & -0.12 & $\begin{array}{l}13.5 \\
\%\end{array}$ & $\begin{array}{l}177.3 \\
\%\end{array}$ & 0.87 & -0.12 & $\begin{array}{l}13.5 \\
\%\end{array}$ & $\begin{array}{l}177 . \\
3 \%\end{array}$ \\
\hline \multirow{2}{*}{\multicolumn{9}{|c|}{$\begin{array}{l}\text { TotalPopulation } \quad 1.06 \quad 0.07 \\
\text { Demographic Group---0.25 Mile } \\
\text { Distance Band Only }\end{array}$}} \\
\hline & & & & & & & & \\
\hline White Non Latino & 1.02 & -0.06 & $-\overline{5.6 \%}$ & $\begin{array}{l}81.5 \\
\%\end{array}$ & 1.02 & 0.09 & $9.1 \%$ & $\begin{array}{l}190 . \\
6 \% \\
-\end{array}$ \\
\hline Other Non Latino & 1.08 & -0.10 & $-9.1 \%$ & $\begin{array}{l}138.4 \\
\%\end{array}$ & 1.08 & 0.12 & $\begin{array}{l}10.9 \\
\%\end{array}$ & $\begin{array}{l}242 . \\
0 \%\end{array}$ \\
\hline & & & - & 74.0 & & & & 40.4 \\
\hline Other Groups & 1.12 & -0.05 & $\begin{array}{l}4.7 \% \\
-\end{array}$ & $\%$ & 1.12 & 0.02 & $\begin{array}{l}1.8 \% \\
-\end{array}$ & $\%$ \\
\hline TotalPopulation & 1.06 & -0.07 & $6.7 \%$ & & 1.06 & -0.05 & $4.6 \%$ & 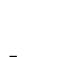 \\
\hline White Non Latino & 1.02 & -0.06 & - & $\begin{array}{l}81.5 \\
\%\end{array}$ & 1.02 & 0.09 & $\begin{array}{l}9.1 \% \\
-\end{array}$ & $\begin{array}{l}190 . \\
6 \%\end{array}$ \\
\hline & & & - & 129.3 & & & 11.6 & 262. \\
\hline Hispanic & 1.10 & -0.09 & $8.3 \%$ & $\%$ & 1.10 & -0.13 & $\%$ & $\begin{array}{l}1 \% \\
-\end{array}$ \\
\hline Other Non Latino & 1.08 & -0.10 & $-9.1 \%$ & $\begin{array}{l}138.4 \\
\% \\
-\end{array}$ & 1.08 & 0.12 & $\begin{array}{l}10.9 \\
\%\end{array}$ & $\begin{array}{l}242 . \\
0 \% \\
-\end{array}$ \\
\hline Other Groups & 1.26 & 0.35 & $\begin{array}{l}27.8 \\
\% \\
-\end{array}$ & $\begin{array}{l}493.7 \\
\%\end{array}$ & 1.26 & 0.02 & $\begin{array}{l}1.6 \% \\
-\end{array}$ & $\begin{array}{l}40.4 \\
\%\end{array}$ \\
\hline TotalPopulation & 1.06 & -0.07 & $\begin{array}{l}6.7 \% \\
-\end{array}$ & & 1.06 & -0.05 & $4.6 \%$ & - \\
\hline White Alone & 1.08 & -0.78 & $\begin{array}{l}71.9 \\
\% \\
-\end{array}$ & $\begin{array}{l}1098 . \\
5 \% \\
135.9\end{array}$ & 1.08 & 0.04 & $\begin{array}{l}3.4 \% \\
-\end{array}$ & $\begin{array}{l}75.2 \\
\% \\
191 .\end{array}$ \\
\hline $\begin{array}{l}\text { Black Alone } \\
\text { Asian and Pacific }\end{array}$ & 1.06 & -0.10 & $\begin{array}{l}9.1 \% \\
-\end{array}$ & $\begin{array}{l}\% \\
37.9\end{array}$ & 1.06 & -0.09 & $8.8 \%$ & $3 \%$ \\
\hline Islander Alone & 1.16 & -0.03 & $2.3 \%$ & $\%$ & 1.16 & 0.00 & $0.0 \%$ & $0.0 \%$ \\
\hline
\end{tabular}




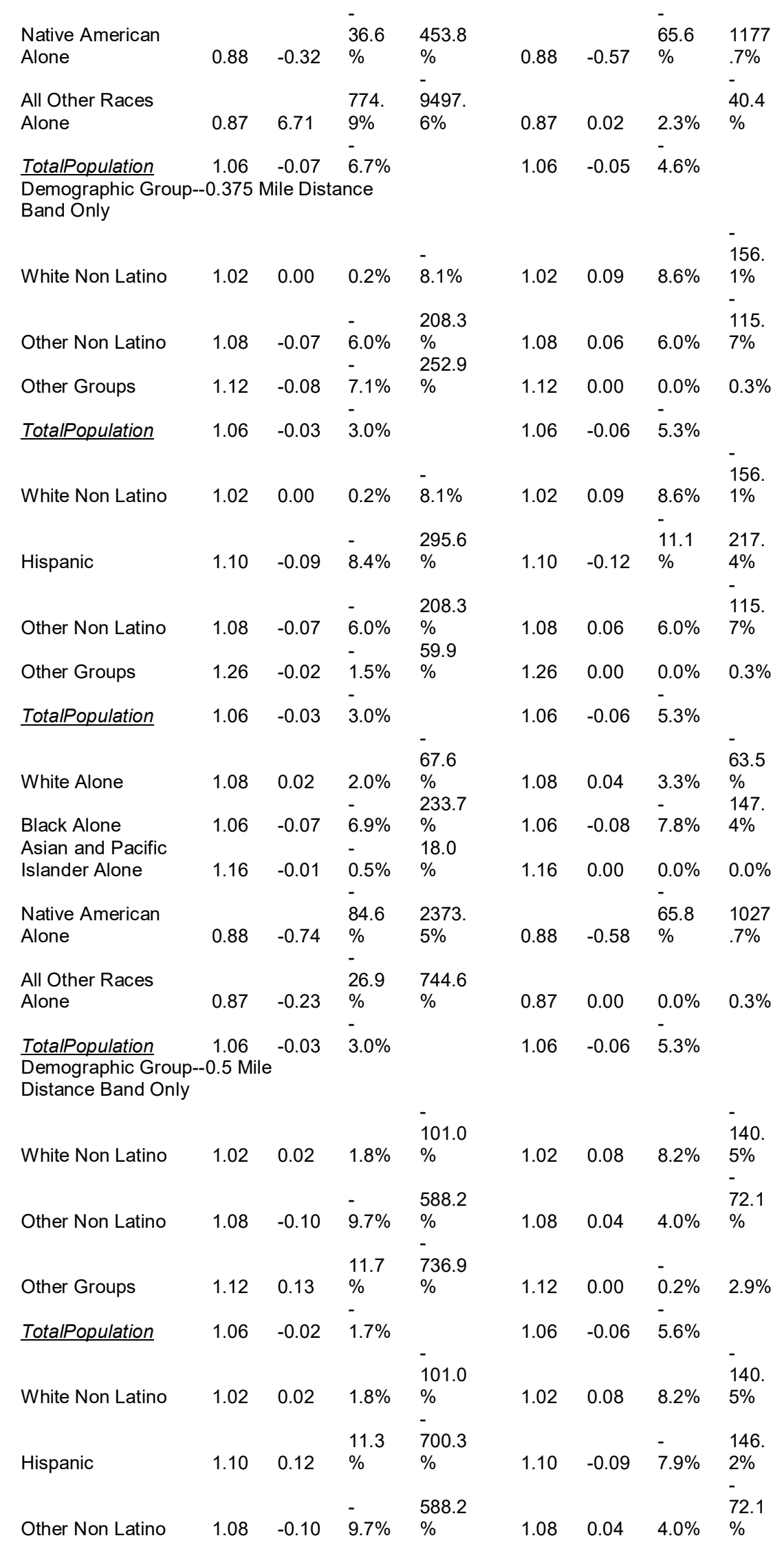




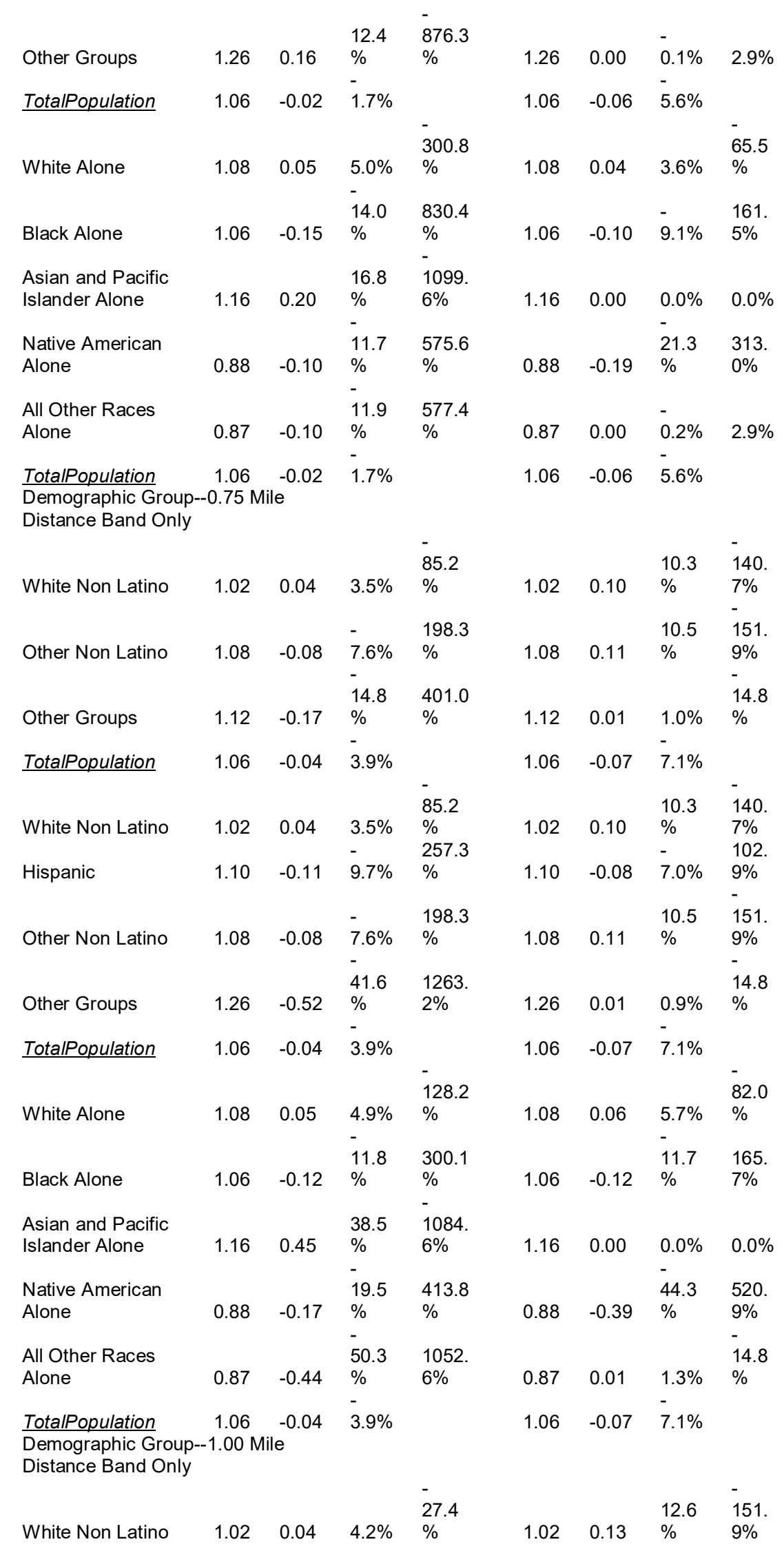




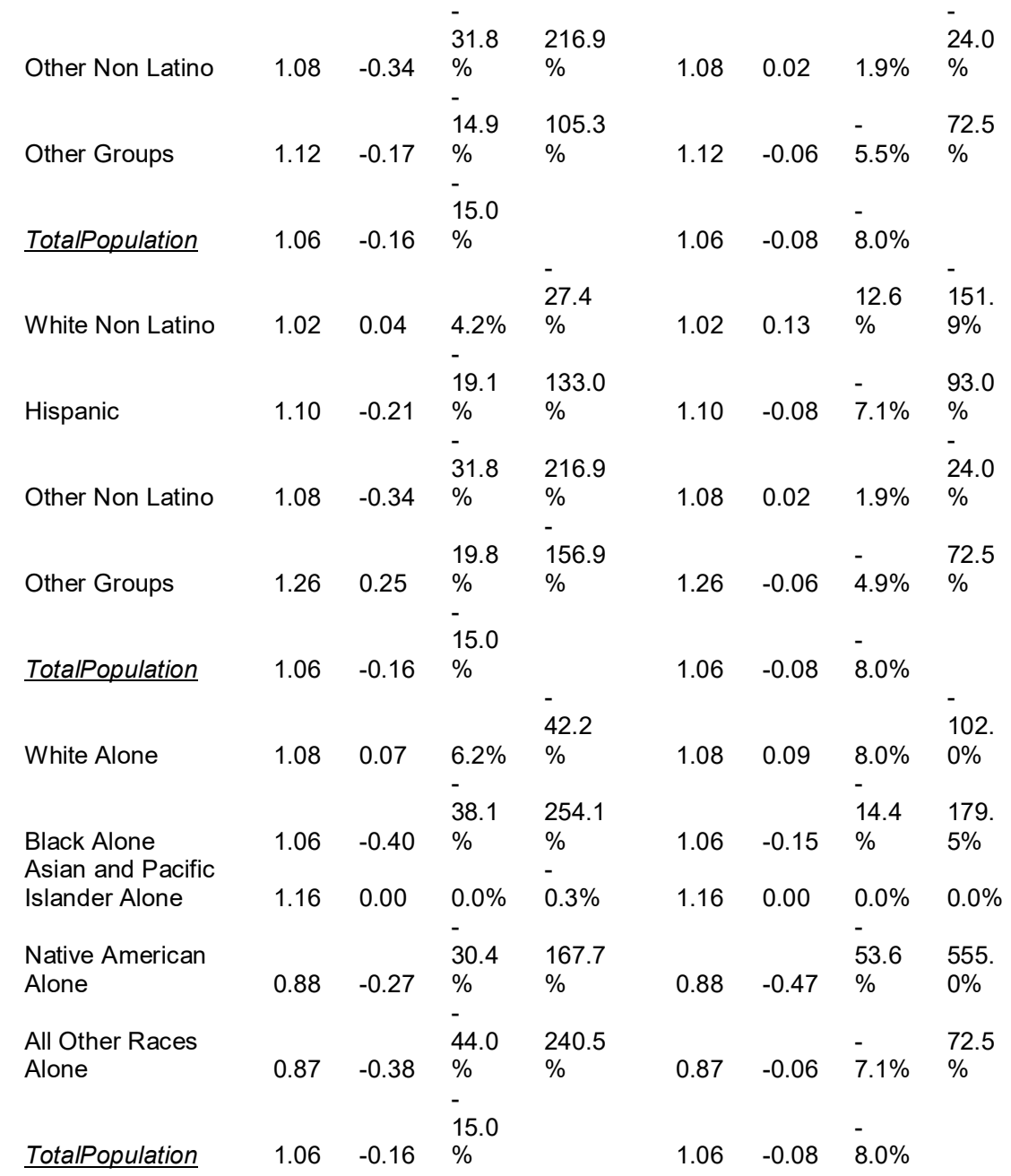

Table 6A.14B Low MA: SCT.

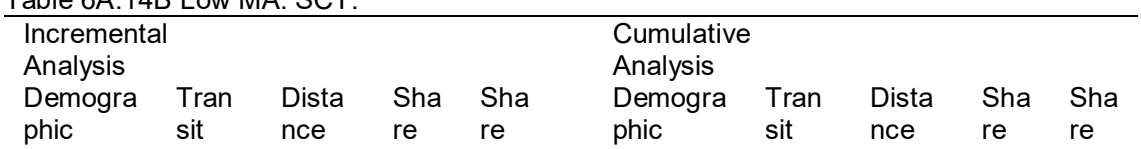




\begin{tabular}{|c|c|c|c|c|c|c|c|c|c|}
\hline $\begin{array}{l}\text { Share-- } \\
\text { Only } \\
\text { Distance } \\
\text { Band } \\
\text { Change }\end{array}$ & $\begin{array}{l}\text { Regi } \\
\text { on } \\
\text { Chan } \\
\text { ge } \\
2010 \\
- \\
2016\end{array}$ & $\begin{array}{l}\text { Band } \\
\text { Chan } \\
\text { ge } \\
2010- \\
2016\end{array}$ & $\begin{array}{l}\text { of } \\
\text { Tra } \\
\text { nsit } \\
\text { Co } \\
\text { unti } \\
\text { es }\end{array}$ & $\begin{array}{l}\text { of } \\
\text { Dist } \\
\text { anc } \\
\text { e } \\
\text { Ban } \\
\text { d } \\
\text { Cha } \\
\text { nge }\end{array}$ & $\begin{array}{l}\text { Share-- } \\
\text { Cumulati } \\
\text { ve } \\
\text { Distance } \\
\text { Band } \\
\text { Change }\end{array}$ & $\begin{array}{l}\text { Regi } \\
\text { on } \\
\text { Chan } \\
\text { ge } \\
2010 \\
- \\
2016\end{array}$ & $\begin{array}{l}\text { Band } \\
\text { Chan } \\
\text { ge } \\
2010- \\
2016\end{array}$ & $\begin{array}{l}\text { of } \\
\text { Tra } \\
\text { nsit } \\
\text { Co } \\
\text { unti } \\
\text { es }\end{array}$ & $\begin{array}{l}\text { of } \\
\text { Dist } \\
\text { anc } \\
\text { e } \\
\text { Ban } \\
\text { d } \\
\text { Ch } \\
\text { ang } \\
\text { e }\end{array}$ \\
\hline \multicolumn{5}{|c|}{$\begin{array}{l}\text { Spatial Share--0.125 Mile } \\
\text { Distance Band Only }\end{array}$} & $\begin{array}{l}\text { Spatial St } \\
\text { Distance } \\
\text { Station }\end{array}$ & $\begin{array}{l}\text { re--0.1 } \\
\text { and On }\end{array}$ & 5 Mile & & \\
\hline $\begin{array}{l}\text { Area } \\
\text { (sq.mi.) }\end{array}$ & $\begin{array}{l}1277 \\
0\end{array}$ & 11 & $\begin{array}{l}0.1 \\
\%\end{array}$ & & $\begin{array}{l}\text { Area } \\
\text { (sq.mi.) }\end{array}$ & $\begin{array}{l}1277 \\
0\end{array}$ & 11 & $\begin{array}{l}0.1 \\
\%\end{array}$ & \\
\hline $\begin{array}{l}\text { Basic DeI } \\
\text { Distance } \\
\text { White }\end{array}$ & $\begin{array}{l}\text { ographi } \\
\text { and Oni }\end{array}$ & $s-0.125$ & Mile & & \multicolumn{2}{|c|}{$\begin{array}{l}\text { Distance Band Only } \\
\text { White }\end{array}$} & & & \\
\hline \multicolumn{3}{|l|}{ Non } & 15. & 239 & \multicolumn{3}{|l|}{ Non } & 15. & 239 \\
\hline \multicolumn{3}{|l|}{ Latino } & $\begin{array}{l}4 \% \\
-\end{array}$ & $\begin{array}{l}.2 \% \\
-\end{array}$ & \multicolumn{3}{|l|}{ Latino } & $\begin{array}{l}4 \% \\
-\end{array}$ & $.2 \%$ \\
\hline \multirow{2}{*}{\multicolumn{3}{|c|}{$\begin{array}{l}\text { Non } \\
\text { Latino }\end{array}$}} & 2.3 & 38. & & 2.3 & 38. \\
\hline & & & $\begin{array}{l}\% \\
-\end{array}$ & $\begin{array}{l}1 \% \\
-\end{array}$ & \multicolumn{3}{|l|}{ Latino } & $\begin{array}{l}\% \\
-\end{array}$ & $\begin{array}{l}1 \% \\
-\end{array}$ \\
\hline \multicolumn{3}{|l|}{ Other } & 2.5 & 42. & \multicolumn{3}{|l|}{ Other } & 2.5 & 42. \\
\hline \multicolumn{3}{|l|}{ Groups } & $\%$ & $4 \%$ & \multicolumn{3}{|l|}{ Groups } & $\%$ & $4 \%$ \\
\hline \multicolumn{3}{|l|}{ TotalPop } & 6.2 & 0.0 & \multicolumn{3}{|l|}{ TotalPop } & 6.2 & 0.0 \\
\hline$\frac{\text { ulation }}{\text { White }}$ & & & $\%$ & $\%$ & $\frac{\text { ulation }}{\text { White }}$ & & & $\%$ & $\%$ \\
\hline Non & & & 15. & 239 & Non & & & 15. & 239 \\
\hline Latino & & & $\begin{array}{l}4 \% \\
- \\
7.4\end{array}$ & $\begin{array}{l}.2 \% \\
- \\
124\end{array}$ & Latino & & & $\begin{array}{l}4 \% \\
- \\
7.4\end{array}$ & $\begin{array}{l}.2 \% \\
- \\
124\end{array}$ \\
\hline Hispanic & & & $\%$ & $.0 \%$ & Hispanic & & & $\%$ & $.0 \%$ \\
\hline Other & & & - & - & Other & & & - & - \\
\hline Non & & & 2.3 & 38. & Non & & & 2.3 & 38. \\
\hline Latino & & & $\%$ & $1 \%$ & Latino & & & $\%$ & $1 \%$ \\
\hline Other & & & 34. & 652 & Other & & & 34. & 652 \\
\hline Groups & & & $2 \%$ & $.8 \%$ & Groups & & & $2 \%$ & $.8 \%$ \\
\hline TotalPop & & & 6.2 & 0.0 & TotalPop & & & 6.2 & 0.0 \\
\hline$\frac{\text { ulation }}{\text { White }}$ & & & $\%$ & $\%$ & ulation & & & $\%$ & $\%$ \\
\hline White & & & 13. & 226 & White & & & 13. & 226 \\
\hline Alone & & & $\begin{array}{l}8 \% \\
-\end{array}$ & $\begin{array}{l}.3 \% \\
-\end{array}$ & Alone & & & $\begin{array}{l}8 \% \\
-\end{array}$ & $\begin{array}{l}.3 \% \\
-\end{array}$ \\
\hline Black & & & 7.8 & 124 & Black & & & 7.8 & 124 \\
\hline Alone & & & $\%$ & $.7 \%$ & Alone & & & $\%$ & $.7 \%$ \\
\hline Asian anc & Pacific & & 29. & 527 & Asian and & Jacific & & 29. & $\begin{array}{l}527 \\
4 \%\end{array}$ \\
\hline $\begin{array}{l}\text { Islander A } \\
\text { Native An }\end{array}$ & $\begin{array}{l}\text { one } \\
\text { erican }\end{array}$ & & $\begin{array}{l}8 \% \\
7.4\end{array}$ & $\begin{array}{l}.4 \% \\
98 .\end{array}$ & $\begin{array}{l}\text { Islander A } \\
\text { Native An }\end{array}$ & rican & & $\begin{array}{l}8 \% \\
7.4\end{array}$ & $\begin{array}{l}.4 \% \\
98\end{array}$ \\
\hline Alone & & & $\begin{array}{l}\% \\
-\end{array}$ & $\begin{array}{l}1 \% \\
-\end{array}$ & Alone & & & $\begin{array}{l}\% \\
-\end{array}$ & $\begin{array}{l}1 \% \\
-\end{array}$ \\
\hline All Other & aces & & 13. & 177 & All Other & aces & & 13. & 177 \\
\hline Alone & & & $5 \%$ & $.3 \%$ & Alone & & & $5 \%$ & $.3 \%$ \\
\hline TotalPop & & & 6.2 & 0.0 & TotalPop & & & 6.2 & 0.0 \\
\hline ulation & & & $\%$ & $\%$ & ulation & & & $\%$ & $\%$ \\
\hline $\begin{array}{l}\text { Spatial S } \\
\text { Distance } \\
\text { Station }\end{array}$ & and On & Mile & & & $\begin{array}{l}\text { Spatial Sr } \\
\text { Distance } \\
\text { Station }\end{array}$ & $\begin{array}{l}\text { re--0.2 } \\
\text { and } \mathrm{Cu}\end{array}$ & $\begin{array}{l}\text { Mile } \\
\text { ulative }\end{array}$ & & \\
\hline $\begin{array}{l}\text { Area } \\
\text { (sq.mi.) }\end{array}$ & $\begin{array}{l}1277 \\
0\end{array}$ & 4 & $\begin{array}{l}0.0 \\
3 \%\end{array}$ & & $\begin{array}{l}\text { Area } \\
\text { (sq.mi.) }\end{array}$ & $\begin{array}{l}1277 \\
0\end{array}$ & 15 & $\begin{array}{l}0.1 \\
\%\end{array}$ & \\
\hline $\begin{array}{l}\text { Demogra } \\
\text { Distance }\end{array}$ & $\begin{array}{l}\text { hic Chat } \\
\text { and On! }\end{array}$ & $g e--0.25$ & Mile & & $\begin{array}{l}\text { Demogra } \\
\text { Distance }\end{array}$ & $\begin{array}{l}\text { ic Cha } \\
\text { and Cu }\end{array}$ & $\begin{array}{l}\text { ge-- } 0.25 \\
\text { ulative }\end{array}$ & Mile & \\
\hline White & & & - & & White & & & & - \\
\hline Non & & & 5.6 & 81. & Non & & & 9.1 & 190 \\
\hline Latino & & & $\%$ & $5 \%$ & Latino & & & $\%$ & $.6 \%$ \\
\hline Other & & & - & & Other & & & & - \\
\hline Non & & & 9.1 & 138 & Non & & & 10. & 242 \\
\hline Latino & & & $\begin{array}{l}\% \\
-\end{array}$ & $.4 \%$ & Latino & & & $9 \%$ & $\begin{array}{l}.0 \% \\
-\end{array}$ \\
\hline Other & & & 4.7 & 74. & Other & & & 1.8 & 40. \\
\hline Groups & & & $\%$ & $0 \%$ & Groups & & & $\%$ & $4 \%$ \\
\hline
\end{tabular}




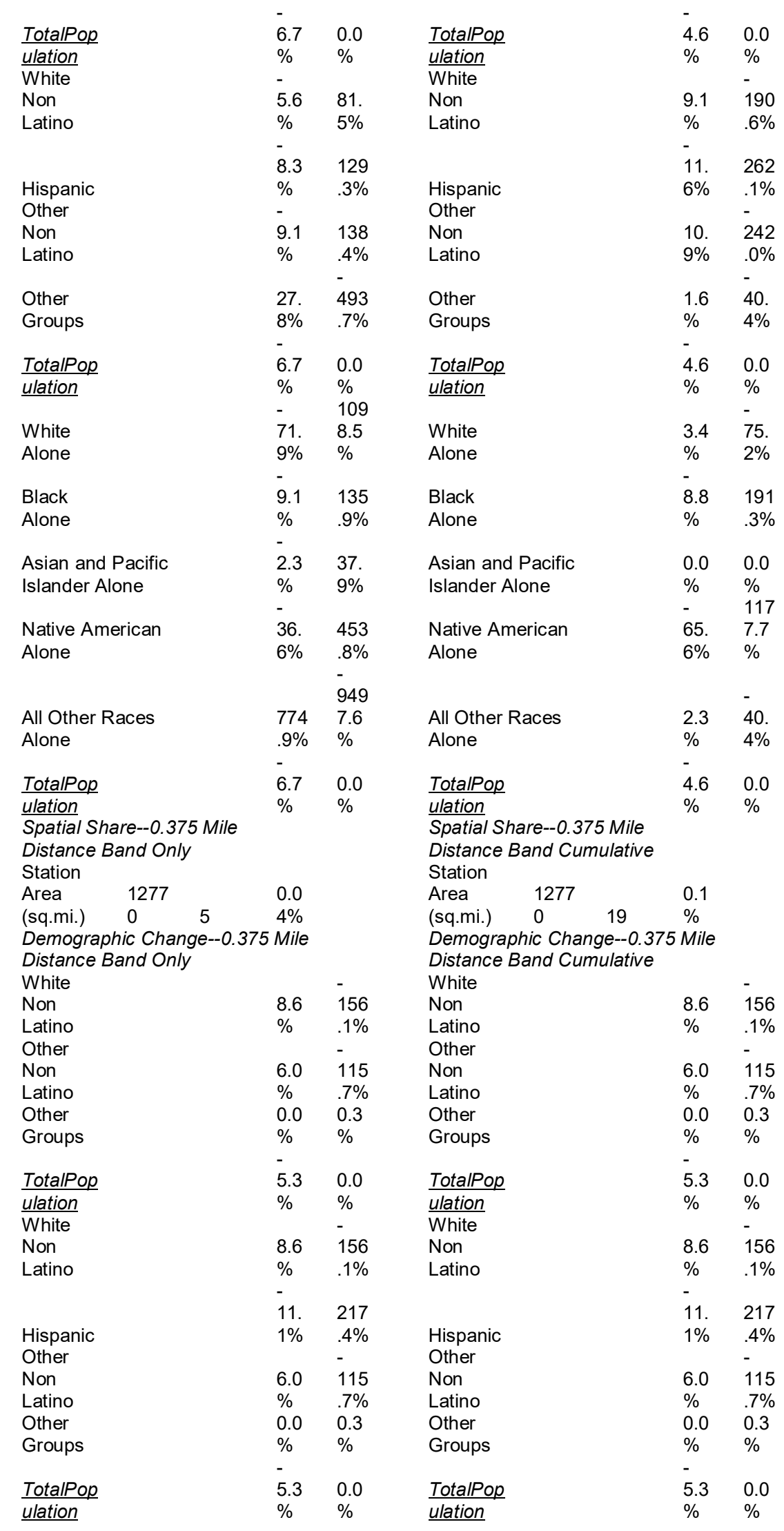




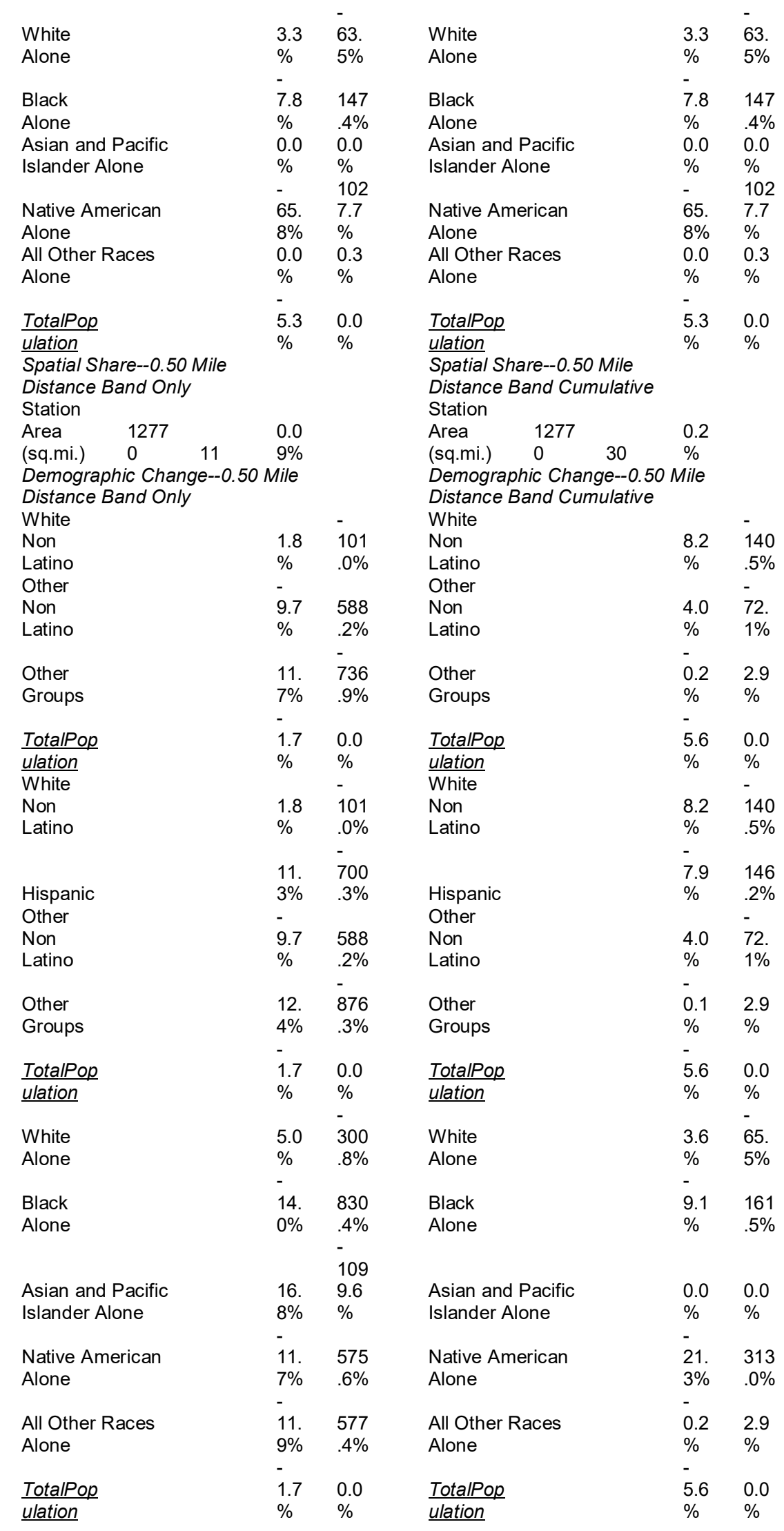


Spatial Share--0.75 Mile

Distance Band Only

Station

$\begin{array}{llll}\text { Area } & 1277 & & 0.1\end{array}$

Demographic Change-0.7

Distance Band Only

White

Non

Latino

Other

Non

Latino

Other

Groups

TotalPop

ulation

White

Non

Latino

Hispanic

Other

Non

Latino

Other

Groups

$\underline{\text { TotalPop }}$

ulation

White

Alone

Black

Alone

Asian and Pacific

Islander Alone

Native American

Alone

All Other Races

Alone

TotalPop

ulation

Spatial Share--1.00 Mile

Distance Band Only

Station

Area $\quad 1277 \quad 0.0$

(sq.mi.) $\quad 0 \quad 3 \quad 2 \%$

Demographic Change--1.00 Mile

Distance Band Only

White

Non

Latino

Other

Non

Latino

Other

Groups

$\%$

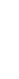

e

3.585.

$\% \quad 2 \%$

$7.6 \quad 198$

$\% \quad .3 \%$

14. 401

$8 \% \quad .0 \%$

$3.9 \quad 0.0$

$\% \quad \%$

3.585

$\% \quad 2 \%$

$9.7 \quad 257$

$\% \quad .3 \%$

$-$

7.6198

$\% \quad .3 \%$

126

41. $\quad 3.2$

$6 \% \quad \%$

$3.9 \quad 0.0$

$\% \quad \%$

$4.9 \quad 128$

$\% \quad .2 \%$

11. 300

$8 \% \quad .1 \%$

108

38. $\quad 4.6$

$5 \% \quad \%$

19. 413

$5 \% \quad .8 \%$

$-\quad 105$

50. 2.6

$3 \% \quad \%$

$3.9 \quad 0.0$

$\% \quad \%$

$\%$

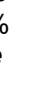

$4.2 \quad-$

$\% \quad 4 \%$

31. 216

$8 \% \quad .9 \%$

14. 105

$9 \% \quad .3 \%$
Spatial Share--0.75 Mile

Distance Band Cumulative

Station

$\begin{array}{llll}\text { Area } & 1277 & & 0.3 \\ \text { (sq.mi.) } & 0 & 40 & \%\end{array}$

Demographic Change--0.75 Mile

Distance Band Cumulative

White

Non

Latino

Other

Non

Latino

Other

Groups

TotalPop

ulation

White

Non

Latino

10. 140

$3 \% \quad .7 \%$

10. 151

$5 \% \quad .9 \%$

1.014

$\% \quad 8 \%$

$7.1 \quad 0.0$

$\% \quad \%$

10. 140

$3 \% \quad .7 \%$

$7.0 \quad 102$

Hispanic $\quad \% \quad .9 \%$

Other

Non 10.151

Latino $\quad 5 \% \quad .9 \%$

$\begin{array}{lll}\text { Other } & 0.9 & 14 .\end{array}$

Groups $\quad \% \quad 8 \%$

$\begin{array}{lll}\text { TotalPop } & 7.1 & 0.0\end{array}$

ulation $\% \quad \%$

$\begin{array}{lll}\text { White } & 5.7 \quad 82 .\end{array}$

Alone $\quad \% \quad 0 \%$

$\begin{array}{lll}\text { Black } & 11 . & 165\end{array}$

Alone $\quad 7 \% \quad .7 \%$

$\begin{array}{lll}\text { Asian and Pacific } & 0.0 \quad 0.0\end{array}$

Islander Alone $\quad \% \quad \%$

Native American $\quad 44.520$

Alone $\quad 3 \% \quad .9 \%$

All Other Races $\quad 1.3 \quad 14$.

Alone $\quad \% \quad 8 \%$

$\begin{array}{lll}\text { TotalPop } & 7.1 & 0.0\end{array}$

ulation $\quad \% \quad \%$

Spatial Share--1.00 Mile

Distance Band Cumulative

Station

$\begin{array}{lll}\text { Area } & 1277 \quad 0.3\end{array}$

(sq.mi.) $0 \quad 44 \quad \%$

Demographic Change--1.00 Mile

Distance Band Cumulative

White

Non

Latino

Other

Non

Latino

Other

Groups

12. 151

$6 \% \quad .9 \%$

1.924

$\% \quad 0 \%$

5.572 .

$\% \quad 5 \%$ 


\begin{tabular}{|c|c|c|c|c|c|}
\hline TotalPop & 15. & 0.0 & TotalPop & 8.0 & 0.0 \\
\hline ulation & $0 \%$ & $\%$ & ulation & $\%$ & $\%$ \\
\hline White & & - & White & & - \\
\hline Non & 4.2 & 27. & Non & 12. & 151 \\
\hline \multirow[t]{2}{*}{ Latino } & $\begin{array}{l}\% \\
-\end{array}$ & $4 \%$ & Latino & $\begin{array}{l}6 \% \\
-\end{array}$ & $.9 \%$ \\
\hline & 19. & 133 & & 7.1 & 93. \\
\hline Hispanic & $1 \%$ & $.0 \%$ & Hispanic & $\%$ & $0 \%$ \\
\hline Other & - & & Other & & - \\
\hline Non & 31. & 216 & Non & 1.9 & 24. \\
\hline Latino & $8 \%$ & $\begin{array}{l}.9 \% \\
-\end{array}$ & Latino & $\begin{array}{l}\% \\
-\end{array}$ & $0 \%$ \\
\hline Other & 19. & 156 & Other & 4.9 & 72. \\
\hline Groups & $\begin{array}{l}8 \% \\
-\end{array}$ & $.9 \%$ & Groups & $\begin{array}{l}\% \\
-\end{array}$ & $5 \%$ \\
\hline TotalPop & 15. & 0.0 & TotalPop & 8.0 & 0.0 \\
\hline ulation & $0 \%$ & $\begin{array}{l}\% \\
-\end{array}$ & ulation & $\%$ & $\begin{array}{l}\% \\
-\end{array}$ \\
\hline White & 6.2 & 42. & White & 8.0 & 102 \\
\hline Alone & $\begin{array}{l}\% \\
-\end{array}$ & $2 \%$ & Alone & $\begin{array}{l}\% \\
-\end{array}$ & $.0 \%$ \\
\hline Black & 38. & 254 & Black & 14. & 179 \\
\hline Alone & $1 \%$ & $\begin{array}{l}.1 \% \\
-\end{array}$ & Alone & $4 \%$ & $.5 \%$ \\
\hline Asian and Pacific & 0.0 & 0.3 & Asian and Pacific & 0.0 & 0.0 \\
\hline Islander Alone & $\begin{array}{l}\% \\
-\end{array}$ & $\%$ & Islander Alone & $\begin{array}{l}\% \\
-\end{array}$ & $\%$ \\
\hline Native American & 30. & 167 & Native American & 53. & 555 \\
\hline Alone & $\begin{array}{l}4 \% \\
-\end{array}$ & $.7 \%$ & Alone & $\begin{array}{l}6 \% \\
-\end{array}$ & $.0 \%$ \\
\hline All Other Races & 44. & 240 & All Other Races & 7.1 & 72. \\
\hline Alone & $\begin{array}{l}0 \% \\
-\end{array}$ & $.5 \%$ & Alone & $\begin{array}{l}\% \\
-\end{array}$ & $5 \%$ \\
\hline TotalPop & 15. & 0.0 & TotalPop & 8.0 & 0.0 \\
\hline ulation & $0 \%$ & $\%$ & ulation & $\%$ & $\%$ \\
\hline
\end{tabular}

Table 6A.15A Mod MA: SCT.

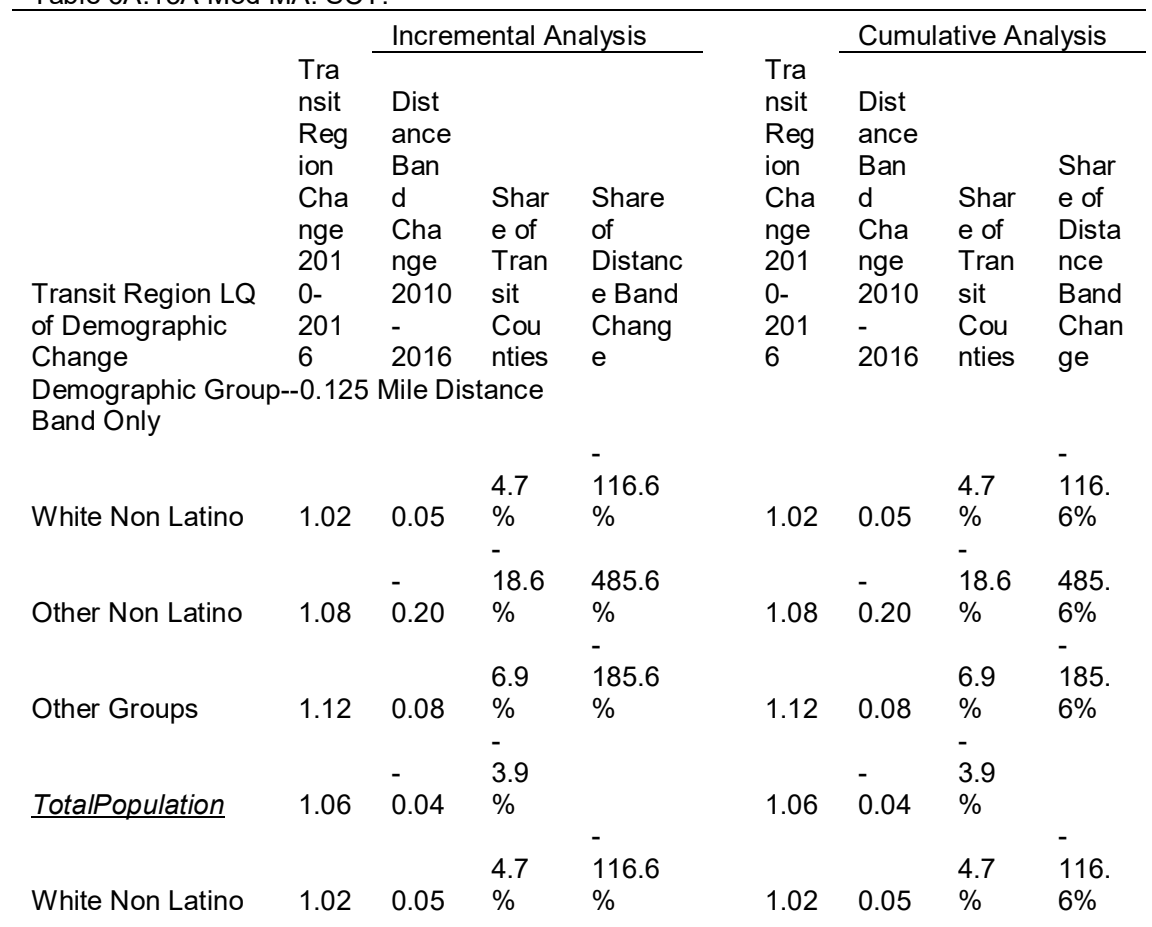




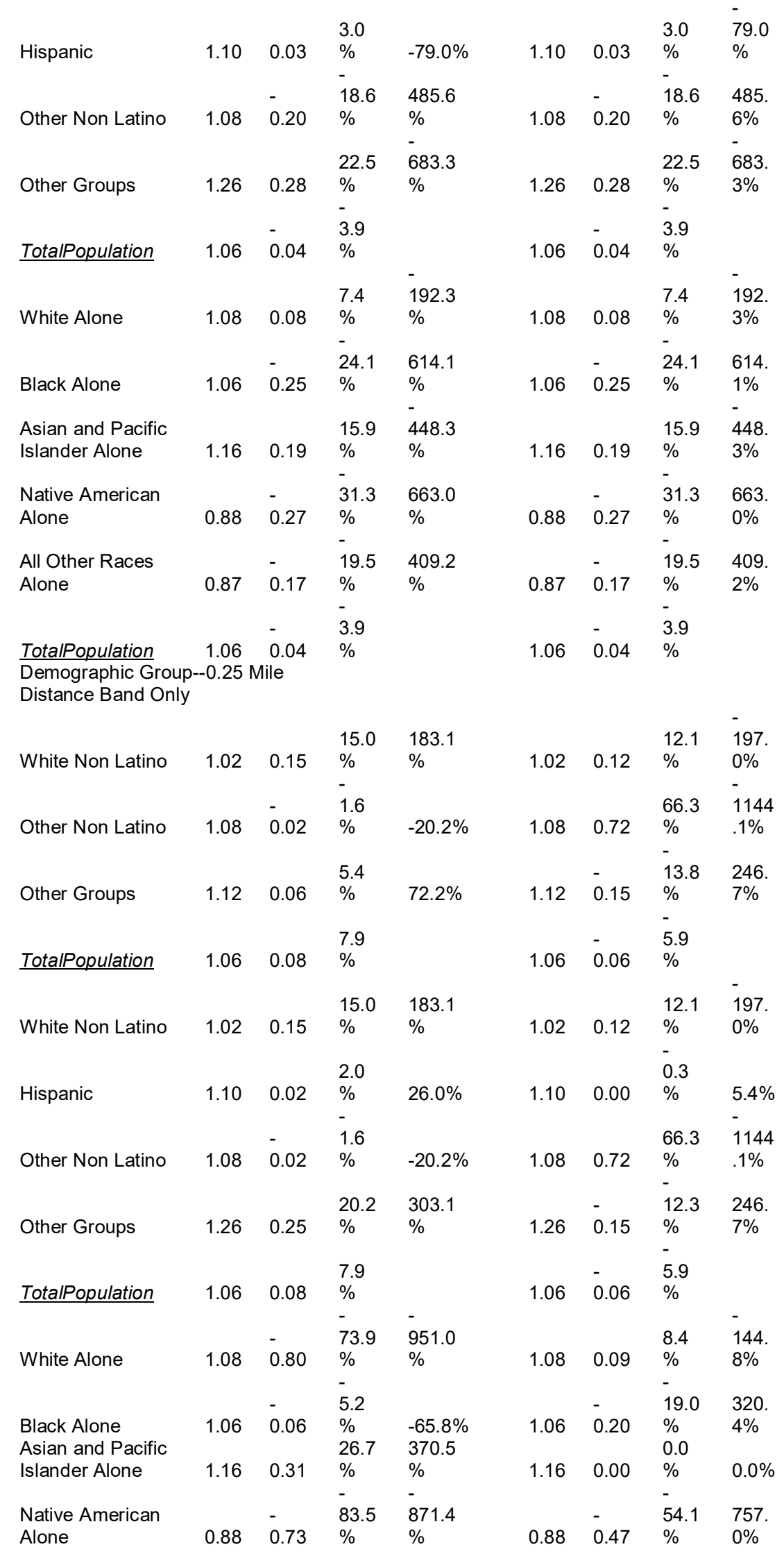




\begin{tabular}{|c|c|c|c|c|c|c|c|c|}
\hline & & & & & & & & \\
\hline $\begin{array}{l}\text { All Other Races } \\
\text { Alone }\end{array}$ & 0.87 & 7.79 & $\begin{array}{l}898 . \\
8 \%\end{array}$ & $\begin{array}{l}9272.7 \\
\%\end{array}$ & 0.87 & $-\overline{0}$ & $\begin{array}{l}17.8 \\
\%\end{array}$ & $\begin{array}{l}246 \\
7 \%\end{array}$ \\
\hline TotalPopulation & 1.06 & 0.08 & $\begin{array}{l}7.9 \\
\%\end{array}$ & & 1.06 & $\overline{-}-06$ & $\begin{array}{l}5.9 \\
\%\end{array}$ & \\
\hline $\begin{array}{l}\text { Demographic Group } \\
\text { Band Only }\end{array}$ & -0.375 & Mile Dis & tance & & & & & \\
\hline White Non Latino & 1.02 & 0.13 & $\begin{array}{l}12.7 \\
\%\end{array}$ & $\begin{array}{l}140.3 \\
\%\end{array}$ & 1.02 & 0.11 & $\begin{array}{l}10.9 \\
\%\end{array}$ & $\begin{array}{l}250 . \\
4 \% \\
-\end{array}$ \\
\hline Other Non Latino & 1.08 & 0.02 & $\begin{array}{l}1.4 \\
\%\end{array}$ & $16.8 \%$ & 1.08 & 0.55 & $\begin{array}{l}51.1 \\
\% \\
-\end{array}$ & $\begin{array}{l}1246 \\
.5 \%\end{array}$ \\
\hline Other Groups & 1.12 & 0.19 & $\begin{array}{l}17.1 \\
\%\end{array}$ & $\begin{array}{l}206.7 \\
\%\end{array}$ & 1.12 & $\overline{-} 0.09$ & $\begin{array}{l}7.6 \\
\%\end{array}$ & $\begin{array}{l}192 . \\
1 \%\end{array}$ \\
\hline TotalPopulation & 1.06 & 0.09 & $\begin{array}{l}8.8 \\
\%\end{array}$ & & 1.06 & $\overline{-}-04$ & $\begin{array}{l}4.2 \\
\%\end{array}$ & - \\
\hline White Non Latino & 1.02 & 0.13 & $\begin{array}{l}12.7 \\
\%\end{array}$ & $\begin{array}{l}140.3 \\
\%\end{array}$ & 1.02 & 0.11 & $\begin{array}{l}10.9 \\
\%\end{array}$ & $\begin{array}{l}250 . \\
4 \% \\
-\end{array}$ \\
\hline Hispanic & 1.10 & 0.16 & $\begin{array}{l}14.3 \\
\%\end{array}$ & $\begin{array}{l}170.2 \\
\%\end{array}$ & 1.10 & 0.01 & $\begin{array}{l}0.5 \\
\%\end{array}$ & $\begin{array}{l}12.3 \\
\% \\
-\end{array}$ \\
\hline Other Non Latino & 1.08 & 0.02 & $\begin{array}{l}1.4 \\
\%\end{array}$ & $16.8 \%$ & 1.08 & 0.55 & $\begin{array}{l}51.1 \\
\% \\
-\end{array}$ & $\begin{array}{l}1246 \\
.5 \%\end{array}$ \\
\hline Other Groups & 1.26 & 0.38 & $\begin{array}{l}30.1 \\
\%\end{array}$ & $\begin{array}{l}407.6 \\
\%\end{array}$ & 1.26 & $\overline{-} .09$ & $\begin{array}{l}6.8 \\
\% \\
-\end{array}$ & $\begin{array}{l}192 . \\
1 \%\end{array}$ \\
\hline TotalPopulation & 1.06 & 0.09 & $\begin{array}{l}8.8 \\
\%\end{array}$ & & 1.06 & $\overline{-} 0.04$ & $\begin{array}{l}4.2 \\
\%\end{array}$ & - \\
\hline White Alone & 1.08 & 0.17 & $\begin{array}{l}15.3 \\
\% \\
-\end{array}$ & $\begin{array}{l}178.7 \\
\%\end{array}$ & 1.08 & 0.08 & $\begin{array}{l}7.4 \\
\% \\
-\end{array}$ & $\begin{array}{l}180 . \\
5 \%\end{array}$ \\
\hline $\begin{array}{l}\text { Black Alone } \\
\text { Asian and Pacific }\end{array}$ & 1.06 & $-\overline{0}$ & $\begin{array}{l}3.0 \\
\% \\
36.6\end{array}$ & $\begin{array}{l}-34.5 \% \\
459.1\end{array}$ & 1.06 & $\overline{-}-18$ & $\begin{array}{l}16.9 \\
\% \\
0.0\end{array}$ & $\begin{array}{l}403 \\
2 \%\end{array}$ \\
\hline Islander Alone & 1.16 & 0.43 & $\%$ & $\%$ & 1.16 & 0.00 & $\begin{array}{l}\% \\
-\end{array}$ & $0.0 \%$ \\
\hline $\begin{array}{l}\text { Native American } \\
\text { Alone }\end{array}$ & 0.88 & 0.12 & $\begin{array}{l}13.4 \\
\%\end{array}$ & $\begin{array}{l}127.0 \\
\%\end{array}$ & 0.88 & $\overline{0}-54$ & $\begin{array}{l}61.5 \\
\% \\
-\end{array}$ & $\begin{array}{l}1217 \\
.2 \%\end{array}$ \\
\hline $\begin{array}{l}\text { All Other Races } \\
\text { Alone }\end{array}$ & 0.87 & 0.02 & $\begin{array}{l}2.4 \\
\%\end{array}$ & $22.6 \%$ & 0.87 & $\overline{-}-09$ & $\begin{array}{l}9.8 \\
\% \\
-\end{array}$ & $\begin{array}{l}192 . \\
1 \%\end{array}$ \\
\hline $\begin{array}{l}\text { TotalPopulation } \\
\text { Demographic Group } \\
\text { Distance Band Only }\end{array}$ & $\begin{array}{l}1.06 \\
-0.5 \mathrm{Mi}\end{array}$ & 0.09 & $\begin{array}{l}8.8 \\
\%\end{array}$ & & 1.06 & $\overline{-}-04$ & $\begin{array}{l}4.2 \\
\%\end{array}$ & \\
\hline White Non Latino & 1.02 & 0.13 & $\begin{array}{l}12.6 \\
\%\end{array}$ & $\begin{array}{l}148.3 \\
\%\end{array}$ & 1.02 & 0.11 & $\begin{array}{l}10.3 \\
\%\end{array}$ & $\begin{array}{l}314 . \\
4 \% \\
-\end{array}$ \\
\hline Other Non Latino & 1.08 & 0.02 & $\begin{array}{l}2.2 \\
\%\end{array}$ & $27.4 \%$ & 1.08 & 0.57 & $\begin{array}{l}52.8 \\
\% \\
-\end{array}$ & $\begin{array}{l}1705 \\
.3 \%\end{array}$ \\
\hline Other Groups & 1.12 & 0.08 & $\begin{array}{l}7.6 \\
\%\end{array}$ & $97.6 \%$ & 1.12 & $\overline{0}-18$ & $\begin{array}{l}15.6 \\
\% \\
-\end{array}$ & $\begin{array}{l}523 . \\
3 \%\end{array}$ \\
\hline TotalPopulation & 1.06 & 0.09 & $\begin{array}{l}8.2 \\
\%\end{array}$ & & 1.06 & $\overline{0}$ & $\begin{array}{l}3.2 \\
\%\end{array}$ & \\
\hline White Non Latino & 1.02 & 0.13 & $\begin{array}{l}12.6 \\
\%\end{array}$ & $\begin{array}{l}148.3 \\
\%\end{array}$ & 1.02 & 0.11 & $\begin{array}{l}10.3 \\
\%\end{array}$ & $\begin{array}{l}314 . \\
4 \%\end{array}$ \\
\hline
\end{tabular}




\begin{tabular}{|c|c|c|c|c|c|c|c|c|}
\hline & & & & & & & & \\
\hline Hispanic & 1.10 & 0.07 & $\begin{array}{l}6.0 \\
\%\end{array}$ & $75.4 \%$ & 1.10 & 0.00 & $\begin{array}{l}0.4 \\
\%\end{array}$ & $\begin{array}{l}14.1 \\
\% \\
-\end{array}$ \\
\hline Other Non Latino & 1.08 & 0.02 & $\begin{array}{l}2.2 \\
\%\end{array}$ & $27.4 \%$ & 1.08 & 0.57 & $\begin{array}{l}52.8 \\
\% \\
-\end{array}$ & $\begin{array}{l}1705 \\
.3 \%\end{array}$ \\
\hline Other Groups & 1.26 & 0.20 & $\begin{array}{l}16.3 \\
\%\end{array}$ & $\begin{array}{l}235.2 \\
\%\end{array}$ & 1.26 & $\overline{-}-18$ & $\begin{array}{l}13.9 \\
\%\end{array}$ & $\begin{array}{l}523 . \\
3 \%\end{array}$ \\
\hline TotalPopulation & 1.06 & 0.09 & $\begin{array}{l}8.2 \\
\%\end{array}$ & & 1.06 & $\overline{-} .03$ & $\begin{array}{l}3.2 \\
\%\end{array}$ & \\
\hline White Alone & 1.08 & 0.21 & $\begin{array}{l}19.1 \\
\% \\
-\end{array}$ & $\begin{array}{l}236.8 \\
\%\end{array}$ & 1.08 & 0.08 & $\begin{array}{l}7.5 \\
\% \\
-\end{array}$ & $\begin{array}{l}242 . \\
8 \%\end{array}$ \\
\hline & & - & 2.0 & & & - & 15.8 & 500 \\
\hline $\begin{array}{l}\text { Black Alone } \\
\text { Asian and Pacific }\end{array}$ & 1.06 & 0.02 & $\begin{array}{l}\% \\
41.8\end{array}$ & $\begin{array}{l}-24.3 \% \\
559.5\end{array}$ & 1.06 & 0.17 & $\begin{array}{l}\% \\
0.0\end{array}$ & $4 \%$ \\
\hline Islander Alone & 1.16 & 0.49 & $\%$ & $\%$ & 1.16 & 0.00 & $\begin{array}{l}\% \\
-\end{array}$ & $0.0 \%$ \\
\hline Native American & & - & 73.2 & 737.5 & & - & 58.6 & 1533 \\
\hline Alone & 0.88 & 0.64 & $\%$ & $\%$ & 0.88 & 0.51 & $\begin{array}{l}\% \\
-\end{array}$ & $.5 \%$ \\
\hline All Other Races & & - & 46.1 & 459.3 & & - & 20.2 & 523. \\
\hline Alone & 0.87 & 0.40 & $\%$ & $\%$ & 0.87 & 0.18 & $\begin{array}{l}\% \\
-\end{array}$ & $3 \%$ \\
\hline TotalPopulation & 1.06 & 0.09 & $\begin{array}{l}8.2 \\
\%\end{array}$ & & 1.06 & $\overline{0}-03$ & $\begin{array}{l}3.2 \\
\%\end{array}$ & \\
\hline $\begin{array}{l}\text { Demographic Group } \\
\text { Distance Band Only }\end{array}$ & -0.75 & lile & & - & & & & \\
\hline White Non Latino & 1.02 & 0.09 & $\begin{array}{l}8.8 \\
\% \\
-\end{array}$ & $\begin{array}{l}173.4 \\
\%\end{array}$ & 1.02 & 0.11 & $\begin{array}{l}10.7 \\
\%\end{array}$ & $\begin{array}{l}267 . \\
6 \% \\
-\end{array}$ \\
\hline Other Non Latino & 1.08 & $\overline{-}-27$ & $\begin{array}{l}24.9 \\
\%\end{array}$ & $\begin{array}{l}519.8 \\
\% \\
-\end{array}$ & 1.08 & 0.66 & $\begin{array}{l}61.2 \\
\% \\
-\end{array}$ & $\begin{array}{l}1622 \\
.3 \%\end{array}$ \\
\hline Other Groups & 1.12 & 0.11 & $\begin{array}{l}9.4 \\
\% \\
-\end{array}$ & $\begin{array}{l}203.5 \\
\%\end{array}$ & 1.12 & $\overline{0}-15$ & $\begin{array}{l}13.8 \\
\% \\
-\end{array}$ & $\begin{array}{l}380 . \\
2 \%\end{array}$ \\
\hline & & - & 4.9 & & & - & 3.9 & \\
\hline TotalPopulation & 1.06 & 0.05 & $\%$ & - & 1.06 & 0.04 & $\%$ & - \\
\hline White Non Latino & 1.02 & 0.09 & $\begin{array}{l}8.8 \\
\%\end{array}$ & $\begin{array}{l}173.4 \\
\% \\
-\end{array}$ & 1.02 & 0.11 & $\begin{array}{l}10.7 \\
\%\end{array}$ & $\begin{array}{l}267 . \\
6 \%\end{array}$ \\
\hline Hispanic & 1.10 & 0.10 & $\begin{array}{l}9.0 \\
\% \\
-\end{array}$ & $\begin{array}{l}191.4 \\
\%\end{array}$ & 1.10 & 0.00 & $\begin{array}{l}0.0 \\
\%\end{array}$ & $\begin{array}{l}- \\
0.5 \%\end{array}$ \\
\hline Other Non Latino & 1.08 & $\overline{-}-27$ & $\begin{array}{l}24.9 \\
\%\end{array}$ & $\begin{array}{l}519.8 \\
\% \\
-\end{array}$ & 1.08 & 0.66 & $\begin{array}{l}61.2 \\
\% \\
-\end{array}$ & $\begin{array}{l}1622 \\
.3 \%\end{array}$ \\
\hline Other Groups & 1.26 & 0.15 & $\begin{array}{l}12.3 \\
\% \\
-\end{array}$ & $\begin{array}{l}297.5 \\
\%\end{array}$ & 1.26 & $\overline{-}-15$ & $\begin{array}{l}12.3 \\
\% \\
-\end{array}$ & $\begin{array}{l}380 \\
2 \%\end{array}$ \\
\hline & & - & 4.9 & & & - & 3.9 & \\
\hline TotalPopulation & 1.06 & 0.05 & $\%$ & - & 1.06 & 0.04 & $\%$ & - \\
\hline White Alone & 1.08 & 0.16 & $\begin{array}{l}15.2 \\
\% \\
-\end{array}$ & $\begin{array}{l}318.0 \\
\%\end{array}$ & 1.08 & 0.09 & $\begin{array}{l}8.3 \\
\% \\
-\end{array}$ & $\begin{array}{l}219 . \\
4 \%\end{array}$ \\
\hline & & - & 29.0 & 592.4 & & - & 15.9 & 410. \\
\hline Black Alone & 1.06 & 0.31 & $\%$ & $\begin{array}{l}\% \\
-\end{array}$ & 1.06 & 0.17 & $\%$ & $9 \%$ \\
\hline $\begin{array}{l}\text { Asian and Pacific } \\
\text { Islander Alone }\end{array}$ & 1.16 & 0.21 & $\begin{array}{l}17.8 \\
\% \\
-\end{array}$ & $\begin{array}{l}400.0 \\
\%\end{array}$ & 1.16 & 0.00 & $\begin{array}{l}0.0 \\
\% \\
-\end{array}$ & $0.0 \%$ \\
\hline Native American & & - & 77.3 & 1307.7 & & - & 34.0 & 730. \\
\hline Alone & 0.88 & 0.68 & $\%$ & & 0.88 & 0.30 & $\%$ & $2 \%$ \\
\hline
\end{tabular}




\begin{tabular}{|c|c|c|c|c|c|c|c|c|}
\hline All Other Races & \multicolumn{2}{|r|}{-} & 25.1 & 419.2 & & - & 17.9 & 380. \\
\hline Alone & 0.87 & 0.22 & $\begin{array}{l}\% \\
-\end{array}$ & $\%$ & 0.87 & 0.15 & $\begin{array}{l}\% \\
-\end{array}$ & $2 \%$ \\
\hline & & - & 4.9 & & & - & 3.9 & \\
\hline TotalPopulation & 1.06 & 0.05 & $\%$ & & 1.06 & 0.04 & $\%$ & \\
\hline \multicolumn{9}{|c|}{$\begin{array}{l}\text { Demographic Group--1.00 Mile } \\
\text { Distance Band Only }\end{array}$} \\
\hline & & & 14.2 & 7754.5 & & & 9.4 & 275. \\
\hline White Non Latino & 1.02 & 0.14 & $\%$ & & 1.02 & 0.10 & $\%$ & $\begin{array}{l}5 \% \\
-\end{array}$ \\
\hline & & - & 18.8 & 10880. & & & 59.1 & 1836 \\
\hline Other Non Latino & 1.08 & 0.20 & $\%$ & $5 \%$ & 1.08 & 0.64 & $\%$ & $.7 \%$ \\
\hline & 112 & 009 & $\begin{array}{l}8.2 \\
\%\end{array}$ & 4948.7 & 112 & - & $\begin{array}{l}13.2 \\
\%\end{array}$ & 426. \\
\hline & & & & & & & - & \\
\hline & & & 0.2 & & & - & 3.3 & \\
\hline TotalPopulation & 1.06 & 0.00 & $\%$ & & 1.06 & 0.03 & $\%$ & \\
\hline White Non Latino & 102 & 014 & 14.2 & 7754.5 & 10 & 010 & $\begin{array}{l}9.4 \\
\%\end{array}$ & $\begin{array}{l}275 . \\
5 \%\end{array}$ \\
\hline & & & & & & & & - \\
\hline & & & 10.0 & 5897.1 & & & 0.5 & 16.3 \\
\hline Hispanic & 1.10 & 0.11 & $\%$ & $\%$ & 1.10 & 0.01 & $\%$ & $\%$ \\
\hline & & & - & - & & & & - \\
\hline & & - & 18.8 & 10880. & & & 59.1 & 1836 \\
\hline Other Non Latino & 1.08 & 0.20 & $\%$ & $5 \%$ & 1.08 & 0.64 & $\%$ & $.7 \%$ \\
\hline & & & - & - & & & - & \\
\hline & & - & 1.3 & 894.1 & & - & 11.8 & 426. \\
\hline Other Groups & 1.26 & 0.02 & $\%$ & $\%$ & 1.26 & 0.15 & $\begin{array}{l}\% \\
-\end{array}$ & $6 \%$ \\
\hline & & & 0.2 & & & - & 3.3 & \\
\hline TotalPopulation & 1.06 & 0.00 & $\%$ & & 1.06 & 0.03 & $\%$ & \\
\hline White Alone & 1.08 & 0.20 & $\begin{array}{l}18.6 \\
\%\end{array}$ & $\begin{array}{l}10753 . \\
0 \%\end{array}$ & 1.08 & 0.08 & $\begin{array}{l}7.4 \\
\%\end{array}$ & $\begin{array}{l}231 . \\
2 \%\end{array}$ \\
\hline & & & - & - & & & - & \\
\hline & & - & 22.2 & 12550. & & - & 13.8 & 417. \\
\hline Black Alone & 1.06 & 0.23 & $\%$ & $3 \%$ & 1.06 & 0.15 & $\%$ & $8 \%$ \\
\hline Asian and Pacific & & & 7.6 & 4726.0 & & & 0.0 & \\
\hline Islander Alone & 1.16 & 0.09 & $\begin{array}{l}\% \\
-\end{array}$ & $\begin{array}{l}\% \\
-\end{array}$ & 1.16 & 0.00 & $\begin{array}{l}\% \\
-\end{array}$ & $0.0 \%$ \\
\hline Native American & & - & 24.9 & 11697. & & - & 48.8 & 1228 \\
\hline Alone & 0.88 & 0.22 & $\%$ & $4 \%$ & 0.88 & 0.43 & $\%$ & $.4 \%$ \\
\hline All Other Races & & - & 24.2 & 11244. & & - & 17.1 & 426. \\
\hline Alone & 0.87 & 0.21 & $\%$ & $1 \%$ & 0.87 & 0.15 & $\begin{array}{l}\% \\
-\end{array}$ & $6 \%$ \\
\hline & & & 0.2 & & & - & 3.3 & \\
\hline TotalPopulation & 1.06 & 0.00 & $\%$ & & 1.06 & 0.03 & $\%$ & \\
\hline
\end{tabular}


Table 6A.15B Mod MA: SCT.

\begin{tabular}{|c|c|c|c|c|c|}
\hline \multicolumn{2}{|l|}{ Incremental Analysis } & \multirow[b]{2}{*}{ Distance } & \multirow[b]{3}{*}{ Share of } & \multirow[b]{2}{*}{ Share of } & \multirow{2}{*}{$\begin{array}{l}\text { Cumulati } \\
\text { Demogra }\end{array}$} \\
\hline Demographic & Transit & & & & \\
\hline Share--Only & Region & Band & & Distance & Share--Ci \\
\hline Distance Band & Change & Change & Transit & Band & Distance I \\
\hline Change & $2010-2016$ & 2010-2016 & Counties & Change & Change \\
\hline \multicolumn{5}{|c|}{ Spatial Share--0.125 Mile Distance Band Only } & Spatial St \\
\hline Station Area (sq.mi.) & 12770 & 5 & $0.04 \%$ & & Station Ar \\
\hline \multicolumn{5}{|c|}{ Basic Demographics--0.125 Mile Distance Band Only } & Basic Der \\
\hline White Non Latino & & & $4.7 \%$ & $-116.6 \%$ & White Nol \\
\hline Other Non Latino & & & $-18.6 \%$ & $485.6 \%$ & Other Nor \\
\hline Other Groups & & & $6.9 \%$ & $-185.6 \%$ & Other Grc \\
\hline$\underline{\text { TotalPopulation }}$ & & & $-3.9 \%$ & $0.0 \%$ & TotalPopl \\
\hline White Non Latino & & & $4.7 \%$ & $-116.6 \%$ & White Nol \\
\hline Hispanic & & & $3.0 \%$ & $-79.0 \%$ & Hispanic \\
\hline Other Non Latino & & & $-18.6 \%$ & $485.6 \%$ & Other Nor \\
\hline Other Groups & & & $22.5 \%$ & $-683.3 \%$ & Other Grc \\
\hline$\underline{\text { TotalPopulation }}$ & & & $-3.9 \%$ & $0.0 \%$ & TotalPopı \\
\hline White Alone & & & $7.4 \%$ & $-192.3 \%$ & White Alo \\
\hline Black Alone & & & $-24.1 \%$ & $614.1 \%$ & Black Aloı \\
\hline Asian and Pacific Isla & der Alone & & $15.9 \%$ & $-448.3 \%$ & Asian anc \\
\hline Native American Alor & & & $-31.3 \%$ & $663.0 \%$ & Native An \\
\hline All Other Races Alon & & & $-19.5 \%$ & $409.2 \%$ & All Other I \\
\hline$\underline{\text { TotalPopulation }}$ & & & $-3.9 \%$ & $0.0 \%$ & $\underline{\text { TotalPopl }}$ \\
\hline \multicolumn{5}{|c|}{ Spatial Share--0.25 Mile Distance Band Only } & Spatial St \\
\hline Station Area (sq.mi.) & 12770 & 12 & $0.1 \%$ & & Station Ar \\
\hline \multicolumn{5}{|c|}{ Demographic Change--0.25 Mile Distance Band Only } & Demogral \\
\hline White Non Latino & & & $15.0 \%$ & $183.1 \%$ & White Nol \\
\hline Other Non Latino & & & $-1.6 \%$ & $-20.2 \%$ & Other Nor \\
\hline Other Groups & & & $5.4 \%$ & $72.2 \%$ & Other Grc \\
\hline$\underline{\text { TotalPopulation }}$ & & & $7.9 \%$ & $0.0 \%$ & $\underline{\text { TotalPop }}$ \\
\hline White Non Latino & & & $15.0 \%$ & $183.1 \%$ & White Nol \\
\hline Hispanic & & & $2.0 \%$ & $26.0 \%$ & Hispanic \\
\hline Other Non Latino & & & $-1.6 \%$ & $-20.2 \%$ & Other Nor \\
\hline Other Groups & & & $20.2 \%$ & $303.1 \%$ & Other Grc \\
\hline$\underline{\text { TotalPopulation }}$ & & & $7.9 \%$ & $0.0 \%$ & $\underline{\text { TotalPopl }}$ \\
\hline White Alone & & & $-73.9 \%$ & $-951.0 \%$ & White Alo \\
\hline Black Alone & & & $-5.2 \%$ & $-65.8 \%$ & Black Aloı \\
\hline Asian and Pacific Isla & der Alone & & $26.7 \%$ & $370.5 \%$ & Asian anc \\
\hline Native American Alor & & & $-83.5 \%$ & $-871.4 \%$ & Native An \\
\hline All Other Races Alon & & & $898.8 \%$ & $9272.7 \%$ & All Other I \\
\hline$\underline{\text { TotalPopulation }}$ & & & $7.9 \%$ & $0.0 \%$ & $\underline{\text { TotalPop }}$ \\
\hline \multicolumn{5}{|c|}{ Spatial Share--0.375 Mile Distance Band Only } & Spatial St \\
\hline Station Area (sq.mi.) & 12770 & 10 & $0.1 \%$ & & Station $\mathrm{Ar}$ \\
\hline \multicolumn{5}{|c|}{ Demographic Change--0.375 Mile Distance Band Only } & Demogra। \\
\hline White Non Latino & & & $10.9 \%$ & $-250.4 \%$ & White Nol \\
\hline Other Non Latino & & & $51.1 \%$ & $-1246.5 \%$ & Other Nor \\
\hline Other Groups & & & $-7.6 \%$ & $192.1 \%$ & Other Grc \\
\hline$\underline{\text { TotalPopulation }}$ & & & $-4.2 \%$ & $0.0 \%$ & $\underline{\text { TotalPop }}$ \\
\hline White Non Latino & & & $10.9 \%$ & $-250.4 \%$ & White Nol \\
\hline Hispanic & & & $0.5 \%$ & $-12.3 \%$ & Hispanic \\
\hline Other Non Latino & & & $51.1 \%$ & $-1246.5 \%$ & Other Nor \\
\hline
\end{tabular}




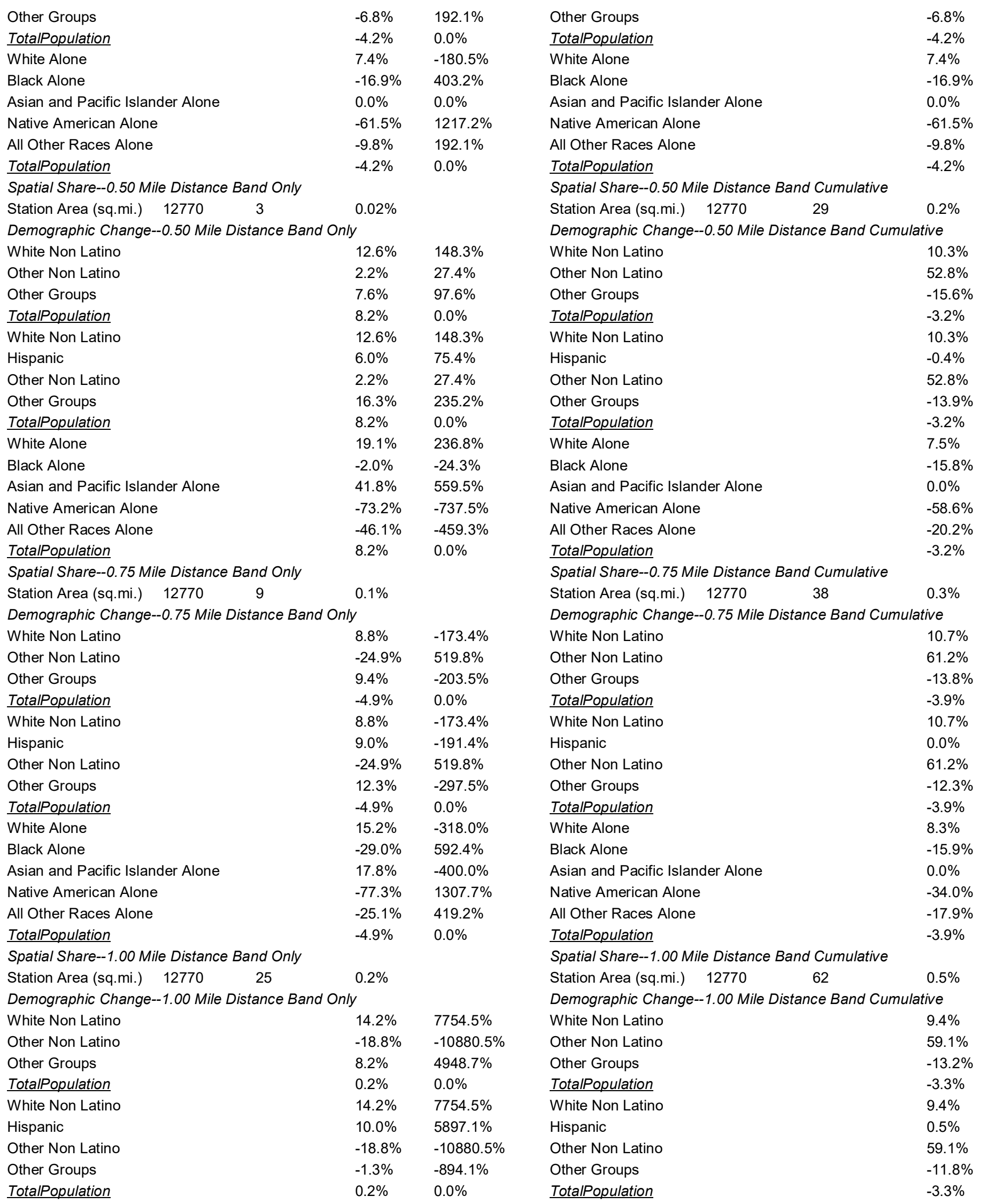




\author{
White Alone \\ Black Alone \\ Asian and Pacific Islander Alone \\ Native American Alone \\ All Other Races Alone \\ TotalPopulation
}

$\begin{array}{lll}18.6 \% & 10753.0 \% & \text { White Alone } \\ -22.2 \% & -12550.3 \% & \text { Black Alone } \\ 7.6 \% & 4726.0 \% & \text { Asian and Pacific Islander Alone } \\ -24.9 \% & -11697.4 \% & \text { Native American Alone } \\ -24.2 \% & -11244.1 \% & \text { All Other Races Alone } \\ 0.2 \% & 0.0 \% & \text { TotalPopulation }\end{array}$

$7.4 \%$

$-13.8 \%$

$0.0 \%$

$-48.8 \%$

$-17.1 \%$

$-3.3 \%$

Table 6A.16A High

MA: SCT.

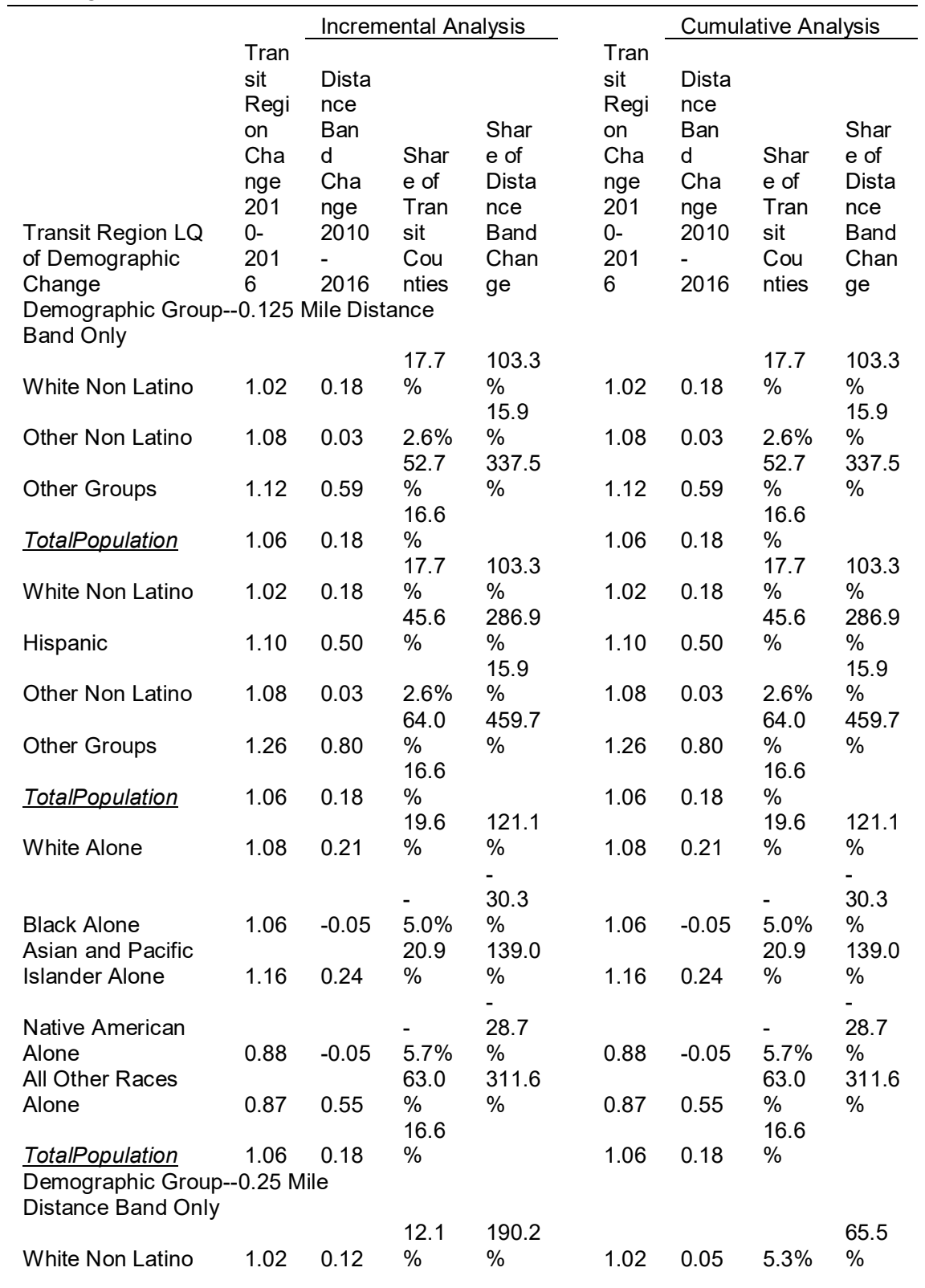




\begin{tabular}{|c|c|c|c|c|c|c|c|c|}
\hline & & & - & 89.0 & & & - & - \\
\hline Other Non Latino & 1.08 & -0.06 & $5.4 \%$ & $\begin{array}{l}\% \\
141.4\end{array}$ & 1.08 & 0.00 & $\begin{array}{l}0.2 \% \\
22.1\end{array}$ & $\begin{array}{l}3.3 \% \\
299.9\end{array}$ \\
\hline Other Groups & 1.12 & 0.09 & $8.2 \%$ & $\%$ & 1.12 & 0.25 & $\%$ & $\%$ \\
\hline TotalPopulation & 1.06 & 0.07 & $\begin{array}{l}6.2 \% \\
121\end{array}$ & & 1.06 & 0.08 & $7.8 \%$ & \\
\hline White Non Latino & 1.02 & 0.12 & $\begin{array}{l}12.1 \\
\%\end{array}$ & $\begin{array}{l}190.2 \\
\% \\
114.5\end{array}$ & 1.02 & 0.05 & $5.3 \%$ & $\begin{array}{l}65.5 \\
\% \\
112.5\end{array}$ \\
\hline Hispanic & 1.10 & 0.07 & $6.8 \%$ & $\%$ & 1.10 & 0.09 & $8.4 \%$ & $\%$ \\
\hline Other Non Latino & 1.08 & -0.06 & $\begin{array}{l}- \\
5.4 \% \\
14.8 \\
\%\end{array}$ & $\begin{array}{l}89.0 \\
\% \\
284.5 \\
\%\end{array}$ & 1.08 & 0.00 & $\begin{array}{l}- \\
0.2 \% \\
19.7 \\
\%\end{array}$ & $\begin{array}{l}- \\
3.3 \% \\
299.9 \\
\%\end{array}$ \\
\hline TotalPopulation & 1.06 & 0.07 & $6.2 \%$ & 10 & 1.06 & 0.08 & $7.8 \%$ & \\
\hline White Alone & 1.08 & -0.72 & $\begin{array}{l}66.8 \\
\% \\
- \\
10.5\end{array}$ & $\begin{array}{l}1105 . \\
8 \% \\
- \\
1699\end{array}$ & 1.08 & 0.03 & $\begin{array}{l}2.5 \% \\
- \\
177\end{array}$ & $\begin{array}{l}32.6 \\
\% \\
- \\
226.6\end{array}$ \\
\hline $\begin{array}{l}\text { Black Alone } \\
\text { Asian and Pacific }\end{array}$ & 1.06 & -0.11 & $\%$ & $\begin{array}{l}109.9 \\
168.8\end{array}$ & 1.06 & -0.19 & $\%$ & $\%$ \\
\hline Islander Alone & 1.16 & 0.11 & $\begin{array}{l}9.5 \% \\
-\end{array}$ & $\begin{array}{l}\% \\
-\end{array}$ & 1.16 & 0.00 & $0.0 \%$ & $0.0 \%$ \\
\hline $\begin{array}{l}\text { Native American } \\
\text { Alone } \\
\text { All Other Races } \\
\text { Alone }\end{array}$ & 0.88 & $\begin{array}{l}-0.22 \\
5.18\end{array}$ & $\begin{array}{l}24.5 \\
\% \\
598 \\
0 \%\end{array}$ & $\begin{array}{l}330.0 \\
\% \\
7945 \\
6 \%\end{array}$ & 0.88 & $\begin{array}{l}-0.79 \\
0.25\end{array}$ & $\begin{array}{l}89.9 \\
\% \\
28.6 \\
\%\end{array}$ & $\begin{array}{l}955.0 \\
\% \\
299.9 \\
\%\end{array}$ \\
\hline TotalPopulation & 1.06 & 0.07 & $6.2 \%$ & & 1.06 & 0.08 & $7.8 \%$ & \\
\hline \multicolumn{9}{|c|}{$\begin{array}{l}\text { Demographic Group--0.375 Mile Distance } \\
\text { Band Only }\end{array}$} \\
\hline White Non Latino & 1.02 & 0.04 & $4.0 \%$ & $\begin{array}{l}37.1 \\
\%\end{array}$ & 1.02 & 0.04 & $3.6 \%$ & $\begin{array}{l}48.9 \\
\% \\
-\end{array}$ \\
\hline Other Non Latino & 1.08 & 0.19 & $\begin{array}{l}17.8 \\
\% \\
22.9\end{array}$ & $\begin{array}{l}175.7 \\
\% \\
234.6\end{array}$ & 1.08 & -0.14 & $\begin{array}{l}13.2 \\
\% \\
17.0\end{array}$ & $\begin{array}{l}188.1 \\
\% \\
250.9\end{array}$ \\
\hline Other Groups & 1.12 & 0.26 & $\begin{array}{l}\% \\
10.3\end{array}$ & $\%$ & 1.12 & 0.19 & $\%$ & $\%$ \\
\hline TotalPopulation & 1.06 & 0.11 & $\%$ & 37.1 & 1.06 & 0.08 & $7.2 \%$ & 48.9 \\
\hline White Non Latino & 1.02 & 0.04 & $4.0 \%$ & $\begin{array}{l}\% \\
81.0\end{array}$ & 1.02 & 0.04 & $3.6 \%$ & $\begin{array}{l}\% \\
94.9\end{array}$ \\
\hline Hispanic & 1.10 & 0.09 & $8.0 \%$ & $\%$ & 1.10 & 0.07 & $6.5 \%$ & $\%$ \\
\hline Other Non Latino & 1.08 & 0.19 & $\begin{array}{l}17.8 \\
\% \\
49.1\end{array}$ & $\begin{array}{l}175.7 \\
\% \\
565.3\end{array}$ & 1.08 & -0.14 & $\begin{array}{l}13.2 \\
\% \\
15.2\end{array}$ & $\begin{array}{l}188.1 \\
\% \\
250.9\end{array}$ \\
\hline Other Groups & 1.26 & 0.62 & $\begin{array}{l}\% \\
10.3\end{array}$ & $\%$ & 1.26 & 0.19 & $\%$ & $\%$ \\
\hline TotalPopulation & 1.06 & 0.11 & $\%$ & 51.6 & 1.06 & 0.08 & $7.2 \%$ & 11.3 \\
\hline White Alone & 1.08 & 0.06 & $5.2 \%$ & $\%$ & 1.08 & 0.01 & $\begin{array}{l}0.8 \% \\
-\end{array}$ & $\%$ \\
\hline $\begin{array}{l}\text { Black Alone } \\
\text { Asian and Pacific }\end{array}$ & 1.06 & 0.18 & $\begin{array}{l}17.4 \\
\% \\
14.3\end{array}$ & $\begin{array}{l}168.2 \\
\% \\
152.8\end{array}$ & 1.06 & -0.13 & $\begin{array}{l}12.6 \\
\%\end{array}$ & $\begin{array}{l}175.6 \\
\%\end{array}$ \\
\hline Islander Alone & 1.16 & 0.17 & $\%$ & $\%$ & 1.16 & 0.00 & $0.0 \%$ & $0.0 \%$ \\
\hline Native American & & & 38.4 & 307.9 & & & 93.2 & 1075. \\
\hline $\begin{array}{l}\text { Alone } \\
\text { All Other Races }\end{array}$ & 0.88 & 0.34 & $\begin{array}{l}\% \\
28.9\end{array}$ & $\begin{array}{l}\% \\
229.6\end{array}$ & 0.88 & -0.82 & $\begin{array}{l}\% \\
22.0\end{array}$ & $\begin{array}{l}6 \% \\
250.9\end{array}$ \\
\hline Alone & 0.87 & 0.25 & $\begin{array}{l}\% \\
10.3\end{array}$ & $\%$ & 0.87 & 0.19 & $\%$ & $\%$ \\
\hline TotalPopulation & 1.06 & 0.11 & $\%$ & & 1.06 & 0.08 & $7.2 \%$ & \\
\hline
\end{tabular}




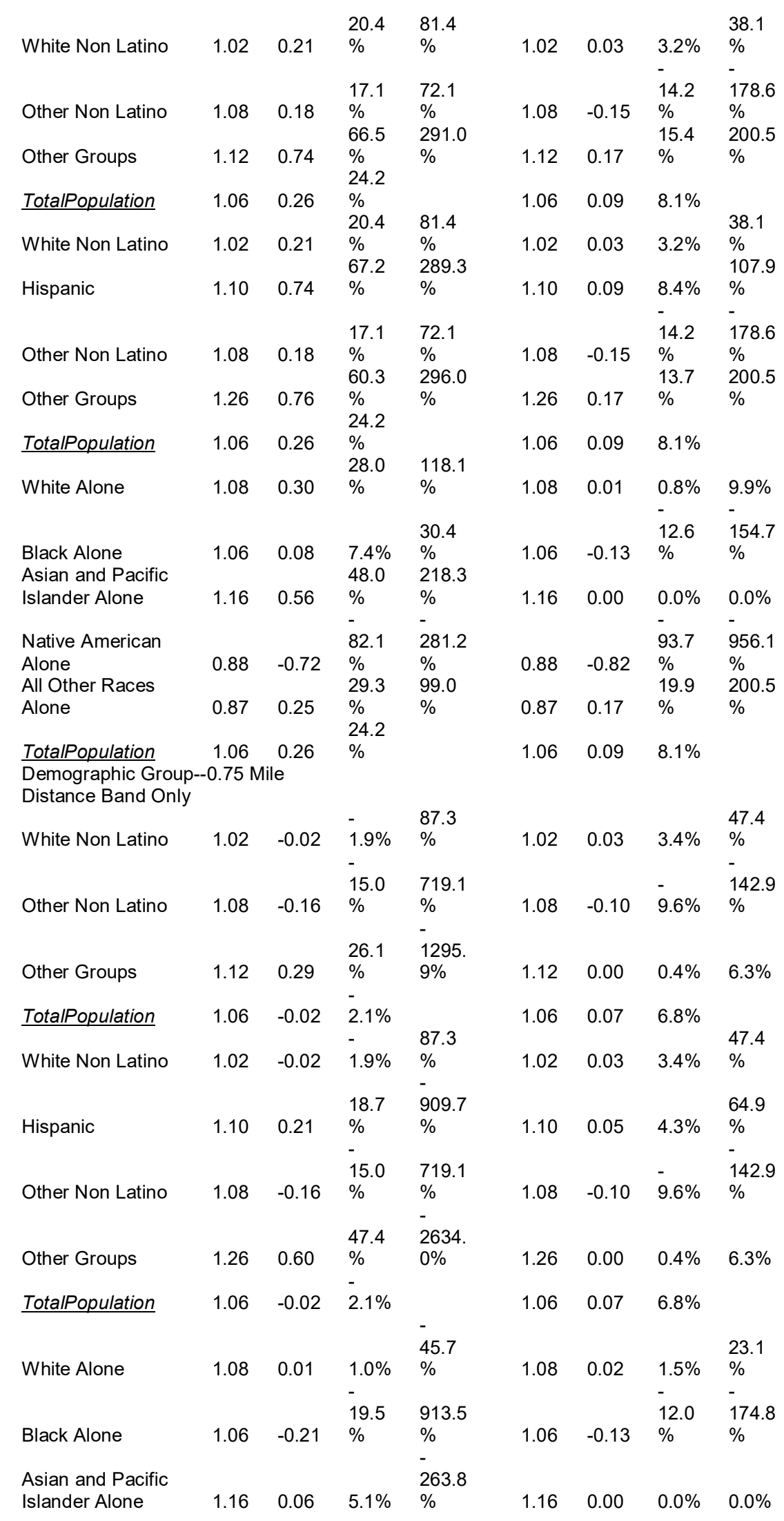




\begin{tabular}{|c|c|c|c|c|c|c|c|c|}
\hline & & & & & & & & \\
\hline Native American & & & 11.0 & 426.5 & & & 93.8 & 1136. \\
\hline Alone & 0.88 & 0.10 & $\%$ & $\%$ & 0.88 & -0.82 & $\%$ & $8 \%$ \\
\hline $\begin{array}{l}\text { All Other Races } \\
\text { Alone }\end{array}$ & 0.87 & 0.25 & $\begin{array}{l}28.7 \\
\% \\
-\end{array}$ & $\begin{array}{l}1099 . \\
0 \%\end{array}$ & 0.87 & 0.00 & $0.5 \%$ & $6.3 \%$ \\
\hline $\begin{array}{l}\text { TotalPopulation } \\
\text { Demographic Group-- } \\
\text { Distance Band Only }\end{array}$ & $\begin{array}{l}1.06 \\
-1.00 \mathrm{Mil}\end{array}$ & $\mathrm{le}^{-0.02}$ & $2.1 \%$ & & 1.06 & 0.07 & $6.8 \%$ & \\
\hline White Non Latino & 1.02 & 0.04 & $4.2 \%$ & $\begin{array}{l}60.7 \\
\%\end{array}$ & 1.02 & 0.04 & $\begin{array}{l}3.9 \% \\
-\end{array}$ & $\begin{array}{l}68.9 \\
\% \\
-\end{array}$ \\
\hline Other Non Latino & 1.08 & 0.10 & $8.9 \%$ & $\begin{array}{l}135.1 \\
\% \\
130.6\end{array}$ & 1.08 & -0.12 & $\begin{array}{l}10.7 \\
\%\end{array}$ & $\begin{array}{l}200.5 \\
\% \\
49.0\end{array}$ \\
\hline Other Groups & 1.12 & 0.09 & $8.3 \%$ & $\%$ & 1.12 & 0.03 & $2.5 \%$ & $\%$ \\
\hline TotalPopulation & 1.06 & 0.07 & $6.7 \%$ & & 1.06 & 0.06 & $5.5 \%$ & \\
\hline White Non Latino & 1.02 & 0.04 & $\begin{array}{l}4.2 \% \\
12.5\end{array}$ & $\begin{array}{l}60.7 \\
\% \\
193.3\end{array}$ & 1.02 & 0.04 & $3.9 \%$ & $\begin{array}{l}68.9 \\
\% \\
66.5\end{array}$ \\
\hline Hispanic & 1.10 & 0.14 & $\%$ & $\%$ & 1.10 & 0.04 & $3.5 \%$ & $\%$ \\
\hline Other Non Latino & 1.08 & 0.10 & $8.9 \%$ & $\begin{array}{l}135.1 \\
\% \\
-\end{array}$ & 1.08 & -0.12 & $\begin{array}{l}10.7 \\
\%\end{array}$ & $\begin{array}{l}200.5 \\
\%\end{array}$ \\
\hline Other Groups & 1.26 & -0.08 & $-\overline{6} .4 \%$ & $\begin{array}{l}113.3 \\
\%\end{array}$ & 1.26 & 0.03 & $2.3 \%$ & $\begin{array}{l}49.0 \\
\%\end{array}$ \\
\hline TotalPopulation & 1.06 & 0.07 & $6.7 \%$ & 103.3 & 1.06 & 0.06 & $5.5 \%$ & 44.2 \\
\hline White Alone & 1.08 & 0.07 & $6.8 \%$ & $\%$ & 1.08 & 0.03 & $\begin{array}{l}2.4 \% \\
-\end{array}$ & $\begin{array}{l}44.2 \\
\% \\
-\end{array}$ \\
\hline $\begin{array}{l}\text { Black Alone } \\
\text { Asian and Pacific }\end{array}$ & 1.06 & 0.05 & $\begin{array}{l}4.3 \% \\
36.7\end{array}$ & $\begin{array}{l}63.7 \\
\% \\
601.7\end{array}$ & 1.06 & -0.12 & $\begin{array}{l}11.3 \\
\%\end{array}$ & $\begin{array}{l}207.3 \\
\%\end{array}$ \\
\hline Islander Alone & 1.16 & 0.43 & $\%$ & $\begin{array}{l}\% \\
-\end{array}$ & 1.16 & 0.00 & $\begin{array}{l}0.0 \% \\
-\end{array}$ & $\begin{array}{l}0.0 \% \\
-\end{array}$ \\
\hline $\begin{array}{l}\text { Native American } \\
\text { Alone }\end{array}$ & 0.88 & -0.60 & $\begin{array}{l}68.5 \\
\%\end{array}$ & $\begin{array}{l}844.7 \\
\% \\
-\end{array}$ & 0.88 & -0.84 & $\begin{array}{l}95.6 \\
\%\end{array}$ & $\begin{array}{l}1448 . \\
1 \%\end{array}$ \\
\hline $\begin{array}{l}\text { All Other Races } \\
\text { Alone }\end{array}$ & 0.87 & -0.06 & $-\overline{6} .8 \%$ & $\begin{array}{l}82.4 \\
\%\end{array}$ & 0.87 & 0.03 & $3.3 \%$ & $\begin{array}{l}49.0 \\
\%\end{array}$ \\
\hline TotalPopulation & 1.06 & 0.07 & $6.7 \%$ & & 1.06 & 0.06 & $5.5 \%$ & \\
\hline
\end{tabular}

Table 6A.16B High MA: SCT. 


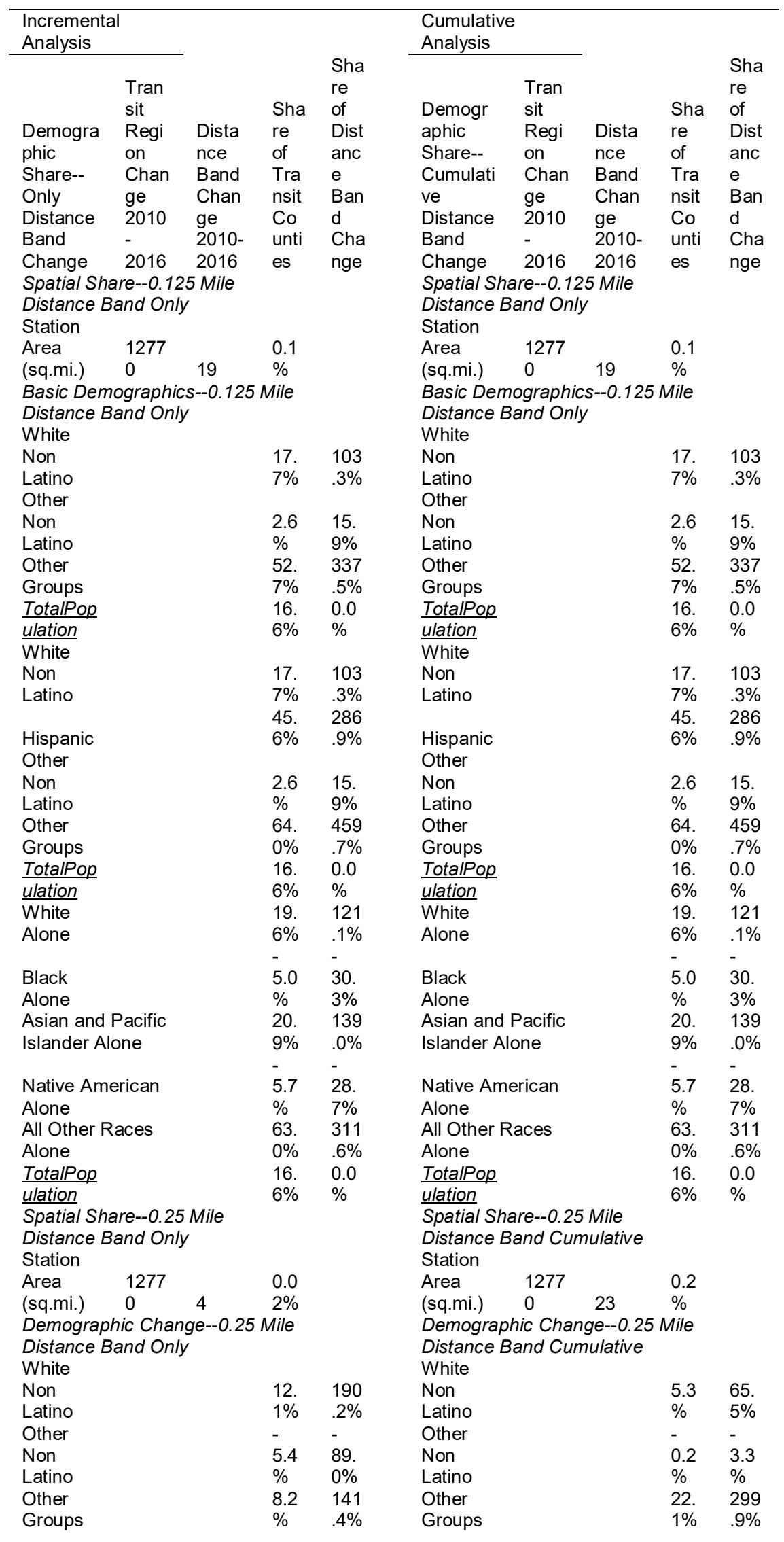




\begin{tabular}{|c|c|c|c|c|c|}
\hline TotalPop & 6.2 & 0.0 & TotalPop & 7.8 & 0.0 \\
\hline ulation & $\%$ & $\%$ & ulation & $\%$ & $\%$ \\
\hline White & & & White & & \\
\hline Non & 12. & 190 & Non & 5.3 & 65. \\
\hline \multirow[t]{2}{*}{ Latino } & $1 \%$ & $.2 \%$ & Latino & $\%$ & $5 \%$ \\
\hline & 6.8 & 114 & & 8.4 & 112 \\
\hline Hispanic & $\%$ & $.5 \%$ & Hispanic & $\%$ & $.5 \%$ \\
\hline Other & - & - & Other & - & - \\
\hline Non & 5.4 & 89. & Non & 0.2 & 3.3 \\
\hline Latino & $\%$ & $0 \%$ & Latino & $\%$ & $\%$ \\
\hline Other & 14. & 284 & Other & 19. & 299 \\
\hline Groups & $8 \%$ & $.5 \%$ & Groups & $7 \%$ & $.9 \%$ \\
\hline TotalPop & 6.2 & 0.0 & TotalPop & 7.8 & 0.0 \\
\hline \multirow[t]{2}{*}{ ulation } & $\%$ & $\%$ & ulation & $\%$ & $\%$ \\
\hline & - & $\overline{110}$ & & & \\
\hline White & 66. & 5.8 & White & 2.5 & 32. \\
\hline \multirow{2}{*}{ Alone } & $8 \%$ & $\%$ & Alone & $\%$ & $6 \%$ \\
\hline & - & - & & - & - \\
\hline Black & 10. & 169 & Black & 17. & 226 \\
\hline Alone & $5 \%$ & $.9 \%$ & Alone & $7 \%$ & $.6 \%$ \\
\hline Asian and Pacific & 9.5 & 168 & Asian and Pacific & 0.0 & 0.0 \\
\hline \multirow[t]{2}{*}{ Islander Alone } & $\%$ & $.8 \%$ & Islander Alone & $\%$ & $\%$ \\
\hline & - & - & & - & - \\
\hline Native American & 24. & 330 & Native American & 89. & 955 \\
\hline Alone & $5 \%$ & $\begin{array}{l}.0 \% \\
794\end{array}$ & Alone & $9 \%$ & $.0 \%$ \\
\hline All Other Races & 598 & 5.6 & All Other Races & 28. & 299 \\
\hline Alone & $.0 \%$ & $\%$ & Alone & $6 \%$ & $.9 \%$ \\
\hline TotalPop & 6.2 & 0.0 & TotalPop & 7.8 & 0.0 \\
\hline ulation & $\%$ & $\%$ & ulation & $\%$ & $\%$ \\
\hline \multirow{2}{*}{\multicolumn{3}{|c|}{$\begin{array}{l}\text { Spatial Share--0.375 Mile } \\
\text { Distance Band Only }\end{array}$}} & Spatial Share--0.375 Mile & & \\
\hline & & & Distance Band Cumulative & & \\
\hline \multicolumn{3}{|l|}{ Station } & Station & & \\
\hline Area & 0.1 & & Area & 0.3 & \\
\hline (sq.mi.) $\quad 0$ & $\%$ & & (sq.mi.) & $\%$ & \\
\hline \multicolumn{3}{|c|}{ Demographic Change--0.375 Mile } & \multicolumn{3}{|c|}{ Demographic Change--0.375 Mile } \\
\hline \multicolumn{3}{|l|}{ Distance Band Only } & \multicolumn{3}{|l|}{ Distance Band Cumulative } \\
\hline White & & & White & & \\
\hline Non & 3.6 & 48. & Non & 3.6 & 48. \\
\hline Latino & $\%$ & $9 \%$ & Latino & $\%$ & $9 \%$ \\
\hline Other & - & - & Other & - & - \\
\hline Non & 13. & 188 & Non & 13. & 188 \\
\hline Latino & $2 \%$ & $.1 \%$ & Latino & $2 \%$ & $.1 \%$ \\
\hline Other & 17. & 250 & Other & 17. & 250 \\
\hline Groups & $0 \%$ & $.9 \%$ & Groups & $0 \%$ & $.9 \%$ \\
\hline TotalPop & 7.2 & 0.0 & TotalPop & 7.2 & 0.0 \\
\hline ulation & $\%$ & $\%$ & ulation & $\%$ & $\%$ \\
\hline$\overline{\text { White }}$ & & & White & & \\
\hline Non & 3.6 & 48. & Non & 3.6 & 48. \\
\hline \multirow[t]{2}{*}{ Latino } & $\%$ & $9 \%$ & Latino & $\%$ & $9 \%$ \\
\hline & 6.5 & 94. & & 6.5 & 94. \\
\hline Hispanic & $\%$ & $9 \%$ & Hispanic & $\%$ & $9 \%$ \\
\hline Other & - & - & Other & - & - \\
\hline Non & 13. & 188 & Non & 13. & 188 \\
\hline Latino & $2 \%$ & $.1 \%$ & Latino & $2 \%$ & $.1 \%$ \\
\hline Other & 15. & 250 & Other & 15. & 250 \\
\hline Groups & $2 \%$ & $.9 \%$ & Groups & $2 \%$ & $.9 \%$ \\
\hline TotalPop & 7.2 & 0.0 & TotalPop & 7.2 & 0.0 \\
\hline ulation & $\%$ & $\%$ & ulation & $\%$ & $\%$ \\
\hline White & 0.8 & 11. & White & 0.8 & 11. \\
\hline Alone & $\%$ & $3 \%$ & Alone & $\%$ & $3 \%$ \\
\hline & - & - & & - & - \\
\hline Black & 12. & 175 & Black & 12. & 175 \\
\hline Alone & $6 \%$ & $.6 \%$ & Alone & $6 \%$ & $.6 \%$ \\
\hline Asian and Pacific & 0.0 & 0.0 & Asian and Pacific & 0.0 & 0.0 \\
\hline Islander Alone & $\%$ & $\%$ & Islander Alone & $\%$ & $\%$ \\
\hline & - & & & - & \\
\hline Native American & 93. & - & Native American & 93. & - \\
\hline Alone & $2 \%$ & 107 & Alone & $2 \%$ & 107 \\
\hline
\end{tabular}




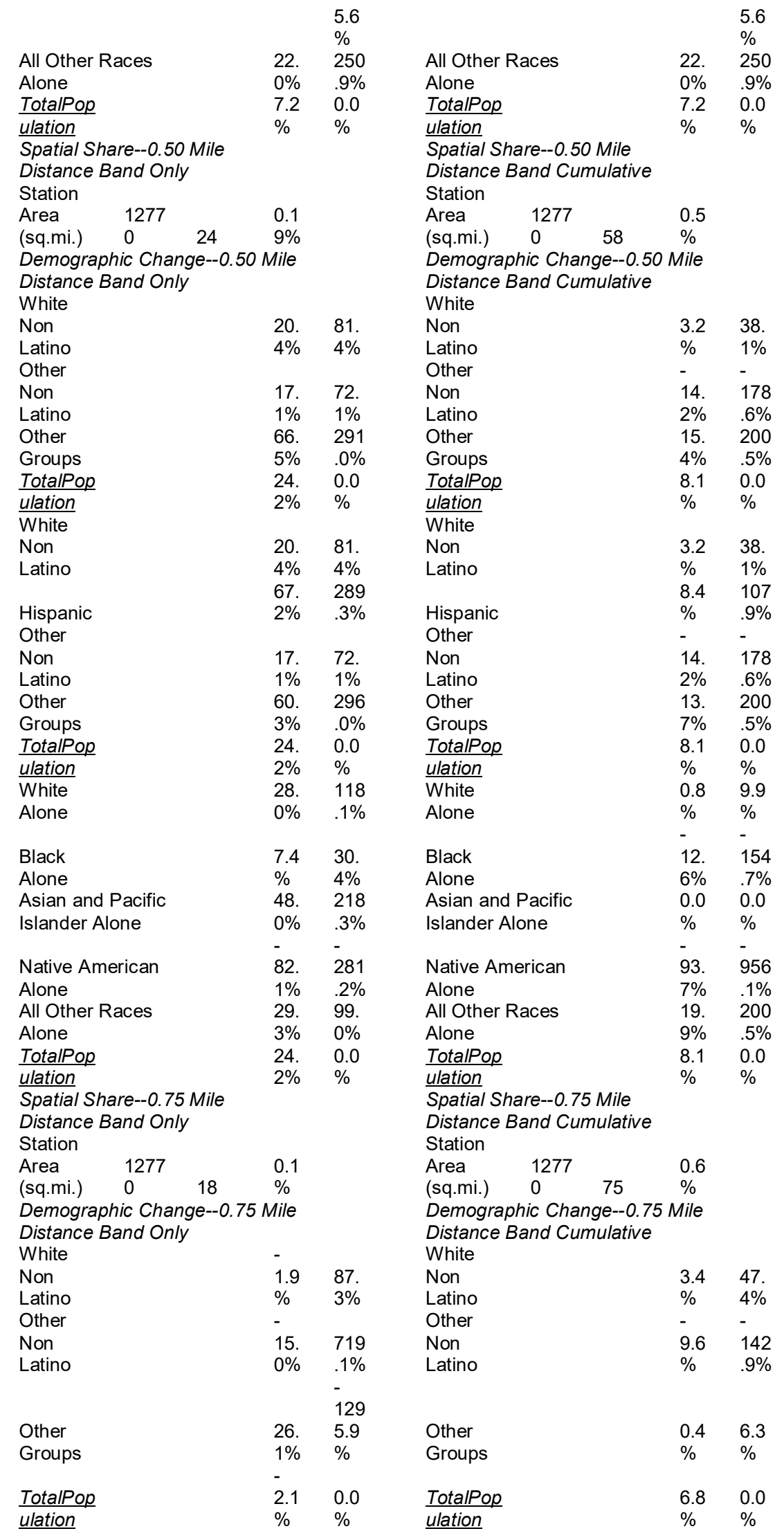




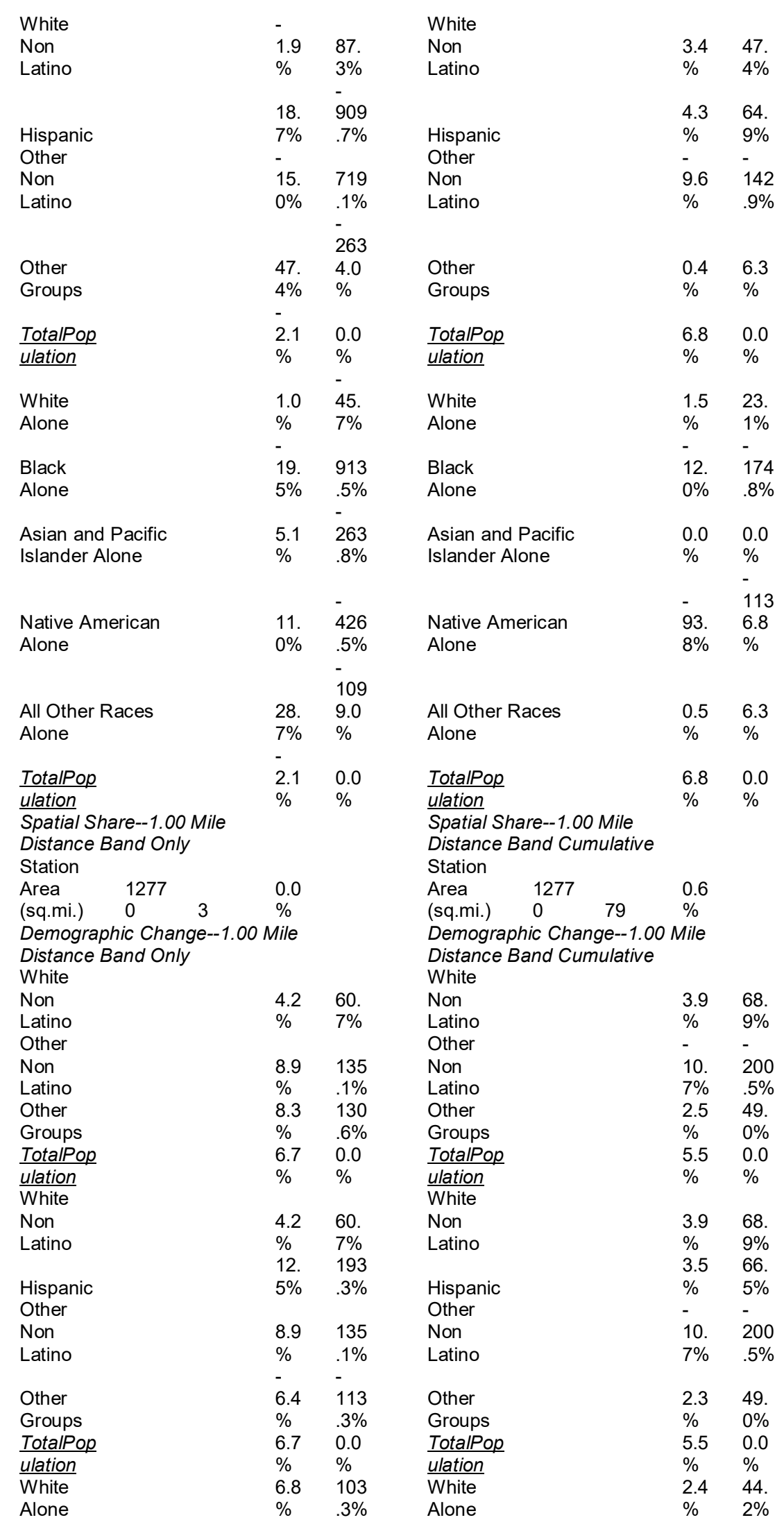




\begin{tabular}{|c|c|c|c|c|c|}
\hline Black & 4.3 & 63. & Black & 11. & 207 \\
\hline Alone & $\%$ & $7 \%$ & Alone & $3 \%$ & $.3 \%$ \\
\hline Asian and Pacific & 36. & 601 & Asian and Pacific & 0.0 & 0.0 \\
\hline \multirow[t]{2}{*}{ Islander Alone } & $7 \%$ & $.7 \%$ & Islander Alone & $\%$ & $\%$ \\
\hline & - & - & & - & 144 \\
\hline Native American & 68. & 844 & Native American & 95. & 8.1 \\
\hline \multirow[t]{2}{*}{ Alone } & $5 \%$ & $.7 \%$ & Alone & $6 \%$ & $\%$ \\
\hline & - & - & & & \\
\hline All Other Races & 6.8 & 82. & All Other Races & 3.3 & 49. \\
\hline Alone & $\%$ & $4 \%$ & Alone & $\%$ & $0 \%$ \\
\hline TotalPop & 6.7 & 0.0 & TotalPop & 5.5 & 0.0 \\
\hline ulation & $\%$ & $\%$ & ulation & $\%$ & $\%$ \\
\hline
\end{tabular}

Table 6A.17 Poor MA BRT

Households

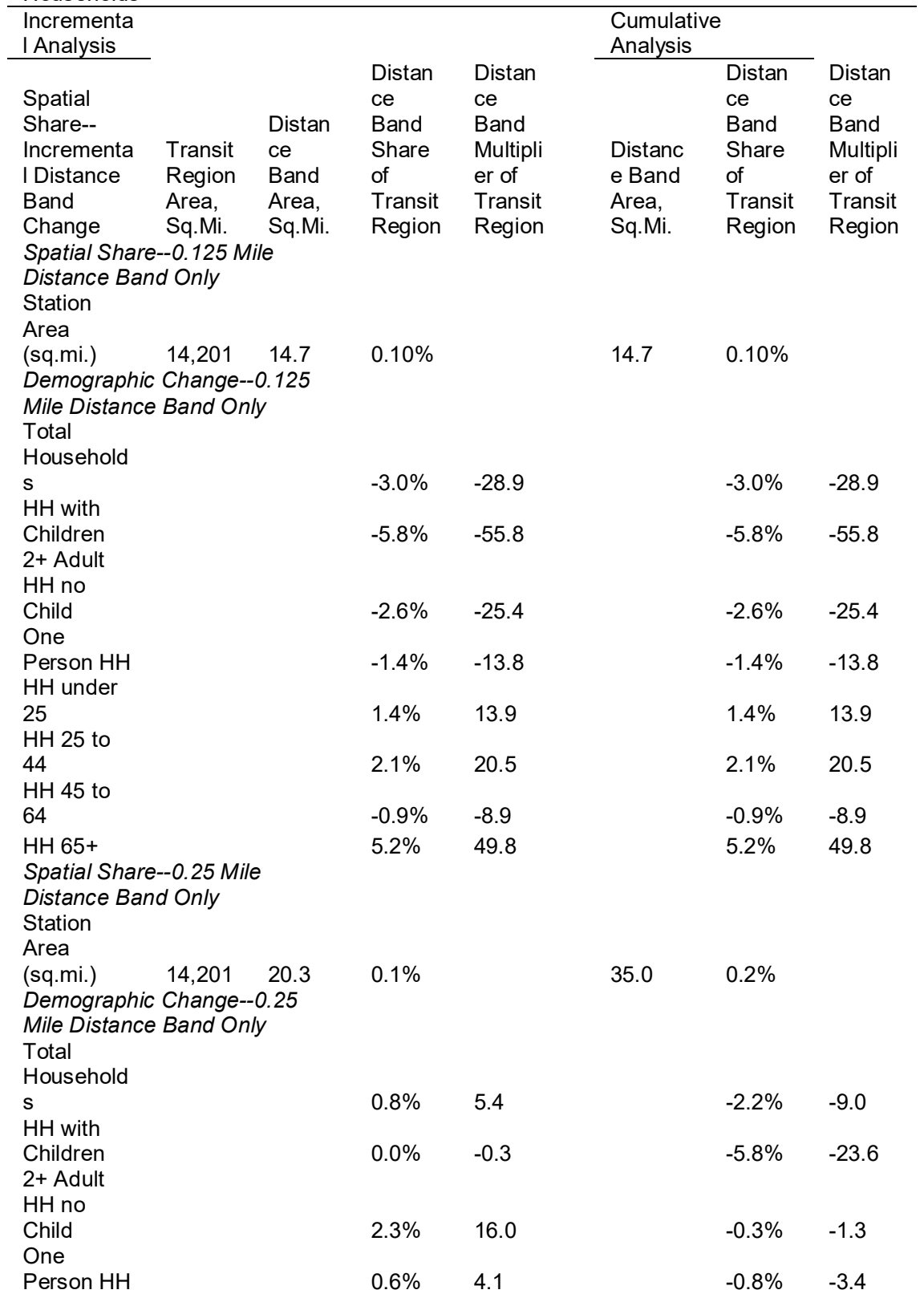




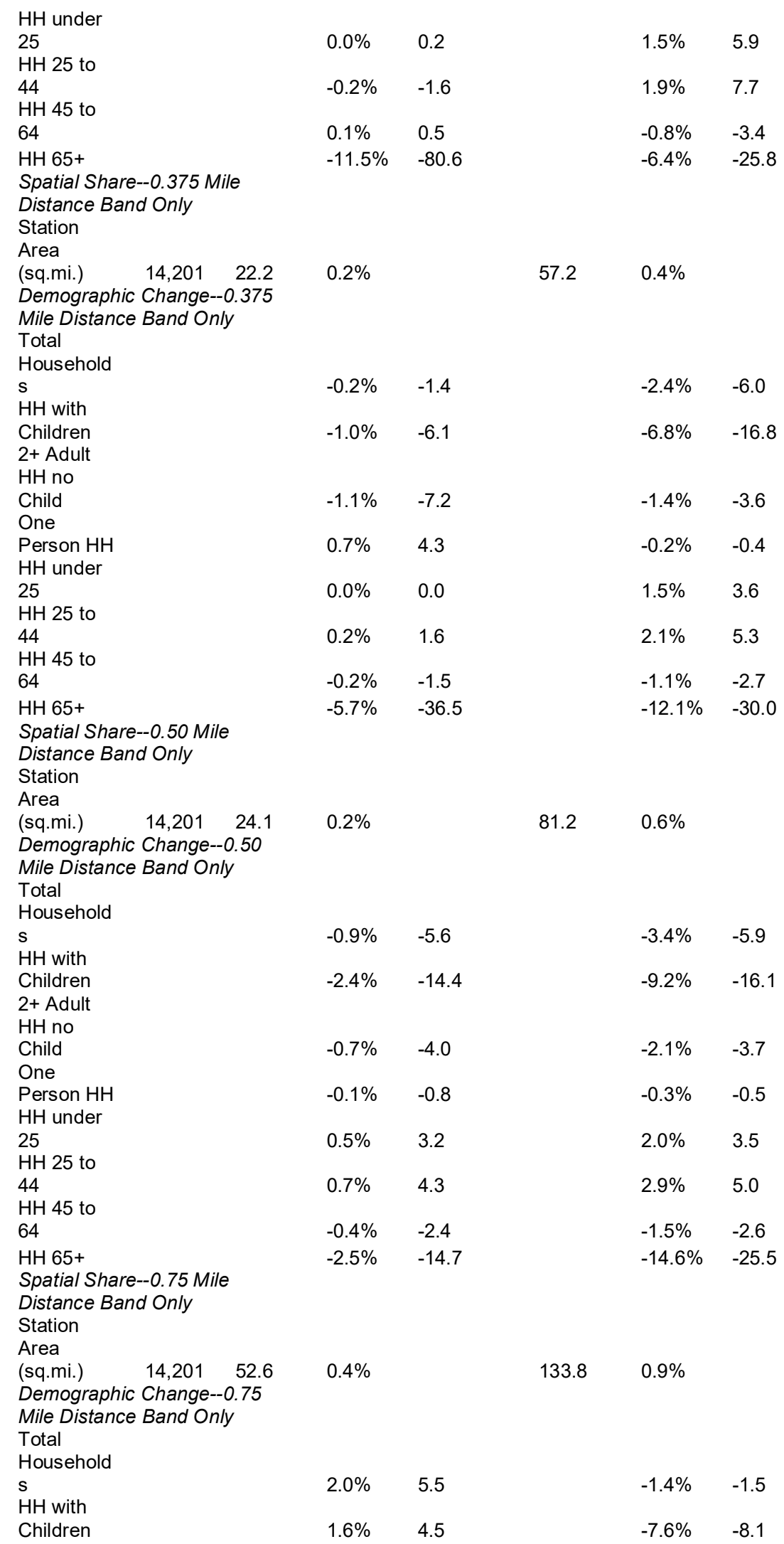




\begin{tabular}{|c|c|c|c|c|c|}
\hline $\begin{array}{l}2+\text { Adult } \\
\mathrm{HH} \text { no }\end{array}$ & & & & & \\
\hline $\begin{array}{l}\text { Child } \\
\text { One }\end{array}$ & $3.6 \%$ & 9.9 & & $1.4 \%$ & 1.5 \\
\hline $\begin{array}{l}\text { Person } \mathrm{HH} \\
\mathrm{HH} \text { under }\end{array}$ & $1.5 \%$ & 4.1 & & $1.2 \%$ & 1.2 \\
\hline $\begin{array}{l}25 \\
\mathrm{HH}\end{array} 25$ to & $0.4 \%$ & 1.2 & & $2.4 \%$ & 2.6 \\
\hline $\begin{array}{l}44 \\
\mathrm{HH}\end{array} 45$ to & $-1.2 \%$ & -3.4 & & $1.6 \%$ & 1.7 \\
\hline 64 & $0.4 \%$ & 1.1 & & $-1.1 \%$ & -1.2 \\
\hline $\begin{array}{l}\mathrm{HH} 65+ \\
\text { Spatial Share--1.00 Mile } \\
\text { Distance Band Only } \\
\text { Station } \\
\text { Area }\end{array}$ & $-16.9 \%$ & -47.0 & & $-31.4 \%$ & -33.4 \\
\hline $\begin{array}{l}\text { Demographic Change--1.00 } \\
\text { Mile Distance Band Only } \\
\text { Total } \\
\text { Household }\end{array}$ & $0.4 \%$ & & 190.5 & $1.3 \%$ & \\
\hline $\begin{array}{l}\mathrm{S} \\
\mathrm{HH} \text { with }\end{array}$ & $-1.1 \%$ & -2.7 & & $-2.4 \%$ & -1.8 \\
\hline $\begin{array}{l}\text { Children } \\
2+\text { Adult } \\
\mathrm{HH} \text { no }\end{array}$ & $-1.8 \%$ & -4.4 & & $-9.3 \%$ & -7.0 \\
\hline $\begin{array}{l}\text { Child } \\
\text { One }\end{array}$ & $-0.7 \%$ & -1.8 & & $0.7 \%$ & 0.5 \\
\hline $\begin{array}{l}\text { Person } \mathrm{HH} \\
\mathrm{HH} \text { under }\end{array}$ & $-0.8 \%$ & -1.9 & & $0.4 \%$ & 0.3 \\
\hline 25 & $0.4 \%$ & 1.0 & & $2.8 \%$ & 2.1 \\
\hline$\stackrel{44}{\mathrm{HH}} 45$ to & $0.9 \%$ & 2.2 & & $2.5 \%$ & 1.9 \\
\hline 64 & $-0.4 \%$ & -0.9 & & $-1.5 \%$ & -1.1 \\
\hline HH 65+ & $0.1 \%$ & 0.3 & & $-31.3 \%$ & -23.3 \\
\hline
\end{tabular}

Table 6A.18 Low MA BRT Households

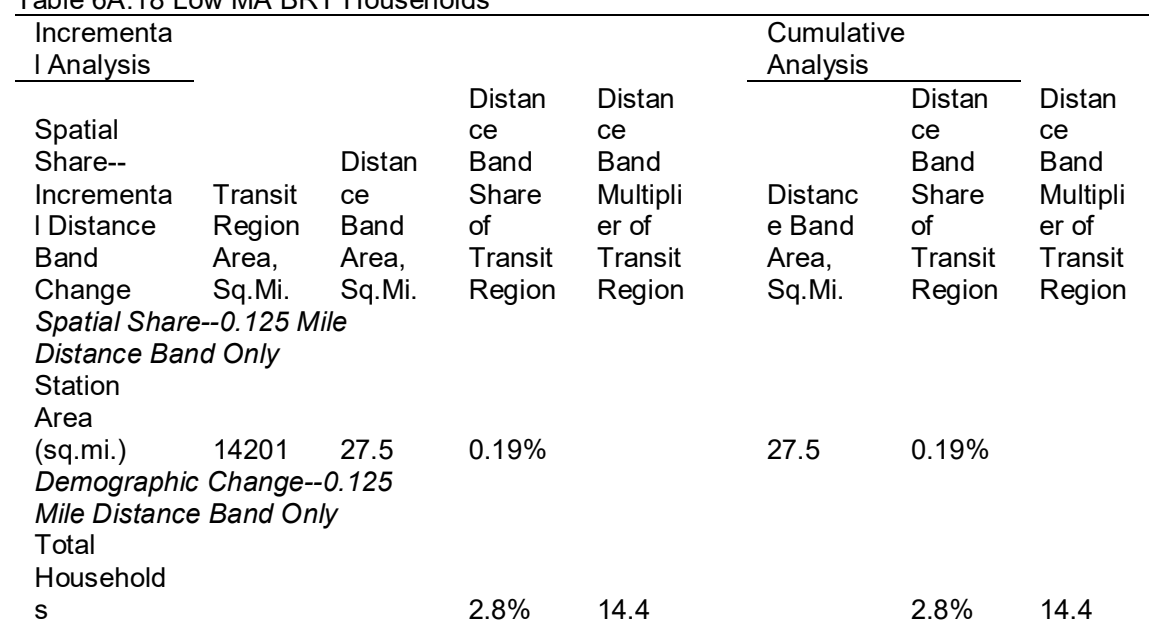




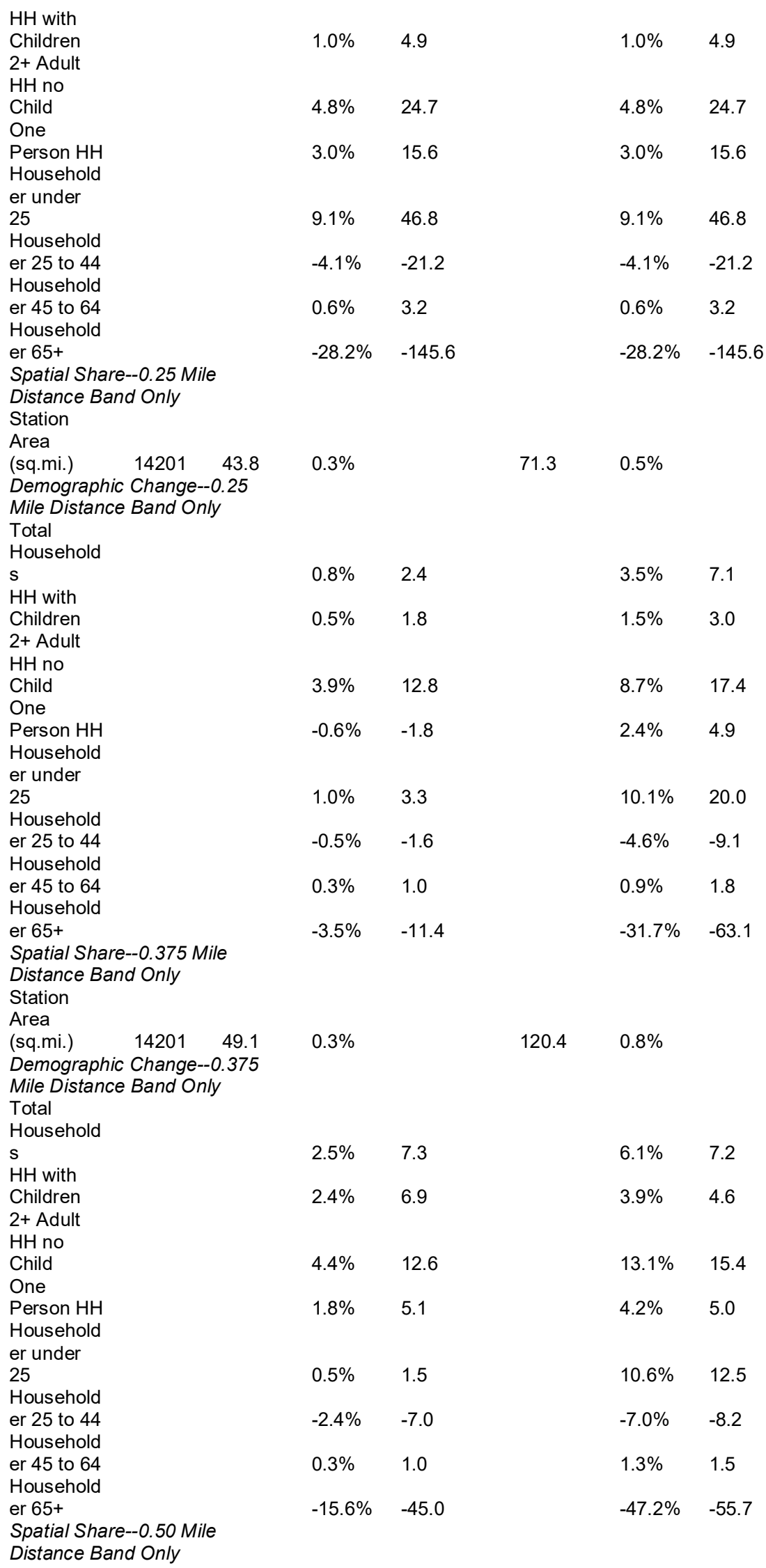




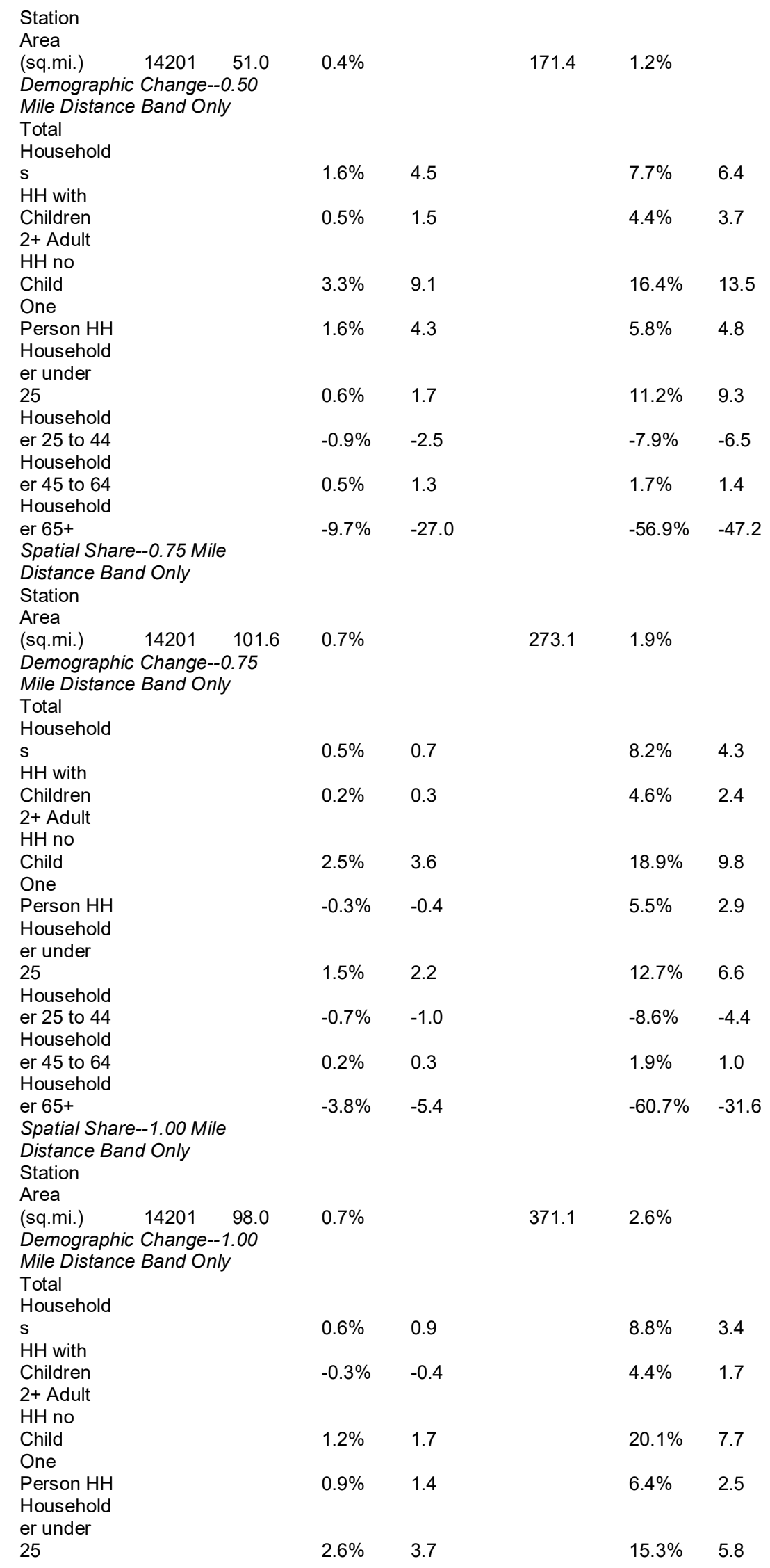




$\begin{array}{lllll}\begin{array}{l}\text { Household } \\ \text { er } 25 \text { to } 44\end{array} & 0.0 \% & -0.1 & -8.6 \% & -3.3 \\ \begin{array}{l}\text { Household } \\ \text { er } 45 \text { to } 64\end{array} & 0.1 \% & 0.2 & 2.1 \% & 0.8 \\ \begin{array}{l}\text { Household } \\ \text { er 65+ }\end{array} & -17.1 \% & -24.7 & -77.8 \% & -29.8\end{array}$

Table 6A.19 Mod MA BRT Households

\begin{tabular}{|c|c|c|c|c|c|c|c|}
\hline $\begin{array}{l}\text { Incrementa } \\
\text { I Analysis }\end{array}$ & & & & & $\begin{array}{l}\text { Cumulat } \\
\text { Analysis }\end{array}$ & & \\
\hline Spatial & & & Distanc & Distanc & & Distanc & Distanc \\
\hline Share-- & & & e Band & e Band & & e Band & e Band \\
\hline $\begin{array}{l}\text { Incrementa } \\
\text { I Distance }\end{array}$ & $\begin{array}{l}\text { Transit } \\
\text { Region }\end{array}$ & $\begin{array}{l}\text { Distanc } \\
\text { e Band }\end{array}$ & $\begin{array}{l}\text { Share } \\
\text { of }\end{array}$ & $\begin{array}{l}\text { Multipli } \\
\text { er of }\end{array}$ & $\begin{array}{l}\text { Distanc } \\
\text { e Band }\end{array}$ & $\begin{array}{l}\text { Share } \\
\text { of }\end{array}$ & $\begin{array}{l}\text { Multipli } \\
\text { er of }\end{array}$ \\
\hline Band & Area, & Area, & Transit & Transit & Area, & Transit & Transit \\
\hline Change & Sq.Mi. & Sq.Mi. & Region & Region & Sq.Mi. & Region & Region \\
\hline Spatial Shar & -0.125 I & & & & & & \\
\hline Distance Ba & d Only & & & & & & \\
\hline Station & & & & & & & \\
\hline $\begin{array}{l}\text { Area } \\
\text { (sq.mi.) }\end{array}$ & 14201 & 22.6 & $0.16 \%$ & & 22.6 & $0.16 \%$ & \\
\hline Demographi & Change & 0.125 & & & & & \\
\hline Mile Distanc & Band O & & & & & & \\
\hline Total & & & & & & & \\
\hline Household & & & & & & & \\
\hline $\begin{array}{l}\mathrm{S} \\
\mathrm{HH} \text { with }\end{array}$ & & & $14.6 \%$ & 91.7 & & $14.6 \%$ & 91.7 \\
\hline $\begin{array}{l}\text { Children } \\
2+\text { Adult }\end{array}$ & & & $13.5 \%$ & 84.7 & & $13.5 \%$ & 84.7 \\
\hline $\mathrm{HH}$ no & & & & & & & \\
\hline $\begin{array}{l}\text { Child } \\
\text { One }\end{array}$ & & & $26.0 \%$ & 163.1 & & $26.0 \%$ & 163.1 \\
\hline $\begin{array}{l}\text { Person HH } \\
\text { Household }\end{array}$ & & & $10.1 \%$ & 63.4 & & $10.1 \%$ & 63.4 \\
\hline er under 25 & & & $5.3 \%$ & 33.2 & & $5.3 \%$ & 33.2 \\
\hline $\begin{array}{l}\text { Household } \\
\text { er } 25 \text { to } 44\end{array}$ & & & $-15.5 \%$ & -97.3 & & $-15.5 \%$ & -97.3 \\
\hline Household & & & & & & & \\
\hline $\begin{array}{l}\text { er } 45 \text { to } 64 \\
\text { Household }\end{array}$ & & & $2.7 \%$ & 17.0 & & $2.7 \%$ & 17.0 \\
\hline $\begin{array}{l}\text { er } 65+ \\
\text { Spatial Shar }\end{array}$ & $-0.25 M$ & & $-73.4 \%$ & -460.4 & & $-73.4 \%$ & -460.4 \\
\hline Distance Ba & d Only & & & & & & \\
\hline $\begin{array}{l}\text { Station } \\
\text { Area }\end{array}$ & & & & & & & \\
\hline (sq.mi.) & 14201 & 38.3 & $0.3 \%$ & & 61.0 & $0.4 \%$ & \\
\hline $\begin{array}{l}\text { Demographi } \\
\text { Distance Ba }\end{array}$ & $\begin{array}{l}\text { Change } \\
\text { d Only }\end{array}$ & 0.25 Mile & & & & & \\
\hline Total & & & & & & & \\
\hline Household & & & & & & & \\
\hline $\begin{array}{l}\mathrm{S} \\
\mathrm{HH} \text { with }\end{array}$ & & & $2.5 \%$ & 9.1 & & $17.1 \%$ & 39.8 \\
\hline Children & & & $3.4 \%$ & 12.5 & & $16.9 \%$ & 39.3 \\
\hline $\begin{array}{l}2+\text { Adult } \\
\mathrm{HH} \text { no }\end{array}$ & & & & & & & \\
\hline Child & & & $2.8 \%$ & 10.5 & & $28.8 \%$ & 67.2 \\
\hline One & & & & & & & \\
\hline Person $\mathrm{HH}$ & & & $1.7 \%$ & 6.4 & & $11.8 \%$ & 27.6 \\
\hline
\end{tabular}




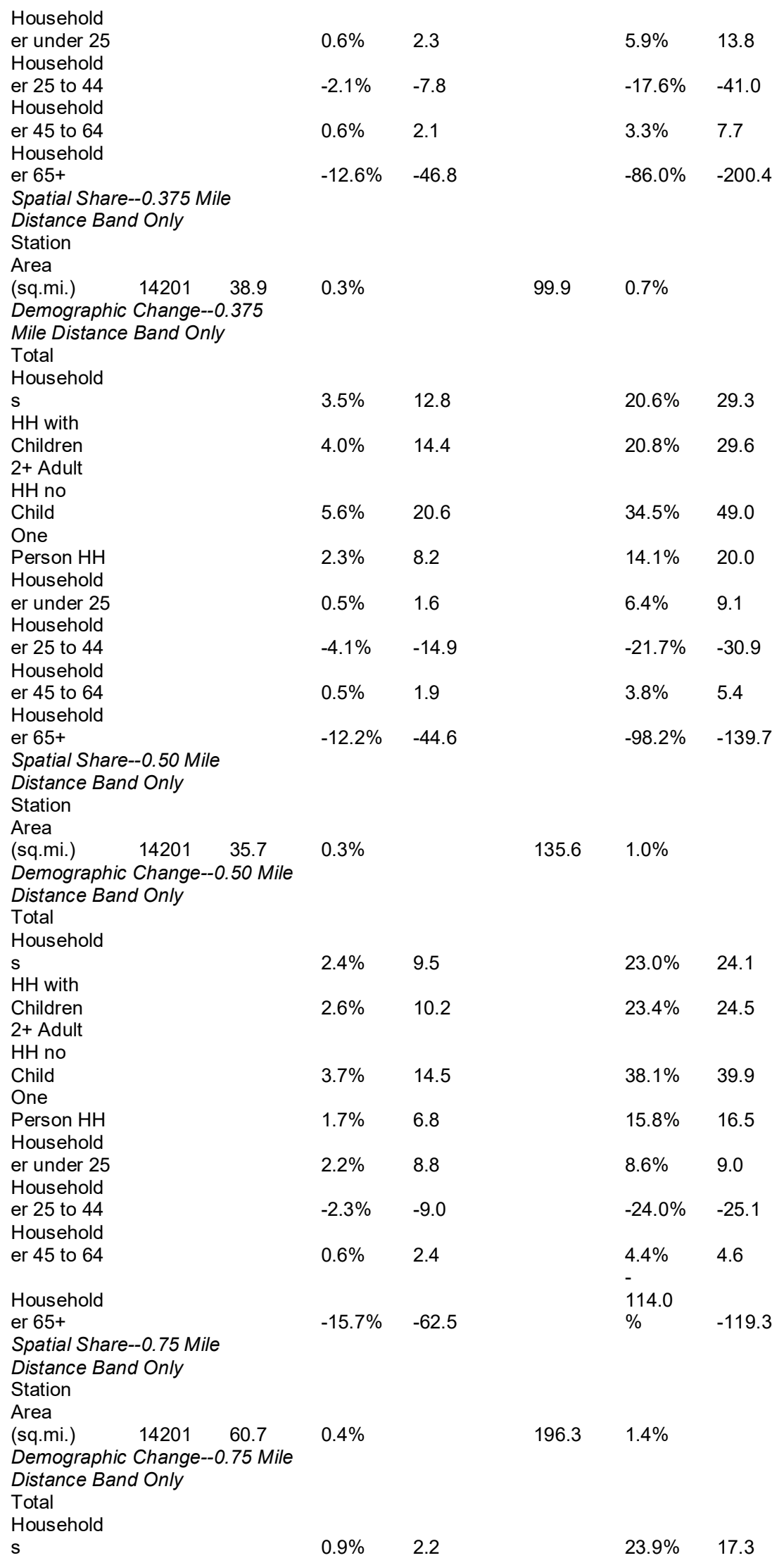




\begin{tabular}{|c|c|c|c|c|c|}
\hline $\begin{array}{l}\mathrm{HH} \text { with } \\
\text { Children } \\
2+\text { Adult } \\
\mathrm{HH} \text { no }\end{array}$ & $1.5 \%$ & 3.6 & & $24.9 \%$ & 18.0 \\
\hline $\begin{array}{l}\text { Child } \\
\text { One }\end{array}$ & $0.6 \%$ & 1.4 & & $38.7 \%$ & 28.0 \\
\hline $\begin{array}{l}\text { Person HH } \\
\text { Household }\end{array}$ & $0.7 \%$ & 1.7 & & $16.5 \%$ & 11.9 \\
\hline $\begin{array}{l}\text { er under } 25 \\
\text { Household }\end{array}$ & $1.1 \%$ & 2.7 & & $9.7 \%$ & 7.0 \\
\hline $\begin{array}{l}\text { er } 25 \text { to } 44 \\
\text { Household }\end{array}$ & $-0.7 \%$ & -1.7 & & $-24.7 \%$ & -17.9 \\
\hline er 45 to 64 & $0.2 \%$ & 0.5 & & $\begin{array}{l}4.6 \% \\
-\end{array}$ & 3.3 \\
\hline $\begin{array}{l}\text { Household } \\
\text { er } 65+ \\
\text { Spatial Share--1.00 Mile } \\
\text { Distance Band Only } \\
\text { Station }\end{array}$ & $-8.0 \%$ & -19.4 & & $\begin{array}{l}122.0 \\
\%\end{array}$ & -88.3 \\
\hline $\begin{array}{l}\text { Area } \\
\text { (sq.mi.) } \quad 14201 \quad 49.7 \\
\text { Demographic Change--1.00 Mile } \\
\text { Distance Band Only } \\
\text { Total } \\
\text { Household }\end{array}$ & $0.3 \%$ & & 246.0 & $1.7 \%$ & \\
\hline $\mathrm{S}$ & $0.8 \%$ & 2.2 & & $24.6 \%$ & 14.2 \\
\hline $\begin{array}{l}\text { Children } \\
2+\text { Adult } \\
\mathrm{HH} \text { no }\end{array}$ & $2.0 \%$ & 5.6 & & $26.8 \%$ & 15.5 \\
\hline $\begin{array}{l}\text { Child } \\
\text { One }\end{array}$ & $0.1 \%$ & 0.2 & & $38.8 \%$ & 22.4 \\
\hline $\begin{array}{l}\text { Person } \mathrm{HH} \\
\text { Household }\end{array}$ & $0.3 \%$ & 1.0 & & $16.8 \%$ & 9.7 \\
\hline $\begin{array}{l}\text { er under } 25 \\
\text { Household }\end{array}$ & $0.7 \%$ & 2.1 & & $10.4 \%$ & 6.0 \\
\hline $\begin{array}{l}\text { er } 25 \text { to } 44 \\
\text { Household }\end{array}$ & $-0.7 \%$ & -2.0 & & $-25.4 \%$ & -14.7 \\
\hline er 45 to 64 & $0.1 \%$ & 0.3 & & $\begin{array}{l}4.7 \% \\
-\end{array}$ & 2.7 \\
\hline $\begin{array}{l}\text { Household } \\
\text { er } 65+\end{array}$ & $-5.6 \%$ & -16.0 & & $\begin{array}{l}127.6 \\
\%\end{array}$ & -73.7 \\
\hline
\end{tabular}

Table 6A.20 High MA BRT Households

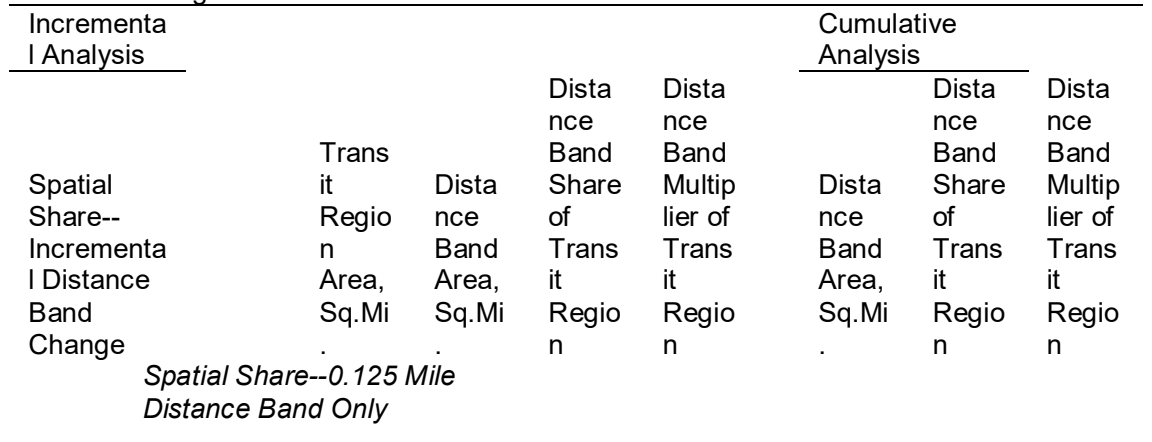




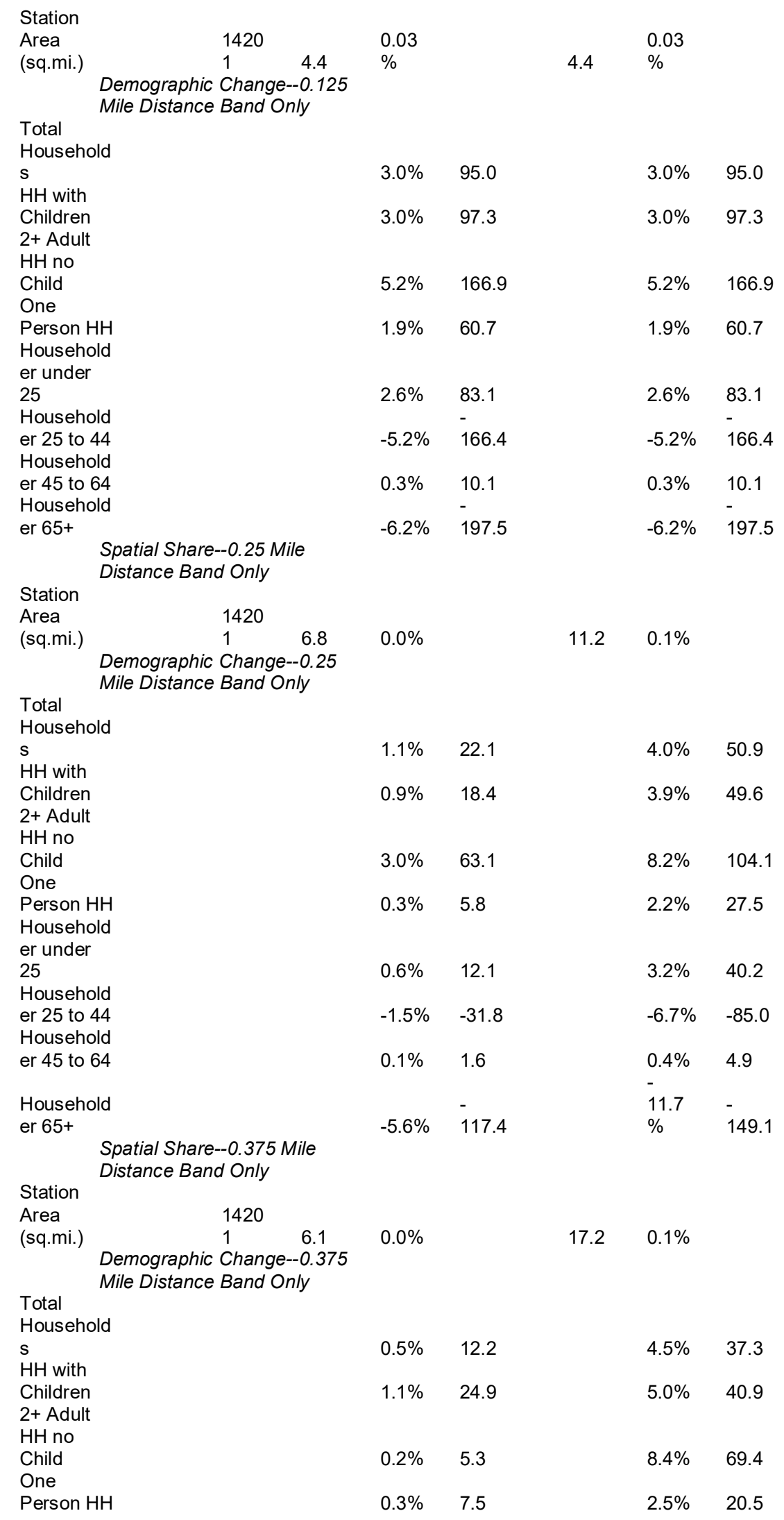




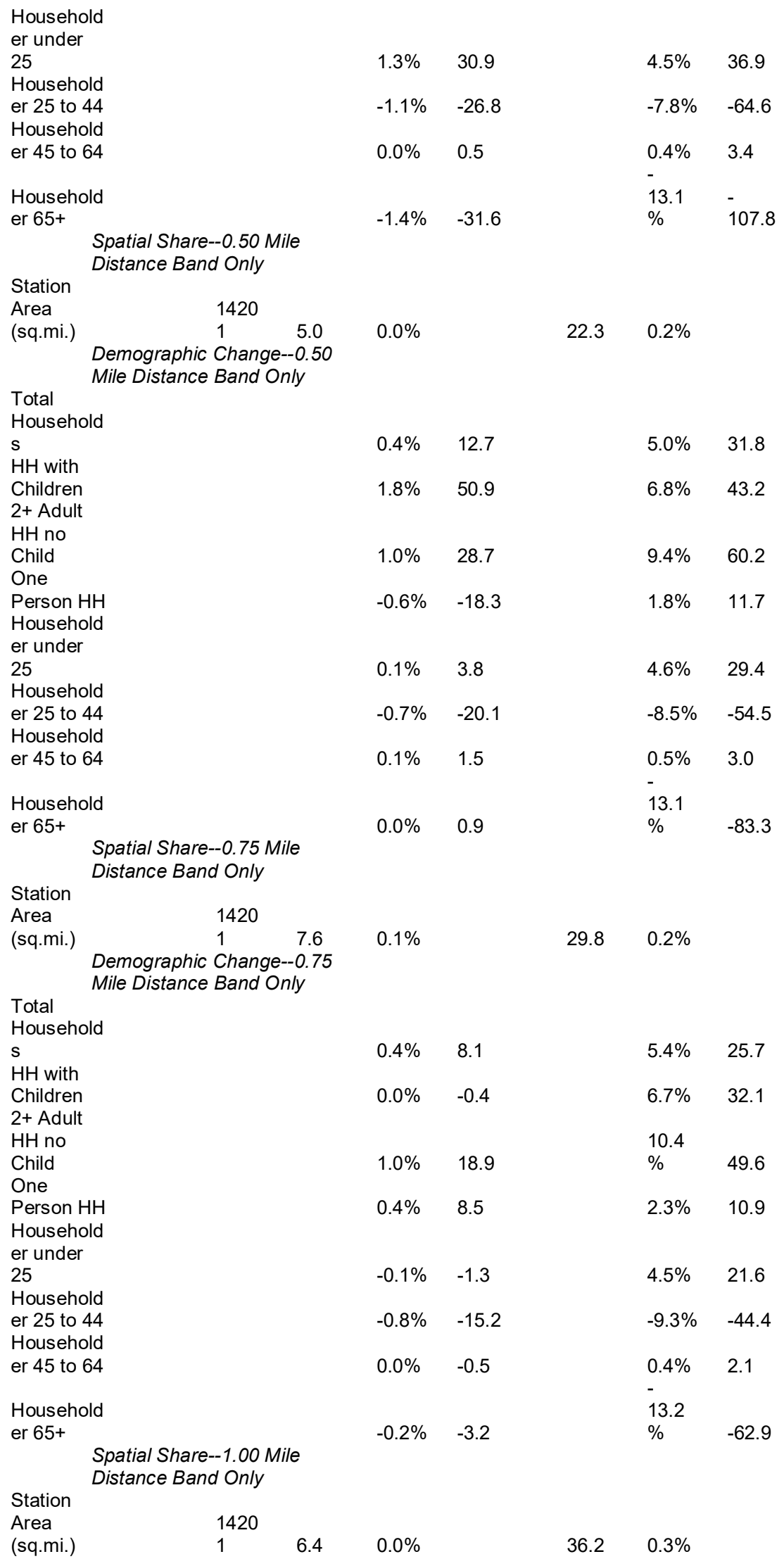




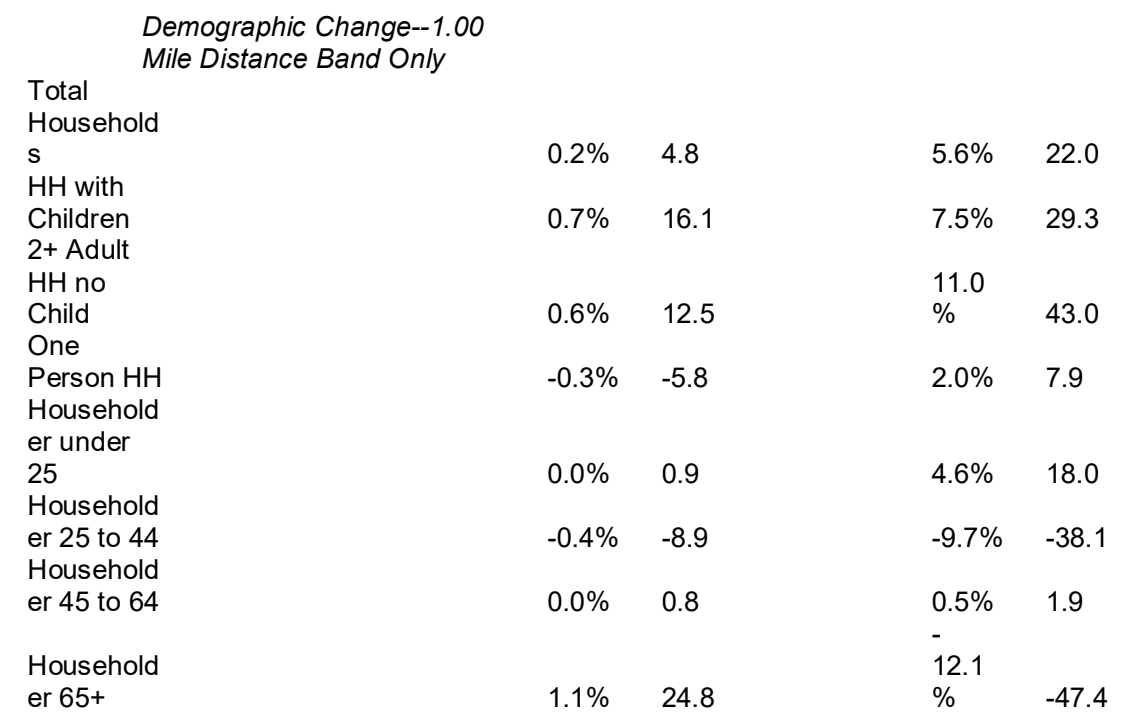

Table 6A.21 Poor MA CRT Households

\begin{tabular}{|c|c|c|c|c|c|c|c|}
\hline $\begin{array}{l}\text { Incrementa } \\
\text { I Analysis }\end{array}$ & & & & & Cumulat & ve Analys & \\
\hline Spatial & & & Distanc & Distanc & & Distanc & Distanc \\
\hline Share-- & & & e Band & e Band & & e Band & e Band \\
\hline Incrementa & Transit & Distanc & Share & Multipli & Distanc & Share & Multipli \\
\hline I Distance & Region & e Band & & er of & e Band & & er of \\
\hline Band & Area, & Area, & Transit & Transit & Area, & Transit & Transit \\
\hline Change & Sq.Mi. & Sq.Mi. & Region & Region & Sq.Mi. & Region & Region \\
\hline Spatial Shar & $-0.125 \Lambda$ & & & & & & \\
\hline Distance Ba & $d$ Only & & & & & & \\
\hline Station & & & & & & & \\
\hline Area & & & & & & & \\
\hline (sq.mi.) & 41703 & 10 & $0.02 \%$ & & 10 & $0.02 \%$ & \\
\hline Demograph & Change & 0.125 & & & & & \\
\hline Mile Distanc & Band $\mathrm{O}$ & & & & & & \\
\hline Total & & & & & & & \\
\hline Household & & & & & & & \\
\hline $\mathrm{s}$ & & & $-1.2 \%$ & -50.4 & & $-1.2 \%$ & -50.4 \\
\hline $\mathrm{HH}$ with & & & & & & & \\
\hline Children & & & $-0.5 \%$ & -19.4 & & $-0.5 \%$ & -19.4 \\
\hline $\begin{array}{l}2+\text { Adult } \\
\mathrm{HH} \text { no }\end{array}$ & & & & & & & \\
\hline Child & & & $-0.3 \%$ & -10.9 & & $-0.3 \%$ & -10.9 \\
\hline One & & & & & & & \\
\hline Person $\mathrm{HH}$ & & & $0.2 \%$ & 6.7 & & $0.2 \%$ & 6.7 \\
\hline Household & & & & & & & \\
\hline $\begin{array}{l}\text { er under } 25 \\
\text { Household }\end{array}$ & & & $0.0 \%$ & 0.4 & & $0.0 \%$ & 0.4 \\
\hline er 25 to 44 & & & $-0.2 \%$ & -10.2 & & $-0.2 \%$ & -10.2 \\
\hline Household & & & & & & & \\
\hline er 45 to 64 & & & $0.3 \%$ & 10.9 & & $0.3 \%$ & 10.9 \\
\hline $\begin{array}{l}\text { Household } \\
\text { er } 65+ \\
\text { Spatial Shar } \\
\text { Distance Ba }\end{array}$ & $\begin{array}{l}0.25 \mathrm{M} \\
\text { Only }\end{array}$ & & $0.4 \%$ & 18.2 & & $0.4 \%$ & 18.2 \\
\hline
\end{tabular}




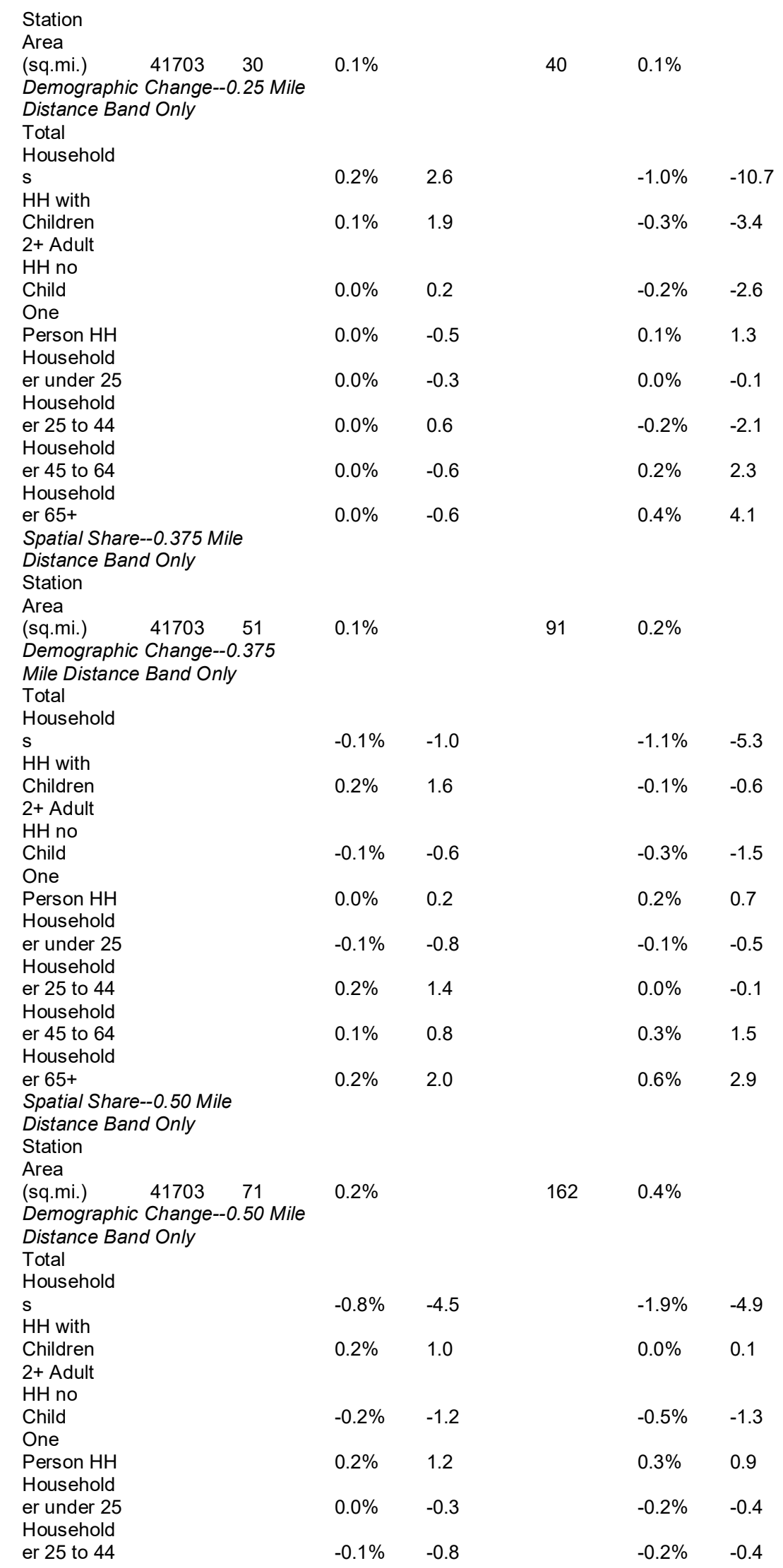




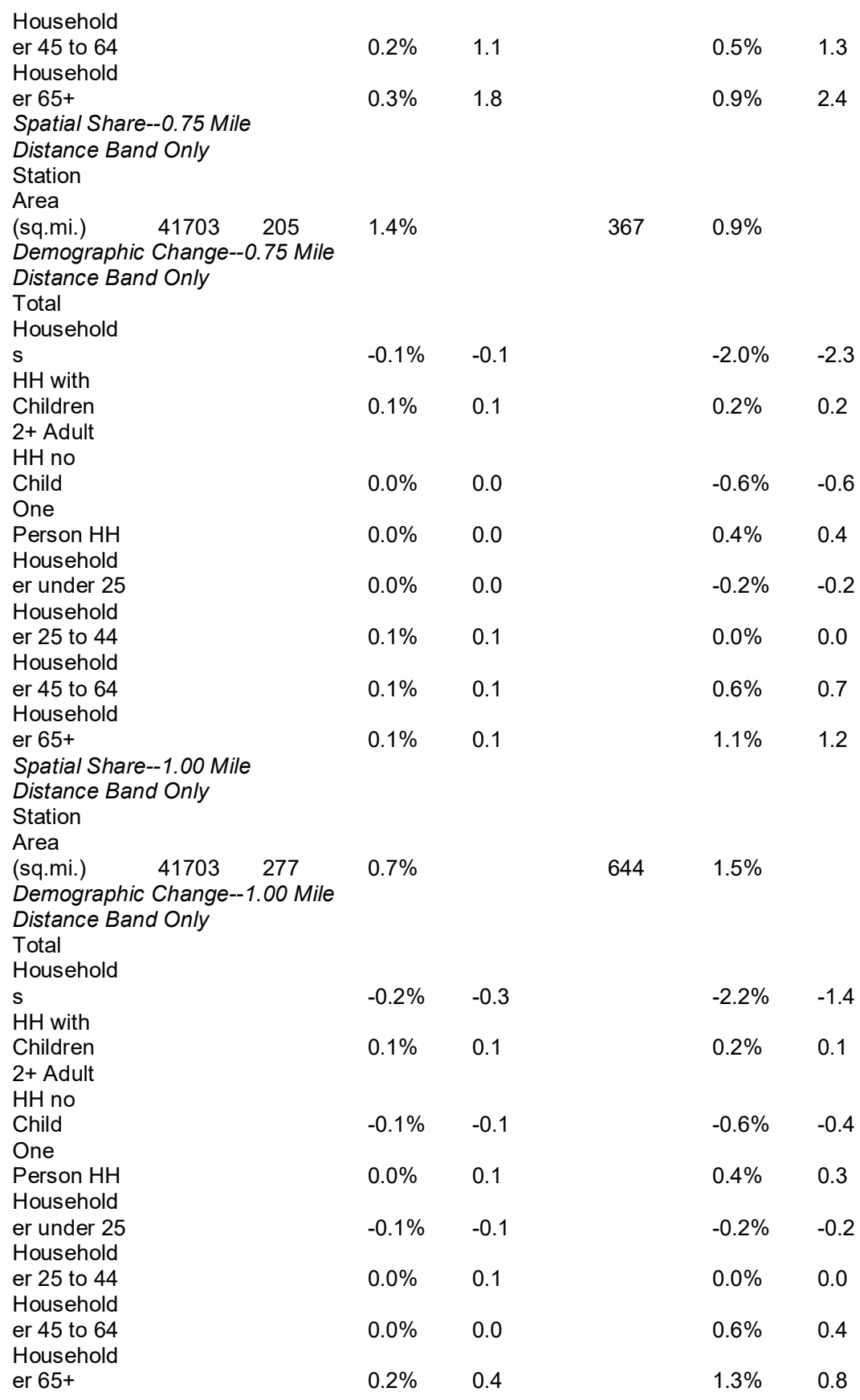

Table 6A.22 Low MA CRT Households

\begin{tabular}{ll}
\hline Incrementa & Cumulative \\
I Analysis & Analysis \\
\hline
\end{tabular}




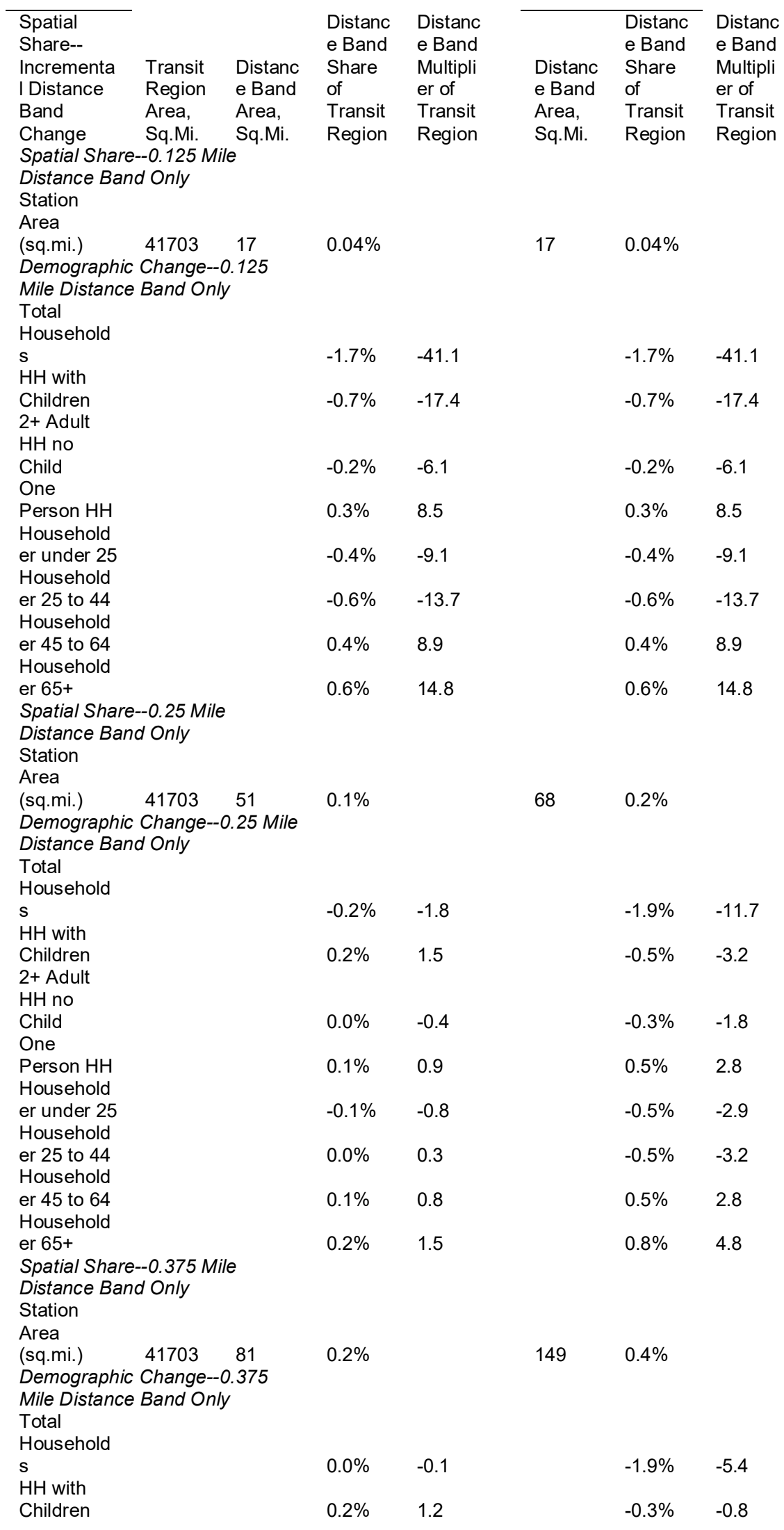




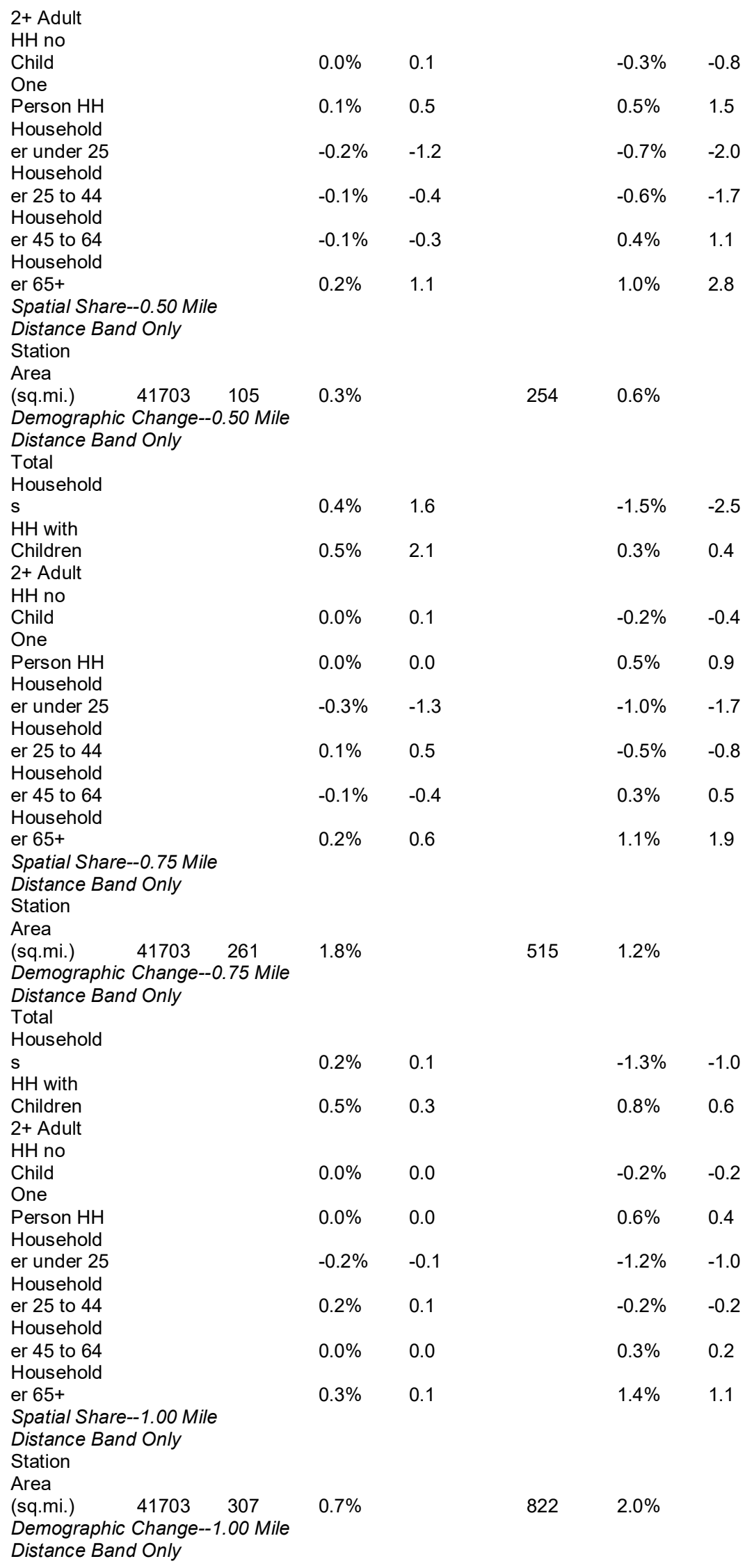


Total

Household

$\mathrm{s}$

$\mathrm{HH}$ with

Children

2+ Adult

$\mathrm{HH}$ no

Child

One

Person HH

Household

er under 25

Household

er 25 to 44

Household

er 45 to 64

Household

er 65+

$\begin{array}{llll}-0.3 \% & -0.4 & -1.6 \% & -0.8 \\ 0.6 \% & 0.8 & 1.4 \% & 0.7 \\ -0.2 \% & -0.2 & -0.4 \% & -0.2 \\ 0.1 \% & 0.2 & 0.7 \% & 0.4 \\ -0.3 \% & -0.5 & -1.6 \% & -0.8 \\ 0.0 \% & 0.1 & -0.2 \% & -0.1 \\ 0.1 \% & 0.2 & 0.4 \% & 0.2 \\ 0.4 \% & 0.6 & 1.8 \% & 0.9\end{array}$

Table 6A.23 Mod MA CRT Households

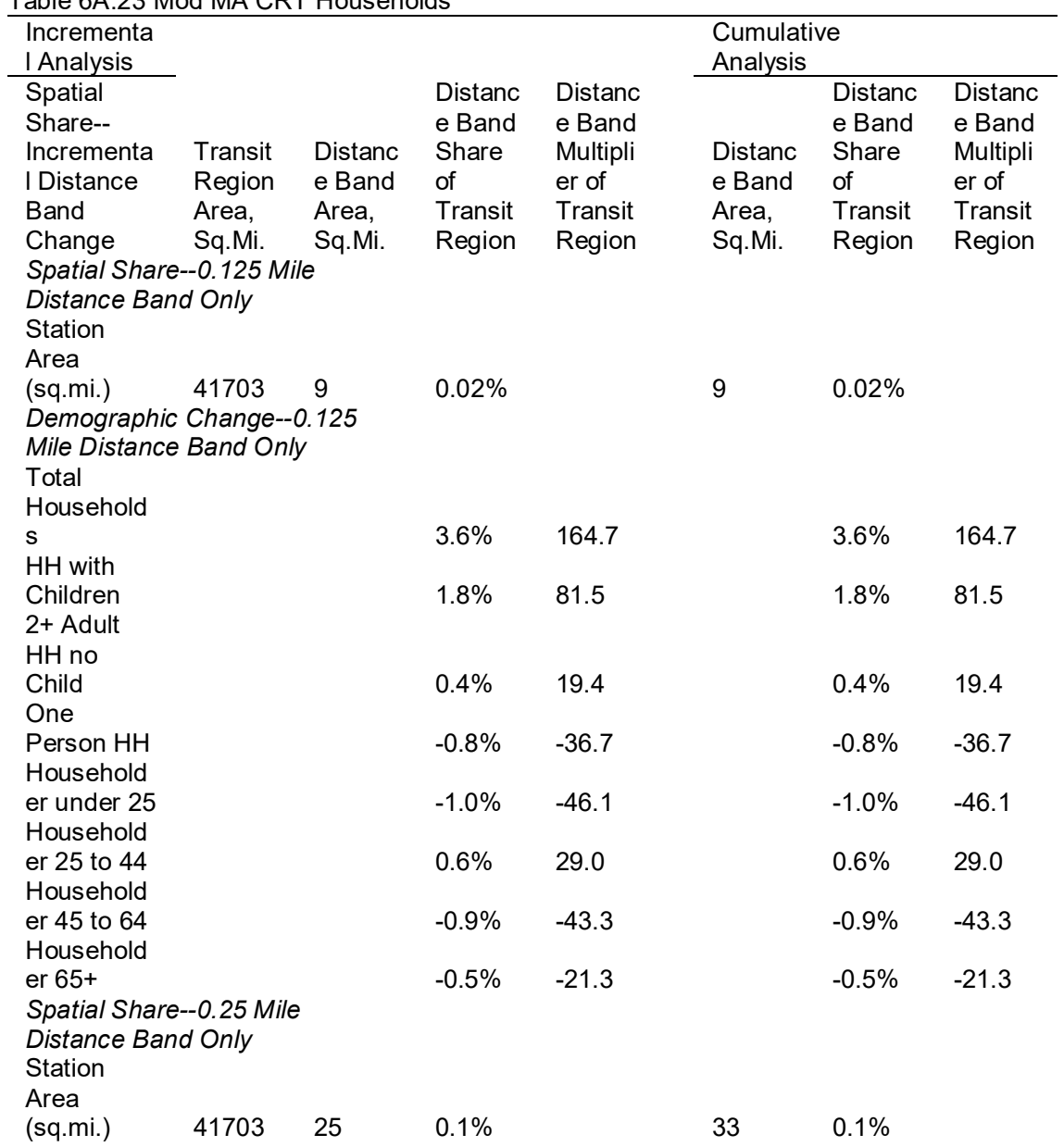




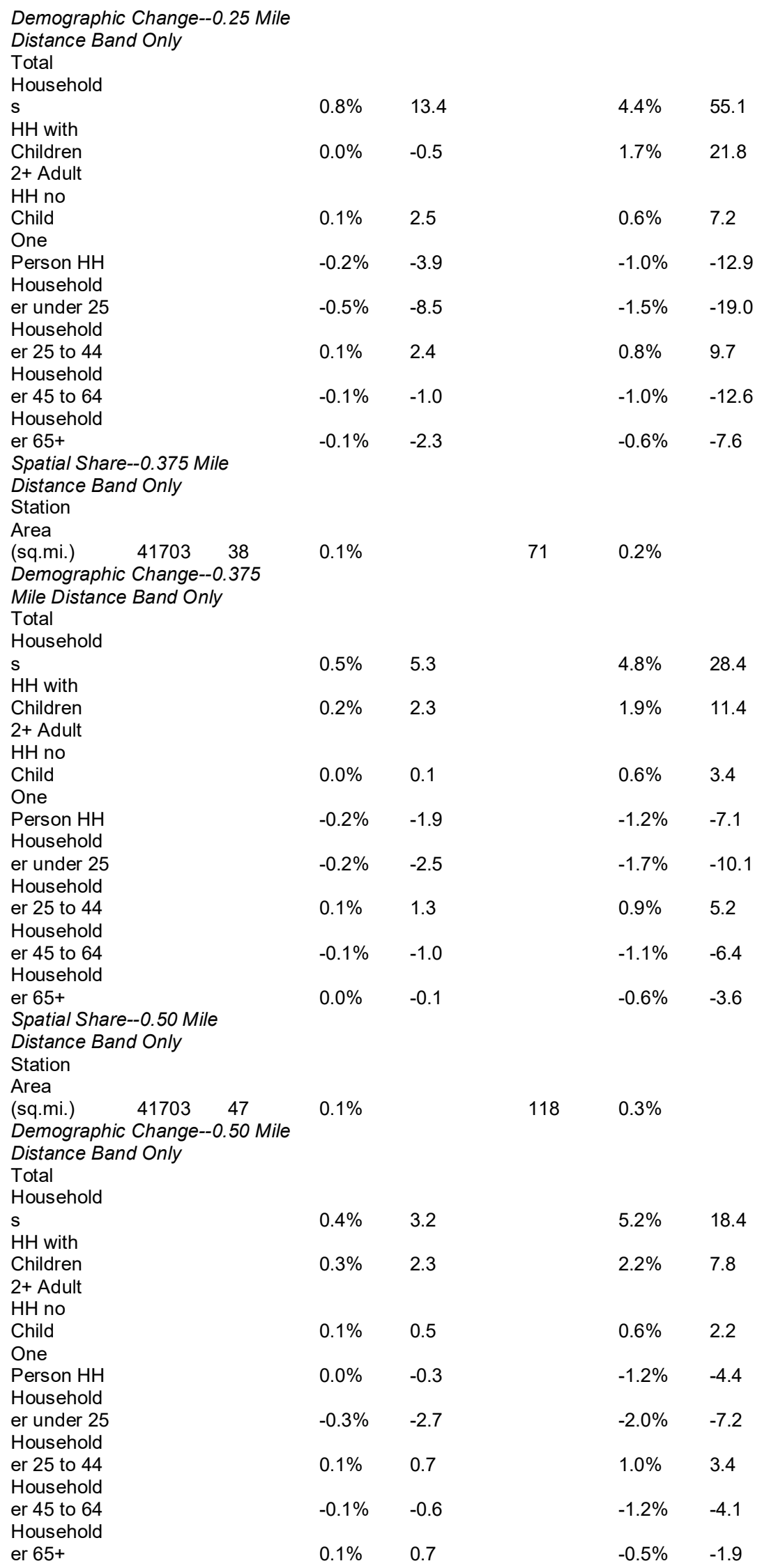




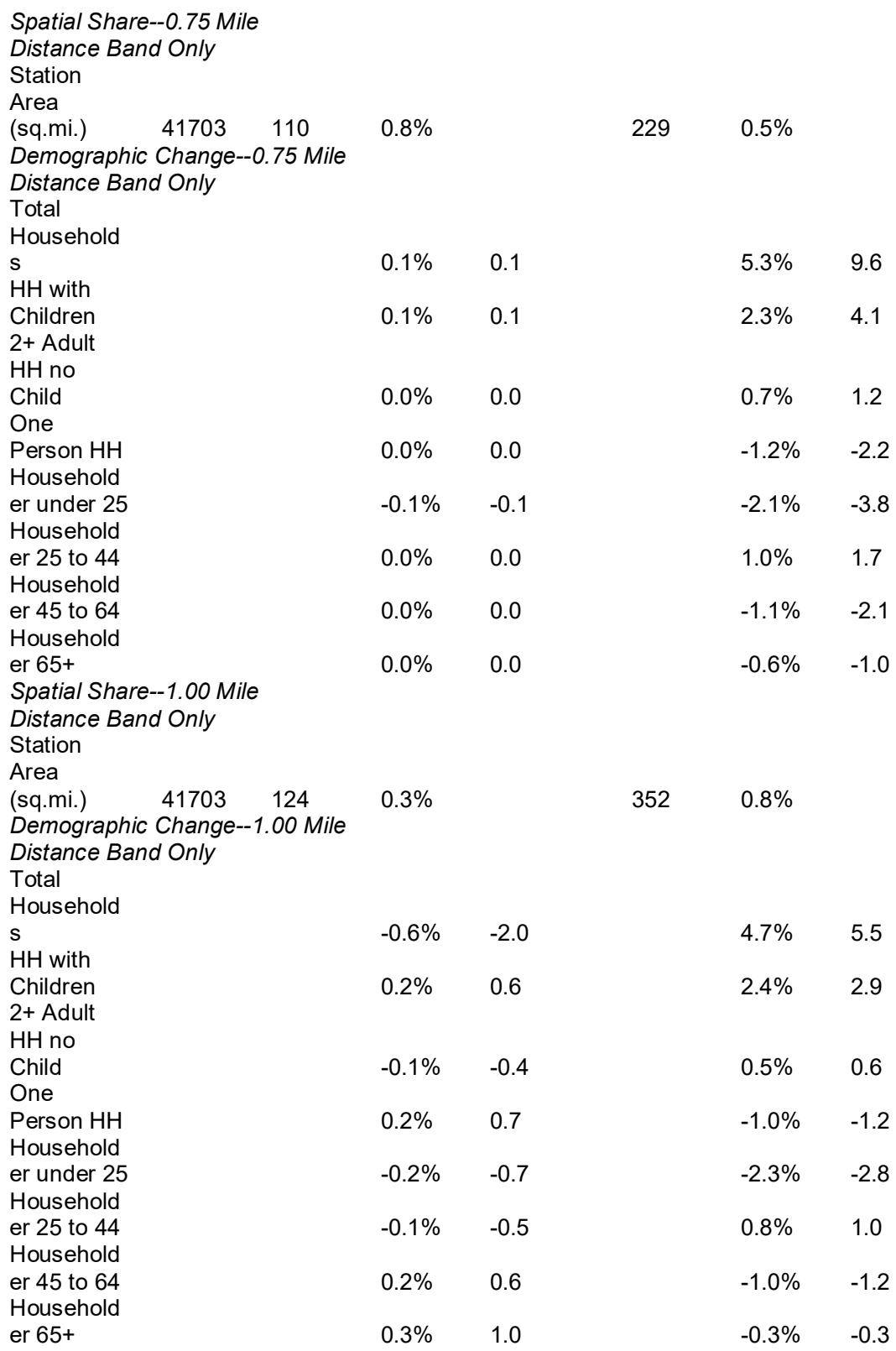

Table 6A.24 High MA CRT Households

\begin{tabular}{|c|c|c|c|c|c|c|c|}
\hline \multicolumn{2}{|l|}{$\begin{array}{l}\text { Incrementa } \\
\text { | Analysis }\end{array}$} & \multirow[b]{2}{*}{$\begin{array}{l}\text { Distanc } \\
\text { e Band } \\
\text { Area, } \\
\text { Sq.Mi. }\end{array}$} & \multirow[b]{2}{*}{$\begin{array}{l}\text { Distanc } \\
\text { e Band } \\
\text { Share } \\
\text { of }\end{array}$} & \multirow[b]{2}{*}{$\begin{array}{l}\text { Distanc } \\
\text { e Band } \\
\text { Multipli } \\
\text { er of }\end{array}$} & \multicolumn{3}{|c|}{ Cumulative Analysis } \\
\hline $\begin{array}{l}\text { Spatial } \\
\text { Share-- } \\
\text { Incrementa } \\
\text { I Distance }\end{array}$ & $\begin{array}{l}\text { Transit } \\
\text { Region } \\
\text { Area, } \\
\text { Sq.Mi. }\end{array}$ & & & & $\begin{array}{l}\text { Distanc } \\
\text { e Band } \\
\text { Area, } \\
\text { Sq.Mi. }\end{array}$ & $\begin{array}{l}\text { Distanc } \\
\text { e Band } \\
\text { Share } \\
\text { of }\end{array}$ & $\begin{array}{l}\text { Distanc } \\
\text { e Band } \\
\text { Multipli } \\
\text { er of }\end{array}$ \\
\hline
\end{tabular}




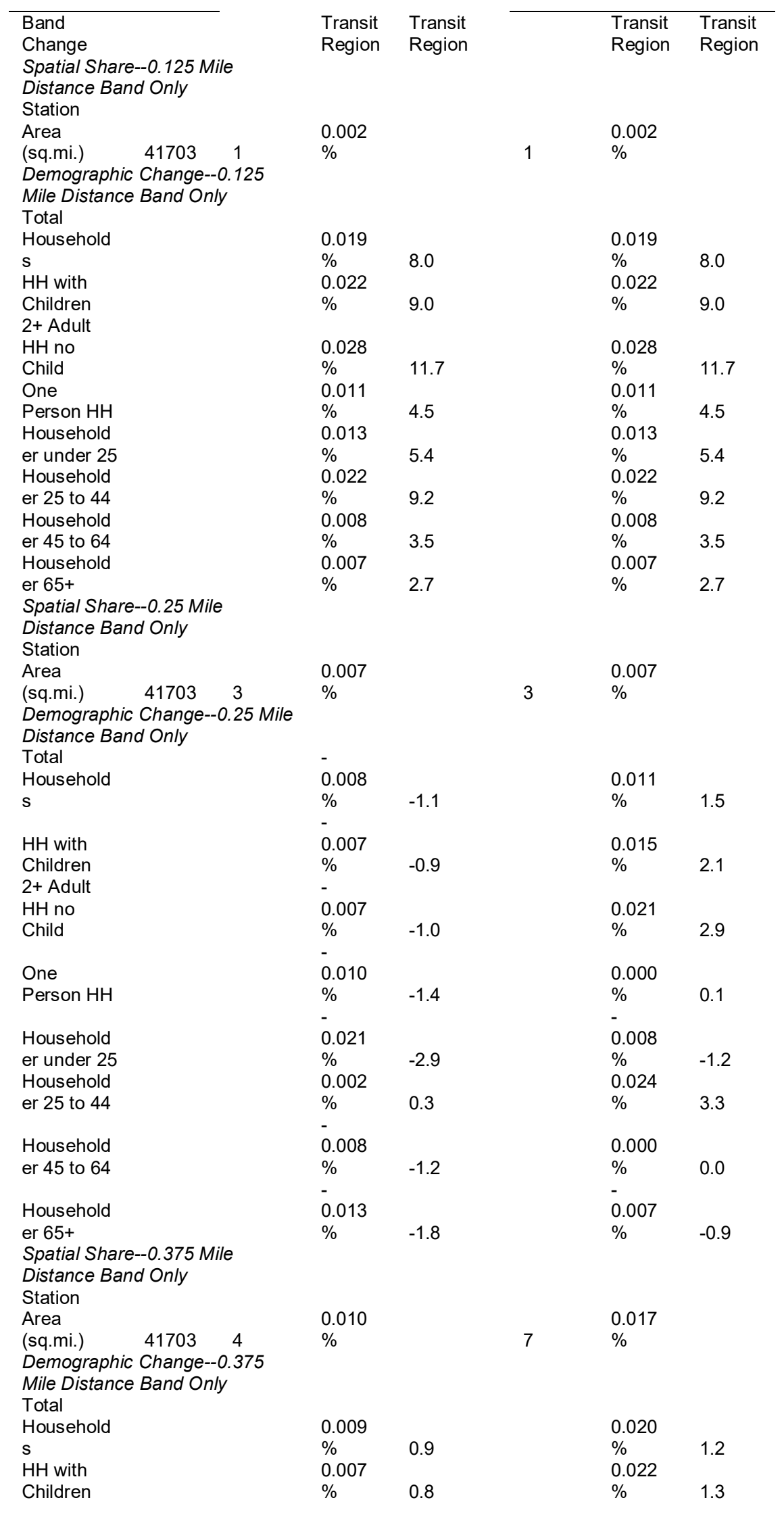




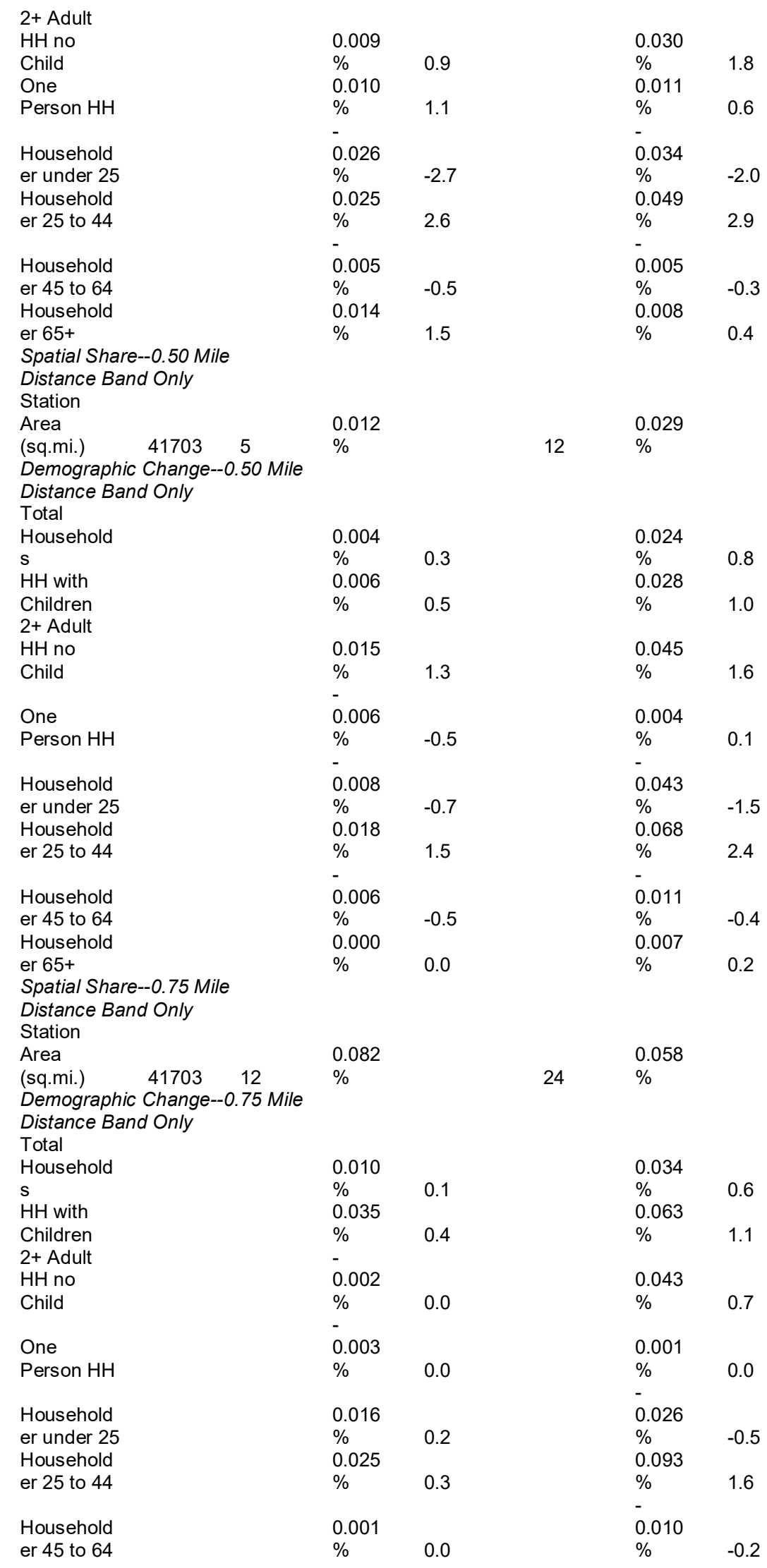




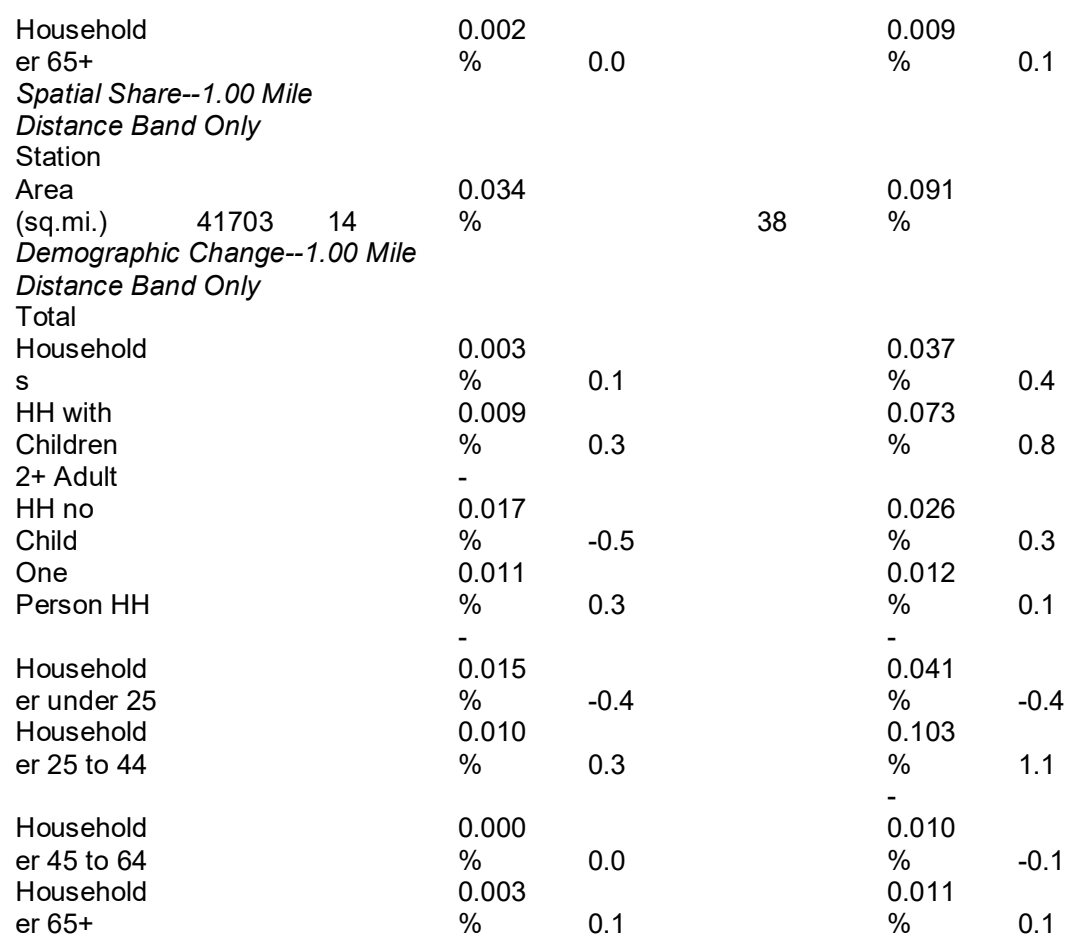

Table 6A.25 Poor MA LRT Households

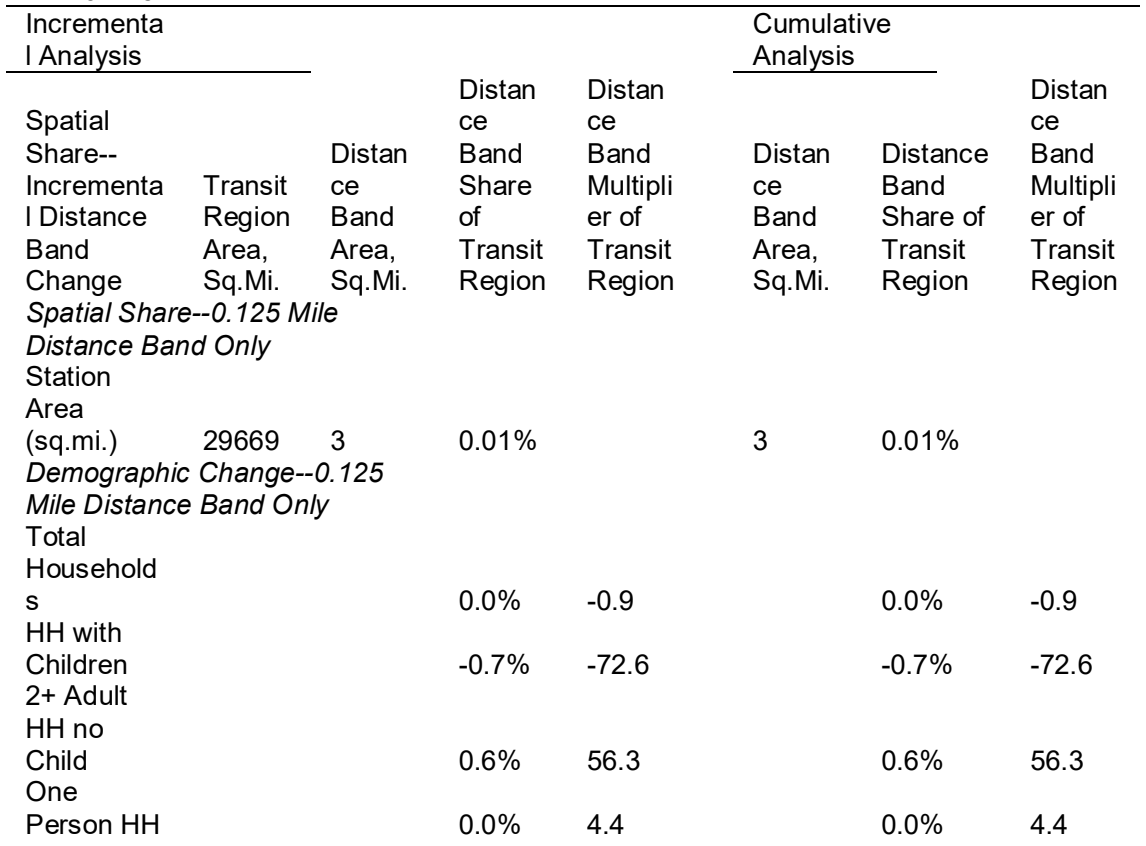




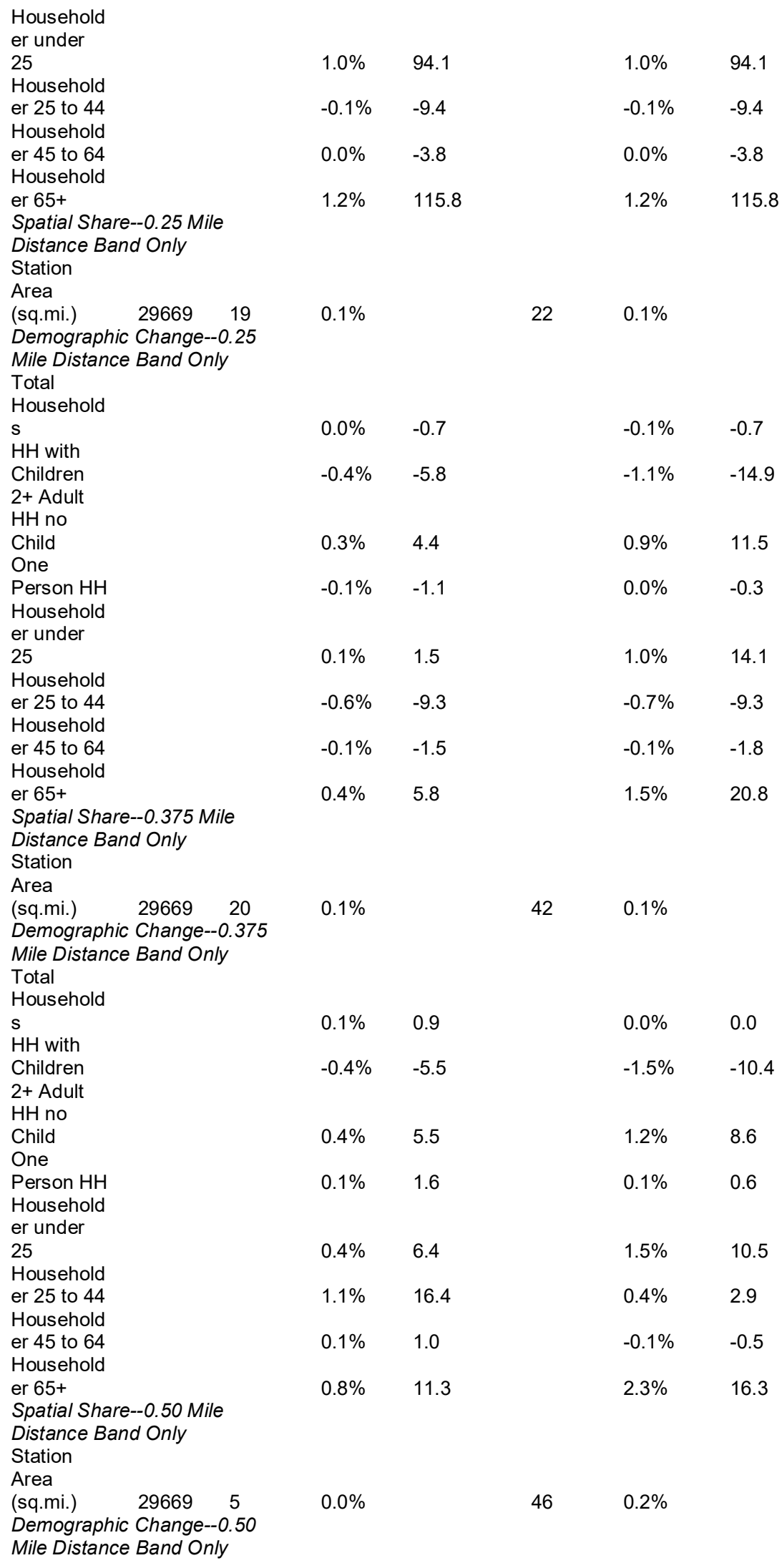


Total

Household

$s$

$\mathrm{HH}$ with

Children

2+ Adult

$\mathrm{HH}$ no

Child

One

Person $\mathrm{HH}$

Household

er under

25

Household

er 25 to 44

Household

er 45 to 64

Household

er 65+

Spatial Share--0.75 Mile

Distance Band Only

Station

$\begin{array}{lll}\text { Area } & & \\ \text { (sq.mi.) } & 29669 & 8\end{array}$

Demographic Change--0.75

Mile Distance Band Only

Total

Household

$\mathrm{HH}$ with

Children

2+ Adult

$\mathrm{HH}$ no

Child

One

Person $\mathrm{HH}$

Household

er under

25

Household

er 25 to 44

Household

er 45 to 64

Household

er 65+

Spatial Share--1.00 Mile

Distance Band Only

Station

Area

(sq.mi.) $\quad 29669 \quad 48$

Demographic Change--1.00

Mile Distance Band Only

Total

Household

$\mathrm{S}$

$\mathrm{HH}$ with

Children

2+ Adult

$\mathrm{HH}$ no

Child

One

Person $\mathrm{HH}$

Household

er under

25

Household

er 25 to 44

Household

er 45 to 64

$\begin{array}{llll}-0.1 \% & -5.5 & -0.1 \% & -0.6 \\ -0.8 \% & -45.5 & -2.2 \% & -14.5 \\ 0.3 \% & 16.1 & 1.5 \% & 9.6 \\ 0.1 \% & 4.6 & 0.2 \% & 1.1 \\ 0.5 \% & 26.9 & 1.9 \% & 12.5 \\ 2.2 \% & 133.3 & 2.7 \% & 17.2 \\ -0.1 \% & -6.2 & -0.2 \% & -1.1 \\ 1.5 \% & 86.2 & 3.8 \% & 24.2\end{array}$

$\begin{array}{lll}0.1 \% & 55 & 0.2 \%\end{array}$

$\begin{array}{llll}0.0 \% & 0.2 & -0.1 \% & -0.4\end{array}$

$\begin{array}{llll}-0.6 \% & -11.4 & -2.9 \% & -15.4\end{array}$

$\begin{array}{llll}0.4 \% & 8.0 & 1.9 \% & 10.4\end{array}$

$\begin{array}{llll}0.1 \% & 2.1 & 0.3 \% & 1.5\end{array}$

$\begin{array}{llll}0.0 \% & -0.8 & 1.9 \% & 10.2\end{array}$

$\begin{array}{llll}0.9 \% & 17.3 & 3.6 \% & 19.5\end{array}$

$\begin{array}{llll}0.0 \% & -0.9 & -0.2 \% & -1.2\end{array}$

$\begin{array}{llll}1.0 \% & 17.7 & 4.7 \% & 25.5\end{array}$

$\begin{array}{llll}0.0 \% & -0.1 & -0.1 \% & -0.2\end{array}$

$\begin{array}{llll}-0.6 \% & -3.6 & -3.4 \% & -9.9\end{array}$

$\begin{array}{llll}0.2 \% & 1.4 & 2.1 \% & 6.2\end{array}$

$\begin{array}{llll}0.2 \% & 1.2 & 0.5 \% & 1.3\end{array}$

$\begin{array}{llll}0.2 \% & 1.2 & 2.1 \% & 6.0\end{array}$

$\begin{array}{lll}1.6 \% & 9.8 & 5.2 \%\end{array}$

$\begin{array}{llll}-0.1 \% & -0.5 & -0.3 \% & -0.8\end{array}$ 
Household

er 65+

Table 6A.26 Low MA LRT Households

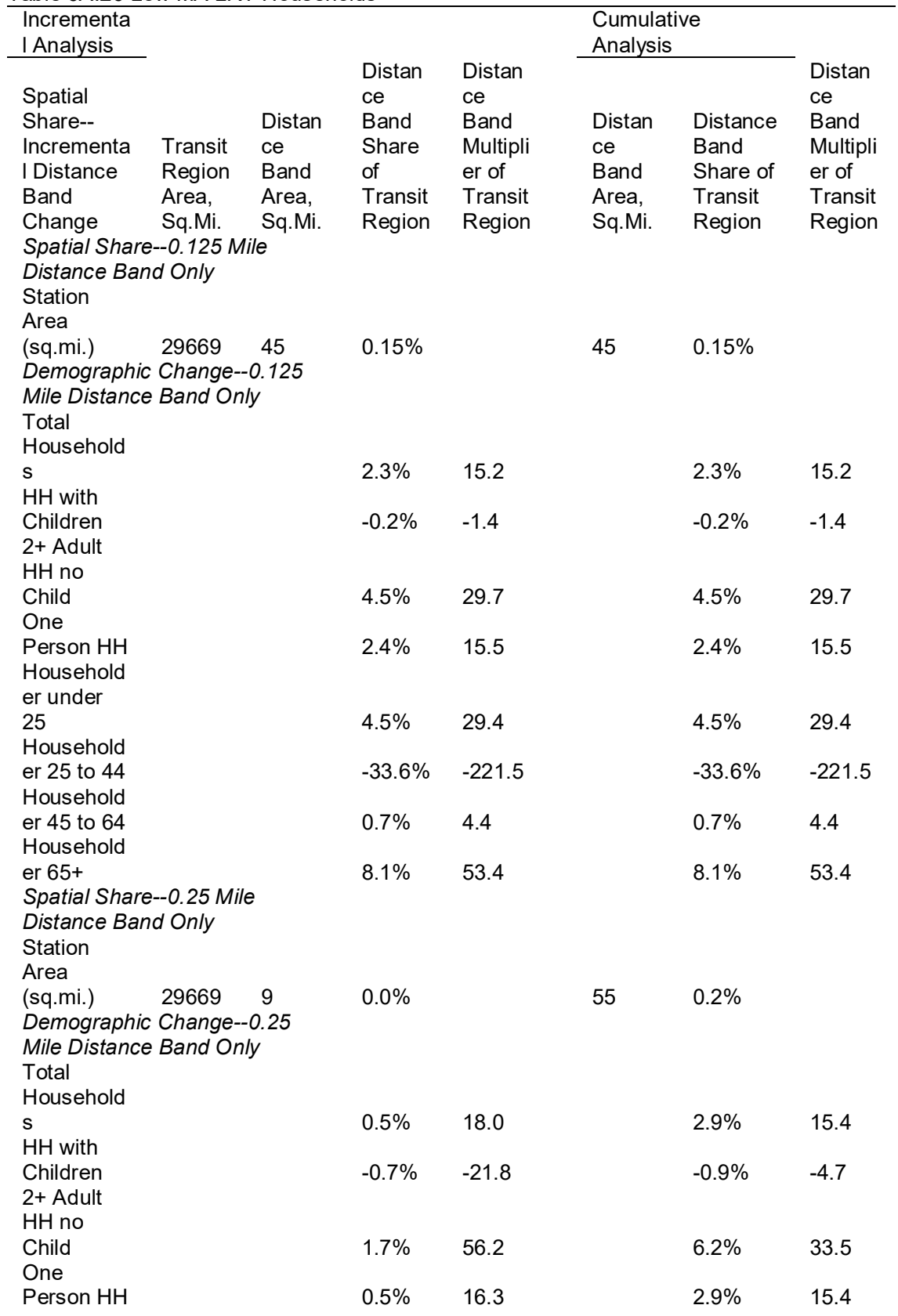




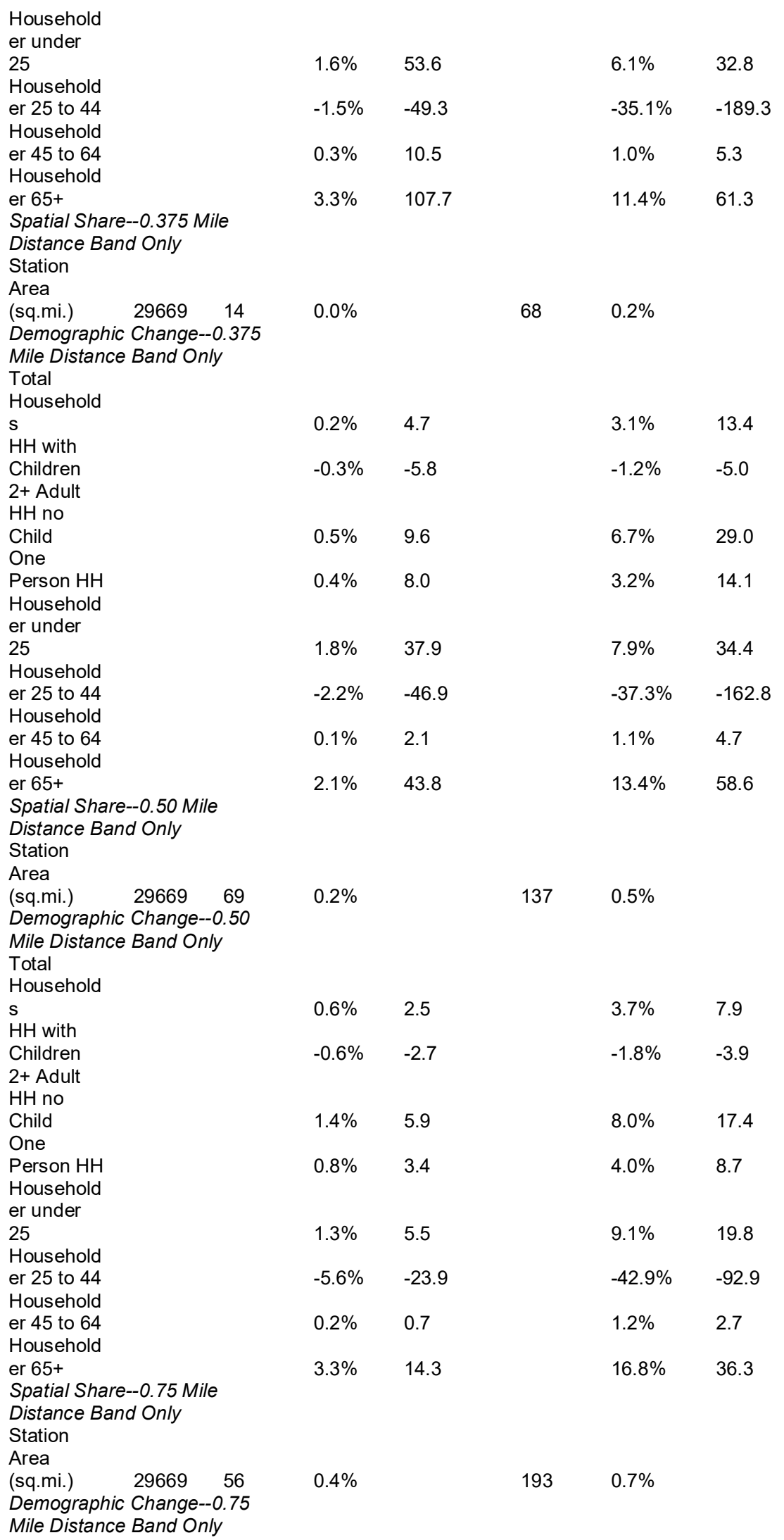


Total

Household

$\mathrm{s}$

$\mathrm{HH}$ with

Children

2+ Adult

$\mathrm{HH}$ no

Child

One

Person $\mathrm{HH}$

Household

er under

25

Household

er 25 to 44

Household

er 45 to 64

Household

er 65+

Spatial Share--1.00 Mile

Distance Band Only

Station

Area

(sq.mi.) $29669 \quad 10$

$0.5 \% \quad 1.2$

Demographic Change--1.00

Mile Distance Band Only

Total

Household

HH with

Children

2+ Adult

$\mathrm{HH}$ no

Child

One

Person $\mathrm{HH}$

Household

er under

25

Household

er 25 to 44

Household

er 45 to 64

Household

er 65+
$-0.5 \% \quad-1.3$

$0.9 \% \quad 2.3$

$0.7 \% \quad 1.9$

$1.4 \% \quad 3.5$

$-3.5 \% \quad-9.1$

$0.1 \% \quad 0.3$

$3.4 \% \quad 9.0$

$-2.3 \%$

$-3.5$

$8.9 \% \quad 13.7$

$4.8 \% \quad 7.3$

$10.5 \% \quad 16.1$

$-46.4 \% \quad-71.3$

$1.4 \% \quad 2.1$

$20.2 \% \quad 31.1$

$\begin{array}{lll}0.0 \% & 203 & 0.7 \%\end{array}$

$0.4 \% \quad 10.7$

$4.5 \% \quad 6.5$

$-0.1 \% \quad-4.4$

$-2.4 \%$

$-3.5$

$0.8 \% \quad 24.2$

$9.7 \% \quad 14.2$

$0.4 \% \quad 10.8$

$5.1 \% \quad 7.5$

$1.5 \% \quad 45.5$

$12.0 \% \quad 17.6$

$-4.5 \% \quad-132.8$

$-50.9 \% \quad-74.3$

$-0.1 \% \quad-1.9$

$1.3 \%$

1.9

$4.1 \%$

122.9

$24.3 \% \quad 35.6$

Table 6A.27 Mod MA LRT Households

\begin{tabular}{|c|c|c|c|c|c|c|c|}
\hline \multicolumn{8}{|l|}{ Incrementa } \\
\hline \multicolumn{5}{|l|}{ I Analysis } & \multicolumn{3}{|c|}{ Cumulative Analysis } \\
\hline Spatial & & & Distanc & Distanc & & Distanc & Distanc \\
\hline Share-- & & & e Band & e Band & & e Band & e Band \\
\hline $\begin{array}{l}\text { Incrementa } \\
\text { I Distance }\end{array}$ & $\begin{array}{l}\text { Transit } \\
\text { Region }\end{array}$ & $\begin{array}{l}\text { Distanc } \\
\text { e Band }\end{array}$ & $\begin{array}{l}\text { Share } \\
\text { of }\end{array}$ & $\begin{array}{l}\text { Multipli } \\
\text { er of }\end{array}$ & $\begin{array}{l}\text { Distanc } \\
\text { e Band }\end{array}$ & $\begin{array}{l}\text { Share } \\
\text { of }\end{array}$ & $\begin{array}{l}\text { Multipli } \\
\text { er of }\end{array}$ \\
\hline Band & Area, & Area, & Transit & Transit & Area, & Transit & Transit \\
\hline Change & Sq.Mi. & Sq.Mi. & Region & & Sq.Mi. & Region & Region \\
\hline \multicolumn{8}{|c|}{ Spatial Share--0.125 Mile } \\
\hline \multicolumn{8}{|c|}{ Distance Band Only } \\
\hline
\end{tabular}




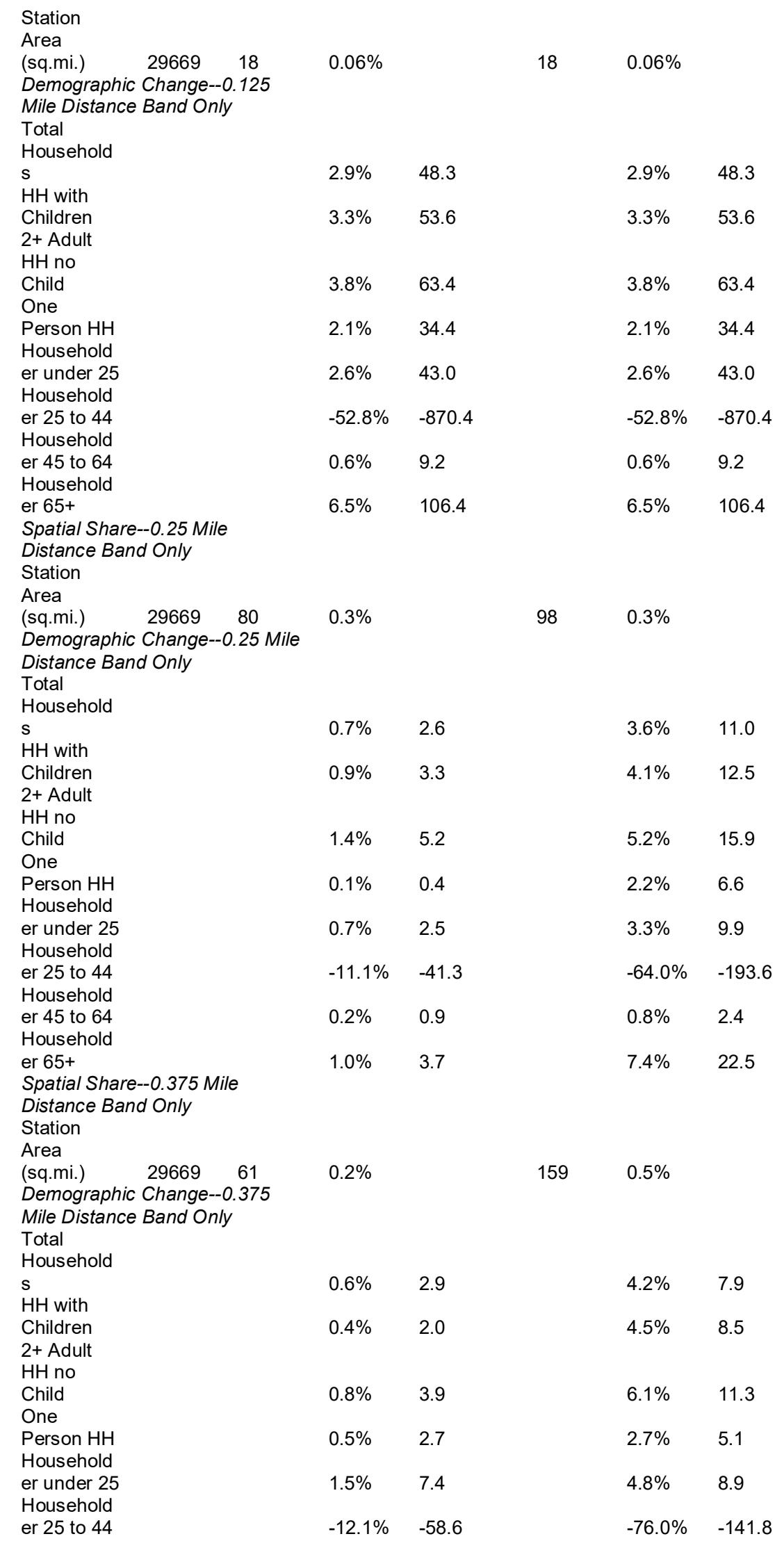




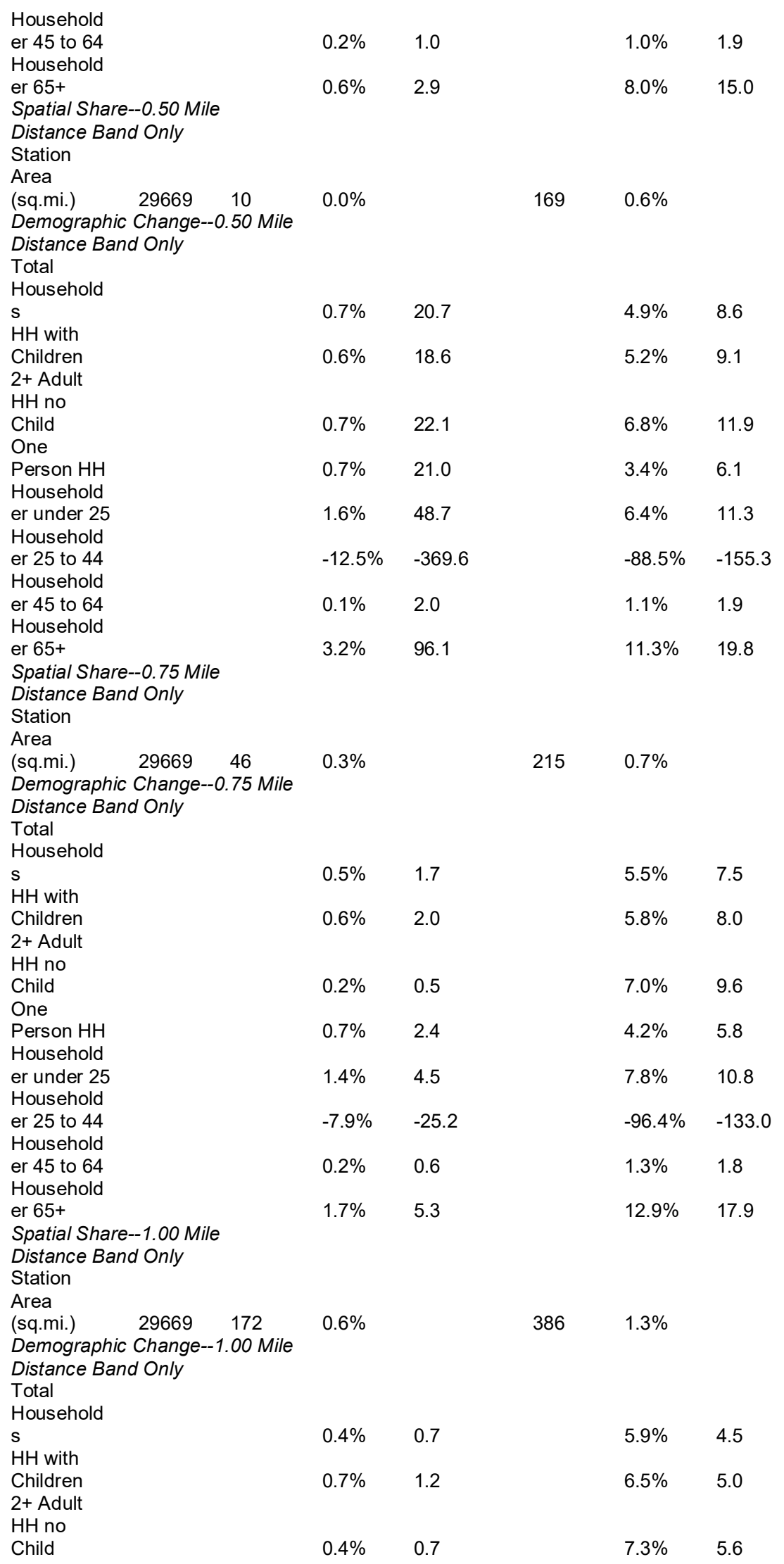




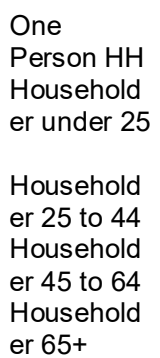

$\begin{array}{ll}0.2 \% & 0.4 \\ 1.3 \% & 2.2 \\ & \\ -8.1 \% & -14.0 \\ 0.1 \% & 0.1 \\ 1.4 \% & 2.5\end{array}$

$4.4 \% \quad 3.4$

$9.1 \% \quad 7.0$

104.5

$\begin{array}{ll}\% & -80.3\end{array}$

Household

Household

$14.4 \% \quad 11.0$

Table 6A.28 High MA LRT Households

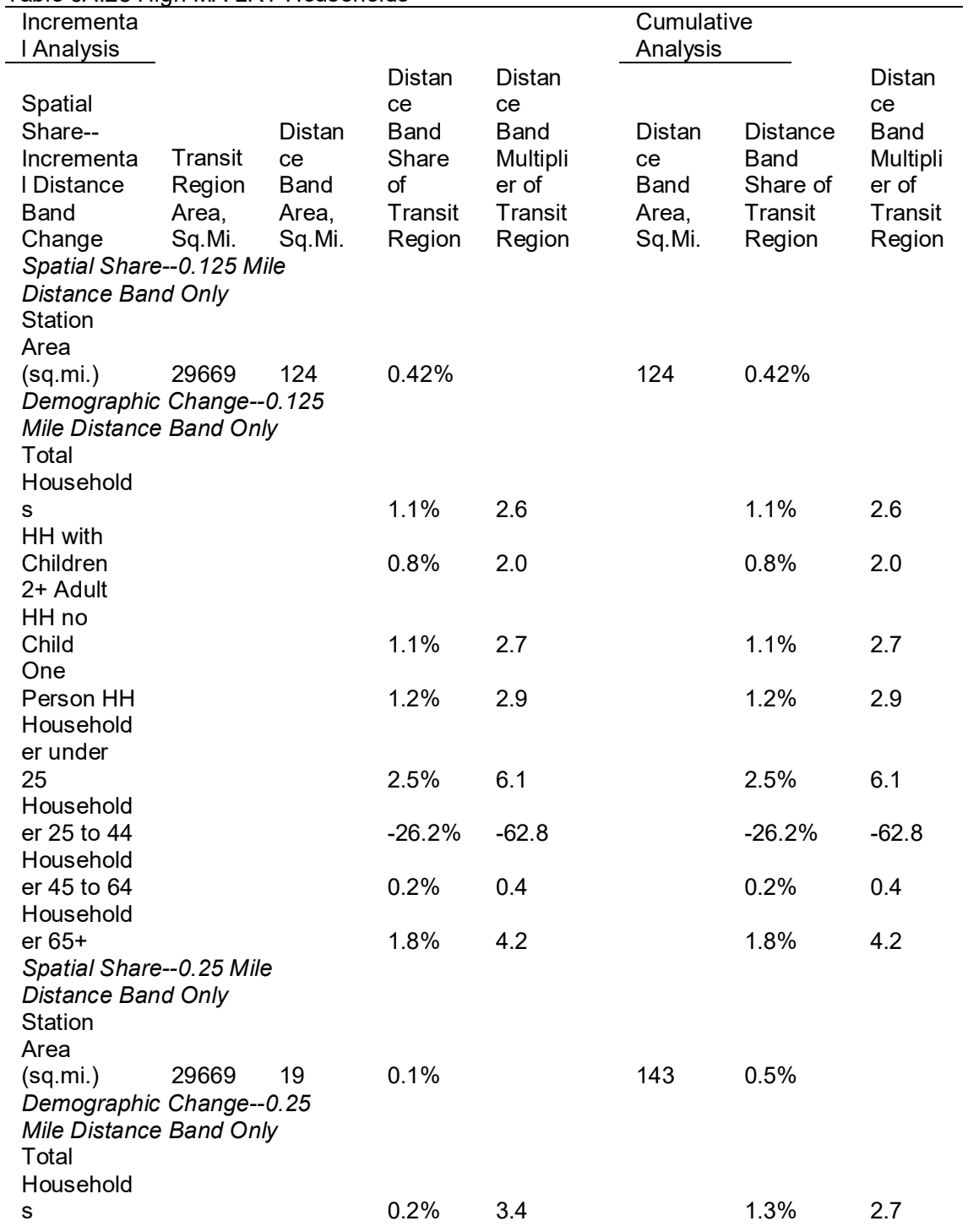




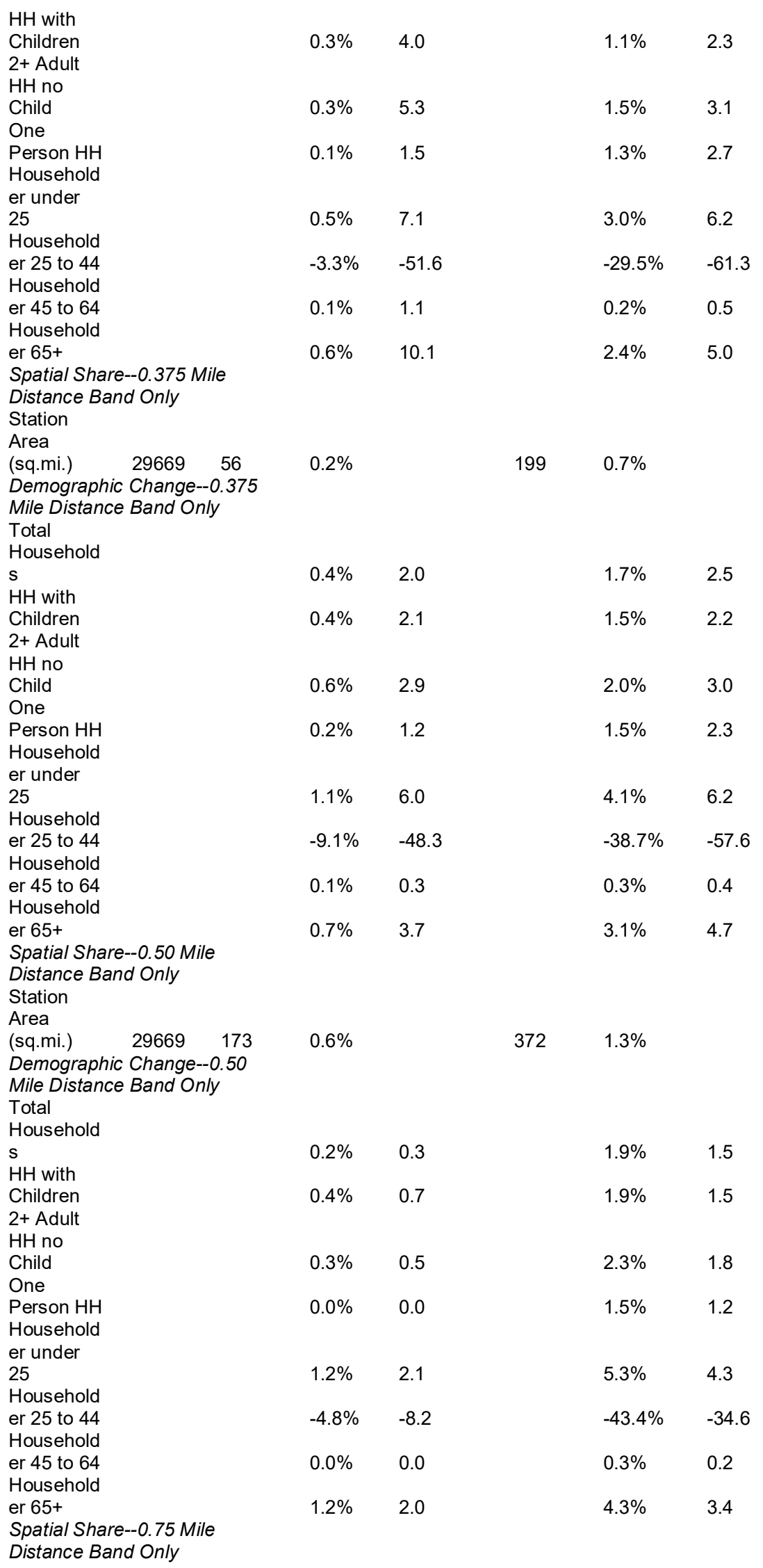




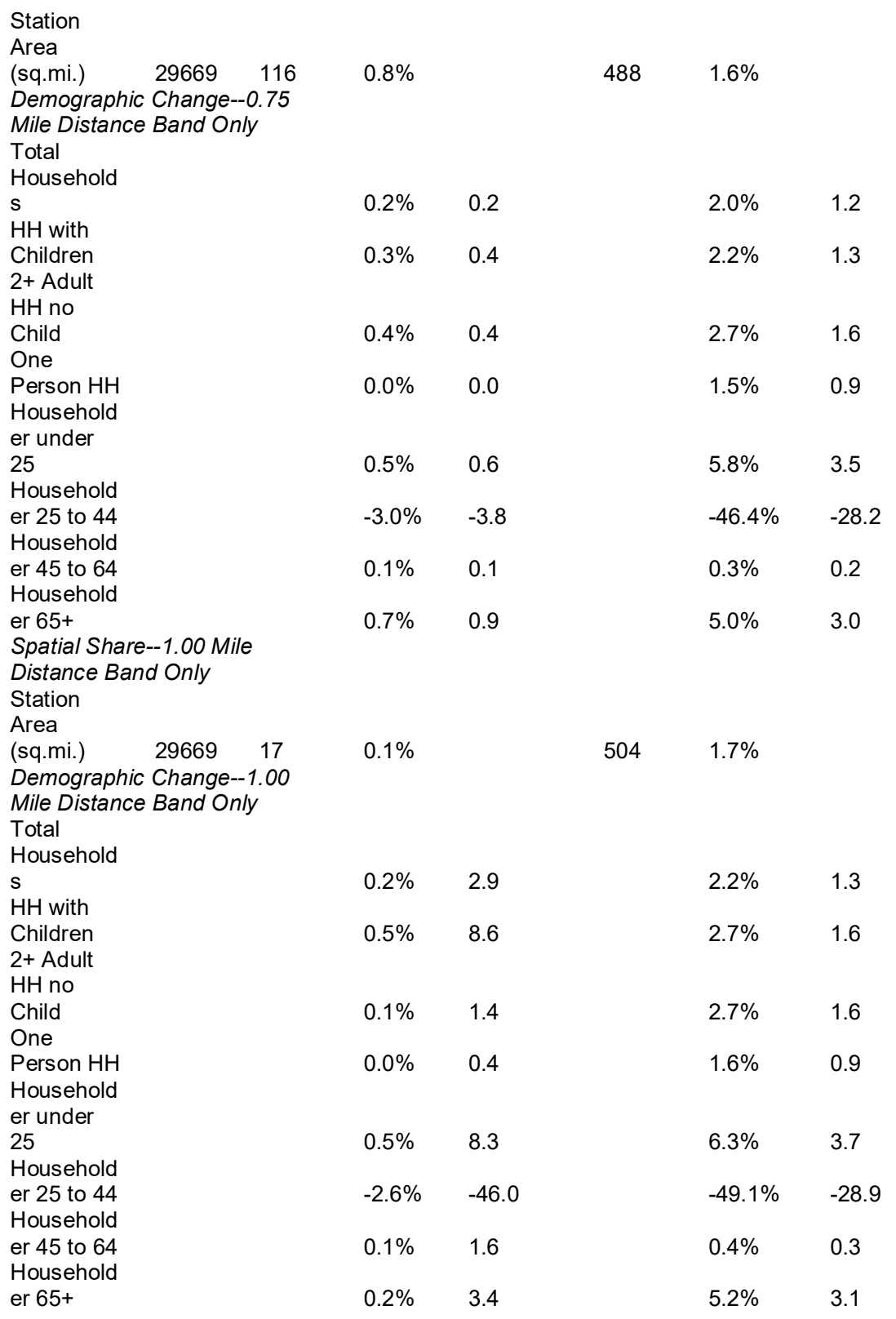

Table 6A.29 Poor MA SCT Households

\begin{tabular}{|c|c|c|c|c|c|c|c|}
\hline $\begin{array}{l}\text { Incrementa } \\
\text { Analysis }\end{array}$ & 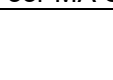 & 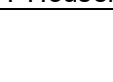 & & & & $\begin{array}{l}\text { umulative } \\
\text { halysis }\end{array}$ & \\
\hline $\begin{array}{l}\text { Spatial } \\
\text { Share-- } \\
\text { Incremen }\end{array}$ & $\begin{array}{l}\text { Transit } \\
\text { Region }\end{array}$ & $\begin{array}{l}\text { Distanc } \\
\text { e Band }\end{array}$ & $\begin{array}{l}\text { Distanc } \\
\text { e Band } \\
\text { Share }\end{array}$ & $\begin{array}{l}\text { Distanc } \\
\text { e Band } \\
\text { Multiplie }\end{array}$ & $\begin{array}{l}\text { Distanc } \\
\text { e Band }\end{array}$ & $\begin{array}{l}\text { Distan } \\
\text { ce } \\
\text { Band }\end{array}$ & $\begin{array}{l}\text { Distan } \\
\text { ce } \\
\text { Band }\end{array}$ \\
\hline
\end{tabular}




\begin{tabular}{|c|c|c|c|c|c|c|c|}
\hline $\begin{array}{l}\text { tal } \\
\text { Distance } \\
\text { Band } \\
\text { Change }\end{array}$ & $\begin{array}{l}\text { Area, } \\
\text { Sq.Mi. }\end{array}$ & $\begin{array}{l}\text { Area, } \\
\text { Sq.Mi. }\end{array}$ & $\begin{array}{l}\text { of } \\
\text { Transit } \\
\text { Region }\end{array}$ & $\begin{array}{l}r \text { of } \\
\text { Transit } \\
\text { Region }\end{array}$ & $\begin{array}{l}\text { Area, } \\
\text { Sq.Mi. }\end{array}$ & $\begin{array}{l}\text { Share } \\
\text { of } \\
\text { Transi } \\
\mathrm{t} \\
\text { Regio } \\
\mathrm{n}\end{array}$ & $\begin{array}{l}\text { Multip } \\
\text { lier of } \\
\text { Trans } \\
\mathrm{t} \\
\text { Regio } \\
\mathrm{n}\end{array}$ \\
\hline \multicolumn{7}{|l|}{$\begin{array}{l}\text { Station } \\
\text { Area }\end{array}$} & \\
\hline \multicolumn{7}{|c|}{$\begin{array}{l}\text { Mile Distance Band Only } \\
\text { Total }\end{array}$} & \\
\hline $\begin{array}{l}\text { Househol } \\
\text { ds } \\
\text { HH with }\end{array}$ & & & $0.0 \%$ & 0.0 & & $0.0 \%$ & 0.0 \\
\hline $\begin{array}{l}\text { Children } \\
2+\text { Adult } \\
\mathrm{HH} \text { no }\end{array}$ & & & $0.0 \%$ & 0.0 & & $0.0 \%$ & 0.0 \\
\hline \multicolumn{8}{|l|}{ One } \\
\hline $\begin{array}{l}\text { Person } \\
\mathrm{HH} \\
\text { Househol } \\
\text { der under }\end{array}$ & & & $0.0 \%$ & 0.0 & & $0.0 \%$ & 0.0 \\
\hline $\begin{array}{l}25 \\
\text { Househol } \\
\text { der } 25 \text { to }\end{array}$ & & & $0.0 \%$ & 0.0 & & $0.0 \%$ & 0.0 \\
\hline $\begin{array}{l}44 \\
\text { Househol } \\
\text { der } 45 \text { to }\end{array}$ & & & $0.0 \%$ & 0.0 & & $0.0 \%$ & 0.0 \\
\hline $\begin{array}{l}64 \\
\text { Househol }\end{array}$ & & & $0.0 \%$ & 0.0 & & $0.0 \%$ & 0.0 \\
\hline $\begin{array}{l}\text { der } 65+ \\
\text { Spatial SI } \\
\text { Distance } \\
\text { Station }\end{array}$ & ind Only & & $0.0 \%$ & 0.0 & & $0.0 \%$ & 0.0 \\
\hline $\begin{array}{l}\text { Area } \\
\text { (sq.mi.) }\end{array}$ & 12770 & 6 & $0.0 \%$ & & 8 & $0.1 \%$ & \\
\hline $\begin{array}{l}\text { Demogra } \\
\text { Distance } \\
\text { Total } \\
\text { Househol }\end{array}$ & $\begin{array}{l}\text { ic Chang } \\
\text { ind Only }\end{array}$ & -0.25 Mile & & & & & \\
\hline $\begin{array}{l}\text { ds } \\
\mathrm{HH} \text { with }\end{array}$ & & & $0.0 \%$ & -0.5 & & $0.0 \%$ & -0.3 \\
\hline $\begin{array}{l}\text { Children } \\
2+\text { Adult } \\
\mathrm{HH} \text { no }\end{array}$ & & & $0.3 \%$ & 7.3 & & $0.3 \%$ & 5.5 \\
\hline $\begin{array}{l}\text { Child } \\
\text { One } \\
\text { Person }\end{array}$ & & & $0.0 \%$ & -1.0 & & $0.0 \%$ & -0.7 \\
\hline $\begin{array}{l}\text { HH } \\
\text { Househol } \\
\text { der under }\end{array}$ & & & $0.0 \%$ & 0.5 & & $0.0 \%$ & 0.4 \\
\hline $\begin{array}{l}25 \\
\text { Househol } \\
\text { der } 25 \text { to }\end{array}$ & & & $-0.1 \%$ & -2.8 & & $-0.1 \%$ & -2.1 \\
\hline $\begin{array}{l}44 \\
\text { Househol } \\
\text { der } 45 \text { to }\end{array}$ & & & $0.0 \%$ & 0.3 & & $0.0 \%$ & 0.2 \\
\hline $\begin{array}{l}64 \\
\text { Househol }\end{array}$ & & & $-0.1 \%$ & -1.4 & & $-0.1 \%$ & -1.0 \\
\hline $\begin{array}{l}\text { der } 65+ \\
\text { Spatial Sh } \\
\text { Distance } \\
\text { Station }\end{array}$ & $\begin{array}{l}\text { re--0.375 } \\
\text { ind Only }\end{array}$ & & $0.3 \%$ & 6.6 & & $0.3 \%$ & 4.9 \\
\hline $\begin{array}{l}\text { Area } \\
\text { (sq.mi.) }\end{array}$ & 12770 & 10 & $0.1 \%$ & & 18 & $0.1 \%$ & \\
\hline
\end{tabular}




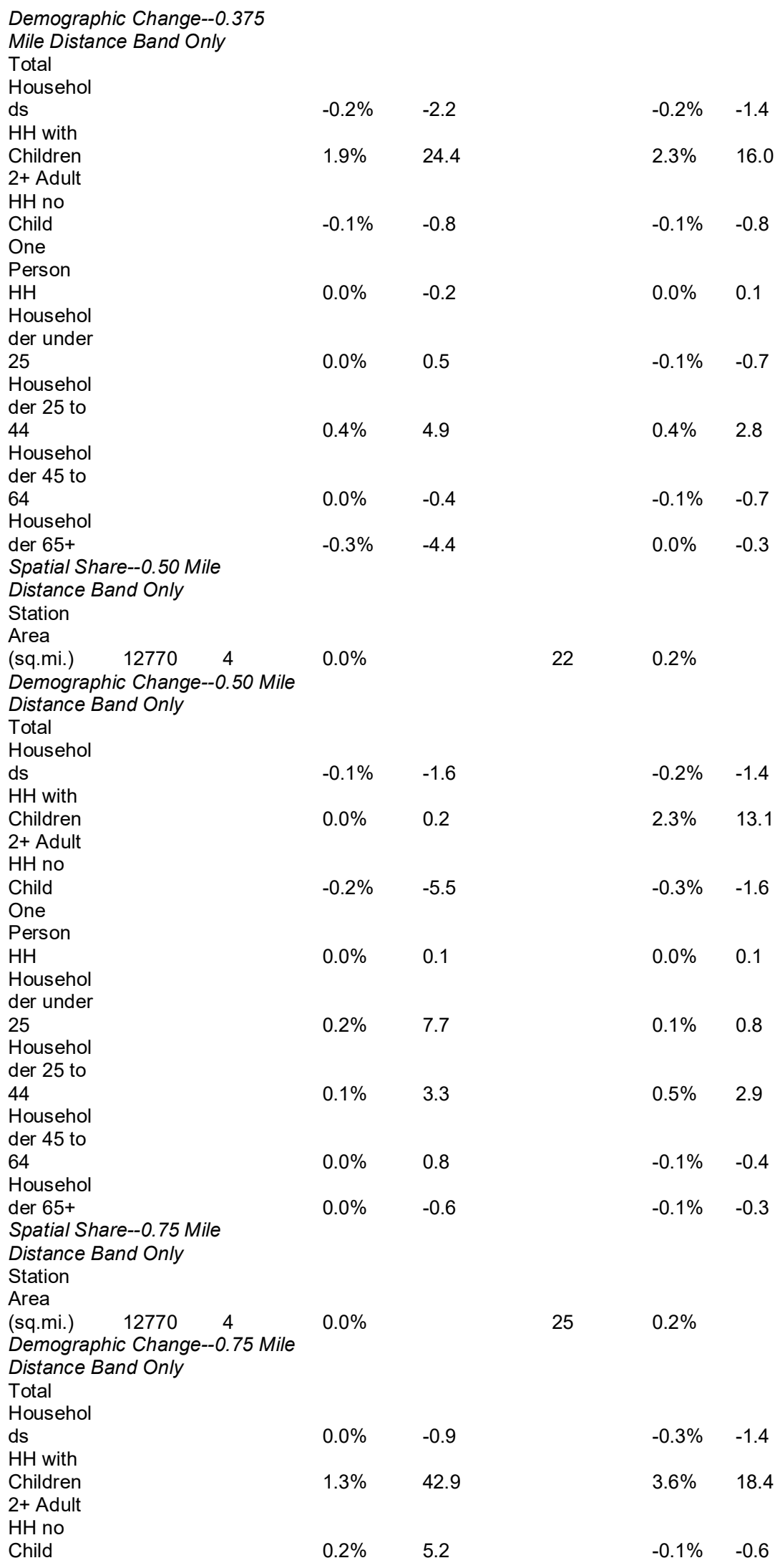




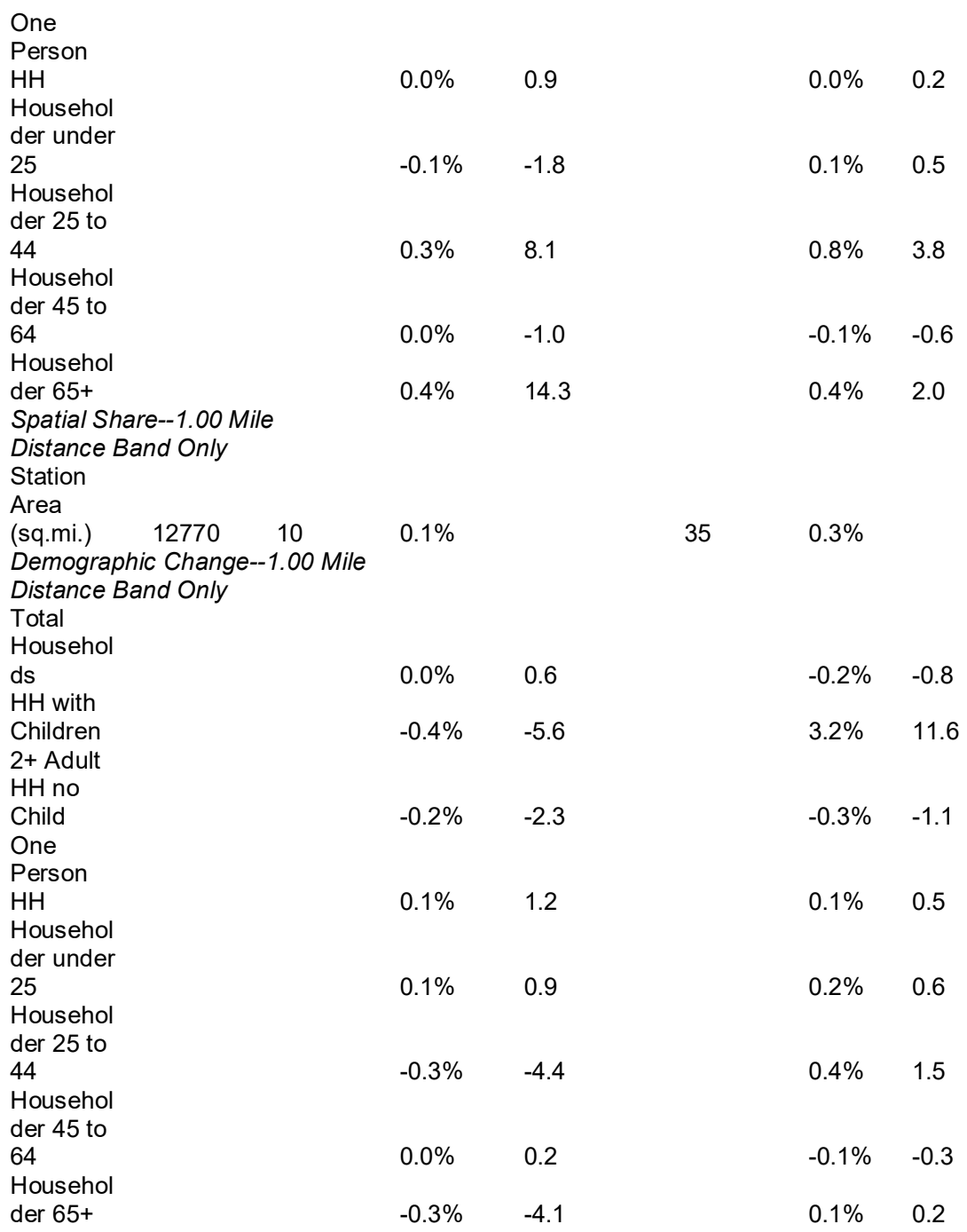

Table 6A.30 Low MA SCT Households

\begin{tabular}{|c|c|c|c|c|c|c|c|}
\hline $\begin{array}{l}\text { Incrementa } \\
\text { I Analysis }\end{array}$ & & & \multirow[b]{2}{*}{ Distanc } & \multirow{3}{*}{$\begin{array}{l}\text { Distanc } \\
\text { e Band }\end{array}$} & \multicolumn{2}{|c|}{ Cumulative } & \multirow{7}{*}{$\begin{array}{l}\text { Distanc } \\
\text { e Band } \\
\text { Multipli } \\
\text { er of } \\
\text { Transit } \\
\text { Region }\end{array}$} \\
\hline Spatial & & & & & & Distanc & \\
\hline Share-- & & & e Band & & & e Band & \\
\hline Incrementa & Transit & Distanc & Share & Multipli & Distanc & Share & \\
\hline I Distance & Region & e Band & & er of & e Band & & \\
\hline Band & Area, & Area, & Transit & Transit & Area, & Transit & \\
\hline Change & Sq.Mi. & Sq.Mi. & Region & Region & Sq.Mi. & Region & \\
\hline \multicolumn{8}{|c|}{ Spatial Share--0.125 Mile } \\
\hline \multicolumn{8}{|c|}{ Distance Band Only } \\
\hline \multicolumn{8}{|l|}{ Station } \\
\hline $\begin{array}{l}\text { Area } \\
\text { (sq.mi.) }\end{array}$ & 12770 & 11 & $0.08 \%$ & & 11 & $0.08 \%$ & \\
\hline
\end{tabular}




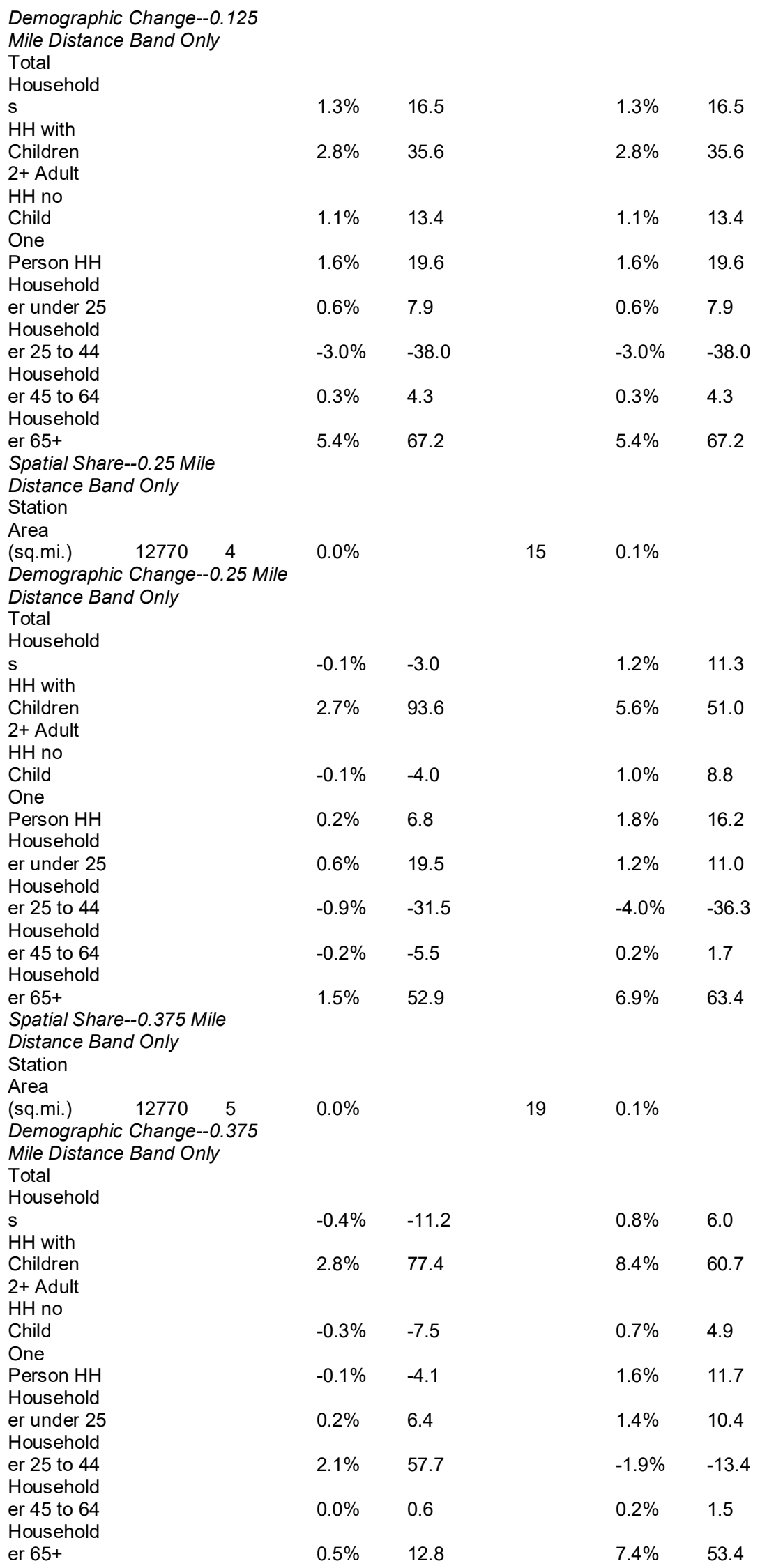




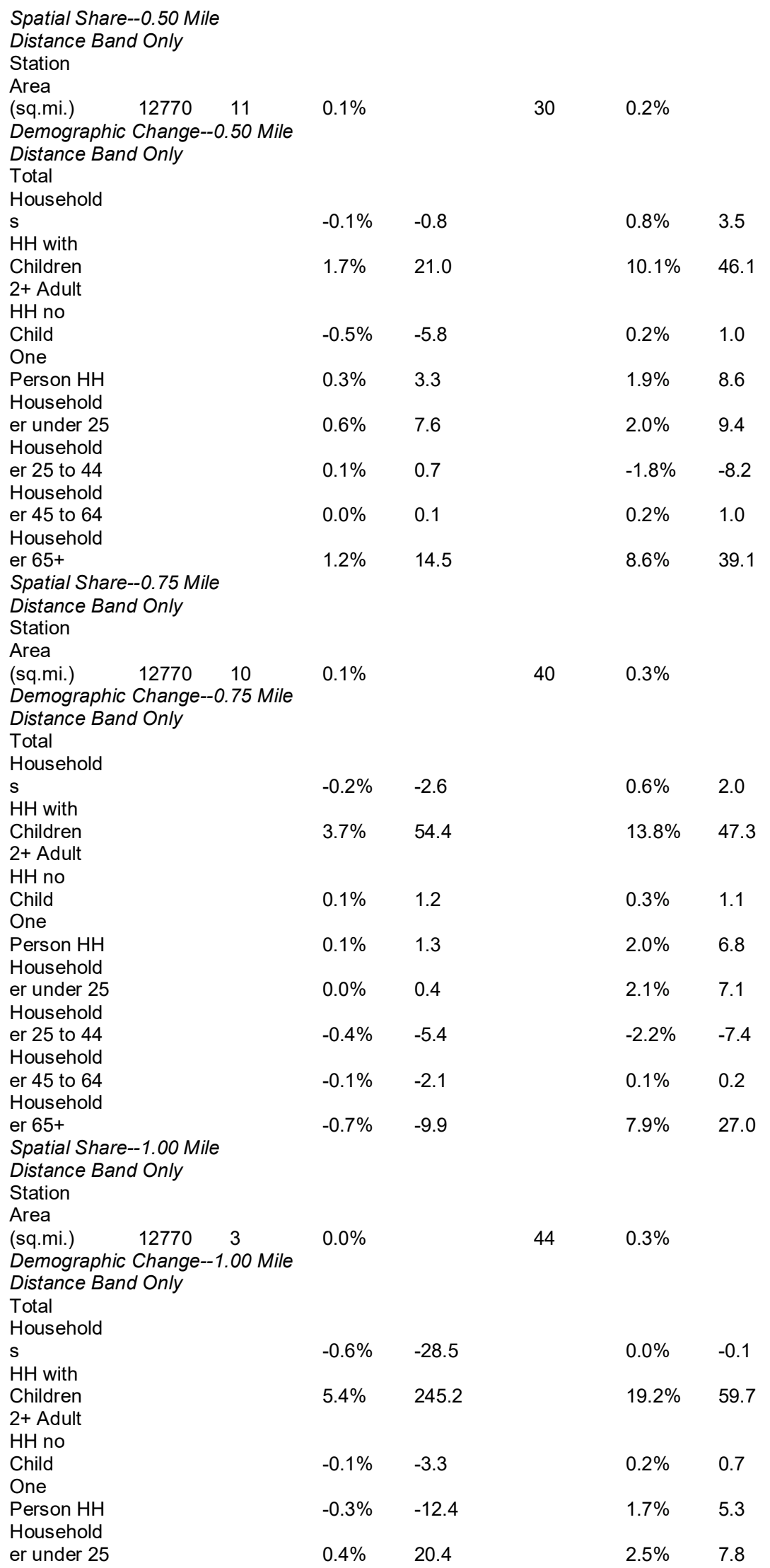




$\begin{array}{lllll}\text { Household } & & & & \\ \text { er } 25 \text { to } 44 & 1.7 \% & 76.8 & -0.5 \% & -1.5 \\ \begin{array}{l}\text { Household } \\ \text { er } 45 \text { to } 64\end{array} & -0.2 \% & -7.3 & -0.1 \% & -0.3 \\ \begin{array}{l}\text { Household } \\ \text { er } 65+\end{array} & 0.8 \% & 36.1 & 8.7 \% & 27.0\end{array}$

Table 6A.31 Mod MA SCT Households

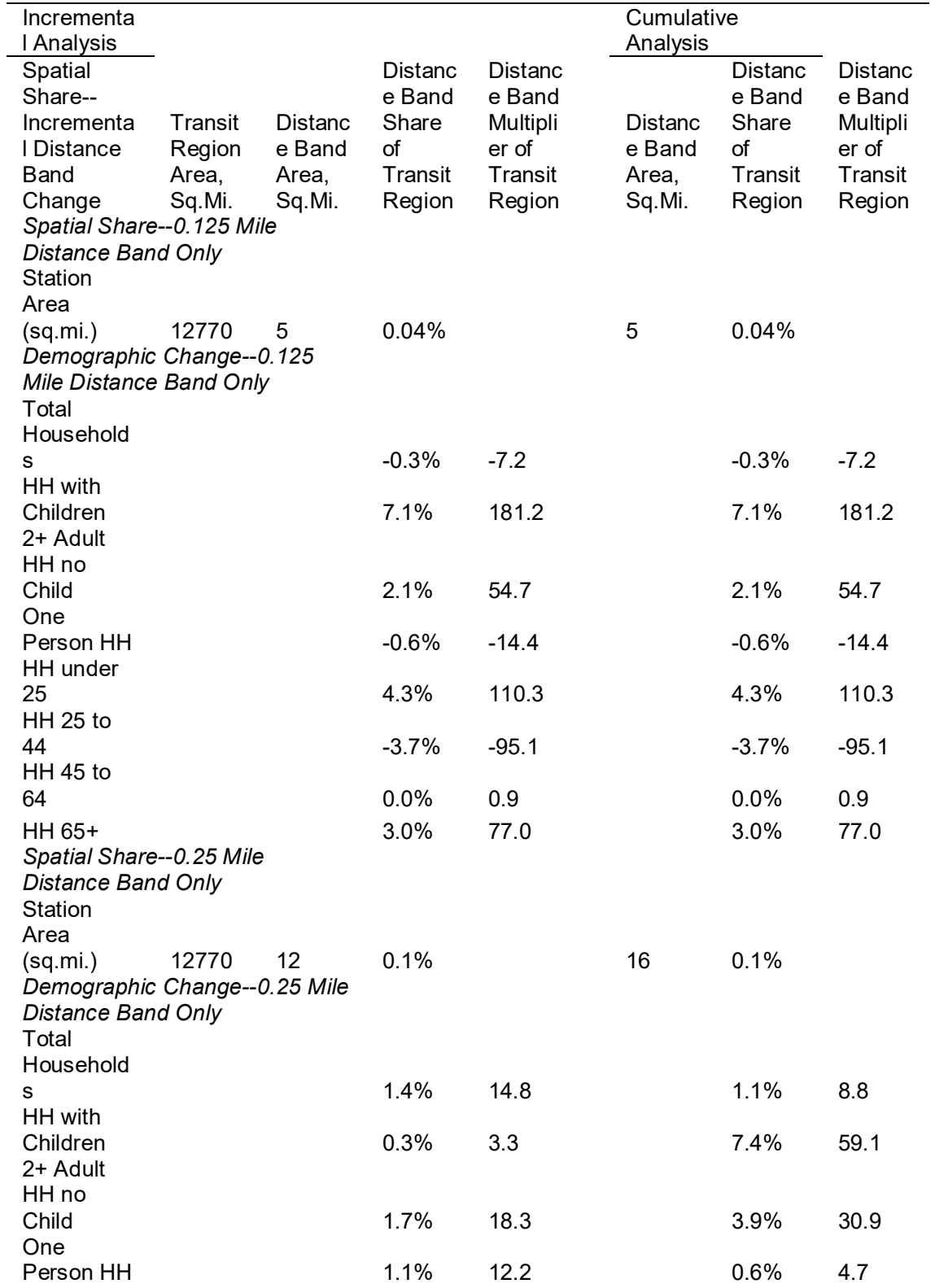




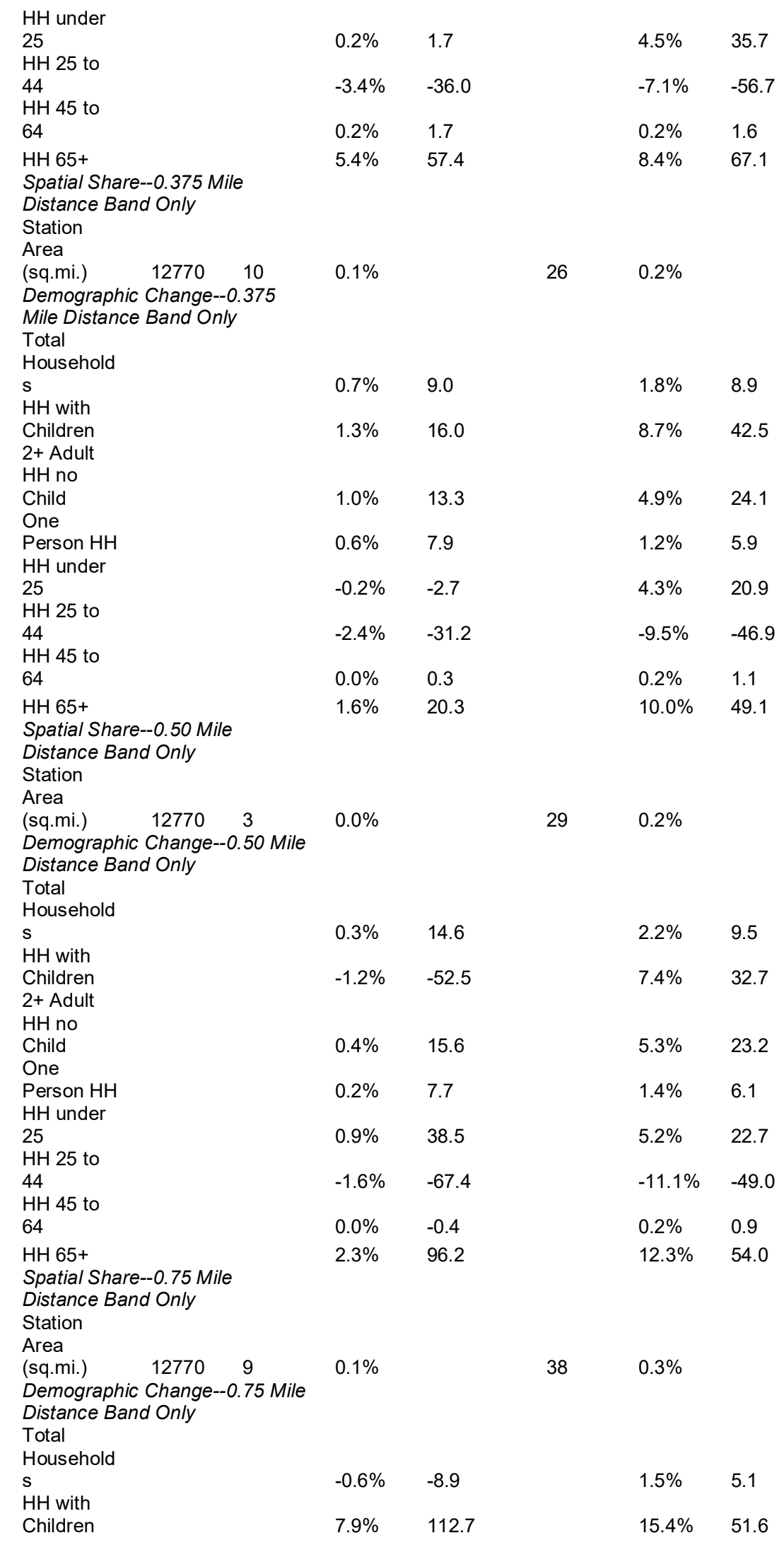




\begin{tabular}{|c|c|c|c|c|c|}
\hline $\begin{array}{l}2+\text { Adult } \\
\mathrm{HH} \text { no }\end{array}$ & & & & & \\
\hline $\begin{array}{l}\text { Child } \\
\text { One }\end{array}$ & $-0.3 \%$ & -4.8 & & $4.9 \%$ & 16.6 \\
\hline $\begin{array}{l}\text { Person } \mathrm{HH} \\
\mathrm{HH} \text { under }\end{array}$ & $0.1 \%$ & 1.1 & & $1.5 \%$ & 4.9 \\
\hline $\begin{array}{l}25 \\
\mathrm{HH} 25 \text { to }\end{array}$ & $1.2 \%$ & 17.7 & & $6.4 \%$ & 21.6 \\
\hline $\begin{array}{l}44 \\
\mathrm{HH}\end{array} 45$ to & $2.2 \%$ & 31.1 & & $-8.9 \%$ & -30.0 \\
\hline 64 & $-0.1 \%$ & -1.0 & & $0.1 \%$ & 0.5 \\
\hline $\begin{array}{l}\mathrm{HH} 65+ \\
\text { Spatial Share--1.00 Mile } \\
\text { Distance Band Only } \\
\text { Station } \\
\text { Area }\end{array}$ & $1.4 \%$ & 19.7 & & $13.6 \%$ & 45.8 \\
\hline $\begin{array}{l}\text { (sq.mi.) } \quad 12770 \quad 25 \\
\text { Demographic Change--1.00 Mile } \\
\text { Distance Band Only } \\
\text { Total } \\
\text { Household }\end{array}$ & $0.2 \%$ & & 62 & $0.5 \%$ & \\
\hline $\begin{array}{l}\mathrm{s} \\
\mathrm{HH} \text { with }\end{array}$ & $-0.2 \%$ & -0.8 & & $1.4 \%$ & 2.8 \\
\hline $\begin{array}{l}\text { Children } \\
2+\text { Adult } \\
\mathrm{HH} \text { no }\end{array}$ & $0.4 \%$ & 2.2 & & $15.8 \%$ & 32.5 \\
\hline $\begin{array}{l}\text { Child } \\
\text { One }\end{array}$ & $-0.1 \%$ & -0.5 & & $4.8 \%$ & 9.9 \\
\hline $\begin{array}{l}\text { Person } \mathrm{HH} \\
\mathrm{HH} \text { under }\end{array}$ & $-0.1 \%$ & -0.6 & & $1.3 \%$ & 2.8 \\
\hline $\begin{array}{l}25 \\
\mathrm{HH} 25 \text { to }\end{array}$ & $1.9 \%$ & 9.9 & & $8.3 \%$ & 17.2 \\
\hline $\begin{array}{l}44 \\
\mathrm{HH} 45 \text { to }\end{array}$ & $-1.1 \%$ & -5.7 & & $-10.0 \%$ & -20.7 \\
\hline 64 & $0.0 \%$ & -0.2 & & $0.1 \%$ & 0.2 \\
\hline HH 65+ & $1.6 \%$ & 8.2 & & $15.3 \%$ & 31.4 \\
\hline
\end{tabular}

Table 6A.32 High MA SCT Households

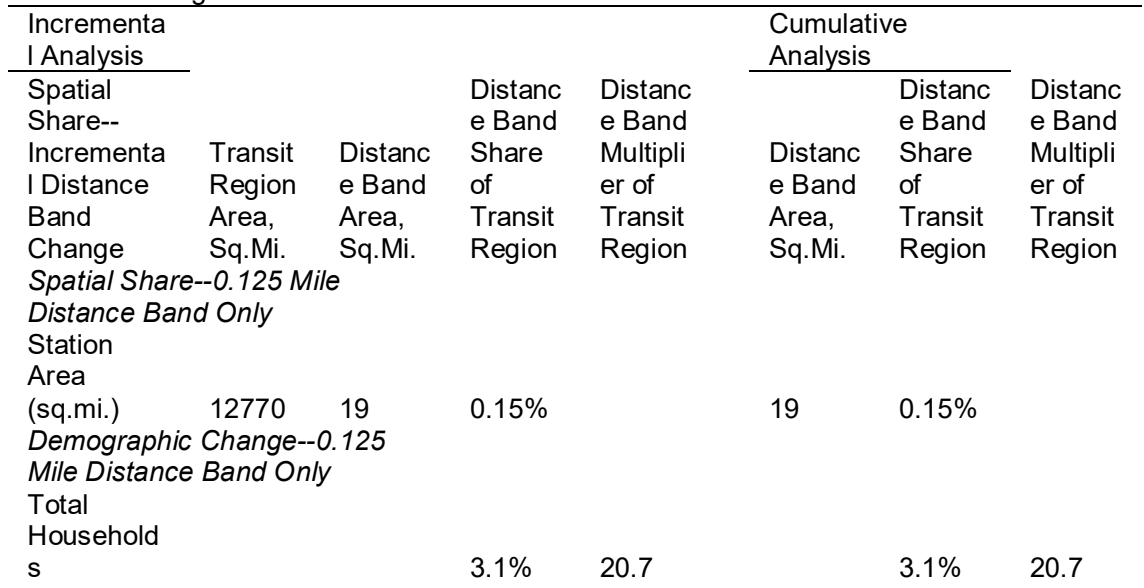




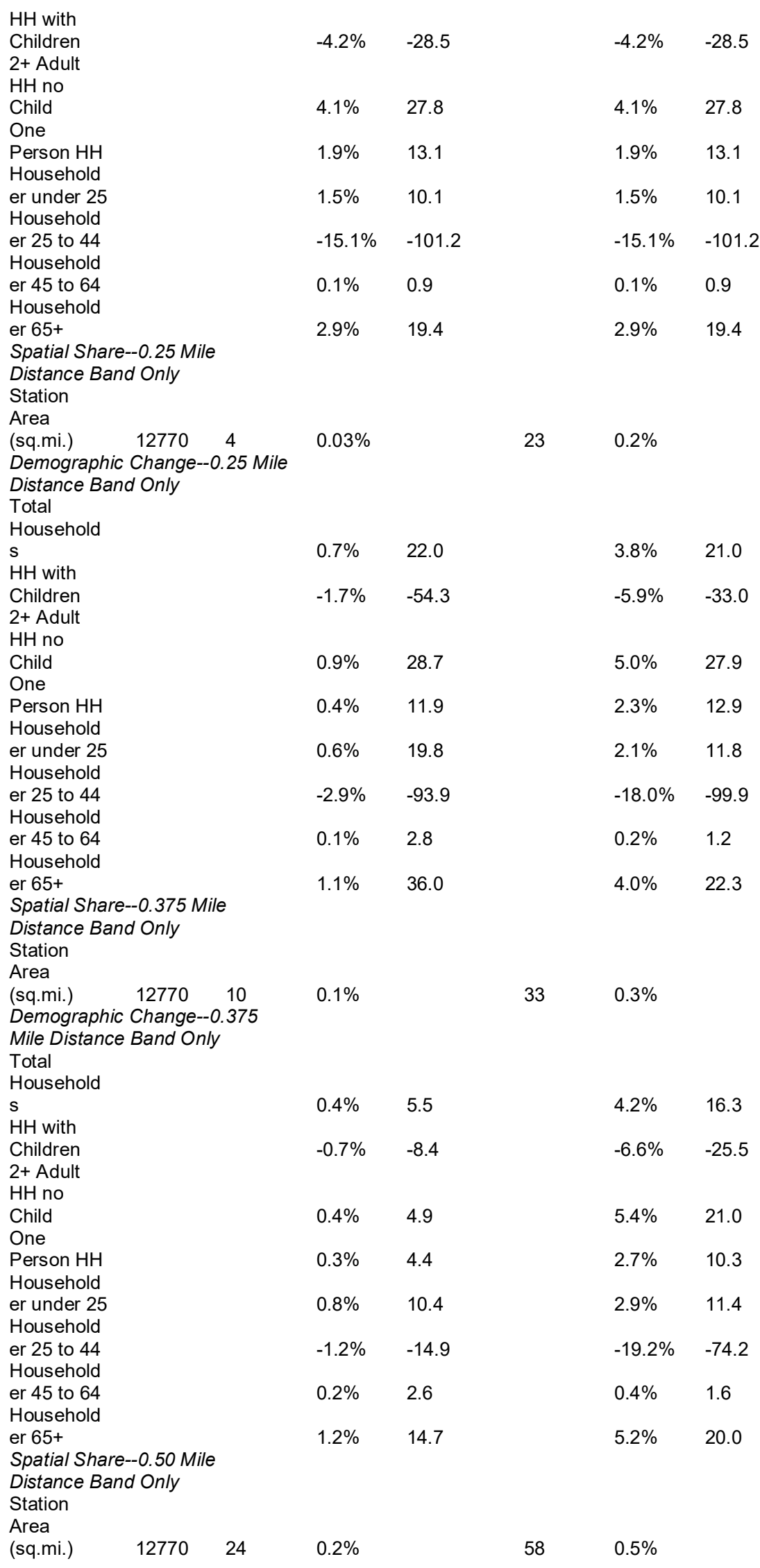




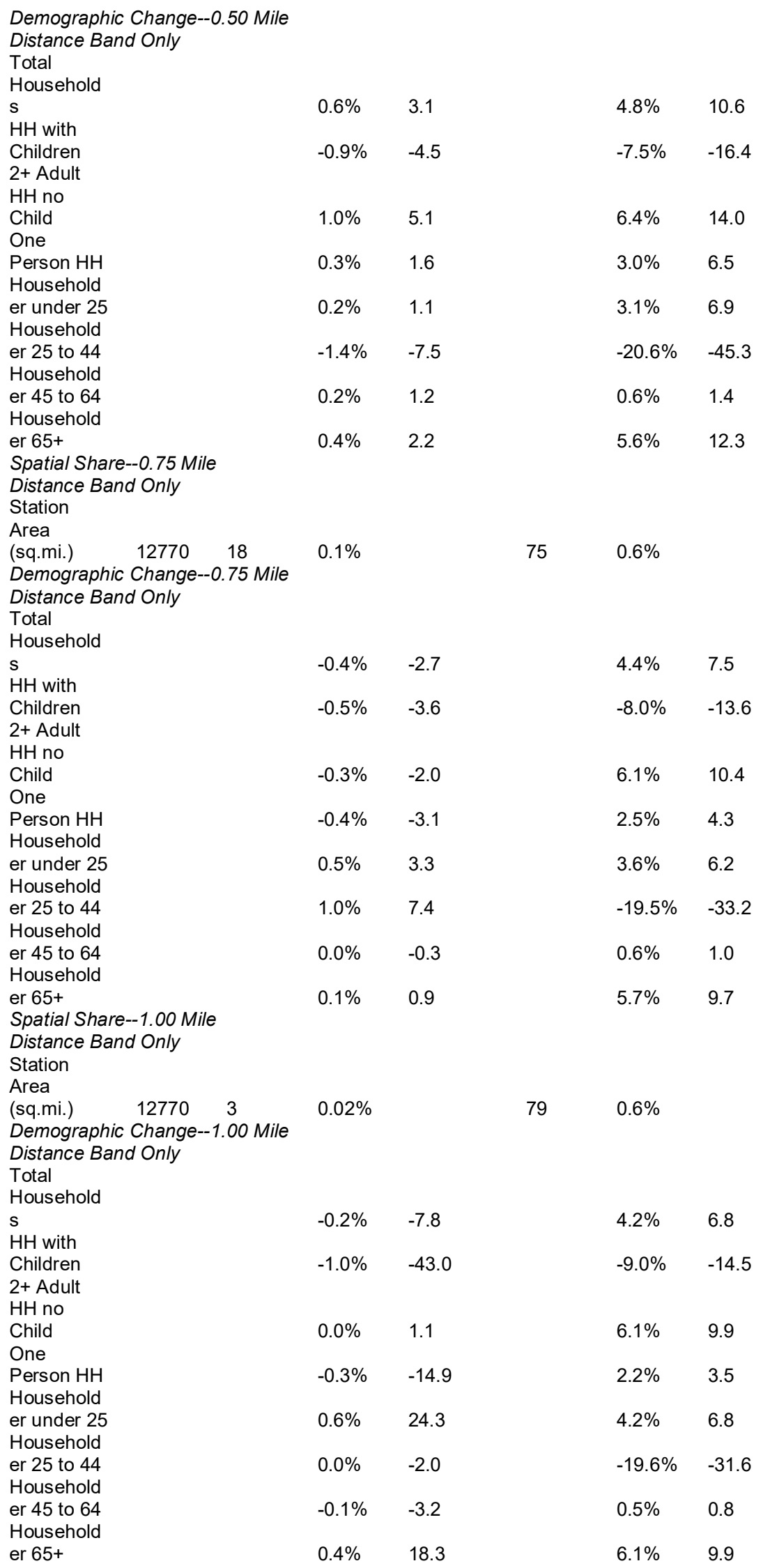




\title{
TRANSIT IMPACTS ON JOBS, PEOPLE AND REAL ESTATE
}

\begin{abstract}
Volume 4
Impact on Real Estate Rents with Respect to Transit Station Proximity Considering Type of Real Estate by Transit Mode and Place with Implications for Transit and Land Use Planning
\end{abstract}
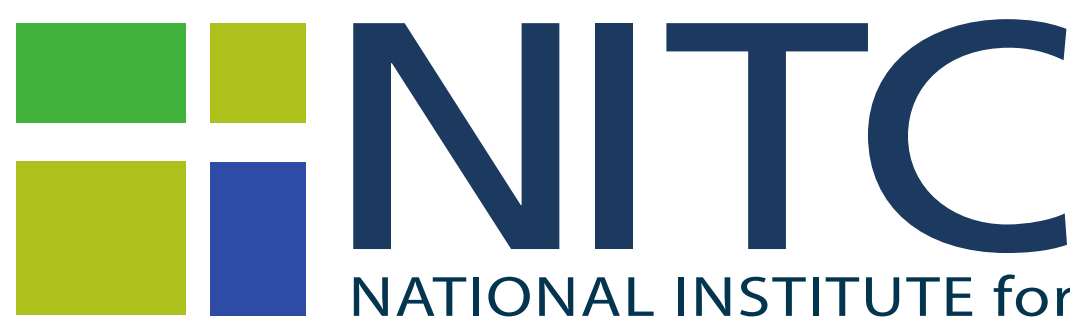

NATIONAL INSTITUTE for

TRANSPORTATION and COMMUNITIES 


\section{VOLUME 4 PREFACE}

Transit Impacts on Jobs, People, and Real Estate is the fourth report in a series that started with funding from the National Institute of Transportation and Communities (NITC), a US DOT funded National University Transportation Center. While it completes the "quadrilogy" of work comprising a unique genre of transit and land use planning research it is by no means the last work-it is more likely the foundation for future work.

This document is Volume 4 of five volumes from the full report Transit Impacts on Jobs, People, and Real Estate:

- Volume 1: Orientation, Executive Summary, Context and Place Typologies

- Volume 2: Impact on Job Location Over Time with Respect to Transit Station Proximity Considering Economic Groups by Transit Mode and Place Typology with Implications for Transit and Land Use Planning

- Volume 3: Impact on Where People Live Over Time with Respect to Transit Station Proximity Considering Race/Ethnicity and Household Type and Household Budget by Transit Mode and Place Typology with Implications for Transit and Land Use Planning

- Volume 4: Impact on Real Estate Rents with Respect to Transit Station Proximity Considering Type of Real Estate by Transit Mode and Place with Implications for Transit and Land Use Planning

- Volume 5: Improving Transit Impacts by Reconsidering Design and Broadening Investment Resources

Each of these volumes, and the full report, can be found at https://nitc.trec.pdx.edu/research/project/1253

The genre of research within which four research projects call is grounded in trend that is common throughout all reports: That America is becoming increasingly focused on the need for transit to meet a growing number of social, economic and environmental objectives. But it is also rooted is simple market dynamics.

America will add at least 100 million new residents, 40 million new households, and 60 million new jobs by 2050 . We know from demographic analysis and consumer preference surveys that at least a third of America's 150 million households (50+ million) in 2050 will want to live in locations providing them with transit options, in addition to mixed-use and mixed-housing options. We also know from research on firm location behavior that up to 100 million jobs will be attracted to locations with transit options. Indeed, some research has estimated that even if all new development to 2050 occurred within one-half mile of existing and planned transit stations-such as transit oriented development (TOD) planning areas-the market demand for such development would not be met.

Our prior research outlines the extent to which fixed route transit (FRT) systems can meet future demand. But each system has its own niche. Light rail transit (LRT) systems serve metropolitan wide markets, connecting multiple nodes to each other. Bus rapid transit (BRT) systems can accomplish many of the same objectives as LRT systems at lower cost per mile but also lower capacity-which is fine for the Eugene-Springfield metropolitan area though not necessarily the Portland metropolitan area which, being four times larger and more densely settled, relies on LRT. At the lowest scale of operations are street car transit (SCT) systems that serve mostly downtowns such as Seattle or connect employment centers near downtown to downtown such as Portland, Tucson and Dallas. At the other end of the spectrum are commuter rail transit 
(CRT) systems that are intercity systems that connect cities within a metropolitan area to downtown such as San Diego's Coaster, or multiple metropolitan areas such as the SeattleTacoma Sounder or the Albuquerque-Santa Fe Rail Runner or the Utah Transit Authority's FrontRunner connecting three metropolitan areas.

Here we will summarize the purpose and key findings of each of the three prior reports and then frame the role of the fourth report. 


\section{Do TODs Make a Difference?}

The first report in the Quadrilogy was Do TODs Make a Difference? (Nelson et al. 2015). NITC contracts 547 and 650 were used to build station area databases for 12 light rail transit (LRT) systems, nine bus rapid transit (BRT) systems, four streetcar transit (SCT), and five commuter rail transit (CRT) systems. In this report, we presented research that measures the outcomes of TOD areas in relation to their metropolitan area controls with respect to:

- Jobs by sector;

- Housing choice for household types based on key demographic characteristics;

- Housing affordability based on transportation costs; and

- Job-worker balance as a measure of accessibility.

Prior literature has not systematically evaluated TOD outcomes in these respects with respect to light rail transit (LRT), commuter rail transit (CRT), bus rapid transit (BRT), and streetcar transit (SCT) systems. Our analysis helps close some of these gaps. We applied our analysis to 23 fixed guideway transit systems operating in 17 metropolitan areas in the South and West that have one or more of those systems. We found:

- Most TOD areas gained jobs in the office, knowledge, education, health care and entertainment sectors, adding more than $\$ 100$ billion in wages capitalized over time;

- In assessing economic resilience associated with LRT systems, jobs continued to shift away from TOD areas before the Great Recession, the pace slowed during the Recession, but reversed during recovery leading us to speculate that LRT TOD areas may have transformed metropolitan economies served by LRT systems;

- Rents for offices, retail stores and apartments were higher when closer to SCT systems, had mixed results with respect LRT systems, but were mostly lower with respect to CRT systems (our earlier BRT sample size was too small to evaluate);

- SCT systems performed best in terms of increasing their TOD area shares of metropolitan population, households and householders by age, housing units, and renters with BRT systems performing less well while LRT and CRT systems experienced a much smaller shift in the share of growth;

- Household transportation costs as a share of budgets increase with respect to distance from LRT transit stations to seven miles suggesting the proximity to LRT stations reduces total household transportation costs;

- Emerging trends that may favor higher-wage jobs locating in transit TOD areas over time than lower or middle wage jobs perhaps because TOD areas attract more investment which requires more productive, higher-paid labor to justify the investment; and

- The share of workers who commute 10 minutes or less to work increases nearly one-half of one percent for each half-mile their resident block group is to an LRT transit station, capping at a gain of 1.3 percent, which is not a trivial gain.

This work identified a missing element of research relating to one of the fastest growing modes of fixed route transit systems: Bus rapid transit (BRT). That led to a second NITC-funded project. 


\section{National Study of BRT Development Outcomes}

The second report was the nation's largest and most comprehensive assessment of the influence of bus rapid transit (BRT) systems on jobs, people and households, and real estate rents (Nelson and Ganning 2016).

Public transit systems are often promoted as offering a plethora of social, economic and environmental benefits to urban populations by transforming urban forms from auto-centric designs into more sustainable ones. The "next big thing" in public transit is bus rapid transit (BRT) systems. From virtually no systems a generation ago, there are now nearly 20 lines operating with at least seven under construction and more than 20 in the planning stages. Part of this recent popularity in BRT stems from its more affordable capital investment costs and its potential to be utilized by municipal planning organizations as an economic development tool. Yet, research into development outcomes associated with BRT station/stop proximity is small. This study found:

- For metropolitan counties with BRT systems, (0.50-mile) transit corridors increased their share of new office space by a third, from 11.4 percent to 15.2 percent and although new multifamily apartment construction was small, its share more than doubled since 2008;

- BRT station areas gained share of central county jobs at a faster pace or even at the expense of the rest of the central county and that more technologically advanced BRT systems may contribute to positive economic development outcomes;

- However, when disaggregating data to sectors, BRT is found to influence employment change in only one sector-manufacturing though that sector is broad and includes such activities as assembly, food processing (think beer making) and fashion design;

- Evidence of an office rent premium for location within a BRT corridor for most albeit not all of the metropolitan areas studied;

- Household transportation costs as a share of budgets increase with respect to CBD distance to about 19 miles and about eight miles with respect to BRT stations;

- Before the recession, the shift in jobs for all wage groups was about the same between BRT station areas and counterfactual locations but during recovery, BRT station areas saw larger shifts compared to counter-factual locations for lower-wage but upper-wage jobs had the largest change share in BRT station areas during recovery while the share of lower-wage jobs in BRT station areas fell; and

- There is little difference in BRT study area performance compared to their metropolitan areas in terms of influencing population and residential patterns though we did find indirect evidence that BRT systems choosing higher-quality design and technology options tended to enjoy better population and housing outcomes than those that chose lesser options.

We conclude that, on the whole, BRT systems are associated with positive development and job location outcomes, though not necessarily population or housing outcomes. By the time this study was completed more robust data had become available allowing for updates and expansions of prior work, which led to the third grant in this genre. 
The Link between Transit Station Proximity and Real Estate Rents, Jobs, People and Housing with Transit and Land Use Planning Implications

This report updates and expands prior research in the genre of research that has used economic base analysis (especially shift-share) and CoStar commercial rent data to estimate the development outcomes to transit (Nelson and Hibberd 2019). The study period for prior economic base analysis was 2002-2011 and census data for 2000 and 2010, as well as CoStar data for 2013. This report expands the number of systems used in analysis to 17 LRT systems, 14 BRT systems, nine SCT systems and 12 CRT systems. It also expands the period of analysis to 2015 for jobs-related data, 2016 for census data, and 2018 for CoStar data. The expanded and updated databases allow for more comprehensive assessment of their outcomes. Key findings include:

- Market rents increase with respect to Fixed Guideway Transit (FGT) station proximity for nearly all commercial types and for all modes, except there no rent premium for BRT in the closet $(0.125$ mile $)$ distance band and office responds positively only within the closets ( 0.125 mile) distance band from LRT stations, with rent premiums extend one to two miles away from FGT stations for many commercial types;

- On the whole, more mature Fixed Guideway Transit (FGT) system saw gains in regional share of jobs in closer in ( 0.25 mile and 0.50 mile) distance bands if not up to the 1.00 mile distance band from transit stations-BRT being an exception in gaining share only in the nearest $(0.25$ mile) distance band- while ones build during and since the Great Recession saw small or negative shifts in regional share;

- There are only modest gains in the regional share of population and housing before/during the Great Recession (2000-2009) bit somewhat more gains afterward (2010-2016) for all transit types except BRT with larger gains associated with households without children and early/middle aged households (35-49); and

- For the most part for all transit modes saw reductions in regional share of driving alone and carpooling, and increases in regional share of transit, biking, walking, and working at home with respect to FGT station proximity.

The report also featured illustrations of "good, bad and ugly" transit station/stop planning and design, suggesting that systems may be underperforming because of these limitations.

A missing element of prior work was the milieu or type of place within which transit stations are located. Addressing this is the key purpose of this report (Nelson, Hibberd and Currans 2021). 
Transit Impacts on Jobs, People and Real Estate

This is the fourth report in the genre of research supported by NITC. This project entailed updating data and disaggregating it to assess outcomes based on station area types or what we call Place Typologies. This research is guided by two overarching questions and analytic contexts:

\begin{abstract}
How do Transit Development Outcomes Vary by Mode and Place Typology? This analysis includes each transit system for each metropolitan area studied during appropriate time periods for that system, as well as systems combined across metros. Trends that are assessed include: (1) Changes in the number and share of jobs by sector with respect to type of system and distance from stations, by type of station based on Place Typology; (2) Changes in the number and share of jobs by wage category with respect to transit mode and station proximity by Place Typology; and (3) Changes in number and share of population, households, householders by age, and housing by tenure with respect to transit mode, station proximity, and Place Typology.
\end{abstract}

\title{
How does the real estate market for office, retail and apartment properties respond to proximity to transit stations by mode and Place Typology? Our prior
} work pioneered the use of CoStar commercial rental data for very broad assessments of real estate market responsiveness to transit by type but not really by location except for corridor distance bands. The new research conducts more refined relationships in those metropolitan areas based on mode and Place Typology where CoStar data are sufficient for analysis.

In addition, we updated our complete database with a codebook for anyone to access through NITC.

\section{References}

Nelson, Arthur C., Matt Miller, Dejan Eskic, Keuntae Kim, Joanna P. Ganning, Reid Ewing, Jenny Liu, Matt Berggren, Zakari Mumuni (2015). Do TODs Make a Difference? Portland OR: Portland State University, National Institute for Transportation and Communities Final Report NITC-RR-547 and NITC-RR-763. Available along with related materials at https://nitc.trec.pdx.edu/research/project/547/Do_TODs_Make_a_Difference?

Nelson, Arthur C. and Joanna P. Ganning (2016). National Study of BRT Development Outcomes. Portland OR: Portland State University, National Institute for Transportation and Communities Final Report 650. Available along with related materials at http://nitc.trec.pdx.edu/research/project/650

Nelson, Arthur C. and Robert Hibberd (2019). The Link between Transit Station Proximity and Real Estate Rents, Jobs, People and Housing with Transit and Land Use Planning Implications. Portland OR: Portland State University, National Institute for Transportation and Communities Final Report 1103. Available along with related materials at https://nitc.trec.pdx.edu/research/project/1103.

Nelson, Arthur C., Robert Hibberd and Kristian Currans with Nicole Iroz-Elardo (2021). Transit Impacts on Jobs, People and Real Estate, five volumes. Portland OR: Portland State University, National Institute for Transportation and Communities Final Report 1253. Available along with related materials at https://nitc.trec.pdx.edu/research/project/1253. 


\section{SYNOPSIS FOR VOLUME 4}

The primary purpose of transit systems-such as heavy, light and commuter rail transit, streetcars, and bus rapid transit-is to move people to, from and between nodes or areas. This is advanced when land uses near transit stations maximize access to them. In turn, this depends mostly on private real estate investment. For their part, real estate developers will make investments near transit stations only if rents are sufficient to generate required rates of return. Rents are affected by the amenity benefit of transit station proximity but can be offset by externalities such as noise, traffic, and simply the unattractiveness of stations and station areas. If amenity benefits exceed externalities, rents will rise the closer a real estate development is to a transit station. If externalities exceed amenity benefits, rents will fall. The spatial relationship between real estate rents and transit station proximity reveals how the real estate market internalizes amenity benefits and externalities.

Following Li and Brown's (1980) pioneering theorizations into the effect of localized amenities and externalities on real estate values, and as applied for the first time in empirical analysis of transit station effects on real estate values by Nelson and McCleksy (1990), we identify four theoretical outcomes of transit station proximity on real estate rents (see Figure 1) that can be used to evaluate transit station area development outcomes.

Figure 1

Theoretical outcomes to relationships between rent and transit station proximity
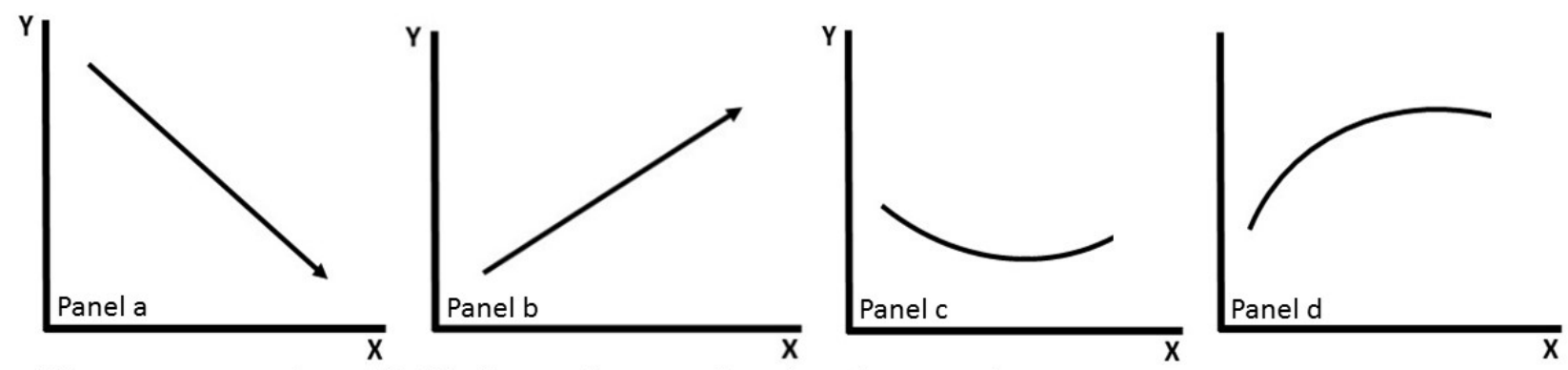

$\mathbf{Y}$ is rent per square foot while $\mathbf{X}$ is distance from transit stations. Interpretations are:

Panel a-Rent falls as distance from a transit station increases signaling proximity is an amenity;

Panel $b$-Rent rises as distance from a transit station increases signaling proximity is an externality;

Panel c-A convex relationship where amenity affects prevail at some point before externality affects do; and

Panel $d-A$ concave relationship where externality affects prevail at some point before amenity affects do.

Transit station area rent slopes consistent with Panels a and $\mathbf{c}$ would seem to advance transit objectives while rent slopes consistent with Panels $\mathbf{b}$ and $\mathbf{d}$ would not.

Our research is guided by two questions:

Is there an association between commercial real estate rent and proximity to rail transit stations ceteris paribus? If so, what is the form of that relationship? 
We apply these questions to real estate rents reported for more than one-half million office, multifamily and retail properties in more than 30 metropolitan areas where more than 50 transit systems operate.

We use a temporal, cross-section quasi-experimental research design. Our time period is 2019 for office and 2018 for multifamily and retail real estate. We test for the association between transit station proximity on real estate rents per square foot within and across multiple metropolitan areas. Though not causal, associations can be used as guidance for transit and land use planning nonetheless. The general model and functional form is:

\section{$\mathrm{Ri}=\mathrm{f}(\mathrm{S} i, \mathrm{SES} i, \mathrm{C} i, \mathrm{Mi}, \mathrm{PT} i, \mathrm{DB} i$,}

Where:

$\mathbf{R}$ is the asking rent per square foot from CoStar;

$\mathbf{S}$ are the structural attributes-size, floors, age, etc. from CoStar;

SES are the set of socioeconomic characteristics-we use income of the census block group;

C are the centrality attributes being distance to the nearest freeway ramps from GIS;

$\mathbf{M}$ is the metropolitan area as a proxy for metropolitan-specific variation in rents;

PT is the Place Typology as an index of urban form and distance to downtown; and

DB is the distance band to transit stations in one-eighth mile units to two miles relative to all cases beyond two miles - the functional form.

Ordinary least squares regression is used where rents are logged and dependent variables are binary or linear. This allows for coefficients to be interpreted reasonably as the percent change in rent with respect to a unit change in the independent variable.

For the most part, we find that transit station areas do not advance transit station area purposes with respect to attracting real estate investment because rents are mostly upward/concave sloping away from transit stations or ambiguous (Nelson, Hibberd, Currans 2021). However, we identify individual systems with downward/convex sloping rent gradients that are worthy of case study analysis to draw lessons for transit station planning, station area land use planning and urban design for other systems to emulate.

Readers are reminded that these outcomes are after controlling for several factors one of which is the location of offices in High-, Moderate-, Low- and Poor-Mixed Use/Accessibility places and areas. In other words, our results be somewhat different than those reported by others where such urban landscape controls are not used.

\section{Light Rail Transit Station Proximity Real Estate Rent Synthesis}

Overall, our analysis suggests that multifamily and retail land uses may push office real estate away from LRT transit stations to about 0.50-mile. But as we see for individual metropolitan areas, this trend is not evident everywhere.

\section{Streetcar Transit Station Proximity Real Estate Rent Synthesis}

Perhaps because they are both similar forms of intra-metropolitan rail transit-sometimes using the same types of rolling stock, the office, multifamily and retail real estate markets respond roughly the same to light rail and streetcar transit station proximity, as will be seen. This despite key differences in their service areas as SCT systems serve mostly built-up downtown and near-downtown areas where LRT systems serve truly regional functions, connection a range of 
activity centers to each other and downtown. Similar to LRT, we surmise that multifamily and retail real estate may be outbidding office real estate at or near SCT stations, pushing office further away. 


\section{Bus Rapid Transit Station Proximity Real Estate Rent Synthesis}

In general, real estate rents do not respond well to bus rapid transit station proximity. For the most part, we find ambiguous office and multifamily market responses to BRT proximity in the first (0.125-mile) distance band but a steeply upward retail rent slope. As we discuss in the concluding section of this chapter, we surmise that for the most part, BRT stations are sources of externalities. It would seem that improved transit and land use planning and better urban design can overcome these externalities thereby making BRT stations sources of amenity value.

\section{Commuter Rail Transit Station Proximity Real Estate Rent Synthesis}

Despite generally ambiguous or weak responses of the real estate market to CRT station proximity, evidence from selected CRT systems suggests that not only can office and retail real estate benefit from proximity to CRT stations but perhaps multifamily as well. While CRT stations can be sources of externalities such as noise, smells, unappealing freight-based rail infrastructure and so forth, perhaps with sensitive transit and land use planning, and especially urban design, these potential nodes of externalities could be turned into places of amenities, or at least where amenity benefits exceed externality effects.

\section{The (Overlooked) Association between Express Bus Station/Stop Proximity and Multifamily Rents with Implications for Transit and Land Use Planning}

Despite hundreds of studies into the association between real estate value and proximity to fixed route transit (FRT) systems, none has assessed the association with respect to express bus transit (XBT) stations/stops. Using a static, cross-section quasi-experimental research design, we evaluate CoStar multifamily (MF) rent per square foot to estimate the difference in rent with respect to proximity to (XBT) stations/stops. However, we are also interested in knowing whether there are synergistic price effects at the intersection of XBT and other FRT systems such as light rail transit (LRT). In this article, we estimate the MF rent premium with respect to XBT and LRT (XBT+LRT) station/stop proximity separately, rent premiums for combined XBT and LRT stations/stops, and for those MF cases that are more than 1.0 mile beyond the nearest LRT station. In all cases, whether separately or combined with LRT stations or away from LRT stations, with find positive associations between MF rent and proximity to XBT stations/stops. However, we also find evidence of negative externalities at or near XBT, LRT, and XBT+LRT stations/stops.

\section{How the Intersection of Light Rail Transit Stations with other Transit Modes Influences Real Estate Rent}

We extend the analysis of the interactive effects of light rail transit (LRT) stations shared with streetcar transit *SCT), bus rapid transit (BRT) and commuter rail transit (CRT) on office, multifamily and retail real estate rents. For the most part, we found that where a metropolitan area includes more than just an LRT system -in our case being one or more of SCT, BRT and CRT systems - it may be important to evaluate interactive effects between them. In nearly all comparisons between the standard model we use earlier and the expanded model here for office and retail estate, the combined LRT+SCT, LRT+BRT and LRT+CRT coefficients were higher meaning interactive effects were greater than just for LRT alone. This is reasonable, $a$ priori.

\section{Overarching Perspectives}

Fixed-route transit (FRT) systems have operated in the US for more than one hundred years with the majority developed during the last half a century. While many single-system studies exist, there has not been rigorous, systematic cross-section analysis of whether and the extent to which these systems influence the real estate market. This Volume helps close the gap. 


\section{CHAPTER 8: The Variation in Real Estate Rents with Respect to Place Typology and Transit Station Proximity}

\section{OVERVIEW}

There is a dearth of systematic research into the relationship between fixed route transit (FRT) systems such as light rail transit (LRT), bus rapid transit (BRT), streetcar transit (SCT) and commuter rail transit (CRT) with respect to real estate rents and transit station proximity. Though there are numerous case studies of individual systems in individual metropolitan areas, they focus mostly on a single property type. Those studies also vary in the type of data used, methodologies, and functional form specifications. In other words, research lacks a consistent cross-section approach to estimate variation in real estate rents between FGT systems and different types of real estate. This chapter seeks to close this gap in the literature.

This chapter presents cross-section regression analysis that uses CoStar, census and GISderived location data in a common methodology to estimate the association between FGT station proximity and office, retail and multifamily rents. In all, nearly 60 FRT systems serving more than 30 metropolitan areas are studied, which includes about 300,000 cases. Numerous variables are used to control for structural attributes, occupancy, socioeconomic characteristics, land use, location and other influences.

For the most part-with some surprising exceptions-real estate rents tend to rise the closer the property is to transit stations. There also appears to be a sorting that occurs between real estate types and transit station proximity, which is to be expected in the competition for locations nearest to transportation services.

Implications for fixed guideway transit system and land use planning are offered. 


\section{Introduction}

America has gone through four fixed guideway transit (FGT) eras. The first is the streetcar era which flourished from the 1880s through the 1940s. To make way for automobiles, they were mostly dismantled from the end of WWII to about 1960. What remained were mostly heritage and tourist-dominated streetcars such as those seen in San Francisco, Philadelphia and New Orleans. Starting in 1892, heavy rail systems were constructed in many of the largest metropolitan areas, with the last new system opening a century later in $1993 .{ }^{115}$ Though some new lines and stations have been added to these systems during the $21^{\text {st }}$ century, it would seem that heavy rail transit is not a preferred transit investment even among the largest metropolitan areas. ${ }^{116}$ While regional commuter rail systems have been serving major Northeastern and Great Lakes metropolitan areas since the early 1900s, most commuter rail systems have been built since the 1970s. ${ }^{117}$

Despite FRT systems operating in the U.S. for more than a century, and most during the last half century, there has not been rigorous, systematic cross-section analysis of whether and the extent to which these systems influence the real estate market. This chapter helps close the gap in research. Specifically, we apply hedonic regression to estimate the association between FRT station proximity and office, multifamily and retail rents. This chapter:

- Starts with a review of literature and theory leading to the research questions;

- Proceeds to the research plan to evaluate the association between real estate rents for office, multifamily and retail land uses with respect to station typology and proximity for each of the four types of transit studied in this report;

- Continues with a presentation and discussion of results; and

- Concludes with implications for transit and land use planning.

We proceed to a review of theory and literature leading to the research question.

\footnotetext{
${ }^{115}$ See https://en.wikipedia.org/wiki/List of United States rapid transit systems by ridership.

${ }^{116}$ See https://en.wikipedia.org/wiki/Bus rapid transit and https://en.wikipedia.org/wiki/List of rail transit systems in the United States.

${ }^{117}$ See https://en.wikipedia.org/wiki/List of suburban and commuter rail systems.
} 


\section{Theory, Literature And Research Question}

It was von Thünen (1826) who first formalized the relationship between the center of cities and land value: as distance is reduced land values rise because land capitalizes both transportation cost savings and that higher densities lead to more economic exchange. More than a century later, a trio of urban economists adapted von Thünen's theory to create modern urban location theory: Alonso (1964), Mills (1967) and Muth (1969). By assuming that all jobs are in the central business district (CBD) the "AMM theory" shows that as transportation costs increase from the $\mathrm{CBD}$, land values fall at a declining rate. In the CBD, where transportation costs are the lowest, land prices are thus the highest. Only those land uses that can outbid others secure land in the center, forcing losing bidders to locate farther away in a process known as urban land use invasion and succession (Park et al. 1925).

But urban areas are not "monocentric." As one relaxes the constraints of the AMM monocentric city model, it is possible to imagine the same principles work only at smaller scales (Hajrasouliha and Hamidi 2017; Bogart 1998). For instance, rail transit stations are often located in or sometimes lead to small-scale versions of CBDs. Some land uses can realize transportation cost savings if they locate near transit stations and may be willing to pay more for proximity (in the form of rent) compared to other land uses. Numerous studies show negative bid-rent gradients with respect to distance from rail transit stations, meaning that as distance from transit stations increase real estate values fall, ceteris paribus (Al-Mosaind et al. 1993; Cervero 1984; Cervero and Duncan 2002; Debrezion et al. 2007; Hamidi et al. 2016; Mulley et al. 2016; Nelson and McClesky 1990; Nelson 1992; Nelson et al. 2015). In effect, station areas can become small scale downtowns. At the regional scale, major centers such as "Edge Cities" may emerge (Garreau 1991).

However, there can be negative proximity effects as well. For instance, suppose a transit station is unattractive - maybe surrounded by parking garages, brownfields, and the like. Real estate values would fall with respect to transit station proximity (Li and Brown 1980; Golub et al. 2012; Nelson and McClesky 1990; Nelson 1992). We explore implications of negative externality influences on real estate rents in our modeling discussion below.

This succinct review of theory and literature leads us to our principal research questions:

Is there an association between commercial real estate rent (per square foot) and proximity to rail transit stations holding other factors including station typology constant?

The principal research question is nuanced as follows:

\section{If there is an association, is there evidence of negative externality or amenity effects with respect to transit station proximity?}

These questions are applied to office, multifamily and retail real estate with respect to LRT, BRT, SCT and CRT station proximity. Among the many controlling influences will be the place typology (see Chapter 1 ) within which stations are located. Our research plan is presented next. 


\section{Research Plan}

This section presents our research plan including research design, general model, functional form, study area, and specific model and data.

\section{Research Design}

We address the research questions through a temporal, cross-section quasi-experimental research design. That is, using one period of time-2019 for office and 2018 for multifamily and retail real estate-we test for the effect of transit station proximity on real estate rents per square foot across multiple metropolitan areas. Though analysis is not causal, associations can be used as guidance for transit and land use planning purposes. For reasons noted below, we use rent instead of sales as a proxy for real estate value (Nelson and Hibberd 2019).

\section{General Model}

Using these theoretical and research design foundations as a guide, we develop the following general model to test the theory. It is adapted from Nelson (2017):

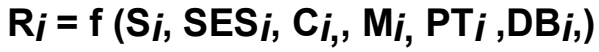

\section{Where:}

$\mathbf{R}$ is the asking rent per square foot for property $i$;

$\mathbf{S}$ is the set of structural attributes of property $i$;

SES is the set of socioeconomic characteristics of the vicinity of property $i$;

$\mathbf{C}$ is a set of centrality attributes of property $i$ in this case being distance to the nearest freeway/expressway ramps because distance to downtown is included as a dimension leading to the Station Type (ST) variable described below;

$\mathbf{M}$ is the metropolitan area within which property $i$ is located-as metropolitan area conditions and markets vary between them, identifying the location of property $i$ within its respective market helps control for metropolitan-specific influences;

PT is the Place Typology based on cluster analysis presented earlier in the report itself based on such factors as measures of urban form of the vicinity of property $i$ and distance to downtown; and

DB is the distance band (see below for specification details) of property $i$ to a transit station. 


\section{Functional Form}

The AMM theory posits that land value will decline with distance from the CBD or other high activity nodes. Linear, semi-log, and double-log functional forms are the dominant forms reported in literature (see Hibbard et al. 2019; Higgins and Kanaroglou 2016; Nelson and Hibberd 2019). Key features of each are summarized as follows:

The linear functional form assumes a straight-line deduction in property value with respect to distance away from a node, such as a transit station.

The semi-log functional form — where the dependent variable is logged-estimates the percent change in value associated with a unit change in an independent variable.

The double-log functional form generates elasticities-continuously measured variables on both sides of the equation are logged though categorical and binary variables are not.

In our view, none of these functional forms are very useful to transit and land use planners who need to know how to arrange transit investments and land use policies to maximize the economic benefits of transit station proximity. Lacking guidance from studies using these conventional functional forms, planners tend to settle on quarter- and half-mile planning areas around stations/stops, with very little empirical justification.

A less-used approach, the quadratic functional form, is specified such that the linear distance term is squared and both terms are included in an analysis:

$$
\mathrm{R}_{i}=\beta_{i}+\beta_{i}^{2}
$$

Where $\boldsymbol{\beta}_{i}$ is the linear coefficient of the value premium with respect to transit station distance in a regression equation while $\boldsymbol{\beta}_{i}{ }^{2}$ is its squared term. Using differential calculus, this equation has the potential to determine the break point in the transit station distance curve. In the context of FRT stations/stops, the concern is that rail stations/stops themselves can be nuisances such that real estate values and rents may be dampened very near them.

As Nelson (1992) and Nelson and McClesky (1990) theorize, the market capitalizes both amenity effects of rail station proximity as well as negative externality effects, for instance those associated with noise (such as dispatching broadcasts at station platforms), and congestion (such as when vehicles use park and ride lots during peak hours). So long as amenity effects outweigh negative externalities, the bid-rent gradient will slope downward and away from rail transit stations/stops. However, in theory it is possible for negative externalities to outweigh amenities. But quadratic functional forms may not be very useful either, especially if both signs are in the same direction (increasing or decreasing value at a faster rate with respect to distance). Even where signs are different, the smaller the second term relative to the first the flatter the slope. For example, if the second term above is 1.00 , the minima is 10 miles which may not be very useful to planners crafting plans around stations/stops.

Figure 8.1 shows numerous potential relationships between rail stations/stops-as both sources of amenities and negative externalities_and real estate value, in our case being multifamily rents (see below):

The line $\mathrm{R}^{\mathrm{a}}$ shows the land rent $(\mathrm{R})$ curve with amenity ("a" for amenity) value from a rail transit station, $\mathrm{u}_{0}$, outward to a point, $\mathrm{u}_{1}$, where the amenity effects of rail transit 
proximity disappear, beyond which the overall market rent, unaffected by the presence of the rail transit station, $\mathrm{R}^{\mathrm{m}}$ is revealed.

Negative externality effects of rail transit stations/stops are shown in line $\mathrm{R}^{\mathrm{n}}$ (" $\mathrm{n}$ " for negative externality). As distance from the rail station increases, the negative externality effects are reduced until they become zero at $u^{1}$.

Amenity and negative externality effects interact in the market leading to overall positive or negative bid rent curves with respect to distance from rail transit stations/stops to $u_{1}$. Line $R^{a}+R^{n}$ is revealed where overall amenity effects outweigh negative ones. Line $R^{a}$ $+R_{2}{ }_{2}$ is revealed where overall negative externality effects outweigh positive ones. Overall effects disappear at $\mathrm{u}_{1}$ beyond which market rent, $\mathrm{R}^{\mathrm{m}}$, in the absence of amenity and negative externality is revealed.

The distance band functional form offers a practical middle ground between knowing whether and the extent to which real estate markets respond to transit stations/stops within discrete distances of FRT stations/stops. They also provide statistical significance test results for each band separately. Unfortunately, most distance-band studies use only one-quarter or one-half mile distance bands (Higgins and Kanaroglou 2016) or occasionally two bands (Nelson 2017). But that assumes all relevant interactions which are useful for planners to know occur only within those distance bands, and that those bands apply to all transit modes in all metropolitan areas. Following Nelson and Hibberd (2019) and Hibberd et al. (2019), we use the distance band functional form described in more detail below.

The foregoing discussion has important implications for evaluating the price or rent effects of transit systems on multifamily real estate. Rail transit usually runs on dedicated tracks that can generate negative externalities in terms of noise, vibration and sometimes glare, among others. For their part, express busses usually operate along collectors, arterials and limited access highways that also generate similar negative externalities in addition to vehicle exhaust. One would expect that, between stations and stops, real estate value would be less along both tracks and XBT-serving highways because of these negative externalities. On the other hand, amenity effects of transit stations/stops occur only proximate to them.

There is still another compounding issue. Income producing real estate usually depends on access to major highways even if they generate negative externalities. Higher density commercial development is especially dependent on major highway access which is why they cluster along them. Nonetheless, highway related negative externalities may dissipate some distance away from highway which may be revealed in rents or prices. On the other hand, the only amenity effect of rail access is with respect to station/stop proximity. These particular nuances of highway and rail proximity are not addressed directly in this research but is part of our longer-term agenda.

Finally, we note the following interpretive strategy. The theory on which Figure 8.1 is based concedes that all we can see are the revealed effects, not the disaggregated ones. However, the rise of values away from a station/stop outward to a peak, followed by declining values forming an inverted $U$ would be a tell-tale sign of externality effects of the station/stop on rents. We will elaborate on this later. 


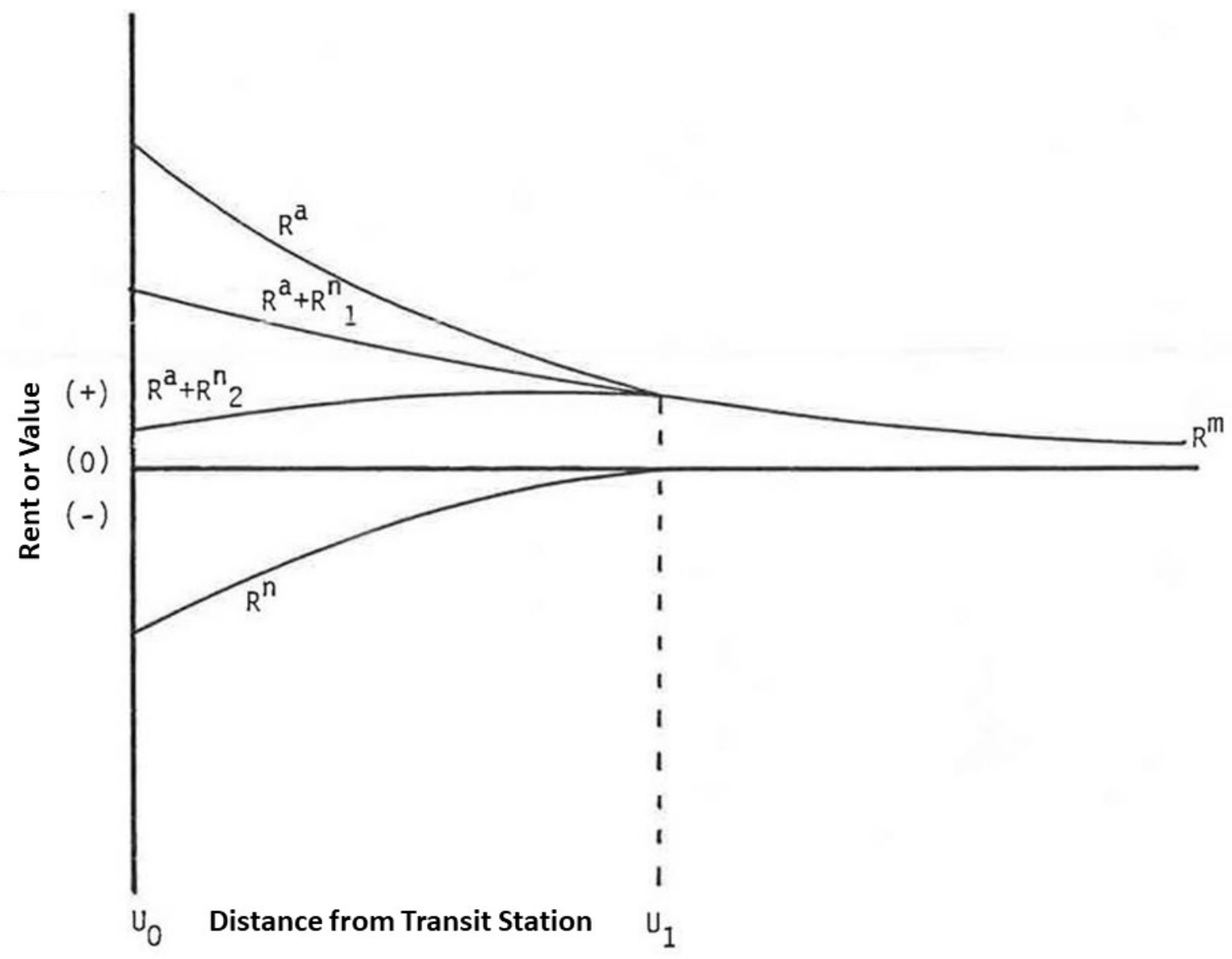

Figure 8.1

Amenity $\left(R^{a}\right)$ and Negative Externality $\left(R^{n}\right)$ influences of transition stations/stops on proximate property values

Source: Nelson and McClesky (1990). 


\section{Study Area}

Our study area includes all the transit regions served by the LRT, BRT, SCT and CRT systems noted in the Introduction. A transit region includes all the counties served by an individual system such as only Multnomah County, Oregon for Portland's streetcar transit system but including Clackamas, Multnomah and Washington counties for the region's light rail transit system.

\section{Specific Model and Data}

We operationalize the general model dimensions and functional form here. Notably, we report the statistical association between rent per square foot for office, multifamily and retail real estate with respect to FRT station proximity in terms of 0.125 -mile distance bands to 1.00 -mile after controlling for other influences with special reference to Place Typology.

We chose 1.00 mile as our threshold for several reasons. Before going into those reasons, we note the conventional approach to transit-oriented development planning and analysis uses the "one-half mile circle". Many transit oriented real estate studies this limit analysis of price effects to just the first 0.50-mile from transit stations (see Higgins and Kanaroglou 2016). The presumption is that 0.50 -mile is about the longest distance people are willing to walk to/from transit stations. But as Canepa (2007) suggests, this is just an artifact and not truly empirically founded, that in fact people are willing to walk longer distances especially of the walking environment lends itself to it. We observe there are also a growing number of "last mile" (or even last two-mile) micro mobility options that are emerging such as e-scooters, grab-and-go bicycles, for-rent bicycles, e-bicycles, and related (see Feignon 2019 research in progress).

Real estate research also confirms that the threshold can be more than 0.50-mile and even close to 2.00-miles. For office and industrial real estate, Ko and Cao (2013) found LRT station proximity price premiums extended up to 0.90 -mile. For multifamily real estate, Petheram et al. (2013) found LRT price premiums up to about 1.25 miles. For office rents, Nelson et al. (2015) found premiums nearly 2.00 miles away though roughly three-quarters of the premium occurred within the first 1.00-mile. Finally, there is the issue of reasonableness. Our sense of the literature is that while price and rent effects may be seen up to two miles away under some circumstances relating to some types of real estate accessed by some types of transit, the 1.00-mile threshold captures nearly all of the effects if there are any (see Nelson and Hibberd 2017; Nelson and Hibberd 2019).

We used the General Transit Feed Specification (GTFS) platform to identify and map FRT systems and their stations (https://transitfeeds.com/). It is the most commonly used format for specifying public transit systems. We also double checked FRT systems identified in the GTFS with a review of transit agency web sites to confirm.

\section{A Word on Transit Data Challenges}

As an aside, we are compelled to comment here on transit system data collection challenges. Use of secondary data is considered an easy, low resource way to quantitatively analyze social phenomena. Yet data quality issues frequently arise due to lack of adherence to best practices, or due to need for further development of those practices. Challenges appear when the original design of the data standard does not anticipate and thus serve the needs of diverse researchers. The GTFS data model and standard - a revolutionary source in expanding general access to transit data - has provided a remarkable tool for the present study. More than 2,000 transit agencies have provided data through the GTFS. However, the agencies and app 
developers do not always format and manage it consistently, notwithstanding the standard's underlying paradigm of uniformity of data (Barbeau 2018).

Our study is a representative case, in which the GTFS standard fails to require consistent categorization of bus systems to distinguish between "bus rapid transit" or "express bus" among the vaguely defined "bus" category in the standard. When that information is provided, it is because the transportation authority decided to provide it, rather than the GTFS standard requiring it. The current relational model for the GTFS further increased the challenge of its use through greatly compounding data size and processing time, reducing computational capacity given the size of the resulting tables. By going to the specific web sites of each BRT agency, however, we were able to distinguish between those types of bus transit systems.

Finally, GTFS could be augmented with additional data describing transit system funding sources, boarding and alighting counts, headway, and station operational start dates. The former data would be of great value in such research efforts as discerning the market's involvement, response to, and investment return on various funding sources. The latter is often used in the literature to analyze temporal patterns of development around transit, such as how the market responds to the announcement of a new transit route.

We will now present details of the specific model.

\section{Dependent Variable}

$\mathbf{R}$ is the Asking Rent per Square Foot for property $i$ reported by CoStar during 2018 for multifamily and retail real estate and 2019 for office real estate. (CoStar has the largest, national commercial property database where data are collected using a standardized protocol.) Rents are monthly per square foot. Normally, statistical analysis is applied to samples of a universe. In this case, the study includes the universe of all commercial properties form which all data are available as reported by CoStar in our study area. As CoStar data come from real estate brokerages participating in its network, the data exclude non-participating brokerages or entities and properties not for rent such as owner-occupied properties. By logging the dependent variable, the semi-log model allows for coefficients to be interpreted as the percent change in rent attributable to a one-unit change in an independent variable such as an individual distance band.

\section{Control Variables}

$\mathbf{S}$ is the bundle of structure and lease restriction attributes for property $i$ reported by CoStar. This includes occupancy characteristics noted below. For all real estate, this includes:

Gross Leasable Area in building square feet with the expectation that there will be a positive association between office and multifamily building area and rent because larger buildings presumably include more amenities than smaller ones. However, this is not the case for retail (see Peiser and Hamilton 2012) where the sign is expected to be negative indicating declining marginal value per square foot with respect to increasing building size.

Effective Year Built which is the later of year of construction or year of renovation as reported by CoStar with the expectation that newer buildings will command more rent than older ones.

Vacancy Rate with the expectation that the higher the vacant rate the lower the rent. However, this may not always be the case as high demand markets could result in high 
vacancy rates as owners wait for higher paying tenants. Accordingly, signs may not be predictable especially considering that the study area is comprised of stable to rapidly growing central counties.

The number of Stories is also included with the expectation that the taller the building the higher the mean rent. However, for retail, Stories are excluded because of scant variation among retail structures.

For only office real estate, this includes:

Class $\boldsymbol{A}$ and Class $\boldsymbol{B}$ office space which are considered the highest and next highest quality in the office market, commanding rents accordingly. Class $C$ office space is the referent.

For only multifamily real estate, this includes:

Occupancy restrictions for Senior or Student housing with Market Rate housing being the referent. The expectation is that relative to Market Rate multifamily units, rents for Student housing will be lower because average annual rents will be based on occupancy during only part of the year. Rents for Senior housing also be lower because they usually impose less wear and tear on units, often rent for longer periods of time, and sometimes include rent subsidies which may limit the rent.

For only retail real estate, this is comprised of the most common types of retail structures reported in standard real estate texts (see Peiser and Hamilton 2012) with all others being the referent. The retail structures used include:

Power Center
Neighborhood Center
Community Center
Regional Center
Lifestyle Center
Outlet Center

The SES dimension is comprised of Median Household Income from the five-year sample of the 2018 American Community Survey (ACS) for the block group within which a CoStar property is located, for which a positive association is expected with respect to rent (Xiao 2016).

Because the PT (Place Typology) variable (see below) includes distance from downtown, one variable comprises the $\mathbf{C}$ dimension: Distance to Freeway. This is defined as distance to the nearest freeway or expressway ramp. Because freeway ramps can be considered nuisances in addition to accessibility benefits, no signs of association are predicted.

The $\mathbf{M}$ dimension is comprised of the individual metropolitan areas within which the FRT systems we studied operate. As these are controls which account for idiosyncrasies of metropolitan markets, no direction of associations is predicted.

\section{Special Reference Control Variables}

Chapter 1 presents our methods and results for creating a Place Typology (PT) to help explain the variation in differences between economic development, population change, commuting and real estate rents (which are the focus of this chapter). We call these the "special reference' 
control variables because they are used to create subsets of analyses of rent premium with respect to transit station proximity for each of these specially designed geographic units. For review, from, Chapter 1, the cluster analysis method used these variables to establish four types of places:

\author{
Jobs per acre \\ Proportion of jobs that are retail and arts \\ Total population per acre \\ Total households per acre \\ Percent of households with no kids \\ Percent of owner-occupied housing \\ Intersections per square mile \\ Proportion of intersections with 3 to 4 vertices
}

The method used LEHD (Longitudinal Employment-Household Dynamics) and census data applied at the block group (BG) level, producing these statistically unique place types which also conform to a priori expectations.

High Mix/Accessibility (High MA) Centers such as downtowns, suburban nodes, and other areas with high concentrations of jobs and people;

Moderate Mix/Accessibility (Moderate MA) areas such as large combinations of BGs with modest mixes of jobs and people and lower connectivity between land uses, and often surrounding High MA centers;

Low Mix/Accessibility (Low MA) areas which are usually low density, residential areas that some might characterize as urban sprawl, and which are usually found between Moderate MA and Poor MA areas; and

Poor Mix/Accessibility (Poor MA) areas which are dominated by very low-density residential development with no employment centers and the lowest levels of accessibility between land uses. Poor MA will be used as the referent in analysis meaning that the variation in rents attributable to Place Typology will be estimated with respect to this variable, all other factors considered.

We predict that controlling for all factors, rents along a continuum will be highest in the High MA centers and lowest in the Poor MA areas.

While all the above variables are the controls, DB or distance band is the treatment variable. In review, DBs are comprised of 0.125-mile increments to 1.00-mile of the nearest transit station, with cases beyond 1.00-mile being the referent. We also measure distance between the parcel and the nearest station, calling it the closest distance to the transit station. We do so assuming that structures will orient themselves to transit stations if they can. We also measure straight line distance; future research will measure network distance.

Table 8.1 summarizes our control and treatment variables, sources of date, measures, and predicted signs. It also includes a synopsis discussion of how the DB magnitude and signs are expected to vary with respect to FRT station distances. That synopsis is based on the statistical interpretation discussion at the end of this subsection.

\title{
Modeling Limitations
}


We acknowledge that our model does not include any transit service-related factors such as the number of bus routes at a station, station spacing, headway, service span and so forth. These quality of service measures may reveal incremental willingness to pay higher rent with respect to distance to specific stations/stops. It is an area ripe for future research mostly because it has never been done in the context of real estate transit value added. Part of that research may include efforts to improve open data standards to meet the needs of transportation researchers, as discussed below. Second, as in all prior real estate value transit added research, our theory is based on incremental change in value (rents) with respect to transit station proximity, not with respect to level and quality of service. Finally, like all real estate transit valued added research, our aim is to determine central tendencies, directions of association, and approximate as opposed to precise estimates of value added with respect to transit station proximity.

\section{Statistical Interpretations}

With tens of thousands of cases, our model includes many times more data than used in most prior studies (see Higgins and Kanaroglou 2016 for comparison). While we have no a priori

expectations of goodness of fit outcomes, literature suggests that ordinary least squares hedonic (regression) analysis usually explain about one fifth to two-thirds of the variation in the observed rent for cases. We note that while some analysts may be preoccupied with achieving high levels of regression model explanation, too many variables can lead to over-specification. It is best to emphasize the variables most relevant to the question along with relevant controls are sufficient to avoid serious omitted variable bias (a form of endogeneity) in the model. Our model is based on both theory and a large body of prior empirical work.

Our key interest is the association between rents per square foot and distance band with respect to the nearest FRT station. While a positive association is expected between DBs and FRT station proximity, negative associations can signal the presence of externality effects noted above. For instance, areas very near stations may have such nuisances as traffic, noise, and poor urban design that offset positive effects of proximity. DBs farther away may reveal positive rent coefficients because negative externality effects will have dissipated. But at some point DB price premiums are expected to decline and perhaps even become negative because accessibility costs would have increased, based on AMM theory and controlling for other influences.

Finally, when we combine possible negative externality effects associated with being near transit stations with increasing rent premiums further away followed by decreasing premiums, we expect to see an inverted $\boldsymbol{U}$ shape. That is, unlike most conventional studies of the association between rents and transit station distance, the DB approach allows us to estimate how far away from transit stations the market values proximity before the premium declines. The reason is that our application of theory allows for both positive and negative signs, with negative signs indicating negative externalities associated with effects of FRT stations on nearby commercial real estate.

This leads us to issues of statistical interpretations. Normally, interpretation of ordinary least squares (OLS) regression coefficients is based either on predicting signs. In cases of pure empirical exploration, perhaps no direction of association is predicted. Where signs are predicted, the 1-tailed t-test of significance can be used. The conventional minimum level of significant is $p<0.10$ meaning there is only a 1 -in-10 chance that the coefficient's magnitude and its direction is incorrect. We accept that threshold for our analysis.

But what if the theoretically predicted sign will change across space? In Figure 8.1, we show that negative externalities at or near transit stations can be revealed in the market as lower rent compared to the mean all factors considered. Procedurally, this would be a negative coefficient for the first (0.125-mile) distance band perhaps extending to other distance bands before 
becoming positive. We thus predict that signs will change if negative externalities are present at or near transit stations.

Or, the coefficient may be positive in the first $(0.125$-mile $)$ distance band with the coefficient increasing in size until it peaks some distance away before declining and perhaps becoming negative.

Or, the coefficient may be positive and have the largest coefficient at the first $(0.125$-mile) distance band, falling outward and perhaps becoming negative. This would indicate planning and urban design that overcame negative externalities at or near transit stations.

Thus, theory allows for the revealed rent gradient to be $\mathrm{R}^{\mathrm{a}}$ or $\mathrm{R}^{\mathrm{n}}$ leading into $\mathrm{R}^{\mathrm{m}}$ in Figure 8.1. But how do we use conventional t-test interpretations? We do so as follows:

Close to the Station

Where 2-tailed $p<0.10$, a negative sign reveals the presence of negative externalities at or near the station but where the sign is positive the amenity value of proximity overcomes negative externalities. In effect, because we can explain the direction based on theory, and theory allows both signs, we have a 1 -tailed $p<0.05$. However, where 2tailed $p>0.10$ but $<0.20$ we call this contingent significance because the theory allows both signs resulting in an interpretive 1 -tailed $p<0.10$ which meets the minimum conventional threshold.

Farther from the Station

Where the first or other DBs are close to the transit station, theory requires that coefficients increase in magnitude to some point away from the station where $R^{a}$ has completely overcome $R^{n}$. Coefficients would decline thereafter, revealing $R^{m}$.

Farthest from the Station within 1.00-Mile

Though coefficients would be expected to fall from where $R^{a}$ overcomes $R^{n}$, it is possible that $R^{m}$ could become negative reflecting complete loss of amenity value at some point away from transit stations.

Our interpretations will be based on all these possibilities because they all conform to theoretical expectations.

We proceed to results of our analysis and discussion. 
Table 8.1

Variables, Data Sources, Measurement Type, and Predicted Association with Respect to Rent per Square Foot

Variable

Rent

Rent per Square Foot (logged)

Structure Controls-All Cases Feet

Gross Leasable Area, Square

Stories

Effective Year Built

Vacancy Rate

Stories

Structure Controls-Office

Class A Office

Class B Office

Class C Office

Occupancy Controls-

Multifamily

Senior

Student

All other

Occupancy Controls-Retail

Power Center

Neighborhood

Community

Regional

Lifestyle

Outlet

All Other

\section{Socioeconomic Control}

Median Household $(\mathrm{HH})$ Income

Location Control

Distance Freeway Ramp

\section{Metropolitan Control}

Metropolitan Area Location

\author{
Data Source \\ Dependent Variable
}

Measure

Predicted Sign

CoStar

Continuous

Control Variables

CoStar

CoStar

CoStar

CoStar

CoStar

CoStar

CoStar

CoStar

CoStar

CoStar

CoStar

CoStar

CoStar

CoStar

CoStar

CoStar

CoStar

Census ACS

Computed

Census
Continuous

Continuous

Continuous

Continuous

Continuous

Binary

Binary

Binary

Binary

Binary

Binary

Binary

Binary

Binary

Binary

Binary

Binary

Continuous

Continuous

Binary na

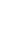

+
+
+
-
+
+
+
+
+

Referent

Referent

na
na
na
na
na
na
Referent

$+$

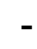

na 
Table 8.1

Variables, Data Sources, Measurement Type, and Predicted Association with Respect to Rent per Square Foot - continued

Variable

\author{
Data Source \\ Measure
}

Predicted Sign

Station Typology Control

High Mix/Accessibility

Moderate Mix/Accessibility

Computed

Computed

Binary

Computed

Binary

Binary

Computed

Binary

Treatment Variable

Distance Band Treatment

$1 / 8$ mile bands to $1.0-$ mile

Computed

Binary

Computed

Binary

See synopsis

Beyond 1.0-mile

Referent

\title{
Synopsis DB expectations
}

A negative association is expected with respect to the first $(0.125-\mathrm{mile}) \mathrm{DB}$ because of negative externalities or if positive the coefficient will be lower than the second (0.125-mile) DB and perhaps others father away from the station. An inverted $U$ form is expected reflecting increase rent premium with respect to station distance because of negative externalities at or near the station, peaking at some distances, then declining and perhaps becoming negative. However, if the coefficient of the first (0.125-mile) DB is higher than those farther away, negative externalities would appear to have been overcome perhaps through planning and urban design. In that case, rent premiums would be expected to decline steadily outward perhaps in some cases becoming negative. There are thus two types of acceptable significance levels:

- Conventional significance where $p<0.10$ using the 2-tailed t-test with no sign predicted; and

- Contingent significance where $p>0.10$ but $<0.20$ using the 2-tailed t-test where a sign is consistent with contingent theoretical expectations such as a negative sign in the first (0.125-mile) DB but positive in the second (0.250-mile) DB if not for others that are father away. 


\section{PRESENTATION AND DISCUSSION OF RESULTS}

In this section we present results for Office, Multifamily and Retail rent analysis, respectively. This is followed by a summary of key findings before moving onto implications for transit and land use planning. But first a summary of our overall analytic plan.

\section{Analytic Plan}

Our analytic plan is comprised of the full regression model applied to each of the four modes (LRT, BRT, SCT and CRT) for each of the three types of real estate (Office, Multifamily, and Retail) for a total 12 regression analyses. We will also limit our focus to key trends, insights, and surprises. We do not report correlation matrices for brevity. Using a conservative correlation coefficient of 0.70 as our threshold (because this number squared, 0.49 , explains less than half of the variation), we found no problem collinearities between variables. Using a variance inflation factor (VIF) of less than 5.0 as our threshold, we find no problematic multicollinearity in our ordinary least squares regression analysis. In the regression tables, we do not report standard errors of coefficient estimates or t-scores also for brevity but we do highlight those coefficients that are significant based on the 2-tailed t-test where $p<0.10$ or meet the threshold of being contingent significant where the 2-tailed t-test is $p>0.10$ but $<0.20$ but only if the coefficient confirms to theoretical expectations illustrated in Figure 8.1 or otherwise explained above. These two types of significant coefficients are often called "relevant" coefficients.

We present results in several ways:

- Results for the full model are presented for the systems as a whole for each type of real estate;

- Results only for distance bands for each Place Typology for each mode and each type of real estate;

- Results for individual metropolitan areas reporting relevant distance band and Place Typology coefficients which also includes-

- A summary assessment of the direction of the association between transit stations and real estate rents up to 0.625-mile away as well as

- A summary assessment of the functional form of that association across the entire 1.00-mile study area; and

- Identification of what we call "exemplars" which are metropolitan areas where the direction and magnitude of the association between rent and transit station distance are positive and downward sloping to at least 0.25-mile from transit stations for each mode and each type of real estate where we also recommend future case study research to understand the transit, land use planning and urban design efforts implemented in those metropolitan areas.

We now present and discuss results of our Office, Multifamily and Retail analyses, respectively. 


\section{The Variation of Office Rents with Respect to Place Typology and Transit Station Proximity}

We first present results for the full model in Table 8.2 for office rents with respect to LRT, BRT, SCT and CRT systems, respectively. For all four equations, the coefficients of determination $\left(R^{2}\right)$ show that the equations explain a reasonable share of the variation of rents and the $F$ ratios show the equations' outcomes to be considerably beyond chance.

We now review results for the control variables first and then those for the Place Typology followed by those for the distance band treatment variables. Excluding metropolitan controls (see below), the control variables performed as expected:

Rent increases as the size of an office building increases, reflecting amenities that are more commonly offered in larger complexes than smaller ones;

Rents for Class A space are higher than for Class B space, which is higher than the referent Class $\mathrm{C}$ space;

As building height increases reflected by the number of floors or stories, mean rent increases reflecting elevation away from the hustle and bustle of the ground level as well as views and perhaps improved air flow;

As the effective year in which the structure was built (or renovated) increases (more recent years have a higher value than earlier years), rent increases;

As the vacancy rate increases rents decrease;

As the median household income of the block group within which the property is located increases so does rent;

As distance from the nearest freeway ramp increases rents also fall; and

As the intensity of mixed use and accessibility decreases from High MA places to Low MA areas (compared to Poor MA areas), office rent decreases as expected.

We note that as controls for metropolitan-specific market characteristics, the coefficients for the metropolitan variables are not directly relevant to the interpretation of results with respect to transit stations/stops. Since we use Virginia Beach as our referent, the coefficient for Seattle indicates only that the mean rent per square foot in the Seattle market is 29.3 percent higher than the mean rent in Virginia Beach. In contrast, the mean rent for the Buffalo market is actually 21.4 percent lower than the mean rent in the Virginia Beach market.

We turn next to evaluating the variation in office rent for each transit mode in three ways:

- Overall variation in office rent with respect to station proximity;

- Variation in the association between office rents and transit station proximity with respect to Place Typologies; and

- Variation in the association between office rents and transit station proximity with respect to individual metropolitan areas. 
Table 8.2

Overall Regression Results for Office Rents with Respect to Place Typology and Transit Station Proximity

Variable
Constant
Structure Controls
Gross Leasable Area
Class A*
Class B*
Stories
Effective Year Built
Vacancy Rate
Socioeconomic
Control
Median HH Income
Location Control
Distance to Freeway
Metropolitan
Control**
Buffalo
Charlotte
Cleveland
Dallas
Denver
Houston
Minneapolis
Phoenix
Pittsburgh

LRT Beta Variable

2.219 Constant

Structure Controls

2.408E-005 Gross Leasable Area

0.318 Class $A^{*}$

0.111 Class $B^{\star}$

0.003 Stories

0.000 Effective Year Built

-0.001 Vacancy Rate

Socioeconomic

Control

1.887E-003 Median HH Income

Centrality Control

-2.623E-003 Distance to Freeway

\section{Metropolitan}

Control $^{* *}$

-0.214 Atlanta

0.152 Cincinnati

-0.188 Dallas

0.093 Kansas City

0.112 New Orleans

0.121 Portland

0.069 Salt Lake City

0.076 Seattle

-0.139 Tucson
SCT Beta Variable

2.075 Constant

Structure Controls

1.173E-

007 Gross Leasable Area

0.153 Class $A^{*}$

0.055 Class $B^{*}$

0.015 Stories

0.000 Effective Year Built

4.154E-

005 Vacancy Rate

\section{Socioeconomic}

Control

2.199E-

006 Median HH Income

Centrality Control

$-2.808 \mathrm{E}-$

006 Distance to Freeway

Metropolitan

Control ${ }^{* *}$

-0.246 Cleveland

-0.453 Eugene

-0.266 Kansas City

-0.369 Minneapolis-St. Paul

-0.352 Nashville

-0.090 Pittsburgh

-0.312 Reno

0.014 Salt Lake City

-0.263 San Antonio
BRT Beta Variable

0.814 Constant

CRT Beta

Structure Controls

7.435E-

008 Gross Leasable Area $\quad$ 9.362E-009

0.321 Class $A^{*}$

0.171

0.043

0.095 Class $B^{*}$

0.016

0.003 Stories

0.000

-0.001 Vacancy Rate

\section{Socioeconomic} Control

1.660E-

006 Median HH Income 2.527E-006 Centrality Control

6.697E-

007 Distance to Freeway $\quad-3.663 E-006$

\section{Metropolitan}

Control**

-0.054 Albuquerque-Santa Fe

$-0.417$

0.192 Austin

0.223

0.005 Dallas-Fort Worth

$-0.226$

-0.106 Denver

$-0.125$

0.115

$\begin{array}{ll}0.053 \text { Minneapolis-St. Paul } & -0.148 \\ 0.135 \text { Nashville } & -0.029\end{array}$

0.078 Orlando $\quad-0.162$

0.353 Portland $\quad-0.094$ 
Table 8.2

Overall Regression Results for Office Rents with Respect to Place Typology Transit Station Proximity-continued

\begin{tabular}{|c|c|c|c|c|c|}
\hline Variable & Variable & SCT Beta & Variable & BRT Beta & CRT Beta \\
\hline Portland & 0.194 & & San Diego & 0.422 Salt Lake City & -0.356 \\
\hline Sacramento & 0.113 & & San Jose & 0.751 San Diego & 0.038 \\
\hline Salt Lake City & -0.060 & & Seattle & 0.374 San Jose-Bay Area & 0.783 \\
\hline San Diego & 0.284 & & & Seattle-Tacoma & 0.041 \\
\hline San Jose & 0.736 & & & San Jose-Stockton & -0.317 \\
\hline Seattle & 0.293 & & & & \\
\hline St. Louis & -0.083 & & & & \\
\hline \multicolumn{3}{|c|}{ Place Typology Control*** } & \multicolumn{3}{|c|}{ Place Typology Control*** } \\
\hline Low MA Areas & 0.026 Low MA Areas & 0.058 & 8 Low MA Areas & 0.013 Low MA Areas & 0.063 \\
\hline Moderate MA Areas & 0.068 Moderate MA Areas & 0.129 & 9 Moderate MA Areas & 0.042 Moderate MA Areas & 0.134 \\
\hline High MA Centers & 0.133 High MA Centers & 0.276 & 6 High MA Centers & 0.084 High MA Centers & 0.247 \\
\hline \multicolumn{3}{|c|}{ Distance Band Treatment ${ }^{* \star * *}$} & \multicolumn{3}{|c|}{ Distance Band Treatment ${ }^{\star * * *}$} \\
\hline$<=0.125$ & $-1.0 \%<=0.125$ & $1.2 \%$ & $\%<=0.125$ & $1.5 \%<=0.125$ & $5.3 \%$ \\
\hline$>0.125-0.250$ & $1.0 \%>0.125-0.250$ & $7.0 \%$ & $\%>0.125-0.250$ & $6.6 \%>0.125-0.250$ & $-3.1 \%$ \\
\hline$>0.250-0.375$ & $1.3 \%>0.250-0.375$ & $13.5 \%$ & $\%>0.250-0.375$ & $4.8 \%>0.250-0.375$ & $2.7 \%$ \\
\hline$>0.375-0.500$ & $2.2 \%>0.375-0.500$ & $-0.4 \%$ & $\%>0.375-0.500$ & $2.5 \%>0.375-0.500$ & $0.1 \%$ \\
\hline$>0.500-0.625$ & $0.5 \%>0.500-0.625$ & $4.1 \%$ & $\%>0.500-0.625$ & $3.2 \%>0.500-0.625$ & $1.8 \%$ \\
\hline$>0.625-0.750$ & $1.1 \%>0.625-0.750$ & $5.0 \%$ & o >0.625-0.750 & $0.8 \%>0.625-0.750$ & $1.8 \%$ \\
\hline$>0.750-0.875$ & $0.6 \%>0.750-0.875$ & $18.0 \%$ & $\%>0.750-0.875$ & $4.9 \%>0.750-0.875$ & $3.2 \%$ \\
\hline$>0.875-1.000$ & $-1.5 \%>0.875-1.000$ & $16.3 \%$ & $\%>0.875-1.000$ & $-0.4 \%>0.875-1.000$ & $4.6 \%$ \\
\hline
\end{tabular}


Table 8.2

Overall Regression Results for Office Rents with Respect to Place Typology Transit Station Proximity-continued

\section{LRT Performance Metrics}

Mean Rent/Square

Foot

Cases

R2 adjusted

Std. Error of Estimate

F-Ratio

${ }^{*}$ Class $\mathrm{C}$ is referent

${ }^{* *}$ Virginia Beach is referent

***Poor MA Places are referent

${ }^{* * * *}$ Cases $>1.00$-mile are referent
SCT Performance Metrics Mean Rent/Square $\$ 26.24$ Foot

62,166 Cases

0.416 R2 adjusted

0.298 Std. Error of Estimate

1,264.602 F-Ratio

${ }^{*}$ Class $\mathrm{C}$ is referent

**Washington is referent

${ }^{* * *}$ Poor MA Places are referent

${ }^{* * * *}$ Cases $>1.00$-mile are referent

\section{BRT Performance Metrics}

Mean Rent/Square

\$27.64 Foot

36,107 Cases

0.340 R2 adjusted

0.328 Std. Error of Estimate

666.599 F-Ratio

${ }^{*}$ Class $C$ is referent

${ }^{* *}$ Albuquerque is referent

***Poor MA Places are referent

${ }^{\star * * *}$ Cases $>1.00$-mile are referent

\section{CRT Performance Metrics}

Mean Rent/Square

\section{$\$ 21.83$ Foot}

$\$ 25.82$

9,777 Cases

68,433

$0.472 \mathrm{R} 2$ adjusted

0.484

0.287 Std. Error of Estimate

282.059 F-Ratio

$1,945.993$

${ }^{*}$ Class $\mathrm{C}$ is referent

${ }^{* *}$ Washington is referent

***Poor MA Places are referent

${ }^{* * * *}$ Cases $>1.00$-mile

are referent

Bold means significant coefficient consistent with theory using 2-tailed t-test $p<0.10$.

Bold italics means contingent significant coefficient consistent with theory using 2-tailed t-test $p>0.10$ but $<0.20$ or alternatively significant using the 1-tailed t-test $p<0.10$. 


\section{Overall Variation in Office Rent with Respect to Station Proximity}

The principal focus of our research is knowing whether and the extent to which transit station proximity influences office rents. We offer the following insights from Table 8.2 which are illustrated in Figure 8.2. Key findings for each system are as follows:

\section{Office Rents and LRT Station Proximity}

Office rents for LRT station proximity at or near stations to about 0.50 -mile then fall. In the first distance band ( 0.125 -mile), rents are below the mean ( -0.10 percent) ceteris paribus indicating the presence of negative externalities. Rents peak at 2.20 percent above the mean in the fourth (0.50-mile) distance band before falling to -1.5 percent in the last (1.00-mile) distance band. This is the only transit system where rents start and end below the mean along the distance band continuum. Why might this be? Obviously, the LRT station and area itself can be a source of negative externalities. But rents may also be depressed as older buildings are depreciating until the time when the market responds through redevelopment. Inasmuch as the typical office building has a useful life of about 40 to 60 years (see Nelson 2013), it could take a few decades for older building at or near LRT stations to be redeveloped. Farther away, not only do the amenity advantages of LRT station proximity dissipate but the market for office space may be in competition for such other uses as residential, retail, institutional and related potentially depressing office rents. This is an area of ongoing study done at the station level.

\section{Office Rents and SCT Station Proximity}

Results for streetcar transit (SCT) systems present their own interesting interpretations. From the first $(0.1235-\mathrm{mile})$ distance band to the third $(0.375$-mile), office rents rise from 1.2 percent above the mean to 13.5 percent, followed by no statistically significant coefficient. Office rents then progress at a lower premium, at 4.1 percent above the mean to 5.0 percent and peaking at 18.0 percent before falling to 16.3 percent in the fifth $(0.625$-mile) to last $(1.00$-mile $)$ distance bands, respectively. We know from prior research (Nelson and Hibberd 2017; Nelson et al. 2015) that office rents may be lower at or near SCT stations not necessarily because of negative externality effects or delayed redevelopment (as suggested for LRT systems above), but because multifamily residential dominates land uses from the SC T stations outward over a few distance bands. We discuss this prospect with respect to multifamily rents below. Office then dominates the latter distance bands because this is where the highest value office spaces are for the region. We observe that for the most part, SCT systems circle or operate somewhat away from downtowns in most of our study areas, hence mean rents rise away from SCT stations.

\section{Office Rents and BRT Station Proximity}

For BRT systems there is no statistically significant association between rent and the first (0.125-mile) distance band even considering our contingent possibility—suggesting that for whatever reason the market does not reveal proximity as a value. However, rents fall from the second $(0.25$-mile) to the fourth $(0.50$-mile) distance bands, from a 6.6 percent premium to 2.5 percent, then rises to 4.9 percent in the seventh $(0.875$-mile) distance band. It would seem that the market values proximity near though not at the BRT station and then also farther away suggesting a second threshold exits. One reason may be that with respect to BRT systems, the pattern of revealed office rents shows amenity value near albeit not close to BRT stations which may merely reflect value of proximity to the major highway along which BRT systems operate. As many major highway systems are laid out with roughly 1.00-mile separations between them, perhaps it is at about 0.50 -mile that office rents are internalizing proximity to the next major highway. It is also telling that the coefficient for the last (1.00-mile) distance is not significant just as it was for the first. This will lead us to more refined research on this potential nuance as applied to BRT stations. 
Office Rents and CRT Station Proximity

CRT systems also have their own unique patterns. Rents are 5.3 percent above the mean in the first (0.125-mile) distance band, fall dramatically -3.1 percent in the second $(0.25$-mile) DB, then rise to 2.7 percent above the mean in the third (0.375-mile) distance band. After the fourth (0.50-mile) distance band where there is no statistically significant coefficient, rents rise from 1.8 percent to 4.6 percent above the mean between the fifth (0.625-mile) and last (1.00-mile) distance bands. This behavior comports to our personal observations as many offices cluster at or near CRT stations especially where other forms of transit intersect. (Some of the highest office rents on the planet are found near Penn Central Station in New York City which serves as a hub for CRT and other transit systems.) But since CRT rail is often aligned with or shares freight rail systems, the advantages of proximity dissipate rapidly as seen in Figure 8.3 before rising consistently to the end of the study area. We surmise one reason for this pattern is that CRT stations themselves are often not located downtown though they are often within one or so miles from downtown.

What can be made of this? For the most part, the variation in office rent with respect to proximity to transit stations varies by transit mode. While we should not be surprised, we are still, nonetheless, for the reason that transit should have the same effects on real estate markets regardless of mode, which we find is not the case. Not only do rent effects of transit effects vary by mode, they also vary by land use, as will be seen below with respect to multifamily and retail rents which are reviewed later.

We next review the association between office rents and transit station proximity with respect to Place Typology. 


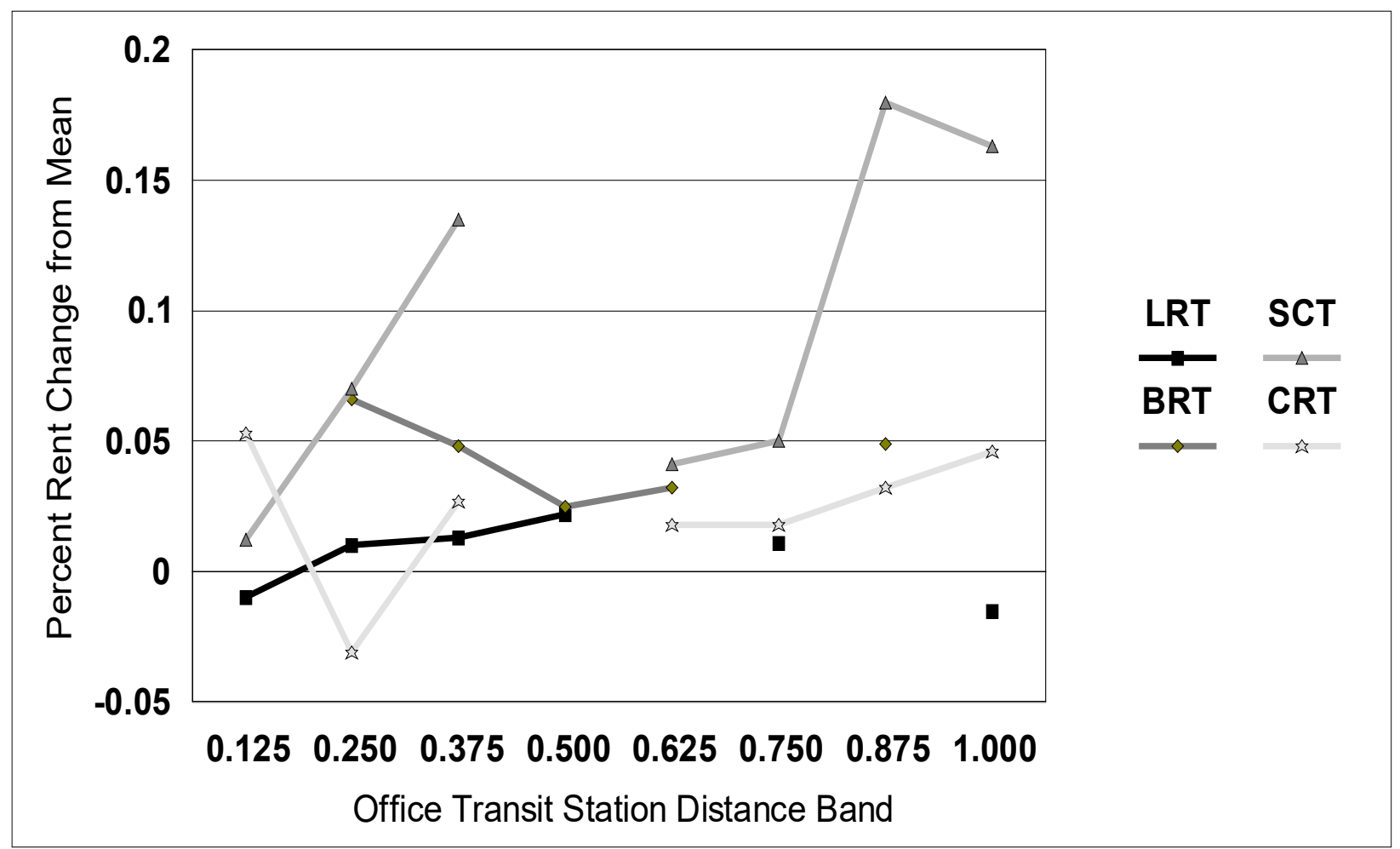

Figure 8.2

Variation in office rent per square foot with respect to distance from LRT, BRT, SCT and CRT stations

Overall but except for CRT, rents increase with distance from transit stations before falling. For $\mathrm{CRT}$, rents fall quickly then rise. 


\section{Variation in the Association between Office Rents and Transit Station Proximity with Respect to Place Typologies}

In Chapter 1, we created four Place Typologies to characterize generally the landscapes served by transit stations: High Mixed-Use/Accessible locations (High MA), Moderate Mixed-

Use/Accessible (Moderate MA) areas; Low Mixed-Use/Accessible (Low MA) areas; and Poor

Mixed-Used/Accessible (Poor MA) areas. In this section, we disaggregate our overall analysis to estimate the variation in office rents with respect to station proximity within each of the Place Typology. Because directions and magnitudes of association are similar to the overall model, regression results reported in Table 8.3 include only distance band coefficients and key performance indicators. The relationships are illustrated in Figure 8.3. We note the following highlights:

Variation in Office Rent with Respect to LRT Station Proximity by Place Typology In High- and Moderate-Mixed Use/Accessible places, Office rent tends to rise with respect distance from LRT transit stations to roughly 0.50 -mile before falling. The significant coefficients to 0.50 -mile are all positive. The implication is that externalities appear to exist at or near LRT stations which dampen rents. In contrast, significant coefficients for Low- and Poor-Mixed Use/Accessible places are mostly negative with respect to distance band. We interpret this to mean that LRT stations are located and/or designed-perhaps in part because of local planning and zoning—do not engender positive real estate market responses.

Variation in Office Rent with Respect to SCT Station Proximity by Place Typology Office rents with respect to SCT station proximity in High-Mixed Use/Accessible places falls sharply suggesting that the office market values proximity as an amenity. After a substantial dip leveling in the second (0.125-mile) and third (0.375-mile) distance bands, rents rise. We surmise that while some types of offices find locating near SCT stations to be amenity, others ae not as sensitive. We also surmise that there is competition between office and multifamily land uses proximate to SCT stations, as seen below. This results in high office and MF rents near SCT stations with MF rents maintaining a high level even as office rents fall to about 0.50 -mile, where office rents rise though only in that band.

In the Moderate- and Low- Mixed Use/Accessible areas, office rents with respect to SCT station proximity fall signaling the presence of externalities or something else-namely completion with MF rents. As will be shown below, MF rents in Moderate-and Low-MA areas are associated with SCT station proximity to such an extent that we surmise it out-competes and thus displaces office activities. We will discuss the implications of these interactions at the end.

As expected, there are no statistically significant associations between office rents and SCT station proximity on Poor-Mixed Use/Accessible areas mostly because SCT systems are limited mostly to built-up areas in and near downtowns.

Variation in Office Rent with Respect to BRT Station Proximity by Place Typology Across all place types, office rents fall with respect to BRT station proximity. The implication is that BRT stations are per se sources of externalities that are internalized by the office market in the form of lower rents. But this is not universally the case. As will be seen in the next subsection on metropolitan area specific results, amenity effects are found in some, disamenity effects in others, and ambiguous effects in the rest. There appears to be evidence suggesting that BRT station location and design affects office rents in ways we will address at the end.

Variation in Office Rent with Respect to CRT Station Proximity by Place Typology 
CRT associations are a study in contrasts though likely based on nuances of each place typology. For instance, with respect to High-Mixed Use/Accessible places, there is no significant association between rent and CRT station proximity in the closest $(0.125$-mile) distance but sizable associations in the second (0.250-mile), fourth (0.50-mile), sixth (0.750-mile) and last (1.00-mile) distance bands. We surmise that given their nature as compact areas with the highest office real estate values in the region, CRT stations may be located at the fringes of and isolated from the main office districts of High-MA places. That there are high rent associations near CRT stations however suggests there may be untapped potential for offices to locate more near to CRR stations than they do.

In all of the other place typologies, office rents are positive in the first $(0.125$-mile) distance band but mostly negative in the others until about the middle-distance bands.

These results lead us to two important insights with respect to the association of office rents as a function of CRT station distance. First, our results are contrary to most other research showing negative price effects with respect to distance. One reason may be the few such studies that exist are realty case studies of specific systems where our analysis is a cross section that includes 13 metropolitan areas. Another is that where other studies typically use 0.25 -mile or 0.50 -mile distance bands only to 0.50 -mile, ours is based on 0.125 -mile distance bands to 1.00-mile. Refined measures allow for refined insights. Which leads us to surmise that transit and land use planners may be overlooking the potential office market demand near or even at CRT stations.

We proceed next to analysis of individual metropolitan areas. 
Table 8.3

Regression Results for Office Rents with Respect to Transit Station Proximity by Place Typology

Distance Band
$<=0.125$
$>0.125-0.250$
$>0.250-0.375$
$>0.375-0.500$
$>0.500-0.625$
$>0.625-0.750$
$>0.750-0.875$
$>0.875-1.000$
Mean Rent/Square Foot
Cases
$\mathrm{R}^{2}$ adjusted

Distance Band

$<=0.125$

$>0.125-0.250$

$>0.250-0.375$

$>0.375-0.500$

$>0.500-0.625$

$>0.625-0.750$

$>0.750-0.875$

$>0.875-1.000$

Mean Rent/Square Foot

Cases

$\mathrm{R}^{2}$ adjusted

\section{Light Rail Transit by Place Typology} LRT High MA LRT Mod MA LRT Low MA LRT Poor MA

\begin{tabular}{|c|c|c|c|}
\hline $2.3 \%$ & $0.4 \%$ & $-3.0 \%$ & $-11.1 \%$ \\
\hline $7.1 \%$ & $1.1 \%$ & $0.0 \%$ & $-11.7 \%$ \\
\hline $1.4 \%$ & $5.6 \%$ & $-5.2 \%$ & $-0.7 \%$ \\
\hline $4.5 \%$ & $7.4 \%$ & $-1.9 \%$ & $-12.8 \%$ \\
\hline $5.8 \%$ & $3.1 \%$ & $-4.4 \%$ & $-0.7 \%$ \\
\hline $1.9 \%$ & $-4.0 \%$ & $3.3 \%$ & $-2.4 \%$ \\
\hline $2.7 \%$ & $1.2 \%$ & $-0.7 \%$ & $-3.5 \%$ \\
\hline$-11.9 \%$ & $3.4 \%$ & $-2.6 \%$ & $-2.9 \%$ \\
\hline 27.834 & 25.976 & 26.290 & 25.914 \\
\hline 4,183 & 21,486 & 29,106 & 7,391 \\
\hline 0.448 & 0.449 & 0.393 & 0.390 \\
\hline
\end{tabular}

Streetcar Transit by Place Typology

SCT High MA SCT Mod MA SCT Low MA SCT Poor MA

$\begin{array}{cccc}13.1 \% & 11.2 \% & 13.5 \% & 0.0 \% \\ 6.5 \% & 11.5 \% & 10.8 \% & 0.0 \% \\ 6.8 \% & 14.8 \% & 3.8 \% & 31.5 \% \\ 10.5 \% & 17.3 \% & 15.8 \% & 0.0 \% \\ -5.7 \% & 18.9 \% & 13.4 \% & 0.0 \% \\ -1.7 \% & 11.2 \% & -3.9 \% & 15.6 \% \\ -3.4 \% & 15.4 \% & 8.2 \% & 54.0 \% \\ -12.8 \% & 5.8 \% & 10.9 \% & 0.0 \% \\ \$ 32.03 & \$ 24.12 & \$ 20.63 & \$ 26.01 \\ 622 & 2,110 & 2,569 & 452 \\ 0.592 & 0.553 & 0.344 & 0.218\end{array}$


Table 8.3

Regression Results for Office Rents with Respect to Transit Station Proximity by Place Typology-continued

Distance Band
$<=0.125$
$>0.125-0.250$
$>0.250-0.375$
$>0.375-0.500$
$>0.500-0.625$
$>0.625-0.750$
$>0.750-0.875$
$>0.875-1.000$
Mean Rent/Square Foot
Cases
$R^{2}$ adjusted

Distance Band

$<=0.125$

$>0.125-0.250$

$>0.250-0.375$

$>0.375-0.500$

$>0.500-0.625$

$>0.625-0.750$

$>0.750-0.875$

$>0.875-1.000$

Mean Rent/Square Foot

Cases

$\mathrm{R}^{2}$ adjusted
Bus Rapid Transit by Place Typology

BRT High MA BRT Mod MA BRT Low MA BRT Poor MA

$\begin{array}{cccc}5.7 \% & \mathbf{5 . 4 \%} & \mathbf{0 . 4 \%} & \mathbf{- 9 . 6 \%} \\ \mathbf{8 . 5 \%} & \mathbf{7 . 6 \%} & \mathbf{8 . 7 \%} & -6.2 \% \\ \mathbf{1 2 . 0 \%} & \mathbf{3 . 9 \%} & \mathbf{7 . 6 \%} & -2.0 \% \\ \mathbf{1 1 . 3 \%} & 3.0 \% & 0.2 \% & \mathbf{2 4 . 7 \%} \\ \mathbf{1 3 . 1 \%} & -0.1 \% & 5.1 \% & 1.8 \% \\ -4.1 \% & -0.1 \% & 3.4 \% & -1.5 \% \\ \mathbf{1 5 . 2} \% & \mathbf{7 . 7 \%} & 1.8 \% & 5.1 \% \\ 6.5 \% & 2.5 \% & \mathbf{- 5 . 1 \%} & 6.6 \% \\ \$ 2.16 & \$ 23.10 & \$ 21.75 & \$ 20.65 \\ 563 & 2,841 & 4,331 & 1,394 \\ 0.468 & 0.516 & 0.486 & 0.459\end{array}$

Commuter Rail Transit by Place Typology

CRT High MA CRT Mod MA CRT Low MA CRT Poor MA

\begin{tabular}{|c|c|c|c|}
\hline$-0.9 \%$ & $5.4 \%$ & $5.1 \%$ & $0.5 \%$ \\
\hline $12.4 \%$ & $-3.8 \%$ & $-5.3 \%$ & $-7.6 \%$ \\
\hline$-0.3 \%$ & $-4.0 \%$ & $2.3 \%$ & $16.5 \%$ \\
\hline $7.8 \%$ & $1.2 \%$ & $-2.5 \%$ & $-3.8 \%$ \\
\hline $1.3 \%$ & $4.1 \%$ & $-4.3 \%$ & $5.9 \%$ \\
\hline $5.9 \%$ & $-0.9 \%$ & $2.6 \%$ & $4.0 \%$ \\
\hline$-2.0 \%$ & $3.3 \%$ & $3.6 \%$ & $-8.2 \%$ \\
\hline $30.8 \%$ & $-1.5 \%$ & $2.8 \%$ & $2.9 \%$ \\
\hline$\$ 30.40$ & $\$ 26.60$ & $\$ 25.36$ & $\$ 24.22$ \\
\hline 5,275 & 25,811 & 30,408 & 6,939 \\
\hline 0.456 & 0.509 & 0.472 & 0.537 \\
\hline
\end{tabular}



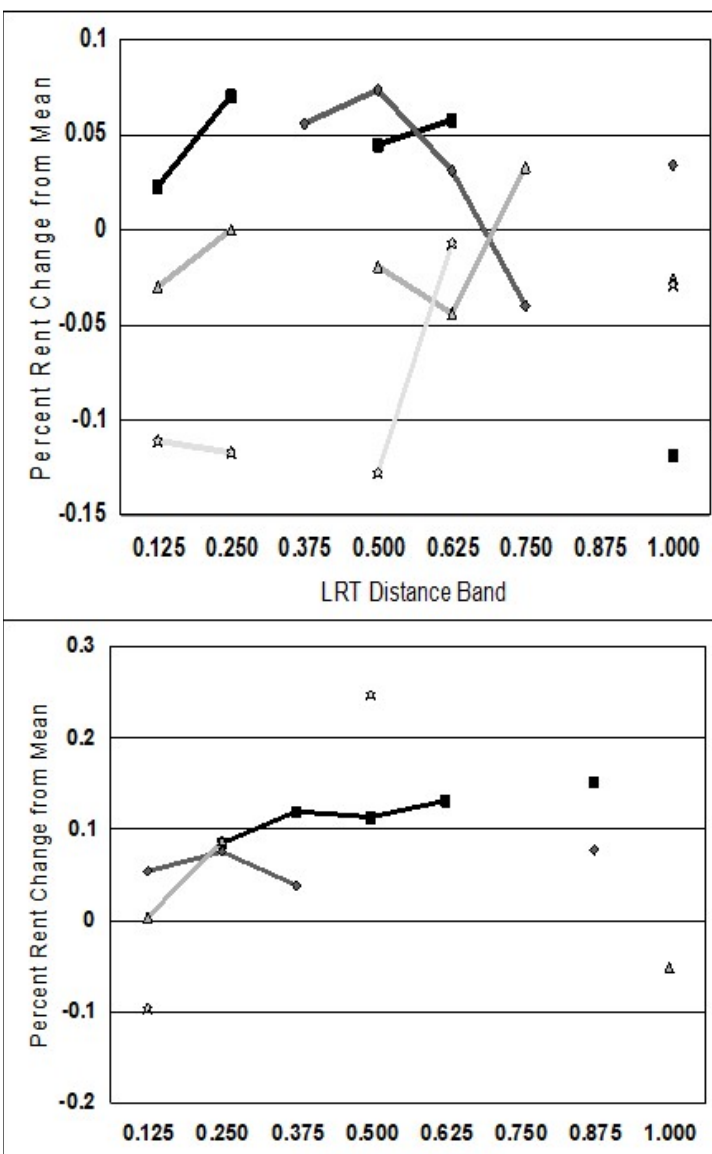

BRT Distance Band

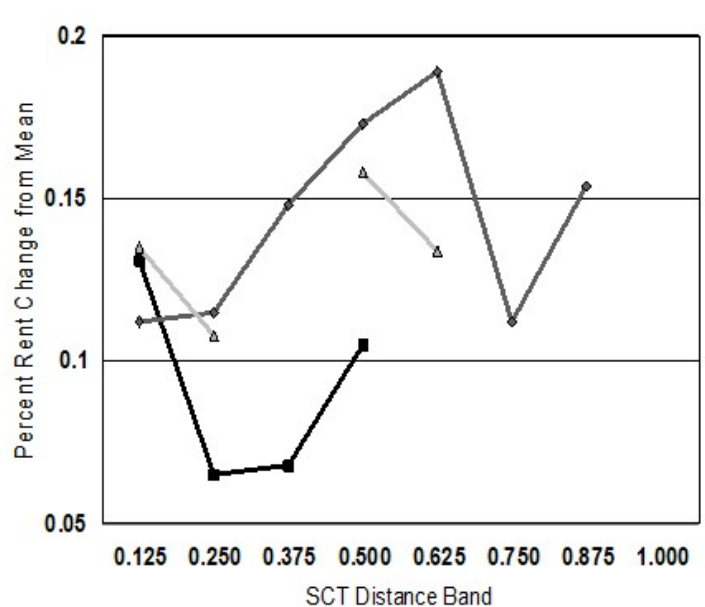

SCT Distance Band

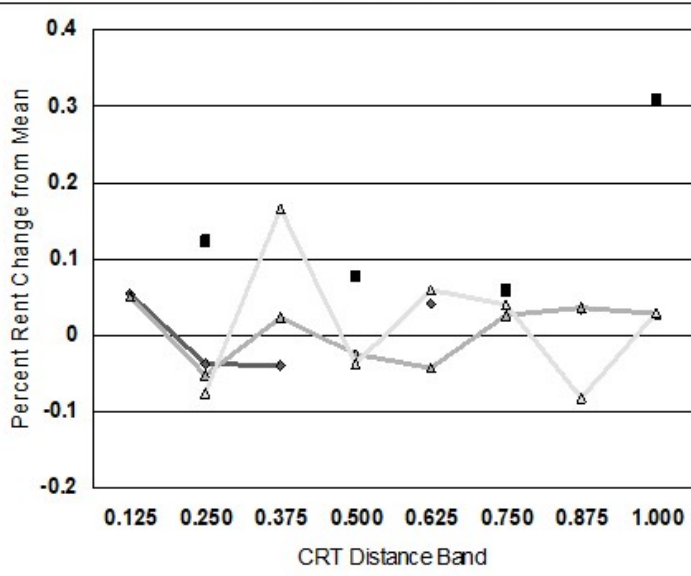

High MA LowMA $\rightarrow-\rightarrow$ $\rightarrow$ POOMA
High MA Low MA Moderate MA Poor MA $\rightarrow$

\section{Figure 8.3}

Plot of relevant LRT, SCT, BRT and CRT office rent coefficients with lines connecting respective points with respect to

\section{Place Typology}

Generally, office rent increases with respect to distance from transit stations indicating the presence of externalities at and near those stations. Exceptions are noted in the text.

Note: Distance bands are in miles. 


\section{Variation in Office Rent with Respect to Transit Station Proximity by Metropolitan Area}

In this subsection, we summarize findings in terms of the variation of office rents with respect to transit station proximity by metropolitan area. We also address the role of Place Typologies in combination with station proximity analysis. Like Table 8.3 , Table 8.4 reports regression coefficients for only distance bands and then for only those that are significant or contingent significant-what we call "relevant coefficients." It also includes relevant coefficients for Place Typologies. In our discussion we look for overall or general patterns of relationships between transit station proximity and office rent. The second-to-last last column in Table 8.4, for instance summarizes overall directional trends from the station $(0.125$-mile distance band) over the next four distance bands or where direction changes or coefficients are ambiguous. The summary patterns of association are:

- "Upward above mean" means rent starts above mean and increase away from transit stations signaling externalities internalized by the market.

- "Downward above mean" means rent starts above mean and fall away from transit stations signaling amenities internalized by the market.

- "Upward below mean" means rent starts below the mean then increase away from stations signaling externalities internalized by the market.

- "Downward below mean" means rent starts below the mean then decrease away from stations signaling externalities internalized by market.

- "Above mean" applicable to those cases where the only relevant coefficient is above the mean rent.

- "Below mean" applicable to those cases where the only relevant coefficient is below the mean rent.

- "Ambiguous" means no statistically significant coefficients in the first (0.125-mile) or second (0.250-mile) distance bands.

The last column summarizes the functional form of the distance relationship. Here we present a framework to present results shown in Table 8.4. Using Figure 8.1 and its related discussion as a guide, we aim to make sense of all these numbers through the use of diagrams. Let us categorize each system for each metropolitan area into five basic forms of association between transit station proximity and office rent, by mode. The five options are:

\section{Ambiguous relationship}

That is, there is no statistically significant association between office proximity to transit stations and rent. Put different, it would be as though the real estate market does not recognize the presence of transit. Alternatively, the amenity value of proximity is perfectly offset by the externality value. One could conclude that this outcome suggest that the transit system has failed to influence the real estate market based on revealed evidence. 
In the absence of externalities at or near the transit station, rents will fall as distance from stations increases as illustrated below. One can construe that the transit station is influencing the real estate market as intended. Of course, the form merely reveals market clearing prices which may mask externality effects that would dampen the slope.

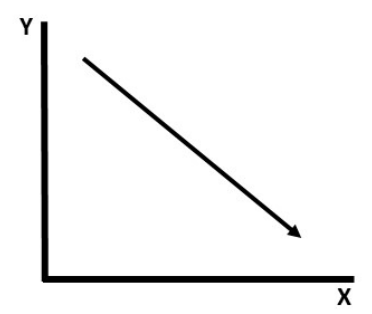

Where $Y$ is rent and $X$ is distance from a transit station

\section{Upward sloping relationship}

In the presence of externalities at or near the transit station, rents will rise as distance from stations increases in the manner shown below. One can construe that the transit station is influencing the real estate market as intended if (a) the market does not value station proximity per se or more likely if (b) externalities exceed amenities across the study area-in our case being 1.00-mile.

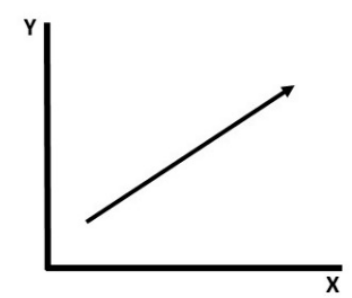

Where $Y$ is rent and $X$ is distance from a transit station

\section{Concave relationship}

A concave relationship would be revealed when externalities exceed amenities at or near transit stations. Then, as distance increases, externality effects dissipate as amenity effects associated with station proximity increase. This is a signal that the market reflects externality effects that might be overcome through better planning and station area design.

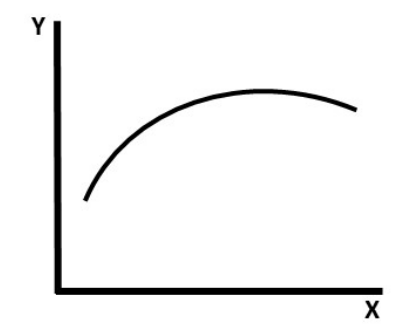

Where $Y$ is rent and $X$ is distance from a transit station 


\section{Convex relationship}

The final alternative is a convex relationship where rent falls with respect to transit station distance to some point before rising. The implication is that while transit station proximity has an amenity effect there is perhaps another influence further away, such as an area of higher quality development commanding higher rents.

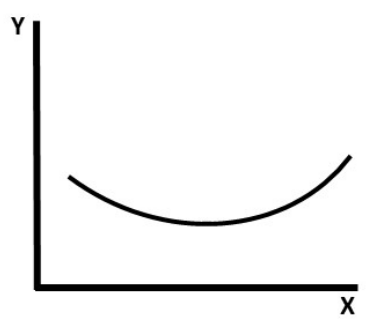

Where $Y$ is rent and $X$ is distance from a transit station

While these are highly generalized relationships, they nonetheless help to describe transit station effects on rent for individual metropolitan areas for each mode, which is presented next.

Finally, we apply this rule to the characterization of functional forms:

There must be at least two significant or contingent significant coefficients within the five distance bands - to 0.625-mile-of transit stations to establish a pattern of association with respect to station proximity. If there are no or just one significant coefficient, we deem the association ambiguous.

These summaries are applied to each mode (LRT, SCT, BRT, CRT) for the office rent regression distance band coefficients that are statistically significant or with contingent significance. We encourage readers to come to their own conclusions with respect to specific metropolitan areas. We pose an interpretative framework and then overall observations and insights next.

Finally, because neither of these assessments includes the role of Place Typologies in influencing rent. We offer observations on their role in distance-based rent variations below. 
Table 8.4

Significant Office Rent Coefficients* with Respect to Place Typology and Station Distance ${ }^{* *}$ by Metropolitan Area

\begin{tabular}{|c|c|c|c|c|c|c|c|c|}
\hline \multirow[b]{2}{*}{$\begin{array}{l}\text { Metropolitan } \\
\text { Area }\end{array}$} & \multicolumn{8}{|c|}{ Light Rail Transit Station Distance Band in Miles } \\
\hline & $<=0.125$ & $\begin{array}{c}>0.125- \\
0.250\end{array}$ & $\begin{array}{c}>0.250- \\
0.375\end{array}$ & $\begin{array}{c}>0.375- \\
0.500\end{array}$ & $\begin{array}{c}>0.500- \\
0.625\end{array}$ & $\begin{array}{c}>0.625- \\
0.750\end{array}$ & $\begin{array}{c}>0.750- \\
0.875\end{array}$ & $\begin{array}{c}>0.875- \\
1.000\end{array}$ \\
\hline Buffalo & $10.1 \%$ & $16.4 \%$ & & & & & & \\
\hline Charlotte & $15.7 \%$ & $14.1 \%$ & $8.7 \%$ & $14.7 \%$ & $9.6 \%$ & $-5.9 \%$ & $14.5 \%$ & $9.5 \%$ \\
\hline Cleveland & $14.2 \%$ & $6.3 \%$ & & & & & & $9.1 \%$ \\
\hline Dallas & $-5.6 \%$ & $-6.3 \%$ & & $10.1 \%$ & $15.4 \%$ & $-6.4 \%$ & & \\
\hline Denver & $4.0 \%$ & $14.9 \%$ & $4.3 \%$ & & $5.8 \%$ & & $6.7 \%$ & $7.5 \%$ \\
\hline Houston & $8.1 \%$ & $11.4 \%$ & $12.0 \%$ & $12.6 \%$ & $12.2 \%$ & $10.5 \%$ & $14.4 \%$ & $13.2 \%$ \\
\hline Minneapolis & & & & & $10.0 \%$ & & & \\
\hline Phoenix & & & $-14.8 \%$ & $4.1 \%$ & $-6.6 \%$ & $-5.5 \%$ & & $-7.8 \%$ \\
\hline Pittsburgh & & & & & & & & \\
\hline Portland & & & $4.4 \%$ & $8.0 \%$ & $7.0 \%$ & & & \\
\hline Sacramento & $3.7 \%$ & & $8.6 \%$ & $5.2 \%$ & & $8.1 \%$ & $6.6 \%$ & \\
\hline Salt Lake City & & $7.2 \%$ & & & & & & \\
\hline San Diego & $-10.5 \%$ & $-12.6 \%$ & $-17.4 \%$ & $-11.2 \%$ & $-16.5 \%$ & $-9.8 \%$ & $-18.8 \%$ & $-13.2 \%$ \\
\hline San Jose & $-27.4 \%$ & $-23.7 \%$ & $-23.7 \%$ & $-21.7 \%$ & $-26.8 \%$ & $2.1 \%$ & $-17.8 \%$ & $-30.0 \%$ \\
\hline Seattle & $7.7 \%$ & $26.7 \%$ & $16.5 \%$ & $16.8 \%$ & $2.0 \%$ & $19.5 \%$ & $11.6 \%$ & $11.9 \%$ \\
\hline St. Louis & $-6.2 \%$ & & & & & & & \\
\hline
\end{tabular}


Table 8.4

Significant Office Rent Coefficients* with Respect to Place Typology and Station Distance ${ }^{* *}$ by Metropolitan Areacontinued

LRT Rent Association with Respect to Place Typology, ${ }^{* *}$ Model Performance, and General Form of Distance Relationship****

\begin{tabular}{|c|c|c|c|c|c|c|c|}
\hline $\begin{array}{l}\text { Metropolitan } \\
\text { Area }\end{array}$ & $\underset{\text { MA }}{\text { High }}$ & $\begin{array}{c}\text { Moderate } \\
\text { MA }\end{array}$ & $\begin{array}{l}\text { Low } \\
\text { MA }\end{array}$ & $\begin{array}{l}\text { Mean Rent/ } \\
\text { Sq.Ft. }\end{array}$ & Cases & R2 & Form from Station \\
\hline Buffalo & & & $-2.4 \%$ & $\$ 16.15$ & 1,703 & 0.172 & $\begin{array}{c}\text { Upward above mean } \\
\text { Downward above }\end{array}$ \\
\hline Charlotte & & & & $\$ 23.74$ & 3,082 & 0.347 & mean \\
\hline Cleveland & & & & $\$ 18.81$ & 2,275 & 0.180 & $\begin{array}{c}\text { Downward above } \\
\text { mean }\end{array}$ \\
\hline Dallas & $17.3 \%$ & $9.2 \%$ & $5.3 \%$ & $\$ 25.82$ & 6,018 & 0.142 & $\begin{array}{c}\text { Downward below } \\
\text { mean }\end{array}$ \\
\hline Denver & $24.5 \%$ & $14.7 \%$ & $6.3 \%$ & $\$ 24.23$ & 4,631 & 0.151 & $\begin{array}{c}\text { Downward above } \\
\text { mean }\end{array}$ \\
\hline Houston & $7.3 \%$ & $4.6 \%$ & $-1.0 \%$ & $\$ 25.66$ & 5,243 & 0.108 & $\begin{array}{c}\text { Downward above } \\
\text { mean }\end{array}$ \\
\hline Minneapolis & & & & $\$ 24.13$ & 3,430 & 0.033 & Ambiguous \\
\hline Phoenix & $5.2 \%$ & $4.1 \%$ & $3.1 \%$ & $\$ 24.54$ & 7,474 & 0.155 & Ambiguous \\
\hline Pittsburgh & $12.4 \%$ & $7.3 \%$ & & $\$ 23.83$ & 2,143 & 0.181 & Ambiguous \\
\hline Portland & $16.0 \%$ & $8.1 \%$ & $3.5 \%$ & $\$ 27.70$ & 3,828 & 0.111 & Ambiguous \\
\hline Sacramento & $15.6 \%$ & $9.9 \%$ & $2.5 \%$ & $\$ 21.95$ & 2,543 & 0.286 & Upward above mean \\
\hline Salt Lake City & & $12.0 \%$ & $7.4 \%$ & $\$ 23.71$ & 2,144 & 0.135 & Above mean \\
\hline San Diego & $16.6 \%$ & $10.2 \%$ & $0.5 \%$ & $\$ 27.51$ & 3,918 & 0.365 & $\begin{array}{l}\text { Upward below mean } \\
\text { Downward below }\end{array}$ \\
\hline San Jose & $-17.8 \%$ & $-7.7 \%$ & $-8.2 \%$ & $\$ 46.65$ & 3,666 & 0.249 & mean \\
\hline Seattle & $22.2 \%$ & $15.0 \%$ & $11.9 \%$ & $\$ 29.30$ & 6,931 & 0.302 & $\begin{array}{c}\text { Downward above } \\
\text { mean }\end{array}$ \\
\hline St. Louis & $-8.8 \%$ & & $3.4 \%$ & $\$ 23.13$ & 2,844 & 0.148 & Below mean \\
\hline
\end{tabular}

Overall

Functional

Form
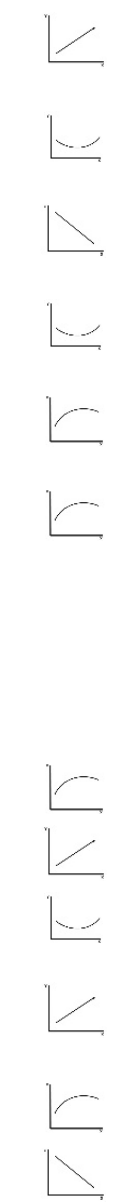
Virginia Beach

$\$ 27.64$

293

0.059

Ambiguous

* Only significant and contingent significant (italics) coefficients are reported for clarity.

** Cases beyond 1.00-mile are the referent.

*** Poor MA is the referent.

**** See text for description.

Table 8.4

Significant Office Rent Coefficients* with Respect to Place Typology and Station Distance ${ }^{* *}$ by Metropolitan Areacontinued

\begin{tabular}{|c|c|c|c|c|c|c|c|c|}
\hline \multirow[b]{2}{*}{$\begin{array}{l}\text { Metropolitan } \\
\text { Area }\end{array}$} & \multicolumn{8}{|c|}{ Streetcar Transit Station Distance Band in Miles } \\
\hline & $<=0.125$ & $\begin{array}{c}>0.125- \\
0.250\end{array}$ & $\begin{array}{c}>0.250- \\
0.375\end{array}$ & $\begin{array}{c}>0.375- \\
0.500\end{array}$ & $\begin{array}{c}>0.500- \\
0.625\end{array}$ & $\begin{array}{c}>0.625- \\
0.750\end{array}$ & $\begin{array}{c}>0.750- \\
0.875\end{array}$ & $\begin{array}{c}>0.875- \\
1.000\end{array}$ \\
\hline Atlanta & $-25.4 \%$ & $-19.4 \%$ & & & & & & \\
\hline Cincinnati & $21.8 \%$ & $25.9 \%$ & & $32.3 \%$ & $33.7 \%$ & & & $41.2 \%$ \\
\hline Dallas & $24.0 \%$ & $25.0 \%$ & $25.6 \%$ & $33.7 \%$ & $30.7 \%$ & $11.3 \%$ & $26.2 \%$ & $39.1 \%$ \\
\hline \multicolumn{9}{|l|}{ Kansas City } \\
\hline Little Rock & $27.3 \%$ & & & $-25.6 \%$ & & & & \\
\hline New Orleans & $71.8 \%$ & $47.3 \%$ & $52.2 \%$ & $64.8 \%$ & & $47.9 \%$ & & $42.1 \%$ \\
\hline Portland & $40.8 \%$ & $36.0 \%$ & $37.7 \%$ & $44.9 \%$ & $27.2 \%$ & $26.5 \%$ & $58.7 \%$ & $28.4 \%$ \\
\hline Salt Lake City & & & & $20.3 \%$ & & $-269.7 \%$ & $0.3 \%$ & $59.0 \%$ \\
\hline Seattle & $22.7 \%$ & $19.0 \%$ & $20.7 \%$ & & & & & \\
\hline \multicolumn{9}{|l|}{ Tacoma } \\
\hline \multicolumn{9}{|l|}{ Tampa } \\
\hline Tucson & & $30.0 \%$ & $22.0 \%$ & $38.1 \%$ & $42.7 \%$ & & & \\
\hline Washington & $-25.4 \%$ & $-19.4 \%$ & & & & & & \\
\hline
\end{tabular}


Table 8.4

Significant Office Rent Coefficients* with Respect to Place Typology and Station Distance ${ }^{* *}$ by Metropolitan Areacontinued

SCT Office Rent Association with Respect to Place Typology, ${ }^{* * *}$ Model Performance, and General Form of Distance Relationship****

\begin{tabular}{|c|c|c|c|c|c|c|c|}
\hline $\begin{array}{l}\text { Metropolitan } \\
\text { Area }\end{array}$ & $\begin{array}{l}\text { High } \\
\text { MA }\end{array}$ & $\begin{array}{l}\text { Moderate } \\
\text { MA }\end{array}$ & $\begin{array}{l}\text { Low } \\
\text { MA }\end{array}$ & $\begin{array}{l}\text { Mean Rent/ } \\
\text { Sq.Ft. }\end{array}$ & Cases & R2 & Form from Station \\
\hline Atlanta & & & & $\$ 30.53$ & 683 & 0.192 & Upward below mean \\
\hline Cincinnati & $21.3 \%$ & & & $\$ 14.45$ & 323 & 0.108 & Upward above mean \\
\hline Dallas & $8.3 \%$ & $10.6 \%$ & & $\$ 19.34$ & 1,123 & 0.337 & Upward above mean \\
\hline Kansas City & $14.4 \%$ & & & $\$ 17.15$ & 193 & 0.287 & Ambiguous \\
\hline Little Rock & & & & $\$ 16.67$ & 152 & 0.120 & Above mean \\
\hline New Orleans & & & $24.4 \%$ & $\$ 18.41$ & 46 & 0.409 & $\begin{array}{c}\text { Downward above } \\
\text { mean }\end{array}$ \\
\hline Portland & & & & $\$ 22.37$ & 310 & 0.338 & $\begin{array}{c}\text { Downward above } \\
\text { mean }\end{array}$ \\
\hline Salt Lake City & & $15.9 \%$ & & $\$ 19.06$ & 428 & 0.404 & Ambiguous \\
\hline Seattle & $28.9 \%$ & $23.1 \%$ & $17.3 \%$ & $\$ 26.30$ & 748 & 0.294 & $\begin{array}{c}\text { Downward above } \\
\text { mean }\end{array}$ \\
\hline Tacoma & & & & $\$ 19.21$ & 216 & 0.021 & Ambiguous \\
\hline Tampa & & & & $\$ 19.24$ & 596 & 0.214 & Ambiguous \\
\hline Tucson & & & & $\$ 17.41$ & 408 & 0.201 & $\begin{array}{c}\text { Downward above } \\
\text { mean }\end{array}$ \\
\hline Washington & & & $-32.7 \%$ & $\$ 45.90$ & 526 & 0.311 & Ambiguous \\
\hline
\end{tabular}

Overall

Functional

Form

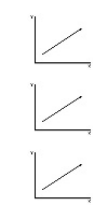

\
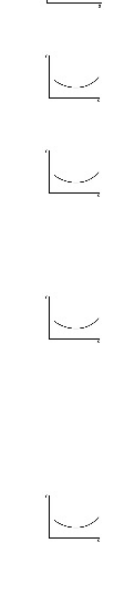
Table 8.4

Significant Office Rent Coefficients* with Respect to Place Typology and Station Distance ${ }^{* *}$ by Metropolitan Areacontinued

\begin{tabular}{|c|c|c|c|c|c|c|c|c|}
\hline \multirow[b]{2}{*}{$\begin{array}{l}\text { Metropolitan } \\
\text { Area }\end{array}$} & \multicolumn{8}{|c|}{ Bus Rapid Transit Station Distance Band in Miles } \\
\hline & $<=0.125$ & $\begin{array}{c}>0.125= \\
0.250\end{array}$ & $\begin{array}{c}>0.250- \\
0.375\end{array}$ & $\begin{array}{c}>0.375- \\
0.500\end{array}$ & $\begin{array}{c}>0.500 \\
0.625\end{array}$ & $\begin{array}{c}>0.625- \\
0.750\end{array}$ & $\begin{array}{c}>0.750- \\
0.875\end{array}$ & $\begin{array}{c}>0.875- \\
1.000\end{array}$ \\
\hline Albuquerque & $6.7 \%$ & $4.6 \%$ & $6.0 \%$ & & & & & \\
\hline Cleveland & $10.2 \%$ & & & $19.3 \%$ & & & & \\
\hline $\begin{array}{l}\text { Eugene- } \\
\text { Springfield }\end{array}$ & & $-36.2 \%$ & & & & & & \\
\hline Kansas City & & & & & $24.1 \%$ & & & \\
\hline \multicolumn{9}{|c|}{ Minneapolis-St. Paul } \\
\hline Nashville & & & $22.3 \%$ & & $26.1 \%$ & & $12.5 \%$ & \\
\hline Pittsburgh & $-4.0 \%$ & $9.3 \%$ & & & $-7.7 \%$ & & & \\
\hline Reno & & & & $-12.6 \%$ & $16.7 \%$ & & & \\
\hline Salt Lake City & $30.7 \%$ & & $-54.1 \%$ & & $60.3 \%$ & & & $-125.2 \%$ \\
\hline San Antonio & $3.8 \%$ & $6.4 \%$ & $3.7 \%$ & $4.6 \%$ & $2.9 \%$ & $5.0 \%$ & $2.6 \%$ & $4.0 \%$ \\
\hline San Diego & & & & $-9.6 \%$ & & $-29.6 \%$ & & \\
\hline San Jose & $34.0 \%$ & $21.5 \%$ & $28.6 \%$ & $23.6 \%$ & $30.0 \%$ & $23.1 \%$ & $46.9 \%$ & \\
\hline Seattle & & $14.7 \%$ & $7.5 \%$ & & & & $15.6 \%$ & \\
\hline
\end{tabular}


Table 8.4

Significant Office Rent Coefficients* with Respect to Place Typology and Station Distance ${ }^{* *}$ by Metropolitan Areacontinued

BRT Office Rent Association with Respect to Place Typology,*** Model Performance, and General Form of Distance Relationship ${ }^{* * *}$

\begin{tabular}{|c|c|c|c|c|c|c|c|}
\hline Metropolitan Area & $\begin{array}{c}\text { High } \\
\text { MA }\end{array}$ & $\begin{array}{l}\text { Moderate } \\
\text { MA }\end{array}$ & $\begin{array}{c}\text { Low } \\
\text { MA }\end{array}$ & $\begin{array}{l}\text { Mean Rent/ } \\
\text { Sq.Ft. }\end{array}$ & Cases & $\mathbf{R}^{2}$ & $\begin{array}{c}\text { Form from Station } \\
\text { Downward above }\end{array}$ \\
\hline Albuquerque & $9.4 \%$ & $10.6 \%$ & $10.2 \%$ & $\$ 14.79$ & 780 & 0.174 & mean \\
\hline Cleveland & & $-8.8 \%$ & & $\$ 15.99$ & 511 & 0.302 & Upward from mean \\
\hline Eugene-Springfield & & & & $\$ 19.65$ & 44 & 0.279 & Ambiguous \\
\hline Kansas City & $14.0 \%$ & & & $\$ 17.20$ & 191 & 0.294 & Ambiguous \\
\hline $\begin{array}{l}\text { Minneapolis-St. } \\
\text { Paul }\end{array}$ & $10.4 \%$ & & & $\$ 15.43$ & 600 & 0.080 & Ambiguous \\
\hline Nashville & $-42.8 \%$ & & & $\$ 22.16$ & 241 & 0.302 & Ambiguous \\
\hline Pittsburgh & $15.0 \%$ & $11.8 \%$ & $5.7 \%$ & $\$ 18.88$ & 864 & 0.379 & Upward below mean \\
\hline Reno & $-55.7 \%$ & $-56.9 \%$ & $-48.8 \%$ & $\$ 18.73$ & 211 & 0.236 & Ambiguous \\
\hline Salt Lake City & & $13.8 \%$ & & $\$ 19.20$ & 417 & 0.359 & Upward above mean \\
\hline San Antonio & & $4.3 \%$ & $2.7 \%$ & $\$ 22.15$ & 3,078 & 0.184 & Upward above mean \\
\hline San Diego & $22.5 \%$ & $12.8 \%$ & & $\$ 27.48$ & 921 & 0.263 & Ambiguous \\
\hline San Jose & $-24.3 \%$ & & & $\$ 40.27$ & 608 & 0.162 & $\begin{array}{l}\text { Upward above mean } \\
\text { Downward above }\end{array}$ \\
\hline Seattle & $29.2 \%$ & $20.7 \%$ & $17.1 \%$ & $\$ 26.40$ & 663 & 0.267 & mean \\
\hline
\end{tabular}

Overall Functional

Form

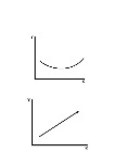

Ambiguous

Ambiguous

ward below mean

pward above mean

Ambiguous

ward above mean mean 
Table 8.4

Significant Office Rent Coefficients* with Respect to Place Typology and Station Distance ${ }^{* *}$ by Metropolitan Areacontinued

$\begin{array}{lc}\text { Metropolitan Area } & <=0.125 \\ \text { Albuquerque-Santa } & 21.8 \% \\ \text { Fe } & \\ \text { Austin } & 14.3 \% \\ \text { Dallas-Fort Worth } & -5.7 \% \\ \text { Denver } & 9.1 \% \\ \text { Miami-SE Florida } & -8.4 \% \\ \text { Minn.-St. Paul } & \\ \text { Nashville } & -12.5 \% \\ \text { Orlando } & 7.2 \% \\ \text { Portland } & -2.6 \% \\ \text { Salt Lake City } & 5.2 \% \\ \text { San Diego } & 24.1 \% \\ \text { San Jose-Stockton } & 38.6 \% \\ \text { Seattle-Tacoma } & -5.2 \% \\ \text { Washington DC } & \end{array}$

$>0.125-$
$\mathbf{0 . 2 5 0}$
$19.9 \%$


$10.8 \%$
$17.3 \%$
$-20.4 \%$
$-8.8 \%$
$-18.0 \%$


$-4.0 \%$
$13.1 \%$
$-9.2 \%$

Commuter Rail Transit Station Distance Band in Miles

\begin{tabular}{|c|c|c|c|c|c|}
\hline $\begin{array}{c}>0.250- \\
0.375\end{array}$ & $\begin{array}{c}>0.375- \\
0.500\end{array}$ & $\begin{array}{c}>0.500- \\
0.625\end{array}$ & $\begin{array}{c}>0.625- \\
0.750\end{array}$ & $\begin{array}{c}>0.750 \\
0.875\end{array}$ & $\begin{array}{c}>0.875- \\
1.000\end{array}$ \\
\hline $25.7 \%$ & $17.1 \%$ & $8.9 \%$ & $12.6 \%$ & & $18.8 \%$ \\
\hline $6.2 \%$ & $18.9 \%$ & & $17.6 \%$ & $16.0 \%$ & $9.1 \%$ \\
\hline $5.6 \%$ & $7.7 \%$ & $8.9 \%$ & $20.9 \%$ & & $4.6 \%$ \\
\hline \multirow[t]{2}{*}{$21.2 \%$} & $20.1 \%$ & & & $9.1 \%$ & $-2.2 \%$ \\
\hline & $-6.9 \%$ & $-11.4 \%$ & $-7.1 \%$ & $-3.6 \%$ & \\
\hline \multirow[t]{2}{*}{$-9.3 \%$} & & & $-16.3 \%$ & & $-9.6 \%$ \\
\hline & $-16.5 \%$ & $-17.4 \%$ & & & \\
\hline \multirow[t]{2}{*}{$4.9 \%$} & $7.0 \%$ & $11.2 \%$ & $3.8 \%$ & $10.5 \%$ & $2.5 \%$ \\
\hline & $2.5 \%$ & & $-4.8 \%$ & $-3.9 \%$ & \\
\hline \multirow[t]{2}{*}{$16.7 \%$} & $11.3 \%$ & $13.6 \%$ & $12.2 \%$ & $17.4 \%$ & $10.3 \%$ \\
\hline & $8.5 \%$ & & $12.3 \%$ & $6.8 \%$ & $-10.1 \%$ \\
\hline$-4.6 \%$ & $-6.1 \%$ & $-6.2 \%$ & $-11.6 \%$ & $4.0 \%$ & $-6.2 \%$ \\
\hline$-22.3 \%$ & $-18.8 \%$ & & & $-5.2 \%$ & $-4.2 \%$ \\
\hline
\end{tabular}




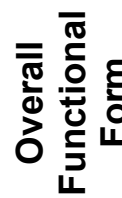

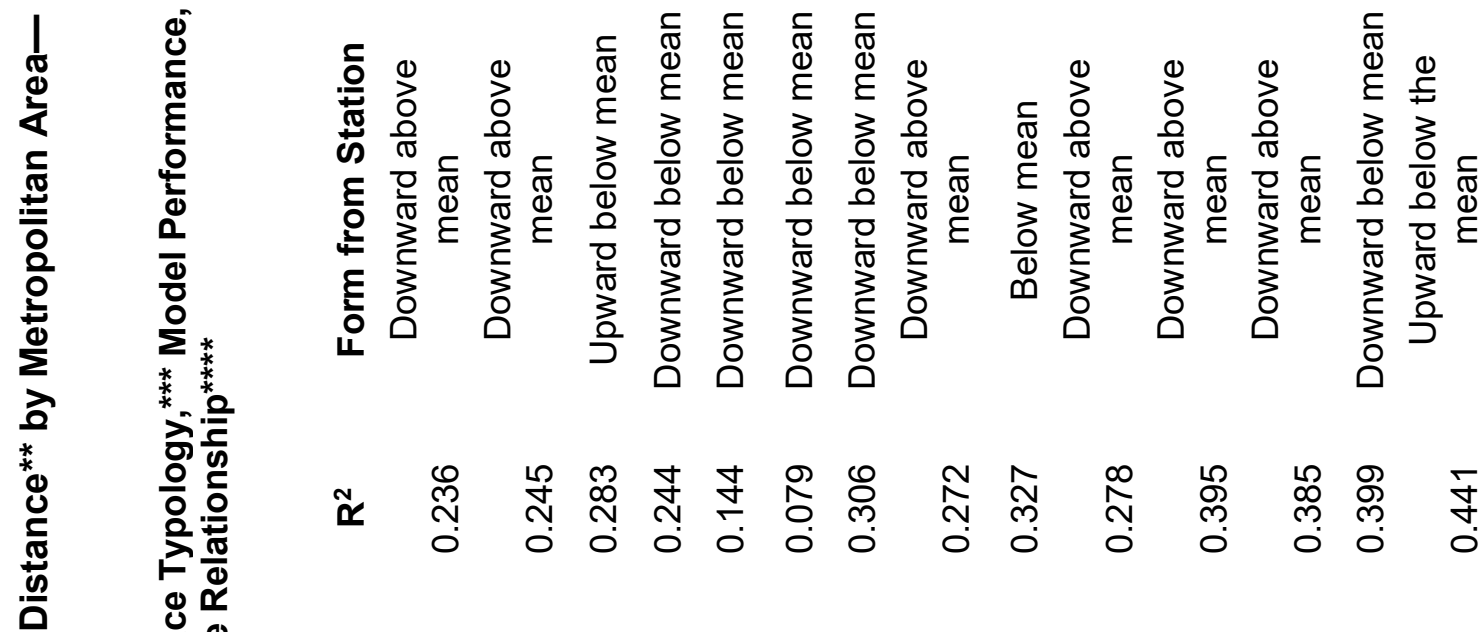

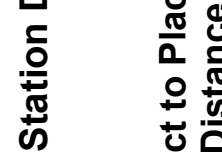

兄

तั

응 눙 눈

$\sum_{0}^{2}$

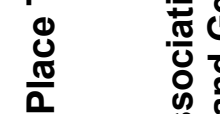

욜

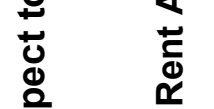

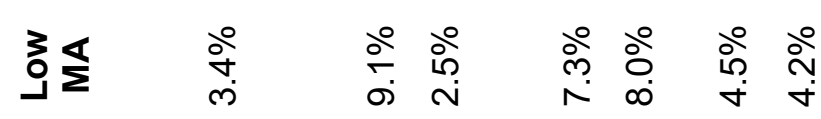

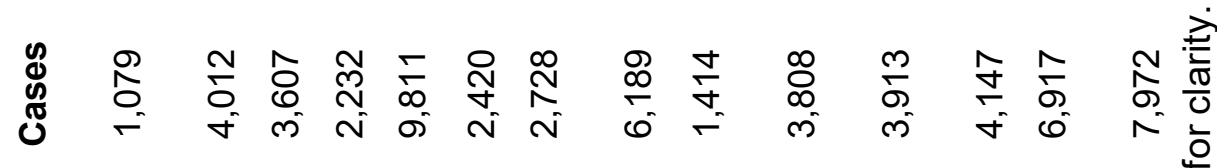

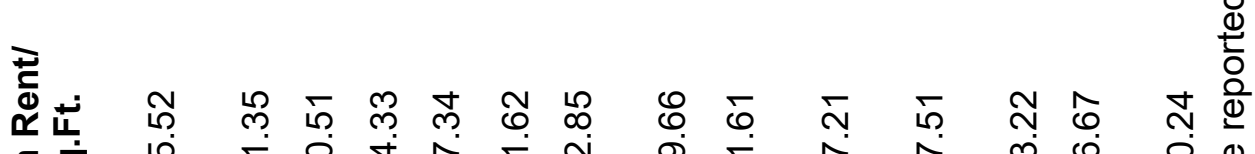

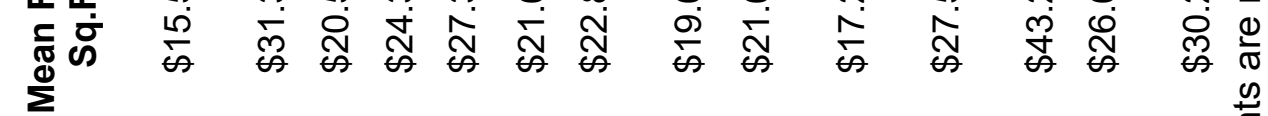

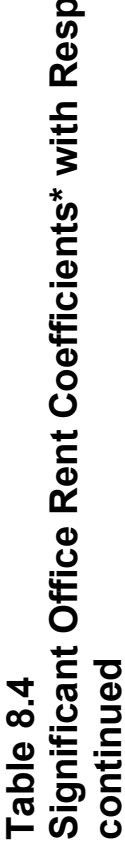

造

它

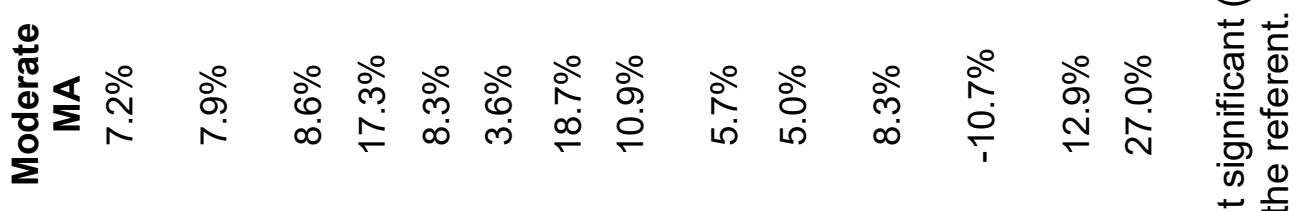

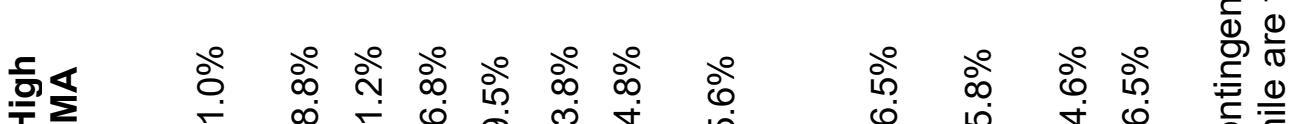

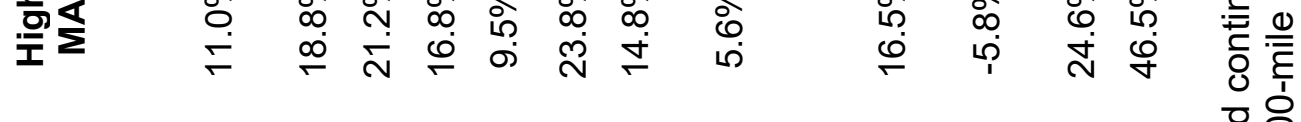

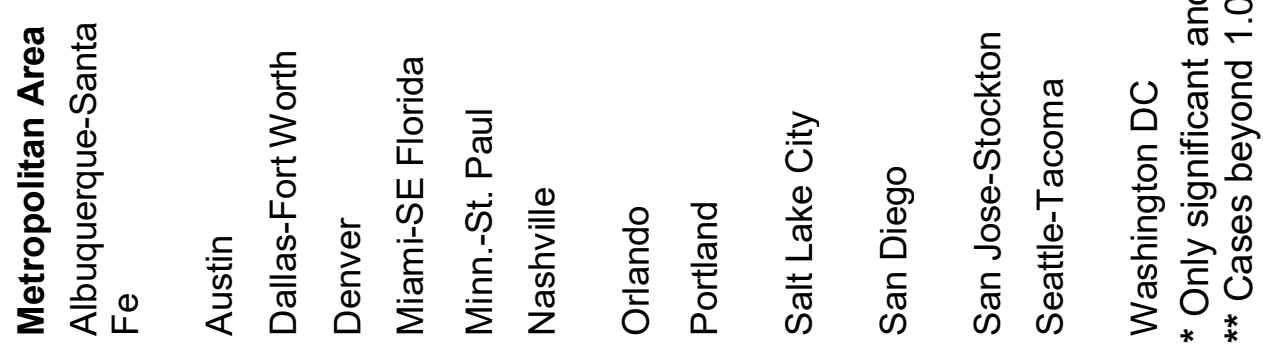


*** Poor MA is the referent. **** See text for description. 
We offer observations for office rent associations for LRT, SCT, BRT and CRT systems respectively.

\section{Light Rail Transit Station Office Rent Proximity Effects by Metropolitan Area}

We first assess ambiguous associations between office rents and LRT station proximity, then upward sloping ones, followed by downward associations. For the most part, we are surprised to find so few systems - seven of 17-where relevant rent coefficients are downward sloping, indicating consistency with standard theory that transit station proximity adds value to real estate. While this is somewhat contradictory to literature (see Higgins and Kanaroglou 2016), our study is the first that includes Place Typologies. As such, we also note that with only one exception (St. Louis), relevant coefficients are highest in the High MA places, next highest in the Moderate MA areas, and smallest in the Low MA areas (where Poor MAs areas are the referent). Thus, our analysis of rent effects associated with transit station distance controls for features inherent in Place Typologies. So, for instance, while Portland's LRT system does not reveal relevant coefficients near transit stations, office rents located in High MA places that include 13 percent of all LRT stations nonetheless enjoy a 16.0 percent rent premium above the regional mean.

Within the first two distance bands (up to 0.25-mile), there is an ambiguous association between LRT station proximity and office rents observed in the Minneapolis-St. Paul, Phoenix, Pittsburgh, Portland, Sacramento and Virginia Beach metropolitan areas. Strictly speaking, one could assume that the market does not reveal proximity as either an amenity or externality. Alternatively, externality effects of stations may just offset amenity effects. But for all except Minneapolis-St. Paul and Virginia Beach, we surmise that Place Typologies may account for variations rather than station distance. For instance, location of offices in High-Mixed Use/Accessible places may render advantages of LRT station proximity ubiquitous meaning no particular location within High MA places has much influences on rents as any other. The same could be said for Moderate-Mixed Use/Accessible areas. Though there may be several reasons for this, two important ones may be transit and land use planning that locates offices near LRT stations and multiple accessibility options that connect offices to LRT stations.

Minneapolis-St. Paul is anomalous because it has a long tradition of steering higher density/intensity development to transit stations. Indeed, prior studies have shown a positive association between LRT station proximity and office value (Cao and Ko 2013). We theorize one reason we did not detect this is that our dependent variable is rent and not value (per square foot). Our analysis could not differentiate rent, for example, based on double or triple net leases (comprised of two or all three of real estate taxes, building insurance, and maintenance), or the variation in leases based on lease periods (long term leases will usually have lower rents per square foot than shorter term ones). Lease concessions for long term tenants, especially government, would also keep rents lower than what they may have been with shorter term leases with other kinds of tenants. Future will be needed to tease out these and related rent subtleties

We are not surprised by results for Virginia Beach, however, as the number of cases is small as is the coefficient of determination $\left(R^{2}\right)$.

Buffalo, Denver, Houston, Sacramento and Seattle show upward sloping rent gradients from LRT stations, though-with the exception of Buffalo-all have a concave functional form meaning that rents fall at some point away from transit stations. In all cases, rents start above the regional mean. This is a classic example of station amenities more than offsetting externalities with externality effects dissipating outward. 
In San Diego and San Jose, rent starts below the regional mean (ceteris paribus) and while it increases with distance, it remains below the regional mean within our study area. This may be a function of those systems being located along freight rail corridors with little connectivity to urban places (Cervero et al. 2004). We also observe that San Jose is unique in having a negative coefficient for the High MA place variable. We surmise that unique features of the San Jose market-as the center of "Silicon Valley"-may make it an outlier.

Only Charlotte and Cleveland have downward gradients from the first (0.125-mile) distance band outward suggesting clear market premiums given to locations close to LRT stations. They are selected as exemplars.

\section{LRT Office Exemplars: Charlotte and Cleveland}

As noted above, only the office real estate markets in Charlotte and Cleveland reveal downward sloping rent gradients from LRT transit stations which is consistent with standard theory illustrated in Figure 8.1. The office rent slopes for these two metropolitan areas are shown in Figure 8.4. Though there may be externality effects as well, the market indicates that amenity benefits exceed externality costs. This is not the case in most metropolitan areas with LRT systems. For Charlotte in particular, the rent premium falls from 15.7 percent above the mean in the first $(0.125$-mile) distance band to 8.7 percent above the mean in the third $(0.375$-mile) DB. The gradient effects are smaller and narrower in Cleveland where the rent premium is 14.2 percent above the mean in the first (0.125-mile) distance band and falls to 6.3 percent above the mean in the second (0.250-mile) DB. While other systems may have more notoriety, these may offer the best case study lessons for light rail transit and land use planning, and urban design from the LRT station outward.

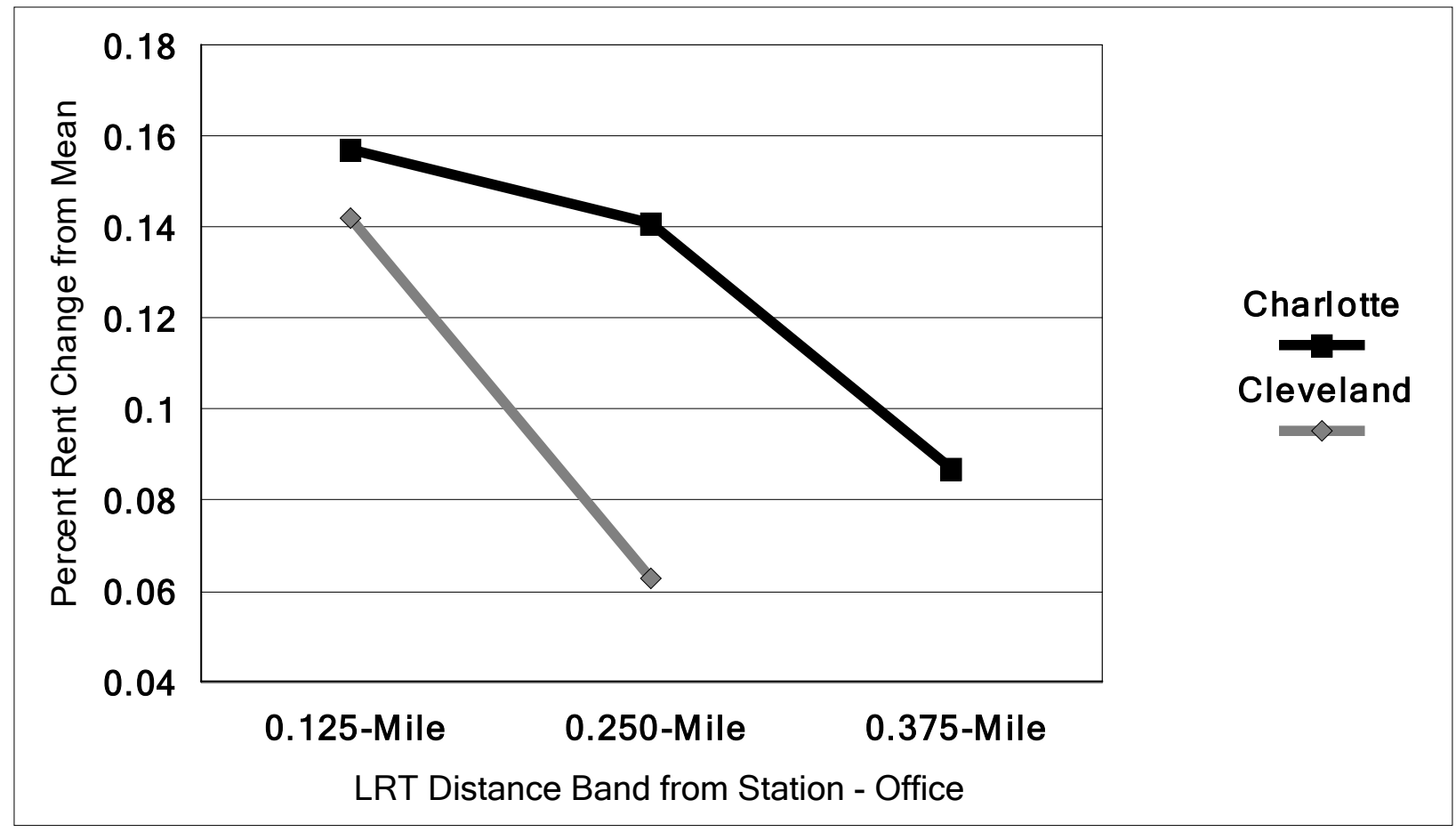

Figure 8.4

Office rent premiums for light rail transit station proximity in Charlotte and Cleveland

We turn next to the influence of streetcar transit station proximity on office rents. 
Streetcar Transit Station Office Rent Proximity Effects by Metropolitan Area

We now discuss results for ambiguous associations between SCT station proximity and office rents, then upward sloping associations that reveal externality transit station proximity effects, and lastly downward sloping associations.

Ambiguous associations between SCT station proximity and office rent are observed for Kansas City, Salt Lake City, Tacoma, Tampa and Washington, DC. There are reasons for each. First, of these only Kansas City also has a significant coefficient for High-Mixed Use/Accessibility. For reasons noted above in the context of LRT systems, location in a High MA place may suggest ubiquitous office rent premiums. The Salt Lake City SCT is isolated from the rest of the metropolitan area, serving only a mature, built out first generation suburban-like community-Sugar House. Tacoma may be the smallest system of any we research, being comprised of only six stations along a 1.6-mile downtown route. The Tampa system is mostly tourist related though its operations connect older residential areas to downtown. The Washington, DC system serves a 2.4-mile stretch of $\mathrm{H}$-Street comprised of eight stations; like the Salt Lake City system, it does not directly connect its service area with downtown or other major centers.

Systems with upward sloping gradients include Atlanta, Cincinnati and Dallas. The Atlanta system is anomalous in that its rent relevant coefficients for the closer distance bands are below the mean for the region, and do not extend beyond the second (0.25-mile) DB. Cincinnati and Dallas both show continually rising rents with respect to SCT station proximity through the 1.00-mile study area suggesting that station proximity is associated with externality effects that dissipate over space.

The remaining systems-Little Rock, New Orleans, Portland, Seattle and Tucson-show downward sloping gradients to a point after which the gradient slopes upward (except for Little Rock). There appears to be a market premium for SCT station proximity from roughly 0.50 -mile inward, and then outward perhaps as other influences are being expressed such as proximity to employment centers or highways.

\section{SCT Office Exemplar:}

New Orleans, Portland and Seattle are exemplars because the slope of office rents fall with respect to streetcar transit station distance to at least 0.25 -mile before slopes either reverse or coefficients are not relevant (see Table 8.4). These associations are illustrated in Figure 8.5. In these metropolitan areas, the rent premiums are 71.8 percent, 40.8 percent and 22.7 percent above the mean in the first ( 0.125 -mile distance band falling to 47.3 percent, 36.0 percent and 20.7 percent above the mean in the second (0.250-mile) DB, respectively.

We find that rent premiums reflecting proximity as an amenity is confined to a narrow area around SCT stations- 0.25 -mile - which is also the radius of first-generation transit-oriented development planning. We recommend these SCT systems for closer analysis to learn transit and land use planning, and urban design lessons for other systems, and new systems.

Office rent results for metropolitan areas served by bus rapid transit systems are discussed next. 


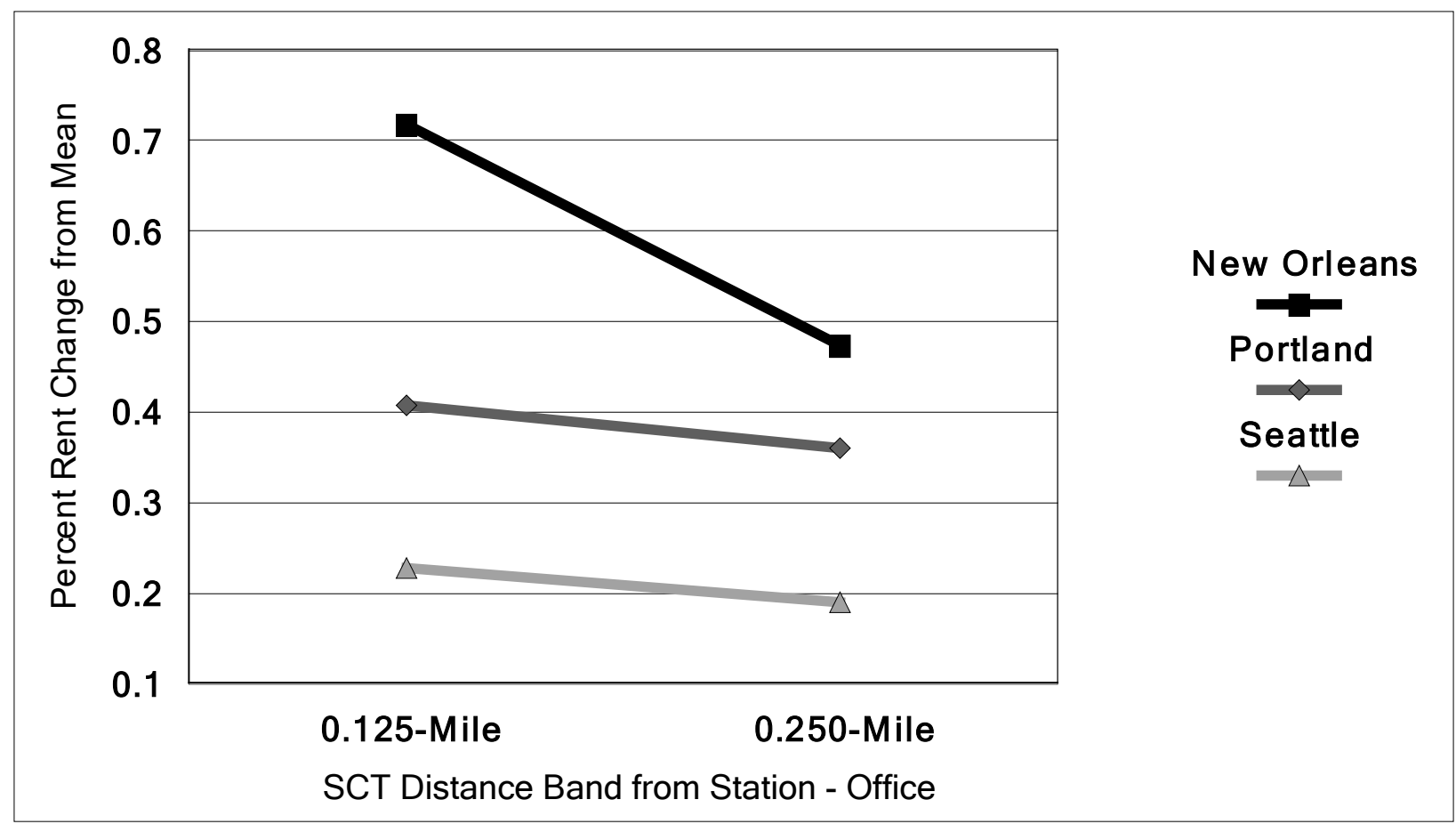

Figure 8.5

Office rent premiums for streetcar transit station proximity in New Orleans, Portland and Seattle 
Bus Rapid Transit Office Rent Proximity Association Effects by Metropolitan Area

We will present observations between BRT station proximity and office rents with respect to ambiguous, upward and then downward sloping associations respectively.

Eugene-Springfield, Kansas City, Minneapolis-St, Paul., Nashville, Reno and San Diego show ambiguous associations. Inasmuch as the Kansas City system serves mostly the downtown and near downtown areas and given that the High-Mixed Use/Accessibility coefficient is positive, we surmise that location in High MA places is more important to the office market than proximity to BRT stations. This is not the case with other BRT systems, however, as they serve much larger areas. We surmise that the office market is not influenced by BRT station proximity in these metropolitan areas. Reasons may include route and land use planning that does not steer office development to those stations, or vice versa.

Cleveland, Pittsburgh and San Antonio all have upward sloping office rent gradients with respect to BRT station proximity, suggesting that externality effects dampen nearby amenity benefits. For Cleveland and to some extent San Jose, one reason may be that multifamily land uses exhibit a strong preference for BRT proximity and thus may outbid offices near BRT stations, though this is not the case for the others. We will address MF in the next section.

All the other systems-Albuquerque, Salt Lake City, San Jose and Seattle-exhibit conventional downward sloping rent gradients with all but Seattle having a convex functional form. In other words, proximity to BRT stations in these metropolitan areas confer important rent premiums in the office market.

\section{BRT Office Exemplar:}

Consistent with our criteria we find the bus rapid transit systems of Albuquerque and San Jose to be exemplars in influencing office rents from BRT stations out to at least 0.25 -mile. Figure 8.6 shows the relationship graphically. For these metropolitan areas, office rents with respect to BRT station distance fall from 6.7 percent to 4.6 percent above the mean, and 34.0 percent to 21.5 percent above the mean from the first (0.125-mile) to the second $(0.250$-mile) distance bands, respectively. While the slopes are similar, the magnitude for San Jose is nearly five times higher in the first DB than Albuquerque. We suspect that competition for office locations near most forms of transit is more intense in San Jose-home of "Silicon Valley"-than in Albuquerque. In any event, transit and land use planners, and urban designers, may wish to study areas near BRT stations in these metropolitan areas for lessons on achieving desired office market responses elsewhere.

We proceed to reviewing implications for proximity to CRT stations. 


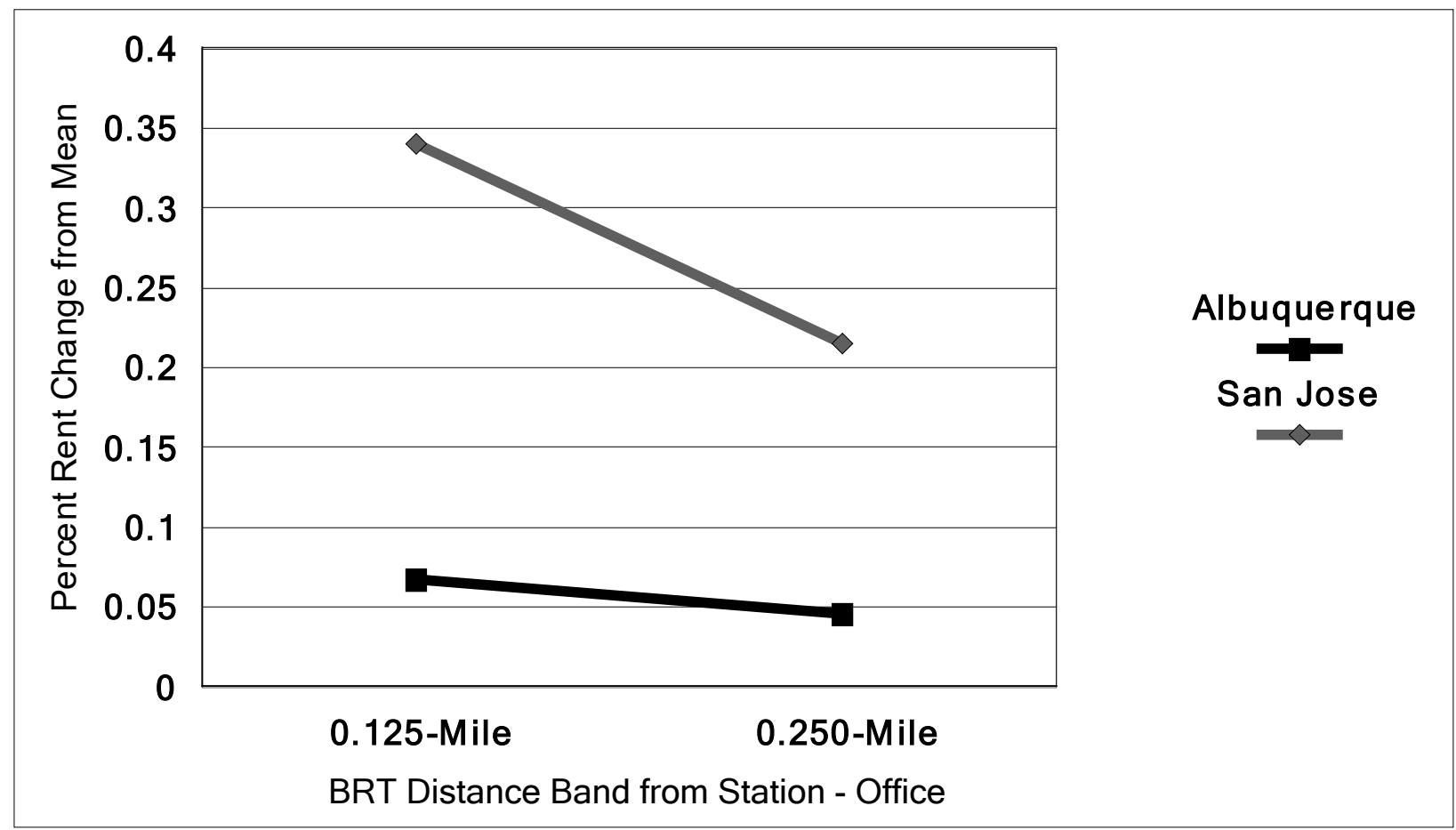

Figure 8.6

Office rent premiums for bus rapid transit station proximity in Albuquerque and San Jose 
Commuter Rail Transit Station Office Rent Proximity Effects by Metropolitan Area

We are surprised that relevant rent coefficients are estimated for all but two of the CRT systems we evaluated (the exceptions being Minneapolis-St. Paul and Washington, DC). We also note that our analysis is the most comprehensive assessment of real estate effects on office values-being rent in our case-yet conducted. We surmise that areason is our methodology that provides more refined measures than other studies, and that we are able to analyze 14 systems. As there are no ambiguous associations between CRT station proximity and office rents within 0.50-mile of CRT stations, we will review results for upward and downward sloping gradients, in order.

Dallas-Fort Worth and Denver are the only systems where rents rise with respect to CRT station distance before falling, presumably after station proximity-based externalities have dissipated.

All other CRT systems have downward sloping office rent gradients to a certain point after which rents rise, seemingly because of other amenities such as proximity to centers, highways or other rent-enhancing amenities. We advise readers to study the relevant coefficients for each system in the context of their knowledge of those metropolitan areas. Among the interesting results we see is a pattern of rent premiums in the first (0.125-mile) distance band, perhaps none in the second, but then smaller premiums in a few others. We surmise that some types of offices are highly attracted to CRT station proximity while others may be repelled. Future research may be able to disaggregate data to evaluate rent proximity effects with respect to specific kinds of offices.

\section{CRT Office Exemplar:}

The above summary notwithstanding, we find only three CRT systems meet our criteria as exemplars: Albuquerque-Santa Fe, Salt Lake City, and San Jose-Stockton. They are also known by their brand names which we will use here, respectively: Rail Runner, FrontRunner and Altamont Corridor Express (ACE). As we saw above for BRT systems, office rents associated with CRT station proximity are highest for ACE followed by Rail Runner and then FrontRunner, falling from 3.40 percent, 21.8 percent and 5.2 percent above the mean from the first (0.122-mile) distance band to 21.5 percent and 19.9 percent above the mean, and 0.40 percent below the mean, respectively. The FrontRunner rents fall below the mean perhaps because it is the newest system, having only been completed in the middle 2010s with planning around and near the stations still a work in progress, as we understand it.

As we note below especially for retail real estate, we suspect planners may not appreciate the extent to which office and retail real estate may value proximity to CRT stations. These systems could be the basis for informative case studies leading to transit and land use planning, and urban design insights to help unlock the market potential for locating near CRT stations.

Overarching conclusions and implications will be offered in the last section of this chapter. For now, we will move on to multifamily rent effects with respect to transit station proximity with reference to Place Typologies. 


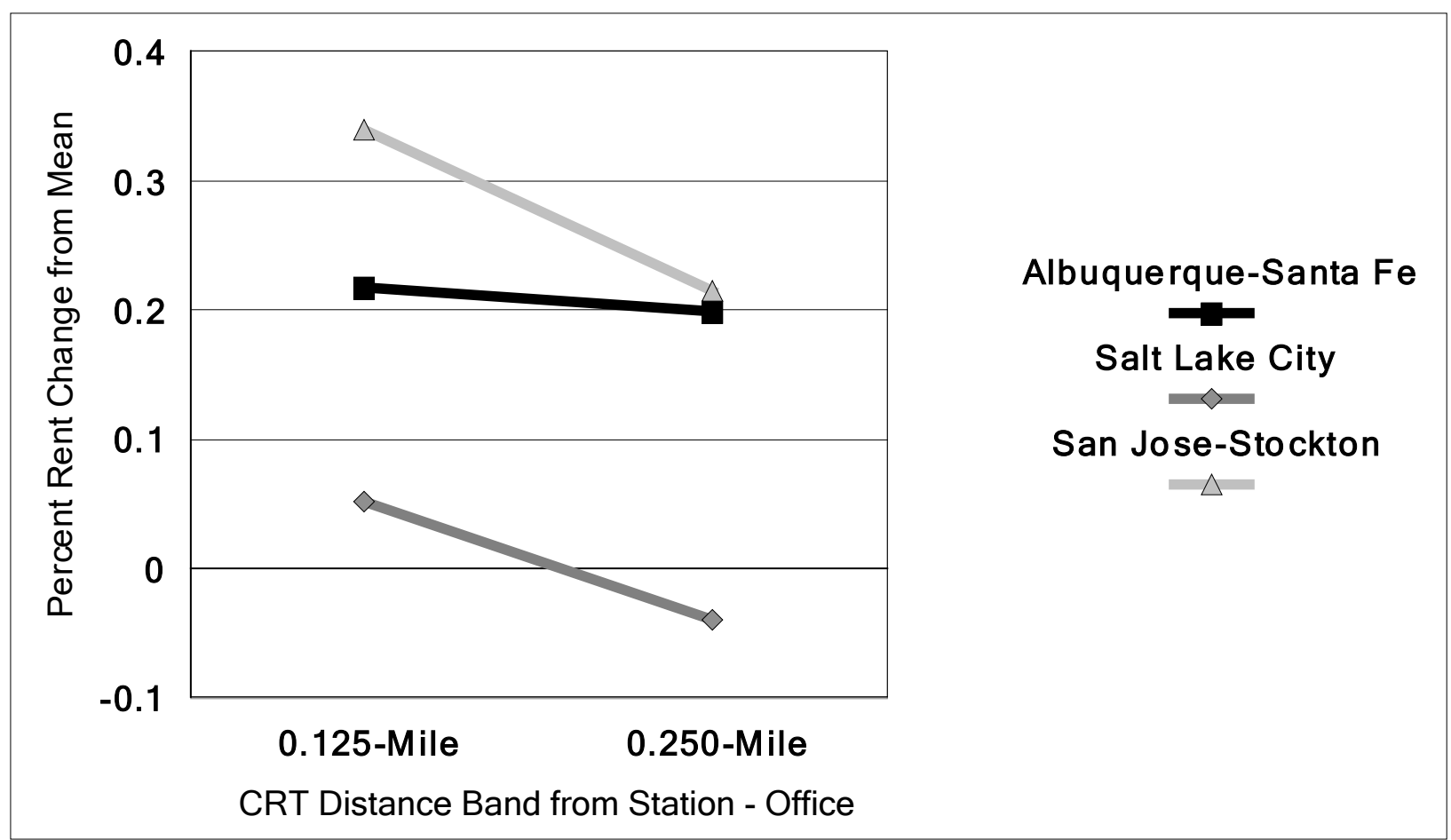

Figure 8.7

Office rent premiums for commuter rail transit station proximity in Albuquerque, Salt Lake City and San Jose-Stockton 


\section{The Variation of Multifamily Rents with Respect to Place Typology and Transit Station Proximity}

We next present results for the full model in Table 8.5 for multifamily (MF) rents with respect to LRT, BRT, SCT and CRT station proximity, respectively. Trends are illustrated in Figure 8.8. As for office, for all four equations, the coefficients of determination $\left(R^{2}\right)$ show that the equations explain a reasonable share of the variation of rents and the F-ratios show the equations outcomes to be considerably beyond chance.

Below, we review results for the control variables first and then those for the Place Typology followed by those for the distance band treatment variables.

As expected, and excluding metropolitan controls (see below), the control variables performed as expected:

Rent increases as the size of a MF structure increases possibly reflecting amenities that are more commonly offered in larger complexes than smaller ones, such as recreation facilities and social opportunities;

However, rent per square foot declines as the size of the unit increases, reflecting declining marginal utility of space, as expected;

As for office, the number of floors or stories is associated with higher rent, reflecting elevation away from the hustle and bustle of the ground level, as well as possibly improved views and air flow on average though logically benefiting tenants in middle and higher floors;

As the effective year in which the structure was built (or renovated) increases (more recent years have a higher value than earlier years), rent increases;

We note that as the vacancy rate increases so do rents we suspect for the expectations noted above, that seniors will get preferential rates by landlords especially if they are expected to stay long periods and students rent only when school is in session so their effective rent is actually based on an entire year;

As the median household income of the block group within which the property is located increases so does rent;

As distance from the nearest freeway ramp increases rents also fall; and

As the degree of mixed use and accessibility increase from Low to High MA (compared to Poor MA), multifamily rent increases as expected.

We note that as controls for metropolitan-specific market characteristics, the coefficients for the metropolitan variables are not directly relevant to the interpretation of results for reasons notes above.

We turn next to evaluating the variation in MF rent for each transit mode studied with special reference to the Place Typology. 
Table 8.5

Regression Results for Multifamily Rents with Respect to Transit Station Proximity with Special Reference to Place Typology

\begin{tabular}{|c|c|c|c|c|c|c|c|}
\hline Variable & LRT Beta & Variable & SCT Beta & Variable & BRT Beta & Variable & CRT Beta \\
\hline Constant & -3.198 & Constant & -2.689 & 9 Constant & -3.405 & 5 Constant & -2.129 \\
\hline Structure Controls & & Structure Controls & & Structure Controls & & Structure Controls & \\
\hline $\begin{array}{l}\text { Gross Leasable Area } \\
\text { (1000sq.ft.) }\end{array}$ & 0.000289 & $\begin{array}{l}\text { Gross Leasable Area } \\
\text { (1000sq.ft.) }\end{array}$ & 0.000205 & $\begin{array}{l}\text { Gross Leasable Area } \\
\text { (1000sq.ft.) }\end{array}$ & 0.000309 & $\begin{array}{l}\text { Gross Leasable Area } \\
9 \text { (1000sq.ft.) }\end{array}$ & 0.000263 \\
\hline Average Unit Size & -0.001 & Average Unit Size & -0.001 & Average Unit Size & -0.001 & 1 Average Unit Size & -0.001 \\
\hline Stories & 0.025 & Stories & 0.029 & Stories & 0.024 & 4 Stories & 0.027 \\
\hline Effective Year Built & 0.002 & Effective Year Built & 0.002 & 2 Effective Year Built & 0.002 & 2 Effective Year Built & 0.001 \\
\hline Vacancy Rate & 0.004 & Vacancy Rate & 0.003 & 3 Vacancy Rate & 0.005 & 5 Vacancy Rate & 0.006 \\
\hline Occupancy Control* & & Occupancy Control* & & Occupancy Control* & & Occupancy Control* & \\
\hline Senior & -0.056 & Senior & -0.041 & Senior & -0.101 & 1 Senior & -0.101 \\
\hline Student & -0.063 & Student & -0.128 & Student & -0.017 & 7 Student & -0.084 \\
\hline $\begin{array}{l}\text { Socioeconomic } \\
\text { Control }\end{array}$ & & $\begin{array}{l}\text { Socioeconomic } \\
\text { Control }\end{array}$ & & $\begin{array}{l}\text { Socioeconomic } \\
\text { Control }\end{array}$ & & $\begin{array}{l}\text { Socioeconomic } \\
\text { Control }\end{array}$ & \\
\hline $\begin{array}{l}\text { Median HH Income } \\
\quad(\$ 1000 \mathrm{~s})\end{array}$ & 0.003734 & $\begin{array}{l}\text { Median HH Income } \\
(\$ 1000 \mathrm{~s})\end{array}$ & 0.004779 & $\begin{array}{l}\text { Median HH Income } \\
\text { (\$1000s) }\end{array}$ & 0.00332 & $\begin{array}{l}\text { Median HH Income } \\
2 \text { (\$1000s) }\end{array}$ & 0.004411 \\
\hline Location Control & & Location Control & & Location Control & & Location Control & \\
\hline $\begin{array}{l}\text { Distance Freeway } \\
\quad \text { (mile) }\end{array}$ & -0.014293 & $\begin{array}{l}\text { Distance Freeway } \\
\text { (mile) }\end{array}$ & -0.002139 & $\begin{array}{l}\text { Distance Freeway } \\
\text { (mile) }\end{array}$ & -0.004686 & $\begin{array}{l}\text { Distance Freeway } \\
6 \text { (mile) }\end{array}$ & -0.004587 \\
\hline Metropolitan Control** & & Metropolitan Control** & & Metropolitan Control* & & & \\
\hline Buffalo & 0.062 & Atlanta & -0.201 & 1 Cleveland & 0.045 & $\begin{array}{l}\text { Albuquerque-Santa } \\
5 \mathrm{Fe}\end{array}$ & -0.350 \\
\hline Charlotte & -0.065 & Cincinnati & -0.410 & Eugene-Springfield & 0.203 & 3 Austin & -0.024 \\
\hline Cleveland & -0.113 & Dallas & -0.214 & 4 Kansas City & 0.001 & 1 Dallas-Fort Worth & -0.185 \\
\hline Dallas & 0.019 & Kansas City & -0.397 & 7 Minneapolis-St. Paul & 0.270 & 0 Denver & 0.067 \\
\hline Denver & 0.251 & Little Rock & -0.509 & 9 Nashville & 0.231 & 1 Miami-SE Florida & 0.042 \\
\hline Houston & -0.065 & New Orleans & -0.208 & 3 Pittsburgh & 0.179 & 9 Minn.-St. Paul & -0.089 \\
\hline Minneapolis & 0.109 & Portland & -0.092 & 2 Reno & 0.168 & 8 Nashville & -0.111 \\
\hline
\end{tabular}


Table 8.5

Regression Results for Multifamily Rents with Respect to Transit Station Proximity with Special Reference to Place Typology-continued

\begin{tabular}{|c|c|c|c|c|c|c|c|}
\hline $\begin{array}{l}\text { Variable } \\
\text { Metropolitan } \\
\text { Control** }^{*}\end{array}$ & LRT Beta & $\begin{array}{l}\text { Variable } \\
\text { Metropolitan } \\
\text { Control** }^{* *}\end{array}$ & SCT Beta & $\begin{array}{l}\text { Variable } \\
\text { Metropolitan } \\
\text { Control }^{* *}\end{array}$ & BRT Beta & $\begin{array}{l}\text { Variable } \\
\text { Metropolitan } \\
\text { Control }^{* *}\end{array}$ & CRT Beta \\
\hline Phoenix & -0.074 & 4 Salt Lake City & -0.229 & 9 Salt Lake City & 0.160 & 0 Orlando & -0.139 \\
\hline Pittsburgh & 0.018 & 3 Seattle & 0.057 & 7 San Antonio & 0.107 & 7 Portland & -0.047 \\
\hline Portland & 0.165 & 5 Tacoma & -0.146 & 6 San Diego & 0.572 & 2 Salt Lake City & -0.198 \\
\hline Sacramento & 0.114 & 4 Tampa & -0.170 & 0 San Jose & 0.758 & 8 San Diego & 0.197 \\
\hline Salt Lake City & -0.019 & 9 Tucson & -0.384 & 4 Seattle & 0.522 & 2 San Jose-Stockton & 0.351 \\
\hline San Diego & 0.409 & & & & & Seattle-Tacoma & 0.083 \\
\hline San Jose & 0.586 & & & & & & \\
\hline Seattle & 0.360 & & & & & & \\
\hline St. Louis & -0.144 & & & & & & \\
\hline $\begin{array}{l}\text { Place Typology } \\
\text { Control }^{* * *}\end{array}$ & & $\begin{array}{l}\text { Place Typology } \\
\text { Control*** }^{* *}\end{array}$ & & $\begin{array}{l}\text { Place Typology } \\
\text { Control }\end{array}$ & & $\begin{array}{l}\text { Place Typology } \\
\text { Control*** }\end{array}$ & \\
\hline Low MA Areas & 0.042 & 2 Low MA Areas & 0.033 & 3 Low MA Areas & 0.057 & 7 Low MA Areas & 0.044 \\
\hline Moderate MA Areas & 0.071 & 1 Moderate MA Areas & 0.090 & 0 Moderate MA Areas & 0.093 & 3 Moderate MA Areas & 0.083 \\
\hline High MA Centers & 0.102 & 2 High MA Centers & 0.182 & 2 High MA Centers & 0.134 & 4 High MA Centers & 0.149 \\
\hline \multicolumn{2}{|c|}{ Distance Band Treatment ${ }^{\star \star \star *}$} & \multicolumn{2}{|c|}{ Distance Band Treatment $^{\star * * *}$} & \multicolumn{2}{|c|}{ Distance Band Treatment ${ }^{\star \star * *}$} & & \\
\hline$<=0.125$ & $3.5 \%$ & $0<=0.125$ & $13.0 \%$ & $0<=0.125$ & $-0.5 \%$ & $\%<=0.125$ & $5.4 \%$ \\
\hline$>0.125-0.250$ & $6.1 \%$ & $>0.125-0.250$ & $13.5 \%$ & $\%>0.125-0.250$ & $-2.5 \%$ & $\%>0.125-0.250$ & $0.9 \%$ \\
\hline$>0.250-0.375$ & $3.7 \%$ & $>0.250-0.375$ & $11.2 \%$ & $\%>0.250-0.375$ & $1.4 \%$ & $\%>0.250-0.375$ & $2.0 \%$ \\
\hline$>0.375-0.500$ & $5.6 \%$ & $0>0.375-0.500$ & $9.0 \%$ & $\%>0.375-0.500$ & $3.0 \%$ & $\%>0.375-0.500$ & $2.8 \%$ \\
\hline$>0.500-0.625$ & $4.6 \%$ & $>0.500-0.625$ & $7.6 \%$ & $0>0.500-0.625$ & $2.5 \%$ & $\%>0.500-0.625$ & $1.0 \%$ \\
\hline$>0.625-0.750$ & $5.5 \%$ & $>0.625-0.750$ & $6.8 \%$ & $\%>0.625-0.750$ & $4.8 \%$ & $\%>0.625-0.750$ & $2.0 \%$ \\
\hline$>0.750-0.875$ & $4.2 \%$ & o $>0.750-0.875$ & $6.8 \%$ & $\%>0.750-0.875$ & $3.7 \%$ & $\%>0.750-0.875$ & $-0.5 \%$ \\
\hline$>0.875-1.000$ & $5.1 \%$ & $6>0.875-1.000$ & $5.0 \%$ & $\%>0.875-1.000$ & $4.1 \%$ & $\%>0.875-1.000$ & $2.3 \%$ \\
\hline
\end{tabular}


Table 8.5

Regression Results for Multifamily Rents with Respect to Transit Station Proximity with Special Reference to Place Typology-continued

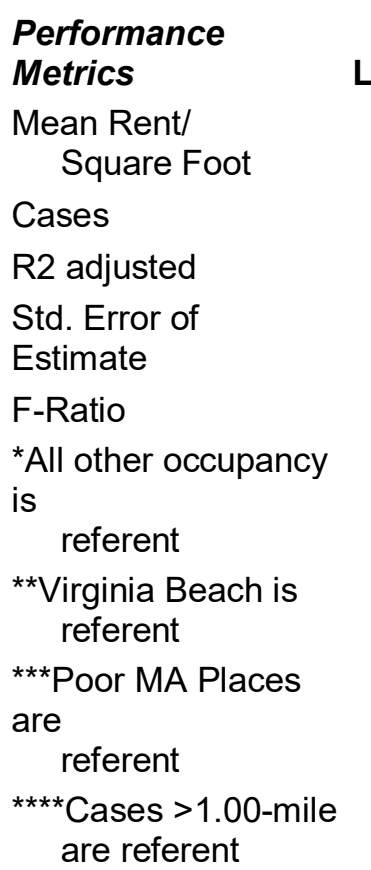

LRT Metrics Performance Metrics
Mean Rent/
$\begin{gathered}\$ 1.64 \quad \text { Square Foot } \\ 4,621 \text { Cases } \\ 0.618 \text { R2 adjusted } \\ 0.262 \text { Std. Error of Estimate } \\ 227.696 \text { F-Ratio } \\ \text { *All other occupancy is } \\ \text { referent } \\ \text { **Washington is } \\ \text { referent } \\ \text { *** Poor MA Places are } \\ \text { referent } \\ * * * \text { Cases }>1.00-\text { mile } \\ \text { are referent }\end{gathered}$

\begin{tabular}{|c|c|}
\hline $\begin{array}{c}\text { SCT } \\
\text { Metrics }\end{array}$ & $\begin{array}{l}\text { Performance } \\
\text { Metrics }\end{array}$ \\
\hline & Mean Rent/ \\
\hline$\$ 1.34$ & Square Foot \\
\hline \multicolumn{2}{|c|}{ 9,946 Cases } \\
\hline \multicolumn{2}{|c|}{0.541 R2 adjusted } \\
\hline \multicolumn{2}{|c|}{0.248 Std. Error of Estimate } \\
\hline 355.838 & F-Ratio \\
\hline & $\begin{array}{l}{ }^{*} \text { All other occupancy } \\
\text { is }\end{array}$ \\
\hline & $\begin{array}{l}{ }^{* *} \text { Albuquerque is } \\
\text { referent }\end{array}$ \\
\hline & $\begin{array}{l}\text { ***Poor MA Places } \\
\text { are } \\
\quad \text { referent }\end{array}$ \\
\hline & $\begin{array}{l}{ }^{* * * *} \text { Cases }>1.00-\text { mile } \\
\text { are referent }\end{array}$ \\
\hline
\end{tabular}

\begin{tabular}{|c|c|c|}
\hline $\begin{array}{c}\text { BRT } \\
\text { Metrics }\end{array}$ & $\begin{array}{l}\text { Performance } \\
\text { Metrics }\end{array}$ & $\begin{array}{c}\text { CRT } \\
\text { Metrics }\end{array}$ \\
\hline & Mean Rent/ & \\
\hline$\$ 1.47$ & Square Foot & $\$ 1.26$ \\
\hline 12,569 & Cases & 1,297 \\
\hline 0.570 & R2 adjusted & 0.506 \\
\hline 0.260 & Std. Error of Estimate & 0.251 \\
\hline 506.798 & F-Ratio & 41.271 \\
\hline & $\begin{array}{l}{ }^{*} \text { All other occupancy } \\
\text { is } \\
\text { referent }\end{array}$ & \\
\hline & $\begin{array}{l}\text { ** Washington is } \\
\text { referent }\end{array}$ & \\
\hline & $\begin{array}{l}{ }^{* * *} \text { Poor MA Places } \\
\text { are } \\
\quad \text { referent }\end{array}$ & \\
\hline & $\begin{array}{l}{ }^{* * *} \text { Cases }>1.00-\text { mile } \\
\text { are referent }\end{array}$ & \\
\hline
\end{tabular}

Bold means significant coefficient consistent with theory using 2-tailed t-test $p<0.10$.

Bold italics means contingent significant coefficient consistent with theory using 2-tailed t-test $p>0.10$ but $<0.20$ or alternatively significant using the 1-tailed t-test $p<0.10$. 


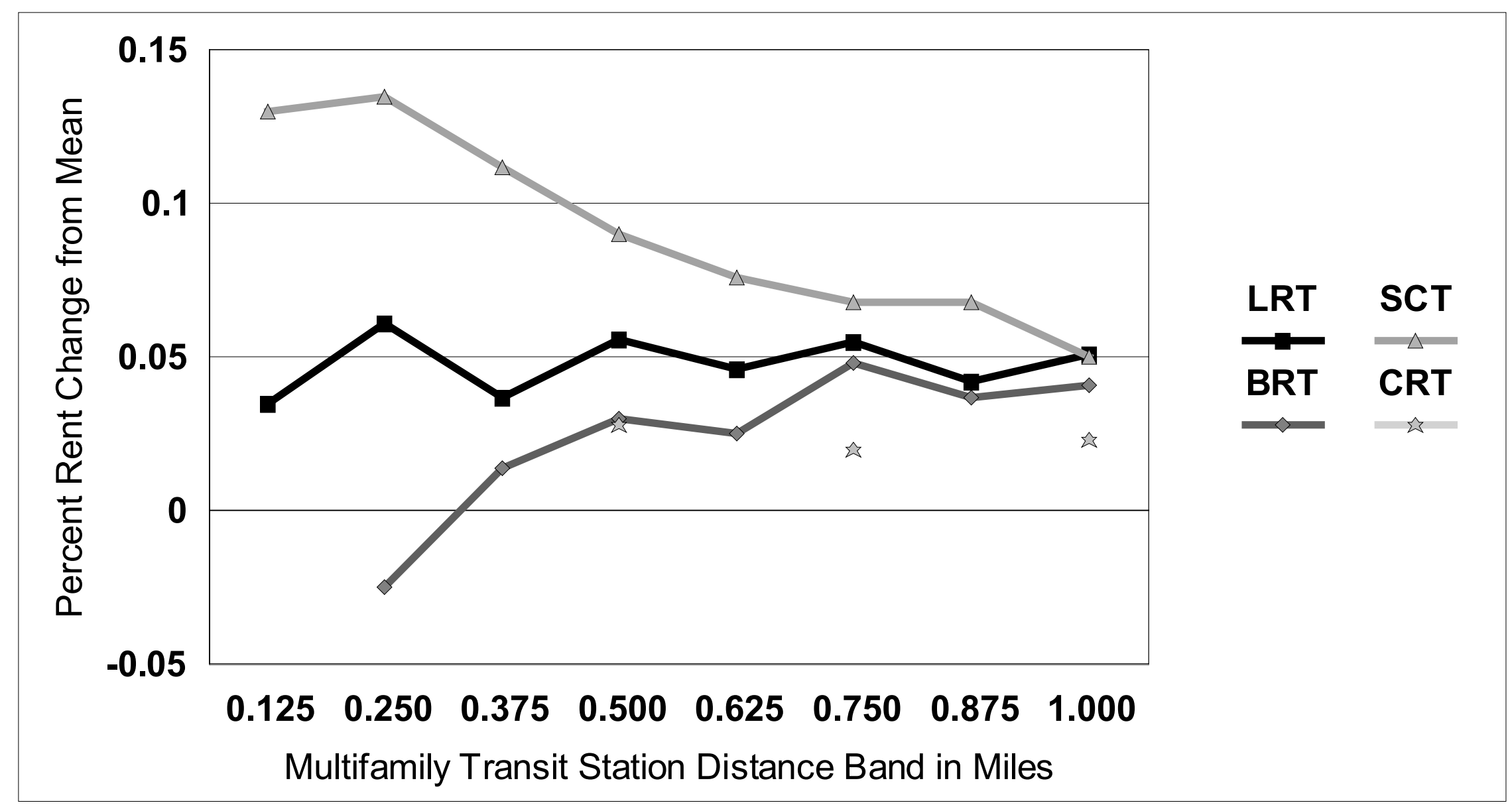

\section{Figure 8.8}

Variation in multifamily rent per square foot with respect to distance from LRT, BRT, SCT and CRT stations

Overall but except for CRT, rents increase with distance from transit stations before falling. For CRT, multifamily rents are not sensitive to station proximity in distance bands to 0.50 -mile. 


\section{Variation in Multifamily Rent with Respect to Transit Station Distance}

We now focus on the link between transit station proximity and multifamily rents. We offer the following insights from Table 8.6 which are illustrated in Figure 8.9. Overall, we find strong associations between multifamily rents and transit station proximity, sometimes having higher coefficients for distance band effects than office. Key findings for each system follows.

\section{Multifamily Rents and LRT Station Proximity}

On the whole, multifamily rents with respect to LRT station proximity rise from 3.5 percent above the mean in the first (0.125-mile) distance band to 6.1 percent in the second $(0.250-\mathrm{mile}) \mathrm{DB}$ then decline to 3.7 percent in the third (0.375-mile) DB before leveling about five percent through the rest of the 1.00-mile study area. Based on the theory discussed above and shown in Figure 8.1, LRT station proximity appears to be associated with externalities that are overcome quickly. But there is something else going on: MF rent premiums with respect to LRT transit station proximity are many times higher than office in the first 0.50 -mile and extend across the entire study area. Moreover, where office rents are below the mean in the first (0.125-mile) distance band, MF rents are above the mean. We surmise that MF rents are more sensitive to LRT station proximity than office at that multifamily market demand may push office activities away from stations.

\section{Multifamily Rents and SCT Station Proximity}

The same trend seen above with respect to LRT station proximity is seen even more so with respect to streetcar transit station proximity. Rents are 13.0 percent higher than the mean in the first (0.125-mile) distance band rising slightly to 13.5 percent above the mean in the second (0.250-mile) DB before falling gradually through the remaining DBs comprising the study area. Though office rents with respect to SCT station proximity are more robust than for LRT station proximity, multifamily rents remain even more so. We suspect that, as for LRT station proximity, MF rents with respect to SCT station proximity may outbid and push office further away.

\section{Multifamily Rents and BRT Station Proximity}

In contrast to LRT and SCT station proximity, multifamily rents are not sensitive to BRT station proximity, at least in the first two $(0.125$ - and 0.250 -mile) distance bands where there are ambiguous and externality associations, respectively. From the third (0.375-nmile) DB outward, rents rise. This is a clear indication that the MF market is repelled somewhat by proximity to BRT stations. We surmise that transit and land use planning, and design, have not been effective at attracting multifamily residential development near BRT stations.

Multifamily Rents and CRT Station Proximity

At first blush, proximity to CRT stations has no statistically significant effect on MF rents but this is deceiving as will be seen in our analysis of individual CRT systems below.

We next review the association between multifamily rents and transit station proximity with respect to Place Typology. 


\section{Variation in the Association between Multifamily Rents and Transit Station Proximity with Respect to Place Typologies}

Our discussion in this subsection is patterned after the discussion above relating to the association between office rents and transit station proximity with respect to place typologies. As for the office regression analysis, because directions and magnitudes of association are similar to the overall model, regression results reported in Table 8.6 include only distance band coefficients and key performance indicators. The relationships are illustrated in Figure 8.9. The following highlights are noted:

\section{Variation in Multifamily Rent with Respect to LRT Station Proximity by Place Typology}

For High-Mixed Use/Accessibility places, there is nearly a straight-line association between light rail transit station proximity and multifamily rent. However, in Moderate-Mixed Use/Accessibility areas, rents rise from the first $(0.125$-mile) to the second $(0.250-\mathrm{mile})$ distance bands, then mostly fall as LRT transit station distance increases. The implication is that in Moderate MA areas, externality effects are seen at or near the station. This pattern is also seen in Low-Mixed Use/Accessibility areas starting with an ambiguous association in the first (0.125-mile) DB. We find no meaningful associations in Poor-Mixed Use/Accessibility areas which suggests that the multifamily market either does not respond to LRT station proximity or more likely there are too few cases spread across these large areas to establish a statistically significant relationship.

Variation in Multifamily Rent with Respect to SCT Station Proximity by Place Typology In both the High-Mixed Use/Accessibility places and Moderate-Mixed Use/Accessibility areas, multifamily rents fall with respect to distance from streetcar stations. We surmise that multifamily rents are sensitive to SCT station proximity in these Place Typologies. In Low-Mixed Use/Accessibility areas, rents rise with respect to distance from SCT stations from the first $(0.125$-mile $)$ to the second $(0.250-$ mile $)$ distance bands, then fall steadily. There is thus some evidence externality effects at or near SCT stations perhaps because those stations are not integrated fully into the development patterns surrounding them. Finally, we are not surprised with the lack of any statistically significant relationship between SCT station proximity and multifamily rents in the Poor-Mixed Use/Accessibility areas.

Variation in Multifamily Rent with Respect to BRT Station Proximity by Place Typology Except for Low-Mixed Use/Accessibility areas, BRT stations have ambiguous or negative effects on multifamily rents in the first two (0.125- and 0.250-mile) distance bands. For Low-Mixed Use/Accessibility areas, however, rents are above the mean in the first (0.125-mile) distance band and fall to the second (0.250-mile) DB. In Moderate MA areas, rents are statistically significant and downward sloping from the third (0.375-mile) and fourth (0.500-mile) DBs with a similar pattern and comparable magnitudes of coefficients in Low MA areas from the fourth (0.500-mile) to fifth (0.525-mile) DBs. Otherwise, there is little evidence that BRT station proximity influences multifamily rent. These patterns change, however, when we look at individual metropolitan areas.

We especially note the paucity of research addressing the role of BRT systems in influencing residential real estate generally (see Perk et al. 2017 for a review) and multifamily rents in particular. In the only relevant published work on this relationship, Nelson (2017) found that multifamily rents were 3.0 percent higher than the regional mean within the first one-half mile of BRT stations/stops and 1.7 percent higher in the next one-half mile distance band. 
Variation in Multifamily Rent with Respect to CRT Station Proximity by Place Typology For the most part, there is no meaningful relationship between multifamily rent and commuter rail transit station proximity. The one possible exception is that rents rise above the mean in the third (0.375-mile) to the fourth (0.500-mile) distance bands then fall to the sixth $(0.625$-mile) in High MA places.

Many patterns will change for individual metropolitan areas as will be seen next. 
Table 8.6

Regression Results for Multifamily Rents with Respect to Transit Station Proximity by Place Typology

Distance Band
$<=0.125$
$>0.125-0.250$
$>0.250-0.375$
$>0.375-0.500$
$>0.500-0.625$
$>0.625-0.750$
$>0.750-0.875$
$>0.875-1.000$
Mean Rent/Square Foot
Cases
$R^{2}$ adjusted
Distance Band
$<=0.125$
$>0.125-0.250$
$>0.250-0.375$
$>0.375-0.500$
$>0.500-0.625$
$>0.625-0.750$
$>0.750-0.875$
$>0.875-1.000$
Mean Rent/Square Foot
Cases
$R^{2}$ adjusted

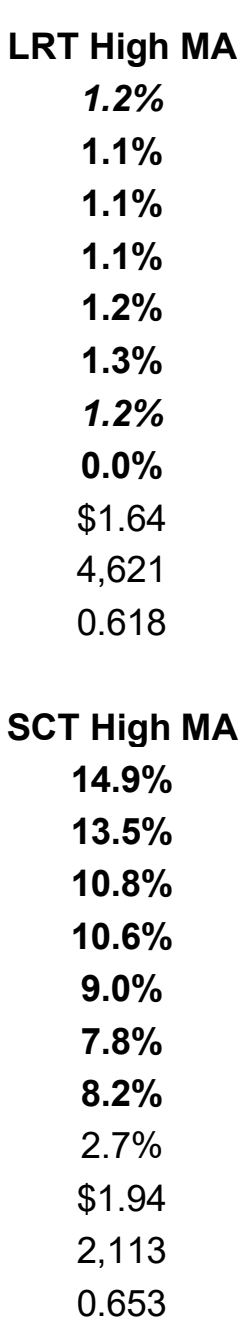

Light Rail Transit by Place Typology LRT Moderate MA LRT Low MA

$\begin{array}{lll}\mathbf{3 . 0} \% & 2.8 \% & -2.3 \% \\ \mathbf{5 . 1} \% & \mathbf{3 . 7 \%} & -8.0 \% \\ \mathbf{2 . 6} \% & \mathbf{3 . 1 \%} & -0.5 \% \\ \mathbf{5 . 1 \%} & \mathbf{2 . 5 \%} & \mathbf{1 6 . 3 \%} \\ \mathbf{7 . 0} \% & 0.0 \% & 2.8 \% \\ \mathbf{5 . 6 \%} & 4.2 \% & \mathbf{9 . 5 \%} \\ \mathbf{4 . 4 \%} & 4.5 \% & 4.5 \% \\ \mathbf{4 . 7} \% & 4.6 \% & 5.5 \% \\ \$ 1.47 & \$ 1.34 & \$ 1.26 \\ 12,569 & 9,946 & 1,297 \\ 0.570 & 0.541 & 0.506\end{array}$

Streetcar Transit by Place Typology SCT Moderate MA SCT Low MA

$14.6 \%$

$11.0 \%$

SCT Poor MA

$14.5 \%$

$16.8 \%$

$-19.2 \%$

$-1.6 \%$

$14.2 \%$

$11.4 \%$

$7.3 \%$

$8.6 \%$

$9.7 \%$

$-2.1 \%$

$7.3 \%$

$9.4 \%$

$5.8 \% \quad 6.3 \%$

$6.6 \% \quad 8.7 \%$

$6.5 \%$

$6.2 \%$

$\$ 1.43$

$\$ 1.24$

$\$ 1.15$

5,879

4,845

635

0.577

0.554

0.500 
Table 8.6

Regression Results for Multifamily Rents with Respect to Transit Station Proximity by Place Typology-Continued

Distance Band
$<=0.125$
$>0.125-0.250$
$>0.250-0.375$
$>0.375-0.500$
$>0.500-0.625$
$>0.625-0.750$
$>0.750-0.875$
$>0.875-1.000$
Mean Rent/Square Foot
Cases
$\mathrm{R}^{2}$ adjusted
Distance Band
$<=0.125$
$>0.125-0.250$
$>0.250-0.375$
$>0.375-0.500$
$>0.500-0.625$
$>0.625-0.750$
$>0.750-0.875$
$>0.875-1.000$
Mean Rent/Square Foot
Cases
$\mathrm{R}^{2}$ adjusted

\section{BRT High MA}

$-1.1 \%$

$-6.8 \%$

$-2.1 \%$

$3.1 \%$

$1.7 \%$

$8.9 \%$

$5.2 \%$

$2.4 \%$

$\$ 1.87$

2,574

0.540

\section{CRT High MA}

$13.6 \%$

$-2.9 \%$

$9.1 \%$

$16.6 \%$

$12.4 \%$

$8.7 \%$

$1.2 \%$

$13.3 \%$

$\$ 1.80$

4,639

0.519
Bus Rapid Transit by Place Typology BRT Moderate MA BRT Low MA

$-1.8 \%$
$-1.2 \%$
$4.3 \%$
$3.6 \%$
$1.5 \%$
$2.5 \%$
$1.5 \%$
$3.4 \%$
$\$ 1.65$
6,694
0.564

$3.3 \%$

$2.7 \%$

$1.2 \%$

$4.3 \%$

$4.0 \%$

$2.7 \%$

$5.7 \%$

$5.2 \%$

$\$ 1.44$

5,225

0.584

Commuter Rail Transit by Place Typology

\section{CRT Moderate MA CRT Low MA}

$-2.8 \%$

$-3.9 \%$

$0.4 \%$

$0.2 \%$

$-1.7 \%$

$5.0 \%$

$-2.2 \%$

$-1.6 \%$

$\$ 1.59$

12,021

0.506
$9.9 \%$

$8.2 \%$

$-1.0 \%$

$0.3 \%$

$1.7 \%$

$-7.6 \%$

$0.7 \%$

$2.9 \%$

$\$ 1.51$

8,473

0.468
BRT Poor MA

$-8.7 \%$

$-25.4 \%$

$2.0 \%$

$0.1 \%$

$0.0 \%$

$10.4 \%$

$-3.6 \%$

$2.1 \%$

$\$ 1.27$

824

0.585

\section{CRT Poor MA}

$0.0 \%$

$0.8 \%$

$20.2 \%$

$-13.2 \%$

$-1.5 \%$

$3.5 \%$

$6.8 \%$

$9.8 \%$

$\$ 1.44$

937

0.453 


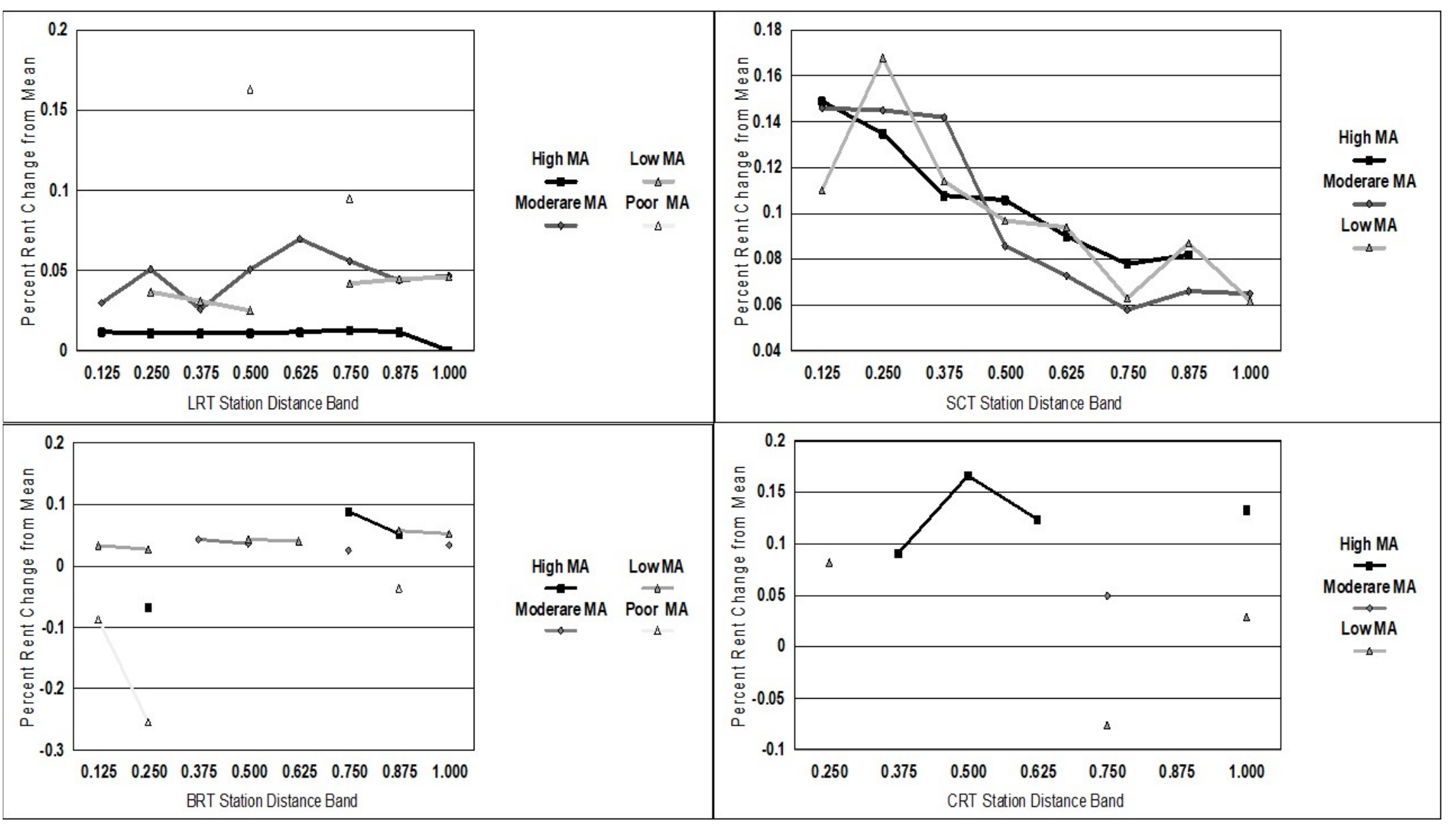

\section{Figure 8.9}

Plot of significant and contingent significant LRT, SCT, BRT and CRT multifamily rent coefficients with lines connecting respective points with respect to Place Typology

With the exception of SCT station proximity, multifamily rent generally increases with respect to distance from transit stations indicating the presence of externalities at and near those stations. Exceptions especially related to SCT station proximity are noted in the text. 
Variation in Multifamily Rent with Respect to Transit Station Proximity by Metropolitan Area

Here, we summarize findings in terms of the variation of multifamily rents with respect to transit station proximity by metropolitan area. We also address the role of Place Typologies in combination with station proximity analysis. This analysis is structured similar to that for office rent variations with respect to transit station proximity by metropolitan area. Table 8.7 reports regression coefficients for only distance bands and then for only those that are significant or contingent significant—-the "relevant coefficients." It also includes relevant coefficients for Place Typologies.

As for offices, we identify overall or general patterns of relationships between transit station proximity and multifamily rent. The second-to-last last column in Table 8.7 summarizes overall directional trends from the station (0.125-mile distance band) over the next four distance bands or where direction changes or coefficients are ambiguous. The last column illustrates the overall functional form for the entire 1.00-mile study areas for those metropolitan areas without ambiguous results reported in the preceding column.

We will present Table 8.7 first, followed by interpretations and identification of exemplar metropolitan areas for each transit type. 
Table 8.7

Significant Multifamily Rent Coefficients* with Respect to Place Typology and Station Distance ${ }^{\star *}$ by Metropolitan Area

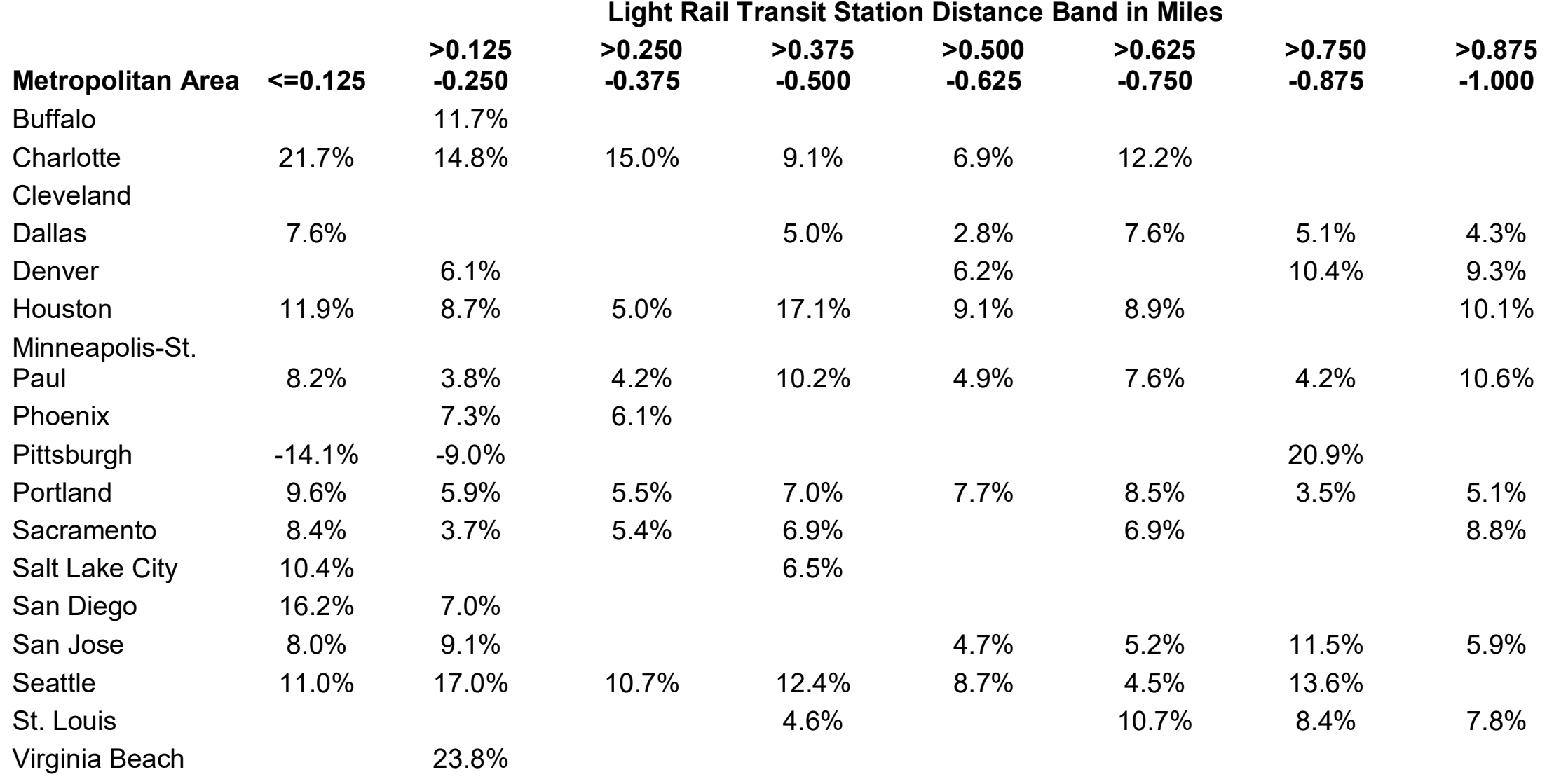


Table 8.7

Significant Multifamily Rent Coefficients* with Respect to Place Typology and Station Distance ${ }^{* *}$ by Metropolitan Areacontinued

LRT Multifamily Rent Association with Respect to Place Typology, and General Form of Distance Relationship****

\begin{tabular}{|c|c|c|c|c|c|c|c|}
\hline $\begin{array}{l}\text { Metropolitan } \\
\text { Area }\end{array}$ & $\begin{array}{c}\text { High } \\
\text { MA }\end{array}$ & $\begin{array}{l}\text { Moderate } \\
\text { MA }\end{array}$ & $\begin{array}{l}\text { Low } \\
\text { MA }\end{array}$ & $\begin{array}{l}\text { Mean Rent/ } \\
\text { Sq.Ft. }\end{array}$ & Cases & R2 & Form from Station \\
\hline Buffalo & $34.2 \%$ & & & $\$ 1.17$ & 315 & 0.419 & Ambiguous \\
\hline Charlotte & & & & $\$ 1.07$ & 613 & 0.674 & $\begin{array}{c}\text { Downward above } \\
\text { mean }\end{array}$ \\
\hline Cleveland & & & $-4.7 \%$ & $\$ 1.00$ & 900 & 0.451 & Ambiguous \\
\hline Dallas & $7.2 \%$ & $5.0 \%$ & $5.7 \%$ & $\$ 1.18$ & 3,386 & 0.480 & Above mean \\
\hline Denver & $6.4 \%$ & $4.0 \%$ & & $\$ 1.58$ & 2,363 & 0.328 & Above mean \\
\hline Houston & $6.2 \%$ & $9.0 \%$ & $6.4 \%$ & $\$ 1.08$ & 2,330 & 0.557 & $\begin{array}{c}\text { Downward above } \\
\text { mean }\end{array}$ \\
\hline Minneapolis & $13.3 \%$ & $7.7 \%$ & $5.0 \%$ & $\$ 1.29$ & 2,200 & 0.409 & $\begin{array}{c}\text { Downward above } \\
\text { mean }\end{array}$ \\
\hline Phoenix & & & & $\$ 1.02$ & 2,458 & 0.393 & $\begin{array}{c}\text { Downward above } \\
\text { mean }\end{array}$ \\
\hline Pittsburgh & $15.8 \%$ & $13.3 \%$ & $6.2 \%$ & $\$ 1.22$ & 808 & 0.505 & $\begin{array}{c}\text { Upward above mean } \\
\text { Downward above }\end{array}$ \\
\hline Portland & $15.3 \%$ & $7.0 \%$ & & $\$ 1.41$ & 1,995 & 0.501 & $\begin{array}{c}\text { mean } \\
\text { Downward above }\end{array}$ \\
\hline Sacramento & $5.2 \%$ & & & $\$ 1.25$ & 1,237 & 0.567 & mean \\
\hline Salt Lake City & & & & $\$ 1.12$ & 461 & 0.458 & Above mean \\
\hline San Diego & $5.1 \%$ & $4.1 \%$ & & $\$ 1.76$ & 3,515 & 0.447 & $\begin{array}{c}\text { Downward above } \\
\text { mean }\end{array}$ \\
\hline San Jose & $8.6 \%$ & & & $\$ 2.41$ & 1,778 & 0.567 & Upward above mean \\
\hline Seattle & $19.2 \%$ & $10.7 \%$ & $4.2 \%$ & $\$ 1.90$ & 2,955 & 0.546 & Upward above mean \\
\hline St. Louis & $-8.9 \%$ & & & $\$ 1.00$ & 824 & 0.500 & Ambiguous \\
\hline
\end{tabular}

Overal Functional

Form

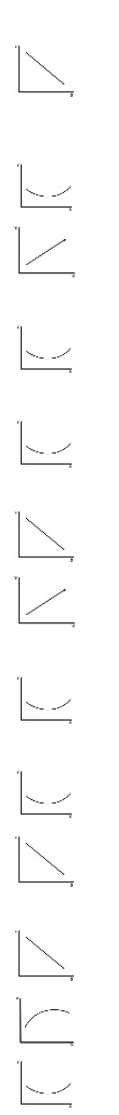




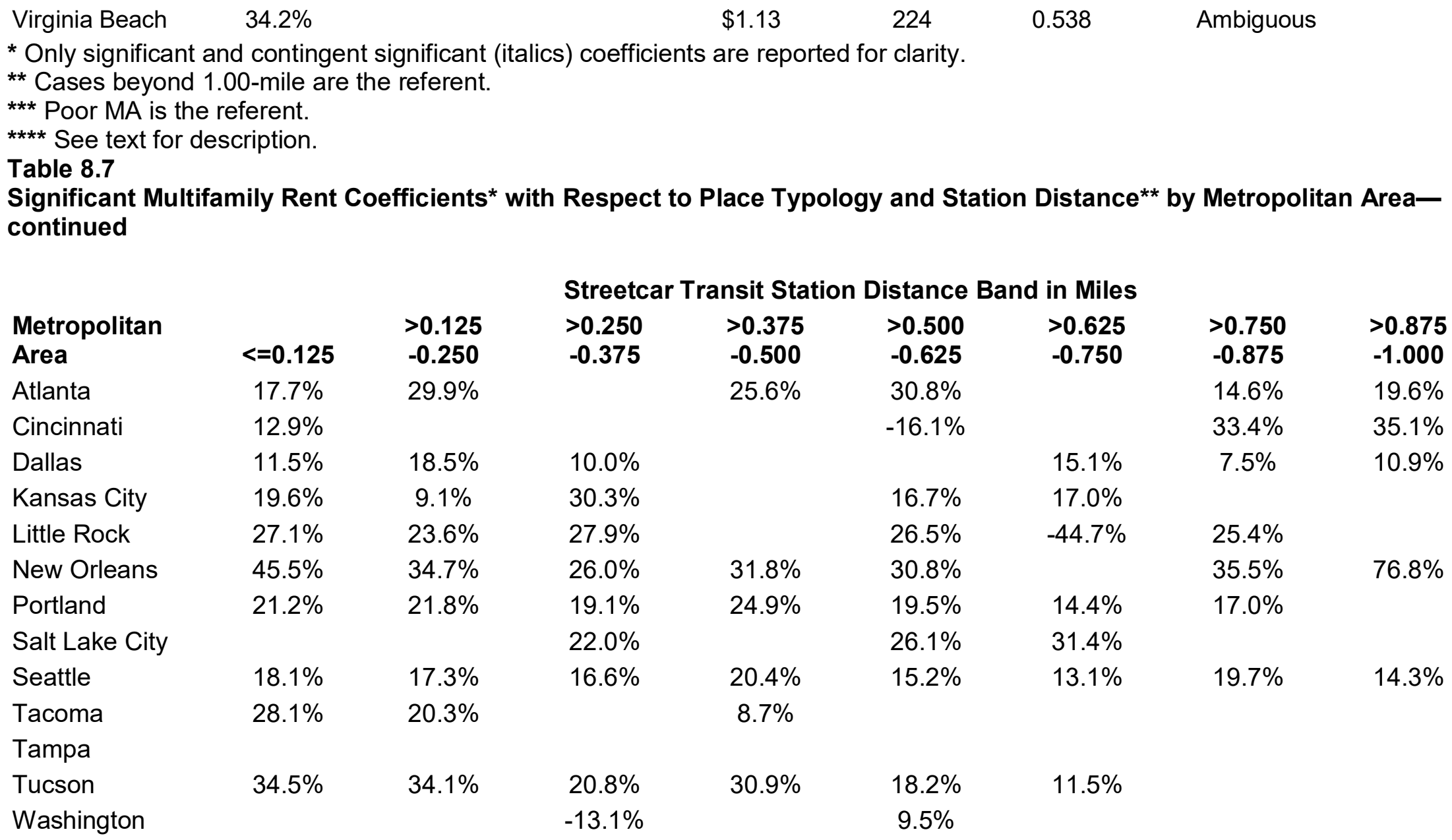


Table 8.7

Significant Multifamily Rent Coefficients* with Respect to Place Typology and Station Distance** by Metropolitan Areacontinued

SCT Multifamily Rent Association with Respect to Place Typology, ${ }^{* * *}$ Model Performance, and General Form of Distance Relationship ${ }^{* * * *}$

\begin{tabular}{|c|c|c|c|c|c|c|c|}
\hline $\begin{array}{l}\text { Metropolitan } \\
\text { Area }\end{array}$ & $\begin{array}{l}\text { High } \\
\text { MA }\end{array}$ & $\begin{array}{l}\text { Moderate } \\
\text { MA }\end{array}$ & $\begin{array}{l}\text { Low } \\
\text { MA }\end{array}$ & $\begin{array}{l}\text { Mean Rent/ } \\
\text { Sq.Ft. }\end{array}$ & Cases & $\mathbf{R 2}$ & Form from Station \\
\hline Atlanta & $13.1 \%$ & $6.5 \%$ & & $\$ 1.22$ & 896 & 0.527 & Upward above mean \\
\hline Cincinnati & $9.8 \%$ & & $-3.4 \%$ & $\$ 0.92$ & 811 & 0.382 & Upward above mean \\
\hline Dallas & $10.9 \%$ & $9.1 \%$ & $8.0 \%$ & $\$ 1.23$ & 1,945 & 0.419 & $\begin{array}{c}\text { Upward above mean } \\
\text { Downward above }\end{array}$ \\
\hline Kansas City & $17.7 \%$ & $15.3 \%$ & $8.3 \%$ & $\$ 0.98$ & 563 & 0.369 & mean \\
\hline Little Rock & & & & $\$ 0.84$ & 248 & 0.446 & $\begin{array}{c}\text { Downward above } \\
\text { mean }\end{array}$ \\
\hline New Orleans & & & & $\$ 1.40$ & 104 & 0.620 & $\begin{array}{c}\text { Downward above } \\
\text { mean }\end{array}$ \\
\hline Portland & $10.8 \%$ & $5.9 \%$ & & $\$ 1.48$ & 1,478 & 0.504 & Upward above mean \\
\hline Salt Lake City & & $9.6 \%$ & & $\$ 1.13$ & 461 & 0.310 & Above mean \\
\hline Seattle & $13.8 \%$ & $7.8 \%$ & $5.5 \%$ & $\$ 1.92$ & 2,955 & 0.459 & $\begin{array}{c}\text { Downward above } \\
\text { mean }\end{array}$ \\
\hline Tacoma & & & & $\$ 1.23$ & 780 & 0.331 & $\begin{array}{c}\text { Downward above } \\
\text { mean }\end{array}$ \\
\hline Tampa & & & & $\$ 1.17$ & 652 & 0.504 & Ambiguous \\
\hline Tucson & & & & $\$ 0.91$ & 854 & 0.365 & $\begin{array}{c}\text { Downward above } \\
\text { mean }\end{array}$ \\
\hline Washington & $35.8 \%$ & $23.6 \%$ & $18.7 \%$ & $\$ 2.30$ & 1,112 & 0.515 & Below mean \\
\hline
\end{tabular}

Overall

Functional

Form
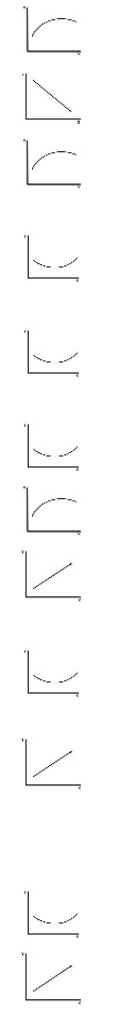

** Cases beyond 1.00-mile are the referent.

Poor MA is the referent. 
**** See text for description. 
Table 8.7

Significant Multifamily Rent Coefficients* with Respect to Place Typology and Station Distance ${ }^{* *}$ by Metropolitan Areacontinued

\begin{tabular}{|c|c|c|c|c|c|c|c|c|}
\hline \multirow[b]{2}{*}{ Metropolitan Area } & \multicolumn{8}{|c|}{ Bus Rapid Transit Station Distance Band in Miles } \\
\hline & $<=0.125$ & $\begin{array}{l}>0.125 \\
-0.250\end{array}$ & $\begin{array}{l}>0.250 \\
-0.375\end{array}$ & $\begin{array}{c}>0.375 \\
-0.500\end{array}$ & $\begin{array}{l}>0.500 \\
-0.625\end{array}$ & $\begin{array}{c}>0.625 \\
-0.750\end{array}$ & $\begin{array}{l}>0.750 \\
-0.875\end{array}$ & $\begin{array}{l}>0.875 \\
-1.000\end{array}$ \\
\hline Albuquerque & & & $-8.0 \%$ & $-7.3 \%$ & $-7.6 \%$ & & & \\
\hline Cleveland & $23.5 \%$ & $11.6 \%$ & $9.3 \%$ & $29.0 \%$ & $8.6 \%$ & & & $23.5 \%$ \\
\hline Eugene-Springfield & & & & & $31.0 \%$ & $-16.4 \%$ & & \\
\hline Kansas City & $18.8 \%$ & $20.7 \%$ & $29.6 \%$ & $27.0 \%$ & $14.7 \%$ & $10.9 \%$ & $25.2 \%$ & $18.8 \%$ \\
\hline $\begin{array}{l}\text { Minneapolis-St. Paul } \\
\text { Nashville }\end{array}$ & & $-6.6 \%$ & & & & & & \\
\hline $\begin{array}{l}\text { Pittsburgh } \\
\text { Reno }\end{array}$ & $-4.8 \%$ & & & & & $-6.7 \%$ & $6.3 \%$ & \\
\hline Salt Lake City & & & $-16.1 \%$ & & & & & \\
\hline San Antonio & & & $5.7 \%$ & & & $13.8 \%$ & $8.4 \%$ & \\
\hline San Diego & & $-5.0 \%$ & $-2.8 \%$ & $-3.0 \%$ & $-9.3 \%$ & & & \\
\hline San Jose & & & $11.6 \%$ & $8.0 \%$ & $15.9 \%$ & $10.4 \%$ & $6.8 \%$ & $12.3 \%$ \\
\hline Seattle & & $-4.4 \%$ & & $5.9 \%$ & $6.1 \%$ & $9.2 \%$ & $6.5 \%$ & $6.1 \%$ \\
\hline
\end{tabular}


Table 8.7

Significant Multifamily Rent Coefficients* with Respect to Place Typology and Station Distance ${ }^{\star *}$ by Metropolitan Areacontinued

BRT Multifamily Rent Association with Respect to Place Typology, ${ }^{* * *}$ Model Performance, and General Form of Distance Relationship****

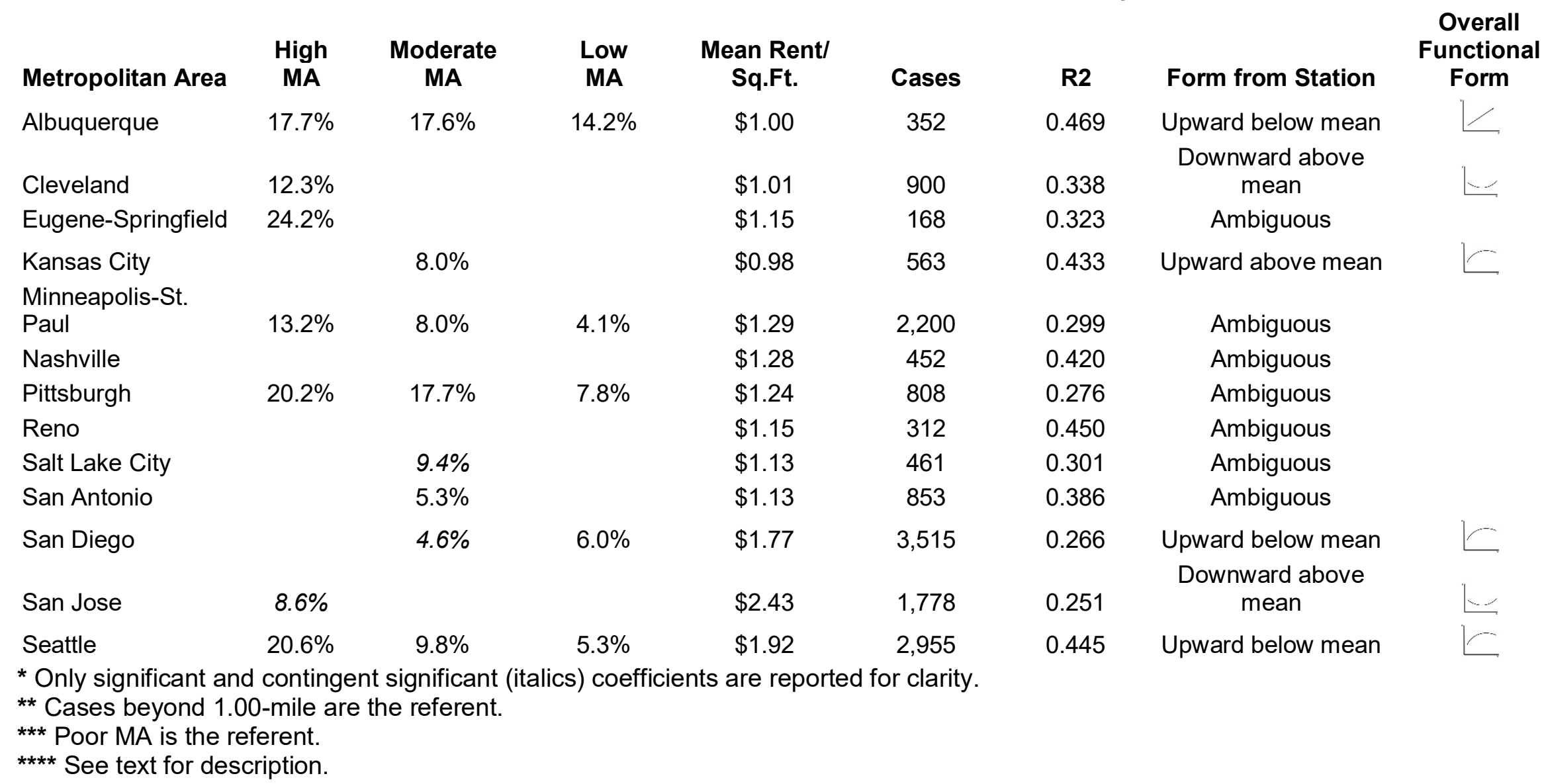


Table 8.7

Significant Multifamily Rent Coefficients* with Respect to Place Typology and Station Distance ${ }^{* *}$ by Metropolitan Areacontinued

Metropolitan Area

Albuquerque-Santa Fe

Austin

Dallas-Fort Worth

Denver

Miami-SE Florida

Minneapolis-St.

Paul

Nashville

Orlando

Portland

Salt Lake City

San Diego

San Jose-Stockton

Seattle-Tacoma

Washington DC

\section{Commuter Rail Transit Station Distance Band in Miles}

$\begin{array}{llllllr}>0.125 & >0.250 & >0.375 & >0.500 & >0.625 & >0.750 & >0.875 \\ -0.250 & -0.375 & -0.500 & -0.625 & -0.750 & -0.875 & -1.000\end{array}$

$8.2 \%$

$9.1 \%$

$22.2 \%$

$9.3 \%$

$21.2 \%$

$\begin{array}{rrrr}22.1 \% & 20.0 \% & 16.6 \% & 19.3 \% \\ -29.8 \% & & -11.9 \% & -8.1 \% \\ & & & 13.3 \% \\ 48.1 \% & 15.9 \% & 12.2 \% & 18.8 \% \\ & 11.7 \% & & \\ & -10.8 \% & -12.4 \% & -21.2 \%\end{array}$

$15.5 \%$

$-5.3 \%$

$-10.1 \%$

$13.9 \%$

$9.5 \%$

$11.8 \%$

$16.5 \%$

$5.0 \%$

$12.6 \%$

$-14.3 \%$

$-7.8 \%$ 
Table 8.7

Significant Multifamily Rent Coefficients* with Respect to Place Typology and Station Distance ${ }^{\star *}$ by Metropolitan Areacontinued

CRT Multifamily Rent Association with Respect to Place Typology, and General Form of Distance Relationship****

\begin{tabular}{|c|c|c|c|c|c|c|c|c|}
\hline Metropolitan Area & $\begin{array}{l}\text { High } \\
\text { MA }\end{array}$ & $\begin{array}{l}\text { Moderate } \\
\text { MA }\end{array}$ & $\begin{array}{l}\text { Low } \\
\text { MA }\end{array}$ & $\begin{array}{l}\text { Mean Rent/ } \\
\text { Sq.Ft. }\end{array}$ & Cases & $\mathbf{R} 2$ & Form from Station & $\begin{array}{c}\text { Overall } \\
\text { Functional } \\
\text { Form }\end{array}$ \\
\hline $\begin{array}{l}\text { Albuquerque-Santa } \\
\mathrm{Fe}\end{array}$ & $14.8 \%$ & $15.0 \%$ & $13.3 \%$ & $\$ 1.00$ & 352 & 0.459 & Ambiguous & \\
\hline Austin & $9.6 \%$ & & & $\$ 1.48$ & 1,083 & 0.343 & Ambiguous & \\
\hline Dallas-Fort Worth & $12.0 \%$ & $9.7 \%$ & $7.7 \%$ & $\$ 1.19$ & 2,956 & 0.385 & Ambiguous & \\
\hline Denver & $10.5 \%$ & $10.3 \%$ & & $\$ 1.67$ & 1,499 & 0.314 & Ambiguous & \\
\hline Miami-SE Florida & & $-5.1 \%$ & $-5.9 \%$ & $\$ 1.45$ & 2,944 & 0.331 & Ambiguous & \\
\hline Minneapolis-St. & & & & & & & & \\
\hline Paul & $13.3 \%$ & $5.2 \%$ & & $\$ 1.32$ & 1,660 & 0.302 & Ambiguous & \\
\hline Nashville & & & & $\$ 1.28$ & 452 & 0.429 & Ambiguous & \\
\hline Orlando & $-19.6 \%$ & & $-9.6 \%$ & $\$ 1.17$ & 556 & 0.479 & $\begin{array}{l}\text { Downward from } \\
\text { mean }\end{array}$ & W \\
\hline Portland & $-6.4 \%$ & & $-6.6 \%$ & $\$ 1.28$ & 517 & 0.413 & Upward from mean & L \\
\hline Salt Lake City & & $9.5 \%$ & & $\$ 1.13$ & 461 & 0.297 & Ambiguous & \\
\hline San Diego & & & $5.0 \%$ & $\$ 1.77$ & 3,515 & 0.276 & $\begin{array}{l}\text { Downward from } \\
\text { mean }\end{array}$ & 世 \\
\hline San Jose-Stockton & $12.3 \%$ & $8.8 \%$ & & $\$ 2.43$ & 1,778 & 0.242 & Ambiguous & \\
\hline Seattle-Tacoma & $22.2 \%$ & $8.7 \%$ & $4.7 \%$ & $\$ 1.78$ & 3,735 & 0.472 & $\begin{array}{c}\text { Downward from } \\
\text { mean }\end{array}$ & 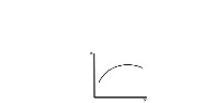 \\
\hline Washington DC & $35.3 \%$ & $22.9 \%$ & $18.1 \%$ & $\$ 2.30$ & 1,112 & 0.513 & Ambiguous & \\
\hline
\end{tabular}


Light Rail Transit Station Multifamily Rent Proximity Effects by Metropolitan Area Buffalo, Cleveland, St. Louis and Virginia Beach have ambiguous relationships between LRT station proximity and multifamily rent. Inasmuch as there are also negative or ambiguous associations with respect to Place Typology, we surmise that the markets in these metropolitan areas simply do not value proximity to LRT stations. In Cleveland, perhaps the reason is that such stations are located in office areas where office rents are influenced positively. Three metropolitan areas_-Denver, Pittsburgh and San Jose_reveal upward sloping multifamily rent gradients suggesting the presence of externalities at or near stations.

Most metropolitan areas-ten including Charlotte, Dallas, Houston, Minneapolis-St. Paul, Phoenix, Portland, Sacramento, Salt Lake City, San Diego and Seattle-reveal downward sloping gradients signaling that the multifamily market values proximity to LRT stations. Most of those (Phoenix, Salt Lake City and San Diego being the exceptions) show gradients declining to some point before rising about 0.500 -mile away.

LRT Multifamily Exemplars: Charlotte, Houston, Portland, Sacramento

We find four LRT systems worthy of being identified as exemplars with respect to how LTR station proximity affects rents positively: Charlotte, Houston, Portland and Sacramento, as shown in Figure 8.10. For all but Sacramento, multifamily rents decline with distance from LRT stations to the third (0.375-mile) distance band-for Sacramento it is the second (0.250-mile) DB. In particular, the rent premium in Charlotte falls from 21.7 percent above the mean in the first $(0.125$-mile) DB to 15.0 percent in the third $(0.375$-mile) while the premiums fall from 11.9 percent to 5.0 percent in Houston, 9.6 percent to 5.5 percent in Portland, and 8.4 percent to 3.7 percent for only the second (0.250-mile) DB in Sacramento.

These distances are less than the one-half mile circle that dominates transit-oriented development literature and planning, so to some extent the half-mile circle is supported empirically. However, we also find that LRT station proximity may have influences up to 1.00 mile away as noted in the discussion of Table 8.7 above. The reason is that our selection of exemplars is based on a strict application of theory that minimizes the area of influence to only the inflection point in a convex (downward sloping) curve. It also does not address the presence of externalities that may overcome amenity benefits, as seen in five metropolitan areasBuffalo, Denver, Pittsburgh, San Jose and St. Louis. Nonetheless, we may recommend that transit and land used planners, and urban designers study the four exemplar metropolitan areas for lessons that can be used to maximize market responsiveness to LRT station proximity.

We consider metropolitan areas with streetcar transit systems next. 


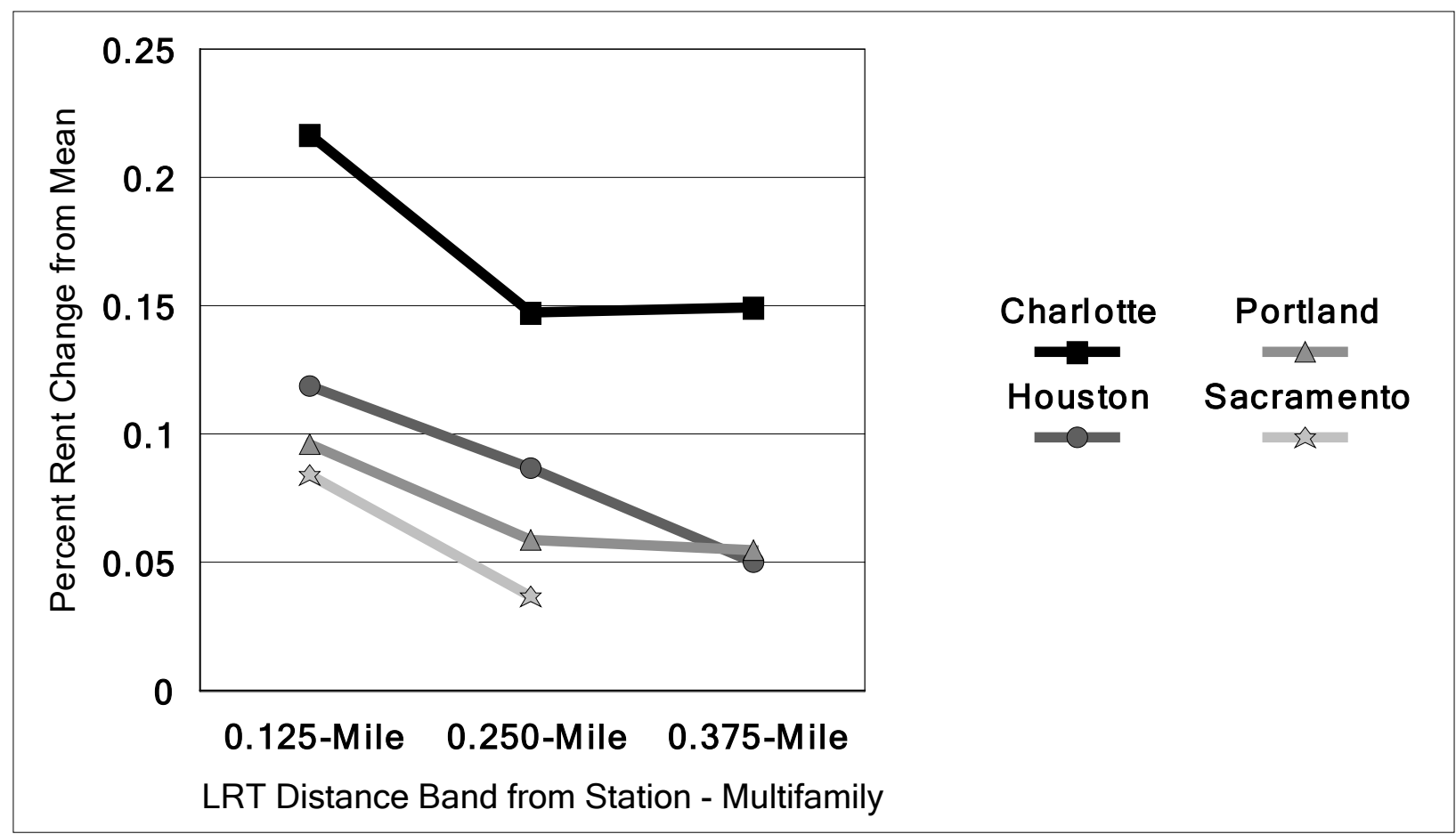

Figure 8.10

Multifamily rent premiums for light rail transit station proximity in Charlotte, Houston, Portland and Sacramento 
Streetcar Transit Station Multifamily Rent Proximity Effects by Metropolitan Area

Only Tampa has an ambiguous relationship between SCT station proximity and multifamily rent, perhaps because it does not directly connect MF development to downtown or other subcenters. Half of the rest-Atlanta, Dallas, Portland, Salt Lake City, Tacoma and Washington have upward sloping or concave gradients indicating externalities are present at or near SCT stations. The remaining six-Cincinnati, Kansas City, Little Rock, New Orleans, Seattle and Tucson have downward sloping or convex gradients indicating that proximity value overcomes externalities. In those cases with convex relationships, the minima or low point of the curve occurs about 0.500 -mile from SCT stations. Overall, we find that the market responds to proximity to transit stations for almost all SCT systems but that for half of them externalities seem to be revealed at or near stations. For these systems, planning and urban design solutions may reduce externalities thereby increasing the attractiveness of SCT station proximity for multifamily real estate.

SCT Multifamily Exemplars: Kansas City, Seattle, Tacoma, Tucson Five metropolitan areas meet our criteria for designation as exemplars when it comes to their streetcar systems having theoretically desired effects on multifamily rents: Kansas City, New Orleans, Seattle, Tacoma and Tucson. Figure 8.11 illustrates this.

Two systems serve only downtown-Seattle and Tacoma, while the other three connect downtown to nearby destination centers such as the convention center in Kansas City, the French Quarter in New Orleans, and the University of Arizona in Tucson. New Orleans, Seattle and Tucson have theoretically desired associations to the third (0.375-mile) distance band where rents start at 45.5 percent, 18.1 percent and 34.5 percent above the mean in the first (0.125-mile) DB falling to 26.0 percent, 16.6 percent and 20.8 percent in the third DB, respectively. The other two, Kansas City and Tacoma, have desired effects only from the first to second DBs where rents fall from 19.6 percent to 9.1 percent and from 28.1 percent to 20.3 percent, respectively. With streetcars gaining popularity around the US, we recommend in depth case studies of these systems to advance streetcar transit and land use planning, and urban design for new or expanding systems.

We turn next to assessing bus rapid transit station effects on multifamily rent. 


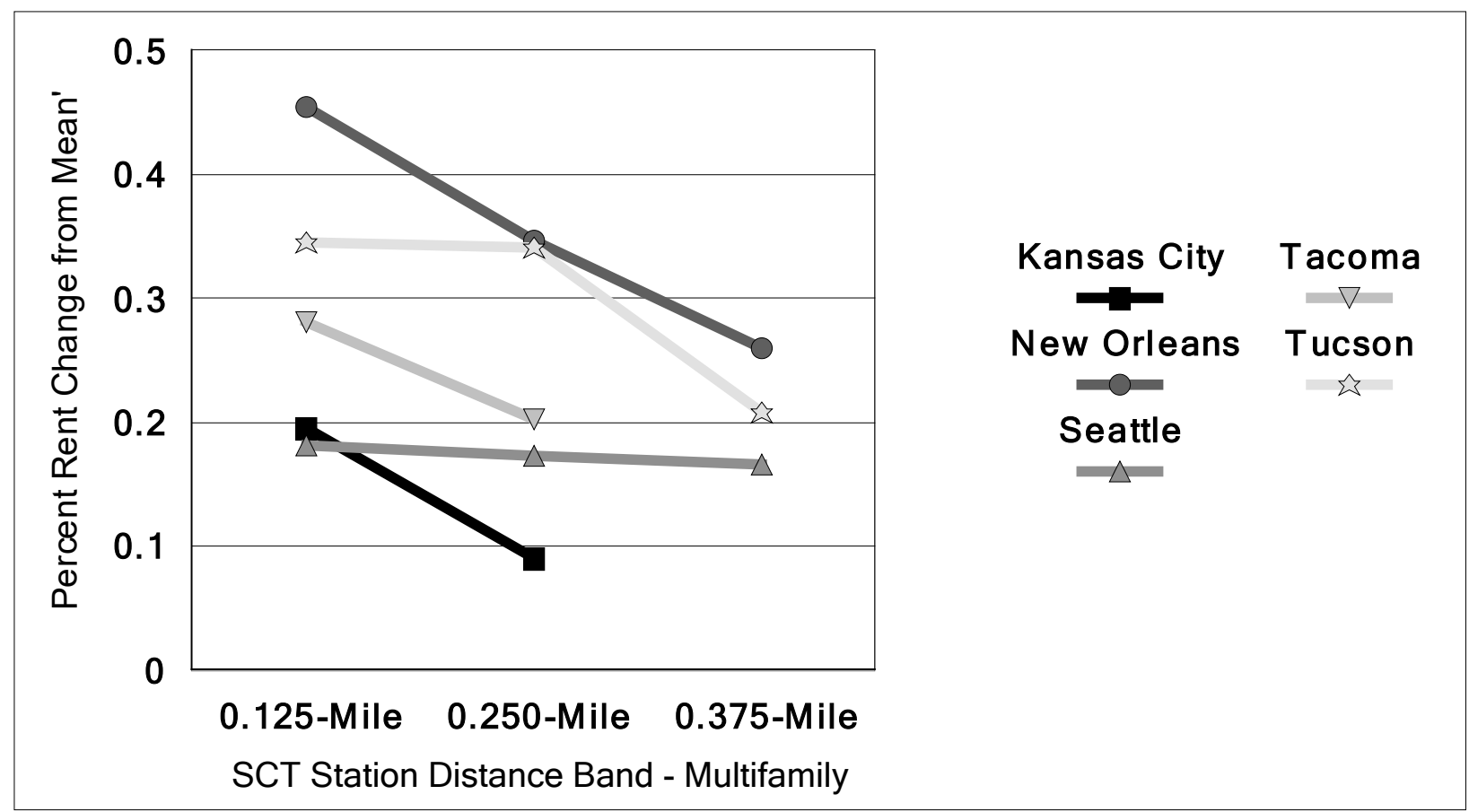

Figure 8.11

Multifamily rent premiums for streetcar transit station proximity in Kansas City, Seattle, Tacoma and Tucson 
Bus Rapid Transit Station Multifamily Rent Proximity Effects by Metropolitan Area We are impressed-actually chagrined-at the paucity of positive BRT station proximity multifamily rent premiums within 0.625-mile. In most metropolitan areas-seven in total-there are ambiguous relationships between BRT station proximity and multifamily rents: EugeneSpringfield, Minneapolis-St. Paul, Nashville, Pittsburgh, Reno, Salt Lake City and San Antonio. Only two metropolitan areas reveal positive associations in that rent declines with distance from transit stations-Cleveland and San Jose. Four other metropolitan areas have upward rent slopes from BRT stations outward indicating the presence of externalities at or near them: Albuquerque, Kansas City, San Diego and Seattle. It may be that locating in places based on their type have more influence on MF rents than station proximity, perhaps in such other metropolitan areas as Albuquerque, Eugene-Springfield, Minneapolis-St. Paul, Pittsburgh, San Jose and Seattle. But this begs the question: if BRT systems are intended to improve accessibility of nearby residents to their metropolitan areas, why does the market not reflect this benefit? We surmise that BRT station planning, location and design is not effective and this can unfortunate implications for long range transit planning.

We raise additional concerns at the end of this chapter.

\section{BRT Multifamily Exemplar: Cleveland}

Only Cleveland's BRT stations appear to be associated with desired effects on multifamily rent, as illustrated in Figure 8.12. Indeed, as noted above, for the most part BRT station proximity has ambiguous or externality effects in all other metropolitan areas studied. We are concerned because it signals that BRT stations may be under-serving residential markets-that is to say, neglecting the transit needs of people where they live. Cleveland's BRT system is noted as a model for planning and investment (see Nelson 2015) though until now its effect on real estate rents has been unknown. We now see that with respect to BRT station proximity, multifamily rents are 23.5 percent above the mean in the first (0.125-mile) distance band, falling to 9.3 percent above the mean in the third (0.3765-mile) DB. Figure 8.12 illustrates this relationship. However, we also note that BRT rent effects are limited to just the first $(0.125-\mathrm{mile})$ distance band for office and retail real estate. Overall, for those transit and land use planners, and urban designers, who are aiding in the development of new or expansion of existing BRT systems, we recommend careful study of the Cleveland's BRT stations with respect to multifamily real estate.

We conclude this subsection with a discussion on commuter rail transit station effects on multifamily rents. 


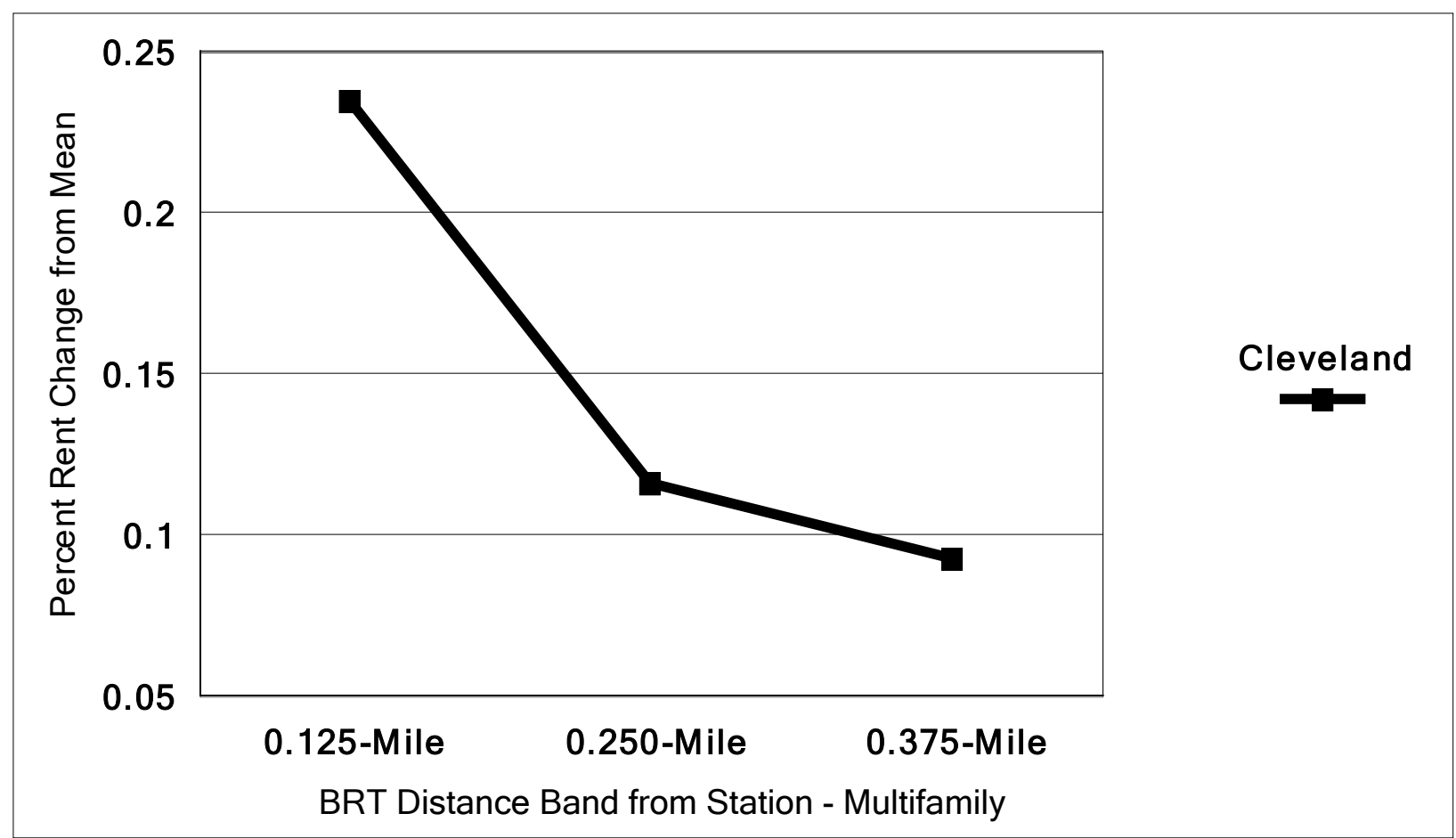

Figure 8.12

Multifamily rent premiums for bus rapid transit station proximity in Cleveland 
Commuter Rail Transit Station Multifamily Rent Proximity Effects by Metropolitan Area In contrast to the BRT MF results, we are not surprised with the paucity of positive station proximity associations with respect to commuter rail systems. Popular perception has these stations being set in industrial freight yards with loud, smelly engines, and not many amenities nearby. That said, we note positive associations between CRT station proximity and multifamily rent: Orlando and San Diego. Two others have multifamily rents rising with respect to CRT station proximity indicating the presence of externalities at or near those stations: Portland and Seattle-Tacoma. We surmise that while one may expect negative associations a priori, that positive associations are revealed in several markets suggests opportunities for planning and design to improve the interaction between CRT stations and multifamily real estate.

\section{CRT Multifamily Exemplar: Orlando, San Diego}

The Orlando "SunRail" and San Diego "Coaster" commuter rail systems are identified as exemplars for their positive influence on multifamily rents, in both cases extending to the third (0.375-mile) distance band. In particular, multifamily rents fall from 22.1 percent to 16.6 percent, and 48.1 percent to 12.2 percent above the mean in those distance bands from SunRail and Coaster CRT stations respectively. Indeed, at nearly half again above the mean, the Coaster has by far the highest association between multifamily rent and location within the first $(0.125-$ mile) DB of CRT stations. As we know the Coaster CRT system reasonably well, we recommend the transit and land use planning, and urban design that clearly integrates Coaster stations into the fabric of urban development along much of its route.

We will finish the analysis by assessing the association between retail rents and transit station proximity. Overarching observations with implications will then be offered. 


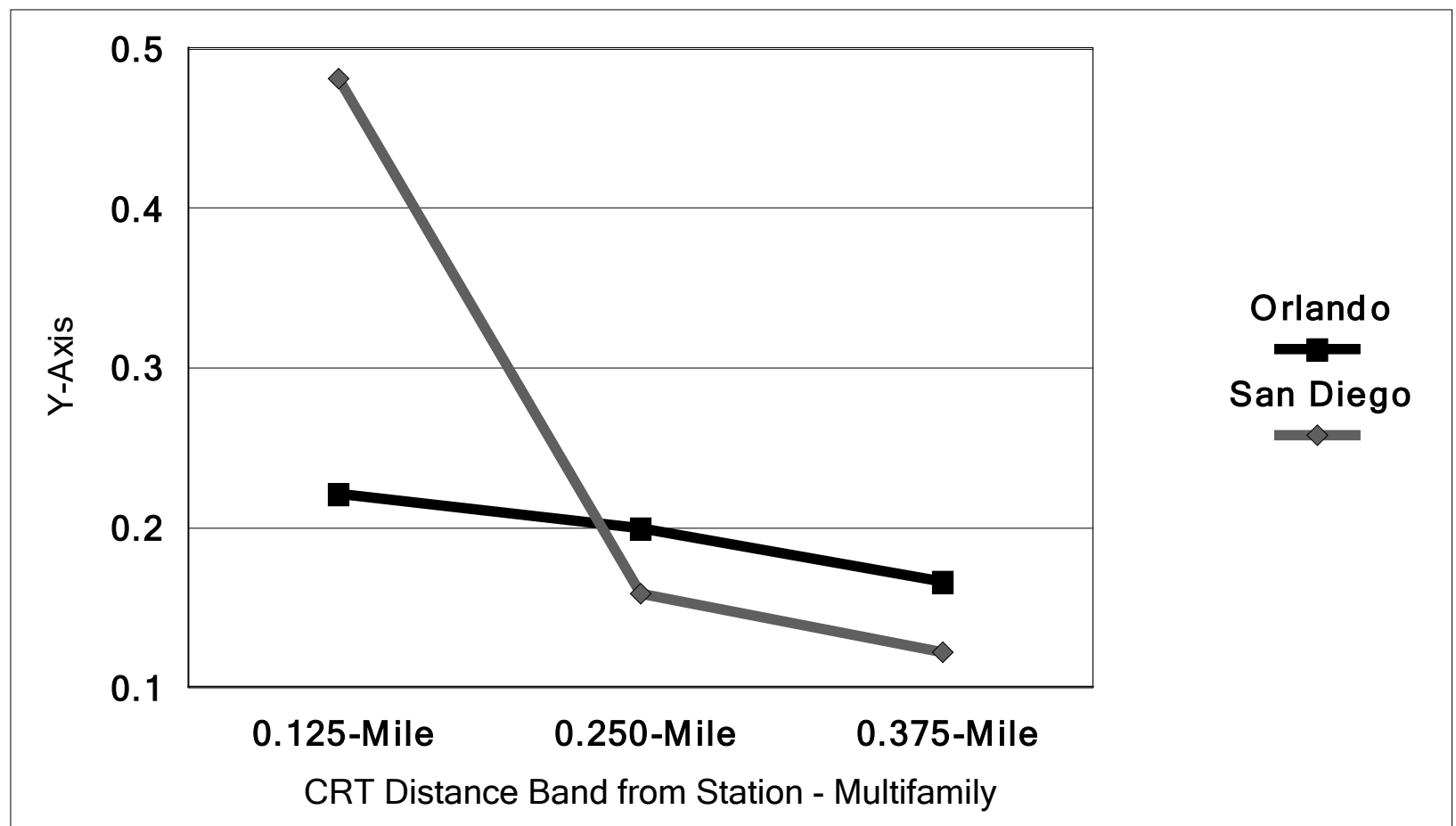

Figure 8.13

Multifamily rent premiums for commuter rail transit station proximity in Orlando and San Diego 


\section{The Variation of Retail Rents with Respect to Place Typology and Transit Station Proximity}

In this section, we present results for the full model in Table 8.8 for retail rents with respect to LRT, BRT, SCT and CRT station proximity, respectively. Trends are illustrated in Figure 8.14. As for office and MF, for all four equations, the coefficients of determination $\left(R^{2}\right)$ show that the equations explain a reasonable share of the variation of rents and the F-ratios show the equations outcomes to be considerably beyond chance.

Next, we review results for the control variables first and then those for the Place Typology followed by those for the distance band treatment variables. Based on theory and results for office and multifamily analysis, and excluding metropolitan controls (see below), the control variables performed as expected:

Rent per square foot declines as the size of the structure increases reflecting declining marginal utility of space;

As the effective year in which the structure was built (or renovated) increases (more recent years have a higher value than earlier years), rent increases;

However, we note that as the vacancy rate increases so do rents in some models-we suspect that in the case of retail rental markets during the study period (2018), landlords earn higher rents generally and may not be pressured into turning units over quickly to bide their time for securing higher rents;

As the median household income of the block group within which the property is located increases so does rent;

As distance from the nearest freeway ramp increases rents also fall; and

As the intensity of land use mix and accessibility decreases (compared to Poor MA areas), retail rents fall consistently from High MA places to Low MA areas.

We note that as controls for metropolitan-specific market characteristics, the coefficients for the metropolitan variables are not directly relevant to the interpretation of results for reasons notes above.

We turn next to evaluating the variation in retail rent for each transit mode studied with special reference to the Place Typology. 
Table 8.8

Regression Results for Retail Rents with Respect to Transit Station Proximity with Special Reference to Place Typology

\begin{tabular}{|c|c|c|c|c|}
\hline Variable & $\begin{array}{l}\text { LRT } \\
\text { Beta }\end{array}$ & Variable & $\begin{array}{l}\text { SCT } \\
\text { Beta }\end{array}$ & Variable \\
\hline Constant & -1.364 & 4 Constant & -3.11 & 1 Constant \\
\hline Structure Controls & & Structure Controls & & Structure Controls \\
\hline $\begin{array}{l}\text { Gross Leasable Area } \\
\text { (000s) }\end{array}$ & 0.000844 & $\begin{array}{l}\text { - Gross Leasable Area } \\
4 \text { (000s) }\end{array}$ & 0.001221 & $\begin{array}{l}\text { - Gross Leasable Area } \\
1 \text { (000s) }\end{array}$ \\
\hline Effective Year Built & 0.002 & 2 Effective Year Built & 0.003 & 3 Effective Year Built \\
\hline Vacancy Rate & 0.000 & Vacancy Rate & -0.001 & 1 Vacancy Rate \\
\hline Facility Control* & & Facility Control* & & Facility Control* \\
\hline Strip & -0.072 & 2 Strip & -0.313 & 3 Strip \\
\hline Power & 0.157 & 7 Power & -0.072 & 2 Power \\
\hline Neighborhood & -0.042 & 2 Neighborhood & -0.284 & 34 Neighborhood \\
\hline Community & 0.033 & 3 Community & -0.208 & 8 Community \\
\hline Regional & 0.314 & 4 Regional & 0.454 & 44 Regional \\
\hline Lifestyle & 0.189 & 9 Lifestyle & -0.039 & 39 Lifestyle \\
\hline Outlet & 0.004 & 4 Outlet & 0.099 & 9 Outlet \\
\hline Retail & 0.017 & 7 Retail & -0.238 & 38 Retail \\
\hline Socioeconomic Control & & Socioeconomic Control & & $\begin{array}{l}\text { Socioeconomic } \\
\text { Control }\end{array}$ \\
\hline $\begin{array}{l}\text { Median HH Income } \\
\quad(\$ 1000 \mathrm{~s})\end{array}$ & 0.0032 & $\begin{array}{l}\text { Median HH Income } \\
(\$ 1000 \mathrm{~s})\end{array}$ & 0.004156 & $6 \begin{array}{l}\text { Median HH Income } \\
(\$ 1000 \mathrm{~s})\end{array}$ \\
\hline $\begin{array}{l}\text { Centrality Control } \\
\text { Distance Freeway }(\mathrm{r}\end{array}$ & 0.010332 & $\begin{array}{l}\text { Centrality Control } \\
\text { Distance Freeway (miles }\end{array}$ & 0.001348 & $\begin{array}{l}\text { Centrality Control } \\
\text { - Distance Freeway } \\
\text { t8 (miles) }\end{array}$ \\
\hline
\end{tabular}

\begin{tabular}{cr} 
BRT & \multicolumn{1}{c}{ CRT Beta } \\
Beta Variable & 2.028 \\
1.33 Constant & \\
Structure Controls & \\
- Gross Leasable Area & $-\mathbf{0 . 0 0 1 0 1 9}$ \\
$\mathbf{0 . 0 0 0 4 8 6}$ (000s) & $\mathbf{0 . 0 0 0}$ \\
$\mathbf{0 . 0 0 1}$ Effective Year Built & $\mathbf{0 . 0 0 1}$ \\
$\mathbf{0 . 0 0 1}$ Vacancy Rate & \\
Facility Control* & \\
0.016 Strip & -0.219 \\
0.303 Power & -0.133 \\
0.081 Neighborhood & 0.233 \\
0.167 Community & 0.014 \\
0.324 Regional & -0.135 \\
0.419 Lifestyle & -0.181 \\
0.261 Outlet & 0.000 \\
0.043 Retail & \\
Socioeconomic & \\
Control & \\
Median HH Income & $\mathbf{1 . 0 0 0 0 0 0}$ \\
$\quad$ Centrality Control & \\
$\mathbf{0 . 0 0 3 2 6 7}$ Distance Freeway & \\
$\mathbf{0 . 0 0 6 9 7 5}$ (miles) & $\mathbf{0 . 2 6 9 0 0 0}$
\end{tabular}


Table 8.8

Regression Results for Retail Rents with Respect to Transit Station Proximity with Special Reference to Place Typologycontinued

$\begin{array}{lll}\begin{array}{l}\text { Variable } \\ \text { Metropolitan Control** }\end{array} & \begin{array}{l}\text { LRTa } \\ \text { Metropolitan Control* }\end{array} & \begin{array}{c}\text { SCT } \\ \text { Meta }\end{array} \\ \text { Buffalo } & -0.136 \text { Atlanta } & \begin{array}{l}\text { Variable } \\ \text { Metropolitan Contro/** }\end{array} \\ \text { Charlotte } & 0.312 \text { Cincinnati } & -0.693 \text { Cleveland } \\ \text { Cleveland } & -0.098 \text { Dallas } & -0.934 \text { Eugene-Springfield } \\ \text { Dallas } & 0.077 \text { Kansas City } & -0.785 \text { Kansas City } \\ \text { Denver } & 0.334 \text { Little Rock } & -0.936 \text { Minneapolis-St. Paul } \\ \text { Houston } & 0.128 \text { New Orleans } & -0.942 \text { Nashville } \\ \text { Minneapolis-St. Paul } & 0.088 \text { Portland } & -0.766 \text { Pittsburgh } \\ \text { Phoenix } & 0.084 \text { Salt Lake City } & -0.634 \text { Reno } \\ \text { Pittsburgh } & -0.001 \text { Seattle } & -0.757 \text { Salt Lake City } \\ \text { Portland } & 0.283 \text { Tacoma } & -0.464 \text { San Antonio } \\ \text { Sacramento } & 0.114 \text { Tampa } & -0.193 \text { San Diego } \\ \text { Salt Lake City } & 0.113 \text { Tucson } & -0.697 \text { San Jose } \\ \text { San Diego } & 0.496 & -0.824 \text { Seattle } \\ \text { San Jose } & 0.639 & \\ \text { Seattle } & 0.426 & \\ \text { St. Louis } & -0.003 & \end{array}$

BRT Beta Variable

Metropolitan Control**

-0.196 Austin

0.149 Dallas-Fort Worth

-0.170 Denver

0.024 Miami SE Florida

0.224 Minneapolis-St. Paul

-0.088 Nashville

0.030 Orlando

0.058 Portland

0.174 SLC-Ogden-Provo

0.446 San Diego

0.576 San Jose-Stockton

0.351 Seattle-Tacoma

Washington
CRT Beta

$-0.000$

$-0.374$

0.219

$-0.234$

0.078

0.242

$-0.202$

0.011

0.054

0.074

$-0.173$

0.204

0.323 
Table 8.8

Regression Results for Retail Rents with Respect to Transit Station Proximity with Special Reference to Place Typologycontinued

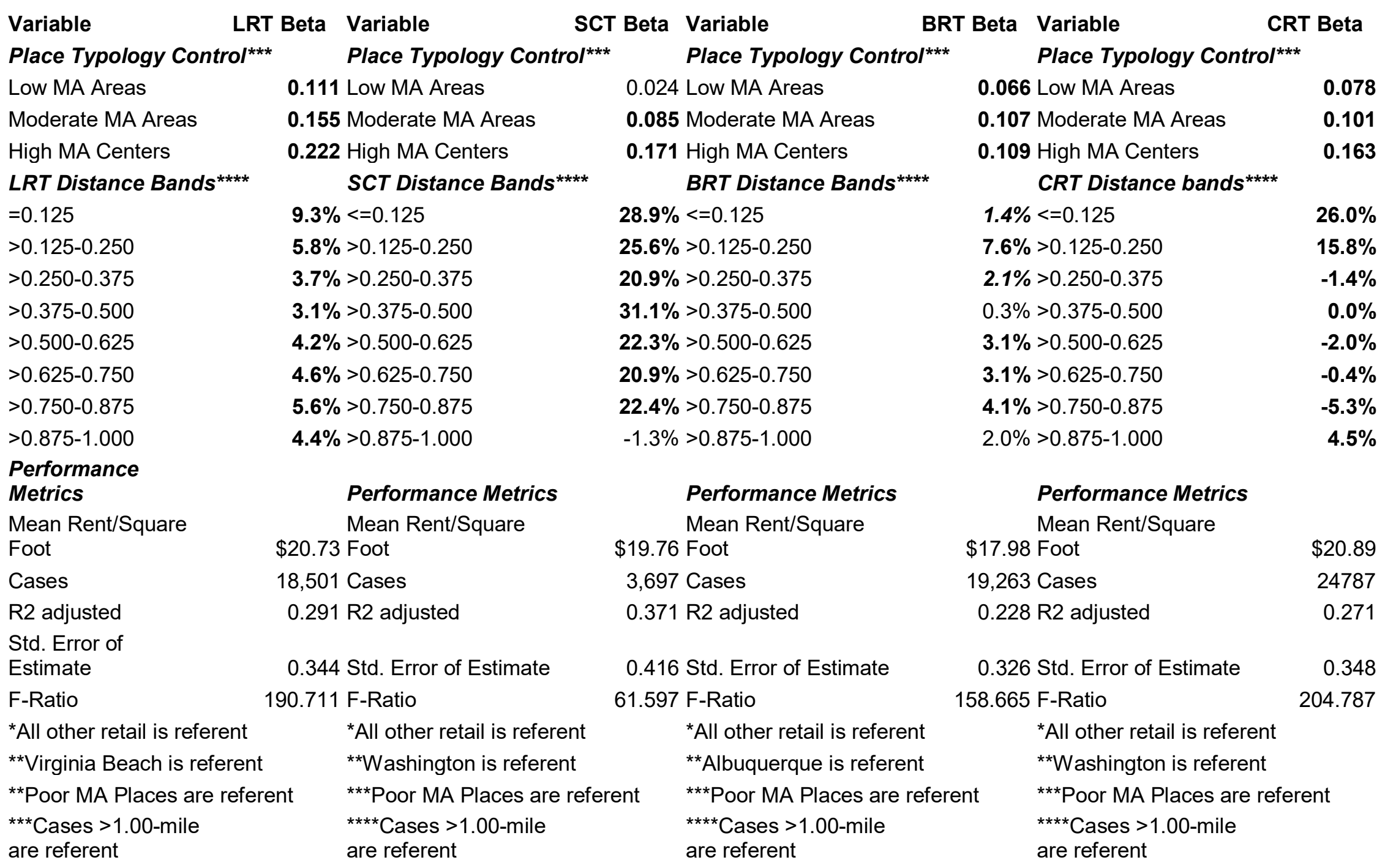




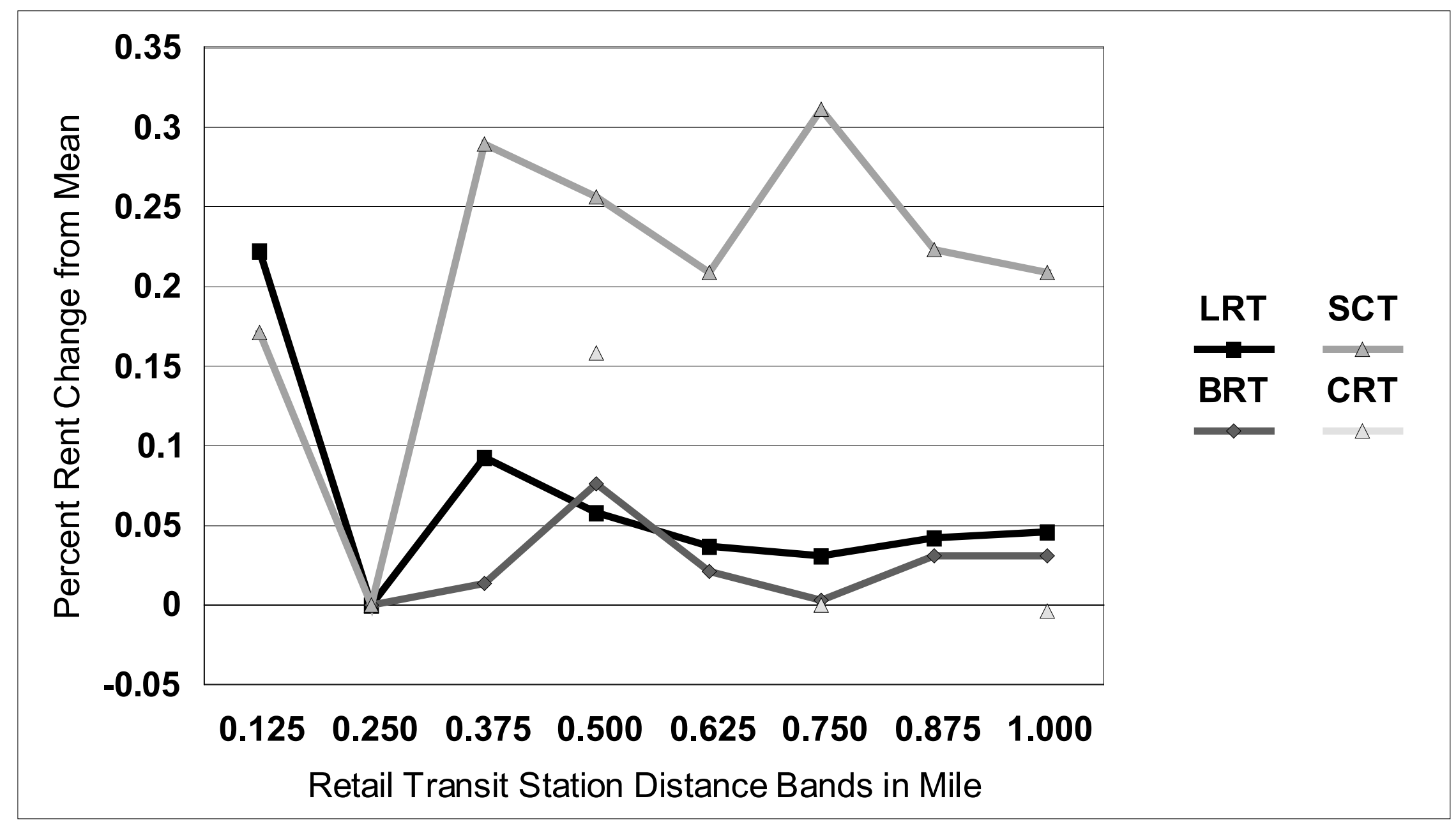

Figure 8.14

Variation in retail rent per square foot with respect to distance from LRT, BRT, SCT and CRT stations

Overall but except for CRT, rents fall initially with distance from transit stations before rising. For CRT, retail rents are not sensitive to station proximity in distance bands to 0.50 -mile. Many metropolitan areas show rent effects close to and near transit stations, as seen below. 


\section{Variation in Retail Rent with Respect to Transit Station Distance}

In this subsection, we focus on the association between transit station proximity and multifamily rents. We offer selected insights from Table 8.8 which are illustrated in Figure 8.15 as follows.

\section{Retail Rents and LRT Station Proximity}

Retail rents with respect to LRT station proximity fall from 9.3 percent above the mean in the first (0.125-mile) distance band to 6.1 percent in the second $(0.250-\mathrm{mile}) \mathrm{DB}$ then decline to 3.1 percent in the fourth (0.500-mile) DB before leveling about five percent through the rest of the 1.00-mile study area. Based on the theory discussed above and shown in Figure 8.1, LRT station proximity appears to be associated with amenity benefits that dissipate to about 0.50 mile. This is interesting because not only do retail rents fall-unlike the general pattern seen for office and multifamily rents-but they are also the largest coefficients of the real estate activities studied and have a steeper downward slope with respect to LRT station distance. We surmise that the retail market values LRT station proximity much more than for office and multifamily real estate. However, there are vast differences between metropolitan areas as will be seen later.

\section{Retail Rents and SCT Station Proximity}

The association between retail rents and streetcar station proximity are the highest at and near SCT stations and more robust across the entire study area than office or multifamily real estate. Rents fall from (a whopping) 28.9 percent above the regional mean in the first (0.125-mile) distance band to 20.9 percent in the third $(0.3750-\mathrm{mile}) \mathrm{DB}$ before rising sharply to 31.1 percent above the mean in the fourth (0.500-mile) DB and then falling across the rest of the study area. This " $w$ " shape suggests amenity value exists at and near SCT stations and then peaks again farther away reflecting possibly amenity value proximate to other activity centers.

\section{Retail Rents and BRT Station Proximity}

In contrast to LRT and SCT station proximity, retail rents are not nearly as sensitive to BRT station proximity and indicate externality effects. Rents rise steeply from 1.4 percent above the mean in the first $(0.125$-mile) distance band to a high of 7.6 percent in the second $(0.250$-mile) DB before leveling off between about three and four percent above the mean through most of the rest of the study area. This pattern also varies considerably among metropolitan areas. We surmise that, overall, BRT system and associated land use planning may not maximize opportunities to attract retail activities near BTRT stations.

\section{Multifamily Rents and CRT Station Proximity}

More so than for LRT and SCT station proximity, retail rents value proximity to commuter rail transit stations in only a narrow band before falling below the mean throughout the rest of the study area. That band starts in the first $(0.125-\mathrm{mile}) \mathrm{DB}$ at 26.0 percent above to mean and falls to 15.8 percent above the mean in the second $(0.250-0$ mile $) \mathrm{DB}$, becoming negative thereafter. We surmise that the retail market values CRT station proximity in about the first one-quarter mile.

We next review the association between retail rents and transit station proximity with respect to Place Typology. 


\section{Variation in the Association between Retail Rents and Transit Station Proximity with Respect to Place Typologies}

As above, in this subsection we review the association between retail rents and transit station proximity with respect to place typologies. Also consistent with earlier discussions, because directions and magnitudes of association are similar to the overall model, regression results reported in Table 8.9 include only distance band coefficients and key performance indicators. The relationships are illustrated in Figure 8.7. We note the following highlights:

Variation in Retail Rent with Respect to LRT Station Proximity by Place Typology Rent rises and then falls the High-Mixed Use/Accessible places to about the fifth (0.625-mile) distance band. That rent falls from the first $(0.125-\mathrm{mile}) \mathrm{DB}$ indicates amenity value at or near the station. We surmise that retail then rises with accessibility to nearby areas of activity within High MA places. Generally, retail rents fall as distance from LRT stations increase in the Moderate- and Low-Mixed Use/Accessibility areas nearly through the entirety of the 1.00-mile study area-perhaps because there are no other areas of activity of consequence from stations. Associations proximate to LRT stations in Poor MA areas (being negative at or near those stations) suggests little discernable retail market responsiveness to LRT station proximity in areas with little land use mix and poor accessibility.

Variation in Retail Rent with Respect to SCT Station Proximity by Place Typology The pattern of association between retail rents and proximity to streetcar stations is similar to that for LRT stations but within a narrow band about 0.250-mile, and there are no statistically significant associations in Poor-Mixed Use/Accessibility areas perhaps because streetcars are limited to mostly built-up areas.

Variation in Retail Rent with Respect to BRT Station Proximity by Place Typology Patterns are mostly the same as above for bus rapid transit station proximity except that those patterns extend to Poor MA areas and all within about the first 0.25-mile. We surmise that BRT systems have consistent effects on retail rents across landscapes of varying mixed use and accessibility.

Variation in Retail Rent with Respect to CRT Station Proximity by Place Typology In contrast to LRT, SCT and BRT station proximity across Place Typologies, as a practical matter there are no clear patterns with respect to commuter rail transit proximity in any Place Typology, except just the first (0.125-mile) distance band in Moderate MA areas.

Many patterns will change for individual metropolitan areas as will be reviewed next. 
Table 8.9

Regression Results for Retail Rents with Respect to Transit Station Proximity by Place Typology

Distance Band
$<=0.125$
$>0.125-0.250$
$>0.250-0.375$
$>0.375-0.500$
$>0.500-0.625$
$>0.625-0.750$
$>0.750-0.875$
$>0.875-1.000$
Mean Rent/Square Foot
Cases
R2 adjusted

Distance Band
$<=0.125$
$>0.125-0.250$
$>0.250-0.375$
$>0.375-0.500$
$>0.500-0.625$
$>0.625-0.750$
$>0.750-0.875$
$>0.875-1.000$
Mean Rent/Square Foot
Cases
R2 adjusted

\section{Light Rail Transit by Place Typology}

LRT Moderate LRT High MA MA

$13.1 \%$

$6.7 \%$

$10.6 \%$

$6.7 \%$

$14.9 \%$

$5.1 \%$

$4.7 \%$

$5.4 \%$

$\$ 21.83$

1,397

0.206
$5.7 \%$

$3.1 \%$

$0.4 \%$

$4.2 \%$

$3.1 \%$

$4.5 \%$

$5.3 \%$

$2.6 \%$

$\$ 21.24$

7,978

0.276

\section{LRT Low MA}

$15.1 \%$

$8.0 \%$

$4.5 \%$

$-0.9 \%$

$3.5 \%$

$5.2 \%$

$6.6 \%$

$5.8 \%$

$\$ 20.44$

7,879

0.324

\section{LRT Poor MA}

$-61.9 \%$

$0.4 \%$

$14.9 \%$

$2.9 \%$

$-0.8 \%$

$-2.8 \%$

$-2.8 \%$

$24.1 \%$

$\$ 18.11$

1,247

0.258

Streetcar Transit by Place Typology

SCT Moderate

\section{SCT High MA}

$13.0 \%$

$15.2 \%$

$2.4 \%$

$11.3 \%$

$14.8 \%$

$14.0 \%$

$-13.7 \%$

$-0.9 \%$

$\$ 27.40$

294

0.637
MA

$31.8 \%$

$23.0 \%$

$14.6 \%$

$31.3 \%$

$9.5 \%$

$13.0 \%$

$23.3 \%$

$-0.4 \%$

$\$ 20.64$

1,548

0.383
SCT Low MA SCT Poor MA

$$
41.5 \%
$$

$55.9 \%$

$20.6 \%$

$43.2 \%$

$39.7 \%$

$36.4 \%$

$34.2 \%$

$-4.9 \%$

$\$ 17.82$

1,652

0.297
$0.0 \%$

$0.0 \%$

$0.0 \%$

$15.7 \%$

$0.0 \%$

$0.0 \%$

$0.0 \%$

$0.0 \%$

$\$ 17.78$

203

0.150 
Table 8.9

Regression Results for Retail Rents with Respect to Transit Station Proximity by Place Typology-continued

\begin{tabular}{|c|c|c|c|c|}
\hline \multirow[b]{3}{*}{ Distance Band } & \multicolumn{4}{|c|}{ Bus Rapid Transit by Place Typology } \\
\hline & \multicolumn{4}{|c|}{ BRT Moderate } \\
\hline & BRT High MA & MA & BRT Low MA & BRT Poor MA \\
\hline$<=0.125$ & $7.6 \%$ & $54.1 \%$ & $67.2 \%$ & $34.6 \%$ \\
\hline$>0.125-0.250$ & $7.8 \%$ & $33.1 \%$ & $31.5 \%$ & $3.0 \%$ \\
\hline$>0.250-0.375$ & $-18.2 \%$ & $2.1 \%$ & $-0.9 \%$ & $34.7 \%$ \\
\hline$>0.375-0.500$ & $-6.5 \%$ & $8.3 \%$ & $4.6 \%$ & $24.5 \%$ \\
\hline$>0.500-0.625$ & $-3.7 \%$ & $1.2 \%$ & $7.3 \%$ & $-4.1 \%$ \\
\hline$>0.625-0.750$ & $5.2 \%$ & $0.6 \%$ & $2.8 \%$ & $16.2 \%$ \\
\hline$>0.750-0.875$ & $-2.5 \%$ & $4.8 \%$ & $2.8 \%$ & $-4.9 \%$ \\
\hline$>0.875-1.000$ & $8.4 \%$ & $1.8 \%$ & $3.9 \%$ & $-8.1 \%$ \\
\hline Mean Rent/Square Foot & $\$ 19.51$ & $\$ 18.41$ & $\$ 17.73$ & $\$ 16.57$ \\
\hline Cases & 1,081 & 7,340 & 9,012 & 1,830 \\
\hline \multirow[t]{3}{*}{$\mathrm{R} 2$ adjusted } & 0.228 & 0.242 & 0.229 & 0.278 \\
\hline & \multicolumn{4}{|c|}{ Commuter Rapid Transit by Place Typology } \\
\hline & CRT High MA & $\begin{array}{c}\text { T Moder } \\
\text { MA }\end{array}$ & CRT Low MA & CRT Poor MA \\
\hline$<=0.125$ & $-43.3 \%$ & $21.6 \%$ & $9.2 \%$ & $0.0 \%$ \\
\hline$>0.125-0.250$ & $-4.9 \%$ & $-0.3 \%$ & $-2.0 \%$ & $13.1 \%$ \\
\hline$>0.250-0.375$ & $2.4 \%$ & $5.9 \%$ & $-7.7 \%$ & $18.0 \%$ \\
\hline$>0.375-0.500$ & $21.7 \%$ & $3.7 \%$ & $-11.0 \%$ & $-26.7 \%$ \\
\hline$>0.500-0.625$ & $3.5 \%$ & $6.0 \%$ & $-8.8 \%$ & $-6.0 \%$ \\
\hline$>0.625-0.750$ & $3.8 \%$ & $-9.4 \%$ & $-3.1 \%$ & $-4.9 \%$ \\
\hline$>0.750-0.875$ & $2.2 \%$ & $-1.6 \%$ & $-5.3 \%$ & $-65.3 \%$ \\
\hline$>0.875-1.000$ & $16.5 \%$ & $0.8 \%$ & $-7.8 \%$ & $1.1 \%$ \\
\hline Mean Rent/Square Foot & $\$ 24.79$ & $\$ 21.14$ & $\$ 20.45$ & $\$ 17.90$ \\
\hline Cases & 1,875 & 11,045 & 9,987 & 1,880 \\
\hline R2 adjusted & 0.269 & 0.302 & 0.254 & 0.267 \\
\hline
\end{tabular}




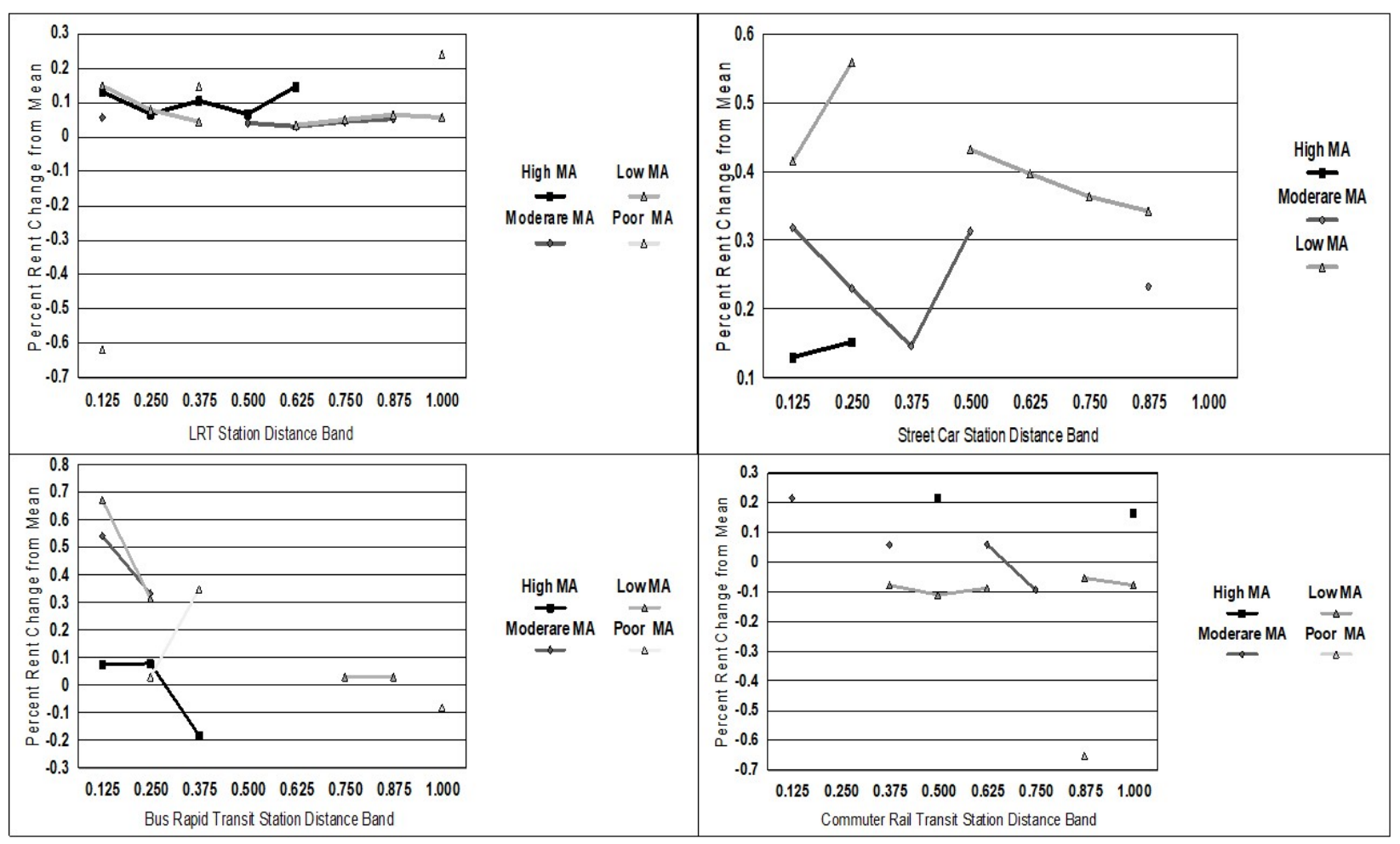

Figure 8.15

Plot of significant and contingent significant LRT, SCT, BRT and CRT retail rent coefficients with lines connecting respective points with respect to Place Typology

Retail rent associations with respect to LRT and BRT station distance are generally downward sloping for the High, Moderate and Low MAs while associations for SCT are upward sloping for High and Low MAs_-indicating externalities near stations - but downward sloping for the Moderate MA and associations for CRT do not appear consistently near stations. 


\section{Variation in Retail Rent with Respect to Transit Station Proximity by Metropolitan Area}

This final subsection addresses the associations between retail rent and transit station proximity by metropolitan area. Results are reported in Table 8.9 using the same format as for office and multifamily real estate rents. The first half of the table shows significant and contingent significant rent coefficients by distance band-we call these the relevant coefficients. The second half of the table shows relevant coefficients for Place Typologies as well as overall model features including mean retail rent per square foot, number of CoStar cases, and the coefficient of determination $\left(R^{2}\right)$. The second-to-last column summarizes overall directional trends from the station (0.125-mile distance band) over the next four distance bands or where direction changes or coefficients are ambiguous. The last column illustrates the overall functional form for the entire 1.00-mile study areas for those metropolitan areas without ambiguous results reported in the preceding column. We present these tables first and then discuss implications for retail real estate. 
Table 8.9

Significant Retail Rent Coefficients* with Respect to Place Typology and Station Distance ${ }^{\star *}$ by Metropolitan Area

\begin{tabular}{|c|c|c|c|c|c|c|c|c|}
\hline \multirow[b]{2}{*}{ Metropolitan Area } & \multicolumn{8}{|c|}{ Light Rail Transit Station Distance Band in Miles } \\
\hline & $<=0.125$ & $\begin{array}{l}>0.125 \\
-0.250\end{array}$ & $\begin{array}{l}>0.250 \\
-0.375\end{array}$ & $\begin{array}{l}>0.375 \\
-0.500\end{array}$ & $\begin{array}{l}>0.500 \\
-0.625\end{array}$ & $\begin{array}{l}>0.625 \\
-0.750\end{array}$ & $\begin{array}{l}>0.750 \\
-0.875\end{array}$ & $\begin{array}{l}>0.875 \\
-1.000\end{array}$ \\
\hline Buffalo & & $41.1 \%$ & $42.9 \%$ & & $48.5 \%$ & & & \\
\hline Charlotte & & $30.7 \%$ & & & & & $89.0 \%$ & \\
\hline $\begin{array}{l}\text { Cleveland } \\
\text { Dallas }\end{array}$ & & & & $78.7 \%$ & & $60.4 \%$ & & $41.3 \%$ \\
\hline $\begin{array}{l}\text { Denver } \\
\text { Houston }\end{array}$ & $13.7 \%$ & $4.3 \%$ & $2.9 \%$ & $2.1 \%$ & $4.4 \%$ & $\begin{array}{l}4.2 \% \\
21.2 \%\end{array}$ & $6.3 \%$ & $\begin{array}{c}3.3 \% \\
39.0 \%\end{array}$ \\
\hline $\begin{array}{l}\text { Minneapolis-St. } \\
\text { Paul }\end{array}$ & & & & & & $47.0 \%$ & & \\
\hline Phoenix & & & & $13.7 \%$ & $11.2 \%$ & $13.4 \%$ & & \\
\hline Pittsburgh & $186.9 \%$ & $-47.9 \%$ & & & & $-44.7 \%$ & & \\
\hline Portland & & $12.6 \%$ & & & & & & \\
\hline Sacramento & & & & & & $15.4 \%$ & & \\
\hline Salt Lake City & $20.6 \%$ & & & $-11.3 \%$ & $-13.9 \%$ & $12.3 \%$ & $-19.7 \%$ & \\
\hline San Diego & $-21.0 \%$ & $-17.2 \%$ & $-14.4 \%$ & & $-19.7 \%$ & $-18.2 \%$ & $-22.0 \%$ & $-22.2 \%$ \\
\hline San Jose & $27.6 \%$ & $36.5 \%$ & & & & $-17.5 \%$ & & $19.5 \%$ \\
\hline Seattle & & & $25.8 \%$ & & & & & \\
\hline St. Louis & & $18.8 \%$ & $44.7 \%$ & $29.4 \%$ & $27.6 \%$ & & & \\
\hline Virginia Beach & $62.1 \%$ & $34.2 \%$ & & & $49.8 \%$ & & & \\
\hline
\end{tabular}


Table 8.9

Significant Retail Rent Coefficients* with Respect to Place Typology and Station Distance ${ }^{\star *}$ by Metropolitan Areacontinued

LRT Retail Rent Association with Respect to Place Typology, ${ }^{* * *}$ Model Performance, and General Form of Distance Relationship****

\begin{tabular}{|c|c|c|c|c|c|c|c|}
\hline Metropolitan Area & $\begin{array}{c}\text { High } \\
\text { MA }\end{array}$ & $\begin{array}{l}\text { Moderate } \\
\text { MA }\end{array}$ & $\begin{array}{l}\text { Low } \\
\text { MA }\end{array}$ & $\begin{array}{l}\text { Mean Rent } \\
\text { /Sq.Ft. }\end{array}$ & Cases & R2 & Form from Station \\
\hline Buffalo & & & & $\$ 12.94$ & 147 & 0.166 & Upward above mean \\
\hline Charlotte & & & & $\$ 21.80$ & 278 & 0.210 & Above mean \\
\hline Cleveland & $50.1 \%$ & & & $\$ 13.01$ & 317 & 0.150 & Ambiguous \\
\hline Dallas & $15.8 \%$ & $8.2 \%$ & & $\$ 17.35$ & 1,456 & 0.234 & Ambiguous \\
\hline Denver & $20.7 \%$ & $16.1 \%$ & $13.7 \%$ & $\$ 22.08$ & 10,356 & 0.123 & $\begin{array}{c}\text { Downward above } \\
\text { mean }\end{array}$ \\
\hline Houston & $26.1 \%$ & $20.2 \%$ & & $\$ 18.63$ & 1,329 & 0.227 & Ambiguous \\
\hline $\begin{array}{l}\text { Minneapolis-St. } \\
\text { Paul }\end{array}$ & $18.6 \%$ & $31.0 \%$ & & $\$ 17.80$ & 303 & 0.094 & Ambiguous \\
\hline Phoenix & $35.6 \%$ & $20.4 \%$ & $18.7 \%$ & $\$ 16.97$ & 1,354 & 0.268 & Ambiguous \\
\hline Pittsburgh & $51.0 \%$ & $28.9 \%$ & & $\$ 15.36$ & 284 & 0.274 & $\begin{array}{c}\text { Downward above } \\
\text { mean }\end{array}$ \\
\hline Portland & $19.6 \%$ & & & $\$ 21.23$ & 245 & 0.203 & Above mean \\
\hline Sacramento & $30.4 \%$ & $18.9 \%$ & $12.1 \%$ & $\$ 16.87$ & 326 & 0.156 & Ambiguous \\
\hline Salt Lake City & & & & $\$ 18.00$ & 347 & 0.153 & $\begin{array}{c}\text { Downward above } \\
\text { mean }\end{array}$ \\
\hline San Diego & $27.0 \%$ & $27.9 \%$ & $14.1 \%$ & $\$ 27.38$ & 477 & 0.148 & Upward below mean \\
\hline San Jose & & & & $\$ 34.76$ & 304 & 0.120 & Upward above mean \\
\hline Seattle & $42.6 \%$ & $30.6 \%$ & $23.4 \%$ & $\$ 25.16$ & 453 & 0.131 & Ambiguous \\
\hline St. Louis & & $14.2 \%$ & & $\$ 15.38$ & 460 & 0.202 & Upward above mean \\
\hline Virginia Beach & $76.1 \%$ & $59.0 \%$ & & $\$ 14.91$ & 65 & 0.080 & $\begin{array}{c}\text { Downward above } \\
\text { mean }\end{array}$ \\
\hline
\end{tabular}

Overall

Functional

Form

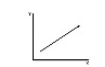

* Only significant and contingent significant (italics) coefficients are reported for clarity. 
** Cases beyond 1.00-mile are the referent. *** Poor MA is the referent.

**** See text for description. 
Table 8.9

Significant Retail Rent Coefficients* with Respect to Place Typology and Station Distance ${ }^{\star *}$ by Metropolitan Areacontinued

\begin{tabular}{|c|c|c|c|c|c|c|c|c|}
\hline \multirow[b]{2}{*}{$\begin{array}{l}\text { Metropolitan } \\
\text { Area }\end{array}$} & \multicolumn{8}{|c|}{ Streetcar Transit Station Distance Band in Miles } \\
\hline & $<=0.125$ & $\begin{array}{l}>0.125 \\
-0.250\end{array}$ & $\begin{array}{l}>0.250 \\
-0.375\end{array}$ & $\begin{array}{l}>0.375 \\
-0.500\end{array}$ & $\begin{array}{l}>0.500 \\
-0.625\end{array}$ & $\begin{array}{l}>0.625 \\
-0.750\end{array}$ & $\begin{array}{l}>0.750 \\
-0.875\end{array}$ & $\begin{array}{l}>0.875 \\
-1.000\end{array}$ \\
\hline Atlanta & $39.5 \%$ & & & & & $68.6 \%$ & & \\
\hline Cincinnati & $46.6 \%$ & & & & & & & \\
\hline Dallas & $42.4 \%$ & $103.7 \%$ & $54.6 \%$ & $47.5 \%$ & $44.4 \%$ & $38.9 \%$ & $30.6 \%$ & $72.2 \%$ \\
\hline Kansas City & $47.9 \%$ & & $29.0 \%$ & & & & $55.2 \%$ & \\
\hline Little Rock & $29.2 \%$ & $36.2 \%$ & & & & $52.2 \%$ & & \\
\hline New Orleans & $84.0 \%$ & $67.1 \%$ & $86.9 \%$ & $71.6 \%$ & & & $123.9 \%$ & \\
\hline Portland & $12.4 \%$ & $22.9 \%$ & $-20.3 \%$ & $22.3 \%$ & & $38.6 \%$ & & \\
\hline Salt Lake City & & $53.7 \%$ & & $50.7 \%$ & & & $-65.6 \%$ & \\
\hline Seattle & & & & & & & & \\
\hline Tacoma & & & & & & & & \\
\hline Tampa & $54.6 \%$ & & & & $-102.8 \%$ & & & \\
\hline Tucson & $49.2 \%$ & $46.7 \%$ & & & & & $41.9 \%$ & \\
\hline Washington & & & & & $54.0 \%$ & $-27.9 \%$ & & \\
\hline
\end{tabular}


Table 8.9

Significant Retail Rent Coefficients* with Respect to Place Typology and Station Distance ${ }^{\star *}$ by Metropolitan Areacontinued

SCT Retail Rent Association with Respect to Place Typology, ${ }^{* * *}$ Model Performance, and General Form of Distance Relationship ${ }^{* * *}$

\begin{tabular}{|c|c|c|c|c|c|c|c|c|}
\hline $\begin{array}{l}\text { Metropolitan } \\
\text { Area }\end{array}$ & $\begin{array}{c}\text { High } \\
\text { MA }\end{array}$ & $\begin{array}{l}\text { Moderate } \\
\text { MA }\end{array}$ & $\begin{array}{l}\text { Low } \\
\text { MA }\end{array}$ & $\begin{array}{l}\text { Mean Rent/ } \\
\text { Sq.Ft. }\end{array}$ & Cases & $\mathbf{R 2}$ & Form from Station & $\begin{array}{c}\text { Overall } \\
\text { Functional } \\
\text { Form }\end{array}$ \\
\hline Atlanta & & & & $\$ 22.92$ & 229 & 0.212 & Upward from mean & $1^{\text {st }} \mathrm{DB}$ only \\
\hline Cincinnati & $77.1 \%$ & & & $\$ 15.12$ & 166 & 0.152 & Upward from mean & $1^{\text {st }} \mathrm{DB}$ only \\
\hline Dallas & $25.5 \%$ & $16.7 \%$ & & $\$ 17.69$ & 616 & 0.263 & $\begin{array}{l}\text { Upward above mean } \\
\text { Downward above }\end{array}$ & \\
\hline Kansas City & $45.8 \%$ & & & $\$ 13.50$ & 290 & 0.130 & mean & \\
\hline Little Rock & & & $16.4 \%$ & $\$ 14.41$ & 143 & 0.234 & $\begin{array}{c}\text { Upward above mean } \\
\text { Downward above }\end{array}$ & \\
\hline New Orleans & & & & $\$ 20.43$ & 49 & 0.538 & mean & \\
\hline Portland & $24.1 \%$ & & & $\$ 19.70$ & 153 & 0.345 & $\begin{array}{c}\text { Upward above mean } \\
\text { Downward above }\end{array}$ & \\
\hline Salt Lake City & & & & $\$ 18.00$ & 347 & 0.167 & mean & \\
\hline Seattle & $41.4 \%$ & $18.2 \%$ & & $\$ 23.47$ & 622 & 0.177 & Ambiguous & \\
\hline Tacoma & & & & $\$ 18.94$ & 169 & 0.236 & Ambiguous & \\
\hline Tampa & $-26.2 \%$ & & & $\$ 17.96$ & 345 & 0.118 & $\begin{array}{l}\text { Upward from mean } \\
\text { Downward above }\end{array}$ & $1^{\text {st }} \mathrm{DB}$ only \\
\hline Tucson & $-15.8 \%$ & & & $\$ 15.52$ & 538 & 0.185 & mean & \\
\hline Washington & $19.6 \%$ & & $-16.0 \%$ & $\$ 45.27$ & 199 & 0.284 & Ambiguous & \\
\hline
\end{tabular}


Table 8.9

Significant Retail Rent Coefficients* with Respect to Place Typology and Station Distance ${ }^{* *}$ by Metropolitan Areacontinued

\begin{tabular}{|c|c|c|c|c|c|c|c|c|}
\hline \multirow[b]{2}{*}{ Metropolitan Area } & \multicolumn{8}{|c|}{ Bus Rapid Transit Station Distance Band in Miles } \\
\hline & $<=0.125$ & $\begin{array}{c}>0.125 \\
-0.250\end{array}$ & $\begin{array}{c}>0.250 \\
-0.375\end{array}$ & $\begin{array}{c}>0.375 \\
-0.500\end{array}$ & $\begin{array}{l}>0.500 \\
-0.625\end{array}$ & $\begin{array}{c}>0.625 \\
-0.750\end{array}$ & $\begin{array}{c}>0.750 \\
-0.875\end{array}$ & $\begin{array}{c}>0.875 \\
-1.000\end{array}$ \\
\hline Albuquerque & & & & $4.0 \%$ & & $5.8 \%$ & & $14.6 \%$ \\
\hline Cleveland & $40.9 \%$ & & $79.2 \%$ & $-24.8 \%$ & & & $77.4 \%$ & \\
\hline Eugene-Springfield & & & & & & & & \\
\hline Kansas City & $22.3 \%$ & $18.8 \%$ & $27.0 \%$ & & $36.0 \%$ & & $35.1 \%$ & $29.3 \%$ \\
\hline Minneapolis-St. Paul & & $41.8 \%$ & $96.4 \%$ & & & & & \\
\hline Nashville & $16.8 \%$ & & & & $-107.1 \%$ & & $94.7 \%$ & $45.3 \%$ \\
\hline Pittsburgh & & $30.5 \%$ & $24.5 \%$ & & & & $15.3 \%$ & \\
\hline Reno & & & & & & $-48.5 \%$ & $-103.4 \%$ & \\
\hline Salt Lake City & $-15.7 \%$ & & & $65.4 \%$ & & & & \\
\hline San Antonio & $8.0 \%$ & $7.7 \%$ & $3.4 \%$ & $4.2 \%$ & $7.6 \%$ & $5.6 \%$ & $4.6 \%$ & $2.0 \%$ \\
\hline San Diego & & $21.2 \%$ & $24.6 \%$ & & & & $28.7 \%$ & \\
\hline San Jose & $25.2 \%$ & $32.0 \%$ & & $39.3 \%$ & $35.7 \%$ & & & \\
\hline Seattle & & $15.0 \%$ & $27.4 \%$ & & & & & \\
\hline
\end{tabular}


Table 8.9

Significant Retail Rent Coefficients* with Respect to Place Typology and Station Distance ${ }^{\star *}$ by Metropolitan Areacontinued

BRT Retail Rent Association with Respect to Place Typology, ${ }^{* * *}$ Model Performance, and General Form of Distance Relationship ${ }^{* * *}$

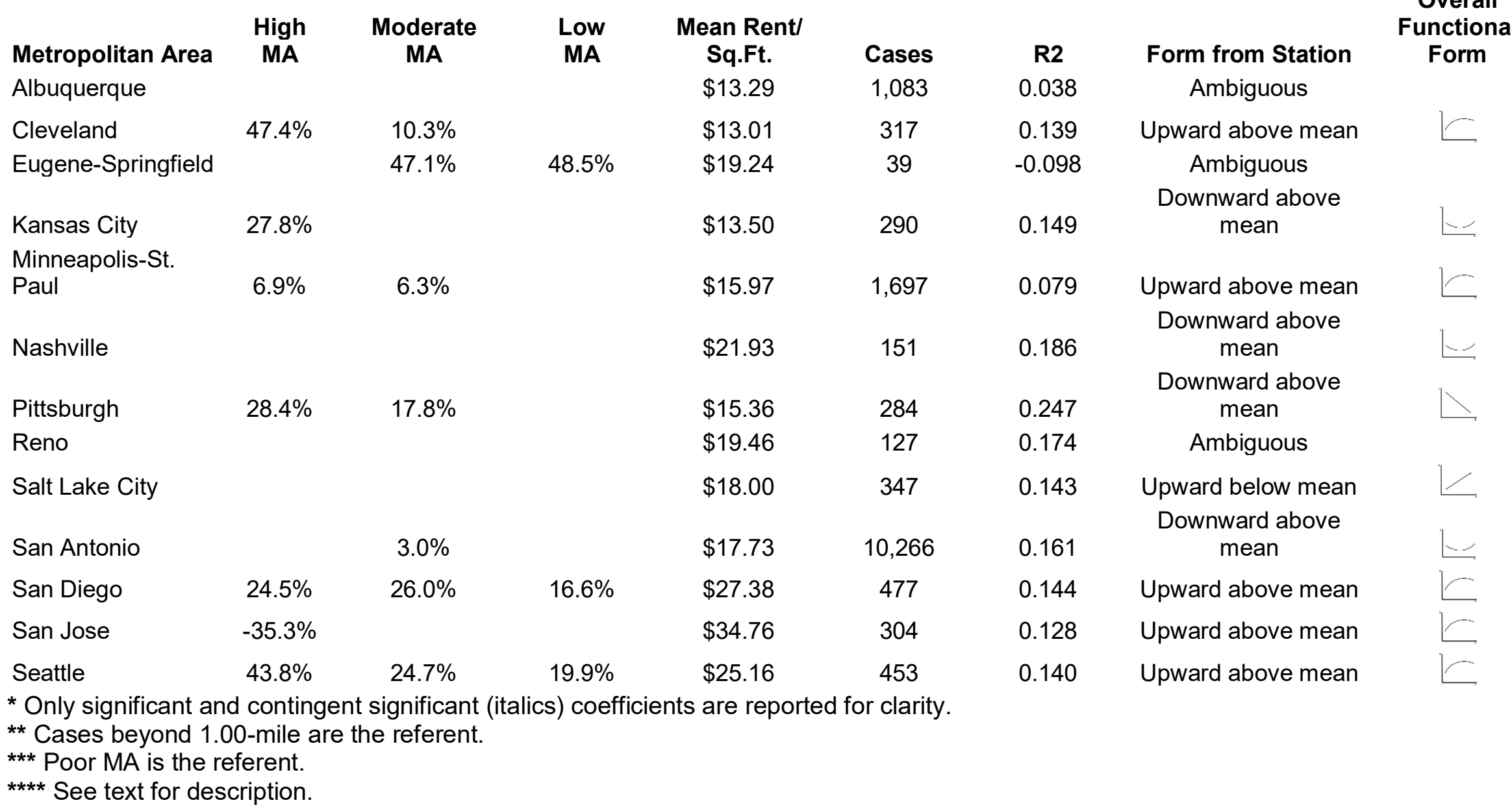


Table 8.9

Significant Retail Rent Coefficients* with Respect to Place Typology and Station Distance ${ }^{\star *}$ by Metropolitan Areacontinued

Metropolitan
Area
Albuquerque
Austin
Dallas-Fort Worth
Denver
Miami SE Florida
Minneapolis-St. Paul
Nashville
Orlando
Portland
SLC-Ogden-
Provo
San Diego
San Jose-
Stockton
Seattle-Tacoma
Washington

\begin{tabular}{|c|c|c|c|c|c|c|c|}
\hline \multirow[t]{8}{*}{$<=0.125$} & $\begin{array}{l}>0.125 \\
-0.250\end{array}$ & $\begin{array}{l}>0.250 \\
-0.375\end{array}$ & $\begin{array}{l}>0.375 \\
-0.500\end{array}$ & $\begin{array}{l}>0.500 \\
-0.625\end{array}$ & $\begin{array}{l}>0.625 \\
-0.750\end{array}$ & $\begin{array}{l}>0.750 \\
-0.875\end{array}$ & $\begin{array}{l}>0.875 \\
-1.000\end{array}$ \\
\hline & & & & $-5.1 \%$ & & & \\
\hline & $-21.1 \%$ & & & & & & \\
\hline & & & $23.6 \%$ & $50.3 \%$ & & & \\
\hline & & $3.6 \%$ & & $5.6 \%$ & $9.3 \%$ & $7.5 \%$ & $5.8 \%$ \\
\hline & & & $-17.9 \%$ & $-19.7 \%$ & $-25.8 \%$ & $-32.9 \%$ & $-28.0 \%$ \\
\hline & & & $125.2 \%$ & & & & \\
\hline & & $104.6 \%$ & $66.8 \%$ & & & & \\
\hline \multirow[t]{4}{*}{$73.2 \%$} & $39.4 \%$ & $82.9 \%$ & & $-47.6 \%$ & $89.2 \%$ & $69.8 \%$ & $73.2 \%$ \\
\hline & $28.0 \%$ & & & & $55.0 \%$ & & \\
\hline & & $21.1 \%$ & & $13.3 \%$ & & & \\
\hline & $54.3 \%$ & & & $27.1 \%$ & & & \\
\hline \multirow[t]{3}{*}{$88.5 \%$} & $39.6 \%$ & & $25.1 \%$ & & & & $88.5 \%$ \\
\hline & & $-25.3 \%$ & & & & & \\
\hline & & $-38.8 \%$ & & & & & \\
\hline
\end{tabular}


Table 8.9

Significant Retail Rent Coefficients* with Respect to Place Typology and Station Distance ${ }^{\star *}$ by Metropolitan Areacontinued

CRT Retail Rent Association with Respect to Place Typology, ${ }^{* * *}$ Model Performance, and General Form of Distance Relationship****

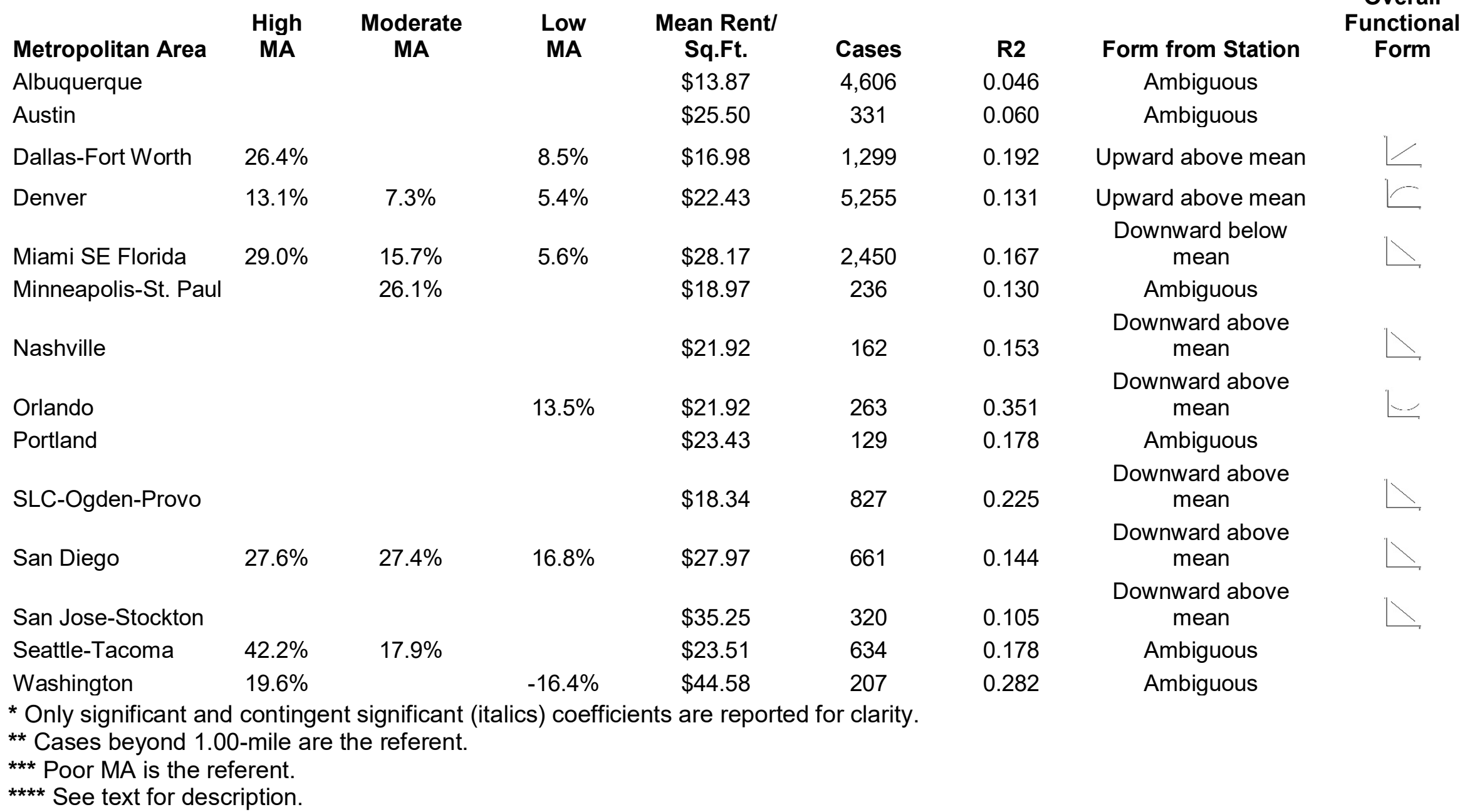


Light Rail Transit Station Retail Rent Proximity Effects by Metropolitan Area

Nearly half of the metropolitan areas revealed no statistically significant association between light rail transit station proximity and retail rents-Cleveland, Dallas, Houston, Minneapolis-St. Paul, Phoenix, Sacramento and Seattle. Four metropolitan areas-Buffalo, San Diego, San Jose and Seattle-revealed externality effects with respect to retail rents proximate to LRT stations. The remaining four metropolitan areas-Denver, Pittsburgh, Salt Lake City and Virginia Beach indicated that proximity to LRT stations was an amenity internalized into retail rents.

But something else is revealed by the market: in 11 of the 17 metropolitan areas, the market does not apparently value proximity to LRT stations in the first (0.125-mile) distance band though nine showed proximity effects in the second (0.250-mile) distance band. The difference between earlier analysis of retail rents overall noted above and those of individual metropolitan areas leads to an important insight:

The weight of statistical evidence shows that retail activities appear to be attracted to LRT station proximity perhaps more so than any other land uses studied in this report. Yet performance by individual metropolitan areas seems considerably less impressive. We surmise that transit and land use planning might do more to attract retail activities near LRT stations based on the overall evidence of the market.

For instance, only three of the 17 LRT systems we studied met our criteria for being exemplars as we discuss next.

LRT Retail Exemplars: Denver, Pittsburgh, Virginia Beach

Denver, Pittsburgh and Virginia Beach are our exemplars for the manner in which retail rent responds to light rail station proximity, though the desirable market response is limited to the first two distance bands-0.125- to 0.250-mile. For Denver and Virginia Beach, rent falls from 13.7 percent and 62.1 percent above the mean to 4.3 percent 34.2 percent. Pittsburgh, however, has the most extreme slope of all our exemplars as retail rents falls from 186.9 percent above the mean to 47.9 percent below the mean-in just one quarter mile, ceteris paribus. These relationships are illustrated in Figure 8.16. We do not have enough information to surmise why this is so. Nonetheless, we recommend at least Denver and Virginia Beach as worthy of detailed case study analysis to help with new or expanded LRT station planning in the future, or perhaps reconfiguring current transit investments along with land use planning along and urban design. 


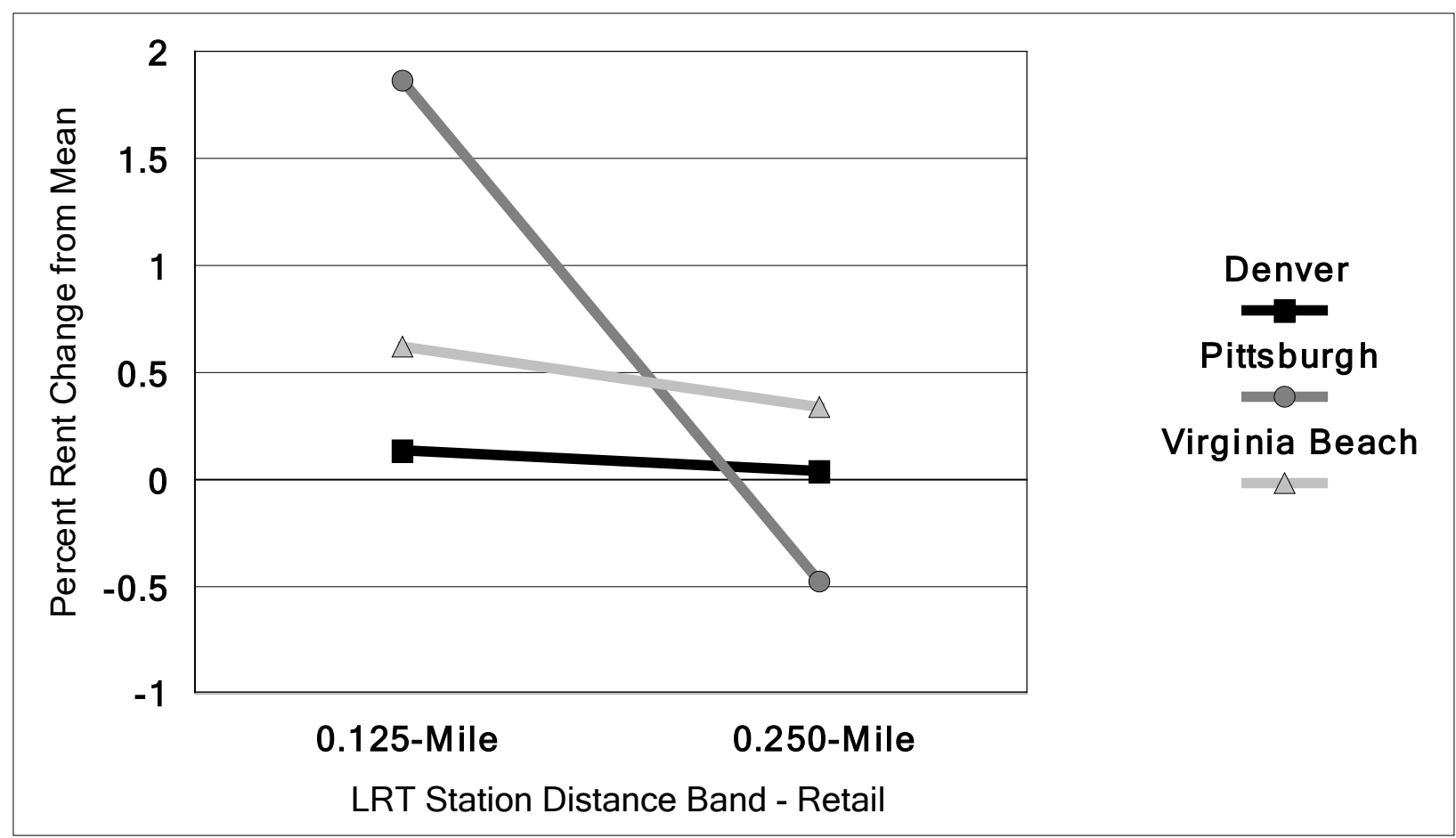

Figure 8.16

Retail rent premiums for light rail transit station proximity in Denver, Pittsburgh and Virginia Beach 
Streetcar Transit Station Retail Rent Proximity Effects by Metropolitan Area

In contrast to LRT systems, the retail market reveals a strong preference to be near streetcar stations. Only four metropolitan areas did not show significant coefficients in the first $(0.125-$ mile) distance band-Salt Lake City, Seattle, Tacoma and Washington. Four metropolitan areas showed amenity effects on rent with respect to SCT station distance-Kansas City, New Orleans, Salt Lake City (from the second, 0.250-mile, distance band outward) and Tucson. Two metropolitan areas-Seattle and Tacoma-showed ambiguous proximity effects on retail rent. The remaining three metropolitan areas-Dallas, Little Rock and Portland-revealed externality effects near SCT stations. We find this result surprising for Portland and Seattle given highly visible efforts to attract development to SCT stations. Perhaps efforts to attract retail activities might be redoubled in those markets.

\section{SCT Retail Exemplars: New Orleans and Tucson}

We are surprised that only two SCT systems meet our criteria as exemplars with respect to retail rent sensitivity to streetcar station proximity: New Orleans and Tucson. Respectively, rents fall from 84.0 percent and 49.2 percent above the mean to 67.1 percent and 46.7 percent above the mean from the first $(0.125$-mile) to the second $(0.250-$ mile $)$ distance bands. These associations are shown in Figure 8.17. We recommend these systems for detailed case studies into understanding how transit and land use planning, and urban design can lead to theoretically preferred associations between retail rent and streetcar station proximity. 


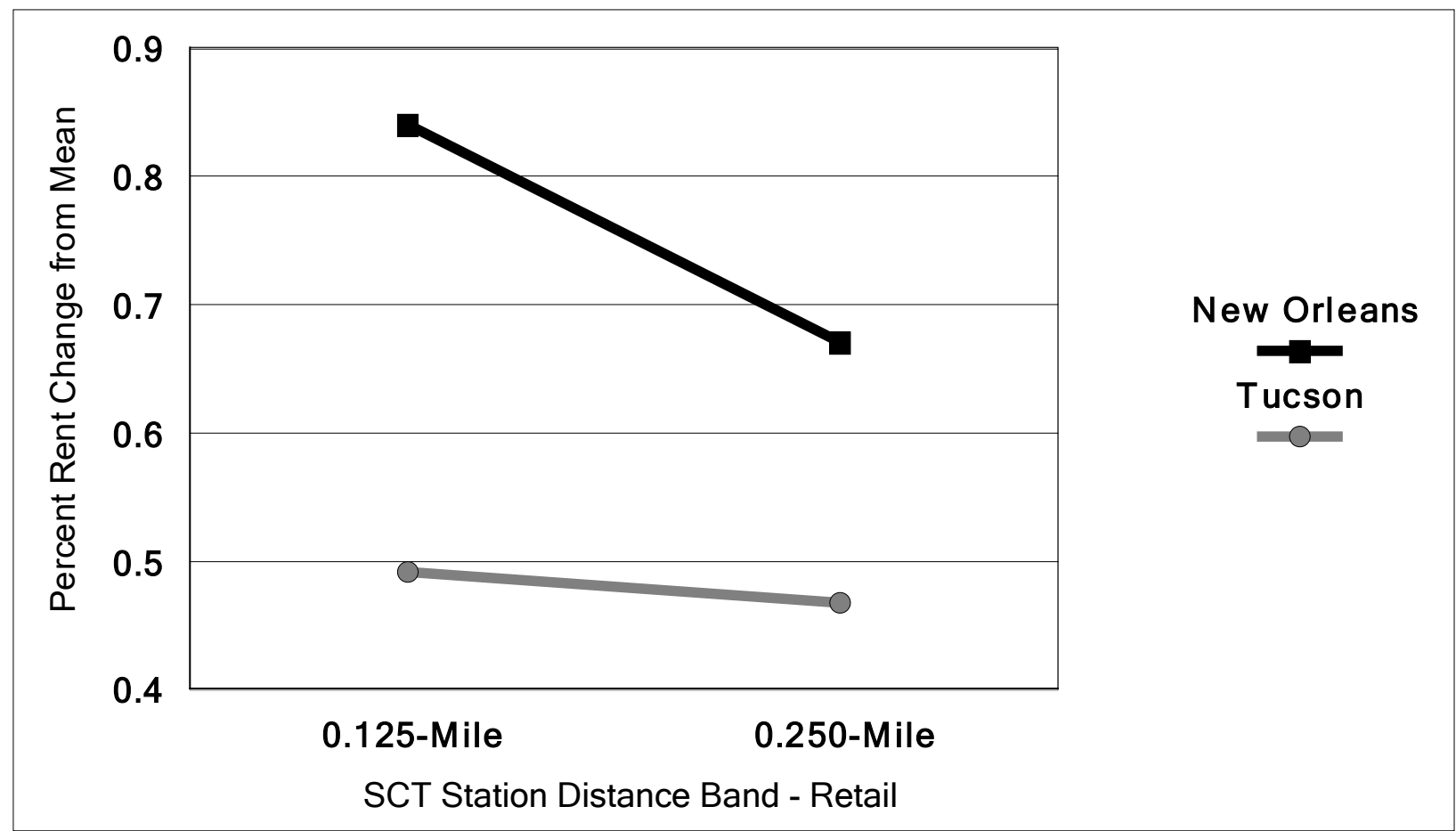

Figure 8.17

Retail rent premiums for streetcar transit station proximity in Dallas and Seattle 
Bus Rapid Transit Station Retail Rent Proximity Effects by Metropolitan Area

Unlike office and multifamily rents which on the whole were not sensitive to BRT station proximity, retail appears to value it. Only three metropolitan areas did not have at least one relevant coefficient that was not significant in the first two (0.125- and 0.250-mile) distance bands-Albuquerque, Eugene-Springfield and Reno. On the other hand, only three metropolitan areas revealed BRT station proximity as an amenity with respect to retail rents-Kansas City, Nashville and San Antonio. All the other metropolitan areas showed that the market values BRT proximity as an externality-Cleveland, Minneapolis-St. Paul, San Diego, San Jose and Seattle.

\section{BRT Retail Exemplars: Kanas City, San Antonio}

We identify the Kansas City and San Antonio BRT systems as exemplars in market-based performance of the association between retail real estate rents and bus rapid transit station proximity. As seen in Figure 8.18, retail rents with respect to BRT station distance fall from 22.3 percent to 18.8 percent above the mean in first two (0.125- to 0.250 -mile) distance bands in Kansas City while they fall from 8.0 percent above the mean to 3.4 percent above the mean between the first and third (0.125- to 0.375-mile) DBs in San Antonio. From the perspective of how the retail real estate market responds to BRT station proximity, we recommend Kansas City and San Antonio for further study. 


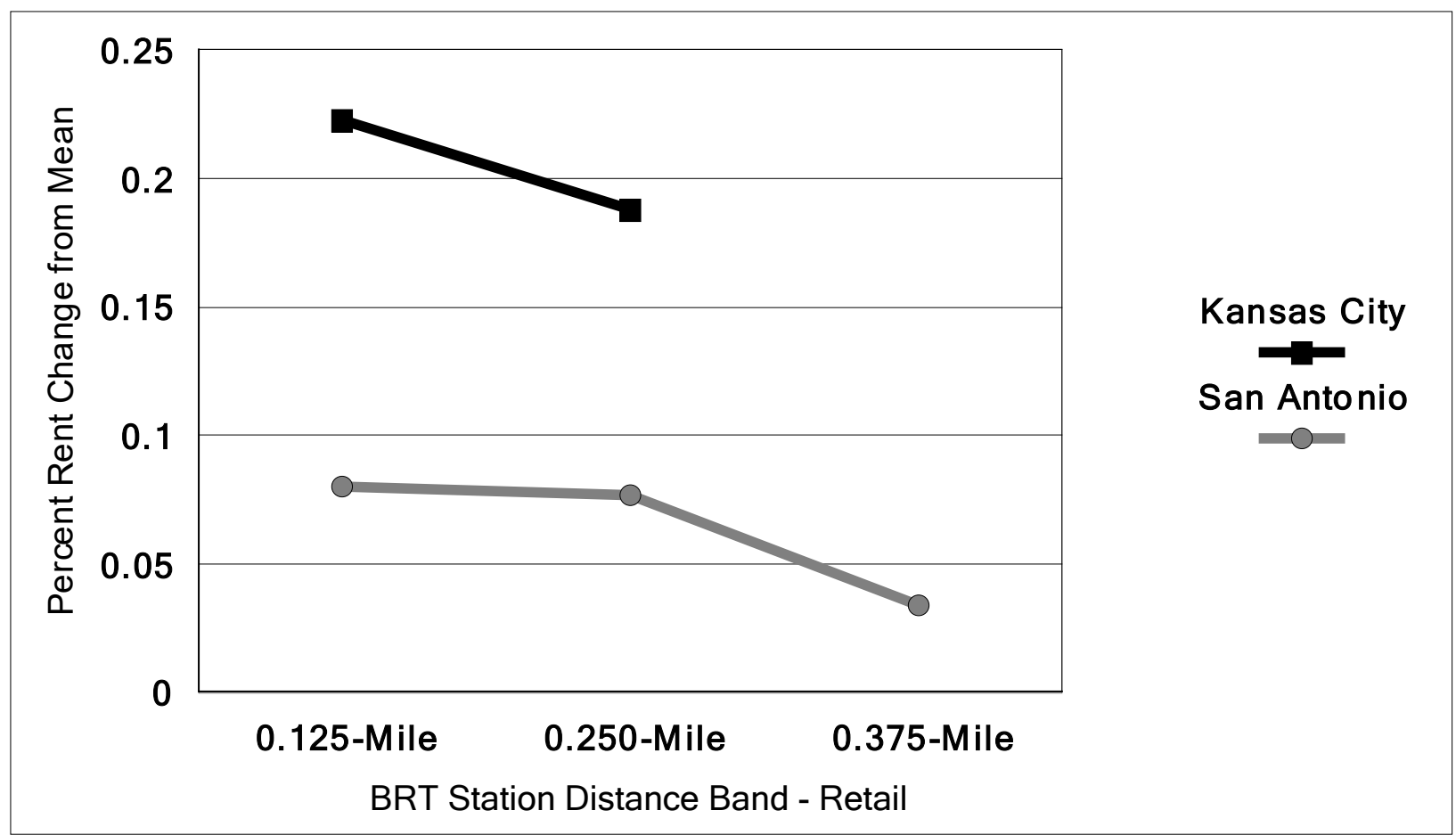

Figure 8.18

Retail rent premiums for bus rapid transit station proximity in Kansas City and San Antonio 
Commuter Rail Transit Station Retail Rent Proximity Effects by Metropolitan Area

The market rent evidence shows very little association between commuter rail transit station proximity and retail rents. Only two metropolitan areas reveal associations in the first $(0.125-$ mile) distance band but they are both among the largest we have seen in our analysis-73.2 percent above the mean for the Orlando Beach system and 88.5 percent for the San JoseStockton system. On the whole, six of 14 systems reveal mostly ambiguous associationsAlbuquerque-Santa Fe, Austin, Minneapolis-St. Paul, Portland, Seattle-Tacoma and Washington. Across the 1.00-mile study area, two systems show overall externality effectsDallas-Fort Worth and Denver while six show amenity effects those mostly in the distance bands away from the closest ones-Miami-SE Florida, Nashville, Orlando Beach, Salt Lake City-Ogden-Provo, San Diego, San Jose-Stockton and Seattle-Tacoma. We surmise that given the evidence of very strong, positive associations between retail rent and CRT station proximity in a few cases, there may be considerable untapped potential in most systems to attract retail activities.

CRT Retail Exemplars: Orlando San Jose-Stockton

The commuter rail systems of Orlando, called the "SunRail", and San-Jose-Stockton called the "Altamont Corridor Express" or "ACE", are our exemplars with respect to how retail real estate responds to CRT station proximity. Rents fall respectively from 73.2 percent and 88.5 percent above the mean to 39.4 percent and 39.6 percent above the mean from the first $(0.125$-mile) to second (0.250-mile) distance bands. We recommend these systems as case studies in transit and land use planning, and urban design, to achieve desired associations between retail real estate rents and proximity to CRT stations.

We will now offer synthesizing observations with respect to the association between transit station proximity and real estate rents. We will conclude this chapter with implications the role of real estate markets as a key factor in transit and land use planning, and urban design. 


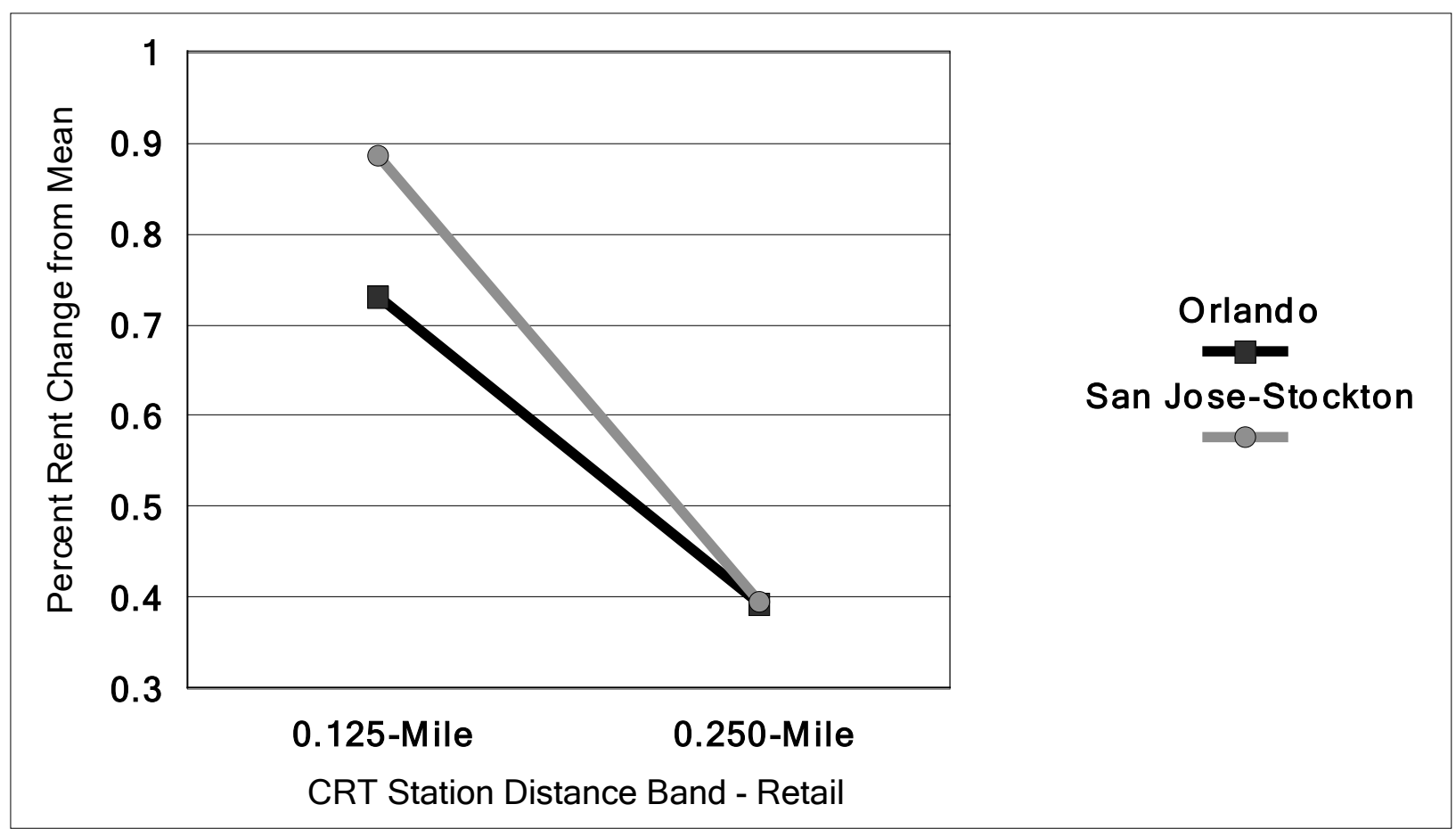

Figure 8.19

Retail rent premiums for commuter rail transit station proximity in Orlando and San JoseStockton 


\section{Synthesizing Observations}

In this section, we synthesize the foregoing analysis into an overall perspective of how all three real estate markets studied are influenced by proximity to transit stations. In particular, we will synthesize overall effects for the office, multifamily and retail markets together when applied to LRT, SCT, BRT and CRT systems respectively. Chapter 9 will advance the analysis by assessing interactive effects, such as when streetcar and light rail transit systems intersect.

\section{Light Rail Transit Station Proximity Real Estate Rent Synthesis}

Figure 8.20 illustrates the real estate rent influences on all three types of real estate we studied: office, multifamily and retail. Clear patterns emerge as discussed below. Readers are reminded that these outcomes are after controlling for several factors one of which is the location of offices in High-, Moderate-, Low- and Poor-Mixed Use/Accessibility places and areas. In other words, our results be somewhat different than those reported by others where such urban landscape controls are not used.

\section{Office Rent Proximate to LRT Stations}

At first blush, office rent behaves as though externality effects exceed amenity benefits as rents rise with respect to LRT station distance-from below the mean rent-to about 0.50-mile before falling, suggesting amenity benefits exceed externality effects thereafter. But we surmise that multifamily and retail real estate outbids office for LRT station proximity, so the source of the prospective externality effects are other kinds of real estate.

\section{Multifamily Rent Proximate to LRT Stations}

For the most part, multifamily rents hover around 5.0 percent above the mean across the 1.00 mile study area. This suggests that the multifamily market responds to LRT station proximity roughly equally across the study area. Though we might suspect a priori that walking a mile to an LRT station itself could be a disamenity_resulting in lower rents farther away-there are reasons why we may not detect this in our study area, such as the opportunity to use buses or other forms of "first/last-mile" public transit, bicycles, e-scooters, and ride hailing services (e.g. Lyft and Uber).

\section{Retail Rent Proximate to LRT Stations}

Retail rents dominate the closer distance bands, falling from 9.3 percent above the mean in the first $(0.125-\mathrm{mile})$ distance band to 3.1 percent above the mean in the fourth $(0.500-\mathrm{mile}) \mathrm{DB}$ and then rising through most of the rest of the study area. This makes sense intuitively as consumers may be less likely to carry goods long distances from LRT transit stations, and those stations become the opportunity for regional-scale retail operations to locate as we find in many metropolitan areas.

Overall, our analysis suggests that multifamily and retail land uses may push office real estate away from LRT transit stations to about 0.50-mile. But as we see for individual metropolitan areas, this trend is not evident everywhere.

We synthesize results for streetcar systems next. 


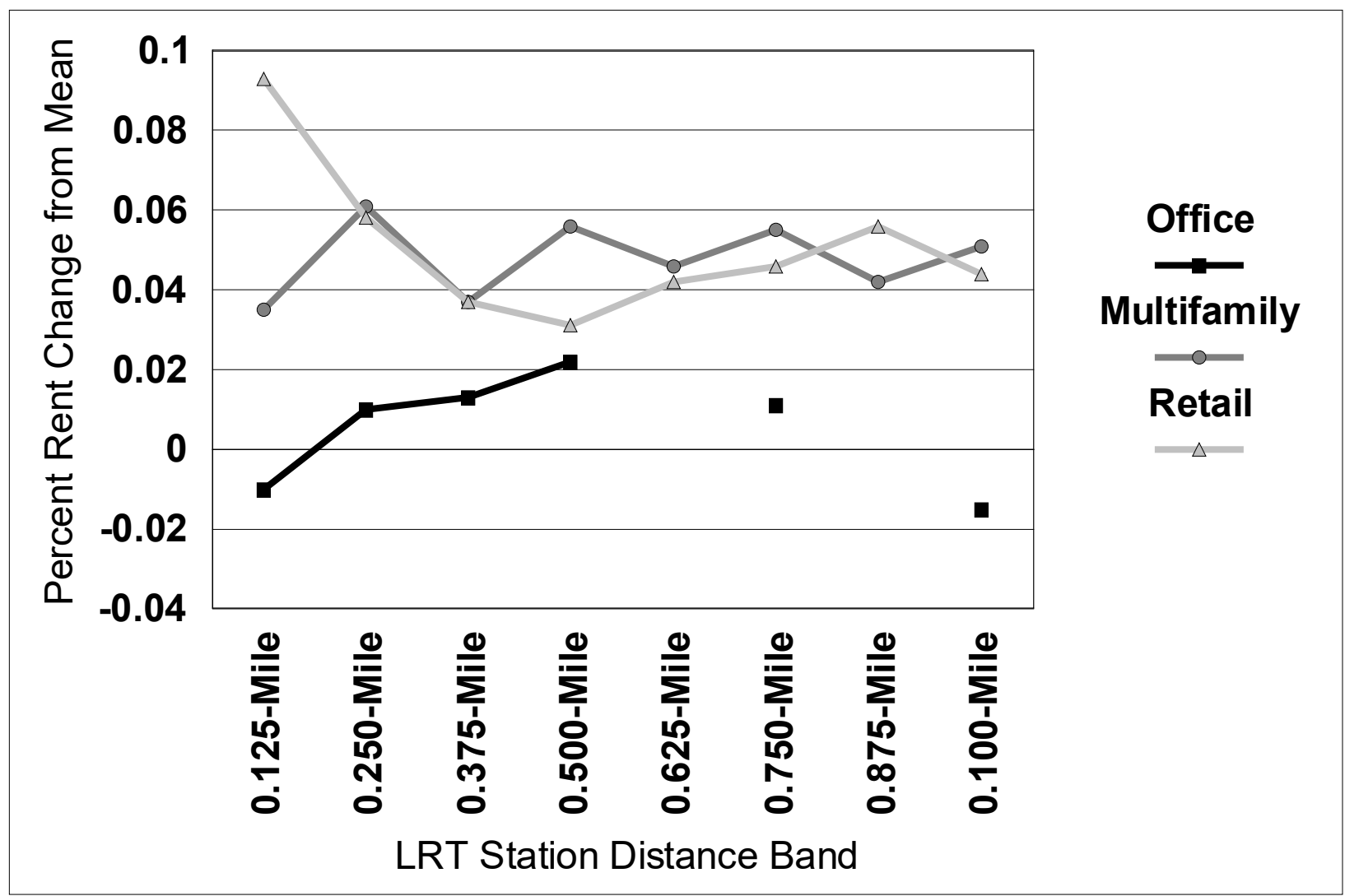

Figure 8.20

Combined office, multifamily and retail rent premiums for streetcar transit station proximity 


\section{Streetcar Transit Station Proximity Real Estate Rent Synthesis}

Perhaps because they are both similar forms of intra-metropolitan rail transit-sometimes using the same types of rolling stock, the office, multifamily and retail real estate markets respond roughly the same to light rail and streetcar transit station proximity, as will be seen. This despite key differences in their service areas as SCT systems serve mostly built-up downtown and near-downtown areas where LRT systems serve truly regional functions, connection a range of activity centers to each other and downtown. The discussion below rates to Figure 8.21 which uses data from tables reported earlier.

\section{Office Rent Proximate to SCT Stations}

Office rents rise from just 1.2 percent above the mean in the first $(0.125$-mile $)$ distance band to 13.5 percent at the third (0.375-mile) DB, then fall to 4.1 percent above the mean in the fifth (0.625-mile) DB and rise to 18 percent above the mean in the seventh $(0.875$-mile) DB before falling slightly toward the end of the study area. As for LRT systems, we surmise that multifamily and retail real estate outbid office real estate near SCT stations, as will be seen next.

\section{Multifamily Rent Proximate to SCT Stations}

Multifamily real estate values are influenced considerably by SCT station proximity. Starting at 13.0 percent above the mean in the first $(0.125$-mile) distance band and rising slightly to 13.5 percent in the second $(0.250$-mile) $\mathrm{DB}$, rents fall steadily to 5.0 percent above the mean in the last (1.00-mile) DB. Clearly, the multifamily rental real estate market values proximity to SCT stations.

\section{Retail Rent Proximate to SCT Stations}

Following the pattern for LRT station proximity, retail rents near SCT stations are the highest of the three types of real estate studied, by quite a margin. Starting at 28.9 percent above the mean in the first $(0.125$-mile) distance band, rents fall to 20.9 percent above the mean in the third (0.375-mile) DB the rise to 31.1 percent above the mean in the fourth $(0.500-\mathrm{mile}) \mathrm{DB}$ and then falling to 22.4 percent above the mean in the seventh $(0.875$-mile) DB. We surmise that more so than other types of real estate, retail is highly responsive to SCT station proximity in the first three distance bands (from 0.125- to 0.375-mile). We suspect that other factors affect retail rents to rise sharply to about 0.50 -mile; indeed, we observe that SCT systems serving downtowns often do not access the heart of downtowns (the "one hundred percent corner" in retail parlance), and instead the heart of downtown is often up to 0.50-mile away from SCT stations. We recommend further case study analysis to assess this assertion.

Overall, we surmise that multifamily and retail real estate may be outbidding office real estate at or near SCT stations, pushing office further away.

We next synthesize results for bus rapid transit systems. 


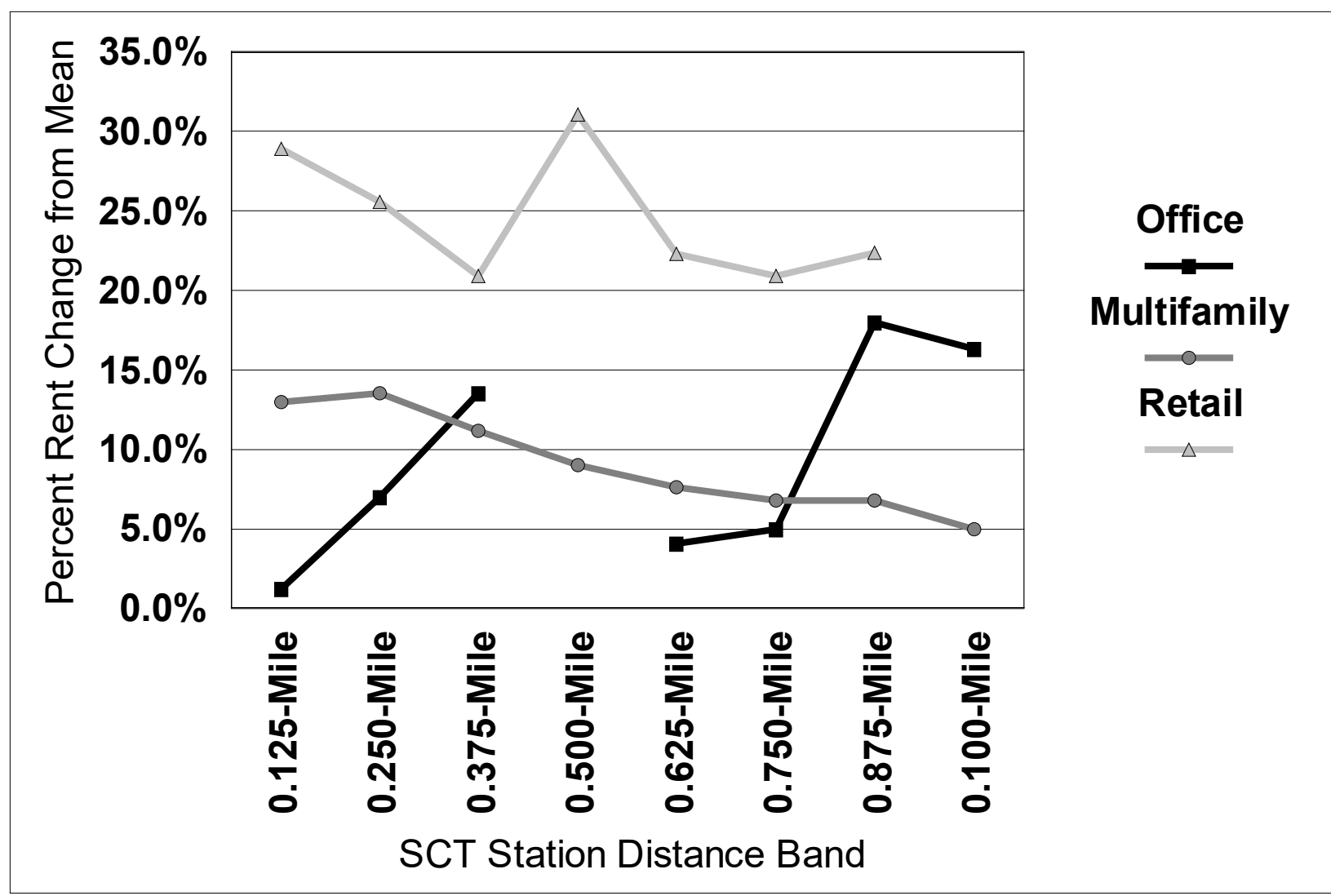

Figure 8.21

Combined office, multifamily and retail rent premiums for light rail transit station proximity 


\section{Bus Rapid Transit Station Proximity Real Estate Rent Synthesis}

In general and as illustrated in Figure 8.22, real estate rents do not respond well to bus rapid transit station proximity. Patterns are presented below.

\section{Office Rent Proximate to BRT Stations}

Starting only in the second (0.250-mile) distance band, office rents fall with respect to BRT station proximity from 6.6 percent above the mean to 2.5 percent above the mean in the fourth (0.250-mile) distance band before rising again to 4.9 percent above the mean in the seventh (0.875-mile) distance band. We surmise that sufficient externalities at or near BRT stations to offset amenity benefits which may be overcome through improved transit and land use planning, or urban design. Otherwise, from the second to fourth (0.250- to 0.50 -mile) distance bands, the functional form of the rent association with respect to BRT station proximity is consistent with theory.

\section{Multifamily Rent Proximate to BRT Stations}

In contrast to office, multifamily rents reveal externality effects that extend from the second (0.250-mile) distance band at 2.5 percent below the mean $(-2.5 \%)$ to 4.1 percent above the mean at the end of the study area, 1.00-mile. Indeed, we note there is an ambiguous association at the first (0.125-mile) DB. Clearly, the multifamily real estate market does not value proximity to BRT stations for reasons we will offer below.

\section{Retail Rent Proximate to BRT Stations}

Retail is just as interesting as the other types of real estate. Rents rise sharply from 1.4 percent above the mean in the first $(0.125$-mile $)$ distance band to 7.6 percent above the mean in the second (0.125-mile) DB, then fall equally sharply to 2.1 percent above the mean in the third (0.3750-mile) DB and finish by rising gradually to 4.1 percent above the mean in the seventh (0.875-mile) DB. We sense the presence of externalities at or near BRT stations that are overcome rapidly by the second (0.250-mile) DB, but then we sense an amenity effect that dissipates rapidly to the third (0.375-mile) DB followed by gradually rising indicating the presence of externalities over a large area from BRT stations.

Overall, we find ambiguous office and multifamily market responses to BRT proximity in the first (0.125-mile) distance band but a steeply upward retail rent slope. As we discuss in the concluding section of this chapter, we surmise that for the most part, BRT stations are sources of externalities. To us, it would seem that improved transit and land use planning and better urban design can overcome these externalities thereby making BRT stations sources of amenity value.

\section{Bus Rapid Transit Station Proximity Real Estate Rent Synthesis}

In general, real estate rents do not respond well to bus rapid transit station proximity. Patterns are presented below.

\section{Office Rent Proximate to BRT Stations}

Starting only in the second (0.250-mile) distance band, office rents fall with respect to BRT station proximity from 6.6 percent above the mean to 2.5 percent above the mean in the fourth (0.250-mile) distance band before rising again to 4.9 percent above the mean in the seventh (0.875-mile) distance band. We surmise that sufficient externalities at or near BRT stations to offset amenity benefits which may be overcome through improved transit and land use planning, or urban design. Otherwise, from the second to fourth (0.250- to 0.50-mile) distance bands, the functional form of the rent association with respect to BRT station proximity is consistent with theory. 
Multifamily Rent Proximate to BRT Stations

In contrast to office, multifamily rents reveal externality effects that extend from the second (0.250-mile) distance band at 2.5 percent below the mean $(-2.5 \%)$ to 4.1 percent above the mean at the end of the study area, 1.00-mile. Indeed, we note there is an ambiguous association at the first (0.125-mile) DB. Clearly, the multifamily real estate market does not value proximity to BRT stations for reasons we will offer below.

\section{Retail Rent Proximate to BRT Stations}

Retail is just as interesting as the other types of real estate. Rents rise sharply from 1.4 percent above the mean in the first $(0.125$-mile) distance band to 7.6 percent above the mean in the second (0.125-mile) DB, then fall equally sharply to 2.1 percent above the mean in the third (0.3750-mile) DB and finish by rising gradually to 4.1 percent above the mean in the seventh (0.875-mile) DB. We sense the presence of externalities at or near BRT stations that are overcome rapidly by the second (0.250-mile) DB, but then we sense an amenity effect that dissipates rapidly to the third (0.375-mile) DB followed by gradually rising indicating the presence of externalities over a large area from BRT stations.

Overall, we find ambiguous office and multifamily market responses to BRT proximity in the first (0.125-mile) distance band but a steeply upward retail rent slope. As we discuss in the concluding section of this chapter, we surmise that for the most part, BRT stations are sources of externalities. To us, it would seem that improved transit and land use planning and better urban design can overcome these externalities thereby making BRT stations sources of amenity value. 


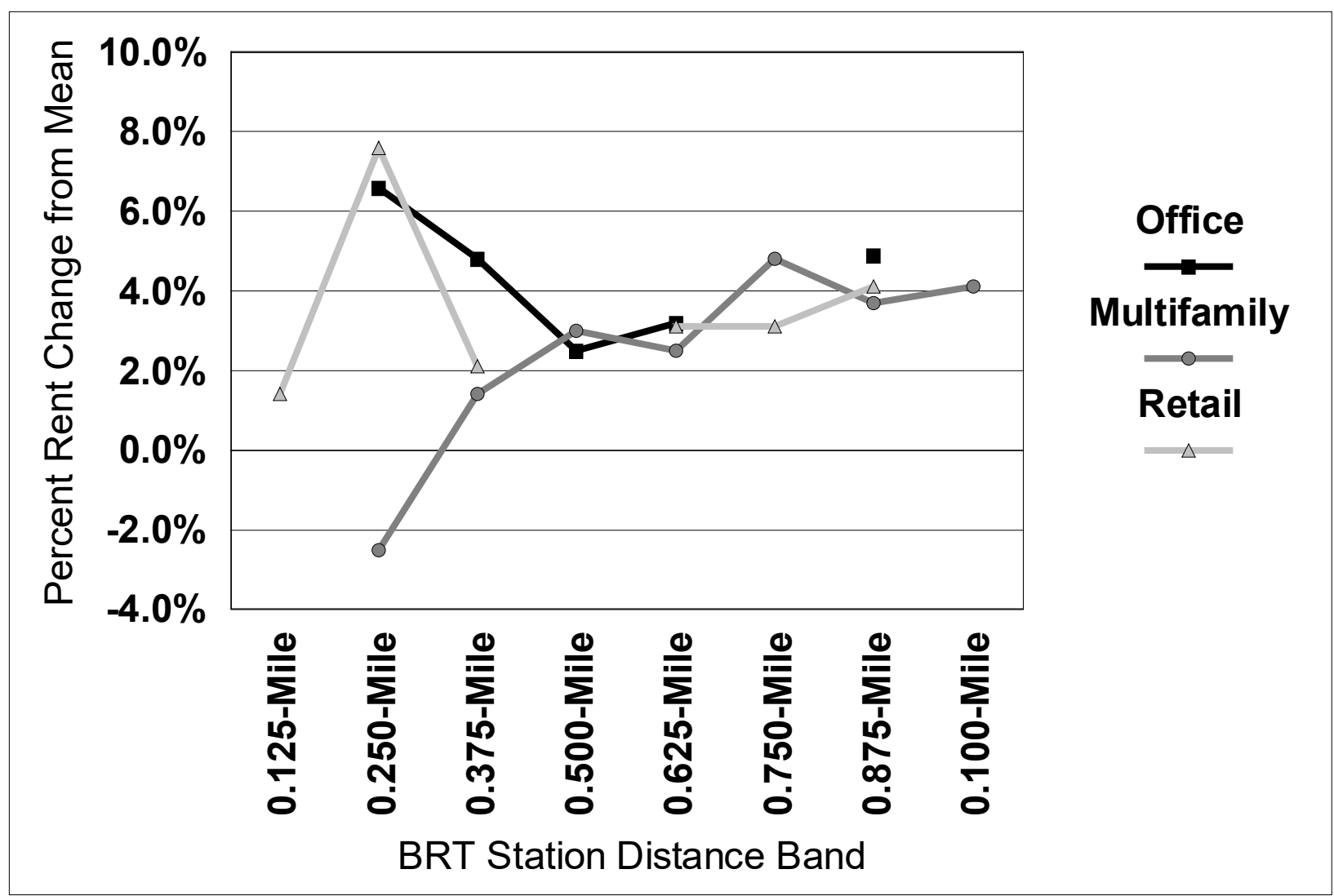

Figure 8.22

Combined office, multifamily and retail rent premiums for bus rapid transit station proximity 


\section{Commuter Rail Transit Station Proximity Real Estate Rent Synthesis}

We conclude this synthesize by reviewing patterns of real estate rents with respect to commuter rail transit station proximity, which are summarized in Figure 8.23. We discuss these patterns next.

\section{Office Rent Proximate to CRT Stations}

Office rents have a declining slope revealing rents that are 5.3 percent above the mean in the first (0.125-mile) distance band, falling to 3.1 percent below the mean in the second $(0.250-\mathrm{mile})$ DB. We surmise that there is a narrow area around CRT stations where offices command a rent premium, but it dissipates quickly. Rents gradually rise as distance from CRT stations increases, reaching 4.6 percent above the mean in the last (1.00-mile) distance band. The overall implication is that except perhaps for certain office functions whose nature requires them to be near CRT stations, those stations are a source of externalities extending a considerable distance away.

\section{Multifamily Rent Proximate to CRT Stations}

For its part, there are only ambiguous multifamily rent associations with respect to CRT station distance in the first 0.50 -mile, and then the association is basically flat, from 2.8 percent above the mean in the fourth (0.50-mile) distance band to 2.3 percent in the last (1.00-mile) DB almost as though there was no market response beyond the first 0.50 -mile. We showed above, however, that there are positive rent associations with respect to CRT transit station proximity in several metropolitan areas.

\section{Retail Rent Proximate to CRT Stations}

The really interesting finding is the magnitude of the retail rent near CRT stations as it falls from 26.0 percent above the mean in the first $(0.125$-mile) distance band to 1.4 percent below ($1.4 \%)$ the mean in the third (0.375-mile) DB and stays below the mean throughout the balance of the 1.00-mile study area. Certain retail activities are clearly attracted to CRT stations. Future research may identify them.

Taking some liberties based on outcomes of selected individual metropolitan areas, we sense that not only can office and retail real estate benefit from proximity to CRT stations but perhaps multifamily as well. While CRT stations can be sources of externalities such as noise, smells, unappealing freight-based rail infrastructure and so forth, perhaps with sensitive transit and land use planning, and especially urban design, these potential nodes of externalities could be turned into places of amenities, or at least where amenity benefits exceed externality effects.

This observation provides a segue into the concluding section of this chapter. 


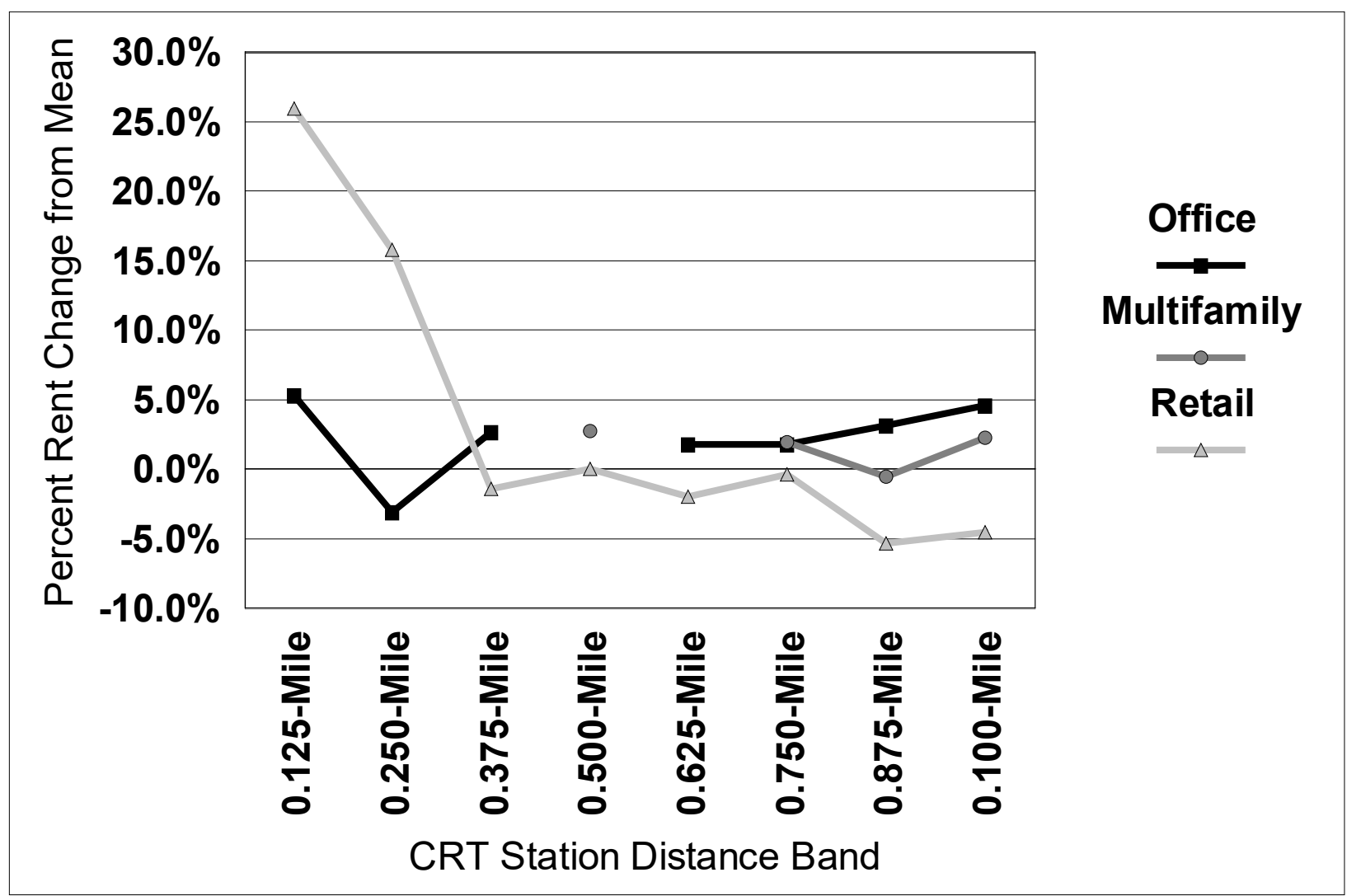

Figure 8.23

Combined office, multifamily and retail rent premiums for commuter rail transit station proximity 


\section{IMPLICATIONS FOR TRANSIT AND LAND USE PLANNING}

Transit systems do a lot things. Of course they move people from Point A to Point B but they are also used to achieve social justice - such as by connecting lower income neighborhoods to regional job opportunities, renewing blighted areas to create jobs within them as well as connecting them to their regions, reducing congestion on roads therefore providing public health benefits, and even elevating the public relations prestige of local and regional governments. But there can be downsides as well. Transit stations can become localized sources of disinvestment if the real estate market-comprised of investors and consumers-are unwilling to invest at or near them. They can also be viewed as contributing to displacement of lower income households by higher income ones through a process called gentrification.

But how do we really know the effects of transit stations on people and the economy? Without meaning to overstate it, the real estate market may be the single best indicator of whether transit stations are having desirable or undesirable effects.

Of course, this assumes that the real estate market is the perfect gauge of outcomes, which it is not. Real estate values, or in this study real estate rents, reflect only what real estate decision makers know about the relationship between real estate and society. Overall, the real estate market does a reasonably good job of reflecting advantages and disadvantages of location, market trends and opportunities, and even the effects of various taxes and fees on investor and consumer behavior. What it does not do well is internalize the positive or negative effects of real estate decisions today that will influence the future, or account for environmental externalities such as air and water pollution, or even account for positive or negative impacts on other real estate in the community and on people living, working and visiting the community. Various forms of regulations are used to identify and then mitigate adverse impacts though often without full success; and few policies are designed to reward positive outcomes associated with real estate investment.

In this chapter, we established a framework for assessing the extent to which transit stations have desirable or undesirable effects on only real estate rent, which is its chief limitation. Our framework shows the different ways in which transit stations can become sources of amenities that are internalized in the market in the form of higher rent near stations-or sources of externalities that are internalized in the market in the form of lower rents near stations. We take it as a given that amenity benefits are the singularly most important outcome from a real estate investment perspective. Alternatively, we also take it as a given that externality effects are the singularly most important outcomes to minimize or mitigate from a real estate investment perspective.

The bottom line is this: we can use the real estate market as a key way in which to determine whether transit stations have desired effects on society, or not. We can also use the market to gauge the extent to which transit and land use planning, and urban design interventions achieve desirable outcomes.

Throughout this chapter, we have identified specific transit systems to study because of their desired effects on the real estate market. We are in fact not aware of any study that links specific transit and land use planning, and urban design efforts to achieving desired real estate value or rent outcomes. That research is desperately needed. Short of this research, we will outline some strategies to improve the performance of real estate markets with respect to transit station proximity. 
Part of that research should focus on the efficacy of limiting transit-oriented development planning to just the "quarter mile" or "half mile" circle. These are scarcely more than arbitrary lines drawn around transit stations reflecting the distance over which people are willing to walk between stations and destinations. Perhaps one reason why so many metropolitan areas revealed desirable interactions between stations and destinations is land use planning limited transit-oriented development to the quarter or half mile circles. Canepa (2007) argues that such local planning does not seize market opportunities for maximizing development throughout the quarter- or half-mile circle and beyond. Indeed, he argues, we believe correctly, that removing impediments to walking combined with urban design could easily allow for one- or even two-mile capture areas around stations, as Chatman and DiPetrillo (2011), and Guthrie and Fan (2017) show. We note that the rise of micro mobility reinforces these researchers' views.

Based on their research of transit systems in several states in the Mountain census region, Nelson and Hibberd (2021) identify the following impediments to maximizing development near transit stations, especially the area between 0.50 - and 1.00 -mile:

- Development regulations are inconsistent with market realities;

- Unpredictable or protracted development approval processes;

- Excessive parking requirements;

- Development exactions that exceed that needed to mitigate adverse impacts;

- Neighborhood opposition;

- Inefficient linkages between development and transit stations (such as multi-lane highways, long blocks, and elevated station platforms among others); and

- Insensitive urban design that makes transit station accessibility physically and even emotionally unpleasant.

There is another consideration. Nelson and Hibberd's (2021) analysis of the area within 0.50mile of transit stations in Albuquerque, Denver, Las Vegas, Salt Lake City, Phoenix and Tucson metropolitan areas indicate that more than half the land not otherwise used for streets, parks, easements and the like is comprised of:

- Surface parking lots;

- Vacant, privately owned land; and

- Land on which there are one- and two-floor structures being more than 30 years old and occupying less than $25 \%$ of the land area.

Real estate development literature indicates such land presents important opportunities for infill and redevelopment (Nelson 2014). Indeed, as Nelson and Hibberd (2021) observe it is not difficult to imagine that all development in major metropolitan area can be accommodated through the redevelopment of parking lots, vacant land, and aging buildings that are already past their highest and best use by 2050 if not beyond. The challenge is finding ways in which to make it happen. We believe that learning the lessons of real estate markets-comprised as they are of people making decisions to advance their interests-can help achieve this outcome. 


\section{REFERENCES}

Al-Mosaind, M. A., Dueker, K. J., \& Strathman, J. G. (1993). Light-Rail Transit Stations and Property Values: A Hedonic Price Approach. Transportation Research Record, 1400.

Alonso W. (1964). Location and Land Use: Toward a General Theory of Land Rent, Cambridge MA: Harvard University Press.

Bogart, W. T. (1998). The Economics of Cities and Suburbs. Upper Saddle River, NJ: Prentice Hall.

Canepa B. (2007). Bursting the Bubble: Determining the Transit-Oriented Development's Walkable Limits. Transportation Research Record: Journal of the Transportation Research Board 1992(1): 28-34. doi:10.3141/1992-04

Cervero, R. (1984). Journal Report: Light Rail Transit and Urban Development. Journal of the American Planning Association, 50(2), 133-147.

Cervero, R., \& Duncan, M. (2002). Benefits of Proximity to Rail on Housing Markets:

Experiences in Santa Clara County. Journal of Public Transportation, 5(1).

Cervero, R., Murphy, S., Ferrell, C., Goguts, N., Tsai, Y-H., Arrington, G.B., Boroski, J., SmithHeimer, J., Golem, R., Peninger, P., Nakajima, E., Chui, E., Dunphy, R., Myers, M., \& McKay, S. (2004). Transit-Oriented Development in the United States: Experiences, Challenges, and Prospects. Transit Cooperative Research Program (TCRP) Report 102, published by the Transportation Research Board, Washington.

Chatman, D. G. and S. E. DiPetrillo (2011). Eliminating Barriers to Transit-Oriented Development. New Brunswick, NJ: Alan M. Voorhees Transportation Center, Rutgers University.

Debrezion, G., Pels, E., \& Rietveld, P. (2007). The Impact of Railway Stations on Residential and Commercial Property Value: A Meta-analysis. The Journal of Real Estate Finance and Economics, 35(2), 161-180.

Feignon, Shanon (2019). Transit and Micro-Mobility, TCRP J-11/Task 37 research in progress. Transportation Research Board.

Garreau, J. (1991). Edge City: Life on the New Frontier. New York, Anchor Books.

Golub, A., Guhathakurta, S., \& Sollapuram, B. (2012). Spatial and Temporal Capitalization Effects of Light Rail in Phoenix: From Conception, Planning, and Construction to Operation. Journal of Planning Education and Research, 32(4), 415-429.

Guthrie, A. and Y. Fan (2017). Specific Strategies for Achieving Transit-Oriented Economic Development Applying National Lessons to the Twin Cities - Phase 2. Minneapolis MN: Center for Transportation Studies, University of Minnesota.

Hamidi, S., Kittrell, K., \& Ewing, R. (2016). Value of Transit as Reflected in U.S. Single-Family Home Premiums: A Meta-Analysis. Transportation Research Record: Journal of the Transportation Research Board 2543(1), 108-115. 
Hajrasouliha, Amir H. and Shima Hamidi (2017). The typology of the American Metropolis: Monocentricity, Polycentricity, or Generalized Dispersion? Urban Geography 38:3, 420-444.

Hibberd, R., A. C. Nelson, K. Currans (2019). Functional Form in Hedonic Regression: Literature Review \& Test of Forms to Determine the End of Significance of Transit Proximity Effects on LVU. University of Arizona.

Higgins, C. D. and P. S. Kanaroglou (2016). Forty years of modelling rapid transit's land value uplift in North America: moving beyond the tip of the iceberg, Transport Reviews, 36:5, 610-634, DOI: $10.1080 / 01441647.2016 .1174748$.

Ko, K. and Cao, X. (2013). The impacts of Hiawatha light rail on commercial and industrial property values in Minneapolis. Journal of Public Transportation 16 (1): 47-66.

Li, M. M. and H. J. Brown (1980). Micro-Neighborhood Externalities and Hedonic Housing Prices. Land Economics 56(2): 125-141.

Mills E. S. (1967). An Aggregative Model of Resource Allocation in a Metropolitan Area, The American Economic Review, Papers and Proceedings, 57(2), pp 197-210. University of Chicago Press, Chicago.

Mulley, C., Ma, L., Clifton, G., Yen, B., \& Burke, M. (2016). Residential property value impacts of proximity to transport infrastructure: An investigation of bus rapid transit and heavy rail networks in Brisbane, Australia. Journal of Transport Geography, 54, 41-52.

Muth, R.F. (1969). Cities and Housing: The Spatial Pattern of Urban Residential Land Use, Third Series: Studies in Business and Society.

Nelson, A. C. (2013). Reshaping Metropolitan America. Washington, DC: Island Press.

Nelson, A. C. (2014). Foundations of Real Estate Finance for Development. Washington, DC: Island Press.

Nelson, A. C. (2015). National Study of BRT Development Outcomes. Portland, OR: National Institute for Transportation and Communities accessible from https://pdxscholar.library.pdx.edu/trec reports/32/

Nelson, A. C. (2017). Transit and Real Estate Rents. Transportation Research Record: Journal of the Transportation Research Board. https://doi.org/10.3141/2651-03)

Nelson, A. C. 1992. "Effects of Heavy-Rail Transit Stations on House Prices With Respect to Neighborhood Income," Transportation Research Record: Journal of the Transportation Research Board. 1359: 127-132.

Nelson A.C. and R. Hibberd (2019). Streetcars and Real Estate Rents with Implications for Transit and Land Use Planning. Transportation Research Record. 2019; 2673(10): 714-725. doi:10.1177/0361198119849916

Nelson A.C. and R. Hibberd (2021). The Influence of Rail Transit on Development Patterns in the Mountain Mega-Region with a Surprise and Implications for Rail Transit and Land Use Planning. Transportation Research Record (forthcoming). 
Nelson, A. C. and R. Hibberd with M. Dixon (2019). The Link between Transit Station Proximity and Real Estate Rents, Jobs, People and Housing with Transit and Land Use Planning Implications. Portland OR: National Institute for Transportation and Communities, Portland State University.

Nelson, A. C. D. Eskic, S. Hamidi, S. J. Petheram, J. H. Liu, and R. Ewing. 2015. Office Rent Premiums with Respect to Distance from Light Rail Transit Stations/stops in Dallas. Transportation Research Record: Journal of the Transportation Research Board. DOI 10.3141/2500-13.

Nelson, A. C. and S. J. McClesky. 1990. "Elevated Rapid Rail Station Impacts on Single-Family House Values," Transportation Research Record, 1266: 173-180.

Nelson, A. C., Eskic, D., Hamidi, S., Petheram, S. J., Ewing, R., \& Liu, J. H. (2015). Office Rent Premiums with Respect to Light Rail Transit Stations: Case Study of Dallas, Texas, with Implications for Planning of transit-Oriented Development. Transportation Research Record: Journal of the Transportation Research Board 2500(1), 110-115.

Park, R. E., E. W. Burgess, R. D. McKenzie, and L. Wirth (1925). The city. Chicago, III: University of Chicago Press.

Periser, R. B. and D. David Hamilton (2012). Professional Real Estate Development: The ULI Guide to the Business. Washington DC: Urban Land Institute.

Perk, Victoria A., Martin Catalá, Maximillian Mantius, and Katrina Corcoran (2017). Impacts of Bus Rapid Transit (BRT) on Surrounding Residential Property Values. Portland OR: National Institute for Transportation and Communities, Portland State University.

Petheram, S. J., A. C. Nelson, M. Miller and R. Ewing (2013). Using the Real Estate Market to Establish Light Rail Station Catchment Areas: Case Study of Attached Residential Property Values in Salt Lake County with respect to Light Rail Station Distance. Transportation Research Record: Journal of the Transportation Research Board. 2357: 95-99.

von Thünen, J. H. (1826). Der isolierte Staat (The Isolated State). 


\section{CHAPTER 8 ADDENDUM A \\ Office, Multifamily and Retail Rents with Respect to Heavy Rail Transit Station Proximity with Special Reference to Place Typology}

Though our scope included analysis of only LRT, SCT, BRT and CRT systems in selected metropolitan areas, four of them included heavy rail transit systems: Atlanta, Cleveland, Miami and Washington, DC. We took advantage of our resources to extent analysis to HRT systems operating in these four metropolitan areas. Following the pattern of analysis presented above, we will highlight findings with respect to office, multifamily and retail real estate with respect to HRT station proximity generally, and station proximity in each of the Place Typologies. More detailed analysis of individual metropolitan areas is in progress.

Table 8.A1 reports the regression results for office, multifamily and retail rents with respect to heavy rail transit (HRT) station distance with special reference to place typology. The coefficients of determination $\left(\mathrm{R}^{2}\right)$ show the model explains 50 percent to 63 percent of the variation in rents while the collinearity coefficients (not reported for brevity) do not show problematic relationships. The control variables are also consistent with expectations. Key implications of the analysis are:

Place Typology performance is mixed and mostly not consistent with patterns we observed in regressions for other transit modes. We reason that because of their high capital and operating costs, HRT stations tend to be located at or near places of high real estate investment regardless of their Place Typology.

Rents decline with distance from HRT stations for all real estate types to the second (0.250mile) distance band then mostly trend upward. This is illustrated in Figure 8.A1. Notably, retail is the highest at or near HRT stations being 35.2 percent above the mean and remains the highest at the second (0.250-mile) DB at 23.6 percent above the mean. We reason that if one is using HRT to access retail opportunities and given that HRT stations will be attracted to (and also attract) high value real estate, one does not want to walk too far to shop or eat or engage in other retail activities.

Office and multifamily rents follow, starting at 14.0 percent and 9.6 percent above the mean, respectively, in the first (0.125-mile) distance band, falling to 10.2 percent and 6.0 percent above the mean in the second $(0.250$-mile) DB, also respectively.

The upward slope beyond the second (0.250-mile) DB is also interesting. We surmise that HRT station proximity is important to a range of real estate activities but perhaps not to most. For those real estate activities, HRT station dictation could be considered mostly an externality to some distance away before externality effects are overcome by amenity benefits.

But we also suspect something else is going on. New, especially higher value real estate investment may be attracted to HRT stations while older real estate farther away undergoes a period of disinvestment-and with it lower rents - until new investment that is farther away occurs, thereby potentially increasing the magnitude of rent closer to stations and reversing the slope farther away.

We extent our brief analysis to express bus transit systems in Addendum B. 
Table 8.A1

Overall Regression Results for Office, Multifamily, and Retail Rents with Respect to Place Typology and Heavy Rail Transit Station Proximity

\author{
Variable \\ Constant \\ Structure Controls \\ Gross Leasable Area \\ (1000sq.ft.) \\ Class $A^{*}$ \\ Class $B^{*}$ \\ Stories \\ Effective Year Built \\ Vacancy Rate
}

Socioeconomic Control

Median $\mathrm{HH}$ Income (\$1000s)

Centrality Control

Distance Freeway

(miles)

Metropolitan Control**

Atlanta

Cleveland

Miami

\author{
Office Beta Variable \\ 2.748 Constant \\ Structure Controls \\ Gross Leasable Area \\ -0.000190 (1000sq.ft.) \\ 0.361 Average Unit Size \\ 0.110 Stories \\ 0.008 Effective Year Built \\ 0.000 Vacancy Rate \\ 0.000 Occupancy Control* \\ Senior \\ Student
}

Socioeconomic Control

Median $\mathrm{HH}$ Income

$\mathbf{0 . 0 0 1 3 7 5}$ (\$1000s)

Location Control

0.005676 Distance Freeway (mile)

Metropolitan Control**

-0.581 Atlanta

-0.834 Cleveland

-0.252 Miami
Multifamily Beta Variable

-2.468 Constant

Structure Controls

Gross Leasable Area

$\mathbf{0 . 0 0 0 2 2 0 ~ ( 1 0 0 0 s q . f t . ) ~}$

-0.001 Effective Year Built

0.016 Vacancy Rate

0.002 Facility Control ${ }^{*}$

0.003 Strip

Power

-0.076 Neighborhood

0.024 Community

Regional

Lifestyle

Retail

Socioeconomic Control

Median HH Income

$\mathbf{0 . 0 0 5 6 9 5}$ (\$1000s)

Location Control

0.003973 Distance Freeway (mile)

Metropolitan Control**

-0.347 Atlanta

-0.466 Cleveland

-0.134 Miami
Retail Beta

$-1.006$

$-0.001497$

0.002

$-0.001$

$-0.562$

$-0.282$

$-0.467$

$-0.463$

0.422

0.100

$-0.388$

0.005245

$-0.028301$

$-0.436$

$-0.694$

0.055 
Table 8.A1

Overall Regression Results for Office, Multifamily, and Retail Rents with Respect to Place Typology and Heavy Rail Transit Station Proximity-continued

\begin{tabular}{|c|c|c|c|c|c|}
\hline \multirow{2}{*}{\multicolumn{2}{|c|}{$\begin{array}{l}\text { Variable Office Beta } \\
\text { Place Typology Control }{ }^{* * *}\end{array}$}} & \multirow{2}{*}{\multicolumn{2}{|c|}{$\begin{array}{l}\text { Variable Multifamily Beta } \\
\text { Place Typology Control }{ }^{* * *}\end{array}$}} & \multirow{2}{*}{\multicolumn{2}{|c|}{$\begin{array}{l}\text { Variable Retail Beta } \\
\text { Place Typology Control*** }\end{array}$}} \\
\hline & & & & & \\
\hline Low MA Areas & $-9.0 \%$ & 6 Low MA Areas & $2.3 \%$ & Low MA Areas & $4.6 \%$ \\
\hline Moderate MA Areas & $-6.6 \%$ & Moderate MA Areas & $6.5 \%$ & Moderate MA Areas & $12.6 \%$ \\
\hline High MA Centers & $2.3 \%$ & o High MA Centers & $16.9 \%$ & High MA Centers & $27.8 \%$ \\
\hline Distance Band Treatment** & & Distance Band Treatment**** & & Distance Band Treatme & $* * * *$ \\
\hline$<=0.125$ & $14.0 \%$ & $\%<=0.125$ & $9.6 \%$ & $<=0.125$ & $35.2 \%$ \\
\hline$>0.125-0.250$ & $10.2 \%$ & $0>0.125-0.250$ & $6.0 \%$ & $>0.125-0.250$ & $23.6 \%$ \\
\hline$>0.250-0.375$ & $12.8 \%$ & $0>0.250-0.375$ & $7.0 \%$ & $>0.250-0.375$ & $4.7 \%$ \\
\hline$>0.375-0.500$ & $3.7 \%$ & $0>0.375-0.500$ & $9.9 \%$ & $>0.375-0.500$ & $3.8 \%$ \\
\hline$>0.500-0.625$ & $9.9 \%$ & $6>0.500-0.625$ & $2.2 \%$ & $>0.500-0.625$ & $12.3 \%$ \\
\hline$>0.625-0.750$ & $15.5 \%$ & o $>0.625-0.750$ & $3.7 \%$ & $>0.625-0.750$ & $10.1 \%$ \\
\hline$>0.750-0.875$ & $20.1 \%$ & $0>0.750-0.875$ & $1.1 \%$ & $>0.750-0.875$ & $12.4 \%$ \\
\hline$>0.875-1.000$ & $10.9 \%$ & $0>0.875-1.000$ & $-0.3 \%$ & $>0.875-1.000$ & \\
\hline Performance Metrics & & Performance Metrics & & Performance Metrics & \\
\hline Mean Rent/Square Foot & $\$ 30.50$ & Mean Rent/Square Foot & $\$ 1.54$ & Mean Rent/Square Foot & $\$ 28.88$ \\
\hline Cases & 2,477 & 7 Cases & 4,151 & Cases & 1,465 \\
\hline $\mathrm{R} 2$ adjusted & 0.574 & 4 R2 adjusted & 0.628 & 3 R2 adjusted & 0.499 \\
\hline $\begin{array}{l}\text { Std. Error of the } \\
\text { Estimate }\end{array}$ & 0.354 & $\begin{array}{l}\text { Std. Error of the } \\
4 \text { Estimate }\end{array}$ & 0.286 & $\begin{array}{l}\text { Std. Error of the } \\
\text { Estimate }\end{array}$ & 0.465 \\
\hline F-Ratio & 152.927 & 7 F-Ratio & 305.312 & F-Ratio & 57.076 \\
\hline${ }^{*}$ Class $\mathrm{C}$ is referent & & ${ }^{*}$ All other occupancy is referent & & $\begin{array}{l}{ }^{*} \text { All other retail is } \\
\text { referent }\end{array}$ & \\
\hline${ }^{* *}$ Washington, $\mathrm{DC}$ is referent & & ${ }^{* *}$ Washington, DC is referent & & ${ }^{* *}$ Washington, $\mathrm{DC}$ is re & \\
\hline${ }^{* * *}$ Poor MA Places are referent & & ${ }^{* * *}$ Poor MA Places are referent & & ${ }^{* * *}$ Poor MA Places are re & rent \\
\hline${ }^{* * * *}$ Cases $>1.00$-mile are referent & & ${ }^{* * * *}$ Cases $>1.00$-mile are referent & & ${ }^{* * * *}$ Cases $>1.00-$ mile are & eferent \\
\hline
\end{tabular}

Note: Bold coefficients are significant. 


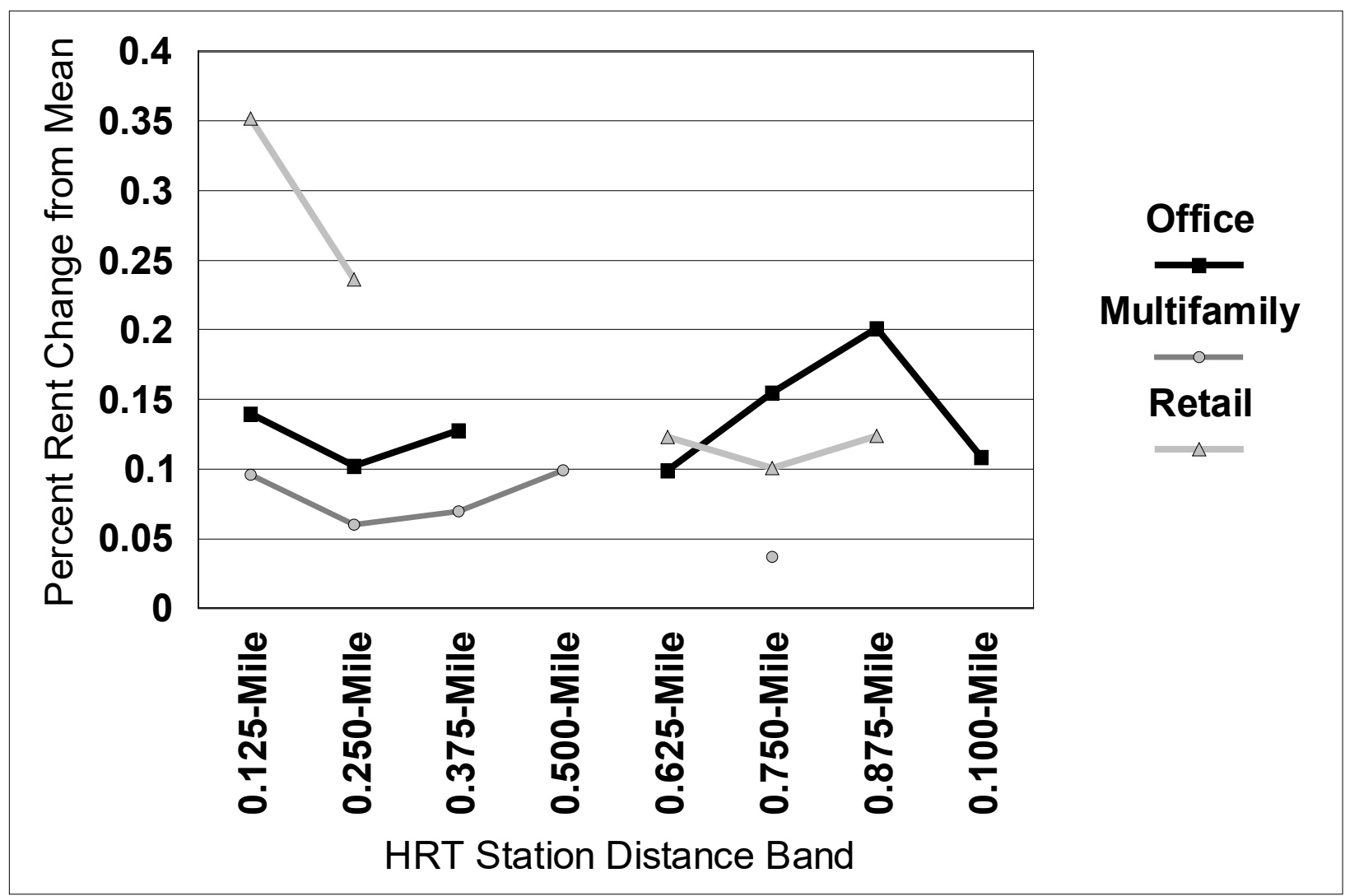

Figure 8.A1

Combined office, multifamily and retail rent premiums for heavy rail transit station proximity 


\section{CHAPTER 7 ADDENDUM B}

Office, Multifamily and Retail Rents with Respect to Express Bus Transit Station/Stop Proximity with Special Reference to Place Typology

In this addendum, we extend our brief analysis to "XBT" systems operating in the 32 metropolitan areas comprising our detailed analysis of LRT, SCT, BRT and CRT systems in the main part of this chapter. As with the brief analysis of HRT station proximity, we highlight findings with respect to office, multifamily and retail real estate proximity with special reference to Place Typologies. In this addendum we characterize XBT stations as also just stops as many seem to be.

Table 8.B1 reports the regression equation for each real estate type. The key indicators of model performance are similar to those reported for HRT systems though the coefficients of determination $\left(R^{2}\right)$ are a bit, though not problematically, lower.

We find that unlike for HRT systems though consistent with our analysis of all other systems, compared to Poor-Mixed Use/Accessibility areas, rents are highest in High-Mixed

Use/Accessibility places, next highest in Moderate-Mixed Use/Accessibility areas, and lowest in Low--Mixed Use/Accessibility areas.

More to the point, we are intrigued with results for individual types of real estate:

Office and multifamily rents rise with respect to distance from XBT stations/stops from 9.1 percent and 3.6 percent above the mean respectively in the first $(0.125$-mile) distance band to 10.5 percent and 5.8 percent above the mean in the second $(0.250$ mile) DB. Externalities appear to exist at or near the XBT station/stop but soon dissipate. Rents fall gradually for both types of real estate through the rest of the 1.00-mile study area. We surmise that the physical XBT station/stop itself may be the key source of externality that could be overcome through urban design.

In contrast, retail rents fall slightly but on the whole are about the same to the seventh (0.875-mile) distance band. Rents are also the lowest after controlling for other factors. We surmise retail real estate views proximity to XBT stations/stops as an amenity though simply being within a longer walking distance is also advantageous.

We explore XBT systems in more detail chapters 9 and 10. 
Table 8.B1

Overall Regression Results for Office, Multifamily, and Retail Rents with Respect to Place Typology and Express Bus Transit Station/Stop Proximity

\section{Variable \\ Constant \\ Structure Controls \\ Gross Leasable Area (1000sq.ft.) \\ Class $A^{*}$ \\ Class $B^{*}$ \\ Stories \\ Effective Year Built \\ Vacancy Rate}

Socioeconomic Control

Median $\mathrm{HH}$ Income (\$1000s)

Centrality Control

Distance Freeway (miles)

\author{
Office Beta Variable \\ 2.239 Constant \\ Structure Controls \\ Gross Leasable Area \\ -0.000079 (1000sq.ft.) \\ 0.330 Average Unit Size \\ 0.098 Stories \\ 0.006 Effective Year Built \\ 0.000 Vacancy Rate \\ -0.001 Occupancy Control* \\ Senior \\ Student
}

Socioeconomic Control

Median HH Income

0.001957 (\$1000s)

Location Control

$\mathbf{0 . 0 0 1 8 3 4}$ Distance Freeway (mile)
Multifamily Beta Variable

-2.722 Constant

\section{Structure Controls}

Gross Leasable Area

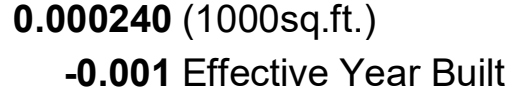

-0.010138 Distance Freeway (mile)
Retail Beta

$-0.085$

$-0.000399$

0.001

0.000

$-0.044$

0.066

$-0.033$

0.001

0.126

$-0.010$

0.114

0.001474

$-0.005734$

Table 8.B1 
Overall Regression Results for Office, Multifamily, and Retail Rents with Respect to Place Typology and Express Bus Transit Station/Stop Proximity-continued

Variable
Metropolitan Control**
Albuquerque
Atlanta
Austin
Buffalo
Charlotte
Cincinnati
Dallas-Fort Worth
Denver
Eugene-Springfield
Houston
Kansas City
Little Rock
Miami-SE Florida
Minneapolis-St. Paul
Nashville
New Orleans
Orlando
Phoenix
Pittsburgh
Portland
Reno
Sacramento

\begin{tabular}{|c|c|}
\hline \multirow{2}{*}{ Office Beta } & Variable \\
\hline & Metropolitan Control* \\
\hline \multicolumn{2}{|c|}{-0.455 Albuquerque } \\
\hline \multicolumn{2}{|c|}{-0.184 Atlanta } \\
\hline \multicolumn{2}{|c|}{-0.088 Austin } \\
\hline \multicolumn{2}{|c|}{-0.467 Buffalo } \\
\hline \multicolumn{2}{|c|}{-0.197 Charlotte } \\
\hline \multicolumn{2}{|c|}{-0.556 Cincinnati } \\
\hline$-0.28 \subseteq$ & 9 Dallas-Fort Worth \\
\hline \multicolumn{2}{|c|}{-0.050 Denver } \\
\hline \multicolumn{2}{|c|}{-0.162 Eugene-Springfield } \\
\hline \multicolumn{2}{|c|}{-0.229 Houston } \\
\hline \multicolumn{2}{|c|}{-0.407 Kansas City } \\
\hline \multicolumn{2}{|c|}{-0.365 Little Rock } \\
\hline \multicolumn{2}{|c|}{-0.040 Miami-SE Florida } \\
\hline \multicolumn{2}{|c|}{-0.436 Minneapolis-St. Paul } \\
\hline \multicolumn{2}{|c|}{-0.122 Nashville } \\
\hline \multicolumn{2}{|c|}{-0.391 New Orleans } \\
\hline \multicolumn{2}{|c|}{-0.153 Orlando } \\
\hline \multicolumn{2}{|c|}{-0.248 Phoenix } \\
\hline \multicolumn{2}{|c|}{-0.296 Pittsburgh } \\
\hline \multicolumn{2}{|c|}{-0.136 Portland } \\
\hline \multicolumn{2}{|c|}{-0.247 Reno } \\
\hline-0.174 & 4 Sacramento \\
\hline
\end{tabular}

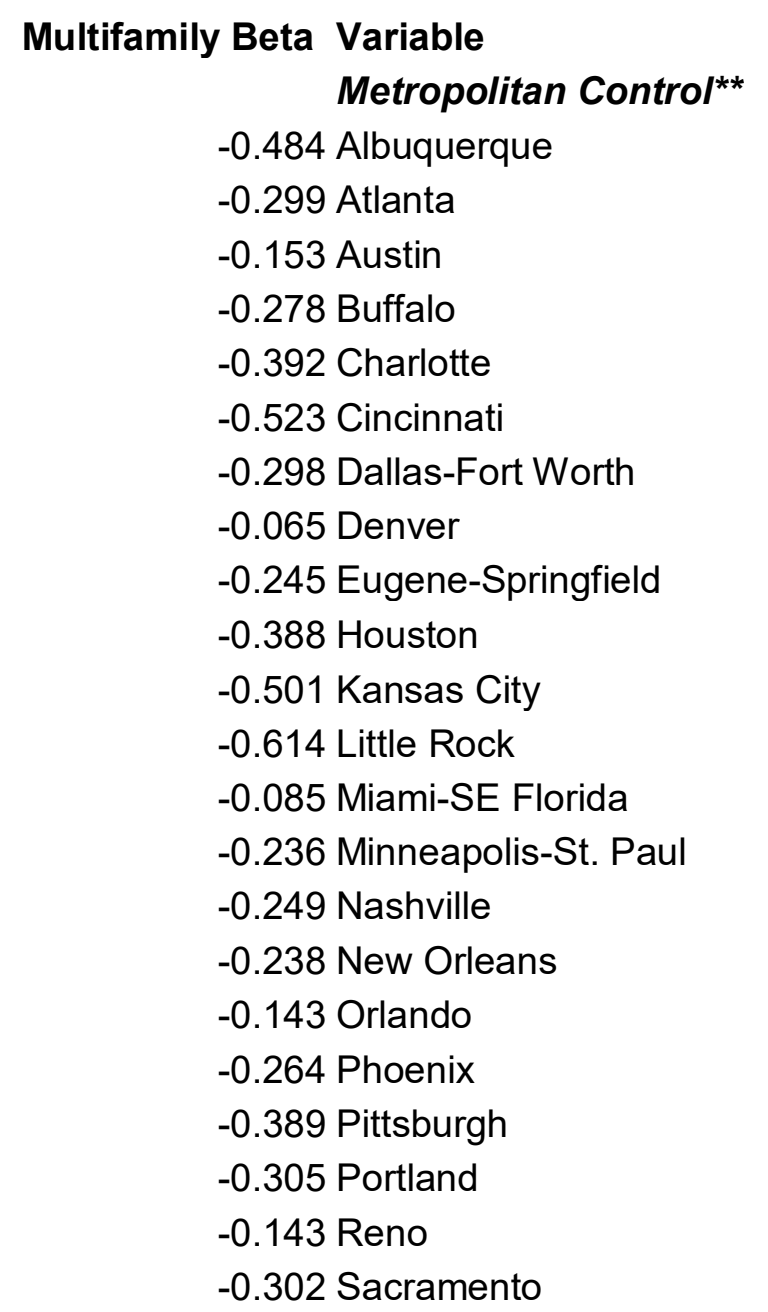

Retail Beta

$-0.315$

$-0.182$

$-0.059$

$-0.338$

$-0.140$

$-0.307$

$-0.233$

$-0.117$

$-0.166$

$-0.210$

$-0.314$

$-0.298$

$-0.036$

$-0.248$

$-0.141$

$-0.180$

$-0.121$

$-0.228$

$-0.268$

$-0.134$

$-0.222$

$-0.211$ 
Table 8.B1

Overall Regression Results for Office, Multifamily, and Retail Rents with Respect to Place Typology and Express Bus Transit Station/Stop Proximity-continued

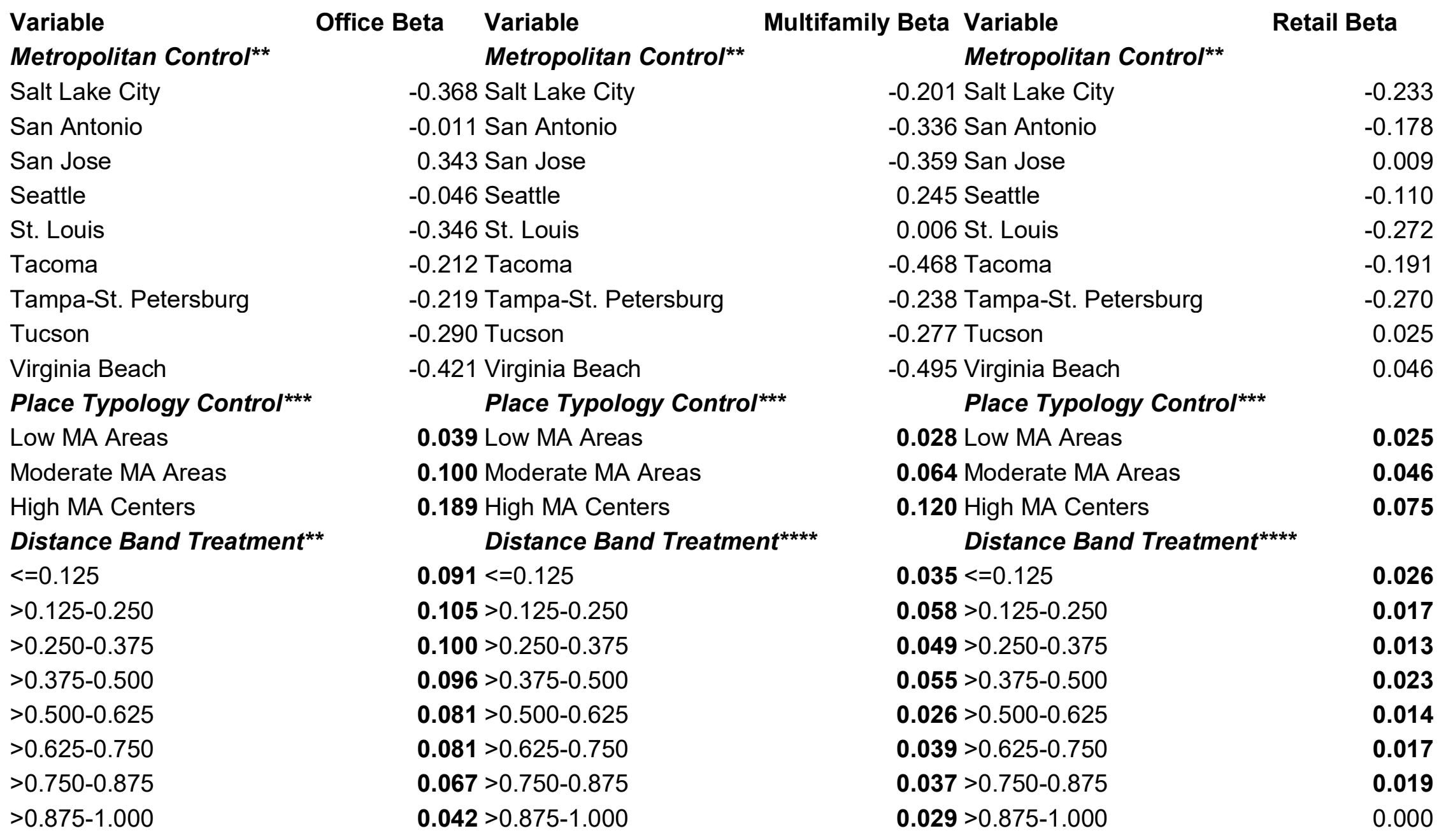


Table 8.B1

Overall Regression Results for Office, Multifamily, and Retail Rents with Respect to Place Typology and Express Bus Transit Station/Stop Proximity-continued

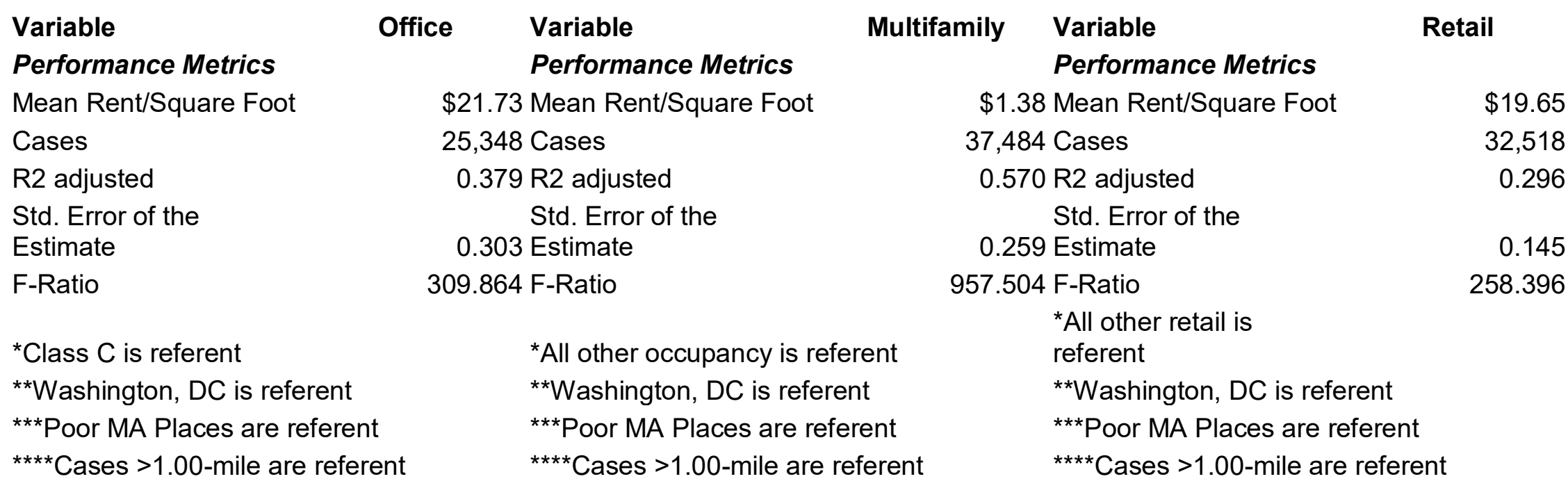




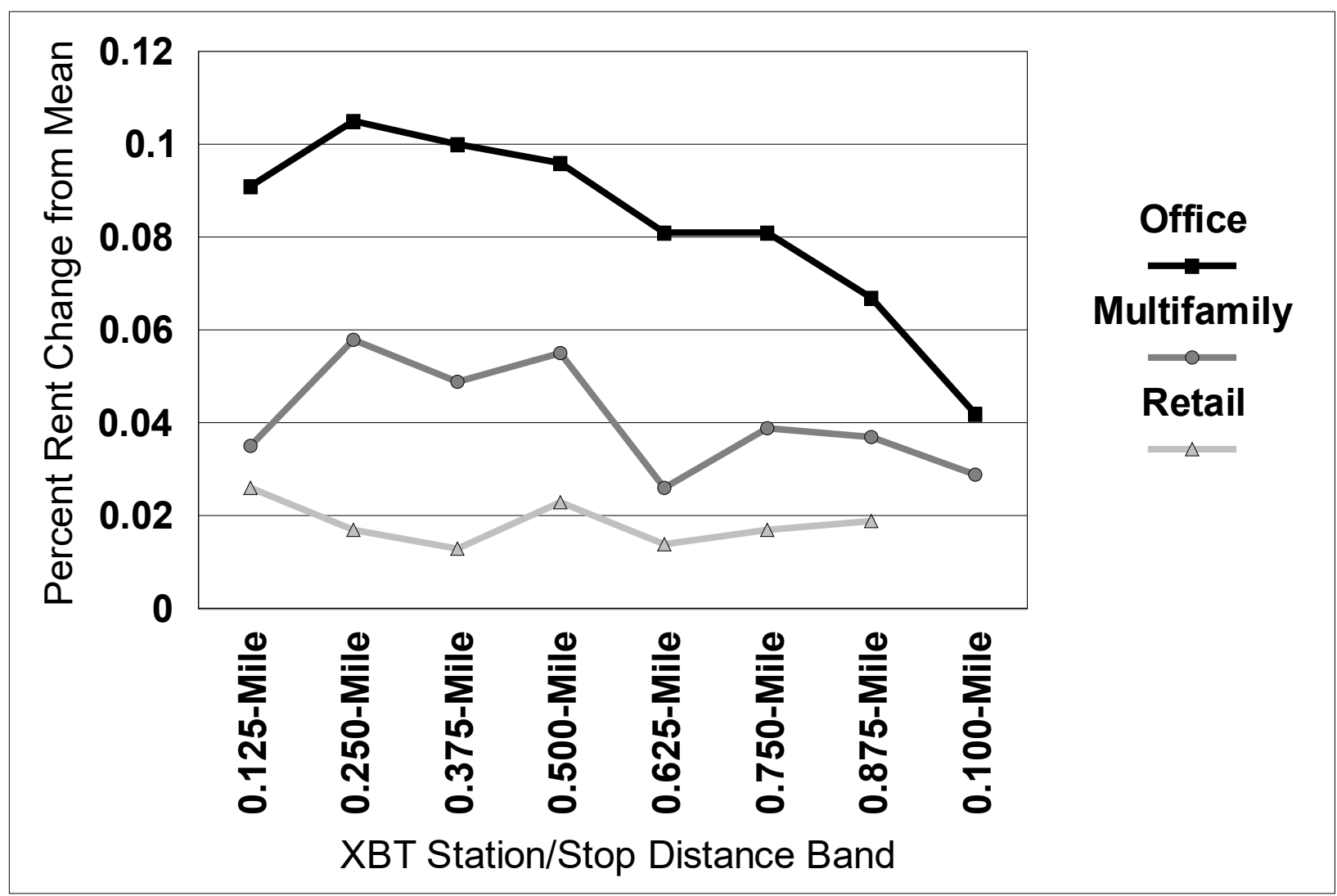

Figure 8.B1

Combined office, multifamily and retail rent premiums for express bus transit station/stop proximity 


\section{CHAPTER 9: The (Overlooked) Association between Express Bus Station/Stop Proximity and Multifamily Rents with Implications for Transit and Land Use Planning}

\section{OVERVIEW}

Despite hundreds of studies into the association between real estate value and proximity to fixed route transit (FRT) systems, none has assessed the association with respect to express bus transit (XBT) stations/stops. Ours is the first to do so. Using a static, cross-section quasiexperimental research design, we evaluate CoStar multifamily (MF) rent per square foot to estimate the difference in rent with respect to proximity to (XBT) stations/stops. However, we are also interested in knowing whether there are synergistic price effects at the intersection of XBT and other FRT systems such as light rail transit (LRT). In this article, we estimate the MF rent premium with respect to XBT and LRT (XBT+LRT) station/stop proximity separately, rent premiums for combined XBT and LRT stations/stops, and for those MF cases that are more than 1.0 mile beyond the nearest LRT station. In all cases, whether separately or combined with LRT stations or away from LRT stations, with find positive associations between MF rent and proximity to XBT stations/stops. However, we also find evidence of negative externalities at or near XBT, LRT, and XBT+LRT stations/stops. Express bus transit and land use planning implications are offered.

The research and modeling used in this chapter is essentially a "proof of concept" in creating a simple yet robust method of measuring interactive effects of two different transit modes intersecting at or near the same location. As the proof of concept appears successful, we expand it in Chapter 9 to include Place Typologies and extend the interactive construct to evaluate differential rent outcomes associated with light rail transit systems intersecting streetcar transit (SCT) systems, bus rapid transit (BRT) systems, and commuter rail transit (CRT) systems. 


\section{Introduction}

This chapter extends theoretical constructs developed in Chapter 7 and applies them to express bus systems. As such, we refer to Chapter 7 for much of the theoretical foundation. Before proceeding, we need to differentiate between types of bus service. The most common is conventional bus service where standard buses make numerous stops along routes that can change frequently.

Then there are bus rapid transit (BRT) and express bus transit (XBT) systems. The Metropolitan Atlanta Rapid Transportation Authority (nd; see also Nikitas and Karlsson 2015) provides a useful way in which to distinguish between XBT and BRT systems as paraphrased below:

Express Buses (also known as commuter bus service) is intended to run faster than normal bus services between the same two commuter or destination points. Express bus service usually has a limited number of stops to decrease the travel time. It uses flexible stop locations with various design options

BRT is a fixed-route bus mode that is characterized by operations primarily in dedicated right-of-way during peak periods and features that emulate rail fixed guideway services, including: (a) defined stations/stops, (b) traffic signal priority, (c) short headway, (d) bidirectional services, (e) pre-board ticketing, (f) platform level boarding and (g) separate branding. BRT may include portions of service that are fixed-guideway and non-fixedguideway. It typically uses fixed stations/stops with a pre-boarding payment. Some systems have flexible stop locations.

We acknowledge that there are important differences between types of express busses from conventional busses to modern, sleek busses designed for express bus purposes (see Figure 9.1). We provide further details on XBT systems below.

Our chapter is comprised of four sections. In the first, we summarize relevant theory from Chapter 7, pose the research questions and outline a research strategy. The second section describes our research plan in terms of the research design, the general model that will be used to guide data and analysis, our choice of functional form, the study area, the specific model and data, and identification of transit data challenges. The third section presents our results and offers discussion. The final section offers our implications for express bus transit and land use planning. 


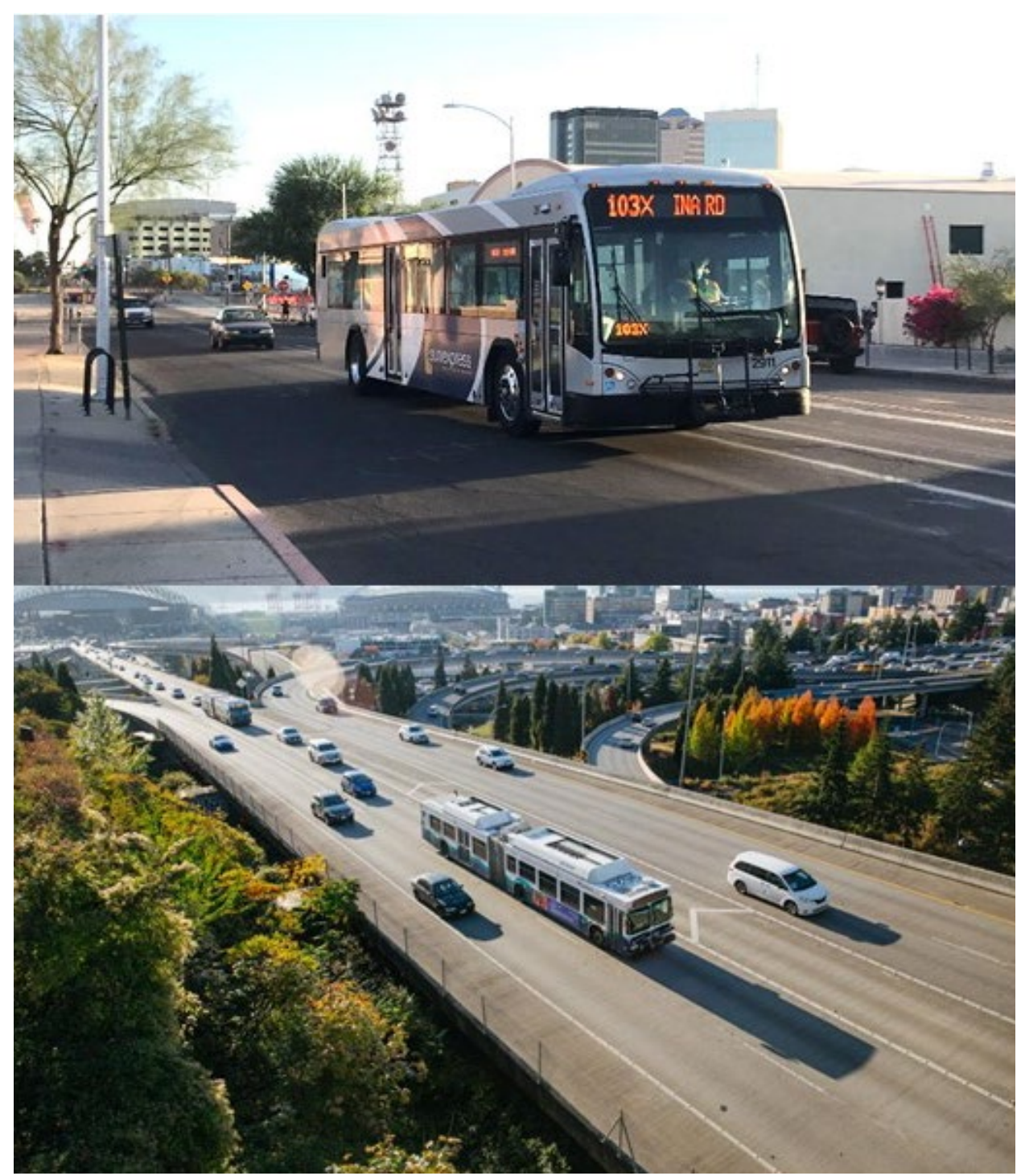

\section{Figure 9.1}

\section{Wide Spectrum of Express Busses}

Express busses come in many different types. The top image is an express bus operating in Tucson, Ariz. It is little more than a conventional bus with express bus routes. (Image courtesy of Koren Manning.) The bottom image is an express bus (with one trailing in the distance) operating in Seattle, Wash. It is an articulated bus that is designed for customer convenience such as comfortable high-back reclining seats, overhead storage, and other amenities. (Image from https://www.soundtransit.org/get-to-know-us/our-brand/photography.) 


\section{Theory And Research Questions}

Conventional urban location theory shows that where all jobs are in the central business district (CBD), the cost of transportation increases with respect to distance from the CBD at a declining rate. Transportation costs reduce land value as distance from the CBD increases. Where transportation costs are lowest, in the CBD, land prices are highest. There is thus competition for location near CBDs considering the land use needs among competing office, retail, institutional, residential and other land uses. Only those land uses that generate the highest economic exchanges win the most central locations. Land uses that cannot compete for CBD locations are pushed outward to areas where they can outbid other land uses, a process called land use invasion and succession based on ecological principles. As one relaxes constraints of the AMM monocentric city model, it is possible to imagine the same principles are at work only at smaller scales in a more distributed fashion that can, for instance, lead to localized, smaller versions of CBDs generally and especially around transit stations. Whether this can occur around express bus transit (XBT) stations or stops has not been investigated. Given XBT systems are primarily a commuting service for suburban residents and in the context of theory and prior research, our research question is:

\section{Do multifamily rents increase with respect to proximity to XBT stations/stops?}

There is another context that we want to explore: the extent to which the interaction between XBT and other types of FRT stations/stops also affects real estate value. Many XBT stations/stops connect to FRT stations/stops either directly or nearby. Indeed, many XBT lines terminate at FRT stations/stops.

Our particular study area includes 16 light rail transit (LRT) systems operating in the US excluding major metropolitan areas of the Northeast and Great Lakes regions (defined as more than five million residents) as well as the Los Angeles and San Francisco metropolitan areas. Those metropolitan areas are excluded because their complex web of different types of transit systems makes it difficult to tease out difference effects attributable to any given transit mode. Our data thus allows us to estimate synergistic or value added association. In particular, we can estimate whether and the extent to which XBT and LRT systems sharing the same stations areas add real estate value because they improve the accessibility of nearby property to more residents in the metropolitan area. We call these combined XBT+LRT stations/stops. Consistent with theoretical expectations, we should find rent positive rent premiums with respect to $\mathrm{XBT+LRT} \mathrm{station/stop} \mathrm{proximity.} \mathrm{Our} \mathrm{second} \mathrm{research} \mathrm{question} \mathrm{is} \mathrm{thus:}$

\section{Do multifamily rents increase with respect to proximity to combined $X B T+L R T$ stations/stops?}

We proceed with our research plan. This is followed by results with interpretations. We conclude our article with implications for XBT stations/stops and land use planning. 


\section{Research Plan}

This section presents our research plan including research design, general model, functional form, study area, and specific model and data.

\section{Research Design}

We apply theory through a static, cross-section quasi-experimental research design. That is, using one period of time (2018), we test for the effect of XBT station and combined XBT+LRT station/stop proximity on multifamily rents across multiple metropolitan areas with XBT and LRT systems. Though analysis is not causal, associations can be used as guidance for transit and land use planning purposes. For reasons noted below, we use rent instead of sales as a proxy for real estate value (Nelson and Hibberd 2019).

\section{General Model}

Using these theoretical and research design foundations as a guide, we develop the following general model to test the theory. It is adapted from Nelson (2017):

\section{$\mathrm{R}_{i}=\mathrm{f}\left(\mathrm{S}_{i}, \mathrm{SES}_{i}, \mathrm{U}_{i}, \mathrm{C}_{i}, \mathrm{DB}_{i}, \mathrm{M}_{i}\right)$}

\section{Where:}

$\mathbf{R}$ is the asking rent per square foot for property $i$;

$\mathbf{S}$ is the set of structural attributes of property $i$ including its architecture, mass, height, age and effective age, interior amenities, flow efficiencies and so forth;

SES is the set of socioeconomic characteristics of the vicinity of property $i$ such as population features, income, education;

$\mathbf{U}$ is a set of measures of urban form of the vicinity of property $i$ such as the nature of surrounding land uses, terrain, physical amenities (such as parks), street characteristics and related;

C is a set of centrality attributes of property $i$ such as distance to downtown and distance to the nearest freeway/expressway ramps;

DB is the distance band (see below for specification details) of property $i$ to an XBT station/stop as well the distance band of the same property to an XBT station within one-half mile of another kind of FRT station, being LRT stations in this case; and

$\mathbf{M}$ is a set of metropolitan area controls. As metropolitan area conditions and markets vary between them, identifying the location of property $i$ within its respective market helps control for metropolitan-specific influences. 


\section{Study Area}

For prior research, we created a dataset comprised of 16 metropolitan areas with LRT systems. These metropolitan areas also have XBT systems which we identified through assembly of General Transit Feed Specification data reported by local transit agencies.

We apply our model to these metropolitan areas. However, we exclude specialized bus services such as "airporters". We note that sometimes XBT bus routes runs parallel with conventional buses but we mapped only XBT stations/stops. We took advantage of another opportunity: Because they include both LRT and XBT systems, we can evaluate interaction effects where or near where they interconnect. We discuss this is more detail below.

Finally, we note that some metropolitan areas served by LRT systems are also served by other forms of FRT systems such as BRT, street car transit, and commuter rail transit systems. Only two metropolitan areas have all systems (Dallas and Salt Lake City) while others have one or two of those systems but not all of them. Future work will extend the analysis presented in this article to the interaction of XBT systems with all those other modes considering all metropolitan areas in which they operate, as well as between other modes such as LRT and BRT systems. In this respect, our article establishes a proof-of-concept for those extended analyses.

\section{Specific Model and Data}

We operationalize the general model dimensions and functional form here. Notably, we report the statistical association between rent per square foot for multifamily properties with respect to XBT station proximity as well as combined XBT and FRT stations/stops using one-eighth mile distance bands to one-half mile, holding other factors constant.

$\mathbf{R}$ is the asking rent per square foot for property $i$ reported by CoStar during 2018. (CoStar has the largest, national commercial property data base where data are collected using a standardized protocol.) Rents are monthly per square foot. Normally, statistical analysis is applied to samples of a universe. In this case, the study includes the universe of all multifamily properties reported by CoStar in our study area. As CoStar data come from real estate brokerages participating in its network, the data exclude non-participating brokerages or entities and properties not for rent such as owner-occupied properties. By logging the dependent variable, the semi-log model allows for coefficients to be interpreted as the percent change in rent attributable to a one unit change in an independent variable such as an individual distance band.

$\mathbf{S}$ is the bundle of structure and lease restriction attributes for property $i$ reported by CoStar. This includes occupancy characteristics noted below. For all properties, this includes:

Gross leasable area in building square feet with the expectation that there will be a positive association between building area and rent because larger buildings presumably include more amenities than smaller ones.

Effective year built which is the later of the year of construction or the year of renovation as reported by CoStar with the expectation that newer buildings will command more rent than older ones.

Vacancy rate with the expectation that the higher the vacant rate the lower the rent. However, this may not always be the case as high demand markets could result in high vacancy rates as owners wait for higher paying tenants. Accordingly, signs may not be 
predictable especially considering that the study area is comprised of stable to rapidly growing central counties.

The number of Stories is also included with the expectation that the taller the building the higher the mean rent. However, for retail, Stories are excluded because of scant variation among retail structures.

Occupancy restrictions are also included, notably Senior or Student housing with Market Rate housing being the referent. The expectation is that relative to Market Rate multifamily units, rents for Student housing will be lower because average annual rents will be based on occupancy during only part of the year. Rents for Senior housing will be higher assuming that seniors will be willing to pay more for apartments where others seniors live and thus enjoy similar interests as well as services. These are binary (yes $=1$, no=0) variables.

The SES dimension is comprised of Median Household Income from the five-year sample of the 2016 American Community Survey (ACS) for the block group within which a CoStar property is located, for which a positive association is expected with respect to rent (Xiao 2016). Two variables comprise the $\mathbf{U}$ dimension: One for a version of jobs-housing balance and the other for entropy as a measure of land use mix.

Workers-per-labor-force-member is our calculation of jobs-housing balance, being the number of jobs in a census block group (BG) from the Longitudinal EmploymentHousehold Dynamics database divided by the number of residents of labor force age (being 15 to 65 years old). The higher the ratio the more people work in the BG relative to those who live there. As such, more pressure is put on rents so we expect a positive association (Stoker and Ewing 2014).

Entropy, is patterned after Ewing and Hamidi (2018) who use an entropy calculation as a proxy for land use mix. The greater the mix, the higher rents should be because of efficiencies gained in the interaction between land uses.

A normalized entropy measure is applied as follows:

$\sum_{i=1}^{n} \sum_{j}\left(\left(P_{j} * L N\left(P_{j}\right)\right) / L N(j)\right)$

where:

$i$ is the enumeration unit-in this case census block groups, $n$ equals the number of units per county, $j$ equals the number of employment sectors, and $P j=$ proportion of jobs in sector $j$. This measure denotes the degree of land use similarity or dissimilarity in each enumeration unit. The normalizing weight is the natural log of the number of sectors. The entropy index is interpreted as follows: the higher the number, which is between 0 and 1 , the more evenly mixed the land uses are by employment sector.

Two variables comprise the $\mathbf{C}$ dimension: one for downtown distance and the other for freeway ramp distance. 
The first location control is Distance from Downtown for which a negative association is expected based on the AMM theory. Using Google Earth, we identified the central most point of each downtown.

The second location control is Distance from Freeway which is defined as the nearest freeway or expressway ramp. Because freeway ramps can be considered nuisances in addition to being an accessibility benefit, no signs of association are predicted.

We now discuss the DB or distance band variable. DB is used in two ways, one for location in a distance band from the nearest XBT station and the other for the distance band nearest to a combined XBT and another FRT station.

For XBT location, distance band is the location of the multifamily property within one-eighth mile distance bands of the nearest XBT station to 0.50 mile. We note this as the DXBT variable. We use closest distance, calling it the "front door", assuming that, over time, structures will orient themselves to be close to transit stations/stops. (We anticipate future research will address network distance.) We also measure straight line distance; future research will measure network distance. The 0.50 mile distance is used because that is the distance within which the largest share of market premiums associated with FRT station proximity occurs (Nelson et al. 2015; Petheram et al. 2013).

The same one-eighth mile distance band measures are used for multifamily properties within 0.50 mile of where XBT and other LRT stations/stops intersect. These are called DBXBT+LRT, stations/stops.

Both sets of DB variables are binary for 0.125 -mile to (0.50-mile mile with cases beyond 0.50 mile being the referent.

The $\mathbf{M}$ dimension is comprised of the individual metropolitan areas within which the LRT systems we used for the XBT analysis operate. As these are controls which account for idiosyncrasies of metropolitan markets, no direction of associations is predicted. We use San Diego as the referent.

We used the General Transit Feed Specification (GTFS) platform to identify XBT systems (33). It is the most commonly used format for specifying public transit systems. We also double checked XBT systems identified in the GTFS with a review of transit agency web sites to confirm.

Though XBT and BRT services are different, as we note above, prior BRT research can shed light on our research expectations. For the most part, prior research has found positive albeit small associations between single family residential values and proximity to BRT stations/stops (Nelson and Ganning 2015; Higgins and Kanaroglou 2016; Perk et al. 2017. Prior research found that multifamily rents were 3.0 percent higher than the regional mean within the first one-half mile of BRT stations/stops and 1.7 percent higher in the next one-half mile distance band (8). Using a much larger database, however, more recent research has found that multifamily rents rise with respect to distance from BRT stations/stops suggestion the presence of negative externalities at BRT stations/stops (Barbeau 2018). Prior research on BRT influences on nearby multifamily rents is thus mixed.

We address the research questions with three sets of regression analyses. We first estimate the association between multifamily rents per square foot and proximity to XBT and LRT stations/stops 
in the same equation. We then estimate the association between rent and proximity to combined XBT+LRT stations/stops. We finally estimate the association between rent and distance from XBT stations/stops for those cases more than 1.0 mile from the nearest LRT station. Table 9.1 reports our variables, data sources, measurement type, and predicted association between the dependent variable (logged rent per square foot) and the independent ones.

We acknowledge that our model does not include any transit service-related factors such as the number of bus routes at a station, station spacing, headway, service span and so forth. These quality of service measures may reveal incremental willingness to pay higher rent with respect to distance to specific stations/stops. It is an area ripe for future research mostly because it has never been done in the context of real estate transit value added. Part of that research may include efforts to improve open data standards to meet the needs of transportation researchers, as discussed below. Second, as in all prior real estate value transit added research, our theory is based on incremental change in value (rents) with respect to transit station proximity, not with respect to level and quality of service. Finally, like all real estate transit valued added research, our aim is to determine central tendencies, directions of association, and proximate as opposed to precise estimates of value added with respect to transit station proximity.

With 27,847 cases, our model includes many times more data than used in most prior studies (see Higgins and Kanaroglou 2016 for comparison). While we have no a priori expectations of goodness of fit outcomes, literature suggests that ordinary least squares hedonic (regression) analysis usually explain about one fifth to two-thirds of the variation in the observed rent for cases. Some analysts may be preoccupied with achieving high levels of regression model explanation. Yet, too many variables can lead to over-specification. It is best to emphasize the variables most relevant to the question along with relevant controls sufficient to avoid serious omitted variable bias (a form of endogeneity) in the model. Our model is based on both theory and a large body of prior empirical work.

Our key interest is the association between rents per square foot and distance band with respect to the nearest XBT station/stop as well as nearest combined XBT+LRT station/stop. While a positive association is expected between DBs and XBT stations/stops, negative associations can signal externality effects noted above. For instance, areas very near stations/stops may have nuisances such as traffic, noise, and poor urban design that offset positive effects of proximity. But DBs farther away may reveal positive rent coefficients. Finally, the DB approach allows us to estimate how far away from transit stations/stops the market values proximity, which is important for transit and land use planning. In the regression results reported below, significant DB coefficients, where $p<0.10$ of the two-tailed test, are noted in bold in Table 9.1. Theory allows for both positive and negative signs, with negative signs indicating negative externalities associated with XBT and LRT stations/stops and nearby MF real estate. 
Table 9.1

Variables, Data Sources, Measurement Type, and Predicted Association with Respect to Rent per Square Foot

\begin{tabular}{|c|c|c|c|}
\hline Variable & Data Source & Measure & Predicted Sign \\
\hline \multicolumn{4}{|l|}{ Rent } \\
\hline Rent per Square Foot (logged) & CoStar & Continuous & na \\
\hline \multicolumn{4}{|l|}{ Structure Controls } \\
\hline Gross Leasable Area, Square & & Continuous & \\
\hline Feet & CoStar & & + \\
\hline Unit Size, Square Feet & CoStar & Continuous & - \\
\hline Stories & CoStar & Continuous & + \\
\hline Effective Year Built & CoStar & & + \\
\hline Vacancy Rate & CoStar & Continuous & - \\
\hline \multicolumn{4}{|l|}{ Occupancy Control } \\
\hline Senior & CoStar & Binary & + \\
\hline Student & CoStar & Binary & - \\
\hline \multicolumn{4}{|l|}{ Socioeconomic Control } \\
\hline Median Household $(\mathrm{HH})$ & & Continuous & \\
\hline Income & Census ACS & & + \\
\hline \multicolumn{4}{|l|}{ Land Use Mix Controls } \\
\hline Workers per Labor Force & & Continuous & \\
\hline Member & LEHD, ACS & & + \\
\hline Entropy & LEHD & Continuous & + \\
\hline \multicolumn{4}{|l|}{ Location Controls } \\
\hline Distance Downtown Center & Computed & Continuous & + \\
\hline Distance Freeway Ramp & Computed & Continuous & $+/-$ \\
\hline \multicolumn{4}{|l|}{ Distance Band } \\
\hline $1 / 8$ mile bands to 1.0 mile & Computed & Categorical & $+/-$ \\
\hline \multicolumn{4}{|l|}{ Metropolitan Area } \\
\hline Metropolitan Area Location & Census & Binary & na \\
\hline
\end{tabular}




\section{RESULTS AND DISCUSSION}

Table 9.2 reports results the three regressions used to address the two research questions as follows:

The first regression estimates the association based on proximity to XBT stations/stops that includes LRT stations in the same equation.

The second regression reports the estimates of rent premium proximity with respect to $\mathrm{XBT}$ and LRT stations/stops in the same location, which we hypothesize as creating a combined XBT+LRT interaction.

The third regression tests for proximity associations for only those cases that are more than 1.0 mile from the nearest LRT station. This avoids potential interactive associations that are addressed in the second regression.

Future research will explore different ways in which to control for interactive effects between transit modes based on types of modes, distances between stations/stops, and types of stations/stops such as park-and-ride versus a downtown multimodal center.

For all three equations, the coefficients of determination $\left(R^{2}\right)$ show that the equations explain more than half of the variation of rents and the F-ratios show the equations outcomes to be considerably beyond chance.

We now review results for the control variables first and then those for the station/stop proximity treatment variables. As expected among the control variables (excluding metropolitan controls):

Rent increases as the size of a multifamily complex increases reflecting amenities that are more commonly offered in larger complexes than smaller ones;

Rent decreases as the average size of an apartment unit increases reflecting declining marginal value to renters;

As building height increases reflected by the number of floors or stories, mean rent increases reflecting elevation away from the hustle and bustle of the ground level as well as views and perhaps improved air flow;

As the effective year in which the structure was built (or renovated) increases (more recent years have a higher value than earlier years), rent increases;

As the structure vacancy rate increases rent also increases though only slightlynormally, higher vacancy rates might be associated with lower rents but in many markets landlords will push rents as units turn over as they capture renters' increasing willingness to pay for housing;

On average rents for units restricted to seniors decreases in part because subsidies may limit rents but also in part because seniors may impose less wear and tear on units which is reflected in lower rents; 
On average rents for units restricted to students decreases in part because their high turnover and large periods of vacancy during summer months lowers the annual average monthly rent;

As the median household income of the block group (BG) in which the multifamily structure is located increases, so does rent;

As the ratio of jobs located in the block increase proportionate to the number of BG residents who are in the labor force, the higher the rent;

Rent increases as the mix of land uses in the BG—entropy-increases;

As distance from the downtown increases rents fall; and

As distance from the nearest freeway ramp increases rents also fall.

We note that as controls for metropolitan-specific market characteristics, the coefficients for the metropolitan variables are not directly relevant to the interpretation of results with respect to transit stations/stops. Since we use Virginia Beach as our referent, the coefficient for Seattle indicates only that the mean rent per square foot in the Seattle market is 33.6 percent higher than the mean rent in Virginia Beach. In contrast, the mean rent for the St. Louis market is actually 14.0 percent lower than the mean rent in the Virginia Beach market.

Results for proximity effects on MF rent per square foot are reviewed next. Figure 9.2 illustrates all four of the proximity related rent associations that are estimated:

Distance from XBT stations/stops;

Distance from LRT stations;

Distance from combined XBT+LRT stations/stops; and

Distance from XBT stations/stops for those cases beyond 1.0 mile from the nearest LRT station. 
Table 9.2

Association between XBT, LRT and XBT+LRT Station/Stop Proximity and Multifamily Rent per Square Foot

Variable
Constant
Structure Controls
Gross Leasable Square Feet.
Average Unit Size, Square
Feet
Stories
Effective Year Built
Vacancy Rate
Senior Restricted*
Student Restricted*
Socioeconomic Control
Median HH Income
Urban Form Controls
BG Labor Force Balance
Entropy
Centrality Controls
Distance Downtown
Distance Freeway Ramp

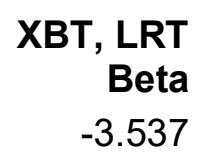

0.024

0.002

0.004

$-0.058$

$-0.050$

4.000E-003

$-5.858 E-006$

0.088

$-1.047 E-006$

$-5.85 \mathrm{E}-007$

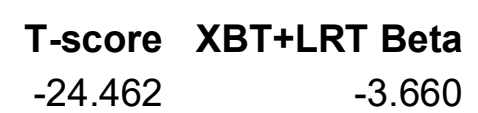

23.914

$-72.047$

31.116

26.282

21.101

$-7.326$

$-2.803$

53.217

$-2.674$

11.960

$-23.720$

$-1.993$

$3.233 E-007$
-0.001
0.022
0.002
0.004
-0.057
-0.051

0.004

$-8.596 E-006$
0.090
-9.180 E- 007
$-9.966 E-007$

T-score
-25.384

24.409

$-71.794$

28.134

27.296

20.947

$-7.159$

$-2.908$

53.522

$-3.927$

12.267

$-20.724$

$-3.461$
XBT1miLRT

Beta

$-3.950$

$\begin{array}{rr}\text { 2.621E-007 } & 18.174 \\ & \\ -\mathbf{0 . 0 0 1} & -57.619 \\ \mathbf{0 . 0 3 9} & 29.532 \\ \mathbf{0 . 0 0 2} & 20.890 \\ \mathbf{0 . 0 0 4} & 16.364 \\ \mathbf{- 0 . 0 3 7} & -4.157 \\ \mathbf{- 0 . 0 5 2} & -2.188\end{array}$

0.003

33.547

0.003

17.503

0.082

9.819

$-6.179 \mathrm{E}-007$

$-6.306 \mathrm{E}-007$
$-11.453$

$-2.094$ 
Table 9.2

Association between XBT, LRT and XBT+LRT Station/Stop Proximity and Multifamily Rent per Square Foot Continued

Variable
Metropolitan Controls**
Buffalo
Charlotte
Dallas
Denver
Houston
Minneapolis St. Paul
Phoenix
Pittsburgh
Portland
Sacramento
Salt Lake City
San Diego
San Jose
Seattle
St. Louis

\begin{tabular}{rrr} 
XBT, LRT Beta & \multicolumn{2}{c}{ T-score XBT+LRT Beta } \\
& & \\
$2.500 E-002$ & 1.106 & 0.032 \\
$-9.100 \mathrm{E}-002$ & -4.498 & -0.083 \\
0.082 & 4.548 & 0.070 \\
0.271 & 14.831 & 0.266 \\
-0.032 & -1.770 & -0.040 \\
0.103 & 5.679 & 0.104 \\
-0.053 & -2.933 & -0.061 \\
0.011 & 0.557 & 0.003 \\
0.184 & 10.064 & 0.186 \\
0.122 & 6.487 & 0.110 \\
-0.030 & -1.428 & -0.033 \\
0.474 & 26.349 & 0.463 \\
0.607 & 32.789 & 0.595 \\
0.336 & 18.763 & 0.333 \\
-0.140 & -7.228 & -0.151
\end{tabular}

$\begin{array}{rrr}\text { T-score } & \begin{array}{r}\text { XBT1miLRT } \\ \text { Beta }\end{array} & \text { T-score } \\ & & \\ 1.415 & 0.014 & 0.539 \\ -4.138 & -0.078 & -3.543 \\ 3.890 & 0.081 & 4.026 \\ 14.656 & 0.270 & 13.173 \\ -2.219 & -0.032 & -1.583 \\ 5.813 & 0.095 & 4.737 \\ -3.390 & -0.023 & -1.169 \\ 0.145 & 0.010 & 0.470 \\ 10.267 & 0.164 & 7.841 \\ 5.920 & 0.192 & 9.008 \\ -1.562 & -0.013 & -0.500 \\ 26.015 & 0.497 & 24.855 \\ 32.254 & 0.692 & 33.009 \\ 18.698 & 0.347 & 17.391 \\ -7.800 & -0.149 & -6.810\end{array}$


Table 9.2

Association between XBT, LRT and XBT+LRT Station/Stop Proximity and Multifamily Rent per Square Foot Continued

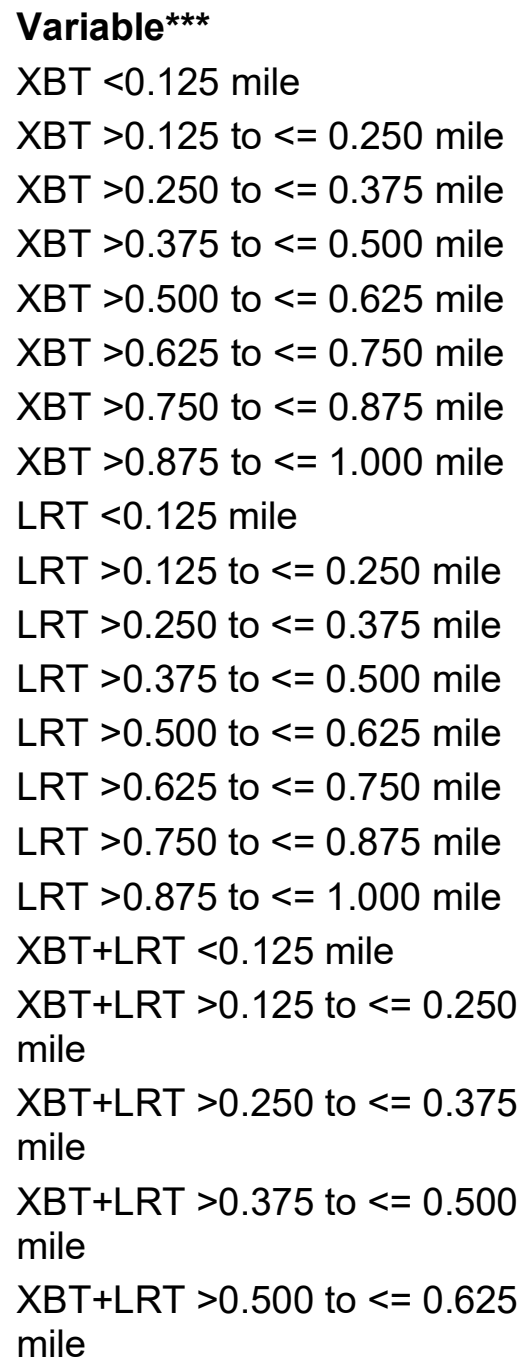

XBT, LRT Beta
0.046
0.067
0.049
0.050
0.034
$\mathbf{0 . 0 4 2}$
$\mathbf{0 . 0 4 6}$
$\mathbf{0 . 0 4 1}$
0.005
$\mathbf{0 . 0 4 0}$
$\mathbf{0 . 0 1 9}$
$\mathbf{0 . 0 3 7}$
$\mathbf{0 . 0 2 9}$
$\mathbf{0 . 0 3 8}$
$\mathbf{0 . 0 2 4}$
$\mathbf{0 . 0 3 9}$

$\begin{array}{rrr} & \text { XBT1miLRT } & \\ \text { T-score } & \text { Beta } & \text { T-score }\end{array}$




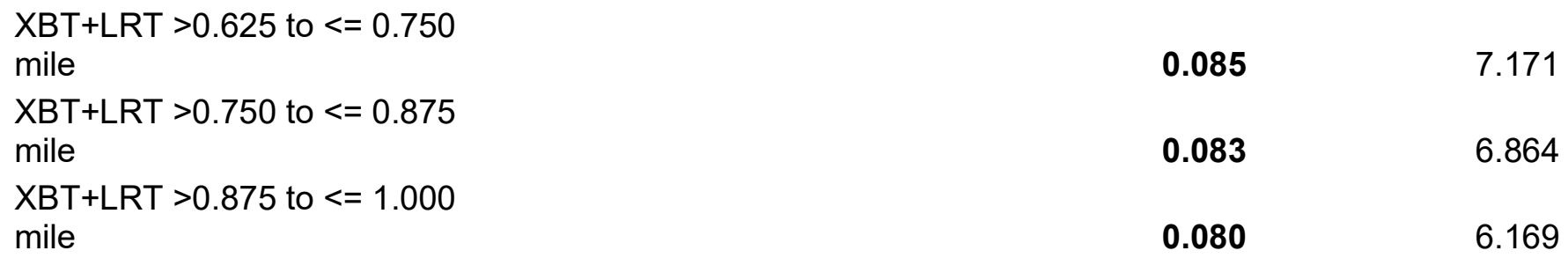

Table 9.2

Association between XBT, LRT and XBT+LRT Station/Stop Proximity and Multifamily Rent per Square Foot Continued

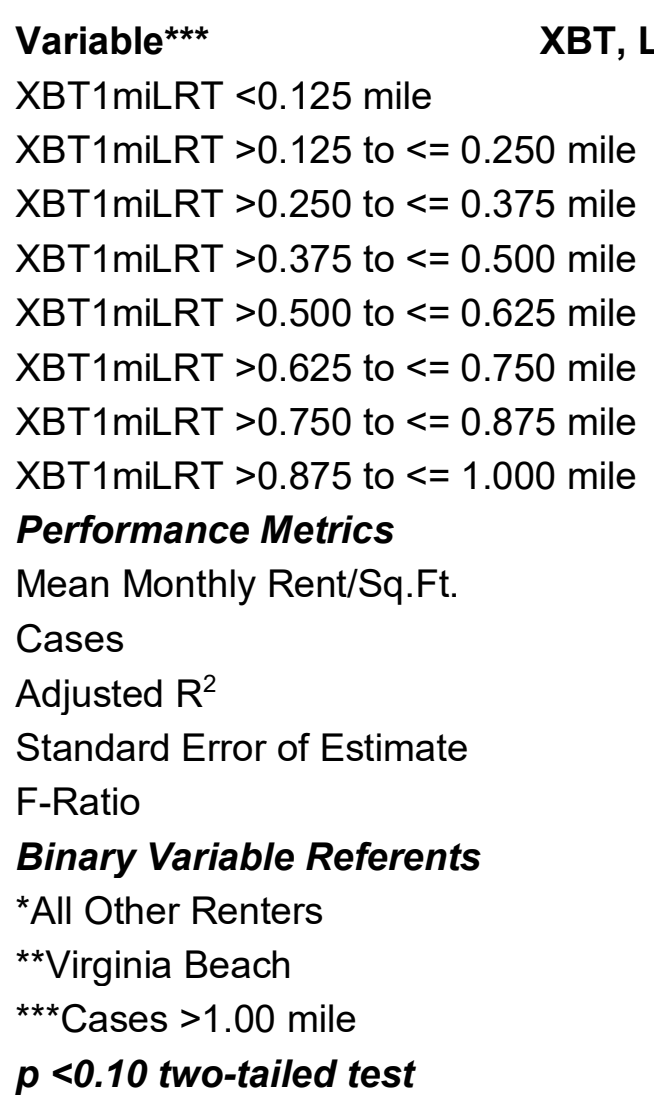

Adjusted $\mathrm{R}^{2}$

Standard Error of Estimate

F-Ratio

Binary Variable Referents

${ }^{*}$ All Other Renters

${ }^{* *}$ Virginia Beach

${ }^{* * *}$ Cases $>1.00$ mile

$p<0.10$ two-tailed test 


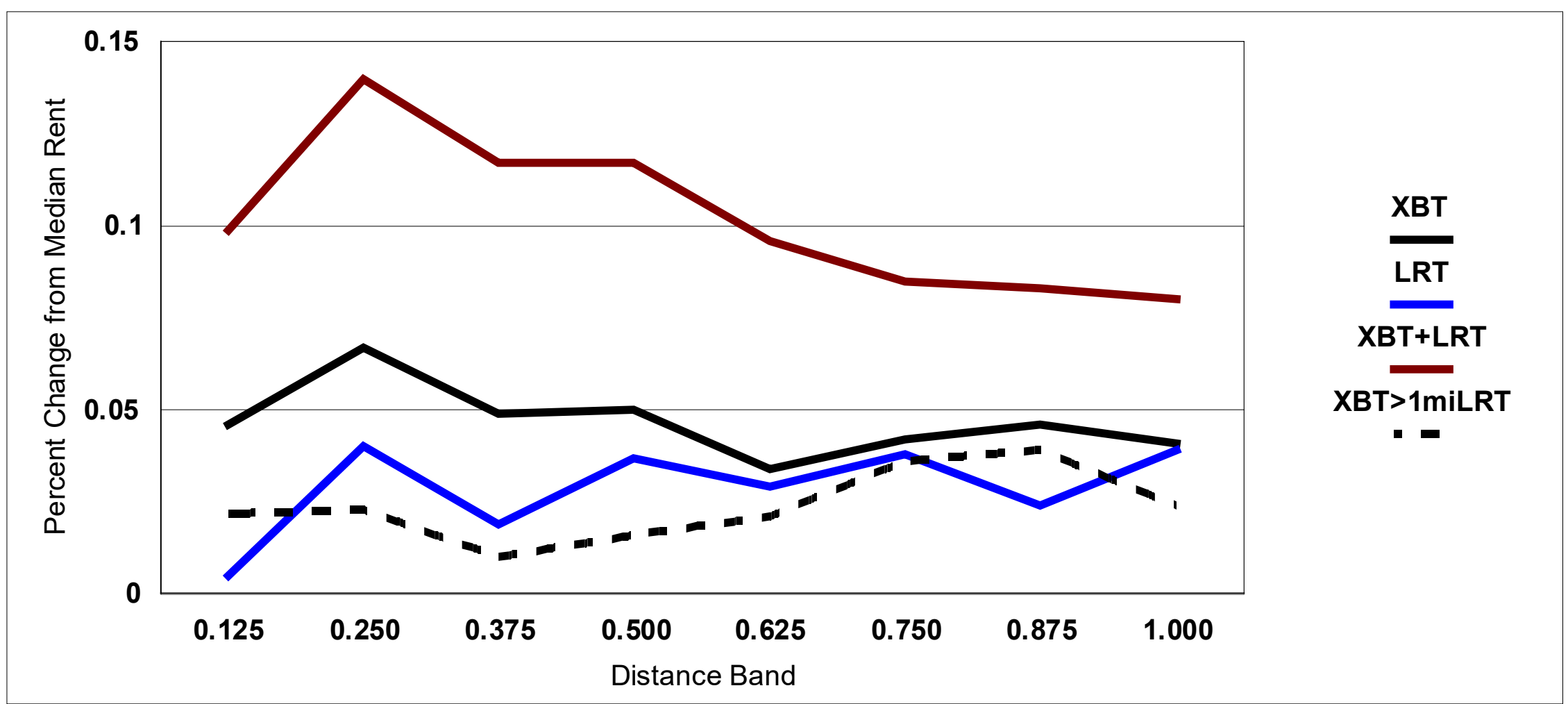

Figure 9.2

Percent multifamily rent per square foot change from mean with respect to proximity from Express Bus Transit (XBT) station/stop, Light Rail Transit (LRT) station, combined XBT+LRT and XBT station/stop more than 1.00-mile from LRT stations. 


\section{XBT Station/Stop Rent Proximity Associations}

We first look at the rent premium with respect to XBT station/stop proximity. All distance band coefficients are positive and statistically significant. Rents rise from $4.6 \%$ above the mean in the first (0.125-mile) distance band to $6.7 \%$ in the second $(0.25$-mile) distance band, then decline gradually to 1.0 mile. Because rents rise from the XBT station/stop outward to the second distance band, the implication is that negative externalities affecting MF rents may exist at or near the XBT station/stop. Externality sources can be noise, traffic, and poor urban design.

\section{LRT Station Rent Proximity Associations}

Relationships are somewhat different with respect to proximity to LRT stations. Here we find an ambiguous (though positive) premium relationship in the first (0.125-mile) distance band with bumpy, positive premium relationships through the remainder of the study area, from $4.0 \%$ in the second $(0.25$-mile) to about the same premium at $3.9 \%$ to the last (1.0-mile) distance band. Although the ambiguous effect at or near LRT stations is contradictory to theory, it was found in more than half of all LRT stations studied individually by Nelson et al. (35). They surmised that inadequate planning and/or urban design may be the cause, as we do here.

\section{Combined XBT+LRT Station/Stop Rent Proximity Associations}

We next consider synergistic effects; that is, we test for the association between MF rents per square foot with respect to proximity to combined XBT+LRT stations/stops. Three observations are offered:

Firstly, all rent premium coefficients are statistically significant and for the most part are the highest of all rent premiums estimated for each distance band. Indeed, the rent premium at the second $(0.25$-mile) distance band is $14.0 \%$ higher than the mean, the highest estimated in our study.

Secondly, like all other relationships we found, the rent premium rises from the first (0.125-mile) distance band to the second (0.25-mile) distance band before falling steady to the study area boundary at 1.0 mile. The persistence of this upward rent premium from the first to the second (0.125- to 0.25 -mile) distance bands signals the presence of negative externalities that may be addressed in future transit and land use planning in ways that we outline below.

Third, we surmise that there is an important synergistic effect between XBT and LRT stations/stops sharing the same area or platform. Reasons may include that presence of these two modes, XBT and LRT, provide accessibility to more destination opportunities throughout the metropolitan area than just one would, and potentially even if both modes serve the same destination, scheduling options are expanded.

\section{XBT Station/Stop Rent Proximity Associations beyond 1.0 Mile of LRT Stations}

We now consider XBT rent premium effects when XBT stations/stops are at least 1.0 mile from the nearest LRT station. We note than the number of cases is reduced from 27,847 observations to 18,929 , reflecting the elimination of cases falling within the 1.0-mile LRT station buffer area. Here we see that compared to the mean rent among those cases, the XBT rent premium proximate to XBT station/stops starts at $2.2 \%$ at or near the station/stop in the first (0.125-mile) distance band, rises to $2.3 \%$ in the second $(0.25$-mile) distance band, then-after an ambiguous though positive coefficient for the third $(0.375$-mile $)$ distance band, peaks at $3.9 \%$ in the seventh (0.875-mile) distance band before falling to $2.4 \%$ in the last (1.00-mile) distance band. This is an interesting finding because the analysis removes much of the potential influence of LRT station proximity on MF rents, leaving bare underlying associations. MF rent proximity associations are smaller than the others but they also rise mostly through the study 
area before falling farther away. We surmise that though XBT proximity is valued, negative externalities at or near XBT stations/stops.

We observe that more than half of the coefficients for the metropolitan controls are significant. That may be an indication that those metropolitan areas are different enough from the referent (Virginia Beach) to warrant individual examination. For instance, recall from Figure 1 that there can be vast differences in the types of express busses used between metropolitan areas. This may affect real estate values and rents. Our ongoing research will disaggregate the data into metropolitan area specific analyses to include the kind of rolling stock used among other factors we raise in the next section.

In review, we produce three sets of estimates for XBT proximity effects on rent. In all cases, the outcomes were similar; that is, rent rises with respect to distance from XBT (and XBR+LRT) stations/stops top some distance away before declining. We infer that the inverted $U$ reveals the presence of negative externalities at or near stations that dissipate at some distance (usually by the second, 0.25-mile distance band). This leads to implications for express bus transit and land use planning that we discuss next. 


\section{Implications for Express Bus Transit and Land Use Planning}

Until now, research into the effects of transit on commercial property such as multifamily rental real estate has been limited to rail transit and BRT stations/stops (see Nelson et al. 2015; Nelson and Ganning 2015; Higgins and Kanaroglou 2016). In this study, we extend analysis to assess how multifamily rents may be influenced by proximity to express bus transit (XBT) stations/stops. We also analyze how XBT stations/stops combined with light rail transit (LRT) stations influence multifamily (MF) rents. Several lessons are offered for express bus transit and land use planning.

We note overall that the market is signaling the desirability of proximity to XBT stations/stops. That is, after controlling structural, socioeconomic, urban form, centrality and metropolitan location influences, multifamily rents capitalize proximity to XBT stations/stops positively. As no literature advances the real estate benefits of XBT systems, perhaps transit and land use planners may have unwittingly overlooked an opportunity to maximize economic returns to XBT investments.

We also note that MF rents rise with respect to distance away from XBT stations increases from the first $(0.125$-mile) to the second $(0.25$-mile) distance band, signaling that externalities may be present at or near XBT stations/stops. This is also the case for combined XBT+LRT stations. However, for XBT station more than 1.00-mile away from LRT stations, the externality effect may extend beyond half-half mile. Finally, externality effects appear in the first (0.125-mile) distance band from LRT stations in the form of a statistically ambivalent coefficient (though still positive). While on the one hand, this is inconsistent with theoretical expectations for only a smoothly declining slope with respect to transit station distance using linear, semi-log or doublelog functional forms (Higgins and Kanaroglou 2016), on the other it is consistent with theoretical expectations for negative externalities that are revealed only through quadratic or, in our case, distance band functional forms (Nelson and McClesky 1990; Nelson 1992).

A key lesson from our research is that more might be done to encourage multifamily residential development close to XBT stations/stops. One reason this might not be happening is the assumption among policy makers that proximity to XBT stations/stops does not convey the kind of market premiums studies that have shown for other types of FRT systems (see see Nelson et al. 2015; Nelson and Ganning 2015; Higgins and Kanaroglou 2016). This assumption may be especially prevalent in suburban jurisdictions where XBT service is the only long-distance transit option for many thousands of workers.

Our over-arching perspective is that future economic returns to local economies and local government resources may be maximized by increasing development opportunities near XBT stations/stops. For instance, while there has been a concerted effort to create transit oriented developments (TODs) across the nation, they tend to focus on rail systems, and recently bus rapid transit systems. We are not aware of any express bus TODs-maybe the time has come. In any event, transit and land use planners would be advised to assess the development potential for multifamily investment and other land uses near XBT stations/stops. Transit and land use planners might also consider rethinking drop-off/park-and-ride lots for their development potential while retaining those options.

Our analysis suggests that because of positive market responsiveness to XBT station/stop proximity, transit agencies may consider expanding XBT services as well as creating more synergies between XBT systems and other transit modes. Though our analysis was of XBT stations/stops within metropolitan areas served by LRT systems, our research suggests that 
more US metropolitan areas may benefit from them, and those with XBT systems may consider adding to their inventory.

We concede that more research is needed to understand how to maximize the real estate market benefits of XBT systems. In-depth, longitudinal case study research could be especially useful to understand the nature of ridership and land use changes associated with features of particular XBT systems, such as frequency of service, features of origin (typically suburban) and destination (typically urban or suburban activity center) stations/stops, and even comforts (seating, Wi Fi, food and beverage, and related).

The bottom line is that express bus transit systems may have been overlooked for their role in influencing real estate markets and by extension development patterns. It is time to reconsider their role in shaping metropolitan development patterns.

As noted at the beginning of this chapter, the research and modeling reported here is a "proof of concept" showing how one may create measures of interactive effects where two transit modes intersect. We will extend this proof of concept to Chapter 9, which will also incorporate the Place Typologies created in Chapter 1 in the manner applied in Chapter 7. 


\section{REFERENCES}

Alonso W (1964). Location and Land Use: Toward a General Theory of Land Rent, Harvard University Press, Cambridge MA.

American Public Transportation Association, Public Transportation: Benefits for the 21st Century Washington, DC: American Public Transportation Association, 2007.

Barbeau, S. J. Quality Control - Lessons Learned from the Deployment and Evaluation of GTFS-Realtime Feeds. Presented at the $97^{\text {th }}$ Annual Meeting of the Transportation Research Board, Washington, D.C., 2018.

Belzer, Dena, Sujata Srivastava, Mason Austin, Tyler Bump, and Jeff Wood.Transit and Regional Economic Development. No. FTA CA-26-1007-03, 2011.

Bettencourt, Luis and Geoffrey West. "A Unified Theory of Urban Living." Nature (October 2010): 467.

Bruegmann, Robert. Sprawl: A Brief History. University of Chicago Press, Chicago, 2006.

Center for Transit Oriented Development (nd). TOD 201: Sustainable Urban Design \& Transit. http://ctod.org/APTAmodules/SUDS201/index.html

Ciconne, Antonio and Robert E. Hall. "Productivity and the Density of Economic Activity." American Economic Review 86(1), (1996): 54-70.

Duany, Andres, Elizabeth Plater-Zyberk and Jeff Speck. Suburban Nation: The Rise of Sprawl and the Decline of the American Dream. North Point Press, New York, NY, 2000.

Duranton, Gilles, and Matthew A. Turner. "The Fundamental Law of Road Congestion: Evidence from US Cities." American Economic Review 101(6), (2011): 216-52.

Ewing, Reid and Shima Hamidi (2018). The Costs of Sprawl. London: Routledge.

Glaeser, Edward, Triumph of the City: How Our Greatest Invention Makes Us Richer, Smarter, Greener, Healthier, and Happier. Penguin, New York, NY, 2011.

Hajrasouliha, Amir H. and Shima Hamidi (2017). The typology of the American metropolis: monocentricity, polycentricity, or generalized dispersion? Urban Geography 38:3, 420-444, DOI: 10.1080/02723638.2016.1165386.

Hibberd, R., A. C. Nelson, K. Currans. Functional Form in Hedonic Regression: Literature Review \& Test of Forms to Determine the End of Significance of Transit Proximity Effects on LVU. University of Arizona.

Higgins, Christopher D. Higgins \& Pavlos S. Kanaroglou (2016). Forty years of modelling rapid transit's land value uplift in North America: moving beyond the tip of the iceberg, Transport Reviews, 36:5, 610-634, DOI: 10.1080/01441647.2016.1174748 
Institute for Transportation \& Development Policy. Best Practices 2013. Accessed from https://www.itdp.org/library/standards-and-guides/the-bus-rapid-transit-standard/best-practices$\underline{2013 /}$

Litman, Todd. Evaluating Public Transit Benefits and Costs. Victoria Transport Institute, Victoria, BC, 2017.

Mills ES (1967). An Aggregative Model of Resource Allocation in a Metropolitan Area, The American Economic Review, Papers and Proceedings, 57(2), pp 197-210. University of Chicago Press, Chicago.

Muth RF (1969). Cities and Housing: The Spatial Pattern of Urban Residential Land Use, Third Series: Studies in Business and Society.

Metropolitan Atlanta Rapid Transit Authority (nd). Types of Transit Services \& Vehicles. Accessible from https://www.itsmarta.com/types-of-transit-services-vehicles.aspx

National Association of City Transportation Officials (2016). Transit Street Design Guide. https://nacto.org/publication/transit-street-design-guide/.

Nelson Arthur C. (2017). Transit and Real Estate Rents. Transportation Research Record: Journal of the Transportation Research Board. https://doi.org/10.3141/2651-03:

Nelson, Arthur C. Dejan Eskic, Shima Hamidi, Susan J. Petheram, Jenny H. Liu, Reid Ewing. 2015. Office Rent Premiums with Respect to Distance from Light Rail Transit Stations/stops in Dallas. Transportation Research Record DOI 10.3141/2500-13.

Nelson, Arthur C.2, Matt Miller, Dejan Eskic, Keuntae Kim, Reid Ewing, Jenny H. Liu, Matt Berggren, Zakari Mumuni. Do TODs Make a Difference? Portland OR: National Institute for Transportation and Communities, Portland State University, OR, 2015.

Nelson, Arthur C. National Study of BRT Development Outcomes. Portland, OR: National Institute for Transportation and Communities accessible from

https://pdxscholar.library.pdx.edu/trec reports/32/ (2015).

Nelson, Arthur C. and Robert Hibberd (2019). Streetcars and Real Estate Rents. Transportation Research Record (forthcoming).

Nelson, Arthur C. and Susan J. McClesky (1990). Elevated Rapid Rail Station Impacts on Single-Family House Values, Transportation Research Record, 1266: 173-180.

Nelson, Arthur C. (1992). Effects of Heavy-Rail Transit Stations/stops on House Prices with Respect to Neighborhood Income, Transportation Research Record, 1359: 127-132.

Nelson, Arthur C. (2017). Transit and Real Estate Rents. Transportation Research Record, 2651(1), 22-30. https://doi.org/10.3141/2651-03

Nelson, Arthur C. and Robert Hibberd, with Matt Dixon (2019). The Link between Transit Station Proximity and Real Estate Rents, Jobs, People and Housing with Transit and Land Use Planning Implications. Portland OR: National Institute for Transportation and Communities, Portland State University. 
Nikitas, Alexandros and MariAnne Karlsson. "A Worldwide State-of-the-Art Analysis for Bus Rapid Transit: Looking for the Success Formula." Journal of Public Transportation 18(1), (2015): 1-33.

Park, Robert Ezra, E. W. Burgess, Roderick Duncan McKenzie, and Louis Wirth. 1925. The city. Chicago, III: University of Chicago Press.

Perk, Victoria A. Martin Catalá, Maximillian Mantius, Katrina Corcoran (2017). Impacts of Bus Rapid Transit (BRT) on Surrounding Residential Property Values. Portland OR: National Institute for Transportation and Communities, Portland State University.

Petheram, Susan J., Arthur C. Nelson, Matt Miller and Reid Ewing (2013). Using the Real Estate Market to Establish Light Rail Station Catchment Areas: Case Study of Attached Residential Property Values in Salt Lake County with respect to Light Rail Station Distance. Transportation Research Record. 2357: 95-99.

Stoker, Philip \& Reid Ewing (2014) Job-Worker Balance and Income Match in the United States, Housing

Weisbrod, Glen, Derek Cutler and Chandler Duncan. Economic Impact of Public Transportation Investment. American Public Transportation Association, Washington, DC, 2014.

Xiao, Yang (2016). Hedonic Housing Price Theory Review in Urban Morphology and Housing Market, pp. 11-40. New York: Springer. 


\section{CHAPTER 10: How the Intersection of Light Rail Transit Stations with other Transit Modes Influences Real Estate Rent}

\section{OVERVIEW}

Using lessons of the "proof of concept" developed in Chapter 9, we extend the analysis of the interactive effects of light rail transit (LRT) stations shared with streetcar transit * $S C T$ ), bus rapid transit (BRT) and commuter rail transit (CRT) on office, multifamily and retail real estate rents.

For the most part, we found that where a metropolitan area includes more than just an LRT system -in our case being one or more of SCT, BRT and CRT systems-it may be important to evaluate interactive effects between them. In nearly all comparisons between the original model in Chapter 8 and the expanded model here for office and retail estate, the combined LRT+SCT, LRT+BRT and LRT+CRT coefficients were higher meaning interactive effects were greater than just for LRT alone. This is reasonable, a priori.

However, less impressive are comparisons with respect to multifamily real estate where relevant coefficients for only the LRT+SCT expanded model were larger than the original model. For $L R T+B R T$ and LRT+CRT, results were less impressive for the first 0.50-mile distance bands. But this begs the question. In these cases, it is important to know that combined LRT+BRT and LRT+CRT stations actually result in multifamily rents falling below the mean in the first 0.50-mile DBs. Perhaps it is also important that the relevant coefficients of the combined LRT+CRT stations exceed those of the original LRT model in distance bands from 0.50-mile to the end of the 1.00-mile study area. Indeed, these particular results suggest that multifamily real estate is more sensitive to potential externalities associated with BRT and CRT stations which is also reasonable, a priori. 


\section{Introduction}

By now there is a very large volume of research on the association between transit station proximity and real estate rents, much of it comprised of our contributions. The theoretical underpinnings of these studies are based on the Alonso (1964), Mills (1967) and Muth (1969) theory that land values and by implication real estate values decline as a function of distance from the city center. As the AMM theory supposed only one regional center-the downtown, others have shown that subcenters can have the same effect on real estate values. By extension, so can transit stations as well.

Complicating the otherwise elegant perspective that real estate values will decline from the downtown or subcenter or transit station is the potential for some centers to actually be sources of externalities. That is, for whatever reason, the closer property is to a center the more it is impacted by externalities associated with the center thereby pushing real estate values down near them. This may especially be the case with respect to transit stations as they can be localized sources of congestion, noise, pollution, and unattractive interaction between land uses perhaps because of poor (no no) urban design. Nelson and colleagues (references later) have pioneered techniques to measure externality effects of transit stations on real estate values and rents. There can this be three effects of transit proximity on real estate value or rents:

Declining value with respect to transit station distance indicating that real estate market prefer to be near those stations, consistent with expectations of the AMM model. In this scheme, transit stations are a form of amenity.

Increasing value with respect to transit station distance indicating that stations may be sources of externalities. As transit station distance increases externalities dissipate possibly allowing amenity benefits to overcome them to some point. Real estate values and rents rise to some point where amenity effects just offset externality effects, and then fall outward consistent with AMM expectations.

Ambiguous relationships wherein either (a) real estate markets simply do not value proximity to transit stations or amenity and externality influences cancel each other out.

Chapter 8 of this report provided an exhaustive assessment of all three outcomes as revealed by the real estate market in more than 30 metropolitan areas offering at least form of fixed route transit (FRT) from among light rail transit (LRT), streetcar transit (SCT), bus rapid transit (BRT) and commuter rail transit (CRT). It also included brief studies of heavy rail transit (HRT) and express bus transit (XBT) systems operating in selected metropolitan areas.

Chapter 9 introduced a new line of analysis in the context of the interactive effects between LRT and XBT stations. ${ }^{118}$ That is, to what extent does the intersection of two FRT systems such as through shared or nearby stations influence real estate rents (and implicitly values)? The context was limited to just LRT and XBT systems as a proof of concept for future research. As we found importation interactive relationships, we extend that new line of research in this chapter.

This chapter is comprised of four sections. In the first, we review theory, pose the research questions and outline a research strategy. The second section describes our research plan in

\footnotetext{
${ }^{118}$ Although express bus transit are comprised substantially of just bus stops, we use the term "station" to mean generically all places where all transit systems stop.
} 
terms of the research design, the general model that will be used to guide data and analysis, our choice of functional form, the study area, the specific model and data, and identification of transit data challenges. The third section presents our results and offers discussion. The final section offers our implications for express bus transit and land use planning.

\section{Theory and Research Questions}

Conventional urban location theory developed by Alonso (1964), Mills (1967), and Muth (1969)_-also known as the AMM theory_shows that where all jobs are in the central business district (CBD), the cost of transportation increases with respect to distance from the CBD at a declining rate. Transportation costs reduce land value as distance from the CBD increases. Where transportation costs are lowest, in the CBD, land prices are highest. There is thus competition for location near CBDs considering the land use needs among competing office, retail, institutional, residential and other land uses. Only those land uses that generate the highest economic exchanges win the most central locations. Land uses that cannot compete for CBD locations are pushed outward to areas where they can outbid other land uses, a process called land use invasion and succession based on ecological principles (Park et al. 1925).

As one relaxes constraints of the AMM monocentric city model, it is possible to imagine the same principles are at work only at smaller scales in a more distributed fashion (Hajrasouliha and Hamidi 2017). In particular, rail transit stations/stops can become localized, smaller versions of CBDs. Accordingly, economic activities will bid up land prices close to rail transit stations/stops; lower value activity is pushed away from stations/stops to locations where they may outbid competing land uses. Dozens of studies confirm negative real estate bid-rent gradients with respect to distance from rail transit stations suggesting these local level outcomes. That is, real estate falls with respect to distance from transit stations, ceteris paribus.

Yet, as noted above, none address the proximity effects of two (or more) different transit modes on real estate values or rents (see Higgins and Kanaroglou 2016). Theoretically, according to the AMM model, any given type of transit station and certainly any combination will lead to higher rents near them as the rent gradient will fall with respect to distance. This leads to our research question, in the context of real estate rents:

\section{Do office, multifamily and retail rents increase with respect to proximity to combined FRT stations?}

However, we also posit upward sloping gradients and even ambiguous relations for reasons we provided in Chapter 8 and will review below.

We proceed with our research plan. This is followed by results with interpretations. We conclude our article with implications for the role of combined fixed route transit station planning and urban design. 


\section{Research Plan}

One can imagine a wide range of FRT station combinations, often involving three or more modes. Denver's Union Station, for instance, combines commuter, light rail, free downtown bus service, and AMTRAK cross-country rail in the same location. It is also a hub for private ride hailing services such as taxis, Lyft and Uber. More commonly, just two modes of transit intersect such as Portland's and Dallas' LRT and SCT systems in and near downtown, Salt Lake City's LRT and CRT systems, Kansas City's BRT and SCT systems, and so forth. To build carefully on prior research, and given this is a new genre of research in its own right, we limit our study to the intersection of just two different modes.

We further narrow our study to just those metropolitan areas for which we have collected LRT date: 17 in all. Not only are they the largest number of systems for any mode in our study, but most of those systems intersect with another mode.

Given the foregoing, this section presents our research plan including research design, general model, functional form, study area, and specific model and data.

\section{Research Design}

We apply theory through a static, cross-section quasi-experimental research design. That is, using one period of time-2018 for multifamily and retail real estate and 2019 for office relate estate, we test for the effect of LRT stations and combined LRT with one of SCT, BRT and CRT stations with respect to proximity to office, multifamily and retail real estate. Although the analysis is not causal, associations can be used as guidance for transit and land use planning purposes. For reasons noted in prior chapters, we use rent instead of sales as a proxy for real estate value.

\section{General Model}

Using these theoretical and research design foundations as a guide, we develop the following general model to test the theory. It is adapted from Nelson (2017):

\section{$\mathrm{R}_{i}=\mathbf{f}\left(\mathrm{S}_{i}, \mathrm{SES}_{i}, \mathrm{U}_{i}, \mathrm{C}_{i}, \mathrm{M}_{i}, \mathrm{PT}_{i}, \mathrm{DB}_{i}\right)$}

\section{Where:}

$\mathbf{R}$ is the asking rent per square foot for property $i$;

$\mathbf{S}$ is the set of structural attributes of property $i$ including its architecture, mass, height, age and effective age, interior amenities, flow efficiencies and so forth;

SES is the set of socioeconomic characteristics of the vicinity of property $i$ such as population features, income, education;

$\mathbf{U}$ is a set of measures of urban form of the vicinity of property $i$ such as the nature of surrounding land uses, terrain, physical amenities (such as parks), street characteristics and related;

C is a set of centrality attributes of property $i$ such as distance to downtown and distance to the nearest freeway/expressway ramps; 
$\mathbf{M}$ is a set of metropolitan area controls. As metropolitan area conditions and markets vary between them, identifying the location of property $i$ within its respective market helps control for metropolitan-specific influences;

PT is a set of Place Typology Controls indicating whether property $i$ is located in a HighMixed Use/Accessible place, Moderate MA area, Low MA area, or Poor MA area as described in Chapter 1; and

DB is the distance band (see below for specification details) of property $i$ to an LRT station as well the distance band of the same property to an SCT, BRT or CRT station that shares the same platform or is otherwise within one-eighth mile from an LRT station. In other words, DB is comprised of two distance elements which will be discussed in more detail below.

\section{Functional Form}

The AMM theory posits that land value will decline with distance from the CBD or other high activity nodes. Linear, semi-log, and double-log functional forms are the dominant forms reported in literature (Higgins and Kanaroglou 2016; Nelson and Hibberd 2017; Hibberd et al. 2019).

The linear functional form assumes a straight line deduction in property value with respect to distance away from a node, such as a transit station.

The semi-log functional form - where the dependent variable is logged-estimates the percent change in value associated with a unit change in an independent variable.

The double-log functional form generates elasticities-continuously measured variables on both sides of the equation are logged although categorical and binary variables are not.

In our view, none of these functional forms are very useful to transit and land use planners who need to know how to arrange transit investments and land use policies to maximize the economic benefits of transit station proximity. Lacking guidance from studies using these conventional functional forms, planners tend to settle on quarter-mile and half-mile planning areas around stations/stops, with very little empirical justification.

A less-used approach, the quadratic functional form, is specified such that the linear distance term is squared and both terms are included in an analysis:

$\mathrm{Ri}=\beta_{i}+\beta_{i}{ }^{2}$

Where in this case $\beta_{i}$ is the linear coefficient of the value premium with respect to transit station distance in a regression equation while $\beta_{i}{ }^{2}$ is its squared term. This equation has the potential to pinpoint the break point in the transit station distance curve. In the context of FRT stations/stops, the concern is that rail stations/stops themselves can be nuisances such that real estate values and rents may be dampened very near them.

Although the following discussion is similar to that presented in Chapter 7 , it is useful to review it again in assure context. As Nelson and McClesky (1990) theorize, the market capitalizes both 
amenity effects of rail station proximity as well as negative externality effects, for instance those associated with noise (such as dispatching broadcasts at station platforms), and congestion (such as when vehicles use park and ride lots during peak hours) (Nelson 1992). So long as amenity effects outweigh negative externalities, the bid-rent gradient will slope downward and away from rail transit stations/stops. However, in theory it is possible for negative externalities to outweigh amenities. But quadratic functional forms may not be very useful either, especially if both signs are in the same direction (increasing or decreasing value at a faster rate with respect to distance). Even where signs are different, the smaller the second term relative to the first the flatter the slope. For example, if the second term above is 1.00 , the minima is 10 miles which may not be very useful to planners crafting plans around stations/stops.

Figure 10.1 shows numerous potential relationships between rail stations/stops-as both sources of amenities and negative externalities - and real estate value, in our case being multifamily rents (see below):

The line $R^{a}$ shows the land rent $(R)$ curve with amenity ("a" for amenity) value from a rail transit station, $\mathrm{u}_{0}$, outward to a point, $\mathrm{u}_{1}$, where the amenity effects of rail transit proximity disappear, beyond which the overall market rent, unaffected by the presence of the rail transit station, $R^{m}$ is revealed.

Negative externality effects of rail transit stations/stops are shown in line $\mathrm{R}^{\mathrm{n}}$ (" $\mathrm{n}$ " for negative externality). As distance from the rail station increases, the negative externality effects are reduced until they become zero at $u_{1}$.

Amenity and negative externality effects interact in the market leading to overall positive or negative bid rent curves with respect to distance from rail transit stations/stops to $u_{1}$. Line $R^{a}+R^{n}{ }_{1}$ is revealed where overall amenity effects outweigh negative ones. Line $R^{a}$ $+R^{n}$ is revealed where overall negative externality effects outweigh positive ones. Overall effects disappear at $u_{1}$ beyond which market rent, $R^{m}$, in the absence of amenity and negative externality is revealed.

Distance bands offer a practical middle ground between knowing whether and the extent to which real estate markets respond to transit stations/stops within discrete distances of FRT stations/stops. They also provide statistical significance test results for each band separately. Unfortunately, most distance-band studies use only one-quarter or one-half mile distance bands, (Higgins and Kanaroglou 2016) or occasionally two bands (Nelson 2017). But that assumes all relevant interactions which are useful for planners to know occur only within those distance bands, and that those bands apply to all transit modes in all metropolitan areas. Following Hibberd et al., (2019) and Nelson and Hibberd (2017) this article uses the distance band functional form described in more detail below. 


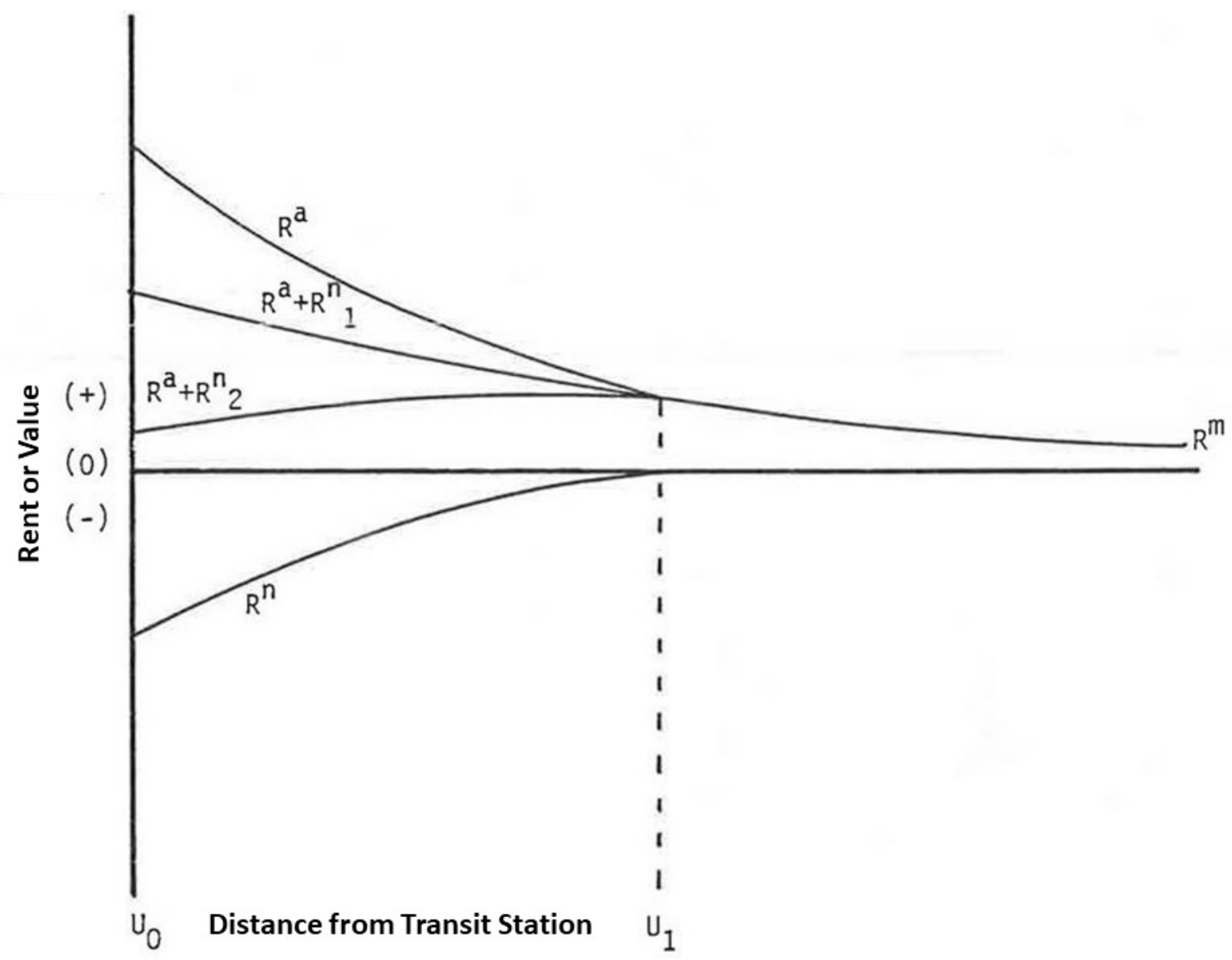

Figure 10.1

Amenity $\left(R^{a}\right)$ and Negative Externality $\left(R^{n}\right)$ influences of transition stations/stops on proximate property values

Source: Nelson and McClesky (1990). 
The foregoing discourse has important implications for evaluating the price or rent effects of transit systems on multifamily real estate. Rail transit usually runs on dedicated tracks that can generate negative externalities in terms of noise, vibration and sometimes glare, among others. For their part, express busses usually operate along collectors, arterials and limited access highways that also generate negative externalities for the same reasons plus exhaust. One would expect that, between stations, real estate value would be less along both tracks and BRTserving highways because of negative externalities. On the other hand, amenity effects of transit stations/stops occur only proximate to them.

There is still another compounding issue. Income producing real estate usually depends on access to major highways even if they generate negative externalities. Higher density commercial development is especially dependent on major highway access which is why they cluster along them. Nonetheless, highway related negative externalities may dissipate some distance away from highway which may be revealed in rents or prices. On the other hand, the only amenity effect of rail access is with respect to station/stop proximity. These particular nuances of highway and rail proximity are not addressed directly in this research but is part of our longer term agenda.

Finally, we note the following interpretive strategy. The theory on which Figure 10.1 is based concedes that all we can see are the revealed effects, not the disaggregated ones. However, the rise of values away from a station/stop outward to a peak, followed by declining values forming an inverted $U$ would be a tell-tale sign of externality effects of the station/stop on rents. We will elaborate on this later.

\section{Study Area}

For prior research, we created a dataset comprised of 17 metropolitan areas with LRT systems (see Figure 10.2). Most of these metropolitan areas also have at least one of SCT, BRT and CRT systems which we identified through assembly of General Transit Feed Specification data reported by local transit agencies. Because they include both LRT and one other systems, we can evaluate interaction effects where or near where they interconnect. We discuss this is more detail below.

Finally, we note that some metropolitan areas served by LRT systems are also served by more than two other FRT systems. Yet, only two metropolitan areas have all systems (Dallas and Salt Lake City) while others have one or two of those systems but not all of them. Future work will extend the analysis presented in this article to the interaction of LRT systems with all those other modes considering all metropolitan areas in which they operate. 


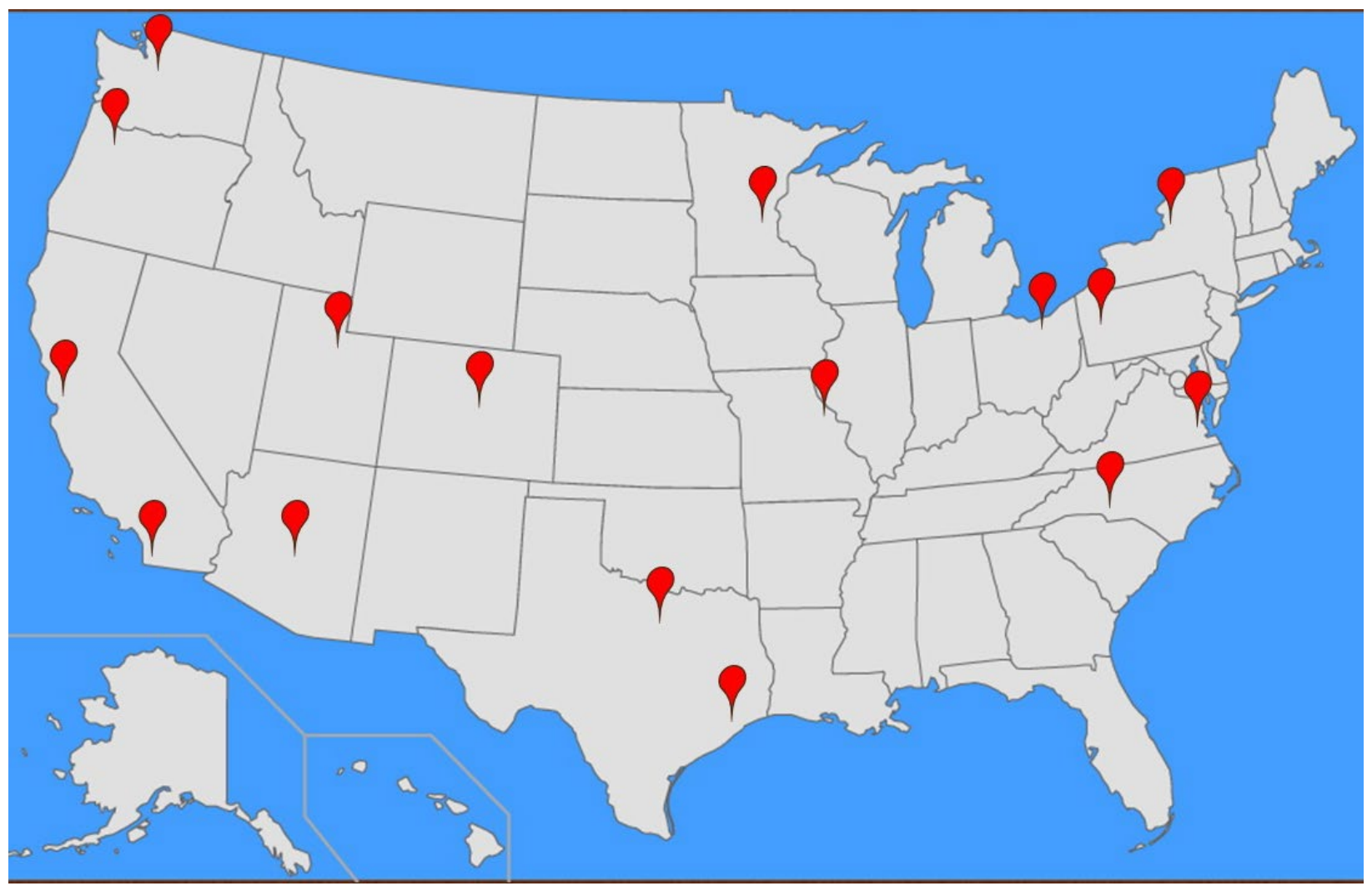

Figure 10.2

Metropolitan study areas with both light rail transit and express bus transit Systems used in analysis.

Source: Authors. 


\section{Specific Model and Data}

We operationalize the general model dimensions and functional form here. Notably, we report the statistical association between rent per square foot for office, multifamily and retail real estate with respect to FRT station proximity in terms of 0.125 -mile distance bands to 1.00 -mile after controlling for other influences with special reference to Place Typology.

We chose 1.00 mile as our threshold for several reasons. Before going into those reasons, we note the conventional approach to transit oriented development planning and analysis uses the "one-half mile circle". Many transit oriented real estate studies this limit analysis of price effects to just the first 0.50-mile from transit stations (see Higgins and Kanaroglou 2016). The presumption is that 0.50 -mile is about the longest distance people are willing to walk to/from transit stations. But as Canepa (2007) suggests, this is just an artifact and not truly empirically founded, that in fact people are willing to walk longer distances especially of the walking environment lends itself to it. We observe there are also a growing number of "last mile" (or even last two-mile) micro mobility options that are merging such as e-scooters, graband-go bicycles, for-rent bicycles, e-bicycles, and related (see Feignon 2019 research in progress).

Real estate research also confirms that the threshold can be more than 0.50-mile and even close to 2.00-miles. For office and industrial real estate, Ko and Cao (2013) found LRT station proximity price premiums extended up to 0.90 -mile. For multifamily real estate, Petheram et al. (2013) found LRT price premiums up to about 1.25 miles. For office rents, Nelson et al. (2015) found premiums nearly 2.00 miles away though roughly three-quarters of the premium occurred within the first 1.00-mile. Finally, there is the concern about reasonableness. Our sense of the literature is what while price and rent effects may be seen up to two miles away under some circumstances relating to some types of real estate accessed by some types of transit, the 1.00-mile threshold captures nearly all of the effects if there are any (see Nelson and Hibberd 2017; Nelson and Hibberd 2019).

We used the General Transit Feed Specification (GTFS) platform to identify and map FRT systems and their stations (https://transitfeeds.com/). It is the most commonly used format for specifying public transit systems. We also double checked FRT systems identified in the GTFS with a review of transit agency web sites to confirm.

\section{A Word on Transit Data Challenges}

As an aside, we are compelled to comment here on transit system data collection challenges. Use of secondary data is considered an easy, low resource way to quantitatively analyze social phenomena. Yet data quality issues frequently arise due to lack of adherence to best practices, or due to need for further development of those practices. Challenges appear when the original design of the data standard does not anticipate and thus serve the needs of diverse researchers. The GTFS data model and standard - a revolutionary source in expanding general access to transit data - has provided a remarkable tool for the present study. More than 2,000 transit agencies have provided data through the GTFS. However, the agencies and app developers do not always format and manage it consistently, notwithstanding the standard's underlying paradigm of uniformity of data (Barbeau 2018).

Our study is a representative case, in which the GTFS standard fails to require consistent categorization of bus systems to distinguish between "bus rapid transit" or "express bus" among the vaguely defined "bus" category in the standard. When that information is provided, it is because the transportation authority decided to provide it, rather than the GTFS standard requiring it. The current relational model for the GTFS further increased the challenge of its use 
through greatly compounding data size and processing time, reducing computational capacity given the size of the resulting tables. By going to the specific web sites of each BRT agency, however, we were able to distinguish between those types of bus transit systems.

Finally, GTFS could be augmented with additional data describing transit system funding sources, boarding and alighting counts, headway, and station operational start dates. The former data would be of great value in such research efforts as discerning the market's involvement, response to, and investment return on various funding sources. The latter is often used in the literature to analyze temporal patterns of development around transit, such as how the market responds to the announcement of a new transit route.

We will now present details of the specific model.

\section{Dependent Variable}

$\mathbf{R}$ is the Asking Rent per Square Foot for property $i$ reported by CoStar during 2018 for multifamily and retail real estate and 2019 for office real estate. (CoStar has the largest, national commercial property data base where data are collected using a standardized protocol.) Rents are monthly per square foot. Normally, statistical analysis is applied to samples of a universe. In this case, the study includes the universe of all commercial properties form which all data are available as reported by CoStar in our study area. As CoStar data come from real estate brokerages participating in its network, the data exclude non-participating brokerages or entities and properties not for rent such as owner-occupied properties. By logging the dependent variable, the semi-log model allows for coefficients to be interpreted as the percent change in rent attributable to a one unit change in an independent variable such as an individual distance band.

\section{Control Variables}

$\mathbf{S}$ is the bundle of structure and lease restriction attributes for property $i$ reported by CoStar. This includes occupancy characteristics noted below. For all real estate, this includes:

Gross Leasable Area in building square feet with the expectation that there will be a positive association between office and multifamily building area and rent because larger buildings presumably include more amenities than smaller ones. However, this is not the case for retail (see Peiser and Hamilton 2012) where the sign is expected to be negative indicating declining marginal value per square foot with respect to increasing building size.

Effective Year Built which is the later of the year of construction or the year of renovation as reported by CoStar with the expectation that newer buildings will command more rent than older ones.

Vacancy Rate with the expectation that the higher the vacant rate the lower the rent. However, this may not always be the case as high demand markets could result in high vacancy rates as owners wait for higher paying tenants. Accordingly, signs may not be predictable especially considering that the study area is comprised of stable to rapidly growing central counties.

The number of Stories is also included with the expectation that the taller the building the higher the mean rent. However, for retail, Stories are excluded because of scant variation among retail structures. 
For only office real estate, this includes:

Class $\boldsymbol{A}$ and Class $\boldsymbol{B}$ office space which are considered the highest and next highest quality in the office market, commanding rents accordingly. Class $C$ office space is the referent.

For only multifamily real estate, this includes:

Occupancy restrictions for Senior or Student housing with Market Rate housing being the referent. The expectation is that relative to Market Rate multifamily units, rents for Student housing will be lower because average annual rents will be based on occupancy during only part of the year. Rents for Senior housing also be lower because they usually impose less wear and tear on units, often rent for longer periods of time, and sometimes include rent subsidies which may limit the rent.

For only retail real estate, this is comprised of the most common types of retail structures reported in standard real estate texts (see Peiser and Hamilton 2012) with all others being the referent. The retail structures used include:

\author{
Power Center \\ Neighborhood Center \\ Community Center \\ Regional Center \\ Lifestyle Center \\ Outlet Center
}

The SES dimension is comprised of Median Household Income from the five-year sample of the 2018 American Community Survey (ACS) for the block group within which a CoStar property is located, for which a positive association is expected with respect to rent (Xiao 2016).

Because the PT (Place Typology) variable (see below) includes distance from downtown, one variable comprises the $\mathbf{C}$ dimension: Distance to Freeway. This is defined as distance to the nearest freeway or expressway ramp. Because freeway ramps can be considered nuisances in addition to being an accessibility benefit, no signs of association are predicted.

The $\mathbf{M}$ dimension is comprised of the individual metropolitan areas within which the FRT systems we studied operate. As these are controls which account for idiosyncrasies of metropolitan markets, no direction of associations is predicted. 


\title{
Special Reference Control Variables
}

Chapter 1 presents our methods and results for creating a Place Typology (PT) to help explain the variation in differences between economic development, population change, commuting, and real estate rents (which are the focus of this chapter). We call these the "special reference' control variables because they are used to create subsets of analyses of rent premium with respect to transit station proximity for each of these specially designed geographic units.

For review, from, Chapter 1, the cluster analysis method used these variables to establish four types of places:

\author{
Jobs per acre \\ Proportion of jobs that are retail and arts \\ Total population per acre \\ Total households per acre \\ Percent of households with no kids \\ Percent of owner occupied housing \\ Intersections per square mile \\ Proportion of intersections with 3 to 4 vertices
}

The method used LEHD (Longitudinal Employment-Household Dynamics) and census data applied at the block group (BG) level, producing these statistically unique place types which also conform to a priori expectations.

High Mix/Accessibility (High MA) Centers such as downtowns, suburban nodes, and other areas with high concentrations of jobs and people;

Moderate Mix/Accessibility (Moderate MA) areas such as large combinations of BGs with modest mixes of jobs and people and lower connectivity between land uses, and often surrounding High MA centers;

Low Mix/Accessibility (Low MA) areas which are usually low density, residential areas that some might characterize as urban sprawl, and which are usually found between Moderate MA and Poor MA areas; and

Poor Mix/Accessibility (Poor MA) areas which are dominated by very low density residential development with no employment centers and the lowest levels of accessibility between land uses. Poor MA will be used as the referent in analysis meaning that the variation in rents attributable to Place Typology will be estimated with respect to this variable, all other factors considered.

We predict that controlling for all factors, rents along a continuum will be highest in the High MA centers and lowest in the Poor MA areas.

While all the above variables as are the controls, DB or distance band is the treatment variable. In review, DBs are comprised of 0.125-mile increments to 1.00-mile of the nearest transit station, with cases beyond 1.00-mile being the referent. We also measure distance between the parcel and the nearest station, calling it the closest distance to the transit station. We do so assuming that structures will orient themselves to transit stations if they can. We also measure straight line distance; future research will measure network distance. 
Table 10.1 summarizes our control and treatment variables, sources of date, measures, and predicted signs. It also includes a synopsis discussion of how the DB magnitude and signs are expected to vary with respect to FRT station distances. That synopsis is based on the statistical interpretation discussion at the end of this subsection.

\section{Modeling Limitations}

We acknowledge that our model does not include any transit service-related factors such as the number of bus routes at a station, station spacing, headway, service span and so forth. These quality of service measures may reveal incremental willingness to pay higher rent with respect to distance to specific stations/stops. It is an area ripe for future research mostly because it has never been done in the context of real estate transit value added. Part of that research may include efforts to improve open data standards to meet the needs of transportation researchers, as discussed below. Second, as in all prior real estate value transit added research, our theory is based on incremental change in value (rents) with respect to transit station proximity, not with respect to level and quality of service. Finally, like all real estate transit valued added research, our aim is to determine central tendencies, directions of association, and proximate as opposed to precise estimates of value added with respect to transit station proximity.

\section{Statistical Interpretations}

With tens of thousands of cases, our model includes many times more data than used in most prior studies (see Higgins and Kanaroglou 2016 for comparison). While we have no a priori expectations of goodness of

fit outcomes, literature suggests that ordinary least squares hedonic (regression) analysis usually explain about one fifth to two-thirds of the variation in the observed rent for cases. We note that while some analysts may be preoccupied with achieving high levels of regression model explanation, too many variables can lead to over-specification. It is best to emphasize the variables most relevant to the question along with relevant controls sufficient to avoid serious omitted variable bias (a form of endogeneity) in the model. Our model is based on both theory and a large body of prior empirical work.

Our key interest is the association between rents per square foot and distance band with respect to the nearest FRT station. While a positive association is expected between DBs and FRT station proximity, negative associations can signal the presence of externality effects noted above. For instance, areas very near stations may have such nuisances as traffic, noise, and poor urban design that offset positive effects of proximity. DBs farther away may reveal positive rent coefficients because negative externality effects will have dissipated. But at some point DB price premiums are expected to decline and perhaps even become negative because accessibility costs would have increased, based on AMM theory and controlling for other influences.

Finally, when we combine possible negative externality effects associated with being near transit stations with increasing rent premiums further away followed by decreasing premiums, we expect to see an inverted $\boldsymbol{U}$ shape. That is, unlike most conventional studies of the association between rents and transit station distance, the DB approach allows us to estimate how far away from transit stations the market values proximity before the premium declines. The reason is that our application of theory allows for both positive and negative signs, with negative signs indicating negative externalities associated with effects of FRT stations on nearby commercial real estate.

This leads us to issues of statistical interpretations. Normally, interpretation of ordinary least squares (OLS) regression coefficients is based either on predicting signs or in cases of pure empirical exploration perhaps no direction of association is predicted. Where signs are predicted, the 1-tailed t-test of significance can be used. The conventional minimum level of 
significant is $p<0.10$ meaning there is only a 1 -in-10 chance that the coefficient's magnitude and its direction is incorrect. We accept that threshold for our analysis.

But what if the theoretically predicted sign will change across space? In Figure 8.1, we show that negative externalities at or near transit stations can be revealed in the market as lower rent compared to the mean all factors considered. Procedurally, this would be a negative coefficient for the first (0.125-mile) distance band perhaps extending to other distance bands before becoming positive. We thus predict that signs will change if negative externalities are present at or near transit stations.

Or, the coefficient may be positive in the first $(0.125$-mile $)$ distance band with the coefficient increasing in size until it peaks some distance away before declining and perhaps becoming negative.

Or, the coefficient may be positive and have the largest coefficient at the first (0.125-mile) distance band, falling outward and perhaps becoming negative. This would indicate planning and urban design that overcame negative externalities at or near transit stations.

Thus, theory allows for the revealed rent gradient to be $\mathrm{R}^{\mathrm{a}}$ or $\mathrm{R}^{\mathrm{n}}$ leading into $\mathrm{R}^{\mathrm{m}}$ in Figure 10.1 . But how do we use conventional t-test interpretations? We do so as follows:

Close to the Station

Where 2-tailed $p<0.10$, a negative sign reveals the presence of negative externalities at or near the station but where the sign is positive the amenity value of proximity overcomes negative externalities. In effect, because we can explain the direction based on theory but theory allows both signs, we have a 1-tailed $p<0.05$. However, where 2tailed $p>0.10$ but $<0.20$ we call this contingent significance because the theory allows both signs resulting in an interpretive 1-tailed $p<0.10$ which meets the minimum conventional threshold.

\section{Farther From the Station}

Where the first or other DBs are close to the transit station, theory requires that coefficients increase in magnitude to some point away from the station where $R^{a}$ has completely overcome $R^{n}$. Coefficients would decline thereafter, revealing $R^{m}$.

Farthest From the Station within 1.00-Mile

Although coefficients would be expected to fall from where $R^{a}$ overcomes $R^{n}$, it is possible that $R^{m}$ could become negative reflecting complete loss of amenity value at some point away from transit stations.

Our interpretations will be based on all these possibilities because they all conform to theoretical expectations.

Table 10.1

Variables, Data Sources, Measurement Type, and Predicted Association with Respect to Rent per Square Foot 
Variable

Rent

Rent per Square Foot (logged)

Structure Controls-All Cases

Gross Leasable Area, Square Feet

Stories

Effective Year Built

Vacancy Rate

Stories

Structure Controls-Office

Class A Office

Class B Office

Class C Office

Occupancy Controls-

Multifamily

Senior

Student

All other

Occupancy Controls-Retail

Power Center

Neighborhood

Community

Regional

Lifestyle

Outlet

All Other

Socioeconomic Control

Median Household $(\mathrm{HH})$

Income

Location Control

Distance Freeway Ramp

\section{Metropolitan Control}

Metropolitan Area Location
Data Source

Dependent Variable

Measure

Predicted Sign

CoStar

Continuous

na

Control Variables

CoStar
CoStar
CoStar
CoStar
CoStar

CoStar

CoStar

CoStar

CoStar

CoStar

CoStar

CoStar

CoStar

CoStar

CoStar

CoStar

CoStar

Census ACS

Computed

Census
Continuous

Continuous

Continuous

Continuous

Continuous

Binary

Binary

Binary

$+/-$

$+$

$+$

$-$

$+$

Binary

Binary

Referent

Binary

Binary

Binary

Binary

Binary

Binary

Binary

Continuous

$+$

Continuous

Binary

na 
Table 10.1

Variables, Data Sources, Measurement Type, and Predicted Association with Respect to Rent per Square Foot - continued

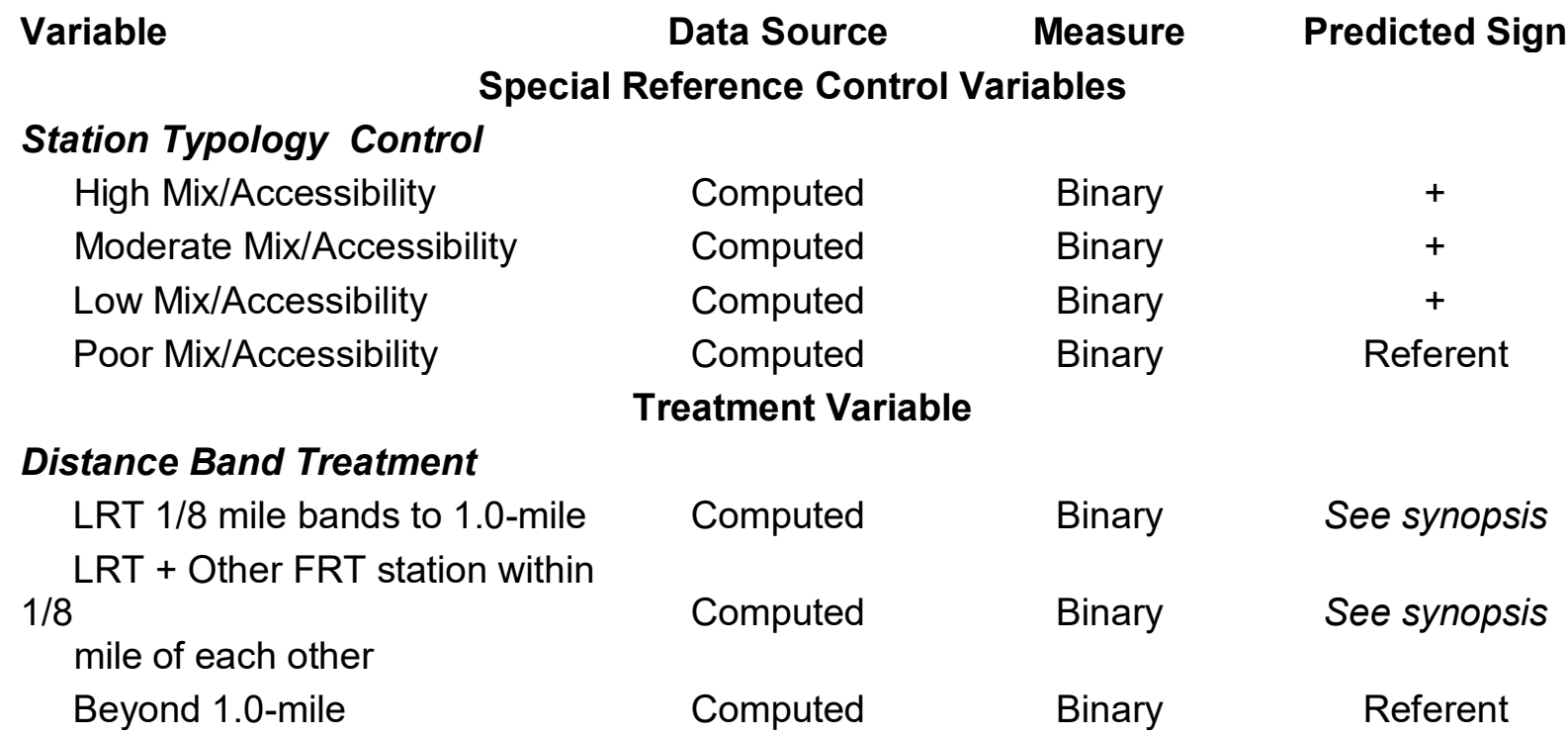

\section{Synopsis DB expectations}

A negative association is expected with respect to the first $(0.125-\mathrm{mile}) \mathrm{DB}$ because of negative externalities or if positive the coefficient will be lower than the second (0.125-mile) $\mathrm{DB}$ and perhaps others father away from the station. An inverted $U$ form is expected reflecting increase rent premium with respect to station distance because of negative externalities at or near the station, peaking at some distances, then declining and perhaps becoming negative. However, if the coefficient of the first (0.125-mile) DB is higher than those farther away, negative externalities would appear to have been overcome perhaps through planning and urban design. In that case, rent premiums would be expected to decline steadily outward perhaps in some cases becoming negative. There are thus two types of acceptable significance levels:

- Conventional significance where $p<0.10$ using the 2-tailed t-test with no sign predicted and

- Contingent significance where $p>0.10$ but $<0.20$ using the 2-tailed t-test where a sign is consistent with contingent theoretical expectations such as a negative sign in the first (0.125-mile) DB but positive in the second (0.250-mile) DB if not others father away. 


\section{Presentation Scheme}

The regression results report below are organized as follows:

Control variables including Place Typologies are in the front portion. We note in bold those non-metropolitan control variables that meet our tests for significance.

Treatment variables are organized into two subsections:

The association between LRT station proximity and office, multifamily and retail rents are presented first. As all metropolitan areas in our study have LRT systems, this variable provides a baseline perspective on the influence of LRT station proximity on rents.

The association between combinations of LRT+SCT, LRT+BRT and LRT+CRT station proximity are reported at the bottom the regression tables. Statistically, they represent only those metropolitan areas with LRT and an intersecting system. Notably, Seattle;

LRT+SCT coefficients apply only to Dallas, Portland, Salt Lake City and

LRT+BRT coefficients apply only to Cleveland, Minneapolis-St. Paul, Pittsburgh, Salt Lake City, San Diego, San Jose and Seattle; and

LRT+CRT coefficients apply only to Dallas, Denver, Minneapolis-St. Paul, Portland, San Diego, San Jose and Seattle.

We proceed to results of our analysis and discussion. 
Results and Discussion

We present full regression results for each of the office, multifamily and retail analyses. We also provide a discussion for each analysis.

\section{The Variation of Office Rents with Respect to LRT Station Proximity and Proximity to Combined LRT+SCT, LRT+BRT, and LRT+CRT Stations}

We first present results for the full model in Table 10.2 for office rents with respect to LRT stations and then combinations of LRT with SCT, BRT and CRT stations, respectively. We do not report the correlation matrix for brevity but noting no problematic collinearities were found. The coefficient of determination $\left(R^{2}\right)$ shows that the equation explains a reasonable share of the variation of rents and the F-ratios shows the equation outcomes to be considerably beyond chance.

Here we review results for the control variables first including Place Typology, then for LRT station distance, and concluding with proximity to combined station proximity. With respect to control variables:

Rent increases as the size of an office building increases reflecting amenities that are more commonly offered in larger complexes than smaller ones;

Rents for Class A space are higher than for Class B space which is higher than the referent, Class C. space;

As building height increases reflected by the number of floors or stories, mean rent increases reflecting elevation away from the hustle and bustle of the ground level as well as views and perhaps improved air flow;

As the effective year in which the structure was built (or renovated) increases (more recent years have a higher value than earlier years), rent increases;

As the vacancy rate increases rents decrease;

As the median household income of the block group within which the property is located increases so does rent;

As distance from the nearest freeway ramp increases rents also fall; and

As the intensity of mixed use and accessibility decreases from High MA places to Low MA areas (compared to Poor MA areas), office rent decreases as expected.

We note that as controls for metropolitan-specific market characteristics, the coefficients for the metropolitan variables are not directly relevant to the interpretation of results with respect to transit stations/stops. Since we use Virginia Beach as our referent, the coefficient for Seattle indicates only that the mean rent per square foot in the Seattle market is 34.0 percent higher than the mean rent in Virginia Beach. In contrast, the mean rent for the Buffalo market is actually 3.4 percent lower $(-3.4 \%)$ than the mean rent in the Virginia Beach market.

Table 10.2 
Regression Results for Office Rents with Respect to LRT Station Proximity and Proximity to Combined LRT+SCT, LRT+BRT, and LRT+CRT Stations

Variable

Constant

Structure Controls

Gross Leasable Area (1k Sq.Ft.)

Class $A^{*}$

Class $B^{*}$

Stories

Effective Year Built

Vacancy Rate

Socioeconomic Control

Median $\mathrm{HH}$ Income (\$1k)

Location Control

Distance Freeway (Mile)

Metropolitan Control**

Buffalo

Charlotte

Cleveland

Dallas-Fort Worth

Denver

Houston

Minneapolis-St. Paul

Phoenix

Pittsburgh

Portland

Sacramento

Salt Lake City

San Diego

San Jose

Seattle

St. Louis

Place Typology Control***

Low MA

Moderate MA

High MA
Office Beta

1.233

$-0.01 \%$

$36.60 \%$

$11.90 \%$

$0.30 \%$

$0.10 \%$

$-0.10 \%$

$0.16 \%$

$-0.86 \%$

$-3.40 \%$

$19.60 \%$

$-4.20 \%$

$8.40 \%$

$31.90 \%$

$16.10 \%$

$-9.90 \%$

$12.90 \%$

$7.20 \%$

$20.30 \%$

$21.50 \%$

$6.50 \%$

$42.70 \%$

$75.30 \%$

$34.00 \%$

$4.00 \%$

$3.50 \%$

$9.40 \%$

$13.40 \%$ 
Table 10.2

Regression Results for Office Rents with Respect to LRT Station Proximity and Proximity to Combined LRT+SCT, LRT+BRT, and LRT+CRT Stations-continued

\begin{tabular}{|c|c|}
\hline Variable & Office Beta \\
\hline \multicolumn{2}{|c|}{ LRT Distance Band Treatment ${ }^{* * * *}$} \\
\hline LRT 0.125 & $-0.40 \%$ \\
\hline LRT 0.250 & $-3.30 \%$ \\
\hline LRT 0.375 & $-4.10 \%$ \\
\hline LRT 0.500 & $-3.60 \%$ \\
\hline LRT 0.625 & $-1.10 \%$ \\
\hline LRT 0.750 & $-3.80 \%$ \\
\hline LRT 0.875 & $-4.90 \%$ \\
\hline LRT 1.000 & $-2.00 \%$ \\
\hline \multicolumn{2}{|c|}{ LRT Intersection DB Treatment ${ }^{* * * *}$} \\
\hline LRT+SCT 0.125 & $18.30 \%$ \\
\hline LRT+SCT 0.250 & $14.90 \%$ \\
\hline LRT+SCT 0.375 & $14.80 \%$ \\
\hline LRT+SCT 0.500 & $18.50 \%$ \\
\hline LRT+SCT 0.625 & $12.30 \%$ \\
\hline LRT+SCT 0.750 & $1.70 \%$ \\
\hline LRT+SCT 0.875 & $11.10 \%$ \\
\hline LRT+SCT 1.000 & $-0.80 \%$ \\
\hline LRT+BRT 0.125 & $2.40 \%$ \\
\hline LRT+BRT 0.250 & $8.50 \%$ \\
\hline LRT+BRT 0.375 & $12.20 \%$ \\
\hline LRT+BRT 0.500 & $9.50 \%$ \\
\hline LRT+BRT 0.625 & $-2.30 \%$ \\
\hline LRT+BRT 0.750 & $-4.50 \%$ \\
\hline LRT+BRT 0.875 & $5.50 \%$ \\
\hline LRT+BRT 1.000 & $-3.20 \%$ \\
\hline LRT+CRT 0.125 & $-2.70 \%$ \\
\hline LRT+CRT 0.250 & $3.60 \%$ \\
\hline LRT+CRT 0.375 & $15.10 \%$ \\
\hline LRT+CRT 0.500 & $19.30 \%$ \\
\hline LRT+CRT 0.625 & $9.10 \%$ \\
\hline LRT+CRT 0.750 & $13.60 \%$ \\
\hline LRT+CRT 0.875 & $9.50 \%$ \\
\hline LRT+CRT 1.000 & $5.70 \%$ \\
\hline
\end{tabular}


Table 10.2

Regression Results for Office Rents with Respect to LRT Station Proximity and Proximity to Combined LRT+SCT, LRT+BRT, and LRT+CRT Stations

\section{Performance Metrics}

Mean Rent/Square Foot

Cases

R2 adjusted

Std. Error of the Estimate

F-Ratio

${ }^{*}$ Class $\mathrm{C}$ the referent

${ }^{* *}$ Virginia Beach is the referent

${ }^{* * *}$ Poor MA is the referent

${ }^{* * * *}$ Cases $>1.00$-mile are the referent
Figure

$\$ 21.65$

15,859

0.405

0.297

183.893

\section{DB Interpretations}

A negative association is expected with respect to the first (0.125-mile) DB because of negative externalities or if positive the coefficient will be lower than the second (0.125-mile) DB and perhaps others father away from the station. An inverted $U$ form is expected reflecting increase rent premium with respect to station distance because of negative externalities at or near the station, peaking at some distances, then declining and perhaps becoming negative. However, if the coefficient of the first (0.125-mile) DB is higher than those farther away, negative externalities would appear to have been overcome perhaps through planning and urban design. In that case, rent premiums would be expected to decline steadily outward perhaps in some cases becoming negative. There are thus two types of acceptable significance levels:

- Conventional significance where $p<0.10$ using the 2-tailed t-test with no sign predicted and

- Contingent significance where $p>0.10$ but $<0.20$ using the 2-tailed t-test where a sign is consistent with contingent theoretical expectations such as a negative sign in the first (0.125-mile) DB but positive in the second (0.250-mile) DB if not others father away.

We next evaluate the association between LRT station proximity and office rents per square foot. From Table 10.2, results of which are illustrated in Figure 10.3, we note that the office rent coefficient is ambiguous in the first $(0.125$-mile) distance band and relevant coefficients are both below the mean and with a roughly flat slope from the second $(0.250-$ mile) DB to the seventh (0.875-mile) DB.

While on the one hand this signals that the office market does not value LRT station proximity positively, this finding may reflect a dynamic that we discovered in Chapter 1: both multifamily and retail rents are positive at and near LRT stations, and have sizable coefficients. It may be that those real estate types outbid office near LRT transit stations. But there is "another hand" as will be shown next.

On the other hand, where LRT systems are combined with other modes, office rents are mostly positive and sizeable although in different patterns: 
Office rents fall from combined LRT+SCT stations from 18.3 percent above the mean in the first (0.125-mile) distance band to 14.8 percent in the third (0.375-mile) DB before rising again to 18.5 percent in the fourth $(0.500-$ mile) DB and then falling, This is an indication the LRT+SCT station proximity is an amenity in the office real estate market through the better part of 0.50-mile.

The relationship with respect to combined LRT+BRT stations is nearly reverse but still notable. Office rents rise from 2.4 percent above the mean in the first 10.125-mile) distance band to 12.2 percent in the third $(0.3745-\mathrm{mile}) \mathrm{DB}$, then fall gradually thereafter. This is an indication that BRT stations even when combined with LRT stations impose externalities on nearby office real estate.

Combined LRT+CRT stations have a pattern similar to LRT+BRT stations in that rent rises from 3.6 percent above the mean in the first $(0.125$-mile) distance band to 19.3 percent above the mean in the third $(0, .375$-mile $) \mathrm{DB}$, then mostly falling through the rest of the 1.00-mile study area.

In all three of these combinations, office rents are higher than the mean compared to just LRT station proximity. We surmise that office rents are sensitive to multiple transit options. 


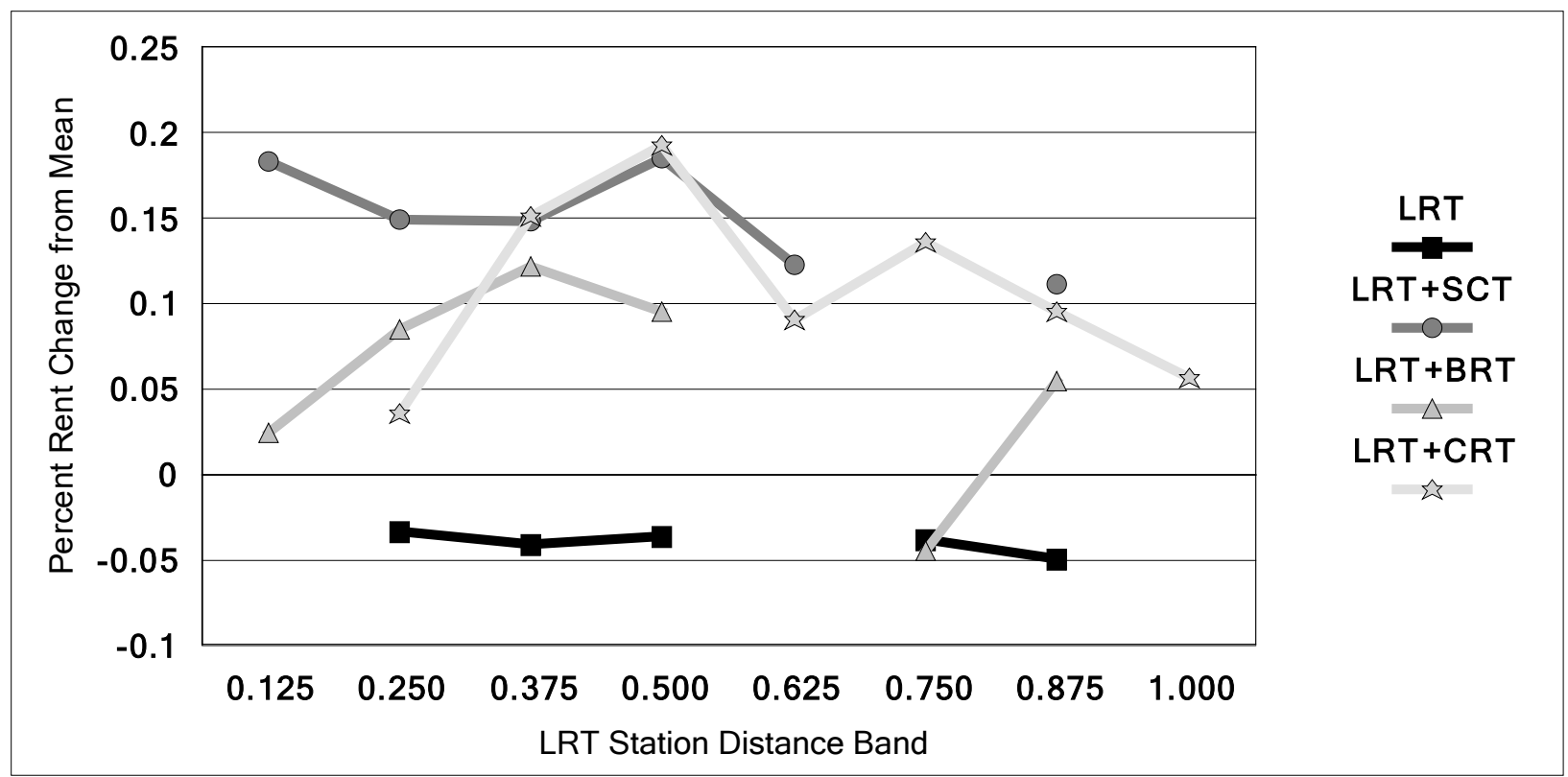

Figure 10.3

Percent change in mean office rent from LRT and combined LRT+SCT, LRT+BRT and LRT+CRT transit stations by distance band

Note: Only relevant coefficients are included in this figure. 


\section{The Variation of Multifamily Rents with Respect to LRT Station Proximity and Proximity to Combined LRT+SCT, LRT+BRT, and LRT+CRT Stations}

We next present results for the full model in Table 10.3 and illustrated in Figure 10.4 for multifamily rents with respect to LRT stations and then combinations of LRT with SCT, BRT and CRT stations, respectively. The coefficient of determination $\left(R^{2}\right)$ shows that the equation explains a reasonable share of the variation of rents and the F-ratios shows the equation outcomes to be considerably beyond chance.

Here we summarize key outcomes of control variables, excluding metropolitan controls (see below). The control variables performed as expected in the context of retail real estate.

Rent increases as the size of a MF structure increases possibly reflecting amenities that are more commonly offered in larger complexes than smaller ones such as recreation facilities and social opportunities;

However, rent per square foot declines as the size of the unit increases reflecting declining marginal utility of space, as expected;

As for office, the number of floors or stories is associated with higher rent reflecting elevation away from the hustle and bustle of the ground level as well as views and perhaps improved air flow on average though logically benefiting tenants in middle and higher floors;

As the effective year in which the structure was built (or renovated) increases (more recent years have a higher value than earlier years), rent increases;

We note that as the vacancy rate increases so do rents we suspect for the expectations noted above, that seniors will get preferential rates by landlords especially if they are expected to stay long periods and students rent only when school is in session so their effective rent is actually based on an entire year;

As the median household income of the block group within which the property is located increases so does rent;

As distance from the nearest freeway ramp increases rents also fall; and

As the degree of mixed use and accessibility increase from Low to High MA (compared to Poor MA), multifamily rent increases as expected.

As noted above and in Chapter 7, we note that as controls for metropolitan-specific market characteristics, the coefficients for the metropolitan variables are not directly relevant to the interpretation of results with respect to transit stations/stops. 
Table 10.3

Regression Results for Multifamily Rents with Respect to LRT Station Proximity and Proximity to Combined LRT+SCT, LRT+BRT, and LRT+CRT Stations

Variable

Constant

Structure Controls

Gross Leasable Area (1kSqFt)

Average Unit Size

Stories

Effective Year Built

Vacancy Rate

Occupancy Controls

Senior*

Student*

Socioeconomic Control

Median HH Income (\$1k)

Location Control

Distance Freeway (mile)

Metropolitan Control**

Buffalo

Charlotte

Cleveland

Dallas

Denver

Houston

Minneapolis-St. Paul

Phoenix

Pittsburgh

Portland

Sacramento

Salt Lake City

San Diego

San Jose

Seattle

St. Louis

Place Typology Control***

Low MA

Moderate MA

High MA

Table 10.3
Multifamily Beta

$-3.579$

$0.03 \%$

$-0.10 \%$

$2.30 \%$

$0.20 \%$

$0.40 \%$

$-5.30 \%$

$-12.40 \%$

$0.36 \%$

$-1.16 \%$

$12.80 \%$

$-0.70 \%$

$-4.70 \%$

$7.20 \%$

$31.60 \%$

$-0.50 \%$

$17.60 \%$

$-1.30 \%$

$8.00 \%$

$20.00 \%$

$18.10 \%$

$3.90 \%$

$47.70 \%$

$65.10 \%$

$39.10 \%$

$-7.20 \%$

$4.20 \%$

$6.70 \%$

$8.10 \%$ 
Regression Results for Multifamily Rents with Respect to LRT Station Proximity and Proximity to Combined LRT+SCT, LRT+BRT, and LRT+CRT Stations-continued

Variable
LRT Distance Band Treatment

LRT 0.125

LRT 0.250

LRT 0.375

LRT 0.500

LRT 0.625

LRT 0.750

LRT 0.875

LRT 1.000

LRT Intersection DB Treatment ${ }^{* * * *}$

LRT+SCT 0.125

LRT+SCT 0.250

LRT+SCT 0.375

LRT+SCT 0.500

LRT+SCT 0.625

LRT+SCT 0.750

LRT+SCT 0.875

LRT+SCT 1.000

LRT+BRT 0.125

LRT+BRT 0.250

LRT+BRT 0.375

LRT+BRT 0.500

LRT+BRT 0.625

LRT+BRT 0.750

LRT+BRT 0.875

LRT+BRT 1.000

LRT+CRT 0.125

LRT+CRT 0.250

LRT+CRT 0.375

LRT+CRT 0.500

LRT+CRT 0.625

LRT+CRT 0.750

LRT+CRT 0.875

LRT+CRT 1.000
Multifamily Beta

$2.60 \%$

$4.50 \%$

$1.90 \%$

$2.70 \%$

$1.30 \%$

$4.20 \%$

$2.20 \%$

$1.90 \%$

$18.20 \%$

$19.10 \%$

$17.60 \%$

$19.80 \%$

$12.70 \%$

$13.60 \%$

$12.50 \%$

$9.70 \%$

$0.60 \%$

$-4.10 \%$

$2.10 \%$

$1.70 \%$

$1.80 \%$

$5.30 \%$

$2.10 \%$

$-1.50 \%$

$-5.00 \%$

$0.70 \%$

$-2.50 \%$

$5.50 \%$

$\mathbf{9 . 4 0 \%}$

$-0.90 \%$

$7.90 \%$

$15.30 \%$ 


\section{Regression Results for Multifamily Rents with Respect to LRT Station Proximity and Proximity to Combined LRT+SCT, LRT+BRT, and LRT+CRT Stations-continued}

\section{Performance Metrics}

Mean Rent/Square Foot

Cases

R2 adjusted

Std. Error of the Estimate

F-Ratio

${ }^{*}$ All other tenant types are referent

${ }^{* *}$ Virginia Beach is the referent

${ }^{* * *}$ Poor MA is the referent
Figure

$\$ 1.44$

28,893

0.578

0.258

660.144

${ }^{* * *}$ Cases $>1.00$-mile are the referent

\section{DB Interpretations}

A negative association is expected with respect to the first $(0.125$-mile) DB because of negative externalities or if positive the coefficient will be lower than the second $(0.125$-mile) DB and perhaps others father away from the station. An inverted $U$ form is expected reflecting increase rent premium with respect to station distance because of negative externalities at or near the station, peaking at some distances, then declining and perhaps becoming negative. However, if the coefficient of the first $(0.125-\mathrm{mile}) \mathrm{DB}$ is higher than those farther away, negative externalities would appear to have been overcome perhaps through planning and urban design. In that case, rent premiums would be expected to decline steadily outward perhaps in some cases becoming negative. There are thus two types of acceptable significance levels:

- Conventional significance where $p<0.10$ using the 2-tailed t-test with no sign predicted and

- Contingent significance where $p>0.10$ but $<0.20$ using the 2-tailed t-test where a sign is consistent with contingent theoretical expectations such as a negative sign in the first (0.125-mile) DB but positive in the second (0.250-mile) DB if not others father away. 
We now assess the association between LRT station proximity and multifamily rents per square foot. We note from able 9.3 which is illustrated in Figure 10.4 that there is a positive association from the first (0.125-mile) distance band through the entire 1.00-mile study area with a fairly flat slope ranging about 2.0 percent above the mean. This is roughly consistent with our findings in Chapter 7.

We then note the especially large magnitude of multifamily rents associated with distance from combined LRT+SCT stations which start at 18.2 percent above the mean in the first $(0.125$ mile) distance band, falling gradually to 9.7 percent above the mean in the last (1.00-mile) DB. The multifamily market would clearly seem responsive to the presence of LRT systems generally within 1.00-mile and the combination of LRT and SCT systems across the same area. We will see an even more pronounced association with respect to retail real estate, leading us to surmise that multifamily and retail real estate may displace office real estate.

In contrast, the multifamily rents rise with respect to proximity from combined LRT+BRT stations as well as combined LRT-CRT stations. In both cases, multifamily rents start below the mean-4.1 percent in the second distance band for LRT+BRT and $-5.0 \mathrm{~m}$ percent in the first distance band for LRT+CRT. The combined LRT+BRT station effect end in the third (0.3750-mile) distance band at 2.1 percent above the mean while the combined LRT+CRT station effect continues through the study area, rising to 15.3 percent above the mean in the last (1.00-mile) DB. We surmise that combined LRT-BRT and LRT-CRT station areas are sources of externalities but that given how robust rents respond to LRT-CRT proximity, we suspect that urban design solutions may improve the interaction, and raise rents.

We finish with the analysis of results with retail findings and proceed to implications for transit and land use planning. 


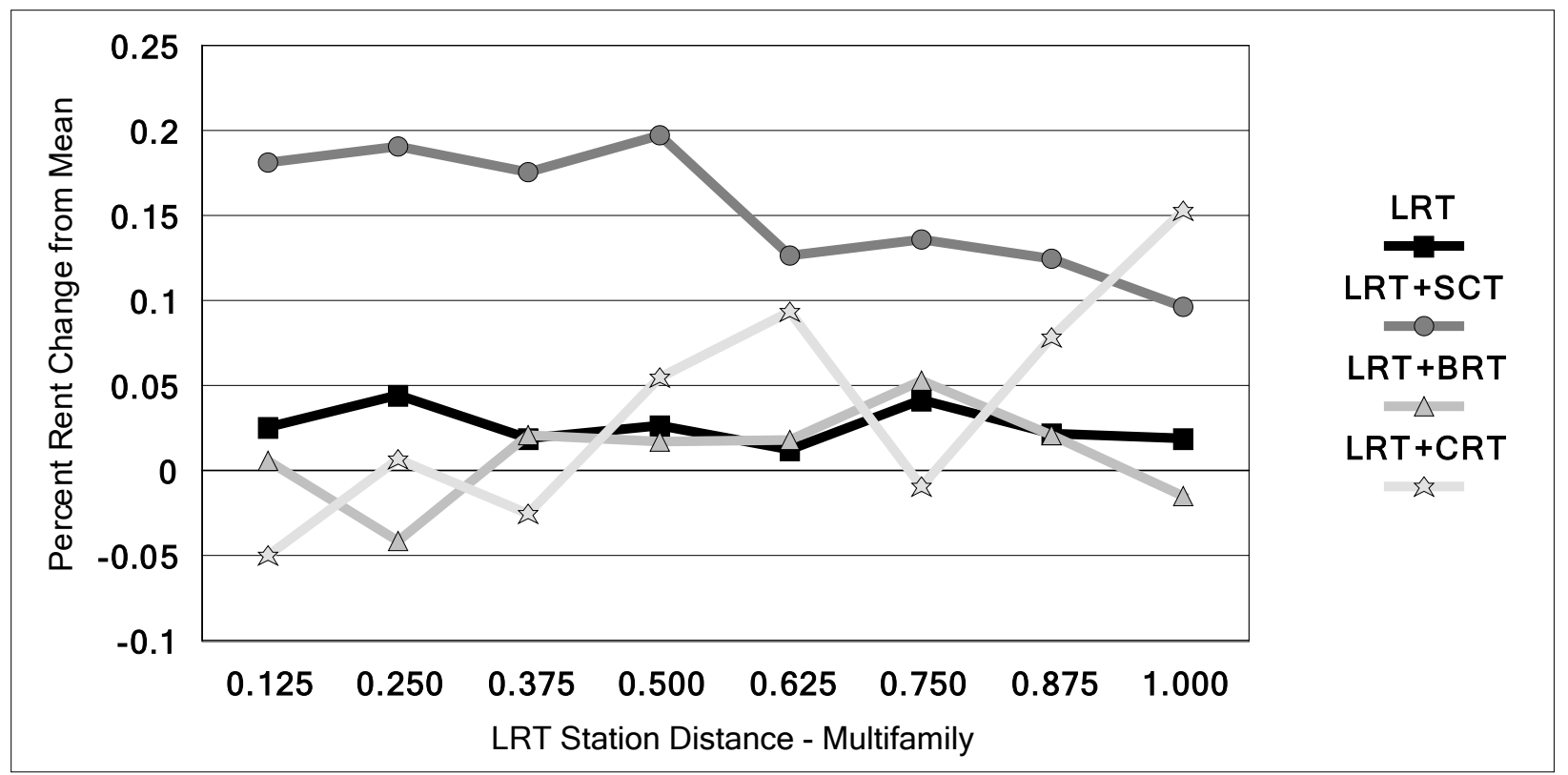

Figure 10.4

Percent change in mean multifamily rent from LRT and combined LRT+SCT, LRT+BRT and LRT+CRT transit stations by distance band

Note: Only relevant coefficients are included in this figure. 


\section{The Variation of Retail Rents with Respect to LRT Station Proximity and Proximity to Combined LRT+SCT, LRT+BRT, and LRT+CRT Stations}

We conclude the analysis by evaluating results for the full retail model in Table 10.4 which are illustrated in Figure 10.5. As expected based on theory and results for office and multifamily analysis, the control variables performed as expected:

Rent per square foot declines as the size of the structure increases reflecting declining marginal utility of space, as expected in the context of retail real estate;

As the effective year in which the structure was built (or renovated) increases (more recent years have a higher value than earlier years), rent increases;

However, we note that as the vacancy rate increases so do rents in some models-we suspect that in the case of retail rental markets during the study period (2018), landlords earn higher rents generally and may not be pressured into turning units over quickly to bide their time for securing higher rents;

As the median household income of the block group within which the property is located increases so does rent;

As distance from the nearest freeway ramp increases rents also fall; and

As the intensity of land use mix and accessibility decreases (compared to Poor MA areas), retail rents fall consistently from High MA places to Low MA areas.

We note that as controls for specific type of retail activities and metropolitan-specific market characteristics, the coefficients for them are not directly relevant to the interpretation.

From Table 10.4 and as seen in Figure 10.5, we note that retail rent falls from 5.0 percent above the mean in the first $(0.125$-mile $)$ distance band 2.3 percent in the third $(0.375$-mile $) \mathrm{DB}$, then gradually increases to 4.8 percent above the mean in the last (1.00-mile) DB. The form suggests moderate externalities from LRT stations outward which is the reverse of the form reported in Chapter 7 . The reason may be refinements in analysis occasioned by introducing the interaction between LRT and other FRT systems as we do in this chapter, though not uniformly. Notably, we find:

For combined LRT+SCT stations, retail rents rise from 23.7 percent above the mean in the first $(0.125-\mathrm{mile})$ distance band to 35.3 percent above the mean in the second (0.250-mile) DB before falling to 22.5 percent above the mean in the fifth (0.625-mile) $\mathrm{DB}$, then rising sharply to more than 35 percent above the mean in the rest of the 1.00mile study area. We surmise that as SCT stations tend to operate somewhat away from the very center of downtowns that the uplift reflects the attractiveness of downtown locations. 
Table 10.4

Regression Results for Retail Rents with Respect to LRT Station Proximity and Proximity to Combined LRT+SCT, LRT+BRT, and LRT+CRT Stations

Variable

Constant

\section{Structure Controls}

Gross Leasable Area (1k SqFt)

Effective Year Built

Vacancy Rate

Strip*

Power*

Neighborhood*

Community*

Regional* $^{*}$

Lifestyle*

Outlet* $^{*}$

Retail $^{\star}$

Socioeconomic Control

Median $\mathrm{HH}$ Income $(\$ 1 \mathrm{k})$

Location Control

Distance Freeway (mile)

Metropolitan Control**

Buffalo

Charlotte

Cleveland

Dallas-Fort Worth

Denver

Houston

Minneapolis-St. Paul

Phoenix

Pittsburgh

Portland

Sacramento

Salt Lake City

San Diego

San Jose

Seattle

St. Louis
Retail Beta

$-1.395$

$-0.08 \%$

$0.20 \%$

$0.00 \%$

$-7.90 \%$

$15.20 \%$

$-4.90 \%$

$2.60 \%$

$30.50 \%$

$17.70 \%$

$0.10 \%$

$0.70 \%$

$0.32 \%$

$-0.94 \%$

$-14.30 \%$

$30.40 \%$

$-10.70 \%$

$6.10 \%$

$32.70 \%$

$11.90 \%$

$7.90 \%$

$7.40 \%$

$-1.70 \%$

$23.50 \%$

$10.90 \%$

$8.70 \%$

$48.20 \%$

$61.80 \%$

$39.00 \%$

$-1.00 \%$ 
Table 10.4

Regression Results for Retail Rents with Respect to LRT Station Proximity and Proximity to Combined LRT+SCT, LRT+BRT, and LRT+CRT Stations-continued

Variable

Place Typology Control***

Low MA

Moderate MA

High MA

LRT Distance Band Treatment****

LRT 0.125

LRT 0.250

LRT 0.375

LRT 0.500

LRT 0.625

LRT 0.750

LRT 0.875

LRT 1.000

LRT Intersection DB Treatment ${ }^{\star * * *}$

LRT+SCT 0.125

LRT+SCT 0.250

LRT+SCT 0.375

LRT+SCT 0.500

LRT+SCT 0.625

LRT+SCT 0.750

LRT+SCT 0.875

LRT+SCT 1.000

LRT+BRT 0.125

LRT+BRT 0.250

LRT+BRT 0.375

LRT+BRT 0.500

LRT+BRT 0.625

LRT+BRT 0.750

LRT+BRT 0.875

LRT+BRT 1.000
Retail Beta

$11.10 \%$

$15.30 \%$

$20.40 \%$

$5.00 \%$

$2.10 \%$

$2.30 \%$

$0.40 \%$

$3.60 \%$

$3.60 \%$

$4.50 \%$

$4.80 \%$

$23.70 \%$

$35.30 \%$

$20.80 \%$

$25.60 \%$

$22.50 \%$

$39.80 \%$

$10.50 \%$

$35.00 \%$

$-2.80 \%$

$9.00 \%$

$20.90 \%$

$-2.00 \%$

$1.10 \%$

$-4.90 \%$

$6.00 \%$

$-4.00 \%$ 
Table 10.4

Regression Results for Retail Rents with Respect to LRT Station Proximity and Proximity to Combined LRT+SCT, LRT+BRT, and LRT+CRT Stations-continued

Variable

LRT+CRT 0.125

LRT+CRT 0.250

LRT+CRT 0.375

LRT+CRT 0.500

LRT+CRT 0.625

LRT+CRT 0.750

LRT+CRT 0.875

LRT+CRT 1.000

Performance Metrics

Mean Rent/Square Foot

Cases

R2 adjusted

Std. Error of the Estimate

F-Ratio

${ }^{*}$ All other retail are the referent

${ }^{* *}$ Virginia Beach is the referent

${ }^{* * *}$ Poor MA is the referent

${ }^{* * *}$ Cases $>1.00$-mile are the referent

\section{Retail Beta}

$17.10 \%$

$16.00 \%$

$5.50 \%$

$13.70 \%$

$0.50 \%$

$6.80 \%$

$5.00 \%$

$-1.80 \%$

Figure

$\$ 20.73$

18,500

0.296

0.343

122.361

\section{DB Interpretations}

A negative association is expected with respect to the first $(0.125-\mathrm{mile}) \mathrm{DB}$ because of negative externalities or if positive the coefficient will be lower than the second (0.125-mile) DB and perhaps others father away from the station. An inverted $U$ form is expected reflecting increase rent premium with respect to station distance because of negative externalities at or near the station, peaking at some distances, then declining and perhaps becoming negative. However, if the coefficient of the first $(0.125-$ mile) DB is higher than those farther away, negative externalities would appear to have been overcome perhaps through planning and urban design. In that case, rent premiums would be expected to decline steadily outward perhaps in some cases becoming negative. There are thus two types of acceptable significance levels:

- Conventional significance where $p<0.10$ using the 2-tailed t-test with no sign predicted and

- Contingent significance where $p>0.10$ but $<0.20$ using the 2-tailed t-test where a sign is consistent with contingent theoretical expectations such as a negative sign in the first (0.125-mile) DB but positive in the second (0.250-mile) DB if not others father away. 


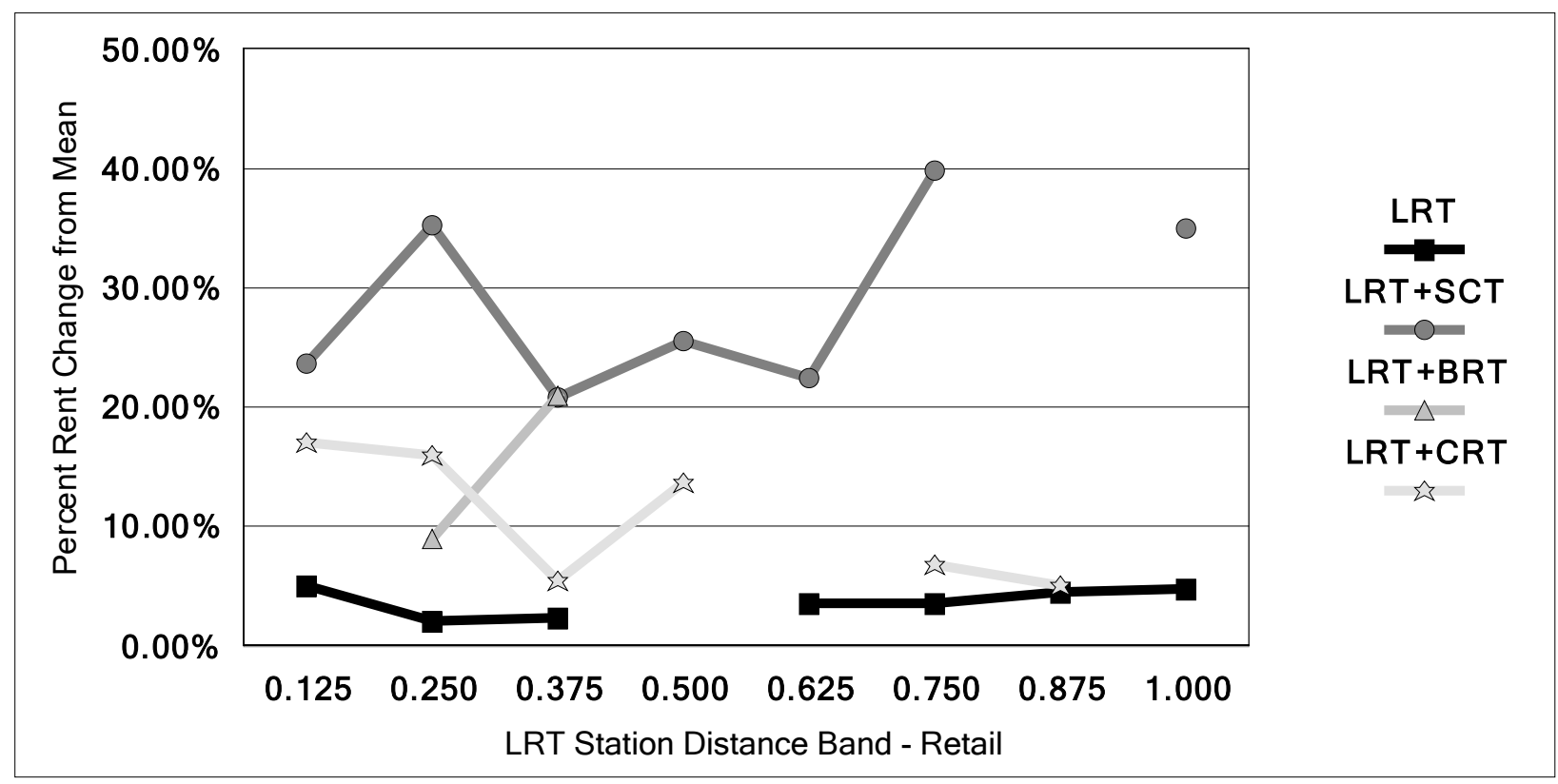

Figure 10.5

Percent change in mean retail rent from LRT and combined LRT+SCT, LRT+BRT and LRT+CRT transit stations by distance band

Note: Only relevant coefficients are included in this figure. 
The relationship with respect to combined LRT+BRT stations is limited to just the second (0.250-mile) and thi4rd (0.375-mile) distance bands where retail rents rise sharply from 9.0 percent to 20.9 percent above the mean, respectively. This is similar to the pattern we reported in Chapter 7 with respect to the form of retail rents with respect to distance from BRT stations. We suspect that even with any advantages of LRT, BRT stations may impose per se externalities on retail real estate.

Contrary to the prospective externalities seen in the prior associations, we find that combined LRT+CRT stations reveal amenity benefits. Rents fall from 17.1 percent above the mean in the first (0-.1125-mile) distance band to 5.5 percent above the mean in the third (0.375-mile) DB, then rise to 13.7 percent in the fourth $(0.500$-mile) DB and fall gradually to 5.0 percent above the mean in the seventh $(0.875-m i l e)$ DB. We surmise that the retail real estate market values proximity to combined LRT+CRT stations-such as Denver. Rents fall with respect to LRT+CRT station proximity then rise suggesting the presence of other nodes of activity such as the centers of downtowns, such as may be seen in San Diego, San Jose and Seattle.

The next section will synthesize these insights into an over-arching perspective. 


\section{Synthesizing Perspectives}

In this section we offer some synthesizing perspectives on the influence that stations that combine LRT and other FRT modes have on real estate rents. We assess LRT+SCT, LRT+BRT and LRT+CRT associations, respectively.

\section{Light Rail Transit + Streetcar Transit Combined Station Associations}

Table 10.5 summarizes the relevant distance band coefficients for the combined LRT+SCT stations for each type of real estate while Figure 10.6 illustrates the associations.

For office and multifamily real estate, LRT+SCT station proximity reveals the desired associations with respect to rent. Both types of real estate begin with rents a bit more than 18 percent above the mean in the first $(0.125$-mile) distance band and mostly decline gradually through the entire (MG) or nearly entire (office) 1.00-mile study area.

Although retail rents start much higher at 23.7 percent above the mean in the first (0.125-mile) distance band, they also rise sharply to 35.3 percent above the mean in the second $(0.250-$ mile) $\mathrm{DB}$, decline, and then rise through the rest of the study area.

We surmise that in the competition for location close to LRT+SCT stations, the combination of office and multifamily real estate commands locations close to those stations while retail real estate competes well a bit further away. Ongoing case studies of individual metropolitan may shed additional light on these interactions.

\section{Light Rail Transit + Bus Rapid Transit Combined Station Associations}

In stark contrast, Table 10.6 and Figure 10.7 reveal externality effects of LRT+BRT station proximity on all three types of real estate we studied. This is a clear indication that better transit and land use planning, or simply better urban design is needed to overcome externality effects near these stations. We recommend redoubled efforts on all three fronts of the kind we outlined in Chapter 7.

\section{Light Rail Transit + Commuter Rail Transit Combined Station Associations}

Splitting the difference, metaphorically speaking, is the association between LRT+CRT proximity and office, multifamily and retail real estate. While office and multifamily trend upward sharply with respect to LRT+CRT station proximity, retail rents drop sharply. For office, an ambiguous rent association appears in the first $(0.125$-mile $)$ distance band with a modest 3.6 percent premium above the mean in the second (0.250-mile) DB and peaking at 19.3 percent above the mean in the fourth (0.500-mile) DB. Multifamily actually starts below the mean at -5.0 percent in the first (0.125-mile) DB then rises steadily to 15.3 percent above the mean in the last (1.00-mile) DB. Clearly, externality effects appear to influence these real estate types.

In contrast, retail rents fall sharply from 17.1 percent above the mean in the first $(0.125$-mile) distance band to 5.5 percent above the mean in the third (0.3765-mile) DB before rising again as noted earlier.

One reason for these dramatically different outcomes is the possibility that LRT+CRT stations serve high activity, sports and recreation centers that would naturally attract retail but repel office and multifamily real estate. This is an area of future research.

We conclude this chapter with additional implications for transit and land use planning.

Table 10.5 
Relevant Associations between LRT+SCT Distance Bands and Rents for Office, Multifamily and Retail Real Estate

$\begin{array}{cccc}\text { Distance Band } & \text { Office } & \text { Multifamily } & \text { Retail } \\ \text { LRT+SCT } 0.125 & 18.3 \% & 18.2 \% & \mathbf{2 3 . 7 \%} \\ \text { LRT+SCT } 0.250 & 14.9 \% & 19.1 \% & 35.3 \% \\ \text { LRT+SCT } 0.375 & 14.8 \% & 17.6 \% & 20.8 \% \\ \text { LRT+SCT } 0.500 & 18.5 \% & 19.8 \% & 25.6 \% \\ \text { LRT+SCT } 0.625 & 12.3 \% & 12.7 \% & \mathbf{2 2 . 5 \%} \\ \text { LRT+SCT } 0.750 & & 13.6 \% & 39.8 \% \\ \text { LRT+SCT } 0.875 & 11.1 \% & 12.5 \% & 35.0 \% \\ \text { LRT+SCT } 1.000 & & 9.7 \% & \end{array}$




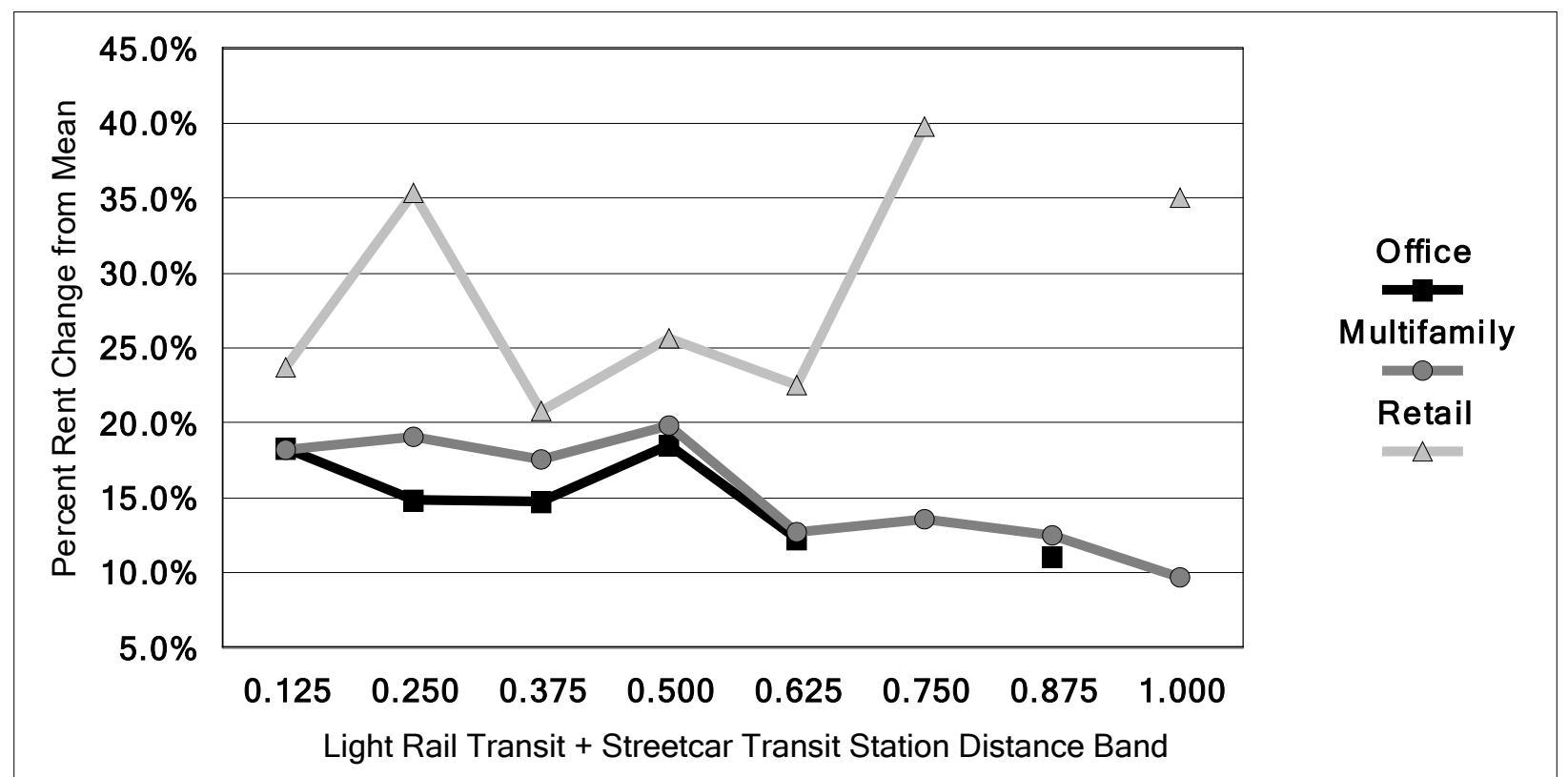

Figure 10.6

Percent rent change from mean for office, multifamily and retail real estate with respect to distance from combined LRT+SCT transit stations 
Table 10.6

Relevant Associations between LRT+BRT Distance Bands and Rents for Office, Multifamily and Retail Real Estate

$\begin{array}{cccc}\text { Distance Band } & \text { Office } & \text { Multifamily } & \text { Retail } \\ \text { LRT+BRT 0.125 } & \mathbf{2 . 4 \%} & & \\ \text { LRT+BRT 0.250 } & \mathbf{8 . 5 \%} & -4.1 \% & \mathbf{9 . 0 \%} \\ \text { LRT+BRT 0.375 } & \mathbf{1 2 . 2 \%} & \mathbf{2 . 1 \%} & \mathbf{2 0 . 9 \%} \\ \text { LRT+BRT 0.500 } & \mathbf{9 . 5 \%} & & \\ \text { LRT+BRT 0.625 } & & & \\ \text { LRT+BRT 0.750 } & \mathbf{- 4 . 5 \%} & \mathbf{5 . 3 \%} & \\ \text { LRT+BRT 0.875 } & 5.5 \% & & \\ \text { LRT+BRT 1.000 } & & & \end{array}$




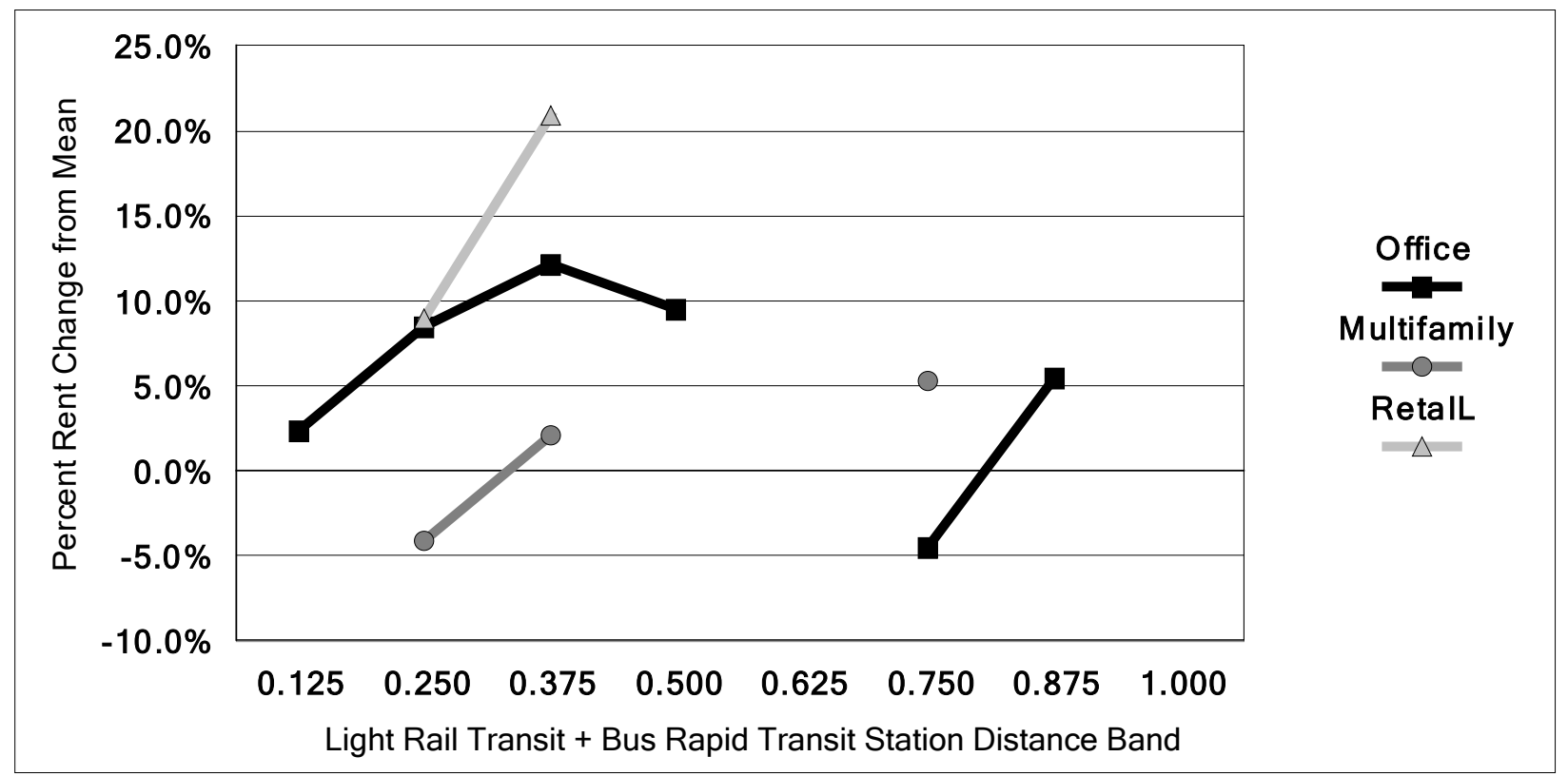

Figure 10.7

Percent rent change from mean for office, multifamily and retail real estate with respect to distance from combined LRT+BRT transit stations 
Table 10.7

Relevant Associations between LRT+CRT Distance Bands and Rents for Office, Multifamily and Retail Real Estate

$\begin{array}{cccc}\text { Distance Band } & \text { Office } & \text { Multifamily } & \begin{array}{c}\text { Retail } \\ \text { LRT+CRT 0.125 }\end{array} \\ \text { LRT+CRT 0.250 } & 3.6 \% & -5.0 \% & 17.1 \% \\ \text { LRT+CRT 0.375 } & 15.1 \% & & 16.0 \% \\ \text { LRT+CRT 0.500 } & 19.3 \% & -2.5 \% & 5.5 \% \\ \text { LRT+CRT 0.625 } & 9.1 \% & & 13.7 \% \\ \text { LRT+CRT 0.750 } & 13.6 \% & 9.4 \% & \\ \text { LRT+CRT 0.875 } & 9.5 \% & & 6.8 \% \\ \text { LRT+CRT } 1.000 & 5.7 \% & 7.9 \% & 5.0 \%\end{array}$




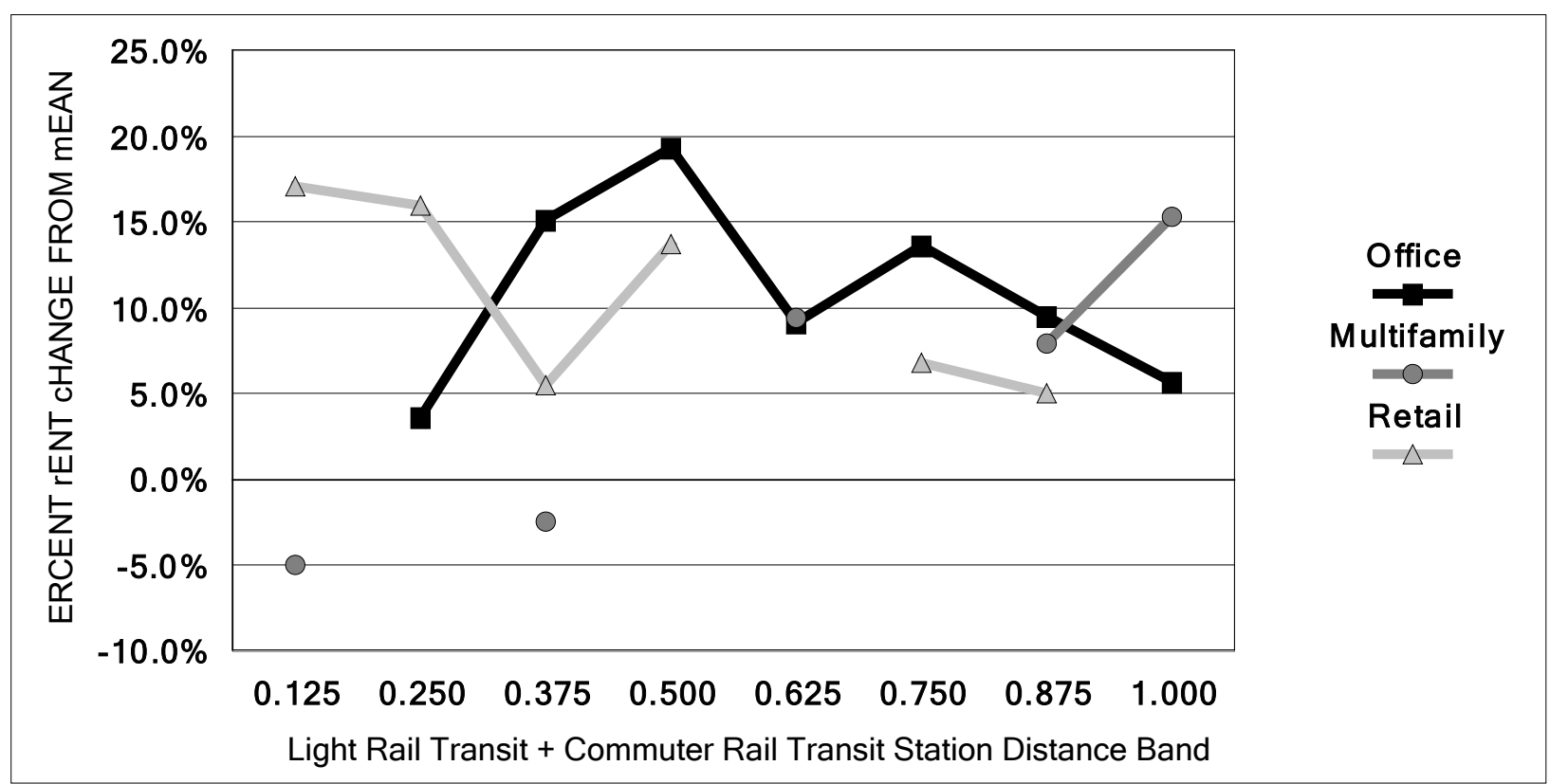

Figure 10.7

Percent rent change from mean for office, multifamily and retail real estate with respect to distance from combined LRT+CRT transit stations 
Implications For Transit, Land Use Planning, And Urban Design

Our analysis reinforces central findings of Chapter 8 and adds new twists when it comes to the intersection of different transit modes. In review, our sample included just those metropolitan areas with light rail transit systems. Because they all have at least one additional transit mode and many have three or all four of those we studied (LRT, SCT, BRT and CRT), we use our LRT database to analyze the nature of market response-in the form of rents- to proximity to situations where LRT stations are shared or are near other FRT stations.

For the most part, we found that where a metropolitan area includes more than just an LRT system -in our case being one or more of SCT, BRT and CRT systems - it may be important to evaluate interactive effects between them. Table 10.8, for instance, shows (in bold red) relevant coefficients from the expanded model presented in this chapter to the original model reported in Chapter 8 . In nearly all comparisons between the original model in Chapter 8 and the expanded model here for office and retail estate, the combined LRT+SCT, LRT+BRT and LRT+CRT coefficients were higher meaning interactive effects were greater than just for LRT alone. This is reasonable, a priori.

However, less impressive are comparisons with respect to multifamily real estate where relevant coefficients for only the LRT+SCT expanded model were larger than the original model. For LRT+BRT and LRT+CRT, results were less impressive for the first 0.50-mile distance bands. But this begs the question. In these cases, it is important to know that combined LRT+BRT and LRT+CRT stations actually result in multifamily rents falling below the mean in the first 0.50-mile DBs. Perhaps it is also important that the relevant coefficients of the combined LRT+CRT stations exceed those of the original LRT model in distance bands from 0.50 -mile to the end of the 1.00-mile study area. Indeed, these particular results suggest that multifamily real estate is more sensitive to potential externalities associated with BRT and CRT stations which is also reasonable, a priori.

Through this chapter and in Chapter 7 as well, we counsel for improved transit and land use planning, and urban design to help overcome externality effects of transit station proximity, and improve rent premiums with respect to transit station proximity. A framework for this is outlined in Chapter 11. 
Table 10.8

Comparisons of Relevant Coefficients between Original Model without Multiple Systems and Expanded Model with Multiple Systems

\begin{tabular}{|c|c|c|c|c|c|c|c|c|}
\hline $\begin{array}{l}\text { Transit } \\
\text { Combination }\end{array}$ & 0.125 & 0.250 & 0.375 & 0.500 & 0.625 & 0.750 & 0.875 & 1.000 \\
\hline & \multicolumn{8}{|c|}{ Office Real Estate Rents } \\
\hline LRT Original Model & $9.3 \%$ & $5.8 \%$ & $3.7 \%$ & $3.1 \%$ & $4.2 \%$ & $4.6 \%$ & $5.6 \%$ & $4.4 \%$ \\
\hline LRT+SCT Model & $18.3 \%$ & $14.9 \%$ & $14.8 \%$ & $18.5 \%$ & $12.3 \%$ & & $11.1 \%$ & \\
\hline LRT+BRT Model & $2.4 \%$ & $8.5 \%$ & $12.2 \%$ & $9.5 \%$ & & $-4.5 \%$ & $5.5 \%$ & \\
\hline \multirow[t]{2}{*}{ LRT+CRT Model } & & $3.6 \%$ & $15.1 \%$ & $19.3 \%$ & $9.1 \%$ & $13.6 \%$ & $9.5 \%$ & $5.7 \%$ \\
\hline & \multicolumn{8}{|c|}{ Multifamily Real Estate Rents } \\
\hline LRT Original Model & $3.5 \%$ & $6.1 \%$ & $3.7 \%$ & $5.6 \%$ & $4.6 \%$ & $5.5 \%$ & $4.2 \%$ & $5.1 \%$ \\
\hline LRT+SCT Model & $18.2 \%$ & $19.1 \%$ & $17.6 \%$ & $19.8 \%$ & $12.7 \%$ & $13.6 \%$ & $12.5 \%$ & $9.7 \%$ \\
\hline LRT+BRT Model & & $-4.1 \%$ & $2.1 \%$ & & & $5.3 \%$ & & \\
\hline \multirow[t]{2}{*}{ LRT+CRT Model } & $-5.0 \%$ & & $-2.5 \%$ & & $9.4 \%$ & & $7.9 \%$ & $15.3 \%$ \\
\hline & \multicolumn{8}{|c|}{ Retail Real Estate Rents } \\
\hline LRT Original Model & $9.3 \%$ & $5.8 \%$ & $3.7 \%$ & $3.1 \%$ & $4.2 \%$ & $4.6 \%$ & $5.6 \%$ & $4.4 \%$ \\
\hline LRT+SCT Model & $23.7 \%$ & $35.3 \%$ & $20.8 \%$ & $25.6 \%$ & $22.5 \%$ & $39.8 \%$ & & $35.0 \%$ \\
\hline LRT+BRT Model & & $9.0 \%$ & $20.9 \%$ & & & & & \\
\hline LRT+CRT Model & $17.1 \%$ & $16.0 \%$ & $5.5 \%$ & $13.7 \%$ & & $6.8 \%$ & $5.0 \%$ & \\
\hline
\end{tabular}




\section{REFERENCES}

Alonso W (1964). Location and Land Use: Toward a General Theory of Land Rent, Harvard University Press, Cambridge MA.

American Public Transportation Association, Public Transportation: Benefits for the 21st Century Washington, DC: American Public Transportation Association, 2007.

Barbeau, S. J. Quality Control - Lessons Learned from the Deployment and Evaluation of GTFS-Realtime Feeds. Presented at the $97^{\text {th }}$ Annual Meeting of the Transportation Research Board, Washington, D.C., 2018.

Belzer, Dena, Sujata Srivastava, Mason Austin, Tyler Bump, and Jeff Wood.Transit and Regional Economic Development. No. FTA CA-26-1007-03, 2011.

Bettencourt, Luis and Geoffrey West. "A Unified Theory of Urban Living." Nature (October 2010): 467.

Bruegmann, Robert. Sprawl: A Brief History. University of Chicago Press, Chicago, 2006.

Center for Transit Oriented Development (nd). TOD 201: Sustainable Urban Design \& Transit. http://ctod.org/APTAmodules/SUDS201/index.html

Ciconne, Antonio and Robert E. Hall. "Productivity and the Density of Economic Activity." American Economic Review 86(1), (1996): 54-70.

Duany, Andres, Elizabeth Plater-Zyberk and Jeff Speck. Suburban Nation: The Rise of Sprawl and the Decline of the American Dream. North Point Press, New York, NY, 2000.

Duranton, Gilles, and Matthew A. Turner. "The Fundamental Law of Road Congestion: Evidence from US Cities." American Economic Review 101(6), (2011): 216-52.

Ewing, Reid and Shima Hamidi (2018). The Costs of Sprawl. London: Routledge.

Glaeser, Edward, Triumph of the City: How Our Greatest Invention Makes Us Richer, Smarter, Greener, Healthier, and Happier. Penguin, New York, NY, 2011.

Hajrasouliha, Amir H. and Shima Hamidi (2017). The typology of the American metropolis: monocentricity, polycentricity, or generalized dispersion? Urban Geography 38:3, 420-444, DOI: 10.1080/02723638.2016.1165386.

Hibberd, R., A. C. Nelson, K. Currans. Functional Form in Hedonic Regression: Literature Review \& Test of Forms to Determine the End of Significance of Transit Proximity Effects on LVU. University of Arizona.

Higgins, Christopher D. Higgins \& Pavlos S. Kanaroglou (2016). Forty years of modelling rapid transit's land value uplift in North America: moving beyond the tip of the iceberg, Transport Reviews, 36:5, 610-634, DOI: $\underline{10.1080 / 01441647.2016 .1174748}$ 
Institute for Transportation \& Development Policy. Best Practices 2013. Accessed from https://www.itdp.org/library/standards-and-guides/the-bus-rapid-transit-standard/best-practices$\underline{2013 /}$

Litman, Todd. Evaluating Public Transit Benefits and Costs. Victoria Transport Institute, Victoria, BC, 2017.

Mills ES (1967). An Aggregative Model of Resource Allocation in a Metropolitan Area, The American Economic Review, Papers and Proceedings, 57(2), pp 197-210. University of Chicago Press, Chicago.

Muth RF (1969). Cities and Housing: The Spatial Pattern of Urban Residential Land Use, Third Series: Studies in Business and Society.

Metropolitan Atlanta Rapid Transit Authority (nd). Types of Transit Services \& Vehicles. Accessible from https://www.itsmarta.com/types-of-transit-services-vehicles.aspx

National Association of City Transportation Officials (2016). Transit Street Design Guide. https://nacto.org/publication/transit-street-design-guide/.

Nelson Arthur C. (2017). Transit and Real Estate Rents. Transportation Research Record: Journal of the Transportation Research Board. https://doi.org/10.3141/2651-03:

Nelson, Arthur C. Dejan Eskic, Shima Hamidi, Susan J. Petheram, Jenny H. Liu, Reid Ewing. 2015. Office Rent Premiums with Respect to Distance from Light Rail Transit Stations/stops in Dallas. Transportation Research Record DOI 10.3141/2500-13.

Nelson, Arthur C., Matt Miller, Dejan Eskic, Keuntae Kim, Reid Ewing, Jenny H. Liu, Matt Berggren, Zakari Mumuni. Do TODs Make a Difference? Portland OR: National Institute for Transportation and Communities, Portland State University, OR, 2015.

Nelson, Arthur C. National Study of BRT Development Outcomes. Portland, OR: National Institute for Transportation and Communities accessible from

https://pdxscholar.library.pdx.edu/trec reports/32/ (2015).

Nelson, Arthur C. and Robert Hibberd (2019). Streetcars and Real Estate Rents. Transportation Research Record (forthcoming).

Nelson, Arthur C. and Susan J. McClesky (1990). Elevated Rapid Rail Station Impacts on Single-Family House Values, Transportation Research Record, 1266: 173-180.

Nelson, Arthur C. (1992). Effects of Heavy-Rail Transit Stations/stops on House Prices with Respect to Neighborhood Income, Transportation Research Record, 1359: 127-132.

Nelson, Arthur C. (2017). Transit and Real Estate Rents. Transportation Research Record, 2651(1), 22-30. https://doi.org/10.3141/2651-03

Nelson, Arthur C. and Robert Hibberd, with Matt Dixon (2019). The Link between Transit Station Proximity and Real Estate Rents, Jobs, People and Housing with Transit and Land Use Planning Implications. Portland OR: National Institute for Transportation and Communities, Portland State University. 
Nikitas, Alexandros and MariAnne Karlsson. "A Worldwide State-of-the-Art Analysis for Bus Rapid Transit: Looking for the Success Formula." Journal of Public Transportation 18(1), (2015): 1-33.

Park, Robert Ezra, E. W. Burgess, Roderick Duncan McKenzie, and Louis Wirth. 1925. The city. Chicago, III: University of Chicago Press.

Perk, Victoria A. Martin Catalá, Maximillian Mantius, Katrina Corcoran (2017). Impacts of Bus Rapid Transit (BRT) on Surrounding Residential Property Values. Portland OR: National Institute for Transportation and Communities, Portland State University.

Petheram, Susan J., Arthur C. Nelson, Matt Miller and Reid Ewing (2013). Using the Real Estate Market to Establish Light Rail Station Catchment Areas: Case Study of Attached Residential Property Values in Salt Lake County with respect to Light Rail Station Distance. Transportation Research Record. 2357: 95-99.

Peiser, Richard B. and David Hamilton (2012). Professional Real Estate Development: The ULI Guide to the Business, 3rd Edition. Washington, DC: Urban Land Institute.

Stoker, Philip \& Reid Ewing (2014) Job-Worker Balance and Income Match in the United States, Housing

Weisbrod, Glen, Derek Cutler and Chandler Duncan. Economic Impact of Public Transportation Investment. American Public Transportation Association, Washington, DC, 2014.

Xiao, Yang (2016). Hedonic Housing Price Theory Review in Urban Morphology and Housing Market, pp. 11-40. New York: Springer. 


\section{CHAPTER 11: Regional Differences in the U.S. Real Estate Market Response towards Proximity of Fixed Route Transit Systems}

\section{OVERVIEW}

Fixed-route transit (FRT) systems have operated in the US for more than one hundred years with the majority developed during the last half a century. While many single-system studies exist, there has not been rigorous, systematic cross-section analysis of whether and the extent to which these systems influence the real estate market. This chapter helps close the gap in research. In particular, in this article we apply hedonic regression to estimate the association between FRT station proximity and office, retail and multifamily rents and extend the analysis to compare the structural differences of these responses across metropolitan areas and markets.

\section{Relevant Literature, Theory and Research Question}

The conventional AMM or bid-rent theories-originally developed by Alonso (1964), Mills (1967), and Muth (1969)—suggests that in monocentric cities, the costs of real estate decrease at a declining rate the further development happens from the central business district (CBD). This is in part due to greater transportation costs the further one gets from downtown, and this results in greater competition across and within different land uses. In other words, firms and households pay a premium for locating in areas with greater levels of accessibility.

Based on these theories, FRT systems should also influence urban development patterns and as such urban real estate markets where multimodal options exist with varying degrees of access and opportunity. If we relax the monocentric city model perspectives of AMM, one might capture local-level variation in accessibilities due to multimodal infrastructure that is attractive to residents, employees, or patrons (Hajrasouliha \& Hamidi, 2017). Further, FRT stations are often developed with increases in local densities and mixed use, which may result in localized versions of bid-rent models which increase (or decrease) rents for some land uses. As a response to local accessibility, firms and households will compete for this accessibility, increasing land prices in areas where the accessibility is of a positive nature, or lowering prices where the access is considered a nuisance in the market. And several studies have confirmed there seem to be this localized bid rent gradients with respect to distance from rail transit stations (Higgins \& Kanaroglou, 2016).

However, Higgins and Kanaroglou (2016) have pointed out in their recent meta-analysis substantial variation in functional forms and positive (or negative) findings relative to different FRT systems and model forms. However, it is challenging to rule out this variation as a result of differing methodological structures-selecting continuous proximity measures versus distance band categories, using semi-log over double-log functional forms, etc. In this article, our goal is to apply AMM theory to areas near FRT stations (or not) to identify whether and where there may be structural differences in the market response to FRT proximity across different metropolitan statistical areas (MSAs). As such, our main research question is: 
Are there structural differences between real estate rent (per square foot) and the proximity to FRT stations for different MSAs, holding other factors constant? The chapter proceeds with an explanation of our research approach and a discussion of the findings. We then focus our concluding thoughts on implications for transit and land use planning.

\section{Data and Methods}

In this study, we were allowed access to the CoStar national commercial real estate data base for this analysis. CoStar is likely the largest U.S. commercial real estate brokers databases, a ubiquitous resource for commercial properties across all major metropolitan areas. While this database includes many types of land uses, our study focuses on the three that are most associated with firms and/or households paying a premium for improved personal transportation accessibility: multifamily residential, office, and retail structures.

We apply this analysis through a quasi-experimental, cross-sectional research design focused on rent data from 2017. We test for a proximity effect of three FRT types (light-rail transit (LRT), bus-rapid transit (BRT), and streetcar transit (SCT)) on rent for three land uses (multifamily, office, and retail) across metropolitan statistical areas (MSAs) in the US. This approach is not intended to capture causality, associations explored here can be used for local land use and transit planning purposes. We apply the general model form, adapted from Nelson (2017), to test this theory:

$R_{i}=f\left(S_{i}, S E S i, L i\right.$, DB i, $\left.M_{i}, D B^{*} M_{i}\right)$

(1)

Where:

- $\mathbf{R}$ is the real estate rent per square feet;

- $\mathbf{S}$ are structural variables;

- SES are socioeconomic controls;

- L includes locational controls;

- $\quad$ DB are the proximity indicators (distance bands, DB);

- $\mathbf{M}$ are the MSA dummy variables; and

- $\mathbf{D B}^{*} \mathbf{M}$ are the interaction terms between the proximity indicators and the metro-area indicators. In other words, the DB categories are dummy variable expressing how far the real estate is from a FRT station, but $\mathbf{D B}^{*} \mathbf{M}$ are the distance categories separated for each MSA in $\mathbf{M}$. It is this interaction term that provides a means to test for structural differences in the market response to proximity to FRT across MSAs.

Each of the variable categories are described below. In Table 11.1, we summarize the expected sign of all of the controls based on previous studies and the authors expertise. 
Table 11.1

Variables, Data Sources, and Predicted Association with Respect to Rent

\begin{tabular}{|c|c|c|c|}
\hline & Description & $\begin{array}{l}\text { Data } \\
\text { Source }\end{array}$ & $\begin{array}{l}\text { Predicted } \\
\text { Sign }\end{array}$ \\
\hline \multicolumn{4}{|l|}{ Structure Controls } \\
\hline $\begin{array}{l}\text { Gross Leasable } \\
\text { Area }\end{array}$ & $\begin{array}{l}\text { Building square feet. Positive association } \\
\text { expected because larger buildings presumably } \\
\text { include more amenities than smaller ones }\end{array}$ & CoStar & + \\
\hline Class A Office & \multirow{2}{*}{$\begin{array}{l}\text { For office properties, with Class } \mathrm{C} \text { as the } \\
\text { referent. Classes } \mathrm{A} \text { and } \mathrm{B} \text { are expected to } \\
\text { increase the rent. }\end{array}$} & CoStar & + \\
\hline Class B Office & & CoStar & + \\
\hline Stories & $\begin{array}{l}\text { Number of floors in the building. Limited } \\
\text { research on retail may confound the } \\
\text { association direction. }\end{array}$ & CoStar & + \\
\hline Effective Year Built & $\begin{array}{l}\text { Latest year of development or renovation. } \\
\text { Newer buildings are expected to have higher } \\
\text { rents. }\end{array}$ & CoStar & + \\
\hline Vacancy Rate & $\begin{array}{l}\text { Proportion of the development vacant. Higher } \\
\text { vacancy rates are expected to lower rents. } \\
\text { This may not always be the case however as } \\
\text { high demand markets could result in high } \\
\text { vacancy rates as owners may wait for higher } \\
\text { paying tenants. Accordingly, signs may not be } \\
\text { predictable especially considering that the } \\
\text { study area is comprised of stable to rapidly } \\
\text { growing central counties. }\end{array}$ & CoStar & - \\
\hline $\begin{array}{l}\text { Power Center, } \\
\text { Neighborhood, } \\
\text { Community, } \\
\text { Regional, Lifestyle, } \\
\text { Outlet }\end{array}$ & $\begin{array}{l}\text { Retail structures are dummy variables. } \\
\text { Literature is unclear about association; } \\
\text { therefore, we do not predict directions of } \\
\text { association. }\end{array}$ & CoStar & na \\
\hline Senior & \multirow{2}{*}{$\begin{array}{l}\text { For multifamily facilities only, these are } \\
\text { restricted to seniors or students. The referent } \\
\text { is "market rate". }\end{array}$} & CoStar & + \\
\hline Student & & CoStar & - \\
\hline \multicolumn{4}{|l|}{$\begin{array}{l}\text { Socioeconomic } \\
\text { Control }\end{array}$} \\
\hline $\begin{array}{l}\text { Median Household } \\
\text { Income }\end{array}$ & $\begin{array}{l}\text { Median Income of the development's block } \\
\text { group. Higher rents are expected in areas with } \\
\text { higher incomes. }\end{array}$ & $\begin{array}{l}\text { Census } \\
\text { ACS }\end{array}$ & + \\
\hline \multicolumn{4}{|l|}{ Location Controls } \\
\hline $\begin{array}{l}\text { Place Type } \\
\text { (controls for more } \\
\text { urban places) }\end{array}$ & $\begin{array}{l}\text { Described in the test, these categories control } \\
\text { for similar levels of density and diversities to } \\
\text { provide comparable } \\
\text { More urban and dense categories are } \\
\text { expected to have higher rents (controlling for } \\
\text { MSA). }\end{array}$ & $\begin{array}{l}\text { LEHD, } \\
\text { ACS }\end{array}$ & + \\
\hline $\begin{array}{l}\text { Distance Freeway } \\
\text { Ramp }\end{array}$ & $\begin{array}{l}\text { Distance (in miles) to the nearest freeway } \\
\text { ramp. Residential land uses are expected to }\end{array}$ & Computed & $+/-$ \\
\hline
\end{tabular}


observe negative associations, but office and

retail may benefit from access to highways. 


\begin{tabular}{|c|c|c|c|}
\hline \multicolumn{4}{|l|}{$\begin{array}{l}\text { Variables of } \\
\text { Interest }\end{array}$} \\
\hline Distance Band (DB) & $\begin{array}{l}\text { Dummy variables noting how far each } \\
\text { development is to the nearest FRT station. } \\
\text { Categories capture within } 0.125 \text { mile, } 0.125 \text { to } \\
0.25 \text { miles, and at quarter miles' increments } \\
\text { though a } 1.50 \text {-mile distance. The referent is any } \\
\text { development further than } 1.5 \text { miles away from a } \\
\text { station. }\end{array}$ & Computed & $\begin{array}{l}\text { Finding } \\
\text { of } \\
\text { Interest }\end{array}$ \\
\hline $\begin{array}{l}\text { Metropolitan } \\
\text { Statistical Areas } \\
\text { (MSA) }\end{array}$ & $\begin{array}{l}\text { Dummy variables capturing which MSA the } \\
\text { development is located in. This captures the } \\
\text { larger differences in rent costs across MSA } \\
\text { markets. }\end{array}$ & Computed & $+/-$ \\
\hline $\begin{array}{l}\text { Distance Band * } \\
\text { MSA Interactions }\end{array}$ & $\begin{array}{l}\text { Dummy variable interaction of DB and MSA. If } \\
\text { significant, these coefficients capture structural } \\
\text { differences in proximity (DB) across regions } \\
\text { (MSA). }\end{array}$ & Computed & $\begin{array}{l}\text { Finding } \\
\text { of } \\
\text { Interest }\end{array}$ \\
\hline
\end{tabular}


Control Variables

$\mathbf{R}$ is the asking rent per square foot reported by CoStar during 2017. We focus on office, retail, and multifamily because residents, employees, and patrons of these three land uses are more likely to consider transit as a benefit, and therefore firms maybe more likely to pay a premium. This data provides a large sample of the universe of land uses, included by only participating brokerages or entities not properties rented as owner-occupied. While we considered multiple model forms as estimated in the literature (Higgins \& Kanaroglou, 2016), in our approach we rely on semi-log functional forms for all models estimated. In semi-log functional forms, the dependent variable is transformed by the natural log and the coefficients estimate the percent difference in value associated with a unit change in an independent variable. This structure makes the coefficients easy to interpret and compare across MSAs where regional market influences vary drastically (i.e., a $5 \%$ increase in rent in Los Angeles is larger than in Tucson).

$\mathbf{S}$ is the matrix including a bundle of structure attributes for property $i$ reported by CoStar. This includes occupancy characteristics noted below, such as architecture, mass, height, age and effective age, interior amenities, flow efficiencies and so forth. In this chapter, we control for some of the most common (see Table 11.1 for descriptions).

The SES vector includes Median Household Income of the census block group for each property. This data was appended from the five-year sample of the 2017 American Community Survey (ACS). We expect higher rents in areas with higher in comes (Xiao, 2017).

$\mathbf{L}$ describes the locational measures that capture urban form features that have been known to influence real estate value (e.g., distance to highway ramps) and regional location (e.g., place type). The Distance from Freeway is defined as the nearest freeway or expressway ramp. Because freeway ramps can be considered nuisances in addition to being an accessibility benefit, both positive and negative expected signs are predicted, depending on land use.

To capture Place Types, we consider our research question and design, which requires that data across distinctly different MSAs are compared. As such, our place types were designed to capture similar built environments across regions. In other words, the density of downtown Tucson is far less than the density of downtown Portland, and so our place types groups contexts with similar built environment features so that a block group in downtown Tucson would be compared against areas with similar densities in other studies. Our place type design uses a method implored in a study of place types conducted in California by Gehrke and Clifton (Clifton et al., 2018; K. J. Clifton \& S. Gehrke, personal communication, August 23, 2016). In this approach, "place types" were created from a series of built environment variables, which enabled environments to be compared across the state in a suite of five dummy variables-a major benefit for a multi-region study. (These urban context categories have since been aggregated to the California add-survey of the National Household Travel Survey.) In our application of these place types, we apply the following built environment variables (aggregated to the census block group): 
- Longitudinal Employer-Household Survey (LEHD, 2017):

- Total jobs per acre;

- Proportion of jobs that are retail or entertainment;

- American Community Survey (ACS, 2017, 5-year):

- Total residential population per acre;

- Total households per acre;

- Proportion of households with no kids (representing smaller dwelling units);

- Proportion of households that are owner occupied;

- Smart Location Database (U.S. EPA, 2014) ${ }^{119}$.

- Intersection density (an indication of connectivity);

- Proportion of intersections that are three-way to those that are four-way (an indication of connectivity.

Next, for each variable we apply a Jenks natural break to segment the spectrum of variables. Each "break" is ranked in terms of the "urbanness" of the categories. I.e., the lowest density category is given a 1, the highest is given a 5 . The sum of these ranking provide an indication of the level of urbaneness for each block group. From here, the sum of rankings is then divided into the number of categories of interest. For our approach, we aggregated the place types into four categories labeled from $1=$ most suburban to $4=$ highly urban. This was an iterative process, rotating between testing variables and ground-truthing them through spatial mapping and observations through Google Streetview.

It is worth noting that in an early iteration of this manuscript, we also entertained the research question "does the proximity to FRT vary structurally across place type (e.g., urban contexts)?" But the findings from this work-similar approach, but interacting the place types documented in this paper and not the MSAs-were limited to some interesting results in associations between offices and BRT. In future work, exploring the proximity effects across place types in MSA might benefit form place types designed to control for similar built environments across metropolitan areas. For example, streetcars are mainly in downtown area used as circulators. So while our place types might capture the density similarities between block groups across regions, in less dense regions it might not capture the "central city" effects of differently size regions that might address the question of structural differences across similar place types. In future work of this nature, we recommend considering also place types defined individually for each region (and not for the sample of MSAs as a whole).

\footnotetext{
${ }^{119}$ Note that while this data is older, intersection density is not something that widely changes from decade to decade in most of the areas that are already developed enough to have FRT.
} 
Variables of Interest

DB defined as the location of the subject property within one-quarter mile distance bands (DBs) of the nearest FRT station outward to 1.5 miles. Previous work had indicated effects as far out as 1.75 miles for light-rail transit and office work (Nelson et al., 2015), but other studies found the influence limited closer to 1.25 miles for multifamily, for example (Petheram et al., 2013). Each distance band is represented as a dummy variable, with all properties greater than 1.5 miles from FRT stations as the "base case" from which the properties in proximity are compared. Positive (or negative) values for coefficients can be interpreted as having higher (or lower) rents within proximity, compared with those that are not.

While a positive association is expected between DBs and FRT stations, negative associations can signal externality effects noted above. For instance, areas very near stations may have nuisances such as traffic, noise, and poor urban design that offset positive effects of proximity. But DBs farther away may have positive coefficients. The DB approach allows us to estimate how far away from transit stations the market values proximity, which is important for transit and land use planning.

Many studies completed previously have considered the relationship between proximity and value to be continuous, resulting in a variety of transformations and interpretations about proximity effects. In this study, we rely on distance bands because they offer a practical middle ground between knowing whether and the extent to which real estate markets respond to transit stations within discrete distances of FRT stations. They also allow for statistical significance testing for each band separately. If distance bands are small, they can reveal negative effects of close proximity to FRT stations and positive effects farther away. Most distance-band studies use only a one quarter or (more often) a one half mile distance band (see (Higgins \& Kanaroglou, 2016)), or occasionally two bands (Nelson, 2017). This approach assumes all relevant interactions useful for planners to know occur only within those few, arguably largearea distance bands. Following Hibberd et al. (n.d.) and Nelson and Hibberd (Nelson \& Hibberd, 2019), we began with more refined distance bands (one-eighth mile) that extended further (up to 2.0 miles), but we found the more refined distance bands had too few observations across different MSAs limiting our ability to test for more robust statistical differences. Thus, we aggregated the distance bands to quarter mile increments. Future work might consider merging multiple years of data, controlling for the temporal variation, and exploring the structural differences of more refined distance bands.

The $\mathbf{M}$ vector is comprised of the individual metropolitan area within which the FRT systems operates (see Table 11.2). As these are controls accounting for idiosyncrasies of metropolitan markets, no direction of associations for each MSA is predicted. The coefficients of the MSAs can be interpreted as relative overall differences in the market areas. Those that are more expensive to rent will have more positive coefficients and interpretations compared with those that are less expensive. We have included some high-level demographics descriptions across each MSA for interpretation purposes. Our analysis is limited to the counties within which these FRT systems operate-not all counties in their metropolitan areas. However, because we want to tease out effects of individual systems, we do not include metropolitan areas that are large and are comprised of numerous, interconnecting systems. 
Table 11.2

Metropolitan Statistical Area (MSA) Fixed Route Transit Systems Studied

\begin{tabular}{|c|c|c|c|c|c|c|}
\hline \multirow[b]{2}{*}{$\begin{array}{l}\text { Metropolitan Statistical } \\
\text { Area }\end{array}$} & \multicolumn{3}{|c|}{ Era of System } & \multicolumn{3}{|c|}{ Demographics } \\
\hline & LRT & BRT & SCT & $\begin{array}{l}\text { Median } \\
\text { Income } \\
\text { (2017 } \\
\text { USD) }\end{array}$ & $\begin{array}{l}\text { Percent } \\
\text { Unem- } \\
\text { ployment } \\
(\%)\end{array}$ & $\begin{array}{c}\text { Pop. } \\
\text { Density } \\
\text { (population } \\
\text { per square } \\
\text { mile) }\end{array}$ \\
\hline Albuquerque (ALQ) & & 2004-06 & & 50,781 & 7.0 & 97 \\
\hline Atlanta (ATL) & & & 2014 & 61,733 & 7.0 & 656 \\
\hline Buffalo (BUF) & 1986 & & & 53,534 & 5.6 & 726 \\
\hline Charlotte (CHR) & 2007 & & & 57,871 & 7.1 & 479 \\
\hline Cincinnati (CIN) & & & 2016 & 59,478 & 5.8 & 518 \\
\hline Cleveland (CLE) & 1913 & $2008-14$ & & 52,446 & 7.5 & 1,032 \\
\hline Dallas (DAL) & $1996-2010$ & & 2015 & 63,870 & 5.3 & 766 \\
\hline Denver (DEN) & $1996-2010$ & & & 71,884 & 4.6 & 335 \\
\hline Eugene-Springfield (EUG) & & 2007 & & 47,710 & 7.6 & 80 \\
\hline Houston (HOU) & 2004-15 & & & 62,922 & 6.1 & 803 \\
\hline Kansas City (KC) & & $2005-11$ & 2016 & 61,479 & 4.9 & 288 \\
\hline Las Vegas (LV) & & $2005-12$ & & 54,882 & 8.3 & 268 \\
\hline Little Rock (LR) & & & & 51,362 & 5.4 & 179 \\
\hline Minneapolis-St. Paul (MSP) & 2004-14 & $2013-16$ & & 73,735 & 4.3 & 462 \\
\hline Nashville (NSH) & & $2009-16$ & & 59,365 & 5.0 & 290 \\
\hline New Orleans (NO) & & & $1835-2013$ & 50,154 & 7.1 & 394 \\
\hline Norfolk (NOR) & 2011 & & & 61,889 & 6.6 & 640 \\
\hline Phoenix (PHX) & 2008 & 2003 & & 57,935 & 6.2 & 313 \\
\hline Pittsburgh (PIT) & UNK & UNK & & 56,073 & 5.7 & 445 \\
\hline Portland (PDX) & 1998-2015 & & 2001-2012 & 66,657 & 6.2 & 356 \\
\hline
\end{tabular}




\begin{tabular}{|c|c|c|c|c|c|c|}
\hline Reno (RNO) & & 2012 & & 58,654 & 6.8 & 68 \\
\hline Sacramento (SAC) & $1987-2012$ & & & 64,407 & 8.1 & 445 \\
\hline Salt Lake City (SLC) & $1999-2011$ & 2008 & 2013 & 67,838 & 4.4 & 152 \\
\hline San Antonio (SATX) & & 2012 & & 56,495 & 5.9 & 325 \\
\hline San Diego (SD) & $1981-2008$ & 2011-14 & & 70,588 & 7.1 & 780 \\
\hline San Jose (SJ) & $1987-1991$ & 2015 & & 105,809 & 5.8 & 735 \\
\hline Seattle (SEA/TAC) & 2003-2009 & $2010-14$ & $2001-16$ & 77,269 & 5.5 & 636 \\
\hline St. Louis (STL) & 1993-2006 & & & 59,046 & 6.3 & 357 \\
\hline Stockton (STO) & & $2007-12$ & & 57,813 & 11.1 & 520 \\
\hline Tampa (TAM) & & & UNK & 50,567 & 6.8 & 1,184 \\
\hline Tucson (TUC) & & & 2014 & 48,676 & 8.4 & 110 \\
\hline Washington DC (WDC) & & UNK & 2016 & 97,148 & 5.5 & 975 \\
\hline
\end{tabular}

Notes: UNK: Unknown at time of publication; Median Income: 2017 American Community Survey (ACS) (5-year), variable: S1901_C01_012E; Population: 2017 v (5-year), variable: B01003_001E; Percent Unemployment, civilians: 2017 ACS (5-year), variable: DP03_0009PE; Average Population Density: 2017 ACS (5-year), total population divided by square miles of land (TIGER files)

$D^{*} \mathbf{M}$ represents the vector of variables controlling for the structural differences for each distance band by each metropolitan area. While $\mathbf{M}$ captures the differences across regional markets, it is the sum of each DB coefficient and $\mathbf{D B}^{*} \mathbf{M}$ interaction coefficient that provides an estimate of the percent difference (higher or lower) in rents across metro areas and proximity bands. However, there are two caveats. First, while the CoStar database is substantial, the use of interaction terms requires that an adequate sample size is provided for each category and subcategory (e.g., $N \geq 30$ ). Coefficients estimated for categories with less than 30 observations tend to capture the anecdotal contexts by which the smaller sample sizes are available. This makes interpretation more than difficult. For each DB and $\mathbf{M}$ alone, there are numerous observations. However, when segmenting the data by DB and $\mathbf{M}$ together (across each FRT system and land use type), some $\mathbf{D B}^{*} \mathbf{M}$ categories could not be estimated and are therefore considered statistically similar to the base case. Second, we estimate each DB, M, and DB*M as dummy variables against a base case. The base case for each model depended on which MSA had a robust sample across each proximity category. For each FRT and land use model estimated, the base case varies.

\section{Statistical Tests and Summarizing the Analysis}

To illuminate the similarities across patterns observed within each FRT and land use model considered, we summarize the findings across distance bands and metro areas and use a simple hierarchical clustering of distance band effects across metro areas to categorize patterns of market responses. From these results, the similarities between metro-area proximity market 
responses are compared by a dendrogram, and cities are grouped by similarities in proximity responses. In other words, we developed an initial grouping of how the market responded across metro areas. We also use the loglikelihood ratio test to consider whether the restricted model versions - those with the interaction effects-contribute to statistically improving the overall model significance, compared with the unrestricted model-the version without the interaction effects.

In this approach, we test nine different models: three each for multifamily residential, office, and retail commercial real estate; and three each for light-rail transit, bus-rapid transit, and streetcar transit. Within each of these models that all the controls, variables of interests, and interaction terms, we estimated upwards of 120 coefficients within each models. Instead of focusing explicitly on the regressions themselves, we include only the summary tables for the suites of models and variables of interest. 


\section{Results}

Our aim of this work is to identify structural differences in the associations between proximity to FRT and regional MSA. As such, we are pooling data from across dozens of regions to control for differences in a structured way. Because of this, our models include substantial more data than typically used for hedonic studies (see (Higgins \& Kanaroglou, 2016) for comparison). While we have no a priori expectations of goodness of fit outcomes based on the model form and variable set selected for this work, literature suggests we might anticipate an OLS hedonic regression to explain between $20-50 \%$ of variation (e.g., adjusted $\mathrm{R}^{2}$ ). For parsimony, we briefly describe the overall performance of the regressions. The full suite of results is provided as supplementary materials in a separate excel spreadsheet. In this short manuscript, we explore only the summarized variables of interest by FRT mode.

- Multifamily

$$
\begin{aligned}
& \text { ○ LRT: } \quad \mathrm{N}=27,032 ; \quad \text { adjusted }-\mathrm{R}^{2}=0.52 \\
& \text { - BRT: } \quad \mathrm{N}=20,120 \text {; adjusted }-\mathrm{R}^{2}=0.58 \\
& \text { - SCT: } N=16,124 ; \quad \text { adjusted- } R^{2}=0.53 \\
& \text { - Office } \\
& \text { - LRT: } \quad \mathrm{N}=15,865 ; \quad \text { adjusted }-\mathrm{R}^{2}=0.40 \\
& \text { - BRT: } \quad \mathrm{N}=11,874 \text {; } \quad \text { adjusted }-\mathrm{R}^{2}=0.54 \\
& \text { - Retail } \\
& \text { - SCT: } \quad \mathrm{N}=5,260 ; \quad \text { adjusted }-\mathrm{R}^{2}=0.48 \\
& \begin{array}{llll}
\circ & \text { LRT: } & N=10,275 ; & \text { adjusted- } R^{2}=0.30 \\
\circ & \text { BRT: } & N=8,616 ; & \text { adjusted- } R^{2}=0.32 \\
\circ & \text { SCT: } & N=4,189 ; & \text { adjusted- } R^{2}=0.35
\end{array}
\end{aligned}
$$

\section{Light-Rail Transit Station Proximity}

The light-rail transit (LRT) station subset of observations had by far the largest sample and best performance; LRTs tend to span larger areas, from downtown districts with greater densities (and number of developments) to suburban area types. In the following two tables (Table 11.2 and Table 11.4), we summarize the estimated percent difference in proximity (distance band) compared with the base case (everything farther than 1.5 miles from a station) for metropolitan areas across multifamily, office, and retail land uses. For example, Seattle's (SEA/TAC) adjacent proximate category $(<0.125$ miles) indicates multifamily developments rent for $18 \%$ more than those more than those 1.5 miles away, while the estimates for Pittsburg (PIT) indicate that adjacent properties rent for approximately $8 \%$ less than those more than 1.5 miles away.

For each land use, we define a "group" that was derived from the hierarchical cluster analysis. In this cluster exercise, we identify the base case (BC)-the metro area with the most substantial sample size, and therefore the case from which other metro areas are comparedand the base case group (BG) - those metro areas with limited statistically significant findings, and therefore statistically similar proximity responses in rent. Additionally, we identify between 1 and 3 additional "clusters" of metro areas with slightly different profiles. Graphically, we provide the summary of each group by land use type in Figure 11.1. 
Table 11.1

Percent difference in real estate rents by proximity to streetcar transit stations and MSA by land use

\begin{tabular}{|c|c|c|c|c|c|c|c|c|c|}
\hline \multirow[b]{2}{*}{ MSA } & \multicolumn{8}{|c|}{ Distance Bands } & \multirow{3}{*}{$\begin{array}{l}\text { 을 } \\
\text { 운 }\end{array}$} \\
\hline & $<0.125$ & $\begin{array}{c}0.125 \text { to } \\
0.25\end{array}$ & $\begin{array}{c}0.25 \text { to } \\
0.50\end{array}$ & $\begin{array}{c}0.50 \text { to } \\
0.75\end{array}$ & $\begin{array}{c}0.75 \text { to } \\
1.00\end{array}$ & $\begin{array}{c}1.00 \text { to } \\
1.25\end{array}$ & $\begin{array}{c}1.25 \text { to } \\
1.50\end{array}$ & $\begin{array}{c}>1.50 \\
(\mathrm{BC})\end{array}$ & \\
\hline \multicolumn{9}{|c|}{ MULTIFAMILY } & \\
\hline SEA/TAC & $18 \%$ & $30 \%$ & $30 \%$ & $22 \%$ & $22 \%$ & $19 \%$ & $13 \%$ & $0 \%$ & $\mathrm{BC}$ \\
\hline BUF & $18 \%+$ & $30 \%+$ & $15 \%$ & $22 \%+$ & $22 \%+$ & $19 \%+$ & $13 \%+$ & $0 \%$ & $\mathrm{BG}$ \\
\hline $\mathrm{CHR}$ & $18 \%+$ & $30 \%+$ & $9 \%$ & $22 \%+$ & $22 \%+$ & $19 \%+$ & $13 \%+$ & $0 \%$ & $B G$ \\
\hline $\mathrm{HOU}$ & $18 \%+$ & $30 \%+$ & $19 \%$ & $12 \%$ & $9 \%$ & $19 \% \#$ & $13 \% \#$ & $0 \%$ & BG \\
\hline NOR & $18 \%+$ & $30 \%+$ & $30 \%+$ & $22 \%+$ & $22 \%+$ & $19 \%+$ & $13 \%+$ & $0 \%$ & BG \\
\hline DAL & $3 \%$ & $-1 \%$ & $4 \%$ & $9 \%$ & $7 \%$ & $6 \%$ & $13 \% \#$ & $0 \%$ & 2 \\
\hline DEN & $18 \%+$ & $3 \%$ & $2 \%$ & $7 \%$ & $14 \%$ & $6 \%$ & $5 \%$ & $0 \%$ & 2 \\
\hline MSP & $18 \%+$ & $6 \%$ & $7 \%$ & $14 \%$ & $14 \%$ & $4 \%$ & $4 \%$ & $0 \%$ & 2 \\
\hline PDX & $18 \% \#$ & $14 \%$ & $14 \%$ & $16 \%$ & $8 \%$ & $3 \%$ & $2 \%$ & $0 \%$ & 2 \\
\hline SLC & $18 \%+$ & $30 \% \#$ & $9 \%$ & $5 \%$ & $-3 \%$ & $0 \%$ & $13 \%+$ & $0 \%$ & 2 \\
\hline SJ & $5 \%$ & $4 \%$ & $-5 \%$ & $-2 \%$ & $3 \%$ & $1 \%$ & $5 \%$ & $0 \%$ & 2 \\
\hline STL & $18 \%+$ & $7 \%$ & $8 \%$ & $22 \% \#$ & $12 \%$ & $6 \%$ & $3 \%$ & $0 \%$ & 2 \\
\hline $\mathrm{PHX}$ & $18 \%+$ & $10 \%$ & $8 \%$ & $3 \%$ & $-3 \%$ & $-3 \%$ & $-1 \%$ & $0 \%$ & 3 \\
\hline SAC & $18 \%+$ & $-6 \%$ & $-2 \%$ & $-8 \%$ & $-3 \%$ & $-5 \%$ & $-3 \%$ & $0 \%$ & 3 \\
\hline SD & $18 \%$ \# & $1 \%$ & $0 \%$ & $-2 \%$ & $-4 \%$ & $-4 \%$ & $-10 \%$ & $0 \%$ & 3 \\
\hline CLE & $3 \%$ & $4 \%$ & $2 \%$ & $22 \%+$ & $22 \%+$ & $19 \%+$ & $13 \%+$ & $0 \%$ & 4 \\
\hline PIT & $-8 \%$ & $-5 \%$ & $-5 \%$ & $-10 \%$ & $22 \%+$ & $19 \%+$ & $13 \%+$ & $0 \%$ & 4 \\
\hline \multicolumn{10}{|l|}{ OFFICE } \\
\hline DEN & $7 \%$ & $6 \%$ & $7 \%$ & $5 \%$ & $0 \%$ & $4 \%$ & $0 \%$ & $0 \%$ & $\mathrm{BC}$ \\
\hline BUF & $-13 \%$ & $6 \%+$ & $7 \% \#$ & $5 \%+$ & $0 \%+$ & $4 \%+$ & $0 \%+$ & $0 \%$ & BG \\
\hline $\mathrm{CHR}$ & $7 \%+$ & $6 \% \#$ & $7 \% \#$ & $5 \%+$ & $0 \%+$ & $4 \%+$ & $0 \%+$ & $0 \%$ & BG \\
\hline CLE & $7 \%+$ & $-7 \%$ & $7 \% \#$ & $5 \%+$ & $0 \%+$ & $4 \% \#$ & $0 \%+$ & $0 \%$ & $B G$ \\
\hline DAL & $7 \% \#$ & $6 \% \#$ & $7 \% \#$ & $5 \% \#$ & $0 \% \#$ & $-8 \%$ & $0 \% \#$ & $0 \%$ & BG \\
\hline $\mathrm{HOU}$ & $7 \%+$ & $6 \%+$ & $7 \%+$ & $5 \%+$ & $0 \%+$ & $4 \%+$ & $0 \%+$ & $0 \%$ & BG \\
\hline PIT & $-14 \%$ & $-9 \%$ & $7 \% \#$ & $5 \% \#$ & $0 \% \#$ & $4 \% \#$ & $0 \% \#$ & $0 \%$ & $B G$ \\
\hline PDX & $20 \%$ & $6 \% \#$ & $7 \% \#$ & $5 \% \#$ & $0 \% \#$ & $4 \% \#$ & $13 \%$ & $0 \%$ & BG \\
\hline SAC & $7 \%+$ & $6 \%+$ & $7 \% \#$ & $5 \% \#$ & $0 \%+$ & $4 \%+$ & $0 \%+$ & $0 \%$ & $B G$ \\
\hline SEA/TAC & $7 \% \#$ & $20 \%$ & $19 \%$ & $5 \%+$ & $0 \%+$ & $4 \%+$ & $0 \%+$ & $0 \%$ & $B G$ \\
\hline NOR & $7 \%+$ & $6 \%+$ & $7 \%+$ & $5 \%+$ & $0 \%+$ & $4 \%+$ & $0 \%+$ & $0 \%$ & BG \\
\hline $\mathrm{PHX}$ & 7\% \# & $6 \% \#$ & $-4 \%$ & $-16 \%$ & $-22 \%$ & $-21 \%$ & $0 \% \#$ & $0 \%$ & 2 \\
\hline SLC & 7\% \# & $6 \% \#$ & $-12 \%$ & $17 \%$ & $-12 \%$ & $-7 \%$ & $0 \%+$ & $0 \%$ & 2 \\
\hline SD & $-12 \%$ & $-7 \%$ & $-12 \%$ & $-17 \%$ & $-11 \%$ & $-14 \%$ & $0 \% \#$ & $0 \%$ & 2 \\
\hline MIN & $-18 \%$ & $-22 \%$ & $-20 \%$ & $5 \%+$ & $0 \%+$ & $4 \%+$ & $0 \%+$ & $0 \%$ & 3 \\
\hline SJ & $-25 \%$ & $-28 \%$ & $-24 \%$ & $-23 \%$ & $-28 \%$ & $-16 \%$ & $-19 \%$ & $0 \%$ & 3 \\
\hline STL & $-22 \%$ & $-15 \%$ & $-8 \%$ & $5 \% \#$ & $0 \% \#$ & $4 \%+$ & $0 \%+$ & $0 \%$ & 3 \\
\hline
\end{tabular}

Notes: BC: Base case - The MSA or distance category all other categories are compared against. BG: Base group - MSAs were there is not enough information to indicate a significant difference from the base case MSA. Only interaction terms that had an adequate sample size $(\mathrm{N} \geq 30)$ and were significant ( $\mathrm{p}$-value $\leq 0.5)$ were included. "\#": Indicates and interaction coefficient that was not signficiantly different from zero. "+": Indicates an interaction category (MSA by Distance band) that had too small a sample to estimate an interaction coefficient $(\mathrm{N}<30)$. 
Table 11.4

Percent difference in real estate rents by proximity to streetcar transit stations and MSA for Retail

\begin{tabular}{|c|c|c|c|c|c|c|c|c|c|}
\hline \multirow[b]{2}{*}{ MSA } & \multicolumn{8}{|c|}{ Distance Bands } & \multirow[b]{2}{*}{$\begin{array}{l}\frac{0}{3} \\
\text { ㅇํㄴ }\end{array}$} \\
\hline & $<0.125$ & $\begin{array}{c}0.125 \text { to } \\
0.25\end{array}$ & $\begin{array}{c}0.25 \text { to } \\
0.50\end{array}$ & $\begin{array}{c}0.50 \text { to } \\
0.75\end{array}$ & $\begin{array}{c}0.75 \text { to } \\
1.00\end{array}$ & $\begin{array}{c}1.00 \text { to } \\
1.25\end{array}$ & $\begin{array}{c}1.25 \text { to } \\
1.50\end{array}$ & $\begin{array}{c}>1.50 \\
(\mathrm{BC})\end{array}$ & \\
\hline \multicolumn{10}{|l|}{ RETAIL } \\
\hline$\overline{\mathrm{DEN}}$ & $14 \%$ & $16 \%$ & $9 \%$ & $19 \%$ & $11 \%$ & $0 \%$ & $0 \%$ & $0 \%$ & $\mathrm{BC}$ \\
\hline BUF & $14 \%+$ & $16 \%+$ & $9 \%+$ & $19 \%+$ & $11 \%+$ & $0 \%+$ & $0 \%+$ & $0 \%$ & BG \\
\hline $\mathrm{CHR}$ & $14 \%+$ & $16 \%+$ & $9 \%+$ & $19 \%+$ & $11 \%+$ & $0 \%+$ & $0 \%+$ & $0 \%$ & $\mathrm{BG}$ \\
\hline CLE & $14 \%+$ & $16 \%+$ & $9 \%+$ & $19 \%+$ & $11 \%+$ & $0 \%+$ & $0 \%+$ & $0 \%$ & BG \\
\hline DAL & $14 \%+$ & $16 \% \#$ & $9 \%$ \# & 19\% \# & $11 \% \#$ & $0 \% \#$ & $0 \% \#$ & $0 \%$ & BG \\
\hline MIN & $14 \%+$ & $16 \%+$ & $9 \%+$ & $19 \%+$ & $11 \%+$ & $0 \%+$ & $0 \%+$ & $0 \%$ & BG \\
\hline SEA & $14 \%+$ & $16 \%+$ & $9 \%+$ & $19 \%+$ & $11 \%+$ & $0 \%+$ & $0 \%+$ & $0 \%$ & BG \\
\hline STL & $14 \%+$ & $16 \%+$ & $9 \% \#$ & $19 \% \#$ & $11 \% \#$ & $0 \%+$ & $0 \% \#$ & $0 \%$ & BG \\
\hline NOR & $14 \%+$ & $16 \%+$ & $9 \%+$ & $19 \%+$ & $11 \%+$ & $0 \% \#$ & $0 \%+$ & $0 \%$ & BG \\
\hline PHX & $-6 \%$ & $16 \% \#$ & $9 \% \#$ & $-1 \%$ & $-15 \%$ & $-19 \%$ & $-32 \%$ & $0 \%$ & 2 \\
\hline SLC & $14 \%+$ & $16 \%$ \# & $-20 \%$ & $-3 \%$ & $-16 \%$ & $-21 \%$ & $-23 \%$ & $0 \%$ & 2 \\
\hline SD & $-21 \%$ & $-5 \%$ & $-11 \%$ & $-17 \%$ & $-21 \%$ & $-27 \%$ & $-26 \%$ & $0 \%$ & 2 \\
\hline $\mathrm{HOU}$ & $-11 \%$ & $16 \%+$ & $9 \% \#$ & $19 \% \#$ & $11 \% \#$ & $0 \% \#$ & $0 \% \#$ & $0 \%$ & 3 \\
\hline PIT & 14\% \# & $-30 \%$ & $9 \%$ \# & $-9 \%$ & $-12 \%$ & $0 \% \#$ & $0 \% \#$ & $0 \%$ & 3 \\
\hline PDX & $14 \%$ \# & $16 \% \#$ & $9 \%$ \# & $0 \%$ & $11 \% \#$ & $0 \% \#$ & $0 \% \#$ & $0 \%$ & 3 \\
\hline SAC & $-10 \%$ & $-14 \%$ & $9 \% \#$ & $-3 \%$ & $11 \%$ \# & $0 \% \#$ & $0 \% \#$ & $0 \%$ & 3 \\
\hline SJ & $14 \%+$ & $16 \%+$ & $9 \% \#$ & $-1 \%$ & $11 \%$ \# & $0 \% \#$ & $0 \%+$ & $0 \%$ & 3 \\
\hline
\end{tabular}

Notes: BC: Base case - The MSA or distance category all other categories are compared against. BG: Base group - MSAs were there is not enough information to indicate a significant difference from the base case MSA. Only interaction terms that had an adequate sample size $(\mathrm{N} \geq 30)$ and were significant ( $\mathrm{p}$-value $\leq 0.5)$ were included. "\#": Indicates and interaction coefficient that was not signficiantly different from zero. "+": Indicates an interaction category (MSA by Distance band) that had too small a sample to estimate an interaction coefficient $(\mathrm{N}<30)$. 
For multifamily residential developments (Figure 11.1, top), we see four general patterns of market responses. Those in the base case group-dominated mainly by the base case MSA, here Seattle-generally show positive, or higher rents, throughout the 1.5-mile proximity to LRT stations. Two additional groups ( 2 and 3 ) have generally positive responses adjacent to the LRT, with decreasing effects as the distance increases. For group 3 , this decreasing effects indicates negative percent differences in rent after a half-mile out. For group 4, the adjacent effects tend to be negative or negligible through roughly a half-mile, after which they increase to be statistically similar to the base case. The rate of effect varies widely across DBs in many cities. This result reveals a great deal of heterogeneity in the land use pattern.

For offices (Figure 11.1, middle), the base case group-dominated mainly by Denver-tends to have generally positive effects. The second group had negligible adjacent effects through a quarter-mile, with a negative rents (relative to those greater than 1.5 miles) through approximately 1.25 miles. The third group of MSAs tends to have generally negative proximity effects that increase through approximately 1.5 miles.

For retail, the positive effects extend beyond the commonly accepted cutoff distance of a halfmile, to provide significant returns up to a mile away in most cities. A portion of the cities have swings in results from positive to negative and back again, suggesting an inconsistent land use pattern near the station. The majority of the cities have positive results ranging from $9 \%$ to $19 \%$. 

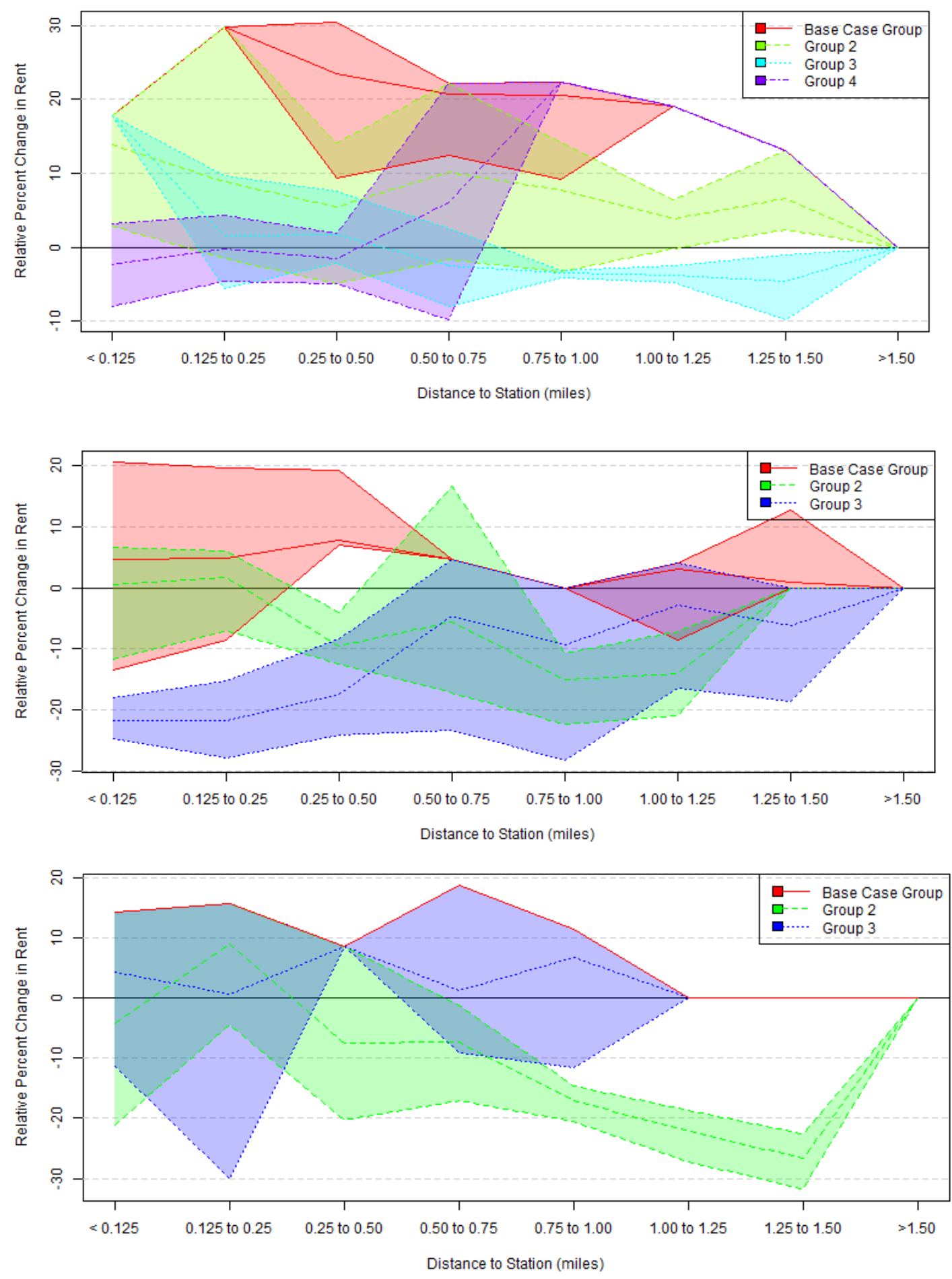

Figure 11.1

Percent difference in real estate rents by proximity to streetcar transit stations and MSA for (top) multifamily, (middle) office, and (bottom) retail.

\section{Bus-Rapid Transit Station Proximity}


The results for bus-rapid transit (BRT) proximities are depicted in a similar way. In Table 11.3, the percent differences in real estate rents by proximity and MSA are shown by land use. Only the results from multifamily developments indicated three generally patterns of proximity effects. In Figure 11.2 (top), we see that the base case (Seattle) observed the highest proximity effects throughout the 1.5 miles. A second group of MSAs had generally positive influences evenly throughout the 1.5 miles. And a third group of MSAs indicated some positive and negative adjacent effects, with generally negative influences up through 1.25 miles. For offices, we see more mixed impacts of BRT stations on office proximity, sometimes positive and negative. San Jose, however, indicated greater positive proximity influences on office rents near BRT stations through 0.75 -miles. For retail land uses, there were limited statistically significant (or adequate sample sizes) to observe large differences from the base case (Pittsburg). Phoenix distinguished itself from the base case, indicating some negative percent differences in rent roughly a mile from the BRT stations. 
Table 11.2

Percent difference in real estate rents by proximity to streetcar transit stations and MSA by land use

\begin{tabular}{|c|c|c|c|c|c|c|c|c|c|}
\hline \multirow[b]{2}{*}{ MSA } & \multicolumn{8}{|c|}{ Distance Bands } & \multirow[b]{2}{*}{$\begin{array}{l}\frac{2}{3} \\
\text { ํํㄴ }\end{array}$} \\
\hline & $<0.125$ & $\begin{array}{c}0.125 \text { to } \\
0.25\end{array}$ & $\begin{array}{c}0.25 \text { to } \\
0.50\end{array}$ & $\begin{array}{c}0.50 \text { to } \\
0.75\end{array}$ & $\begin{array}{c}0.75 \text { to } \\
1.00\end{array}$ & $\begin{array}{c}1.00 \text { to } \\
1.25\end{array}$ & $\begin{array}{c}1.25 \text { to } \\
1.50\end{array}$ & $\begin{array}{c}>1.50 \\
\text { (BC) }\end{array}$ & \\
\hline \multicolumn{10}{|c|}{ MULTIFAMILY } \\
\hline SEA/TAC & $12 \%$ & $9 \%$ & $14 \%$ & $21 \%$ & $19 \%$ & $13 \%$ & $11 \%$ & $0 \%$ & $B C$ \\
\hline EUG & $12 \%+$ & $9 \% \#$ & $14 \%+$ & $21 \%+$ & $19 \%+$ & $13 \%+$ & $11 \%+$ & $0 \%$ & BG \\
\hline KC & $12 \% \#$ & $9 \% \#$ & $27 \%$ & $21 \% \#$ & $19 \%+$ & $13 \%+$ & $11 \%+$ & $0 \%$ & BG \\
\hline SLC & $12 \%+$ & $9 \%+$ & $14 \%+$ & $21 \%+$ & $19 \%+$ & $13 \%+$ & $11 \%+$ & $0 \%$ & BG \\
\hline SATX & $12 \%+$ & $9 \% \#$ & $14 \%$ \# & $10 \%$ & $19 \%$ \# & $13 \%+$ & $11 \%+$ & $0 \%$ & BG \\
\hline WDC & $12 \%+$ & $9 \%+$ & $14 \%+$ & $21 \%+$ & $19 \%+$ & $13 \%+$ & $11 \%+$ & $0 \%$ & BG \\
\hline ALQ & $12 \%+$ & $9 \% \#$ & $1 \%$ & $-3 \%$ & $3 \%$ & $-4 \%$ & $-11 \%$ & $0 \%$ & 2 \\
\hline LV & $6 \%$ & $-6 \%$ & $-4 \%$ & $-6 \%$ & $-4 \%$ & $-6 \%$ & $-2 \%$ & $0 \%$ & 2 \\
\hline MSP & $12 \%+$ & $-7 \%$ & $-2 \%$ & $-6 \%$ & $-3 \%$ & $-1 \%$ & $0 \%$ & $0 \%$ & 2 \\
\hline $\mathrm{PHX}$ & $12 \%+$ & $9 \%+$ & $14 \%$ \# & $1 \%$ & $-7 \%$ & $-11 \%$ & $-9 \%$ & $0 \%$ & 2 \\
\hline SD & $-4 \%$ & $-8 \%$ & $-4 \%$ & $-3 \%$ & $1 \%$ & $-7 \%$ & $11 \% \#$ & $0 \%$ & 2 \\
\hline CLE & $12 \% \#$ & $9 \%+$ & $14 \%+$ & $4 \%$ & $-2 \%$ & $13 \%+$ & $11 \%+$ & $0 \%$ & 3 \\
\hline $\mathrm{NSH}$ & $12 \%+$ & $9 \% \#$ & $14 \%$ \# & $10 \%$ & $4 \%$ & $13 \%+$ & $11 \% \#$ & $0 \%$ & 3 \\
\hline PIT & $12 \% \#$ & $9 \% \#$ & $14 \%$ \# & $8 \%$ & $10 \%$ & $13 \%$ \# & $21 \%$ & $0 \%$ & 3 \\
\hline RNO & $12 \%+$ & $9 \%+$ & $-3 \%$ & $3 \%$ & $-5 \%$ & $13 \%+$ & $11 \%+$ & $0 \%$ & 3 \\
\hline SJ & $0 \%$ & $-1 \%$ & $14 \%$ \# & $14 \%$ & $8 \%$ & $13 \% \#$ & $11 \% \#$ & $0 \%$ & 3 \\
\hline \multicolumn{10}{|l|}{ OFFICE } \\
\hline SEA/TAC & $11 \%$ & $14 \%$ & $0 \%$ & $0 \%$ & $9 \%$ & $0 \%$ & $0 \%$ & $0 \%$ & $B C$ \\
\hline ESP & $11 \%+$ & $14 \%+$ & $0 \%+$ & $0 \%+$ & $9 \%+$ & $0 \%+$ & $0 \%+$ & $0 \%$ & BG \\
\hline KC & $-9 \%$ & $1 \%$ & $0 \%+$ & $0 \%+$ & $9 \%+$ & $0 \%+$ & $0 \%+$ & $0 \%$ & BG \\
\hline MIN & $11 \%+$ & $14 \%+$ & $0 \%+$ & $0 \%+$ & $9 \%+$ & $0 \%+$ & $0 \%+$ & $0 \%$ & BG \\
\hline $\mathrm{PHX}$ & $11 \%+$ & $14 \%+$ & $0 \%$ \# & $0 \%+$ & $-11 \%$ & $0 \% \#$ & $0 \%+$ & $0 \%$ & BG \\
\hline PIT & $-5 \%$ & $14 \%$ \# & $0 \% \#$ & $0 \% \#$ & $9 \% \#$ & $0 \% \#$ & $14 \%$ & $0 \%$ & BG \\
\hline REN & $11 \%+$ & $14 \%+$ & $0 \%$ \# & $0 \% \#$ & $9 \%+$ & $0 \%+$ & $0 \%+$ & $0 \%$ & BG \\
\hline SLC & $11 \%+$ & $14 \%+$ & $0 \%+$ & $0 \%+$ & $9 \%+$ & $0 \%+$ & $0 \%+$ & $0 \%$ & BG \\
\hline SATX & $2 \%$ & $4 \%$ & $0 \% \#$ & $0 \% \#$ & $9 \% \#$ & $0 \% \#$ & $0 \% \#$ & $0 \%$ & BG \\
\hline WDC & $11 \%$ & $14 \%+$ & $0 \%$ & $0 \%+$ & $9 \%+$ & $0 \%+$ & $0 \%+$ & $0 \%$ & BG \\
\hline$A B Q$ & $11 \% \#$ & $-1 \%$ & $0 \% \#$ & $0 \% \#$ & $-4 \%$ & $0 \% \#$ & $0 \% \#$ & $0 \%$ & 2 \\
\hline CLE & $11 \%$ \# & $-9 \%$ & $0 \% \#$ & $0 \%+$ & $9 \%+$ & $0 \%+$ & $0 \%+$ & $0 \%$ & 2 \\
\hline LV & $-7 \%$ & $-4 \%$ & $0 \%$ \# & $-12 \%$ & $9 \%$ \# & $-11 \%$ & $0 \% \#$ & $0 \%$ & 2 \\
\hline NAS & $11 \% \#$ & $-3 \%$ & $0 \% \#$ & $0 \%+$ & $9 \% \#$ & $0 \%+$ & $0 \%+$ & $0 \%$ & 2 \\
\hline SD & $-1 \%$ & $2 \%$ & $0 \% \#$ & $-17 \%$ & $-5 \%$ & $-13 \%$ & $0 \% \#$ & $0 \%$ & 2 \\
\hline SJ & $33 \%$ & $14 \%$ \# & $19 \%$ & $23 \%$ & $9 \%+$ & $0 \%+$ & $14 \%$ & $0 \%$ & 3 \\
\hline \multicolumn{10}{|l|}{ RETAIL } \\
\hline PIT & $0 \%$ & $22 \%$ & $14 \%$ & $11 \%$ & $14 \%$ & $0 \%$ & $0 \%$ & $0 \%$ & $B C$ \\
\hline CLE & $0 \%+$ & $22 \%+$ & $14 \%+$ & $11 \%+$ & $14 \%+$ & $0 \%+$ & $0 \%+$ & $0 \%$ & BG \\
\hline ESP & $0 \%+$ & $22 \%+$ & $14 \%+$ & $11 \%+$ & $14 \%+$ & $0 \%+$ & $0 \%+$ & $0 \%$ & BG \\
\hline KC & $0 \% \#$ & $22 \%+$ & $14 \%+$ & $11 \%+$ & $14 \%+$ & $0 \%+$ & $0 \%+$ & $0 \%$ & BG \\
\hline MIN & $0 \%+$ & $22 \%+$ & $14 \%+$ & $11 \%+$ & $14 \%+$ & $0 \%+$ & $0 \%+$ & $0 \%$ & BG \\
\hline NAS & $0 \% \#$ & $22 \% \#$ & $14 \%$ \# & $11 \%+$ & $14 \%+$ & $0 \%+$ & $0 \%+$ & $0 \%$ & BG \\
\hline PHX & $0 \% \#$ & $-7 \%$ & $14 \%$ \# & $11 \% \#$ & $-5 \%$ & $-20 \%$ & $-17 \%$ & $0 \%$ & BG \\
\hline REN & $0 \%+$ & $22 \%+$ & $14 \%$ \# & $11 \%+$ & $14 \%+$ & $0 \%+$ & $0 \%+$ & $0 \%$ & BG \\
\hline SLC & $0 \%+$ & $22 \%+$ & $14 \%+$ & $11 \%+$ & $14 \%+$ & $0 \%+$ & $0 \%+$ & $0 \%$ & BG \\
\hline SATX & $0 \% \#$ & $22 \% \#$ & $14 \%$ \# & $11 \% \#$ & $14 \% \#$ & $0 \% \#$ & $0 \% \#$ & $0 \%$ & BG \\
\hline SD & $0 \% \#$ & $22 \% \#$ & $14 \%$ \# & $11 \%$ \# & $14 \%$ \# & $0 \% \#$ & $0 \% \#$ & $0 \%$ & BG \\
\hline SJ & $0 \% \#$ & $22 \%+$ & $14 \%$ \# & 11\% \# & $14 \%+$ & $-28 \%$ & $0 \%+$ & $0 \%$ & BG \\
\hline SEA/TAC & $0 \% \#$ & $22 \% \#$ & $14 \%$ \# & $11 \% \#$ & $14 \%+$ & $0 \%+$ & $0 \%+$ & $0 \%$ & BG \\
\hline WDC & $0 \%+$ & $22 \%+$ & $14 \%+$ & $11 \%+$ & $14 \%+$ & $0 \%+$ & $0 \%+$ & $0 \%$ & BG \\
\hline ALQ & $0 \% \#$ & $22 \% \#$ & $-3 \%$ & $11 \%$ \# & $-22 \%$ & $0 \% \#$ & $0 \% \#$ & $0 \%$ & 2 \\
\hline LV & $0 \% \#$ & $22 \% \#$ & $-5 \%$ & $-8 \%$ & $-8 \%$ & $0 \% \#$ & $0 \% \#$ & $0 \%$ & 2 \\
\hline
\end{tabular}

Notes: BC: Base case - The MSA or distance category all other categories are compared against. BG: Base group - MSAs were there is not enough information to indicate a significant difference from the base case MSA. Only interaction terms that had an adequate sample size $(\mathrm{N} \geq 30)$ and were significant ( $\mathrm{p}$-value $\leq 0.5$ ) were included. "\#": Indicates and interaction coefficient that was not signficiantly different from zero. "+": Indicates an interaction category (MSA by Distance band) that had too small a sample to estimate an interaction coefficient $(\mathrm{N}<30)$. 

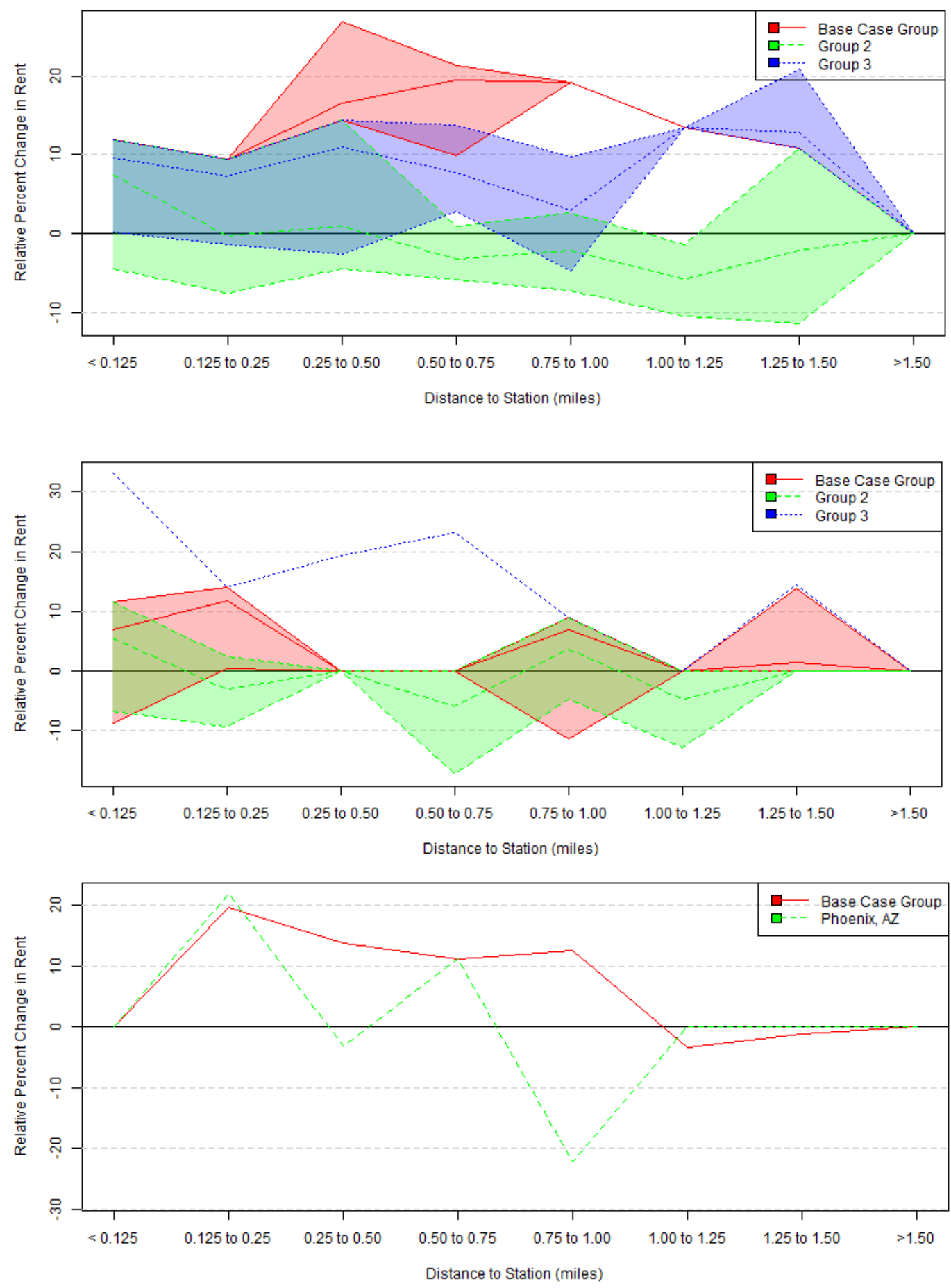

Figure 11.2

Percent difference in real estate rents by proximity to streetcar transit stations and MSA for (top) multifamily, (middle) office, and (bottom) retail.

\section{Streetcar Transit Station Proximity}


Streetcar transit (SCT) proximity impacts had some of the lowest sample sizes across interaction term categories (see Table 11.6 and Figure 11.3). This is most likely because streetcar systems are currently smaller in many metropolitan areas, acting as circulators within more urbanized areas. For office rents, too few observations existed within any proximity category after 0.5 -miles of distance. For that reason, we aggregated the controls to be anything outside of 0.5 -miles (instead of 1.5 miles). Overall, the influence of proximity to SCT tends to be generally positive, compared with areas further out, with little statistical variation in effects outside of a few cases for multifamily. While we see less variation in proximity response here, the results suggest that there is not enough information to distinguish statistically between most regions for these land uses. Still the overall influences of SCT on rent remain mostly positive, with some MSAs showing a notable exception by not responding, or responding negatively to the SCT presence. 
Table 11.6

Percent difference in real estate rents by proximity to streetcar transit stations and MSA by land use

\begin{tabular}{|c|c|c|c|c|c|c|c|c|c|}
\hline \multirow[b]{2}{*}{ MSA } & \multicolumn{8}{|c|}{ Distance Bands } & \multirow{3}{*}{$\begin{array}{l}\text { 을 } \\
\text { 운 }\end{array}$} \\
\hline & $<0.125$ & $\begin{array}{c}0.125 \text { to } \\
0.25\end{array}$ & $\begin{array}{c}0.25 \text { to } \\
0.50\end{array}$ & $\begin{array}{c}0.50 \text { to } \\
0.75\end{array}$ & $\begin{array}{c}0.75 \text { to } \\
1.00\end{array}$ & $\begin{array}{c}1.00 \text { to } \\
1.25\end{array}$ & $\begin{array}{c}1.25 \text { to } \\
1.50\end{array}$ & $\begin{array}{c}>1.50 \\
(\mathrm{BC})\end{array}$ & \\
\hline \multicolumn{9}{|c|}{ MULTIFAMILY } & \\
\hline SEA/TAC & $23 \%$ & $27 \%$ & $19 \%$ & $16 \%$ & $11 \%$ & $14 \%$ & $14 \%$ & $0 \%$ & $\mathrm{BC}$ \\
\hline ATL & $23 \%+$ & $27 \%+$ & $19 \%+$ & $16 \%+$ & $11 \%+$ & $14 \% \#$ & $14 \% \#$ & $0 \%$ & $\mathrm{BG}$ \\
\hline $\mathrm{CHR}$ & $23 \%+$ & $27 \%+$ & $19 \%+$ & $16 \%+$ & $11 \%+$ & $14 \%+$ & $14 \%+$ & $0 \%$ & $B G$ \\
\hline LR & $23 \%+$ & $27 \%+$ & $19 \%+$ & $16 \%+$ & $11 \%+$ & $14 \%+$ & $14 \%+$ & $0 \%$ & $B G$ \\
\hline NO & $23 \% \#$ & $27 \%+$ & $19 \%+$ & $16 \%+$ & $11 \%+$ & $14 \%+$ & $14 \%+$ & $0 \%$ & BG \\
\hline SLC & $23 \%+$ & $27 \%+$ & $19 \%+$ & $16 \%+$ & $11 \%+$ & $14 \%+$ & $14 \%+$ & $0 \%$ & BG \\
\hline TAM & $23 \%+$ & $27 \%+$ & $19 \%+$ & $16 \%+$ & $11 \%+$ & $14 \%+$ & $14 \%+$ & $0 \%$ & BG \\
\hline $\mathrm{CIN}$ & $23 \%+$ & $4 \%$ & $19 \%+$ & $16 \%+$ & $11 \%+$ & $14 \%+$ & $14 \%+$ & $0 \%$ & 2 \\
\hline PDX & $32 \%$ & $27 \% \#$ & $36 \%$ & $16 \%$ \# & $11 \% \#$ & $14 \% \#$ & $14 \% \#$ & $0 \%$ & 2 \\
\hline TUC & $23 \%+$ & $27 \%+$ & $19 \%+$ & $16 \%+$ & $11 \%+$ & $14 \%+$ & $-2 \%$ & $0 \%$ & 2 \\
\hline $\mathrm{DAL}$ & $4 \%$ & $27 \%+$ & $-1 \%$ & $16 \%$ \# & $11 \%$ \# & $14 \%$ \# & $14 \% \#$ & $0 \%$ & 3 \\
\hline $\mathrm{KC}$ & $23 \%+$ & $27 \%+$ & $19 \%+$ & $16 \%+$ & $11 \%+$ & $14 \%+$ & $37 \%$ & $0 \%$ & 3 \\
\hline WDC & $23 \%+$ & $27 \%+$ & $-3 \%$ & $16 \%$ \# & $11 \%+$ & $-3 \%$ & $14 \% \#$ & $0 \%$ & 3 \\
\hline OFFICE & $<0.125$ & 0.125 to & 0.25 to & $>0.50$ (Base & & & & & \\
\hline SEA/TAC & $0 \%$ & $8 \%$ & $0 \%$ & $0 \%$ & & & & & $\mathrm{BC}$ \\
\hline ATL & $0 \%+$ & $8 \%+$ & $0 \%+$ & $0 \% \#$ & & & & & $\mathrm{BG}$ \\
\hline $\mathrm{CIN}$ & $0 \% \#$ & $8 \%+$ & $0 \%+$ & $0 \% \#$ & & & & & BG \\
\hline $\mathrm{KS}$ & $0 \% \#$ & $8 \%+$ & $0 \%+$ & $0 \% \#$ & & & & & $B G$ \\
\hline NO & $0 \% \#$ & $8 \%+$ & $0 \%+$ & $0 \% \#$ & & & & & $B G$ \\
\hline SLC & $0 \%+$ & $8 \%+$ & $0 \%+$ & $0 \% \#$ & & & & & BG \\
\hline WDC & $0 \%+$ & $8 \%+$ & $0 \%+$ & $0 \% \#$ & & & & & BG \\
\hline DAL & $0 \% \#$ & $8 \% \#$ & $14 \%$ & $0 \% \#$ & & & & & 2 \\
\hline PDX & $17 \%$ & $8 \% \#$ & $16 \%$ & $0 \% \#$ & & & & & 3 \\
\hline \multicolumn{10}{|l|}{ RETAIL } \\
\hline SEA/TAC & $23 \%$ & $23 \%$ & $21 \%$ & $23 \%$ & $0 \%$ & $25 \%$ & $0 \%$ & $0 \%$ & $\mathrm{BC}$ \\
\hline ATL & $23 \%+$ & $23 \%+$ & $21 \%+$ & $23 \%+$ & $0 \%+$ & $25 \%+$ & $0 \%+$ & $0 \%$ & BG \\
\hline CIN & $23 \%+$ & $23 \%+$ & $21 \%+$ & $23 \%+$ & $0 \%+$ & $25 \%+$ & $0 \%+$ & $0 \%$ & $\mathrm{BG}$ \\
\hline DAL & $23 \%+$ & $23 \%+$ & $21 \% \#$ & $23 \% \#$ & $0 \%+$ & $25 \%+$ & $0 \%+$ & $0 \%$ & BG \\
\hline $\mathrm{KC}$ & $23 \%+$ & $23 \%+$ & $21 \%+$ & $23 \%+$ & $0 \%+$ & $25 \%+$ & $0 \%+$ & $0 \%$ & BG \\
\hline LR & $23 \%+$ & $23 \%+$ & $21 \%+$ & $23 \%+$ & $0 \%+$ & $25 \%+$ & $0 \%+$ & $0 \%$ & BG \\
\hline NO & $23 \%+$ & $23 \%+$ & $21 \%+$ & $23 \%+$ & $0 \%+$ & $25 \%+$ & $0 \%+$ & $0 \%$ & BG \\
\hline PDX & $23 \% \#$ & $23 \%+$ & $21 \%+$ & $23 \%+$ & $0 \%+$ & $25 \%+$ & $0 \%+$ & $0 \%$ & BG \\
\hline SLC & $23 \%+$ & $23 \%+$ & $21 \%+$ & $23 \%+$ & $0 \%+$ & $25 \%+$ & $0 \%+$ & $0 \%$ & BG \\
\hline TAM & $23 \%+$ & $23 \%+$ & $21 \%+$ & $23 \%+$ & $0 \%+$ & $25 \%+$ & $0 \%+$ & $0 \%$ & BG \\
\hline TUC & $23 \%+$ & $23 \%+$ & $21 \%+$ & $23 \%+$ & $0 \%+$ & $25 \%+$ & $0 \%+$ & $0 \%$ & BG \\
\hline WDC & $23 \%+$ & $23 \%+$ & $21 \%+$ & $23 \%+$ & $0 \%+$ & $25 \% \#$ & $0 \%+$ & $0 \%$ & BG \\
\hline
\end{tabular}

Notes: BC: Base case - The MSA or distance category all other categories are compared against. BG: Base group - MSAs were there is not enough information to indicate a significant difference from the base case MSA. Only interaction terms that had an adequate sample size $(\mathrm{N} \geq 30)$ and were significant ( $\mathrm{p}$-value $\leq 0.5)$ were included. "\#": Indicates and interaction coefficient that was not signficiantly different from zero. "+": Indicates an interaction category (MSA by Distance band) that had too small a sample to estimate an interaction coefficient $(\mathrm{N}<30)$. 

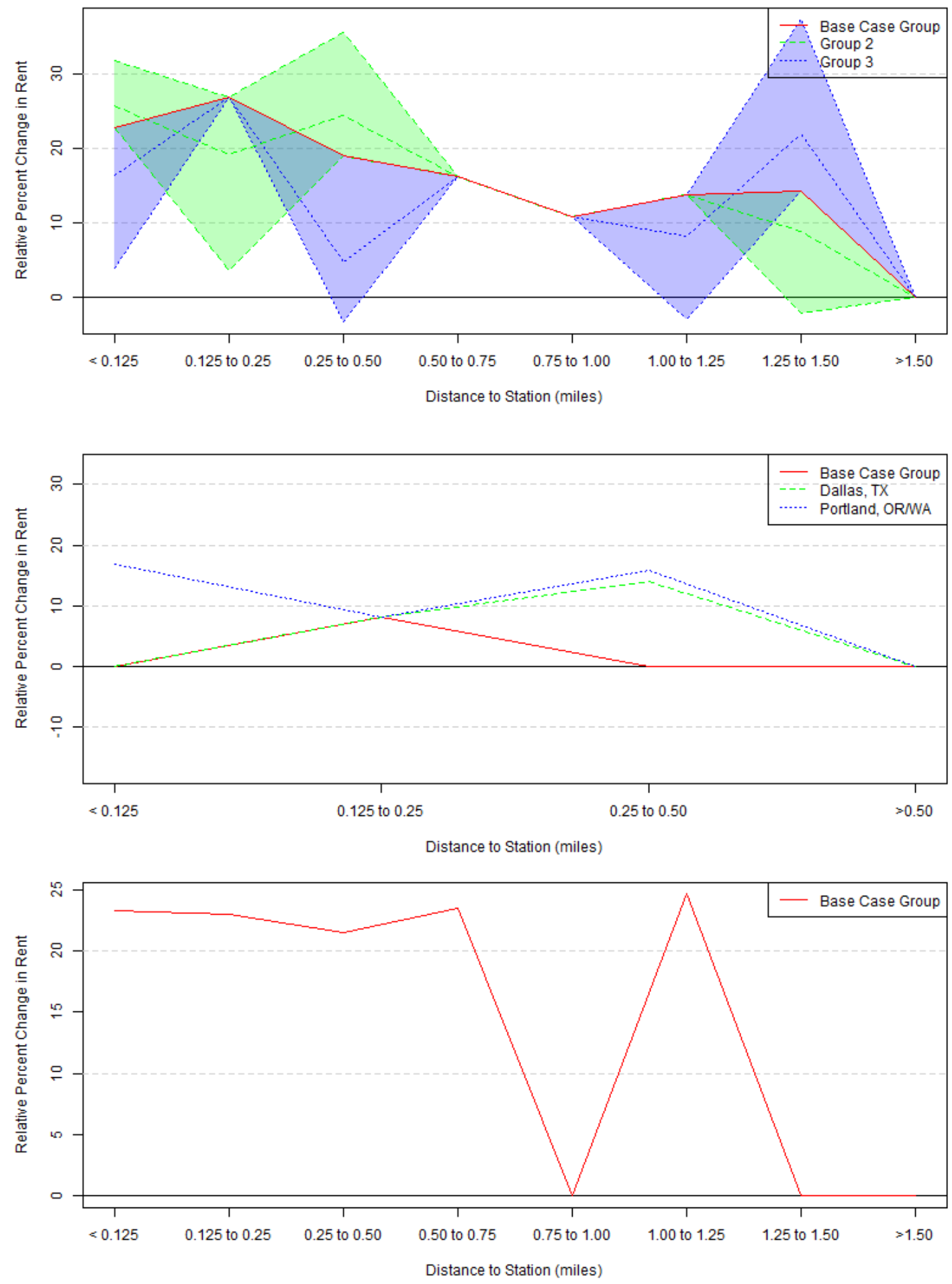

Figure 11.3

Percent difference in real estate rents by proximity to streetcar transit stations and MSA for (top) multifamily, (middle) office, and (bottom) retail. 


\section{Discussion}

In this chapter, we explored the structural differences between associations of proximity to Fixed-Route Transit and real estate rents across regions. The summaries of this analysis explored in the paper (and documented further in the supplementary material) indicate some clear patterns of market responses to light-rail transit and bus-rapid transit, mostly when considering associations with multifamily and office land uses. For streetcar, we were generally limited by small sample sizes in the distance band buffers across regions. While the overall interpretation of streetcar indicates generally positive associations with rent and proximity, this may be conflated by the fact that most streetcar systems are circulators in central city areas where rents are generally high anyway. A larger sample size of developments in proximity to streetcar may help parse out the implications across different cities.

For cities planning FRT expansions or additions in their region, these results help inform other cities that may be useful case comparisons to set expectations. These findings also hint at the contexts in which new FRT additions or expansions might pressure low-income residents. In many cases, access to high-quality transit can elevate travel opportunities low-income households towards lower cost choices. If FRT systems and corresponding land use development are expected to add competition associated with increases in rent, this information can help inform mitigation strategies near FRT to reduce gentrification pressures and avoid pushing out low-income residents in the name of higher rents.

In its current state, this chapter provides some initial patterns exploring regional differences in the market response to proximity to FRT. But the question becomes, why do some cities have more positive (or negative) associations? Or a faster decline in the localized bid-rent gradient? We have three hypotheses for why these patterns might exist. First, we expect FRT systems developed without clear "best practices" would result in lower rent provides accounting for poor design or aesthetics and weak connections between transit and community. Associations between adjacent locations and negative rent profiles, for example, may reflect the nuisances of being adjacent to a bus-rapid transit station without best practice mitigation strategies.

Second, for some low-performing cities, we may be observing influences of decaying urban cores -in which no amount of FRT can overcome general economic decline combined with the stigma of transit in some neighborhoods. Future work could investigate if negative associations of transit with the trajectory of income and/or population densities in those regions. A related hypothesis is that some systems may reflect the application of a FRT system in a context better served for another type of FRT transit. For example, a small light-rail system along one line may not contribute to large increases in regional accessibility in order to drive the competition necessary to see higher premiums paid. In future work, we will explore how these observed patterns relate to any number of these system and regional characteristics. 


\section{REFERENCES}

Alonso, W. (1964). Location and land use. Toward a general theory of land rent. Ecological Bulletins.

Clifton, K. J., Currans, K. M., Howell, A., Schneider, R. J., \& Handy, S. L. (2018). Affordable Housing Trip Generation Strategies and Rates [Research Report]. California Department of Transportation (Caltrans).

Clifton, K. J., \& Gehrke, S. (2016, August 23). Technical Memorandum: Place Typology Data Sources and Development Procedure [Memo].

Hajrasouliha, A. H., \& Hamidi, S. (2017). The typology of the American metropolis: Monocentricity, polycentricity, or generalized dispersion? Urban Geography, 38(3), 420444.

Hibberd, R., Nelson, A. C., \& Currans, K. M. (n.d.). Functional Form in Hedonic Regression: Literature Review \& Test of Forms to Determine the End of Significance of Transit Proximity Effects on LVU.

Higgins, C. D., \& Kanaroglou, P. S. (2016). Forty years of modelling rapid transit's land value uplift in North America: Moving beyond the tip of the iceberg. Transport Reviews, 36(5), 610-634. https://doi.org/11.1080/01441647.2016.1174748

Mills, E. S. (1967). An aggregative model of resource allocation in a metropolitan area. The American Economic Review, 57(2), 197-211.

Muth, R. F. (1969). CITIES AND HOUSING; THE SPATIAL PATTERN OF URBAN RESIDENTIAL LAND USE.

Nelson, A. C. (2017). Transit and Real Estate Rents. Transportation Research Record: Journal of the Transportation Research Board, 2651. https://doi.org/11.3141/2651-03

Nelson, A. C., Eskic, D., Hamidi, S., Petheram, S. J., Ewing, R., \& Liu, J. H. (2015). Office Rent Premiums with Respect to Light Rail Transit Stations: Case Study of Dallas, Texas, with Implications for Planning of transit-Oriented Development. Transportation Research Record, 2500(1), 110-115. https://doi.org/11.3141/2500-13

Nelson, A. C., \& Hibberd, R. (2019). Streetcars and Real Estate Rents with Implications for Transit and Land Use Planning. Transportation Research Record, 2673(10), 714-725.

Petheram, S., Nelson, A., Miller, M., \& Ewing, R. (2013). Use of the Real Estate Market to Establish Light Rail Station Catchment Areas: Case Study of Attached Residential Property Values in Salt Lake County, Utah, by Light Rail Station Distance. Transportation Research Record: Journal of the Transportation Research Board, 2357, 95-99.

U.S. EPA. (2014). Smart Location Database. https://www.epa.gov/smartgrowth/smart-locationmapping

Xiao, Y. (2017). Hedonic housing price theory review. In Urban morphology and housing market (pp. 11-40). Springer. 


\section{TRANSIT IMPACTS ON JOBS, PEOPLE AND REAL ESTATE}

\section{Volume 5 \\ Improving Transit Impacts by Reconsidering Design and Broadening Investment Resources}
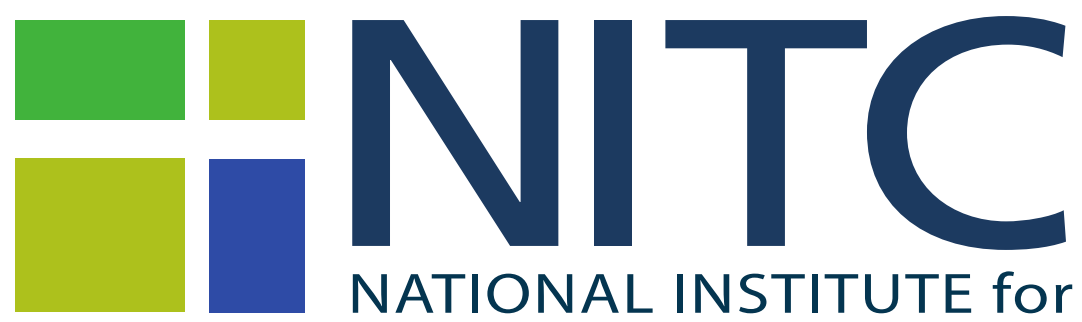

TRANSPORTATION and COMMUNITIES 


\section{VOLUME 5 PREFACE}

Transit Impacts on Jobs, People, and Real Estate is the fourth report in a series that started with funding from the National Institute of Transportation and Communities (NITC), a US DOT funded National University Transportation Center. While it completes the "quadrilogy" of work comprising a unique genre of transit and land use planning research it is by no means the last work-it is more likely the foundation for future work.

This document is Volume 5 of five volumes from the full report Transit Impacts on Jobs, People, and Real Estate:

- Volume 1: Orientation, Executive Summary, Context and Place Typologies

- Volume 2: Impact on Job Location Over Time with Respect to Transit Station Proximity Considering Economic Groups by Transit Mode and Place Typology with Implications for Transit and Land Use Planning

- Volume 3: Impact on Where People Live Over Time with Respect to Transit Station Proximity Considering Race/Ethnicity and Household Type and Household Budget by Transit Mode and Place Typology with Implications for Transit and Land Use Planning

- Volume 4: Impact on Real Estate Rents with Respect to Transit Station Proximity Considering Type of Real Estate by Transit Mode and Place with Implications for Transit and Land Use Planning

- Volume 5: Improving Transit Impacts by Reconsidering Design and Broadening Investment Resources

Each of these volumes, and the full report, can be found at https://nitc.trec.pdx.edu/research/project/1253

The genre of research within which four research projects call is grounded in trend that is common throughout all reports: That America is becoming increasingly focused on the need for transit to meet a growing number of social, economic and environmental objectives. But it is also rooted is simple market dynamics.

America will add at least 100 million new residents, 40 million new households, and 60 million new jobs by 2050 . We know from demographic analysis and consumer preference surveys that at least a third of America's 150 million households (50+ million) in 2050 will want to live in locations providing them with transit options, in addition to mixed-use and mixed-housing options. We also know from research on firm location behavior that up to 100 million jobs will be attracted to locations with transit options. Indeed, some research has estimated that even if all new development to 2050 occurred within one-half mile of existing and planned transit stations-such as transit oriented development (TOD) planning areas-the market demand for such development would not be met.

Our prior research outlines the extent to which fixed route transit (FRT) systems can meet future demand. But each system has its own niche. Light rail transit (LRT) systems serve metropolitan wide markets, connecting multiple nodes to each other. Bus rapid transit (BRT) systems can accomplish many of the same objectives as LRT systems at lower cost per mile but also lower capacity-which is fine for the Eugene-Springfield metropolitan area though not necessarily the Portland metropolitan area which, being four times larger and more densely settled, relies on LRT. At the lowest scale of operations are street car transit (SCT) systems that serve mostly downtowns such as Seattle or connect employment centers near downtown to downtown such as Portland, Tucson and Dallas. At the other end of the spectrum are commuter rail transit 
(CRT) systems that are intercity systems that connect cities within a metropolitan area to downtown such as San Diego's Coaster, or multiple metropolitan areas such as the SeattleTacoma Sounder or the Albuquerque-Santa Fe Rail Runner or the Utah Transit Authority's FrontRunner connecting three metropolitan areas.

Here we will summarize the purpose and key findings of each of the three prior reports and then frame the role of the fourth report. 


\section{Do TODs Make a Difference?}

The first report in the Quadrilogy was Do TODs Make a Difference? (Nelson et al. 2015). NITC contracts 547 and 650 were used to build station area databases for 12 light rail transit (LRT) systems, nine bus rapid transit (BRT) systems, four streetcar transit (SCT), and five commuter rail transit (CRT) systems. In this report, we presented research that measures the outcomes of TOD areas in relation to their metropolitan area controls with respect to:

- Jobs by sector;

- Housing choice for household types based on key demographic characteristics;

- Housing affordability based on transportation costs; and

- Job-worker balance as a measure of accessibility.

Prior literature has not systematically evaluated TOD outcomes in these respects with respect to light rail transit (LRT), commuter rail transit (CRT), bus rapid transit (BRT), and streetcar transit (SCT) systems. Our analysis helps close some of these gaps. We applied our analysis to 23 fixed guideway transit systems operating in 17 metropolitan areas in the South and West that have one or more of those systems. We found:

- Most TOD areas gained jobs in the office, knowledge, education, health care and entertainment sectors, adding more than $\$ 100$ billion in wages capitalized over time;

- In assessing economic resilience associated with LRT systems, jobs continued to shift away from TOD areas before the Great Recession, the pace slowed during the Recession, but reversed during recovery leading us to speculate that LRT TOD areas may have transformed metropolitan economies served by LRT systems;

- Rents for offices, retail stores and apartments were higher when closer to SCT systems, had mixed results with respect LRT systems, but were mostly lower with respect to CRT systems (our earlier BRT sample size was too small to evaluate);

- SCT systems performed best in terms of increasing their TOD area shares of metropolitan population, households and householders by age, housing units, and renters with BRT systems performing less well while LRT and CRT systems experienced a much smaller shift in the share of growth;

- Household transportation costs as a share of budgets increase with respect to distance from LRT transit stations to seven miles suggesting the proximity to LRT stations reduces total household transportation costs;

- Emerging trends that may favor higher-wage jobs locating in transit TOD areas over time than lower or middle wage jobs perhaps because TOD areas attract more investment which requires more productive, higher-paid labor to justify the investment; and

- The share of workers who commute 10 minutes or less to work increases nearly one-half of one percent for each half-mile their resident block group is to an LRT transit station, capping at a gain of 1.3 percent, which is not a trivial gain.

This work identified a missing element of research relating to one of the fastest growing modes of fixed route transit systems: Bus rapid transit (BRT). That led to a second NITC-funded project. 


\section{National Study of BRT Development Outcomes}

The second report was the nation's largest and most comprehensive assessment of the influence of bus rapid transit (BRT) systems on jobs, people and households, and real estate rents (Nelson and Ganning 2016).

Public transit systems are often promoted as offering a plethora of social, economic and environmental benefits to urban populations by transforming urban forms from auto-centric designs into more sustainable ones. The "next big thing" in public transit is bus rapid transit (BRT) systems. From virtually no systems a generation ago, there are now nearly 20 lines operating with at least seven under construction and more than 20 in the planning stages. Part of this recent popularity in BRT stems from its more affordable capital investment costs and its potential to be utilized by municipal planning organizations as an economic development tool. Yet, research into development outcomes associated with BRT station/stop proximity is small. This study found:

- For metropolitan counties with BRT systems, (0.50-mile) transit corridors increased their share of new office space by a third, from 11.4 percent to 15.2 percent and although new multifamily apartment construction was small, its share more than doubled since 2008;

- BRT station areas gained share of central county jobs at a faster pace or even at the expense of the rest of the central county and that more technologically advanced BRT systems may contribute to positive economic development outcomes;

- However, when disaggregating data to sectors, BRT is found to influence employment change in only one sector-manufacturing though that sector is broad and includes such activities as assembly, food processing (think beer making) and fashion design;

- Evidence of an office rent premium for location within a BRT corridor for most albeit not all of the metropolitan areas studied;

- Household transportation costs as a share of budgets increase with respect to CBD distance to about 19 miles and about eight miles with respect to BRT stations;

- Before the recession, the shift in jobs for all wage groups was about the same between BRT station areas and counterfactual locations but during recovery, BRT station areas saw larger shifts compared to counter-factual locations for lower-wage but upper-wage jobs had the largest change share in BRT station areas during recovery while the share of lower-wage jobs in BRT station areas fell; and

- There is little difference in BRT study area performance compared to their metropolitan areas in terms of influencing population and residential patterns though we did find indirect evidence that BRT systems choosing higher-quality design and technology options tended to enjoy better population and housing outcomes than those that chose lesser options.

We conclude that, on the whole, BRT systems are associated with positive development and job location outcomes, though not necessarily population or housing outcomes. By the time this study was completed more robust data had become available allowing for updates and expansions of prior work, which led to the third grant in this genre. 
The Link between Transit Station Proximity and Real Estate Rents, Jobs, People and Housing with Transit and Land Use Planning Implications

This report updates and expands prior research in the genre of research that has used economic base analysis (especially shift-share) and CoStar commercial rent data to estimate the development outcomes to transit (Nelson and Hibberd 2019). The study period for prior economic base analysis was 2002-2011 and census data for 2000 and 2010, as well as CoStar data for 2013. This report expands the number of systems used in analysis to 17 LRT systems, 14 BRT systems, nine SCT systems and 12 CRT systems. It also expands the period of analysis to 2015 for jobs-related data, 2016 for census data, and 2018 for CoStar data. The expanded and updated databases allow for more comprehensive assessment of their outcomes. Key findings include:

- Market rents increase with respect to Fixed Guideway Transit (FGT) station proximity for nearly all commercial types and for all modes, except there no rent premium for BRT in the closet $(0.125$ mile) distance band and office responds positively only within the closets ( 0.125 mile) distance band from LRT stations, with rent premiums extend one to two miles away from FGT stations for many commercial types;

- On the whole, more mature Fixed Guideway Transit (FGT) system saw gains in regional share of jobs in closer in ( 0.25 mile and 0.50 mile) distance bands if not up to the 1.00 mile distance band from transit stations-BRT being an exception in gaining share only in the nearest $(0.25$ mile) distance band- while ones build during and since the Great Recession saw small or negative shifts in regional share;

- There are only modest gains in the regional share of population and housing before/during the Great Recession (2000-2009) bit somewhat more gains afterward (2010-2016) for all transit types except BRT with larger gains associated with households without children and early/middle aged households (35-49); and

- For the most part for all transit modes saw reductions in regional share of driving alone and carpooling, and increases in regional share of transit, biking, walking, and working at home with respect to FGT station proximity.

The report also featured illustrations of "good, bad and ugly" transit station/stop planning and design, suggesting that systems may be underperforming because of these limitations.

A missing element of prior work was the milieu or type of place within which transit stations are located. Addressing this is the key purpose of this report (Nelson, Hibberd and Currans 2021). 
Transit Impacts on Jobs, People and Real Estate

This is the fourth report in the genre of research supported by NITC. This project entailed updating data and disaggregating it to assess outcomes based on station area types or what we call Place Typologies. This research is guided by two overarching questions and analytic contexts:

\begin{abstract}
How do Transit Development Outcomes Vary by Mode and Place Typology? This analysis includes each transit system for each metropolitan area studied during appropriate time periods for that system, as well as systems combined across metros. Trends that are assessed include: (1) Changes in the number and share of jobs by sector with respect to type of system and distance from stations, by type of station based on Place Typology; (2) Changes in the number and share of jobs by wage category with respect to transit mode and station proximity by Place Typology; and (3) Changes in number and share of population, households, householders by age, and housing by tenure with respect to transit mode, station proximity, and Place Typology.
\end{abstract}

\title{
How does the real estate market for office, retail and apartment properties respond to proximity to transit stations by mode and Place Typology? Our prior
} work pioneered the use of CoStar commercial rental data for very broad assessments of real estate market responsiveness to transit by type but not really by location except for corridor distance bands. The new research conducts more refined relationships in those metropolitan areas based on mode and Place Typology where CoStar data are sufficient for analysis.

In addition, we updated our complete database with a codebook for anyone to access through NITC.

\section{References}

Nelson, Arthur C., Matt Miller, Dejan Eskic, Keuntae Kim, Joanna P. Ganning, Reid Ewing, Jenny Liu, Matt Berggren, Zakari Mumuni (2015). Do TODs Make a Difference? Portland OR: Portland State University, National Institute for Transportation and Communities Final Report NITC-RR-547 and NITC-RR-763. Available along with related materials at https://nitc.trec.pdx.edu/research/project/547/Do_TODs_Make_a_Difference?

Nelson, Arthur C. and Joanna P. Ganning (2016). National Study of BRT Development Outcomes. Portland OR: Portland State University, National Institute for Transportation and Communities Final Report 650. Available along with related materials at http://nitc.trec.pdx.edu/research/project/650

Nelson, Arthur C. and Robert Hibberd (2019). The Link between Transit Station Proximity and Real Estate Rents, Jobs, People and Housing with Transit and Land Use Planning Implications. Portland OR: Portland State University, National Institute for Transportation and Communities Final Report 1103. Available along with related materials at https://nitc.trec.pdx.edu/research/project/1103.

Nelson, Arthur C., Robert Hibberd and Kristian Currans with Nicole Iroz-Elardo (2021). Transit Impacts on Jobs, People and Real Estate, five volumes. Portland OR: Portland State University, National Institute for Transportation and Communities Final Report 1253. Available along with related materials at https://nitc.trec.pdx.edu/research/project/1253. 


\section{SYNOPSIS FOR VOLUME 5}

Fixed route transit (FRT) station planning (the process leading to locations) and design (how stations are integrated with transport systems and nearby land uses) can dictate (a) use of the system by passengers, (b) development outcomes around the station, sometimes to a few miles away, and (c) real estate markets. The vast literature on FRT station planning and design may boil down to these over-arching principles that FRT systems and their stations can:

- Reduce adverse impacts of transit stations on surrounding land uses;

- Facilitate positive interactions between land uses near stations; and

- Maximize accessibility of passengers to transit stations and nearby land uses.

Unfortunately, the statistical evidence presented especially in Volume 4 but seen throughout our study, indicates that poor station planning and design can undermine the very purposes and promises of transit in America. Indeed, beyond scope, we undertook a remote visual reconnaissance of what we call "good" and "bad" and even "ugly" station locations and design. We conclude that there does not appear to be an easy way to predict transit station development outcomes based on transit station planning and design. This is an area where new research is needed.

Nonetheless, our research demonstrates that FRT systems confer both regional and local benefits. Regionally, they elevate overall economic performance as well as provide a wide range of public goods such as lower levels of greenhouse gas emissions and more mobility options. Locally, they generate value to private property that is spatially related to transit station proximity. Based on economic development, real estate value added, and fiscal benefits, there is much to be said for expanding existing systems and launching new ones.

However, in these days of declining federal support for fixed-guideway transit capital investments, new sources of funding are needed. The inventory is surprisingly large but largely untapped. In some cases, state enabling legislation may be needed but in others local popular and political support needs to be generated. The choice of funding option can make a difference. In this Volume, we introduce the role of fixed-guideway transit in creating value, identify numerous transit funding options, review criteria that may be used to choose those options that maximize key public finance objectives including capturing part of the value created by transit investments, and posing a funding approach that captures part of the value-added to regions and to areas around transit stations in relation to the distance of benefiting property from those stations.

The nation will add about 100 million people between now and mid-century. One of us (Nelson 2013) has estimated that about a quarter of American households want to live near fixed guideway transit opportunities though less than 20 percent have those options now. Perhaps one reason is that Americans understand the cost savings associated with living near transit stations. Yet, even if all new homes built between now and mid-century were located near 
existing or planned fixed-guideway transit stations the demand for living near those stations would still not be met. 


\section{Chapter 12: The Need for Good Transit and Land Use Planning, and Design}

\section{OVERVIEW}

In this chapter we assert that fixed route transit (FRT) station planning (the process leading to locations) and design (how stations are integrated with transport systems and nearby land uses) can dictate (a) use of the system by passengers, (b) development outcomes around the station, sometimes to a few miles away, and (c) real estate markets. The vast literature on FRT station planning and design may boil down to these over-arching principles that FRT systems and their stations can:

- Reduce adverse impacts of transit stations on surrounding land uses;

- Facilitate positive interactions between land uses near stations; and

- Maximize accessibility of passengers to transit stations and nearby land uses.

Unfortunately, the statistical evidence presented especially in Chapter 8 but seen throughout our study, indicates that poor station planning and design can undermine the very purposes and promises of transit in America. Indeed, beyond scope, we undertook a remote visual reconnaissance of what we call "good" and "bad" and even "ugly" station locations and design. This reported in Appendix H. We include walk, bike and transit (WBT) scores for each example. Some "good" station locations and design have low to modest WBT scores while others that in our opinion are "bad" locations and design have modest to high WBT scores. We conclude that there does not appear to be an easy way to predict transit station development outcomes based on transit station planning and design. This is an area where new research is needed. This is the theme of the first section of this chapter. The second section identifies the need for future research and includes an overall perspective on the role of transit in meeting America's market demand for mixed-use communities that are accessible to transit.

\section{Good, Bad and Ugly Transit Station Planning and Design}

With apologies to the 1966 movie The Good, The Bad and The Ugly, we postulated that poor fixed route transit (FRT) station planning and design can suppress real estate market rents and compromise employment and population/housing outcomes with respect to FRT station proximity. This chapter explores these concepts. It:

- Begins with a review of the theory of the link between FRT systems and urban development patterns;

- Outlines principles of FRT station planning and design that advance development outcomes; and

- Shows how externalities perhaps caused by features of FRT station planning and design may undermine expected development outcomes; and

We offer implications for transit and land use planning. 


\section{Transit and the Theory of Urban Development}

Although we have described the following in other chapters, it is useful to do so again here in our effort to synthesize key concepts.

Conventional urban location theory articulated by Alonso (1964), Muth (1969) and Mills (1972) shows that in a monocentric city where all jobs are in the central business district (CBD), the cost of transportation increases as distance increases from the CBD at a declining rate, as a function of increasing land area of the commuting shed. Transportation costs thus affect land value so that the "bid rent" curve for land also declines as distance increases. Where transportation costs are lowest, in the CBD, land prices are highest. To afford higher land prices ("rent") in the CBD, more economic exchange is needed, resulting in higher development intensities among office, retail, and high-value multifamily housing land uses among others. Economic activities that cannot compete for CBD locations are pushed outward to locations where they can outbid other land uses, a process called urban land use invasion and succession (Park and Burgess 1927).

In relaxing the strict monocentric city model, one can imagine the same principles at work only at smaller scales that are distributed across the landscape. For instance, in focusing transportation activity at nodes, rail transit stations can become small version of CBDs. Economic activities will bid up land prices close to rail transit stations; lower value activity moves away from transitions to location where they can outbid competing land uses.

One consequence of this sorting of land uses is the assembly of economic activities that can create agglomeration economies that can perpetuate and expand economic productivity. The American Public Transit Association notes:

There has been significant attention in the transportation research field regarding the extent to which public transportation investment supports "agglomeration economies" -the ability of business firms to realize productivity gains because of greater market access. One particular way to get at this same issue is to consider the emerging role of public transportation in enabling the growth of technology-oriented business sectors that are fast growing drivers of America's economy. To a significant degree, businesses in this sector of the economy tend to cluster (agglomerate) in specific urban locations where they can best access research centers, information sharing and a large, skilled workforce (Weisbrod, Cuter, and Duncan 2013: 5)

Transit is an important component in the growth of cities and their metropolitan areas (Glaeser, 2010, 2011). Since World War II, however, the rise of the automobile has challenged this notion. Highway expansion has allowed metropolitan areas to become ever larger as economies of agglomeration in some sectors are exploited through dispersion (Ciccone and Hall, 1996). Nonetheless, if metropolitan areas grow too large, highway congestion becomes a counterproductive force (Bogart, 1998; Boarnet, 1997; Boarnet and Haughwout, 2000).

One role of modern-day transit is to offset the adverse effects of highway congestion effects on agglomeration economies. Voith (1998) characterizes public transit as essentially "noncongestible" and is best suited to sustaining agglomeration economies in downtowns and secondary activity centers, and along the corridors that connect nodes (see also Nelson et al., 2009; Littman, 2009; Graham, 2007). The bottom line is that FRT systems and their stations should generate development around them. 
Principles of Transit Station Planning and Design to Advance Development In 2012, the Transit Cooperative Research Program (TCRP) publish its report, Guidelines for Providing Access to Public Transportation Stations (Coffel et al, 2012) that we use substantially for this discussion. It identifies these selected elements of transit station planning and design:

- Providing access to rapid transit stations should be a cooperative effort by appropriate transit and transportation agencies coordinated with planning agencies and engaging the surrounding community.

- Station access plans should result from comprehensive and cooperative planning processes that identify needs and opportunities and lead to effective and accepted results.

- Station access generally should be multi-modal.

- The predominant access travel modes depend upon type of land use, street spacing, and development density, among other factors. Walking dominates station access in the city center and in contiguous high-density residential areas. Both walking and bus access are the main means of reaching stations within the central city.

- Improvements to station access should consider the planned build-out of the station area so as not to conflict with or inhibit future planning.

- Development adjacent to stations should feature transit-oriented design characteristics (e.g., pedestrian-friendly, direct transit access from local land uses) to maximize ridership potential.

- Pedestrian circulation should form the foundation of the station access plan. Transit passengers walk between home and bus stops, between bus stops and station entrances, and between parking facilities and station entrances. They then walk through the station to the rail or bus platforms. Each step of this trip should be convenient and safe.

(The foregoing was adapted mostly verbatim from Coffel et al. 2012: 2-3)

The vast literature on FRT station planning and design may boil down to these over-arching principles:

- Reduce adverse impacts of transit stations on surrounding land uses;

- Facilitate positive interactions between land uses near stations; and

- Maximize accessibility of passengers to transit stations and nearby land uses.

Unfortunately, as we will show below, poor station planning and design can actually undermine these principles thereby dampening development outcomes. 


\section{Negative Externalities and Development Outcomes}

Transit stations themselves can be nuisances such that land value may be dampened very near them. The market capitalizes both positive amenity effects of rail station proximity as well as negative amenity effects such as those associated with noise and congestion (Nelson and McCleksy 1990; Nelson 1992). So long as positive amenity effects outweigh negative ones, the bid rent gradient will be sloping downward and away from rail transit stations. In theory, however, it is possible for negative amenity effects to outweigh positive ones. These interactions are illustrated in Figure 12.1, described as follows:

The line $R^{a}$ shows the land rent $(R)$ curve with full amenity ("a" for positive amenity) value from a rail transit station, $\mathrm{u}_{0}$, outward to a point, $\mathrm{u}_{1}$, where the amenity effects of rail transit proximity disappear, beyond which the overall market rent, $\mathrm{R}^{\mathrm{m}}$ is revealed.

Negative effects of rail transit stations are shown in line $\mathrm{R}^{\mathrm{n}}$ (" $\mathrm{n}$ " for negative amenity). As distance from the rail station increases, the negative amenity effects are reduced until they become zero at $u^{1}$.

Positive and negative amenity effects interact in the market leading to overall positive or negative bid rent curves with respect to distance from rail transit stations to $u_{1}$. Line $R^{a}+$ $\mathrm{R}^{\mathrm{n}}{ }_{1}$ is revealed where overall positive amenity effects outweigh negative ones. Line $\mathrm{R}^{\mathrm{a}}+$ $\mathrm{R}_{2}^{\mathrm{n}}$ is revealed where overall positive amenity effects outweigh positive ones. Overall effects disappear at $\mathrm{u}_{1}$ beyond which market rent, $\mathrm{R}^{\mathrm{m}}$, in the absence of positive and negative amenity is revealed.

While numerous studies show negative bid rent gradients with respect to distance from rail transit stations-meaning the market values proximity to transit stations, others reveal that positive rent gradients occur meaning negative externalities are present that may stifle development (Higgins and Kanaroglou 2016).

We now pose a very basic typology of transit stations based on whether they may be considered good, bad or even ugly based on how the real estate market responds to them. 


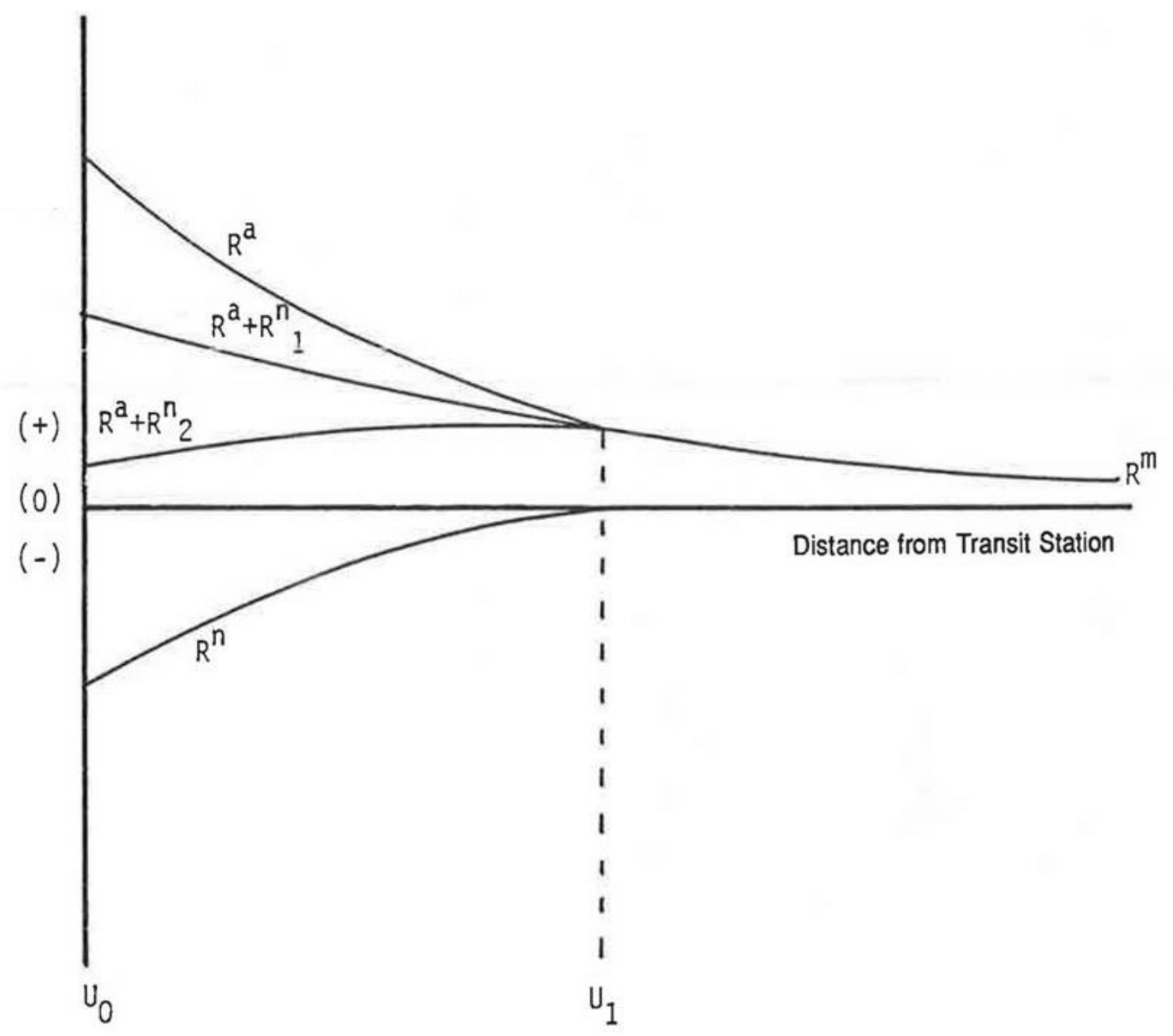

Figure 12.1

Positive Amenity $\left(R^{a}\right)$ and Negative Amenity $\left(R^{n}\right)$ influences of transition stations on proximate property values 


\section{Toward A Typology Of Good, Bad and Ugly Transit Station Planning and Design}

Chapter 7 especially shows that development near FRT stations is mixed though this outcome underlies nearly all other chapters. Although much development occurs very new transit stations - notably within a narrow band about one-eighth $(0.125)$ mile around stationsdevelopment usually falls dramatically so that at the scale of a one-half mile around stations it may be difficult to detect whether transit stations impact development patterns.

Recall that for the most part, outcomes in most metropolitan areas are not consistent with theoretical outcomes especially near transit stations. This led us to presume that theory is either incorrect or planning and design does not overcome externalities or, worse, creates them. We use findings from Chapter 7 to help create a conceptual typology of what is desired and not desired as outcomes to transit station planning and design. Tables 12.1 through 12.4 report relevant coefficients (see Chapter 7 for description) for LRT, SCT, BRTY, and CRT systems operating in the metropolitan areas we studied. We limit this to just the first two $(0.125$-mile and 0.250 -mile) distance bands as they are the closest to transit stations. For the most part, one could conclude that the results are disappointing. In these tables, we assess system performance in terms of real estate rent outcomes as:

Amenity where results show positive rent at or near transit stations (being the 0.125 mile DB) and then decline to the next (0.250-mile) DB. This outcome is both consistent with theory and desirable from an economic perspective.

Limited Amenity where there is a positive rent coefficient in the first (0.125-mile) distance band only.

Externality where results show positive rent at or near transit stations but then rise to the next (0.250-mile) distance band indicating that the station and its immediate are create externalities in the market.

Negative meaning that in the first $(0.125$-mile) though sometimes extending to the second (0.250-mile) distance bands rents are below the mean, which is per se evidence of undesirable real estate outcomes.

Ambiguous where there are no significant coefficients in the first (0.125-mile) distance band.

This will lead us to generalized, over-arching characterizations. 
Table 12.1

Association between Real Estate Rent and Light Rail Transit Station Proximity

\begin{tabular}{|c|c|c|c|c|c|c|c|c|c|}
\hline \multirow[b]{2}{*}{ Metropolitan Area } & \multicolumn{3}{|c|}{ LRT Office } & \multicolumn{3}{|c|}{ LRT Multifamily } & \multicolumn{3}{|c|}{ LRT Retail } \\
\hline & $<=0.125$ & $\begin{array}{c}>0.125- \\
0.250\end{array}$ & Assessment & $<=0.125$ & $\begin{array}{c}>0.125- \\
0.250\end{array}$ & Assessment & $<=0.125$ & $\begin{array}{c}>0.125- \\
0.250\end{array}$ & Assessment \\
\hline Buffalo & $10.1 \%$ & $16.4 \%$ & Externality & & $11.7 \%$ & Ambiguous & & $41.1 \%$ & Ambiguous \\
\hline Charlotte & $15.7 \%$ & $14.1 \%$ & Amenity & $21.7 \%$ & $14.8 \%$ & Amenity & & $30.7 \%$ & Ambiguous \\
\hline Cleveland & $14.2 \%$ & $6.3 \%$ & Amenity & & & Ambiguous & & & Ambiguous \\
\hline Dallas & $-5.6 \%$ & $-6.3 \%$ & Negative & $7.6 \%$ & & Ambiguous & & & Ambiguous \\
\hline Denver & $4.0 \%$ & $14.9 \%$ & Externality & & $6.1 \%$ & Ambiguous & $13.7 \%$ & $4.3 \%$ & Amenity \\
\hline Houston & $8.1 \%$ & $11.4 \%$ & Externality & $11.9 \%$ & $8.7 \%$ & Amenity & & & Ambiguous \\
\hline Minneapolis & & & Ambiguous & $8.2 \%$ & $3.8 \%$ & Amenity & & & Ambiguous \\
\hline Phoenix & & & Ambiguous & & $7.3 \%$ & Ambiguous & & & Ambiguous \\
\hline Pittsburgh & & & Ambiguous & $-14.1 \%$ & $-9.0 \%$ & Negative & $186.9 \%$ & $-47.9 \%$ & Amenity \\
\hline Portland & & & Ambiguous & $9.6 \%$ & $5.9 \%$ & Amenity & & $12.6 \%$ & Ambiguous \\
\hline Sacramento & $3.7 \%$ & & $\begin{array}{l}\text { Limited } \\
\text { Amenity }\end{array}$ & $8.4 \%$ & $3.7 \%$ & Amenity & & & Ambiguous \\
\hline Salt Lake City & & $7.2 \%$ & Ambiguous & $10.4 \%$ & & Ambiguous & $20.6 \%$ & & Ambiguous \\
\hline San Diego & $-10.5 \%$ & $-12.6 \%$ & Negative & $16.2 \%$ & $7.0 \%$ & Amenity & $-21.0 \%$ & $-17.2 \%$ & Negative \\
\hline San Jose & $-27.4 \%$ & $-23.7 \%$ & Negative & $8.0 \%$ & $9.1 \%$ & Externality & $27.6 \%$ & $36.5 \%$ & Externality \\
\hline Seattle & $7.7 \%$ & $26.7 \%$ & Externality & $11.0 \%$ & $17.0 \%$ & Externality & & & Ambiguous \\
\hline St. Louis & $-6.2 \%$ & & Negative & & & Ambiguous & & $18.8 \%$ & Ambiguous \\
\hline Norfolk & & & Ambiguous & & $23.8 \%$ & Ambiguous & $62.1 \%$ & $34.2 \%$ & Amenity \\
\hline
\end{tabular}


Table 12.2

Association between Real Estate Rent and Streetcar Transit Station Proximity

\begin{tabular}{|c|c|c|c|c|c|c|c|c|c|}
\hline \multirow{2}{*}{ Metropolitan Area } & \multicolumn{3}{|c|}{ SCT Office } & \multicolumn{3}{|c|}{ SCT Multifamily } & \multicolumn{3}{|c|}{ SCT Retail } \\
\hline & $<=0.125$ & $\begin{array}{c}>0.125- \\
0.250\end{array}$ & Assessment & $<=0.125$ & $\begin{array}{c}>0.125- \\
0.250\end{array}$ & Assessment & $<=0.125$ & $\begin{array}{c}>0.125- \\
0.250\end{array}$ & Assessment \\
\hline Atlanta & $-25.4 \%$ & $-19.4 \%$ & Negative & $17.7 \%$ & $29.9 \%$ & Externality & $39.5 \%$ & & $\begin{array}{l}\text { Limited } \\
\text { Amenity }\end{array}$ \\
\hline Cincinnati & $21.8 \%$ & $25.9 \%$ & Externality & $12.9 \%$ & & Ambiguous & $46.6 \%$ & & $\begin{array}{l}\text { Limited } \\
\text { Amenity }\end{array}$ \\
\hline Dallas & $24.0 \%$ & $25.0 \%$ & Externality & $11.5 \%$ & $18.5 \%$ & Externality & $42.4 \%$ & $103.7 \%$ & Externality \\
\hline Kansas City & & & Ambiguous & $19.6 \%$ & $9.1 \%$ & Amenity & $47.9 \%$ & & $\begin{array}{l}\text { Limited } \\
\text { Amenity }\end{array}$ \\
\hline Little Rock & $27.3 \%$ & & $\begin{array}{l}\text { Limited } \\
\text { Amenity }\end{array}$ & $27.1 \%$ & $23.6 \%$ & Amenity & $29.2 \%$ & $36.2 \%$ & Externality \\
\hline New Orleans & $71.8 \%$ & $47.3 \%$ & Amenity & $45.5 \%$ & $34.7 \%$ & Amenity & $84.0 \%$ & $67.1 \%$ & Amenity \\
\hline Portland & $40.8 \%$ & $36.0 \%$ & Amenity & $21.2 \%$ & $21.8 \%$ & Externality & $12.4 \%$ & $22.9 \%$ & Externality \\
\hline Salt Lake City & & & Ambiguous & & & Ambiguous & & $53.7 \%$ & Ambiguous \\
\hline Seattle & $22.7 \%$ & $19.0 \%$ & Amenity & $18.1 \%$ & $17.3 \%$ & Amenity & & & Ambiguous \\
\hline Tacoma & & & Ambiguous & $28.1 \%$ & $20.3 \%$ & Amenity & & & Ambiguous \\
\hline Tampa & & & Ambiguous & & & Ambiguous & $54.6 \%$ & & $\begin{array}{l}\text { Limited } \\
\text { Amenity }\end{array}$ \\
\hline Tucson & & $30.0 \%$ & Ambiguous & $34.5 \%$ & $34.1 \%$ & Amenity & $49.2 \%$ & $46.7 \%$ & Amenity \\
\hline Washington & $-25.4 \%$ & $-19.4 \%$ & Negative & & & Ambiguous & & & Ambiguous \\
\hline
\end{tabular}


Table 12.3

Association between Real Estate Rent and Bus Rapid Transit Station Proximity

\begin{tabular}{|c|c|c|c|c|c|c|c|c|c|}
\hline \multirow[b]{2}{*}{ Metropolitan Area } & \multicolumn{3}{|c|}{ BRT Office } & \multicolumn{3}{|c|}{ BRT Multifamily } & \multicolumn{3}{|c|}{ BRT Retail } \\
\hline & $<=0.125$ & $\begin{array}{c}>0.125- \\
0.250\end{array}$ & Assessment & $<=0.125$ & $\begin{array}{c}>0.125- \\
0.250\end{array}$ & Assessment & $<=0.125$ & $\begin{array}{c}>0.125- \\
0.250\end{array}$ & Assessment \\
\hline Albuquerque & $6.7 \%$ & $4.6 \%$ & Amenity & & & Ambiguous & & & Ambiguous \\
\hline Cleveland & $10.2 \%$ & & $\begin{array}{l}\text { Limited } \\
\text { Amenity }\end{array}$ & $23.5 \%$ & $11.6 \%$ & Amenity & $40.9 \%$ & & Ambiguous \\
\hline Eugene-Springfield & & $-36.2 \%$ & Externality & & & Ambiguous & & & Ambiguous \\
\hline Kansas City & & & Ambiguous & $18.8 \%$ & $20.7 \%$ & Externality & $22.3 \%$ & $18.8 \%$ & Amenity \\
\hline Minneapolis-St. Paul & & & Ambiguous & & $-6.6 \%$ & Ambiguous & & $41.8 \%$ & Ambiguous \\
\hline Nashville & & & Ambiguous & & & Ambiguous & $16.8 \%$ & & $\begin{array}{l}\text { Limited } \\
\text { Amenity }\end{array}$ \\
\hline Pittsburgh & $-4.0 \%$ & $9.3 \%$ & Externality & $-4.8 \%$ & & Ambiguous & & $30.5 \%$ & Ambiguous \\
\hline Reno & & & Ambiguous & & & Ambiguous & & & Ambiguous \\
\hline Salt Lake City & $30.7 \%$ & & $\begin{array}{l}\text { Limited } \\
\text { Amenity }\end{array}$ & & & Ambiguous & $-15.7 \%$ & & Negative \\
\hline San Antonio & $3.8 \%$ & $6.4 \%$ & Externality & & & Ambiguous & $8.0 \%$ & $7.7 \%$ & Amenity \\
\hline San Diego & & & Ambiguous & & $-5.0 \%$ & Ambiguous & & $21.2 \%$ & Ambiguous \\
\hline San Jose & $34.0 \%$ & $21.5 \%$ & Amenity & & & Ambiguous & $25.2 \%$ & $32.0 \%$ & Externality \\
\hline Seattle & & $14.7 \%$ & Ambiguous & & $-4.4 \%$ & Ambiguous & & $15.0 \%$ & Ambiguous \\
\hline
\end{tabular}


Table 12.4

Association between Real Estate Rent and Commuter Rail Transit Station Proximity

CRT Office

$>0.125-$

Metropolitan Area

Albuquerque-Santa

$\mathrm{Fe}$

Austin

Dallas-Fort Worth

Denver

Miami-SE Florida

Minn.-St. Paul

Nashville

Orlando

Portland

Salt Lake City

San Diego

San Jose-Stockton

Seattle-Tacoma

Washington DC

$<=0.125$

0.250

$21.8 \%$

$19.9 \%$

$14.3 \%$

$-5.7 \%$

$9.1 \%$

$10.8 \%$

$-8.4 \%$

$17.3 \%$

$-8.8 \%$

$-12.5 \%$

$7.2 \%$

$-18.0 \%$

$-2.6 \%$

$5.2 \%$

$-4.0 \%$

$24.1 \%$

$38.6 \%$

$-5.2 \%$

$13.1 \%$

\section{CRT Multifamily}

$>0.125-$

Assessment

$<=0.125$

0.250

Assessment

Amenity

Limited

Amenity

Externality

Negative

Externality

Negative

Limited

Amenity

Negative

Limited

Amenity

Limited

Amenity

Amenity

Negative

Ambiguous
Ambiguous

Ambiguous

Ambiguous

9.3\% Ambiguous

Ambiguous

Ambiguous

$22.1 \%$

$-29.8 \%$

$20.0 \%$

Amenity

Negative

Ambiguous

$48.1 \%$

15.9\% Amenity

$11.7 \%$ Ambiguous

$-10.8 \%$ Ambiguous

Ambiguous
Ambiguous
CRT Retail

$>0.125-$

0.250

Assessment

Ambiguous

$-21.1 \%$ Ambiguous

Ambiguous

Ambiguous

Ambiguous

Ambiguous

Ambiguous

$73.2 \%$

$39.4 \%$

$28.0 \%$

Amenity

Ambiguous

Ambiguous

$54.3 \%$ Ambiguous

39.6\% Amenity

Ambiguous

Ambiguous 
Based on theory, many of the stations comprising these systems would have such externalities-nuisances - that the market discounts transit station proximity. While there may be design and land use planning approaches to offset negative effects of transit station proximity on office rents, they may require substantial resources or major land use decisions.

Appendix $\mathrm{G}$ of this report provides visual examples of our assessment of what may be "good" and "bad" FRT station planning and design. Our criteria include:

- Whether the station is easily accessible on foot or bicycle;

- Whether it is planned into the fabric of the existing community or it is separated from it;

- Whether it is elevated (thereby compromising ease of accessibility);

- Whether it is visually attractive (though we are not experts in this criterion);

- Whether there is comfortable separation between street traffic and the FRT vehicle;

- The extent to which the station is isolated by multiple-lane highways; and

- Whether passengers have to traverse parking lots to access the station unless they are parking and driving their own vehicle.

We concede that what appears to us to be "good" or "bad" planning and design may be just the opposite of experts' opinions. On the other hand, one of us (Nelson) reminds students that when they are assessing the qualities of an area for development, infill, redevelopment or related real estate activities: "You know more than you think."

When studying Appendix G, readers may be struck that occasionally what we consider a "good" or "bad" station actually has non-intuitive walk-bike-transit scores. A "good" station may have lower walk-bike-transit scores than a "bad" station. The difference is the context of the station itself. Indeed, for all LRT systems in our study, we calculated the mean walk-bike-transit scores, and their overall means, and compared the systems based on our market rent analysis to our Good-Bad-Ugly market rent typology. Results are reported in Table 12.5. Though the "Ugly" LRT systems from the perspective of market rent performance tend to be in the lower portion of the table, clear patterns using just these scores are not entirely evident. 
Table 12.5

Comparing Market Rent Typology to LRT System Mean Walk-Bike-Transit Scores from Highest to Lowest

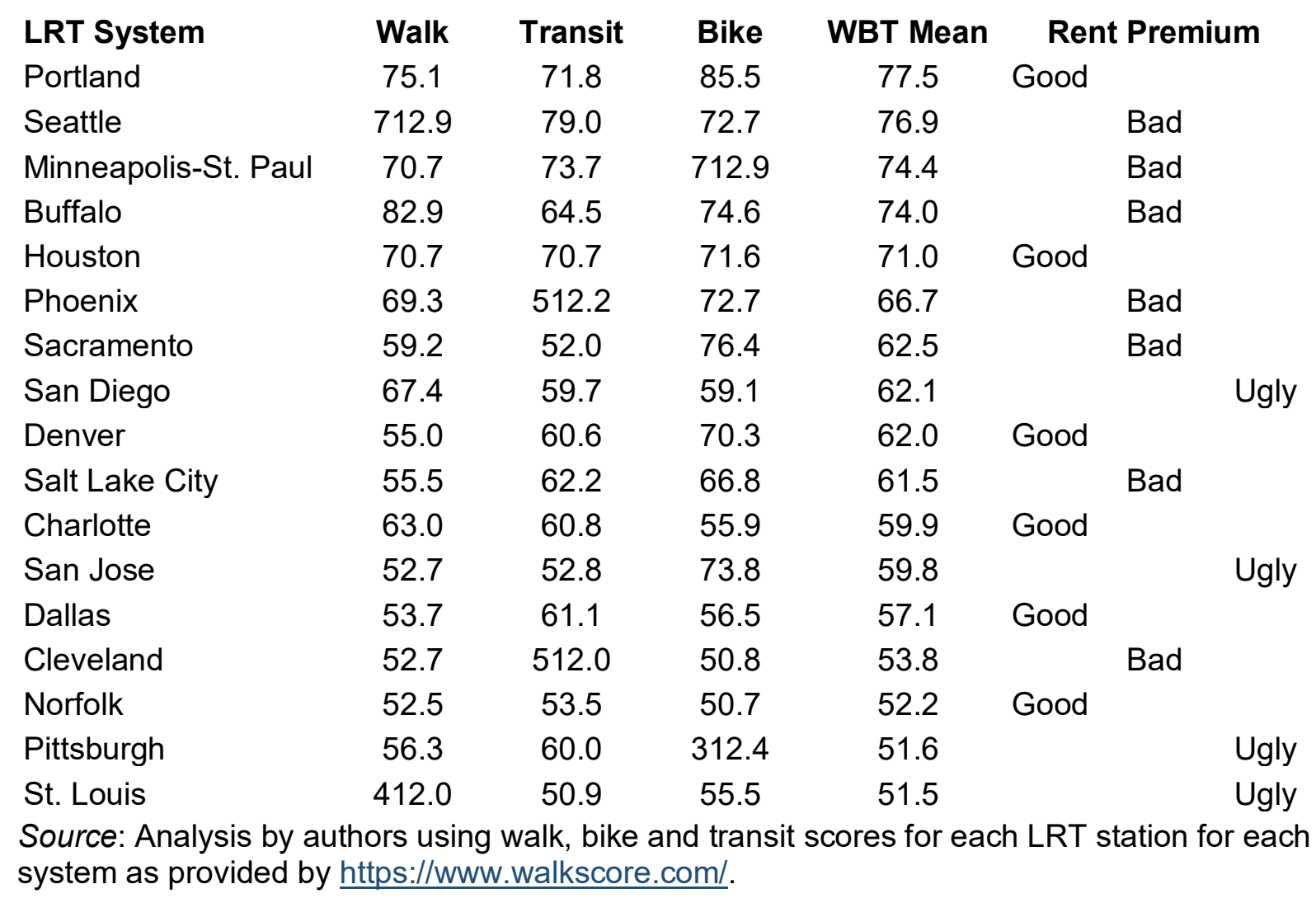




\section{Improved Transit Station Planning and Design To Achieve Positive Outcomes}

In this section, we identify approaches to (a) reducing externality effects of transit stations and (b) advance amenity benefits. We are impressed with overall guidelines for FRT station area planning and design advanced by the City of Vancouver, BC. Using most of their words, these "6 Ds" of transit station planning and design are informative (TransLink 2012: 10-11):

\section{D1 Destinations}

Coordinate land use and transportation. When land use and transportation are well coordinated, transit can provide fast, direct, and cost-effective access to more destinations for more people. Transit-oriented communities coordinate land use and transportation in two important ways: At the neighborhood scale they locate most new development along reasonably direct corridors so that most destinations are 'on the way' to other destinations. At the regional scale they locate the highest densities of development and the most important destinations at the intersection of several frequent transit corridors.

\section{D2 Distance}

Create a well-connected street network $A$ well-connected street network shortens travel distances, making it possible for people to quickly and conveniently walk or cycle to where they want to go, or to easily connect with transit en route to their destination.

\section{D3 Design}

Create places for people Transit-oriented communities are carefully designed with the needs of people in mind. Whether walking, cycling, pushing a stroller, catching a bus, or using a mobility device, people of all ages and abilities should be able to access and enjoy a comfortable, safe, delightful, and inviting public realm.

\section{D4 Density}

Concentrate and intensify activities near frequent transit Transit-oriented communities concentrate most growth and development within a short walk of frequent transit stops and stations. A higher density of homes, jobs, and other activities creates a market for transit, allowing frequent service to operate efficiently. The form of development varies from community to community based on local goals, character, and needs, and there is no 'one-size-fits-all' approach to achieving an appropriate level of density to support transit.

\section{D5 Diversity}

Encourage a mix of uses A vibrant mix of land uses helps to create complete, walkable neighborhoods around transit stations and stops, and supports a transit system that is well-utilized throughout the day. Transit-oriented communities encourage a mix of land uses at both the neighborhood and corridor scales.

\section{D6 Demand Management}

Discourage unnecessary driving Transit-oriented communities use TDM strategies to discourage unnecessary driving and to promote walking, cycling, and transit. TDM provides incentives for travelers to shift automobile trips to other modes in a number of ways, including increasing travel options, setting appropriate prices for parking or road usage, providing information and marketing, and allocating more road space to transit, cycling, and pedestrian uses. 
These concepts assume that a principal objective of FRT systems is to create communities around transit stations to at least 0.50 -mile if not 1.00 -mile or more. Doing so will create agglomeration economies that advance local and regional economic development, meet at least part of the unmet demand for homes, and create places in which people want to live, work, and enjoy their leisure. It also helps assure that taxpayers receive a reasonable return on their investments.

We conclude the analytic part of our report with over-arching observations about emerging research needs and perspectives on reshaping America's metropolitan areas through transit and station area planning, and design, to realize theorized promises. An epilogue completes our report by exploring ways in which transit and station area planning, and design, can increase real estate values in ways that can also lead society to recapture a share of those gains to achieve other policy purposes, especially those that advance social equity. 


\section{Research Agenda to Further Understand the Role of Fixed Route Transit Systems in Shaping Development Patterns}

During the 2010s, we created a new genre of transit research. It combines novel applications of economic base theory with the nation's only cross-section analysis of how real estate markets respond to transit station proximity. More needs to be done, however.

\section{Spatial Economic Analysis}

Our prior and ongoing research uses quasi-experimental, economic base methods to assess change in concentration in workers and their wages by economic groups; people and households by race/ethnicity, age, type and other demographic features; housing by tenure; and mode choice to work. Using factor/cluster analysis, we fashioned Place Typologies that improved overall research performance. It was based on land use mix (an entropy measure), jobs-population balance (a measure of jobs versus population concentration), distance to downtown and other major activity centers (a centrality measure), employment sector composition (a measure of economic concentration); and socioeconomic composition (a measure of demographic concentration).

There were surprises compared to our earlier work, such as gains in concentration at types of transit stations that otherwise saw losses of concentration for systems as a whole, and vice versa. Although our analysis generated insights useful for conditions of the 2010s, the COVID19 epidemic of the period 2019-2021 certainly changed patterns. For instance, while working from home became necessary, conventional wisdom would assume that much of all work will remain done at home. If so, this will affect long term urban development patterns. But what if conventional wisdom is mostly incorrect, as is usually the case?

And what about the rise of autonomous vehicles (AVs)? Conventional wisdom also has it that an AV world will lead to sprawl on steroids, and undermine economies of agglomeration which are the very economic foundation of cities. That wisdom also assumes the doom of transit as know it. These are avenues of future research that can build on the insights we generated through a decade of research.

\section{Hedonic Analysis}

We also pioneered the use of CoStar rent data to assess the association between transit station distance and rent with respect to different system types and metropolitan areas. Our current research disaggregated systems into types of stations based on factor/cluster analysis outlined above. However, future work would include more rigorous analyses such as larger numbers of economic, demographic and spatial controls. We anticipate advancing work in this field in another way: assessing the interactive effect of transit station type and distance on commercial properties within discrete distance bands of stations. In our current work, we have discovered that real estate markets express segmentation effects based on distance to transit stations, by mode. For instance, real estate rents are much more responsive, adversely, to BRT station proximity than to SCT proximity for reasons that are different between these systems. Future research is needed to explore these refinements to market responses to transit systems by mode, type and distance.

Continually studying effects of transit stations on real estate rents can uncover important, albeit subtle market signals. For instance, future CoStar-based hedonic rent analyses can help us understand the effects of the COVID-19 pandemic and as well as effects of AVs. For example, suppose AVs reduce the demand for parking lots so that trillions of dollars in well-located real 
estate is unlocked. Will cities be redeveloped wholesale, or will we have a sprawling landscape that puts current sprawling patterns to shame?

We conclude with a review of why all this research is important.

\section{Concluding Perspectives About the Role of Fixed Route Transit Systems in Meeting America's Future Development Needs}

Two perspectives emerge from this research. First, the real estate market values proximity to various forms of transit, often extending up to two miles away. In other words, the real estate market confers a premium on rents for many kinds of commercial real estate beyond the standard half-mile circle that seems to dominate transit-oriented development (TOD) planning.

The second is that for the most part changes in jobs, people and households are confined to the very closest distance bands around transit stations. While it makes sense for development that values transit station proximity to occur nearby, there may be opportunities for transit-oriented development farther away that are unrealized. For instance, a substantial literature indicates that firms are attracted to transit stations up to a mile and often further away. It is not that workers are necessarily willing to walk longer distances but often feeder buses, shuttles, and even pleasant and barrier free walkways/bikeways facilitate accessibility.

Moreover, there is a growing literature based on market surveys indicating that people would choose to live a half mile away, or more, from transit stations if they had the opportunity. One indicator of this willingness is the presence of market premiums for light rail and streetcar proximity well beyond one mile. Yet, the largest share of the change people and households occurs within one-eighth (0.125) mile of LRT and SCT stations. For workers it is the first quarter $(0.25)$ mile. Why is this?

It may be that local planning does not seize market opportunities for maximizing development throughout the half-mile circle or beyond. Among many barriers identified in the literature combined with our own professional observations include:

- Development regulations that are inconsistent with market realities;

- Unpredictable or protracted development approval processes;

- Excessive parking requirements;

- Development exactions that exceed that needed to mitigate adverse impacts;

- Neighborhood opposition;

- Inefficient linkages between development and transit stations (such as multi-lane highways, long blocks, and elevated station platforms among others); and

- Insensitive urban design that makes transit station accessibility physically and even emotionally unpleasant.

But for these barriers, more jobs, people and households are likely to locate within a half mile, a mile or more from transit stations. For example, suppose development across the entire 0.50mile area around transit stations were similar to that observed for the first 0.125 -mile. For instance, in metropolitan Denver, the 0.125 -mile LRT station areas absorbed $12.7 \%$ of all household growth despite comprising only $0.4 \%$ of the urban land area. If extended over $0.50-$ mile, 1.5 times more than all of the Denver metropolitan area's household growth 2010-2016 could have been absorbed. Not all households would choose to live near transit stations, of 
course. Still, market surveys produced by the National Association of Realtors suggest that even if all new housing built between 2010 and 2050 were within 0.50-mile of existing transit stations, market demand for housing proximate to transit stations would remain unmet.

There is another consideration. Our preliminary analysis of the land area within 0.50 mile of transit stations in many of the metropolitan areas investigated in our study indicate that more than half the area is comprised of

- Surface parking lots,

- Vacant, privately owned land, and

- Land on which there are one- and two-floor structures being more than 30 years old and occupying less than $25 \%$ of the land area. ${ }^{120}$

Real estate development literature indicates such land presents important opportunities for infill and redevelopment. One may imagine that much of the America's market demand for living and working near transit stations can be accommodated through the redevelopment of parking lots, vacant land, and aging buildings that are already beyond their highest and best use.

Perhaps the greatest challenge for America's metropolitan areas is to meet the market demand for jobs and housing near rail transit stations by simply facilitating the redevelopment of its parking lots and aging, low intensity structures.

${ }^{120}$ These analyses are based on assessor records and Marshall and Swift depreciation schedules by building types. 


\section{REFERENCES}

Alonso, William (1964). Location and land use: Toward a general theory of land rent. Cambridge, MA: Harvard University Press.

Boarnet, Marlon (1997). Highways and economic productivity: Interpreting recent evidence. Journal of Planning Literature 11(4): 476-486.

Boarnet, Marlon G. and Andrew F. Haughwout. (2000). Do Highways Matter? Evidence and Policy Implications of Highways Influence on Metropolitan Development. Washington, DC: The Brookings Institution, Center on Urban and Metropolitan Policy.

Bogart, William T. (1998). The Economics of Cities and Suburbs. Upper Saddle River, NJ: Prentice Hall.

Canepa, Brian, (2007). Bursting the Bubble: Determining Transit-Oriented Development's Walkable Limits. Transportation Research Record: Journal of the Transportation Research Board, 1992, pp 28-34.

Chatman, Daniel G. and Stephanie E. DiPetrillo (2011). Eliminating Barriers to Transit-Oriented Development. New Brunswick NJ: Alan M. Voorhees Transportation Center, Rutgers University.

Coffel, Kathryn, Jamie Parks, Conor Semler, Paul Ryus, David Sampson, Carol Kachadoorian, Herbert S. Levinson and Joseph L. Schofer (2012). Guidelines for Providing Access to Public Transportation Stations. Washington, DC: Transportation Research Board, Transit Cooperative Research Program.

Glaeser, Edward L. Ed (2010). Agglomeration Economics. Chicago: University of Chicago Press.

Graham, D. J. (2007). Agglomeration, productivity and transport investment. Journal of Transport Economics and Policy 41(3), September: 317-343. www.ingentaconnect.com/content/lse/jtep/2007/00000041/00000003/art00003.

Guthrie, Andrew and Yingling Fan (2017). Specific Strategies for Achieving Transit-Oriented Economic Development Applying National Lessons to the Twin Cities - Phase 2. Minneapolos MN: Center for Transportation Studies, University of Minnesota. Available at http://www.cts.umn.edu/Publications/ResearchReports/

Litman, Todd A. (2009). Evaluating Transportation Economic Development Impacts. Victoria, BC: Victoria Transportation Institute, http://www.vtpi.org/econ dev.pdf.

Mills, Edwin S. (1972). Studies in the structure of the urban economy. Baltimore, MD: Johns Hopkins University Press.

Muth, Richard F. (1969). Cities and housing: The spatial structure of urban residential land use. Chicago: University of Chicago Press.

Nelson, Arthur C. and Susan J. McClesky (1990). Elevated Rapid Rail Station Impacts on Single-Family House Values, Transportation Research Record, 1266: 173-180. 
Nelson, Arthur C. with John Genereux and Michelle Genereux (1992). Price Effects of Landfills on Vacant Residential Land Values. Journal of Urban Planning and Development 128137.

Nelson, Arthur C., Geoff Anderson, Reid Ewing, Pamela Perlich, Thomas W. Sanchez, and Keith Bartholomew (2009). The Best Stimulus for the Money: Briefing Papers on the Economics of Transportation Spending. Salt Lake City: Metropolitan Research Center at the University of Utah for Smart Growth America. http://www.smartgrowthamerica.org/documents/thebeststimulus.pdf.

Nelson, Arthur C. (2013). Reshaping Metropolitan America. Washington, DC: Island Press.

Nelson, Arthur C. (2014). Foundations of Real Estate Finance for Development. Washington, DC: Island Press.

Park, Robert E.; Burgess, Ernest W. (1925). The Growth of the City: An Introduction to a Research Project. The City. University of Chicago Press. pp. 47-62. Summarized in OECD/ITF Discussion Paper 2007-11, www.internationaltransportforum.org/jtrc/DiscussionPapers/DiscussionPaper11.pdf.

Petheram, Susan J., Arthur C. Nelson, Matt Miller and Reid Ewing (2013). Using the Real Estate Markt to Establish Light Rail Station Catchment Areas: Case Study of Attached Residential Property Values in Salt Lake County with respect to Light Rail Station Distance. Transportation Research Record. 2357: 95-99.

TransLink (2012). Transit-Oriented Communities Design Guidelines: Creating more livable places around transit in Metro Vancouver. Burnaby BC: TransLink Strategic Planning and Policy.

Weisbrod, Glen, Derek Cuter and Chandler Duncan (2013). The Role of Transit in Support of High Growth Business Clusters in the U.S. Washington, DC: American Public Transit Association 


\section{EPILOGUE: Transit Funding Options, Assessments, and Approach to Capturing Regional and Spatially-Related Value Toward A Proportionate-Share, Spatially-Related Value Capture Funding Scheme for Transit}

\section{OVERVIEW}

As our research demonstrates, fixed-route transit (FRT) systems confer both regional and local benefits. Regionally, they elevate overall economic performance as well as provide a wide range of public goods such as lower levels of greenhouse gas emissions and more mobility options. Locally, they generate value to private property that is spatially related to transit station proximity. Based on economic development, real estate value added, and fiscal benefits, there is much to be said for expanding existing systems and launching new ones.

However, in these days of declining federal support for fixed-guideway transit capital investments, new sources of funding are needed. The inventory is surprisingly large but largely untapped. In some cases, state enabling legislation may be needed but in others local popular and political support needs to be generated. The choice of funding option can make a difference. In this report, we introduce the role of fixed-guideway transit in creating value, identify numerous transit funding options, review criteria that may be used to choose those options that maximize key public finance objectives including capturing part of the value created by transit investments, and posing a funding approach that captures part of the value-added to regions and to areas around transit stations in relation to the distance of benefiting property from those stations.

This chapter is comprised of four sections:

Section 1 reviews how transit can improve property values and it includes the proposition that a portion of the value-added can be captured to help finance transit.

In Section 2, we present a large list of transit funding options including how they operate and the extent to which they address initial capital investment, operations and maintenance, and long-term capital repair-rehabilitation-replacement costs.

Section 3 identifies public finance criteria that should be used to guide the selection of funding options to best meet planning, efficiency, equity, administrative and other objectives.

We conclude this chapter with Section 4 that poses an approach to fairly apportion the burdens of financing transit across a region that broadly benefits from its services and within areas around transit stations based on spatially-related benefits. 


\section{How Transit Improves Property Values 121}

Cities are formed and grow in large part by creating agglomeration economies (Glaeser 2011). Annas, Arnott, and Small (1998) define the term as "the decline in average cost as more production occurs within a specified geographical area" (p. 1427). They arise specific to certain economic sectors, however. As more firms in a related sector cluster together, costs of production fall as productivity increases (Holmes 1999). Cities can become ever larger as economies of agglomeration are exploited (Ciccone and Hall 1996) especially through expansion of surface transportation systems (Glaesser 2011). As surface transportation systems are expanded, metropolitan-wide land values should increase. Conceptually, we characterize this as the Baseline Metropolitan Land Values line in Figure E.1.

If cities get too large, however, congestion occurs, which leads to diseconomies of scale. The result may be relocation of firms, but this can weaken economies of scale (Bogart 1998). Highways connecting the city to outlying areas can induce firms to relocate, thereby reducing agglomeration diseconomies of scale through sacrificing some economies, though overall economic improvement is debatable (Boarnet 1997). Cities thus spread out, and although the urban area may contain more people and jobs, the advantages of agglomeration economies are weakened. One way to preserve agglomeration economies and reduce diseconomies is to improve transportation systems; this is a role of fixed-guideway transit systems. Conceptually, therefore, metropolitan areas with fixed-guideway transit systems should see overall economic gains relative to metropolitan areas without them. Those gains should be capitalized at least in part as higher land values. We characterize this as the Transit-related Improvement in Metropolitan Land Values line in Figure E.1.

A large and growing literature shows another transit effect, however. The value of property and by implication land usually increases the more accessible it is to fixed-guideway transit stations. Extensive reviews of the transit-related capitalization are offered by Higgins and Kanaroglou (2015) and Suzuki et al. (2015). This is noted conceptually as the line Exclusive Land Value Capitalization of Transit in Figure E.1.

As transit is expensive, finding means to pay for it need to be identified. Conceptually, funding would come from the benefits generated by transit itself, known as value recapture. This is introduced in the next section.

${ }^{121}$ The terms "land value" and "property value" are used interchangeably throughout this chapter. 


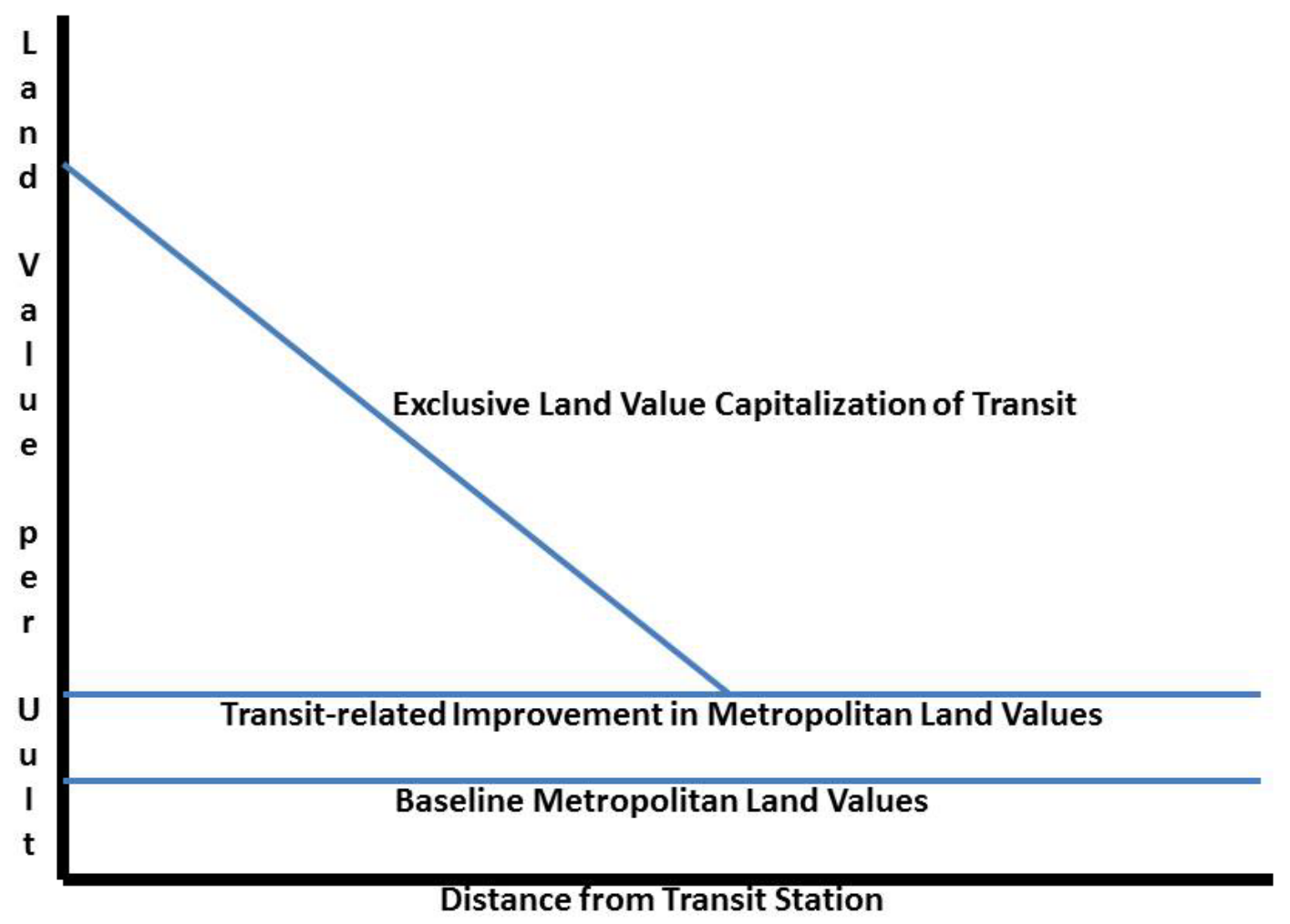

Figure E.1

Capitalization of transit improvements into land

\section{The Theory of Value Capture}

A basic tenet of economics is that the internalization of externalities will lead to more efficient decisions. In planning, "externalities" often refers to the negative effect of development on the community which needs to be mitigated by the developer. Externalities can also be positive as when a public investment makes land more valuable. The development that follows generates economic activity. An efficient public investment requires the returns must at least equal the costs. One measure of return is the improvement in property value. Logically, if a public investment such as transit improves property values, the public may wish to be reimbursed for its investment by recapturing a share of the increase in value. This is called value recapture. As applied to land value recapture, the concept dates back to David Ricardo (1821) and Henry George (1879).

Value capture is based on the principle that property value is determined its several factors such as the intrinsic value of land, value created by private investment, value created by increasing demand for a location through population and economic growth, and valued-added by publicsector decisions such as changes in land use regulations, infrastructure investments, and the provision of services. These contributions to property value are illustrated in Figure E.2. 


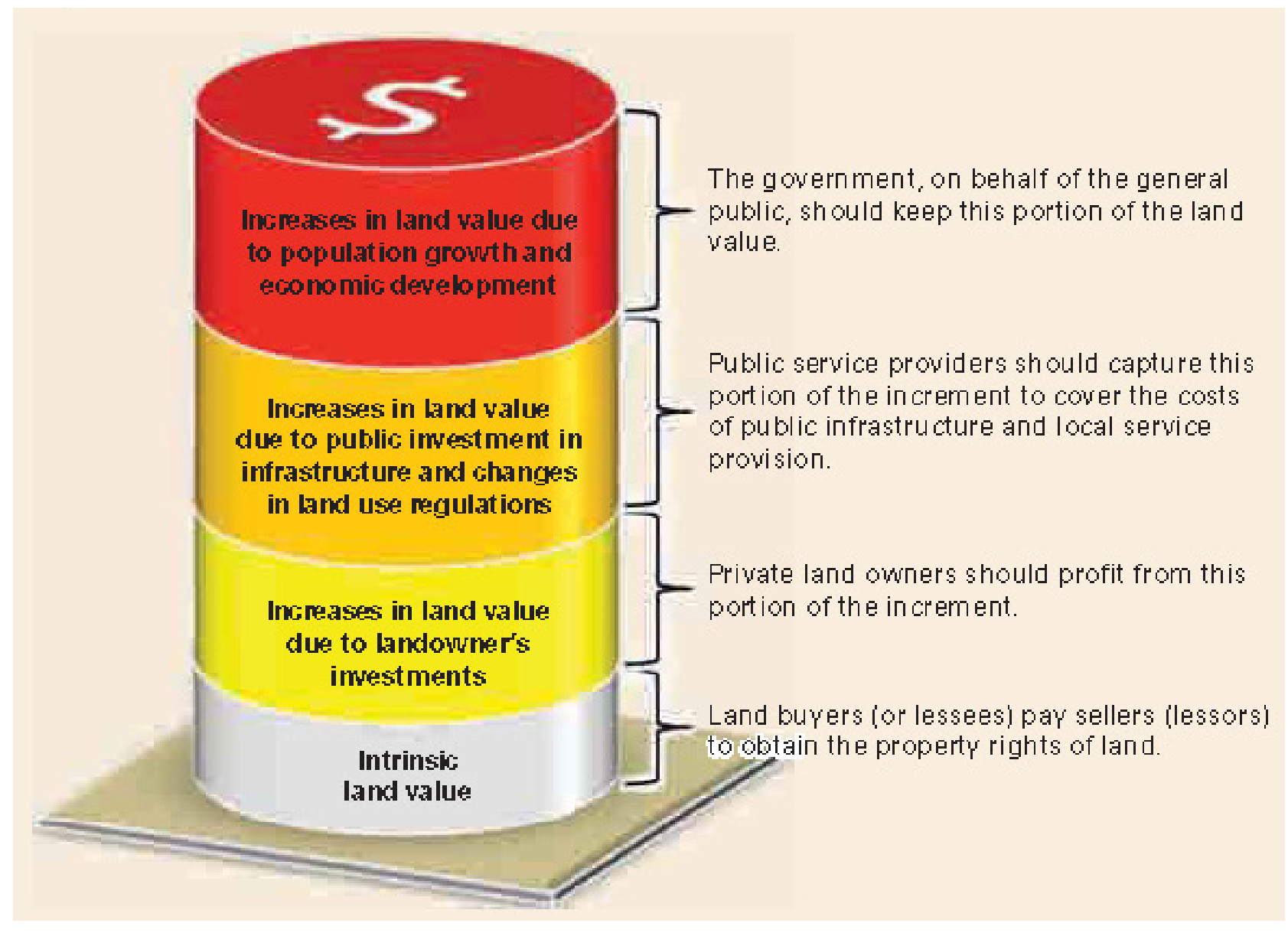

Figure E.2

Components of Land Value Capture

Source: Hong and Brubaker (2010), reproduced from Susuki et al, (2015). 
Economists and policy analysts alike seem to share sentiments of the United Nations (1976) that "the beneficiaries of the public investments or the public decisions that increase their land values should partly cover public investment costs or return their benefit to the public." Conceptually, in Figure 1.1, the LVC would be comprised of two parts. The first would be the difference between the Transit-related Improvement in Metropolitan Land Values line and the Baseline Metropolitan Land Values line in Figure 1 reflecting the top portion of the cylinder in Figure E.2 as it represents the broad benefits conferred on the public from the actions it takes to create land value.

The second would be the difference between the Exclusive Land Value Capitalization of Transit line and the Transit-related Improvement in Metropolitan Land Values line in Figure 1. Because transit investments benefit property in decreasing amounts with respect to distance from transit stations, the value capture would also decline. The amount recaptured would reflect only the public investment as seen in the second-from-the-top cylinder in Figure E.2.

There is another form of value capture that is often overlooked: non-capitalized environmental and social benefits. While the market for property may capitalize proximity to transit as seen in Figure 1.1, the market normally does not capitalize several other benefits. For instance, if air pollution is reduced because more people use transit instead of automobiles, the market does not capitalize the benefits of reduced air pollution because its market value is unknown. Likewise, improving accessibility options to transportation-dependent populations is not directly capitalized in the real estate market. These are social and public good (Musgrave and Musgrave 1989) that benefit society as a whole and should be financed by society through general taxation. A sample of social and public goods generated from transit is provided in Table E.1.

We turn next to identifying transit funding options, especially those related to value capture. 
Table E.1

Transit-related social and environmental benefits

\begin{tabular}{|c|c|c|}
\hline Health Benefit & Public Transit Impacts & $\begin{array}{c}\text { Consideration In Conventional } \\
\text { Planning } \\
\end{array}$ \\
\hline $\begin{array}{l}\text { Traffic safety. Reduced traffic } \\
\text { crash injuries, disabilities and } \\
\text { deaths. }\end{array}$ & $\begin{array}{l}\text { Significant reductions in per capita } \\
\text { injuries and deaths, particularly if total } \\
\text { vehicle travel is reduced. }\end{array}$ & $\begin{array}{l}\text { Considers per-mile crash and injury } \\
\text { rates, but often ignores mileage } \\
\text { reduction safety benefits. }\end{array}$ \\
\hline $\begin{array}{l}\text { Pollution reduction. Reduced } \\
\text { exposure to harmful air, water } \\
\text { and noise pollution. }\end{array}$ & $\begin{array}{l}\text { Generally reduces emissions per } \\
\text { passenger-mile and per capita, } \\
\text { particularly if transit uses alternative } \\
\text { fuels or state-of-the-art emission } \\
\text { controls. }\end{array}$ & $\begin{array}{l}\text { Considers differences in emission } \\
\text { rates per vehicle-mile, but often } \\
\text { ignores mileage reduction impacts. }\end{array}$ \\
\hline $\begin{array}{l}\text { Physical fitness. Increased } \\
\text { physical activity by walking and } \\
\text { cycling. }\end{array}$ & $\begin{array}{l}\text { Since most transit trips involve walking } \\
\text { or cycling links, and TOD improves } \\
\text { nonmotorized conditions, transit } \\
\text { improvements tend to increase fitness. }\end{array}$ & $\begin{array}{l}\text { Not generally considered a } \\
\text { transportation planning issue and } \\
\text { generally overlooked in quantitative } \\
\text { analysis. }\end{array}$ \\
\hline $\begin{array}{l}\text { Mental health. Reduced } \\
\text { emotional stress. }\end{array}$ & $\begin{array}{l}\text { High quality transit and transit oriented } \\
\text { development can reduce emotional } \\
\text { stresses and improve access to economic, } \\
\text { social and recreational opportunities. }\end{array}$ & $\begin{array}{l}\text { Not generally considered a } \\
\text { transportation planning issue and } \\
\text { generally overlooked in quantitative } \\
\text { analysis. }\end{array}$ \\
\hline $\begin{array}{l}\text { Affordability. Reduced financial } \\
\text { burdens, particularly for lower- } \\
\text { income households. }\end{array}$ & $\begin{array}{l}\text { Public transit and transit-oriented } \\
\text { development can reduce transportation } \\
\text { costs, which leaves money to purchase } \\
\text { housing, healthy food and medical care. }\end{array}$ & $\begin{array}{l}\text { Sometimes considered but not } \\
\text { generally quantified. }\end{array}$ \\
\hline $\begin{array}{l}\text { Basic mobility. Ability for people } \\
\text { to access essential goods and } \\
\text { services. }\end{array}$ & $\begin{array}{l}\text { Public transit and transit-oriented } \\
\text { development provide basic mobility and } \\
\text { accessibility. }\end{array}$ & $\begin{array}{l}\text { Sometimes considered when } \\
\text { evaluating specific policies and } \\
\text { projects, but not generally quantified. }\end{array}$ \\
\hline
\end{tabular}

Source: Litman (2010) 


\section{Local and Regional Transit Funding Options}

In this section, we identify as many reasonable sources of revenue to finance public transit systems offered by literature. We also identify the extent to which they may be available help with initial capital investment $(\mathrm{ICI})$, operations and maintenance (O\&M), and major repairs, rehabilitation and replacement (RRR) as well as their key advantages and disadvantages. We conclude the section with examples of transit-related special service districts and their funding sources across the nation.

We identified four publications that identified and assessed a reasonably comprehensive list of local and regional transit funding options. In chronological order they are:

Bowles and Nelson (2007);

Cambridge Systematics et al. (2009);

Omnitrans et al. (2012); and

Litman $(2014,2015)$.

Each of these publications identified options and then developed and applied criteria to assess them along several dimensions. To this list add a few more options based on other literature, usually pertaining to a single new option. We are drawn to the categories of funding options developed in the Cambridge Systematics et al. (2009) report to the Transportation Research Board. We adapt many of its categories of options while adding our own based on other reports.

Here we itemize the funding option by category used in the Cambridge Systematics report. Beside each option we denote its principal source as CS (Cambridge Systematics), BN (Bowles and Nelson), $\mathbf{O}$ (Omnitrans et al.) or $\mathbf{L}$ (Litman). We then report mostly verbatim (in italics with specific page references to the primary source) what each option is and how it works. After each option we note our assessment of whether it would be highly $(\mathbf{H})$, moderately $(\mathbf{M})$, less $(\mathbf{L})$ or inappropriate (I) to be used for $\mathrm{ICl}, \mathrm{O} \& \mathrm{M}$ and RRR. We also include advantages and disadvantages notes from the primary sources (italicized) or our own (non-italicized).

We also note a web site sponsored by the University Transportation Center for Mobility through Texas A\&M's Texas Transportation Institute that identities many but not all of these same funding options along with examples of their application. It is:

\section{http://utcm.tamu.edu/tfo/transit/summary.stm}


Tax- and Fee-Based Transit Options

These options include:

General Revenues CS (16)

General Sales Taxes CS (16)

Motor Fuel Taxes (CS 35-36)

Parking Sales Taxes (L 22, 24)

Property Taxes CS (16-17)

Utility Fees/Taxes CS (20)

Fare Increases (L 11)

"Sin" Taxes (CS 36)

Airport Passenger Facility Charges (CS 37) 


\section{General Revenues CS (16)}

The terms "general revenues" and "general funds" refer to revenues combined from any number of local and regional sources, including those described below. General funds serve as a resource to support any and all public purposes. Frequently, general funds are committed to support public transportation on an annual or biennial basis in amounts that can vary from budget cycle to budget cycle depending on local budget priorities. The sometimes uneven flow of general funds to transit on annual or biennial budget cycles is contrasted with the more predictable and reliable flow of revenues from specific sources dedicated all, or in part, to transit.

$\mathrm{ICl}$

O\&M

RRR

Advantages

Disadvantages
$\mathrm{H}$

$\mathrm{H}$

$\mathrm{H}$

Transit has benefits that are spread broadly across community and across users and non-users.

Typically requires no legislative action. Subject to annual appropriation/budgeting process Used to fund other local public services, which may have priority over transit. 


\section{General Sales Taxes CS (16)}

Sales taxes are the most widely used source of dedicated local and regional funding for transit. Generally, sales taxes provide the greatest yield and stability as well as being among the most broadly acceptable sources of funding for public transportation. State funding for public transportation frequently relies on this source: all but five states have state sales taxes with rates ranging from 4 to 7.25 percent. At the local and regional level, additional sales taxes enacted for transit typically range from 0.25 to 1 percent. Some sales taxes are perpetual; others require reenactment or extension through periodic popular votes. Sales taxes typically exempt various combinations of food, clothing, and prescription drugs or apply lower rates to selected goods and services.

$\begin{array}{ll}\text { ICI } & H \\ \text { O\&M } & H \\ \text { RRR } & H\end{array}$

Advantages $\quad$ Broad tax base; generally produces high revenue yields for a low marginal tax rate.

Keeps pace with inflation.

If already in place, very low cost for adjusting rates.

Moderately equitable in that individuals of comparable means pay roughly the same amount of tax.

All transportation system users pay, including commuters/visitors.

Transit is linked to economic health.

Disadvantages Revenues variable with changes in the economy, negative as well as positive.

Considered somewhat regressive; burden is higher on poorer households although benefits of transit may be greater.

Possible complications in the geographic limits of taxation and services delivered (users can be from outside the taxing jurisdiction).

Must have state legislative authority in place for local enactment.

Typically require voter approval for local enactment. 
Motor Fuel Taxes (CS 35-36)

Motor fuel taxes are a type of sales tax or excise tax applied by all states to gasoline, diesel fuel, and gasohol at varying rates. State gasoline tax rates range widely. Although it has not been a common source of transit revenue, a number of states have authorized local option gasoline taxes. In over 30 states, state constitutional provisions or state statutes preclude the direct use of state motor fuel tax revenues for purposes other than funding highways.

$\mathrm{ICl}$

O\&M

RRR

Advantages

Disadvantages downturns.
$\mathrm{H}$

$\mathrm{H}$

$\mathrm{H}$

Strong historic growth in yield from increases in ownership and use.

More progressive than general sales taxes.

Significant potential for decline with economic

Often difficult to divert from general funds.

Revenues may decline in future with shifts away from petroleumbased vehicles. 
Parking Sales Taxes (L 22, 24)

Parking sales taxes would be a special tax on parking transactions (when motorists pay directly for parking). Only a small portion (perhaps 5-10\%) of parking activity is priced. It could encourage more businesses to provide free parking to employees and customers. This option could be expanded where and when public parking is priced, such as metering currently unpriced on-street parking spaces in urban neighborhoods, and charging for off-street parking at public facilities such as for government employees, at schools and parks. This is best implemented as part of a comprehensive parking management program that also includes better pricing systems, user information and enforcement practices.

$\mathrm{ICl}$

O\&M

RRR

Advantages

Disadvantages downturns.
$\mathrm{H}$

$\mathrm{H}$

$\mathrm{H}$

Strong historic growth in yield from increases in ownership and use.

More progressive than general sales taxes.

Significant potential for decline with economic

Often difficult to divert from general funds.

Revenues may decline in future with shifts away from petroleumbased vehicles. 


\section{Property Taxes CS (16-17)}

Property taxes or ad valorem taxes on land and building value are generally the principal source of revenue for local governments and typically are unrestricted in their use. Portions of local property taxes are, however, also widely authorized for use by special districts and authorities, including transit authorities and school districts, and for other specific public functions like police and sanitation.

Revenues are generated by applying a tax or "mill rate" to the value of the property. Socalled "fair market" values frequently are adjusted to determine the "assessed value" used as the basis for the mill rate. A mill is equivalent to 1/1,000 of a dollar. Although these taxes are assessed locally, states and localities act to control valuations or otherwise provide some type of property tax relief in the form of targeted exemptions, or "circuit-breakers," limiting the percentage of income required to be paid via property taxes.

"Special assessments" and "local improvement levies" are also types of property tax that are applied in direct relation to a benefit received from their imposition and expenditure, typically on local public improvements, as discussed in the section "Value Capture and Beneficiary Charges."

$\mathrm{ICl}$

O\&M

RRR

Advantages

Disadvantages

\section{$\mathrm{H}$}

$\mathrm{H}$

$\mathrm{H}$

All households and businesses must pay.

Generally a broad tax base.

Revenues are generally not impacted dramatically with

changes in the economy.

Indexed for inflation (but only in property values).

Relevant to and allowed for transit investment as a basic public service.

Ease of administration and low evasion.

Low compliance cost.

Variable political and public acceptability.

Moderately regressive; e.g., some households could be property-rich but income-poor (e.g., retirees).

Revenue growth may be limited by tax limitation statutes in some areas.

Susceptible to potential yield swings from periodic speculation and housing cycles. 
Utility Fees/Taxes CS (20)

Utility fees can encompass taxes on a wide range of public services and businesses, including telephone, sewer and water, electricity, gas, and garbage utilities. Revenues are typically provided to a jurisdiction's general fund as well as to public works facilities. In Pullman, Washington, utilities are paid monthly by subscribers (households and businesses). The prior month's fees are paid in turn to the city every month, i.e., there is a month's lag in city receipt of the fees. The tax is levied in lieu of a business and occupation tax and a sales tax. Rates vary by utility from 0.10 percent to 5 percent. $\begin{array}{ll}\text { ICl } & \mathrm{H} \\ \text { O\&M } & \mathrm{H} \\ \text { RRR } & \mathrm{H}\end{array}$

Advantages All households pay.

Has proven to be a useful alternative funding source in areas where scale of the economy and sales taxes may not provide a broad tax base to support transit.

Disadvantages Revenues from some utilities are impacted by energy conservation policies. 
Fare Increases (L 11)

In most urban transit systems, current adult fares average $\$ 2$ to $\$ 3$ per trip or $\$ 50$ to $\$ 80$ for a monthly pass, with discounted (concession) fares for youths, seniors and people with disabilities. It is possible to increase all fares, selected categories, or change price structures, for example, to include higher fares for longer-distance trips or for special services such as light rail or express commuter buses.

$\mathrm{ICl}$

O\&M

RRR

$\mathrm{H}$

$\mathrm{H}$

Advantages

H

Disadvantages

Reasonable discretion to raise rates.

Can be politically difficult.

Unless fares reflect distance-based cost differences, increases can be inequitable. 


\section{"Sin" Taxes (CS 36)}

A number of taxing mechanisms, grouped under the heading of "sin" taxes, have existed at the state level for hundreds of years, including cigarette taxes; liquor, beer, and wine taxes; gambling taxes; and lottery proceeds. These are typically state-level taxing mechanisms, often with local analogs, that are used to support health and education programs and general spending, but are rarely used for transit investment. Exceptions include the use of state cigarette tax revenues to support Portland's MAX light rail transit system, the dedication of state lottery proceeds to transit services for elderly persons in Pennsylvania, and the use of a Casino Revenue Fund to support paratransit in New Jersey. "Sin" taxes can provide considerable revenue along with providing a disincentive to engaging in behavior that is considered undesirable by many.

$\mathrm{ICl}$

O\&M

RRR

Advantages

Disadvantages
$\mathrm{H}$

$\mathrm{H}$

$\mathrm{H}$

Fees collected from those who voluntarily engage in smoking, drinking certain products, and gambling.

Visitors as well as locals contribute.

Narrow tax base.

Lottery fees are strongly regressive. Gambling may cause social and personal problems. 
Airport Passenger Facility Charges (CS 37)

In 1990, the federal government authorized local and regional airport authorities (or other public agencies responsible for commercial airport ownership and operations) to collect fees on a sliding scale for each "enplaned passenger." Several billion dollars are raised from passenger facility charges (PFCs) each year and used directly to fund FAAapproved projects that enhance safety, security, or capacity; reduce noise; or increase air carrier competition. These funds can also be used as leverage for debt to make such improvements. Because of overall levels of traffic congestion, "land-side" access to airports has become a major challenge, and increasing consideration is being given to using airport revenues in coordination with revenues from other agencies to support transit access to airports.

$\mathrm{ICl}$

O\&M

RRR

Advantages

Disadvantages
$\mathrm{H}$

$\mathrm{H}$

$\mathrm{H}$

Assures provision of multi-modal options connecting airport facilities to other venues.

May require state enabling legislation.

Transfers funds otherwise earmarked for airport operations to other purposes. 


\section{Business, Activity, and Related Funding Options}

These funding options include:

Employer/Payroll Taxes CS (18-19)

Corporate Franchise Taxes/ Business License Fees CS (20)

Income Taxes (Personal and Corporate) (CS 36)

Vehicle Fees (title, registration, tags, inspection) CS (18)

Car Rental Fees CS (19)

Vehicle Lease Fees CS (19)

Parking Fees CS (19)

Realty Transfer Taxes/Mortgage Recording Fees CS (19-20)

Employer/Payroll Taxes CS (18-19)

Corporate Franchise Taxes/ Business License Fees CS (20)

Income Taxes (Personal and Corporate) (CS 36)

Vehicle Fees (title, registration, tags, inspection) CS (18)

Car Rental Fees CS (19)

Vehicle Lease Fees CS (19)

Parking Fees CS (19)

Realty Transfer Taxes/Mortgage Recording Fees CS (19-20)

Room/Occupancy Taxes CS (20) 


\section{Employer/Payroll Taxes CS (18-19)}

Employer taxes enacted to support transit are typically imposed directly on the employer for the amount of gross payroll paid for services performed within the transit district. Employer taxes are usually administered by the state revenue agency on behalf of the transit agencies or jurisdictions authorized to raise and expend the revenue and typically are collected quarterly. Authorizing legislation along with associated regulations and guidelines define the specific types of wages and payments to which the tax is applied as well as the organizations that may be declared exempt from the tax, such as federal agencies, school districts, and tax-exempt organizations.

$\begin{array}{ll}\text { ICl } & \mathrm{H} \\ \text { O\&M } & \mathrm{H} \\ \text { RRR } & \mathrm{H} \\ \text { Advantages } & \text { Enst }\end{array}$

Advantages Ensures that commuters and businesses contribute to and support transit.

Ease of compliance and administration.

Responsive to inflation.

Disadvantages Commuters have no say within the local government that imposes the tax.

May provide incentive for businesses to locate outside the taxing jurisdiction. 
Corporate Franchise Taxes/ Business License Fees CS (20)

A franchise tax is a tax levied on the profit and taxable assets of a business or firm. Franchise taxes impose a tax on corporations for doing business, employing capital, owning or leasing property, or maintaining an office. Franchise taxes often are targeted to specific industries and economic activities.

General

$\mathrm{ICl}$

O\&M

RRR

$\mathrm{H}$

Advantages

$\mathrm{H}$

$\mathrm{H}$

Advantages

Disadvantages

Ensures that employers contribute/support transit services that benefit them.

Progressive in comparison to other options.

May provide incentive for businesses to locate outside the taxing jurisdiction. 
Income Taxes (Personal and Corporate) (CS 36)

State and federal income taxes, both personal and corporate, are well-known major revenue sources. Local income taxes are far less common. Rare examples are the three county-level, local option income taxes collected in some Indiana counties and used predominantly for property tax relief. In Lafayette, Indiana, these taxes are used for transit as well. A related revenue source is the business and occupation (B\&O) tax. The $B \& O$ tax is a gross receipts tax assessed on the value of products, gross proceeds of sale, or gross income of the business.

$\mathrm{ICl}$

O\&M

RRR

Advantages

Disadvantages
$\mathrm{H}$

$\mathrm{H}$

$\mathrm{H}$

All households pay (except those with very low incomes). Progressive, directly related to income status.

Broad tax base. Indexed for inflation.

Revenues may be affected during economic recession due to potential increases in unemployment.

May be difficult to capture nonresident revenues. 
Vehicle Fees (title, registration, tags, inspection) CS (18)

A variety of fees are charged to vehicle owners and operators by state governments. These fees are based on vehicle value, weight, and/or age. The fees are charged for issuance of titles, licenses, registration, and/or inspection. The authority to collect vehicle fees is sometimes provided to local governments in the form of a local option. Revenues from these fees are typically dedicated to covering the cost of administering these activities, to enforcement, to transportation generally, or to general revenues. It is very seldom that revenues from vehicle fees are dedicated directly to public transportation.

$\mathrm{ICl}$

O\&M

RRR

Advantages

Disadvantages
$\mathrm{H}$

$\mathrm{H}$

$\mathrm{H}$

Revenues are generally not impacted by changes in the economy.

Allow for revenue collection from varied vehicle classes, differential value (i.e., a form of personal property tax) or vehicles using alternative fuels, etc., without establishing new collection mechanisms.

Already in place; little added administrative cost for revenue increases.

Revenues adjust to inflation.

Ad valorem fees are more progressive.

Flat fees are regressive.

Potential for inequities among vehicle classes.

Not indexed for inflation.

Limited base; only households that own vehicles pay.

Relation to transit is often not acknowledged, e.g., drivers may benefit from transit improvements that reduce congestion.

Typically require legislative action to change or increase rates, structure. 


\section{Car Rental Fees CS (19)}

Rental car taxes are paid by the consumer on the rental of a passenger car for a specified period of time, e.g., rentals lasting less than 30 days. Rental companies typically report and remit the tax to state revenue departments along with applicable retail sales tax receipts. Rental car revenues may be reallocated back to authorized local governments or agencies with funds often dedicated to specific projects or purposes, including public transportation. Rates typically range from 1 to 2 percent.

$\begin{array}{ll}\mathrm{ICl} & \mathrm{H} \\ \text { O\&M } & \mathrm{H} \\ \text { RRR } & \mathrm{H} \\ \text { Advantages } & \text { Easy }\end{array}$

Advantages Eas.

Revenues may be impacted by economic changes.

Responsive to inflation if fee placed on value.

Disadvantages People paying the tax have no say within the local government imposing the tax.

Narrow tax base. 
Vehicle Lease Fees CS (19)

When vehicles are leased or purchased, there are taxes and fees applied to the transactions. Fees can differ by dealer, leasing company, and the state in which the lease occurs. Lease taxes typically take the form of a sales tax on the amount of the monthly lease payment, but there are variations from state to state and region to region.

$\mathrm{ICl}$

O\&M

RRR

Advantages

Disadvantages
$\mathrm{H}$

$\mathrm{H}$

$\mathrm{H}$

Responsive to inflation if fee placed on value.

Assures collection with regard to leased vehicles. Narrow tax base.

If not ad valorem taxes, not responsive to inflation. Only households that lease vehicles pay. 


\section{Parking Fees CS (19)}

Parking fees are established to achieve multiple goals. These include revenue generation; traffic management; shifts in mode choice; and balance in accommodating residents', shoppers', and employees' access needs. Parking fee structures and revenue use are almost always a local matter, managed either by local jurisdictions or, in the case of some locales, a separate parking authority. Revenues typically go to parking and vehicle enforcement, roads, and general funds. Transit agencies also receive parking revenues from surface lots and structured parking facilities that they own. In the case of larger systems, operation of parking is often contracted out to a parking management firm. Parking demand is thought to be largely "inelastic" with respect to price, providing an opportunity to increase revenues directly through price increases. Fees typically are charged on a per-space and duration basis and sometimes through areawide surcharges.
$\mathrm{ICl}$
O\&M
$\mathrm{H}$
RRR
$\mathrm{H}$
Advantages
Ensures that commuters contribute/support transit services that benefit them.
Highly progressive.
Disadvantages
Narrow tax base. 
Realty Transfer Taxes/Mortgage Recording Fees CS (19-20)

A "real estate transfer tax" is a tax levied on the sale of certain classes of propertyresidential, commercial, or industrial - that increases with the size of the property being sold or transferred. Sometimes sellers (who have typically seen the value of their homes rise over the years) foot the bill. Other times, the cost is imposed on buyers-who, it is argued, are making an investment in the future of a community.

"Tax rates and dispositions vary from state to state: some states have no real estate transfer tax enabling legislation; some direct the revenues to the state general fund (although collection

remains a county responsibility); and still others give local governments the authority to collect and keep tax revenues" for such programs as land conservation, parks and open space, and less frequently, public transportation. Rates are highly variable across types of property and property value, ranging from 1/100th of a cent to 2 percent.

$\mathrm{ICI}$

O\&M

RRR

Advantages

Disadvantages
$\mathrm{H}$

$\mathrm{H}$

$\mathrm{H}$

New property owners pay a share of transit costs provided in the area.

Highly related to economic activity. Responsive to inflation. Narrow tax base.

Considered moderately regressive.

Susceptible to potential yield swings from periodic speculation and housing cycles. 


\section{Room/Occupancy Taxes CS (20)}

Sometimes called a hotel-motel tax, room or occupancy taxes (or "transient occupancy taxes) are consumer taxes on the cost of lodging at hotels, motels, rooming houses, private campgrounds, RV parks, and similar facilities. They are frequently limited to a specified consecutive period of days. Rates may vary depending on the size of the facility and/or by location. Revenues may be collected by the state and, where dedicated for local use, reallocated to the levying municipalities and counties. Alternatively, revenues may be collected by local jurisdictions where state authority is provided. Often these revenues are used for promotion of tourism or construction and operation of tourism-related facilities, as in counties throughout the state of Washington and in Allegheny County, Pennsylvania

$\mathrm{ICl}$

O\&M

RRR

Advantages

Disadvantages
$\mathrm{H}$

$\mathrm{H}$

$\mathrm{H}$

Politically attractive; only visitors pay the tax. Generally based on value; inflation sensitive.

People paying tax have no direct say in the local government that imposes the tax. 


\section{Revenue Stream Options}

These options include:

Contract or Purchase-of-Service Revenues (by human service agencies, school/universities, private organizations, etc.) CS (17)

Discounted Bulk Transit Passes (L 13)

Lease Revenues CS (18)

Advertising Revenues CS (18)

Concessions revenues CS (18)

Right-of-Way Leasing CS (30)

Station Air Rights (Tompkins 2010)

Intellectual Property (0 12)

Energy Cost Savings (0 12)

Sale of Naming Rights (0 13)

Donations CS (20) 
Contract or Purchase-of-Service Revenues (by human service agencies, school/universities, private organizations, etc.) CS (17)

Transit systems often provide transportation services in addition to their regularly scheduled services for which revenues are received based on agreed-upon levels of service and rates. Municipal government, individual businesses and industries, health and social service agencies, and educational institutions may purchase transit services. The revenues received may or may not cover "fully allocated costs," or fully allocated costs plus an added amount. The rates charged may be calculated and applied on a perhour basis, a per-vehicle basis, or per-trip basis.

$\mathrm{ICl}$

O\&M

RRR

Advantages

Disadvantages
$\mathrm{H}$

$\mathrm{H}$

$\mathrm{H}$

Allows pricing to be tailored to service levels and their contingencies.

Terms typically reviewed/revised on a regular schedule. costs. 
Discounted Bulk Transit Passes (L 13)

Public transit agencies can sell transit passes to a group, such as all students at a college or university, all employees at a worksite or all residents of a neighborhood.

They are often designed to be revenue neutral - the additional transit service costs are at least offset by the additional revenues. For example, if standard monthly passes are priced at $\$ 80$ and used for 40 average monthly trips, the transit agency can sell $\$ 40$ discounted passes to a group of students that average 20 monthly trips or $\$ 20$ to a group of residents that average 10 monthly trips.

[We note that the University of Utah actually provides each of its 30,000 students and 10,000 faculty and staff members with a free pass to use buses, light rail, bus rapid transit, commuter rail and street cars operated by the Utah Transit Authority. The cost is about \$5 million per year. Not only has ridership increased and street congestion decreased near the campus, the university saves land by not building parking lots or garages, thereby converting that land into more economically productive uses.]

$\mathrm{ICl}$

O\&M

$\mathrm{H}$

RRR

$\mathrm{H}$

Advantages

Allows pricing to be tailored to service levels and their contingencies

Terms typically reviewed/revised on a regular schedule costs

Disadvantages Negotiated rates may or may not cover fully allocated 


\section{Lease Revenues CS (18)}

Transit systems often generate income through leasing (at market rates) portions of physical facilities, typically terminal, station, transfer, or parking facilities. Transit agencies with rail or other fixed rights-of-way also can lease these to private interests, like telecommunications companies (typically for fiberoptic networks), and sometimes negotiate for free use for the agency for command and control. Leases can be annual, with rate adjustments, or multiyear.

$\mathrm{ICl}$

O\&M

RRR

Advantages

Disadvantages
$\mathrm{H}$

$\mathrm{H}$

$\mathrm{H}$

Maximizes return/revenue to assets

Periodically responsible for response to markets Integrates transit with other community interests Marginal opportunity/yield except to largest systems Requires market and lease transaction capacity 


\section{Advertising Revenues CS (18)}

Most transit agencies solicit and accept advertising on their vehicles, facilities (such as stations and shelters), and materials (such as tickets, schedules, and maps). Advertising serves as a source of earned income and provides a means to establish broader community partnerships as well as a means to capture and maintain interest and support for transit and other public services. Print and electronic media are in use, as are "sponsorship" programs that fund particular vehicles, services, or events. The majority of transit agencies contract advertising programs and their management to private media and advertising companies, although many advertising programs are managed by inhouse staff in medium and smaller systems. Revenues from advertising flow directly or indirectly to the operating agencies from single or multiyear advertising contracts and agreements as well as from time-limited and event-based arrangements. Limitations are often placed on advertising content as well as on the types of organizations from which advertising is accepted. Revenue from advertising is typically modest, from 0.1 percent to over 3.0 percent of operating revenue. In dollar terms, however, advertising revenues are producing $\$ 500$ million for transit agencies annually, ranging from thousands of dollars to millions of dollars a year, depending on system size.

$\mathrm{ICl}$

O\&M

RRR

Advantages

Disadvantages
$\mathrm{H}$

$\mathrm{H}$

$\mathrm{H}$

Increasing range of techniques and technologies available to expand reach, impact.

Can be brokered through private agents.

Low yield. 


\section{Concessions revenues CS (18)}

Larger transit agencies with significant space in terminal and station facilities may enter into concession agreements (an income-generating strategy similar to leasing) with a variety of commercial and retail enterprises. These enterprises include newsstands, food stands, ATMs, gift shops, vending machine operations, music stores, florists, photoprocessing stores, shoe repair and sales shops, and so forth. Concession agreements are typically multiyear and are bid on competitively, with payments received as revenue or in the form of direct contributions to capital improvements. As a measure of the potential for concessions as a source of revenue, the New York Metropolitan Transit Authority (MTA) estimates that the minimum threshold to support a single store is 5,000 passengers a day.

$\mathrm{ICl}$

O\&M

RRR

Advantages

Disadvantages
$\mathrm{H}$

$\mathrm{H}$

$\mathrm{H}$

Revenue can be optimized by charging a premium based on location

Can be adjusted to reflect market conditions

Low yield, not traditionally a major revenue generating

tool 
Right-of-Way Leasing CS (30)

Linear rights-of-way owned and maintained by transit agencies providing fixed guideway services have the potential to serve a number of emerging private business needs. Development of cable and fiber-optic networks, in particular, can benefit from joint use of transit rights-of-way through lease arrangements, providing the transit agency with a new source of revenue on the local and regional level. In addition, there is the possibility that the network provided for private-sector use and services marketed to the public can be utilized by the transit agency at a reduced cost for operational communications. The Bi-State Development Agency (BSDA) in St. Louis, Missouri, the operator of the region's Metrolink rail transit service, entered into a partnership with WorldCom in 1991 for joint use of its right-of-way. The agreement provides BSDA with access to the network for operational purposes at a minimal cost and provides for projected lease payments from WorldCom on a linear foot basis over a 25-year period.

$\mathrm{ICl}$

O\&M

RRR

$\mathrm{H}$

Advantages

tool.

Disadvantages

$\mathrm{H}$

$\mathrm{H}$

Capitalizes on local assets.

Low yield, not traditionally a major revenue generating 
Station Air Rights (Tompkins 2010)

Most transit stations in the US do not include developments over the stations

themselves. In addition, many stations use considerable areas of land. Selling or leasing

the rights to build over transit stations could generate substantial new revenue.

$\mathrm{ICl}$

O\&M

$\mathrm{H}$

RRR

$\mathrm{H}$

Advantages

$\mathrm{H}$

Disadvantages

Capitalizes on local assets

Low yield in most cases because of high capital costs to use air rights. 
Intellectual Property (O 12)

Intellectual property (IP) is a term referring to a number of distinct types of expressions for which a set of rights are recognized under the corresponding fields of law. Under intellectual property law, owners are granted certain exclusive rights to various markets, machines, musical, literary, and artistic works; discoveries and inventions; and applications. Common types of intellectual property rights include copyrights, trademarks, patents, industrial design rights, and trade secrets in some jurisdictions. Several transit agencies have developed technological solutions for operations, communications or security issues that are faced by a wide range of agencies. Often these have been developed using in-house resources and agency staff. As a result, these agencies have identified opportunities to leverage these investments into new revenue sources by selling the rights to these services or technologies, or in some cases acting as "consultants" to other agencies.

$\mathrm{ICl}$

O\&M

RRR

$\mathrm{H}$

Advantages

tool.

Disadvantages

$\mathrm{H}$

$\mathrm{H}$

Capitalizes on local inventiveness.

Low yield, not traditionally a major revenue generating 


\section{Energy Cost Savings (0 12)}

Many U.S. transit agencies are instituting policies and programs to reduce energy needs as a means to offset operating costs. In addition, several of the systems surveyed are pursuing opportunities to generate revenue through the implementation of alternative energy technologies; by selling energy that the agency produces to support transit operations; or entering into joint development agreements for energy facilities using publicly-owned land. Benefits of these approaches can include:

- Serving long-term agency sustainability programs goals;

- Developing new, annually recurring revenue streams that can be used for operations; and

- Leveraging of existing assets such as publicly-owned right of way.

Some of the challenges with these approaches are the complexity of these deals, and the long lead time needed to implement them. Additionally, there are a range of legal and institutional restrictions associated with the use of publicly-owned assets in publicprivate partnerships.

$\mathrm{ICl}$

O\&M

RRR

Advantages

Disadvantages
$\mathrm{H}$

$\mathrm{H}$

$\mathrm{H}$

Capitalizes on economies associated with transit. Difficult to predict revenue yield. 
Sale of Naming Rights (0 13)

Many state and local governments across the United States have entered into agreements to sell or lease the rights to name publicly owned or operated facilities, such as stadiums, buildings and other infrastructure. Similarly, transit agencies have begun to explore opportunities to sell or lease the ability for private companies to add their names or logos to transit stations, typically for a defined period of time. These practices are becoming more widely used, and are often viewed as an extension of an agency's current advertising practices. For the transit agencies, benefits of this approach include:

- Ability to generate revenue using existing facilities;

- Obtaining a recurring source of revenues for operations;

- Establishing a "sense of place" for a neighborhood surrounding a transit station; and

$\mathrm{ICl}$

- Developing a positive economic development relationships within the community.

O\&M

RRR

Advantages

Disadvantages
$\mathrm{H}$

$\mathrm{H}$

$\mathrm{H}$

Creative way of generating new revenue. Low yield.

Selection of naming awardees can create political problems. 


\section{Donations CS (20)}

Support for public transportation may also be available through donations from various types of philanthropic, charitable, service organizations like the United Way, as well as for-profit businesses. Typically, donations are directed toward a particular service, subarea, or client group.

$\mathrm{ICl}$

O\&M

RRR

Advantages

Disadvantages
Subject to donor restrictions

Subject to donor restrictions

Subject to donor restrictions

No governmental actions necessary.

Not a stable revenue source.

Extremely low yields. 


\section{Direct Value Capture and Exaction Options}

These options include:

Transit-Oriented Development CS (27-28)

Joint Development, aka Public-Private Partnerships (0 11-12)

Value Capture/Beneficiary Charges CS (28)

Negotiated Development Exactions (BN 24)

Development Agreements (BN 24)

Impact Fees CS (28)

Impact Taxes BN (26)

Mobility Fees (Seggermann et al. 2009: 3-4)

Transportation Utility Fee (Nelson, Nicholas and Juergensmeyer 2009: 344)

Special Assessment Districts including variants called Community Improvement Districts, Community

Tax-Increment Financing Districts BN (26) 
Transit-Oriented Development CS (27-28)

(I)n the pursuit of joint development ... significant opportunities arise to provide a new funding stream for public transit derived from the value to private businesses, developers, and real estate owners of proximity to transit services and the expected or planned mix of uses typically associated with TOD. These revenue streams typically come in two forms. Research has shown that nearly two-thirds of joint development projects involve significant cost-sharing, one quarter involve new revenue generation to directly support transit services and facilities, and 40 percent of joint development projects involve some degree of both.

$\mathrm{ICl}$

O\&M

RRR

Advantages

Disadvantages
$\mathrm{M}$

$\mathrm{M}$

$\mathrm{M}$

Direct relationship to transit and ease of access. New development pays for needed transportation improvements to support increased demand.

Subject to state enabling legislation restrictions. 
Joint Development, aka Public-Private Partnerships (0 11-12)

Joint development refers to arrangements between public sector and private developers to develop assets, such land. Joint development is often used by transit agencies to construct stations, enhance station access, or build parking facilities. Joint development can also be used to attract private developers to adjacent land and properties and stations because of their advantageous access. A private investor enters the joint development agreement to enhance the property in partnership with the transit agency. Revenues can be used for the capital costs of a new project; or, in cases when lease revenues are provided on an annual basis to a transit agency, these revenues can be used to fund agency operating costs. Many transit agencies have implemented joint development programs that actively seek to leverage the agency's property to generate revenue from private development.

Joint development can lead to increased revenue, ridership, or both. A Joint development project often enhances the financial viability of a project through the involvement of multiple uses. Additionally, a transit agency can benefit from private sector expertise in land development.

One challenge of joint development projects is that the deals are often complex and may take several years to implement. There are a myriad of Federal and state laws that govern the use of publicly-owned land and other assets. A transit agency will often need to hire outside legal, financial or design experts to help structure a joint development project. Finally, some partnerships have been impacted by a negative public perception that a private developer may be receiving an unfair advantage in the marketplace.

$\mathrm{ICl}$

O\&M

RRR

Advantages

Disadvantages
$\mathrm{M}$

$\mathrm{M}$

M

Direct relationship to transit and ease of access.

New development pays for needed transportation improvements to support increased demand.

Subject to state enabling legislation restrictions. 
Value Capture/Beneficiary Charges CS (28)

Value capture and beneficiary charges refer to circumstances in which the provision of a public service or facilities such as public transportation increases the market value of surrounding real estate, and measures are enacted to capture some or all of that increase to defray public expense. Various mechanisms are used to capture either the current or future value created by public investment.

$\mathrm{ICl}$

O\&M

RRR

$\mathrm{M}$

Advantages

Direct relationship to transit and ease of access.

New development pays for needed transportation

Disadvantages

improvements to support increased demand.

Subject to state enabling legislation restrictions. 


\section{Negotiated Development Exactions (BN 24)}

Monetary or in-kind exactions are generally the result of open-ended negotiations between the developer and the local government, rather than from the application of a previously defined methodology. They may be imposed at any stage of the development process, particularly during requests for regulatory approvals such as zoning, special permits, or planned unit developments, where the local governing body has broad discretionary authority. Such exactions typically involve public improvements in close proximity to the development.

While negotiated exactions are standard procedure in many communities, they are tightly regulated in some states. In North Carolina and Virginia, for example, the state governments have authorized two kinds of zoning districts: general-use districts and conditional-use districts. Local governments cannot require developer contributions as a condition of granting general-use zoning, and can accept proffers only when conditionaluse zoning is requested. In Virginia, jurisdictions outside of Northern Virginia and the Eastern Shore that have not been expressly granted conditional zoning authority are severely limited by the types of proffers that may legally be accepted.

In comparison with land-dedication requirements, negotiated exactions may cover the capital cost of public facilities in addition to land costs. Since such exactions are based on the specifics of an individual development proposal, they can address public-facility improvement needs, such as driveway turning lanes, that are directly related to the development.

$\mathrm{ICl}$

O\&M

RRR

Advantages

Disadvantages
M

$\mathrm{M}$

$\mathrm{M}$

Direct relationship to transit and ease of access. New development pays for needed transportation improvements to support increased demand.

Subject to state enabling legislation restrictions. 


\section{Development Agreements (BN 24)}

Development agreements are negotiated between the developer and the local government. Unlike mandatory dedications and negotiated exactions, development agreements cover a broad range of facilities (and other issues), provide for timing, phasing, and financing schedules, establish obligations of both parties, and help to settle issues that may otherwise have emerged in the future. Once in place, development agreements provide certainty to both the developer and local government on what to expect as the project builds out.

$\mathrm{ICl}$

O\&M

RRR

Advantages

Disadvantages
$\mathrm{M}$

$\mathrm{M}$

$\mathrm{M}$

Direct relationship to transit and ease of access. New development pays for needed transportation improvements to support increased demand.

Subject to state enabling legislation restrictions. 


\section{Impact Fees CS (28)}

Development brings with it a sizeable demand for new public facilities and services, including added transportation capacity. In urban settings particularly, it is increasingly important to satisfy the need for additional transportation capacity through multimodal strategies and investments, including additional public transportation services. Impact fees are frequently levied against new development to provide the revenues to meet the public facility demands of new development. The use of impact fee revenue to support transit investment and operations, however, is not yet widespread in the area of transit. Impact fees are typically one-time "charges on new development to pay for the construction or expansion of off-site capital improvements that are necessitated by and benefit the new development." Impact fees are most effective in rapid growing areas where development markets are strong.

$\mathrm{ICl}$

O\&M

RRR

Advantages

Disadvantages
$\mathrm{M}$

I

$$
\text { I }
$$

Direct relationship to transit and ease of access; new development pays for needed transportation improvements to support increased demand.

Higher revenue yield in high-growth areas.

Subject to state enabling legislation restrictions.

Does not usually address O\&M or RRR. 
Impact Taxes BN (26)

A development impact tax, also called an improvement tax, is a tax on new construction, usually assessed at the time of application for a building permit. Impact taxes are generally based on the value of new improvements, and tend to be more popular than other kinds of taxes because they are levied on new construction rather than existing development. However, re-roofing, remodeling, and alterations to existing structures are also subject to such a tax.

Unlike impact fees, impact taxes need not be based on the cost of facilities needed to serve the development, and the special studies required to justify impact fees are not required. In addition, revenues from such taxes may be spent in any way the local jurisdiction sees fit, subject to the provisions of state enabling legislation.

$\mathrm{ICl}$

O\&M

RRR

Advantages

Disadvantages
$\mathrm{M}$

$L$

$\mathrm{L}$

Direct relationship to transit and ease of access; new development pays for needed transportation improvements to support increased demand.

Higher revenue yield in high- growth areas.

Subject to state enabling legislation restrictions. 
Mobility Fees (Seggermann et al. 2009: 3-4)

The mobility fee working concept is an impact fee on new development that is modified for sensitivity to vehicle miles traveled (VMT). A transportation utility fee is also suggested as an optional mechanism for use in urban centers and along transit corridors to fund localized mobility needs including transit operating expenses.

Modifying the standard impact fee equation to increase sensitivity to VMT will reward developments that locate in or near urban centers and those that offer a balanced mix of uses with lower fees. This would help foster compact, mixed use development. All new development would be subject to the impact fee proportionate to the impact of that development on the transportation system. Application of the fee to all new development would result in equitable treatment among developers in a given region.

A limitation of any impact fee is that revenue depends upon growth and is therefore cyclical.

Although it provides funding for new capacity, revenue sources for backlogs, operations (particularly transit), and maintenance would still be needed. Given these limitations, the working concept also proposes an optional transportation utility fee for application in urban centers. The utility fee would be most beneficial to urban counties and municipalities with transit service and localized multimodal needs, particularly where all other optional revenue sources have been exhausted.

Because it is assessed on all system users, the transportation utility fee is a stable revenue source. By supporting expansion of modal alternatives within urban centers, it is expected to have some impact on reducing VMT and fostering compact, mixed use development.

$\mathrm{ICl}$

O\&M

RRR

Advantages

Disadvantages
M

I

I

Direct relationship to transit and ease of access; new development pays for needed transportation improvements to support increased demand.

Higher revenue yield in high- growth areas.

Subject to state enabling legislation restrictions.

Does not usually address O\&M or RRR. 
Transportation Utility Fee (Nelson, Nicholas and Juergensmeyer 2009: 344)

Historically, cities have paid for transportation operating and maintenance (O\&M) costs and capital improvements through a combination of vehicle fuel taxes, system development charges, property taxes, and developer or landowner installed improvements. There is one other method, however, that is growing in popularity - a "transportation utility fee".

A transportation utility fee is similar to a water or sewer rate. It is a monthly fee collected on residences and businesses within a jurisdiction-essentially, a user's fee tied to the use and "consumption" of the transportation system. Similar in concept to water and sewer rates, transportation utility fee revenues can be used only for transportation purposes. The fee is based on the number of trips a particular use generates, on average, and is typically included on the city's regular monthly sewer and water bill.

The revenues can be used for annual operating and maintenance costs or for capital improvements. In its most general state the revenue can be used for any mode of transportation: roadways, walkways, bikeways, bridges, truck routes, transit, signalization and signage, street lighting, and the administration, management and planning of the transportation system.

$\mathrm{ICl}$

O\&M

RRR

Advantages

Disadvantages
$\mathrm{M}$

I

I

Direct relationship to transit and ease of access; new development pays for needed transportation improvements to support increased demand.

Higher revenue yield in high- growth areas.

Subject to state enabling legislation restrictions.

Does not usually address O\&M or RRR. 
Special Assessment Districts including variants called Community Improvement Districts, Community Facilities Districts, Local Improvement Districts, and all others of this genre BN (24)

While developer exactions may be gaining in popularity, they do have their limitations. Exactions are only one-time assessments usually dedicated to capital improvements.

As such, developer exactions have little relationship to maintenance and operating expenses, and they do not aid in the process of getting existing development to contribute its proportionate share of capital improvements. Special assessment techniques reviewed here help solve this problem. Many local governments will use both developer exactions and special assessment programs.

Special assessment districts are the broad title that includes local improvement districts, municipal utility districts, and other sub-jurisdictional entities whose purpose is to finance and often maintain capital facilities to accommodate growth and development. They are commonly characterized as geographic areas within which fees or taxes are collected (in addition to jurisdiction-wide general taxes) to fund capital investments or special services that clearly benefit properties within the district. The distinctive feature of special assessment districts is the very close and visible tie between the facility constructed or maintained and those who benefit from and pay for it. Unlike other financing options that target new development to pay for a share of communitywide improvements, special assessment districts assess all properties in a defined area for the range of facilities being provided. Assessments can finance debt service needed to provide the initial capital facilities and subsequently finance operations and maintenance costs. It is perhaps for this reason that they are the largest growing segment of American government.

$\mathrm{ICl}$

O\&M

RRR

Advantages

Disadvantages
M

$\mathrm{M}$

$\mathrm{M}$

Direct relationship to transit and ease of access. New development pays for needed transportation improvements to support increased demand. Subject to state enabling legislation restrictions. 
Tax-Increment Financing Districts BN (26)

A variant of special assessment districts are tax increment financing (TIF) districts. They differ from other special financing districts in that no special fees are assessed in addition to jurisdiction-wide taxes. District revenues consist of a diversion of that portion of revenues attributable to new development within the district. District revenues are used to retire bonds that finance the initial improvements that stimulated the new development. It is this internal financing, or bootstrap redevelopment, approach that accounts for much of the popularity of the TIF technique.

TIF is particularly attractive to cities because other taxing authorities, such as counties and school districts, may be required to contribute to the redevelopment fund, and that fund is ordinarily under the control of the city or its redevelopment agency. In theory, the other jurisdictions do not lose revenue because there would be no growth in the TIF district's tax base without the stimulating public investment. Even if this were true, however, the development attracted to the TIF district might have otherwise occurred elsewhere in the region. TIF is usually limited to capital investments, however.

$\mathrm{ICl}$

O\&M

RRR $\mathrm{M}$

Advantages Direct relationship to transit and ease of access.

New development pays for needed transportation improvements to support increased demand.

Disadvantages

Subject to state enabling legislation restrictions.

Does not usually address O\&M or RRR. 


\section{Indirect User Benefit Funding Options}

These options include:

Tolling (fixed, variable, and dynamic; bridge and roadway) CS (30)

Congestion Pricing CS (31)

Emissions Fees CS (31-32)

VMT Fees CS (32)

Vehicle Levy (L 17) 
Tolling (fixed, variable, and dynamic; bridge and roadway) CS (30)

In the United States, there is a split of approximately 60/40 between rural and urban settings. Tolling has become a subject of widespread interest around the country as the concept of managed lanes and the theory and practice of pricing has expanded into the metropolitan transportation arena and technologies have emerged that allow for variable or "dynamic" pricing as traffic conditions change. In the process, tolling has become a two-pronged strategy to raise new revenues to support and expand highway infrastructure and to influence more efficient traffic flow under congested conditions. The notion of public-private partnerships in toll facility development and pricing has become a focus of attention as well within the broader rubric of "Public-Private Partnerships (PPP) in transportation.

$\mathrm{ICl}$

O\&M

$\mathrm{H}$

RRR

$\mathrm{H}$

Advantages

$\mathrm{H}$

Disadvantages

Potential source of new revenue.

Requires legislation allowing for transit use of these revenues. 


\section{Congestion Pricing CS (31)}

Congestion pricing is a specific variant of tolling or pricing road, bridge, or tunnel use that is based on varying the cost to users depending on the volume of traffic and/or level of congestion being experienced and the performance goals for the route or area in question. The objective is generally to set prices higher in peak hours or to set prices dynamically through electronic means to ensure high speed and/or free flow along specific routes. A variation involves charging vehicles for access to and/ or through particular areas of a community to ensure that the local street system can function efficiently throughout the day.

$\mathrm{ICl}$

O\&M

RRR

Advantages

Disadvantages
$\mathrm{H}$

$\mathrm{H}$

$\mathrm{H}$

Potential source of new revenue.

Requires legislation allowing for transit use of these revenues. 


\section{Emissions Fees CS (31-32)}

Converging concerns about congestion, energy consumption, and air quality have heightened interest in charging emission fees based on the amount of key "criteria pollutants" (hydrocarbons [HC], carbon monoxide [CO], and nitrogen oxide [NOx]) released by individual vehicles. This effort can be thought of as part of a larger approach - charging "carbon fees"- that would be potentially applied to all business and industry, not just motor vehicles. Like congestion fees and other roadway pricing schemes, emission fees represent an approach to achieving air quality goals, energy independence goals, and congestion goals rooted in the application of economic incentives and disincentives.

To date, there have been no applications of emissions fees have been attempted to date in the United States. To be implemented, emissions fees would certainly require federal and state authorization as well as application on a broader level than the local and regional level to be effective.

$\mathrm{ICl}$

O\&M

RRR

Advantages

Disadvantages
$\mathrm{H}$

$\mathrm{H}$

$\mathrm{H}$

Potential source of new revenue.

Requires legislation allowing for transit use of these revenues. 


\section{VMT Fees CS (32)}

The concept of basing fees on VMT is getting much greater attention as concern mounts over the inadequacy of federal and state motor fuel tax revenues as a continuing funding source for highway and transit investment. While a VMT fee also represents a direct way to reduce congestion through reduced vehicle use, opponents suggest that VMT fees are less directly effective in addressing other urgent problems-such as vehicle emissions, energy use, and air quality-because VMT fees don't directly address the wide variability that exists in vehicle performance due to vehicle age, make, and model.

$\mathrm{ICl}$

O\&M

RRR

Advantages

Disadvantages
$\mathrm{H}$

$\mathrm{H}$

$\mathrm{H}$

Potential source of new revenue.

Requires legislation allowing for transit use of these revenues. 
Vehicle Levy (L 17)

Vehicle levies are periodically assessed registration fees or supplemental levies such as when the vehicle is registered within transit districts. Although vehicle levies can be any size, most are \$20-60 annual per vehicle, only a portion of which is dedicated to public transit where this is enabled. High levies can motivate some motorists to register their vehicles in other jurisdictions. In the United States, 33 states and 27 local jurisdictions have vehicle registration fees which help finance transportation improvements, which often include public transit.

$\mathrm{ICl}$

O\&M

RRR

$\mathrm{H}$

$\mathrm{H}$

Advantages

$\mathrm{H}$

Disadvantages

Potential source of new revenue.

Requires legislation allowing for transit use of these revenues. 


\section{Capital Facility Financing Mechanisms}

We note that all the following financing mechanisms are for the purpose of new or expanded physical infrastructure or its repair, rehabilitation or replacement. While many of these revenues derive from federal and state governments they also offer unique opportunities to use local resources to leverage them. They include:

General Obligation (GO) Bonds CS (33)

Private Activity Bonds (PABs) CS (33)

Tax Credit Bonds CS (33)

Grant Anticipation Notes (GANs) CS (33)

Grant Anticipation Revenue Vehicles (GARVEEs) CS (34)

Revenue Anticipation Notes (RANs) CS (34)

Certificates of Participation (COPs) CS (34)

State Infrastructure Bank (SIB) loans CS (34) 


\section{General Obligation (GO) Bonds CS (33)}

GO bonds are issued by municipalities, counties, states, and special districts serving public purposes ("municipal bonds" whether literally issued by municipalities or not). They are generally long term and are repaid along with tax-exempt interest from general revenues of the issuing jurisdiction. GO bonds are secured by the "full faith and credit" of the issuing jurisdiction rather than through the dedication of a specific tax or revenue source, a commitment that mandates repayment of the debt with interest regardless of the source of funds. Proceeds from GO bonds can be used to match federal grant funds.

$\mathrm{ICl}$

O\&M

RRR

Advantages

Disadvantages
$\mathrm{H}$

I

L

Potential source of new revenue.

These bonds are typically used for new capital investment and to a lesser extent RRR. 
Private Activity Bonds (PABs) CS (33)

$P A B s$ are a special category of borrowing that may also be tax exempt if certain conditions are met. PABs involve the private sector in projects or activities that serve specific public purposes where project implementation and management skills may provide advantages for the public sector. The use of PABs is subject to strict limitations in federal law, however.

$\mathrm{ICl}$

O\&M

RRR

$\mathrm{H}$

I

Advantages

Potential source of new revenue.

Disadvantages

These bonds are typically used for new capital investment. 


\section{Tax Credit Bonds CS (33)}

"Tax-credit bonds allow bondholders to receive a credit against their Federal income tax liability instead of cash interest. . . . The range of potential issuers of tax-credit bonds spans both governmental and nongovernmental entities. State and local governments are candidates to use tax-credit bonds. Although no use has been made of credit bonds at the local or state level for transit, the approach may gain relevance in future reauthorization cycles of federal highway and transit programs, given the mounting investment needs. In all prior proposals to authorize tax credit bonds, however, their effect has been to provide a federal subsidy to entities outside the purview of the federal budget, a notion that is not universally embraced.

$\mathrm{ICl}$

O\&M

RRR

Advantages

Disadvantages
$\mathrm{H}$

I

L

Potential source of new revenue.

These bonds are typically used for new capital investment. 
Grant Anticipation Notes (GANs) CS (33)

GANs are a variety of debt whose purpose is to pledge funds from future federal or state grants in exchange for immediately available funds offered by the note purchasers. GAN funding arrangements have been covering a wider range of timeframes. GANs provide a potentially useful advantage in that they typically do not count against a jurisdiction's local debt limitations.

$\mathrm{ICl}$

O\&M

RRR

$\mathrm{H}$

Advantages

1

Disadvantages

Potential source of new revenue.

These bonds are typically used for new capital investment. 


\section{Grant Anticipation Revenue Vehicles (GARVEEs) CS (34)}

GARVEEs are like GANs, but they have been largely restricted to use in financing highway improvements, generally in conjunction with advance construction to enable using federal aid funds for future debt service payments. About half of the states have issued GARVEE bonds, and authority to use GARVEEs has been established in nine more.

$\mathrm{ICl}$

$\mathrm{H}$

O\&M

RRR

I

Advantages

$\mathrm{L}$ Disadvantages

Potential source of new revenue.

These bonds are typically used for new capital investment. 


\section{Revenue Anticipation Notes (RANs) CS (34)}

Flows of funds other than grant monies may be available to be borrowed against, depending on their strength, yield, and reliability. Although not in widespread use, a transit agency's earned income is available to be bonded against, including farebox revenues.

$\mathrm{ICl}$

O\&M

RRR

$\mathrm{H}$

L

Advantages

Potential source of new revenue.

Disadvantages

These bonds are typically used for new capital investment. 


\section{Certificates of Participation (COPs) CS (34)}

Acquiring the use of capital equipment through leasing instead of outright, large capital purchases represents a capital budgeting and programming action that lies within agencies' traditional administrative authority, providing transit agencies a way of avoiding long-term debt as well as the associated need for voter approval. COPs are tax-free securities that represent the right to purchase a future stream of revenue made up of lease payments for capital equipment. COPs have been used by local government agencies for a variety of projects, generally with mid-level time horizons (10 to 12 years). For transit systems, COPs are most often used for the acquisition of rolling stockbuses, subway cars, locomotives, and so forth. COPs have proven useful to large and small transit agencies for many years.

$\mathrm{ICl}$

O\&M

RRR

Advantages

Disadvantages
$\mathrm{H}$

I

$\mathrm{L}$

Potential source of new revenue.

These bonds are typically used for new capital investment. 
State Infrastructure Bank (SIB) loans CS (34)

Federal law authorizes every state to set up a state infrastructure bank (SIB) that can manage a revolving loan fund, provide credit enhancements, or issue bonds capitalized with seed money from federal and state sources. The use of SIB loans is included here because it represents a means by which local transit agencies can exercise added leverage in attracting and using the full range of local and regional funding sources available. More than half the states have SIBs.

$\mathrm{ICI}$

O\&M

RRR

$\mathrm{H}$

Advantages

Disadvantages

Potential source of new revenue.

These bonds are typically used for new capital investment. 


\section{Transit-Related Special Service Districts and Joint Development Ventures}

Many transit-related special service districts use multiple funding options to achieve their objectives. There are also examples of large-scale joint developments engaging the public and private sectors in public-private partnerships that use multiple funding options as well. These two approaches are reviewed here

\section{Examples of Transit-Related Special Service Districts}

Here are some examples reported by the American Public Transportation Association (2015 verbatim):

\section{Washington, DC Area- Silver Line (Special Assessment District)}

Washington Metro is the second-busiest heavy rail system in the U.S. The Silver Line is an extension to the Metro system being designed and built by the Metropolitan Washington Airports Authority (MWAA). Phase 1 consists of 11.6 miles of rail and five stations in Fairfax County, Virginia, and is in the final stages of construction. Phase 2 will add 11.5 miles of rail and six stations in Fairfax and Loudoun Counties, including a station at Dulles International Airport. In total, the project will increase the size of the Metro system by over 20 percent. Value capture elements will fund portions of both phases of the project. Fairfax County established a special tax district on commercial and industrial properties in 2004 to fund the county's portion of Phase 1 of the project. The district consists of most of the Tysons Corner Urban Center and an area around the Phase 1 stations, and the tax rate is $\$ 0.22$ per $\$ 100$ of value. In 2009 the county established a special tax district consisting of the area around its Phase 2 stations to pay for that portion of the project; the tax rate started at $\$ 0.05$ per $\$ 100$ and increases five cents each year to $\$ 0.20$ per $\$ 100$ in FY 2014 . Loudoun County also implemented a Metrorail Service District to pay for its portion of Phase 2 of the project. The district consists of properties around the Phase 2 stations in Loudoun County. The levy within the district is $\$ 0.20$ per $\$ 100$ of value.

Denver, CO - Union Station Metropolitan District (TIF) Union Station will be the hub of Denver's FasTracks rail system. The project will create a multimodal transportation hub for Denver, integrating bus, light rail, commuter rail, and Amtrak. Voters approved a $0.4 \%$ sales tax increase in 2004 to help fund the project. In 2008, the city council created a Tax Increment Financing (TIF) district (Colorado calls them Metropolitan Districts) consisting of the station and surrounding 20 acres. The additional revenues from growth in the TIF district will be used to pay off federal TIFIA and RRIF loans. Construction on the station began in December 2012 and is expected to open in 2014.

\section{Seattle, WA - SLU streetcar (Special Assessment District)}

The South Lake Union Streetcar is a 1.3-mile streetcar line that connects Downtown Seattle with the South Lake Union neighborhood. It was the first line constructed of the future Seattle Streetcar Network; a second streetcar line east of South Lake Union began construction in 2012 and is expected to open in 2014. A Local Improvement District (LID) was approved by voters in 2005 . Ninety-eight percent of property owners in the area agreed to finance the project through the improvement district. The LID funded over half of the streetcar costs, providing \$25.7 million in project funding. LID fees were based on property value, parcel type, and proximity to the streetcar line. Properties had the choice to either pay the fee up front, or over an 18 -year period at $4.4 \%$ interest. The streetcar has had a positive effect on the South Lake Union neighborhood. Since the project was approved in 2005, 3.3 million square feet of office space and 6,100 
residential units were built within four blocks of the streetcar. Employers in the neighborhood recognize the value of quality streetcar service and have contributed to ongoing operating costs with multiple rounds of funding

\section{Houston, TX - Uptown Tax Increment Reinvestment Zone (TIF)}

Houston's Tax Increment Reinvestment Zones (TIRZ) are districts created by the city council to attract new investment to areas around the city. The TIRZ can encourage development in undervalued areas by providing financing incentives. Similar to Chicago, to be included in a TIRZ an area must "substantially arrest or impair the sound growth of the municipality or county creating the zone." Certain criteria help define these areas. Houston's TIRZ criteria specifically mention transportation. Areas where "the predominance of defective or inadequate sidewalk or street layout" is present can be included in a TIRZ. TIRZs use tax increment financing to collect revenues - property tax revenues are capped at a certain amount and any revenue collected over that amount is directed into the tax increment fund. Uptown Houston is a neighborhood six miles west of downtown, centered along Post Oak Boulevard. It is a growing commercial and office space area, with more than $18 \%$ of Houston's class A office space. The Uptown TIRZ was created in 1999 to improve mobility in the area. In 2013 Houston Mayor Annise Parker announced a plan to build a Bus Rapid Transit (BRT) line on Post Oak Boulevard in Uptown, connecting Uptown to two public transit centers to the north and south of the area. The total cost of the public transit center improvements and BRT is projected at $\$ 177$ million, with $46 \%$ of the cost paid for by Uptown TIRZ revenues. The preliminary plan calls for separated bus lanes in the median of Post Oak Boulevard, a new public transit center to the south of the neighborhood, and new infrastructure connecting the project to the Northwest Transit Center.

Dallas-Ft Worth, TX - Cotton Belt Rail Corridor (Potential for Value Capture) The Cotton Belt Corridor is a planned 67-mile rail line in the Dallas-Fort Worth (DFW) area. The corridor runs from an area southwest of downtown Fort Worth, past DFW airport, to Plano at the northern end of the Red Line of the Dallas Area Rapid Transit light rail system. The portion of the corridor from Fort Worth to the airport is currently being planned by the Fort Worth Transportation Authority as the TEX Rail project. The North Texas Council of Governments, the regional MPO, has conducted research into innovative financing options for the rail project, including value capture. Their report concluded that a special assessment district for TOD around station areas could generate over $\$ 300$ million in funding over a 40 -year period. Additionally, the report concluded that if $35 \%$ of the tax increment on a number of taxes in the area were directed to the public transportation project, $\$ 2.3$ billion in funding would be provided during the 40-year period.

The last two examples from Texas are noteworthy because Texas enabling statutes allow for assessments to vary by station area reflecting differential costs between them. ${ }^{122}$ We will allude to the significance of this in the next section.

\footnotetext{
122 See Texas Attorney General Opinion Re: Validity of collecting a Regional Transportation Authority's sales and use tax at different levels in separate subregions (RQ-0677-GA).
} 


\section{Joint Development/Public-Private Partnerships}

We conclude this section with a review of "joint development". This is a form of public-private partnership that is designed to reduce transit system development and O\&M costs (National Council for Urban Economic Development 1989). Landis et al. (1991) refine the concept of joint development as any formal arrangement between a public transit agency and a private, forprofit entity that involves that entity either making payments to the public sector to receive transit benefits sharing capital costs with the public sector. Needless to say, there are many forms of joint-development related public-private partnerships.

Zhao, Das and Larson (2012) consider joint development is a value capture technique because in return for private sector financial participation in providing public transit facilities the private sector earns a profit. A key advantage to the public sector is that successful joint development projects hedges public sector financial shortfalls and improve market efficiency. A wide range of joint development approaches are available, as seen in Table E.2.

Despite several examples, joint development remains a largely ad hoc process. In many states, Zhao, Das and Larson observe that it remains unavailable as a public-private partnership tool. Joint development would seem to be especially promising at the front-end of long-range transit planning; for one thing, properly done transit and land use plans could anticipates ways in which private sector involvement could leverage desired development outcomes through joint development.

In Section 3, we will identify public finance principles that need to be applied to transit funding options to help select the right mix of those options for a given transit investment opportunity. 
Table E.2

Examples of Joint Development and Tools

\begin{tabular}{|c|c|c|c|c|}
\hline \multirow{2}{*}{\multicolumn{2}{|c|}{ Joint Development Method }} & \multirow[b]{2}{*}{ Examples } & \multicolumn{2}{|c|}{ Fund Usage } \\
\hline & & & $\begin{array}{l}\text { Cost- } \\
\text { sharing }\end{array}$ & $\begin{array}{l}\text { Revenue- } \\
\text { sharing }\end{array}$ \\
\hline \multicolumn{5}{|c|}{ Public Ownership: } \\
\hline \multirow[t]{2}{*}{ Property } & Sale for funding & $\begin{array}{l}\text { Land-banking by WMATA (Washington, } \\
\text { D.C.) }\end{array}$ & $\mathrm{X}$ & \\
\hline & Lease for funding & $\begin{array}{l}\text { Commercial space lease by SEPTA } \\
\text { (Philadelphia) }\end{array}$ & & $\mathrm{X}$ \\
\hline \multirow{3}{*}{$\begin{array}{l}\text { Development } \\
\text { rights }\end{array}$} & Sale for funding & Development rights sale (Hong Kong) & $\mathrm{X}$ & \\
\hline & Lease for funding & $\begin{array}{l}\text { Development rights lease, Washington, D.C. } \\
\text { Rail-property model (Hong Kong) }\end{array}$ & $\begin{array}{l}X \\
X\end{array}$ & \\
\hline & $\begin{array}{l}\text { Exchange for } \\
\text { private contributions }\end{array}$ & $\begin{array}{l}\text { Development rights award (Portland) } \\
\text { Development rights award (Taipei) }\end{array}$ & $\begin{array}{l}X \\
X\end{array}$ & \\
\hline \multicolumn{5}{|c|}{ Private Ownership: } \\
\hline Property & $\begin{array}{l}\text { Exaction through } \\
\text { joint development }\end{array}$ & $\begin{array}{l}\text { Land readjustment (Tokyo) } \\
\text { Land acquisition (Taipei) } \\
\text { Land consolidation (Taipei) }\end{array}$ & $\begin{array}{l}X \\
X \\
X\end{array}$ & \\
\hline \multirow[t]{2}{*}{$\begin{array}{l}\text { Development } \\
\text { rights }\end{array}$} & $\begin{array}{l}\text { Usage adjustments in exchange } \\
\text { for private contributions }\end{array}$ & $\begin{array}{l}\text { Comprehensive plan change (Taipei) } \\
\text { Commercial-industrial mixed use (Taipei) }\end{array}$ & $\begin{array}{l}X \\
X\end{array}$ & $\mathrm{X}$ \\
\hline & $\begin{array}{l}\text { Density bonus in exchange } \\
\text { for private contributions }\end{array}$ & Density bonus program (New York City) & $\mathrm{X}$ & $\mathrm{X}$ \\
\hline
\end{tabular}

Source: Zhao, Das and Larson (2012) 


\section{Application of Public Finance Principles to Transit Funding Options}

In this section we identify key public finance principles that should guide decisions on selecting transit funding options to achieve key economic and social objectives. We then apply these principles to the finance options reviewed in Section 2. The result will be the selection of a range of options that perform best in meeting principles and achieving key objectives.

Public finance principles are synthesized from three of the four sources we used to derive financing options reviewed in Section 2: Bowles and Nelson (2007) [BN], Cambridge Systematics (2009)[CS], and Litman (2014, 2015)[L]. We use italics and source pages where we recite individual contributions verbatim or paraphrase substantially. We also add additional principles. We divide the principles into these categories:

- Desired Transit Outcomes

- Efficiency and Equity

- Policy Implementation

\section{Desired Transit Outcomes}

The choice of transit funding must achieve desired outcomes in terms of:

- Travel Impacts

- Achieving Strategic Objectives

\section{Travel Impacts}

This refers to the effects an option has on how and how much people travel, and whether this supports or contradicts strategic transport planning objectives, such as objectives to reduced automobile travel and increased use of alternative modes. These are estimated based on our understanding of price impacts on travel activity. $\mathbf{L}(9)$

\section{Achieving Strategic Objectives}

This refers to the effects an option has on the type and location of development and whether this supports or contradicts strategic planning objectives such as objectives to encourage more compact, accessible development and discourage sprawl. These are estimated based on our understanding of tax and price impacts on development patterns. $\mathbf{L}$ (9)

\section{Efficiency and Equity}

In our view, efficiency and equity includes these principles:

- Assessment Base

- Accounting for Externalities

- Efficient Pricing

- Proportionality or Equity

- Geographic Equity

- Social Equity 


\section{Assessment Base}

A key public finance principle is that everybody who benefits pays. At one extreme, this might mean that all transit riders pay fares covering all capital and O\&M costs. Because society benefits in numerous ways (see Section 1), the revenue base for transit includes federal funding along with local and regional sales, property taxes, and other sources. Suppose, however, that the regional transit agency pays all costs in various forms. If a person living outside the region uses transit on a visit and perhaps spends no money in the region (perhaps just a site-seeing daytrip), that person is not paying anything for transit service and is called a free rider. Transit revenue bases must be large enough to reduce if not eliminate free riders.

\section{Accounting for Externalities}

Related to designing large assessment bases to prevent free riders, the manner of assessment must recognize positive and even negative externalities. If transit investments create more value for one property owner (positive externality) but none for another, the benefiting property should pay more than the property not changing in value. This is the central issue addressed in Section 1. But if a transit investment reduces property value (a negative externality) some adjustment may need to be made to offset the loss.

\section{Efficient Pricing}

Economic efficiency in transportation is intended to reflect whether the marginal cost to all travelers and society as a whole of an additional trip taken is captured in the price paid by the trip maker. The concept is most familiar in congestion pricing, sometimes referred to as "value pricing." The underlying issue in this research project is to what degree potential additional revenue sources enhance this balance or economic efficiency. CS (47)

\section{Proportionality}

This is the connection between the demand for facilities created by new development, the cost of meeting those demands, and the extent to which the alternative apportions those costs to new development. Proportionality can also mean geographic equity and housing affordability if costs vary appropriately, but these two issues are separately discussed below.

Proportionality relates to equity, but equity comes in two broad forms: horizontal and vertical. Horizontal equity means essentially that similarly situated people will be treated similarly. Impact fees have survived challenge on this charge because at their simplest they meet this equity principle. Vertical equity considers differences within the same class based on objective measures or criteria. The trouble is that impact fees can be horizontally equitable but vertically inequitable. For example, under horizontal equity all dwellings would be assessed the same impact fee for parks. If dwelling units differ by the number of people living in them based on type or size of dwelling then vertical equity is not achieved. Federal data show, for example, that in 2013 the average household size of units less than 500 square feet was nearly 2.0 while for units over 2,500 square feet it was more than 3.0. Charging each unit the same means that the smaller unit over-pays with respect to its occupancy level while the larger unit under-pays. BN (29)

We prefer the term "proportionality" to equity in this context because many impact fee enabling statutes define and use this term in the context of generating funds from development to help pay for new or expanded capital facilities in relation to development's impact on those facilities. 


\section{Geographic Equity}

Some areas are more costly to serve than others. This is one area where marginal cost pricing can become an element of policy-making even where the political will to charge prices based on marginal cost may not otherwise be present. An element of geographic equity is infill and redevelopment, since we often find older areas have excess infrastructure capacity (such as under-utilized schools). Even where the infrastructure needs to be upgraded, the cost can be less per unit of development if infill and redevelopment is encouraged. BN (29)

\section{Social Equity}

Social equity addresses the issue of differential incidence of a tax or fee on a class of people relative to another in ways that may be regressive or progressive. Sales taxes are considered regressive because lower income people spend a proportionately higher share of their income no taxable items than higher income people, so they pay proportionately more sales taxes. The situation is exacerbated when considering that disposable after deducting housing, transportation, medical and other expenses is considerably less than among lower income people than higher income ones. On the other hand, property taxes tend to be less regressive because on average higher income people own more taxable property than lower income ones. We will consider the extent to which a tax or fee system is more or less regressive.

\section{Policy Implementation}

Though certain funding options may lead to more desirable outcomes or best achieve certain economic and equity principles, they must also be implementable. This can lead to "second best" choices given such principles as:

- Revenue Potential

- Revenue Stability

- Administrative Ease

- Technical Feasibility

- Public and Political Acceptance

\section{Revenue Potential}

Any financing scheme must generate sufficient revenue to meet needs. In this context, however, revenue potential means the ability to generate revenue roughly concurrent with the development as well as the ability to use the revenue as supplemental security for general obligation and revenue bonds and for certificates of participation that are used to finance largescale improvements meeting present and future needs. Finally, revenue potential means the ability to have all development contribute revenues, not just certain development under certain conditions. BN (28)

\section{Revenue Stability}

Revenue Stability refers to whether there are uncertain revenue fluctuations that can impact an agency's ability to manage resources. Enactment of taxes and fees for any public investment is difficult at best. If the effort is to be made, it should be focused directly on achieving adequate, predictable, and reliable revenue yields. CS (42)

\section{Administrative Ease}

This factor refers to whether an alternative can be administered efficiently, and whether compliance can be achieved at reasonable cost considering the potential for evasion and the cost of enforcement. BN (29)

\section{Technical Feasibility}


Technical feasibility reflects how advancements, including geographic information systems (GIS), global positioning systems (GPS), and electronic transfer mechanisms, may reduce the cost of administration and compliance in a broad array of areas, including taxation generally and transportation-related taxation and revenue handling, specifically. These technologies enable a more simple, straightforward, and accurate allocation of costs, but they can also pose difficulties for traditional methods of funding. CS (47)

\section{Public and Political Acceptance}

Above all, the alternative policy must have the potential for receiving broad public acceptance. In our view, this means that current taxpayers/ratepayers will not face higher taxes or rates for the benefit of new development, both in the near and long terms. (BN 29)

\section{Summary Assessment}

The range of transit funding options is large and we suppose we have not identified all possible options. Before selecting any option, however, it must be consistent with relevant laws, especially state enabling legislation. For instance, while impact fees may theoretically be an attractive revenue option for financing transit facilities along transit corridors, most states with impact fee enabling legislation do allow this use of impact fee revenues.

Moreover, some revenue options are better suited to a range of purposes than others. For instance, tax increment financing districts may facilitate the financing of transit capital investment but they are not designed to provide long term operations and maintenance or repair, rehabilitation or replacement of transit facilities.

Finally, different sources of revenue generate vastly different levels of funding mostly because of differences in assessment bases. But, broader assessment bases may be more complex to establish for such dedicated purposes as transit because (a) enabling legislation may be needed and (b) local popular and political support is also needed. This is illustrated in Figure E.3.

In Section 4, we will pose a hypothetical set of transit funding options to achieve all the public finance principles presented in the epilogue. 


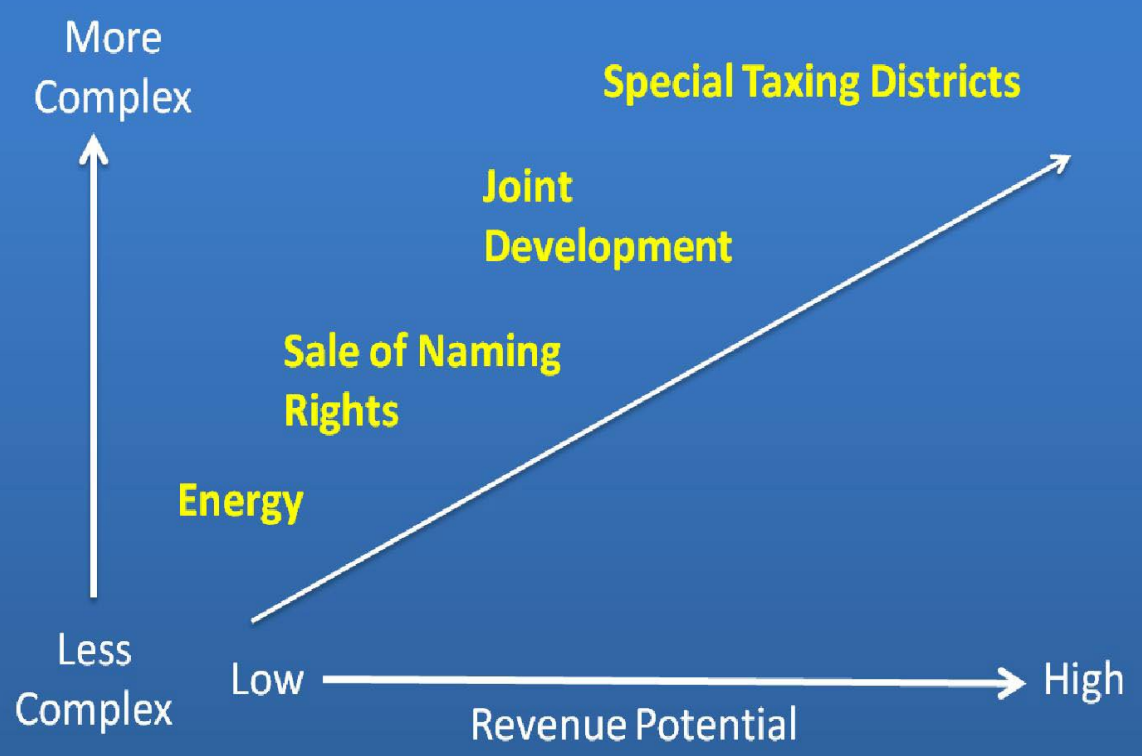

Figure E.3

Differences in funding levels from differences in assessment bases

Source: Omitrans et al. (2012) 


\section{Toward a Proportionate-Share, Spatially-Related Value Capture Funding Scheme for Transit}

Each alternative likely has its own limitations, so how does one know which is best from the perspective of local government's need to meet facility financing needs and society's interest in supporting housing affordability? The following sections identify certain policy-making criteria and apply them to a comparative assessment.

\section{Designing a Transit Value Capture Program}

In our view, there are two classes of beneficiaries from transit systems that form the basis for assessment: regional beneficiaries and station-area beneficiaries. In this section, we offer an approach to designing a program that fairly captures transit benefits and apportions costs proportionately and equitably among beneficiaries. We consider initial capital investment (ICI) operations and maintenance (O\&M), and long-term capital repair-rehabilitation-replacement (RRR). We adapt the "proportionate-share" public facility financing approach developed by Nelson, Nicholas and Juergensmeyer (2008) for this purpose. The key criteria include:

- $\quad$ Service area design

- Assessment

A two-tiered assessment approach is recommended. The regional tier would recognize the benefits of transit broadly enjoyed by all residents, workers and visitors to the region even if they do not use transit services. The reason is that to some extent the regional economy benefits from transit (as shown in Figure 1.1) while transit also confers other important social and public goods benefits (see Table 1). On the other hand, property near transit stations enjoys higher value because of their proximity. Among other benefits, occupants of space near those stations are more likely to use transit that occupants of space farther away.

\section{Designing Service Areas}

Proportionate-share assessments require that revenues are collected and spent within a service area. For regional assessments, the service area is the region itself. For station areas this is different. We recommend the following approach.

We know from literature that office land uses capitalize proximity to light rail (and presumably street car and bus rapid transit) stations to nearly two miles away (Nelson et al. 2015). However, roughly three-quarters of the premium dissipates at about one mile. We also know that apartment residential (as presumably townhouse and condominium) properties capitalize light rail station proximity to about 1.25 miles also with about three-quarters of the premium dissipating at about one mile (Petheram, Nelson et al. 2013). The station-area tier of the transit assessment would thus emanate one mile from the center of the transit station. However, at each one-eighth mile increment the assessment would fall in equal increments to the last eighth mile-seventh-eights to one mile. The sliding-scale assessment would be based on the eighthmile band with which the parcel centroid fell.

The two-tiered assessments would thus apply to all property in the transit region as the first tier and then property within one mile of a transit station as the second tier. Property within one mile of transit stations would be assessed both the regional and station-area assessments. 


\section{Assessment}

Let us make certain assumptions shown in Table E.3. Suppose a regional transit investment (ICI) is \$200 million with \$10 million annual O\&M and \$4 million annual RRR. Suppose further that 25 percent of these costs are apportioned to the region as a whole. Annualized costs to the region are shown in Table E.3 with a hypothesized millage rate applied to region's total taxable value of real property. The balance of 75 percent is apportioned to a Transit Benefit Area (TBA).

The $\$ 50$ million in ICl apportioned to the TBA can be recovered as illustrated in Table E.4. The calculation apportions $\mathrm{ICl}$ assessments based on one-eighth mile benefit bands from the station center to one mile. Table E.4 shows the capital recovery portion of new development on a peracre basis. The calculation could also be a supplemental annualized assessment that is on top of the regional assessment; the $\mathrm{ICl}$ recovery could be the basis for impact fees, development agreements, and related charges.

Table E.5 shows the calculation for TBA O\&M assessments while Table E. 6 shows the same for TBA RRR assessments and Table E.7 reports total O\&M and RRR annual assessments.

A key observation is that within the hypothetical TBA there are considerable differences in assessments between distance bands. As we noted earlier, a growing body of literature is establishing that the closer many types of development are to transit stations the more value is created. To achieve proportionality in assessment, funding programs of the future should recognize this relationship. We have posed a simple way in which to accomplish this. 
Table E.3

Transit Initial Capital Investment, Operations and Maintenance, and RepairRehabilitation-Replacement Assumptions

Repair-

Measure

Initial Capital Operations \&

Total Assumptions Investment Maintenance

Rehabilitation-

Replacement $\$ 200,000,000$

Pmt @ 3.5\%, 30

Annualized

years

$\$ 10,874,266 \quad \$ 10,000,000$

$\$ 4,000,000$

Regional Share

$25.00 \%$

$\$ 2,718,567$

$\$ 2,500,000$

$\$ 1,000,000$

Transit Benefit Area

Share

$75.00 \%$

$\$ 150,000,000$

$\$ 7,500,000$

$\$ 3,000,000$

Region Taxable Value $\$ 500,000,000,000$

Region Millage Rate (x

1000)

0.0217

0.0050

0.0020 
Table E.4

Initial Capital Investment Apportioned to Transit Benefit Area by $1 / 8^{\text {th }}$ Mile Distance Band from Transit Station

\begin{tabular}{|c|c|c|c|c|c|c|c|}
\hline \multirow[b]{2}{*}{ Mile Band } & \multirow[b]{2}{*}{$\begin{array}{c}\text { Acres } \\
\text { within Band }\end{array}$} & \multirow[b]{2}{*}{$\begin{array}{l}\text { Declining } \\
\text { Value }\end{array}$} & \multirow[b]{2}{*}{$\begin{array}{l}\text { Apportionment } \\
\text { Index }\end{array}$} & \multicolumn{3}{|c|}{$\begin{array}{c}\text { Assessment } \\
\text { Amount @ }\end{array}$} & \multirow[b]{2}{*}{$\begin{array}{c}\text { Assessment } \\
\text { per Square } \\
\text { Foot }\end{array}$} \\
\hline & & & & $\begin{array}{l}\text { Assessment } \\
\text { Share }\end{array}$ & $\$ 150,000,000$ & $\begin{array}{l}\text { Assessment } \\
\text { per Acre }\end{array}$ & \\
\hline $0-1 / 8$ & 31 & 1.00 & 31.42 & $3.92 \%$ & $\$ 5,882,353$ & $\$ 187,241$ & $\$ 4.30$ \\
\hline $1 / 8-2 / 8$ & 94 & 0.88 & 82.47 & $10.29 \%$ & $\$ 15,441,176$ & $\$ 163,836$ & $\$ 3.76$ \\
\hline $2 / 8-3 / 8$ & 157 & 0.75 & 117.81 & $14.71 \%$ & $\$ 22,058,824$ & $\$ 140,431$ & $\$ 3.22$ \\
\hline $3 / 8-4 / 8$ & 220 & 0.63 & 137.44 & $17.16 \%$ & $\$ 25,735,294$ & $\$ 117,026$ & $\$ 2.69$ \\
\hline $4 / 8-5 / 8$ & 283 & 0.50 & 141.37 & $17.65 \%$ & $\$ 26,470,588$ & $\$ 93,621$ & $\$ 2.15$ \\
\hline $5 / 8-6 / 8$ & 346 & 0.38 & 129.59 & $16.18 \%$ & $\$ 24,264,706$ & $\$ 70,215$ & $\$ 1.61$ \\
\hline $6 / 8-7 / 8$ & 408 & 0.25 & 102.10 & $12.75 \%$ & $\$ 19,117,647$ & $\$ 46,810$ & $\$ 1.07$ \\
\hline $7 / 8-1.0$ & 471 & 0.13 & 58.90 & $7.35 \%$ & $\$ 11,029,412$ & $\$ 23,405$ & $\$ 0.54$ \\
\hline Total/Average & 2,011 & & 801.11 & $100.00 \%$ & $\$ 150,000,000$ & $\$ 74,604$ & $\$ 1.71$ \\
\hline
\end{tabular}


Table E.5

Operations and Maintenance Annual Assessment Apportioned to Transit Benefit Area by $1 / 8^{\text {th }}$ Mile Distance Band from Transit Station

\begin{tabular}{|c|c|c|c|c|c|c|c|}
\hline & & & & & $\begin{array}{c}\text { Assessment } \\
\text { Amount @ }\end{array}$ & & \\
\hline Band & Acres & $\begin{array}{l}\text { Declining } \\
\text { Value }\end{array}$ & $\begin{array}{l}\text { Apportionment } \\
\text { Index }\end{array}$ & $\begin{array}{l}\text { Assessment } \\
\text { Share }\end{array}$ & $\$ 7,500,000$ & $\begin{array}{l}\text { Assessment } \\
\text { per Acre }\end{array}$ & $\begin{array}{l}\text { Assessment } \\
\text { per Square } \\
\text { Foot }\end{array}$ \\
\hline $0-1 / 8$ & 31 & 1.00 & 31.42 & $3.92 \%$ & $\$ 294,118$ & $\$ 9,362$ & $\$ 0.21$ \\
\hline $1 / 8-2 / 8$ & 94 & 0.88 & 82.47 & $10.29 \%$ & $\$ 772,059$ & $\$ 8,192$ & $\$ 0.19$ \\
\hline 2/8-3/8 & 157 & 0.75 & 117.81 & $14.71 \%$ & $\$ 1,102,941$ & $\$ 7,022$ & $\$ 0.16$ \\
\hline $3 / 8-4 / 8$ & 220 & 0.63 & 137.44 & $17.16 \%$ & $\$ 1,286,765$ & $\$ 5,851$ & $\$ 0.13$ \\
\hline $4 / 8-5 / 8$ & 283 & 0.50 & 141.37 & $17.65 \%$ & $\$ 1,323,529$ & $\$ 4,681$ & $\$ 0.11$ \\
\hline $5 / 8-6 / 8$ & 346 & 0.38 & 129.59 & $16.18 \%$ & $\$ 1,213,235$ & $\$ 3,511$ & $\$ 0.08$ \\
\hline $6 / 8-7 / 8$ & 408 & 0.25 & 102.10 & $12.75 \%$ & $\$ 955,882$ & $\$ 2,341$ & $\$ 0.05$ \\
\hline $7 / 8-1.0$ & 471 & 0.13 & 58.90 & $7.35 \%$ & $\$ 551,471$ & $\$ 1,170$ & $\$ 0.03$ \\
\hline Total/Average & 2,011 & & 801.11 & $100.00 \%$ & $\$ 7,500,000$ & $\$ 3,730$ & $\$ 0.09$ \\
\hline
\end{tabular}


Table E.6

Repair-Rehabilitation-Replacement Annual Assessment Apportioned to Transit Benefit Area by $1 / 8^{\text {th }}$ Mile Distance Band from Transit Station

\begin{tabular}{|c|c|c|c|c|c|c|c|}
\hline & & & & & $\begin{array}{c}\text { Assessment } \\
\text { Amount @ }\end{array}$ & & \\
\hline Band & Acres & $\begin{array}{l}\text { Declining } \\
\text { Value }\end{array}$ & $\begin{array}{c}\text { Apportionment } \\
\text { Index }\end{array}$ & $\begin{array}{c}\text { Assessment } \\
\text { Share }\end{array}$ & $\$ 3,000,000$ & $\begin{array}{l}\text { Assessment } \\
\text { per Acre }\end{array}$ & $\begin{array}{c}\text { Assessment } \\
\text { per Square } \\
\text { Foot }\end{array}$ \\
\hline $0-1 / 8$ & 31 & 1.00 & 31.42 & $3.92 \%$ & $\$ 117,647$ & $\$ 3,745$ & $\$ 0.09$ \\
\hline $1 / 8-2 / 8$ & 94 & 0.88 & 82.47 & $10.29 \%$ & $\$ 308,824$ & $\$ 3,277$ & $\$ 0.08$ \\
\hline $2 / 8-3 / 8$ & 157 & 0.75 & 117.81 & $14.71 \%$ & $\$ 441,176$ & $\$ 2,809$ & $\$ 0.06$ \\
\hline $3 / 8-4 / 8$ & 220 & 0.63 & 137.44 & $17.16 \%$ & $\$ 514,706$ & $\$ 2,341$ & $\$ 0.05$ \\
\hline $4 / 8-5 / 8$ & 283 & 0.50 & 141.37 & $17.65 \%$ & $\$ 529,412$ & $\$ 1,872$ & $\$ 0.04$ \\
\hline $5 / 8-6 / 8$ & 346 & 0.38 & 129.59 & $16.18 \%$ & $\$ 485,294$ & $\$ 1,404$ & $\$ 0.03$ \\
\hline $6 / 8-7 / 8$ & 408 & 0.25 & 102.10 & $12.75 \%$ & $\$ 382,353$ & $\$ 936$ & $\$ 0.02$ \\
\hline $7 / 8-1.0$ & 471 & 0.13 & 58.90 & $7.35 \%$ & $\$ 220,588$ & $\$ 468$ & $\$ 0.01$ \\
\hline Total/Average & 2,011 & & 801.11 & $100.00 \%$ & $\$ 3,000,000$ & $\$ 1,492$ & $\$ 0.03$ \\
\hline
\end{tabular}


Table E.7

Total Annual O\&M and RRR Assessment Apportioned to Transit Benefit Area by $1 / 8^{\text {th }}$ Mile Distance Band from Transit Station

Band
$0-1 / 8$
$1 / 8-2 / 8$
$2 / 8-3 / 8$
$3 / 8-4 / 8$
$4 / 8-5 / 8$
$5 / 8-6 / 8$
$6 / 8-7 / 8$
$7 / 8-1.0$
Total/Average

$\begin{gathered}\text { Assessment } \\ \text { per Acre }\end{gathered}$
$\$ 13,107$
$\$ 11,469$
$\$ 9,830$
$\$ 8,192$
$\$ 6,553$
$\$ 4,915$
$\$ 3,277$
$\$ 1,638$
$\$ 5,222$

Assessment per
Square Foot

$\$ 0.30$

$\$ 0.26$

$\$ 0.23$

$\$ 0.19$

$\$ 0.15$

$\$ 0.11$

$\$ 0.08$

$\$ 0.04$

$\$ 0.12$ 


\section{Conclusion Perspectives}

Fixed-guideway transit systems confer both regional and local benefits. Regionally, they elevate overall economic performance as well as provide a wide range of public goods such as lower levels of greenhouse gas emissions and more mobility options. Locally, they generate value to private property that is spatially related to transit station proximity.

In these days of declining federal support for fixed-guideway transit capital investments, new sources of funding are needed. The inventory is surprisingly large but largely untapped. In some cases, state enabling legislation may be needed but in others local popular and political support needs to be generated. The choice of funding option can make a difference. In this chapter, our epilogue, we introduce the role of fixed-guideway transit in creating value, identify numerous transit funding options, review criteria that may be used to choose those options that maximize key public finance objectives including capturing part of the value created by transit investments, and posing a funding approach that captures part of the value-added to regions and to areas around transit stations in relation to the distance of benefiting property from those stations.

The nation will add about 100 million people between now and mid-century. One of us (Nelson 2013) has estimated that about a quarter of American households want to live near fixed guideway transit opportunities though less than 20 percent have those options now. Perhaps one reason is that Americans understand the cost savings associated with living near transit stations. Yet, even if all new homes built between now and mid-century were located near existing or planned fixed-guideway transit stations the demand for living near those stations would still not be met. 


\section{References}

American Public Transportation Association (2015). Value Capture for Public Transportation Projects: Examples. Washington, DC: American Public Transportation Association.

Anas, A., R. Arnott, and K. A. Small. 1998. Urban spatial structure. Journal of Economic Literature 36(3): 1426-1464.

Belzer, Dena, Sujata Srivastava, and Mason Austin. 2011. Transit and Regional Economic Development. Oakland, CA: Center for Transit-Oriented Development.

Boarnet, Marlon. 1997. Highways and economic productivity: Interpreting recent evidence. Journal of Planning Literature 11(4): 476-486.

Bogart, William T. (1998). The Economics of Cities and Suburbs. Upper Saddle River, NJ: Prentice Hall.

Bowles, Liza K., and Arthur C. Nelson. 2007. Impact Fees: Equity and Housing Affordability; A Guidebook for Practitioners. Washington, DC: U.S. Department of Housing and Urban Development.

Cambridge Systematics, KFH Group, Inc., McCollum Management Consulting, Inc., and Brendon Hemily (2009). Local and Regional Funding Mechanisms for Public Transportation. Washington, DC: Transportation Research Board.

Ciccone, Antonio, and Robert E. Hall. 1996. Productivity and the density of economic activity. American Economic Review 86: 54-70.

George, Henry. 1879. Progress and Poverty: An Inquiry into the Cause of Industrial Depressions and of Increase of Want with Increase of Wealth: The Remedy. Garden City, NY: Doubleday.

Gihring, Thomas A. (2009). The Value Capture Approach To Stimulating Transit Oriented Development And Financing Transit Station Area Improvements. Victoria, BC: Victoria Transport Policy Institute.

Glaeser, Edward. 2011. Triumph of the City How Our Greatest Invention Makes Us Richer, Smarter, Greener, Healthier, and Happier. New York: Penguin Books.

Hong, Yu-Hung, and Diana Brubaker. 2010. Integrating the Proposed Property Tax with the Public Leasehold System. In China's Local Public Finance in Transition, Joyce Y. Man and YuHung Hong, Eds, 165-90. Cambridge, MA: Lincoln Institute of Land Policy.

Landis, J., R. Cervero, and P. Hall. 1991. Transit joint development in the USA: Inventory and policy assessment. Environment and Planning, 9(4):431.

Langley, Joe (2015). Value Capture Roadmap. Syndey, AU: Consult Australia and AECOM.

Litman, Todd (2010). Evaluating Public Transportation Health Benefits. Victoria, BC: Victoria Transport Policy Institute. 
Litman, Todd (2014). Evaluating Public Transportation Local Funding Options, Journal of Public Transportation, 17(1): 43-74.

Litman, Todd (2015). Local Funding Options for Public Transportation. Victoria, BC: Victoria Transport Policy Institute.

Musgrave, Richard A. and Peggy B. Musgrave (1989). Public Finance in Theory and Practice, $5^{\text {th }}$ edition. New York: McGraw-Hill.

National Council for Urban Economic Development (1989). Moving towards joint developmenttransit partnership. Washington, DC: Urban Mass Transit Administration.

Nelson, Arthur C., James C. Nicholas, Julian Conrad Juergensmeyer (2008). Impact Fees: Principles and Practice of Proportionate-Share Development Fees. Chicago: American Planning Association.

Omnitrans, Utah Transit Authority, Parsons Brinkerhoff, Lochner and Denver Regional Transit Authority (2012). Innovative Funding Sources for Transit. Washington, DC: American Public Transportation Association.

Seggerman, Karen, E., Kristine M. Williams, Pei-Sung Lin, Aldo Fabregas, Arthur C. Nelson, and James C. Nicholas (2009). Florida Mobility Fee Study. Tallahassee, FL: Department of Community Affairs.

Suzuki, Hiroaki Jin Murakami, Yu-Hung Hong, and Beth Tamayose (2015). Financing TransitOriented Development with Land Values. Washington, DC: International Bank for Reconstruction and Development/The World Bank.

Ricardo, David. 1821. On the Principles of Political Economy and Taxation. 3rd ed. London: John Murray.

Seggerman, Karen, Kristine Williams, Pei-Sung Lin, Aldo Fabregas, Arthur C. Nelson, James C. Nicholas (2010). Methodology of Impact Fees Emphasizing Vehicle Miles Traveled.

Transportation Research Record 2187: 36-43.

Tompkins, James (2010), “'Air Rights' In Ottawa: Maximizing The Value Of Public Transit Infrastructure," Journal of Public Transit in Ottawa (www.transitottawa.ca), at http://transitottawa.netfirms.com/transitottawa.ca/JPTO_Vol1_W2010.pdf

United Nations (1976). The Vancouver Action Plan-Recommendation D.3. United Nations Conference on Human Settlement, Vancouver, Canada. Accessed October 25, 2015 from http://www.un-documents.net/vp-d.htm\#D-3

Zhao, Zhirong Jerry, Kirti Vardhan Das, and Kerstin Larson (2012). Joint development as a value capture strategy for public transit finance. The Journal of Transport and Land Use, 5(1): 5-17. 


\section{APPENDIX H: Selected FRT Stations for Perceptual Good-Bad- Ugly Assessment}

The following visualizations are perceptions of "good" and "bad" FRT station planning and design. Examples for each LRT, BRT, SCT and CRT system, respectively, include "good" and "bad" stations based on their location, design, relationship to nearby land uses, and walk-biketransit scores. This is not intended to be a definitive assessment but rather a preliminary exploration intended to encourage future research.

\section{METHOD}

In addition to the four features mentioned above, there were an additional pair of elements that researchers tried to include in the qualitative hedonic analysis of transit stations seen below:

1. Location: the station needed to obviously be on each city's respective line. It also needed to show visually, either from photos or a map or birds-eye view, that the station was located near amenities relative to land use type.

2. Design: A station in the "good" category needed to be one which was subjectively pleasing to the viewers' eye. A station in the "bad" category needed to be subjectively poorly designed, with little regard of how the user might interact with it, even though there may be other stations on the same line which were recently redone.

3. Relationship to nearby uses: Stations were analyzed based on the proximity to nearby amenities respective to users which may use said amenities.

4. Walk-bike-transit scores: Walk, bike and transit scores were looked at to see if a station was in an area which had other non-car means of transportation after users get off the transit system.

5. Perspective of potential user or investor: Stations were analyzed subjectively from the lens of a potential investor as well as a new potential user. Stations in areas with diverse land uses were more favorable compared to stations located along a busy highway surrounded by acres of parking lots.

6. Ease of access from the street: Stations which were located in the middle of the road or at a large, multi-way intersection were typically included in "bad" sections of analysis. Stations which did not have a clear access-point were also included in the "bad" sections of analysis, forcing users to make their own in some cases. 


\section{LIGHT RAIL TRANSIT Good Office}

Portland

Lincoln St/SW $3^{\text {rd }}$ Ave MAX Station

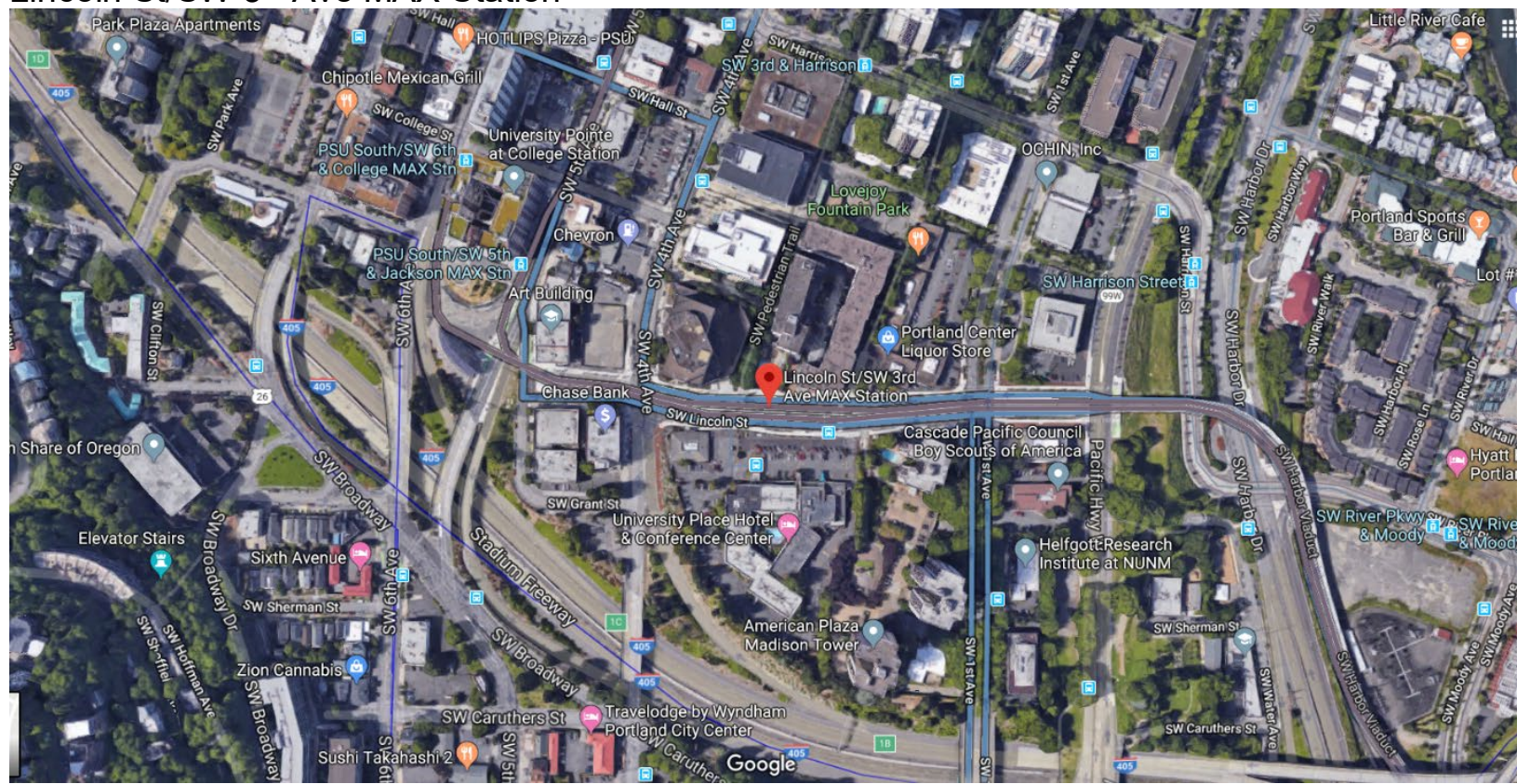

Aerial view.

Source: https://www.google.com/maps/place/Lincoln+St\%2FSW+3rd+Ave+MAX+Station/@45.508029,122.6807813,601m/data=!3m1!1e3!4m5!3m4!1s0x54950a14f663d46f:0x2f83f0c64f110d85!8m2!3d45.507936!4d$\underline{122.6807085}$ 


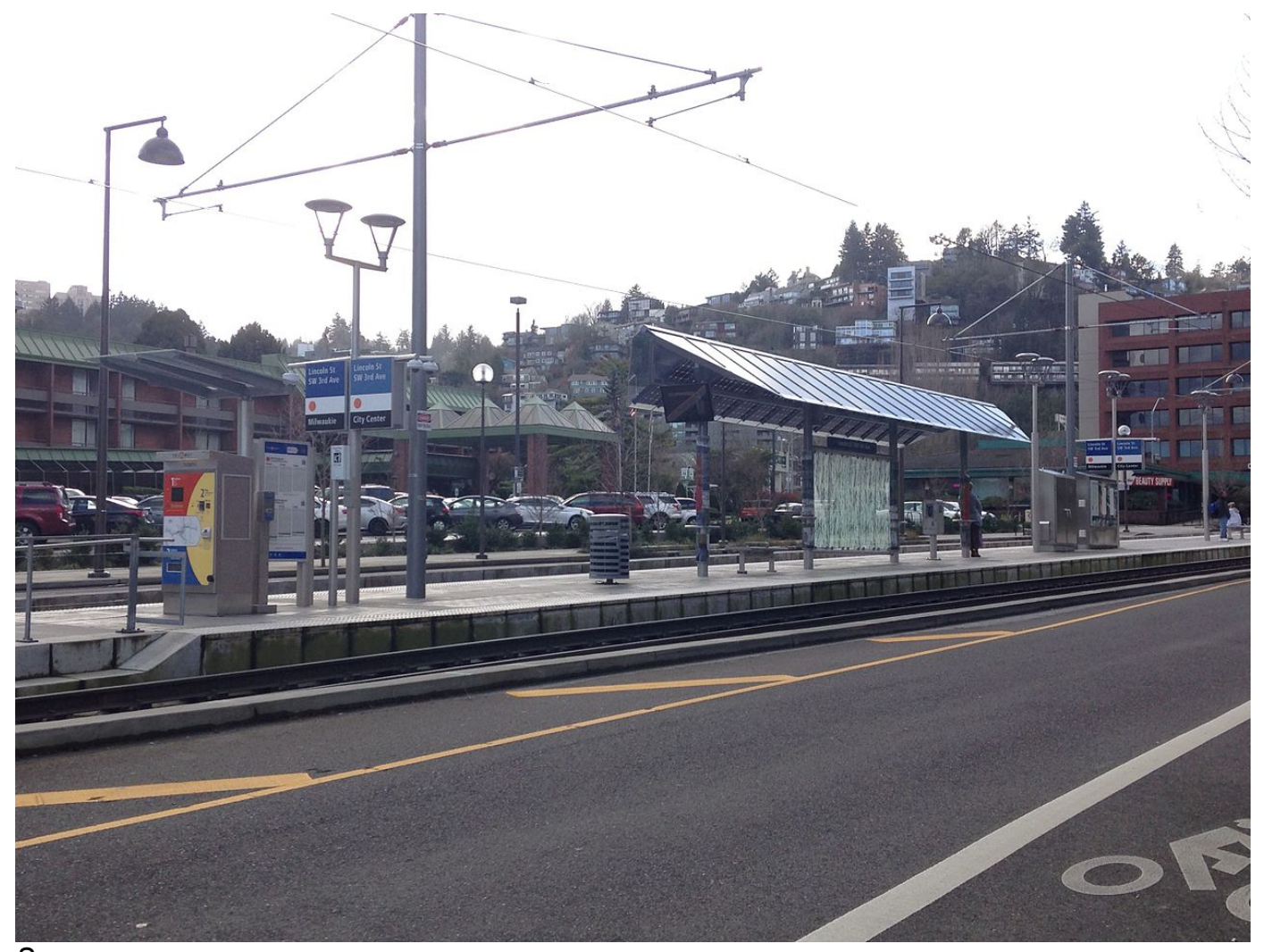

Source:

https://en.wikipedia.org/wiki/Lincoln_Street/Southwest_3rd_Avenue_station\#/media/File:SW_Lincoln_\%26_3rd_Ave_ MAX_Station2.jpg

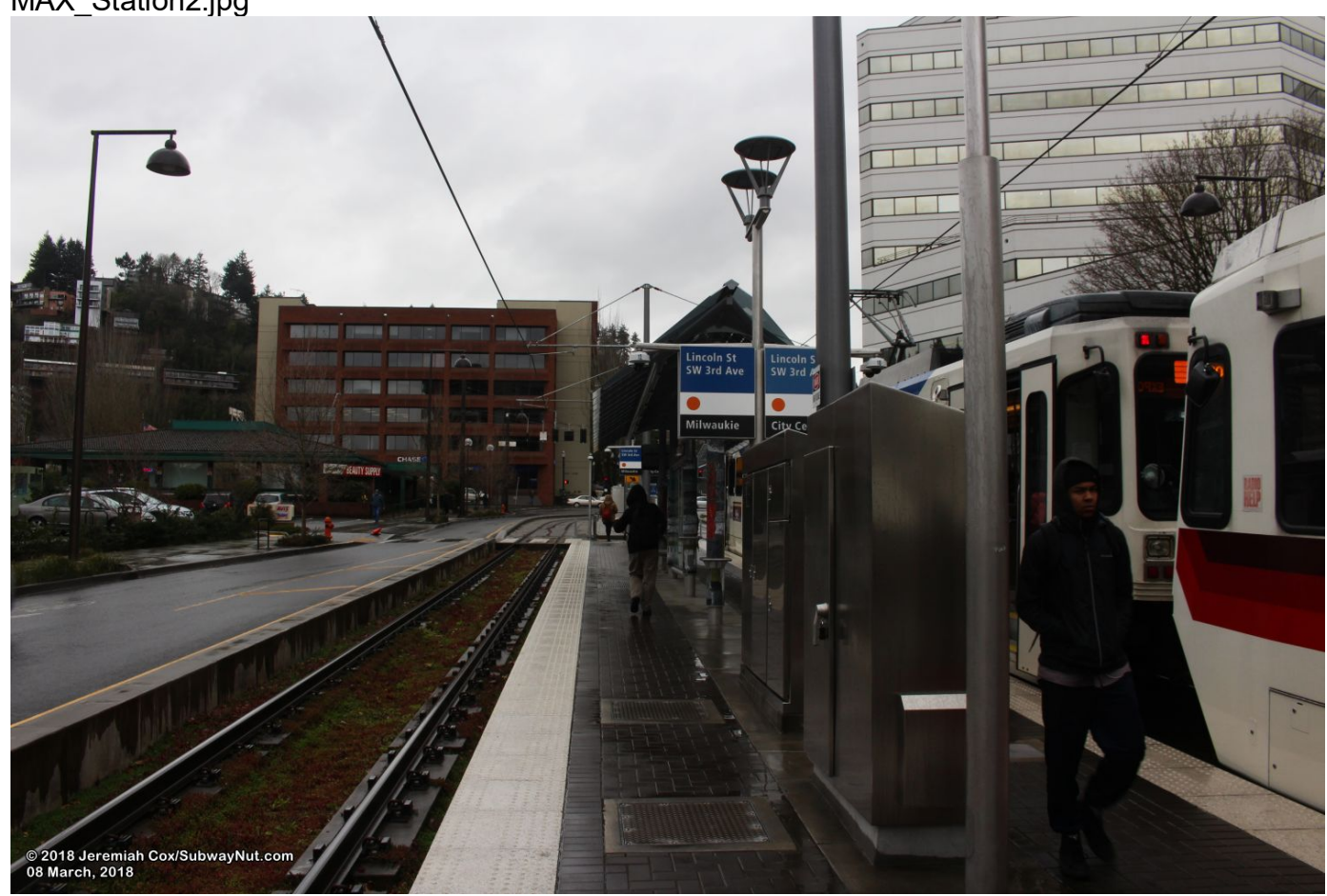

Source: http://subwaynut.com/pnw/max/lincoln_sw_3rd/ 


\section{SW Lincoln St}

Downtown, Portland, 97201

More about 245 SW Lincoln St 룰

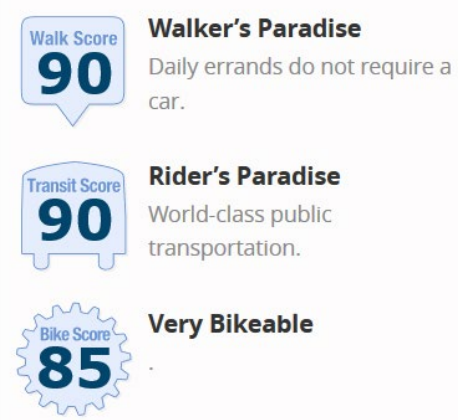

About your score

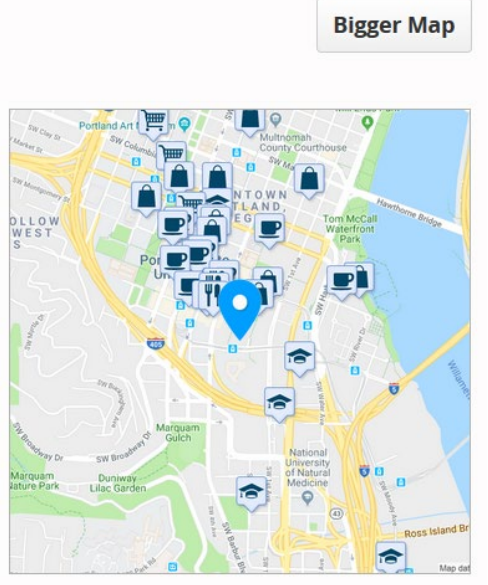

Add scores to your site

Source: https://www.walkscore.com/score/245-sw-lincoln-st-portland-or-97201

The Lincoln St/SW $3^{\text {rd }}$ Ave MAX station in Portland, Oregon opened in 2015. It is located within one mile of the downtown core of the city, and many different amenities are even closer including small office buildings, a hotel, retail space, and more. Additionally, this station is not difficult for pedestrians to get and does not offer a park-and-ride. ${ }^{123}$

\section{Denver}

$18^{\text {th }} \&$ Stout/California

\footnotetext{
${ }^{123}$ Adapted from https://en.wikipedia.org/wiki/Lincoln_Street/Southwest_3rd_Avenue_station.
} 


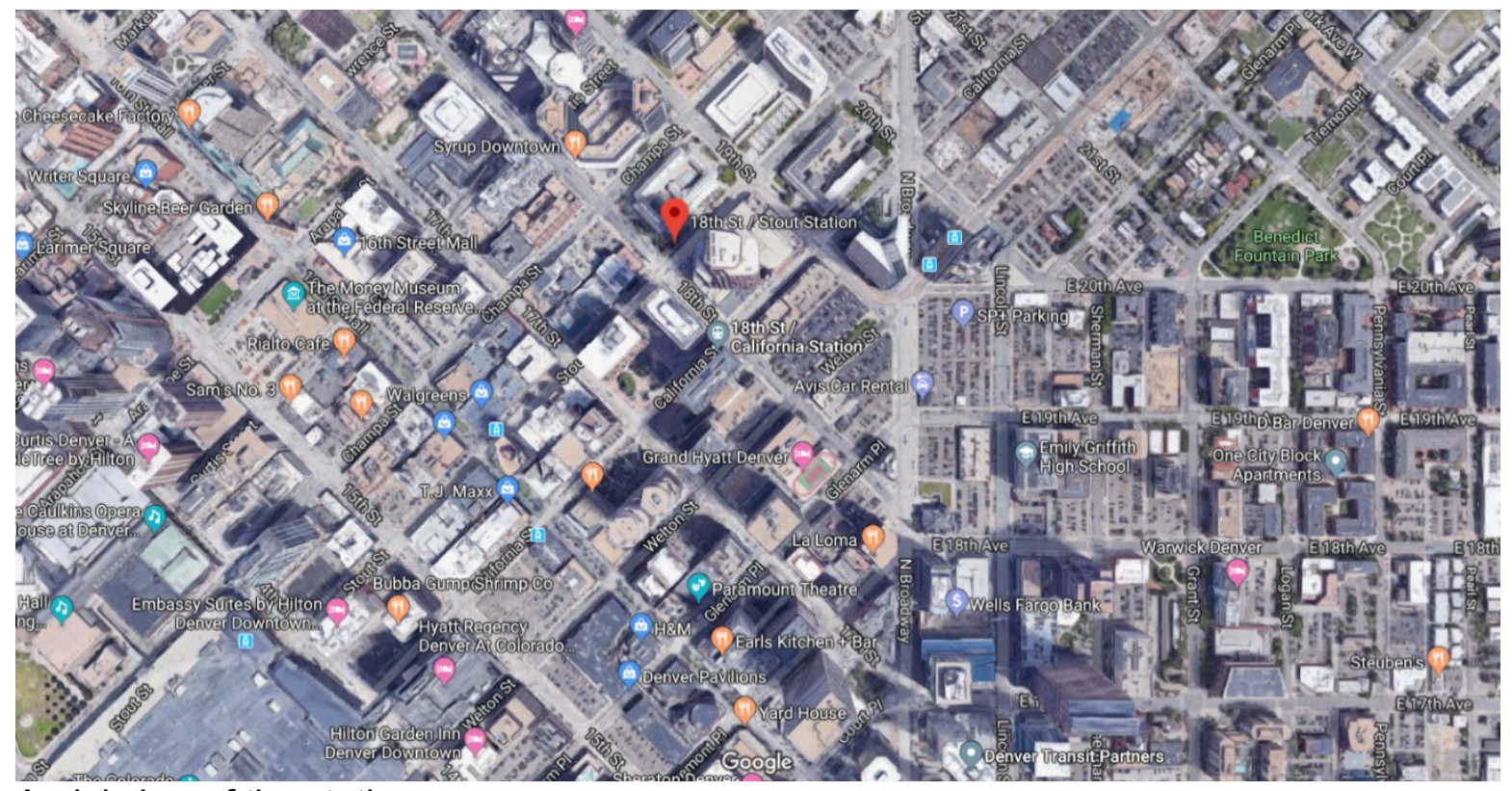

\section{Aerial view of the stations.}

Source: https://www.google.com/maps/place/18th+St+\%2F+Stout+Station/@39.7469954,-

$104.9890315,944 \mathrm{~m} / \mathrm{data}=! 3 \mathrm{~m} 1$ ! $1 \mathrm{e} 3$ ! $4 \mathrm{~m} 5 ! 3 \mathrm{~m} 4$ ! 1s0x876c78d9e72ed8e3:0x99d1ff08024f2f42!8m2!3d39.7479509!4d$\underline{104.9905121}$

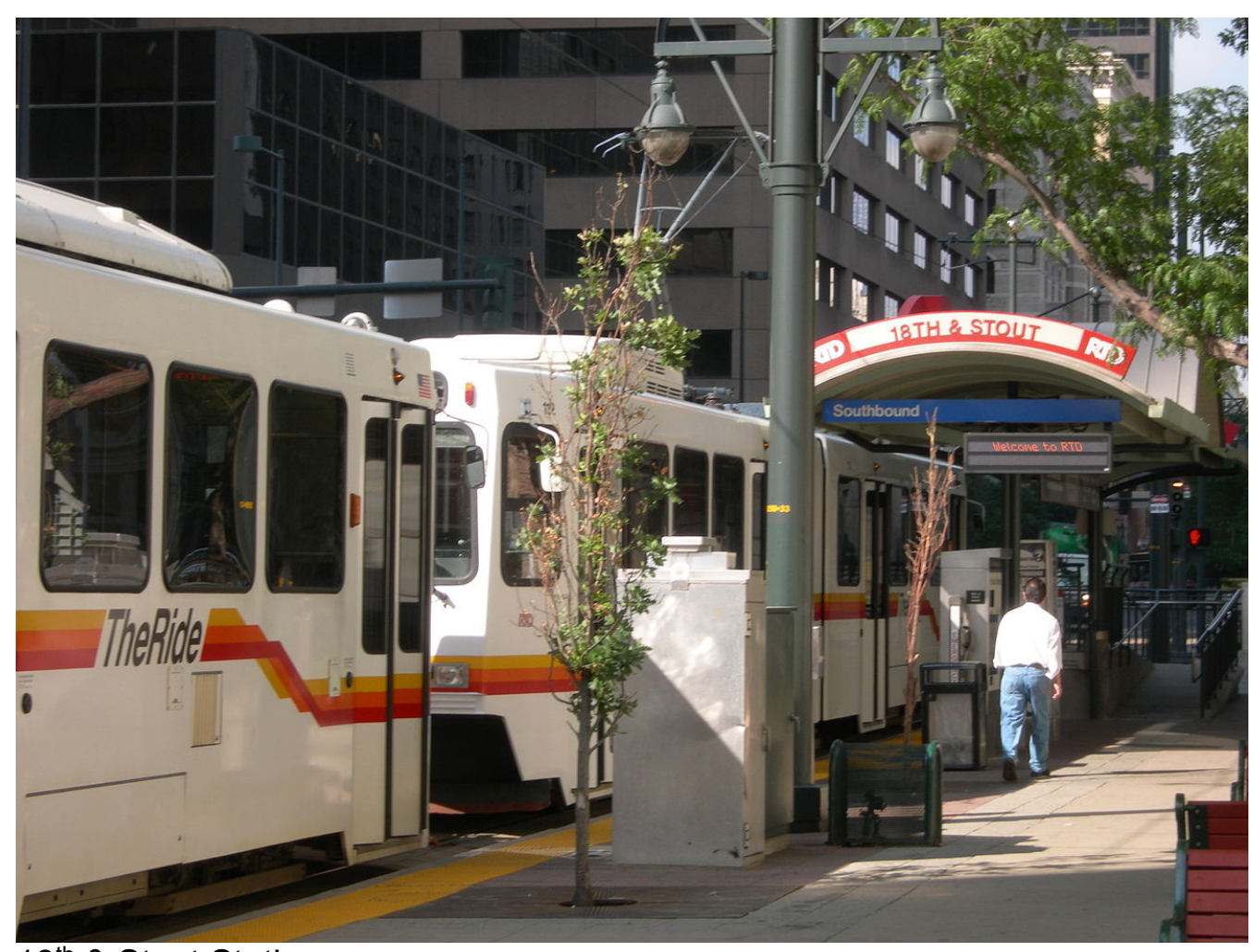

$18^{\text {th }} \&$ Stout Station

Source: https://en.wikipedia.org/wiki/18th_\%26_California_and_18th_\%26_Stout_stations\#/media/File:18th-stoutrtd.jpg 

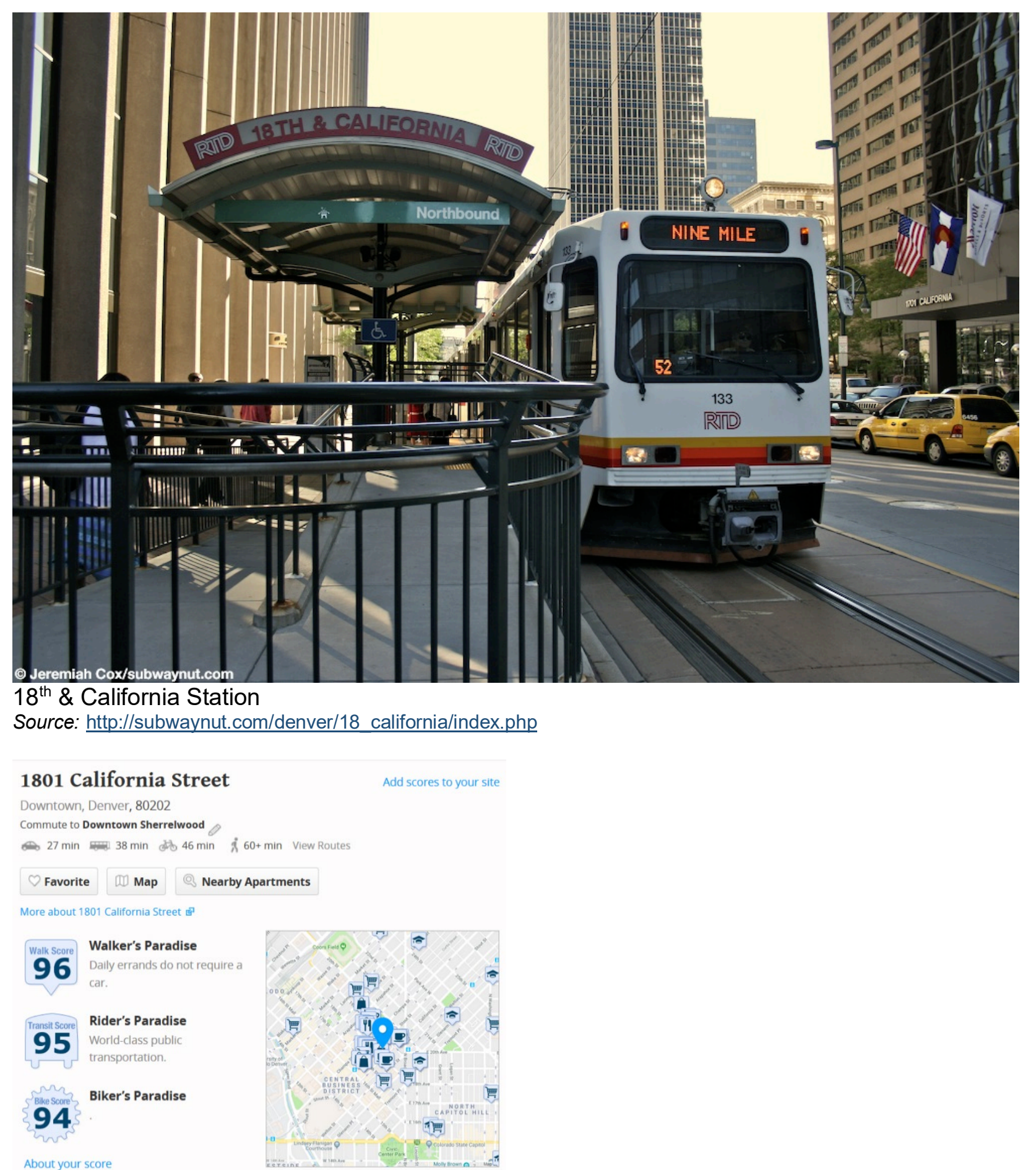

Source: https://www.walkscore.com/score/1801-california-st-denver-co-80202

Serving Denver's Light Rail System, the sister stations along $18^{\text {th }}$ St. at Stout and California are single-tracked running north- and southbound, respectively. These stations are located in the downtown central business district within walking distance. ${ }^{124}$

${ }^{124}$ Adapted from https://en.wikipedia.org/wiki/18th_\%26_California_and_18th_\%26_Stout_stations. 


\section{Bad Office}

\section{San Diego}

\section{$32^{\text {nd }}$ St/Commercial St Station}

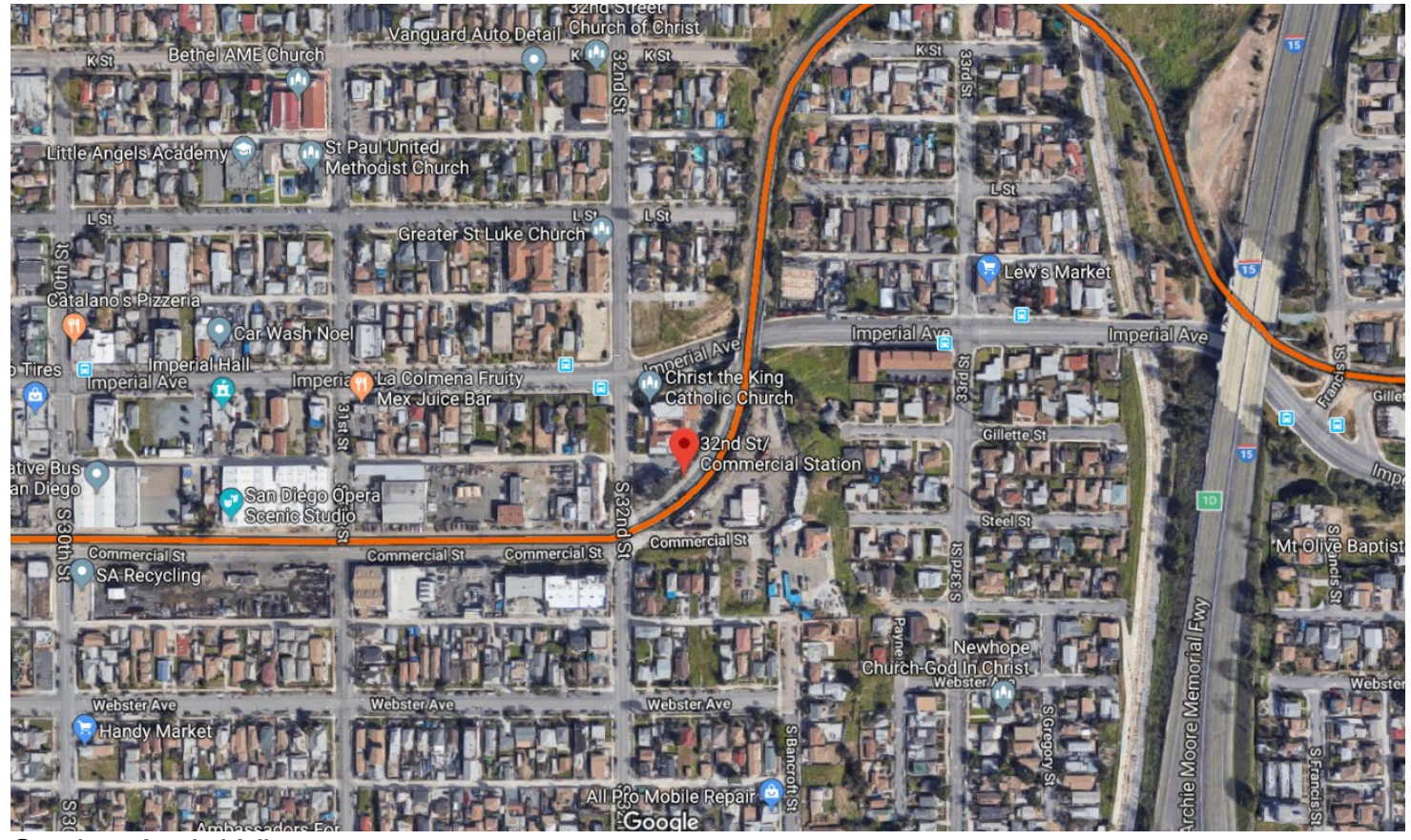

\section{Station Aerial View}

Source: https://www.google.com/maps/place/32nd+St\%2FCommercial+Station/@32.7061786,117.1249304,639m/data=!3m1!1e3!4m12!1m6!3m5!1s0x80d9536e5f5c0c3f:0x9f276c28072e7ccb!2s25th\%2FComm ercial+St+Station!8m2!3d32.7053062!4d-

117.1413655!3m4!1s0x80d9539e437d4aa31:0x4697c3b2c6fbb176!8m2!3d32.70577!4d-117.1247533

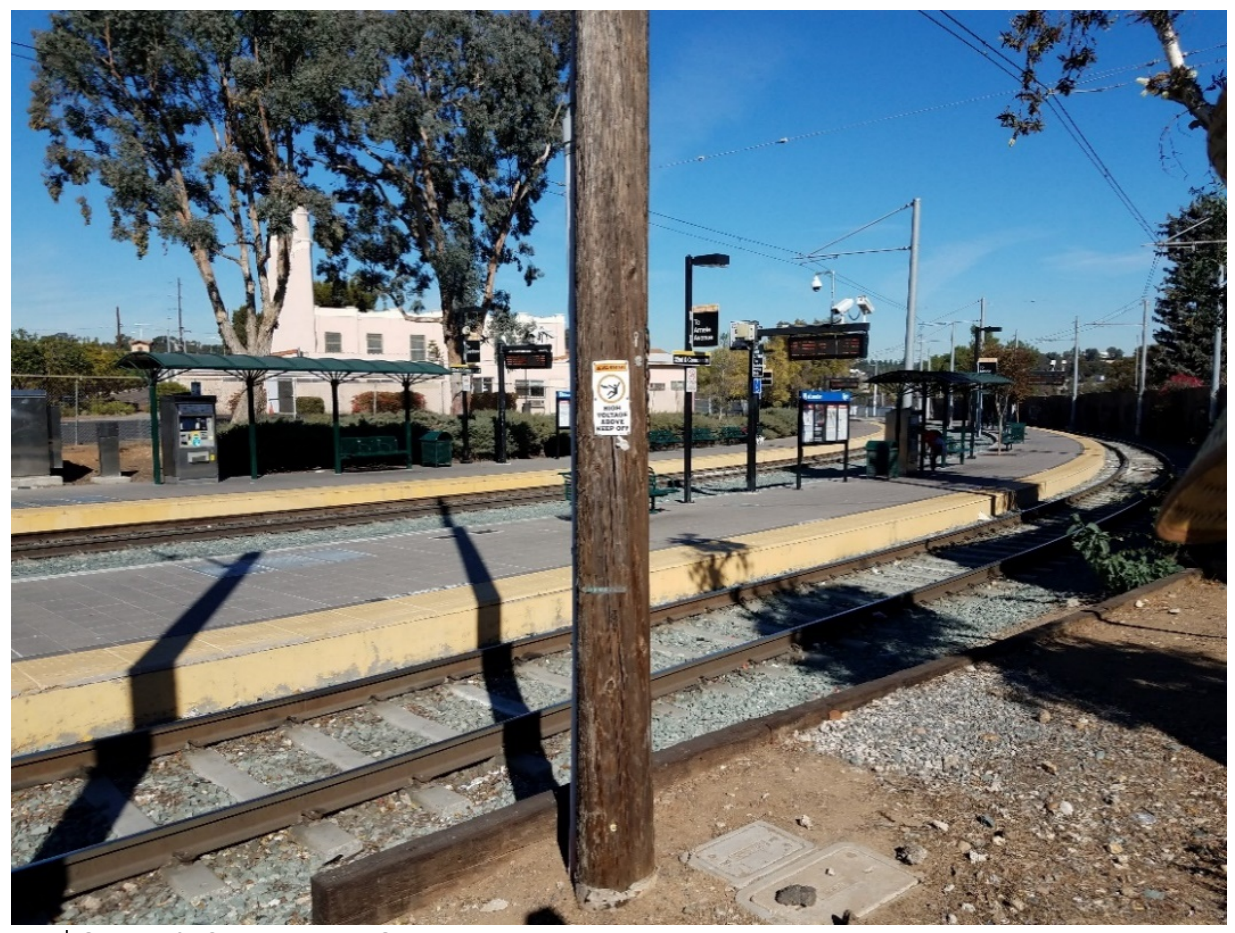

$32^{\text {nd }}$ Street \& Commercial Station

Source: https://upload.wikimedia.org/wikipedia/commons/5/57/32nd \%26 Commerical trolley station - 3.jpg 


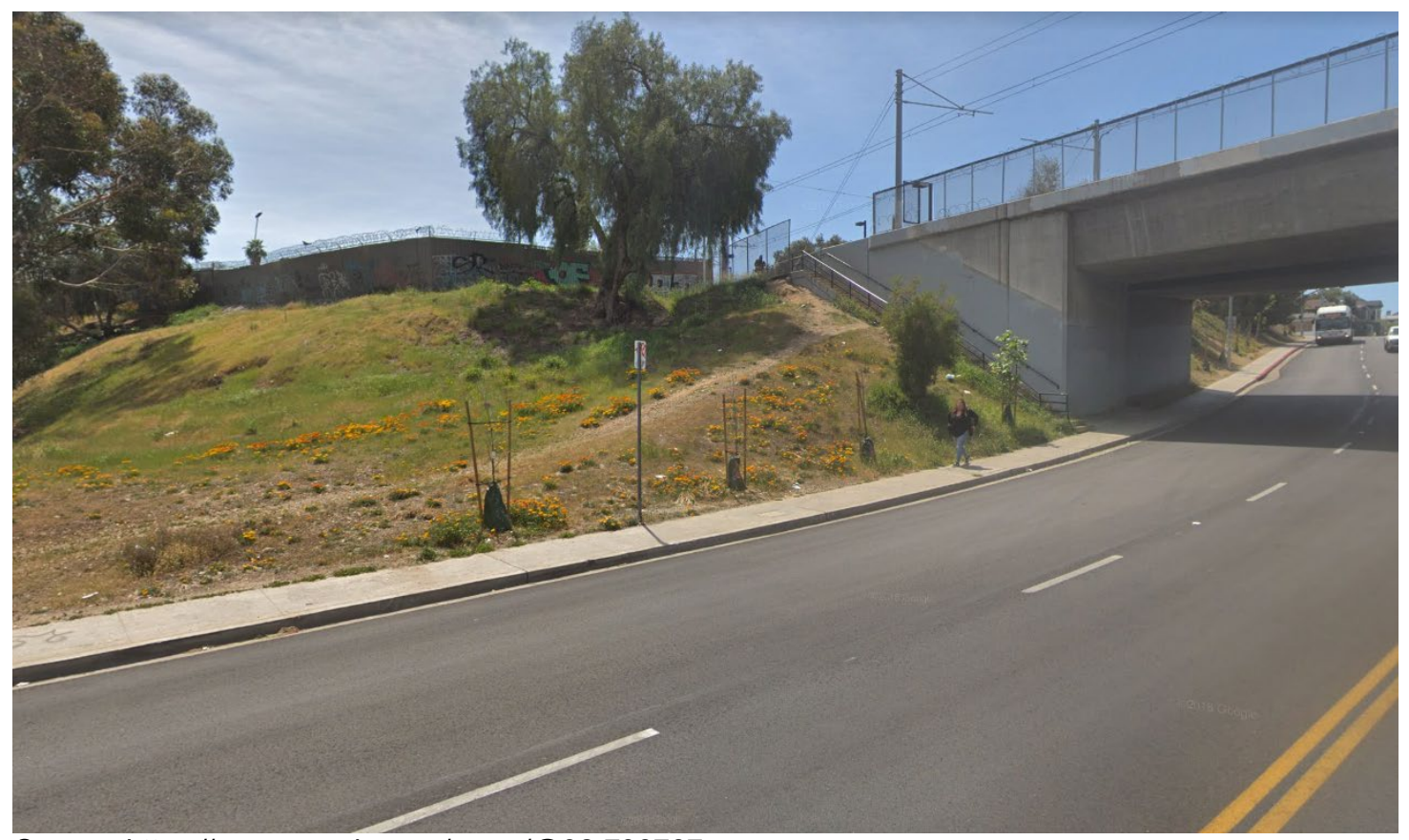

Source: https://www.google.com/maps/@32.706767,-

117.1239071,3a,89.6y,225.76h,88.28t/data=!3m6!1e1!3m4!1sZHsZ3wxTLXI42PG4-DytZQ!2e0!7i16384!8i8192

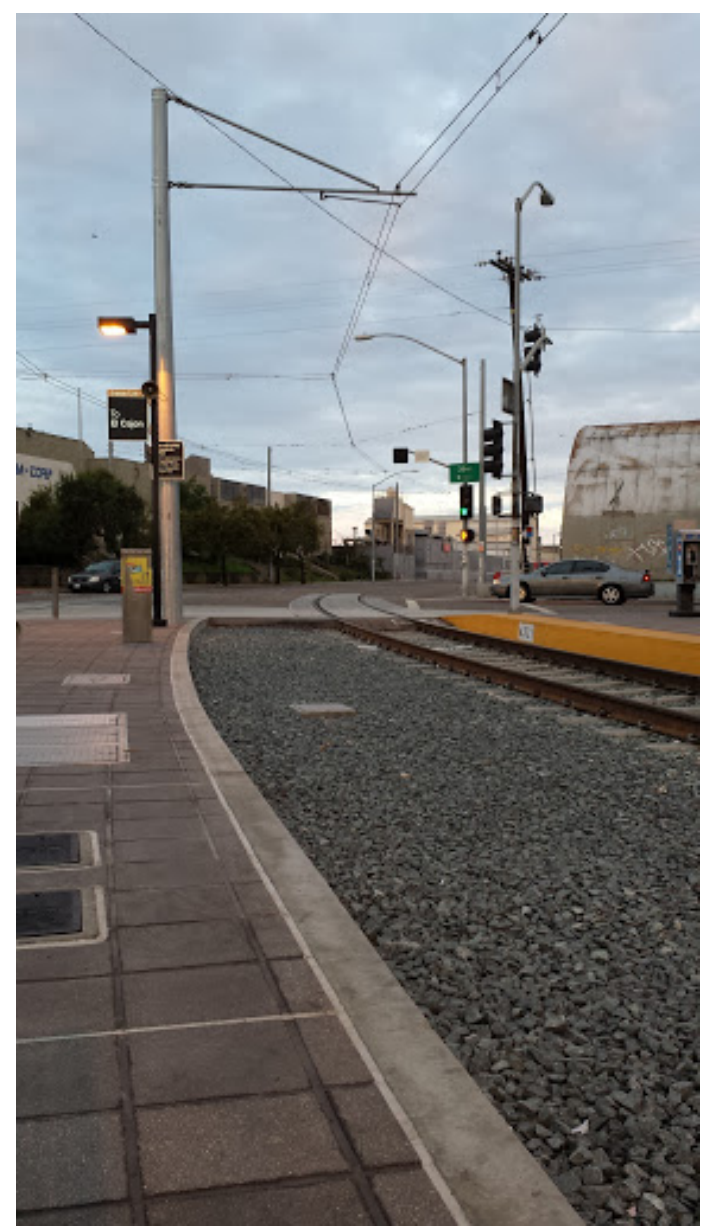

Source: https://outgress.com/portals/32nd-commercial-trolley-station.35750/ 


\section{Commercial Street}
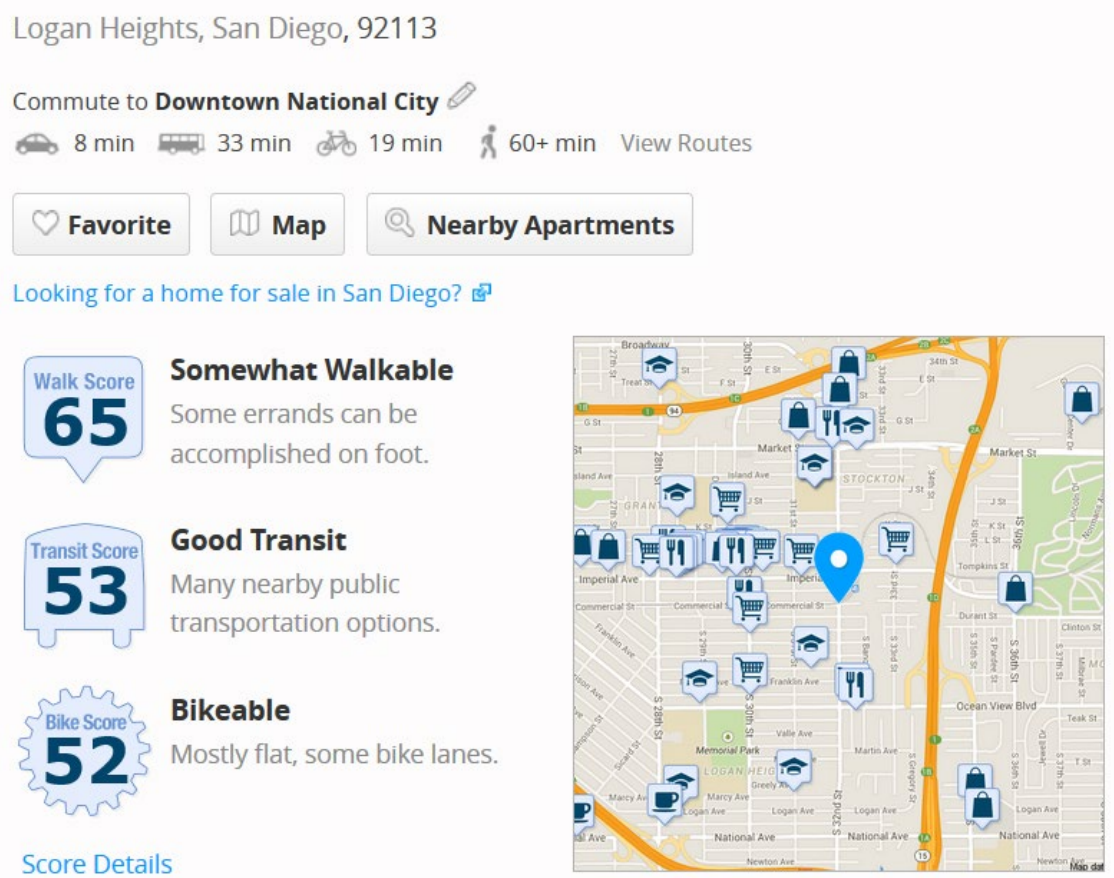

Source: https://www.walkscore.com/score/3200-commercial-st-san-diego-ca-92113

The station at $32^{\text {nd }}$ and Commercial is located at a curve in the track and is the only station for a mile. Not only is this difficult to walk to anyway, but one of two platforms is located in between inbound and outbound tracks. Additionally, eastern access to the station (where the next nearest station is almost 2.5 miles away) is via a flight of stairs right off a busy four lane road. ${ }^{125}$

${ }^{125}$ Adapted from photos used and Google Maps. 


\section{San Jose}

\section{Hamilton Station}

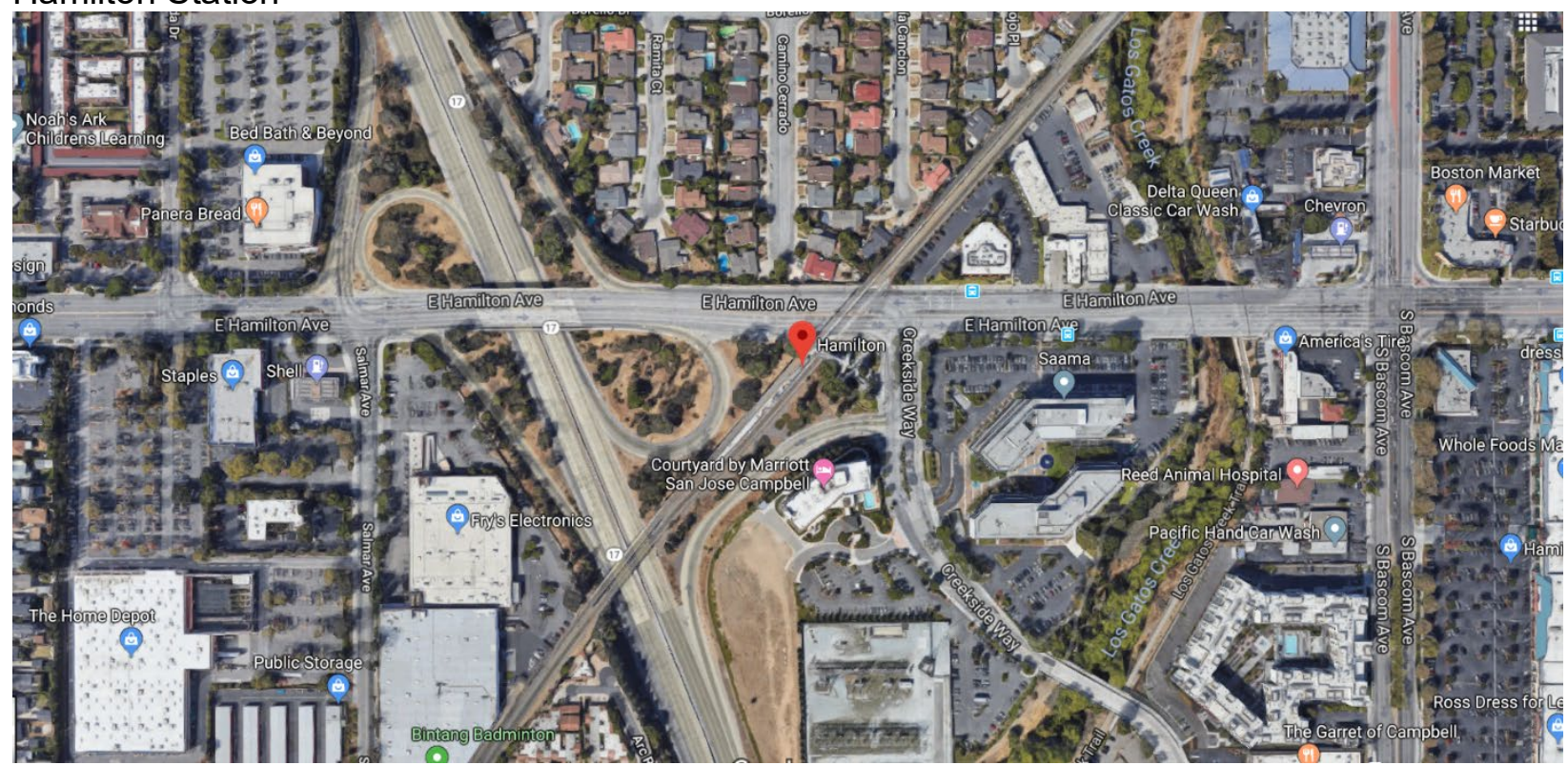

\section{Aerial View}

Source: https://www.google.com/maps/place/Hamilton/@37.2937907,-

$121.9365345,556 \mathrm{~m} / \mathrm{data}=! 3 \mathrm{~m} 1 ! 1 \mathrm{e} 3 ! 4 \mathrm{~m} 5 ! 3 \mathrm{~m} 4$ ! 1s0x808e34db28b6b6d3:0xf1253d86479443c2!8m2!3d37.2939558!4d121.9362717

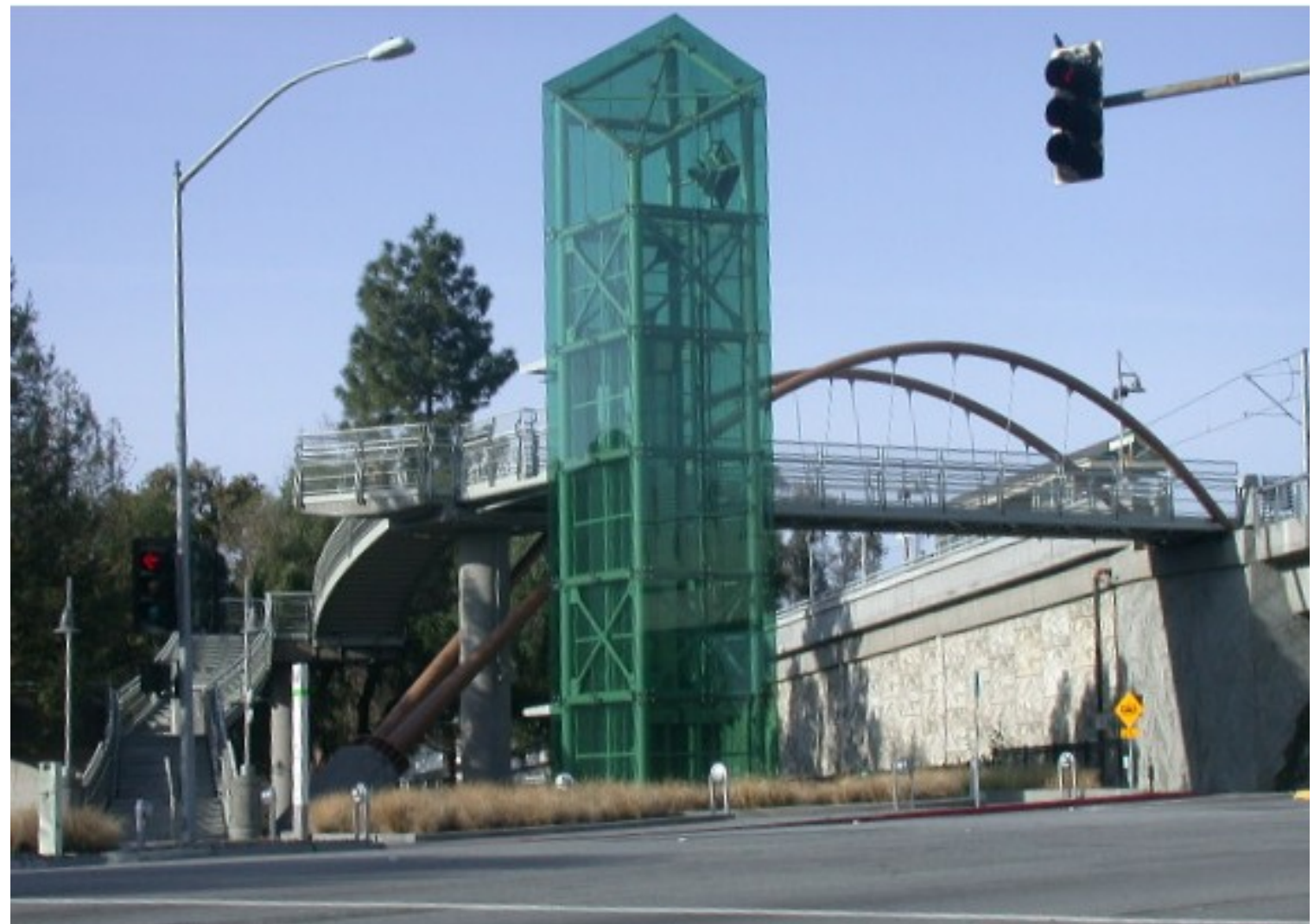

Street View

Source: https://upload.wikimedia.org/wikipedia/commons/e/e0/HamiltonStreetLevel030406.jpg 


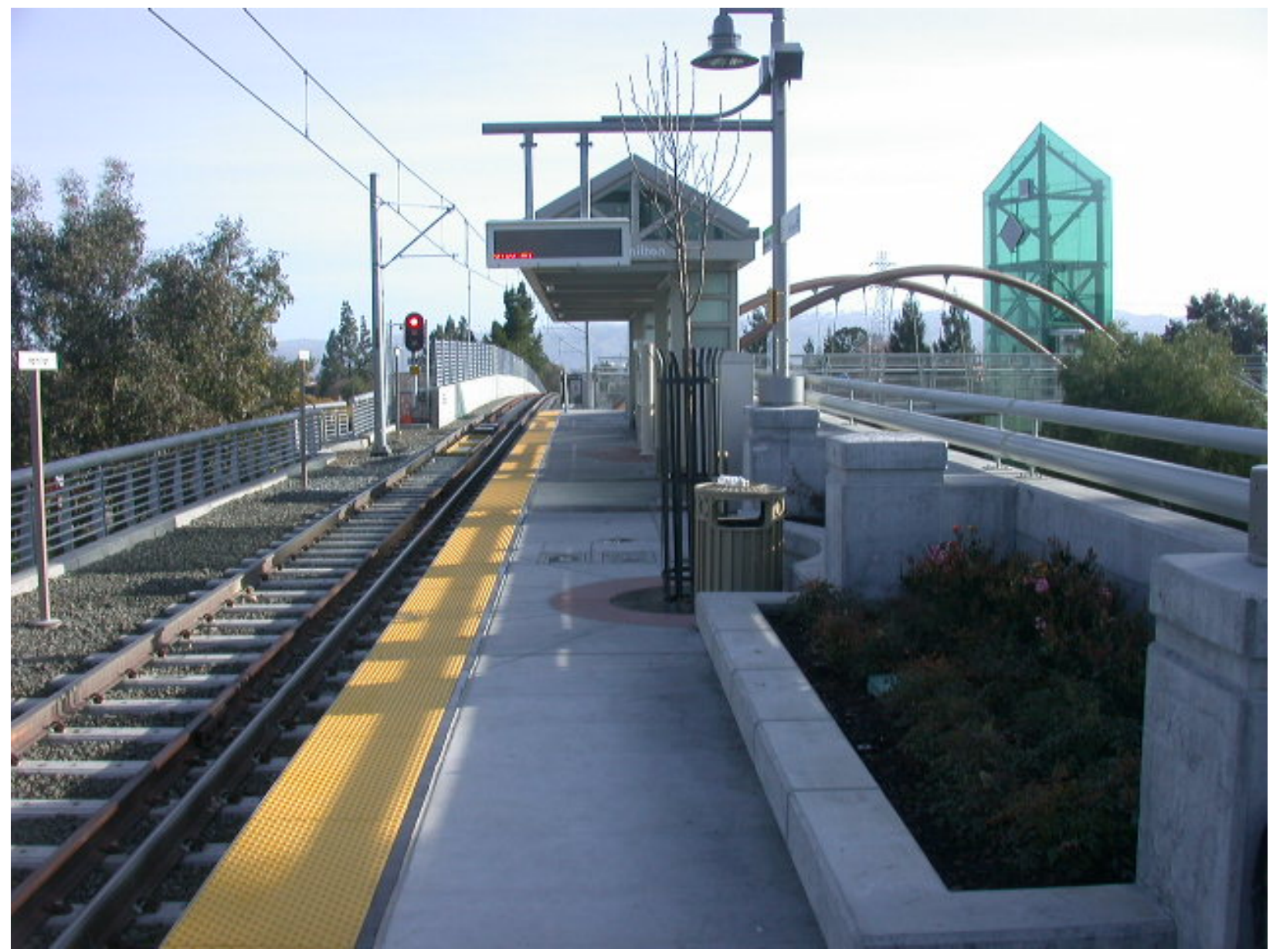

Source: https://en.wikipedia.org/wiki/Hamilton_station_(VTA)\#/media/File:HamiltonVTAPlatformLevel030406.JPG

655 Creekside Way

East Campbell, Campbell, 95008

Commute to Downtown Campbell

$\Leftrightarrow 3 \mathrm{~min}=16 \mathrm{~min}$ at $5 \mathrm{~min} \quad \grave{2} 23 \mathrm{~min}$ View Routes

Favorite 10 Map $\bigcirc$ Nearby Apartments

Looking for a home for sale in Campbell? 훙

\section{4 \\ Some errands can be \\ accomplished on foot. \\ Transit Score Some Transit
A few nearby public
transportation options.}

\section{8}

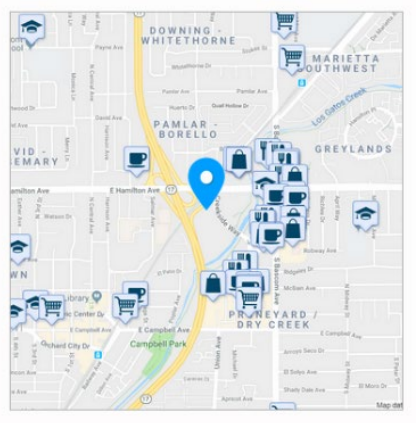

Source: https://www.walkscore.com/score/655-creekside-way-campbell-ca-95008

The Hamilton Station is not only cumbersomely elevated, but it is located at likely the least accessible intersection of all of Silicon Valley 


\section{Good Multifamily}

Cleveland

Settlers Landing Station

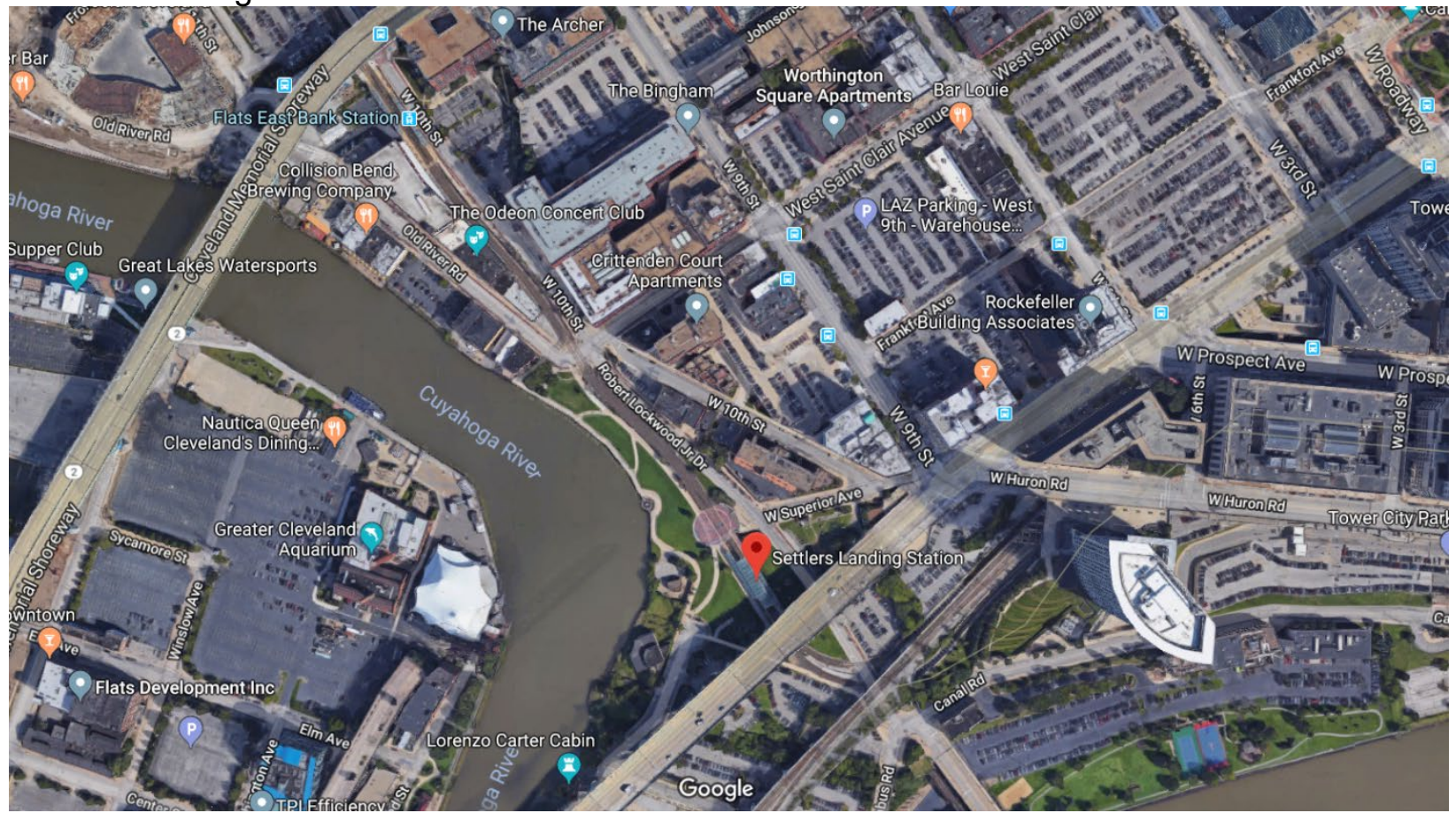

Source: https://www.google.com/maps/place/Settlers+Landing+Station/@41.4963661,--

81.7026049,652m/data=!3m1!1e3!4m5!3m4!1s0x8830f07c9ae6e45f:0xd9c17e871a23ba18!8m2!3d41.4963661!4d-

$\underline{81.7004162}$ 


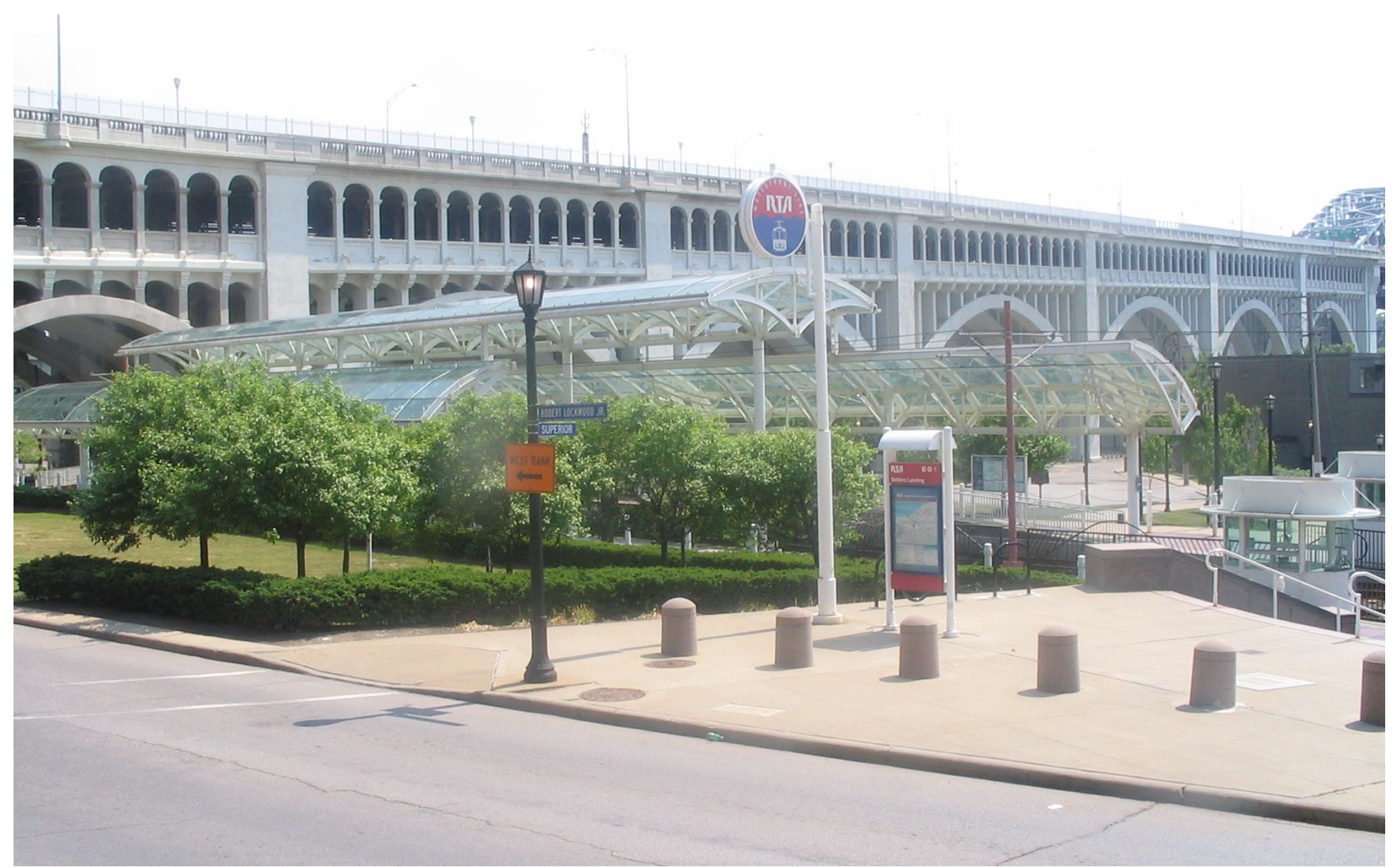

Source: https://commons.wikimedia.org/wiki/File:Settlers Landing Cleveland RTA station.jpg 


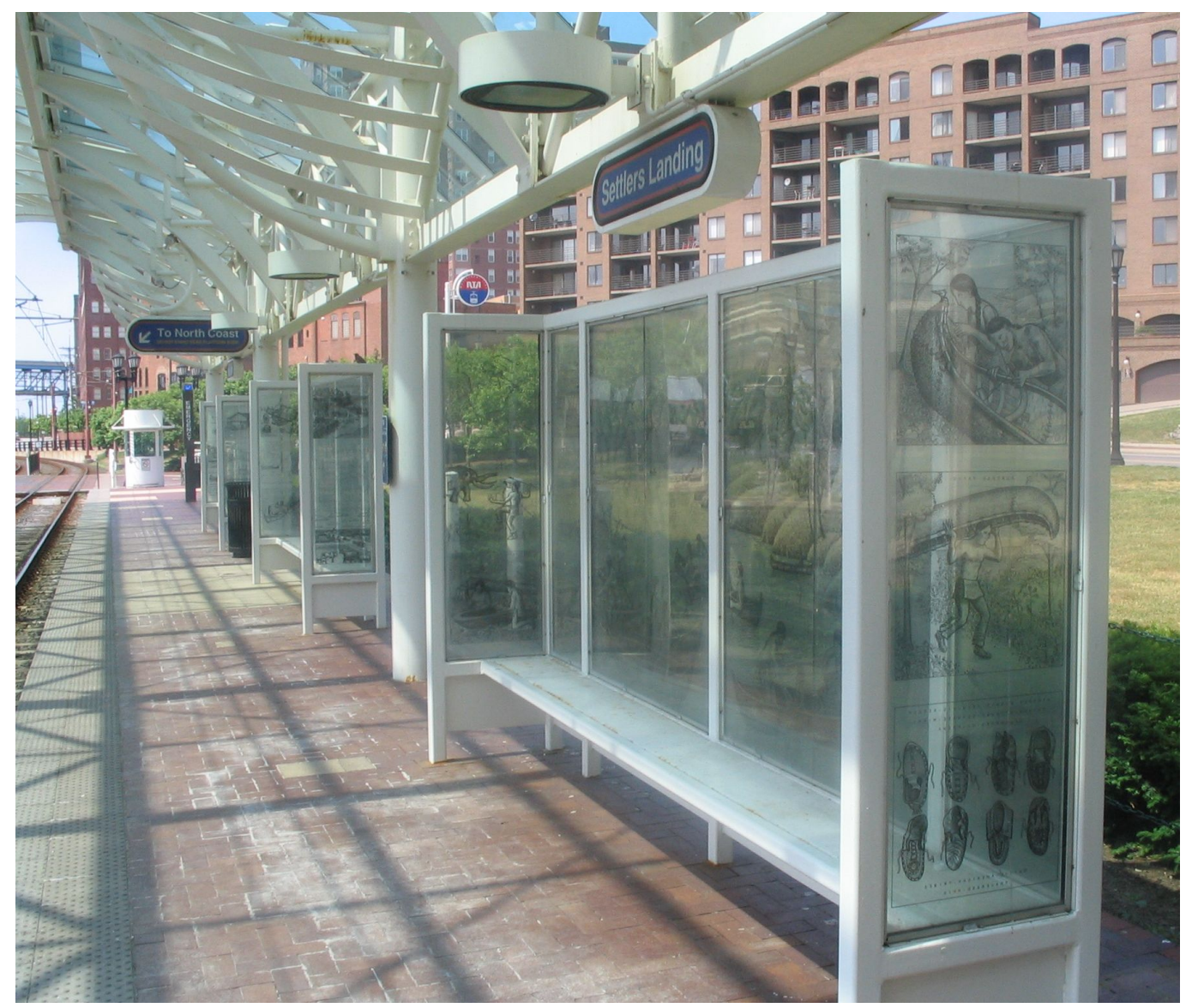

Source: https://commons.wikimedia.org/wiki/File:Settlers_Landing_Cleveland_RTA_station_1.jpg 


\section{West 10th Street \\ Downtown, Cleveland, 44113 \\ Commute to Downtown Cleveland \\ $\Leftrightarrow 3 \mathrm{~min} 15 \mathrm{~min} 6 \mathrm{~min} ; 21 \mathrm{~min}$ View Routes \\ Favorite W Map @ Nearby Apartments}

More about 1444 West 10th Street 뚠
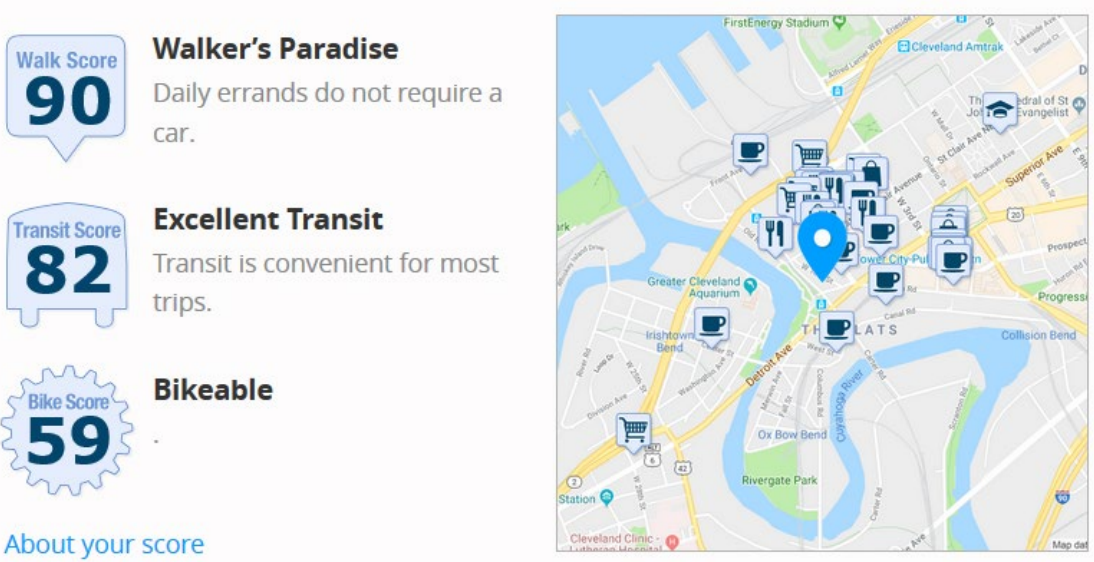

Source: https://www.walkscore.com/score/1444-w-10th-st-cleveland-oh-44113

The Settlers landing station is at street level and at human scale in downtown Cleveland, Ohio. It is located just south of Lake Erie along the Cuyahoga River near many residential developments and employment centers 


\section{St. Louis}

\section{Forest Park Metrolink Station}

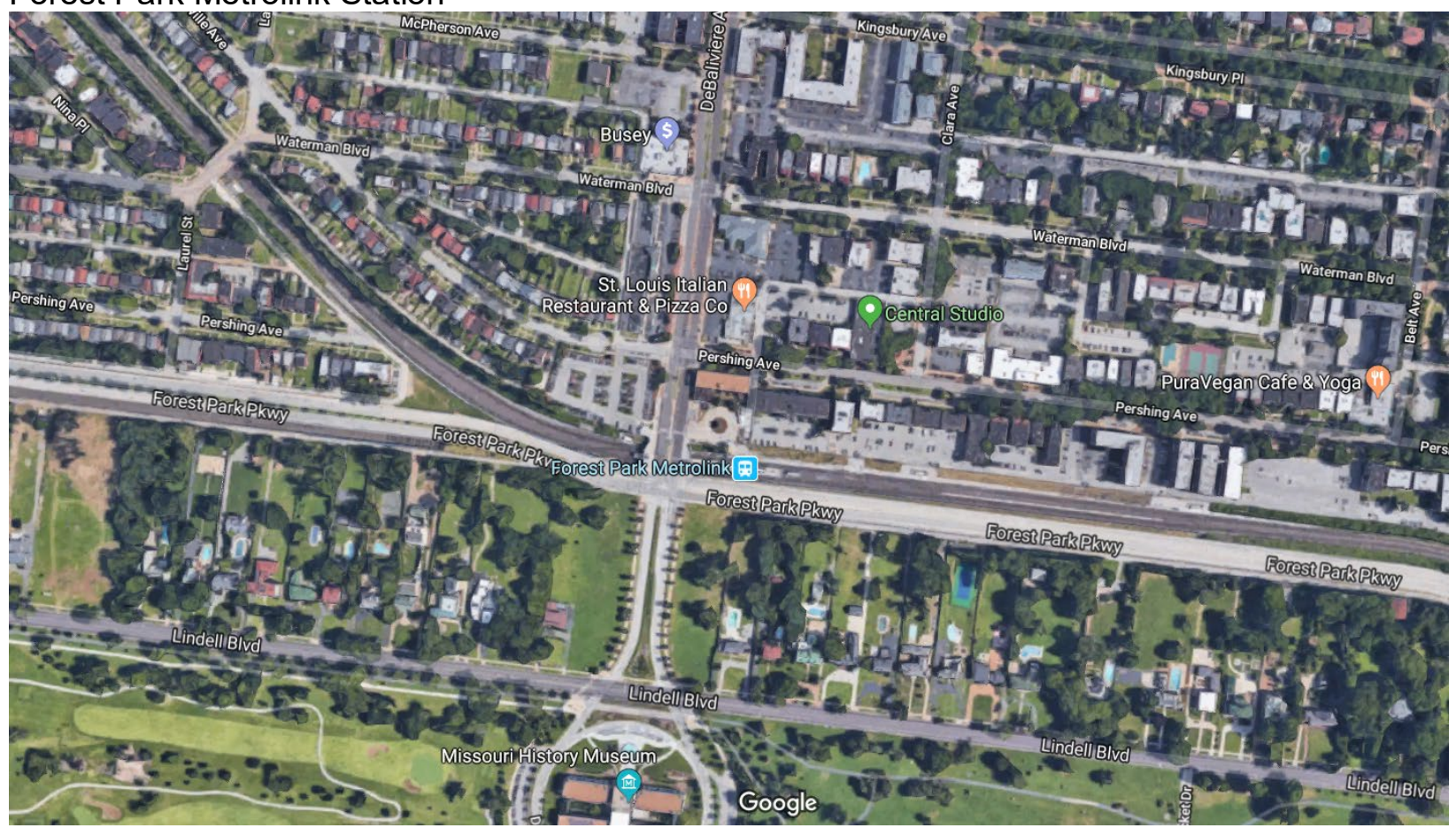

Source: https://www.google.com/maps/place/Clayton/@38.6484173,--

90.2842951,765m/data=!3m1!1e3!4m6!3m5!1s0x87d8cb29a3e4c6c3:0x2319170b82acdbb3!4b1!8m2!3d38.6456221! 4d-90.3399076

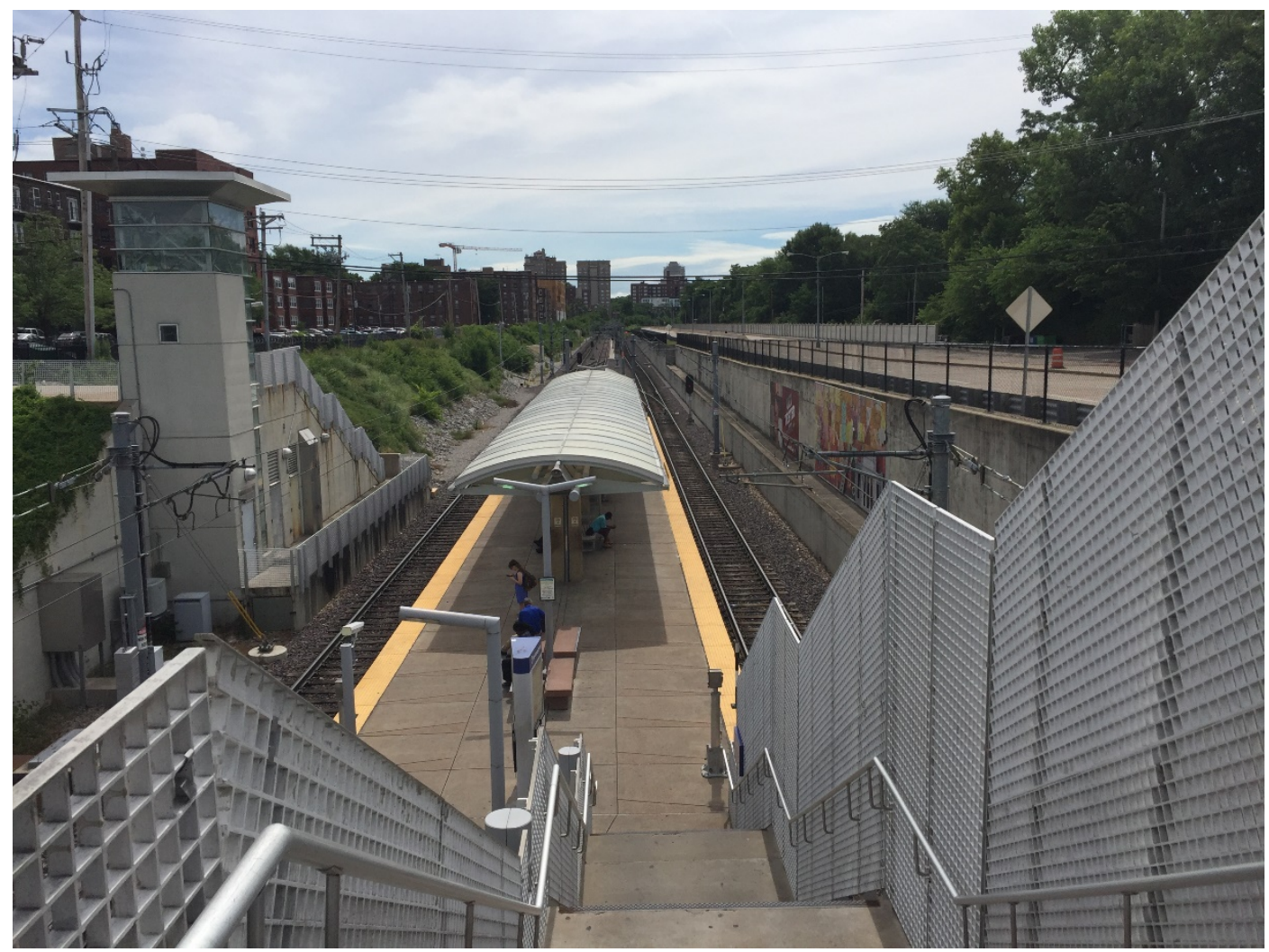

Source: https://en.wikipedia.org/wiki/Forest Park\%E2\%80\%93DeBaliviere station 


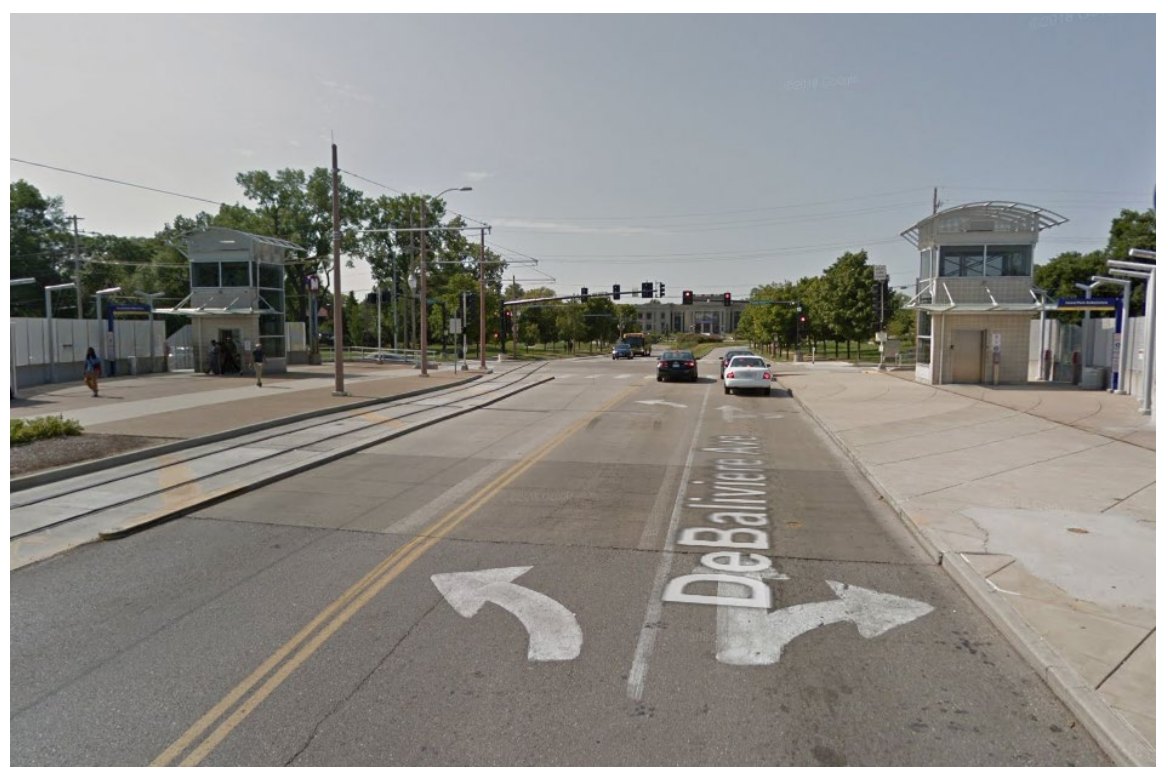

Source: https://www.google.com/maps/@38.6481572,-

90.2854107,3a,75y,175.34h,85.83t/data=!3m6!1e1!3m4!1s6CceL8Yr VpVCPkVuxiJXQ!2e0!7i13312!8i6656

\section{DeBaliviere Avenue}

Add scores to your site

DeBaliviere Place, St. Louis, 63112

Commute to Downtown St. Louis

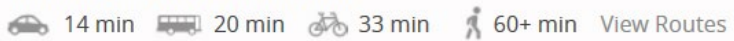
Favorite
(1) Map
Nearby Apartments

Looking for a home for sale in St. Louis? ⿷匚⿳⺈⿴囗十

Walk Score Somewhat Walkable

64 Some errands can be

accomplished on foot.

83 Flat as a pancake, excellent bike

lanes.

About your score

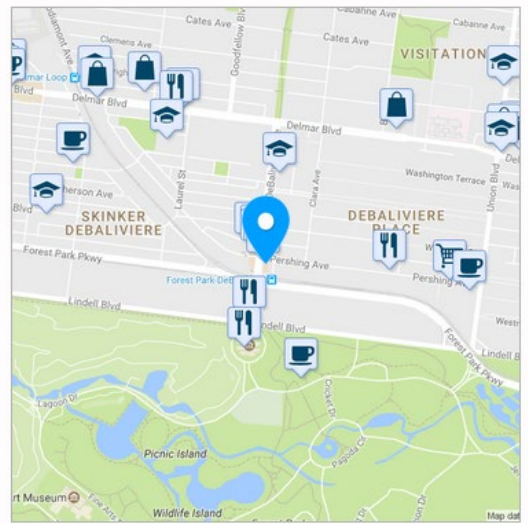

Source: https://www.walkscore.com/score/280-debaliviere-ave-st-louis-mo-63112

Forest Park Metrolink Station is in a walkable area just west of St. Louis neear a park and residential area. It is easy to get to the station (which is below street level) from both sides of the street and includes elevators for ease of all people. 


\section{Seattle}

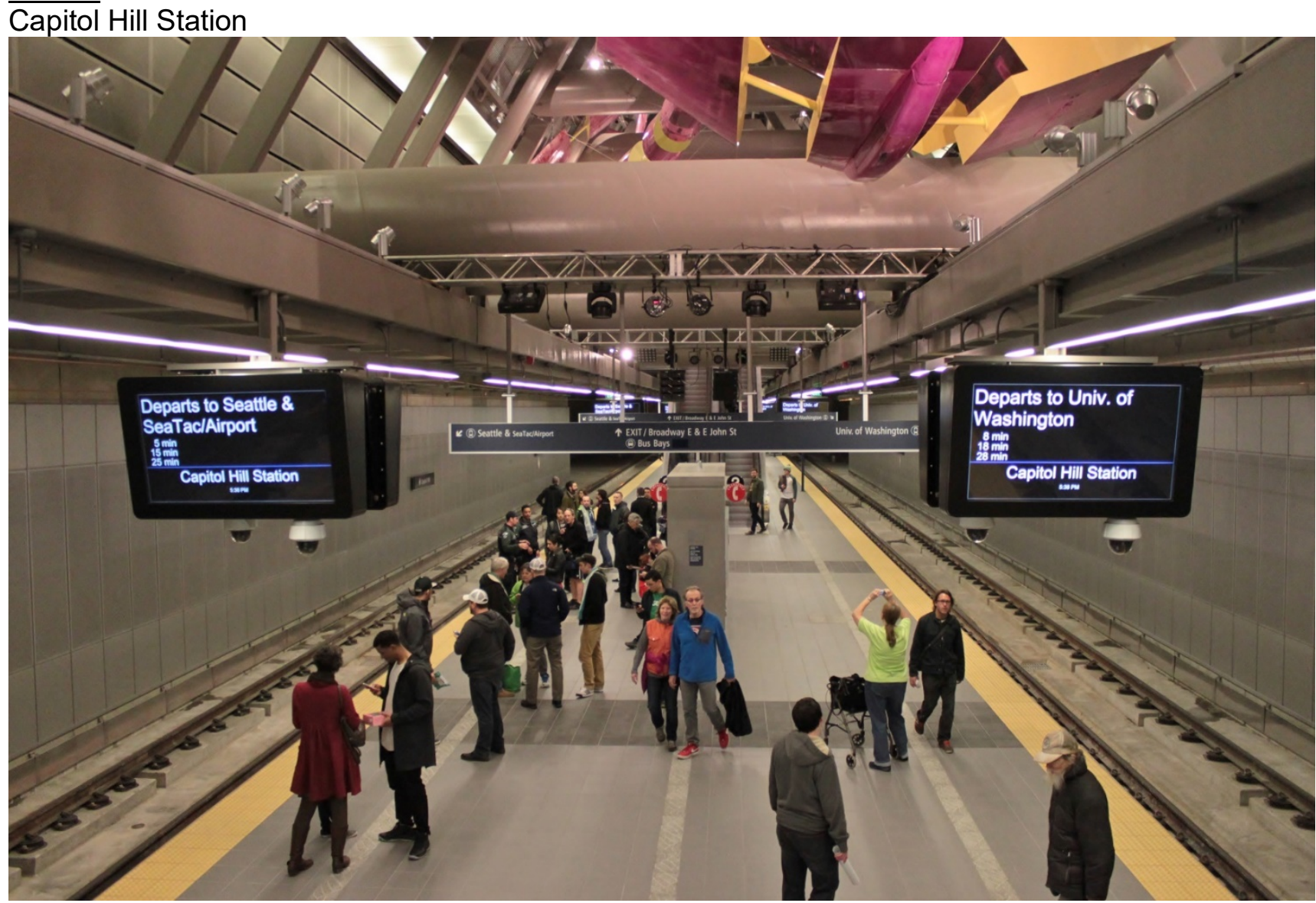

Source: https://en.wikipedia.org/wiki/Capitol_Hill_station 


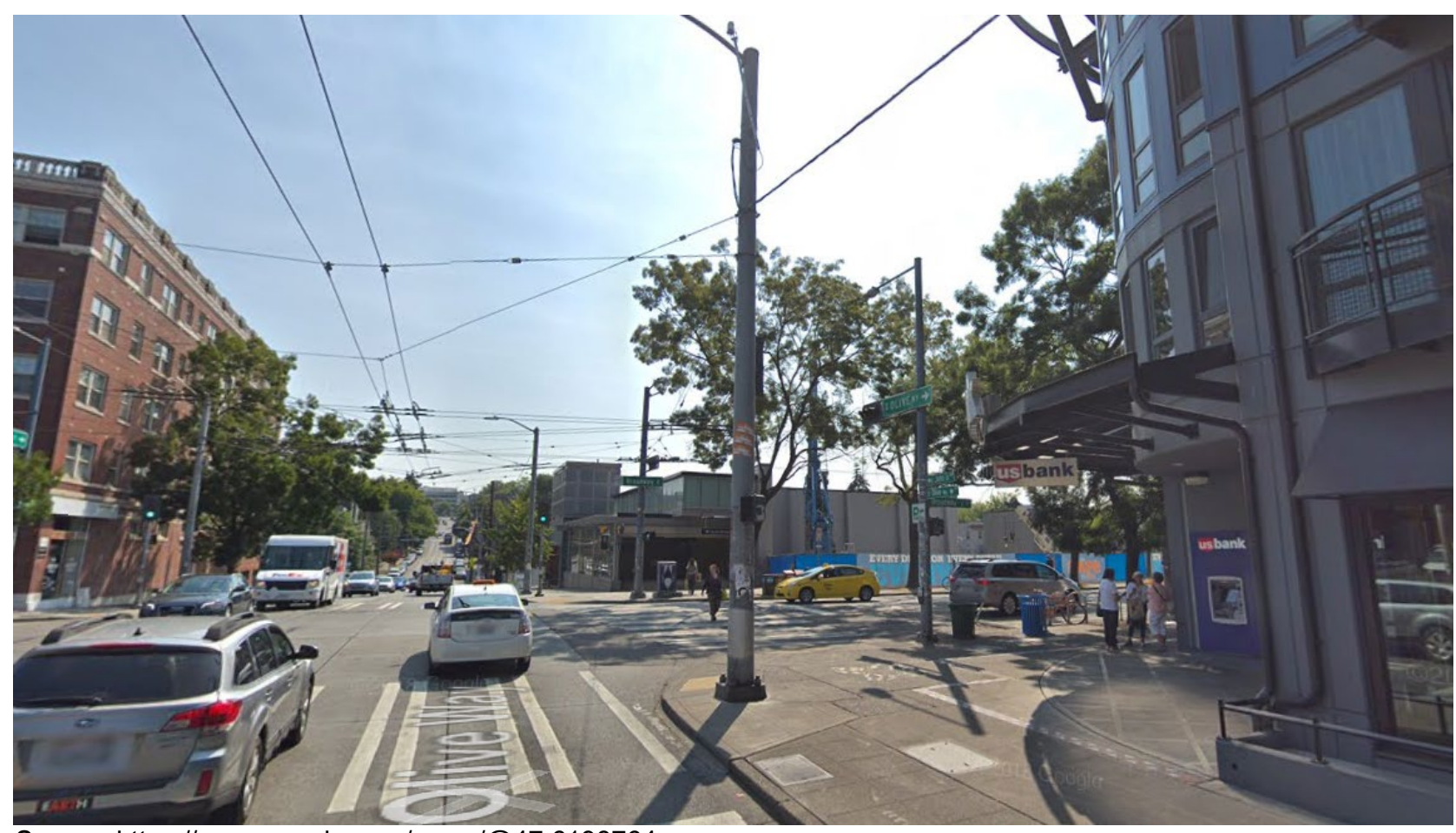

Source: https://www.google.com/maps/@47.6198764,-

122.3212135,3a,75y, 109.86h,99.02t/=!3m6!1e1!3m4!1sW1eRwab1ZoPbiJFwoXTJpg!2e0!7i16384!8i8192

\section{East John Street}

Capitol Hill, Seattle, 98102

Commute to Downtown Seattle

क $42 \mathrm{~min}$ min $8 \mathrm{~min} 28 \mathrm{~min}$ View Routes

\section{$\checkmark$ Favorite W Map O Nearby Apartments}

Looking for a home for sale in Seattle? 뚱

\section{Walk Score Walker's Paradise}

98 Daily errands do not require a car.

83 Transit is convenient for most

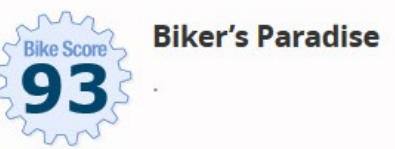

About your score

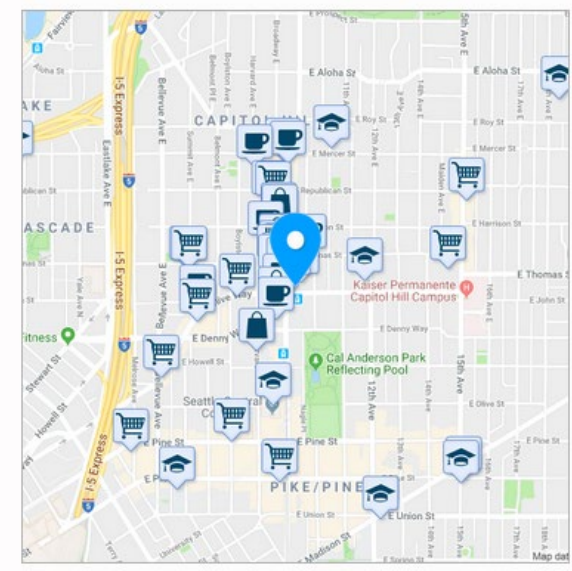

Source: https://www.walkscore.com/score/906-e-john-st-seattle-wa-98102

Located in one of the most popular Seattle neighborhoods, the Capitol Hill station is in a walkable area with abundant new construction and rehabilitation of multifamily properties. 


\section{Bad Multifamily}

\section{San Jose}

\section{Bonaventura Station}

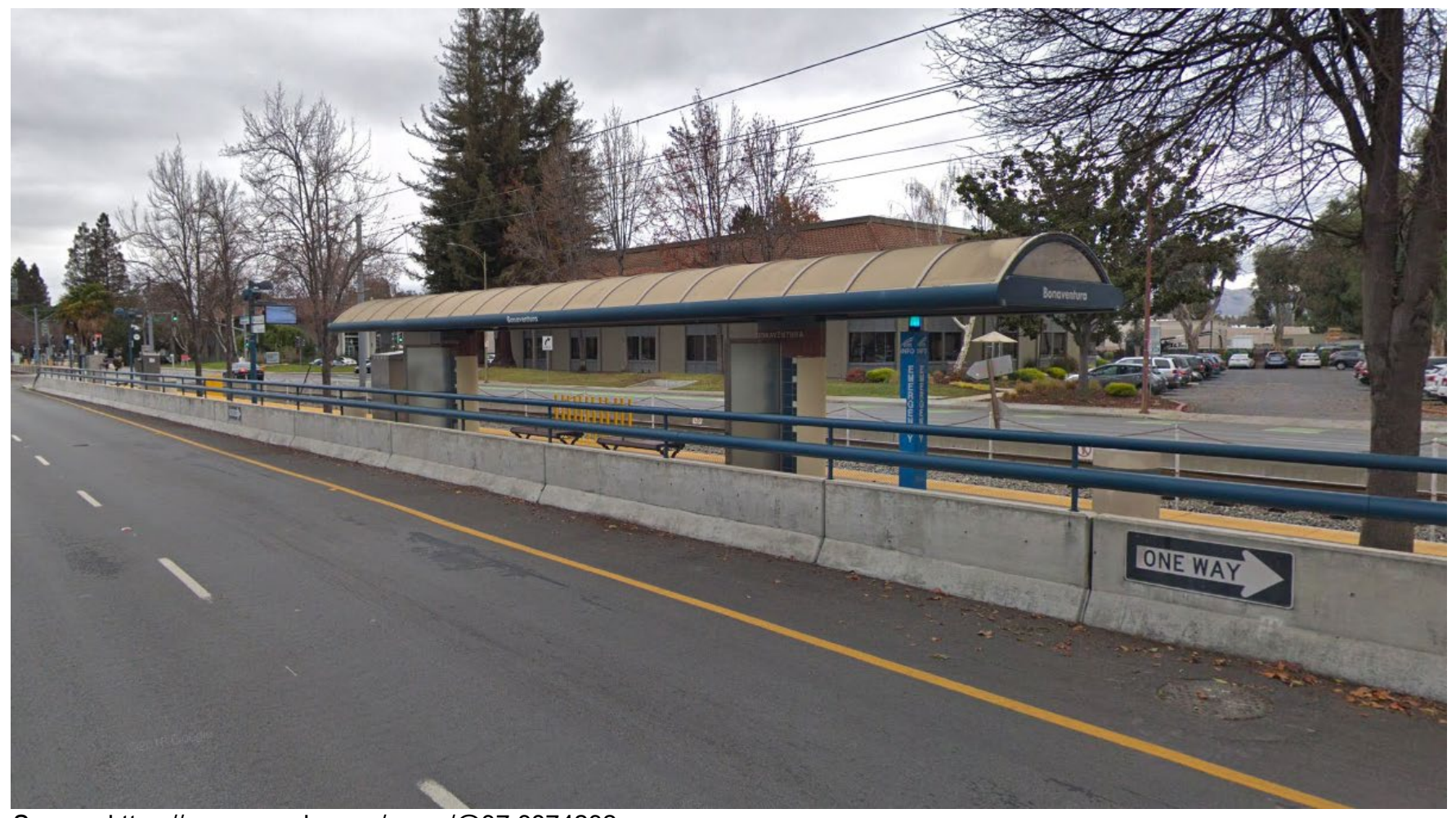

Source: https://www.google.com/maps/@37.3874232,-

121.9290004,3a,60y,27.29h,84.76t/data=!3m6!1e1!3m4!1sGPCh5xe3xviSenYNIvezBA!2e0!7i16384!8i8192

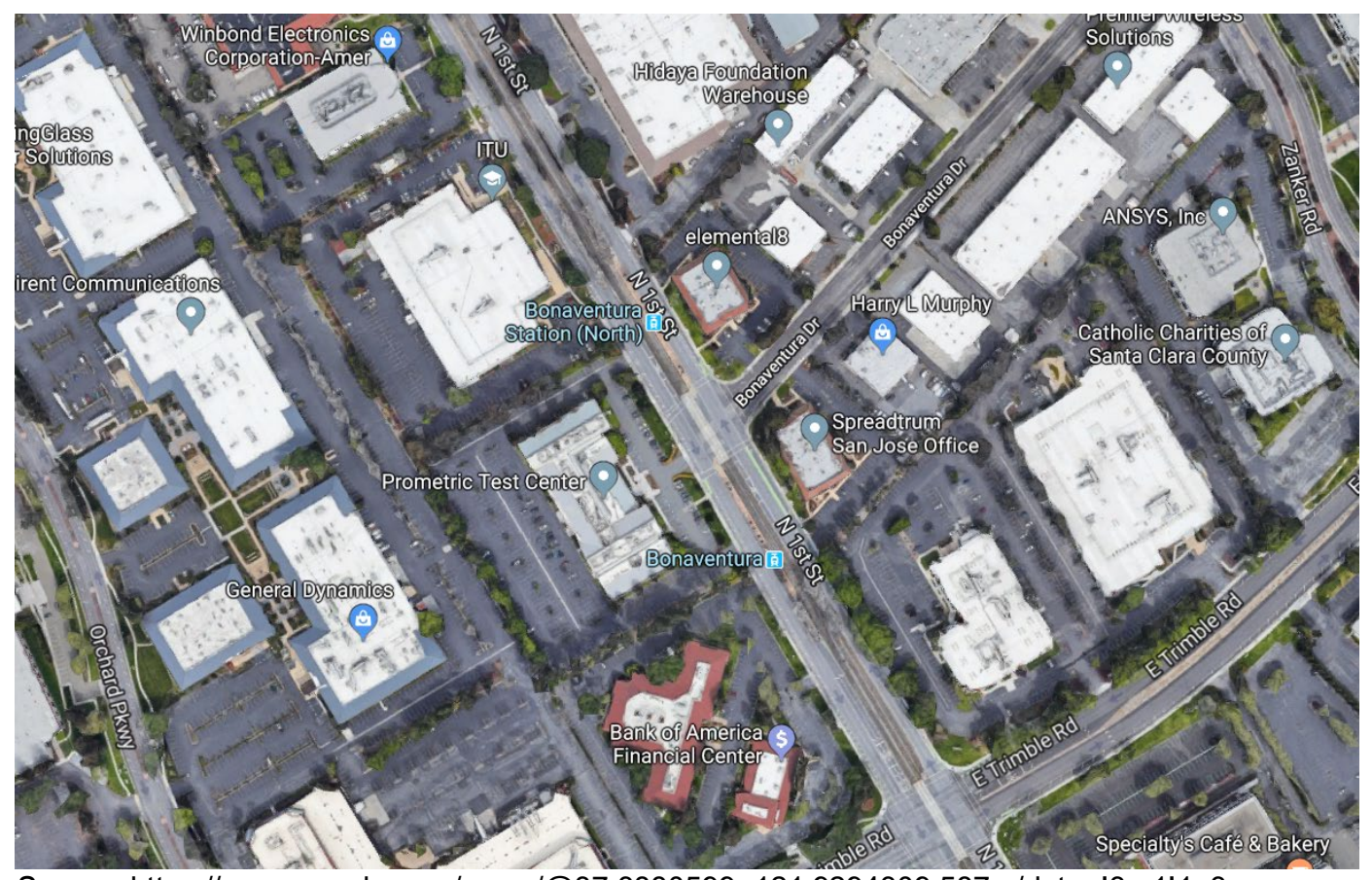

Source: https://www.google.com/maps/@37.3880599,-121.9294309,587m/data=!3m1!1e3 


\section{North 1st Street}

San Jose, California, 95134

Commute to Downtown Santa Clara

$11 \mathrm{~min} 44 \mathrm{~min} 26 \mathrm{~min} \quad$ i $60+\mathrm{min}$ View Routes

Favorite $\mathbb{D}$ Map (O) Nearby Apartments

Looking for a home for sale in San Jose? 쭝

\section{Walk Score Car-Dependent}

29 Most errands require a car.

Transit Score Good Transit

51 Many nearby public

transportation options.

Bikescore Very Bikeable

73

About your score

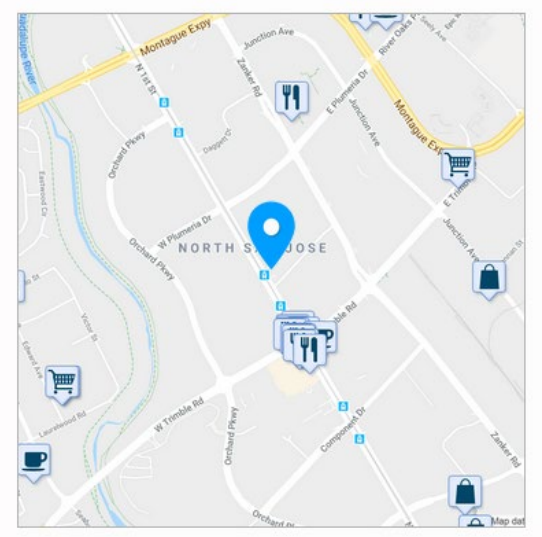

Source: https://www.walkscore.com/score/2680-n-1st-st-san-jose-ca-95134

This station in the greater San Jose area is located in the middle of a four-lane road. Additionally, Bonaventura Station is in a heavily commercial and industrial area and looks daunting to users. 


\section{Sacramento}

\section{8th St Station}

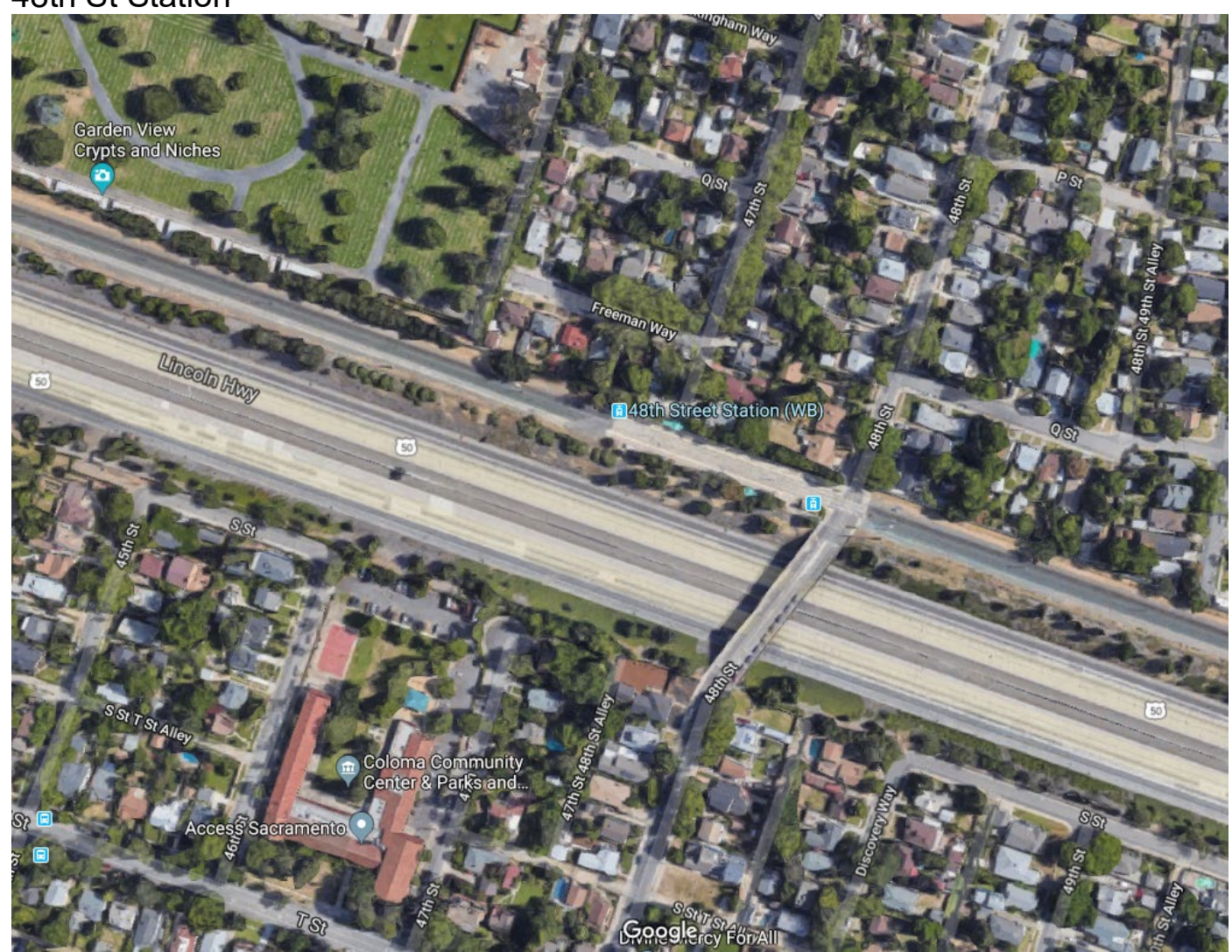

Source: https://www.google.com/maps/@38.5585449,-121.4491221,515m/data=!3m1!1e3

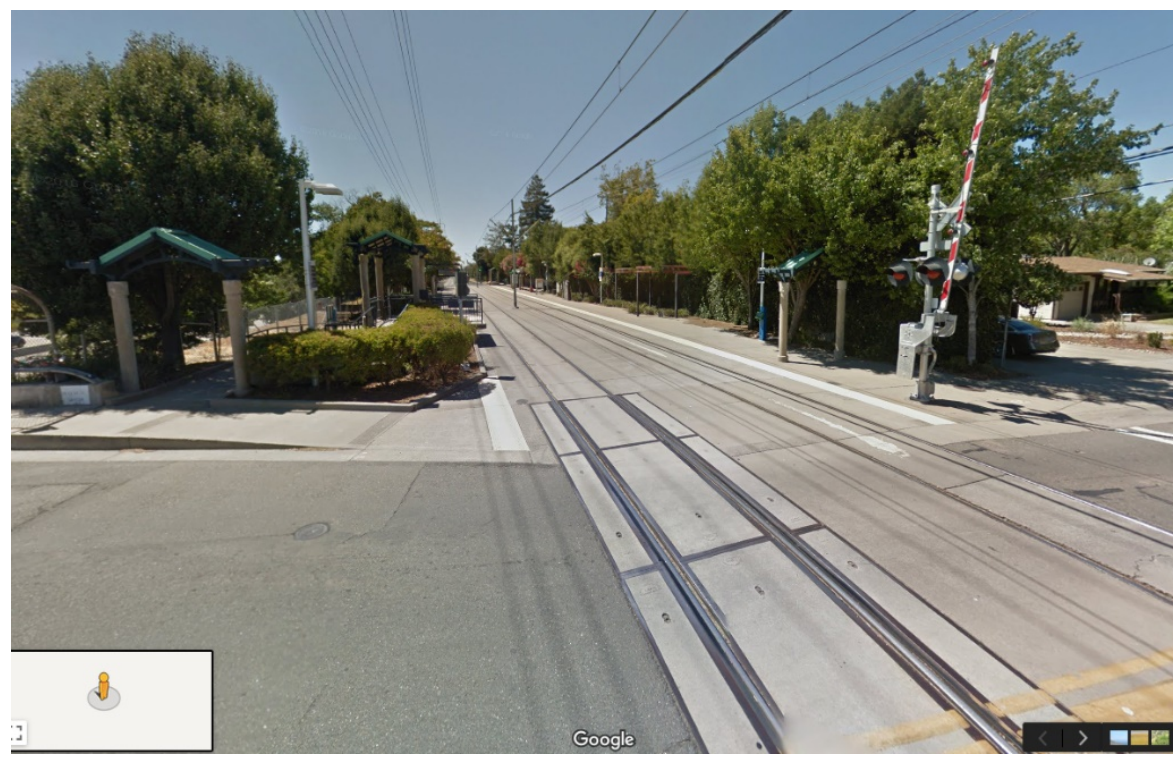

Source: https://www.google.com/maps/@38.5581819,-

121.4480943,3a,60y,272.08h,90t/data=!3m6!1e1!3m4!1s15CQclpYacGA2ECTaaca3w!2e0!7i13312!8i6656 


\section{Somewhat Walkable}

East Sacramento, Sacramento, 95819

Commute to Downtown Sacramento

$28 \mathrm{~min} 19 \mathrm{~min} \quad 200+$ min View Routes

Favorite $\quad$ Map $\bigcirc$ Nearby Apartments

Looking for a home for sale in Sacramento? 줍

Walk Score Somewhat Walkable

65 Some errands can be

accomplished on foot

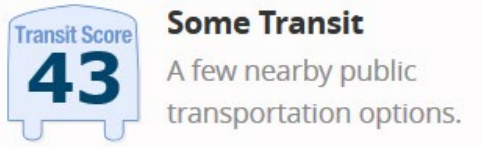

Bike Score $\}$ Very Bikeable

About your score

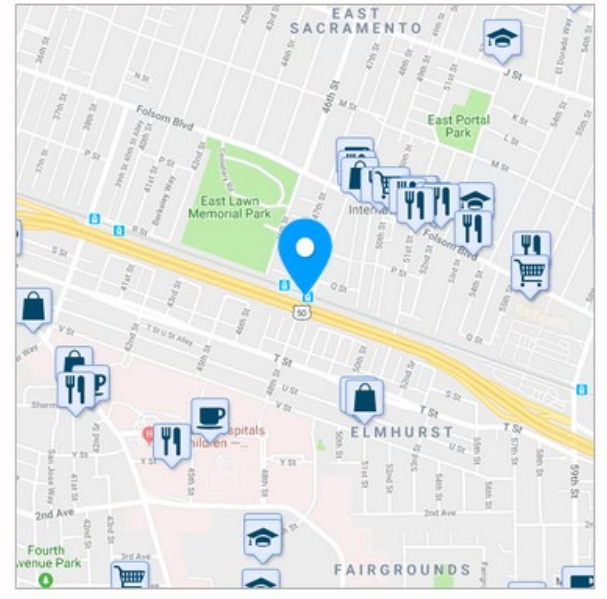

Source: https://www.walkscore.com/score/1740-48th-st-sacramento-ca-95819

The $48^{\text {th }}$ Street Station in Sacramento, California is not only located just above a major highway but in an area where retail is not a major element. Additionally, the area is not walkable and likely not a destination for those who do not live close nearby. 


\section{Good Retail}

\section{Buffalo}

Lafayette Station

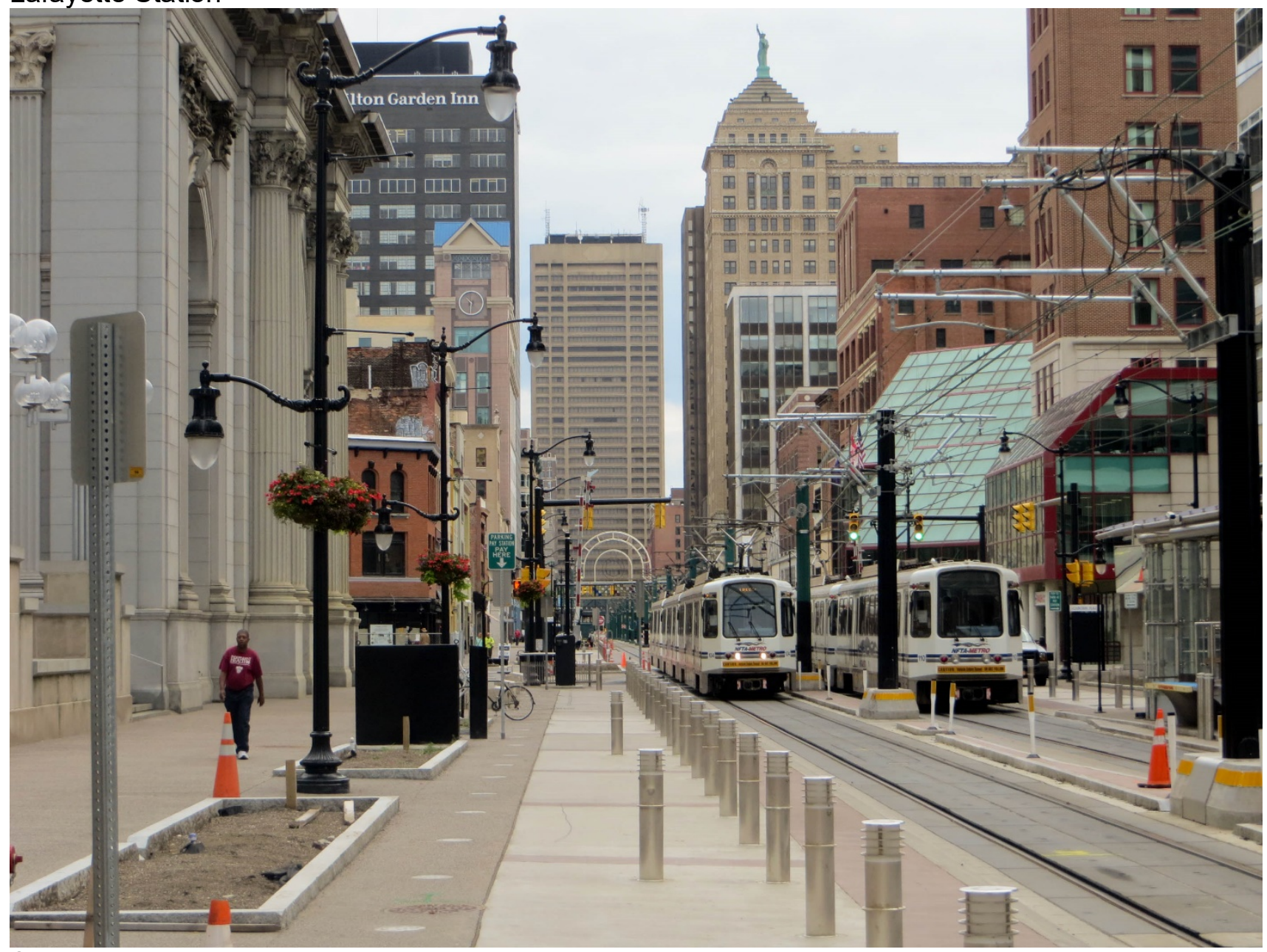

Source:

https://en.wikipedia.org/wiki/Buffalo Metro Rail\#/media/File:20150827 61 NFTA Light Rail at Fountain Plaza (21990211710).jpg 


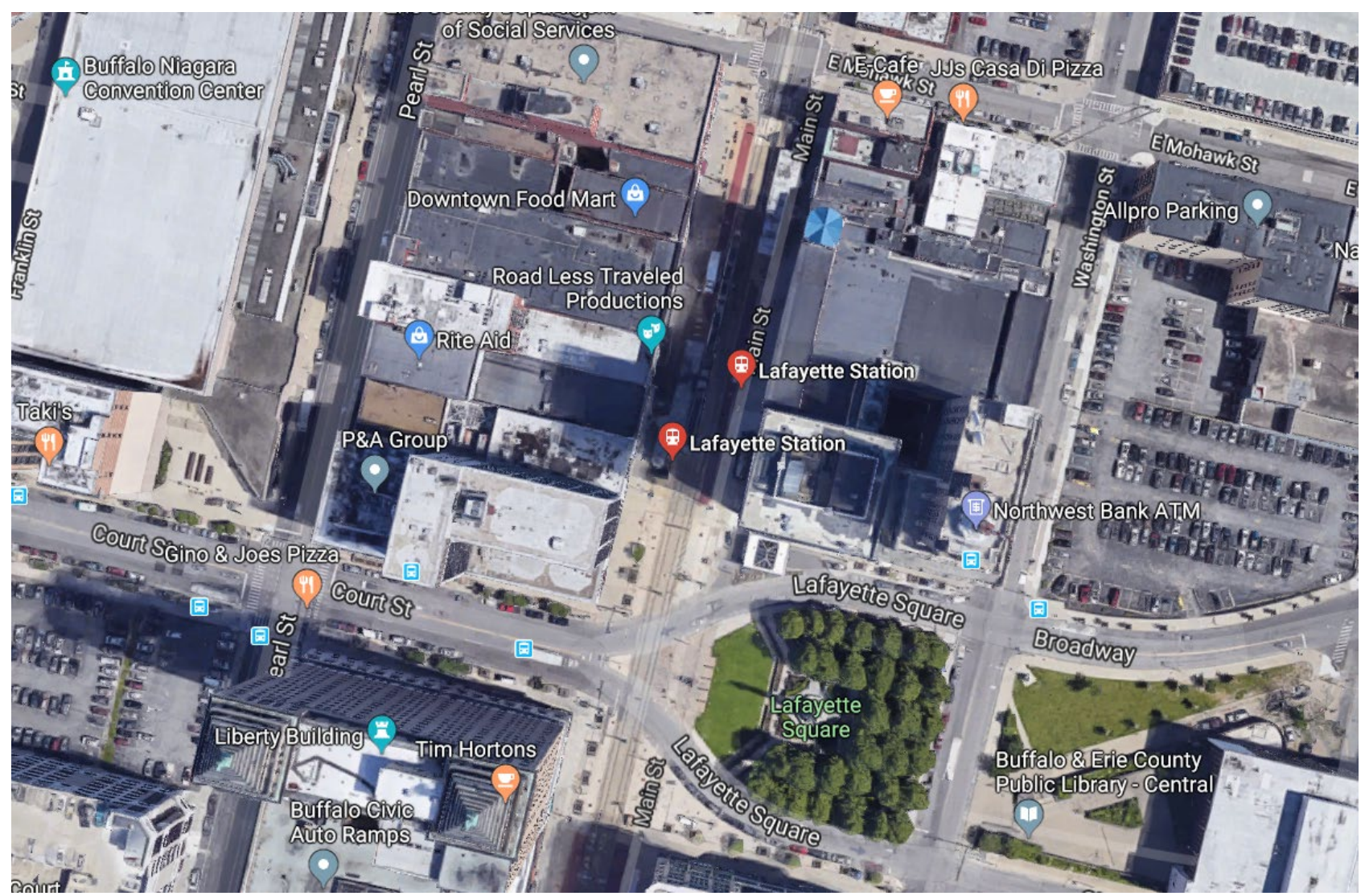

Source: https://www.google.com/maps/search/light+rail+stop/@42.8862939,-78.8740207,277m/data=!3m1!1e3

\section{Walker's Paradise?}

Central Business District, Buffalo

Commute to Downtown Buffalo

$1 \mathrm{~min} 4 \mathrm{~min}$. 1 min $6 \mathrm{~min}$ View Routes

Favorite D Map Q Nearby Apartments

Looking for a home for sale in Buffalo? [יㅜㄹ

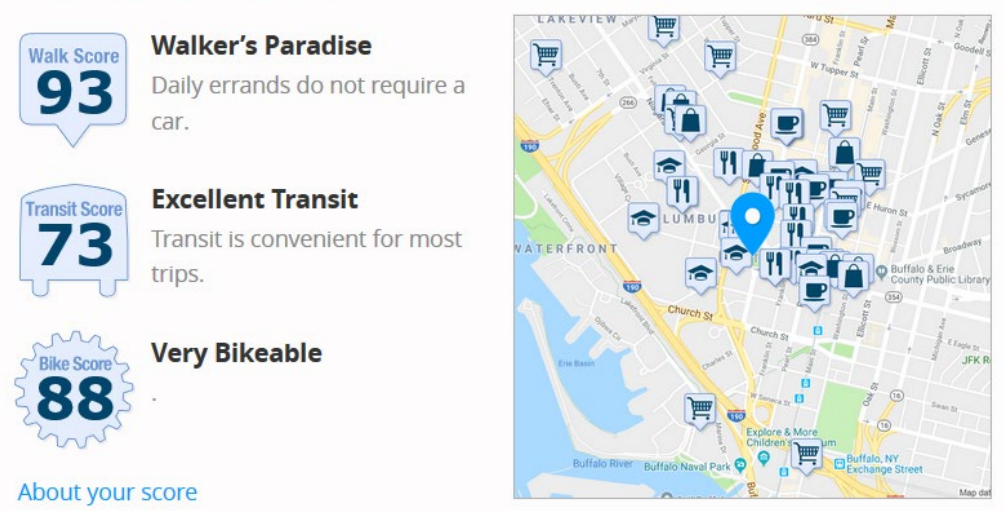

Source: https://www.walkscore.com/score/489-main-street-buffalo

Right in downtown Buffalo, Lafayette Station not only offers commuters easy access to the central business district but allows for people to enjoy dining and shopping options steps from the station 


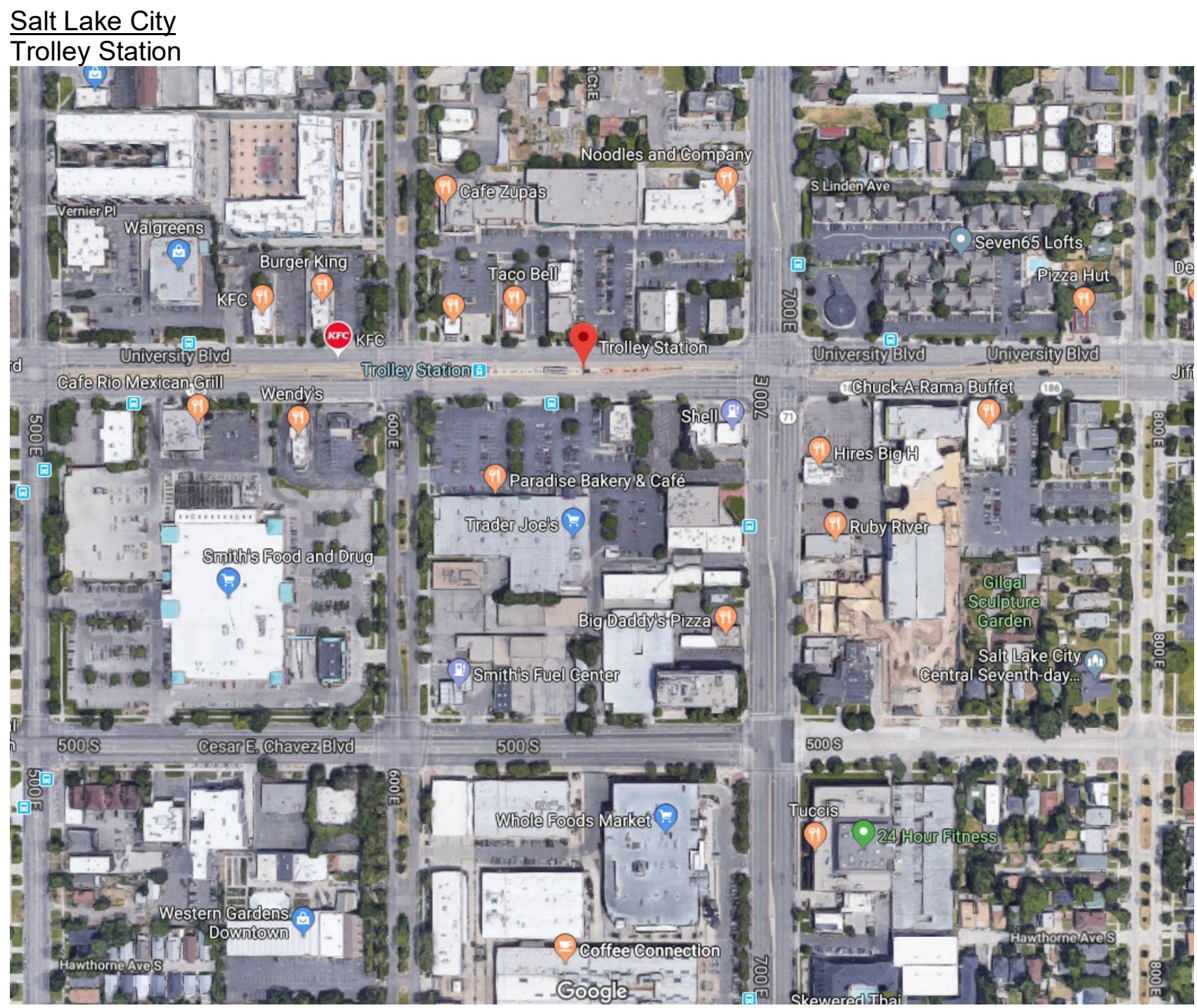

Source: https://www.google.com/maps/place/Trolley+Station/@40.7598346,-

111.8724531,666m/data=!3m1!1e3!4m5!3m4!1s0x8752f5693caa0ba9:0x5191b560b3aee6fa!8m2!3d40.760663!4d-

111.8725267 


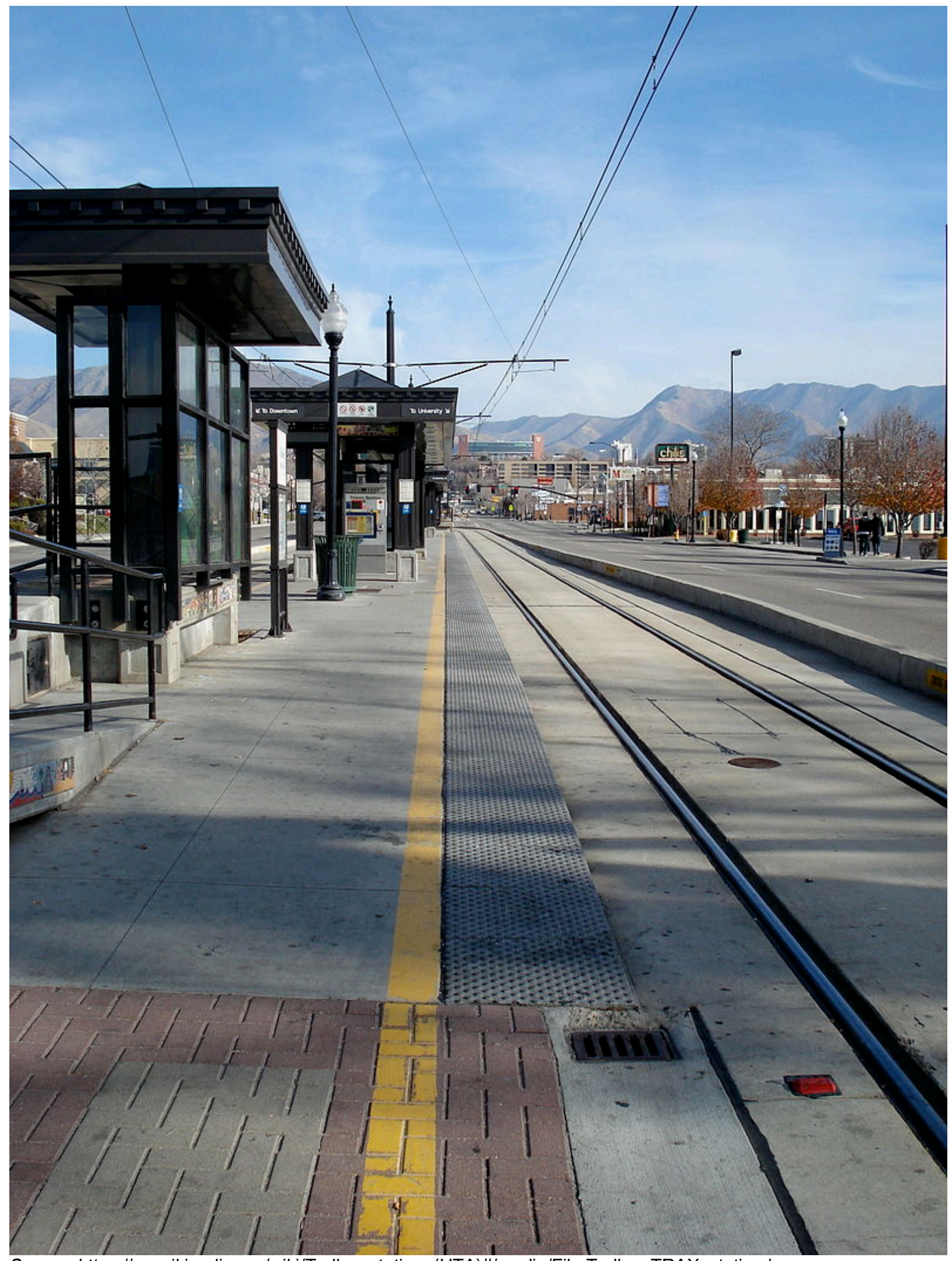

Source: https://en.wikipedia.org/wiki/Trolley_station_(UTA)\#/media/File:Trolley_TRAX_station.jpg 


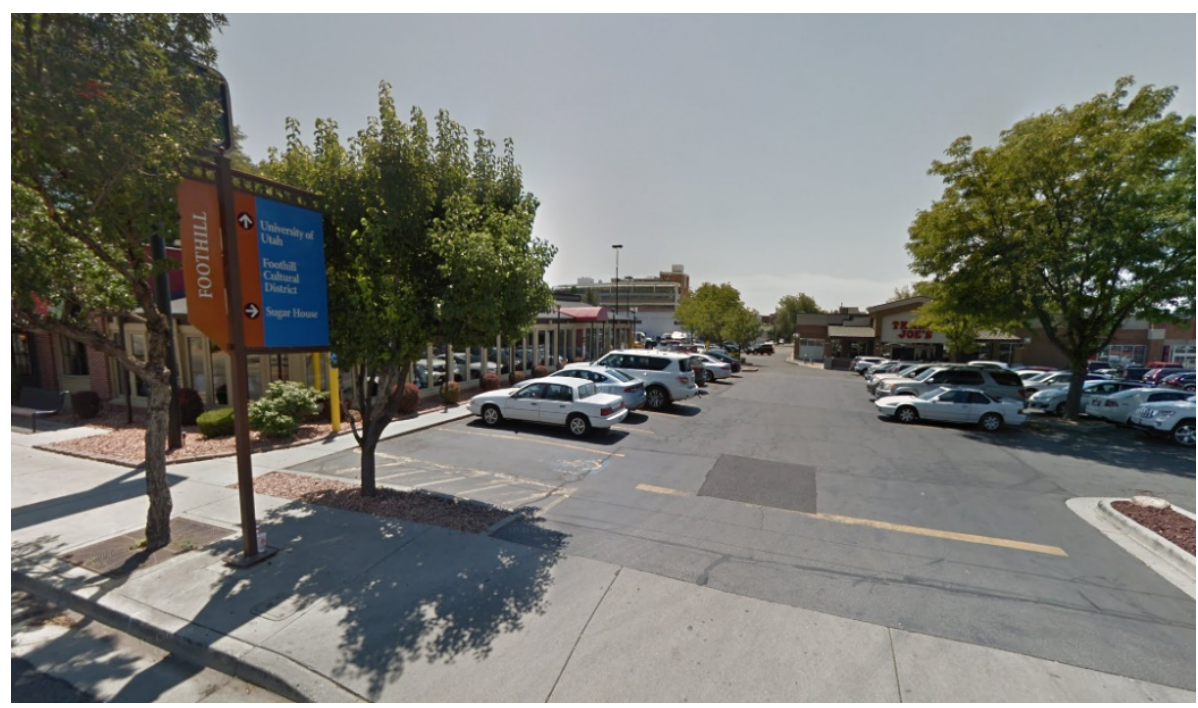

Source: https://www.google.com/maps/@40.7602023,-

111.8725206,3a,75y,243.18h,82.85t/data=!3m6!1e1!3m4!1ssj5HIApqA0KWUuJb0vE1RQ!2e0!7i13312!8i6656

\section{Walker's Paradise \\ Central City, Salt Lake City, 84102 \\ Commute to Downtown Salt Lake City \\ Looking for a home for sale in Salt Lake City? 뚱

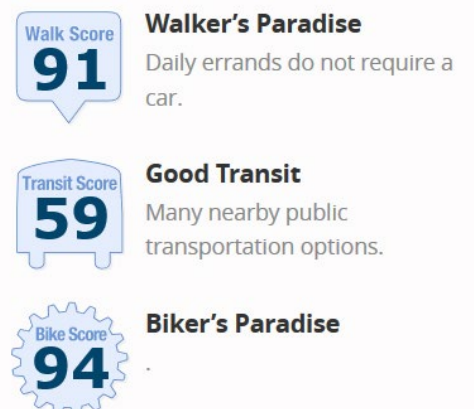

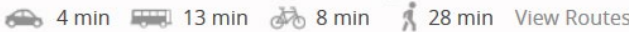

$\checkmark$ Favorite $\mathbb{W}$ Map @ Nearby Apartments

About your score

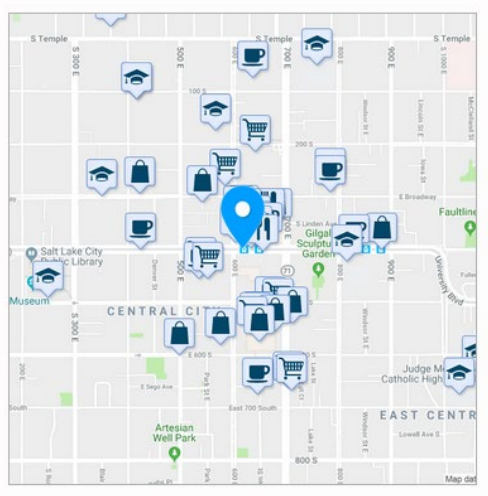

Source: https://www.walkscore.com/score/605-e-400-s-salt-lake-city-ut-84102

The Trolley Station in Salt Lake City, Utah is located between downtown and the University of Utah. It is easily accessible from many existing retail options, making it an ideal location for potential users and investors. 


\section{Bad Retail}

\section{Virginia Beach \\ Ingleside Road Station}

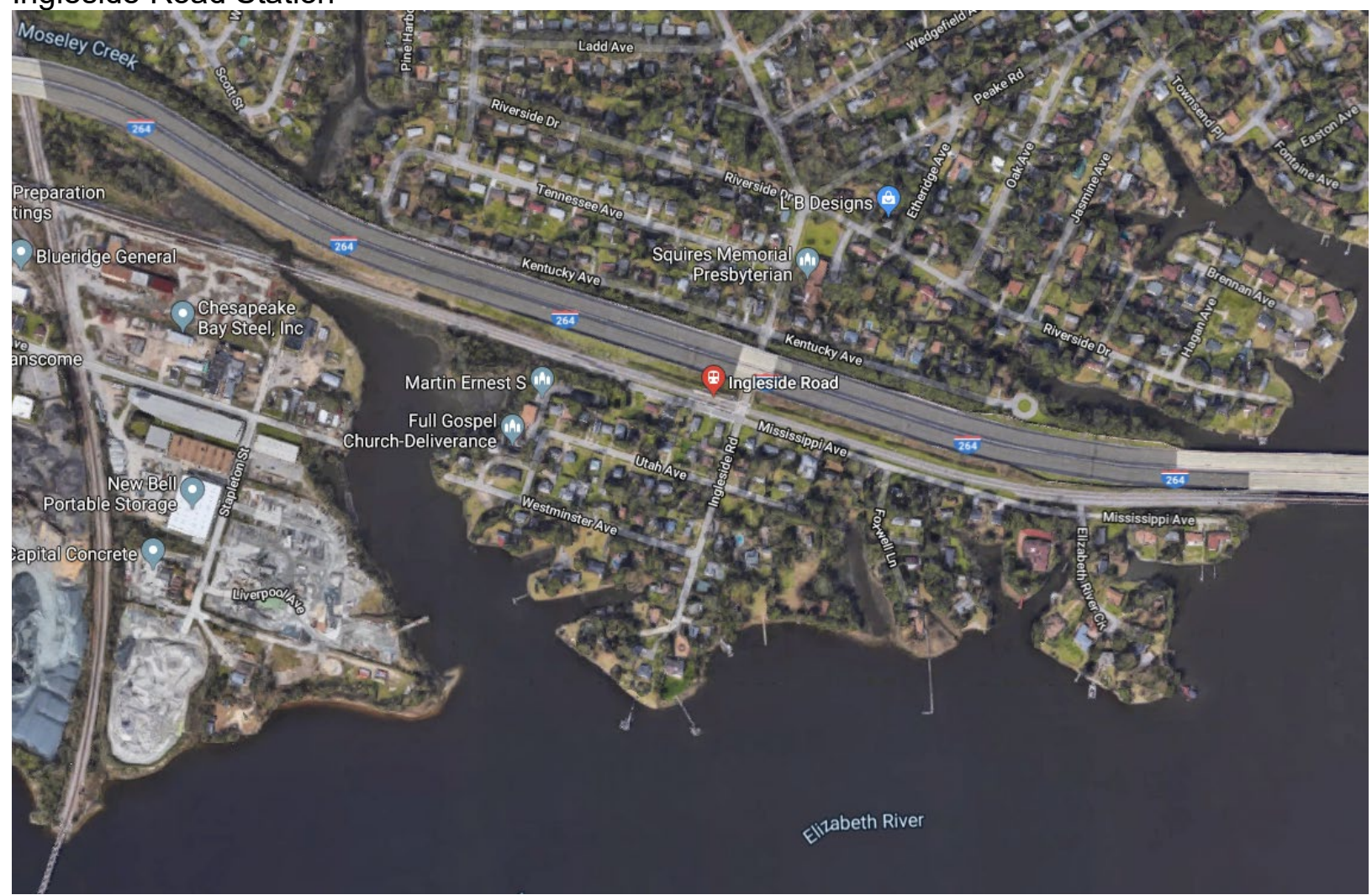

Source: https://www.google.com/maps/search/tide+light+rail+stations+virginia/@36.8420384,$76.2352878,1202 \mathrm{~m} /$ data $=! 3 \mathrm{~m} 1 ! 1 \mathrm{e} 3$ 


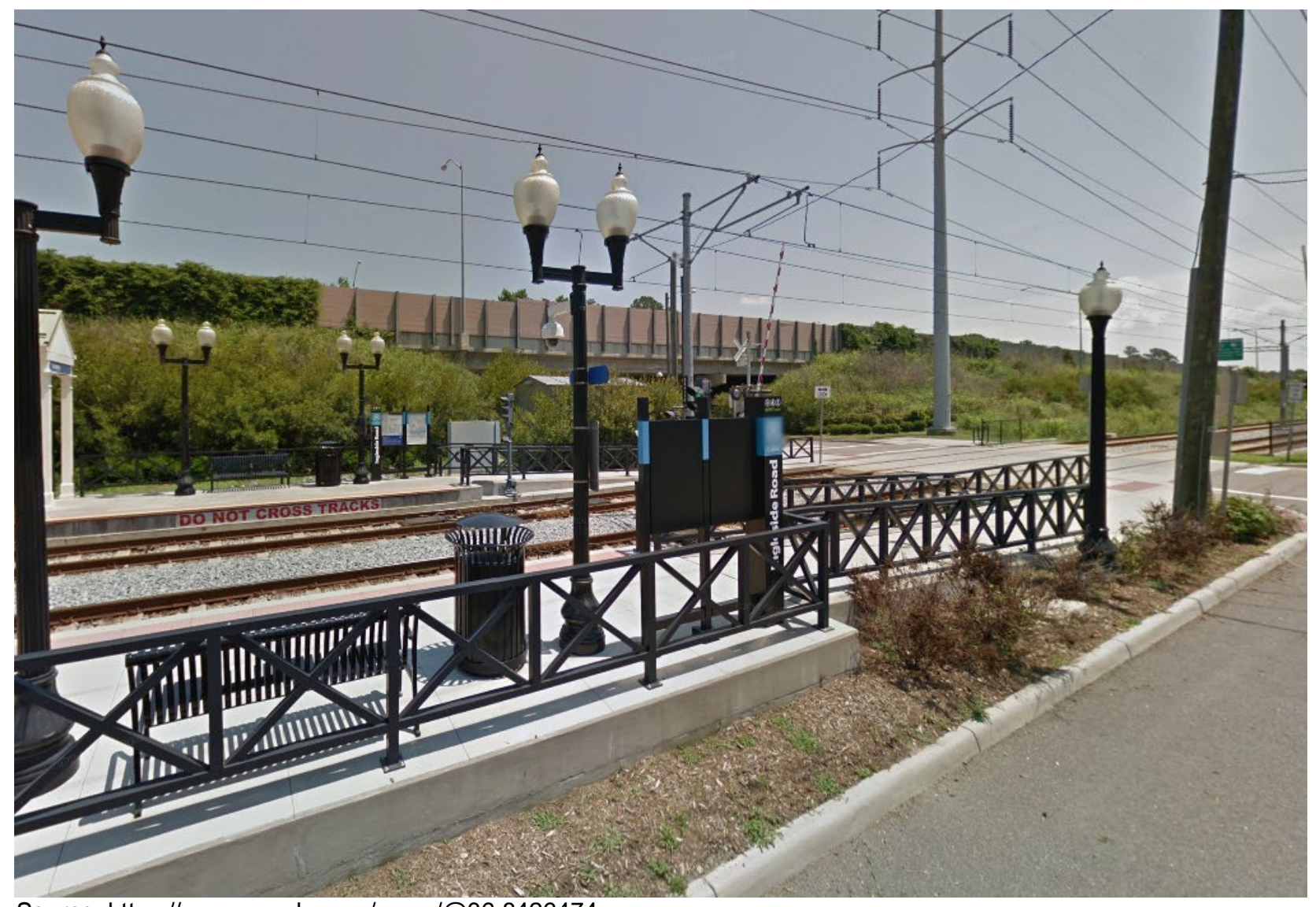

Source: https://www.google.com/maps/@36.8426474,-

76.234997,3a,60y,90t/data=!3m6!1e1!3m4!1sSE8Zzz5zkQjdrSZiTEQfLw!2e0!7i13312!8i6656 


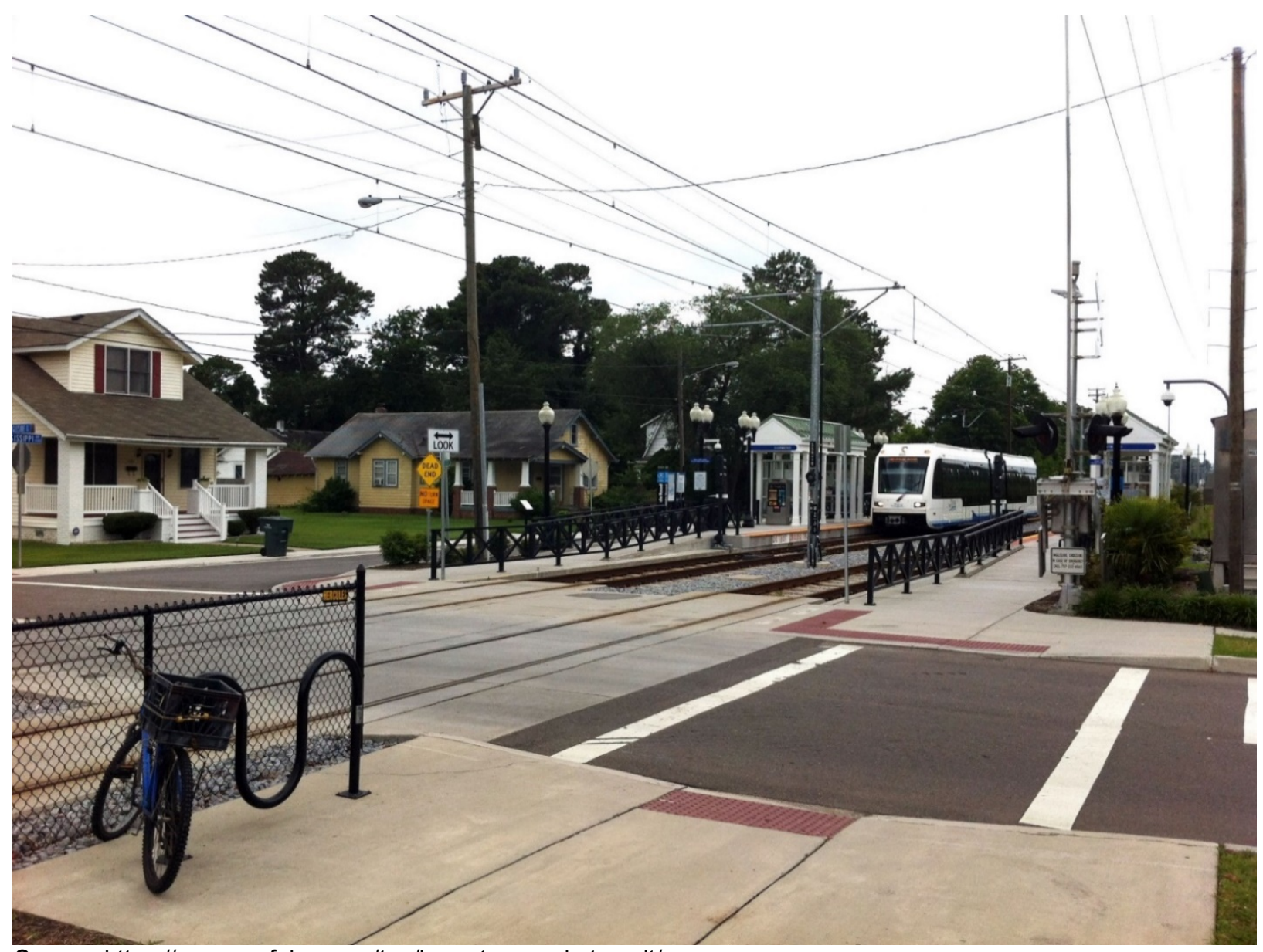

Source: https://www.gmfplus.com/tag/hampton-roads-transit/ 


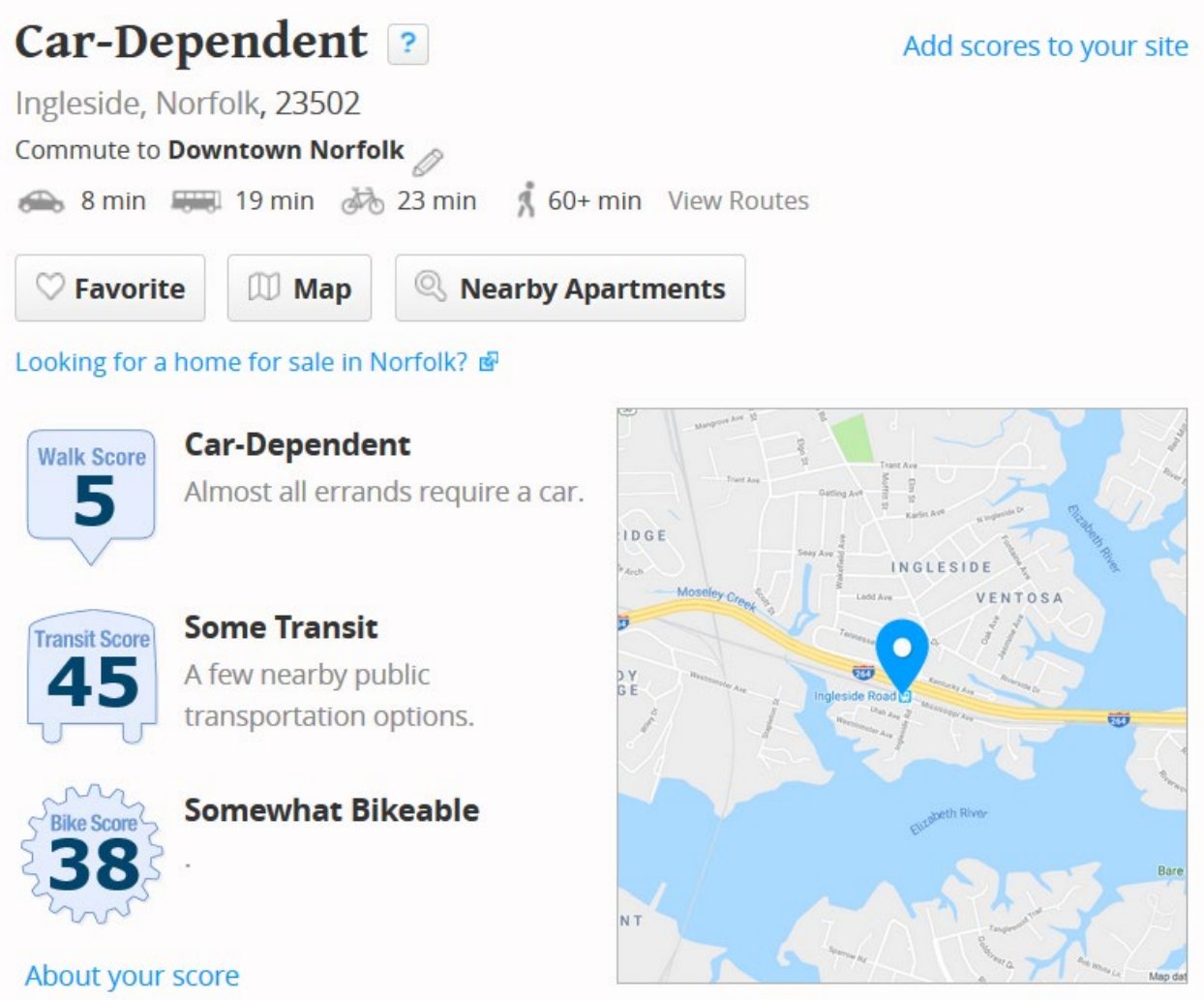

Source: https://www.walkscore.com/score/ingleside-road-station

The Ingleside Road Station in Norfolk, Virginia is located just off interstate 264 in an area not suitable for retail, and certainly not a retail destination. 


\section{San Diego}

\section{Harborside Station}

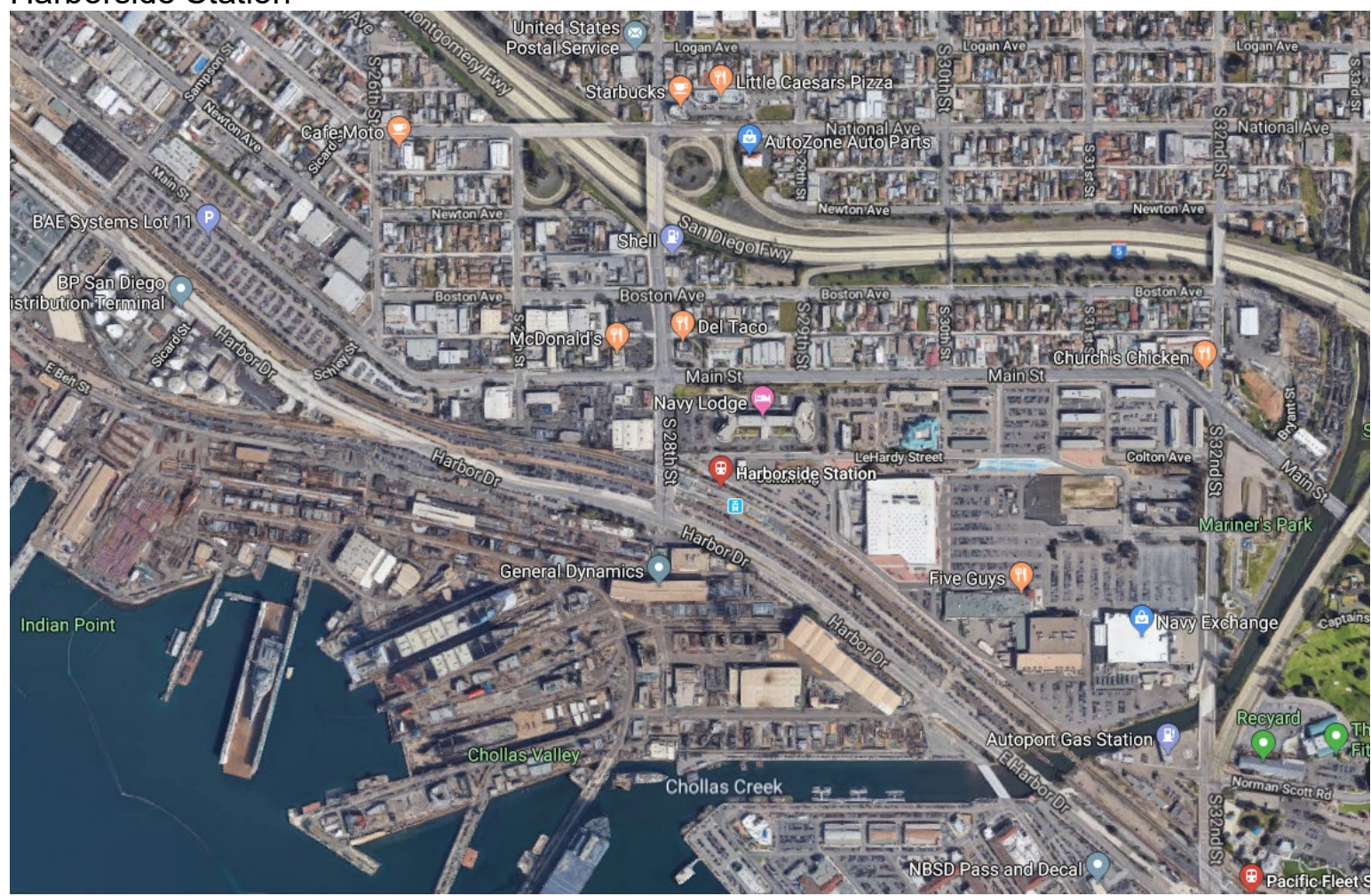

Source: https://www.google.com/maps/search/san+diego+trolley+stations/@32.6916006,$117.1335951,1543 \mathrm{~m} /$ data $=! 3 \mathrm{~m} 1 ! 1 \mathrm{e} 3$ 


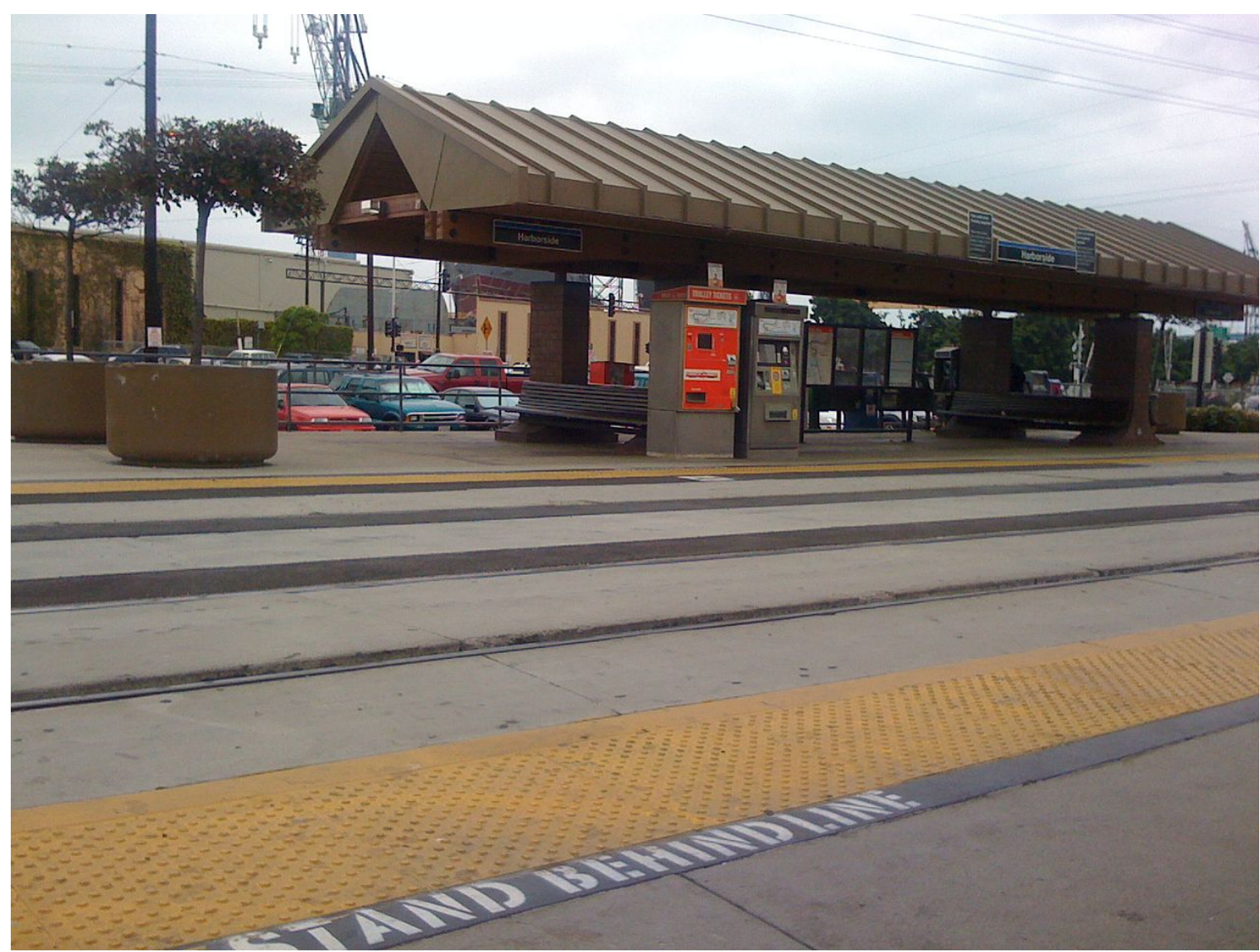

Source: https://en.wikipedia.org/wiki/Harborside_station_(San_Diego_Trolley)\#/media/File:Harborside_Station.JPG 


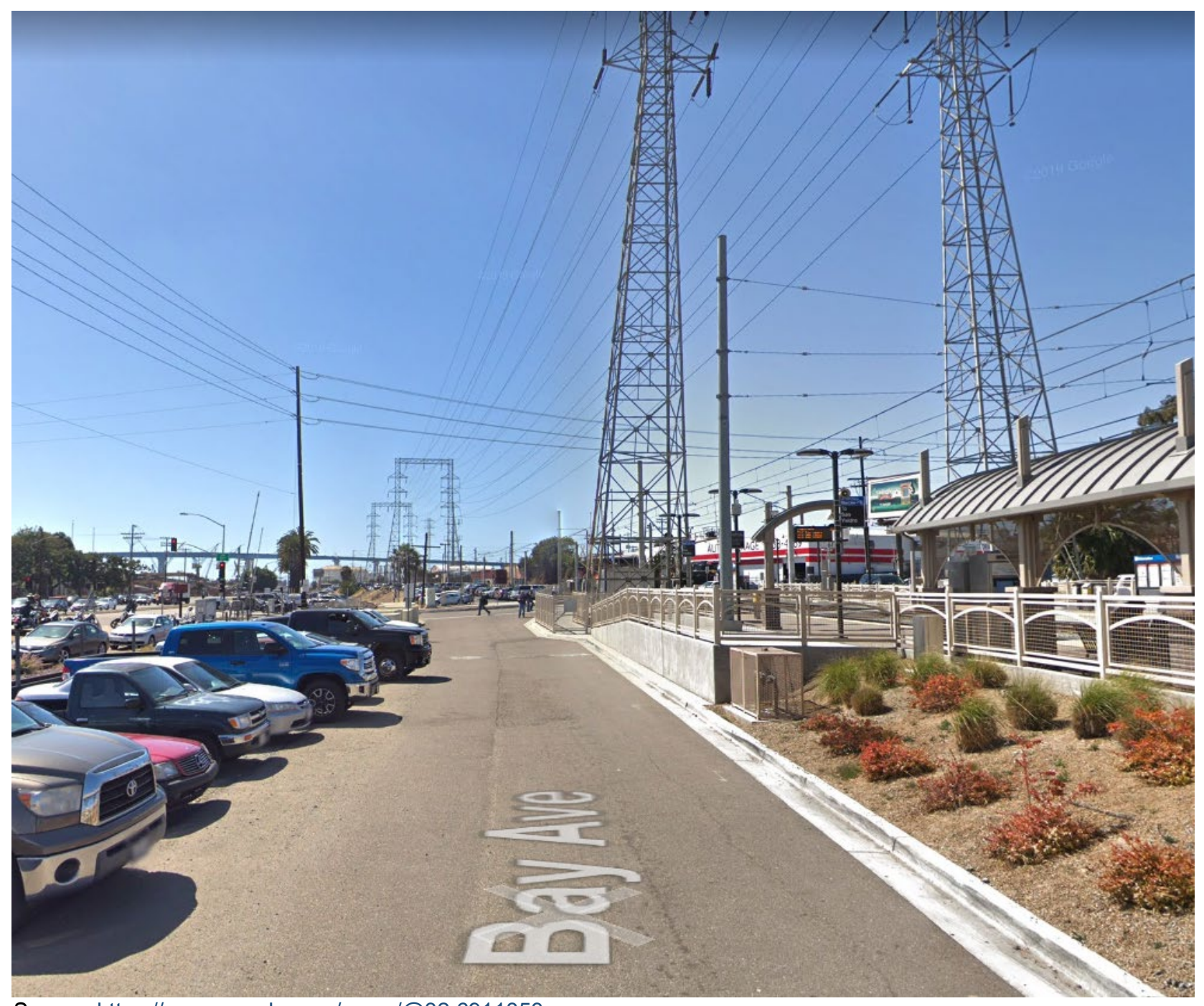

Source: https://www.google.com/maps/@32.6911853,-

117.1329973,3a,75y,293.31h,94.79t/data=!3m6!1e1!3m4!1sq5nKh5K9KmWx09vzQxA-Xg!2e0!7i16384!8i8192 
Barrio Logan, San Diego, 92113

Commute to Downtown National City

$\Leftrightarrow 6 \mathrm{~min} 23 \mathrm{~min}$ ob $15 \mathrm{~min} \quad$ i $49 \mathrm{~min}$ View Routes

Favorite W Map Q Nearby Apartments

Looking for a home for sale in San Diego? 중

55

\section{Somewhat Walkable}

Some errands can be

accomplished on foot.

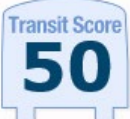

\section{Good Transit}

Many nearby public

transportation options.

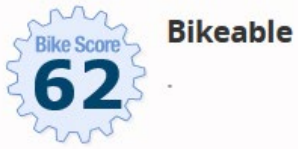

About your score

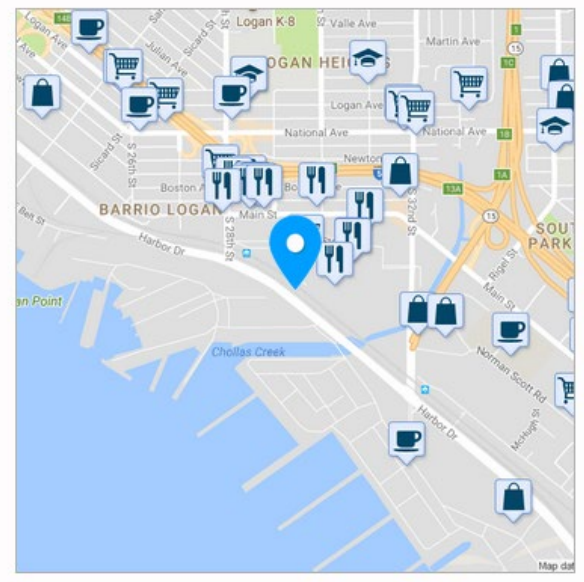

Source: https://www.walkscore.com/score/harborside-station-san-diego

The Harborside Station in San Diego is located in a heavy industrial area near the Port of San Diego, and the station is dated and uninviting. Retail uses nearby would likely not thrive.

\section{BUS RAPID TRANSIT Good Office}

Kansas City

$10^{\text {th }} \&$ Main Station 


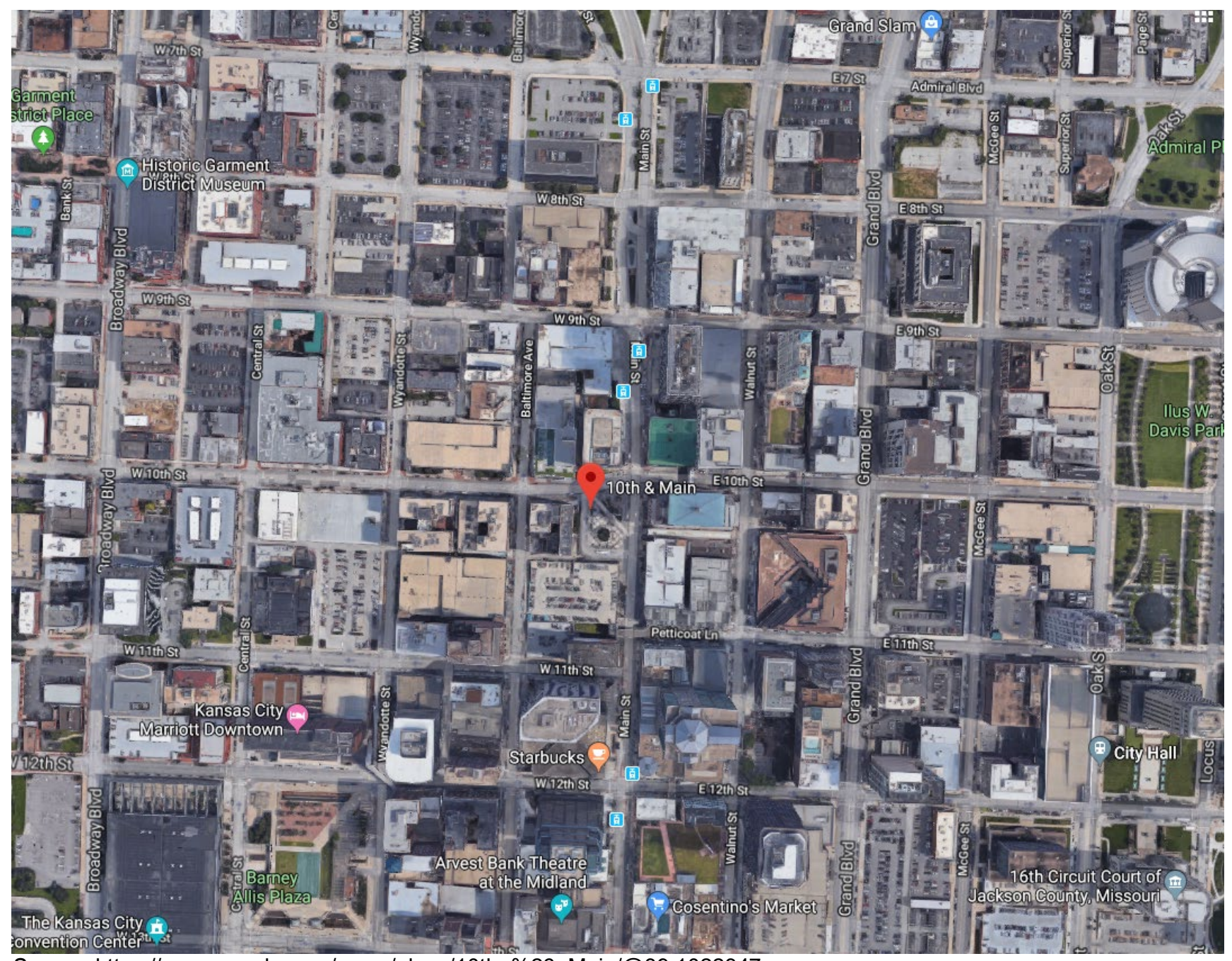

Source: https://www.google.com/maps/place/10th+\%26+Main/@39.1022347,-

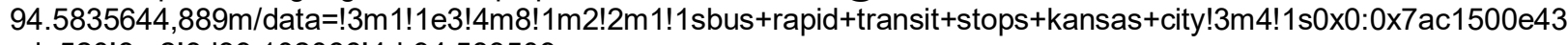
cda520!8m2!3d39.102066!4d-94.583509 


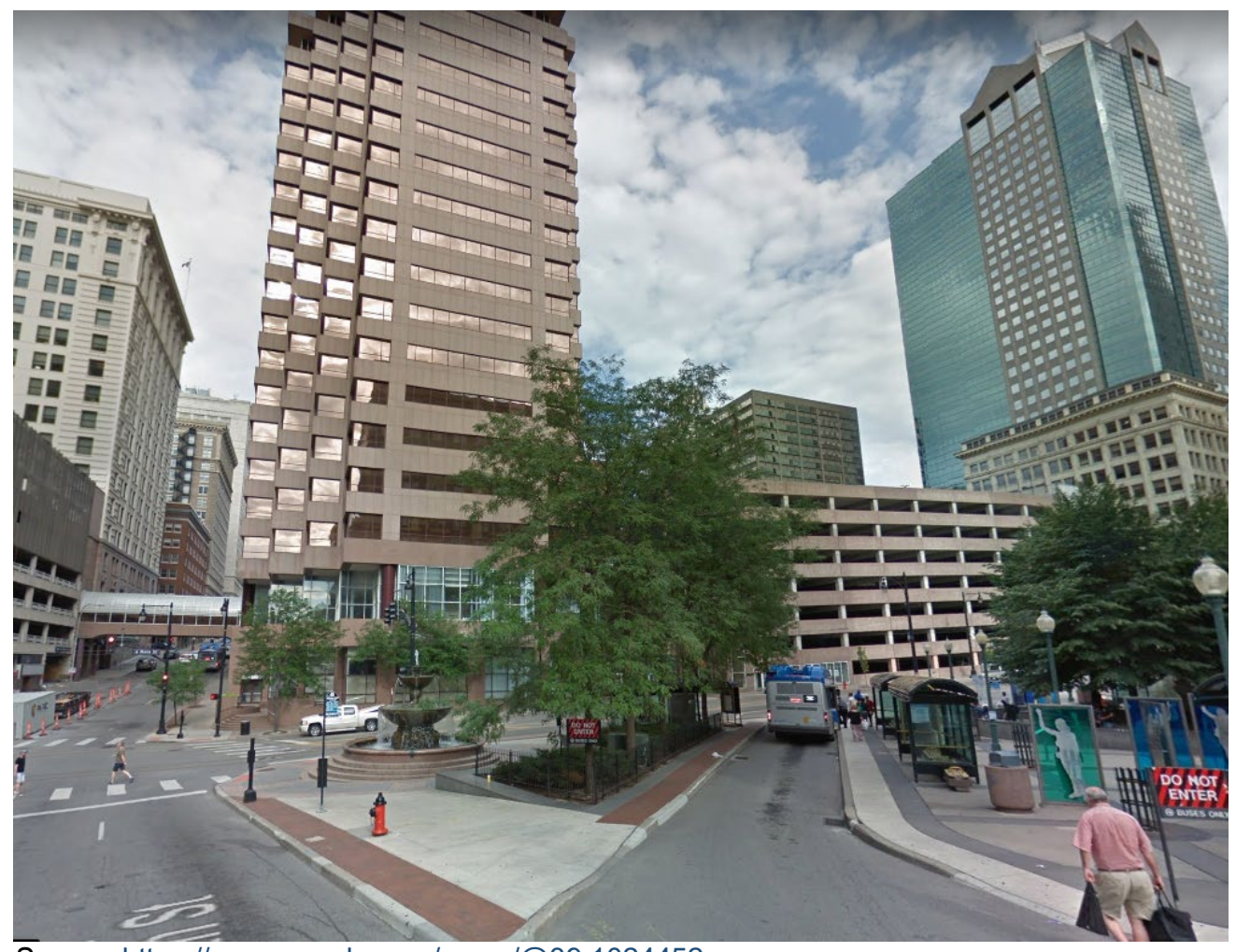

Source: https://www.google.com/maps/@39.1024452,-

$\underline{94.583126,3 a, 75 y, 111.76 h, 101.27 t / d a t a=! 3 m 6 ! 1 e 1 ! 3 m 4 ! 1 s c d k r i G e x d B r D w 507 g C 8 T U A ! 2 e 0 ! 7 i 13312 ! 8 i 6656 ~}$ 


\section{Main Street}

Downtown Loop, Kansas City, 64105
Commute to Downtown Kansas City

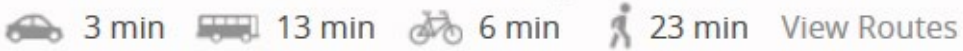

\section{$\checkmark$ Favorite 10 Map $\&$ Nearby Apartments}

Looking for a home for sale in Kansas City? «

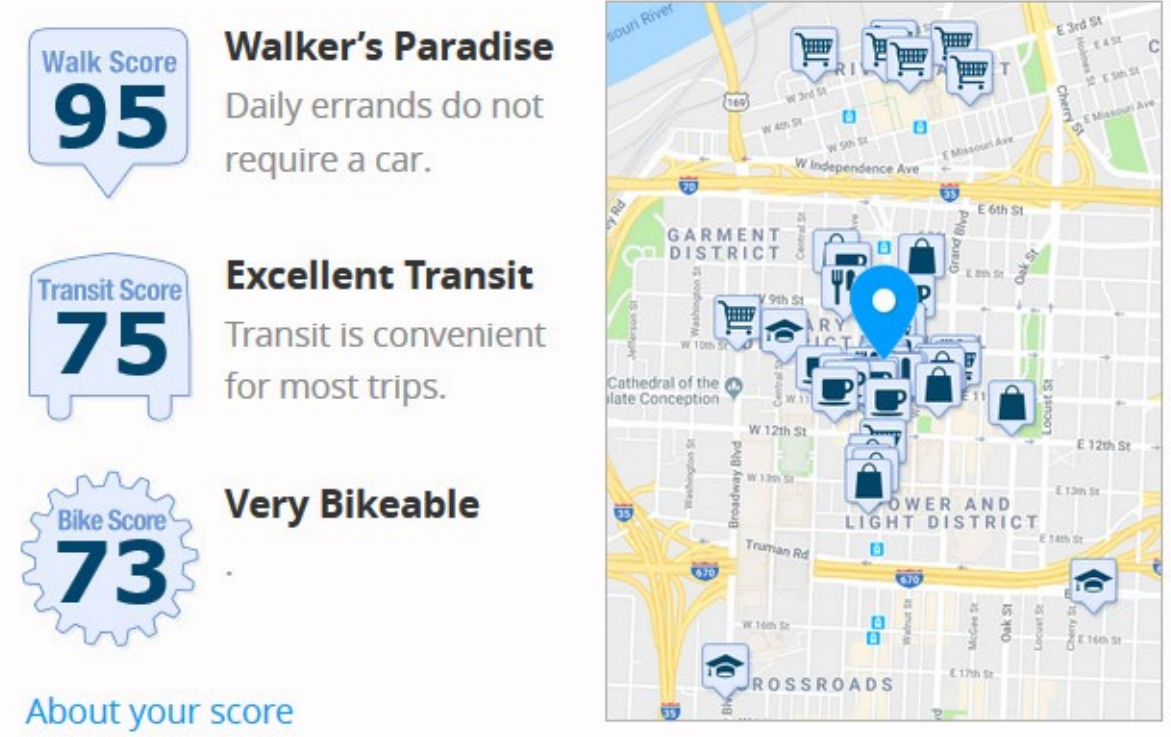

Add scores to your site

Source: https://www.walkscore.com/score/1020-main-st-kansas-city-mo-64105

The $10^{\text {th }}$ and Main Station along Kansas City's BRT line is ideal for office tenants because many employees are able to commute via bus and end their journey within a short walk of many major employers.

\section{San Jose}

Santa Clara \& $1^{\text {st }}$ 


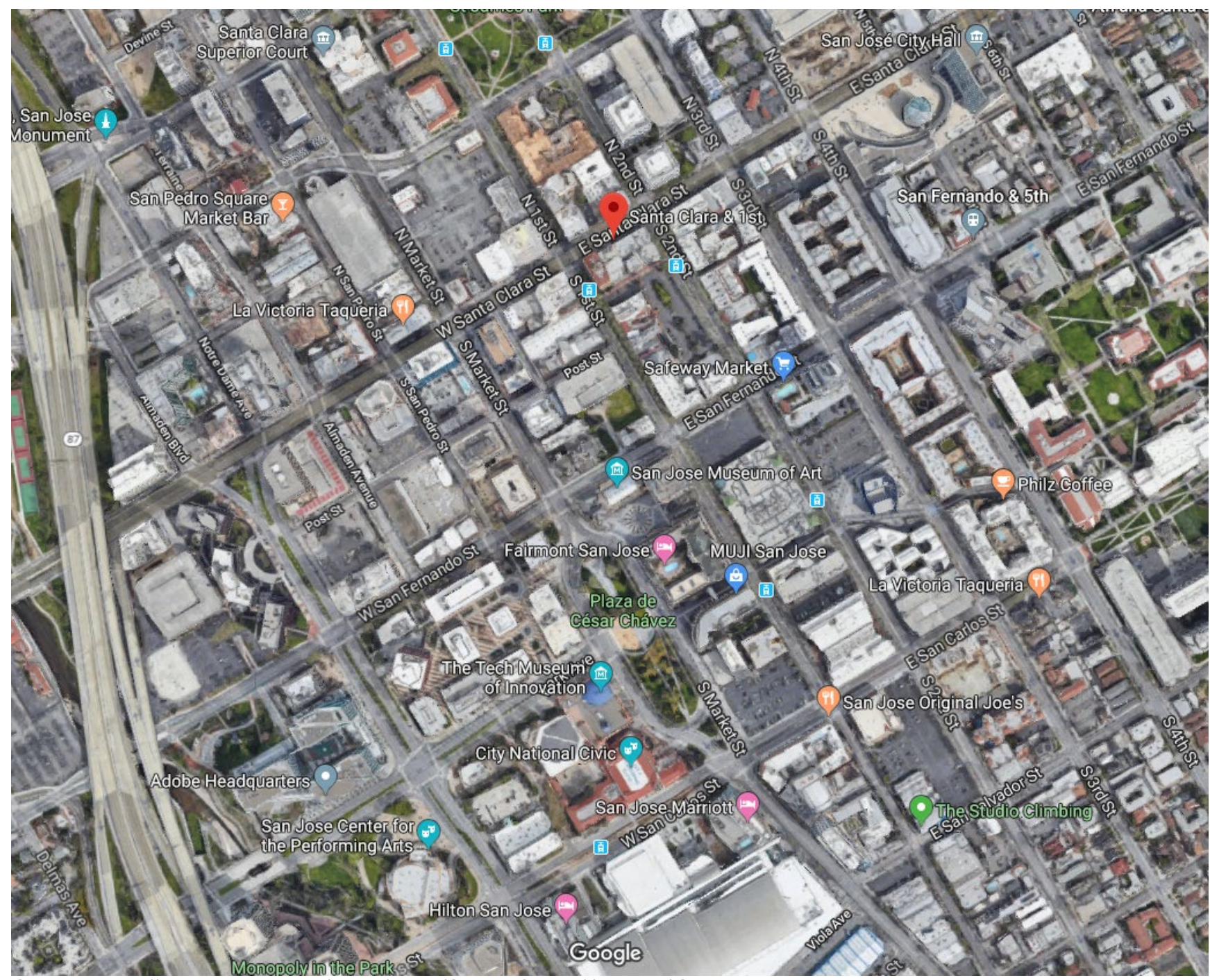

Source: https://www.google.com/maps/place/Santa+Clara+\%26+1st/@37.3340008,-

121.8900695,1222m/data=!3m1!1e3!4m5!3m4!1s0x808fccbcd0334635:0xa361fdb5ffa497cd!8m2!3d37.336336!4d121.8899779 


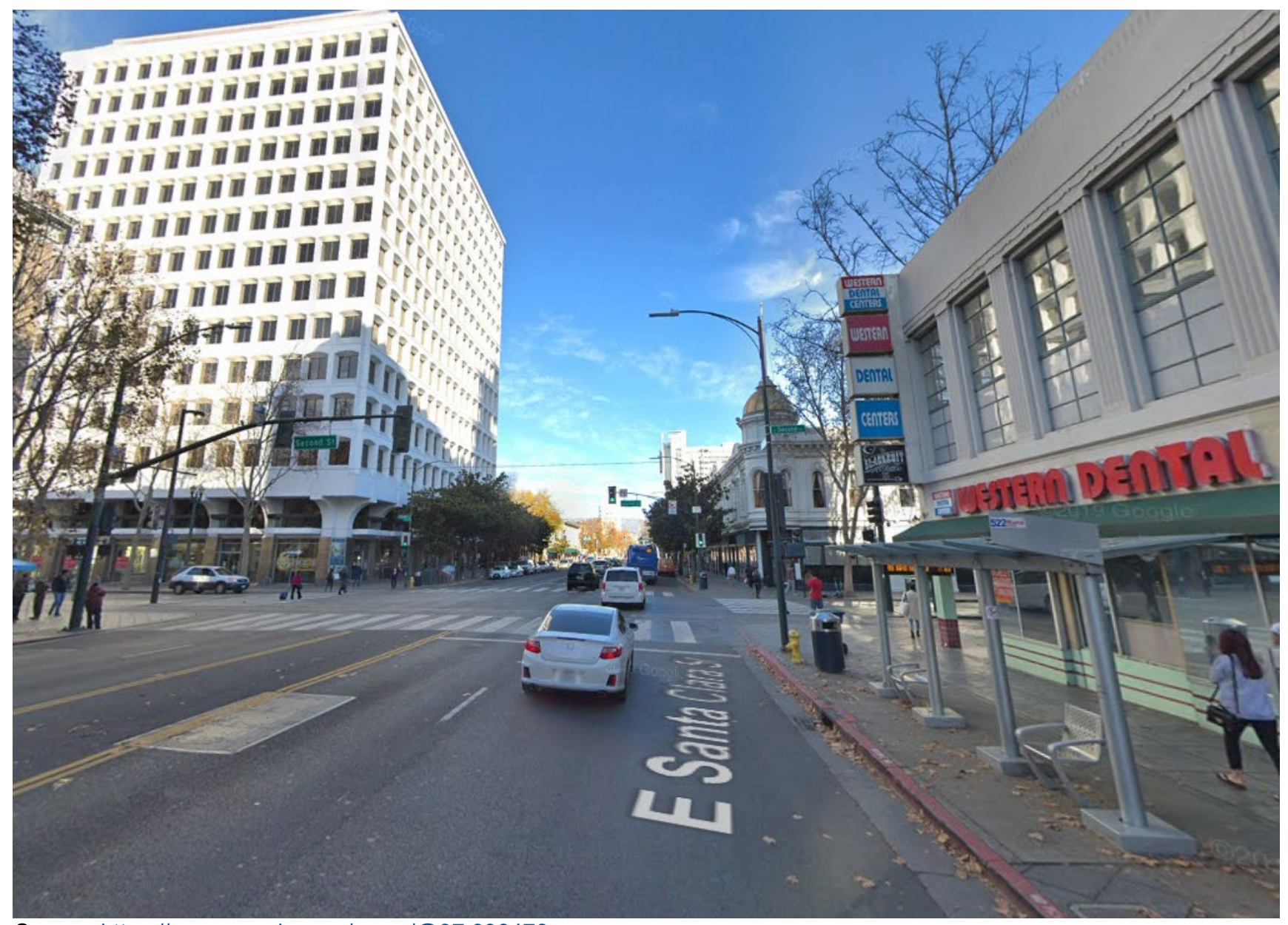

Source: https://www.google.com/maps/@37.336478,-

121.8897791,3a,90y,51.86h,103.1t/data=!3m6!1e1!3m4!1sJgKh6m7VBXyTReyQvdwVog!2e0!7i16384!8i8192 


\section{South 1st Street}

Downtown, San Jose, 95113

Commute to Downtown San Jose

$\Leftrightarrow 1 \mathrm{~min} 3 \mathrm{~min}$. $14 \mathrm{~min}$ View Routes

\section{Favorite W Map O Nearby Apartments}

Looking for a home for sale in San Jose? 줄

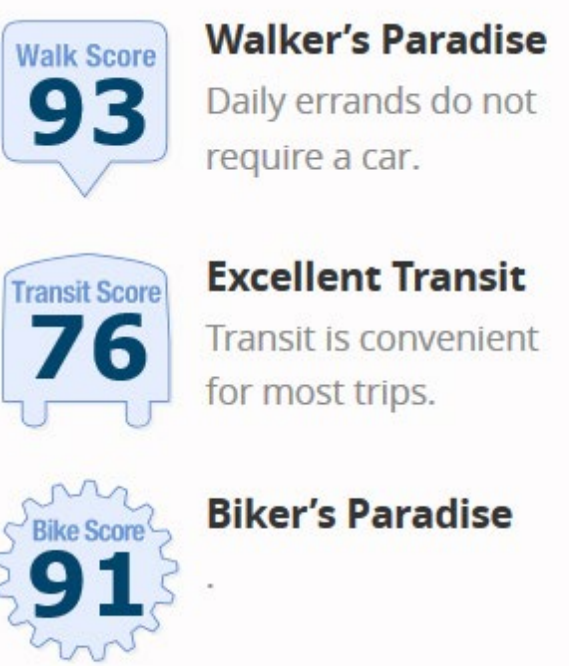

About your score

Add scores to your site

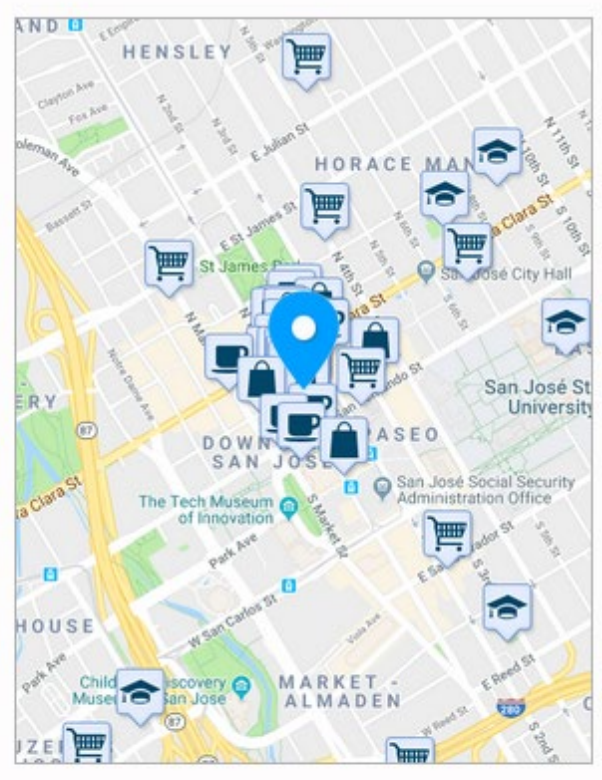

Source: https://www.walkscore.com/score/52-s-1st-st-san-jose-ca-95113

The Santa Clara \& First Station along a BRT route is located in downtown San Jose, near Adobe's headquarters and other major office areas. 


\section{Bad Office}

\section{Reno}

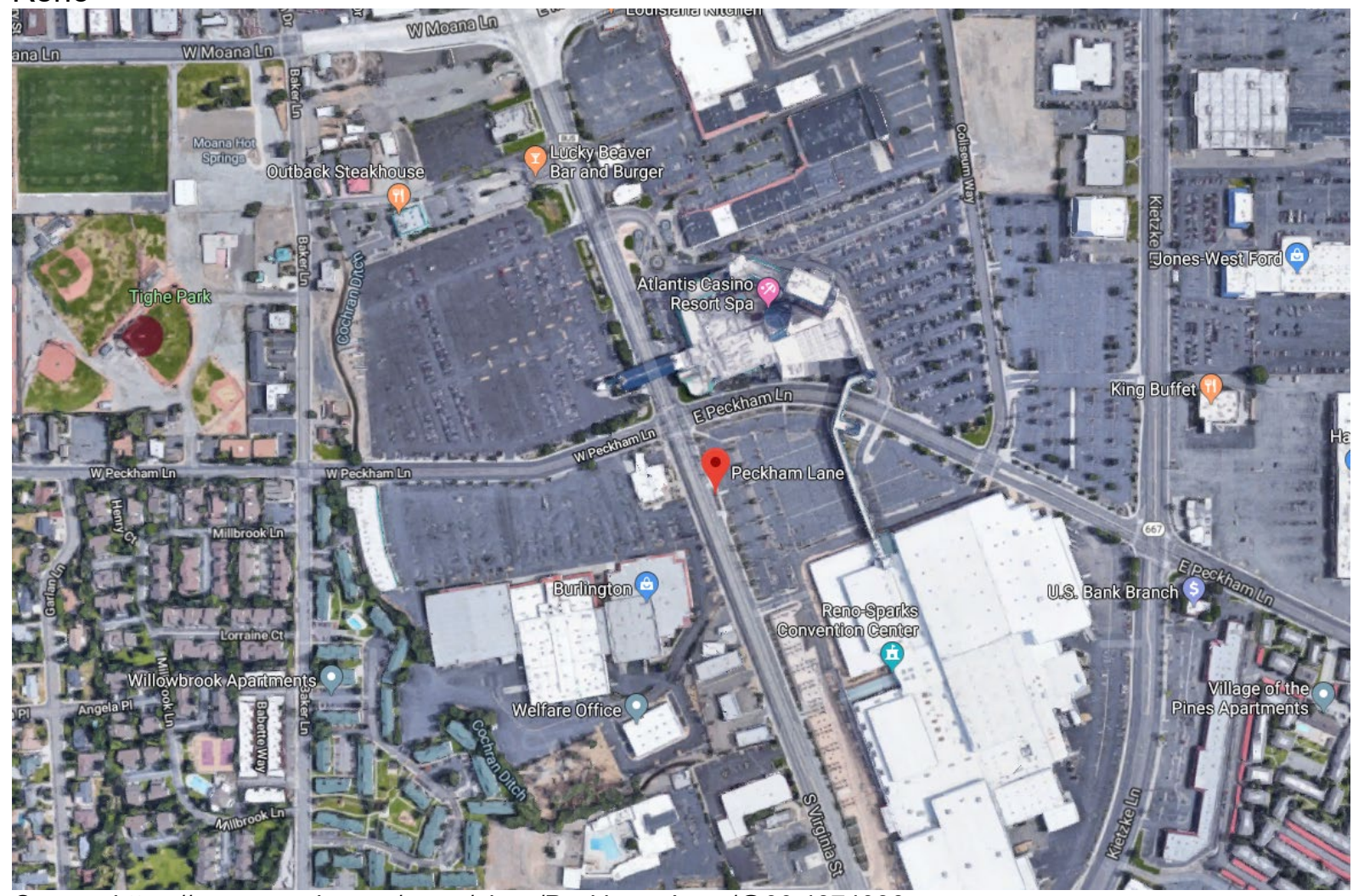

Source: https://www.google.com/maps/place/Peckham+Lane/@39.4874986,119.7944312,1000m/data=!3m1!1e3!4m8!1m2!2m1!1sbus+stop!3m4!1s0x809940797a3587f3:0x5ae89992b34c78cd! $8 \mathrm{~m} 2 ! 3 \mathrm{~d} 39.487395 ! 4 \mathrm{~d}-119.7940803$ 


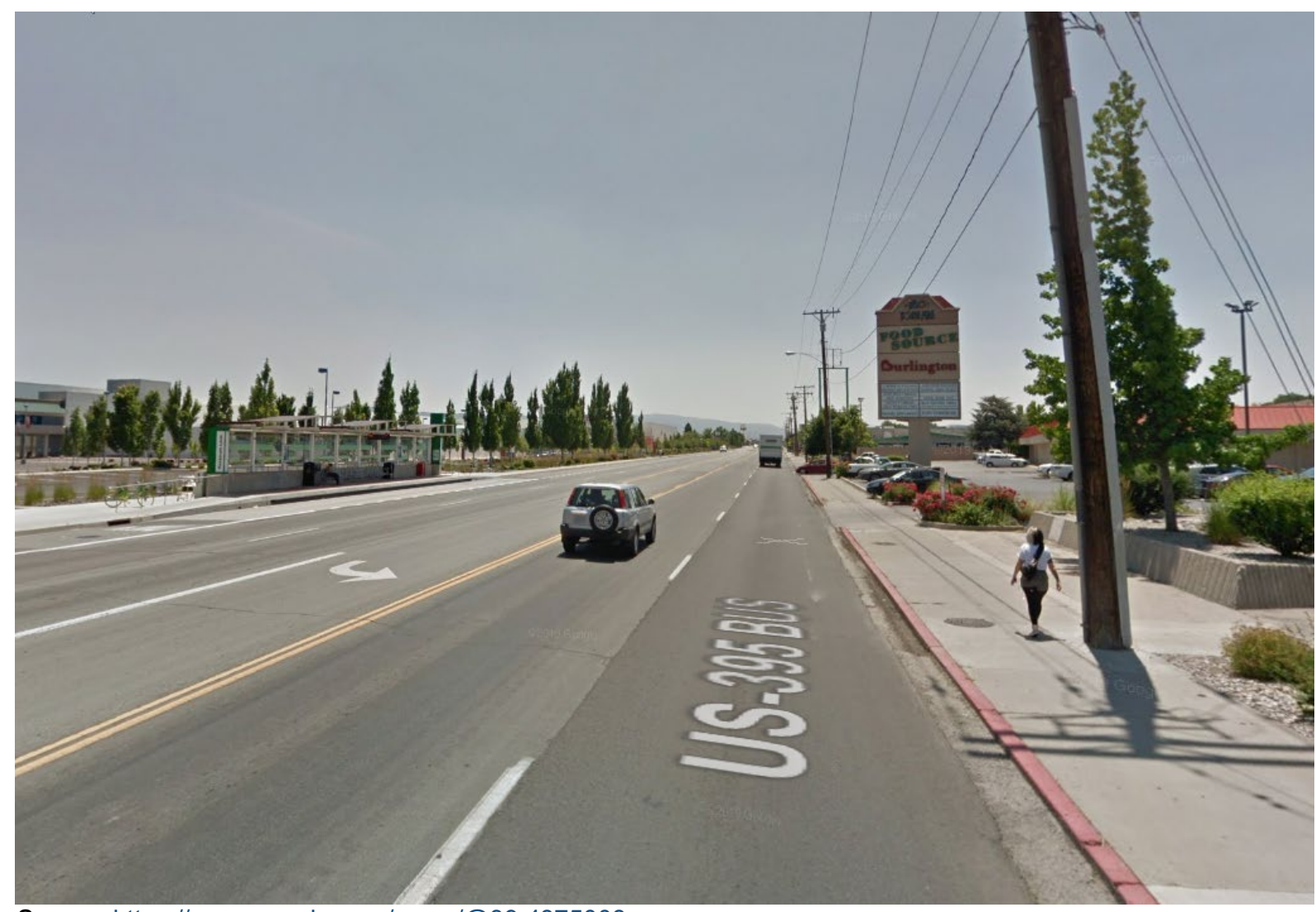

Source: https://www.google.com/maps/@39.4875008,-

$\underline{119.7944015,3 a, 60 y, 110.79 h, 81.59 t / d a t a=! 3 m 6 ! 1 \mathrm{e} 1 ! 3 \mathrm{~m} 4 ! 1 \mathrm{sBH} 9 \mathrm{mCaPseGtNdnlozm}-\mathrm{NrA} \mathrm{I} 2 \mathrm{e} 0 ! 7 \mathrm{i} 13312 ! 8 i 6656}$ 


\section{East Peckham Lane}

Convention Center, Reno, 89502

Commute to Downtown Reno

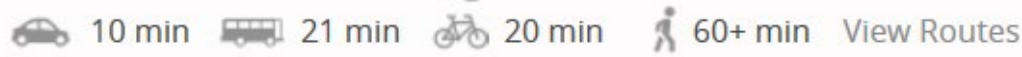

\section{Favorite D Map \& Nearby Apartments}

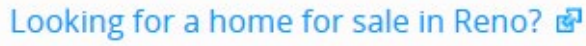

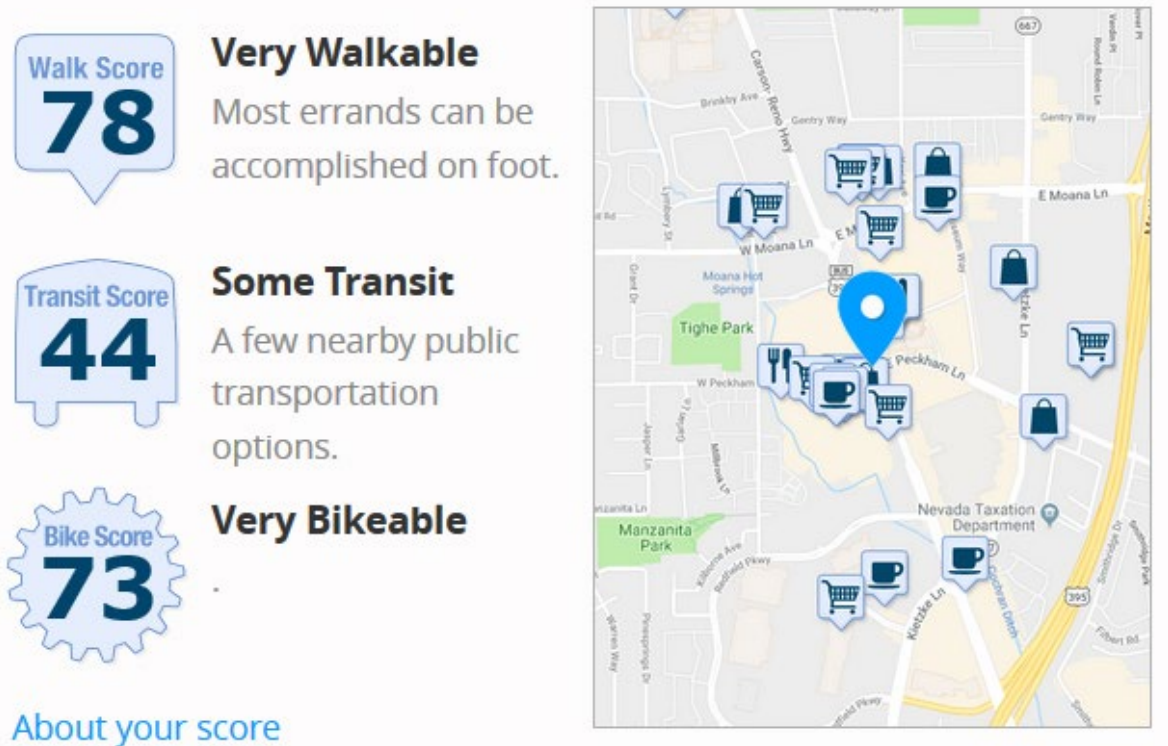

Add scores to your site

Source: https://www.walkscore.com/score/1-e-peckham-In-reno-nv-89502

The Peckham Lane bus rapid transit station in Reno, Nevada is located along a line not suitable for office development. Enormous vacant lots and gambling establishments may be to blame for the low success of office in this area. 


\section{Seattle}

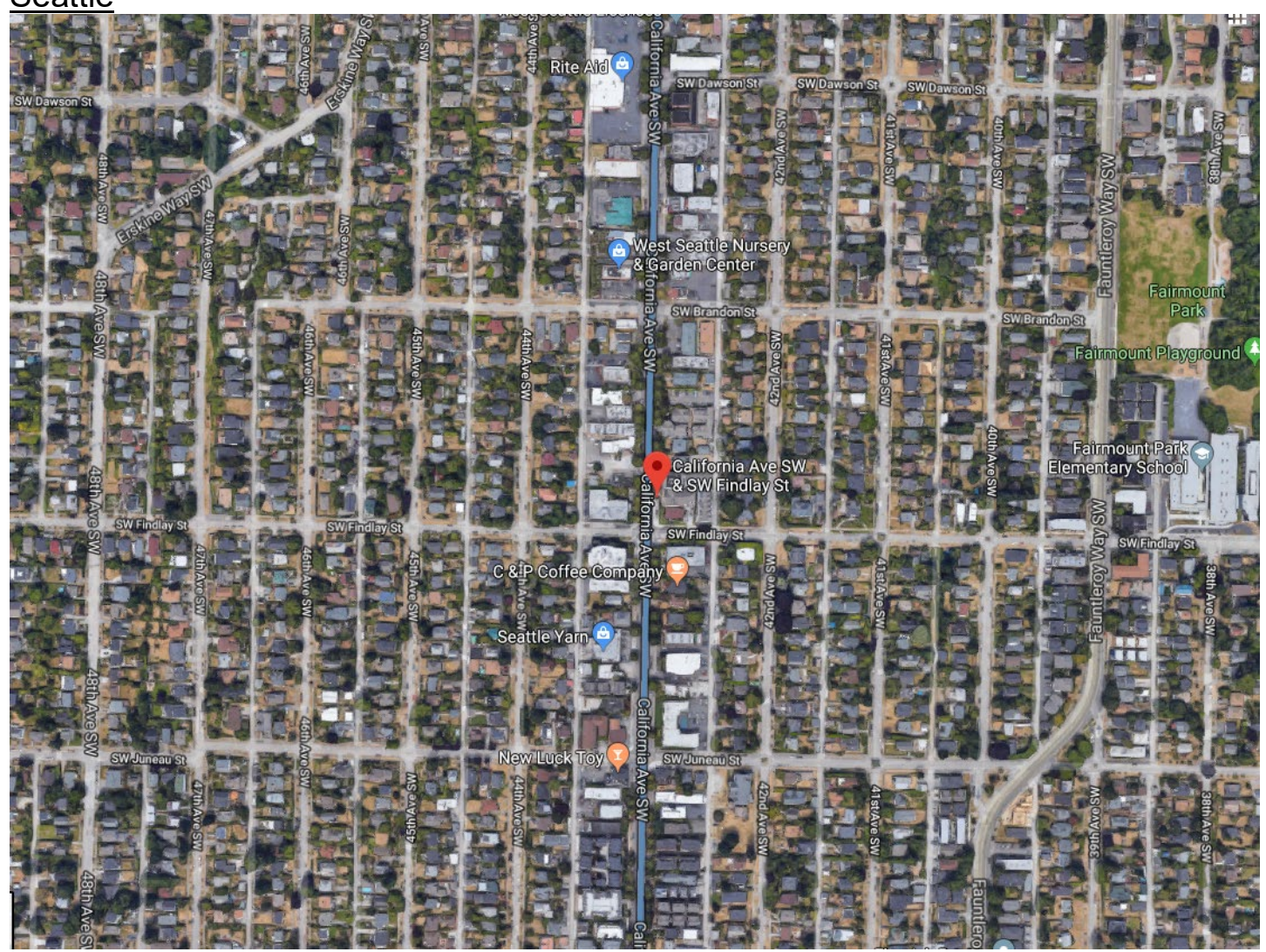

Source: https://www.google.com/maps/place/California+Ave+SW+\%26+SW+Findlay+St/@47.5524442,$122.3873602,909 \mathrm{~m} / \mathrm{data}=! 3 \mathrm{~m} 1$ ! $1 \mathrm{e} 3 ! 4 \mathrm{~m} 5 ! 3 \mathrm{~m} 4$ ! 1s0x5490411d50e4dff9:0x529dbbd0573586da!8m2!3d47.5523683!4d122.3869322 


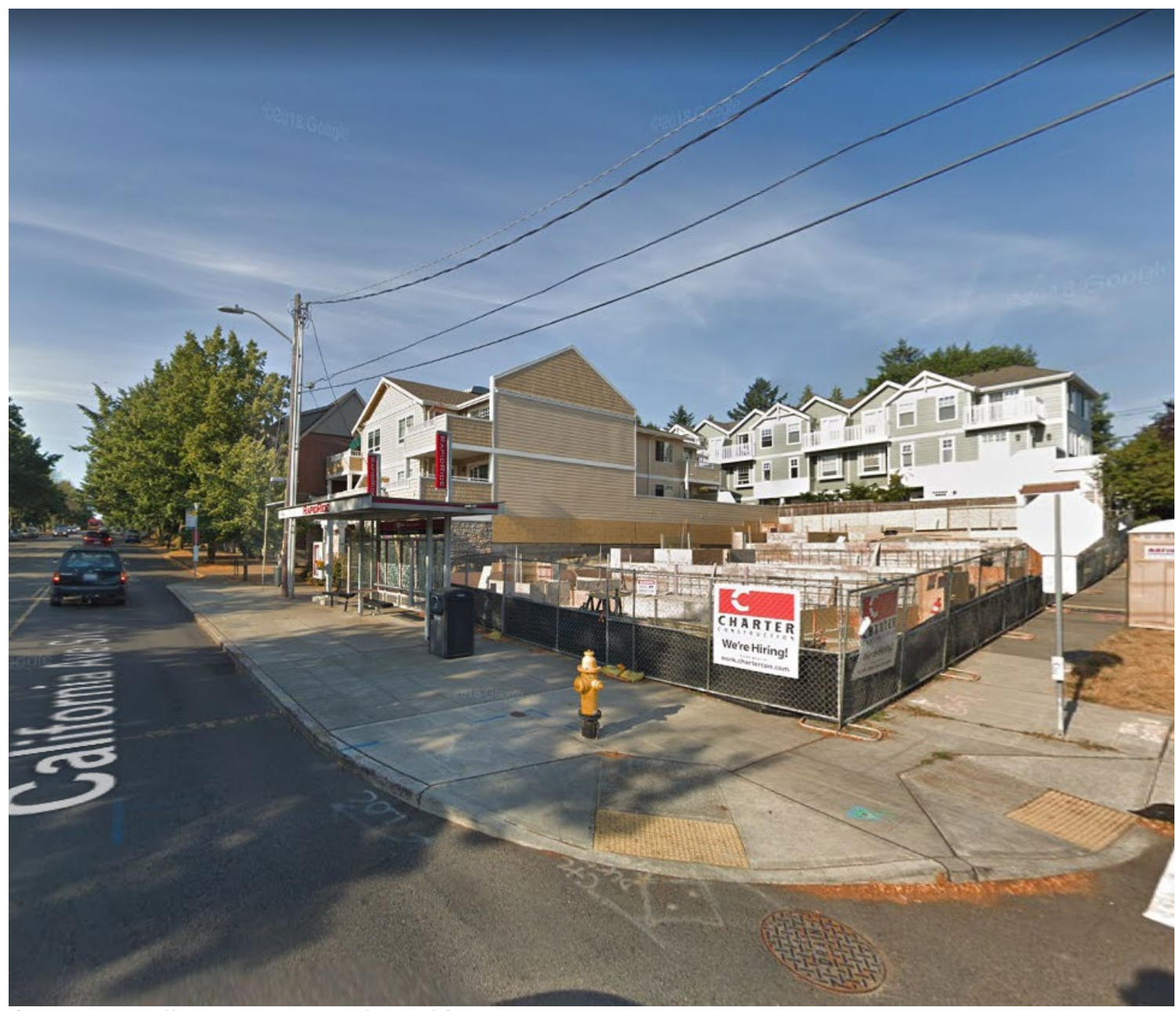

Source: https://www.google.com/maps/@47.5521529,-

122.3870095,3a,90y,35.56h,92.22t/data=!3m6!1e1!3m4!1sq|Kv zHfTAZ7psT60c3Wiw!2e0!7i16384!8i8192 


\section{California Avenue Southwest}

Seaview, Seattle, 98136

Commute to Downtown Seattle

$21 \mathrm{~min} 22 \mathrm{~min} 37 \mathrm{~min} \quad \$ 60+$ min View Routes

\section{Favorite $\mathbb{D}$ Map @ Nearby Apartments}

Looking for a home for sale in Seattle? 뚱
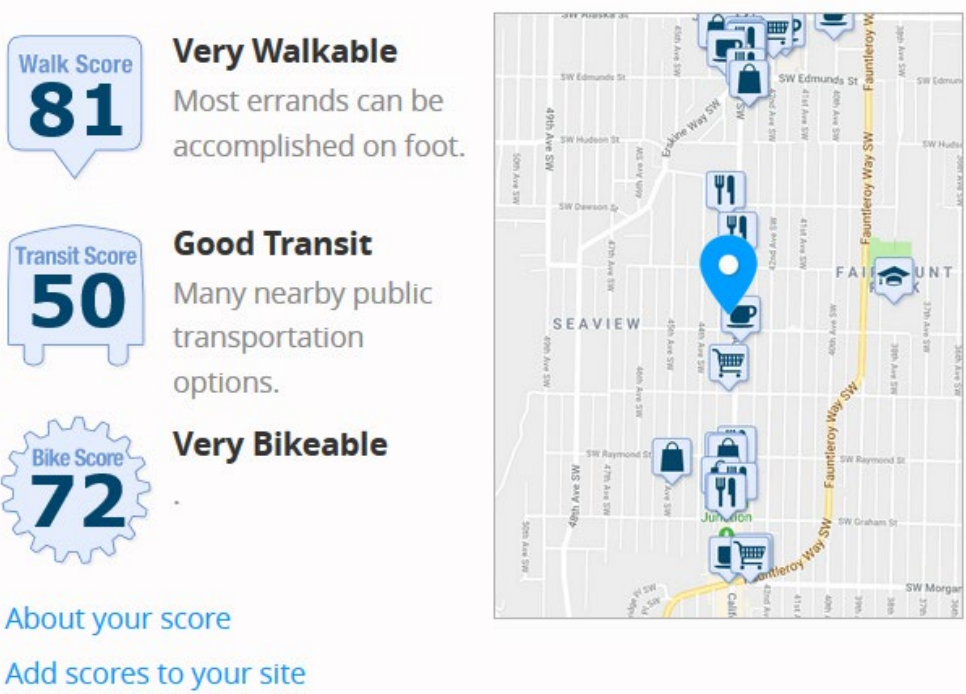

Source: https://www.walkscore.com/score/5445-california-ave-sw-seattle-wa-98136

Many of the stops along Seattle's RapidRide routes are in heavily residential areas, making them unattractive for office developments. 


\section{Good Multifamily}

\section{Cleveland}

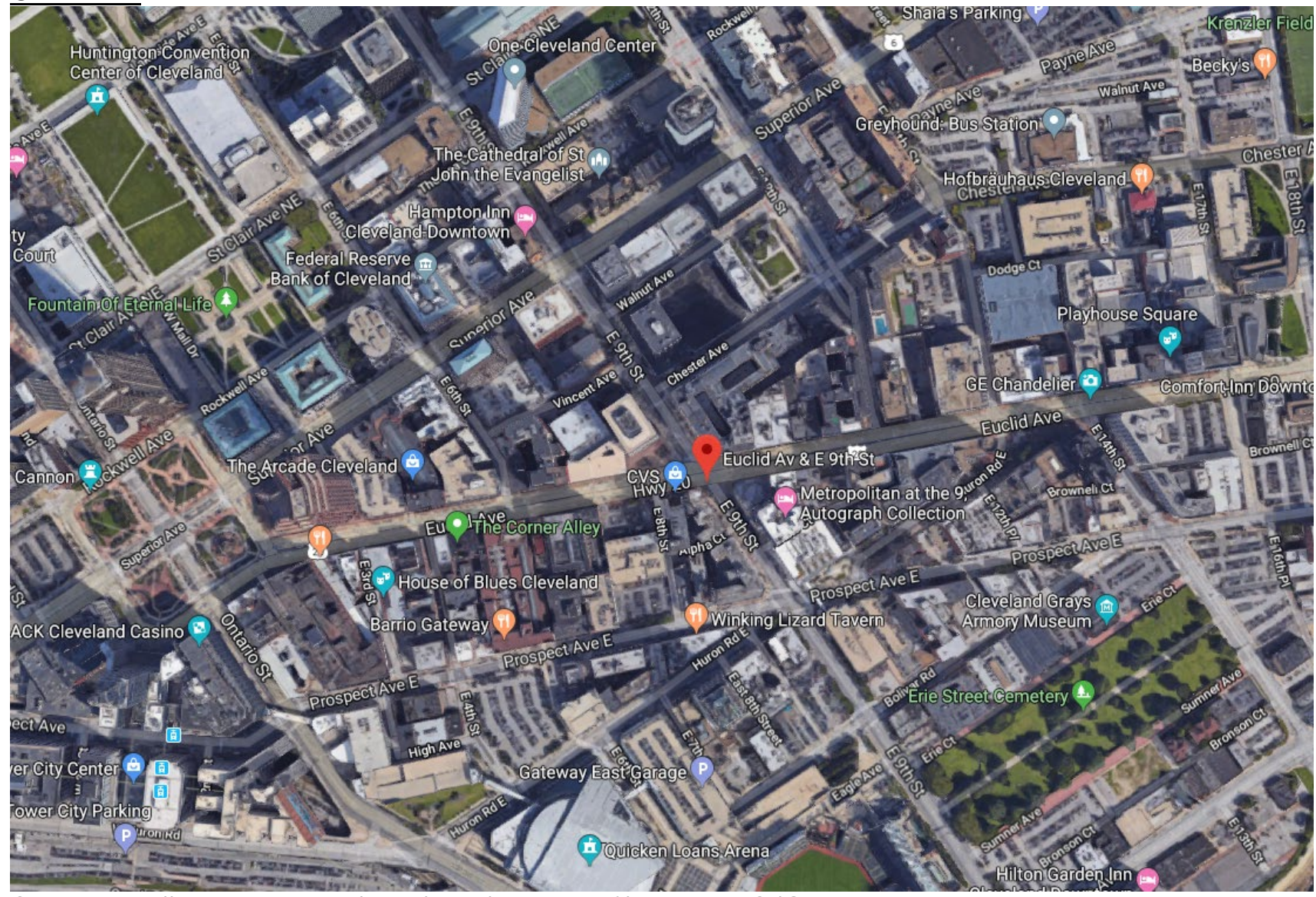

Source: https://www.google.com/maps/place/Euclid+Av+\%26+E+9th+St/@41.5001976,-

$81.6873358,1149 \mathrm{~m} / \mathrm{data}=! 3 \mathrm{~m} 1 ! 1 \mathrm{e} 3 ! 4 \mathrm{~m} 5 ! 3 \mathrm{~m} 4$ ! 1s0x8830fa7e1e98ad47:0xf5e69eec97212fe1!8m2!3d41.5001241!4d-

81.6867292 


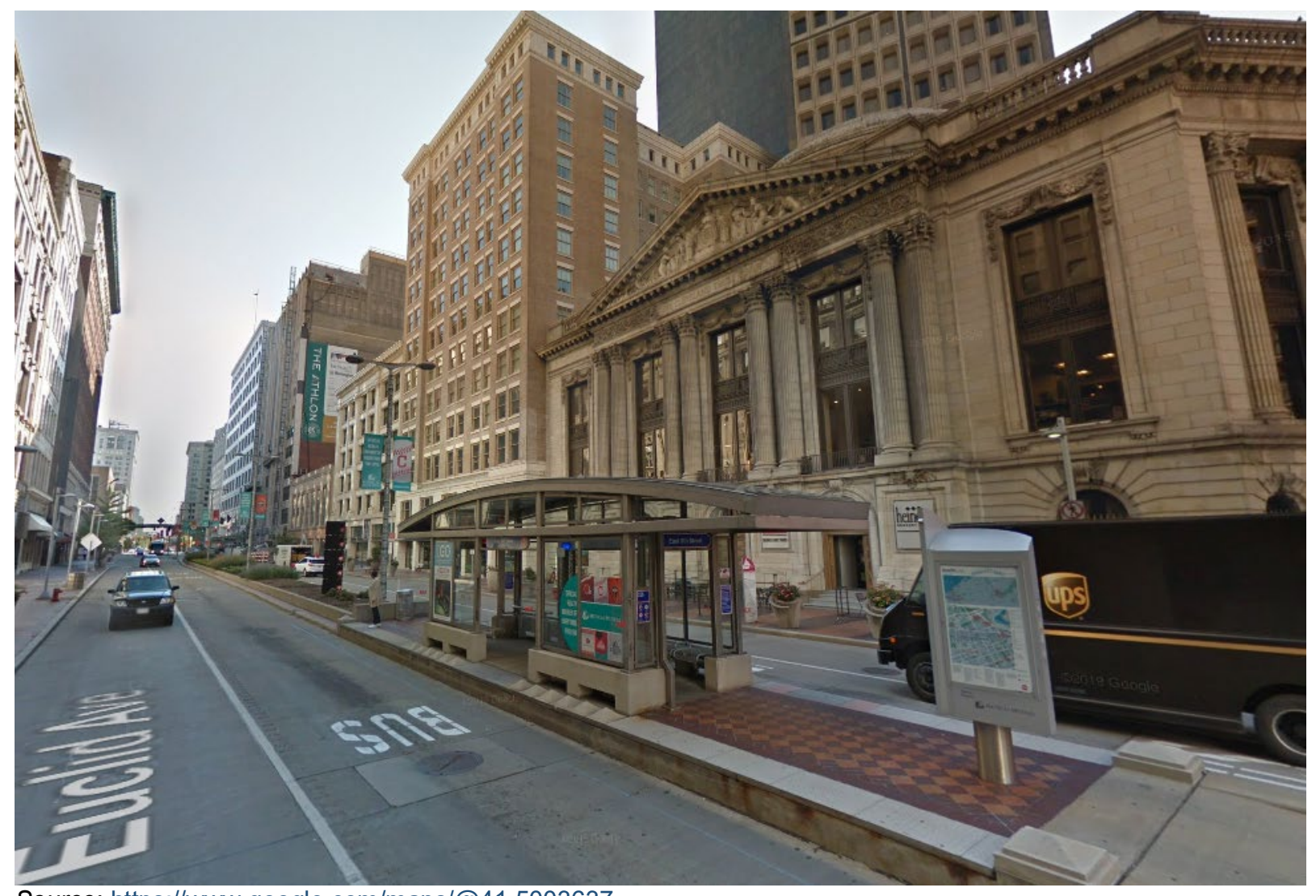

Source: https://www.google.com/maps/@41.5003637,-

$\underline{81.686437,3 a, 90 y, 114.97 h, 99.28 t / d a t a=! 3 m 6 ! 1 e 1 ! 3 m 4 ! 1 s F I S n 1 N 3 o 6 o U Z m 64 Z G J ~ i n g ! 2 e 0 ! 7 i 13312 ! 8 i 6656 ~}$ 


\section{Euclid Avenue}

Downtown, Cleveland, 44115

Commute to Downtown Cleveland

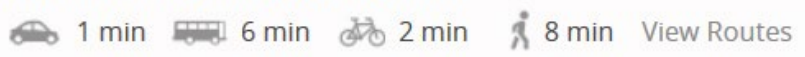

Favorite W Map @ Nearby Apartments

Looking for a home for sale in Cleveland? 뚱

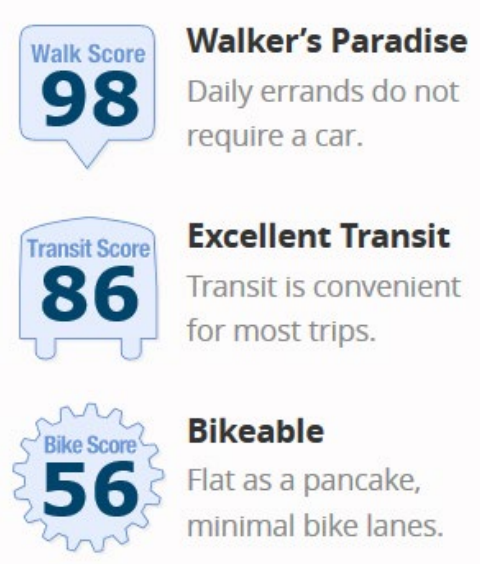

About your score

Add scores to your site

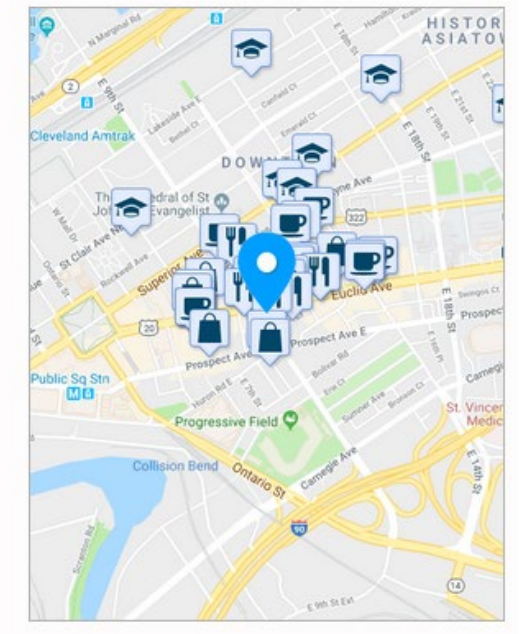

(14)

Source: https://www.walkscore.com/score/900-euclid-ave-cleveland-oh-44115

Many high-end multifamily developments are blooming along the HealthLine in Cleveland, Ohio, including The Athlon shown middle left in this photo. 
Kansas City

Grand \& $17^{\text {th }}$ Station

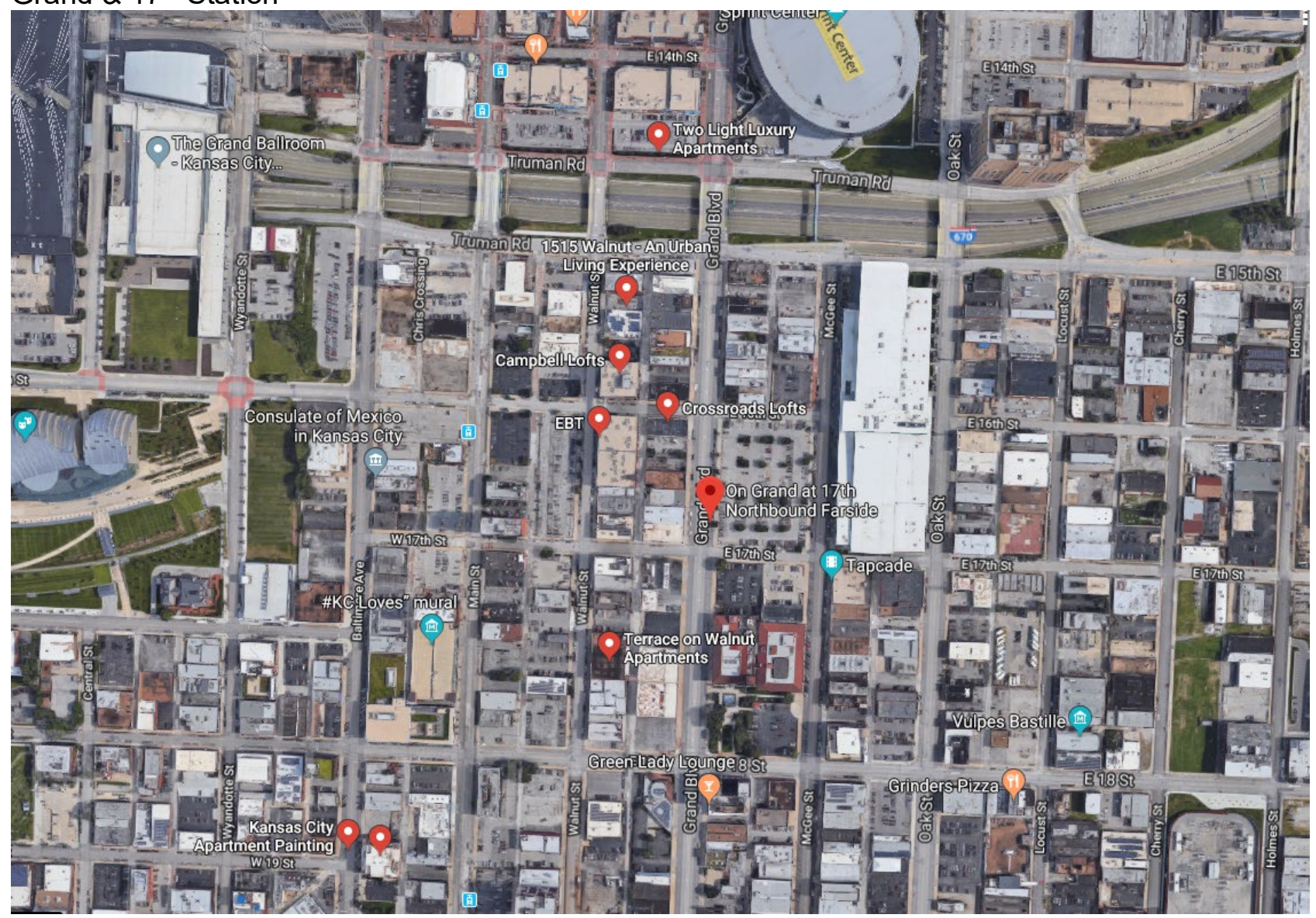

Source: https://www.google.com/maps/place/On+Grand+at+17th+Northbound+Farside/@39.093743,-

$94.5814283,900 \mathrm{~m} /$ data=!3m1!1e3!4m8!1m2!2m1!1sapartments!3m4!1s0x87c0f0684cd780b5:0x946910d852a1a 10f!8 $\mathrm{m} 2$ !3d39.0935622! $4 \mathrm{~d}-94.5811513$ 


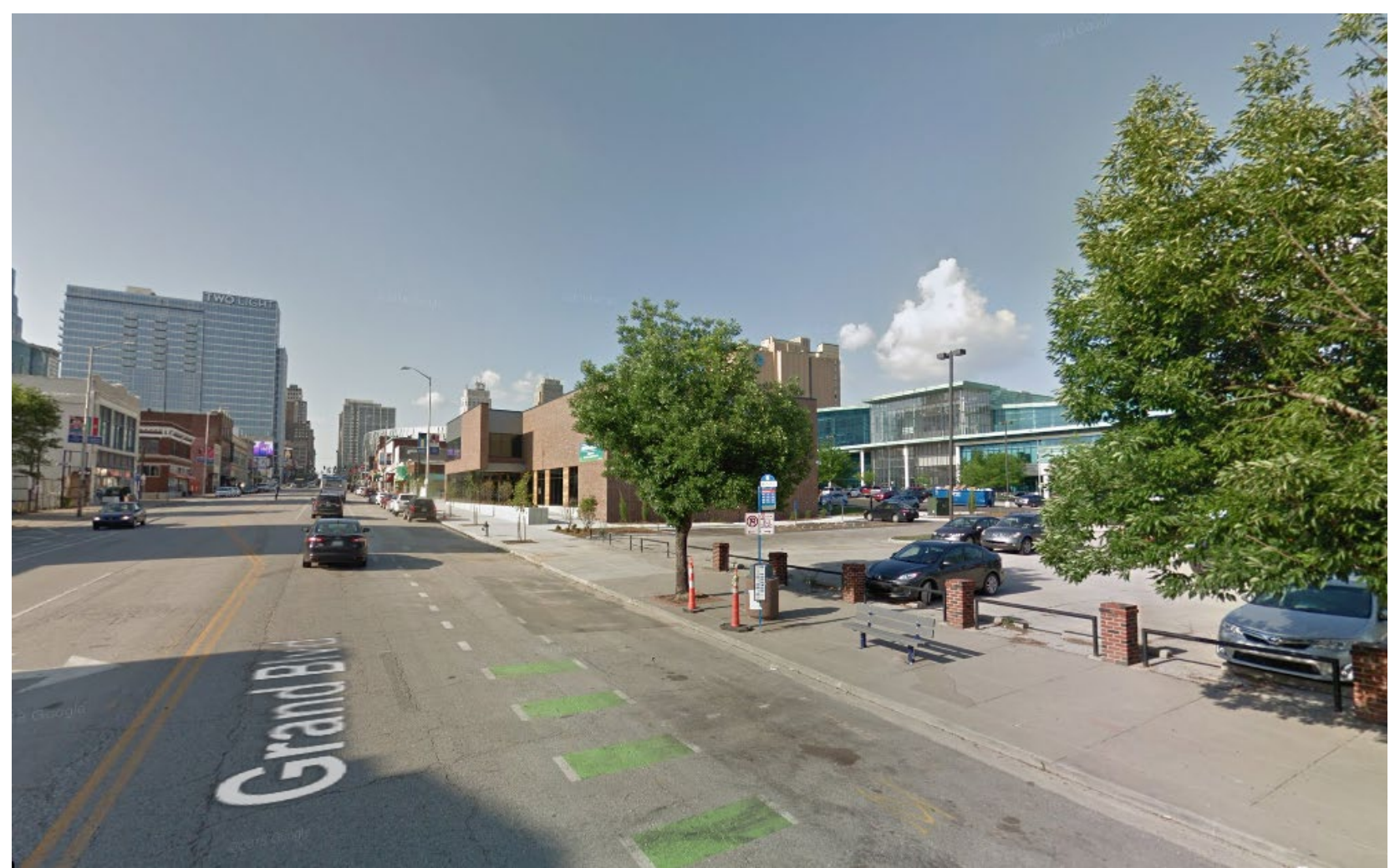

Source: https://www.google.com/maps/@39.0935947,--

$\underline{94.5811981,3 a, 90 y, 30.76 h, 93.32 t / d a t a=! 3 m 6 ! 1 e 1 ! 3 m 4 ! 1 s \mid J E L J E q Y s I 1 S R x P m o P M Z n w ! 2 e 0 ! 7 i 13312 ! 8 i 6656 ~}$ 


\section{Grand Boulevard}

Crossroads, Kansas City, 64108

Commute to Downtown Kansas City

2 min 12 min 3 min \& 15 min View Routes

Favorite 10 Map @ Nearby Apartments

More about 1600 Grand Boulevard 뚱

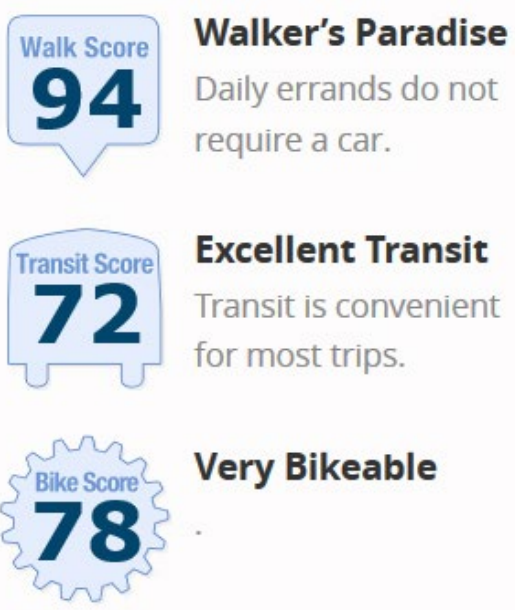

About your score

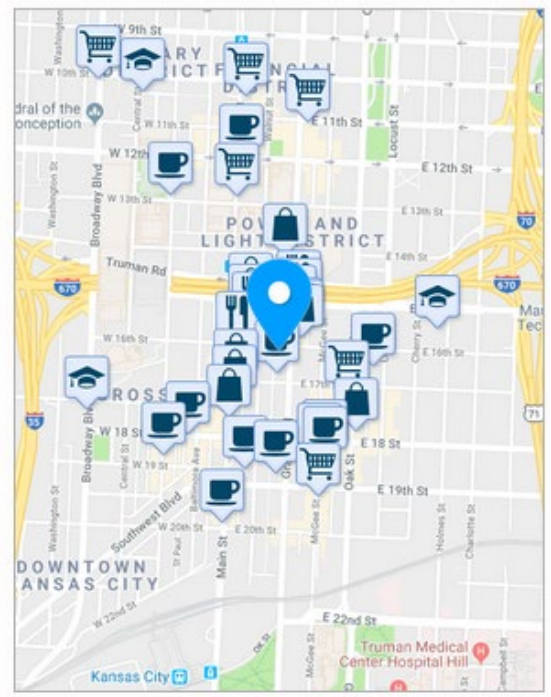

Add scores to your site

Source: https://www.walkscore.com/score/1600-grand-blvd-kansas-city-mo-64108

The Grand and $17^{\text {th }}$ Station in Kansas City, Missouri is within two city blocks of many new higher end multifamily developments. Its proximity to downtown and closeness to popular retail amenities makes it a gleaming investment area. 


\section{Bad Multifamily}

\section{Las Vegas}

Sahara at Fremont Stop

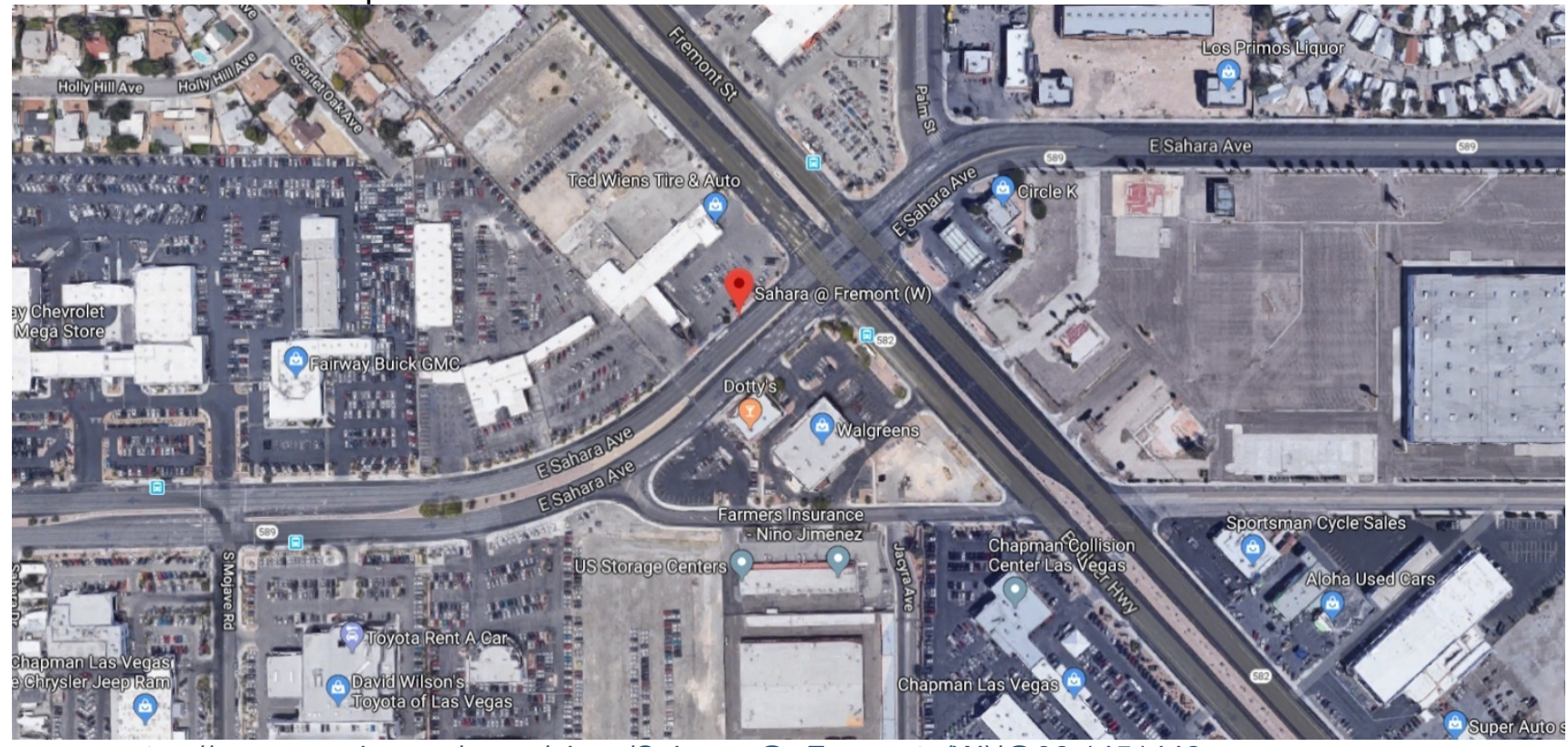

Source: https://www.google.com/maps/place/Sahara+@+Fremont+(W)/@36.1451442,-

115.1020135,494m/data=!3m1!1e3!4m5!3m4!1s0x80c8c4b11784a407:0x73b91b7d3fd0a282!8m2!3d36.1 $\underline{45385 ! 4 d-115.1021558}$

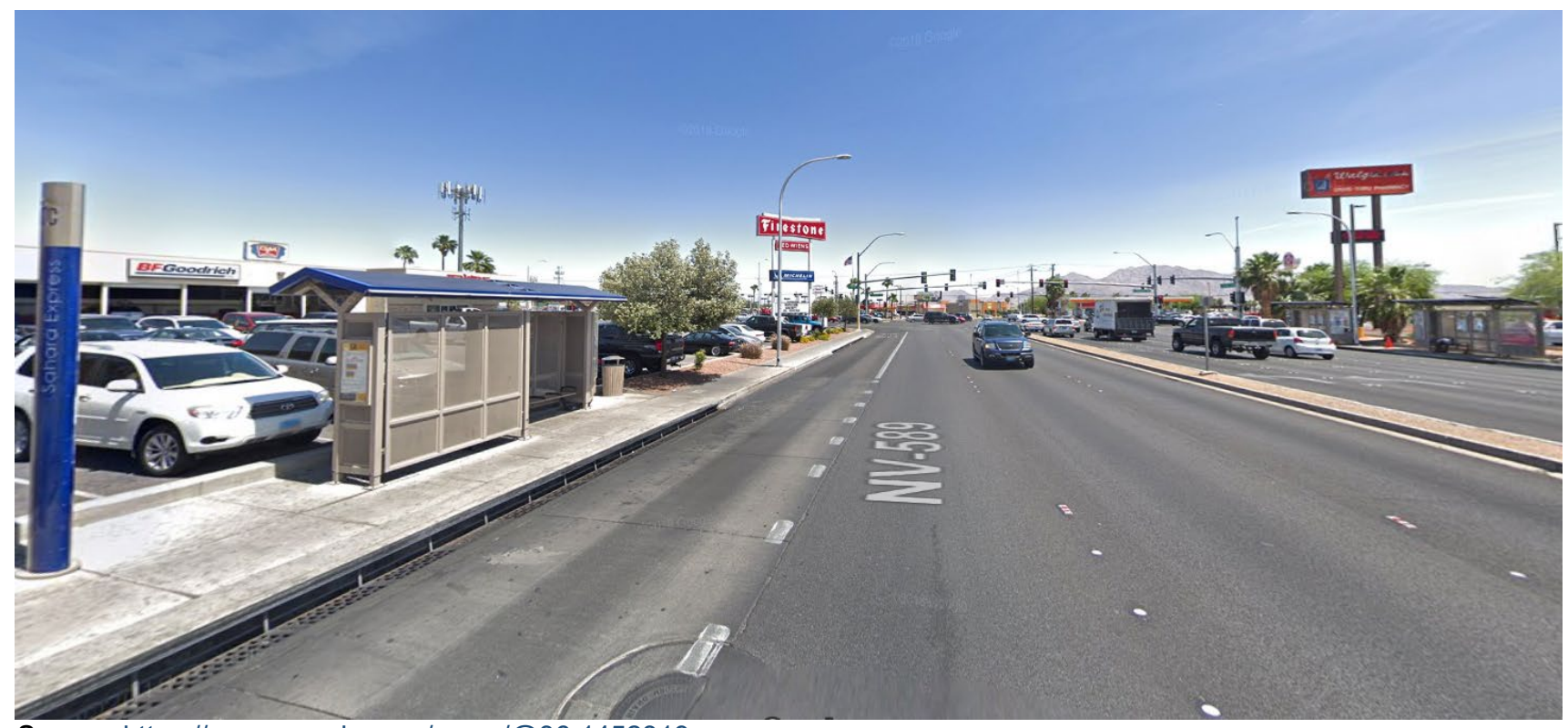

Source: https://www.google.com/maps/@36.1452319,-

115.1022884,3a,90y,33.93h,91.44t/data=!3m6!1e1!3m4!1sQiHmszR6VFwm0j9vyTQqrg!2e0!7i16384!8i8192 


\section{Fremont Street}

Winchester, Nevada, 89104

Commute to Downtown Winchester

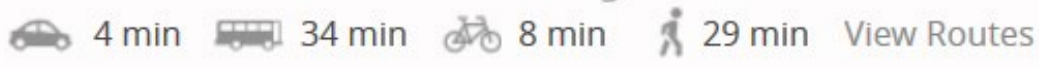

\section{Favorite $\quad 00$ Map O Nearby Apartments}

Looking for a home for sale in Winchester? 뿡
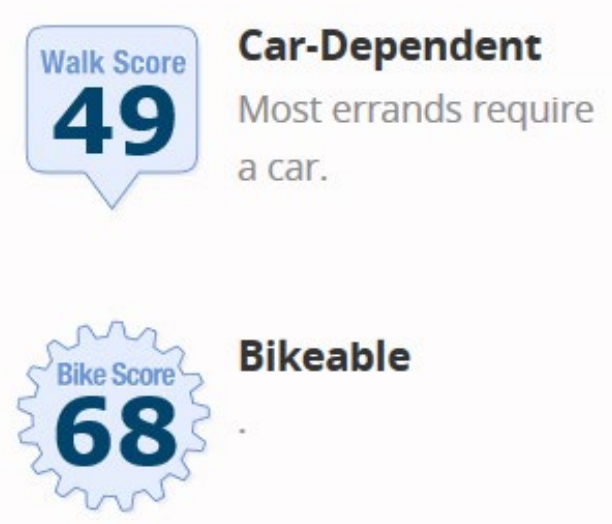

About your score

Add scores to your site

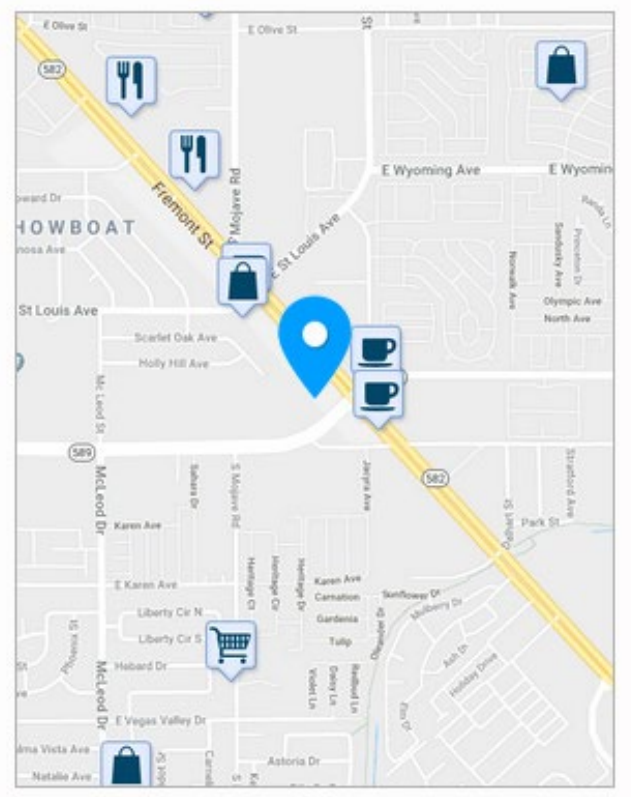

Source: https://www.walkscore.com/score/3352-fremont-st-las-vegas-nv-89104

The Sahara at Fremont Stop along one of Las Vegas' BRT routes is in a less than ideal area for multifamily. It is highly commercialized and sits at an intersection of two major six-lane roadways. 


\section{Seattle}

Wyoming \& S. Spokane St.

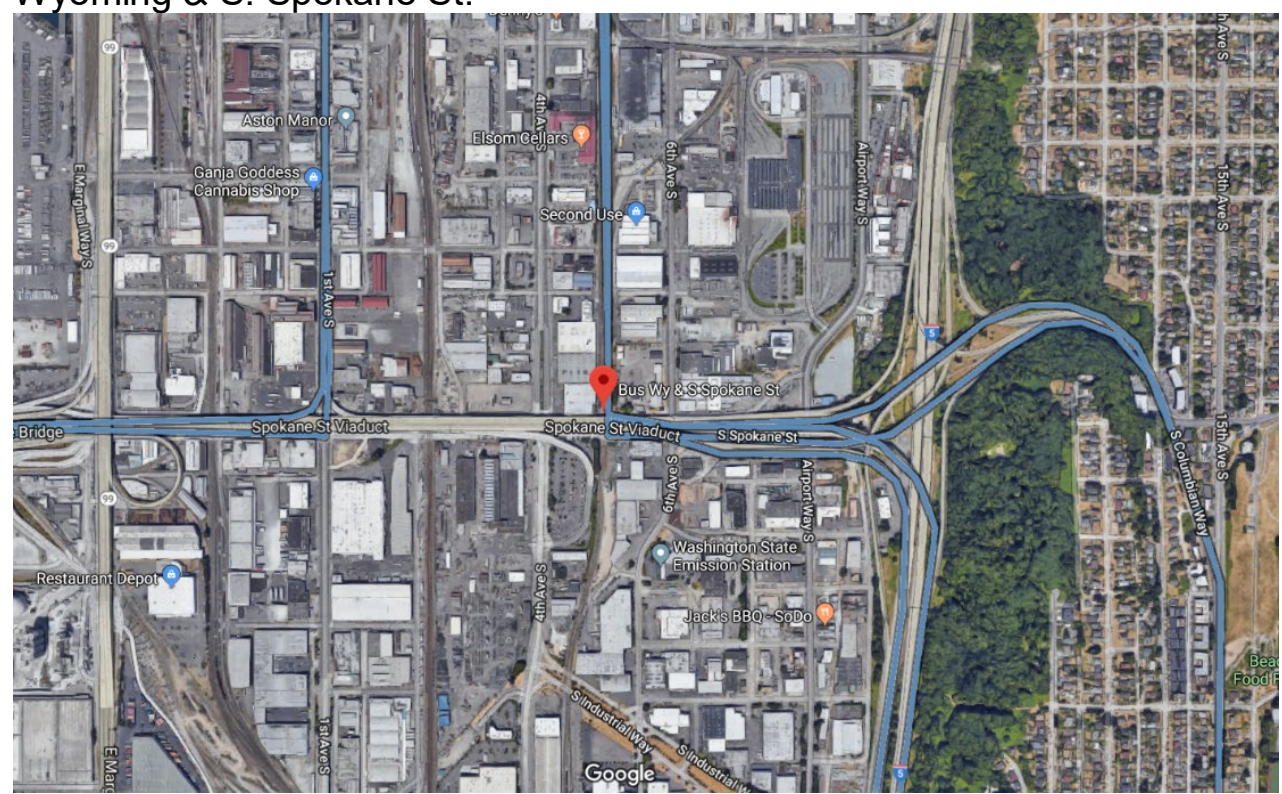

Source: https://www.google.com/maps/place/Bus+Wy+\%26+S+Spokane+St/@47.57226,-

$122.3268236,1217 \mathrm{~m} / \mathrm{data}=! 3 \mathrm{~m} 1 ! 1 \mathrm{e} 3 ! 4 \mathrm{~m} 5 ! 3 \mathrm{~m} 4 ! 1 \mathrm{~s} 0 \times 5490402 \mathrm{cb} 5960633: 0 \times c 1 \mathrm{e} 24436 \mathrm{df} 4 \mathrm{fe} 867 ! 8 \mathrm{~m} 2 ! 3 \mathrm{~d} 47.5717558 ! 4 \mathrm{~d}$ $\underline{-122.3275977}$

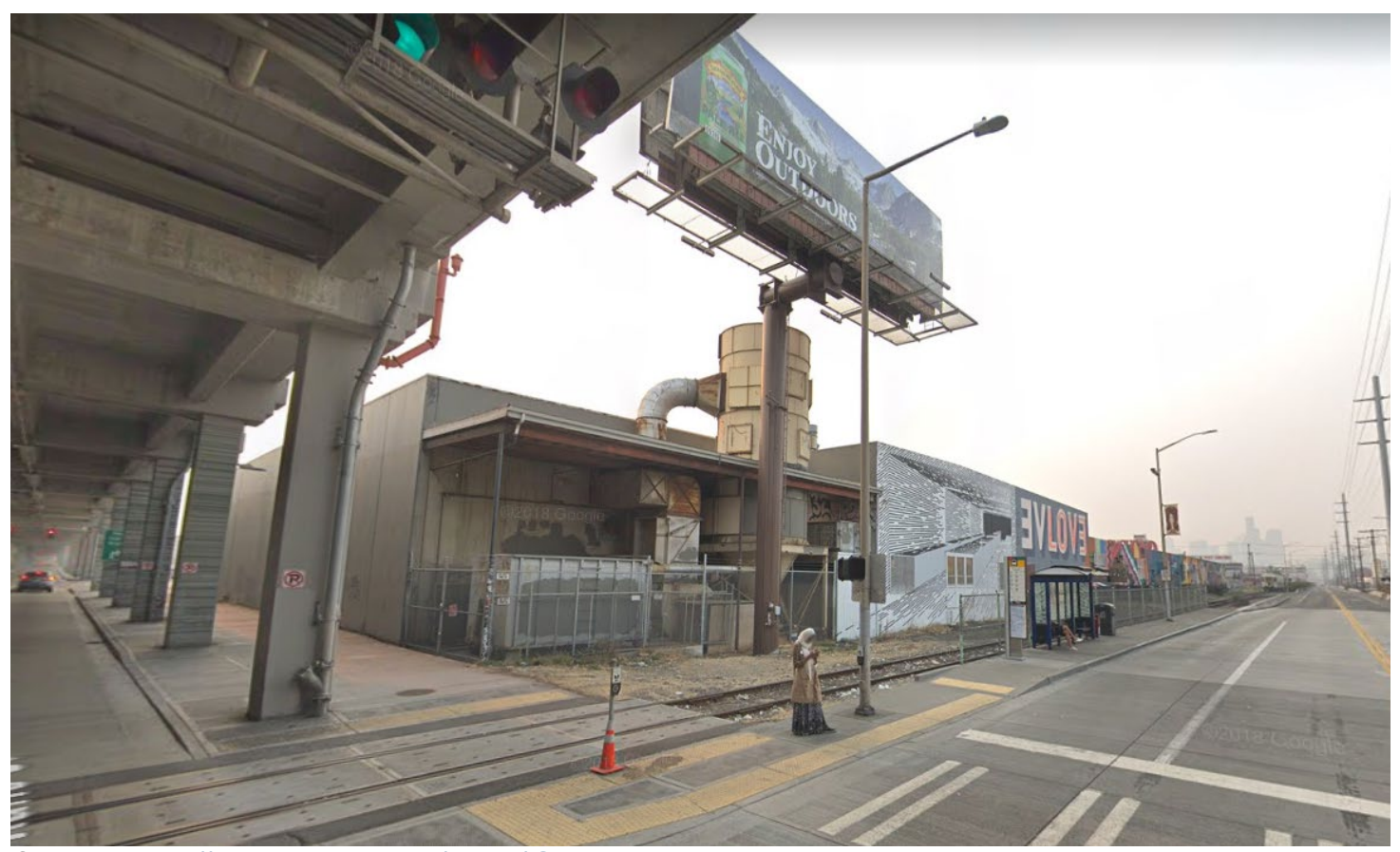

Source: https://www.google.com/maps/@47.5716876,-

122.3275591,3a,82y,320.45h,98.15t/data=!3m6!1e1!3m4!1sUxFJwq7oXUPeiD6nUxz4Aw!2e0!7i16384!8i8192 


\section{4th Avenue South}

Industrial District, Seattle, 98134

Commute to Downtown Seattle

$\curvearrowleft 7 \mathrm{~min} 19 \mathrm{~min} 15 \mathrm{~min} \quad \hat{\mathrm{i}} 48 \mathrm{~min}$ View Routes

\section{Favorite $\mathbb{0}$ Map $\bigcirc$ Nearby Apartments}

Looking for a home for sale in Seattle? 뚱

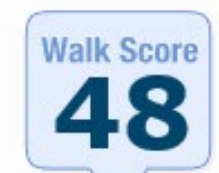

Car-Dependent

Most errands require

a car.

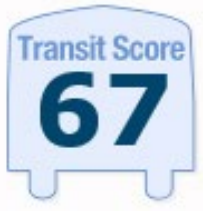

Good Transit

Many nearby public

transportation

options.

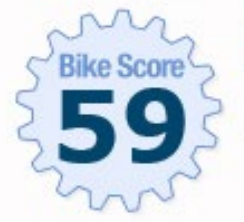

About your score

\section{Bikeable}

\section{Add scores to your site}

Source: https://www.walkscore.com/score/3540-4th-ave-s-seattle-wa-98134

The station at Wyoming and S. Spokane St. is in a less than inviting area right underneath a busy highway. 


\section{Good Retail}

\section{Cleveland}

Euclid \& E $21^{\text {st }}$ Stop

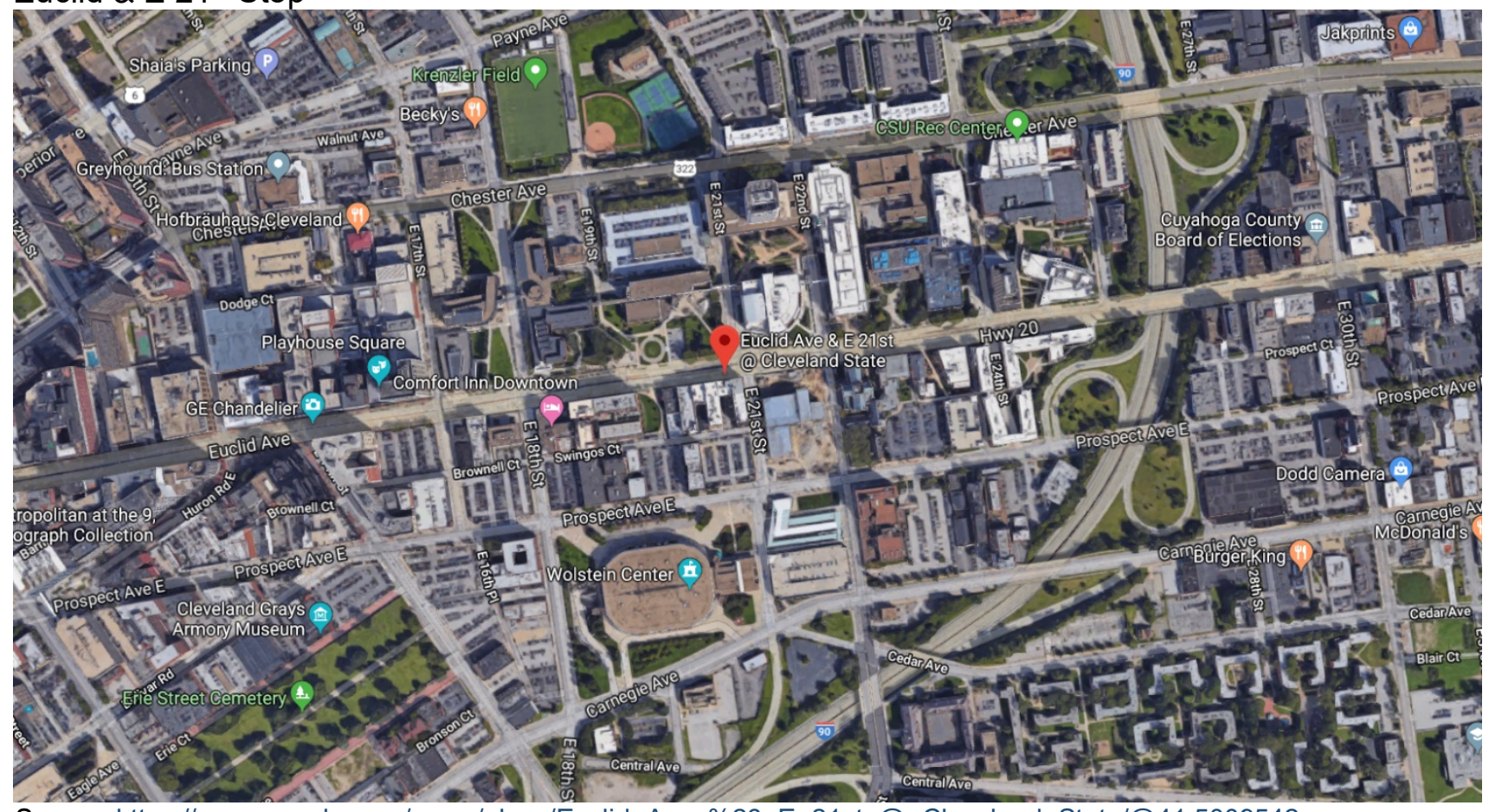

Source: https://www.google.com/maps/place/Euclid+Ave+\%26+E+21st+@+Cleveland+State/@41.5009542,-

$81.676002,1016 \mathrm{~m} / \mathrm{data}=! 3 \mathrm{~m} 1 ! 1 \mathrm{e} 3 ! 4 \mathrm{~m} 5 ! 3 \mathrm{~m} 4 ! 1 \mathrm{~s} 0 \times 8830 \mathrm{fa} 62350 \mathrm{ac} 47 \mathrm{~d}: 0 \times 265 \mathrm{bf8bc} 05 \mathrm{fe} 3 \mathrm{df0}$ !8m2!3d41.5014499!4d$\underline{81.6760091}$ 


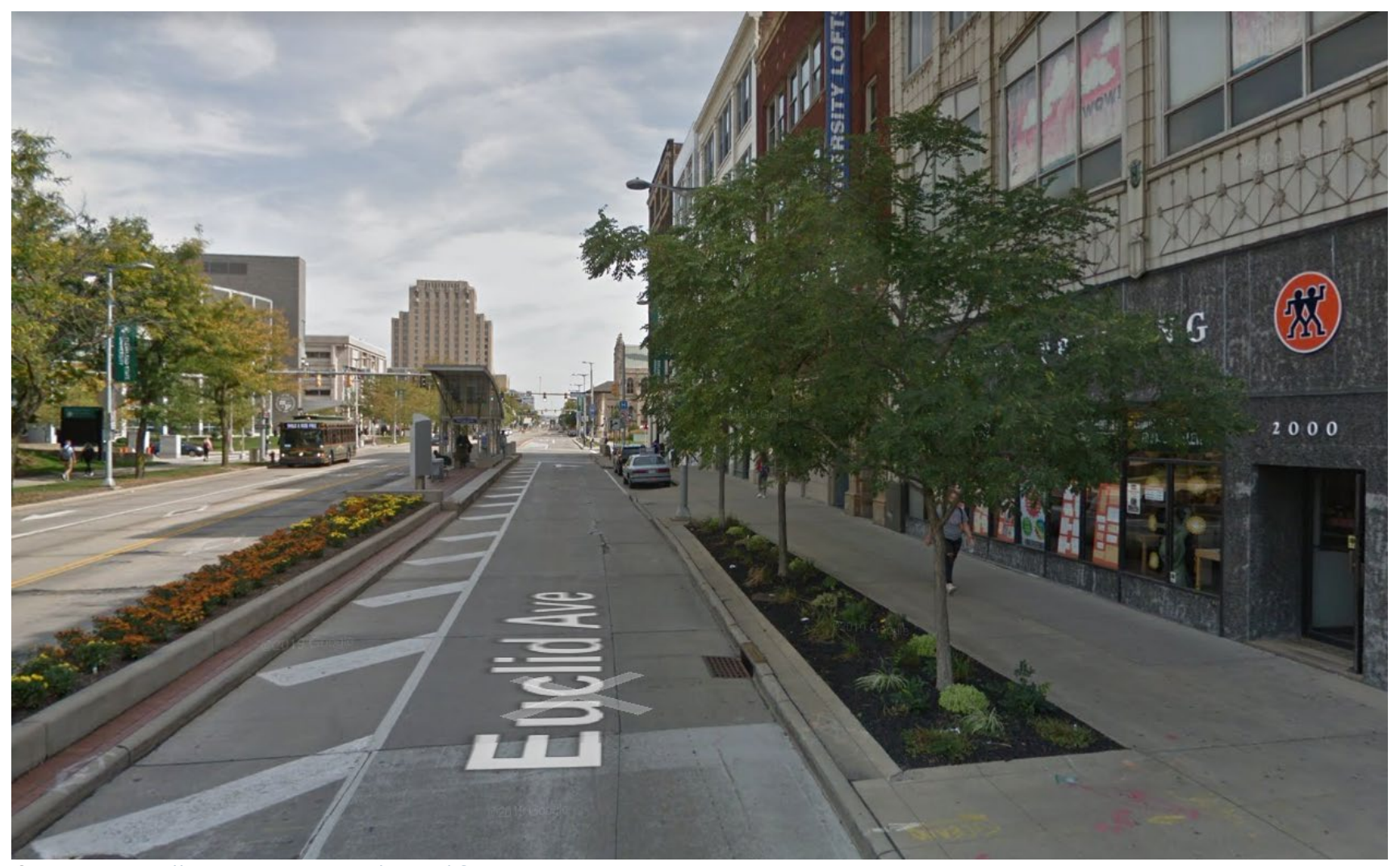

Source: https://www.google.com/maps/@41.501421,--

81.6767492,3a,60y,91.26h,90.21t/data=!3m6!1e1!3m4!1swT0QZYBIDom1DZmVNRenAg!2e0!7i13312!8i6656 


\section{Euclid Avenue}

Central, Cleveland, 44115

Commute to Downtown Cleveland

$2 \mathrm{~min} 8 \mathrm{~min} 3 \mathrm{~min}$ i $14 \mathrm{~min}$ View Routes

\section{Favorite 10 Map \& Nearby Apartments}

Looking for a home for sale in Cleveland? 준

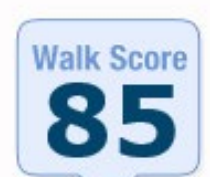

Very Walkable

Most errands can be accomplished on foot.

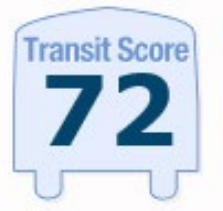

\section{Excellent Transit}

Transit is convenient for most trips.

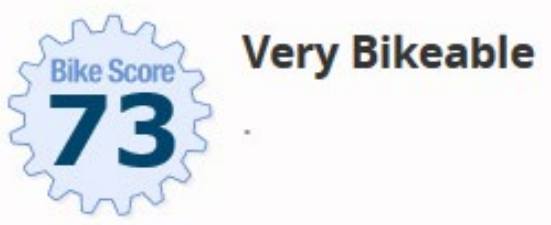

About your score

Add scores to your site

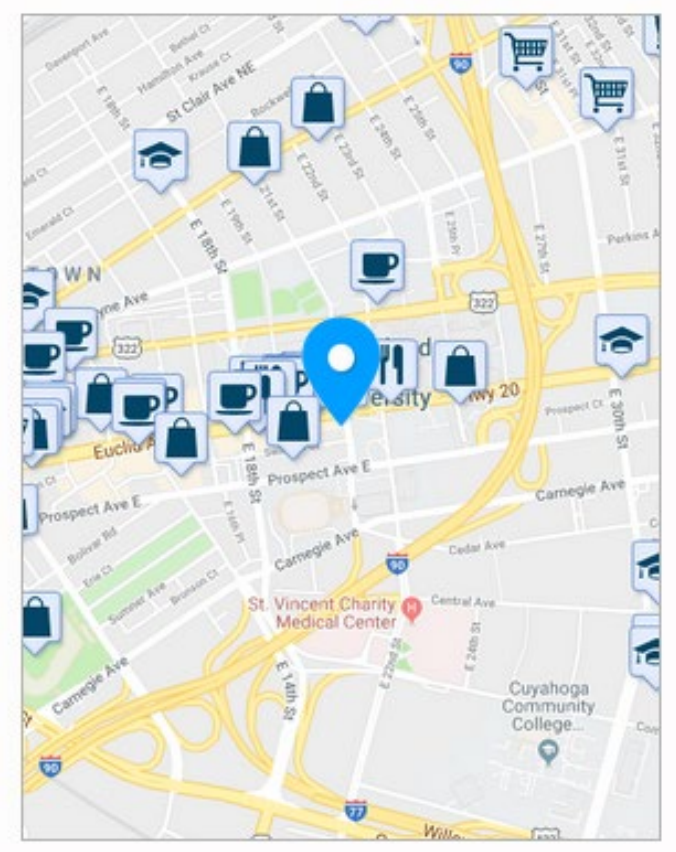

Source: https://www.walkscore.com/score/2044-euclid-ave-cleveland-oh-44115

Located near a university, the stop at Euclid \& $E 21^{\text {st }}$ in Cleveland, Ohio is attractive for retail developers because of its proximity to students and overall walkability. 


\section{Kansas City}

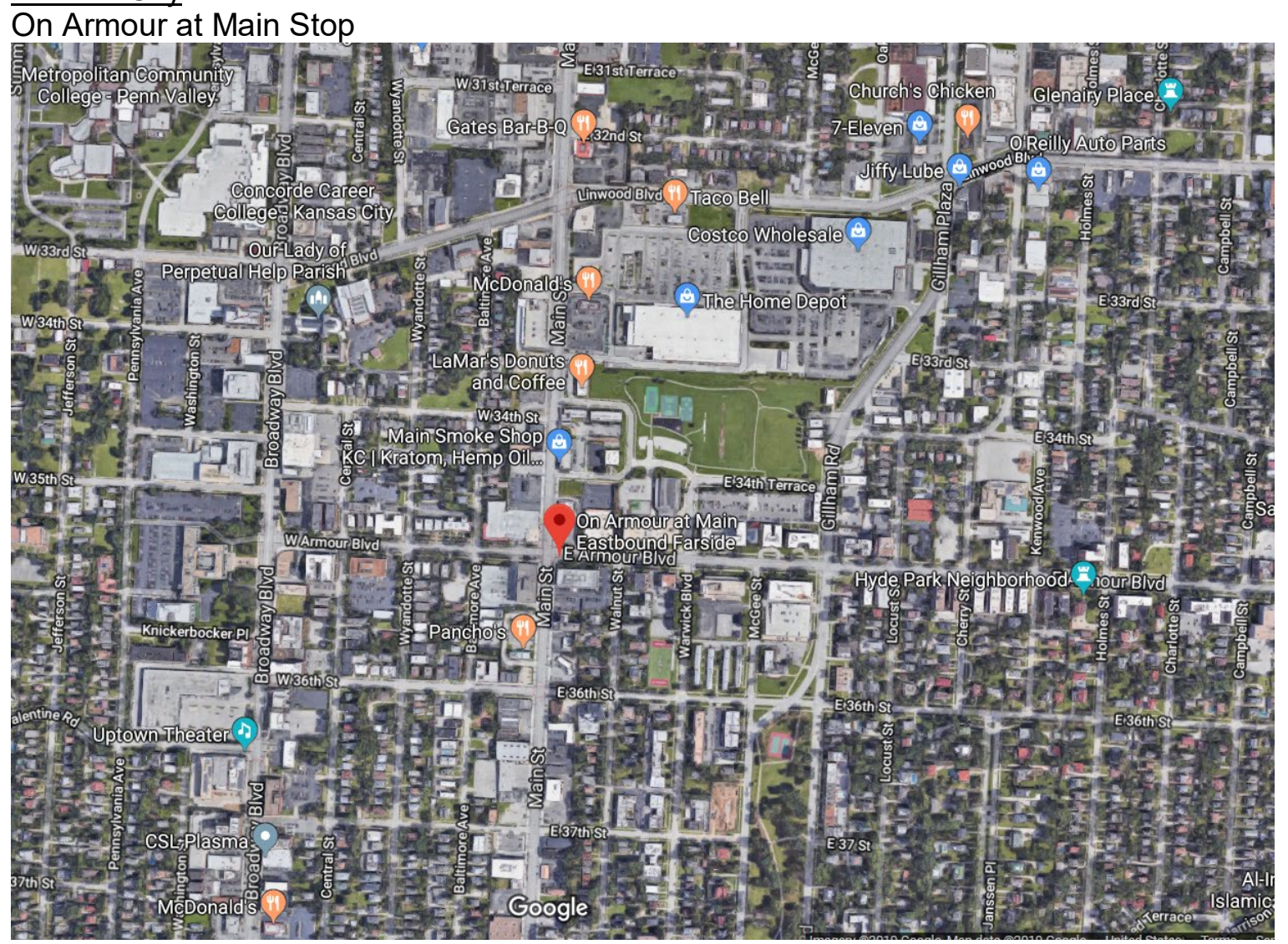

Source: https://www.google.com/maps/place/On+Armour+at+Main+Eastbound+Farside/@39.0647066,-94.5856559,1344m/data=!3m1!1e3!4m13!1m7!3m6!1s0x87c0efe241eb773d:0xc7c61f390077fe0c!2sE+Armour+Blvd, +Kansas+City,+MO!3b1!8m2!3d39.0634712!4d-

94.5775229!3m4!1s0x87c0efdf9ce49493:0x1aeab81854f588b5!8m2!3d39.0636928!4d-94.585473 


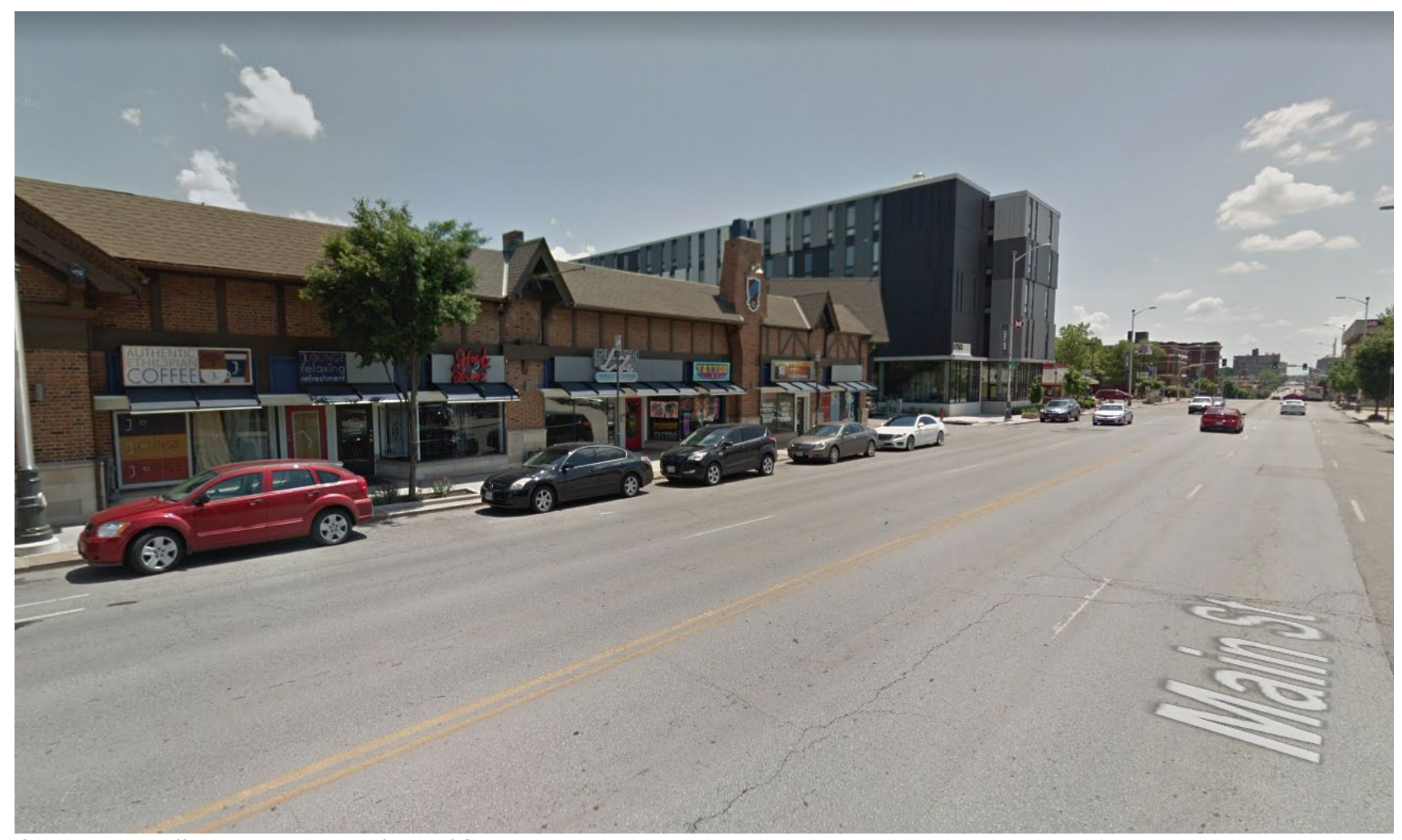

Source: https://www.google.com/maps/@39.0652035,-

94.5856689,3a,75y,138.74h,85.22t/data=!3m6!1e1!3m4!1sxR54AVJ1IMCI_SHWo7D4fQ!2e0!7i13312!8i6656 


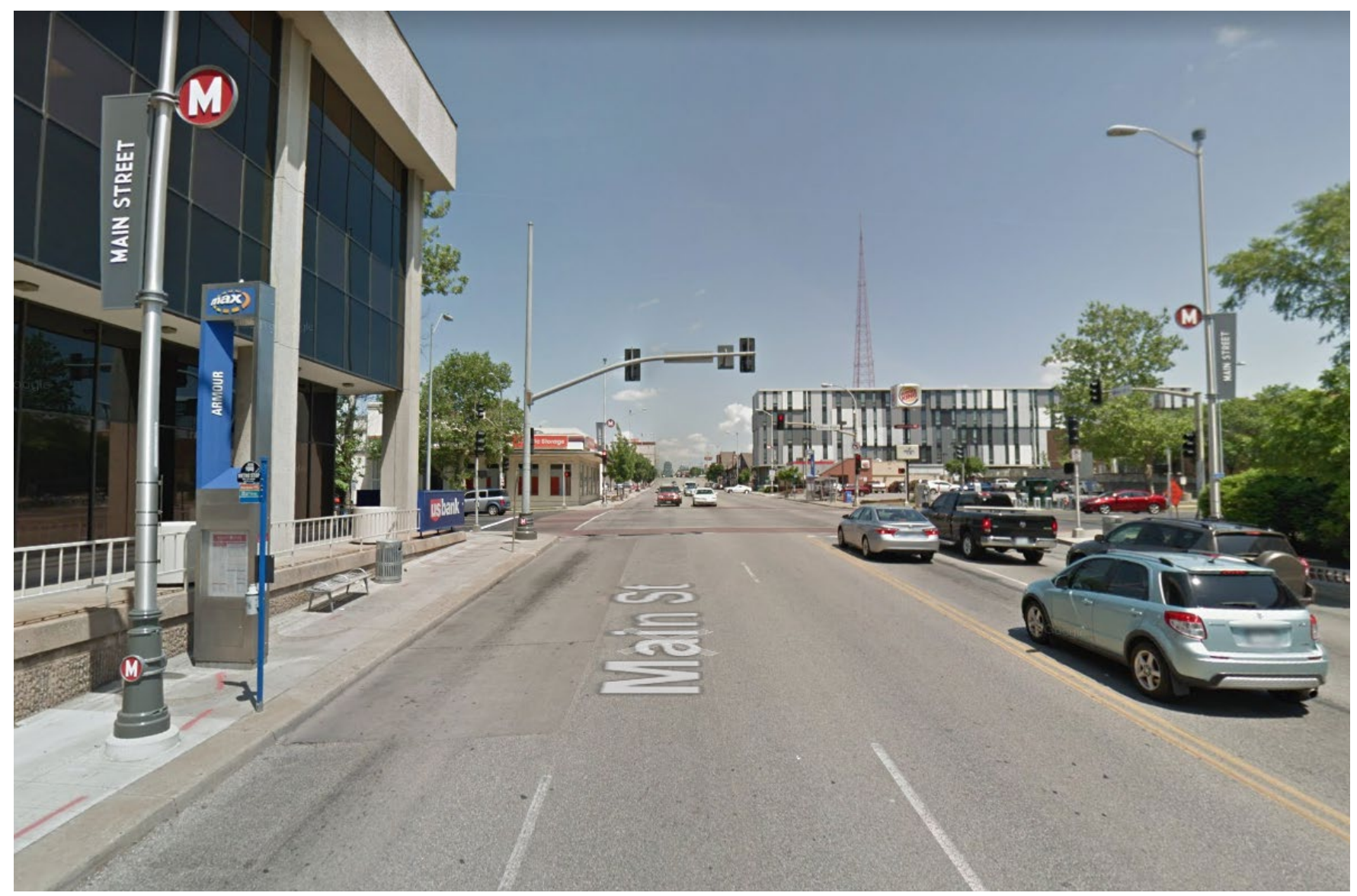

Source: https://www.google.com/maps/@39.0634292,-

94.5857625,3a,75y,357.22h,93.04t/data=!3m6!1e1!3m4!1sP2md7ID3Lpq7beCbht4DdA!2e0!7i13312!8i6656 


\section{E Armour Blvd}

Broadway Gillham, Kansas City, 64111

Commute to Downtown Kansas City

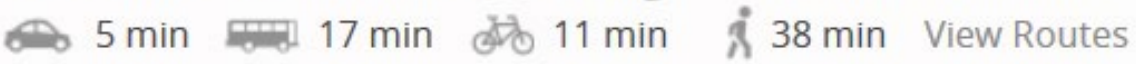

\section{Favorite $\mathbb{D}$ Map Q Nearby Apartments}

Looking for a home for sale in Kansas City? 불

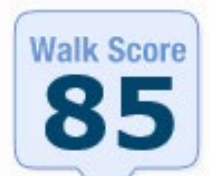

Very Walkable

Most errands can be accomplished on foot.

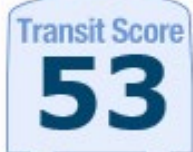

Good Transit

Many nearby public

transportation

options.

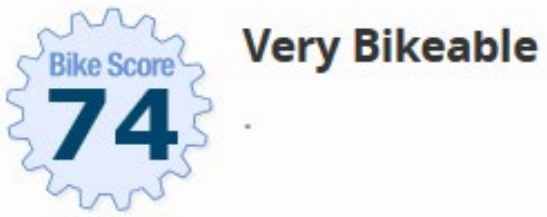

About your score

Add scores to your site

Source: https://www.walkscore.com/score/1-e-armour-blvd-kansas-city-mo-64111

The Armour stop along Main Street in Kansas City, Missouri is near healthy retail as well as new commercial development.

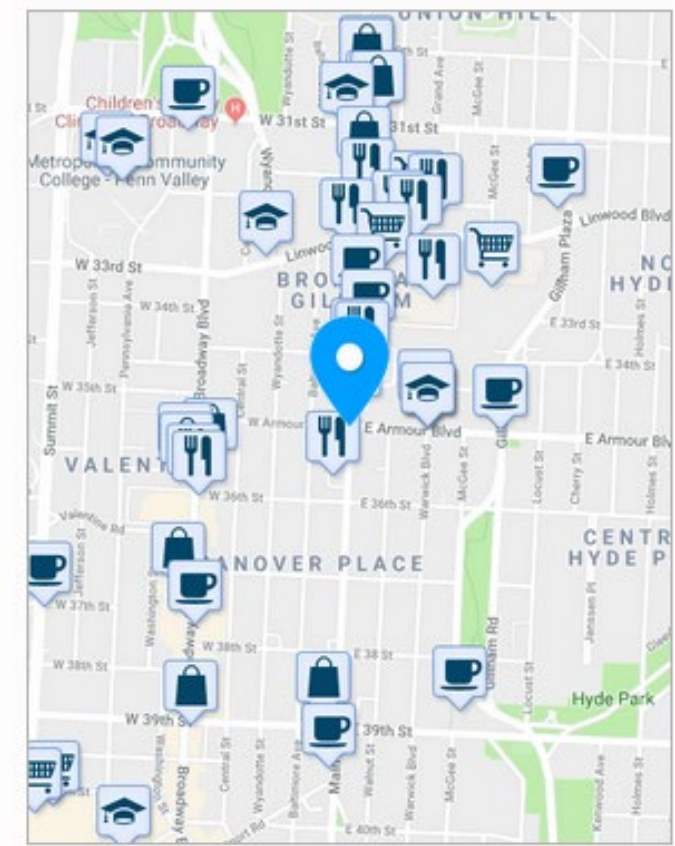

\section{1}




\section{Bad Retail}

\section{Phoenix}

Southshore \& Lakeshore Stop

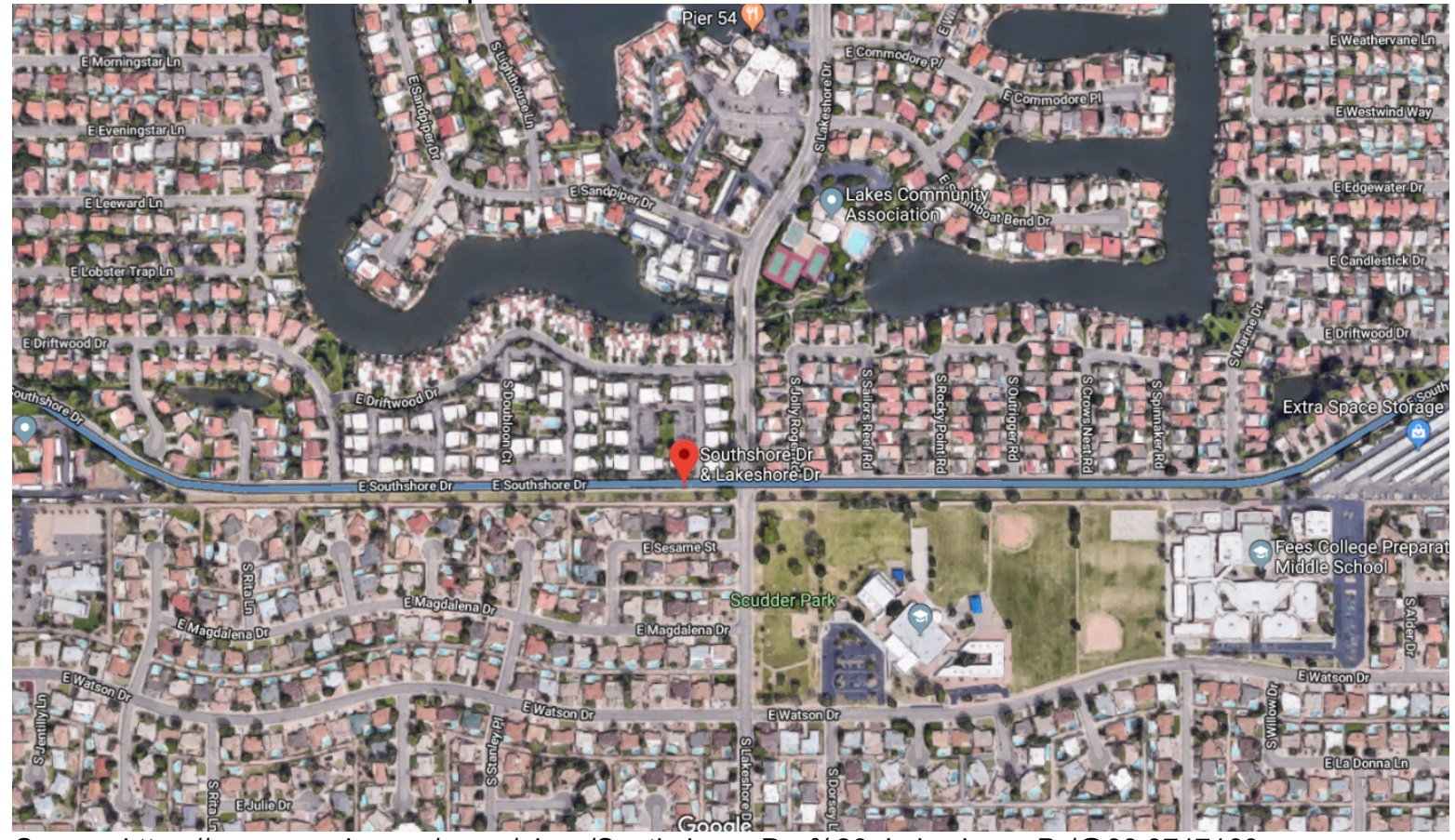

Source: https://www.google.com/maps/place/Southshore+Dr+\%26+Lakeshore+Dr/@33.3717169,--

111.920298,902m/data=!3m1!1e3!4m5!3m4!1s0x872b063bd938bf9d:0xf86f2f08b7f4993!8m2!3d33.371157!4d111.9206509 


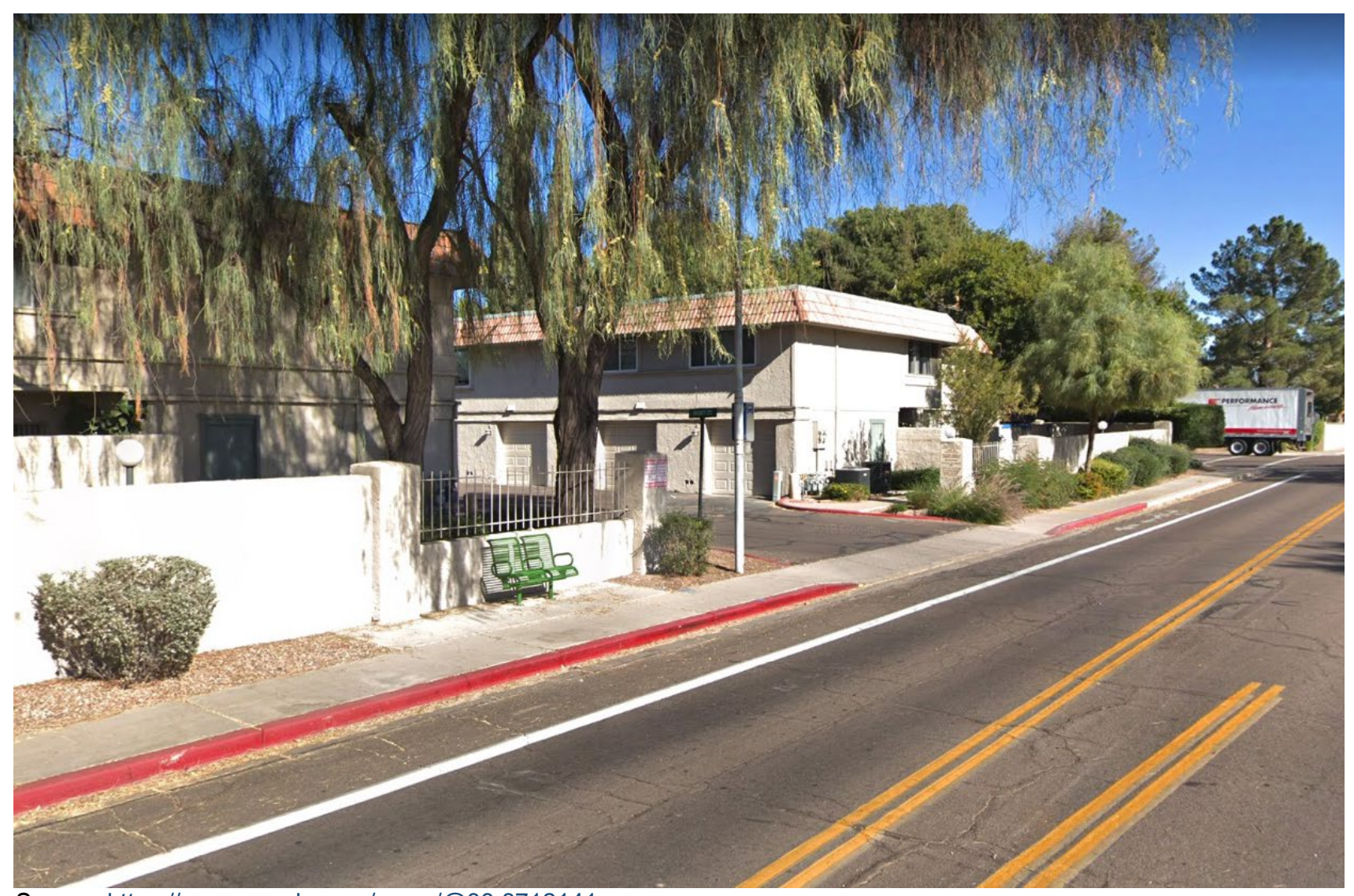

Source: https://www.google.com/maps/@33.3712141,--

$111.9207054,3 \mathrm{a}, 48.9 \mathrm{y}, 51.55 \mathrm{~h}, 87.39 \mathrm{t} / \mathrm{data}=! 3 \mathrm{~m} 6 ! 1 \mathrm{e} 1 ! 3 \mathrm{~m} 4$ ! $1 \mathrm{sPEHXGEhhrtBCvDcrrrl8Uw!2e0!7i16384!8i8192}$ 


\section{East South Shore Drive}

Scudder Park West, Tempe, 85283

Commute to Downtown Tempe

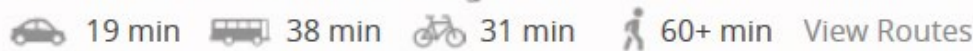

\section{$\checkmark$ Favorite $\mathbb{0}$ Map $\&$ Nearby Apartments}

Looking for a home for sale in Tempe? 뿐

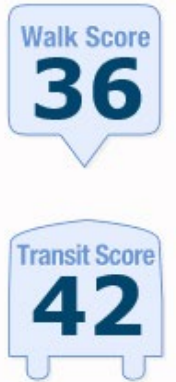

\section{Car-Dependent}

Most errands require

a car.

\section{Some Transit}

A few nearby public

transportation

options.

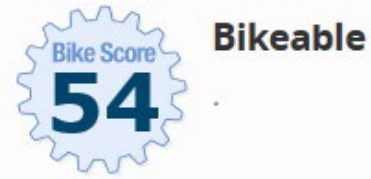

About your score

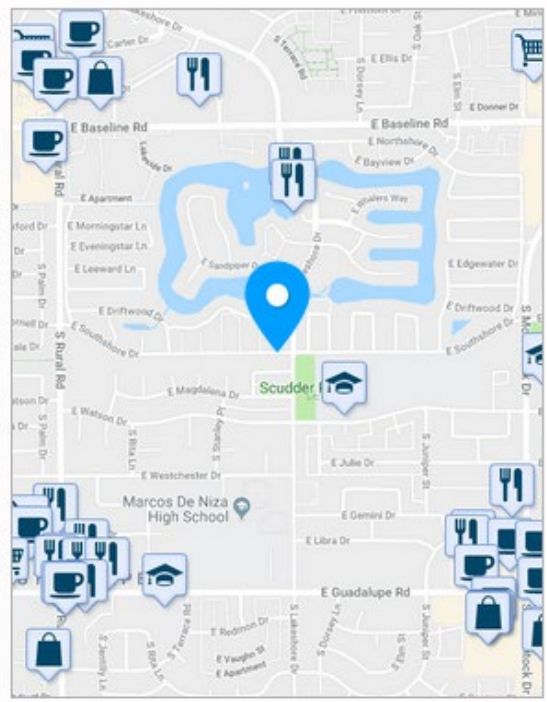

Add scores to your site

Source: https://www.walkscore.com/score/1166-e-s-shore-dr-tempe-az-85283

The stop at Southshore and Lakeshore is located in a highly residential area with no room for retail growth. 


\section{Salt Lake City}

\section{S@6261W Stop}

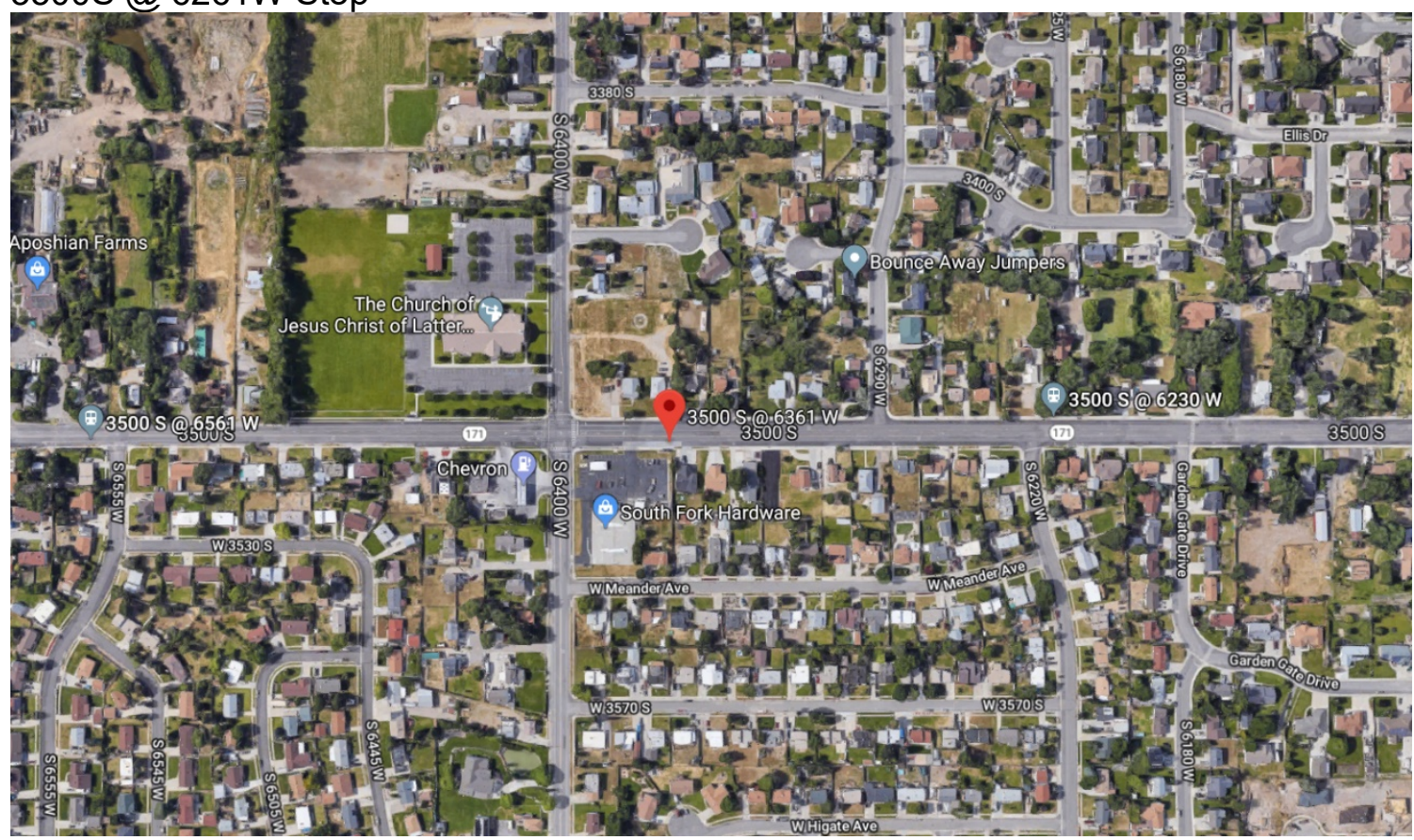

Source: https://www.google.com/maps/place/3500+S+@+6361+W/@40.6965532,-

112.043025,663m/data=!3m1!1e3!4m5!3m4!1s0x87528d56de664dcb:0xd36d0d084d22cc57!8m2!3d40.696452!4d112.0430267 


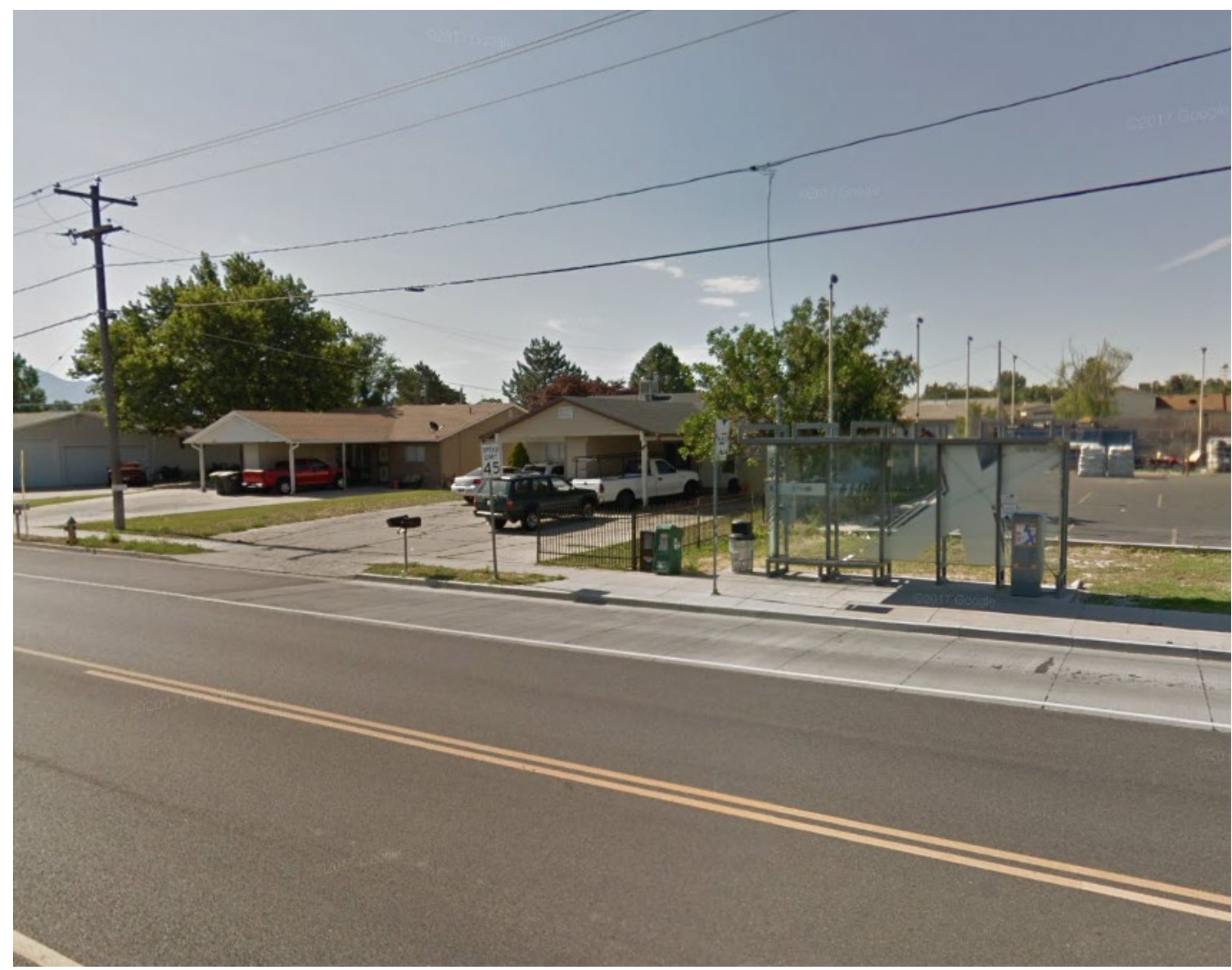

Source: https://www.google.com/maps/@40.6965684,-

112.0431371,3a, 73.8y, 151.68h,85.69t/data=!3m6!1e1!3m4!1spJETljcWQtAZcAUOfGX8vg!2e0!7i13312!8i6656 


\section{South}
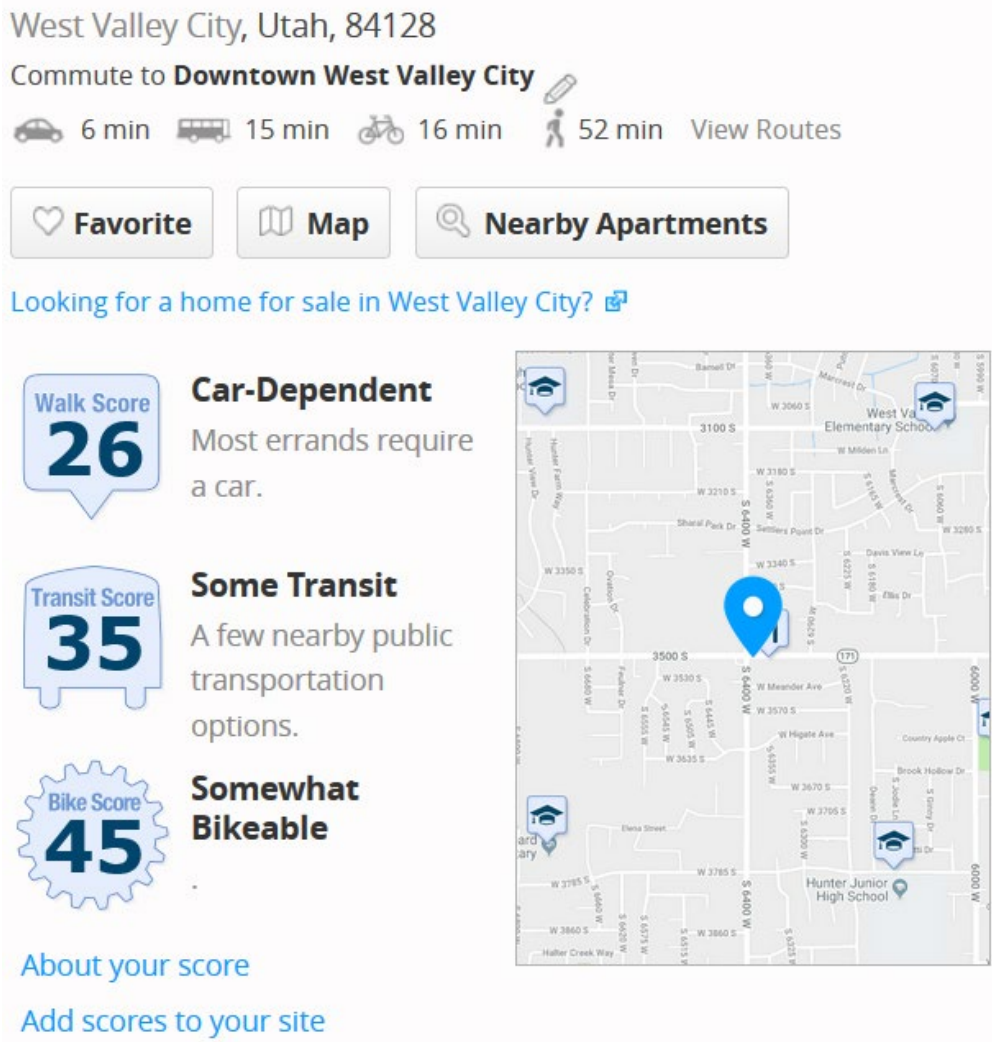

Source: https://www.walkscore.com/score/6383-3500-s-w-valley-city-ut-84128

The stop at 3500 S @ 6261W is not in a retail area and will likely not become a retail destination due to high volumes of single-family homes. 


\section{STREETCAR TRANSIT Good Office}

Portland

SW $5^{\text {th }}$ and Market Stop

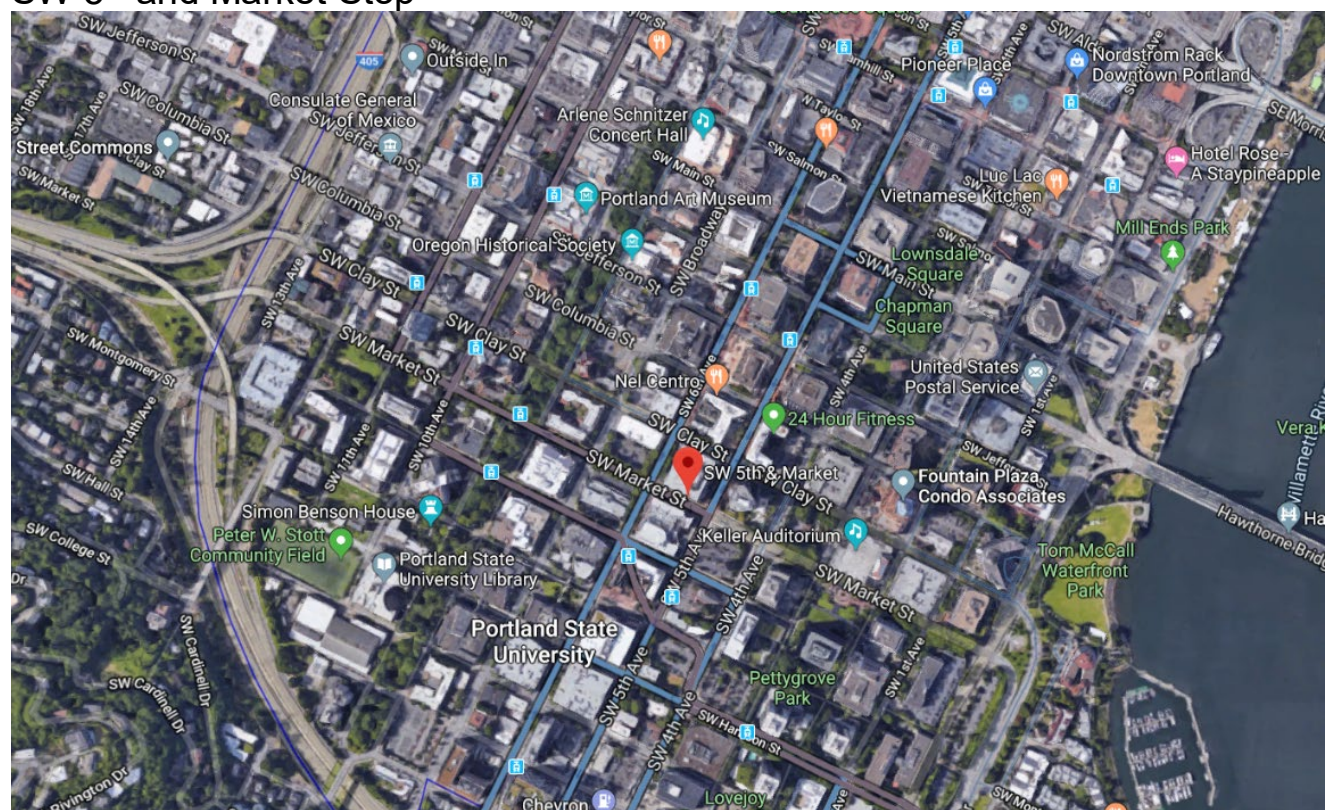

Source: https://www.google.com/maps/place/SW+5th+\%26+Market/@45.5138928,-

122.6796218,1855a,35y,354.25h/data=!3m1!1e3!4m12!1m6!3m5!1s0x54950a111c91d09d:0x9bbdf890bf5edef!2sSW +5 th+\%26+Market! $8 \mathrm{~m} 2 ! 3 \mathrm{~d} 45.512954 ! 4 \mathrm{~d}-$

$\underline{122.680837 ! 3 \mathrm{~m} 4 ! 1 \mathrm{~s} 0 \times 54950 \mathrm{a} 111 \mathrm{c} 693521: 0 \times 17 \mathrm{ec} 19 \mathrm{adb} 5510290 ! 8 \mathrm{~m} 2 ! 3 \mathrm{~d} 45.5129534 ! 4 \mathrm{~d}-122.6811846}$

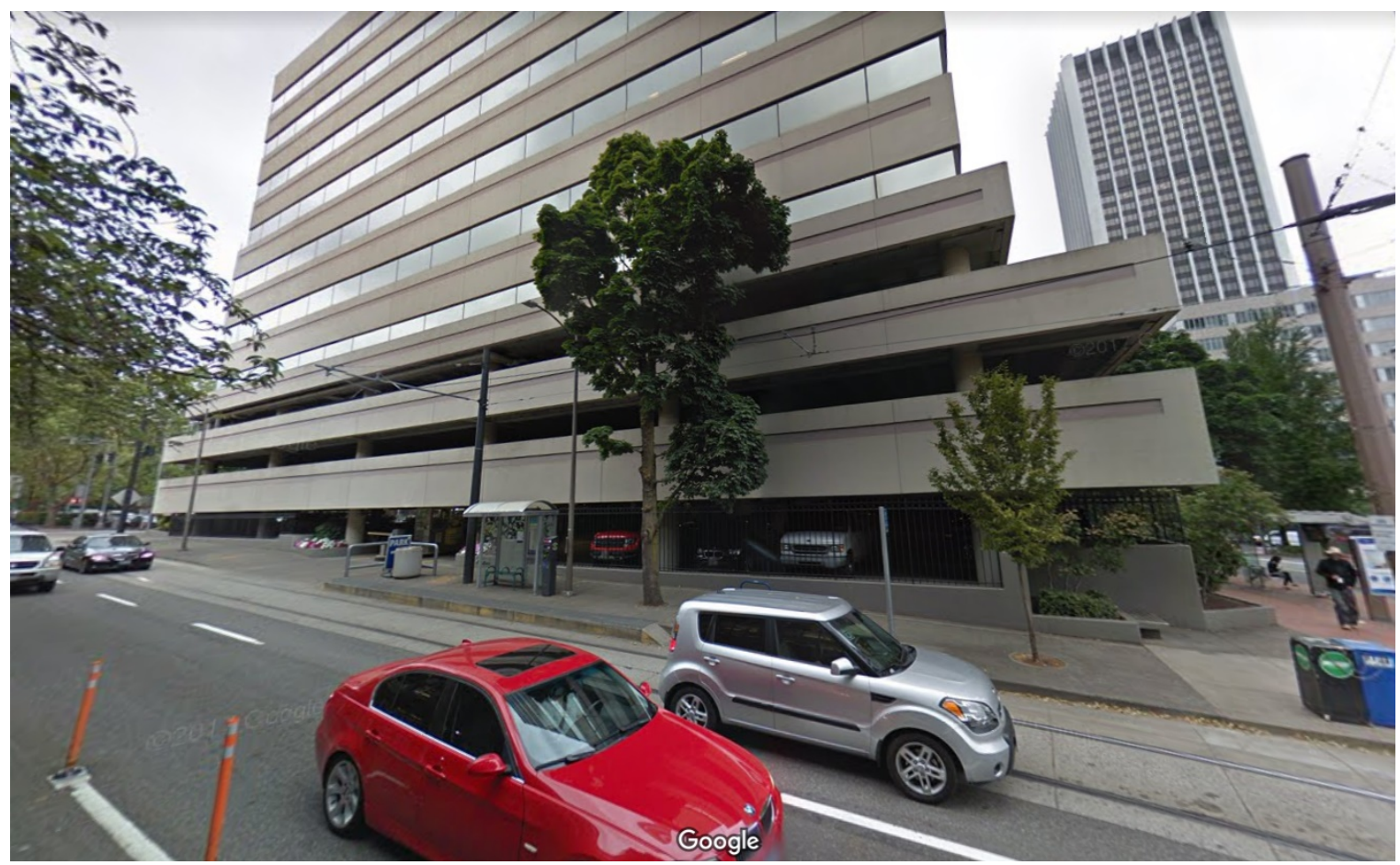

Source: https://www.google.com/maps/@45.5128351,-

122.6810868,3a,89.1y,354.25h,101.33t,0.44r/data=!3m6!1e1!3m4!1sS7nE7I5EYaXTGNFaH39Tzw!2e0!7i13312!8i66 56 


\section{Southwest 5th Avenue}

Downtown, Portland, 97201

Commute to Downtown Portland

2 2 min $7 \mathrm{~min} 2 \mathrm{~min}$ iे 1 min View Routes

\section{Favorite $\mathbb{D}$ Map @ Nearby Apartments}

More about 1500 Southwest 5th Avenue ⿶ㅜㅇ

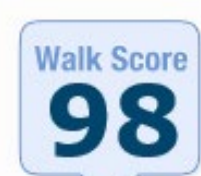

Walker's Paradise

Daily errands do not

require a car.

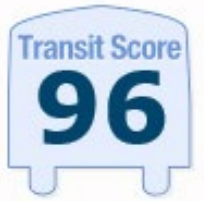

Rider's Paradise

World-class public

transportation.

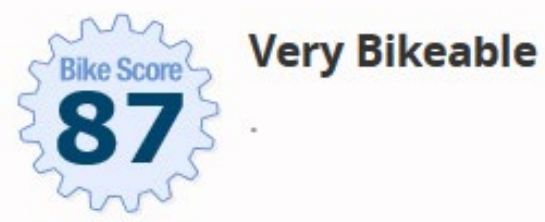

About your score

Add scores to your site

Source: https://www.walkscore.com/score/1500-sw-5th-ave-portland-or-97201

The stop at SW $5^{\text {th }}$ and Market in downtown Portland, Oregon is a good indication of healthy office development. It is within walking distance of the central business district and near the light rail stations as well.

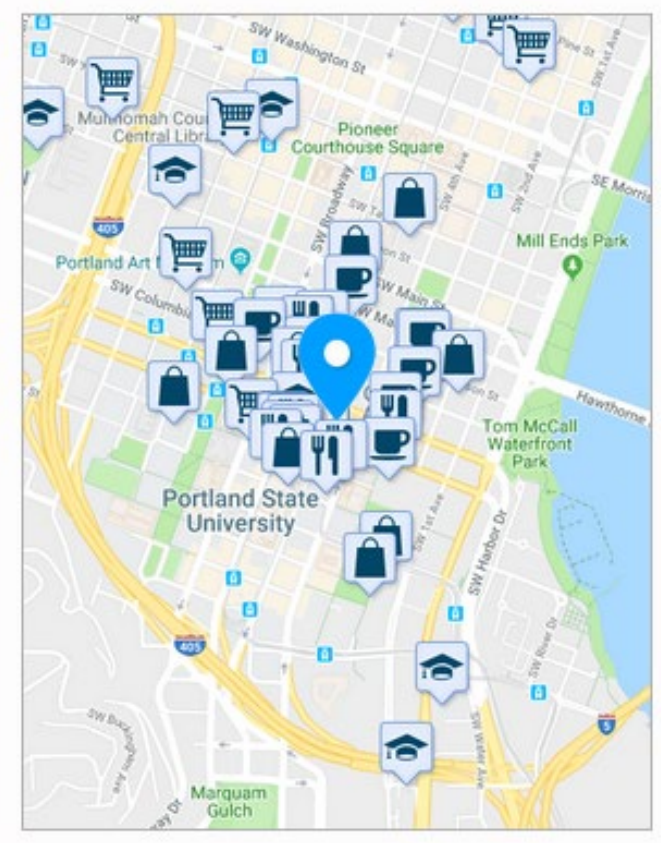

$\pi$ 


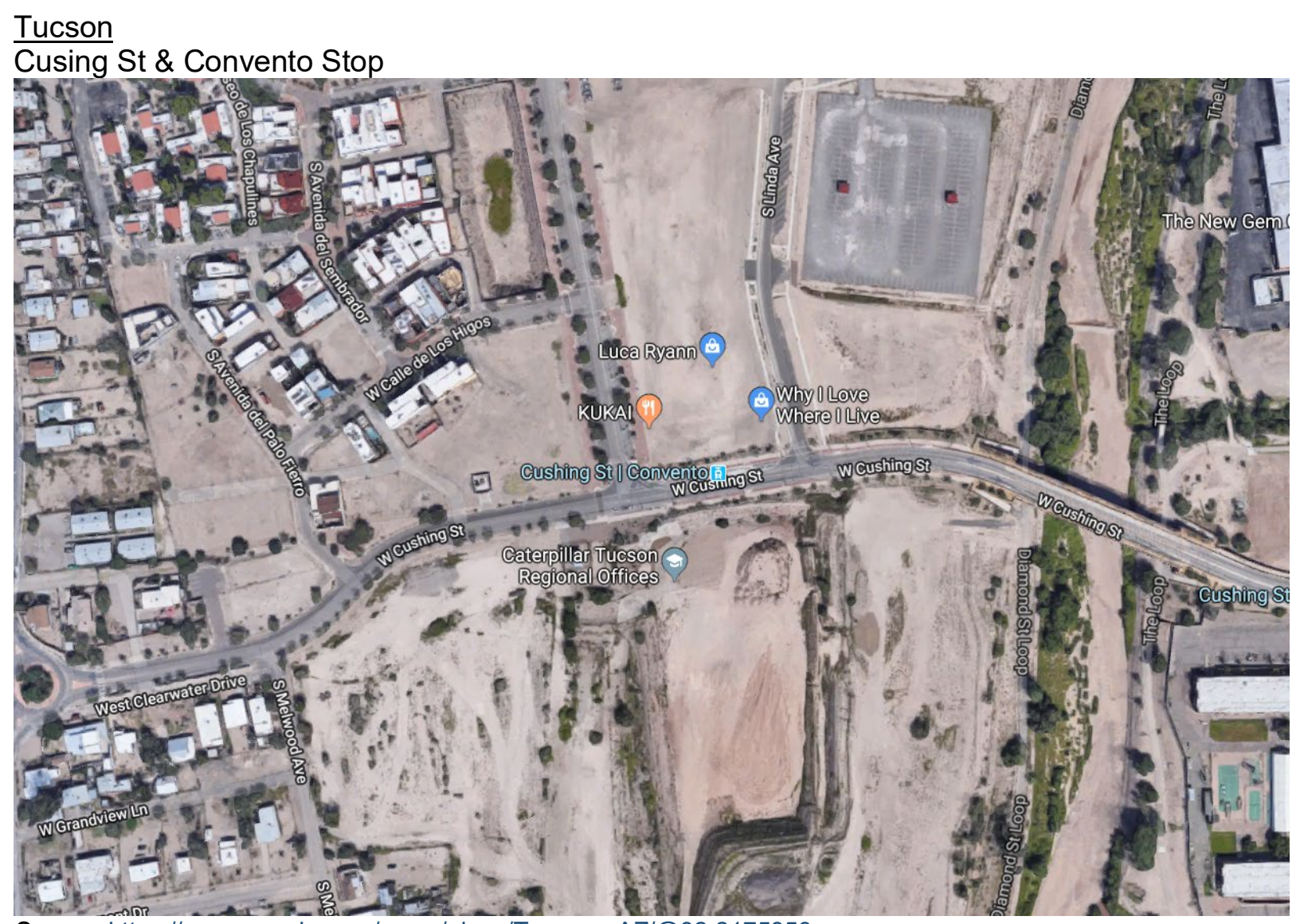

Source: https://www.google.com/maps/place/Tucson,+AZ/@32.2175853,$110.9843801,481 \mathrm{~m} / \mathrm{data}=! 3 \mathrm{~m} 1 ! 1 \mathrm{e} 3 ! 4 \mathrm{~m} 5 ! 3 \mathrm{~m} 4 ! 1 \mathrm{~s} 0 \times 86 \mathrm{~d} 665410 \mathrm{~b} 2 \mathrm{ced} 2 \mathrm{~b}: 0 \times 73 \mathrm{c} 32 \mathrm{~d} 384 \mathrm{~d} 16 \mathrm{c} 715 ! 8 \mathrm{~m} 2 ! 3 \mathrm{~d} 32.2226066 ! 4 \mathrm{~d}$ $\underline{-110.9747108}$ 


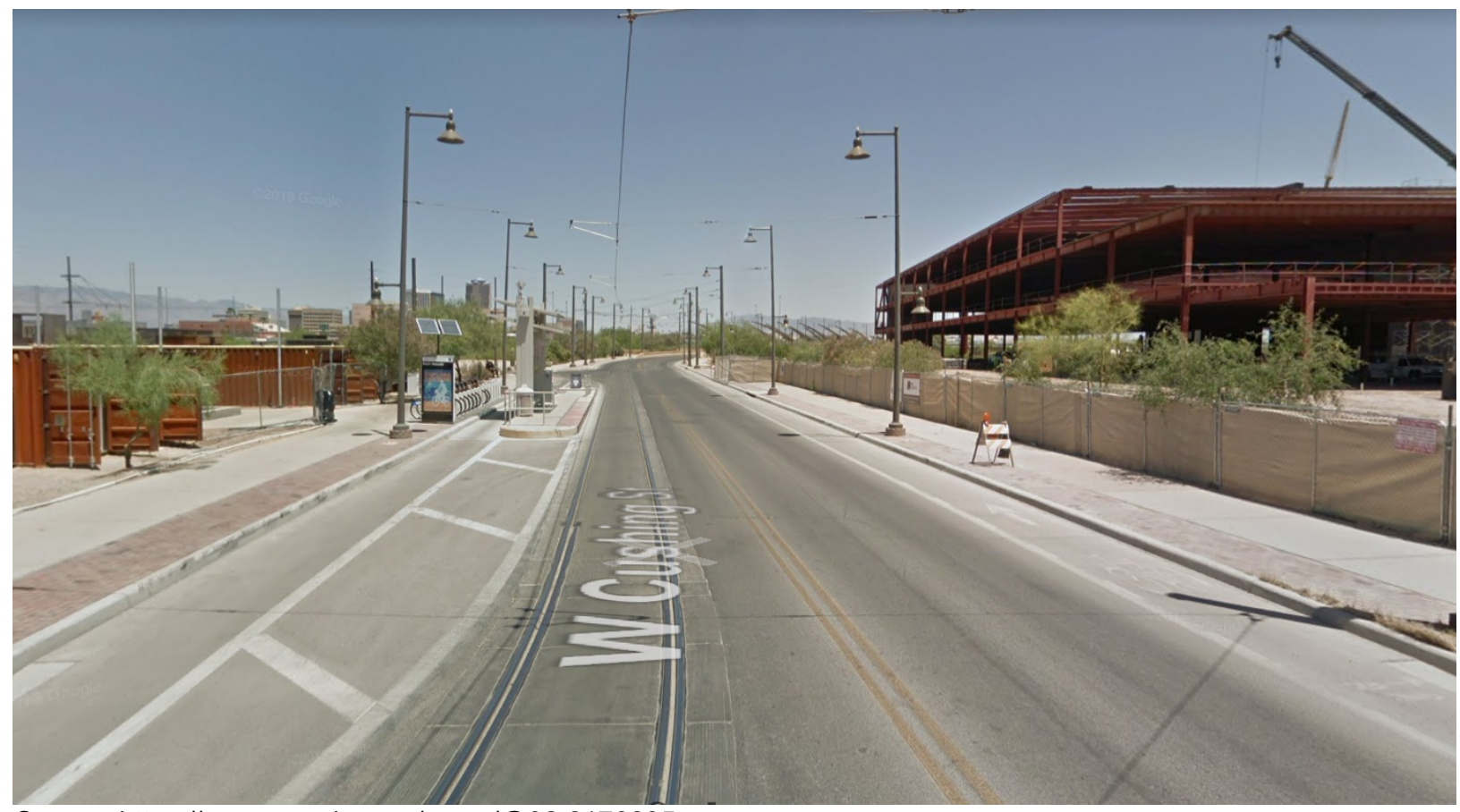

Source: https://www.google.com/maps/@32.2176635,-

110.9846266,3a,60y,86.53h,86.34t/data=!3m6!1e1!3m4!1sgrUW2oujgSscjBQgP49dUw!2e0!7i13312!8i6656 


\title{
875 West Cushing Street
}

\author{
Menlo Park, Tucson, 85745
}

Commute to Downtown Drexel Heights

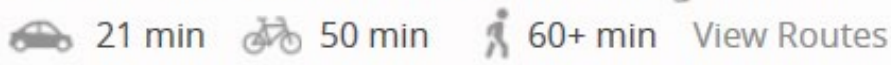

$\checkmark$ Favorite $\mathbb{0}$ Map $\bigcirc$ Nearby Apartments

Looking for a home for sale in Tucson? 땁

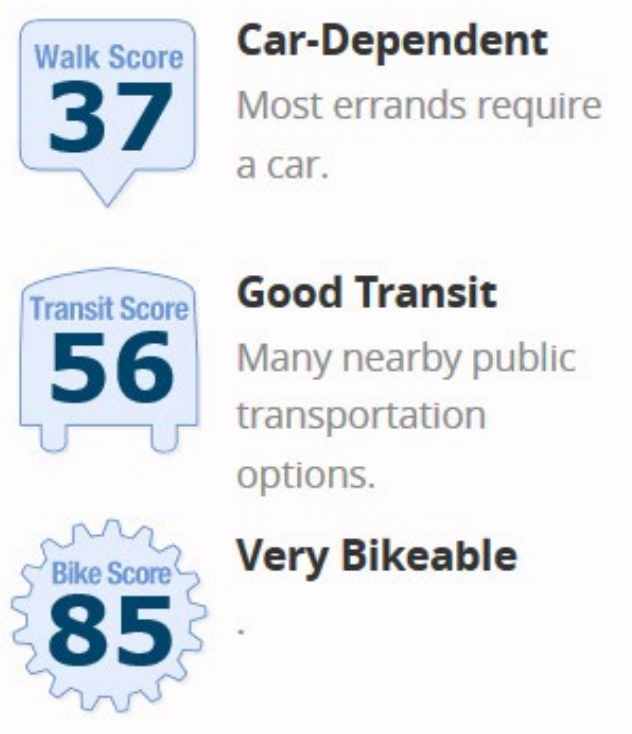

About your score

Add scores to your site

Source: https://www.walkscore.com/score/875-w-cushing-st-tucson-az-85745

The streetcar system in Tucson, Arizona can be attributed to major redevelopment on the western side of downtown. Shown above, Caterpillar's new mining headquarters is under construction right across from a streetcar stop allowing residents to live downtown and commute via streetcar. 


\section{New Orleans}

Canal Street at St. Charles Stop

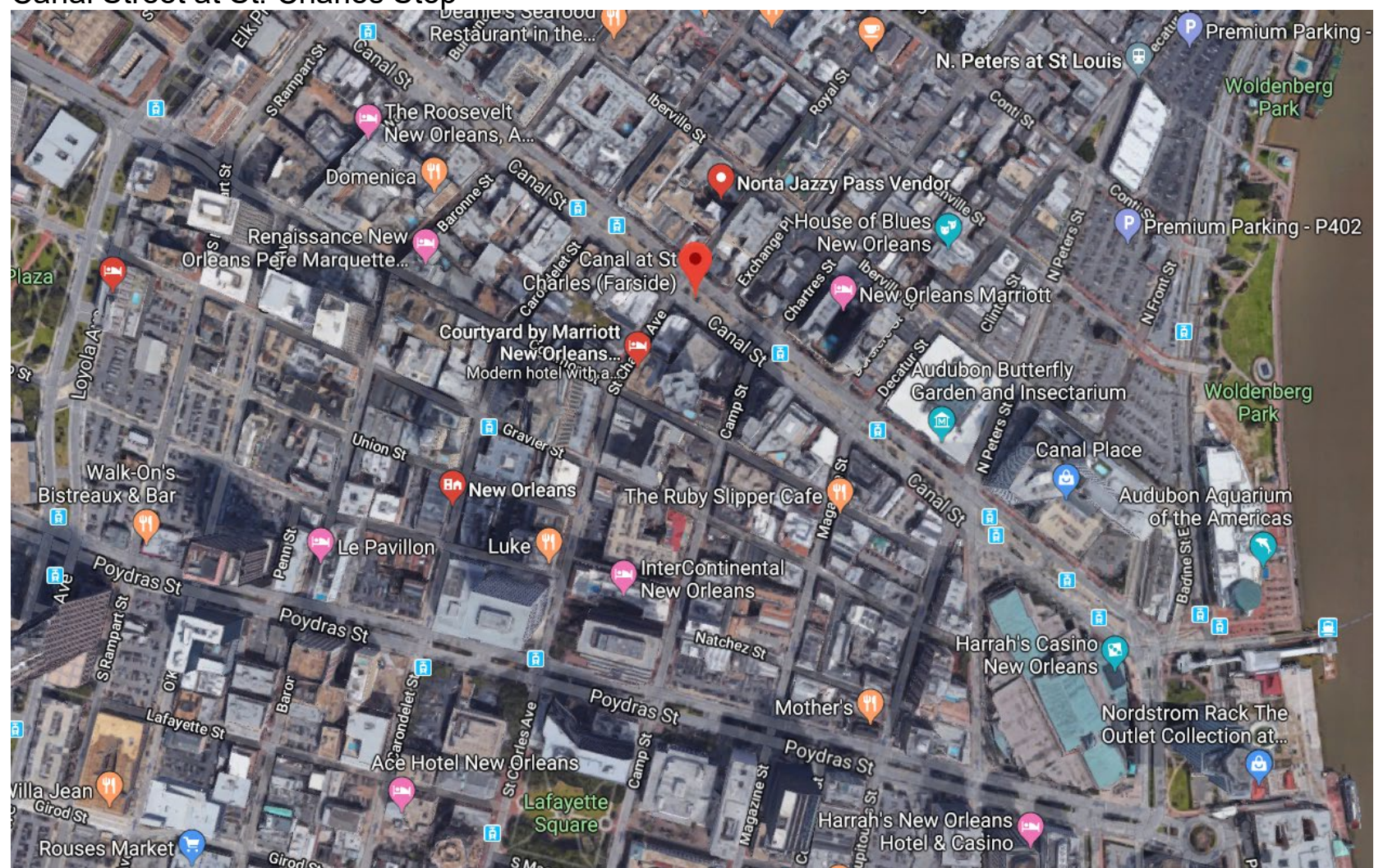

Source: https://www.google.com/maps/place/Canal+at+St+Charles+(Farside)/@29.9517936,-

$90.0690338,1014 \mathrm{~m} /$ data $=$ !3m1!1e3!4m8!1m2!2m1!1snew+orleans+streetcar!3m4!1s0x8620a60c927eb1b9:0xc0aae3 cf4c24f021!8m2!3d29.9530063!4d-90.0689294 


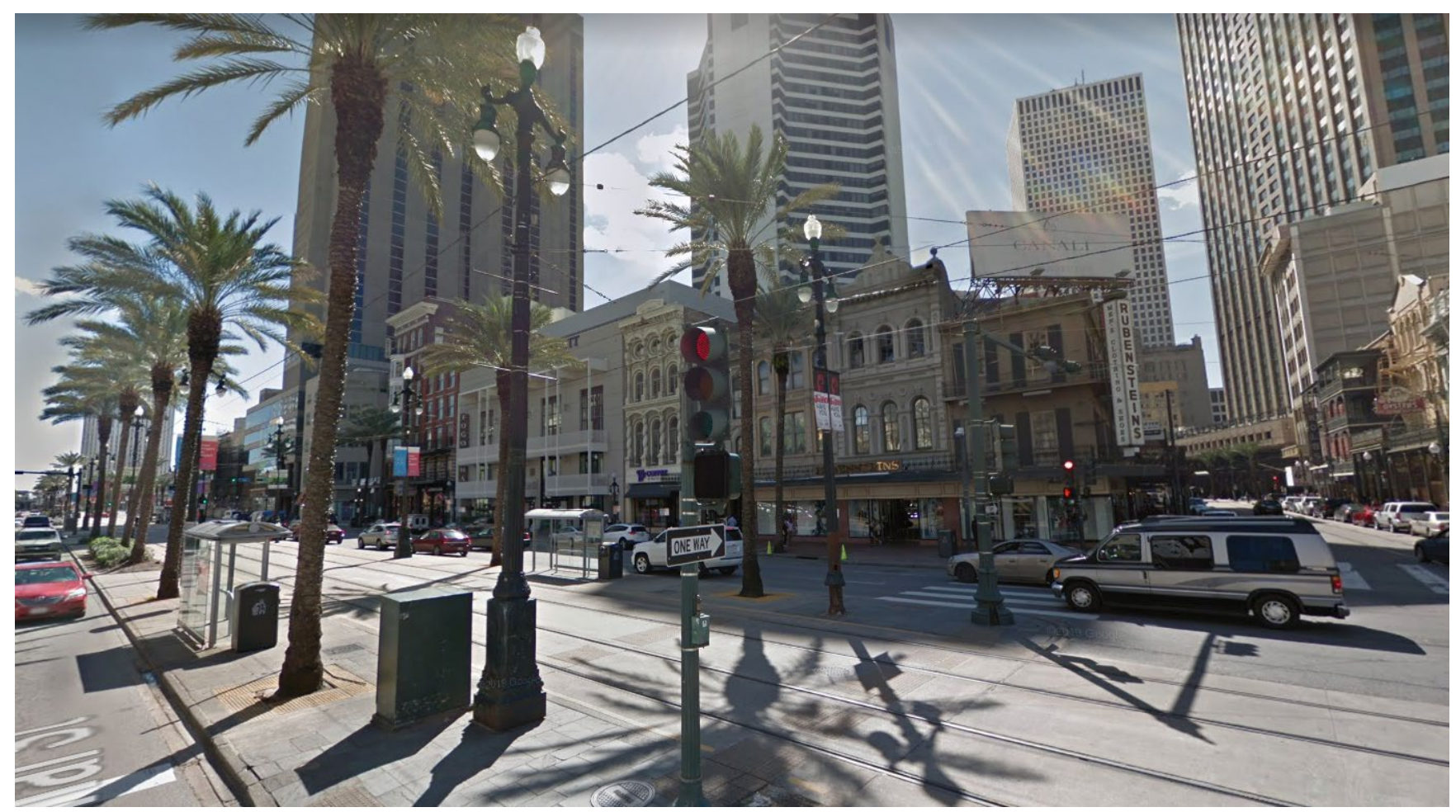

Source: https://www.google.com/maps/@29.9533279,-90.0689815,3a,75y,181.93h,96.87t/data=!3m6!1e1!3m4!1sSA4DwhsY5KxokkPuZ-5IA!2e0!7i13312!8i6656 


\section{Canal Street}

Central Business District, New Orleans, 70130

Commute to Downtown New Orleans

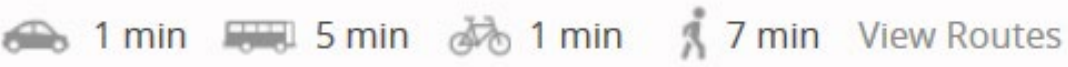

\section{Favorite T) Map @ Nearby Apartments}

Looking for a home for sale in New Orleans? 뿡
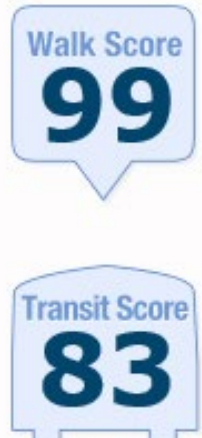

$\mathbf{6 6}$

Bikeable

Very steep hills, excellent bike lanes.

About your score

Add scores to your site

Source: https://www.walkscore.com/score/700-canal-st-new-orleans-la-70130

The Canal Street at St. Charles stop in downtown New Orleans, Louisiana is in a very walkable area with abundant access to major office buildings in the area.

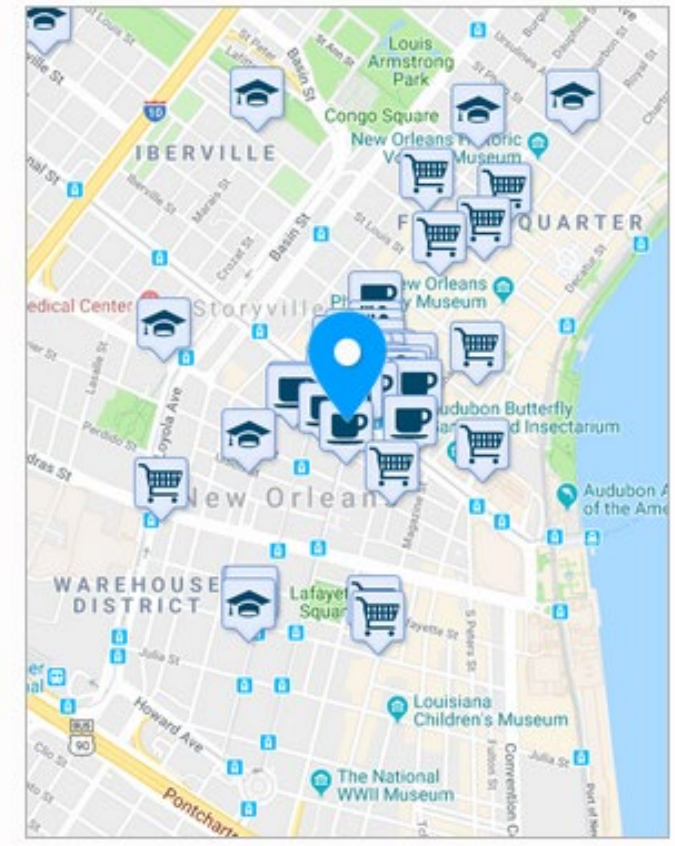
for most trips. require a car.

\section{Excellent Transit}

Transit is convenient 


\section{Bad Office}

Tacoma

\section{South $25^{\text {th }}$ St Station}

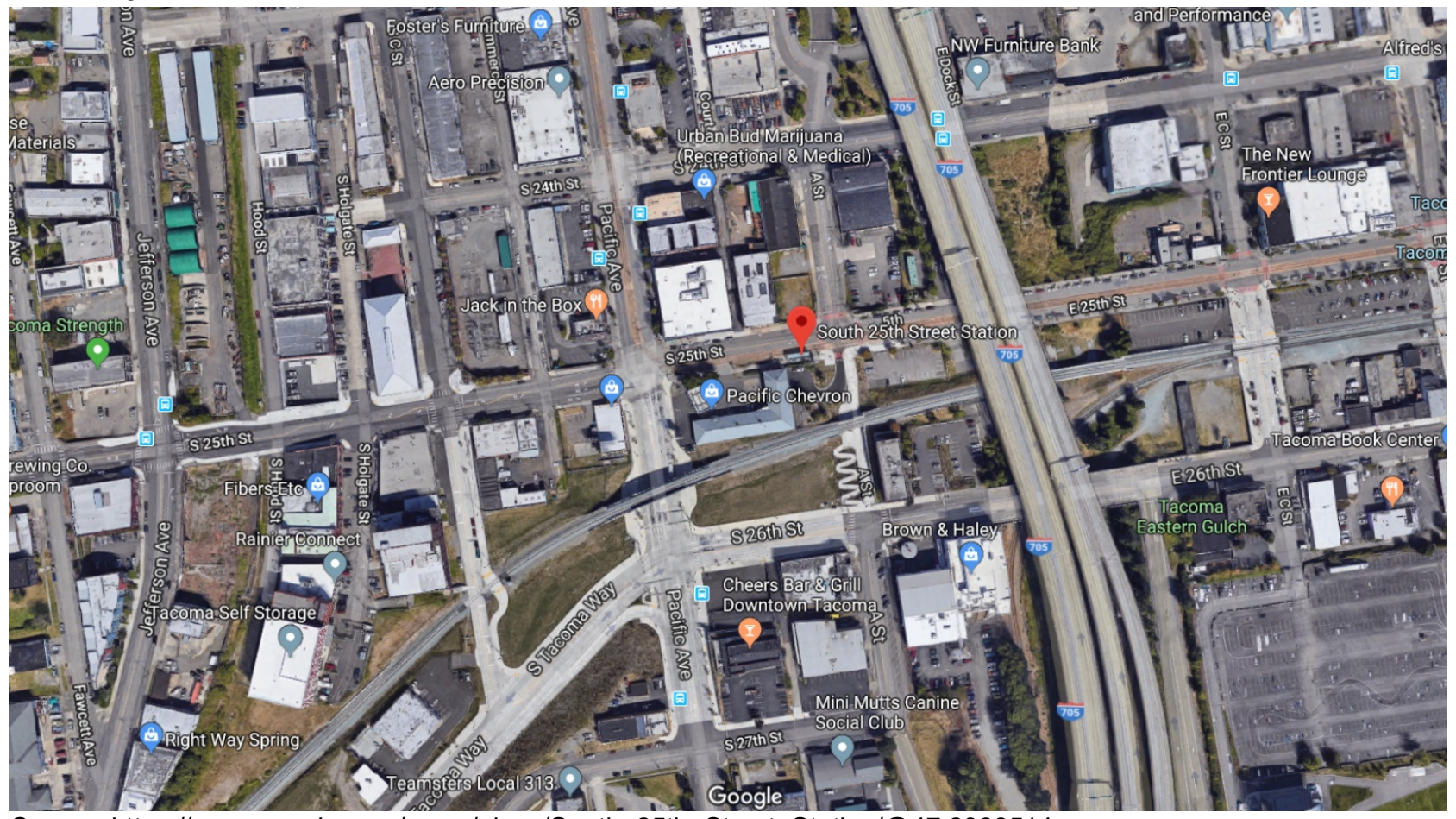

Source: https://www.google.com/maps/place/South+25th+Street+Station/@47.2388514,-

122.4345994,496m/data=!3m1!1e3!4m5!3m4!1s0x5490557bbdc4d0f1:0x30c0042012b6bf!8m2!3d47.2390675!4d122.434176

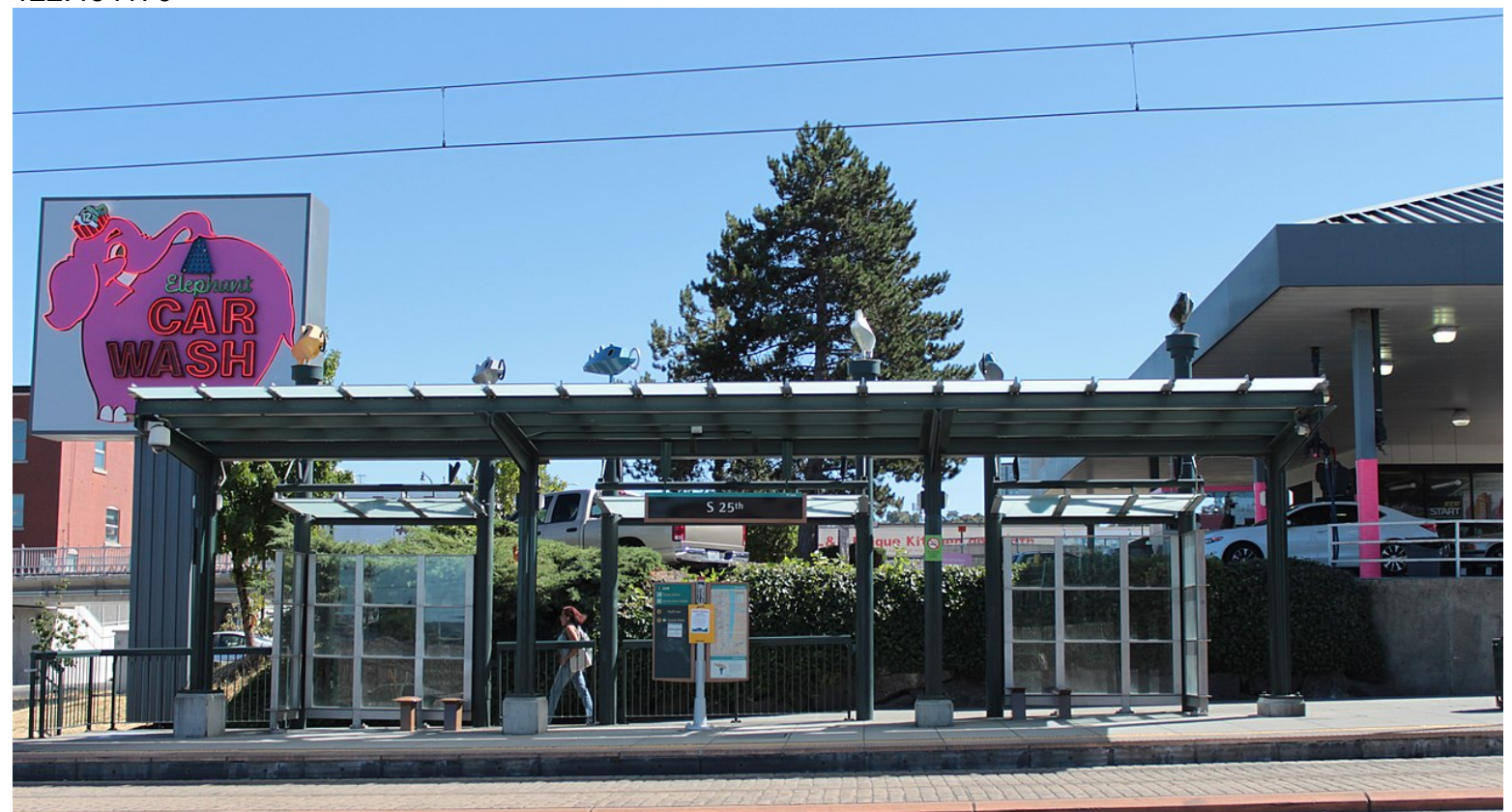

Source: https://en.wikipedia.org/wiki/South_25th_Street_station\#/media/File:South_25th_Station_platform.jpg 


\section{South 25th Street}

New Tacoma, Tacoma, 98402

Commute to Downtown Tacoma

$\Leftrightarrow 4 \mathrm{~min} 15 \mathrm{~min}$. $726 \mathrm{~min}$ View Routes

\section{Favorite $\mathbb{0}$ Map $\bigcirc$ Nearby Apartments}

Looking for a home for sale in Tacoma?
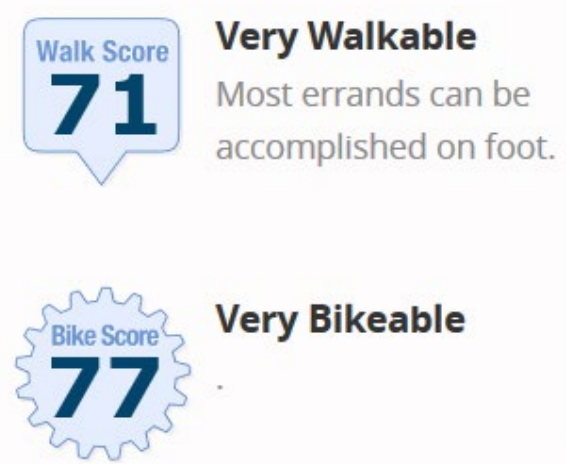

About your score

Add scores to your site

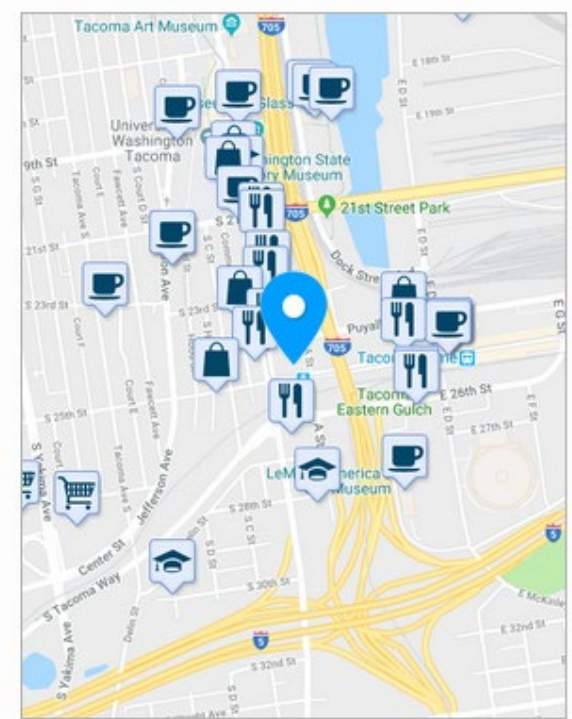

Source: https://www.walkscore.com/score/109-s-25th-st-tacoma-wa-98402

The South $25^{\text {th }}$ St. Station in Tacoma, Washington is in an area with very little office potential, as it is located in a transitional industrial area with no real access to downtown Tacoma. 


\section{Seattle}

Fairview Ave $\mathrm{N}$ and Aloha St

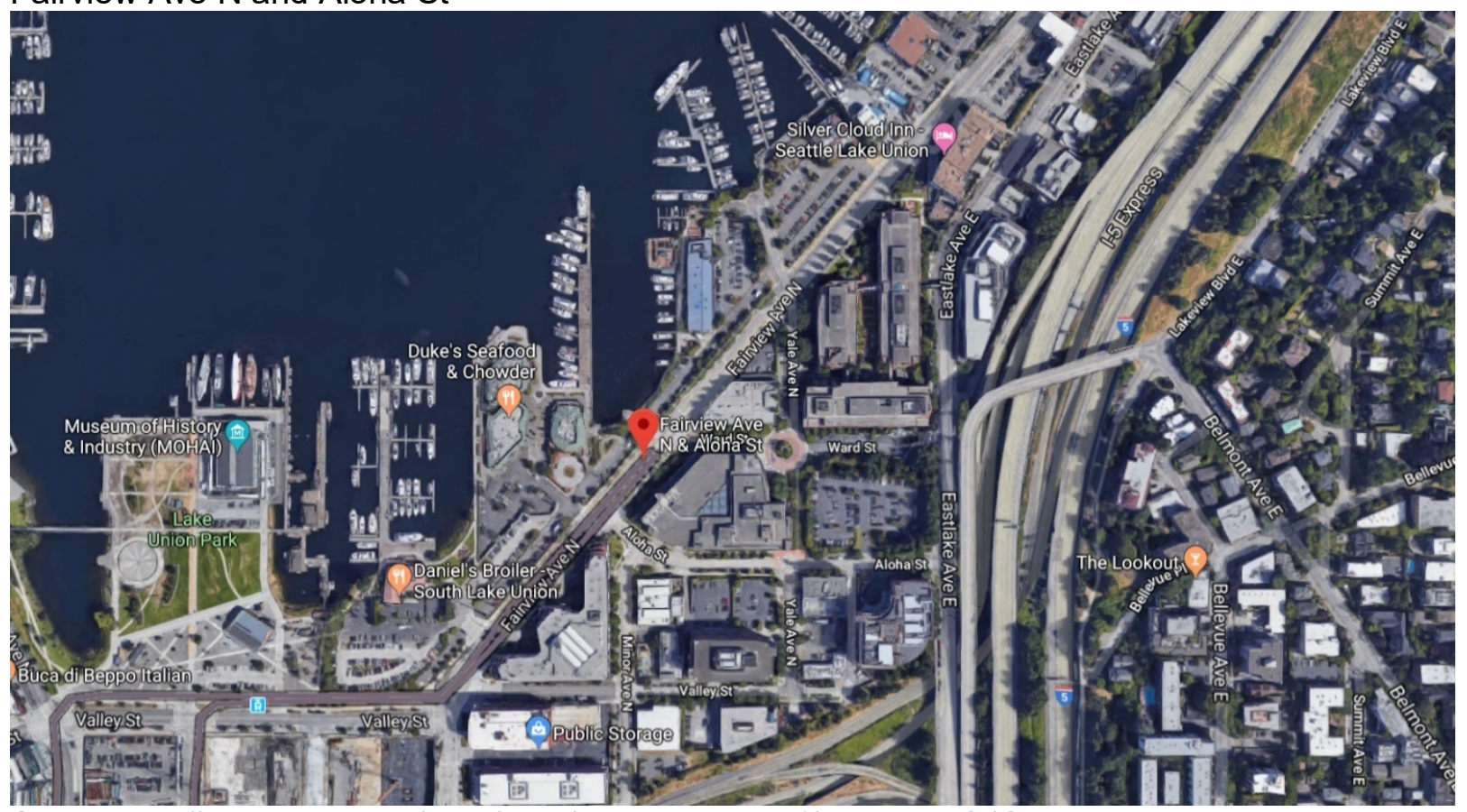

Source: https://www.google.com/maps/place/Fairview+Ave+N+\%26+Aloha+St/@47.6279396,-

$122.3311609,705 \mathrm{~m} / \mathrm{data}=! 3 \mathrm{~m} 1 ! 1 \mathrm{e} 3 ! 4 \mathrm{~m} 5 ! 3 \mathrm{~m} 4 ! 1 \mathrm{~s} 0 \times 5490153 \mathrm{ae} 007 \mathrm{c} 3 \mathrm{a} 9: 0 \times 6 \mathrm{c} 4 \mathrm{db0e9c676fcca!8m} 2 ! 3 \mathrm{~d} 47.6275711 ! 4 \mathrm{~d}-$ $\underline{122.3323989}$

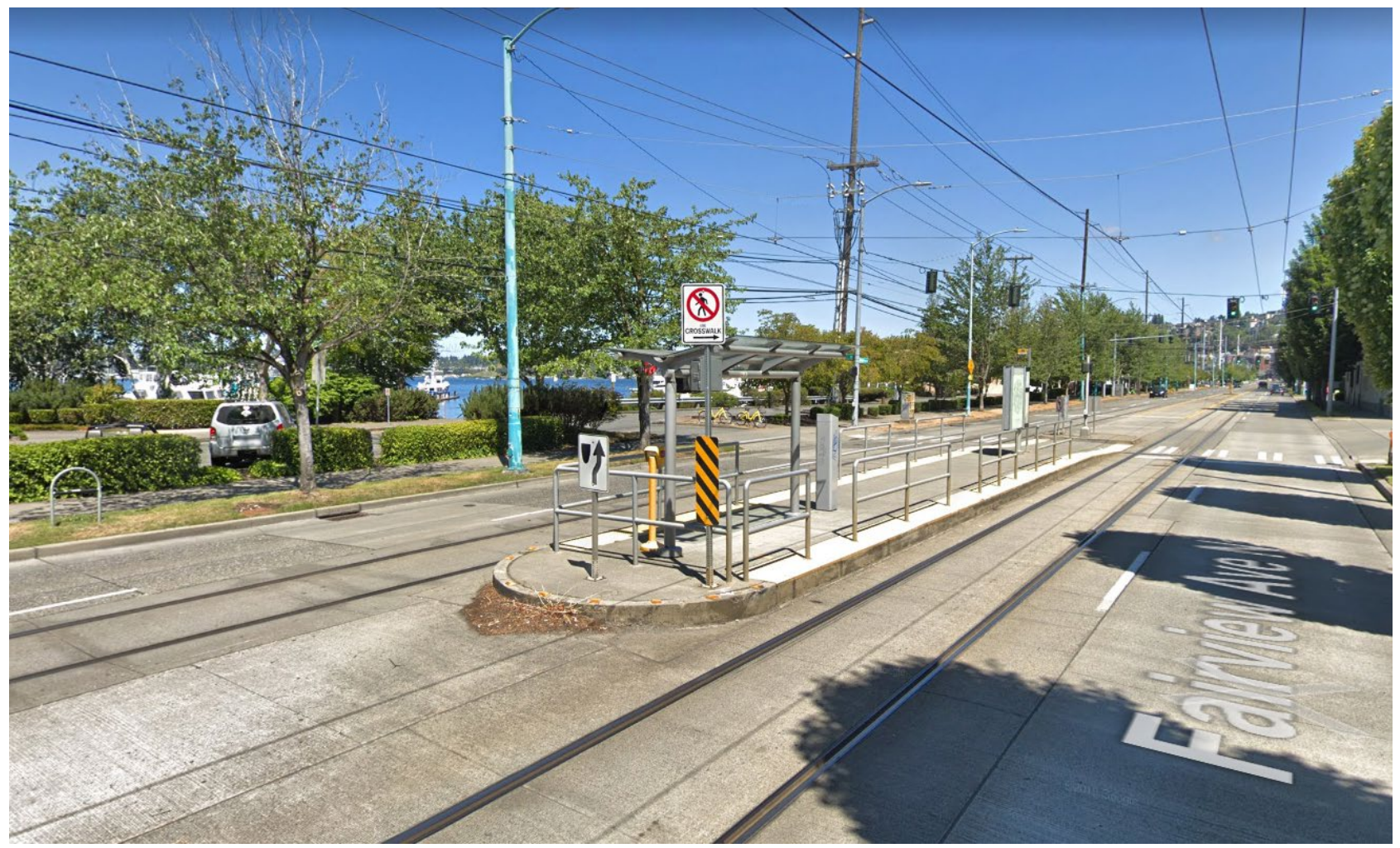

Source: https://www.google.com/maps/@47.6274628,-

122.3324255,3a,60y,5.88h,86.75t/data=!3m6!1e1!3m4!1spxTN42anYuUja8voc21kGQ!2e0!7i16384!8i8192 


\title{
991 Aloha Street
}

\author{
South Lake Union, Seattle, 98109
}

Commute to Downtown Seattle

$4 \mathrm{~min} 18 \mathrm{~min} 10 \mathrm{~min} \quad \grave{3} 34 \mathrm{~min}$ View Routes

Favorite

\section{Map}

Nearby Apartments

Looking for a home for sale in Seattle? 뚠
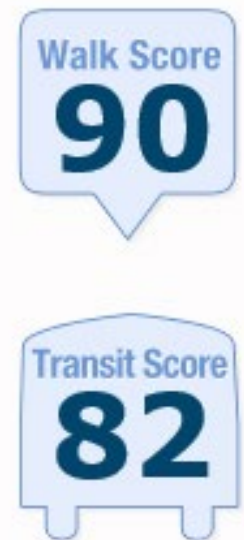

Excellent Transit

Transit is convenient for most trips.

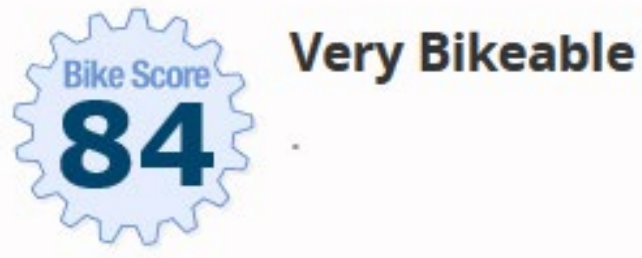

About your score

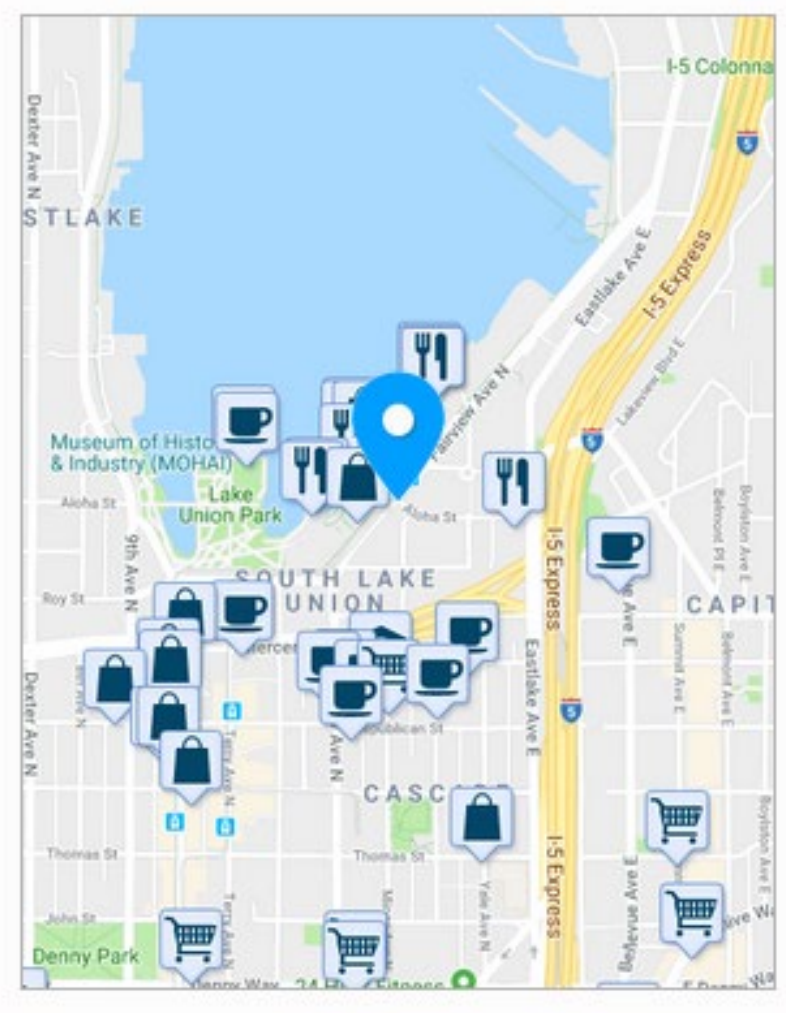

\section{Add scores to your site}

Source: https://www.walkscore.com/score/991-aloha-st-seattle-wa-98109

The Fairview Ave $\mathrm{N}$ and Aloha St streetcar stop in Seattle, Washington is in an area far from the central business district and features a less than inviting platform. 


\section{Good Multifamily}

\section{Atlanta}

Auburn at Piedmont Stop

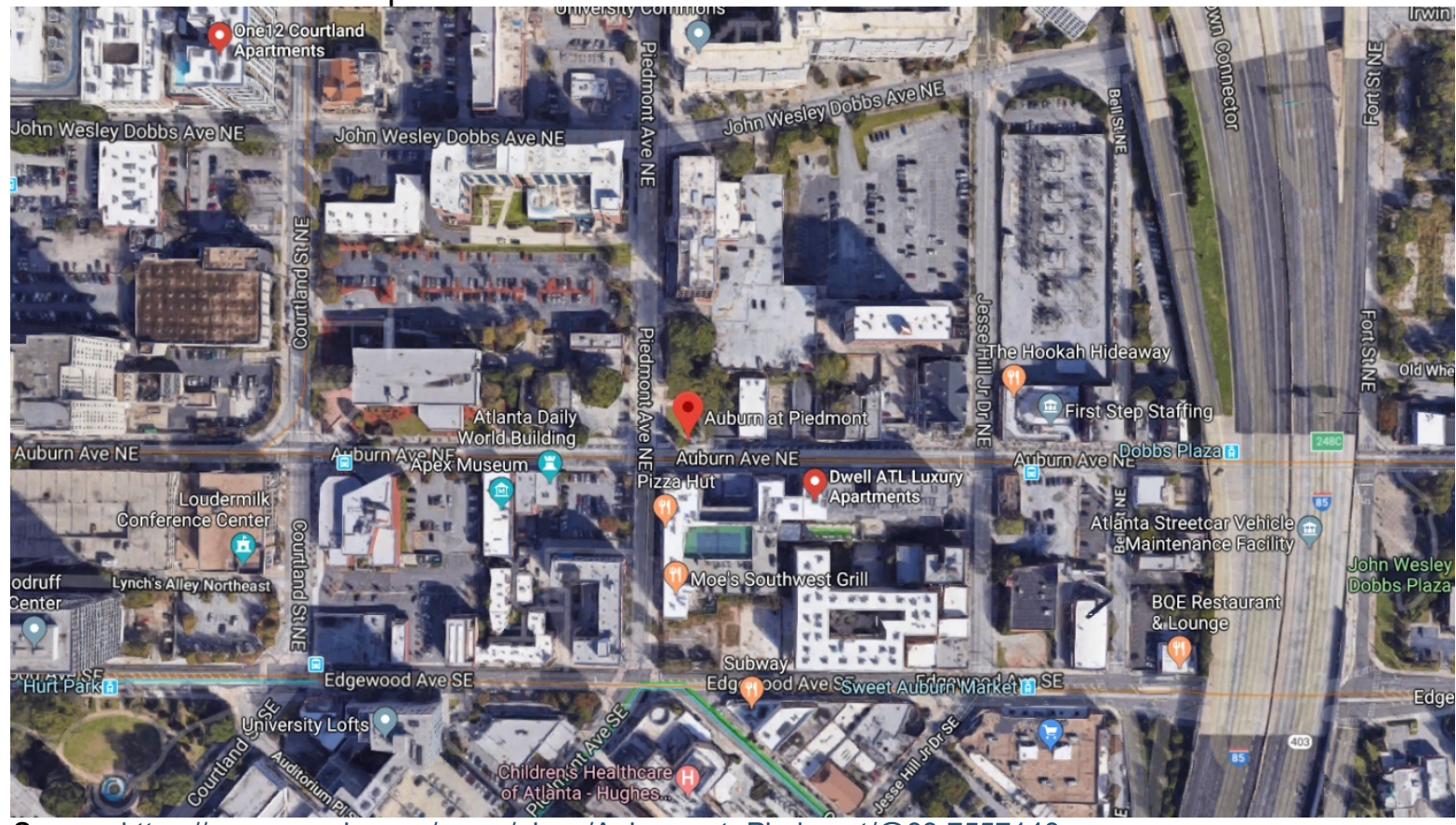

Source: https://www.google.com/maps/place/Auburn+at+Piedmont/@33.7557148,-

84.3820988,490m/data=!3m1!1e3!4m8!1m2!2m1!1sapartments!3m4!1s0x88f50389a0ec539b:0x5059d0dedc8b190d! $\underline{8 m 2 ! 3 d 33.7556026 ! 4 d-84.3820012}$

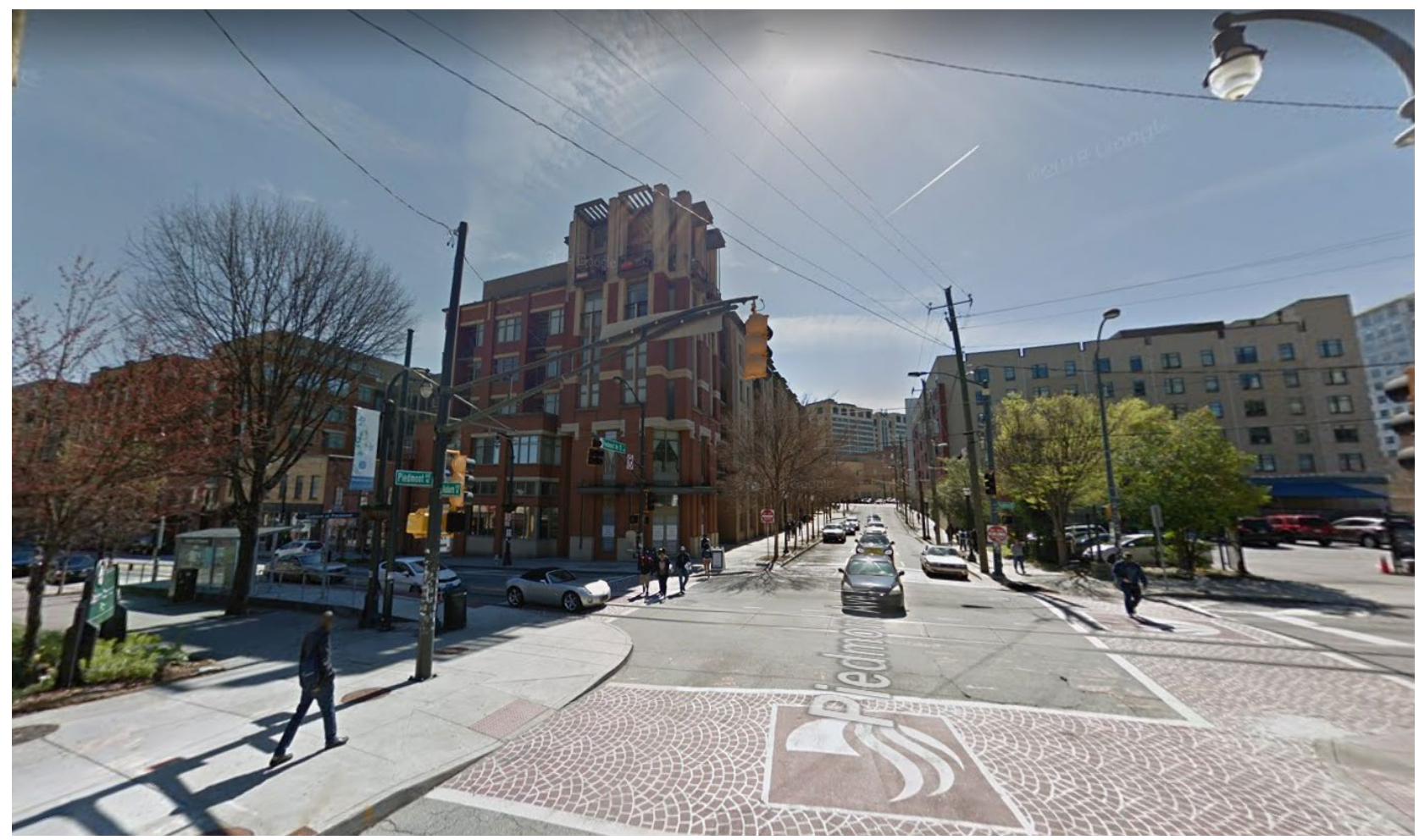

Source: https://www.google.com/maps/place/Auburn+at+Piedmont/@33.755706,$\underline{84.3822313,3 \mathrm{a}, 60 \mathrm{y}, 157.79 \mathrm{~h}, 90 \mathrm{t} / \mathrm{data}=! 3 \mathrm{~m} 6 ! 1 \mathrm{e} 1 ! 3 \mathrm{~m} 4 ! 1 \mathrm{sdPcdW}-}$ 


\section{Piedmont Avenue Northeast}

Peachtree Center, Atlanta, 30305

Commute to Downtown Atlanta

$1 \mathrm{~min} 6 \mathrm{~min} 2 \mathrm{~min}$ i $8 \mathrm{~min}$ View Routes

Favorite

Map

Nearby Apartments

Looking for a home for sale in Atlanta? 뚠
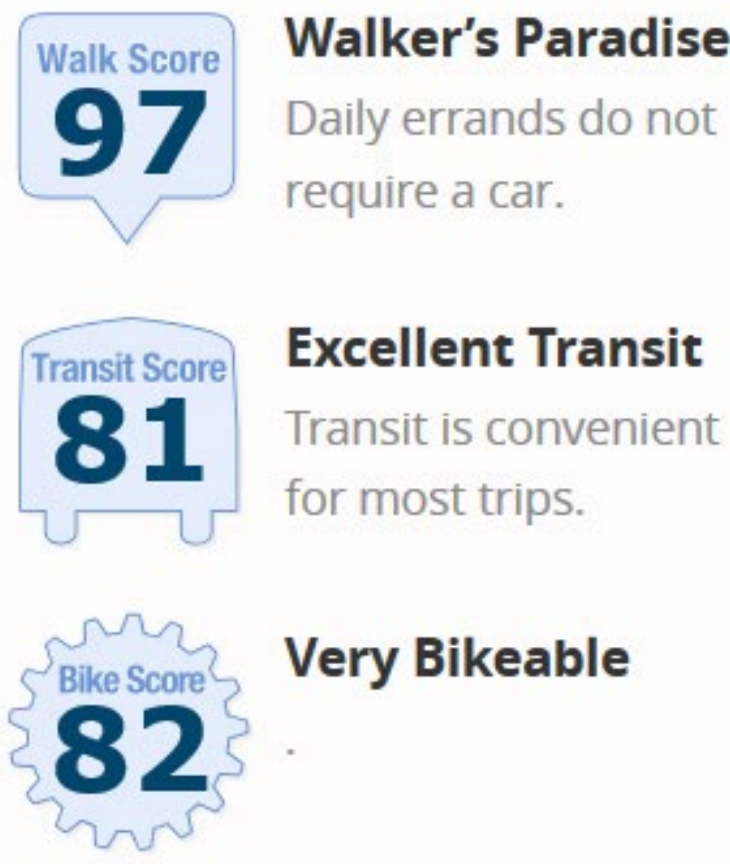

About your score

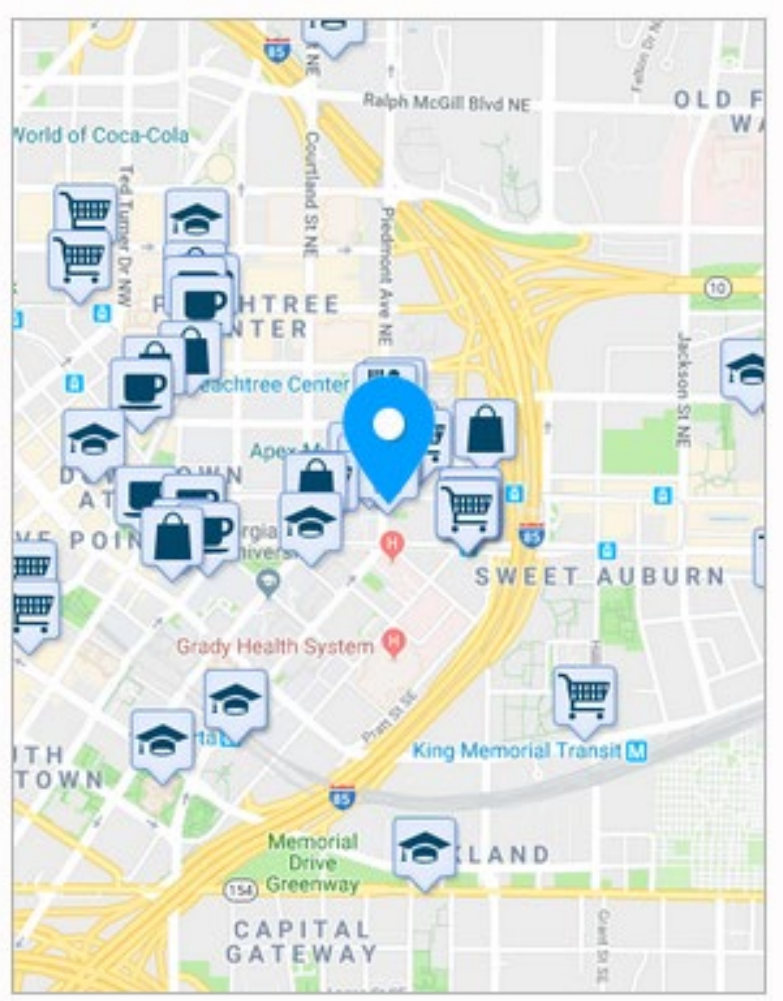

\section{Add scores to your site}

Source: https://www.walkscore.com/score/27-piedmont-ave-ne-atlanta-ga-30305

Located near Georgia State University, the Auburn at Piedmont stop along Downtown Atlanta's streetcar line is bringing multifamily investment due to its walkability and access to local amenities. 


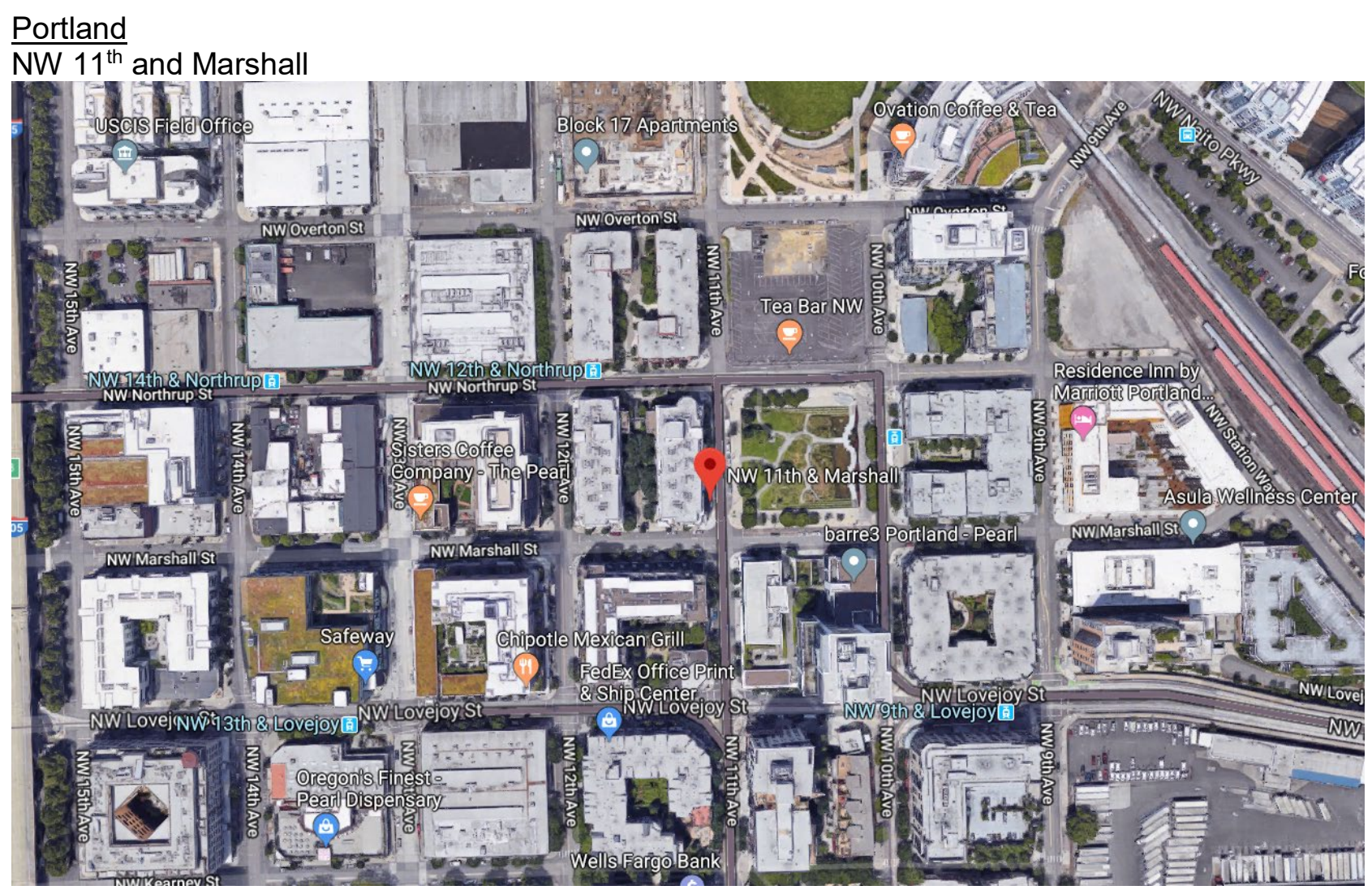

Source: https://www.google.com/maps/place/NW+11th+\%26+Marshall/@45.5311174,-

122.6828371,463m/data=!3m1!1e3!4m5!3m4!1s0x549509fe7445b217:0x547d9efe2d30643b!8m2!3d45.5309623!4d$\underline{122.6824956}$ 


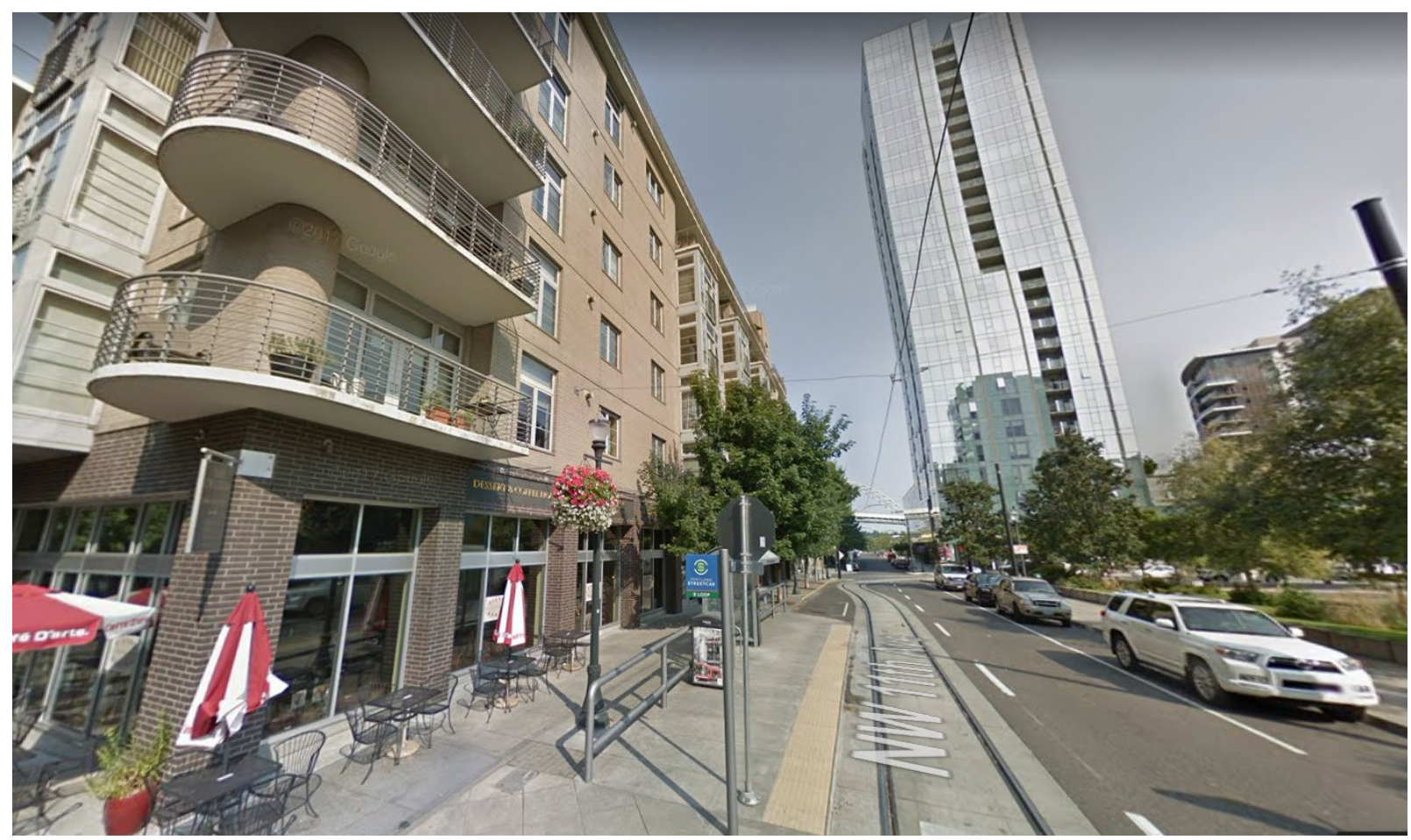

Source: https://www.google.com/maps/@45.5308558,-

122.682453,3a,90y,336.37h,102.22t/data=!3m6!1e1!3m4!1s_aWOf41xSnnWHuJrSkbrOA!2e0!7i13312!8i6656 


\title{
1030 Northwest Marshall Street
}

\author{
Pearl District, Portland, 97209
}

Commute to Downtown Portland

$2 \mathrm{~min} 12 \mathrm{~min}$. $3 \mathrm{~min} 15 \mathrm{~min}$ View Routes
Favorite
[1] Map
Nearby Apartments

Looking for a home for sale in Portland? ⿷匚⿳⺈⿴囗十

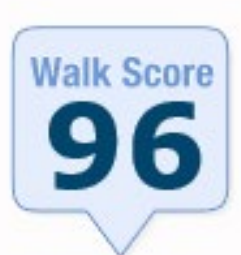

82

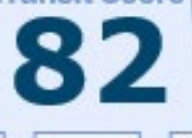

$4 \longdiv { 6 }$

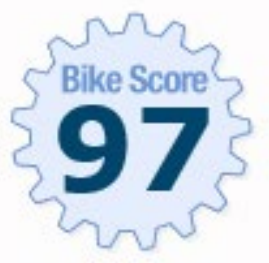

Excellent Transit

Transit is convenient for most trips.

\section{Biker's Paradise}

Flat as a pancake, excellent bike lanes.

\section{Score Details}

Daily errands do not require a car.

Source: https://www.walkscore.com/score/1030-nw-marshall-st-portland-or-97209

Downtown Portland is booming with multifamily in general, but the projects located along the streetcar line are popular and successful. 


\section{Seattle}

Terry Ave \& N Republican Station

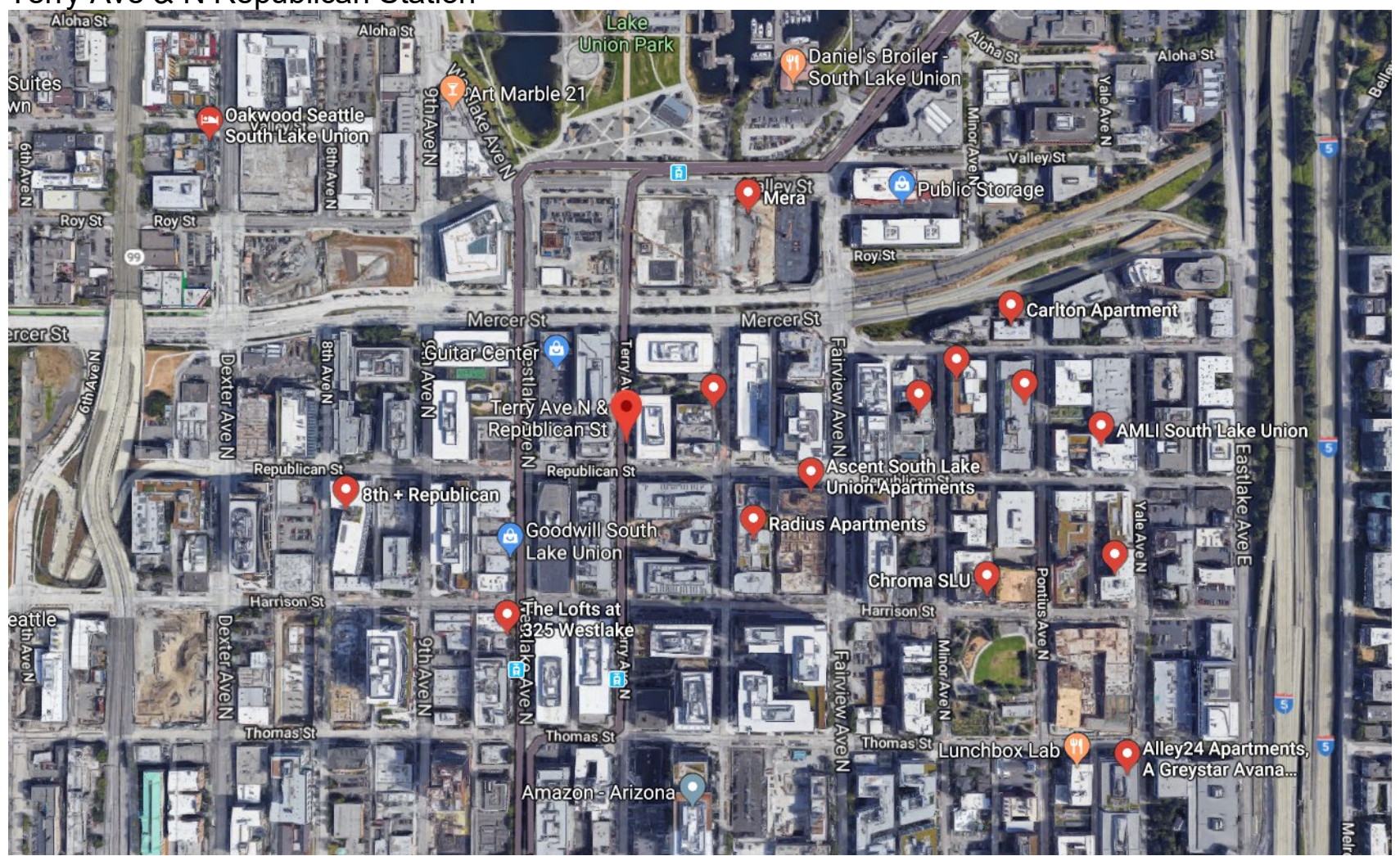

Source: https://www.google.com/maps/place/Terry+Ave+N+\%26+Republican+St/@47.6235382,-

122.336211,940m/data=!3m1!1e3!4m8!1m2!2m1!1sapartments!3m4!1s0x54901539d8b17a53:0xd4a6eadec05346b7 $\underline{\text { !8m2!3d47.6234169! } 4 \mathrm{~d}-122.337135}$

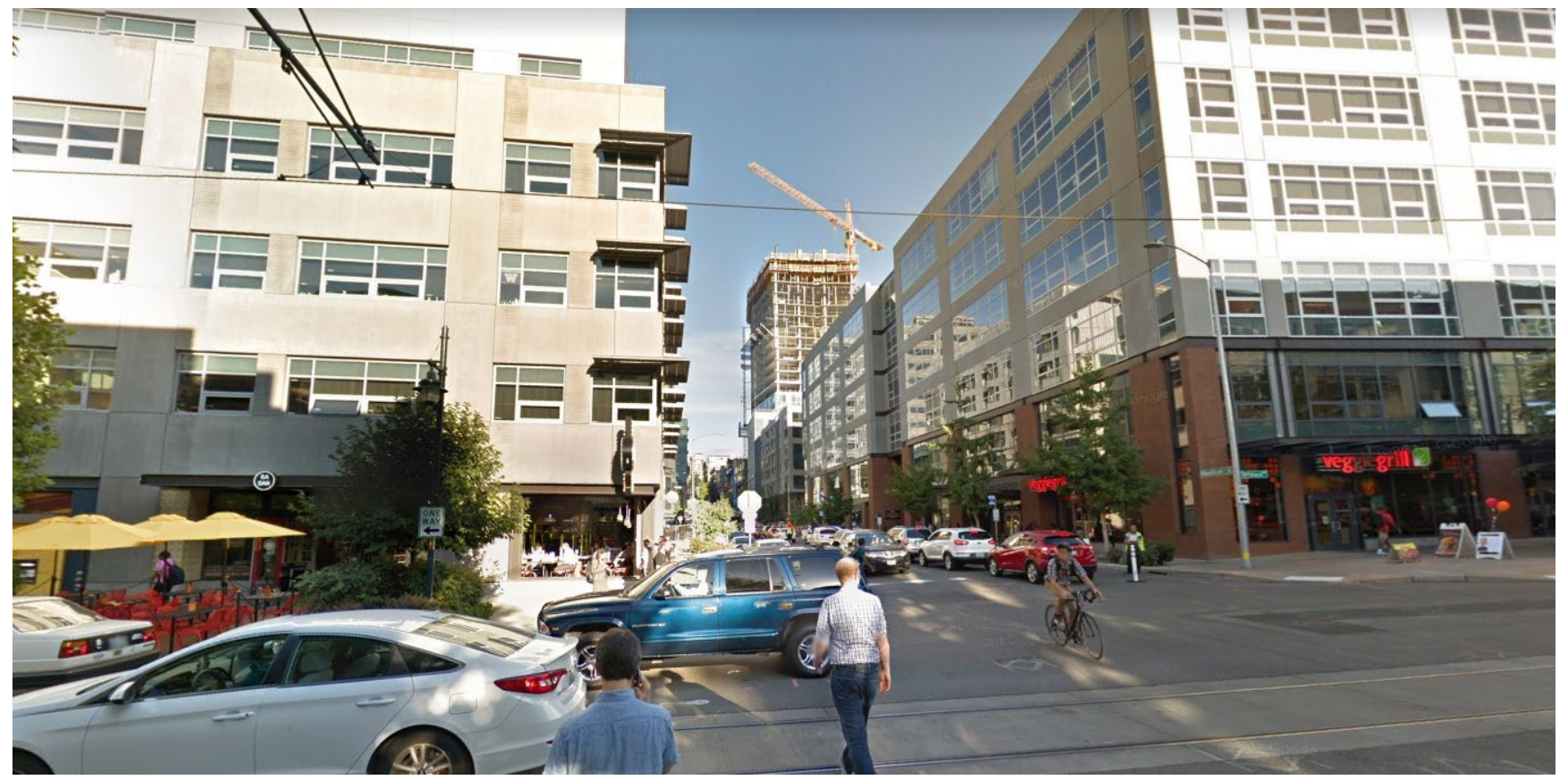

Source: https://www.google.com/maps/@47.6230881,-

122.337207,3a,75y,97.85h,97.98t/data=!3m6!1e1!3m4!1s8Wcli7vA7yvrJDJoADG5BQ!2e0!7i13312!8i6656 


\title{
446 Terry Avenue North
}

\author{
South Lake Union, Seattle, 98109
}

Commute to Downtown Seattle

$\Leftrightarrow 4 \mathrm{~min} 17 \mathrm{~min}$ \% $8 \mathrm{~min} 28 \mathrm{~min}$ View Routes

\section{Favorite}

Map

Nearby Apartments

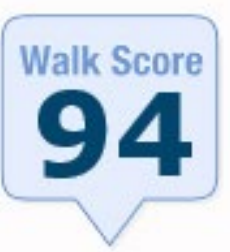

Walker's Paradise

Daily errands do not

require a car.

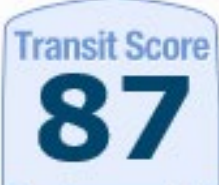

\section{Excellent Transit}

Transit is convenient for most trips.

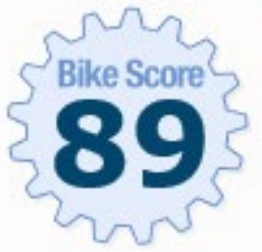

\section{Very Bikeable}

Mostly flat, excellent bike lanes.

\section{Score Details}

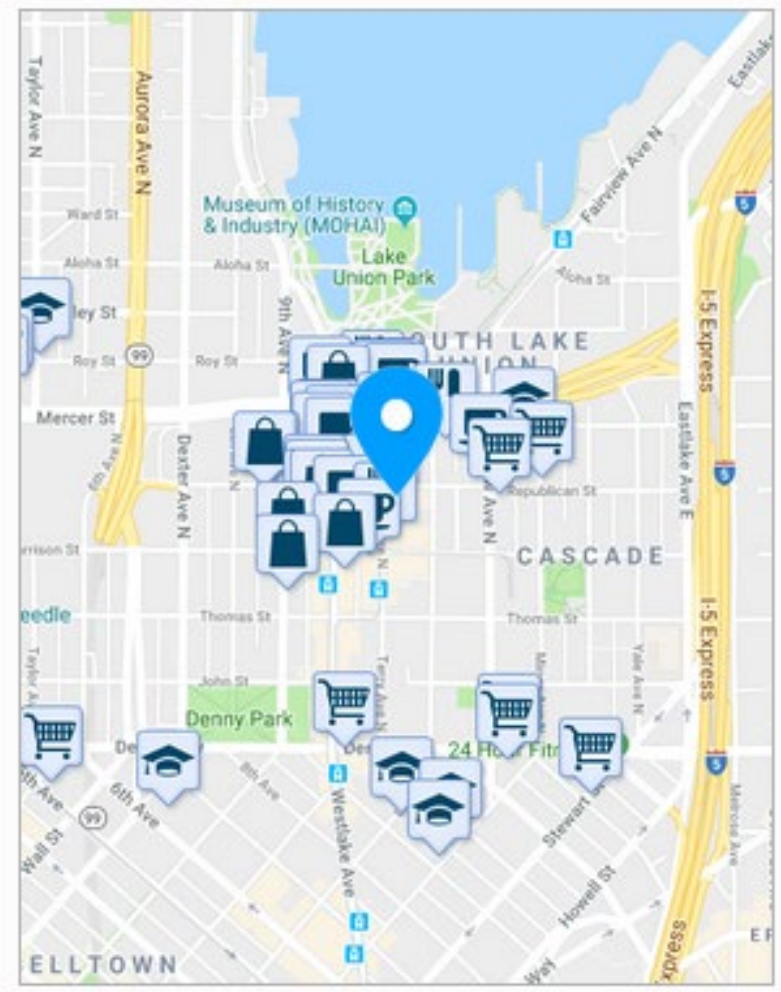

Source: https://www.walkscore.com/score/446-terry-ave-n-seattle-wa-98109

Located just north of the central business district, the stop at Terry Ave \& N Republican is along the streetcar line that is able to take residents straight into downtown. 


\section{Tucson}

Broadway \& Stone Station

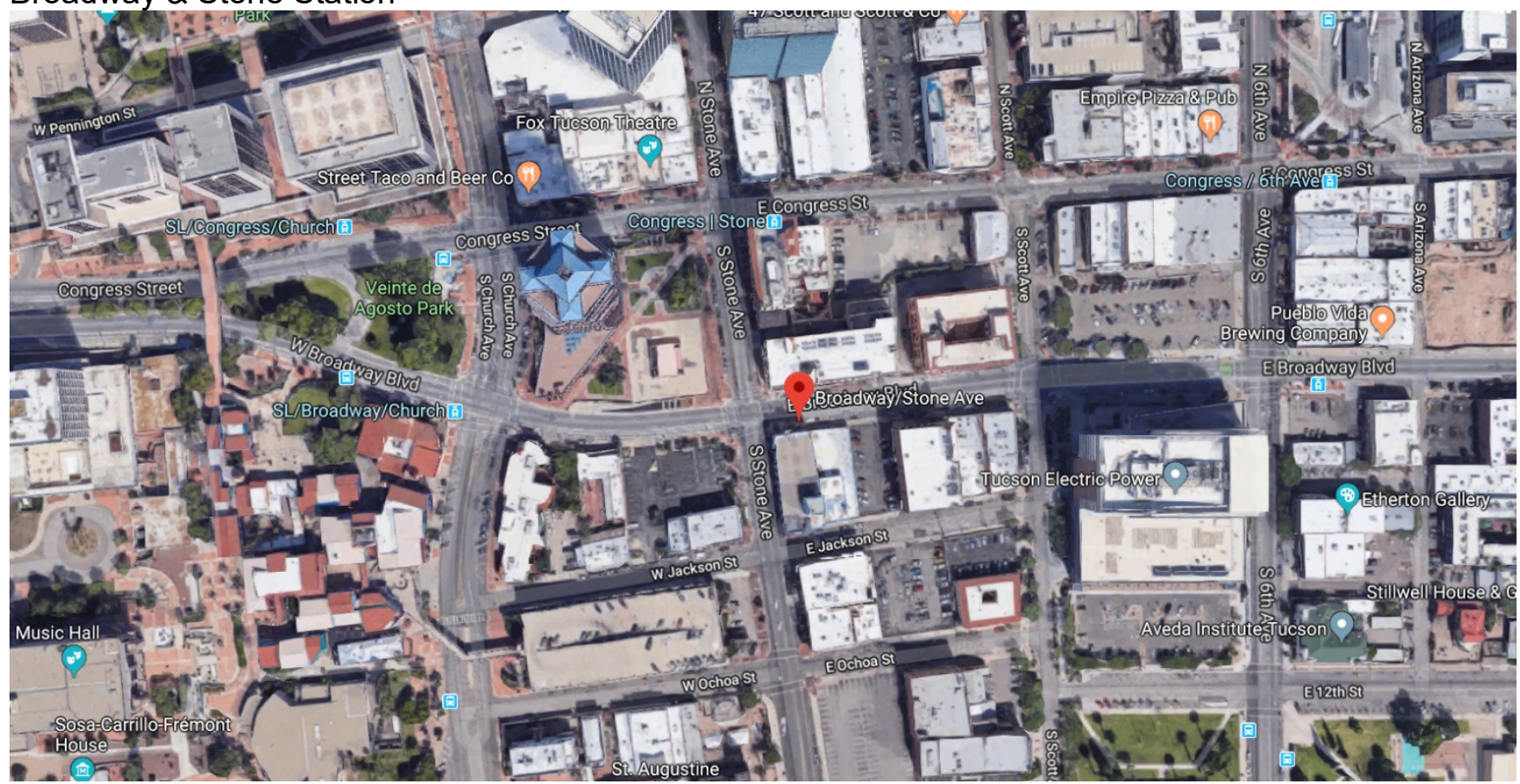

Source: https://www.google.com/maps/place/Broadway\%2FStone+Ave/@32.2210569,-

$110.9714624,399 \mathrm{~m} /$ data $=$ !3m1!1e3!4m13!1 7 ! 3m6!1s0x86d665410b2ced2b:0x73c32d 384d16c715!2sTucson, + AZ! 3 b1!8m2!3d32.2226066!4d-110.9747108!3m4!1s0x86d670e1aff682c1:0x8520fd816e1e0cd0!8m2!3d32.2209817!4d$\underline{110.9708861}$

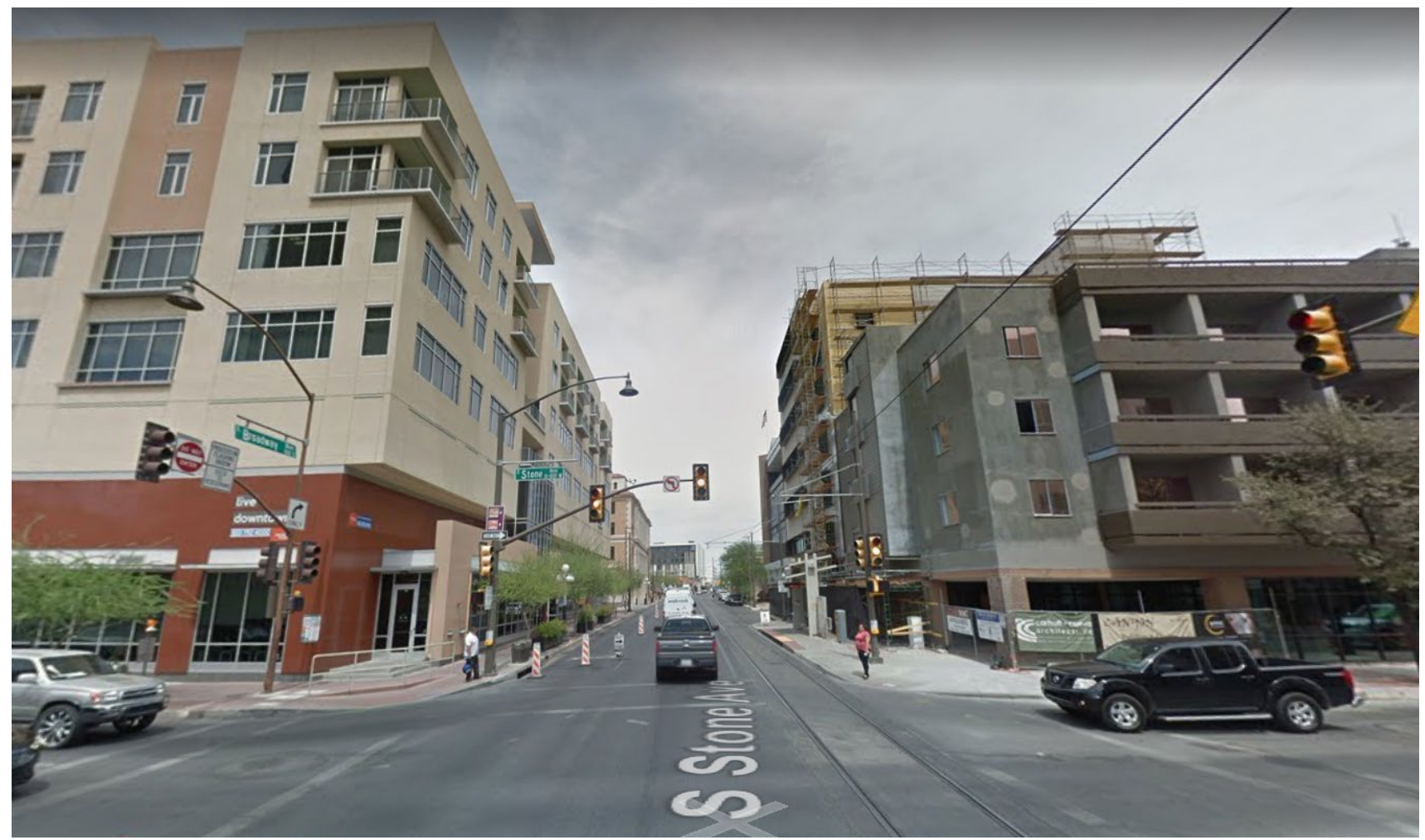

Source: https://www.google.com/maps/@32.221008,-

110.9712269,3a,83y,81.62h,103.44t/data=!3m6!1e1!3m4!1scJVSGm6y1sKrEjb9q26vJg!2e0!7i13312!8i6656 


\section{E Broadway Blvd}

Tucson, Arizona, 85701

Bigger Map

Looking for a home for sale in Tucson? 룬

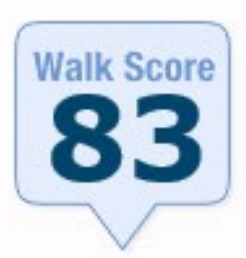

Very Walkable

Most errands can be accomplished on foot.

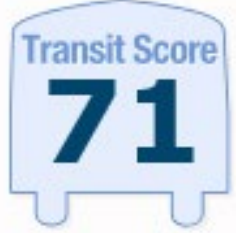

\section{Excellent Transit}

Transit is convenient for most trips.

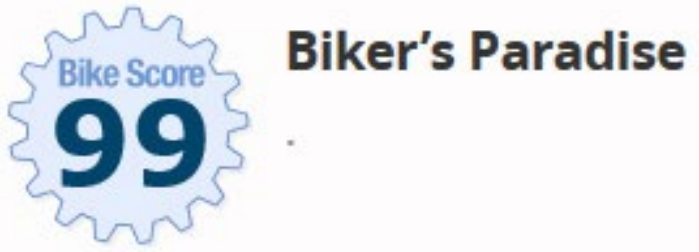

\section{About your score}

\section{Add scores to your site}

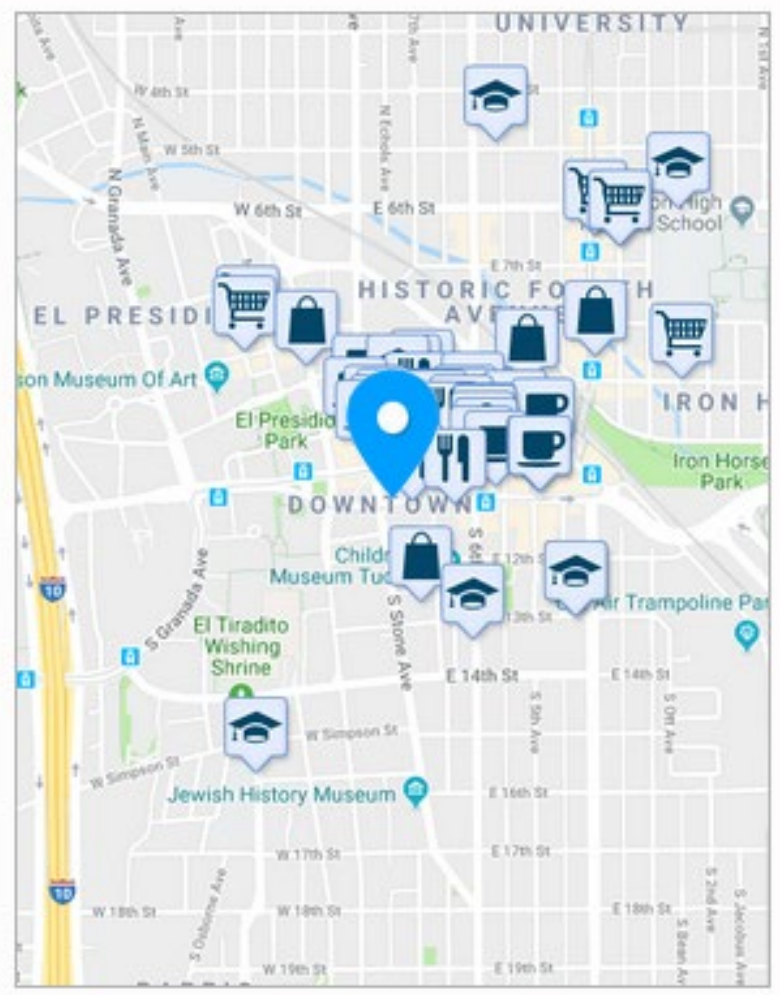

Source: https://www.walkscore.com/score/1-e-broadway-blvd-tucson-az-85701

The streetcar line in Tucson, Arizona is spurring many new development projects along in, particularly multifamily development, pictured on the left and right sides of the street above. 


\section{Little Rock}

$3^{\text {rd }}$ St and River Market Ave

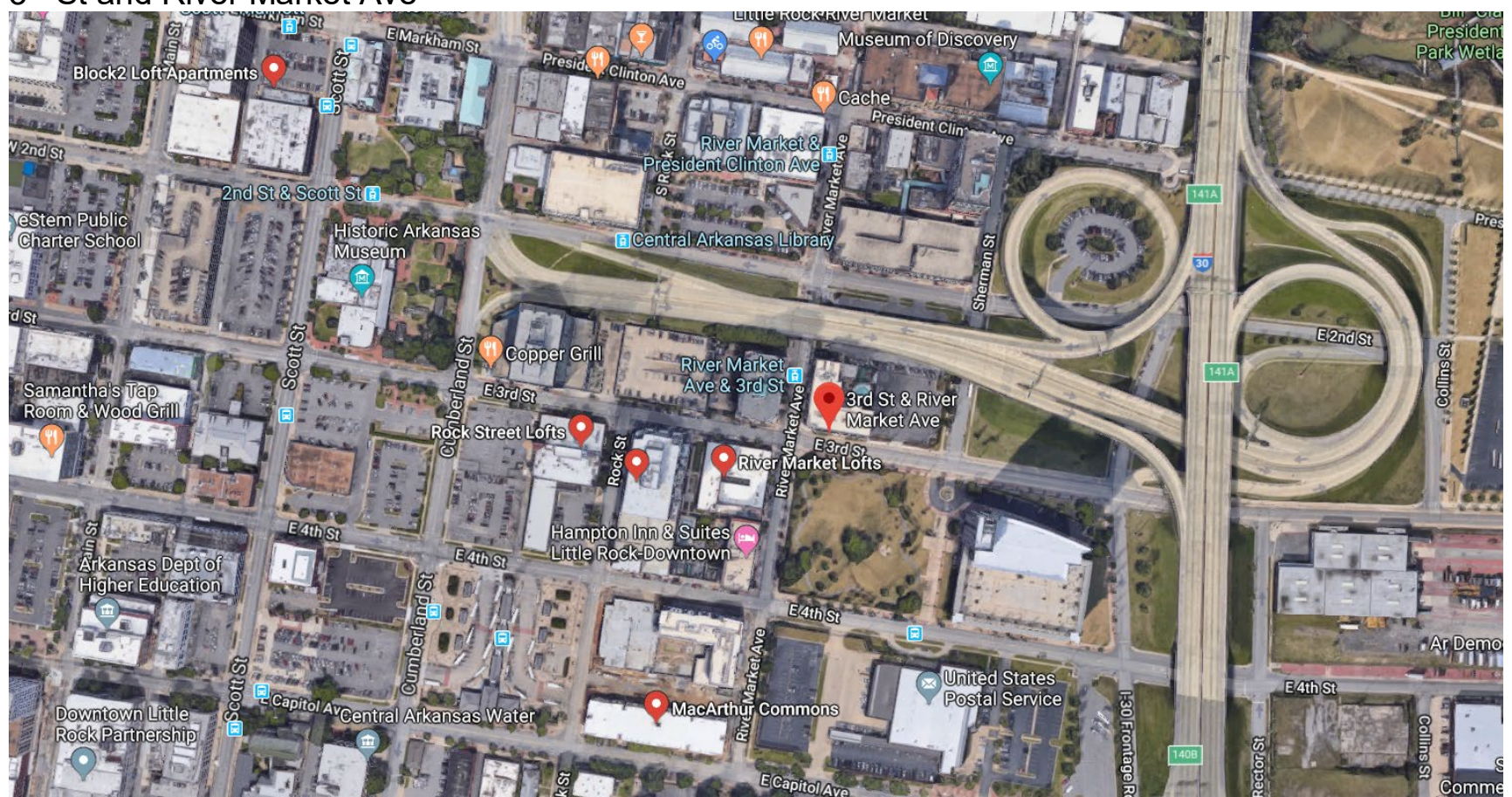

Source: https://www.google.com/maps/place/3rd+St+\%26+River+Market+Ave/@34.7457099,-

92.2662146,595m/data=!3m1!1e3!4m8!1m2!2m1!1sapartments!3m4!1s0x87d2bb791d2cdc5f:0xd46d0b128e9e37b!8 $\underline{\mathrm{m} 2 ! 3 \mathrm{~d} 34.745502 ! 4 \mathrm{~d}-92.2656278}$

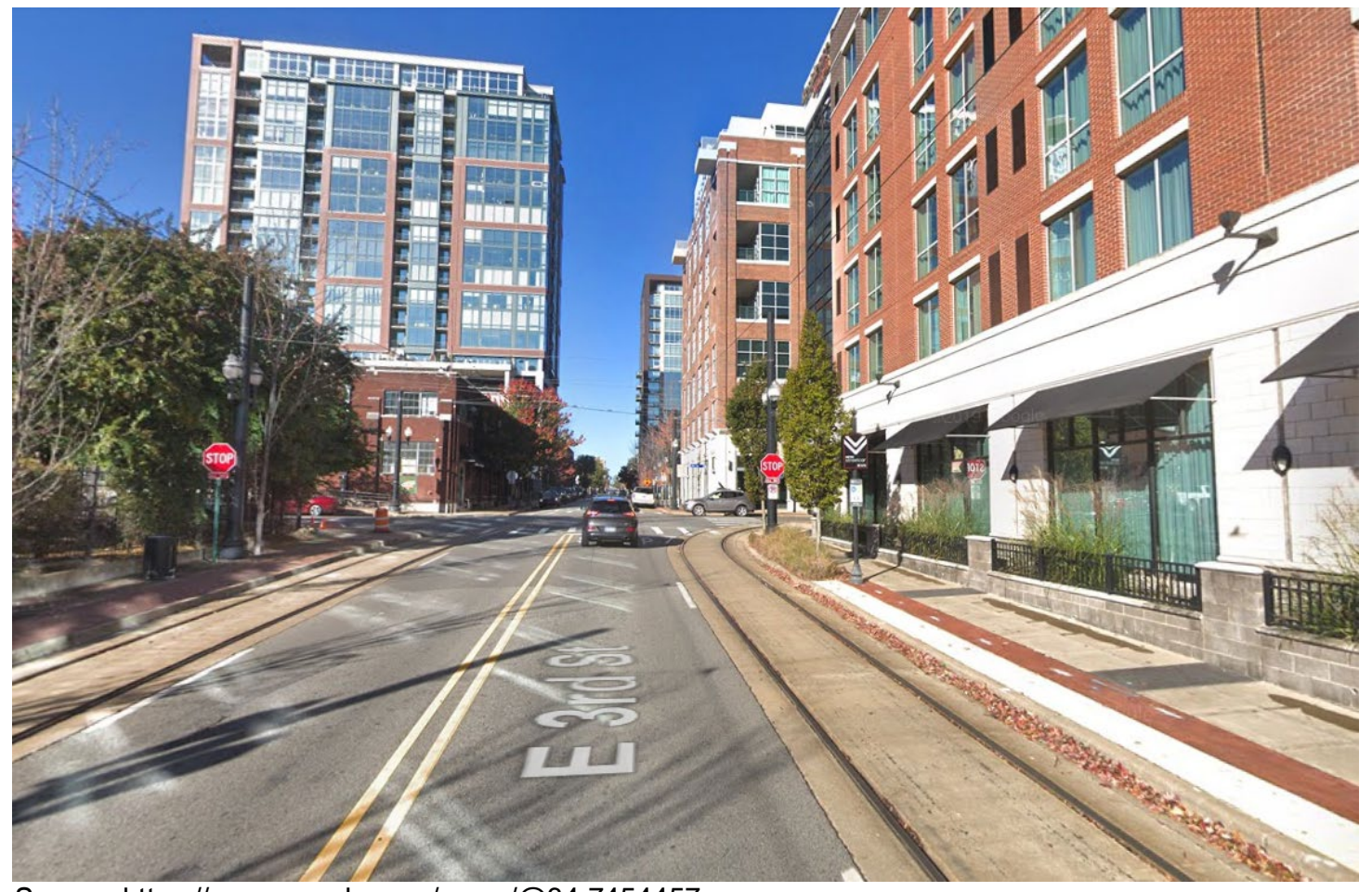

Source: https://www.google.com/maps/@34.7454457,-

92.2654802,3a,75y,288.43h,95.15t/data=!3m6!1e1!3m4!1sHcSg4b9165BSuHEnK7Bdwg!2e0!7i16384!8i8192 


\title{
219 River Market Avenue
}

\author{
Downtown, Little Rock, 72201
}

Commute to Downtown North Little Rock

$4 \mathrm{~min} 16 \mathrm{~min} 11 \mathrm{~min} 38 \mathrm{~min}$ View Routes

\section{Favorite 10 Map O Nearby Apartments}

Looking for a home for sale in Little Rock? 푼

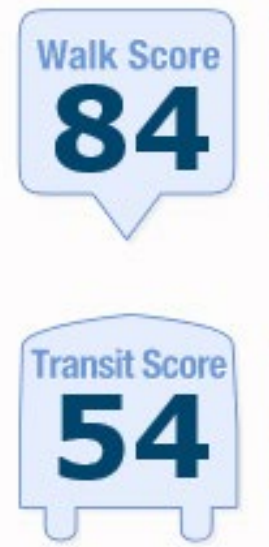

Very Walkable

Most errands can be

accomplished on foot.

Good Transit

Many nearby public

transportation

options.

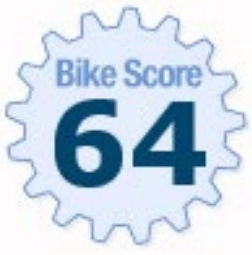

\section{Bikeable}

\section{About your score}

\section{Add scores to your site}

Source: https://www.walkscore.com/score/219-river-market-ave-little-rock-ar-72201

Many new multifamily buildings along the streetcar line in Little Rock, Arkansas have been developed indicating the value of public transportation in the city. 


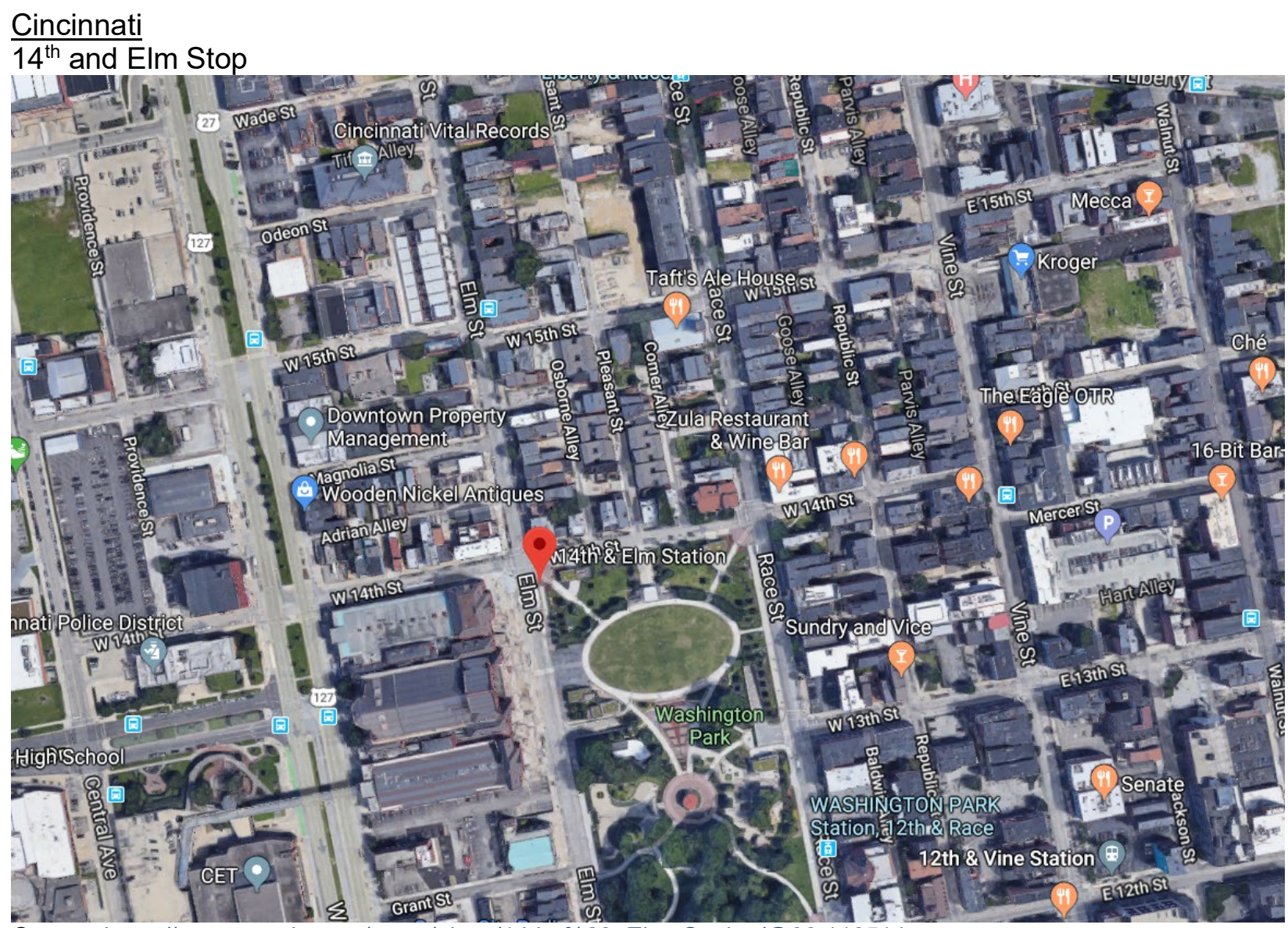

Source: https://www.google.com/maps/place/14th+\%26+Elm+Station/@39.110514,-

84.5180848,589m/data=!3m1!1e3!4m5!3m4!1s0x8841b3fe3e890d4d:0x10e00462cda960b1!8m2!3d39.1099798!4d$\underline{84.5184633}$ 


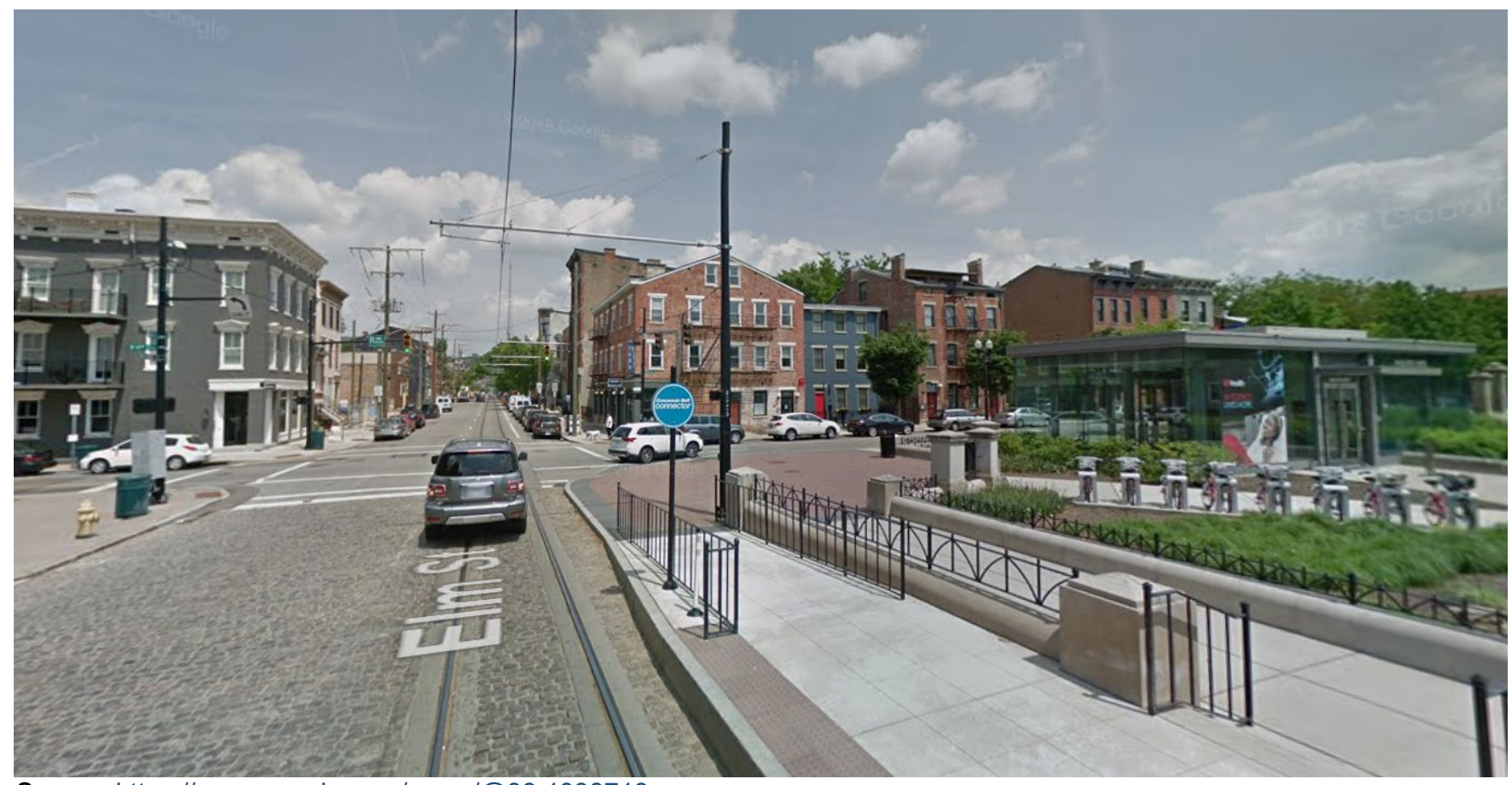

Source: https://www.google.com/maps/@39.1098719,-

$\underline{84.5185041,3 \mathrm{a}, 80.9 \mathrm{y}, 7.25 \mathrm{~h}, 92.72 \mathrm{t} / \mathrm{data}=! 3 \mathrm{m6} 6 \text { !1e1!3m4!1sRecT9Qd-cURxFmAT5elDPQ!2e0!7i13312!8i6656 }}$ 


\section{Elm Street}

Over-The Rhine, Cincinnati, 45202

Commute to Downtown Cincinnati

$2 \mathrm{~min} 9 \mathrm{~min} 4 \mathrm{~min} ; 16 \mathrm{~min}$ View Routes

Favorite

(1) Map

Nearby Apartments

More about 1400 Elm Street 눈
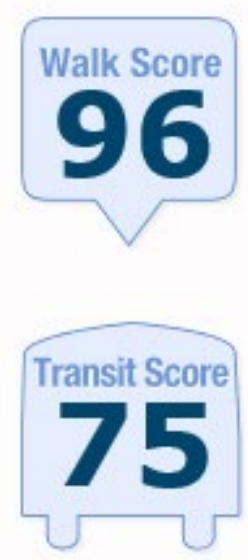

55

\section{Bikeable}

Flat as a pancake, minimal bike lanes.

\section{About your score}

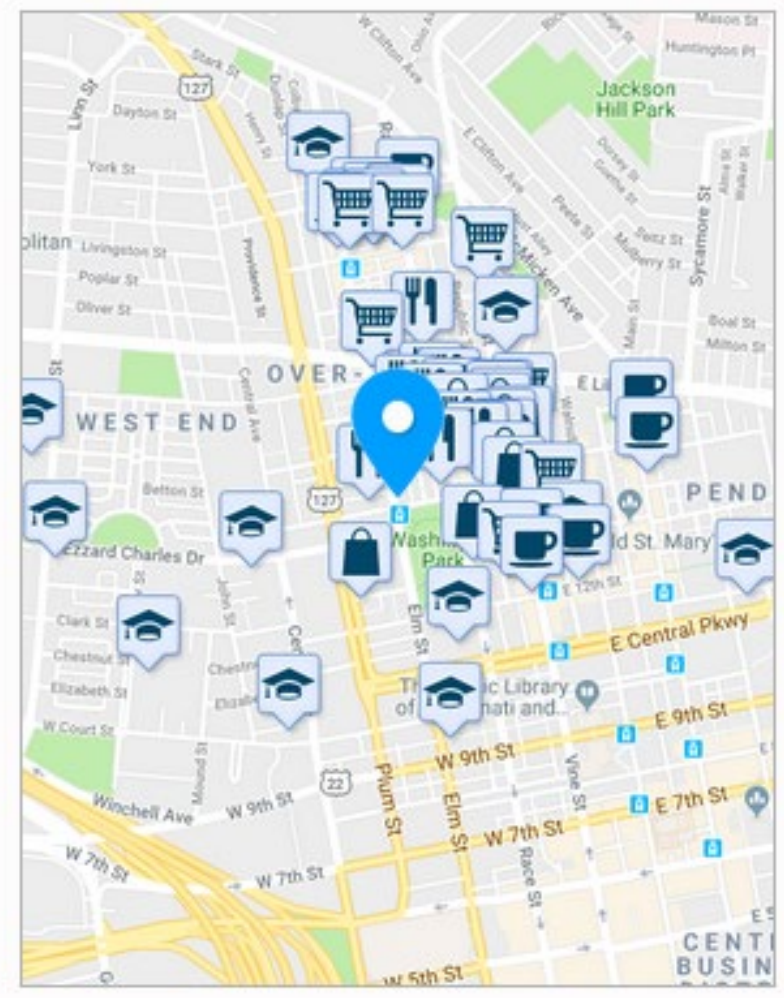

\section{Add scores to your site}

Source: https://www.walkscore.com/score/1400-elm-st-cincinnati-oh-45202

Broad walkability and human-scale stations are some of the reasons why the $14^{\text {th }}$ and Elm Station in Cincinnati, Ohio is a good example of successful multifamily development. 


\section{Dallas}

\section{Oakenwald Streetcar Station}

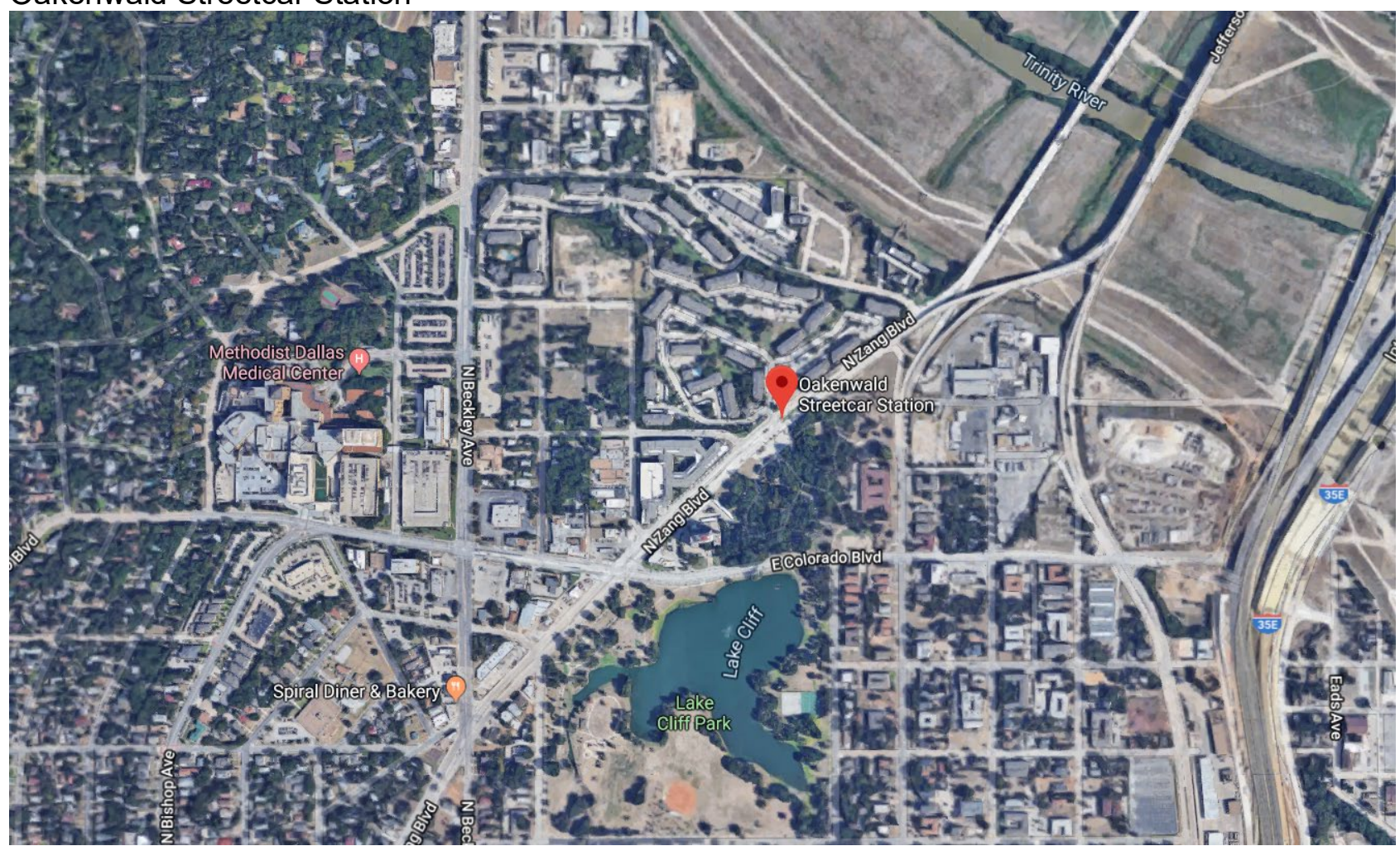

Source: https://www.google.com/maps/@32.760454,-96.8179383,1472m/data=!3m1!1e3

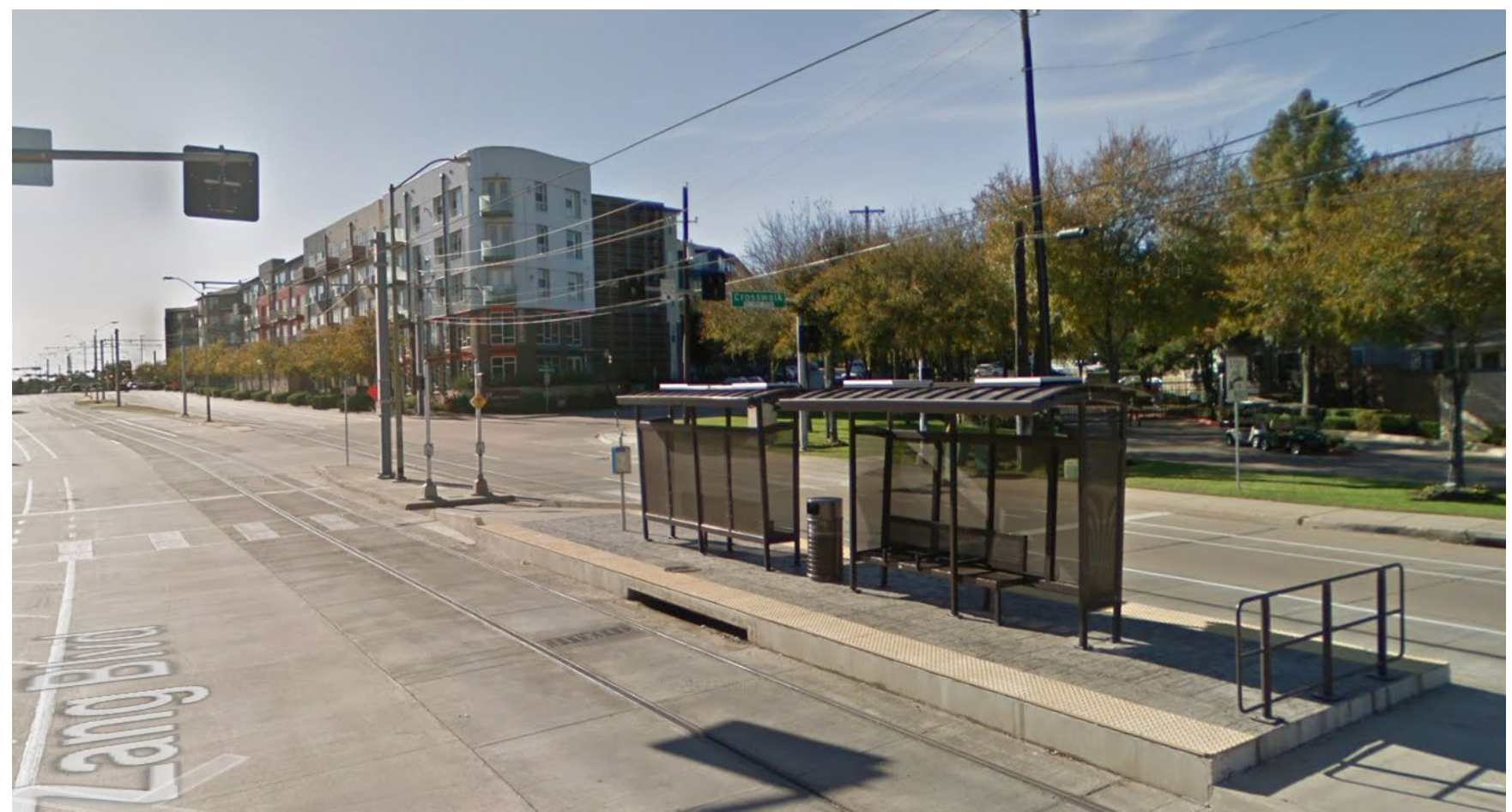

Source: https://www.google.com/maps/@32.7605861,-

96.8177698,3a,52.4y,260.82h,89.03t/data=!3m6!1e1!3m4!1sXG0tYkD-dn-mEa3zJSBN-Q!2e0!7i13312!8i6656 


\section{North Zang Boulevard}

Lake Cliff, Dallas, 75203

Commute to Downtown Dallas

$6 \mathrm{~min} 13 \mathrm{~min}$. $11 \mathrm{~min} 38 \mathrm{~min}$ View Routes

Favorite

Looking for a home for sale in Dallas? ⿷匚⿳⺈⿴囗十

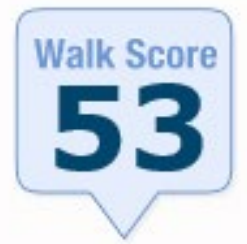

Somewhat

Walkable

Some errands can be accomplished on foot.

Transit Score

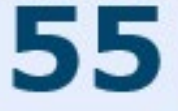

चए

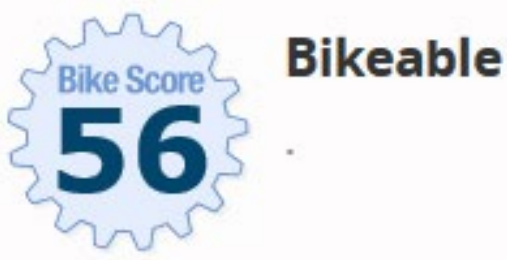

About your score

Many nearby public

transportation

options.

\section{Bikeable}

\section{Add scores to your site}

Source: https://www.walkscore.com/score/1408-n-zang-blvd-dallas-tx-75203

The Oakenwald Streetcar station in the Dallas, Texas area has seen new multifamily development over the past few years and can in part be attributed to the streetcar line. 


\section{Bad Multifamily}

Salt Lake City

700 E Station

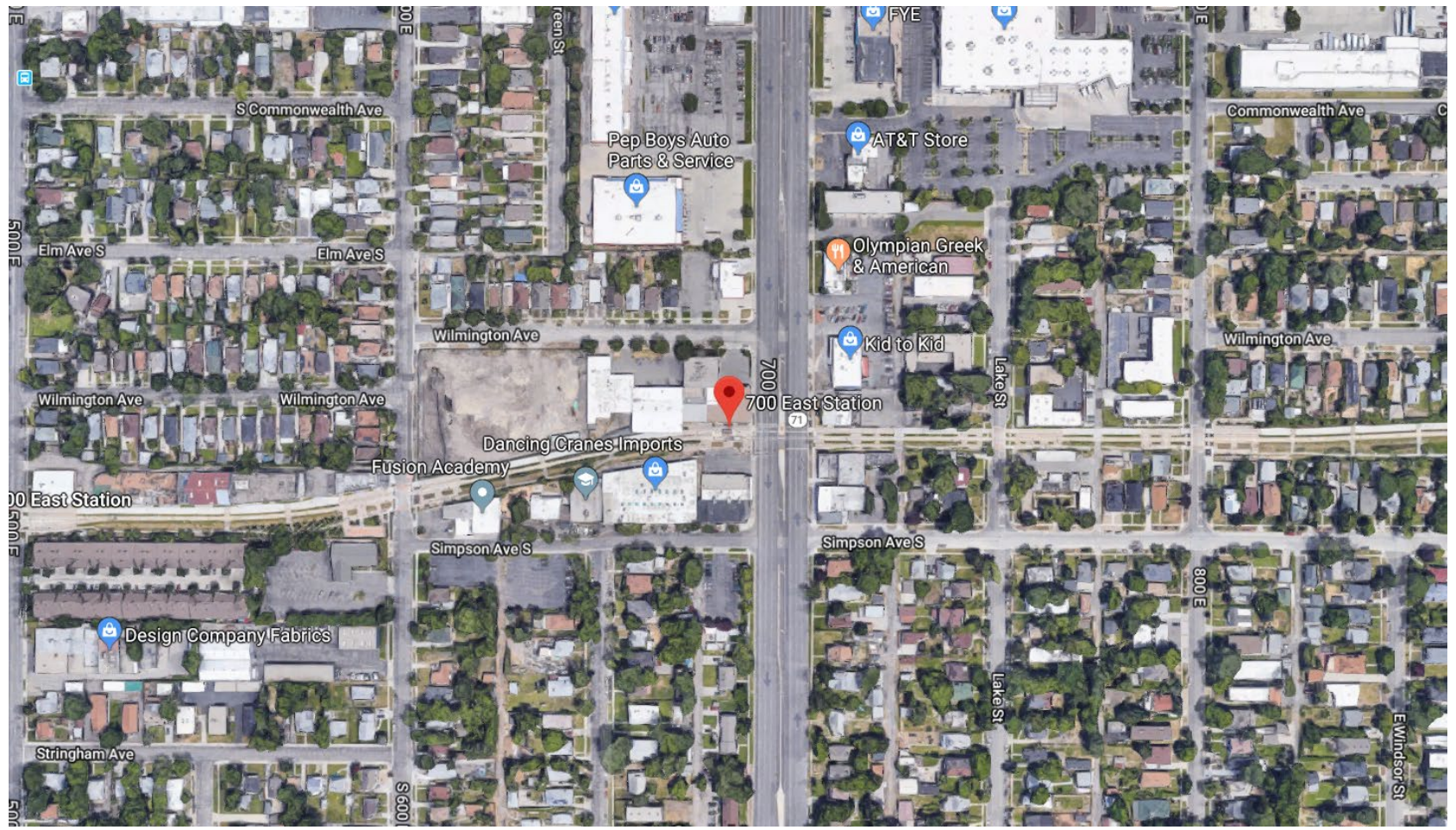

Source: https://www.google.com/maps/place/700+East+Station/@40.722837,--

$111.8717663,551 \mathrm{~m} / \mathrm{data}=! 3 \mathrm{~m} 1 ! 1 \mathrm{e} 3 ! 4 \mathrm{~m} 5 ! 3 \mathrm{~m} 4 ! 1 \mathrm{~s} 0 \times 87528 \mathrm{abc80d} 31 \mathrm{~d} 83: 0 \times 5 \mathrm{cfa} 5 \mathrm{f} 23 \mathrm{aa} 010 \mathrm{f} 6 \mathrm{f} ! 8 \mathrm{~m} 2 ! 3 \mathrm{~d} 40.722798 ! 4 \mathrm{~d}-$ $\underline{111.8716121}$

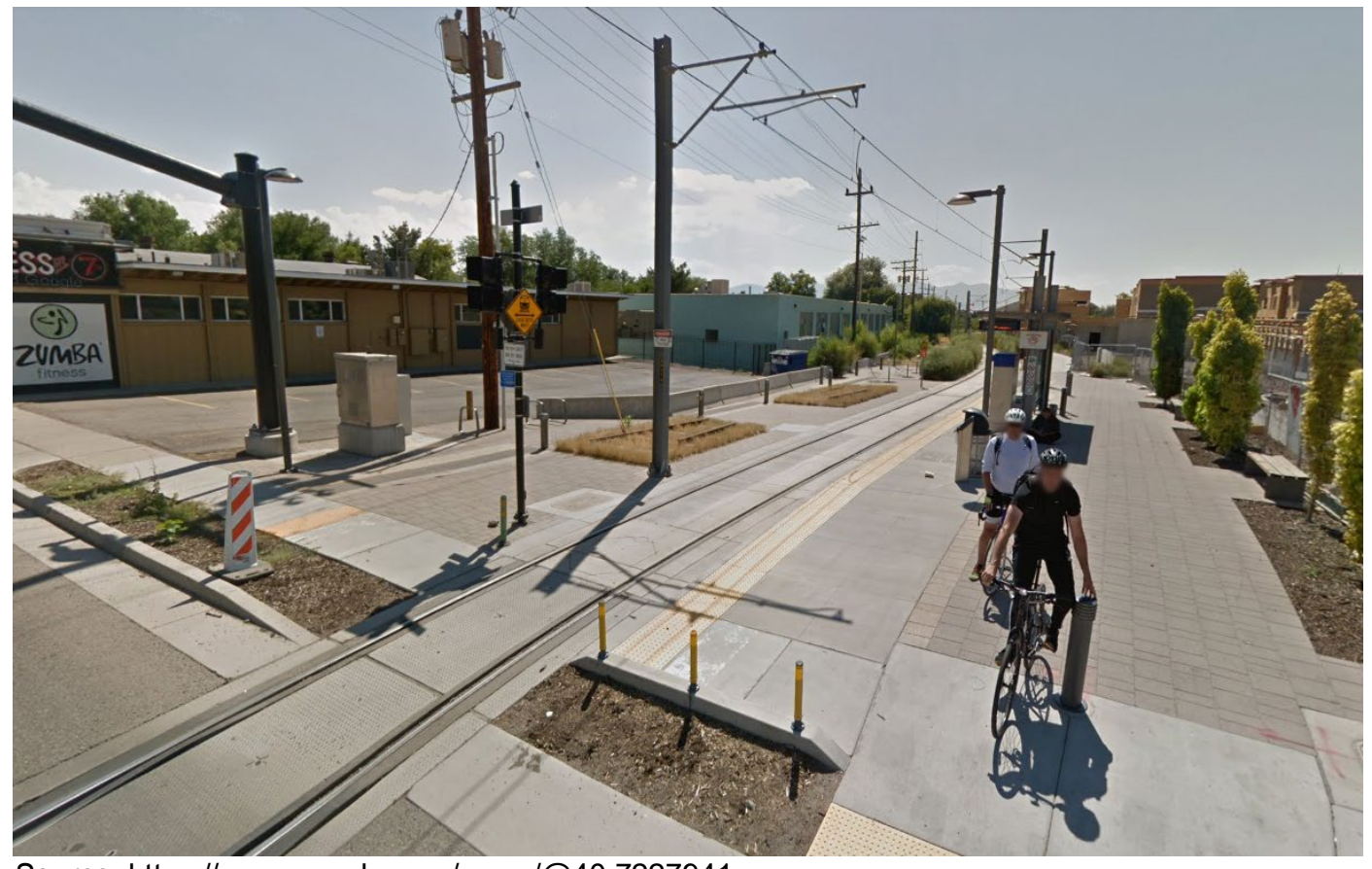

Source: https://www.google.com/maps/@40.7227941,-

111.8713986,3a,75y,238.67h,81.13t/data=!3m6!1e1!3m4!1sUTDSc2F0rKbxlfoBN6VP-g!2e0!7i13312!8i6656 


\section{East}

Sugar House, Salt Lake City, 84106

Commute to Downtown South Salt Lake

3 min 14 min 7 min 23 min View Routes

\section{Favorite 10 Map \& Nearby Apartments}

Looking for a home for sale in Salt Lake City? 뚤

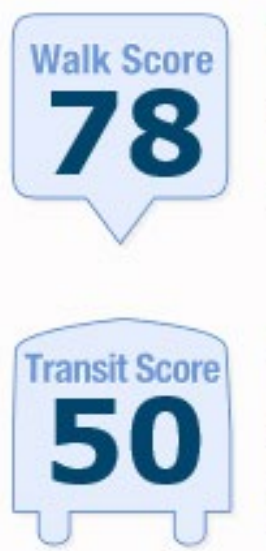

Very Walkable

Most errands can be accomplished on foot.

Good Transit

Many nearby public

transportation

options.

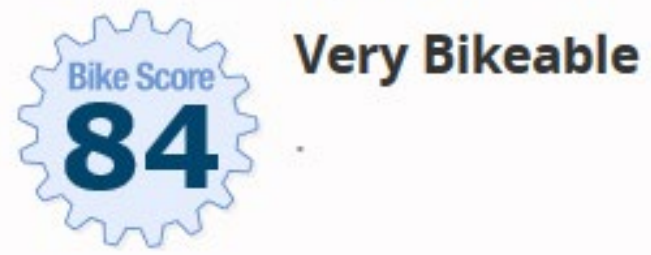

\section{About your score}

\section{Add scores to your site}

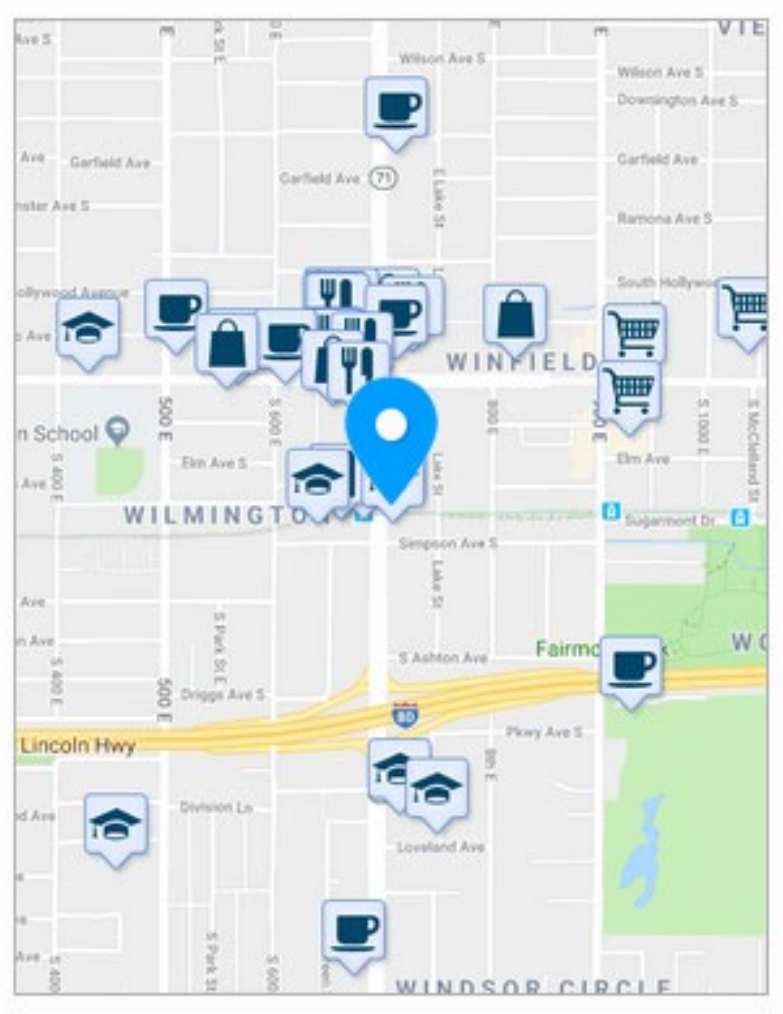

Source: https://www.walkscore.com/score/2207-700-e-salt-lake-city-ut-84106

Located in a mainly single-family area, any new multifamily development near the 700 east streetcar station may be met with community criticism. 
Washington, D.C.

Benning Road \& $19^{\text {th }}$ St NE

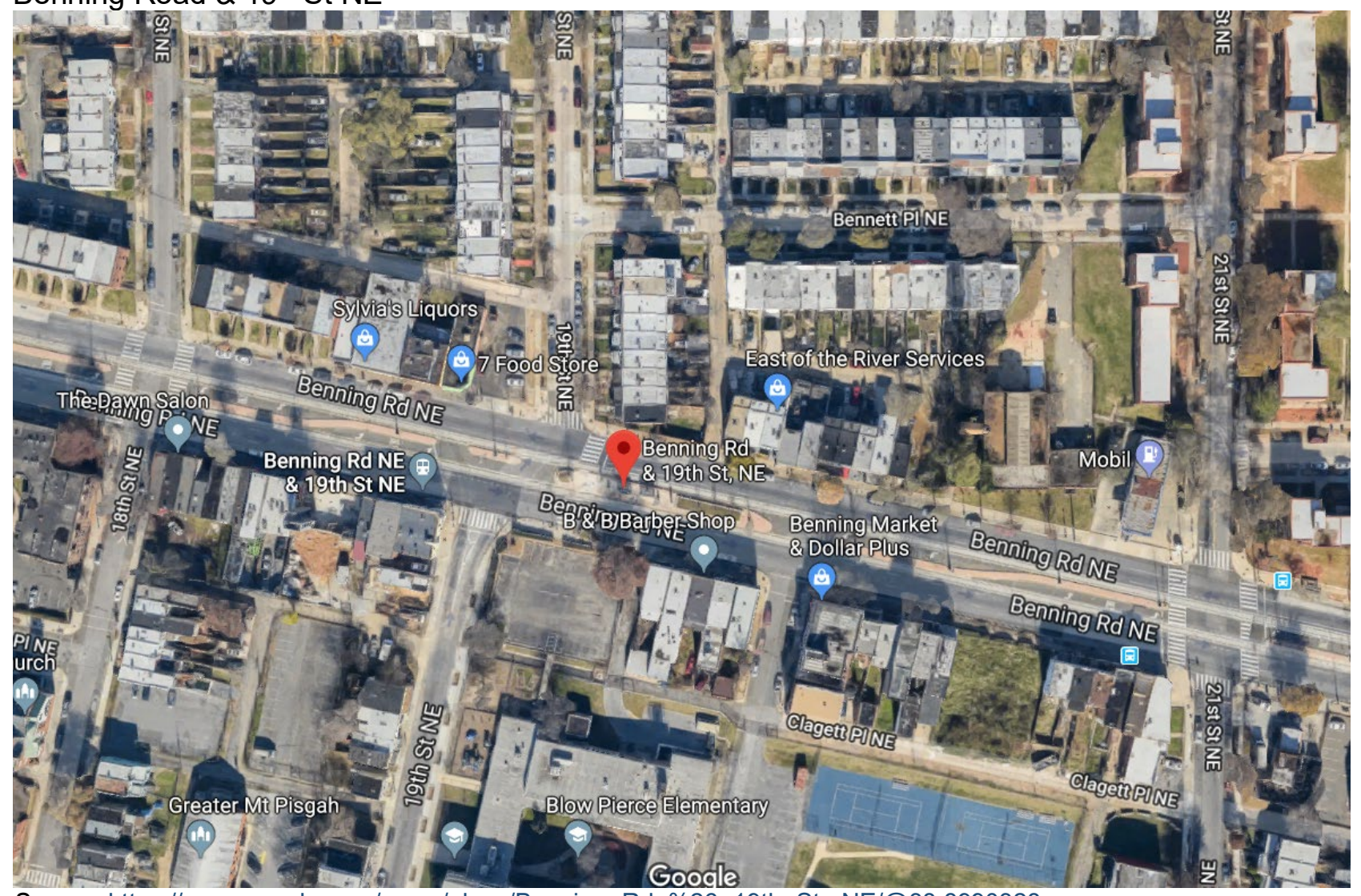

Source: https://www.google.com/maps/place/Benning+Rd+\%26+19th+St,+NE/@38.8990328,-

76.975816,282m/data=!3m1!1e3!4m5!3m4!1s0x89b7b842b03f222f:0x8a20d3dc0b11d40b!8m2!3d38.8988246!4d-

76.9760359 


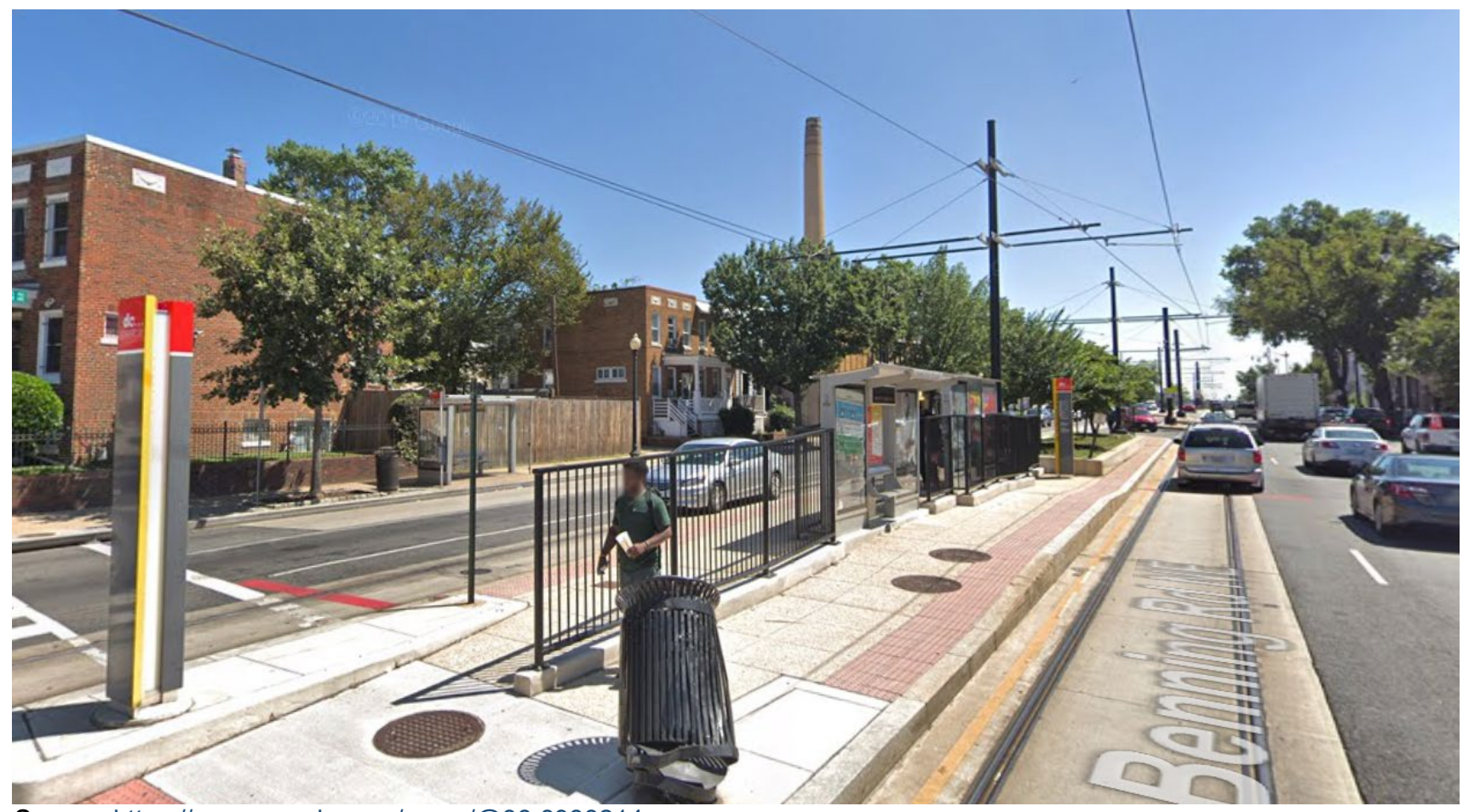

Source: https://www.google.com/maps/@38.8988214,--

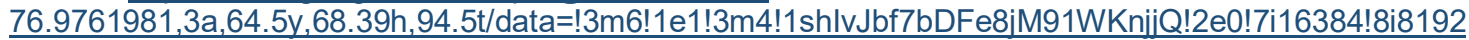




\section{Benning Road Northeast}

Kingman Park, Washington D.C., 20002

Commute to Downtown Washington D.C.

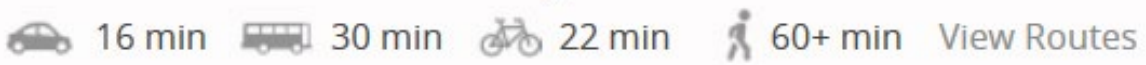

\section{Favorite [D Map @ Nearby Apartments}

Looking for a home for sale in Washington D.C.? 분

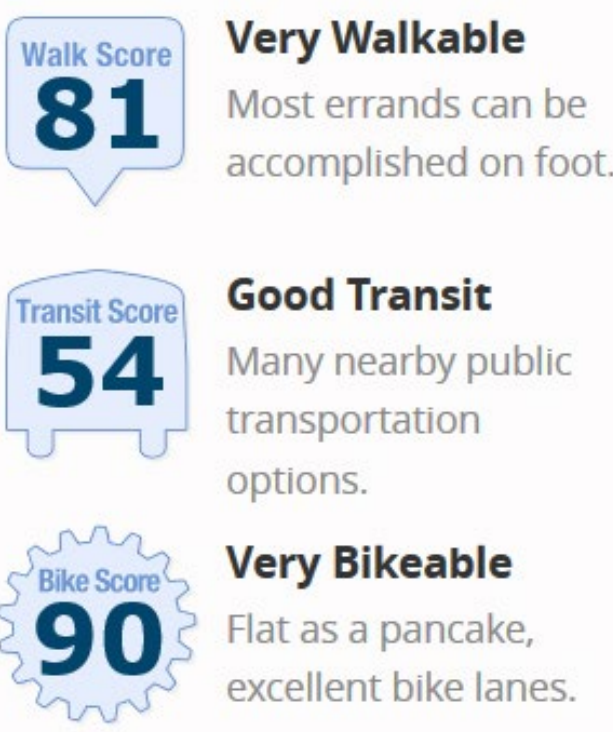

About your score

\section{Add scores to your site}

Source: https://www.walkscore.com/score/1919-benning-rd-ne-washington-dc-20002

In an area which has not seen recent significant investment and is filled with single-family rowhomes, the Benning \& $19^{\text {th }}$ streetcar stop in Washington, D.C. is not popular for multifamily development. 


\section{Good Retail}

\section{Tucson}

$6^{\text {th }} \&$ Congress

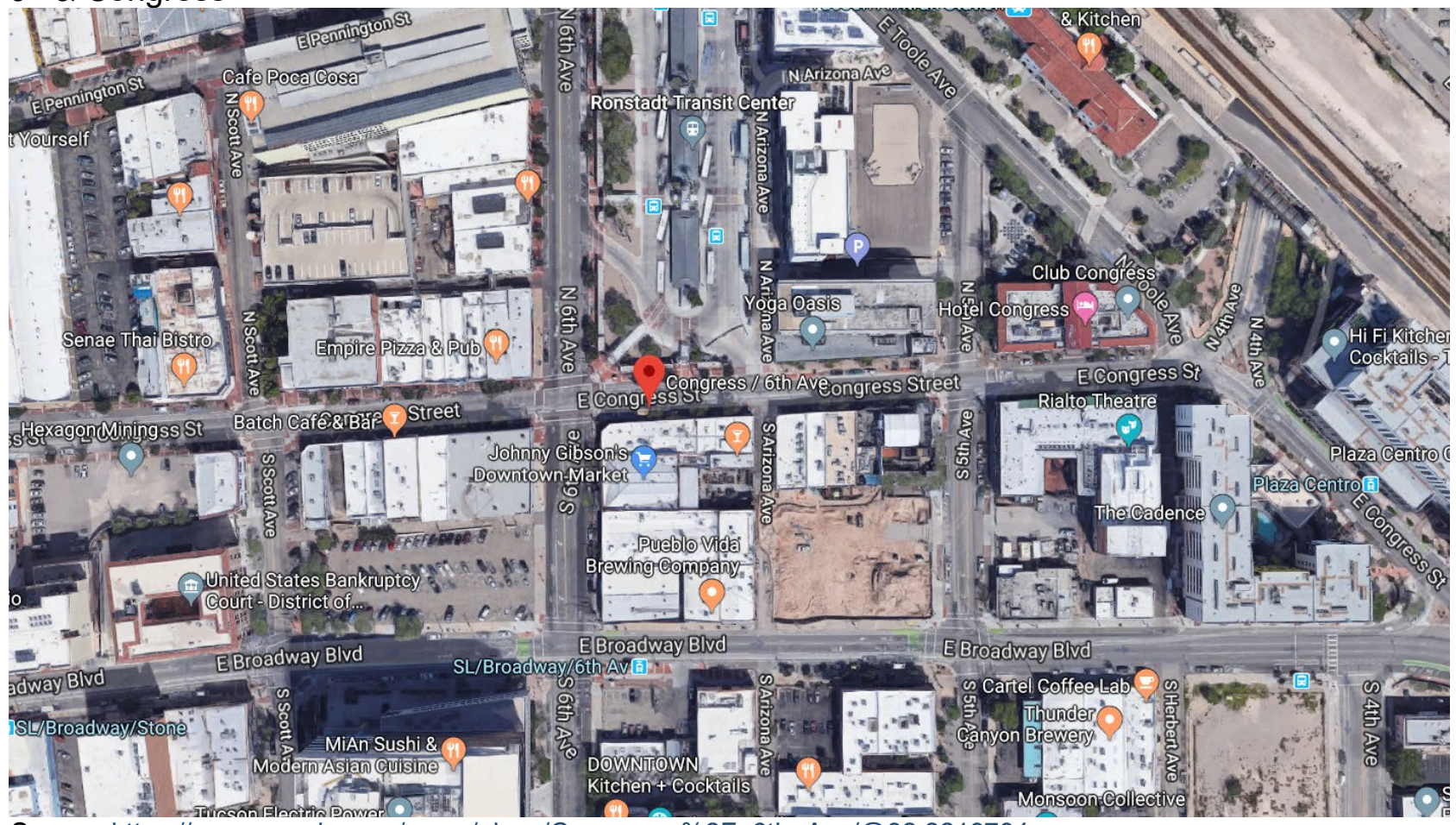

Source: https://www.google.com/maps/place/Congress+\%2F+6th+Ave/@32.2219784,--

$110.9682112,332 \mathrm{~m} / \mathrm{data}=! 3 \mathrm{~m} 1 ! 1 \mathrm{e} 3 ! 4 \mathrm{~m} 5 ! 3 \mathrm{~m} 4 ! 1 \mathrm{~s} 0 \times 86 \mathrm{~d} 670 \mathrm{e} 18 \mathrm{a} 6 \mathrm{eed} 2 \mathrm{~b}: 0 \times f 8 f 950 \mathrm{c} 8 \mathrm{a} 79 \mathrm{e} 1668 ! 8 \mathrm{~m} 2 ! 3 \mathrm{~d} 32.2219869 ! 4 \mathrm{~d}-$ 110.9683071 


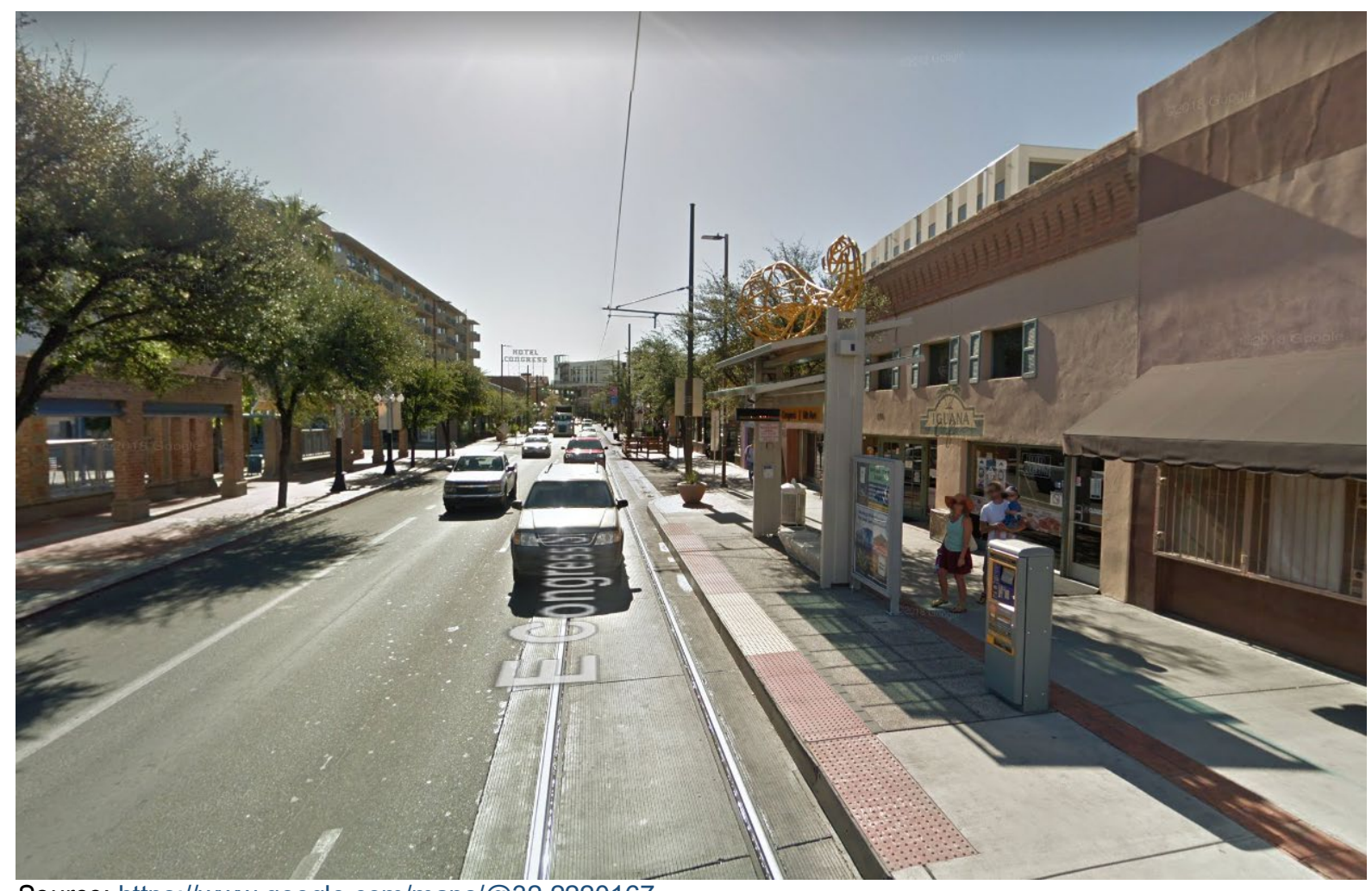

Source: https://www.google.com/maps/@32.2220167,-

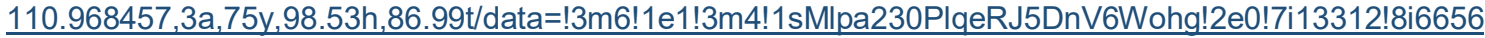




\section{East Congress Street}

Pie Allen, Tucson, 85701

Commute to Downtown Drexel Heights

$\approx 23 \mathrm{~min} 55 \mathrm{~min} 57 \mathrm{~min} \quad \AA 60+\mathrm{min}$ View Routes

\section{Favorite 10 Map \& Nearby Apartments}

Looking for a home for sale in Tucson? 룽

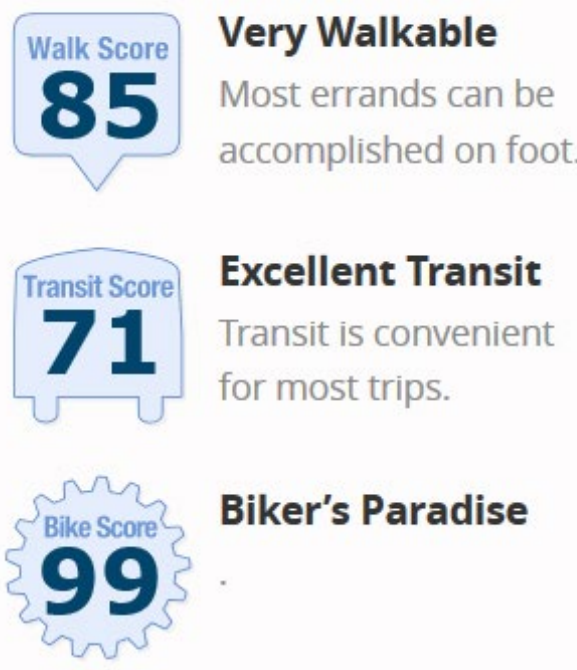

About your score

Add scores to your site

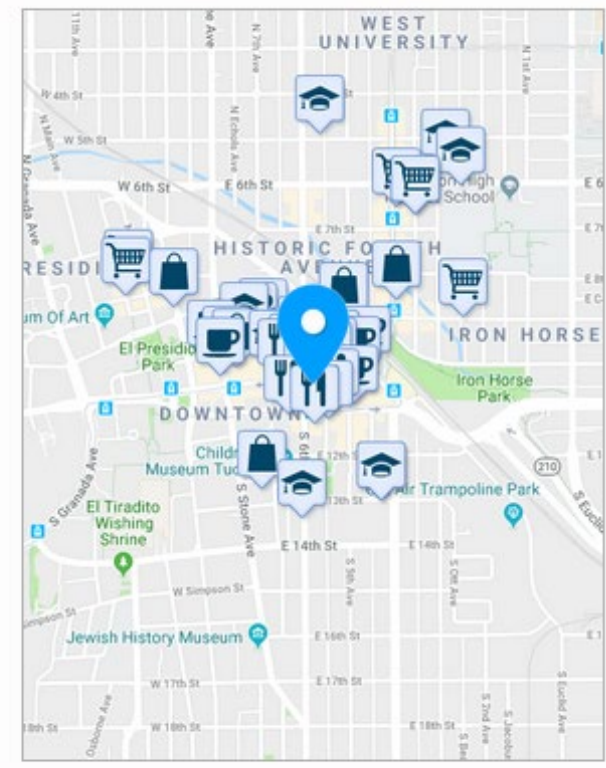

Source: https://www.walkscore.com/score/216-e-congress-st-tucson-az-85701

Located along popular Congress Street in downtown Tucson, the SunLink streetcar brings people from all over Tucson to the downtown area. 


\section{Seattle}

Westlake $\& 9^{\text {th }}$ Stop

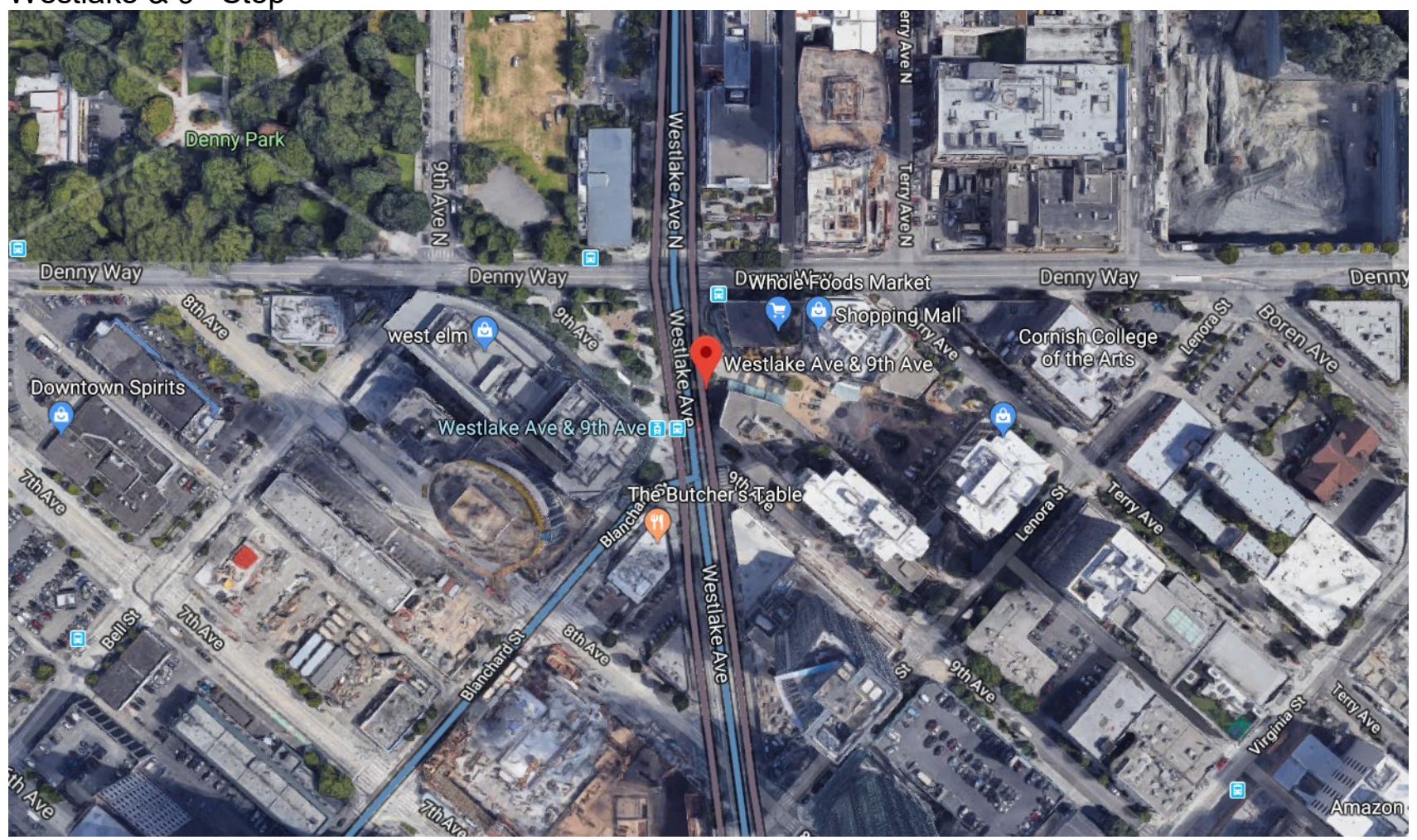

Source: https://www.google.com/maps/place/Westlake+Ave+\%26+9th+Ave/@47.6179967,-

$122.3379403,409 \mathrm{~m} /$ data $=$ !3m1!1e3!4m13!1 7 ! 3m6!1s0x5490154a53251ccf:0x126d02dc82ec9c57!2sWestlake+Ave $+\% 26+7$ th + Ave, + Seattle, + WA+98121!3b1! $8 \mathrm{~m} 2 ! 3 \mathrm{~d} 47.615282 ! 4 \mathrm{~d}-$

122.337839!3m4!1s0x54901549efbea023:0x16d88c22364a4e8f! $8 \mathrm{~m} 2$ !3d47.6180954!4d-122.3382998

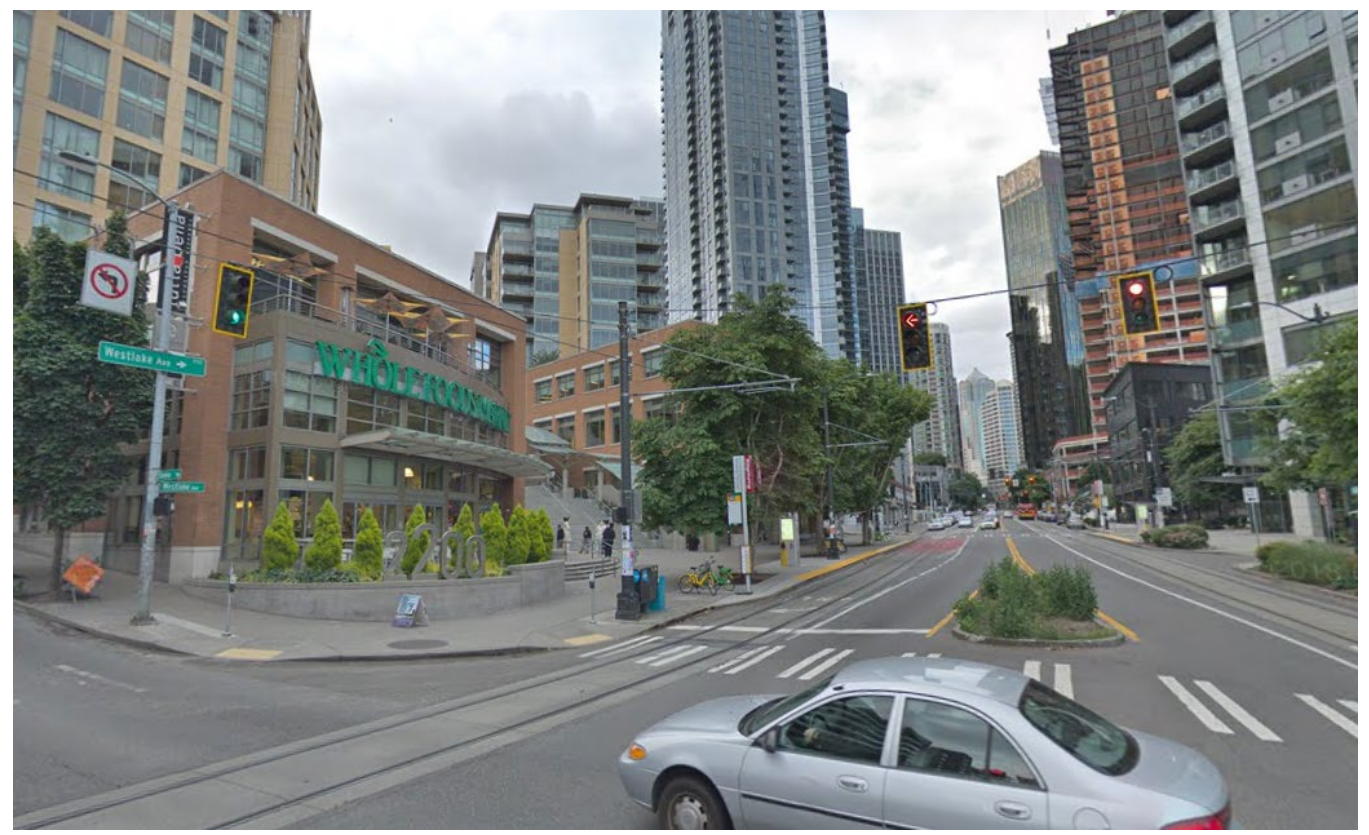

Source: https://www.google.com/maps/@47.6185547,-

122.3385098,3a,75y, 145.66h,99.31t/data=!3m6!1e1!3m4!1sbAURbF5MiHOljQ7EYAxL4g!2e0!7i16384!8i8192 


\section{Westlake Avenue}

South Lake Union, Seattle, 98121

Commute to Downtown Seattle

$\therefore 3$ min 13 min 6 min $\$ 21$ min View Routes

\section{Favorite TI Map Q Nearby Apartments}

Looking for a home for sale in Seattle? 뚱

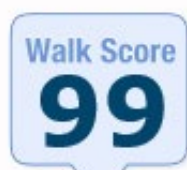

Walker's Paradise

Daily errands do not

require a car.

100

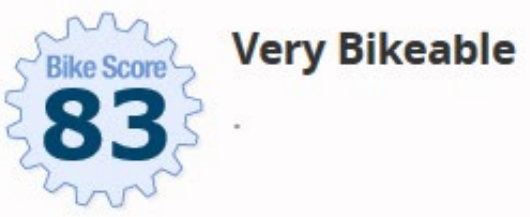

About your score

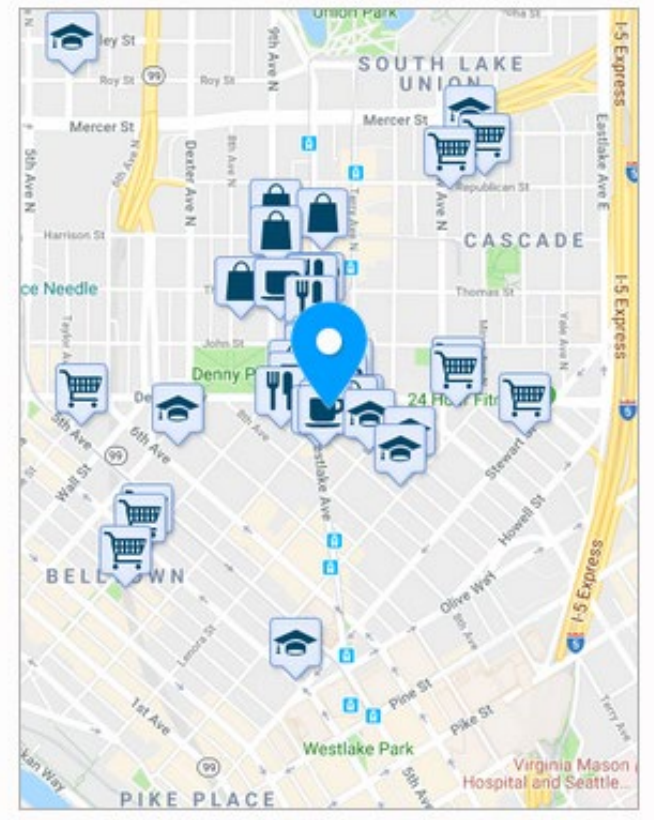

Add scores to your site

Source: https://www.walkscore.com/score/2210-westlake-ave-seattle-wa-98121

The Westlake $\& 7^{\text {th }}$ stop for Seattle's streetcar line is near many retail options, like Whole Foods and West Elm, including new development shown in the construction phase on the aerial map. 


\section{Bad Retail}

\section{Dallas}

$6^{\text {th }}$ Streetcar Station

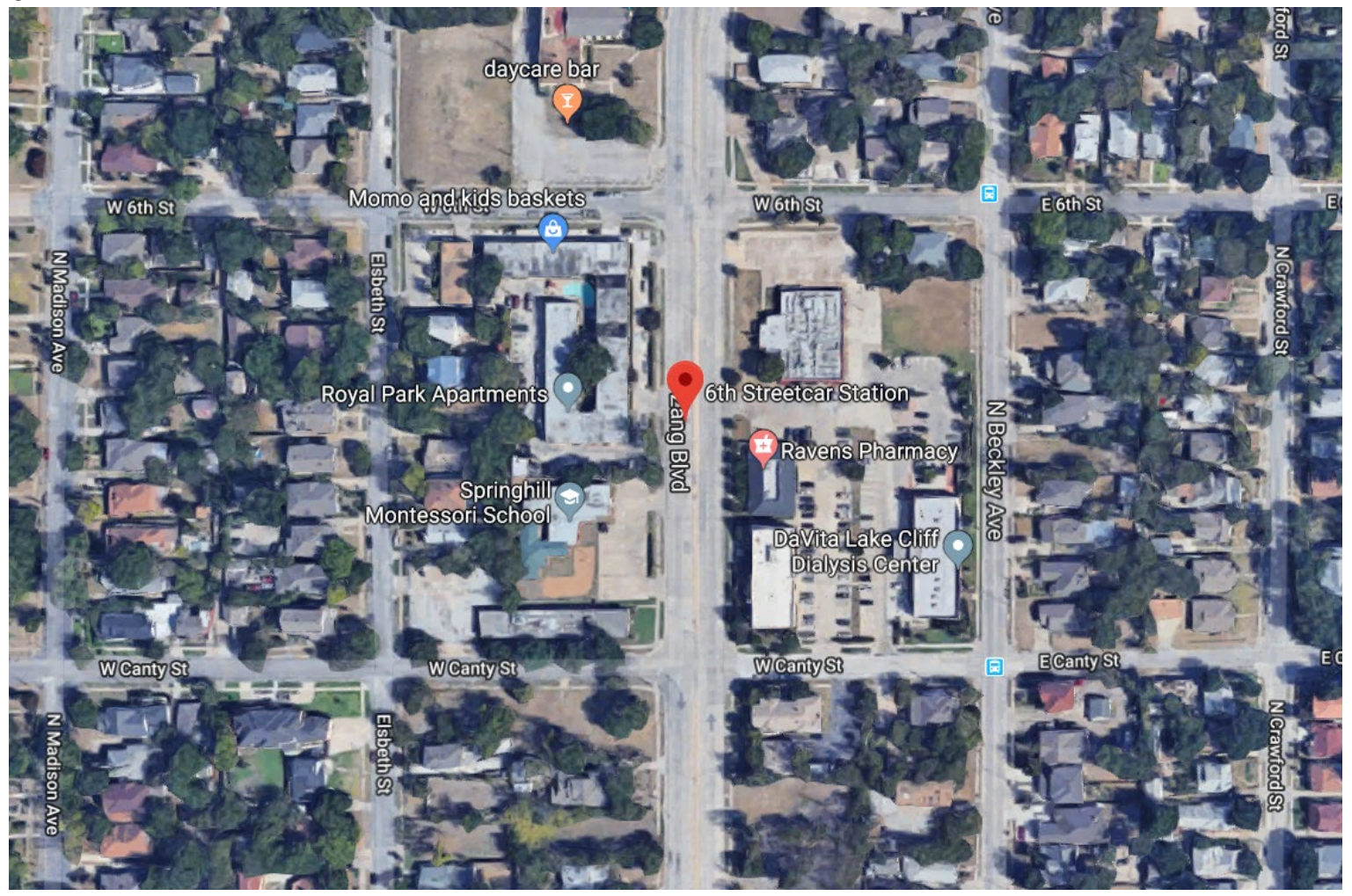

Source: https://www.google.com/maps/place/6th+Streetcar+Station/@32.7530783,-

96.8235356,399m/data=!3m1!1e3!4m5!3m4!1s0x864e999cb6aaa15b:0xfe06fdcf71878269!8m2!3d32.7530392!4d$\underline{96.8241258}$ 


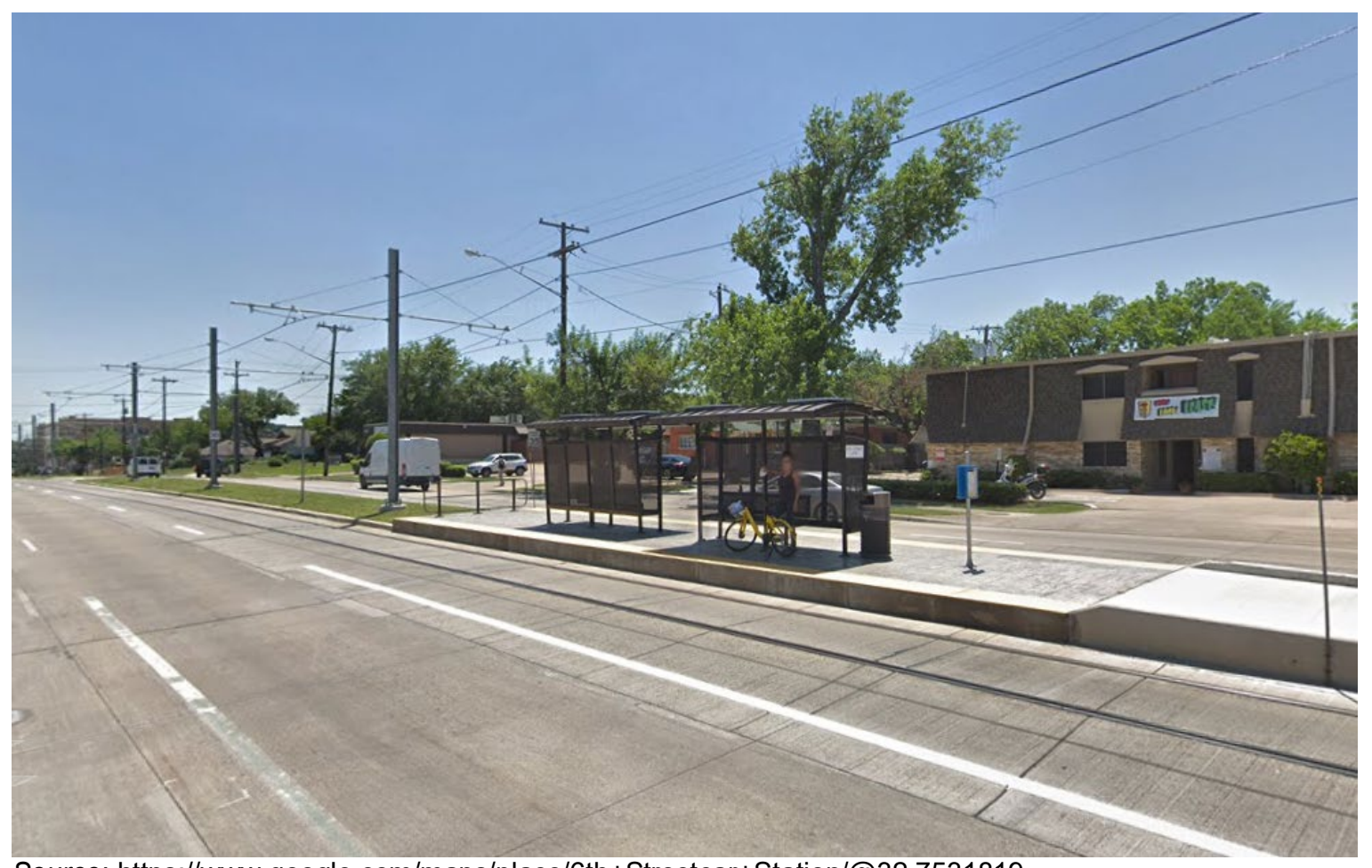

Source: https://www.google.com/maps/place/6th+Streetcar+Station/@32.7531819,-

96.8240009,3a,75y,226.11h,90.55t/data=!3m6!1e1!3m4!1s6KDHaS5o9LooF4KM2xnw3Q!2e0!7i16384!8i8192!4m5!3 $\mathrm{m} 4$ !1s0x864e999cb6aaa15b:0xfe06fdcf71878269!8m2!3d32.7530392!4d-96.8241258 


\section{North Zang Boulevard}

Lake Cliff, Dallas, 75208

Commute to Downtown Dallas

$\Leftrightarrow 9 \mathrm{~min} 21 \mathrm{~min} 15 \mathrm{~min} \quad \AA 51 \mathrm{~min}$ View Routes

\section{Favorite TI Map @ Nearby Apartments}

Looking for a home for sale in Dallas? 중

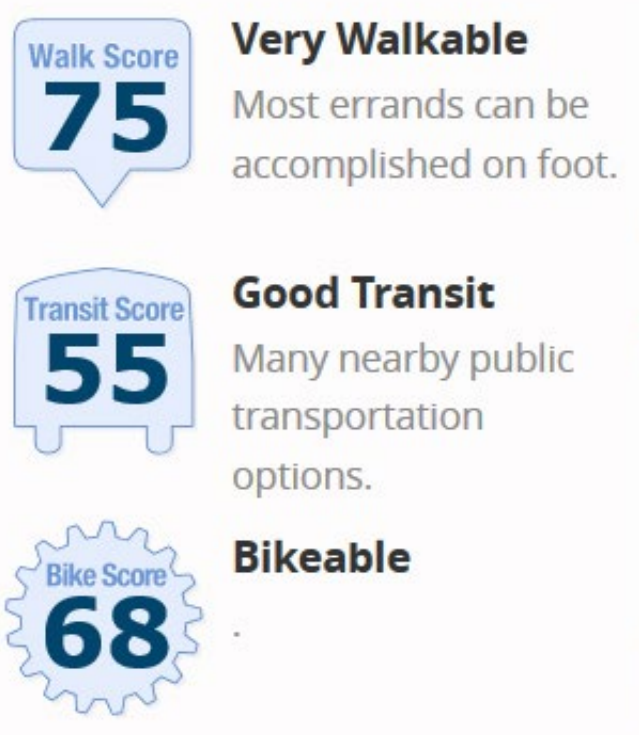

About your score

Add scores to your site

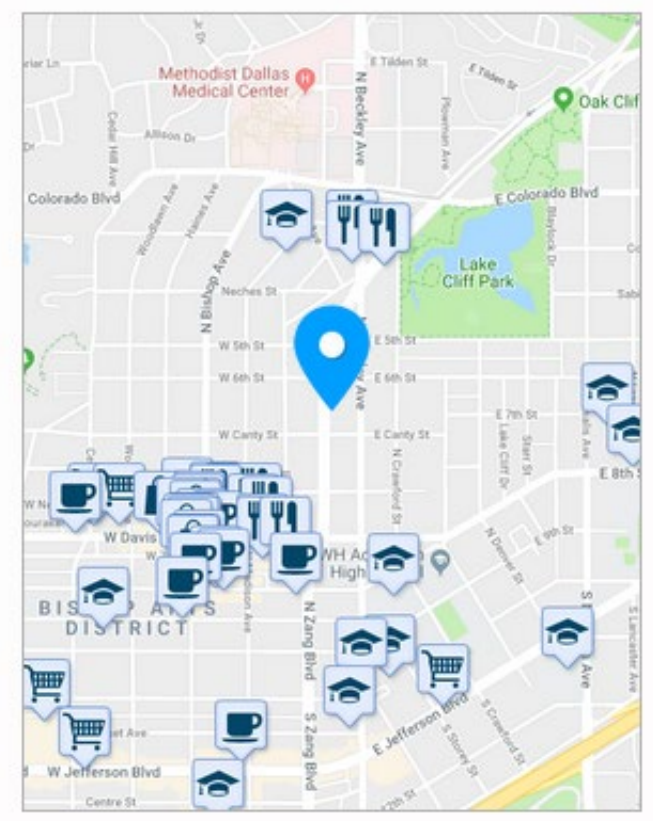

Source: https://www.walkscore.com/score/820-n-zang-blvd-dallas-tx-75208

The $6^{\text {th }}$ Streetcar Station in Dallas, Texas is in an area which has not seen much reinvestment with little room for retail development. 
Washington, D.C.

Benning Road \& $15^{\text {th }}$ St Northeast Station

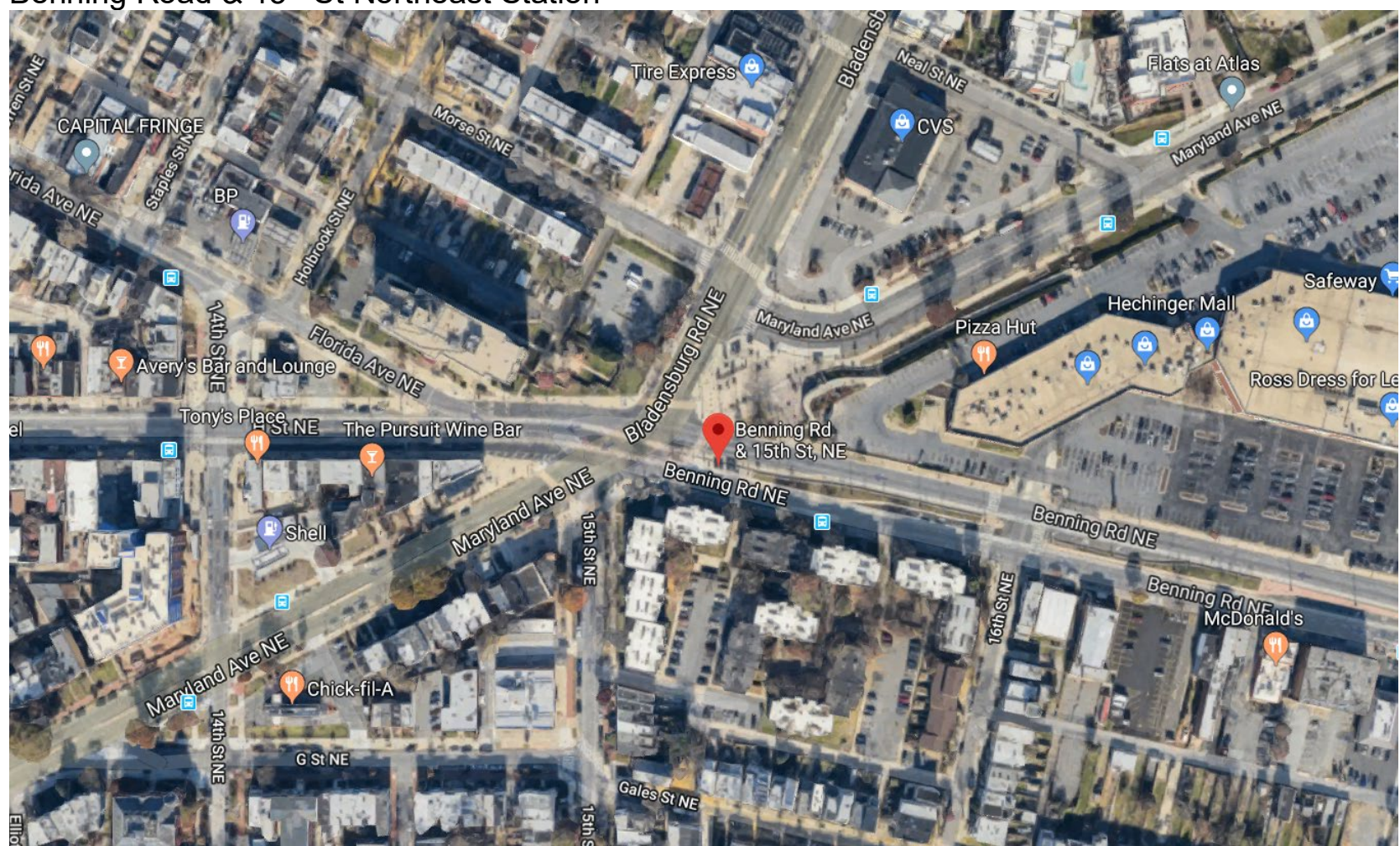

Source: https://www.google.com/maps/place/Benning+Rd+\%26+15th+St,+NE/@38.9001584,-

76.9831995,405m/data=!3m1!1e3!4m5!3m4!1s0x89b7b841de69c663:0x90355d4fc31317777!8m2!3d38.90004!4d$\underline{76.9829909}$

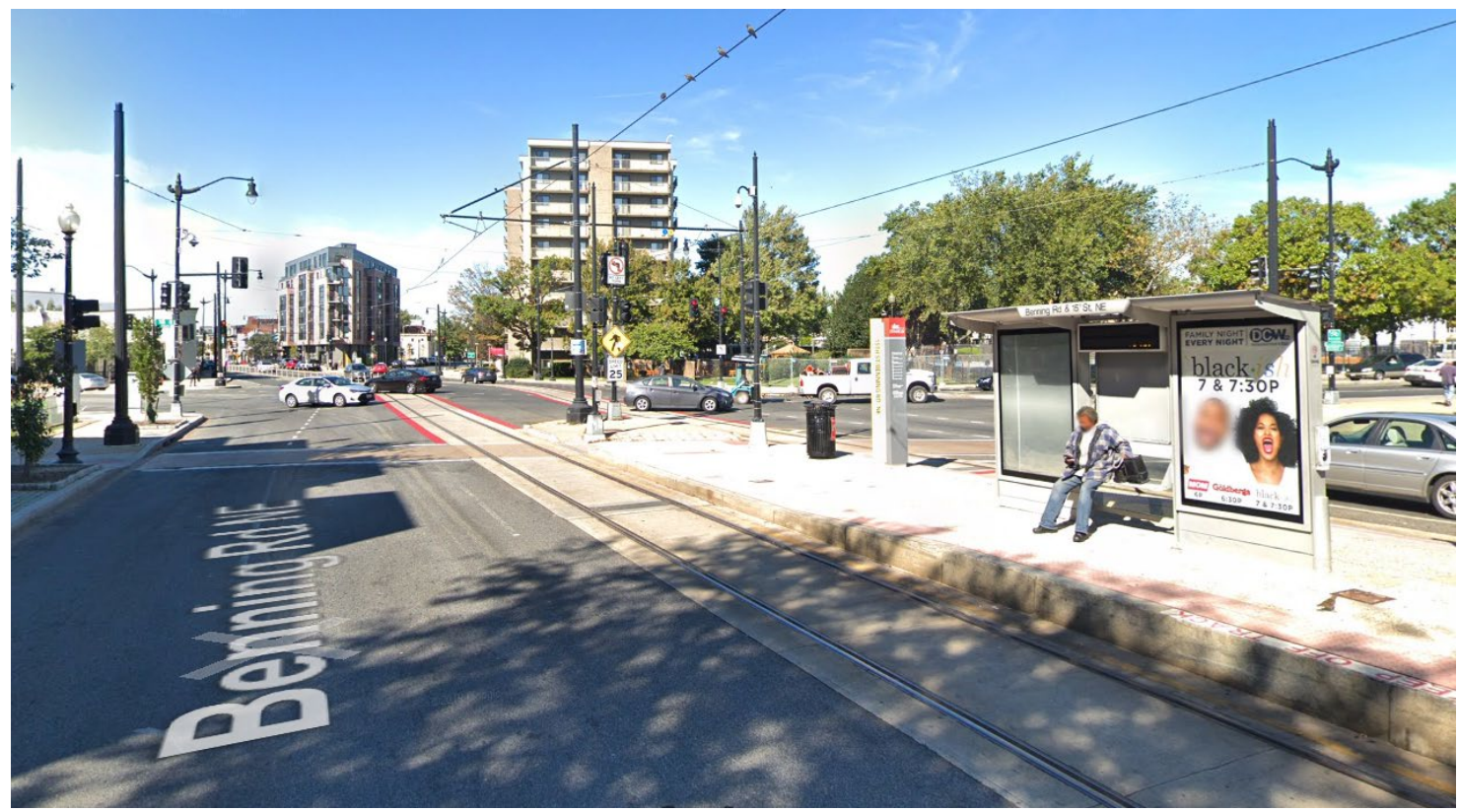

Source: https://www.google.com/maps/@38.8999676,-

76.9829342,3a,60y,306.02h,89.91t/data=!3m6!1e1!3m4!1sF1sLIO5mT3hH12U0qtpMRA!2e0!7i16384!8i8192 


\section{Maryland Avenue Northeast}

Carver, Washington D.C., 20002

Commute to Downtown Washington D.C.

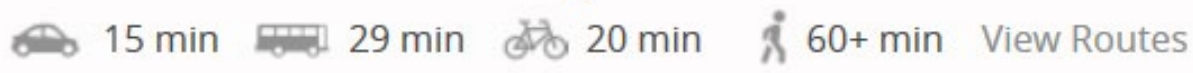

\section{Favorite Top Map @ Nearby Apartments}

Looking for a home for sale in Washington D.C.? 뚱

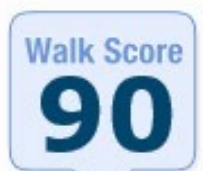

Walker's Paradise

Daily errands do not

require a car.

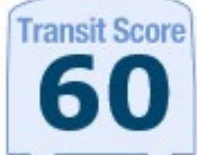

72

\section{Good Transit}

Many nearby public

transportation

options.

\section{Score Details}

\section{Very Bikeable}

Flat as a pancake, some bike lanes.

Source: https://www.walkscore.com/score/1501-maryland-ave-ne-washington-dc-20002

The Benning Road and $15^{\text {th }}$ St. NE stop along D.C.'s streetcar line is in a busy, convoluted intersection which may deter retail development due to its low ease of access. 


\section{COMMUTER RAIL TRANSIT Good Office}

Orlando

Church St. Station

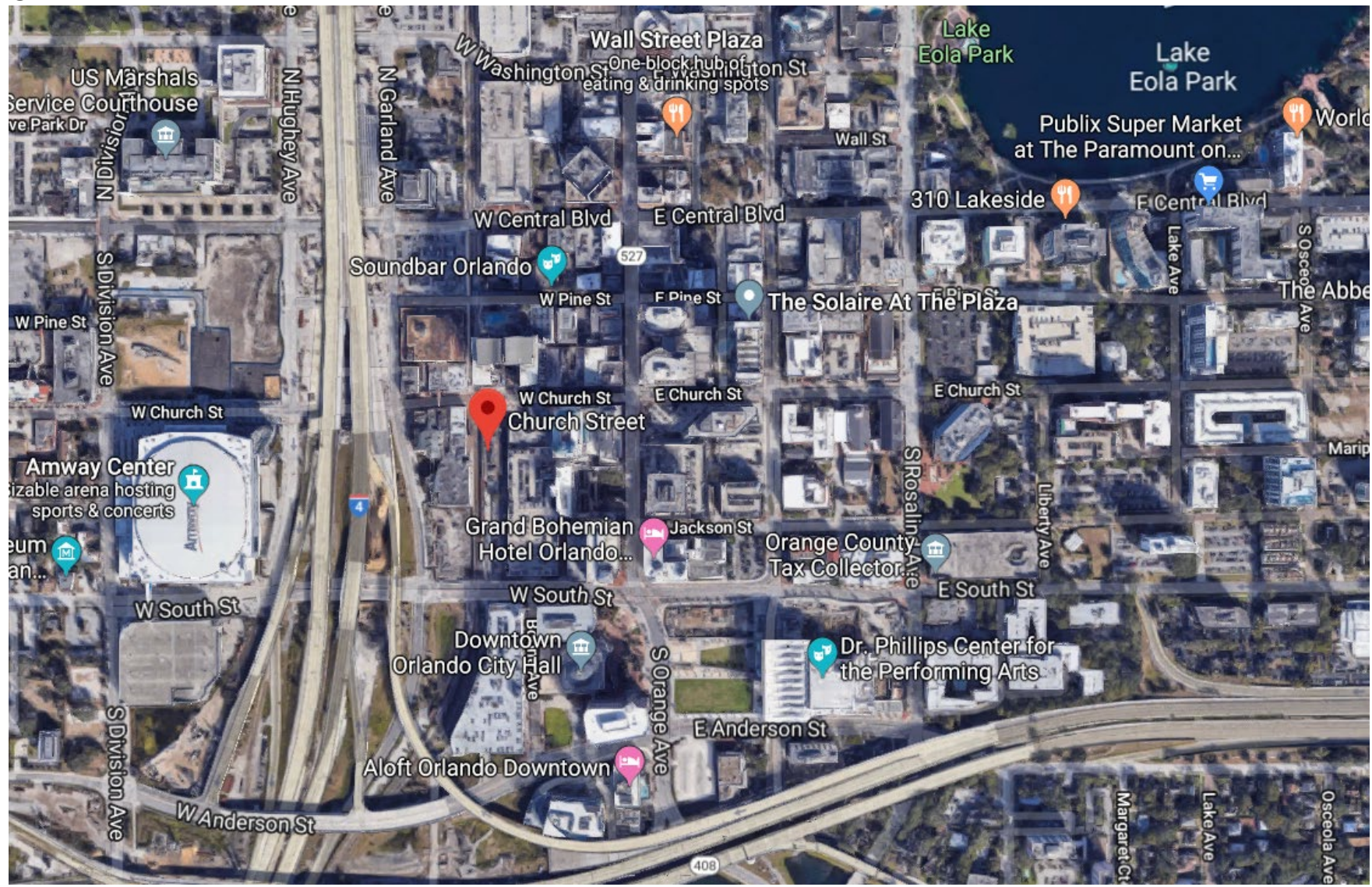

Source: https://www.google.com/maps/place/Church+Street/@28.5402373,-

$81.3782769,1220 \mathrm{~m} / \mathrm{data}=! 3 \mathrm{~m} 1 ! 1 \mathrm{e} 3 ! 4 \mathrm{~m} 12$ ! $1 \mathrm{~m} 6 ! 3 \mathrm{~m} 5 ! 1 \mathrm{~s} 0 \times 88 \mathrm{e} 77 \mathrm{~b} 01 \mathrm{~d} 1938535: 0 \times \mathrm{xe} 8252 \mathrm{f09f9764615!2sChurch}+$ Street! 8m2!3d28.5397556!4d-81.3806525!3m4!1s0x88e77b01d1938535:0xe8252f09f9764615!8m2!3d28.5397556!4d81.3806525 


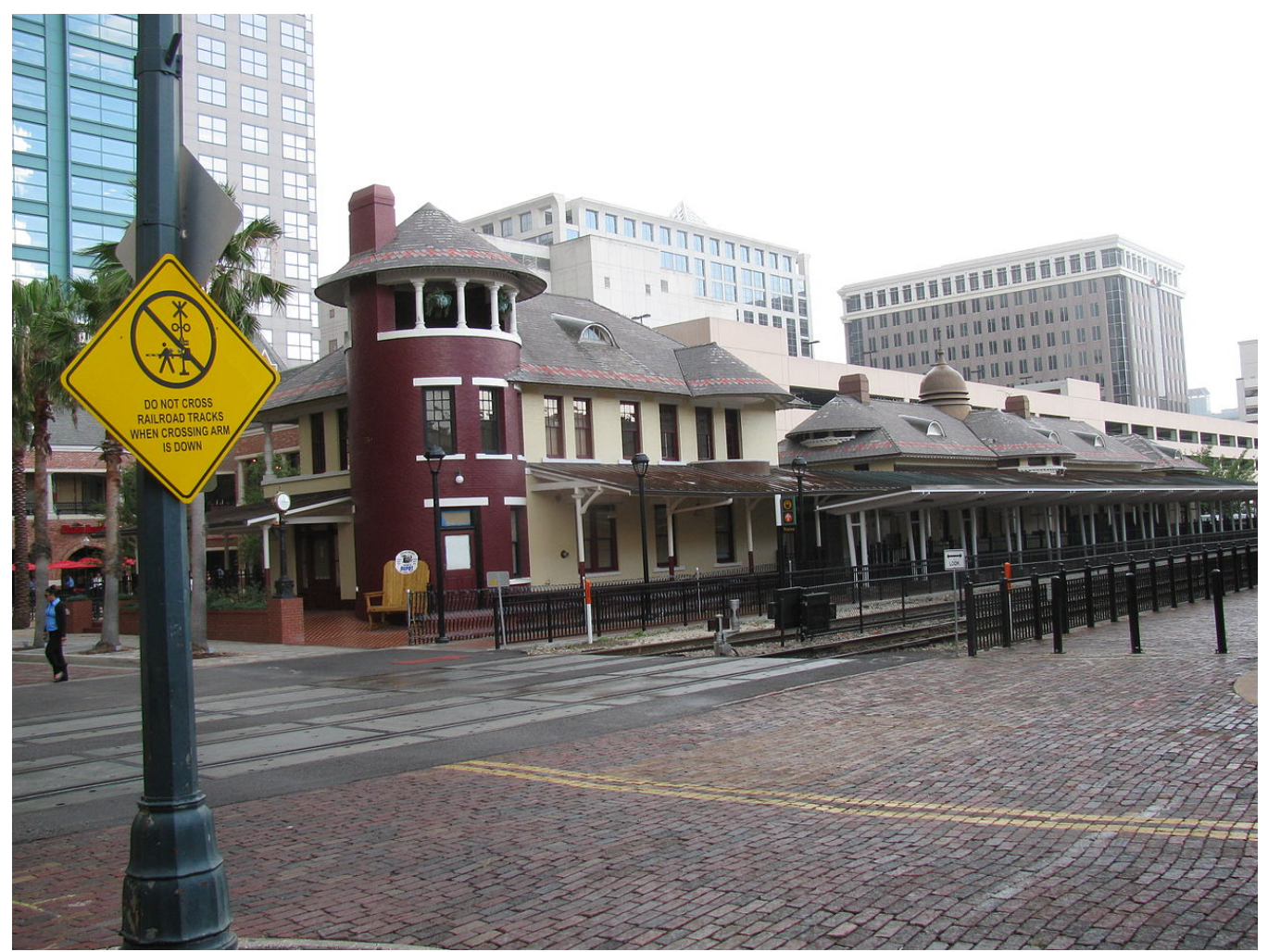

Source: https://en.wikipedia.org/wiki/Church Street Station (Orlando)\#/media/File:SunRail Church Street.jpg 


\section{West Church Street}

Central Business District, Orlando, 32801

Commute to Downtown Winter Park

$214 \mathrm{~min} 21 \mathrm{~min} 31 \mathrm{~min}$ i $60+\mathrm{min}$ View Routes

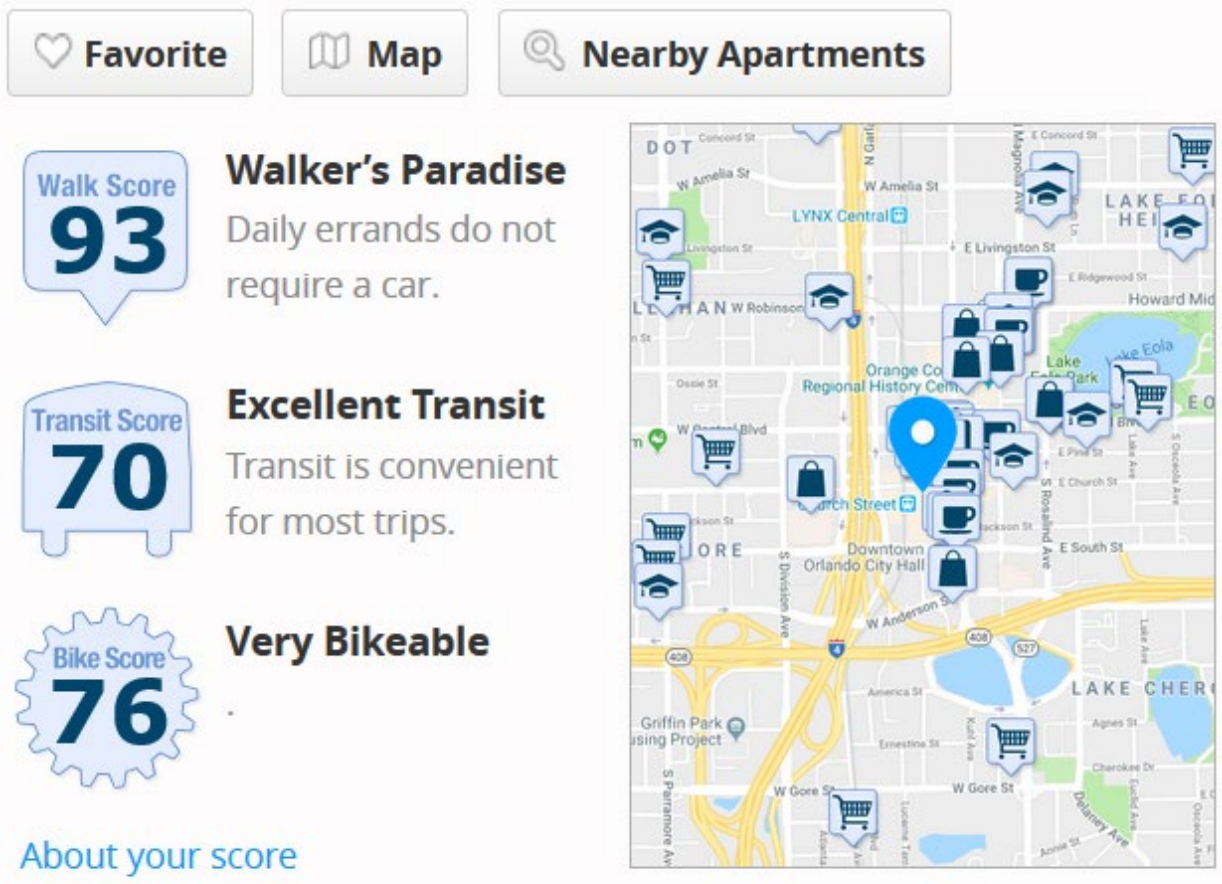

Add scores to your site

Source: https://www.walkscore.com/score/54-w-church-st-orlando-fl-32801

With connections to Orlando's bus route, the Church St. Station in downtown Orlando, Florida offers passengers access to employment hubs as well as other attractions and amenities. 


\section{San Jose}

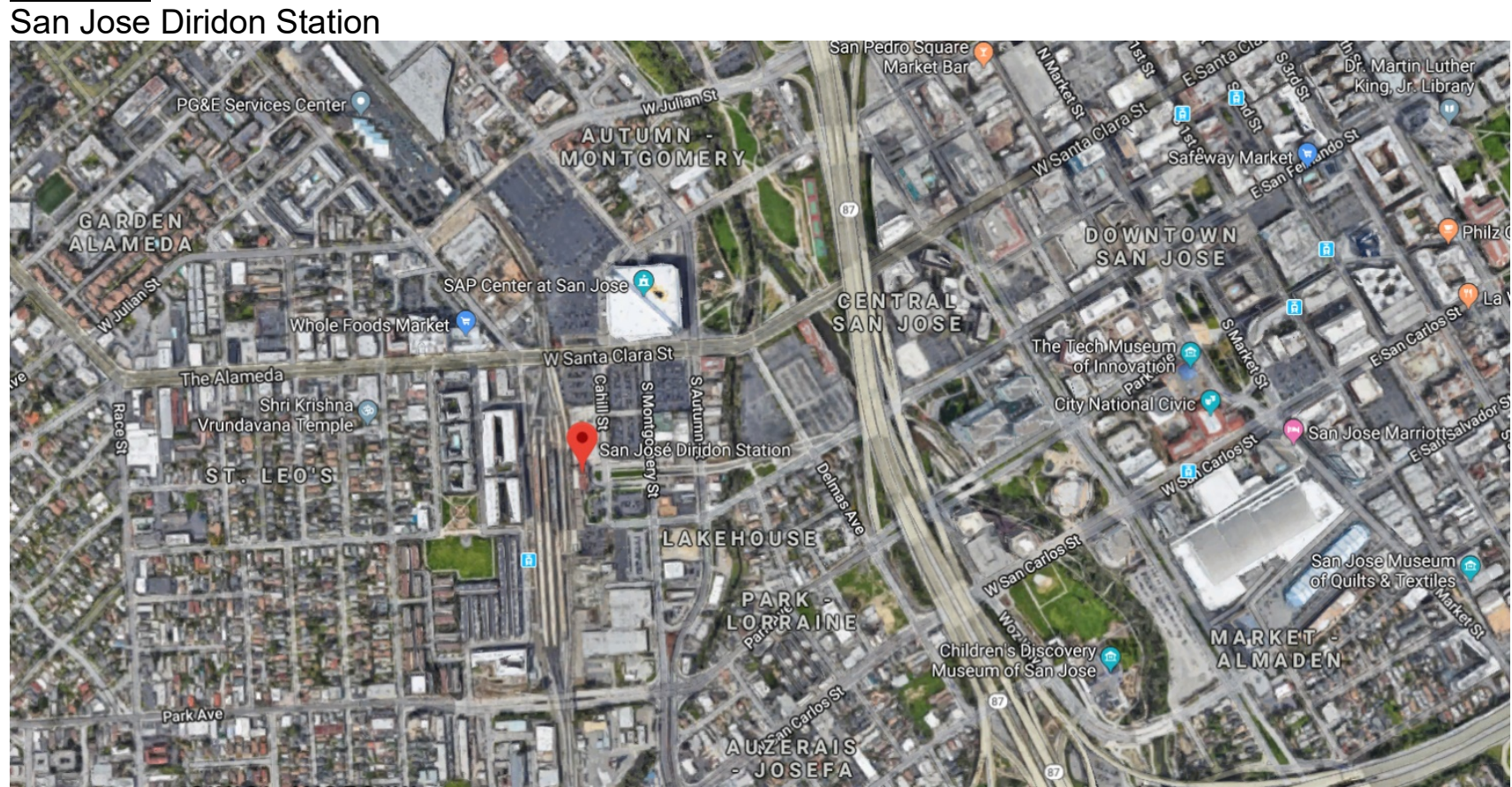

Source: https://www.google.com/maps/place/San+Jos\%C3\%A9+Diridon+Station/@37.3312146,-

$121.8988756,1644 \mathrm{~m} / \mathrm{data}=! 3 \mathrm{~m} 1 ! 1 \mathrm{e} 3 ! 4 \mathrm{~m} 8 ! 1 \mathrm{~m} 2 ! 2 \mathrm{~m} 1 ! 1 \mathrm{sACE}+$ station!3m4!1s0x0:0x9e3ba7280649281a!8m2!3d37.329 $\underline{9289 ! 4 \mathrm{~d}-121.9025052}$

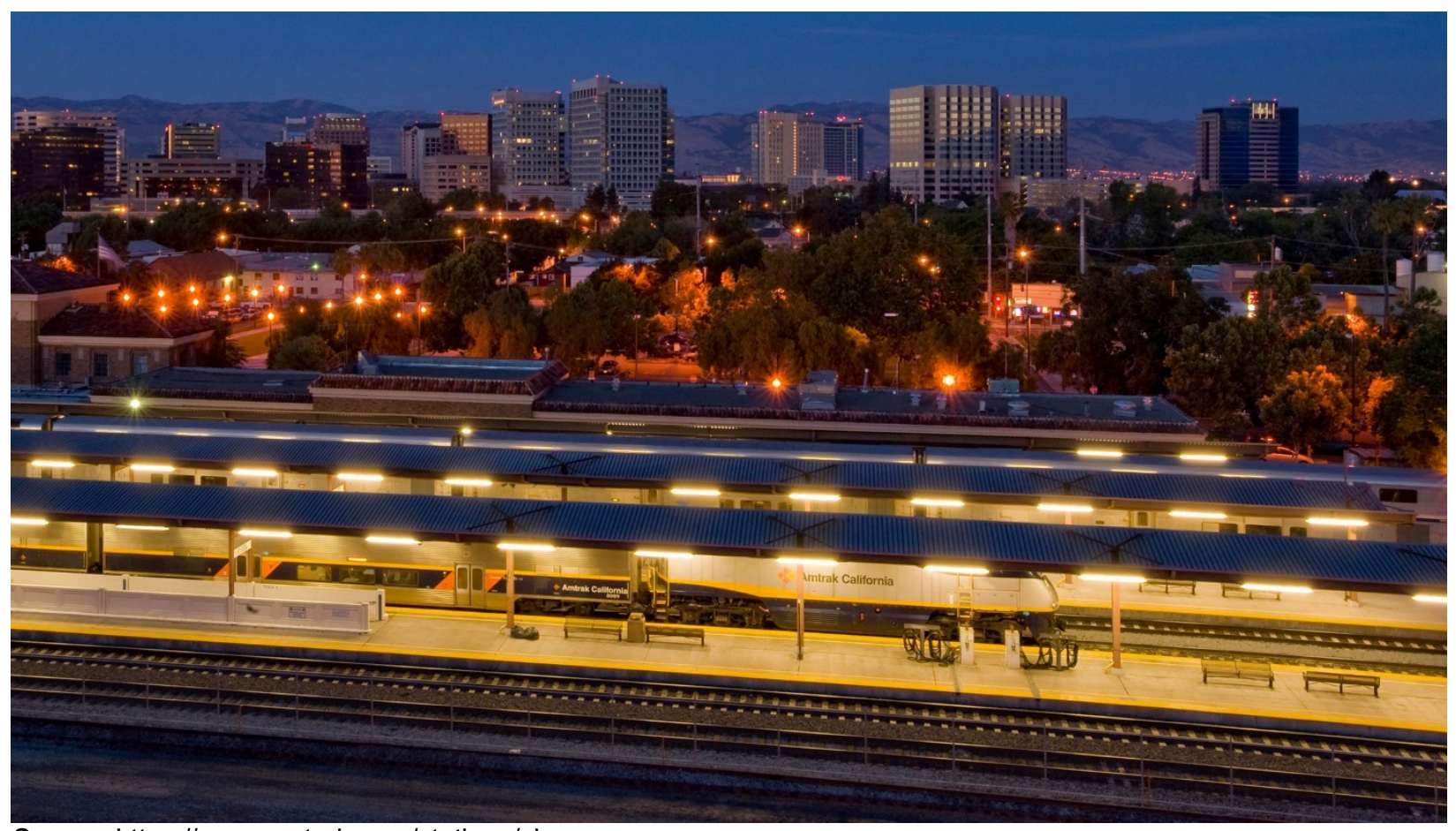

Source: https://www.amtrak.com/stations/sjc 


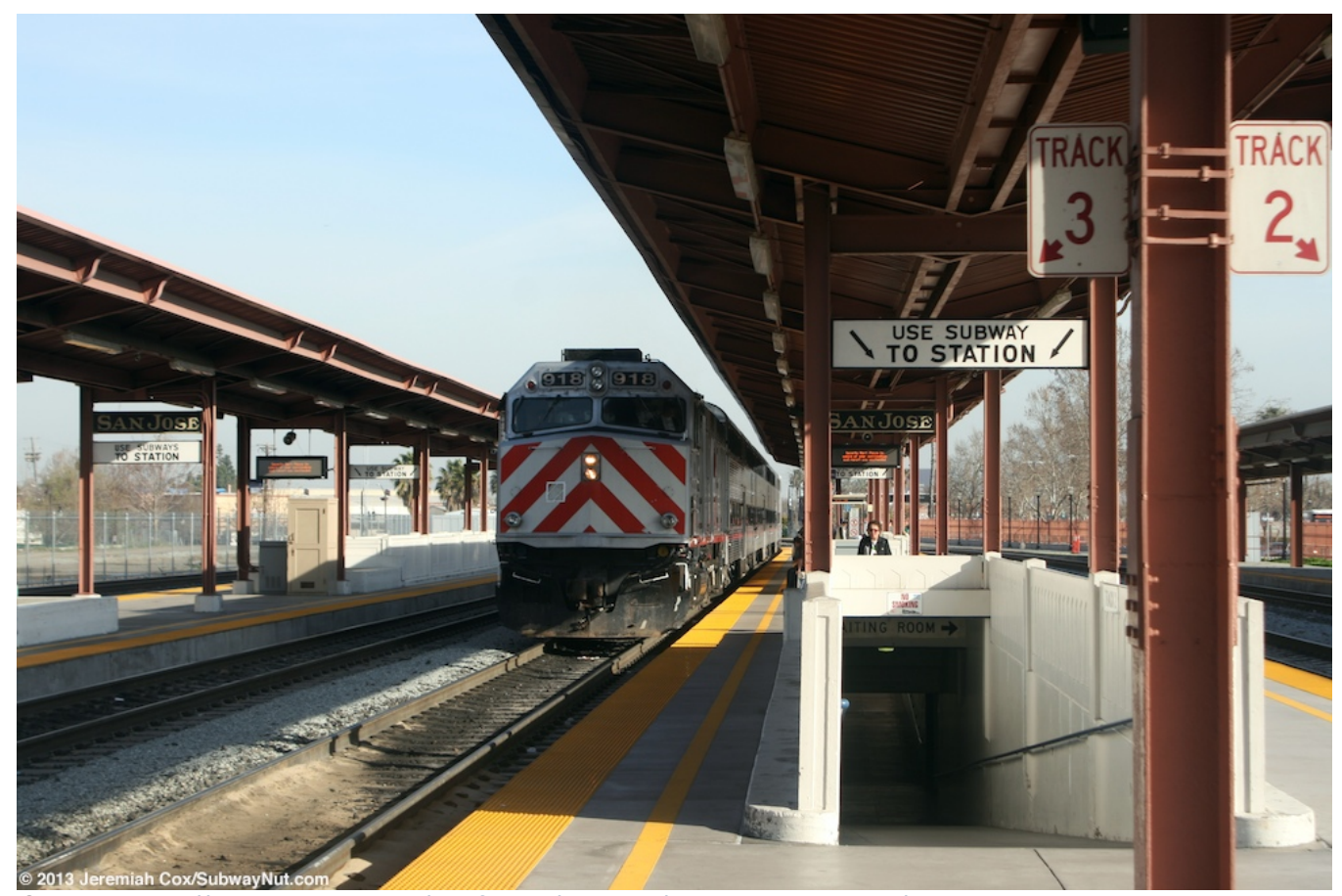

Source: http://subwaynut.com/california/caltrain/san jose diridon/san jose diridon13.jpg 


\section{Crandall Street}

San Jose, California, 95110

Commute to Downtown San Jose

$2 \mathrm{~min} \quad 8 \mathrm{~min} 4 \mathrm{~min}$ iो $13 \mathrm{~min}$ View Routes

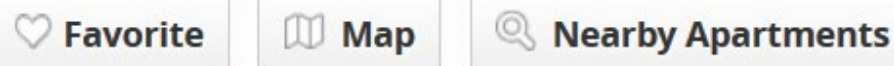

Looking for a home for sale in San Jose? 빵

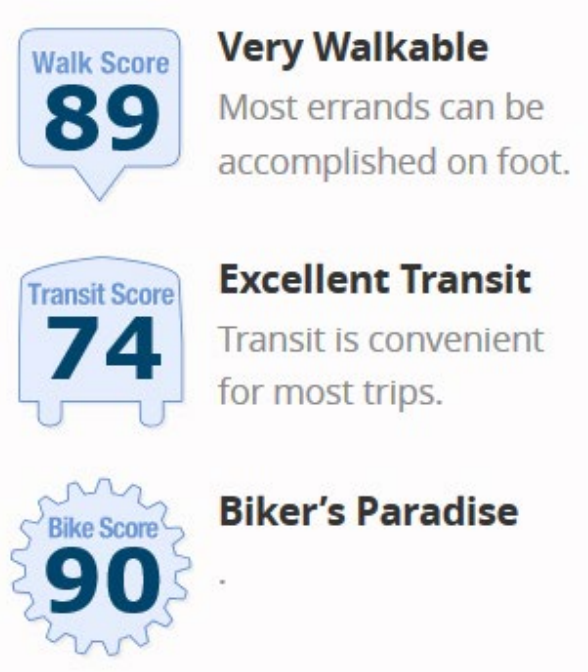

About your score

Add scores to your site

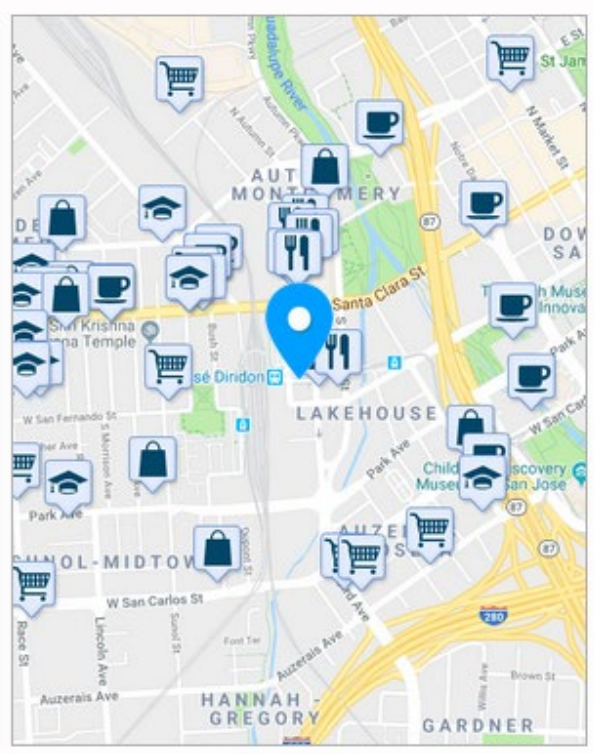

Source: https://www.walkscore.com/score/549-crandall-st-san-jose-ca-95110

Serving the Altamont Corridor Express in the San Jose area, the Diridon Station in near downtown San Jose offers passengers connections to other regional transit options and employment centers. 


\section{Bad Office}

Austin

Highland Station

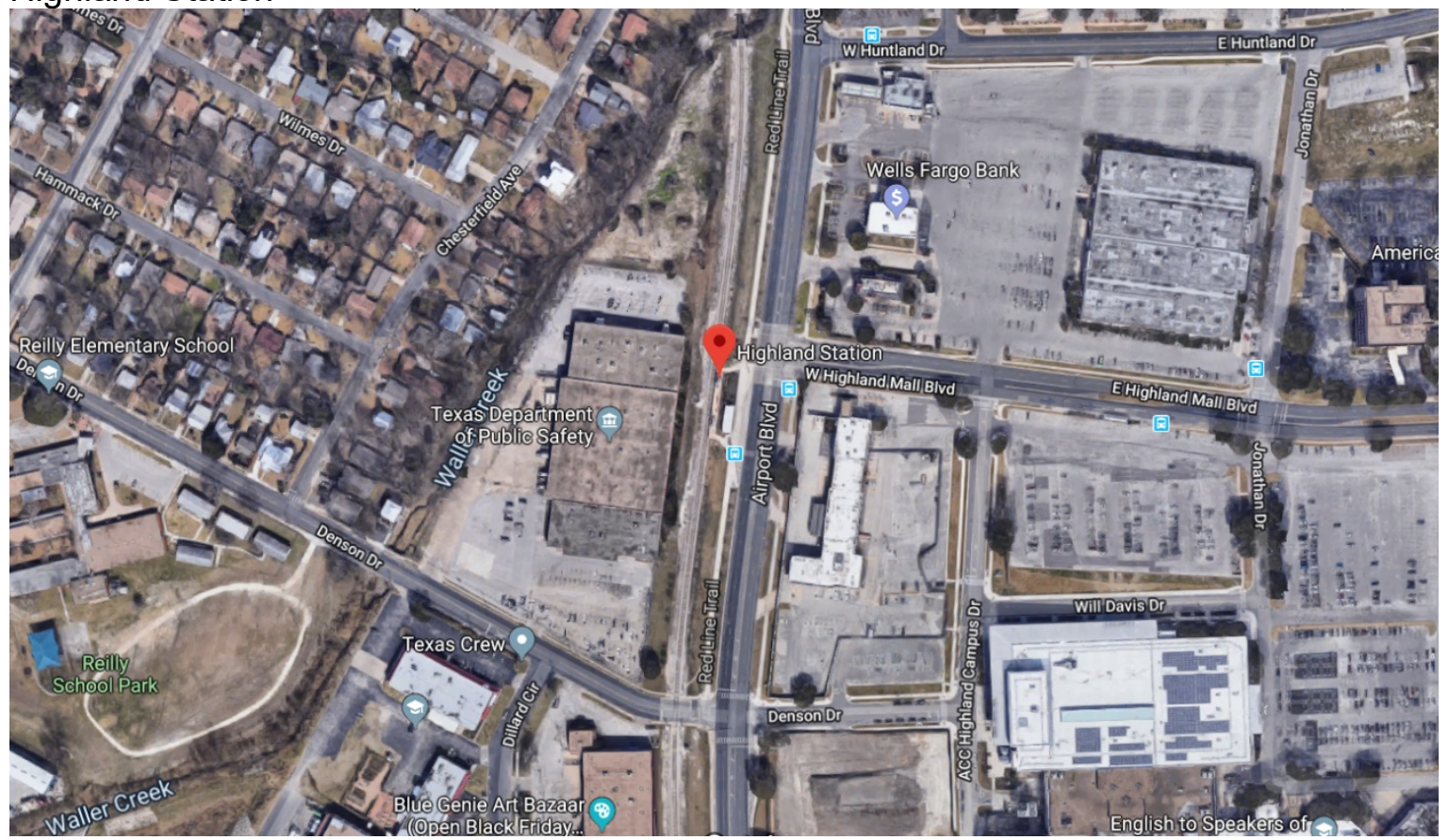

Source: https://www.google.com/maps/place/Highland+Station/@30.3285646,-

97.7160181,536m/data=!3m1!1e3!4m5!3m4!1s0x8644ca3ec94b03ef:0xa987d20e7ab39de5!8m2!3d30.3286992!4d97.7161708 


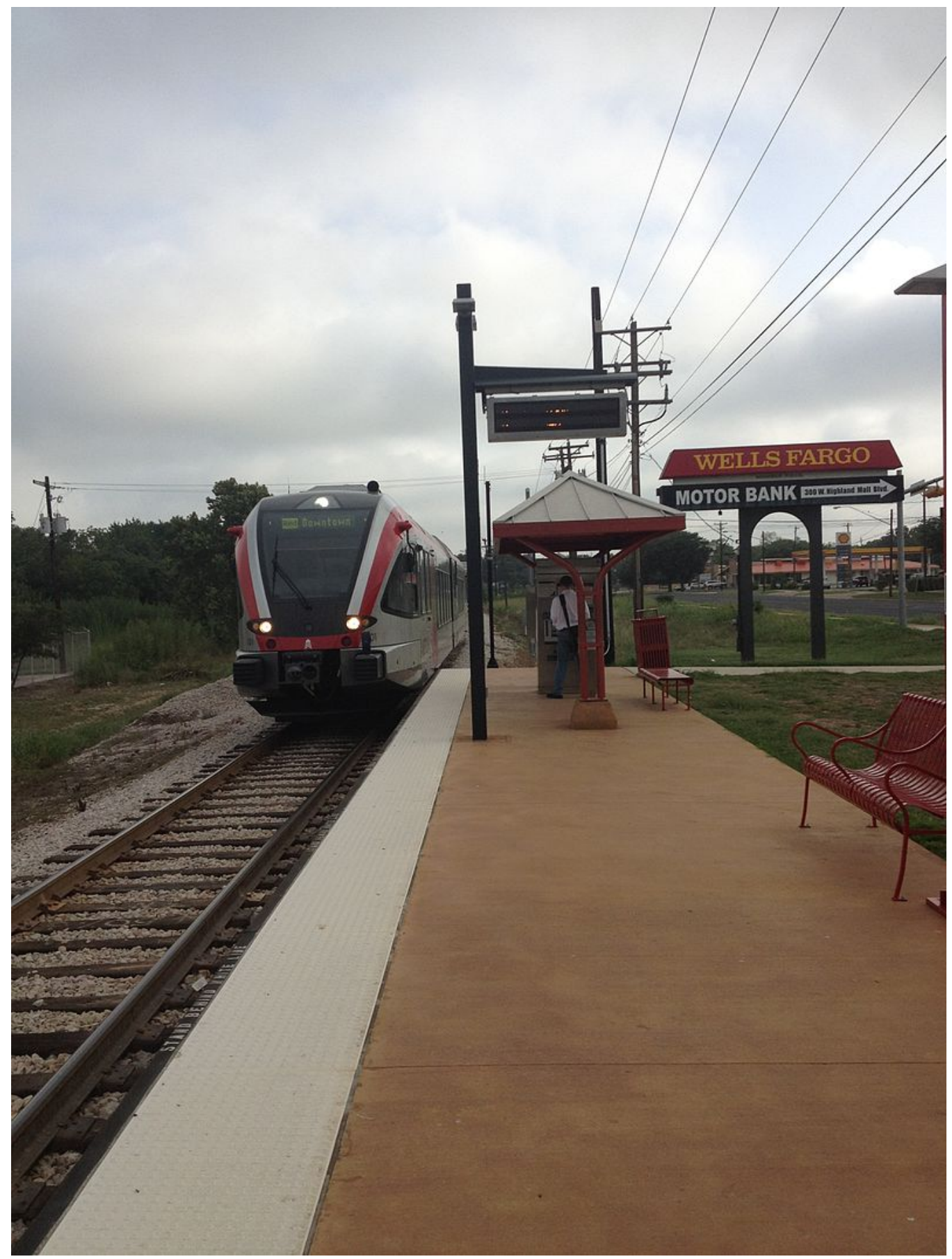

Source: https://en.wikipedia.org/wiki/Highland_station_(Capital_MetroRail)\#/media/File:Highlandstation1.jpg 


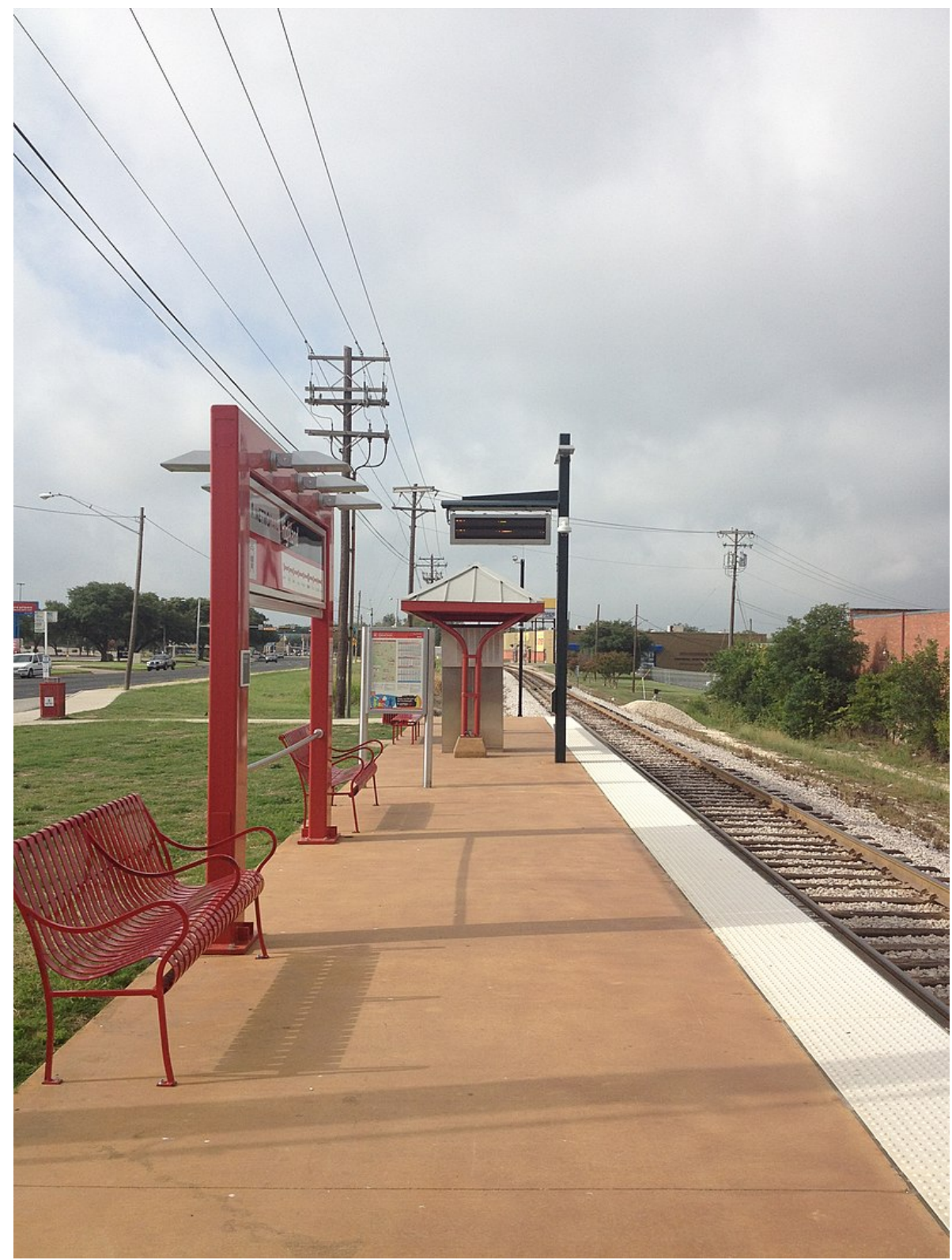

Source: https://en.wikipedia.org/wiki/Highland_station_(Capital_MetroRail)\#/media/File:Highlandstation.jpg 


\section{Airport Boulevard}

Highland, Austin, 78752

Commute to Downtown Austin

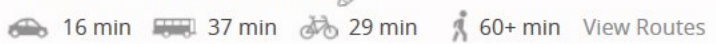

Favorite $\mathbb{D}$ Map $\bigcirc$ Nearby Apartments

Looking for a home for sale in Austin? 중

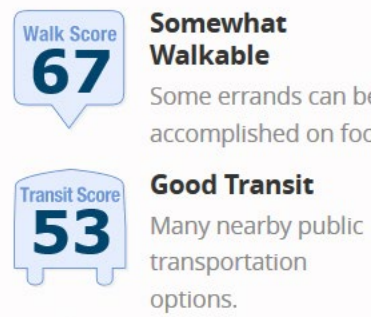

Bikescores Very Bikeable 87

About your score

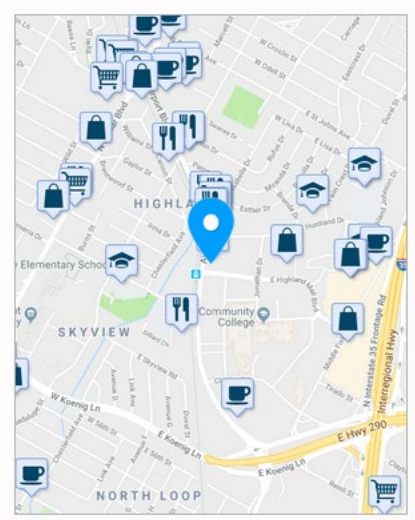

Add scores to your site

Source: https://www.walkscore.com/score/6419-airport-blvd-austin-tx-78752

Austin's Highland Station serving the Capital Metro Rail features only a narrow sidewalk to get to the uninviting platform. Moreover, there are no major employment centers or residential centers nearby for passengers to easily get to and from. 


\section{Portland}

\section{Wilsonville WES Station}

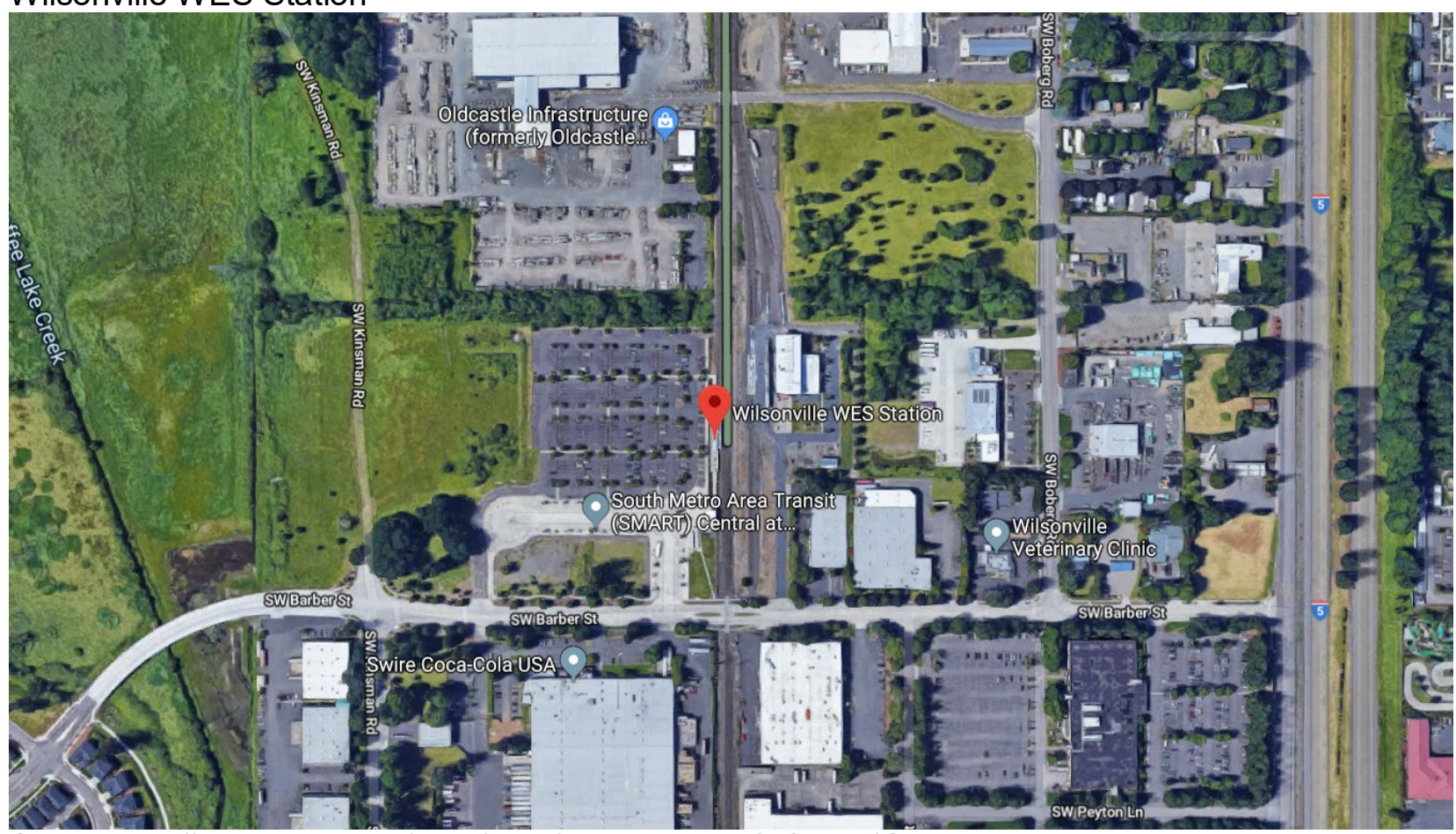

Source: https://www.google.com/maps/place/Wilsonville+WES+Station/@45.3114897. -

$122.7748018,735 \mathrm{~m} / \mathrm{data}=! 3 \mathrm{~m} 1 ! 1 \mathrm{e} 3 ! 4 \mathrm{~m} 5 ! 3 \mathrm{~m} 4 ! 1 \mathrm{~s} 0 \times 54956 \mathrm{e} 8 \mathrm{dc5}$ cbb48d:0xaddaf1cc6c689682!8m2!3d45.3113545!4d$\underline{122.7753188}$

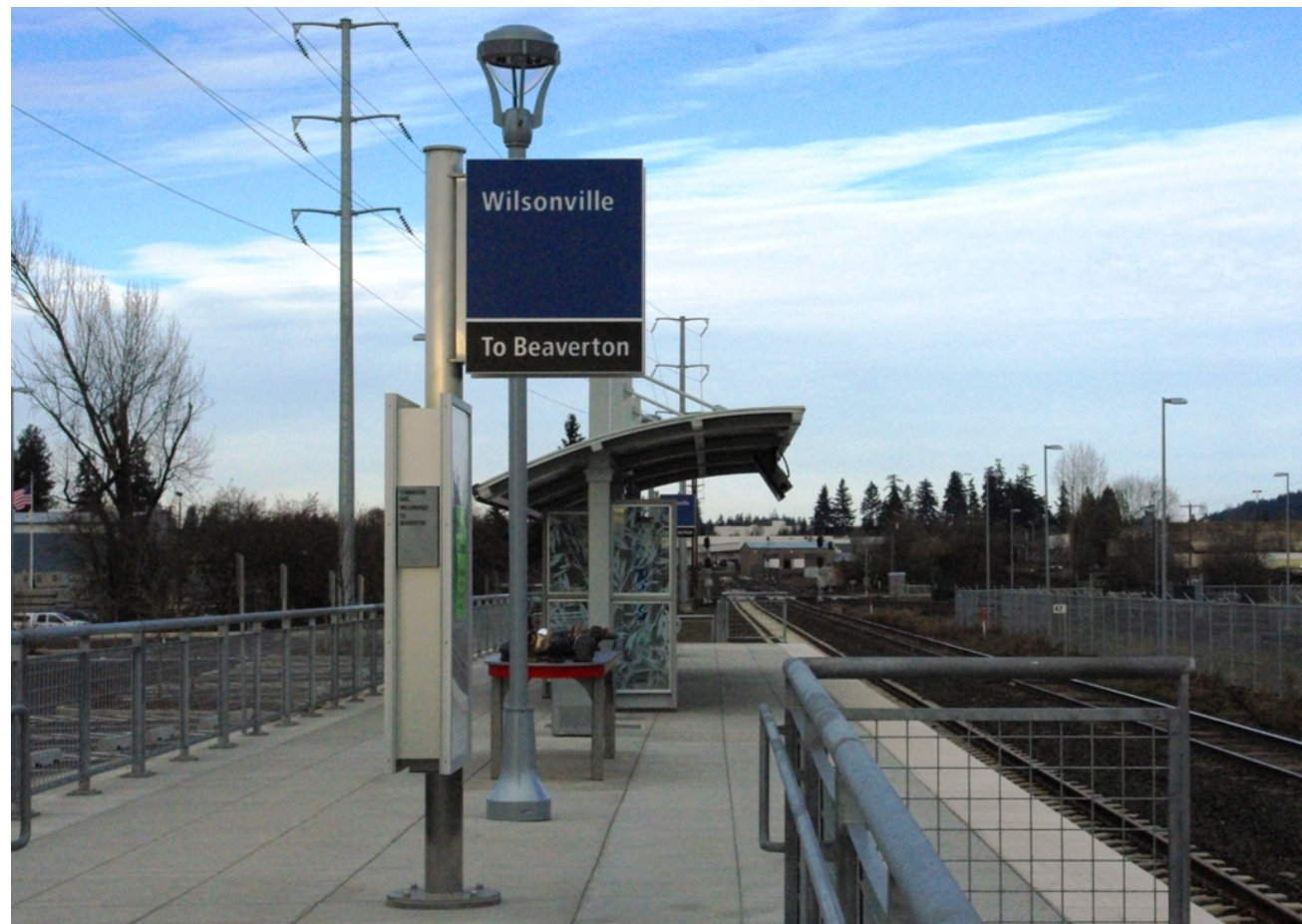

Source: https://en.wikipedia.org/wiki/Wilsonville_station\#/media/File:Wilsonville_Station_Jan_2009.JPG 


\section{Southwest Barber Street}

Wilsonville, Oregon, 97070

Commute to Downtown Wilsonville

$\Leftrightarrow 6 \mathrm{~min} 12 \mathrm{~min} 11 \mathrm{~min}$ i $44 \mathrm{~min}$ View Routes

\section{Favorite (1) Map Q Nearby Apartments}

Looking for a home for sale in Wilsonville? [ㅜㅜ

\section{4}

Car-Dependent

Almost all errands

require a car.

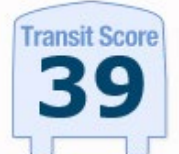

Some Transit

A few nearby public

transportation

options.

About your score

Add scores to your site

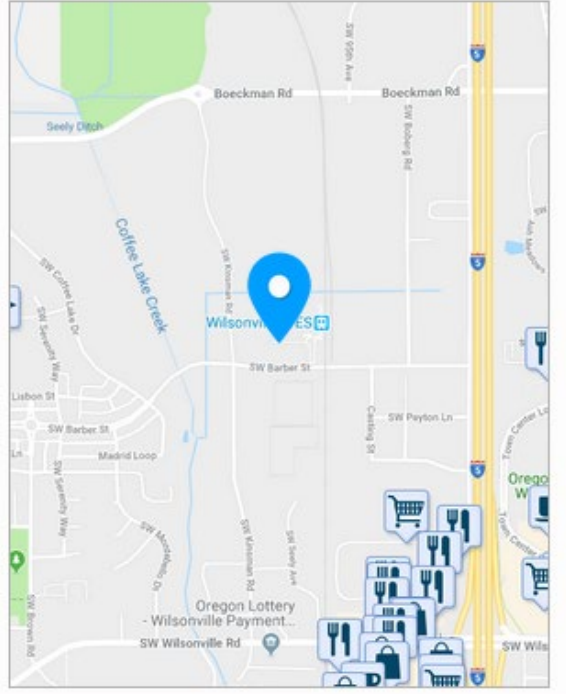

Source: https://www.walkscore.com/score/9699-sw-barber-st-wilsonville-or-97070

Portland's Wilsonville Station serving the WES commuter rail system is in a hardly walkable area with little development, especially office uses. 


\section{Good Multifamily}

\section{Minneapolis}

\section{Elk River Station}

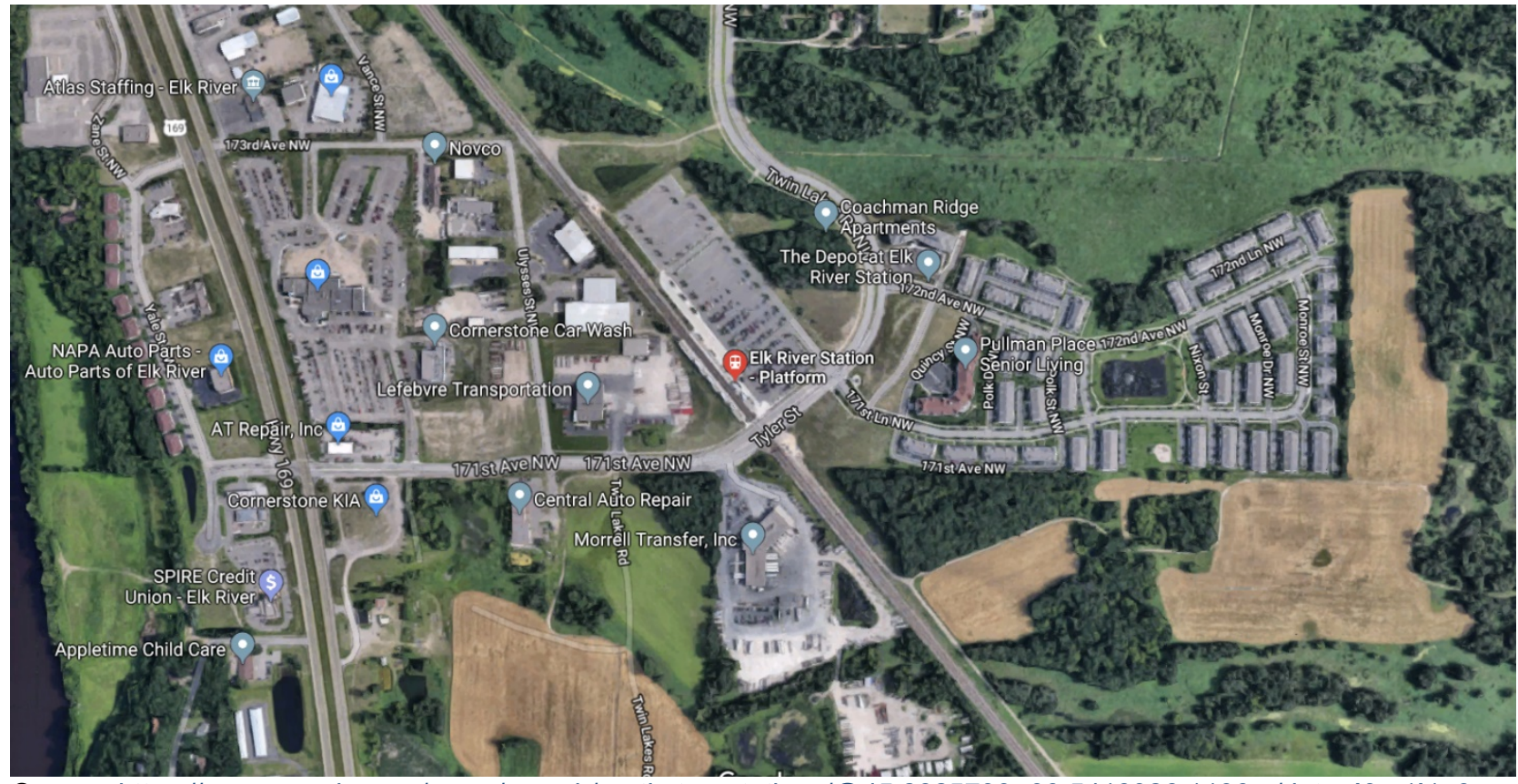

Source: https://www.google.com/maps/search/northstar+stations/@45.2825733,-93.5416326,1130m/data=!3m1!1e3

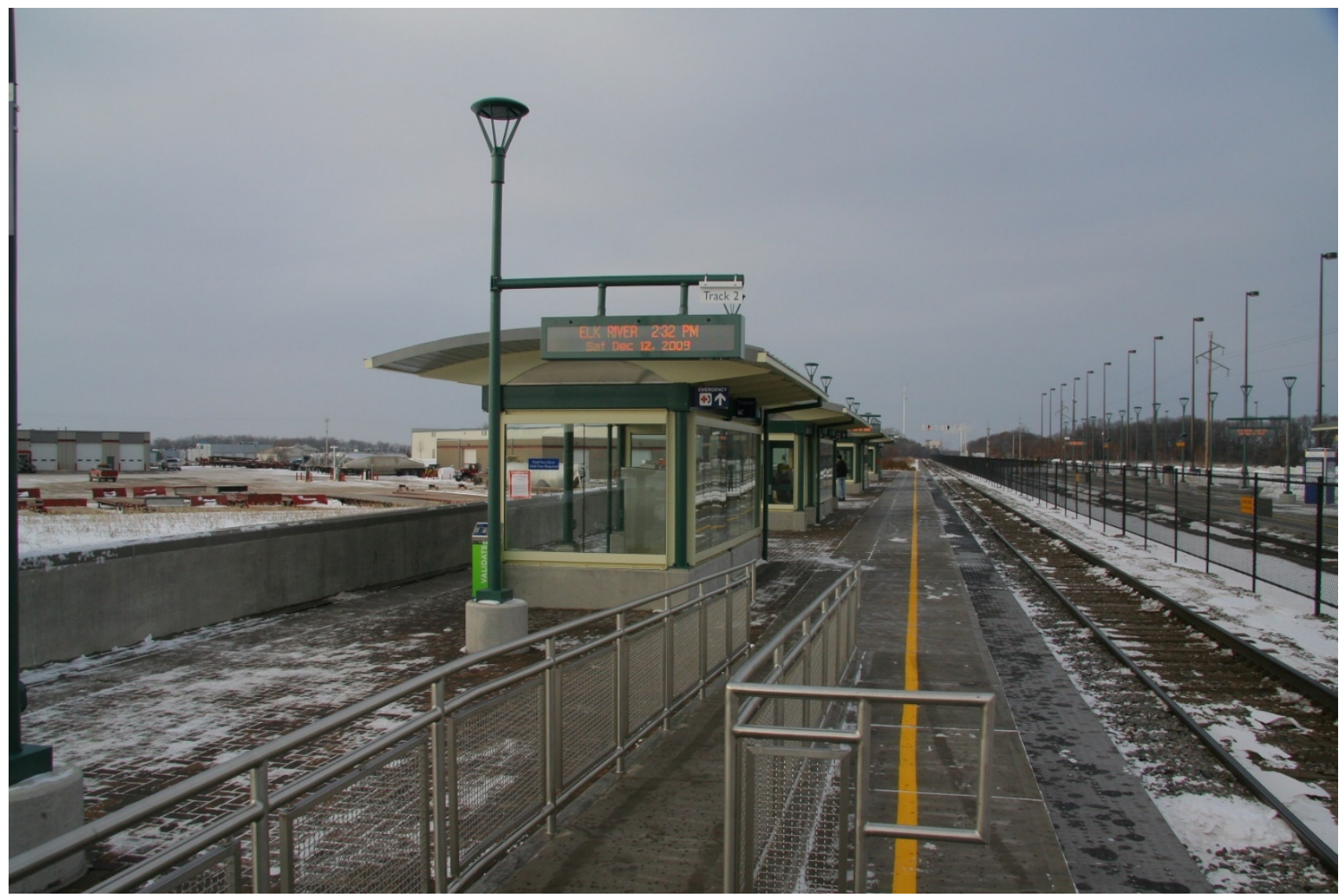

Source: https://en.wikipedia.org/wiki/Elk_River_station 


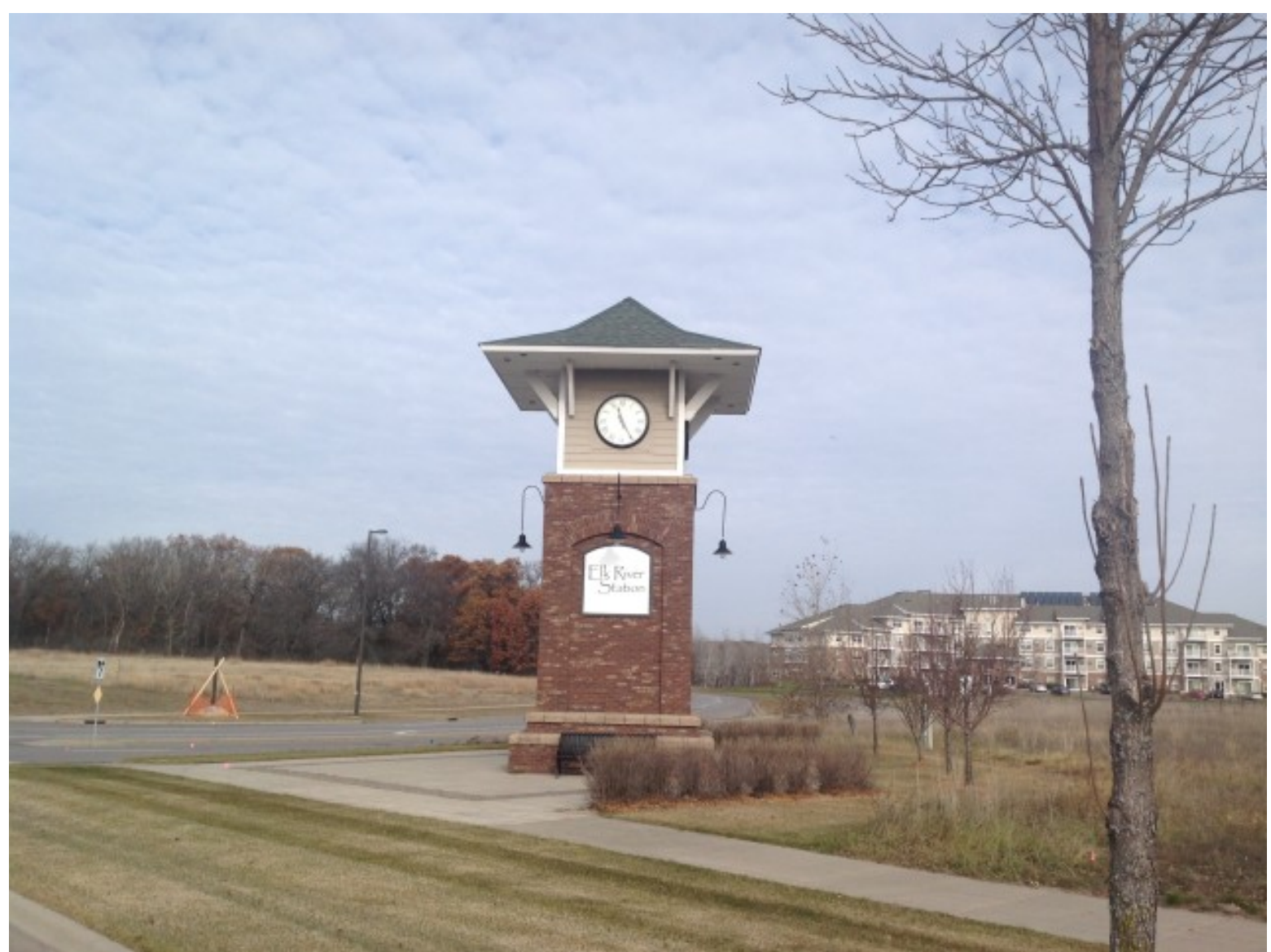

Source: http://mnhomeshop.com/elk-river-station-townhomes/ 


\section{Twin Lakes Road Northwest}

\section{Elk River, Minnesota, 55330}

\section{Commute to Downtown Elk River}
$13 \mathrm{~min}$
bt $35 \mathrm{~min}$
i $60+$ min
View Routes

\section{Favorite}

[1] Map

Nearby Apartments

Looking for a home for sale in Elk River? 뚱

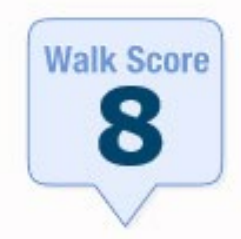

\section{Car-Dependent}

Almost all errands

require a car.

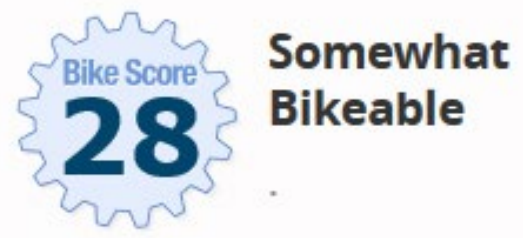

\section{About your score}

Add scores to your site

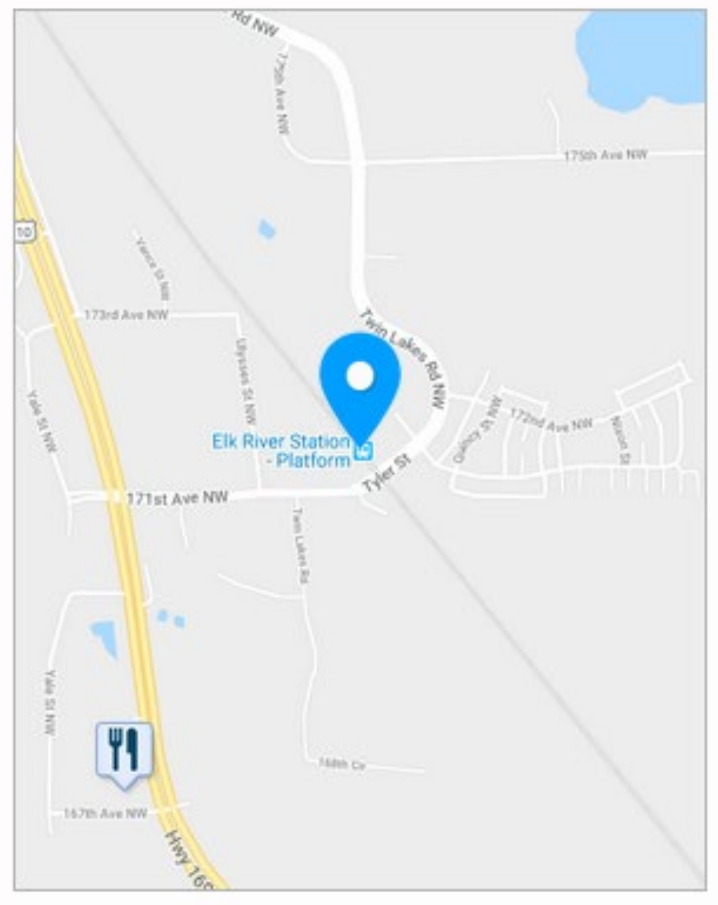

Source: https://www.walkscore.com/score/17200-twin-lakes-rd-nw-elk-river-mn-55330

Elk River Station serving the Minneapolis, Minnesota area has parking for over 750 cars as well as bike lockers for commuters. Additionally, the area has seen an abundance of multifamily development, like Elk River Station Townhomes located just east of the station itself. 


\section{San Diego}

Carlsbad Village Station

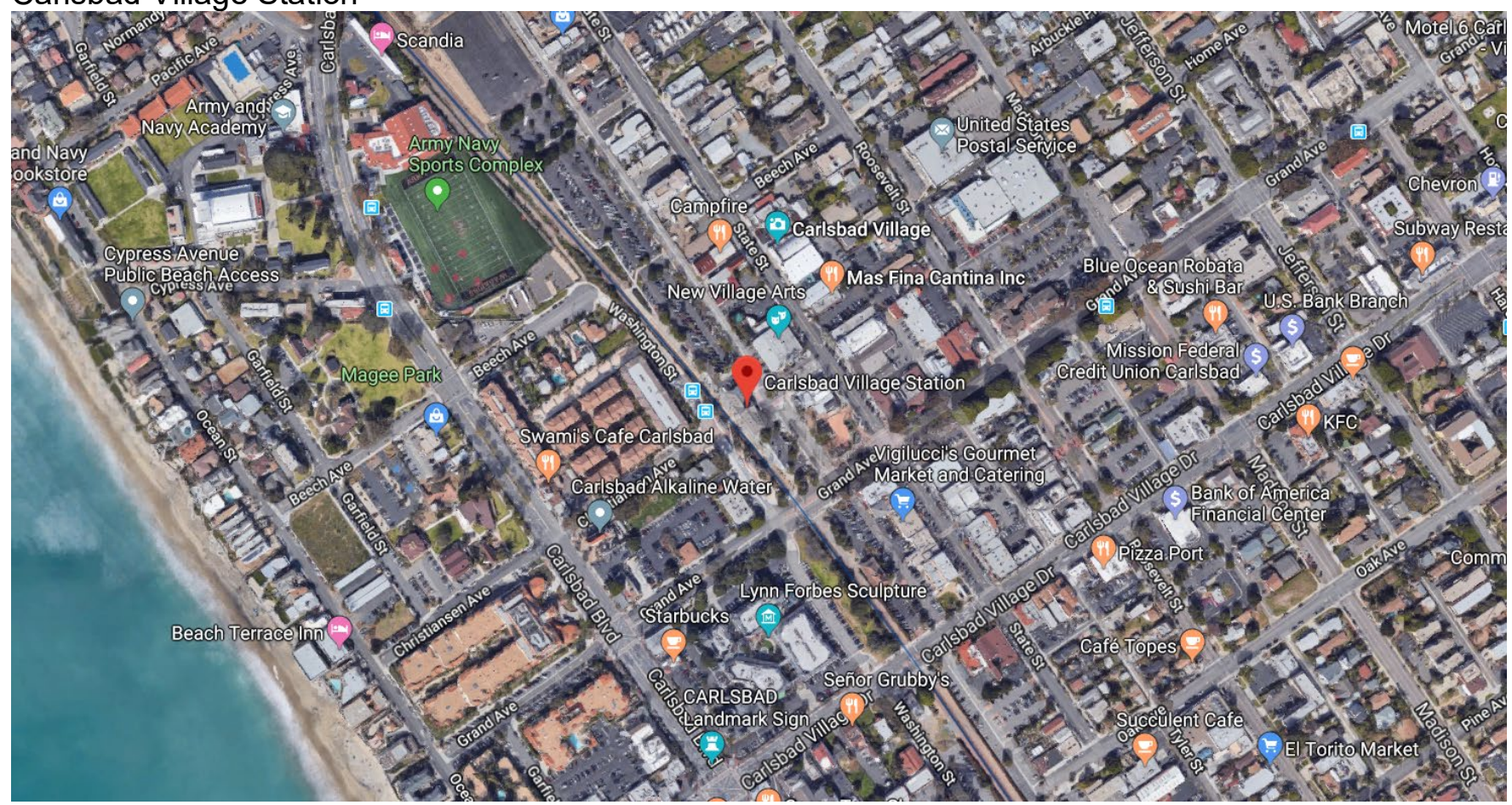

Source: https://www.google.com/maps/place/Carlsbad+Village+Station/@33.1610267.-

$117.3515688,725 \mathrm{~m} / \mathrm{data}=! 3 \mathrm{~m} 1 ! 1 \mathrm{e} 3 ! 4 \mathrm{~m} 5 ! 3 \mathrm{~m} 4 ! 1 \mathrm{~s} 0 \times 80 \mathrm{dc} 7205457 \mathrm{f} 7 \mathrm{ceb}: 0 \times 971 \mathrm{~d} 8 \mathrm{a} 05671$ bec14!8m2!3d33.1609289!4d117.3508223

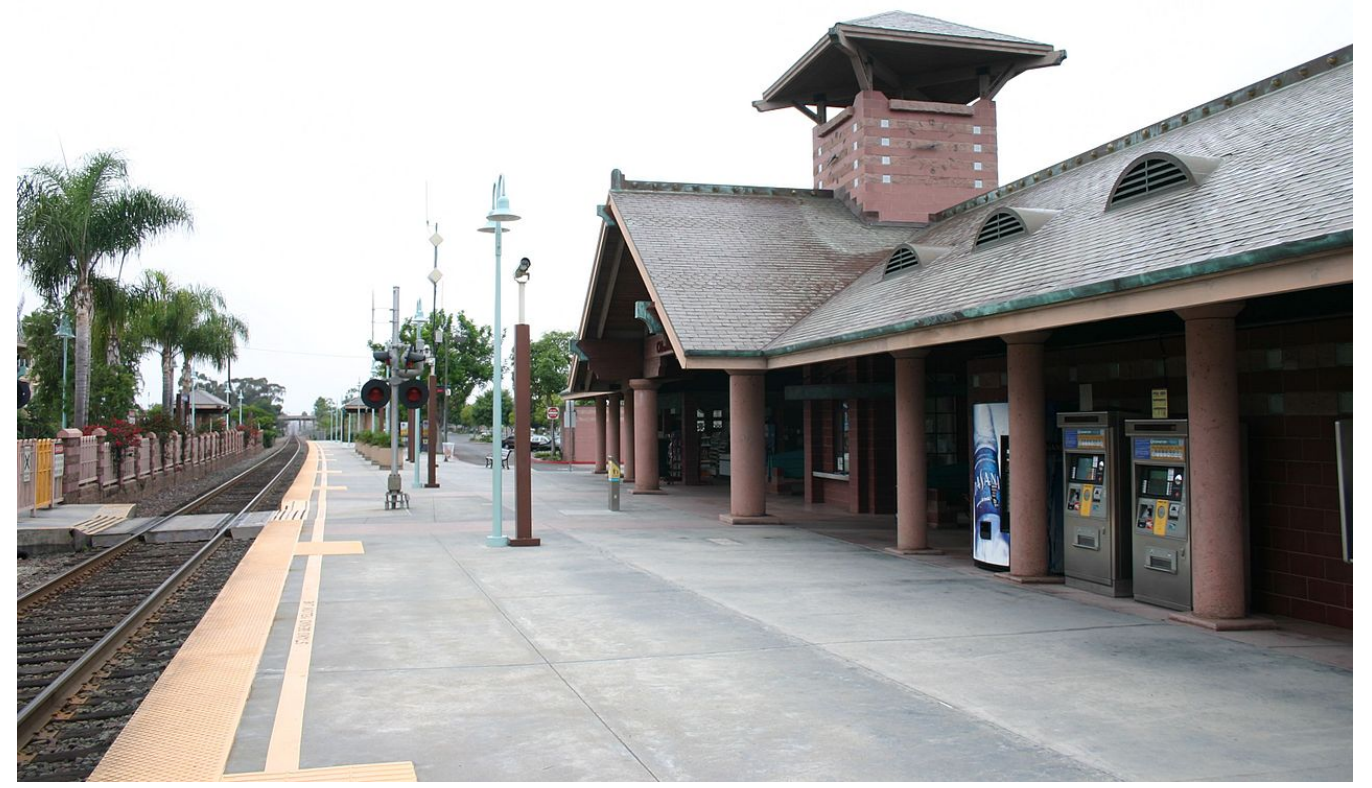

Source: https://en.wikipedia.org/wiki/Carlsbad_Village_station\#/media/File:Carlsbad_Village_Station_3.jpg 


\section{State Street}

\section{Carlsbad, California, 92008}

Commute to Downtown Carlsbad

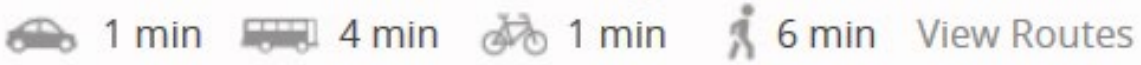

\section{$\checkmark$ Favorite $\square$ Map $\bigcirc$ Nearby Apartments}

Looking for a home for sale in Carlsbad? एᄄ

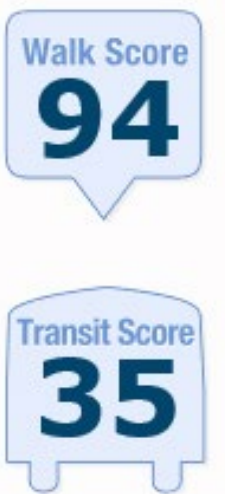

Walker's Paradise

Daily errands do not

require a car.

Some Transit

A few nearby public

transportation

options.

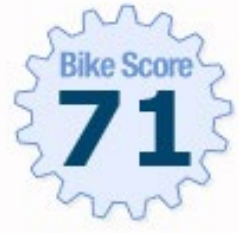

\section{Very Bikeable}

About your score

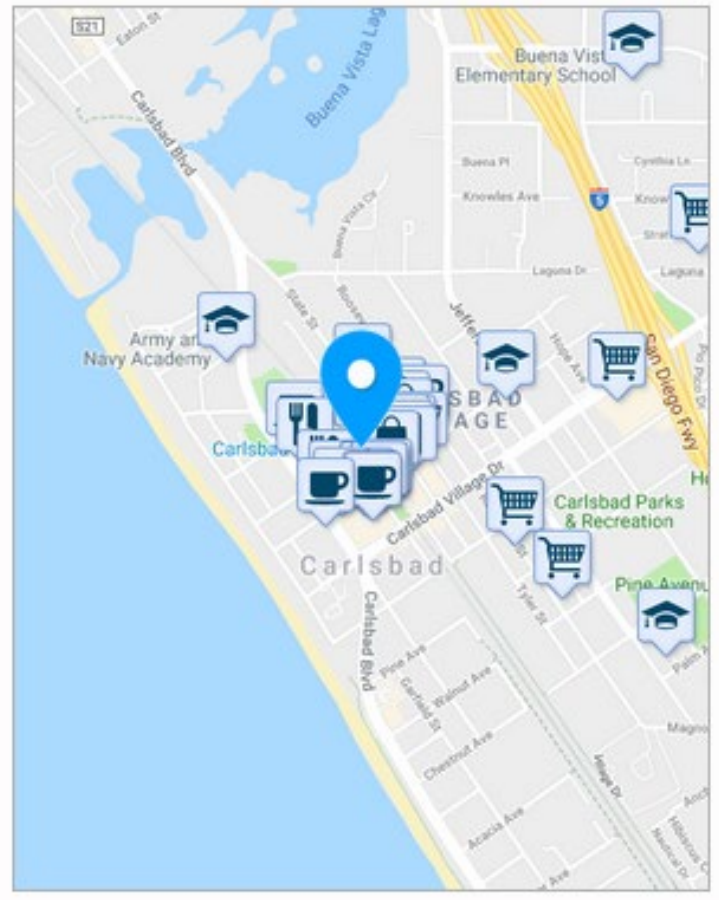

\section{Add scores to your site}

Source: https://www.walkscore.com/score/2775-state-st-carlsbad-ca-92008

With access to local amenities and overall walkability, Carlsbad Village Station serving San Diego's COASTER commuter rail system is ideal for multifamily development. 


\section{Bad Multifamily}

Austin

Howard Station

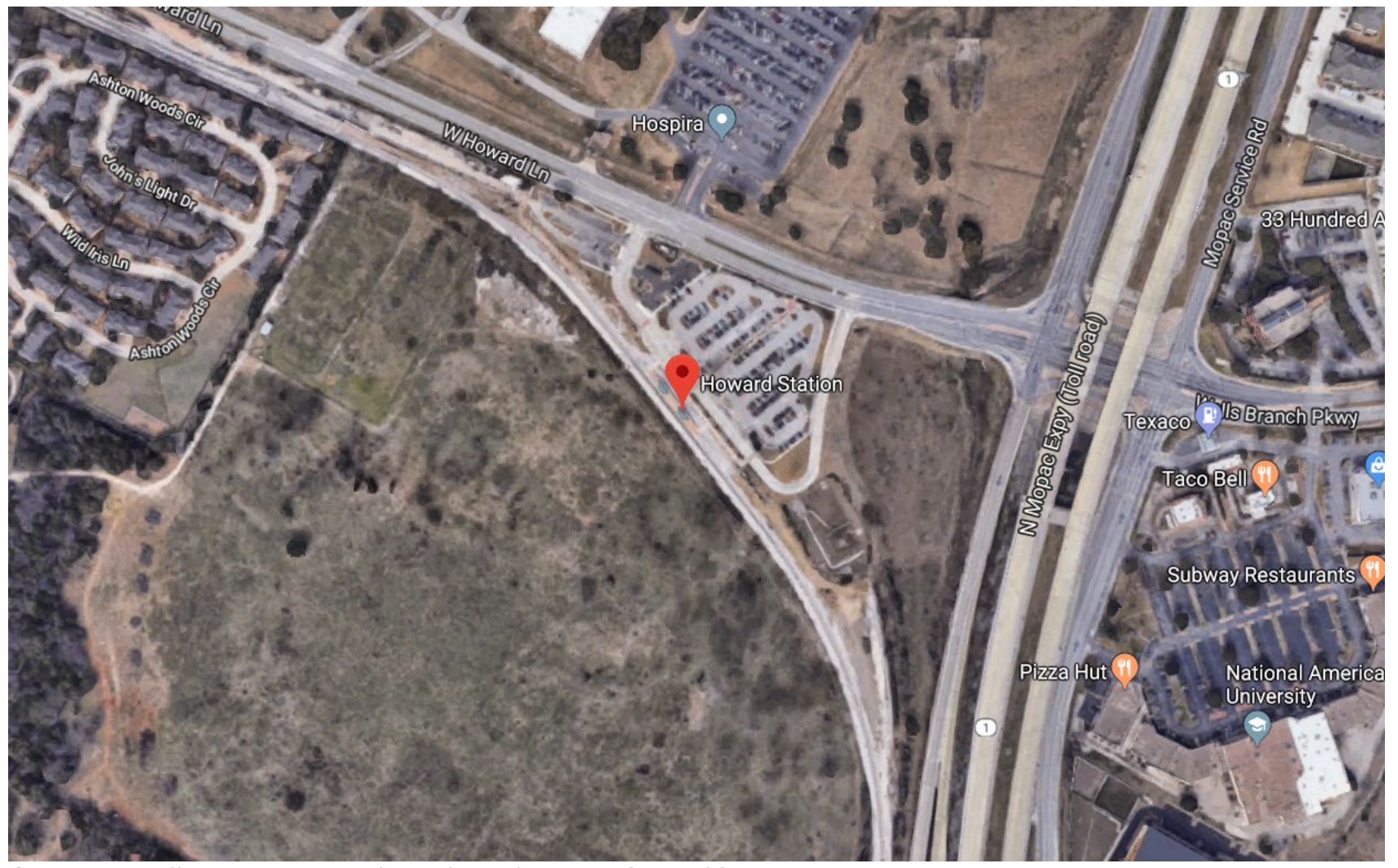

Source: https://www.google.com/maps/place/Howard+Station/@30.4397724,-

97.7012333,750m/data=!3m1!1e3!4m5!3m4!1s0x8644cdd4c2e3baa5:0xde5e2ee8d005cc04!8m2!3d30.4399288!4d$\underline{97.7016144}$ 


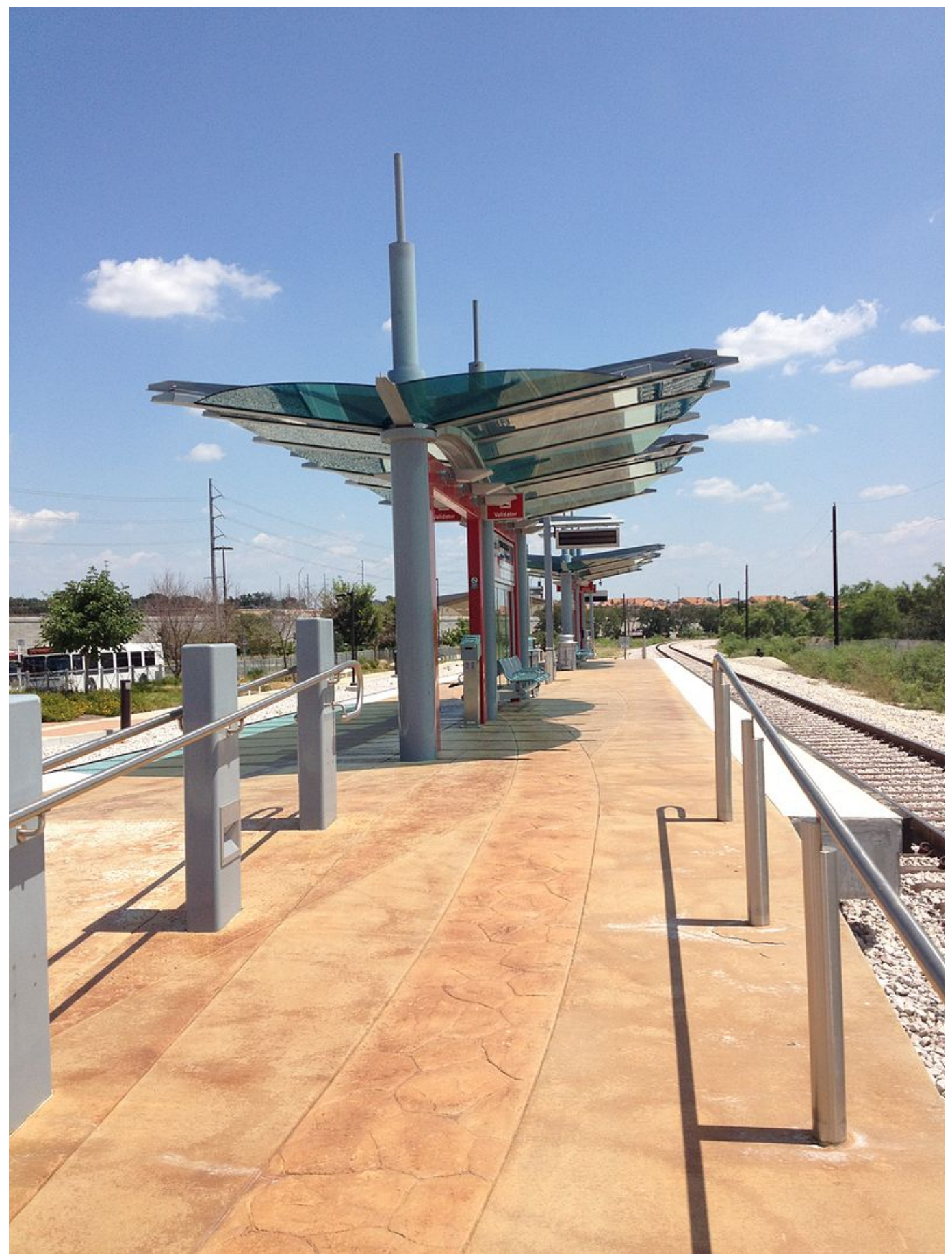

Source: https://en.wikipedia.org/wiki/Howard_station_(Capital_MetroRail)\#/media/File:Howard_Station_Platform.jpg 


\section{West Howard Lane}

Austin, Texas, 78728

Commute to Downtown Brushy Creek

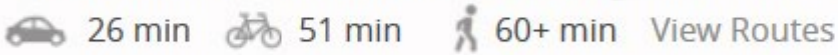

\section{Favorite $\mathbb{W}$ Map $\bigcirc$ Nearby Apartments}

Looking for a home for sale in Austin? 뚠
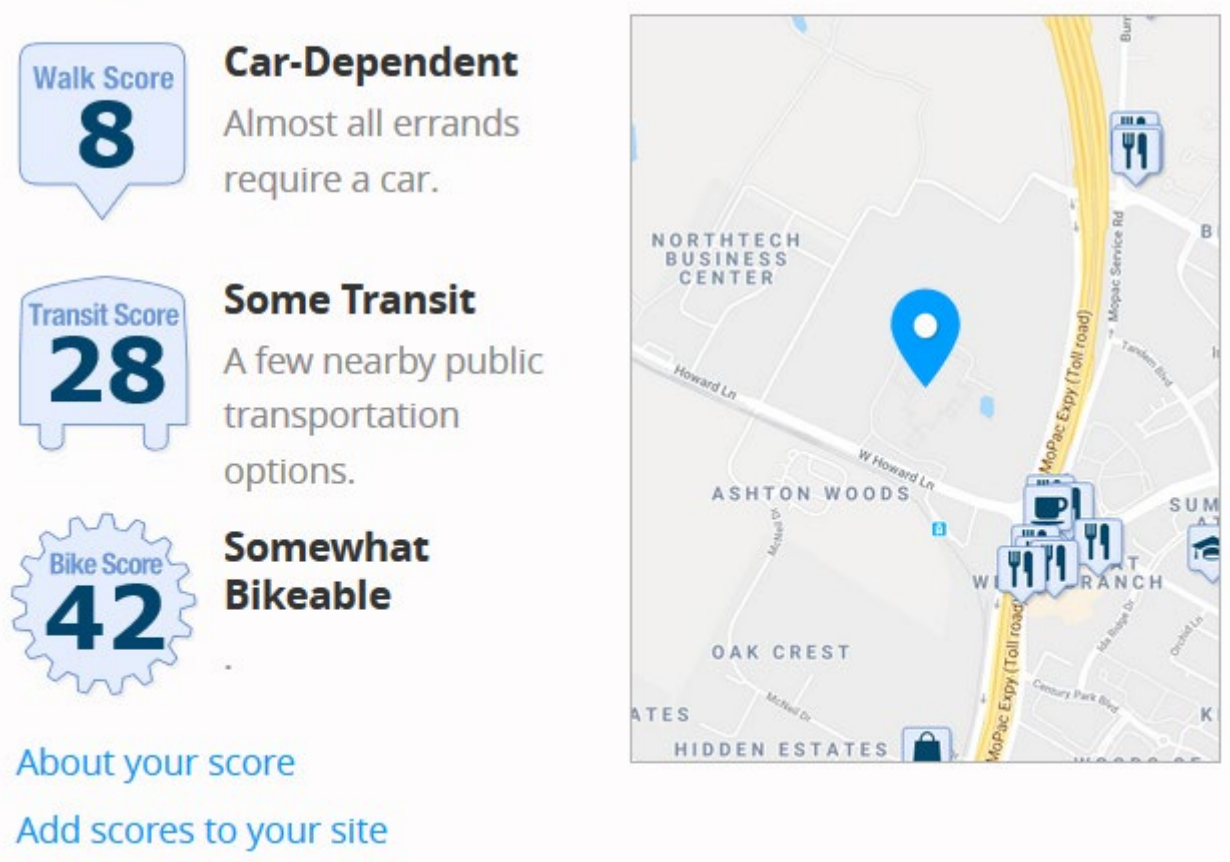

Source: https://www.walkscore.com/score/3900-w-howard-In-austin-tx-78728

The Howard Station in the Austin, Texas area is located near a junction of multiple major roads and highways, an overall less than ideal spot for multifamily development. 


\section{Nashville}

\section{Donelson Station}

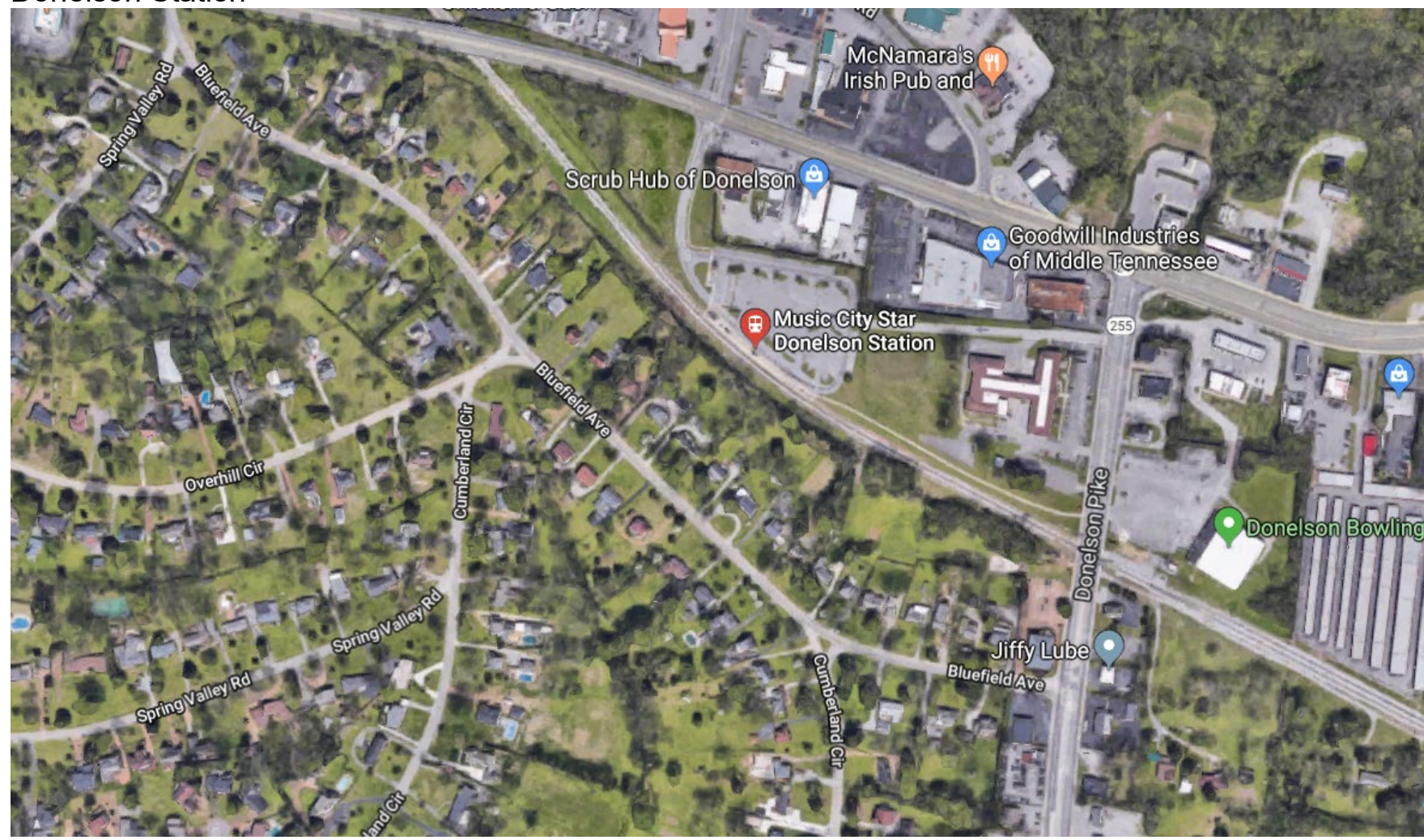

Source: https://www.google.com/maps/search/music+city+star/@36.1669646,-86.6659145,841m/data=!3m1!1e3

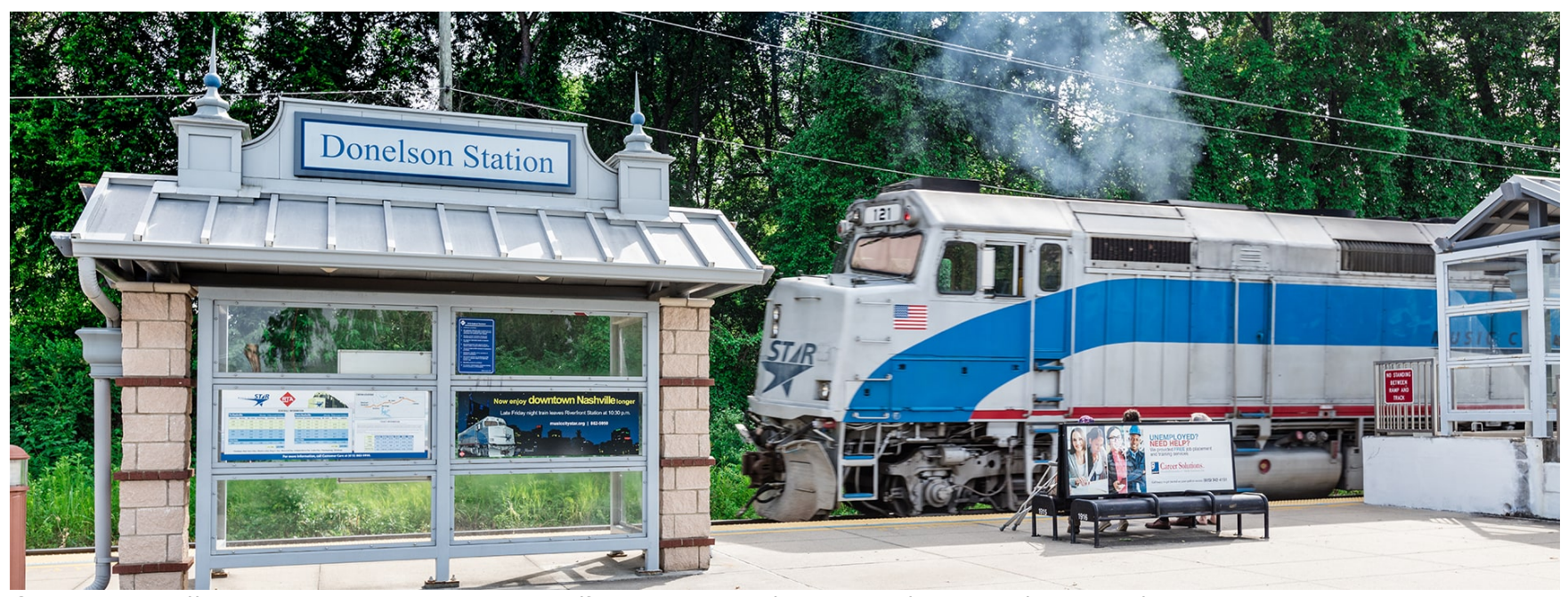

Source: https://www.centurycommunities.com/find-your-home/tennessee/nashville/nashville/donelson-downs 


\section{Lebanon Pike}

Bluefields, Nashville-Davidson, 37214

Commute to Downtown Nashville-Davidson

$\curvearrowleft 29 \mathrm{~min} 52 \mathrm{~min}$ i $60+$ min View Routes

\section{Favorite (1) Map @ Nearby Apartments}

Looking for a home for sale in Nashville-Davidson? 뚠

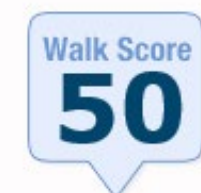

\$0

Somewhat

Bikeable

Flat as a pancake, minimal bike lanes.

About your score

Add scores to your site

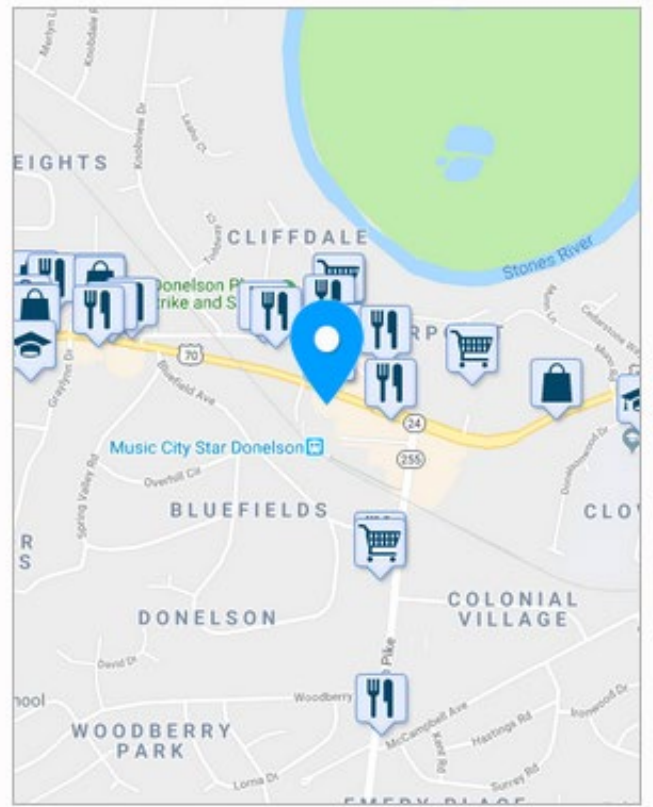

Source: https://www.walkscore.com/score/2721-lebanon-pike-nashville-tn-37214

Donelson Station is located in a highly single-family residential area and any new development of multifamily homes would likely be met with community opposition. 


\section{Good Retail}

\section{San Jose}

Fremont ACE Station

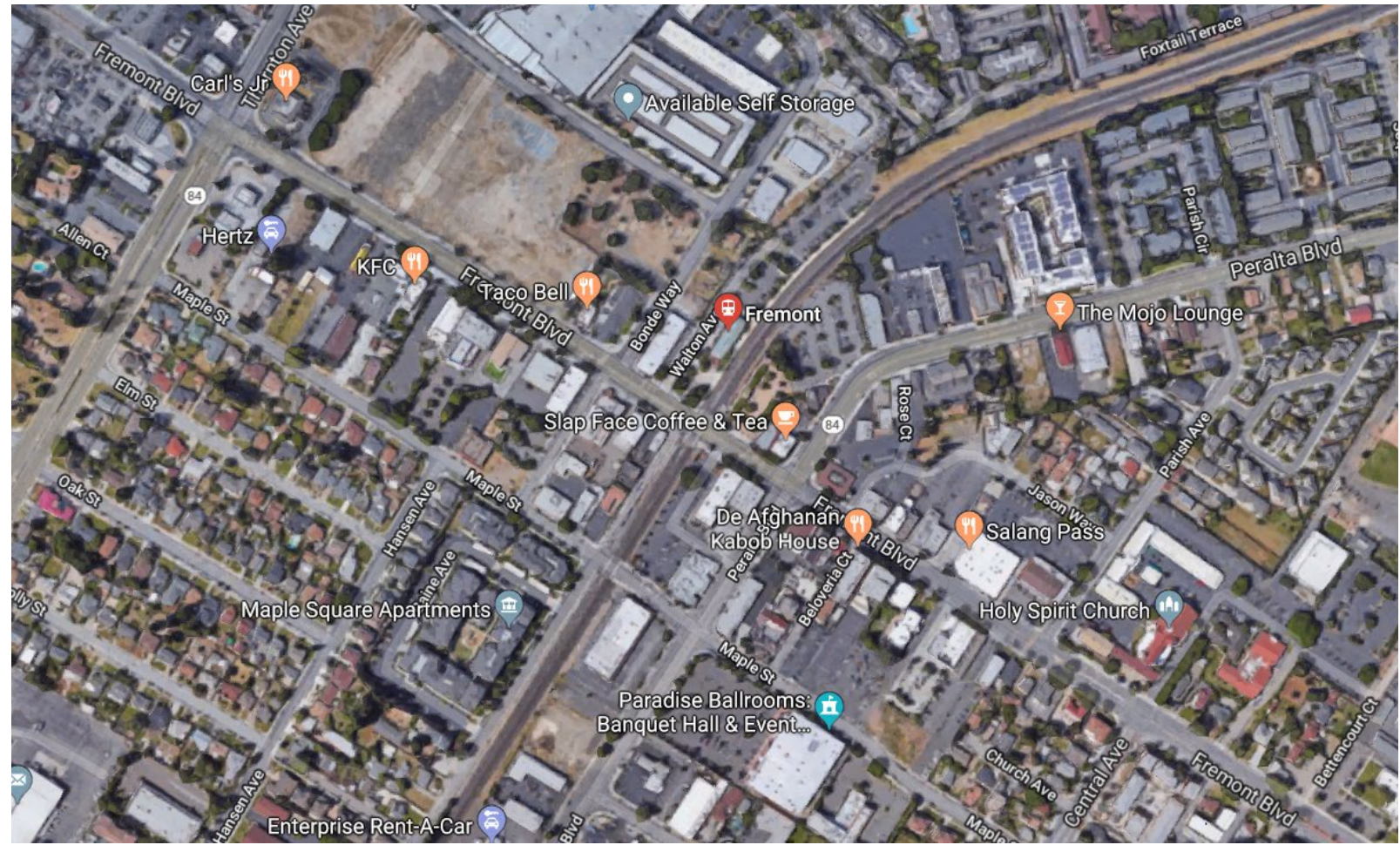

Source: https://www.google.com/maps/search/ace+station/@37.5588555,-122.007058,808m/data=!3m1!1e3 


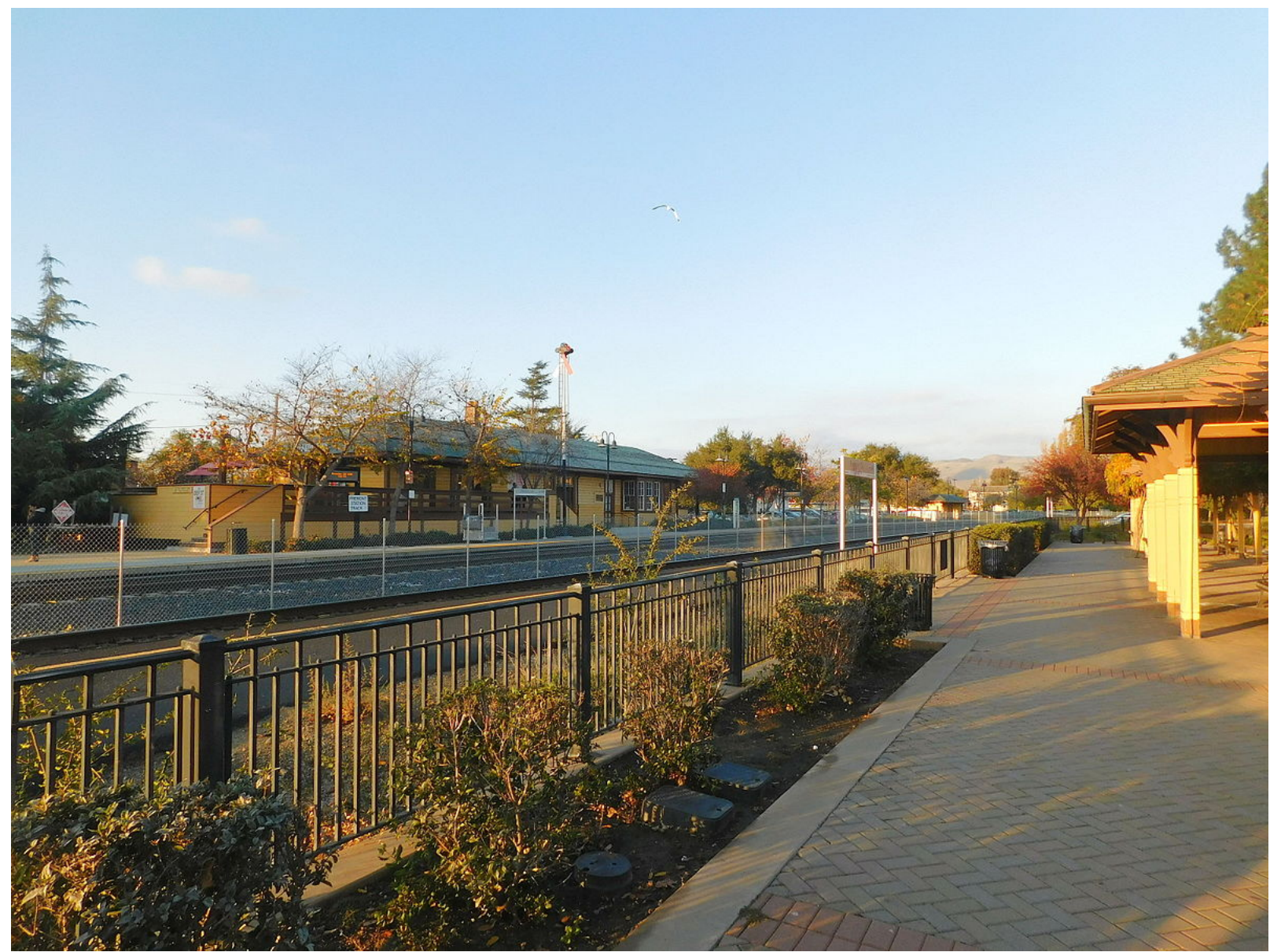

Source: https://upload. wikimedia.org/wikipedia/commons/thumb/5/52/Fremont Station November 2015.jpg/1200px-Fremont Station - November 2015.jpg 


\section{Fremont Boulevard}

Centerville, Fremont, 94536

Commute to Downtown Fremont

$\Leftrightarrow 6 \mathrm{~min} 13 \mathrm{~min}$ ) $11 \mathrm{~min} 36 \mathrm{~min}$ View Routes

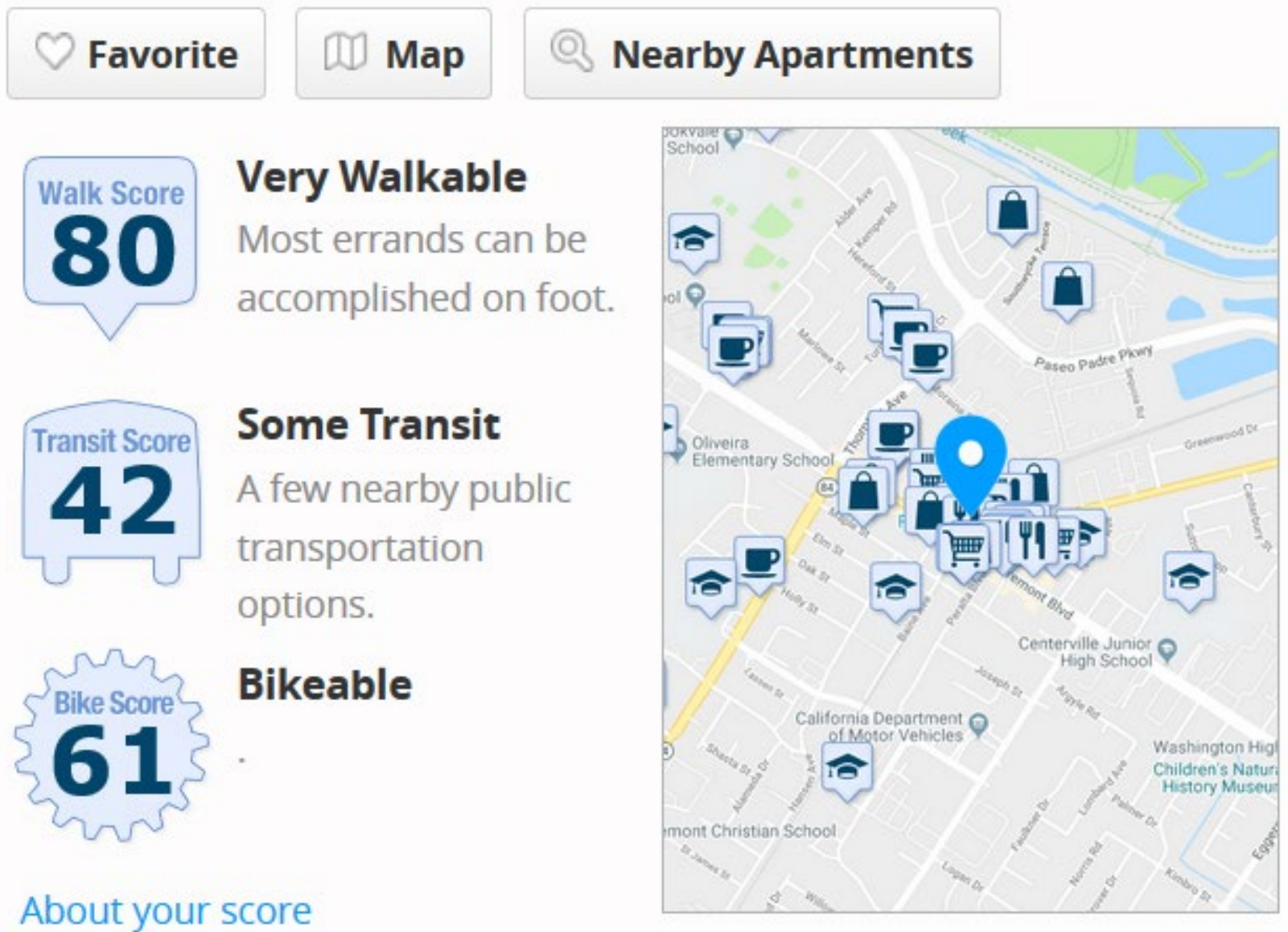

Add scores to your site

Source: https://www.walkscore.com/score/37260-fremont-blvd-fremont-ca-94536

The Fremont Station along the Altamont Corridor Express in the San Jose area is in a generally walkable area near many retail establishments. 


\section{Orlando}

\section{Winter Par Sunrail Station}

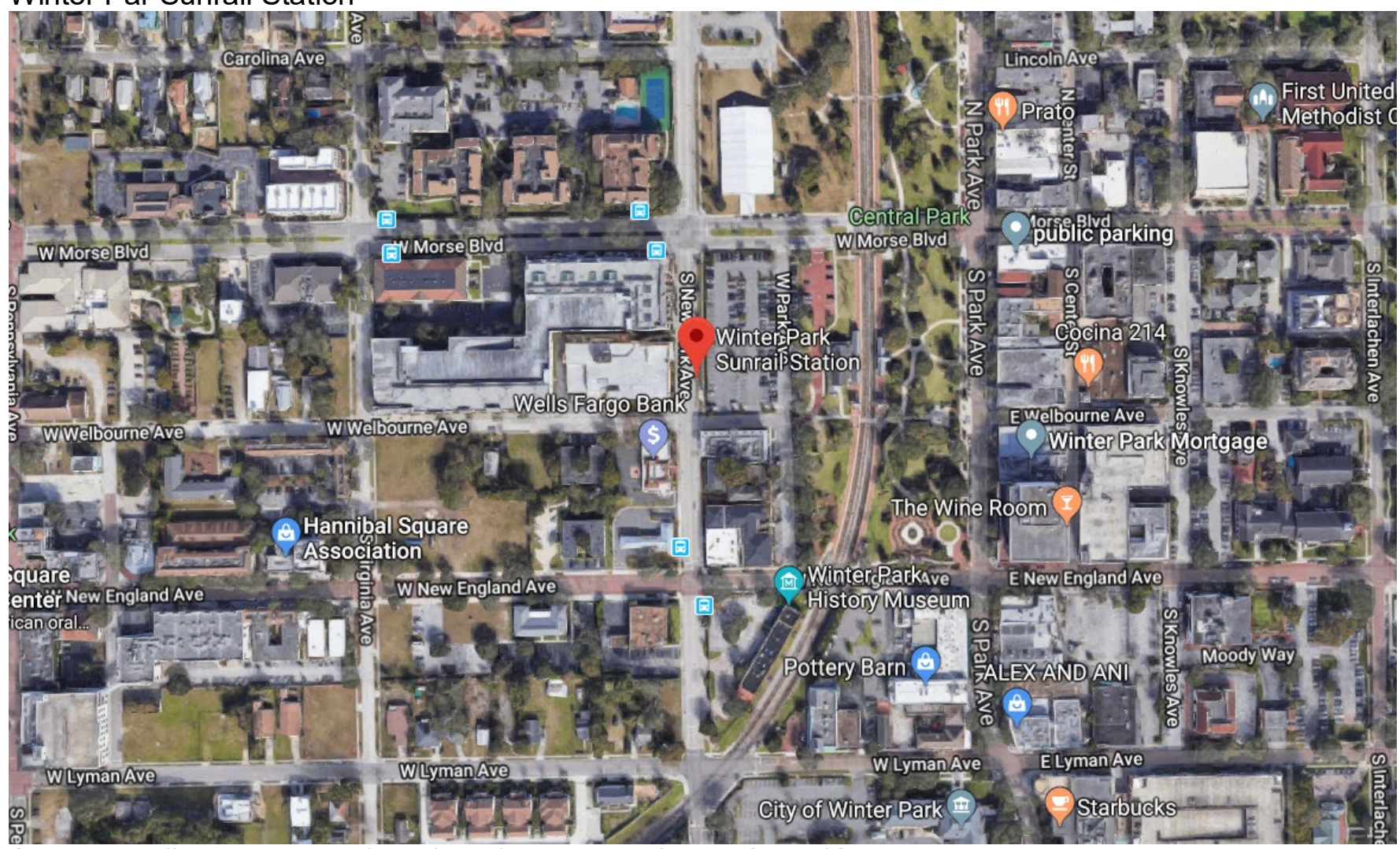

Source: https://www.google.com/maps/place/Winter+Park+Sunrail+Station/@28.5958122,-

$81.3514201,636 \mathrm{~m} / \mathrm{data}=! 3 \mathrm{~m} 1 ! 1 \mathrm{e} 3 ! 4 \mathrm{~m} 5 ! 3 \mathrm{~m} 4 ! 1 \mathrm{~s} 0 \times 88 \mathrm{e} 7701046 \mathrm{bd} 4097: 0 \times \mathrm{bb} 46 \mathrm{fbb} 31 \mathrm{~d} 27 \mathrm{afa} 70 ! 8 \mathrm{~m} 2 ! 3 \mathrm{~d} 28.596973 ! 4 \mathrm{~d}-$ $\underline{81.352741}$

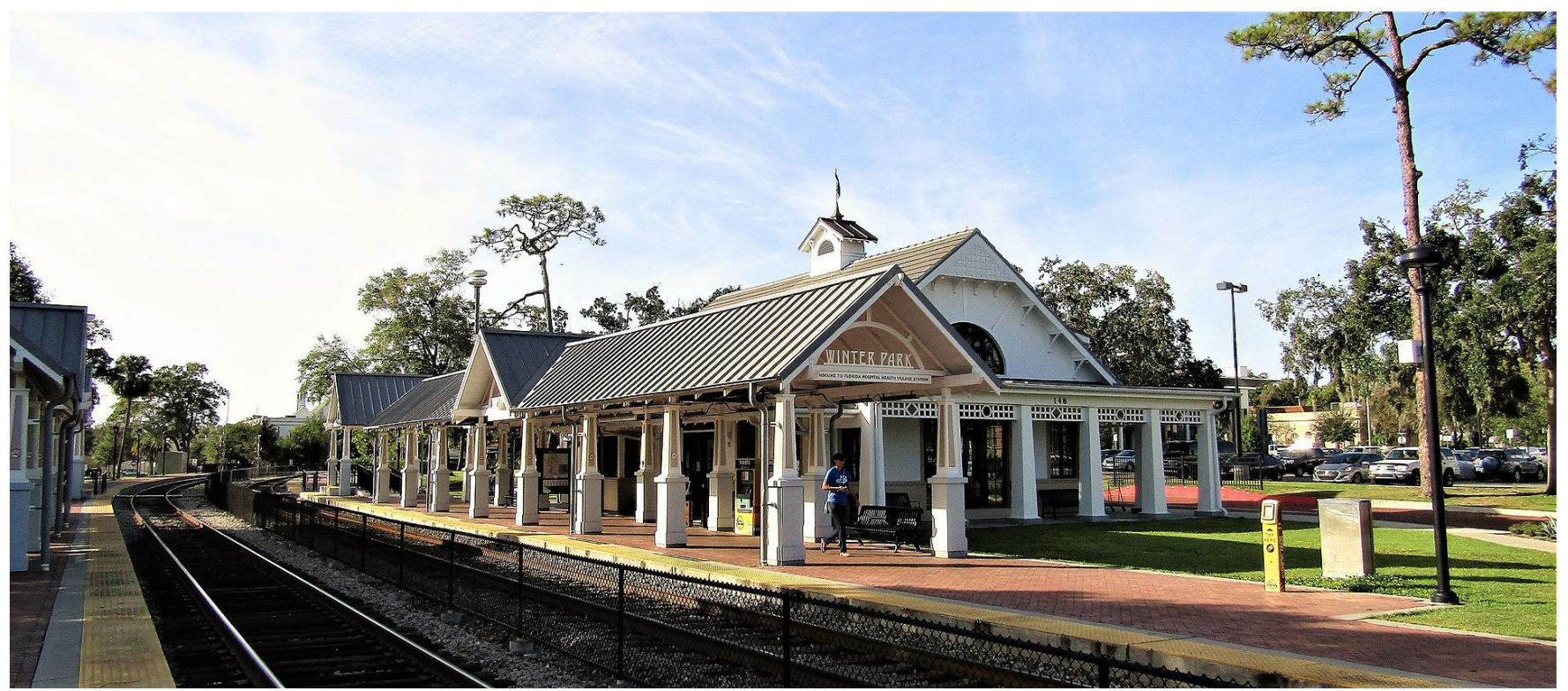

Source: https://en.wikipedia.org/wiki/Winter_Park_station\#/media/File:Winter_Park_Station_IMG_1444.jpg 


\section{South New York Avenue}

Winter Park, Florida, 32789

Commute to Downtown Winter Park

क $3 \mathrm{~min} 11 \mathrm{~min} 7 \mathrm{~min} \quad$ i $26 \mathrm{~min}$ View Routes

Favorite W Map (O) Nearby Apartments

More about 141 South New York Avenue 분

Walk Score Walker's Paradise

About your score

Add scores to your site

Source: https://www.walkscore.com/score/141-s-new-york-ave-winter-park-fl-32789

Located a few blocks west of Winter Park's main corridor, the Winter Park Sunrail station is not only a popular spot for commuters to board for work but a pleasant destination for those looking to shop or dine. 
Salt Lake City

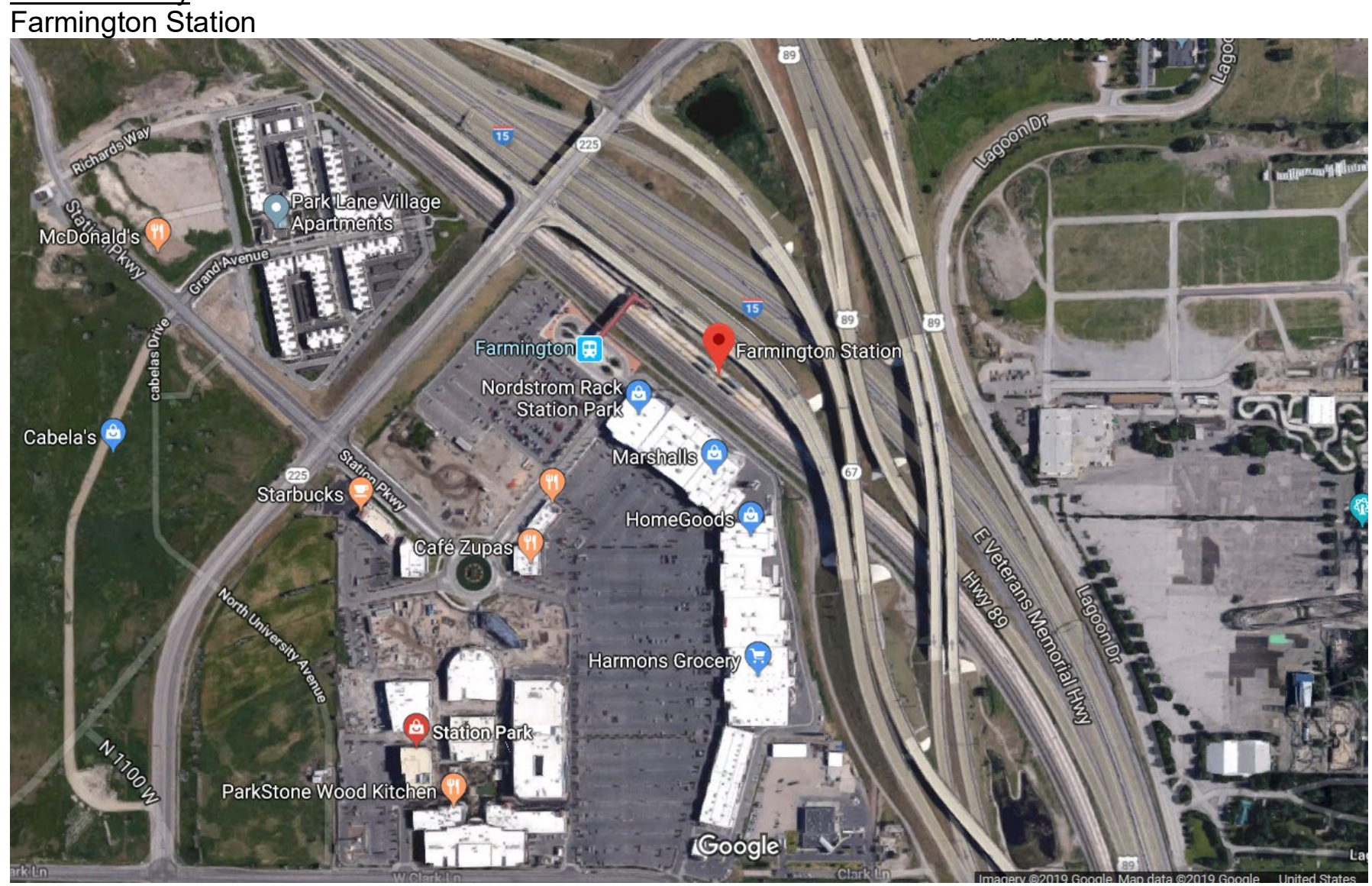

Source: https://www.google.com/maps/place/Farmington+Station/@40.9869015,-

$111.9033874,1091 \mathrm{~m} /$ data $=$ !3m1!1e3!4m8!1m2!2m1!1sfarmington+station!3m4!1s0x8752ff1 de504cfb7:0xdf351b9c40 c90b52!8m2!3d40.9872662!4d-111.9036668 


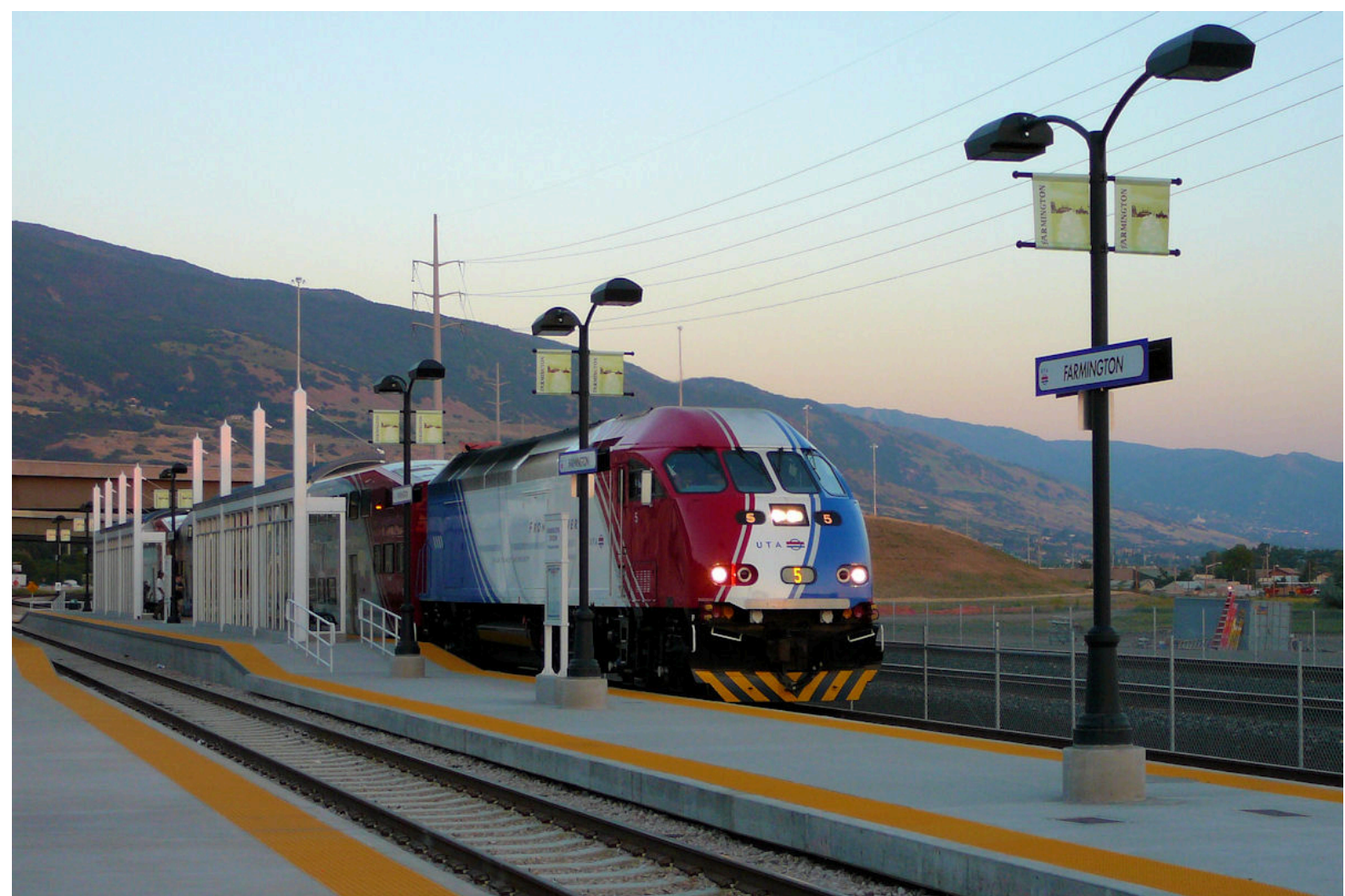

Source: https://en.wikipedia.org/wiki/Farmington_station\#/media/File:FrontRunner_Farmington.jpg 


\title{
380 Station Parkway
}

\author{
Farmington, Utah, 84025
}

\section{Commute to Downtown Farmington}

$4 \mathrm{~min} 12 \mathrm{~min} 7 \mathrm{~min}$ ì $29 \mathrm{~min}$ View Routes

\section{Favorite TI Map @ Nearby Apartments}

Looking for a home for sale in Farmington? 뚠

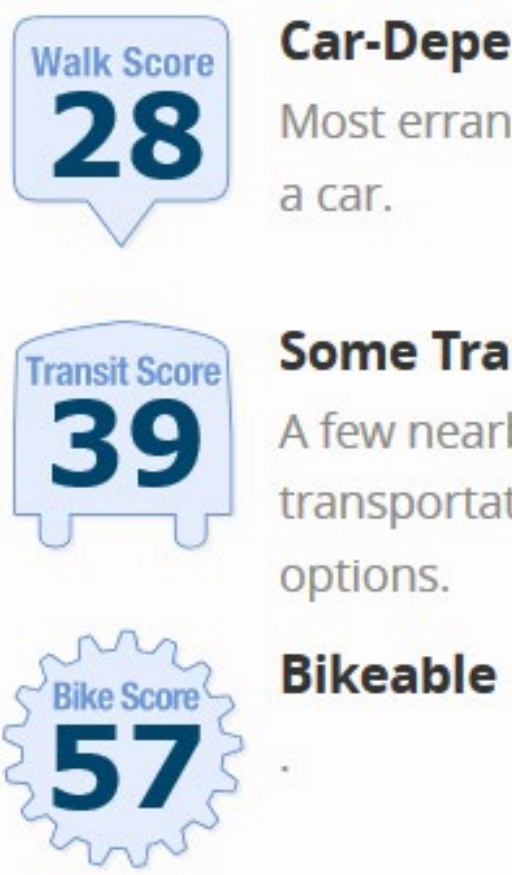

\section{About your score}

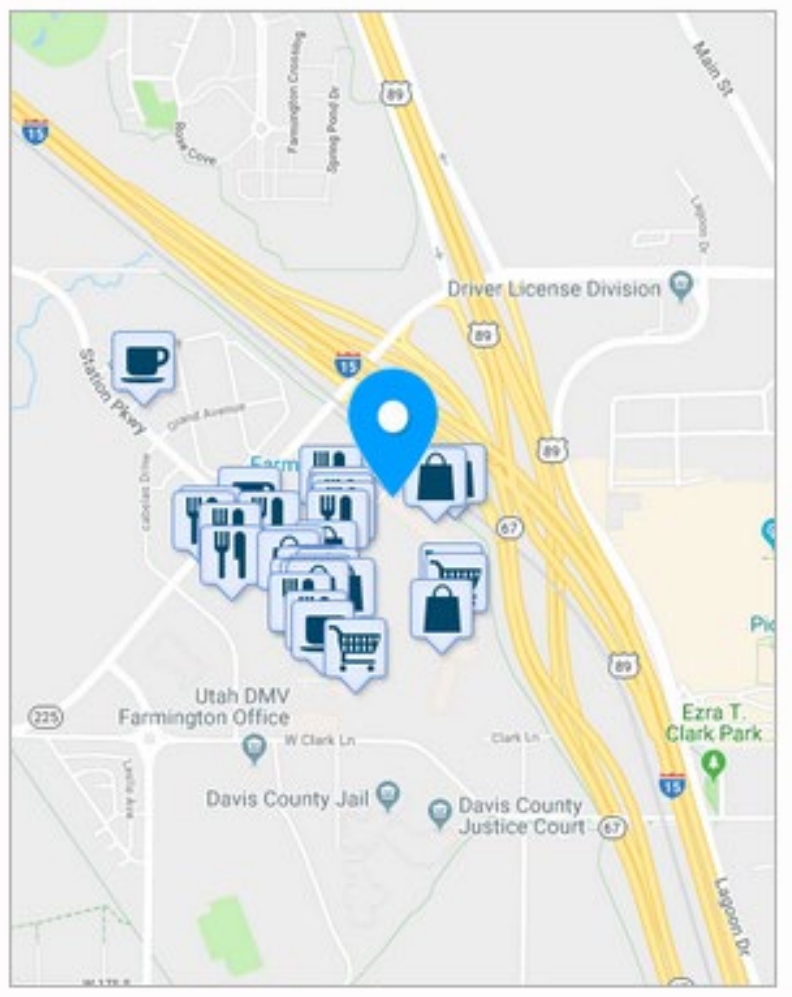

\section{Add scores to your site}

Source: https://www.walkscore.com/score/380-station-pkwy-farmington-ut-84025

The Farmington Station serving the Front Runner commuter rail system in the Salt Lake City, Utah area is located just outside of a new retail center called "Station Park." This is an example of how transit systems can spur development. 


\section{Bad Retail}

Austin

\section{Leander Station}

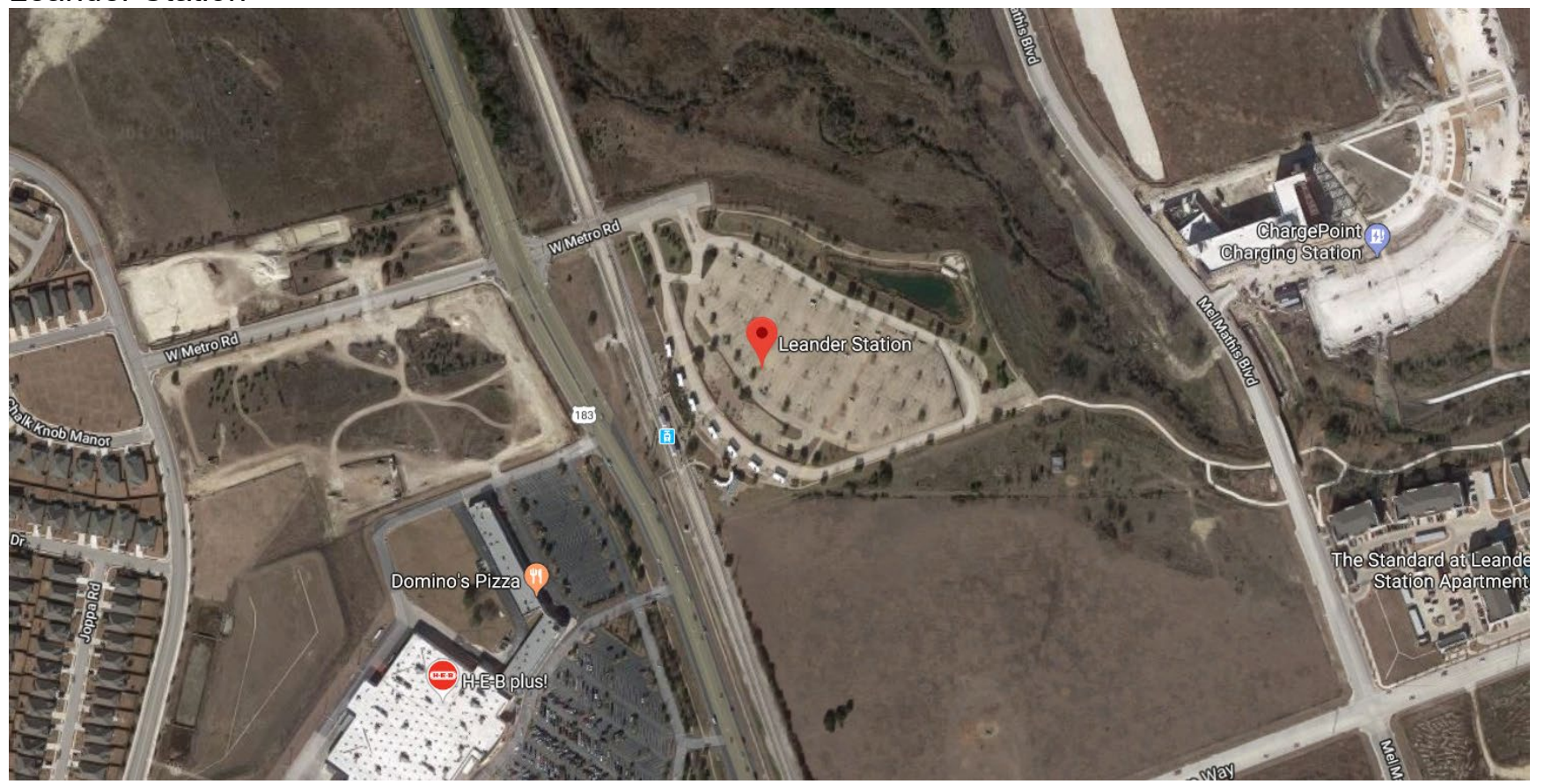

Source: https://www.google.com/maps/place/Leander+Station/@30.5868313,-

$97.8547579,752 \mathrm{~m} /$ data $=$ !3m1!1e3!4m5!3m4!1s0x865b2bebd40bea43:0x4b24118ee77518c9!8m2!3d30.5868688!4d$\underline{97.8549242}$

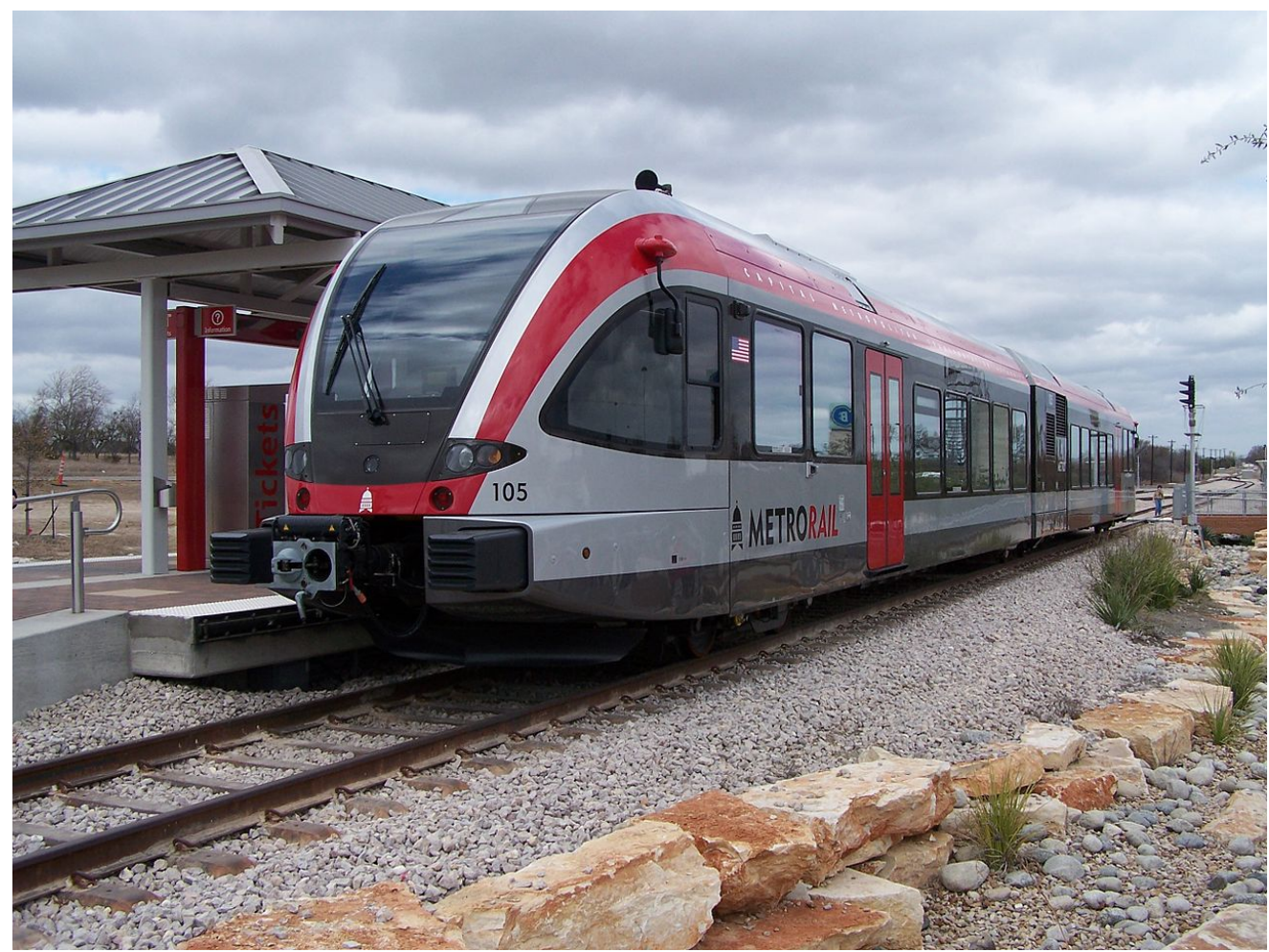

Source: https://en.wikipedia.org/wiki/Leander_station\#/media/File:Leander1.jpg 


\section{U.S. 183}

Leander, Texas, 78641

Commute to Downtown Leander

$\Leftrightarrow 1 \mathrm{~min} 8 \mathrm{~min} 2 \mathrm{~min}$ i $11 \mathrm{~min}$ View Routes

\section{Favorite 0 Map \& Nearby Apartments}

More about 651 U.S. 183 룰

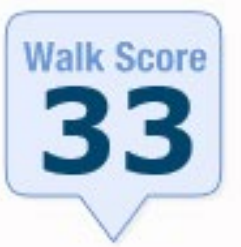

Car-Dependent

Most errands require

a car.

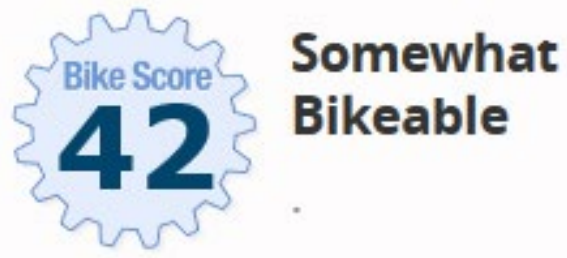

About your score

Add scores to your site

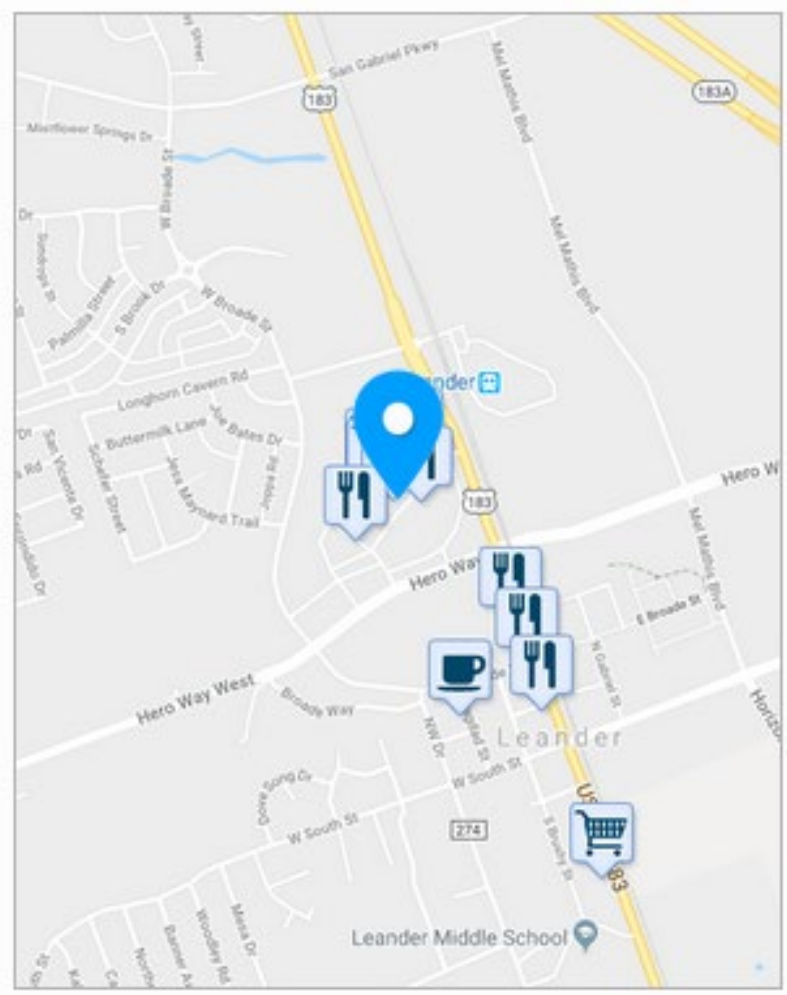

Source: https://www.walkscore.com/score/651-us-183-leander-tx-78641

Being a terminus of the Austin, Texas MetroRail system, there is little incentive for developing a retail destination other than neighborhood essential centers. 


\section{Minneapolis}

\section{Anoka Station}

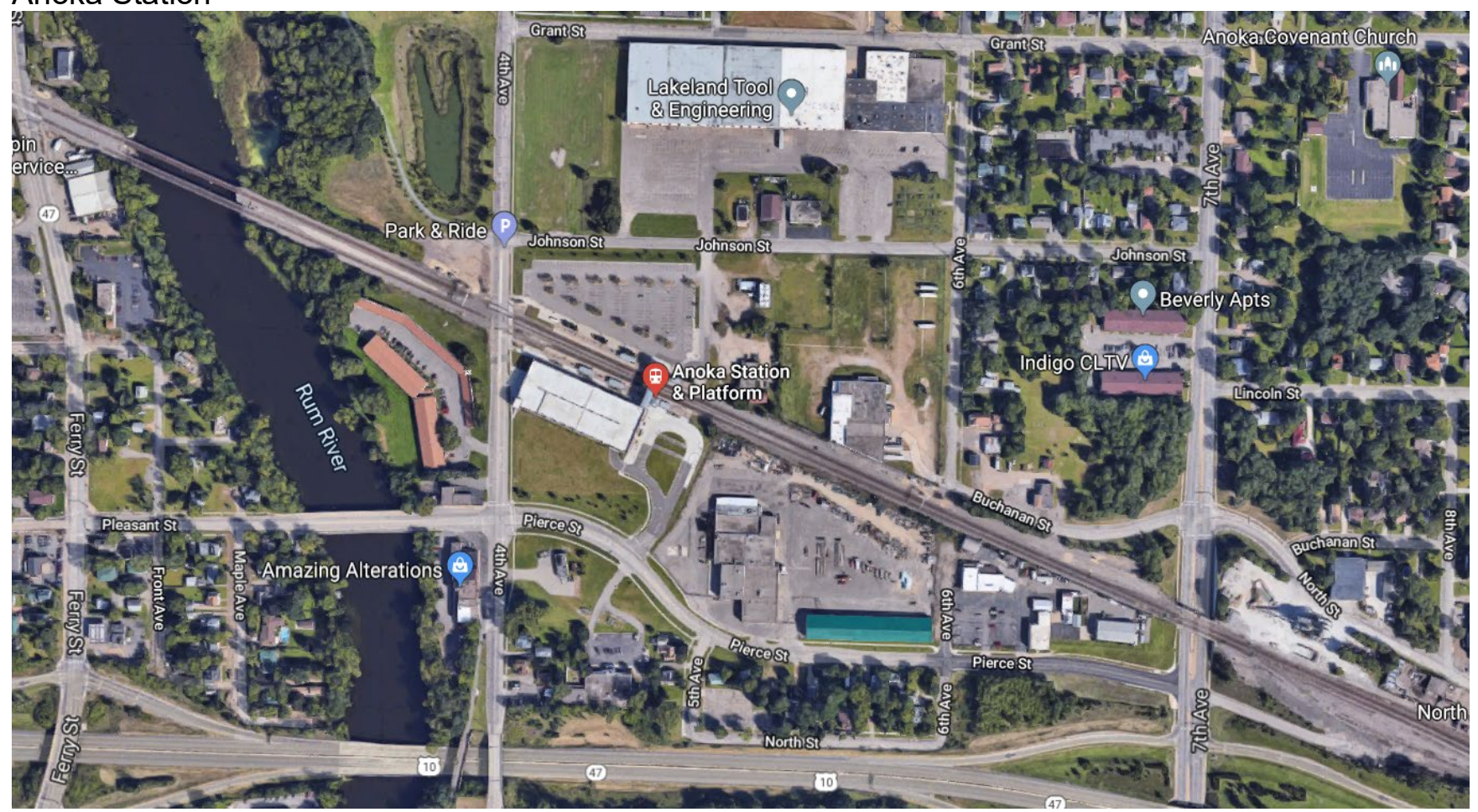

Source: https://www.google.com/maps/search/northstar+stations/@45.2074987,-93.3833862,782m/data=!3m1!1e3

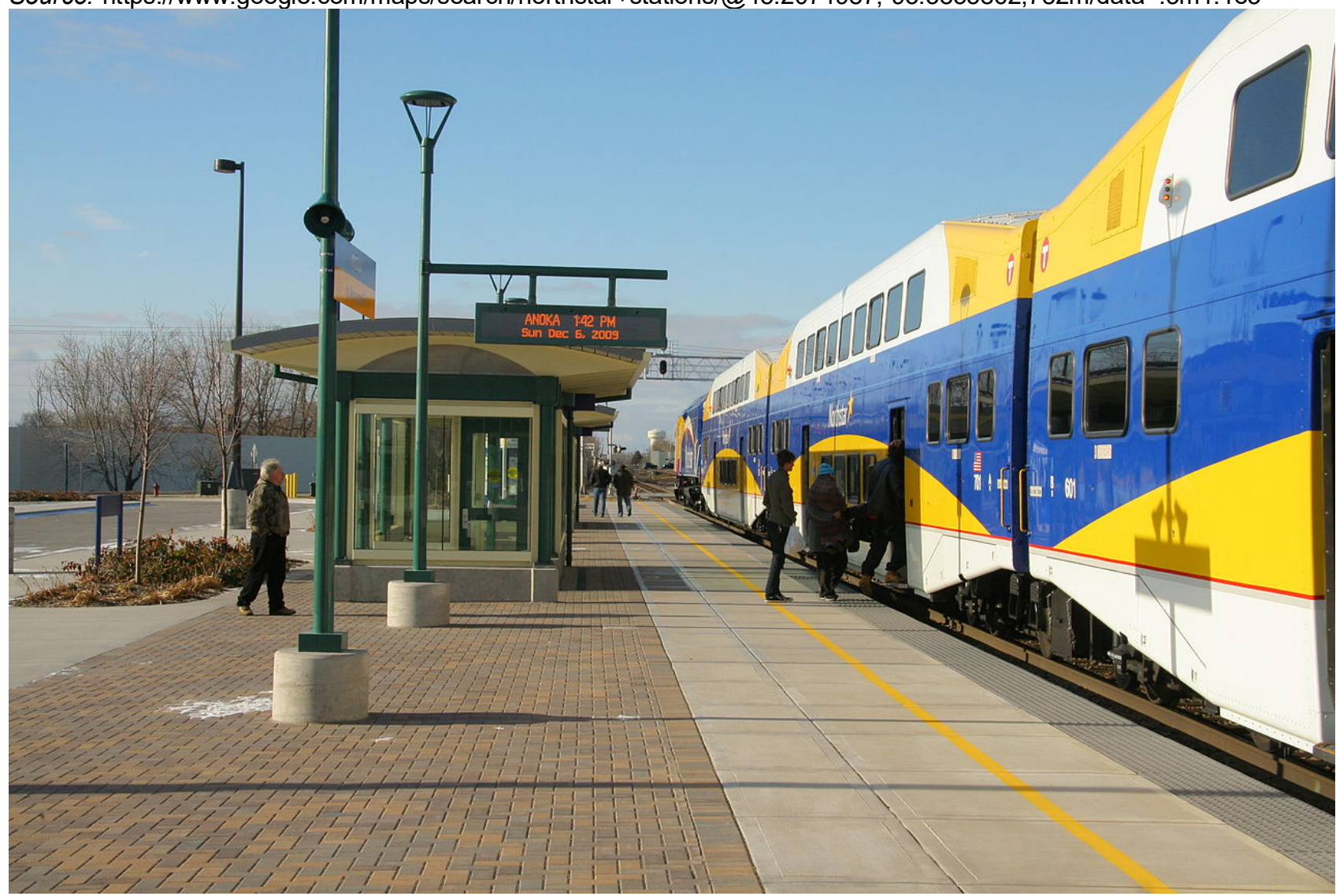

Source: https://en.wikipedia.org/wiki/Anoka_station\#/media/File:Northstar_Commuter_Anoka_station.jpg 


\section{Pierce Street}

Anoka, Minnesota, 55303

Commute to Downtown Anoka

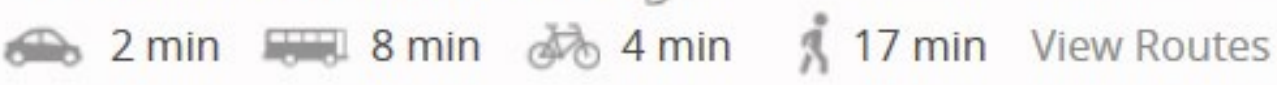

\section{Favorite 0 Map $\bigcirc$ Nearby Apartments}

Looking for a home for sale in Anoka? ⿷匚⿳丨コ丨

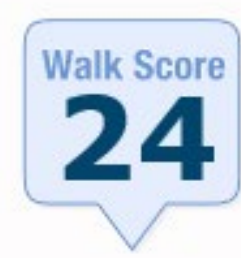

\section{Car-Dependent}

Almost all errands

require a car.

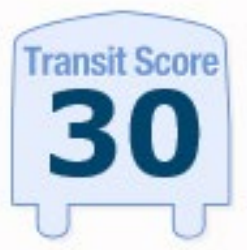

\section{Some Transit}

A few nearby public

transportation

options.

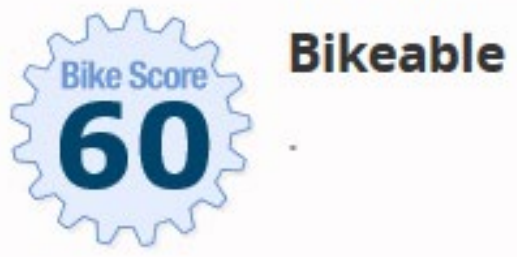

\section{About your score}

\section{Add scores to your site}

Source: https://www.walkscore.com/score/501-pierce-st-anoka-mn-55303

Anoka Station serving the Minneapolis area's Northstar commuter rail system is in a highly industrial area with little perceived potential for retail development. 